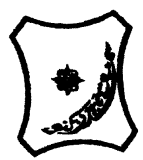

Bayero Journal of Pure and Applied Sciences, 14(1): 54 - 63

Received: November, 2020

Accepted: April, 2021

ISSN $2006-6996$

\title{
STABILITY CONSTANTS OF COMPLEXES OF METAL IONS WITH PEATSOIL HUMIC ACIDS UNDER NON-ACID-CONDITIONS
}

\author{
${ }^{* 1}$ Sabo, Yusuf ${ }^{2}$ Jimoh, W.L.O., ${ }^{3}$ Isa Baba Koki and ${ }^{4}$ Sholadoye, Q. 0. \\ ${ }^{1}$ Department of Pure and Industrial Chemistry, Bayero University, Kano \\ ${ }^{3}$ Department of Chemistry, Yusuf Maitama Sule University Kano. P.M.B. 3220 Kano, Nigeria. \\ ${ }^{4}$ Department of Chemistry, Nigerian Police Academy, Wudil, Kano-Nigeria
}

*Correspondence E-mail; saboyusuf18@yahoo.com

ABSTRACT

Stability constants of complexes of four divalent metal ions viz. $\mathrm{Cu}^{2+}, \mathrm{Pb}^{2+}, \mathrm{Mg}^{2+}$ and $\mathrm{Cd}^{2+}$ with humic acids (HA) were determined by potentiometric titration of humic acids with the corresponding salt of the divalent metals in aqueous media under non-acid-condition. The log $K$ (logarithm of the stability constant) ranged from 1.0942 to 2.7471 for metalhumic acid complexes were determined using point-wise computational method. The order of stability constants were obtained as follows: $\mathrm{Cu}>\mathrm{Pb}>\mathrm{Cd}>\mathrm{Mg}$ for metal $-\mathrm{HA}$ complexes respectively, indicating a higher degree of complexation with Cu metal ion.

Keywords: stability constant, humic acid, potentiometric titration, divalent metals, acid hydrolysis.

\section{NTRODUCTION}

The stability constant of a complex is the numerical expression of its stability and provides a quantitative measure of affinity of the metal ion to the complexing agent. An understanding of the relative stability of metal-complexes helps in predicting the behavior of metal ions in the soil (Ram and Raman, 1982). Extensive researches has been done to determine the stability constants of the complexes formed between humic acid (HA) with a number of metal ions. Ashok et al., (2000) reported that humic acid with hydroxyl, phenoxyl and carboxyl reactive groups can form coordination compound with metal ions at $\mathrm{pH}$ 3.5. The stability constants(Log K) for different metalhumic acid complexes indicated the following order of the stabilities of complexes formed between humic acid and metal ion, $\mathrm{Cu}>\mathrm{Fe}$ $>\mathrm{Pb}>\mathrm{Ni}>\mathrm{Co}>\mathrm{Ca}>\mathrm{Cd}>\mathrm{Zn}>\mathrm{Mn}>\mathrm{Mg}$. Andelkovic et al., (2010) investigated the binding of $\mathrm{Cd}$ (II) to soil humic acid at pH 6.5 and in $0.1 \mathrm{M} \mathrm{KNO}_{3}$ ionic medium. The stability constant for binding indicating greater stability in the case when carboxyl groups are involved in complexation reaction. Kostic et al.,(2012) investigated the complexation of humic acid with certain heavy metal ions (Co(II), $\mathrm{Ni}(\mathrm{II}), \mathrm{Cu}(\mathrm{II})$,
$\mathrm{Zn}(\mathrm{II})$, and $\mathrm{Pb}(\mathrm{II})$. The experiment was performed at $25^{\circ} \mathrm{C}$, at pH 4.0 and ionic strength of $0.01 \mathrm{M}$. Stability constant of complex between $\mathrm{Pb}$ (II) ions and humic acid is greater than stability constants of other investigated metalhumate complexes. Bogata and Sokolowska (2016) analyses the interaction between humic acids from different soils and $\mathrm{Zn}$ (II) ions at wide concentration ranges and at $\mathrm{pH} 5$. Studies have showed significant impact of $\mathrm{Zn}$ concentration, $\mathrm{pH}$ and some properties of humic acids with zinc.But all of these studies were limited to acidic $\mathrm{pH}$ range. Therefore, the present study was carried out to determine and compare the stability constants of complexes of metal ions with hydrolysed peat soil humic acid and unhydrolysed peat soil humic under non-acid conditions.

\section{MATERIALS AND METHODS}

Analytical grade chemicals used includes hydrochloric acid $(\mathrm{HCl})$, nitric acid $\left(\mathrm{HNO}_{3}\right)$, sodium hydroxide $(\mathrm{NaOH})$, lead nitrate $\mathrm{Pb}\left(\mathrm{NO}_{3}\right)_{2}$, copper nitrate $\mathrm{Cu}\left(\mathrm{NO}_{3}\right)_{2} \cdot 3 \mathrm{H}_{2} \mathrm{O}$, cadmium nitrate $\mathrm{Cd}\left(\mathrm{NO}_{3}\right)_{2} \cdot 4 \mathrm{H}_{2} \mathrm{O}$, magnesium nitrate $\mathrm{Mg}\left(\mathrm{NO}_{3}\right)_{2} \cdot 6 \mathrm{H}_{2} \mathrm{O}$, potassium nitrate $\left(\mathrm{KNO}_{3}\right)$, calcium chloride $\left(\mathrm{CaCl}_{2}\right)$, (sigma-Aldrich). Dowex 50WX8, (20-50 mesh) from Fluka. 


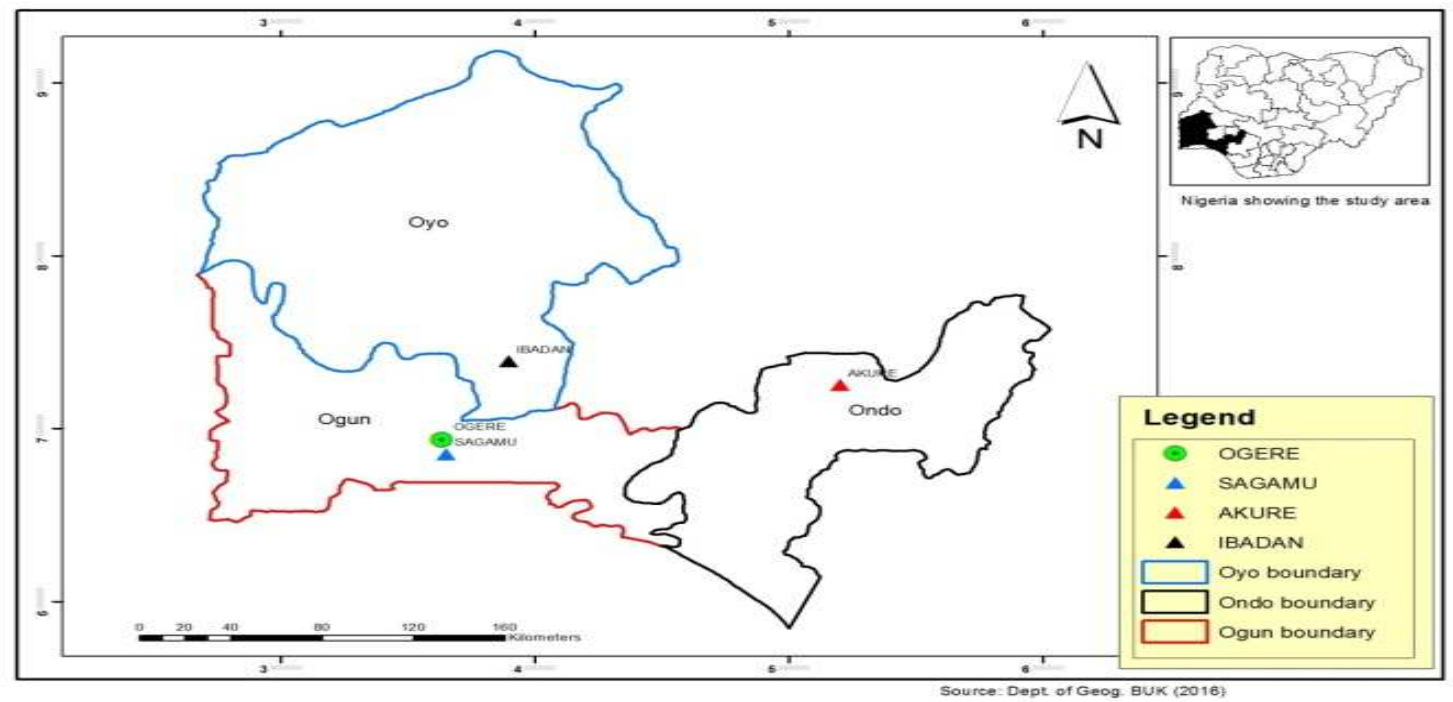

Figure 1: Map showing the sampling point at Sagamu Town, Ogun State.

\section{Description of Sampling Area}

Sagamu has geographical coordinates between $6^{\circ} 50^{\prime}$ north; $3^{\circ} 38^{\prime}$ east is located in south western region of Nigeria. The region has tropical wet and dry climate with a lengthy wet season and relatively constant temperatures throughout the course of the year. Wet season runs from March to October, November to December forms the region dry season. The vegetation type of the region is savannah which is really grassland with small bushes and occasional big trees. Grassland soils have substantially higher organic matter content than forest soils (Novackova, 2011).

\section{Sample Collection}

The Peatsoil samples were collected from four different sampling points $(0-10 \mathrm{~cm}$ depth) in Sagamu into polyethylene bag with plastic spoons. Samples were taken to the laboratory, extraneous materials were removed; the samples were air-dried, crushed and ground to a fine powder in a mortar passed through a $0.20 \mathrm{~mm}$ sieve. The samples were kept for analysis.

\section{Isolation and purification of humic acid from peat soil sample}

Peatsoil sample $(100 \mathrm{~g})$ was mixed with 1000 $\mathrm{cm}^{3}$ of $0.1 \mathrm{M} \mathrm{NaOH}$ solution, shaken for 3hours and left to stand overnight. Dark-coloured supernatant was obtained and decanted from solid residue. The dark-coloured supernatant was acidified to $(\mathrm{pH}=1.0)$ with $6 \mathrm{M} \mathrm{HCl}$ stirred and allowed to stand for 6 hours. Yellowish brown supernatant and dark-brown precipitate were obtained. The yellowish brown supernatant was decanted followed by centrifuge and discarded. The dark-brown precipitate was mixed with $500 \mathrm{~cm}^{3}$ of $0.1 \mathrm{M} \mathrm{NaOH}$ solution followed by passing through dowex resin. The dark-brown solution was acidified to $(\mathrm{pH}=1.0)$ with $6 \mathrm{M} \mathrm{HCl}$ stirred and allowed to stand for 3 hours. The dark-brown precipitate was washed several times with deionized water. The supernatant was treated with $\mathrm{AgNO}_{3}$ solution until no white precipitate observed. The humic acid was transferred to weighed crucible and dried at $60^{\circ} \mathrm{C}$ in an oven for 12 hours. The humic acid was cooled and dried in the desiccator, weighed and recorded. The obtained humic acid was dried again at $60^{\circ} \mathrm{C}$ for additional 6 hours cooled and dried in the desiccator, weighed and recorded constant weight was obtained (Baruah et al., 2015).

\section{FT-IR analysis}

FT-IR spectra of humic acid sample was analysed using Carry 630 FT-IR Agilent Technologies.

Unhydrolysed compost humic acid

The unhydrolysed humic acid was obtained after isolation and purification of compost humic acid and kept for investigation.

\section{Acid hydrolysis of Peatsoil acid}

Peatsoil humic acid sample (1g) was refluxed for 12 hours at $\left(160^{\circ} \mathrm{C}\right)$ with $50 \mathrm{~cm}^{3}$ of $6 \mathrm{M} \mathrm{HCl}$. The mixture was allowed to cool, decanted, and centrifuged after hydrolysis. The insoluble residues were washed with distilled water via centrifugation several times, and the supernatant was treated with $\mathrm{AgNO}_{3}$ solution until no white precipitate was observed. The residue was thoroughly dried over $\mathrm{CaCl}_{2}$ in a desiccator at room temperature (Chefetz et al., 2002). Finally, the obtained hydrolysed humic acid was kept for investigation. 
BAJOPAS Volume 14 Number 1,June, 2021 Potentiometric Titrations

Potentiometric measurements were carried out using a pH-meter Jenway (model 3510) with combine electrode, the sensitivity of the $\mathrm{pH}$ meter is 0.01 units. The $\mathrm{pH}$ meter was switched on half an hour before starting the titration for initial warm up of the instrument. The instrument was calibrated with an aqueous standard buffer solution of $\mathrm{pH} 4.00$ and 10.0 (borate buffer) prepared from a "Qualigens" buffer tablets.

The following sets of solutions were prepared in a $250 \mathrm{~cm}^{3}$ volumetric flask separately for $\mathrm{pH}$ metric titrations.

(i) $5 \mathrm{~cm}^{3} 0.1 \mathrm{M} \mathrm{HCl}+40 \mathrm{~cm}^{3}$ deionized water

(ii) $5 \mathrm{~cm}^{3} 0.1 \mathrm{M} \mathrm{HCl}+39 \mathrm{~cm}^{3}$ deionized water $+1 \mathrm{~cm}^{3} 0.15 \mathrm{gcm}^{-3}$ humic acid

(iii) $5 \mathrm{~cm}^{3} 0.1 \mathrm{M} \mathrm{HCl}+37 \mathrm{~cm}^{3}$ deionized water $+1 \mathrm{~cm}^{3} 0.15 \mathrm{gcm}^{-3}$ humic acid

$$
+2 \mathrm{~cm}^{3} \quad 0.01 \mathrm{M} \mathrm{Cu} \text { (II) }
$$

The solutions were titrated against standardized $0.110 \mathrm{MNaOH}$ separately. The total volume of each mixture was adjusted to $50 \mathrm{~cm}^{3}$ and the ionic strength of the solutions was maintained constant at by adding appropriate amount of stock solution of $1 \mathrm{M} \mathrm{KNO}_{3}$ (Gamal, 2015; Omar and Ali, 2015). A magnetic stirrer was used to achieve thorough mixing of the interacting solutions at $550 \mathrm{rpm}$. The same set of experimental conditions was applied for potentiometric titration of remaining samples.

\section{Evaluation of pKa of Hydrolysed peat soil Humic Acids}

The proton-ligand formation number $\mathrm{n}_{\mathbf{A}}$ were calculated by Irving and Rossotti expression (Omar and Ali, 2015).

$\mathrm{nA}=\mathrm{Y}-\frac{(\mathrm{V} 2-\mathrm{V1})(\mathrm{No}-\mathrm{Eo})}{(\mathrm{VO}+\mathrm{V1}) \mathrm{TCL}}$ 1

Where: $Y$ is number of dissociable proton, $\left(\mathrm{V}_{2^{-}}\right.$ $V_{1}$ ) is the measure of displacement of the ligand curve relative to acid curve, $\mathrm{N}^{\circ}$ and $\mathrm{E}^{\circ}$ are the resultant concentration of alkali solution, free acid solution, $\mathrm{T}_{\mathrm{cL}}{ }^{\circ}$ is the total ligand concentration, $\mathrm{V}^{\circ}$ is the total volume of titration solution, $V_{1}$ is the volume of alkali added to acid solution, $V_{2}$ is the volume of alkali added to acid solution + ligand solution, acid dissociation constants (pKa - values) of ligand were calculated by algebraic method point wise calculation (Tables 1 ). The dissociation constants (pKa) were calculated according to the following relation:

$\mathrm{pKa}=\mathrm{pH}+\log \left(\frac{n A}{1-n A}\right)$ 2

Where: pKa is the acid dissociation constant, $\mathrm{n}_{\mathrm{A}}$ is the Proton-ligand formation number and $\mathrm{pH}$ is the pH-values (Omar and Ali, 2015).

\section{Determination of metal-ligand stability constants $(\log K)$ of complexes}

The potentiometric measurement for the determination of stability constant of a complex in solution is based on the fact that the redox potential of the couple $\frac{M^{+(m-n)}}{M^{+m}}$ is shifted significantly on complexation of the metal ion with the ligand. This method involves change in hydrogen ion concentration $\left[\mathrm{H}^{+}\right]$due to the displacement or association of one or more protons taking place during complexation reaction. This change can be found out by titrating the solutions containing free acid, acid with ligand, and acid with ligand and metal ion, individually against a standard alkali solution at a constant ionic strength or temperature. Either ionic strength or temperature may be varied for different sets of solutions. In all the cases, the change in the $\mathrm{pH}$ of the solution is measured after each addition of a known amount of alkali to the reaction cell which contains the reaction mixture. The titration curves are then drawn by plotting the measured $\mathrm{pH}$ values against the corresponding volume of alkali added and the stability constants of the complexes are determined from the titration curves by employing $\mathrm{pH}$-metric titration technique given by (Irving and Rossoti).

Metal-ligand stability constants ( $\log \mathrm{K}$ ) were determined by using the following relations:

$$
\bar{n}=\frac{\left(V_{3}-V_{2}\right)\left(E^{0}+N^{0}\right)}{\left(V^{0}+V_{2}\right) \bar{n}_{A} T_{m}^{0}}
$$

and

$$
P L=\log _{10}\left\{\frac{1+\beta_{n}^{H} \frac{1}{[\text { anti } \log \mathrm{pH}]^{\mathrm{n}}}}{\mathrm{T}_{\mathrm{L}}^{0}-n \bar{T}_{m}^{0}} \mathrm{X} \frac{\left(V^{0}+V_{3}\right)}{V^{0}}\right\}
$$


BAJOPAS Volume 14 Number 1,June, 2021

Where $T_{L}, T^{\circ}, E^{\circ}$, and $V^{\circ}$ havethe same significance as in equation (1) above, $T_{m}$ denotes the total concentration of metal present in solution, $V_{3}$ is the volume of metal ions present in solution and $\beta^{H}$ is the overall proton ligand stability constant. The metal-ligand stability constants (log K) were determined by employing point wise computational Method (eq. 5 and 6).

$\log _{1}=\log \left(\frac{n}{1-n}\right)+\mathrm{pL}$ .5

$\operatorname{LogK}_{2}=\log \left(\frac{1-n}{2-n}\right)+\mathrm{pL}$ ...6

Where: Log $\mathrm{K}$ is the metal-ligand stability constant, $\mathrm{pL}$ is the Free ligand exponent function, $\mathbf{n}$ is the Average number of ligand attached with metal ion (Janraoet al., 2014). The results obtained were analyzed by an ORIGIN 2016 program using titration data and then the proton-ligand stability constants (pKa) and Metal-ligand stability constant (LogK) calculated (Omar and Ali, 2015).

\section{RESULTS AND DISCUSSION}

Fourier transformed infrared (FT-IR) spectra of isolated humic acid from peat soils Figure 2 had distinct clear absorption bands indicating the presence of major humic acid structural elemental groups such as $\mathrm{H}$ bonded $\mathrm{OH}$ $\left(3680 \mathrm{~cm}^{-1}\right.$ peak $), C=0$ of carbonyl $\left(1721 \mathrm{~cm}^{-1}\right.$ peak), functional groups of aliphatic components $\mathrm{CH}_{2}\left(2918 \mathrm{~cm}^{-1}\right.$ peak) and $\mathrm{C}-\mathrm{O}$ stretching of polysaccharide $\left(1168 \mathrm{~cm}^{-1}\right.$ peak). The positions of the absorption bands of the spectra fell within typical major absorption bands of humic acid which is at frequencies 3680, 2918, 1721, 1168 $\mathrm{cm}^{-1}$. The first peak centred in the vicinity of $3680 \mathrm{~cm}^{-1}$ region is attributed to phenol $\mathrm{OH}$ group bounded by intermolecular $\mathrm{H}$ bonds. The $2918 \mathrm{~cm}^{-1}$ band usually has absorption maximum at $2918 \mathrm{~cm}^{-1}$ which is due to $\mathrm{C}-\mathrm{H}$ stretching of alkane group $\left(\mathrm{CH}_{2}\right)$. The next major absorption band is $1721 \mathrm{~cm}^{-1}$. This band has been commonly ascribed to $\mathrm{C}=\mathrm{O}$ stretching of mainly carboxyl group $(\mathrm{COOH})$ with trace amount of ketones. The last peak was observed at 1168 $\mathrm{cm}^{-1}$ due to $\mathrm{C}-\mathrm{O}$ stretching of polysaccharides and this peak appeared also in the spectra of humic acid from peat soil. The FTIR spectra of the isolated humic acid contained all major characteristic absorption peaks of humic acid. These absorption peaks indicated the presence of the major structural elements of humic acid namely $\mathrm{H}$ bonded $\mathrm{OH}, \mathrm{C}=\mathrm{C}$ of aromatic ring, $\mathrm{C}=\mathrm{O}$ of carbonyl group (both carboxyl and ketonic), $\mathrm{CH}_{2}$ group. This strongly supports the presence of humic acid.

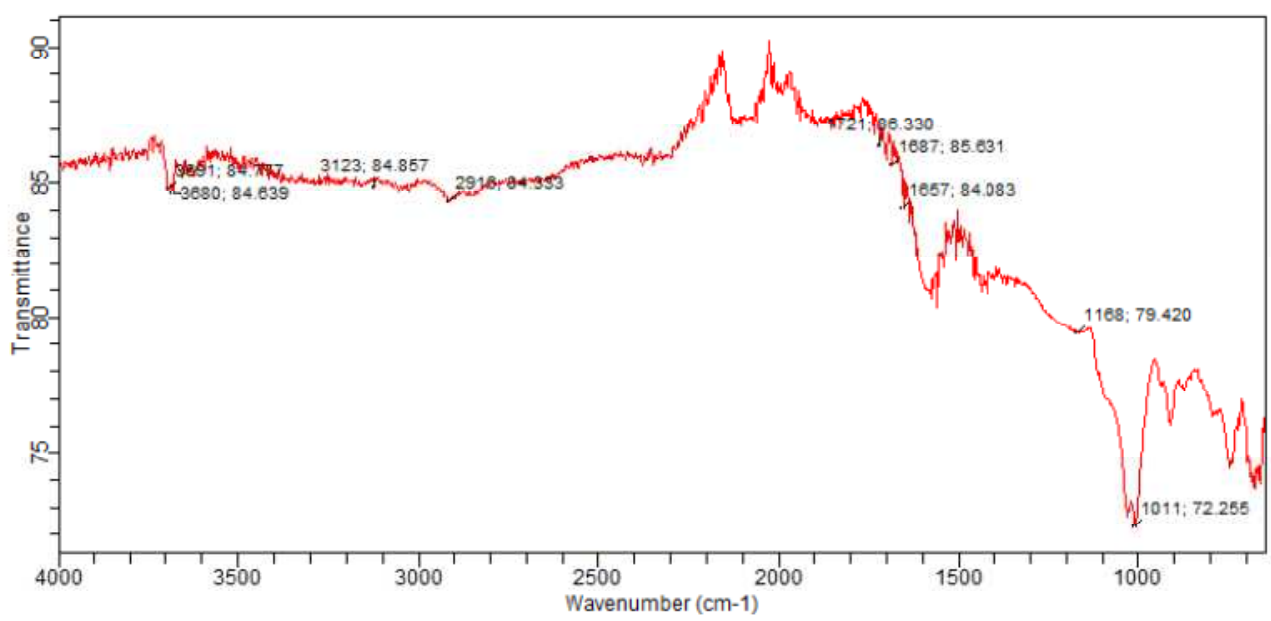

Fig. 2 : FT-IR spectraof peatsoilhumic acid (PSHA)

\section{Evaluation of acid dissociation constant (pka) of acid hydrolysed peat soil humicacid at phenolic group}

The value of the dissociation constant of the peat soil humic acid (PSHA) that underwent acidhydrolysis studied was found to be 8.9299 as shown Table 1, which is lower than the literaturevalues reported by Almeida and Szpoganics, (2015), Borges et al., (2005); Badr et al., (2012)and Fernandes et al,.(2009) of $9.73,9.47$ and 10.30. The difference between the obtained valuesand the reported values in this study might be probably as a result of acid hydrolysis of humicacid. 
BAJOPAS Volume 14 Number 1,June, 2021

Table 1: PKa of (Hydrolysed PSHA)

\begin{tabular}{|l|l|l|l|l|l|l|}
\hline $\mathrm{pH}$ & $\mathrm{BV}_{1}$ & $\mathrm{BV}_{2}$ & $\mathrm{~V}_{2}-\mathrm{V}_{1}$ & $\mathrm{nA}$ & $\log \left(\frac{n A}{1-n A}\right)$ & $\mathrm{pKa}$ \\
\hline 8.50 & 5.30 & 6.29 & 0.99 & 0.3594 & -0.2510 & 8.2490 \\
8.72 & 5.35 & 6.37 & 1.02 & 0.3400 & -0.2880 & 8.4320 \\
9.00 & 5.40 & 6.46 & 1.06 & 0.3141 & -0.3391 & 8.6609 \\
9.22 & 5.45 & 6.55 & 1.10 & 0.2882 & -0.3927 & 8.8273 \\
9.51 & 5.50 & 6.66 & 1.16 & 0.2494 & -0.4786 & 9.0314 \\
9.73 & 5.55 & 6.78 & 1.23 & 0.2041 & -0.5910 & 9.1390 \\
10.00 & 5.60 & 6.90 & 1.30 & 0.1589 & -0.7238 & 9.2762 \\
10.23 & 5.65 & 7.05 & 1.40 & 0.0941 & -0.9835 & 9.2465 \\
10.49 & 5.70 & 7.10 & 1.40 & 0.0941 & -0.9835 & 9.5065 \\
\hline
\end{tabular}

Average pKa $=8.9299 \pm 0.4186$

Table 2: PKa of (Unhydrolysed PSHA)

\begin{tabular}{|l|l|l|l|l|l|l|}
\hline $\mathrm{pH}$ & $\mathrm{BV}_{1}$ & $\mathrm{BV}_{2}$ & $\mathrm{~V}_{2}-\mathrm{V}_{1}$ & $\mathrm{nA}$ & $\log \left(\frac{\boldsymbol{n A}}{1-\boldsymbol{n}}\right)$ & $\mathrm{pKa}$ \\
\hline 8.50 & 5.30 & 5.81 & 0.51 & 0.6619 & 0.2919 & 8.7919 \\
8.72 & 5.35 & 5.90 & 0.55 & 0.6357 & 0.2418 & 8.9618 \\
9.00 & 5.40 & 6.00 & 0.60 & 0.6029 & 0.1813 & 9.1813 \\
9.22 & 5.45 & 6.10 & 0.65 & 0.5701 & 0.1226 & 9.3426 \\
9.51 & 5.50 & 6.20 & 0.70 & 0.5376 & 0.0654 & 9.5754 \\
9.73 & 5.55 & 6.33 & 0.78 & 0.4851 & -0.0259 & 9.7041 \\
10.00 & 5.60 & 6.47 & 0.87 & 0.4262 & -0.1291 & 9.8709 \\
10.23 & 5.65 & 6.62 & 0.99 & 0.3609 & -0.2481 & 9.9819 \\
10.49 & 5.70 & 6.80 & 1.10 & 0.2759 & -0.4690 & 10.0210 \\
\hline
\end{tabular}

Average pKa $=9.4923 \pm 0.4410$

Metal-ligand stability constant ( $\log \mathrm{K}$ )

The stabilityconstants require the accurate values of proton-ligand stability constants (Anil and Maroti, 2008). Metal titration curves crossed over ligand titration curve indicated the formation of complex upon proton release (Santosh, et al., 2011). If the values of n- are within range $0.2-0.8$ and $1.2-18$ this indicates the formation of $1: 1$ and 1:2 complexes (Sayyed and Mazahar, 2012).

The metal (II)-humate stepwise stability constants (log k) at phenolic group (Tables 318)

Table 3: Point-wise method, $\mathrm{Cu}$-(Hydrolysed PSHA)

\begin{tabular}{|l|l|l|l|l|l|l|l|l|}
\hline $\mathrm{pH}$ & $\mathrm{BV}_{1}$ & $\mathrm{BV}_{2}$ & $\mathrm{BV}_{3}$ & $\left(\mathrm{~V}_{3}-\mathrm{V}_{2}\right)$ & $\mathrm{n}$ & $\mathrm{pL}$ & $\log \left(\frac{n}{1-n}\right)$ & LogK $_{1}$ \\
\hline 8.50 & 5.30 & 6.29 & 6.33 & 0.04 & 0.5500 & 2.66 & 0.0871 & 2.7471 \\
8.72 & 5.35 & 6.37 & 6.41 & 0.04 & 0.5714 & 2.43 & 0.1249 & 2.5549 \\
9.00 & 5.40 & 6.46 & 6.50 & 0.04 & 0.6198 & 2.16 & 0.2122 & 2.3722 \\
9.22 & 5.45 & 6.55 & 6.59 & 0.04 & 0.6667 & 1.94 & 0.3010 & 2.2410 \\
\hline
\end{tabular}

LogK $_{1}$ (Average value) $=2.4788 \pm 0.2203$

Table 4: Point-wise method, $\mathrm{Cu}$-(Hydrolysed PSHA)

\begin{tabular}{|l|l|l|l|l|l|l|l|l|}
\hline $\mathrm{pH}$ & $\mathrm{BV}_{1}$ & $\mathrm{BV}_{2}$ & $\mathrm{BV}_{3}$ & $\left(\mathrm{~V}_{3}-\mathrm{V}_{2}\right)$ & $\mathrm{n}$ & $\mathrm{pL}$ & $\log \left(\frac{n-1}{2-n}\right)$ & LogK $_{2}$ \\
\hline 9.51 & 5.50 & 6.66 & 6.73 & 0.07 & 1.3509 & 1.70 & -0.2671 & 1.4329 \\
9.73 & 5.55 & 6.78 & 6.85 & 0.07 & 1.6383 & 1.51 & 0.2467 & 1.7567 \\
10.00 & 5.60 & 6.90 & 6.98 & 0.08 & 2.1783 & 1.31 & -0.2158 & 1.0942 \\
10.23 & 5.65 & 7.05 & 7.13 & 0.08 & 4.1904 & 1.27 & & \\
10.49 & 5.70 & 7.10 & 7.19 & 0.09 & 4.6920 & & & \\
\hline
\end{tabular}

Log $K_{2}($ Average value $)=1.4280 \pm 0.3312$ 
BAJOPAS Volume 14 Number 1,June, 2021

Table 5: Point-wise method, $\mathrm{Cu}$ (Unhydrolysed PSHA)

\begin{tabular}{|l|l|l|l|l|l|l|l|l|}
\hline $\mathrm{pH}$ & $\mathrm{BV}_{1}$ & $\mathrm{BV}_{2}$ & $\mathrm{BV}_{3}$ & $\left(\mathrm{~V}_{3}-\mathrm{V}_{2}\right)$ & $\mathrm{n}$ & $\mathrm{pL}$ & $\log \left(\frac{n}{n-1}\right)$ & Log $_{1}$ \\
\hline 8.50 & 5.30 & 5.81 & 5.85 & 0.04 & 0.2973 & 2.88 & -0.3736 & 2.5064 \\
8.72 & 5.35 & 5.90 & 5.95 & 0.05 & 0.3873 & 2.66 & -0.1992 & 2.4608 \\
9.00 & 5.40 & 6.00 & 6.05 & 0.05 & 0.4044 & 2.38 & -0.1681 & 2.2119 \\
9.22 & 5.45 & 6.10 & 6.15 & 0.06 & 0.5157 & 2.18 & -0.0272 & 2.2072 \\
9.51 & 5.50 & 6.20 & 6.27 & 0.07 & 0.6417 & 1.89 & 0.2530 & 1.1430 \\
\hline
\end{tabular}

$\operatorname{LogK}_{1}($ Average value $)=2.3059 \pm 0.6153$

Table 6:Point-wise method, $\mathrm{Cu}$ (Unhydrolysed PSHA)

\begin{tabular}{|l|l|l|l|l|l|l|l|l|}
\hline $\mathrm{pH}$ & $\mathrm{BV}_{1}$ & $\mathrm{BV}_{2}$ & $\mathrm{BV}_{3}$ & $\mathrm{~V}_{3}-\mathrm{V}_{2}$ & $\mathrm{n}$ & $\mathrm{pL}$ & $\log \left(\frac{n-1}{2-n}\right)$ & $\log \mathrm{K}_{2}$ \\
\hline 9.73 & 5.55 & 6.33 & 6.42 & 0.09 & 0.9000 & 1.69 & & \\
10.00 & 5.60 & 6.47 & 6.58 & 0.11 & 1.2578 & 1.44 & -0.4592 & 0.9808 \\
10.23 & 5.65 & 6.62 & 6.84 & 0.12 & 1.6137 & 1.26 & -0.2010 & 1.4610 \\
10.49 & 5.70 & 6.80 & 6.92 & 0.12 & 2.1052 & 1.03 & & \\
\hline
\end{tabular}

$\operatorname{LogK}_{2}$ (Average value) $=1.2209 \pm 0.3398$

Table 7:Point-wise method, Pb (Hydrolysed PSHA)

\begin{tabular}{|l|l|l|l|l|l|l|l|l|}
\hline $\mathrm{pH}$ & $\mathrm{BV}_{1}$ & $\mathrm{BV}_{2}$ & $\mathrm{BV}_{3}$ & $\left(\mathrm{~V}_{3}-\mathrm{V}_{2}\right)$ & $\mathrm{n}$ & $\mathrm{pL}$ & $\log \left(\frac{n}{1-n}\right)$ & LogK $_{1}$ \\
\hline 8.50 & 5.30 & 6.29 & 6.33 & 0.04 & 0.5500 & 2.66 & 0.0871 & 2.7471 \\
8.72 & 5.35 & 6.37 & 6.41 & 0.04 & 0.5714 & 2.43 & 0.1249 & 2.5549 \\
9.00 & 5.40 & 6.46 & 6.50 & 0.04 & 0.6198 & 2.16 & 0.2122 & 2.3722 \\
9.22 & 5.45 & 6.55 & 6.60 & 0.05 & 0.8333 & 1.96 & 0.6989 & 2.6589 \\
\hline
\end{tabular}

Log $_{\mathbf{1}}($ Average value $)=2.5832 \pm 0.1614$

Table 8:Point-wise method, Pb-(Hydrolysed PSHA)

\begin{tabular}{|l|l|l|l|l|l|l|l|l|}
\hline $\mathrm{pH}$ & $\mathrm{BV}_{1}$ & $\mathrm{BV}_{2}$ & $\mathrm{BV}_{3}$ & $\left(\mathrm{~V}_{3}-\mathrm{V}_{2}\right)$ & $\mathrm{n}$ & $\mathrm{pL}$ & $\log \left(\frac{n-1}{2-n}\right)$ & $\log \mathrm{K}_{2}$ \\
\hline 9.51 & 5.50 & 6.66 & 6.71 & 0.05 & 0.9650 & 1.67 & & \\
9.73 & 5.55 & 6.78 & 6.83 & 0.05 & 1.1702 & 1.44 & & \\
10.00 & 5.60 & 6.90 & 6.90 & 0.05 & 1.4864 & 1.22 & -0.0237 & 1.1963 \\
10.23 & 5.65 & 7.05 & 7.10 & 0.05 & 2.0190 & 1.09 & & \\
10.49 & 5.70 & 7.10 & 7.17 & 0.07 & 3.6492 & 1.00 & & \\
\hline
\end{tabular}

Log $K_{2}$ (Average value) $=1.1963$

Table 9: Point-wise method, Pb (Unhydrolysed PSHA)

\begin{tabular}{|l|l|l|l|l|l|l|l|l|}
\hline $\mathrm{pH}$ & $\mathrm{BV}_{1}$ & $\mathrm{BV}_{2}$ & $\mathrm{BV}_{3}$ & $\mathrm{~V}_{3}-\mathrm{V}_{2}$ & $\mathrm{n}$ & $\mathrm{pL}$ & $\begin{array}{l}\text { Log } \\
\left(\frac{n}{n-1}\right)\end{array}$ & Log $\mathrm{K}_{1}$ \\
\hline 8.50 & 5.30 & 5.81 & 5.85 & 0.04 & 0.2973 & 2.88 & -0.3736 & 2.5064 \\
8.72 & 5.35 & 5.90 & 5.94 & 0.04 & 0.3099 & 2.66 & -0.5477 & 2.3123 \\
9.00 & 5.40 & 6.00 & 6.05 & 0.05 & 0.4044 & 2.38 & -0.1681 & 2.2119 \\
9.22 & 5.45 & 6.10 & 6.15 & 0.06 & 0.5157 & 2.18 & 0.0272 & 2.2072 \\
9.51 & 5.50 & 6.20 & 6.26 & 0.07 & 0.6417 & 1.89 & 0.2530 & 2.1430 \\
9.73 & 5.55 & 6.40 & 6.40 & 0.07 & 0.7000 & 1.67 & 0.3680 & 2.0380 \\
\hline
\end{tabular}

LogK $_{1}$ (Average value) $=2.2364 \pm 0.1602$

Table 10: Point-wise method, Pb (Unhydrolysed PSHA)

\begin{tabular}{|l|l|l|l|l|l|l|l|l|}
\hline $\mathrm{pH}$ & $\mathrm{BV}_{1}$ & $\mathrm{BV}_{2}$ & $\mathrm{BV}_{3}$ & $\mathrm{~V}_{3}-\mathrm{V}_{2}$ & $\mathrm{n}$ & $\mathrm{pL}$ & $\log \left(\frac{n-1}{2-n}\right)$ & $\log \mathrm{K}_{2}$ \\
\hline 10.00 & 5.60 & 6.47 & 6.55 & 0.08 & 1.9503 & 1.41 & & \\
10.23 & 5.65 & 6.62 & 6.72 & 0.11 & 1.4792 & 1.26 & -0.0361 & 1.2239 \\
\hline
\end{tabular}

$\operatorname{LogK}_{2}$ (Average value) $=1.2239$

Table 11: Point-wise method, Mg (Hydrolysed PSHA)

\begin{tabular}{|l|l|l|l|l|l|l|l|l|}
\hline $\mathrm{pH}$ & $\mathrm{BV}_{1}$ & $\mathrm{BV}_{2}$ & $\mathrm{BV}_{3}$ & $\left(\mathrm{~V}_{3}-\mathrm{V}_{2}\right)$ & $\mathrm{n}$ & $\mathrm{pL}$ & $\log \left(\frac{n}{n-1}\right)$ & LogK $_{1}$ \\
\hline 8.50 & 5.30 & 6.29 & 6.31 & 0.02 & 0.2750 & 2.64 & -0.4290 & 2.2110 \\
8.72 & 5.35 & 6.37 & 6.39 & 0.02 & 0.2858 & 2.42 & -0.3978 & 2.0222 \\
9.00 & 5.40 & 6.46 & 6.49 & 0.03 & 0.4648 & 2.14 & -0.0612 & 2.0788 \\
9.22 & 5.45 & 6.55 & 6.59 & 0.04 & 0.6667 & 1.94 & 0.3010 & 2.2410 \\
\hline
\end{tabular}

$\log _{\mathbf{1}}($ Average value) $=2.1382 \pm 0.1046$ 
BAJOPAS Volume 14 Number 1,June, 2021

Table 12: Point-wise method, Mg (Hydrolysed PSHA)

\begin{tabular}{|l|l|l|l|l|l|l|l|l|}
\hline $\mathrm{pH}$ & $\mathrm{BV}_{1}$ & $\mathrm{BV}_{2}$ & $\mathrm{BV}_{3}$ & $\left(\mathrm{~V}_{3}-\mathrm{V}_{2}\right)$ & $\mathrm{n}$ & $\mathrm{pL}$ & $\log \left(\frac{n-1}{2-n}\right)$ & LogK $_{2}$ \\
\hline 9.51 & 5.55 & 6.66 & 6.71 & 0.05 & 0.9650 & 1.67 & & \\
9.73 & 5.55 & 6.78 & 6.84 & 0.06 & 1.4042 & 1.47 & -0.1686 & 1.3014 \\
10.00 & 5.60 & 6.90 & 6.93 & 0.06 & 1.7838 & 1.23 & 0.5593 & 1.7893 \\
10.23 & 5.65 & 7.05 & 7.10 & 0.06 & 3.1429 & 1.10 & & \\
10.49 & 5.70 & 7.10 & 7.18 & 0.07 & 3.6492 & 0.83 & & \\
\hline
\end{tabular}

LogK $_{2}($ Average value $)=1.5453 \pm 0.3450$

Table 13: Point-wise method, Mg (Unhydrolysed PSHA)

\begin{tabular}{|l|l|l|l|l|l|l|l|l|}
\hline $\mathrm{pH}$ & $\mathrm{BV}_{1}$ & $\mathrm{BV}_{2}$ & $\mathrm{BV}_{3}$ & $\mathrm{~V}_{3}-\mathrm{V}_{2}$ & $\mathrm{n}$ & $\mathrm{pL}$ & $\log \left(\frac{n}{n-1}\right)$ & $\operatorname{Log~}_{1}$ \\
\hline 8.50 & 5.30 & 5.81 & 5.85 & 0.04 & 0.2973 & 2.88 & -0.3736 & 2.5064 \\
8.72 & 5.35 & 5.90 & 5.94 & 0.04 & 0.3099 & 2.66 & -0.3477 & 2.3123 \\
9.00 & 5.40 & 6.00 & 6.04 & 0.04 & 0.3236 & 2.38 & -0.3202 & 2.0598 \\
9.22 & 5.45 & 6.10 & 6.15 & 0.05 & 0.4297 & 2.17 & -0.1230 & 2.0470 \\
9.51 & 5.50 & 6.20 & 6.26 & 0.06 & 0.5500 & 1.89 & 0.0871 & 1.9771 \\
9.73 & 5.55 & 6.33 & 6.40 & 0.07 & 0.7000 & 1.67 & 0.3680 & 2.0380 \\
\hline
\end{tabular}

LogK $_{1}$ (Average value) $=2.1568 \pm 0.2069$

Table 14: Point-wise method, Mg (Unhydrolysed PSHA)

\begin{tabular}{|l|l|l|l|l|l|l|l|l|}
\hline $\mathrm{pH}$ & $\mathrm{BV}_{1}$ & $\mathrm{BV}_{2}$ & $\mathrm{BV}_{3}$ & $\mathrm{~V}_{3}-\mathrm{V}_{2}$ & $\mathrm{n}$ & $\mathrm{pL}$ & $\log \left(\frac{n-1}{2-n}\right)$ & $\log \mathrm{K}_{2}$ \\
\hline 10.00 & 5.60 & 6.47 & 6.55 & 0.08 & 0.9148 & 1.41 & & \\
10.23 & 5.65 & 6.62 & 6.71 & 0.09 & 1.2102 & 1.20 & -0.5749 & 0.6251 \\
10.49 & 5.70 & 6.80 & 6.92 & 0.09 & 1.5968 & 1.03 & 0.1703 & 1.2003 \\
\hline
\end{tabular}

LogK $_{2}$ (Average value) $=0.9127 \pm 0.4070$

Table15:Point-wise method, Cd (Hydrolysed PSHA)

\begin{tabular}{|l|l|l|l|l|l|l|l|l|}
\hline $\mathrm{pH}$ & $\mathrm{BV}_{1}$ & $\mathrm{BV}_{2}$ & $\mathrm{BV}_{3}$ & $\left(\mathrm{~V}_{3}-\mathrm{V}_{2}\right)$ & $\mathrm{n}$ & $\mathrm{pL}$ & $\log \left(\frac{n}{1-n}\right)$ & LogK $_{1}$ \\
\hline 8.50 & 5.30 & 6.29 & 6.31 & 0.02 & 0.2750 & 2.64 & -0.4210 & 2.2190 \\
8.72 & 5.35 & 6.37 & 6.40 & 0.03 & 0.4286 & 2.42 & -0.1249 & 2.2951 \\
9.00 & 5.40 & 6.46 & 6.49 & 0.03 & 0.4648 & 2.14 & -0.0612 & 2.0788 \\
9.22 & 5.45 & 6.55 & 6.59 & 0.04 & 0.6667 & 1.96 & 0.3010 & 2.2610 \\
9.51 & 5.55 & 6.66 & 6.70 & 0.04 & 0.7720 & 1.67 & 0.5297 & 2.1997 \\
\hline
\end{tabular}

LogK $_{\mathbf{1}}$ (Average value) $=2.2108 \pm 0.0825$

Table 16: Point-wise method, Cd (Hydrolysed PSHA)

\begin{tabular}{|l|l|l|l|l|l|l|l|l|}
\hline $\mathrm{pH}$ & $\mathrm{BV}_{1}$ & $\mathrm{BV}_{2}$ & $\mathrm{BV}_{3}$ & $\left(\mathrm{~V}_{3}-\mathrm{V}_{2}\right)$ & $\mathrm{n}$ & $\mathrm{pL}$ & $\log \left(\frac{n-1}{2-n}\right)$ & Log $_{2}$ \\
\hline 9.73 & 5.55 & 6.78 & 6.83 & 0.06 & 1.4042 & 1.47 & -0.1686 & 1.3014 \\
10.00 & 5.60 & 6.90 & 6.95 & 0.06 & 1.7838 & 1.23 & 0.5593 & 1.7893 \\
10.23 & 5.65 & 7.05 & 7.10 & 0.06 & 3.1429 & 1.09 & & \\
10.49 & 5.70 & 7.10 & 7.16 & 0.06 & 3.1429 & 0.89 & & \\
& & & & & & & & \\
\hline
\end{tabular}

$\operatorname{LogK}_{2}$ (Average value) $=1.5453 \pm 0.3450$

Table 17: Point-wise method, Cd (Unhydrolysed PSHA)

\begin{tabular}{|l|l|l|l|l|l|l|l|l|}
\hline $\mathrm{pH}$ & $\mathrm{BV}_{1}$ & $\mathrm{BV}_{2}$ & $\mathrm{BV}_{3}$ & $\mathrm{~V}_{3}-\mathrm{V}_{2}$ & $\mathrm{n}$ & $\mathrm{pL}$ & $\log \left(\frac{n}{n-1}\right)$ & $\operatorname{Log~}_{1}$ \\
\hline 8.50 & 5.30 & 5.81 & 5.86 & 0.05 & 0.3717 & 2.88 & -0.2280 & 2.6520 \\
8.72 & 5.35 & 5.90 & 5.95 & 0.05 & 0.3873 & 2.66 & -0.1992 & 2.4608 \\
9.00 & 5.40 & 6.00 & 6.06 & 0.06 & 0.4853 & 2.38 & -0.0255 & 2.3545 \\
9.22 & 5.45 & 6.10 & 6.16 & 0.06 & 0.5157 & 2.18 & -0.0272 & 2.2072 \\
9.51 & 5.50 & 6.20 & 6.27 & 0.07 & 0.6417 & 1.89 & 0.2530 & 1.1430 \\
9.73 & 5.55 & 6.33 & 6.41 & 0.08 & 0.8000 & 1.69 & 0.6020 & 2.2920 \\
& & & & & & & & \\
\hline
\end{tabular}

$\operatorname{LogK}_{1}($ Average value $)=2.2516 \pm 0.5380$ 
BAJOPAS Volume 14 Number 1,June, 2021

Table 18: Point-wise method, Cd (Unhydrolysed PSHA)

\begin{tabular}{|l|l|l|l|l|l|l|l|l|}
\hline $\mathrm{pH}$ & $\mathrm{BV}_{1}$ & $\mathrm{BV}_{2}$ & $\mathrm{BV}_{3}$ & $\mathrm{~V}_{3}-\mathrm{V}_{2}$ & $\mathrm{n}$ & $\mathrm{pL}$ & $\log \left(\frac{n-1}{2-n}\right)$ & $\log \mathrm{K}_{2}$ \\
\hline 10.00 & 5.60 & 6.47 & 6.57 & 0.10 & 1.1434 & 1.43 & & \\
10.23 & 5.65 & 6.62 & 6.72 & 0.10 & 1.3448 & 1.23 & -0.2788 & 0.9512 \\
10.49 & 5.70 & 6.80 & 6.90 & 0.10 & 1.7742 & 1.03 & 0.5351 & 1.5651 \\
\hline
\end{tabular}

$\operatorname{LogK}_{2}($ Average value $)=1.2581 \pm 0.4340$

Table 19: Stepwise and overall Stability constants of thehydrolysed and unhydrolysed divalent metal (II) complexes

\begin{tabular}{|c|c|c|c|}
\hline Chelates & LogK $_{1}$ & $\log _{2}$ & Log $\beta$ \\
\hline [Cu (Hydrolysed PSHA-1) $\left.{ }_{2}\right]$ & 2.4788 & 1.4280 & 3.9068 \\
\hline$\left[\mathrm{Pb}(\text { Hydrolysed PSHA-1) })_{2}\right]$ & 2.5832 & 1.1963 & 3.7795 \\
\hline$\left[\mathrm{Cd}(\text { Hydrolysed PSHA-1 })_{2}\right]$ & 2.2108 & 1.5453 & 3.7561 \\
\hline$\left[\mathrm{Mg}(\text { Hydrolysed PSHA-1 })_{2}\right]$ & 2.1382 & 1.5453 & 3.6835 \\
\hline [Cu (Unhydrolysed PSHA-1) & 2.3059 & 1.2209 & 3.5268 \\
\hline$[\mathrm{Pb}$ (Unhydrolysed PSHA-1) 2$]$ & 2.2364 & 1.2239 & 3.4603 \\
\hline [Cd (Unhydrolysed PSHA-1) 2 ] & 2.2516 & 1.2581 & 3.5097 \\
\hline$[\mathrm{Mg}$ (Unydrolysed PSHA-1) & 2.1568 & 0.9127 & 3.0695 \\
\hline
\end{tabular}

The results obtained (Table19) shows the stepwise and overall stability constants to be not high indicating low stability of the complexes, because the solubility of most metal ions in the basic $\mathrm{pH}$ range is minimal due to metal hydroxide precipitation (Karimi, 2017). In general, the stepwise stability constants $\left(K_{1}\right.$ and $K_{2}$ ) follow the order $K_{1}>K_{2}$ for the copper, lead, magnesium and cadmium complexes respectively. The steady decrease of the values with increasing number of ligands is in agreement with the prediction made by researchers (Na'aliya, 2013). The decrease could be attributed to the fact that as the number of the ligands (Humate ions) that enters the coordination zone increases the aqua molecules available for replacement by the ligands become less. Thus, the metal ions become less electron loving with progressive intake of the ligand and this results in the decrease in the values of the constants (Na'aliya, 2013). Also the stability of the complexes is influenced by the size and number of the chelate rings(Mackay and Mackay,2002).All the complexes form rings in their structure as humate, a bidentate ligand, bond the metal ions in the ratio 1:2 (Boguta and Sokolowska, 2016) forming chelate rings. The values of the overall stability constants $(\log \beta)$ obtained for humate complexes are not high indicating low stability as the values are not high. LogK values for copper-humates (Table 3 to 6) obtained in this study are lower than those reported for the complexes of humic acids (Pandey et al., 2015; Dinu, 2013; Kaschl et al., 2010 and Gilbeto and Jorg, 2001). The values of LogK(Table 7 to 10 ) forlead-humates are lower than those reported for the lead in the literature (Dinu, 2013; Gilbeto and Jorg 2001). Log K values(Table 11 to 14 ) for magnesium-humates obtained in this study are close to those reported by (Pandey et al., 2015). Log K values of cadmium-humates (Table 15 to 18 ) obtained in this work near to the one reported by (Dinu, 2013 and Pandey et al., 2015).The difference between the reported values and the values obtained in this study might be probably as a result of acid hydrolysis of humic acid. The values of the overall stability constants $(\log \beta)$ of the copper humates complexes presented in Table 19 is high than that of other metal humate complexes, show relatively high stability of CuHA complexes, show the following order of stability: $\mathrm{Cu}>\mathrm{Pb}>\mathrm{Cd}>\mathrm{Mg}$; which are in close agreement to the findings of (Dinu, 2013 and Pandey et al., 2015).The high stability of Cuhumate chelate could be attributed to the existence of coordinate covalent bond between the complexing agents and the $\mathrm{Cu}^{2+}$ ions. Since, $\mathrm{Cu}^{2+}$ being a metal of the transitional series with $3 d^{9}$ electronic configurations can accept the electrons from the complexing agents. Similarly, the low stabilities of $\mathrm{Pb}, \mathrm{Cd}$ and $\mathrm{Mg}$ complexes could be explained by that $\mathrm{Pb}^{2+}$ with $6 s^{2}, \mathrm{Cd}^{2+}$ with $4 \mathrm{~d}^{10}$ and $\mathrm{Mg}^{2+}$ with $2 \mathrm{p}^{6}$ their electronic configuration has a completely filled $\mathrm{d}, \mathrm{p}$ and $\mathrm{s}$ orbitals. Moreover, the stabilities of metal ions with hydrolysed humic acid from peat soil were higher than those with unhydrolysed humic acid from peat soil; which is ascribed to the high content of acidity in hydrolysed humic acid than unhydrolysed humic acid. 
BAJOPAS Volume 14 Number 1,June, 2021 CONCLUSION

The values of logk for $\mathrm{Cu}(\mathrm{II})$ hydrolysed humic acid complex was higher followed by $\mathrm{Pb}$ (II), $\mathrm{Cd}(\mathrm{II})$ and $\mathrm{Mg}$ (II) hydrolysed humic acid complexes as compared with metal(II) unhydrolysed humic acid complexes. This indicates acid hydrolysis of humic acid can

\section{REFERENCES}

Almeida, V.R. and Szpoganicz, B. (2015). Humic Acid Potentiometric Response Patterns:Out- of Equilibrium Properties and Species Distribution Modelling. Chemical. Biol. Technol. Agric. 2: 17.

Anđelković, T., Nikolić, R., Bojić, A.,Anđelković, D., and Nikolic G.,(2010). Binding of Cadmium to Soil Humic Acid as A Function of Carboxyl Group Content. Macedonian Journal of Chemistry and Chemical Engineering.29(2): 215-224.

Anil, B. N. and Maroti, N. (2008). Studies on Influence of Die-Lectric Constants on Complex Equilibria between Substituted Py-Razalines and Lanthanide Metal Ions pH-Metrically. Amer.-Euras. scient. Res. 3(2): 212-216.

Ashok, K., Pandey, S. P. and Misra, V (2000). Stability Constants of Metal-Humic Acid Complexes and its Role in Environmental Detoxification. Journal of Ecotoxicology and Environmental Safety. 47(2):157-200.

Badr, M. H., El-Halafawi, M. H. and Abd El-al Zeid, E. R. (2012). Comparison Between the Effect of Ionic Strength on Acidity and Dissociation Constants of Humic Acids Extracted from Sewage Sludge and Nile Water Hyacinth Composts.Global Journal of Environmental Research 6 (1): 36-43.

Baruah, M.K., Borah, D., Saikia, P.P., Paul, S., Sharma, T. (2015). Evaluation of pKa Values of Soil Humic Acids and their Complexation Properties. International Journal of Plant \& Soil Science 6(4) : 218-228.

Boguta, P. Sokolowska, Z. (2016). Interactions of $\mathrm{Zn}$ (II) Ions with Humic Acids Isolated from Various Types of Soils. Effect of $\mathrm{pH}, \mathrm{Zn}$ Concentrations and Humic Acids Chemical Properties. Journal of Geochemical Explaration 168. 119-126.

Borges, F., Guimaraes, C., Lima, L.F.C., Pinto, I. and Reis, S.(2005). Potentiometric Studies on the Complexation of Copper(II) by Phenolic Acids as Discrete Ligand Models of enhance the complexation behavior of humic acid with metal (II) ions. However, the higher values of $\log \beta$ for $\mathrm{Cu}(\mathrm{II}), \mathrm{Pb}(\mathrm{II}), \mathrm{Cd}(\mathrm{II})$ and $\mathrm{Mg}(\mathrm{II})$ hydrolysed humic acid complexes indicates more stable stepwise complexes formed as compared with $\mathrm{Cu}(\mathrm{II}), \mathrm{Pb}$ (II), $\mathrm{Cd}$ (II) and $\mathrm{Mg}(\mathrm{II})$ unhydrolysed humic acid complexes.

Humic Substances Talanta 66 (2005) 670-673.

Chefetz, B., Salloum, M. J., Deshmulkin, A. P. and Hatcher, P. (2002). Structural Components of Humic Acids as Determined by Chemical Modifications and Carbon-13 NMR, Pyrolysis, and Thermochemolysis- Gas Chromatography/Mass Spectrometry. Soil Science Society of American Journal Abstract Division S-2- Soil Chemistry66. 1159-1171.

Dinu, M. I. (2013). Metals Complexation with Humic Acids in Surface Water of Different Environ. Sci. Technol. 31(1): 1-17.

Fernandes, A.N., Giacomelli, C., Giovanela, M. Vaz, D.V. Szpoganicz, B. and Maria M. D. (2009). Potentiometric Acidity Determination in Humic Substances Influenced by Different Analytical Procedures.J. Braz. Chem. Soc. 20 (9):14.

Gamal, A. H. (2015). Stability Constants of Rhenium (V) Metal Complexes with Selected Drugs. Pyrex Journal of Research in Environmental Studies. 2(2): 006-014.

Janrao, D. M., Pathan, J., Kayande, D.D., and Mulla, J.J. (2014). An Over View of Potentiometric Determination of Stability Constants of Metal Complexes. Sci. Revs. Chem. Commun.: 4(1), 2014, 11-24.

Karimi, H. (2017). Effect of pH and Initial Pb(II) Concentration on the Lead Removal Efficiency from Waste Water Using $\mathrm{Ca}(\mathrm{OH})_{2}$. International Journal of Water and Waste Water Treatment 3.2

Kaschl, A. Romheld, V. and Chen, Y. (2010). Binding of Cadmium, Copper and Zinc to Humic Substances Originating from Municipal Solid Waste Compost. Israel Journal of Chemistry Vol. 42(1): 89-98.

Kostic, I. S., Tatjana, P, A., Nikolic, R. S., Cvetkovic, T. P., Pavlovic, D. D., Aleksandar, L.J. and Bojic, A. (2012). Comparative Study of Binding Strengths of Heavy Metals with Humic Acid. J.serb. Chem. Soc. 76(9) pp 1-20. 
BAJOPAS Volume 14 Number 1,June, 2021

Na'aliya, J. (2013). Determination of Stepwise Stability Constants and Gibbs free Energy Change of Trisprolina to Complexes of some Divalent Transition Metal ions. Bayero Journal of Pure and Applied Sciences 6(2): 112-114.

Omar, A. A. and Ali, E. A. (2015). Potentiometric Studies on Complexes of $\mathrm{Cr}$ (III) and $\mathrm{Zr}$ (IV) with some Carboxylic Acids. International Journal of Advanced Chemistry, 3(1) 25-

37.

Pandey, A. K. Pandey, S. D. and Misr, V. (2015).Stability Constants of Metal- Humic Acid Complexes and Its Role in Environmental Detoxification. J. Ecotoxicology and Environmental Safety. 47(1):195-200.

Ram, N. and Raman, K.V. (1984). Stability Constants of Complexes of Metals with
Humicand Fuvic Acids under Non- acidConditions. Journal of Plant Nutrition and Soil Sciences.

147:171-176.

Santosh, D. D., Ashok, B. K., Vijay, J. T., Shivraj, G. W. and Vinay, V. W. (2011). Potentiometric Studies of Elec-Trolyte Effects on Complex Equilibria of Some Substituted 5-(2-hydroxy Phenyl) Pyrazoles. Der pharm. 3 (6): 75-83.

Sayyed, H. and Abdul Rahim, M. F. (2012). Studies of Binary Complexes of Metal Ions with Mandelic Acid by Potentiometry. Chem. J. 02 (6): 206209.

Shirvani, M. Moradian, E. Khalili, B. Bakhtiary, S. (2015). Interaction of $\mathrm{Cd}$ and $\mathrm{Pb}$ with Humate-Palygorskite and HumateSepiolite Complexes. Journal of water, air and pollution 3: 220-228. 


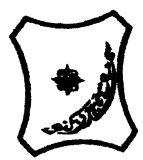

Bayero Journal of Pure and Applied Sciences, 14(1): 54 - 63

Received: November, 2020

Accepted: April, 2021

ISSN $2006-6996$

\title{
STABILITY CONSTANTS OF COMPLEXES OF METAL IONS WITH PEATSOIL HUMIC ACIDS UNDER NON-ACID-CONDITIONS
}

\author{
${ }^{* 1}$ Sabo, Yusuf ${ }^{2}$ Jimoh, W.L.O., ${ }^{3}$ Isa Baba Koki and ${ }^{4}$ Sholadoye, Q. 0. \\ ${ }^{1}$ Department of Pure and Industrial Chemistry, Bayero University, Kano \\ ${ }^{3}$ Department of Chemistry, Yusuf Maitama Sule University Kano. P.M.B. 3220 Kano, Nigeria. \\ ${ }^{4}$ Department of Chemistry, Nigerian Police Academy, Wudil, Kano-Nigeria
}

*Correspondence E-mail; saboyusuf18@yahoo.com

ABSTRACT

Stability constants of complexes of four divalent metal ions viz. $\mathrm{Cu}^{2+}, \mathrm{Pb}^{2+}, \mathrm{Mg}^{2+}$ and $\mathrm{Cd}^{2+}$ with humic acids (HA) were determined by potentiometric titration of humic acids with the corresponding salt of the divalent metals in aqueous media under non-acid-condition. The log $K$ (logarithm of the stability constant) ranged from 1.0942 to 2.7471 for metalhumic acid complexes were determined using point-wise computational method. The order of stability constants were obtained as follows: $\mathrm{Cu}>\mathrm{Pb}>\mathrm{Cd}>\mathrm{Mg}$ for metal $-\mathrm{HA}$ complexes respectively, indicating a higher degree of complexation with Cu metal ion.

Keywords: stability constant, humic acid, potentiometric titration, divalent metals, acid hydrolysis.

\section{NTRODUCTION}

The stability constant of a complex is the numerical expression of its stability and provides a quantitative measure of affinity of the metal ion to the complexing agent. An understanding of the relative stability of metal-complexes helps in predicting the behavior of metal ions in the soil (Ram and Raman, 1982). Extensive researches has been done to determine the stability constants of the complexes formed between humic acid (HA) with a number of metal ions. Ashok et al., (2000) reported that humic acid with hydroxyl, phenoxyl and carboxyl reactive groups can form coordination compound with metal ions at $\mathrm{pH}$ 3.5. The stability constants(Log K) for different metalhumic acid complexes indicated the following order of the stabilities of complexes formed between humic acid and metal ion, $\mathrm{Cu}>\mathrm{Fe}$ $>\mathrm{Pb}>\mathrm{Ni}>\mathrm{Co}>\mathrm{Ca}>\mathrm{Cd}>\mathrm{Zn}>\mathrm{Mn}>\mathrm{Mg}$. Andelkovic et al., (2010) investigated the binding of $\mathrm{Cd}$ (II) to soil humic acid at pH 6.5 and in $0.1 \mathrm{M} \mathrm{KNO}_{3}$ ionic medium. The stability constant for binding indicating greater stability in the case when carboxyl groups are involved in complexation reaction. Kostic et al.,(2012) investigated the complexation of humic acid with certain heavy metal ions (Co(II), $\mathrm{Ni}(\mathrm{II}), \mathrm{Cu}(\mathrm{II})$,
$\mathrm{Zn}(\mathrm{II})$, and $\mathrm{Pb}(\mathrm{II})$. The experiment was performed at $25^{\circ} \mathrm{C}$, at pH 4.0 and ionic strength of $0.01 \mathrm{M}$. Stability constant of complex between $\mathrm{Pb}$ (II) ions and humic acid is greater than stability constants of other investigated metalhumate complexes. Bogata and Sokolowska (2016) analyses the interaction between humic acids from different soils and $\mathrm{Zn}$ (II) ions at wide concentration ranges and at $\mathrm{pH} 5$. Studies have showed significant impact of $\mathrm{Zn}$ concentration, $\mathrm{pH}$ and some properties of humic acids with zinc.But all of these studies were limited to acidic $\mathrm{pH}$ range. Therefore, the present study was carried out to determine and compare the stability constants of complexes of metal ions with hydrolysed peat soil humic acid and unhydrolysed peat soil humic under non-acid conditions.

\section{MATERIALS AND METHODS}

Analytical grade chemicals used includes hydrochloric acid $(\mathrm{HCl})$, nitric acid $\left(\mathrm{HNO}_{3}\right)$, sodium hydroxide $(\mathrm{NaOH})$, lead nitrate $\mathrm{Pb}\left(\mathrm{NO}_{3}\right)_{2}$, copper nitrate $\mathrm{Cu}\left(\mathrm{NO}_{3}\right)_{2} \cdot 3 \mathrm{H}_{2} \mathrm{O}$, cadmium nitrate $\mathrm{Cd}\left(\mathrm{NO}_{3}\right)_{2} \cdot 4 \mathrm{H}_{2} \mathrm{O}$, magnesium nitrate $\mathrm{Mg}\left(\mathrm{NO}_{3}\right)_{2} \cdot 6 \mathrm{H}_{2} \mathrm{O}$, potassium nitrate $\left(\mathrm{KNO}_{3}\right)$, calcium chloride $\left(\mathrm{CaCl}_{2}\right)$, (sigma-Aldrich). Dowex 50WX8, (20-50 mesh) from Fluka. 


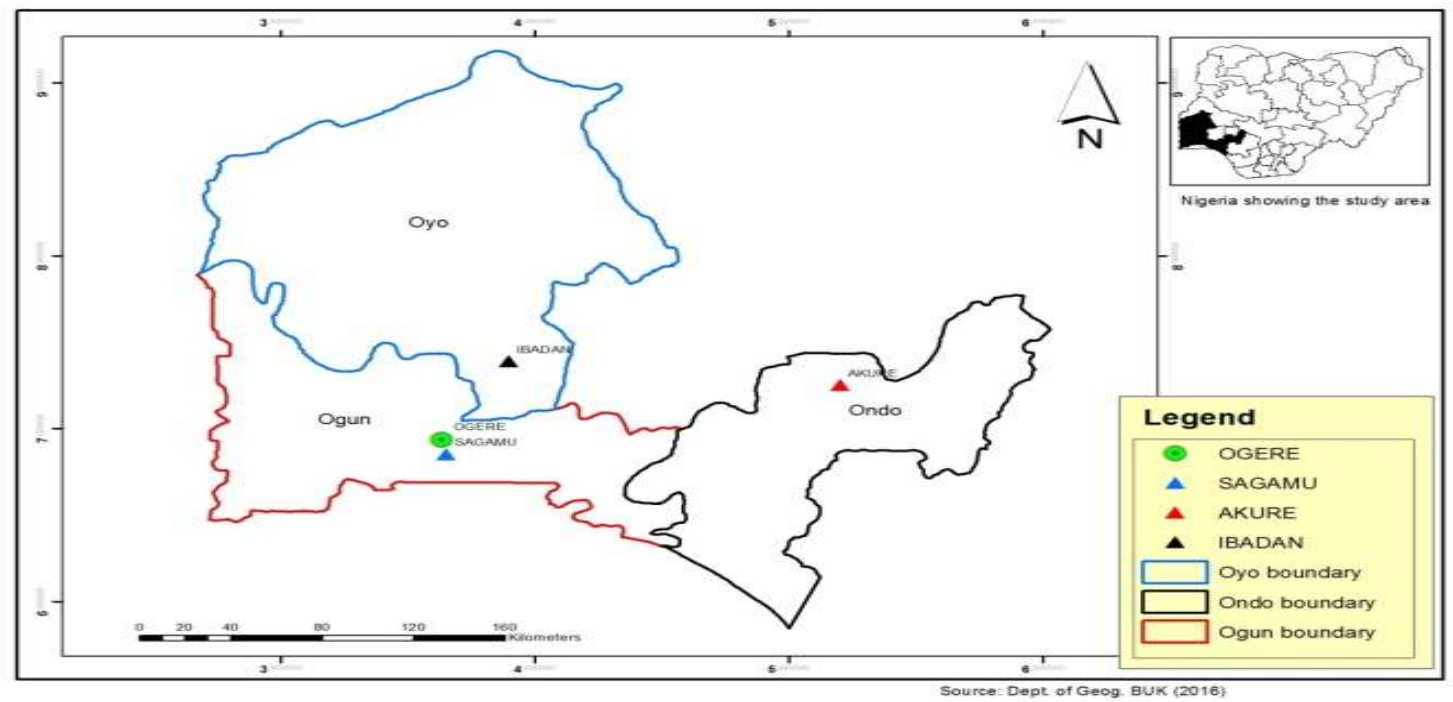

Figure 1: Map showing the sampling point at Sagamu Town, Ogun State.

\section{Description of Sampling Area}

Sagamu has geographical coordinates between $6^{\circ} 50^{\prime}$ north; $3^{\circ} 38^{\prime}$ east is located in south western region of Nigeria. The region has tropical wet and dry climate with a lengthy wet season and relatively constant temperatures throughout the course of the year. Wet season runs from March to October, November to December forms the region dry season. The vegetation type of the region is savannah which is really grassland with small bushes and occasional big trees. Grassland soils have substantially higher organic matter content than forest soils (Novackova, 2011).

\section{Sample Collection}

The Peatsoil samples were collected from four different sampling points $(0-10 \mathrm{~cm}$ depth) in Sagamu into polyethylene bag with plastic spoons. Samples were taken to the laboratory, extraneous materials were removed; the samples were air-dried, crushed and ground to a fine powder in a mortar passed through a $0.20 \mathrm{~mm}$ sieve. The samples were kept for analysis.

\section{Isolation and purification of humic acid from peat soil sample}

Peatsoil sample $(100 \mathrm{~g})$ was mixed with 1000 $\mathrm{cm}^{3}$ of $0.1 \mathrm{M} \mathrm{NaOH}$ solution, shaken for 3hours and left to stand overnight. Dark-coloured supernatant was obtained and decanted from solid residue. The dark-coloured supernatant was acidified to $(\mathrm{pH}=1.0)$ with $6 \mathrm{M} \mathrm{HCl}$ stirred and allowed to stand for 6 hours. Yellowish brown supernatant and dark-brown precipitate were obtained. The yellowish brown supernatant was decanted followed by centrifuge and discarded. The dark-brown precipitate was mixed with $500 \mathrm{~cm}^{3}$ of $0.1 \mathrm{M} \mathrm{NaOH}$ solution followed by passing through dowex resin. The dark-brown solution was acidified to $(\mathrm{pH}=1.0)$ with $6 \mathrm{M} \mathrm{HCl}$ stirred and allowed to stand for 3 hours. The dark-brown precipitate was washed several times with deionized water. The supernatant was treated with $\mathrm{AgNO}_{3}$ solution until no white precipitate observed. The humic acid was transferred to weighed crucible and dried at $60^{\circ} \mathrm{C}$ in an oven for 12 hours. The humic acid was cooled and dried in the desiccator, weighed and recorded. The obtained humic acid was dried again at $60^{\circ} \mathrm{C}$ for additional 6 hours cooled and dried in the desiccator, weighed and recorded constant weight was obtained (Baruah et al., 2015).

\section{FT-IR analysis}

FT-IR spectra of humic acid sample was analysed using Carry 630 FT-IR Agilent Technologies.

Unhydrolysed compost humic acid

The unhydrolysed humic acid was obtained after isolation and purification of compost humic acid and kept for investigation.

\section{Acid hydrolysis of Peatsoil acid}

Peatsoil humic acid sample (1g) was refluxed for 12 hours at $\left(160^{\circ} \mathrm{C}\right)$ with $50 \mathrm{~cm}^{3}$ of $6 \mathrm{M} \mathrm{HCl}$. The mixture was allowed to cool, decanted, and centrifuged after hydrolysis. The insoluble residues were washed with distilled water via centrifugation several times, and the supernatant was treated with $\mathrm{AgNO}_{3}$ solution until no white precipitate was observed. The residue was thoroughly dried over $\mathrm{CaCl}_{2}$ in a desiccator at room temperature (Chefetz et al., 2002). Finally, the obtained hydrolysed humic acid was kept for investigation. 
BAJOPAS Volume 14 Number 1,June, 2021 Potentiometric Titrations

Potentiometric measurements were carried out using a pH-meter Jenway (model 3510) with combine electrode, the sensitivity of the $\mathrm{pH}$ meter is 0.01 units. The $\mathrm{pH}$ meter was switched on half an hour before starting the titration for initial warm up of the instrument. The instrument was calibrated with an aqueous standard buffer solution of $\mathrm{pH} 4.00$ and 10.0 (borate buffer) prepared from a "Qualigens" buffer tablets.

The following sets of solutions were prepared in a $250 \mathrm{~cm}^{3}$ volumetric flask separately for $\mathrm{pH}$ metric titrations.

(i) $5 \mathrm{~cm}^{3} 0.1 \mathrm{M} \mathrm{HCl}+40 \mathrm{~cm}^{3}$ deionized water

(ii) $5 \mathrm{~cm}^{3} 0.1 \mathrm{M} \mathrm{HCl}+39 \mathrm{~cm}^{3}$ deionized water $+1 \mathrm{~cm}^{3} 0.15 \mathrm{gcm}^{-3}$ humic acid

(iii) $5 \mathrm{~cm}^{3} 0.1 \mathrm{M} \mathrm{HCl}+37 \mathrm{~cm}^{3}$ deionized water $+1 \mathrm{~cm}^{3} 0.15 \mathrm{gcm}^{-3}$ humic acid

$$
+2 \mathrm{~cm}^{3} \quad 0.01 \mathrm{M} \mathrm{Cu} \text { (II) }
$$

The solutions were titrated against standardized $0.110 \mathrm{MNaOH}$ separately. The total volume of each mixture was adjusted to $50 \mathrm{~cm}^{3}$ and the ionic strength of the solutions was maintained constant at by adding appropriate amount of stock solution of $1 \mathrm{M} \mathrm{KNO}_{3}$ (Gamal, 2015; Omar and Ali, 2015). A magnetic stirrer was used to achieve thorough mixing of the interacting solutions at $550 \mathrm{rpm}$. The same set of experimental conditions was applied for potentiometric titration of remaining samples.

\section{Evaluation of pKa of Hydrolysed peat soil Humic Acids}

The proton-ligand formation number $\mathrm{n}_{\mathbf{A}}$ were calculated by Irving and Rossotti expression (Omar and Ali, 2015).

$\mathrm{nA}=\mathrm{Y}-\frac{(\mathrm{V} 2-\mathrm{V1})(\mathrm{No}-\mathrm{Eo})}{(\mathrm{VO}+\mathrm{V1}) \mathrm{TCL}}$ 1

Where: $Y$ is number of dissociable proton, $\left(\mathrm{V}_{2^{-}}\right.$ $V_{1}$ ) is the measure of displacement of the ligand curve relative to acid curve, $\mathrm{N}^{\circ}$ and $\mathrm{E}^{\circ}$ are the resultant concentration of alkali solution, free acid solution, $\mathrm{T}_{\mathrm{cL}}{ }^{\circ}$ is the total ligand concentration, $\mathrm{V}^{\circ}$ is the total volume of titration solution, $V_{1}$ is the volume of alkali added to acid solution, $V_{2}$ is the volume of alkali added to acid solution + ligand solution, acid dissociation constants (pKa - values) of ligand were calculated by algebraic method point wise calculation (Tables 1 ). The dissociation constants (pKa) were calculated according to the following relation:

$\mathrm{pKa}=\mathrm{pH}+\log \left(\frac{n A}{1-n A}\right)$ 2

Where: pKa is the acid dissociation constant, $\mathrm{n}_{\mathrm{A}}$ is the Proton-ligand formation number and $\mathrm{pH}$ is the pH-values (Omar and Ali, 2015).

\section{Determination of metal-ligand stability constants $(\log K)$ of complexes}

The potentiometric measurement for the determination of stability constant of a complex in solution is based on the fact that the redox potential of the couple $\frac{M^{+(m-n)}}{M^{+m}}$ is shifted significantly on complexation of the metal ion with the ligand. This method involves change in hydrogen ion concentration $\left[\mathrm{H}^{+}\right]$due to the displacement or association of one or more protons taking place during complexation reaction. This change can be found out by titrating the solutions containing free acid, acid with ligand, and acid with ligand and metal ion, individually against a standard alkali solution at a constant ionic strength or temperature. Either ionic strength or temperature may be varied for different sets of solutions. In all the cases, the change in the $\mathrm{pH}$ of the solution is measured after each addition of a known amount of alkali to the reaction cell which contains the reaction mixture. The titration curves are then drawn by plotting the measured $\mathrm{pH}$ values against the corresponding volume of alkali added and the stability constants of the complexes are determined from the titration curves by employing $\mathrm{pH}$-metric titration technique given by (Irving and Rossoti).

Metal-ligand stability constants ( $\log \mathrm{K}$ ) were determined by using the following relations:

$$
\bar{n}=\frac{\left(V_{3}-V_{2}\right)\left(E^{0}+N^{0}\right)}{\left(V^{0}+V_{2}\right) \bar{n}_{A} T_{m}^{0}}
$$

and

$$
P L=\log _{10}\left\{\frac{1+\beta_{n}^{H} \frac{1}{[\text { anti } \log \mathrm{pH}]^{\mathrm{n}}}}{\mathrm{T}_{\mathrm{L}}^{0}-n \bar{T}_{m}^{0}} \mathrm{X} \frac{\left(V^{0}+V_{3}\right)}{V^{0}}\right\}
$$


BAJOPAS Volume 14 Number 1,June, 2021

Where $T_{L}, T^{\circ}, E^{\circ}$, and $V^{\circ}$ havethe same significance as in equation (1) above, $T_{m}$ denotes the total concentration of metal present in solution, $V_{3}$ is the volume of metal ions present in solution and $\beta^{H}$ is the overall proton ligand stability constant. The metal-ligand stability constants (log K) were determined by employing point wise computational Method (eq. 5 and 6).

$\operatorname{LogK}_{1}=\log \left(\frac{n}{1-n}\right)+\mathrm{pL}$ .5

$\operatorname{LogK}_{2}=\log \left(\frac{1-n}{2-n}\right)+\mathrm{pL}$ ...6

Where: Log $\mathrm{K}$ is the metal-ligand stability constant, $\mathrm{pL}$ is the Free ligand exponent function, $\mathbf{n}$ is the Average number of ligand attached with metal ion (Janraoet al., 2014). The results obtained were analyzed by an ORIGIN 2016 program using titration data and then the proton-ligand stability constants (pKa) and Metal-ligand stability constant (LogK) calculated (Omar and Ali, 2015).

\section{RESULTS AND DISCUSSION}

Fourier transformed infrared (FT-IR) spectra of isolated humic acid from peat soils Figure 2 had distinct clear absorption bands indicating the presence of major humic acid structural elemental groups such as $\mathrm{H}$ bonded $\mathrm{OH}$ $\left(3680 \mathrm{~cm}^{-1}\right.$ peak $), C=0$ of carbonyl $\left(1721 \mathrm{~cm}^{-1}\right.$ peak), functional groups of aliphatic components $\mathrm{CH}_{2}\left(2918 \mathrm{~cm}^{-1}\right.$ peak) and $\mathrm{C}-\mathrm{O}$ stretching of polysaccharide $\left(1168 \mathrm{~cm}^{-1}\right.$ peak). The positions of the absorption bands of the spectra fell within typical major absorption bands of humic acid which is at frequencies 3680, 2918, 1721, 1168 $\mathrm{cm}^{-1}$. The first peak centred in the vicinity of $3680 \mathrm{~cm}^{-1}$ region is attributed to phenol $\mathrm{OH}$ group bounded by intermolecular $\mathrm{H}$ bonds. The $2918 \mathrm{~cm}^{-1}$ band usually has absorption maximum at $2918 \mathrm{~cm}^{-1}$ which is due to $\mathrm{C}-\mathrm{H}$ stretching of alkane group $\left(\mathrm{CH}_{2}\right)$. The next major absorption band is $1721 \mathrm{~cm}^{-1}$. This band has been commonly ascribed to $\mathrm{C}=\mathrm{O}$ stretching of mainly carboxyl group $(\mathrm{COOH})$ with trace amount of ketones. The last peak was observed at 1168 $\mathrm{cm}^{-1}$ due to $\mathrm{C}-\mathrm{O}$ stretching of polysaccharides and this peak appeared also in the spectra of humic acid from peat soil. The FTIR spectra of the isolated humic acid contained all major characteristic absorption peaks of humic acid. These absorption peaks indicated the presence of the major structural elements of humic acid namely $\mathrm{H}$ bonded $\mathrm{OH}, \mathrm{C}=\mathrm{C}$ of aromatic ring, $\mathrm{C}=\mathrm{O}$ of carbonyl group (both carboxyl and ketonic), $\mathrm{CH}_{2}$ group. This strongly supports the presence of humic acid.

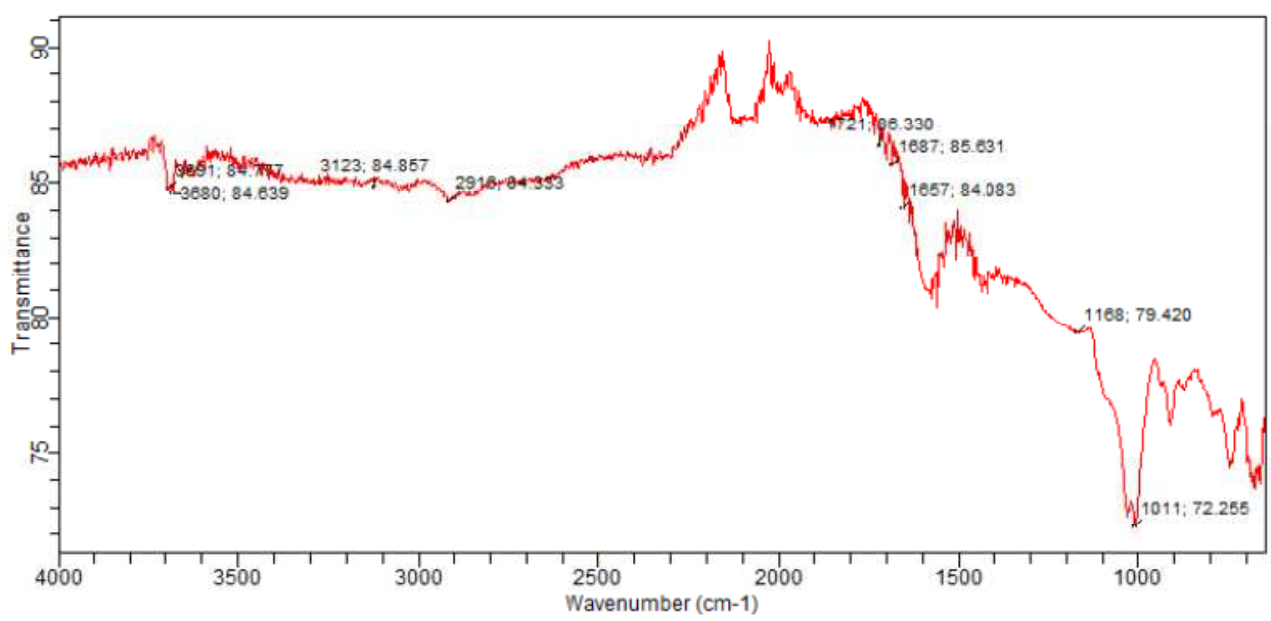

Fig. 2 : FT-IR spectraof peatsoilhumic acid (PSHA)

\section{Evaluation of acid dissociation constant (pka) of acid hydrolysed peat soil humicacid at phenolic group}

The value of the dissociation constant of the peat soil humic acid (PSHA) that underwent acidhydrolysis studied was found to be 8.9299 as shown Table 1, which is lower than the literaturevalues reported by Almeida and Szpoganics, (2015), Borges et al., (2005); Badr et al., (2012)and Fernandes et al,.(2009) of $9.73,9.47$ and 10.30. The difference between the obtained valuesand the reported values in this study might be probably as a result of acid hydrolysis of humicacid. 
BAJOPAS Volume 14 Number 1,June, 2021

Table 1: PKa of (Hydrolysed PSHA)

\begin{tabular}{|l|l|l|l|l|l|l|}
\hline $\mathrm{pH}$ & $\mathrm{BV}_{1}$ & $\mathrm{BV}_{2}$ & $\mathrm{~V}_{2}-\mathrm{V}_{1}$ & $\mathrm{nA}$ & $\log \left(\frac{n A}{1-n A}\right)$ & $\mathrm{pKa}$ \\
\hline 8.50 & 5.30 & 6.29 & 0.99 & 0.3594 & -0.2510 & 8.2490 \\
8.72 & 5.35 & 6.37 & 1.02 & 0.3400 & -0.2880 & 8.4320 \\
9.00 & 5.40 & 6.46 & 1.06 & 0.3141 & -0.3391 & 8.6609 \\
9.22 & 5.45 & 6.55 & 1.10 & 0.2882 & -0.3927 & 8.8273 \\
9.51 & 5.50 & 6.66 & 1.16 & 0.2494 & -0.4786 & 9.0314 \\
9.73 & 5.55 & 6.78 & 1.23 & 0.2041 & -0.5910 & 9.1390 \\
10.00 & 5.60 & 6.90 & 1.30 & 0.1589 & -0.7238 & 9.2762 \\
10.23 & 5.65 & 7.05 & 1.40 & 0.0941 & -0.9835 & 9.2465 \\
10.49 & 5.70 & 7.10 & 1.40 & 0.0941 & -0.9835 & 9.5065 \\
\hline
\end{tabular}

Average pKa $=8.9299 \pm 0.4186$

Table 2: PKa of (Unhydrolysed PSHA)

\begin{tabular}{|l|l|l|l|l|l|l|}
\hline $\mathrm{pH}$ & $\mathrm{BV}_{1}$ & $\mathrm{BV}_{2}$ & $\mathrm{~V}_{2}-\mathrm{V}_{1}$ & $\mathrm{nA}$ & $\log \left(\frac{\boldsymbol{n A}}{1-\boldsymbol{n}}\right)$ & $\mathrm{pKa}$ \\
\hline 8.50 & 5.30 & 5.81 & 0.51 & 0.6619 & 0.2919 & 8.7919 \\
8.72 & 5.35 & 5.90 & 0.55 & 0.6357 & 0.2418 & 8.9618 \\
9.00 & 5.40 & 6.00 & 0.60 & 0.6029 & 0.1813 & 9.1813 \\
9.22 & 5.45 & 6.10 & 0.65 & 0.5701 & 0.1226 & 9.3426 \\
9.51 & 5.50 & 6.20 & 0.70 & 0.5376 & 0.0654 & 9.5754 \\
9.73 & 5.55 & 6.33 & 0.78 & 0.4851 & -0.0259 & 9.7041 \\
10.00 & 5.60 & 6.47 & 0.87 & 0.4262 & -0.1291 & 9.8709 \\
10.23 & 5.65 & 6.62 & 0.99 & 0.3609 & -0.2481 & 9.9819 \\
10.49 & 5.70 & 6.80 & 1.10 & 0.2759 & -0.4690 & 10.0210 \\
\hline
\end{tabular}

Average pKa $=9.4923 \pm 0.4410$

Metal-ligand stability constant ( $\log \mathrm{K}$ )

The stabilityconstants require the accurate values of proton-ligand stability constants (Anil and Maroti, 2008). Metal titration curves crossed over ligand titration curve indicated the formation of complex upon proton release (Santosh, et al., 2011). If the values of n- are within range $0.2-0.8$ and $1.2-18$ this indicates the formation of $1: 1$ and 1:2 complexes (Sayyed and Mazahar, 2012).

The metal (II)-humate stepwise stability constants (log k) at phenolic group (Tables 318)

Table 3: Point-wise method, $\mathrm{Cu}$-(Hydrolysed PSHA)

\begin{tabular}{|l|l|l|l|l|l|l|l|l|}
\hline $\mathrm{pH}$ & $\mathrm{BV}_{1}$ & $\mathrm{BV}_{2}$ & $\mathrm{BV}_{3}$ & $\left(\mathrm{~V}_{3}-\mathrm{V}_{2}\right)$ & $\mathrm{n}$ & $\mathrm{pL}$ & $\log \left(\frac{n}{1-n}\right)$ & LogK $_{1}$ \\
\hline 8.50 & 5.30 & 6.29 & 6.33 & 0.04 & 0.5500 & 2.66 & 0.0871 & 2.7471 \\
8.72 & 5.35 & 6.37 & 6.41 & 0.04 & 0.5714 & 2.43 & 0.1249 & 2.5549 \\
9.00 & 5.40 & 6.46 & 6.50 & 0.04 & 0.6198 & 2.16 & 0.2122 & 2.3722 \\
9.22 & 5.45 & 6.55 & 6.59 & 0.04 & 0.6667 & 1.94 & 0.3010 & 2.2410 \\
\hline
\end{tabular}

LogK $_{1}$ (Average value) $=2.4788 \pm 0.2203$

Table 4: Point-wise method, $\mathrm{Cu}$-(Hydrolysed PSHA)

\begin{tabular}{|l|l|l|l|l|l|l|l|l|}
\hline $\mathrm{pH}$ & $\mathrm{BV}_{1}$ & $\mathrm{BV}_{2}$ & $\mathrm{BV}_{3}$ & $\left(\mathrm{~V}_{3}-\mathrm{V}_{2}\right)$ & $\mathrm{n}$ & $\mathrm{pL}$ & $\log \left(\frac{n-1}{2-n}\right)$ & LogK $_{2}$ \\
\hline 9.51 & 5.50 & 6.66 & 6.73 & 0.07 & 1.3509 & 1.70 & -0.2671 & 1.4329 \\
9.73 & 5.55 & 6.78 & 6.85 & 0.07 & 1.6383 & 1.51 & 0.2467 & 1.7567 \\
10.00 & 5.60 & 6.90 & 6.98 & 0.08 & 2.1783 & 1.31 & -0.2158 & 1.0942 \\
10.23 & 5.65 & 7.05 & 7.13 & 0.08 & 4.1904 & 1.27 & & \\
10.49 & 5.70 & 7.10 & 7.19 & 0.09 & 4.6920 & & & \\
\hline
\end{tabular}

Log $K_{2}($ Average value $)=1.4280 \pm 0.3312$ 
BAJOPAS Volume 14 Number 1,June, 2021

Table 5: Point-wise method, $\mathrm{Cu}$ (Unhydrolysed PSHA)

\begin{tabular}{|l|l|l|l|l|l|l|l|l|}
\hline $\mathrm{pH}$ & $\mathrm{BV}_{1}$ & $\mathrm{BV}_{2}$ & $\mathrm{BV}_{3}$ & $\left(\mathrm{~V}_{3}-\mathrm{V}_{2}\right)$ & $\mathrm{n}$ & $\mathrm{pL}$ & $\log \left(\frac{n}{n-1}\right)$ & Log $_{1}$ \\
\hline 8.50 & 5.30 & 5.81 & 5.85 & 0.04 & 0.2973 & 2.88 & -0.3736 & 2.5064 \\
8.72 & 5.35 & 5.90 & 5.95 & 0.05 & 0.3873 & 2.66 & -0.1992 & 2.4608 \\
9.00 & 5.40 & 6.00 & 6.05 & 0.05 & 0.4044 & 2.38 & -0.1681 & 2.2119 \\
9.22 & 5.45 & 6.10 & 6.15 & 0.06 & 0.5157 & 2.18 & -0.0272 & 2.2072 \\
9.51 & 5.50 & 6.20 & 6.27 & 0.07 & 0.6417 & 1.89 & 0.2530 & 1.1430 \\
\hline
\end{tabular}

$\operatorname{LogK}_{1}($ Average value $)=2.3059 \pm 0.6153$

Table 6:Point-wise method, $\mathrm{Cu}$ (Unhydrolysed PSHA)

\begin{tabular}{|l|l|l|l|l|l|l|l|l|}
\hline $\mathrm{pH}$ & $\mathrm{BV}_{1}$ & $\mathrm{BV}_{2}$ & $\mathrm{BV}_{3}$ & $\mathrm{~V}_{3}-\mathrm{V}_{2}$ & $\mathrm{n}$ & $\mathrm{pL}$ & $\log \left(\frac{n-1}{2-n}\right)$ & $\log \mathrm{K}_{2}$ \\
\hline 9.73 & 5.55 & 6.33 & 6.42 & 0.09 & 0.9000 & 1.69 & & \\
10.00 & 5.60 & 6.47 & 6.58 & 0.11 & 1.2578 & 1.44 & -0.4592 & 0.9808 \\
10.23 & 5.65 & 6.62 & 6.84 & 0.12 & 1.6137 & 1.26 & -0.2010 & 1.4610 \\
10.49 & 5.70 & 6.80 & 6.92 & 0.12 & 2.1052 & 1.03 & & \\
\hline
\end{tabular}

$\operatorname{LogK}_{2}$ (Average value) $=1.2209 \pm 0.3398$

Table 7:Point-wise method, Pb (Hydrolysed PSHA)

\begin{tabular}{|l|l|l|l|l|l|l|l|l|}
\hline $\mathrm{pH}$ & $\mathrm{BV}_{1}$ & $\mathrm{BV}_{2}$ & $\mathrm{BV}_{3}$ & $\left(\mathrm{~V}_{3}-\mathrm{V}_{2}\right)$ & $\mathrm{n}$ & $\mathrm{pL}$ & $\log \left(\frac{n}{1-n}\right)$ & LogK $_{1}$ \\
\hline 8.50 & 5.30 & 6.29 & 6.33 & 0.04 & 0.5500 & 2.66 & 0.0871 & 2.7471 \\
8.72 & 5.35 & 6.37 & 6.41 & 0.04 & 0.5714 & 2.43 & 0.1249 & 2.5549 \\
9.00 & 5.40 & 6.46 & 6.50 & 0.04 & 0.6198 & 2.16 & 0.2122 & 2.3722 \\
9.22 & 5.45 & 6.55 & 6.60 & 0.05 & 0.8333 & 1.96 & 0.6989 & 2.6589 \\
\hline
\end{tabular}

Log $_{\mathbf{1}}($ Average value $)=2.5832 \pm 0.1614$

Table 8:Point-wise method, Pb-(Hydrolysed PSHA)

\begin{tabular}{|l|l|l|l|l|l|l|l|l|}
\hline $\mathrm{pH}$ & $\mathrm{BV}_{1}$ & $\mathrm{BV}_{2}$ & $\mathrm{BV}_{3}$ & $\left(\mathrm{~V}_{3}-\mathrm{V}_{2}\right)$ & $\mathrm{n}$ & $\mathrm{pL}$ & $\log \left(\frac{n-1}{2-n}\right)$ & $\log \mathrm{K}_{2}$ \\
\hline 9.51 & 5.50 & 6.66 & 6.71 & 0.05 & 0.9650 & 1.67 & & \\
9.73 & 5.55 & 6.78 & 6.83 & 0.05 & 1.1702 & 1.44 & & \\
10.00 & 5.60 & 6.90 & 6.90 & 0.05 & 1.4864 & 1.22 & -0.0237 & 1.1963 \\
10.23 & 5.65 & 7.05 & 7.10 & 0.05 & 2.0190 & 1.09 & & \\
10.49 & 5.70 & 7.10 & 7.17 & 0.07 & 3.6492 & 1.00 & & \\
\hline
\end{tabular}

Log $K_{2}$ (Average value) $=1.1963$

Table 9: Point-wise method, Pb (Unhydrolysed PSHA)

\begin{tabular}{|l|l|l|l|l|l|l|l|l|}
\hline $\mathrm{pH}$ & $\mathrm{BV}_{1}$ & $\mathrm{BV}_{2}$ & $\mathrm{BV}_{3}$ & $\mathrm{~V}_{3}-\mathrm{V}_{2}$ & $\mathrm{n}$ & $\mathrm{pL}$ & $\begin{array}{l}\text { Log } \\
\left(\frac{n}{n-1}\right)\end{array}$ & Log $\mathrm{K}_{1}$ \\
\hline 8.50 & 5.30 & 5.81 & 5.85 & 0.04 & 0.2973 & 2.88 & -0.3736 & 2.5064 \\
8.72 & 5.35 & 5.90 & 5.94 & 0.04 & 0.3099 & 2.66 & -0.5477 & 2.3123 \\
9.00 & 5.40 & 6.00 & 6.05 & 0.05 & 0.4044 & 2.38 & -0.1681 & 2.2119 \\
9.22 & 5.45 & 6.10 & 6.15 & 0.06 & 0.5157 & 2.18 & 0.0272 & 2.2072 \\
9.51 & 5.50 & 6.20 & 6.26 & 0.07 & 0.6417 & 1.89 & 0.2530 & 2.1430 \\
9.73 & 5.55 & 6.40 & 6.40 & 0.07 & 0.7000 & 1.67 & 0.3680 & 2.0380 \\
\hline
\end{tabular}

LogK $_{1}$ (Average value) $=2.2364 \pm 0.1602$

Table 10: Point-wise method, Pb (Unhydrolysed PSHA)

\begin{tabular}{|l|l|l|l|l|l|l|l|l|}
\hline $\mathrm{pH}$ & $\mathrm{BV}_{1}$ & $\mathrm{BV}_{2}$ & $\mathrm{BV}_{3}$ & $\mathrm{~V}_{3}-\mathrm{V}_{2}$ & $\mathrm{n}$ & $\mathrm{pL}$ & $\log \left(\frac{n-1}{2-n}\right)$ & $\log \mathrm{K}_{2}$ \\
\hline 10.00 & 5.60 & 6.47 & 6.55 & 0.08 & 1.9503 & 1.41 & & \\
10.23 & 5.65 & 6.62 & 6.72 & 0.11 & 1.4792 & 1.26 & -0.0361 & 1.2239 \\
\hline
\end{tabular}

$\operatorname{LogK}_{2}$ (Average value) $=1.2239$

Table 11: Point-wise method, Mg (Hydrolysed PSHA)

\begin{tabular}{|l|l|l|l|l|l|l|l|l|}
\hline $\mathrm{pH}$ & $\mathrm{BV}_{1}$ & $\mathrm{BV}_{2}$ & $\mathrm{BV}_{3}$ & $\left(\mathrm{~V}_{3}-\mathrm{V}_{2}\right)$ & $\mathrm{n}$ & $\mathrm{pL}$ & $\log \left(\frac{n}{n-1}\right)$ & LogK $_{1}$ \\
\hline 8.50 & 5.30 & 6.29 & 6.31 & 0.02 & 0.2750 & 2.64 & -0.4290 & 2.2110 \\
8.72 & 5.35 & 6.37 & 6.39 & 0.02 & 0.2858 & 2.42 & -0.3978 & 2.0222 \\
9.00 & 5.40 & 6.46 & 6.49 & 0.03 & 0.4648 & 2.14 & -0.0612 & 2.0788 \\
9.22 & 5.45 & 6.55 & 6.59 & 0.04 & 0.6667 & 1.94 & 0.3010 & 2.2410 \\
\hline
\end{tabular}

$\log _{\mathbf{1}}($ Average value) $=2.1382 \pm 0.1046$ 
BAJOPAS Volume 14 Number 1,June, 2021

Table 12: Point-wise method, Mg (Hydrolysed PSHA)

\begin{tabular}{|l|l|l|l|l|l|l|l|l|}
\hline $\mathrm{pH}$ & $\mathrm{BV}_{1}$ & $\mathrm{BV}_{2}$ & $\mathrm{BV}_{3}$ & $\left(\mathrm{~V}_{3}-\mathrm{V}_{2}\right)$ & $\mathrm{n}$ & $\mathrm{pL}$ & $\log \left(\frac{n-1}{2-n}\right)$ & LogK $_{2}$ \\
\hline 9.51 & 5.55 & 6.66 & 6.71 & 0.05 & 0.9650 & 1.67 & & \\
9.73 & 5.55 & 6.78 & 6.84 & 0.06 & 1.4042 & 1.47 & -0.1686 & 1.3014 \\
10.00 & 5.60 & 6.90 & 6.93 & 0.06 & 1.7838 & 1.23 & 0.5593 & 1.7893 \\
10.23 & 5.65 & 7.05 & 7.10 & 0.06 & 3.1429 & 1.10 & & \\
10.49 & 5.70 & 7.10 & 7.18 & 0.07 & 3.6492 & 0.83 & & \\
\hline
\end{tabular}

LogK $_{2}($ Average value $)=1.5453 \pm 0.3450$

Table 13: Point-wise method, Mg (Unhydrolysed PSHA)

\begin{tabular}{|l|l|l|l|l|l|l|l|l|}
\hline $\mathrm{pH}$ & $\mathrm{BV}_{1}$ & $\mathrm{BV}_{2}$ & $\mathrm{BV}_{3}$ & $\mathrm{~V}_{3}-\mathrm{V}_{2}$ & $\mathrm{n}$ & $\mathrm{pL}$ & $\log \left(\frac{n}{n-1}\right)$ & $\operatorname{Log~}_{1}$ \\
\hline 8.50 & 5.30 & 5.81 & 5.85 & 0.04 & 0.2973 & 2.88 & -0.3736 & 2.5064 \\
8.72 & 5.35 & 5.90 & 5.94 & 0.04 & 0.3099 & 2.66 & -0.3477 & 2.3123 \\
9.00 & 5.40 & 6.00 & 6.04 & 0.04 & 0.3236 & 2.38 & -0.3202 & 2.0598 \\
9.22 & 5.45 & 6.10 & 6.15 & 0.05 & 0.4297 & 2.17 & -0.1230 & 2.0470 \\
9.51 & 5.50 & 6.20 & 6.26 & 0.06 & 0.5500 & 1.89 & 0.0871 & 1.9771 \\
9.73 & 5.55 & 6.33 & 6.40 & 0.07 & 0.7000 & 1.67 & 0.3680 & 2.0380 \\
\hline
\end{tabular}

LogK $_{1}$ (Average value) $=2.1568 \pm 0.2069$

Table 14: Point-wise method, Mg (Unhydrolysed PSHA)

\begin{tabular}{|l|l|l|l|l|l|l|l|l|}
\hline $\mathrm{pH}$ & $\mathrm{BV}_{1}$ & $\mathrm{BV}_{2}$ & $\mathrm{BV}_{3}$ & $\mathrm{~V}_{3}-\mathrm{V}_{2}$ & $\mathrm{n}$ & $\mathrm{pL}$ & $\log \left(\frac{n-1}{2-n}\right)$ & $\log \mathrm{K}_{2}$ \\
\hline 10.00 & 5.60 & 6.47 & 6.55 & 0.08 & 0.9148 & 1.41 & & \\
10.23 & 5.65 & 6.62 & 6.71 & 0.09 & 1.2102 & 1.20 & -0.5749 & 0.6251 \\
10.49 & 5.70 & 6.80 & 6.92 & 0.09 & 1.5968 & 1.03 & 0.1703 & 1.2003 \\
\hline
\end{tabular}

LogK $_{2}$ (Average value) $=0.9127 \pm 0.4070$

Table15:Point-wise method, Cd (Hydrolysed PSHA)

\begin{tabular}{|l|l|l|l|l|l|l|l|l|}
\hline $\mathrm{pH}$ & $\mathrm{BV}_{1}$ & $\mathrm{BV}_{2}$ & $\mathrm{BV}_{3}$ & $\left(\mathrm{~V}_{3}-\mathrm{V}_{2}\right)$ & $\mathrm{n}$ & $\mathrm{pL}$ & $\log \left(\frac{n}{1-n}\right)$ & LogK $_{1}$ \\
\hline 8.50 & 5.30 & 6.29 & 6.31 & 0.02 & 0.2750 & 2.64 & -0.4210 & 2.2190 \\
8.72 & 5.35 & 6.37 & 6.40 & 0.03 & 0.4286 & 2.42 & -0.1249 & 2.2951 \\
9.00 & 5.40 & 6.46 & 6.49 & 0.03 & 0.4648 & 2.14 & -0.0612 & 2.0788 \\
9.22 & 5.45 & 6.55 & 6.59 & 0.04 & 0.6667 & 1.96 & 0.3010 & 2.2610 \\
9.51 & 5.55 & 6.66 & 6.70 & 0.04 & 0.7720 & 1.67 & 0.5297 & 2.1997 \\
\hline
\end{tabular}

LogK $_{\mathbf{1}}$ (Average value) $=2.2108 \pm 0.0825$

Table 16: Point-wise method, Cd (Hydrolysed PSHA)

\begin{tabular}{|l|l|l|l|l|l|l|l|l|}
\hline $\mathrm{pH}$ & $\mathrm{BV}_{1}$ & $\mathrm{BV}_{2}$ & $\mathrm{BV}_{3}$ & $\left(\mathrm{~V}_{3}-\mathrm{V}_{2}\right)$ & $\mathrm{n}$ & $\mathrm{pL}$ & $\log \left(\frac{n-1}{2-n}\right)$ & Log $_{2}$ \\
\hline 9.73 & 5.55 & 6.78 & 6.83 & 0.06 & 1.4042 & 1.47 & -0.1686 & 1.3014 \\
10.00 & 5.60 & 6.90 & 6.95 & 0.06 & 1.7838 & 1.23 & 0.5593 & 1.7893 \\
10.23 & 5.65 & 7.05 & 7.10 & 0.06 & 3.1429 & 1.09 & & \\
10.49 & 5.70 & 7.10 & 7.16 & 0.06 & 3.1429 & 0.89 & & \\
& & & & & & & & \\
\hline
\end{tabular}

$\operatorname{LogK}_{2}$ (Average value) $=1.5453 \pm 0.3450$

Table 17: Point-wise method, Cd (Unhydrolysed PSHA)

\begin{tabular}{|l|l|l|l|l|l|l|l|l|}
\hline $\mathrm{pH}$ & $\mathrm{BV}_{1}$ & $\mathrm{BV}_{2}$ & $\mathrm{BV}_{3}$ & $\mathrm{~V}_{3}-\mathrm{V}_{2}$ & $\mathrm{n}$ & $\mathrm{pL}$ & $\log \left(\frac{n}{n-1}\right)$ & $\operatorname{Log~}_{1}$ \\
\hline 8.50 & 5.30 & 5.81 & 5.86 & 0.05 & 0.3717 & 2.88 & -0.2280 & 2.6520 \\
8.72 & 5.35 & 5.90 & 5.95 & 0.05 & 0.3873 & 2.66 & -0.1992 & 2.4608 \\
9.00 & 5.40 & 6.00 & 6.06 & 0.06 & 0.4853 & 2.38 & -0.0255 & 2.3545 \\
9.22 & 5.45 & 6.10 & 6.16 & 0.06 & 0.5157 & 2.18 & -0.0272 & 2.2072 \\
9.51 & 5.50 & 6.20 & 6.27 & 0.07 & 0.6417 & 1.89 & 0.2530 & 1.1430 \\
9.73 & 5.55 & 6.33 & 6.41 & 0.08 & 0.8000 & 1.69 & 0.6020 & 2.2920 \\
& & & & & & & & \\
\hline
\end{tabular}

$\operatorname{LogK}_{1}($ Average value $)=2.2516 \pm 0.5380$ 
BAJOPAS Volume 14 Number 1,June, 2021

Table 18: Point-wise method, Cd (Unhydrolysed PSHA)

\begin{tabular}{|l|l|l|l|l|l|l|l|l|}
\hline $\mathrm{pH}$ & $\mathrm{BV}_{1}$ & $\mathrm{BV}_{2}$ & $\mathrm{BV}_{3}$ & $\mathrm{~V}_{3}-\mathrm{V}_{2}$ & $\mathrm{n}$ & $\mathrm{pL}$ & $\log \left(\frac{n-1}{2-n}\right)$ & $\log \mathrm{K}_{2}$ \\
\hline 10.00 & 5.60 & 6.47 & 6.57 & 0.10 & 1.1434 & 1.43 & & \\
10.23 & 5.65 & 6.62 & 6.72 & 0.10 & 1.3448 & 1.23 & -0.2788 & 0.9512 \\
10.49 & 5.70 & 6.80 & 6.90 & 0.10 & 1.7742 & 1.03 & 0.5351 & 1.5651 \\
\hline
\end{tabular}

$\operatorname{LogK}_{2}($ Average value $)=1.2581 \pm 0.4340$

Table 19: Stepwise and overall Stability constants of thehydrolysed and unhydrolysed divalent metal (II) complexes

\begin{tabular}{|c|c|c|c|}
\hline Chelates & LogK $_{1}$ & $\log _{2}$ & Log $\beta$ \\
\hline [Cu (Hydrolysed PSHA-1) $\left.{ }_{2}\right]$ & 2.4788 & 1.4280 & 3.9068 \\
\hline$\left[\mathrm{Pb}(\text { Hydrolysed PSHA-1) })_{2}\right]$ & 2.5832 & 1.1963 & 3.7795 \\
\hline$\left[\mathrm{Cd}(\text { Hydrolysed PSHA-1 })_{2}\right]$ & 2.2108 & 1.5453 & 3.7561 \\
\hline$\left[\mathrm{Mg}(\text { Hydrolysed PSHA-1 })_{2}\right]$ & 2.1382 & 1.5453 & 3.6835 \\
\hline [Cu (Unhydrolysed PSHA-1) & 2.3059 & 1.2209 & 3.5268 \\
\hline$[\mathrm{Pb}$ (Unhydrolysed PSHA-1) 2$]$ & 2.2364 & 1.2239 & 3.4603 \\
\hline [Cd (Unhydrolysed PSHA-1) 2 ] & 2.2516 & 1.2581 & 3.5097 \\
\hline$[\mathrm{Mg}$ (Unydrolysed PSHA-1) & 2.1568 & 0.9127 & 3.0695 \\
\hline
\end{tabular}

The results obtained (Table19) shows the stepwise and overall stability constants to be not high indicating low stability of the complexes, because the solubility of most metal ions in the basic $\mathrm{pH}$ range is minimal due to metal hydroxide precipitation (Karimi, 2017). In general, the stepwise stability constants $\left(K_{1}\right.$ and $K_{2}$ ) follow the order $K_{1}>K_{2}$ for the copper, lead, magnesium and cadmium complexes respectively. The steady decrease of the values with increasing number of ligands is in agreement with the prediction made by researchers (Na'aliya, 2013). The decrease could be attributed to the fact that as the number of the ligands (Humate ions) that enters the coordination zone increases the aqua molecules available for replacement by the ligands become less. Thus, the metal ions become less electron loving with progressive intake of the ligand and this results in the decrease in the values of the constants (Na'aliya, 2013). Also the stability of the complexes is influenced by the size and number of the chelate rings(Mackay and Mackay,2002).All the complexes form rings in their structure as humate, a bidentate ligand, bond the metal ions in the ratio 1:2 (Boguta and Sokolowska, 2016) forming chelate rings. The values of the overall stability constants $(\log \beta)$ obtained for humate complexes are not high indicating low stability as the values are not high. LogK values for copper-humates (Table 3 to 6) obtained in this study are lower than those reported for the complexes of humic acids (Pandey et al., 2015; Dinu, 2013; Kaschl et al., 2010 and Gilbeto and Jorg, 2001). The values of LogK(Table 7 to 10 ) forlead-humates are lower than those reported for the lead in the literature (Dinu, 2013; Gilbeto and Jorg 2001). Log K values(Table 11 to 14 ) for magnesium-humates obtained in this study are close to those reported by (Pandey et al., 2015). Log K values of cadmium-humates (Table 15 to 18 ) obtained in this work near to the one reported by (Dinu, 2013 and Pandey et al., 2015).The difference between the reported values and the values obtained in this study might be probably as a result of acid hydrolysis of humic acid. The values of the overall stability constants $(\log \beta)$ of the copper humates complexes presented in Table 19 is high than that of other metal humate complexes, show relatively high stability of CuHA complexes, show the following order of stability: $\mathrm{Cu}>\mathrm{Pb}>\mathrm{Cd}>\mathrm{Mg}$; which are in close agreement to the findings of (Dinu, 2013 and Pandey et al., 2015).The high stability of Cuhumate chelate could be attributed to the existence of coordinate covalent bond between the complexing agents and the $\mathrm{Cu}^{2+}$ ions. Since, $\mathrm{Cu}^{2+}$ being a metal of the transitional series with $3 d^{9}$ electronic configurations can accept the electrons from the complexing agents. Similarly, the low stabilities of $\mathrm{Pb}, \mathrm{Cd}$ and $\mathrm{Mg}$ complexes could be explained by that $\mathrm{Pb}^{2+}$ with $6 s^{2}, \mathrm{Cd}^{2+}$ with $4 \mathrm{~d}^{10}$ and $\mathrm{Mg}^{2+}$ with $2 \mathrm{p}^{6}$ their electronic configuration has a completely filled $\mathrm{d}, \mathrm{p}$ and $\mathrm{s}$ orbitals. Moreover, the stabilities of metal ions with hydrolysed humic acid from peat soil were higher than those with unhydrolysed humic acid from peat soil; which is ascribed to the high content of acidity in hydrolysed humic acid than unhydrolysed humic acid. 
BAJOPAS Volume 14 Number 1,June, 2021 CONCLUSION

The values of logk for $\mathrm{Cu}(\mathrm{II})$ hydrolysed humic acid complex was higher followed by $\mathrm{Pb}$ (II), $\mathrm{Cd}(\mathrm{II})$ and $\mathrm{Mg}$ (II) hydrolysed humic acid complexes as compared with metal(II) unhydrolysed humic acid complexes. This indicates acid hydrolysis of humic acid can

\section{REFERENCES}

Almeida, V.R. and Szpoganicz, B. (2015). Humic Acid Potentiometric Response Patterns:Out- of Equilibrium Properties and Species Distribution Modelling. Chemical. Biol. Technol. Agric. 2: 17.

Anđelković, T., Nikolić, R., Bojić, A.,Anđelković, D., and Nikolic G.,(2010). Binding of Cadmium to Soil Humic Acid as A Function of Carboxyl Group Content. Macedonian Journal of Chemistry and Chemical Engineering.29(2): 215-224.

Anil, B. N. and Maroti, N. (2008). Studies on Influence of Die-Lectric Constants on Complex Equilibria between Substituted Py-Razalines and Lanthanide Metal Ions pH-Metrically. Amer.-Euras. scient. Res. 3(2): 212-216.

Ashok, K., Pandey, S. P. and Misra, V (2000). Stability Constants of Metal-Humic Acid Complexes and its Role in Environmental Detoxification. Journal of Ecotoxicology and Environmental Safety. 47(2):157-200.

Badr, M. H., El-Halafawi, M. H. and Abd El-al Zeid, E. R. (2012). Comparison Between the Effect of Ionic Strength on Acidity and Dissociation Constants of Humic Acids Extracted from Sewage Sludge and Nile Water Hyacinth Composts.Global Journal of Environmental Research 6 (1): 36-43.

Baruah, M.K., Borah, D., Saikia, P.P., Paul, S., Sharma, T. (2015). Evaluation of pKa Values of Soil Humic Acids and their Complexation Properties. International Journal of Plant \& Soil Science 6(4) : 218-228.

Boguta, P. Sokolowska, Z. (2016). Interactions of $\mathrm{Zn}$ (II) Ions with Humic Acids Isolated from Various Types of Soils. Effect of $\mathrm{pH}, \mathrm{Zn}$ Concentrations and Humic Acids Chemical Properties. Journal of Geochemical Explaration 168. 119-126.

Borges, F., Guimaraes, C., Lima, L.F.C., Pinto, I. and Reis, S.(2005). Potentiometric Studies on the Complexation of Copper(II) by Phenolic Acids as Discrete Ligand Models of enhance the complexation behavior of humic acid with metal (II) ions. However, the higher values of $\log \beta$ for $\mathrm{Cu}(\mathrm{II}), \mathrm{Pb}(\mathrm{II}), \mathrm{Cd}(\mathrm{II})$ and $\mathrm{Mg}(\mathrm{II})$ hydrolysed humic acid complexes indicates more stable stepwise complexes formed as compared with $\mathrm{Cu}(\mathrm{II}), \mathrm{Pb}$ (II), $\mathrm{Cd}$ (II) and $\mathrm{Mg}(\mathrm{II})$ unhydrolysed humic acid complexes.

Humic Substances Talanta 66 (2005) 670-673.

Chefetz, B., Salloum, M. J., Deshmulkin, A. P. and Hatcher, P. (2002). Structural Components of Humic Acids as Determined by Chemical Modifications and Carbon-13 NMR, Pyrolysis, and Thermochemolysis- Gas Chromatography/Mass Spectrometry. Soil Science Society of American Journal Abstract Division S-2- Soil Chemistry66. 1159-1171.

Dinu, M. I. (2013). Metals Complexation with Humic Acids in Surface Water of Different Environ. Sci. Technol. 31(1): 1-17.

Fernandes, A.N., Giacomelli, C., Giovanela, M. Vaz, D.V. Szpoganicz, B. and Maria M. D. (2009). Potentiometric Acidity Determination in Humic Substances Influenced by Different Analytical Procedures.J. Braz. Chem. Soc. 20 (9):14.

Gamal, A. H. (2015). Stability Constants of Rhenium (V) Metal Complexes with Selected Drugs. Pyrex Journal of Research in Environmental Studies. 2(2): 006-014.

Janrao, D. M., Pathan, J., Kayande, D.D., and Mulla, J.J. (2014). An Over View of Potentiometric Determination of Stability Constants of Metal Complexes. Sci. Revs. Chem. Commun.: 4(1), 2014, 11-24.

Karimi, H. (2017). Effect of pH and Initial Pb(II) Concentration on the Lead Removal Efficiency from Waste Water Using $\mathrm{Ca}(\mathrm{OH})_{2}$. International Journal of Water and Waste Water Treatment 3.2

Kaschl, A. Romheld, V. and Chen, Y. (2010). Binding of Cadmium, Copper and Zinc to Humic Substances Originating from Municipal Solid Waste Compost. Israel Journal of Chemistry Vol. 42(1): 89-98.

Kostic, I. S., Tatjana, P, A., Nikolic, R. S., Cvetkovic, T. P., Pavlovic, D. D., Aleksandar, L.J. and Bojic, A. (2012). Comparative Study of Binding Strengths of Heavy Metals with Humic Acid. J.serb. Chem. Soc. 76(9) pp 1-20. 
BAJOPAS Volume 14 Number 1,June, 2021

Na'aliya, J. (2013). Determination of Stepwise Stability Constants and Gibbs free Energy Change of Trisprolina to Complexes of some Divalent Transition Metal ions. Bayero Journal of Pure and Applied Sciences 6(2): 112-114.

Omar, A. A. and Ali, E. A. (2015). Potentiometric Studies on Complexes of $\mathrm{Cr}$ (III) and $\mathrm{Zr}$ (IV) with some Carboxylic Acids. International Journal of Advanced Chemistry, 3(1) 25-

37.

Pandey, A. K. Pandey, S. D. and Misr, V. (2015).Stability Constants of Metal- Humic Acid Complexes and Its Role in Environmental Detoxification. J. Ecotoxicology and Environmental Safety. 47(1):195-200.

Ram, N. and Raman, K.V. (1984). Stability Constants of Complexes of Metals with
Humicand Fuvic Acids under Non- acidConditions. Journal of Plant Nutrition and Soil Sciences.

147:171-176.

Santosh, D. D., Ashok, B. K., Vijay, J. T., Shivraj, G. W. and Vinay, V. W. (2011). Potentiometric Studies of Elec-Trolyte Effects on Complex Equilibria of Some Substituted 5-(2-hydroxy Phenyl) Pyrazoles. Der pharm. 3 (6): 75-83.

Sayyed, H. and Abdul Rahim, M. F. (2012). Studies of Binary Complexes of Metal Ions with Mandelic Acid by Potentiometry. Chem. J. 02 (6): 206209.

Shirvani, M. Moradian, E. Khalili, B. Bakhtiary, S. (2015). Interaction of $\mathrm{Cd}$ and $\mathrm{Pb}$ with Humate-Palygorskite and HumateSepiolite Complexes. Journal of water, air and pollution 3: 220-228. 


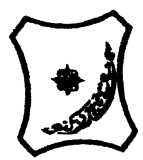

Bayero Journal of Pure and Applied Sciences, 14(1): 54 - 63

Received: November, 2020

Accepted: April, 2021

ISSN $2006-6996$

\title{
STABILITY CONSTANTS OF COMPLEXES OF METAL IONS WITH PEATSOIL HUMIC ACIDS UNDER NON-ACID-CONDITIONS
}

\author{
${ }^{* 1}$ Sabo, Yusuf ${ }^{2}$ Jimoh, W.L.O., ${ }^{3}$ Isa Baba Koki and ${ }^{4}$ Sholadoye, Q. 0. \\ ${ }^{1}$ Department of Pure and Industrial Chemistry, Bayero University, Kano \\ ${ }^{3}$ Department of Chemistry, Yusuf Maitama Sule University Kano. P.M.B. 3220 Kano, Nigeria. \\ ${ }^{4}$ Department of Chemistry, Nigerian Police Academy, Wudil, Kano-Nigeria
}

*Correspondence E-mail; saboyusuf18@yahoo.com

ABSTRACT

Stability constants of complexes of four divalent metal ions viz. $\mathrm{Cu}^{2+}, \mathrm{Pb}^{2+}, \mathrm{Mg}^{2+}$ and $\mathrm{Cd}^{2+}$ with humic acids (HA) were determined by potentiometric titration of humic acids with the corresponding salt of the divalent metals in aqueous media under non-acid-condition. The log $K$ (logarithm of the stability constant) ranged from 1.0942 to 2.7471 for metalhumic acid complexes were determined using point-wise computational method. The order of stability constants were obtained as follows: $\mathrm{Cu}>\mathrm{Pb}>\mathrm{Cd}>\mathrm{Mg}$ for metal $-\mathrm{HA}$ complexes respectively, indicating a higher degree of complexation with Cu metal ion.

Keywords: stability constant, humic acid, potentiometric titration, divalent metals, acid hydrolysis.

\section{NTRODUCTION}

The stability constant of a complex is the numerical expression of its stability and provides a quantitative measure of affinity of the metal ion to the complexing agent. An understanding of the relative stability of metal-complexes helps in predicting the behavior of metal ions in the soil (Ram and Raman, 1982). Extensive researches has been done to determine the stability constants of the complexes formed between humic acid (HA) with a number of metal ions. Ashok et al., (2000) reported that humic acid with hydroxyl, phenoxyl and carboxyl reactive groups can form coordination compound with metal ions at $\mathrm{pH}$ 3.5. The stability constants(Log K) for different metalhumic acid complexes indicated the following order of the stabilities of complexes formed between humic acid and metal ion, $\mathrm{Cu}>\mathrm{Fe}$ $>\mathrm{Pb}>\mathrm{Ni}>\mathrm{Co}>\mathrm{Ca}>\mathrm{Cd}>\mathrm{Zn}>\mathrm{Mn}>\mathrm{Mg}$. Andelkovic et al., (2010) investigated the binding of $\mathrm{Cd}$ (II) to soil humic acid at pH 6.5 and in $0.1 \mathrm{M} \mathrm{KNO}_{3}$ ionic medium. The stability constant for binding indicating greater stability in the case when carboxyl groups are involved in complexation reaction. Kostic et al.,(2012) investigated the complexation of humic acid with certain heavy metal ions (Co(II), $\mathrm{Ni}(\mathrm{II}), \mathrm{Cu}(\mathrm{II})$,
$\mathrm{Zn}(\mathrm{II})$, and $\mathrm{Pb}(\mathrm{II})$. The experiment was performed at $25^{\circ} \mathrm{C}$, at pH 4.0 and ionic strength of $0.01 \mathrm{M}$. Stability constant of complex between $\mathrm{Pb}$ (II) ions and humic acid is greater than stability constants of other investigated metalhumate complexes. Bogata and Sokolowska (2016) analyses the interaction between humic acids from different soils and $\mathrm{Zn}$ (II) ions at wide concentration ranges and at $\mathrm{pH} 5$. Studies have showed significant impact of $\mathrm{Zn}$ concentration, $\mathrm{pH}$ and some properties of humic acids with zinc.But all of these studies were limited to acidic $\mathrm{pH}$ range. Therefore, the present study was carried out to determine and compare the stability constants of complexes of metal ions with hydrolysed peat soil humic acid and unhydrolysed peat soil humic under non-acid conditions.

\section{MATERIALS AND METHODS}

Analytical grade chemicals used includes hydrochloric acid $(\mathrm{HCl})$, nitric acid $\left(\mathrm{HNO}_{3}\right)$, sodium hydroxide $(\mathrm{NaOH})$, lead nitrate $\mathrm{Pb}\left(\mathrm{NO}_{3}\right)_{2}$, copper nitrate $\mathrm{Cu}\left(\mathrm{NO}_{3}\right)_{2} \cdot 3 \mathrm{H}_{2} \mathrm{O}$, cadmium nitrate $\mathrm{Cd}\left(\mathrm{NO}_{3}\right)_{2} \cdot 4 \mathrm{H}_{2} \mathrm{O}$, magnesium nitrate $\mathrm{Mg}\left(\mathrm{NO}_{3}\right)_{2} \cdot 6 \mathrm{H}_{2} \mathrm{O}$, potassium nitrate $\left(\mathrm{KNO}_{3}\right)$, calcium chloride $\left(\mathrm{CaCl}_{2}\right)$, (sigma-Aldrich). Dowex 50WX8, (20-50 mesh) from Fluka. 


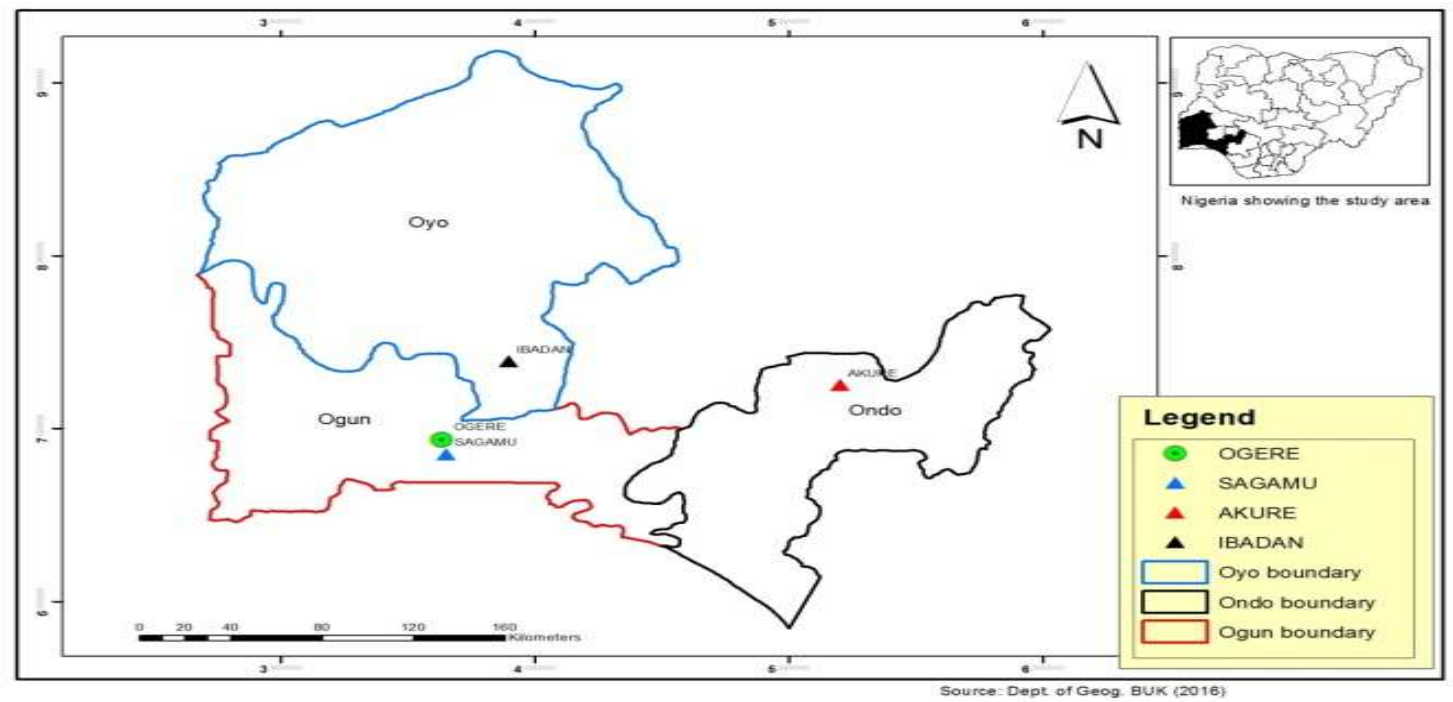

Figure 1: Map showing the sampling point at Sagamu Town, Ogun State.

\section{Description of Sampling Area}

Sagamu has geographical coordinates between $6^{\circ} 50^{\prime}$ north; $3^{\circ} 38^{\prime}$ east is located in south western region of Nigeria. The region has tropical wet and dry climate with a lengthy wet season and relatively constant temperatures throughout the course of the year. Wet season runs from March to October, November to December forms the region dry season. The vegetation type of the region is savannah which is really grassland with small bushes and occasional big trees. Grassland soils have substantially higher organic matter content than forest soils (Novackova, 2011).

\section{Sample Collection}

The Peatsoil samples were collected from four different sampling points $(0-10 \mathrm{~cm}$ depth) in Sagamu into polyethylene bag with plastic spoons. Samples were taken to the laboratory, extraneous materials were removed; the samples were air-dried, crushed and ground to a fine powder in a mortar passed through a $0.20 \mathrm{~mm}$ sieve. The samples were kept for analysis.

\section{Isolation and purification of humic acid from peat soil sample}

Peatsoil sample $(100 \mathrm{~g})$ was mixed with 1000 $\mathrm{cm}^{3}$ of $0.1 \mathrm{M} \mathrm{NaOH}$ solution, shaken for 3hours and left to stand overnight. Dark-coloured supernatant was obtained and decanted from solid residue. The dark-coloured supernatant was acidified to $(\mathrm{pH}=1.0)$ with $6 \mathrm{M} \mathrm{HCl}$ stirred and allowed to stand for 6 hours. Yellowish brown supernatant and dark-brown precipitate were obtained. The yellowish brown supernatant was decanted followed by centrifuge and discarded. The dark-brown precipitate was mixed with $500 \mathrm{~cm}^{3}$ of $0.1 \mathrm{M} \mathrm{NaOH}$ solution followed by passing through dowex resin. The dark-brown solution was acidified to $(\mathrm{pH}=1.0)$ with $6 \mathrm{M} \mathrm{HCl}$ stirred and allowed to stand for 3 hours. The dark-brown precipitate was washed several times with deionized water. The supernatant was treated with $\mathrm{AgNO}_{3}$ solution until no white precipitate observed. The humic acid was transferred to weighed crucible and dried at $60^{\circ} \mathrm{C}$ in an oven for 12 hours. The humic acid was cooled and dried in the desiccator, weighed and recorded. The obtained humic acid was dried again at $60^{\circ} \mathrm{C}$ for additional 6 hours cooled and dried in the desiccator, weighed and recorded constant weight was obtained (Baruah et al., 2015).

\section{FT-IR analysis}

FT-IR spectra of humic acid sample was analysed using Carry 630 FT-IR Agilent Technologies.

Unhydrolysed compost humic acid

The unhydrolysed humic acid was obtained after isolation and purification of compost humic acid and kept for investigation.

\section{Acid hydrolysis of Peatsoil acid}

Peatsoil humic acid sample (1g) was refluxed for 12 hours at $\left(160^{\circ} \mathrm{C}\right)$ with $50 \mathrm{~cm}^{3}$ of $6 \mathrm{M} \mathrm{HCl}$. The mixture was allowed to cool, decanted, and centrifuged after hydrolysis. The insoluble residues were washed with distilled water via centrifugation several times, and the supernatant was treated with $\mathrm{AgNO}_{3}$ solution until no white precipitate was observed. The residue was thoroughly dried over $\mathrm{CaCl}_{2}$ in a desiccator at room temperature (Chefetz et al., 2002). Finally, the obtained hydrolysed humic acid was kept for investigation. 
BAJOPAS Volume 14 Number 1,June, 2021 Potentiometric Titrations

Potentiometric measurements were carried out using a pH-meter Jenway (model 3510) with combine electrode, the sensitivity of the $\mathrm{pH}$ meter is 0.01 units. The $\mathrm{pH}$ meter was switched on half an hour before starting the titration for initial warm up of the instrument. The instrument was calibrated with an aqueous standard buffer solution of $\mathrm{pH} 4.00$ and 10.0 (borate buffer) prepared from a "Qualigens" buffer tablets.

The following sets of solutions were prepared in a $250 \mathrm{~cm}^{3}$ volumetric flask separately for $\mathrm{pH}$ metric titrations.

(i) $5 \mathrm{~cm}^{3} 0.1 \mathrm{M} \mathrm{HCl}+40 \mathrm{~cm}^{3}$ deionized water

(ii) $5 \mathrm{~cm}^{3} 0.1 \mathrm{M} \mathrm{HCl}+39 \mathrm{~cm}^{3}$ deionized water $+1 \mathrm{~cm}^{3} 0.15 \mathrm{gcm}^{-3}$ humic acid

(iii) $5 \mathrm{~cm}^{3} 0.1 \mathrm{M} \mathrm{HCl}+37 \mathrm{~cm}^{3}$ deionized water $+1 \mathrm{~cm}^{3} 0.15 \mathrm{gcm}^{-3}$ humic acid

$$
+2 \mathrm{~cm}^{3} \quad 0.01 \mathrm{M} \mathrm{Cu} \text { (II) }
$$

The solutions were titrated against standardized $0.110 \mathrm{MNaOH}$ separately. The total volume of each mixture was adjusted to $50 \mathrm{~cm}^{3}$ and the ionic strength of the solutions was maintained constant at by adding appropriate amount of stock solution of $1 \mathrm{M} \mathrm{KNO}_{3}$ (Gamal, 2015; Omar and Ali, 2015). A magnetic stirrer was used to achieve thorough mixing of the interacting solutions at $550 \mathrm{rpm}$. The same set of experimental conditions was applied for potentiometric titration of remaining samples.

\section{Evaluation of pKa of Hydrolysed peat soil Humic Acids}

The proton-ligand formation number $\mathrm{n}_{\mathbf{A}}$ were calculated by Irving and Rossotti expression (Omar and Ali, 2015).

$\mathrm{nA}=\mathrm{Y}-\frac{(\mathrm{V} 2-\mathrm{V1})(\mathrm{No}-\mathrm{Eo})}{(\mathrm{VO}+\mathrm{V1}) \mathrm{TCL}}$ 1

Where: $Y$ is number of dissociable proton, $\left(\mathrm{V}_{2^{-}}\right.$ $V_{1}$ ) is the measure of displacement of the ligand curve relative to acid curve, $\mathrm{N}^{\circ}$ and $\mathrm{E}^{\circ}$ are the resultant concentration of alkali solution, free acid solution, $\mathrm{T}_{\mathrm{cL}}{ }^{\circ}$ is the total ligand concentration, $\mathrm{V}^{\circ}$ is the total volume of titration solution, $V_{1}$ is the volume of alkali added to acid solution, $V_{2}$ is the volume of alkali added to acid solution + ligand solution, acid dissociation constants (pKa - values) of ligand were calculated by algebraic method point wise calculation (Tables 1 ). The dissociation constants (pKa) were calculated according to the following relation:

$\mathrm{pKa}=\mathrm{pH}+\log \left(\frac{n A}{1-n A}\right)$ 2

Where: pKa is the acid dissociation constant, $\mathrm{n}_{\mathrm{A}}$ is the Proton-ligand formation number and $\mathrm{pH}$ is the pH-values (Omar and Ali, 2015).

\section{Determination of metal-ligand stability constants $(\log K)$ of complexes}

The potentiometric measurement for the determination of stability constant of a complex in solution is based on the fact that the redox potential of the couple $\frac{M^{+(m-n)}}{M^{+m}}$ is shifted significantly on complexation of the metal ion with the ligand. This method involves change in hydrogen ion concentration $\left[\mathrm{H}^{+}\right]$due to the displacement or association of one or more protons taking place during complexation reaction. This change can be found out by titrating the solutions containing free acid, acid with ligand, and acid with ligand and metal ion, individually against a standard alkali solution at a constant ionic strength or temperature. Either ionic strength or temperature may be varied for different sets of solutions. In all the cases, the change in the $\mathrm{pH}$ of the solution is measured after each addition of a known amount of alkali to the reaction cell which contains the reaction mixture. The titration curves are then drawn by plotting the measured $\mathrm{pH}$ values against the corresponding volume of alkali added and the stability constants of the complexes are determined from the titration curves by employing $\mathrm{pH}$-metric titration technique given by (Irving and Rossoti).

Metal-ligand stability constants ( $\log \mathrm{K}$ ) were determined by using the following relations:

$$
\bar{n}=\frac{\left(V_{3}-V_{2}\right)\left(E^{0}+N^{0}\right)}{\left(V^{0}+V_{2}\right) \bar{n}_{A} T_{m}^{0}}
$$

and

$$
P L=\log _{10}\left\{\frac{1+\beta_{n}^{H} \frac{1}{[\text { anti } \log \mathrm{pH}]^{\mathrm{n}}}}{\mathrm{T}_{\mathrm{L}}^{0}-n \bar{T}_{m}^{0}} \mathrm{X} \frac{\left(V^{0}+V_{3}\right)}{V^{0}}\right\}
$$


BAJOPAS Volume 14 Number 1,June, 2021

Where $T_{L}, T^{\circ}, E^{\circ}$, and $V^{\circ}$ havethe same significance as in equation (1) above, $T_{m}$ denotes the total concentration of metal present in solution, $V_{3}$ is the volume of metal ions present in solution and $\beta^{H}$ is the overall proton ligand stability constant. The metal-ligand stability constants (log K) were determined by employing point wise computational Method (eq. 5 and 6).

$\operatorname{LogK}_{1}=\log \left(\frac{n}{1-n}\right)+\mathrm{pL}$ .5

$\operatorname{LogK}_{2}=\log \left(\frac{1-n}{2-n}\right)+\mathrm{pL}$ ...6

Where: Log $\mathrm{K}$ is the metal-ligand stability constant, $\mathrm{pL}$ is the Free ligand exponent function, $\mathbf{n}$ is the Average number of ligand attached with metal ion (Janraoet al., 2014). The results obtained were analyzed by an ORIGIN 2016 program using titration data and then the proton-ligand stability constants (pKa) and Metal-ligand stability constant (LogK) calculated (Omar and Ali, 2015).

\section{RESULTS AND DISCUSSION}

Fourier transformed infrared (FT-IR) spectra of isolated humic acid from peat soils Figure 2 had distinct clear absorption bands indicating the presence of major humic acid structural elemental groups such as $\mathrm{H}$ bonded $\mathrm{OH}$ $\left(3680 \mathrm{~cm}^{-1}\right.$ peak $), C=0$ of carbonyl $\left(1721 \mathrm{~cm}^{-1}\right.$ peak), functional groups of aliphatic components $\mathrm{CH}_{2}\left(2918 \mathrm{~cm}^{-1}\right.$ peak) and $\mathrm{C}-\mathrm{O}$ stretching of polysaccharide $\left(1168 \mathrm{~cm}^{-1}\right.$ peak). The positions of the absorption bands of the spectra fell within typical major absorption bands of humic acid which is at frequencies 3680, 2918, 1721, 1168 $\mathrm{cm}^{-1}$. The first peak centred in the vicinity of $3680 \mathrm{~cm}^{-1}$ region is attributed to phenol $\mathrm{OH}$ group bounded by intermolecular $\mathrm{H}$ bonds. The $2918 \mathrm{~cm}^{-1}$ band usually has absorption maximum at $2918 \mathrm{~cm}^{-1}$ which is due to $\mathrm{C}-\mathrm{H}$ stretching of alkane group $\left(\mathrm{CH}_{2}\right)$. The next major absorption band is $1721 \mathrm{~cm}^{-1}$. This band has been commonly ascribed to $\mathrm{C}=\mathrm{O}$ stretching of mainly carboxyl group $(\mathrm{COOH})$ with trace amount of ketones. The last peak was observed at 1168 $\mathrm{cm}^{-1}$ due to $\mathrm{C}-\mathrm{O}$ stretching of polysaccharides and this peak appeared also in the spectra of humic acid from peat soil. The FTIR spectra of the isolated humic acid contained all major characteristic absorption peaks of humic acid. These absorption peaks indicated the presence of the major structural elements of humic acid namely $\mathrm{H}$ bonded $\mathrm{OH}, \mathrm{C}=\mathrm{C}$ of aromatic ring, $\mathrm{C}=\mathrm{O}$ of carbonyl group (both carboxyl and ketonic), $\mathrm{CH}_{2}$ group. This strongly supports the presence of humic acid.

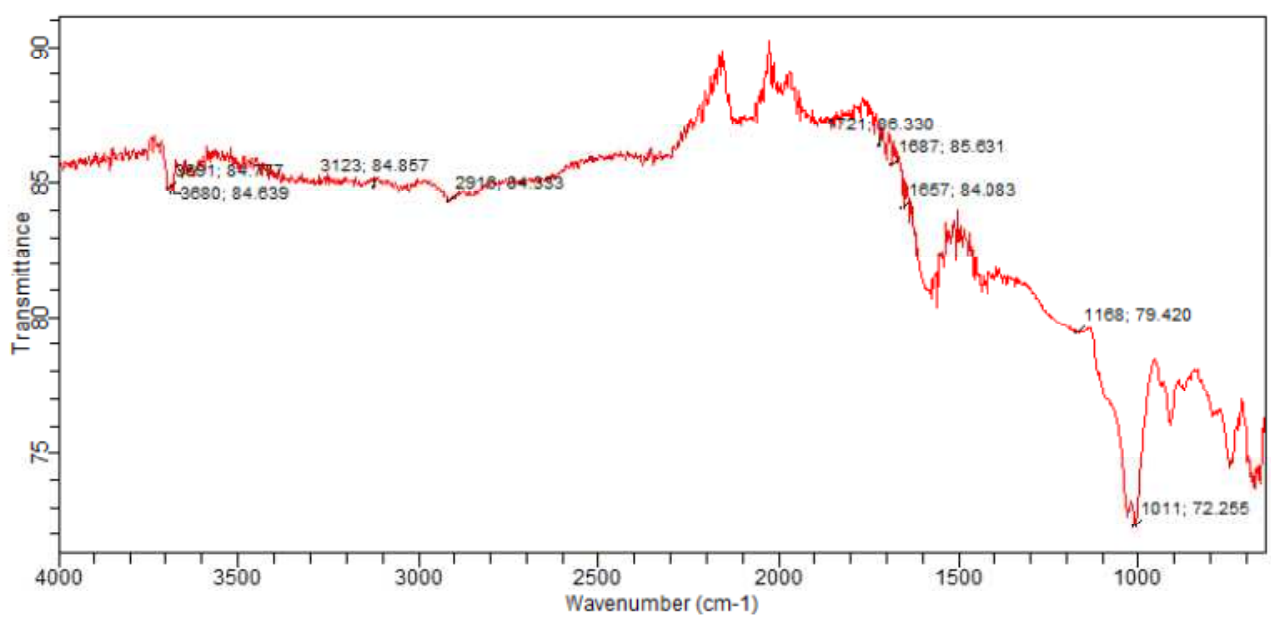

Fig. 2 : FT-IR spectraof peatsoilhumic acid (PSHA)

\section{Evaluation of acid dissociation constant (pka) of acid hydrolysed peat soil humicacid at phenolic group}

The value of the dissociation constant of the peat soil humic acid (PSHA) that underwent acidhydrolysis studied was found to be 8.9299 as shown Table 1, which is lower than the literaturevalues reported by Almeida and Szpoganics, (2015), Borges et al., (2005); Badr et al., (2012)and Fernandes et al,.(2009) of $9.73,9.47$ and 10.30. The difference between the obtained valuesand the reported values in this study might be probably as a result of acid hydrolysis of humicacid. 
BAJOPAS Volume 14 Number 1,June, 2021

Table 1: PKa of (Hydrolysed PSHA)

\begin{tabular}{|l|l|l|l|l|l|l|}
\hline $\mathrm{pH}$ & $\mathrm{BV}_{1}$ & $\mathrm{BV}_{2}$ & $\mathrm{~V}_{2}-\mathrm{V}_{1}$ & $\mathrm{nA}$ & $\log \left(\frac{n A}{1-n A}\right)$ & $\mathrm{pKa}$ \\
\hline 8.50 & 5.30 & 6.29 & 0.99 & 0.3594 & -0.2510 & 8.2490 \\
8.72 & 5.35 & 6.37 & 1.02 & 0.3400 & -0.2880 & 8.4320 \\
9.00 & 5.40 & 6.46 & 1.06 & 0.3141 & -0.3391 & 8.6609 \\
9.22 & 5.45 & 6.55 & 1.10 & 0.2882 & -0.3927 & 8.8273 \\
9.51 & 5.50 & 6.66 & 1.16 & 0.2494 & -0.4786 & 9.0314 \\
9.73 & 5.55 & 6.78 & 1.23 & 0.2041 & -0.5910 & 9.1390 \\
10.00 & 5.60 & 6.90 & 1.30 & 0.1589 & -0.7238 & 9.2762 \\
10.23 & 5.65 & 7.05 & 1.40 & 0.0941 & -0.9835 & 9.2465 \\
10.49 & 5.70 & 7.10 & 1.40 & 0.0941 & -0.9835 & 9.5065 \\
\hline
\end{tabular}

Average pKa $=8.9299 \pm 0.4186$

Table 2: PKa of (Unhydrolysed PSHA)

\begin{tabular}{|l|l|l|l|l|l|l|}
\hline $\mathrm{pH}$ & $\mathrm{BV}_{1}$ & $\mathrm{BV}_{2}$ & $\mathrm{~V}_{2}-\mathrm{V}_{1}$ & $\mathrm{nA}$ & $\log \left(\frac{\boldsymbol{n A}}{1-\boldsymbol{n}}\right)$ & $\mathrm{pKa}$ \\
\hline 8.50 & 5.30 & 5.81 & 0.51 & 0.6619 & 0.2919 & 8.7919 \\
8.72 & 5.35 & 5.90 & 0.55 & 0.6357 & 0.2418 & 8.9618 \\
9.00 & 5.40 & 6.00 & 0.60 & 0.6029 & 0.1813 & 9.1813 \\
9.22 & 5.45 & 6.10 & 0.65 & 0.5701 & 0.1226 & 9.3426 \\
9.51 & 5.50 & 6.20 & 0.70 & 0.5376 & 0.0654 & 9.5754 \\
9.73 & 5.55 & 6.33 & 0.78 & 0.4851 & -0.0259 & 9.7041 \\
10.00 & 5.60 & 6.47 & 0.87 & 0.4262 & -0.1291 & 9.8709 \\
10.23 & 5.65 & 6.62 & 0.99 & 0.3609 & -0.2481 & 9.9819 \\
10.49 & 5.70 & 6.80 & 1.10 & 0.2759 & -0.4690 & 10.0210 \\
\hline
\end{tabular}

Average pKa $=9.4923 \pm 0.4410$

Metal-ligand stability constant ( $\log \mathrm{K}$ )

The stabilityconstants require the accurate values of proton-ligand stability constants (Anil and Maroti, 2008). Metal titration curves crossed over ligand titration curve indicated the formation of complex upon proton release (Santosh, et al., 2011). If the values of n- are within range $0.2-0.8$ and $1.2-18$ this indicates the formation of $1: 1$ and 1:2 complexes (Sayyed and Mazahar, 2012).

The metal (II)-humate stepwise stability constants (log k) at phenolic group (Tables 318)

Table 3: Point-wise method, $\mathrm{Cu}$-(Hydrolysed PSHA)

\begin{tabular}{|l|l|l|l|l|l|l|l|l|}
\hline $\mathrm{pH}$ & $\mathrm{BV}_{1}$ & $\mathrm{BV}_{2}$ & $\mathrm{BV}_{3}$ & $\left(\mathrm{~V}_{3}-\mathrm{V}_{2}\right)$ & $\mathrm{n}$ & $\mathrm{pL}$ & $\log \left(\frac{n}{1-n}\right)$ & LogK $_{1}$ \\
\hline 8.50 & 5.30 & 6.29 & 6.33 & 0.04 & 0.5500 & 2.66 & 0.0871 & 2.7471 \\
8.72 & 5.35 & 6.37 & 6.41 & 0.04 & 0.5714 & 2.43 & 0.1249 & 2.5549 \\
9.00 & 5.40 & 6.46 & 6.50 & 0.04 & 0.6198 & 2.16 & 0.2122 & 2.3722 \\
9.22 & 5.45 & 6.55 & 6.59 & 0.04 & 0.6667 & 1.94 & 0.3010 & 2.2410 \\
\hline
\end{tabular}

LogK $_{1}$ (Average value) $=2.4788 \pm 0.2203$

Table 4: Point-wise method, $\mathrm{Cu}$-(Hydrolysed PSHA)

\begin{tabular}{|l|l|l|l|l|l|l|l|l|}
\hline $\mathrm{pH}$ & $\mathrm{BV}_{1}$ & $\mathrm{BV}_{2}$ & $\mathrm{BV}_{3}$ & $\left(\mathrm{~V}_{3}-\mathrm{V}_{2}\right)$ & $\mathrm{n}$ & $\mathrm{pL}$ & $\log \left(\frac{n-1}{2-n}\right)$ & LogK $_{2}$ \\
\hline 9.51 & 5.50 & 6.66 & 6.73 & 0.07 & 1.3509 & 1.70 & -0.2671 & 1.4329 \\
9.73 & 5.55 & 6.78 & 6.85 & 0.07 & 1.6383 & 1.51 & 0.2467 & 1.7567 \\
10.00 & 5.60 & 6.90 & 6.98 & 0.08 & 2.1783 & 1.31 & -0.2158 & 1.0942 \\
10.23 & 5.65 & 7.05 & 7.13 & 0.08 & 4.1904 & 1.27 & & \\
10.49 & 5.70 & 7.10 & 7.19 & 0.09 & 4.6920 & & & \\
\hline
\end{tabular}

Log $K_{2}($ Average value $)=1.4280 \pm 0.3312$ 
BAJOPAS Volume 14 Number 1,June, 2021

Table 5: Point-wise method, $\mathrm{Cu}$ (Unhydrolysed PSHA)

\begin{tabular}{|l|l|l|l|l|l|l|l|l|}
\hline $\mathrm{pH}$ & $\mathrm{BV}_{1}$ & $\mathrm{BV}_{2}$ & $\mathrm{BV}_{3}$ & $\left(\mathrm{~V}_{3}-\mathrm{V}_{2}\right)$ & $\mathrm{n}$ & $\mathrm{pL}$ & $\log \left(\frac{n}{n-1}\right)$ & Log $_{1}$ \\
\hline 8.50 & 5.30 & 5.81 & 5.85 & 0.04 & 0.2973 & 2.88 & -0.3736 & 2.5064 \\
8.72 & 5.35 & 5.90 & 5.95 & 0.05 & 0.3873 & 2.66 & -0.1992 & 2.4608 \\
9.00 & 5.40 & 6.00 & 6.05 & 0.05 & 0.4044 & 2.38 & -0.1681 & 2.2119 \\
9.22 & 5.45 & 6.10 & 6.15 & 0.06 & 0.5157 & 2.18 & -0.0272 & 2.2072 \\
9.51 & 5.50 & 6.20 & 6.27 & 0.07 & 0.6417 & 1.89 & 0.2530 & 1.1430 \\
\hline
\end{tabular}

$\operatorname{LogK}_{1}($ Average value $)=2.3059 \pm 0.6153$

Table 6:Point-wise method, $\mathrm{Cu}$ (Unhydrolysed PSHA)

\begin{tabular}{|l|l|l|l|l|l|l|l|l|}
\hline $\mathrm{pH}$ & $\mathrm{BV}_{1}$ & $\mathrm{BV}_{2}$ & $\mathrm{BV}_{3}$ & $\mathrm{~V}_{3}-\mathrm{V}_{2}$ & $\mathrm{n}$ & $\mathrm{pL}$ & $\log \left(\frac{n-1}{2-n}\right)$ & $\log \mathrm{K}_{2}$ \\
\hline 9.73 & 5.55 & 6.33 & 6.42 & 0.09 & 0.9000 & 1.69 & & \\
10.00 & 5.60 & 6.47 & 6.58 & 0.11 & 1.2578 & 1.44 & -0.4592 & 0.9808 \\
10.23 & 5.65 & 6.62 & 6.84 & 0.12 & 1.6137 & 1.26 & -0.2010 & 1.4610 \\
10.49 & 5.70 & 6.80 & 6.92 & 0.12 & 2.1052 & 1.03 & & \\
\hline
\end{tabular}

$\operatorname{LogK}_{2}$ (Average value) $=1.2209 \pm 0.3398$

Table 7:Point-wise method, Pb (Hydrolysed PSHA)

\begin{tabular}{|l|l|l|l|l|l|l|l|l|}
\hline $\mathrm{pH}$ & $\mathrm{BV}_{1}$ & $\mathrm{BV}_{2}$ & $\mathrm{BV}_{3}$ & $\left(\mathrm{~V}_{3}-\mathrm{V}_{2}\right)$ & $\mathrm{n}$ & $\mathrm{pL}$ & $\log \left(\frac{n}{1-n}\right)$ & LogK $_{1}$ \\
\hline 8.50 & 5.30 & 6.29 & 6.33 & 0.04 & 0.5500 & 2.66 & 0.0871 & 2.7471 \\
8.72 & 5.35 & 6.37 & 6.41 & 0.04 & 0.5714 & 2.43 & 0.1249 & 2.5549 \\
9.00 & 5.40 & 6.46 & 6.50 & 0.04 & 0.6198 & 2.16 & 0.2122 & 2.3722 \\
9.22 & 5.45 & 6.55 & 6.60 & 0.05 & 0.8333 & 1.96 & 0.6989 & 2.6589 \\
\hline
\end{tabular}

Log $_{\mathbf{1}}($ Average value $)=2.5832 \pm 0.1614$

Table 8:Point-wise method, Pb-(Hydrolysed PSHA)

\begin{tabular}{|l|l|l|l|l|l|l|l|l|}
\hline $\mathrm{pH}$ & $\mathrm{BV}_{1}$ & $\mathrm{BV}_{2}$ & $\mathrm{BV}_{3}$ & $\left(\mathrm{~V}_{3}-\mathrm{V}_{2}\right)$ & $\mathrm{n}$ & $\mathrm{pL}$ & $\log \left(\frac{n-1}{2-n}\right)$ & $\log \mathrm{K}_{2}$ \\
\hline 9.51 & 5.50 & 6.66 & 6.71 & 0.05 & 0.9650 & 1.67 & & \\
9.73 & 5.55 & 6.78 & 6.83 & 0.05 & 1.1702 & 1.44 & & \\
10.00 & 5.60 & 6.90 & 6.90 & 0.05 & 1.4864 & 1.22 & -0.0237 & 1.1963 \\
10.23 & 5.65 & 7.05 & 7.10 & 0.05 & 2.0190 & 1.09 & & \\
10.49 & 5.70 & 7.10 & 7.17 & 0.07 & 3.6492 & 1.00 & & \\
\hline
\end{tabular}

Log $K_{2}$ (Average value) $=1.1963$

Table 9: Point-wise method, Pb (Unhydrolysed PSHA)

\begin{tabular}{|l|l|l|l|l|l|l|l|l|}
\hline $\mathrm{pH}$ & $\mathrm{BV}_{1}$ & $\mathrm{BV}_{2}$ & $\mathrm{BV}_{3}$ & $\mathrm{~V}_{3}-\mathrm{V}_{2}$ & $\mathrm{n}$ & $\mathrm{pL}$ & $\begin{array}{l}\text { Log } \\
\left(\frac{n}{n-1}\right)\end{array}$ & Log $\mathrm{K}_{1}$ \\
\hline 8.50 & 5.30 & 5.81 & 5.85 & 0.04 & 0.2973 & 2.88 & -0.3736 & 2.5064 \\
8.72 & 5.35 & 5.90 & 5.94 & 0.04 & 0.3099 & 2.66 & -0.5477 & 2.3123 \\
9.00 & 5.40 & 6.00 & 6.05 & 0.05 & 0.4044 & 2.38 & -0.1681 & 2.2119 \\
9.22 & 5.45 & 6.10 & 6.15 & 0.06 & 0.5157 & 2.18 & 0.0272 & 2.2072 \\
9.51 & 5.50 & 6.20 & 6.26 & 0.07 & 0.6417 & 1.89 & 0.2530 & 2.1430 \\
9.73 & 5.55 & 6.40 & 6.40 & 0.07 & 0.7000 & 1.67 & 0.3680 & 2.0380 \\
\hline
\end{tabular}

LogK $_{1}$ (Average value) $=2.2364 \pm 0.1602$

Table 10: Point-wise method, Pb (Unhydrolysed PSHA)

\begin{tabular}{|l|l|l|l|l|l|l|l|l|}
\hline $\mathrm{pH}$ & $\mathrm{BV}_{1}$ & $\mathrm{BV}_{2}$ & $\mathrm{BV}_{3}$ & $\mathrm{~V}_{3}-\mathrm{V}_{2}$ & $\mathrm{n}$ & $\mathrm{pL}$ & $\log \left(\frac{n-1}{2-n}\right)$ & $\log \mathrm{K}_{2}$ \\
\hline 10.00 & 5.60 & 6.47 & 6.55 & 0.08 & 1.9503 & 1.41 & & \\
10.23 & 5.65 & 6.62 & 6.72 & 0.11 & 1.4792 & 1.26 & -0.0361 & 1.2239 \\
\hline
\end{tabular}

$\operatorname{LogK}_{2}$ (Average value) $=1.2239$

Table 11: Point-wise method, Mg (Hydrolysed PSHA)

\begin{tabular}{|l|l|l|l|l|l|l|l|l|}
\hline $\mathrm{pH}$ & $\mathrm{BV}_{1}$ & $\mathrm{BV}_{2}$ & $\mathrm{BV}_{3}$ & $\left(\mathrm{~V}_{3}-\mathrm{V}_{2}\right)$ & $\mathrm{n}$ & $\mathrm{pL}$ & $\log \left(\frac{n}{n-1}\right)$ & LogK $_{1}$ \\
\hline 8.50 & 5.30 & 6.29 & 6.31 & 0.02 & 0.2750 & 2.64 & -0.4290 & 2.2110 \\
8.72 & 5.35 & 6.37 & 6.39 & 0.02 & 0.2858 & 2.42 & -0.3978 & 2.0222 \\
9.00 & 5.40 & 6.46 & 6.49 & 0.03 & 0.4648 & 2.14 & -0.0612 & 2.0788 \\
9.22 & 5.45 & 6.55 & 6.59 & 0.04 & 0.6667 & 1.94 & 0.3010 & 2.2410 \\
\hline
\end{tabular}

$\log _{\mathbf{1}}($ Average value) $=2.1382 \pm 0.1046$ 
BAJOPAS Volume 14 Number 1,June, 2021

Table 12: Point-wise method, Mg (Hydrolysed PSHA)

\begin{tabular}{|l|l|l|l|l|l|l|l|l|}
\hline $\mathrm{pH}$ & $\mathrm{BV}_{1}$ & $\mathrm{BV}_{2}$ & $\mathrm{BV}_{3}$ & $\left(\mathrm{~V}_{3}-\mathrm{V}_{2}\right)$ & $\mathrm{n}$ & $\mathrm{pL}$ & $\log \left(\frac{n-1}{2-n}\right)$ & LogK $_{2}$ \\
\hline 9.51 & 5.55 & 6.66 & 6.71 & 0.05 & 0.9650 & 1.67 & & \\
9.73 & 5.55 & 6.78 & 6.84 & 0.06 & 1.4042 & 1.47 & -0.1686 & 1.3014 \\
10.00 & 5.60 & 6.90 & 6.93 & 0.06 & 1.7838 & 1.23 & 0.5593 & 1.7893 \\
10.23 & 5.65 & 7.05 & 7.10 & 0.06 & 3.1429 & 1.10 & & \\
10.49 & 5.70 & 7.10 & 7.18 & 0.07 & 3.6492 & 0.83 & & \\
\hline
\end{tabular}

LogK $_{2}($ Average value $)=1.5453 \pm 0.3450$

Table 13: Point-wise method, Mg (Unhydrolysed PSHA)

\begin{tabular}{|l|l|l|l|l|l|l|l|l|}
\hline $\mathrm{pH}$ & $\mathrm{BV}_{1}$ & $\mathrm{BV}_{2}$ & $\mathrm{BV}_{3}$ & $\mathrm{~V}_{3}-\mathrm{V}_{2}$ & $\mathrm{n}$ & $\mathrm{pL}$ & $\log \left(\frac{n}{n-1}\right)$ & $\operatorname{Log~}_{1}$ \\
\hline 8.50 & 5.30 & 5.81 & 5.85 & 0.04 & 0.2973 & 2.88 & -0.3736 & 2.5064 \\
8.72 & 5.35 & 5.90 & 5.94 & 0.04 & 0.3099 & 2.66 & -0.3477 & 2.3123 \\
9.00 & 5.40 & 6.00 & 6.04 & 0.04 & 0.3236 & 2.38 & -0.3202 & 2.0598 \\
9.22 & 5.45 & 6.10 & 6.15 & 0.05 & 0.4297 & 2.17 & -0.1230 & 2.0470 \\
9.51 & 5.50 & 6.20 & 6.26 & 0.06 & 0.5500 & 1.89 & 0.0871 & 1.9771 \\
9.73 & 5.55 & 6.33 & 6.40 & 0.07 & 0.7000 & 1.67 & 0.3680 & 2.0380 \\
\hline
\end{tabular}

LogK $_{1}$ (Average value) $=2.1568 \pm 0.2069$

Table 14: Point-wise method, Mg (Unhydrolysed PSHA)

\begin{tabular}{|l|l|l|l|l|l|l|l|l|}
\hline $\mathrm{pH}$ & $\mathrm{BV}_{1}$ & $\mathrm{BV}_{2}$ & $\mathrm{BV}_{3}$ & $\mathrm{~V}_{3}-\mathrm{V}_{2}$ & $\mathrm{n}$ & $\mathrm{pL}$ & $\log \left(\frac{n-1}{2-n}\right)$ & $\log \mathrm{K}_{2}$ \\
\hline 10.00 & 5.60 & 6.47 & 6.55 & 0.08 & 0.9148 & 1.41 & & \\
10.23 & 5.65 & 6.62 & 6.71 & 0.09 & 1.2102 & 1.20 & -0.5749 & 0.6251 \\
10.49 & 5.70 & 6.80 & 6.92 & 0.09 & 1.5968 & 1.03 & 0.1703 & 1.2003 \\
\hline
\end{tabular}

LogK $_{2}$ (Average value) $=0.9127 \pm 0.4070$

Table15:Point-wise method, Cd (Hydrolysed PSHA)

\begin{tabular}{|l|l|l|l|l|l|l|l|l|}
\hline $\mathrm{pH}$ & $\mathrm{BV}_{1}$ & $\mathrm{BV}_{2}$ & $\mathrm{BV}_{3}$ & $\left(\mathrm{~V}_{3}-\mathrm{V}_{2}\right)$ & $\mathrm{n}$ & $\mathrm{pL}$ & $\log \left(\frac{n}{1-n}\right)$ & LogK $_{1}$ \\
\hline 8.50 & 5.30 & 6.29 & 6.31 & 0.02 & 0.2750 & 2.64 & -0.4210 & 2.2190 \\
8.72 & 5.35 & 6.37 & 6.40 & 0.03 & 0.4286 & 2.42 & -0.1249 & 2.2951 \\
9.00 & 5.40 & 6.46 & 6.49 & 0.03 & 0.4648 & 2.14 & -0.0612 & 2.0788 \\
9.22 & 5.45 & 6.55 & 6.59 & 0.04 & 0.6667 & 1.96 & 0.3010 & 2.2610 \\
9.51 & 5.55 & 6.66 & 6.70 & 0.04 & 0.7720 & 1.67 & 0.5297 & 2.1997 \\
\hline
\end{tabular}

LogK $_{\mathbf{1}}$ (Average value) $=2.2108 \pm 0.0825$

Table 16: Point-wise method, Cd (Hydrolysed PSHA)

\begin{tabular}{|l|l|l|l|l|l|l|l|l|}
\hline $\mathrm{pH}$ & $\mathrm{BV}_{1}$ & $\mathrm{BV}_{2}$ & $\mathrm{BV}_{3}$ & $\left(\mathrm{~V}_{3}-\mathrm{V}_{2}\right)$ & $\mathrm{n}$ & $\mathrm{pL}$ & $\log \left(\frac{n-1}{2-n}\right)$ & Log $_{2}$ \\
\hline 9.73 & 5.55 & 6.78 & 6.83 & 0.06 & 1.4042 & 1.47 & -0.1686 & 1.3014 \\
10.00 & 5.60 & 6.90 & 6.95 & 0.06 & 1.7838 & 1.23 & 0.5593 & 1.7893 \\
10.23 & 5.65 & 7.05 & 7.10 & 0.06 & 3.1429 & 1.09 & & \\
10.49 & 5.70 & 7.10 & 7.16 & 0.06 & 3.1429 & 0.89 & & \\
& & & & & & & & \\
\hline
\end{tabular}

$\operatorname{LogK}_{2}$ (Average value) $=1.5453 \pm 0.3450$

Table 17: Point-wise method, Cd (Unhydrolysed PSHA)

\begin{tabular}{|l|l|l|l|l|l|l|l|l|}
\hline $\mathrm{pH}$ & $\mathrm{BV}_{1}$ & $\mathrm{BV}_{2}$ & $\mathrm{BV}_{3}$ & $\mathrm{~V}_{3}-\mathrm{V}_{2}$ & $\mathrm{n}$ & $\mathrm{pL}$ & $\log \left(\frac{n}{n-1}\right)$ & $\operatorname{Log~}_{1}$ \\
\hline 8.50 & 5.30 & 5.81 & 5.86 & 0.05 & 0.3717 & 2.88 & -0.2280 & 2.6520 \\
8.72 & 5.35 & 5.90 & 5.95 & 0.05 & 0.3873 & 2.66 & -0.1992 & 2.4608 \\
9.00 & 5.40 & 6.00 & 6.06 & 0.06 & 0.4853 & 2.38 & -0.0255 & 2.3545 \\
9.22 & 5.45 & 6.10 & 6.16 & 0.06 & 0.5157 & 2.18 & -0.0272 & 2.2072 \\
9.51 & 5.50 & 6.20 & 6.27 & 0.07 & 0.6417 & 1.89 & 0.2530 & 1.1430 \\
9.73 & 5.55 & 6.33 & 6.41 & 0.08 & 0.8000 & 1.69 & 0.6020 & 2.2920 \\
& & & & & & & & \\
\hline
\end{tabular}

$\operatorname{LogK}_{1}($ Average value $)=2.2516 \pm 0.5380$ 
BAJOPAS Volume 14 Number 1,June, 2021

Table 18: Point-wise method, Cd (Unhydrolysed PSHA)

\begin{tabular}{|l|l|l|l|l|l|l|l|l|}
\hline $\mathrm{pH}$ & $\mathrm{BV}_{1}$ & $\mathrm{BV}_{2}$ & $\mathrm{BV}_{3}$ & $\mathrm{~V}_{3}-\mathrm{V}_{2}$ & $\mathrm{n}$ & $\mathrm{pL}$ & $\log \left(\frac{n-1}{2-n}\right)$ & $\log \mathrm{K}_{2}$ \\
\hline 10.00 & 5.60 & 6.47 & 6.57 & 0.10 & 1.1434 & 1.43 & & \\
10.23 & 5.65 & 6.62 & 6.72 & 0.10 & 1.3448 & 1.23 & -0.2788 & 0.9512 \\
10.49 & 5.70 & 6.80 & 6.90 & 0.10 & 1.7742 & 1.03 & 0.5351 & 1.5651 \\
\hline
\end{tabular}

$\operatorname{LogK}_{2}($ Average value $)=1.2581 \pm 0.4340$

Table 19: Stepwise and overall Stability constants of thehydrolysed and unhydrolysed divalent metal (II) complexes

\begin{tabular}{|c|c|c|c|}
\hline Chelates & LogK $_{1}$ & $\log _{2}$ & Log $\beta$ \\
\hline [Cu (Hydrolysed PSHA-1) $\left.{ }_{2}\right]$ & 2.4788 & 1.4280 & 3.9068 \\
\hline$\left[\mathrm{Pb}(\text { Hydrolysed PSHA-1) })_{2}\right]$ & 2.5832 & 1.1963 & 3.7795 \\
\hline$\left[\mathrm{Cd}(\text { Hydrolysed PSHA-1 })_{2}\right]$ & 2.2108 & 1.5453 & 3.7561 \\
\hline$\left[\mathrm{Mg}(\text { Hydrolysed PSHA-1 })_{2}\right]$ & 2.1382 & 1.5453 & 3.6835 \\
\hline [Cu (Unhydrolysed PSHA-1) & 2.3059 & 1.2209 & 3.5268 \\
\hline$[\mathrm{Pb}$ (Unhydrolysed PSHA-1) 2$]$ & 2.2364 & 1.2239 & 3.4603 \\
\hline [Cd (Unhydrolysed PSHA-1) 2 ] & 2.2516 & 1.2581 & 3.5097 \\
\hline$[\mathrm{Mg}$ (Unydrolysed PSHA-1) & 2.1568 & 0.9127 & 3.0695 \\
\hline
\end{tabular}

The results obtained (Table19) shows the stepwise and overall stability constants to be not high indicating low stability of the complexes, because the solubility of most metal ions in the basic $\mathrm{pH}$ range is minimal due to metal hydroxide precipitation (Karimi, 2017). In general, the stepwise stability constants $\left(K_{1}\right.$ and $K_{2}$ ) follow the order $K_{1}>K_{2}$ for the copper, lead, magnesium and cadmium complexes respectively. The steady decrease of the values with increasing number of ligands is in agreement with the prediction made by researchers (Na'aliya, 2013). The decrease could be attributed to the fact that as the number of the ligands (Humate ions) that enters the coordination zone increases the aqua molecules available for replacement by the ligands become less. Thus, the metal ions become less electron loving with progressive intake of the ligand and this results in the decrease in the values of the constants (Na'aliya, 2013). Also the stability of the complexes is influenced by the size and number of the chelate rings(Mackay and Mackay,2002).All the complexes form rings in their structure as humate, a bidentate ligand, bond the metal ions in the ratio 1:2 (Boguta and Sokolowska, 2016) forming chelate rings. The values of the overall stability constants $(\log \beta)$ obtained for humate complexes are not high indicating low stability as the values are not high. LogK values for copper-humates (Table 3 to 6) obtained in this study are lower than those reported for the complexes of humic acids (Pandey et al., 2015; Dinu, 2013; Kaschl et al., 2010 and Gilbeto and Jorg, 2001). The values of LogK(Table 7 to 10 ) forlead-humates are lower than those reported for the lead in the literature (Dinu, 2013; Gilbeto and Jorg 2001). Log K values(Table 11 to 14 ) for magnesium-humates obtained in this study are close to those reported by (Pandey et al., 2015). Log K values of cadmium-humates (Table 15 to 18 ) obtained in this work near to the one reported by (Dinu, 2013 and Pandey et al., 2015).The difference between the reported values and the values obtained in this study might be probably as a result of acid hydrolysis of humic acid. The values of the overall stability constants $(\log \beta)$ of the copper humates complexes presented in Table 19 is high than that of other metal humate complexes, show relatively high stability of CuHA complexes, show the following order of stability: $\mathrm{Cu}>\mathrm{Pb}>\mathrm{Cd}>\mathrm{Mg}$; which are in close agreement to the findings of (Dinu, 2013 and Pandey et al., 2015).The high stability of Cuhumate chelate could be attributed to the existence of coordinate covalent bond between the complexing agents and the $\mathrm{Cu}^{2+}$ ions. Since, $\mathrm{Cu}^{2+}$ being a metal of the transitional series with $3 d^{9}$ electronic configurations can accept the electrons from the complexing agents. Similarly, the low stabilities of $\mathrm{Pb}, \mathrm{Cd}$ and $\mathrm{Mg}$ complexes could be explained by that $\mathrm{Pb}^{2+}$ with $6 s^{2}, \mathrm{Cd}^{2+}$ with $4 \mathrm{~d}^{10}$ and $\mathrm{Mg}^{2+}$ with $2 \mathrm{p}^{6}$ their electronic configuration has a completely filled $\mathrm{d}, \mathrm{p}$ and $\mathrm{s}$ orbitals. Moreover, the stabilities of metal ions with hydrolysed humic acid from peat soil were higher than those with unhydrolysed humic acid from peat soil; which is ascribed to the high content of acidity in hydrolysed humic acid than unhydrolysed humic acid. 
BAJOPAS Volume 14 Number 1,June, 2021 CONCLUSION

The values of logk for $\mathrm{Cu}(\mathrm{II})$ hydrolysed humic acid complex was higher followed by $\mathrm{Pb}$ (II), $\mathrm{Cd}(\mathrm{II})$ and $\mathrm{Mg}$ (II) hydrolysed humic acid complexes as compared with metal(II) unhydrolysed humic acid complexes. This indicates acid hydrolysis of humic acid can

\section{REFERENCES}

Almeida, V.R. and Szpoganicz, B. (2015). Humic Acid Potentiometric Response Patterns:Out- of Equilibrium Properties and Species Distribution Modelling. Chemical. Biol. Technol. Agric. 2: 17.

Anđelković, T., Nikolić, R., Bojić, A.,Anđelković, D., and Nikolic G.,(2010). Binding of Cadmium to Soil Humic Acid as A Function of Carboxyl Group Content. Macedonian Journal of Chemistry and Chemical Engineering.29(2): 215-224.

Anil, B. N. and Maroti, N. (2008). Studies on Influence of Die-Lectric Constants on Complex Equilibria between Substituted Py-Razalines and Lanthanide Metal Ions pH-Metrically. Amer.-Euras. scient. Res. 3(2): 212-216.

Ashok, K., Pandey, S. P. and Misra, V (2000). Stability Constants of Metal-Humic Acid Complexes and its Role in Environmental Detoxification. Journal of Ecotoxicology and Environmental Safety. 47(2):157-200.

Badr, M. H., El-Halafawi, M. H. and Abd El-al Zeid, E. R. (2012). Comparison Between the Effect of Ionic Strength on Acidity and Dissociation Constants of Humic Acids Extracted from Sewage Sludge and Nile Water Hyacinth Composts.Global Journal of Environmental Research 6 (1): 36-43.

Baruah, M.K., Borah, D., Saikia, P.P., Paul, S., Sharma, T. (2015). Evaluation of pKa Values of Soil Humic Acids and their Complexation Properties. International Journal of Plant \& Soil Science 6(4) : 218-228.

Boguta, P. Sokolowska, Z. (2016). Interactions of $\mathrm{Zn}$ (II) Ions with Humic Acids Isolated from Various Types of Soils. Effect of $\mathrm{pH}, \mathrm{Zn}$ Concentrations and Humic Acids Chemical Properties. Journal of Geochemical Explaration 168. 119-126.

Borges, F., Guimaraes, C., Lima, L.F.C., Pinto, I. and Reis, S.(2005). Potentiometric Studies on the Complexation of Copper(II) by Phenolic Acids as Discrete Ligand Models of enhance the complexation behavior of humic acid with metal (II) ions. However, the higher values of $\log \beta$ for $\mathrm{Cu}(\mathrm{II}), \mathrm{Pb}(\mathrm{II}), \mathrm{Cd}(\mathrm{II})$ and $\mathrm{Mg}(\mathrm{II})$ hydrolysed humic acid complexes indicates more stable stepwise complexes formed as compared with $\mathrm{Cu}(\mathrm{II}), \mathrm{Pb}$ (II), $\mathrm{Cd}$ (II) and $\mathrm{Mg}(\mathrm{II})$ unhydrolysed humic acid complexes.

Humic Substances Talanta 66 (2005) 670-673.

Chefetz, B., Salloum, M. J., Deshmulkin, A. P. and Hatcher, P. (2002). Structural Components of Humic Acids as Determined by Chemical Modifications and Carbon-13 NMR, Pyrolysis, and Thermochemolysis- Gas Chromatography/Mass Spectrometry. Soil Science Society of American Journal Abstract Division S-2- Soil Chemistry66. 1159-1171.

Dinu, M. I. (2013). Metals Complexation with Humic Acids in Surface Water of Different Environ. Sci. Technol. 31(1): 1-17.

Fernandes, A.N., Giacomelli, C., Giovanela, M. Vaz, D.V. Szpoganicz, B. and Maria M. D. (2009). Potentiometric Acidity Determination in Humic Substances Influenced by Different Analytical Procedures.J. Braz. Chem. Soc. 20 (9):14.

Gamal, A. H. (2015). Stability Constants of Rhenium (V) Metal Complexes with Selected Drugs. Pyrex Journal of Research in Environmental Studies. 2(2): 006-014.

Janrao, D. M., Pathan, J., Kayande, D.D., and Mulla, J.J. (2014). An Over View of Potentiometric Determination of Stability Constants of Metal Complexes. Sci. Revs. Chem. Commun.: 4(1), 2014, 11-24.

Karimi, H. (2017). Effect of pH and Initial Pb(II) Concentration on the Lead Removal Efficiency from Waste Water Using $\mathrm{Ca}(\mathrm{OH})_{2}$. International Journal of Water and Waste Water Treatment 3.2

Kaschl, A. Romheld, V. and Chen, Y. (2010). Binding of Cadmium, Copper and Zinc to Humic Substances Originating from Municipal Solid Waste Compost. Israel Journal of Chemistry Vol. 42(1): 89-98.

Kostic, I. S., Tatjana, P, A., Nikolic, R. S., Cvetkovic, T. P., Pavlovic, D. D., Aleksandar, L.J. and Bojic, A. (2012). Comparative Study of Binding Strengths of Heavy Metals with Humic Acid. J.serb. Chem. Soc. 76(9) pp 1-20. 
BAJOPAS Volume 14 Number 1,June, 2021

Na'aliya, J. (2013). Determination of Stepwise Stability Constants and Gibbs free Energy Change of Trisprolina to Complexes of some Divalent Transition Metal ions. Bayero Journal of Pure and Applied Sciences 6(2): 112-114.

Omar, A. A. and Ali, E. A. (2015). Potentiometric Studies on Complexes of $\mathrm{Cr}$ (III) and $\mathrm{Zr}$ (IV) with some Carboxylic Acids. International Journal of Advanced Chemistry, 3(1) 25-

37.

Pandey, A. K. Pandey, S. D. and Misr, V. (2015).Stability Constants of Metal- Humic Acid Complexes and Its Role in Environmental Detoxification. J. Ecotoxicology and Environmental Safety. 47(1):195-200.

Ram, N. and Raman, K.V. (1984). Stability Constants of Complexes of Metals with
Humicand Fuvic Acids under Non- acidConditions. Journal of Plant Nutrition and Soil Sciences.

147:171-176.

Santosh, D. D., Ashok, B. K., Vijay, J. T., Shivraj, G. W. and Vinay, V. W. (2011). Potentiometric Studies of Elec-Trolyte Effects on Complex Equilibria of Some Substituted 5-(2-hydroxy Phenyl) Pyrazoles. Der pharm. 3 (6): 75-83.

Sayyed, H. and Abdul Rahim, M. F. (2012). Studies of Binary Complexes of Metal Ions with Mandelic Acid by Potentiometry. Chem. J. 02 (6): 206209.

Shirvani, M. Moradian, E. Khalili, B. Bakhtiary, S. (2015). Interaction of $\mathrm{Cd}$ and $\mathrm{Pb}$ with Humate-Palygorskite and HumateSepiolite Complexes. Journal of water, air and pollution 3: 220-228. 


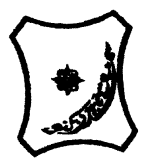

Bayero Journal of Pure and Applied Sciences, 14(1): 54 - 63

Received: November, 2020

Accepted: April, 2021

ISSN $2006-6996$

\title{
STABILITY CONSTANTS OF COMPLEXES OF METAL IONS WITH PEATSOIL HUMIC ACIDS UNDER NON-ACID-CONDITIONS
}

\author{
${ }^{* 1}$ Sabo, Yusuf ${ }^{2}$ Jimoh, W.L.O., ${ }^{3}$ Isa Baba Koki and ${ }^{4}$ Sholadoye, Q. 0. \\ ${ }^{1}$ Department of Pure and Industrial Chemistry, Bayero University, Kano \\ ${ }^{3}$ Department of Chemistry, Yusuf Maitama Sule University Kano. P.M.B. 3220 Kano, Nigeria. \\ ${ }^{4}$ Department of Chemistry, Nigerian Police Academy, Wudil, Kano-Nigeria
}

*Correspondence E-mail; saboyusuf18@yahoo.com

ABSTRACT

Stability constants of complexes of four divalent metal ions viz. $\mathrm{Cu}^{2+}, \mathrm{Pb}^{2+}, \mathrm{Mg}^{2+}$ and $\mathrm{Cd}^{2+}$ with humic acids (HA) were determined by potentiometric titration of humic acids with the corresponding salt of the divalent metals in aqueous media under non-acid-condition. The log $K$ (logarithm of the stability constant) ranged from 1.0942 to 2.7471 for metalhumic acid complexes were determined using point-wise computational method. The order of stability constants were obtained as follows: $\mathrm{Cu}>\mathrm{Pb}>\mathrm{Cd}>\mathrm{Mg}$ for metal $-\mathrm{HA}$ complexes respectively, indicating a higher degree of complexation with Cu metal ion.

Keywords: stability constant, humic acid, potentiometric titration, divalent metals, acid hydrolysis.

\section{NTRODUCTION}

The stability constant of a complex is the numerical expression of its stability and provides a quantitative measure of affinity of the metal ion to the complexing agent. An understanding of the relative stability of metal-complexes helps in predicting the behavior of metal ions in the soil (Ram and Raman, 1982). Extensive researches has been done to determine the stability constants of the complexes formed between humic acid (HA) with a number of metal ions. Ashok et al., (2000) reported that humic acid with hydroxyl, phenoxyl and carboxyl reactive groups can form coordination compound with metal ions at $\mathrm{pH}$ 3.5. The stability constants(Log K) for different metalhumic acid complexes indicated the following order of the stabilities of complexes formed between humic acid and metal ion, $\mathrm{Cu}>\mathrm{Fe}$ $>\mathrm{Pb}>\mathrm{Ni}>\mathrm{Co}>\mathrm{Ca}>\mathrm{Cd}>\mathrm{Zn}>\mathrm{Mn}>\mathrm{Mg}$. Andelkovic et al., (2010) investigated the binding of $\mathrm{Cd}$ (II) to soil humic acid at pH 6.5 and in $0.1 \mathrm{M} \mathrm{KNO}_{3}$ ionic medium. The stability constant for binding indicating greater stability in the case when carboxyl groups are involved in complexation reaction. Kostic et al.,(2012) investigated the complexation of humic acid with certain heavy metal ions (Co(II), $\mathrm{Ni}(\mathrm{II}), \mathrm{Cu}(\mathrm{II})$,
$\mathrm{Zn}(\mathrm{II})$, and $\mathrm{Pb}(\mathrm{II})$. The experiment was performed at $25^{\circ} \mathrm{C}$, at pH 4.0 and ionic strength of $0.01 \mathrm{M}$. Stability constant of complex between $\mathrm{Pb}$ (II) ions and humic acid is greater than stability constants of other investigated metalhumate complexes. Bogata and Sokolowska (2016) analyses the interaction between humic acids from different soils and $\mathrm{Zn}$ (II) ions at wide concentration ranges and at $\mathrm{pH} 5$. Studies have showed significant impact of $\mathrm{Zn}$ concentration, $\mathrm{pH}$ and some properties of humic acids with zinc.But all of these studies were limited to acidic $\mathrm{pH}$ range. Therefore, the present study was carried out to determine and compare the stability constants of complexes of metal ions with hydrolysed peat soil humic acid and unhydrolysed peat soil humic under non-acid conditions.

\section{MATERIALS AND METHODS}

Analytical grade chemicals used includes hydrochloric acid $(\mathrm{HCl})$, nitric acid $\left(\mathrm{HNO}_{3}\right)$, sodium hydroxide $(\mathrm{NaOH})$, lead nitrate $\mathrm{Pb}\left(\mathrm{NO}_{3}\right)_{2}$, copper nitrate $\mathrm{Cu}\left(\mathrm{NO}_{3}\right)_{2} \cdot 3 \mathrm{H}_{2} \mathrm{O}$, cadmium nitrate $\mathrm{Cd}\left(\mathrm{NO}_{3}\right)_{2} \cdot 4 \mathrm{H}_{2} \mathrm{O}$, magnesium nitrate $\mathrm{Mg}\left(\mathrm{NO}_{3}\right)_{2} \cdot 6 \mathrm{H}_{2} \mathrm{O}$, potassium nitrate $\left(\mathrm{KNO}_{3}\right)$, calcium chloride $\left(\mathrm{CaCl}_{2}\right)$, (sigma-Aldrich). Dowex 50WX8, (20-50 mesh) from Fluka. 


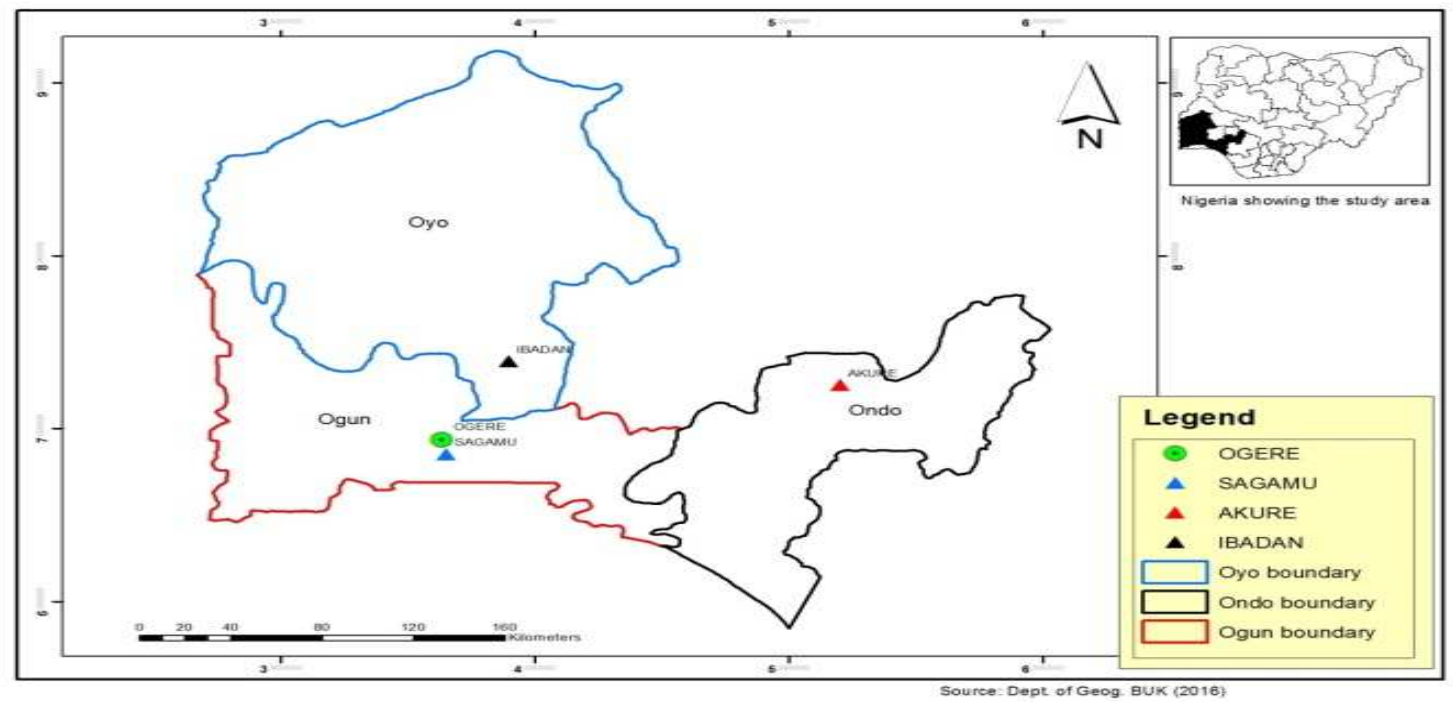

Figure 1: Map showing the sampling point at Sagamu Town, Ogun State.

\section{Description of Sampling Area}

Sagamu has geographical coordinates between $6^{\circ} 50^{\prime}$ north; $3^{\circ} 38^{\prime}$ east is located in south western region of Nigeria. The region has tropical wet and dry climate with a lengthy wet season and relatively constant temperatures throughout the course of the year. Wet season runs from March to October, November to December forms the region dry season. The vegetation type of the region is savannah which is really grassland with small bushes and occasional big trees. Grassland soils have substantially higher organic matter content than forest soils (Novackova, 2011).

\section{Sample Collection}

The Peatsoil samples were collected from four different sampling points $(0-10 \mathrm{~cm}$ depth) in Sagamu into polyethylene bag with plastic spoons. Samples were taken to the laboratory, extraneous materials were removed; the samples were air-dried, crushed and ground to a fine powder in a mortar passed through a $0.20 \mathrm{~mm}$ sieve. The samples were kept for analysis.

\section{Isolation and purification of humic acid from peat soil sample}

Peatsoil sample $(100 \mathrm{~g})$ was mixed with 1000 $\mathrm{cm}^{3}$ of $0.1 \mathrm{M} \mathrm{NaOH}$ solution, shaken for 3hours and left to stand overnight. Dark-coloured supernatant was obtained and decanted from solid residue. The dark-coloured supernatant was acidified to $(\mathrm{pH}=1.0)$ with $6 \mathrm{M} \mathrm{HCl}$ stirred and allowed to stand for 6 hours. Yellowish brown supernatant and dark-brown precipitate were obtained. The yellowish brown supernatant was decanted followed by centrifuge and discarded. The dark-brown precipitate was mixed with $500 \mathrm{~cm}^{3}$ of $0.1 \mathrm{M} \mathrm{NaOH}$ solution followed by passing through dowex resin. The dark-brown solution was acidified to $(\mathrm{pH}=1.0)$ with $6 \mathrm{M} \mathrm{HCl}$ stirred and allowed to stand for 3 hours. The dark-brown precipitate was washed several times with deionized water. The supernatant was treated with $\mathrm{AgNO}_{3}$ solution until no white precipitate observed. The humic acid was transferred to weighed crucible and dried at $60^{\circ} \mathrm{C}$ in an oven for 12 hours. The humic acid was cooled and dried in the desiccator, weighed and recorded. The obtained humic acid was dried again at $60^{\circ} \mathrm{C}$ for additional 6 hours cooled and dried in the desiccator, weighed and recorded constant weight was obtained (Baruah et al., 2015).

\section{FT-IR analysis}

FT-IR spectra of humic acid sample was analysed using Carry 630 FT-IR Agilent Technologies.

Unhydrolysed compost humic acid

The unhydrolysed humic acid was obtained after isolation and purification of compost humic acid and kept for investigation.

\section{Acid hydrolysis of Peatsoil acid}

Peatsoil humic acid sample (1g) was refluxed for 12 hours at $\left(160^{\circ} \mathrm{C}\right)$ with $50 \mathrm{~cm}^{3}$ of $6 \mathrm{M} \mathrm{HCl}$. The mixture was allowed to cool, decanted, and centrifuged after hydrolysis. The insoluble residues were washed with distilled water via centrifugation several times, and the supernatant was treated with $\mathrm{AgNO}_{3}$ solution until no white precipitate was observed. The residue was thoroughly dried over $\mathrm{CaCl}_{2}$ in a desiccator at room temperature (Chefetz et al., 2002). Finally, the obtained hydrolysed humic acid was kept for investigation. 
BAJOPAS Volume 14 Number 1,June, 2021 Potentiometric Titrations

Potentiometric measurements were carried out using a pH-meter Jenway (model 3510) with combine electrode, the sensitivity of the $\mathrm{pH}$ meter is 0.01 units. The $\mathrm{pH}$ meter was switched on half an hour before starting the titration for initial warm up of the instrument. The instrument was calibrated with an aqueous standard buffer solution of $\mathrm{pH} 4.00$ and 10.0 (borate buffer) prepared from a "Qualigens" buffer tablets.

The following sets of solutions were prepared in a $250 \mathrm{~cm}^{3}$ volumetric flask separately for $\mathrm{pH}$ metric titrations.

(i) $5 \mathrm{~cm}^{3} 0.1 \mathrm{M} \mathrm{HCl}+40 \mathrm{~cm}^{3}$ deionized water

(ii) $5 \mathrm{~cm}^{3} 0.1 \mathrm{M} \mathrm{HCl}+39 \mathrm{~cm}^{3}$ deionized water $+1 \mathrm{~cm}^{3} 0.15 \mathrm{gcm}^{-3}$ humic acid

(iii) $5 \mathrm{~cm}^{3} 0.1 \mathrm{M} \mathrm{HCl}+37 \mathrm{~cm}^{3}$ deionized water $+1 \mathrm{~cm}^{3} 0.15 \mathrm{gcm}^{-3}$ humic acid

$$
+2 \mathrm{~cm}^{3} \quad 0.01 \mathrm{M} \mathrm{Cu} \text { (II) }
$$

The solutions were titrated against standardized $0.110 \mathrm{MNaOH}$ separately. The total volume of each mixture was adjusted to $50 \mathrm{~cm}^{3}$ and the ionic strength of the solutions was maintained constant at by adding appropriate amount of stock solution of $1 \mathrm{M} \mathrm{KNO}_{3}$ (Gamal, 2015; Omar and Ali, 2015). A magnetic stirrer was used to achieve thorough mixing of the interacting solutions at $550 \mathrm{rpm}$. The same set of experimental conditions was applied for potentiometric titration of remaining samples.

\section{Evaluation of pKa of Hydrolysed peat soil Humic Acids}

The proton-ligand formation number $\mathrm{n}_{\mathbf{A}}$ were calculated by Irving and Rossotti expression (Omar and Ali, 2015).

$\mathrm{nA}=\mathrm{Y}-\frac{(\mathrm{V} 2-\mathrm{V1})(\mathrm{No}-\mathrm{Eo})}{(\mathrm{VO}+\mathrm{V1}) \mathrm{TCL}}$ 1

Where: $Y$ is number of dissociable proton, $\left(\mathrm{V}_{2^{-}}\right.$ $V_{1}$ ) is the measure of displacement of the ligand curve relative to acid curve, $\mathrm{N}^{\circ}$ and $\mathrm{E}^{\circ}$ are the resultant concentration of alkali solution, free acid solution, $\mathrm{T}_{\mathrm{cL}}{ }^{\circ}$ is the total ligand concentration, $\mathrm{V}^{\circ}$ is the total volume of titration solution, $V_{1}$ is the volume of alkali added to acid solution, $V_{2}$ is the volume of alkali added to acid solution + ligand solution, acid dissociation constants (pKa - values) of ligand were calculated by algebraic method point wise calculation (Tables 1 ). The dissociation constants (pKa) were calculated according to the following relation:

$\mathrm{pKa}=\mathrm{pH}+\log \left(\frac{n A}{1-n A}\right)$ 2

Where: pKa is the acid dissociation constant, $\mathrm{n}_{\mathrm{A}}$ is the Proton-ligand formation number and $\mathrm{pH}$ is the pH-values (Omar and Ali, 2015).

\section{Determination of metal-ligand stability constants $(\log K)$ of complexes}

The potentiometric measurement for the determination of stability constant of a complex in solution is based on the fact that the redox potential of the couple $\frac{M^{+(m-n)}}{M^{+m}}$ is shifted significantly on complexation of the metal ion with the ligand. This method involves change in hydrogen ion concentration $\left[\mathrm{H}^{+}\right]$due to the displacement or association of one or more protons taking place during complexation reaction. This change can be found out by titrating the solutions containing free acid, acid with ligand, and acid with ligand and metal ion, individually against a standard alkali solution at a constant ionic strength or temperature. Either ionic strength or temperature may be varied for different sets of solutions. In all the cases, the change in the $\mathrm{pH}$ of the solution is measured after each addition of a known amount of alkali to the reaction cell which contains the reaction mixture. The titration curves are then drawn by plotting the measured $\mathrm{pH}$ values against the corresponding volume of alkali added and the stability constants of the complexes are determined from the titration curves by employing $\mathrm{pH}$-metric titration technique given by (Irving and Rossoti).

Metal-ligand stability constants ( $\log \mathrm{K}$ ) were determined by using the following relations:

$$
\bar{n}=\frac{\left(V_{3}-V_{2}\right)\left(E^{0}+N^{0}\right)}{\left(V^{0}+V_{2}\right) \bar{n}_{A} T_{m}^{0}}
$$

and

$$
P L=\log _{10}\left\{\frac{1+\beta_{n}^{H} \frac{1}{[\text { anti } \log \mathrm{pH}]^{\mathrm{n}}}}{\mathrm{T}_{\mathrm{L}}^{0}-n \bar{T}_{m}^{0}} \mathrm{X} \frac{\left(V^{0}+V_{3}\right)}{V^{0}}\right\}
$$


BAJOPAS Volume 14 Number 1,June, 2021

Where $T_{L}, T^{\circ}, E^{\circ}$, and $V^{\circ}$ havethe same significance as in equation (1) above, $T_{m}$ denotes the total concentration of metal present in solution, $V_{3}$ is the volume of metal ions present in solution and $\beta^{H}$ is the overall proton ligand stability constant. The metal-ligand stability constants (log K) were determined by employing point wise computational Method (eq. 5 and 6).

$\operatorname{LogK}_{1}=\log \left(\frac{n}{1-n}\right)+\mathrm{pL}$ .5

$\operatorname{LogK}_{2}=\log \left(\frac{1-n}{2-n}\right)+\mathrm{pL}$ ...6

Where: Log $\mathrm{K}$ is the metal-ligand stability constant, $\mathrm{pL}$ is the Free ligand exponent function, $\mathbf{n}$ is the Average number of ligand attached with metal ion (Janraoet al., 2014). The results obtained were analyzed by an ORIGIN 2016 program using titration data and then the proton-ligand stability constants (pKa) and Metal-ligand stability constant (LogK) calculated (Omar and Ali, 2015).

\section{RESULTS AND DISCUSSION}

Fourier transformed infrared (FT-IR) spectra of isolated humic acid from peat soils Figure 2 had distinct clear absorption bands indicating the presence of major humic acid structural elemental groups such as $\mathrm{H}$ bonded $\mathrm{OH}$ $\left(3680 \mathrm{~cm}^{-1}\right.$ peak $), C=0$ of carbonyl $\left(1721 \mathrm{~cm}^{-1}\right.$ peak), functional groups of aliphatic components $\mathrm{CH}_{2}\left(2918 \mathrm{~cm}^{-1}\right.$ peak) and $\mathrm{C}-\mathrm{O}$ stretching of polysaccharide $\left(1168 \mathrm{~cm}^{-1}\right.$ peak). The positions of the absorption bands of the spectra fell within typical major absorption bands of humic acid which is at frequencies 3680, 2918, 1721, 1168 $\mathrm{cm}^{-1}$. The first peak centred in the vicinity of $3680 \mathrm{~cm}^{-1}$ region is attributed to phenol $\mathrm{OH}$ group bounded by intermolecular $\mathrm{H}$ bonds. The $2918 \mathrm{~cm}^{-1}$ band usually has absorption maximum at $2918 \mathrm{~cm}^{-1}$ which is due to $\mathrm{C}-\mathrm{H}$ stretching of alkane group $\left(\mathrm{CH}_{2}\right)$. The next major absorption band is $1721 \mathrm{~cm}^{-1}$. This band has been commonly ascribed to $\mathrm{C}=\mathrm{O}$ stretching of mainly carboxyl group $(\mathrm{COOH})$ with trace amount of ketones. The last peak was observed at 1168 $\mathrm{cm}^{-1}$ due to $\mathrm{C}-\mathrm{O}$ stretching of polysaccharides and this peak appeared also in the spectra of humic acid from peat soil. The FTIR spectra of the isolated humic acid contained all major characteristic absorption peaks of humic acid. These absorption peaks indicated the presence of the major structural elements of humic acid namely $\mathrm{H}$ bonded $\mathrm{OH}, \mathrm{C}=\mathrm{C}$ of aromatic ring, $\mathrm{C}=\mathrm{O}$ of carbonyl group (both carboxyl and ketonic), $\mathrm{CH}_{2}$ group. This strongly supports the presence of humic acid.

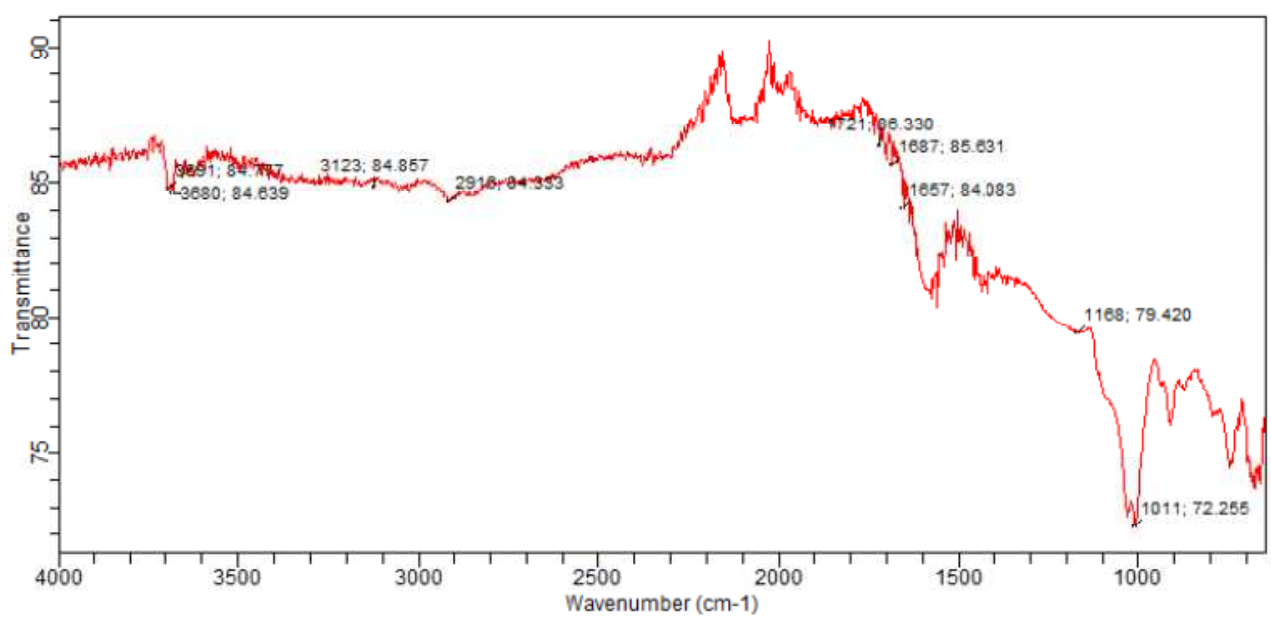

Fig. 2 : FT-IR spectraof peatsoilhumic acid (PSHA)

\section{Evaluation of acid dissociation constant (pka) of acid hydrolysed peat soil humicacid at phenolic group}

The value of the dissociation constant of the peat soil humic acid (PSHA) that underwent acidhydrolysis studied was found to be 8.9299 as shown Table 1, which is lower than the literaturevalues reported by Almeida and Szpoganics, (2015), Borges et al., (2005); Badr et al., (2012)and Fernandes et al,.(2009) of $9.73,9.47$ and 10.30. The difference between the obtained valuesand the reported values in this study might be probably as a result of acid hydrolysis of humicacid. 
BAJOPAS Volume 14 Number 1,June, 2021

Table 1: PKa of (Hydrolysed PSHA)

\begin{tabular}{|l|l|l|l|l|l|l|}
\hline $\mathrm{pH}$ & $\mathrm{BV}_{1}$ & $\mathrm{BV}_{2}$ & $\mathrm{~V}_{2}-\mathrm{V}_{1}$ & $\mathrm{nA}$ & $\log \left(\frac{n A}{1-n A}\right)$ & $\mathrm{pKa}$ \\
\hline 8.50 & 5.30 & 6.29 & 0.99 & 0.3594 & -0.2510 & 8.2490 \\
8.72 & 5.35 & 6.37 & 1.02 & 0.3400 & -0.2880 & 8.4320 \\
9.00 & 5.40 & 6.46 & 1.06 & 0.3141 & -0.3391 & 8.6609 \\
9.22 & 5.45 & 6.55 & 1.10 & 0.2882 & -0.3927 & 8.8273 \\
9.51 & 5.50 & 6.66 & 1.16 & 0.2494 & -0.4786 & 9.0314 \\
9.73 & 5.55 & 6.78 & 1.23 & 0.2041 & -0.5910 & 9.1390 \\
10.00 & 5.60 & 6.90 & 1.30 & 0.1589 & -0.7238 & 9.2762 \\
10.23 & 5.65 & 7.05 & 1.40 & 0.0941 & -0.9835 & 9.2465 \\
10.49 & 5.70 & 7.10 & 1.40 & 0.0941 & -0.9835 & 9.5065 \\
\hline
\end{tabular}

Average pKa $=8.9299 \pm 0.4186$

Table 2: PKa of (Unhydrolysed PSHA)

\begin{tabular}{|l|l|l|l|l|l|l|}
\hline $\mathrm{pH}$ & $\mathrm{BV}_{1}$ & $\mathrm{BV}_{2}$ & $\mathrm{~V}_{2}-\mathrm{V}_{1}$ & $\mathrm{nA}$ & $\log \left(\frac{\boldsymbol{n A}}{1-\boldsymbol{n}}\right)$ & $\mathrm{pKa}$ \\
\hline 8.50 & 5.30 & 5.81 & 0.51 & 0.6619 & 0.2919 & 8.7919 \\
8.72 & 5.35 & 5.90 & 0.55 & 0.6357 & 0.2418 & 8.9618 \\
9.00 & 5.40 & 6.00 & 0.60 & 0.6029 & 0.1813 & 9.1813 \\
9.22 & 5.45 & 6.10 & 0.65 & 0.5701 & 0.1226 & 9.3426 \\
9.51 & 5.50 & 6.20 & 0.70 & 0.5376 & 0.0654 & 9.5754 \\
9.73 & 5.55 & 6.33 & 0.78 & 0.4851 & -0.0259 & 9.7041 \\
10.00 & 5.60 & 6.47 & 0.87 & 0.4262 & -0.1291 & 9.8709 \\
10.23 & 5.65 & 6.62 & 0.99 & 0.3609 & -0.2481 & 9.9819 \\
10.49 & 5.70 & 6.80 & 1.10 & 0.2759 & -0.4690 & 10.0210 \\
\hline
\end{tabular}

Average pKa $=9.4923 \pm 0.4410$

Metal-ligand stability constant ( $\log \mathrm{K}$ )

The stabilityconstants require the accurate values of proton-ligand stability constants (Anil and Maroti, 2008). Metal titration curves crossed over ligand titration curve indicated the formation of complex upon proton release (Santosh, et al., 2011). If the values of n- are within range $0.2-0.8$ and $1.2-18$ this indicates the formation of $1: 1$ and 1:2 complexes (Sayyed and Mazahar, 2012).

The metal (II)-humate stepwise stability constants (log k) at phenolic group (Tables 318)

Table 3: Point-wise method, $\mathrm{Cu}$-(Hydrolysed PSHA)

\begin{tabular}{|l|l|l|l|l|l|l|l|l|}
\hline $\mathrm{pH}$ & $\mathrm{BV}_{1}$ & $\mathrm{BV}_{2}$ & $\mathrm{BV}_{3}$ & $\left(\mathrm{~V}_{3}-\mathrm{V}_{2}\right)$ & $\mathrm{n}$ & $\mathrm{pL}$ & $\log \left(\frac{n}{1-n}\right)$ & LogK $_{1}$ \\
\hline 8.50 & 5.30 & 6.29 & 6.33 & 0.04 & 0.5500 & 2.66 & 0.0871 & 2.7471 \\
8.72 & 5.35 & 6.37 & 6.41 & 0.04 & 0.5714 & 2.43 & 0.1249 & 2.5549 \\
9.00 & 5.40 & 6.46 & 6.50 & 0.04 & 0.6198 & 2.16 & 0.2122 & 2.3722 \\
9.22 & 5.45 & 6.55 & 6.59 & 0.04 & 0.6667 & 1.94 & 0.3010 & 2.2410 \\
\hline
\end{tabular}

LogK $_{1}$ (Average value) $=2.4788 \pm 0.2203$

Table 4: Point-wise method, $\mathrm{Cu}$-(Hydrolysed PSHA)

\begin{tabular}{|l|l|l|l|l|l|l|l|l|}
\hline $\mathrm{pH}$ & $\mathrm{BV}_{1}$ & $\mathrm{BV}_{2}$ & $\mathrm{BV}_{3}$ & $\left(\mathrm{~V}_{3}-\mathrm{V}_{2}\right)$ & $\mathrm{n}$ & $\mathrm{pL}$ & $\log \left(\frac{n-1}{2-n}\right)$ & LogK $_{2}$ \\
\hline 9.51 & 5.50 & 6.66 & 6.73 & 0.07 & 1.3509 & 1.70 & -0.2671 & 1.4329 \\
9.73 & 5.55 & 6.78 & 6.85 & 0.07 & 1.6383 & 1.51 & 0.2467 & 1.7567 \\
10.00 & 5.60 & 6.90 & 6.98 & 0.08 & 2.1783 & 1.31 & -0.2158 & 1.0942 \\
10.23 & 5.65 & 7.05 & 7.13 & 0.08 & 4.1904 & 1.27 & & \\
10.49 & 5.70 & 7.10 & 7.19 & 0.09 & 4.6920 & & & \\
\hline
\end{tabular}

Log $K_{2}($ Average value $)=1.4280 \pm 0.3312$ 
BAJOPAS Volume 14 Number 1,June, 2021

Table 5: Point-wise method, $\mathrm{Cu}$ (Unhydrolysed PSHA)

\begin{tabular}{|l|l|l|l|l|l|l|l|l|}
\hline $\mathrm{pH}$ & $\mathrm{BV}_{1}$ & $\mathrm{BV}_{2}$ & $\mathrm{BV}_{3}$ & $\left(\mathrm{~V}_{3}-\mathrm{V}_{2}\right)$ & $\mathrm{n}$ & $\mathrm{pL}$ & $\log \left(\frac{n}{n-1}\right)$ & Log $_{1}$ \\
\hline 8.50 & 5.30 & 5.81 & 5.85 & 0.04 & 0.2973 & 2.88 & -0.3736 & 2.5064 \\
8.72 & 5.35 & 5.90 & 5.95 & 0.05 & 0.3873 & 2.66 & -0.1992 & 2.4608 \\
9.00 & 5.40 & 6.00 & 6.05 & 0.05 & 0.4044 & 2.38 & -0.1681 & 2.2119 \\
9.22 & 5.45 & 6.10 & 6.15 & 0.06 & 0.5157 & 2.18 & -0.0272 & 2.2072 \\
9.51 & 5.50 & 6.20 & 6.27 & 0.07 & 0.6417 & 1.89 & 0.2530 & 1.1430 \\
\hline
\end{tabular}

$\operatorname{LogK}_{1}($ Average value $)=2.3059 \pm 0.6153$

Table 6:Point-wise method, $\mathrm{Cu}$ (Unhydrolysed PSHA)

\begin{tabular}{|l|l|l|l|l|l|l|l|l|}
\hline $\mathrm{pH}$ & $\mathrm{BV}_{1}$ & $\mathrm{BV}_{2}$ & $\mathrm{BV}_{3}$ & $\mathrm{~V}_{3}-\mathrm{V}_{2}$ & $\mathrm{n}$ & $\mathrm{pL}$ & $\log \left(\frac{n-1}{2-n}\right)$ & $\log \mathrm{K}_{2}$ \\
\hline 9.73 & 5.55 & 6.33 & 6.42 & 0.09 & 0.9000 & 1.69 & & \\
10.00 & 5.60 & 6.47 & 6.58 & 0.11 & 1.2578 & 1.44 & -0.4592 & 0.9808 \\
10.23 & 5.65 & 6.62 & 6.84 & 0.12 & 1.6137 & 1.26 & -0.2010 & 1.4610 \\
10.49 & 5.70 & 6.80 & 6.92 & 0.12 & 2.1052 & 1.03 & & \\
\hline
\end{tabular}

$\operatorname{LogK}_{2}$ (Average value) $=1.2209 \pm 0.3398$

Table 7:Point-wise method, Pb (Hydrolysed PSHA)

\begin{tabular}{|l|l|l|l|l|l|l|l|l|}
\hline $\mathrm{pH}$ & $\mathrm{BV}_{1}$ & $\mathrm{BV}_{2}$ & $\mathrm{BV}_{3}$ & $\left(\mathrm{~V}_{3}-\mathrm{V}_{2}\right)$ & $\mathrm{n}$ & $\mathrm{pL}$ & $\log \left(\frac{n}{1-n}\right)$ & LogK $_{1}$ \\
\hline 8.50 & 5.30 & 6.29 & 6.33 & 0.04 & 0.5500 & 2.66 & 0.0871 & 2.7471 \\
8.72 & 5.35 & 6.37 & 6.41 & 0.04 & 0.5714 & 2.43 & 0.1249 & 2.5549 \\
9.00 & 5.40 & 6.46 & 6.50 & 0.04 & 0.6198 & 2.16 & 0.2122 & 2.3722 \\
9.22 & 5.45 & 6.55 & 6.60 & 0.05 & 0.8333 & 1.96 & 0.6989 & 2.6589 \\
\hline
\end{tabular}

Log $_{\mathbf{1}}($ Average value $)=2.5832 \pm 0.1614$

Table 8:Point-wise method, Pb-(Hydrolysed PSHA)

\begin{tabular}{|l|l|l|l|l|l|l|l|l|}
\hline $\mathrm{pH}$ & $\mathrm{BV}_{1}$ & $\mathrm{BV}_{2}$ & $\mathrm{BV}_{3}$ & $\left(\mathrm{~V}_{3}-\mathrm{V}_{2}\right)$ & $\mathrm{n}$ & $\mathrm{pL}$ & $\log \left(\frac{n-1}{2-n}\right)$ & $\log \mathrm{K}_{2}$ \\
\hline 9.51 & 5.50 & 6.66 & 6.71 & 0.05 & 0.9650 & 1.67 & & \\
9.73 & 5.55 & 6.78 & 6.83 & 0.05 & 1.1702 & 1.44 & & \\
10.00 & 5.60 & 6.90 & 6.90 & 0.05 & 1.4864 & 1.22 & -0.0237 & 1.1963 \\
10.23 & 5.65 & 7.05 & 7.10 & 0.05 & 2.0190 & 1.09 & & \\
10.49 & 5.70 & 7.10 & 7.17 & 0.07 & 3.6492 & 1.00 & & \\
\hline
\end{tabular}

Log $K_{2}$ (Average value) $=1.1963$

Table 9: Point-wise method, Pb (Unhydrolysed PSHA)

\begin{tabular}{|l|l|l|l|l|l|l|l|l|}
\hline $\mathrm{pH}$ & $\mathrm{BV}_{1}$ & $\mathrm{BV}_{2}$ & $\mathrm{BV}_{3}$ & $\mathrm{~V}_{3}-\mathrm{V}_{2}$ & $\mathrm{n}$ & $\mathrm{pL}$ & $\begin{array}{l}\text { Log } \\
\left(\frac{n}{n-1}\right)\end{array}$ & Log $\mathrm{K}_{1}$ \\
\hline 8.50 & 5.30 & 5.81 & 5.85 & 0.04 & 0.2973 & 2.88 & -0.3736 & 2.5064 \\
8.72 & 5.35 & 5.90 & 5.94 & 0.04 & 0.3099 & 2.66 & -0.5477 & 2.3123 \\
9.00 & 5.40 & 6.00 & 6.05 & 0.05 & 0.4044 & 2.38 & -0.1681 & 2.2119 \\
9.22 & 5.45 & 6.10 & 6.15 & 0.06 & 0.5157 & 2.18 & 0.0272 & 2.2072 \\
9.51 & 5.50 & 6.20 & 6.26 & 0.07 & 0.6417 & 1.89 & 0.2530 & 2.1430 \\
9.73 & 5.55 & 6.40 & 6.40 & 0.07 & 0.7000 & 1.67 & 0.3680 & 2.0380 \\
\hline
\end{tabular}

LogK $_{1}$ (Average value) $=2.2364 \pm 0.1602$

Table 10: Point-wise method, Pb (Unhydrolysed PSHA)

\begin{tabular}{|l|l|l|l|l|l|l|l|l|}
\hline $\mathrm{pH}$ & $\mathrm{BV}_{1}$ & $\mathrm{BV}_{2}$ & $\mathrm{BV}_{3}$ & $\mathrm{~V}_{3}-\mathrm{V}_{2}$ & $\mathrm{n}$ & $\mathrm{pL}$ & $\log \left(\frac{n-1}{2-n}\right)$ & $\log \mathrm{K}_{2}$ \\
\hline 10.00 & 5.60 & 6.47 & 6.55 & 0.08 & 1.9503 & 1.41 & & \\
10.23 & 5.65 & 6.62 & 6.72 & 0.11 & 1.4792 & 1.26 & -0.0361 & 1.2239 \\
\hline
\end{tabular}

$\operatorname{LogK}_{2}$ (Average value) $=1.2239$

Table 11: Point-wise method, Mg (Hydrolysed PSHA)

\begin{tabular}{|l|l|l|l|l|l|l|l|l|}
\hline $\mathrm{pH}$ & $\mathrm{BV}_{1}$ & $\mathrm{BV}_{2}$ & $\mathrm{BV}_{3}$ & $\left(\mathrm{~V}_{3}-\mathrm{V}_{2}\right)$ & $\mathrm{n}$ & $\mathrm{pL}$ & $\log \left(\frac{n}{n-1}\right)$ & LogK $_{1}$ \\
\hline 8.50 & 5.30 & 6.29 & 6.31 & 0.02 & 0.2750 & 2.64 & -0.4290 & 2.2110 \\
8.72 & 5.35 & 6.37 & 6.39 & 0.02 & 0.2858 & 2.42 & -0.3978 & 2.0222 \\
9.00 & 5.40 & 6.46 & 6.49 & 0.03 & 0.4648 & 2.14 & -0.0612 & 2.0788 \\
9.22 & 5.45 & 6.55 & 6.59 & 0.04 & 0.6667 & 1.94 & 0.3010 & 2.2410 \\
\hline
\end{tabular}

$\log _{\mathbf{1}}($ Average value) $=2.1382 \pm 0.1046$ 
BAJOPAS Volume 14 Number 1,June, 2021

Table 12: Point-wise method, Mg (Hydrolysed PSHA)

\begin{tabular}{|l|l|l|l|l|l|l|l|l|}
\hline $\mathrm{pH}$ & $\mathrm{BV}_{1}$ & $\mathrm{BV}_{2}$ & $\mathrm{BV}_{3}$ & $\left(\mathrm{~V}_{3}-\mathrm{V}_{2}\right)$ & $\mathrm{n}$ & $\mathrm{pL}$ & $\log \left(\frac{n-1}{2-n}\right)$ & LogK $_{2}$ \\
\hline 9.51 & 5.55 & 6.66 & 6.71 & 0.05 & 0.9650 & 1.67 & & \\
9.73 & 5.55 & 6.78 & 6.84 & 0.06 & 1.4042 & 1.47 & -0.1686 & 1.3014 \\
10.00 & 5.60 & 6.90 & 6.93 & 0.06 & 1.7838 & 1.23 & 0.5593 & 1.7893 \\
10.23 & 5.65 & 7.05 & 7.10 & 0.06 & 3.1429 & 1.10 & & \\
10.49 & 5.70 & 7.10 & 7.18 & 0.07 & 3.6492 & 0.83 & & \\
\hline
\end{tabular}

LogK $_{2}($ Average value $)=1.5453 \pm 0.3450$

Table 13: Point-wise method, Mg (Unhydrolysed PSHA)

\begin{tabular}{|l|l|l|l|l|l|l|l|l|}
\hline $\mathrm{pH}$ & $\mathrm{BV}_{1}$ & $\mathrm{BV}_{2}$ & $\mathrm{BV}_{3}$ & $\mathrm{~V}_{3}-\mathrm{V}_{2}$ & $\mathrm{n}$ & $\mathrm{pL}$ & $\log \left(\frac{n}{n-1}\right)$ & $\operatorname{Log~}_{1}$ \\
\hline 8.50 & 5.30 & 5.81 & 5.85 & 0.04 & 0.2973 & 2.88 & -0.3736 & 2.5064 \\
8.72 & 5.35 & 5.90 & 5.94 & 0.04 & 0.3099 & 2.66 & -0.3477 & 2.3123 \\
9.00 & 5.40 & 6.00 & 6.04 & 0.04 & 0.3236 & 2.38 & -0.3202 & 2.0598 \\
9.22 & 5.45 & 6.10 & 6.15 & 0.05 & 0.4297 & 2.17 & -0.1230 & 2.0470 \\
9.51 & 5.50 & 6.20 & 6.26 & 0.06 & 0.5500 & 1.89 & 0.0871 & 1.9771 \\
9.73 & 5.55 & 6.33 & 6.40 & 0.07 & 0.7000 & 1.67 & 0.3680 & 2.0380 \\
\hline
\end{tabular}

LogK $_{1}$ (Average value) $=2.1568 \pm 0.2069$

Table 14: Point-wise method, Mg (Unhydrolysed PSHA)

\begin{tabular}{|l|l|l|l|l|l|l|l|l|}
\hline $\mathrm{pH}$ & $\mathrm{BV}_{1}$ & $\mathrm{BV}_{2}$ & $\mathrm{BV}_{3}$ & $\mathrm{~V}_{3}-\mathrm{V}_{2}$ & $\mathrm{n}$ & $\mathrm{pL}$ & $\log \left(\frac{n-1}{2-n}\right)$ & $\log \mathrm{K}_{2}$ \\
\hline 10.00 & 5.60 & 6.47 & 6.55 & 0.08 & 0.9148 & 1.41 & & \\
10.23 & 5.65 & 6.62 & 6.71 & 0.09 & 1.2102 & 1.20 & -0.5749 & 0.6251 \\
10.49 & 5.70 & 6.80 & 6.92 & 0.09 & 1.5968 & 1.03 & 0.1703 & 1.2003 \\
\hline
\end{tabular}

LogK $_{2}$ (Average value) $=0.9127 \pm 0.4070$

Table15:Point-wise method, Cd (Hydrolysed PSHA)

\begin{tabular}{|l|l|l|l|l|l|l|l|l|}
\hline $\mathrm{pH}$ & $\mathrm{BV}_{1}$ & $\mathrm{BV}_{2}$ & $\mathrm{BV}_{3}$ & $\left(\mathrm{~V}_{3}-\mathrm{V}_{2}\right)$ & $\mathrm{n}$ & $\mathrm{pL}$ & $\log \left(\frac{n}{1-n}\right)$ & LogK $_{1}$ \\
\hline 8.50 & 5.30 & 6.29 & 6.31 & 0.02 & 0.2750 & 2.64 & -0.4210 & 2.2190 \\
8.72 & 5.35 & 6.37 & 6.40 & 0.03 & 0.4286 & 2.42 & -0.1249 & 2.2951 \\
9.00 & 5.40 & 6.46 & 6.49 & 0.03 & 0.4648 & 2.14 & -0.0612 & 2.0788 \\
9.22 & 5.45 & 6.55 & 6.59 & 0.04 & 0.6667 & 1.96 & 0.3010 & 2.2610 \\
9.51 & 5.55 & 6.66 & 6.70 & 0.04 & 0.7720 & 1.67 & 0.5297 & 2.1997 \\
\hline
\end{tabular}

LogK $_{\mathbf{1}}$ (Average value) $=2.2108 \pm 0.0825$

Table 16: Point-wise method, Cd (Hydrolysed PSHA)

\begin{tabular}{|l|l|l|l|l|l|l|l|l|}
\hline $\mathrm{pH}$ & $\mathrm{BV}_{1}$ & $\mathrm{BV}_{2}$ & $\mathrm{BV}_{3}$ & $\left(\mathrm{~V}_{3}-\mathrm{V}_{2}\right)$ & $\mathrm{n}$ & $\mathrm{pL}$ & $\log \left(\frac{n-1}{2-n}\right)$ & Log $_{2}$ \\
\hline 9.73 & 5.55 & 6.78 & 6.83 & 0.06 & 1.4042 & 1.47 & -0.1686 & 1.3014 \\
10.00 & 5.60 & 6.90 & 6.95 & 0.06 & 1.7838 & 1.23 & 0.5593 & 1.7893 \\
10.23 & 5.65 & 7.05 & 7.10 & 0.06 & 3.1429 & 1.09 & & \\
10.49 & 5.70 & 7.10 & 7.16 & 0.06 & 3.1429 & 0.89 & & \\
& & & & & & & & \\
\hline
\end{tabular}

$\operatorname{LogK}_{2}$ (Average value) $=1.5453 \pm 0.3450$

Table 17: Point-wise method, Cd (Unhydrolysed PSHA)

\begin{tabular}{|l|l|l|l|l|l|l|l|l|}
\hline $\mathrm{pH}$ & $\mathrm{BV}_{1}$ & $\mathrm{BV}_{2}$ & $\mathrm{BV}_{3}$ & $\mathrm{~V}_{3}-\mathrm{V}_{2}$ & $\mathrm{n}$ & $\mathrm{pL}$ & $\log \left(\frac{n}{n-1}\right)$ & $\operatorname{Log~}_{1}$ \\
\hline 8.50 & 5.30 & 5.81 & 5.86 & 0.05 & 0.3717 & 2.88 & -0.2280 & 2.6520 \\
8.72 & 5.35 & 5.90 & 5.95 & 0.05 & 0.3873 & 2.66 & -0.1992 & 2.4608 \\
9.00 & 5.40 & 6.00 & 6.06 & 0.06 & 0.4853 & 2.38 & -0.0255 & 2.3545 \\
9.22 & 5.45 & 6.10 & 6.16 & 0.06 & 0.5157 & 2.18 & -0.0272 & 2.2072 \\
9.51 & 5.50 & 6.20 & 6.27 & 0.07 & 0.6417 & 1.89 & 0.2530 & 1.1430 \\
9.73 & 5.55 & 6.33 & 6.41 & 0.08 & 0.8000 & 1.69 & 0.6020 & 2.2920 \\
& & & & & & & & \\
\hline
\end{tabular}

$\operatorname{LogK}_{1}($ Average value $)=2.2516 \pm 0.5380$ 
BAJOPAS Volume 14 Number 1,June, 2021

Table 18: Point-wise method, Cd (Unhydrolysed PSHA)

\begin{tabular}{|l|l|l|l|l|l|l|l|l|}
\hline $\mathrm{pH}$ & $\mathrm{BV}_{1}$ & $\mathrm{BV}_{2}$ & $\mathrm{BV}_{3}$ & $\mathrm{~V}_{3}-\mathrm{V}_{2}$ & $\mathrm{n}$ & $\mathrm{pL}$ & $\log \left(\frac{n-1}{2-n}\right)$ & $\log \mathrm{K}_{2}$ \\
\hline 10.00 & 5.60 & 6.47 & 6.57 & 0.10 & 1.1434 & 1.43 & & \\
10.23 & 5.65 & 6.62 & 6.72 & 0.10 & 1.3448 & 1.23 & -0.2788 & 0.9512 \\
10.49 & 5.70 & 6.80 & 6.90 & 0.10 & 1.7742 & 1.03 & 0.5351 & 1.5651 \\
\hline
\end{tabular}

$\operatorname{LogK}_{2}($ Average value $)=1.2581 \pm 0.4340$

Table 19: Stepwise and overall Stability constants of thehydrolysed and unhydrolysed divalent metal (II) complexes

\begin{tabular}{|c|c|c|c|}
\hline Chelates & LogK $_{1}$ & $\log _{2}$ & Log $\beta$ \\
\hline [Cu (Hydrolysed PSHA-1) $\left.{ }_{2}\right]$ & 2.4788 & 1.4280 & 3.9068 \\
\hline$\left[\mathrm{Pb}(\text { Hydrolysed PSHA-1) })_{2}\right]$ & 2.5832 & 1.1963 & 3.7795 \\
\hline$\left[\mathrm{Cd}(\text { Hydrolysed PSHA-1 })_{2}\right]$ & 2.2108 & 1.5453 & 3.7561 \\
\hline$\left[\mathrm{Mg}(\text { Hydrolysed PSHA-1 })_{2}\right]$ & 2.1382 & 1.5453 & 3.6835 \\
\hline [Cu (Unhydrolysed PSHA-1) & 2.3059 & 1.2209 & 3.5268 \\
\hline$[\mathrm{Pb}$ (Unhydrolysed PSHA-1) 2$]$ & 2.2364 & 1.2239 & 3.4603 \\
\hline [Cd (Unhydrolysed PSHA-1) 2 ] & 2.2516 & 1.2581 & 3.5097 \\
\hline$[\mathrm{Mg}$ (Unydrolysed PSHA-1) & 2.1568 & 0.9127 & 3.0695 \\
\hline
\end{tabular}

The results obtained (Table19) shows the stepwise and overall stability constants to be not high indicating low stability of the complexes, because the solubility of most metal ions in the basic $\mathrm{pH}$ range is minimal due to metal hydroxide precipitation (Karimi, 2017). In general, the stepwise stability constants $\left(K_{1}\right.$ and $K_{2}$ ) follow the order $K_{1}>K_{2}$ for the copper, lead, magnesium and cadmium complexes respectively. The steady decrease of the values with increasing number of ligands is in agreement with the prediction made by researchers (Na'aliya, 2013). The decrease could be attributed to the fact that as the number of the ligands (Humate ions) that enters the coordination zone increases the aqua molecules available for replacement by the ligands become less. Thus, the metal ions become less electron loving with progressive intake of the ligand and this results in the decrease in the values of the constants (Na'aliya, 2013). Also the stability of the complexes is influenced by the size and number of the chelate rings(Mackay and Mackay,2002).All the complexes form rings in their structure as humate, a bidentate ligand, bond the metal ions in the ratio 1:2 (Boguta and Sokolowska, 2016) forming chelate rings. The values of the overall stability constants $(\log \beta)$ obtained for humate complexes are not high indicating low stability as the values are not high. LogK values for copper-humates (Table 3 to 6) obtained in this study are lower than those reported for the complexes of humic acids (Pandey et al., 2015; Dinu, 2013; Kaschl et al., 2010 and Gilbeto and Jorg, 2001). The values of LogK(Table 7 to 10 ) forlead-humates are lower than those reported for the lead in the literature (Dinu, 2013; Gilbeto and Jorg 2001). Log K values(Table 11 to 14 ) for magnesium-humates obtained in this study are close to those reported by (Pandey et al., 2015). Log K values of cadmium-humates (Table 15 to 18 ) obtained in this work near to the one reported by (Dinu, 2013 and Pandey et al., 2015).The difference between the reported values and the values obtained in this study might be probably as a result of acid hydrolysis of humic acid. The values of the overall stability constants $(\log \beta)$ of the copper humates complexes presented in Table 19 is high than that of other metal humate complexes, show relatively high stability of CuHA complexes, show the following order of stability: $\mathrm{Cu}>\mathrm{Pb}>\mathrm{Cd}>\mathrm{Mg}$; which are in close agreement to the findings of (Dinu, 2013 and Pandey et al., 2015).The high stability of Cuhumate chelate could be attributed to the existence of coordinate covalent bond between the complexing agents and the $\mathrm{Cu}^{2+}$ ions. Since, $\mathrm{Cu}^{2+}$ being a metal of the transitional series with $3 d^{9}$ electronic configurations can accept the electrons from the complexing agents. Similarly, the low stabilities of $\mathrm{Pb}, \mathrm{Cd}$ and $\mathrm{Mg}$ complexes could be explained by that $\mathrm{Pb}^{2+}$ with $6 s^{2}, \mathrm{Cd}^{2+}$ with $4 \mathrm{~d}^{10}$ and $\mathrm{Mg}^{2+}$ with $2 \mathrm{p}^{6}$ their electronic configuration has a completely filled $\mathrm{d}, \mathrm{p}$ and $\mathrm{s}$ orbitals. Moreover, the stabilities of metal ions with hydrolysed humic acid from peat soil were higher than those with unhydrolysed humic acid from peat soil; which is ascribed to the high content of acidity in hydrolysed humic acid than unhydrolysed humic acid. 
BAJOPAS Volume 14 Number 1,June, 2021 CONCLUSION

The values of logk for $\mathrm{Cu}(\mathrm{II})$ hydrolysed humic acid complex was higher followed by $\mathrm{Pb}$ (II), $\mathrm{Cd}(\mathrm{II})$ and $\mathrm{Mg}$ (II) hydrolysed humic acid complexes as compared with metal(II) unhydrolysed humic acid complexes. This indicates acid hydrolysis of humic acid can

\section{REFERENCES}

Almeida, V.R. and Szpoganicz, B. (2015). Humic Acid Potentiometric Response Patterns:Out- of Equilibrium Properties and Species Distribution Modelling. Chemical. Biol. Technol. Agric. 2: 17.

Anđelković, T., Nikolić, R., Bojić, A.,Anđelković, D., and Nikolic G.,(2010). Binding of Cadmium to Soil Humic Acid as A Function of Carboxyl Group Content. Macedonian Journal of Chemistry and Chemical Engineering.29(2): 215-224.

Anil, B. N. and Maroti, N. (2008). Studies on Influence of Die-Lectric Constants on Complex Equilibria between Substituted Py-Razalines and Lanthanide Metal Ions pH-Metrically. Amer.-Euras. scient. Res. 3(2): 212-216.

Ashok, K., Pandey, S. P. and Misra, V (2000). Stability Constants of Metal-Humic Acid Complexes and its Role in Environmental Detoxification. Journal of Ecotoxicology and Environmental Safety. 47(2):157-200.

Badr, M. H., El-Halafawi, M. H. and Abd El-al Zeid, E. R. (2012). Comparison Between the Effect of Ionic Strength on Acidity and Dissociation Constants of Humic Acids Extracted from Sewage Sludge and Nile Water Hyacinth Composts.Global Journal of Environmental Research 6 (1): 36-43.

Baruah, M.K., Borah, D., Saikia, P.P., Paul, S., Sharma, T. (2015). Evaluation of pKa Values of Soil Humic Acids and their Complexation Properties. International Journal of Plant \& Soil Science 6(4) : 218-228.

Boguta, P. Sokolowska, Z. (2016). Interactions of $\mathrm{Zn}$ (II) Ions with Humic Acids Isolated from Various Types of Soils. Effect of $\mathrm{pH}, \mathrm{Zn}$ Concentrations and Humic Acids Chemical Properties. Journal of Geochemical Explaration 168. 119-126.

Borges, F., Guimaraes, C., Lima, L.F.C., Pinto, I. and Reis, S.(2005). Potentiometric Studies on the Complexation of Copper(II) by Phenolic Acids as Discrete Ligand Models of enhance the complexation behavior of humic acid with metal (II) ions. However, the higher values of $\log \beta$ for $\mathrm{Cu}(\mathrm{II}), \mathrm{Pb}(\mathrm{II}), \mathrm{Cd}(\mathrm{II})$ and $\mathrm{Mg}(\mathrm{II})$ hydrolysed humic acid complexes indicates more stable stepwise complexes formed as compared with $\mathrm{Cu}(\mathrm{II}), \mathrm{Pb}$ (II), $\mathrm{Cd}$ (II) and $\mathrm{Mg}(\mathrm{II})$ unhydrolysed humic acid complexes.

Humic Substances Talanta 66 (2005) 670-673.

Chefetz, B., Salloum, M. J., Deshmulkin, A. P. and Hatcher, P. (2002). Structural Components of Humic Acids as Determined by Chemical Modifications and Carbon-13 NMR, Pyrolysis, and Thermochemolysis- Gas Chromatography/Mass Spectrometry. Soil Science Society of American Journal Abstract Division S-2- Soil Chemistry66. 1159-1171.

Dinu, M. I. (2013). Metals Complexation with Humic Acids in Surface Water of Different Environ. Sci. Technol. 31(1): 1-17.

Fernandes, A.N., Giacomelli, C., Giovanela, M. Vaz, D.V. Szpoganicz, B. and Maria M. D. (2009). Potentiometric Acidity Determination in Humic Substances Influenced by Different Analytical Procedures.J. Braz. Chem. Soc. 20 (9):14.

Gamal, A. H. (2015). Stability Constants of Rhenium (V) Metal Complexes with Selected Drugs. Pyrex Journal of Research in Environmental Studies. 2(2): 006-014.

Janrao, D. M., Pathan, J., Kayande, D.D., and Mulla, J.J. (2014). An Over View of Potentiometric Determination of Stability Constants of Metal Complexes. Sci. Revs. Chem. Commun.: 4(1), 2014, 11-24.

Karimi, H. (2017). Effect of pH and Initial Pb(II) Concentration on the Lead Removal Efficiency from Waste Water Using $\mathrm{Ca}(\mathrm{OH})_{2}$. International Journal of Water and Waste Water Treatment 3.2

Kaschl, A. Romheld, V. and Chen, Y. (2010). Binding of Cadmium, Copper and Zinc to Humic Substances Originating from Municipal Solid Waste Compost. Israel Journal of Chemistry Vol. 42(1): 89-98.

Kostic, I. S., Tatjana, P, A., Nikolic, R. S., Cvetkovic, T. P., Pavlovic, D. D., Aleksandar, L.J. and Bojic, A. (2012). Comparative Study of Binding Strengths of Heavy Metals with Humic Acid. J.serb. Chem. Soc. 76(9) pp 1-20. 
BAJOPAS Volume 14 Number 1,June, 2021

Na'aliya, J. (2013). Determination of Stepwise Stability Constants and Gibbs free Energy Change of Trisprolina to Complexes of some Divalent Transition Metal ions. Bayero Journal of Pure and Applied Sciences 6(2): 112-114.

Omar, A. A. and Ali, E. A. (2015). Potentiometric Studies on Complexes of $\mathrm{Cr}$ (III) and $\mathrm{Zr}$ (IV) with some Carboxylic Acids. International Journal of Advanced Chemistry, 3(1) 25-

37.

Pandey, A. K. Pandey, S. D. and Misr, V. (2015).Stability Constants of Metal- Humic Acid Complexes and Its Role in Environmental Detoxification. J. Ecotoxicology and Environmental Safety. 47(1):195-200.

Ram, N. and Raman, K.V. (1984). Stability Constants of Complexes of Metals with
Humicand Fuvic Acids under Non- acidConditions. Journal of Plant Nutrition and Soil Sciences.

147:171-176.

Santosh, D. D., Ashok, B. K., Vijay, J. T., Shivraj, G. W. and Vinay, V. W. (2011). Potentiometric Studies of Elec-Trolyte Effects on Complex Equilibria of Some Substituted 5-(2-hydroxy Phenyl) Pyrazoles. Der pharm. 3 (6): 75-83.

Sayyed, H. and Abdul Rahim, M. F. (2012). Studies of Binary Complexes of Metal Ions with Mandelic Acid by Potentiometry. Chem. J. 02 (6): 206209.

Shirvani, M. Moradian, E. Khalili, B. Bakhtiary, S. (2015). Interaction of $\mathrm{Cd}$ and $\mathrm{Pb}$ with Humate-Palygorskite and HumateSepiolite Complexes. Journal of water, air and pollution 3: 220-228. 


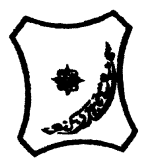

Bayero Journal of Pure and Applied Sciences, 14(1): 54 - 63

Received: November, 2020

Accepted: April, 2021

ISSN $2006-6996$

\title{
STABILITY CONSTANTS OF COMPLEXES OF METAL IONS WITH PEATSOIL HUMIC ACIDS UNDER NON-ACID-CONDITIONS
}

\author{
${ }^{* 1}$ Sabo, Yusuf ${ }^{2}$ Jimoh, W.L.O., ${ }^{3}$ Isa Baba Koki and ${ }^{4}$ Sholadoye, Q. 0. \\ ${ }^{1}$ Department of Pure and Industrial Chemistry, Bayero University, Kano \\ ${ }^{3}$ Department of Chemistry, Yusuf Maitama Sule University Kano. P.M.B. 3220 Kano, Nigeria. \\ ${ }^{4}$ Department of Chemistry, Nigerian Police Academy, Wudil, Kano-Nigeria
}

*Correspondence E-mail; saboyusuf18@yahoo.com

ABSTRACT

Stability constants of complexes of four divalent metal ions viz. $\mathrm{Cu}^{2+}, \mathrm{Pb}^{2+}, \mathrm{Mg}^{2+}$ and $\mathrm{Cd}^{2+}$ with humic acids (HA) were determined by potentiometric titration of humic acids with the corresponding salt of the divalent metals in aqueous media under non-acid-condition. The log $K$ (logarithm of the stability constant) ranged from 1.0942 to 2.7471 for metalhumic acid complexes were determined using point-wise computational method. The order of stability constants were obtained as follows: $\mathrm{Cu}>\mathrm{Pb}>\mathrm{Cd}>\mathrm{Mg}$ for metal $-\mathrm{HA}$ complexes respectively, indicating a higher degree of complexation with Cu metal ion.

Keywords: stability constant, humic acid, potentiometric titration, divalent metals, acid hydrolysis.

\section{NTRODUCTION}

The stability constant of a complex is the numerical expression of its stability and provides a quantitative measure of affinity of the metal ion to the complexing agent. An understanding of the relative stability of metal-complexes helps in predicting the behavior of metal ions in the soil (Ram and Raman, 1982). Extensive researches has been done to determine the stability constants of the complexes formed between humic acid (HA) with a number of metal ions. Ashok et al., (2000) reported that humic acid with hydroxyl, phenoxyl and carboxyl reactive groups can form coordination compound with metal ions at $\mathrm{pH}$ 3.5. The stability constants(Log K) for different metalhumic acid complexes indicated the following order of the stabilities of complexes formed between humic acid and metal ion, $\mathrm{Cu}>\mathrm{Fe}$ $>\mathrm{Pb}>\mathrm{Ni}>\mathrm{Co}>\mathrm{Ca}>\mathrm{Cd}>\mathrm{Zn}>\mathrm{Mn}>\mathrm{Mg}$. Andelkovic et al., (2010) investigated the binding of $\mathrm{Cd}$ (II) to soil humic acid at pH 6.5 and in $0.1 \mathrm{M} \mathrm{KNO}_{3}$ ionic medium. The stability constant for binding indicating greater stability in the case when carboxyl groups are involved in complexation reaction. Kostic et al.,(2012) investigated the complexation of humic acid with certain heavy metal ions (Co(II), $\mathrm{Ni}(\mathrm{II}), \mathrm{Cu}(\mathrm{II})$,
$\mathrm{Zn}(\mathrm{II})$, and $\mathrm{Pb}(\mathrm{II})$. The experiment was performed at $25^{\circ} \mathrm{C}$, at pH 4.0 and ionic strength of $0.01 \mathrm{M}$. Stability constant of complex between $\mathrm{Pb}$ (II) ions and humic acid is greater than stability constants of other investigated metalhumate complexes. Bogata and Sokolowska (2016) analyses the interaction between humic acids from different soils and $\mathrm{Zn}$ (II) ions at wide concentration ranges and at $\mathrm{pH} 5$. Studies have showed significant impact of $\mathrm{Zn}$ concentration, $\mathrm{pH}$ and some properties of humic acids with zinc.But all of these studies were limited to acidic $\mathrm{pH}$ range. Therefore, the present study was carried out to determine and compare the stability constants of complexes of metal ions with hydrolysed peat soil humic acid and unhydrolysed peat soil humic under non-acid conditions.

\section{MATERIALS AND METHODS}

Analytical grade chemicals used includes hydrochloric acid $(\mathrm{HCl})$, nitric acid $\left(\mathrm{HNO}_{3}\right)$, sodium hydroxide $(\mathrm{NaOH})$, lead nitrate $\mathrm{Pb}\left(\mathrm{NO}_{3}\right)_{2}$, copper nitrate $\mathrm{Cu}\left(\mathrm{NO}_{3}\right)_{2} \cdot 3 \mathrm{H}_{2} \mathrm{O}$, cadmium nitrate $\mathrm{Cd}\left(\mathrm{NO}_{3}\right)_{2} \cdot 4 \mathrm{H}_{2} \mathrm{O}$, magnesium nitrate $\mathrm{Mg}\left(\mathrm{NO}_{3}\right)_{2} \cdot 6 \mathrm{H}_{2} \mathrm{O}$, potassium nitrate $\left(\mathrm{KNO}_{3}\right)$, calcium chloride $\left(\mathrm{CaCl}_{2}\right)$, (sigma-Aldrich). Dowex 50WX8, (20-50 mesh) from Fluka. 


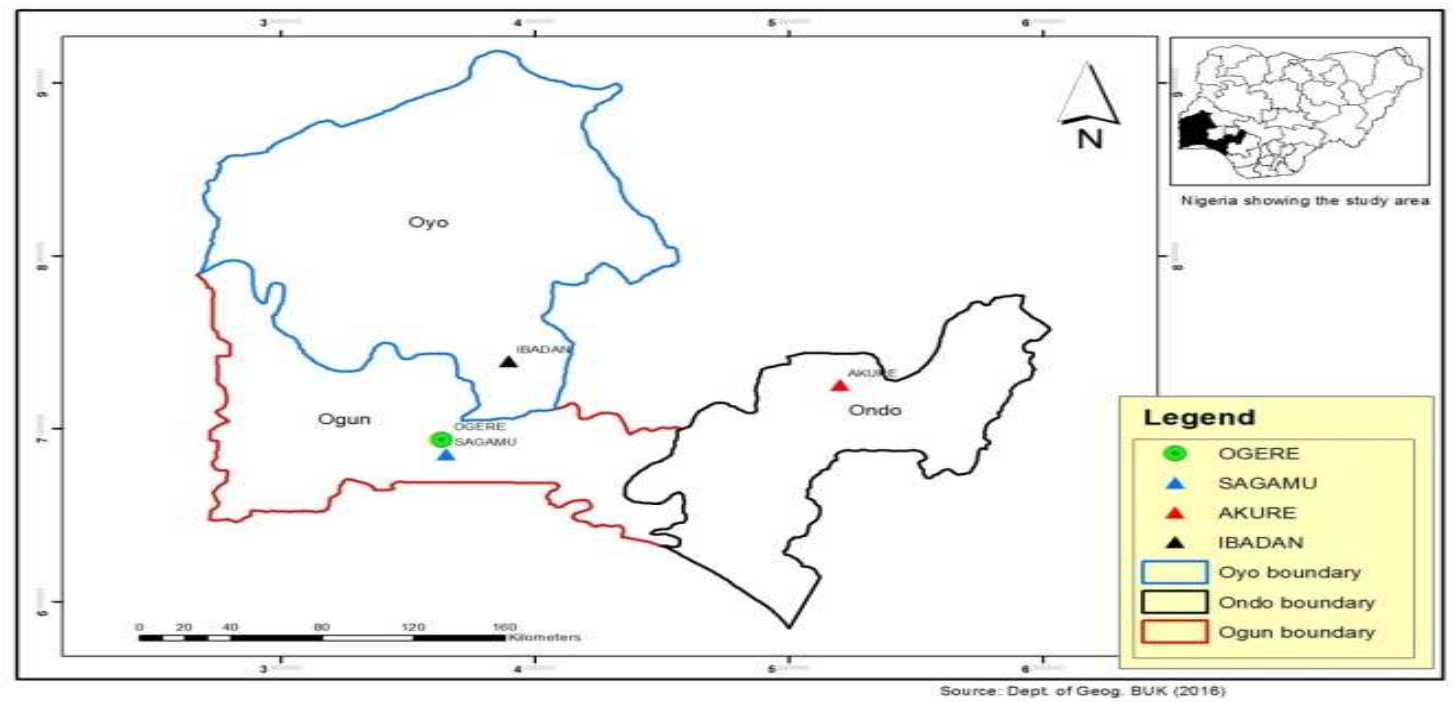

Figure 1: Map showing the sampling point at Sagamu Town, Ogun State.

\section{Description of Sampling Area}

Sagamu has geographical coordinates between $6^{\circ} 50^{\prime}$ north; $3^{\circ} 38^{\prime}$ east is located in south western region of Nigeria. The region has tropical wet and dry climate with a lengthy wet season and relatively constant temperatures throughout the course of the year. Wet season runs from March to October, November to December forms the region dry season. The vegetation type of the region is savannah which is really grassland with small bushes and occasional big trees. Grassland soils have substantially higher organic matter content than forest soils (Novackova, 2011).

\section{Sample Collection}

The Peatsoil samples were collected from four different sampling points $(0-10 \mathrm{~cm}$ depth) in Sagamu into polyethylene bag with plastic spoons. Samples were taken to the laboratory, extraneous materials were removed; the samples were air-dried, crushed and ground to a fine powder in a mortar passed through a $0.20 \mathrm{~mm}$ sieve. The samples were kept for analysis.

\section{Isolation and purification of humic acid from peat soil sample}

Peatsoil sample $(100 \mathrm{~g})$ was mixed with 1000 $\mathrm{cm}^{3}$ of $0.1 \mathrm{M} \mathrm{NaOH}$ solution, shaken for 3hours and left to stand overnight. Dark-coloured supernatant was obtained and decanted from solid residue. The dark-coloured supernatant was acidified to $(\mathrm{pH}=1.0)$ with $6 \mathrm{M} \mathrm{HCl}$ stirred and allowed to stand for 6 hours. Yellowish brown supernatant and dark-brown precipitate were obtained. The yellowish brown supernatant was decanted followed by centrifuge and discarded. The dark-brown precipitate was mixed with $500 \mathrm{~cm}^{3}$ of $0.1 \mathrm{M} \mathrm{NaOH}$ solution followed by passing through dowex resin. The dark-brown solution was acidified to $(\mathrm{pH}=1.0)$ with $6 \mathrm{M} \mathrm{HCl}$ stirred and allowed to stand for 3 hours. The dark-brown precipitate was washed several times with deionized water. The supernatant was treated with $\mathrm{AgNO}_{3}$ solution until no white precipitate observed. The humic acid was transferred to weighed crucible and dried at $60^{\circ} \mathrm{C}$ in an oven for 12 hours. The humic acid was cooled and dried in the desiccator, weighed and recorded. The obtained humic acid was dried again at $60^{\circ} \mathrm{C}$ for additional 6 hours cooled and dried in the desiccator, weighed and recorded constant weight was obtained (Baruah et al., 2015).

\section{FT-IR analysis}

FT-IR spectra of humic acid sample was analysed using Carry 630 FT-IR Agilent Technologies.

Unhydrolysed compost humic acid

The unhydrolysed humic acid was obtained after isolation and purification of compost humic acid and kept for investigation.

\section{Acid hydrolysis of Peatsoil acid}

Peatsoil humic acid sample (1g) was refluxed for 12 hours at $\left(160^{\circ} \mathrm{C}\right)$ with $50 \mathrm{~cm}^{3}$ of $6 \mathrm{M} \mathrm{HCl}$. The mixture was allowed to cool, decanted, and centrifuged after hydrolysis. The insoluble residues were washed with distilled water via centrifugation several times, and the supernatant was treated with $\mathrm{AgNO}_{3}$ solution until no white precipitate was observed. The residue was thoroughly dried over $\mathrm{CaCl}_{2}$ in a desiccator at room temperature (Chefetz et al., 2002). Finally, the obtained hydrolysed humic acid was kept for investigation. 
BAJOPAS Volume 14 Number 1,June, 2021 Potentiometric Titrations

Potentiometric measurements were carried out using a pH-meter Jenway (model 3510) with combine electrode, the sensitivity of the $\mathrm{pH}$ meter is 0.01 units. The $\mathrm{pH}$ meter was switched on half an hour before starting the titration for initial warm up of the instrument. The instrument was calibrated with an aqueous standard buffer solution of $\mathrm{pH} 4.00$ and 10.0 (borate buffer) prepared from a "Qualigens" buffer tablets.

The following sets of solutions were prepared in a $250 \mathrm{~cm}^{3}$ volumetric flask separately for $\mathrm{pH}$ metric titrations.

(i) $5 \mathrm{~cm}^{3} 0.1 \mathrm{M} \mathrm{HCl}+40 \mathrm{~cm}^{3}$ deionized water

(ii) $5 \mathrm{~cm}^{3} 0.1 \mathrm{M} \mathrm{HCl}+39 \mathrm{~cm}^{3}$ deionized water $+1 \mathrm{~cm}^{3} 0.15 \mathrm{gcm}^{-3}$ humic acid

(iii) $5 \mathrm{~cm}^{3} 0.1 \mathrm{M} \mathrm{HCl}+37 \mathrm{~cm}^{3}$ deionized water $+1 \mathrm{~cm}^{3} 0.15 \mathrm{gcm}^{-3}$ humic acid

$$
+2 \mathrm{~cm}^{3} \quad 0.01 \mathrm{M} \mathrm{Cu} \text { (II) }
$$

The solutions were titrated against standardized $0.110 \mathrm{MNaOH}$ separately. The total volume of each mixture was adjusted to $50 \mathrm{~cm}^{3}$ and the ionic strength of the solutions was maintained constant at by adding appropriate amount of stock solution of $1 \mathrm{M} \mathrm{KNO}_{3}$ (Gamal, 2015; Omar and Ali, 2015). A magnetic stirrer was used to achieve thorough mixing of the interacting solutions at $550 \mathrm{rpm}$. The same set of experimental conditions was applied for potentiometric titration of remaining samples.

\section{Evaluation of pKa of Hydrolysed peat soil Humic Acids}

The proton-ligand formation number $\mathrm{n}_{\mathbf{A}}$ were calculated by Irving and Rossotti expression (Omar and Ali, 2015).

$\mathrm{nA}=\mathrm{Y}-\frac{(\mathrm{V} 2-\mathrm{V1})(\mathrm{No}-\mathrm{Eo})}{(\mathrm{VO}+\mathrm{V1}) \mathrm{TCL}}$ 1

Where: $Y$ is number of dissociable proton, $\left(\mathrm{V}_{2^{-}}\right.$ $V_{1}$ ) is the measure of displacement of the ligand curve relative to acid curve, $\mathrm{N}^{\circ}$ and $\mathrm{E}^{\circ}$ are the resultant concentration of alkali solution, free acid solution, $\mathrm{T}_{\mathrm{cL}}{ }^{\circ}$ is the total ligand concentration, $\mathrm{V}^{\circ}$ is the total volume of titration solution, $V_{1}$ is the volume of alkali added to acid solution, $V_{2}$ is the volume of alkali added to acid solution + ligand solution, acid dissociation constants (pKa - values) of ligand were calculated by algebraic method point wise calculation (Tables 1 ). The dissociation constants (pKa) were calculated according to the following relation:

$\mathrm{pKa}=\mathrm{pH}+\log \left(\frac{n A}{1-n A}\right)$ 2

Where: pKa is the acid dissociation constant, $\mathrm{n}_{\mathrm{A}}$ is the Proton-ligand formation number and $\mathrm{pH}$ is the pH-values (Omar and Ali, 2015).

\section{Determination of metal-ligand stability constants $(\log K)$ of complexes}

The potentiometric measurement for the determination of stability constant of a complex in solution is based on the fact that the redox potential of the couple $\frac{M^{+(m-n)}}{M^{+m}}$ is shifted significantly on complexation of the metal ion with the ligand. This method involves change in hydrogen ion concentration $\left[\mathrm{H}^{+}\right]$due to the displacement or association of one or more protons taking place during complexation reaction. This change can be found out by titrating the solutions containing free acid, acid with ligand, and acid with ligand and metal ion, individually against a standard alkali solution at a constant ionic strength or temperature. Either ionic strength or temperature may be varied for different sets of solutions. In all the cases, the change in the $\mathrm{pH}$ of the solution is measured after each addition of a known amount of alkali to the reaction cell which contains the reaction mixture. The titration curves are then drawn by plotting the measured $\mathrm{pH}$ values against the corresponding volume of alkali added and the stability constants of the complexes are determined from the titration curves by employing $\mathrm{pH}$-metric titration technique given by (Irving and Rossoti).

Metal-ligand stability constants ( $\log \mathrm{K}$ ) were determined by using the following relations:

$$
\bar{n}=\frac{\left(V_{3}-V_{2}\right)\left(E^{0}+N^{0}\right)}{\left(V^{0}+V_{2}\right) \bar{n}_{A} T_{m}^{0}}
$$

and

$$
P L=\log _{10}\left\{\frac{1+\beta_{n}^{H} \frac{1}{[\text { anti } \log \mathrm{pH}]^{\mathrm{n}}}}{\mathrm{T}_{\mathrm{L}}^{0}-n \bar{T}_{m}^{0}} \mathrm{X} \frac{\left(V^{0}+V_{3}\right)}{V^{0}}\right\}
$$


BAJOPAS Volume 14 Number 1,June, 2021

Where $T_{L}, T^{\circ}, E^{\circ}$, and $V^{\circ}$ havethe same significance as in equation (1) above, $T_{m}$ denotes the total concentration of metal present in solution, $V_{3}$ is the volume of metal ions present in solution and $\beta^{H}$ is the overall proton ligand stability constant. The metal-ligand stability constants (log K) were determined by employing point wise computational Method (eq. 5 and 6).

$\operatorname{LogK}_{1}=\log \left(\frac{n}{1-n}\right)+\mathrm{pL}$ .5

$\operatorname{LogK}_{2}=\log \left(\frac{1-n}{2-n}\right)+\mathrm{pL}$ ...6

Where: Log $\mathrm{K}$ is the metal-ligand stability constant, $\mathrm{pL}$ is the Free ligand exponent function, $\mathbf{n}$ is the Average number of ligand attached with metal ion (Janraoet al., 2014). The results obtained were analyzed by an ORIGIN 2016 program using titration data and then the proton-ligand stability constants (pKa) and Metal-ligand stability constant (LogK) calculated (Omar and Ali, 2015).

\section{RESULTS AND DISCUSSION}

Fourier transformed infrared (FT-IR) spectra of isolated humic acid from peat soils Figure 2 had distinct clear absorption bands indicating the presence of major humic acid structural elemental groups such as $\mathrm{H}$ bonded $\mathrm{OH}$ $\left(3680 \mathrm{~cm}^{-1}\right.$ peak $), C=0$ of carbonyl $\left(1721 \mathrm{~cm}^{-1}\right.$ peak), functional groups of aliphatic components $\mathrm{CH}_{2}\left(2918 \mathrm{~cm}^{-1}\right.$ peak) and $\mathrm{C}-\mathrm{O}$ stretching of polysaccharide $\left(1168 \mathrm{~cm}^{-1}\right.$ peak). The positions of the absorption bands of the spectra fell within typical major absorption bands of humic acid which is at frequencies 3680, 2918, 1721, 1168 $\mathrm{cm}^{-1}$. The first peak centred in the vicinity of $3680 \mathrm{~cm}^{-1}$ region is attributed to phenol $\mathrm{OH}$ group bounded by intermolecular $\mathrm{H}$ bonds. The $2918 \mathrm{~cm}^{-1}$ band usually has absorption maximum at $2918 \mathrm{~cm}^{-1}$ which is due to $\mathrm{C}-\mathrm{H}$ stretching of alkane group $\left(\mathrm{CH}_{2}\right)$. The next major absorption band is $1721 \mathrm{~cm}^{-1}$. This band has been commonly ascribed to $\mathrm{C}=\mathrm{O}$ stretching of mainly carboxyl group $(\mathrm{COOH})$ with trace amount of ketones. The last peak was observed at 1168 $\mathrm{cm}^{-1}$ due to $\mathrm{C}-\mathrm{O}$ stretching of polysaccharides and this peak appeared also in the spectra of humic acid from peat soil. The FTIR spectra of the isolated humic acid contained all major characteristic absorption peaks of humic acid. These absorption peaks indicated the presence of the major structural elements of humic acid namely $\mathrm{H}$ bonded $\mathrm{OH}, \mathrm{C}=\mathrm{C}$ of aromatic ring, $\mathrm{C}=\mathrm{O}$ of carbonyl group (both carboxyl and ketonic), $\mathrm{CH}_{2}$ group. This strongly supports the presence of humic acid.

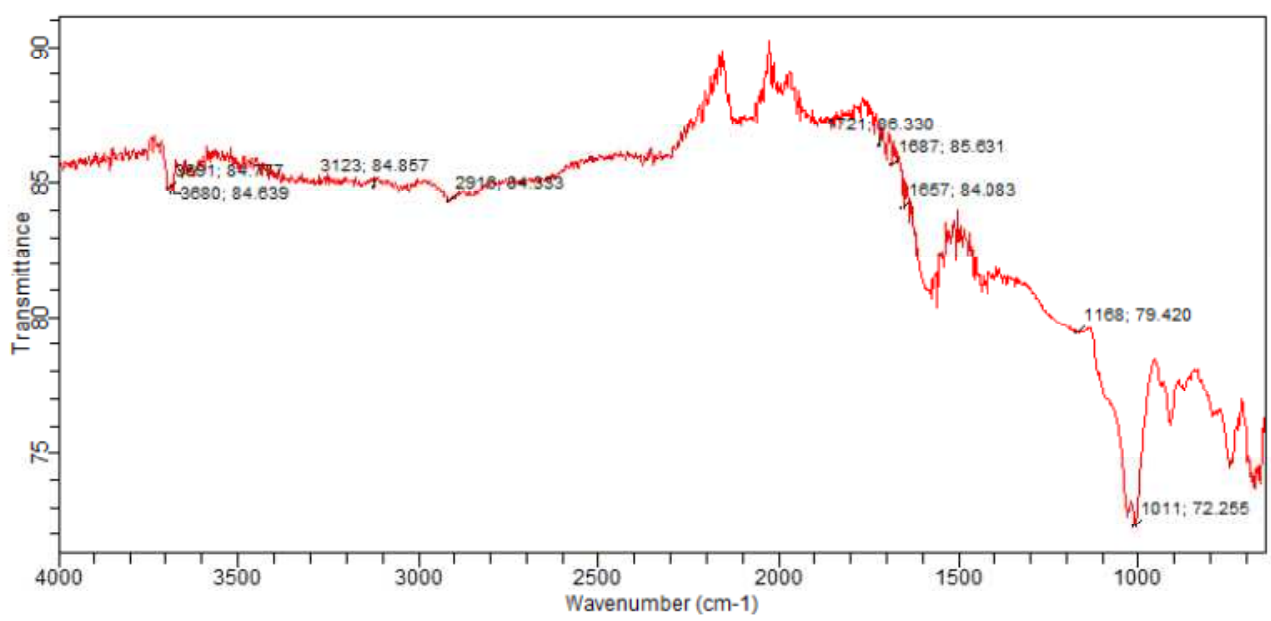

Fig. 2 : FT-IR spectraof peatsoilhumic acid (PSHA)

\section{Evaluation of acid dissociation constant (pka) of acid hydrolysed peat soil humicacid at phenolic group}

The value of the dissociation constant of the peat soil humic acid (PSHA) that underwent acidhydrolysis studied was found to be 8.9299 as shown Table 1, which is lower than the literaturevalues reported by Almeida and Szpoganics, (2015), Borges et al., (2005); Badr et al., (2012)and Fernandes et al,.(2009) of $9.73,9.47$ and 10.30. The difference between the obtained valuesand the reported values in this study might be probably as a result of acid hydrolysis of humicacid. 
BAJOPAS Volume 14 Number 1,June, 2021

Table 1: PKa of (Hydrolysed PSHA)

\begin{tabular}{|l|l|l|l|l|l|l|}
\hline $\mathrm{pH}$ & $\mathrm{BV}_{1}$ & $\mathrm{BV}_{2}$ & $\mathrm{~V}_{2}-\mathrm{V}_{1}$ & $\mathrm{nA}$ & $\log \left(\frac{n A}{1-n A}\right)$ & $\mathrm{pKa}$ \\
\hline 8.50 & 5.30 & 6.29 & 0.99 & 0.3594 & -0.2510 & 8.2490 \\
8.72 & 5.35 & 6.37 & 1.02 & 0.3400 & -0.2880 & 8.4320 \\
9.00 & 5.40 & 6.46 & 1.06 & 0.3141 & -0.3391 & 8.6609 \\
9.22 & 5.45 & 6.55 & 1.10 & 0.2882 & -0.3927 & 8.8273 \\
9.51 & 5.50 & 6.66 & 1.16 & 0.2494 & -0.4786 & 9.0314 \\
9.73 & 5.55 & 6.78 & 1.23 & 0.2041 & -0.5910 & 9.1390 \\
10.00 & 5.60 & 6.90 & 1.30 & 0.1589 & -0.7238 & 9.2762 \\
10.23 & 5.65 & 7.05 & 1.40 & 0.0941 & -0.9835 & 9.2465 \\
10.49 & 5.70 & 7.10 & 1.40 & 0.0941 & -0.9835 & 9.5065 \\
\hline
\end{tabular}

Average pKa $=8.9299 \pm 0.4186$

Table 2: PKa of (Unhydrolysed PSHA)

\begin{tabular}{|l|l|l|l|l|l|l|}
\hline $\mathrm{pH}$ & $\mathrm{BV}_{1}$ & $\mathrm{BV}_{2}$ & $\mathrm{~V}_{2}-\mathrm{V}_{1}$ & $\mathrm{nA}$ & $\log \left(\frac{\boldsymbol{n A}}{1-\boldsymbol{n}}\right)$ & $\mathrm{pKa}$ \\
\hline 8.50 & 5.30 & 5.81 & 0.51 & 0.6619 & 0.2919 & 8.7919 \\
8.72 & 5.35 & 5.90 & 0.55 & 0.6357 & 0.2418 & 8.9618 \\
9.00 & 5.40 & 6.00 & 0.60 & 0.6029 & 0.1813 & 9.1813 \\
9.22 & 5.45 & 6.10 & 0.65 & 0.5701 & 0.1226 & 9.3426 \\
9.51 & 5.50 & 6.20 & 0.70 & 0.5376 & 0.0654 & 9.5754 \\
9.73 & 5.55 & 6.33 & 0.78 & 0.4851 & -0.0259 & 9.7041 \\
10.00 & 5.60 & 6.47 & 0.87 & 0.4262 & -0.1291 & 9.8709 \\
10.23 & 5.65 & 6.62 & 0.99 & 0.3609 & -0.2481 & 9.9819 \\
10.49 & 5.70 & 6.80 & 1.10 & 0.2759 & -0.4690 & 10.0210 \\
\hline
\end{tabular}

Average pKa $=9.4923 \pm 0.4410$

Metal-ligand stability constant ( $\log \mathrm{K}$ )

The stabilityconstants require the accurate values of proton-ligand stability constants (Anil and Maroti, 2008). Metal titration curves crossed over ligand titration curve indicated the formation of complex upon proton release (Santosh, et al., 2011). If the values of n- are within range $0.2-0.8$ and $1.2-18$ this indicates the formation of $1: 1$ and 1:2 complexes (Sayyed and Mazahar, 2012).

The metal (II)-humate stepwise stability constants (log k) at phenolic group (Tables 318)

Table 3: Point-wise method, $\mathrm{Cu}$-(Hydrolysed PSHA)

\begin{tabular}{|l|l|l|l|l|l|l|l|l|}
\hline $\mathrm{pH}$ & $\mathrm{BV}_{1}$ & $\mathrm{BV}_{2}$ & $\mathrm{BV}_{3}$ & $\left(\mathrm{~V}_{3}-\mathrm{V}_{2}\right)$ & $\mathrm{n}$ & $\mathrm{pL}$ & $\log \left(\frac{n}{1-n}\right)$ & LogK $_{1}$ \\
\hline 8.50 & 5.30 & 6.29 & 6.33 & 0.04 & 0.5500 & 2.66 & 0.0871 & 2.7471 \\
8.72 & 5.35 & 6.37 & 6.41 & 0.04 & 0.5714 & 2.43 & 0.1249 & 2.5549 \\
9.00 & 5.40 & 6.46 & 6.50 & 0.04 & 0.6198 & 2.16 & 0.2122 & 2.3722 \\
9.22 & 5.45 & 6.55 & 6.59 & 0.04 & 0.6667 & 1.94 & 0.3010 & 2.2410 \\
\hline
\end{tabular}

LogK $_{1}$ (Average value) $=2.4788 \pm 0.2203$

Table 4: Point-wise method, $\mathrm{Cu}$-(Hydrolysed PSHA)

\begin{tabular}{|l|l|l|l|l|l|l|l|l|}
\hline $\mathrm{pH}$ & $\mathrm{BV}_{1}$ & $\mathrm{BV}_{2}$ & $\mathrm{BV}_{3}$ & $\left(\mathrm{~V}_{3}-\mathrm{V}_{2}\right)$ & $\mathrm{n}$ & $\mathrm{pL}$ & $\log \left(\frac{n-1}{2-n}\right)$ & LogK $_{2}$ \\
\hline 9.51 & 5.50 & 6.66 & 6.73 & 0.07 & 1.3509 & 1.70 & -0.2671 & 1.4329 \\
9.73 & 5.55 & 6.78 & 6.85 & 0.07 & 1.6383 & 1.51 & 0.2467 & 1.7567 \\
10.00 & 5.60 & 6.90 & 6.98 & 0.08 & 2.1783 & 1.31 & -0.2158 & 1.0942 \\
10.23 & 5.65 & 7.05 & 7.13 & 0.08 & 4.1904 & 1.27 & & \\
10.49 & 5.70 & 7.10 & 7.19 & 0.09 & 4.6920 & & & \\
\hline
\end{tabular}

Log $K_{2}($ Average value $)=1.4280 \pm 0.3312$ 
BAJOPAS Volume 14 Number 1,June, 2021

Table 5: Point-wise method, $\mathrm{Cu}$ (Unhydrolysed PSHA)

\begin{tabular}{|l|l|l|l|l|l|l|l|l|}
\hline $\mathrm{pH}$ & $\mathrm{BV}_{1}$ & $\mathrm{BV}_{2}$ & $\mathrm{BV}_{3}$ & $\left(\mathrm{~V}_{3}-\mathrm{V}_{2}\right)$ & $\mathrm{n}$ & $\mathrm{pL}$ & $\log \left(\frac{n}{n-1}\right)$ & Log $_{1}$ \\
\hline 8.50 & 5.30 & 5.81 & 5.85 & 0.04 & 0.2973 & 2.88 & -0.3736 & 2.5064 \\
8.72 & 5.35 & 5.90 & 5.95 & 0.05 & 0.3873 & 2.66 & -0.1992 & 2.4608 \\
9.00 & 5.40 & 6.00 & 6.05 & 0.05 & 0.4044 & 2.38 & -0.1681 & 2.2119 \\
9.22 & 5.45 & 6.10 & 6.15 & 0.06 & 0.5157 & 2.18 & -0.0272 & 2.2072 \\
9.51 & 5.50 & 6.20 & 6.27 & 0.07 & 0.6417 & 1.89 & 0.2530 & 1.1430 \\
\hline
\end{tabular}

$\operatorname{LogK}_{1}($ Average value $)=2.3059 \pm 0.6153$

Table 6:Point-wise method, $\mathrm{Cu}$ (Unhydrolysed PSHA)

\begin{tabular}{|l|l|l|l|l|l|l|l|l|}
\hline $\mathrm{pH}$ & $\mathrm{BV}_{1}$ & $\mathrm{BV}_{2}$ & $\mathrm{BV}_{3}$ & $\mathrm{~V}_{3}-\mathrm{V}_{2}$ & $\mathrm{n}$ & $\mathrm{pL}$ & $\log \left(\frac{n-1}{2-n}\right)$ & $\log \mathrm{K}_{2}$ \\
\hline 9.73 & 5.55 & 6.33 & 6.42 & 0.09 & 0.9000 & 1.69 & & \\
10.00 & 5.60 & 6.47 & 6.58 & 0.11 & 1.2578 & 1.44 & -0.4592 & 0.9808 \\
10.23 & 5.65 & 6.62 & 6.84 & 0.12 & 1.6137 & 1.26 & -0.2010 & 1.4610 \\
10.49 & 5.70 & 6.80 & 6.92 & 0.12 & 2.1052 & 1.03 & & \\
\hline
\end{tabular}

$\operatorname{LogK}_{2}$ (Average value) $=1.2209 \pm 0.3398$

Table 7:Point-wise method, Pb (Hydrolysed PSHA)

\begin{tabular}{|l|l|l|l|l|l|l|l|l|}
\hline $\mathrm{pH}$ & $\mathrm{BV}_{1}$ & $\mathrm{BV}_{2}$ & $\mathrm{BV}_{3}$ & $\left(\mathrm{~V}_{3}-\mathrm{V}_{2}\right)$ & $\mathrm{n}$ & $\mathrm{pL}$ & $\log \left(\frac{n}{1-n}\right)$ & LogK $_{1}$ \\
\hline 8.50 & 5.30 & 6.29 & 6.33 & 0.04 & 0.5500 & 2.66 & 0.0871 & 2.7471 \\
8.72 & 5.35 & 6.37 & 6.41 & 0.04 & 0.5714 & 2.43 & 0.1249 & 2.5549 \\
9.00 & 5.40 & 6.46 & 6.50 & 0.04 & 0.6198 & 2.16 & 0.2122 & 2.3722 \\
9.22 & 5.45 & 6.55 & 6.60 & 0.05 & 0.8333 & 1.96 & 0.6989 & 2.6589 \\
\hline
\end{tabular}

Log $_{\mathbf{1}}($ Average value $)=2.5832 \pm 0.1614$

Table 8:Point-wise method, Pb-(Hydrolysed PSHA)

\begin{tabular}{|l|l|l|l|l|l|l|l|l|}
\hline $\mathrm{pH}$ & $\mathrm{BV}_{1}$ & $\mathrm{BV}_{2}$ & $\mathrm{BV}_{3}$ & $\left(\mathrm{~V}_{3}-\mathrm{V}_{2}\right)$ & $\mathrm{n}$ & $\mathrm{pL}$ & $\log \left(\frac{n-1}{2-n}\right)$ & $\log \mathrm{K}_{2}$ \\
\hline 9.51 & 5.50 & 6.66 & 6.71 & 0.05 & 0.9650 & 1.67 & & \\
9.73 & 5.55 & 6.78 & 6.83 & 0.05 & 1.1702 & 1.44 & & \\
10.00 & 5.60 & 6.90 & 6.90 & 0.05 & 1.4864 & 1.22 & -0.0237 & 1.1963 \\
10.23 & 5.65 & 7.05 & 7.10 & 0.05 & 2.0190 & 1.09 & & \\
10.49 & 5.70 & 7.10 & 7.17 & 0.07 & 3.6492 & 1.00 & & \\
\hline
\end{tabular}

Log $K_{2}$ (Average value) $=1.1963$

Table 9: Point-wise method, Pb (Unhydrolysed PSHA)

\begin{tabular}{|l|l|l|l|l|l|l|l|l|}
\hline $\mathrm{pH}$ & $\mathrm{BV}_{1}$ & $\mathrm{BV}_{2}$ & $\mathrm{BV}_{3}$ & $\mathrm{~V}_{3}-\mathrm{V}_{2}$ & $\mathrm{n}$ & $\mathrm{pL}$ & $\begin{array}{l}\text { Log } \\
\left(\frac{n}{n-1}\right)\end{array}$ & Log $\mathrm{K}_{1}$ \\
\hline 8.50 & 5.30 & 5.81 & 5.85 & 0.04 & 0.2973 & 2.88 & -0.3736 & 2.5064 \\
8.72 & 5.35 & 5.90 & 5.94 & 0.04 & 0.3099 & 2.66 & -0.5477 & 2.3123 \\
9.00 & 5.40 & 6.00 & 6.05 & 0.05 & 0.4044 & 2.38 & -0.1681 & 2.2119 \\
9.22 & 5.45 & 6.10 & 6.15 & 0.06 & 0.5157 & 2.18 & 0.0272 & 2.2072 \\
9.51 & 5.50 & 6.20 & 6.26 & 0.07 & 0.6417 & 1.89 & 0.2530 & 2.1430 \\
9.73 & 5.55 & 6.40 & 6.40 & 0.07 & 0.7000 & 1.67 & 0.3680 & 2.0380 \\
\hline
\end{tabular}

LogK $_{1}$ (Average value) $=2.2364 \pm 0.1602$

Table 10: Point-wise method, Pb (Unhydrolysed PSHA)

\begin{tabular}{|l|l|l|l|l|l|l|l|l|}
\hline $\mathrm{pH}$ & $\mathrm{BV}_{1}$ & $\mathrm{BV}_{2}$ & $\mathrm{BV}_{3}$ & $\mathrm{~V}_{3}-\mathrm{V}_{2}$ & $\mathrm{n}$ & $\mathrm{pL}$ & $\log \left(\frac{n-1}{2-n}\right)$ & $\log \mathrm{K}_{2}$ \\
\hline 10.00 & 5.60 & 6.47 & 6.55 & 0.08 & 1.9503 & 1.41 & & \\
10.23 & 5.65 & 6.62 & 6.72 & 0.11 & 1.4792 & 1.26 & -0.0361 & 1.2239 \\
\hline
\end{tabular}

$\operatorname{LogK}_{2}$ (Average value) $=1.2239$

Table 11: Point-wise method, Mg (Hydrolysed PSHA)

\begin{tabular}{|l|l|l|l|l|l|l|l|l|}
\hline $\mathrm{pH}$ & $\mathrm{BV}_{1}$ & $\mathrm{BV}_{2}$ & $\mathrm{BV}_{3}$ & $\left(\mathrm{~V}_{3}-\mathrm{V}_{2}\right)$ & $\mathrm{n}$ & $\mathrm{pL}$ & $\log \left(\frac{n}{n-1}\right)$ & LogK $_{1}$ \\
\hline 8.50 & 5.30 & 6.29 & 6.31 & 0.02 & 0.2750 & 2.64 & -0.4290 & 2.2110 \\
8.72 & 5.35 & 6.37 & 6.39 & 0.02 & 0.2858 & 2.42 & -0.3978 & 2.0222 \\
9.00 & 5.40 & 6.46 & 6.49 & 0.03 & 0.4648 & 2.14 & -0.0612 & 2.0788 \\
9.22 & 5.45 & 6.55 & 6.59 & 0.04 & 0.6667 & 1.94 & 0.3010 & 2.2410 \\
\hline
\end{tabular}

$\log _{\mathbf{1}}($ Average value) $=2.1382 \pm 0.1046$ 
BAJOPAS Volume 14 Number 1,June, 2021

Table 12: Point-wise method, Mg (Hydrolysed PSHA)

\begin{tabular}{|l|l|l|l|l|l|l|l|l|}
\hline $\mathrm{pH}$ & $\mathrm{BV}_{1}$ & $\mathrm{BV}_{2}$ & $\mathrm{BV}_{3}$ & $\left(\mathrm{~V}_{3}-\mathrm{V}_{2}\right)$ & $\mathrm{n}$ & $\mathrm{pL}$ & $\log \left(\frac{n-1}{2-n}\right)$ & LogK $_{2}$ \\
\hline 9.51 & 5.55 & 6.66 & 6.71 & 0.05 & 0.9650 & 1.67 & & \\
9.73 & 5.55 & 6.78 & 6.84 & 0.06 & 1.4042 & 1.47 & -0.1686 & 1.3014 \\
10.00 & 5.60 & 6.90 & 6.93 & 0.06 & 1.7838 & 1.23 & 0.5593 & 1.7893 \\
10.23 & 5.65 & 7.05 & 7.10 & 0.06 & 3.1429 & 1.10 & & \\
10.49 & 5.70 & 7.10 & 7.18 & 0.07 & 3.6492 & 0.83 & & \\
\hline
\end{tabular}

LogK $_{2}($ Average value $)=1.5453 \pm 0.3450$

Table 13: Point-wise method, Mg (Unhydrolysed PSHA)

\begin{tabular}{|l|l|l|l|l|l|l|l|l|}
\hline $\mathrm{pH}$ & $\mathrm{BV}_{1}$ & $\mathrm{BV}_{2}$ & $\mathrm{BV}_{3}$ & $\mathrm{~V}_{3}-\mathrm{V}_{2}$ & $\mathrm{n}$ & $\mathrm{pL}$ & $\log \left(\frac{n}{n-1}\right)$ & $\operatorname{Log~}_{1}$ \\
\hline 8.50 & 5.30 & 5.81 & 5.85 & 0.04 & 0.2973 & 2.88 & -0.3736 & 2.5064 \\
8.72 & 5.35 & 5.90 & 5.94 & 0.04 & 0.3099 & 2.66 & -0.3477 & 2.3123 \\
9.00 & 5.40 & 6.00 & 6.04 & 0.04 & 0.3236 & 2.38 & -0.3202 & 2.0598 \\
9.22 & 5.45 & 6.10 & 6.15 & 0.05 & 0.4297 & 2.17 & -0.1230 & 2.0470 \\
9.51 & 5.50 & 6.20 & 6.26 & 0.06 & 0.5500 & 1.89 & 0.0871 & 1.9771 \\
9.73 & 5.55 & 6.33 & 6.40 & 0.07 & 0.7000 & 1.67 & 0.3680 & 2.0380 \\
\hline
\end{tabular}

LogK $_{1}$ (Average value) $=2.1568 \pm 0.2069$

Table 14: Point-wise method, Mg (Unhydrolysed PSHA)

\begin{tabular}{|l|l|l|l|l|l|l|l|l|}
\hline $\mathrm{pH}$ & $\mathrm{BV}_{1}$ & $\mathrm{BV}_{2}$ & $\mathrm{BV}_{3}$ & $\mathrm{~V}_{3}-\mathrm{V}_{2}$ & $\mathrm{n}$ & $\mathrm{pL}$ & $\log \left(\frac{n-1}{2-n}\right)$ & $\log \mathrm{K}_{2}$ \\
\hline 10.00 & 5.60 & 6.47 & 6.55 & 0.08 & 0.9148 & 1.41 & & \\
10.23 & 5.65 & 6.62 & 6.71 & 0.09 & 1.2102 & 1.20 & -0.5749 & 0.6251 \\
10.49 & 5.70 & 6.80 & 6.92 & 0.09 & 1.5968 & 1.03 & 0.1703 & 1.2003 \\
\hline
\end{tabular}

LogK $_{2}$ (Average value) $=0.9127 \pm 0.4070$

Table15:Point-wise method, Cd (Hydrolysed PSHA)

\begin{tabular}{|l|l|l|l|l|l|l|l|l|}
\hline $\mathrm{pH}$ & $\mathrm{BV}_{1}$ & $\mathrm{BV}_{2}$ & $\mathrm{BV}_{3}$ & $\left(\mathrm{~V}_{3}-\mathrm{V}_{2}\right)$ & $\mathrm{n}$ & $\mathrm{pL}$ & $\log \left(\frac{n}{1-n}\right)$ & LogK $_{1}$ \\
\hline 8.50 & 5.30 & 6.29 & 6.31 & 0.02 & 0.2750 & 2.64 & -0.4210 & 2.2190 \\
8.72 & 5.35 & 6.37 & 6.40 & 0.03 & 0.4286 & 2.42 & -0.1249 & 2.2951 \\
9.00 & 5.40 & 6.46 & 6.49 & 0.03 & 0.4648 & 2.14 & -0.0612 & 2.0788 \\
9.22 & 5.45 & 6.55 & 6.59 & 0.04 & 0.6667 & 1.96 & 0.3010 & 2.2610 \\
9.51 & 5.55 & 6.66 & 6.70 & 0.04 & 0.7720 & 1.67 & 0.5297 & 2.1997 \\
\hline
\end{tabular}

LogK $_{\mathbf{1}}$ (Average value) $=2.2108 \pm 0.0825$

Table 16: Point-wise method, Cd (Hydrolysed PSHA)

\begin{tabular}{|l|l|l|l|l|l|l|l|l|}
\hline $\mathrm{pH}$ & $\mathrm{BV}_{1}$ & $\mathrm{BV}_{2}$ & $\mathrm{BV}_{3}$ & $\left(\mathrm{~V}_{3}-\mathrm{V}_{2}\right)$ & $\mathrm{n}$ & $\mathrm{pL}$ & $\log \left(\frac{n-1}{2-n}\right)$ & Log $_{2}$ \\
\hline 9.73 & 5.55 & 6.78 & 6.83 & 0.06 & 1.4042 & 1.47 & -0.1686 & 1.3014 \\
10.00 & 5.60 & 6.90 & 6.95 & 0.06 & 1.7838 & 1.23 & 0.5593 & 1.7893 \\
10.23 & 5.65 & 7.05 & 7.10 & 0.06 & 3.1429 & 1.09 & & \\
10.49 & 5.70 & 7.10 & 7.16 & 0.06 & 3.1429 & 0.89 & & \\
& & & & & & & & \\
\hline
\end{tabular}

$\operatorname{LogK}_{2}$ (Average value) $=1.5453 \pm 0.3450$

Table 17: Point-wise method, Cd (Unhydrolysed PSHA)

\begin{tabular}{|l|l|l|l|l|l|l|l|l|}
\hline $\mathrm{pH}$ & $\mathrm{BV}_{1}$ & $\mathrm{BV}_{2}$ & $\mathrm{BV}_{3}$ & $\mathrm{~V}_{3}-\mathrm{V}_{2}$ & $\mathrm{n}$ & $\mathrm{pL}$ & $\log \left(\frac{n}{n-1}\right)$ & $\operatorname{Log~}_{1}$ \\
\hline 8.50 & 5.30 & 5.81 & 5.86 & 0.05 & 0.3717 & 2.88 & -0.2280 & 2.6520 \\
8.72 & 5.35 & 5.90 & 5.95 & 0.05 & 0.3873 & 2.66 & -0.1992 & 2.4608 \\
9.00 & 5.40 & 6.00 & 6.06 & 0.06 & 0.4853 & 2.38 & -0.0255 & 2.3545 \\
9.22 & 5.45 & 6.10 & 6.16 & 0.06 & 0.5157 & 2.18 & -0.0272 & 2.2072 \\
9.51 & 5.50 & 6.20 & 6.27 & 0.07 & 0.6417 & 1.89 & 0.2530 & 1.1430 \\
9.73 & 5.55 & 6.33 & 6.41 & 0.08 & 0.8000 & 1.69 & 0.6020 & 2.2920 \\
& & & & & & & & \\
\hline
\end{tabular}

$\operatorname{LogK}_{1}($ Average value $)=2.2516 \pm 0.5380$ 
BAJOPAS Volume 14 Number 1,June, 2021

Table 18: Point-wise method, Cd (Unhydrolysed PSHA)

\begin{tabular}{|l|l|l|l|l|l|l|l|l|}
\hline $\mathrm{pH}$ & $\mathrm{BV}_{1}$ & $\mathrm{BV}_{2}$ & $\mathrm{BV}_{3}$ & $\mathrm{~V}_{3}-\mathrm{V}_{2}$ & $\mathrm{n}$ & $\mathrm{pL}$ & $\log \left(\frac{n-1}{2-n}\right)$ & $\log \mathrm{K}_{2}$ \\
\hline 10.00 & 5.60 & 6.47 & 6.57 & 0.10 & 1.1434 & 1.43 & & \\
10.23 & 5.65 & 6.62 & 6.72 & 0.10 & 1.3448 & 1.23 & -0.2788 & 0.9512 \\
10.49 & 5.70 & 6.80 & 6.90 & 0.10 & 1.7742 & 1.03 & 0.5351 & 1.5651 \\
\hline
\end{tabular}

$\operatorname{LogK}_{2}($ Average value $)=1.2581 \pm 0.4340$

Table 19: Stepwise and overall Stability constants of thehydrolysed and unhydrolysed divalent metal (II) complexes

\begin{tabular}{|c|c|c|c|}
\hline Chelates & LogK $_{1}$ & $\log _{2}$ & Log $\beta$ \\
\hline [Cu (Hydrolysed PSHA-1) $\left.{ }_{2}\right]$ & 2.4788 & 1.4280 & 3.9068 \\
\hline$\left[\mathrm{Pb}(\text { Hydrolysed PSHA-1) })_{2}\right]$ & 2.5832 & 1.1963 & 3.7795 \\
\hline$\left[\mathrm{Cd}(\text { Hydrolysed PSHA-1 })_{2}\right]$ & 2.2108 & 1.5453 & 3.7561 \\
\hline$\left[\mathrm{Mg}(\text { Hydrolysed PSHA-1 })_{2}\right]$ & 2.1382 & 1.5453 & 3.6835 \\
\hline [Cu (Unhydrolysed PSHA-1) & 2.3059 & 1.2209 & 3.5268 \\
\hline$[\mathrm{Pb}$ (Unhydrolysed PSHA-1) 2$]$ & 2.2364 & 1.2239 & 3.4603 \\
\hline [Cd (Unhydrolysed PSHA-1) 2 ] & 2.2516 & 1.2581 & 3.5097 \\
\hline$[\mathrm{Mg}$ (Unydrolysed PSHA-1) & 2.1568 & 0.9127 & 3.0695 \\
\hline
\end{tabular}

The results obtained (Table19) shows the stepwise and overall stability constants to be not high indicating low stability of the complexes, because the solubility of most metal ions in the basic $\mathrm{pH}$ range is minimal due to metal hydroxide precipitation (Karimi, 2017). In general, the stepwise stability constants $\left(K_{1}\right.$ and $K_{2}$ ) follow the order $K_{1}>K_{2}$ for the copper, lead, magnesium and cadmium complexes respectively. The steady decrease of the values with increasing number of ligands is in agreement with the prediction made by researchers (Na'aliya, 2013). The decrease could be attributed to the fact that as the number of the ligands (Humate ions) that enters the coordination zone increases the aqua molecules available for replacement by the ligands become less. Thus, the metal ions become less electron loving with progressive intake of the ligand and this results in the decrease in the values of the constants (Na'aliya, 2013). Also the stability of the complexes is influenced by the size and number of the chelate rings(Mackay and Mackay,2002).All the complexes form rings in their structure as humate, a bidentate ligand, bond the metal ions in the ratio 1:2 (Boguta and Sokolowska, 2016) forming chelate rings. The values of the overall stability constants $(\log \beta)$ obtained for humate complexes are not high indicating low stability as the values are not high. LogK values for copper-humates (Table 3 to 6) obtained in this study are lower than those reported for the complexes of humic acids (Pandey et al., 2015; Dinu, 2013; Kaschl et al., 2010 and Gilbeto and Jorg, 2001). The values of LogK(Table 7 to 10 ) forlead-humates are lower than those reported for the lead in the literature (Dinu, 2013; Gilbeto and Jorg 2001). Log K values(Table 11 to 14 ) for magnesium-humates obtained in this study are close to those reported by (Pandey et al., 2015). Log K values of cadmium-humates (Table 15 to 18 ) obtained in this work near to the one reported by (Dinu, 2013 and Pandey et al., 2015).The difference between the reported values and the values obtained in this study might be probably as a result of acid hydrolysis of humic acid. The values of the overall stability constants $(\log \beta)$ of the copper humates complexes presented in Table 19 is high than that of other metal humate complexes, show relatively high stability of CuHA complexes, show the following order of stability: $\mathrm{Cu}>\mathrm{Pb}>\mathrm{Cd}>\mathrm{Mg}$; which are in close agreement to the findings of (Dinu, 2013 and Pandey et al., 2015).The high stability of Cuhumate chelate could be attributed to the existence of coordinate covalent bond between the complexing agents and the $\mathrm{Cu}^{2+}$ ions. Since, $\mathrm{Cu}^{2+}$ being a metal of the transitional series with $3 d^{9}$ electronic configurations can accept the electrons from the complexing agents. Similarly, the low stabilities of $\mathrm{Pb}, \mathrm{Cd}$ and $\mathrm{Mg}$ complexes could be explained by that $\mathrm{Pb}^{2+}$ with $6 s^{2}, \mathrm{Cd}^{2+}$ with $4 \mathrm{~d}^{10}$ and $\mathrm{Mg}^{2+}$ with $2 \mathrm{p}^{6}$ their electronic configuration has a completely filled $\mathrm{d}, \mathrm{p}$ and $\mathrm{s}$ orbitals. Moreover, the stabilities of metal ions with hydrolysed humic acid from peat soil were higher than those with unhydrolysed humic acid from peat soil; which is ascribed to the high content of acidity in hydrolysed humic acid than unhydrolysed humic acid. 
BAJOPAS Volume 14 Number 1,June, 2021 CONCLUSION

The values of logk for $\mathrm{Cu}(\mathrm{II})$ hydrolysed humic acid complex was higher followed by $\mathrm{Pb}$ (II), $\mathrm{Cd}(\mathrm{II})$ and $\mathrm{Mg}$ (II) hydrolysed humic acid complexes as compared with metal(II) unhydrolysed humic acid complexes. This indicates acid hydrolysis of humic acid can

\section{REFERENCES}

Almeida, V.R. and Szpoganicz, B. (2015). Humic Acid Potentiometric Response Patterns:Out- of Equilibrium Properties and Species Distribution Modelling. Chemical. Biol. Technol. Agric. 2: 17.

Anđelković, T., Nikolić, R., Bojić, A.,Anđelković, D., and Nikolic G.,(2010). Binding of Cadmium to Soil Humic Acid as A Function of Carboxyl Group Content. Macedonian Journal of Chemistry and Chemical Engineering.29(2): 215-224.

Anil, B. N. and Maroti, N. (2008). Studies on Influence of Die-Lectric Constants on Complex Equilibria between Substituted Py-Razalines and Lanthanide Metal Ions pH-Metrically. Amer.-Euras. scient. Res. 3(2): 212-216.

Ashok, K., Pandey, S. P. and Misra, V (2000). Stability Constants of Metal-Humic Acid Complexes and its Role in Environmental Detoxification. Journal of Ecotoxicology and Environmental Safety. 47(2):157-200.

Badr, M. H., El-Halafawi, M. H. and Abd El-al Zeid, E. R. (2012). Comparison Between the Effect of Ionic Strength on Acidity and Dissociation Constants of Humic Acids Extracted from Sewage Sludge and Nile Water Hyacinth Composts.Global Journal of Environmental Research 6 (1): 36-43.

Baruah, M.K., Borah, D., Saikia, P.P., Paul, S., Sharma, T. (2015). Evaluation of pKa Values of Soil Humic Acids and their Complexation Properties. International Journal of Plant \& Soil Science 6(4) : 218-228.

Boguta, P. Sokolowska, Z. (2016). Interactions of $\mathrm{Zn}$ (II) Ions with Humic Acids Isolated from Various Types of Soils. Effect of $\mathrm{pH}, \mathrm{Zn}$ Concentrations and Humic Acids Chemical Properties. Journal of Geochemical Explaration 168. 119-126.

Borges, F., Guimaraes, C., Lima, L.F.C., Pinto, I. and Reis, S.(2005). Potentiometric Studies on the Complexation of Copper(II) by Phenolic Acids as Discrete Ligand Models of enhance the complexation behavior of humic acid with metal (II) ions. However, the higher values of $\log \beta$ for $\mathrm{Cu}(\mathrm{II}), \mathrm{Pb}(\mathrm{II}), \mathrm{Cd}(\mathrm{II})$ and $\mathrm{Mg}(\mathrm{II})$ hydrolysed humic acid complexes indicates more stable stepwise complexes formed as compared with $\mathrm{Cu}(\mathrm{II}), \mathrm{Pb}$ (II), $\mathrm{Cd}$ (II) and $\mathrm{Mg}(\mathrm{II})$ unhydrolysed humic acid complexes.

Humic Substances Talanta 66 (2005) 670-673.

Chefetz, B., Salloum, M. J., Deshmulkin, A. P. and Hatcher, P. (2002). Structural Components of Humic Acids as Determined by Chemical Modifications and Carbon-13 NMR, Pyrolysis, and Thermochemolysis- Gas Chromatography/Mass Spectrometry. Soil Science Society of American Journal Abstract Division S-2- Soil Chemistry66. 1159-1171.

Dinu, M. I. (2013). Metals Complexation with Humic Acids in Surface Water of Different Environ. Sci. Technol. 31(1): 1-17.

Fernandes, A.N., Giacomelli, C., Giovanela, M. Vaz, D.V. Szpoganicz, B. and Maria M. D. (2009). Potentiometric Acidity Determination in Humic Substances Influenced by Different Analytical Procedures.J. Braz. Chem. Soc. 20 (9):14.

Gamal, A. H. (2015). Stability Constants of Rhenium (V) Metal Complexes with Selected Drugs. Pyrex Journal of Research in Environmental Studies. 2(2): 006-014.

Janrao, D. M., Pathan, J., Kayande, D.D., and Mulla, J.J. (2014). An Over View of Potentiometric Determination of Stability Constants of Metal Complexes. Sci. Revs. Chem. Commun.: 4(1), 2014, 11-24.

Karimi, H. (2017). Effect of pH and Initial Pb(II) Concentration on the Lead Removal Efficiency from Waste Water Using $\mathrm{Ca}(\mathrm{OH})_{2}$. International Journal of Water and Waste Water Treatment 3.2

Kaschl, A. Romheld, V. and Chen, Y. (2010). Binding of Cadmium, Copper and Zinc to Humic Substances Originating from Municipal Solid Waste Compost. Israel Journal of Chemistry Vol. 42(1): 89-98.

Kostic, I. S., Tatjana, P, A., Nikolic, R. S., Cvetkovic, T. P., Pavlovic, D. D., Aleksandar, L.J. and Bojic, A. (2012). Comparative Study of Binding Strengths of Heavy Metals with Humic Acid. J.serb. Chem. Soc. 76(9) pp 1-20. 
BAJOPAS Volume 14 Number 1,June, 2021

Na'aliya, J. (2013). Determination of Stepwise Stability Constants and Gibbs free Energy Change of Trisprolina to Complexes of some Divalent Transition Metal ions. Bayero Journal of Pure and Applied Sciences 6(2): 112-114.

Omar, A. A. and Ali, E. A. (2015). Potentiometric Studies on Complexes of $\mathrm{Cr}$ (III) and $\mathrm{Zr}$ (IV) with some Carboxylic Acids. International Journal of Advanced Chemistry, 3(1) 25-

37.

Pandey, A. K. Pandey, S. D. and Misr, V. (2015).Stability Constants of Metal- Humic Acid Complexes and Its Role in Environmental Detoxification. J. Ecotoxicology and Environmental Safety. 47(1):195-200.

Ram, N. and Raman, K.V. (1984). Stability Constants of Complexes of Metals with
Humicand Fuvic Acids under Non- acidConditions. Journal of Plant Nutrition and Soil Sciences.

147:171-176.

Santosh, D. D., Ashok, B. K., Vijay, J. T., Shivraj, G. W. and Vinay, V. W. (2011). Potentiometric Studies of Elec-Trolyte Effects on Complex Equilibria of Some Substituted 5-(2-hydroxy Phenyl) Pyrazoles. Der pharm. 3 (6): 75-83.

Sayyed, H. and Abdul Rahim, M. F. (2012). Studies of Binary Complexes of Metal Ions with Mandelic Acid by Potentiometry. Chem. J. 02 (6): 206209.

Shirvani, M. Moradian, E. Khalili, B. Bakhtiary, S. (2015). Interaction of $\mathrm{Cd}$ and $\mathrm{Pb}$ with Humate-Palygorskite and HumateSepiolite Complexes. Journal of water, air and pollution 3: 220-228. 


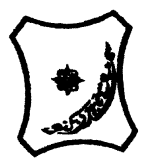

Bayero Journal of Pure and Applied Sciences, 14(1): 54 - 63

Received: November, 2020

Accepted: April, 2021

ISSN $2006-6996$

\title{
STABILITY CONSTANTS OF COMPLEXES OF METAL IONS WITH PEATSOIL HUMIC ACIDS UNDER NON-ACID-CONDITIONS
}

\author{
${ }^{* 1}$ Sabo, Yusuf ${ }^{2}$ Jimoh, W.L.O., ${ }^{3}$ Isa Baba Koki and ${ }^{4}$ Sholadoye, Q. 0. \\ ${ }^{1}$ Department of Pure and Industrial Chemistry, Bayero University, Kano \\ ${ }^{3}$ Department of Chemistry, Yusuf Maitama Sule University Kano. P.M.B. 3220 Kano, Nigeria. \\ ${ }^{4}$ Department of Chemistry, Nigerian Police Academy, Wudil, Kano-Nigeria
}

*Correspondence E-mail; saboyusuf18@yahoo.com

ABSTRACT

Stability constants of complexes of four divalent metal ions viz. $\mathrm{Cu}^{2+}, \mathrm{Pb}^{2+}, \mathrm{Mg}^{2+}$ and $\mathrm{Cd}^{2+}$ with humic acids (HA) were determined by potentiometric titration of humic acids with the corresponding salt of the divalent metals in aqueous media under non-acid-condition. The log $K$ (logarithm of the stability constant) ranged from 1.0942 to 2.7471 for metalhumic acid complexes were determined using point-wise computational method. The order of stability constants were obtained as follows: $\mathrm{Cu}>\mathrm{Pb}>\mathrm{Cd}>\mathrm{Mg}$ for metal $-\mathrm{HA}$ complexes respectively, indicating a higher degree of complexation with Cu metal ion.

Keywords: stability constant, humic acid, potentiometric titration, divalent metals, acid hydrolysis.

\section{NTRODUCTION}

The stability constant of a complex is the numerical expression of its stability and provides a quantitative measure of affinity of the metal ion to the complexing agent. An understanding of the relative stability of metal-complexes helps in predicting the behavior of metal ions in the soil (Ram and Raman, 1982). Extensive researches has been done to determine the stability constants of the complexes formed between humic acid (HA) with a number of metal ions. Ashok et al., (2000) reported that humic acid with hydroxyl, phenoxyl and carboxyl reactive groups can form coordination compound with metal ions at $\mathrm{pH}$ 3.5. The stability constants(Log K) for different metalhumic acid complexes indicated the following order of the stabilities of complexes formed between humic acid and metal ion, $\mathrm{Cu}>\mathrm{Fe}$ $>\mathrm{Pb}>\mathrm{Ni}>\mathrm{Co}>\mathrm{Ca}>\mathrm{Cd}>\mathrm{Zn}>\mathrm{Mn}>\mathrm{Mg}$. Andelkovic et al., (2010) investigated the binding of $\mathrm{Cd}$ (II) to soil humic acid at pH 6.5 and in $0.1 \mathrm{M} \mathrm{KNO}_{3}$ ionic medium. The stability constant for binding indicating greater stability in the case when carboxyl groups are involved in complexation reaction. Kostic et al.,(2012) investigated the complexation of humic acid with certain heavy metal ions (Co(II), $\mathrm{Ni}(\mathrm{II}), \mathrm{Cu}(\mathrm{II})$,
$\mathrm{Zn}(\mathrm{II})$, and $\mathrm{Pb}(\mathrm{II})$. The experiment was performed at $25^{\circ} \mathrm{C}$, at pH 4.0 and ionic strength of $0.01 \mathrm{M}$. Stability constant of complex between $\mathrm{Pb}$ (II) ions and humic acid is greater than stability constants of other investigated metalhumate complexes. Bogata and Sokolowska (2016) analyses the interaction between humic acids from different soils and $\mathrm{Zn}$ (II) ions at wide concentration ranges and at $\mathrm{pH} 5$. Studies have showed significant impact of $\mathrm{Zn}$ concentration, $\mathrm{pH}$ and some properties of humic acids with zinc.But all of these studies were limited to acidic $\mathrm{pH}$ range. Therefore, the present study was carried out to determine and compare the stability constants of complexes of metal ions with hydrolysed peat soil humic acid and unhydrolysed peat soil humic under non-acid conditions.

\section{MATERIALS AND METHODS}

Analytical grade chemicals used includes hydrochloric acid $(\mathrm{HCl})$, nitric acid $\left(\mathrm{HNO}_{3}\right)$, sodium hydroxide $(\mathrm{NaOH})$, lead nitrate $\mathrm{Pb}\left(\mathrm{NO}_{3}\right)_{2}$, copper nitrate $\mathrm{Cu}\left(\mathrm{NO}_{3}\right)_{2} \cdot 3 \mathrm{H}_{2} \mathrm{O}$, cadmium nitrate $\mathrm{Cd}\left(\mathrm{NO}_{3}\right)_{2} \cdot 4 \mathrm{H}_{2} \mathrm{O}$, magnesium nitrate $\mathrm{Mg}\left(\mathrm{NO}_{3}\right)_{2} \cdot 6 \mathrm{H}_{2} \mathrm{O}$, potassium nitrate $\left(\mathrm{KNO}_{3}\right)$, calcium chloride $\left(\mathrm{CaCl}_{2}\right)$, (sigma-Aldrich). Dowex 50WX8, (20-50 mesh) from Fluka. 


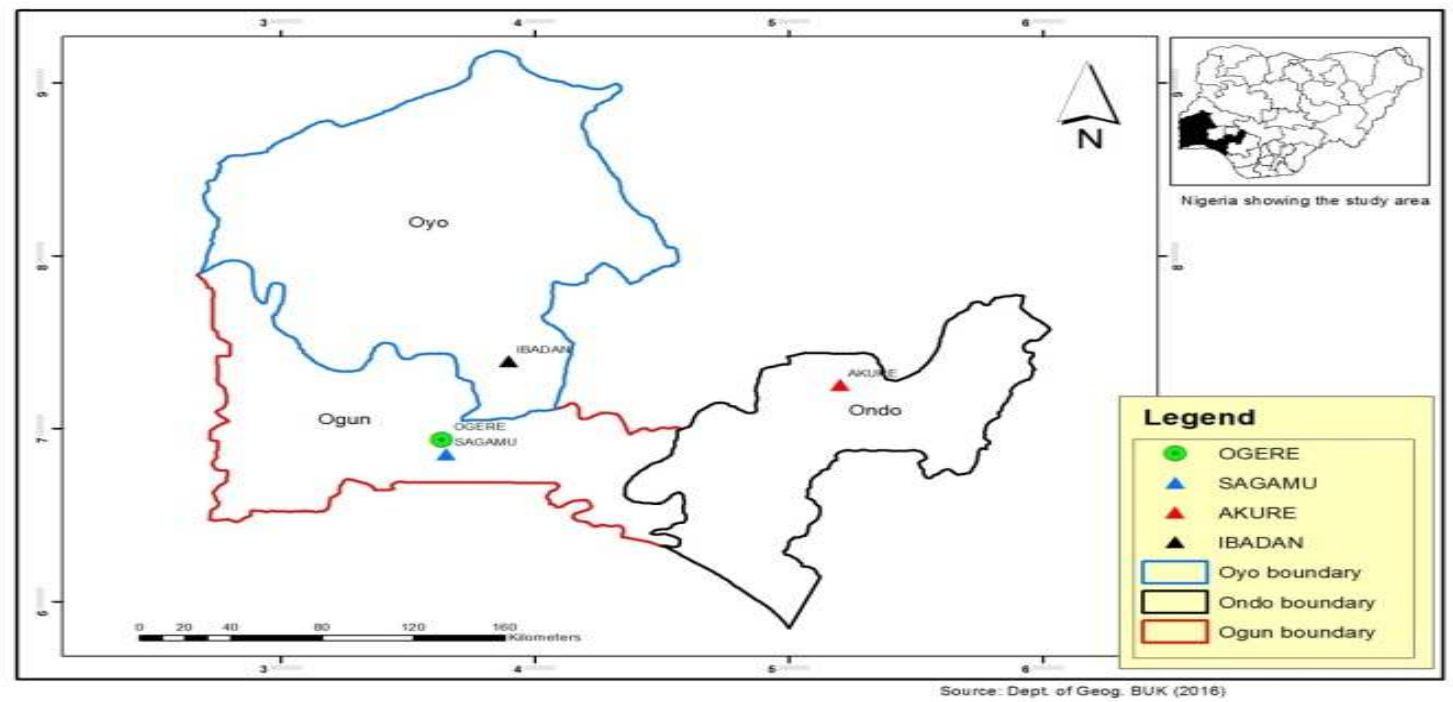

Figure 1: Map showing the sampling point at Sagamu Town, Ogun State.

\section{Description of Sampling Area}

Sagamu has geographical coordinates between $6^{\circ} 50^{\prime}$ north; $3^{\circ} 38^{\prime}$ east is located in south western region of Nigeria. The region has tropical wet and dry climate with a lengthy wet season and relatively constant temperatures throughout the course of the year. Wet season runs from March to October, November to December forms the region dry season. The vegetation type of the region is savannah which is really grassland with small bushes and occasional big trees. Grassland soils have substantially higher organic matter content than forest soils (Novackova, 2011).

\section{Sample Collection}

The Peatsoil samples were collected from four different sampling points $(0-10 \mathrm{~cm}$ depth) in Sagamu into polyethylene bag with plastic spoons. Samples were taken to the laboratory, extraneous materials were removed; the samples were air-dried, crushed and ground to a fine powder in a mortar passed through a $0.20 \mathrm{~mm}$ sieve. The samples were kept for analysis.

\section{Isolation and purification of humic acid from peat soil sample}

Peatsoil sample $(100 \mathrm{~g})$ was mixed with 1000 $\mathrm{cm}^{3}$ of $0.1 \mathrm{M} \mathrm{NaOH}$ solution, shaken for 3hours and left to stand overnight. Dark-coloured supernatant was obtained and decanted from solid residue. The dark-coloured supernatant was acidified to $(\mathrm{pH}=1.0)$ with $6 \mathrm{M} \mathrm{HCl}$ stirred and allowed to stand for 6 hours. Yellowish brown supernatant and dark-brown precipitate were obtained. The yellowish brown supernatant was decanted followed by centrifuge and discarded. The dark-brown precipitate was mixed with $500 \mathrm{~cm}^{3}$ of $0.1 \mathrm{M} \mathrm{NaOH}$ solution followed by passing through dowex resin. The dark-brown solution was acidified to $(\mathrm{pH}=1.0)$ with $6 \mathrm{M} \mathrm{HCl}$ stirred and allowed to stand for 3 hours. The dark-brown precipitate was washed several times with deionized water. The supernatant was treated with $\mathrm{AgNO}_{3}$ solution until no white precipitate observed. The humic acid was transferred to weighed crucible and dried at $60^{\circ} \mathrm{C}$ in an oven for 12 hours. The humic acid was cooled and dried in the desiccator, weighed and recorded. The obtained humic acid was dried again at $60^{\circ} \mathrm{C}$ for additional 6 hours cooled and dried in the desiccator, weighed and recorded constant weight was obtained (Baruah et al., 2015).

\section{FT-IR analysis}

FT-IR spectra of humic acid sample was analysed using Carry 630 FT-IR Agilent Technologies.

Unhydrolysed compost humic acid

The unhydrolysed humic acid was obtained after isolation and purification of compost humic acid and kept for investigation.

\section{Acid hydrolysis of Peatsoil acid}

Peatsoil humic acid sample (1g) was refluxed for 12 hours at $\left(160^{\circ} \mathrm{C}\right)$ with $50 \mathrm{~cm}^{3}$ of $6 \mathrm{M} \mathrm{HCl}$. The mixture was allowed to cool, decanted, and centrifuged after hydrolysis. The insoluble residues were washed with distilled water via centrifugation several times, and the supernatant was treated with $\mathrm{AgNO}_{3}$ solution until no white precipitate was observed. The residue was thoroughly dried over $\mathrm{CaCl}_{2}$ in a desiccator at room temperature (Chefetz et al., 2002). Finally, the obtained hydrolysed humic acid was kept for investigation. 
BAJOPAS Volume 14 Number 1,June, 2021 Potentiometric Titrations

Potentiometric measurements were carried out using a pH-meter Jenway (model 3510) with combine electrode, the sensitivity of the $\mathrm{pH}$ meter is 0.01 units. The $\mathrm{pH}$ meter was switched on half an hour before starting the titration for initial warm up of the instrument. The instrument was calibrated with an aqueous standard buffer solution of $\mathrm{pH} 4.00$ and 10.0 (borate buffer) prepared from a "Qualigens" buffer tablets.

The following sets of solutions were prepared in a $250 \mathrm{~cm}^{3}$ volumetric flask separately for $\mathrm{pH}$ metric titrations.

(i) $5 \mathrm{~cm}^{3} 0.1 \mathrm{M} \mathrm{HCl}+40 \mathrm{~cm}^{3}$ deionized water

(ii) $5 \mathrm{~cm}^{3} 0.1 \mathrm{M} \mathrm{HCl}+39 \mathrm{~cm}^{3}$ deionized water $+1 \mathrm{~cm}^{3} 0.15 \mathrm{gcm}^{-3}$ humic acid

(iii) $5 \mathrm{~cm}^{3} 0.1 \mathrm{M} \mathrm{HCl}+37 \mathrm{~cm}^{3}$ deionized water $+1 \mathrm{~cm}^{3} 0.15 \mathrm{gcm}^{-3}$ humic acid

$$
+2 \mathrm{~cm}^{3} \quad 0.01 \mathrm{M} \mathrm{Cu} \text { (II) }
$$

The solutions were titrated against standardized $0.110 \mathrm{MNaOH}$ separately. The total volume of each mixture was adjusted to $50 \mathrm{~cm}^{3}$ and the ionic strength of the solutions was maintained constant at by adding appropriate amount of stock solution of $1 \mathrm{M} \mathrm{KNO}_{3}$ (Gamal, 2015; Omar and Ali, 2015). A magnetic stirrer was used to achieve thorough mixing of the interacting solutions at $550 \mathrm{rpm}$. The same set of experimental conditions was applied for potentiometric titration of remaining samples.

\section{Evaluation of pKa of Hydrolysed peat soil Humic Acids}

The proton-ligand formation number $\mathrm{n}_{\mathbf{A}}$ were calculated by Irving and Rossotti expression (Omar and Ali, 2015).

$\mathrm{nA}=\mathrm{Y}-\frac{(\mathrm{V} 2-\mathrm{V1})(\mathrm{No}-\mathrm{Eo})}{(\mathrm{VO}+\mathrm{V1}) \mathrm{TCL}}$ 1

Where: $Y$ is number of dissociable proton, $\left(\mathrm{V}_{2^{-}}\right.$ $V_{1}$ ) is the measure of displacement of the ligand curve relative to acid curve, $\mathrm{N}^{\circ}$ and $\mathrm{E}^{\circ}$ are the resultant concentration of alkali solution, free acid solution, $\mathrm{T}_{\mathrm{cL}}{ }^{\circ}$ is the total ligand concentration, $\mathrm{V}^{\circ}$ is the total volume of titration solution, $V_{1}$ is the volume of alkali added to acid solution, $V_{2}$ is the volume of alkali added to acid solution + ligand solution, acid dissociation constants (pKa - values) of ligand were calculated by algebraic method point wise calculation (Tables 1 ). The dissociation constants (pKa) were calculated according to the following relation:

$\mathrm{pKa}=\mathrm{pH}+\log \left(\frac{n A}{1-n A}\right)$ 2

Where: pKa is the acid dissociation constant, $\mathrm{n}_{\mathrm{A}}$ is the Proton-ligand formation number and $\mathrm{pH}$ is the pH-values (Omar and Ali, 2015).

\section{Determination of metal-ligand stability constants $(\log K)$ of complexes}

The potentiometric measurement for the determination of stability constant of a complex in solution is based on the fact that the redox potential of the couple $\frac{M^{+(m-n)}}{M^{+m}}$ is shifted significantly on complexation of the metal ion with the ligand. This method involves change in hydrogen ion concentration $\left[\mathrm{H}^{+}\right]$due to the displacement or association of one or more protons taking place during complexation reaction. This change can be found out by titrating the solutions containing free acid, acid with ligand, and acid with ligand and metal ion, individually against a standard alkali solution at a constant ionic strength or temperature. Either ionic strength or temperature may be varied for different sets of solutions. In all the cases, the change in the $\mathrm{pH}$ of the solution is measured after each addition of a known amount of alkali to the reaction cell which contains the reaction mixture. The titration curves are then drawn by plotting the measured $\mathrm{pH}$ values against the corresponding volume of alkali added and the stability constants of the complexes are determined from the titration curves by employing $\mathrm{pH}$-metric titration technique given by (Irving and Rossoti).

Metal-ligand stability constants ( $\log \mathrm{K}$ ) were determined by using the following relations:

$$
\bar{n}=\frac{\left(V_{3}-V_{2}\right)\left(E^{0}+N^{0}\right)}{\left(V^{0}+V_{2}\right) \bar{n}_{A} T_{m}^{0}}
$$

and

$$
P L=\log _{10}\left\{\frac{1+\beta_{n}^{H} \frac{1}{[\text { anti } \log \mathrm{pH}]^{\mathrm{n}}}}{\mathrm{T}_{\mathrm{L}}^{0}-n \bar{T}_{m}^{0}} \mathrm{X} \frac{\left(V^{0}+V_{3}\right)}{V^{0}}\right\}
$$


BAJOPAS Volume 14 Number 1,June, 2021

Where $T_{L}, T^{\circ}, E^{\circ}$, and $V^{\circ}$ havethe same significance as in equation (1) above, $T_{m}$ denotes the total concentration of metal present in solution, $V_{3}$ is the volume of metal ions present in solution and $\beta^{H}$ is the overall proton ligand stability constant. The metal-ligand stability constants (log K) were determined by employing point wise computational Method (eq. 5 and 6).

$\operatorname{LogK}_{1}=\log \left(\frac{n}{1-n}\right)+\mathrm{pL}$ .5

$\operatorname{LogK}_{2}=\log \left(\frac{1-n}{2-n}\right)+\mathrm{pL}$ ...6

Where: Log $\mathrm{K}$ is the metal-ligand stability constant, $\mathrm{pL}$ is the Free ligand exponent function, $\mathbf{n}$ is the Average number of ligand attached with metal ion (Janraoet al., 2014). The results obtained were analyzed by an ORIGIN 2016 program using titration data and then the proton-ligand stability constants (pKa) and Metal-ligand stability constant (LogK) calculated (Omar and Ali, 2015).

\section{RESULTS AND DISCUSSION}

Fourier transformed infrared (FT-IR) spectra of isolated humic acid from peat soils Figure 2 had distinct clear absorption bands indicating the presence of major humic acid structural elemental groups such as $\mathrm{H}$ bonded $\mathrm{OH}$ $\left(3680 \mathrm{~cm}^{-1}\right.$ peak $), C=0$ of carbonyl $\left(1721 \mathrm{~cm}^{-1}\right.$ peak), functional groups of aliphatic components $\mathrm{CH}_{2}\left(2918 \mathrm{~cm}^{-1}\right.$ peak) and $\mathrm{C}-\mathrm{O}$ stretching of polysaccharide $\left(1168 \mathrm{~cm}^{-1}\right.$ peak). The positions of the absorption bands of the spectra fell within typical major absorption bands of humic acid which is at frequencies 3680, 2918, 1721, 1168 $\mathrm{cm}^{-1}$. The first peak centred in the vicinity of $3680 \mathrm{~cm}^{-1}$ region is attributed to phenol $\mathrm{OH}$ group bounded by intermolecular $\mathrm{H}$ bonds. The $2918 \mathrm{~cm}^{-1}$ band usually has absorption maximum at $2918 \mathrm{~cm}^{-1}$ which is due to $\mathrm{C}-\mathrm{H}$ stretching of alkane group $\left(\mathrm{CH}_{2}\right)$. The next major absorption band is $1721 \mathrm{~cm}^{-1}$. This band has been commonly ascribed to $\mathrm{C}=\mathrm{O}$ stretching of mainly carboxyl group $(\mathrm{COOH})$ with trace amount of ketones. The last peak was observed at 1168 $\mathrm{cm}^{-1}$ due to $\mathrm{C}-\mathrm{O}$ stretching of polysaccharides and this peak appeared also in the spectra of humic acid from peat soil. The FTIR spectra of the isolated humic acid contained all major characteristic absorption peaks of humic acid. These absorption peaks indicated the presence of the major structural elements of humic acid namely $\mathrm{H}$ bonded $\mathrm{OH}, \mathrm{C}=\mathrm{C}$ of aromatic ring, $\mathrm{C}=\mathrm{O}$ of carbonyl group (both carboxyl and ketonic), $\mathrm{CH}_{2}$ group. This strongly supports the presence of humic acid.

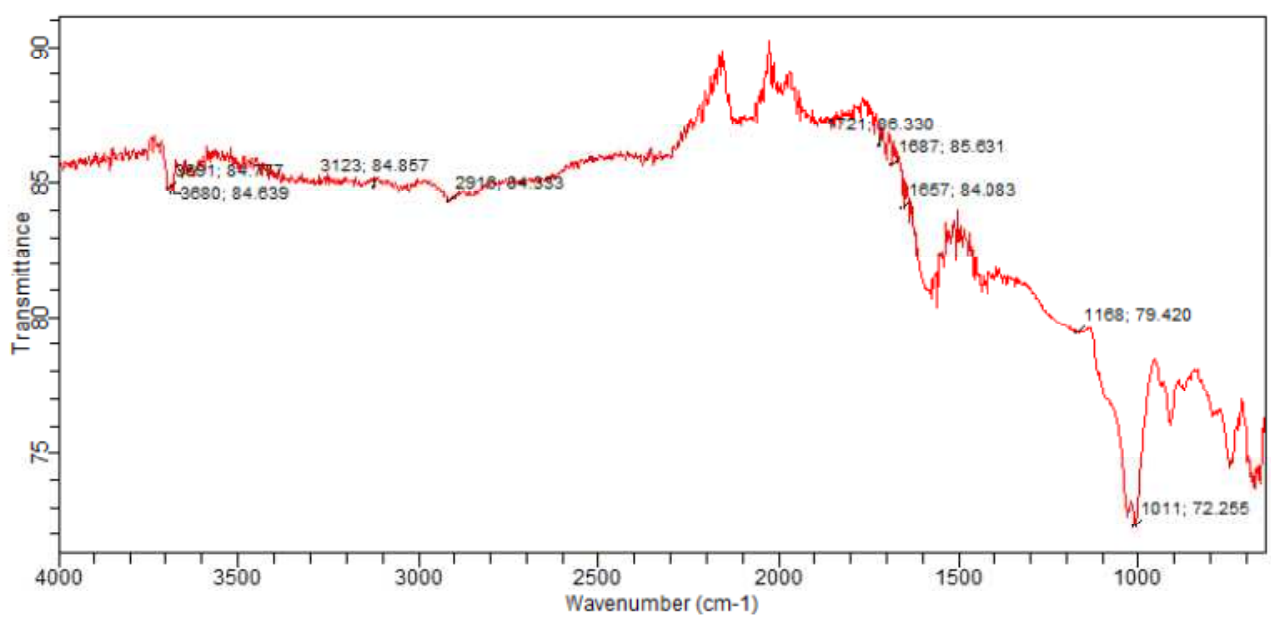

Fig. 2 : FT-IR spectraof peatsoilhumic acid (PSHA)

\section{Evaluation of acid dissociation constant (pka) of acid hydrolysed peat soil humicacid at phenolic group}

The value of the dissociation constant of the peat soil humic acid (PSHA) that underwent acidhydrolysis studied was found to be 8.9299 as shown Table 1, which is lower than the literaturevalues reported by Almeida and Szpoganics, (2015), Borges et al., (2005); Badr et al., (2012)and Fernandes et al,.(2009) of $9.73,9.47$ and 10.30. The difference between the obtained valuesand the reported values in this study might be probably as a result of acid hydrolysis of humicacid. 
BAJOPAS Volume 14 Number 1,June, 2021

Table 1: PKa of (Hydrolysed PSHA)

\begin{tabular}{|l|l|l|l|l|l|l|}
\hline $\mathrm{pH}$ & $\mathrm{BV}_{1}$ & $\mathrm{BV}_{2}$ & $\mathrm{~V}_{2}-\mathrm{V}_{1}$ & $\mathrm{nA}$ & $\log \left(\frac{n A}{1-n A}\right)$ & $\mathrm{pKa}$ \\
\hline 8.50 & 5.30 & 6.29 & 0.99 & 0.3594 & -0.2510 & 8.2490 \\
8.72 & 5.35 & 6.37 & 1.02 & 0.3400 & -0.2880 & 8.4320 \\
9.00 & 5.40 & 6.46 & 1.06 & 0.3141 & -0.3391 & 8.6609 \\
9.22 & 5.45 & 6.55 & 1.10 & 0.2882 & -0.3927 & 8.8273 \\
9.51 & 5.50 & 6.66 & 1.16 & 0.2494 & -0.4786 & 9.0314 \\
9.73 & 5.55 & 6.78 & 1.23 & 0.2041 & -0.5910 & 9.1390 \\
10.00 & 5.60 & 6.90 & 1.30 & 0.1589 & -0.7238 & 9.2762 \\
10.23 & 5.65 & 7.05 & 1.40 & 0.0941 & -0.9835 & 9.2465 \\
10.49 & 5.70 & 7.10 & 1.40 & 0.0941 & -0.9835 & 9.5065 \\
\hline
\end{tabular}

Average pKa $=8.9299 \pm 0.4186$

Table 2: PKa of (Unhydrolysed PSHA)

\begin{tabular}{|l|l|l|l|l|l|l|}
\hline $\mathrm{pH}$ & $\mathrm{BV}_{1}$ & $\mathrm{BV}_{2}$ & $\mathrm{~V}_{2}-\mathrm{V}_{1}$ & $\mathrm{nA}$ & $\log \left(\frac{\boldsymbol{n A}}{1-\boldsymbol{n}}\right)$ & $\mathrm{pKa}$ \\
\hline 8.50 & 5.30 & 5.81 & 0.51 & 0.6619 & 0.2919 & 8.7919 \\
8.72 & 5.35 & 5.90 & 0.55 & 0.6357 & 0.2418 & 8.9618 \\
9.00 & 5.40 & 6.00 & 0.60 & 0.6029 & 0.1813 & 9.1813 \\
9.22 & 5.45 & 6.10 & 0.65 & 0.5701 & 0.1226 & 9.3426 \\
9.51 & 5.50 & 6.20 & 0.70 & 0.5376 & 0.0654 & 9.5754 \\
9.73 & 5.55 & 6.33 & 0.78 & 0.4851 & -0.0259 & 9.7041 \\
10.00 & 5.60 & 6.47 & 0.87 & 0.4262 & -0.1291 & 9.8709 \\
10.23 & 5.65 & 6.62 & 0.99 & 0.3609 & -0.2481 & 9.9819 \\
10.49 & 5.70 & 6.80 & 1.10 & 0.2759 & -0.4690 & 10.0210 \\
\hline
\end{tabular}

Average pKa $=9.4923 \pm 0.4410$

Metal-ligand stability constant ( $\log \mathrm{K}$ )

The stabilityconstants require the accurate values of proton-ligand stability constants (Anil and Maroti, 2008). Metal titration curves crossed over ligand titration curve indicated the formation of complex upon proton release (Santosh, et al., 2011). If the values of n- are within range $0.2-0.8$ and $1.2-18$ this indicates the formation of $1: 1$ and 1:2 complexes (Sayyed and Mazahar, 2012).

The metal (II)-humate stepwise stability constants (log k) at phenolic group (Tables 318)

Table 3: Point-wise method, $\mathrm{Cu}$-(Hydrolysed PSHA)

\begin{tabular}{|l|l|l|l|l|l|l|l|l|}
\hline $\mathrm{pH}$ & $\mathrm{BV}_{1}$ & $\mathrm{BV}_{2}$ & $\mathrm{BV}_{3}$ & $\left(\mathrm{~V}_{3}-\mathrm{V}_{2}\right)$ & $\mathrm{n}$ & $\mathrm{pL}$ & $\log \left(\frac{n}{1-n}\right)$ & LogK $_{1}$ \\
\hline 8.50 & 5.30 & 6.29 & 6.33 & 0.04 & 0.5500 & 2.66 & 0.0871 & 2.7471 \\
8.72 & 5.35 & 6.37 & 6.41 & 0.04 & 0.5714 & 2.43 & 0.1249 & 2.5549 \\
9.00 & 5.40 & 6.46 & 6.50 & 0.04 & 0.6198 & 2.16 & 0.2122 & 2.3722 \\
9.22 & 5.45 & 6.55 & 6.59 & 0.04 & 0.6667 & 1.94 & 0.3010 & 2.2410 \\
\hline
\end{tabular}

LogK $_{1}$ (Average value) $=2.4788 \pm 0.2203$

Table 4: Point-wise method, $\mathrm{Cu}$-(Hydrolysed PSHA)

\begin{tabular}{|l|l|l|l|l|l|l|l|l|}
\hline $\mathrm{pH}$ & $\mathrm{BV}_{1}$ & $\mathrm{BV}_{2}$ & $\mathrm{BV}_{3}$ & $\left(\mathrm{~V}_{3}-\mathrm{V}_{2}\right)$ & $\mathrm{n}$ & $\mathrm{pL}$ & $\log \left(\frac{n-1}{2-n}\right)$ & LogK $_{2}$ \\
\hline 9.51 & 5.50 & 6.66 & 6.73 & 0.07 & 1.3509 & 1.70 & -0.2671 & 1.4329 \\
9.73 & 5.55 & 6.78 & 6.85 & 0.07 & 1.6383 & 1.51 & 0.2467 & 1.7567 \\
10.00 & 5.60 & 6.90 & 6.98 & 0.08 & 2.1783 & 1.31 & -0.2158 & 1.0942 \\
10.23 & 5.65 & 7.05 & 7.13 & 0.08 & 4.1904 & 1.27 & & \\
10.49 & 5.70 & 7.10 & 7.19 & 0.09 & 4.6920 & & & \\
\hline
\end{tabular}

Log $K_{2}($ Average value $)=1.4280 \pm 0.3312$ 
BAJOPAS Volume 14 Number 1,June, 2021

Table 5: Point-wise method, $\mathrm{Cu}$ (Unhydrolysed PSHA)

\begin{tabular}{|l|l|l|l|l|l|l|l|l|}
\hline $\mathrm{pH}$ & $\mathrm{BV}_{1}$ & $\mathrm{BV}_{2}$ & $\mathrm{BV}_{3}$ & $\left(\mathrm{~V}_{3}-\mathrm{V}_{2}\right)$ & $\mathrm{n}$ & $\mathrm{pL}$ & $\log \left(\frac{n}{n-1}\right)$ & Log $_{1}$ \\
\hline 8.50 & 5.30 & 5.81 & 5.85 & 0.04 & 0.2973 & 2.88 & -0.3736 & 2.5064 \\
8.72 & 5.35 & 5.90 & 5.95 & 0.05 & 0.3873 & 2.66 & -0.1992 & 2.4608 \\
9.00 & 5.40 & 6.00 & 6.05 & 0.05 & 0.4044 & 2.38 & -0.1681 & 2.2119 \\
9.22 & 5.45 & 6.10 & 6.15 & 0.06 & 0.5157 & 2.18 & -0.0272 & 2.2072 \\
9.51 & 5.50 & 6.20 & 6.27 & 0.07 & 0.6417 & 1.89 & 0.2530 & 1.1430 \\
\hline
\end{tabular}

$\operatorname{LogK}_{1}($ Average value $)=2.3059 \pm 0.6153$

Table 6:Point-wise method, $\mathrm{Cu}$ (Unhydrolysed PSHA)

\begin{tabular}{|l|l|l|l|l|l|l|l|l|}
\hline $\mathrm{pH}$ & $\mathrm{BV}_{1}$ & $\mathrm{BV}_{2}$ & $\mathrm{BV}_{3}$ & $\mathrm{~V}_{3}-\mathrm{V}_{2}$ & $\mathrm{n}$ & $\mathrm{pL}$ & $\log \left(\frac{n-1}{2-n}\right)$ & $\log \mathrm{K}_{2}$ \\
\hline 9.73 & 5.55 & 6.33 & 6.42 & 0.09 & 0.9000 & 1.69 & & \\
10.00 & 5.60 & 6.47 & 6.58 & 0.11 & 1.2578 & 1.44 & -0.4592 & 0.9808 \\
10.23 & 5.65 & 6.62 & 6.84 & 0.12 & 1.6137 & 1.26 & -0.2010 & 1.4610 \\
10.49 & 5.70 & 6.80 & 6.92 & 0.12 & 2.1052 & 1.03 & & \\
\hline
\end{tabular}

$\operatorname{LogK}_{2}$ (Average value) $=1.2209 \pm 0.3398$

Table 7:Point-wise method, Pb (Hydrolysed PSHA)

\begin{tabular}{|l|l|l|l|l|l|l|l|l|}
\hline $\mathrm{pH}$ & $\mathrm{BV}_{1}$ & $\mathrm{BV}_{2}$ & $\mathrm{BV}_{3}$ & $\left(\mathrm{~V}_{3}-\mathrm{V}_{2}\right)$ & $\mathrm{n}$ & $\mathrm{pL}$ & $\log \left(\frac{n}{1-n}\right)$ & LogK $_{1}$ \\
\hline 8.50 & 5.30 & 6.29 & 6.33 & 0.04 & 0.5500 & 2.66 & 0.0871 & 2.7471 \\
8.72 & 5.35 & 6.37 & 6.41 & 0.04 & 0.5714 & 2.43 & 0.1249 & 2.5549 \\
9.00 & 5.40 & 6.46 & 6.50 & 0.04 & 0.6198 & 2.16 & 0.2122 & 2.3722 \\
9.22 & 5.45 & 6.55 & 6.60 & 0.05 & 0.8333 & 1.96 & 0.6989 & 2.6589 \\
\hline
\end{tabular}

Log $_{\mathbf{1}}($ Average value $)=2.5832 \pm 0.1614$

Table 8:Point-wise method, Pb-(Hydrolysed PSHA)

\begin{tabular}{|l|l|l|l|l|l|l|l|l|}
\hline $\mathrm{pH}$ & $\mathrm{BV}_{1}$ & $\mathrm{BV}_{2}$ & $\mathrm{BV}_{3}$ & $\left(\mathrm{~V}_{3}-\mathrm{V}_{2}\right)$ & $\mathrm{n}$ & $\mathrm{pL}$ & $\log \left(\frac{n-1}{2-n}\right)$ & $\log \mathrm{K}_{2}$ \\
\hline 9.51 & 5.50 & 6.66 & 6.71 & 0.05 & 0.9650 & 1.67 & & \\
9.73 & 5.55 & 6.78 & 6.83 & 0.05 & 1.1702 & 1.44 & & \\
10.00 & 5.60 & 6.90 & 6.90 & 0.05 & 1.4864 & 1.22 & -0.0237 & 1.1963 \\
10.23 & 5.65 & 7.05 & 7.10 & 0.05 & 2.0190 & 1.09 & & \\
10.49 & 5.70 & 7.10 & 7.17 & 0.07 & 3.6492 & 1.00 & & \\
\hline
\end{tabular}

Log $K_{2}$ (Average value) $=1.1963$

Table 9: Point-wise method, Pb (Unhydrolysed PSHA)

\begin{tabular}{|l|l|l|l|l|l|l|l|l|}
\hline $\mathrm{pH}$ & $\mathrm{BV}_{1}$ & $\mathrm{BV}_{2}$ & $\mathrm{BV}_{3}$ & $\mathrm{~V}_{3}-\mathrm{V}_{2}$ & $\mathrm{n}$ & $\mathrm{pL}$ & $\begin{array}{l}\text { Log } \\
\left(\frac{n}{n-1}\right)\end{array}$ & Log $\mathrm{K}_{1}$ \\
\hline 8.50 & 5.30 & 5.81 & 5.85 & 0.04 & 0.2973 & 2.88 & -0.3736 & 2.5064 \\
8.72 & 5.35 & 5.90 & 5.94 & 0.04 & 0.3099 & 2.66 & -0.5477 & 2.3123 \\
9.00 & 5.40 & 6.00 & 6.05 & 0.05 & 0.4044 & 2.38 & -0.1681 & 2.2119 \\
9.22 & 5.45 & 6.10 & 6.15 & 0.06 & 0.5157 & 2.18 & 0.0272 & 2.2072 \\
9.51 & 5.50 & 6.20 & 6.26 & 0.07 & 0.6417 & 1.89 & 0.2530 & 2.1430 \\
9.73 & 5.55 & 6.40 & 6.40 & 0.07 & 0.7000 & 1.67 & 0.3680 & 2.0380 \\
\hline
\end{tabular}

LogK $_{1}$ (Average value) $=2.2364 \pm 0.1602$

Table 10: Point-wise method, Pb (Unhydrolysed PSHA)

\begin{tabular}{|l|l|l|l|l|l|l|l|l|}
\hline $\mathrm{pH}$ & $\mathrm{BV}_{1}$ & $\mathrm{BV}_{2}$ & $\mathrm{BV}_{3}$ & $\mathrm{~V}_{3}-\mathrm{V}_{2}$ & $\mathrm{n}$ & $\mathrm{pL}$ & $\log \left(\frac{n-1}{2-n}\right)$ & $\log \mathrm{K}_{2}$ \\
\hline 10.00 & 5.60 & 6.47 & 6.55 & 0.08 & 1.9503 & 1.41 & & \\
10.23 & 5.65 & 6.62 & 6.72 & 0.11 & 1.4792 & 1.26 & -0.0361 & 1.2239 \\
\hline
\end{tabular}

$\operatorname{LogK}_{2}$ (Average value) $=1.2239$

Table 11: Point-wise method, Mg (Hydrolysed PSHA)

\begin{tabular}{|l|l|l|l|l|l|l|l|l|}
\hline $\mathrm{pH}$ & $\mathrm{BV}_{1}$ & $\mathrm{BV}_{2}$ & $\mathrm{BV}_{3}$ & $\left(\mathrm{~V}_{3}-\mathrm{V}_{2}\right)$ & $\mathrm{n}$ & $\mathrm{pL}$ & $\log \left(\frac{n}{n-1}\right)$ & LogK $_{1}$ \\
\hline 8.50 & 5.30 & 6.29 & 6.31 & 0.02 & 0.2750 & 2.64 & -0.4290 & 2.2110 \\
8.72 & 5.35 & 6.37 & 6.39 & 0.02 & 0.2858 & 2.42 & -0.3978 & 2.0222 \\
9.00 & 5.40 & 6.46 & 6.49 & 0.03 & 0.4648 & 2.14 & -0.0612 & 2.0788 \\
9.22 & 5.45 & 6.55 & 6.59 & 0.04 & 0.6667 & 1.94 & 0.3010 & 2.2410 \\
\hline
\end{tabular}

$\log _{\mathbf{1}}($ Average value) $=2.1382 \pm 0.1046$ 
BAJOPAS Volume 14 Number 1,June, 2021

Table 12: Point-wise method, Mg (Hydrolysed PSHA)

\begin{tabular}{|l|l|l|l|l|l|l|l|l|}
\hline $\mathrm{pH}$ & $\mathrm{BV}_{1}$ & $\mathrm{BV}_{2}$ & $\mathrm{BV}_{3}$ & $\left(\mathrm{~V}_{3}-\mathrm{V}_{2}\right)$ & $\mathrm{n}$ & $\mathrm{pL}$ & $\log \left(\frac{n-1}{2-n}\right)$ & LogK $_{2}$ \\
\hline 9.51 & 5.55 & 6.66 & 6.71 & 0.05 & 0.9650 & 1.67 & & \\
9.73 & 5.55 & 6.78 & 6.84 & 0.06 & 1.4042 & 1.47 & -0.1686 & 1.3014 \\
10.00 & 5.60 & 6.90 & 6.93 & 0.06 & 1.7838 & 1.23 & 0.5593 & 1.7893 \\
10.23 & 5.65 & 7.05 & 7.10 & 0.06 & 3.1429 & 1.10 & & \\
10.49 & 5.70 & 7.10 & 7.18 & 0.07 & 3.6492 & 0.83 & & \\
\hline
\end{tabular}

LogK $_{2}($ Average value $)=1.5453 \pm 0.3450$

Table 13: Point-wise method, Mg (Unhydrolysed PSHA)

\begin{tabular}{|l|l|l|l|l|l|l|l|l|}
\hline $\mathrm{pH}$ & $\mathrm{BV}_{1}$ & $\mathrm{BV}_{2}$ & $\mathrm{BV}_{3}$ & $\mathrm{~V}_{3}-\mathrm{V}_{2}$ & $\mathrm{n}$ & $\mathrm{pL}$ & $\log \left(\frac{n}{n-1}\right)$ & $\operatorname{Log~}_{1}$ \\
\hline 8.50 & 5.30 & 5.81 & 5.85 & 0.04 & 0.2973 & 2.88 & -0.3736 & 2.5064 \\
8.72 & 5.35 & 5.90 & 5.94 & 0.04 & 0.3099 & 2.66 & -0.3477 & 2.3123 \\
9.00 & 5.40 & 6.00 & 6.04 & 0.04 & 0.3236 & 2.38 & -0.3202 & 2.0598 \\
9.22 & 5.45 & 6.10 & 6.15 & 0.05 & 0.4297 & 2.17 & -0.1230 & 2.0470 \\
9.51 & 5.50 & 6.20 & 6.26 & 0.06 & 0.5500 & 1.89 & 0.0871 & 1.9771 \\
9.73 & 5.55 & 6.33 & 6.40 & 0.07 & 0.7000 & 1.67 & 0.3680 & 2.0380 \\
\hline
\end{tabular}

LogK $_{1}$ (Average value) $=2.1568 \pm 0.2069$

Table 14: Point-wise method, Mg (Unhydrolysed PSHA)

\begin{tabular}{|l|l|l|l|l|l|l|l|l|}
\hline $\mathrm{pH}$ & $\mathrm{BV}_{1}$ & $\mathrm{BV}_{2}$ & $\mathrm{BV}_{3}$ & $\mathrm{~V}_{3}-\mathrm{V}_{2}$ & $\mathrm{n}$ & $\mathrm{pL}$ & $\log \left(\frac{n-1}{2-n}\right)$ & $\log \mathrm{K}_{2}$ \\
\hline 10.00 & 5.60 & 6.47 & 6.55 & 0.08 & 0.9148 & 1.41 & & \\
10.23 & 5.65 & 6.62 & 6.71 & 0.09 & 1.2102 & 1.20 & -0.5749 & 0.6251 \\
10.49 & 5.70 & 6.80 & 6.92 & 0.09 & 1.5968 & 1.03 & 0.1703 & 1.2003 \\
\hline
\end{tabular}

LogK $_{2}$ (Average value) $=0.9127 \pm 0.4070$

Table15:Point-wise method, Cd (Hydrolysed PSHA)

\begin{tabular}{|l|l|l|l|l|l|l|l|l|}
\hline $\mathrm{pH}$ & $\mathrm{BV}_{1}$ & $\mathrm{BV}_{2}$ & $\mathrm{BV}_{3}$ & $\left(\mathrm{~V}_{3}-\mathrm{V}_{2}\right)$ & $\mathrm{n}$ & $\mathrm{pL}$ & $\log \left(\frac{n}{1-n}\right)$ & LogK $_{1}$ \\
\hline 8.50 & 5.30 & 6.29 & 6.31 & 0.02 & 0.2750 & 2.64 & -0.4210 & 2.2190 \\
8.72 & 5.35 & 6.37 & 6.40 & 0.03 & 0.4286 & 2.42 & -0.1249 & 2.2951 \\
9.00 & 5.40 & 6.46 & 6.49 & 0.03 & 0.4648 & 2.14 & -0.0612 & 2.0788 \\
9.22 & 5.45 & 6.55 & 6.59 & 0.04 & 0.6667 & 1.96 & 0.3010 & 2.2610 \\
9.51 & 5.55 & 6.66 & 6.70 & 0.04 & 0.7720 & 1.67 & 0.5297 & 2.1997 \\
\hline
\end{tabular}

LogK $_{\mathbf{1}}$ (Average value) $=2.2108 \pm 0.0825$

Table 16: Point-wise method, Cd (Hydrolysed PSHA)

\begin{tabular}{|l|l|l|l|l|l|l|l|l|}
\hline $\mathrm{pH}$ & $\mathrm{BV}_{1}$ & $\mathrm{BV}_{2}$ & $\mathrm{BV}_{3}$ & $\left(\mathrm{~V}_{3}-\mathrm{V}_{2}\right)$ & $\mathrm{n}$ & $\mathrm{pL}$ & $\log \left(\frac{n-1}{2-n}\right)$ & Log $_{2}$ \\
\hline 9.73 & 5.55 & 6.78 & 6.83 & 0.06 & 1.4042 & 1.47 & -0.1686 & 1.3014 \\
10.00 & 5.60 & 6.90 & 6.95 & 0.06 & 1.7838 & 1.23 & 0.5593 & 1.7893 \\
10.23 & 5.65 & 7.05 & 7.10 & 0.06 & 3.1429 & 1.09 & & \\
10.49 & 5.70 & 7.10 & 7.16 & 0.06 & 3.1429 & 0.89 & & \\
& & & & & & & & \\
\hline
\end{tabular}

$\operatorname{LogK}_{2}$ (Average value) $=1.5453 \pm 0.3450$

Table 17: Point-wise method, Cd (Unhydrolysed PSHA)

\begin{tabular}{|l|l|l|l|l|l|l|l|l|}
\hline $\mathrm{pH}$ & $\mathrm{BV}_{1}$ & $\mathrm{BV}_{2}$ & $\mathrm{BV}_{3}$ & $\mathrm{~V}_{3}-\mathrm{V}_{2}$ & $\mathrm{n}$ & $\mathrm{pL}$ & $\log \left(\frac{n}{n-1}\right)$ & $\operatorname{Log~}_{1}$ \\
\hline 8.50 & 5.30 & 5.81 & 5.86 & 0.05 & 0.3717 & 2.88 & -0.2280 & 2.6520 \\
8.72 & 5.35 & 5.90 & 5.95 & 0.05 & 0.3873 & 2.66 & -0.1992 & 2.4608 \\
9.00 & 5.40 & 6.00 & 6.06 & 0.06 & 0.4853 & 2.38 & -0.0255 & 2.3545 \\
9.22 & 5.45 & 6.10 & 6.16 & 0.06 & 0.5157 & 2.18 & -0.0272 & 2.2072 \\
9.51 & 5.50 & 6.20 & 6.27 & 0.07 & 0.6417 & 1.89 & 0.2530 & 1.1430 \\
9.73 & 5.55 & 6.33 & 6.41 & 0.08 & 0.8000 & 1.69 & 0.6020 & 2.2920 \\
& & & & & & & & \\
\hline
\end{tabular}

$\operatorname{LogK}_{1}($ Average value $)=2.2516 \pm 0.5380$ 
BAJOPAS Volume 14 Number 1,June, 2021

Table 18: Point-wise method, Cd (Unhydrolysed PSHA)

\begin{tabular}{|l|l|l|l|l|l|l|l|l|}
\hline $\mathrm{pH}$ & $\mathrm{BV}_{1}$ & $\mathrm{BV}_{2}$ & $\mathrm{BV}_{3}$ & $\mathrm{~V}_{3}-\mathrm{V}_{2}$ & $\mathrm{n}$ & $\mathrm{pL}$ & $\log \left(\frac{n-1}{2-n}\right)$ & $\log \mathrm{K}_{2}$ \\
\hline 10.00 & 5.60 & 6.47 & 6.57 & 0.10 & 1.1434 & 1.43 & & \\
10.23 & 5.65 & 6.62 & 6.72 & 0.10 & 1.3448 & 1.23 & -0.2788 & 0.9512 \\
10.49 & 5.70 & 6.80 & 6.90 & 0.10 & 1.7742 & 1.03 & 0.5351 & 1.5651 \\
\hline
\end{tabular}

$\operatorname{LogK}_{2}($ Average value $)=1.2581 \pm 0.4340$

Table 19: Stepwise and overall Stability constants of thehydrolysed and unhydrolysed divalent metal (II) complexes

\begin{tabular}{|c|c|c|c|}
\hline Chelates & LogK $_{1}$ & $\log _{2}$ & Log $\beta$ \\
\hline [Cu (Hydrolysed PSHA-1) $\left.{ }_{2}\right]$ & 2.4788 & 1.4280 & 3.9068 \\
\hline$\left[\mathrm{Pb}(\text { Hydrolysed PSHA-1) })_{2}\right]$ & 2.5832 & 1.1963 & 3.7795 \\
\hline$\left[\mathrm{Cd}(\text { Hydrolysed PSHA-1 })_{2}\right]$ & 2.2108 & 1.5453 & 3.7561 \\
\hline$\left[\mathrm{Mg}(\text { Hydrolysed PSHA-1 })_{2}\right]$ & 2.1382 & 1.5453 & 3.6835 \\
\hline [Cu (Unhydrolysed PSHA-1) & 2.3059 & 1.2209 & 3.5268 \\
\hline$[\mathrm{Pb}$ (Unhydrolysed PSHA-1) 2$]$ & 2.2364 & 1.2239 & 3.4603 \\
\hline [Cd (Unhydrolysed PSHA-1) 2 ] & 2.2516 & 1.2581 & 3.5097 \\
\hline$[\mathrm{Mg}$ (Unydrolysed PSHA-1) & 2.1568 & 0.9127 & 3.0695 \\
\hline
\end{tabular}

The results obtained (Table19) shows the stepwise and overall stability constants to be not high indicating low stability of the complexes, because the solubility of most metal ions in the basic $\mathrm{pH}$ range is minimal due to metal hydroxide precipitation (Karimi, 2017). In general, the stepwise stability constants $\left(K_{1}\right.$ and $K_{2}$ ) follow the order $K_{1}>K_{2}$ for the copper, lead, magnesium and cadmium complexes respectively. The steady decrease of the values with increasing number of ligands is in agreement with the prediction made by researchers (Na'aliya, 2013). The decrease could be attributed to the fact that as the number of the ligands (Humate ions) that enters the coordination zone increases the aqua molecules available for replacement by the ligands become less. Thus, the metal ions become less electron loving with progressive intake of the ligand and this results in the decrease in the values of the constants (Na'aliya, 2013). Also the stability of the complexes is influenced by the size and number of the chelate rings(Mackay and Mackay,2002).All the complexes form rings in their structure as humate, a bidentate ligand, bond the metal ions in the ratio 1:2 (Boguta and Sokolowska, 2016) forming chelate rings. The values of the overall stability constants $(\log \beta)$ obtained for humate complexes are not high indicating low stability as the values are not high. LogK values for copper-humates (Table 3 to 6) obtained in this study are lower than those reported for the complexes of humic acids (Pandey et al., 2015; Dinu, 2013; Kaschl et al., 2010 and Gilbeto and Jorg, 2001). The values of LogK(Table 7 to 10 ) forlead-humates are lower than those reported for the lead in the literature (Dinu, 2013; Gilbeto and Jorg 2001). Log K values(Table 11 to 14 ) for magnesium-humates obtained in this study are close to those reported by (Pandey et al., 2015). Log K values of cadmium-humates (Table 15 to 18 ) obtained in this work near to the one reported by (Dinu, 2013 and Pandey et al., 2015).The difference between the reported values and the values obtained in this study might be probably as a result of acid hydrolysis of humic acid. The values of the overall stability constants $(\log \beta)$ of the copper humates complexes presented in Table 19 is high than that of other metal humate complexes, show relatively high stability of CuHA complexes, show the following order of stability: $\mathrm{Cu}>\mathrm{Pb}>\mathrm{Cd}>\mathrm{Mg}$; which are in close agreement to the findings of (Dinu, 2013 and Pandey et al., 2015).The high stability of Cuhumate chelate could be attributed to the existence of coordinate covalent bond between the complexing agents and the $\mathrm{Cu}^{2+}$ ions. Since, $\mathrm{Cu}^{2+}$ being a metal of the transitional series with $3 d^{9}$ electronic configurations can accept the electrons from the complexing agents. Similarly, the low stabilities of $\mathrm{Pb}, \mathrm{Cd}$ and $\mathrm{Mg}$ complexes could be explained by that $\mathrm{Pb}^{2+}$ with $6 s^{2}, \mathrm{Cd}^{2+}$ with $4 \mathrm{~d}^{10}$ and $\mathrm{Mg}^{2+}$ with $2 \mathrm{p}^{6}$ their electronic configuration has a completely filled $\mathrm{d}, \mathrm{p}$ and $\mathrm{s}$ orbitals. Moreover, the stabilities of metal ions with hydrolysed humic acid from peat soil were higher than those with unhydrolysed humic acid from peat soil; which is ascribed to the high content of acidity in hydrolysed humic acid than unhydrolysed humic acid. 
BAJOPAS Volume 14 Number 1,June, 2021 CONCLUSION

The values of logk for $\mathrm{Cu}(\mathrm{II})$ hydrolysed humic acid complex was higher followed by $\mathrm{Pb}$ (II), $\mathrm{Cd}(\mathrm{II})$ and $\mathrm{Mg}$ (II) hydrolysed humic acid complexes as compared with metal(II) unhydrolysed humic acid complexes. This indicates acid hydrolysis of humic acid can

\section{REFERENCES}

Almeida, V.R. and Szpoganicz, B. (2015). Humic Acid Potentiometric Response Patterns:Out- of Equilibrium Properties and Species Distribution Modelling. Chemical. Biol. Technol. Agric. 2: 17.

Anđelković, T., Nikolić, R., Bojić, A.,Anđelković, D., and Nikolic G.,(2010). Binding of Cadmium to Soil Humic Acid as A Function of Carboxyl Group Content. Macedonian Journal of Chemistry and Chemical Engineering.29(2): 215-224.

Anil, B. N. and Maroti, N. (2008). Studies on Influence of Die-Lectric Constants on Complex Equilibria between Substituted Py-Razalines and Lanthanide Metal Ions pH-Metrically. Amer.-Euras. scient. Res. 3(2): 212-216.

Ashok, K., Pandey, S. P. and Misra, V (2000). Stability Constants of Metal-Humic Acid Complexes and its Role in Environmental Detoxification. Journal of Ecotoxicology and Environmental Safety. 47(2):157-200.

Badr, M. H., El-Halafawi, M. H. and Abd El-al Zeid, E. R. (2012). Comparison Between the Effect of Ionic Strength on Acidity and Dissociation Constants of Humic Acids Extracted from Sewage Sludge and Nile Water Hyacinth Composts.Global Journal of Environmental Research 6 (1): 36-43.

Baruah, M.K., Borah, D., Saikia, P.P., Paul, S., Sharma, T. (2015). Evaluation of pKa Values of Soil Humic Acids and their Complexation Properties. International Journal of Plant \& Soil Science 6(4) : 218-228.

Boguta, P. Sokolowska, Z. (2016). Interactions of $\mathrm{Zn}$ (II) Ions with Humic Acids Isolated from Various Types of Soils. Effect of $\mathrm{pH}, \mathrm{Zn}$ Concentrations and Humic Acids Chemical Properties. Journal of Geochemical Explaration 168. 119-126.

Borges, F., Guimaraes, C., Lima, L.F.C., Pinto, I. and Reis, S.(2005). Potentiometric Studies on the Complexation of Copper(II) by Phenolic Acids as Discrete Ligand Models of enhance the complexation behavior of humic acid with metal (II) ions. However, the higher values of $\log \beta$ for $\mathrm{Cu}(\mathrm{II}), \mathrm{Pb}(\mathrm{II}), \mathrm{Cd}(\mathrm{II})$ and $\mathrm{Mg}(\mathrm{II})$ hydrolysed humic acid complexes indicates more stable stepwise complexes formed as compared with $\mathrm{Cu}(\mathrm{II}), \mathrm{Pb}$ (II), $\mathrm{Cd}$ (II) and $\mathrm{Mg}(\mathrm{II})$ unhydrolysed humic acid complexes.

Humic Substances Talanta 66 (2005) 670-673.

Chefetz, B., Salloum, M. J., Deshmulkin, A. P. and Hatcher, P. (2002). Structural Components of Humic Acids as Determined by Chemical Modifications and Carbon-13 NMR, Pyrolysis, and Thermochemolysis- Gas Chromatography/Mass Spectrometry. Soil Science Society of American Journal Abstract Division S-2- Soil Chemistry66. 1159-1171.

Dinu, M. I. (2013). Metals Complexation with Humic Acids in Surface Water of Different Environ. Sci. Technol. 31(1): 1-17.

Fernandes, A.N., Giacomelli, C., Giovanela, M. Vaz, D.V. Szpoganicz, B. and Maria M. D. (2009). Potentiometric Acidity Determination in Humic Substances Influenced by Different Analytical Procedures.J. Braz. Chem. Soc. 20 (9):14.

Gamal, A. H. (2015). Stability Constants of Rhenium (V) Metal Complexes with Selected Drugs. Pyrex Journal of Research in Environmental Studies. 2(2): 006-014.

Janrao, D. M., Pathan, J., Kayande, D.D., and Mulla, J.J. (2014). An Over View of Potentiometric Determination of Stability Constants of Metal Complexes. Sci. Revs. Chem. Commun.: 4(1), 2014, 11-24.

Karimi, H. (2017). Effect of pH and Initial Pb(II) Concentration on the Lead Removal Efficiency from Waste Water Using $\mathrm{Ca}(\mathrm{OH})_{2}$. International Journal of Water and Waste Water Treatment 3.2

Kaschl, A. Romheld, V. and Chen, Y. (2010). Binding of Cadmium, Copper and Zinc to Humic Substances Originating from Municipal Solid Waste Compost. Israel Journal of Chemistry Vol. 42(1): 89-98.

Kostic, I. S., Tatjana, P, A., Nikolic, R. S., Cvetkovic, T. P., Pavlovic, D. D., Aleksandar, L.J. and Bojic, A. (2012). Comparative Study of Binding Strengths of Heavy Metals with Humic Acid. J.serb. Chem. Soc. 76(9) pp 1-20. 
BAJOPAS Volume 14 Number 1,June, 2021

Na'aliya, J. (2013). Determination of Stepwise Stability Constants and Gibbs free Energy Change of Trisprolina to Complexes of some Divalent Transition Metal ions. Bayero Journal of Pure and Applied Sciences 6(2): 112-114.

Omar, A. A. and Ali, E. A. (2015). Potentiometric Studies on Complexes of $\mathrm{Cr}$ (III) and $\mathrm{Zr}$ (IV) with some Carboxylic Acids. International Journal of Advanced Chemistry, 3(1) 25-

37.

Pandey, A. K. Pandey, S. D. and Misr, V. (2015).Stability Constants of Metal- Humic Acid Complexes and Its Role in Environmental Detoxification. J. Ecotoxicology and Environmental Safety. 47(1):195-200.

Ram, N. and Raman, K.V. (1984). Stability Constants of Complexes of Metals with
Humicand Fuvic Acids under Non- acidConditions. Journal of Plant Nutrition and Soil Sciences.

147:171-176.

Santosh, D. D., Ashok, B. K., Vijay, J. T., Shivraj, G. W. and Vinay, V. W. (2011). Potentiometric Studies of Elec-Trolyte Effects on Complex Equilibria of Some Substituted 5-(2-hydroxy Phenyl) Pyrazoles. Der pharm. 3 (6): 75-83.

Sayyed, H. and Abdul Rahim, M. F. (2012). Studies of Binary Complexes of Metal Ions with Mandelic Acid by Potentiometry. Chem. J. 02 (6): 206209.

Shirvani, M. Moradian, E. Khalili, B. Bakhtiary, S. (2015). Interaction of $\mathrm{Cd}$ and $\mathrm{Pb}$ with Humate-Palygorskite and HumateSepiolite Complexes. Journal of water, air and pollution 3: 220-228. 


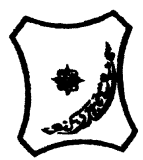

Bayero Journal of Pure and Applied Sciences, 14(1): 54 - 63

Received: November, 2020

Accepted: April, 2021

ISSN $2006-6996$

\title{
STABILITY CONSTANTS OF COMPLEXES OF METAL IONS WITH PEATSOIL HUMIC ACIDS UNDER NON-ACID-CONDITIONS
}

\author{
${ }^{* 1}$ Sabo, Yusuf ${ }^{2}$ Jimoh, W.L.O., ${ }^{3}$ Isa Baba Koki and ${ }^{4}$ Sholadoye, Q. 0. \\ ${ }^{1}$ Department of Pure and Industrial Chemistry, Bayero University, Kano \\ ${ }^{3}$ Department of Chemistry, Yusuf Maitama Sule University Kano. P.M.B. 3220 Kano, Nigeria. \\ ${ }^{4}$ Department of Chemistry, Nigerian Police Academy, Wudil, Kano-Nigeria
}

*Correspondence E-mail; saboyusuf18@yahoo.com

ABSTRACT

Stability constants of complexes of four divalent metal ions viz. $\mathrm{Cu}^{2+}, \mathrm{Pb}^{2+}, \mathrm{Mg}^{2+}$ and $\mathrm{Cd}^{2+}$ with humic acids (HA) were determined by potentiometric titration of humic acids with the corresponding salt of the divalent metals in aqueous media under non-acid-condition. The log $K$ (logarithm of the stability constant) ranged from 1.0942 to 2.7471 for metalhumic acid complexes were determined using point-wise computational method. The order of stability constants were obtained as follows: $\mathrm{Cu}>\mathrm{Pb}>\mathrm{Cd}>\mathrm{Mg}$ for metal $-\mathrm{HA}$ complexes respectively, indicating a higher degree of complexation with Cu metal ion.

Keywords: stability constant, humic acid, potentiometric titration, divalent metals, acid hydrolysis.

\section{NTRODUCTION}

The stability constant of a complex is the numerical expression of its stability and provides a quantitative measure of affinity of the metal ion to the complexing agent. An understanding of the relative stability of metal-complexes helps in predicting the behavior of metal ions in the soil (Ram and Raman, 1982). Extensive researches has been done to determine the stability constants of the complexes formed between humic acid (HA) with a number of metal ions. Ashok et al., (2000) reported that humic acid with hydroxyl, phenoxyl and carboxyl reactive groups can form coordination compound with metal ions at $\mathrm{pH}$ 3.5. The stability constants(Log K) for different metalhumic acid complexes indicated the following order of the stabilities of complexes formed between humic acid and metal ion, $\mathrm{Cu}>\mathrm{Fe}$ $>\mathrm{Pb}>\mathrm{Ni}>\mathrm{Co}>\mathrm{Ca}>\mathrm{Cd}>\mathrm{Zn}>\mathrm{Mn}>\mathrm{Mg}$. Andelkovic et al., (2010) investigated the binding of $\mathrm{Cd}$ (II) to soil humic acid at pH 6.5 and in $0.1 \mathrm{M} \mathrm{KNO}_{3}$ ionic medium. The stability constant for binding indicating greater stability in the case when carboxyl groups are involved in complexation reaction. Kostic et al.,(2012) investigated the complexation of humic acid with certain heavy metal ions (Co(II), $\mathrm{Ni}(\mathrm{II}), \mathrm{Cu}(\mathrm{II})$,
$\mathrm{Zn}(\mathrm{II})$, and $\mathrm{Pb}(\mathrm{II})$. The experiment was performed at $25^{\circ} \mathrm{C}$, at pH 4.0 and ionic strength of $0.01 \mathrm{M}$. Stability constant of complex between $\mathrm{Pb}$ (II) ions and humic acid is greater than stability constants of other investigated metalhumate complexes. Bogata and Sokolowska (2016) analyses the interaction between humic acids from different soils and $\mathrm{Zn}$ (II) ions at wide concentration ranges and at $\mathrm{pH} 5$. Studies have showed significant impact of $\mathrm{Zn}$ concentration, $\mathrm{pH}$ and some properties of humic acids with zinc.But all of these studies were limited to acidic $\mathrm{pH}$ range. Therefore, the present study was carried out to determine and compare the stability constants of complexes of metal ions with hydrolysed peat soil humic acid and unhydrolysed peat soil humic under non-acid conditions.

\section{MATERIALS AND METHODS}

Analytical grade chemicals used includes hydrochloric acid $(\mathrm{HCl})$, nitric acid $\left(\mathrm{HNO}_{3}\right)$, sodium hydroxide $(\mathrm{NaOH})$, lead nitrate $\mathrm{Pb}\left(\mathrm{NO}_{3}\right)_{2}$, copper nitrate $\mathrm{Cu}\left(\mathrm{NO}_{3}\right)_{2} \cdot 3 \mathrm{H}_{2} \mathrm{O}$, cadmium nitrate $\mathrm{Cd}\left(\mathrm{NO}_{3}\right)_{2} \cdot 4 \mathrm{H}_{2} \mathrm{O}$, magnesium nitrate $\mathrm{Mg}\left(\mathrm{NO}_{3}\right)_{2} \cdot 6 \mathrm{H}_{2} \mathrm{O}$, potassium nitrate $\left(\mathrm{KNO}_{3}\right)$, calcium chloride $\left(\mathrm{CaCl}_{2}\right)$, (sigma-Aldrich). Dowex 50WX8, (20-50 mesh) from Fluka. 


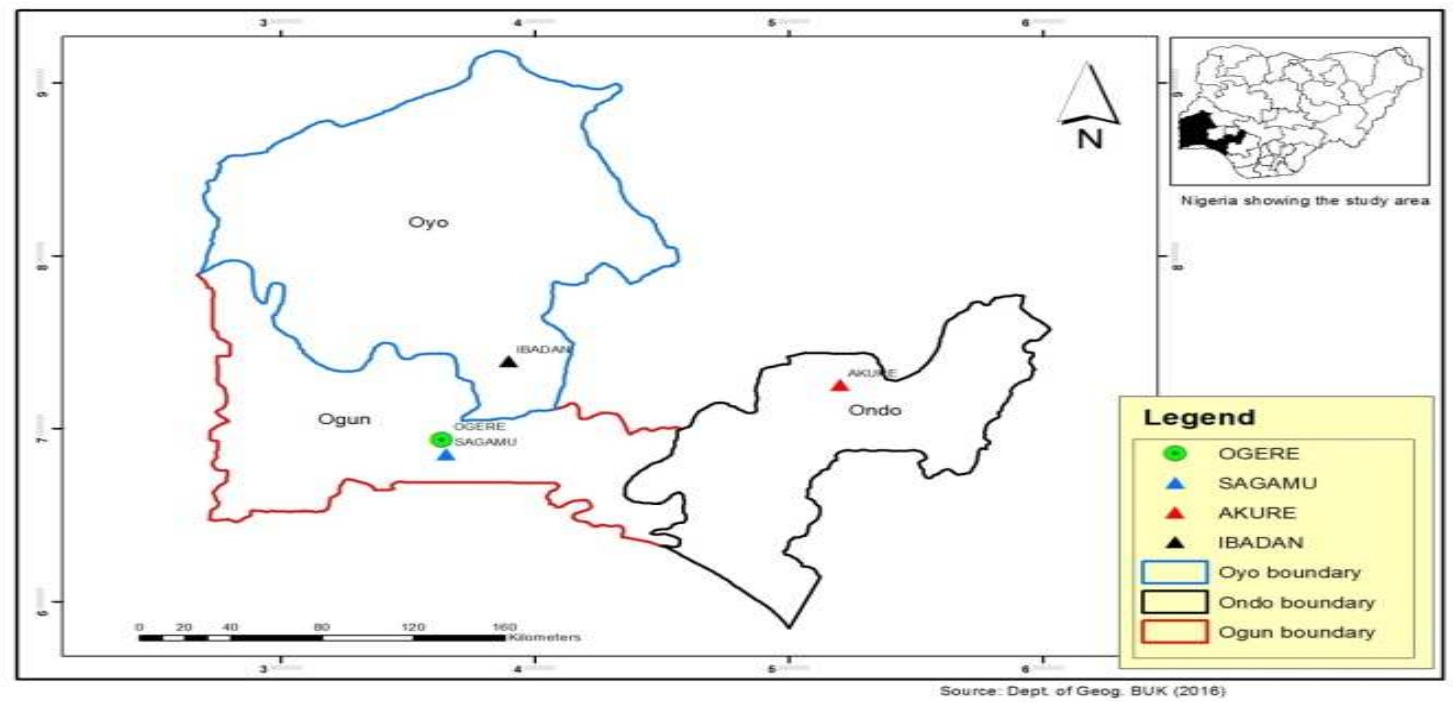

Figure 1: Map showing the sampling point at Sagamu Town, Ogun State.

\section{Description of Sampling Area}

Sagamu has geographical coordinates between $6^{\circ} 50^{\prime}$ north; $3^{\circ} 38^{\prime}$ east is located in south western region of Nigeria. The region has tropical wet and dry climate with a lengthy wet season and relatively constant temperatures throughout the course of the year. Wet season runs from March to October, November to December forms the region dry season. The vegetation type of the region is savannah which is really grassland with small bushes and occasional big trees. Grassland soils have substantially higher organic matter content than forest soils (Novackova, 2011).

\section{Sample Collection}

The Peatsoil samples were collected from four different sampling points $(0-10 \mathrm{~cm}$ depth) in Sagamu into polyethylene bag with plastic spoons. Samples were taken to the laboratory, extraneous materials were removed; the samples were air-dried, crushed and ground to a fine powder in a mortar passed through a $0.20 \mathrm{~mm}$ sieve. The samples were kept for analysis.

\section{Isolation and purification of humic acid from peat soil sample}

Peatsoil sample $(100 \mathrm{~g})$ was mixed with 1000 $\mathrm{cm}^{3}$ of $0.1 \mathrm{M} \mathrm{NaOH}$ solution, shaken for 3hours and left to stand overnight. Dark-coloured supernatant was obtained and decanted from solid residue. The dark-coloured supernatant was acidified to $(\mathrm{pH}=1.0)$ with $6 \mathrm{M} \mathrm{HCl}$ stirred and allowed to stand for 6 hours. Yellowish brown supernatant and dark-brown precipitate were obtained. The yellowish brown supernatant was decanted followed by centrifuge and discarded. The dark-brown precipitate was mixed with $500 \mathrm{~cm}^{3}$ of $0.1 \mathrm{M} \mathrm{NaOH}$ solution followed by passing through dowex resin. The dark-brown solution was acidified to $(\mathrm{pH}=1.0)$ with $6 \mathrm{M} \mathrm{HCl}$ stirred and allowed to stand for 3 hours. The dark-brown precipitate was washed several times with deionized water. The supernatant was treated with $\mathrm{AgNO}_{3}$ solution until no white precipitate observed. The humic acid was transferred to weighed crucible and dried at $60^{\circ} \mathrm{C}$ in an oven for 12 hours. The humic acid was cooled and dried in the desiccator, weighed and recorded. The obtained humic acid was dried again at $60^{\circ} \mathrm{C}$ for additional 6 hours cooled and dried in the desiccator, weighed and recorded constant weight was obtained (Baruah et al., 2015).

\section{FT-IR analysis}

FT-IR spectra of humic acid sample was analysed using Carry 630 FT-IR Agilent Technologies.

Unhydrolysed compost humic acid

The unhydrolysed humic acid was obtained after isolation and purification of compost humic acid and kept for investigation.

\section{Acid hydrolysis of Peatsoil acid}

Peatsoil humic acid sample (1g) was refluxed for 12 hours at $\left(160^{\circ} \mathrm{C}\right)$ with $50 \mathrm{~cm}^{3}$ of $6 \mathrm{M} \mathrm{HCl}$. The mixture was allowed to cool, decanted, and centrifuged after hydrolysis. The insoluble residues were washed with distilled water via centrifugation several times, and the supernatant was treated with $\mathrm{AgNO}_{3}$ solution until no white precipitate was observed. The residue was thoroughly dried over $\mathrm{CaCl}_{2}$ in a desiccator at room temperature (Chefetz et al., 2002). Finally, the obtained hydrolysed humic acid was kept for investigation. 
BAJOPAS Volume 14 Number 1,June, 2021 Potentiometric Titrations

Potentiometric measurements were carried out using a pH-meter Jenway (model 3510) with combine electrode, the sensitivity of the $\mathrm{pH}$ meter is 0.01 units. The $\mathrm{pH}$ meter was switched on half an hour before starting the titration for initial warm up of the instrument. The instrument was calibrated with an aqueous standard buffer solution of $\mathrm{pH} 4.00$ and 10.0 (borate buffer) prepared from a "Qualigens" buffer tablets.

The following sets of solutions were prepared in a $250 \mathrm{~cm}^{3}$ volumetric flask separately for $\mathrm{pH}$ metric titrations.

(i) $5 \mathrm{~cm}^{3} 0.1 \mathrm{M} \mathrm{HCl}+40 \mathrm{~cm}^{3}$ deionized water

(ii) $5 \mathrm{~cm}^{3} 0.1 \mathrm{M} \mathrm{HCl}+39 \mathrm{~cm}^{3}$ deionized water $+1 \mathrm{~cm}^{3} 0.15 \mathrm{gcm}^{-3}$ humic acid

(iii) $5 \mathrm{~cm}^{3} 0.1 \mathrm{M} \mathrm{HCl}+37 \mathrm{~cm}^{3}$ deionized water $+1 \mathrm{~cm}^{3} 0.15 \mathrm{gcm}^{-3}$ humic acid

$$
+2 \mathrm{~cm}^{3} \quad 0.01 \mathrm{M} \mathrm{Cu} \text { (II) }
$$

The solutions were titrated against standardized $0.110 \mathrm{MNaOH}$ separately. The total volume of each mixture was adjusted to $50 \mathrm{~cm}^{3}$ and the ionic strength of the solutions was maintained constant at by adding appropriate amount of stock solution of $1 \mathrm{M} \mathrm{KNO}_{3}$ (Gamal, 2015; Omar and Ali, 2015). A magnetic stirrer was used to achieve thorough mixing of the interacting solutions at $550 \mathrm{rpm}$. The same set of experimental conditions was applied for potentiometric titration of remaining samples.

\section{Evaluation of pKa of Hydrolysed peat soil Humic Acids}

The proton-ligand formation number $\mathrm{n}_{\mathbf{A}}$ were calculated by Irving and Rossotti expression (Omar and Ali, 2015).

$\mathrm{nA}=\mathrm{Y}-\frac{(\mathrm{V} 2-\mathrm{V1})(\mathrm{No}-\mathrm{Eo})}{(\mathrm{VO}+\mathrm{V1}) \mathrm{TCL}}$ 1

Where: $Y$ is number of dissociable proton, $\left(\mathrm{V}_{2^{-}}\right.$ $V_{1}$ ) is the measure of displacement of the ligand curve relative to acid curve, $\mathrm{N}^{\circ}$ and $\mathrm{E}^{\circ}$ are the resultant concentration of alkali solution, free acid solution, $\mathrm{T}_{\mathrm{cL}}{ }^{\circ}$ is the total ligand concentration, $\mathrm{V}^{\circ}$ is the total volume of titration solution, $V_{1}$ is the volume of alkali added to acid solution, $V_{2}$ is the volume of alkali added to acid solution + ligand solution, acid dissociation constants (pKa - values) of ligand were calculated by algebraic method point wise calculation (Tables 1 ). The dissociation constants (pKa) were calculated according to the following relation:

$\mathrm{pKa}=\mathrm{pH}+\log \left(\frac{n A}{1-n A}\right)$ 2

Where: pKa is the acid dissociation constant, $\mathrm{n}_{\mathrm{A}}$ is the Proton-ligand formation number and $\mathrm{pH}$ is the pH-values (Omar and Ali, 2015).

\section{Determination of metal-ligand stability constants $(\log K)$ of complexes}

The potentiometric measurement for the determination of stability constant of a complex in solution is based on the fact that the redox potential of the couple $\frac{M^{+(m-n)}}{M^{+m}}$ is shifted significantly on complexation of the metal ion with the ligand. This method involves change in hydrogen ion concentration $\left[\mathrm{H}^{+}\right]$due to the displacement or association of one or more protons taking place during complexation reaction. This change can be found out by titrating the solutions containing free acid, acid with ligand, and acid with ligand and metal ion, individually against a standard alkali solution at a constant ionic strength or temperature. Either ionic strength or temperature may be varied for different sets of solutions. In all the cases, the change in the $\mathrm{pH}$ of the solution is measured after each addition of a known amount of alkali to the reaction cell which contains the reaction mixture. The titration curves are then drawn by plotting the measured $\mathrm{pH}$ values against the corresponding volume of alkali added and the stability constants of the complexes are determined from the titration curves by employing $\mathrm{pH}$-metric titration technique given by (Irving and Rossoti).

Metal-ligand stability constants ( $\log \mathrm{K}$ ) were determined by using the following relations:

$$
\bar{n}=\frac{\left(V_{3}-V_{2}\right)\left(E^{0}+N^{0}\right)}{\left(V^{0}+V_{2}\right) \bar{n}_{A} T_{m}^{0}}
$$

and

$$
P L=\log _{10}\left\{\frac{1+\beta_{n}^{H} \frac{1}{[\text { anti } \log \mathrm{pH}]^{\mathrm{n}}}}{\mathrm{T}_{\mathrm{L}}^{0}-n \bar{T}_{m}^{0}} \mathrm{X} \frac{\left(V^{0}+V_{3}\right)}{V^{0}}\right\}
$$


BAJOPAS Volume 14 Number 1,June, 2021

Where $T_{L}, T^{\circ}, E^{\circ}$, and $V^{\circ}$ havethe same significance as in equation (1) above, $T_{m}$ denotes the total concentration of metal present in solution, $V_{3}$ is the volume of metal ions present in solution and $\beta^{H}$ is the overall proton ligand stability constant. The metal-ligand stability constants (log K) were determined by employing point wise computational Method (eq. 5 and 6).

$\operatorname{LogK}_{1}=\log \left(\frac{n}{1-n}\right)+\mathrm{pL}$ .5

$\operatorname{LogK}_{2}=\log \left(\frac{1-n}{2-n}\right)+\mathrm{pL}$ ...6

Where: Log $\mathrm{K}$ is the metal-ligand stability constant, $\mathrm{pL}$ is the Free ligand exponent function, $\mathbf{n}$ is the Average number of ligand attached with metal ion (Janraoet al., 2014). The results obtained were analyzed by an ORIGIN 2016 program using titration data and then the proton-ligand stability constants (pKa) and Metal-ligand stability constant (LogK) calculated (Omar and Ali, 2015).

\section{RESULTS AND DISCUSSION}

Fourier transformed infrared (FT-IR) spectra of isolated humic acid from peat soils Figure 2 had distinct clear absorption bands indicating the presence of major humic acid structural elemental groups such as $\mathrm{H}$ bonded $\mathrm{OH}$ $\left(3680 \mathrm{~cm}^{-1}\right.$ peak $), C=0$ of carbonyl $\left(1721 \mathrm{~cm}^{-1}\right.$ peak), functional groups of aliphatic components $\mathrm{CH}_{2}\left(2918 \mathrm{~cm}^{-1}\right.$ peak) and $\mathrm{C}-\mathrm{O}$ stretching of polysaccharide $\left(1168 \mathrm{~cm}^{-1}\right.$ peak). The positions of the absorption bands of the spectra fell within typical major absorption bands of humic acid which is at frequencies 3680, 2918, 1721, 1168 $\mathrm{cm}^{-1}$. The first peak centred in the vicinity of $3680 \mathrm{~cm}^{-1}$ region is attributed to phenol $\mathrm{OH}$ group bounded by intermolecular $\mathrm{H}$ bonds. The $2918 \mathrm{~cm}^{-1}$ band usually has absorption maximum at $2918 \mathrm{~cm}^{-1}$ which is due to $\mathrm{C}-\mathrm{H}$ stretching of alkane group $\left(\mathrm{CH}_{2}\right)$. The next major absorption band is $1721 \mathrm{~cm}^{-1}$. This band has been commonly ascribed to $\mathrm{C}=\mathrm{O}$ stretching of mainly carboxyl group $(\mathrm{COOH})$ with trace amount of ketones. The last peak was observed at 1168 $\mathrm{cm}^{-1}$ due to $\mathrm{C}-\mathrm{O}$ stretching of polysaccharides and this peak appeared also in the spectra of humic acid from peat soil. The FTIR spectra of the isolated humic acid contained all major characteristic absorption peaks of humic acid. These absorption peaks indicated the presence of the major structural elements of humic acid namely $\mathrm{H}$ bonded $\mathrm{OH}, \mathrm{C}=\mathrm{C}$ of aromatic ring, $\mathrm{C}=\mathrm{O}$ of carbonyl group (both carboxyl and ketonic), $\mathrm{CH}_{2}$ group. This strongly supports the presence of humic acid.

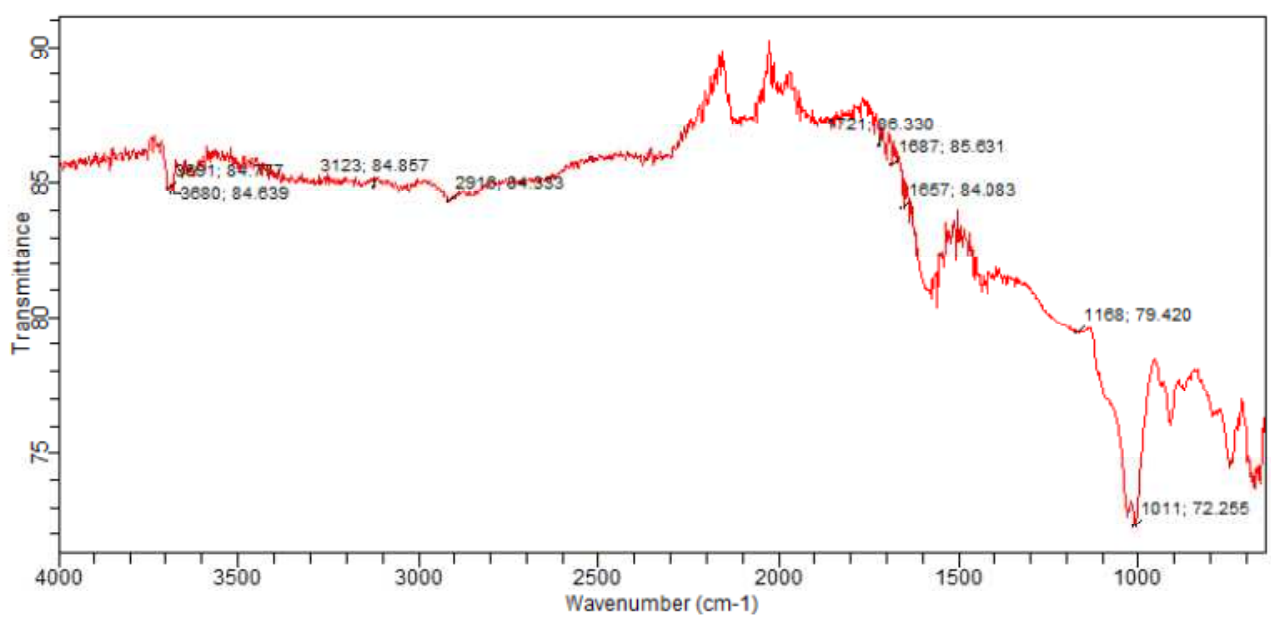

Fig. 2 : FT-IR spectraof peatsoilhumic acid (PSHA)

\section{Evaluation of acid dissociation constant (pka) of acid hydrolysed peat soil humicacid at phenolic group}

The value of the dissociation constant of the peat soil humic acid (PSHA) that underwent acidhydrolysis studied was found to be 8.9299 as shown Table 1, which is lower than the literaturevalues reported by Almeida and Szpoganics, (2015), Borges et al., (2005); Badr et al., (2012)and Fernandes et al,.(2009) of $9.73,9.47$ and 10.30. The difference between the obtained valuesand the reported values in this study might be probably as a result of acid hydrolysis of humicacid. 
BAJOPAS Volume 14 Number 1,June, 2021

Table 1: PKa of (Hydrolysed PSHA)

\begin{tabular}{|l|l|l|l|l|l|l|}
\hline $\mathrm{pH}$ & $\mathrm{BV}_{1}$ & $\mathrm{BV}_{2}$ & $\mathrm{~V}_{2}-\mathrm{V}_{1}$ & $\mathrm{nA}$ & $\log \left(\frac{n A}{1-n A}\right)$ & $\mathrm{pKa}$ \\
\hline 8.50 & 5.30 & 6.29 & 0.99 & 0.3594 & -0.2510 & 8.2490 \\
8.72 & 5.35 & 6.37 & 1.02 & 0.3400 & -0.2880 & 8.4320 \\
9.00 & 5.40 & 6.46 & 1.06 & 0.3141 & -0.3391 & 8.6609 \\
9.22 & 5.45 & 6.55 & 1.10 & 0.2882 & -0.3927 & 8.8273 \\
9.51 & 5.50 & 6.66 & 1.16 & 0.2494 & -0.4786 & 9.0314 \\
9.73 & 5.55 & 6.78 & 1.23 & 0.2041 & -0.5910 & 9.1390 \\
10.00 & 5.60 & 6.90 & 1.30 & 0.1589 & -0.7238 & 9.2762 \\
10.23 & 5.65 & 7.05 & 1.40 & 0.0941 & -0.9835 & 9.2465 \\
10.49 & 5.70 & 7.10 & 1.40 & 0.0941 & -0.9835 & 9.5065 \\
\hline
\end{tabular}

Average pKa $=8.9299 \pm 0.4186$

Table 2: PKa of (Unhydrolysed PSHA)

\begin{tabular}{|l|l|l|l|l|l|l|}
\hline $\mathrm{pH}$ & $\mathrm{BV}_{1}$ & $\mathrm{BV}_{2}$ & $\mathrm{~V}_{2}-\mathrm{V}_{1}$ & $\mathrm{nA}$ & $\log \left(\frac{\boldsymbol{n A}}{1-\boldsymbol{n}}\right)$ & $\mathrm{pKa}$ \\
\hline 8.50 & 5.30 & 5.81 & 0.51 & 0.6619 & 0.2919 & 8.7919 \\
8.72 & 5.35 & 5.90 & 0.55 & 0.6357 & 0.2418 & 8.9618 \\
9.00 & 5.40 & 6.00 & 0.60 & 0.6029 & 0.1813 & 9.1813 \\
9.22 & 5.45 & 6.10 & 0.65 & 0.5701 & 0.1226 & 9.3426 \\
9.51 & 5.50 & 6.20 & 0.70 & 0.5376 & 0.0654 & 9.5754 \\
9.73 & 5.55 & 6.33 & 0.78 & 0.4851 & -0.0259 & 9.7041 \\
10.00 & 5.60 & 6.47 & 0.87 & 0.4262 & -0.1291 & 9.8709 \\
10.23 & 5.65 & 6.62 & 0.99 & 0.3609 & -0.2481 & 9.9819 \\
10.49 & 5.70 & 6.80 & 1.10 & 0.2759 & -0.4690 & 10.0210 \\
\hline
\end{tabular}

Average pKa $=9.4923 \pm 0.4410$

Metal-ligand stability constant ( $\log \mathrm{K}$ )

The stabilityconstants require the accurate values of proton-ligand stability constants (Anil and Maroti, 2008). Metal titration curves crossed over ligand titration curve indicated the formation of complex upon proton release (Santosh, et al., 2011). If the values of n- are within range $0.2-0.8$ and $1.2-18$ this indicates the formation of $1: 1$ and 1:2 complexes (Sayyed and Mazahar, 2012).

The metal (II)-humate stepwise stability constants (log k) at phenolic group (Tables 318)

Table 3: Point-wise method, $\mathrm{Cu}$-(Hydrolysed PSHA)

\begin{tabular}{|l|l|l|l|l|l|l|l|l|}
\hline $\mathrm{pH}$ & $\mathrm{BV}_{1}$ & $\mathrm{BV}_{2}$ & $\mathrm{BV}_{3}$ & $\left(\mathrm{~V}_{3}-\mathrm{V}_{2}\right)$ & $\mathrm{n}$ & $\mathrm{pL}$ & $\log \left(\frac{n}{1-n}\right)$ & LogK $_{1}$ \\
\hline 8.50 & 5.30 & 6.29 & 6.33 & 0.04 & 0.5500 & 2.66 & 0.0871 & 2.7471 \\
8.72 & 5.35 & 6.37 & 6.41 & 0.04 & 0.5714 & 2.43 & 0.1249 & 2.5549 \\
9.00 & 5.40 & 6.46 & 6.50 & 0.04 & 0.6198 & 2.16 & 0.2122 & 2.3722 \\
9.22 & 5.45 & 6.55 & 6.59 & 0.04 & 0.6667 & 1.94 & 0.3010 & 2.2410 \\
\hline
\end{tabular}

LogK $_{1}$ (Average value) $=2.4788 \pm 0.2203$

Table 4: Point-wise method, $\mathrm{Cu}$-(Hydrolysed PSHA)

\begin{tabular}{|l|l|l|l|l|l|l|l|l|}
\hline $\mathrm{pH}$ & $\mathrm{BV}_{1}$ & $\mathrm{BV}_{2}$ & $\mathrm{BV}_{3}$ & $\left(\mathrm{~V}_{3}-\mathrm{V}_{2}\right)$ & $\mathrm{n}$ & $\mathrm{pL}$ & $\log \left(\frac{n-1}{2-n}\right)$ & LogK $_{2}$ \\
\hline 9.51 & 5.50 & 6.66 & 6.73 & 0.07 & 1.3509 & 1.70 & -0.2671 & 1.4329 \\
9.73 & 5.55 & 6.78 & 6.85 & 0.07 & 1.6383 & 1.51 & 0.2467 & 1.7567 \\
10.00 & 5.60 & 6.90 & 6.98 & 0.08 & 2.1783 & 1.31 & -0.2158 & 1.0942 \\
10.23 & 5.65 & 7.05 & 7.13 & 0.08 & 4.1904 & 1.27 & & \\
10.49 & 5.70 & 7.10 & 7.19 & 0.09 & 4.6920 & & & \\
\hline
\end{tabular}

Log $K_{2}($ Average value $)=1.4280 \pm 0.3312$ 
BAJOPAS Volume 14 Number 1,June, 2021

Table 5: Point-wise method, $\mathrm{Cu}$ (Unhydrolysed PSHA)

\begin{tabular}{|l|l|l|l|l|l|l|l|l|}
\hline $\mathrm{pH}$ & $\mathrm{BV}_{1}$ & $\mathrm{BV}_{2}$ & $\mathrm{BV}_{3}$ & $\left(\mathrm{~V}_{3}-\mathrm{V}_{2}\right)$ & $\mathrm{n}$ & $\mathrm{pL}$ & $\log \left(\frac{n}{n-1}\right)$ & Log $_{1}$ \\
\hline 8.50 & 5.30 & 5.81 & 5.85 & 0.04 & 0.2973 & 2.88 & -0.3736 & 2.5064 \\
8.72 & 5.35 & 5.90 & 5.95 & 0.05 & 0.3873 & 2.66 & -0.1992 & 2.4608 \\
9.00 & 5.40 & 6.00 & 6.05 & 0.05 & 0.4044 & 2.38 & -0.1681 & 2.2119 \\
9.22 & 5.45 & 6.10 & 6.15 & 0.06 & 0.5157 & 2.18 & -0.0272 & 2.2072 \\
9.51 & 5.50 & 6.20 & 6.27 & 0.07 & 0.6417 & 1.89 & 0.2530 & 1.1430 \\
\hline
\end{tabular}

$\operatorname{LogK}_{1}($ Average value $)=2.3059 \pm 0.6153$

Table 6:Point-wise method, $\mathrm{Cu}$ (Unhydrolysed PSHA)

\begin{tabular}{|l|l|l|l|l|l|l|l|l|}
\hline $\mathrm{pH}$ & $\mathrm{BV}_{1}$ & $\mathrm{BV}_{2}$ & $\mathrm{BV}_{3}$ & $\mathrm{~V}_{3}-\mathrm{V}_{2}$ & $\mathrm{n}$ & $\mathrm{pL}$ & $\log \left(\frac{n-1}{2-n}\right)$ & $\log \mathrm{K}_{2}$ \\
\hline 9.73 & 5.55 & 6.33 & 6.42 & 0.09 & 0.9000 & 1.69 & & \\
10.00 & 5.60 & 6.47 & 6.58 & 0.11 & 1.2578 & 1.44 & -0.4592 & 0.9808 \\
10.23 & 5.65 & 6.62 & 6.84 & 0.12 & 1.6137 & 1.26 & -0.2010 & 1.4610 \\
10.49 & 5.70 & 6.80 & 6.92 & 0.12 & 2.1052 & 1.03 & & \\
\hline
\end{tabular}

$\operatorname{LogK}_{2}$ (Average value) $=1.2209 \pm 0.3398$

Table 7:Point-wise method, Pb (Hydrolysed PSHA)

\begin{tabular}{|l|l|l|l|l|l|l|l|l|}
\hline $\mathrm{pH}$ & $\mathrm{BV}_{1}$ & $\mathrm{BV}_{2}$ & $\mathrm{BV}_{3}$ & $\left(\mathrm{~V}_{3}-\mathrm{V}_{2}\right)$ & $\mathrm{n}$ & $\mathrm{pL}$ & $\log \left(\frac{n}{1-n}\right)$ & LogK $_{1}$ \\
\hline 8.50 & 5.30 & 6.29 & 6.33 & 0.04 & 0.5500 & 2.66 & 0.0871 & 2.7471 \\
8.72 & 5.35 & 6.37 & 6.41 & 0.04 & 0.5714 & 2.43 & 0.1249 & 2.5549 \\
9.00 & 5.40 & 6.46 & 6.50 & 0.04 & 0.6198 & 2.16 & 0.2122 & 2.3722 \\
9.22 & 5.45 & 6.55 & 6.60 & 0.05 & 0.8333 & 1.96 & 0.6989 & 2.6589 \\
\hline
\end{tabular}

Log $_{\mathbf{1}}($ Average value $)=2.5832 \pm 0.1614$

Table 8:Point-wise method, Pb-(Hydrolysed PSHA)

\begin{tabular}{|l|l|l|l|l|l|l|l|l|}
\hline $\mathrm{pH}$ & $\mathrm{BV}_{1}$ & $\mathrm{BV}_{2}$ & $\mathrm{BV}_{3}$ & $\left(\mathrm{~V}_{3}-\mathrm{V}_{2}\right)$ & $\mathrm{n}$ & $\mathrm{pL}$ & $\log \left(\frac{n-1}{2-n}\right)$ & $\log \mathrm{K}_{2}$ \\
\hline 9.51 & 5.50 & 6.66 & 6.71 & 0.05 & 0.9650 & 1.67 & & \\
9.73 & 5.55 & 6.78 & 6.83 & 0.05 & 1.1702 & 1.44 & & \\
10.00 & 5.60 & 6.90 & 6.90 & 0.05 & 1.4864 & 1.22 & -0.0237 & 1.1963 \\
10.23 & 5.65 & 7.05 & 7.10 & 0.05 & 2.0190 & 1.09 & & \\
10.49 & 5.70 & 7.10 & 7.17 & 0.07 & 3.6492 & 1.00 & & \\
\hline
\end{tabular}

Log $K_{2}$ (Average value) $=1.1963$

Table 9: Point-wise method, Pb (Unhydrolysed PSHA)

\begin{tabular}{|l|l|l|l|l|l|l|l|l|}
\hline $\mathrm{pH}$ & $\mathrm{BV}_{1}$ & $\mathrm{BV}_{2}$ & $\mathrm{BV}_{3}$ & $\mathrm{~V}_{3}-\mathrm{V}_{2}$ & $\mathrm{n}$ & $\mathrm{pL}$ & $\begin{array}{l}\text { Log } \\
\left(\frac{n}{n-1}\right)\end{array}$ & Log $\mathrm{K}_{1}$ \\
\hline 8.50 & 5.30 & 5.81 & 5.85 & 0.04 & 0.2973 & 2.88 & -0.3736 & 2.5064 \\
8.72 & 5.35 & 5.90 & 5.94 & 0.04 & 0.3099 & 2.66 & -0.5477 & 2.3123 \\
9.00 & 5.40 & 6.00 & 6.05 & 0.05 & 0.4044 & 2.38 & -0.1681 & 2.2119 \\
9.22 & 5.45 & 6.10 & 6.15 & 0.06 & 0.5157 & 2.18 & 0.0272 & 2.2072 \\
9.51 & 5.50 & 6.20 & 6.26 & 0.07 & 0.6417 & 1.89 & 0.2530 & 2.1430 \\
9.73 & 5.55 & 6.40 & 6.40 & 0.07 & 0.7000 & 1.67 & 0.3680 & 2.0380 \\
\hline
\end{tabular}

LogK $_{1}$ (Average value) $=2.2364 \pm 0.1602$

Table 10: Point-wise method, Pb (Unhydrolysed PSHA)

\begin{tabular}{|l|l|l|l|l|l|l|l|l|}
\hline $\mathrm{pH}$ & $\mathrm{BV}_{1}$ & $\mathrm{BV}_{2}$ & $\mathrm{BV}_{3}$ & $\mathrm{~V}_{3}-\mathrm{V}_{2}$ & $\mathrm{n}$ & $\mathrm{pL}$ & $\log \left(\frac{n-1}{2-n}\right)$ & $\log \mathrm{K}_{2}$ \\
\hline 10.00 & 5.60 & 6.47 & 6.55 & 0.08 & 1.9503 & 1.41 & & \\
10.23 & 5.65 & 6.62 & 6.72 & 0.11 & 1.4792 & 1.26 & -0.0361 & 1.2239 \\
\hline
\end{tabular}

$\operatorname{LogK}_{2}$ (Average value) $=1.2239$

Table 11: Point-wise method, Mg (Hydrolysed PSHA)

\begin{tabular}{|l|l|l|l|l|l|l|l|l|}
\hline $\mathrm{pH}$ & $\mathrm{BV}_{1}$ & $\mathrm{BV}_{2}$ & $\mathrm{BV}_{3}$ & $\left(\mathrm{~V}_{3}-\mathrm{V}_{2}\right)$ & $\mathrm{n}$ & $\mathrm{pL}$ & $\log \left(\frac{n}{n-1}\right)$ & LogK $_{1}$ \\
\hline 8.50 & 5.30 & 6.29 & 6.31 & 0.02 & 0.2750 & 2.64 & -0.4290 & 2.2110 \\
8.72 & 5.35 & 6.37 & 6.39 & 0.02 & 0.2858 & 2.42 & -0.3978 & 2.0222 \\
9.00 & 5.40 & 6.46 & 6.49 & 0.03 & 0.4648 & 2.14 & -0.0612 & 2.0788 \\
9.22 & 5.45 & 6.55 & 6.59 & 0.04 & 0.6667 & 1.94 & 0.3010 & 2.2410 \\
\hline
\end{tabular}

$\log _{\mathbf{1}}($ Average value) $=2.1382 \pm 0.1046$ 
BAJOPAS Volume 14 Number 1,June, 2021

Table 12: Point-wise method, Mg (Hydrolysed PSHA)

\begin{tabular}{|l|l|l|l|l|l|l|l|l|}
\hline $\mathrm{pH}$ & $\mathrm{BV}_{1}$ & $\mathrm{BV}_{2}$ & $\mathrm{BV}_{3}$ & $\left(\mathrm{~V}_{3}-\mathrm{V}_{2}\right)$ & $\mathrm{n}$ & $\mathrm{pL}$ & $\log \left(\frac{n-1}{2-n}\right)$ & LogK $_{2}$ \\
\hline 9.51 & 5.55 & 6.66 & 6.71 & 0.05 & 0.9650 & 1.67 & & \\
9.73 & 5.55 & 6.78 & 6.84 & 0.06 & 1.4042 & 1.47 & -0.1686 & 1.3014 \\
10.00 & 5.60 & 6.90 & 6.93 & 0.06 & 1.7838 & 1.23 & 0.5593 & 1.7893 \\
10.23 & 5.65 & 7.05 & 7.10 & 0.06 & 3.1429 & 1.10 & & \\
10.49 & 5.70 & 7.10 & 7.18 & 0.07 & 3.6492 & 0.83 & & \\
\hline
\end{tabular}

LogK $_{2}($ Average value $)=1.5453 \pm 0.3450$

Table 13: Point-wise method, Mg (Unhydrolysed PSHA)

\begin{tabular}{|l|l|l|l|l|l|l|l|l|}
\hline $\mathrm{pH}$ & $\mathrm{BV}_{1}$ & $\mathrm{BV}_{2}$ & $\mathrm{BV}_{3}$ & $\mathrm{~V}_{3}-\mathrm{V}_{2}$ & $\mathrm{n}$ & $\mathrm{pL}$ & $\log \left(\frac{n}{n-1}\right)$ & $\operatorname{Log~}_{1}$ \\
\hline 8.50 & 5.30 & 5.81 & 5.85 & 0.04 & 0.2973 & 2.88 & -0.3736 & 2.5064 \\
8.72 & 5.35 & 5.90 & 5.94 & 0.04 & 0.3099 & 2.66 & -0.3477 & 2.3123 \\
9.00 & 5.40 & 6.00 & 6.04 & 0.04 & 0.3236 & 2.38 & -0.3202 & 2.0598 \\
9.22 & 5.45 & 6.10 & 6.15 & 0.05 & 0.4297 & 2.17 & -0.1230 & 2.0470 \\
9.51 & 5.50 & 6.20 & 6.26 & 0.06 & 0.5500 & 1.89 & 0.0871 & 1.9771 \\
9.73 & 5.55 & 6.33 & 6.40 & 0.07 & 0.7000 & 1.67 & 0.3680 & 2.0380 \\
\hline
\end{tabular}

LogK $_{1}$ (Average value) $=2.1568 \pm 0.2069$

Table 14: Point-wise method, Mg (Unhydrolysed PSHA)

\begin{tabular}{|l|l|l|l|l|l|l|l|l|}
\hline $\mathrm{pH}$ & $\mathrm{BV}_{1}$ & $\mathrm{BV}_{2}$ & $\mathrm{BV}_{3}$ & $\mathrm{~V}_{3}-\mathrm{V}_{2}$ & $\mathrm{n}$ & $\mathrm{pL}$ & $\log \left(\frac{n-1}{2-n}\right)$ & $\log \mathrm{K}_{2}$ \\
\hline 10.00 & 5.60 & 6.47 & 6.55 & 0.08 & 0.9148 & 1.41 & & \\
10.23 & 5.65 & 6.62 & 6.71 & 0.09 & 1.2102 & 1.20 & -0.5749 & 0.6251 \\
10.49 & 5.70 & 6.80 & 6.92 & 0.09 & 1.5968 & 1.03 & 0.1703 & 1.2003 \\
\hline
\end{tabular}

LogK $_{2}$ (Average value) $=0.9127 \pm 0.4070$

Table15:Point-wise method, Cd (Hydrolysed PSHA)

\begin{tabular}{|l|l|l|l|l|l|l|l|l|}
\hline $\mathrm{pH}$ & $\mathrm{BV}_{1}$ & $\mathrm{BV}_{2}$ & $\mathrm{BV}_{3}$ & $\left(\mathrm{~V}_{3}-\mathrm{V}_{2}\right)$ & $\mathrm{n}$ & $\mathrm{pL}$ & $\log \left(\frac{n}{1-n}\right)$ & LogK $_{1}$ \\
\hline 8.50 & 5.30 & 6.29 & 6.31 & 0.02 & 0.2750 & 2.64 & -0.4210 & 2.2190 \\
8.72 & 5.35 & 6.37 & 6.40 & 0.03 & 0.4286 & 2.42 & -0.1249 & 2.2951 \\
9.00 & 5.40 & 6.46 & 6.49 & 0.03 & 0.4648 & 2.14 & -0.0612 & 2.0788 \\
9.22 & 5.45 & 6.55 & 6.59 & 0.04 & 0.6667 & 1.96 & 0.3010 & 2.2610 \\
9.51 & 5.55 & 6.66 & 6.70 & 0.04 & 0.7720 & 1.67 & 0.5297 & 2.1997 \\
\hline
\end{tabular}

LogK $_{\mathbf{1}}$ (Average value) $=2.2108 \pm 0.0825$

Table 16: Point-wise method, Cd (Hydrolysed PSHA)

\begin{tabular}{|l|l|l|l|l|l|l|l|l|}
\hline $\mathrm{pH}$ & $\mathrm{BV}_{1}$ & $\mathrm{BV}_{2}$ & $\mathrm{BV}_{3}$ & $\left(\mathrm{~V}_{3}-\mathrm{V}_{2}\right)$ & $\mathrm{n}$ & $\mathrm{pL}$ & $\log \left(\frac{n-1}{2-n}\right)$ & Log $_{2}$ \\
\hline 9.73 & 5.55 & 6.78 & 6.83 & 0.06 & 1.4042 & 1.47 & -0.1686 & 1.3014 \\
10.00 & 5.60 & 6.90 & 6.95 & 0.06 & 1.7838 & 1.23 & 0.5593 & 1.7893 \\
10.23 & 5.65 & 7.05 & 7.10 & 0.06 & 3.1429 & 1.09 & & \\
10.49 & 5.70 & 7.10 & 7.16 & 0.06 & 3.1429 & 0.89 & & \\
& & & & & & & & \\
\hline
\end{tabular}

$\operatorname{LogK}_{2}$ (Average value) $=1.5453 \pm 0.3450$

Table 17: Point-wise method, Cd (Unhydrolysed PSHA)

\begin{tabular}{|l|l|l|l|l|l|l|l|l|}
\hline $\mathrm{pH}$ & $\mathrm{BV}_{1}$ & $\mathrm{BV}_{2}$ & $\mathrm{BV}_{3}$ & $\mathrm{~V}_{3}-\mathrm{V}_{2}$ & $\mathrm{n}$ & $\mathrm{pL}$ & $\log \left(\frac{n}{n-1}\right)$ & $\operatorname{Log~}_{1}$ \\
\hline 8.50 & 5.30 & 5.81 & 5.86 & 0.05 & 0.3717 & 2.88 & -0.2280 & 2.6520 \\
8.72 & 5.35 & 5.90 & 5.95 & 0.05 & 0.3873 & 2.66 & -0.1992 & 2.4608 \\
9.00 & 5.40 & 6.00 & 6.06 & 0.06 & 0.4853 & 2.38 & -0.0255 & 2.3545 \\
9.22 & 5.45 & 6.10 & 6.16 & 0.06 & 0.5157 & 2.18 & -0.0272 & 2.2072 \\
9.51 & 5.50 & 6.20 & 6.27 & 0.07 & 0.6417 & 1.89 & 0.2530 & 1.1430 \\
9.73 & 5.55 & 6.33 & 6.41 & 0.08 & 0.8000 & 1.69 & 0.6020 & 2.2920 \\
& & & & & & & & \\
\hline
\end{tabular}

$\operatorname{LogK}_{1}($ Average value $)=2.2516 \pm 0.5380$ 
BAJOPAS Volume 14 Number 1,June, 2021

Table 18: Point-wise method, Cd (Unhydrolysed PSHA)

\begin{tabular}{|l|l|l|l|l|l|l|l|l|}
\hline $\mathrm{pH}$ & $\mathrm{BV}_{1}$ & $\mathrm{BV}_{2}$ & $\mathrm{BV}_{3}$ & $\mathrm{~V}_{3}-\mathrm{V}_{2}$ & $\mathrm{n}$ & $\mathrm{pL}$ & $\log \left(\frac{n-1}{2-n}\right)$ & $\log \mathrm{K}_{2}$ \\
\hline 10.00 & 5.60 & 6.47 & 6.57 & 0.10 & 1.1434 & 1.43 & & \\
10.23 & 5.65 & 6.62 & 6.72 & 0.10 & 1.3448 & 1.23 & -0.2788 & 0.9512 \\
10.49 & 5.70 & 6.80 & 6.90 & 0.10 & 1.7742 & 1.03 & 0.5351 & 1.5651 \\
\hline
\end{tabular}

$\operatorname{LogK}_{2}($ Average value $)=1.2581 \pm 0.4340$

Table 19: Stepwise and overall Stability constants of thehydrolysed and unhydrolysed divalent metal (II) complexes

\begin{tabular}{|c|c|c|c|}
\hline Chelates & LogK $_{1}$ & $\log _{2}$ & Log $\beta$ \\
\hline [Cu (Hydrolysed PSHA-1) $\left.{ }_{2}\right]$ & 2.4788 & 1.4280 & 3.9068 \\
\hline$\left[\mathrm{Pb}(\text { Hydrolysed PSHA-1) })_{2}\right]$ & 2.5832 & 1.1963 & 3.7795 \\
\hline$\left[\mathrm{Cd}(\text { Hydrolysed PSHA-1 })_{2}\right]$ & 2.2108 & 1.5453 & 3.7561 \\
\hline$\left[\mathrm{Mg}(\text { Hydrolysed PSHA-1 })_{2}\right]$ & 2.1382 & 1.5453 & 3.6835 \\
\hline [Cu (Unhydrolysed PSHA-1) & 2.3059 & 1.2209 & 3.5268 \\
\hline$[\mathrm{Pb}$ (Unhydrolysed PSHA-1) 2$]$ & 2.2364 & 1.2239 & 3.4603 \\
\hline [Cd (Unhydrolysed PSHA-1) 2 ] & 2.2516 & 1.2581 & 3.5097 \\
\hline$[\mathrm{Mg}$ (Unydrolysed PSHA-1) & 2.1568 & 0.9127 & 3.0695 \\
\hline
\end{tabular}

The results obtained (Table19) shows the stepwise and overall stability constants to be not high indicating low stability of the complexes, because the solubility of most metal ions in the basic $\mathrm{pH}$ range is minimal due to metal hydroxide precipitation (Karimi, 2017). In general, the stepwise stability constants $\left(K_{1}\right.$ and $K_{2}$ ) follow the order $K_{1}>K_{2}$ for the copper, lead, magnesium and cadmium complexes respectively. The steady decrease of the values with increasing number of ligands is in agreement with the prediction made by researchers (Na'aliya, 2013). The decrease could be attributed to the fact that as the number of the ligands (Humate ions) that enters the coordination zone increases the aqua molecules available for replacement by the ligands become less. Thus, the metal ions become less electron loving with progressive intake of the ligand and this results in the decrease in the values of the constants (Na'aliya, 2013). Also the stability of the complexes is influenced by the size and number of the chelate rings(Mackay and Mackay,2002).All the complexes form rings in their structure as humate, a bidentate ligand, bond the metal ions in the ratio 1:2 (Boguta and Sokolowska, 2016) forming chelate rings. The values of the overall stability constants $(\log \beta)$ obtained for humate complexes are not high indicating low stability as the values are not high. LogK values for copper-humates (Table 3 to 6) obtained in this study are lower than those reported for the complexes of humic acids (Pandey et al., 2015; Dinu, 2013; Kaschl et al., 2010 and Gilbeto and Jorg, 2001). The values of LogK(Table 7 to 10 ) forlead-humates are lower than those reported for the lead in the literature (Dinu, 2013; Gilbeto and Jorg 2001). Log K values(Table 11 to 14 ) for magnesium-humates obtained in this study are close to those reported by (Pandey et al., 2015). Log K values of cadmium-humates (Table 15 to 18 ) obtained in this work near to the one reported by (Dinu, 2013 and Pandey et al., 2015).The difference between the reported values and the values obtained in this study might be probably as a result of acid hydrolysis of humic acid. The values of the overall stability constants $(\log \beta)$ of the copper humates complexes presented in Table 19 is high than that of other metal humate complexes, show relatively high stability of CuHA complexes, show the following order of stability: $\mathrm{Cu}>\mathrm{Pb}>\mathrm{Cd}>\mathrm{Mg}$; which are in close agreement to the findings of (Dinu, 2013 and Pandey et al., 2015).The high stability of Cuhumate chelate could be attributed to the existence of coordinate covalent bond between the complexing agents and the $\mathrm{Cu}^{2+}$ ions. Since, $\mathrm{Cu}^{2+}$ being a metal of the transitional series with $3 d^{9}$ electronic configurations can accept the electrons from the complexing agents. Similarly, the low stabilities of $\mathrm{Pb}, \mathrm{Cd}$ and $\mathrm{Mg}$ complexes could be explained by that $\mathrm{Pb}^{2+}$ with $6 s^{2}, \mathrm{Cd}^{2+}$ with $4 \mathrm{~d}^{10}$ and $\mathrm{Mg}^{2+}$ with $2 \mathrm{p}^{6}$ their electronic configuration has a completely filled $\mathrm{d}, \mathrm{p}$ and $\mathrm{s}$ orbitals. Moreover, the stabilities of metal ions with hydrolysed humic acid from peat soil were higher than those with unhydrolysed humic acid from peat soil; which is ascribed to the high content of acidity in hydrolysed humic acid than unhydrolysed humic acid. 
BAJOPAS Volume 14 Number 1,June, 2021 CONCLUSION

The values of logk for $\mathrm{Cu}(\mathrm{II})$ hydrolysed humic acid complex was higher followed by $\mathrm{Pb}$ (II), $\mathrm{Cd}(\mathrm{II})$ and $\mathrm{Mg}$ (II) hydrolysed humic acid complexes as compared with metal(II) unhydrolysed humic acid complexes. This indicates acid hydrolysis of humic acid can

\section{REFERENCES}

Almeida, V.R. and Szpoganicz, B. (2015). Humic Acid Potentiometric Response Patterns:Out- of Equilibrium Properties and Species Distribution Modelling. Chemical. Biol. Technol. Agric. 2: 17.

Anđelković, T., Nikolić, R., Bojić, A.,Anđelković, D., and Nikolic G.,(2010). Binding of Cadmium to Soil Humic Acid as A Function of Carboxyl Group Content. Macedonian Journal of Chemistry and Chemical Engineering.29(2): 215-224.

Anil, B. N. and Maroti, N. (2008). Studies on Influence of Die-Lectric Constants on Complex Equilibria between Substituted Py-Razalines and Lanthanide Metal Ions pH-Metrically. Amer.-Euras. scient. Res. 3(2): 212-216.

Ashok, K., Pandey, S. P. and Misra, V (2000). Stability Constants of Metal-Humic Acid Complexes and its Role in Environmental Detoxification. Journal of Ecotoxicology and Environmental Safety. 47(2):157-200.

Badr, M. H., El-Halafawi, M. H. and Abd El-al Zeid, E. R. (2012). Comparison Between the Effect of Ionic Strength on Acidity and Dissociation Constants of Humic Acids Extracted from Sewage Sludge and Nile Water Hyacinth Composts.Global Journal of Environmental Research 6 (1): 36-43.

Baruah, M.K., Borah, D., Saikia, P.P., Paul, S., Sharma, T. (2015). Evaluation of pKa Values of Soil Humic Acids and their Complexation Properties. International Journal of Plant \& Soil Science 6(4) : 218-228.

Boguta, P. Sokolowska, Z. (2016). Interactions of $\mathrm{Zn}$ (II) Ions with Humic Acids Isolated from Various Types of Soils. Effect of $\mathrm{pH}, \mathrm{Zn}$ Concentrations and Humic Acids Chemical Properties. Journal of Geochemical Explaration 168. 119-126.

Borges, F., Guimaraes, C., Lima, L.F.C., Pinto, I. and Reis, S.(2005). Potentiometric Studies on the Complexation of Copper(II) by Phenolic Acids as Discrete Ligand Models of enhance the complexation behavior of humic acid with metal (II) ions. However, the higher values of $\log \beta$ for $\mathrm{Cu}(\mathrm{II}), \mathrm{Pb}(\mathrm{II}), \mathrm{Cd}(\mathrm{II})$ and $\mathrm{Mg}(\mathrm{II})$ hydrolysed humic acid complexes indicates more stable stepwise complexes formed as compared with $\mathrm{Cu}(\mathrm{II}), \mathrm{Pb}$ (II), $\mathrm{Cd}$ (II) and $\mathrm{Mg}(\mathrm{II})$ unhydrolysed humic acid complexes.

Humic Substances Talanta 66 (2005) 670-673.

Chefetz, B., Salloum, M. J., Deshmulkin, A. P. and Hatcher, P. (2002). Structural Components of Humic Acids as Determined by Chemical Modifications and Carbon-13 NMR, Pyrolysis, and Thermochemolysis- Gas Chromatography/Mass Spectrometry. Soil Science Society of American Journal Abstract Division S-2- Soil Chemistry66. 1159-1171.

Dinu, M. I. (2013). Metals Complexation with Humic Acids in Surface Water of Different Environ. Sci. Technol. 31(1): 1-17.

Fernandes, A.N., Giacomelli, C., Giovanela, M. Vaz, D.V. Szpoganicz, B. and Maria M. D. (2009). Potentiometric Acidity Determination in Humic Substances Influenced by Different Analytical Procedures.J. Braz. Chem. Soc. 20 (9):14.

Gamal, A. H. (2015). Stability Constants of Rhenium (V) Metal Complexes with Selected Drugs. Pyrex Journal of Research in Environmental Studies. 2(2): 006-014.

Janrao, D. M., Pathan, J., Kayande, D.D., and Mulla, J.J. (2014). An Over View of Potentiometric Determination of Stability Constants of Metal Complexes. Sci. Revs. Chem. Commun.: 4(1), 2014, 11-24.

Karimi, H. (2017). Effect of pH and Initial Pb(II) Concentration on the Lead Removal Efficiency from Waste Water Using $\mathrm{Ca}(\mathrm{OH})_{2}$. International Journal of Water and Waste Water Treatment 3.2

Kaschl, A. Romheld, V. and Chen, Y. (2010). Binding of Cadmium, Copper and Zinc to Humic Substances Originating from Municipal Solid Waste Compost. Israel Journal of Chemistry Vol. 42(1): 89-98.

Kostic, I. S., Tatjana, P, A., Nikolic, R. S., Cvetkovic, T. P., Pavlovic, D. D., Aleksandar, L.J. and Bojic, A. (2012). Comparative Study of Binding Strengths of Heavy Metals with Humic Acid. J.serb. Chem. Soc. 76(9) pp 1-20. 
BAJOPAS Volume 14 Number 1,June, 2021

Na'aliya, J. (2013). Determination of Stepwise Stability Constants and Gibbs free Energy Change of Trisprolina to Complexes of some Divalent Transition Metal ions. Bayero Journal of Pure and Applied Sciences 6(2): 112-114.

Omar, A. A. and Ali, E. A. (2015). Potentiometric Studies on Complexes of $\mathrm{Cr}$ (III) and $\mathrm{Zr}$ (IV) with some Carboxylic Acids. International Journal of Advanced Chemistry, 3(1) 25-

37.

Pandey, A. K. Pandey, S. D. and Misr, V. (2015).Stability Constants of Metal- Humic Acid Complexes and Its Role in Environmental Detoxification. J. Ecotoxicology and Environmental Safety. 47(1):195-200.

Ram, N. and Raman, K.V. (1984). Stability Constants of Complexes of Metals with
Humicand Fuvic Acids under Non- acidConditions. Journal of Plant Nutrition and Soil Sciences.

147:171-176.

Santosh, D. D., Ashok, B. K., Vijay, J. T., Shivraj, G. W. and Vinay, V. W. (2011). Potentiometric Studies of Elec-Trolyte Effects on Complex Equilibria of Some Substituted 5-(2-hydroxy Phenyl) Pyrazoles. Der pharm. 3 (6): 75-83.

Sayyed, H. and Abdul Rahim, M. F. (2012). Studies of Binary Complexes of Metal Ions with Mandelic Acid by Potentiometry. Chem. J. 02 (6): 206209.

Shirvani, M. Moradian, E. Khalili, B. Bakhtiary, S. (2015). Interaction of $\mathrm{Cd}$ and $\mathrm{Pb}$ with Humate-Palygorskite and HumateSepiolite Complexes. Journal of water, air and pollution 3: 220-228. 


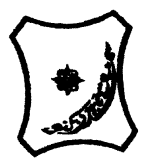

Bayero Journal of Pure and Applied Sciences, 14(1): 54 - 63

Received: November, 2020

Accepted: April, 2021

ISSN $2006-6996$

\title{
STABILITY CONSTANTS OF COMPLEXES OF METAL IONS WITH PEATSOIL HUMIC ACIDS UNDER NON-ACID-CONDITIONS
}

\author{
${ }^{* 1}$ Sabo, Yusuf ${ }^{2}$ Jimoh, W.L.O., ${ }^{3}$ Isa Baba Koki and ${ }^{4}$ Sholadoye, Q. 0. \\ ${ }^{1}$ Department of Pure and Industrial Chemistry, Bayero University, Kano \\ ${ }^{3}$ Department of Chemistry, Yusuf Maitama Sule University Kano. P.M.B. 3220 Kano, Nigeria. \\ ${ }^{4}$ Department of Chemistry, Nigerian Police Academy, Wudil, Kano-Nigeria
}

*Correspondence E-mail; saboyusuf18@yahoo.com

ABSTRACT

Stability constants of complexes of four divalent metal ions viz. $\mathrm{Cu}^{2+}, \mathrm{Pb}^{2+}, \mathrm{Mg}^{2+}$ and $\mathrm{Cd}^{2+}$ with humic acids (HA) were determined by potentiometric titration of humic acids with the corresponding salt of the divalent metals in aqueous media under non-acid-condition. The log $K$ (logarithm of the stability constant) ranged from 1.0942 to 2.7471 for metalhumic acid complexes were determined using point-wise computational method. The order of stability constants were obtained as follows: $\mathrm{Cu}>\mathrm{Pb}>\mathrm{Cd}>\mathrm{Mg}$ for metal $-\mathrm{HA}$ complexes respectively, indicating a higher degree of complexation with Cu metal ion.

Keywords: stability constant, humic acid, potentiometric titration, divalent metals, acid hydrolysis.

\section{NTRODUCTION}

The stability constant of a complex is the numerical expression of its stability and provides a quantitative measure of affinity of the metal ion to the complexing agent. An understanding of the relative stability of metal-complexes helps in predicting the behavior of metal ions in the soil (Ram and Raman, 1982). Extensive researches has been done to determine the stability constants of the complexes formed between humic acid (HA) with a number of metal ions. Ashok et al., (2000) reported that humic acid with hydroxyl, phenoxyl and carboxyl reactive groups can form coordination compound with metal ions at $\mathrm{pH}$ 3.5. The stability constants(Log K) for different metalhumic acid complexes indicated the following order of the stabilities of complexes formed between humic acid and metal ion, $\mathrm{Cu}>\mathrm{Fe}$ $>\mathrm{Pb}>\mathrm{Ni}>\mathrm{Co}>\mathrm{Ca}>\mathrm{Cd}>\mathrm{Zn}>\mathrm{Mn}>\mathrm{Mg}$. Andelkovic et al., (2010) investigated the binding of $\mathrm{Cd}$ (II) to soil humic acid at pH 6.5 and in $0.1 \mathrm{M} \mathrm{KNO}_{3}$ ionic medium. The stability constant for binding indicating greater stability in the case when carboxyl groups are involved in complexation reaction. Kostic et al.,(2012) investigated the complexation of humic acid with certain heavy metal ions (Co(II), $\mathrm{Ni}(\mathrm{II}), \mathrm{Cu}(\mathrm{II})$,
$\mathrm{Zn}(\mathrm{II})$, and $\mathrm{Pb}(\mathrm{II})$. The experiment was performed at $25^{\circ} \mathrm{C}$, at pH 4.0 and ionic strength of $0.01 \mathrm{M}$. Stability constant of complex between $\mathrm{Pb}$ (II) ions and humic acid is greater than stability constants of other investigated metalhumate complexes. Bogata and Sokolowska (2016) analyses the interaction between humic acids from different soils and $\mathrm{Zn}$ (II) ions at wide concentration ranges and at $\mathrm{pH} 5$. Studies have showed significant impact of $\mathrm{Zn}$ concentration, $\mathrm{pH}$ and some properties of humic acids with zinc.But all of these studies were limited to acidic $\mathrm{pH}$ range. Therefore, the present study was carried out to determine and compare the stability constants of complexes of metal ions with hydrolysed peat soil humic acid and unhydrolysed peat soil humic under non-acid conditions.

\section{MATERIALS AND METHODS}

Analytical grade chemicals used includes hydrochloric acid $(\mathrm{HCl})$, nitric acid $\left(\mathrm{HNO}_{3}\right)$, sodium hydroxide $(\mathrm{NaOH})$, lead nitrate $\mathrm{Pb}\left(\mathrm{NO}_{3}\right)_{2}$, copper nitrate $\mathrm{Cu}\left(\mathrm{NO}_{3}\right)_{2} \cdot 3 \mathrm{H}_{2} \mathrm{O}$, cadmium nitrate $\mathrm{Cd}\left(\mathrm{NO}_{3}\right)_{2} \cdot 4 \mathrm{H}_{2} \mathrm{O}$, magnesium nitrate $\mathrm{Mg}\left(\mathrm{NO}_{3}\right)_{2} \cdot 6 \mathrm{H}_{2} \mathrm{O}$, potassium nitrate $\left(\mathrm{KNO}_{3}\right)$, calcium chloride $\left(\mathrm{CaCl}_{2}\right)$, (sigma-Aldrich). Dowex 50WX8, (20-50 mesh) from Fluka. 


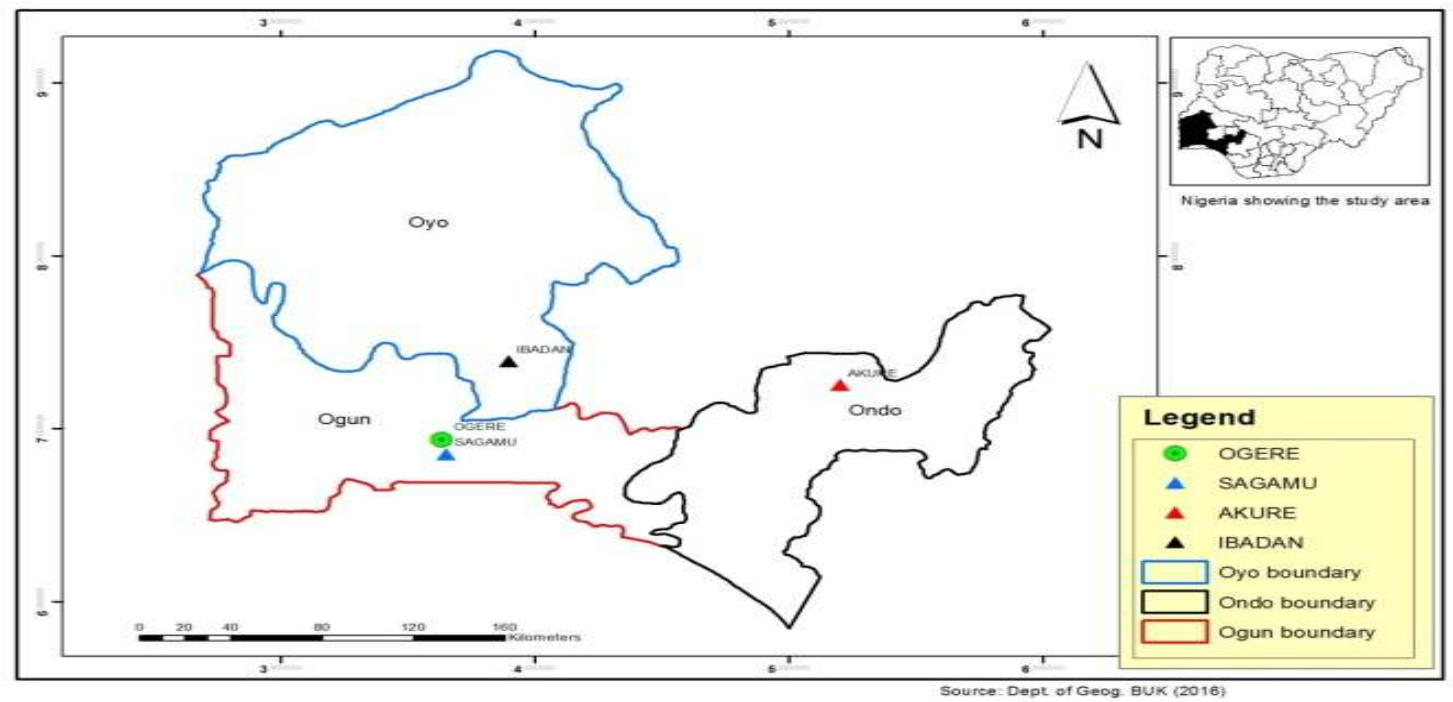

Figure 1: Map showing the sampling point at Sagamu Town, Ogun State.

\section{Description of Sampling Area}

Sagamu has geographical coordinates between $6^{\circ} 50^{\prime}$ north; $3^{\circ} 38^{\prime}$ east is located in south western region of Nigeria. The region has tropical wet and dry climate with a lengthy wet season and relatively constant temperatures throughout the course of the year. Wet season runs from March to October, November to December forms the region dry season. The vegetation type of the region is savannah which is really grassland with small bushes and occasional big trees. Grassland soils have substantially higher organic matter content than forest soils (Novackova, 2011).

\section{Sample Collection}

The Peatsoil samples were collected from four different sampling points $(0-10 \mathrm{~cm}$ depth) in Sagamu into polyethylene bag with plastic spoons. Samples were taken to the laboratory, extraneous materials were removed; the samples were air-dried, crushed and ground to a fine powder in a mortar passed through a $0.20 \mathrm{~mm}$ sieve. The samples were kept for analysis.

\section{Isolation and purification of humic acid from peat soil sample}

Peatsoil sample $(100 \mathrm{~g})$ was mixed with 1000 $\mathrm{cm}^{3}$ of $0.1 \mathrm{M} \mathrm{NaOH}$ solution, shaken for 3hours and left to stand overnight. Dark-coloured supernatant was obtained and decanted from solid residue. The dark-coloured supernatant was acidified to $(\mathrm{pH}=1.0)$ with $6 \mathrm{M} \mathrm{HCl}$ stirred and allowed to stand for 6 hours. Yellowish brown supernatant and dark-brown precipitate were obtained. The yellowish brown supernatant was decanted followed by centrifuge and discarded. The dark-brown precipitate was mixed with $500 \mathrm{~cm}^{3}$ of $0.1 \mathrm{M} \mathrm{NaOH}$ solution followed by passing through dowex resin. The dark-brown solution was acidified to $(\mathrm{pH}=1.0)$ with $6 \mathrm{M} \mathrm{HCl}$ stirred and allowed to stand for 3 hours. The dark-brown precipitate was washed several times with deionized water. The supernatant was treated with $\mathrm{AgNO}_{3}$ solution until no white precipitate observed. The humic acid was transferred to weighed crucible and dried at $60^{\circ} \mathrm{C}$ in an oven for 12 hours. The humic acid was cooled and dried in the desiccator, weighed and recorded. The obtained humic acid was dried again at $60^{\circ} \mathrm{C}$ for additional 6 hours cooled and dried in the desiccator, weighed and recorded constant weight was obtained (Baruah et al., 2015).

\section{FT-IR analysis}

FT-IR spectra of humic acid sample was analysed using Carry 630 FT-IR Agilent Technologies.

Unhydrolysed compost humic acid

The unhydrolysed humic acid was obtained after isolation and purification of compost humic acid and kept for investigation.

\section{Acid hydrolysis of Peatsoil acid}

Peatsoil humic acid sample (1g) was refluxed for 12 hours at $\left(160^{\circ} \mathrm{C}\right)$ with $50 \mathrm{~cm}^{3}$ of $6 \mathrm{M} \mathrm{HCl}$. The mixture was allowed to cool, decanted, and centrifuged after hydrolysis. The insoluble residues were washed with distilled water via centrifugation several times, and the supernatant was treated with $\mathrm{AgNO}_{3}$ solution until no white precipitate was observed. The residue was thoroughly dried over $\mathrm{CaCl}_{2}$ in a desiccator at room temperature (Chefetz et al., 2002). Finally, the obtained hydrolysed humic acid was kept for investigation. 
BAJOPAS Volume 14 Number 1,June, 2021 Potentiometric Titrations

Potentiometric measurements were carried out using a pH-meter Jenway (model 3510) with combine electrode, the sensitivity of the $\mathrm{pH}$ meter is 0.01 units. The $\mathrm{pH}$ meter was switched on half an hour before starting the titration for initial warm up of the instrument. The instrument was calibrated with an aqueous standard buffer solution of $\mathrm{pH} 4.00$ and 10.0 (borate buffer) prepared from a "Qualigens" buffer tablets.

The following sets of solutions were prepared in a $250 \mathrm{~cm}^{3}$ volumetric flask separately for $\mathrm{pH}$ metric titrations.

(i) $5 \mathrm{~cm}^{3} 0.1 \mathrm{M} \mathrm{HCl}+40 \mathrm{~cm}^{3}$ deionized water

(ii) $5 \mathrm{~cm}^{3} 0.1 \mathrm{M} \mathrm{HCl}+39 \mathrm{~cm}^{3}$ deionized water $+1 \mathrm{~cm}^{3} 0.15 \mathrm{gcm}^{-3}$ humic acid

(iii) $5 \mathrm{~cm}^{3} 0.1 \mathrm{M} \mathrm{HCl}+37 \mathrm{~cm}^{3}$ deionized water $+1 \mathrm{~cm}^{3} 0.15 \mathrm{gcm}^{-3}$ humic acid

$$
+2 \mathrm{~cm}^{3} \quad 0.01 \mathrm{M} \mathrm{Cu} \text { (II) }
$$

The solutions were titrated against standardized $0.110 \mathrm{MNaOH}$ separately. The total volume of each mixture was adjusted to $50 \mathrm{~cm}^{3}$ and the ionic strength of the solutions was maintained constant at by adding appropriate amount of stock solution of $1 \mathrm{M} \mathrm{KNO}_{3}$ (Gamal, 2015; Omar and Ali, 2015). A magnetic stirrer was used to achieve thorough mixing of the interacting solutions at $550 \mathrm{rpm}$. The same set of experimental conditions was applied for potentiometric titration of remaining samples.

\section{Evaluation of pKa of Hydrolysed peat soil Humic Acids}

The proton-ligand formation number $\mathrm{n}_{\mathbf{A}}$ were calculated by Irving and Rossotti expression (Omar and Ali, 2015).

$\mathrm{nA}=\mathrm{Y}-\frac{(\mathrm{V} 2-\mathrm{V1})(\mathrm{No}-\mathrm{Eo})}{(\mathrm{VO}+\mathrm{V1}) \mathrm{TCL}}$ 1

Where: $Y$ is number of dissociable proton, $\left(\mathrm{V}_{2^{-}}\right.$ $V_{1}$ ) is the measure of displacement of the ligand curve relative to acid curve, $\mathrm{N}^{\circ}$ and $\mathrm{E}^{\circ}$ are the resultant concentration of alkali solution, free acid solution, $\mathrm{T}_{\mathrm{cL}}{ }^{\circ}$ is the total ligand concentration, $\mathrm{V}^{\circ}$ is the total volume of titration solution, $V_{1}$ is the volume of alkali added to acid solution, $V_{2}$ is the volume of alkali added to acid solution + ligand solution, acid dissociation constants (pKa - values) of ligand were calculated by algebraic method point wise calculation (Tables 1 ). The dissociation constants (pKa) were calculated according to the following relation:

$\mathrm{pKa}=\mathrm{pH}+\log \left(\frac{n A}{1-n A}\right)$ 2

Where: pKa is the acid dissociation constant, $\mathrm{n}_{\mathrm{A}}$ is the Proton-ligand formation number and $\mathrm{pH}$ is the pH-values (Omar and Ali, 2015).

\section{Determination of metal-ligand stability constants $(\log K)$ of complexes}

The potentiometric measurement for the determination of stability constant of a complex in solution is based on the fact that the redox potential of the couple $\frac{M^{+(m-n)}}{M^{+m}}$ is shifted significantly on complexation of the metal ion with the ligand. This method involves change in hydrogen ion concentration $\left[\mathrm{H}^{+}\right]$due to the displacement or association of one or more protons taking place during complexation reaction. This change can be found out by titrating the solutions containing free acid, acid with ligand, and acid with ligand and metal ion, individually against a standard alkali solution at a constant ionic strength or temperature. Either ionic strength or temperature may be varied for different sets of solutions. In all the cases, the change in the $\mathrm{pH}$ of the solution is measured after each addition of a known amount of alkali to the reaction cell which contains the reaction mixture. The titration curves are then drawn by plotting the measured $\mathrm{pH}$ values against the corresponding volume of alkali added and the stability constants of the complexes are determined from the titration curves by employing $\mathrm{pH}$-metric titration technique given by (Irving and Rossoti).

Metal-ligand stability constants ( $\log \mathrm{K}$ ) were determined by using the following relations:

$$
\bar{n}=\frac{\left(V_{3}-V_{2}\right)\left(E^{0}+N^{0}\right)}{\left(V^{0}+V_{2}\right) \bar{n}_{A} T_{m}^{0}}
$$

and

$$
P L=\log _{10}\left\{\frac{1+\beta_{n}^{H} \frac{1}{[\text { anti } \log \mathrm{pH}]^{\mathrm{n}}}}{\mathrm{T}_{\mathrm{L}}^{0}-n \bar{T}_{m}^{0}} \mathrm{X} \frac{\left(V^{0}+V_{3}\right)}{V^{0}}\right\}
$$


BAJOPAS Volume 14 Number 1,June, 2021

Where $T_{L}, T^{\circ}, E^{\circ}$, and $V^{\circ}$ havethe same significance as in equation (1) above, $T_{m}$ denotes the total concentration of metal present in solution, $V_{3}$ is the volume of metal ions present in solution and $\beta^{H}$ is the overall proton ligand stability constant. The metal-ligand stability constants (log K) were determined by employing point wise computational Method (eq. 5 and 6).

$\operatorname{LogK}_{1}=\log \left(\frac{n}{1-n}\right)+\mathrm{pL}$ .5

$\operatorname{LogK}_{2}=\log \left(\frac{1-n}{2-n}\right)+\mathrm{pL}$ ...6

Where: Log $\mathrm{K}$ is the metal-ligand stability constant, $\mathrm{pL}$ is the Free ligand exponent function, $\mathbf{n}$ is the Average number of ligand attached with metal ion (Janraoet al., 2014). The results obtained were analyzed by an ORIGIN 2016 program using titration data and then the proton-ligand stability constants (pKa) and Metal-ligand stability constant (LogK) calculated (Omar and Ali, 2015).

\section{RESULTS AND DISCUSSION}

Fourier transformed infrared (FT-IR) spectra of isolated humic acid from peat soils Figure 2 had distinct clear absorption bands indicating the presence of major humic acid structural elemental groups such as $\mathrm{H}$ bonded $\mathrm{OH}$ $\left(3680 \mathrm{~cm}^{-1}\right.$ peak $), C=0$ of carbonyl $\left(1721 \mathrm{~cm}^{-1}\right.$ peak), functional groups of aliphatic components $\mathrm{CH}_{2}\left(2918 \mathrm{~cm}^{-1}\right.$ peak) and $\mathrm{C}-\mathrm{O}$ stretching of polysaccharide $\left(1168 \mathrm{~cm}^{-1}\right.$ peak). The positions of the absorption bands of the spectra fell within typical major absorption bands of humic acid which is at frequencies 3680, 2918, 1721, 1168 $\mathrm{cm}^{-1}$. The first peak centred in the vicinity of $3680 \mathrm{~cm}^{-1}$ region is attributed to phenol $\mathrm{OH}$ group bounded by intermolecular $\mathrm{H}$ bonds. The $2918 \mathrm{~cm}^{-1}$ band usually has absorption maximum at $2918 \mathrm{~cm}^{-1}$ which is due to $\mathrm{C}-\mathrm{H}$ stretching of alkane group $\left(\mathrm{CH}_{2}\right)$. The next major absorption band is $1721 \mathrm{~cm}^{-1}$. This band has been commonly ascribed to $\mathrm{C}=\mathrm{O}$ stretching of mainly carboxyl group $(\mathrm{COOH})$ with trace amount of ketones. The last peak was observed at 1168 $\mathrm{cm}^{-1}$ due to $\mathrm{C}-\mathrm{O}$ stretching of polysaccharides and this peak appeared also in the spectra of humic acid from peat soil. The FTIR spectra of the isolated humic acid contained all major characteristic absorption peaks of humic acid. These absorption peaks indicated the presence of the major structural elements of humic acid namely $\mathrm{H}$ bonded $\mathrm{OH}, \mathrm{C}=\mathrm{C}$ of aromatic ring, $\mathrm{C}=\mathrm{O}$ of carbonyl group (both carboxyl and ketonic), $\mathrm{CH}_{2}$ group. This strongly supports the presence of humic acid.

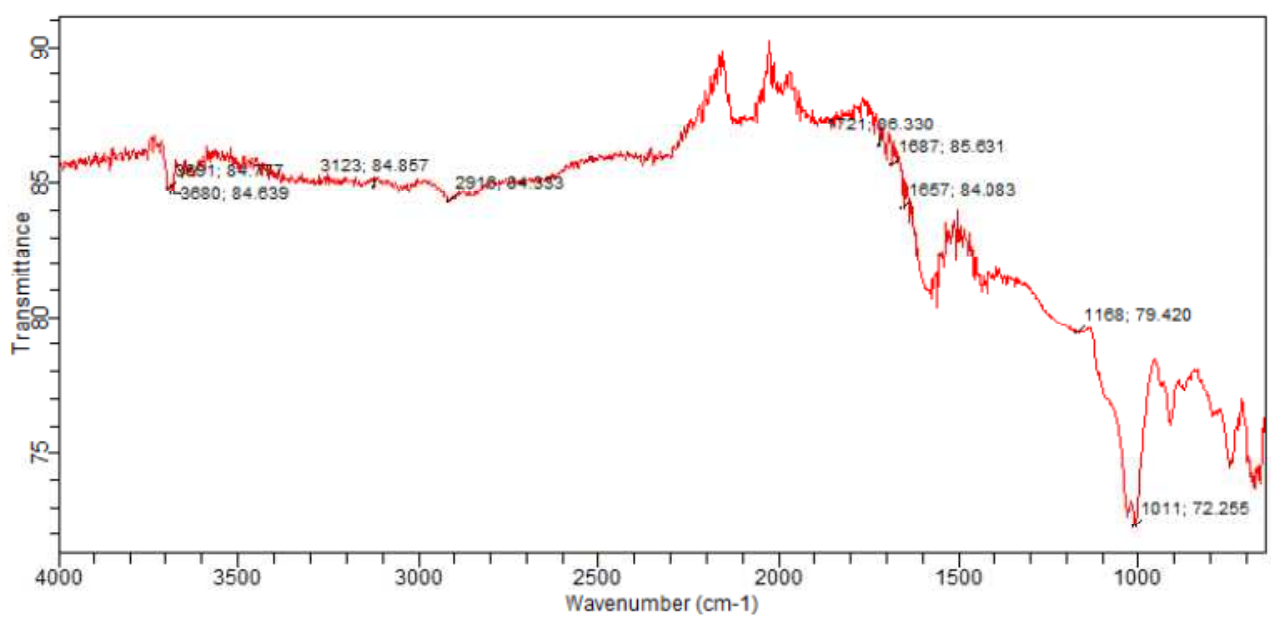

Fig. 2 : FT-IR spectraof peatsoilhumic acid (PSHA)

\section{Evaluation of acid dissociation constant (pka) of acid hydrolysed peat soil humicacid at phenolic group}

The value of the dissociation constant of the peat soil humic acid (PSHA) that underwent acidhydrolysis studied was found to be 8.9299 as shown Table 1, which is lower than the literaturevalues reported by Almeida and Szpoganics, (2015), Borges et al., (2005); Badr et al., (2012)and Fernandes et al,.(2009) of $9.73,9.47$ and 10.30. The difference between the obtained valuesand the reported values in this study might be probably as a result of acid hydrolysis of humicacid. 
BAJOPAS Volume 14 Number 1,June, 2021

Table 1: PKa of (Hydrolysed PSHA)

\begin{tabular}{|l|l|l|l|l|l|l|}
\hline $\mathrm{pH}$ & $\mathrm{BV}_{1}$ & $\mathrm{BV}_{2}$ & $\mathrm{~V}_{2}-\mathrm{V}_{1}$ & $\mathrm{nA}$ & $\log \left(\frac{n A}{1-n A}\right)$ & $\mathrm{pKa}$ \\
\hline 8.50 & 5.30 & 6.29 & 0.99 & 0.3594 & -0.2510 & 8.2490 \\
8.72 & 5.35 & 6.37 & 1.02 & 0.3400 & -0.2880 & 8.4320 \\
9.00 & 5.40 & 6.46 & 1.06 & 0.3141 & -0.3391 & 8.6609 \\
9.22 & 5.45 & 6.55 & 1.10 & 0.2882 & -0.3927 & 8.8273 \\
9.51 & 5.50 & 6.66 & 1.16 & 0.2494 & -0.4786 & 9.0314 \\
9.73 & 5.55 & 6.78 & 1.23 & 0.2041 & -0.5910 & 9.1390 \\
10.00 & 5.60 & 6.90 & 1.30 & 0.1589 & -0.7238 & 9.2762 \\
10.23 & 5.65 & 7.05 & 1.40 & 0.0941 & -0.9835 & 9.2465 \\
10.49 & 5.70 & 7.10 & 1.40 & 0.0941 & -0.9835 & 9.5065 \\
\hline
\end{tabular}

Average pKa $=8.9299 \pm 0.4186$

Table 2: PKa of (Unhydrolysed PSHA)

\begin{tabular}{|l|l|l|l|l|l|l|}
\hline $\mathrm{pH}$ & $\mathrm{BV}_{1}$ & $\mathrm{BV}_{2}$ & $\mathrm{~V}_{2}-\mathrm{V}_{1}$ & $\mathrm{nA}$ & $\log \left(\frac{\boldsymbol{n A}}{1-\boldsymbol{n}}\right)$ & $\mathrm{pKa}$ \\
\hline 8.50 & 5.30 & 5.81 & 0.51 & 0.6619 & 0.2919 & 8.7919 \\
8.72 & 5.35 & 5.90 & 0.55 & 0.6357 & 0.2418 & 8.9618 \\
9.00 & 5.40 & 6.00 & 0.60 & 0.6029 & 0.1813 & 9.1813 \\
9.22 & 5.45 & 6.10 & 0.65 & 0.5701 & 0.1226 & 9.3426 \\
9.51 & 5.50 & 6.20 & 0.70 & 0.5376 & 0.0654 & 9.5754 \\
9.73 & 5.55 & 6.33 & 0.78 & 0.4851 & -0.0259 & 9.7041 \\
10.00 & 5.60 & 6.47 & 0.87 & 0.4262 & -0.1291 & 9.8709 \\
10.23 & 5.65 & 6.62 & 0.99 & 0.3609 & -0.2481 & 9.9819 \\
10.49 & 5.70 & 6.80 & 1.10 & 0.2759 & -0.4690 & 10.0210 \\
\hline
\end{tabular}

Average pKa $=9.4923 \pm 0.4410$

Metal-ligand stability constant ( $\log \mathrm{K}$ )

The stabilityconstants require the accurate values of proton-ligand stability constants (Anil and Maroti, 2008). Metal titration curves crossed over ligand titration curve indicated the formation of complex upon proton release (Santosh, et al., 2011). If the values of n- are within range $0.2-0.8$ and $1.2-18$ this indicates the formation of $1: 1$ and 1:2 complexes (Sayyed and Mazahar, 2012).

The metal (II)-humate stepwise stability constants (log k) at phenolic group (Tables 318)

Table 3: Point-wise method, $\mathrm{Cu}$-(Hydrolysed PSHA)

\begin{tabular}{|l|l|l|l|l|l|l|l|l|}
\hline $\mathrm{pH}$ & $\mathrm{BV}_{1}$ & $\mathrm{BV}_{2}$ & $\mathrm{BV}_{3}$ & $\left(\mathrm{~V}_{3}-\mathrm{V}_{2}\right)$ & $\mathrm{n}$ & $\mathrm{pL}$ & $\log \left(\frac{n}{1-n}\right)$ & LogK $_{1}$ \\
\hline 8.50 & 5.30 & 6.29 & 6.33 & 0.04 & 0.5500 & 2.66 & 0.0871 & 2.7471 \\
8.72 & 5.35 & 6.37 & 6.41 & 0.04 & 0.5714 & 2.43 & 0.1249 & 2.5549 \\
9.00 & 5.40 & 6.46 & 6.50 & 0.04 & 0.6198 & 2.16 & 0.2122 & 2.3722 \\
9.22 & 5.45 & 6.55 & 6.59 & 0.04 & 0.6667 & 1.94 & 0.3010 & 2.2410 \\
\hline
\end{tabular}

LogK $_{1}$ (Average value) $=2.4788 \pm 0.2203$

Table 4: Point-wise method, $\mathrm{Cu}$-(Hydrolysed PSHA)

\begin{tabular}{|l|l|l|l|l|l|l|l|l|}
\hline $\mathrm{pH}$ & $\mathrm{BV}_{1}$ & $\mathrm{BV}_{2}$ & $\mathrm{BV}_{3}$ & $\left(\mathrm{~V}_{3}-\mathrm{V}_{2}\right)$ & $\mathrm{n}$ & $\mathrm{pL}$ & $\log \left(\frac{n-1}{2-n}\right)$ & LogK $_{2}$ \\
\hline 9.51 & 5.50 & 6.66 & 6.73 & 0.07 & 1.3509 & 1.70 & -0.2671 & 1.4329 \\
9.73 & 5.55 & 6.78 & 6.85 & 0.07 & 1.6383 & 1.51 & 0.2467 & 1.7567 \\
10.00 & 5.60 & 6.90 & 6.98 & 0.08 & 2.1783 & 1.31 & -0.2158 & 1.0942 \\
10.23 & 5.65 & 7.05 & 7.13 & 0.08 & 4.1904 & 1.27 & & \\
10.49 & 5.70 & 7.10 & 7.19 & 0.09 & 4.6920 & & & \\
\hline
\end{tabular}

Log $K_{2}($ Average value $)=1.4280 \pm 0.3312$ 
BAJOPAS Volume 14 Number 1,June, 2021

Table 5: Point-wise method, $\mathrm{Cu}$ (Unhydrolysed PSHA)

\begin{tabular}{|l|l|l|l|l|l|l|l|l|}
\hline $\mathrm{pH}$ & $\mathrm{BV}_{1}$ & $\mathrm{BV}_{2}$ & $\mathrm{BV}_{3}$ & $\left(\mathrm{~V}_{3}-\mathrm{V}_{2}\right)$ & $\mathrm{n}$ & $\mathrm{pL}$ & $\log \left(\frac{n}{n-1}\right)$ & Log $_{1}$ \\
\hline 8.50 & 5.30 & 5.81 & 5.85 & 0.04 & 0.2973 & 2.88 & -0.3736 & 2.5064 \\
8.72 & 5.35 & 5.90 & 5.95 & 0.05 & 0.3873 & 2.66 & -0.1992 & 2.4608 \\
9.00 & 5.40 & 6.00 & 6.05 & 0.05 & 0.4044 & 2.38 & -0.1681 & 2.2119 \\
9.22 & 5.45 & 6.10 & 6.15 & 0.06 & 0.5157 & 2.18 & -0.0272 & 2.2072 \\
9.51 & 5.50 & 6.20 & 6.27 & 0.07 & 0.6417 & 1.89 & 0.2530 & 1.1430 \\
\hline
\end{tabular}

$\operatorname{LogK}_{1}($ Average value $)=2.3059 \pm 0.6153$

Table 6:Point-wise method, $\mathrm{Cu}$ (Unhydrolysed PSHA)

\begin{tabular}{|l|l|l|l|l|l|l|l|l|}
\hline $\mathrm{pH}$ & $\mathrm{BV}_{1}$ & $\mathrm{BV}_{2}$ & $\mathrm{BV}_{3}$ & $\mathrm{~V}_{3}-\mathrm{V}_{2}$ & $\mathrm{n}$ & $\mathrm{pL}$ & $\log \left(\frac{n-1}{2-n}\right)$ & $\log \mathrm{K}_{2}$ \\
\hline 9.73 & 5.55 & 6.33 & 6.42 & 0.09 & 0.9000 & 1.69 & & \\
10.00 & 5.60 & 6.47 & 6.58 & 0.11 & 1.2578 & 1.44 & -0.4592 & 0.9808 \\
10.23 & 5.65 & 6.62 & 6.84 & 0.12 & 1.6137 & 1.26 & -0.2010 & 1.4610 \\
10.49 & 5.70 & 6.80 & 6.92 & 0.12 & 2.1052 & 1.03 & & \\
\hline
\end{tabular}

$\operatorname{LogK}_{2}$ (Average value) $=1.2209 \pm 0.3398$

Table 7:Point-wise method, Pb (Hydrolysed PSHA)

\begin{tabular}{|l|l|l|l|l|l|l|l|l|}
\hline $\mathrm{pH}$ & $\mathrm{BV}_{1}$ & $\mathrm{BV}_{2}$ & $\mathrm{BV}_{3}$ & $\left(\mathrm{~V}_{3}-\mathrm{V}_{2}\right)$ & $\mathrm{n}$ & $\mathrm{pL}$ & $\log \left(\frac{n}{1-n}\right)$ & LogK $_{1}$ \\
\hline 8.50 & 5.30 & 6.29 & 6.33 & 0.04 & 0.5500 & 2.66 & 0.0871 & 2.7471 \\
8.72 & 5.35 & 6.37 & 6.41 & 0.04 & 0.5714 & 2.43 & 0.1249 & 2.5549 \\
9.00 & 5.40 & 6.46 & 6.50 & 0.04 & 0.6198 & 2.16 & 0.2122 & 2.3722 \\
9.22 & 5.45 & 6.55 & 6.60 & 0.05 & 0.8333 & 1.96 & 0.6989 & 2.6589 \\
\hline
\end{tabular}

Log $_{\mathbf{1}}($ Average value $)=2.5832 \pm 0.1614$

Table 8:Point-wise method, Pb-(Hydrolysed PSHA)

\begin{tabular}{|l|l|l|l|l|l|l|l|l|}
\hline $\mathrm{pH}$ & $\mathrm{BV}_{1}$ & $\mathrm{BV}_{2}$ & $\mathrm{BV}_{3}$ & $\left(\mathrm{~V}_{3}-\mathrm{V}_{2}\right)$ & $\mathrm{n}$ & $\mathrm{pL}$ & $\log \left(\frac{n-1}{2-n}\right)$ & $\log \mathrm{K}_{2}$ \\
\hline 9.51 & 5.50 & 6.66 & 6.71 & 0.05 & 0.9650 & 1.67 & & \\
9.73 & 5.55 & 6.78 & 6.83 & 0.05 & 1.1702 & 1.44 & & \\
10.00 & 5.60 & 6.90 & 6.90 & 0.05 & 1.4864 & 1.22 & -0.0237 & 1.1963 \\
10.23 & 5.65 & 7.05 & 7.10 & 0.05 & 2.0190 & 1.09 & & \\
10.49 & 5.70 & 7.10 & 7.17 & 0.07 & 3.6492 & 1.00 & & \\
\hline
\end{tabular}

Log $K_{2}$ (Average value) $=1.1963$

Table 9: Point-wise method, Pb (Unhydrolysed PSHA)

\begin{tabular}{|l|l|l|l|l|l|l|l|l|}
\hline $\mathrm{pH}$ & $\mathrm{BV}_{1}$ & $\mathrm{BV}_{2}$ & $\mathrm{BV}_{3}$ & $\mathrm{~V}_{3}-\mathrm{V}_{2}$ & $\mathrm{n}$ & $\mathrm{pL}$ & $\begin{array}{l}\text { Log } \\
\left(\frac{n}{n-1}\right)\end{array}$ & Log $\mathrm{K}_{1}$ \\
\hline 8.50 & 5.30 & 5.81 & 5.85 & 0.04 & 0.2973 & 2.88 & -0.3736 & 2.5064 \\
8.72 & 5.35 & 5.90 & 5.94 & 0.04 & 0.3099 & 2.66 & -0.5477 & 2.3123 \\
9.00 & 5.40 & 6.00 & 6.05 & 0.05 & 0.4044 & 2.38 & -0.1681 & 2.2119 \\
9.22 & 5.45 & 6.10 & 6.15 & 0.06 & 0.5157 & 2.18 & 0.0272 & 2.2072 \\
9.51 & 5.50 & 6.20 & 6.26 & 0.07 & 0.6417 & 1.89 & 0.2530 & 2.1430 \\
9.73 & 5.55 & 6.40 & 6.40 & 0.07 & 0.7000 & 1.67 & 0.3680 & 2.0380 \\
\hline
\end{tabular}

LogK $_{1}$ (Average value) $=2.2364 \pm 0.1602$

Table 10: Point-wise method, Pb (Unhydrolysed PSHA)

\begin{tabular}{|l|l|l|l|l|l|l|l|l|}
\hline $\mathrm{pH}$ & $\mathrm{BV}_{1}$ & $\mathrm{BV}_{2}$ & $\mathrm{BV}_{3}$ & $\mathrm{~V}_{3}-\mathrm{V}_{2}$ & $\mathrm{n}$ & $\mathrm{pL}$ & $\log \left(\frac{n-1}{2-n}\right)$ & $\log \mathrm{K}_{2}$ \\
\hline 10.00 & 5.60 & 6.47 & 6.55 & 0.08 & 1.9503 & 1.41 & & \\
10.23 & 5.65 & 6.62 & 6.72 & 0.11 & 1.4792 & 1.26 & -0.0361 & 1.2239 \\
\hline
\end{tabular}

$\operatorname{LogK}_{2}$ (Average value) $=1.2239$

Table 11: Point-wise method, Mg (Hydrolysed PSHA)

\begin{tabular}{|l|l|l|l|l|l|l|l|l|}
\hline $\mathrm{pH}$ & $\mathrm{BV}_{1}$ & $\mathrm{BV}_{2}$ & $\mathrm{BV}_{3}$ & $\left(\mathrm{~V}_{3}-\mathrm{V}_{2}\right)$ & $\mathrm{n}$ & $\mathrm{pL}$ & $\log \left(\frac{n}{n-1}\right)$ & LogK $_{1}$ \\
\hline 8.50 & 5.30 & 6.29 & 6.31 & 0.02 & 0.2750 & 2.64 & -0.4290 & 2.2110 \\
8.72 & 5.35 & 6.37 & 6.39 & 0.02 & 0.2858 & 2.42 & -0.3978 & 2.0222 \\
9.00 & 5.40 & 6.46 & 6.49 & 0.03 & 0.4648 & 2.14 & -0.0612 & 2.0788 \\
9.22 & 5.45 & 6.55 & 6.59 & 0.04 & 0.6667 & 1.94 & 0.3010 & 2.2410 \\
\hline
\end{tabular}

$\log _{\mathbf{1}}($ Average value) $=2.1382 \pm 0.1046$ 
BAJOPAS Volume 14 Number 1,June, 2021

Table 12: Point-wise method, Mg (Hydrolysed PSHA)

\begin{tabular}{|l|l|l|l|l|l|l|l|l|}
\hline $\mathrm{pH}$ & $\mathrm{BV}_{1}$ & $\mathrm{BV}_{2}$ & $\mathrm{BV}_{3}$ & $\left(\mathrm{~V}_{3}-\mathrm{V}_{2}\right)$ & $\mathrm{n}$ & $\mathrm{pL}$ & $\log \left(\frac{n-1}{2-n}\right)$ & LogK $_{2}$ \\
\hline 9.51 & 5.55 & 6.66 & 6.71 & 0.05 & 0.9650 & 1.67 & & \\
9.73 & 5.55 & 6.78 & 6.84 & 0.06 & 1.4042 & 1.47 & -0.1686 & 1.3014 \\
10.00 & 5.60 & 6.90 & 6.93 & 0.06 & 1.7838 & 1.23 & 0.5593 & 1.7893 \\
10.23 & 5.65 & 7.05 & 7.10 & 0.06 & 3.1429 & 1.10 & & \\
10.49 & 5.70 & 7.10 & 7.18 & 0.07 & 3.6492 & 0.83 & & \\
\hline
\end{tabular}

LogK $_{2}($ Average value $)=1.5453 \pm 0.3450$

Table 13: Point-wise method, Mg (Unhydrolysed PSHA)

\begin{tabular}{|l|l|l|l|l|l|l|l|l|}
\hline $\mathrm{pH}$ & $\mathrm{BV}_{1}$ & $\mathrm{BV}_{2}$ & $\mathrm{BV}_{3}$ & $\mathrm{~V}_{3}-\mathrm{V}_{2}$ & $\mathrm{n}$ & $\mathrm{pL}$ & $\log \left(\frac{n}{n-1}\right)$ & $\operatorname{Log~}_{1}$ \\
\hline 8.50 & 5.30 & 5.81 & 5.85 & 0.04 & 0.2973 & 2.88 & -0.3736 & 2.5064 \\
8.72 & 5.35 & 5.90 & 5.94 & 0.04 & 0.3099 & 2.66 & -0.3477 & 2.3123 \\
9.00 & 5.40 & 6.00 & 6.04 & 0.04 & 0.3236 & 2.38 & -0.3202 & 2.0598 \\
9.22 & 5.45 & 6.10 & 6.15 & 0.05 & 0.4297 & 2.17 & -0.1230 & 2.0470 \\
9.51 & 5.50 & 6.20 & 6.26 & 0.06 & 0.5500 & 1.89 & 0.0871 & 1.9771 \\
9.73 & 5.55 & 6.33 & 6.40 & 0.07 & 0.7000 & 1.67 & 0.3680 & 2.0380 \\
\hline
\end{tabular}

LogK $_{1}$ (Average value) $=2.1568 \pm 0.2069$

Table 14: Point-wise method, Mg (Unhydrolysed PSHA)

\begin{tabular}{|l|l|l|l|l|l|l|l|l|}
\hline $\mathrm{pH}$ & $\mathrm{BV}_{1}$ & $\mathrm{BV}_{2}$ & $\mathrm{BV}_{3}$ & $\mathrm{~V}_{3}-\mathrm{V}_{2}$ & $\mathrm{n}$ & $\mathrm{pL}$ & $\log \left(\frac{n-1}{2-n}\right)$ & $\log \mathrm{K}_{2}$ \\
\hline 10.00 & 5.60 & 6.47 & 6.55 & 0.08 & 0.9148 & 1.41 & & \\
10.23 & 5.65 & 6.62 & 6.71 & 0.09 & 1.2102 & 1.20 & -0.5749 & 0.6251 \\
10.49 & 5.70 & 6.80 & 6.92 & 0.09 & 1.5968 & 1.03 & 0.1703 & 1.2003 \\
\hline
\end{tabular}

LogK $_{2}$ (Average value) $=0.9127 \pm 0.4070$

Table15:Point-wise method, Cd (Hydrolysed PSHA)

\begin{tabular}{|l|l|l|l|l|l|l|l|l|}
\hline $\mathrm{pH}$ & $\mathrm{BV}_{1}$ & $\mathrm{BV}_{2}$ & $\mathrm{BV}_{3}$ & $\left(\mathrm{~V}_{3}-\mathrm{V}_{2}\right)$ & $\mathrm{n}$ & $\mathrm{pL}$ & $\log \left(\frac{n}{1-n}\right)$ & LogK $_{1}$ \\
\hline 8.50 & 5.30 & 6.29 & 6.31 & 0.02 & 0.2750 & 2.64 & -0.4210 & 2.2190 \\
8.72 & 5.35 & 6.37 & 6.40 & 0.03 & 0.4286 & 2.42 & -0.1249 & 2.2951 \\
9.00 & 5.40 & 6.46 & 6.49 & 0.03 & 0.4648 & 2.14 & -0.0612 & 2.0788 \\
9.22 & 5.45 & 6.55 & 6.59 & 0.04 & 0.6667 & 1.96 & 0.3010 & 2.2610 \\
9.51 & 5.55 & 6.66 & 6.70 & 0.04 & 0.7720 & 1.67 & 0.5297 & 2.1997 \\
\hline
\end{tabular}

LogK $_{\mathbf{1}}$ (Average value) $=2.2108 \pm 0.0825$

Table 16: Point-wise method, Cd (Hydrolysed PSHA)

\begin{tabular}{|l|l|l|l|l|l|l|l|l|}
\hline $\mathrm{pH}$ & $\mathrm{BV}_{1}$ & $\mathrm{BV}_{2}$ & $\mathrm{BV}_{3}$ & $\left(\mathrm{~V}_{3}-\mathrm{V}_{2}\right)$ & $\mathrm{n}$ & $\mathrm{pL}$ & $\log \left(\frac{n-1}{2-n}\right)$ & Log $_{2}$ \\
\hline 9.73 & 5.55 & 6.78 & 6.83 & 0.06 & 1.4042 & 1.47 & -0.1686 & 1.3014 \\
10.00 & 5.60 & 6.90 & 6.95 & 0.06 & 1.7838 & 1.23 & 0.5593 & 1.7893 \\
10.23 & 5.65 & 7.05 & 7.10 & 0.06 & 3.1429 & 1.09 & & \\
10.49 & 5.70 & 7.10 & 7.16 & 0.06 & 3.1429 & 0.89 & & \\
& & & & & & & & \\
\hline
\end{tabular}

$\operatorname{LogK}_{2}$ (Average value) $=1.5453 \pm 0.3450$

Table 17: Point-wise method, Cd (Unhydrolysed PSHA)

\begin{tabular}{|l|l|l|l|l|l|l|l|l|}
\hline $\mathrm{pH}$ & $\mathrm{BV}_{1}$ & $\mathrm{BV}_{2}$ & $\mathrm{BV}_{3}$ & $\mathrm{~V}_{3}-\mathrm{V}_{2}$ & $\mathrm{n}$ & $\mathrm{pL}$ & $\log \left(\frac{n}{n-1}\right)$ & $\operatorname{Log~}_{1}$ \\
\hline 8.50 & 5.30 & 5.81 & 5.86 & 0.05 & 0.3717 & 2.88 & -0.2280 & 2.6520 \\
8.72 & 5.35 & 5.90 & 5.95 & 0.05 & 0.3873 & 2.66 & -0.1992 & 2.4608 \\
9.00 & 5.40 & 6.00 & 6.06 & 0.06 & 0.4853 & 2.38 & -0.0255 & 2.3545 \\
9.22 & 5.45 & 6.10 & 6.16 & 0.06 & 0.5157 & 2.18 & -0.0272 & 2.2072 \\
9.51 & 5.50 & 6.20 & 6.27 & 0.07 & 0.6417 & 1.89 & 0.2530 & 1.1430 \\
9.73 & 5.55 & 6.33 & 6.41 & 0.08 & 0.8000 & 1.69 & 0.6020 & 2.2920 \\
& & & & & & & & \\
\hline
\end{tabular}

$\operatorname{LogK}_{1}($ Average value $)=2.2516 \pm 0.5380$ 
BAJOPAS Volume 14 Number 1,June, 2021

Table 18: Point-wise method, Cd (Unhydrolysed PSHA)

\begin{tabular}{|l|l|l|l|l|l|l|l|l|}
\hline $\mathrm{pH}$ & $\mathrm{BV}_{1}$ & $\mathrm{BV}_{2}$ & $\mathrm{BV}_{3}$ & $\mathrm{~V}_{3}-\mathrm{V}_{2}$ & $\mathrm{n}$ & $\mathrm{pL}$ & $\log \left(\frac{n-1}{2-n}\right)$ & $\log \mathrm{K}_{2}$ \\
\hline 10.00 & 5.60 & 6.47 & 6.57 & 0.10 & 1.1434 & 1.43 & & \\
10.23 & 5.65 & 6.62 & 6.72 & 0.10 & 1.3448 & 1.23 & -0.2788 & 0.9512 \\
10.49 & 5.70 & 6.80 & 6.90 & 0.10 & 1.7742 & 1.03 & 0.5351 & 1.5651 \\
\hline
\end{tabular}

$\operatorname{LogK}_{2}($ Average value $)=1.2581 \pm 0.4340$

Table 19: Stepwise and overall Stability constants of thehydrolysed and unhydrolysed divalent metal (II) complexes

\begin{tabular}{|c|c|c|c|}
\hline Chelates & LogK $_{1}$ & $\log _{2}$ & Log $\beta$ \\
\hline [Cu (Hydrolysed PSHA-1) $\left.{ }_{2}\right]$ & 2.4788 & 1.4280 & 3.9068 \\
\hline$\left[\mathrm{Pb}(\text { Hydrolysed PSHA-1) })_{2}\right]$ & 2.5832 & 1.1963 & 3.7795 \\
\hline$\left[\mathrm{Cd}(\text { Hydrolysed PSHA-1 })_{2}\right]$ & 2.2108 & 1.5453 & 3.7561 \\
\hline$\left[\mathrm{Mg}(\text { Hydrolysed PSHA-1 })_{2}\right]$ & 2.1382 & 1.5453 & 3.6835 \\
\hline [Cu (Unhydrolysed PSHA-1) & 2.3059 & 1.2209 & 3.5268 \\
\hline$[\mathrm{Pb}$ (Unhydrolysed PSHA-1) 2$]$ & 2.2364 & 1.2239 & 3.4603 \\
\hline [Cd (Unhydrolysed PSHA-1) 2 ] & 2.2516 & 1.2581 & 3.5097 \\
\hline$[\mathrm{Mg}$ (Unydrolysed PSHA-1) & 2.1568 & 0.9127 & 3.0695 \\
\hline
\end{tabular}

The results obtained (Table19) shows the stepwise and overall stability constants to be not high indicating low stability of the complexes, because the solubility of most metal ions in the basic $\mathrm{pH}$ range is minimal due to metal hydroxide precipitation (Karimi, 2017). In general, the stepwise stability constants $\left(K_{1}\right.$ and $K_{2}$ ) follow the order $K_{1}>K_{2}$ for the copper, lead, magnesium and cadmium complexes respectively. The steady decrease of the values with increasing number of ligands is in agreement with the prediction made by researchers (Na'aliya, 2013). The decrease could be attributed to the fact that as the number of the ligands (Humate ions) that enters the coordination zone increases the aqua molecules available for replacement by the ligands become less. Thus, the metal ions become less electron loving with progressive intake of the ligand and this results in the decrease in the values of the constants (Na'aliya, 2013). Also the stability of the complexes is influenced by the size and number of the chelate rings(Mackay and Mackay,2002).All the complexes form rings in their structure as humate, a bidentate ligand, bond the metal ions in the ratio 1:2 (Boguta and Sokolowska, 2016) forming chelate rings. The values of the overall stability constants $(\log \beta)$ obtained for humate complexes are not high indicating low stability as the values are not high. LogK values for copper-humates (Table 3 to 6) obtained in this study are lower than those reported for the complexes of humic acids (Pandey et al., 2015; Dinu, 2013; Kaschl et al., 2010 and Gilbeto and Jorg, 2001). The values of LogK(Table 7 to 10 ) forlead-humates are lower than those reported for the lead in the literature (Dinu, 2013; Gilbeto and Jorg 2001). Log K values(Table 11 to 14 ) for magnesium-humates obtained in this study are close to those reported by (Pandey et al., 2015). Log K values of cadmium-humates (Table 15 to 18 ) obtained in this work near to the one reported by (Dinu, 2013 and Pandey et al., 2015).The difference between the reported values and the values obtained in this study might be probably as a result of acid hydrolysis of humic acid. The values of the overall stability constants $(\log \beta)$ of the copper humates complexes presented in Table 19 is high than that of other metal humate complexes, show relatively high stability of CuHA complexes, show the following order of stability: $\mathrm{Cu}>\mathrm{Pb}>\mathrm{Cd}>\mathrm{Mg}$; which are in close agreement to the findings of (Dinu, 2013 and Pandey et al., 2015).The high stability of Cuhumate chelate could be attributed to the existence of coordinate covalent bond between the complexing agents and the $\mathrm{Cu}^{2+}$ ions. Since, $\mathrm{Cu}^{2+}$ being a metal of the transitional series with $3 d^{9}$ electronic configurations can accept the electrons from the complexing agents. Similarly, the low stabilities of $\mathrm{Pb}, \mathrm{Cd}$ and $\mathrm{Mg}$ complexes could be explained by that $\mathrm{Pb}^{2+}$ with $6 s^{2}, \mathrm{Cd}^{2+}$ with $4 \mathrm{~d}^{10}$ and $\mathrm{Mg}^{2+}$ with $2 \mathrm{p}^{6}$ their electronic configuration has a completely filled $\mathrm{d}, \mathrm{p}$ and $\mathrm{s}$ orbitals. Moreover, the stabilities of metal ions with hydrolysed humic acid from peat soil were higher than those with unhydrolysed humic acid from peat soil; which is ascribed to the high content of acidity in hydrolysed humic acid than unhydrolysed humic acid. 
BAJOPAS Volume 14 Number 1,June, 2021 CONCLUSION

The values of logk for $\mathrm{Cu}(\mathrm{II})$ hydrolysed humic acid complex was higher followed by $\mathrm{Pb}$ (II), $\mathrm{Cd}(\mathrm{II})$ and $\mathrm{Mg}$ (II) hydrolysed humic acid complexes as compared with metal(II) unhydrolysed humic acid complexes. This indicates acid hydrolysis of humic acid can

\section{REFERENCES}

Almeida, V.R. and Szpoganicz, B. (2015). Humic Acid Potentiometric Response Patterns:Out- of Equilibrium Properties and Species Distribution Modelling. Chemical. Biol. Technol. Agric. 2: 17.

Anđelković, T., Nikolić, R., Bojić, A.,Anđelković, D., and Nikolic G.,(2010). Binding of Cadmium to Soil Humic Acid as A Function of Carboxyl Group Content. Macedonian Journal of Chemistry and Chemical Engineering.29(2): 215-224.

Anil, B. N. and Maroti, N. (2008). Studies on Influence of Die-Lectric Constants on Complex Equilibria between Substituted Py-Razalines and Lanthanide Metal Ions pH-Metrically. Amer.-Euras. scient. Res. 3(2): 212-216.

Ashok, K., Pandey, S. P. and Misra, V (2000). Stability Constants of Metal-Humic Acid Complexes and its Role in Environmental Detoxification. Journal of Ecotoxicology and Environmental Safety. 47(2):157-200.

Badr, M. H., El-Halafawi, M. H. and Abd El-al Zeid, E. R. (2012). Comparison Between the Effect of Ionic Strength on Acidity and Dissociation Constants of Humic Acids Extracted from Sewage Sludge and Nile Water Hyacinth Composts.Global Journal of Environmental Research 6 (1): 36-43.

Baruah, M.K., Borah, D., Saikia, P.P., Paul, S., Sharma, T. (2015). Evaluation of pKa Values of Soil Humic Acids and their Complexation Properties. International Journal of Plant \& Soil Science 6(4) : 218-228.

Boguta, P. Sokolowska, Z. (2016). Interactions of $\mathrm{Zn}$ (II) Ions with Humic Acids Isolated from Various Types of Soils. Effect of $\mathrm{pH}, \mathrm{Zn}$ Concentrations and Humic Acids Chemical Properties. Journal of Geochemical Explaration 168. 119-126.

Borges, F., Guimaraes, C., Lima, L.F.C., Pinto, I. and Reis, S.(2005). Potentiometric Studies on the Complexation of Copper(II) by Phenolic Acids as Discrete Ligand Models of enhance the complexation behavior of humic acid with metal (II) ions. However, the higher values of $\log \beta$ for $\mathrm{Cu}(\mathrm{II}), \mathrm{Pb}(\mathrm{II}), \mathrm{Cd}(\mathrm{II})$ and $\mathrm{Mg}(\mathrm{II})$ hydrolysed humic acid complexes indicates more stable stepwise complexes formed as compared with $\mathrm{Cu}(\mathrm{II}), \mathrm{Pb}$ (II), $\mathrm{Cd}$ (II) and $\mathrm{Mg}(\mathrm{II})$ unhydrolysed humic acid complexes.

Humic Substances Talanta 66 (2005) 670-673.

Chefetz, B., Salloum, M. J., Deshmulkin, A. P. and Hatcher, P. (2002). Structural Components of Humic Acids as Determined by Chemical Modifications and Carbon-13 NMR, Pyrolysis, and Thermochemolysis- Gas Chromatography/Mass Spectrometry. Soil Science Society of American Journal Abstract Division S-2- Soil Chemistry66. 1159-1171.

Dinu, M. I. (2013). Metals Complexation with Humic Acids in Surface Water of Different Environ. Sci. Technol. 31(1): 1-17.

Fernandes, A.N., Giacomelli, C., Giovanela, M. Vaz, D.V. Szpoganicz, B. and Maria M. D. (2009). Potentiometric Acidity Determination in Humic Substances Influenced by Different Analytical Procedures.J. Braz. Chem. Soc. 20 (9):14.

Gamal, A. H. (2015). Stability Constants of Rhenium (V) Metal Complexes with Selected Drugs. Pyrex Journal of Research in Environmental Studies. 2(2): 006-014.

Janrao, D. M., Pathan, J., Kayande, D.D., and Mulla, J.J. (2014). An Over View of Potentiometric Determination of Stability Constants of Metal Complexes. Sci. Revs. Chem. Commun.: 4(1), 2014, 11-24.

Karimi, H. (2017). Effect of pH and Initial Pb(II) Concentration on the Lead Removal Efficiency from Waste Water Using $\mathrm{Ca}(\mathrm{OH})_{2}$. International Journal of Water and Waste Water Treatment 3.2

Kaschl, A. Romheld, V. and Chen, Y. (2010). Binding of Cadmium, Copper and Zinc to Humic Substances Originating from Municipal Solid Waste Compost. Israel Journal of Chemistry Vol. 42(1): 89-98.

Kostic, I. S., Tatjana, P, A., Nikolic, R. S., Cvetkovic, T. P., Pavlovic, D. D., Aleksandar, L.J. and Bojic, A. (2012). Comparative Study of Binding Strengths of Heavy Metals with Humic Acid. J.serb. Chem. Soc. 76(9) pp 1-20. 
BAJOPAS Volume 14 Number 1,June, 2021

Na'aliya, J. (2013). Determination of Stepwise Stability Constants and Gibbs free Energy Change of Trisprolina to Complexes of some Divalent Transition Metal ions. Bayero Journal of Pure and Applied Sciences 6(2): 112-114.

Omar, A. A. and Ali, E. A. (2015). Potentiometric Studies on Complexes of $\mathrm{Cr}$ (III) and $\mathrm{Zr}$ (IV) with some Carboxylic Acids. International Journal of Advanced Chemistry, 3(1) 25-

37.

Pandey, A. K. Pandey, S. D. and Misr, V. (2015).Stability Constants of Metal- Humic Acid Complexes and Its Role in Environmental Detoxification. J. Ecotoxicology and Environmental Safety. 47(1):195-200.

Ram, N. and Raman, K.V. (1984). Stability Constants of Complexes of Metals with
Humicand Fuvic Acids under Non- acidConditions. Journal of Plant Nutrition and Soil Sciences.

147:171-176.

Santosh, D. D., Ashok, B. K., Vijay, J. T., Shivraj, G. W. and Vinay, V. W. (2011). Potentiometric Studies of Elec-Trolyte Effects on Complex Equilibria of Some Substituted 5-(2-hydroxy Phenyl) Pyrazoles. Der pharm. 3 (6): 75-83.

Sayyed, H. and Abdul Rahim, M. F. (2012). Studies of Binary Complexes of Metal Ions with Mandelic Acid by Potentiometry. Chem. J. 02 (6): 206209.

Shirvani, M. Moradian, E. Khalili, B. Bakhtiary, S. (2015). Interaction of $\mathrm{Cd}$ and $\mathrm{Pb}$ with Humate-Palygorskite and HumateSepiolite Complexes. Journal of water, air and pollution 3: 220-228. 


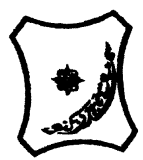

Bayero Journal of Pure and Applied Sciences, 14(1): 54 - 63

Received: November, 2020

Accepted: April, 2021

ISSN $2006-6996$

\title{
STABILITY CONSTANTS OF COMPLEXES OF METAL IONS WITH PEATSOIL HUMIC ACIDS UNDER NON-ACID-CONDITIONS
}

\author{
${ }^{* 1}$ Sabo, Yusuf ${ }^{2}$ Jimoh, W.L.O., ${ }^{3}$ Isa Baba Koki and ${ }^{4}$ Sholadoye, Q. 0. \\ ${ }^{1}$ Department of Pure and Industrial Chemistry, Bayero University, Kano \\ ${ }^{3}$ Department of Chemistry, Yusuf Maitama Sule University Kano. P.M.B. 3220 Kano, Nigeria. \\ ${ }^{4}$ Department of Chemistry, Nigerian Police Academy, Wudil, Kano-Nigeria
}

*Correspondence E-mail; saboyusuf18@yahoo.com

ABSTRACT

Stability constants of complexes of four divalent metal ions viz. $\mathrm{Cu}^{2+}, \mathrm{Pb}^{2+}, \mathrm{Mg}^{2+}$ and $\mathrm{Cd}^{2+}$ with humic acids (HA) were determined by potentiometric titration of humic acids with the corresponding salt of the divalent metals in aqueous media under non-acid-condition. The log $K$ (logarithm of the stability constant) ranged from 1.0942 to 2.7471 for metalhumic acid complexes were determined using point-wise computational method. The order of stability constants were obtained as follows: $\mathrm{Cu}>\mathrm{Pb}>\mathrm{Cd}>\mathrm{Mg}$ for metal $-\mathrm{HA}$ complexes respectively, indicating a higher degree of complexation with Cu metal ion.

Keywords: stability constant, humic acid, potentiometric titration, divalent metals, acid hydrolysis.

\section{NTRODUCTION}

The stability constant of a complex is the numerical expression of its stability and provides a quantitative measure of affinity of the metal ion to the complexing agent. An understanding of the relative stability of metal-complexes helps in predicting the behavior of metal ions in the soil (Ram and Raman, 1982). Extensive researches has been done to determine the stability constants of the complexes formed between humic acid (HA) with a number of metal ions. Ashok et al., (2000) reported that humic acid with hydroxyl, phenoxyl and carboxyl reactive groups can form coordination compound with metal ions at $\mathrm{pH}$ 3.5. The stability constants(Log K) for different metalhumic acid complexes indicated the following order of the stabilities of complexes formed between humic acid and metal ion, $\mathrm{Cu}>\mathrm{Fe}$ $>\mathrm{Pb}>\mathrm{Ni}>\mathrm{Co}>\mathrm{Ca}>\mathrm{Cd}>\mathrm{Zn}>\mathrm{Mn}>\mathrm{Mg}$. Andelkovic et al., (2010) investigated the binding of $\mathrm{Cd}$ (II) to soil humic acid at pH 6.5 and in $0.1 \mathrm{M} \mathrm{KNO}_{3}$ ionic medium. The stability constant for binding indicating greater stability in the case when carboxyl groups are involved in complexation reaction. Kostic et al.,(2012) investigated the complexation of humic acid with certain heavy metal ions (Co(II), $\mathrm{Ni}(\mathrm{II}), \mathrm{Cu}(\mathrm{II})$,
$\mathrm{Zn}(\mathrm{II})$, and $\mathrm{Pb}(\mathrm{II})$. The experiment was performed at $25^{\circ} \mathrm{C}$, at pH 4.0 and ionic strength of $0.01 \mathrm{M}$. Stability constant of complex between $\mathrm{Pb}$ (II) ions and humic acid is greater than stability constants of other investigated metalhumate complexes. Bogata and Sokolowska (2016) analyses the interaction between humic acids from different soils and $\mathrm{Zn}$ (II) ions at wide concentration ranges and at $\mathrm{pH} 5$. Studies have showed significant impact of $\mathrm{Zn}$ concentration, $\mathrm{pH}$ and some properties of humic acids with zinc.But all of these studies were limited to acidic $\mathrm{pH}$ range. Therefore, the present study was carried out to determine and compare the stability constants of complexes of metal ions with hydrolysed peat soil humic acid and unhydrolysed peat soil humic under non-acid conditions.

\section{MATERIALS AND METHODS}

Analytical grade chemicals used includes hydrochloric acid $(\mathrm{HCl})$, nitric acid $\left(\mathrm{HNO}_{3}\right)$, sodium hydroxide $(\mathrm{NaOH})$, lead nitrate $\mathrm{Pb}\left(\mathrm{NO}_{3}\right)_{2}$, copper nitrate $\mathrm{Cu}\left(\mathrm{NO}_{3}\right)_{2} \cdot 3 \mathrm{H}_{2} \mathrm{O}$, cadmium nitrate $\mathrm{Cd}\left(\mathrm{NO}_{3}\right)_{2} \cdot 4 \mathrm{H}_{2} \mathrm{O}$, magnesium nitrate $\mathrm{Mg}\left(\mathrm{NO}_{3}\right)_{2} \cdot 6 \mathrm{H}_{2} \mathrm{O}$, potassium nitrate $\left(\mathrm{KNO}_{3}\right)$, calcium chloride $\left(\mathrm{CaCl}_{2}\right)$, (sigma-Aldrich). Dowex 50WX8, (20-50 mesh) from Fluka. 


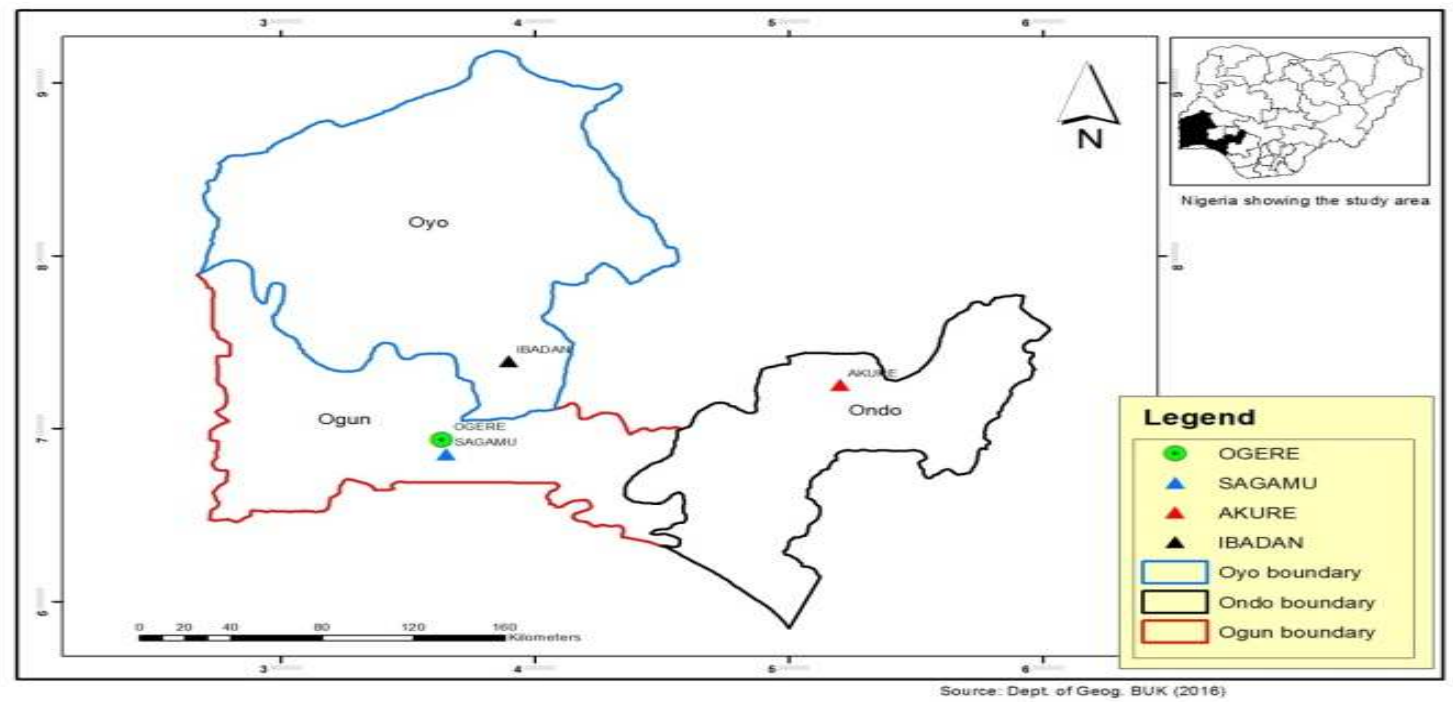

Figure 1: Map showing the sampling point at Sagamu Town, Ogun State.

\section{Description of Sampling Area}

Sagamu has geographical coordinates between $6^{\circ} 50^{\prime}$ north; $3^{\circ} 38^{\prime}$ east is located in south western region of Nigeria. The region has tropical wet and dry climate with a lengthy wet season and relatively constant temperatures throughout the course of the year. Wet season runs from March to October, November to December forms the region dry season. The vegetation type of the region is savannah which is really grassland with small bushes and occasional big trees. Grassland soils have substantially higher organic matter content than forest soils (Novackova, 2011).

\section{Sample Collection}

The Peatsoil samples were collected from four different sampling points $(0-10 \mathrm{~cm}$ depth) in Sagamu into polyethylene bag with plastic spoons. Samples were taken to the laboratory, extraneous materials were removed; the samples were air-dried, crushed and ground to a fine powder in a mortar passed through a $0.20 \mathrm{~mm}$ sieve. The samples were kept for analysis.

\section{Isolation and purification of humic acid from peat soil sample}

Peatsoil sample $(100 \mathrm{~g})$ was mixed with 1000 $\mathrm{cm}^{3}$ of $0.1 \mathrm{M} \mathrm{NaOH}$ solution, shaken for 3hours and left to stand overnight. Dark-coloured supernatant was obtained and decanted from solid residue. The dark-coloured supernatant was acidified to $(\mathrm{pH}=1.0)$ with $6 \mathrm{M} \mathrm{HCl}$ stirred and allowed to stand for 6 hours. Yellowish brown supernatant and dark-brown precipitate were obtained. The yellowish brown supernatant was decanted followed by centrifuge and discarded. The dark-brown precipitate was mixed with $500 \mathrm{~cm}^{3}$ of $0.1 \mathrm{M} \mathrm{NaOH}$ solution followed by passing through dowex resin. The dark-brown solution was acidified to $(\mathrm{pH}=1.0)$ with $6 \mathrm{M} \mathrm{HCl}$ stirred and allowed to stand for 3 hours. The dark-brown precipitate was washed several times with deionized water. The supernatant was treated with $\mathrm{AgNO}_{3}$ solution until no white precipitate observed. The humic acid was transferred to weighed crucible and dried at $60^{\circ} \mathrm{C}$ in an oven for 12 hours. The humic acid was cooled and dried in the desiccator, weighed and recorded. The obtained humic acid was dried again at $60^{\circ} \mathrm{C}$ for additional 6 hours cooled and dried in the desiccator, weighed and recorded constant weight was obtained (Baruah et al., 2015).

\section{FT-IR analysis}

FT-IR spectra of humic acid sample was analysed using Carry 630 FT-IR Agilent Technologies.

Unhydrolysed compost humic acid

The unhydrolysed humic acid was obtained after isolation and purification of compost humic acid and kept for investigation.

\section{Acid hydrolysis of Peatsoil acid}

Peatsoil humic acid sample (1g) was refluxed for 12 hours at $\left(160^{\circ} \mathrm{C}\right)$ with $50 \mathrm{~cm}^{3}$ of $6 \mathrm{M} \mathrm{HCl}$. The mixture was allowed to cool, decanted, and centrifuged after hydrolysis. The insoluble residues were washed with distilled water via centrifugation several times, and the supernatant was treated with $\mathrm{AgNO}_{3}$ solution until no white precipitate was observed. The residue was thoroughly dried over $\mathrm{CaCl}_{2}$ in a desiccator at room temperature (Chefetz et al., 2002). Finally, the obtained hydrolysed humic acid was kept for investigation. 
BAJOPAS Volume 14 Number 1,June, 2021 Potentiometric Titrations

Potentiometric measurements were carried out using a pH-meter Jenway (model 3510) with combine electrode, the sensitivity of the $\mathrm{pH}$ meter is 0.01 units. The $\mathrm{pH}$ meter was switched on half an hour before starting the titration for initial warm up of the instrument. The instrument was calibrated with an aqueous standard buffer solution of $\mathrm{pH} 4.00$ and 10.0 (borate buffer) prepared from a "Qualigens" buffer tablets.

The following sets of solutions were prepared in a $250 \mathrm{~cm}^{3}$ volumetric flask separately for $\mathrm{pH}$ metric titrations.

(i) $5 \mathrm{~cm}^{3} 0.1 \mathrm{M} \mathrm{HCl}+40 \mathrm{~cm}^{3}$ deionized water

(ii) $5 \mathrm{~cm}^{3} 0.1 \mathrm{M} \mathrm{HCl}+39 \mathrm{~cm}^{3}$ deionized water $+1 \mathrm{~cm}^{3} 0.15 \mathrm{gcm}^{-3}$ humic acid

(iii) $5 \mathrm{~cm}^{3} 0.1 \mathrm{M} \mathrm{HCl}+37 \mathrm{~cm}^{3}$ deionized water $+1 \mathrm{~cm}^{3} 0.15 \mathrm{gcm}^{-3}$ humic acid

$$
+2 \mathrm{~cm}^{3} \quad 0.01 \mathrm{M} \mathrm{Cu} \text { (II) }
$$

The solutions were titrated against standardized $0.110 \mathrm{MNaOH}$ separately. The total volume of each mixture was adjusted to $50 \mathrm{~cm}^{3}$ and the ionic strength of the solutions was maintained constant at by adding appropriate amount of stock solution of $1 \mathrm{M} \mathrm{KNO}_{3}$ (Gamal, 2015; Omar and Ali, 2015). A magnetic stirrer was used to achieve thorough mixing of the interacting solutions at $550 \mathrm{rpm}$. The same set of experimental conditions was applied for potentiometric titration of remaining samples.

\section{Evaluation of pKa of Hydrolysed peat soil Humic Acids}

The proton-ligand formation number $\mathrm{n}_{\mathbf{A}}$ were calculated by Irving and Rossotti expression (Omar and Ali, 2015).

$\mathrm{nA}=\mathrm{Y}-\frac{(\mathrm{V} 2-\mathrm{V1})(\mathrm{No}-\mathrm{Eo})}{(\mathrm{VO}+\mathrm{V1}) \mathrm{TCL}}$ 1

Where: $Y$ is number of dissociable proton, $\left(\mathrm{V}_{2^{-}}\right.$ $V_{1}$ ) is the measure of displacement of the ligand curve relative to acid curve, $\mathrm{N}^{\circ}$ and $\mathrm{E}^{\circ}$ are the resultant concentration of alkali solution, free acid solution, $\mathrm{T}_{\mathrm{cL}}{ }^{\circ}$ is the total ligand concentration, $\mathrm{V}^{\circ}$ is the total volume of titration solution, $V_{1}$ is the volume of alkali added to acid solution, $V_{2}$ is the volume of alkali added to acid solution + ligand solution, acid dissociation constants (pKa - values) of ligand were calculated by algebraic method point wise calculation (Tables 1 ). The dissociation constants (pKa) were calculated according to the following relation:

$\mathrm{pKa}=\mathrm{pH}+\log \left(\frac{n A}{1-n A}\right)$ 2

Where: pKa is the acid dissociation constant, $\mathrm{n}_{\mathrm{A}}$ is the Proton-ligand formation number and $\mathrm{pH}$ is the pH-values (Omar and Ali, 2015).

\section{Determination of metal-ligand stability constants $(\log K)$ of complexes}

The potentiometric measurement for the determination of stability constant of a complex in solution is based on the fact that the redox potential of the couple $\frac{M^{+(m-n)}}{M^{+m}}$ is shifted significantly on complexation of the metal ion with the ligand. This method involves change in hydrogen ion concentration $\left[\mathrm{H}^{+}\right]$due to the displacement or association of one or more protons taking place during complexation reaction. This change can be found out by titrating the solutions containing free acid, acid with ligand, and acid with ligand and metal ion, individually against a standard alkali solution at a constant ionic strength or temperature. Either ionic strength or temperature may be varied for different sets of solutions. In all the cases, the change in the $\mathrm{pH}$ of the solution is measured after each addition of a known amount of alkali to the reaction cell which contains the reaction mixture. The titration curves are then drawn by plotting the measured $\mathrm{pH}$ values against the corresponding volume of alkali added and the stability constants of the complexes are determined from the titration curves by employing $\mathrm{pH}$-metric titration technique given by (Irving and Rossoti).

Metal-ligand stability constants ( $\log \mathrm{K}$ ) were determined by using the following relations:

$$
\bar{n}=\frac{\left(V_{3}-V_{2}\right)\left(E^{0}+N^{0}\right)}{\left(V^{0}+V_{2}\right) \bar{n}_{A} T_{m}^{0}}
$$

and

$$
P L=\log _{10}\left\{\frac{1+\beta_{n}^{H} \frac{1}{[\text { anti } \log \mathrm{pH}]^{\mathrm{n}}}}{\mathrm{T}_{\mathrm{L}}^{0}-n \bar{T}_{m}^{0}} \mathrm{X} \frac{\left(V^{0}+V_{3}\right)}{V^{0}}\right\}
$$


BAJOPAS Volume 14 Number 1,June, 2021

Where $T_{L}, T^{\circ}, E^{\circ}$, and $V^{\circ}$ havethe same significance as in equation (1) above, $T_{m}$ denotes the total concentration of metal present in solution, $V_{3}$ is the volume of metal ions present in solution and $\beta^{H}$ is the overall proton ligand stability constant. The metal-ligand stability constants (log K) were determined by employing point wise computational Method (eq. 5 and 6).

$\operatorname{LogK}_{1}=\log \left(\frac{n}{1-n}\right)+\mathrm{pL}$ .5

$\operatorname{LogK}_{2}=\log \left(\frac{1-n}{2-n}\right)+\mathrm{pL}$ ...6

Where: Log $\mathrm{K}$ is the metal-ligand stability constant, $\mathrm{pL}$ is the Free ligand exponent function, $\mathbf{n}$ is the Average number of ligand attached with metal ion (Janraoet al., 2014). The results obtained were analyzed by an ORIGIN 2016 program using titration data and then the proton-ligand stability constants (pKa) and Metal-ligand stability constant (LogK) calculated (Omar and Ali, 2015).

\section{RESULTS AND DISCUSSION}

Fourier transformed infrared (FT-IR) spectra of isolated humic acid from peat soils Figure 2 had distinct clear absorption bands indicating the presence of major humic acid structural elemental groups such as $\mathrm{H}$ bonded $\mathrm{OH}$ $\left(3680 \mathrm{~cm}^{-1}\right.$ peak $), C=0$ of carbonyl $\left(1721 \mathrm{~cm}^{-1}\right.$ peak), functional groups of aliphatic components $\mathrm{CH}_{2}\left(2918 \mathrm{~cm}^{-1}\right.$ peak) and $\mathrm{C}-\mathrm{O}$ stretching of polysaccharide $\left(1168 \mathrm{~cm}^{-1}\right.$ peak). The positions of the absorption bands of the spectra fell within typical major absorption bands of humic acid which is at frequencies 3680, 2918, 1721, 1168 $\mathrm{cm}^{-1}$. The first peak centred in the vicinity of $3680 \mathrm{~cm}^{-1}$ region is attributed to phenol $\mathrm{OH}$ group bounded by intermolecular $\mathrm{H}$ bonds. The $2918 \mathrm{~cm}^{-1}$ band usually has absorption maximum at $2918 \mathrm{~cm}^{-1}$ which is due to $\mathrm{C}-\mathrm{H}$ stretching of alkane group $\left(\mathrm{CH}_{2}\right)$. The next major absorption band is $1721 \mathrm{~cm}^{-1}$. This band has been commonly ascribed to $\mathrm{C}=\mathrm{O}$ stretching of mainly carboxyl group $(\mathrm{COOH})$ with trace amount of ketones. The last peak was observed at 1168 $\mathrm{cm}^{-1}$ due to $\mathrm{C}-\mathrm{O}$ stretching of polysaccharides and this peak appeared also in the spectra of humic acid from peat soil. The FTIR spectra of the isolated humic acid contained all major characteristic absorption peaks of humic acid. These absorption peaks indicated the presence of the major structural elements of humic acid namely $\mathrm{H}$ bonded $\mathrm{OH}, \mathrm{C}=\mathrm{C}$ of aromatic ring, $\mathrm{C}=\mathrm{O}$ of carbonyl group (both carboxyl and ketonic), $\mathrm{CH}_{2}$ group. This strongly supports the presence of humic acid.

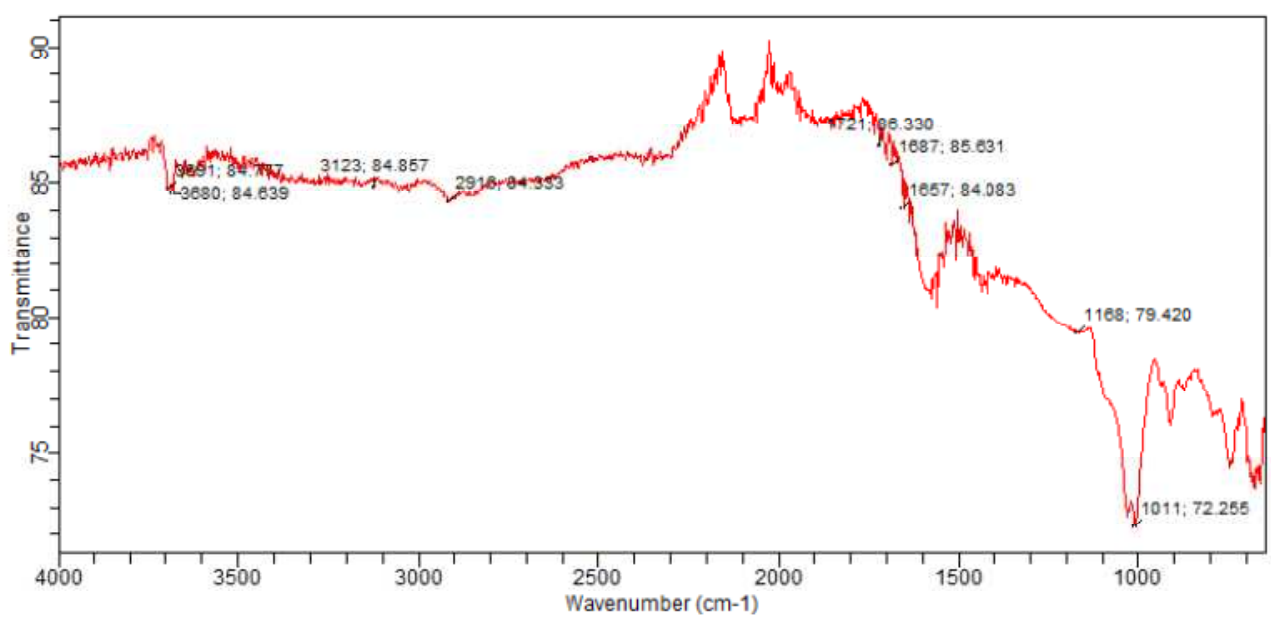

Fig. 2 : FT-IR spectraof peatsoilhumic acid (PSHA)

\section{Evaluation of acid dissociation constant (pka) of acid hydrolysed peat soil humicacid at phenolic group}

The value of the dissociation constant of the peat soil humic acid (PSHA) that underwent acidhydrolysis studied was found to be 8.9299 as shown Table 1, which is lower than the literaturevalues reported by Almeida and Szpoganics, (2015), Borges et al., (2005); Badr et al., (2012)and Fernandes et al,.(2009) of $9.73,9.47$ and 10.30. The difference between the obtained valuesand the reported values in this study might be probably as a result of acid hydrolysis of humicacid. 
BAJOPAS Volume 14 Number 1,June, 2021

Table 1: PKa of (Hydrolysed PSHA)

\begin{tabular}{|l|l|l|l|l|l|l|}
\hline $\mathrm{pH}$ & $\mathrm{BV}_{1}$ & $\mathrm{BV}_{2}$ & $\mathrm{~V}_{2}-\mathrm{V}_{1}$ & $\mathrm{nA}$ & $\log \left(\frac{n A}{1-n A}\right)$ & $\mathrm{pKa}$ \\
\hline 8.50 & 5.30 & 6.29 & 0.99 & 0.3594 & -0.2510 & 8.2490 \\
8.72 & 5.35 & 6.37 & 1.02 & 0.3400 & -0.2880 & 8.4320 \\
9.00 & 5.40 & 6.46 & 1.06 & 0.3141 & -0.3391 & 8.6609 \\
9.22 & 5.45 & 6.55 & 1.10 & 0.2882 & -0.3927 & 8.8273 \\
9.51 & 5.50 & 6.66 & 1.16 & 0.2494 & -0.4786 & 9.0314 \\
9.73 & 5.55 & 6.78 & 1.23 & 0.2041 & -0.5910 & 9.1390 \\
10.00 & 5.60 & 6.90 & 1.30 & 0.1589 & -0.7238 & 9.2762 \\
10.23 & 5.65 & 7.05 & 1.40 & 0.0941 & -0.9835 & 9.2465 \\
10.49 & 5.70 & 7.10 & 1.40 & 0.0941 & -0.9835 & 9.5065 \\
\hline
\end{tabular}

Average pKa $=8.9299 \pm 0.4186$

Table 2: PKa of (Unhydrolysed PSHA)

\begin{tabular}{|l|l|l|l|l|l|l|}
\hline $\mathrm{pH}$ & $\mathrm{BV}_{1}$ & $\mathrm{BV}_{2}$ & $\mathrm{~V}_{2}-\mathrm{V}_{1}$ & $\mathrm{nA}$ & $\log \left(\frac{\boldsymbol{n A}}{1-\boldsymbol{n}}\right)$ & $\mathrm{pKa}$ \\
\hline 8.50 & 5.30 & 5.81 & 0.51 & 0.6619 & 0.2919 & 8.7919 \\
8.72 & 5.35 & 5.90 & 0.55 & 0.6357 & 0.2418 & 8.9618 \\
9.00 & 5.40 & 6.00 & 0.60 & 0.6029 & 0.1813 & 9.1813 \\
9.22 & 5.45 & 6.10 & 0.65 & 0.5701 & 0.1226 & 9.3426 \\
9.51 & 5.50 & 6.20 & 0.70 & 0.5376 & 0.0654 & 9.5754 \\
9.73 & 5.55 & 6.33 & 0.78 & 0.4851 & -0.0259 & 9.7041 \\
10.00 & 5.60 & 6.47 & 0.87 & 0.4262 & -0.1291 & 9.8709 \\
10.23 & 5.65 & 6.62 & 0.99 & 0.3609 & -0.2481 & 9.9819 \\
10.49 & 5.70 & 6.80 & 1.10 & 0.2759 & -0.4690 & 10.0210 \\
\hline
\end{tabular}

Average pKa $=9.4923 \pm 0.4410$

Metal-ligand stability constant ( $\log \mathrm{K}$ )

The stabilityconstants require the accurate values of proton-ligand stability constants (Anil and Maroti, 2008). Metal titration curves crossed over ligand titration curve indicated the formation of complex upon proton release (Santosh, et al., 2011). If the values of n- are within range $0.2-0.8$ and $1.2-18$ this indicates the formation of $1: 1$ and 1:2 complexes (Sayyed and Mazahar, 2012).

The metal (II)-humate stepwise stability constants (log k) at phenolic group (Tables 318)

Table 3: Point-wise method, $\mathrm{Cu}$-(Hydrolysed PSHA)

\begin{tabular}{|l|l|l|l|l|l|l|l|l|}
\hline $\mathrm{pH}$ & $\mathrm{BV}_{1}$ & $\mathrm{BV}_{2}$ & $\mathrm{BV}_{3}$ & $\left(\mathrm{~V}_{3}-\mathrm{V}_{2}\right)$ & $\mathrm{n}$ & $\mathrm{pL}$ & $\log \left(\frac{n}{1-n}\right)$ & LogK $_{1}$ \\
\hline 8.50 & 5.30 & 6.29 & 6.33 & 0.04 & 0.5500 & 2.66 & 0.0871 & 2.7471 \\
8.72 & 5.35 & 6.37 & 6.41 & 0.04 & 0.5714 & 2.43 & 0.1249 & 2.5549 \\
9.00 & 5.40 & 6.46 & 6.50 & 0.04 & 0.6198 & 2.16 & 0.2122 & 2.3722 \\
9.22 & 5.45 & 6.55 & 6.59 & 0.04 & 0.6667 & 1.94 & 0.3010 & 2.2410 \\
\hline
\end{tabular}

LogK $_{1}$ (Average value) $=2.4788 \pm 0.2203$

Table 4: Point-wise method, $\mathrm{Cu}$-(Hydrolysed PSHA)

\begin{tabular}{|l|l|l|l|l|l|l|l|l|}
\hline $\mathrm{pH}$ & $\mathrm{BV}_{1}$ & $\mathrm{BV}_{2}$ & $\mathrm{BV}_{3}$ & $\left(\mathrm{~V}_{3}-\mathrm{V}_{2}\right)$ & $\mathrm{n}$ & $\mathrm{pL}$ & $\log \left(\frac{n-1}{2-n}\right)$ & LogK $_{2}$ \\
\hline 9.51 & 5.50 & 6.66 & 6.73 & 0.07 & 1.3509 & 1.70 & -0.2671 & 1.4329 \\
9.73 & 5.55 & 6.78 & 6.85 & 0.07 & 1.6383 & 1.51 & 0.2467 & 1.7567 \\
10.00 & 5.60 & 6.90 & 6.98 & 0.08 & 2.1783 & 1.31 & -0.2158 & 1.0942 \\
10.23 & 5.65 & 7.05 & 7.13 & 0.08 & 4.1904 & 1.27 & & \\
10.49 & 5.70 & 7.10 & 7.19 & 0.09 & 4.6920 & & & \\
\hline
\end{tabular}

Log $K_{2}($ Average value $)=1.4280 \pm 0.3312$ 
BAJOPAS Volume 14 Number 1,June, 2021

Table 5: Point-wise method, $\mathrm{Cu}$ (Unhydrolysed PSHA)

\begin{tabular}{|l|l|l|l|l|l|l|l|l|}
\hline $\mathrm{pH}$ & $\mathrm{BV}_{1}$ & $\mathrm{BV}_{2}$ & $\mathrm{BV}_{3}$ & $\left(\mathrm{~V}_{3}-\mathrm{V}_{2}\right)$ & $\mathrm{n}$ & $\mathrm{pL}$ & $\log \left(\frac{n}{n-1}\right)$ & Log $_{1}$ \\
\hline 8.50 & 5.30 & 5.81 & 5.85 & 0.04 & 0.2973 & 2.88 & -0.3736 & 2.5064 \\
8.72 & 5.35 & 5.90 & 5.95 & 0.05 & 0.3873 & 2.66 & -0.1992 & 2.4608 \\
9.00 & 5.40 & 6.00 & 6.05 & 0.05 & 0.4044 & 2.38 & -0.1681 & 2.2119 \\
9.22 & 5.45 & 6.10 & 6.15 & 0.06 & 0.5157 & 2.18 & -0.0272 & 2.2072 \\
9.51 & 5.50 & 6.20 & 6.27 & 0.07 & 0.6417 & 1.89 & 0.2530 & 1.1430 \\
\hline
\end{tabular}

$\operatorname{LogK}_{1}($ Average value $)=2.3059 \pm 0.6153$

Table 6:Point-wise method, $\mathrm{Cu}$ (Unhydrolysed PSHA)

\begin{tabular}{|l|l|l|l|l|l|l|l|l|}
\hline $\mathrm{pH}$ & $\mathrm{BV}_{1}$ & $\mathrm{BV}_{2}$ & $\mathrm{BV}_{3}$ & $\mathrm{~V}_{3}-\mathrm{V}_{2}$ & $\mathrm{n}$ & $\mathrm{pL}$ & $\log \left(\frac{n-1}{2-n}\right)$ & $\log \mathrm{K}_{2}$ \\
\hline 9.73 & 5.55 & 6.33 & 6.42 & 0.09 & 0.9000 & 1.69 & & \\
10.00 & 5.60 & 6.47 & 6.58 & 0.11 & 1.2578 & 1.44 & -0.4592 & 0.9808 \\
10.23 & 5.65 & 6.62 & 6.84 & 0.12 & 1.6137 & 1.26 & -0.2010 & 1.4610 \\
10.49 & 5.70 & 6.80 & 6.92 & 0.12 & 2.1052 & 1.03 & & \\
\hline
\end{tabular}

$\operatorname{LogK}_{2}$ (Average value) $=1.2209 \pm 0.3398$

Table 7:Point-wise method, Pb (Hydrolysed PSHA)

\begin{tabular}{|l|l|l|l|l|l|l|l|l|}
\hline $\mathrm{pH}$ & $\mathrm{BV}_{1}$ & $\mathrm{BV}_{2}$ & $\mathrm{BV}_{3}$ & $\left(\mathrm{~V}_{3}-\mathrm{V}_{2}\right)$ & $\mathrm{n}$ & $\mathrm{pL}$ & $\log \left(\frac{n}{1-n}\right)$ & LogK $_{1}$ \\
\hline 8.50 & 5.30 & 6.29 & 6.33 & 0.04 & 0.5500 & 2.66 & 0.0871 & 2.7471 \\
8.72 & 5.35 & 6.37 & 6.41 & 0.04 & 0.5714 & 2.43 & 0.1249 & 2.5549 \\
9.00 & 5.40 & 6.46 & 6.50 & 0.04 & 0.6198 & 2.16 & 0.2122 & 2.3722 \\
9.22 & 5.45 & 6.55 & 6.60 & 0.05 & 0.8333 & 1.96 & 0.6989 & 2.6589 \\
\hline
\end{tabular}

Log $_{\mathbf{1}}($ Average value $)=2.5832 \pm 0.1614$

Table 8:Point-wise method, Pb-(Hydrolysed PSHA)

\begin{tabular}{|l|l|l|l|l|l|l|l|l|}
\hline $\mathrm{pH}$ & $\mathrm{BV}_{1}$ & $\mathrm{BV}_{2}$ & $\mathrm{BV}_{3}$ & $\left(\mathrm{~V}_{3}-\mathrm{V}_{2}\right)$ & $\mathrm{n}$ & $\mathrm{pL}$ & $\log \left(\frac{n-1}{2-n}\right)$ & $\log \mathrm{K}_{2}$ \\
\hline 9.51 & 5.50 & 6.66 & 6.71 & 0.05 & 0.9650 & 1.67 & & \\
9.73 & 5.55 & 6.78 & 6.83 & 0.05 & 1.1702 & 1.44 & & \\
10.00 & 5.60 & 6.90 & 6.90 & 0.05 & 1.4864 & 1.22 & -0.0237 & 1.1963 \\
10.23 & 5.65 & 7.05 & 7.10 & 0.05 & 2.0190 & 1.09 & & \\
10.49 & 5.70 & 7.10 & 7.17 & 0.07 & 3.6492 & 1.00 & & \\
\hline
\end{tabular}

Log $K_{2}$ (Average value) $=1.1963$

Table 9: Point-wise method, Pb (Unhydrolysed PSHA)

\begin{tabular}{|l|l|l|l|l|l|l|l|l|}
\hline $\mathrm{pH}$ & $\mathrm{BV}_{1}$ & $\mathrm{BV}_{2}$ & $\mathrm{BV}_{3}$ & $\mathrm{~V}_{3}-\mathrm{V}_{2}$ & $\mathrm{n}$ & $\mathrm{pL}$ & $\begin{array}{l}\text { Log } \\
\left(\frac{n}{n-1}\right)\end{array}$ & Log $\mathrm{K}_{1}$ \\
\hline 8.50 & 5.30 & 5.81 & 5.85 & 0.04 & 0.2973 & 2.88 & -0.3736 & 2.5064 \\
8.72 & 5.35 & 5.90 & 5.94 & 0.04 & 0.3099 & 2.66 & -0.5477 & 2.3123 \\
9.00 & 5.40 & 6.00 & 6.05 & 0.05 & 0.4044 & 2.38 & -0.1681 & 2.2119 \\
9.22 & 5.45 & 6.10 & 6.15 & 0.06 & 0.5157 & 2.18 & 0.0272 & 2.2072 \\
9.51 & 5.50 & 6.20 & 6.26 & 0.07 & 0.6417 & 1.89 & 0.2530 & 2.1430 \\
9.73 & 5.55 & 6.40 & 6.40 & 0.07 & 0.7000 & 1.67 & 0.3680 & 2.0380 \\
\hline
\end{tabular}

LogK $_{1}$ (Average value) $=2.2364 \pm 0.1602$

Table 10: Point-wise method, Pb (Unhydrolysed PSHA)

\begin{tabular}{|l|l|l|l|l|l|l|l|l|}
\hline $\mathrm{pH}$ & $\mathrm{BV}_{1}$ & $\mathrm{BV}_{2}$ & $\mathrm{BV}_{3}$ & $\mathrm{~V}_{3}-\mathrm{V}_{2}$ & $\mathrm{n}$ & $\mathrm{pL}$ & $\log \left(\frac{n-1}{2-n}\right)$ & $\log \mathrm{K}_{2}$ \\
\hline 10.00 & 5.60 & 6.47 & 6.55 & 0.08 & 1.9503 & 1.41 & & \\
10.23 & 5.65 & 6.62 & 6.72 & 0.11 & 1.4792 & 1.26 & -0.0361 & 1.2239 \\
\hline
\end{tabular}

$\operatorname{LogK}_{2}$ (Average value) $=1.2239$

Table 11: Point-wise method, Mg (Hydrolysed PSHA)

\begin{tabular}{|l|l|l|l|l|l|l|l|l|}
\hline $\mathrm{pH}$ & $\mathrm{BV}_{1}$ & $\mathrm{BV}_{2}$ & $\mathrm{BV}_{3}$ & $\left(\mathrm{~V}_{3}-\mathrm{V}_{2}\right)$ & $\mathrm{n}$ & $\mathrm{pL}$ & $\log \left(\frac{n}{n-1}\right)$ & LogK $_{1}$ \\
\hline 8.50 & 5.30 & 6.29 & 6.31 & 0.02 & 0.2750 & 2.64 & -0.4290 & 2.2110 \\
8.72 & 5.35 & 6.37 & 6.39 & 0.02 & 0.2858 & 2.42 & -0.3978 & 2.0222 \\
9.00 & 5.40 & 6.46 & 6.49 & 0.03 & 0.4648 & 2.14 & -0.0612 & 2.0788 \\
9.22 & 5.45 & 6.55 & 6.59 & 0.04 & 0.6667 & 1.94 & 0.3010 & 2.2410 \\
\hline
\end{tabular}

$\log _{\mathbf{1}}($ Average value) $=2.1382 \pm 0.1046$ 
BAJOPAS Volume 14 Number 1,June, 2021

Table 12: Point-wise method, Mg (Hydrolysed PSHA)

\begin{tabular}{|l|l|l|l|l|l|l|l|l|}
\hline $\mathrm{pH}$ & $\mathrm{BV}_{1}$ & $\mathrm{BV}_{2}$ & $\mathrm{BV}_{3}$ & $\left(\mathrm{~V}_{3}-\mathrm{V}_{2}\right)$ & $\mathrm{n}$ & $\mathrm{pL}$ & $\log \left(\frac{n-1}{2-n}\right)$ & LogK $_{2}$ \\
\hline 9.51 & 5.55 & 6.66 & 6.71 & 0.05 & 0.9650 & 1.67 & & \\
9.73 & 5.55 & 6.78 & 6.84 & 0.06 & 1.4042 & 1.47 & -0.1686 & 1.3014 \\
10.00 & 5.60 & 6.90 & 6.93 & 0.06 & 1.7838 & 1.23 & 0.5593 & 1.7893 \\
10.23 & 5.65 & 7.05 & 7.10 & 0.06 & 3.1429 & 1.10 & & \\
10.49 & 5.70 & 7.10 & 7.18 & 0.07 & 3.6492 & 0.83 & & \\
\hline
\end{tabular}

LogK $_{2}($ Average value $)=1.5453 \pm 0.3450$

Table 13: Point-wise method, Mg (Unhydrolysed PSHA)

\begin{tabular}{|l|l|l|l|l|l|l|l|l|}
\hline $\mathrm{pH}$ & $\mathrm{BV}_{1}$ & $\mathrm{BV}_{2}$ & $\mathrm{BV}_{3}$ & $\mathrm{~V}_{3}-\mathrm{V}_{2}$ & $\mathrm{n}$ & $\mathrm{pL}$ & $\log \left(\frac{n}{n-1}\right)$ & $\operatorname{Log~}_{1}$ \\
\hline 8.50 & 5.30 & 5.81 & 5.85 & 0.04 & 0.2973 & 2.88 & -0.3736 & 2.5064 \\
8.72 & 5.35 & 5.90 & 5.94 & 0.04 & 0.3099 & 2.66 & -0.3477 & 2.3123 \\
9.00 & 5.40 & 6.00 & 6.04 & 0.04 & 0.3236 & 2.38 & -0.3202 & 2.0598 \\
9.22 & 5.45 & 6.10 & 6.15 & 0.05 & 0.4297 & 2.17 & -0.1230 & 2.0470 \\
9.51 & 5.50 & 6.20 & 6.26 & 0.06 & 0.5500 & 1.89 & 0.0871 & 1.9771 \\
9.73 & 5.55 & 6.33 & 6.40 & 0.07 & 0.7000 & 1.67 & 0.3680 & 2.0380 \\
\hline
\end{tabular}

LogK $_{1}$ (Average value) $=2.1568 \pm 0.2069$

Table 14: Point-wise method, Mg (Unhydrolysed PSHA)

\begin{tabular}{|l|l|l|l|l|l|l|l|l|}
\hline $\mathrm{pH}$ & $\mathrm{BV}_{1}$ & $\mathrm{BV}_{2}$ & $\mathrm{BV}_{3}$ & $\mathrm{~V}_{3}-\mathrm{V}_{2}$ & $\mathrm{n}$ & $\mathrm{pL}$ & $\log \left(\frac{n-1}{2-n}\right)$ & $\log \mathrm{K}_{2}$ \\
\hline 10.00 & 5.60 & 6.47 & 6.55 & 0.08 & 0.9148 & 1.41 & & \\
10.23 & 5.65 & 6.62 & 6.71 & 0.09 & 1.2102 & 1.20 & -0.5749 & 0.6251 \\
10.49 & 5.70 & 6.80 & 6.92 & 0.09 & 1.5968 & 1.03 & 0.1703 & 1.2003 \\
\hline
\end{tabular}

LogK $_{2}$ (Average value) $=0.9127 \pm 0.4070$

Table15:Point-wise method, Cd (Hydrolysed PSHA)

\begin{tabular}{|l|l|l|l|l|l|l|l|l|}
\hline $\mathrm{pH}$ & $\mathrm{BV}_{1}$ & $\mathrm{BV}_{2}$ & $\mathrm{BV}_{3}$ & $\left(\mathrm{~V}_{3}-\mathrm{V}_{2}\right)$ & $\mathrm{n}$ & $\mathrm{pL}$ & $\log \left(\frac{n}{1-n}\right)$ & LogK $_{1}$ \\
\hline 8.50 & 5.30 & 6.29 & 6.31 & 0.02 & 0.2750 & 2.64 & -0.4210 & 2.2190 \\
8.72 & 5.35 & 6.37 & 6.40 & 0.03 & 0.4286 & 2.42 & -0.1249 & 2.2951 \\
9.00 & 5.40 & 6.46 & 6.49 & 0.03 & 0.4648 & 2.14 & -0.0612 & 2.0788 \\
9.22 & 5.45 & 6.55 & 6.59 & 0.04 & 0.6667 & 1.96 & 0.3010 & 2.2610 \\
9.51 & 5.55 & 6.66 & 6.70 & 0.04 & 0.7720 & 1.67 & 0.5297 & 2.1997 \\
\hline
\end{tabular}

LogK $_{\mathbf{1}}$ (Average value) $=2.2108 \pm 0.0825$

Table 16: Point-wise method, Cd (Hydrolysed PSHA)

\begin{tabular}{|l|l|l|l|l|l|l|l|l|}
\hline $\mathrm{pH}$ & $\mathrm{BV}_{1}$ & $\mathrm{BV}_{2}$ & $\mathrm{BV}_{3}$ & $\left(\mathrm{~V}_{3}-\mathrm{V}_{2}\right)$ & $\mathrm{n}$ & $\mathrm{pL}$ & $\log \left(\frac{n-1}{2-n}\right)$ & Log $_{2}$ \\
\hline 9.73 & 5.55 & 6.78 & 6.83 & 0.06 & 1.4042 & 1.47 & -0.1686 & 1.3014 \\
10.00 & 5.60 & 6.90 & 6.95 & 0.06 & 1.7838 & 1.23 & 0.5593 & 1.7893 \\
10.23 & 5.65 & 7.05 & 7.10 & 0.06 & 3.1429 & 1.09 & & \\
10.49 & 5.70 & 7.10 & 7.16 & 0.06 & 3.1429 & 0.89 & & \\
& & & & & & & & \\
\hline
\end{tabular}

$\operatorname{LogK}_{2}$ (Average value) $=1.5453 \pm 0.3450$

Table 17: Point-wise method, Cd (Unhydrolysed PSHA)

\begin{tabular}{|l|l|l|l|l|l|l|l|l|}
\hline $\mathrm{pH}$ & $\mathrm{BV}_{1}$ & $\mathrm{BV}_{2}$ & $\mathrm{BV}_{3}$ & $\mathrm{~V}_{3}-\mathrm{V}_{2}$ & $\mathrm{n}$ & $\mathrm{pL}$ & $\log \left(\frac{n}{n-1}\right)$ & $\operatorname{Log~}_{1}$ \\
\hline 8.50 & 5.30 & 5.81 & 5.86 & 0.05 & 0.3717 & 2.88 & -0.2280 & 2.6520 \\
8.72 & 5.35 & 5.90 & 5.95 & 0.05 & 0.3873 & 2.66 & -0.1992 & 2.4608 \\
9.00 & 5.40 & 6.00 & 6.06 & 0.06 & 0.4853 & 2.38 & -0.0255 & 2.3545 \\
9.22 & 5.45 & 6.10 & 6.16 & 0.06 & 0.5157 & 2.18 & -0.0272 & 2.2072 \\
9.51 & 5.50 & 6.20 & 6.27 & 0.07 & 0.6417 & 1.89 & 0.2530 & 1.1430 \\
9.73 & 5.55 & 6.33 & 6.41 & 0.08 & 0.8000 & 1.69 & 0.6020 & 2.2920 \\
& & & & & & & & \\
\hline
\end{tabular}

$\operatorname{LogK}_{1}($ Average value $)=2.2516 \pm 0.5380$ 
BAJOPAS Volume 14 Number 1,June, 2021

Table 18: Point-wise method, Cd (Unhydrolysed PSHA)

\begin{tabular}{|l|l|l|l|l|l|l|l|l|}
\hline $\mathrm{pH}$ & $\mathrm{BV}_{1}$ & $\mathrm{BV}_{2}$ & $\mathrm{BV}_{3}$ & $\mathrm{~V}_{3}-\mathrm{V}_{2}$ & $\mathrm{n}$ & $\mathrm{pL}$ & $\log \left(\frac{n-1}{2-n}\right)$ & $\log \mathrm{K}_{2}$ \\
\hline 10.00 & 5.60 & 6.47 & 6.57 & 0.10 & 1.1434 & 1.43 & & \\
10.23 & 5.65 & 6.62 & 6.72 & 0.10 & 1.3448 & 1.23 & -0.2788 & 0.9512 \\
10.49 & 5.70 & 6.80 & 6.90 & 0.10 & 1.7742 & 1.03 & 0.5351 & 1.5651 \\
\hline
\end{tabular}

$\operatorname{LogK}_{2}($ Average value $)=1.2581 \pm 0.4340$

Table 19: Stepwise and overall Stability constants of thehydrolysed and unhydrolysed divalent metal (II) complexes

\begin{tabular}{|c|c|c|c|}
\hline Chelates & LogK $_{1}$ & $\log _{2}$ & Log $\beta$ \\
\hline [Cu (Hydrolysed PSHA-1) $\left.{ }_{2}\right]$ & 2.4788 & 1.4280 & 3.9068 \\
\hline$\left[\mathrm{Pb}(\text { Hydrolysed PSHA-1) })_{2}\right]$ & 2.5832 & 1.1963 & 3.7795 \\
\hline$\left[\mathrm{Cd}(\text { Hydrolysed PSHA-1 })_{2}\right]$ & 2.2108 & 1.5453 & 3.7561 \\
\hline$\left[\mathrm{Mg}(\text { Hydrolysed PSHA-1 })_{2}\right]$ & 2.1382 & 1.5453 & 3.6835 \\
\hline [Cu (Unhydrolysed PSHA-1) & 2.3059 & 1.2209 & 3.5268 \\
\hline$[\mathrm{Pb}$ (Unhydrolysed PSHA-1) 2$]$ & 2.2364 & 1.2239 & 3.4603 \\
\hline [Cd (Unhydrolysed PSHA-1) 2 ] & 2.2516 & 1.2581 & 3.5097 \\
\hline$[\mathrm{Mg}$ (Unydrolysed PSHA-1) & 2.1568 & 0.9127 & 3.0695 \\
\hline
\end{tabular}

The results obtained (Table19) shows the stepwise and overall stability constants to be not high indicating low stability of the complexes, because the solubility of most metal ions in the basic $\mathrm{pH}$ range is minimal due to metal hydroxide precipitation (Karimi, 2017). In general, the stepwise stability constants $\left(K_{1}\right.$ and $K_{2}$ ) follow the order $K_{1}>K_{2}$ for the copper, lead, magnesium and cadmium complexes respectively. The steady decrease of the values with increasing number of ligands is in agreement with the prediction made by researchers (Na'aliya, 2013). The decrease could be attributed to the fact that as the number of the ligands (Humate ions) that enters the coordination zone increases the aqua molecules available for replacement by the ligands become less. Thus, the metal ions become less electron loving with progressive intake of the ligand and this results in the decrease in the values of the constants (Na'aliya, 2013). Also the stability of the complexes is influenced by the size and number of the chelate rings(Mackay and Mackay,2002).All the complexes form rings in their structure as humate, a bidentate ligand, bond the metal ions in the ratio 1:2 (Boguta and Sokolowska, 2016) forming chelate rings. The values of the overall stability constants $(\log \beta)$ obtained for humate complexes are not high indicating low stability as the values are not high. LogK values for copper-humates (Table 3 to 6) obtained in this study are lower than those reported for the complexes of humic acids (Pandey et al., 2015; Dinu, 2013; Kaschl et al., 2010 and Gilbeto and Jorg, 2001). The values of LogK(Table 7 to 10 ) forlead-humates are lower than those reported for the lead in the literature (Dinu, 2013; Gilbeto and Jorg 2001). Log K values(Table 11 to 14 ) for magnesium-humates obtained in this study are close to those reported by (Pandey et al., 2015). Log K values of cadmium-humates (Table 15 to 18 ) obtained in this work near to the one reported by (Dinu, 2013 and Pandey et al., 2015).The difference between the reported values and the values obtained in this study might be probably as a result of acid hydrolysis of humic acid. The values of the overall stability constants $(\log \beta)$ of the copper humates complexes presented in Table 19 is high than that of other metal humate complexes, show relatively high stability of CuHA complexes, show the following order of stability: $\mathrm{Cu}>\mathrm{Pb}>\mathrm{Cd}>\mathrm{Mg}$; which are in close agreement to the findings of (Dinu, 2013 and Pandey et al., 2015).The high stability of Cuhumate chelate could be attributed to the existence of coordinate covalent bond between the complexing agents and the $\mathrm{Cu}^{2+}$ ions. Since, $\mathrm{Cu}^{2+}$ being a metal of the transitional series with $3 d^{9}$ electronic configurations can accept the electrons from the complexing agents. Similarly, the low stabilities of $\mathrm{Pb}, \mathrm{Cd}$ and $\mathrm{Mg}$ complexes could be explained by that $\mathrm{Pb}^{2+}$ with $6 s^{2}, \mathrm{Cd}^{2+}$ with $4 \mathrm{~d}^{10}$ and $\mathrm{Mg}^{2+}$ with $2 \mathrm{p}^{6}$ their electronic configuration has a completely filled $\mathrm{d}, \mathrm{p}$ and $\mathrm{s}$ orbitals. Moreover, the stabilities of metal ions with hydrolysed humic acid from peat soil were higher than those with unhydrolysed humic acid from peat soil; which is ascribed to the high content of acidity in hydrolysed humic acid than unhydrolysed humic acid. 
BAJOPAS Volume 14 Number 1,June, 2021 CONCLUSION

The values of logk for $\mathrm{Cu}(\mathrm{II})$ hydrolysed humic acid complex was higher followed by $\mathrm{Pb}$ (II), $\mathrm{Cd}(\mathrm{II})$ and $\mathrm{Mg}$ (II) hydrolysed humic acid complexes as compared with metal(II) unhydrolysed humic acid complexes. This indicates acid hydrolysis of humic acid can

\section{REFERENCES}

Almeida, V.R. and Szpoganicz, B. (2015). Humic Acid Potentiometric Response Patterns:Out- of Equilibrium Properties and Species Distribution Modelling. Chemical. Biol. Technol. Agric. 2: 17.

Anđelković, T., Nikolić, R., Bojić, A.,Anđelković, D., and Nikolic G.,(2010). Binding of Cadmium to Soil Humic Acid as A Function of Carboxyl Group Content. Macedonian Journal of Chemistry and Chemical Engineering.29(2): 215-224.

Anil, B. N. and Maroti, N. (2008). Studies on Influence of Die-Lectric Constants on Complex Equilibria between Substituted Py-Razalines and Lanthanide Metal Ions pH-Metrically. Amer.-Euras. scient. Res. 3(2): 212-216.

Ashok, K., Pandey, S. P. and Misra, V (2000). Stability Constants of Metal-Humic Acid Complexes and its Role in Environmental Detoxification. Journal of Ecotoxicology and Environmental Safety. 47(2):157-200.

Badr, M. H., El-Halafawi, M. H. and Abd El-al Zeid, E. R. (2012). Comparison Between the Effect of Ionic Strength on Acidity and Dissociation Constants of Humic Acids Extracted from Sewage Sludge and Nile Water Hyacinth Composts.Global Journal of Environmental Research 6 (1): 36-43.

Baruah, M.K., Borah, D., Saikia, P.P., Paul, S., Sharma, T. (2015). Evaluation of pKa Values of Soil Humic Acids and their Complexation Properties. International Journal of Plant \& Soil Science 6(4) : 218-228.

Boguta, P. Sokolowska, Z. (2016). Interactions of $\mathrm{Zn}$ (II) Ions with Humic Acids Isolated from Various Types of Soils. Effect of $\mathrm{pH}, \mathrm{Zn}$ Concentrations and Humic Acids Chemical Properties. Journal of Geochemical Explaration 168. 119-126.

Borges, F., Guimaraes, C., Lima, L.F.C., Pinto, I. and Reis, S.(2005). Potentiometric Studies on the Complexation of Copper(II) by Phenolic Acids as Discrete Ligand Models of enhance the complexation behavior of humic acid with metal (II) ions. However, the higher values of $\log \beta$ for $\mathrm{Cu}(\mathrm{II}), \mathrm{Pb}(\mathrm{II}), \mathrm{Cd}(\mathrm{II})$ and $\mathrm{Mg}(\mathrm{II})$ hydrolysed humic acid complexes indicates more stable stepwise complexes formed as compared with $\mathrm{Cu}(\mathrm{II}), \mathrm{Pb}$ (II), $\mathrm{Cd}$ (II) and $\mathrm{Mg}(\mathrm{II})$ unhydrolysed humic acid complexes.

Humic Substances Talanta 66 (2005) 670-673.

Chefetz, B., Salloum, M. J., Deshmulkin, A. P. and Hatcher, P. (2002). Structural Components of Humic Acids as Determined by Chemical Modifications and Carbon-13 NMR, Pyrolysis, and Thermochemolysis- Gas Chromatography/Mass Spectrometry. Soil Science Society of American Journal Abstract Division S-2- Soil Chemistry66. 1159-1171.

Dinu, M. I. (2013). Metals Complexation with Humic Acids in Surface Water of Different Environ. Sci. Technol. 31(1): 1-17.

Fernandes, A.N., Giacomelli, C., Giovanela, M. Vaz, D.V. Szpoganicz, B. and Maria M. D. (2009). Potentiometric Acidity Determination in Humic Substances Influenced by Different Analytical Procedures.J. Braz. Chem. Soc. 20 (9):14.

Gamal, A. H. (2015). Stability Constants of Rhenium (V) Metal Complexes with Selected Drugs. Pyrex Journal of Research in Environmental Studies. 2(2): 006-014.

Janrao, D. M., Pathan, J., Kayande, D.D., and Mulla, J.J. (2014). An Over View of Potentiometric Determination of Stability Constants of Metal Complexes. Sci. Revs. Chem. Commun.: 4(1), 2014, 11-24.

Karimi, H. (2017). Effect of pH and Initial Pb(II) Concentration on the Lead Removal Efficiency from Waste Water Using $\mathrm{Ca}(\mathrm{OH})_{2}$. International Journal of Water and Waste Water Treatment 3.2

Kaschl, A. Romheld, V. and Chen, Y. (2010). Binding of Cadmium, Copper and Zinc to Humic Substances Originating from Municipal Solid Waste Compost. Israel Journal of Chemistry Vol. 42(1): 89-98.

Kostic, I. S., Tatjana, P, A., Nikolic, R. S., Cvetkovic, T. P., Pavlovic, D. D., Aleksandar, L.J. and Bojic, A. (2012). Comparative Study of Binding Strengths of Heavy Metals with Humic Acid. J.serb. Chem. Soc. 76(9) pp 1-20. 
BAJOPAS Volume 14 Number 1,June, 2021

Na'aliya, J. (2013). Determination of Stepwise Stability Constants and Gibbs free Energy Change of Trisprolina to Complexes of some Divalent Transition Metal ions. Bayero Journal of Pure and Applied Sciences 6(2): 112-114.

Omar, A. A. and Ali, E. A. (2015). Potentiometric Studies on Complexes of $\mathrm{Cr}$ (III) and $\mathrm{Zr}$ (IV) with some Carboxylic Acids. International Journal of Advanced Chemistry, 3(1) 25-

37.

Pandey, A. K. Pandey, S. D. and Misr, V. (2015).Stability Constants of Metal- Humic Acid Complexes and Its Role in Environmental Detoxification. J. Ecotoxicology and Environmental Safety. 47(1):195-200.

Ram, N. and Raman, K.V. (1984). Stability Constants of Complexes of Metals with
Humicand Fuvic Acids under Non- acidConditions. Journal of Plant Nutrition and Soil Sciences.

147:171-176.

Santosh, D. D., Ashok, B. K., Vijay, J. T., Shivraj, G. W. and Vinay, V. W. (2011). Potentiometric Studies of Elec-Trolyte Effects on Complex Equilibria of Some Substituted 5-(2-hydroxy Phenyl) Pyrazoles. Der pharm. 3 (6): 75-83.

Sayyed, H. and Abdul Rahim, M. F. (2012). Studies of Binary Complexes of Metal Ions with Mandelic Acid by Potentiometry. Chem. J. 02 (6): 206209.

Shirvani, M. Moradian, E. Khalili, B. Bakhtiary, S. (2015). Interaction of $\mathrm{Cd}$ and $\mathrm{Pb}$ with Humate-Palygorskite and HumateSepiolite Complexes. Journal of water, air and pollution 3: 220-228. 


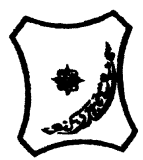

Bayero Journal of Pure and Applied Sciences, 14(1): 54 - 63

Received: November, 2020

Accepted: April, 2021

ISSN $2006-6996$

\title{
STABILITY CONSTANTS OF COMPLEXES OF METAL IONS WITH PEATSOIL HUMIC ACIDS UNDER NON-ACID-CONDITIONS
}

\author{
${ }^{* 1}$ Sabo, Yusuf ${ }^{2}$ Jimoh, W.L.O., ${ }^{3}$ Isa Baba Koki and ${ }^{4}$ Sholadoye, Q. 0. \\ ${ }^{1}$ Department of Pure and Industrial Chemistry, Bayero University, Kano \\ ${ }^{3}$ Department of Chemistry, Yusuf Maitama Sule University Kano. P.M.B. 3220 Kano, Nigeria. \\ ${ }^{4}$ Department of Chemistry, Nigerian Police Academy, Wudil, Kano-Nigeria
}

*Correspondence E-mail; saboyusuf18@yahoo.com

ABSTRACT

Stability constants of complexes of four divalent metal ions viz. $\mathrm{Cu}^{2+}, \mathrm{Pb}^{2+}, \mathrm{Mg}^{2+}$ and $\mathrm{Cd}^{2+}$ with humic acids (HA) were determined by potentiometric titration of humic acids with the corresponding salt of the divalent metals in aqueous media under non-acid-condition. The log $K$ (logarithm of the stability constant) ranged from 1.0942 to 2.7471 for metalhumic acid complexes were determined using point-wise computational method. The order of stability constants were obtained as follows: $\mathrm{Cu}>\mathrm{Pb}>\mathrm{Cd}>\mathrm{Mg}$ for metal $-\mathrm{HA}$ complexes respectively, indicating a higher degree of complexation with Cu metal ion.

Keywords: stability constant, humic acid, potentiometric titration, divalent metals, acid hydrolysis.

\section{NTRODUCTION}

The stability constant of a complex is the numerical expression of its stability and provides a quantitative measure of affinity of the metal ion to the complexing agent. An understanding of the relative stability of metal-complexes helps in predicting the behavior of metal ions in the soil (Ram and Raman, 1982). Extensive researches has been done to determine the stability constants of the complexes formed between humic acid (HA) with a number of metal ions. Ashok et al., (2000) reported that humic acid with hydroxyl, phenoxyl and carboxyl reactive groups can form coordination compound with metal ions at $\mathrm{pH}$ 3.5. The stability constants(Log K) for different metalhumic acid complexes indicated the following order of the stabilities of complexes formed between humic acid and metal ion, $\mathrm{Cu}>\mathrm{Fe}$ $>\mathrm{Pb}>\mathrm{Ni}>\mathrm{Co}>\mathrm{Ca}>\mathrm{Cd}>\mathrm{Zn}>\mathrm{Mn}>\mathrm{Mg}$. Andelkovic et al., (2010) investigated the binding of $\mathrm{Cd}$ (II) to soil humic acid at pH 6.5 and in $0.1 \mathrm{M} \mathrm{KNO}_{3}$ ionic medium. The stability constant for binding indicating greater stability in the case when carboxyl groups are involved in complexation reaction. Kostic et al.,(2012) investigated the complexation of humic acid with certain heavy metal ions (Co(II), $\mathrm{Ni}(\mathrm{II}), \mathrm{Cu}(\mathrm{II})$,
$\mathrm{Zn}(\mathrm{II})$, and $\mathrm{Pb}(\mathrm{II})$. The experiment was performed at $25^{\circ} \mathrm{C}$, at pH 4.0 and ionic strength of $0.01 \mathrm{M}$. Stability constant of complex between $\mathrm{Pb}$ (II) ions and humic acid is greater than stability constants of other investigated metalhumate complexes. Bogata and Sokolowska (2016) analyses the interaction between humic acids from different soils and $\mathrm{Zn}$ (II) ions at wide concentration ranges and at $\mathrm{pH} 5$. Studies have showed significant impact of $\mathrm{Zn}$ concentration, $\mathrm{pH}$ and some properties of humic acids with zinc.But all of these studies were limited to acidic $\mathrm{pH}$ range. Therefore, the present study was carried out to determine and compare the stability constants of complexes of metal ions with hydrolysed peat soil humic acid and unhydrolysed peat soil humic under non-acid conditions.

\section{MATERIALS AND METHODS}

Analytical grade chemicals used includes hydrochloric acid $(\mathrm{HCl})$, nitric acid $\left(\mathrm{HNO}_{3}\right)$, sodium hydroxide $(\mathrm{NaOH})$, lead nitrate $\mathrm{Pb}\left(\mathrm{NO}_{3}\right)_{2}$, copper nitrate $\mathrm{Cu}\left(\mathrm{NO}_{3}\right)_{2} \cdot 3 \mathrm{H}_{2} \mathrm{O}$, cadmium nitrate $\mathrm{Cd}\left(\mathrm{NO}_{3}\right)_{2} \cdot 4 \mathrm{H}_{2} \mathrm{O}$, magnesium nitrate $\mathrm{Mg}\left(\mathrm{NO}_{3}\right)_{2} \cdot 6 \mathrm{H}_{2} \mathrm{O}$, potassium nitrate $\left(\mathrm{KNO}_{3}\right)$, calcium chloride $\left(\mathrm{CaCl}_{2}\right)$, (sigma-Aldrich). Dowex 50WX8, (20-50 mesh) from Fluka. 


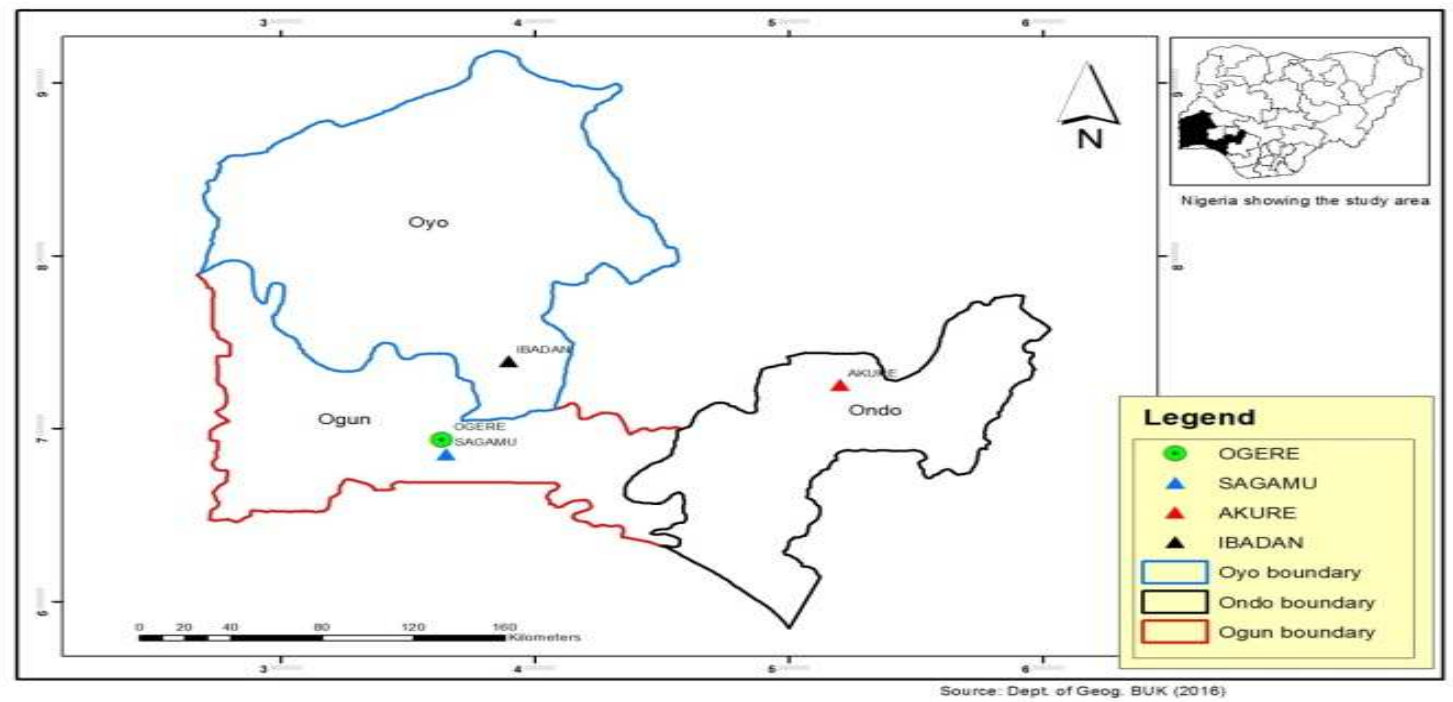

Figure 1: Map showing the sampling point at Sagamu Town, Ogun State.

\section{Description of Sampling Area}

Sagamu has geographical coordinates between $6^{\circ} 50^{\prime}$ north; $3^{\circ} 38^{\prime}$ east is located in south western region of Nigeria. The region has tropical wet and dry climate with a lengthy wet season and relatively constant temperatures throughout the course of the year. Wet season runs from March to October, November to December forms the region dry season. The vegetation type of the region is savannah which is really grassland with small bushes and occasional big trees. Grassland soils have substantially higher organic matter content than forest soils (Novackova, 2011).

\section{Sample Collection}

The Peatsoil samples were collected from four different sampling points $(0-10 \mathrm{~cm}$ depth) in Sagamu into polyethylene bag with plastic spoons. Samples were taken to the laboratory, extraneous materials were removed; the samples were air-dried, crushed and ground to a fine powder in a mortar passed through a $0.20 \mathrm{~mm}$ sieve. The samples were kept for analysis.

\section{Isolation and purification of humic acid from peat soil sample}

Peatsoil sample $(100 \mathrm{~g})$ was mixed with 1000 $\mathrm{cm}^{3}$ of $0.1 \mathrm{M} \mathrm{NaOH}$ solution, shaken for 3hours and left to stand overnight. Dark-coloured supernatant was obtained and decanted from solid residue. The dark-coloured supernatant was acidified to $(\mathrm{pH}=1.0)$ with $6 \mathrm{M} \mathrm{HCl}$ stirred and allowed to stand for 6 hours. Yellowish brown supernatant and dark-brown precipitate were obtained. The yellowish brown supernatant was decanted followed by centrifuge and discarded. The dark-brown precipitate was mixed with $500 \mathrm{~cm}^{3}$ of $0.1 \mathrm{M} \mathrm{NaOH}$ solution followed by passing through dowex resin. The dark-brown solution was acidified to $(\mathrm{pH}=1.0)$ with $6 \mathrm{M} \mathrm{HCl}$ stirred and allowed to stand for 3 hours. The dark-brown precipitate was washed several times with deionized water. The supernatant was treated with $\mathrm{AgNO}_{3}$ solution until no white precipitate observed. The humic acid was transferred to weighed crucible and dried at $60^{\circ} \mathrm{C}$ in an oven for 12 hours. The humic acid was cooled and dried in the desiccator, weighed and recorded. The obtained humic acid was dried again at $60^{\circ} \mathrm{C}$ for additional 6 hours cooled and dried in the desiccator, weighed and recorded constant weight was obtained (Baruah et al., 2015).

\section{FT-IR analysis}

FT-IR spectra of humic acid sample was analysed using Carry 630 FT-IR Agilent Technologies.

Unhydrolysed compost humic acid

The unhydrolysed humic acid was obtained after isolation and purification of compost humic acid and kept for investigation.

\section{Acid hydrolysis of Peatsoil acid}

Peatsoil humic acid sample (1g) was refluxed for 12 hours at $\left(160^{\circ} \mathrm{C}\right)$ with $50 \mathrm{~cm}^{3}$ of $6 \mathrm{M} \mathrm{HCl}$. The mixture was allowed to cool, decanted, and centrifuged after hydrolysis. The insoluble residues were washed with distilled water via centrifugation several times, and the supernatant was treated with $\mathrm{AgNO}_{3}$ solution until no white precipitate was observed. The residue was thoroughly dried over $\mathrm{CaCl}_{2}$ in a desiccator at room temperature (Chefetz et al., 2002). Finally, the obtained hydrolysed humic acid was kept for investigation. 
BAJOPAS Volume 14 Number 1,June, 2021 Potentiometric Titrations

Potentiometric measurements were carried out using a pH-meter Jenway (model 3510) with combine electrode, the sensitivity of the $\mathrm{pH}$ meter is 0.01 units. The $\mathrm{pH}$ meter was switched on half an hour before starting the titration for initial warm up of the instrument. The instrument was calibrated with an aqueous standard buffer solution of $\mathrm{pH} 4.00$ and 10.0 (borate buffer) prepared from a "Qualigens" buffer tablets.

The following sets of solutions were prepared in a $250 \mathrm{~cm}^{3}$ volumetric flask separately for $\mathrm{pH}$ metric titrations.

(i) $5 \mathrm{~cm}^{3} 0.1 \mathrm{M} \mathrm{HCl}+40 \mathrm{~cm}^{3}$ deionized water

(ii) $5 \mathrm{~cm}^{3} 0.1 \mathrm{M} \mathrm{HCl}+39 \mathrm{~cm}^{3}$ deionized water $+1 \mathrm{~cm}^{3} 0.15 \mathrm{gcm}^{-3}$ humic acid

(iii) $5 \mathrm{~cm}^{3} 0.1 \mathrm{M} \mathrm{HCl}+37 \mathrm{~cm}^{3}$ deionized water $+1 \mathrm{~cm}^{3} 0.15 \mathrm{gcm}^{-3}$ humic acid

$$
+2 \mathrm{~cm}^{3} \quad 0.01 \mathrm{M} \mathrm{Cu} \text { (II) }
$$

The solutions were titrated against standardized $0.110 \mathrm{MNaOH}$ separately. The total volume of each mixture was adjusted to $50 \mathrm{~cm}^{3}$ and the ionic strength of the solutions was maintained constant at by adding appropriate amount of stock solution of $1 \mathrm{M} \mathrm{KNO}_{3}$ (Gamal, 2015; Omar and Ali, 2015). A magnetic stirrer was used to achieve thorough mixing of the interacting solutions at $550 \mathrm{rpm}$. The same set of experimental conditions was applied for potentiometric titration of remaining samples.

\section{Evaluation of pKa of Hydrolysed peat soil Humic Acids}

The proton-ligand formation number $\mathrm{n}_{\mathbf{A}}$ were calculated by Irving and Rossotti expression (Omar and Ali, 2015).

$\mathrm{nA}=\mathrm{Y}-\frac{(\mathrm{V} 2-\mathrm{V1})(\mathrm{No}-\mathrm{Eo})}{(\mathrm{VO}+\mathrm{V1}) \mathrm{TCL}}$ 1

Where: $Y$ is number of dissociable proton, $\left(\mathrm{V}_{2^{-}}\right.$ $V_{1}$ ) is the measure of displacement of the ligand curve relative to acid curve, $\mathrm{N}^{\circ}$ and $\mathrm{E}^{\circ}$ are the resultant concentration of alkali solution, free acid solution, $\mathrm{T}_{\mathrm{cL}}{ }^{\circ}$ is the total ligand concentration, $\mathrm{V}^{\circ}$ is the total volume of titration solution, $V_{1}$ is the volume of alkali added to acid solution, $V_{2}$ is the volume of alkali added to acid solution + ligand solution, acid dissociation constants (pKa - values) of ligand were calculated by algebraic method point wise calculation (Tables 1 ). The dissociation constants (pKa) were calculated according to the following relation:

$\mathrm{pKa}=\mathrm{pH}+\log \left(\frac{n A}{1-n A}\right)$ 2

Where: pKa is the acid dissociation constant, $\mathrm{n}_{\mathrm{A}}$ is the Proton-ligand formation number and $\mathrm{pH}$ is the pH-values (Omar and Ali, 2015).

\section{Determination of metal-ligand stability constants $(\log K)$ of complexes}

The potentiometric measurement for the determination of stability constant of a complex in solution is based on the fact that the redox potential of the couple $\frac{M^{+(m-n)}}{M^{+m}}$ is shifted significantly on complexation of the metal ion with the ligand. This method involves change in hydrogen ion concentration $\left[\mathrm{H}^{+}\right]$due to the displacement or association of one or more protons taking place during complexation reaction. This change can be found out by titrating the solutions containing free acid, acid with ligand, and acid with ligand and metal ion, individually against a standard alkali solution at a constant ionic strength or temperature. Either ionic strength or temperature may be varied for different sets of solutions. In all the cases, the change in the $\mathrm{pH}$ of the solution is measured after each addition of a known amount of alkali to the reaction cell which contains the reaction mixture. The titration curves are then drawn by plotting the measured $\mathrm{pH}$ values against the corresponding volume of alkali added and the stability constants of the complexes are determined from the titration curves by employing $\mathrm{pH}$-metric titration technique given by (Irving and Rossoti).

Metal-ligand stability constants ( $\log \mathrm{K}$ ) were determined by using the following relations:

$$
\bar{n}=\frac{\left(V_{3}-V_{2}\right)\left(E^{0}+N^{0}\right)}{\left(V^{0}+V_{2}\right) \bar{n}_{A} T_{m}^{0}}
$$

and

$$
P L=\log _{10}\left\{\frac{1+\beta_{n}^{H} \frac{1}{[\text { anti } \log \mathrm{pH}]^{\mathrm{n}}}}{\mathrm{T}_{\mathrm{L}}^{0}-n \bar{T}_{m}^{0}} \mathrm{X} \frac{\left(V^{0}+V_{3}\right)}{V^{0}}\right\}
$$


BAJOPAS Volume 14 Number 1,June, 2021

Where $T_{L}, T^{\circ}, E^{\circ}$, and $V^{\circ}$ havethe same significance as in equation (1) above, $T_{m}$ denotes the total concentration of metal present in solution, $V_{3}$ is the volume of metal ions present in solution and $\beta^{H}$ is the overall proton ligand stability constant. The metal-ligand stability constants (log K) were determined by employing point wise computational Method (eq. 5 and 6).

$\operatorname{LogK}_{1}=\log \left(\frac{n}{1-n}\right)+\mathrm{pL}$ .5

$\operatorname{LogK}_{2}=\log \left(\frac{1-n}{2-n}\right)+\mathrm{pL}$ ...6

Where: Log $\mathrm{K}$ is the metal-ligand stability constant, $\mathrm{pL}$ is the Free ligand exponent function, $\mathbf{n}$ is the Average number of ligand attached with metal ion (Janraoet al., 2014). The results obtained were analyzed by an ORIGIN 2016 program using titration data and then the proton-ligand stability constants (pKa) and Metal-ligand stability constant (LogK) calculated (Omar and Ali, 2015).

\section{RESULTS AND DISCUSSION}

Fourier transformed infrared (FT-IR) spectra of isolated humic acid from peat soils Figure 2 had distinct clear absorption bands indicating the presence of major humic acid structural elemental groups such as $\mathrm{H}$ bonded $\mathrm{OH}$ $\left(3680 \mathrm{~cm}^{-1}\right.$ peak $), C=0$ of carbonyl $\left(1721 \mathrm{~cm}^{-1}\right.$ peak), functional groups of aliphatic components $\mathrm{CH}_{2}\left(2918 \mathrm{~cm}^{-1}\right.$ peak) and $\mathrm{C}-\mathrm{O}$ stretching of polysaccharide $\left(1168 \mathrm{~cm}^{-1}\right.$ peak). The positions of the absorption bands of the spectra fell within typical major absorption bands of humic acid which is at frequencies 3680, 2918, 1721, 1168 $\mathrm{cm}^{-1}$. The first peak centred in the vicinity of $3680 \mathrm{~cm}^{-1}$ region is attributed to phenol $\mathrm{OH}$ group bounded by intermolecular $\mathrm{H}$ bonds. The $2918 \mathrm{~cm}^{-1}$ band usually has absorption maximum at $2918 \mathrm{~cm}^{-1}$ which is due to $\mathrm{C}-\mathrm{H}$ stretching of alkane group $\left(\mathrm{CH}_{2}\right)$. The next major absorption band is $1721 \mathrm{~cm}^{-1}$. This band has been commonly ascribed to $\mathrm{C}=\mathrm{O}$ stretching of mainly carboxyl group $(\mathrm{COOH})$ with trace amount of ketones. The last peak was observed at 1168 $\mathrm{cm}^{-1}$ due to $\mathrm{C}-\mathrm{O}$ stretching of polysaccharides and this peak appeared also in the spectra of humic acid from peat soil. The FTIR spectra of the isolated humic acid contained all major characteristic absorption peaks of humic acid. These absorption peaks indicated the presence of the major structural elements of humic acid namely $\mathrm{H}$ bonded $\mathrm{OH}, \mathrm{C}=\mathrm{C}$ of aromatic ring, $\mathrm{C}=\mathrm{O}$ of carbonyl group (both carboxyl and ketonic), $\mathrm{CH}_{2}$ group. This strongly supports the presence of humic acid.

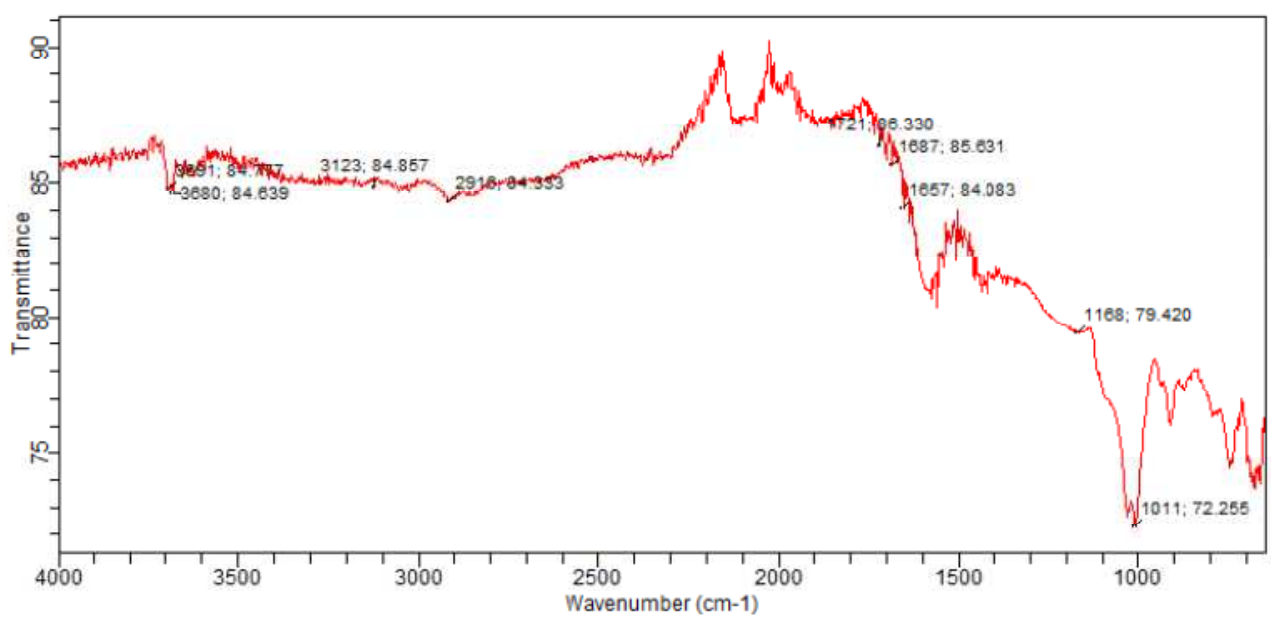

Fig. 2 : FT-IR spectraof peatsoilhumic acid (PSHA)

\section{Evaluation of acid dissociation constant (pka) of acid hydrolysed peat soil humicacid at phenolic group}

The value of the dissociation constant of the peat soil humic acid (PSHA) that underwent acidhydrolysis studied was found to be 8.9299 as shown Table 1, which is lower than the literaturevalues reported by Almeida and Szpoganics, (2015), Borges et al., (2005); Badr et al., (2012)and Fernandes et al,.(2009) of $9.73,9.47$ and 10.30. The difference between the obtained valuesand the reported values in this study might be probably as a result of acid hydrolysis of humicacid. 
BAJOPAS Volume 14 Number 1,June, 2021

Table 1: PKa of (Hydrolysed PSHA)

\begin{tabular}{|l|l|l|l|l|l|l|}
\hline $\mathrm{pH}$ & $\mathrm{BV}_{1}$ & $\mathrm{BV}_{2}$ & $\mathrm{~V}_{2}-\mathrm{V}_{1}$ & $\mathrm{nA}$ & $\log \left(\frac{n A}{1-n A}\right)$ & $\mathrm{pKa}$ \\
\hline 8.50 & 5.30 & 6.29 & 0.99 & 0.3594 & -0.2510 & 8.2490 \\
8.72 & 5.35 & 6.37 & 1.02 & 0.3400 & -0.2880 & 8.4320 \\
9.00 & 5.40 & 6.46 & 1.06 & 0.3141 & -0.3391 & 8.6609 \\
9.22 & 5.45 & 6.55 & 1.10 & 0.2882 & -0.3927 & 8.8273 \\
9.51 & 5.50 & 6.66 & 1.16 & 0.2494 & -0.4786 & 9.0314 \\
9.73 & 5.55 & 6.78 & 1.23 & 0.2041 & -0.5910 & 9.1390 \\
10.00 & 5.60 & 6.90 & 1.30 & 0.1589 & -0.7238 & 9.2762 \\
10.23 & 5.65 & 7.05 & 1.40 & 0.0941 & -0.9835 & 9.2465 \\
10.49 & 5.70 & 7.10 & 1.40 & 0.0941 & -0.9835 & 9.5065 \\
\hline
\end{tabular}

Average pKa $=8.9299 \pm 0.4186$

Table 2: PKa of (Unhydrolysed PSHA)

\begin{tabular}{|l|l|l|l|l|l|l|}
\hline $\mathrm{pH}$ & $\mathrm{BV}_{1}$ & $\mathrm{BV}_{2}$ & $\mathrm{~V}_{2}-\mathrm{V}_{1}$ & $\mathrm{nA}$ & $\log \left(\frac{\boldsymbol{n A}}{1-\boldsymbol{n}}\right)$ & $\mathrm{pKa}$ \\
\hline 8.50 & 5.30 & 5.81 & 0.51 & 0.6619 & 0.2919 & 8.7919 \\
8.72 & 5.35 & 5.90 & 0.55 & 0.6357 & 0.2418 & 8.9618 \\
9.00 & 5.40 & 6.00 & 0.60 & 0.6029 & 0.1813 & 9.1813 \\
9.22 & 5.45 & 6.10 & 0.65 & 0.5701 & 0.1226 & 9.3426 \\
9.51 & 5.50 & 6.20 & 0.70 & 0.5376 & 0.0654 & 9.5754 \\
9.73 & 5.55 & 6.33 & 0.78 & 0.4851 & -0.0259 & 9.7041 \\
10.00 & 5.60 & 6.47 & 0.87 & 0.4262 & -0.1291 & 9.8709 \\
10.23 & 5.65 & 6.62 & 0.99 & 0.3609 & -0.2481 & 9.9819 \\
10.49 & 5.70 & 6.80 & 1.10 & 0.2759 & -0.4690 & 10.0210 \\
\hline
\end{tabular}

Average pKa $=9.4923 \pm 0.4410$

Metal-ligand stability constant ( $\log \mathrm{K}$ )

The stabilityconstants require the accurate values of proton-ligand stability constants (Anil and Maroti, 2008). Metal titration curves crossed over ligand titration curve indicated the formation of complex upon proton release (Santosh, et al., 2011). If the values of n- are within range $0.2-0.8$ and $1.2-18$ this indicates the formation of $1: 1$ and 1:2 complexes (Sayyed and Mazahar, 2012).

The metal (II)-humate stepwise stability constants (log k) at phenolic group (Tables 318)

Table 3: Point-wise method, $\mathrm{Cu}$-(Hydrolysed PSHA)

\begin{tabular}{|l|l|l|l|l|l|l|l|l|}
\hline $\mathrm{pH}$ & $\mathrm{BV}_{1}$ & $\mathrm{BV}_{2}$ & $\mathrm{BV}_{3}$ & $\left(\mathrm{~V}_{3}-\mathrm{V}_{2}\right)$ & $\mathrm{n}$ & $\mathrm{pL}$ & $\log \left(\frac{n}{1-n}\right)$ & LogK $_{1}$ \\
\hline 8.50 & 5.30 & 6.29 & 6.33 & 0.04 & 0.5500 & 2.66 & 0.0871 & 2.7471 \\
8.72 & 5.35 & 6.37 & 6.41 & 0.04 & 0.5714 & 2.43 & 0.1249 & 2.5549 \\
9.00 & 5.40 & 6.46 & 6.50 & 0.04 & 0.6198 & 2.16 & 0.2122 & 2.3722 \\
9.22 & 5.45 & 6.55 & 6.59 & 0.04 & 0.6667 & 1.94 & 0.3010 & 2.2410 \\
\hline
\end{tabular}

LogK $_{1}$ (Average value) $=2.4788 \pm 0.2203$

Table 4: Point-wise method, $\mathrm{Cu}$-(Hydrolysed PSHA)

\begin{tabular}{|l|l|l|l|l|l|l|l|l|}
\hline $\mathrm{pH}$ & $\mathrm{BV}_{1}$ & $\mathrm{BV}_{2}$ & $\mathrm{BV}_{3}$ & $\left(\mathrm{~V}_{3}-\mathrm{V}_{2}\right)$ & $\mathrm{n}$ & $\mathrm{pL}$ & $\log \left(\frac{n-1}{2-n}\right)$ & LogK $_{2}$ \\
\hline 9.51 & 5.50 & 6.66 & 6.73 & 0.07 & 1.3509 & 1.70 & -0.2671 & 1.4329 \\
9.73 & 5.55 & 6.78 & 6.85 & 0.07 & 1.6383 & 1.51 & 0.2467 & 1.7567 \\
10.00 & 5.60 & 6.90 & 6.98 & 0.08 & 2.1783 & 1.31 & -0.2158 & 1.0942 \\
10.23 & 5.65 & 7.05 & 7.13 & 0.08 & 4.1904 & 1.27 & & \\
10.49 & 5.70 & 7.10 & 7.19 & 0.09 & 4.6920 & & & \\
\hline
\end{tabular}

Log $K_{2}($ Average value $)=1.4280 \pm 0.3312$ 
BAJOPAS Volume 14 Number 1,June, 2021

Table 5: Point-wise method, $\mathrm{Cu}$ (Unhydrolysed PSHA)

\begin{tabular}{|l|l|l|l|l|l|l|l|l|}
\hline $\mathrm{pH}$ & $\mathrm{BV}_{1}$ & $\mathrm{BV}_{2}$ & $\mathrm{BV}_{3}$ & $\left(\mathrm{~V}_{3}-\mathrm{V}_{2}\right)$ & $\mathrm{n}$ & $\mathrm{pL}$ & $\log \left(\frac{n}{n-1}\right)$ & Log $_{1}$ \\
\hline 8.50 & 5.30 & 5.81 & 5.85 & 0.04 & 0.2973 & 2.88 & -0.3736 & 2.5064 \\
8.72 & 5.35 & 5.90 & 5.95 & 0.05 & 0.3873 & 2.66 & -0.1992 & 2.4608 \\
9.00 & 5.40 & 6.00 & 6.05 & 0.05 & 0.4044 & 2.38 & -0.1681 & 2.2119 \\
9.22 & 5.45 & 6.10 & 6.15 & 0.06 & 0.5157 & 2.18 & -0.0272 & 2.2072 \\
9.51 & 5.50 & 6.20 & 6.27 & 0.07 & 0.6417 & 1.89 & 0.2530 & 1.1430 \\
\hline
\end{tabular}

$\operatorname{LogK}_{1}($ Average value $)=2.3059 \pm 0.6153$

Table 6:Point-wise method, $\mathrm{Cu}$ (Unhydrolysed PSHA)

\begin{tabular}{|l|l|l|l|l|l|l|l|l|}
\hline $\mathrm{pH}$ & $\mathrm{BV}_{1}$ & $\mathrm{BV}_{2}$ & $\mathrm{BV}_{3}$ & $\mathrm{~V}_{3}-\mathrm{V}_{2}$ & $\mathrm{n}$ & $\mathrm{pL}$ & $\log \left(\frac{n-1}{2-n}\right)$ & $\log \mathrm{K}_{2}$ \\
\hline 9.73 & 5.55 & 6.33 & 6.42 & 0.09 & 0.9000 & 1.69 & & \\
10.00 & 5.60 & 6.47 & 6.58 & 0.11 & 1.2578 & 1.44 & -0.4592 & 0.9808 \\
10.23 & 5.65 & 6.62 & 6.84 & 0.12 & 1.6137 & 1.26 & -0.2010 & 1.4610 \\
10.49 & 5.70 & 6.80 & 6.92 & 0.12 & 2.1052 & 1.03 & & \\
\hline
\end{tabular}

$\operatorname{LogK}_{2}$ (Average value) $=1.2209 \pm 0.3398$

Table 7:Point-wise method, Pb (Hydrolysed PSHA)

\begin{tabular}{|l|l|l|l|l|l|l|l|l|}
\hline $\mathrm{pH}$ & $\mathrm{BV}_{1}$ & $\mathrm{BV}_{2}$ & $\mathrm{BV}_{3}$ & $\left(\mathrm{~V}_{3}-\mathrm{V}_{2}\right)$ & $\mathrm{n}$ & $\mathrm{pL}$ & $\log \left(\frac{n}{1-n}\right)$ & LogK $_{1}$ \\
\hline 8.50 & 5.30 & 6.29 & 6.33 & 0.04 & 0.5500 & 2.66 & 0.0871 & 2.7471 \\
8.72 & 5.35 & 6.37 & 6.41 & 0.04 & 0.5714 & 2.43 & 0.1249 & 2.5549 \\
9.00 & 5.40 & 6.46 & 6.50 & 0.04 & 0.6198 & 2.16 & 0.2122 & 2.3722 \\
9.22 & 5.45 & 6.55 & 6.60 & 0.05 & 0.8333 & 1.96 & 0.6989 & 2.6589 \\
\hline
\end{tabular}

Log $_{\mathbf{1}}($ Average value $)=2.5832 \pm 0.1614$

Table 8:Point-wise method, Pb-(Hydrolysed PSHA)

\begin{tabular}{|l|l|l|l|l|l|l|l|l|}
\hline $\mathrm{pH}$ & $\mathrm{BV}_{1}$ & $\mathrm{BV}_{2}$ & $\mathrm{BV}_{3}$ & $\left(\mathrm{~V}_{3}-\mathrm{V}_{2}\right)$ & $\mathrm{n}$ & $\mathrm{pL}$ & $\log \left(\frac{n-1}{2-n}\right)$ & $\log \mathrm{K}_{2}$ \\
\hline 9.51 & 5.50 & 6.66 & 6.71 & 0.05 & 0.9650 & 1.67 & & \\
9.73 & 5.55 & 6.78 & 6.83 & 0.05 & 1.1702 & 1.44 & & \\
10.00 & 5.60 & 6.90 & 6.90 & 0.05 & 1.4864 & 1.22 & -0.0237 & 1.1963 \\
10.23 & 5.65 & 7.05 & 7.10 & 0.05 & 2.0190 & 1.09 & & \\
10.49 & 5.70 & 7.10 & 7.17 & 0.07 & 3.6492 & 1.00 & & \\
\hline
\end{tabular}

Log $K_{2}$ (Average value) $=1.1963$

Table 9: Point-wise method, Pb (Unhydrolysed PSHA)

\begin{tabular}{|l|l|l|l|l|l|l|l|l|}
\hline $\mathrm{pH}$ & $\mathrm{BV}_{1}$ & $\mathrm{BV}_{2}$ & $\mathrm{BV}_{3}$ & $\mathrm{~V}_{3}-\mathrm{V}_{2}$ & $\mathrm{n}$ & $\mathrm{pL}$ & $\begin{array}{l}\text { Log } \\
\left(\frac{n}{n-1}\right)\end{array}$ & Log $\mathrm{K}_{1}$ \\
\hline 8.50 & 5.30 & 5.81 & 5.85 & 0.04 & 0.2973 & 2.88 & -0.3736 & 2.5064 \\
8.72 & 5.35 & 5.90 & 5.94 & 0.04 & 0.3099 & 2.66 & -0.5477 & 2.3123 \\
9.00 & 5.40 & 6.00 & 6.05 & 0.05 & 0.4044 & 2.38 & -0.1681 & 2.2119 \\
9.22 & 5.45 & 6.10 & 6.15 & 0.06 & 0.5157 & 2.18 & 0.0272 & 2.2072 \\
9.51 & 5.50 & 6.20 & 6.26 & 0.07 & 0.6417 & 1.89 & 0.2530 & 2.1430 \\
9.73 & 5.55 & 6.40 & 6.40 & 0.07 & 0.7000 & 1.67 & 0.3680 & 2.0380 \\
\hline
\end{tabular}

LogK $_{1}$ (Average value) $=2.2364 \pm 0.1602$

Table 10: Point-wise method, Pb (Unhydrolysed PSHA)

\begin{tabular}{|l|l|l|l|l|l|l|l|l|}
\hline $\mathrm{pH}$ & $\mathrm{BV}_{1}$ & $\mathrm{BV}_{2}$ & $\mathrm{BV}_{3}$ & $\mathrm{~V}_{3}-\mathrm{V}_{2}$ & $\mathrm{n}$ & $\mathrm{pL}$ & $\log \left(\frac{n-1}{2-n}\right)$ & $\log \mathrm{K}_{2}$ \\
\hline 10.00 & 5.60 & 6.47 & 6.55 & 0.08 & 1.9503 & 1.41 & & \\
10.23 & 5.65 & 6.62 & 6.72 & 0.11 & 1.4792 & 1.26 & -0.0361 & 1.2239 \\
\hline
\end{tabular}

$\operatorname{LogK}_{2}$ (Average value) $=1.2239$

Table 11: Point-wise method, Mg (Hydrolysed PSHA)

\begin{tabular}{|l|l|l|l|l|l|l|l|l|}
\hline $\mathrm{pH}$ & $\mathrm{BV}_{1}$ & $\mathrm{BV}_{2}$ & $\mathrm{BV}_{3}$ & $\left(\mathrm{~V}_{3}-\mathrm{V}_{2}\right)$ & $\mathrm{n}$ & $\mathrm{pL}$ & $\log \left(\frac{n}{n-1}\right)$ & LogK $_{1}$ \\
\hline 8.50 & 5.30 & 6.29 & 6.31 & 0.02 & 0.2750 & 2.64 & -0.4290 & 2.2110 \\
8.72 & 5.35 & 6.37 & 6.39 & 0.02 & 0.2858 & 2.42 & -0.3978 & 2.0222 \\
9.00 & 5.40 & 6.46 & 6.49 & 0.03 & 0.4648 & 2.14 & -0.0612 & 2.0788 \\
9.22 & 5.45 & 6.55 & 6.59 & 0.04 & 0.6667 & 1.94 & 0.3010 & 2.2410 \\
\hline
\end{tabular}

$\log _{\mathbf{1}}($ Average value) $=2.1382 \pm 0.1046$ 
BAJOPAS Volume 14 Number 1,June, 2021

Table 12: Point-wise method, Mg (Hydrolysed PSHA)

\begin{tabular}{|l|l|l|l|l|l|l|l|l|}
\hline $\mathrm{pH}$ & $\mathrm{BV}_{1}$ & $\mathrm{BV}_{2}$ & $\mathrm{BV}_{3}$ & $\left(\mathrm{~V}_{3}-\mathrm{V}_{2}\right)$ & $\mathrm{n}$ & $\mathrm{pL}$ & $\log \left(\frac{n-1}{2-n}\right)$ & LogK $_{2}$ \\
\hline 9.51 & 5.55 & 6.66 & 6.71 & 0.05 & 0.9650 & 1.67 & & \\
9.73 & 5.55 & 6.78 & 6.84 & 0.06 & 1.4042 & 1.47 & -0.1686 & 1.3014 \\
10.00 & 5.60 & 6.90 & 6.93 & 0.06 & 1.7838 & 1.23 & 0.5593 & 1.7893 \\
10.23 & 5.65 & 7.05 & 7.10 & 0.06 & 3.1429 & 1.10 & & \\
10.49 & 5.70 & 7.10 & 7.18 & 0.07 & 3.6492 & 0.83 & & \\
\hline
\end{tabular}

LogK $_{2}($ Average value $)=1.5453 \pm 0.3450$

Table 13: Point-wise method, Mg (Unhydrolysed PSHA)

\begin{tabular}{|l|l|l|l|l|l|l|l|l|}
\hline $\mathrm{pH}$ & $\mathrm{BV}_{1}$ & $\mathrm{BV}_{2}$ & $\mathrm{BV}_{3}$ & $\mathrm{~V}_{3}-\mathrm{V}_{2}$ & $\mathrm{n}$ & $\mathrm{pL}$ & $\log \left(\frac{n}{n-1}\right)$ & $\operatorname{Log~}_{1}$ \\
\hline 8.50 & 5.30 & 5.81 & 5.85 & 0.04 & 0.2973 & 2.88 & -0.3736 & 2.5064 \\
8.72 & 5.35 & 5.90 & 5.94 & 0.04 & 0.3099 & 2.66 & -0.3477 & 2.3123 \\
9.00 & 5.40 & 6.00 & 6.04 & 0.04 & 0.3236 & 2.38 & -0.3202 & 2.0598 \\
9.22 & 5.45 & 6.10 & 6.15 & 0.05 & 0.4297 & 2.17 & -0.1230 & 2.0470 \\
9.51 & 5.50 & 6.20 & 6.26 & 0.06 & 0.5500 & 1.89 & 0.0871 & 1.9771 \\
9.73 & 5.55 & 6.33 & 6.40 & 0.07 & 0.7000 & 1.67 & 0.3680 & 2.0380 \\
\hline
\end{tabular}

LogK $_{1}$ (Average value) $=2.1568 \pm 0.2069$

Table 14: Point-wise method, Mg (Unhydrolysed PSHA)

\begin{tabular}{|l|l|l|l|l|l|l|l|l|}
\hline $\mathrm{pH}$ & $\mathrm{BV}_{1}$ & $\mathrm{BV}_{2}$ & $\mathrm{BV}_{3}$ & $\mathrm{~V}_{3}-\mathrm{V}_{2}$ & $\mathrm{n}$ & $\mathrm{pL}$ & $\log \left(\frac{n-1}{2-n}\right)$ & $\log \mathrm{K}_{2}$ \\
\hline 10.00 & 5.60 & 6.47 & 6.55 & 0.08 & 0.9148 & 1.41 & & \\
10.23 & 5.65 & 6.62 & 6.71 & 0.09 & 1.2102 & 1.20 & -0.5749 & 0.6251 \\
10.49 & 5.70 & 6.80 & 6.92 & 0.09 & 1.5968 & 1.03 & 0.1703 & 1.2003 \\
\hline
\end{tabular}

LogK $_{2}$ (Average value) $=0.9127 \pm 0.4070$

Table15:Point-wise method, Cd (Hydrolysed PSHA)

\begin{tabular}{|l|l|l|l|l|l|l|l|l|}
\hline $\mathrm{pH}$ & $\mathrm{BV}_{1}$ & $\mathrm{BV}_{2}$ & $\mathrm{BV}_{3}$ & $\left(\mathrm{~V}_{3}-\mathrm{V}_{2}\right)$ & $\mathrm{n}$ & $\mathrm{pL}$ & $\log \left(\frac{n}{1-n}\right)$ & LogK $_{1}$ \\
\hline 8.50 & 5.30 & 6.29 & 6.31 & 0.02 & 0.2750 & 2.64 & -0.4210 & 2.2190 \\
8.72 & 5.35 & 6.37 & 6.40 & 0.03 & 0.4286 & 2.42 & -0.1249 & 2.2951 \\
9.00 & 5.40 & 6.46 & 6.49 & 0.03 & 0.4648 & 2.14 & -0.0612 & 2.0788 \\
9.22 & 5.45 & 6.55 & 6.59 & 0.04 & 0.6667 & 1.96 & 0.3010 & 2.2610 \\
9.51 & 5.55 & 6.66 & 6.70 & 0.04 & 0.7720 & 1.67 & 0.5297 & 2.1997 \\
\hline
\end{tabular}

LogK $_{\mathbf{1}}$ (Average value) $=2.2108 \pm 0.0825$

Table 16: Point-wise method, Cd (Hydrolysed PSHA)

\begin{tabular}{|l|l|l|l|l|l|l|l|l|}
\hline $\mathrm{pH}$ & $\mathrm{BV}_{1}$ & $\mathrm{BV}_{2}$ & $\mathrm{BV}_{3}$ & $\left(\mathrm{~V}_{3}-\mathrm{V}_{2}\right)$ & $\mathrm{n}$ & $\mathrm{pL}$ & $\log \left(\frac{n-1}{2-n}\right)$ & Log $_{2}$ \\
\hline 9.73 & 5.55 & 6.78 & 6.83 & 0.06 & 1.4042 & 1.47 & -0.1686 & 1.3014 \\
10.00 & 5.60 & 6.90 & 6.95 & 0.06 & 1.7838 & 1.23 & 0.5593 & 1.7893 \\
10.23 & 5.65 & 7.05 & 7.10 & 0.06 & 3.1429 & 1.09 & & \\
10.49 & 5.70 & 7.10 & 7.16 & 0.06 & 3.1429 & 0.89 & & \\
& & & & & & & & \\
\hline
\end{tabular}

$\operatorname{LogK}_{2}$ (Average value) $=1.5453 \pm 0.3450$

Table 17: Point-wise method, Cd (Unhydrolysed PSHA)

\begin{tabular}{|l|l|l|l|l|l|l|l|l|}
\hline $\mathrm{pH}$ & $\mathrm{BV}_{1}$ & $\mathrm{BV}_{2}$ & $\mathrm{BV}_{3}$ & $\mathrm{~V}_{3}-\mathrm{V}_{2}$ & $\mathrm{n}$ & $\mathrm{pL}$ & $\log \left(\frac{n}{n-1}\right)$ & $\operatorname{Log~}_{1}$ \\
\hline 8.50 & 5.30 & 5.81 & 5.86 & 0.05 & 0.3717 & 2.88 & -0.2280 & 2.6520 \\
8.72 & 5.35 & 5.90 & 5.95 & 0.05 & 0.3873 & 2.66 & -0.1992 & 2.4608 \\
9.00 & 5.40 & 6.00 & 6.06 & 0.06 & 0.4853 & 2.38 & -0.0255 & 2.3545 \\
9.22 & 5.45 & 6.10 & 6.16 & 0.06 & 0.5157 & 2.18 & -0.0272 & 2.2072 \\
9.51 & 5.50 & 6.20 & 6.27 & 0.07 & 0.6417 & 1.89 & 0.2530 & 1.1430 \\
9.73 & 5.55 & 6.33 & 6.41 & 0.08 & 0.8000 & 1.69 & 0.6020 & 2.2920 \\
& & & & & & & & \\
\hline
\end{tabular}

$\operatorname{LogK}_{1}($ Average value $)=2.2516 \pm 0.5380$ 
BAJOPAS Volume 14 Number 1,June, 2021

Table 18: Point-wise method, Cd (Unhydrolysed PSHA)

\begin{tabular}{|l|l|l|l|l|l|l|l|l|}
\hline $\mathrm{pH}$ & $\mathrm{BV}_{1}$ & $\mathrm{BV}_{2}$ & $\mathrm{BV}_{3}$ & $\mathrm{~V}_{3}-\mathrm{V}_{2}$ & $\mathrm{n}$ & $\mathrm{pL}$ & $\log \left(\frac{n-1}{2-n}\right)$ & $\log \mathrm{K}_{2}$ \\
\hline 10.00 & 5.60 & 6.47 & 6.57 & 0.10 & 1.1434 & 1.43 & & \\
10.23 & 5.65 & 6.62 & 6.72 & 0.10 & 1.3448 & 1.23 & -0.2788 & 0.9512 \\
10.49 & 5.70 & 6.80 & 6.90 & 0.10 & 1.7742 & 1.03 & 0.5351 & 1.5651 \\
\hline
\end{tabular}

$\operatorname{LogK}_{2}($ Average value $)=1.2581 \pm 0.4340$

Table 19: Stepwise and overall Stability constants of thehydrolysed and unhydrolysed divalent metal (II) complexes

\begin{tabular}{|c|c|c|c|}
\hline Chelates & LogK $_{1}$ & $\log _{2}$ & Log $\beta$ \\
\hline [Cu (Hydrolysed PSHA-1) $\left.{ }_{2}\right]$ & 2.4788 & 1.4280 & 3.9068 \\
\hline$\left[\mathrm{Pb}(\text { Hydrolysed PSHA-1) })_{2}\right]$ & 2.5832 & 1.1963 & 3.7795 \\
\hline$\left[\mathrm{Cd}(\text { Hydrolysed PSHA-1 })_{2}\right]$ & 2.2108 & 1.5453 & 3.7561 \\
\hline$\left[\mathrm{Mg}(\text { Hydrolysed PSHA-1 })_{2}\right]$ & 2.1382 & 1.5453 & 3.6835 \\
\hline [Cu (Unhydrolysed PSHA-1) & 2.3059 & 1.2209 & 3.5268 \\
\hline$[\mathrm{Pb}$ (Unhydrolysed PSHA-1) 2$]$ & 2.2364 & 1.2239 & 3.4603 \\
\hline [Cd (Unhydrolysed PSHA-1) 2 ] & 2.2516 & 1.2581 & 3.5097 \\
\hline$[\mathrm{Mg}$ (Unydrolysed PSHA-1) & 2.1568 & 0.9127 & 3.0695 \\
\hline
\end{tabular}

The results obtained (Table19) shows the stepwise and overall stability constants to be not high indicating low stability of the complexes, because the solubility of most metal ions in the basic $\mathrm{pH}$ range is minimal due to metal hydroxide precipitation (Karimi, 2017). In general, the stepwise stability constants $\left(K_{1}\right.$ and $K_{2}$ ) follow the order $K_{1}>K_{2}$ for the copper, lead, magnesium and cadmium complexes respectively. The steady decrease of the values with increasing number of ligands is in agreement with the prediction made by researchers (Na'aliya, 2013). The decrease could be attributed to the fact that as the number of the ligands (Humate ions) that enters the coordination zone increases the aqua molecules available for replacement by the ligands become less. Thus, the metal ions become less electron loving with progressive intake of the ligand and this results in the decrease in the values of the constants (Na'aliya, 2013). Also the stability of the complexes is influenced by the size and number of the chelate rings(Mackay and Mackay,2002).All the complexes form rings in their structure as humate, a bidentate ligand, bond the metal ions in the ratio 1:2 (Boguta and Sokolowska, 2016) forming chelate rings. The values of the overall stability constants $(\log \beta)$ obtained for humate complexes are not high indicating low stability as the values are not high. LogK values for copper-humates (Table 3 to 6) obtained in this study are lower than those reported for the complexes of humic acids (Pandey et al., 2015; Dinu, 2013; Kaschl et al., 2010 and Gilbeto and Jorg, 2001). The values of LogK(Table 7 to 10 ) forlead-humates are lower than those reported for the lead in the literature (Dinu, 2013; Gilbeto and Jorg 2001). Log K values(Table 11 to 14 ) for magnesium-humates obtained in this study are close to those reported by (Pandey et al., 2015). Log K values of cadmium-humates (Table 15 to 18 ) obtained in this work near to the one reported by (Dinu, 2013 and Pandey et al., 2015).The difference between the reported values and the values obtained in this study might be probably as a result of acid hydrolysis of humic acid. The values of the overall stability constants $(\log \beta)$ of the copper humates complexes presented in Table 19 is high than that of other metal humate complexes, show relatively high stability of CuHA complexes, show the following order of stability: $\mathrm{Cu}>\mathrm{Pb}>\mathrm{Cd}>\mathrm{Mg}$; which are in close agreement to the findings of (Dinu, 2013 and Pandey et al., 2015).The high stability of Cuhumate chelate could be attributed to the existence of coordinate covalent bond between the complexing agents and the $\mathrm{Cu}^{2+}$ ions. Since, $\mathrm{Cu}^{2+}$ being a metal of the transitional series with $3 d^{9}$ electronic configurations can accept the electrons from the complexing agents. Similarly, the low stabilities of $\mathrm{Pb}, \mathrm{Cd}$ and $\mathrm{Mg}$ complexes could be explained by that $\mathrm{Pb}^{2+}$ with $6 s^{2}, \mathrm{Cd}^{2+}$ with $4 \mathrm{~d}^{10}$ and $\mathrm{Mg}^{2+}$ with $2 \mathrm{p}^{6}$ their electronic configuration has a completely filled $\mathrm{d}, \mathrm{p}$ and $\mathrm{s}$ orbitals. Moreover, the stabilities of metal ions with hydrolysed humic acid from peat soil were higher than those with unhydrolysed humic acid from peat soil; which is ascribed to the high content of acidity in hydrolysed humic acid than unhydrolysed humic acid. 
BAJOPAS Volume 14 Number 1,June, 2021 CONCLUSION

The values of logk for $\mathrm{Cu}(\mathrm{II})$ hydrolysed humic acid complex was higher followed by $\mathrm{Pb}$ (II), $\mathrm{Cd}(\mathrm{II})$ and $\mathrm{Mg}$ (II) hydrolysed humic acid complexes as compared with metal(II) unhydrolysed humic acid complexes. This indicates acid hydrolysis of humic acid can

\section{REFERENCES}

Almeida, V.R. and Szpoganicz, B. (2015). Humic Acid Potentiometric Response Patterns:Out- of Equilibrium Properties and Species Distribution Modelling. Chemical. Biol. Technol. Agric. 2: 17.

Anđelković, T., Nikolić, R., Bojić, A.,Anđelković, D., and Nikolic G.,(2010). Binding of Cadmium to Soil Humic Acid as A Function of Carboxyl Group Content. Macedonian Journal of Chemistry and Chemical Engineering.29(2): 215-224.

Anil, B. N. and Maroti, N. (2008). Studies on Influence of Die-Lectric Constants on Complex Equilibria between Substituted Py-Razalines and Lanthanide Metal Ions pH-Metrically. Amer.-Euras. scient. Res. 3(2): 212-216.

Ashok, K., Pandey, S. P. and Misra, V (2000). Stability Constants of Metal-Humic Acid Complexes and its Role in Environmental Detoxification. Journal of Ecotoxicology and Environmental Safety. 47(2):157-200.

Badr, M. H., El-Halafawi, M. H. and Abd El-al Zeid, E. R. (2012). Comparison Between the Effect of Ionic Strength on Acidity and Dissociation Constants of Humic Acids Extracted from Sewage Sludge and Nile Water Hyacinth Composts.Global Journal of Environmental Research 6 (1): 36-43.

Baruah, M.K., Borah, D., Saikia, P.P., Paul, S., Sharma, T. (2015). Evaluation of pKa Values of Soil Humic Acids and their Complexation Properties. International Journal of Plant \& Soil Science 6(4) : 218-228.

Boguta, P. Sokolowska, Z. (2016). Interactions of $\mathrm{Zn}$ (II) Ions with Humic Acids Isolated from Various Types of Soils. Effect of $\mathrm{pH}, \mathrm{Zn}$ Concentrations and Humic Acids Chemical Properties. Journal of Geochemical Explaration 168. 119-126.

Borges, F., Guimaraes, C., Lima, L.F.C., Pinto, I. and Reis, S.(2005). Potentiometric Studies on the Complexation of Copper(II) by Phenolic Acids as Discrete Ligand Models of enhance the complexation behavior of humic acid with metal (II) ions. However, the higher values of $\log \beta$ for $\mathrm{Cu}(\mathrm{II}), \mathrm{Pb}(\mathrm{II}), \mathrm{Cd}(\mathrm{II})$ and $\mathrm{Mg}(\mathrm{II})$ hydrolysed humic acid complexes indicates more stable stepwise complexes formed as compared with $\mathrm{Cu}(\mathrm{II}), \mathrm{Pb}$ (II), $\mathrm{Cd}$ (II) and $\mathrm{Mg}(\mathrm{II})$ unhydrolysed humic acid complexes.

Humic Substances Talanta 66 (2005) 670-673.

Chefetz, B., Salloum, M. J., Deshmulkin, A. P. and Hatcher, P. (2002). Structural Components of Humic Acids as Determined by Chemical Modifications and Carbon-13 NMR, Pyrolysis, and Thermochemolysis- Gas Chromatography/Mass Spectrometry. Soil Science Society of American Journal Abstract Division S-2- Soil Chemistry66. 1159-1171.

Dinu, M. I. (2013). Metals Complexation with Humic Acids in Surface Water of Different Environ. Sci. Technol. 31(1): 1-17.

Fernandes, A.N., Giacomelli, C., Giovanela, M. Vaz, D.V. Szpoganicz, B. and Maria M. D. (2009). Potentiometric Acidity Determination in Humic Substances Influenced by Different Analytical Procedures.J. Braz. Chem. Soc. 20 (9):14.

Gamal, A. H. (2015). Stability Constants of Rhenium (V) Metal Complexes with Selected Drugs. Pyrex Journal of Research in Environmental Studies. 2(2): 006-014.

Janrao, D. M., Pathan, J., Kayande, D.D., and Mulla, J.J. (2014). An Over View of Potentiometric Determination of Stability Constants of Metal Complexes. Sci. Revs. Chem. Commun.: 4(1), 2014, 11-24.

Karimi, H. (2017). Effect of pH and Initial Pb(II) Concentration on the Lead Removal Efficiency from Waste Water Using $\mathrm{Ca}(\mathrm{OH})_{2}$. International Journal of Water and Waste Water Treatment 3.2

Kaschl, A. Romheld, V. and Chen, Y. (2010). Binding of Cadmium, Copper and Zinc to Humic Substances Originating from Municipal Solid Waste Compost. Israel Journal of Chemistry Vol. 42(1): 89-98.

Kostic, I. S., Tatjana, P, A., Nikolic, R. S., Cvetkovic, T. P., Pavlovic, D. D., Aleksandar, L.J. and Bojic, A. (2012). Comparative Study of Binding Strengths of Heavy Metals with Humic Acid. J.serb. Chem. Soc. 76(9) pp 1-20. 
BAJOPAS Volume 14 Number 1,June, 2021

Na'aliya, J. (2013). Determination of Stepwise Stability Constants and Gibbs free Energy Change of Trisprolina to Complexes of some Divalent Transition Metal ions. Bayero Journal of Pure and Applied Sciences 6(2): 112-114.

Omar, A. A. and Ali, E. A. (2015). Potentiometric Studies on Complexes of $\mathrm{Cr}$ (III) and $\mathrm{Zr}$ (IV) with some Carboxylic Acids. International Journal of Advanced Chemistry, 3(1) 25-

37.

Pandey, A. K. Pandey, S. D. and Misr, V. (2015).Stability Constants of Metal- Humic Acid Complexes and Its Role in Environmental Detoxification. J. Ecotoxicology and Environmental Safety. 47(1):195-200.

Ram, N. and Raman, K.V. (1984). Stability Constants of Complexes of Metals with
Humicand Fuvic Acids under Non- acidConditions. Journal of Plant Nutrition and Soil Sciences.

147:171-176.

Santosh, D. D., Ashok, B. K., Vijay, J. T., Shivraj, G. W. and Vinay, V. W. (2011). Potentiometric Studies of Elec-Trolyte Effects on Complex Equilibria of Some Substituted 5-(2-hydroxy Phenyl) Pyrazoles. Der pharm. 3 (6): 75-83.

Sayyed, H. and Abdul Rahim, M. F. (2012). Studies of Binary Complexes of Metal Ions with Mandelic Acid by Potentiometry. Chem. J. 02 (6): 206209.

Shirvani, M. Moradian, E. Khalili, B. Bakhtiary, S. (2015). Interaction of $\mathrm{Cd}$ and $\mathrm{Pb}$ with Humate-Palygorskite and HumateSepiolite Complexes. Journal of water, air and pollution 3: 220-228. 


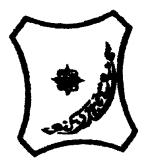

Bayero Journal of Pure and Applied Sciences, 14(1): 54 - 63

Received: November, 2020

Accepted: April, 2021

ISSN $2006-6996$

\title{
STABILITY CONSTANTS OF COMPLEXES OF METAL IONS WITH PEATSOIL HUMIC ACIDS UNDER NON-ACID-CONDITIONS
}

\author{
${ }^{* 1}$ Sabo, Yusuf ${ }^{2}$ Jimoh, W.L.O., ${ }^{3}$ Isa Baba Koki and ${ }^{4}$ Sholadoye, Q. 0. \\ ${ }^{1}$ Department of Pure and Industrial Chemistry, Bayero University, Kano \\ ${ }^{3}$ Department of Chemistry, Yusuf Maitama Sule University Kano. P.M.B. 3220 Kano, Nigeria. \\ ${ }^{4}$ Department of Chemistry, Nigerian Police Academy, Wudil, Kano-Nigeria
}

*Correspondence E-mail; saboyusuf18@yahoo.com

ABSTRACT

Stability constants of complexes of four divalent metal ions viz. $\mathrm{Cu}^{2+}, \mathrm{Pb}^{2+}, \mathrm{Mg}^{2+}$ and $\mathrm{Cd}^{2+}$ with humic acids (HA) were determined by potentiometric titration of humic acids with the corresponding salt of the divalent metals in aqueous media under non-acid-condition. The log $K$ (logarithm of the stability constant) ranged from 1.0942 to 2.7471 for metalhumic acid complexes were determined using point-wise computational method. The order of stability constants were obtained as follows: $\mathrm{Cu}>\mathrm{Pb}>\mathrm{Cd}>\mathrm{Mg}$ for metal $-\mathrm{HA}$ complexes respectively, indicating a higher degree of complexation with Cu metal ion.

Keywords: stability constant, humic acid, potentiometric titration, divalent metals, acid hydrolysis.

\section{NTRODUCTION}

The stability constant of a complex is the numerical expression of its stability and provides a quantitative measure of affinity of the metal ion to the complexing agent. An understanding of the relative stability of metal-complexes helps in predicting the behavior of metal ions in the soil (Ram and Raman, 1982). Extensive researches has been done to determine the stability constants of the complexes formed between humic acid (HA) with a number of metal ions. Ashok et al., (2000) reported that humic acid with hydroxyl, phenoxyl and carboxyl reactive groups can form coordination compound with metal ions at $\mathrm{pH}$ 3.5. The stability constants(Log K) for different metalhumic acid complexes indicated the following order of the stabilities of complexes formed between humic acid and metal ion, $\mathrm{Cu}>\mathrm{Fe}$ $>\mathrm{Pb}>\mathrm{Ni}>\mathrm{Co}>\mathrm{Ca}>\mathrm{Cd}>\mathrm{Zn}>\mathrm{Mn}>\mathrm{Mg}$. Andelkovic et al., (2010) investigated the binding of $\mathrm{Cd}$ (II) to soil humic acid at pH 6.5 and in $0.1 \mathrm{M} \mathrm{KNO}_{3}$ ionic medium. The stability constant for binding indicating greater stability in the case when carboxyl groups are involved in complexation reaction. Kostic et al.,(2012) investigated the complexation of humic acid with certain heavy metal ions (Co(II), $\mathrm{Ni}(\mathrm{II}), \mathrm{Cu}(\mathrm{II})$,
$\mathrm{Zn}(\mathrm{II})$, and $\mathrm{Pb}(\mathrm{II})$. The experiment was performed at $25^{\circ} \mathrm{C}$, at pH 4.0 and ionic strength of $0.01 \mathrm{M}$. Stability constant of complex between $\mathrm{Pb}$ (II) ions and humic acid is greater than stability constants of other investigated metalhumate complexes. Bogata and Sokolowska (2016) analyses the interaction between humic acids from different soils and $\mathrm{Zn}$ (II) ions at wide concentration ranges and at $\mathrm{pH} 5$. Studies have showed significant impact of $\mathrm{Zn}$ concentration, $\mathrm{pH}$ and some properties of humic acids with zinc.But all of these studies were limited to acidic $\mathrm{pH}$ range. Therefore, the present study was carried out to determine and compare the stability constants of complexes of metal ions with hydrolysed peat soil humic acid and unhydrolysed peat soil humic under non-acid conditions.

\section{MATERIALS AND METHODS}

Analytical grade chemicals used includes hydrochloric acid $(\mathrm{HCl})$, nitric acid $\left(\mathrm{HNO}_{3}\right)$, sodium hydroxide $(\mathrm{NaOH})$, lead nitrate $\mathrm{Pb}\left(\mathrm{NO}_{3}\right)_{2}$, copper nitrate $\mathrm{Cu}\left(\mathrm{NO}_{3}\right)_{2} \cdot 3 \mathrm{H}_{2} \mathrm{O}$, cadmium nitrate $\mathrm{Cd}\left(\mathrm{NO}_{3}\right)_{2} \cdot 4 \mathrm{H}_{2} \mathrm{O}$, magnesium nitrate $\mathrm{Mg}\left(\mathrm{NO}_{3}\right)_{2} \cdot 6 \mathrm{H}_{2} \mathrm{O}$, potassium nitrate $\left(\mathrm{KNO}_{3}\right)$, calcium chloride $\left(\mathrm{CaCl}_{2}\right)$, (sigma-Aldrich). Dowex 50WX8, (20-50 mesh) from Fluka. 


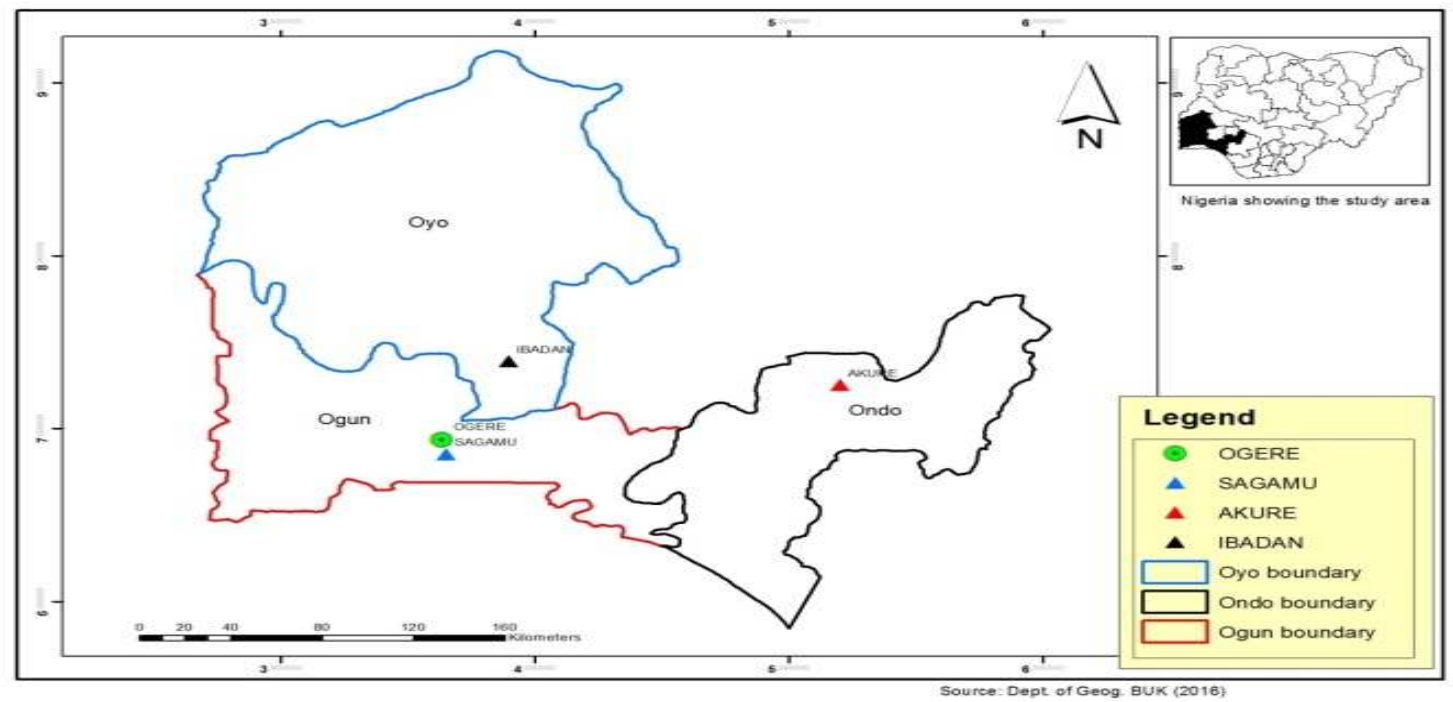

Figure 1: Map showing the sampling point at Sagamu Town, Ogun State.

\section{Description of Sampling Area}

Sagamu has geographical coordinates between $6^{\circ} 50^{\prime}$ north; $3^{\circ} 38^{\prime}$ east is located in south western region of Nigeria. The region has tropical wet and dry climate with a lengthy wet season and relatively constant temperatures throughout the course of the year. Wet season runs from March to October, November to December forms the region dry season. The vegetation type of the region is savannah which is really grassland with small bushes and occasional big trees. Grassland soils have substantially higher organic matter content than forest soils (Novackova, 2011).

\section{Sample Collection}

The Peatsoil samples were collected from four different sampling points $(0-10 \mathrm{~cm}$ depth) in Sagamu into polyethylene bag with plastic spoons. Samples were taken to the laboratory, extraneous materials were removed; the samples were air-dried, crushed and ground to a fine powder in a mortar passed through a $0.20 \mathrm{~mm}$ sieve. The samples were kept for analysis.

\section{Isolation and purification of humic acid from peat soil sample}

Peatsoil sample $(100 \mathrm{~g})$ was mixed with 1000 $\mathrm{cm}^{3}$ of $0.1 \mathrm{M} \mathrm{NaOH}$ solution, shaken for 3hours and left to stand overnight. Dark-coloured supernatant was obtained and decanted from solid residue. The dark-coloured supernatant was acidified to $(\mathrm{pH}=1.0)$ with $6 \mathrm{M} \mathrm{HCl}$ stirred and allowed to stand for 6 hours. Yellowish brown supernatant and dark-brown precipitate were obtained. The yellowish brown supernatant was decanted followed by centrifuge and discarded. The dark-brown precipitate was mixed with $500 \mathrm{~cm}^{3}$ of $0.1 \mathrm{M} \mathrm{NaOH}$ solution followed by passing through dowex resin. The dark-brown solution was acidified to $(\mathrm{pH}=1.0)$ with $6 \mathrm{M} \mathrm{HCl}$ stirred and allowed to stand for 3 hours. The dark-brown precipitate was washed several times with deionized water. The supernatant was treated with $\mathrm{AgNO}_{3}$ solution until no white precipitate observed. The humic acid was transferred to weighed crucible and dried at $60^{\circ} \mathrm{C}$ in an oven for 12 hours. The humic acid was cooled and dried in the desiccator, weighed and recorded. The obtained humic acid was dried again at $60^{\circ} \mathrm{C}$ for additional 6 hours cooled and dried in the desiccator, weighed and recorded constant weight was obtained (Baruah et al., 2015).

\section{FT-IR analysis}

FT-IR spectra of humic acid sample was analysed using Carry 630 FT-IR Agilent Technologies.

Unhydrolysed compost humic acid

The unhydrolysed humic acid was obtained after isolation and purification of compost humic acid and kept for investigation.

\section{Acid hydrolysis of Peatsoil acid}

Peatsoil humic acid sample (1g) was refluxed for 12 hours at $\left(160^{\circ} \mathrm{C}\right)$ with $50 \mathrm{~cm}^{3}$ of $6 \mathrm{M} \mathrm{HCl}$. The mixture was allowed to cool, decanted, and centrifuged after hydrolysis. The insoluble residues were washed with distilled water via centrifugation several times, and the supernatant was treated with $\mathrm{AgNO}_{3}$ solution until no white precipitate was observed. The residue was thoroughly dried over $\mathrm{CaCl}_{2}$ in a desiccator at room temperature (Chefetz et al., 2002). Finally, the obtained hydrolysed humic acid was kept for investigation. 
BAJOPAS Volume 14 Number 1,June, 2021 Potentiometric Titrations

Potentiometric measurements were carried out using a pH-meter Jenway (model 3510) with combine electrode, the sensitivity of the $\mathrm{pH}$ meter is 0.01 units. The $\mathrm{pH}$ meter was switched on half an hour before starting the titration for initial warm up of the instrument. The instrument was calibrated with an aqueous standard buffer solution of $\mathrm{pH} 4.00$ and 10.0 (borate buffer) prepared from a "Qualigens" buffer tablets.

The following sets of solutions were prepared in a $250 \mathrm{~cm}^{3}$ volumetric flask separately for $\mathrm{pH}$ metric titrations.

(i) $5 \mathrm{~cm}^{3} 0.1 \mathrm{M} \mathrm{HCl}+40 \mathrm{~cm}^{3}$ deionized water

(ii) $5 \mathrm{~cm}^{3} 0.1 \mathrm{M} \mathrm{HCl}+39 \mathrm{~cm}^{3}$ deionized water $+1 \mathrm{~cm}^{3} 0.15 \mathrm{gcm}^{-3}$ humic acid

(iii) $5 \mathrm{~cm}^{3} 0.1 \mathrm{M} \mathrm{HCl}+37 \mathrm{~cm}^{3}$ deionized water $+1 \mathrm{~cm}^{3} 0.15 \mathrm{gcm}^{-3}$ humic acid

$$
+2 \mathrm{~cm}^{3} \quad 0.01 \mathrm{M} \mathrm{Cu} \text { (II) }
$$

The solutions were titrated against standardized $0.110 \mathrm{MNaOH}$ separately. The total volume of each mixture was adjusted to $50 \mathrm{~cm}^{3}$ and the ionic strength of the solutions was maintained constant at by adding appropriate amount of stock solution of $1 \mathrm{M} \mathrm{KNO}_{3}$ (Gamal, 2015; Omar and Ali, 2015). A magnetic stirrer was used to achieve thorough mixing of the interacting solutions at $550 \mathrm{rpm}$. The same set of experimental conditions was applied for potentiometric titration of remaining samples.

\section{Evaluation of pKa of Hydrolysed peat soil Humic Acids}

The proton-ligand formation number $\mathrm{n}_{\mathbf{A}}$ were calculated by Irving and Rossotti expression (Omar and Ali, 2015).

$\mathrm{nA}=\mathrm{Y}-\frac{(\mathrm{V} 2-\mathrm{V1})(\mathrm{No}-\mathrm{Eo})}{(\mathrm{VO}+\mathrm{V1}) \mathrm{TCL}}$ 1

Where: $Y$ is number of dissociable proton, $\left(\mathrm{V}_{2^{-}}\right.$ $V_{1}$ ) is the measure of displacement of the ligand curve relative to acid curve, $\mathrm{N}^{\circ}$ and $\mathrm{E}^{\circ}$ are the resultant concentration of alkali solution, free acid solution, $\mathrm{T}_{\mathrm{cL}}{ }^{\circ}$ is the total ligand concentration, $\mathrm{V}^{\circ}$ is the total volume of titration solution, $V_{1}$ is the volume of alkali added to acid solution, $V_{2}$ is the volume of alkali added to acid solution + ligand solution, acid dissociation constants (pKa - values) of ligand were calculated by algebraic method point wise calculation (Tables 1 ). The dissociation constants (pKa) were calculated according to the following relation:

$\mathrm{pKa}=\mathrm{pH}+\log \left(\frac{n A}{1-n A}\right)$ 2

Where: pKa is the acid dissociation constant, $\mathrm{n}_{\mathrm{A}}$ is the Proton-ligand formation number and $\mathrm{pH}$ is the pH-values (Omar and Ali, 2015).

\section{Determination of metal-ligand stability constants $(\log K)$ of complexes}

The potentiometric measurement for the determination of stability constant of a complex in solution is based on the fact that the redox potential of the couple $\frac{M^{+(m-n)}}{M^{+m}}$ is shifted significantly on complexation of the metal ion with the ligand. This method involves change in hydrogen ion concentration $\left[\mathrm{H}^{+}\right]$due to the displacement or association of one or more protons taking place during complexation reaction. This change can be found out by titrating the solutions containing free acid, acid with ligand, and acid with ligand and metal ion, individually against a standard alkali solution at a constant ionic strength or temperature. Either ionic strength or temperature may be varied for different sets of solutions. In all the cases, the change in the $\mathrm{pH}$ of the solution is measured after each addition of a known amount of alkali to the reaction cell which contains the reaction mixture. The titration curves are then drawn by plotting the measured $\mathrm{pH}$ values against the corresponding volume of alkali added and the stability constants of the complexes are determined from the titration curves by employing $\mathrm{pH}$-metric titration technique given by (Irving and Rossoti).

Metal-ligand stability constants ( $\log \mathrm{K}$ ) were determined by using the following relations:

$$
\bar{n}=\frac{\left(V_{3}-V_{2}\right)\left(E^{0}+N^{0}\right)}{\left(V^{0}+V_{2}\right) \bar{n}_{A} T_{m}^{0}}
$$

and

$$
P L=\log _{10}\left\{\frac{1+\beta_{n}^{H} \frac{1}{[\text { anti } \log \mathrm{pH}]^{\mathrm{n}}}}{\mathrm{T}_{\mathrm{L}}^{0}-n \bar{T}_{m}^{0}} \mathrm{X} \frac{\left(V^{0}+V_{3}\right)}{V^{0}}\right\}
$$


BAJOPAS Volume 14 Number 1,June, 2021

Where $T_{L}, T^{\circ}, E^{\circ}$, and $V^{\circ}$ havethe same significance as in equation (1) above, $T_{m}$ denotes the total concentration of metal present in solution, $V_{3}$ is the volume of metal ions present in solution and $\beta^{H}$ is the overall proton ligand stability constant. The metal-ligand stability constants (log K) were determined by employing point wise computational Method (eq. 5 and 6).

$\operatorname{LogK}_{1}=\log \left(\frac{n}{1-n}\right)+\mathrm{pL}$ .5

$\operatorname{LogK}_{2}=\log \left(\frac{1-n}{2-n}\right)+\mathrm{pL}$ ...6

Where: Log $\mathrm{K}$ is the metal-ligand stability constant, $\mathrm{pL}$ is the Free ligand exponent function, $\mathbf{n}$ is the Average number of ligand attached with metal ion (Janraoet al., 2014). The results obtained were analyzed by an ORIGIN 2016 program using titration data and then the proton-ligand stability constants (pKa) and Metal-ligand stability constant (LogK) calculated (Omar and Ali, 2015).

\section{RESULTS AND DISCUSSION}

Fourier transformed infrared (FT-IR) spectra of isolated humic acid from peat soils Figure 2 had distinct clear absorption bands indicating the presence of major humic acid structural elemental groups such as $\mathrm{H}$ bonded $\mathrm{OH}$ $\left(3680 \mathrm{~cm}^{-1}\right.$ peak $), C=0$ of carbonyl $\left(1721 \mathrm{~cm}^{-1}\right.$ peak), functional groups of aliphatic components $\mathrm{CH}_{2}\left(2918 \mathrm{~cm}^{-1}\right.$ peak) and $\mathrm{C}-\mathrm{O}$ stretching of polysaccharide $\left(1168 \mathrm{~cm}^{-1}\right.$ peak). The positions of the absorption bands of the spectra fell within typical major absorption bands of humic acid which is at frequencies 3680, 2918, 1721, 1168 $\mathrm{cm}^{-1}$. The first peak centred in the vicinity of $3680 \mathrm{~cm}^{-1}$ region is attributed to phenol $\mathrm{OH}$ group bounded by intermolecular $\mathrm{H}$ bonds. The $2918 \mathrm{~cm}^{-1}$ band usually has absorption maximum at $2918 \mathrm{~cm}^{-1}$ which is due to $\mathrm{C}-\mathrm{H}$ stretching of alkane group $\left(\mathrm{CH}_{2}\right)$. The next major absorption band is $1721 \mathrm{~cm}^{-1}$. This band has been commonly ascribed to $\mathrm{C}=\mathrm{O}$ stretching of mainly carboxyl group $(\mathrm{COOH})$ with trace amount of ketones. The last peak was observed at 1168 $\mathrm{cm}^{-1}$ due to $\mathrm{C}-\mathrm{O}$ stretching of polysaccharides and this peak appeared also in the spectra of humic acid from peat soil. The FTIR spectra of the isolated humic acid contained all major characteristic absorption peaks of humic acid. These absorption peaks indicated the presence of the major structural elements of humic acid namely $\mathrm{H}$ bonded $\mathrm{OH}, \mathrm{C}=\mathrm{C}$ of aromatic ring, $\mathrm{C}=\mathrm{O}$ of carbonyl group (both carboxyl and ketonic), $\mathrm{CH}_{2}$ group. This strongly supports the presence of humic acid.

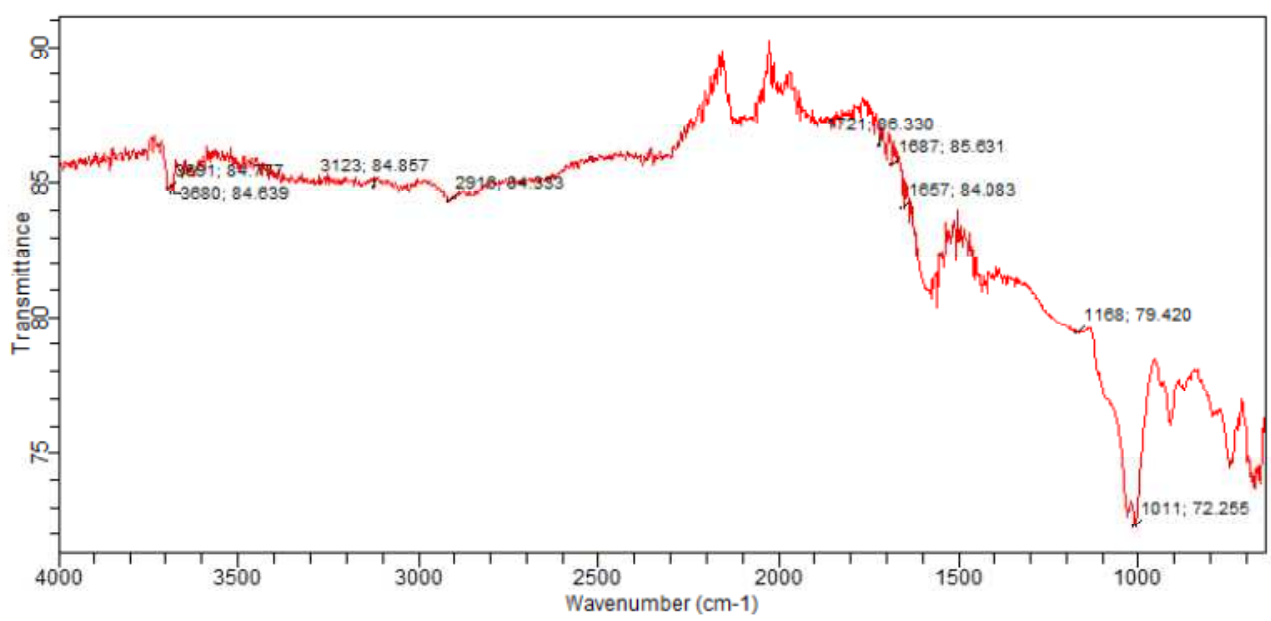

Fig. 2 : FT-IR spectraof peatsoilhumic acid (PSHA)

\section{Evaluation of acid dissociation constant (pka) of acid hydrolysed peat soil humicacid at phenolic group}

The value of the dissociation constant of the peat soil humic acid (PSHA) that underwent acidhydrolysis studied was found to be 8.9299 as shown Table 1, which is lower than the literaturevalues reported by Almeida and Szpoganics, (2015), Borges et al., (2005); Badr et al., (2012)and Fernandes et al,.(2009) of $9.73,9.47$ and 10.30. The difference between the obtained valuesand the reported values in this study might be probably as a result of acid hydrolysis of humicacid. 
BAJOPAS Volume 14 Number 1,June, 2021

Table 1: PKa of (Hydrolysed PSHA)

\begin{tabular}{|l|l|l|l|l|l|l|}
\hline $\mathrm{pH}$ & $\mathrm{BV}_{1}$ & $\mathrm{BV}_{2}$ & $\mathrm{~V}_{2}-\mathrm{V}_{1}$ & $\mathrm{nA}$ & $\log \left(\frac{n A}{1-n A}\right)$ & $\mathrm{pKa}$ \\
\hline 8.50 & 5.30 & 6.29 & 0.99 & 0.3594 & -0.2510 & 8.2490 \\
8.72 & 5.35 & 6.37 & 1.02 & 0.3400 & -0.2880 & 8.4320 \\
9.00 & 5.40 & 6.46 & 1.06 & 0.3141 & -0.3391 & 8.6609 \\
9.22 & 5.45 & 6.55 & 1.10 & 0.2882 & -0.3927 & 8.8273 \\
9.51 & 5.50 & 6.66 & 1.16 & 0.2494 & -0.4786 & 9.0314 \\
9.73 & 5.55 & 6.78 & 1.23 & 0.2041 & -0.5910 & 9.1390 \\
10.00 & 5.60 & 6.90 & 1.30 & 0.1589 & -0.7238 & 9.2762 \\
10.23 & 5.65 & 7.05 & 1.40 & 0.0941 & -0.9835 & 9.2465 \\
10.49 & 5.70 & 7.10 & 1.40 & 0.0941 & -0.9835 & 9.5065 \\
\hline
\end{tabular}

Average pKa $=8.9299 \pm 0.4186$

Table 2: PKa of (Unhydrolysed PSHA)

\begin{tabular}{|l|l|l|l|l|l|l|}
\hline $\mathrm{pH}$ & $\mathrm{BV}_{1}$ & $\mathrm{BV}_{2}$ & $\mathrm{~V}_{2}-\mathrm{V}_{1}$ & $\mathrm{nA}$ & $\log \left(\frac{\boldsymbol{n A}}{1-\boldsymbol{n}}\right)$ & $\mathrm{pKa}$ \\
\hline 8.50 & 5.30 & 5.81 & 0.51 & 0.6619 & 0.2919 & 8.7919 \\
8.72 & 5.35 & 5.90 & 0.55 & 0.6357 & 0.2418 & 8.9618 \\
9.00 & 5.40 & 6.00 & 0.60 & 0.6029 & 0.1813 & 9.1813 \\
9.22 & 5.45 & 6.10 & 0.65 & 0.5701 & 0.1226 & 9.3426 \\
9.51 & 5.50 & 6.20 & 0.70 & 0.5376 & 0.0654 & 9.5754 \\
9.73 & 5.55 & 6.33 & 0.78 & 0.4851 & -0.0259 & 9.7041 \\
10.00 & 5.60 & 6.47 & 0.87 & 0.4262 & -0.1291 & 9.8709 \\
10.23 & 5.65 & 6.62 & 0.99 & 0.3609 & -0.2481 & 9.9819 \\
10.49 & 5.70 & 6.80 & 1.10 & 0.2759 & -0.4690 & 10.0210 \\
\hline
\end{tabular}

Average pKa $=9.4923 \pm 0.4410$

Metal-ligand stability constant ( $\log \mathrm{K}$ )

The stabilityconstants require the accurate values of proton-ligand stability constants (Anil and Maroti, 2008). Metal titration curves crossed over ligand titration curve indicated the formation of complex upon proton release (Santosh, et al., 2011). If the values of n- are within range $0.2-0.8$ and $1.2-18$ this indicates the formation of $1: 1$ and 1:2 complexes (Sayyed and Mazahar, 2012).

The metal (II)-humate stepwise stability constants (log k) at phenolic group (Tables 318)

Table 3: Point-wise method, $\mathrm{Cu}$-(Hydrolysed PSHA)

\begin{tabular}{|l|l|l|l|l|l|l|l|l|}
\hline $\mathrm{pH}$ & $\mathrm{BV}_{1}$ & $\mathrm{BV}_{2}$ & $\mathrm{BV}_{3}$ & $\left(\mathrm{~V}_{3}-\mathrm{V}_{2}\right)$ & $\mathrm{n}$ & $\mathrm{pL}$ & $\log \left(\frac{n}{1-n}\right)$ & LogK $_{1}$ \\
\hline 8.50 & 5.30 & 6.29 & 6.33 & 0.04 & 0.5500 & 2.66 & 0.0871 & 2.7471 \\
8.72 & 5.35 & 6.37 & 6.41 & 0.04 & 0.5714 & 2.43 & 0.1249 & 2.5549 \\
9.00 & 5.40 & 6.46 & 6.50 & 0.04 & 0.6198 & 2.16 & 0.2122 & 2.3722 \\
9.22 & 5.45 & 6.55 & 6.59 & 0.04 & 0.6667 & 1.94 & 0.3010 & 2.2410 \\
\hline
\end{tabular}

LogK $_{1}$ (Average value) $=2.4788 \pm 0.2203$

Table 4: Point-wise method, $\mathrm{Cu}$-(Hydrolysed PSHA)

\begin{tabular}{|l|l|l|l|l|l|l|l|l|}
\hline $\mathrm{pH}$ & $\mathrm{BV}_{1}$ & $\mathrm{BV}_{2}$ & $\mathrm{BV}_{3}$ & $\left(\mathrm{~V}_{3}-\mathrm{V}_{2}\right)$ & $\mathrm{n}$ & $\mathrm{pL}$ & $\log \left(\frac{n-1}{2-n}\right)$ & LogK $_{2}$ \\
\hline 9.51 & 5.50 & 6.66 & 6.73 & 0.07 & 1.3509 & 1.70 & -0.2671 & 1.4329 \\
9.73 & 5.55 & 6.78 & 6.85 & 0.07 & 1.6383 & 1.51 & 0.2467 & 1.7567 \\
10.00 & 5.60 & 6.90 & 6.98 & 0.08 & 2.1783 & 1.31 & -0.2158 & 1.0942 \\
10.23 & 5.65 & 7.05 & 7.13 & 0.08 & 4.1904 & 1.27 & & \\
10.49 & 5.70 & 7.10 & 7.19 & 0.09 & 4.6920 & & & \\
\hline
\end{tabular}

Log $K_{2}($ Average value $)=1.4280 \pm 0.3312$ 
BAJOPAS Volume 14 Number 1,June, 2021

Table 5: Point-wise method, $\mathrm{Cu}$ (Unhydrolysed PSHA)

\begin{tabular}{|l|l|l|l|l|l|l|l|l|}
\hline $\mathrm{pH}$ & $\mathrm{BV}_{1}$ & $\mathrm{BV}_{2}$ & $\mathrm{BV}_{3}$ & $\left(\mathrm{~V}_{3}-\mathrm{V}_{2}\right)$ & $\mathrm{n}$ & $\mathrm{pL}$ & $\log \left(\frac{n}{n-1}\right)$ & Log $_{1}$ \\
\hline 8.50 & 5.30 & 5.81 & 5.85 & 0.04 & 0.2973 & 2.88 & -0.3736 & 2.5064 \\
8.72 & 5.35 & 5.90 & 5.95 & 0.05 & 0.3873 & 2.66 & -0.1992 & 2.4608 \\
9.00 & 5.40 & 6.00 & 6.05 & 0.05 & 0.4044 & 2.38 & -0.1681 & 2.2119 \\
9.22 & 5.45 & 6.10 & 6.15 & 0.06 & 0.5157 & 2.18 & -0.0272 & 2.2072 \\
9.51 & 5.50 & 6.20 & 6.27 & 0.07 & 0.6417 & 1.89 & 0.2530 & 1.1430 \\
\hline
\end{tabular}

$\operatorname{LogK}_{1}($ Average value $)=2.3059 \pm 0.6153$

Table 6:Point-wise method, $\mathrm{Cu}$ (Unhydrolysed PSHA)

\begin{tabular}{|l|l|l|l|l|l|l|l|l|}
\hline $\mathrm{pH}$ & $\mathrm{BV}_{1}$ & $\mathrm{BV}_{2}$ & $\mathrm{BV}_{3}$ & $\mathrm{~V}_{3}-\mathrm{V}_{2}$ & $\mathrm{n}$ & $\mathrm{pL}$ & $\log \left(\frac{n-1}{2-n}\right)$ & $\log \mathrm{K}_{2}$ \\
\hline 9.73 & 5.55 & 6.33 & 6.42 & 0.09 & 0.9000 & 1.69 & & \\
10.00 & 5.60 & 6.47 & 6.58 & 0.11 & 1.2578 & 1.44 & -0.4592 & 0.9808 \\
10.23 & 5.65 & 6.62 & 6.84 & 0.12 & 1.6137 & 1.26 & -0.2010 & 1.4610 \\
10.49 & 5.70 & 6.80 & 6.92 & 0.12 & 2.1052 & 1.03 & & \\
\hline
\end{tabular}

$\operatorname{LogK}_{2}$ (Average value) $=1.2209 \pm 0.3398$

Table 7:Point-wise method, Pb (Hydrolysed PSHA)

\begin{tabular}{|l|l|l|l|l|l|l|l|l|}
\hline $\mathrm{pH}$ & $\mathrm{BV}_{1}$ & $\mathrm{BV}_{2}$ & $\mathrm{BV}_{3}$ & $\left(\mathrm{~V}_{3}-\mathrm{V}_{2}\right)$ & $\mathrm{n}$ & $\mathrm{pL}$ & $\log \left(\frac{n}{1-n}\right)$ & LogK $_{1}$ \\
\hline 8.50 & 5.30 & 6.29 & 6.33 & 0.04 & 0.5500 & 2.66 & 0.0871 & 2.7471 \\
8.72 & 5.35 & 6.37 & 6.41 & 0.04 & 0.5714 & 2.43 & 0.1249 & 2.5549 \\
9.00 & 5.40 & 6.46 & 6.50 & 0.04 & 0.6198 & 2.16 & 0.2122 & 2.3722 \\
9.22 & 5.45 & 6.55 & 6.60 & 0.05 & 0.8333 & 1.96 & 0.6989 & 2.6589 \\
\hline
\end{tabular}

Log $_{\mathbf{1}}($ Average value $)=2.5832 \pm 0.1614$

Table 8:Point-wise method, Pb-(Hydrolysed PSHA)

\begin{tabular}{|l|l|l|l|l|l|l|l|l|}
\hline $\mathrm{pH}$ & $\mathrm{BV}_{1}$ & $\mathrm{BV}_{2}$ & $\mathrm{BV}_{3}$ & $\left(\mathrm{~V}_{3}-\mathrm{V}_{2}\right)$ & $\mathrm{n}$ & $\mathrm{pL}$ & $\log \left(\frac{n-1}{2-n}\right)$ & $\log \mathrm{K}_{2}$ \\
\hline 9.51 & 5.50 & 6.66 & 6.71 & 0.05 & 0.9650 & 1.67 & & \\
9.73 & 5.55 & 6.78 & 6.83 & 0.05 & 1.1702 & 1.44 & & \\
10.00 & 5.60 & 6.90 & 6.90 & 0.05 & 1.4864 & 1.22 & -0.0237 & 1.1963 \\
10.23 & 5.65 & 7.05 & 7.10 & 0.05 & 2.0190 & 1.09 & & \\
10.49 & 5.70 & 7.10 & 7.17 & 0.07 & 3.6492 & 1.00 & & \\
\hline
\end{tabular}

Log $K_{2}$ (Average value) $=1.1963$

Table 9: Point-wise method, Pb (Unhydrolysed PSHA)

\begin{tabular}{|l|l|l|l|l|l|l|l|l|}
\hline $\mathrm{pH}$ & $\mathrm{BV}_{1}$ & $\mathrm{BV}_{2}$ & $\mathrm{BV}_{3}$ & $\mathrm{~V}_{3}-\mathrm{V}_{2}$ & $\mathrm{n}$ & $\mathrm{pL}$ & $\begin{array}{l}\text { Log } \\
\left(\frac{n}{n-1}\right)\end{array}$ & Log $\mathrm{K}_{1}$ \\
\hline 8.50 & 5.30 & 5.81 & 5.85 & 0.04 & 0.2973 & 2.88 & -0.3736 & 2.5064 \\
8.72 & 5.35 & 5.90 & 5.94 & 0.04 & 0.3099 & 2.66 & -0.5477 & 2.3123 \\
9.00 & 5.40 & 6.00 & 6.05 & 0.05 & 0.4044 & 2.38 & -0.1681 & 2.2119 \\
9.22 & 5.45 & 6.10 & 6.15 & 0.06 & 0.5157 & 2.18 & 0.0272 & 2.2072 \\
9.51 & 5.50 & 6.20 & 6.26 & 0.07 & 0.6417 & 1.89 & 0.2530 & 2.1430 \\
9.73 & 5.55 & 6.40 & 6.40 & 0.07 & 0.7000 & 1.67 & 0.3680 & 2.0380 \\
\hline
\end{tabular}

LogK $_{1}$ (Average value) $=2.2364 \pm 0.1602$

Table 10: Point-wise method, Pb (Unhydrolysed PSHA)

\begin{tabular}{|l|l|l|l|l|l|l|l|l|}
\hline $\mathrm{pH}$ & $\mathrm{BV}_{1}$ & $\mathrm{BV}_{2}$ & $\mathrm{BV}_{3}$ & $\mathrm{~V}_{3}-\mathrm{V}_{2}$ & $\mathrm{n}$ & $\mathrm{pL}$ & $\log \left(\frac{n-1}{2-n}\right)$ & $\log \mathrm{K}_{2}$ \\
\hline 10.00 & 5.60 & 6.47 & 6.55 & 0.08 & 1.9503 & 1.41 & & \\
10.23 & 5.65 & 6.62 & 6.72 & 0.11 & 1.4792 & 1.26 & -0.0361 & 1.2239 \\
\hline
\end{tabular}

$\operatorname{LogK}_{2}$ (Average value) $=1.2239$

Table 11: Point-wise method, Mg (Hydrolysed PSHA)

\begin{tabular}{|l|l|l|l|l|l|l|l|l|}
\hline $\mathrm{pH}$ & $\mathrm{BV}_{1}$ & $\mathrm{BV}_{2}$ & $\mathrm{BV}_{3}$ & $\left(\mathrm{~V}_{3}-\mathrm{V}_{2}\right)$ & $\mathrm{n}$ & $\mathrm{pL}$ & $\log \left(\frac{n}{n-1}\right)$ & LogK $_{1}$ \\
\hline 8.50 & 5.30 & 6.29 & 6.31 & 0.02 & 0.2750 & 2.64 & -0.4290 & 2.2110 \\
8.72 & 5.35 & 6.37 & 6.39 & 0.02 & 0.2858 & 2.42 & -0.3978 & 2.0222 \\
9.00 & 5.40 & 6.46 & 6.49 & 0.03 & 0.4648 & 2.14 & -0.0612 & 2.0788 \\
9.22 & 5.45 & 6.55 & 6.59 & 0.04 & 0.6667 & 1.94 & 0.3010 & 2.2410 \\
\hline
\end{tabular}

$\log _{\mathbf{1}}($ Average value) $=2.1382 \pm 0.1046$ 
BAJOPAS Volume 14 Number 1,June, 2021

Table 12: Point-wise method, Mg (Hydrolysed PSHA)

\begin{tabular}{|l|l|l|l|l|l|l|l|l|}
\hline $\mathrm{pH}$ & $\mathrm{BV}_{1}$ & $\mathrm{BV}_{2}$ & $\mathrm{BV}_{3}$ & $\left(\mathrm{~V}_{3}-\mathrm{V}_{2}\right)$ & $\mathrm{n}$ & $\mathrm{pL}$ & $\log \left(\frac{n-1}{2-n}\right)$ & LogK $_{2}$ \\
\hline 9.51 & 5.55 & 6.66 & 6.71 & 0.05 & 0.9650 & 1.67 & & \\
9.73 & 5.55 & 6.78 & 6.84 & 0.06 & 1.4042 & 1.47 & -0.1686 & 1.3014 \\
10.00 & 5.60 & 6.90 & 6.93 & 0.06 & 1.7838 & 1.23 & 0.5593 & 1.7893 \\
10.23 & 5.65 & 7.05 & 7.10 & 0.06 & 3.1429 & 1.10 & & \\
10.49 & 5.70 & 7.10 & 7.18 & 0.07 & 3.6492 & 0.83 & & \\
\hline
\end{tabular}

LogK $_{2}($ Average value $)=1.5453 \pm 0.3450$

Table 13: Point-wise method, Mg (Unhydrolysed PSHA)

\begin{tabular}{|l|l|l|l|l|l|l|l|l|}
\hline $\mathrm{pH}$ & $\mathrm{BV}_{1}$ & $\mathrm{BV}_{2}$ & $\mathrm{BV}_{3}$ & $\mathrm{~V}_{3}-\mathrm{V}_{2}$ & $\mathrm{n}$ & $\mathrm{pL}$ & $\log \left(\frac{n}{n-1}\right)$ & $\operatorname{Log~}_{1}$ \\
\hline 8.50 & 5.30 & 5.81 & 5.85 & 0.04 & 0.2973 & 2.88 & -0.3736 & 2.5064 \\
8.72 & 5.35 & 5.90 & 5.94 & 0.04 & 0.3099 & 2.66 & -0.3477 & 2.3123 \\
9.00 & 5.40 & 6.00 & 6.04 & 0.04 & 0.3236 & 2.38 & -0.3202 & 2.0598 \\
9.22 & 5.45 & 6.10 & 6.15 & 0.05 & 0.4297 & 2.17 & -0.1230 & 2.0470 \\
9.51 & 5.50 & 6.20 & 6.26 & 0.06 & 0.5500 & 1.89 & 0.0871 & 1.9771 \\
9.73 & 5.55 & 6.33 & 6.40 & 0.07 & 0.7000 & 1.67 & 0.3680 & 2.0380 \\
\hline
\end{tabular}

LogK $_{1}$ (Average value) $=2.1568 \pm 0.2069$

Table 14: Point-wise method, Mg (Unhydrolysed PSHA)

\begin{tabular}{|l|l|l|l|l|l|l|l|l|}
\hline $\mathrm{pH}$ & $\mathrm{BV}_{1}$ & $\mathrm{BV}_{2}$ & $\mathrm{BV}_{3}$ & $\mathrm{~V}_{3}-\mathrm{V}_{2}$ & $\mathrm{n}$ & $\mathrm{pL}$ & $\log \left(\frac{n-1}{2-n}\right)$ & $\log \mathrm{K}_{2}$ \\
\hline 10.00 & 5.60 & 6.47 & 6.55 & 0.08 & 0.9148 & 1.41 & & \\
10.23 & 5.65 & 6.62 & 6.71 & 0.09 & 1.2102 & 1.20 & -0.5749 & 0.6251 \\
10.49 & 5.70 & 6.80 & 6.92 & 0.09 & 1.5968 & 1.03 & 0.1703 & 1.2003 \\
\hline
\end{tabular}

LogK $_{2}$ (Average value) $=0.9127 \pm 0.4070$

Table15:Point-wise method, Cd (Hydrolysed PSHA)

\begin{tabular}{|l|l|l|l|l|l|l|l|l|}
\hline $\mathrm{pH}$ & $\mathrm{BV}_{1}$ & $\mathrm{BV}_{2}$ & $\mathrm{BV}_{3}$ & $\left(\mathrm{~V}_{3}-\mathrm{V}_{2}\right)$ & $\mathrm{n}$ & $\mathrm{pL}$ & $\log \left(\frac{n}{1-n}\right)$ & LogK $_{1}$ \\
\hline 8.50 & 5.30 & 6.29 & 6.31 & 0.02 & 0.2750 & 2.64 & -0.4210 & 2.2190 \\
8.72 & 5.35 & 6.37 & 6.40 & 0.03 & 0.4286 & 2.42 & -0.1249 & 2.2951 \\
9.00 & 5.40 & 6.46 & 6.49 & 0.03 & 0.4648 & 2.14 & -0.0612 & 2.0788 \\
9.22 & 5.45 & 6.55 & 6.59 & 0.04 & 0.6667 & 1.96 & 0.3010 & 2.2610 \\
9.51 & 5.55 & 6.66 & 6.70 & 0.04 & 0.7720 & 1.67 & 0.5297 & 2.1997 \\
\hline
\end{tabular}

LogK $_{\mathbf{1}}$ (Average value) $=2.2108 \pm 0.0825$

Table 16: Point-wise method, Cd (Hydrolysed PSHA)

\begin{tabular}{|l|l|l|l|l|l|l|l|l|}
\hline $\mathrm{pH}$ & $\mathrm{BV}_{1}$ & $\mathrm{BV}_{2}$ & $\mathrm{BV}_{3}$ & $\left(\mathrm{~V}_{3}-\mathrm{V}_{2}\right)$ & $\mathrm{n}$ & $\mathrm{pL}$ & $\log \left(\frac{n-1}{2-n}\right)$ & Log $_{2}$ \\
\hline 9.73 & 5.55 & 6.78 & 6.83 & 0.06 & 1.4042 & 1.47 & -0.1686 & 1.3014 \\
10.00 & 5.60 & 6.90 & 6.95 & 0.06 & 1.7838 & 1.23 & 0.5593 & 1.7893 \\
10.23 & 5.65 & 7.05 & 7.10 & 0.06 & 3.1429 & 1.09 & & \\
10.49 & 5.70 & 7.10 & 7.16 & 0.06 & 3.1429 & 0.89 & & \\
& & & & & & & & \\
\hline
\end{tabular}

$\operatorname{LogK}_{2}$ (Average value) $=1.5453 \pm 0.3450$

Table 17: Point-wise method, Cd (Unhydrolysed PSHA)

\begin{tabular}{|l|l|l|l|l|l|l|l|l|}
\hline $\mathrm{pH}$ & $\mathrm{BV}_{1}$ & $\mathrm{BV}_{2}$ & $\mathrm{BV}_{3}$ & $\mathrm{~V}_{3}-\mathrm{V}_{2}$ & $\mathrm{n}$ & $\mathrm{pL}$ & $\log \left(\frac{n}{n-1}\right)$ & $\operatorname{Log~}_{1}$ \\
\hline 8.50 & 5.30 & 5.81 & 5.86 & 0.05 & 0.3717 & 2.88 & -0.2280 & 2.6520 \\
8.72 & 5.35 & 5.90 & 5.95 & 0.05 & 0.3873 & 2.66 & -0.1992 & 2.4608 \\
9.00 & 5.40 & 6.00 & 6.06 & 0.06 & 0.4853 & 2.38 & -0.0255 & 2.3545 \\
9.22 & 5.45 & 6.10 & 6.16 & 0.06 & 0.5157 & 2.18 & -0.0272 & 2.2072 \\
9.51 & 5.50 & 6.20 & 6.27 & 0.07 & 0.6417 & 1.89 & 0.2530 & 1.1430 \\
9.73 & 5.55 & 6.33 & 6.41 & 0.08 & 0.8000 & 1.69 & 0.6020 & 2.2920 \\
& & & & & & & & \\
\hline
\end{tabular}

$\operatorname{LogK}_{1}($ Average value $)=2.2516 \pm 0.5380$ 
BAJOPAS Volume 14 Number 1,June, 2021

Table 18: Point-wise method, Cd (Unhydrolysed PSHA)

\begin{tabular}{|l|l|l|l|l|l|l|l|l|}
\hline $\mathrm{pH}$ & $\mathrm{BV}_{1}$ & $\mathrm{BV}_{2}$ & $\mathrm{BV}_{3}$ & $\mathrm{~V}_{3}-\mathrm{V}_{2}$ & $\mathrm{n}$ & $\mathrm{pL}$ & $\log \left(\frac{n-1}{2-n}\right)$ & $\log \mathrm{K}_{2}$ \\
\hline 10.00 & 5.60 & 6.47 & 6.57 & 0.10 & 1.1434 & 1.43 & & \\
10.23 & 5.65 & 6.62 & 6.72 & 0.10 & 1.3448 & 1.23 & -0.2788 & 0.9512 \\
10.49 & 5.70 & 6.80 & 6.90 & 0.10 & 1.7742 & 1.03 & 0.5351 & 1.5651 \\
\hline
\end{tabular}

$\operatorname{LogK}_{2}($ Average value $)=1.2581 \pm 0.4340$

Table 19: Stepwise and overall Stability constants of thehydrolysed and unhydrolysed divalent metal (II) complexes

\begin{tabular}{|c|c|c|c|}
\hline Chelates & LogK $_{1}$ & $\log _{2}$ & Log $\beta$ \\
\hline [Cu (Hydrolysed PSHA-1) $\left.{ }_{2}\right]$ & 2.4788 & 1.4280 & 3.9068 \\
\hline$\left[\mathrm{Pb}(\text { Hydrolysed PSHA-1) })_{2}\right]$ & 2.5832 & 1.1963 & 3.7795 \\
\hline$\left[\mathrm{Cd}(\text { Hydrolysed PSHA-1 })_{2}\right]$ & 2.2108 & 1.5453 & 3.7561 \\
\hline$\left[\mathrm{Mg}(\text { Hydrolysed PSHA-1 })_{2}\right]$ & 2.1382 & 1.5453 & 3.6835 \\
\hline [Cu (Unhydrolysed PSHA-1) & 2.3059 & 1.2209 & 3.5268 \\
\hline$[\mathrm{Pb}$ (Unhydrolysed PSHA-1) 2$]$ & 2.2364 & 1.2239 & 3.4603 \\
\hline [Cd (Unhydrolysed PSHA-1) 2 ] & 2.2516 & 1.2581 & 3.5097 \\
\hline$[\mathrm{Mg}$ (Unydrolysed PSHA-1) & 2.1568 & 0.9127 & 3.0695 \\
\hline
\end{tabular}

The results obtained (Table19) shows the stepwise and overall stability constants to be not high indicating low stability of the complexes, because the solubility of most metal ions in the basic $\mathrm{pH}$ range is minimal due to metal hydroxide precipitation (Karimi, 2017). In general, the stepwise stability constants $\left(K_{1}\right.$ and $K_{2}$ ) follow the order $K_{1}>K_{2}$ for the copper, lead, magnesium and cadmium complexes respectively. The steady decrease of the values with increasing number of ligands is in agreement with the prediction made by researchers (Na'aliya, 2013). The decrease could be attributed to the fact that as the number of the ligands (Humate ions) that enters the coordination zone increases the aqua molecules available for replacement by the ligands become less. Thus, the metal ions become less electron loving with progressive intake of the ligand and this results in the decrease in the values of the constants (Na'aliya, 2013). Also the stability of the complexes is influenced by the size and number of the chelate rings(Mackay and Mackay,2002).All the complexes form rings in their structure as humate, a bidentate ligand, bond the metal ions in the ratio 1:2 (Boguta and Sokolowska, 2016) forming chelate rings. The values of the overall stability constants $(\log \beta)$ obtained for humate complexes are not high indicating low stability as the values are not high. LogK values for copper-humates (Table 3 to 6) obtained in this study are lower than those reported for the complexes of humic acids (Pandey et al., 2015; Dinu, 2013; Kaschl et al., 2010 and Gilbeto and Jorg, 2001). The values of LogK(Table 7 to 10 ) forlead-humates are lower than those reported for the lead in the literature (Dinu, 2013; Gilbeto and Jorg 2001). Log K values(Table 11 to 14 ) for magnesium-humates obtained in this study are close to those reported by (Pandey et al., 2015). Log K values of cadmium-humates (Table 15 to 18 ) obtained in this work near to the one reported by (Dinu, 2013 and Pandey et al., 2015).The difference between the reported values and the values obtained in this study might be probably as a result of acid hydrolysis of humic acid. The values of the overall stability constants $(\log \beta)$ of the copper humates complexes presented in Table 19 is high than that of other metal humate complexes, show relatively high stability of CuHA complexes, show the following order of stability: $\mathrm{Cu}>\mathrm{Pb}>\mathrm{Cd}>\mathrm{Mg}$; which are in close agreement to the findings of (Dinu, 2013 and Pandey et al., 2015).The high stability of Cuhumate chelate could be attributed to the existence of coordinate covalent bond between the complexing agents and the $\mathrm{Cu}^{2+}$ ions. Since, $\mathrm{Cu}^{2+}$ being a metal of the transitional series with $3 d^{9}$ electronic configurations can accept the electrons from the complexing agents. Similarly, the low stabilities of $\mathrm{Pb}, \mathrm{Cd}$ and $\mathrm{Mg}$ complexes could be explained by that $\mathrm{Pb}^{2+}$ with $6 s^{2}, \mathrm{Cd}^{2+}$ with $4 \mathrm{~d}^{10}$ and $\mathrm{Mg}^{2+}$ with $2 \mathrm{p}^{6}$ their electronic configuration has a completely filled $\mathrm{d}, \mathrm{p}$ and $\mathrm{s}$ orbitals. Moreover, the stabilities of metal ions with hydrolysed humic acid from peat soil were higher than those with unhydrolysed humic acid from peat soil; which is ascribed to the high content of acidity in hydrolysed humic acid than unhydrolysed humic acid. 
BAJOPAS Volume 14 Number 1,June, 2021 CONCLUSION

The values of logk for $\mathrm{Cu}(\mathrm{II})$ hydrolysed humic acid complex was higher followed by $\mathrm{Pb}$ (II), $\mathrm{Cd}(\mathrm{II})$ and $\mathrm{Mg}$ (II) hydrolysed humic acid complexes as compared with metal(II) unhydrolysed humic acid complexes. This indicates acid hydrolysis of humic acid can

\section{REFERENCES}

Almeida, V.R. and Szpoganicz, B. (2015). Humic Acid Potentiometric Response Patterns:Out- of Equilibrium Properties and Species Distribution Modelling. Chemical. Biol. Technol. Agric. 2: 17.

Anđelković, T., Nikolić, R., Bojić, A.,Anđelković, D., and Nikolic G.,(2010). Binding of Cadmium to Soil Humic Acid as A Function of Carboxyl Group Content. Macedonian Journal of Chemistry and Chemical Engineering.29(2): 215-224.

Anil, B. N. and Maroti, N. (2008). Studies on Influence of Die-Lectric Constants on Complex Equilibria between Substituted Py-Razalines and Lanthanide Metal Ions pH-Metrically. Amer.-Euras. scient. Res. 3(2): 212-216.

Ashok, K., Pandey, S. P. and Misra, V (2000). Stability Constants of Metal-Humic Acid Complexes and its Role in Environmental Detoxification. Journal of Ecotoxicology and Environmental Safety. 47(2):157-200.

Badr, M. H., El-Halafawi, M. H. and Abd El-al Zeid, E. R. (2012). Comparison Between the Effect of Ionic Strength on Acidity and Dissociation Constants of Humic Acids Extracted from Sewage Sludge and Nile Water Hyacinth Composts.Global Journal of Environmental Research 6 (1): 36-43.

Baruah, M.K., Borah, D., Saikia, P.P., Paul, S., Sharma, T. (2015). Evaluation of pKa Values of Soil Humic Acids and their Complexation Properties. International Journal of Plant \& Soil Science 6(4) : 218-228.

Boguta, P. Sokolowska, Z. (2016). Interactions of $\mathrm{Zn}$ (II) Ions with Humic Acids Isolated from Various Types of Soils. Effect of $\mathrm{pH}, \mathrm{Zn}$ Concentrations and Humic Acids Chemical Properties. Journal of Geochemical Explaration 168. 119-126.

Borges, F., Guimaraes, C., Lima, L.F.C., Pinto, I. and Reis, S.(2005). Potentiometric Studies on the Complexation of Copper(II) by Phenolic Acids as Discrete Ligand Models of enhance the complexation behavior of humic acid with metal (II) ions. However, the higher values of $\log \beta$ for $\mathrm{Cu}(\mathrm{II}), \mathrm{Pb}(\mathrm{II}), \mathrm{Cd}(\mathrm{II})$ and $\mathrm{Mg}(\mathrm{II})$ hydrolysed humic acid complexes indicates more stable stepwise complexes formed as compared with $\mathrm{Cu}(\mathrm{II}), \mathrm{Pb}$ (II), $\mathrm{Cd}$ (II) and $\mathrm{Mg}(\mathrm{II})$ unhydrolysed humic acid complexes.

Humic Substances Talanta 66 (2005) 670-673.

Chefetz, B., Salloum, M. J., Deshmulkin, A. P. and Hatcher, P. (2002). Structural Components of Humic Acids as Determined by Chemical Modifications and Carbon-13 NMR, Pyrolysis, and Thermochemolysis- Gas Chromatography/Mass Spectrometry. Soil Science Society of American Journal Abstract Division S-2- Soil Chemistry66. 1159-1171.

Dinu, M. I. (2013). Metals Complexation with Humic Acids in Surface Water of Different Environ. Sci. Technol. 31(1): 1-17.

Fernandes, A.N., Giacomelli, C., Giovanela, M. Vaz, D.V. Szpoganicz, B. and Maria M. D. (2009). Potentiometric Acidity Determination in Humic Substances Influenced by Different Analytical Procedures.J. Braz. Chem. Soc. 20 (9):14.

Gamal, A. H. (2015). Stability Constants of Rhenium (V) Metal Complexes with Selected Drugs. Pyrex Journal of Research in Environmental Studies. 2(2): 006-014.

Janrao, D. M., Pathan, J., Kayande, D.D., and Mulla, J.J. (2014). An Over View of Potentiometric Determination of Stability Constants of Metal Complexes. Sci. Revs. Chem. Commun.: 4(1), 2014, 11-24.

Karimi, H. (2017). Effect of pH and Initial Pb(II) Concentration on the Lead Removal Efficiency from Waste Water Using $\mathrm{Ca}(\mathrm{OH})_{2}$. International Journal of Water and Waste Water Treatment 3.2

Kaschl, A. Romheld, V. and Chen, Y. (2010). Binding of Cadmium, Copper and Zinc to Humic Substances Originating from Municipal Solid Waste Compost. Israel Journal of Chemistry Vol. 42(1): 89-98.

Kostic, I. S., Tatjana, P, A., Nikolic, R. S., Cvetkovic, T. P., Pavlovic, D. D., Aleksandar, L.J. and Bojic, A. (2012). Comparative Study of Binding Strengths of Heavy Metals with Humic Acid. J.serb. Chem. Soc. 76(9) pp 1-20. 
BAJOPAS Volume 14 Number 1,June, 2021

Na'aliya, J. (2013). Determination of Stepwise Stability Constants and Gibbs free Energy Change of Trisprolina to Complexes of some Divalent Transition Metal ions. Bayero Journal of Pure and Applied Sciences 6(2): 112-114.

Omar, A. A. and Ali, E. A. (2015). Potentiometric Studies on Complexes of $\mathrm{Cr}$ (III) and $\mathrm{Zr}$ (IV) with some Carboxylic Acids. International Journal of Advanced Chemistry, 3(1) 25-

37.

Pandey, A. K. Pandey, S. D. and Misr, V. (2015).Stability Constants of Metal- Humic Acid Complexes and Its Role in Environmental Detoxification. J. Ecotoxicology and Environmental Safety. 47(1):195-200.

Ram, N. and Raman, K.V. (1984). Stability Constants of Complexes of Metals with
Humicand Fuvic Acids under Non- acidConditions. Journal of Plant Nutrition and Soil Sciences.

147:171-176.

Santosh, D. D., Ashok, B. K., Vijay, J. T., Shivraj, G. W. and Vinay, V. W. (2011). Potentiometric Studies of Elec-Trolyte Effects on Complex Equilibria of Some Substituted 5-(2-hydroxy Phenyl) Pyrazoles. Der pharm. 3 (6): 75-83.

Sayyed, H. and Abdul Rahim, M. F. (2012). Studies of Binary Complexes of Metal Ions with Mandelic Acid by Potentiometry. Chem. J. 02 (6): 206209.

Shirvani, M. Moradian, E. Khalili, B. Bakhtiary, S. (2015). Interaction of $\mathrm{Cd}$ and $\mathrm{Pb}$ with Humate-Palygorskite and HumateSepiolite Complexes. Journal of water, air and pollution 3: 220-228. 


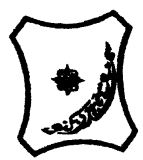

Bayero Journal of Pure and Applied Sciences, 14(1): 54 - 63

Received: November, 2020

Accepted: April, 2021

ISSN $2006-6996$

\title{
STABILITY CONSTANTS OF COMPLEXES OF METAL IONS WITH PEATSOIL HUMIC ACIDS UNDER NON-ACID-CONDITIONS
}

\author{
${ }^{* 1}$ Sabo, Yusuf ${ }^{2}$ Jimoh, W.L.O., ${ }^{3}$ Isa Baba Koki and ${ }^{4}$ Sholadoye, Q. 0. \\ ${ }^{1}$ Department of Pure and Industrial Chemistry, Bayero University, Kano \\ ${ }^{3}$ Department of Chemistry, Yusuf Maitama Sule University Kano. P.M.B. 3220 Kano, Nigeria. \\ ${ }^{4}$ Department of Chemistry, Nigerian Police Academy, Wudil, Kano-Nigeria
}

*Correspondence E-mail; saboyusuf18@yahoo.com

ABSTRACT

Stability constants of complexes of four divalent metal ions viz. $\mathrm{Cu}^{2+}, \mathrm{Pb}^{2+}, \mathrm{Mg}^{2+}$ and $\mathrm{Cd}^{2+}$ with humic acids (HA) were determined by potentiometric titration of humic acids with the corresponding salt of the divalent metals in aqueous media under non-acid-condition. The log $K$ (logarithm of the stability constant) ranged from 1.0942 to 2.7471 for metalhumic acid complexes were determined using point-wise computational method. The order of stability constants were obtained as follows: $\mathrm{Cu}>\mathrm{Pb}>\mathrm{Cd}>\mathrm{Mg}$ for metal $-\mathrm{HA}$ complexes respectively, indicating a higher degree of complexation with Cu metal ion.

Keywords: stability constant, humic acid, potentiometric titration, divalent metals, acid hydrolysis.

\section{NTRODUCTION}

The stability constant of a complex is the numerical expression of its stability and provides a quantitative measure of affinity of the metal ion to the complexing agent. An understanding of the relative stability of metal-complexes helps in predicting the behavior of metal ions in the soil (Ram and Raman, 1982). Extensive researches has been done to determine the stability constants of the complexes formed between humic acid (HA) with a number of metal ions. Ashok et al., (2000) reported that humic acid with hydroxyl, phenoxyl and carboxyl reactive groups can form coordination compound with metal ions at $\mathrm{pH}$ 3.5. The stability constants(Log K) for different metalhumic acid complexes indicated the following order of the stabilities of complexes formed between humic acid and metal ion, $\mathrm{Cu}>\mathrm{Fe}$ $>\mathrm{Pb}>\mathrm{Ni}>\mathrm{Co}>\mathrm{Ca}>\mathrm{Cd}>\mathrm{Zn}>\mathrm{Mn}>\mathrm{Mg}$. Andelkovic et al., (2010) investigated the binding of $\mathrm{Cd}$ (II) to soil humic acid at pH 6.5 and in $0.1 \mathrm{M} \mathrm{KNO}_{3}$ ionic medium. The stability constant for binding indicating greater stability in the case when carboxyl groups are involved in complexation reaction. Kostic et al.,(2012) investigated the complexation of humic acid with certain heavy metal ions (Co(II), $\mathrm{Ni}(\mathrm{II}), \mathrm{Cu}(\mathrm{II})$,
$\mathrm{Zn}(\mathrm{II})$, and $\mathrm{Pb}(\mathrm{II})$. The experiment was performed at $25^{\circ} \mathrm{C}$, at pH 4.0 and ionic strength of $0.01 \mathrm{M}$. Stability constant of complex between $\mathrm{Pb}$ (II) ions and humic acid is greater than stability constants of other investigated metalhumate complexes. Bogata and Sokolowska (2016) analyses the interaction between humic acids from different soils and $\mathrm{Zn}$ (II) ions at wide concentration ranges and at $\mathrm{pH} 5$. Studies have showed significant impact of $\mathrm{Zn}$ concentration, $\mathrm{pH}$ and some properties of humic acids with zinc.But all of these studies were limited to acidic $\mathrm{pH}$ range. Therefore, the present study was carried out to determine and compare the stability constants of complexes of metal ions with hydrolysed peat soil humic acid and unhydrolysed peat soil humic under non-acid conditions.

\section{MATERIALS AND METHODS}

Analytical grade chemicals used includes hydrochloric acid $(\mathrm{HCl})$, nitric acid $\left(\mathrm{HNO}_{3}\right)$, sodium hydroxide $(\mathrm{NaOH})$, lead nitrate $\mathrm{Pb}\left(\mathrm{NO}_{3}\right)_{2}$, copper nitrate $\mathrm{Cu}\left(\mathrm{NO}_{3}\right)_{2} \cdot 3 \mathrm{H}_{2} \mathrm{O}$, cadmium nitrate $\mathrm{Cd}\left(\mathrm{NO}_{3}\right)_{2} \cdot 4 \mathrm{H}_{2} \mathrm{O}$, magnesium nitrate $\mathrm{Mg}\left(\mathrm{NO}_{3}\right)_{2} \cdot 6 \mathrm{H}_{2} \mathrm{O}$, potassium nitrate $\left(\mathrm{KNO}_{3}\right)$, calcium chloride $\left(\mathrm{CaCl}_{2}\right)$, (sigma-Aldrich). Dowex 50WX8, (20-50 mesh) from Fluka. 


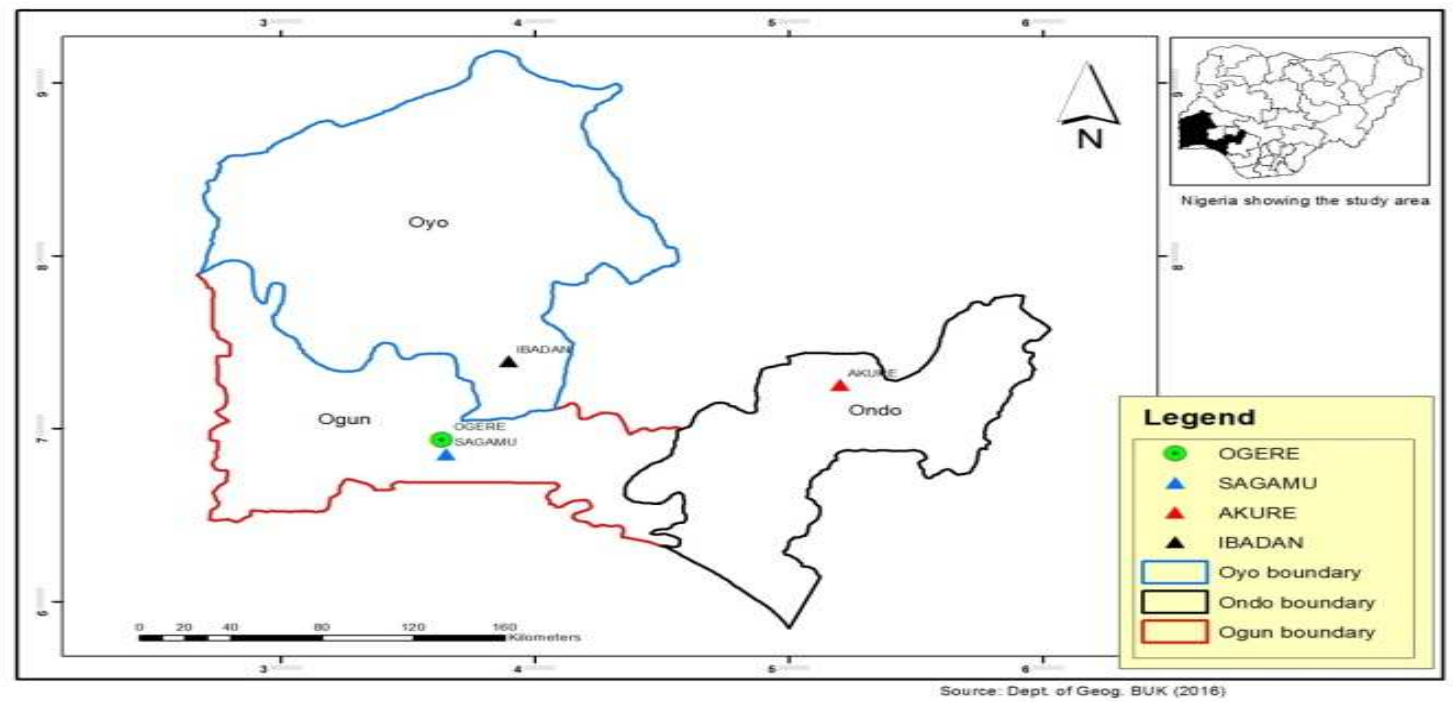

Figure 1: Map showing the sampling point at Sagamu Town, Ogun State.

\section{Description of Sampling Area}

Sagamu has geographical coordinates between $6^{\circ} 50^{\prime}$ north; $3^{\circ} 38^{\prime}$ east is located in south western region of Nigeria. The region has tropical wet and dry climate with a lengthy wet season and relatively constant temperatures throughout the course of the year. Wet season runs from March to October, November to December forms the region dry season. The vegetation type of the region is savannah which is really grassland with small bushes and occasional big trees. Grassland soils have substantially higher organic matter content than forest soils (Novackova, 2011).

\section{Sample Collection}

The Peatsoil samples were collected from four different sampling points $(0-10 \mathrm{~cm}$ depth) in Sagamu into polyethylene bag with plastic spoons. Samples were taken to the laboratory, extraneous materials were removed; the samples were air-dried, crushed and ground to a fine powder in a mortar passed through a $0.20 \mathrm{~mm}$ sieve. The samples were kept for analysis.

\section{Isolation and purification of humic acid from peat soil sample}

Peatsoil sample $(100 \mathrm{~g})$ was mixed with 1000 $\mathrm{cm}^{3}$ of $0.1 \mathrm{M} \mathrm{NaOH}$ solution, shaken for 3hours and left to stand overnight. Dark-coloured supernatant was obtained and decanted from solid residue. The dark-coloured supernatant was acidified to $(\mathrm{pH}=1.0)$ with $6 \mathrm{M} \mathrm{HCl}$ stirred and allowed to stand for 6 hours. Yellowish brown supernatant and dark-brown precipitate were obtained. The yellowish brown supernatant was decanted followed by centrifuge and discarded. The dark-brown precipitate was mixed with $500 \mathrm{~cm}^{3}$ of $0.1 \mathrm{M} \mathrm{NaOH}$ solution followed by passing through dowex resin. The dark-brown solution was acidified to $(\mathrm{pH}=1.0)$ with $6 \mathrm{M} \mathrm{HCl}$ stirred and allowed to stand for 3 hours. The dark-brown precipitate was washed several times with deionized water. The supernatant was treated with $\mathrm{AgNO}_{3}$ solution until no white precipitate observed. The humic acid was transferred to weighed crucible and dried at $60^{\circ} \mathrm{C}$ in an oven for 12 hours. The humic acid was cooled and dried in the desiccator, weighed and recorded. The obtained humic acid was dried again at $60^{\circ} \mathrm{C}$ for additional 6 hours cooled and dried in the desiccator, weighed and recorded constant weight was obtained (Baruah et al., 2015).

\section{FT-IR analysis}

FT-IR spectra of humic acid sample was analysed using Carry 630 FT-IR Agilent Technologies.

Unhydrolysed compost humic acid

The unhydrolysed humic acid was obtained after isolation and purification of compost humic acid and kept for investigation.

\section{Acid hydrolysis of Peatsoil acid}

Peatsoil humic acid sample (1g) was refluxed for 12 hours at $\left(160^{\circ} \mathrm{C}\right)$ with $50 \mathrm{~cm}^{3}$ of $6 \mathrm{M} \mathrm{HCl}$. The mixture was allowed to cool, decanted, and centrifuged after hydrolysis. The insoluble residues were washed with distilled water via centrifugation several times, and the supernatant was treated with $\mathrm{AgNO}_{3}$ solution until no white precipitate was observed. The residue was thoroughly dried over $\mathrm{CaCl}_{2}$ in a desiccator at room temperature (Chefetz et al., 2002). Finally, the obtained hydrolysed humic acid was kept for investigation. 
BAJOPAS Volume 14 Number 1,June, 2021 Potentiometric Titrations

Potentiometric measurements were carried out using a pH-meter Jenway (model 3510) with combine electrode, the sensitivity of the $\mathrm{pH}$ meter is 0.01 units. The $\mathrm{pH}$ meter was switched on half an hour before starting the titration for initial warm up of the instrument. The instrument was calibrated with an aqueous standard buffer solution of $\mathrm{pH} 4.00$ and 10.0 (borate buffer) prepared from a "Qualigens" buffer tablets.

The following sets of solutions were prepared in a $250 \mathrm{~cm}^{3}$ volumetric flask separately for $\mathrm{pH}$ metric titrations.

(i) $5 \mathrm{~cm}^{3} 0.1 \mathrm{M} \mathrm{HCl}+40 \mathrm{~cm}^{3}$ deionized water

(ii) $5 \mathrm{~cm}^{3} 0.1 \mathrm{M} \mathrm{HCl}+39 \mathrm{~cm}^{3}$ deionized water $+1 \mathrm{~cm}^{3} 0.15 \mathrm{gcm}^{-3}$ humic acid

(iii) $5 \mathrm{~cm}^{3} 0.1 \mathrm{M} \mathrm{HCl}+37 \mathrm{~cm}^{3}$ deionized water $+1 \mathrm{~cm}^{3} 0.15 \mathrm{gcm}^{-3}$ humic acid

$$
+2 \mathrm{~cm}^{3} \quad 0.01 \mathrm{M} \mathrm{Cu} \text { (II) }
$$

The solutions were titrated against standardized $0.110 \mathrm{MNaOH}$ separately. The total volume of each mixture was adjusted to $50 \mathrm{~cm}^{3}$ and the ionic strength of the solutions was maintained constant at by adding appropriate amount of stock solution of $1 \mathrm{M} \mathrm{KNO}_{3}$ (Gamal, 2015; Omar and Ali, 2015). A magnetic stirrer was used to achieve thorough mixing of the interacting solutions at $550 \mathrm{rpm}$. The same set of experimental conditions was applied for potentiometric titration of remaining samples.

\section{Evaluation of pKa of Hydrolysed peat soil Humic Acids}

The proton-ligand formation number $\mathrm{n}_{\mathbf{A}}$ were calculated by Irving and Rossotti expression (Omar and Ali, 2015).

$\mathrm{nA}=\mathrm{Y}-\frac{(\mathrm{V} 2-\mathrm{V1})(\mathrm{No}-\mathrm{Eo})}{(\mathrm{VO}+\mathrm{V1}) \mathrm{TCL}}$ 1

Where: $Y$ is number of dissociable proton, $\left(\mathrm{V}_{2^{-}}\right.$ $V_{1}$ ) is the measure of displacement of the ligand curve relative to acid curve, $\mathrm{N}^{\circ}$ and $\mathrm{E}^{\circ}$ are the resultant concentration of alkali solution, free acid solution, $\mathrm{T}_{\mathrm{cL}}{ }^{\circ}$ is the total ligand concentration, $\mathrm{V}^{\circ}$ is the total volume of titration solution, $V_{1}$ is the volume of alkali added to acid solution, $V_{2}$ is the volume of alkali added to acid solution + ligand solution, acid dissociation constants (pKa - values) of ligand were calculated by algebraic method point wise calculation (Tables 1 ). The dissociation constants (pKa) were calculated according to the following relation:

$\mathrm{pKa}=\mathrm{pH}+\log \left(\frac{n A}{1-n A}\right)$ 2

Where: pKa is the acid dissociation constant, $\mathrm{n}_{\mathrm{A}}$ is the Proton-ligand formation number and $\mathrm{pH}$ is the pH-values (Omar and Ali, 2015).

\section{Determination of metal-ligand stability constants $(\log K)$ of complexes}

The potentiometric measurement for the determination of stability constant of a complex in solution is based on the fact that the redox potential of the couple $\frac{M^{+(m-n)}}{M^{+m}}$ is shifted significantly on complexation of the metal ion with the ligand. This method involves change in hydrogen ion concentration $\left[\mathrm{H}^{+}\right]$due to the displacement or association of one or more protons taking place during complexation reaction. This change can be found out by titrating the solutions containing free acid, acid with ligand, and acid with ligand and metal ion, individually against a standard alkali solution at a constant ionic strength or temperature. Either ionic strength or temperature may be varied for different sets of solutions. In all the cases, the change in the $\mathrm{pH}$ of the solution is measured after each addition of a known amount of alkali to the reaction cell which contains the reaction mixture. The titration curves are then drawn by plotting the measured $\mathrm{pH}$ values against the corresponding volume of alkali added and the stability constants of the complexes are determined from the titration curves by employing $\mathrm{pH}$-metric titration technique given by (Irving and Rossoti).

Metal-ligand stability constants ( $\log \mathrm{K}$ ) were determined by using the following relations:

$$
\bar{n}=\frac{\left(V_{3}-V_{2}\right)\left(E^{0}+N^{0}\right)}{\left(V^{0}+V_{2}\right) \bar{n}_{A} T_{m}^{0}}
$$

and

$$
P L=\log _{10}\left\{\frac{1+\beta_{n}^{H} \frac{1}{[\text { anti } \log \mathrm{pH}]^{\mathrm{n}}}}{\mathrm{T}_{\mathrm{L}}^{0}-n \bar{T}_{m}^{0}} \mathrm{X} \frac{\left(V^{0}+V_{3}\right)}{V^{0}}\right\}
$$


BAJOPAS Volume 14 Number 1,June, 2021

Where $T_{L}, T^{\circ}, E^{\circ}$, and $V^{\circ}$ havethe same significance as in equation (1) above, $T_{m}$ denotes the total concentration of metal present in solution, $V_{3}$ is the volume of metal ions present in solution and $\beta^{H}$ is the overall proton ligand stability constant. The metal-ligand stability constants (log K) were determined by employing point wise computational Method (eq. 5 and 6).

$\operatorname{LogK}_{1}=\log \left(\frac{n}{1-n}\right)+\mathrm{pL}$ .5

$\operatorname{LogK}_{2}=\log \left(\frac{1-n}{2-n}\right)+\mathrm{pL}$ ...6

Where: Log $\mathrm{K}$ is the metal-ligand stability constant, $\mathrm{pL}$ is the Free ligand exponent function, $\mathbf{n}$ is the Average number of ligand attached with metal ion (Janraoet al., 2014). The results obtained were analyzed by an ORIGIN 2016 program using titration data and then the proton-ligand stability constants (pKa) and Metal-ligand stability constant (LogK) calculated (Omar and Ali, 2015).

\section{RESULTS AND DISCUSSION}

Fourier transformed infrared (FT-IR) spectra of isolated humic acid from peat soils Figure 2 had distinct clear absorption bands indicating the presence of major humic acid structural elemental groups such as $\mathrm{H}$ bonded $\mathrm{OH}$ $\left(3680 \mathrm{~cm}^{-1}\right.$ peak $), C=0$ of carbonyl $\left(1721 \mathrm{~cm}^{-1}\right.$ peak), functional groups of aliphatic components $\mathrm{CH}_{2}\left(2918 \mathrm{~cm}^{-1}\right.$ peak) and $\mathrm{C}-\mathrm{O}$ stretching of polysaccharide $\left(1168 \mathrm{~cm}^{-1}\right.$ peak). The positions of the absorption bands of the spectra fell within typical major absorption bands of humic acid which is at frequencies 3680, 2918, 1721, 1168 $\mathrm{cm}^{-1}$. The first peak centred in the vicinity of $3680 \mathrm{~cm}^{-1}$ region is attributed to phenol $\mathrm{OH}$ group bounded by intermolecular $\mathrm{H}$ bonds. The $2918 \mathrm{~cm}^{-1}$ band usually has absorption maximum at $2918 \mathrm{~cm}^{-1}$ which is due to $\mathrm{C}-\mathrm{H}$ stretching of alkane group $\left(\mathrm{CH}_{2}\right)$. The next major absorption band is $1721 \mathrm{~cm}^{-1}$. This band has been commonly ascribed to $\mathrm{C}=\mathrm{O}$ stretching of mainly carboxyl group $(\mathrm{COOH})$ with trace amount of ketones. The last peak was observed at 1168 $\mathrm{cm}^{-1}$ due to $\mathrm{C}-\mathrm{O}$ stretching of polysaccharides and this peak appeared also in the spectra of humic acid from peat soil. The FTIR spectra of the isolated humic acid contained all major characteristic absorption peaks of humic acid. These absorption peaks indicated the presence of the major structural elements of humic acid namely $\mathrm{H}$ bonded $\mathrm{OH}, \mathrm{C}=\mathrm{C}$ of aromatic ring, $\mathrm{C}=\mathrm{O}$ of carbonyl group (both carboxyl and ketonic), $\mathrm{CH}_{2}$ group. This strongly supports the presence of humic acid.

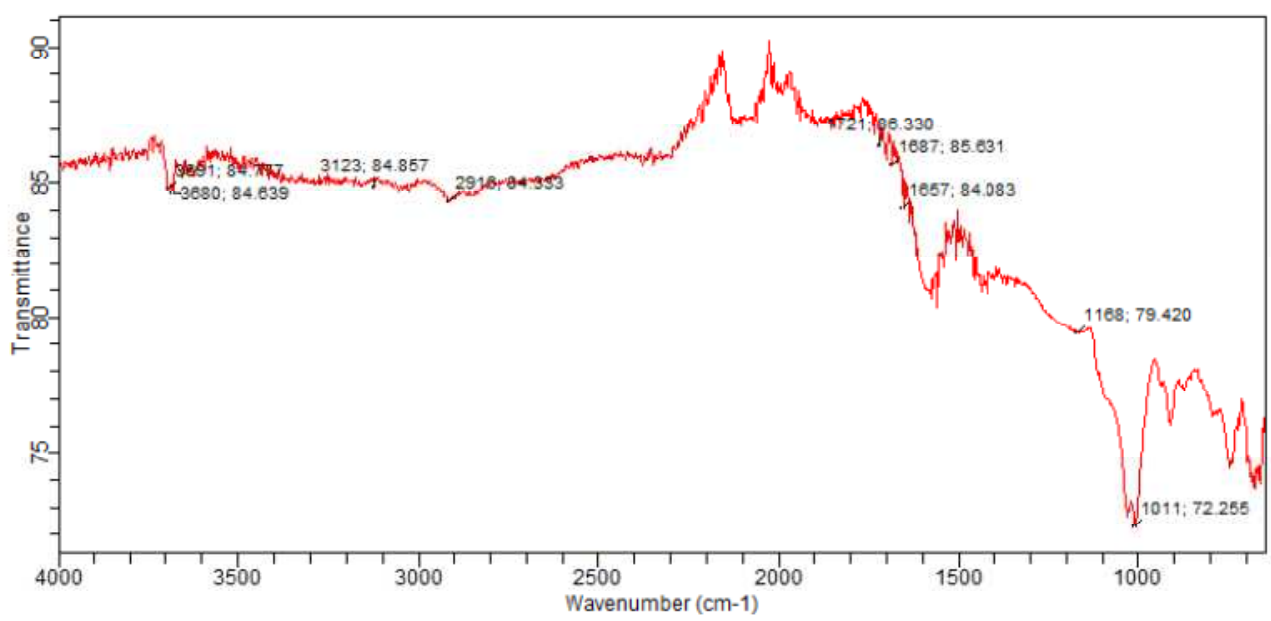

Fig. 2 : FT-IR spectraof peatsoilhumic acid (PSHA)

\section{Evaluation of acid dissociation constant (pka) of acid hydrolysed peat soil humicacid at phenolic group}

The value of the dissociation constant of the peat soil humic acid (PSHA) that underwent acidhydrolysis studied was found to be 8.9299 as shown Table 1, which is lower than the literaturevalues reported by Almeida and Szpoganics, (2015), Borges et al., (2005); Badr et al., (2012)and Fernandes et al,.(2009) of $9.73,9.47$ and 10.30. The difference between the obtained valuesand the reported values in this study might be probably as a result of acid hydrolysis of humicacid. 
BAJOPAS Volume 14 Number 1,June, 2021

Table 1: PKa of (Hydrolysed PSHA)

\begin{tabular}{|l|l|l|l|l|l|l|}
\hline $\mathrm{pH}$ & $\mathrm{BV}_{1}$ & $\mathrm{BV}_{2}$ & $\mathrm{~V}_{2}-\mathrm{V}_{1}$ & $\mathrm{nA}$ & $\log \left(\frac{n A}{1-n A}\right)$ & $\mathrm{pKa}$ \\
\hline 8.50 & 5.30 & 6.29 & 0.99 & 0.3594 & -0.2510 & 8.2490 \\
8.72 & 5.35 & 6.37 & 1.02 & 0.3400 & -0.2880 & 8.4320 \\
9.00 & 5.40 & 6.46 & 1.06 & 0.3141 & -0.3391 & 8.6609 \\
9.22 & 5.45 & 6.55 & 1.10 & 0.2882 & -0.3927 & 8.8273 \\
9.51 & 5.50 & 6.66 & 1.16 & 0.2494 & -0.4786 & 9.0314 \\
9.73 & 5.55 & 6.78 & 1.23 & 0.2041 & -0.5910 & 9.1390 \\
10.00 & 5.60 & 6.90 & 1.30 & 0.1589 & -0.7238 & 9.2762 \\
10.23 & 5.65 & 7.05 & 1.40 & 0.0941 & -0.9835 & 9.2465 \\
10.49 & 5.70 & 7.10 & 1.40 & 0.0941 & -0.9835 & 9.5065 \\
\hline
\end{tabular}

Average pKa $=8.9299 \pm 0.4186$

Table 2: PKa of (Unhydrolysed PSHA)

\begin{tabular}{|l|l|l|l|l|l|l|}
\hline $\mathrm{pH}$ & $\mathrm{BV}_{1}$ & $\mathrm{BV}_{2}$ & $\mathrm{~V}_{2}-\mathrm{V}_{1}$ & $\mathrm{nA}$ & $\log \left(\frac{\boldsymbol{n A}}{1-\boldsymbol{n}}\right)$ & $\mathrm{pKa}$ \\
\hline 8.50 & 5.30 & 5.81 & 0.51 & 0.6619 & 0.2919 & 8.7919 \\
8.72 & 5.35 & 5.90 & 0.55 & 0.6357 & 0.2418 & 8.9618 \\
9.00 & 5.40 & 6.00 & 0.60 & 0.6029 & 0.1813 & 9.1813 \\
9.22 & 5.45 & 6.10 & 0.65 & 0.5701 & 0.1226 & 9.3426 \\
9.51 & 5.50 & 6.20 & 0.70 & 0.5376 & 0.0654 & 9.5754 \\
9.73 & 5.55 & 6.33 & 0.78 & 0.4851 & -0.0259 & 9.7041 \\
10.00 & 5.60 & 6.47 & 0.87 & 0.4262 & -0.1291 & 9.8709 \\
10.23 & 5.65 & 6.62 & 0.99 & 0.3609 & -0.2481 & 9.9819 \\
10.49 & 5.70 & 6.80 & 1.10 & 0.2759 & -0.4690 & 10.0210 \\
\hline
\end{tabular}

Average pKa $=9.4923 \pm 0.4410$

Metal-ligand stability constant ( $\log \mathrm{K}$ )

The stabilityconstants require the accurate values of proton-ligand stability constants (Anil and Maroti, 2008). Metal titration curves crossed over ligand titration curve indicated the formation of complex upon proton release (Santosh, et al., 2011). If the values of n- are within range $0.2-0.8$ and $1.2-18$ this indicates the formation of $1: 1$ and 1:2 complexes (Sayyed and Mazahar, 2012).

The metal (II)-humate stepwise stability constants (log k) at phenolic group (Tables 318)

Table 3: Point-wise method, $\mathrm{Cu}$-(Hydrolysed PSHA)

\begin{tabular}{|l|l|l|l|l|l|l|l|l|}
\hline $\mathrm{pH}$ & $\mathrm{BV}_{1}$ & $\mathrm{BV}_{2}$ & $\mathrm{BV}_{3}$ & $\left(\mathrm{~V}_{3}-\mathrm{V}_{2}\right)$ & $\mathrm{n}$ & $\mathrm{pL}$ & $\log \left(\frac{n}{1-n}\right)$ & LogK $_{1}$ \\
\hline 8.50 & 5.30 & 6.29 & 6.33 & 0.04 & 0.5500 & 2.66 & 0.0871 & 2.7471 \\
8.72 & 5.35 & 6.37 & 6.41 & 0.04 & 0.5714 & 2.43 & 0.1249 & 2.5549 \\
9.00 & 5.40 & 6.46 & 6.50 & 0.04 & 0.6198 & 2.16 & 0.2122 & 2.3722 \\
9.22 & 5.45 & 6.55 & 6.59 & 0.04 & 0.6667 & 1.94 & 0.3010 & 2.2410 \\
\hline
\end{tabular}

LogK $_{1}$ (Average value) $=2.4788 \pm 0.2203$

Table 4: Point-wise method, $\mathrm{Cu}$-(Hydrolysed PSHA)

\begin{tabular}{|l|l|l|l|l|l|l|l|l|}
\hline $\mathrm{pH}$ & $\mathrm{BV}_{1}$ & $\mathrm{BV}_{2}$ & $\mathrm{BV}_{3}$ & $\left(\mathrm{~V}_{3}-\mathrm{V}_{2}\right)$ & $\mathrm{n}$ & $\mathrm{pL}$ & $\log \left(\frac{n-1}{2-n}\right)$ & LogK $_{2}$ \\
\hline 9.51 & 5.50 & 6.66 & 6.73 & 0.07 & 1.3509 & 1.70 & -0.2671 & 1.4329 \\
9.73 & 5.55 & 6.78 & 6.85 & 0.07 & 1.6383 & 1.51 & 0.2467 & 1.7567 \\
10.00 & 5.60 & 6.90 & 6.98 & 0.08 & 2.1783 & 1.31 & -0.2158 & 1.0942 \\
10.23 & 5.65 & 7.05 & 7.13 & 0.08 & 4.1904 & 1.27 & & \\
10.49 & 5.70 & 7.10 & 7.19 & 0.09 & 4.6920 & & & \\
\hline
\end{tabular}

Log $K_{2}($ Average value $)=1.4280 \pm 0.3312$ 
BAJOPAS Volume 14 Number 1,June, 2021

Table 5: Point-wise method, $\mathrm{Cu}$ (Unhydrolysed PSHA)

\begin{tabular}{|l|l|l|l|l|l|l|l|l|}
\hline $\mathrm{pH}$ & $\mathrm{BV}_{1}$ & $\mathrm{BV}_{2}$ & $\mathrm{BV}_{3}$ & $\left(\mathrm{~V}_{3}-\mathrm{V}_{2}\right)$ & $\mathrm{n}$ & $\mathrm{pL}$ & $\log \left(\frac{n}{n-1}\right)$ & Log $_{1}$ \\
\hline 8.50 & 5.30 & 5.81 & 5.85 & 0.04 & 0.2973 & 2.88 & -0.3736 & 2.5064 \\
8.72 & 5.35 & 5.90 & 5.95 & 0.05 & 0.3873 & 2.66 & -0.1992 & 2.4608 \\
9.00 & 5.40 & 6.00 & 6.05 & 0.05 & 0.4044 & 2.38 & -0.1681 & 2.2119 \\
9.22 & 5.45 & 6.10 & 6.15 & 0.06 & 0.5157 & 2.18 & -0.0272 & 2.2072 \\
9.51 & 5.50 & 6.20 & 6.27 & 0.07 & 0.6417 & 1.89 & 0.2530 & 1.1430 \\
\hline
\end{tabular}

$\operatorname{LogK}_{1}($ Average value $)=2.3059 \pm 0.6153$

Table 6:Point-wise method, $\mathrm{Cu}$ (Unhydrolysed PSHA)

\begin{tabular}{|l|l|l|l|l|l|l|l|l|}
\hline $\mathrm{pH}$ & $\mathrm{BV}_{1}$ & $\mathrm{BV}_{2}$ & $\mathrm{BV}_{3}$ & $\mathrm{~V}_{3}-\mathrm{V}_{2}$ & $\mathrm{n}$ & $\mathrm{pL}$ & $\log \left(\frac{n-1}{2-n}\right)$ & $\log \mathrm{K}_{2}$ \\
\hline 9.73 & 5.55 & 6.33 & 6.42 & 0.09 & 0.9000 & 1.69 & & \\
10.00 & 5.60 & 6.47 & 6.58 & 0.11 & 1.2578 & 1.44 & -0.4592 & 0.9808 \\
10.23 & 5.65 & 6.62 & 6.84 & 0.12 & 1.6137 & 1.26 & -0.2010 & 1.4610 \\
10.49 & 5.70 & 6.80 & 6.92 & 0.12 & 2.1052 & 1.03 & & \\
\hline
\end{tabular}

$\operatorname{LogK}_{2}$ (Average value) $=1.2209 \pm 0.3398$

Table 7:Point-wise method, Pb (Hydrolysed PSHA)

\begin{tabular}{|l|l|l|l|l|l|l|l|l|}
\hline $\mathrm{pH}$ & $\mathrm{BV}_{1}$ & $\mathrm{BV}_{2}$ & $\mathrm{BV}_{3}$ & $\left(\mathrm{~V}_{3}-\mathrm{V}_{2}\right)$ & $\mathrm{n}$ & $\mathrm{pL}$ & $\log \left(\frac{n}{1-n}\right)$ & LogK $_{1}$ \\
\hline 8.50 & 5.30 & 6.29 & 6.33 & 0.04 & 0.5500 & 2.66 & 0.0871 & 2.7471 \\
8.72 & 5.35 & 6.37 & 6.41 & 0.04 & 0.5714 & 2.43 & 0.1249 & 2.5549 \\
9.00 & 5.40 & 6.46 & 6.50 & 0.04 & 0.6198 & 2.16 & 0.2122 & 2.3722 \\
9.22 & 5.45 & 6.55 & 6.60 & 0.05 & 0.8333 & 1.96 & 0.6989 & 2.6589 \\
\hline
\end{tabular}

Log $_{\mathbf{1}}($ Average value $)=2.5832 \pm 0.1614$

Table 8:Point-wise method, Pb-(Hydrolysed PSHA)

\begin{tabular}{|l|l|l|l|l|l|l|l|l|}
\hline $\mathrm{pH}$ & $\mathrm{BV}_{1}$ & $\mathrm{BV}_{2}$ & $\mathrm{BV}_{3}$ & $\left(\mathrm{~V}_{3}-\mathrm{V}_{2}\right)$ & $\mathrm{n}$ & $\mathrm{pL}$ & $\log \left(\frac{n-1}{2-n}\right)$ & $\log \mathrm{K}_{2}$ \\
\hline 9.51 & 5.50 & 6.66 & 6.71 & 0.05 & 0.9650 & 1.67 & & \\
9.73 & 5.55 & 6.78 & 6.83 & 0.05 & 1.1702 & 1.44 & & \\
10.00 & 5.60 & 6.90 & 6.90 & 0.05 & 1.4864 & 1.22 & -0.0237 & 1.1963 \\
10.23 & 5.65 & 7.05 & 7.10 & 0.05 & 2.0190 & 1.09 & & \\
10.49 & 5.70 & 7.10 & 7.17 & 0.07 & 3.6492 & 1.00 & & \\
\hline
\end{tabular}

Log $K_{2}$ (Average value) $=1.1963$

Table 9: Point-wise method, Pb (Unhydrolysed PSHA)

\begin{tabular}{|l|l|l|l|l|l|l|l|l|}
\hline $\mathrm{pH}$ & $\mathrm{BV}_{1}$ & $\mathrm{BV}_{2}$ & $\mathrm{BV}_{3}$ & $\mathrm{~V}_{3}-\mathrm{V}_{2}$ & $\mathrm{n}$ & $\mathrm{pL}$ & $\begin{array}{l}\text { Log } \\
\left(\frac{n}{n-1}\right)\end{array}$ & Log $\mathrm{K}_{1}$ \\
\hline 8.50 & 5.30 & 5.81 & 5.85 & 0.04 & 0.2973 & 2.88 & -0.3736 & 2.5064 \\
8.72 & 5.35 & 5.90 & 5.94 & 0.04 & 0.3099 & 2.66 & -0.5477 & 2.3123 \\
9.00 & 5.40 & 6.00 & 6.05 & 0.05 & 0.4044 & 2.38 & -0.1681 & 2.2119 \\
9.22 & 5.45 & 6.10 & 6.15 & 0.06 & 0.5157 & 2.18 & 0.0272 & 2.2072 \\
9.51 & 5.50 & 6.20 & 6.26 & 0.07 & 0.6417 & 1.89 & 0.2530 & 2.1430 \\
9.73 & 5.55 & 6.40 & 6.40 & 0.07 & 0.7000 & 1.67 & 0.3680 & 2.0380 \\
\hline
\end{tabular}

LogK $_{1}$ (Average value) $=2.2364 \pm 0.1602$

Table 10: Point-wise method, Pb (Unhydrolysed PSHA)

\begin{tabular}{|l|l|l|l|l|l|l|l|l|}
\hline $\mathrm{pH}$ & $\mathrm{BV}_{1}$ & $\mathrm{BV}_{2}$ & $\mathrm{BV}_{3}$ & $\mathrm{~V}_{3}-\mathrm{V}_{2}$ & $\mathrm{n}$ & $\mathrm{pL}$ & $\log \left(\frac{n-1}{2-n}\right)$ & $\log \mathrm{K}_{2}$ \\
\hline 10.00 & 5.60 & 6.47 & 6.55 & 0.08 & 1.9503 & 1.41 & & \\
10.23 & 5.65 & 6.62 & 6.72 & 0.11 & 1.4792 & 1.26 & -0.0361 & 1.2239 \\
\hline
\end{tabular}

$\operatorname{LogK}_{2}$ (Average value) $=1.2239$

Table 11: Point-wise method, Mg (Hydrolysed PSHA)

\begin{tabular}{|l|l|l|l|l|l|l|l|l|}
\hline $\mathrm{pH}$ & $\mathrm{BV}_{1}$ & $\mathrm{BV}_{2}$ & $\mathrm{BV}_{3}$ & $\left(\mathrm{~V}_{3}-\mathrm{V}_{2}\right)$ & $\mathrm{n}$ & $\mathrm{pL}$ & $\log \left(\frac{n}{n-1}\right)$ & LogK $_{1}$ \\
\hline 8.50 & 5.30 & 6.29 & 6.31 & 0.02 & 0.2750 & 2.64 & -0.4290 & 2.2110 \\
8.72 & 5.35 & 6.37 & 6.39 & 0.02 & 0.2858 & 2.42 & -0.3978 & 2.0222 \\
9.00 & 5.40 & 6.46 & 6.49 & 0.03 & 0.4648 & 2.14 & -0.0612 & 2.0788 \\
9.22 & 5.45 & 6.55 & 6.59 & 0.04 & 0.6667 & 1.94 & 0.3010 & 2.2410 \\
\hline
\end{tabular}

$\log _{\mathbf{1}}($ Average value) $=2.1382 \pm 0.1046$ 
BAJOPAS Volume 14 Number 1,June, 2021

Table 12: Point-wise method, Mg (Hydrolysed PSHA)

\begin{tabular}{|l|l|l|l|l|l|l|l|l|}
\hline $\mathrm{pH}$ & $\mathrm{BV}_{1}$ & $\mathrm{BV}_{2}$ & $\mathrm{BV}_{3}$ & $\left(\mathrm{~V}_{3}-\mathrm{V}_{2}\right)$ & $\mathrm{n}$ & $\mathrm{pL}$ & $\log \left(\frac{n-1}{2-n}\right)$ & LogK $_{2}$ \\
\hline 9.51 & 5.55 & 6.66 & 6.71 & 0.05 & 0.9650 & 1.67 & & \\
9.73 & 5.55 & 6.78 & 6.84 & 0.06 & 1.4042 & 1.47 & -0.1686 & 1.3014 \\
10.00 & 5.60 & 6.90 & 6.93 & 0.06 & 1.7838 & 1.23 & 0.5593 & 1.7893 \\
10.23 & 5.65 & 7.05 & 7.10 & 0.06 & 3.1429 & 1.10 & & \\
10.49 & 5.70 & 7.10 & 7.18 & 0.07 & 3.6492 & 0.83 & & \\
\hline
\end{tabular}

LogK $_{2}($ Average value $)=1.5453 \pm 0.3450$

Table 13: Point-wise method, Mg (Unhydrolysed PSHA)

\begin{tabular}{|l|l|l|l|l|l|l|l|l|}
\hline $\mathrm{pH}$ & $\mathrm{BV}_{1}$ & $\mathrm{BV}_{2}$ & $\mathrm{BV}_{3}$ & $\mathrm{~V}_{3}-\mathrm{V}_{2}$ & $\mathrm{n}$ & $\mathrm{pL}$ & $\log \left(\frac{n}{n-1}\right)$ & $\operatorname{Log~}_{1}$ \\
\hline 8.50 & 5.30 & 5.81 & 5.85 & 0.04 & 0.2973 & 2.88 & -0.3736 & 2.5064 \\
8.72 & 5.35 & 5.90 & 5.94 & 0.04 & 0.3099 & 2.66 & -0.3477 & 2.3123 \\
9.00 & 5.40 & 6.00 & 6.04 & 0.04 & 0.3236 & 2.38 & -0.3202 & 2.0598 \\
9.22 & 5.45 & 6.10 & 6.15 & 0.05 & 0.4297 & 2.17 & -0.1230 & 2.0470 \\
9.51 & 5.50 & 6.20 & 6.26 & 0.06 & 0.5500 & 1.89 & 0.0871 & 1.9771 \\
9.73 & 5.55 & 6.33 & 6.40 & 0.07 & 0.7000 & 1.67 & 0.3680 & 2.0380 \\
\hline
\end{tabular}

LogK $_{1}$ (Average value) $=2.1568 \pm 0.2069$

Table 14: Point-wise method, Mg (Unhydrolysed PSHA)

\begin{tabular}{|l|l|l|l|l|l|l|l|l|}
\hline $\mathrm{pH}$ & $\mathrm{BV}_{1}$ & $\mathrm{BV}_{2}$ & $\mathrm{BV}_{3}$ & $\mathrm{~V}_{3}-\mathrm{V}_{2}$ & $\mathrm{n}$ & $\mathrm{pL}$ & $\log \left(\frac{n-1}{2-n}\right)$ & $\log \mathrm{K}_{2}$ \\
\hline 10.00 & 5.60 & 6.47 & 6.55 & 0.08 & 0.9148 & 1.41 & & \\
10.23 & 5.65 & 6.62 & 6.71 & 0.09 & 1.2102 & 1.20 & -0.5749 & 0.6251 \\
10.49 & 5.70 & 6.80 & 6.92 & 0.09 & 1.5968 & 1.03 & 0.1703 & 1.2003 \\
\hline
\end{tabular}

LogK $_{2}$ (Average value) $=0.9127 \pm 0.4070$

Table15:Point-wise method, Cd (Hydrolysed PSHA)

\begin{tabular}{|l|l|l|l|l|l|l|l|l|}
\hline $\mathrm{pH}$ & $\mathrm{BV}_{1}$ & $\mathrm{BV}_{2}$ & $\mathrm{BV}_{3}$ & $\left(\mathrm{~V}_{3}-\mathrm{V}_{2}\right)$ & $\mathrm{n}$ & $\mathrm{pL}$ & $\log \left(\frac{n}{1-n}\right)$ & LogK $_{1}$ \\
\hline 8.50 & 5.30 & 6.29 & 6.31 & 0.02 & 0.2750 & 2.64 & -0.4210 & 2.2190 \\
8.72 & 5.35 & 6.37 & 6.40 & 0.03 & 0.4286 & 2.42 & -0.1249 & 2.2951 \\
9.00 & 5.40 & 6.46 & 6.49 & 0.03 & 0.4648 & 2.14 & -0.0612 & 2.0788 \\
9.22 & 5.45 & 6.55 & 6.59 & 0.04 & 0.6667 & 1.96 & 0.3010 & 2.2610 \\
9.51 & 5.55 & 6.66 & 6.70 & 0.04 & 0.7720 & 1.67 & 0.5297 & 2.1997 \\
\hline
\end{tabular}

LogK $_{\mathbf{1}}$ (Average value) $=2.2108 \pm 0.0825$

Table 16: Point-wise method, Cd (Hydrolysed PSHA)

\begin{tabular}{|l|l|l|l|l|l|l|l|l|}
\hline $\mathrm{pH}$ & $\mathrm{BV}_{1}$ & $\mathrm{BV}_{2}$ & $\mathrm{BV}_{3}$ & $\left(\mathrm{~V}_{3}-\mathrm{V}_{2}\right)$ & $\mathrm{n}$ & $\mathrm{pL}$ & $\log \left(\frac{n-1}{2-n}\right)$ & Log $_{2}$ \\
\hline 9.73 & 5.55 & 6.78 & 6.83 & 0.06 & 1.4042 & 1.47 & -0.1686 & 1.3014 \\
10.00 & 5.60 & 6.90 & 6.95 & 0.06 & 1.7838 & 1.23 & 0.5593 & 1.7893 \\
10.23 & 5.65 & 7.05 & 7.10 & 0.06 & 3.1429 & 1.09 & & \\
10.49 & 5.70 & 7.10 & 7.16 & 0.06 & 3.1429 & 0.89 & & \\
& & & & & & & & \\
\hline
\end{tabular}

$\operatorname{LogK}_{2}$ (Average value) $=1.5453 \pm 0.3450$

Table 17: Point-wise method, Cd (Unhydrolysed PSHA)

\begin{tabular}{|l|l|l|l|l|l|l|l|l|}
\hline $\mathrm{pH}$ & $\mathrm{BV}_{1}$ & $\mathrm{BV}_{2}$ & $\mathrm{BV}_{3}$ & $\mathrm{~V}_{3}-\mathrm{V}_{2}$ & $\mathrm{n}$ & $\mathrm{pL}$ & $\log \left(\frac{n}{n-1}\right)$ & $\operatorname{Log~}_{1}$ \\
\hline 8.50 & 5.30 & 5.81 & 5.86 & 0.05 & 0.3717 & 2.88 & -0.2280 & 2.6520 \\
8.72 & 5.35 & 5.90 & 5.95 & 0.05 & 0.3873 & 2.66 & -0.1992 & 2.4608 \\
9.00 & 5.40 & 6.00 & 6.06 & 0.06 & 0.4853 & 2.38 & -0.0255 & 2.3545 \\
9.22 & 5.45 & 6.10 & 6.16 & 0.06 & 0.5157 & 2.18 & -0.0272 & 2.2072 \\
9.51 & 5.50 & 6.20 & 6.27 & 0.07 & 0.6417 & 1.89 & 0.2530 & 1.1430 \\
9.73 & 5.55 & 6.33 & 6.41 & 0.08 & 0.8000 & 1.69 & 0.6020 & 2.2920 \\
& & & & & & & & \\
\hline
\end{tabular}

$\operatorname{LogK}_{1}($ Average value $)=2.2516 \pm 0.5380$ 
BAJOPAS Volume 14 Number 1,June, 2021

Table 18: Point-wise method, Cd (Unhydrolysed PSHA)

\begin{tabular}{|l|l|l|l|l|l|l|l|l|}
\hline $\mathrm{pH}$ & $\mathrm{BV}_{1}$ & $\mathrm{BV}_{2}$ & $\mathrm{BV}_{3}$ & $\mathrm{~V}_{3}-\mathrm{V}_{2}$ & $\mathrm{n}$ & $\mathrm{pL}$ & $\log \left(\frac{n-1}{2-n}\right)$ & $\log \mathrm{K}_{2}$ \\
\hline 10.00 & 5.60 & 6.47 & 6.57 & 0.10 & 1.1434 & 1.43 & & \\
10.23 & 5.65 & 6.62 & 6.72 & 0.10 & 1.3448 & 1.23 & -0.2788 & 0.9512 \\
10.49 & 5.70 & 6.80 & 6.90 & 0.10 & 1.7742 & 1.03 & 0.5351 & 1.5651 \\
\hline
\end{tabular}

$\operatorname{LogK}_{2}($ Average value $)=1.2581 \pm 0.4340$

Table 19: Stepwise and overall Stability constants of thehydrolysed and unhydrolysed divalent metal (II) complexes

\begin{tabular}{|c|c|c|c|}
\hline Chelates & LogK $_{1}$ & $\log _{2}$ & Log $\beta$ \\
\hline [Cu (Hydrolysed PSHA-1) $\left.{ }_{2}\right]$ & 2.4788 & 1.4280 & 3.9068 \\
\hline$\left[\mathrm{Pb}(\text { Hydrolysed PSHA-1) })_{2}\right]$ & 2.5832 & 1.1963 & 3.7795 \\
\hline$\left[\mathrm{Cd}(\text { Hydrolysed PSHA-1 })_{2}\right]$ & 2.2108 & 1.5453 & 3.7561 \\
\hline$\left[\mathrm{Mg}(\text { Hydrolysed PSHA-1 })_{2}\right]$ & 2.1382 & 1.5453 & 3.6835 \\
\hline [Cu (Unhydrolysed PSHA-1) & 2.3059 & 1.2209 & 3.5268 \\
\hline$[\mathrm{Pb}$ (Unhydrolysed PSHA-1) 2$]$ & 2.2364 & 1.2239 & 3.4603 \\
\hline [Cd (Unhydrolysed PSHA-1) 2 ] & 2.2516 & 1.2581 & 3.5097 \\
\hline$[\mathrm{Mg}$ (Unydrolysed PSHA-1) & 2.1568 & 0.9127 & 3.0695 \\
\hline
\end{tabular}

The results obtained (Table19) shows the stepwise and overall stability constants to be not high indicating low stability of the complexes, because the solubility of most metal ions in the basic $\mathrm{pH}$ range is minimal due to metal hydroxide precipitation (Karimi, 2017). In general, the stepwise stability constants $\left(K_{1}\right.$ and $K_{2}$ ) follow the order $K_{1}>K_{2}$ for the copper, lead, magnesium and cadmium complexes respectively. The steady decrease of the values with increasing number of ligands is in agreement with the prediction made by researchers (Na'aliya, 2013). The decrease could be attributed to the fact that as the number of the ligands (Humate ions) that enters the coordination zone increases the aqua molecules available for replacement by the ligands become less. Thus, the metal ions become less electron loving with progressive intake of the ligand and this results in the decrease in the values of the constants (Na'aliya, 2013). Also the stability of the complexes is influenced by the size and number of the chelate rings(Mackay and Mackay,2002).All the complexes form rings in their structure as humate, a bidentate ligand, bond the metal ions in the ratio 1:2 (Boguta and Sokolowska, 2016) forming chelate rings. The values of the overall stability constants $(\log \beta)$ obtained for humate complexes are not high indicating low stability as the values are not high. LogK values for copper-humates (Table 3 to 6) obtained in this study are lower than those reported for the complexes of humic acids (Pandey et al., 2015; Dinu, 2013; Kaschl et al., 2010 and Gilbeto and Jorg, 2001). The values of LogK(Table 7 to 10 ) forlead-humates are lower than those reported for the lead in the literature (Dinu, 2013; Gilbeto and Jorg 2001). Log K values(Table 11 to 14 ) for magnesium-humates obtained in this study are close to those reported by (Pandey et al., 2015). Log K values of cadmium-humates (Table 15 to 18 ) obtained in this work near to the one reported by (Dinu, 2013 and Pandey et al., 2015).The difference between the reported values and the values obtained in this study might be probably as a result of acid hydrolysis of humic acid. The values of the overall stability constants $(\log \beta)$ of the copper humates complexes presented in Table 19 is high than that of other metal humate complexes, show relatively high stability of CuHA complexes, show the following order of stability: $\mathrm{Cu}>\mathrm{Pb}>\mathrm{Cd}>\mathrm{Mg}$; which are in close agreement to the findings of (Dinu, 2013 and Pandey et al., 2015).The high stability of Cuhumate chelate could be attributed to the existence of coordinate covalent bond between the complexing agents and the $\mathrm{Cu}^{2+}$ ions. Since, $\mathrm{Cu}^{2+}$ being a metal of the transitional series with $3 d^{9}$ electronic configurations can accept the electrons from the complexing agents. Similarly, the low stabilities of $\mathrm{Pb}, \mathrm{Cd}$ and $\mathrm{Mg}$ complexes could be explained by that $\mathrm{Pb}^{2+}$ with $6 s^{2}, \mathrm{Cd}^{2+}$ with $4 \mathrm{~d}^{10}$ and $\mathrm{Mg}^{2+}$ with $2 \mathrm{p}^{6}$ their electronic configuration has a completely filled $\mathrm{d}, \mathrm{p}$ and $\mathrm{s}$ orbitals. Moreover, the stabilities of metal ions with hydrolysed humic acid from peat soil were higher than those with unhydrolysed humic acid from peat soil; which is ascribed to the high content of acidity in hydrolysed humic acid than unhydrolysed humic acid. 
BAJOPAS Volume 14 Number 1,June, 2021 CONCLUSION

The values of logk for $\mathrm{Cu}(\mathrm{II})$ hydrolysed humic acid complex was higher followed by $\mathrm{Pb}$ (II), $\mathrm{Cd}(\mathrm{II})$ and $\mathrm{Mg}$ (II) hydrolysed humic acid complexes as compared with metal(II) unhydrolysed humic acid complexes. This indicates acid hydrolysis of humic acid can

\section{REFERENCES}

Almeida, V.R. and Szpoganicz, B. (2015). Humic Acid Potentiometric Response Patterns:Out- of Equilibrium Properties and Species Distribution Modelling. Chemical. Biol. Technol. Agric. 2: 17.

Anđelković, T., Nikolić, R., Bojić, A.,Anđelković, D., and Nikolic G.,(2010). Binding of Cadmium to Soil Humic Acid as A Function of Carboxyl Group Content. Macedonian Journal of Chemistry and Chemical Engineering.29(2): 215-224.

Anil, B. N. and Maroti, N. (2008). Studies on Influence of Die-Lectric Constants on Complex Equilibria between Substituted Py-Razalines and Lanthanide Metal Ions pH-Metrically. Amer.-Euras. scient. Res. 3(2): 212-216.

Ashok, K., Pandey, S. P. and Misra, V (2000). Stability Constants of Metal-Humic Acid Complexes and its Role in Environmental Detoxification. Journal of Ecotoxicology and Environmental Safety. 47(2):157-200.

Badr, M. H., El-Halafawi, M. H. and Abd El-al Zeid, E. R. (2012). Comparison Between the Effect of Ionic Strength on Acidity and Dissociation Constants of Humic Acids Extracted from Sewage Sludge and Nile Water Hyacinth Composts.Global Journal of Environmental Research 6 (1): 36-43.

Baruah, M.K., Borah, D., Saikia, P.P., Paul, S., Sharma, T. (2015). Evaluation of pKa Values of Soil Humic Acids and their Complexation Properties. International Journal of Plant \& Soil Science 6(4) : 218-228.

Boguta, P. Sokolowska, Z. (2016). Interactions of $\mathrm{Zn}$ (II) Ions with Humic Acids Isolated from Various Types of Soils. Effect of $\mathrm{pH}, \mathrm{Zn}$ Concentrations and Humic Acids Chemical Properties. Journal of Geochemical Explaration 168. 119-126.

Borges, F., Guimaraes, C., Lima, L.F.C., Pinto, I. and Reis, S.(2005). Potentiometric Studies on the Complexation of Copper(II) by Phenolic Acids as Discrete Ligand Models of enhance the complexation behavior of humic acid with metal (II) ions. However, the higher values of $\log \beta$ for $\mathrm{Cu}(\mathrm{II}), \mathrm{Pb}(\mathrm{II}), \mathrm{Cd}(\mathrm{II})$ and $\mathrm{Mg}(\mathrm{II})$ hydrolysed humic acid complexes indicates more stable stepwise complexes formed as compared with $\mathrm{Cu}(\mathrm{II}), \mathrm{Pb}$ (II), $\mathrm{Cd}$ (II) and $\mathrm{Mg}(\mathrm{II})$ unhydrolysed humic acid complexes.

Humic Substances Talanta 66 (2005) 670-673.

Chefetz, B., Salloum, M. J., Deshmulkin, A. P. and Hatcher, P. (2002). Structural Components of Humic Acids as Determined by Chemical Modifications and Carbon-13 NMR, Pyrolysis, and Thermochemolysis- Gas Chromatography/Mass Spectrometry. Soil Science Society of American Journal Abstract Division S-2- Soil Chemistry66. 1159-1171.

Dinu, M. I. (2013). Metals Complexation with Humic Acids in Surface Water of Different Environ. Sci. Technol. 31(1): 1-17.

Fernandes, A.N., Giacomelli, C., Giovanela, M. Vaz, D.V. Szpoganicz, B. and Maria M. D. (2009). Potentiometric Acidity Determination in Humic Substances Influenced by Different Analytical Procedures.J. Braz. Chem. Soc. 20 (9):14.

Gamal, A. H. (2015). Stability Constants of Rhenium (V) Metal Complexes with Selected Drugs. Pyrex Journal of Research in Environmental Studies. 2(2): 006-014.

Janrao, D. M., Pathan, J., Kayande, D.D., and Mulla, J.J. (2014). An Over View of Potentiometric Determination of Stability Constants of Metal Complexes. Sci. Revs. Chem. Commun.: 4(1), 2014, 11-24.

Karimi, H. (2017). Effect of pH and Initial Pb(II) Concentration on the Lead Removal Efficiency from Waste Water Using $\mathrm{Ca}(\mathrm{OH})_{2}$. International Journal of Water and Waste Water Treatment 3.2

Kaschl, A. Romheld, V. and Chen, Y. (2010). Binding of Cadmium, Copper and Zinc to Humic Substances Originating from Municipal Solid Waste Compost. Israel Journal of Chemistry Vol. 42(1): 89-98.

Kostic, I. S., Tatjana, P, A., Nikolic, R. S., Cvetkovic, T. P., Pavlovic, D. D., Aleksandar, L.J. and Bojic, A. (2012). Comparative Study of Binding Strengths of Heavy Metals with Humic Acid. J.serb. Chem. Soc. 76(9) pp 1-20. 
BAJOPAS Volume 14 Number 1,June, 2021

Na'aliya, J. (2013). Determination of Stepwise Stability Constants and Gibbs free Energy Change of Trisprolina to Complexes of some Divalent Transition Metal ions. Bayero Journal of Pure and Applied Sciences 6(2): 112-114.

Omar, A. A. and Ali, E. A. (2015). Potentiometric Studies on Complexes of $\mathrm{Cr}$ (III) and $\mathrm{Zr}$ (IV) with some Carboxylic Acids. International Journal of Advanced Chemistry, 3(1) 25-

37.

Pandey, A. K. Pandey, S. D. and Misr, V. (2015).Stability Constants of Metal- Humic Acid Complexes and Its Role in Environmental Detoxification. J. Ecotoxicology and Environmental Safety. 47(1):195-200.

Ram, N. and Raman, K.V. (1984). Stability Constants of Complexes of Metals with
Humicand Fuvic Acids under Non- acidConditions. Journal of Plant Nutrition and Soil Sciences.

147:171-176.

Santosh, D. D., Ashok, B. K., Vijay, J. T., Shivraj, G. W. and Vinay, V. W. (2011). Potentiometric Studies of Elec-Trolyte Effects on Complex Equilibria of Some Substituted 5-(2-hydroxy Phenyl) Pyrazoles. Der pharm. 3 (6): 75-83.

Sayyed, H. and Abdul Rahim, M. F. (2012). Studies of Binary Complexes of Metal Ions with Mandelic Acid by Potentiometry. Chem. J. 02 (6): 206209.

Shirvani, M. Moradian, E. Khalili, B. Bakhtiary, S. (2015). Interaction of $\mathrm{Cd}$ and $\mathrm{Pb}$ with Humate-Palygorskite and HumateSepiolite Complexes. Journal of water, air and pollution 3: 220-228. 


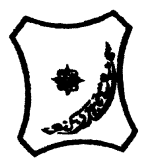

Bayero Journal of Pure and Applied Sciences, 14(1): 54 - 63

Received: November, 2020

Accepted: April, 2021

ISSN $2006-6996$

\title{
STABILITY CONSTANTS OF COMPLEXES OF METAL IONS WITH PEATSOIL HUMIC ACIDS UNDER NON-ACID-CONDITIONS
}

\author{
${ }^{* 1}$ Sabo, Yusuf ${ }^{2}$ Jimoh, W.L.O., ${ }^{3}$ Isa Baba Koki and ${ }^{4}$ Sholadoye, Q. 0. \\ ${ }^{1}$ Department of Pure and Industrial Chemistry, Bayero University, Kano \\ ${ }^{3}$ Department of Chemistry, Yusuf Maitama Sule University Kano. P.M.B. 3220 Kano, Nigeria. \\ ${ }^{4}$ Department of Chemistry, Nigerian Police Academy, Wudil, Kano-Nigeria
}

*Correspondence E-mail; saboyusuf18@yahoo.com

ABSTRACT

Stability constants of complexes of four divalent metal ions viz. $\mathrm{Cu}^{2+}, \mathrm{Pb}^{2+}, \mathrm{Mg}^{2+}$ and $\mathrm{Cd}^{2+}$ with humic acids (HA) were determined by potentiometric titration of humic acids with the corresponding salt of the divalent metals in aqueous media under non-acid-condition. The log $K$ (logarithm of the stability constant) ranged from 1.0942 to 2.7471 for metalhumic acid complexes were determined using point-wise computational method. The order of stability constants were obtained as follows: $\mathrm{Cu}>\mathrm{Pb}>\mathrm{Cd}>\mathrm{Mg}$ for metal $-\mathrm{HA}$ complexes respectively, indicating a higher degree of complexation with Cu metal ion.

Keywords: stability constant, humic acid, potentiometric titration, divalent metals, acid hydrolysis.

\section{NTRODUCTION}

The stability constant of a complex is the numerical expression of its stability and provides a quantitative measure of affinity of the metal ion to the complexing agent. An understanding of the relative stability of metal-complexes helps in predicting the behavior of metal ions in the soil (Ram and Raman, 1982). Extensive researches has been done to determine the stability constants of the complexes formed between humic acid (HA) with a number of metal ions. Ashok et al., (2000) reported that humic acid with hydroxyl, phenoxyl and carboxyl reactive groups can form coordination compound with metal ions at $\mathrm{pH}$ 3.5. The stability constants(Log K) for different metalhumic acid complexes indicated the following order of the stabilities of complexes formed between humic acid and metal ion, $\mathrm{Cu}>\mathrm{Fe}$ $>\mathrm{Pb}>\mathrm{Ni}>\mathrm{Co}>\mathrm{Ca}>\mathrm{Cd}>\mathrm{Zn}>\mathrm{Mn}>\mathrm{Mg}$. Andelkovic et al., (2010) investigated the binding of $\mathrm{Cd}$ (II) to soil humic acid at pH 6.5 and in $0.1 \mathrm{M} \mathrm{KNO}_{3}$ ionic medium. The stability constant for binding indicating greater stability in the case when carboxyl groups are involved in complexation reaction. Kostic et al.,(2012) investigated the complexation of humic acid with certain heavy metal ions (Co(II), $\mathrm{Ni}(\mathrm{II}), \mathrm{Cu}(\mathrm{II})$,
$\mathrm{Zn}(\mathrm{II})$, and $\mathrm{Pb}(\mathrm{II})$. The experiment was performed at $25^{\circ} \mathrm{C}$, at pH 4.0 and ionic strength of $0.01 \mathrm{M}$. Stability constant of complex between $\mathrm{Pb}$ (II) ions and humic acid is greater than stability constants of other investigated metalhumate complexes. Bogata and Sokolowska (2016) analyses the interaction between humic acids from different soils and $\mathrm{Zn}$ (II) ions at wide concentration ranges and at $\mathrm{pH} 5$. Studies have showed significant impact of $\mathrm{Zn}$ concentration, $\mathrm{pH}$ and some properties of humic acids with zinc.But all of these studies were limited to acidic $\mathrm{pH}$ range. Therefore, the present study was carried out to determine and compare the stability constants of complexes of metal ions with hydrolysed peat soil humic acid and unhydrolysed peat soil humic under non-acid conditions.

\section{MATERIALS AND METHODS}

Analytical grade chemicals used includes hydrochloric acid $(\mathrm{HCl})$, nitric acid $\left(\mathrm{HNO}_{3}\right)$, sodium hydroxide $(\mathrm{NaOH})$, lead nitrate $\mathrm{Pb}\left(\mathrm{NO}_{3}\right)_{2}$, copper nitrate $\mathrm{Cu}\left(\mathrm{NO}_{3}\right)_{2} \cdot 3 \mathrm{H}_{2} \mathrm{O}$, cadmium nitrate $\mathrm{Cd}\left(\mathrm{NO}_{3}\right)_{2} \cdot 4 \mathrm{H}_{2} \mathrm{O}$, magnesium nitrate $\mathrm{Mg}\left(\mathrm{NO}_{3}\right)_{2} \cdot 6 \mathrm{H}_{2} \mathrm{O}$, potassium nitrate $\left(\mathrm{KNO}_{3}\right)$, calcium chloride $\left(\mathrm{CaCl}_{2}\right)$, (sigma-Aldrich). Dowex 50WX8, (20-50 mesh) from Fluka. 


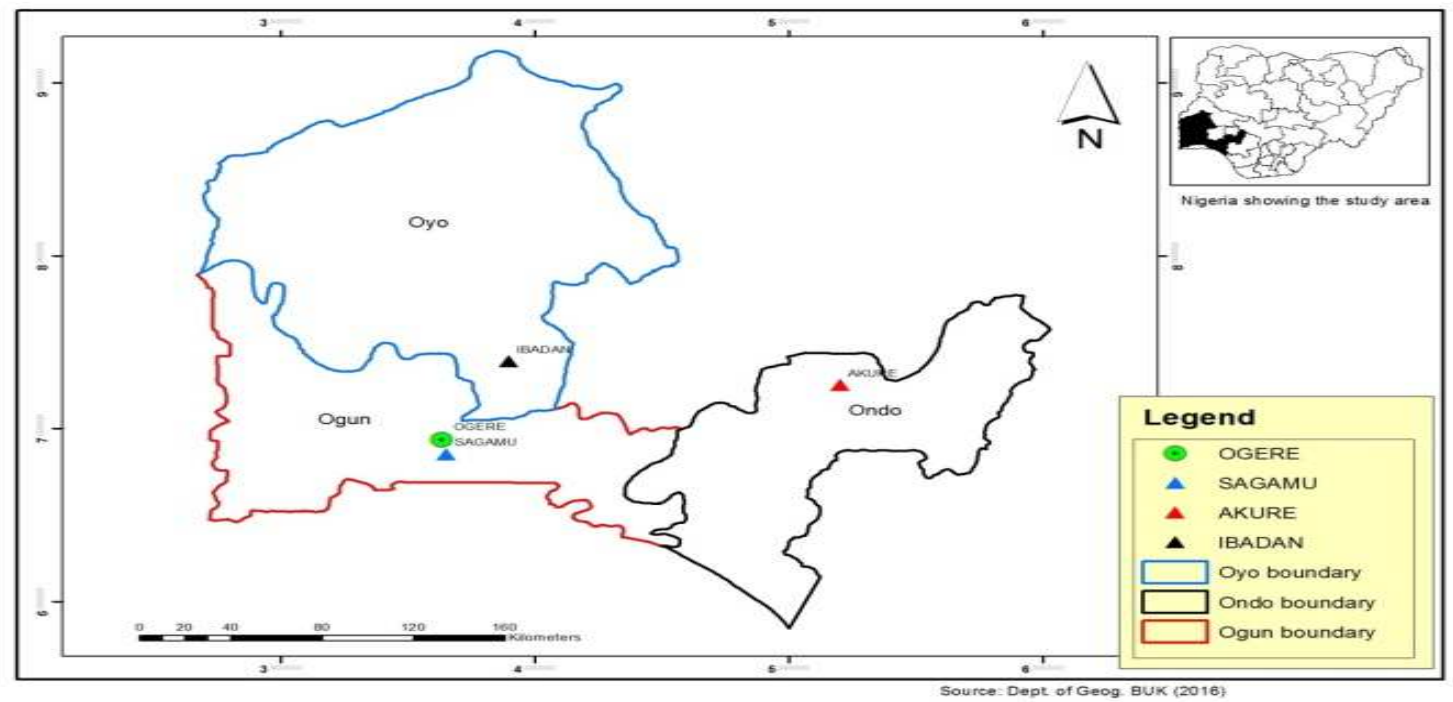

Figure 1: Map showing the sampling point at Sagamu Town, Ogun State.

\section{Description of Sampling Area}

Sagamu has geographical coordinates between $6^{\circ} 50^{\prime}$ north; $3^{\circ} 38^{\prime}$ east is located in south western region of Nigeria. The region has tropical wet and dry climate with a lengthy wet season and relatively constant temperatures throughout the course of the year. Wet season runs from March to October, November to December forms the region dry season. The vegetation type of the region is savannah which is really grassland with small bushes and occasional big trees. Grassland soils have substantially higher organic matter content than forest soils (Novackova, 2011).

\section{Sample Collection}

The Peatsoil samples were collected from four different sampling points $(0-10 \mathrm{~cm}$ depth) in Sagamu into polyethylene bag with plastic spoons. Samples were taken to the laboratory, extraneous materials were removed; the samples were air-dried, crushed and ground to a fine powder in a mortar passed through a $0.20 \mathrm{~mm}$ sieve. The samples were kept for analysis.

\section{Isolation and purification of humic acid from peat soil sample}

Peatsoil sample $(100 \mathrm{~g})$ was mixed with 1000 $\mathrm{cm}^{3}$ of $0.1 \mathrm{M} \mathrm{NaOH}$ solution, shaken for 3hours and left to stand overnight. Dark-coloured supernatant was obtained and decanted from solid residue. The dark-coloured supernatant was acidified to $(\mathrm{pH}=1.0)$ with $6 \mathrm{M} \mathrm{HCl}$ stirred and allowed to stand for 6 hours. Yellowish brown supernatant and dark-brown precipitate were obtained. The yellowish brown supernatant was decanted followed by centrifuge and discarded. The dark-brown precipitate was mixed with $500 \mathrm{~cm}^{3}$ of $0.1 \mathrm{M} \mathrm{NaOH}$ solution followed by passing through dowex resin. The dark-brown solution was acidified to $(\mathrm{pH}=1.0)$ with $6 \mathrm{M} \mathrm{HCl}$ stirred and allowed to stand for 3 hours. The dark-brown precipitate was washed several times with deionized water. The supernatant was treated with $\mathrm{AgNO}_{3}$ solution until no white precipitate observed. The humic acid was transferred to weighed crucible and dried at $60^{\circ} \mathrm{C}$ in an oven for 12 hours. The humic acid was cooled and dried in the desiccator, weighed and recorded. The obtained humic acid was dried again at $60^{\circ} \mathrm{C}$ for additional 6 hours cooled and dried in the desiccator, weighed and recorded constant weight was obtained (Baruah et al., 2015).

\section{FT-IR analysis}

FT-IR spectra of humic acid sample was analysed using Carry 630 FT-IR Agilent Technologies.

Unhydrolysed compost humic acid

The unhydrolysed humic acid was obtained after isolation and purification of compost humic acid and kept for investigation.

\section{Acid hydrolysis of Peatsoil acid}

Peatsoil humic acid sample (1g) was refluxed for 12 hours at $\left(160^{\circ} \mathrm{C}\right)$ with $50 \mathrm{~cm}^{3}$ of $6 \mathrm{M} \mathrm{HCl}$. The mixture was allowed to cool, decanted, and centrifuged after hydrolysis. The insoluble residues were washed with distilled water via centrifugation several times, and the supernatant was treated with $\mathrm{AgNO}_{3}$ solution until no white precipitate was observed. The residue was thoroughly dried over $\mathrm{CaCl}_{2}$ in a desiccator at room temperature (Chefetz et al., 2002). Finally, the obtained hydrolysed humic acid was kept for investigation. 
BAJOPAS Volume 14 Number 1,June, 2021 Potentiometric Titrations

Potentiometric measurements were carried out using a pH-meter Jenway (model 3510) with combine electrode, the sensitivity of the $\mathrm{pH}$ meter is 0.01 units. The $\mathrm{pH}$ meter was switched on half an hour before starting the titration for initial warm up of the instrument. The instrument was calibrated with an aqueous standard buffer solution of $\mathrm{pH} 4.00$ and 10.0 (borate buffer) prepared from a "Qualigens" buffer tablets.

The following sets of solutions were prepared in a $250 \mathrm{~cm}^{3}$ volumetric flask separately for $\mathrm{pH}$ metric titrations.

(i) $5 \mathrm{~cm}^{3} 0.1 \mathrm{M} \mathrm{HCl}+40 \mathrm{~cm}^{3}$ deionized water

(ii) $5 \mathrm{~cm}^{3} 0.1 \mathrm{M} \mathrm{HCl}+39 \mathrm{~cm}^{3}$ deionized water $+1 \mathrm{~cm}^{3} 0.15 \mathrm{gcm}^{-3}$ humic acid

(iii) $5 \mathrm{~cm}^{3} 0.1 \mathrm{M} \mathrm{HCl}+37 \mathrm{~cm}^{3}$ deionized water $+1 \mathrm{~cm}^{3} 0.15 \mathrm{gcm}^{-3}$ humic acid

$$
+2 \mathrm{~cm}^{3} \quad 0.01 \mathrm{M} \mathrm{Cu} \text { (II) }
$$

The solutions were titrated against standardized $0.110 \mathrm{MNaOH}$ separately. The total volume of each mixture was adjusted to $50 \mathrm{~cm}^{3}$ and the ionic strength of the solutions was maintained constant at by adding appropriate amount of stock solution of $1 \mathrm{M} \mathrm{KNO}_{3}$ (Gamal, 2015; Omar and Ali, 2015). A magnetic stirrer was used to achieve thorough mixing of the interacting solutions at $550 \mathrm{rpm}$. The same set of experimental conditions was applied for potentiometric titration of remaining samples.

\section{Evaluation of pKa of Hydrolysed peat soil Humic Acids}

The proton-ligand formation number $\mathrm{n}_{\mathbf{A}}$ were calculated by Irving and Rossotti expression (Omar and Ali, 2015).

$\mathrm{nA}=\mathrm{Y}-\frac{(\mathrm{V} 2-\mathrm{V1})(\mathrm{No}-\mathrm{Eo})}{(\mathrm{VO}+\mathrm{V1}) \mathrm{TCL}}$ 1

Where: $Y$ is number of dissociable proton, $\left(\mathrm{V}_{2^{-}}\right.$ $V_{1}$ ) is the measure of displacement of the ligand curve relative to acid curve, $\mathrm{N}^{\circ}$ and $\mathrm{E}^{\circ}$ are the resultant concentration of alkali solution, free acid solution, $\mathrm{T}_{\mathrm{cL}}{ }^{\circ}$ is the total ligand concentration, $\mathrm{V}^{\circ}$ is the total volume of titration solution, $V_{1}$ is the volume of alkali added to acid solution, $V_{2}$ is the volume of alkali added to acid solution + ligand solution, acid dissociation constants (pKa - values) of ligand were calculated by algebraic method point wise calculation (Tables 1 ). The dissociation constants (pKa) were calculated according to the following relation:

$\mathrm{pKa}=\mathrm{pH}+\log \left(\frac{n A}{1-n A}\right)$ 2

Where: pKa is the acid dissociation constant, $\mathrm{n}_{\mathrm{A}}$ is the Proton-ligand formation number and $\mathrm{pH}$ is the pH-values (Omar and Ali, 2015).

\section{Determination of metal-ligand stability constants $(\log K)$ of complexes}

The potentiometric measurement for the determination of stability constant of a complex in solution is based on the fact that the redox potential of the couple $\frac{M^{+(m-n)}}{M^{+m}}$ is shifted significantly on complexation of the metal ion with the ligand. This method involves change in hydrogen ion concentration $\left[\mathrm{H}^{+}\right]$due to the displacement or association of one or more protons taking place during complexation reaction. This change can be found out by titrating the solutions containing free acid, acid with ligand, and acid with ligand and metal ion, individually against a standard alkali solution at a constant ionic strength or temperature. Either ionic strength or temperature may be varied for different sets of solutions. In all the cases, the change in the $\mathrm{pH}$ of the solution is measured after each addition of a known amount of alkali to the reaction cell which contains the reaction mixture. The titration curves are then drawn by plotting the measured $\mathrm{pH}$ values against the corresponding volume of alkali added and the stability constants of the complexes are determined from the titration curves by employing $\mathrm{pH}$-metric titration technique given by (Irving and Rossoti).

Metal-ligand stability constants ( $\log \mathrm{K}$ ) were determined by using the following relations:

$$
\bar{n}=\frac{\left(V_{3}-V_{2}\right)\left(E^{0}+N^{0}\right)}{\left(V^{0}+V_{2}\right) \bar{n}_{A} T_{m}^{0}}
$$

and

$$
P L=\log _{10}\left\{\frac{1+\beta_{n}^{H} \frac{1}{[\text { anti } \log \mathrm{pH}]^{\mathrm{n}}}}{\mathrm{T}_{\mathrm{L}}^{0}-n \bar{T}_{m}^{0}} \mathrm{X} \frac{\left(V^{0}+V_{3}\right)}{V^{0}}\right\}
$$


BAJOPAS Volume 14 Number 1,June, 2021

Where $T_{L}, T^{\circ}, E^{\circ}$, and $V^{\circ}$ havethe same significance as in equation (1) above, $T_{m}$ denotes the total concentration of metal present in solution, $V_{3}$ is the volume of metal ions present in solution and $\beta^{H}$ is the overall proton ligand stability constant. The metal-ligand stability constants (log K) were determined by employing point wise computational Method (eq. 5 and 6).

$\operatorname{LogK}_{1}=\log \left(\frac{n}{1-n}\right)+\mathrm{pL}$ .5

$\operatorname{LogK}_{2}=\log \left(\frac{1-n}{2-n}\right)+\mathrm{pL}$ ...6

Where: Log $\mathrm{K}$ is the metal-ligand stability constant, $\mathrm{pL}$ is the Free ligand exponent function, $\mathbf{n}$ is the Average number of ligand attached with metal ion (Janraoet al., 2014). The results obtained were analyzed by an ORIGIN 2016 program using titration data and then the proton-ligand stability constants (pKa) and Metal-ligand stability constant (LogK) calculated (Omar and Ali, 2015).

\section{RESULTS AND DISCUSSION}

Fourier transformed infrared (FT-IR) spectra of isolated humic acid from peat soils Figure 2 had distinct clear absorption bands indicating the presence of major humic acid structural elemental groups such as $\mathrm{H}$ bonded $\mathrm{OH}$ $\left(3680 \mathrm{~cm}^{-1}\right.$ peak $), C=0$ of carbonyl $\left(1721 \mathrm{~cm}^{-1}\right.$ peak), functional groups of aliphatic components $\mathrm{CH}_{2}\left(2918 \mathrm{~cm}^{-1}\right.$ peak) and $\mathrm{C}-\mathrm{O}$ stretching of polysaccharide $\left(1168 \mathrm{~cm}^{-1}\right.$ peak). The positions of the absorption bands of the spectra fell within typical major absorption bands of humic acid which is at frequencies 3680, 2918, 1721, 1168 $\mathrm{cm}^{-1}$. The first peak centred in the vicinity of $3680 \mathrm{~cm}^{-1}$ region is attributed to phenol $\mathrm{OH}$ group bounded by intermolecular $\mathrm{H}$ bonds. The $2918 \mathrm{~cm}^{-1}$ band usually has absorption maximum at $2918 \mathrm{~cm}^{-1}$ which is due to $\mathrm{C}-\mathrm{H}$ stretching of alkane group $\left(\mathrm{CH}_{2}\right)$. The next major absorption band is $1721 \mathrm{~cm}^{-1}$. This band has been commonly ascribed to $\mathrm{C}=\mathrm{O}$ stretching of mainly carboxyl group $(\mathrm{COOH})$ with trace amount of ketones. The last peak was observed at 1168 $\mathrm{cm}^{-1}$ due to $\mathrm{C}-\mathrm{O}$ stretching of polysaccharides and this peak appeared also in the spectra of humic acid from peat soil. The FTIR spectra of the isolated humic acid contained all major characteristic absorption peaks of humic acid. These absorption peaks indicated the presence of the major structural elements of humic acid namely $\mathrm{H}$ bonded $\mathrm{OH}, \mathrm{C}=\mathrm{C}$ of aromatic ring, $\mathrm{C}=\mathrm{O}$ of carbonyl group (both carboxyl and ketonic), $\mathrm{CH}_{2}$ group. This strongly supports the presence of humic acid.

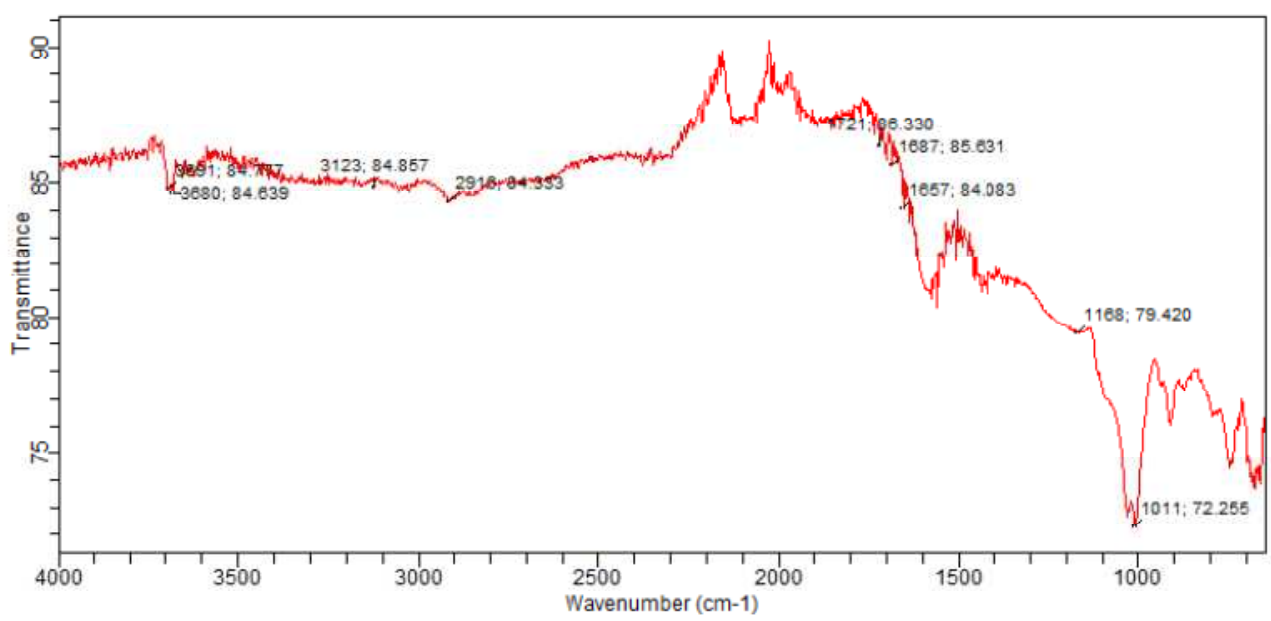

Fig. 2 : FT-IR spectraof peatsoilhumic acid (PSHA)

\section{Evaluation of acid dissociation constant (pka) of acid hydrolysed peat soil humicacid at phenolic group}

The value of the dissociation constant of the peat soil humic acid (PSHA) that underwent acidhydrolysis studied was found to be 8.9299 as shown Table 1, which is lower than the literaturevalues reported by Almeida and Szpoganics, (2015), Borges et al., (2005); Badr et al., (2012)and Fernandes et al,.(2009) of $9.73,9.47$ and 10.30. The difference between the obtained valuesand the reported values in this study might be probably as a result of acid hydrolysis of humicacid. 
BAJOPAS Volume 14 Number 1,June, 2021

Table 1: PKa of (Hydrolysed PSHA)

\begin{tabular}{|l|l|l|l|l|l|l|}
\hline $\mathrm{pH}$ & $\mathrm{BV}_{1}$ & $\mathrm{BV}_{2}$ & $\mathrm{~V}_{2}-\mathrm{V}_{1}$ & $\mathrm{nA}$ & $\log \left(\frac{n A}{1-n A}\right)$ & $\mathrm{pKa}$ \\
\hline 8.50 & 5.30 & 6.29 & 0.99 & 0.3594 & -0.2510 & 8.2490 \\
8.72 & 5.35 & 6.37 & 1.02 & 0.3400 & -0.2880 & 8.4320 \\
9.00 & 5.40 & 6.46 & 1.06 & 0.3141 & -0.3391 & 8.6609 \\
9.22 & 5.45 & 6.55 & 1.10 & 0.2882 & -0.3927 & 8.8273 \\
9.51 & 5.50 & 6.66 & 1.16 & 0.2494 & -0.4786 & 9.0314 \\
9.73 & 5.55 & 6.78 & 1.23 & 0.2041 & -0.5910 & 9.1390 \\
10.00 & 5.60 & 6.90 & 1.30 & 0.1589 & -0.7238 & 9.2762 \\
10.23 & 5.65 & 7.05 & 1.40 & 0.0941 & -0.9835 & 9.2465 \\
10.49 & 5.70 & 7.10 & 1.40 & 0.0941 & -0.9835 & 9.5065 \\
\hline
\end{tabular}

Average pKa $=8.9299 \pm 0.4186$

Table 2: PKa of (Unhydrolysed PSHA)

\begin{tabular}{|l|l|l|l|l|l|l|}
\hline $\mathrm{pH}$ & $\mathrm{BV}_{1}$ & $\mathrm{BV}_{2}$ & $\mathrm{~V}_{2}-\mathrm{V}_{1}$ & $\mathrm{nA}$ & $\log \left(\frac{\boldsymbol{n A}}{1-\boldsymbol{n}}\right)$ & $\mathrm{pKa}$ \\
\hline 8.50 & 5.30 & 5.81 & 0.51 & 0.6619 & 0.2919 & 8.7919 \\
8.72 & 5.35 & 5.90 & 0.55 & 0.6357 & 0.2418 & 8.9618 \\
9.00 & 5.40 & 6.00 & 0.60 & 0.6029 & 0.1813 & 9.1813 \\
9.22 & 5.45 & 6.10 & 0.65 & 0.5701 & 0.1226 & 9.3426 \\
9.51 & 5.50 & 6.20 & 0.70 & 0.5376 & 0.0654 & 9.5754 \\
9.73 & 5.55 & 6.33 & 0.78 & 0.4851 & -0.0259 & 9.7041 \\
10.00 & 5.60 & 6.47 & 0.87 & 0.4262 & -0.1291 & 9.8709 \\
10.23 & 5.65 & 6.62 & 0.99 & 0.3609 & -0.2481 & 9.9819 \\
10.49 & 5.70 & 6.80 & 1.10 & 0.2759 & -0.4690 & 10.0210 \\
\hline
\end{tabular}

Average pKa $=9.4923 \pm 0.4410$

Metal-ligand stability constant ( $\log \mathrm{K}$ )

The stabilityconstants require the accurate values of proton-ligand stability constants (Anil and Maroti, 2008). Metal titration curves crossed over ligand titration curve indicated the formation of complex upon proton release (Santosh, et al., 2011). If the values of n- are within range $0.2-0.8$ and $1.2-18$ this indicates the formation of $1: 1$ and 1:2 complexes (Sayyed and Mazahar, 2012).

The metal (II)-humate stepwise stability constants (log k) at phenolic group (Tables 318)

Table 3: Point-wise method, $\mathrm{Cu}$-(Hydrolysed PSHA)

\begin{tabular}{|l|l|l|l|l|l|l|l|l|}
\hline $\mathrm{pH}$ & $\mathrm{BV}_{1}$ & $\mathrm{BV}_{2}$ & $\mathrm{BV}_{3}$ & $\left(\mathrm{~V}_{3}-\mathrm{V}_{2}\right)$ & $\mathrm{n}$ & $\mathrm{pL}$ & $\log \left(\frac{n}{1-n}\right)$ & LogK $_{1}$ \\
\hline 8.50 & 5.30 & 6.29 & 6.33 & 0.04 & 0.5500 & 2.66 & 0.0871 & 2.7471 \\
8.72 & 5.35 & 6.37 & 6.41 & 0.04 & 0.5714 & 2.43 & 0.1249 & 2.5549 \\
9.00 & 5.40 & 6.46 & 6.50 & 0.04 & 0.6198 & 2.16 & 0.2122 & 2.3722 \\
9.22 & 5.45 & 6.55 & 6.59 & 0.04 & 0.6667 & 1.94 & 0.3010 & 2.2410 \\
\hline
\end{tabular}

LogK $_{1}$ (Average value) $=2.4788 \pm 0.2203$

Table 4: Point-wise method, $\mathrm{Cu}$-(Hydrolysed PSHA)

\begin{tabular}{|l|l|l|l|l|l|l|l|l|}
\hline $\mathrm{pH}$ & $\mathrm{BV}_{1}$ & $\mathrm{BV}_{2}$ & $\mathrm{BV}_{3}$ & $\left(\mathrm{~V}_{3}-\mathrm{V}_{2}\right)$ & $\mathrm{n}$ & $\mathrm{pL}$ & $\log \left(\frac{n-1}{2-n}\right)$ & LogK $_{2}$ \\
\hline 9.51 & 5.50 & 6.66 & 6.73 & 0.07 & 1.3509 & 1.70 & -0.2671 & 1.4329 \\
9.73 & 5.55 & 6.78 & 6.85 & 0.07 & 1.6383 & 1.51 & 0.2467 & 1.7567 \\
10.00 & 5.60 & 6.90 & 6.98 & 0.08 & 2.1783 & 1.31 & -0.2158 & 1.0942 \\
10.23 & 5.65 & 7.05 & 7.13 & 0.08 & 4.1904 & 1.27 & & \\
10.49 & 5.70 & 7.10 & 7.19 & 0.09 & 4.6920 & & & \\
\hline
\end{tabular}

Log $K_{2}($ Average value $)=1.4280 \pm 0.3312$ 
BAJOPAS Volume 14 Number 1,June, 2021

Table 5: Point-wise method, $\mathrm{Cu}$ (Unhydrolysed PSHA)

\begin{tabular}{|l|l|l|l|l|l|l|l|l|}
\hline $\mathrm{pH}$ & $\mathrm{BV}_{1}$ & $\mathrm{BV}_{2}$ & $\mathrm{BV}_{3}$ & $\left(\mathrm{~V}_{3}-\mathrm{V}_{2}\right)$ & $\mathrm{n}$ & $\mathrm{pL}$ & $\log \left(\frac{n}{n-1}\right)$ & Log $_{1}$ \\
\hline 8.50 & 5.30 & 5.81 & 5.85 & 0.04 & 0.2973 & 2.88 & -0.3736 & 2.5064 \\
8.72 & 5.35 & 5.90 & 5.95 & 0.05 & 0.3873 & 2.66 & -0.1992 & 2.4608 \\
9.00 & 5.40 & 6.00 & 6.05 & 0.05 & 0.4044 & 2.38 & -0.1681 & 2.2119 \\
9.22 & 5.45 & 6.10 & 6.15 & 0.06 & 0.5157 & 2.18 & -0.0272 & 2.2072 \\
9.51 & 5.50 & 6.20 & 6.27 & 0.07 & 0.6417 & 1.89 & 0.2530 & 1.1430 \\
\hline
\end{tabular}

$\operatorname{LogK}_{1}($ Average value $)=2.3059 \pm 0.6153$

Table 6:Point-wise method, $\mathrm{Cu}$ (Unhydrolysed PSHA)

\begin{tabular}{|l|l|l|l|l|l|l|l|l|}
\hline $\mathrm{pH}$ & $\mathrm{BV}_{1}$ & $\mathrm{BV}_{2}$ & $\mathrm{BV}_{3}$ & $\mathrm{~V}_{3}-\mathrm{V}_{2}$ & $\mathrm{n}$ & $\mathrm{pL}$ & $\log \left(\frac{n-1}{2-n}\right)$ & $\log \mathrm{K}_{2}$ \\
\hline 9.73 & 5.55 & 6.33 & 6.42 & 0.09 & 0.9000 & 1.69 & & \\
10.00 & 5.60 & 6.47 & 6.58 & 0.11 & 1.2578 & 1.44 & -0.4592 & 0.9808 \\
10.23 & 5.65 & 6.62 & 6.84 & 0.12 & 1.6137 & 1.26 & -0.2010 & 1.4610 \\
10.49 & 5.70 & 6.80 & 6.92 & 0.12 & 2.1052 & 1.03 & & \\
\hline
\end{tabular}

$\operatorname{LogK}_{2}$ (Average value) $=1.2209 \pm 0.3398$

Table 7:Point-wise method, Pb (Hydrolysed PSHA)

\begin{tabular}{|l|l|l|l|l|l|l|l|l|}
\hline $\mathrm{pH}$ & $\mathrm{BV}_{1}$ & $\mathrm{BV}_{2}$ & $\mathrm{BV}_{3}$ & $\left(\mathrm{~V}_{3}-\mathrm{V}_{2}\right)$ & $\mathrm{n}$ & $\mathrm{pL}$ & $\log \left(\frac{n}{1-n}\right)$ & LogK $_{1}$ \\
\hline 8.50 & 5.30 & 6.29 & 6.33 & 0.04 & 0.5500 & 2.66 & 0.0871 & 2.7471 \\
8.72 & 5.35 & 6.37 & 6.41 & 0.04 & 0.5714 & 2.43 & 0.1249 & 2.5549 \\
9.00 & 5.40 & 6.46 & 6.50 & 0.04 & 0.6198 & 2.16 & 0.2122 & 2.3722 \\
9.22 & 5.45 & 6.55 & 6.60 & 0.05 & 0.8333 & 1.96 & 0.6989 & 2.6589 \\
\hline
\end{tabular}

Log $_{\mathbf{1}}($ Average value $)=2.5832 \pm 0.1614$

Table 8:Point-wise method, Pb-(Hydrolysed PSHA)

\begin{tabular}{|l|l|l|l|l|l|l|l|l|}
\hline $\mathrm{pH}$ & $\mathrm{BV}_{1}$ & $\mathrm{BV}_{2}$ & $\mathrm{BV}_{3}$ & $\left(\mathrm{~V}_{3}-\mathrm{V}_{2}\right)$ & $\mathrm{n}$ & $\mathrm{pL}$ & $\log \left(\frac{n-1}{2-n}\right)$ & $\log \mathrm{K}_{2}$ \\
\hline 9.51 & 5.50 & 6.66 & 6.71 & 0.05 & 0.9650 & 1.67 & & \\
9.73 & 5.55 & 6.78 & 6.83 & 0.05 & 1.1702 & 1.44 & & \\
10.00 & 5.60 & 6.90 & 6.90 & 0.05 & 1.4864 & 1.22 & -0.0237 & 1.1963 \\
10.23 & 5.65 & 7.05 & 7.10 & 0.05 & 2.0190 & 1.09 & & \\
10.49 & 5.70 & 7.10 & 7.17 & 0.07 & 3.6492 & 1.00 & & \\
\hline
\end{tabular}

Log $K_{2}$ (Average value) $=1.1963$

Table 9: Point-wise method, Pb (Unhydrolysed PSHA)

\begin{tabular}{|l|l|l|l|l|l|l|l|l|}
\hline $\mathrm{pH}$ & $\mathrm{BV}_{1}$ & $\mathrm{BV}_{2}$ & $\mathrm{BV}_{3}$ & $\mathrm{~V}_{3}-\mathrm{V}_{2}$ & $\mathrm{n}$ & $\mathrm{pL}$ & $\begin{array}{l}\text { Log } \\
\left(\frac{n}{n-1}\right)\end{array}$ & Log $\mathrm{K}_{1}$ \\
\hline 8.50 & 5.30 & 5.81 & 5.85 & 0.04 & 0.2973 & 2.88 & -0.3736 & 2.5064 \\
8.72 & 5.35 & 5.90 & 5.94 & 0.04 & 0.3099 & 2.66 & -0.5477 & 2.3123 \\
9.00 & 5.40 & 6.00 & 6.05 & 0.05 & 0.4044 & 2.38 & -0.1681 & 2.2119 \\
9.22 & 5.45 & 6.10 & 6.15 & 0.06 & 0.5157 & 2.18 & 0.0272 & 2.2072 \\
9.51 & 5.50 & 6.20 & 6.26 & 0.07 & 0.6417 & 1.89 & 0.2530 & 2.1430 \\
9.73 & 5.55 & 6.40 & 6.40 & 0.07 & 0.7000 & 1.67 & 0.3680 & 2.0380 \\
\hline
\end{tabular}

LogK $_{1}$ (Average value) $=2.2364 \pm 0.1602$

Table 10: Point-wise method, Pb (Unhydrolysed PSHA)

\begin{tabular}{|l|l|l|l|l|l|l|l|l|}
\hline $\mathrm{pH}$ & $\mathrm{BV}_{1}$ & $\mathrm{BV}_{2}$ & $\mathrm{BV}_{3}$ & $\mathrm{~V}_{3}-\mathrm{V}_{2}$ & $\mathrm{n}$ & $\mathrm{pL}$ & $\log \left(\frac{n-1}{2-n}\right)$ & $\log \mathrm{K}_{2}$ \\
\hline 10.00 & 5.60 & 6.47 & 6.55 & 0.08 & 1.9503 & 1.41 & & \\
10.23 & 5.65 & 6.62 & 6.72 & 0.11 & 1.4792 & 1.26 & -0.0361 & 1.2239 \\
\hline
\end{tabular}

$\operatorname{LogK}_{2}$ (Average value) $=1.2239$

Table 11: Point-wise method, Mg (Hydrolysed PSHA)

\begin{tabular}{|l|l|l|l|l|l|l|l|l|}
\hline $\mathrm{pH}$ & $\mathrm{BV}_{1}$ & $\mathrm{BV}_{2}$ & $\mathrm{BV}_{3}$ & $\left(\mathrm{~V}_{3}-\mathrm{V}_{2}\right)$ & $\mathrm{n}$ & $\mathrm{pL}$ & $\log \left(\frac{n}{n-1}\right)$ & LogK $_{1}$ \\
\hline 8.50 & 5.30 & 6.29 & 6.31 & 0.02 & 0.2750 & 2.64 & -0.4290 & 2.2110 \\
8.72 & 5.35 & 6.37 & 6.39 & 0.02 & 0.2858 & 2.42 & -0.3978 & 2.0222 \\
9.00 & 5.40 & 6.46 & 6.49 & 0.03 & 0.4648 & 2.14 & -0.0612 & 2.0788 \\
9.22 & 5.45 & 6.55 & 6.59 & 0.04 & 0.6667 & 1.94 & 0.3010 & 2.2410 \\
\hline
\end{tabular}

$\log _{\mathbf{1}}($ Average value) $=2.1382 \pm 0.1046$ 
BAJOPAS Volume 14 Number 1,June, 2021

Table 12: Point-wise method, Mg (Hydrolysed PSHA)

\begin{tabular}{|l|l|l|l|l|l|l|l|l|}
\hline $\mathrm{pH}$ & $\mathrm{BV}_{1}$ & $\mathrm{BV}_{2}$ & $\mathrm{BV}_{3}$ & $\left(\mathrm{~V}_{3}-\mathrm{V}_{2}\right)$ & $\mathrm{n}$ & $\mathrm{pL}$ & $\log \left(\frac{n-1}{2-n}\right)$ & LogK $_{2}$ \\
\hline 9.51 & 5.55 & 6.66 & 6.71 & 0.05 & 0.9650 & 1.67 & & \\
9.73 & 5.55 & 6.78 & 6.84 & 0.06 & 1.4042 & 1.47 & -0.1686 & 1.3014 \\
10.00 & 5.60 & 6.90 & 6.93 & 0.06 & 1.7838 & 1.23 & 0.5593 & 1.7893 \\
10.23 & 5.65 & 7.05 & 7.10 & 0.06 & 3.1429 & 1.10 & & \\
10.49 & 5.70 & 7.10 & 7.18 & 0.07 & 3.6492 & 0.83 & & \\
\hline
\end{tabular}

LogK $_{2}($ Average value $)=1.5453 \pm 0.3450$

Table 13: Point-wise method, Mg (Unhydrolysed PSHA)

\begin{tabular}{|l|l|l|l|l|l|l|l|l|}
\hline $\mathrm{pH}$ & $\mathrm{BV}_{1}$ & $\mathrm{BV}_{2}$ & $\mathrm{BV}_{3}$ & $\mathrm{~V}_{3}-\mathrm{V}_{2}$ & $\mathrm{n}$ & $\mathrm{pL}$ & $\log \left(\frac{n}{n-1}\right)$ & $\operatorname{Log~}_{1}$ \\
\hline 8.50 & 5.30 & 5.81 & 5.85 & 0.04 & 0.2973 & 2.88 & -0.3736 & 2.5064 \\
8.72 & 5.35 & 5.90 & 5.94 & 0.04 & 0.3099 & 2.66 & -0.3477 & 2.3123 \\
9.00 & 5.40 & 6.00 & 6.04 & 0.04 & 0.3236 & 2.38 & -0.3202 & 2.0598 \\
9.22 & 5.45 & 6.10 & 6.15 & 0.05 & 0.4297 & 2.17 & -0.1230 & 2.0470 \\
9.51 & 5.50 & 6.20 & 6.26 & 0.06 & 0.5500 & 1.89 & 0.0871 & 1.9771 \\
9.73 & 5.55 & 6.33 & 6.40 & 0.07 & 0.7000 & 1.67 & 0.3680 & 2.0380 \\
\hline
\end{tabular}

LogK $_{1}$ (Average value) $=2.1568 \pm 0.2069$

Table 14: Point-wise method, Mg (Unhydrolysed PSHA)

\begin{tabular}{|l|l|l|l|l|l|l|l|l|}
\hline $\mathrm{pH}$ & $\mathrm{BV}_{1}$ & $\mathrm{BV}_{2}$ & $\mathrm{BV}_{3}$ & $\mathrm{~V}_{3}-\mathrm{V}_{2}$ & $\mathrm{n}$ & $\mathrm{pL}$ & $\log \left(\frac{n-1}{2-n}\right)$ & $\log \mathrm{K}_{2}$ \\
\hline 10.00 & 5.60 & 6.47 & 6.55 & 0.08 & 0.9148 & 1.41 & & \\
10.23 & 5.65 & 6.62 & 6.71 & 0.09 & 1.2102 & 1.20 & -0.5749 & 0.6251 \\
10.49 & 5.70 & 6.80 & 6.92 & 0.09 & 1.5968 & 1.03 & 0.1703 & 1.2003 \\
\hline
\end{tabular}

LogK $_{2}$ (Average value) $=0.9127 \pm 0.4070$

Table15:Point-wise method, Cd (Hydrolysed PSHA)

\begin{tabular}{|l|l|l|l|l|l|l|l|l|}
\hline $\mathrm{pH}$ & $\mathrm{BV}_{1}$ & $\mathrm{BV}_{2}$ & $\mathrm{BV}_{3}$ & $\left(\mathrm{~V}_{3}-\mathrm{V}_{2}\right)$ & $\mathrm{n}$ & $\mathrm{pL}$ & $\log \left(\frac{n}{1-n}\right)$ & LogK $_{1}$ \\
\hline 8.50 & 5.30 & 6.29 & 6.31 & 0.02 & 0.2750 & 2.64 & -0.4210 & 2.2190 \\
8.72 & 5.35 & 6.37 & 6.40 & 0.03 & 0.4286 & 2.42 & -0.1249 & 2.2951 \\
9.00 & 5.40 & 6.46 & 6.49 & 0.03 & 0.4648 & 2.14 & -0.0612 & 2.0788 \\
9.22 & 5.45 & 6.55 & 6.59 & 0.04 & 0.6667 & 1.96 & 0.3010 & 2.2610 \\
9.51 & 5.55 & 6.66 & 6.70 & 0.04 & 0.7720 & 1.67 & 0.5297 & 2.1997 \\
\hline
\end{tabular}

LogK $_{\mathbf{1}}$ (Average value) $=2.2108 \pm 0.0825$

Table 16: Point-wise method, Cd (Hydrolysed PSHA)

\begin{tabular}{|l|l|l|l|l|l|l|l|l|}
\hline $\mathrm{pH}$ & $\mathrm{BV}_{1}$ & $\mathrm{BV}_{2}$ & $\mathrm{BV}_{3}$ & $\left(\mathrm{~V}_{3}-\mathrm{V}_{2}\right)$ & $\mathrm{n}$ & $\mathrm{pL}$ & $\log \left(\frac{n-1}{2-n}\right)$ & Log $_{2}$ \\
\hline 9.73 & 5.55 & 6.78 & 6.83 & 0.06 & 1.4042 & 1.47 & -0.1686 & 1.3014 \\
10.00 & 5.60 & 6.90 & 6.95 & 0.06 & 1.7838 & 1.23 & 0.5593 & 1.7893 \\
10.23 & 5.65 & 7.05 & 7.10 & 0.06 & 3.1429 & 1.09 & & \\
10.49 & 5.70 & 7.10 & 7.16 & 0.06 & 3.1429 & 0.89 & & \\
& & & & & & & & \\
\hline
\end{tabular}

$\operatorname{LogK}_{2}$ (Average value) $=1.5453 \pm 0.3450$

Table 17: Point-wise method, Cd (Unhydrolysed PSHA)

\begin{tabular}{|l|l|l|l|l|l|l|l|l|}
\hline $\mathrm{pH}$ & $\mathrm{BV}_{1}$ & $\mathrm{BV}_{2}$ & $\mathrm{BV}_{3}$ & $\mathrm{~V}_{3}-\mathrm{V}_{2}$ & $\mathrm{n}$ & $\mathrm{pL}$ & $\log \left(\frac{n}{n-1}\right)$ & $\operatorname{Log~}_{1}$ \\
\hline 8.50 & 5.30 & 5.81 & 5.86 & 0.05 & 0.3717 & 2.88 & -0.2280 & 2.6520 \\
8.72 & 5.35 & 5.90 & 5.95 & 0.05 & 0.3873 & 2.66 & -0.1992 & 2.4608 \\
9.00 & 5.40 & 6.00 & 6.06 & 0.06 & 0.4853 & 2.38 & -0.0255 & 2.3545 \\
9.22 & 5.45 & 6.10 & 6.16 & 0.06 & 0.5157 & 2.18 & -0.0272 & 2.2072 \\
9.51 & 5.50 & 6.20 & 6.27 & 0.07 & 0.6417 & 1.89 & 0.2530 & 1.1430 \\
9.73 & 5.55 & 6.33 & 6.41 & 0.08 & 0.8000 & 1.69 & 0.6020 & 2.2920 \\
& & & & & & & & \\
\hline
\end{tabular}

$\operatorname{LogK}_{1}($ Average value $)=2.2516 \pm 0.5380$ 
BAJOPAS Volume 14 Number 1,June, 2021

Table 18: Point-wise method, Cd (Unhydrolysed PSHA)

\begin{tabular}{|l|l|l|l|l|l|l|l|l|}
\hline $\mathrm{pH}$ & $\mathrm{BV}_{1}$ & $\mathrm{BV}_{2}$ & $\mathrm{BV}_{3}$ & $\mathrm{~V}_{3}-\mathrm{V}_{2}$ & $\mathrm{n}$ & $\mathrm{pL}$ & $\log \left(\frac{n-1}{2-n}\right)$ & $\log \mathrm{K}_{2}$ \\
\hline 10.00 & 5.60 & 6.47 & 6.57 & 0.10 & 1.1434 & 1.43 & & \\
10.23 & 5.65 & 6.62 & 6.72 & 0.10 & 1.3448 & 1.23 & -0.2788 & 0.9512 \\
10.49 & 5.70 & 6.80 & 6.90 & 0.10 & 1.7742 & 1.03 & 0.5351 & 1.5651 \\
\hline
\end{tabular}

$\operatorname{LogK}_{2}($ Average value $)=1.2581 \pm 0.4340$

Table 19: Stepwise and overall Stability constants of thehydrolysed and unhydrolysed divalent metal (II) complexes

\begin{tabular}{|c|c|c|c|}
\hline Chelates & LogK $_{1}$ & $\log _{2}$ & Log $\beta$ \\
\hline [Cu (Hydrolysed PSHA-1) $\left.{ }_{2}\right]$ & 2.4788 & 1.4280 & 3.9068 \\
\hline$\left[\mathrm{Pb}(\text { Hydrolysed PSHA-1) })_{2}\right]$ & 2.5832 & 1.1963 & 3.7795 \\
\hline$\left[\mathrm{Cd}(\text { Hydrolysed PSHA-1 })_{2}\right]$ & 2.2108 & 1.5453 & 3.7561 \\
\hline$\left[\mathrm{Mg}(\text { Hydrolysed PSHA-1 })_{2}\right]$ & 2.1382 & 1.5453 & 3.6835 \\
\hline [Cu (Unhydrolysed PSHA-1) & 2.3059 & 1.2209 & 3.5268 \\
\hline$[\mathrm{Pb}$ (Unhydrolysed PSHA-1) 2$]$ & 2.2364 & 1.2239 & 3.4603 \\
\hline [Cd (Unhydrolysed PSHA-1) 2 ] & 2.2516 & 1.2581 & 3.5097 \\
\hline$[\mathrm{Mg}$ (Unydrolysed PSHA-1) & 2.1568 & 0.9127 & 3.0695 \\
\hline
\end{tabular}

The results obtained (Table19) shows the stepwise and overall stability constants to be not high indicating low stability of the complexes, because the solubility of most metal ions in the basic $\mathrm{pH}$ range is minimal due to metal hydroxide precipitation (Karimi, 2017). In general, the stepwise stability constants $\left(K_{1}\right.$ and $K_{2}$ ) follow the order $K_{1}>K_{2}$ for the copper, lead, magnesium and cadmium complexes respectively. The steady decrease of the values with increasing number of ligands is in agreement with the prediction made by researchers (Na'aliya, 2013). The decrease could be attributed to the fact that as the number of the ligands (Humate ions) that enters the coordination zone increases the aqua molecules available for replacement by the ligands become less. Thus, the metal ions become less electron loving with progressive intake of the ligand and this results in the decrease in the values of the constants (Na'aliya, 2013). Also the stability of the complexes is influenced by the size and number of the chelate rings(Mackay and Mackay,2002).All the complexes form rings in their structure as humate, a bidentate ligand, bond the metal ions in the ratio 1:2 (Boguta and Sokolowska, 2016) forming chelate rings. The values of the overall stability constants $(\log \beta)$ obtained for humate complexes are not high indicating low stability as the values are not high. LogK values for copper-humates (Table 3 to 6) obtained in this study are lower than those reported for the complexes of humic acids (Pandey et al., 2015; Dinu, 2013; Kaschl et al., 2010 and Gilbeto and Jorg, 2001). The values of LogK(Table 7 to 10 ) forlead-humates are lower than those reported for the lead in the literature (Dinu, 2013; Gilbeto and Jorg 2001). Log K values(Table 11 to 14 ) for magnesium-humates obtained in this study are close to those reported by (Pandey et al., 2015). Log K values of cadmium-humates (Table 15 to 18 ) obtained in this work near to the one reported by (Dinu, 2013 and Pandey et al., 2015).The difference between the reported values and the values obtained in this study might be probably as a result of acid hydrolysis of humic acid. The values of the overall stability constants $(\log \beta)$ of the copper humates complexes presented in Table 19 is high than that of other metal humate complexes, show relatively high stability of CuHA complexes, show the following order of stability: $\mathrm{Cu}>\mathrm{Pb}>\mathrm{Cd}>\mathrm{Mg}$; which are in close agreement to the findings of (Dinu, 2013 and Pandey et al., 2015).The high stability of Cuhumate chelate could be attributed to the existence of coordinate covalent bond between the complexing agents and the $\mathrm{Cu}^{2+}$ ions. Since, $\mathrm{Cu}^{2+}$ being a metal of the transitional series with $3 d^{9}$ electronic configurations can accept the electrons from the complexing agents. Similarly, the low stabilities of $\mathrm{Pb}, \mathrm{Cd}$ and $\mathrm{Mg}$ complexes could be explained by that $\mathrm{Pb}^{2+}$ with $6 s^{2}, \mathrm{Cd}^{2+}$ with $4 \mathrm{~d}^{10}$ and $\mathrm{Mg}^{2+}$ with $2 \mathrm{p}^{6}$ their electronic configuration has a completely filled $\mathrm{d}, \mathrm{p}$ and $\mathrm{s}$ orbitals. Moreover, the stabilities of metal ions with hydrolysed humic acid from peat soil were higher than those with unhydrolysed humic acid from peat soil; which is ascribed to the high content of acidity in hydrolysed humic acid than unhydrolysed humic acid. 
BAJOPAS Volume 14 Number 1,June, 2021 CONCLUSION

The values of logk for $\mathrm{Cu}(\mathrm{II})$ hydrolysed humic acid complex was higher followed by $\mathrm{Pb}$ (II), $\mathrm{Cd}(\mathrm{II})$ and $\mathrm{Mg}$ (II) hydrolysed humic acid complexes as compared with metal(II) unhydrolysed humic acid complexes. This indicates acid hydrolysis of humic acid can

\section{REFERENCES}

Almeida, V.R. and Szpoganicz, B. (2015). Humic Acid Potentiometric Response Patterns:Out- of Equilibrium Properties and Species Distribution Modelling. Chemical. Biol. Technol. Agric. 2: 17.

Anđelković, T., Nikolić, R., Bojić, A.,Anđelković, D., and Nikolic G.,(2010). Binding of Cadmium to Soil Humic Acid as A Function of Carboxyl Group Content. Macedonian Journal of Chemistry and Chemical Engineering.29(2): 215-224.

Anil, B. N. and Maroti, N. (2008). Studies on Influence of Die-Lectric Constants on Complex Equilibria between Substituted Py-Razalines and Lanthanide Metal Ions pH-Metrically. Amer.-Euras. scient. Res. 3(2): 212-216.

Ashok, K., Pandey, S. P. and Misra, V (2000). Stability Constants of Metal-Humic Acid Complexes and its Role in Environmental Detoxification. Journal of Ecotoxicology and Environmental Safety. 47(2):157-200.

Badr, M. H., El-Halafawi, M. H. and Abd El-al Zeid, E. R. (2012). Comparison Between the Effect of Ionic Strength on Acidity and Dissociation Constants of Humic Acids Extracted from Sewage Sludge and Nile Water Hyacinth Composts.Global Journal of Environmental Research 6 (1): 36-43.

Baruah, M.K., Borah, D., Saikia, P.P., Paul, S., Sharma, T. (2015). Evaluation of pKa Values of Soil Humic Acids and their Complexation Properties. International Journal of Plant \& Soil Science 6(4) : 218-228.

Boguta, P. Sokolowska, Z. (2016). Interactions of $\mathrm{Zn}$ (II) Ions with Humic Acids Isolated from Various Types of Soils. Effect of $\mathrm{pH}, \mathrm{Zn}$ Concentrations and Humic Acids Chemical Properties. Journal of Geochemical Explaration 168. 119-126.

Borges, F., Guimaraes, C., Lima, L.F.C., Pinto, I. and Reis, S.(2005). Potentiometric Studies on the Complexation of Copper(II) by Phenolic Acids as Discrete Ligand Models of enhance the complexation behavior of humic acid with metal (II) ions. However, the higher values of $\log \beta$ for $\mathrm{Cu}(\mathrm{II}), \mathrm{Pb}(\mathrm{II}), \mathrm{Cd}(\mathrm{II})$ and $\mathrm{Mg}(\mathrm{II})$ hydrolysed humic acid complexes indicates more stable stepwise complexes formed as compared with $\mathrm{Cu}(\mathrm{II}), \mathrm{Pb}$ (II), $\mathrm{Cd}$ (II) and $\mathrm{Mg}(\mathrm{II})$ unhydrolysed humic acid complexes.

Humic Substances Talanta 66 (2005) 670-673.

Chefetz, B., Salloum, M. J., Deshmulkin, A. P. and Hatcher, P. (2002). Structural Components of Humic Acids as Determined by Chemical Modifications and Carbon-13 NMR, Pyrolysis, and Thermochemolysis- Gas Chromatography/Mass Spectrometry. Soil Science Society of American Journal Abstract Division S-2- Soil Chemistry66. 1159-1171.

Dinu, M. I. (2013). Metals Complexation with Humic Acids in Surface Water of Different Environ. Sci. Technol. 31(1): 1-17.

Fernandes, A.N., Giacomelli, C., Giovanela, M. Vaz, D.V. Szpoganicz, B. and Maria M. D. (2009). Potentiometric Acidity Determination in Humic Substances Influenced by Different Analytical Procedures.J. Braz. Chem. Soc. 20 (9):14.

Gamal, A. H. (2015). Stability Constants of Rhenium (V) Metal Complexes with Selected Drugs. Pyrex Journal of Research in Environmental Studies. 2(2): 006-014.

Janrao, D. M., Pathan, J., Kayande, D.D., and Mulla, J.J. (2014). An Over View of Potentiometric Determination of Stability Constants of Metal Complexes. Sci. Revs. Chem. Commun.: 4(1), 2014, 11-24.

Karimi, H. (2017). Effect of pH and Initial Pb(II) Concentration on the Lead Removal Efficiency from Waste Water Using $\mathrm{Ca}(\mathrm{OH})_{2}$. International Journal of Water and Waste Water Treatment 3.2

Kaschl, A. Romheld, V. and Chen, Y. (2010). Binding of Cadmium, Copper and Zinc to Humic Substances Originating from Municipal Solid Waste Compost. Israel Journal of Chemistry Vol. 42(1): 89-98.

Kostic, I. S., Tatjana, P, A., Nikolic, R. S., Cvetkovic, T. P., Pavlovic, D. D., Aleksandar, L.J. and Bojic, A. (2012). Comparative Study of Binding Strengths of Heavy Metals with Humic Acid. J.serb. Chem. Soc. 76(9) pp 1-20. 
BAJOPAS Volume 14 Number 1,June, 2021

Na'aliya, J. (2013). Determination of Stepwise Stability Constants and Gibbs free Energy Change of Trisprolina to Complexes of some Divalent Transition Metal ions. Bayero Journal of Pure and Applied Sciences 6(2): 112-114.

Omar, A. A. and Ali, E. A. (2015). Potentiometric Studies on Complexes of $\mathrm{Cr}$ (III) and $\mathrm{Zr}$ (IV) with some Carboxylic Acids. International Journal of Advanced Chemistry, 3(1) 25-

37.

Pandey, A. K. Pandey, S. D. and Misr, V. (2015).Stability Constants of Metal- Humic Acid Complexes and Its Role in Environmental Detoxification. J. Ecotoxicology and Environmental Safety. 47(1):195-200.

Ram, N. and Raman, K.V. (1984). Stability Constants of Complexes of Metals with
Humicand Fuvic Acids under Non- acidConditions. Journal of Plant Nutrition and Soil Sciences.

147:171-176.

Santosh, D. D., Ashok, B. K., Vijay, J. T., Shivraj, G. W. and Vinay, V. W. (2011). Potentiometric Studies of Elec-Trolyte Effects on Complex Equilibria of Some Substituted 5-(2-hydroxy Phenyl) Pyrazoles. Der pharm. 3 (6): 75-83.

Sayyed, H. and Abdul Rahim, M. F. (2012). Studies of Binary Complexes of Metal Ions with Mandelic Acid by Potentiometry. Chem. J. 02 (6): 206209.

Shirvani, M. Moradian, E. Khalili, B. Bakhtiary, S. (2015). Interaction of $\mathrm{Cd}$ and $\mathrm{Pb}$ with Humate-Palygorskite and HumateSepiolite Complexes. Journal of water, air and pollution 3: 220-228. 


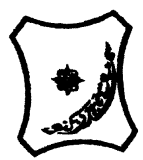

Bayero Journal of Pure and Applied Sciences, 14(1): 54 - 63

Received: November, 2020

Accepted: April, 2021

ISSN $2006-6996$

\title{
STABILITY CONSTANTS OF COMPLEXES OF METAL IONS WITH PEATSOIL HUMIC ACIDS UNDER NON-ACID-CONDITIONS
}

\author{
${ }^{* 1}$ Sabo, Yusuf ${ }^{2}$ Jimoh, W.L.O., ${ }^{3}$ Isa Baba Koki and ${ }^{4}$ Sholadoye, Q. 0. \\ ${ }^{1}$ Department of Pure and Industrial Chemistry, Bayero University, Kano \\ ${ }^{3}$ Department of Chemistry, Yusuf Maitama Sule University Kano. P.M.B. 3220 Kano, Nigeria. \\ ${ }^{4}$ Department of Chemistry, Nigerian Police Academy, Wudil, Kano-Nigeria
}

*Correspondence E-mail; saboyusuf18@yahoo.com

ABSTRACT

Stability constants of complexes of four divalent metal ions viz. $\mathrm{Cu}^{2+}, \mathrm{Pb}^{2+}, \mathrm{Mg}^{2+}$ and $\mathrm{Cd}^{2+}$ with humic acids (HA) were determined by potentiometric titration of humic acids with the corresponding salt of the divalent metals in aqueous media under non-acid-condition. The log $K$ (logarithm of the stability constant) ranged from 1.0942 to 2.7471 for metalhumic acid complexes were determined using point-wise computational method. The order of stability constants were obtained as follows: $\mathrm{Cu}>\mathrm{Pb}>\mathrm{Cd}>\mathrm{Mg}$ for metal $-\mathrm{HA}$ complexes respectively, indicating a higher degree of complexation with Cu metal ion.

Keywords: stability constant, humic acid, potentiometric titration, divalent metals, acid hydrolysis.

\section{NTRODUCTION}

The stability constant of a complex is the numerical expression of its stability and provides a quantitative measure of affinity of the metal ion to the complexing agent. An understanding of the relative stability of metal-complexes helps in predicting the behavior of metal ions in the soil (Ram and Raman, 1982). Extensive researches has been done to determine the stability constants of the complexes formed between humic acid (HA) with a number of metal ions. Ashok et al., (2000) reported that humic acid with hydroxyl, phenoxyl and carboxyl reactive groups can form coordination compound with metal ions at $\mathrm{pH}$ 3.5. The stability constants(Log K) for different metalhumic acid complexes indicated the following order of the stabilities of complexes formed between humic acid and metal ion, $\mathrm{Cu}>\mathrm{Fe}$ $>\mathrm{Pb}>\mathrm{Ni}>\mathrm{Co}>\mathrm{Ca}>\mathrm{Cd}>\mathrm{Zn}>\mathrm{Mn}>\mathrm{Mg}$. Andelkovic et al., (2010) investigated the binding of $\mathrm{Cd}$ (II) to soil humic acid at pH 6.5 and in $0.1 \mathrm{M} \mathrm{KNO}_{3}$ ionic medium. The stability constant for binding indicating greater stability in the case when carboxyl groups are involved in complexation reaction. Kostic et al.,(2012) investigated the complexation of humic acid with certain heavy metal ions (Co(II), $\mathrm{Ni}(\mathrm{II}), \mathrm{Cu}(\mathrm{II})$,
$\mathrm{Zn}(\mathrm{II})$, and $\mathrm{Pb}(\mathrm{II})$. The experiment was performed at $25^{\circ} \mathrm{C}$, at pH 4.0 and ionic strength of $0.01 \mathrm{M}$. Stability constant of complex between $\mathrm{Pb}$ (II) ions and humic acid is greater than stability constants of other investigated metalhumate complexes. Bogata and Sokolowska (2016) analyses the interaction between humic acids from different soils and $\mathrm{Zn}$ (II) ions at wide concentration ranges and at $\mathrm{pH} 5$. Studies have showed significant impact of $\mathrm{Zn}$ concentration, $\mathrm{pH}$ and some properties of humic acids with zinc.But all of these studies were limited to acidic $\mathrm{pH}$ range. Therefore, the present study was carried out to determine and compare the stability constants of complexes of metal ions with hydrolysed peat soil humic acid and unhydrolysed peat soil humic under non-acid conditions.

\section{MATERIALS AND METHODS}

Analytical grade chemicals used includes hydrochloric acid $(\mathrm{HCl})$, nitric acid $\left(\mathrm{HNO}_{3}\right)$, sodium hydroxide $(\mathrm{NaOH})$, lead nitrate $\mathrm{Pb}\left(\mathrm{NO}_{3}\right)_{2}$, copper nitrate $\mathrm{Cu}\left(\mathrm{NO}_{3}\right)_{2} \cdot 3 \mathrm{H}_{2} \mathrm{O}$, cadmium nitrate $\mathrm{Cd}\left(\mathrm{NO}_{3}\right)_{2} \cdot 4 \mathrm{H}_{2} \mathrm{O}$, magnesium nitrate $\mathrm{Mg}\left(\mathrm{NO}_{3}\right)_{2} \cdot 6 \mathrm{H}_{2} \mathrm{O}$, potassium nitrate $\left(\mathrm{KNO}_{3}\right)$, calcium chloride $\left(\mathrm{CaCl}_{2}\right)$, (sigma-Aldrich). Dowex 50WX8, (20-50 mesh) from Fluka. 


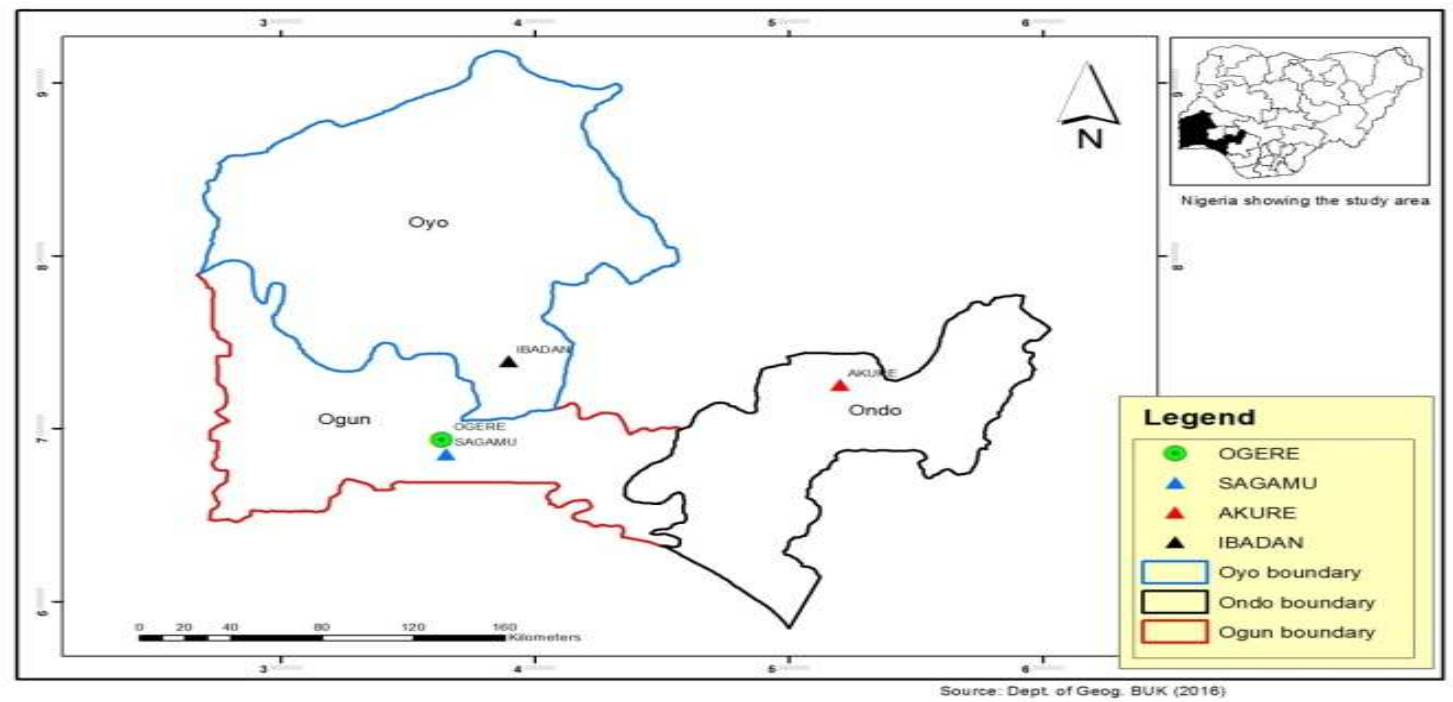

Figure 1: Map showing the sampling point at Sagamu Town, Ogun State.

\section{Description of Sampling Area}

Sagamu has geographical coordinates between $6^{\circ} 50^{\prime}$ north; $3^{\circ} 38^{\prime}$ east is located in south western region of Nigeria. The region has tropical wet and dry climate with a lengthy wet season and relatively constant temperatures throughout the course of the year. Wet season runs from March to October, November to December forms the region dry season. The vegetation type of the region is savannah which is really grassland with small bushes and occasional big trees. Grassland soils have substantially higher organic matter content than forest soils (Novackova, 2011).

\section{Sample Collection}

The Peatsoil samples were collected from four different sampling points $(0-10 \mathrm{~cm}$ depth) in Sagamu into polyethylene bag with plastic spoons. Samples were taken to the laboratory, extraneous materials were removed; the samples were air-dried, crushed and ground to a fine powder in a mortar passed through a $0.20 \mathrm{~mm}$ sieve. The samples were kept for analysis.

\section{Isolation and purification of humic acid from peat soil sample}

Peatsoil sample $(100 \mathrm{~g})$ was mixed with 1000 $\mathrm{cm}^{3}$ of $0.1 \mathrm{M} \mathrm{NaOH}$ solution, shaken for 3hours and left to stand overnight. Dark-coloured supernatant was obtained and decanted from solid residue. The dark-coloured supernatant was acidified to $(\mathrm{pH}=1.0)$ with $6 \mathrm{M} \mathrm{HCl}$ stirred and allowed to stand for 6 hours. Yellowish brown supernatant and dark-brown precipitate were obtained. The yellowish brown supernatant was decanted followed by centrifuge and discarded. The dark-brown precipitate was mixed with $500 \mathrm{~cm}^{3}$ of $0.1 \mathrm{M} \mathrm{NaOH}$ solution followed by passing through dowex resin. The dark-brown solution was acidified to $(\mathrm{pH}=1.0)$ with $6 \mathrm{M} \mathrm{HCl}$ stirred and allowed to stand for 3 hours. The dark-brown precipitate was washed several times with deionized water. The supernatant was treated with $\mathrm{AgNO}_{3}$ solution until no white precipitate observed. The humic acid was transferred to weighed crucible and dried at $60^{\circ} \mathrm{C}$ in an oven for 12 hours. The humic acid was cooled and dried in the desiccator, weighed and recorded. The obtained humic acid was dried again at $60^{\circ} \mathrm{C}$ for additional 6 hours cooled and dried in the desiccator, weighed and recorded constant weight was obtained (Baruah et al., 2015).

\section{FT-IR analysis}

FT-IR spectra of humic acid sample was analysed using Carry 630 FT-IR Agilent Technologies.

Unhydrolysed compost humic acid

The unhydrolysed humic acid was obtained after isolation and purification of compost humic acid and kept for investigation.

\section{Acid hydrolysis of Peatsoil acid}

Peatsoil humic acid sample (1g) was refluxed for 12 hours at $\left(160^{\circ} \mathrm{C}\right)$ with $50 \mathrm{~cm}^{3}$ of $6 \mathrm{M} \mathrm{HCl}$. The mixture was allowed to cool, decanted, and centrifuged after hydrolysis. The insoluble residues were washed with distilled water via centrifugation several times, and the supernatant was treated with $\mathrm{AgNO}_{3}$ solution until no white precipitate was observed. The residue was thoroughly dried over $\mathrm{CaCl}_{2}$ in a desiccator at room temperature (Chefetz et al., 2002). Finally, the obtained hydrolysed humic acid was kept for investigation. 
BAJOPAS Volume 14 Number 1,June, 2021 Potentiometric Titrations

Potentiometric measurements were carried out using a pH-meter Jenway (model 3510) with combine electrode, the sensitivity of the $\mathrm{pH}$ meter is 0.01 units. The $\mathrm{pH}$ meter was switched on half an hour before starting the titration for initial warm up of the instrument. The instrument was calibrated with an aqueous standard buffer solution of $\mathrm{pH} 4.00$ and 10.0 (borate buffer) prepared from a "Qualigens" buffer tablets.

The following sets of solutions were prepared in a $250 \mathrm{~cm}^{3}$ volumetric flask separately for $\mathrm{pH}$ metric titrations.

(i) $5 \mathrm{~cm}^{3} 0.1 \mathrm{M} \mathrm{HCl}+40 \mathrm{~cm}^{3}$ deionized water

(ii) $5 \mathrm{~cm}^{3} 0.1 \mathrm{M} \mathrm{HCl}+39 \mathrm{~cm}^{3}$ deionized water $+1 \mathrm{~cm}^{3} 0.15 \mathrm{gcm}^{-3}$ humic acid

(iii) $5 \mathrm{~cm}^{3} 0.1 \mathrm{M} \mathrm{HCl}+37 \mathrm{~cm}^{3}$ deionized water $+1 \mathrm{~cm}^{3} 0.15 \mathrm{gcm}^{-3}$ humic acid

$$
+2 \mathrm{~cm}^{3} \quad 0.01 \mathrm{M} \mathrm{Cu} \text { (II) }
$$

The solutions were titrated against standardized $0.110 \mathrm{MNaOH}$ separately. The total volume of each mixture was adjusted to $50 \mathrm{~cm}^{3}$ and the ionic strength of the solutions was maintained constant at by adding appropriate amount of stock solution of $1 \mathrm{M} \mathrm{KNO}_{3}$ (Gamal, 2015; Omar and Ali, 2015). A magnetic stirrer was used to achieve thorough mixing of the interacting solutions at $550 \mathrm{rpm}$. The same set of experimental conditions was applied for potentiometric titration of remaining samples.

\section{Evaluation of pKa of Hydrolysed peat soil Humic Acids}

The proton-ligand formation number $\mathrm{n}_{\mathbf{A}}$ were calculated by Irving and Rossotti expression (Omar and Ali, 2015).

$\mathrm{nA}=\mathrm{Y}-\frac{(\mathrm{V} 2-\mathrm{V1})(\mathrm{No}-\mathrm{Eo})}{(\mathrm{VO}+\mathrm{V1}) \mathrm{TCL}}$ 1

Where: $Y$ is number of dissociable proton, $\left(\mathrm{V}_{2^{-}}\right.$ $V_{1}$ ) is the measure of displacement of the ligand curve relative to acid curve, $\mathrm{N}^{\circ}$ and $\mathrm{E}^{\circ}$ are the resultant concentration of alkali solution, free acid solution, $\mathrm{T}_{\mathrm{cL}}{ }^{\circ}$ is the total ligand concentration, $\mathrm{V}^{\circ}$ is the total volume of titration solution, $V_{1}$ is the volume of alkali added to acid solution, $V_{2}$ is the volume of alkali added to acid solution + ligand solution, acid dissociation constants (pKa - values) of ligand were calculated by algebraic method point wise calculation (Tables 1 ). The dissociation constants (pKa) were calculated according to the following relation:

$\mathrm{pKa}=\mathrm{pH}+\log \left(\frac{n A}{1-n A}\right)$ 2

Where: pKa is the acid dissociation constant, $\mathrm{n}_{\mathrm{A}}$ is the Proton-ligand formation number and $\mathrm{pH}$ is the pH-values (Omar and Ali, 2015).

\section{Determination of metal-ligand stability constants $(\log K)$ of complexes}

The potentiometric measurement for the determination of stability constant of a complex in solution is based on the fact that the redox potential of the couple $\frac{M^{+(m-n)}}{M^{+m}}$ is shifted significantly on complexation of the metal ion with the ligand. This method involves change in hydrogen ion concentration $\left[\mathrm{H}^{+}\right]$due to the displacement or association of one or more protons taking place during complexation reaction. This change can be found out by titrating the solutions containing free acid, acid with ligand, and acid with ligand and metal ion, individually against a standard alkali solution at a constant ionic strength or temperature. Either ionic strength or temperature may be varied for different sets of solutions. In all the cases, the change in the $\mathrm{pH}$ of the solution is measured after each addition of a known amount of alkali to the reaction cell which contains the reaction mixture. The titration curves are then drawn by plotting the measured $\mathrm{pH}$ values against the corresponding volume of alkali added and the stability constants of the complexes are determined from the titration curves by employing $\mathrm{pH}$-metric titration technique given by (Irving and Rossoti).

Metal-ligand stability constants ( $\log \mathrm{K}$ ) were determined by using the following relations:

$$
\bar{n}=\frac{\left(V_{3}-V_{2}\right)\left(E^{0}+N^{0}\right)}{\left(V^{0}+V_{2}\right) \bar{n}_{A} T_{m}^{0}}
$$

and

$$
P L=\log _{10}\left\{\frac{1+\beta_{n}^{H} \frac{1}{[\text { anti } \log \mathrm{pH}]^{\mathrm{n}}}}{\mathrm{T}_{\mathrm{L}}^{0}-n \bar{T}_{m}^{0}} \mathrm{X} \frac{\left(V^{0}+V_{3}\right)}{V^{0}}\right\}
$$


BAJOPAS Volume 14 Number 1,June, 2021

Where $T_{L}, T^{\circ}, E^{\circ}$, and $V^{\circ}$ havethe same significance as in equation (1) above, $T_{m}$ denotes the total concentration of metal present in solution, $V_{3}$ is the volume of metal ions present in solution and $\beta^{H}$ is the overall proton ligand stability constant. The metal-ligand stability constants (log K) were determined by employing point wise computational Method (eq. 5 and 6).

$\operatorname{LogK}_{1}=\log \left(\frac{n}{1-n}\right)+\mathrm{pL}$ .5

$\operatorname{LogK}_{2}=\log \left(\frac{1-n}{2-n}\right)+\mathrm{pL}$ ...6

Where: Log $\mathrm{K}$ is the metal-ligand stability constant, $\mathrm{pL}$ is the Free ligand exponent function, $\mathbf{n}$ is the Average number of ligand attached with metal ion (Janraoet al., 2014). The results obtained were analyzed by an ORIGIN 2016 program using titration data and then the proton-ligand stability constants (pKa) and Metal-ligand stability constant (LogK) calculated (Omar and Ali, 2015).

\section{RESULTS AND DISCUSSION}

Fourier transformed infrared (FT-IR) spectra of isolated humic acid from peat soils Figure 2 had distinct clear absorption bands indicating the presence of major humic acid structural elemental groups such as $\mathrm{H}$ bonded $\mathrm{OH}$ $\left(3680 \mathrm{~cm}^{-1}\right.$ peak $), C=0$ of carbonyl $\left(1721 \mathrm{~cm}^{-1}\right.$ peak), functional groups of aliphatic components $\mathrm{CH}_{2}\left(2918 \mathrm{~cm}^{-1}\right.$ peak) and $\mathrm{C}-\mathrm{O}$ stretching of polysaccharide $\left(1168 \mathrm{~cm}^{-1}\right.$ peak). The positions of the absorption bands of the spectra fell within typical major absorption bands of humic acid which is at frequencies 3680, 2918, 1721, 1168 $\mathrm{cm}^{-1}$. The first peak centred in the vicinity of $3680 \mathrm{~cm}^{-1}$ region is attributed to phenol $\mathrm{OH}$ group bounded by intermolecular $\mathrm{H}$ bonds. The $2918 \mathrm{~cm}^{-1}$ band usually has absorption maximum at $2918 \mathrm{~cm}^{-1}$ which is due to $\mathrm{C}-\mathrm{H}$ stretching of alkane group $\left(\mathrm{CH}_{2}\right)$. The next major absorption band is $1721 \mathrm{~cm}^{-1}$. This band has been commonly ascribed to $\mathrm{C}=\mathrm{O}$ stretching of mainly carboxyl group $(\mathrm{COOH})$ with trace amount of ketones. The last peak was observed at 1168 $\mathrm{cm}^{-1}$ due to $\mathrm{C}-\mathrm{O}$ stretching of polysaccharides and this peak appeared also in the spectra of humic acid from peat soil. The FTIR spectra of the isolated humic acid contained all major characteristic absorption peaks of humic acid. These absorption peaks indicated the presence of the major structural elements of humic acid namely $\mathrm{H}$ bonded $\mathrm{OH}, \mathrm{C}=\mathrm{C}$ of aromatic ring, $\mathrm{C}=\mathrm{O}$ of carbonyl group (both carboxyl and ketonic), $\mathrm{CH}_{2}$ group. This strongly supports the presence of humic acid.

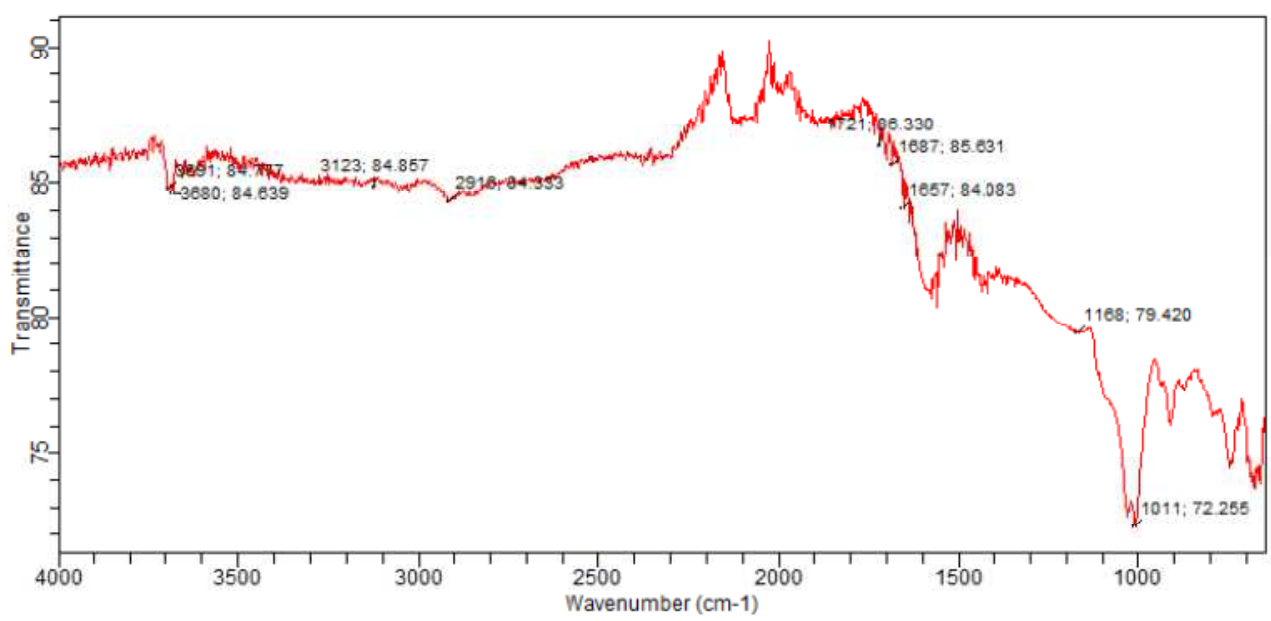

Fig. 2 : FT-IR spectraof peatsoilhumic acid (PSHA)

\section{Evaluation of acid dissociation constant (pka) of acid hydrolysed peat soil humicacid at phenolic group}

The value of the dissociation constant of the peat soil humic acid (PSHA) that underwent acidhydrolysis studied was found to be 8.9299 as shown Table 1, which is lower than the literaturevalues reported by Almeida and Szpoganics, (2015), Borges et al., (2005); Badr et al., (2012)and Fernandes et al,.(2009) of $9.73,9.47$ and 10.30. The difference between the obtained valuesand the reported values in this study might be probably as a result of acid hydrolysis of humicacid. 
BAJOPAS Volume 14 Number 1,June, 2021

Table 1: PKa of (Hydrolysed PSHA)

\begin{tabular}{|l|l|l|l|l|l|l|}
\hline $\mathrm{pH}$ & $\mathrm{BV}_{1}$ & $\mathrm{BV}_{2}$ & $\mathrm{~V}_{2}-\mathrm{V}_{1}$ & $\mathrm{nA}$ & $\log \left(\frac{n A}{1-n A}\right)$ & $\mathrm{pKa}$ \\
\hline 8.50 & 5.30 & 6.29 & 0.99 & 0.3594 & -0.2510 & 8.2490 \\
8.72 & 5.35 & 6.37 & 1.02 & 0.3400 & -0.2880 & 8.4320 \\
9.00 & 5.40 & 6.46 & 1.06 & 0.3141 & -0.3391 & 8.6609 \\
9.22 & 5.45 & 6.55 & 1.10 & 0.2882 & -0.3927 & 8.8273 \\
9.51 & 5.50 & 6.66 & 1.16 & 0.2494 & -0.4786 & 9.0314 \\
9.73 & 5.55 & 6.78 & 1.23 & 0.2041 & -0.5910 & 9.1390 \\
10.00 & 5.60 & 6.90 & 1.30 & 0.1589 & -0.7238 & 9.2762 \\
10.23 & 5.65 & 7.05 & 1.40 & 0.0941 & -0.9835 & 9.2465 \\
10.49 & 5.70 & 7.10 & 1.40 & 0.0941 & -0.9835 & 9.5065 \\
\hline
\end{tabular}

Average pKa $=8.9299 \pm 0.4186$

Table 2: PKa of (Unhydrolysed PSHA)

\begin{tabular}{|l|l|l|l|l|l|l|}
\hline $\mathrm{pH}$ & $\mathrm{BV}_{1}$ & $\mathrm{BV}_{2}$ & $\mathrm{~V}_{2}-\mathrm{V}_{1}$ & $\mathrm{nA}$ & $\log \left(\frac{\boldsymbol{n A}}{1-\boldsymbol{n}}\right)$ & $\mathrm{pKa}$ \\
\hline 8.50 & 5.30 & 5.81 & 0.51 & 0.6619 & 0.2919 & 8.7919 \\
8.72 & 5.35 & 5.90 & 0.55 & 0.6357 & 0.2418 & 8.9618 \\
9.00 & 5.40 & 6.00 & 0.60 & 0.6029 & 0.1813 & 9.1813 \\
9.22 & 5.45 & 6.10 & 0.65 & 0.5701 & 0.1226 & 9.3426 \\
9.51 & 5.50 & 6.20 & 0.70 & 0.5376 & 0.0654 & 9.5754 \\
9.73 & 5.55 & 6.33 & 0.78 & 0.4851 & -0.0259 & 9.7041 \\
10.00 & 5.60 & 6.47 & 0.87 & 0.4262 & -0.1291 & 9.8709 \\
10.23 & 5.65 & 6.62 & 0.99 & 0.3609 & -0.2481 & 9.9819 \\
10.49 & 5.70 & 6.80 & 1.10 & 0.2759 & -0.4690 & 10.0210 \\
\hline
\end{tabular}

Average pKa $=9.4923 \pm 0.4410$

Metal-ligand stability constant ( $\log \mathrm{K}$ )

The stabilityconstants require the accurate values of proton-ligand stability constants (Anil and Maroti, 2008). Metal titration curves crossed over ligand titration curve indicated the formation of complex upon proton release (Santosh, et al., 2011). If the values of n- are within range $0.2-0.8$ and $1.2-18$ this indicates the formation of $1: 1$ and 1:2 complexes (Sayyed and Mazahar, 2012).

The metal (II)-humate stepwise stability constants (log k) at phenolic group (Tables 318)

Table 3: Point-wise method, $\mathrm{Cu}$-(Hydrolysed PSHA)

\begin{tabular}{|l|l|l|l|l|l|l|l|l|}
\hline $\mathrm{pH}$ & $\mathrm{BV}_{1}$ & $\mathrm{BV}_{2}$ & $\mathrm{BV}_{3}$ & $\left(\mathrm{~V}_{3}-\mathrm{V}_{2}\right)$ & $\mathrm{n}$ & $\mathrm{pL}$ & $\log \left(\frac{n}{1-n}\right)$ & LogK $_{1}$ \\
\hline 8.50 & 5.30 & 6.29 & 6.33 & 0.04 & 0.5500 & 2.66 & 0.0871 & 2.7471 \\
8.72 & 5.35 & 6.37 & 6.41 & 0.04 & 0.5714 & 2.43 & 0.1249 & 2.5549 \\
9.00 & 5.40 & 6.46 & 6.50 & 0.04 & 0.6198 & 2.16 & 0.2122 & 2.3722 \\
9.22 & 5.45 & 6.55 & 6.59 & 0.04 & 0.6667 & 1.94 & 0.3010 & 2.2410 \\
\hline
\end{tabular}

LogK $_{1}$ (Average value) $=2.4788 \pm 0.2203$

Table 4: Point-wise method, $\mathrm{Cu}$-(Hydrolysed PSHA)

\begin{tabular}{|l|l|l|l|l|l|l|l|l|}
\hline $\mathrm{pH}$ & $\mathrm{BV}_{1}$ & $\mathrm{BV}_{2}$ & $\mathrm{BV}_{3}$ & $\left(\mathrm{~V}_{3}-\mathrm{V}_{2}\right)$ & $\mathrm{n}$ & $\mathrm{pL}$ & $\log \left(\frac{n-1}{2-n}\right)$ & LogK $_{2}$ \\
\hline 9.51 & 5.50 & 6.66 & 6.73 & 0.07 & 1.3509 & 1.70 & -0.2671 & 1.4329 \\
9.73 & 5.55 & 6.78 & 6.85 & 0.07 & 1.6383 & 1.51 & 0.2467 & 1.7567 \\
10.00 & 5.60 & 6.90 & 6.98 & 0.08 & 2.1783 & 1.31 & -0.2158 & 1.0942 \\
10.23 & 5.65 & 7.05 & 7.13 & 0.08 & 4.1904 & 1.27 & & \\
10.49 & 5.70 & 7.10 & 7.19 & 0.09 & 4.6920 & & & \\
\hline
\end{tabular}

Log $K_{2}($ Average value $)=1.4280 \pm 0.3312$ 
BAJOPAS Volume 14 Number 1,June, 2021

Table 5: Point-wise method, $\mathrm{Cu}$ (Unhydrolysed PSHA)

\begin{tabular}{|l|l|l|l|l|l|l|l|l|}
\hline $\mathrm{pH}$ & $\mathrm{BV}_{1}$ & $\mathrm{BV}_{2}$ & $\mathrm{BV}_{3}$ & $\left(\mathrm{~V}_{3}-\mathrm{V}_{2}\right)$ & $\mathrm{n}$ & $\mathrm{pL}$ & $\log \left(\frac{n}{n-1}\right)$ & Log $_{1}$ \\
\hline 8.50 & 5.30 & 5.81 & 5.85 & 0.04 & 0.2973 & 2.88 & -0.3736 & 2.5064 \\
8.72 & 5.35 & 5.90 & 5.95 & 0.05 & 0.3873 & 2.66 & -0.1992 & 2.4608 \\
9.00 & 5.40 & 6.00 & 6.05 & 0.05 & 0.4044 & 2.38 & -0.1681 & 2.2119 \\
9.22 & 5.45 & 6.10 & 6.15 & 0.06 & 0.5157 & 2.18 & -0.0272 & 2.2072 \\
9.51 & 5.50 & 6.20 & 6.27 & 0.07 & 0.6417 & 1.89 & 0.2530 & 1.1430 \\
\hline
\end{tabular}

$\operatorname{LogK}_{1}($ Average value $)=2.3059 \pm 0.6153$

Table 6:Point-wise method, $\mathrm{Cu}$ (Unhydrolysed PSHA)

\begin{tabular}{|l|l|l|l|l|l|l|l|l|}
\hline $\mathrm{pH}$ & $\mathrm{BV}_{1}$ & $\mathrm{BV}_{2}$ & $\mathrm{BV}_{3}$ & $\mathrm{~V}_{3}-\mathrm{V}_{2}$ & $\mathrm{n}$ & $\mathrm{pL}$ & $\log \left(\frac{n-1}{2-n}\right)$ & $\log \mathrm{K}_{2}$ \\
\hline 9.73 & 5.55 & 6.33 & 6.42 & 0.09 & 0.9000 & 1.69 & & \\
10.00 & 5.60 & 6.47 & 6.58 & 0.11 & 1.2578 & 1.44 & -0.4592 & 0.9808 \\
10.23 & 5.65 & 6.62 & 6.84 & 0.12 & 1.6137 & 1.26 & -0.2010 & 1.4610 \\
10.49 & 5.70 & 6.80 & 6.92 & 0.12 & 2.1052 & 1.03 & & \\
\hline
\end{tabular}

$\operatorname{LogK}_{2}$ (Average value) $=1.2209 \pm 0.3398$

Table 7:Point-wise method, Pb (Hydrolysed PSHA)

\begin{tabular}{|l|l|l|l|l|l|l|l|l|}
\hline $\mathrm{pH}$ & $\mathrm{BV}_{1}$ & $\mathrm{BV}_{2}$ & $\mathrm{BV}_{3}$ & $\left(\mathrm{~V}_{3}-\mathrm{V}_{2}\right)$ & $\mathrm{n}$ & $\mathrm{pL}$ & $\log \left(\frac{n}{1-n}\right)$ & LogK $_{1}$ \\
\hline 8.50 & 5.30 & 6.29 & 6.33 & 0.04 & 0.5500 & 2.66 & 0.0871 & 2.7471 \\
8.72 & 5.35 & 6.37 & 6.41 & 0.04 & 0.5714 & 2.43 & 0.1249 & 2.5549 \\
9.00 & 5.40 & 6.46 & 6.50 & 0.04 & 0.6198 & 2.16 & 0.2122 & 2.3722 \\
9.22 & 5.45 & 6.55 & 6.60 & 0.05 & 0.8333 & 1.96 & 0.6989 & 2.6589 \\
\hline
\end{tabular}

Log $_{\mathbf{1}}($ Average value $)=2.5832 \pm 0.1614$

Table 8:Point-wise method, Pb-(Hydrolysed PSHA)

\begin{tabular}{|l|l|l|l|l|l|l|l|l|}
\hline $\mathrm{pH}$ & $\mathrm{BV}_{1}$ & $\mathrm{BV}_{2}$ & $\mathrm{BV}_{3}$ & $\left(\mathrm{~V}_{3}-\mathrm{V}_{2}\right)$ & $\mathrm{n}$ & $\mathrm{pL}$ & $\log \left(\frac{n-1}{2-n}\right)$ & $\log \mathrm{K}_{2}$ \\
\hline 9.51 & 5.50 & 6.66 & 6.71 & 0.05 & 0.9650 & 1.67 & & \\
9.73 & 5.55 & 6.78 & 6.83 & 0.05 & 1.1702 & 1.44 & & \\
10.00 & 5.60 & 6.90 & 6.90 & 0.05 & 1.4864 & 1.22 & -0.0237 & 1.1963 \\
10.23 & 5.65 & 7.05 & 7.10 & 0.05 & 2.0190 & 1.09 & & \\
10.49 & 5.70 & 7.10 & 7.17 & 0.07 & 3.6492 & 1.00 & & \\
\hline
\end{tabular}

Log $K_{2}$ (Average value) $=1.1963$

Table 9: Point-wise method, Pb (Unhydrolysed PSHA)

\begin{tabular}{|l|l|l|l|l|l|l|l|l|}
\hline $\mathrm{pH}$ & $\mathrm{BV}_{1}$ & $\mathrm{BV}_{2}$ & $\mathrm{BV}_{3}$ & $\mathrm{~V}_{3}-\mathrm{V}_{2}$ & $\mathrm{n}$ & $\mathrm{pL}$ & $\begin{array}{l}\text { Log } \\
\left(\frac{n}{n-1}\right)\end{array}$ & Log $\mathrm{K}_{1}$ \\
\hline 8.50 & 5.30 & 5.81 & 5.85 & 0.04 & 0.2973 & 2.88 & -0.3736 & 2.5064 \\
8.72 & 5.35 & 5.90 & 5.94 & 0.04 & 0.3099 & 2.66 & -0.5477 & 2.3123 \\
9.00 & 5.40 & 6.00 & 6.05 & 0.05 & 0.4044 & 2.38 & -0.1681 & 2.2119 \\
9.22 & 5.45 & 6.10 & 6.15 & 0.06 & 0.5157 & 2.18 & 0.0272 & 2.2072 \\
9.51 & 5.50 & 6.20 & 6.26 & 0.07 & 0.6417 & 1.89 & 0.2530 & 2.1430 \\
9.73 & 5.55 & 6.40 & 6.40 & 0.07 & 0.7000 & 1.67 & 0.3680 & 2.0380 \\
\hline
\end{tabular}

LogK $_{1}$ (Average value) $=2.2364 \pm 0.1602$

Table 10: Point-wise method, Pb (Unhydrolysed PSHA)

\begin{tabular}{|l|l|l|l|l|l|l|l|l|}
\hline $\mathrm{pH}$ & $\mathrm{BV}_{1}$ & $\mathrm{BV}_{2}$ & $\mathrm{BV}_{3}$ & $\mathrm{~V}_{3}-\mathrm{V}_{2}$ & $\mathrm{n}$ & $\mathrm{pL}$ & $\log \left(\frac{n-1}{2-n}\right)$ & $\log \mathrm{K}_{2}$ \\
\hline 10.00 & 5.60 & 6.47 & 6.55 & 0.08 & 1.9503 & 1.41 & & \\
10.23 & 5.65 & 6.62 & 6.72 & 0.11 & 1.4792 & 1.26 & -0.0361 & 1.2239 \\
\hline
\end{tabular}

$\operatorname{LogK}_{2}$ (Average value) $=1.2239$

Table 11: Point-wise method, Mg (Hydrolysed PSHA)

\begin{tabular}{|l|l|l|l|l|l|l|l|l|}
\hline $\mathrm{pH}$ & $\mathrm{BV}_{1}$ & $\mathrm{BV}_{2}$ & $\mathrm{BV}_{3}$ & $\left(\mathrm{~V}_{3}-\mathrm{V}_{2}\right)$ & $\mathrm{n}$ & $\mathrm{pL}$ & $\log \left(\frac{n}{n-1}\right)$ & LogK $_{1}$ \\
\hline 8.50 & 5.30 & 6.29 & 6.31 & 0.02 & 0.2750 & 2.64 & -0.4290 & 2.2110 \\
8.72 & 5.35 & 6.37 & 6.39 & 0.02 & 0.2858 & 2.42 & -0.3978 & 2.0222 \\
9.00 & 5.40 & 6.46 & 6.49 & 0.03 & 0.4648 & 2.14 & -0.0612 & 2.0788 \\
9.22 & 5.45 & 6.55 & 6.59 & 0.04 & 0.6667 & 1.94 & 0.3010 & 2.2410 \\
\hline
\end{tabular}

$\log _{\mathbf{1}}($ Average value) $=2.1382 \pm 0.1046$ 
BAJOPAS Volume 14 Number 1,June, 2021

Table 12: Point-wise method, Mg (Hydrolysed PSHA)

\begin{tabular}{|l|l|l|l|l|l|l|l|l|}
\hline $\mathrm{pH}$ & $\mathrm{BV}_{1}$ & $\mathrm{BV}_{2}$ & $\mathrm{BV}_{3}$ & $\left(\mathrm{~V}_{3}-\mathrm{V}_{2}\right)$ & $\mathrm{n}$ & $\mathrm{pL}$ & $\log \left(\frac{n-1}{2-n}\right)$ & LogK $_{2}$ \\
\hline 9.51 & 5.55 & 6.66 & 6.71 & 0.05 & 0.9650 & 1.67 & & \\
9.73 & 5.55 & 6.78 & 6.84 & 0.06 & 1.4042 & 1.47 & -0.1686 & 1.3014 \\
10.00 & 5.60 & 6.90 & 6.93 & 0.06 & 1.7838 & 1.23 & 0.5593 & 1.7893 \\
10.23 & 5.65 & 7.05 & 7.10 & 0.06 & 3.1429 & 1.10 & & \\
10.49 & 5.70 & 7.10 & 7.18 & 0.07 & 3.6492 & 0.83 & & \\
\hline
\end{tabular}

LogK $_{2}($ Average value $)=1.5453 \pm 0.3450$

Table 13: Point-wise method, Mg (Unhydrolysed PSHA)

\begin{tabular}{|l|l|l|l|l|l|l|l|l|}
\hline $\mathrm{pH}$ & $\mathrm{BV}_{1}$ & $\mathrm{BV}_{2}$ & $\mathrm{BV}_{3}$ & $\mathrm{~V}_{3}-\mathrm{V}_{2}$ & $\mathrm{n}$ & $\mathrm{pL}$ & $\log \left(\frac{n}{n-1}\right)$ & $\operatorname{Log~}_{1}$ \\
\hline 8.50 & 5.30 & 5.81 & 5.85 & 0.04 & 0.2973 & 2.88 & -0.3736 & 2.5064 \\
8.72 & 5.35 & 5.90 & 5.94 & 0.04 & 0.3099 & 2.66 & -0.3477 & 2.3123 \\
9.00 & 5.40 & 6.00 & 6.04 & 0.04 & 0.3236 & 2.38 & -0.3202 & 2.0598 \\
9.22 & 5.45 & 6.10 & 6.15 & 0.05 & 0.4297 & 2.17 & -0.1230 & 2.0470 \\
9.51 & 5.50 & 6.20 & 6.26 & 0.06 & 0.5500 & 1.89 & 0.0871 & 1.9771 \\
9.73 & 5.55 & 6.33 & 6.40 & 0.07 & 0.7000 & 1.67 & 0.3680 & 2.0380 \\
\hline
\end{tabular}

LogK $_{1}$ (Average value) $=2.1568 \pm 0.2069$

Table 14: Point-wise method, Mg (Unhydrolysed PSHA)

\begin{tabular}{|l|l|l|l|l|l|l|l|l|}
\hline $\mathrm{pH}$ & $\mathrm{BV}_{1}$ & $\mathrm{BV}_{2}$ & $\mathrm{BV}_{3}$ & $\mathrm{~V}_{3}-\mathrm{V}_{2}$ & $\mathrm{n}$ & $\mathrm{pL}$ & $\log \left(\frac{n-1}{2-n}\right)$ & $\log \mathrm{K}_{2}$ \\
\hline 10.00 & 5.60 & 6.47 & 6.55 & 0.08 & 0.9148 & 1.41 & & \\
10.23 & 5.65 & 6.62 & 6.71 & 0.09 & 1.2102 & 1.20 & -0.5749 & 0.6251 \\
10.49 & 5.70 & 6.80 & 6.92 & 0.09 & 1.5968 & 1.03 & 0.1703 & 1.2003 \\
\hline
\end{tabular}

LogK $_{2}$ (Average value) $=0.9127 \pm 0.4070$

Table15:Point-wise method, Cd (Hydrolysed PSHA)

\begin{tabular}{|l|l|l|l|l|l|l|l|l|}
\hline $\mathrm{pH}$ & $\mathrm{BV}_{1}$ & $\mathrm{BV}_{2}$ & $\mathrm{BV}_{3}$ & $\left(\mathrm{~V}_{3}-\mathrm{V}_{2}\right)$ & $\mathrm{n}$ & $\mathrm{pL}$ & $\log \left(\frac{n}{1-n}\right)$ & LogK $_{1}$ \\
\hline 8.50 & 5.30 & 6.29 & 6.31 & 0.02 & 0.2750 & 2.64 & -0.4210 & 2.2190 \\
8.72 & 5.35 & 6.37 & 6.40 & 0.03 & 0.4286 & 2.42 & -0.1249 & 2.2951 \\
9.00 & 5.40 & 6.46 & 6.49 & 0.03 & 0.4648 & 2.14 & -0.0612 & 2.0788 \\
9.22 & 5.45 & 6.55 & 6.59 & 0.04 & 0.6667 & 1.96 & 0.3010 & 2.2610 \\
9.51 & 5.55 & 6.66 & 6.70 & 0.04 & 0.7720 & 1.67 & 0.5297 & 2.1997 \\
\hline
\end{tabular}

LogK $_{\mathbf{1}}$ (Average value) $=2.2108 \pm 0.0825$

Table 16: Point-wise method, Cd (Hydrolysed PSHA)

\begin{tabular}{|l|l|l|l|l|l|l|l|l|}
\hline $\mathrm{pH}$ & $\mathrm{BV}_{1}$ & $\mathrm{BV}_{2}$ & $\mathrm{BV}_{3}$ & $\left(\mathrm{~V}_{3}-\mathrm{V}_{2}\right)$ & $\mathrm{n}$ & $\mathrm{pL}$ & $\log \left(\frac{n-1}{2-n}\right)$ & Log $_{2}$ \\
\hline 9.73 & 5.55 & 6.78 & 6.83 & 0.06 & 1.4042 & 1.47 & -0.1686 & 1.3014 \\
10.00 & 5.60 & 6.90 & 6.95 & 0.06 & 1.7838 & 1.23 & 0.5593 & 1.7893 \\
10.23 & 5.65 & 7.05 & 7.10 & 0.06 & 3.1429 & 1.09 & & \\
10.49 & 5.70 & 7.10 & 7.16 & 0.06 & 3.1429 & 0.89 & & \\
& & & & & & & & \\
\hline
\end{tabular}

$\operatorname{LogK}_{2}$ (Average value) $=1.5453 \pm 0.3450$

Table 17: Point-wise method, Cd (Unhydrolysed PSHA)

\begin{tabular}{|l|l|l|l|l|l|l|l|l|}
\hline $\mathrm{pH}$ & $\mathrm{BV}_{1}$ & $\mathrm{BV}_{2}$ & $\mathrm{BV}_{3}$ & $\mathrm{~V}_{3}-\mathrm{V}_{2}$ & $\mathrm{n}$ & $\mathrm{pL}$ & $\log \left(\frac{n}{n-1}\right)$ & $\operatorname{Log~}_{1}$ \\
\hline 8.50 & 5.30 & 5.81 & 5.86 & 0.05 & 0.3717 & 2.88 & -0.2280 & 2.6520 \\
8.72 & 5.35 & 5.90 & 5.95 & 0.05 & 0.3873 & 2.66 & -0.1992 & 2.4608 \\
9.00 & 5.40 & 6.00 & 6.06 & 0.06 & 0.4853 & 2.38 & -0.0255 & 2.3545 \\
9.22 & 5.45 & 6.10 & 6.16 & 0.06 & 0.5157 & 2.18 & -0.0272 & 2.2072 \\
9.51 & 5.50 & 6.20 & 6.27 & 0.07 & 0.6417 & 1.89 & 0.2530 & 1.1430 \\
9.73 & 5.55 & 6.33 & 6.41 & 0.08 & 0.8000 & 1.69 & 0.6020 & 2.2920 \\
& & & & & & & & \\
\hline
\end{tabular}

$\operatorname{LogK}_{1}($ Average value $)=2.2516 \pm 0.5380$ 
BAJOPAS Volume 14 Number 1,June, 2021

Table 18: Point-wise method, Cd (Unhydrolysed PSHA)

\begin{tabular}{|l|l|l|l|l|l|l|l|l|}
\hline $\mathrm{pH}$ & $\mathrm{BV}_{1}$ & $\mathrm{BV}_{2}$ & $\mathrm{BV}_{3}$ & $\mathrm{~V}_{3}-\mathrm{V}_{2}$ & $\mathrm{n}$ & $\mathrm{pL}$ & $\log \left(\frac{n-1}{2-n}\right)$ & $\log \mathrm{K}_{2}$ \\
\hline 10.00 & 5.60 & 6.47 & 6.57 & 0.10 & 1.1434 & 1.43 & & \\
10.23 & 5.65 & 6.62 & 6.72 & 0.10 & 1.3448 & 1.23 & -0.2788 & 0.9512 \\
10.49 & 5.70 & 6.80 & 6.90 & 0.10 & 1.7742 & 1.03 & 0.5351 & 1.5651 \\
\hline
\end{tabular}

$\operatorname{LogK}_{2}($ Average value $)=1.2581 \pm 0.4340$

Table 19: Stepwise and overall Stability constants of thehydrolysed and unhydrolysed divalent metal (II) complexes

\begin{tabular}{|c|c|c|c|}
\hline Chelates & LogK $_{1}$ & $\log _{2}$ & Log $\beta$ \\
\hline [Cu (Hydrolysed PSHA-1) $\left.{ }_{2}\right]$ & 2.4788 & 1.4280 & 3.9068 \\
\hline$\left[\mathrm{Pb}(\text { Hydrolysed PSHA-1) })_{2}\right]$ & 2.5832 & 1.1963 & 3.7795 \\
\hline$\left[\mathrm{Cd}(\text { Hydrolysed PSHA-1 })_{2}\right]$ & 2.2108 & 1.5453 & 3.7561 \\
\hline$\left[\mathrm{Mg}(\text { Hydrolysed PSHA-1 })_{2}\right]$ & 2.1382 & 1.5453 & 3.6835 \\
\hline [Cu (Unhydrolysed PSHA-1) & 2.3059 & 1.2209 & 3.5268 \\
\hline$[\mathrm{Pb}$ (Unhydrolysed PSHA-1) 2$]$ & 2.2364 & 1.2239 & 3.4603 \\
\hline [Cd (Unhydrolysed PSHA-1) 2 ] & 2.2516 & 1.2581 & 3.5097 \\
\hline$[\mathrm{Mg}$ (Unydrolysed PSHA-1) & 2.1568 & 0.9127 & 3.0695 \\
\hline
\end{tabular}

The results obtained (Table19) shows the stepwise and overall stability constants to be not high indicating low stability of the complexes, because the solubility of most metal ions in the basic $\mathrm{pH}$ range is minimal due to metal hydroxide precipitation (Karimi, 2017). In general, the stepwise stability constants $\left(K_{1}\right.$ and $K_{2}$ ) follow the order $K_{1}>K_{2}$ for the copper, lead, magnesium and cadmium complexes respectively. The steady decrease of the values with increasing number of ligands is in agreement with the prediction made by researchers (Na'aliya, 2013). The decrease could be attributed to the fact that as the number of the ligands (Humate ions) that enters the coordination zone increases the aqua molecules available for replacement by the ligands become less. Thus, the metal ions become less electron loving with progressive intake of the ligand and this results in the decrease in the values of the constants (Na'aliya, 2013). Also the stability of the complexes is influenced by the size and number of the chelate rings(Mackay and Mackay,2002).All the complexes form rings in their structure as humate, a bidentate ligand, bond the metal ions in the ratio 1:2 (Boguta and Sokolowska, 2016) forming chelate rings. The values of the overall stability constants $(\log \beta)$ obtained for humate complexes are not high indicating low stability as the values are not high. LogK values for copper-humates (Table 3 to 6) obtained in this study are lower than those reported for the complexes of humic acids (Pandey et al., 2015; Dinu, 2013; Kaschl et al., 2010 and Gilbeto and Jorg, 2001). The values of LogK(Table 7 to 10 ) forlead-humates are lower than those reported for the lead in the literature (Dinu, 2013; Gilbeto and Jorg 2001). Log K values(Table 11 to 14 ) for magnesium-humates obtained in this study are close to those reported by (Pandey et al., 2015). Log K values of cadmium-humates (Table 15 to 18 ) obtained in this work near to the one reported by (Dinu, 2013 and Pandey et al., 2015).The difference between the reported values and the values obtained in this study might be probably as a result of acid hydrolysis of humic acid. The values of the overall stability constants $(\log \beta)$ of the copper humates complexes presented in Table 19 is high than that of other metal humate complexes, show relatively high stability of CuHA complexes, show the following order of stability: $\mathrm{Cu}>\mathrm{Pb}>\mathrm{Cd}>\mathrm{Mg}$; which are in close agreement to the findings of (Dinu, 2013 and Pandey et al., 2015).The high stability of Cuhumate chelate could be attributed to the existence of coordinate covalent bond between the complexing agents and the $\mathrm{Cu}^{2+}$ ions. Since, $\mathrm{Cu}^{2+}$ being a metal of the transitional series with $3 d^{9}$ electronic configurations can accept the electrons from the complexing agents. Similarly, the low stabilities of $\mathrm{Pb}, \mathrm{Cd}$ and $\mathrm{Mg}$ complexes could be explained by that $\mathrm{Pb}^{2+}$ with $6 s^{2}, \mathrm{Cd}^{2+}$ with $4 \mathrm{~d}^{10}$ and $\mathrm{Mg}^{2+}$ with $2 \mathrm{p}^{6}$ their electronic configuration has a completely filled $\mathrm{d}, \mathrm{p}$ and $\mathrm{s}$ orbitals. Moreover, the stabilities of metal ions with hydrolysed humic acid from peat soil were higher than those with unhydrolysed humic acid from peat soil; which is ascribed to the high content of acidity in hydrolysed humic acid than unhydrolysed humic acid. 
BAJOPAS Volume 14 Number 1,June, 2021 CONCLUSION

The values of logk for $\mathrm{Cu}(\mathrm{II})$ hydrolysed humic acid complex was higher followed by $\mathrm{Pb}$ (II), $\mathrm{Cd}(\mathrm{II})$ and $\mathrm{Mg}$ (II) hydrolysed humic acid complexes as compared with metal(II) unhydrolysed humic acid complexes. This indicates acid hydrolysis of humic acid can

\section{REFERENCES}

Almeida, V.R. and Szpoganicz, B. (2015). Humic Acid Potentiometric Response Patterns:Out- of Equilibrium Properties and Species Distribution Modelling. Chemical. Biol. Technol. Agric. 2: 17.

Anđelković, T., Nikolić, R., Bojić, A.,Anđelković, D., and Nikolic G.,(2010). Binding of Cadmium to Soil Humic Acid as A Function of Carboxyl Group Content. Macedonian Journal of Chemistry and Chemical Engineering.29(2): 215-224.

Anil, B. N. and Maroti, N. (2008). Studies on Influence of Die-Lectric Constants on Complex Equilibria between Substituted Py-Razalines and Lanthanide Metal Ions pH-Metrically. Amer.-Euras. scient. Res. 3(2): 212-216.

Ashok, K., Pandey, S. P. and Misra, V (2000). Stability Constants of Metal-Humic Acid Complexes and its Role in Environmental Detoxification. Journal of Ecotoxicology and Environmental Safety. 47(2):157-200.

Badr, M. H., El-Halafawi, M. H. and Abd El-al Zeid, E. R. (2012). Comparison Between the Effect of Ionic Strength on Acidity and Dissociation Constants of Humic Acids Extracted from Sewage Sludge and Nile Water Hyacinth Composts.Global Journal of Environmental Research 6 (1): 36-43.

Baruah, M.K., Borah, D., Saikia, P.P., Paul, S., Sharma, T. (2015). Evaluation of pKa Values of Soil Humic Acids and their Complexation Properties. International Journal of Plant \& Soil Science 6(4) : 218-228.

Boguta, P. Sokolowska, Z. (2016). Interactions of $\mathrm{Zn}$ (II) Ions with Humic Acids Isolated from Various Types of Soils. Effect of $\mathrm{pH}, \mathrm{Zn}$ Concentrations and Humic Acids Chemical Properties. Journal of Geochemical Explaration 168. 119-126.

Borges, F., Guimaraes, C., Lima, L.F.C., Pinto, I. and Reis, S.(2005). Potentiometric Studies on the Complexation of Copper(II) by Phenolic Acids as Discrete Ligand Models of enhance the complexation behavior of humic acid with metal (II) ions. However, the higher values of $\log \beta$ for $\mathrm{Cu}(\mathrm{II}), \mathrm{Pb}(\mathrm{II}), \mathrm{Cd}(\mathrm{II})$ and $\mathrm{Mg}(\mathrm{II})$ hydrolysed humic acid complexes indicates more stable stepwise complexes formed as compared with $\mathrm{Cu}(\mathrm{II}), \mathrm{Pb}$ (II), $\mathrm{Cd}$ (II) and $\mathrm{Mg}(\mathrm{II})$ unhydrolysed humic acid complexes.

Humic Substances Talanta 66 (2005) 670-673.

Chefetz, B., Salloum, M. J., Deshmulkin, A. P. and Hatcher, P. (2002). Structural Components of Humic Acids as Determined by Chemical Modifications and Carbon-13 NMR, Pyrolysis, and Thermochemolysis- Gas Chromatography/Mass Spectrometry. Soil Science Society of American Journal Abstract Division S-2- Soil Chemistry66. 1159-1171.

Dinu, M. I. (2013). Metals Complexation with Humic Acids in Surface Water of Different Environ. Sci. Technol. 31(1): 1-17.

Fernandes, A.N., Giacomelli, C., Giovanela, M. Vaz, D.V. Szpoganicz, B. and Maria M. D. (2009). Potentiometric Acidity Determination in Humic Substances Influenced by Different Analytical Procedures.J. Braz. Chem. Soc. 20 (9):14.

Gamal, A. H. (2015). Stability Constants of Rhenium (V) Metal Complexes with Selected Drugs. Pyrex Journal of Research in Environmental Studies. 2(2): 006-014.

Janrao, D. M., Pathan, J., Kayande, D.D., and Mulla, J.J. (2014). An Over View of Potentiometric Determination of Stability Constants of Metal Complexes. Sci. Revs. Chem. Commun.: 4(1), 2014, 11-24.

Karimi, H. (2017). Effect of pH and Initial Pb(II) Concentration on the Lead Removal Efficiency from Waste Water Using $\mathrm{Ca}(\mathrm{OH})_{2}$. International Journal of Water and Waste Water Treatment 3.2

Kaschl, A. Romheld, V. and Chen, Y. (2010). Binding of Cadmium, Copper and Zinc to Humic Substances Originating from Municipal Solid Waste Compost. Israel Journal of Chemistry Vol. 42(1): 89-98.

Kostic, I. S., Tatjana, P, A., Nikolic, R. S., Cvetkovic, T. P., Pavlovic, D. D., Aleksandar, L.J. and Bojic, A. (2012). Comparative Study of Binding Strengths of Heavy Metals with Humic Acid. J.serb. Chem. Soc. 76(9) pp 1-20. 
BAJOPAS Volume 14 Number 1,June, 2021

Na'aliya, J. (2013). Determination of Stepwise Stability Constants and Gibbs free Energy Change of Trisprolina to Complexes of some Divalent Transition Metal ions. Bayero Journal of Pure and Applied Sciences 6(2): 112-114.

Omar, A. A. and Ali, E. A. (2015). Potentiometric Studies on Complexes of $\mathrm{Cr}$ (III) and $\mathrm{Zr}$ (IV) with some Carboxylic Acids. International Journal of Advanced Chemistry, 3(1) 25-

37.

Pandey, A. K. Pandey, S. D. and Misr, V. (2015).Stability Constants of Metal- Humic Acid Complexes and Its Role in Environmental Detoxification. J. Ecotoxicology and Environmental Safety. 47(1):195-200.

Ram, N. and Raman, K.V. (1984). Stability Constants of Complexes of Metals with
Humicand Fuvic Acids under Non- acidConditions. Journal of Plant Nutrition and Soil Sciences.

147:171-176.

Santosh, D. D., Ashok, B. K., Vijay, J. T., Shivraj, G. W. and Vinay, V. W. (2011). Potentiometric Studies of Elec-Trolyte Effects on Complex Equilibria of Some Substituted 5-(2-hydroxy Phenyl) Pyrazoles. Der pharm. 3 (6): 75-83.

Sayyed, H. and Abdul Rahim, M. F. (2012). Studies of Binary Complexes of Metal Ions with Mandelic Acid by Potentiometry. Chem. J. 02 (6): 206209.

Shirvani, M. Moradian, E. Khalili, B. Bakhtiary, S. (2015). Interaction of $\mathrm{Cd}$ and $\mathrm{Pb}$ with Humate-Palygorskite and HumateSepiolite Complexes. Journal of water, air and pollution 3: 220-228. 


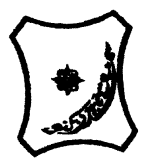

Bayero Journal of Pure and Applied Sciences, 14(1): 54 - 63

Received: November, 2020

Accepted: April, 2021

ISSN $2006-6996$

\title{
STABILITY CONSTANTS OF COMPLEXES OF METAL IONS WITH PEATSOIL HUMIC ACIDS UNDER NON-ACID-CONDITIONS
}

\author{
${ }^{* 1}$ Sabo, Yusuf ${ }^{2}$ Jimoh, W.L.O., ${ }^{3}$ Isa Baba Koki and ${ }^{4}$ Sholadoye, Q. 0. \\ ${ }^{1}$ Department of Pure and Industrial Chemistry, Bayero University, Kano \\ ${ }^{3}$ Department of Chemistry, Yusuf Maitama Sule University Kano. P.M.B. 3220 Kano, Nigeria. \\ ${ }^{4}$ Department of Chemistry, Nigerian Police Academy, Wudil, Kano-Nigeria
}

*Correspondence E-mail; saboyusuf18@yahoo.com

ABSTRACT

Stability constants of complexes of four divalent metal ions viz. $\mathrm{Cu}^{2+}, \mathrm{Pb}^{2+}, \mathrm{Mg}^{2+}$ and $\mathrm{Cd}^{2+}$ with humic acids (HA) were determined by potentiometric titration of humic acids with the corresponding salt of the divalent metals in aqueous media under non-acid-condition. The log $K$ (logarithm of the stability constant) ranged from 1.0942 to 2.7471 for metalhumic acid complexes were determined using point-wise computational method. The order of stability constants were obtained as follows: $\mathrm{Cu}>\mathrm{Pb}>\mathrm{Cd}>\mathrm{Mg}$ for metal $-\mathrm{HA}$ complexes respectively, indicating a higher degree of complexation with Cu metal ion.

Keywords: stability constant, humic acid, potentiometric titration, divalent metals, acid hydrolysis.

\section{NTRODUCTION}

The stability constant of a complex is the numerical expression of its stability and provides a quantitative measure of affinity of the metal ion to the complexing agent. An understanding of the relative stability of metal-complexes helps in predicting the behavior of metal ions in the soil (Ram and Raman, 1982). Extensive researches has been done to determine the stability constants of the complexes formed between humic acid (HA) with a number of metal ions. Ashok et al., (2000) reported that humic acid with hydroxyl, phenoxyl and carboxyl reactive groups can form coordination compound with metal ions at $\mathrm{pH}$ 3.5. The stability constants(Log K) for different metalhumic acid complexes indicated the following order of the stabilities of complexes formed between humic acid and metal ion, $\mathrm{Cu}>\mathrm{Fe}$ $>\mathrm{Pb}>\mathrm{Ni}>\mathrm{Co}>\mathrm{Ca}>\mathrm{Cd}>\mathrm{Zn}>\mathrm{Mn}>\mathrm{Mg}$. Andelkovic et al., (2010) investigated the binding of $\mathrm{Cd}$ (II) to soil humic acid at pH 6.5 and in $0.1 \mathrm{M} \mathrm{KNO}_{3}$ ionic medium. The stability constant for binding indicating greater stability in the case when carboxyl groups are involved in complexation reaction. Kostic et al.,(2012) investigated the complexation of humic acid with certain heavy metal ions (Co(II), $\mathrm{Ni}(\mathrm{II}), \mathrm{Cu}(\mathrm{II})$,
$\mathrm{Zn}(\mathrm{II})$, and $\mathrm{Pb}(\mathrm{II})$. The experiment was performed at $25^{\circ} \mathrm{C}$, at pH 4.0 and ionic strength of $0.01 \mathrm{M}$. Stability constant of complex between $\mathrm{Pb}$ (II) ions and humic acid is greater than stability constants of other investigated metalhumate complexes. Bogata and Sokolowska (2016) analyses the interaction between humic acids from different soils and $\mathrm{Zn}$ (II) ions at wide concentration ranges and at $\mathrm{pH} 5$. Studies have showed significant impact of $\mathrm{Zn}$ concentration, $\mathrm{pH}$ and some properties of humic acids with zinc.But all of these studies were limited to acidic $\mathrm{pH}$ range. Therefore, the present study was carried out to determine and compare the stability constants of complexes of metal ions with hydrolysed peat soil humic acid and unhydrolysed peat soil humic under non-acid conditions.

\section{MATERIALS AND METHODS}

Analytical grade chemicals used includes hydrochloric acid $(\mathrm{HCl})$, nitric acid $\left(\mathrm{HNO}_{3}\right)$, sodium hydroxide $(\mathrm{NaOH})$, lead nitrate $\mathrm{Pb}\left(\mathrm{NO}_{3}\right)_{2}$, copper nitrate $\mathrm{Cu}\left(\mathrm{NO}_{3}\right)_{2} \cdot 3 \mathrm{H}_{2} \mathrm{O}$, cadmium nitrate $\mathrm{Cd}\left(\mathrm{NO}_{3}\right)_{2} \cdot 4 \mathrm{H}_{2} \mathrm{O}$, magnesium nitrate $\mathrm{Mg}\left(\mathrm{NO}_{3}\right)_{2} \cdot 6 \mathrm{H}_{2} \mathrm{O}$, potassium nitrate $\left(\mathrm{KNO}_{3}\right)$, calcium chloride $\left(\mathrm{CaCl}_{2}\right)$, (sigma-Aldrich). Dowex 50WX8, (20-50 mesh) from Fluka. 


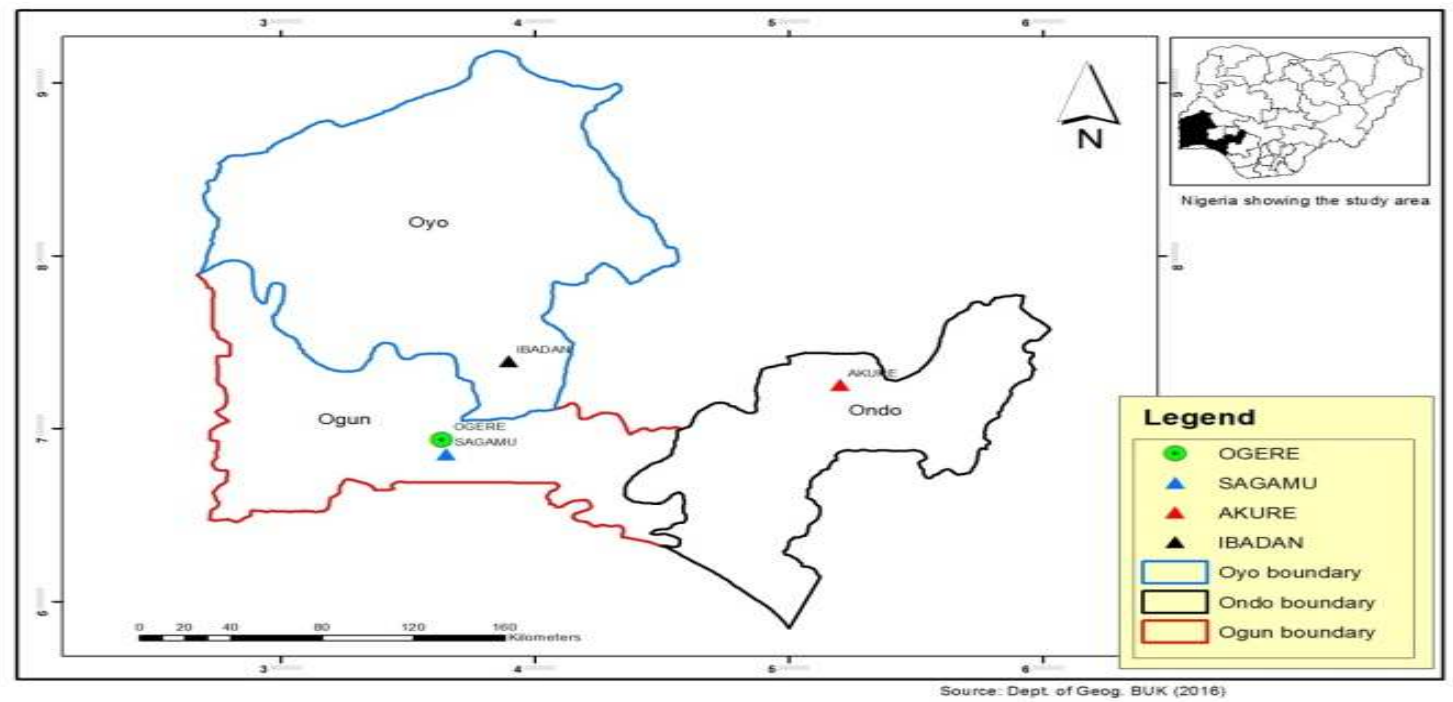

Figure 1: Map showing the sampling point at Sagamu Town, Ogun State.

\section{Description of Sampling Area}

Sagamu has geographical coordinates between $6^{\circ} 50^{\prime}$ north; $3^{\circ} 38^{\prime}$ east is located in south western region of Nigeria. The region has tropical wet and dry climate with a lengthy wet season and relatively constant temperatures throughout the course of the year. Wet season runs from March to October, November to December forms the region dry season. The vegetation type of the region is savannah which is really grassland with small bushes and occasional big trees. Grassland soils have substantially higher organic matter content than forest soils (Novackova, 2011).

\section{Sample Collection}

The Peatsoil samples were collected from four different sampling points $(0-10 \mathrm{~cm}$ depth) in Sagamu into polyethylene bag with plastic spoons. Samples were taken to the laboratory, extraneous materials were removed; the samples were air-dried, crushed and ground to a fine powder in a mortar passed through a $0.20 \mathrm{~mm}$ sieve. The samples were kept for analysis.

\section{Isolation and purification of humic acid from peat soil sample}

Peatsoil sample $(100 \mathrm{~g})$ was mixed with 1000 $\mathrm{cm}^{3}$ of $0.1 \mathrm{M} \mathrm{NaOH}$ solution, shaken for 3hours and left to stand overnight. Dark-coloured supernatant was obtained and decanted from solid residue. The dark-coloured supernatant was acidified to $(\mathrm{pH}=1.0)$ with $6 \mathrm{M} \mathrm{HCl}$ stirred and allowed to stand for 6 hours. Yellowish brown supernatant and dark-brown precipitate were obtained. The yellowish brown supernatant was decanted followed by centrifuge and discarded. The dark-brown precipitate was mixed with $500 \mathrm{~cm}^{3}$ of $0.1 \mathrm{M} \mathrm{NaOH}$ solution followed by passing through dowex resin. The dark-brown solution was acidified to $(\mathrm{pH}=1.0)$ with $6 \mathrm{M} \mathrm{HCl}$ stirred and allowed to stand for 3 hours. The dark-brown precipitate was washed several times with deionized water. The supernatant was treated with $\mathrm{AgNO}_{3}$ solution until no white precipitate observed. The humic acid was transferred to weighed crucible and dried at $60^{\circ} \mathrm{C}$ in an oven for 12 hours. The humic acid was cooled and dried in the desiccator, weighed and recorded. The obtained humic acid was dried again at $60^{\circ} \mathrm{C}$ for additional 6 hours cooled and dried in the desiccator, weighed and recorded constant weight was obtained (Baruah et al., 2015).

\section{FT-IR analysis}

FT-IR spectra of humic acid sample was analysed using Carry 630 FT-IR Agilent Technologies.

Unhydrolysed compost humic acid

The unhydrolysed humic acid was obtained after isolation and purification of compost humic acid and kept for investigation.

\section{Acid hydrolysis of Peatsoil acid}

Peatsoil humic acid sample (1g) was refluxed for 12 hours at $\left(160^{\circ} \mathrm{C}\right)$ with $50 \mathrm{~cm}^{3}$ of $6 \mathrm{M} \mathrm{HCl}$. The mixture was allowed to cool, decanted, and centrifuged after hydrolysis. The insoluble residues were washed with distilled water via centrifugation several times, and the supernatant was treated with $\mathrm{AgNO}_{3}$ solution until no white precipitate was observed. The residue was thoroughly dried over $\mathrm{CaCl}_{2}$ in a desiccator at room temperature (Chefetz et al., 2002). Finally, the obtained hydrolysed humic acid was kept for investigation. 
BAJOPAS Volume 14 Number 1,June, 2021 Potentiometric Titrations

Potentiometric measurements were carried out using a pH-meter Jenway (model 3510) with combine electrode, the sensitivity of the $\mathrm{pH}$ meter is 0.01 units. The $\mathrm{pH}$ meter was switched on half an hour before starting the titration for initial warm up of the instrument. The instrument was calibrated with an aqueous standard buffer solution of $\mathrm{pH} 4.00$ and 10.0 (borate buffer) prepared from a "Qualigens" buffer tablets.

The following sets of solutions were prepared in a $250 \mathrm{~cm}^{3}$ volumetric flask separately for $\mathrm{pH}$ metric titrations.

(i) $5 \mathrm{~cm}^{3} 0.1 \mathrm{M} \mathrm{HCl}+40 \mathrm{~cm}^{3}$ deionized water

(ii) $5 \mathrm{~cm}^{3} 0.1 \mathrm{M} \mathrm{HCl}+39 \mathrm{~cm}^{3}$ deionized water $+1 \mathrm{~cm}^{3} 0.15 \mathrm{gcm}^{-3}$ humic acid

(iii) $5 \mathrm{~cm}^{3} 0.1 \mathrm{M} \mathrm{HCl}+37 \mathrm{~cm}^{3}$ deionized water $+1 \mathrm{~cm}^{3} 0.15 \mathrm{gcm}^{-3}$ humic acid

$$
+2 \mathrm{~cm}^{3} \quad 0.01 \mathrm{M} \mathrm{Cu} \text { (II) }
$$

The solutions were titrated against standardized $0.110 \mathrm{MNaOH}$ separately. The total volume of each mixture was adjusted to $50 \mathrm{~cm}^{3}$ and the ionic strength of the solutions was maintained constant at by adding appropriate amount of stock solution of $1 \mathrm{M} \mathrm{KNO}_{3}$ (Gamal, 2015; Omar and Ali, 2015). A magnetic stirrer was used to achieve thorough mixing of the interacting solutions at $550 \mathrm{rpm}$. The same set of experimental conditions was applied for potentiometric titration of remaining samples.

\section{Evaluation of pKa of Hydrolysed peat soil Humic Acids}

The proton-ligand formation number $\mathrm{n}_{\mathbf{A}}$ were calculated by Irving and Rossotti expression (Omar and Ali, 2015).

$\mathrm{nA}=\mathrm{Y}-\frac{(\mathrm{V} 2-\mathrm{V1})(\mathrm{No}-\mathrm{Eo})}{(\mathrm{VO}+\mathrm{V1}) \mathrm{TCL}}$ 1

Where: $Y$ is number of dissociable proton, $\left(\mathrm{V}_{2^{-}}\right.$ $V_{1}$ ) is the measure of displacement of the ligand curve relative to acid curve, $\mathrm{N}^{\circ}$ and $\mathrm{E}^{\circ}$ are the resultant concentration of alkali solution, free acid solution, $\mathrm{T}_{\mathrm{cL}}{ }^{\circ}$ is the total ligand concentration, $\mathrm{V}^{\circ}$ is the total volume of titration solution, $V_{1}$ is the volume of alkali added to acid solution, $V_{2}$ is the volume of alkali added to acid solution + ligand solution, acid dissociation constants (pKa - values) of ligand were calculated by algebraic method point wise calculation (Tables 1 ). The dissociation constants (pKa) were calculated according to the following relation:

$\mathrm{pKa}=\mathrm{pH}+\log \left(\frac{n A}{1-n A}\right)$ 2

Where: pKa is the acid dissociation constant, $\mathrm{n}_{\mathrm{A}}$ is the Proton-ligand formation number and $\mathrm{pH}$ is the pH-values (Omar and Ali, 2015).

\section{Determination of metal-ligand stability constants $(\log K)$ of complexes}

The potentiometric measurement for the determination of stability constant of a complex in solution is based on the fact that the redox potential of the couple $\frac{M^{+(m-n)}}{M^{+m}}$ is shifted significantly on complexation of the metal ion with the ligand. This method involves change in hydrogen ion concentration $\left[\mathrm{H}^{+}\right]$due to the displacement or association of one or more protons taking place during complexation reaction. This change can be found out by titrating the solutions containing free acid, acid with ligand, and acid with ligand and metal ion, individually against a standard alkali solution at a constant ionic strength or temperature. Either ionic strength or temperature may be varied for different sets of solutions. In all the cases, the change in the $\mathrm{pH}$ of the solution is measured after each addition of a known amount of alkali to the reaction cell which contains the reaction mixture. The titration curves are then drawn by plotting the measured $\mathrm{pH}$ values against the corresponding volume of alkali added and the stability constants of the complexes are determined from the titration curves by employing $\mathrm{pH}$-metric titration technique given by (Irving and Rossoti).

Metal-ligand stability constants ( $\log \mathrm{K}$ ) were determined by using the following relations:

$$
\bar{n}=\frac{\left(V_{3}-V_{2}\right)\left(E^{0}+N^{0}\right)}{\left(V^{0}+V_{2}\right) \bar{n}_{A} T_{m}^{0}}
$$

and

$$
P L=\log _{10}\left\{\frac{1+\beta_{n}^{H} \frac{1}{[\text { anti } \log \mathrm{pH}]^{\mathrm{n}}}}{\mathrm{T}_{\mathrm{L}}^{0}-n \bar{T}_{m}^{0}} \mathrm{X} \frac{\left(V^{0}+V_{3}\right)}{V^{0}}\right\}
$$


BAJOPAS Volume 14 Number 1,June, 2021

Where $T_{L}, T^{\circ}, E^{\circ}$, and $V^{\circ}$ havethe same significance as in equation (1) above, $T_{m}$ denotes the total concentration of metal present in solution, $V_{3}$ is the volume of metal ions present in solution and $\beta^{H}$ is the overall proton ligand stability constant. The metal-ligand stability constants (log K) were determined by employing point wise computational Method (eq. 5 and 6).

$\operatorname{LogK}_{1}=\log \left(\frac{n}{1-n}\right)+\mathrm{pL}$ .5

$\operatorname{LogK}_{2}=\log \left(\frac{1-n}{2-n}\right)+\mathrm{pL}$ ...6

Where: Log $\mathrm{K}$ is the metal-ligand stability constant, $\mathrm{pL}$ is the Free ligand exponent function, $\mathbf{n}$ is the Average number of ligand attached with metal ion (Janraoet al., 2014). The results obtained were analyzed by an ORIGIN 2016 program using titration data and then the proton-ligand stability constants (pKa) and Metal-ligand stability constant (LogK) calculated (Omar and Ali, 2015).

\section{RESULTS AND DISCUSSION}

Fourier transformed infrared (FT-IR) spectra of isolated humic acid from peat soils Figure 2 had distinct clear absorption bands indicating the presence of major humic acid structural elemental groups such as $\mathrm{H}$ bonded $\mathrm{OH}$ $\left(3680 \mathrm{~cm}^{-1}\right.$ peak $), C=0$ of carbonyl $\left(1721 \mathrm{~cm}^{-1}\right.$ peak), functional groups of aliphatic components $\mathrm{CH}_{2}\left(2918 \mathrm{~cm}^{-1}\right.$ peak) and $\mathrm{C}-\mathrm{O}$ stretching of polysaccharide $\left(1168 \mathrm{~cm}^{-1}\right.$ peak). The positions of the absorption bands of the spectra fell within typical major absorption bands of humic acid which is at frequencies 3680, 2918, 1721, 1168 $\mathrm{cm}^{-1}$. The first peak centred in the vicinity of $3680 \mathrm{~cm}^{-1}$ region is attributed to phenol $\mathrm{OH}$ group bounded by intermolecular $\mathrm{H}$ bonds. The $2918 \mathrm{~cm}^{-1}$ band usually has absorption maximum at $2918 \mathrm{~cm}^{-1}$ which is due to $\mathrm{C}-\mathrm{H}$ stretching of alkane group $\left(\mathrm{CH}_{2}\right)$. The next major absorption band is $1721 \mathrm{~cm}^{-1}$. This band has been commonly ascribed to $\mathrm{C}=\mathrm{O}$ stretching of mainly carboxyl group $(\mathrm{COOH})$ with trace amount of ketones. The last peak was observed at 1168 $\mathrm{cm}^{-1}$ due to $\mathrm{C}-\mathrm{O}$ stretching of polysaccharides and this peak appeared also in the spectra of humic acid from peat soil. The FTIR spectra of the isolated humic acid contained all major characteristic absorption peaks of humic acid. These absorption peaks indicated the presence of the major structural elements of humic acid namely $\mathrm{H}$ bonded $\mathrm{OH}, \mathrm{C}=\mathrm{C}$ of aromatic ring, $\mathrm{C}=\mathrm{O}$ of carbonyl group (both carboxyl and ketonic), $\mathrm{CH}_{2}$ group. This strongly supports the presence of humic acid.

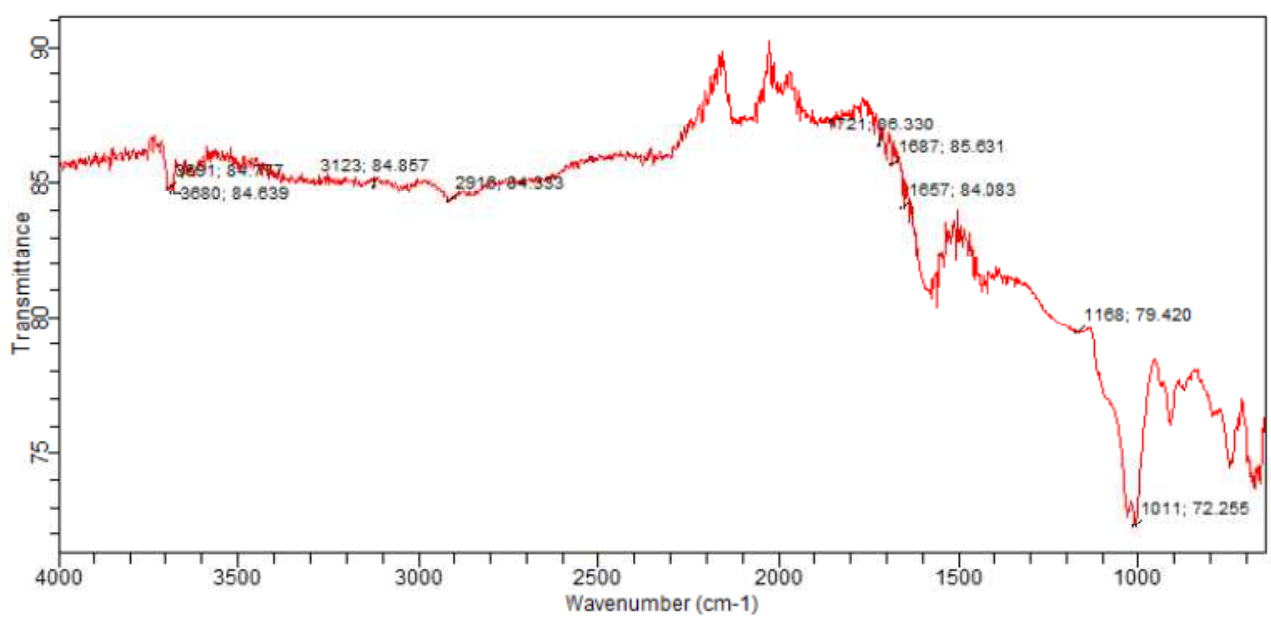

Fig. 2 : FT-IR spectraof peatsoilhumic acid (PSHA)

\section{Evaluation of acid dissociation constant (pka) of acid hydrolysed peat soil humicacid at phenolic group}

The value of the dissociation constant of the peat soil humic acid (PSHA) that underwent acidhydrolysis studied was found to be 8.9299 as shown Table 1, which is lower than the literaturevalues reported by Almeida and Szpoganics, (2015), Borges et al., (2005); Badr et al., (2012)and Fernandes et al,.(2009) of $9.73,9.47$ and 10.30. The difference between the obtained valuesand the reported values in this study might be probably as a result of acid hydrolysis of humicacid. 
BAJOPAS Volume 14 Number 1,June, 2021

Table 1: PKa of (Hydrolysed PSHA)

\begin{tabular}{|l|l|l|l|l|l|l|}
\hline $\mathrm{pH}$ & $\mathrm{BV}_{1}$ & $\mathrm{BV}_{2}$ & $\mathrm{~V}_{2}-\mathrm{V}_{1}$ & $\mathrm{nA}$ & $\log \left(\frac{n A}{1-n A}\right)$ & $\mathrm{pKa}$ \\
\hline 8.50 & 5.30 & 6.29 & 0.99 & 0.3594 & -0.2510 & 8.2490 \\
8.72 & 5.35 & 6.37 & 1.02 & 0.3400 & -0.2880 & 8.4320 \\
9.00 & 5.40 & 6.46 & 1.06 & 0.3141 & -0.3391 & 8.6609 \\
9.22 & 5.45 & 6.55 & 1.10 & 0.2882 & -0.3927 & 8.8273 \\
9.51 & 5.50 & 6.66 & 1.16 & 0.2494 & -0.4786 & 9.0314 \\
9.73 & 5.55 & 6.78 & 1.23 & 0.2041 & -0.5910 & 9.1390 \\
10.00 & 5.60 & 6.90 & 1.30 & 0.1589 & -0.7238 & 9.2762 \\
10.23 & 5.65 & 7.05 & 1.40 & 0.0941 & -0.9835 & 9.2465 \\
10.49 & 5.70 & 7.10 & 1.40 & 0.0941 & -0.9835 & 9.5065 \\
\hline
\end{tabular}

Average pKa $=8.9299 \pm 0.4186$

Table 2: PKa of (Unhydrolysed PSHA)

\begin{tabular}{|l|l|l|l|l|l|l|}
\hline $\mathrm{pH}$ & $\mathrm{BV}_{1}$ & $\mathrm{BV}_{2}$ & $\mathrm{~V}_{2}-\mathrm{V}_{1}$ & $\mathrm{nA}$ & $\log \left(\frac{\boldsymbol{n A}}{1-\boldsymbol{n}}\right)$ & $\mathrm{pKa}$ \\
\hline 8.50 & 5.30 & 5.81 & 0.51 & 0.6619 & 0.2919 & 8.7919 \\
8.72 & 5.35 & 5.90 & 0.55 & 0.6357 & 0.2418 & 8.9618 \\
9.00 & 5.40 & 6.00 & 0.60 & 0.6029 & 0.1813 & 9.1813 \\
9.22 & 5.45 & 6.10 & 0.65 & 0.5701 & 0.1226 & 9.3426 \\
9.51 & 5.50 & 6.20 & 0.70 & 0.5376 & 0.0654 & 9.5754 \\
9.73 & 5.55 & 6.33 & 0.78 & 0.4851 & -0.0259 & 9.7041 \\
10.00 & 5.60 & 6.47 & 0.87 & 0.4262 & -0.1291 & 9.8709 \\
10.23 & 5.65 & 6.62 & 0.99 & 0.3609 & -0.2481 & 9.9819 \\
10.49 & 5.70 & 6.80 & 1.10 & 0.2759 & -0.4690 & 10.0210 \\
\hline
\end{tabular}

Average pKa $=9.4923 \pm 0.4410$

Metal-ligand stability constant ( $\log \mathrm{K}$ )

The stabilityconstants require the accurate values of proton-ligand stability constants (Anil and Maroti, 2008). Metal titration curves crossed over ligand titration curve indicated the formation of complex upon proton release (Santosh, et al., 2011). If the values of n- are within range $0.2-0.8$ and $1.2-18$ this indicates the formation of $1: 1$ and 1:2 complexes (Sayyed and Mazahar, 2012).

The metal (II)-humate stepwise stability constants (log k) at phenolic group (Tables 318)

Table 3: Point-wise method, $\mathrm{Cu}$-(Hydrolysed PSHA)

\begin{tabular}{|l|l|l|l|l|l|l|l|l|}
\hline $\mathrm{pH}$ & $\mathrm{BV}_{1}$ & $\mathrm{BV}_{2}$ & $\mathrm{BV}_{3}$ & $\left(\mathrm{~V}_{3}-\mathrm{V}_{2}\right)$ & $\mathrm{n}$ & $\mathrm{pL}$ & $\log \left(\frac{n}{1-n}\right)$ & LogK $_{1}$ \\
\hline 8.50 & 5.30 & 6.29 & 6.33 & 0.04 & 0.5500 & 2.66 & 0.0871 & 2.7471 \\
8.72 & 5.35 & 6.37 & 6.41 & 0.04 & 0.5714 & 2.43 & 0.1249 & 2.5549 \\
9.00 & 5.40 & 6.46 & 6.50 & 0.04 & 0.6198 & 2.16 & 0.2122 & 2.3722 \\
9.22 & 5.45 & 6.55 & 6.59 & 0.04 & 0.6667 & 1.94 & 0.3010 & 2.2410 \\
\hline
\end{tabular}

LogK $_{1}$ (Average value) $=2.4788 \pm 0.2203$

Table 4: Point-wise method, $\mathrm{Cu}$-(Hydrolysed PSHA)

\begin{tabular}{|l|l|l|l|l|l|l|l|l|}
\hline $\mathrm{pH}$ & $\mathrm{BV}_{1}$ & $\mathrm{BV}_{2}$ & $\mathrm{BV}_{3}$ & $\left(\mathrm{~V}_{3}-\mathrm{V}_{2}\right)$ & $\mathrm{n}$ & $\mathrm{pL}$ & $\log \left(\frac{n-1}{2-n}\right)$ & LogK $_{2}$ \\
\hline 9.51 & 5.50 & 6.66 & 6.73 & 0.07 & 1.3509 & 1.70 & -0.2671 & 1.4329 \\
9.73 & 5.55 & 6.78 & 6.85 & 0.07 & 1.6383 & 1.51 & 0.2467 & 1.7567 \\
10.00 & 5.60 & 6.90 & 6.98 & 0.08 & 2.1783 & 1.31 & -0.2158 & 1.0942 \\
10.23 & 5.65 & 7.05 & 7.13 & 0.08 & 4.1904 & 1.27 & & \\
10.49 & 5.70 & 7.10 & 7.19 & 0.09 & 4.6920 & & & \\
\hline
\end{tabular}

Log $K_{2}($ Average value $)=1.4280 \pm 0.3312$ 
BAJOPAS Volume 14 Number 1,June, 2021

Table 5: Point-wise method, $\mathrm{Cu}$ (Unhydrolysed PSHA)

\begin{tabular}{|l|l|l|l|l|l|l|l|l|}
\hline $\mathrm{pH}$ & $\mathrm{BV}_{1}$ & $\mathrm{BV}_{2}$ & $\mathrm{BV}_{3}$ & $\left(\mathrm{~V}_{3}-\mathrm{V}_{2}\right)$ & $\mathrm{n}$ & $\mathrm{pL}$ & $\log \left(\frac{n}{n-1}\right)$ & Log $_{1}$ \\
\hline 8.50 & 5.30 & 5.81 & 5.85 & 0.04 & 0.2973 & 2.88 & -0.3736 & 2.5064 \\
8.72 & 5.35 & 5.90 & 5.95 & 0.05 & 0.3873 & 2.66 & -0.1992 & 2.4608 \\
9.00 & 5.40 & 6.00 & 6.05 & 0.05 & 0.4044 & 2.38 & -0.1681 & 2.2119 \\
9.22 & 5.45 & 6.10 & 6.15 & 0.06 & 0.5157 & 2.18 & -0.0272 & 2.2072 \\
9.51 & 5.50 & 6.20 & 6.27 & 0.07 & 0.6417 & 1.89 & 0.2530 & 1.1430 \\
\hline
\end{tabular}

$\operatorname{LogK}_{1}($ Average value $)=2.3059 \pm 0.6153$

Table 6:Point-wise method, $\mathrm{Cu}$ (Unhydrolysed PSHA)

\begin{tabular}{|l|l|l|l|l|l|l|l|l|}
\hline $\mathrm{pH}$ & $\mathrm{BV}_{1}$ & $\mathrm{BV}_{2}$ & $\mathrm{BV}_{3}$ & $\mathrm{~V}_{3}-\mathrm{V}_{2}$ & $\mathrm{n}$ & $\mathrm{pL}$ & $\log \left(\frac{n-1}{2-n}\right)$ & $\log \mathrm{K}_{2}$ \\
\hline 9.73 & 5.55 & 6.33 & 6.42 & 0.09 & 0.9000 & 1.69 & & \\
10.00 & 5.60 & 6.47 & 6.58 & 0.11 & 1.2578 & 1.44 & -0.4592 & 0.9808 \\
10.23 & 5.65 & 6.62 & 6.84 & 0.12 & 1.6137 & 1.26 & -0.2010 & 1.4610 \\
10.49 & 5.70 & 6.80 & 6.92 & 0.12 & 2.1052 & 1.03 & & \\
\hline
\end{tabular}

$\operatorname{LogK}_{2}$ (Average value) $=1.2209 \pm 0.3398$

Table 7:Point-wise method, Pb (Hydrolysed PSHA)

\begin{tabular}{|l|l|l|l|l|l|l|l|l|}
\hline $\mathrm{pH}$ & $\mathrm{BV}_{1}$ & $\mathrm{BV}_{2}$ & $\mathrm{BV}_{3}$ & $\left(\mathrm{~V}_{3}-\mathrm{V}_{2}\right)$ & $\mathrm{n}$ & $\mathrm{pL}$ & $\log \left(\frac{n}{1-n}\right)$ & LogK $_{1}$ \\
\hline 8.50 & 5.30 & 6.29 & 6.33 & 0.04 & 0.5500 & 2.66 & 0.0871 & 2.7471 \\
8.72 & 5.35 & 6.37 & 6.41 & 0.04 & 0.5714 & 2.43 & 0.1249 & 2.5549 \\
9.00 & 5.40 & 6.46 & 6.50 & 0.04 & 0.6198 & 2.16 & 0.2122 & 2.3722 \\
9.22 & 5.45 & 6.55 & 6.60 & 0.05 & 0.8333 & 1.96 & 0.6989 & 2.6589 \\
\hline
\end{tabular}

Log $_{\mathbf{1}}($ Average value $)=2.5832 \pm 0.1614$

Table 8:Point-wise method, Pb-(Hydrolysed PSHA)

\begin{tabular}{|l|l|l|l|l|l|l|l|l|}
\hline $\mathrm{pH}$ & $\mathrm{BV}_{1}$ & $\mathrm{BV}_{2}$ & $\mathrm{BV}_{3}$ & $\left(\mathrm{~V}_{3}-\mathrm{V}_{2}\right)$ & $\mathrm{n}$ & $\mathrm{pL}$ & $\log \left(\frac{n-1}{2-n}\right)$ & $\log \mathrm{K}_{2}$ \\
\hline 9.51 & 5.50 & 6.66 & 6.71 & 0.05 & 0.9650 & 1.67 & & \\
9.73 & 5.55 & 6.78 & 6.83 & 0.05 & 1.1702 & 1.44 & & \\
10.00 & 5.60 & 6.90 & 6.90 & 0.05 & 1.4864 & 1.22 & -0.0237 & 1.1963 \\
10.23 & 5.65 & 7.05 & 7.10 & 0.05 & 2.0190 & 1.09 & & \\
10.49 & 5.70 & 7.10 & 7.17 & 0.07 & 3.6492 & 1.00 & & \\
\hline
\end{tabular}

Log $K_{2}$ (Average value) $=1.1963$

Table 9: Point-wise method, Pb (Unhydrolysed PSHA)

\begin{tabular}{|l|l|l|l|l|l|l|l|l|}
\hline $\mathrm{pH}$ & $\mathrm{BV}_{1}$ & $\mathrm{BV}_{2}$ & $\mathrm{BV}_{3}$ & $\mathrm{~V}_{3}-\mathrm{V}_{2}$ & $\mathrm{n}$ & $\mathrm{pL}$ & $\begin{array}{l}\text { Log } \\
\left(\frac{n}{n-1}\right)\end{array}$ & Log $\mathrm{K}_{1}$ \\
\hline 8.50 & 5.30 & 5.81 & 5.85 & 0.04 & 0.2973 & 2.88 & -0.3736 & 2.5064 \\
8.72 & 5.35 & 5.90 & 5.94 & 0.04 & 0.3099 & 2.66 & -0.5477 & 2.3123 \\
9.00 & 5.40 & 6.00 & 6.05 & 0.05 & 0.4044 & 2.38 & -0.1681 & 2.2119 \\
9.22 & 5.45 & 6.10 & 6.15 & 0.06 & 0.5157 & 2.18 & 0.0272 & 2.2072 \\
9.51 & 5.50 & 6.20 & 6.26 & 0.07 & 0.6417 & 1.89 & 0.2530 & 2.1430 \\
9.73 & 5.55 & 6.40 & 6.40 & 0.07 & 0.7000 & 1.67 & 0.3680 & 2.0380 \\
\hline
\end{tabular}

LogK $_{1}$ (Average value) $=2.2364 \pm 0.1602$

Table 10: Point-wise method, Pb (Unhydrolysed PSHA)

\begin{tabular}{|l|l|l|l|l|l|l|l|l|}
\hline $\mathrm{pH}$ & $\mathrm{BV}_{1}$ & $\mathrm{BV}_{2}$ & $\mathrm{BV}_{3}$ & $\mathrm{~V}_{3}-\mathrm{V}_{2}$ & $\mathrm{n}$ & $\mathrm{pL}$ & $\log \left(\frac{n-1}{2-n}\right)$ & $\log \mathrm{K}_{2}$ \\
\hline 10.00 & 5.60 & 6.47 & 6.55 & 0.08 & 1.9503 & 1.41 & & \\
10.23 & 5.65 & 6.62 & 6.72 & 0.11 & 1.4792 & 1.26 & -0.0361 & 1.2239 \\
\hline
\end{tabular}

$\operatorname{LogK}_{2}$ (Average value) $=1.2239$

Table 11: Point-wise method, Mg (Hydrolysed PSHA)

\begin{tabular}{|l|l|l|l|l|l|l|l|l|}
\hline $\mathrm{pH}$ & $\mathrm{BV}_{1}$ & $\mathrm{BV}_{2}$ & $\mathrm{BV}_{3}$ & $\left(\mathrm{~V}_{3}-\mathrm{V}_{2}\right)$ & $\mathrm{n}$ & $\mathrm{pL}$ & $\log \left(\frac{n}{n-1}\right)$ & LogK $_{1}$ \\
\hline 8.50 & 5.30 & 6.29 & 6.31 & 0.02 & 0.2750 & 2.64 & -0.4290 & 2.2110 \\
8.72 & 5.35 & 6.37 & 6.39 & 0.02 & 0.2858 & 2.42 & -0.3978 & 2.0222 \\
9.00 & 5.40 & 6.46 & 6.49 & 0.03 & 0.4648 & 2.14 & -0.0612 & 2.0788 \\
9.22 & 5.45 & 6.55 & 6.59 & 0.04 & 0.6667 & 1.94 & 0.3010 & 2.2410 \\
\hline
\end{tabular}

$\log _{\mathbf{1}}($ Average value) $=2.1382 \pm 0.1046$ 
BAJOPAS Volume 14 Number 1,June, 2021

Table 12: Point-wise method, Mg (Hydrolysed PSHA)

\begin{tabular}{|l|l|l|l|l|l|l|l|l|}
\hline $\mathrm{pH}$ & $\mathrm{BV}_{1}$ & $\mathrm{BV}_{2}$ & $\mathrm{BV}_{3}$ & $\left(\mathrm{~V}_{3}-\mathrm{V}_{2}\right)$ & $\mathrm{n}$ & $\mathrm{pL}$ & $\log \left(\frac{n-1}{2-n}\right)$ & LogK $_{2}$ \\
\hline 9.51 & 5.55 & 6.66 & 6.71 & 0.05 & 0.9650 & 1.67 & & \\
9.73 & 5.55 & 6.78 & 6.84 & 0.06 & 1.4042 & 1.47 & -0.1686 & 1.3014 \\
10.00 & 5.60 & 6.90 & 6.93 & 0.06 & 1.7838 & 1.23 & 0.5593 & 1.7893 \\
10.23 & 5.65 & 7.05 & 7.10 & 0.06 & 3.1429 & 1.10 & & \\
10.49 & 5.70 & 7.10 & 7.18 & 0.07 & 3.6492 & 0.83 & & \\
\hline
\end{tabular}

LogK $_{2}($ Average value $)=1.5453 \pm 0.3450$

Table 13: Point-wise method, Mg (Unhydrolysed PSHA)

\begin{tabular}{|l|l|l|l|l|l|l|l|l|}
\hline $\mathrm{pH}$ & $\mathrm{BV}_{1}$ & $\mathrm{BV}_{2}$ & $\mathrm{BV}_{3}$ & $\mathrm{~V}_{3}-\mathrm{V}_{2}$ & $\mathrm{n}$ & $\mathrm{pL}$ & $\log \left(\frac{n}{n-1}\right)$ & $\operatorname{Log~}_{1}$ \\
\hline 8.50 & 5.30 & 5.81 & 5.85 & 0.04 & 0.2973 & 2.88 & -0.3736 & 2.5064 \\
8.72 & 5.35 & 5.90 & 5.94 & 0.04 & 0.3099 & 2.66 & -0.3477 & 2.3123 \\
9.00 & 5.40 & 6.00 & 6.04 & 0.04 & 0.3236 & 2.38 & -0.3202 & 2.0598 \\
9.22 & 5.45 & 6.10 & 6.15 & 0.05 & 0.4297 & 2.17 & -0.1230 & 2.0470 \\
9.51 & 5.50 & 6.20 & 6.26 & 0.06 & 0.5500 & 1.89 & 0.0871 & 1.9771 \\
9.73 & 5.55 & 6.33 & 6.40 & 0.07 & 0.7000 & 1.67 & 0.3680 & 2.0380 \\
\hline
\end{tabular}

LogK $_{1}$ (Average value) $=2.1568 \pm 0.2069$

Table 14: Point-wise method, Mg (Unhydrolysed PSHA)

\begin{tabular}{|l|l|l|l|l|l|l|l|l|}
\hline $\mathrm{pH}$ & $\mathrm{BV}_{1}$ & $\mathrm{BV}_{2}$ & $\mathrm{BV}_{3}$ & $\mathrm{~V}_{3}-\mathrm{V}_{2}$ & $\mathrm{n}$ & $\mathrm{pL}$ & $\log \left(\frac{n-1}{2-n}\right)$ & $\log \mathrm{K}_{2}$ \\
\hline 10.00 & 5.60 & 6.47 & 6.55 & 0.08 & 0.9148 & 1.41 & & \\
10.23 & 5.65 & 6.62 & 6.71 & 0.09 & 1.2102 & 1.20 & -0.5749 & 0.6251 \\
10.49 & 5.70 & 6.80 & 6.92 & 0.09 & 1.5968 & 1.03 & 0.1703 & 1.2003 \\
\hline
\end{tabular}

LogK $_{2}$ (Average value) $=0.9127 \pm 0.4070$

Table15:Point-wise method, Cd (Hydrolysed PSHA)

\begin{tabular}{|l|l|l|l|l|l|l|l|l|}
\hline $\mathrm{pH}$ & $\mathrm{BV}_{1}$ & $\mathrm{BV}_{2}$ & $\mathrm{BV}_{3}$ & $\left(\mathrm{~V}_{3}-\mathrm{V}_{2}\right)$ & $\mathrm{n}$ & $\mathrm{pL}$ & $\log \left(\frac{n}{1-n}\right)$ & LogK $_{1}$ \\
\hline 8.50 & 5.30 & 6.29 & 6.31 & 0.02 & 0.2750 & 2.64 & -0.4210 & 2.2190 \\
8.72 & 5.35 & 6.37 & 6.40 & 0.03 & 0.4286 & 2.42 & -0.1249 & 2.2951 \\
9.00 & 5.40 & 6.46 & 6.49 & 0.03 & 0.4648 & 2.14 & -0.0612 & 2.0788 \\
9.22 & 5.45 & 6.55 & 6.59 & 0.04 & 0.6667 & 1.96 & 0.3010 & 2.2610 \\
9.51 & 5.55 & 6.66 & 6.70 & 0.04 & 0.7720 & 1.67 & 0.5297 & 2.1997 \\
\hline
\end{tabular}

LogK $_{\mathbf{1}}$ (Average value) $=2.2108 \pm 0.0825$

Table 16: Point-wise method, Cd (Hydrolysed PSHA)

\begin{tabular}{|l|l|l|l|l|l|l|l|l|}
\hline $\mathrm{pH}$ & $\mathrm{BV}_{1}$ & $\mathrm{BV}_{2}$ & $\mathrm{BV}_{3}$ & $\left(\mathrm{~V}_{3}-\mathrm{V}_{2}\right)$ & $\mathrm{n}$ & $\mathrm{pL}$ & $\log \left(\frac{n-1}{2-n}\right)$ & Log $_{2}$ \\
\hline 9.73 & 5.55 & 6.78 & 6.83 & 0.06 & 1.4042 & 1.47 & -0.1686 & 1.3014 \\
10.00 & 5.60 & 6.90 & 6.95 & 0.06 & 1.7838 & 1.23 & 0.5593 & 1.7893 \\
10.23 & 5.65 & 7.05 & 7.10 & 0.06 & 3.1429 & 1.09 & & \\
10.49 & 5.70 & 7.10 & 7.16 & 0.06 & 3.1429 & 0.89 & & \\
& & & & & & & & \\
\hline
\end{tabular}

$\operatorname{LogK}_{2}$ (Average value) $=1.5453 \pm 0.3450$

Table 17: Point-wise method, Cd (Unhydrolysed PSHA)

\begin{tabular}{|l|l|l|l|l|l|l|l|l|}
\hline $\mathrm{pH}$ & $\mathrm{BV}_{1}$ & $\mathrm{BV}_{2}$ & $\mathrm{BV}_{3}$ & $\mathrm{~V}_{3}-\mathrm{V}_{2}$ & $\mathrm{n}$ & $\mathrm{pL}$ & $\log \left(\frac{n}{n-1}\right)$ & $\operatorname{Log~}_{1}$ \\
\hline 8.50 & 5.30 & 5.81 & 5.86 & 0.05 & 0.3717 & 2.88 & -0.2280 & 2.6520 \\
8.72 & 5.35 & 5.90 & 5.95 & 0.05 & 0.3873 & 2.66 & -0.1992 & 2.4608 \\
9.00 & 5.40 & 6.00 & 6.06 & 0.06 & 0.4853 & 2.38 & -0.0255 & 2.3545 \\
9.22 & 5.45 & 6.10 & 6.16 & 0.06 & 0.5157 & 2.18 & -0.0272 & 2.2072 \\
9.51 & 5.50 & 6.20 & 6.27 & 0.07 & 0.6417 & 1.89 & 0.2530 & 1.1430 \\
9.73 & 5.55 & 6.33 & 6.41 & 0.08 & 0.8000 & 1.69 & 0.6020 & 2.2920 \\
& & & & & & & & \\
\hline
\end{tabular}

$\operatorname{LogK}_{1}($ Average value $)=2.2516 \pm 0.5380$ 
BAJOPAS Volume 14 Number 1,June, 2021

Table 18: Point-wise method, Cd (Unhydrolysed PSHA)

\begin{tabular}{|l|l|l|l|l|l|l|l|l|}
\hline $\mathrm{pH}$ & $\mathrm{BV}_{1}$ & $\mathrm{BV}_{2}$ & $\mathrm{BV}_{3}$ & $\mathrm{~V}_{3}-\mathrm{V}_{2}$ & $\mathrm{n}$ & $\mathrm{pL}$ & $\log \left(\frac{n-1}{2-n}\right)$ & $\log \mathrm{K}_{2}$ \\
\hline 10.00 & 5.60 & 6.47 & 6.57 & 0.10 & 1.1434 & 1.43 & & \\
10.23 & 5.65 & 6.62 & 6.72 & 0.10 & 1.3448 & 1.23 & -0.2788 & 0.9512 \\
10.49 & 5.70 & 6.80 & 6.90 & 0.10 & 1.7742 & 1.03 & 0.5351 & 1.5651 \\
\hline
\end{tabular}

$\operatorname{LogK}_{2}($ Average value $)=1.2581 \pm 0.4340$

Table 19: Stepwise and overall Stability constants of thehydrolysed and unhydrolysed divalent metal (II) complexes

\begin{tabular}{|c|c|c|c|}
\hline Chelates & LogK $_{1}$ & $\log _{2}$ & Log $\beta$ \\
\hline [Cu (Hydrolysed PSHA-1) $\left.{ }_{2}\right]$ & 2.4788 & 1.4280 & 3.9068 \\
\hline$\left[\mathrm{Pb}(\text { Hydrolysed PSHA-1) })_{2}\right]$ & 2.5832 & 1.1963 & 3.7795 \\
\hline$\left[\mathrm{Cd}(\text { Hydrolysed PSHA-1 })_{2}\right]$ & 2.2108 & 1.5453 & 3.7561 \\
\hline$\left[\mathrm{Mg}(\text { Hydrolysed PSHA-1 })_{2}\right]$ & 2.1382 & 1.5453 & 3.6835 \\
\hline [Cu (Unhydrolysed PSHA-1) & 2.3059 & 1.2209 & 3.5268 \\
\hline$[\mathrm{Pb}$ (Unhydrolysed PSHA-1) 2$]$ & 2.2364 & 1.2239 & 3.4603 \\
\hline [Cd (Unhydrolysed PSHA-1) 2 ] & 2.2516 & 1.2581 & 3.5097 \\
\hline$[\mathrm{Mg}$ (Unydrolysed PSHA-1) & 2.1568 & 0.9127 & 3.0695 \\
\hline
\end{tabular}

The results obtained (Table19) shows the stepwise and overall stability constants to be not high indicating low stability of the complexes, because the solubility of most metal ions in the basic $\mathrm{pH}$ range is minimal due to metal hydroxide precipitation (Karimi, 2017). In general, the stepwise stability constants $\left(K_{1}\right.$ and $K_{2}$ ) follow the order $K_{1}>K_{2}$ for the copper, lead, magnesium and cadmium complexes respectively. The steady decrease of the values with increasing number of ligands is in agreement with the prediction made by researchers (Na'aliya, 2013). The decrease could be attributed to the fact that as the number of the ligands (Humate ions) that enters the coordination zone increases the aqua molecules available for replacement by the ligands become less. Thus, the metal ions become less electron loving with progressive intake of the ligand and this results in the decrease in the values of the constants (Na'aliya, 2013). Also the stability of the complexes is influenced by the size and number of the chelate rings(Mackay and Mackay,2002).All the complexes form rings in their structure as humate, a bidentate ligand, bond the metal ions in the ratio 1:2 (Boguta and Sokolowska, 2016) forming chelate rings. The values of the overall stability constants $(\log \beta)$ obtained for humate complexes are not high indicating low stability as the values are not high. LogK values for copper-humates (Table 3 to 6) obtained in this study are lower than those reported for the complexes of humic acids (Pandey et al., 2015; Dinu, 2013; Kaschl et al., 2010 and Gilbeto and Jorg, 2001). The values of LogK(Table 7 to 10 ) forlead-humates are lower than those reported for the lead in the literature (Dinu, 2013; Gilbeto and Jorg 2001). Log K values(Table 11 to 14 ) for magnesium-humates obtained in this study are close to those reported by (Pandey et al., 2015). Log K values of cadmium-humates (Table 15 to 18 ) obtained in this work near to the one reported by (Dinu, 2013 and Pandey et al., 2015).The difference between the reported values and the values obtained in this study might be probably as a result of acid hydrolysis of humic acid. The values of the overall stability constants $(\log \beta)$ of the copper humates complexes presented in Table 19 is high than that of other metal humate complexes, show relatively high stability of CuHA complexes, show the following order of stability: $\mathrm{Cu}>\mathrm{Pb}>\mathrm{Cd}>\mathrm{Mg}$; which are in close agreement to the findings of (Dinu, 2013 and Pandey et al., 2015).The high stability of Cuhumate chelate could be attributed to the existence of coordinate covalent bond between the complexing agents and the $\mathrm{Cu}^{2+}$ ions. Since, $\mathrm{Cu}^{2+}$ being a metal of the transitional series with $3 d^{9}$ electronic configurations can accept the electrons from the complexing agents. Similarly, the low stabilities of $\mathrm{Pb}, \mathrm{Cd}$ and $\mathrm{Mg}$ complexes could be explained by that $\mathrm{Pb}^{2+}$ with $6 s^{2}, \mathrm{Cd}^{2+}$ with $4 \mathrm{~d}^{10}$ and $\mathrm{Mg}^{2+}$ with $2 \mathrm{p}^{6}$ their electronic configuration has a completely filled $\mathrm{d}, \mathrm{p}$ and $\mathrm{s}$ orbitals. Moreover, the stabilities of metal ions with hydrolysed humic acid from peat soil were higher than those with unhydrolysed humic acid from peat soil; which is ascribed to the high content of acidity in hydrolysed humic acid than unhydrolysed humic acid. 
BAJOPAS Volume 14 Number 1,June, 2021 CONCLUSION

The values of logk for $\mathrm{Cu}(\mathrm{II})$ hydrolysed humic acid complex was higher followed by $\mathrm{Pb}$ (II), $\mathrm{Cd}(\mathrm{II})$ and $\mathrm{Mg}$ (II) hydrolysed humic acid complexes as compared with metal(II) unhydrolysed humic acid complexes. This indicates acid hydrolysis of humic acid can

\section{REFERENCES}

Almeida, V.R. and Szpoganicz, B. (2015). Humic Acid Potentiometric Response Patterns:Out- of Equilibrium Properties and Species Distribution Modelling. Chemical. Biol. Technol. Agric. 2: 17.

Anđelković, T., Nikolić, R., Bojić, A.,Anđelković, D., and Nikolic G.,(2010). Binding of Cadmium to Soil Humic Acid as A Function of Carboxyl Group Content. Macedonian Journal of Chemistry and Chemical Engineering.29(2): 215-224.

Anil, B. N. and Maroti, N. (2008). Studies on Influence of Die-Lectric Constants on Complex Equilibria between Substituted Py-Razalines and Lanthanide Metal Ions pH-Metrically. Amer.-Euras. scient. Res. 3(2): 212-216.

Ashok, K., Pandey, S. P. and Misra, V (2000). Stability Constants of Metal-Humic Acid Complexes and its Role in Environmental Detoxification. Journal of Ecotoxicology and Environmental Safety. 47(2):157-200.

Badr, M. H., El-Halafawi, M. H. and Abd El-al Zeid, E. R. (2012). Comparison Between the Effect of Ionic Strength on Acidity and Dissociation Constants of Humic Acids Extracted from Sewage Sludge and Nile Water Hyacinth Composts.Global Journal of Environmental Research 6 (1): 36-43.

Baruah, M.K., Borah, D., Saikia, P.P., Paul, S., Sharma, T. (2015). Evaluation of pKa Values of Soil Humic Acids and their Complexation Properties. International Journal of Plant \& Soil Science 6(4) : 218-228.

Boguta, P. Sokolowska, Z. (2016). Interactions of $\mathrm{Zn}$ (II) Ions with Humic Acids Isolated from Various Types of Soils. Effect of $\mathrm{pH}, \mathrm{Zn}$ Concentrations and Humic Acids Chemical Properties. Journal of Geochemical Explaration 168. 119-126.

Borges, F., Guimaraes, C., Lima, L.F.C., Pinto, I. and Reis, S.(2005). Potentiometric Studies on the Complexation of Copper(II) by Phenolic Acids as Discrete Ligand Models of enhance the complexation behavior of humic acid with metal (II) ions. However, the higher values of $\log \beta$ for $\mathrm{Cu}(\mathrm{II}), \mathrm{Pb}(\mathrm{II}), \mathrm{Cd}(\mathrm{II})$ and $\mathrm{Mg}(\mathrm{II})$ hydrolysed humic acid complexes indicates more stable stepwise complexes formed as compared with $\mathrm{Cu}(\mathrm{II}), \mathrm{Pb}$ (II), $\mathrm{Cd}$ (II) and $\mathrm{Mg}(\mathrm{II})$ unhydrolysed humic acid complexes.

Humic Substances Talanta 66 (2005) 670-673.

Chefetz, B., Salloum, M. J., Deshmulkin, A. P. and Hatcher, P. (2002). Structural Components of Humic Acids as Determined by Chemical Modifications and Carbon-13 NMR, Pyrolysis, and Thermochemolysis- Gas Chromatography/Mass Spectrometry. Soil Science Society of American Journal Abstract Division S-2- Soil Chemistry66. 1159-1171.

Dinu, M. I. (2013). Metals Complexation with Humic Acids in Surface Water of Different Environ. Sci. Technol. 31(1): 1-17.

Fernandes, A.N., Giacomelli, C., Giovanela, M. Vaz, D.V. Szpoganicz, B. and Maria M. D. (2009). Potentiometric Acidity Determination in Humic Substances Influenced by Different Analytical Procedures.J. Braz. Chem. Soc. 20 (9):14.

Gamal, A. H. (2015). Stability Constants of Rhenium (V) Metal Complexes with Selected Drugs. Pyrex Journal of Research in Environmental Studies. 2(2): 006-014.

Janrao, D. M., Pathan, J., Kayande, D.D., and Mulla, J.J. (2014). An Over View of Potentiometric Determination of Stability Constants of Metal Complexes. Sci. Revs. Chem. Commun.: 4(1), 2014, 11-24.

Karimi, H. (2017). Effect of pH and Initial Pb(II) Concentration on the Lead Removal Efficiency from Waste Water Using $\mathrm{Ca}(\mathrm{OH})_{2}$. International Journal of Water and Waste Water Treatment 3.2

Kaschl, A. Romheld, V. and Chen, Y. (2010). Binding of Cadmium, Copper and Zinc to Humic Substances Originating from Municipal Solid Waste Compost. Israel Journal of Chemistry Vol. 42(1): 89-98.

Kostic, I. S., Tatjana, P, A., Nikolic, R. S., Cvetkovic, T. P., Pavlovic, D. D., Aleksandar, L.J. and Bojic, A. (2012). Comparative Study of Binding Strengths of Heavy Metals with Humic Acid. J.serb. Chem. Soc. 76(9) pp 1-20. 
BAJOPAS Volume 14 Number 1,June, 2021

Na'aliya, J. (2013). Determination of Stepwise Stability Constants and Gibbs free Energy Change of Trisprolina to Complexes of some Divalent Transition Metal ions. Bayero Journal of Pure and Applied Sciences 6(2): 112-114.

Omar, A. A. and Ali, E. A. (2015). Potentiometric Studies on Complexes of $\mathrm{Cr}$ (III) and $\mathrm{Zr}$ (IV) with some Carboxylic Acids. International Journal of Advanced Chemistry, 3(1) 25-

37.

Pandey, A. K. Pandey, S. D. and Misr, V. (2015).Stability Constants of Metal- Humic Acid Complexes and Its Role in Environmental Detoxification. J. Ecotoxicology and Environmental Safety. 47(1):195-200.

Ram, N. and Raman, K.V. (1984). Stability Constants of Complexes of Metals with
Humicand Fuvic Acids under Non- acidConditions. Journal of Plant Nutrition and Soil Sciences.

147:171-176.

Santosh, D. D., Ashok, B. K., Vijay, J. T., Shivraj, G. W. and Vinay, V. W. (2011). Potentiometric Studies of Elec-Trolyte Effects on Complex Equilibria of Some Substituted 5-(2-hydroxy Phenyl) Pyrazoles. Der pharm. 3 (6): 75-83.

Sayyed, H. and Abdul Rahim, M. F. (2012). Studies of Binary Complexes of Metal Ions with Mandelic Acid by Potentiometry. Chem. J. 02 (6): 206209.

Shirvani, M. Moradian, E. Khalili, B. Bakhtiary, S. (2015). Interaction of $\mathrm{Cd}$ and $\mathrm{Pb}$ with Humate-Palygorskite and HumateSepiolite Complexes. Journal of water, air and pollution 3: 220-228. 


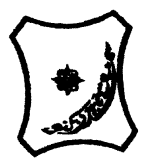

Bayero Journal of Pure and Applied Sciences, 14(1): 54 - 63

Received: November, 2020

Accepted: April, 2021

ISSN $2006-6996$

\title{
STABILITY CONSTANTS OF COMPLEXES OF METAL IONS WITH PEATSOIL HUMIC ACIDS UNDER NON-ACID-CONDITIONS
}

\author{
${ }^{* 1}$ Sabo, Yusuf ${ }^{2}$ Jimoh, W.L.O., ${ }^{3}$ Isa Baba Koki and ${ }^{4}$ Sholadoye, Q. 0. \\ ${ }^{1}$ Department of Pure and Industrial Chemistry, Bayero University, Kano \\ ${ }^{3}$ Department of Chemistry, Yusuf Maitama Sule University Kano. P.M.B. 3220 Kano, Nigeria. \\ ${ }^{4}$ Department of Chemistry, Nigerian Police Academy, Wudil, Kano-Nigeria
}

*Correspondence E-mail; saboyusuf18@yahoo.com

ABSTRACT

Stability constants of complexes of four divalent metal ions viz. $\mathrm{Cu}^{2+}, \mathrm{Pb}^{2+}, \mathrm{Mg}^{2+}$ and $\mathrm{Cd}^{2+}$ with humic acids (HA) were determined by potentiometric titration of humic acids with the corresponding salt of the divalent metals in aqueous media under non-acid-condition. The log $K$ (logarithm of the stability constant) ranged from 1.0942 to 2.7471 for metalhumic acid complexes were determined using point-wise computational method. The order of stability constants were obtained as follows: $\mathrm{Cu}>\mathrm{Pb}>\mathrm{Cd}>\mathrm{Mg}$ for metal $-\mathrm{HA}$ complexes respectively, indicating a higher degree of complexation with Cu metal ion.

Keywords: stability constant, humic acid, potentiometric titration, divalent metals, acid hydrolysis.

\section{NTRODUCTION}

The stability constant of a complex is the numerical expression of its stability and provides a quantitative measure of affinity of the metal ion to the complexing agent. An understanding of the relative stability of metal-complexes helps in predicting the behavior of metal ions in the soil (Ram and Raman, 1982). Extensive researches has been done to determine the stability constants of the complexes formed between humic acid (HA) with a number of metal ions. Ashok et al., (2000) reported that humic acid with hydroxyl, phenoxyl and carboxyl reactive groups can form coordination compound with metal ions at $\mathrm{pH}$ 3.5. The stability constants(Log K) for different metalhumic acid complexes indicated the following order of the stabilities of complexes formed between humic acid and metal ion, $\mathrm{Cu}>\mathrm{Fe}$ $>\mathrm{Pb}>\mathrm{Ni}>\mathrm{Co}>\mathrm{Ca}>\mathrm{Cd}>\mathrm{Zn}>\mathrm{Mn}>\mathrm{Mg}$. Andelkovic et al., (2010) investigated the binding of $\mathrm{Cd}$ (II) to soil humic acid at pH 6.5 and in $0.1 \mathrm{M} \mathrm{KNO}_{3}$ ionic medium. The stability constant for binding indicating greater stability in the case when carboxyl groups are involved in complexation reaction. Kostic et al.,(2012) investigated the complexation of humic acid with certain heavy metal ions (Co(II), $\mathrm{Ni}(\mathrm{II}), \mathrm{Cu}(\mathrm{II})$,
$\mathrm{Zn}(\mathrm{II})$, and $\mathrm{Pb}(\mathrm{II})$. The experiment was performed at $25^{\circ} \mathrm{C}$, at pH 4.0 and ionic strength of $0.01 \mathrm{M}$. Stability constant of complex between $\mathrm{Pb}$ (II) ions and humic acid is greater than stability constants of other investigated metalhumate complexes. Bogata and Sokolowska (2016) analyses the interaction between humic acids from different soils and $\mathrm{Zn}$ (II) ions at wide concentration ranges and at $\mathrm{pH} 5$. Studies have showed significant impact of $\mathrm{Zn}$ concentration, $\mathrm{pH}$ and some properties of humic acids with zinc.But all of these studies were limited to acidic $\mathrm{pH}$ range. Therefore, the present study was carried out to determine and compare the stability constants of complexes of metal ions with hydrolysed peat soil humic acid and unhydrolysed peat soil humic under non-acid conditions.

\section{MATERIALS AND METHODS}

Analytical grade chemicals used includes hydrochloric acid $(\mathrm{HCl})$, nitric acid $\left(\mathrm{HNO}_{3}\right)$, sodium hydroxide $(\mathrm{NaOH})$, lead nitrate $\mathrm{Pb}\left(\mathrm{NO}_{3}\right)_{2}$, copper nitrate $\mathrm{Cu}\left(\mathrm{NO}_{3}\right)_{2} \cdot 3 \mathrm{H}_{2} \mathrm{O}$, cadmium nitrate $\mathrm{Cd}\left(\mathrm{NO}_{3}\right)_{2} \cdot 4 \mathrm{H}_{2} \mathrm{O}$, magnesium nitrate $\mathrm{Mg}\left(\mathrm{NO}_{3}\right)_{2} \cdot 6 \mathrm{H}_{2} \mathrm{O}$, potassium nitrate $\left(\mathrm{KNO}_{3}\right)$, calcium chloride $\left(\mathrm{CaCl}_{2}\right)$, (sigma-Aldrich). Dowex 50WX8, (20-50 mesh) from Fluka. 


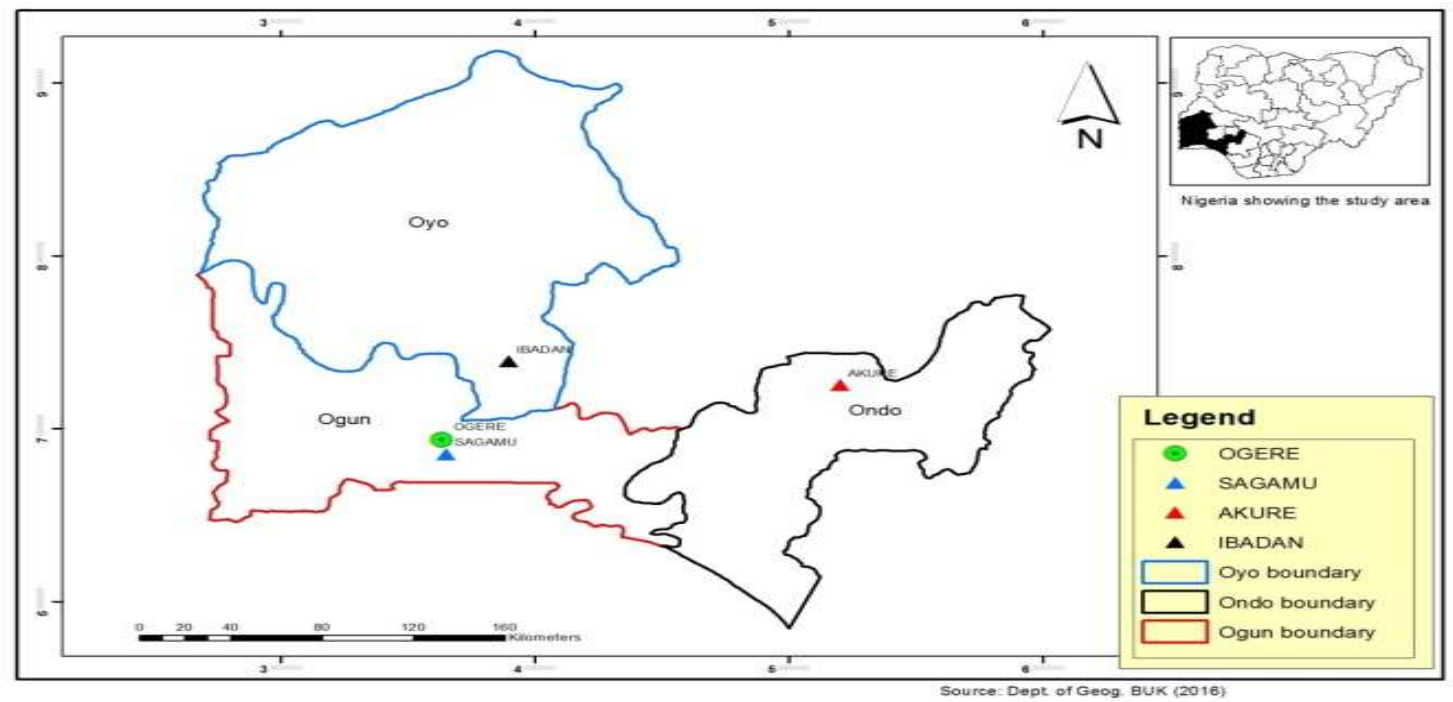

Figure 1: Map showing the sampling point at Sagamu Town, Ogun State.

\section{Description of Sampling Area}

Sagamu has geographical coordinates between $6^{\circ} 50^{\prime}$ north; $3^{\circ} 38^{\prime}$ east is located in south western region of Nigeria. The region has tropical wet and dry climate with a lengthy wet season and relatively constant temperatures throughout the course of the year. Wet season runs from March to October, November to December forms the region dry season. The vegetation type of the region is savannah which is really grassland with small bushes and occasional big trees. Grassland soils have substantially higher organic matter content than forest soils (Novackova, 2011).

\section{Sample Collection}

The Peatsoil samples were collected from four different sampling points $(0-10 \mathrm{~cm}$ depth) in Sagamu into polyethylene bag with plastic spoons. Samples were taken to the laboratory, extraneous materials were removed; the samples were air-dried, crushed and ground to a fine powder in a mortar passed through a $0.20 \mathrm{~mm}$ sieve. The samples were kept for analysis.

\section{Isolation and purification of humic acid from peat soil sample}

Peatsoil sample $(100 \mathrm{~g})$ was mixed with 1000 $\mathrm{cm}^{3}$ of $0.1 \mathrm{M} \mathrm{NaOH}$ solution, shaken for 3hours and left to stand overnight. Dark-coloured supernatant was obtained and decanted from solid residue. The dark-coloured supernatant was acidified to $(\mathrm{pH}=1.0)$ with $6 \mathrm{M} \mathrm{HCl}$ stirred and allowed to stand for 6 hours. Yellowish brown supernatant and dark-brown precipitate were obtained. The yellowish brown supernatant was decanted followed by centrifuge and discarded. The dark-brown precipitate was mixed with $500 \mathrm{~cm}^{3}$ of $0.1 \mathrm{M} \mathrm{NaOH}$ solution followed by passing through dowex resin. The dark-brown solution was acidified to $(\mathrm{pH}=1.0)$ with $6 \mathrm{M} \mathrm{HCl}$ stirred and allowed to stand for 3 hours. The dark-brown precipitate was washed several times with deionized water. The supernatant was treated with $\mathrm{AgNO}_{3}$ solution until no white precipitate observed. The humic acid was transferred to weighed crucible and dried at $60^{\circ} \mathrm{C}$ in an oven for 12 hours. The humic acid was cooled and dried in the desiccator, weighed and recorded. The obtained humic acid was dried again at $60^{\circ} \mathrm{C}$ for additional 6 hours cooled and dried in the desiccator, weighed and recorded constant weight was obtained (Baruah et al., 2015).

\section{FT-IR analysis}

FT-IR spectra of humic acid sample was analysed using Carry 630 FT-IR Agilent Technologies.

Unhydrolysed compost humic acid

The unhydrolysed humic acid was obtained after isolation and purification of compost humic acid and kept for investigation.

\section{Acid hydrolysis of Peatsoil acid}

Peatsoil humic acid sample (1g) was refluxed for 12 hours at $\left(160^{\circ} \mathrm{C}\right)$ with $50 \mathrm{~cm}^{3}$ of $6 \mathrm{M} \mathrm{HCl}$. The mixture was allowed to cool, decanted, and centrifuged after hydrolysis. The insoluble residues were washed with distilled water via centrifugation several times, and the supernatant was treated with $\mathrm{AgNO}_{3}$ solution until no white precipitate was observed. The residue was thoroughly dried over $\mathrm{CaCl}_{2}$ in a desiccator at room temperature (Chefetz et al., 2002). Finally, the obtained hydrolysed humic acid was kept for investigation. 
BAJOPAS Volume 14 Number 1,June, 2021 Potentiometric Titrations

Potentiometric measurements were carried out using a pH-meter Jenway (model 3510) with combine electrode, the sensitivity of the $\mathrm{pH}$ meter is 0.01 units. The $\mathrm{pH}$ meter was switched on half an hour before starting the titration for initial warm up of the instrument. The instrument was calibrated with an aqueous standard buffer solution of $\mathrm{pH} 4.00$ and 10.0 (borate buffer) prepared from a "Qualigens" buffer tablets.

The following sets of solutions were prepared in a $250 \mathrm{~cm}^{3}$ volumetric flask separately for $\mathrm{pH}$ metric titrations.

(i) $5 \mathrm{~cm}^{3} 0.1 \mathrm{M} \mathrm{HCl}+40 \mathrm{~cm}^{3}$ deionized water

(ii) $5 \mathrm{~cm}^{3} 0.1 \mathrm{M} \mathrm{HCl}+39 \mathrm{~cm}^{3}$ deionized water $+1 \mathrm{~cm}^{3} 0.15 \mathrm{gcm}^{-3}$ humic acid

(iii) $5 \mathrm{~cm}^{3} 0.1 \mathrm{M} \mathrm{HCl}+37 \mathrm{~cm}^{3}$ deionized water $+1 \mathrm{~cm}^{3} 0.15 \mathrm{gcm}^{-3}$ humic acid

$$
+2 \mathrm{~cm}^{3} \quad 0.01 \mathrm{M} \mathrm{Cu} \text { (II) }
$$

The solutions were titrated against standardized $0.110 \mathrm{MNaOH}$ separately. The total volume of each mixture was adjusted to $50 \mathrm{~cm}^{3}$ and the ionic strength of the solutions was maintained constant at by adding appropriate amount of stock solution of $1 \mathrm{M} \mathrm{KNO}_{3}$ (Gamal, 2015; Omar and Ali, 2015). A magnetic stirrer was used to achieve thorough mixing of the interacting solutions at $550 \mathrm{rpm}$. The same set of experimental conditions was applied for potentiometric titration of remaining samples.

\section{Evaluation of pKa of Hydrolysed peat soil Humic Acids}

The proton-ligand formation number $\mathrm{n}_{\mathbf{A}}$ were calculated by Irving and Rossotti expression (Omar and Ali, 2015).

$\mathrm{nA}=\mathrm{Y}-\frac{(\mathrm{V} 2-\mathrm{V1})(\mathrm{No}-\mathrm{Eo})}{(\mathrm{VO}+\mathrm{V1}) \mathrm{TCL}}$ 1

Where: $Y$ is number of dissociable proton, $\left(\mathrm{V}_{2^{-}}\right.$ $V_{1}$ ) is the measure of displacement of the ligand curve relative to acid curve, $\mathrm{N}^{\circ}$ and $\mathrm{E}^{\circ}$ are the resultant concentration of alkali solution, free acid solution, $\mathrm{T}_{\mathrm{cL}}{ }^{\circ}$ is the total ligand concentration, $\mathrm{V}^{\circ}$ is the total volume of titration solution, $V_{1}$ is the volume of alkali added to acid solution, $V_{2}$ is the volume of alkali added to acid solution + ligand solution, acid dissociation constants (pKa - values) of ligand were calculated by algebraic method point wise calculation (Tables 1 ). The dissociation constants (pKa) were calculated according to the following relation:

$\mathrm{pKa}=\mathrm{pH}+\log \left(\frac{n A}{1-n A}\right)$ 2

Where: pKa is the acid dissociation constant, $\mathrm{n}_{\mathrm{A}}$ is the Proton-ligand formation number and $\mathrm{pH}$ is the pH-values (Omar and Ali, 2015).

\section{Determination of metal-ligand stability constants $(\log K)$ of complexes}

The potentiometric measurement for the determination of stability constant of a complex in solution is based on the fact that the redox potential of the couple $\frac{M^{+(m-n)}}{M^{+m}}$ is shifted significantly on complexation of the metal ion with the ligand. This method involves change in hydrogen ion concentration $\left[\mathrm{H}^{+}\right]$due to the displacement or association of one or more protons taking place during complexation reaction. This change can be found out by titrating the solutions containing free acid, acid with ligand, and acid with ligand and metal ion, individually against a standard alkali solution at a constant ionic strength or temperature. Either ionic strength or temperature may be varied for different sets of solutions. In all the cases, the change in the $\mathrm{pH}$ of the solution is measured after each addition of a known amount of alkali to the reaction cell which contains the reaction mixture. The titration curves are then drawn by plotting the measured $\mathrm{pH}$ values against the corresponding volume of alkali added and the stability constants of the complexes are determined from the titration curves by employing $\mathrm{pH}$-metric titration technique given by (Irving and Rossoti).

Metal-ligand stability constants ( $\log \mathrm{K}$ ) were determined by using the following relations:

$$
\bar{n}=\frac{\left(V_{3}-V_{2}\right)\left(E^{0}+N^{0}\right)}{\left(V^{0}+V_{2}\right) \bar{n}_{A} T_{m}^{0}}
$$

and

$$
P L=\log _{10}\left\{\frac{1+\beta_{n}^{H} \frac{1}{[\text { anti } \log \mathrm{pH}]^{\mathrm{n}}}}{\mathrm{T}_{\mathrm{L}}^{0}-n \bar{T}_{m}^{0}} \mathrm{X} \frac{\left(V^{0}+V_{3}\right)}{V^{0}}\right\}
$$


BAJOPAS Volume 14 Number 1,June, 2021

Where $T_{L}, T^{\circ}, E^{\circ}$, and $V^{\circ}$ havethe same significance as in equation (1) above, $T_{m}$ denotes the total concentration of metal present in solution, $V_{3}$ is the volume of metal ions present in solution and $\beta^{H}$ is the overall proton ligand stability constant. The metal-ligand stability constants (log K) were determined by employing point wise computational Method (eq. 5 and 6).

$\operatorname{LogK}_{1}=\log \left(\frac{n}{1-n}\right)+\mathrm{pL}$ .5

$\operatorname{LogK}_{2}=\log \left(\frac{1-n}{2-n}\right)+\mathrm{pL}$ ...6

Where: Log $\mathrm{K}$ is the metal-ligand stability constant, $\mathrm{pL}$ is the Free ligand exponent function, $\mathbf{n}$ is the Average number of ligand attached with metal ion (Janraoet al., 2014). The results obtained were analyzed by an ORIGIN 2016 program using titration data and then the proton-ligand stability constants (pKa) and Metal-ligand stability constant (LogK) calculated (Omar and Ali, 2015).

\section{RESULTS AND DISCUSSION}

Fourier transformed infrared (FT-IR) spectra of isolated humic acid from peat soils Figure 2 had distinct clear absorption bands indicating the presence of major humic acid structural elemental groups such as $\mathrm{H}$ bonded $\mathrm{OH}$ $\left(3680 \mathrm{~cm}^{-1}\right.$ peak $), C=0$ of carbonyl $\left(1721 \mathrm{~cm}^{-1}\right.$ peak), functional groups of aliphatic components $\mathrm{CH}_{2}\left(2918 \mathrm{~cm}^{-1}\right.$ peak) and $\mathrm{C}-\mathrm{O}$ stretching of polysaccharide $\left(1168 \mathrm{~cm}^{-1}\right.$ peak). The positions of the absorption bands of the spectra fell within typical major absorption bands of humic acid which is at frequencies 3680, 2918, 1721, 1168 $\mathrm{cm}^{-1}$. The first peak centred in the vicinity of $3680 \mathrm{~cm}^{-1}$ region is attributed to phenol $\mathrm{OH}$ group bounded by intermolecular $\mathrm{H}$ bonds. The $2918 \mathrm{~cm}^{-1}$ band usually has absorption maximum at $2918 \mathrm{~cm}^{-1}$ which is due to $\mathrm{C}-\mathrm{H}$ stretching of alkane group $\left(\mathrm{CH}_{2}\right)$. The next major absorption band is $1721 \mathrm{~cm}^{-1}$. This band has been commonly ascribed to $\mathrm{C}=\mathrm{O}$ stretching of mainly carboxyl group $(\mathrm{COOH})$ with trace amount of ketones. The last peak was observed at 1168 $\mathrm{cm}^{-1}$ due to $\mathrm{C}-\mathrm{O}$ stretching of polysaccharides and this peak appeared also in the spectra of humic acid from peat soil. The FTIR spectra of the isolated humic acid contained all major characteristic absorption peaks of humic acid. These absorption peaks indicated the presence of the major structural elements of humic acid namely $\mathrm{H}$ bonded $\mathrm{OH}, \mathrm{C}=\mathrm{C}$ of aromatic ring, $\mathrm{C}=\mathrm{O}$ of carbonyl group (both carboxyl and ketonic), $\mathrm{CH}_{2}$ group. This strongly supports the presence of humic acid.

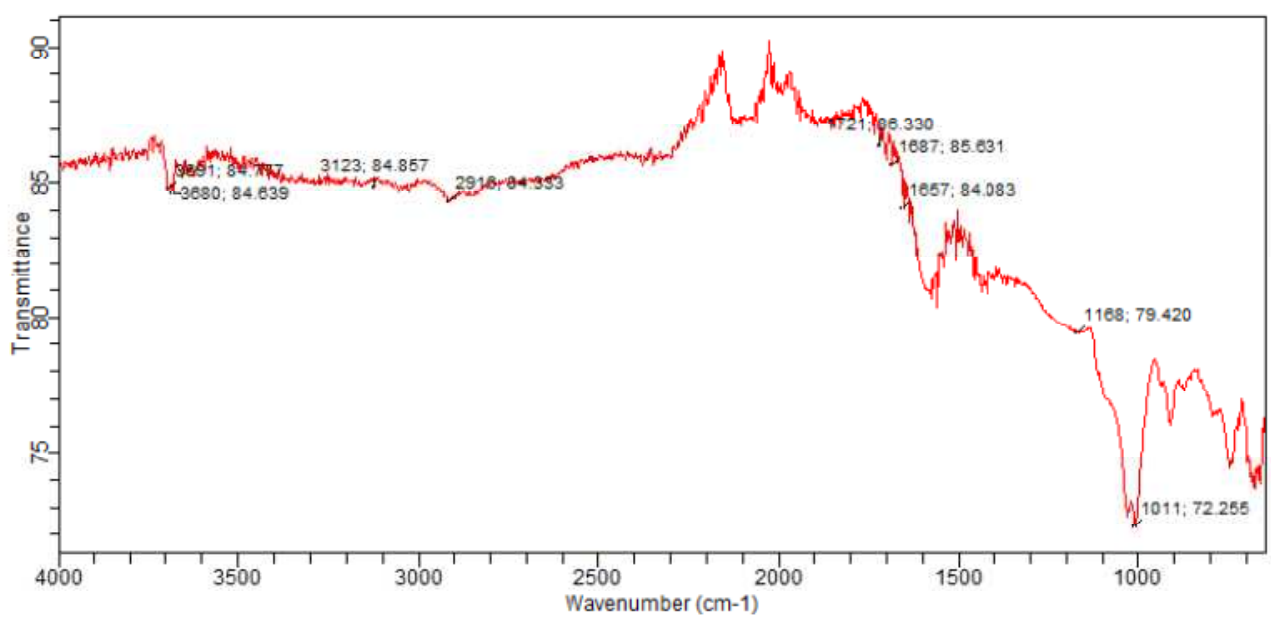

Fig. 2 : FT-IR spectraof peatsoilhumic acid (PSHA)

\section{Evaluation of acid dissociation constant (pka) of acid hydrolysed peat soil humicacid at phenolic group}

The value of the dissociation constant of the peat soil humic acid (PSHA) that underwent acidhydrolysis studied was found to be 8.9299 as shown Table 1, which is lower than the literaturevalues reported by Almeida and Szpoganics, (2015), Borges et al., (2005); Badr et al., (2012)and Fernandes et al,.(2009) of $9.73,9.47$ and 10.30. The difference between the obtained valuesand the reported values in this study might be probably as a result of acid hydrolysis of humicacid. 
BAJOPAS Volume 14 Number 1,June, 2021

Table 1: PKa of (Hydrolysed PSHA)

\begin{tabular}{|l|l|l|l|l|l|l|}
\hline $\mathrm{pH}$ & $\mathrm{BV}_{1}$ & $\mathrm{BV}_{2}$ & $\mathrm{~V}_{2}-\mathrm{V}_{1}$ & $\mathrm{nA}$ & $\log \left(\frac{n A}{1-n A}\right)$ & $\mathrm{pKa}$ \\
\hline 8.50 & 5.30 & 6.29 & 0.99 & 0.3594 & -0.2510 & 8.2490 \\
8.72 & 5.35 & 6.37 & 1.02 & 0.3400 & -0.2880 & 8.4320 \\
9.00 & 5.40 & 6.46 & 1.06 & 0.3141 & -0.3391 & 8.6609 \\
9.22 & 5.45 & 6.55 & 1.10 & 0.2882 & -0.3927 & 8.8273 \\
9.51 & 5.50 & 6.66 & 1.16 & 0.2494 & -0.4786 & 9.0314 \\
9.73 & 5.55 & 6.78 & 1.23 & 0.2041 & -0.5910 & 9.1390 \\
10.00 & 5.60 & 6.90 & 1.30 & 0.1589 & -0.7238 & 9.2762 \\
10.23 & 5.65 & 7.05 & 1.40 & 0.0941 & -0.9835 & 9.2465 \\
10.49 & 5.70 & 7.10 & 1.40 & 0.0941 & -0.9835 & 9.5065 \\
\hline
\end{tabular}

Average pKa $=8.9299 \pm 0.4186$

Table 2: PKa of (Unhydrolysed PSHA)

\begin{tabular}{|l|l|l|l|l|l|l|}
\hline $\mathrm{pH}$ & $\mathrm{BV}_{1}$ & $\mathrm{BV}_{2}$ & $\mathrm{~V}_{2}-\mathrm{V}_{1}$ & $\mathrm{nA}$ & $\log \left(\frac{\boldsymbol{n A}}{1-\boldsymbol{n}}\right)$ & $\mathrm{pKa}$ \\
\hline 8.50 & 5.30 & 5.81 & 0.51 & 0.6619 & 0.2919 & 8.7919 \\
8.72 & 5.35 & 5.90 & 0.55 & 0.6357 & 0.2418 & 8.9618 \\
9.00 & 5.40 & 6.00 & 0.60 & 0.6029 & 0.1813 & 9.1813 \\
9.22 & 5.45 & 6.10 & 0.65 & 0.5701 & 0.1226 & 9.3426 \\
9.51 & 5.50 & 6.20 & 0.70 & 0.5376 & 0.0654 & 9.5754 \\
9.73 & 5.55 & 6.33 & 0.78 & 0.4851 & -0.0259 & 9.7041 \\
10.00 & 5.60 & 6.47 & 0.87 & 0.4262 & -0.1291 & 9.8709 \\
10.23 & 5.65 & 6.62 & 0.99 & 0.3609 & -0.2481 & 9.9819 \\
10.49 & 5.70 & 6.80 & 1.10 & 0.2759 & -0.4690 & 10.0210 \\
\hline
\end{tabular}

Average pKa $=9.4923 \pm 0.4410$

Metal-ligand stability constant ( $\log \mathrm{K}$ )

The stabilityconstants require the accurate values of proton-ligand stability constants (Anil and Maroti, 2008). Metal titration curves crossed over ligand titration curve indicated the formation of complex upon proton release (Santosh, et al., 2011). If the values of n- are within range $0.2-0.8$ and $1.2-18$ this indicates the formation of $1: 1$ and 1:2 complexes (Sayyed and Mazahar, 2012).

The metal (II)-humate stepwise stability constants (log k) at phenolic group (Tables 318)

Table 3: Point-wise method, $\mathrm{Cu}$-(Hydrolysed PSHA)

\begin{tabular}{|l|l|l|l|l|l|l|l|l|}
\hline $\mathrm{pH}$ & $\mathrm{BV}_{1}$ & $\mathrm{BV}_{2}$ & $\mathrm{BV}_{3}$ & $\left(\mathrm{~V}_{3}-\mathrm{V}_{2}\right)$ & $\mathrm{n}$ & $\mathrm{pL}$ & $\log \left(\frac{n}{1-n}\right)$ & LogK $_{1}$ \\
\hline 8.50 & 5.30 & 6.29 & 6.33 & 0.04 & 0.5500 & 2.66 & 0.0871 & 2.7471 \\
8.72 & 5.35 & 6.37 & 6.41 & 0.04 & 0.5714 & 2.43 & 0.1249 & 2.5549 \\
9.00 & 5.40 & 6.46 & 6.50 & 0.04 & 0.6198 & 2.16 & 0.2122 & 2.3722 \\
9.22 & 5.45 & 6.55 & 6.59 & 0.04 & 0.6667 & 1.94 & 0.3010 & 2.2410 \\
\hline
\end{tabular}

LogK $_{1}$ (Average value) $=2.4788 \pm 0.2203$

Table 4: Point-wise method, $\mathrm{Cu}$-(Hydrolysed PSHA)

\begin{tabular}{|l|l|l|l|l|l|l|l|l|}
\hline $\mathrm{pH}$ & $\mathrm{BV}_{1}$ & $\mathrm{BV}_{2}$ & $\mathrm{BV}_{3}$ & $\left(\mathrm{~V}_{3}-\mathrm{V}_{2}\right)$ & $\mathrm{n}$ & $\mathrm{pL}$ & $\log \left(\frac{n-1}{2-n}\right)$ & LogK $_{2}$ \\
\hline 9.51 & 5.50 & 6.66 & 6.73 & 0.07 & 1.3509 & 1.70 & -0.2671 & 1.4329 \\
9.73 & 5.55 & 6.78 & 6.85 & 0.07 & 1.6383 & 1.51 & 0.2467 & 1.7567 \\
10.00 & 5.60 & 6.90 & 6.98 & 0.08 & 2.1783 & 1.31 & -0.2158 & 1.0942 \\
10.23 & 5.65 & 7.05 & 7.13 & 0.08 & 4.1904 & 1.27 & & \\
10.49 & 5.70 & 7.10 & 7.19 & 0.09 & 4.6920 & & & \\
\hline
\end{tabular}

Log $K_{2}($ Average value $)=1.4280 \pm 0.3312$ 
BAJOPAS Volume 14 Number 1,June, 2021

Table 5: Point-wise method, $\mathrm{Cu}$ (Unhydrolysed PSHA)

\begin{tabular}{|l|l|l|l|l|l|l|l|l|}
\hline $\mathrm{pH}$ & $\mathrm{BV}_{1}$ & $\mathrm{BV}_{2}$ & $\mathrm{BV}_{3}$ & $\left(\mathrm{~V}_{3}-\mathrm{V}_{2}\right)$ & $\mathrm{n}$ & $\mathrm{pL}$ & $\log \left(\frac{n}{n-1}\right)$ & Log $_{1}$ \\
\hline 8.50 & 5.30 & 5.81 & 5.85 & 0.04 & 0.2973 & 2.88 & -0.3736 & 2.5064 \\
8.72 & 5.35 & 5.90 & 5.95 & 0.05 & 0.3873 & 2.66 & -0.1992 & 2.4608 \\
9.00 & 5.40 & 6.00 & 6.05 & 0.05 & 0.4044 & 2.38 & -0.1681 & 2.2119 \\
9.22 & 5.45 & 6.10 & 6.15 & 0.06 & 0.5157 & 2.18 & -0.0272 & 2.2072 \\
9.51 & 5.50 & 6.20 & 6.27 & 0.07 & 0.6417 & 1.89 & 0.2530 & 1.1430 \\
\hline
\end{tabular}

$\operatorname{LogK}_{1}($ Average value $)=2.3059 \pm 0.6153$

Table 6:Point-wise method, $\mathrm{Cu}$ (Unhydrolysed PSHA)

\begin{tabular}{|l|l|l|l|l|l|l|l|l|}
\hline $\mathrm{pH}$ & $\mathrm{BV}_{1}$ & $\mathrm{BV}_{2}$ & $\mathrm{BV}_{3}$ & $\mathrm{~V}_{3}-\mathrm{V}_{2}$ & $\mathrm{n}$ & $\mathrm{pL}$ & $\log \left(\frac{n-1}{2-n}\right)$ & $\log \mathrm{K}_{2}$ \\
\hline 9.73 & 5.55 & 6.33 & 6.42 & 0.09 & 0.9000 & 1.69 & & \\
10.00 & 5.60 & 6.47 & 6.58 & 0.11 & 1.2578 & 1.44 & -0.4592 & 0.9808 \\
10.23 & 5.65 & 6.62 & 6.84 & 0.12 & 1.6137 & 1.26 & -0.2010 & 1.4610 \\
10.49 & 5.70 & 6.80 & 6.92 & 0.12 & 2.1052 & 1.03 & & \\
\hline
\end{tabular}

$\operatorname{LogK}_{2}$ (Average value) $=1.2209 \pm 0.3398$

Table 7:Point-wise method, Pb (Hydrolysed PSHA)

\begin{tabular}{|l|l|l|l|l|l|l|l|l|}
\hline $\mathrm{pH}$ & $\mathrm{BV}_{1}$ & $\mathrm{BV}_{2}$ & $\mathrm{BV}_{3}$ & $\left(\mathrm{~V}_{3}-\mathrm{V}_{2}\right)$ & $\mathrm{n}$ & $\mathrm{pL}$ & $\log \left(\frac{n}{1-n}\right)$ & LogK $_{1}$ \\
\hline 8.50 & 5.30 & 6.29 & 6.33 & 0.04 & 0.5500 & 2.66 & 0.0871 & 2.7471 \\
8.72 & 5.35 & 6.37 & 6.41 & 0.04 & 0.5714 & 2.43 & 0.1249 & 2.5549 \\
9.00 & 5.40 & 6.46 & 6.50 & 0.04 & 0.6198 & 2.16 & 0.2122 & 2.3722 \\
9.22 & 5.45 & 6.55 & 6.60 & 0.05 & 0.8333 & 1.96 & 0.6989 & 2.6589 \\
\hline
\end{tabular}

Log $_{\mathbf{1}}($ Average value $)=2.5832 \pm 0.1614$

Table 8:Point-wise method, Pb-(Hydrolysed PSHA)

\begin{tabular}{|l|l|l|l|l|l|l|l|l|}
\hline $\mathrm{pH}$ & $\mathrm{BV}_{1}$ & $\mathrm{BV}_{2}$ & $\mathrm{BV}_{3}$ & $\left(\mathrm{~V}_{3}-\mathrm{V}_{2}\right)$ & $\mathrm{n}$ & $\mathrm{pL}$ & $\log \left(\frac{n-1}{2-n}\right)$ & $\log \mathrm{K}_{2}$ \\
\hline 9.51 & 5.50 & 6.66 & 6.71 & 0.05 & 0.9650 & 1.67 & & \\
9.73 & 5.55 & 6.78 & 6.83 & 0.05 & 1.1702 & 1.44 & & \\
10.00 & 5.60 & 6.90 & 6.90 & 0.05 & 1.4864 & 1.22 & -0.0237 & 1.1963 \\
10.23 & 5.65 & 7.05 & 7.10 & 0.05 & 2.0190 & 1.09 & & \\
10.49 & 5.70 & 7.10 & 7.17 & 0.07 & 3.6492 & 1.00 & & \\
\hline
\end{tabular}

Log $K_{2}$ (Average value) $=1.1963$

Table 9: Point-wise method, Pb (Unhydrolysed PSHA)

\begin{tabular}{|l|l|l|l|l|l|l|l|l|}
\hline $\mathrm{pH}$ & $\mathrm{BV}_{1}$ & $\mathrm{BV}_{2}$ & $\mathrm{BV}_{3}$ & $\mathrm{~V}_{3}-\mathrm{V}_{2}$ & $\mathrm{n}$ & $\mathrm{pL}$ & $\begin{array}{l}\text { Log } \\
\left(\frac{n}{n-1}\right)\end{array}$ & Log $\mathrm{K}_{1}$ \\
\hline 8.50 & 5.30 & 5.81 & 5.85 & 0.04 & 0.2973 & 2.88 & -0.3736 & 2.5064 \\
8.72 & 5.35 & 5.90 & 5.94 & 0.04 & 0.3099 & 2.66 & -0.5477 & 2.3123 \\
9.00 & 5.40 & 6.00 & 6.05 & 0.05 & 0.4044 & 2.38 & -0.1681 & 2.2119 \\
9.22 & 5.45 & 6.10 & 6.15 & 0.06 & 0.5157 & 2.18 & 0.0272 & 2.2072 \\
9.51 & 5.50 & 6.20 & 6.26 & 0.07 & 0.6417 & 1.89 & 0.2530 & 2.1430 \\
9.73 & 5.55 & 6.40 & 6.40 & 0.07 & 0.7000 & 1.67 & 0.3680 & 2.0380 \\
\hline
\end{tabular}

LogK $_{1}$ (Average value) $=2.2364 \pm 0.1602$

Table 10: Point-wise method, Pb (Unhydrolysed PSHA)

\begin{tabular}{|l|l|l|l|l|l|l|l|l|}
\hline $\mathrm{pH}$ & $\mathrm{BV}_{1}$ & $\mathrm{BV}_{2}$ & $\mathrm{BV}_{3}$ & $\mathrm{~V}_{3}-\mathrm{V}_{2}$ & $\mathrm{n}$ & $\mathrm{pL}$ & $\log \left(\frac{n-1}{2-n}\right)$ & $\log \mathrm{K}_{2}$ \\
\hline 10.00 & 5.60 & 6.47 & 6.55 & 0.08 & 1.9503 & 1.41 & & \\
10.23 & 5.65 & 6.62 & 6.72 & 0.11 & 1.4792 & 1.26 & -0.0361 & 1.2239 \\
\hline
\end{tabular}

$\operatorname{LogK}_{2}$ (Average value) $=1.2239$

Table 11: Point-wise method, Mg (Hydrolysed PSHA)

\begin{tabular}{|l|l|l|l|l|l|l|l|l|}
\hline $\mathrm{pH}$ & $\mathrm{BV}_{1}$ & $\mathrm{BV}_{2}$ & $\mathrm{BV}_{3}$ & $\left(\mathrm{~V}_{3}-\mathrm{V}_{2}\right)$ & $\mathrm{n}$ & $\mathrm{pL}$ & $\log \left(\frac{n}{n-1}\right)$ & LogK $_{1}$ \\
\hline 8.50 & 5.30 & 6.29 & 6.31 & 0.02 & 0.2750 & 2.64 & -0.4290 & 2.2110 \\
8.72 & 5.35 & 6.37 & 6.39 & 0.02 & 0.2858 & 2.42 & -0.3978 & 2.0222 \\
9.00 & 5.40 & 6.46 & 6.49 & 0.03 & 0.4648 & 2.14 & -0.0612 & 2.0788 \\
9.22 & 5.45 & 6.55 & 6.59 & 0.04 & 0.6667 & 1.94 & 0.3010 & 2.2410 \\
\hline
\end{tabular}

$\log _{\mathbf{1}}($ Average value) $=2.1382 \pm 0.1046$ 
BAJOPAS Volume 14 Number 1,June, 2021

Table 12: Point-wise method, Mg (Hydrolysed PSHA)

\begin{tabular}{|l|l|l|l|l|l|l|l|l|}
\hline $\mathrm{pH}$ & $\mathrm{BV}_{1}$ & $\mathrm{BV}_{2}$ & $\mathrm{BV}_{3}$ & $\left(\mathrm{~V}_{3}-\mathrm{V}_{2}\right)$ & $\mathrm{n}$ & $\mathrm{pL}$ & $\log \left(\frac{n-1}{2-n}\right)$ & LogK $_{2}$ \\
\hline 9.51 & 5.55 & 6.66 & 6.71 & 0.05 & 0.9650 & 1.67 & & \\
9.73 & 5.55 & 6.78 & 6.84 & 0.06 & 1.4042 & 1.47 & -0.1686 & 1.3014 \\
10.00 & 5.60 & 6.90 & 6.93 & 0.06 & 1.7838 & 1.23 & 0.5593 & 1.7893 \\
10.23 & 5.65 & 7.05 & 7.10 & 0.06 & 3.1429 & 1.10 & & \\
10.49 & 5.70 & 7.10 & 7.18 & 0.07 & 3.6492 & 0.83 & & \\
\hline
\end{tabular}

LogK $_{2}($ Average value $)=1.5453 \pm 0.3450$

Table 13: Point-wise method, Mg (Unhydrolysed PSHA)

\begin{tabular}{|l|l|l|l|l|l|l|l|l|}
\hline $\mathrm{pH}$ & $\mathrm{BV}_{1}$ & $\mathrm{BV}_{2}$ & $\mathrm{BV}_{3}$ & $\mathrm{~V}_{3}-\mathrm{V}_{2}$ & $\mathrm{n}$ & $\mathrm{pL}$ & $\log \left(\frac{n}{n-1}\right)$ & $\operatorname{Log~}_{1}$ \\
\hline 8.50 & 5.30 & 5.81 & 5.85 & 0.04 & 0.2973 & 2.88 & -0.3736 & 2.5064 \\
8.72 & 5.35 & 5.90 & 5.94 & 0.04 & 0.3099 & 2.66 & -0.3477 & 2.3123 \\
9.00 & 5.40 & 6.00 & 6.04 & 0.04 & 0.3236 & 2.38 & -0.3202 & 2.0598 \\
9.22 & 5.45 & 6.10 & 6.15 & 0.05 & 0.4297 & 2.17 & -0.1230 & 2.0470 \\
9.51 & 5.50 & 6.20 & 6.26 & 0.06 & 0.5500 & 1.89 & 0.0871 & 1.9771 \\
9.73 & 5.55 & 6.33 & 6.40 & 0.07 & 0.7000 & 1.67 & 0.3680 & 2.0380 \\
\hline
\end{tabular}

LogK $_{1}$ (Average value) $=2.1568 \pm 0.2069$

Table 14: Point-wise method, Mg (Unhydrolysed PSHA)

\begin{tabular}{|l|l|l|l|l|l|l|l|l|}
\hline $\mathrm{pH}$ & $\mathrm{BV}_{1}$ & $\mathrm{BV}_{2}$ & $\mathrm{BV}_{3}$ & $\mathrm{~V}_{3}-\mathrm{V}_{2}$ & $\mathrm{n}$ & $\mathrm{pL}$ & $\log \left(\frac{n-1}{2-n}\right)$ & $\log \mathrm{K}_{2}$ \\
\hline 10.00 & 5.60 & 6.47 & 6.55 & 0.08 & 0.9148 & 1.41 & & \\
10.23 & 5.65 & 6.62 & 6.71 & 0.09 & 1.2102 & 1.20 & -0.5749 & 0.6251 \\
10.49 & 5.70 & 6.80 & 6.92 & 0.09 & 1.5968 & 1.03 & 0.1703 & 1.2003 \\
\hline
\end{tabular}

LogK $_{2}$ (Average value) $=0.9127 \pm 0.4070$

Table15:Point-wise method, Cd (Hydrolysed PSHA)

\begin{tabular}{|l|l|l|l|l|l|l|l|l|}
\hline $\mathrm{pH}$ & $\mathrm{BV}_{1}$ & $\mathrm{BV}_{2}$ & $\mathrm{BV}_{3}$ & $\left(\mathrm{~V}_{3}-\mathrm{V}_{2}\right)$ & $\mathrm{n}$ & $\mathrm{pL}$ & $\log \left(\frac{n}{1-n}\right)$ & LogK $_{1}$ \\
\hline 8.50 & 5.30 & 6.29 & 6.31 & 0.02 & 0.2750 & 2.64 & -0.4210 & 2.2190 \\
8.72 & 5.35 & 6.37 & 6.40 & 0.03 & 0.4286 & 2.42 & -0.1249 & 2.2951 \\
9.00 & 5.40 & 6.46 & 6.49 & 0.03 & 0.4648 & 2.14 & -0.0612 & 2.0788 \\
9.22 & 5.45 & 6.55 & 6.59 & 0.04 & 0.6667 & 1.96 & 0.3010 & 2.2610 \\
9.51 & 5.55 & 6.66 & 6.70 & 0.04 & 0.7720 & 1.67 & 0.5297 & 2.1997 \\
\hline
\end{tabular}

LogK $_{\mathbf{1}}$ (Average value) $=2.2108 \pm 0.0825$

Table 16: Point-wise method, Cd (Hydrolysed PSHA)

\begin{tabular}{|l|l|l|l|l|l|l|l|l|}
\hline $\mathrm{pH}$ & $\mathrm{BV}_{1}$ & $\mathrm{BV}_{2}$ & $\mathrm{BV}_{3}$ & $\left(\mathrm{~V}_{3}-\mathrm{V}_{2}\right)$ & $\mathrm{n}$ & $\mathrm{pL}$ & $\log \left(\frac{n-1}{2-n}\right)$ & Log $_{2}$ \\
\hline 9.73 & 5.55 & 6.78 & 6.83 & 0.06 & 1.4042 & 1.47 & -0.1686 & 1.3014 \\
10.00 & 5.60 & 6.90 & 6.95 & 0.06 & 1.7838 & 1.23 & 0.5593 & 1.7893 \\
10.23 & 5.65 & 7.05 & 7.10 & 0.06 & 3.1429 & 1.09 & & \\
10.49 & 5.70 & 7.10 & 7.16 & 0.06 & 3.1429 & 0.89 & & \\
& & & & & & & & \\
\hline
\end{tabular}

$\operatorname{LogK}_{2}$ (Average value) $=1.5453 \pm 0.3450$

Table 17: Point-wise method, Cd (Unhydrolysed PSHA)

\begin{tabular}{|l|l|l|l|l|l|l|l|l|}
\hline $\mathrm{pH}$ & $\mathrm{BV}_{1}$ & $\mathrm{BV}_{2}$ & $\mathrm{BV}_{3}$ & $\mathrm{~V}_{3}-\mathrm{V}_{2}$ & $\mathrm{n}$ & $\mathrm{pL}$ & $\log \left(\frac{n}{n-1}\right)$ & $\operatorname{Log~}_{1}$ \\
\hline 8.50 & 5.30 & 5.81 & 5.86 & 0.05 & 0.3717 & 2.88 & -0.2280 & 2.6520 \\
8.72 & 5.35 & 5.90 & 5.95 & 0.05 & 0.3873 & 2.66 & -0.1992 & 2.4608 \\
9.00 & 5.40 & 6.00 & 6.06 & 0.06 & 0.4853 & 2.38 & -0.0255 & 2.3545 \\
9.22 & 5.45 & 6.10 & 6.16 & 0.06 & 0.5157 & 2.18 & -0.0272 & 2.2072 \\
9.51 & 5.50 & 6.20 & 6.27 & 0.07 & 0.6417 & 1.89 & 0.2530 & 1.1430 \\
9.73 & 5.55 & 6.33 & 6.41 & 0.08 & 0.8000 & 1.69 & 0.6020 & 2.2920 \\
& & & & & & & & \\
\hline
\end{tabular}

$\operatorname{LogK}_{1}($ Average value $)=2.2516 \pm 0.5380$ 
BAJOPAS Volume 14 Number 1,June, 2021

Table 18: Point-wise method, Cd (Unhydrolysed PSHA)

\begin{tabular}{|l|l|l|l|l|l|l|l|l|}
\hline $\mathrm{pH}$ & $\mathrm{BV}_{1}$ & $\mathrm{BV}_{2}$ & $\mathrm{BV}_{3}$ & $\mathrm{~V}_{3}-\mathrm{V}_{2}$ & $\mathrm{n}$ & $\mathrm{pL}$ & $\log \left(\frac{n-1}{2-n}\right)$ & $\log \mathrm{K}_{2}$ \\
\hline 10.00 & 5.60 & 6.47 & 6.57 & 0.10 & 1.1434 & 1.43 & & \\
10.23 & 5.65 & 6.62 & 6.72 & 0.10 & 1.3448 & 1.23 & -0.2788 & 0.9512 \\
10.49 & 5.70 & 6.80 & 6.90 & 0.10 & 1.7742 & 1.03 & 0.5351 & 1.5651 \\
\hline
\end{tabular}

$\operatorname{LogK}_{2}($ Average value $)=1.2581 \pm 0.4340$

Table 19: Stepwise and overall Stability constants of thehydrolysed and unhydrolysed divalent metal (II) complexes

\begin{tabular}{|c|c|c|c|}
\hline Chelates & LogK $_{1}$ & $\log _{2}$ & Log $\beta$ \\
\hline [Cu (Hydrolysed PSHA-1) $\left.{ }_{2}\right]$ & 2.4788 & 1.4280 & 3.9068 \\
\hline$\left[\mathrm{Pb}(\text { Hydrolysed PSHA-1) })_{2}\right]$ & 2.5832 & 1.1963 & 3.7795 \\
\hline$\left[\mathrm{Cd}(\text { Hydrolysed PSHA-1 })_{2}\right]$ & 2.2108 & 1.5453 & 3.7561 \\
\hline$\left[\mathrm{Mg}(\text { Hydrolysed PSHA-1 })_{2}\right]$ & 2.1382 & 1.5453 & 3.6835 \\
\hline [Cu (Unhydrolysed PSHA-1) & 2.3059 & 1.2209 & 3.5268 \\
\hline$[\mathrm{Pb}$ (Unhydrolysed PSHA-1) 2$]$ & 2.2364 & 1.2239 & 3.4603 \\
\hline [Cd (Unhydrolysed PSHA-1) 2 ] & 2.2516 & 1.2581 & 3.5097 \\
\hline$[\mathrm{Mg}$ (Unydrolysed PSHA-1) & 2.1568 & 0.9127 & 3.0695 \\
\hline
\end{tabular}

The results obtained (Table19) shows the stepwise and overall stability constants to be not high indicating low stability of the complexes, because the solubility of most metal ions in the basic $\mathrm{pH}$ range is minimal due to metal hydroxide precipitation (Karimi, 2017). In general, the stepwise stability constants $\left(K_{1}\right.$ and $K_{2}$ ) follow the order $K_{1}>K_{2}$ for the copper, lead, magnesium and cadmium complexes respectively. The steady decrease of the values with increasing number of ligands is in agreement with the prediction made by researchers (Na'aliya, 2013). The decrease could be attributed to the fact that as the number of the ligands (Humate ions) that enters the coordination zone increases the aqua molecules available for replacement by the ligands become less. Thus, the metal ions become less electron loving with progressive intake of the ligand and this results in the decrease in the values of the constants (Na'aliya, 2013). Also the stability of the complexes is influenced by the size and number of the chelate rings(Mackay and Mackay,2002).All the complexes form rings in their structure as humate, a bidentate ligand, bond the metal ions in the ratio 1:2 (Boguta and Sokolowska, 2016) forming chelate rings. The values of the overall stability constants $(\log \beta)$ obtained for humate complexes are not high indicating low stability as the values are not high. LogK values for copper-humates (Table 3 to 6) obtained in this study are lower than those reported for the complexes of humic acids (Pandey et al., 2015; Dinu, 2013; Kaschl et al., 2010 and Gilbeto and Jorg, 2001). The values of LogK(Table 7 to 10 ) forlead-humates are lower than those reported for the lead in the literature (Dinu, 2013; Gilbeto and Jorg 2001). Log K values(Table 11 to 14 ) for magnesium-humates obtained in this study are close to those reported by (Pandey et al., 2015). Log K values of cadmium-humates (Table 15 to 18 ) obtained in this work near to the one reported by (Dinu, 2013 and Pandey et al., 2015).The difference between the reported values and the values obtained in this study might be probably as a result of acid hydrolysis of humic acid. The values of the overall stability constants $(\log \beta)$ of the copper humates complexes presented in Table 19 is high than that of other metal humate complexes, show relatively high stability of CuHA complexes, show the following order of stability: $\mathrm{Cu}>\mathrm{Pb}>\mathrm{Cd}>\mathrm{Mg}$; which are in close agreement to the findings of (Dinu, 2013 and Pandey et al., 2015).The high stability of Cuhumate chelate could be attributed to the existence of coordinate covalent bond between the complexing agents and the $\mathrm{Cu}^{2+}$ ions. Since, $\mathrm{Cu}^{2+}$ being a metal of the transitional series with $3 d^{9}$ electronic configurations can accept the electrons from the complexing agents. Similarly, the low stabilities of $\mathrm{Pb}, \mathrm{Cd}$ and $\mathrm{Mg}$ complexes could be explained by that $\mathrm{Pb}^{2+}$ with $6 s^{2}, \mathrm{Cd}^{2+}$ with $4 \mathrm{~d}^{10}$ and $\mathrm{Mg}^{2+}$ with $2 \mathrm{p}^{6}$ their electronic configuration has a completely filled $\mathrm{d}, \mathrm{p}$ and $\mathrm{s}$ orbitals. Moreover, the stabilities of metal ions with hydrolysed humic acid from peat soil were higher than those with unhydrolysed humic acid from peat soil; which is ascribed to the high content of acidity in hydrolysed humic acid than unhydrolysed humic acid. 
BAJOPAS Volume 14 Number 1,June, 2021 CONCLUSION

The values of logk for $\mathrm{Cu}(\mathrm{II})$ hydrolysed humic acid complex was higher followed by $\mathrm{Pb}$ (II), $\mathrm{Cd}(\mathrm{II})$ and $\mathrm{Mg}$ (II) hydrolysed humic acid complexes as compared with metal(II) unhydrolysed humic acid complexes. This indicates acid hydrolysis of humic acid can

\section{REFERENCES}

Almeida, V.R. and Szpoganicz, B. (2015). Humic Acid Potentiometric Response Patterns:Out- of Equilibrium Properties and Species Distribution Modelling. Chemical. Biol. Technol. Agric. 2: 17.

Anđelković, T., Nikolić, R., Bojić, A.,Anđelković, D., and Nikolic G.,(2010). Binding of Cadmium to Soil Humic Acid as A Function of Carboxyl Group Content. Macedonian Journal of Chemistry and Chemical Engineering.29(2): 215-224.

Anil, B. N. and Maroti, N. (2008). Studies on Influence of Die-Lectric Constants on Complex Equilibria between Substituted Py-Razalines and Lanthanide Metal Ions pH-Metrically. Amer.-Euras. scient. Res. 3(2): 212-216.

Ashok, K., Pandey, S. P. and Misra, V (2000). Stability Constants of Metal-Humic Acid Complexes and its Role in Environmental Detoxification. Journal of Ecotoxicology and Environmental Safety. 47(2):157-200.

Badr, M. H., El-Halafawi, M. H. and Abd El-al Zeid, E. R. (2012). Comparison Between the Effect of Ionic Strength on Acidity and Dissociation Constants of Humic Acids Extracted from Sewage Sludge and Nile Water Hyacinth Composts.Global Journal of Environmental Research 6 (1): 36-43.

Baruah, M.K., Borah, D., Saikia, P.P., Paul, S., Sharma, T. (2015). Evaluation of pKa Values of Soil Humic Acids and their Complexation Properties. International Journal of Plant \& Soil Science 6(4) : 218-228.

Boguta, P. Sokolowska, Z. (2016). Interactions of $\mathrm{Zn}$ (II) Ions with Humic Acids Isolated from Various Types of Soils. Effect of $\mathrm{pH}, \mathrm{Zn}$ Concentrations and Humic Acids Chemical Properties. Journal of Geochemical Explaration 168. 119-126.

Borges, F., Guimaraes, C., Lima, L.F.C., Pinto, I. and Reis, S.(2005). Potentiometric Studies on the Complexation of Copper(II) by Phenolic Acids as Discrete Ligand Models of enhance the complexation behavior of humic acid with metal (II) ions. However, the higher values of $\log \beta$ for $\mathrm{Cu}(\mathrm{II}), \mathrm{Pb}(\mathrm{II}), \mathrm{Cd}(\mathrm{II})$ and $\mathrm{Mg}(\mathrm{II})$ hydrolysed humic acid complexes indicates more stable stepwise complexes formed as compared with $\mathrm{Cu}(\mathrm{II}), \mathrm{Pb}$ (II), $\mathrm{Cd}$ (II) and $\mathrm{Mg}(\mathrm{II})$ unhydrolysed humic acid complexes.

Humic Substances Talanta 66 (2005) 670-673.

Chefetz, B., Salloum, M. J., Deshmulkin, A. P. and Hatcher, P. (2002). Structural Components of Humic Acids as Determined by Chemical Modifications and Carbon-13 NMR, Pyrolysis, and Thermochemolysis- Gas Chromatography/Mass Spectrometry. Soil Science Society of American Journal Abstract Division S-2- Soil Chemistry66. 1159-1171.

Dinu, M. I. (2013). Metals Complexation with Humic Acids in Surface Water of Different Environ. Sci. Technol. 31(1): 1-17.

Fernandes, A.N., Giacomelli, C., Giovanela, M. Vaz, D.V. Szpoganicz, B. and Maria M. D. (2009). Potentiometric Acidity Determination in Humic Substances Influenced by Different Analytical Procedures.J. Braz. Chem. Soc. 20 (9):14.

Gamal, A. H. (2015). Stability Constants of Rhenium (V) Metal Complexes with Selected Drugs. Pyrex Journal of Research in Environmental Studies. 2(2): 006-014.

Janrao, D. M., Pathan, J., Kayande, D.D., and Mulla, J.J. (2014). An Over View of Potentiometric Determination of Stability Constants of Metal Complexes. Sci. Revs. Chem. Commun.: 4(1), 2014, 11-24.

Karimi, H. (2017). Effect of pH and Initial Pb(II) Concentration on the Lead Removal Efficiency from Waste Water Using $\mathrm{Ca}(\mathrm{OH})_{2}$. International Journal of Water and Waste Water Treatment 3.2

Kaschl, A. Romheld, V. and Chen, Y. (2010). Binding of Cadmium, Copper and Zinc to Humic Substances Originating from Municipal Solid Waste Compost. Israel Journal of Chemistry Vol. 42(1): 89-98.

Kostic, I. S., Tatjana, P, A., Nikolic, R. S., Cvetkovic, T. P., Pavlovic, D. D., Aleksandar, L.J. and Bojic, A. (2012). Comparative Study of Binding Strengths of Heavy Metals with Humic Acid. J.serb. Chem. Soc. 76(9) pp 1-20. 
BAJOPAS Volume 14 Number 1,June, 2021

Na'aliya, J. (2013). Determination of Stepwise Stability Constants and Gibbs free Energy Change of Trisprolina to Complexes of some Divalent Transition Metal ions. Bayero Journal of Pure and Applied Sciences 6(2): 112-114.

Omar, A. A. and Ali, E. A. (2015). Potentiometric Studies on Complexes of $\mathrm{Cr}$ (III) and $\mathrm{Zr}$ (IV) with some Carboxylic Acids. International Journal of Advanced Chemistry, 3(1) 25-

37.

Pandey, A. K. Pandey, S. D. and Misr, V. (2015).Stability Constants of Metal- Humic Acid Complexes and Its Role in Environmental Detoxification. J. Ecotoxicology and Environmental Safety. 47(1):195-200.

Ram, N. and Raman, K.V. (1984). Stability Constants of Complexes of Metals with
Humicand Fuvic Acids under Non- acidConditions. Journal of Plant Nutrition and Soil Sciences.

147:171-176.

Santosh, D. D., Ashok, B. K., Vijay, J. T., Shivraj, G. W. and Vinay, V. W. (2011). Potentiometric Studies of Elec-Trolyte Effects on Complex Equilibria of Some Substituted 5-(2-hydroxy Phenyl) Pyrazoles. Der pharm. 3 (6): 75-83.

Sayyed, H. and Abdul Rahim, M. F. (2012). Studies of Binary Complexes of Metal Ions with Mandelic Acid by Potentiometry. Chem. J. 02 (6): 206209.

Shirvani, M. Moradian, E. Khalili, B. Bakhtiary, S. (2015). Interaction of $\mathrm{Cd}$ and $\mathrm{Pb}$ with Humate-Palygorskite and HumateSepiolite Complexes. Journal of water, air and pollution 3: 220-228. 


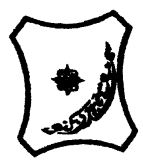

Bayero Journal of Pure and Applied Sciences, 14(1): 54 - 63

Received: November, 2020

Accepted: April, 2021

ISSN $2006-6996$

\title{
STABILITY CONSTANTS OF COMPLEXES OF METAL IONS WITH PEATSOIL HUMIC ACIDS UNDER NON-ACID-CONDITIONS
}

\author{
${ }^{* 1}$ Sabo, Yusuf ${ }^{2}$ Jimoh, W.L.O., ${ }^{3}$ Isa Baba Koki and ${ }^{4}$ Sholadoye, Q. 0. \\ ${ }^{1}$ Department of Pure and Industrial Chemistry, Bayero University, Kano \\ ${ }^{3}$ Department of Chemistry, Yusuf Maitama Sule University Kano. P.M.B. 3220 Kano, Nigeria. \\ ${ }^{4}$ Department of Chemistry, Nigerian Police Academy, Wudil, Kano-Nigeria
}

*Correspondence E-mail; saboyusuf18@yahoo.com

ABSTRACT

Stability constants of complexes of four divalent metal ions viz. $\mathrm{Cu}^{2+}, \mathrm{Pb}^{2+}, \mathrm{Mg}^{2+}$ and $\mathrm{Cd}^{2+}$ with humic acids (HA) were determined by potentiometric titration of humic acids with the corresponding salt of the divalent metals in aqueous media under non-acid-condition. The log $K$ (logarithm of the stability constant) ranged from 1.0942 to 2.7471 for metalhumic acid complexes were determined using point-wise computational method. The order of stability constants were obtained as follows: $\mathrm{Cu}>\mathrm{Pb}>\mathrm{Cd}>\mathrm{Mg}$ for metal $-\mathrm{HA}$ complexes respectively, indicating a higher degree of complexation with Cu metal ion.

Keywords: stability constant, humic acid, potentiometric titration, divalent metals, acid hydrolysis.

\section{NTRODUCTION}

The stability constant of a complex is the numerical expression of its stability and provides a quantitative measure of affinity of the metal ion to the complexing agent. An understanding of the relative stability of metal-complexes helps in predicting the behavior of metal ions in the soil (Ram and Raman, 1982). Extensive researches has been done to determine the stability constants of the complexes formed between humic acid (HA) with a number of metal ions. Ashok et al., (2000) reported that humic acid with hydroxyl, phenoxyl and carboxyl reactive groups can form coordination compound with metal ions at $\mathrm{pH}$ 3.5. The stability constants(Log K) for different metalhumic acid complexes indicated the following order of the stabilities of complexes formed between humic acid and metal ion, $\mathrm{Cu}>\mathrm{Fe}$ $>\mathrm{Pb}>\mathrm{Ni}>\mathrm{Co}>\mathrm{Ca}>\mathrm{Cd}>\mathrm{Zn}>\mathrm{Mn}>\mathrm{Mg}$. Andelkovic et al., (2010) investigated the binding of $\mathrm{Cd}$ (II) to soil humic acid at pH 6.5 and in $0.1 \mathrm{M} \mathrm{KNO}_{3}$ ionic medium. The stability constant for binding indicating greater stability in the case when carboxyl groups are involved in complexation reaction. Kostic et al.,(2012) investigated the complexation of humic acid with certain heavy metal ions (Co(II), $\mathrm{Ni}(\mathrm{II}), \mathrm{Cu}(\mathrm{II})$,
$\mathrm{Zn}(\mathrm{II})$, and $\mathrm{Pb}(\mathrm{II})$. The experiment was performed at $25^{\circ} \mathrm{C}$, at pH 4.0 and ionic strength of $0.01 \mathrm{M}$. Stability constant of complex between $\mathrm{Pb}$ (II) ions and humic acid is greater than stability constants of other investigated metalhumate complexes. Bogata and Sokolowska (2016) analyses the interaction between humic acids from different soils and $\mathrm{Zn}$ (II) ions at wide concentration ranges and at $\mathrm{pH} 5$. Studies have showed significant impact of $\mathrm{Zn}$ concentration, $\mathrm{pH}$ and some properties of humic acids with zinc.But all of these studies were limited to acidic $\mathrm{pH}$ range. Therefore, the present study was carried out to determine and compare the stability constants of complexes of metal ions with hydrolysed peat soil humic acid and unhydrolysed peat soil humic under non-acid conditions.

\section{MATERIALS AND METHODS}

Analytical grade chemicals used includes hydrochloric acid $(\mathrm{HCl})$, nitric acid $\left(\mathrm{HNO}_{3}\right)$, sodium hydroxide $(\mathrm{NaOH})$, lead nitrate $\mathrm{Pb}\left(\mathrm{NO}_{3}\right)_{2}$, copper nitrate $\mathrm{Cu}\left(\mathrm{NO}_{3}\right)_{2} \cdot 3 \mathrm{H}_{2} \mathrm{O}$, cadmium nitrate $\mathrm{Cd}\left(\mathrm{NO}_{3}\right)_{2} \cdot 4 \mathrm{H}_{2} \mathrm{O}$, magnesium nitrate $\mathrm{Mg}\left(\mathrm{NO}_{3}\right)_{2} \cdot 6 \mathrm{H}_{2} \mathrm{O}$, potassium nitrate $\left(\mathrm{KNO}_{3}\right)$, calcium chloride $\left(\mathrm{CaCl}_{2}\right)$, (sigma-Aldrich). Dowex 50WX8, (20-50 mesh) from Fluka. 


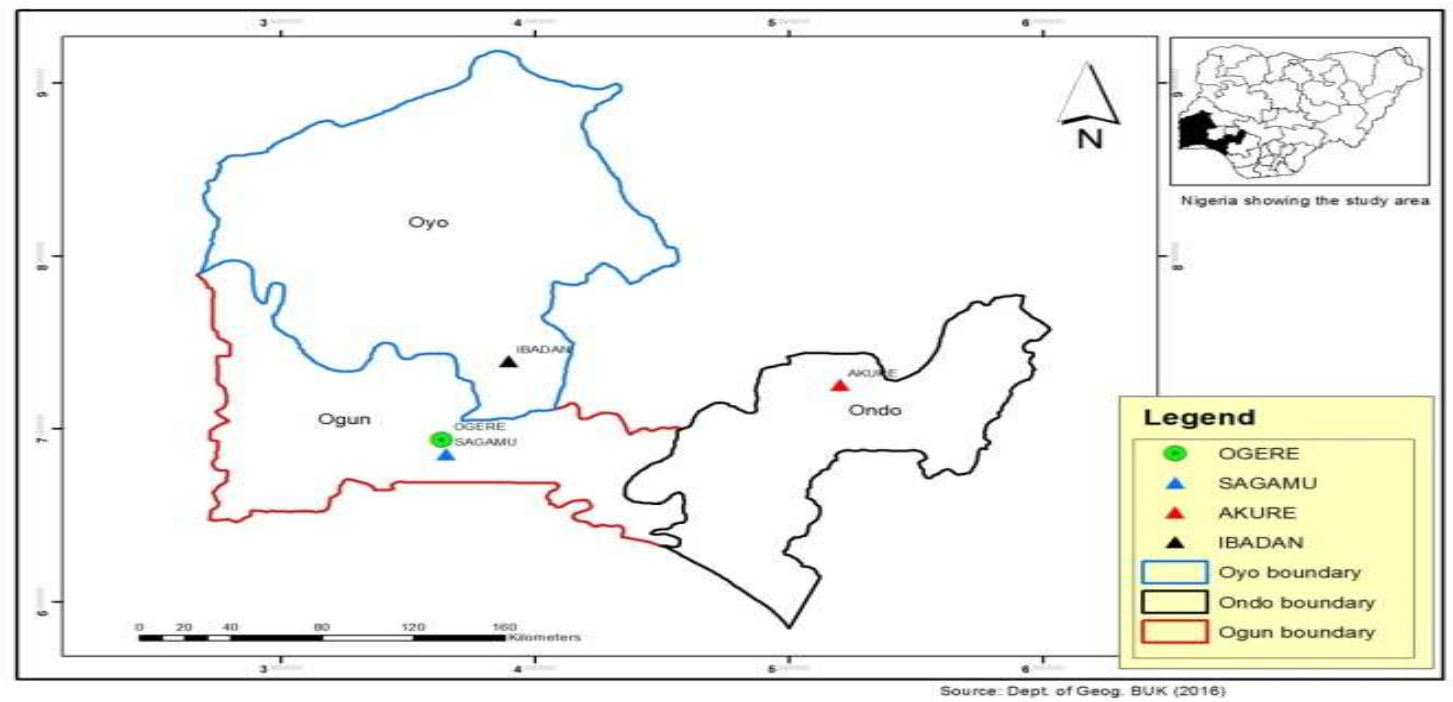

Figure 1: Map showing the sampling point at Sagamu Town, Ogun State.

\section{Description of Sampling Area}

Sagamu has geographical coordinates between $6^{\circ} 50^{\prime}$ north; $3^{\circ} 38^{\prime}$ east is located in south western region of Nigeria. The region has tropical wet and dry climate with a lengthy wet season and relatively constant temperatures throughout the course of the year. Wet season runs from March to October, November to December forms the region dry season. The vegetation type of the region is savannah which is really grassland with small bushes and occasional big trees. Grassland soils have substantially higher organic matter content than forest soils (Novackova, 2011).

\section{Sample Collection}

The Peatsoil samples were collected from four different sampling points $(0-10 \mathrm{~cm}$ depth) in Sagamu into polyethylene bag with plastic spoons. Samples were taken to the laboratory, extraneous materials were removed; the samples were air-dried, crushed and ground to a fine powder in a mortar passed through a $0.20 \mathrm{~mm}$ sieve. The samples were kept for analysis.

\section{Isolation and purification of humic acid from peat soil sample}

Peatsoil sample $(100 \mathrm{~g})$ was mixed with 1000 $\mathrm{cm}^{3}$ of $0.1 \mathrm{M} \mathrm{NaOH}$ solution, shaken for 3hours and left to stand overnight. Dark-coloured supernatant was obtained and decanted from solid residue. The dark-coloured supernatant was acidified to $(\mathrm{pH}=1.0)$ with $6 \mathrm{M} \mathrm{HCl}$ stirred and allowed to stand for 6 hours. Yellowish brown supernatant and dark-brown precipitate were obtained. The yellowish brown supernatant was decanted followed by centrifuge and discarded. The dark-brown precipitate was mixed with $500 \mathrm{~cm}^{3}$ of $0.1 \mathrm{M} \mathrm{NaOH}$ solution followed by passing through dowex resin. The dark-brown solution was acidified to $(\mathrm{pH}=1.0)$ with $6 \mathrm{M} \mathrm{HCl}$ stirred and allowed to stand for 3 hours. The dark-brown precipitate was washed several times with deionized water. The supernatant was treated with $\mathrm{AgNO}_{3}$ solution until no white precipitate observed. The humic acid was transferred to weighed crucible and dried at $60^{\circ} \mathrm{C}$ in an oven for 12 hours. The humic acid was cooled and dried in the desiccator, weighed and recorded. The obtained humic acid was dried again at $60^{\circ} \mathrm{C}$ for additional 6 hours cooled and dried in the desiccator, weighed and recorded constant weight was obtained (Baruah et al., 2015).

\section{FT-IR analysis}

FT-IR spectra of humic acid sample was analysed using Carry 630 FT-IR Agilent Technologies.

Unhydrolysed compost humic acid

The unhydrolysed humic acid was obtained after isolation and purification of compost humic acid and kept for investigation.

\section{Acid hydrolysis of Peatsoil acid}

Peatsoil humic acid sample (1g) was refluxed for 12 hours at $\left(160^{\circ} \mathrm{C}\right)$ with $50 \mathrm{~cm}^{3}$ of $6 \mathrm{M} \mathrm{HCl}$. The mixture was allowed to cool, decanted, and centrifuged after hydrolysis. The insoluble residues were washed with distilled water via centrifugation several times, and the supernatant was treated with $\mathrm{AgNO}_{3}$ solution until no white precipitate was observed. The residue was thoroughly dried over $\mathrm{CaCl}_{2}$ in a desiccator at room temperature (Chefetz et al., 2002). Finally, the obtained hydrolysed humic acid was kept for investigation. 
BAJOPAS Volume 14 Number 1,June, 2021 Potentiometric Titrations

Potentiometric measurements were carried out using a pH-meter Jenway (model 3510) with combine electrode, the sensitivity of the $\mathrm{pH}$ meter is 0.01 units. The $\mathrm{pH}$ meter was switched on half an hour before starting the titration for initial warm up of the instrument. The instrument was calibrated with an aqueous standard buffer solution of $\mathrm{pH} 4.00$ and 10.0 (borate buffer) prepared from a "Qualigens" buffer tablets.

The following sets of solutions were prepared in a $250 \mathrm{~cm}^{3}$ volumetric flask separately for $\mathrm{pH}$ metric titrations.

(i) $5 \mathrm{~cm}^{3} 0.1 \mathrm{M} \mathrm{HCl}+40 \mathrm{~cm}^{3}$ deionized water

(ii) $5 \mathrm{~cm}^{3} 0.1 \mathrm{M} \mathrm{HCl}+39 \mathrm{~cm}^{3}$ deionized water $+1 \mathrm{~cm}^{3} 0.15 \mathrm{gcm}^{-3}$ humic acid

(iii) $5 \mathrm{~cm}^{3} 0.1 \mathrm{M} \mathrm{HCl}+37 \mathrm{~cm}^{3}$ deionized water $+1 \mathrm{~cm}^{3} 0.15 \mathrm{gcm}^{-3}$ humic acid

$$
+2 \mathrm{~cm}^{3} \quad 0.01 \mathrm{M} \mathrm{Cu} \text { (II) }
$$

The solutions were titrated against standardized $0.110 \mathrm{MNaOH}$ separately. The total volume of each mixture was adjusted to $50 \mathrm{~cm}^{3}$ and the ionic strength of the solutions was maintained constant at by adding appropriate amount of stock solution of $1 \mathrm{M} \mathrm{KNO}_{3}$ (Gamal, 2015; Omar and Ali, 2015). A magnetic stirrer was used to achieve thorough mixing of the interacting solutions at $550 \mathrm{rpm}$. The same set of experimental conditions was applied for potentiometric titration of remaining samples.

\section{Evaluation of pKa of Hydrolysed peat soil Humic Acids}

The proton-ligand formation number $\mathrm{n}_{\mathbf{A}}$ were calculated by Irving and Rossotti expression (Omar and Ali, 2015).

$\mathrm{nA}=\mathrm{Y}-\frac{(\mathrm{V} 2-\mathrm{V1})(\mathrm{No}-\mathrm{Eo})}{(\mathrm{VO}+\mathrm{V1}) \mathrm{TCL}}$ 1

Where: $Y$ is number of dissociable proton, $\left(\mathrm{V}_{2^{-}}\right.$ $V_{1}$ ) is the measure of displacement of the ligand curve relative to acid curve, $\mathrm{N}^{\circ}$ and $\mathrm{E}^{\circ}$ are the resultant concentration of alkali solution, free acid solution, $\mathrm{T}_{\mathrm{cL}}{ }^{\circ}$ is the total ligand concentration, $\mathrm{V}^{\circ}$ is the total volume of titration solution, $V_{1}$ is the volume of alkali added to acid solution, $V_{2}$ is the volume of alkali added to acid solution + ligand solution, acid dissociation constants (pKa - values) of ligand were calculated by algebraic method point wise calculation (Tables 1 ). The dissociation constants (pKa) were calculated according to the following relation:

$\mathrm{pKa}=\mathrm{pH}+\log \left(\frac{n A}{1-n A}\right)$ 2

Where: pKa is the acid dissociation constant, $\mathrm{n}_{\mathrm{A}}$ is the Proton-ligand formation number and $\mathrm{pH}$ is the pH-values (Omar and Ali, 2015).

\section{Determination of metal-ligand stability constants $(\log K)$ of complexes}

The potentiometric measurement for the determination of stability constant of a complex in solution is based on the fact that the redox potential of the couple $\frac{M^{+(m-n)}}{M^{+m}}$ is shifted significantly on complexation of the metal ion with the ligand. This method involves change in hydrogen ion concentration $\left[\mathrm{H}^{+}\right]$due to the displacement or association of one or more protons taking place during complexation reaction. This change can be found out by titrating the solutions containing free acid, acid with ligand, and acid with ligand and metal ion, individually against a standard alkali solution at a constant ionic strength or temperature. Either ionic strength or temperature may be varied for different sets of solutions. In all the cases, the change in the $\mathrm{pH}$ of the solution is measured after each addition of a known amount of alkali to the reaction cell which contains the reaction mixture. The titration curves are then drawn by plotting the measured $\mathrm{pH}$ values against the corresponding volume of alkali added and the stability constants of the complexes are determined from the titration curves by employing $\mathrm{pH}$-metric titration technique given by (Irving and Rossoti).

Metal-ligand stability constants ( $\log \mathrm{K}$ ) were determined by using the following relations:

$$
\bar{n}=\frac{\left(V_{3}-V_{2}\right)\left(E^{0}+N^{0}\right)}{\left(V^{0}+V_{2}\right) \bar{n}_{A} T_{m}^{0}}
$$

and

$$
P L=\log _{10}\left\{\frac{1+\beta_{n}^{H} \frac{1}{[\text { anti } \log \mathrm{pH}]^{\mathrm{n}}}}{\mathrm{T}_{\mathrm{L}}^{0}-n \bar{T}_{m}^{0}} \mathrm{X} \frac{\left(V^{0}+V_{3}\right)}{V^{0}}\right\}
$$


BAJOPAS Volume 14 Number 1,June, 2021

Where $T_{L}, T^{\circ}, E^{\circ}$, and $V^{\circ}$ havethe same significance as in equation (1) above, $T_{m}$ denotes the total concentration of metal present in solution, $V_{3}$ is the volume of metal ions present in solution and $\beta^{H}$ is the overall proton ligand stability constant. The metal-ligand stability constants (log K) were determined by employing point wise computational Method (eq. 5 and 6).

$\operatorname{LogK}_{1}=\log \left(\frac{n}{1-n}\right)+\mathrm{pL}$ .5

$\operatorname{LogK}_{2}=\log \left(\frac{1-n}{2-n}\right)+\mathrm{pL}$ ...6

Where: Log $\mathrm{K}$ is the metal-ligand stability constant, $\mathrm{pL}$ is the Free ligand exponent function, $\mathbf{n}$ is the Average number of ligand attached with metal ion (Janraoet al., 2014). The results obtained were analyzed by an ORIGIN 2016 program using titration data and then the proton-ligand stability constants (pKa) and Metal-ligand stability constant (LogK) calculated (Omar and Ali, 2015).

\section{RESULTS AND DISCUSSION}

Fourier transformed infrared (FT-IR) spectra of isolated humic acid from peat soils Figure 2 had distinct clear absorption bands indicating the presence of major humic acid structural elemental groups such as $\mathrm{H}$ bonded $\mathrm{OH}$ $\left(3680 \mathrm{~cm}^{-1}\right.$ peak $), C=0$ of carbonyl $\left(1721 \mathrm{~cm}^{-1}\right.$ peak), functional groups of aliphatic components $\mathrm{CH}_{2}\left(2918 \mathrm{~cm}^{-1}\right.$ peak) and $\mathrm{C}-\mathrm{O}$ stretching of polysaccharide $\left(1168 \mathrm{~cm}^{-1}\right.$ peak). The positions of the absorption bands of the spectra fell within typical major absorption bands of humic acid which is at frequencies 3680, 2918, 1721, 1168 $\mathrm{cm}^{-1}$. The first peak centred in the vicinity of $3680 \mathrm{~cm}^{-1}$ region is attributed to phenol $\mathrm{OH}$ group bounded by intermolecular $\mathrm{H}$ bonds. The $2918 \mathrm{~cm}^{-1}$ band usually has absorption maximum at $2918 \mathrm{~cm}^{-1}$ which is due to $\mathrm{C}-\mathrm{H}$ stretching of alkane group $\left(\mathrm{CH}_{2}\right)$. The next major absorption band is $1721 \mathrm{~cm}^{-1}$. This band has been commonly ascribed to $\mathrm{C}=\mathrm{O}$ stretching of mainly carboxyl group $(\mathrm{COOH})$ with trace amount of ketones. The last peak was observed at 1168 $\mathrm{cm}^{-1}$ due to $\mathrm{C}-\mathrm{O}$ stretching of polysaccharides and this peak appeared also in the spectra of humic acid from peat soil. The FTIR spectra of the isolated humic acid contained all major characteristic absorption peaks of humic acid. These absorption peaks indicated the presence of the major structural elements of humic acid namely $\mathrm{H}$ bonded $\mathrm{OH}, \mathrm{C}=\mathrm{C}$ of aromatic ring, $\mathrm{C}=\mathrm{O}$ of carbonyl group (both carboxyl and ketonic), $\mathrm{CH}_{2}$ group. This strongly supports the presence of humic acid.

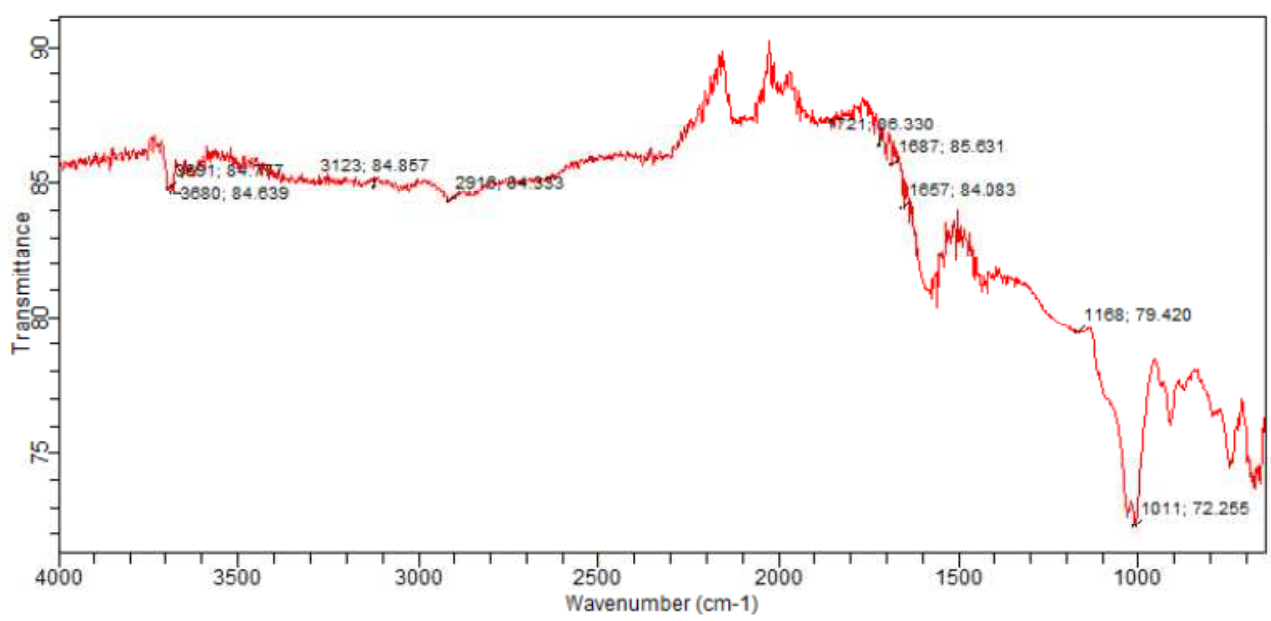

Fig. 2 : FT-IR spectraof peatsoilhumic acid (PSHA)

\section{Evaluation of acid dissociation constant (pka) of acid hydrolysed peat soil humicacid at phenolic group}

The value of the dissociation constant of the peat soil humic acid (PSHA) that underwent acidhydrolysis studied was found to be 8.9299 as shown Table 1, which is lower than the literaturevalues reported by Almeida and Szpoganics, (2015), Borges et al., (2005); Badr et al., (2012)and Fernandes et al,.(2009) of $9.73,9.47$ and 10.30. The difference between the obtained valuesand the reported values in this study might be probably as a result of acid hydrolysis of humicacid. 
BAJOPAS Volume 14 Number 1,June, 2021

Table 1: PKa of (Hydrolysed PSHA)

\begin{tabular}{|l|l|l|l|l|l|l|}
\hline $\mathrm{pH}$ & $\mathrm{BV}_{1}$ & $\mathrm{BV}_{2}$ & $\mathrm{~V}_{2}-\mathrm{V}_{1}$ & $\mathrm{nA}$ & $\log \left(\frac{n A}{1-n A}\right)$ & $\mathrm{pKa}$ \\
\hline 8.50 & 5.30 & 6.29 & 0.99 & 0.3594 & -0.2510 & 8.2490 \\
8.72 & 5.35 & 6.37 & 1.02 & 0.3400 & -0.2880 & 8.4320 \\
9.00 & 5.40 & 6.46 & 1.06 & 0.3141 & -0.3391 & 8.6609 \\
9.22 & 5.45 & 6.55 & 1.10 & 0.2882 & -0.3927 & 8.8273 \\
9.51 & 5.50 & 6.66 & 1.16 & 0.2494 & -0.4786 & 9.0314 \\
9.73 & 5.55 & 6.78 & 1.23 & 0.2041 & -0.5910 & 9.1390 \\
10.00 & 5.60 & 6.90 & 1.30 & 0.1589 & -0.7238 & 9.2762 \\
10.23 & 5.65 & 7.05 & 1.40 & 0.0941 & -0.9835 & 9.2465 \\
10.49 & 5.70 & 7.10 & 1.40 & 0.0941 & -0.9835 & 9.5065 \\
\hline
\end{tabular}

Average pKa $=8.9299 \pm 0.4186$

Table 2: PKa of (Unhydrolysed PSHA)

\begin{tabular}{|l|l|l|l|l|l|l|}
\hline $\mathrm{pH}$ & $\mathrm{BV}_{1}$ & $\mathrm{BV}_{2}$ & $\mathrm{~V}_{2}-\mathrm{V}_{1}$ & $\mathrm{nA}$ & $\log \left(\frac{\boldsymbol{n A}}{1-\boldsymbol{n}}\right)$ & $\mathrm{pKa}$ \\
\hline 8.50 & 5.30 & 5.81 & 0.51 & 0.6619 & 0.2919 & 8.7919 \\
8.72 & 5.35 & 5.90 & 0.55 & 0.6357 & 0.2418 & 8.9618 \\
9.00 & 5.40 & 6.00 & 0.60 & 0.6029 & 0.1813 & 9.1813 \\
9.22 & 5.45 & 6.10 & 0.65 & 0.5701 & 0.1226 & 9.3426 \\
9.51 & 5.50 & 6.20 & 0.70 & 0.5376 & 0.0654 & 9.5754 \\
9.73 & 5.55 & 6.33 & 0.78 & 0.4851 & -0.0259 & 9.7041 \\
10.00 & 5.60 & 6.47 & 0.87 & 0.4262 & -0.1291 & 9.8709 \\
10.23 & 5.65 & 6.62 & 0.99 & 0.3609 & -0.2481 & 9.9819 \\
10.49 & 5.70 & 6.80 & 1.10 & 0.2759 & -0.4690 & 10.0210 \\
\hline
\end{tabular}

Average pKa $=9.4923 \pm 0.4410$

Metal-ligand stability constant ( $\log \mathrm{K}$ )

The stabilityconstants require the accurate values of proton-ligand stability constants (Anil and Maroti, 2008). Metal titration curves crossed over ligand titration curve indicated the formation of complex upon proton release (Santosh, et al., 2011). If the values of n- are within range $0.2-0.8$ and $1.2-18$ this indicates the formation of $1: 1$ and 1:2 complexes (Sayyed and Mazahar, 2012).

The metal (II)-humate stepwise stability constants (log k) at phenolic group (Tables 318)

Table 3: Point-wise method, $\mathrm{Cu}$-(Hydrolysed PSHA)

\begin{tabular}{|l|l|l|l|l|l|l|l|l|}
\hline $\mathrm{pH}$ & $\mathrm{BV}_{1}$ & $\mathrm{BV}_{2}$ & $\mathrm{BV}_{3}$ & $\left(\mathrm{~V}_{3}-\mathrm{V}_{2}\right)$ & $\mathrm{n}$ & $\mathrm{pL}$ & $\log \left(\frac{n}{1-n}\right)$ & LogK $_{1}$ \\
\hline 8.50 & 5.30 & 6.29 & 6.33 & 0.04 & 0.5500 & 2.66 & 0.0871 & 2.7471 \\
8.72 & 5.35 & 6.37 & 6.41 & 0.04 & 0.5714 & 2.43 & 0.1249 & 2.5549 \\
9.00 & 5.40 & 6.46 & 6.50 & 0.04 & 0.6198 & 2.16 & 0.2122 & 2.3722 \\
9.22 & 5.45 & 6.55 & 6.59 & 0.04 & 0.6667 & 1.94 & 0.3010 & 2.2410 \\
\hline
\end{tabular}

LogK $_{1}$ (Average value) $=2.4788 \pm 0.2203$

Table 4: Point-wise method, $\mathrm{Cu}$-(Hydrolysed PSHA)

\begin{tabular}{|l|l|l|l|l|l|l|l|l|}
\hline $\mathrm{pH}$ & $\mathrm{BV}_{1}$ & $\mathrm{BV}_{2}$ & $\mathrm{BV}_{3}$ & $\left(\mathrm{~V}_{3}-\mathrm{V}_{2}\right)$ & $\mathrm{n}$ & $\mathrm{pL}$ & $\log \left(\frac{n-1}{2-n}\right)$ & LogK $_{2}$ \\
\hline 9.51 & 5.50 & 6.66 & 6.73 & 0.07 & 1.3509 & 1.70 & -0.2671 & 1.4329 \\
9.73 & 5.55 & 6.78 & 6.85 & 0.07 & 1.6383 & 1.51 & 0.2467 & 1.7567 \\
10.00 & 5.60 & 6.90 & 6.98 & 0.08 & 2.1783 & 1.31 & -0.2158 & 1.0942 \\
10.23 & 5.65 & 7.05 & 7.13 & 0.08 & 4.1904 & 1.27 & & \\
10.49 & 5.70 & 7.10 & 7.19 & 0.09 & 4.6920 & & & \\
\hline
\end{tabular}

Log $K_{2}($ Average value $)=1.4280 \pm 0.3312$ 
BAJOPAS Volume 14 Number 1,June, 2021

Table 5: Point-wise method, $\mathrm{Cu}$ (Unhydrolysed PSHA)

\begin{tabular}{|l|l|l|l|l|l|l|l|l|}
\hline $\mathrm{pH}$ & $\mathrm{BV}_{1}$ & $\mathrm{BV}_{2}$ & $\mathrm{BV}_{3}$ & $\left(\mathrm{~V}_{3}-\mathrm{V}_{2}\right)$ & $\mathrm{n}$ & $\mathrm{pL}$ & $\log \left(\frac{n}{n-1}\right)$ & Log $_{1}$ \\
\hline 8.50 & 5.30 & 5.81 & 5.85 & 0.04 & 0.2973 & 2.88 & -0.3736 & 2.5064 \\
8.72 & 5.35 & 5.90 & 5.95 & 0.05 & 0.3873 & 2.66 & -0.1992 & 2.4608 \\
9.00 & 5.40 & 6.00 & 6.05 & 0.05 & 0.4044 & 2.38 & -0.1681 & 2.2119 \\
9.22 & 5.45 & 6.10 & 6.15 & 0.06 & 0.5157 & 2.18 & -0.0272 & 2.2072 \\
9.51 & 5.50 & 6.20 & 6.27 & 0.07 & 0.6417 & 1.89 & 0.2530 & 1.1430 \\
\hline
\end{tabular}

$\operatorname{LogK}_{1}($ Average value $)=2.3059 \pm 0.6153$

Table 6:Point-wise method, $\mathrm{Cu}$ (Unhydrolysed PSHA)

\begin{tabular}{|l|l|l|l|l|l|l|l|l|}
\hline $\mathrm{pH}$ & $\mathrm{BV}_{1}$ & $\mathrm{BV}_{2}$ & $\mathrm{BV}_{3}$ & $\mathrm{~V}_{3}-\mathrm{V}_{2}$ & $\mathrm{n}$ & $\mathrm{pL}$ & $\log \left(\frac{n-1}{2-n}\right)$ & $\log \mathrm{K}_{2}$ \\
\hline 9.73 & 5.55 & 6.33 & 6.42 & 0.09 & 0.9000 & 1.69 & & \\
10.00 & 5.60 & 6.47 & 6.58 & 0.11 & 1.2578 & 1.44 & -0.4592 & 0.9808 \\
10.23 & 5.65 & 6.62 & 6.84 & 0.12 & 1.6137 & 1.26 & -0.2010 & 1.4610 \\
10.49 & 5.70 & 6.80 & 6.92 & 0.12 & 2.1052 & 1.03 & & \\
\hline
\end{tabular}

$\operatorname{LogK}_{2}$ (Average value) $=1.2209 \pm 0.3398$

Table 7:Point-wise method, Pb (Hydrolysed PSHA)

\begin{tabular}{|l|l|l|l|l|l|l|l|l|}
\hline $\mathrm{pH}$ & $\mathrm{BV}_{1}$ & $\mathrm{BV}_{2}$ & $\mathrm{BV}_{3}$ & $\left(\mathrm{~V}_{3}-\mathrm{V}_{2}\right)$ & $\mathrm{n}$ & $\mathrm{pL}$ & $\log \left(\frac{n}{1-n}\right)$ & LogK $_{1}$ \\
\hline 8.50 & 5.30 & 6.29 & 6.33 & 0.04 & 0.5500 & 2.66 & 0.0871 & 2.7471 \\
8.72 & 5.35 & 6.37 & 6.41 & 0.04 & 0.5714 & 2.43 & 0.1249 & 2.5549 \\
9.00 & 5.40 & 6.46 & 6.50 & 0.04 & 0.6198 & 2.16 & 0.2122 & 2.3722 \\
9.22 & 5.45 & 6.55 & 6.60 & 0.05 & 0.8333 & 1.96 & 0.6989 & 2.6589 \\
\hline
\end{tabular}

Log $_{\mathbf{1}}($ Average value $)=2.5832 \pm 0.1614$

Table 8:Point-wise method, Pb-(Hydrolysed PSHA)

\begin{tabular}{|l|l|l|l|l|l|l|l|l|}
\hline $\mathrm{pH}$ & $\mathrm{BV}_{1}$ & $\mathrm{BV}_{2}$ & $\mathrm{BV}_{3}$ & $\left(\mathrm{~V}_{3}-\mathrm{V}_{2}\right)$ & $\mathrm{n}$ & $\mathrm{pL}$ & $\log \left(\frac{n-1}{2-n}\right)$ & $\log \mathrm{K}_{2}$ \\
\hline 9.51 & 5.50 & 6.66 & 6.71 & 0.05 & 0.9650 & 1.67 & & \\
9.73 & 5.55 & 6.78 & 6.83 & 0.05 & 1.1702 & 1.44 & & \\
10.00 & 5.60 & 6.90 & 6.90 & 0.05 & 1.4864 & 1.22 & -0.0237 & 1.1963 \\
10.23 & 5.65 & 7.05 & 7.10 & 0.05 & 2.0190 & 1.09 & & \\
10.49 & 5.70 & 7.10 & 7.17 & 0.07 & 3.6492 & 1.00 & & \\
\hline
\end{tabular}

Log $K_{2}$ (Average value) $=1.1963$

Table 9: Point-wise method, Pb (Unhydrolysed PSHA)

\begin{tabular}{|l|l|l|l|l|l|l|l|l|}
\hline $\mathrm{pH}$ & $\mathrm{BV}_{1}$ & $\mathrm{BV}_{2}$ & $\mathrm{BV}_{3}$ & $\mathrm{~V}_{3}-\mathrm{V}_{2}$ & $\mathrm{n}$ & $\mathrm{pL}$ & $\begin{array}{l}\text { Log } \\
\left(\frac{n}{n-1}\right)\end{array}$ & Log $\mathrm{K}_{1}$ \\
\hline 8.50 & 5.30 & 5.81 & 5.85 & 0.04 & 0.2973 & 2.88 & -0.3736 & 2.5064 \\
8.72 & 5.35 & 5.90 & 5.94 & 0.04 & 0.3099 & 2.66 & -0.5477 & 2.3123 \\
9.00 & 5.40 & 6.00 & 6.05 & 0.05 & 0.4044 & 2.38 & -0.1681 & 2.2119 \\
9.22 & 5.45 & 6.10 & 6.15 & 0.06 & 0.5157 & 2.18 & 0.0272 & 2.2072 \\
9.51 & 5.50 & 6.20 & 6.26 & 0.07 & 0.6417 & 1.89 & 0.2530 & 2.1430 \\
9.73 & 5.55 & 6.40 & 6.40 & 0.07 & 0.7000 & 1.67 & 0.3680 & 2.0380 \\
\hline
\end{tabular}

LogK $_{1}$ (Average value) $=2.2364 \pm 0.1602$

Table 10: Point-wise method, Pb (Unhydrolysed PSHA)

\begin{tabular}{|l|l|l|l|l|l|l|l|l|}
\hline $\mathrm{pH}$ & $\mathrm{BV}_{1}$ & $\mathrm{BV}_{2}$ & $\mathrm{BV}_{3}$ & $\mathrm{~V}_{3}-\mathrm{V}_{2}$ & $\mathrm{n}$ & $\mathrm{pL}$ & $\log \left(\frac{n-1}{2-n}\right)$ & $\log \mathrm{K}_{2}$ \\
\hline 10.00 & 5.60 & 6.47 & 6.55 & 0.08 & 1.9503 & 1.41 & & \\
10.23 & 5.65 & 6.62 & 6.72 & 0.11 & 1.4792 & 1.26 & -0.0361 & 1.2239 \\
\hline
\end{tabular}

$\operatorname{LogK}_{2}$ (Average value) $=1.2239$

Table 11: Point-wise method, Mg (Hydrolysed PSHA)

\begin{tabular}{|l|l|l|l|l|l|l|l|l|}
\hline $\mathrm{pH}$ & $\mathrm{BV}_{1}$ & $\mathrm{BV}_{2}$ & $\mathrm{BV}_{3}$ & $\left(\mathrm{~V}_{3}-\mathrm{V}_{2}\right)$ & $\mathrm{n}$ & $\mathrm{pL}$ & $\log \left(\frac{n}{n-1}\right)$ & LogK $_{1}$ \\
\hline 8.50 & 5.30 & 6.29 & 6.31 & 0.02 & 0.2750 & 2.64 & -0.4290 & 2.2110 \\
8.72 & 5.35 & 6.37 & 6.39 & 0.02 & 0.2858 & 2.42 & -0.3978 & 2.0222 \\
9.00 & 5.40 & 6.46 & 6.49 & 0.03 & 0.4648 & 2.14 & -0.0612 & 2.0788 \\
9.22 & 5.45 & 6.55 & 6.59 & 0.04 & 0.6667 & 1.94 & 0.3010 & 2.2410 \\
\hline
\end{tabular}

$\log _{\mathbf{1}}($ Average value) $=2.1382 \pm 0.1046$ 
BAJOPAS Volume 14 Number 1,June, 2021

Table 12: Point-wise method, Mg (Hydrolysed PSHA)

\begin{tabular}{|l|l|l|l|l|l|l|l|l|}
\hline $\mathrm{pH}$ & $\mathrm{BV}_{1}$ & $\mathrm{BV}_{2}$ & $\mathrm{BV}_{3}$ & $\left(\mathrm{~V}_{3}-\mathrm{V}_{2}\right)$ & $\mathrm{n}$ & $\mathrm{pL}$ & $\log \left(\frac{n-1}{2-n}\right)$ & LogK $_{2}$ \\
\hline 9.51 & 5.55 & 6.66 & 6.71 & 0.05 & 0.9650 & 1.67 & & \\
9.73 & 5.55 & 6.78 & 6.84 & 0.06 & 1.4042 & 1.47 & -0.1686 & 1.3014 \\
10.00 & 5.60 & 6.90 & 6.93 & 0.06 & 1.7838 & 1.23 & 0.5593 & 1.7893 \\
10.23 & 5.65 & 7.05 & 7.10 & 0.06 & 3.1429 & 1.10 & & \\
10.49 & 5.70 & 7.10 & 7.18 & 0.07 & 3.6492 & 0.83 & & \\
\hline
\end{tabular}

LogK $_{2}($ Average value $)=1.5453 \pm 0.3450$

Table 13: Point-wise method, Mg (Unhydrolysed PSHA)

\begin{tabular}{|l|l|l|l|l|l|l|l|l|}
\hline $\mathrm{pH}$ & $\mathrm{BV}_{1}$ & $\mathrm{BV}_{2}$ & $\mathrm{BV}_{3}$ & $\mathrm{~V}_{3}-\mathrm{V}_{2}$ & $\mathrm{n}$ & $\mathrm{pL}$ & $\log \left(\frac{n}{n-1}\right)$ & $\operatorname{Log~}_{1}$ \\
\hline 8.50 & 5.30 & 5.81 & 5.85 & 0.04 & 0.2973 & 2.88 & -0.3736 & 2.5064 \\
8.72 & 5.35 & 5.90 & 5.94 & 0.04 & 0.3099 & 2.66 & -0.3477 & 2.3123 \\
9.00 & 5.40 & 6.00 & 6.04 & 0.04 & 0.3236 & 2.38 & -0.3202 & 2.0598 \\
9.22 & 5.45 & 6.10 & 6.15 & 0.05 & 0.4297 & 2.17 & -0.1230 & 2.0470 \\
9.51 & 5.50 & 6.20 & 6.26 & 0.06 & 0.5500 & 1.89 & 0.0871 & 1.9771 \\
9.73 & 5.55 & 6.33 & 6.40 & 0.07 & 0.7000 & 1.67 & 0.3680 & 2.0380 \\
\hline
\end{tabular}

LogK $_{1}$ (Average value) $=2.1568 \pm 0.2069$

Table 14: Point-wise method, Mg (Unhydrolysed PSHA)

\begin{tabular}{|l|l|l|l|l|l|l|l|l|}
\hline $\mathrm{pH}$ & $\mathrm{BV}_{1}$ & $\mathrm{BV}_{2}$ & $\mathrm{BV}_{3}$ & $\mathrm{~V}_{3}-\mathrm{V}_{2}$ & $\mathrm{n}$ & $\mathrm{pL}$ & $\log \left(\frac{n-1}{2-n}\right)$ & $\log \mathrm{K}_{2}$ \\
\hline 10.00 & 5.60 & 6.47 & 6.55 & 0.08 & 0.9148 & 1.41 & & \\
10.23 & 5.65 & 6.62 & 6.71 & 0.09 & 1.2102 & 1.20 & -0.5749 & 0.6251 \\
10.49 & 5.70 & 6.80 & 6.92 & 0.09 & 1.5968 & 1.03 & 0.1703 & 1.2003 \\
\hline
\end{tabular}

LogK $_{2}$ (Average value) $=0.9127 \pm 0.4070$

Table15:Point-wise method, Cd (Hydrolysed PSHA)

\begin{tabular}{|l|l|l|l|l|l|l|l|l|}
\hline $\mathrm{pH}$ & $\mathrm{BV}_{1}$ & $\mathrm{BV}_{2}$ & $\mathrm{BV}_{3}$ & $\left(\mathrm{~V}_{3}-\mathrm{V}_{2}\right)$ & $\mathrm{n}$ & $\mathrm{pL}$ & $\log \left(\frac{n}{1-n}\right)$ & LogK $_{1}$ \\
\hline 8.50 & 5.30 & 6.29 & 6.31 & 0.02 & 0.2750 & 2.64 & -0.4210 & 2.2190 \\
8.72 & 5.35 & 6.37 & 6.40 & 0.03 & 0.4286 & 2.42 & -0.1249 & 2.2951 \\
9.00 & 5.40 & 6.46 & 6.49 & 0.03 & 0.4648 & 2.14 & -0.0612 & 2.0788 \\
9.22 & 5.45 & 6.55 & 6.59 & 0.04 & 0.6667 & 1.96 & 0.3010 & 2.2610 \\
9.51 & 5.55 & 6.66 & 6.70 & 0.04 & 0.7720 & 1.67 & 0.5297 & 2.1997 \\
\hline
\end{tabular}

LogK $_{\mathbf{1}}$ (Average value) $=2.2108 \pm 0.0825$

Table 16: Point-wise method, Cd (Hydrolysed PSHA)

\begin{tabular}{|l|l|l|l|l|l|l|l|l|}
\hline $\mathrm{pH}$ & $\mathrm{BV}_{1}$ & $\mathrm{BV}_{2}$ & $\mathrm{BV}_{3}$ & $\left(\mathrm{~V}_{3}-\mathrm{V}_{2}\right)$ & $\mathrm{n}$ & $\mathrm{pL}$ & $\log \left(\frac{n-1}{2-n}\right)$ & Log $_{2}$ \\
\hline 9.73 & 5.55 & 6.78 & 6.83 & 0.06 & 1.4042 & 1.47 & -0.1686 & 1.3014 \\
10.00 & 5.60 & 6.90 & 6.95 & 0.06 & 1.7838 & 1.23 & 0.5593 & 1.7893 \\
10.23 & 5.65 & 7.05 & 7.10 & 0.06 & 3.1429 & 1.09 & & \\
10.49 & 5.70 & 7.10 & 7.16 & 0.06 & 3.1429 & 0.89 & & \\
& & & & & & & & \\
\hline
\end{tabular}

$\operatorname{LogK}_{2}$ (Average value) $=1.5453 \pm 0.3450$

Table 17: Point-wise method, Cd (Unhydrolysed PSHA)

\begin{tabular}{|l|l|l|l|l|l|l|l|l|}
\hline $\mathrm{pH}$ & $\mathrm{BV}_{1}$ & $\mathrm{BV}_{2}$ & $\mathrm{BV}_{3}$ & $\mathrm{~V}_{3}-\mathrm{V}_{2}$ & $\mathrm{n}$ & $\mathrm{pL}$ & $\log \left(\frac{n}{n-1}\right)$ & $\operatorname{Log~}_{1}$ \\
\hline 8.50 & 5.30 & 5.81 & 5.86 & 0.05 & 0.3717 & 2.88 & -0.2280 & 2.6520 \\
8.72 & 5.35 & 5.90 & 5.95 & 0.05 & 0.3873 & 2.66 & -0.1992 & 2.4608 \\
9.00 & 5.40 & 6.00 & 6.06 & 0.06 & 0.4853 & 2.38 & -0.0255 & 2.3545 \\
9.22 & 5.45 & 6.10 & 6.16 & 0.06 & 0.5157 & 2.18 & -0.0272 & 2.2072 \\
9.51 & 5.50 & 6.20 & 6.27 & 0.07 & 0.6417 & 1.89 & 0.2530 & 1.1430 \\
9.73 & 5.55 & 6.33 & 6.41 & 0.08 & 0.8000 & 1.69 & 0.6020 & 2.2920 \\
& & & & & & & & \\
\hline
\end{tabular}

$\operatorname{LogK}_{1}($ Average value $)=2.2516 \pm 0.5380$ 
BAJOPAS Volume 14 Number 1,June, 2021

Table 18: Point-wise method, Cd (Unhydrolysed PSHA)

\begin{tabular}{|l|l|l|l|l|l|l|l|l|}
\hline $\mathrm{pH}$ & $\mathrm{BV}_{1}$ & $\mathrm{BV}_{2}$ & $\mathrm{BV}_{3}$ & $\mathrm{~V}_{3}-\mathrm{V}_{2}$ & $\mathrm{n}$ & $\mathrm{pL}$ & $\log \left(\frac{n-1}{2-n}\right)$ & $\log \mathrm{K}_{2}$ \\
\hline 10.00 & 5.60 & 6.47 & 6.57 & 0.10 & 1.1434 & 1.43 & & \\
10.23 & 5.65 & 6.62 & 6.72 & 0.10 & 1.3448 & 1.23 & -0.2788 & 0.9512 \\
10.49 & 5.70 & 6.80 & 6.90 & 0.10 & 1.7742 & 1.03 & 0.5351 & 1.5651 \\
\hline
\end{tabular}

$\operatorname{LogK}_{2}($ Average value $)=1.2581 \pm 0.4340$

Table 19: Stepwise and overall Stability constants of thehydrolysed and unhydrolysed divalent metal (II) complexes

\begin{tabular}{|c|c|c|c|}
\hline Chelates & LogK $_{1}$ & $\log _{2}$ & Log $\beta$ \\
\hline [Cu (Hydrolysed PSHA-1) $\left.{ }_{2}\right]$ & 2.4788 & 1.4280 & 3.9068 \\
\hline$\left[\mathrm{Pb}(\text { Hydrolysed PSHA-1) })_{2}\right]$ & 2.5832 & 1.1963 & 3.7795 \\
\hline$\left[\mathrm{Cd}(\text { Hydrolysed PSHA-1 })_{2}\right]$ & 2.2108 & 1.5453 & 3.7561 \\
\hline$\left[\mathrm{Mg}(\text { Hydrolysed PSHA-1 })_{2}\right]$ & 2.1382 & 1.5453 & 3.6835 \\
\hline [Cu (Unhydrolysed PSHA-1) & 2.3059 & 1.2209 & 3.5268 \\
\hline$[\mathrm{Pb}$ (Unhydrolysed PSHA-1) 2$]$ & 2.2364 & 1.2239 & 3.4603 \\
\hline [Cd (Unhydrolysed PSHA-1) 2 ] & 2.2516 & 1.2581 & 3.5097 \\
\hline$[\mathrm{Mg}$ (Unydrolysed PSHA-1) & 2.1568 & 0.9127 & 3.0695 \\
\hline
\end{tabular}

The results obtained (Table19) shows the stepwise and overall stability constants to be not high indicating low stability of the complexes, because the solubility of most metal ions in the basic $\mathrm{pH}$ range is minimal due to metal hydroxide precipitation (Karimi, 2017). In general, the stepwise stability constants $\left(K_{1}\right.$ and $K_{2}$ ) follow the order $K_{1}>K_{2}$ for the copper, lead, magnesium and cadmium complexes respectively. The steady decrease of the values with increasing number of ligands is in agreement with the prediction made by researchers (Na'aliya, 2013). The decrease could be attributed to the fact that as the number of the ligands (Humate ions) that enters the coordination zone increases the aqua molecules available for replacement by the ligands become less. Thus, the metal ions become less electron loving with progressive intake of the ligand and this results in the decrease in the values of the constants (Na'aliya, 2013). Also the stability of the complexes is influenced by the size and number of the chelate rings(Mackay and Mackay,2002).All the complexes form rings in their structure as humate, a bidentate ligand, bond the metal ions in the ratio 1:2 (Boguta and Sokolowska, 2016) forming chelate rings. The values of the overall stability constants $(\log \beta)$ obtained for humate complexes are not high indicating low stability as the values are not high. LogK values for copper-humates (Table 3 to 6) obtained in this study are lower than those reported for the complexes of humic acids (Pandey et al., 2015; Dinu, 2013; Kaschl et al., 2010 and Gilbeto and Jorg, 2001). The values of LogK(Table 7 to 10 ) forlead-humates are lower than those reported for the lead in the literature (Dinu, 2013; Gilbeto and Jorg 2001). Log K values(Table 11 to 14 ) for magnesium-humates obtained in this study are close to those reported by (Pandey et al., 2015). Log K values of cadmium-humates (Table 15 to 18 ) obtained in this work near to the one reported by (Dinu, 2013 and Pandey et al., 2015).The difference between the reported values and the values obtained in this study might be probably as a result of acid hydrolysis of humic acid. The values of the overall stability constants $(\log \beta)$ of the copper humates complexes presented in Table 19 is high than that of other metal humate complexes, show relatively high stability of CuHA complexes, show the following order of stability: $\mathrm{Cu}>\mathrm{Pb}>\mathrm{Cd}>\mathrm{Mg}$; which are in close agreement to the findings of (Dinu, 2013 and Pandey et al., 2015).The high stability of Cuhumate chelate could be attributed to the existence of coordinate covalent bond between the complexing agents and the $\mathrm{Cu}^{2+}$ ions. Since, $\mathrm{Cu}^{2+}$ being a metal of the transitional series with $3 d^{9}$ electronic configurations can accept the electrons from the complexing agents. Similarly, the low stabilities of $\mathrm{Pb}, \mathrm{Cd}$ and $\mathrm{Mg}$ complexes could be explained by that $\mathrm{Pb}^{2+}$ with $6 s^{2}, \mathrm{Cd}^{2+}$ with $4 \mathrm{~d}^{10}$ and $\mathrm{Mg}^{2+}$ with $2 \mathrm{p}^{6}$ their electronic configuration has a completely filled $\mathrm{d}, \mathrm{p}$ and $\mathrm{s}$ orbitals. Moreover, the stabilities of metal ions with hydrolysed humic acid from peat soil were higher than those with unhydrolysed humic acid from peat soil; which is ascribed to the high content of acidity in hydrolysed humic acid than unhydrolysed humic acid. 
BAJOPAS Volume 14 Number 1,June, 2021 CONCLUSION

The values of logk for $\mathrm{Cu}(\mathrm{II})$ hydrolysed humic acid complex was higher followed by $\mathrm{Pb}$ (II), $\mathrm{Cd}(\mathrm{II})$ and $\mathrm{Mg}$ (II) hydrolysed humic acid complexes as compared with metal(II) unhydrolysed humic acid complexes. This indicates acid hydrolysis of humic acid can

\section{REFERENCES}

Almeida, V.R. and Szpoganicz, B. (2015). Humic Acid Potentiometric Response Patterns:Out- of Equilibrium Properties and Species Distribution Modelling. Chemical. Biol. Technol. Agric. 2: 17.

Anđelković, T., Nikolić, R., Bojić, A.,Anđelković, D., and Nikolic G.,(2010). Binding of Cadmium to Soil Humic Acid as A Function of Carboxyl Group Content. Macedonian Journal of Chemistry and Chemical Engineering.29(2): 215-224.

Anil, B. N. and Maroti, N. (2008). Studies on Influence of Die-Lectric Constants on Complex Equilibria between Substituted Py-Razalines and Lanthanide Metal Ions pH-Metrically. Amer.-Euras. scient. Res. 3(2): 212-216.

Ashok, K., Pandey, S. P. and Misra, V (2000). Stability Constants of Metal-Humic Acid Complexes and its Role in Environmental Detoxification. Journal of Ecotoxicology and Environmental Safety. 47(2):157-200.

Badr, M. H., El-Halafawi, M. H. and Abd El-al Zeid, E. R. (2012). Comparison Between the Effect of Ionic Strength on Acidity and Dissociation Constants of Humic Acids Extracted from Sewage Sludge and Nile Water Hyacinth Composts.Global Journal of Environmental Research 6 (1): 36-43.

Baruah, M.K., Borah, D., Saikia, P.P., Paul, S., Sharma, T. (2015). Evaluation of pKa Values of Soil Humic Acids and their Complexation Properties. International Journal of Plant \& Soil Science 6(4) : 218-228.

Boguta, P. Sokolowska, Z. (2016). Interactions of $\mathrm{Zn}$ (II) Ions with Humic Acids Isolated from Various Types of Soils. Effect of $\mathrm{pH}, \mathrm{Zn}$ Concentrations and Humic Acids Chemical Properties. Journal of Geochemical Explaration 168. 119-126.

Borges, F., Guimaraes, C., Lima, L.F.C., Pinto, I. and Reis, S.(2005). Potentiometric Studies on the Complexation of Copper(II) by Phenolic Acids as Discrete Ligand Models of enhance the complexation behavior of humic acid with metal (II) ions. However, the higher values of $\log \beta$ for $\mathrm{Cu}(\mathrm{II}), \mathrm{Pb}(\mathrm{II}), \mathrm{Cd}(\mathrm{II})$ and $\mathrm{Mg}(\mathrm{II})$ hydrolysed humic acid complexes indicates more stable stepwise complexes formed as compared with $\mathrm{Cu}(\mathrm{II}), \mathrm{Pb}$ (II), $\mathrm{Cd}$ (II) and $\mathrm{Mg}(\mathrm{II})$ unhydrolysed humic acid complexes.

Humic Substances Talanta 66 (2005) 670-673.

Chefetz, B., Salloum, M. J., Deshmulkin, A. P. and Hatcher, P. (2002). Structural Components of Humic Acids as Determined by Chemical Modifications and Carbon-13 NMR, Pyrolysis, and Thermochemolysis- Gas Chromatography/Mass Spectrometry. Soil Science Society of American Journal Abstract Division S-2- Soil Chemistry66. 1159-1171.

Dinu, M. I. (2013). Metals Complexation with Humic Acids in Surface Water of Different Environ. Sci. Technol. 31(1): 1-17.

Fernandes, A.N., Giacomelli, C., Giovanela, M. Vaz, D.V. Szpoganicz, B. and Maria M. D. (2009). Potentiometric Acidity Determination in Humic Substances Influenced by Different Analytical Procedures.J. Braz. Chem. Soc. 20 (9):14.

Gamal, A. H. (2015). Stability Constants of Rhenium (V) Metal Complexes with Selected Drugs. Pyrex Journal of Research in Environmental Studies. 2(2): 006-014.

Janrao, D. M., Pathan, J., Kayande, D.D., and Mulla, J.J. (2014). An Over View of Potentiometric Determination of Stability Constants of Metal Complexes. Sci. Revs. Chem. Commun.: 4(1), 2014, 11-24.

Karimi, H. (2017). Effect of pH and Initial Pb(II) Concentration on the Lead Removal Efficiency from Waste Water Using $\mathrm{Ca}(\mathrm{OH})_{2}$. International Journal of Water and Waste Water Treatment 3.2

Kaschl, A. Romheld, V. and Chen, Y. (2010). Binding of Cadmium, Copper and Zinc to Humic Substances Originating from Municipal Solid Waste Compost. Israel Journal of Chemistry Vol. 42(1): 89-98.

Kostic, I. S., Tatjana, P, A., Nikolic, R. S., Cvetkovic, T. P., Pavlovic, D. D., Aleksandar, L.J. and Bojic, A. (2012). Comparative Study of Binding Strengths of Heavy Metals with Humic Acid. J.serb. Chem. Soc. 76(9) pp 1-20. 
BAJOPAS Volume 14 Number 1,June, 2021

Na'aliya, J. (2013). Determination of Stepwise Stability Constants and Gibbs free Energy Change of Trisprolina to Complexes of some Divalent Transition Metal ions. Bayero Journal of Pure and Applied Sciences 6(2): 112-114.

Omar, A. A. and Ali, E. A. (2015). Potentiometric Studies on Complexes of $\mathrm{Cr}$ (III) and $\mathrm{Zr}$ (IV) with some Carboxylic Acids. International Journal of Advanced Chemistry, 3(1) 25-

37.

Pandey, A. K. Pandey, S. D. and Misr, V. (2015).Stability Constants of Metal- Humic Acid Complexes and Its Role in Environmental Detoxification. J. Ecotoxicology and Environmental Safety. 47(1):195-200.

Ram, N. and Raman, K.V. (1984). Stability Constants of Complexes of Metals with
Humicand Fuvic Acids under Non- acidConditions. Journal of Plant Nutrition and Soil Sciences.

147:171-176.

Santosh, D. D., Ashok, B. K., Vijay, J. T., Shivraj, G. W. and Vinay, V. W. (2011). Potentiometric Studies of Elec-Trolyte Effects on Complex Equilibria of Some Substituted 5-(2-hydroxy Phenyl) Pyrazoles. Der pharm. 3 (6): 75-83.

Sayyed, H. and Abdul Rahim, M. F. (2012). Studies of Binary Complexes of Metal Ions with Mandelic Acid by Potentiometry. Chem. J. 02 (6): 206209.

Shirvani, M. Moradian, E. Khalili, B. Bakhtiary, S. (2015). Interaction of $\mathrm{Cd}$ and $\mathrm{Pb}$ with Humate-Palygorskite and HumateSepiolite Complexes. Journal of water, air and pollution 3: 220-228. 


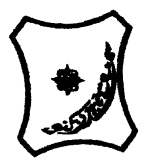

Bayero Journal of Pure and Applied Sciences, 14(1): 54 - 63

Received: November, 2020

Accepted: April, 2021

ISSN $2006-6996$

\title{
STABILITY CONSTANTS OF COMPLEXES OF METAL IONS WITH PEATSOIL HUMIC ACIDS UNDER NON-ACID-CONDITIONS
}

\author{
${ }^{* 1}$ Sabo, Yusuf ${ }^{2}$ Jimoh, W.L.O., ${ }^{3}$ Isa Baba Koki and ${ }^{4}$ Sholadoye, Q. 0. \\ ${ }^{1}$ Department of Pure and Industrial Chemistry, Bayero University, Kano \\ ${ }^{3}$ Department of Chemistry, Yusuf Maitama Sule University Kano. P.M.B. 3220 Kano, Nigeria. \\ ${ }^{4}$ Department of Chemistry, Nigerian Police Academy, Wudil, Kano-Nigeria
}

*Correspondence E-mail; saboyusuf18@yahoo.com

ABSTRACT

Stability constants of complexes of four divalent metal ions viz. $\mathrm{Cu}^{2+}, \mathrm{Pb}^{2+}, \mathrm{Mg}^{2+}$ and $\mathrm{Cd}^{2+}$ with humic acids (HA) were determined by potentiometric titration of humic acids with the corresponding salt of the divalent metals in aqueous media under non-acid-condition. The log $K$ (logarithm of the stability constant) ranged from 1.0942 to 2.7471 for metalhumic acid complexes were determined using point-wise computational method. The order of stability constants were obtained as follows: $\mathrm{Cu}>\mathrm{Pb}>\mathrm{Cd}>\mathrm{Mg}$ for metal $-\mathrm{HA}$ complexes respectively, indicating a higher degree of complexation with Cu metal ion.

Keywords: stability constant, humic acid, potentiometric titration, divalent metals, acid hydrolysis.

\section{NTRODUCTION}

The stability constant of a complex is the numerical expression of its stability and provides a quantitative measure of affinity of the metal ion to the complexing agent. An understanding of the relative stability of metal-complexes helps in predicting the behavior of metal ions in the soil (Ram and Raman, 1982). Extensive researches has been done to determine the stability constants of the complexes formed between humic acid (HA) with a number of metal ions. Ashok et al., (2000) reported that humic acid with hydroxyl, phenoxyl and carboxyl reactive groups can form coordination compound with metal ions at $\mathrm{pH}$ 3.5. The stability constants(Log K) for different metalhumic acid complexes indicated the following order of the stabilities of complexes formed between humic acid and metal ion, $\mathrm{Cu}>\mathrm{Fe}$ $>\mathrm{Pb}>\mathrm{Ni}>\mathrm{Co}>\mathrm{Ca}>\mathrm{Cd}>\mathrm{Zn}>\mathrm{Mn}>\mathrm{Mg}$. Andelkovic et al., (2010) investigated the binding of $\mathrm{Cd}$ (II) to soil humic acid at pH 6.5 and in $0.1 \mathrm{M} \mathrm{KNO}_{3}$ ionic medium. The stability constant for binding indicating greater stability in the case when carboxyl groups are involved in complexation reaction. Kostic et al.,(2012) investigated the complexation of humic acid with certain heavy metal ions (Co(II), $\mathrm{Ni}(\mathrm{II}), \mathrm{Cu}(\mathrm{II})$,
$\mathrm{Zn}(\mathrm{II})$, and $\mathrm{Pb}(\mathrm{II})$. The experiment was performed at $25^{\circ} \mathrm{C}$, at pH 4.0 and ionic strength of $0.01 \mathrm{M}$. Stability constant of complex between $\mathrm{Pb}$ (II) ions and humic acid is greater than stability constants of other investigated metalhumate complexes. Bogata and Sokolowska (2016) analyses the interaction between humic acids from different soils and $\mathrm{Zn}$ (II) ions at wide concentration ranges and at $\mathrm{pH} 5$. Studies have showed significant impact of $\mathrm{Zn}$ concentration, $\mathrm{pH}$ and some properties of humic acids with zinc.But all of these studies were limited to acidic $\mathrm{pH}$ range. Therefore, the present study was carried out to determine and compare the stability constants of complexes of metal ions with hydrolysed peat soil humic acid and unhydrolysed peat soil humic under non-acid conditions.

\section{MATERIALS AND METHODS}

Analytical grade chemicals used includes hydrochloric acid $(\mathrm{HCl})$, nitric acid $\left(\mathrm{HNO}_{3}\right)$, sodium hydroxide $(\mathrm{NaOH})$, lead nitrate $\mathrm{Pb}\left(\mathrm{NO}_{3}\right)_{2}$, copper nitrate $\mathrm{Cu}\left(\mathrm{NO}_{3}\right)_{2} \cdot 3 \mathrm{H}_{2} \mathrm{O}$, cadmium nitrate $\mathrm{Cd}\left(\mathrm{NO}_{3}\right)_{2} \cdot 4 \mathrm{H}_{2} \mathrm{O}$, magnesium nitrate $\mathrm{Mg}\left(\mathrm{NO}_{3}\right)_{2} \cdot 6 \mathrm{H}_{2} \mathrm{O}$, potassium nitrate $\left(\mathrm{KNO}_{3}\right)$, calcium chloride $\left(\mathrm{CaCl}_{2}\right)$, (sigma-Aldrich). Dowex 50WX8, (20-50 mesh) from Fluka. 


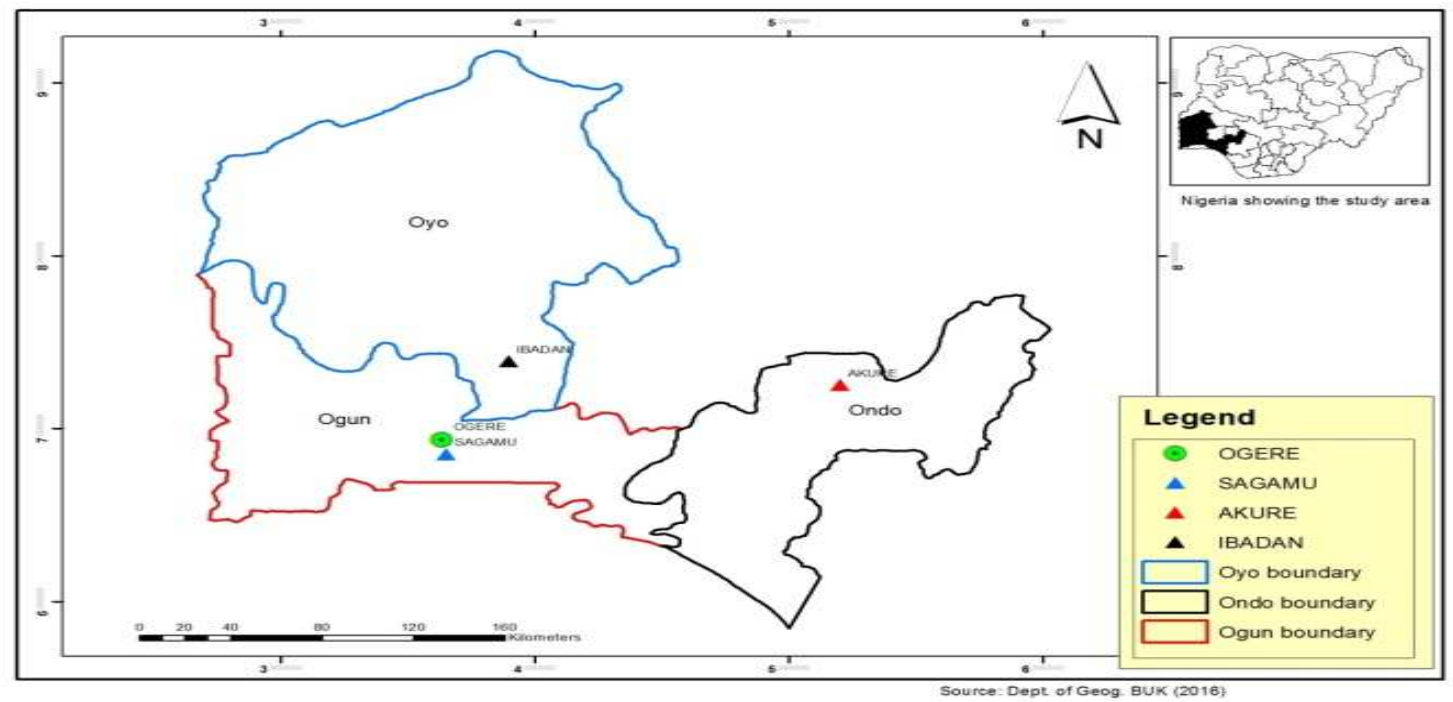

Figure 1: Map showing the sampling point at Sagamu Town, Ogun State.

\section{Description of Sampling Area}

Sagamu has geographical coordinates between $6^{\circ} 50^{\prime}$ north; $3^{\circ} 38^{\prime}$ east is located in south western region of Nigeria. The region has tropical wet and dry climate with a lengthy wet season and relatively constant temperatures throughout the course of the year. Wet season runs from March to October, November to December forms the region dry season. The vegetation type of the region is savannah which is really grassland with small bushes and occasional big trees. Grassland soils have substantially higher organic matter content than forest soils (Novackova, 2011).

\section{Sample Collection}

The Peatsoil samples were collected from four different sampling points $(0-10 \mathrm{~cm}$ depth) in Sagamu into polyethylene bag with plastic spoons. Samples were taken to the laboratory, extraneous materials were removed; the samples were air-dried, crushed and ground to a fine powder in a mortar passed through a $0.20 \mathrm{~mm}$ sieve. The samples were kept for analysis.

\section{Isolation and purification of humic acid from peat soil sample}

Peatsoil sample $(100 \mathrm{~g})$ was mixed with 1000 $\mathrm{cm}^{3}$ of $0.1 \mathrm{M} \mathrm{NaOH}$ solution, shaken for 3hours and left to stand overnight. Dark-coloured supernatant was obtained and decanted from solid residue. The dark-coloured supernatant was acidified to $(\mathrm{pH}=1.0)$ with $6 \mathrm{M} \mathrm{HCl}$ stirred and allowed to stand for 6 hours. Yellowish brown supernatant and dark-brown precipitate were obtained. The yellowish brown supernatant was decanted followed by centrifuge and discarded. The dark-brown precipitate was mixed with $500 \mathrm{~cm}^{3}$ of $0.1 \mathrm{M} \mathrm{NaOH}$ solution followed by passing through dowex resin. The dark-brown solution was acidified to $(\mathrm{pH}=1.0)$ with $6 \mathrm{M} \mathrm{HCl}$ stirred and allowed to stand for 3 hours. The dark-brown precipitate was washed several times with deionized water. The supernatant was treated with $\mathrm{AgNO}_{3}$ solution until no white precipitate observed. The humic acid was transferred to weighed crucible and dried at $60^{\circ} \mathrm{C}$ in an oven for 12 hours. The humic acid was cooled and dried in the desiccator, weighed and recorded. The obtained humic acid was dried again at $60^{\circ} \mathrm{C}$ for additional 6 hours cooled and dried in the desiccator, weighed and recorded constant weight was obtained (Baruah et al., 2015).

\section{FT-IR analysis}

FT-IR spectra of humic acid sample was analysed using Carry 630 FT-IR Agilent Technologies.

Unhydrolysed compost humic acid

The unhydrolysed humic acid was obtained after isolation and purification of compost humic acid and kept for investigation.

\section{Acid hydrolysis of Peatsoil acid}

Peatsoil humic acid sample (1g) was refluxed for 12 hours at $\left(160^{\circ} \mathrm{C}\right)$ with $50 \mathrm{~cm}^{3}$ of $6 \mathrm{M} \mathrm{HCl}$. The mixture was allowed to cool, decanted, and centrifuged after hydrolysis. The insoluble residues were washed with distilled water via centrifugation several times, and the supernatant was treated with $\mathrm{AgNO}_{3}$ solution until no white precipitate was observed. The residue was thoroughly dried over $\mathrm{CaCl}_{2}$ in a desiccator at room temperature (Chefetz et al., 2002). Finally, the obtained hydrolysed humic acid was kept for investigation. 
BAJOPAS Volume 14 Number 1,June, 2021 Potentiometric Titrations

Potentiometric measurements were carried out using a pH-meter Jenway (model 3510) with combine electrode, the sensitivity of the $\mathrm{pH}$ meter is 0.01 units. The $\mathrm{pH}$ meter was switched on half an hour before starting the titration for initial warm up of the instrument. The instrument was calibrated with an aqueous standard buffer solution of $\mathrm{pH} 4.00$ and 10.0 (borate buffer) prepared from a "Qualigens" buffer tablets.

The following sets of solutions were prepared in a $250 \mathrm{~cm}^{3}$ volumetric flask separately for $\mathrm{pH}$ metric titrations.

(i) $5 \mathrm{~cm}^{3} 0.1 \mathrm{M} \mathrm{HCl}+40 \mathrm{~cm}^{3}$ deionized water

(ii) $5 \mathrm{~cm}^{3} 0.1 \mathrm{M} \mathrm{HCl}+39 \mathrm{~cm}^{3}$ deionized water $+1 \mathrm{~cm}^{3} 0.15 \mathrm{gcm}^{-3}$ humic acid

(iii) $5 \mathrm{~cm}^{3} 0.1 \mathrm{M} \mathrm{HCl}+37 \mathrm{~cm}^{3}$ deionized water $+1 \mathrm{~cm}^{3} 0.15 \mathrm{gcm}^{-3}$ humic acid

$$
+2 \mathrm{~cm}^{3} \quad 0.01 \mathrm{M} \mathrm{Cu} \text { (II) }
$$

The solutions were titrated against standardized $0.110 \mathrm{MNaOH}$ separately. The total volume of each mixture was adjusted to $50 \mathrm{~cm}^{3}$ and the ionic strength of the solutions was maintained constant at by adding appropriate amount of stock solution of $1 \mathrm{M} \mathrm{KNO}_{3}$ (Gamal, 2015; Omar and Ali, 2015). A magnetic stirrer was used to achieve thorough mixing of the interacting solutions at $550 \mathrm{rpm}$. The same set of experimental conditions was applied for potentiometric titration of remaining samples.

\section{Evaluation of pKa of Hydrolysed peat soil Humic Acids}

The proton-ligand formation number $\mathrm{n}_{\mathbf{A}}$ were calculated by Irving and Rossotti expression (Omar and Ali, 2015).

$\mathrm{nA}=\mathrm{Y}-\frac{(\mathrm{V} 2-\mathrm{V1})(\mathrm{No}-\mathrm{Eo})}{(\mathrm{VO}+\mathrm{V1}) \mathrm{TCL}}$ 1

Where: $Y$ is number of dissociable proton, $\left(\mathrm{V}_{2^{-}}\right.$ $V_{1}$ ) is the measure of displacement of the ligand curve relative to acid curve, $\mathrm{N}^{\circ}$ and $\mathrm{E}^{\circ}$ are the resultant concentration of alkali solution, free acid solution, $\mathrm{T}_{\mathrm{cL}}{ }^{\circ}$ is the total ligand concentration, $\mathrm{V}^{\circ}$ is the total volume of titration solution, $V_{1}$ is the volume of alkali added to acid solution, $V_{2}$ is the volume of alkali added to acid solution + ligand solution, acid dissociation constants (pKa - values) of ligand were calculated by algebraic method point wise calculation (Tables 1 ). The dissociation constants (pKa) were calculated according to the following relation:

$\mathrm{pKa}=\mathrm{pH}+\log \left(\frac{n A}{1-n A}\right)$ 2

Where: pKa is the acid dissociation constant, $\mathrm{n}_{\mathrm{A}}$ is the Proton-ligand formation number and $\mathrm{pH}$ is the pH-values (Omar and Ali, 2015).

\section{Determination of metal-ligand stability constants $(\log K)$ of complexes}

The potentiometric measurement for the determination of stability constant of a complex in solution is based on the fact that the redox potential of the couple $\frac{M^{+(m-n)}}{M^{+m}}$ is shifted significantly on complexation of the metal ion with the ligand. This method involves change in hydrogen ion concentration $\left[\mathrm{H}^{+}\right]$due to the displacement or association of one or more protons taking place during complexation reaction. This change can be found out by titrating the solutions containing free acid, acid with ligand, and acid with ligand and metal ion, individually against a standard alkali solution at a constant ionic strength or temperature. Either ionic strength or temperature may be varied for different sets of solutions. In all the cases, the change in the $\mathrm{pH}$ of the solution is measured after each addition of a known amount of alkali to the reaction cell which contains the reaction mixture. The titration curves are then drawn by plotting the measured $\mathrm{pH}$ values against the corresponding volume of alkali added and the stability constants of the complexes are determined from the titration curves by employing $\mathrm{pH}$-metric titration technique given by (Irving and Rossoti).

Metal-ligand stability constants ( $\log \mathrm{K}$ ) were determined by using the following relations:

$$
\bar{n}=\frac{\left(V_{3}-V_{2}\right)\left(E^{0}+N^{0}\right)}{\left(V^{0}+V_{2}\right) \bar{n}_{A} T_{m}^{0}}
$$

and

$$
P L=\log _{10}\left\{\frac{1+\beta_{n}^{H} \frac{1}{[\text { anti } \log \mathrm{pH}]^{\mathrm{n}}}}{\mathrm{T}_{\mathrm{L}}^{0}-n \bar{T}_{m}^{0}} \mathrm{X} \frac{\left(V^{0}+V_{3}\right)}{V^{0}}\right\}
$$


BAJOPAS Volume 14 Number 1,June, 2021

Where $T_{L}, T^{\circ}, E^{\circ}$, and $V^{\circ}$ havethe same significance as in equation (1) above, $T_{m}$ denotes the total concentration of metal present in solution, $V_{3}$ is the volume of metal ions present in solution and $\beta^{H}$ is the overall proton ligand stability constant. The metal-ligand stability constants (log K) were determined by employing point wise computational Method (eq. 5 and 6).

$\operatorname{LogK}_{1}=\log \left(\frac{n}{1-n}\right)+\mathrm{pL}$ .5

$\operatorname{LogK}_{2}=\log \left(\frac{1-n}{2-n}\right)+\mathrm{pL}$ ...6

Where: Log $\mathrm{K}$ is the metal-ligand stability constant, $\mathrm{pL}$ is the Free ligand exponent function, $\mathbf{n}$ is the Average number of ligand attached with metal ion (Janraoet al., 2014). The results obtained were analyzed by an ORIGIN 2016 program using titration data and then the proton-ligand stability constants (pKa) and Metal-ligand stability constant (LogK) calculated (Omar and Ali, 2015).

\section{RESULTS AND DISCUSSION}

Fourier transformed infrared (FT-IR) spectra of isolated humic acid from peat soils Figure 2 had distinct clear absorption bands indicating the presence of major humic acid structural elemental groups such as $\mathrm{H}$ bonded $\mathrm{OH}$ $\left(3680 \mathrm{~cm}^{-1}\right.$ peak $), C=0$ of carbonyl $\left(1721 \mathrm{~cm}^{-1}\right.$ peak), functional groups of aliphatic components $\mathrm{CH}_{2}\left(2918 \mathrm{~cm}^{-1}\right.$ peak) and $\mathrm{C}-\mathrm{O}$ stretching of polysaccharide $\left(1168 \mathrm{~cm}^{-1}\right.$ peak). The positions of the absorption bands of the spectra fell within typical major absorption bands of humic acid which is at frequencies 3680, 2918, 1721, 1168 $\mathrm{cm}^{-1}$. The first peak centred in the vicinity of $3680 \mathrm{~cm}^{-1}$ region is attributed to phenol $\mathrm{OH}$ group bounded by intermolecular $\mathrm{H}$ bonds. The $2918 \mathrm{~cm}^{-1}$ band usually has absorption maximum at $2918 \mathrm{~cm}^{-1}$ which is due to $\mathrm{C}-\mathrm{H}$ stretching of alkane group $\left(\mathrm{CH}_{2}\right)$. The next major absorption band is $1721 \mathrm{~cm}^{-1}$. This band has been commonly ascribed to $\mathrm{C}=\mathrm{O}$ stretching of mainly carboxyl group $(\mathrm{COOH})$ with trace amount of ketones. The last peak was observed at 1168 $\mathrm{cm}^{-1}$ due to $\mathrm{C}-\mathrm{O}$ stretching of polysaccharides and this peak appeared also in the spectra of humic acid from peat soil. The FTIR spectra of the isolated humic acid contained all major characteristic absorption peaks of humic acid. These absorption peaks indicated the presence of the major structural elements of humic acid namely $\mathrm{H}$ bonded $\mathrm{OH}, \mathrm{C}=\mathrm{C}$ of aromatic ring, $\mathrm{C}=\mathrm{O}$ of carbonyl group (both carboxyl and ketonic), $\mathrm{CH}_{2}$ group. This strongly supports the presence of humic acid.

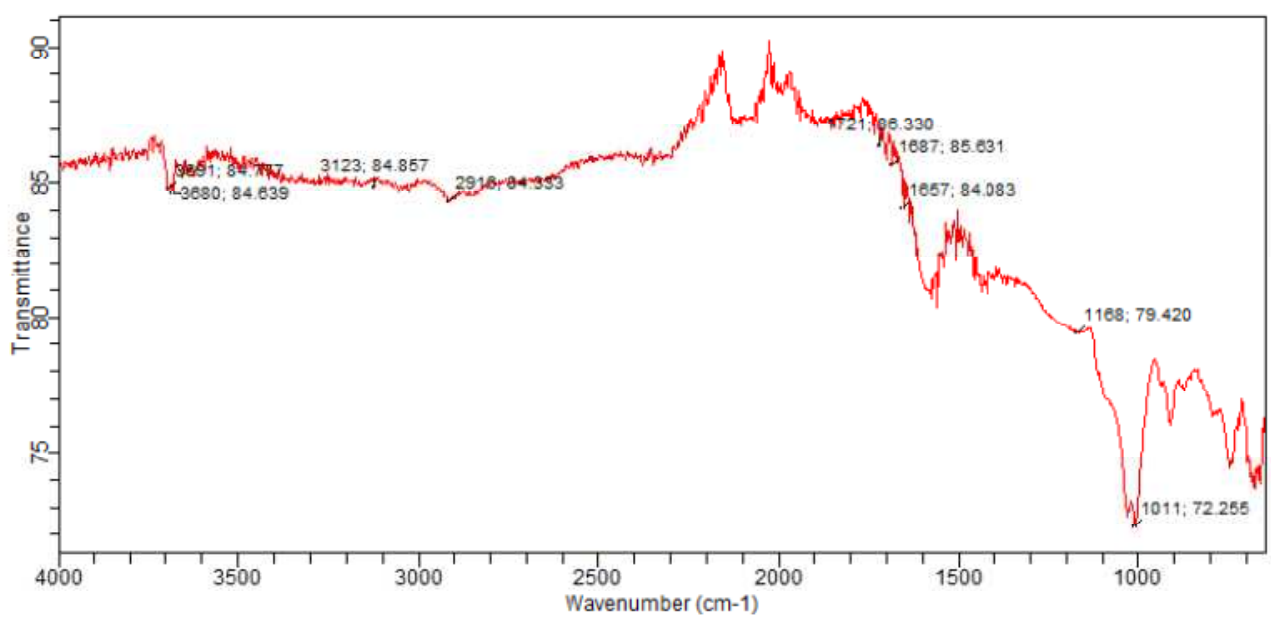

Fig. 2 : FT-IR spectraof peatsoilhumic acid (PSHA)

\section{Evaluation of acid dissociation constant (pka) of acid hydrolysed peat soil humicacid at phenolic group}

The value of the dissociation constant of the peat soil humic acid (PSHA) that underwent acidhydrolysis studied was found to be 8.9299 as shown Table 1, which is lower than the literaturevalues reported by Almeida and Szpoganics, (2015), Borges et al., (2005); Badr et al., (2012)and Fernandes et al,.(2009) of $9.73,9.47$ and 10.30. The difference between the obtained valuesand the reported values in this study might be probably as a result of acid hydrolysis of humicacid. 
BAJOPAS Volume 14 Number 1,June, 2021

Table 1: PKa of (Hydrolysed PSHA)

\begin{tabular}{|l|l|l|l|l|l|l|}
\hline $\mathrm{pH}$ & $\mathrm{BV}_{1}$ & $\mathrm{BV}_{2}$ & $\mathrm{~V}_{2}-\mathrm{V}_{1}$ & $\mathrm{nA}$ & $\log \left(\frac{n A}{1-n A}\right)$ & $\mathrm{pKa}$ \\
\hline 8.50 & 5.30 & 6.29 & 0.99 & 0.3594 & -0.2510 & 8.2490 \\
8.72 & 5.35 & 6.37 & 1.02 & 0.3400 & -0.2880 & 8.4320 \\
9.00 & 5.40 & 6.46 & 1.06 & 0.3141 & -0.3391 & 8.6609 \\
9.22 & 5.45 & 6.55 & 1.10 & 0.2882 & -0.3927 & 8.8273 \\
9.51 & 5.50 & 6.66 & 1.16 & 0.2494 & -0.4786 & 9.0314 \\
9.73 & 5.55 & 6.78 & 1.23 & 0.2041 & -0.5910 & 9.1390 \\
10.00 & 5.60 & 6.90 & 1.30 & 0.1589 & -0.7238 & 9.2762 \\
10.23 & 5.65 & 7.05 & 1.40 & 0.0941 & -0.9835 & 9.2465 \\
10.49 & 5.70 & 7.10 & 1.40 & 0.0941 & -0.9835 & 9.5065 \\
\hline
\end{tabular}

Average pKa $=8.9299 \pm 0.4186$

Table 2: PKa of (Unhydrolysed PSHA)

\begin{tabular}{|l|l|l|l|l|l|l|}
\hline $\mathrm{pH}$ & $\mathrm{BV}_{1}$ & $\mathrm{BV}_{2}$ & $\mathrm{~V}_{2}-\mathrm{V}_{1}$ & $\mathrm{nA}$ & $\log \left(\frac{\boldsymbol{n A}}{1-\boldsymbol{n}}\right)$ & $\mathrm{pKa}$ \\
\hline 8.50 & 5.30 & 5.81 & 0.51 & 0.6619 & 0.2919 & 8.7919 \\
8.72 & 5.35 & 5.90 & 0.55 & 0.6357 & 0.2418 & 8.9618 \\
9.00 & 5.40 & 6.00 & 0.60 & 0.6029 & 0.1813 & 9.1813 \\
9.22 & 5.45 & 6.10 & 0.65 & 0.5701 & 0.1226 & 9.3426 \\
9.51 & 5.50 & 6.20 & 0.70 & 0.5376 & 0.0654 & 9.5754 \\
9.73 & 5.55 & 6.33 & 0.78 & 0.4851 & -0.0259 & 9.7041 \\
10.00 & 5.60 & 6.47 & 0.87 & 0.4262 & -0.1291 & 9.8709 \\
10.23 & 5.65 & 6.62 & 0.99 & 0.3609 & -0.2481 & 9.9819 \\
10.49 & 5.70 & 6.80 & 1.10 & 0.2759 & -0.4690 & 10.0210 \\
\hline
\end{tabular}

Average pKa $=9.4923 \pm 0.4410$

Metal-ligand stability constant ( $\log \mathrm{K}$ )

The stabilityconstants require the accurate values of proton-ligand stability constants (Anil and Maroti, 2008). Metal titration curves crossed over ligand titration curve indicated the formation of complex upon proton release (Santosh, et al., 2011). If the values of n- are within range $0.2-0.8$ and $1.2-18$ this indicates the formation of $1: 1$ and 1:2 complexes (Sayyed and Mazahar, 2012).

The metal (II)-humate stepwise stability constants (log k) at phenolic group (Tables 318)

Table 3: Point-wise method, $\mathrm{Cu}$-(Hydrolysed PSHA)

\begin{tabular}{|l|l|l|l|l|l|l|l|l|}
\hline $\mathrm{pH}$ & $\mathrm{BV}_{1}$ & $\mathrm{BV}_{2}$ & $\mathrm{BV}_{3}$ & $\left(\mathrm{~V}_{3}-\mathrm{V}_{2}\right)$ & $\mathrm{n}$ & $\mathrm{pL}$ & $\log \left(\frac{n}{1-n}\right)$ & LogK $_{1}$ \\
\hline 8.50 & 5.30 & 6.29 & 6.33 & 0.04 & 0.5500 & 2.66 & 0.0871 & 2.7471 \\
8.72 & 5.35 & 6.37 & 6.41 & 0.04 & 0.5714 & 2.43 & 0.1249 & 2.5549 \\
9.00 & 5.40 & 6.46 & 6.50 & 0.04 & 0.6198 & 2.16 & 0.2122 & 2.3722 \\
9.22 & 5.45 & 6.55 & 6.59 & 0.04 & 0.6667 & 1.94 & 0.3010 & 2.2410 \\
\hline
\end{tabular}

LogK $_{1}$ (Average value) $=2.4788 \pm 0.2203$

Table 4: Point-wise method, $\mathrm{Cu}$-(Hydrolysed PSHA)

\begin{tabular}{|l|l|l|l|l|l|l|l|l|}
\hline $\mathrm{pH}$ & $\mathrm{BV}_{1}$ & $\mathrm{BV}_{2}$ & $\mathrm{BV}_{3}$ & $\left(\mathrm{~V}_{3}-\mathrm{V}_{2}\right)$ & $\mathrm{n}$ & $\mathrm{pL}$ & $\log \left(\frac{n-1}{2-n}\right)$ & LogK $_{2}$ \\
\hline 9.51 & 5.50 & 6.66 & 6.73 & 0.07 & 1.3509 & 1.70 & -0.2671 & 1.4329 \\
9.73 & 5.55 & 6.78 & 6.85 & 0.07 & 1.6383 & 1.51 & 0.2467 & 1.7567 \\
10.00 & 5.60 & 6.90 & 6.98 & 0.08 & 2.1783 & 1.31 & -0.2158 & 1.0942 \\
10.23 & 5.65 & 7.05 & 7.13 & 0.08 & 4.1904 & 1.27 & & \\
10.49 & 5.70 & 7.10 & 7.19 & 0.09 & 4.6920 & & & \\
\hline
\end{tabular}

Log $K_{2}($ Average value $)=1.4280 \pm 0.3312$ 
BAJOPAS Volume 14 Number 1,June, 2021

Table 5: Point-wise method, $\mathrm{Cu}$ (Unhydrolysed PSHA)

\begin{tabular}{|l|l|l|l|l|l|l|l|l|}
\hline $\mathrm{pH}$ & $\mathrm{BV}_{1}$ & $\mathrm{BV}_{2}$ & $\mathrm{BV}_{3}$ & $\left(\mathrm{~V}_{3}-\mathrm{V}_{2}\right)$ & $\mathrm{n}$ & $\mathrm{pL}$ & $\log \left(\frac{n}{n-1}\right)$ & Log $_{1}$ \\
\hline 8.50 & 5.30 & 5.81 & 5.85 & 0.04 & 0.2973 & 2.88 & -0.3736 & 2.5064 \\
8.72 & 5.35 & 5.90 & 5.95 & 0.05 & 0.3873 & 2.66 & -0.1992 & 2.4608 \\
9.00 & 5.40 & 6.00 & 6.05 & 0.05 & 0.4044 & 2.38 & -0.1681 & 2.2119 \\
9.22 & 5.45 & 6.10 & 6.15 & 0.06 & 0.5157 & 2.18 & -0.0272 & 2.2072 \\
9.51 & 5.50 & 6.20 & 6.27 & 0.07 & 0.6417 & 1.89 & 0.2530 & 1.1430 \\
\hline
\end{tabular}

$\operatorname{LogK}_{1}($ Average value $)=2.3059 \pm 0.6153$

Table 6:Point-wise method, $\mathrm{Cu}$ (Unhydrolysed PSHA)

\begin{tabular}{|l|l|l|l|l|l|l|l|l|}
\hline $\mathrm{pH}$ & $\mathrm{BV}_{1}$ & $\mathrm{BV}_{2}$ & $\mathrm{BV}_{3}$ & $\mathrm{~V}_{3}-\mathrm{V}_{2}$ & $\mathrm{n}$ & $\mathrm{pL}$ & $\log \left(\frac{n-1}{2-n}\right)$ & $\log \mathrm{K}_{2}$ \\
\hline 9.73 & 5.55 & 6.33 & 6.42 & 0.09 & 0.9000 & 1.69 & & \\
10.00 & 5.60 & 6.47 & 6.58 & 0.11 & 1.2578 & 1.44 & -0.4592 & 0.9808 \\
10.23 & 5.65 & 6.62 & 6.84 & 0.12 & 1.6137 & 1.26 & -0.2010 & 1.4610 \\
10.49 & 5.70 & 6.80 & 6.92 & 0.12 & 2.1052 & 1.03 & & \\
\hline
\end{tabular}

$\operatorname{LogK}_{2}$ (Average value) $=1.2209 \pm 0.3398$

Table 7:Point-wise method, Pb (Hydrolysed PSHA)

\begin{tabular}{|l|l|l|l|l|l|l|l|l|}
\hline $\mathrm{pH}$ & $\mathrm{BV}_{1}$ & $\mathrm{BV}_{2}$ & $\mathrm{BV}_{3}$ & $\left(\mathrm{~V}_{3}-\mathrm{V}_{2}\right)$ & $\mathrm{n}$ & $\mathrm{pL}$ & $\log \left(\frac{n}{1-n}\right)$ & LogK $_{1}$ \\
\hline 8.50 & 5.30 & 6.29 & 6.33 & 0.04 & 0.5500 & 2.66 & 0.0871 & 2.7471 \\
8.72 & 5.35 & 6.37 & 6.41 & 0.04 & 0.5714 & 2.43 & 0.1249 & 2.5549 \\
9.00 & 5.40 & 6.46 & 6.50 & 0.04 & 0.6198 & 2.16 & 0.2122 & 2.3722 \\
9.22 & 5.45 & 6.55 & 6.60 & 0.05 & 0.8333 & 1.96 & 0.6989 & 2.6589 \\
\hline
\end{tabular}

Log $_{\mathbf{1}}($ Average value $)=2.5832 \pm 0.1614$

Table 8:Point-wise method, Pb-(Hydrolysed PSHA)

\begin{tabular}{|l|l|l|l|l|l|l|l|l|}
\hline $\mathrm{pH}$ & $\mathrm{BV}_{1}$ & $\mathrm{BV}_{2}$ & $\mathrm{BV}_{3}$ & $\left(\mathrm{~V}_{3}-\mathrm{V}_{2}\right)$ & $\mathrm{n}$ & $\mathrm{pL}$ & $\log \left(\frac{n-1}{2-n}\right)$ & $\log \mathrm{K}_{2}$ \\
\hline 9.51 & 5.50 & 6.66 & 6.71 & 0.05 & 0.9650 & 1.67 & & \\
9.73 & 5.55 & 6.78 & 6.83 & 0.05 & 1.1702 & 1.44 & & \\
10.00 & 5.60 & 6.90 & 6.90 & 0.05 & 1.4864 & 1.22 & -0.0237 & 1.1963 \\
10.23 & 5.65 & 7.05 & 7.10 & 0.05 & 2.0190 & 1.09 & & \\
10.49 & 5.70 & 7.10 & 7.17 & 0.07 & 3.6492 & 1.00 & & \\
\hline
\end{tabular}

Log $K_{2}$ (Average value) $=1.1963$

Table 9: Point-wise method, Pb (Unhydrolysed PSHA)

\begin{tabular}{|l|l|l|l|l|l|l|l|l|}
\hline $\mathrm{pH}$ & $\mathrm{BV}_{1}$ & $\mathrm{BV}_{2}$ & $\mathrm{BV}_{3}$ & $\mathrm{~V}_{3}-\mathrm{V}_{2}$ & $\mathrm{n}$ & $\mathrm{pL}$ & $\begin{array}{l}\text { Log } \\
\left(\frac{n}{n-1}\right)\end{array}$ & Log $\mathrm{K}_{1}$ \\
\hline 8.50 & 5.30 & 5.81 & 5.85 & 0.04 & 0.2973 & 2.88 & -0.3736 & 2.5064 \\
8.72 & 5.35 & 5.90 & 5.94 & 0.04 & 0.3099 & 2.66 & -0.5477 & 2.3123 \\
9.00 & 5.40 & 6.00 & 6.05 & 0.05 & 0.4044 & 2.38 & -0.1681 & 2.2119 \\
9.22 & 5.45 & 6.10 & 6.15 & 0.06 & 0.5157 & 2.18 & 0.0272 & 2.2072 \\
9.51 & 5.50 & 6.20 & 6.26 & 0.07 & 0.6417 & 1.89 & 0.2530 & 2.1430 \\
9.73 & 5.55 & 6.40 & 6.40 & 0.07 & 0.7000 & 1.67 & 0.3680 & 2.0380 \\
\hline
\end{tabular}

LogK $_{1}$ (Average value) $=2.2364 \pm 0.1602$

Table 10: Point-wise method, Pb (Unhydrolysed PSHA)

\begin{tabular}{|l|l|l|l|l|l|l|l|l|}
\hline $\mathrm{pH}$ & $\mathrm{BV}_{1}$ & $\mathrm{BV}_{2}$ & $\mathrm{BV}_{3}$ & $\mathrm{~V}_{3}-\mathrm{V}_{2}$ & $\mathrm{n}$ & $\mathrm{pL}$ & $\log \left(\frac{n-1}{2-n}\right)$ & $\log \mathrm{K}_{2}$ \\
\hline 10.00 & 5.60 & 6.47 & 6.55 & 0.08 & 1.9503 & 1.41 & & \\
10.23 & 5.65 & 6.62 & 6.72 & 0.11 & 1.4792 & 1.26 & -0.0361 & 1.2239 \\
\hline
\end{tabular}

$\operatorname{LogK}_{2}$ (Average value) $=1.2239$

Table 11: Point-wise method, Mg (Hydrolysed PSHA)

\begin{tabular}{|l|l|l|l|l|l|l|l|l|}
\hline $\mathrm{pH}$ & $\mathrm{BV}_{1}$ & $\mathrm{BV}_{2}$ & $\mathrm{BV}_{3}$ & $\left(\mathrm{~V}_{3}-\mathrm{V}_{2}\right)$ & $\mathrm{n}$ & $\mathrm{pL}$ & $\log \left(\frac{n}{n-1}\right)$ & LogK $_{1}$ \\
\hline 8.50 & 5.30 & 6.29 & 6.31 & 0.02 & 0.2750 & 2.64 & -0.4290 & 2.2110 \\
8.72 & 5.35 & 6.37 & 6.39 & 0.02 & 0.2858 & 2.42 & -0.3978 & 2.0222 \\
9.00 & 5.40 & 6.46 & 6.49 & 0.03 & 0.4648 & 2.14 & -0.0612 & 2.0788 \\
9.22 & 5.45 & 6.55 & 6.59 & 0.04 & 0.6667 & 1.94 & 0.3010 & 2.2410 \\
\hline
\end{tabular}

$\log _{\mathbf{1}}($ Average value) $=2.1382 \pm 0.1046$ 
BAJOPAS Volume 14 Number 1,June, 2021

Table 12: Point-wise method, Mg (Hydrolysed PSHA)

\begin{tabular}{|l|l|l|l|l|l|l|l|l|}
\hline $\mathrm{pH}$ & $\mathrm{BV}_{1}$ & $\mathrm{BV}_{2}$ & $\mathrm{BV}_{3}$ & $\left(\mathrm{~V}_{3}-\mathrm{V}_{2}\right)$ & $\mathrm{n}$ & $\mathrm{pL}$ & $\log \left(\frac{n-1}{2-n}\right)$ & LogK $_{2}$ \\
\hline 9.51 & 5.55 & 6.66 & 6.71 & 0.05 & 0.9650 & 1.67 & & \\
9.73 & 5.55 & 6.78 & 6.84 & 0.06 & 1.4042 & 1.47 & -0.1686 & 1.3014 \\
10.00 & 5.60 & 6.90 & 6.93 & 0.06 & 1.7838 & 1.23 & 0.5593 & 1.7893 \\
10.23 & 5.65 & 7.05 & 7.10 & 0.06 & 3.1429 & 1.10 & & \\
10.49 & 5.70 & 7.10 & 7.18 & 0.07 & 3.6492 & 0.83 & & \\
\hline
\end{tabular}

LogK $_{2}($ Average value $)=1.5453 \pm 0.3450$

Table 13: Point-wise method, Mg (Unhydrolysed PSHA)

\begin{tabular}{|l|l|l|l|l|l|l|l|l|}
\hline $\mathrm{pH}$ & $\mathrm{BV}_{1}$ & $\mathrm{BV}_{2}$ & $\mathrm{BV}_{3}$ & $\mathrm{~V}_{3}-\mathrm{V}_{2}$ & $\mathrm{n}$ & $\mathrm{pL}$ & $\log \left(\frac{n}{n-1}\right)$ & $\operatorname{Log~}_{1}$ \\
\hline 8.50 & 5.30 & 5.81 & 5.85 & 0.04 & 0.2973 & 2.88 & -0.3736 & 2.5064 \\
8.72 & 5.35 & 5.90 & 5.94 & 0.04 & 0.3099 & 2.66 & -0.3477 & 2.3123 \\
9.00 & 5.40 & 6.00 & 6.04 & 0.04 & 0.3236 & 2.38 & -0.3202 & 2.0598 \\
9.22 & 5.45 & 6.10 & 6.15 & 0.05 & 0.4297 & 2.17 & -0.1230 & 2.0470 \\
9.51 & 5.50 & 6.20 & 6.26 & 0.06 & 0.5500 & 1.89 & 0.0871 & 1.9771 \\
9.73 & 5.55 & 6.33 & 6.40 & 0.07 & 0.7000 & 1.67 & 0.3680 & 2.0380 \\
\hline
\end{tabular}

LogK $_{1}$ (Average value) $=2.1568 \pm 0.2069$

Table 14: Point-wise method, Mg (Unhydrolysed PSHA)

\begin{tabular}{|l|l|l|l|l|l|l|l|l|}
\hline $\mathrm{pH}$ & $\mathrm{BV}_{1}$ & $\mathrm{BV}_{2}$ & $\mathrm{BV}_{3}$ & $\mathrm{~V}_{3}-\mathrm{V}_{2}$ & $\mathrm{n}$ & $\mathrm{pL}$ & $\log \left(\frac{n-1}{2-n}\right)$ & $\log \mathrm{K}_{2}$ \\
\hline 10.00 & 5.60 & 6.47 & 6.55 & 0.08 & 0.9148 & 1.41 & & \\
10.23 & 5.65 & 6.62 & 6.71 & 0.09 & 1.2102 & 1.20 & -0.5749 & 0.6251 \\
10.49 & 5.70 & 6.80 & 6.92 & 0.09 & 1.5968 & 1.03 & 0.1703 & 1.2003 \\
\hline
\end{tabular}

LogK $_{2}$ (Average value) $=0.9127 \pm 0.4070$

Table15:Point-wise method, Cd (Hydrolysed PSHA)

\begin{tabular}{|l|l|l|l|l|l|l|l|l|}
\hline $\mathrm{pH}$ & $\mathrm{BV}_{1}$ & $\mathrm{BV}_{2}$ & $\mathrm{BV}_{3}$ & $\left(\mathrm{~V}_{3}-\mathrm{V}_{2}\right)$ & $\mathrm{n}$ & $\mathrm{pL}$ & $\log \left(\frac{n}{1-n}\right)$ & LogK $_{1}$ \\
\hline 8.50 & 5.30 & 6.29 & 6.31 & 0.02 & 0.2750 & 2.64 & -0.4210 & 2.2190 \\
8.72 & 5.35 & 6.37 & 6.40 & 0.03 & 0.4286 & 2.42 & -0.1249 & 2.2951 \\
9.00 & 5.40 & 6.46 & 6.49 & 0.03 & 0.4648 & 2.14 & -0.0612 & 2.0788 \\
9.22 & 5.45 & 6.55 & 6.59 & 0.04 & 0.6667 & 1.96 & 0.3010 & 2.2610 \\
9.51 & 5.55 & 6.66 & 6.70 & 0.04 & 0.7720 & 1.67 & 0.5297 & 2.1997 \\
\hline
\end{tabular}

LogK $_{\mathbf{1}}$ (Average value) $=2.2108 \pm 0.0825$

Table 16: Point-wise method, Cd (Hydrolysed PSHA)

\begin{tabular}{|l|l|l|l|l|l|l|l|l|}
\hline $\mathrm{pH}$ & $\mathrm{BV}_{1}$ & $\mathrm{BV}_{2}$ & $\mathrm{BV}_{3}$ & $\left(\mathrm{~V}_{3}-\mathrm{V}_{2}\right)$ & $\mathrm{n}$ & $\mathrm{pL}$ & $\log \left(\frac{n-1}{2-n}\right)$ & Log $_{2}$ \\
\hline 9.73 & 5.55 & 6.78 & 6.83 & 0.06 & 1.4042 & 1.47 & -0.1686 & 1.3014 \\
10.00 & 5.60 & 6.90 & 6.95 & 0.06 & 1.7838 & 1.23 & 0.5593 & 1.7893 \\
10.23 & 5.65 & 7.05 & 7.10 & 0.06 & 3.1429 & 1.09 & & \\
10.49 & 5.70 & 7.10 & 7.16 & 0.06 & 3.1429 & 0.89 & & \\
& & & & & & & & \\
\hline
\end{tabular}

$\operatorname{LogK}_{2}$ (Average value) $=1.5453 \pm 0.3450$

Table 17: Point-wise method, Cd (Unhydrolysed PSHA)

\begin{tabular}{|l|l|l|l|l|l|l|l|l|}
\hline $\mathrm{pH}$ & $\mathrm{BV}_{1}$ & $\mathrm{BV}_{2}$ & $\mathrm{BV}_{3}$ & $\mathrm{~V}_{3}-\mathrm{V}_{2}$ & $\mathrm{n}$ & $\mathrm{pL}$ & $\log \left(\frac{n}{n-1}\right)$ & $\operatorname{Log~}_{1}$ \\
\hline 8.50 & 5.30 & 5.81 & 5.86 & 0.05 & 0.3717 & 2.88 & -0.2280 & 2.6520 \\
8.72 & 5.35 & 5.90 & 5.95 & 0.05 & 0.3873 & 2.66 & -0.1992 & 2.4608 \\
9.00 & 5.40 & 6.00 & 6.06 & 0.06 & 0.4853 & 2.38 & -0.0255 & 2.3545 \\
9.22 & 5.45 & 6.10 & 6.16 & 0.06 & 0.5157 & 2.18 & -0.0272 & 2.2072 \\
9.51 & 5.50 & 6.20 & 6.27 & 0.07 & 0.6417 & 1.89 & 0.2530 & 1.1430 \\
9.73 & 5.55 & 6.33 & 6.41 & 0.08 & 0.8000 & 1.69 & 0.6020 & 2.2920 \\
& & & & & & & & \\
\hline
\end{tabular}

$\operatorname{LogK}_{1}($ Average value $)=2.2516 \pm 0.5380$ 
BAJOPAS Volume 14 Number 1,June, 2021

Table 18: Point-wise method, Cd (Unhydrolysed PSHA)

\begin{tabular}{|l|l|l|l|l|l|l|l|l|}
\hline $\mathrm{pH}$ & $\mathrm{BV}_{1}$ & $\mathrm{BV}_{2}$ & $\mathrm{BV}_{3}$ & $\mathrm{~V}_{3}-\mathrm{V}_{2}$ & $\mathrm{n}$ & $\mathrm{pL}$ & $\log \left(\frac{n-1}{2-n}\right)$ & $\log \mathrm{K}_{2}$ \\
\hline 10.00 & 5.60 & 6.47 & 6.57 & 0.10 & 1.1434 & 1.43 & & \\
10.23 & 5.65 & 6.62 & 6.72 & 0.10 & 1.3448 & 1.23 & -0.2788 & 0.9512 \\
10.49 & 5.70 & 6.80 & 6.90 & 0.10 & 1.7742 & 1.03 & 0.5351 & 1.5651 \\
\hline
\end{tabular}

$\operatorname{LogK}_{2}($ Average value $)=1.2581 \pm 0.4340$

Table 19: Stepwise and overall Stability constants of thehydrolysed and unhydrolysed divalent metal (II) complexes

\begin{tabular}{|c|c|c|c|}
\hline Chelates & LogK $_{1}$ & $\log _{2}$ & Log $\beta$ \\
\hline [Cu (Hydrolysed PSHA-1) $\left.{ }_{2}\right]$ & 2.4788 & 1.4280 & 3.9068 \\
\hline$\left[\mathrm{Pb}(\text { Hydrolysed PSHA-1) })_{2}\right]$ & 2.5832 & 1.1963 & 3.7795 \\
\hline$\left[\mathrm{Cd}(\text { Hydrolysed PSHA-1 })_{2}\right]$ & 2.2108 & 1.5453 & 3.7561 \\
\hline$\left[\mathrm{Mg}(\text { Hydrolysed PSHA-1 })_{2}\right]$ & 2.1382 & 1.5453 & 3.6835 \\
\hline [Cu (Unhydrolysed PSHA-1) & 2.3059 & 1.2209 & 3.5268 \\
\hline$[\mathrm{Pb}$ (Unhydrolysed PSHA-1) 2$]$ & 2.2364 & 1.2239 & 3.4603 \\
\hline [Cd (Unhydrolysed PSHA-1) 2 ] & 2.2516 & 1.2581 & 3.5097 \\
\hline$[\mathrm{Mg}$ (Unydrolysed PSHA-1) & 2.1568 & 0.9127 & 3.0695 \\
\hline
\end{tabular}

The results obtained (Table19) shows the stepwise and overall stability constants to be not high indicating low stability of the complexes, because the solubility of most metal ions in the basic $\mathrm{pH}$ range is minimal due to metal hydroxide precipitation (Karimi, 2017). In general, the stepwise stability constants $\left(K_{1}\right.$ and $K_{2}$ ) follow the order $K_{1}>K_{2}$ for the copper, lead, magnesium and cadmium complexes respectively. The steady decrease of the values with increasing number of ligands is in agreement with the prediction made by researchers (Na'aliya, 2013). The decrease could be attributed to the fact that as the number of the ligands (Humate ions) that enters the coordination zone increases the aqua molecules available for replacement by the ligands become less. Thus, the metal ions become less electron loving with progressive intake of the ligand and this results in the decrease in the values of the constants (Na'aliya, 2013). Also the stability of the complexes is influenced by the size and number of the chelate rings(Mackay and Mackay,2002).All the complexes form rings in their structure as humate, a bidentate ligand, bond the metal ions in the ratio 1:2 (Boguta and Sokolowska, 2016) forming chelate rings. The values of the overall stability constants $(\log \beta)$ obtained for humate complexes are not high indicating low stability as the values are not high. LogK values for copper-humates (Table 3 to 6) obtained in this study are lower than those reported for the complexes of humic acids (Pandey et al., 2015; Dinu, 2013; Kaschl et al., 2010 and Gilbeto and Jorg, 2001). The values of LogK(Table 7 to 10 ) forlead-humates are lower than those reported for the lead in the literature (Dinu, 2013; Gilbeto and Jorg 2001). Log K values(Table 11 to 14 ) for magnesium-humates obtained in this study are close to those reported by (Pandey et al., 2015). Log K values of cadmium-humates (Table 15 to 18 ) obtained in this work near to the one reported by (Dinu, 2013 and Pandey et al., 2015).The difference between the reported values and the values obtained in this study might be probably as a result of acid hydrolysis of humic acid. The values of the overall stability constants $(\log \beta)$ of the copper humates complexes presented in Table 19 is high than that of other metal humate complexes, show relatively high stability of CuHA complexes, show the following order of stability: $\mathrm{Cu}>\mathrm{Pb}>\mathrm{Cd}>\mathrm{Mg}$; which are in close agreement to the findings of (Dinu, 2013 and Pandey et al., 2015).The high stability of Cuhumate chelate could be attributed to the existence of coordinate covalent bond between the complexing agents and the $\mathrm{Cu}^{2+}$ ions. Since, $\mathrm{Cu}^{2+}$ being a metal of the transitional series with $3 d^{9}$ electronic configurations can accept the electrons from the complexing agents. Similarly, the low stabilities of $\mathrm{Pb}, \mathrm{Cd}$ and $\mathrm{Mg}$ complexes could be explained by that $\mathrm{Pb}^{2+}$ with $6 s^{2}, \mathrm{Cd}^{2+}$ with $4 \mathrm{~d}^{10}$ and $\mathrm{Mg}^{2+}$ with $2 \mathrm{p}^{6}$ their electronic configuration has a completely filled $\mathrm{d}, \mathrm{p}$ and $\mathrm{s}$ orbitals. Moreover, the stabilities of metal ions with hydrolysed humic acid from peat soil were higher than those with unhydrolysed humic acid from peat soil; which is ascribed to the high content of acidity in hydrolysed humic acid than unhydrolysed humic acid. 
BAJOPAS Volume 14 Number 1,June, 2021 CONCLUSION

The values of logk for $\mathrm{Cu}(\mathrm{II})$ hydrolysed humic acid complex was higher followed by $\mathrm{Pb}$ (II), $\mathrm{Cd}(\mathrm{II})$ and $\mathrm{Mg}$ (II) hydrolysed humic acid complexes as compared with metal(II) unhydrolysed humic acid complexes. This indicates acid hydrolysis of humic acid can

\section{REFERENCES}

Almeida, V.R. and Szpoganicz, B. (2015). Humic Acid Potentiometric Response Patterns:Out- of Equilibrium Properties and Species Distribution Modelling. Chemical. Biol. Technol. Agric. 2: 17.

Anđelković, T., Nikolić, R., Bojić, A.,Anđelković, D., and Nikolic G.,(2010). Binding of Cadmium to Soil Humic Acid as A Function of Carboxyl Group Content. Macedonian Journal of Chemistry and Chemical Engineering.29(2): 215-224.

Anil, B. N. and Maroti, N. (2008). Studies on Influence of Die-Lectric Constants on Complex Equilibria between Substituted Py-Razalines and Lanthanide Metal Ions pH-Metrically. Amer.-Euras. scient. Res. 3(2): 212-216.

Ashok, K., Pandey, S. P. and Misra, V (2000). Stability Constants of Metal-Humic Acid Complexes and its Role in Environmental Detoxification. Journal of Ecotoxicology and Environmental Safety. 47(2):157-200.

Badr, M. H., El-Halafawi, M. H. and Abd El-al Zeid, E. R. (2012). Comparison Between the Effect of Ionic Strength on Acidity and Dissociation Constants of Humic Acids Extracted from Sewage Sludge and Nile Water Hyacinth Composts.Global Journal of Environmental Research 6 (1): 36-43.

Baruah, M.K., Borah, D., Saikia, P.P., Paul, S., Sharma, T. (2015). Evaluation of pKa Values of Soil Humic Acids and their Complexation Properties. International Journal of Plant \& Soil Science 6(4) : 218-228.

Boguta, P. Sokolowska, Z. (2016). Interactions of $\mathrm{Zn}$ (II) Ions with Humic Acids Isolated from Various Types of Soils. Effect of $\mathrm{pH}, \mathrm{Zn}$ Concentrations and Humic Acids Chemical Properties. Journal of Geochemical Explaration 168. 119-126.

Borges, F., Guimaraes, C., Lima, L.F.C., Pinto, I. and Reis, S.(2005). Potentiometric Studies on the Complexation of Copper(II) by Phenolic Acids as Discrete Ligand Models of enhance the complexation behavior of humic acid with metal (II) ions. However, the higher values of $\log \beta$ for $\mathrm{Cu}(\mathrm{II}), \mathrm{Pb}(\mathrm{II}), \mathrm{Cd}(\mathrm{II})$ and $\mathrm{Mg}(\mathrm{II})$ hydrolysed humic acid complexes indicates more stable stepwise complexes formed as compared with $\mathrm{Cu}(\mathrm{II}), \mathrm{Pb}$ (II), $\mathrm{Cd}$ (II) and $\mathrm{Mg}(\mathrm{II})$ unhydrolysed humic acid complexes.

Humic Substances Talanta 66 (2005) 670-673.

Chefetz, B., Salloum, M. J., Deshmulkin, A. P. and Hatcher, P. (2002). Structural Components of Humic Acids as Determined by Chemical Modifications and Carbon-13 NMR, Pyrolysis, and Thermochemolysis- Gas Chromatography/Mass Spectrometry. Soil Science Society of American Journal Abstract Division S-2- Soil Chemistry66. 1159-1171.

Dinu, M. I. (2013). Metals Complexation with Humic Acids in Surface Water of Different Environ. Sci. Technol. 31(1): 1-17.

Fernandes, A.N., Giacomelli, C., Giovanela, M. Vaz, D.V. Szpoganicz, B. and Maria M. D. (2009). Potentiometric Acidity Determination in Humic Substances Influenced by Different Analytical Procedures.J. Braz. Chem. Soc. 20 (9):14.

Gamal, A. H. (2015). Stability Constants of Rhenium (V) Metal Complexes with Selected Drugs. Pyrex Journal of Research in Environmental Studies. 2(2): 006-014.

Janrao, D. M., Pathan, J., Kayande, D.D., and Mulla, J.J. (2014). An Over View of Potentiometric Determination of Stability Constants of Metal Complexes. Sci. Revs. Chem. Commun.: 4(1), 2014, 11-24.

Karimi, H. (2017). Effect of pH and Initial Pb(II) Concentration on the Lead Removal Efficiency from Waste Water Using $\mathrm{Ca}(\mathrm{OH})_{2}$. International Journal of Water and Waste Water Treatment 3.2

Kaschl, A. Romheld, V. and Chen, Y. (2010). Binding of Cadmium, Copper and Zinc to Humic Substances Originating from Municipal Solid Waste Compost. Israel Journal of Chemistry Vol. 42(1): 89-98.

Kostic, I. S., Tatjana, P, A., Nikolic, R. S., Cvetkovic, T. P., Pavlovic, D. D., Aleksandar, L.J. and Bojic, A. (2012). Comparative Study of Binding Strengths of Heavy Metals with Humic Acid. J.serb. Chem. Soc. 76(9) pp 1-20. 
BAJOPAS Volume 14 Number 1,June, 2021

Na'aliya, J. (2013). Determination of Stepwise Stability Constants and Gibbs free Energy Change of Trisprolina to Complexes of some Divalent Transition Metal ions. Bayero Journal of Pure and Applied Sciences 6(2): 112-114.

Omar, A. A. and Ali, E. A. (2015). Potentiometric Studies on Complexes of $\mathrm{Cr}$ (III) and $\mathrm{Zr}$ (IV) with some Carboxylic Acids. International Journal of Advanced Chemistry, 3(1) 25-

37.

Pandey, A. K. Pandey, S. D. and Misr, V. (2015).Stability Constants of Metal- Humic Acid Complexes and Its Role in Environmental Detoxification. J. Ecotoxicology and Environmental Safety. 47(1):195-200.

Ram, N. and Raman, K.V. (1984). Stability Constants of Complexes of Metals with
Humicand Fuvic Acids under Non- acidConditions. Journal of Plant Nutrition and Soil Sciences.

147:171-176.

Santosh, D. D., Ashok, B. K., Vijay, J. T., Shivraj, G. W. and Vinay, V. W. (2011). Potentiometric Studies of Elec-Trolyte Effects on Complex Equilibria of Some Substituted 5-(2-hydroxy Phenyl) Pyrazoles. Der pharm. 3 (6): 75-83.

Sayyed, H. and Abdul Rahim, M. F. (2012). Studies of Binary Complexes of Metal Ions with Mandelic Acid by Potentiometry. Chem. J. 02 (6): 206209.

Shirvani, M. Moradian, E. Khalili, B. Bakhtiary, S. (2015). Interaction of $\mathrm{Cd}$ and $\mathrm{Pb}$ with Humate-Palygorskite and HumateSepiolite Complexes. Journal of water, air and pollution 3: 220-228. 


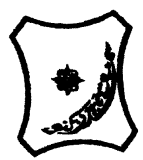

Bayero Journal of Pure and Applied Sciences, 14(1): 54 - 63

Received: November, 2020

Accepted: April, 2021

ISSN $2006-6996$

\title{
STABILITY CONSTANTS OF COMPLEXES OF METAL IONS WITH PEATSOIL HUMIC ACIDS UNDER NON-ACID-CONDITIONS
}

\author{
${ }^{* 1}$ Sabo, Yusuf ${ }^{2}$ Jimoh, W.L.O., ${ }^{3}$ Isa Baba Koki and ${ }^{4}$ Sholadoye, Q. 0. \\ ${ }^{1}$ Department of Pure and Industrial Chemistry, Bayero University, Kano \\ ${ }^{3}$ Department of Chemistry, Yusuf Maitama Sule University Kano. P.M.B. 3220 Kano, Nigeria. \\ ${ }^{4}$ Department of Chemistry, Nigerian Police Academy, Wudil, Kano-Nigeria
}

*Correspondence E-mail; saboyusuf18@yahoo.com

ABSTRACT

Stability constants of complexes of four divalent metal ions viz. $\mathrm{Cu}^{2+}, \mathrm{Pb}^{2+}, \mathrm{Mg}^{2+}$ and $\mathrm{Cd}^{2+}$ with humic acids (HA) were determined by potentiometric titration of humic acids with the corresponding salt of the divalent metals in aqueous media under non-acid-condition. The log $K$ (logarithm of the stability constant) ranged from 1.0942 to 2.7471 for metalhumic acid complexes were determined using point-wise computational method. The order of stability constants were obtained as follows: $\mathrm{Cu}>\mathrm{Pb}>\mathrm{Cd}>\mathrm{Mg}$ for metal $-\mathrm{HA}$ complexes respectively, indicating a higher degree of complexation with Cu metal ion.

Keywords: stability constant, humic acid, potentiometric titration, divalent metals, acid hydrolysis.

\section{NTRODUCTION}

The stability constant of a complex is the numerical expression of its stability and provides a quantitative measure of affinity of the metal ion to the complexing agent. An understanding of the relative stability of metal-complexes helps in predicting the behavior of metal ions in the soil (Ram and Raman, 1982). Extensive researches has been done to determine the stability constants of the complexes formed between humic acid (HA) with a number of metal ions. Ashok et al., (2000) reported that humic acid with hydroxyl, phenoxyl and carboxyl reactive groups can form coordination compound with metal ions at $\mathrm{pH}$ 3.5. The stability constants(Log K) for different metalhumic acid complexes indicated the following order of the stabilities of complexes formed between humic acid and metal ion, $\mathrm{Cu}>\mathrm{Fe}$ $>\mathrm{Pb}>\mathrm{Ni}>\mathrm{Co}>\mathrm{Ca}>\mathrm{Cd}>\mathrm{Zn}>\mathrm{Mn}>\mathrm{Mg}$. Andelkovic et al., (2010) investigated the binding of $\mathrm{Cd}$ (II) to soil humic acid at pH 6.5 and in $0.1 \mathrm{M} \mathrm{KNO}_{3}$ ionic medium. The stability constant for binding indicating greater stability in the case when carboxyl groups are involved in complexation reaction. Kostic et al.,(2012) investigated the complexation of humic acid with certain heavy metal ions (Co(II), $\mathrm{Ni}(\mathrm{II}), \mathrm{Cu}(\mathrm{II})$,
$\mathrm{Zn}(\mathrm{II})$, and $\mathrm{Pb}(\mathrm{II})$. The experiment was performed at $25^{\circ} \mathrm{C}$, at pH 4.0 and ionic strength of $0.01 \mathrm{M}$. Stability constant of complex between $\mathrm{Pb}$ (II) ions and humic acid is greater than stability constants of other investigated metalhumate complexes. Bogata and Sokolowska (2016) analyses the interaction between humic acids from different soils and $\mathrm{Zn}$ (II) ions at wide concentration ranges and at $\mathrm{pH} 5$. Studies have showed significant impact of $\mathrm{Zn}$ concentration, $\mathrm{pH}$ and some properties of humic acids with zinc.But all of these studies were limited to acidic $\mathrm{pH}$ range. Therefore, the present study was carried out to determine and compare the stability constants of complexes of metal ions with hydrolysed peat soil humic acid and unhydrolysed peat soil humic under non-acid conditions.

\section{MATERIALS AND METHODS}

Analytical grade chemicals used includes hydrochloric acid $(\mathrm{HCl})$, nitric acid $\left(\mathrm{HNO}_{3}\right)$, sodium hydroxide $(\mathrm{NaOH})$, lead nitrate $\mathrm{Pb}\left(\mathrm{NO}_{3}\right)_{2}$, copper nitrate $\mathrm{Cu}\left(\mathrm{NO}_{3}\right)_{2} \cdot 3 \mathrm{H}_{2} \mathrm{O}$, cadmium nitrate $\mathrm{Cd}\left(\mathrm{NO}_{3}\right)_{2} \cdot 4 \mathrm{H}_{2} \mathrm{O}$, magnesium nitrate $\mathrm{Mg}\left(\mathrm{NO}_{3}\right)_{2} \cdot 6 \mathrm{H}_{2} \mathrm{O}$, potassium nitrate $\left(\mathrm{KNO}_{3}\right)$, calcium chloride $\left(\mathrm{CaCl}_{2}\right)$, (sigma-Aldrich). Dowex 50WX8, (20-50 mesh) from Fluka. 


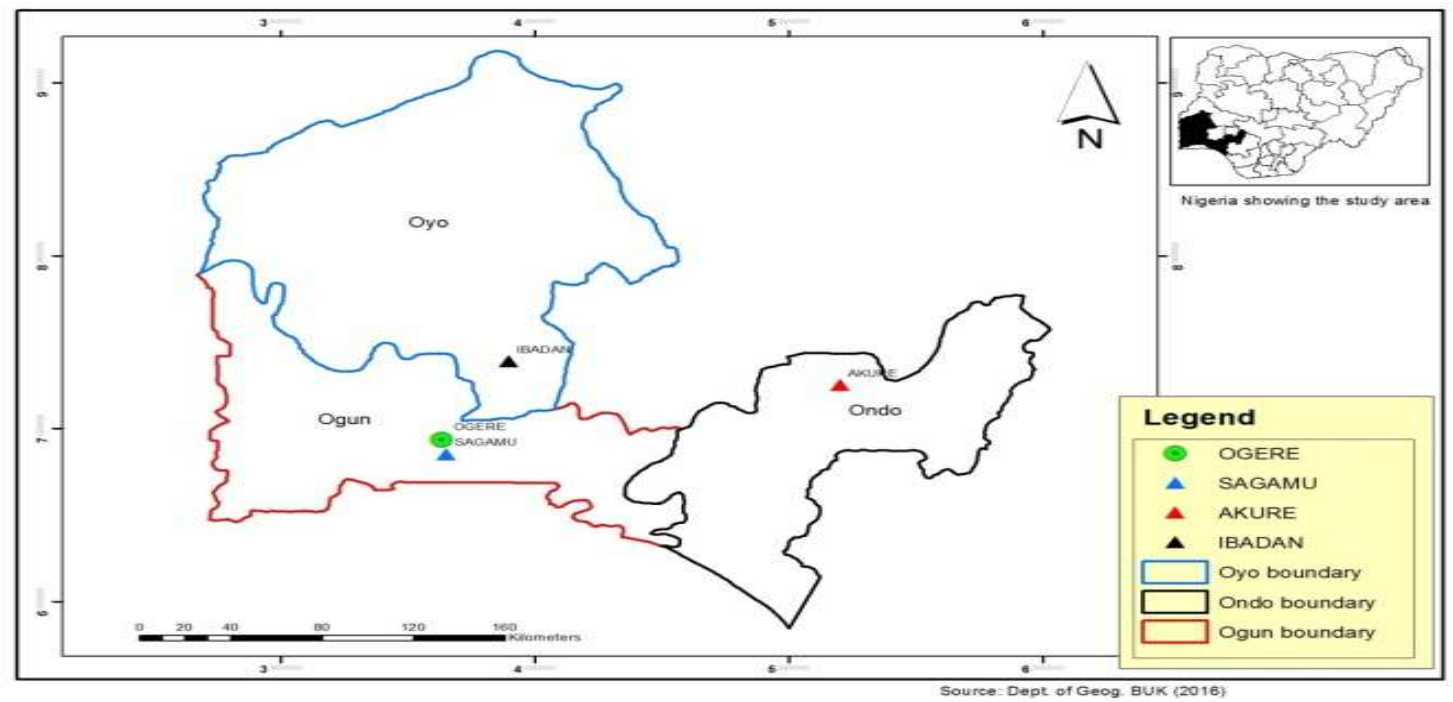

Figure 1: Map showing the sampling point at Sagamu Town, Ogun State.

\section{Description of Sampling Area}

Sagamu has geographical coordinates between $6^{\circ} 50^{\prime}$ north; $3^{\circ} 38^{\prime}$ east is located in south western region of Nigeria. The region has tropical wet and dry climate with a lengthy wet season and relatively constant temperatures throughout the course of the year. Wet season runs from March to October, November to December forms the region dry season. The vegetation type of the region is savannah which is really grassland with small bushes and occasional big trees. Grassland soils have substantially higher organic matter content than forest soils (Novackova, 2011).

\section{Sample Collection}

The Peatsoil samples were collected from four different sampling points $(0-10 \mathrm{~cm}$ depth) in Sagamu into polyethylene bag with plastic spoons. Samples were taken to the laboratory, extraneous materials were removed; the samples were air-dried, crushed and ground to a fine powder in a mortar passed through a $0.20 \mathrm{~mm}$ sieve. The samples were kept for analysis.

\section{Isolation and purification of humic acid from peat soil sample}

Peatsoil sample $(100 \mathrm{~g})$ was mixed with 1000 $\mathrm{cm}^{3}$ of $0.1 \mathrm{M} \mathrm{NaOH}$ solution, shaken for 3hours and left to stand overnight. Dark-coloured supernatant was obtained and decanted from solid residue. The dark-coloured supernatant was acidified to $(\mathrm{pH}=1.0)$ with $6 \mathrm{M} \mathrm{HCl}$ stirred and allowed to stand for 6 hours. Yellowish brown supernatant and dark-brown precipitate were obtained. The yellowish brown supernatant was decanted followed by centrifuge and discarded. The dark-brown precipitate was mixed with $500 \mathrm{~cm}^{3}$ of $0.1 \mathrm{M} \mathrm{NaOH}$ solution followed by passing through dowex resin. The dark-brown solution was acidified to $(\mathrm{pH}=1.0)$ with $6 \mathrm{M} \mathrm{HCl}$ stirred and allowed to stand for 3 hours. The dark-brown precipitate was washed several times with deionized water. The supernatant was treated with $\mathrm{AgNO}_{3}$ solution until no white precipitate observed. The humic acid was transferred to weighed crucible and dried at $60^{\circ} \mathrm{C}$ in an oven for 12 hours. The humic acid was cooled and dried in the desiccator, weighed and recorded. The obtained humic acid was dried again at $60^{\circ} \mathrm{C}$ for additional 6 hours cooled and dried in the desiccator, weighed and recorded constant weight was obtained (Baruah et al., 2015).

\section{FT-IR analysis}

FT-IR spectra of humic acid sample was analysed using Carry 630 FT-IR Agilent Technologies.

Unhydrolysed compost humic acid

The unhydrolysed humic acid was obtained after isolation and purification of compost humic acid and kept for investigation.

\section{Acid hydrolysis of Peatsoil acid}

Peatsoil humic acid sample (1g) was refluxed for 12 hours at $\left(160^{\circ} \mathrm{C}\right)$ with $50 \mathrm{~cm}^{3}$ of $6 \mathrm{M} \mathrm{HCl}$. The mixture was allowed to cool, decanted, and centrifuged after hydrolysis. The insoluble residues were washed with distilled water via centrifugation several times, and the supernatant was treated with $\mathrm{AgNO}_{3}$ solution until no white precipitate was observed. The residue was thoroughly dried over $\mathrm{CaCl}_{2}$ in a desiccator at room temperature (Chefetz et al., 2002). Finally, the obtained hydrolysed humic acid was kept for investigation. 
BAJOPAS Volume 14 Number 1,June, 2021 Potentiometric Titrations

Potentiometric measurements were carried out using a pH-meter Jenway (model 3510) with combine electrode, the sensitivity of the $\mathrm{pH}$ meter is 0.01 units. The $\mathrm{pH}$ meter was switched on half an hour before starting the titration for initial warm up of the instrument. The instrument was calibrated with an aqueous standard buffer solution of $\mathrm{pH} 4.00$ and 10.0 (borate buffer) prepared from a "Qualigens" buffer tablets.

The following sets of solutions were prepared in a $250 \mathrm{~cm}^{3}$ volumetric flask separately for $\mathrm{pH}$ metric titrations.

(i) $5 \mathrm{~cm}^{3} 0.1 \mathrm{M} \mathrm{HCl}+40 \mathrm{~cm}^{3}$ deionized water

(ii) $5 \mathrm{~cm}^{3} 0.1 \mathrm{M} \mathrm{HCl}+39 \mathrm{~cm}^{3}$ deionized water $+1 \mathrm{~cm}^{3} 0.15 \mathrm{gcm}^{-3}$ humic acid

(iii) $5 \mathrm{~cm}^{3} 0.1 \mathrm{M} \mathrm{HCl}+37 \mathrm{~cm}^{3}$ deionized water $+1 \mathrm{~cm}^{3} 0.15 \mathrm{gcm}^{-3}$ humic acid

$$
+2 \mathrm{~cm}^{3} \quad 0.01 \mathrm{M} \mathrm{Cu} \text { (II) }
$$

The solutions were titrated against standardized $0.110 \mathrm{MNaOH}$ separately. The total volume of each mixture was adjusted to $50 \mathrm{~cm}^{3}$ and the ionic strength of the solutions was maintained constant at by adding appropriate amount of stock solution of $1 \mathrm{M} \mathrm{KNO}_{3}$ (Gamal, 2015; Omar and Ali, 2015). A magnetic stirrer was used to achieve thorough mixing of the interacting solutions at $550 \mathrm{rpm}$. The same set of experimental conditions was applied for potentiometric titration of remaining samples.

\section{Evaluation of pKa of Hydrolysed peat soil Humic Acids}

The proton-ligand formation number $\mathrm{n}_{\mathbf{A}}$ were calculated by Irving and Rossotti expression (Omar and Ali, 2015).

$\mathrm{nA}=\mathrm{Y}-\frac{(\mathrm{V} 2-\mathrm{V1})(\mathrm{No}-\mathrm{Eo})}{(\mathrm{VO}+\mathrm{V1}) \mathrm{TCL}}$ 1

Where: $Y$ is number of dissociable proton, $\left(\mathrm{V}_{2^{-}}\right.$ $V_{1}$ ) is the measure of displacement of the ligand curve relative to acid curve, $\mathrm{N}^{\circ}$ and $\mathrm{E}^{\circ}$ are the resultant concentration of alkali solution, free acid solution, $\mathrm{T}_{\mathrm{cL}}{ }^{\circ}$ is the total ligand concentration, $\mathrm{V}^{\circ}$ is the total volume of titration solution, $V_{1}$ is the volume of alkali added to acid solution, $V_{2}$ is the volume of alkali added to acid solution + ligand solution, acid dissociation constants (pKa - values) of ligand were calculated by algebraic method point wise calculation (Tables 1 ). The dissociation constants (pKa) were calculated according to the following relation:

$\mathrm{pKa}=\mathrm{pH}+\log \left(\frac{n A}{1-n A}\right)$ 2

Where: pKa is the acid dissociation constant, $\mathrm{n}_{\mathrm{A}}$ is the Proton-ligand formation number and $\mathrm{pH}$ is the pH-values (Omar and Ali, 2015).

\section{Determination of metal-ligand stability constants $(\log K)$ of complexes}

The potentiometric measurement for the determination of stability constant of a complex in solution is based on the fact that the redox potential of the couple $\frac{M^{+(m-n)}}{M^{+m}}$ is shifted significantly on complexation of the metal ion with the ligand. This method involves change in hydrogen ion concentration $\left[\mathrm{H}^{+}\right]$due to the displacement or association of one or more protons taking place during complexation reaction. This change can be found out by titrating the solutions containing free acid, acid with ligand, and acid with ligand and metal ion, individually against a standard alkali solution at a constant ionic strength or temperature. Either ionic strength or temperature may be varied for different sets of solutions. In all the cases, the change in the $\mathrm{pH}$ of the solution is measured after each addition of a known amount of alkali to the reaction cell which contains the reaction mixture. The titration curves are then drawn by plotting the measured $\mathrm{pH}$ values against the corresponding volume of alkali added and the stability constants of the complexes are determined from the titration curves by employing $\mathrm{pH}$-metric titration technique given by (Irving and Rossoti).

Metal-ligand stability constants ( $\log \mathrm{K}$ ) were determined by using the following relations:

$$
\bar{n}=\frac{\left(V_{3}-V_{2}\right)\left(E^{0}+N^{0}\right)}{\left(V^{0}+V_{2}\right) \bar{n}_{A} T_{m}^{0}}
$$

and

$$
P L=\log _{10}\left\{\frac{1+\beta_{n}^{H} \frac{1}{[\text { anti } \log \mathrm{pH}]^{\mathrm{n}}}}{\mathrm{T}_{\mathrm{L}}^{0}-n \bar{T}_{m}^{0}} \mathrm{X} \frac{\left(V^{0}+V_{3}\right)}{V^{0}}\right\}
$$


BAJOPAS Volume 14 Number 1,June, 2021

Where $T_{L}, T^{\circ}, E^{\circ}$, and $V^{\circ}$ havethe same significance as in equation (1) above, $T_{m}$ denotes the total concentration of metal present in solution, $V_{3}$ is the volume of metal ions present in solution and $\beta^{H}$ is the overall proton ligand stability constant. The metal-ligand stability constants (log K) were determined by employing point wise computational Method (eq. 5 and 6).

$\operatorname{LogK}_{1}=\log \left(\frac{n}{1-n}\right)+\mathrm{pL}$ .5

$\operatorname{LogK}_{2}=\log \left(\frac{1-n}{2-n}\right)+\mathrm{pL}$ ...6

Where: Log $\mathrm{K}$ is the metal-ligand stability constant, $\mathrm{pL}$ is the Free ligand exponent function, $\mathbf{n}$ is the Average number of ligand attached with metal ion (Janraoet al., 2014). The results obtained were analyzed by an ORIGIN 2016 program using titration data and then the proton-ligand stability constants (pKa) and Metal-ligand stability constant (LogK) calculated (Omar and Ali, 2015).

\section{RESULTS AND DISCUSSION}

Fourier transformed infrared (FT-IR) spectra of isolated humic acid from peat soils Figure 2 had distinct clear absorption bands indicating the presence of major humic acid structural elemental groups such as $\mathrm{H}$ bonded $\mathrm{OH}$ $\left(3680 \mathrm{~cm}^{-1}\right.$ peak $), C=0$ of carbonyl $\left(1721 \mathrm{~cm}^{-1}\right.$ peak), functional groups of aliphatic components $\mathrm{CH}_{2}\left(2918 \mathrm{~cm}^{-1}\right.$ peak) and $\mathrm{C}-\mathrm{O}$ stretching of polysaccharide $\left(1168 \mathrm{~cm}^{-1}\right.$ peak). The positions of the absorption bands of the spectra fell within typical major absorption bands of humic acid which is at frequencies 3680, 2918, 1721, 1168 $\mathrm{cm}^{-1}$. The first peak centred in the vicinity of $3680 \mathrm{~cm}^{-1}$ region is attributed to phenol $\mathrm{OH}$ group bounded by intermolecular $\mathrm{H}$ bonds. The $2918 \mathrm{~cm}^{-1}$ band usually has absorption maximum at $2918 \mathrm{~cm}^{-1}$ which is due to $\mathrm{C}-\mathrm{H}$ stretching of alkane group $\left(\mathrm{CH}_{2}\right)$. The next major absorption band is $1721 \mathrm{~cm}^{-1}$. This band has been commonly ascribed to $\mathrm{C}=\mathrm{O}$ stretching of mainly carboxyl group $(\mathrm{COOH})$ with trace amount of ketones. The last peak was observed at 1168 $\mathrm{cm}^{-1}$ due to $\mathrm{C}-\mathrm{O}$ stretching of polysaccharides and this peak appeared also in the spectra of humic acid from peat soil. The FTIR spectra of the isolated humic acid contained all major characteristic absorption peaks of humic acid. These absorption peaks indicated the presence of the major structural elements of humic acid namely $\mathrm{H}$ bonded $\mathrm{OH}, \mathrm{C}=\mathrm{C}$ of aromatic ring, $\mathrm{C}=\mathrm{O}$ of carbonyl group (both carboxyl and ketonic), $\mathrm{CH}_{2}$ group. This strongly supports the presence of humic acid.

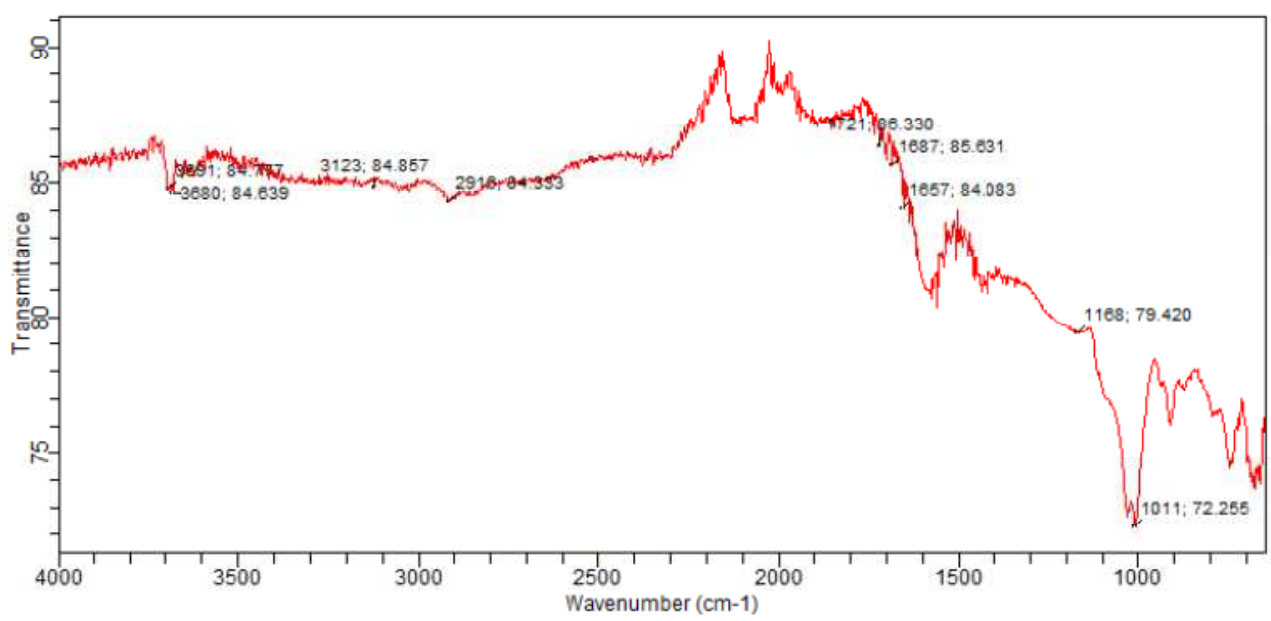

Fig. 2 : FT-IR spectraof peatsoilhumic acid (PSHA)

\section{Evaluation of acid dissociation constant (pka) of acid hydrolysed peat soil humicacid at phenolic group}

The value of the dissociation constant of the peat soil humic acid (PSHA) that underwent acidhydrolysis studied was found to be 8.9299 as shown Table 1, which is lower than the literaturevalues reported by Almeida and Szpoganics, (2015), Borges et al., (2005); Badr et al., (2012)and Fernandes et al,.(2009) of $9.73,9.47$ and 10.30. The difference between the obtained valuesand the reported values in this study might be probably as a result of acid hydrolysis of humicacid. 
BAJOPAS Volume 14 Number 1,June, 2021

Table 1: PKa of (Hydrolysed PSHA)

\begin{tabular}{|l|l|l|l|l|l|l|}
\hline $\mathrm{pH}$ & $\mathrm{BV}_{1}$ & $\mathrm{BV}_{2}$ & $\mathrm{~V}_{2}-\mathrm{V}_{1}$ & $\mathrm{nA}$ & $\log \left(\frac{n A}{1-n A}\right)$ & $\mathrm{pKa}$ \\
\hline 8.50 & 5.30 & 6.29 & 0.99 & 0.3594 & -0.2510 & 8.2490 \\
8.72 & 5.35 & 6.37 & 1.02 & 0.3400 & -0.2880 & 8.4320 \\
9.00 & 5.40 & 6.46 & 1.06 & 0.3141 & -0.3391 & 8.6609 \\
9.22 & 5.45 & 6.55 & 1.10 & 0.2882 & -0.3927 & 8.8273 \\
9.51 & 5.50 & 6.66 & 1.16 & 0.2494 & -0.4786 & 9.0314 \\
9.73 & 5.55 & 6.78 & 1.23 & 0.2041 & -0.5910 & 9.1390 \\
10.00 & 5.60 & 6.90 & 1.30 & 0.1589 & -0.7238 & 9.2762 \\
10.23 & 5.65 & 7.05 & 1.40 & 0.0941 & -0.9835 & 9.2465 \\
10.49 & 5.70 & 7.10 & 1.40 & 0.0941 & -0.9835 & 9.5065 \\
\hline
\end{tabular}

Average pKa $=8.9299 \pm 0.4186$

Table 2: PKa of (Unhydrolysed PSHA)

\begin{tabular}{|l|l|l|l|l|l|l|}
\hline $\mathrm{pH}$ & $\mathrm{BV}_{1}$ & $\mathrm{BV}_{2}$ & $\mathrm{~V}_{2}-\mathrm{V}_{1}$ & $\mathrm{nA}$ & $\log \left(\frac{\boldsymbol{n A}}{1-\boldsymbol{n}}\right)$ & $\mathrm{pKa}$ \\
\hline 8.50 & 5.30 & 5.81 & 0.51 & 0.6619 & 0.2919 & 8.7919 \\
8.72 & 5.35 & 5.90 & 0.55 & 0.6357 & 0.2418 & 8.9618 \\
9.00 & 5.40 & 6.00 & 0.60 & 0.6029 & 0.1813 & 9.1813 \\
9.22 & 5.45 & 6.10 & 0.65 & 0.5701 & 0.1226 & 9.3426 \\
9.51 & 5.50 & 6.20 & 0.70 & 0.5376 & 0.0654 & 9.5754 \\
9.73 & 5.55 & 6.33 & 0.78 & 0.4851 & -0.0259 & 9.7041 \\
10.00 & 5.60 & 6.47 & 0.87 & 0.4262 & -0.1291 & 9.8709 \\
10.23 & 5.65 & 6.62 & 0.99 & 0.3609 & -0.2481 & 9.9819 \\
10.49 & 5.70 & 6.80 & 1.10 & 0.2759 & -0.4690 & 10.0210 \\
\hline
\end{tabular}

Average pKa $=9.4923 \pm 0.4410$

Metal-ligand stability constant ( $\log \mathrm{K}$ )

The stabilityconstants require the accurate values of proton-ligand stability constants (Anil and Maroti, 2008). Metal titration curves crossed over ligand titration curve indicated the formation of complex upon proton release (Santosh, et al., 2011). If the values of n- are within range $0.2-0.8$ and $1.2-18$ this indicates the formation of $1: 1$ and 1:2 complexes (Sayyed and Mazahar, 2012).

The metal (II)-humate stepwise stability constants (log k) at phenolic group (Tables 318)

Table 3: Point-wise method, $\mathrm{Cu}$-(Hydrolysed PSHA)

\begin{tabular}{|l|l|l|l|l|l|l|l|l|}
\hline $\mathrm{pH}$ & $\mathrm{BV}_{1}$ & $\mathrm{BV}_{2}$ & $\mathrm{BV}_{3}$ & $\left(\mathrm{~V}_{3}-\mathrm{V}_{2}\right)$ & $\mathrm{n}$ & $\mathrm{pL}$ & $\log \left(\frac{n}{1-n}\right)$ & LogK $_{1}$ \\
\hline 8.50 & 5.30 & 6.29 & 6.33 & 0.04 & 0.5500 & 2.66 & 0.0871 & 2.7471 \\
8.72 & 5.35 & 6.37 & 6.41 & 0.04 & 0.5714 & 2.43 & 0.1249 & 2.5549 \\
9.00 & 5.40 & 6.46 & 6.50 & 0.04 & 0.6198 & 2.16 & 0.2122 & 2.3722 \\
9.22 & 5.45 & 6.55 & 6.59 & 0.04 & 0.6667 & 1.94 & 0.3010 & 2.2410 \\
\hline
\end{tabular}

LogK $_{1}$ (Average value) $=2.4788 \pm 0.2203$

Table 4: Point-wise method, $\mathrm{Cu}$-(Hydrolysed PSHA)

\begin{tabular}{|l|l|l|l|l|l|l|l|l|}
\hline $\mathrm{pH}$ & $\mathrm{BV}_{1}$ & $\mathrm{BV}_{2}$ & $\mathrm{BV}_{3}$ & $\left(\mathrm{~V}_{3}-\mathrm{V}_{2}\right)$ & $\mathrm{n}$ & $\mathrm{pL}$ & $\log \left(\frac{n-1}{2-n}\right)$ & LogK $_{2}$ \\
\hline 9.51 & 5.50 & 6.66 & 6.73 & 0.07 & 1.3509 & 1.70 & -0.2671 & 1.4329 \\
9.73 & 5.55 & 6.78 & 6.85 & 0.07 & 1.6383 & 1.51 & 0.2467 & 1.7567 \\
10.00 & 5.60 & 6.90 & 6.98 & 0.08 & 2.1783 & 1.31 & -0.2158 & 1.0942 \\
10.23 & 5.65 & 7.05 & 7.13 & 0.08 & 4.1904 & 1.27 & & \\
10.49 & 5.70 & 7.10 & 7.19 & 0.09 & 4.6920 & & & \\
\hline
\end{tabular}

Log $K_{2}($ Average value $)=1.4280 \pm 0.3312$ 
BAJOPAS Volume 14 Number 1,June, 2021

Table 5: Point-wise method, $\mathrm{Cu}$ (Unhydrolysed PSHA)

\begin{tabular}{|l|l|l|l|l|l|l|l|l|}
\hline $\mathrm{pH}$ & $\mathrm{BV}_{1}$ & $\mathrm{BV}_{2}$ & $\mathrm{BV}_{3}$ & $\left(\mathrm{~V}_{3}-\mathrm{V}_{2}\right)$ & $\mathrm{n}$ & $\mathrm{pL}$ & $\log \left(\frac{n}{n-1}\right)$ & Log $_{1}$ \\
\hline 8.50 & 5.30 & 5.81 & 5.85 & 0.04 & 0.2973 & 2.88 & -0.3736 & 2.5064 \\
8.72 & 5.35 & 5.90 & 5.95 & 0.05 & 0.3873 & 2.66 & -0.1992 & 2.4608 \\
9.00 & 5.40 & 6.00 & 6.05 & 0.05 & 0.4044 & 2.38 & -0.1681 & 2.2119 \\
9.22 & 5.45 & 6.10 & 6.15 & 0.06 & 0.5157 & 2.18 & -0.0272 & 2.2072 \\
9.51 & 5.50 & 6.20 & 6.27 & 0.07 & 0.6417 & 1.89 & 0.2530 & 1.1430 \\
\hline
\end{tabular}

$\operatorname{LogK}_{1}($ Average value $)=2.3059 \pm 0.6153$

Table 6:Point-wise method, $\mathrm{Cu}$ (Unhydrolysed PSHA)

\begin{tabular}{|l|l|l|l|l|l|l|l|l|}
\hline $\mathrm{pH}$ & $\mathrm{BV}_{1}$ & $\mathrm{BV}_{2}$ & $\mathrm{BV}_{3}$ & $\mathrm{~V}_{3}-\mathrm{V}_{2}$ & $\mathrm{n}$ & $\mathrm{pL}$ & $\log \left(\frac{n-1}{2-n}\right)$ & $\log \mathrm{K}_{2}$ \\
\hline 9.73 & 5.55 & 6.33 & 6.42 & 0.09 & 0.9000 & 1.69 & & \\
10.00 & 5.60 & 6.47 & 6.58 & 0.11 & 1.2578 & 1.44 & -0.4592 & 0.9808 \\
10.23 & 5.65 & 6.62 & 6.84 & 0.12 & 1.6137 & 1.26 & -0.2010 & 1.4610 \\
10.49 & 5.70 & 6.80 & 6.92 & 0.12 & 2.1052 & 1.03 & & \\
\hline
\end{tabular}

$\operatorname{LogK}_{2}$ (Average value) $=1.2209 \pm 0.3398$

Table 7:Point-wise method, Pb (Hydrolysed PSHA)

\begin{tabular}{|l|l|l|l|l|l|l|l|l|}
\hline $\mathrm{pH}$ & $\mathrm{BV}_{1}$ & $\mathrm{BV}_{2}$ & $\mathrm{BV}_{3}$ & $\left(\mathrm{~V}_{3}-\mathrm{V}_{2}\right)$ & $\mathrm{n}$ & $\mathrm{pL}$ & $\log \left(\frac{n}{1-n}\right)$ & LogK $_{1}$ \\
\hline 8.50 & 5.30 & 6.29 & 6.33 & 0.04 & 0.5500 & 2.66 & 0.0871 & 2.7471 \\
8.72 & 5.35 & 6.37 & 6.41 & 0.04 & 0.5714 & 2.43 & 0.1249 & 2.5549 \\
9.00 & 5.40 & 6.46 & 6.50 & 0.04 & 0.6198 & 2.16 & 0.2122 & 2.3722 \\
9.22 & 5.45 & 6.55 & 6.60 & 0.05 & 0.8333 & 1.96 & 0.6989 & 2.6589 \\
\hline
\end{tabular}

Log $_{\mathbf{1}}($ Average value $)=2.5832 \pm 0.1614$

Table 8:Point-wise method, Pb-(Hydrolysed PSHA)

\begin{tabular}{|l|l|l|l|l|l|l|l|l|}
\hline $\mathrm{pH}$ & $\mathrm{BV}_{1}$ & $\mathrm{BV}_{2}$ & $\mathrm{BV}_{3}$ & $\left(\mathrm{~V}_{3}-\mathrm{V}_{2}\right)$ & $\mathrm{n}$ & $\mathrm{pL}$ & $\log \left(\frac{n-1}{2-n}\right)$ & $\log \mathrm{K}_{2}$ \\
\hline 9.51 & 5.50 & 6.66 & 6.71 & 0.05 & 0.9650 & 1.67 & & \\
9.73 & 5.55 & 6.78 & 6.83 & 0.05 & 1.1702 & 1.44 & & \\
10.00 & 5.60 & 6.90 & 6.90 & 0.05 & 1.4864 & 1.22 & -0.0237 & 1.1963 \\
10.23 & 5.65 & 7.05 & 7.10 & 0.05 & 2.0190 & 1.09 & & \\
10.49 & 5.70 & 7.10 & 7.17 & 0.07 & 3.6492 & 1.00 & & \\
\hline
\end{tabular}

Log $K_{2}$ (Average value) $=1.1963$

Table 9: Point-wise method, Pb (Unhydrolysed PSHA)

\begin{tabular}{|l|l|l|l|l|l|l|l|l|}
\hline $\mathrm{pH}$ & $\mathrm{BV}_{1}$ & $\mathrm{BV}_{2}$ & $\mathrm{BV}_{3}$ & $\mathrm{~V}_{3}-\mathrm{V}_{2}$ & $\mathrm{n}$ & $\mathrm{pL}$ & $\begin{array}{l}\text { Log } \\
\left(\frac{n}{n-1}\right)\end{array}$ & Log $\mathrm{K}_{1}$ \\
\hline 8.50 & 5.30 & 5.81 & 5.85 & 0.04 & 0.2973 & 2.88 & -0.3736 & 2.5064 \\
8.72 & 5.35 & 5.90 & 5.94 & 0.04 & 0.3099 & 2.66 & -0.5477 & 2.3123 \\
9.00 & 5.40 & 6.00 & 6.05 & 0.05 & 0.4044 & 2.38 & -0.1681 & 2.2119 \\
9.22 & 5.45 & 6.10 & 6.15 & 0.06 & 0.5157 & 2.18 & 0.0272 & 2.2072 \\
9.51 & 5.50 & 6.20 & 6.26 & 0.07 & 0.6417 & 1.89 & 0.2530 & 2.1430 \\
9.73 & 5.55 & 6.40 & 6.40 & 0.07 & 0.7000 & 1.67 & 0.3680 & 2.0380 \\
\hline
\end{tabular}

LogK $_{1}$ (Average value) $=2.2364 \pm 0.1602$

Table 10: Point-wise method, Pb (Unhydrolysed PSHA)

\begin{tabular}{|l|l|l|l|l|l|l|l|l|}
\hline $\mathrm{pH}$ & $\mathrm{BV}_{1}$ & $\mathrm{BV}_{2}$ & $\mathrm{BV}_{3}$ & $\mathrm{~V}_{3}-\mathrm{V}_{2}$ & $\mathrm{n}$ & $\mathrm{pL}$ & $\log \left(\frac{n-1}{2-n}\right)$ & $\log \mathrm{K}_{2}$ \\
\hline 10.00 & 5.60 & 6.47 & 6.55 & 0.08 & 1.9503 & 1.41 & & \\
10.23 & 5.65 & 6.62 & 6.72 & 0.11 & 1.4792 & 1.26 & -0.0361 & 1.2239 \\
\hline
\end{tabular}

$\operatorname{LogK}_{2}$ (Average value) $=1.2239$

Table 11: Point-wise method, Mg (Hydrolysed PSHA)

\begin{tabular}{|l|l|l|l|l|l|l|l|l|}
\hline $\mathrm{pH}$ & $\mathrm{BV}_{1}$ & $\mathrm{BV}_{2}$ & $\mathrm{BV}_{3}$ & $\left(\mathrm{~V}_{3}-\mathrm{V}_{2}\right)$ & $\mathrm{n}$ & $\mathrm{pL}$ & $\log \left(\frac{n}{n-1}\right)$ & LogK $_{1}$ \\
\hline 8.50 & 5.30 & 6.29 & 6.31 & 0.02 & 0.2750 & 2.64 & -0.4290 & 2.2110 \\
8.72 & 5.35 & 6.37 & 6.39 & 0.02 & 0.2858 & 2.42 & -0.3978 & 2.0222 \\
9.00 & 5.40 & 6.46 & 6.49 & 0.03 & 0.4648 & 2.14 & -0.0612 & 2.0788 \\
9.22 & 5.45 & 6.55 & 6.59 & 0.04 & 0.6667 & 1.94 & 0.3010 & 2.2410 \\
\hline
\end{tabular}

$\log _{\mathbf{1}}($ Average value) $=2.1382 \pm 0.1046$ 
BAJOPAS Volume 14 Number 1,June, 2021

Table 12: Point-wise method, Mg (Hydrolysed PSHA)

\begin{tabular}{|l|l|l|l|l|l|l|l|l|}
\hline $\mathrm{pH}$ & $\mathrm{BV}_{1}$ & $\mathrm{BV}_{2}$ & $\mathrm{BV}_{3}$ & $\left(\mathrm{~V}_{3}-\mathrm{V}_{2}\right)$ & $\mathrm{n}$ & $\mathrm{pL}$ & $\log \left(\frac{n-1}{2-n}\right)$ & LogK $_{2}$ \\
\hline 9.51 & 5.55 & 6.66 & 6.71 & 0.05 & 0.9650 & 1.67 & & \\
9.73 & 5.55 & 6.78 & 6.84 & 0.06 & 1.4042 & 1.47 & -0.1686 & 1.3014 \\
10.00 & 5.60 & 6.90 & 6.93 & 0.06 & 1.7838 & 1.23 & 0.5593 & 1.7893 \\
10.23 & 5.65 & 7.05 & 7.10 & 0.06 & 3.1429 & 1.10 & & \\
10.49 & 5.70 & 7.10 & 7.18 & 0.07 & 3.6492 & 0.83 & & \\
\hline
\end{tabular}

LogK $_{2}($ Average value $)=1.5453 \pm 0.3450$

Table 13: Point-wise method, Mg (Unhydrolysed PSHA)

\begin{tabular}{|l|l|l|l|l|l|l|l|l|}
\hline $\mathrm{pH}$ & $\mathrm{BV}_{1}$ & $\mathrm{BV}_{2}$ & $\mathrm{BV}_{3}$ & $\mathrm{~V}_{3}-\mathrm{V}_{2}$ & $\mathrm{n}$ & $\mathrm{pL}$ & $\log \left(\frac{n}{n-1}\right)$ & $\operatorname{Log~}_{1}$ \\
\hline 8.50 & 5.30 & 5.81 & 5.85 & 0.04 & 0.2973 & 2.88 & -0.3736 & 2.5064 \\
8.72 & 5.35 & 5.90 & 5.94 & 0.04 & 0.3099 & 2.66 & -0.3477 & 2.3123 \\
9.00 & 5.40 & 6.00 & 6.04 & 0.04 & 0.3236 & 2.38 & -0.3202 & 2.0598 \\
9.22 & 5.45 & 6.10 & 6.15 & 0.05 & 0.4297 & 2.17 & -0.1230 & 2.0470 \\
9.51 & 5.50 & 6.20 & 6.26 & 0.06 & 0.5500 & 1.89 & 0.0871 & 1.9771 \\
9.73 & 5.55 & 6.33 & 6.40 & 0.07 & 0.7000 & 1.67 & 0.3680 & 2.0380 \\
\hline
\end{tabular}

LogK $_{1}$ (Average value) $=2.1568 \pm 0.2069$

Table 14: Point-wise method, Mg (Unhydrolysed PSHA)

\begin{tabular}{|l|l|l|l|l|l|l|l|l|}
\hline $\mathrm{pH}$ & $\mathrm{BV}_{1}$ & $\mathrm{BV}_{2}$ & $\mathrm{BV}_{3}$ & $\mathrm{~V}_{3}-\mathrm{V}_{2}$ & $\mathrm{n}$ & $\mathrm{pL}$ & $\log \left(\frac{n-1}{2-n}\right)$ & $\log \mathrm{K}_{2}$ \\
\hline 10.00 & 5.60 & 6.47 & 6.55 & 0.08 & 0.9148 & 1.41 & & \\
10.23 & 5.65 & 6.62 & 6.71 & 0.09 & 1.2102 & 1.20 & -0.5749 & 0.6251 \\
10.49 & 5.70 & 6.80 & 6.92 & 0.09 & 1.5968 & 1.03 & 0.1703 & 1.2003 \\
\hline
\end{tabular}

LogK $_{2}$ (Average value) $=0.9127 \pm 0.4070$

Table15:Point-wise method, Cd (Hydrolysed PSHA)

\begin{tabular}{|l|l|l|l|l|l|l|l|l|}
\hline $\mathrm{pH}$ & $\mathrm{BV}_{1}$ & $\mathrm{BV}_{2}$ & $\mathrm{BV}_{3}$ & $\left(\mathrm{~V}_{3}-\mathrm{V}_{2}\right)$ & $\mathrm{n}$ & $\mathrm{pL}$ & $\log \left(\frac{n}{1-n}\right)$ & LogK $_{1}$ \\
\hline 8.50 & 5.30 & 6.29 & 6.31 & 0.02 & 0.2750 & 2.64 & -0.4210 & 2.2190 \\
8.72 & 5.35 & 6.37 & 6.40 & 0.03 & 0.4286 & 2.42 & -0.1249 & 2.2951 \\
9.00 & 5.40 & 6.46 & 6.49 & 0.03 & 0.4648 & 2.14 & -0.0612 & 2.0788 \\
9.22 & 5.45 & 6.55 & 6.59 & 0.04 & 0.6667 & 1.96 & 0.3010 & 2.2610 \\
9.51 & 5.55 & 6.66 & 6.70 & 0.04 & 0.7720 & 1.67 & 0.5297 & 2.1997 \\
\hline
\end{tabular}

LogK $_{\mathbf{1}}$ (Average value) $=2.2108 \pm 0.0825$

Table 16: Point-wise method, Cd (Hydrolysed PSHA)

\begin{tabular}{|l|l|l|l|l|l|l|l|l|}
\hline $\mathrm{pH}$ & $\mathrm{BV}_{1}$ & $\mathrm{BV}_{2}$ & $\mathrm{BV}_{3}$ & $\left(\mathrm{~V}_{3}-\mathrm{V}_{2}\right)$ & $\mathrm{n}$ & $\mathrm{pL}$ & $\log \left(\frac{n-1}{2-n}\right)$ & Log $_{2}$ \\
\hline 9.73 & 5.55 & 6.78 & 6.83 & 0.06 & 1.4042 & 1.47 & -0.1686 & 1.3014 \\
10.00 & 5.60 & 6.90 & 6.95 & 0.06 & 1.7838 & 1.23 & 0.5593 & 1.7893 \\
10.23 & 5.65 & 7.05 & 7.10 & 0.06 & 3.1429 & 1.09 & & \\
10.49 & 5.70 & 7.10 & 7.16 & 0.06 & 3.1429 & 0.89 & & \\
& & & & & & & & \\
\hline
\end{tabular}

$\operatorname{LogK}_{2}$ (Average value) $=1.5453 \pm 0.3450$

Table 17: Point-wise method, Cd (Unhydrolysed PSHA)

\begin{tabular}{|l|l|l|l|l|l|l|l|l|}
\hline $\mathrm{pH}$ & $\mathrm{BV}_{1}$ & $\mathrm{BV}_{2}$ & $\mathrm{BV}_{3}$ & $\mathrm{~V}_{3}-\mathrm{V}_{2}$ & $\mathrm{n}$ & $\mathrm{pL}$ & $\log \left(\frac{n}{n-1}\right)$ & $\operatorname{Log~}_{1}$ \\
\hline 8.50 & 5.30 & 5.81 & 5.86 & 0.05 & 0.3717 & 2.88 & -0.2280 & 2.6520 \\
8.72 & 5.35 & 5.90 & 5.95 & 0.05 & 0.3873 & 2.66 & -0.1992 & 2.4608 \\
9.00 & 5.40 & 6.00 & 6.06 & 0.06 & 0.4853 & 2.38 & -0.0255 & 2.3545 \\
9.22 & 5.45 & 6.10 & 6.16 & 0.06 & 0.5157 & 2.18 & -0.0272 & 2.2072 \\
9.51 & 5.50 & 6.20 & 6.27 & 0.07 & 0.6417 & 1.89 & 0.2530 & 1.1430 \\
9.73 & 5.55 & 6.33 & 6.41 & 0.08 & 0.8000 & 1.69 & 0.6020 & 2.2920 \\
& & & & & & & & \\
\hline
\end{tabular}

$\operatorname{LogK}_{1}($ Average value $)=2.2516 \pm 0.5380$ 
BAJOPAS Volume 14 Number 1,June, 2021

Table 18: Point-wise method, Cd (Unhydrolysed PSHA)

\begin{tabular}{|l|l|l|l|l|l|l|l|l|}
\hline $\mathrm{pH}$ & $\mathrm{BV}_{1}$ & $\mathrm{BV}_{2}$ & $\mathrm{BV}_{3}$ & $\mathrm{~V}_{3}-\mathrm{V}_{2}$ & $\mathrm{n}$ & $\mathrm{pL}$ & $\log \left(\frac{n-1}{2-n}\right)$ & $\log \mathrm{K}_{2}$ \\
\hline 10.00 & 5.60 & 6.47 & 6.57 & 0.10 & 1.1434 & 1.43 & & \\
10.23 & 5.65 & 6.62 & 6.72 & 0.10 & 1.3448 & 1.23 & -0.2788 & 0.9512 \\
10.49 & 5.70 & 6.80 & 6.90 & 0.10 & 1.7742 & 1.03 & 0.5351 & 1.5651 \\
\hline
\end{tabular}

$\operatorname{LogK}_{2}($ Average value $)=1.2581 \pm 0.4340$

Table 19: Stepwise and overall Stability constants of thehydrolysed and unhydrolysed divalent metal (II) complexes

\begin{tabular}{|c|c|c|c|}
\hline Chelates & LogK $_{1}$ & $\log _{2}$ & Log $\beta$ \\
\hline [Cu (Hydrolysed PSHA-1) $\left.{ }_{2}\right]$ & 2.4788 & 1.4280 & 3.9068 \\
\hline$\left[\mathrm{Pb}(\text { Hydrolysed PSHA-1) })_{2}\right]$ & 2.5832 & 1.1963 & 3.7795 \\
\hline$\left[\mathrm{Cd}(\text { Hydrolysed PSHA-1 })_{2}\right]$ & 2.2108 & 1.5453 & 3.7561 \\
\hline$\left[\mathrm{Mg}(\text { Hydrolysed PSHA-1 })_{2}\right]$ & 2.1382 & 1.5453 & 3.6835 \\
\hline [Cu (Unhydrolysed PSHA-1) & 2.3059 & 1.2209 & 3.5268 \\
\hline$[\mathrm{Pb}$ (Unhydrolysed PSHA-1) 2$]$ & 2.2364 & 1.2239 & 3.4603 \\
\hline [Cd (Unhydrolysed PSHA-1) 2 ] & 2.2516 & 1.2581 & 3.5097 \\
\hline$[\mathrm{Mg}$ (Unydrolysed PSHA-1) & 2.1568 & 0.9127 & 3.0695 \\
\hline
\end{tabular}

The results obtained (Table19) shows the stepwise and overall stability constants to be not high indicating low stability of the complexes, because the solubility of most metal ions in the basic $\mathrm{pH}$ range is minimal due to metal hydroxide precipitation (Karimi, 2017). In general, the stepwise stability constants $\left(K_{1}\right.$ and $K_{2}$ ) follow the order $K_{1}>K_{2}$ for the copper, lead, magnesium and cadmium complexes respectively. The steady decrease of the values with increasing number of ligands is in agreement with the prediction made by researchers (Na'aliya, 2013). The decrease could be attributed to the fact that as the number of the ligands (Humate ions) that enters the coordination zone increases the aqua molecules available for replacement by the ligands become less. Thus, the metal ions become less electron loving with progressive intake of the ligand and this results in the decrease in the values of the constants (Na'aliya, 2013). Also the stability of the complexes is influenced by the size and number of the chelate rings(Mackay and Mackay,2002).All the complexes form rings in their structure as humate, a bidentate ligand, bond the metal ions in the ratio 1:2 (Boguta and Sokolowska, 2016) forming chelate rings. The values of the overall stability constants $(\log \beta)$ obtained for humate complexes are not high indicating low stability as the values are not high. LogK values for copper-humates (Table 3 to 6) obtained in this study are lower than those reported for the complexes of humic acids (Pandey et al., 2015; Dinu, 2013; Kaschl et al., 2010 and Gilbeto and Jorg, 2001). The values of LogK(Table 7 to 10 ) forlead-humates are lower than those reported for the lead in the literature (Dinu, 2013; Gilbeto and Jorg 2001). Log K values(Table 11 to 14 ) for magnesium-humates obtained in this study are close to those reported by (Pandey et al., 2015). Log K values of cadmium-humates (Table 15 to 18 ) obtained in this work near to the one reported by (Dinu, 2013 and Pandey et al., 2015).The difference between the reported values and the values obtained in this study might be probably as a result of acid hydrolysis of humic acid. The values of the overall stability constants $(\log \beta)$ of the copper humates complexes presented in Table 19 is high than that of other metal humate complexes, show relatively high stability of CuHA complexes, show the following order of stability: $\mathrm{Cu}>\mathrm{Pb}>\mathrm{Cd}>\mathrm{Mg}$; which are in close agreement to the findings of (Dinu, 2013 and Pandey et al., 2015).The high stability of Cuhumate chelate could be attributed to the existence of coordinate covalent bond between the complexing agents and the $\mathrm{Cu}^{2+}$ ions. Since, $\mathrm{Cu}^{2+}$ being a metal of the transitional series with $3 d^{9}$ electronic configurations can accept the electrons from the complexing agents. Similarly, the low stabilities of $\mathrm{Pb}, \mathrm{Cd}$ and $\mathrm{Mg}$ complexes could be explained by that $\mathrm{Pb}^{2+}$ with $6 s^{2}, \mathrm{Cd}^{2+}$ with $4 \mathrm{~d}^{10}$ and $\mathrm{Mg}^{2+}$ with $2 \mathrm{p}^{6}$ their electronic configuration has a completely filled $\mathrm{d}, \mathrm{p}$ and $\mathrm{s}$ orbitals. Moreover, the stabilities of metal ions with hydrolysed humic acid from peat soil were higher than those with unhydrolysed humic acid from peat soil; which is ascribed to the high content of acidity in hydrolysed humic acid than unhydrolysed humic acid. 
BAJOPAS Volume 14 Number 1,June, 2021 CONCLUSION

The values of logk for $\mathrm{Cu}(\mathrm{II})$ hydrolysed humic acid complex was higher followed by $\mathrm{Pb}$ (II), $\mathrm{Cd}(\mathrm{II})$ and $\mathrm{Mg}$ (II) hydrolysed humic acid complexes as compared with metal(II) unhydrolysed humic acid complexes. This indicates acid hydrolysis of humic acid can

\section{REFERENCES}

Almeida, V.R. and Szpoganicz, B. (2015). Humic Acid Potentiometric Response Patterns:Out- of Equilibrium Properties and Species Distribution Modelling. Chemical. Biol. Technol. Agric. 2: 17.

Anđelković, T., Nikolić, R., Bojić, A.,Anđelković, D., and Nikolic G.,(2010). Binding of Cadmium to Soil Humic Acid as A Function of Carboxyl Group Content. Macedonian Journal of Chemistry and Chemical Engineering.29(2): 215-224.

Anil, B. N. and Maroti, N. (2008). Studies on Influence of Die-Lectric Constants on Complex Equilibria between Substituted Py-Razalines and Lanthanide Metal Ions pH-Metrically. Amer.-Euras. scient. Res. 3(2): 212-216.

Ashok, K., Pandey, S. P. and Misra, V (2000). Stability Constants of Metal-Humic Acid Complexes and its Role in Environmental Detoxification. Journal of Ecotoxicology and Environmental Safety. 47(2):157-200.

Badr, M. H., El-Halafawi, M. H. and Abd El-al Zeid, E. R. (2012). Comparison Between the Effect of Ionic Strength on Acidity and Dissociation Constants of Humic Acids Extracted from Sewage Sludge and Nile Water Hyacinth Composts.Global Journal of Environmental Research 6 (1): 36-43.

Baruah, M.K., Borah, D., Saikia, P.P., Paul, S., Sharma, T. (2015). Evaluation of pKa Values of Soil Humic Acids and their Complexation Properties. International Journal of Plant \& Soil Science 6(4) : 218-228.

Boguta, P. Sokolowska, Z. (2016). Interactions of $\mathrm{Zn}$ (II) Ions with Humic Acids Isolated from Various Types of Soils. Effect of $\mathrm{pH}, \mathrm{Zn}$ Concentrations and Humic Acids Chemical Properties. Journal of Geochemical Explaration 168. 119-126.

Borges, F., Guimaraes, C., Lima, L.F.C., Pinto, I. and Reis, S.(2005). Potentiometric Studies on the Complexation of Copper(II) by Phenolic Acids as Discrete Ligand Models of enhance the complexation behavior of humic acid with metal (II) ions. However, the higher values of $\log \beta$ for $\mathrm{Cu}(\mathrm{II}), \mathrm{Pb}(\mathrm{II}), \mathrm{Cd}(\mathrm{II})$ and $\mathrm{Mg}(\mathrm{II})$ hydrolysed humic acid complexes indicates more stable stepwise complexes formed as compared with $\mathrm{Cu}(\mathrm{II}), \mathrm{Pb}$ (II), $\mathrm{Cd}$ (II) and $\mathrm{Mg}(\mathrm{II})$ unhydrolysed humic acid complexes.

Humic Substances Talanta 66 (2005) 670-673.

Chefetz, B., Salloum, M. J., Deshmulkin, A. P. and Hatcher, P. (2002). Structural Components of Humic Acids as Determined by Chemical Modifications and Carbon-13 NMR, Pyrolysis, and Thermochemolysis- Gas Chromatography/Mass Spectrometry. Soil Science Society of American Journal Abstract Division S-2- Soil Chemistry66. 1159-1171.

Dinu, M. I. (2013). Metals Complexation with Humic Acids in Surface Water of Different Environ. Sci. Technol. 31(1): 1-17.

Fernandes, A.N., Giacomelli, C., Giovanela, M. Vaz, D.V. Szpoganicz, B. and Maria M. D. (2009). Potentiometric Acidity Determination in Humic Substances Influenced by Different Analytical Procedures.J. Braz. Chem. Soc. 20 (9):14.

Gamal, A. H. (2015). Stability Constants of Rhenium (V) Metal Complexes with Selected Drugs. Pyrex Journal of Research in Environmental Studies. 2(2): 006-014.

Janrao, D. M., Pathan, J., Kayande, D.D., and Mulla, J.J. (2014). An Over View of Potentiometric Determination of Stability Constants of Metal Complexes. Sci. Revs. Chem. Commun.: 4(1), 2014, 11-24.

Karimi, H. (2017). Effect of pH and Initial Pb(II) Concentration on the Lead Removal Efficiency from Waste Water Using $\mathrm{Ca}(\mathrm{OH})_{2}$. International Journal of Water and Waste Water Treatment 3.2

Kaschl, A. Romheld, V. and Chen, Y. (2010). Binding of Cadmium, Copper and Zinc to Humic Substances Originating from Municipal Solid Waste Compost. Israel Journal of Chemistry Vol. 42(1): 89-98.

Kostic, I. S., Tatjana, P, A., Nikolic, R. S., Cvetkovic, T. P., Pavlovic, D. D., Aleksandar, L.J. and Bojic, A. (2012). Comparative Study of Binding Strengths of Heavy Metals with Humic Acid. J.serb. Chem. Soc. 76(9) pp 1-20. 
BAJOPAS Volume 14 Number 1,June, 2021

Na'aliya, J. (2013). Determination of Stepwise Stability Constants and Gibbs free Energy Change of Trisprolina to Complexes of some Divalent Transition Metal ions. Bayero Journal of Pure and Applied Sciences 6(2): 112-114.

Omar, A. A. and Ali, E. A. (2015). Potentiometric Studies on Complexes of $\mathrm{Cr}$ (III) and $\mathrm{Zr}$ (IV) with some Carboxylic Acids. International Journal of Advanced Chemistry, 3(1) 25-

37.

Pandey, A. K. Pandey, S. D. and Misr, V. (2015).Stability Constants of Metal- Humic Acid Complexes and Its Role in Environmental Detoxification. J. Ecotoxicology and Environmental Safety. 47(1):195-200.

Ram, N. and Raman, K.V. (1984). Stability Constants of Complexes of Metals with
Humicand Fuvic Acids under Non- acidConditions. Journal of Plant Nutrition and Soil Sciences.

147:171-176.

Santosh, D. D., Ashok, B. K., Vijay, J. T., Shivraj, G. W. and Vinay, V. W. (2011). Potentiometric Studies of Elec-Trolyte Effects on Complex Equilibria of Some Substituted 5-(2-hydroxy Phenyl) Pyrazoles. Der pharm. 3 (6): 75-83.

Sayyed, H. and Abdul Rahim, M. F. (2012). Studies of Binary Complexes of Metal Ions with Mandelic Acid by Potentiometry. Chem. J. 02 (6): 206209.

Shirvani, M. Moradian, E. Khalili, B. Bakhtiary, S. (2015). Interaction of $\mathrm{Cd}$ and $\mathrm{Pb}$ with Humate-Palygorskite and HumateSepiolite Complexes. Journal of water, air and pollution 3: 220-228. 


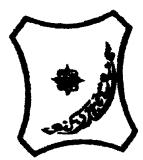

Bayero Journal of Pure and Applied Sciences, 14(1): 54 - 63

Received: November, 2020

Accepted: April, 2021

ISSN $2006-6996$

\title{
STABILITY CONSTANTS OF COMPLEXES OF METAL IONS WITH PEATSOIL HUMIC ACIDS UNDER NON-ACID-CONDITIONS
}

\author{
${ }^{* 1}$ Sabo, Yusuf ${ }^{2}$ Jimoh, W.L.O., ${ }^{3}$ Isa Baba Koki and ${ }^{4}$ Sholadoye, Q. 0. \\ ${ }^{1}$ Department of Pure and Industrial Chemistry, Bayero University, Kano \\ ${ }^{3}$ Department of Chemistry, Yusuf Maitama Sule University Kano. P.M.B. 3220 Kano, Nigeria. \\ ${ }^{4}$ Department of Chemistry, Nigerian Police Academy, Wudil, Kano-Nigeria
}

*Correspondence E-mail; saboyusuf18@yahoo.com

ABSTRACT

Stability constants of complexes of four divalent metal ions viz. $\mathrm{Cu}^{2+}, \mathrm{Pb}^{2+}, \mathrm{Mg}^{2+}$ and $\mathrm{Cd}^{2+}$ with humic acids (HA) were determined by potentiometric titration of humic acids with the corresponding salt of the divalent metals in aqueous media under non-acid-condition. The log $K$ (logarithm of the stability constant) ranged from 1.0942 to 2.7471 for metalhumic acid complexes were determined using point-wise computational method. The order of stability constants were obtained as follows: $\mathrm{Cu}>\mathrm{Pb}>\mathrm{Cd}>\mathrm{Mg}$ for metal $-\mathrm{HA}$ complexes respectively, indicating a higher degree of complexation with Cu metal ion.

Keywords: stability constant, humic acid, potentiometric titration, divalent metals, acid hydrolysis.

\section{NTRODUCTION}

The stability constant of a complex is the numerical expression of its stability and provides a quantitative measure of affinity of the metal ion to the complexing agent. An understanding of the relative stability of metal-complexes helps in predicting the behavior of metal ions in the soil (Ram and Raman, 1982). Extensive researches has been done to determine the stability constants of the complexes formed between humic acid (HA) with a number of metal ions. Ashok et al., (2000) reported that humic acid with hydroxyl, phenoxyl and carboxyl reactive groups can form coordination compound with metal ions at $\mathrm{pH}$ 3.5. The stability constants(Log K) for different metalhumic acid complexes indicated the following order of the stabilities of complexes formed between humic acid and metal ion, $\mathrm{Cu}>\mathrm{Fe}$ $>\mathrm{Pb}>\mathrm{Ni}>\mathrm{Co}>\mathrm{Ca}>\mathrm{Cd}>\mathrm{Zn}>\mathrm{Mn}>\mathrm{Mg}$. Andelkovic et al., (2010) investigated the binding of $\mathrm{Cd}$ (II) to soil humic acid at pH 6.5 and in $0.1 \mathrm{M} \mathrm{KNO}_{3}$ ionic medium. The stability constant for binding indicating greater stability in the case when carboxyl groups are involved in complexation reaction. Kostic et al.,(2012) investigated the complexation of humic acid with certain heavy metal ions (Co(II), $\mathrm{Ni}(\mathrm{II}), \mathrm{Cu}(\mathrm{II})$,
$\mathrm{Zn}(\mathrm{II})$, and $\mathrm{Pb}(\mathrm{II})$. The experiment was performed at $25^{\circ} \mathrm{C}$, at pH 4.0 and ionic strength of $0.01 \mathrm{M}$. Stability constant of complex between $\mathrm{Pb}$ (II) ions and humic acid is greater than stability constants of other investigated metalhumate complexes. Bogata and Sokolowska (2016) analyses the interaction between humic acids from different soils and $\mathrm{Zn}$ (II) ions at wide concentration ranges and at $\mathrm{pH} 5$. Studies have showed significant impact of $\mathrm{Zn}$ concentration, $\mathrm{pH}$ and some properties of humic acids with zinc.But all of these studies were limited to acidic $\mathrm{pH}$ range. Therefore, the present study was carried out to determine and compare the stability constants of complexes of metal ions with hydrolysed peat soil humic acid and unhydrolysed peat soil humic under non-acid conditions.

\section{MATERIALS AND METHODS}

Analytical grade chemicals used includes hydrochloric acid $(\mathrm{HCl})$, nitric acid $\left(\mathrm{HNO}_{3}\right)$, sodium hydroxide $(\mathrm{NaOH})$, lead nitrate $\mathrm{Pb}\left(\mathrm{NO}_{3}\right)_{2}$, copper nitrate $\mathrm{Cu}\left(\mathrm{NO}_{3}\right)_{2} \cdot 3 \mathrm{H}_{2} \mathrm{O}$, cadmium nitrate $\mathrm{Cd}\left(\mathrm{NO}_{3}\right)_{2} \cdot 4 \mathrm{H}_{2} \mathrm{O}$, magnesium nitrate $\mathrm{Mg}\left(\mathrm{NO}_{3}\right)_{2} \cdot 6 \mathrm{H}_{2} \mathrm{O}$, potassium nitrate $\left(\mathrm{KNO}_{3}\right)$, calcium chloride $\left(\mathrm{CaCl}_{2}\right)$, (sigma-Aldrich). Dowex 50WX8, (20-50 mesh) from Fluka. 


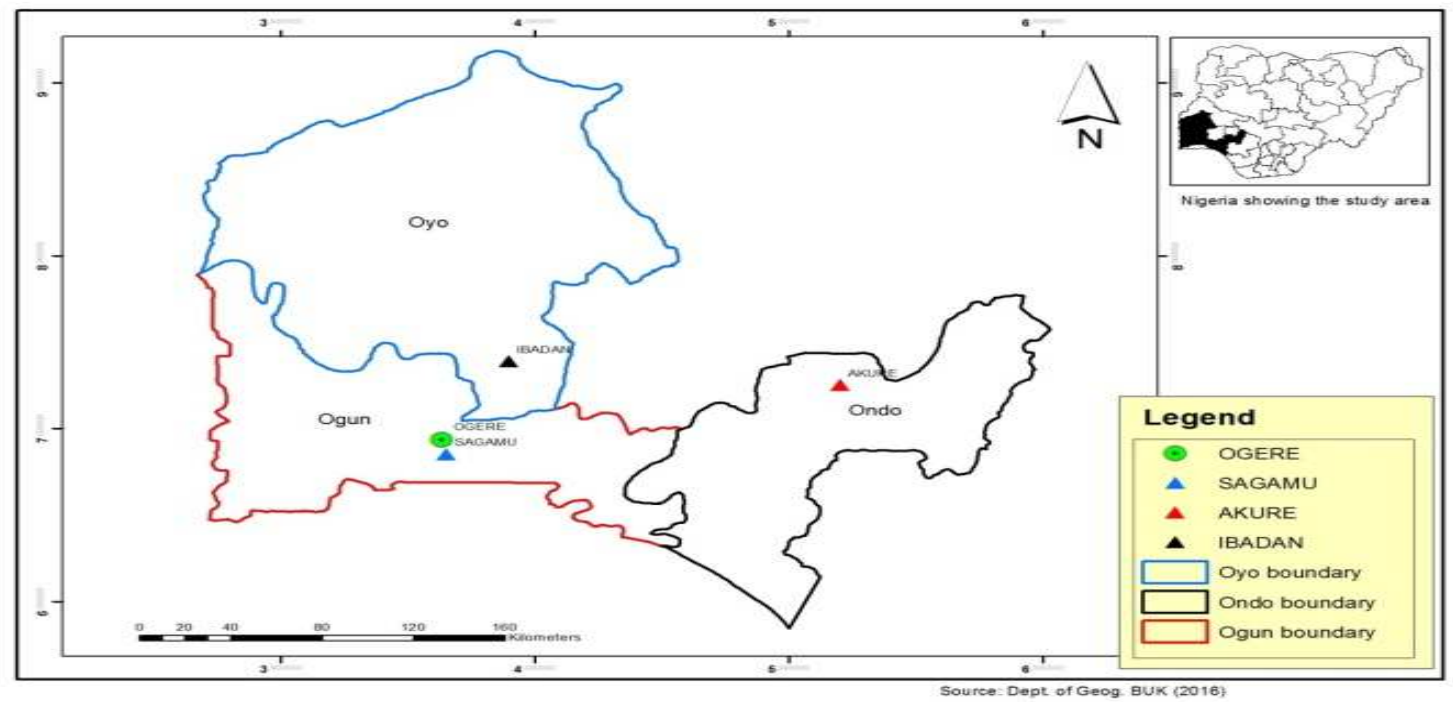

Figure 1: Map showing the sampling point at Sagamu Town, Ogun State.

\section{Description of Sampling Area}

Sagamu has geographical coordinates between $6^{\circ} 50^{\prime}$ north; $3^{\circ} 38^{\prime}$ east is located in south western region of Nigeria. The region has tropical wet and dry climate with a lengthy wet season and relatively constant temperatures throughout the course of the year. Wet season runs from March to October, November to December forms the region dry season. The vegetation type of the region is savannah which is really grassland with small bushes and occasional big trees. Grassland soils have substantially higher organic matter content than forest soils (Novackova, 2011).

\section{Sample Collection}

The Peatsoil samples were collected from four different sampling points $(0-10 \mathrm{~cm}$ depth) in Sagamu into polyethylene bag with plastic spoons. Samples were taken to the laboratory, extraneous materials were removed; the samples were air-dried, crushed and ground to a fine powder in a mortar passed through a $0.20 \mathrm{~mm}$ sieve. The samples were kept for analysis.

\section{Isolation and purification of humic acid from peat soil sample}

Peatsoil sample $(100 \mathrm{~g})$ was mixed with 1000 $\mathrm{cm}^{3}$ of $0.1 \mathrm{M} \mathrm{NaOH}$ solution, shaken for 3hours and left to stand overnight. Dark-coloured supernatant was obtained and decanted from solid residue. The dark-coloured supernatant was acidified to $(\mathrm{pH}=1.0)$ with $6 \mathrm{M} \mathrm{HCl}$ stirred and allowed to stand for 6 hours. Yellowish brown supernatant and dark-brown precipitate were obtained. The yellowish brown supernatant was decanted followed by centrifuge and discarded. The dark-brown precipitate was mixed with $500 \mathrm{~cm}^{3}$ of $0.1 \mathrm{M} \mathrm{NaOH}$ solution followed by passing through dowex resin. The dark-brown solution was acidified to $(\mathrm{pH}=1.0)$ with $6 \mathrm{M} \mathrm{HCl}$ stirred and allowed to stand for 3 hours. The dark-brown precipitate was washed several times with deionized water. The supernatant was treated with $\mathrm{AgNO}_{3}$ solution until no white precipitate observed. The humic acid was transferred to weighed crucible and dried at $60^{\circ} \mathrm{C}$ in an oven for 12 hours. The humic acid was cooled and dried in the desiccator, weighed and recorded. The obtained humic acid was dried again at $60^{\circ} \mathrm{C}$ for additional 6 hours cooled and dried in the desiccator, weighed and recorded constant weight was obtained (Baruah et al., 2015).

\section{FT-IR analysis}

FT-IR spectra of humic acid sample was analysed using Carry 630 FT-IR Agilent Technologies.

Unhydrolysed compost humic acid

The unhydrolysed humic acid was obtained after isolation and purification of compost humic acid and kept for investigation.

\section{Acid hydrolysis of Peatsoil acid}

Peatsoil humic acid sample (1g) was refluxed for 12 hours at $\left(160^{\circ} \mathrm{C}\right)$ with $50 \mathrm{~cm}^{3}$ of $6 \mathrm{M} \mathrm{HCl}$. The mixture was allowed to cool, decanted, and centrifuged after hydrolysis. The insoluble residues were washed with distilled water via centrifugation several times, and the supernatant was treated with $\mathrm{AgNO}_{3}$ solution until no white precipitate was observed. The residue was thoroughly dried over $\mathrm{CaCl}_{2}$ in a desiccator at room temperature (Chefetz et al., 2002). Finally, the obtained hydrolysed humic acid was kept for investigation. 
BAJOPAS Volume 14 Number 1,June, 2021 Potentiometric Titrations

Potentiometric measurements were carried out using a pH-meter Jenway (model 3510) with combine electrode, the sensitivity of the $\mathrm{pH}$ meter is 0.01 units. The $\mathrm{pH}$ meter was switched on half an hour before starting the titration for initial warm up of the instrument. The instrument was calibrated with an aqueous standard buffer solution of $\mathrm{pH} 4.00$ and 10.0 (borate buffer) prepared from a "Qualigens" buffer tablets.

The following sets of solutions were prepared in a $250 \mathrm{~cm}^{3}$ volumetric flask separately for $\mathrm{pH}$ metric titrations.

(i) $5 \mathrm{~cm}^{3} 0.1 \mathrm{M} \mathrm{HCl}+40 \mathrm{~cm}^{3}$ deionized water

(ii) $5 \mathrm{~cm}^{3} 0.1 \mathrm{M} \mathrm{HCl}+39 \mathrm{~cm}^{3}$ deionized water $+1 \mathrm{~cm}^{3} 0.15 \mathrm{gcm}^{-3}$ humic acid

(iii) $5 \mathrm{~cm}^{3} 0.1 \mathrm{M} \mathrm{HCl}+37 \mathrm{~cm}^{3}$ deionized water $+1 \mathrm{~cm}^{3} 0.15 \mathrm{gcm}^{-3}$ humic acid

$$
+2 \mathrm{~cm}^{3} \quad 0.01 \mathrm{M} \mathrm{Cu} \text { (II) }
$$

The solutions were titrated against standardized $0.110 \mathrm{MNaOH}$ separately. The total volume of each mixture was adjusted to $50 \mathrm{~cm}^{3}$ and the ionic strength of the solutions was maintained constant at by adding appropriate amount of stock solution of $1 \mathrm{M} \mathrm{KNO}_{3}$ (Gamal, 2015; Omar and Ali, 2015). A magnetic stirrer was used to achieve thorough mixing of the interacting solutions at $550 \mathrm{rpm}$. The same set of experimental conditions was applied for potentiometric titration of remaining samples.

\section{Evaluation of pKa of Hydrolysed peat soil Humic Acids}

The proton-ligand formation number $\mathrm{n}_{\mathbf{A}}$ were calculated by Irving and Rossotti expression (Omar and Ali, 2015).

$\mathrm{nA}=\mathrm{Y}-\frac{(\mathrm{V} 2-\mathrm{V1})(\mathrm{No}-\mathrm{Eo})}{(\mathrm{VO}+\mathrm{V1}) \mathrm{TCL}}$ 1

Where: $Y$ is number of dissociable proton, $\left(\mathrm{V}_{2^{-}}\right.$ $V_{1}$ ) is the measure of displacement of the ligand curve relative to acid curve, $\mathrm{N}^{\circ}$ and $\mathrm{E}^{\circ}$ are the resultant concentration of alkali solution, free acid solution, $\mathrm{T}_{\mathrm{cL}}{ }^{\circ}$ is the total ligand concentration, $\mathrm{V}^{\circ}$ is the total volume of titration solution, $V_{1}$ is the volume of alkali added to acid solution, $V_{2}$ is the volume of alkali added to acid solution + ligand solution, acid dissociation constants (pKa - values) of ligand were calculated by algebraic method point wise calculation (Tables 1 ). The dissociation constants (pKa) were calculated according to the following relation:

$\mathrm{pKa}=\mathrm{pH}+\log \left(\frac{n A}{1-n A}\right)$ 2

Where: pKa is the acid dissociation constant, $\mathrm{n}_{\mathrm{A}}$ is the Proton-ligand formation number and $\mathrm{pH}$ is the pH-values (Omar and Ali, 2015).

\section{Determination of metal-ligand stability constants $(\log K)$ of complexes}

The potentiometric measurement for the determination of stability constant of a complex in solution is based on the fact that the redox potential of the couple $\frac{M^{+(m-n)}}{M^{+m}}$ is shifted significantly on complexation of the metal ion with the ligand. This method involves change in hydrogen ion concentration $\left[\mathrm{H}^{+}\right]$due to the displacement or association of one or more protons taking place during complexation reaction. This change can be found out by titrating the solutions containing free acid, acid with ligand, and acid with ligand and metal ion, individually against a standard alkali solution at a constant ionic strength or temperature. Either ionic strength or temperature may be varied for different sets of solutions. In all the cases, the change in the $\mathrm{pH}$ of the solution is measured after each addition of a known amount of alkali to the reaction cell which contains the reaction mixture. The titration curves are then drawn by plotting the measured $\mathrm{pH}$ values against the corresponding volume of alkali added and the stability constants of the complexes are determined from the titration curves by employing $\mathrm{pH}$-metric titration technique given by (Irving and Rossoti).

Metal-ligand stability constants ( $\log \mathrm{K}$ ) were determined by using the following relations:

$$
\bar{n}=\frac{\left(V_{3}-V_{2}\right)\left(E^{0}+N^{0}\right)}{\left(V^{0}+V_{2}\right) \bar{n}_{A} T_{m}^{0}}
$$

and

$$
P L=\log _{10}\left\{\frac{1+\beta_{n}^{H} \frac{1}{[\text { anti } \log \mathrm{pH}]^{\mathrm{n}}}}{\mathrm{T}_{\mathrm{L}}^{0}-n \bar{T}_{m}^{0}} \mathrm{X} \frac{\left(V^{0}+V_{3}\right)}{V^{0}}\right\}
$$


BAJOPAS Volume 14 Number 1,June, 2021

Where $T_{L}, T^{\circ}, E^{\circ}$, and $V^{\circ}$ havethe same significance as in equation (1) above, $T_{m}$ denotes the total concentration of metal present in solution, $V_{3}$ is the volume of metal ions present in solution and $\beta^{H}$ is the overall proton ligand stability constant. The metal-ligand stability constants (log K) were determined by employing point wise computational Method (eq. 5 and 6).

$\operatorname{LogK}_{1}=\log \left(\frac{n}{1-n}\right)+\mathrm{pL}$ .5

$\operatorname{LogK}_{2}=\log \left(\frac{1-n}{2-n}\right)+\mathrm{pL}$ ...6

Where: Log $\mathrm{K}$ is the metal-ligand stability constant, $\mathrm{pL}$ is the Free ligand exponent function, $\mathbf{n}$ is the Average number of ligand attached with metal ion (Janraoet al., 2014). The results obtained were analyzed by an ORIGIN 2016 program using titration data and then the proton-ligand stability constants (pKa) and Metal-ligand stability constant (LogK) calculated (Omar and Ali, 2015).

\section{RESULTS AND DISCUSSION}

Fourier transformed infrared (FT-IR) spectra of isolated humic acid from peat soils Figure 2 had distinct clear absorption bands indicating the presence of major humic acid structural elemental groups such as $\mathrm{H}$ bonded $\mathrm{OH}$ $\left(3680 \mathrm{~cm}^{-1}\right.$ peak $), C=0$ of carbonyl $\left(1721 \mathrm{~cm}^{-1}\right.$ peak), functional groups of aliphatic components $\mathrm{CH}_{2}\left(2918 \mathrm{~cm}^{-1}\right.$ peak) and $\mathrm{C}-\mathrm{O}$ stretching of polysaccharide $\left(1168 \mathrm{~cm}^{-1}\right.$ peak). The positions of the absorption bands of the spectra fell within typical major absorption bands of humic acid which is at frequencies 3680, 2918, 1721, 1168 $\mathrm{cm}^{-1}$. The first peak centred in the vicinity of $3680 \mathrm{~cm}^{-1}$ region is attributed to phenol $\mathrm{OH}$ group bounded by intermolecular $\mathrm{H}$ bonds. The $2918 \mathrm{~cm}^{-1}$ band usually has absorption maximum at $2918 \mathrm{~cm}^{-1}$ which is due to $\mathrm{C}-\mathrm{H}$ stretching of alkane group $\left(\mathrm{CH}_{2}\right)$. The next major absorption band is $1721 \mathrm{~cm}^{-1}$. This band has been commonly ascribed to $\mathrm{C}=\mathrm{O}$ stretching of mainly carboxyl group $(\mathrm{COOH})$ with trace amount of ketones. The last peak was observed at 1168 $\mathrm{cm}^{-1}$ due to $\mathrm{C}-\mathrm{O}$ stretching of polysaccharides and this peak appeared also in the spectra of humic acid from peat soil. The FTIR spectra of the isolated humic acid contained all major characteristic absorption peaks of humic acid. These absorption peaks indicated the presence of the major structural elements of humic acid namely $\mathrm{H}$ bonded $\mathrm{OH}, \mathrm{C}=\mathrm{C}$ of aromatic ring, $\mathrm{C}=\mathrm{O}$ of carbonyl group (both carboxyl and ketonic), $\mathrm{CH}_{2}$ group. This strongly supports the presence of humic acid.

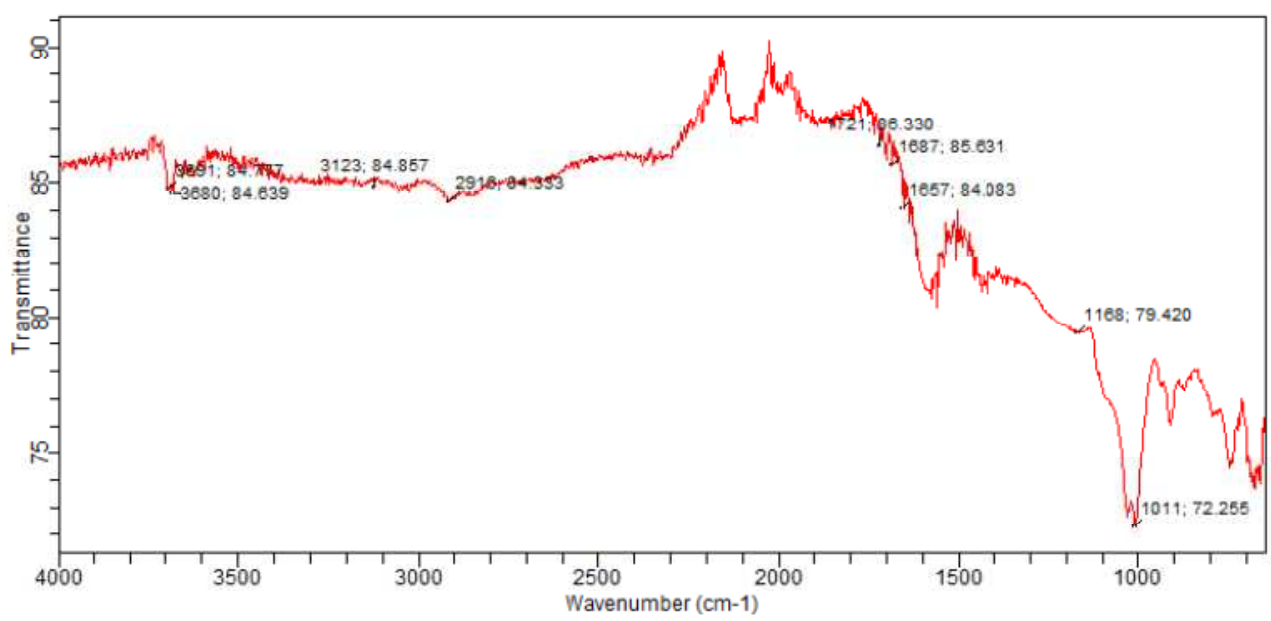

Fig. 2 : FT-IR spectraof peatsoilhumic acid (PSHA)

\section{Evaluation of acid dissociation constant (pka) of acid hydrolysed peat soil humicacid at phenolic group}

The value of the dissociation constant of the peat soil humic acid (PSHA) that underwent acidhydrolysis studied was found to be 8.9299 as shown Table 1, which is lower than the literaturevalues reported by Almeida and Szpoganics, (2015), Borges et al., (2005); Badr et al., (2012)and Fernandes et al,.(2009) of $9.73,9.47$ and 10.30. The difference between the obtained valuesand the reported values in this study might be probably as a result of acid hydrolysis of humicacid. 
BAJOPAS Volume 14 Number 1,June, 2021

Table 1: PKa of (Hydrolysed PSHA)

\begin{tabular}{|l|l|l|l|l|l|l|}
\hline $\mathrm{pH}$ & $\mathrm{BV}_{1}$ & $\mathrm{BV}_{2}$ & $\mathrm{~V}_{2}-\mathrm{V}_{1}$ & $\mathrm{nA}$ & $\log \left(\frac{n A}{1-n A}\right)$ & $\mathrm{pKa}$ \\
\hline 8.50 & 5.30 & 6.29 & 0.99 & 0.3594 & -0.2510 & 8.2490 \\
8.72 & 5.35 & 6.37 & 1.02 & 0.3400 & -0.2880 & 8.4320 \\
9.00 & 5.40 & 6.46 & 1.06 & 0.3141 & -0.3391 & 8.6609 \\
9.22 & 5.45 & 6.55 & 1.10 & 0.2882 & -0.3927 & 8.8273 \\
9.51 & 5.50 & 6.66 & 1.16 & 0.2494 & -0.4786 & 9.0314 \\
9.73 & 5.55 & 6.78 & 1.23 & 0.2041 & -0.5910 & 9.1390 \\
10.00 & 5.60 & 6.90 & 1.30 & 0.1589 & -0.7238 & 9.2762 \\
10.23 & 5.65 & 7.05 & 1.40 & 0.0941 & -0.9835 & 9.2465 \\
10.49 & 5.70 & 7.10 & 1.40 & 0.0941 & -0.9835 & 9.5065 \\
\hline
\end{tabular}

Average pKa $=8.9299 \pm 0.4186$

Table 2: PKa of (Unhydrolysed PSHA)

\begin{tabular}{|l|l|l|l|l|l|l|}
\hline $\mathrm{pH}$ & $\mathrm{BV}_{1}$ & $\mathrm{BV}_{2}$ & $\mathrm{~V}_{2}-\mathrm{V}_{1}$ & $\mathrm{nA}$ & $\log \left(\frac{\boldsymbol{n A}}{1-\boldsymbol{n}}\right)$ & $\mathrm{pKa}$ \\
\hline 8.50 & 5.30 & 5.81 & 0.51 & 0.6619 & 0.2919 & 8.7919 \\
8.72 & 5.35 & 5.90 & 0.55 & 0.6357 & 0.2418 & 8.9618 \\
9.00 & 5.40 & 6.00 & 0.60 & 0.6029 & 0.1813 & 9.1813 \\
9.22 & 5.45 & 6.10 & 0.65 & 0.5701 & 0.1226 & 9.3426 \\
9.51 & 5.50 & 6.20 & 0.70 & 0.5376 & 0.0654 & 9.5754 \\
9.73 & 5.55 & 6.33 & 0.78 & 0.4851 & -0.0259 & 9.7041 \\
10.00 & 5.60 & 6.47 & 0.87 & 0.4262 & -0.1291 & 9.8709 \\
10.23 & 5.65 & 6.62 & 0.99 & 0.3609 & -0.2481 & 9.9819 \\
10.49 & 5.70 & 6.80 & 1.10 & 0.2759 & -0.4690 & 10.0210 \\
\hline
\end{tabular}

Average pKa $=9.4923 \pm 0.4410$

Metal-ligand stability constant ( $\log \mathrm{K}$ )

The stabilityconstants require the accurate values of proton-ligand stability constants (Anil and Maroti, 2008). Metal titration curves crossed over ligand titration curve indicated the formation of complex upon proton release (Santosh, et al., 2011). If the values of n- are within range $0.2-0.8$ and $1.2-18$ this indicates the formation of $1: 1$ and 1:2 complexes (Sayyed and Mazahar, 2012).

The metal (II)-humate stepwise stability constants (log k) at phenolic group (Tables 318)

Table 3: Point-wise method, $\mathrm{Cu}$-(Hydrolysed PSHA)

\begin{tabular}{|l|l|l|l|l|l|l|l|l|}
\hline $\mathrm{pH}$ & $\mathrm{BV}_{1}$ & $\mathrm{BV}_{2}$ & $\mathrm{BV}_{3}$ & $\left(\mathrm{~V}_{3}-\mathrm{V}_{2}\right)$ & $\mathrm{n}$ & $\mathrm{pL}$ & $\log \left(\frac{n}{1-n}\right)$ & LogK $_{1}$ \\
\hline 8.50 & 5.30 & 6.29 & 6.33 & 0.04 & 0.5500 & 2.66 & 0.0871 & 2.7471 \\
8.72 & 5.35 & 6.37 & 6.41 & 0.04 & 0.5714 & 2.43 & 0.1249 & 2.5549 \\
9.00 & 5.40 & 6.46 & 6.50 & 0.04 & 0.6198 & 2.16 & 0.2122 & 2.3722 \\
9.22 & 5.45 & 6.55 & 6.59 & 0.04 & 0.6667 & 1.94 & 0.3010 & 2.2410 \\
\hline
\end{tabular}

LogK $_{1}$ (Average value) $=2.4788 \pm 0.2203$

Table 4: Point-wise method, $\mathrm{Cu}$-(Hydrolysed PSHA)

\begin{tabular}{|l|l|l|l|l|l|l|l|l|}
\hline $\mathrm{pH}$ & $\mathrm{BV}_{1}$ & $\mathrm{BV}_{2}$ & $\mathrm{BV}_{3}$ & $\left(\mathrm{~V}_{3}-\mathrm{V}_{2}\right)$ & $\mathrm{n}$ & $\mathrm{pL}$ & $\log \left(\frac{n-1}{2-n}\right)$ & LogK $_{2}$ \\
\hline 9.51 & 5.50 & 6.66 & 6.73 & 0.07 & 1.3509 & 1.70 & -0.2671 & 1.4329 \\
9.73 & 5.55 & 6.78 & 6.85 & 0.07 & 1.6383 & 1.51 & 0.2467 & 1.7567 \\
10.00 & 5.60 & 6.90 & 6.98 & 0.08 & 2.1783 & 1.31 & -0.2158 & 1.0942 \\
10.23 & 5.65 & 7.05 & 7.13 & 0.08 & 4.1904 & 1.27 & & \\
10.49 & 5.70 & 7.10 & 7.19 & 0.09 & 4.6920 & & & \\
\hline
\end{tabular}

Log $K_{2}($ Average value $)=1.4280 \pm 0.3312$ 
BAJOPAS Volume 14 Number 1,June, 2021

Table 5: Point-wise method, $\mathrm{Cu}$ (Unhydrolysed PSHA)

\begin{tabular}{|l|l|l|l|l|l|l|l|l|}
\hline $\mathrm{pH}$ & $\mathrm{BV}_{1}$ & $\mathrm{BV}_{2}$ & $\mathrm{BV}_{3}$ & $\left(\mathrm{~V}_{3}-\mathrm{V}_{2}\right)$ & $\mathrm{n}$ & $\mathrm{pL}$ & $\log \left(\frac{n}{n-1}\right)$ & Log $_{1}$ \\
\hline 8.50 & 5.30 & 5.81 & 5.85 & 0.04 & 0.2973 & 2.88 & -0.3736 & 2.5064 \\
8.72 & 5.35 & 5.90 & 5.95 & 0.05 & 0.3873 & 2.66 & -0.1992 & 2.4608 \\
9.00 & 5.40 & 6.00 & 6.05 & 0.05 & 0.4044 & 2.38 & -0.1681 & 2.2119 \\
9.22 & 5.45 & 6.10 & 6.15 & 0.06 & 0.5157 & 2.18 & -0.0272 & 2.2072 \\
9.51 & 5.50 & 6.20 & 6.27 & 0.07 & 0.6417 & 1.89 & 0.2530 & 1.1430 \\
\hline
\end{tabular}

$\operatorname{LogK}_{1}($ Average value $)=2.3059 \pm 0.6153$

Table 6:Point-wise method, $\mathrm{Cu}$ (Unhydrolysed PSHA)

\begin{tabular}{|l|l|l|l|l|l|l|l|l|}
\hline $\mathrm{pH}$ & $\mathrm{BV}_{1}$ & $\mathrm{BV}_{2}$ & $\mathrm{BV}_{3}$ & $\mathrm{~V}_{3}-\mathrm{V}_{2}$ & $\mathrm{n}$ & $\mathrm{pL}$ & $\log \left(\frac{n-1}{2-n}\right)$ & $\log \mathrm{K}_{2}$ \\
\hline 9.73 & 5.55 & 6.33 & 6.42 & 0.09 & 0.9000 & 1.69 & & \\
10.00 & 5.60 & 6.47 & 6.58 & 0.11 & 1.2578 & 1.44 & -0.4592 & 0.9808 \\
10.23 & 5.65 & 6.62 & 6.84 & 0.12 & 1.6137 & 1.26 & -0.2010 & 1.4610 \\
10.49 & 5.70 & 6.80 & 6.92 & 0.12 & 2.1052 & 1.03 & & \\
\hline
\end{tabular}

$\operatorname{LogK}_{2}$ (Average value) $=1.2209 \pm 0.3398$

Table 7:Point-wise method, Pb (Hydrolysed PSHA)

\begin{tabular}{|l|l|l|l|l|l|l|l|l|}
\hline $\mathrm{pH}$ & $\mathrm{BV}_{1}$ & $\mathrm{BV}_{2}$ & $\mathrm{BV}_{3}$ & $\left(\mathrm{~V}_{3}-\mathrm{V}_{2}\right)$ & $\mathrm{n}$ & $\mathrm{pL}$ & $\log \left(\frac{n}{1-n}\right)$ & LogK $_{1}$ \\
\hline 8.50 & 5.30 & 6.29 & 6.33 & 0.04 & 0.5500 & 2.66 & 0.0871 & 2.7471 \\
8.72 & 5.35 & 6.37 & 6.41 & 0.04 & 0.5714 & 2.43 & 0.1249 & 2.5549 \\
9.00 & 5.40 & 6.46 & 6.50 & 0.04 & 0.6198 & 2.16 & 0.2122 & 2.3722 \\
9.22 & 5.45 & 6.55 & 6.60 & 0.05 & 0.8333 & 1.96 & 0.6989 & 2.6589 \\
\hline
\end{tabular}

Log $_{\mathbf{1}}($ Average value $)=2.5832 \pm 0.1614$

Table 8:Point-wise method, Pb-(Hydrolysed PSHA)

\begin{tabular}{|l|l|l|l|l|l|l|l|l|}
\hline $\mathrm{pH}$ & $\mathrm{BV}_{1}$ & $\mathrm{BV}_{2}$ & $\mathrm{BV}_{3}$ & $\left(\mathrm{~V}_{3}-\mathrm{V}_{2}\right)$ & $\mathrm{n}$ & $\mathrm{pL}$ & $\log \left(\frac{n-1}{2-n}\right)$ & $\log \mathrm{K}_{2}$ \\
\hline 9.51 & 5.50 & 6.66 & 6.71 & 0.05 & 0.9650 & 1.67 & & \\
9.73 & 5.55 & 6.78 & 6.83 & 0.05 & 1.1702 & 1.44 & & \\
10.00 & 5.60 & 6.90 & 6.90 & 0.05 & 1.4864 & 1.22 & -0.0237 & 1.1963 \\
10.23 & 5.65 & 7.05 & 7.10 & 0.05 & 2.0190 & 1.09 & & \\
10.49 & 5.70 & 7.10 & 7.17 & 0.07 & 3.6492 & 1.00 & & \\
\hline
\end{tabular}

Log $K_{2}$ (Average value) $=1.1963$

Table 9: Point-wise method, Pb (Unhydrolysed PSHA)

\begin{tabular}{|l|l|l|l|l|l|l|l|l|}
\hline $\mathrm{pH}$ & $\mathrm{BV}_{1}$ & $\mathrm{BV}_{2}$ & $\mathrm{BV}_{3}$ & $\mathrm{~V}_{3}-\mathrm{V}_{2}$ & $\mathrm{n}$ & $\mathrm{pL}$ & $\begin{array}{l}\text { Log } \\
\left(\frac{n}{n-1}\right)\end{array}$ & Log $\mathrm{K}_{1}$ \\
\hline 8.50 & 5.30 & 5.81 & 5.85 & 0.04 & 0.2973 & 2.88 & -0.3736 & 2.5064 \\
8.72 & 5.35 & 5.90 & 5.94 & 0.04 & 0.3099 & 2.66 & -0.5477 & 2.3123 \\
9.00 & 5.40 & 6.00 & 6.05 & 0.05 & 0.4044 & 2.38 & -0.1681 & 2.2119 \\
9.22 & 5.45 & 6.10 & 6.15 & 0.06 & 0.5157 & 2.18 & 0.0272 & 2.2072 \\
9.51 & 5.50 & 6.20 & 6.26 & 0.07 & 0.6417 & 1.89 & 0.2530 & 2.1430 \\
9.73 & 5.55 & 6.40 & 6.40 & 0.07 & 0.7000 & 1.67 & 0.3680 & 2.0380 \\
\hline
\end{tabular}

LogK $_{1}$ (Average value) $=2.2364 \pm 0.1602$

Table 10: Point-wise method, Pb (Unhydrolysed PSHA)

\begin{tabular}{|l|l|l|l|l|l|l|l|l|}
\hline $\mathrm{pH}$ & $\mathrm{BV}_{1}$ & $\mathrm{BV}_{2}$ & $\mathrm{BV}_{3}$ & $\mathrm{~V}_{3}-\mathrm{V}_{2}$ & $\mathrm{n}$ & $\mathrm{pL}$ & $\log \left(\frac{n-1}{2-n}\right)$ & $\log \mathrm{K}_{2}$ \\
\hline 10.00 & 5.60 & 6.47 & 6.55 & 0.08 & 1.9503 & 1.41 & & \\
10.23 & 5.65 & 6.62 & 6.72 & 0.11 & 1.4792 & 1.26 & -0.0361 & 1.2239 \\
\hline
\end{tabular}

$\operatorname{LogK}_{2}$ (Average value) $=1.2239$

Table 11: Point-wise method, Mg (Hydrolysed PSHA)

\begin{tabular}{|l|l|l|l|l|l|l|l|l|}
\hline $\mathrm{pH}$ & $\mathrm{BV}_{1}$ & $\mathrm{BV}_{2}$ & $\mathrm{BV}_{3}$ & $\left(\mathrm{~V}_{3}-\mathrm{V}_{2}\right)$ & $\mathrm{n}$ & $\mathrm{pL}$ & $\log \left(\frac{n}{n-1}\right)$ & LogK $_{1}$ \\
\hline 8.50 & 5.30 & 6.29 & 6.31 & 0.02 & 0.2750 & 2.64 & -0.4290 & 2.2110 \\
8.72 & 5.35 & 6.37 & 6.39 & 0.02 & 0.2858 & 2.42 & -0.3978 & 2.0222 \\
9.00 & 5.40 & 6.46 & 6.49 & 0.03 & 0.4648 & 2.14 & -0.0612 & 2.0788 \\
9.22 & 5.45 & 6.55 & 6.59 & 0.04 & 0.6667 & 1.94 & 0.3010 & 2.2410 \\
\hline
\end{tabular}

$\log _{\mathbf{1}}($ Average value) $=2.1382 \pm 0.1046$ 
BAJOPAS Volume 14 Number 1,June, 2021

Table 12: Point-wise method, Mg (Hydrolysed PSHA)

\begin{tabular}{|l|l|l|l|l|l|l|l|l|}
\hline $\mathrm{pH}$ & $\mathrm{BV}_{1}$ & $\mathrm{BV}_{2}$ & $\mathrm{BV}_{3}$ & $\left(\mathrm{~V}_{3}-\mathrm{V}_{2}\right)$ & $\mathrm{n}$ & $\mathrm{pL}$ & $\log \left(\frac{n-1}{2-n}\right)$ & LogK $_{2}$ \\
\hline 9.51 & 5.55 & 6.66 & 6.71 & 0.05 & 0.9650 & 1.67 & & \\
9.73 & 5.55 & 6.78 & 6.84 & 0.06 & 1.4042 & 1.47 & -0.1686 & 1.3014 \\
10.00 & 5.60 & 6.90 & 6.93 & 0.06 & 1.7838 & 1.23 & 0.5593 & 1.7893 \\
10.23 & 5.65 & 7.05 & 7.10 & 0.06 & 3.1429 & 1.10 & & \\
10.49 & 5.70 & 7.10 & 7.18 & 0.07 & 3.6492 & 0.83 & & \\
\hline
\end{tabular}

LogK $_{2}($ Average value $)=1.5453 \pm 0.3450$

Table 13: Point-wise method, Mg (Unhydrolysed PSHA)

\begin{tabular}{|l|l|l|l|l|l|l|l|l|}
\hline $\mathrm{pH}$ & $\mathrm{BV}_{1}$ & $\mathrm{BV}_{2}$ & $\mathrm{BV}_{3}$ & $\mathrm{~V}_{3}-\mathrm{V}_{2}$ & $\mathrm{n}$ & $\mathrm{pL}$ & $\log \left(\frac{n}{n-1}\right)$ & $\operatorname{Log~}_{1}$ \\
\hline 8.50 & 5.30 & 5.81 & 5.85 & 0.04 & 0.2973 & 2.88 & -0.3736 & 2.5064 \\
8.72 & 5.35 & 5.90 & 5.94 & 0.04 & 0.3099 & 2.66 & -0.3477 & 2.3123 \\
9.00 & 5.40 & 6.00 & 6.04 & 0.04 & 0.3236 & 2.38 & -0.3202 & 2.0598 \\
9.22 & 5.45 & 6.10 & 6.15 & 0.05 & 0.4297 & 2.17 & -0.1230 & 2.0470 \\
9.51 & 5.50 & 6.20 & 6.26 & 0.06 & 0.5500 & 1.89 & 0.0871 & 1.9771 \\
9.73 & 5.55 & 6.33 & 6.40 & 0.07 & 0.7000 & 1.67 & 0.3680 & 2.0380 \\
\hline
\end{tabular}

LogK $_{1}$ (Average value) $=2.1568 \pm 0.2069$

Table 14: Point-wise method, Mg (Unhydrolysed PSHA)

\begin{tabular}{|l|l|l|l|l|l|l|l|l|}
\hline $\mathrm{pH}$ & $\mathrm{BV}_{1}$ & $\mathrm{BV}_{2}$ & $\mathrm{BV}_{3}$ & $\mathrm{~V}_{3}-\mathrm{V}_{2}$ & $\mathrm{n}$ & $\mathrm{pL}$ & $\log \left(\frac{n-1}{2-n}\right)$ & $\log \mathrm{K}_{2}$ \\
\hline 10.00 & 5.60 & 6.47 & 6.55 & 0.08 & 0.9148 & 1.41 & & \\
10.23 & 5.65 & 6.62 & 6.71 & 0.09 & 1.2102 & 1.20 & -0.5749 & 0.6251 \\
10.49 & 5.70 & 6.80 & 6.92 & 0.09 & 1.5968 & 1.03 & 0.1703 & 1.2003 \\
\hline
\end{tabular}

LogK $_{2}$ (Average value) $=0.9127 \pm 0.4070$

Table15:Point-wise method, Cd (Hydrolysed PSHA)

\begin{tabular}{|l|l|l|l|l|l|l|l|l|}
\hline $\mathrm{pH}$ & $\mathrm{BV}_{1}$ & $\mathrm{BV}_{2}$ & $\mathrm{BV}_{3}$ & $\left(\mathrm{~V}_{3}-\mathrm{V}_{2}\right)$ & $\mathrm{n}$ & $\mathrm{pL}$ & $\log \left(\frac{n}{1-n}\right)$ & LogK $_{1}$ \\
\hline 8.50 & 5.30 & 6.29 & 6.31 & 0.02 & 0.2750 & 2.64 & -0.4210 & 2.2190 \\
8.72 & 5.35 & 6.37 & 6.40 & 0.03 & 0.4286 & 2.42 & -0.1249 & 2.2951 \\
9.00 & 5.40 & 6.46 & 6.49 & 0.03 & 0.4648 & 2.14 & -0.0612 & 2.0788 \\
9.22 & 5.45 & 6.55 & 6.59 & 0.04 & 0.6667 & 1.96 & 0.3010 & 2.2610 \\
9.51 & 5.55 & 6.66 & 6.70 & 0.04 & 0.7720 & 1.67 & 0.5297 & 2.1997 \\
\hline
\end{tabular}

LogK $_{\mathbf{1}}$ (Average value) $=2.2108 \pm 0.0825$

Table 16: Point-wise method, Cd (Hydrolysed PSHA)

\begin{tabular}{|l|l|l|l|l|l|l|l|l|}
\hline $\mathrm{pH}$ & $\mathrm{BV}_{1}$ & $\mathrm{BV}_{2}$ & $\mathrm{BV}_{3}$ & $\left(\mathrm{~V}_{3}-\mathrm{V}_{2}\right)$ & $\mathrm{n}$ & $\mathrm{pL}$ & $\log \left(\frac{n-1}{2-n}\right)$ & Log $_{2}$ \\
\hline 9.73 & 5.55 & 6.78 & 6.83 & 0.06 & 1.4042 & 1.47 & -0.1686 & 1.3014 \\
10.00 & 5.60 & 6.90 & 6.95 & 0.06 & 1.7838 & 1.23 & 0.5593 & 1.7893 \\
10.23 & 5.65 & 7.05 & 7.10 & 0.06 & 3.1429 & 1.09 & & \\
10.49 & 5.70 & 7.10 & 7.16 & 0.06 & 3.1429 & 0.89 & & \\
& & & & & & & & \\
\hline
\end{tabular}

$\operatorname{LogK}_{2}$ (Average value) $=1.5453 \pm 0.3450$

Table 17: Point-wise method, Cd (Unhydrolysed PSHA)

\begin{tabular}{|l|l|l|l|l|l|l|l|l|}
\hline $\mathrm{pH}$ & $\mathrm{BV}_{1}$ & $\mathrm{BV}_{2}$ & $\mathrm{BV}_{3}$ & $\mathrm{~V}_{3}-\mathrm{V}_{2}$ & $\mathrm{n}$ & $\mathrm{pL}$ & $\log \left(\frac{n}{n-1}\right)$ & $\operatorname{Log~}_{1}$ \\
\hline 8.50 & 5.30 & 5.81 & 5.86 & 0.05 & 0.3717 & 2.88 & -0.2280 & 2.6520 \\
8.72 & 5.35 & 5.90 & 5.95 & 0.05 & 0.3873 & 2.66 & -0.1992 & 2.4608 \\
9.00 & 5.40 & 6.00 & 6.06 & 0.06 & 0.4853 & 2.38 & -0.0255 & 2.3545 \\
9.22 & 5.45 & 6.10 & 6.16 & 0.06 & 0.5157 & 2.18 & -0.0272 & 2.2072 \\
9.51 & 5.50 & 6.20 & 6.27 & 0.07 & 0.6417 & 1.89 & 0.2530 & 1.1430 \\
9.73 & 5.55 & 6.33 & 6.41 & 0.08 & 0.8000 & 1.69 & 0.6020 & 2.2920 \\
& & & & & & & & \\
\hline
\end{tabular}

$\operatorname{LogK}_{1}($ Average value $)=2.2516 \pm 0.5380$ 
BAJOPAS Volume 14 Number 1,June, 2021

Table 18: Point-wise method, Cd (Unhydrolysed PSHA)

\begin{tabular}{|l|l|l|l|l|l|l|l|l|}
\hline $\mathrm{pH}$ & $\mathrm{BV}_{1}$ & $\mathrm{BV}_{2}$ & $\mathrm{BV}_{3}$ & $\mathrm{~V}_{3}-\mathrm{V}_{2}$ & $\mathrm{n}$ & $\mathrm{pL}$ & $\log \left(\frac{n-1}{2-n}\right)$ & $\log \mathrm{K}_{2}$ \\
\hline 10.00 & 5.60 & 6.47 & 6.57 & 0.10 & 1.1434 & 1.43 & & \\
10.23 & 5.65 & 6.62 & 6.72 & 0.10 & 1.3448 & 1.23 & -0.2788 & 0.9512 \\
10.49 & 5.70 & 6.80 & 6.90 & 0.10 & 1.7742 & 1.03 & 0.5351 & 1.5651 \\
\hline
\end{tabular}

$\operatorname{LogK}_{2}($ Average value $)=1.2581 \pm 0.4340$

Table 19: Stepwise and overall Stability constants of thehydrolysed and unhydrolysed divalent metal (II) complexes

\begin{tabular}{|c|c|c|c|}
\hline Chelates & LogK $_{1}$ & $\log _{2}$ & Log $\beta$ \\
\hline [Cu (Hydrolysed PSHA-1) $\left.{ }_{2}\right]$ & 2.4788 & 1.4280 & 3.9068 \\
\hline$\left[\mathrm{Pb}(\text { Hydrolysed PSHA-1) })_{2}\right]$ & 2.5832 & 1.1963 & 3.7795 \\
\hline$\left[\mathrm{Cd}(\text { Hydrolysed PSHA-1 })_{2}\right]$ & 2.2108 & 1.5453 & 3.7561 \\
\hline$\left[\mathrm{Mg}(\text { Hydrolysed PSHA-1 })_{2}\right]$ & 2.1382 & 1.5453 & 3.6835 \\
\hline [Cu (Unhydrolysed PSHA-1) & 2.3059 & 1.2209 & 3.5268 \\
\hline$[\mathrm{Pb}$ (Unhydrolysed PSHA-1) 2$]$ & 2.2364 & 1.2239 & 3.4603 \\
\hline [Cd (Unhydrolysed PSHA-1) 2 ] & 2.2516 & 1.2581 & 3.5097 \\
\hline$[\mathrm{Mg}$ (Unydrolysed PSHA-1) & 2.1568 & 0.9127 & 3.0695 \\
\hline
\end{tabular}

The results obtained (Table19) shows the stepwise and overall stability constants to be not high indicating low stability of the complexes, because the solubility of most metal ions in the basic $\mathrm{pH}$ range is minimal due to metal hydroxide precipitation (Karimi, 2017). In general, the stepwise stability constants $\left(K_{1}\right.$ and $K_{2}$ ) follow the order $K_{1}>K_{2}$ for the copper, lead, magnesium and cadmium complexes respectively. The steady decrease of the values with increasing number of ligands is in agreement with the prediction made by researchers (Na'aliya, 2013). The decrease could be attributed to the fact that as the number of the ligands (Humate ions) that enters the coordination zone increases the aqua molecules available for replacement by the ligands become less. Thus, the metal ions become less electron loving with progressive intake of the ligand and this results in the decrease in the values of the constants (Na'aliya, 2013). Also the stability of the complexes is influenced by the size and number of the chelate rings(Mackay and Mackay,2002).All the complexes form rings in their structure as humate, a bidentate ligand, bond the metal ions in the ratio 1:2 (Boguta and Sokolowska, 2016) forming chelate rings. The values of the overall stability constants $(\log \beta)$ obtained for humate complexes are not high indicating low stability as the values are not high. LogK values for copper-humates (Table 3 to 6) obtained in this study are lower than those reported for the complexes of humic acids (Pandey et al., 2015; Dinu, 2013; Kaschl et al., 2010 and Gilbeto and Jorg, 2001). The values of LogK(Table 7 to 10 ) forlead-humates are lower than those reported for the lead in the literature (Dinu, 2013; Gilbeto and Jorg 2001). Log K values(Table 11 to 14 ) for magnesium-humates obtained in this study are close to those reported by (Pandey et al., 2015). Log K values of cadmium-humates (Table 15 to 18 ) obtained in this work near to the one reported by (Dinu, 2013 and Pandey et al., 2015).The difference between the reported values and the values obtained in this study might be probably as a result of acid hydrolysis of humic acid. The values of the overall stability constants $(\log \beta)$ of the copper humates complexes presented in Table 19 is high than that of other metal humate complexes, show relatively high stability of CuHA complexes, show the following order of stability: $\mathrm{Cu}>\mathrm{Pb}>\mathrm{Cd}>\mathrm{Mg}$; which are in close agreement to the findings of (Dinu, 2013 and Pandey et al., 2015).The high stability of Cuhumate chelate could be attributed to the existence of coordinate covalent bond between the complexing agents and the $\mathrm{Cu}^{2+}$ ions. Since, $\mathrm{Cu}^{2+}$ being a metal of the transitional series with $3 d^{9}$ electronic configurations can accept the electrons from the complexing agents. Similarly, the low stabilities of $\mathrm{Pb}, \mathrm{Cd}$ and $\mathrm{Mg}$ complexes could be explained by that $\mathrm{Pb}^{2+}$ with $6 s^{2}, \mathrm{Cd}^{2+}$ with $4 \mathrm{~d}^{10}$ and $\mathrm{Mg}^{2+}$ with $2 \mathrm{p}^{6}$ their electronic configuration has a completely filled $\mathrm{d}, \mathrm{p}$ and $\mathrm{s}$ orbitals. Moreover, the stabilities of metal ions with hydrolysed humic acid from peat soil were higher than those with unhydrolysed humic acid from peat soil; which is ascribed to the high content of acidity in hydrolysed humic acid than unhydrolysed humic acid. 
BAJOPAS Volume 14 Number 1,June, 2021 CONCLUSION

The values of logk for $\mathrm{Cu}(\mathrm{II})$ hydrolysed humic acid complex was higher followed by $\mathrm{Pb}$ (II), $\mathrm{Cd}(\mathrm{II})$ and $\mathrm{Mg}$ (II) hydrolysed humic acid complexes as compared with metal(II) unhydrolysed humic acid complexes. This indicates acid hydrolysis of humic acid can

\section{REFERENCES}

Almeida, V.R. and Szpoganicz, B. (2015). Humic Acid Potentiometric Response Patterns:Out- of Equilibrium Properties and Species Distribution Modelling. Chemical. Biol. Technol. Agric. 2: 17.

Anđelković, T., Nikolić, R., Bojić, A.,Anđelković, D., and Nikolic G.,(2010). Binding of Cadmium to Soil Humic Acid as A Function of Carboxyl Group Content. Macedonian Journal of Chemistry and Chemical Engineering.29(2): 215-224.

Anil, B. N. and Maroti, N. (2008). Studies on Influence of Die-Lectric Constants on Complex Equilibria between Substituted Py-Razalines and Lanthanide Metal Ions pH-Metrically. Amer.-Euras. scient. Res. 3(2): 212-216.

Ashok, K., Pandey, S. P. and Misra, V (2000). Stability Constants of Metal-Humic Acid Complexes and its Role in Environmental Detoxification. Journal of Ecotoxicology and Environmental Safety. 47(2):157-200.

Badr, M. H., El-Halafawi, M. H. and Abd El-al Zeid, E. R. (2012). Comparison Between the Effect of Ionic Strength on Acidity and Dissociation Constants of Humic Acids Extracted from Sewage Sludge and Nile Water Hyacinth Composts.Global Journal of Environmental Research 6 (1): 36-43.

Baruah, M.K., Borah, D., Saikia, P.P., Paul, S., Sharma, T. (2015). Evaluation of pKa Values of Soil Humic Acids and their Complexation Properties. International Journal of Plant \& Soil Science 6(4) : 218-228.

Boguta, P. Sokolowska, Z. (2016). Interactions of $\mathrm{Zn}$ (II) Ions with Humic Acids Isolated from Various Types of Soils. Effect of $\mathrm{pH}, \mathrm{Zn}$ Concentrations and Humic Acids Chemical Properties. Journal of Geochemical Explaration 168. 119-126.

Borges, F., Guimaraes, C., Lima, L.F.C., Pinto, I. and Reis, S.(2005). Potentiometric Studies on the Complexation of Copper(II) by Phenolic Acids as Discrete Ligand Models of enhance the complexation behavior of humic acid with metal (II) ions. However, the higher values of $\log \beta$ for $\mathrm{Cu}(\mathrm{II}), \mathrm{Pb}(\mathrm{II}), \mathrm{Cd}(\mathrm{II})$ and $\mathrm{Mg}(\mathrm{II})$ hydrolysed humic acid complexes indicates more stable stepwise complexes formed as compared with $\mathrm{Cu}(\mathrm{II}), \mathrm{Pb}$ (II), $\mathrm{Cd}$ (II) and $\mathrm{Mg}(\mathrm{II})$ unhydrolysed humic acid complexes.

Humic Substances Talanta 66 (2005) 670-673.

Chefetz, B., Salloum, M. J., Deshmulkin, A. P. and Hatcher, P. (2002). Structural Components of Humic Acids as Determined by Chemical Modifications and Carbon-13 NMR, Pyrolysis, and Thermochemolysis- Gas Chromatography/Mass Spectrometry. Soil Science Society of American Journal Abstract Division S-2- Soil Chemistry66. 1159-1171.

Dinu, M. I. (2013). Metals Complexation with Humic Acids in Surface Water of Different Environ. Sci. Technol. 31(1): 1-17.

Fernandes, A.N., Giacomelli, C., Giovanela, M. Vaz, D.V. Szpoganicz, B. and Maria M. D. (2009). Potentiometric Acidity Determination in Humic Substances Influenced by Different Analytical Procedures.J. Braz. Chem. Soc. 20 (9):14.

Gamal, A. H. (2015). Stability Constants of Rhenium (V) Metal Complexes with Selected Drugs. Pyrex Journal of Research in Environmental Studies. 2(2): 006-014.

Janrao, D. M., Pathan, J., Kayande, D.D., and Mulla, J.J. (2014). An Over View of Potentiometric Determination of Stability Constants of Metal Complexes. Sci. Revs. Chem. Commun.: 4(1), 2014, 11-24.

Karimi, H. (2017). Effect of pH and Initial Pb(II) Concentration on the Lead Removal Efficiency from Waste Water Using $\mathrm{Ca}(\mathrm{OH})_{2}$. International Journal of Water and Waste Water Treatment 3.2

Kaschl, A. Romheld, V. and Chen, Y. (2010). Binding of Cadmium, Copper and Zinc to Humic Substances Originating from Municipal Solid Waste Compost. Israel Journal of Chemistry Vol. 42(1): 89-98.

Kostic, I. S., Tatjana, P, A., Nikolic, R. S., Cvetkovic, T. P., Pavlovic, D. D., Aleksandar, L.J. and Bojic, A. (2012). Comparative Study of Binding Strengths of Heavy Metals with Humic Acid. J.serb. Chem. Soc. 76(9) pp 1-20. 
BAJOPAS Volume 14 Number 1,June, 2021

Na'aliya, J. (2013). Determination of Stepwise Stability Constants and Gibbs free Energy Change of Trisprolina to Complexes of some Divalent Transition Metal ions. Bayero Journal of Pure and Applied Sciences 6(2): 112-114.

Omar, A. A. and Ali, E. A. (2015). Potentiometric Studies on Complexes of $\mathrm{Cr}$ (III) and $\mathrm{Zr}$ (IV) with some Carboxylic Acids. International Journal of Advanced Chemistry, 3(1) 25-

37.

Pandey, A. K. Pandey, S. D. and Misr, V. (2015).Stability Constants of Metal- Humic Acid Complexes and Its Role in Environmental Detoxification. J. Ecotoxicology and Environmental Safety. 47(1):195-200.

Ram, N. and Raman, K.V. (1984). Stability Constants of Complexes of Metals with
Humicand Fuvic Acids under Non- acidConditions. Journal of Plant Nutrition and Soil Sciences.

147:171-176.

Santosh, D. D., Ashok, B. K., Vijay, J. T., Shivraj, G. W. and Vinay, V. W. (2011). Potentiometric Studies of Elec-Trolyte Effects on Complex Equilibria of Some Substituted 5-(2-hydroxy Phenyl) Pyrazoles. Der pharm. 3 (6): 75-83.

Sayyed, H. and Abdul Rahim, M. F. (2012). Studies of Binary Complexes of Metal Ions with Mandelic Acid by Potentiometry. Chem. J. 02 (6): 206209.

Shirvani, M. Moradian, E. Khalili, B. Bakhtiary, S. (2015). Interaction of $\mathrm{Cd}$ and $\mathrm{Pb}$ with Humate-Palygorskite and HumateSepiolite Complexes. Journal of water, air and pollution 3: 220-228. 


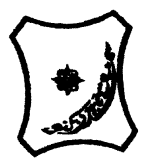

Bayero Journal of Pure and Applied Sciences, 14(1): 54 - 63

Received: November, 2020

Accepted: April, 2021

ISSN $2006-6996$

\title{
STABILITY CONSTANTS OF COMPLEXES OF METAL IONS WITH PEATSOIL HUMIC ACIDS UNDER NON-ACID-CONDITIONS
}

\author{
${ }^{* 1}$ Sabo, Yusuf ${ }^{2}$ Jimoh, W.L.O., ${ }^{3}$ Isa Baba Koki and ${ }^{4}$ Sholadoye, Q. 0. \\ ${ }^{1}$ Department of Pure and Industrial Chemistry, Bayero University, Kano \\ ${ }^{3}$ Department of Chemistry, Yusuf Maitama Sule University Kano. P.M.B. 3220 Kano, Nigeria. \\ ${ }^{4}$ Department of Chemistry, Nigerian Police Academy, Wudil, Kano-Nigeria
}

*Correspondence E-mail; saboyusuf18@yahoo.com

ABSTRACT

Stability constants of complexes of four divalent metal ions viz. $\mathrm{Cu}^{2+}, \mathrm{Pb}^{2+}, \mathrm{Mg}^{2+}$ and $\mathrm{Cd}^{2+}$ with humic acids (HA) were determined by potentiometric titration of humic acids with the corresponding salt of the divalent metals in aqueous media under non-acid-condition. The log $K$ (logarithm of the stability constant) ranged from 1.0942 to 2.7471 for metalhumic acid complexes were determined using point-wise computational method. The order of stability constants were obtained as follows: $\mathrm{Cu}>\mathrm{Pb}>\mathrm{Cd}>\mathrm{Mg}$ for metal $-\mathrm{HA}$ complexes respectively, indicating a higher degree of complexation with Cu metal ion.

Keywords: stability constant, humic acid, potentiometric titration, divalent metals, acid hydrolysis.

\section{NTRODUCTION}

The stability constant of a complex is the numerical expression of its stability and provides a quantitative measure of affinity of the metal ion to the complexing agent. An understanding of the relative stability of metal-complexes helps in predicting the behavior of metal ions in the soil (Ram and Raman, 1982). Extensive researches has been done to determine the stability constants of the complexes formed between humic acid (HA) with a number of metal ions. Ashok et al., (2000) reported that humic acid with hydroxyl, phenoxyl and carboxyl reactive groups can form coordination compound with metal ions at $\mathrm{pH}$ 3.5. The stability constants(Log K) for different metalhumic acid complexes indicated the following order of the stabilities of complexes formed between humic acid and metal ion, $\mathrm{Cu}>\mathrm{Fe}$ $>\mathrm{Pb}>\mathrm{Ni}>\mathrm{Co}>\mathrm{Ca}>\mathrm{Cd}>\mathrm{Zn}>\mathrm{Mn}>\mathrm{Mg}$. Andelkovic et al., (2010) investigated the binding of $\mathrm{Cd}$ (II) to soil humic acid at pH 6.5 and in $0.1 \mathrm{M} \mathrm{KNO}_{3}$ ionic medium. The stability constant for binding indicating greater stability in the case when carboxyl groups are involved in complexation reaction. Kostic et al.,(2012) investigated the complexation of humic acid with certain heavy metal ions (Co(II), $\mathrm{Ni}(\mathrm{II}), \mathrm{Cu}(\mathrm{II})$,
$\mathrm{Zn}(\mathrm{II})$, and $\mathrm{Pb}(\mathrm{II})$. The experiment was performed at $25^{\circ} \mathrm{C}$, at pH 4.0 and ionic strength of $0.01 \mathrm{M}$. Stability constant of complex between $\mathrm{Pb}$ (II) ions and humic acid is greater than stability constants of other investigated metalhumate complexes. Bogata and Sokolowska (2016) analyses the interaction between humic acids from different soils and $\mathrm{Zn}$ (II) ions at wide concentration ranges and at $\mathrm{pH} 5$. Studies have showed significant impact of $\mathrm{Zn}$ concentration, $\mathrm{pH}$ and some properties of humic acids with zinc.But all of these studies were limited to acidic $\mathrm{pH}$ range. Therefore, the present study was carried out to determine and compare the stability constants of complexes of metal ions with hydrolysed peat soil humic acid and unhydrolysed peat soil humic under non-acid conditions.

\section{MATERIALS AND METHODS}

Analytical grade chemicals used includes hydrochloric acid $(\mathrm{HCl})$, nitric acid $\left(\mathrm{HNO}_{3}\right)$, sodium hydroxide $(\mathrm{NaOH})$, lead nitrate $\mathrm{Pb}\left(\mathrm{NO}_{3}\right)_{2}$, copper nitrate $\mathrm{Cu}\left(\mathrm{NO}_{3}\right)_{2} \cdot 3 \mathrm{H}_{2} \mathrm{O}$, cadmium nitrate $\mathrm{Cd}\left(\mathrm{NO}_{3}\right)_{2} \cdot 4 \mathrm{H}_{2} \mathrm{O}$, magnesium nitrate $\mathrm{Mg}\left(\mathrm{NO}_{3}\right)_{2} \cdot 6 \mathrm{H}_{2} \mathrm{O}$, potassium nitrate $\left(\mathrm{KNO}_{3}\right)$, calcium chloride $\left(\mathrm{CaCl}_{2}\right)$, (sigma-Aldrich). Dowex 50WX8, (20-50 mesh) from Fluka. 


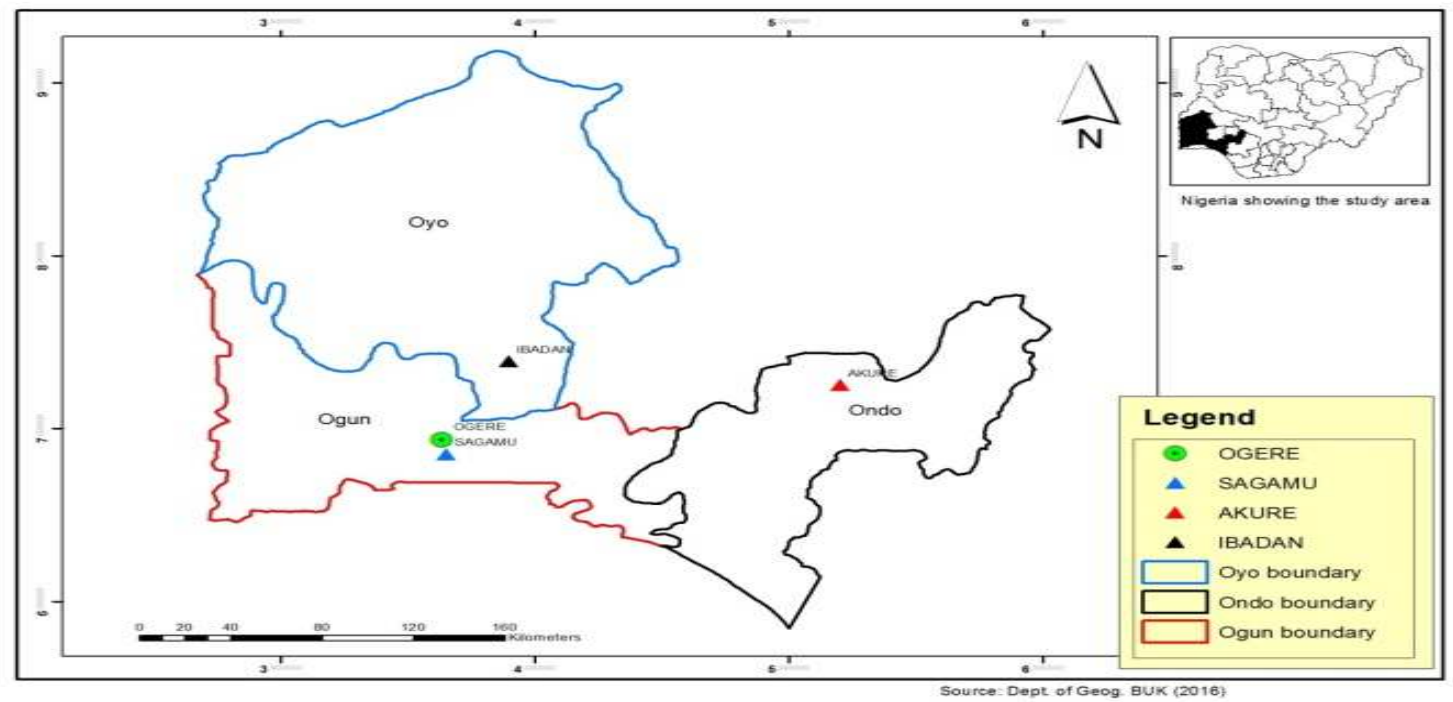

Figure 1: Map showing the sampling point at Sagamu Town, Ogun State.

\section{Description of Sampling Area}

Sagamu has geographical coordinates between $6^{\circ} 50^{\prime}$ north; $3^{\circ} 38^{\prime}$ east is located in south western region of Nigeria. The region has tropical wet and dry climate with a lengthy wet season and relatively constant temperatures throughout the course of the year. Wet season runs from March to October, November to December forms the region dry season. The vegetation type of the region is savannah which is really grassland with small bushes and occasional big trees. Grassland soils have substantially higher organic matter content than forest soils (Novackova, 2011).

\section{Sample Collection}

The Peatsoil samples were collected from four different sampling points $(0-10 \mathrm{~cm}$ depth) in Sagamu into polyethylene bag with plastic spoons. Samples were taken to the laboratory, extraneous materials were removed; the samples were air-dried, crushed and ground to a fine powder in a mortar passed through a $0.20 \mathrm{~mm}$ sieve. The samples were kept for analysis.

\section{Isolation and purification of humic acid from peat soil sample}

Peatsoil sample $(100 \mathrm{~g})$ was mixed with 1000 $\mathrm{cm}^{3}$ of $0.1 \mathrm{M} \mathrm{NaOH}$ solution, shaken for 3hours and left to stand overnight. Dark-coloured supernatant was obtained and decanted from solid residue. The dark-coloured supernatant was acidified to $(\mathrm{pH}=1.0)$ with $6 \mathrm{M} \mathrm{HCl}$ stirred and allowed to stand for 6 hours. Yellowish brown supernatant and dark-brown precipitate were obtained. The yellowish brown supernatant was decanted followed by centrifuge and discarded. The dark-brown precipitate was mixed with $500 \mathrm{~cm}^{3}$ of $0.1 \mathrm{M} \mathrm{NaOH}$ solution followed by passing through dowex resin. The dark-brown solution was acidified to $(\mathrm{pH}=1.0)$ with $6 \mathrm{M} \mathrm{HCl}$ stirred and allowed to stand for 3 hours. The dark-brown precipitate was washed several times with deionized water. The supernatant was treated with $\mathrm{AgNO}_{3}$ solution until no white precipitate observed. The humic acid was transferred to weighed crucible and dried at $60^{\circ} \mathrm{C}$ in an oven for 12 hours. The humic acid was cooled and dried in the desiccator, weighed and recorded. The obtained humic acid was dried again at $60^{\circ} \mathrm{C}$ for additional 6 hours cooled and dried in the desiccator, weighed and recorded constant weight was obtained (Baruah et al., 2015).

\section{FT-IR analysis}

FT-IR spectra of humic acid sample was analysed using Carry 630 FT-IR Agilent Technologies.

Unhydrolysed compost humic acid

The unhydrolysed humic acid was obtained after isolation and purification of compost humic acid and kept for investigation.

\section{Acid hydrolysis of Peatsoil acid}

Peatsoil humic acid sample (1g) was refluxed for 12 hours at $\left(160^{\circ} \mathrm{C}\right)$ with $50 \mathrm{~cm}^{3}$ of $6 \mathrm{M} \mathrm{HCl}$. The mixture was allowed to cool, decanted, and centrifuged after hydrolysis. The insoluble residues were washed with distilled water via centrifugation several times, and the supernatant was treated with $\mathrm{AgNO}_{3}$ solution until no white precipitate was observed. The residue was thoroughly dried over $\mathrm{CaCl}_{2}$ in a desiccator at room temperature (Chefetz et al., 2002). Finally, the obtained hydrolysed humic acid was kept for investigation. 
BAJOPAS Volume 14 Number 1,June, 2021 Potentiometric Titrations

Potentiometric measurements were carried out using a pH-meter Jenway (model 3510) with combine electrode, the sensitivity of the $\mathrm{pH}$ meter is 0.01 units. The $\mathrm{pH}$ meter was switched on half an hour before starting the titration for initial warm up of the instrument. The instrument was calibrated with an aqueous standard buffer solution of $\mathrm{pH} 4.00$ and 10.0 (borate buffer) prepared from a "Qualigens" buffer tablets.

The following sets of solutions were prepared in a $250 \mathrm{~cm}^{3}$ volumetric flask separately for $\mathrm{pH}$ metric titrations.

(i) $5 \mathrm{~cm}^{3} 0.1 \mathrm{M} \mathrm{HCl}+40 \mathrm{~cm}^{3}$ deionized water

(ii) $5 \mathrm{~cm}^{3} 0.1 \mathrm{M} \mathrm{HCl}+39 \mathrm{~cm}^{3}$ deionized water $+1 \mathrm{~cm}^{3} 0.15 \mathrm{gcm}^{-3}$ humic acid

(iii) $5 \mathrm{~cm}^{3} 0.1 \mathrm{M} \mathrm{HCl}+37 \mathrm{~cm}^{3}$ deionized water $+1 \mathrm{~cm}^{3} 0.15 \mathrm{gcm}^{-3}$ humic acid

$$
+2 \mathrm{~cm}^{3} \quad 0.01 \mathrm{M} \mathrm{Cu} \text { (II) }
$$

The solutions were titrated against standardized $0.110 \mathrm{MNaOH}$ separately. The total volume of each mixture was adjusted to $50 \mathrm{~cm}^{3}$ and the ionic strength of the solutions was maintained constant at by adding appropriate amount of stock solution of $1 \mathrm{M} \mathrm{KNO}_{3}$ (Gamal, 2015; Omar and Ali, 2015). A magnetic stirrer was used to achieve thorough mixing of the interacting solutions at $550 \mathrm{rpm}$. The same set of experimental conditions was applied for potentiometric titration of remaining samples.

\section{Evaluation of pKa of Hydrolysed peat soil Humic Acids}

The proton-ligand formation number $\mathrm{n}_{\mathbf{A}}$ were calculated by Irving and Rossotti expression (Omar and Ali, 2015).

$\mathrm{nA}=\mathrm{Y}-\frac{(\mathrm{V} 2-\mathrm{V1})(\mathrm{No}-\mathrm{Eo})}{(\mathrm{VO}+\mathrm{V1}) \mathrm{TCL}}$ 1

Where: $Y$ is number of dissociable proton, $\left(\mathrm{V}_{2^{-}}\right.$ $V_{1}$ ) is the measure of displacement of the ligand curve relative to acid curve, $\mathrm{N}^{\circ}$ and $\mathrm{E}^{\circ}$ are the resultant concentration of alkali solution, free acid solution, $\mathrm{T}_{\mathrm{cL}}{ }^{\circ}$ is the total ligand concentration, $\mathrm{V}^{\circ}$ is the total volume of titration solution, $V_{1}$ is the volume of alkali added to acid solution, $V_{2}$ is the volume of alkali added to acid solution + ligand solution, acid dissociation constants (pKa - values) of ligand were calculated by algebraic method point wise calculation (Tables 1 ). The dissociation constants (pKa) were calculated according to the following relation:

$\mathrm{pKa}=\mathrm{pH}+\log \left(\frac{n A}{1-n A}\right)$ 2

Where: pKa is the acid dissociation constant, $\mathrm{n}_{\mathrm{A}}$ is the Proton-ligand formation number and $\mathrm{pH}$ is the pH-values (Omar and Ali, 2015).

\section{Determination of metal-ligand stability constants $(\log K)$ of complexes}

The potentiometric measurement for the determination of stability constant of a complex in solution is based on the fact that the redox potential of the couple $\frac{M^{+(m-n)}}{M^{+m}}$ is shifted significantly on complexation of the metal ion with the ligand. This method involves change in hydrogen ion concentration $\left[\mathrm{H}^{+}\right]$due to the displacement or association of one or more protons taking place during complexation reaction. This change can be found out by titrating the solutions containing free acid, acid with ligand, and acid with ligand and metal ion, individually against a standard alkali solution at a constant ionic strength or temperature. Either ionic strength or temperature may be varied for different sets of solutions. In all the cases, the change in the $\mathrm{pH}$ of the solution is measured after each addition of a known amount of alkali to the reaction cell which contains the reaction mixture. The titration curves are then drawn by plotting the measured $\mathrm{pH}$ values against the corresponding volume of alkali added and the stability constants of the complexes are determined from the titration curves by employing $\mathrm{pH}$-metric titration technique given by (Irving and Rossoti).

Metal-ligand stability constants ( $\log \mathrm{K}$ ) were determined by using the following relations:

$$
\bar{n}=\frac{\left(V_{3}-V_{2}\right)\left(E^{0}+N^{0}\right)}{\left(V^{0}+V_{2}\right) \bar{n}_{A} T_{m}^{0}}
$$

and

$$
P L=\log _{10}\left\{\frac{1+\beta_{n}^{H} \frac{1}{[\text { anti } \log \mathrm{pH}]^{\mathrm{n}}}}{\mathrm{T}_{\mathrm{L}}^{0}-n \bar{T}_{m}^{0}} \mathrm{X} \frac{\left(V^{0}+V_{3}\right)}{V^{0}}\right\}
$$


BAJOPAS Volume 14 Number 1,June, 2021

Where $T_{L}, T^{\circ}, E^{\circ}$, and $V^{\circ}$ havethe same significance as in equation (1) above, $T_{m}$ denotes the total concentration of metal present in solution, $V_{3}$ is the volume of metal ions present in solution and $\beta^{H}$ is the overall proton ligand stability constant. The metal-ligand stability constants (log K) were determined by employing point wise computational Method (eq. 5 and 6).

$\operatorname{LogK}_{1}=\log \left(\frac{n}{1-n}\right)+\mathrm{pL}$ .5

$\operatorname{LogK}_{2}=\log \left(\frac{1-n}{2-n}\right)+\mathrm{pL}$ ...6

Where: Log $\mathrm{K}$ is the metal-ligand stability constant, $\mathrm{pL}$ is the Free ligand exponent function, $\mathbf{n}$ is the Average number of ligand attached with metal ion (Janraoet al., 2014). The results obtained were analyzed by an ORIGIN 2016 program using titration data and then the proton-ligand stability constants (pKa) and Metal-ligand stability constant (LogK) calculated (Omar and Ali, 2015).

\section{RESULTS AND DISCUSSION}

Fourier transformed infrared (FT-IR) spectra of isolated humic acid from peat soils Figure 2 had distinct clear absorption bands indicating the presence of major humic acid structural elemental groups such as $\mathrm{H}$ bonded $\mathrm{OH}$ $\left(3680 \mathrm{~cm}^{-1}\right.$ peak $), C=0$ of carbonyl $\left(1721 \mathrm{~cm}^{-1}\right.$ peak), functional groups of aliphatic components $\mathrm{CH}_{2}\left(2918 \mathrm{~cm}^{-1}\right.$ peak) and $\mathrm{C}-\mathrm{O}$ stretching of polysaccharide $\left(1168 \mathrm{~cm}^{-1}\right.$ peak). The positions of the absorption bands of the spectra fell within typical major absorption bands of humic acid which is at frequencies 3680, 2918, 1721, 1168 $\mathrm{cm}^{-1}$. The first peak centred in the vicinity of $3680 \mathrm{~cm}^{-1}$ region is attributed to phenol $\mathrm{OH}$ group bounded by intermolecular $\mathrm{H}$ bonds. The $2918 \mathrm{~cm}^{-1}$ band usually has absorption maximum at $2918 \mathrm{~cm}^{-1}$ which is due to $\mathrm{C}-\mathrm{H}$ stretching of alkane group $\left(\mathrm{CH}_{2}\right)$. The next major absorption band is $1721 \mathrm{~cm}^{-1}$. This band has been commonly ascribed to $\mathrm{C}=\mathrm{O}$ stretching of mainly carboxyl group $(\mathrm{COOH})$ with trace amount of ketones. The last peak was observed at 1168 $\mathrm{cm}^{-1}$ due to $\mathrm{C}-\mathrm{O}$ stretching of polysaccharides and this peak appeared also in the spectra of humic acid from peat soil. The FTIR spectra of the isolated humic acid contained all major characteristic absorption peaks of humic acid. These absorption peaks indicated the presence of the major structural elements of humic acid namely $\mathrm{H}$ bonded $\mathrm{OH}, \mathrm{C}=\mathrm{C}$ of aromatic ring, $\mathrm{C}=\mathrm{O}$ of carbonyl group (both carboxyl and ketonic), $\mathrm{CH}_{2}$ group. This strongly supports the presence of humic acid.

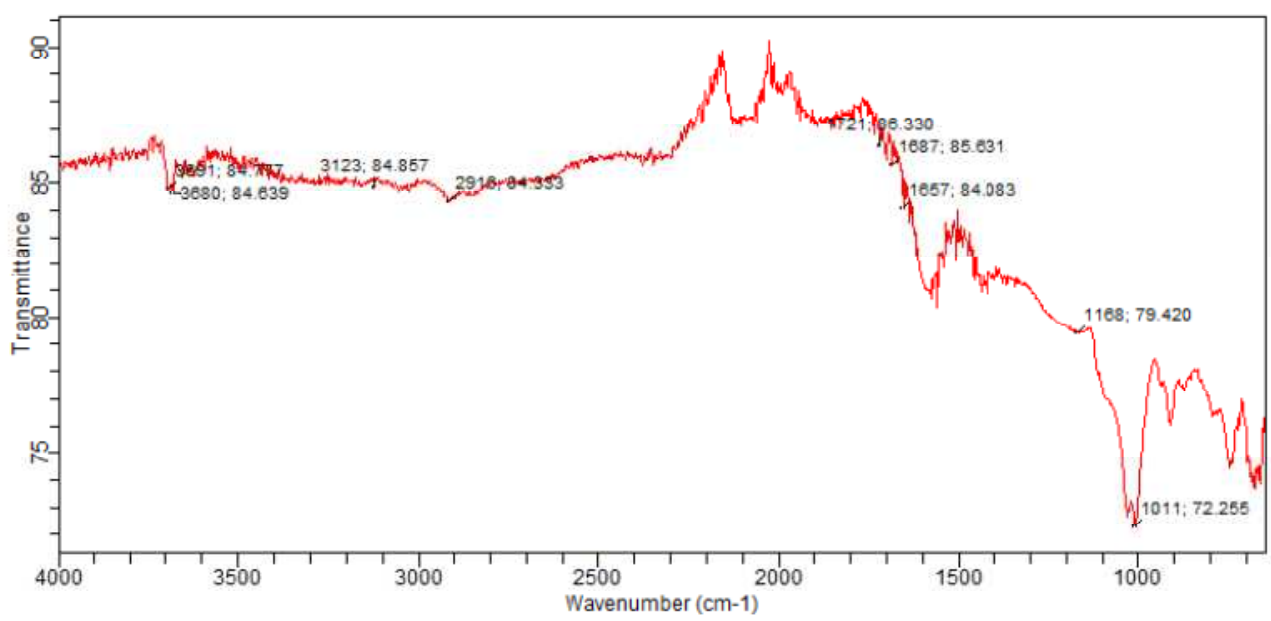

Fig. 2 : FT-IR spectraof peatsoilhumic acid (PSHA)

\section{Evaluation of acid dissociation constant (pka) of acid hydrolysed peat soil humicacid at phenolic group}

The value of the dissociation constant of the peat soil humic acid (PSHA) that underwent acidhydrolysis studied was found to be 8.9299 as shown Table 1, which is lower than the literaturevalues reported by Almeida and Szpoganics, (2015), Borges et al., (2005); Badr et al., (2012)and Fernandes et al,.(2009) of $9.73,9.47$ and 10.30. The difference between the obtained valuesand the reported values in this study might be probably as a result of acid hydrolysis of humicacid. 
BAJOPAS Volume 14 Number 1,June, 2021

Table 1: PKa of (Hydrolysed PSHA)

\begin{tabular}{|l|l|l|l|l|l|l|}
\hline $\mathrm{pH}$ & $\mathrm{BV}_{1}$ & $\mathrm{BV}_{2}$ & $\mathrm{~V}_{2}-\mathrm{V}_{1}$ & $\mathrm{nA}$ & $\log \left(\frac{n A}{1-n A}\right)$ & $\mathrm{pKa}$ \\
\hline 8.50 & 5.30 & 6.29 & 0.99 & 0.3594 & -0.2510 & 8.2490 \\
8.72 & 5.35 & 6.37 & 1.02 & 0.3400 & -0.2880 & 8.4320 \\
9.00 & 5.40 & 6.46 & 1.06 & 0.3141 & -0.3391 & 8.6609 \\
9.22 & 5.45 & 6.55 & 1.10 & 0.2882 & -0.3927 & 8.8273 \\
9.51 & 5.50 & 6.66 & 1.16 & 0.2494 & -0.4786 & 9.0314 \\
9.73 & 5.55 & 6.78 & 1.23 & 0.2041 & -0.5910 & 9.1390 \\
10.00 & 5.60 & 6.90 & 1.30 & 0.1589 & -0.7238 & 9.2762 \\
10.23 & 5.65 & 7.05 & 1.40 & 0.0941 & -0.9835 & 9.2465 \\
10.49 & 5.70 & 7.10 & 1.40 & 0.0941 & -0.9835 & 9.5065 \\
\hline
\end{tabular}

Average pKa $=8.9299 \pm 0.4186$

Table 2: PKa of (Unhydrolysed PSHA)

\begin{tabular}{|l|l|l|l|l|l|l|}
\hline $\mathrm{pH}$ & $\mathrm{BV}_{1}$ & $\mathrm{BV}_{2}$ & $\mathrm{~V}_{2}-\mathrm{V}_{1}$ & $\mathrm{nA}$ & $\log \left(\frac{\boldsymbol{n A}}{1-\boldsymbol{n}}\right)$ & $\mathrm{pKa}$ \\
\hline 8.50 & 5.30 & 5.81 & 0.51 & 0.6619 & 0.2919 & 8.7919 \\
8.72 & 5.35 & 5.90 & 0.55 & 0.6357 & 0.2418 & 8.9618 \\
9.00 & 5.40 & 6.00 & 0.60 & 0.6029 & 0.1813 & 9.1813 \\
9.22 & 5.45 & 6.10 & 0.65 & 0.5701 & 0.1226 & 9.3426 \\
9.51 & 5.50 & 6.20 & 0.70 & 0.5376 & 0.0654 & 9.5754 \\
9.73 & 5.55 & 6.33 & 0.78 & 0.4851 & -0.0259 & 9.7041 \\
10.00 & 5.60 & 6.47 & 0.87 & 0.4262 & -0.1291 & 9.8709 \\
10.23 & 5.65 & 6.62 & 0.99 & 0.3609 & -0.2481 & 9.9819 \\
10.49 & 5.70 & 6.80 & 1.10 & 0.2759 & -0.4690 & 10.0210 \\
\hline
\end{tabular}

Average pKa $=9.4923 \pm 0.4410$

Metal-ligand stability constant ( $\log \mathrm{K}$ )

The stabilityconstants require the accurate values of proton-ligand stability constants (Anil and Maroti, 2008). Metal titration curves crossed over ligand titration curve indicated the formation of complex upon proton release (Santosh, et al., 2011). If the values of n- are within range $0.2-0.8$ and $1.2-18$ this indicates the formation of $1: 1$ and 1:2 complexes (Sayyed and Mazahar, 2012).

The metal (II)-humate stepwise stability constants (log k) at phenolic group (Tables 318)

Table 3: Point-wise method, $\mathrm{Cu}$-(Hydrolysed PSHA)

\begin{tabular}{|l|l|l|l|l|l|l|l|l|}
\hline $\mathrm{pH}$ & $\mathrm{BV}_{1}$ & $\mathrm{BV}_{2}$ & $\mathrm{BV}_{3}$ & $\left(\mathrm{~V}_{3}-\mathrm{V}_{2}\right)$ & $\mathrm{n}$ & $\mathrm{pL}$ & $\log \left(\frac{n}{1-n}\right)$ & LogK $_{1}$ \\
\hline 8.50 & 5.30 & 6.29 & 6.33 & 0.04 & 0.5500 & 2.66 & 0.0871 & 2.7471 \\
8.72 & 5.35 & 6.37 & 6.41 & 0.04 & 0.5714 & 2.43 & 0.1249 & 2.5549 \\
9.00 & 5.40 & 6.46 & 6.50 & 0.04 & 0.6198 & 2.16 & 0.2122 & 2.3722 \\
9.22 & 5.45 & 6.55 & 6.59 & 0.04 & 0.6667 & 1.94 & 0.3010 & 2.2410 \\
\hline
\end{tabular}

LogK $_{1}$ (Average value) $=2.4788 \pm 0.2203$

Table 4: Point-wise method, $\mathrm{Cu}$-(Hydrolysed PSHA)

\begin{tabular}{|l|l|l|l|l|l|l|l|l|}
\hline $\mathrm{pH}$ & $\mathrm{BV}_{1}$ & $\mathrm{BV}_{2}$ & $\mathrm{BV}_{3}$ & $\left(\mathrm{~V}_{3}-\mathrm{V}_{2}\right)$ & $\mathrm{n}$ & $\mathrm{pL}$ & $\log \left(\frac{n-1}{2-n}\right)$ & LogK $_{2}$ \\
\hline 9.51 & 5.50 & 6.66 & 6.73 & 0.07 & 1.3509 & 1.70 & -0.2671 & 1.4329 \\
9.73 & 5.55 & 6.78 & 6.85 & 0.07 & 1.6383 & 1.51 & 0.2467 & 1.7567 \\
10.00 & 5.60 & 6.90 & 6.98 & 0.08 & 2.1783 & 1.31 & -0.2158 & 1.0942 \\
10.23 & 5.65 & 7.05 & 7.13 & 0.08 & 4.1904 & 1.27 & & \\
10.49 & 5.70 & 7.10 & 7.19 & 0.09 & 4.6920 & & & \\
\hline
\end{tabular}

Log $K_{2}($ Average value $)=1.4280 \pm 0.3312$ 
BAJOPAS Volume 14 Number 1,June, 2021

Table 5: Point-wise method, $\mathrm{Cu}$ (Unhydrolysed PSHA)

\begin{tabular}{|l|l|l|l|l|l|l|l|l|}
\hline $\mathrm{pH}$ & $\mathrm{BV}_{1}$ & $\mathrm{BV}_{2}$ & $\mathrm{BV}_{3}$ & $\left(\mathrm{~V}_{3}-\mathrm{V}_{2}\right)$ & $\mathrm{n}$ & $\mathrm{pL}$ & $\log \left(\frac{n}{n-1}\right)$ & Log $_{1}$ \\
\hline 8.50 & 5.30 & 5.81 & 5.85 & 0.04 & 0.2973 & 2.88 & -0.3736 & 2.5064 \\
8.72 & 5.35 & 5.90 & 5.95 & 0.05 & 0.3873 & 2.66 & -0.1992 & 2.4608 \\
9.00 & 5.40 & 6.00 & 6.05 & 0.05 & 0.4044 & 2.38 & -0.1681 & 2.2119 \\
9.22 & 5.45 & 6.10 & 6.15 & 0.06 & 0.5157 & 2.18 & -0.0272 & 2.2072 \\
9.51 & 5.50 & 6.20 & 6.27 & 0.07 & 0.6417 & 1.89 & 0.2530 & 1.1430 \\
\hline
\end{tabular}

$\operatorname{LogK}_{1}($ Average value $)=2.3059 \pm 0.6153$

Table 6:Point-wise method, $\mathrm{Cu}$ (Unhydrolysed PSHA)

\begin{tabular}{|l|l|l|l|l|l|l|l|l|}
\hline $\mathrm{pH}$ & $\mathrm{BV}_{1}$ & $\mathrm{BV}_{2}$ & $\mathrm{BV}_{3}$ & $\mathrm{~V}_{3}-\mathrm{V}_{2}$ & $\mathrm{n}$ & $\mathrm{pL}$ & $\log \left(\frac{n-1}{2-n}\right)$ & $\log \mathrm{K}_{2}$ \\
\hline 9.73 & 5.55 & 6.33 & 6.42 & 0.09 & 0.9000 & 1.69 & & \\
10.00 & 5.60 & 6.47 & 6.58 & 0.11 & 1.2578 & 1.44 & -0.4592 & 0.9808 \\
10.23 & 5.65 & 6.62 & 6.84 & 0.12 & 1.6137 & 1.26 & -0.2010 & 1.4610 \\
10.49 & 5.70 & 6.80 & 6.92 & 0.12 & 2.1052 & 1.03 & & \\
\hline
\end{tabular}

$\operatorname{LogK}_{2}$ (Average value) $=1.2209 \pm 0.3398$

Table 7:Point-wise method, Pb (Hydrolysed PSHA)

\begin{tabular}{|l|l|l|l|l|l|l|l|l|}
\hline $\mathrm{pH}$ & $\mathrm{BV}_{1}$ & $\mathrm{BV}_{2}$ & $\mathrm{BV}_{3}$ & $\left(\mathrm{~V}_{3}-\mathrm{V}_{2}\right)$ & $\mathrm{n}$ & $\mathrm{pL}$ & $\log \left(\frac{n}{1-n}\right)$ & LogK $_{1}$ \\
\hline 8.50 & 5.30 & 6.29 & 6.33 & 0.04 & 0.5500 & 2.66 & 0.0871 & 2.7471 \\
8.72 & 5.35 & 6.37 & 6.41 & 0.04 & 0.5714 & 2.43 & 0.1249 & 2.5549 \\
9.00 & 5.40 & 6.46 & 6.50 & 0.04 & 0.6198 & 2.16 & 0.2122 & 2.3722 \\
9.22 & 5.45 & 6.55 & 6.60 & 0.05 & 0.8333 & 1.96 & 0.6989 & 2.6589 \\
\hline
\end{tabular}

Log $_{\mathbf{1}}($ Average value $)=2.5832 \pm 0.1614$

Table 8:Point-wise method, Pb-(Hydrolysed PSHA)

\begin{tabular}{|l|l|l|l|l|l|l|l|l|}
\hline $\mathrm{pH}$ & $\mathrm{BV}_{1}$ & $\mathrm{BV}_{2}$ & $\mathrm{BV}_{3}$ & $\left(\mathrm{~V}_{3}-\mathrm{V}_{2}\right)$ & $\mathrm{n}$ & $\mathrm{pL}$ & $\log \left(\frac{n-1}{2-n}\right)$ & $\log \mathrm{K}_{2}$ \\
\hline 9.51 & 5.50 & 6.66 & 6.71 & 0.05 & 0.9650 & 1.67 & & \\
9.73 & 5.55 & 6.78 & 6.83 & 0.05 & 1.1702 & 1.44 & & \\
10.00 & 5.60 & 6.90 & 6.90 & 0.05 & 1.4864 & 1.22 & -0.0237 & 1.1963 \\
10.23 & 5.65 & 7.05 & 7.10 & 0.05 & 2.0190 & 1.09 & & \\
10.49 & 5.70 & 7.10 & 7.17 & 0.07 & 3.6492 & 1.00 & & \\
\hline
\end{tabular}

Log $K_{2}$ (Average value) $=1.1963$

Table 9: Point-wise method, Pb (Unhydrolysed PSHA)

\begin{tabular}{|l|l|l|l|l|l|l|l|l|}
\hline $\mathrm{pH}$ & $\mathrm{BV}_{1}$ & $\mathrm{BV}_{2}$ & $\mathrm{BV}_{3}$ & $\mathrm{~V}_{3}-\mathrm{V}_{2}$ & $\mathrm{n}$ & $\mathrm{pL}$ & $\begin{array}{l}\text { Log } \\
\left(\frac{n}{n-1}\right)\end{array}$ & Log $\mathrm{K}_{1}$ \\
\hline 8.50 & 5.30 & 5.81 & 5.85 & 0.04 & 0.2973 & 2.88 & -0.3736 & 2.5064 \\
8.72 & 5.35 & 5.90 & 5.94 & 0.04 & 0.3099 & 2.66 & -0.5477 & 2.3123 \\
9.00 & 5.40 & 6.00 & 6.05 & 0.05 & 0.4044 & 2.38 & -0.1681 & 2.2119 \\
9.22 & 5.45 & 6.10 & 6.15 & 0.06 & 0.5157 & 2.18 & 0.0272 & 2.2072 \\
9.51 & 5.50 & 6.20 & 6.26 & 0.07 & 0.6417 & 1.89 & 0.2530 & 2.1430 \\
9.73 & 5.55 & 6.40 & 6.40 & 0.07 & 0.7000 & 1.67 & 0.3680 & 2.0380 \\
\hline
\end{tabular}

LogK $_{1}$ (Average value) $=2.2364 \pm 0.1602$

Table 10: Point-wise method, Pb (Unhydrolysed PSHA)

\begin{tabular}{|l|l|l|l|l|l|l|l|l|}
\hline $\mathrm{pH}$ & $\mathrm{BV}_{1}$ & $\mathrm{BV}_{2}$ & $\mathrm{BV}_{3}$ & $\mathrm{~V}_{3}-\mathrm{V}_{2}$ & $\mathrm{n}$ & $\mathrm{pL}$ & $\log \left(\frac{n-1}{2-n}\right)$ & $\log \mathrm{K}_{2}$ \\
\hline 10.00 & 5.60 & 6.47 & 6.55 & 0.08 & 1.9503 & 1.41 & & \\
10.23 & 5.65 & 6.62 & 6.72 & 0.11 & 1.4792 & 1.26 & -0.0361 & 1.2239 \\
\hline
\end{tabular}

$\operatorname{LogK}_{2}$ (Average value) $=1.2239$

Table 11: Point-wise method, Mg (Hydrolysed PSHA)

\begin{tabular}{|l|l|l|l|l|l|l|l|l|}
\hline $\mathrm{pH}$ & $\mathrm{BV}_{1}$ & $\mathrm{BV}_{2}$ & $\mathrm{BV}_{3}$ & $\left(\mathrm{~V}_{3}-\mathrm{V}_{2}\right)$ & $\mathrm{n}$ & $\mathrm{pL}$ & $\log \left(\frac{n}{n-1}\right)$ & LogK $_{1}$ \\
\hline 8.50 & 5.30 & 6.29 & 6.31 & 0.02 & 0.2750 & 2.64 & -0.4290 & 2.2110 \\
8.72 & 5.35 & 6.37 & 6.39 & 0.02 & 0.2858 & 2.42 & -0.3978 & 2.0222 \\
9.00 & 5.40 & 6.46 & 6.49 & 0.03 & 0.4648 & 2.14 & -0.0612 & 2.0788 \\
9.22 & 5.45 & 6.55 & 6.59 & 0.04 & 0.6667 & 1.94 & 0.3010 & 2.2410 \\
\hline
\end{tabular}

$\log _{\mathbf{1}}($ Average value) $=2.1382 \pm 0.1046$ 
BAJOPAS Volume 14 Number 1,June, 2021

Table 12: Point-wise method, Mg (Hydrolysed PSHA)

\begin{tabular}{|l|l|l|l|l|l|l|l|l|}
\hline $\mathrm{pH}$ & $\mathrm{BV}_{1}$ & $\mathrm{BV}_{2}$ & $\mathrm{BV}_{3}$ & $\left(\mathrm{~V}_{3}-\mathrm{V}_{2}\right)$ & $\mathrm{n}$ & $\mathrm{pL}$ & $\log \left(\frac{n-1}{2-n}\right)$ & LogK $_{2}$ \\
\hline 9.51 & 5.55 & 6.66 & 6.71 & 0.05 & 0.9650 & 1.67 & & \\
9.73 & 5.55 & 6.78 & 6.84 & 0.06 & 1.4042 & 1.47 & -0.1686 & 1.3014 \\
10.00 & 5.60 & 6.90 & 6.93 & 0.06 & 1.7838 & 1.23 & 0.5593 & 1.7893 \\
10.23 & 5.65 & 7.05 & 7.10 & 0.06 & 3.1429 & 1.10 & & \\
10.49 & 5.70 & 7.10 & 7.18 & 0.07 & 3.6492 & 0.83 & & \\
\hline
\end{tabular}

LogK $_{2}($ Average value $)=1.5453 \pm 0.3450$

Table 13: Point-wise method, Mg (Unhydrolysed PSHA)

\begin{tabular}{|l|l|l|l|l|l|l|l|l|}
\hline $\mathrm{pH}$ & $\mathrm{BV}_{1}$ & $\mathrm{BV}_{2}$ & $\mathrm{BV}_{3}$ & $\mathrm{~V}_{3}-\mathrm{V}_{2}$ & $\mathrm{n}$ & $\mathrm{pL}$ & $\log \left(\frac{n}{n-1}\right)$ & $\operatorname{Log~}_{1}$ \\
\hline 8.50 & 5.30 & 5.81 & 5.85 & 0.04 & 0.2973 & 2.88 & -0.3736 & 2.5064 \\
8.72 & 5.35 & 5.90 & 5.94 & 0.04 & 0.3099 & 2.66 & -0.3477 & 2.3123 \\
9.00 & 5.40 & 6.00 & 6.04 & 0.04 & 0.3236 & 2.38 & -0.3202 & 2.0598 \\
9.22 & 5.45 & 6.10 & 6.15 & 0.05 & 0.4297 & 2.17 & -0.1230 & 2.0470 \\
9.51 & 5.50 & 6.20 & 6.26 & 0.06 & 0.5500 & 1.89 & 0.0871 & 1.9771 \\
9.73 & 5.55 & 6.33 & 6.40 & 0.07 & 0.7000 & 1.67 & 0.3680 & 2.0380 \\
\hline
\end{tabular}

LogK $_{1}$ (Average value) $=2.1568 \pm 0.2069$

Table 14: Point-wise method, Mg (Unhydrolysed PSHA)

\begin{tabular}{|l|l|l|l|l|l|l|l|l|}
\hline $\mathrm{pH}$ & $\mathrm{BV}_{1}$ & $\mathrm{BV}_{2}$ & $\mathrm{BV}_{3}$ & $\mathrm{~V}_{3}-\mathrm{V}_{2}$ & $\mathrm{n}$ & $\mathrm{pL}$ & $\log \left(\frac{n-1}{2-n}\right)$ & $\log \mathrm{K}_{2}$ \\
\hline 10.00 & 5.60 & 6.47 & 6.55 & 0.08 & 0.9148 & 1.41 & & \\
10.23 & 5.65 & 6.62 & 6.71 & 0.09 & 1.2102 & 1.20 & -0.5749 & 0.6251 \\
10.49 & 5.70 & 6.80 & 6.92 & 0.09 & 1.5968 & 1.03 & 0.1703 & 1.2003 \\
\hline
\end{tabular}

LogK $_{2}$ (Average value) $=0.9127 \pm 0.4070$

Table15:Point-wise method, Cd (Hydrolysed PSHA)

\begin{tabular}{|l|l|l|l|l|l|l|l|l|}
\hline $\mathrm{pH}$ & $\mathrm{BV}_{1}$ & $\mathrm{BV}_{2}$ & $\mathrm{BV}_{3}$ & $\left(\mathrm{~V}_{3}-\mathrm{V}_{2}\right)$ & $\mathrm{n}$ & $\mathrm{pL}$ & $\log \left(\frac{n}{1-n}\right)$ & LogK $_{1}$ \\
\hline 8.50 & 5.30 & 6.29 & 6.31 & 0.02 & 0.2750 & 2.64 & -0.4210 & 2.2190 \\
8.72 & 5.35 & 6.37 & 6.40 & 0.03 & 0.4286 & 2.42 & -0.1249 & 2.2951 \\
9.00 & 5.40 & 6.46 & 6.49 & 0.03 & 0.4648 & 2.14 & -0.0612 & 2.0788 \\
9.22 & 5.45 & 6.55 & 6.59 & 0.04 & 0.6667 & 1.96 & 0.3010 & 2.2610 \\
9.51 & 5.55 & 6.66 & 6.70 & 0.04 & 0.7720 & 1.67 & 0.5297 & 2.1997 \\
\hline
\end{tabular}

LogK $_{\mathbf{1}}$ (Average value) $=2.2108 \pm 0.0825$

Table 16: Point-wise method, Cd (Hydrolysed PSHA)

\begin{tabular}{|l|l|l|l|l|l|l|l|l|}
\hline $\mathrm{pH}$ & $\mathrm{BV}_{1}$ & $\mathrm{BV}_{2}$ & $\mathrm{BV}_{3}$ & $\left(\mathrm{~V}_{3}-\mathrm{V}_{2}\right)$ & $\mathrm{n}$ & $\mathrm{pL}$ & $\log \left(\frac{n-1}{2-n}\right)$ & Log $_{2}$ \\
\hline 9.73 & 5.55 & 6.78 & 6.83 & 0.06 & 1.4042 & 1.47 & -0.1686 & 1.3014 \\
10.00 & 5.60 & 6.90 & 6.95 & 0.06 & 1.7838 & 1.23 & 0.5593 & 1.7893 \\
10.23 & 5.65 & 7.05 & 7.10 & 0.06 & 3.1429 & 1.09 & & \\
10.49 & 5.70 & 7.10 & 7.16 & 0.06 & 3.1429 & 0.89 & & \\
& & & & & & & & \\
\hline
\end{tabular}

$\operatorname{LogK}_{2}$ (Average value) $=1.5453 \pm 0.3450$

Table 17: Point-wise method, Cd (Unhydrolysed PSHA)

\begin{tabular}{|l|l|l|l|l|l|l|l|l|}
\hline $\mathrm{pH}$ & $\mathrm{BV}_{1}$ & $\mathrm{BV}_{2}$ & $\mathrm{BV}_{3}$ & $\mathrm{~V}_{3}-\mathrm{V}_{2}$ & $\mathrm{n}$ & $\mathrm{pL}$ & $\log \left(\frac{n}{n-1}\right)$ & $\operatorname{Log~}_{1}$ \\
\hline 8.50 & 5.30 & 5.81 & 5.86 & 0.05 & 0.3717 & 2.88 & -0.2280 & 2.6520 \\
8.72 & 5.35 & 5.90 & 5.95 & 0.05 & 0.3873 & 2.66 & -0.1992 & 2.4608 \\
9.00 & 5.40 & 6.00 & 6.06 & 0.06 & 0.4853 & 2.38 & -0.0255 & 2.3545 \\
9.22 & 5.45 & 6.10 & 6.16 & 0.06 & 0.5157 & 2.18 & -0.0272 & 2.2072 \\
9.51 & 5.50 & 6.20 & 6.27 & 0.07 & 0.6417 & 1.89 & 0.2530 & 1.1430 \\
9.73 & 5.55 & 6.33 & 6.41 & 0.08 & 0.8000 & 1.69 & 0.6020 & 2.2920 \\
& & & & & & & & \\
\hline
\end{tabular}

$\operatorname{LogK}_{1}($ Average value $)=2.2516 \pm 0.5380$ 
BAJOPAS Volume 14 Number 1,June, 2021

Table 18: Point-wise method, Cd (Unhydrolysed PSHA)

\begin{tabular}{|l|l|l|l|l|l|l|l|l|}
\hline $\mathrm{pH}$ & $\mathrm{BV}_{1}$ & $\mathrm{BV}_{2}$ & $\mathrm{BV}_{3}$ & $\mathrm{~V}_{3}-\mathrm{V}_{2}$ & $\mathrm{n}$ & $\mathrm{pL}$ & $\log \left(\frac{n-1}{2-n}\right)$ & $\log \mathrm{K}_{2}$ \\
\hline 10.00 & 5.60 & 6.47 & 6.57 & 0.10 & 1.1434 & 1.43 & & \\
10.23 & 5.65 & 6.62 & 6.72 & 0.10 & 1.3448 & 1.23 & -0.2788 & 0.9512 \\
10.49 & 5.70 & 6.80 & 6.90 & 0.10 & 1.7742 & 1.03 & 0.5351 & 1.5651 \\
\hline
\end{tabular}

$\operatorname{LogK}_{2}($ Average value $)=1.2581 \pm 0.4340$

Table 19: Stepwise and overall Stability constants of thehydrolysed and unhydrolysed divalent metal (II) complexes

\begin{tabular}{|c|c|c|c|}
\hline Chelates & LogK $_{1}$ & $\log _{2}$ & Log $\beta$ \\
\hline [Cu (Hydrolysed PSHA-1) $\left.{ }_{2}\right]$ & 2.4788 & 1.4280 & 3.9068 \\
\hline$\left[\mathrm{Pb}(\text { Hydrolysed PSHA-1) })_{2}\right]$ & 2.5832 & 1.1963 & 3.7795 \\
\hline$\left[\mathrm{Cd}(\text { Hydrolysed PSHA-1 })_{2}\right]$ & 2.2108 & 1.5453 & 3.7561 \\
\hline$\left[\mathrm{Mg}(\text { Hydrolysed PSHA-1 })_{2}\right]$ & 2.1382 & 1.5453 & 3.6835 \\
\hline [Cu (Unhydrolysed PSHA-1) & 2.3059 & 1.2209 & 3.5268 \\
\hline$[\mathrm{Pb}$ (Unhydrolysed PSHA-1) 2$]$ & 2.2364 & 1.2239 & 3.4603 \\
\hline [Cd (Unhydrolysed PSHA-1) 2 ] & 2.2516 & 1.2581 & 3.5097 \\
\hline$[\mathrm{Mg}$ (Unydrolysed PSHA-1) & 2.1568 & 0.9127 & 3.0695 \\
\hline
\end{tabular}

The results obtained (Table19) shows the stepwise and overall stability constants to be not high indicating low stability of the complexes, because the solubility of most metal ions in the basic $\mathrm{pH}$ range is minimal due to metal hydroxide precipitation (Karimi, 2017). In general, the stepwise stability constants $\left(K_{1}\right.$ and $K_{2}$ ) follow the order $K_{1}>K_{2}$ for the copper, lead, magnesium and cadmium complexes respectively. The steady decrease of the values with increasing number of ligands is in agreement with the prediction made by researchers (Na'aliya, 2013). The decrease could be attributed to the fact that as the number of the ligands (Humate ions) that enters the coordination zone increases the aqua molecules available for replacement by the ligands become less. Thus, the metal ions become less electron loving with progressive intake of the ligand and this results in the decrease in the values of the constants (Na'aliya, 2013). Also the stability of the complexes is influenced by the size and number of the chelate rings(Mackay and Mackay,2002).All the complexes form rings in their structure as humate, a bidentate ligand, bond the metal ions in the ratio 1:2 (Boguta and Sokolowska, 2016) forming chelate rings. The values of the overall stability constants $(\log \beta)$ obtained for humate complexes are not high indicating low stability as the values are not high. LogK values for copper-humates (Table 3 to 6) obtained in this study are lower than those reported for the complexes of humic acids (Pandey et al., 2015; Dinu, 2013; Kaschl et al., 2010 and Gilbeto and Jorg, 2001). The values of LogK(Table 7 to 10 ) forlead-humates are lower than those reported for the lead in the literature (Dinu, 2013; Gilbeto and Jorg 2001). Log K values(Table 11 to 14 ) for magnesium-humates obtained in this study are close to those reported by (Pandey et al., 2015). Log K values of cadmium-humates (Table 15 to 18 ) obtained in this work near to the one reported by (Dinu, 2013 and Pandey et al., 2015).The difference between the reported values and the values obtained in this study might be probably as a result of acid hydrolysis of humic acid. The values of the overall stability constants $(\log \beta)$ of the copper humates complexes presented in Table 19 is high than that of other metal humate complexes, show relatively high stability of CuHA complexes, show the following order of stability: $\mathrm{Cu}>\mathrm{Pb}>\mathrm{Cd}>\mathrm{Mg}$; which are in close agreement to the findings of (Dinu, 2013 and Pandey et al., 2015).The high stability of Cuhumate chelate could be attributed to the existence of coordinate covalent bond between the complexing agents and the $\mathrm{Cu}^{2+}$ ions. Since, $\mathrm{Cu}^{2+}$ being a metal of the transitional series with $3 d^{9}$ electronic configurations can accept the electrons from the complexing agents. Similarly, the low stabilities of $\mathrm{Pb}, \mathrm{Cd}$ and $\mathrm{Mg}$ complexes could be explained by that $\mathrm{Pb}^{2+}$ with $6 s^{2}, \mathrm{Cd}^{2+}$ with $4 \mathrm{~d}^{10}$ and $\mathrm{Mg}^{2+}$ with $2 \mathrm{p}^{6}$ their electronic configuration has a completely filled $\mathrm{d}, \mathrm{p}$ and $\mathrm{s}$ orbitals. Moreover, the stabilities of metal ions with hydrolysed humic acid from peat soil were higher than those with unhydrolysed humic acid from peat soil; which is ascribed to the high content of acidity in hydrolysed humic acid than unhydrolysed humic acid. 
BAJOPAS Volume 14 Number 1,June, 2021 CONCLUSION

The values of logk for $\mathrm{Cu}(\mathrm{II})$ hydrolysed humic acid complex was higher followed by $\mathrm{Pb}$ (II), $\mathrm{Cd}(\mathrm{II})$ and $\mathrm{Mg}$ (II) hydrolysed humic acid complexes as compared with metal(II) unhydrolysed humic acid complexes. This indicates acid hydrolysis of humic acid can

\section{REFERENCES}

Almeida, V.R. and Szpoganicz, B. (2015). Humic Acid Potentiometric Response Patterns:Out- of Equilibrium Properties and Species Distribution Modelling. Chemical. Biol. Technol. Agric. 2: 17.

Anđelković, T., Nikolić, R., Bojić, A.,Anđelković, D., and Nikolic G.,(2010). Binding of Cadmium to Soil Humic Acid as A Function of Carboxyl Group Content. Macedonian Journal of Chemistry and Chemical Engineering.29(2): 215-224.

Anil, B. N. and Maroti, N. (2008). Studies on Influence of Die-Lectric Constants on Complex Equilibria between Substituted Py-Razalines and Lanthanide Metal Ions pH-Metrically. Amer.-Euras. scient. Res. 3(2): 212-216.

Ashok, K., Pandey, S. P. and Misra, V (2000). Stability Constants of Metal-Humic Acid Complexes and its Role in Environmental Detoxification. Journal of Ecotoxicology and Environmental Safety. 47(2):157-200.

Badr, M. H., El-Halafawi, M. H. and Abd El-al Zeid, E. R. (2012). Comparison Between the Effect of Ionic Strength on Acidity and Dissociation Constants of Humic Acids Extracted from Sewage Sludge and Nile Water Hyacinth Composts.Global Journal of Environmental Research 6 (1): 36-43.

Baruah, M.K., Borah, D., Saikia, P.P., Paul, S., Sharma, T. (2015). Evaluation of pKa Values of Soil Humic Acids and their Complexation Properties. International Journal of Plant \& Soil Science 6(4) : 218-228.

Boguta, P. Sokolowska, Z. (2016). Interactions of $\mathrm{Zn}$ (II) Ions with Humic Acids Isolated from Various Types of Soils. Effect of $\mathrm{pH}, \mathrm{Zn}$ Concentrations and Humic Acids Chemical Properties. Journal of Geochemical Explaration 168. 119-126.

Borges, F., Guimaraes, C., Lima, L.F.C., Pinto, I. and Reis, S.(2005). Potentiometric Studies on the Complexation of Copper(II) by Phenolic Acids as Discrete Ligand Models of enhance the complexation behavior of humic acid with metal (II) ions. However, the higher values of $\log \beta$ for $\mathrm{Cu}(\mathrm{II}), \mathrm{Pb}(\mathrm{II}), \mathrm{Cd}(\mathrm{II})$ and $\mathrm{Mg}(\mathrm{II})$ hydrolysed humic acid complexes indicates more stable stepwise complexes formed as compared with $\mathrm{Cu}(\mathrm{II}), \mathrm{Pb}$ (II), $\mathrm{Cd}$ (II) and $\mathrm{Mg}(\mathrm{II})$ unhydrolysed humic acid complexes.

Humic Substances Talanta 66 (2005) 670-673.

Chefetz, B., Salloum, M. J., Deshmulkin, A. P. and Hatcher, P. (2002). Structural Components of Humic Acids as Determined by Chemical Modifications and Carbon-13 NMR, Pyrolysis, and Thermochemolysis- Gas Chromatography/Mass Spectrometry. Soil Science Society of American Journal Abstract Division S-2- Soil Chemistry66. 1159-1171.

Dinu, M. I. (2013). Metals Complexation with Humic Acids in Surface Water of Different Environ. Sci. Technol. 31(1): 1-17.

Fernandes, A.N., Giacomelli, C., Giovanela, M. Vaz, D.V. Szpoganicz, B. and Maria M. D. (2009). Potentiometric Acidity Determination in Humic Substances Influenced by Different Analytical Procedures.J. Braz. Chem. Soc. 20 (9):14.

Gamal, A. H. (2015). Stability Constants of Rhenium (V) Metal Complexes with Selected Drugs. Pyrex Journal of Research in Environmental Studies. 2(2): 006-014.

Janrao, D. M., Pathan, J., Kayande, D.D., and Mulla, J.J. (2014). An Over View of Potentiometric Determination of Stability Constants of Metal Complexes. Sci. Revs. Chem. Commun.: 4(1), 2014, 11-24.

Karimi, H. (2017). Effect of pH and Initial Pb(II) Concentration on the Lead Removal Efficiency from Waste Water Using $\mathrm{Ca}(\mathrm{OH})_{2}$. International Journal of Water and Waste Water Treatment 3.2

Kaschl, A. Romheld, V. and Chen, Y. (2010). Binding of Cadmium, Copper and Zinc to Humic Substances Originating from Municipal Solid Waste Compost. Israel Journal of Chemistry Vol. 42(1): 89-98.

Kostic, I. S., Tatjana, P, A., Nikolic, R. S., Cvetkovic, T. P., Pavlovic, D. D., Aleksandar, L.J. and Bojic, A. (2012). Comparative Study of Binding Strengths of Heavy Metals with Humic Acid. J.serb. Chem. Soc. 76(9) pp 1-20. 
BAJOPAS Volume 14 Number 1,June, 2021

Na'aliya, J. (2013). Determination of Stepwise Stability Constants and Gibbs free Energy Change of Trisprolina to Complexes of some Divalent Transition Metal ions. Bayero Journal of Pure and Applied Sciences 6(2): 112-114.

Omar, A. A. and Ali, E. A. (2015). Potentiometric Studies on Complexes of $\mathrm{Cr}$ (III) and $\mathrm{Zr}$ (IV) with some Carboxylic Acids. International Journal of Advanced Chemistry, 3(1) 25-

37.

Pandey, A. K. Pandey, S. D. and Misr, V. (2015).Stability Constants of Metal- Humic Acid Complexes and Its Role in Environmental Detoxification. J. Ecotoxicology and Environmental Safety. 47(1):195-200.

Ram, N. and Raman, K.V. (1984). Stability Constants of Complexes of Metals with
Humicand Fuvic Acids under Non- acidConditions. Journal of Plant Nutrition and Soil Sciences.

147:171-176.

Santosh, D. D., Ashok, B. K., Vijay, J. T., Shivraj, G. W. and Vinay, V. W. (2011). Potentiometric Studies of Elec-Trolyte Effects on Complex Equilibria of Some Substituted 5-(2-hydroxy Phenyl) Pyrazoles. Der pharm. 3 (6): 75-83.

Sayyed, H. and Abdul Rahim, M. F. (2012). Studies of Binary Complexes of Metal Ions with Mandelic Acid by Potentiometry. Chem. J. 02 (6): 206209.

Shirvani, M. Moradian, E. Khalili, B. Bakhtiary, S. (2015). Interaction of $\mathrm{Cd}$ and $\mathrm{Pb}$ with Humate-Palygorskite and HumateSepiolite Complexes. Journal of water, air and pollution 3: 220-228. 


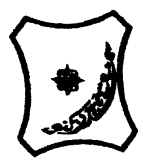

Bayero Journal of Pure and Applied Sciences, 14(1): 54 - 63

Received: November, 2020

Accepted: April, 2021

ISSN $2006-6996$

\title{
STABILITY CONSTANTS OF COMPLEXES OF METAL IONS WITH PEATSOIL HUMIC ACIDS UNDER NON-ACID-CONDITIONS
}

\author{
${ }^{* 1}$ Sabo, Yusuf ${ }^{2}$ Jimoh, W.L.O., ${ }^{3}$ Isa Baba Koki and ${ }^{4}$ Sholadoye, Q. 0. \\ ${ }^{1}$ Department of Pure and Industrial Chemistry, Bayero University, Kano \\ ${ }^{3}$ Department of Chemistry, Yusuf Maitama Sule University Kano. P.M.B. 3220 Kano, Nigeria. \\ ${ }^{4}$ Department of Chemistry, Nigerian Police Academy, Wudil, Kano-Nigeria
}

*Correspondence E-mail; saboyusuf18@yahoo.com

ABSTRACT

Stability constants of complexes of four divalent metal ions viz. $\mathrm{Cu}^{2+}, \mathrm{Pb}^{2+}, \mathrm{Mg}^{2+}$ and $\mathrm{Cd}^{2+}$ with humic acids (HA) were determined by potentiometric titration of humic acids with the corresponding salt of the divalent metals in aqueous media under non-acid-condition. The log $K$ (logarithm of the stability constant) ranged from 1.0942 to 2.7471 for metalhumic acid complexes were determined using point-wise computational method. The order of stability constants were obtained as follows: $\mathrm{Cu}>\mathrm{Pb}>\mathrm{Cd}>\mathrm{Mg}$ for metal $-\mathrm{HA}$ complexes respectively, indicating a higher degree of complexation with Cu metal ion.

Keywords: stability constant, humic acid, potentiometric titration, divalent metals, acid hydrolysis.

\section{NTRODUCTION}

The stability constant of a complex is the numerical expression of its stability and provides a quantitative measure of affinity of the metal ion to the complexing agent. An understanding of the relative stability of metal-complexes helps in predicting the behavior of metal ions in the soil (Ram and Raman, 1982). Extensive researches has been done to determine the stability constants of the complexes formed between humic acid (HA) with a number of metal ions. Ashok et al., (2000) reported that humic acid with hydroxyl, phenoxyl and carboxyl reactive groups can form coordination compound with metal ions at $\mathrm{pH}$ 3.5. The stability constants(Log K) for different metalhumic acid complexes indicated the following order of the stabilities of complexes formed between humic acid and metal ion, $\mathrm{Cu}>\mathrm{Fe}$ $>\mathrm{Pb}>\mathrm{Ni}>\mathrm{Co}>\mathrm{Ca}>\mathrm{Cd}>\mathrm{Zn}>\mathrm{Mn}>\mathrm{Mg}$. Andelkovic et al., (2010) investigated the binding of $\mathrm{Cd}$ (II) to soil humic acid at pH 6.5 and in $0.1 \mathrm{M} \mathrm{KNO}_{3}$ ionic medium. The stability constant for binding indicating greater stability in the case when carboxyl groups are involved in complexation reaction. Kostic et al.,(2012) investigated the complexation of humic acid with certain heavy metal ions (Co(II), $\mathrm{Ni}(\mathrm{II}), \mathrm{Cu}(\mathrm{II})$,
$\mathrm{Zn}(\mathrm{II})$, and $\mathrm{Pb}(\mathrm{II})$. The experiment was performed at $25^{\circ} \mathrm{C}$, at pH 4.0 and ionic strength of $0.01 \mathrm{M}$. Stability constant of complex between $\mathrm{Pb}$ (II) ions and humic acid is greater than stability constants of other investigated metalhumate complexes. Bogata and Sokolowska (2016) analyses the interaction between humic acids from different soils and $\mathrm{Zn}$ (II) ions at wide concentration ranges and at $\mathrm{pH} 5$. Studies have showed significant impact of $\mathrm{Zn}$ concentration, $\mathrm{pH}$ and some properties of humic acids with zinc.But all of these studies were limited to acidic $\mathrm{pH}$ range. Therefore, the present study was carried out to determine and compare the stability constants of complexes of metal ions with hydrolysed peat soil humic acid and unhydrolysed peat soil humic under non-acid conditions.

\section{MATERIALS AND METHODS}

Analytical grade chemicals used includes hydrochloric acid $(\mathrm{HCl})$, nitric acid $\left(\mathrm{HNO}_{3}\right)$, sodium hydroxide $(\mathrm{NaOH})$, lead nitrate $\mathrm{Pb}\left(\mathrm{NO}_{3}\right)_{2}$, copper nitrate $\mathrm{Cu}\left(\mathrm{NO}_{3}\right)_{2} \cdot 3 \mathrm{H}_{2} \mathrm{O}$, cadmium nitrate $\mathrm{Cd}\left(\mathrm{NO}_{3}\right)_{2} \cdot 4 \mathrm{H}_{2} \mathrm{O}$, magnesium nitrate $\mathrm{Mg}\left(\mathrm{NO}_{3}\right)_{2} \cdot 6 \mathrm{H}_{2} \mathrm{O}$, potassium nitrate $\left(\mathrm{KNO}_{3}\right)$, calcium chloride $\left(\mathrm{CaCl}_{2}\right)$, (sigma-Aldrich). Dowex 50WX8, (20-50 mesh) from Fluka. 


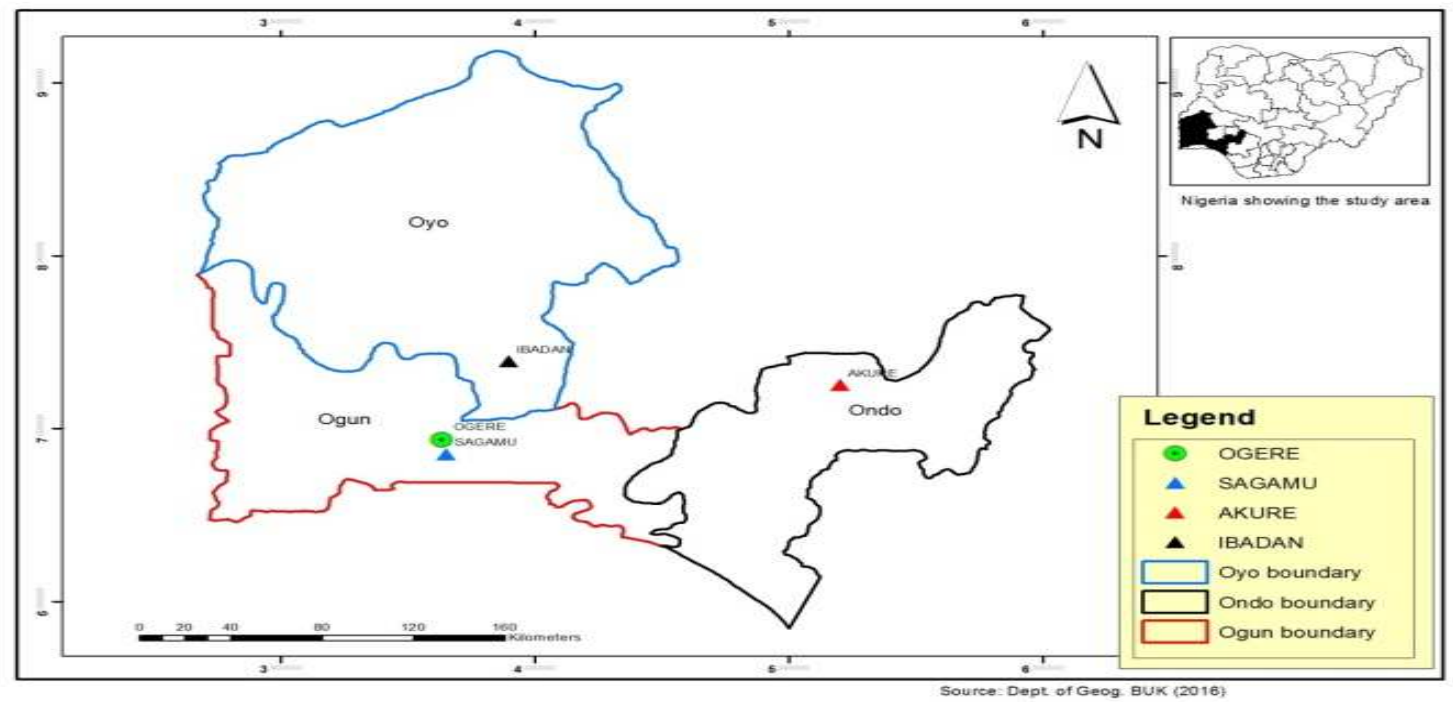

Figure 1: Map showing the sampling point at Sagamu Town, Ogun State.

\section{Description of Sampling Area}

Sagamu has geographical coordinates between $6^{\circ} 50^{\prime}$ north; $3^{\circ} 38^{\prime}$ east is located in south western region of Nigeria. The region has tropical wet and dry climate with a lengthy wet season and relatively constant temperatures throughout the course of the year. Wet season runs from March to October, November to December forms the region dry season. The vegetation type of the region is savannah which is really grassland with small bushes and occasional big trees. Grassland soils have substantially higher organic matter content than forest soils (Novackova, 2011).

\section{Sample Collection}

The Peatsoil samples were collected from four different sampling points $(0-10 \mathrm{~cm}$ depth) in Sagamu into polyethylene bag with plastic spoons. Samples were taken to the laboratory, extraneous materials were removed; the samples were air-dried, crushed and ground to a fine powder in a mortar passed through a $0.20 \mathrm{~mm}$ sieve. The samples were kept for analysis.

\section{Isolation and purification of humic acid from peat soil sample}

Peatsoil sample $(100 \mathrm{~g})$ was mixed with 1000 $\mathrm{cm}^{3}$ of $0.1 \mathrm{M} \mathrm{NaOH}$ solution, shaken for 3hours and left to stand overnight. Dark-coloured supernatant was obtained and decanted from solid residue. The dark-coloured supernatant was acidified to $(\mathrm{pH}=1.0)$ with $6 \mathrm{M} \mathrm{HCl}$ stirred and allowed to stand for 6 hours. Yellowish brown supernatant and dark-brown precipitate were obtained. The yellowish brown supernatant was decanted followed by centrifuge and discarded. The dark-brown precipitate was mixed with $500 \mathrm{~cm}^{3}$ of $0.1 \mathrm{M} \mathrm{NaOH}$ solution followed by passing through dowex resin. The dark-brown solution was acidified to $(\mathrm{pH}=1.0)$ with $6 \mathrm{M} \mathrm{HCl}$ stirred and allowed to stand for 3 hours. The dark-brown precipitate was washed several times with deionized water. The supernatant was treated with $\mathrm{AgNO}_{3}$ solution until no white precipitate observed. The humic acid was transferred to weighed crucible and dried at $60^{\circ} \mathrm{C}$ in an oven for 12 hours. The humic acid was cooled and dried in the desiccator, weighed and recorded. The obtained humic acid was dried again at $60^{\circ} \mathrm{C}$ for additional 6 hours cooled and dried in the desiccator, weighed and recorded constant weight was obtained (Baruah et al., 2015).

\section{FT-IR analysis}

FT-IR spectra of humic acid sample was analysed using Carry 630 FT-IR Agilent Technologies.

Unhydrolysed compost humic acid

The unhydrolysed humic acid was obtained after isolation and purification of compost humic acid and kept for investigation.

\section{Acid hydrolysis of Peatsoil acid}

Peatsoil humic acid sample (1g) was refluxed for 12 hours at $\left(160^{\circ} \mathrm{C}\right)$ with $50 \mathrm{~cm}^{3}$ of $6 \mathrm{M} \mathrm{HCl}$. The mixture was allowed to cool, decanted, and centrifuged after hydrolysis. The insoluble residues were washed with distilled water via centrifugation several times, and the supernatant was treated with $\mathrm{AgNO}_{3}$ solution until no white precipitate was observed. The residue was thoroughly dried over $\mathrm{CaCl}_{2}$ in a desiccator at room temperature (Chefetz et al., 2002). Finally, the obtained hydrolysed humic acid was kept for investigation. 
BAJOPAS Volume 14 Number 1,June, 2021 Potentiometric Titrations

Potentiometric measurements were carried out using a pH-meter Jenway (model 3510) with combine electrode, the sensitivity of the $\mathrm{pH}$ meter is 0.01 units. The $\mathrm{pH}$ meter was switched on half an hour before starting the titration for initial warm up of the instrument. The instrument was calibrated with an aqueous standard buffer solution of $\mathrm{pH} 4.00$ and 10.0 (borate buffer) prepared from a "Qualigens" buffer tablets.

The following sets of solutions were prepared in a $250 \mathrm{~cm}^{3}$ volumetric flask separately for $\mathrm{pH}$ metric titrations.

(i) $5 \mathrm{~cm}^{3} 0.1 \mathrm{M} \mathrm{HCl}+40 \mathrm{~cm}^{3}$ deionized water

(ii) $5 \mathrm{~cm}^{3} 0.1 \mathrm{M} \mathrm{HCl}+39 \mathrm{~cm}^{3}$ deionized water $+1 \mathrm{~cm}^{3} 0.15 \mathrm{gcm}^{-3}$ humic acid

(iii) $5 \mathrm{~cm}^{3} 0.1 \mathrm{M} \mathrm{HCl}+37 \mathrm{~cm}^{3}$ deionized water $+1 \mathrm{~cm}^{3} 0.15 \mathrm{gcm}^{-3}$ humic acid

$$
+2 \mathrm{~cm}^{3} \quad 0.01 \mathrm{M} \mathrm{Cu} \text { (II) }
$$

The solutions were titrated against standardized $0.110 \mathrm{MNaOH}$ separately. The total volume of each mixture was adjusted to $50 \mathrm{~cm}^{3}$ and the ionic strength of the solutions was maintained constant at by adding appropriate amount of stock solution of $1 \mathrm{M} \mathrm{KNO}_{3}$ (Gamal, 2015; Omar and Ali, 2015). A magnetic stirrer was used to achieve thorough mixing of the interacting solutions at $550 \mathrm{rpm}$. The same set of experimental conditions was applied for potentiometric titration of remaining samples.

\section{Evaluation of pKa of Hydrolysed peat soil Humic Acids}

The proton-ligand formation number $\mathrm{n}_{\mathbf{A}}$ were calculated by Irving and Rossotti expression (Omar and Ali, 2015).

$\mathrm{nA}=\mathrm{Y}-\frac{(\mathrm{V} 2-\mathrm{V1})(\mathrm{No}-\mathrm{Eo})}{(\mathrm{VO}+\mathrm{V1}) \mathrm{TCL}}$ 1

Where: $Y$ is number of dissociable proton, $\left(\mathrm{V}_{2^{-}}\right.$ $V_{1}$ ) is the measure of displacement of the ligand curve relative to acid curve, $\mathrm{N}^{\circ}$ and $\mathrm{E}^{\circ}$ are the resultant concentration of alkali solution, free acid solution, $\mathrm{T}_{\mathrm{cL}}{ }^{\circ}$ is the total ligand concentration, $\mathrm{V}^{\circ}$ is the total volume of titration solution, $V_{1}$ is the volume of alkali added to acid solution, $V_{2}$ is the volume of alkali added to acid solution + ligand solution, acid dissociation constants (pKa - values) of ligand were calculated by algebraic method point wise calculation (Tables 1 ). The dissociation constants (pKa) were calculated according to the following relation:

$\mathrm{pKa}=\mathrm{pH}+\log \left(\frac{n A}{1-n A}\right)$ 2

Where: pKa is the acid dissociation constant, $\mathrm{n}_{\mathrm{A}}$ is the Proton-ligand formation number and $\mathrm{pH}$ is the pH-values (Omar and Ali, 2015).

\section{Determination of metal-ligand stability constants $(\log K)$ of complexes}

The potentiometric measurement for the determination of stability constant of a complex in solution is based on the fact that the redox potential of the couple $\frac{M^{+(m-n)}}{M^{+m}}$ is shifted significantly on complexation of the metal ion with the ligand. This method involves change in hydrogen ion concentration $\left[\mathrm{H}^{+}\right]$due to the displacement or association of one or more protons taking place during complexation reaction. This change can be found out by titrating the solutions containing free acid, acid with ligand, and acid with ligand and metal ion, individually against a standard alkali solution at a constant ionic strength or temperature. Either ionic strength or temperature may be varied for different sets of solutions. In all the cases, the change in the $\mathrm{pH}$ of the solution is measured after each addition of a known amount of alkali to the reaction cell which contains the reaction mixture. The titration curves are then drawn by plotting the measured $\mathrm{pH}$ values against the corresponding volume of alkali added and the stability constants of the complexes are determined from the titration curves by employing $\mathrm{pH}$-metric titration technique given by (Irving and Rossoti).

Metal-ligand stability constants ( $\log \mathrm{K}$ ) were determined by using the following relations:

$$
\bar{n}=\frac{\left(V_{3}-V_{2}\right)\left(E^{0}+N^{0}\right)}{\left(V^{0}+V_{2}\right) \bar{n}_{A} T_{m}^{0}}
$$

and

$$
P L=\log _{10}\left\{\frac{1+\beta_{n}^{H} \frac{1}{[\text { anti } \log \mathrm{pH}]^{\mathrm{n}}}}{\mathrm{T}_{\mathrm{L}}^{0}-n \bar{T}_{m}^{0}} \mathrm{X} \frac{\left(V^{0}+V_{3}\right)}{V^{0}}\right\}
$$


BAJOPAS Volume 14 Number 1,June, 2021

Where $T_{L}, T^{\circ}, E^{\circ}$, and $V^{\circ}$ havethe same significance as in equation (1) above, $T_{m}$ denotes the total concentration of metal present in solution, $V_{3}$ is the volume of metal ions present in solution and $\beta^{H}$ is the overall proton ligand stability constant. The metal-ligand stability constants (log K) were determined by employing point wise computational Method (eq. 5 and 6).

$\operatorname{LogK}_{1}=\log \left(\frac{n}{1-n}\right)+\mathrm{pL}$ .5

$\operatorname{LogK}_{2}=\log \left(\frac{1-n}{2-n}\right)+\mathrm{pL}$ ...6

Where: Log $\mathrm{K}$ is the metal-ligand stability constant, $\mathrm{pL}$ is the Free ligand exponent function, $\mathbf{n}$ is the Average number of ligand attached with metal ion (Janraoet al., 2014). The results obtained were analyzed by an ORIGIN 2016 program using titration data and then the proton-ligand stability constants (pKa) and Metal-ligand stability constant (LogK) calculated (Omar and Ali, 2015).

\section{RESULTS AND DISCUSSION}

Fourier transformed infrared (FT-IR) spectra of isolated humic acid from peat soils Figure 2 had distinct clear absorption bands indicating the presence of major humic acid structural elemental groups such as $\mathrm{H}$ bonded $\mathrm{OH}$ $\left(3680 \mathrm{~cm}^{-1}\right.$ peak $), C=0$ of carbonyl $\left(1721 \mathrm{~cm}^{-1}\right.$ peak), functional groups of aliphatic components $\mathrm{CH}_{2}\left(2918 \mathrm{~cm}^{-1}\right.$ peak) and $\mathrm{C}-\mathrm{O}$ stretching of polysaccharide $\left(1168 \mathrm{~cm}^{-1}\right.$ peak). The positions of the absorption bands of the spectra fell within typical major absorption bands of humic acid which is at frequencies 3680, 2918, 1721, 1168 $\mathrm{cm}^{-1}$. The first peak centred in the vicinity of $3680 \mathrm{~cm}^{-1}$ region is attributed to phenol $\mathrm{OH}$ group bounded by intermolecular $\mathrm{H}$ bonds. The $2918 \mathrm{~cm}^{-1}$ band usually has absorption maximum at $2918 \mathrm{~cm}^{-1}$ which is due to $\mathrm{C}-\mathrm{H}$ stretching of alkane group $\left(\mathrm{CH}_{2}\right)$. The next major absorption band is $1721 \mathrm{~cm}^{-1}$. This band has been commonly ascribed to $\mathrm{C}=\mathrm{O}$ stretching of mainly carboxyl group $(\mathrm{COOH})$ with trace amount of ketones. The last peak was observed at 1168 $\mathrm{cm}^{-1}$ due to $\mathrm{C}-\mathrm{O}$ stretching of polysaccharides and this peak appeared also in the spectra of humic acid from peat soil. The FTIR spectra of the isolated humic acid contained all major characteristic absorption peaks of humic acid. These absorption peaks indicated the presence of the major structural elements of humic acid namely $\mathrm{H}$ bonded $\mathrm{OH}, \mathrm{C}=\mathrm{C}$ of aromatic ring, $\mathrm{C}=\mathrm{O}$ of carbonyl group (both carboxyl and ketonic), $\mathrm{CH}_{2}$ group. This strongly supports the presence of humic acid.

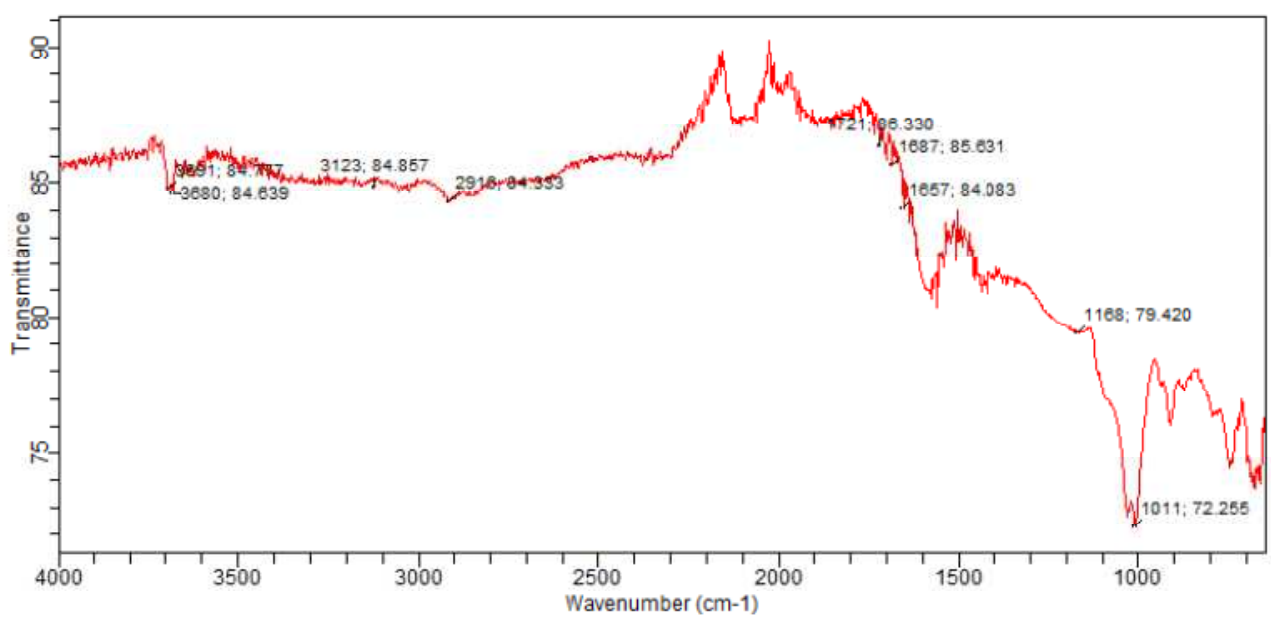

Fig. 2 : FT-IR spectraof peatsoilhumic acid (PSHA)

\section{Evaluation of acid dissociation constant (pka) of acid hydrolysed peat soil humicacid at phenolic group}

The value of the dissociation constant of the peat soil humic acid (PSHA) that underwent acidhydrolysis studied was found to be 8.9299 as shown Table 1, which is lower than the literaturevalues reported by Almeida and Szpoganics, (2015), Borges et al., (2005); Badr et al., (2012)and Fernandes et al,.(2009) of $9.73,9.47$ and 10.30. The difference between the obtained valuesand the reported values in this study might be probably as a result of acid hydrolysis of humicacid. 
BAJOPAS Volume 14 Number 1,June, 2021

Table 1: PKa of (Hydrolysed PSHA)

\begin{tabular}{|l|l|l|l|l|l|l|}
\hline $\mathrm{pH}$ & $\mathrm{BV}_{1}$ & $\mathrm{BV}_{2}$ & $\mathrm{~V}_{2}-\mathrm{V}_{1}$ & $\mathrm{nA}$ & $\log \left(\frac{n A}{1-n A}\right)$ & $\mathrm{pKa}$ \\
\hline 8.50 & 5.30 & 6.29 & 0.99 & 0.3594 & -0.2510 & 8.2490 \\
8.72 & 5.35 & 6.37 & 1.02 & 0.3400 & -0.2880 & 8.4320 \\
9.00 & 5.40 & 6.46 & 1.06 & 0.3141 & -0.3391 & 8.6609 \\
9.22 & 5.45 & 6.55 & 1.10 & 0.2882 & -0.3927 & 8.8273 \\
9.51 & 5.50 & 6.66 & 1.16 & 0.2494 & -0.4786 & 9.0314 \\
9.73 & 5.55 & 6.78 & 1.23 & 0.2041 & -0.5910 & 9.1390 \\
10.00 & 5.60 & 6.90 & 1.30 & 0.1589 & -0.7238 & 9.2762 \\
10.23 & 5.65 & 7.05 & 1.40 & 0.0941 & -0.9835 & 9.2465 \\
10.49 & 5.70 & 7.10 & 1.40 & 0.0941 & -0.9835 & 9.5065 \\
\hline
\end{tabular}

Average pKa $=8.9299 \pm 0.4186$

Table 2: PKa of (Unhydrolysed PSHA)

\begin{tabular}{|l|l|l|l|l|l|l|}
\hline $\mathrm{pH}$ & $\mathrm{BV}_{1}$ & $\mathrm{BV}_{2}$ & $\mathrm{~V}_{2}-\mathrm{V}_{1}$ & $\mathrm{nA}$ & $\log \left(\frac{\boldsymbol{n A}}{1-\boldsymbol{n}}\right)$ & $\mathrm{pKa}$ \\
\hline 8.50 & 5.30 & 5.81 & 0.51 & 0.6619 & 0.2919 & 8.7919 \\
8.72 & 5.35 & 5.90 & 0.55 & 0.6357 & 0.2418 & 8.9618 \\
9.00 & 5.40 & 6.00 & 0.60 & 0.6029 & 0.1813 & 9.1813 \\
9.22 & 5.45 & 6.10 & 0.65 & 0.5701 & 0.1226 & 9.3426 \\
9.51 & 5.50 & 6.20 & 0.70 & 0.5376 & 0.0654 & 9.5754 \\
9.73 & 5.55 & 6.33 & 0.78 & 0.4851 & -0.0259 & 9.7041 \\
10.00 & 5.60 & 6.47 & 0.87 & 0.4262 & -0.1291 & 9.8709 \\
10.23 & 5.65 & 6.62 & 0.99 & 0.3609 & -0.2481 & 9.9819 \\
10.49 & 5.70 & 6.80 & 1.10 & 0.2759 & -0.4690 & 10.0210 \\
\hline
\end{tabular}

Average pKa $=9.4923 \pm 0.4410$

Metal-ligand stability constant ( $\log \mathrm{K}$ )

The stabilityconstants require the accurate values of proton-ligand stability constants (Anil and Maroti, 2008). Metal titration curves crossed over ligand titration curve indicated the formation of complex upon proton release (Santosh, et al., 2011). If the values of n- are within range $0.2-0.8$ and $1.2-18$ this indicates the formation of $1: 1$ and 1:2 complexes (Sayyed and Mazahar, 2012).

The metal (II)-humate stepwise stability constants (log k) at phenolic group (Tables 318)

Table 3: Point-wise method, $\mathrm{Cu}$-(Hydrolysed PSHA)

\begin{tabular}{|l|l|l|l|l|l|l|l|l|}
\hline $\mathrm{pH}$ & $\mathrm{BV}_{1}$ & $\mathrm{BV}_{2}$ & $\mathrm{BV}_{3}$ & $\left(\mathrm{~V}_{3}-\mathrm{V}_{2}\right)$ & $\mathrm{n}$ & $\mathrm{pL}$ & $\log \left(\frac{n}{1-n}\right)$ & LogK $_{1}$ \\
\hline 8.50 & 5.30 & 6.29 & 6.33 & 0.04 & 0.5500 & 2.66 & 0.0871 & 2.7471 \\
8.72 & 5.35 & 6.37 & 6.41 & 0.04 & 0.5714 & 2.43 & 0.1249 & 2.5549 \\
9.00 & 5.40 & 6.46 & 6.50 & 0.04 & 0.6198 & 2.16 & 0.2122 & 2.3722 \\
9.22 & 5.45 & 6.55 & 6.59 & 0.04 & 0.6667 & 1.94 & 0.3010 & 2.2410 \\
\hline
\end{tabular}

LogK $_{1}$ (Average value) $=2.4788 \pm 0.2203$

Table 4: Point-wise method, $\mathrm{Cu}$-(Hydrolysed PSHA)

\begin{tabular}{|l|l|l|l|l|l|l|l|l|}
\hline $\mathrm{pH}$ & $\mathrm{BV}_{1}$ & $\mathrm{BV}_{2}$ & $\mathrm{BV}_{3}$ & $\left(\mathrm{~V}_{3}-\mathrm{V}_{2}\right)$ & $\mathrm{n}$ & $\mathrm{pL}$ & $\log \left(\frac{n-1}{2-n}\right)$ & LogK $_{2}$ \\
\hline 9.51 & 5.50 & 6.66 & 6.73 & 0.07 & 1.3509 & 1.70 & -0.2671 & 1.4329 \\
9.73 & 5.55 & 6.78 & 6.85 & 0.07 & 1.6383 & 1.51 & 0.2467 & 1.7567 \\
10.00 & 5.60 & 6.90 & 6.98 & 0.08 & 2.1783 & 1.31 & -0.2158 & 1.0942 \\
10.23 & 5.65 & 7.05 & 7.13 & 0.08 & 4.1904 & 1.27 & & \\
10.49 & 5.70 & 7.10 & 7.19 & 0.09 & 4.6920 & & & \\
\hline
\end{tabular}

Log $K_{2}($ Average value $)=1.4280 \pm 0.3312$ 
BAJOPAS Volume 14 Number 1,June, 2021

Table 5: Point-wise method, $\mathrm{Cu}$ (Unhydrolysed PSHA)

\begin{tabular}{|l|l|l|l|l|l|l|l|l|}
\hline $\mathrm{pH}$ & $\mathrm{BV}_{1}$ & $\mathrm{BV}_{2}$ & $\mathrm{BV}_{3}$ & $\left(\mathrm{~V}_{3}-\mathrm{V}_{2}\right)$ & $\mathrm{n}$ & $\mathrm{pL}$ & $\log \left(\frac{n}{n-1}\right)$ & Log $_{1}$ \\
\hline 8.50 & 5.30 & 5.81 & 5.85 & 0.04 & 0.2973 & 2.88 & -0.3736 & 2.5064 \\
8.72 & 5.35 & 5.90 & 5.95 & 0.05 & 0.3873 & 2.66 & -0.1992 & 2.4608 \\
9.00 & 5.40 & 6.00 & 6.05 & 0.05 & 0.4044 & 2.38 & -0.1681 & 2.2119 \\
9.22 & 5.45 & 6.10 & 6.15 & 0.06 & 0.5157 & 2.18 & -0.0272 & 2.2072 \\
9.51 & 5.50 & 6.20 & 6.27 & 0.07 & 0.6417 & 1.89 & 0.2530 & 1.1430 \\
\hline
\end{tabular}

$\operatorname{LogK}_{1}($ Average value $)=2.3059 \pm 0.6153$

Table 6:Point-wise method, $\mathrm{Cu}$ (Unhydrolysed PSHA)

\begin{tabular}{|l|l|l|l|l|l|l|l|l|}
\hline $\mathrm{pH}$ & $\mathrm{BV}_{1}$ & $\mathrm{BV}_{2}$ & $\mathrm{BV}_{3}$ & $\mathrm{~V}_{3}-\mathrm{V}_{2}$ & $\mathrm{n}$ & $\mathrm{pL}$ & $\log \left(\frac{n-1}{2-n}\right)$ & $\log \mathrm{K}_{2}$ \\
\hline 9.73 & 5.55 & 6.33 & 6.42 & 0.09 & 0.9000 & 1.69 & & \\
10.00 & 5.60 & 6.47 & 6.58 & 0.11 & 1.2578 & 1.44 & -0.4592 & 0.9808 \\
10.23 & 5.65 & 6.62 & 6.84 & 0.12 & 1.6137 & 1.26 & -0.2010 & 1.4610 \\
10.49 & 5.70 & 6.80 & 6.92 & 0.12 & 2.1052 & 1.03 & & \\
\hline
\end{tabular}

$\operatorname{LogK}_{2}$ (Average value) $=1.2209 \pm 0.3398$

Table 7:Point-wise method, Pb (Hydrolysed PSHA)

\begin{tabular}{|l|l|l|l|l|l|l|l|l|}
\hline $\mathrm{pH}$ & $\mathrm{BV}_{1}$ & $\mathrm{BV}_{2}$ & $\mathrm{BV}_{3}$ & $\left(\mathrm{~V}_{3}-\mathrm{V}_{2}\right)$ & $\mathrm{n}$ & $\mathrm{pL}$ & $\log \left(\frac{n}{1-n}\right)$ & LogK $_{1}$ \\
\hline 8.50 & 5.30 & 6.29 & 6.33 & 0.04 & 0.5500 & 2.66 & 0.0871 & 2.7471 \\
8.72 & 5.35 & 6.37 & 6.41 & 0.04 & 0.5714 & 2.43 & 0.1249 & 2.5549 \\
9.00 & 5.40 & 6.46 & 6.50 & 0.04 & 0.6198 & 2.16 & 0.2122 & 2.3722 \\
9.22 & 5.45 & 6.55 & 6.60 & 0.05 & 0.8333 & 1.96 & 0.6989 & 2.6589 \\
\hline
\end{tabular}

Log $_{\mathbf{1}}($ Average value $)=2.5832 \pm 0.1614$

Table 8:Point-wise method, Pb-(Hydrolysed PSHA)

\begin{tabular}{|l|l|l|l|l|l|l|l|l|}
\hline $\mathrm{pH}$ & $\mathrm{BV}_{1}$ & $\mathrm{BV}_{2}$ & $\mathrm{BV}_{3}$ & $\left(\mathrm{~V}_{3}-\mathrm{V}_{2}\right)$ & $\mathrm{n}$ & $\mathrm{pL}$ & $\log \left(\frac{n-1}{2-n}\right)$ & $\log \mathrm{K}_{2}$ \\
\hline 9.51 & 5.50 & 6.66 & 6.71 & 0.05 & 0.9650 & 1.67 & & \\
9.73 & 5.55 & 6.78 & 6.83 & 0.05 & 1.1702 & 1.44 & & \\
10.00 & 5.60 & 6.90 & 6.90 & 0.05 & 1.4864 & 1.22 & -0.0237 & 1.1963 \\
10.23 & 5.65 & 7.05 & 7.10 & 0.05 & 2.0190 & 1.09 & & \\
10.49 & 5.70 & 7.10 & 7.17 & 0.07 & 3.6492 & 1.00 & & \\
\hline
\end{tabular}

Log $K_{2}$ (Average value) $=1.1963$

Table 9: Point-wise method, Pb (Unhydrolysed PSHA)

\begin{tabular}{|l|l|l|l|l|l|l|l|l|}
\hline $\mathrm{pH}$ & $\mathrm{BV}_{1}$ & $\mathrm{BV}_{2}$ & $\mathrm{BV}_{3}$ & $\mathrm{~V}_{3}-\mathrm{V}_{2}$ & $\mathrm{n}$ & $\mathrm{pL}$ & $\begin{array}{l}\text { Log } \\
\left(\frac{n}{n-1}\right)\end{array}$ & Log $\mathrm{K}_{1}$ \\
\hline 8.50 & 5.30 & 5.81 & 5.85 & 0.04 & 0.2973 & 2.88 & -0.3736 & 2.5064 \\
8.72 & 5.35 & 5.90 & 5.94 & 0.04 & 0.3099 & 2.66 & -0.5477 & 2.3123 \\
9.00 & 5.40 & 6.00 & 6.05 & 0.05 & 0.4044 & 2.38 & -0.1681 & 2.2119 \\
9.22 & 5.45 & 6.10 & 6.15 & 0.06 & 0.5157 & 2.18 & 0.0272 & 2.2072 \\
9.51 & 5.50 & 6.20 & 6.26 & 0.07 & 0.6417 & 1.89 & 0.2530 & 2.1430 \\
9.73 & 5.55 & 6.40 & 6.40 & 0.07 & 0.7000 & 1.67 & 0.3680 & 2.0380 \\
\hline
\end{tabular}

LogK $_{1}$ (Average value) $=2.2364 \pm 0.1602$

Table 10: Point-wise method, Pb (Unhydrolysed PSHA)

\begin{tabular}{|l|l|l|l|l|l|l|l|l|}
\hline $\mathrm{pH}$ & $\mathrm{BV}_{1}$ & $\mathrm{BV}_{2}$ & $\mathrm{BV}_{3}$ & $\mathrm{~V}_{3}-\mathrm{V}_{2}$ & $\mathrm{n}$ & $\mathrm{pL}$ & $\log \left(\frac{n-1}{2-n}\right)$ & $\log \mathrm{K}_{2}$ \\
\hline 10.00 & 5.60 & 6.47 & 6.55 & 0.08 & 1.9503 & 1.41 & & \\
10.23 & 5.65 & 6.62 & 6.72 & 0.11 & 1.4792 & 1.26 & -0.0361 & 1.2239 \\
\hline
\end{tabular}

$\operatorname{LogK}_{2}$ (Average value) $=1.2239$

Table 11: Point-wise method, Mg (Hydrolysed PSHA)

\begin{tabular}{|l|l|l|l|l|l|l|l|l|}
\hline $\mathrm{pH}$ & $\mathrm{BV}_{1}$ & $\mathrm{BV}_{2}$ & $\mathrm{BV}_{3}$ & $\left(\mathrm{~V}_{3}-\mathrm{V}_{2}\right)$ & $\mathrm{n}$ & $\mathrm{pL}$ & $\log \left(\frac{n}{n-1}\right)$ & LogK $_{1}$ \\
\hline 8.50 & 5.30 & 6.29 & 6.31 & 0.02 & 0.2750 & 2.64 & -0.4290 & 2.2110 \\
8.72 & 5.35 & 6.37 & 6.39 & 0.02 & 0.2858 & 2.42 & -0.3978 & 2.0222 \\
9.00 & 5.40 & 6.46 & 6.49 & 0.03 & 0.4648 & 2.14 & -0.0612 & 2.0788 \\
9.22 & 5.45 & 6.55 & 6.59 & 0.04 & 0.6667 & 1.94 & 0.3010 & 2.2410 \\
\hline
\end{tabular}

$\log _{\mathbf{1}}($ Average value) $=2.1382 \pm 0.1046$ 
BAJOPAS Volume 14 Number 1,June, 2021

Table 12: Point-wise method, Mg (Hydrolysed PSHA)

\begin{tabular}{|l|l|l|l|l|l|l|l|l|}
\hline $\mathrm{pH}$ & $\mathrm{BV}_{1}$ & $\mathrm{BV}_{2}$ & $\mathrm{BV}_{3}$ & $\left(\mathrm{~V}_{3}-\mathrm{V}_{2}\right)$ & $\mathrm{n}$ & $\mathrm{pL}$ & $\log \left(\frac{n-1}{2-n}\right)$ & LogK $_{2}$ \\
\hline 9.51 & 5.55 & 6.66 & 6.71 & 0.05 & 0.9650 & 1.67 & & \\
9.73 & 5.55 & 6.78 & 6.84 & 0.06 & 1.4042 & 1.47 & -0.1686 & 1.3014 \\
10.00 & 5.60 & 6.90 & 6.93 & 0.06 & 1.7838 & 1.23 & 0.5593 & 1.7893 \\
10.23 & 5.65 & 7.05 & 7.10 & 0.06 & 3.1429 & 1.10 & & \\
10.49 & 5.70 & 7.10 & 7.18 & 0.07 & 3.6492 & 0.83 & & \\
\hline
\end{tabular}

LogK $_{2}($ Average value $)=1.5453 \pm 0.3450$

Table 13: Point-wise method, Mg (Unhydrolysed PSHA)

\begin{tabular}{|l|l|l|l|l|l|l|l|l|}
\hline $\mathrm{pH}$ & $\mathrm{BV}_{1}$ & $\mathrm{BV}_{2}$ & $\mathrm{BV}_{3}$ & $\mathrm{~V}_{3}-\mathrm{V}_{2}$ & $\mathrm{n}$ & $\mathrm{pL}$ & $\log \left(\frac{n}{n-1}\right)$ & $\operatorname{Log~}_{1}$ \\
\hline 8.50 & 5.30 & 5.81 & 5.85 & 0.04 & 0.2973 & 2.88 & -0.3736 & 2.5064 \\
8.72 & 5.35 & 5.90 & 5.94 & 0.04 & 0.3099 & 2.66 & -0.3477 & 2.3123 \\
9.00 & 5.40 & 6.00 & 6.04 & 0.04 & 0.3236 & 2.38 & -0.3202 & 2.0598 \\
9.22 & 5.45 & 6.10 & 6.15 & 0.05 & 0.4297 & 2.17 & -0.1230 & 2.0470 \\
9.51 & 5.50 & 6.20 & 6.26 & 0.06 & 0.5500 & 1.89 & 0.0871 & 1.9771 \\
9.73 & 5.55 & 6.33 & 6.40 & 0.07 & 0.7000 & 1.67 & 0.3680 & 2.0380 \\
\hline
\end{tabular}

LogK $_{1}$ (Average value) $=2.1568 \pm 0.2069$

Table 14: Point-wise method, Mg (Unhydrolysed PSHA)

\begin{tabular}{|l|l|l|l|l|l|l|l|l|}
\hline $\mathrm{pH}$ & $\mathrm{BV}_{1}$ & $\mathrm{BV}_{2}$ & $\mathrm{BV}_{3}$ & $\mathrm{~V}_{3}-\mathrm{V}_{2}$ & $\mathrm{n}$ & $\mathrm{pL}$ & $\log \left(\frac{n-1}{2-n}\right)$ & $\log \mathrm{K}_{2}$ \\
\hline 10.00 & 5.60 & 6.47 & 6.55 & 0.08 & 0.9148 & 1.41 & & \\
10.23 & 5.65 & 6.62 & 6.71 & 0.09 & 1.2102 & 1.20 & -0.5749 & 0.6251 \\
10.49 & 5.70 & 6.80 & 6.92 & 0.09 & 1.5968 & 1.03 & 0.1703 & 1.2003 \\
\hline
\end{tabular}

LogK $_{2}$ (Average value) $=0.9127 \pm 0.4070$

Table15:Point-wise method, Cd (Hydrolysed PSHA)

\begin{tabular}{|l|l|l|l|l|l|l|l|l|}
\hline $\mathrm{pH}$ & $\mathrm{BV}_{1}$ & $\mathrm{BV}_{2}$ & $\mathrm{BV}_{3}$ & $\left(\mathrm{~V}_{3}-\mathrm{V}_{2}\right)$ & $\mathrm{n}$ & $\mathrm{pL}$ & $\log \left(\frac{n}{1-n}\right)$ & LogK $_{1}$ \\
\hline 8.50 & 5.30 & 6.29 & 6.31 & 0.02 & 0.2750 & 2.64 & -0.4210 & 2.2190 \\
8.72 & 5.35 & 6.37 & 6.40 & 0.03 & 0.4286 & 2.42 & -0.1249 & 2.2951 \\
9.00 & 5.40 & 6.46 & 6.49 & 0.03 & 0.4648 & 2.14 & -0.0612 & 2.0788 \\
9.22 & 5.45 & 6.55 & 6.59 & 0.04 & 0.6667 & 1.96 & 0.3010 & 2.2610 \\
9.51 & 5.55 & 6.66 & 6.70 & 0.04 & 0.7720 & 1.67 & 0.5297 & 2.1997 \\
\hline
\end{tabular}

LogK $_{\mathbf{1}}$ (Average value) $=2.2108 \pm 0.0825$

Table 16: Point-wise method, Cd (Hydrolysed PSHA)

\begin{tabular}{|l|l|l|l|l|l|l|l|l|}
\hline $\mathrm{pH}$ & $\mathrm{BV}_{1}$ & $\mathrm{BV}_{2}$ & $\mathrm{BV}_{3}$ & $\left(\mathrm{~V}_{3}-\mathrm{V}_{2}\right)$ & $\mathrm{n}$ & $\mathrm{pL}$ & $\log \left(\frac{n-1}{2-n}\right)$ & Log $_{2}$ \\
\hline 9.73 & 5.55 & 6.78 & 6.83 & 0.06 & 1.4042 & 1.47 & -0.1686 & 1.3014 \\
10.00 & 5.60 & 6.90 & 6.95 & 0.06 & 1.7838 & 1.23 & 0.5593 & 1.7893 \\
10.23 & 5.65 & 7.05 & 7.10 & 0.06 & 3.1429 & 1.09 & & \\
10.49 & 5.70 & 7.10 & 7.16 & 0.06 & 3.1429 & 0.89 & & \\
& & & & & & & & \\
\hline
\end{tabular}

$\operatorname{LogK}_{2}$ (Average value) $=1.5453 \pm 0.3450$

Table 17: Point-wise method, Cd (Unhydrolysed PSHA)

\begin{tabular}{|l|l|l|l|l|l|l|l|l|}
\hline $\mathrm{pH}$ & $\mathrm{BV}_{1}$ & $\mathrm{BV}_{2}$ & $\mathrm{BV}_{3}$ & $\mathrm{~V}_{3}-\mathrm{V}_{2}$ & $\mathrm{n}$ & $\mathrm{pL}$ & $\log \left(\frac{n}{n-1}\right)$ & $\operatorname{Log~}_{1}$ \\
\hline 8.50 & 5.30 & 5.81 & 5.86 & 0.05 & 0.3717 & 2.88 & -0.2280 & 2.6520 \\
8.72 & 5.35 & 5.90 & 5.95 & 0.05 & 0.3873 & 2.66 & -0.1992 & 2.4608 \\
9.00 & 5.40 & 6.00 & 6.06 & 0.06 & 0.4853 & 2.38 & -0.0255 & 2.3545 \\
9.22 & 5.45 & 6.10 & 6.16 & 0.06 & 0.5157 & 2.18 & -0.0272 & 2.2072 \\
9.51 & 5.50 & 6.20 & 6.27 & 0.07 & 0.6417 & 1.89 & 0.2530 & 1.1430 \\
9.73 & 5.55 & 6.33 & 6.41 & 0.08 & 0.8000 & 1.69 & 0.6020 & 2.2920 \\
& & & & & & & & \\
\hline
\end{tabular}

$\operatorname{LogK}_{1}($ Average value $)=2.2516 \pm 0.5380$ 
BAJOPAS Volume 14 Number 1,June, 2021

Table 18: Point-wise method, Cd (Unhydrolysed PSHA)

\begin{tabular}{|l|l|l|l|l|l|l|l|l|}
\hline $\mathrm{pH}$ & $\mathrm{BV}_{1}$ & $\mathrm{BV}_{2}$ & $\mathrm{BV}_{3}$ & $\mathrm{~V}_{3}-\mathrm{V}_{2}$ & $\mathrm{n}$ & $\mathrm{pL}$ & $\log \left(\frac{n-1}{2-n}\right)$ & $\log \mathrm{K}_{2}$ \\
\hline 10.00 & 5.60 & 6.47 & 6.57 & 0.10 & 1.1434 & 1.43 & & \\
10.23 & 5.65 & 6.62 & 6.72 & 0.10 & 1.3448 & 1.23 & -0.2788 & 0.9512 \\
10.49 & 5.70 & 6.80 & 6.90 & 0.10 & 1.7742 & 1.03 & 0.5351 & 1.5651 \\
\hline
\end{tabular}

$\operatorname{LogK}_{2}($ Average value $)=1.2581 \pm 0.4340$

Table 19: Stepwise and overall Stability constants of thehydrolysed and unhydrolysed divalent metal (II) complexes

\begin{tabular}{|c|c|c|c|}
\hline Chelates & LogK $_{1}$ & $\log _{2}$ & Log $\beta$ \\
\hline [Cu (Hydrolysed PSHA-1) $\left.{ }_{2}\right]$ & 2.4788 & 1.4280 & 3.9068 \\
\hline$\left[\mathrm{Pb}(\text { Hydrolysed PSHA-1) })_{2}\right]$ & 2.5832 & 1.1963 & 3.7795 \\
\hline$\left[\mathrm{Cd}(\text { Hydrolysed PSHA-1 })_{2}\right]$ & 2.2108 & 1.5453 & 3.7561 \\
\hline$\left[\mathrm{Mg}(\text { Hydrolysed PSHA-1 })_{2}\right]$ & 2.1382 & 1.5453 & 3.6835 \\
\hline [Cu (Unhydrolysed PSHA-1) & 2.3059 & 1.2209 & 3.5268 \\
\hline$[\mathrm{Pb}$ (Unhydrolysed PSHA-1) 2$]$ & 2.2364 & 1.2239 & 3.4603 \\
\hline [Cd (Unhydrolysed PSHA-1) 2 ] & 2.2516 & 1.2581 & 3.5097 \\
\hline$[\mathrm{Mg}$ (Unydrolysed PSHA-1) & 2.1568 & 0.9127 & 3.0695 \\
\hline
\end{tabular}

The results obtained (Table19) shows the stepwise and overall stability constants to be not high indicating low stability of the complexes, because the solubility of most metal ions in the basic $\mathrm{pH}$ range is minimal due to metal hydroxide precipitation (Karimi, 2017). In general, the stepwise stability constants $\left(K_{1}\right.$ and $K_{2}$ ) follow the order $K_{1}>K_{2}$ for the copper, lead, magnesium and cadmium complexes respectively. The steady decrease of the values with increasing number of ligands is in agreement with the prediction made by researchers (Na'aliya, 2013). The decrease could be attributed to the fact that as the number of the ligands (Humate ions) that enters the coordination zone increases the aqua molecules available for replacement by the ligands become less. Thus, the metal ions become less electron loving with progressive intake of the ligand and this results in the decrease in the values of the constants (Na'aliya, 2013). Also the stability of the complexes is influenced by the size and number of the chelate rings(Mackay and Mackay,2002).All the complexes form rings in their structure as humate, a bidentate ligand, bond the metal ions in the ratio 1:2 (Boguta and Sokolowska, 2016) forming chelate rings. The values of the overall stability constants $(\log \beta)$ obtained for humate complexes are not high indicating low stability as the values are not high. LogK values for copper-humates (Table 3 to 6) obtained in this study are lower than those reported for the complexes of humic acids (Pandey et al., 2015; Dinu, 2013; Kaschl et al., 2010 and Gilbeto and Jorg, 2001). The values of LogK(Table 7 to 10 ) forlead-humates are lower than those reported for the lead in the literature (Dinu, 2013; Gilbeto and Jorg 2001). Log K values(Table 11 to 14 ) for magnesium-humates obtained in this study are close to those reported by (Pandey et al., 2015). Log K values of cadmium-humates (Table 15 to 18 ) obtained in this work near to the one reported by (Dinu, 2013 and Pandey et al., 2015).The difference between the reported values and the values obtained in this study might be probably as a result of acid hydrolysis of humic acid. The values of the overall stability constants $(\log \beta)$ of the copper humates complexes presented in Table 19 is high than that of other metal humate complexes, show relatively high stability of CuHA complexes, show the following order of stability: $\mathrm{Cu}>\mathrm{Pb}>\mathrm{Cd}>\mathrm{Mg}$; which are in close agreement to the findings of (Dinu, 2013 and Pandey et al., 2015).The high stability of Cuhumate chelate could be attributed to the existence of coordinate covalent bond between the complexing agents and the $\mathrm{Cu}^{2+}$ ions. Since, $\mathrm{Cu}^{2+}$ being a metal of the transitional series with $3 d^{9}$ electronic configurations can accept the electrons from the complexing agents. Similarly, the low stabilities of $\mathrm{Pb}, \mathrm{Cd}$ and $\mathrm{Mg}$ complexes could be explained by that $\mathrm{Pb}^{2+}$ with $6 s^{2}, \mathrm{Cd}^{2+}$ with $4 \mathrm{~d}^{10}$ and $\mathrm{Mg}^{2+}$ with $2 \mathrm{p}^{6}$ their electronic configuration has a completely filled $\mathrm{d}, \mathrm{p}$ and $\mathrm{s}$ orbitals. Moreover, the stabilities of metal ions with hydrolysed humic acid from peat soil were higher than those with unhydrolysed humic acid from peat soil; which is ascribed to the high content of acidity in hydrolysed humic acid than unhydrolysed humic acid. 
BAJOPAS Volume 14 Number 1,June, 2021 CONCLUSION

The values of logk for $\mathrm{Cu}(\mathrm{II})$ hydrolysed humic acid complex was higher followed by $\mathrm{Pb}$ (II), $\mathrm{Cd}(\mathrm{II})$ and $\mathrm{Mg}$ (II) hydrolysed humic acid complexes as compared with metal(II) unhydrolysed humic acid complexes. This indicates acid hydrolysis of humic acid can

\section{REFERENCES}

Almeida, V.R. and Szpoganicz, B. (2015). Humic Acid Potentiometric Response Patterns:Out- of Equilibrium Properties and Species Distribution Modelling. Chemical. Biol. Technol. Agric. 2: 17.

Anđelković, T., Nikolić, R., Bojić, A.,Anđelković, D., and Nikolic G.,(2010). Binding of Cadmium to Soil Humic Acid as A Function of Carboxyl Group Content. Macedonian Journal of Chemistry and Chemical Engineering.29(2): 215-224.

Anil, B. N. and Maroti, N. (2008). Studies on Influence of Die-Lectric Constants on Complex Equilibria between Substituted Py-Razalines and Lanthanide Metal Ions pH-Metrically. Amer.-Euras. scient. Res. 3(2): 212-216.

Ashok, K., Pandey, S. P. and Misra, V (2000). Stability Constants of Metal-Humic Acid Complexes and its Role in Environmental Detoxification. Journal of Ecotoxicology and Environmental Safety. 47(2):157-200.

Badr, M. H., El-Halafawi, M. H. and Abd El-al Zeid, E. R. (2012). Comparison Between the Effect of Ionic Strength on Acidity and Dissociation Constants of Humic Acids Extracted from Sewage Sludge and Nile Water Hyacinth Composts.Global Journal of Environmental Research 6 (1): 36-43.

Baruah, M.K., Borah, D., Saikia, P.P., Paul, S., Sharma, T. (2015). Evaluation of pKa Values of Soil Humic Acids and their Complexation Properties. International Journal of Plant \& Soil Science 6(4) : 218-228.

Boguta, P. Sokolowska, Z. (2016). Interactions of $\mathrm{Zn}$ (II) Ions with Humic Acids Isolated from Various Types of Soils. Effect of $\mathrm{pH}, \mathrm{Zn}$ Concentrations and Humic Acids Chemical Properties. Journal of Geochemical Explaration 168. 119-126.

Borges, F., Guimaraes, C., Lima, L.F.C., Pinto, I. and Reis, S.(2005). Potentiometric Studies on the Complexation of Copper(II) by Phenolic Acids as Discrete Ligand Models of enhance the complexation behavior of humic acid with metal (II) ions. However, the higher values of $\log \beta$ for $\mathrm{Cu}(\mathrm{II}), \mathrm{Pb}(\mathrm{II}), \mathrm{Cd}(\mathrm{II})$ and $\mathrm{Mg}(\mathrm{II})$ hydrolysed humic acid complexes indicates more stable stepwise complexes formed as compared with $\mathrm{Cu}(\mathrm{II}), \mathrm{Pb}$ (II), $\mathrm{Cd}$ (II) and $\mathrm{Mg}(\mathrm{II})$ unhydrolysed humic acid complexes.

Humic Substances Talanta 66 (2005) 670-673.

Chefetz, B., Salloum, M. J., Deshmulkin, A. P. and Hatcher, P. (2002). Structural Components of Humic Acids as Determined by Chemical Modifications and Carbon-13 NMR, Pyrolysis, and Thermochemolysis- Gas Chromatography/Mass Spectrometry. Soil Science Society of American Journal Abstract Division S-2- Soil Chemistry66. 1159-1171.

Dinu, M. I. (2013). Metals Complexation with Humic Acids in Surface Water of Different Environ. Sci. Technol. 31(1): 1-17.

Fernandes, A.N., Giacomelli, C., Giovanela, M. Vaz, D.V. Szpoganicz, B. and Maria M. D. (2009). Potentiometric Acidity Determination in Humic Substances Influenced by Different Analytical Procedures.J. Braz. Chem. Soc. 20 (9):14.

Gamal, A. H. (2015). Stability Constants of Rhenium (V) Metal Complexes with Selected Drugs. Pyrex Journal of Research in Environmental Studies. 2(2): 006-014.

Janrao, D. M., Pathan, J., Kayande, D.D., and Mulla, J.J. (2014). An Over View of Potentiometric Determination of Stability Constants of Metal Complexes. Sci. Revs. Chem. Commun.: 4(1), 2014, 11-24.

Karimi, H. (2017). Effect of pH and Initial Pb(II) Concentration on the Lead Removal Efficiency from Waste Water Using $\mathrm{Ca}(\mathrm{OH})_{2}$. International Journal of Water and Waste Water Treatment 3.2

Kaschl, A. Romheld, V. and Chen, Y. (2010). Binding of Cadmium, Copper and Zinc to Humic Substances Originating from Municipal Solid Waste Compost. Israel Journal of Chemistry Vol. 42(1): 89-98.

Kostic, I. S., Tatjana, P, A., Nikolic, R. S., Cvetkovic, T. P., Pavlovic, D. D., Aleksandar, L.J. and Bojic, A. (2012). Comparative Study of Binding Strengths of Heavy Metals with Humic Acid. J.serb. Chem. Soc. 76(9) pp 1-20. 
BAJOPAS Volume 14 Number 1,June, 2021

Na'aliya, J. (2013). Determination of Stepwise Stability Constants and Gibbs free Energy Change of Trisprolina to Complexes of some Divalent Transition Metal ions. Bayero Journal of Pure and Applied Sciences 6(2): 112-114.

Omar, A. A. and Ali, E. A. (2015). Potentiometric Studies on Complexes of $\mathrm{Cr}$ (III) and $\mathrm{Zr}$ (IV) with some Carboxylic Acids. International Journal of Advanced Chemistry, 3(1) 25-

37.

Pandey, A. K. Pandey, S. D. and Misr, V. (2015).Stability Constants of Metal- Humic Acid Complexes and Its Role in Environmental Detoxification. J. Ecotoxicology and Environmental Safety. 47(1):195-200.

Ram, N. and Raman, K.V. (1984). Stability Constants of Complexes of Metals with
Humicand Fuvic Acids under Non- acidConditions. Journal of Plant Nutrition and Soil Sciences.

147:171-176.

Santosh, D. D., Ashok, B. K., Vijay, J. T., Shivraj, G. W. and Vinay, V. W. (2011). Potentiometric Studies of Elec-Trolyte Effects on Complex Equilibria of Some Substituted 5-(2-hydroxy Phenyl) Pyrazoles. Der pharm. 3 (6): 75-83.

Sayyed, H. and Abdul Rahim, M. F. (2012). Studies of Binary Complexes of Metal Ions with Mandelic Acid by Potentiometry. Chem. J. 02 (6): 206209.

Shirvani, M. Moradian, E. Khalili, B. Bakhtiary, S. (2015). Interaction of $\mathrm{Cd}$ and $\mathrm{Pb}$ with Humate-Palygorskite and HumateSepiolite Complexes. Journal of water, air and pollution 3: 220-228. 


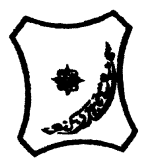

Bayero Journal of Pure and Applied Sciences, 14(1): 54 - 63

Received: November, 2020

Accepted: April, 2021

ISSN $2006-6996$

\title{
STABILITY CONSTANTS OF COMPLEXES OF METAL IONS WITH PEATSOIL HUMIC ACIDS UNDER NON-ACID-CONDITIONS
}

\author{
${ }^{* 1}$ Sabo, Yusuf ${ }^{2}$ Jimoh, W.L.O., ${ }^{3}$ Isa Baba Koki and ${ }^{4}$ Sholadoye, Q. 0. \\ ${ }^{1}$ Department of Pure and Industrial Chemistry, Bayero University, Kano \\ ${ }^{3}$ Department of Chemistry, Yusuf Maitama Sule University Kano. P.M.B. 3220 Kano, Nigeria. \\ ${ }^{4}$ Department of Chemistry, Nigerian Police Academy, Wudil, Kano-Nigeria
}

*Correspondence E-mail; saboyusuf18@yahoo.com

ABSTRACT

Stability constants of complexes of four divalent metal ions viz. $\mathrm{Cu}^{2+}, \mathrm{Pb}^{2+}, \mathrm{Mg}^{2+}$ and $\mathrm{Cd}^{2+}$ with humic acids (HA) were determined by potentiometric titration of humic acids with the corresponding salt of the divalent metals in aqueous media under non-acid-condition. The log $K$ (logarithm of the stability constant) ranged from 1.0942 to 2.7471 for metalhumic acid complexes were determined using point-wise computational method. The order of stability constants were obtained as follows: $\mathrm{Cu}>\mathrm{Pb}>\mathrm{Cd}>\mathrm{Mg}$ for metal $-\mathrm{HA}$ complexes respectively, indicating a higher degree of complexation with Cu metal ion.

Keywords: stability constant, humic acid, potentiometric titration, divalent metals, acid hydrolysis.

\section{NTRODUCTION}

The stability constant of a complex is the numerical expression of its stability and provides a quantitative measure of affinity of the metal ion to the complexing agent. An understanding of the relative stability of metal-complexes helps in predicting the behavior of metal ions in the soil (Ram and Raman, 1982). Extensive researches has been done to determine the stability constants of the complexes formed between humic acid (HA) with a number of metal ions. Ashok et al., (2000) reported that humic acid with hydroxyl, phenoxyl and carboxyl reactive groups can form coordination compound with metal ions at $\mathrm{pH}$ 3.5. The stability constants(Log K) for different metalhumic acid complexes indicated the following order of the stabilities of complexes formed between humic acid and metal ion, $\mathrm{Cu}>\mathrm{Fe}$ $>\mathrm{Pb}>\mathrm{Ni}>\mathrm{Co}>\mathrm{Ca}>\mathrm{Cd}>\mathrm{Zn}>\mathrm{Mn}>\mathrm{Mg}$. Andelkovic et al., (2010) investigated the binding of $\mathrm{Cd}$ (II) to soil humic acid at pH 6.5 and in $0.1 \mathrm{M} \mathrm{KNO}_{3}$ ionic medium. The stability constant for binding indicating greater stability in the case when carboxyl groups are involved in complexation reaction. Kostic et al.,(2012) investigated the complexation of humic acid with certain heavy metal ions (Co(II), $\mathrm{Ni}(\mathrm{II}), \mathrm{Cu}(\mathrm{II})$,
$\mathrm{Zn}(\mathrm{II})$, and $\mathrm{Pb}(\mathrm{II})$. The experiment was performed at $25^{\circ} \mathrm{C}$, at pH 4.0 and ionic strength of $0.01 \mathrm{M}$. Stability constant of complex between $\mathrm{Pb}$ (II) ions and humic acid is greater than stability constants of other investigated metalhumate complexes. Bogata and Sokolowska (2016) analyses the interaction between humic acids from different soils and $\mathrm{Zn}$ (II) ions at wide concentration ranges and at $\mathrm{pH} 5$. Studies have showed significant impact of $\mathrm{Zn}$ concentration, $\mathrm{pH}$ and some properties of humic acids with zinc.But all of these studies were limited to acidic $\mathrm{pH}$ range. Therefore, the present study was carried out to determine and compare the stability constants of complexes of metal ions with hydrolysed peat soil humic acid and unhydrolysed peat soil humic under non-acid conditions.

\section{MATERIALS AND METHODS}

Analytical grade chemicals used includes hydrochloric acid $(\mathrm{HCl})$, nitric acid $\left(\mathrm{HNO}_{3}\right)$, sodium hydroxide $(\mathrm{NaOH})$, lead nitrate $\mathrm{Pb}\left(\mathrm{NO}_{3}\right)_{2}$, copper nitrate $\mathrm{Cu}\left(\mathrm{NO}_{3}\right)_{2} \cdot 3 \mathrm{H}_{2} \mathrm{O}$, cadmium nitrate $\mathrm{Cd}\left(\mathrm{NO}_{3}\right)_{2} \cdot 4 \mathrm{H}_{2} \mathrm{O}$, magnesium nitrate $\mathrm{Mg}\left(\mathrm{NO}_{3}\right)_{2} \cdot 6 \mathrm{H}_{2} \mathrm{O}$, potassium nitrate $\left(\mathrm{KNO}_{3}\right)$, calcium chloride $\left(\mathrm{CaCl}_{2}\right)$, (sigma-Aldrich). Dowex 50WX8, (20-50 mesh) from Fluka. 


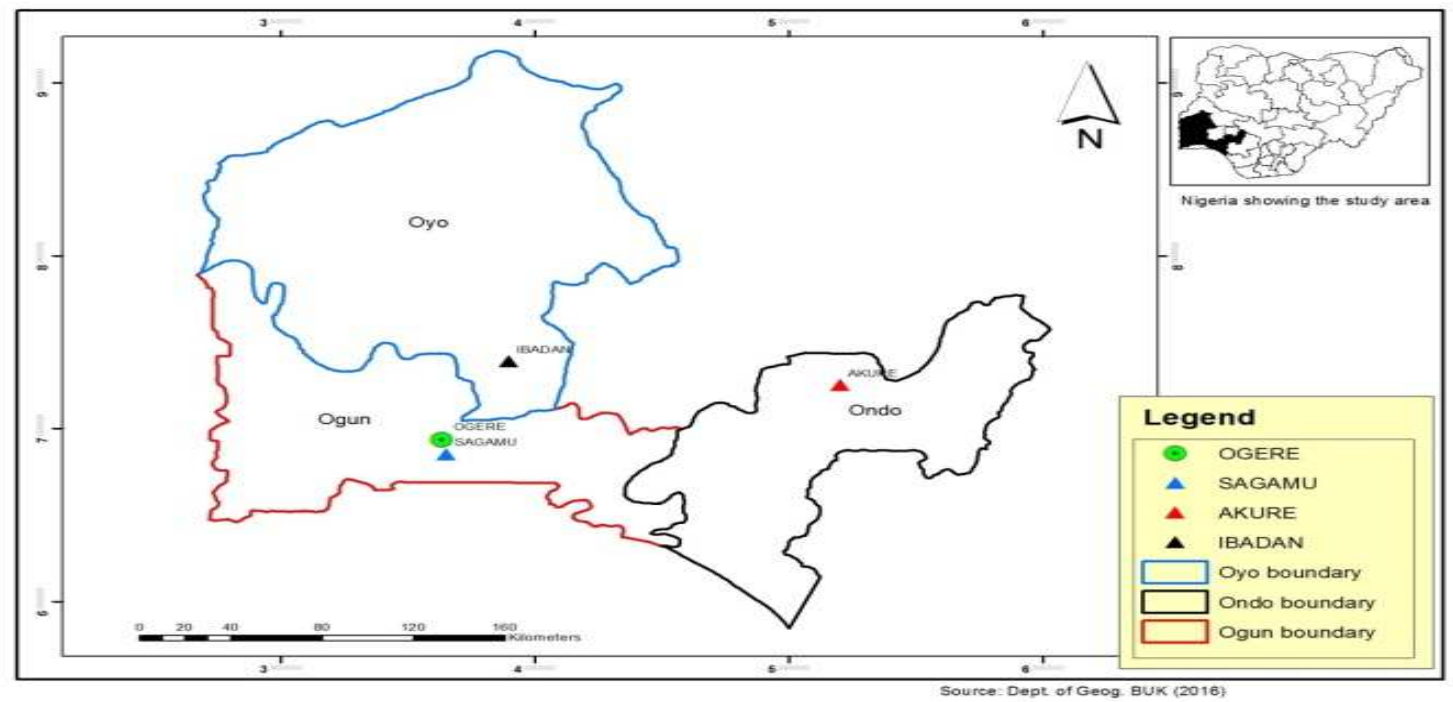

Figure 1: Map showing the sampling point at Sagamu Town, Ogun State.

\section{Description of Sampling Area}

Sagamu has geographical coordinates between $6^{\circ} 50^{\prime}$ north; $3^{\circ} 38^{\prime}$ east is located in south western region of Nigeria. The region has tropical wet and dry climate with a lengthy wet season and relatively constant temperatures throughout the course of the year. Wet season runs from March to October, November to December forms the region dry season. The vegetation type of the region is savannah which is really grassland with small bushes and occasional big trees. Grassland soils have substantially higher organic matter content than forest soils (Novackova, 2011).

\section{Sample Collection}

The Peatsoil samples were collected from four different sampling points $(0-10 \mathrm{~cm}$ depth) in Sagamu into polyethylene bag with plastic spoons. Samples were taken to the laboratory, extraneous materials were removed; the samples were air-dried, crushed and ground to a fine powder in a mortar passed through a $0.20 \mathrm{~mm}$ sieve. The samples were kept for analysis.

\section{Isolation and purification of humic acid from peat soil sample}

Peatsoil sample $(100 \mathrm{~g})$ was mixed with 1000 $\mathrm{cm}^{3}$ of $0.1 \mathrm{M} \mathrm{NaOH}$ solution, shaken for 3hours and left to stand overnight. Dark-coloured supernatant was obtained and decanted from solid residue. The dark-coloured supernatant was acidified to $(\mathrm{pH}=1.0)$ with $6 \mathrm{M} \mathrm{HCl}$ stirred and allowed to stand for 6 hours. Yellowish brown supernatant and dark-brown precipitate were obtained. The yellowish brown supernatant was decanted followed by centrifuge and discarded. The dark-brown precipitate was mixed with $500 \mathrm{~cm}^{3}$ of $0.1 \mathrm{M} \mathrm{NaOH}$ solution followed by passing through dowex resin. The dark-brown solution was acidified to $(\mathrm{pH}=1.0)$ with $6 \mathrm{M} \mathrm{HCl}$ stirred and allowed to stand for 3 hours. The dark-brown precipitate was washed several times with deionized water. The supernatant was treated with $\mathrm{AgNO}_{3}$ solution until no white precipitate observed. The humic acid was transferred to weighed crucible and dried at $60^{\circ} \mathrm{C}$ in an oven for 12 hours. The humic acid was cooled and dried in the desiccator, weighed and recorded. The obtained humic acid was dried again at $60^{\circ} \mathrm{C}$ for additional 6 hours cooled and dried in the desiccator, weighed and recorded constant weight was obtained (Baruah et al., 2015).

\section{FT-IR analysis}

FT-IR spectra of humic acid sample was analysed using Carry 630 FT-IR Agilent Technologies.

Unhydrolysed compost humic acid

The unhydrolysed humic acid was obtained after isolation and purification of compost humic acid and kept for investigation.

\section{Acid hydrolysis of Peatsoil acid}

Peatsoil humic acid sample (1g) was refluxed for 12 hours at $\left(160^{\circ} \mathrm{C}\right)$ with $50 \mathrm{~cm}^{3}$ of $6 \mathrm{M} \mathrm{HCl}$. The mixture was allowed to cool, decanted, and centrifuged after hydrolysis. The insoluble residues were washed with distilled water via centrifugation several times, and the supernatant was treated with $\mathrm{AgNO}_{3}$ solution until no white precipitate was observed. The residue was thoroughly dried over $\mathrm{CaCl}_{2}$ in a desiccator at room temperature (Chefetz et al., 2002). Finally, the obtained hydrolysed humic acid was kept for investigation. 
BAJOPAS Volume 14 Number 1,June, 2021 Potentiometric Titrations

Potentiometric measurements were carried out using a pH-meter Jenway (model 3510) with combine electrode, the sensitivity of the $\mathrm{pH}$ meter is 0.01 units. The $\mathrm{pH}$ meter was switched on half an hour before starting the titration for initial warm up of the instrument. The instrument was calibrated with an aqueous standard buffer solution of $\mathrm{pH} 4.00$ and 10.0 (borate buffer) prepared from a "Qualigens" buffer tablets.

The following sets of solutions were prepared in a $250 \mathrm{~cm}^{3}$ volumetric flask separately for $\mathrm{pH}$ metric titrations.

(i) $5 \mathrm{~cm}^{3} 0.1 \mathrm{M} \mathrm{HCl}+40 \mathrm{~cm}^{3}$ deionized water

(ii) $5 \mathrm{~cm}^{3} 0.1 \mathrm{M} \mathrm{HCl}+39 \mathrm{~cm}^{3}$ deionized water $+1 \mathrm{~cm}^{3} 0.15 \mathrm{gcm}^{-3}$ humic acid

(iii) $5 \mathrm{~cm}^{3} 0.1 \mathrm{M} \mathrm{HCl}+37 \mathrm{~cm}^{3}$ deionized water $+1 \mathrm{~cm}^{3} 0.15 \mathrm{gcm}^{-3}$ humic acid

$$
+2 \mathrm{~cm}^{3} \quad 0.01 \mathrm{M} \mathrm{Cu} \text { (II) }
$$

The solutions were titrated against standardized $0.110 \mathrm{MNaOH}$ separately. The total volume of each mixture was adjusted to $50 \mathrm{~cm}^{3}$ and the ionic strength of the solutions was maintained constant at by adding appropriate amount of stock solution of $1 \mathrm{M} \mathrm{KNO}_{3}$ (Gamal, 2015; Omar and Ali, 2015). A magnetic stirrer was used to achieve thorough mixing of the interacting solutions at $550 \mathrm{rpm}$. The same set of experimental conditions was applied for potentiometric titration of remaining samples.

\section{Evaluation of pKa of Hydrolysed peat soil Humic Acids}

The proton-ligand formation number $\mathrm{n}_{\mathbf{A}}$ were calculated by Irving and Rossotti expression (Omar and Ali, 2015).

$\mathrm{nA}=\mathrm{Y}-\frac{(\mathrm{V} 2-\mathrm{V1})(\mathrm{No}-\mathrm{Eo})}{(\mathrm{VO}+\mathrm{V1}) \mathrm{TCL}}$ 1

Where: $Y$ is number of dissociable proton, $\left(\mathrm{V}_{2^{-}}\right.$ $V_{1}$ ) is the measure of displacement of the ligand curve relative to acid curve, $\mathrm{N}^{\circ}$ and $\mathrm{E}^{\circ}$ are the resultant concentration of alkali solution, free acid solution, $\mathrm{T}_{\mathrm{cL}}{ }^{\circ}$ is the total ligand concentration, $\mathrm{V}^{\circ}$ is the total volume of titration solution, $V_{1}$ is the volume of alkali added to acid solution, $V_{2}$ is the volume of alkali added to acid solution + ligand solution, acid dissociation constants (pKa - values) of ligand were calculated by algebraic method point wise calculation (Tables 1 ). The dissociation constants (pKa) were calculated according to the following relation:

$\mathrm{pKa}=\mathrm{pH}+\log \left(\frac{n A}{1-n A}\right)$ 2

Where: pKa is the acid dissociation constant, $\mathrm{n}_{\mathrm{A}}$ is the Proton-ligand formation number and $\mathrm{pH}$ is the pH-values (Omar and Ali, 2015).

\section{Determination of metal-ligand stability constants $(\log K)$ of complexes}

The potentiometric measurement for the determination of stability constant of a complex in solution is based on the fact that the redox potential of the couple $\frac{M^{+(m-n)}}{M^{+m}}$ is shifted significantly on complexation of the metal ion with the ligand. This method involves change in hydrogen ion concentration $\left[\mathrm{H}^{+}\right]$due to the displacement or association of one or more protons taking place during complexation reaction. This change can be found out by titrating the solutions containing free acid, acid with ligand, and acid with ligand and metal ion, individually against a standard alkali solution at a constant ionic strength or temperature. Either ionic strength or temperature may be varied for different sets of solutions. In all the cases, the change in the $\mathrm{pH}$ of the solution is measured after each addition of a known amount of alkali to the reaction cell which contains the reaction mixture. The titration curves are then drawn by plotting the measured $\mathrm{pH}$ values against the corresponding volume of alkali added and the stability constants of the complexes are determined from the titration curves by employing $\mathrm{pH}$-metric titration technique given by (Irving and Rossoti).

Metal-ligand stability constants ( $\log \mathrm{K}$ ) were determined by using the following relations:

$$
\bar{n}=\frac{\left(V_{3}-V_{2}\right)\left(E^{0}+N^{0}\right)}{\left(V^{0}+V_{2}\right) \bar{n}_{A} T_{m}^{0}}
$$

and

$$
P L=\log _{10}\left\{\frac{1+\beta_{n}^{H} \frac{1}{[\text { anti } \log \mathrm{pH}]^{\mathrm{n}}}}{\mathrm{T}_{\mathrm{L}}^{0}-n \bar{T}_{m}^{0}} \mathrm{X} \frac{\left(V^{0}+V_{3}\right)}{V^{0}}\right\}
$$


BAJOPAS Volume 14 Number 1,June, 2021

Where $T_{L}, T^{\circ}, E^{\circ}$, and $V^{\circ}$ havethe same significance as in equation (1) above, $T_{m}$ denotes the total concentration of metal present in solution, $V_{3}$ is the volume of metal ions present in solution and $\beta^{H}$ is the overall proton ligand stability constant. The metal-ligand stability constants (log K) were determined by employing point wise computational Method (eq. 5 and 6).

$\operatorname{LogK}_{1}=\log \left(\frac{n}{1-n}\right)+\mathrm{pL}$ .5

$\operatorname{LogK}_{2}=\log \left(\frac{1-n}{2-n}\right)+\mathrm{pL}$ ...6

Where: Log $\mathrm{K}$ is the metal-ligand stability constant, $\mathrm{pL}$ is the Free ligand exponent function, $\mathbf{n}$ is the Average number of ligand attached with metal ion (Janraoet al., 2014). The results obtained were analyzed by an ORIGIN 2016 program using titration data and then the proton-ligand stability constants (pKa) and Metal-ligand stability constant (LogK) calculated (Omar and Ali, 2015).

\section{RESULTS AND DISCUSSION}

Fourier transformed infrared (FT-IR) spectra of isolated humic acid from peat soils Figure 2 had distinct clear absorption bands indicating the presence of major humic acid structural elemental groups such as $\mathrm{H}$ bonded $\mathrm{OH}$ $\left(3680 \mathrm{~cm}^{-1}\right.$ peak $), C=0$ of carbonyl $\left(1721 \mathrm{~cm}^{-1}\right.$ peak), functional groups of aliphatic components $\mathrm{CH}_{2}\left(2918 \mathrm{~cm}^{-1}\right.$ peak) and $\mathrm{C}-\mathrm{O}$ stretching of polysaccharide $\left(1168 \mathrm{~cm}^{-1}\right.$ peak). The positions of the absorption bands of the spectra fell within typical major absorption bands of humic acid which is at frequencies 3680, 2918, 1721, 1168 $\mathrm{cm}^{-1}$. The first peak centred in the vicinity of $3680 \mathrm{~cm}^{-1}$ region is attributed to phenol $\mathrm{OH}$ group bounded by intermolecular $\mathrm{H}$ bonds. The $2918 \mathrm{~cm}^{-1}$ band usually has absorption maximum at $2918 \mathrm{~cm}^{-1}$ which is due to $\mathrm{C}-\mathrm{H}$ stretching of alkane group $\left(\mathrm{CH}_{2}\right)$. The next major absorption band is $1721 \mathrm{~cm}^{-1}$. This band has been commonly ascribed to $\mathrm{C}=\mathrm{O}$ stretching of mainly carboxyl group $(\mathrm{COOH})$ with trace amount of ketones. The last peak was observed at 1168 $\mathrm{cm}^{-1}$ due to $\mathrm{C}-\mathrm{O}$ stretching of polysaccharides and this peak appeared also in the spectra of humic acid from peat soil. The FTIR spectra of the isolated humic acid contained all major characteristic absorption peaks of humic acid. These absorption peaks indicated the presence of the major structural elements of humic acid namely $\mathrm{H}$ bonded $\mathrm{OH}, \mathrm{C}=\mathrm{C}$ of aromatic ring, $\mathrm{C}=\mathrm{O}$ of carbonyl group (both carboxyl and ketonic), $\mathrm{CH}_{2}$ group. This strongly supports the presence of humic acid.

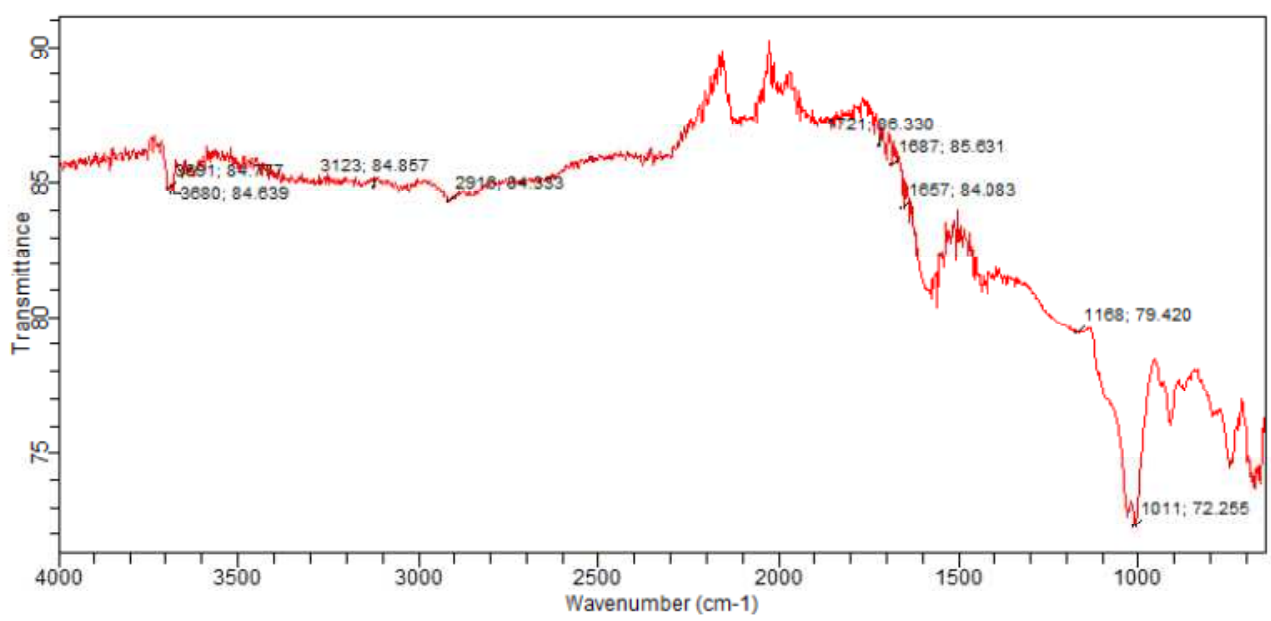

Fig. 2 : FT-IR spectraof peatsoilhumic acid (PSHA)

\section{Evaluation of acid dissociation constant (pka) of acid hydrolysed peat soil humicacid at phenolic group}

The value of the dissociation constant of the peat soil humic acid (PSHA) that underwent acidhydrolysis studied was found to be 8.9299 as shown Table 1, which is lower than the literaturevalues reported by Almeida and Szpoganics, (2015), Borges et al., (2005); Badr et al., (2012)and Fernandes et al,.(2009) of $9.73,9.47$ and 10.30. The difference between the obtained valuesand the reported values in this study might be probably as a result of acid hydrolysis of humicacid. 
BAJOPAS Volume 14 Number 1,June, 2021

Table 1: PKa of (Hydrolysed PSHA)

\begin{tabular}{|l|l|l|l|l|l|l|}
\hline $\mathrm{pH}$ & $\mathrm{BV}_{1}$ & $\mathrm{BV}_{2}$ & $\mathrm{~V}_{2}-\mathrm{V}_{1}$ & $\mathrm{nA}$ & $\log \left(\frac{n A}{1-n A}\right)$ & $\mathrm{pKa}$ \\
\hline 8.50 & 5.30 & 6.29 & 0.99 & 0.3594 & -0.2510 & 8.2490 \\
8.72 & 5.35 & 6.37 & 1.02 & 0.3400 & -0.2880 & 8.4320 \\
9.00 & 5.40 & 6.46 & 1.06 & 0.3141 & -0.3391 & 8.6609 \\
9.22 & 5.45 & 6.55 & 1.10 & 0.2882 & -0.3927 & 8.8273 \\
9.51 & 5.50 & 6.66 & 1.16 & 0.2494 & -0.4786 & 9.0314 \\
9.73 & 5.55 & 6.78 & 1.23 & 0.2041 & -0.5910 & 9.1390 \\
10.00 & 5.60 & 6.90 & 1.30 & 0.1589 & -0.7238 & 9.2762 \\
10.23 & 5.65 & 7.05 & 1.40 & 0.0941 & -0.9835 & 9.2465 \\
10.49 & 5.70 & 7.10 & 1.40 & 0.0941 & -0.9835 & 9.5065 \\
\hline
\end{tabular}

Average pKa $=8.9299 \pm 0.4186$

Table 2: PKa of (Unhydrolysed PSHA)

\begin{tabular}{|l|l|l|l|l|l|l|}
\hline $\mathrm{pH}$ & $\mathrm{BV}_{1}$ & $\mathrm{BV}_{2}$ & $\mathrm{~V}_{2}-\mathrm{V}_{1}$ & $\mathrm{nA}$ & $\log \left(\frac{\boldsymbol{n A}}{1-\boldsymbol{n}}\right)$ & $\mathrm{pKa}$ \\
\hline 8.50 & 5.30 & 5.81 & 0.51 & 0.6619 & 0.2919 & 8.7919 \\
8.72 & 5.35 & 5.90 & 0.55 & 0.6357 & 0.2418 & 8.9618 \\
9.00 & 5.40 & 6.00 & 0.60 & 0.6029 & 0.1813 & 9.1813 \\
9.22 & 5.45 & 6.10 & 0.65 & 0.5701 & 0.1226 & 9.3426 \\
9.51 & 5.50 & 6.20 & 0.70 & 0.5376 & 0.0654 & 9.5754 \\
9.73 & 5.55 & 6.33 & 0.78 & 0.4851 & -0.0259 & 9.7041 \\
10.00 & 5.60 & 6.47 & 0.87 & 0.4262 & -0.1291 & 9.8709 \\
10.23 & 5.65 & 6.62 & 0.99 & 0.3609 & -0.2481 & 9.9819 \\
10.49 & 5.70 & 6.80 & 1.10 & 0.2759 & -0.4690 & 10.0210 \\
\hline
\end{tabular}

Average pKa $=9.4923 \pm 0.4410$

Metal-ligand stability constant ( $\log \mathrm{K}$ )

The stabilityconstants require the accurate values of proton-ligand stability constants (Anil and Maroti, 2008). Metal titration curves crossed over ligand titration curve indicated the formation of complex upon proton release (Santosh, et al., 2011). If the values of n- are within range $0.2-0.8$ and $1.2-18$ this indicates the formation of $1: 1$ and 1:2 complexes (Sayyed and Mazahar, 2012).

The metal (II)-humate stepwise stability constants (log k) at phenolic group (Tables 318)

Table 3: Point-wise method, $\mathrm{Cu}$-(Hydrolysed PSHA)

\begin{tabular}{|l|l|l|l|l|l|l|l|l|}
\hline $\mathrm{pH}$ & $\mathrm{BV}_{1}$ & $\mathrm{BV}_{2}$ & $\mathrm{BV}_{3}$ & $\left(\mathrm{~V}_{3}-\mathrm{V}_{2}\right)$ & $\mathrm{n}$ & $\mathrm{pL}$ & $\log \left(\frac{n}{1-n}\right)$ & LogK $_{1}$ \\
\hline 8.50 & 5.30 & 6.29 & 6.33 & 0.04 & 0.5500 & 2.66 & 0.0871 & 2.7471 \\
8.72 & 5.35 & 6.37 & 6.41 & 0.04 & 0.5714 & 2.43 & 0.1249 & 2.5549 \\
9.00 & 5.40 & 6.46 & 6.50 & 0.04 & 0.6198 & 2.16 & 0.2122 & 2.3722 \\
9.22 & 5.45 & 6.55 & 6.59 & 0.04 & 0.6667 & 1.94 & 0.3010 & 2.2410 \\
\hline
\end{tabular}

LogK $_{1}$ (Average value) $=2.4788 \pm 0.2203$

Table 4: Point-wise method, $\mathrm{Cu}$-(Hydrolysed PSHA)

\begin{tabular}{|l|l|l|l|l|l|l|l|l|}
\hline $\mathrm{pH}$ & $\mathrm{BV}_{1}$ & $\mathrm{BV}_{2}$ & $\mathrm{BV}_{3}$ & $\left(\mathrm{~V}_{3}-\mathrm{V}_{2}\right)$ & $\mathrm{n}$ & $\mathrm{pL}$ & $\log \left(\frac{n-1}{2-n}\right)$ & LogK $_{2}$ \\
\hline 9.51 & 5.50 & 6.66 & 6.73 & 0.07 & 1.3509 & 1.70 & -0.2671 & 1.4329 \\
9.73 & 5.55 & 6.78 & 6.85 & 0.07 & 1.6383 & 1.51 & 0.2467 & 1.7567 \\
10.00 & 5.60 & 6.90 & 6.98 & 0.08 & 2.1783 & 1.31 & -0.2158 & 1.0942 \\
10.23 & 5.65 & 7.05 & 7.13 & 0.08 & 4.1904 & 1.27 & & \\
10.49 & 5.70 & 7.10 & 7.19 & 0.09 & 4.6920 & & & \\
\hline
\end{tabular}

Log $K_{2}($ Average value $)=1.4280 \pm 0.3312$ 
BAJOPAS Volume 14 Number 1,June, 2021

Table 5: Point-wise method, $\mathrm{Cu}$ (Unhydrolysed PSHA)

\begin{tabular}{|l|l|l|l|l|l|l|l|l|}
\hline $\mathrm{pH}$ & $\mathrm{BV}_{1}$ & $\mathrm{BV}_{2}$ & $\mathrm{BV}_{3}$ & $\left(\mathrm{~V}_{3}-\mathrm{V}_{2}\right)$ & $\mathrm{n}$ & $\mathrm{pL}$ & $\log \left(\frac{n}{n-1}\right)$ & Log $_{1}$ \\
\hline 8.50 & 5.30 & 5.81 & 5.85 & 0.04 & 0.2973 & 2.88 & -0.3736 & 2.5064 \\
8.72 & 5.35 & 5.90 & 5.95 & 0.05 & 0.3873 & 2.66 & -0.1992 & 2.4608 \\
9.00 & 5.40 & 6.00 & 6.05 & 0.05 & 0.4044 & 2.38 & -0.1681 & 2.2119 \\
9.22 & 5.45 & 6.10 & 6.15 & 0.06 & 0.5157 & 2.18 & -0.0272 & 2.2072 \\
9.51 & 5.50 & 6.20 & 6.27 & 0.07 & 0.6417 & 1.89 & 0.2530 & 1.1430 \\
\hline
\end{tabular}

$\operatorname{LogK}_{1}($ Average value $)=2.3059 \pm 0.6153$

Table 6:Point-wise method, $\mathrm{Cu}$ (Unhydrolysed PSHA)

\begin{tabular}{|l|l|l|l|l|l|l|l|l|}
\hline $\mathrm{pH}$ & $\mathrm{BV}_{1}$ & $\mathrm{BV}_{2}$ & $\mathrm{BV}_{3}$ & $\mathrm{~V}_{3}-\mathrm{V}_{2}$ & $\mathrm{n}$ & $\mathrm{pL}$ & $\log \left(\frac{n-1}{2-n}\right)$ & $\log \mathrm{K}_{2}$ \\
\hline 9.73 & 5.55 & 6.33 & 6.42 & 0.09 & 0.9000 & 1.69 & & \\
10.00 & 5.60 & 6.47 & 6.58 & 0.11 & 1.2578 & 1.44 & -0.4592 & 0.9808 \\
10.23 & 5.65 & 6.62 & 6.84 & 0.12 & 1.6137 & 1.26 & -0.2010 & 1.4610 \\
10.49 & 5.70 & 6.80 & 6.92 & 0.12 & 2.1052 & 1.03 & & \\
\hline
\end{tabular}

$\operatorname{LogK}_{2}$ (Average value) $=1.2209 \pm 0.3398$

Table 7:Point-wise method, Pb (Hydrolysed PSHA)

\begin{tabular}{|l|l|l|l|l|l|l|l|l|}
\hline $\mathrm{pH}$ & $\mathrm{BV}_{1}$ & $\mathrm{BV}_{2}$ & $\mathrm{BV}_{3}$ & $\left(\mathrm{~V}_{3}-\mathrm{V}_{2}\right)$ & $\mathrm{n}$ & $\mathrm{pL}$ & $\log \left(\frac{n}{1-n}\right)$ & LogK $_{1}$ \\
\hline 8.50 & 5.30 & 6.29 & 6.33 & 0.04 & 0.5500 & 2.66 & 0.0871 & 2.7471 \\
8.72 & 5.35 & 6.37 & 6.41 & 0.04 & 0.5714 & 2.43 & 0.1249 & 2.5549 \\
9.00 & 5.40 & 6.46 & 6.50 & 0.04 & 0.6198 & 2.16 & 0.2122 & 2.3722 \\
9.22 & 5.45 & 6.55 & 6.60 & 0.05 & 0.8333 & 1.96 & 0.6989 & 2.6589 \\
\hline
\end{tabular}

Log $_{\mathbf{1}}($ Average value $)=2.5832 \pm 0.1614$

Table 8:Point-wise method, Pb-(Hydrolysed PSHA)

\begin{tabular}{|l|l|l|l|l|l|l|l|l|}
\hline $\mathrm{pH}$ & $\mathrm{BV}_{1}$ & $\mathrm{BV}_{2}$ & $\mathrm{BV}_{3}$ & $\left(\mathrm{~V}_{3}-\mathrm{V}_{2}\right)$ & $\mathrm{n}$ & $\mathrm{pL}$ & $\log \left(\frac{n-1}{2-n}\right)$ & $\log \mathrm{K}_{2}$ \\
\hline 9.51 & 5.50 & 6.66 & 6.71 & 0.05 & 0.9650 & 1.67 & & \\
9.73 & 5.55 & 6.78 & 6.83 & 0.05 & 1.1702 & 1.44 & & \\
10.00 & 5.60 & 6.90 & 6.90 & 0.05 & 1.4864 & 1.22 & -0.0237 & 1.1963 \\
10.23 & 5.65 & 7.05 & 7.10 & 0.05 & 2.0190 & 1.09 & & \\
10.49 & 5.70 & 7.10 & 7.17 & 0.07 & 3.6492 & 1.00 & & \\
\hline
\end{tabular}

Log $K_{2}$ (Average value) $=1.1963$

Table 9: Point-wise method, Pb (Unhydrolysed PSHA)

\begin{tabular}{|l|l|l|l|l|l|l|l|l|}
\hline $\mathrm{pH}$ & $\mathrm{BV}_{1}$ & $\mathrm{BV}_{2}$ & $\mathrm{BV}_{3}$ & $\mathrm{~V}_{3}-\mathrm{V}_{2}$ & $\mathrm{n}$ & $\mathrm{pL}$ & $\begin{array}{l}\text { Log } \\
\left(\frac{n}{n-1}\right)\end{array}$ & Log $\mathrm{K}_{1}$ \\
\hline 8.50 & 5.30 & 5.81 & 5.85 & 0.04 & 0.2973 & 2.88 & -0.3736 & 2.5064 \\
8.72 & 5.35 & 5.90 & 5.94 & 0.04 & 0.3099 & 2.66 & -0.5477 & 2.3123 \\
9.00 & 5.40 & 6.00 & 6.05 & 0.05 & 0.4044 & 2.38 & -0.1681 & 2.2119 \\
9.22 & 5.45 & 6.10 & 6.15 & 0.06 & 0.5157 & 2.18 & 0.0272 & 2.2072 \\
9.51 & 5.50 & 6.20 & 6.26 & 0.07 & 0.6417 & 1.89 & 0.2530 & 2.1430 \\
9.73 & 5.55 & 6.40 & 6.40 & 0.07 & 0.7000 & 1.67 & 0.3680 & 2.0380 \\
\hline
\end{tabular}

LogK $_{1}$ (Average value) $=2.2364 \pm 0.1602$

Table 10: Point-wise method, Pb (Unhydrolysed PSHA)

\begin{tabular}{|l|l|l|l|l|l|l|l|l|}
\hline $\mathrm{pH}$ & $\mathrm{BV}_{1}$ & $\mathrm{BV}_{2}$ & $\mathrm{BV}_{3}$ & $\mathrm{~V}_{3}-\mathrm{V}_{2}$ & $\mathrm{n}$ & $\mathrm{pL}$ & $\log \left(\frac{n-1}{2-n}\right)$ & $\log \mathrm{K}_{2}$ \\
\hline 10.00 & 5.60 & 6.47 & 6.55 & 0.08 & 1.9503 & 1.41 & & \\
10.23 & 5.65 & 6.62 & 6.72 & 0.11 & 1.4792 & 1.26 & -0.0361 & 1.2239 \\
\hline
\end{tabular}

$\operatorname{LogK}_{2}$ (Average value) $=1.2239$

Table 11: Point-wise method, Mg (Hydrolysed PSHA)

\begin{tabular}{|l|l|l|l|l|l|l|l|l|}
\hline $\mathrm{pH}$ & $\mathrm{BV}_{1}$ & $\mathrm{BV}_{2}$ & $\mathrm{BV}_{3}$ & $\left(\mathrm{~V}_{3}-\mathrm{V}_{2}\right)$ & $\mathrm{n}$ & $\mathrm{pL}$ & $\log \left(\frac{n}{n-1}\right)$ & LogK $_{1}$ \\
\hline 8.50 & 5.30 & 6.29 & 6.31 & 0.02 & 0.2750 & 2.64 & -0.4290 & 2.2110 \\
8.72 & 5.35 & 6.37 & 6.39 & 0.02 & 0.2858 & 2.42 & -0.3978 & 2.0222 \\
9.00 & 5.40 & 6.46 & 6.49 & 0.03 & 0.4648 & 2.14 & -0.0612 & 2.0788 \\
9.22 & 5.45 & 6.55 & 6.59 & 0.04 & 0.6667 & 1.94 & 0.3010 & 2.2410 \\
\hline
\end{tabular}

$\log _{\mathbf{1}}($ Average value) $=2.1382 \pm 0.1046$ 
BAJOPAS Volume 14 Number 1,June, 2021

Table 12: Point-wise method, Mg (Hydrolysed PSHA)

\begin{tabular}{|l|l|l|l|l|l|l|l|l|}
\hline $\mathrm{pH}$ & $\mathrm{BV}_{1}$ & $\mathrm{BV}_{2}$ & $\mathrm{BV}_{3}$ & $\left(\mathrm{~V}_{3}-\mathrm{V}_{2}\right)$ & $\mathrm{n}$ & $\mathrm{pL}$ & $\log \left(\frac{n-1}{2-n}\right)$ & LogK $_{2}$ \\
\hline 9.51 & 5.55 & 6.66 & 6.71 & 0.05 & 0.9650 & 1.67 & & \\
9.73 & 5.55 & 6.78 & 6.84 & 0.06 & 1.4042 & 1.47 & -0.1686 & 1.3014 \\
10.00 & 5.60 & 6.90 & 6.93 & 0.06 & 1.7838 & 1.23 & 0.5593 & 1.7893 \\
10.23 & 5.65 & 7.05 & 7.10 & 0.06 & 3.1429 & 1.10 & & \\
10.49 & 5.70 & 7.10 & 7.18 & 0.07 & 3.6492 & 0.83 & & \\
\hline
\end{tabular}

LogK $_{2}($ Average value $)=1.5453 \pm 0.3450$

Table 13: Point-wise method, Mg (Unhydrolysed PSHA)

\begin{tabular}{|l|l|l|l|l|l|l|l|l|}
\hline $\mathrm{pH}$ & $\mathrm{BV}_{1}$ & $\mathrm{BV}_{2}$ & $\mathrm{BV}_{3}$ & $\mathrm{~V}_{3}-\mathrm{V}_{2}$ & $\mathrm{n}$ & $\mathrm{pL}$ & $\log \left(\frac{n}{n-1}\right)$ & $\operatorname{Log~}_{1}$ \\
\hline 8.50 & 5.30 & 5.81 & 5.85 & 0.04 & 0.2973 & 2.88 & -0.3736 & 2.5064 \\
8.72 & 5.35 & 5.90 & 5.94 & 0.04 & 0.3099 & 2.66 & -0.3477 & 2.3123 \\
9.00 & 5.40 & 6.00 & 6.04 & 0.04 & 0.3236 & 2.38 & -0.3202 & 2.0598 \\
9.22 & 5.45 & 6.10 & 6.15 & 0.05 & 0.4297 & 2.17 & -0.1230 & 2.0470 \\
9.51 & 5.50 & 6.20 & 6.26 & 0.06 & 0.5500 & 1.89 & 0.0871 & 1.9771 \\
9.73 & 5.55 & 6.33 & 6.40 & 0.07 & 0.7000 & 1.67 & 0.3680 & 2.0380 \\
\hline
\end{tabular}

LogK $_{1}$ (Average value) $=2.1568 \pm 0.2069$

Table 14: Point-wise method, Mg (Unhydrolysed PSHA)

\begin{tabular}{|l|l|l|l|l|l|l|l|l|}
\hline $\mathrm{pH}$ & $\mathrm{BV}_{1}$ & $\mathrm{BV}_{2}$ & $\mathrm{BV}_{3}$ & $\mathrm{~V}_{3}-\mathrm{V}_{2}$ & $\mathrm{n}$ & $\mathrm{pL}$ & $\log \left(\frac{n-1}{2-n}\right)$ & $\log \mathrm{K}_{2}$ \\
\hline 10.00 & 5.60 & 6.47 & 6.55 & 0.08 & 0.9148 & 1.41 & & \\
10.23 & 5.65 & 6.62 & 6.71 & 0.09 & 1.2102 & 1.20 & -0.5749 & 0.6251 \\
10.49 & 5.70 & 6.80 & 6.92 & 0.09 & 1.5968 & 1.03 & 0.1703 & 1.2003 \\
\hline
\end{tabular}

LogK $_{2}$ (Average value) $=0.9127 \pm 0.4070$

Table15:Point-wise method, Cd (Hydrolysed PSHA)

\begin{tabular}{|l|l|l|l|l|l|l|l|l|}
\hline $\mathrm{pH}$ & $\mathrm{BV}_{1}$ & $\mathrm{BV}_{2}$ & $\mathrm{BV}_{3}$ & $\left(\mathrm{~V}_{3}-\mathrm{V}_{2}\right)$ & $\mathrm{n}$ & $\mathrm{pL}$ & $\log \left(\frac{n}{1-n}\right)$ & LogK $_{1}$ \\
\hline 8.50 & 5.30 & 6.29 & 6.31 & 0.02 & 0.2750 & 2.64 & -0.4210 & 2.2190 \\
8.72 & 5.35 & 6.37 & 6.40 & 0.03 & 0.4286 & 2.42 & -0.1249 & 2.2951 \\
9.00 & 5.40 & 6.46 & 6.49 & 0.03 & 0.4648 & 2.14 & -0.0612 & 2.0788 \\
9.22 & 5.45 & 6.55 & 6.59 & 0.04 & 0.6667 & 1.96 & 0.3010 & 2.2610 \\
9.51 & 5.55 & 6.66 & 6.70 & 0.04 & 0.7720 & 1.67 & 0.5297 & 2.1997 \\
\hline
\end{tabular}

LogK $_{\mathbf{1}}$ (Average value) $=2.2108 \pm 0.0825$

Table 16: Point-wise method, Cd (Hydrolysed PSHA)

\begin{tabular}{|l|l|l|l|l|l|l|l|l|}
\hline $\mathrm{pH}$ & $\mathrm{BV}_{1}$ & $\mathrm{BV}_{2}$ & $\mathrm{BV}_{3}$ & $\left(\mathrm{~V}_{3}-\mathrm{V}_{2}\right)$ & $\mathrm{n}$ & $\mathrm{pL}$ & $\log \left(\frac{n-1}{2-n}\right)$ & Log $_{2}$ \\
\hline 9.73 & 5.55 & 6.78 & 6.83 & 0.06 & 1.4042 & 1.47 & -0.1686 & 1.3014 \\
10.00 & 5.60 & 6.90 & 6.95 & 0.06 & 1.7838 & 1.23 & 0.5593 & 1.7893 \\
10.23 & 5.65 & 7.05 & 7.10 & 0.06 & 3.1429 & 1.09 & & \\
10.49 & 5.70 & 7.10 & 7.16 & 0.06 & 3.1429 & 0.89 & & \\
& & & & & & & & \\
\hline
\end{tabular}

$\operatorname{LogK}_{2}$ (Average value) $=1.5453 \pm 0.3450$

Table 17: Point-wise method, Cd (Unhydrolysed PSHA)

\begin{tabular}{|l|l|l|l|l|l|l|l|l|}
\hline $\mathrm{pH}$ & $\mathrm{BV}_{1}$ & $\mathrm{BV}_{2}$ & $\mathrm{BV}_{3}$ & $\mathrm{~V}_{3}-\mathrm{V}_{2}$ & $\mathrm{n}$ & $\mathrm{pL}$ & $\log \left(\frac{n}{n-1}\right)$ & $\operatorname{Log~}_{1}$ \\
\hline 8.50 & 5.30 & 5.81 & 5.86 & 0.05 & 0.3717 & 2.88 & -0.2280 & 2.6520 \\
8.72 & 5.35 & 5.90 & 5.95 & 0.05 & 0.3873 & 2.66 & -0.1992 & 2.4608 \\
9.00 & 5.40 & 6.00 & 6.06 & 0.06 & 0.4853 & 2.38 & -0.0255 & 2.3545 \\
9.22 & 5.45 & 6.10 & 6.16 & 0.06 & 0.5157 & 2.18 & -0.0272 & 2.2072 \\
9.51 & 5.50 & 6.20 & 6.27 & 0.07 & 0.6417 & 1.89 & 0.2530 & 1.1430 \\
9.73 & 5.55 & 6.33 & 6.41 & 0.08 & 0.8000 & 1.69 & 0.6020 & 2.2920 \\
& & & & & & & & \\
\hline
\end{tabular}

$\operatorname{LogK}_{1}($ Average value $)=2.2516 \pm 0.5380$ 
BAJOPAS Volume 14 Number 1,June, 2021

Table 18: Point-wise method, Cd (Unhydrolysed PSHA)

\begin{tabular}{|l|l|l|l|l|l|l|l|l|}
\hline $\mathrm{pH}$ & $\mathrm{BV}_{1}$ & $\mathrm{BV}_{2}$ & $\mathrm{BV}_{3}$ & $\mathrm{~V}_{3}-\mathrm{V}_{2}$ & $\mathrm{n}$ & $\mathrm{pL}$ & $\log \left(\frac{n-1}{2-n}\right)$ & $\log \mathrm{K}_{2}$ \\
\hline 10.00 & 5.60 & 6.47 & 6.57 & 0.10 & 1.1434 & 1.43 & & \\
10.23 & 5.65 & 6.62 & 6.72 & 0.10 & 1.3448 & 1.23 & -0.2788 & 0.9512 \\
10.49 & 5.70 & 6.80 & 6.90 & 0.10 & 1.7742 & 1.03 & 0.5351 & 1.5651 \\
\hline
\end{tabular}

$\operatorname{LogK}_{2}($ Average value $)=1.2581 \pm 0.4340$

Table 19: Stepwise and overall Stability constants of thehydrolysed and unhydrolysed divalent metal (II) complexes

\begin{tabular}{|c|c|c|c|}
\hline Chelates & LogK $_{1}$ & $\log _{2}$ & Log $\beta$ \\
\hline [Cu (Hydrolysed PSHA-1) $\left.{ }_{2}\right]$ & 2.4788 & 1.4280 & 3.9068 \\
\hline$\left[\mathrm{Pb}(\text { Hydrolysed PSHA-1) })_{2}\right]$ & 2.5832 & 1.1963 & 3.7795 \\
\hline$\left[\mathrm{Cd}(\text { Hydrolysed PSHA-1 })_{2}\right]$ & 2.2108 & 1.5453 & 3.7561 \\
\hline$\left[\mathrm{Mg}(\text { Hydrolysed PSHA-1 })_{2}\right]$ & 2.1382 & 1.5453 & 3.6835 \\
\hline [Cu (Unhydrolysed PSHA-1) & 2.3059 & 1.2209 & 3.5268 \\
\hline$[\mathrm{Pb}$ (Unhydrolysed PSHA-1) 2$]$ & 2.2364 & 1.2239 & 3.4603 \\
\hline [Cd (Unhydrolysed PSHA-1) 2 ] & 2.2516 & 1.2581 & 3.5097 \\
\hline$[\mathrm{Mg}$ (Unydrolysed PSHA-1) & 2.1568 & 0.9127 & 3.0695 \\
\hline
\end{tabular}

The results obtained (Table19) shows the stepwise and overall stability constants to be not high indicating low stability of the complexes, because the solubility of most metal ions in the basic $\mathrm{pH}$ range is minimal due to metal hydroxide precipitation (Karimi, 2017). In general, the stepwise stability constants $\left(K_{1}\right.$ and $K_{2}$ ) follow the order $K_{1}>K_{2}$ for the copper, lead, magnesium and cadmium complexes respectively. The steady decrease of the values with increasing number of ligands is in agreement with the prediction made by researchers (Na'aliya, 2013). The decrease could be attributed to the fact that as the number of the ligands (Humate ions) that enters the coordination zone increases the aqua molecules available for replacement by the ligands become less. Thus, the metal ions become less electron loving with progressive intake of the ligand and this results in the decrease in the values of the constants (Na'aliya, 2013). Also the stability of the complexes is influenced by the size and number of the chelate rings(Mackay and Mackay,2002).All the complexes form rings in their structure as humate, a bidentate ligand, bond the metal ions in the ratio 1:2 (Boguta and Sokolowska, 2016) forming chelate rings. The values of the overall stability constants $(\log \beta)$ obtained for humate complexes are not high indicating low stability as the values are not high. LogK values for copper-humates (Table 3 to 6) obtained in this study are lower than those reported for the complexes of humic acids (Pandey et al., 2015; Dinu, 2013; Kaschl et al., 2010 and Gilbeto and Jorg, 2001). The values of LogK(Table 7 to 10 ) forlead-humates are lower than those reported for the lead in the literature (Dinu, 2013; Gilbeto and Jorg 2001). Log K values(Table 11 to 14 ) for magnesium-humates obtained in this study are close to those reported by (Pandey et al., 2015). Log K values of cadmium-humates (Table 15 to 18 ) obtained in this work near to the one reported by (Dinu, 2013 and Pandey et al., 2015).The difference between the reported values and the values obtained in this study might be probably as a result of acid hydrolysis of humic acid. The values of the overall stability constants $(\log \beta)$ of the copper humates complexes presented in Table 19 is high than that of other metal humate complexes, show relatively high stability of CuHA complexes, show the following order of stability: $\mathrm{Cu}>\mathrm{Pb}>\mathrm{Cd}>\mathrm{Mg}$; which are in close agreement to the findings of (Dinu, 2013 and Pandey et al., 2015).The high stability of Cuhumate chelate could be attributed to the existence of coordinate covalent bond between the complexing agents and the $\mathrm{Cu}^{2+}$ ions. Since, $\mathrm{Cu}^{2+}$ being a metal of the transitional series with $3 d^{9}$ electronic configurations can accept the electrons from the complexing agents. Similarly, the low stabilities of $\mathrm{Pb}, \mathrm{Cd}$ and $\mathrm{Mg}$ complexes could be explained by that $\mathrm{Pb}^{2+}$ with $6 s^{2}, \mathrm{Cd}^{2+}$ with $4 \mathrm{~d}^{10}$ and $\mathrm{Mg}^{2+}$ with $2 \mathrm{p}^{6}$ their electronic configuration has a completely filled $\mathrm{d}, \mathrm{p}$ and $\mathrm{s}$ orbitals. Moreover, the stabilities of metal ions with hydrolysed humic acid from peat soil were higher than those with unhydrolysed humic acid from peat soil; which is ascribed to the high content of acidity in hydrolysed humic acid than unhydrolysed humic acid. 
BAJOPAS Volume 14 Number 1,June, 2021 CONCLUSION

The values of logk for $\mathrm{Cu}(\mathrm{II})$ hydrolysed humic acid complex was higher followed by $\mathrm{Pb}$ (II), $\mathrm{Cd}(\mathrm{II})$ and $\mathrm{Mg}$ (II) hydrolysed humic acid complexes as compared with metal(II) unhydrolysed humic acid complexes. This indicates acid hydrolysis of humic acid can

\section{REFERENCES}

Almeida, V.R. and Szpoganicz, B. (2015). Humic Acid Potentiometric Response Patterns:Out- of Equilibrium Properties and Species Distribution Modelling. Chemical. Biol. Technol. Agric. 2: 17.

Anđelković, T., Nikolić, R., Bojić, A.,Anđelković, D., and Nikolic G.,(2010). Binding of Cadmium to Soil Humic Acid as A Function of Carboxyl Group Content. Macedonian Journal of Chemistry and Chemical Engineering.29(2): 215-224.

Anil, B. N. and Maroti, N. (2008). Studies on Influence of Die-Lectric Constants on Complex Equilibria between Substituted Py-Razalines and Lanthanide Metal Ions pH-Metrically. Amer.-Euras. scient. Res. 3(2): 212-216.

Ashok, K., Pandey, S. P. and Misra, V (2000). Stability Constants of Metal-Humic Acid Complexes and its Role in Environmental Detoxification. Journal of Ecotoxicology and Environmental Safety. 47(2):157-200.

Badr, M. H., El-Halafawi, M. H. and Abd El-al Zeid, E. R. (2012). Comparison Between the Effect of Ionic Strength on Acidity and Dissociation Constants of Humic Acids Extracted from Sewage Sludge and Nile Water Hyacinth Composts.Global Journal of Environmental Research 6 (1): 36-43.

Baruah, M.K., Borah, D., Saikia, P.P., Paul, S., Sharma, T. (2015). Evaluation of pKa Values of Soil Humic Acids and their Complexation Properties. International Journal of Plant \& Soil Science 6(4) : 218-228.

Boguta, P. Sokolowska, Z. (2016). Interactions of $\mathrm{Zn}$ (II) Ions with Humic Acids Isolated from Various Types of Soils. Effect of $\mathrm{pH}, \mathrm{Zn}$ Concentrations and Humic Acids Chemical Properties. Journal of Geochemical Explaration 168. 119-126.

Borges, F., Guimaraes, C., Lima, L.F.C., Pinto, I. and Reis, S.(2005). Potentiometric Studies on the Complexation of Copper(II) by Phenolic Acids as Discrete Ligand Models of enhance the complexation behavior of humic acid with metal (II) ions. However, the higher values of $\log \beta$ for $\mathrm{Cu}(\mathrm{II}), \mathrm{Pb}(\mathrm{II}), \mathrm{Cd}(\mathrm{II})$ and $\mathrm{Mg}(\mathrm{II})$ hydrolysed humic acid complexes indicates more stable stepwise complexes formed as compared with $\mathrm{Cu}(\mathrm{II}), \mathrm{Pb}$ (II), $\mathrm{Cd}$ (II) and $\mathrm{Mg}(\mathrm{II})$ unhydrolysed humic acid complexes.

Humic Substances Talanta 66 (2005) 670-673.

Chefetz, B., Salloum, M. J., Deshmulkin, A. P. and Hatcher, P. (2002). Structural Components of Humic Acids as Determined by Chemical Modifications and Carbon-13 NMR, Pyrolysis, and Thermochemolysis- Gas Chromatography/Mass Spectrometry. Soil Science Society of American Journal Abstract Division S-2- Soil Chemistry66. 1159-1171.

Dinu, M. I. (2013). Metals Complexation with Humic Acids in Surface Water of Different Environ. Sci. Technol. 31(1): 1-17.

Fernandes, A.N., Giacomelli, C., Giovanela, M. Vaz, D.V. Szpoganicz, B. and Maria M. D. (2009). Potentiometric Acidity Determination in Humic Substances Influenced by Different Analytical Procedures.J. Braz. Chem. Soc. 20 (9):14.

Gamal, A. H. (2015). Stability Constants of Rhenium (V) Metal Complexes with Selected Drugs. Pyrex Journal of Research in Environmental Studies. 2(2): 006-014.

Janrao, D. M., Pathan, J., Kayande, D.D., and Mulla, J.J. (2014). An Over View of Potentiometric Determination of Stability Constants of Metal Complexes. Sci. Revs. Chem. Commun.: 4(1), 2014, 11-24.

Karimi, H. (2017). Effect of pH and Initial Pb(II) Concentration on the Lead Removal Efficiency from Waste Water Using $\mathrm{Ca}(\mathrm{OH})_{2}$. International Journal of Water and Waste Water Treatment 3.2

Kaschl, A. Romheld, V. and Chen, Y. (2010). Binding of Cadmium, Copper and Zinc to Humic Substances Originating from Municipal Solid Waste Compost. Israel Journal of Chemistry Vol. 42(1): 89-98.

Kostic, I. S., Tatjana, P, A., Nikolic, R. S., Cvetkovic, T. P., Pavlovic, D. D., Aleksandar, L.J. and Bojic, A. (2012). Comparative Study of Binding Strengths of Heavy Metals with Humic Acid. J.serb. Chem. Soc. 76(9) pp 1-20. 
BAJOPAS Volume 14 Number 1,June, 2021

Na'aliya, J. (2013). Determination of Stepwise Stability Constants and Gibbs free Energy Change of Trisprolina to Complexes of some Divalent Transition Metal ions. Bayero Journal of Pure and Applied Sciences 6(2): 112-114.

Omar, A. A. and Ali, E. A. (2015). Potentiometric Studies on Complexes of $\mathrm{Cr}$ (III) and $\mathrm{Zr}$ (IV) with some Carboxylic Acids. International Journal of Advanced Chemistry, 3(1) 25-

37.

Pandey, A. K. Pandey, S. D. and Misr, V. (2015).Stability Constants of Metal- Humic Acid Complexes and Its Role in Environmental Detoxification. J. Ecotoxicology and Environmental Safety. 47(1):195-200.

Ram, N. and Raman, K.V. (1984). Stability Constants of Complexes of Metals with
Humicand Fuvic Acids under Non- acidConditions. Journal of Plant Nutrition and Soil Sciences.

147:171-176.

Santosh, D. D., Ashok, B. K., Vijay, J. T., Shivraj, G. W. and Vinay, V. W. (2011). Potentiometric Studies of Elec-Trolyte Effects on Complex Equilibria of Some Substituted 5-(2-hydroxy Phenyl) Pyrazoles. Der pharm. 3 (6): 75-83.

Sayyed, H. and Abdul Rahim, M. F. (2012). Studies of Binary Complexes of Metal Ions with Mandelic Acid by Potentiometry. Chem. J. 02 (6): 206209.

Shirvani, M. Moradian, E. Khalili, B. Bakhtiary, S. (2015). Interaction of $\mathrm{Cd}$ and $\mathrm{Pb}$ with Humate-Palygorskite and HumateSepiolite Complexes. Journal of water, air and pollution 3: 220-228. 


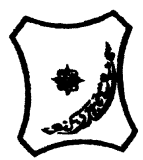

Bayero Journal of Pure and Applied Sciences, 14(1): 54 - 63

Received: November, 2020

Accepted: April, 2021

ISSN $2006-6996$

\title{
STABILITY CONSTANTS OF COMPLEXES OF METAL IONS WITH PEATSOIL HUMIC ACIDS UNDER NON-ACID-CONDITIONS
}

\author{
${ }^{* 1}$ Sabo, Yusuf ${ }^{2}$ Jimoh, W.L.O., ${ }^{3}$ Isa Baba Koki and ${ }^{4}$ Sholadoye, Q. 0. \\ ${ }^{1}$ Department of Pure and Industrial Chemistry, Bayero University, Kano \\ ${ }^{3}$ Department of Chemistry, Yusuf Maitama Sule University Kano. P.M.B. 3220 Kano, Nigeria. \\ ${ }^{4}$ Department of Chemistry, Nigerian Police Academy, Wudil, Kano-Nigeria
}

*Correspondence E-mail; saboyusuf18@yahoo.com

ABSTRACT

Stability constants of complexes of four divalent metal ions viz. $\mathrm{Cu}^{2+}, \mathrm{Pb}^{2+}, \mathrm{Mg}^{2+}$ and $\mathrm{Cd}^{2+}$ with humic acids (HA) were determined by potentiometric titration of humic acids with the corresponding salt of the divalent metals in aqueous media under non-acid-condition. The log $K$ (logarithm of the stability constant) ranged from 1.0942 to 2.7471 for metalhumic acid complexes were determined using point-wise computational method. The order of stability constants were obtained as follows: $\mathrm{Cu}>\mathrm{Pb}>\mathrm{Cd}>\mathrm{Mg}$ for metal $-\mathrm{HA}$ complexes respectively, indicating a higher degree of complexation with Cu metal ion.

Keywords: stability constant, humic acid, potentiometric titration, divalent metals, acid hydrolysis.

\section{NTRODUCTION}

The stability constant of a complex is the numerical expression of its stability and provides a quantitative measure of affinity of the metal ion to the complexing agent. An understanding of the relative stability of metal-complexes helps in predicting the behavior of metal ions in the soil (Ram and Raman, 1982). Extensive researches has been done to determine the stability constants of the complexes formed between humic acid (HA) with a number of metal ions. Ashok et al., (2000) reported that humic acid with hydroxyl, phenoxyl and carboxyl reactive groups can form coordination compound with metal ions at $\mathrm{pH}$ 3.5. The stability constants(Log K) for different metalhumic acid complexes indicated the following order of the stabilities of complexes formed between humic acid and metal ion, $\mathrm{Cu}>\mathrm{Fe}$ $>\mathrm{Pb}>\mathrm{Ni}>\mathrm{Co}>\mathrm{Ca}>\mathrm{Cd}>\mathrm{Zn}>\mathrm{Mn}>\mathrm{Mg}$. Andelkovic et al., (2010) investigated the binding of $\mathrm{Cd}$ (II) to soil humic acid at pH 6.5 and in $0.1 \mathrm{M} \mathrm{KNO}_{3}$ ionic medium. The stability constant for binding indicating greater stability in the case when carboxyl groups are involved in complexation reaction. Kostic et al.,(2012) investigated the complexation of humic acid with certain heavy metal ions (Co(II), $\mathrm{Ni}(\mathrm{II}), \mathrm{Cu}(\mathrm{II})$,
$\mathrm{Zn}(\mathrm{II})$, and $\mathrm{Pb}(\mathrm{II})$. The experiment was performed at $25^{\circ} \mathrm{C}$, at pH 4.0 and ionic strength of $0.01 \mathrm{M}$. Stability constant of complex between $\mathrm{Pb}$ (II) ions and humic acid is greater than stability constants of other investigated metalhumate complexes. Bogata and Sokolowska (2016) analyses the interaction between humic acids from different soils and $\mathrm{Zn}$ (II) ions at wide concentration ranges and at $\mathrm{pH} 5$. Studies have showed significant impact of $\mathrm{Zn}$ concentration, $\mathrm{pH}$ and some properties of humic acids with zinc.But all of these studies were limited to acidic $\mathrm{pH}$ range. Therefore, the present study was carried out to determine and compare the stability constants of complexes of metal ions with hydrolysed peat soil humic acid and unhydrolysed peat soil humic under non-acid conditions.

\section{MATERIALS AND METHODS}

Analytical grade chemicals used includes hydrochloric acid $(\mathrm{HCl})$, nitric acid $\left(\mathrm{HNO}_{3}\right)$, sodium hydroxide $(\mathrm{NaOH})$, lead nitrate $\mathrm{Pb}\left(\mathrm{NO}_{3}\right)_{2}$, copper nitrate $\mathrm{Cu}\left(\mathrm{NO}_{3}\right)_{2} \cdot 3 \mathrm{H}_{2} \mathrm{O}$, cadmium nitrate $\mathrm{Cd}\left(\mathrm{NO}_{3}\right)_{2} \cdot 4 \mathrm{H}_{2} \mathrm{O}$, magnesium nitrate $\mathrm{Mg}\left(\mathrm{NO}_{3}\right)_{2} \cdot 6 \mathrm{H}_{2} \mathrm{O}$, potassium nitrate $\left(\mathrm{KNO}_{3}\right)$, calcium chloride $\left(\mathrm{CaCl}_{2}\right)$, (sigma-Aldrich). Dowex 50WX8, (20-50 mesh) from Fluka. 


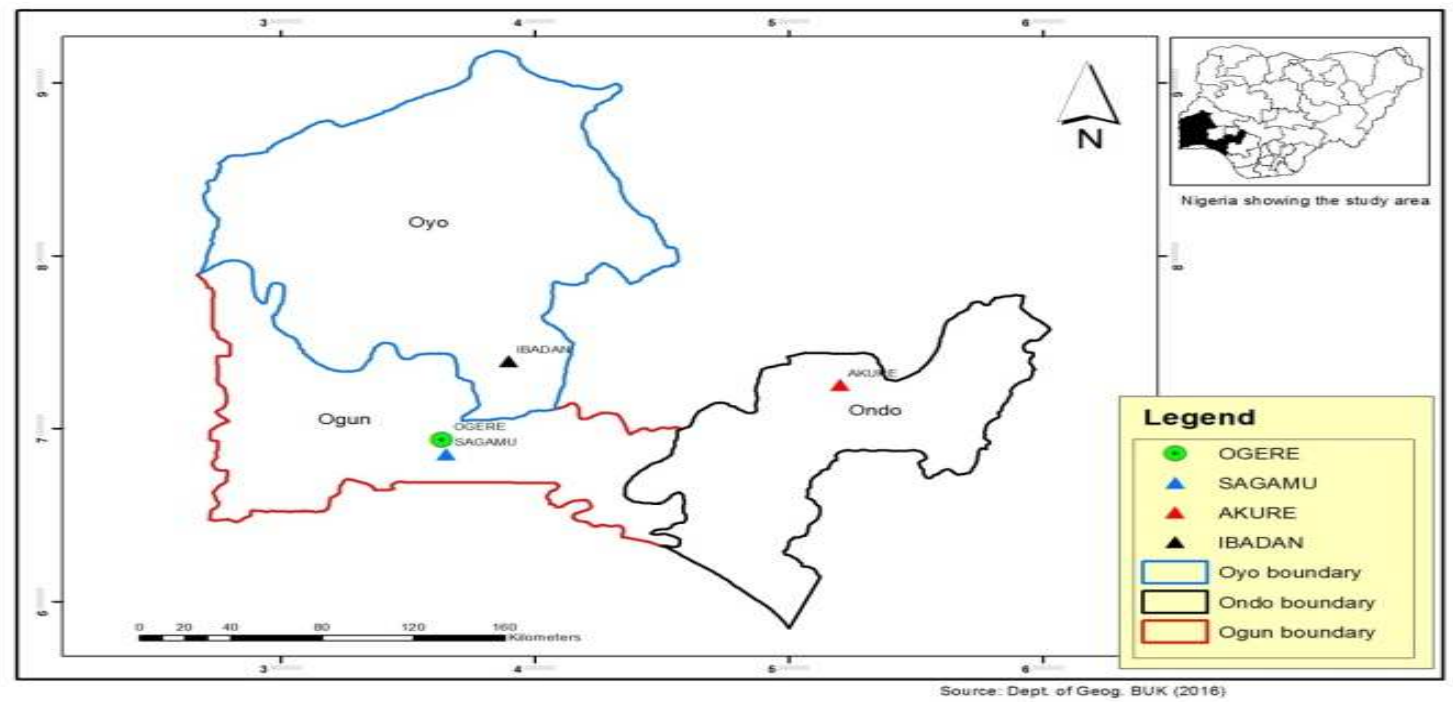

Figure 1: Map showing the sampling point at Sagamu Town, Ogun State.

\section{Description of Sampling Area}

Sagamu has geographical coordinates between $6^{\circ} 50^{\prime}$ north; $3^{\circ} 38^{\prime}$ east is located in south western region of Nigeria. The region has tropical wet and dry climate with a lengthy wet season and relatively constant temperatures throughout the course of the year. Wet season runs from March to October, November to December forms the region dry season. The vegetation type of the region is savannah which is really grassland with small bushes and occasional big trees. Grassland soils have substantially higher organic matter content than forest soils (Novackova, 2011).

\section{Sample Collection}

The Peatsoil samples were collected from four different sampling points $(0-10 \mathrm{~cm}$ depth) in Sagamu into polyethylene bag with plastic spoons. Samples were taken to the laboratory, extraneous materials were removed; the samples were air-dried, crushed and ground to a fine powder in a mortar passed through a $0.20 \mathrm{~mm}$ sieve. The samples were kept for analysis.

\section{Isolation and purification of humic acid from peat soil sample}

Peatsoil sample $(100 \mathrm{~g})$ was mixed with 1000 $\mathrm{cm}^{3}$ of $0.1 \mathrm{M} \mathrm{NaOH}$ solution, shaken for 3hours and left to stand overnight. Dark-coloured supernatant was obtained and decanted from solid residue. The dark-coloured supernatant was acidified to $(\mathrm{pH}=1.0)$ with $6 \mathrm{M} \mathrm{HCl}$ stirred and allowed to stand for 6 hours. Yellowish brown supernatant and dark-brown precipitate were obtained. The yellowish brown supernatant was decanted followed by centrifuge and discarded. The dark-brown precipitate was mixed with $500 \mathrm{~cm}^{3}$ of $0.1 \mathrm{M} \mathrm{NaOH}$ solution followed by passing through dowex resin. The dark-brown solution was acidified to $(\mathrm{pH}=1.0)$ with $6 \mathrm{M} \mathrm{HCl}$ stirred and allowed to stand for 3 hours. The dark-brown precipitate was washed several times with deionized water. The supernatant was treated with $\mathrm{AgNO}_{3}$ solution until no white precipitate observed. The humic acid was transferred to weighed crucible and dried at $60^{\circ} \mathrm{C}$ in an oven for 12 hours. The humic acid was cooled and dried in the desiccator, weighed and recorded. The obtained humic acid was dried again at $60^{\circ} \mathrm{C}$ for additional 6 hours cooled and dried in the desiccator, weighed and recorded constant weight was obtained (Baruah et al., 2015).

\section{FT-IR analysis}

FT-IR spectra of humic acid sample was analysed using Carry 630 FT-IR Agilent Technologies.

Unhydrolysed compost humic acid

The unhydrolysed humic acid was obtained after isolation and purification of compost humic acid and kept for investigation.

\section{Acid hydrolysis of Peatsoil acid}

Peatsoil humic acid sample (1g) was refluxed for 12 hours at $\left(160^{\circ} \mathrm{C}\right)$ with $50 \mathrm{~cm}^{3}$ of $6 \mathrm{M} \mathrm{HCl}$. The mixture was allowed to cool, decanted, and centrifuged after hydrolysis. The insoluble residues were washed with distilled water via centrifugation several times, and the supernatant was treated with $\mathrm{AgNO}_{3}$ solution until no white precipitate was observed. The residue was thoroughly dried over $\mathrm{CaCl}_{2}$ in a desiccator at room temperature (Chefetz et al., 2002). Finally, the obtained hydrolysed humic acid was kept for investigation. 
BAJOPAS Volume 14 Number 1,June, 2021 Potentiometric Titrations

Potentiometric measurements were carried out using a pH-meter Jenway (model 3510) with combine electrode, the sensitivity of the $\mathrm{pH}$ meter is 0.01 units. The $\mathrm{pH}$ meter was switched on half an hour before starting the titration for initial warm up of the instrument. The instrument was calibrated with an aqueous standard buffer solution of $\mathrm{pH} 4.00$ and 10.0 (borate buffer) prepared from a "Qualigens" buffer tablets.

The following sets of solutions were prepared in a $250 \mathrm{~cm}^{3}$ volumetric flask separately for $\mathrm{pH}$ metric titrations.

(i) $5 \mathrm{~cm}^{3} 0.1 \mathrm{M} \mathrm{HCl}+40 \mathrm{~cm}^{3}$ deionized water

(ii) $5 \mathrm{~cm}^{3} 0.1 \mathrm{M} \mathrm{HCl}+39 \mathrm{~cm}^{3}$ deionized water $+1 \mathrm{~cm}^{3} 0.15 \mathrm{gcm}^{-3}$ humic acid

(iii) $5 \mathrm{~cm}^{3} 0.1 \mathrm{M} \mathrm{HCl}+37 \mathrm{~cm}^{3}$ deionized water $+1 \mathrm{~cm}^{3} 0.15 \mathrm{gcm}^{-3}$ humic acid

$$
+2 \mathrm{~cm}^{3} \quad 0.01 \mathrm{M} \mathrm{Cu} \text { (II) }
$$

The solutions were titrated against standardized $0.110 \mathrm{MNaOH}$ separately. The total volume of each mixture was adjusted to $50 \mathrm{~cm}^{3}$ and the ionic strength of the solutions was maintained constant at by adding appropriate amount of stock solution of $1 \mathrm{M} \mathrm{KNO}_{3}$ (Gamal, 2015; Omar and Ali, 2015). A magnetic stirrer was used to achieve thorough mixing of the interacting solutions at $550 \mathrm{rpm}$. The same set of experimental conditions was applied for potentiometric titration of remaining samples.

\section{Evaluation of pKa of Hydrolysed peat soil Humic Acids}

The proton-ligand formation number $\mathrm{n}_{\mathbf{A}}$ were calculated by Irving and Rossotti expression (Omar and Ali, 2015).

$\mathrm{nA}=\mathrm{Y}-\frac{(\mathrm{V} 2-\mathrm{V1})(\mathrm{No}-\mathrm{Eo})}{(\mathrm{VO}+\mathrm{V1}) \mathrm{TCL}}$ 1

Where: $Y$ is number of dissociable proton, $\left(\mathrm{V}_{2^{-}}\right.$ $V_{1}$ ) is the measure of displacement of the ligand curve relative to acid curve, $\mathrm{N}^{\circ}$ and $\mathrm{E}^{\circ}$ are the resultant concentration of alkali solution, free acid solution, $\mathrm{T}_{\mathrm{cL}}{ }^{\circ}$ is the total ligand concentration, $\mathrm{V}^{\circ}$ is the total volume of titration solution, $V_{1}$ is the volume of alkali added to acid solution, $V_{2}$ is the volume of alkali added to acid solution + ligand solution, acid dissociation constants (pKa - values) of ligand were calculated by algebraic method point wise calculation (Tables 1 ). The dissociation constants (pKa) were calculated according to the following relation:

$\mathrm{pKa}=\mathrm{pH}+\log \left(\frac{n A}{1-n A}\right)$ 2

Where: pKa is the acid dissociation constant, $\mathrm{n}_{\mathrm{A}}$ is the Proton-ligand formation number and $\mathrm{pH}$ is the pH-values (Omar and Ali, 2015).

\section{Determination of metal-ligand stability constants $(\log K)$ of complexes}

The potentiometric measurement for the determination of stability constant of a complex in solution is based on the fact that the redox potential of the couple $\frac{M^{+(m-n)}}{M^{+m}}$ is shifted significantly on complexation of the metal ion with the ligand. This method involves change in hydrogen ion concentration $\left[\mathrm{H}^{+}\right]$due to the displacement or association of one or more protons taking place during complexation reaction. This change can be found out by titrating the solutions containing free acid, acid with ligand, and acid with ligand and metal ion, individually against a standard alkali solution at a constant ionic strength or temperature. Either ionic strength or temperature may be varied for different sets of solutions. In all the cases, the change in the $\mathrm{pH}$ of the solution is measured after each addition of a known amount of alkali to the reaction cell which contains the reaction mixture. The titration curves are then drawn by plotting the measured $\mathrm{pH}$ values against the corresponding volume of alkali added and the stability constants of the complexes are determined from the titration curves by employing $\mathrm{pH}$-metric titration technique given by (Irving and Rossoti).

Metal-ligand stability constants ( $\log \mathrm{K}$ ) were determined by using the following relations:

$$
\bar{n}=\frac{\left(V_{3}-V_{2}\right)\left(E^{0}+N^{0}\right)}{\left(V^{0}+V_{2}\right) \bar{n}_{A} T_{m}^{0}}
$$

and

$$
P L=\log _{10}\left\{\frac{1+\beta_{n}^{H} \frac{1}{[\text { anti } \log \mathrm{pH}]^{\mathrm{n}}}}{\mathrm{T}_{\mathrm{L}}^{0}-n \bar{T}_{m}^{0}} \mathrm{X} \frac{\left(V^{0}+V_{3}\right)}{V^{0}}\right\}
$$


BAJOPAS Volume 14 Number 1,June, 2021

Where $T_{L}, T^{\circ}, E^{\circ}$, and $V^{\circ}$ havethe same significance as in equation (1) above, $T_{m}$ denotes the total concentration of metal present in solution, $V_{3}$ is the volume of metal ions present in solution and $\beta^{H}$ is the overall proton ligand stability constant. The metal-ligand stability constants (log K) were determined by employing point wise computational Method (eq. 5 and 6).

$\operatorname{LogK}_{1}=\log \left(\frac{n}{1-n}\right)+\mathrm{pL}$ .5

$\operatorname{LogK}_{2}=\log \left(\frac{1-n}{2-n}\right)+\mathrm{pL}$ ...6

Where: Log $\mathrm{K}$ is the metal-ligand stability constant, $\mathrm{pL}$ is the Free ligand exponent function, $\mathbf{n}$ is the Average number of ligand attached with metal ion (Janraoet al., 2014). The results obtained were analyzed by an ORIGIN 2016 program using titration data and then the proton-ligand stability constants (pKa) and Metal-ligand stability constant (LogK) calculated (Omar and Ali, 2015).

\section{RESULTS AND DISCUSSION}

Fourier transformed infrared (FT-IR) spectra of isolated humic acid from peat soils Figure 2 had distinct clear absorption bands indicating the presence of major humic acid structural elemental groups such as $\mathrm{H}$ bonded $\mathrm{OH}$ $\left(3680 \mathrm{~cm}^{-1}\right.$ peak $), C=0$ of carbonyl $\left(1721 \mathrm{~cm}^{-1}\right.$ peak), functional groups of aliphatic components $\mathrm{CH}_{2}\left(2918 \mathrm{~cm}^{-1}\right.$ peak) and $\mathrm{C}-\mathrm{O}$ stretching of polysaccharide $\left(1168 \mathrm{~cm}^{-1}\right.$ peak). The positions of the absorption bands of the spectra fell within typical major absorption bands of humic acid which is at frequencies 3680, 2918, 1721, 1168 $\mathrm{cm}^{-1}$. The first peak centred in the vicinity of $3680 \mathrm{~cm}^{-1}$ region is attributed to phenol $\mathrm{OH}$ group bounded by intermolecular $\mathrm{H}$ bonds. The $2918 \mathrm{~cm}^{-1}$ band usually has absorption maximum at $2918 \mathrm{~cm}^{-1}$ which is due to $\mathrm{C}-\mathrm{H}$ stretching of alkane group $\left(\mathrm{CH}_{2}\right)$. The next major absorption band is $1721 \mathrm{~cm}^{-1}$. This band has been commonly ascribed to $\mathrm{C}=\mathrm{O}$ stretching of mainly carboxyl group $(\mathrm{COOH})$ with trace amount of ketones. The last peak was observed at 1168 $\mathrm{cm}^{-1}$ due to $\mathrm{C}-\mathrm{O}$ stretching of polysaccharides and this peak appeared also in the spectra of humic acid from peat soil. The FTIR spectra of the isolated humic acid contained all major characteristic absorption peaks of humic acid. These absorption peaks indicated the presence of the major structural elements of humic acid namely $\mathrm{H}$ bonded $\mathrm{OH}, \mathrm{C}=\mathrm{C}$ of aromatic ring, $\mathrm{C}=\mathrm{O}$ of carbonyl group (both carboxyl and ketonic), $\mathrm{CH}_{2}$ group. This strongly supports the presence of humic acid.

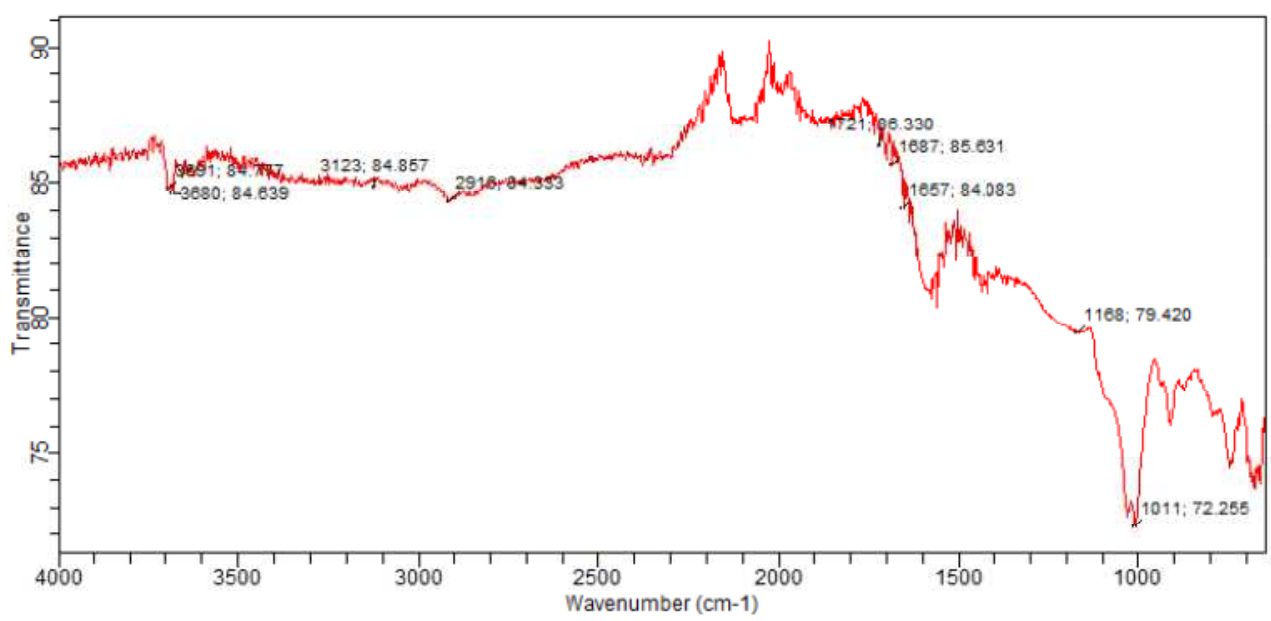

Fig. 2 : FT-IR spectraof peatsoilhumic acid (PSHA)

\section{Evaluation of acid dissociation constant (pka) of acid hydrolysed peat soil humicacid at phenolic group}

The value of the dissociation constant of the peat soil humic acid (PSHA) that underwent acidhydrolysis studied was found to be 8.9299 as shown Table 1, which is lower than the literaturevalues reported by Almeida and Szpoganics, (2015), Borges et al., (2005); Badr et al., (2012)and Fernandes et al,.(2009) of $9.73,9.47$ and 10.30. The difference between the obtained valuesand the reported values in this study might be probably as a result of acid hydrolysis of humicacid. 
BAJOPAS Volume 14 Number 1,June, 2021

Table 1: PKa of (Hydrolysed PSHA)

\begin{tabular}{|l|l|l|l|l|l|l|}
\hline $\mathrm{pH}$ & $\mathrm{BV}_{1}$ & $\mathrm{BV}_{2}$ & $\mathrm{~V}_{2}-\mathrm{V}_{1}$ & $\mathrm{nA}$ & $\log \left(\frac{n A}{1-n A}\right)$ & $\mathrm{pKa}$ \\
\hline 8.50 & 5.30 & 6.29 & 0.99 & 0.3594 & -0.2510 & 8.2490 \\
8.72 & 5.35 & 6.37 & 1.02 & 0.3400 & -0.2880 & 8.4320 \\
9.00 & 5.40 & 6.46 & 1.06 & 0.3141 & -0.3391 & 8.6609 \\
9.22 & 5.45 & 6.55 & 1.10 & 0.2882 & -0.3927 & 8.8273 \\
9.51 & 5.50 & 6.66 & 1.16 & 0.2494 & -0.4786 & 9.0314 \\
9.73 & 5.55 & 6.78 & 1.23 & 0.2041 & -0.5910 & 9.1390 \\
10.00 & 5.60 & 6.90 & 1.30 & 0.1589 & -0.7238 & 9.2762 \\
10.23 & 5.65 & 7.05 & 1.40 & 0.0941 & -0.9835 & 9.2465 \\
10.49 & 5.70 & 7.10 & 1.40 & 0.0941 & -0.9835 & 9.5065 \\
\hline
\end{tabular}

Average pKa $=8.9299 \pm 0.4186$

Table 2: PKa of (Unhydrolysed PSHA)

\begin{tabular}{|l|l|l|l|l|l|l|}
\hline $\mathrm{pH}$ & $\mathrm{BV}_{1}$ & $\mathrm{BV}_{2}$ & $\mathrm{~V}_{2}-\mathrm{V}_{1}$ & $\mathrm{nA}$ & $\log \left(\frac{\boldsymbol{n A}}{1-\boldsymbol{n}}\right)$ & $\mathrm{pKa}$ \\
\hline 8.50 & 5.30 & 5.81 & 0.51 & 0.6619 & 0.2919 & 8.7919 \\
8.72 & 5.35 & 5.90 & 0.55 & 0.6357 & 0.2418 & 8.9618 \\
9.00 & 5.40 & 6.00 & 0.60 & 0.6029 & 0.1813 & 9.1813 \\
9.22 & 5.45 & 6.10 & 0.65 & 0.5701 & 0.1226 & 9.3426 \\
9.51 & 5.50 & 6.20 & 0.70 & 0.5376 & 0.0654 & 9.5754 \\
9.73 & 5.55 & 6.33 & 0.78 & 0.4851 & -0.0259 & 9.7041 \\
10.00 & 5.60 & 6.47 & 0.87 & 0.4262 & -0.1291 & 9.8709 \\
10.23 & 5.65 & 6.62 & 0.99 & 0.3609 & -0.2481 & 9.9819 \\
10.49 & 5.70 & 6.80 & 1.10 & 0.2759 & -0.4690 & 10.0210 \\
\hline
\end{tabular}

Average pKa $=9.4923 \pm 0.4410$

Metal-ligand stability constant ( $\log \mathrm{K}$ )

The stabilityconstants require the accurate values of proton-ligand stability constants (Anil and Maroti, 2008). Metal titration curves crossed over ligand titration curve indicated the formation of complex upon proton release (Santosh, et al., 2011). If the values of n- are within range $0.2-0.8$ and $1.2-18$ this indicates the formation of $1: 1$ and 1:2 complexes (Sayyed and Mazahar, 2012).

The metal (II)-humate stepwise stability constants (log k) at phenolic group (Tables 318)

Table 3: Point-wise method, $\mathrm{Cu}$-(Hydrolysed PSHA)

\begin{tabular}{|l|l|l|l|l|l|l|l|l|}
\hline $\mathrm{pH}$ & $\mathrm{BV}_{1}$ & $\mathrm{BV}_{2}$ & $\mathrm{BV}_{3}$ & $\left(\mathrm{~V}_{3}-\mathrm{V}_{2}\right)$ & $\mathrm{n}$ & $\mathrm{pL}$ & $\log \left(\frac{n}{1-n}\right)$ & LogK $_{1}$ \\
\hline 8.50 & 5.30 & 6.29 & 6.33 & 0.04 & 0.5500 & 2.66 & 0.0871 & 2.7471 \\
8.72 & 5.35 & 6.37 & 6.41 & 0.04 & 0.5714 & 2.43 & 0.1249 & 2.5549 \\
9.00 & 5.40 & 6.46 & 6.50 & 0.04 & 0.6198 & 2.16 & 0.2122 & 2.3722 \\
9.22 & 5.45 & 6.55 & 6.59 & 0.04 & 0.6667 & 1.94 & 0.3010 & 2.2410 \\
\hline
\end{tabular}

LogK $_{1}$ (Average value) $=2.4788 \pm 0.2203$

Table 4: Point-wise method, $\mathrm{Cu}$-(Hydrolysed PSHA)

\begin{tabular}{|l|l|l|l|l|l|l|l|l|}
\hline $\mathrm{pH}$ & $\mathrm{BV}_{1}$ & $\mathrm{BV}_{2}$ & $\mathrm{BV}_{3}$ & $\left(\mathrm{~V}_{3}-\mathrm{V}_{2}\right)$ & $\mathrm{n}$ & $\mathrm{pL}$ & $\log \left(\frac{n-1}{2-n}\right)$ & LogK $_{2}$ \\
\hline 9.51 & 5.50 & 6.66 & 6.73 & 0.07 & 1.3509 & 1.70 & -0.2671 & 1.4329 \\
9.73 & 5.55 & 6.78 & 6.85 & 0.07 & 1.6383 & 1.51 & 0.2467 & 1.7567 \\
10.00 & 5.60 & 6.90 & 6.98 & 0.08 & 2.1783 & 1.31 & -0.2158 & 1.0942 \\
10.23 & 5.65 & 7.05 & 7.13 & 0.08 & 4.1904 & 1.27 & & \\
10.49 & 5.70 & 7.10 & 7.19 & 0.09 & 4.6920 & & & \\
\hline
\end{tabular}

Log $K_{2}($ Average value $)=1.4280 \pm 0.3312$ 
BAJOPAS Volume 14 Number 1,June, 2021

Table 5: Point-wise method, $\mathrm{Cu}$ (Unhydrolysed PSHA)

\begin{tabular}{|l|l|l|l|l|l|l|l|l|}
\hline $\mathrm{pH}$ & $\mathrm{BV}_{1}$ & $\mathrm{BV}_{2}$ & $\mathrm{BV}_{3}$ & $\left(\mathrm{~V}_{3}-\mathrm{V}_{2}\right)$ & $\mathrm{n}$ & $\mathrm{pL}$ & $\log \left(\frac{n}{n-1}\right)$ & Log $_{1}$ \\
\hline 8.50 & 5.30 & 5.81 & 5.85 & 0.04 & 0.2973 & 2.88 & -0.3736 & 2.5064 \\
8.72 & 5.35 & 5.90 & 5.95 & 0.05 & 0.3873 & 2.66 & -0.1992 & 2.4608 \\
9.00 & 5.40 & 6.00 & 6.05 & 0.05 & 0.4044 & 2.38 & -0.1681 & 2.2119 \\
9.22 & 5.45 & 6.10 & 6.15 & 0.06 & 0.5157 & 2.18 & -0.0272 & 2.2072 \\
9.51 & 5.50 & 6.20 & 6.27 & 0.07 & 0.6417 & 1.89 & 0.2530 & 1.1430 \\
\hline
\end{tabular}

$\operatorname{LogK}_{1}($ Average value $)=2.3059 \pm 0.6153$

Table 6:Point-wise method, $\mathrm{Cu}$ (Unhydrolysed PSHA)

\begin{tabular}{|l|l|l|l|l|l|l|l|l|}
\hline $\mathrm{pH}$ & $\mathrm{BV}_{1}$ & $\mathrm{BV}_{2}$ & $\mathrm{BV}_{3}$ & $\mathrm{~V}_{3}-\mathrm{V}_{2}$ & $\mathrm{n}$ & $\mathrm{pL}$ & $\log \left(\frac{n-1}{2-n}\right)$ & $\log \mathrm{K}_{2}$ \\
\hline 9.73 & 5.55 & 6.33 & 6.42 & 0.09 & 0.9000 & 1.69 & & \\
10.00 & 5.60 & 6.47 & 6.58 & 0.11 & 1.2578 & 1.44 & -0.4592 & 0.9808 \\
10.23 & 5.65 & 6.62 & 6.84 & 0.12 & 1.6137 & 1.26 & -0.2010 & 1.4610 \\
10.49 & 5.70 & 6.80 & 6.92 & 0.12 & 2.1052 & 1.03 & & \\
\hline
\end{tabular}

$\operatorname{LogK}_{2}$ (Average value) $=1.2209 \pm 0.3398$

Table 7:Point-wise method, Pb (Hydrolysed PSHA)

\begin{tabular}{|l|l|l|l|l|l|l|l|l|}
\hline $\mathrm{pH}$ & $\mathrm{BV}_{1}$ & $\mathrm{BV}_{2}$ & $\mathrm{BV}_{3}$ & $\left(\mathrm{~V}_{3}-\mathrm{V}_{2}\right)$ & $\mathrm{n}$ & $\mathrm{pL}$ & $\log \left(\frac{n}{1-n}\right)$ & LogK $_{1}$ \\
\hline 8.50 & 5.30 & 6.29 & 6.33 & 0.04 & 0.5500 & 2.66 & 0.0871 & 2.7471 \\
8.72 & 5.35 & 6.37 & 6.41 & 0.04 & 0.5714 & 2.43 & 0.1249 & 2.5549 \\
9.00 & 5.40 & 6.46 & 6.50 & 0.04 & 0.6198 & 2.16 & 0.2122 & 2.3722 \\
9.22 & 5.45 & 6.55 & 6.60 & 0.05 & 0.8333 & 1.96 & 0.6989 & 2.6589 \\
\hline
\end{tabular}

Log $_{\mathbf{1}}($ Average value $)=2.5832 \pm 0.1614$

Table 8:Point-wise method, Pb-(Hydrolysed PSHA)

\begin{tabular}{|l|l|l|l|l|l|l|l|l|}
\hline $\mathrm{pH}$ & $\mathrm{BV}_{1}$ & $\mathrm{BV}_{2}$ & $\mathrm{BV}_{3}$ & $\left(\mathrm{~V}_{3}-\mathrm{V}_{2}\right)$ & $\mathrm{n}$ & $\mathrm{pL}$ & $\log \left(\frac{n-1}{2-n}\right)$ & $\log \mathrm{K}_{2}$ \\
\hline 9.51 & 5.50 & 6.66 & 6.71 & 0.05 & 0.9650 & 1.67 & & \\
9.73 & 5.55 & 6.78 & 6.83 & 0.05 & 1.1702 & 1.44 & & \\
10.00 & 5.60 & 6.90 & 6.90 & 0.05 & 1.4864 & 1.22 & -0.0237 & 1.1963 \\
10.23 & 5.65 & 7.05 & 7.10 & 0.05 & 2.0190 & 1.09 & & \\
10.49 & 5.70 & 7.10 & 7.17 & 0.07 & 3.6492 & 1.00 & & \\
\hline
\end{tabular}

Log $K_{2}$ (Average value) $=1.1963$

Table 9: Point-wise method, Pb (Unhydrolysed PSHA)

\begin{tabular}{|l|l|l|l|l|l|l|l|l|}
\hline $\mathrm{pH}$ & $\mathrm{BV}_{1}$ & $\mathrm{BV}_{2}$ & $\mathrm{BV}_{3}$ & $\mathrm{~V}_{3}-\mathrm{V}_{2}$ & $\mathrm{n}$ & $\mathrm{pL}$ & $\begin{array}{l}\text { Log } \\
\left(\frac{n}{n-1}\right)\end{array}$ & Log $\mathrm{K}_{1}$ \\
\hline 8.50 & 5.30 & 5.81 & 5.85 & 0.04 & 0.2973 & 2.88 & -0.3736 & 2.5064 \\
8.72 & 5.35 & 5.90 & 5.94 & 0.04 & 0.3099 & 2.66 & -0.5477 & 2.3123 \\
9.00 & 5.40 & 6.00 & 6.05 & 0.05 & 0.4044 & 2.38 & -0.1681 & 2.2119 \\
9.22 & 5.45 & 6.10 & 6.15 & 0.06 & 0.5157 & 2.18 & 0.0272 & 2.2072 \\
9.51 & 5.50 & 6.20 & 6.26 & 0.07 & 0.6417 & 1.89 & 0.2530 & 2.1430 \\
9.73 & 5.55 & 6.40 & 6.40 & 0.07 & 0.7000 & 1.67 & 0.3680 & 2.0380 \\
\hline
\end{tabular}

LogK $_{1}$ (Average value) $=2.2364 \pm 0.1602$

Table 10: Point-wise method, Pb (Unhydrolysed PSHA)

\begin{tabular}{|l|l|l|l|l|l|l|l|l|}
\hline $\mathrm{pH}$ & $\mathrm{BV}_{1}$ & $\mathrm{BV}_{2}$ & $\mathrm{BV}_{3}$ & $\mathrm{~V}_{3}-\mathrm{V}_{2}$ & $\mathrm{n}$ & $\mathrm{pL}$ & $\log \left(\frac{n-1}{2-n}\right)$ & $\log \mathrm{K}_{2}$ \\
\hline 10.00 & 5.60 & 6.47 & 6.55 & 0.08 & 1.9503 & 1.41 & & \\
10.23 & 5.65 & 6.62 & 6.72 & 0.11 & 1.4792 & 1.26 & -0.0361 & 1.2239 \\
\hline
\end{tabular}

$\operatorname{LogK}_{2}$ (Average value) $=1.2239$

Table 11: Point-wise method, Mg (Hydrolysed PSHA)

\begin{tabular}{|l|l|l|l|l|l|l|l|l|}
\hline $\mathrm{pH}$ & $\mathrm{BV}_{1}$ & $\mathrm{BV}_{2}$ & $\mathrm{BV}_{3}$ & $\left(\mathrm{~V}_{3}-\mathrm{V}_{2}\right)$ & $\mathrm{n}$ & $\mathrm{pL}$ & $\log \left(\frac{n}{n-1}\right)$ & LogK $_{1}$ \\
\hline 8.50 & 5.30 & 6.29 & 6.31 & 0.02 & 0.2750 & 2.64 & -0.4290 & 2.2110 \\
8.72 & 5.35 & 6.37 & 6.39 & 0.02 & 0.2858 & 2.42 & -0.3978 & 2.0222 \\
9.00 & 5.40 & 6.46 & 6.49 & 0.03 & 0.4648 & 2.14 & -0.0612 & 2.0788 \\
9.22 & 5.45 & 6.55 & 6.59 & 0.04 & 0.6667 & 1.94 & 0.3010 & 2.2410 \\
\hline
\end{tabular}

$\log _{\mathbf{1}}($ Average value) $=2.1382 \pm 0.1046$ 
BAJOPAS Volume 14 Number 1,June, 2021

Table 12: Point-wise method, Mg (Hydrolysed PSHA)

\begin{tabular}{|l|l|l|l|l|l|l|l|l|}
\hline $\mathrm{pH}$ & $\mathrm{BV}_{1}$ & $\mathrm{BV}_{2}$ & $\mathrm{BV}_{3}$ & $\left(\mathrm{~V}_{3}-\mathrm{V}_{2}\right)$ & $\mathrm{n}$ & $\mathrm{pL}$ & $\log \left(\frac{n-1}{2-n}\right)$ & LogK $_{2}$ \\
\hline 9.51 & 5.55 & 6.66 & 6.71 & 0.05 & 0.9650 & 1.67 & & \\
9.73 & 5.55 & 6.78 & 6.84 & 0.06 & 1.4042 & 1.47 & -0.1686 & 1.3014 \\
10.00 & 5.60 & 6.90 & 6.93 & 0.06 & 1.7838 & 1.23 & 0.5593 & 1.7893 \\
10.23 & 5.65 & 7.05 & 7.10 & 0.06 & 3.1429 & 1.10 & & \\
10.49 & 5.70 & 7.10 & 7.18 & 0.07 & 3.6492 & 0.83 & & \\
\hline
\end{tabular}

LogK $_{2}($ Average value $)=1.5453 \pm 0.3450$

Table 13: Point-wise method, Mg (Unhydrolysed PSHA)

\begin{tabular}{|l|l|l|l|l|l|l|l|l|}
\hline $\mathrm{pH}$ & $\mathrm{BV}_{1}$ & $\mathrm{BV}_{2}$ & $\mathrm{BV}_{3}$ & $\mathrm{~V}_{3}-\mathrm{V}_{2}$ & $\mathrm{n}$ & $\mathrm{pL}$ & $\log \left(\frac{n}{n-1}\right)$ & $\operatorname{Log~}_{1}$ \\
\hline 8.50 & 5.30 & 5.81 & 5.85 & 0.04 & 0.2973 & 2.88 & -0.3736 & 2.5064 \\
8.72 & 5.35 & 5.90 & 5.94 & 0.04 & 0.3099 & 2.66 & -0.3477 & 2.3123 \\
9.00 & 5.40 & 6.00 & 6.04 & 0.04 & 0.3236 & 2.38 & -0.3202 & 2.0598 \\
9.22 & 5.45 & 6.10 & 6.15 & 0.05 & 0.4297 & 2.17 & -0.1230 & 2.0470 \\
9.51 & 5.50 & 6.20 & 6.26 & 0.06 & 0.5500 & 1.89 & 0.0871 & 1.9771 \\
9.73 & 5.55 & 6.33 & 6.40 & 0.07 & 0.7000 & 1.67 & 0.3680 & 2.0380 \\
\hline
\end{tabular}

LogK $_{1}$ (Average value) $=2.1568 \pm 0.2069$

Table 14: Point-wise method, Mg (Unhydrolysed PSHA)

\begin{tabular}{|l|l|l|l|l|l|l|l|l|}
\hline $\mathrm{pH}$ & $\mathrm{BV}_{1}$ & $\mathrm{BV}_{2}$ & $\mathrm{BV}_{3}$ & $\mathrm{~V}_{3}-\mathrm{V}_{2}$ & $\mathrm{n}$ & $\mathrm{pL}$ & $\log \left(\frac{n-1}{2-n}\right)$ & $\log \mathrm{K}_{2}$ \\
\hline 10.00 & 5.60 & 6.47 & 6.55 & 0.08 & 0.9148 & 1.41 & & \\
10.23 & 5.65 & 6.62 & 6.71 & 0.09 & 1.2102 & 1.20 & -0.5749 & 0.6251 \\
10.49 & 5.70 & 6.80 & 6.92 & 0.09 & 1.5968 & 1.03 & 0.1703 & 1.2003 \\
\hline
\end{tabular}

LogK $_{2}$ (Average value) $=0.9127 \pm 0.4070$

Table15:Point-wise method, Cd (Hydrolysed PSHA)

\begin{tabular}{|l|l|l|l|l|l|l|l|l|}
\hline $\mathrm{pH}$ & $\mathrm{BV}_{1}$ & $\mathrm{BV}_{2}$ & $\mathrm{BV}_{3}$ & $\left(\mathrm{~V}_{3}-\mathrm{V}_{2}\right)$ & $\mathrm{n}$ & $\mathrm{pL}$ & $\log \left(\frac{n}{1-n}\right)$ & LogK $_{1}$ \\
\hline 8.50 & 5.30 & 6.29 & 6.31 & 0.02 & 0.2750 & 2.64 & -0.4210 & 2.2190 \\
8.72 & 5.35 & 6.37 & 6.40 & 0.03 & 0.4286 & 2.42 & -0.1249 & 2.2951 \\
9.00 & 5.40 & 6.46 & 6.49 & 0.03 & 0.4648 & 2.14 & -0.0612 & 2.0788 \\
9.22 & 5.45 & 6.55 & 6.59 & 0.04 & 0.6667 & 1.96 & 0.3010 & 2.2610 \\
9.51 & 5.55 & 6.66 & 6.70 & 0.04 & 0.7720 & 1.67 & 0.5297 & 2.1997 \\
\hline
\end{tabular}

LogK $_{\mathbf{1}}$ (Average value) $=2.2108 \pm 0.0825$

Table 16: Point-wise method, Cd (Hydrolysed PSHA)

\begin{tabular}{|l|l|l|l|l|l|l|l|l|}
\hline $\mathrm{pH}$ & $\mathrm{BV}_{1}$ & $\mathrm{BV}_{2}$ & $\mathrm{BV}_{3}$ & $\left(\mathrm{~V}_{3}-\mathrm{V}_{2}\right)$ & $\mathrm{n}$ & $\mathrm{pL}$ & $\log \left(\frac{n-1}{2-n}\right)$ & Log $_{2}$ \\
\hline 9.73 & 5.55 & 6.78 & 6.83 & 0.06 & 1.4042 & 1.47 & -0.1686 & 1.3014 \\
10.00 & 5.60 & 6.90 & 6.95 & 0.06 & 1.7838 & 1.23 & 0.5593 & 1.7893 \\
10.23 & 5.65 & 7.05 & 7.10 & 0.06 & 3.1429 & 1.09 & & \\
10.49 & 5.70 & 7.10 & 7.16 & 0.06 & 3.1429 & 0.89 & & \\
& & & & & & & & \\
\hline
\end{tabular}

$\operatorname{LogK}_{2}$ (Average value) $=1.5453 \pm 0.3450$

Table 17: Point-wise method, Cd (Unhydrolysed PSHA)

\begin{tabular}{|l|l|l|l|l|l|l|l|l|}
\hline $\mathrm{pH}$ & $\mathrm{BV}_{1}$ & $\mathrm{BV}_{2}$ & $\mathrm{BV}_{3}$ & $\mathrm{~V}_{3}-\mathrm{V}_{2}$ & $\mathrm{n}$ & $\mathrm{pL}$ & $\log \left(\frac{n}{n-1}\right)$ & $\operatorname{Log~}_{1}$ \\
\hline 8.50 & 5.30 & 5.81 & 5.86 & 0.05 & 0.3717 & 2.88 & -0.2280 & 2.6520 \\
8.72 & 5.35 & 5.90 & 5.95 & 0.05 & 0.3873 & 2.66 & -0.1992 & 2.4608 \\
9.00 & 5.40 & 6.00 & 6.06 & 0.06 & 0.4853 & 2.38 & -0.0255 & 2.3545 \\
9.22 & 5.45 & 6.10 & 6.16 & 0.06 & 0.5157 & 2.18 & -0.0272 & 2.2072 \\
9.51 & 5.50 & 6.20 & 6.27 & 0.07 & 0.6417 & 1.89 & 0.2530 & 1.1430 \\
9.73 & 5.55 & 6.33 & 6.41 & 0.08 & 0.8000 & 1.69 & 0.6020 & 2.2920 \\
& & & & & & & & \\
\hline
\end{tabular}

$\operatorname{LogK}_{1}($ Average value $)=2.2516 \pm 0.5380$ 
BAJOPAS Volume 14 Number 1,June, 2021

Table 18: Point-wise method, Cd (Unhydrolysed PSHA)

\begin{tabular}{|l|l|l|l|l|l|l|l|l|}
\hline $\mathrm{pH}$ & $\mathrm{BV}_{1}$ & $\mathrm{BV}_{2}$ & $\mathrm{BV}_{3}$ & $\mathrm{~V}_{3}-\mathrm{V}_{2}$ & $\mathrm{n}$ & $\mathrm{pL}$ & $\log \left(\frac{n-1}{2-n}\right)$ & $\log \mathrm{K}_{2}$ \\
\hline 10.00 & 5.60 & 6.47 & 6.57 & 0.10 & 1.1434 & 1.43 & & \\
10.23 & 5.65 & 6.62 & 6.72 & 0.10 & 1.3448 & 1.23 & -0.2788 & 0.9512 \\
10.49 & 5.70 & 6.80 & 6.90 & 0.10 & 1.7742 & 1.03 & 0.5351 & 1.5651 \\
\hline
\end{tabular}

$\operatorname{LogK}_{2}($ Average value $)=1.2581 \pm 0.4340$

Table 19: Stepwise and overall Stability constants of thehydrolysed and unhydrolysed divalent metal (II) complexes

\begin{tabular}{|c|c|c|c|}
\hline Chelates & LogK $_{1}$ & $\log _{2}$ & Log $\beta$ \\
\hline [Cu (Hydrolysed PSHA-1) $\left.{ }_{2}\right]$ & 2.4788 & 1.4280 & 3.9068 \\
\hline$\left[\mathrm{Pb}(\text { Hydrolysed PSHA-1) })_{2}\right]$ & 2.5832 & 1.1963 & 3.7795 \\
\hline$\left[\mathrm{Cd}(\text { Hydrolysed PSHA-1 })_{2}\right]$ & 2.2108 & 1.5453 & 3.7561 \\
\hline$\left[\mathrm{Mg}(\text { Hydrolysed PSHA-1 })_{2}\right]$ & 2.1382 & 1.5453 & 3.6835 \\
\hline [Cu (Unhydrolysed PSHA-1) & 2.3059 & 1.2209 & 3.5268 \\
\hline$[\mathrm{Pb}$ (Unhydrolysed PSHA-1) 2$]$ & 2.2364 & 1.2239 & 3.4603 \\
\hline [Cd (Unhydrolysed PSHA-1) 2 ] & 2.2516 & 1.2581 & 3.5097 \\
\hline$[\mathrm{Mg}$ (Unydrolysed PSHA-1) & 2.1568 & 0.9127 & 3.0695 \\
\hline
\end{tabular}

The results obtained (Table19) shows the stepwise and overall stability constants to be not high indicating low stability of the complexes, because the solubility of most metal ions in the basic $\mathrm{pH}$ range is minimal due to metal hydroxide precipitation (Karimi, 2017). In general, the stepwise stability constants $\left(K_{1}\right.$ and $K_{2}$ ) follow the order $K_{1}>K_{2}$ for the copper, lead, magnesium and cadmium complexes respectively. The steady decrease of the values with increasing number of ligands is in agreement with the prediction made by researchers (Na'aliya, 2013). The decrease could be attributed to the fact that as the number of the ligands (Humate ions) that enters the coordination zone increases the aqua molecules available for replacement by the ligands become less. Thus, the metal ions become less electron loving with progressive intake of the ligand and this results in the decrease in the values of the constants (Na'aliya, 2013). Also the stability of the complexes is influenced by the size and number of the chelate rings(Mackay and Mackay,2002).All the complexes form rings in their structure as humate, a bidentate ligand, bond the metal ions in the ratio 1:2 (Boguta and Sokolowska, 2016) forming chelate rings. The values of the overall stability constants $(\log \beta)$ obtained for humate complexes are not high indicating low stability as the values are not high. LogK values for copper-humates (Table 3 to 6) obtained in this study are lower than those reported for the complexes of humic acids (Pandey et al., 2015; Dinu, 2013; Kaschl et al., 2010 and Gilbeto and Jorg, 2001). The values of LogK(Table 7 to 10 ) forlead-humates are lower than those reported for the lead in the literature (Dinu, 2013; Gilbeto and Jorg 2001). Log K values(Table 11 to 14 ) for magnesium-humates obtained in this study are close to those reported by (Pandey et al., 2015). Log K values of cadmium-humates (Table 15 to 18 ) obtained in this work near to the one reported by (Dinu, 2013 and Pandey et al., 2015).The difference between the reported values and the values obtained in this study might be probably as a result of acid hydrolysis of humic acid. The values of the overall stability constants $(\log \beta)$ of the copper humates complexes presented in Table 19 is high than that of other metal humate complexes, show relatively high stability of CuHA complexes, show the following order of stability: $\mathrm{Cu}>\mathrm{Pb}>\mathrm{Cd}>\mathrm{Mg}$; which are in close agreement to the findings of (Dinu, 2013 and Pandey et al., 2015).The high stability of Cuhumate chelate could be attributed to the existence of coordinate covalent bond between the complexing agents and the $\mathrm{Cu}^{2+}$ ions. Since, $\mathrm{Cu}^{2+}$ being a metal of the transitional series with $3 d^{9}$ electronic configurations can accept the electrons from the complexing agents. Similarly, the low stabilities of $\mathrm{Pb}, \mathrm{Cd}$ and $\mathrm{Mg}$ complexes could be explained by that $\mathrm{Pb}^{2+}$ with $6 s^{2}, \mathrm{Cd}^{2+}$ with $4 \mathrm{~d}^{10}$ and $\mathrm{Mg}^{2+}$ with $2 \mathrm{p}^{6}$ their electronic configuration has a completely filled $\mathrm{d}, \mathrm{p}$ and $\mathrm{s}$ orbitals. Moreover, the stabilities of metal ions with hydrolysed humic acid from peat soil were higher than those with unhydrolysed humic acid from peat soil; which is ascribed to the high content of acidity in hydrolysed humic acid than unhydrolysed humic acid. 
BAJOPAS Volume 14 Number 1,June, 2021 CONCLUSION

The values of logk for $\mathrm{Cu}(\mathrm{II})$ hydrolysed humic acid complex was higher followed by $\mathrm{Pb}$ (II), $\mathrm{Cd}(\mathrm{II})$ and $\mathrm{Mg}$ (II) hydrolysed humic acid complexes as compared with metal(II) unhydrolysed humic acid complexes. This indicates acid hydrolysis of humic acid can

\section{REFERENCES}

Almeida, V.R. and Szpoganicz, B. (2015). Humic Acid Potentiometric Response Patterns:Out- of Equilibrium Properties and Species Distribution Modelling. Chemical. Biol. Technol. Agric. 2: 17.

Anđelković, T., Nikolić, R., Bojić, A.,Anđelković, D., and Nikolic G.,(2010). Binding of Cadmium to Soil Humic Acid as A Function of Carboxyl Group Content. Macedonian Journal of Chemistry and Chemical Engineering.29(2): 215-224.

Anil, B. N. and Maroti, N. (2008). Studies on Influence of Die-Lectric Constants on Complex Equilibria between Substituted Py-Razalines and Lanthanide Metal Ions pH-Metrically. Amer.-Euras. scient. Res. 3(2): 212-216.

Ashok, K., Pandey, S. P. and Misra, V (2000). Stability Constants of Metal-Humic Acid Complexes and its Role in Environmental Detoxification. Journal of Ecotoxicology and Environmental Safety. 47(2):157-200.

Badr, M. H., El-Halafawi, M. H. and Abd El-al Zeid, E. R. (2012). Comparison Between the Effect of Ionic Strength on Acidity and Dissociation Constants of Humic Acids Extracted from Sewage Sludge and Nile Water Hyacinth Composts.Global Journal of Environmental Research 6 (1): 36-43.

Baruah, M.K., Borah, D., Saikia, P.P., Paul, S., Sharma, T. (2015). Evaluation of pKa Values of Soil Humic Acids and their Complexation Properties. International Journal of Plant \& Soil Science 6(4) : 218-228.

Boguta, P. Sokolowska, Z. (2016). Interactions of $\mathrm{Zn}$ (II) Ions with Humic Acids Isolated from Various Types of Soils. Effect of $\mathrm{pH}, \mathrm{Zn}$ Concentrations and Humic Acids Chemical Properties. Journal of Geochemical Explaration 168. 119-126.

Borges, F., Guimaraes, C., Lima, L.F.C., Pinto, I. and Reis, S.(2005). Potentiometric Studies on the Complexation of Copper(II) by Phenolic Acids as Discrete Ligand Models of enhance the complexation behavior of humic acid with metal (II) ions. However, the higher values of $\log \beta$ for $\mathrm{Cu}(\mathrm{II}), \mathrm{Pb}(\mathrm{II}), \mathrm{Cd}(\mathrm{II})$ and $\mathrm{Mg}(\mathrm{II})$ hydrolysed humic acid complexes indicates more stable stepwise complexes formed as compared with $\mathrm{Cu}(\mathrm{II}), \mathrm{Pb}$ (II), $\mathrm{Cd}$ (II) and $\mathrm{Mg}(\mathrm{II})$ unhydrolysed humic acid complexes.

Humic Substances Talanta 66 (2005) 670-673.

Chefetz, B., Salloum, M. J., Deshmulkin, A. P. and Hatcher, P. (2002). Structural Components of Humic Acids as Determined by Chemical Modifications and Carbon-13 NMR, Pyrolysis, and Thermochemolysis- Gas Chromatography/Mass Spectrometry. Soil Science Society of American Journal Abstract Division S-2- Soil Chemistry66. 1159-1171.

Dinu, M. I. (2013). Metals Complexation with Humic Acids in Surface Water of Different Environ. Sci. Technol. 31(1): 1-17.

Fernandes, A.N., Giacomelli, C., Giovanela, M. Vaz, D.V. Szpoganicz, B. and Maria M. D. (2009). Potentiometric Acidity Determination in Humic Substances Influenced by Different Analytical Procedures.J. Braz. Chem. Soc. 20 (9):14.

Gamal, A. H. (2015). Stability Constants of Rhenium (V) Metal Complexes with Selected Drugs. Pyrex Journal of Research in Environmental Studies. 2(2): 006-014.

Janrao, D. M., Pathan, J., Kayande, D.D., and Mulla, J.J. (2014). An Over View of Potentiometric Determination of Stability Constants of Metal Complexes. Sci. Revs. Chem. Commun.: 4(1), 2014, 11-24.

Karimi, H. (2017). Effect of pH and Initial Pb(II) Concentration on the Lead Removal Efficiency from Waste Water Using $\mathrm{Ca}(\mathrm{OH})_{2}$. International Journal of Water and Waste Water Treatment 3.2

Kaschl, A. Romheld, V. and Chen, Y. (2010). Binding of Cadmium, Copper and Zinc to Humic Substances Originating from Municipal Solid Waste Compost. Israel Journal of Chemistry Vol. 42(1): 89-98.

Kostic, I. S., Tatjana, P, A., Nikolic, R. S., Cvetkovic, T. P., Pavlovic, D. D., Aleksandar, L.J. and Bojic, A. (2012). Comparative Study of Binding Strengths of Heavy Metals with Humic Acid. J.serb. Chem. Soc. 76(9) pp 1-20. 
BAJOPAS Volume 14 Number 1,June, 2021

Na'aliya, J. (2013). Determination of Stepwise Stability Constants and Gibbs free Energy Change of Trisprolina to Complexes of some Divalent Transition Metal ions. Bayero Journal of Pure and Applied Sciences 6(2): 112-114.

Omar, A. A. and Ali, E. A. (2015). Potentiometric Studies on Complexes of $\mathrm{Cr}$ (III) and $\mathrm{Zr}$ (IV) with some Carboxylic Acids. International Journal of Advanced Chemistry, 3(1) 25-

37.

Pandey, A. K. Pandey, S. D. and Misr, V. (2015).Stability Constants of Metal- Humic Acid Complexes and Its Role in Environmental Detoxification. J. Ecotoxicology and Environmental Safety. 47(1):195-200.

Ram, N. and Raman, K.V. (1984). Stability Constants of Complexes of Metals with
Humicand Fuvic Acids under Non- acidConditions. Journal of Plant Nutrition and Soil Sciences.

147:171-176.

Santosh, D. D., Ashok, B. K., Vijay, J. T., Shivraj, G. W. and Vinay, V. W. (2011). Potentiometric Studies of Elec-Trolyte Effects on Complex Equilibria of Some Substituted 5-(2-hydroxy Phenyl) Pyrazoles. Der pharm. 3 (6): 75-83.

Sayyed, H. and Abdul Rahim, M. F. (2012). Studies of Binary Complexes of Metal Ions with Mandelic Acid by Potentiometry. Chem. J. 02 (6): 206209.

Shirvani, M. Moradian, E. Khalili, B. Bakhtiary, S. (2015). Interaction of $\mathrm{Cd}$ and $\mathrm{Pb}$ with Humate-Palygorskite and HumateSepiolite Complexes. Journal of water, air and pollution 3: 220-228. 


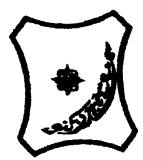

Bayero Journal of Pure and Applied Sciences, 14(1): 54 - 63

Received: November, 2020

Accepted: April, 2021

ISSN $2006-6996$

\title{
STABILITY CONSTANTS OF COMPLEXES OF METAL IONS WITH PEATSOIL HUMIC ACIDS UNDER NON-ACID-CONDITIONS
}

\author{
${ }^{* 1}$ Sabo, Yusuf ${ }^{2}$ Jimoh, W.L.O., ${ }^{3}$ Isa Baba Koki and ${ }^{4}$ Sholadoye, Q. 0. \\ ${ }^{1}$ Department of Pure and Industrial Chemistry, Bayero University, Kano \\ ${ }^{3}$ Department of Chemistry, Yusuf Maitama Sule University Kano. P.M.B. 3220 Kano, Nigeria. \\ ${ }^{4}$ Department of Chemistry, Nigerian Police Academy, Wudil, Kano-Nigeria
}

*Correspondence E-mail; saboyusuf18@yahoo.com

ABSTRACT

Stability constants of complexes of four divalent metal ions viz. $\mathrm{Cu}^{2+}, \mathrm{Pb}^{2+}, \mathrm{Mg}^{2+}$ and $\mathrm{Cd}^{2+}$ with humic acids (HA) were determined by potentiometric titration of humic acids with the corresponding salt of the divalent metals in aqueous media under non-acid-condition. The log $K$ (logarithm of the stability constant) ranged from 1.0942 to 2.7471 for metalhumic acid complexes were determined using point-wise computational method. The order of stability constants were obtained as follows: $\mathrm{Cu}>\mathrm{Pb}>\mathrm{Cd}>\mathrm{Mg}$ for metal $-\mathrm{HA}$ complexes respectively, indicating a higher degree of complexation with Cu metal ion.

Keywords: stability constant, humic acid, potentiometric titration, divalent metals, acid hydrolysis.

\section{NTRODUCTION}

The stability constant of a complex is the numerical expression of its stability and provides a quantitative measure of affinity of the metal ion to the complexing agent. An understanding of the relative stability of metal-complexes helps in predicting the behavior of metal ions in the soil (Ram and Raman, 1982). Extensive researches has been done to determine the stability constants of the complexes formed between humic acid (HA) with a number of metal ions. Ashok et al., (2000) reported that humic acid with hydroxyl, phenoxyl and carboxyl reactive groups can form coordination compound with metal ions at $\mathrm{pH}$ 3.5. The stability constants(Log K) for different metalhumic acid complexes indicated the following order of the stabilities of complexes formed between humic acid and metal ion, $\mathrm{Cu}>\mathrm{Fe}$ $>\mathrm{Pb}>\mathrm{Ni}>\mathrm{Co}>\mathrm{Ca}>\mathrm{Cd}>\mathrm{Zn}>\mathrm{Mn}>\mathrm{Mg}$. Andelkovic et al., (2010) investigated the binding of $\mathrm{Cd}$ (II) to soil humic acid at pH 6.5 and in $0.1 \mathrm{M} \mathrm{KNO}_{3}$ ionic medium. The stability constant for binding indicating greater stability in the case when carboxyl groups are involved in complexation reaction. Kostic et al.,(2012) investigated the complexation of humic acid with certain heavy metal ions (Co(II), $\mathrm{Ni}(\mathrm{II}), \mathrm{Cu}(\mathrm{II})$,
$\mathrm{Zn}(\mathrm{II})$, and $\mathrm{Pb}(\mathrm{II})$. The experiment was performed at $25^{\circ} \mathrm{C}$, at pH 4.0 and ionic strength of $0.01 \mathrm{M}$. Stability constant of complex between $\mathrm{Pb}$ (II) ions and humic acid is greater than stability constants of other investigated metalhumate complexes. Bogata and Sokolowska (2016) analyses the interaction between humic acids from different soils and $\mathrm{Zn}$ (II) ions at wide concentration ranges and at $\mathrm{pH} 5$. Studies have showed significant impact of $\mathrm{Zn}$ concentration, $\mathrm{pH}$ and some properties of humic acids with zinc.But all of these studies were limited to acidic $\mathrm{pH}$ range. Therefore, the present study was carried out to determine and compare the stability constants of complexes of metal ions with hydrolysed peat soil humic acid and unhydrolysed peat soil humic under non-acid conditions.

\section{MATERIALS AND METHODS}

Analytical grade chemicals used includes hydrochloric acid $(\mathrm{HCl})$, nitric acid $\left(\mathrm{HNO}_{3}\right)$, sodium hydroxide $(\mathrm{NaOH})$, lead nitrate $\mathrm{Pb}\left(\mathrm{NO}_{3}\right)_{2}$, copper nitrate $\mathrm{Cu}\left(\mathrm{NO}_{3}\right)_{2} \cdot 3 \mathrm{H}_{2} \mathrm{O}$, cadmium nitrate $\mathrm{Cd}\left(\mathrm{NO}_{3}\right)_{2} \cdot 4 \mathrm{H}_{2} \mathrm{O}$, magnesium nitrate $\mathrm{Mg}\left(\mathrm{NO}_{3}\right)_{2} \cdot 6 \mathrm{H}_{2} \mathrm{O}$, potassium nitrate $\left(\mathrm{KNO}_{3}\right)$, calcium chloride $\left(\mathrm{CaCl}_{2}\right)$, (sigma-Aldrich). Dowex 50WX8, (20-50 mesh) from Fluka. 


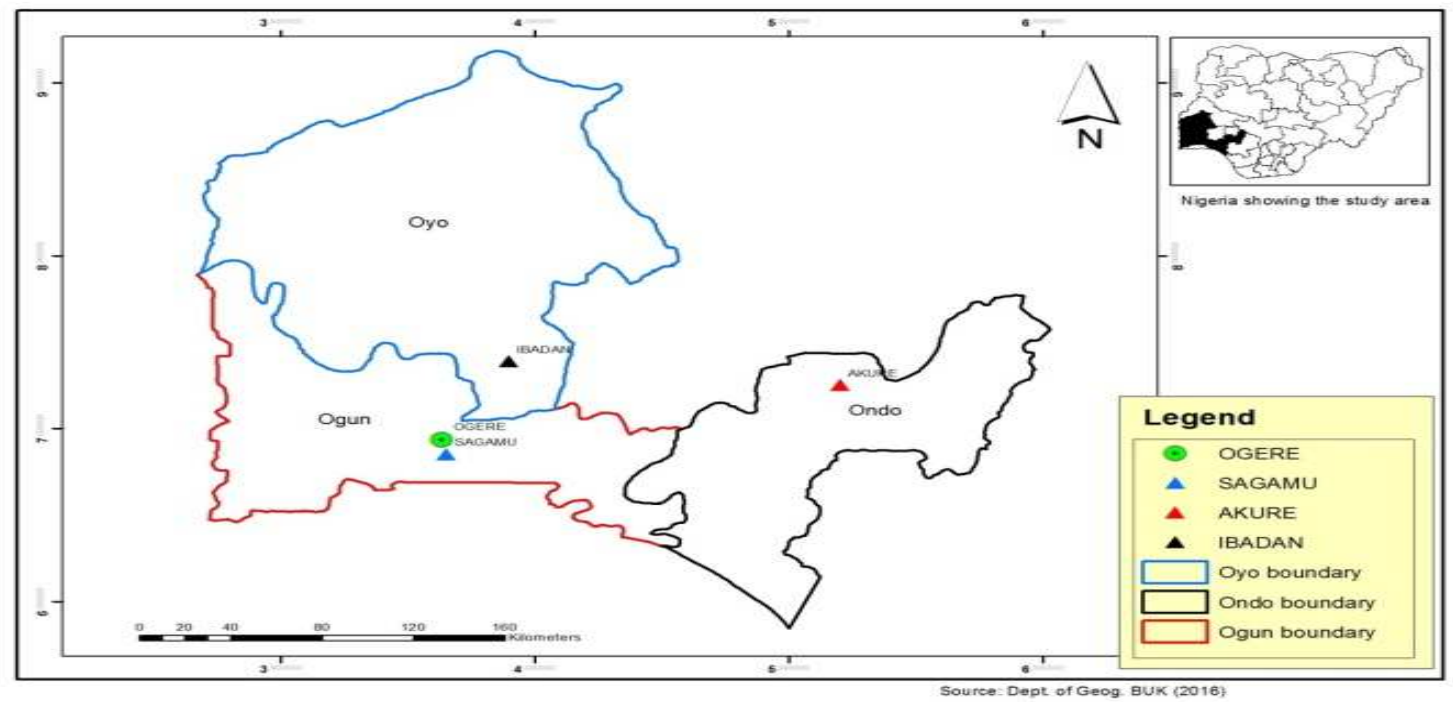

Figure 1: Map showing the sampling point at Sagamu Town, Ogun State.

\section{Description of Sampling Area}

Sagamu has geographical coordinates between $6^{\circ} 50^{\prime}$ north; $3^{\circ} 38^{\prime}$ east is located in south western region of Nigeria. The region has tropical wet and dry climate with a lengthy wet season and relatively constant temperatures throughout the course of the year. Wet season runs from March to October, November to December forms the region dry season. The vegetation type of the region is savannah which is really grassland with small bushes and occasional big trees. Grassland soils have substantially higher organic matter content than forest soils (Novackova, 2011).

\section{Sample Collection}

The Peatsoil samples were collected from four different sampling points $(0-10 \mathrm{~cm}$ depth) in Sagamu into polyethylene bag with plastic spoons. Samples were taken to the laboratory, extraneous materials were removed; the samples were air-dried, crushed and ground to a fine powder in a mortar passed through a $0.20 \mathrm{~mm}$ sieve. The samples were kept for analysis.

\section{Isolation and purification of humic acid from peat soil sample}

Peatsoil sample $(100 \mathrm{~g})$ was mixed with 1000 $\mathrm{cm}^{3}$ of $0.1 \mathrm{M} \mathrm{NaOH}$ solution, shaken for 3hours and left to stand overnight. Dark-coloured supernatant was obtained and decanted from solid residue. The dark-coloured supernatant was acidified to $(\mathrm{pH}=1.0)$ with $6 \mathrm{M} \mathrm{HCl}$ stirred and allowed to stand for 6 hours. Yellowish brown supernatant and dark-brown precipitate were obtained. The yellowish brown supernatant was decanted followed by centrifuge and discarded. The dark-brown precipitate was mixed with $500 \mathrm{~cm}^{3}$ of $0.1 \mathrm{M} \mathrm{NaOH}$ solution followed by passing through dowex resin. The dark-brown solution was acidified to $(\mathrm{pH}=1.0)$ with $6 \mathrm{M} \mathrm{HCl}$ stirred and allowed to stand for 3 hours. The dark-brown precipitate was washed several times with deionized water. The supernatant was treated with $\mathrm{AgNO}_{3}$ solution until no white precipitate observed. The humic acid was transferred to weighed crucible and dried at $60^{\circ} \mathrm{C}$ in an oven for 12 hours. The humic acid was cooled and dried in the desiccator, weighed and recorded. The obtained humic acid was dried again at $60^{\circ} \mathrm{C}$ for additional 6 hours cooled and dried in the desiccator, weighed and recorded constant weight was obtained (Baruah et al., 2015).

\section{FT-IR analysis}

FT-IR spectra of humic acid sample was analysed using Carry 630 FT-IR Agilent Technologies.

Unhydrolysed compost humic acid

The unhydrolysed humic acid was obtained after isolation and purification of compost humic acid and kept for investigation.

\section{Acid hydrolysis of Peatsoil acid}

Peatsoil humic acid sample (1g) was refluxed for 12 hours at $\left(160^{\circ} \mathrm{C}\right)$ with $50 \mathrm{~cm}^{3}$ of $6 \mathrm{M} \mathrm{HCl}$. The mixture was allowed to cool, decanted, and centrifuged after hydrolysis. The insoluble residues were washed with distilled water via centrifugation several times, and the supernatant was treated with $\mathrm{AgNO}_{3}$ solution until no white precipitate was observed. The residue was thoroughly dried over $\mathrm{CaCl}_{2}$ in a desiccator at room temperature (Chefetz et al., 2002). Finally, the obtained hydrolysed humic acid was kept for investigation. 
BAJOPAS Volume 14 Number 1,June, 2021 Potentiometric Titrations

Potentiometric measurements were carried out using a pH-meter Jenway (model 3510) with combine electrode, the sensitivity of the $\mathrm{pH}$ meter is 0.01 units. The $\mathrm{pH}$ meter was switched on half an hour before starting the titration for initial warm up of the instrument. The instrument was calibrated with an aqueous standard buffer solution of $\mathrm{pH} 4.00$ and 10.0 (borate buffer) prepared from a "Qualigens" buffer tablets.

The following sets of solutions were prepared in a $250 \mathrm{~cm}^{3}$ volumetric flask separately for $\mathrm{pH}$ metric titrations.

(i) $5 \mathrm{~cm}^{3} 0.1 \mathrm{M} \mathrm{HCl}+40 \mathrm{~cm}^{3}$ deionized water

(ii) $5 \mathrm{~cm}^{3} 0.1 \mathrm{M} \mathrm{HCl}+39 \mathrm{~cm}^{3}$ deionized water $+1 \mathrm{~cm}^{3} 0.15 \mathrm{gcm}^{-3}$ humic acid

(iii) $5 \mathrm{~cm}^{3} 0.1 \mathrm{M} \mathrm{HCl}+37 \mathrm{~cm}^{3}$ deionized water $+1 \mathrm{~cm}^{3} 0.15 \mathrm{gcm}^{-3}$ humic acid

$$
+2 \mathrm{~cm}^{3} \quad 0.01 \mathrm{M} \mathrm{Cu} \text { (II) }
$$

The solutions were titrated against standardized $0.110 \mathrm{MNaOH}$ separately. The total volume of each mixture was adjusted to $50 \mathrm{~cm}^{3}$ and the ionic strength of the solutions was maintained constant at by adding appropriate amount of stock solution of $1 \mathrm{M} \mathrm{KNO}_{3}$ (Gamal, 2015; Omar and Ali, 2015). A magnetic stirrer was used to achieve thorough mixing of the interacting solutions at $550 \mathrm{rpm}$. The same set of experimental conditions was applied for potentiometric titration of remaining samples.

\section{Evaluation of pKa of Hydrolysed peat soil Humic Acids}

The proton-ligand formation number $\mathrm{n}_{\mathbf{A}}$ were calculated by Irving and Rossotti expression (Omar and Ali, 2015).

$\mathrm{nA}=\mathrm{Y}-\frac{(\mathrm{V} 2-\mathrm{V1})(\mathrm{No}-\mathrm{Eo})}{(\mathrm{VO}+\mathrm{V1}) \mathrm{TCL}}$ 1

Where: $Y$ is number of dissociable proton, $\left(\mathrm{V}_{2^{-}}\right.$ $V_{1}$ ) is the measure of displacement of the ligand curve relative to acid curve, $\mathrm{N}^{\circ}$ and $\mathrm{E}^{\circ}$ are the resultant concentration of alkali solution, free acid solution, $\mathrm{T}_{\mathrm{cL}}{ }^{\circ}$ is the total ligand concentration, $\mathrm{V}^{\circ}$ is the total volume of titration solution, $V_{1}$ is the volume of alkali added to acid solution, $V_{2}$ is the volume of alkali added to acid solution + ligand solution, acid dissociation constants (pKa - values) of ligand were calculated by algebraic method point wise calculation (Tables 1 ). The dissociation constants (pKa) were calculated according to the following relation:

$\mathrm{pKa}=\mathrm{pH}+\log \left(\frac{n A}{1-n A}\right)$ 2

Where: pKa is the acid dissociation constant, $\mathrm{n}_{\mathrm{A}}$ is the Proton-ligand formation number and $\mathrm{pH}$ is the pH-values (Omar and Ali, 2015).

\section{Determination of metal-ligand stability constants $(\log K)$ of complexes}

The potentiometric measurement for the determination of stability constant of a complex in solution is based on the fact that the redox potential of the couple $\frac{M^{+(m-n)}}{M^{+m}}$ is shifted significantly on complexation of the metal ion with the ligand. This method involves change in hydrogen ion concentration $\left[\mathrm{H}^{+}\right]$due to the displacement or association of one or more protons taking place during complexation reaction. This change can be found out by titrating the solutions containing free acid, acid with ligand, and acid with ligand and metal ion, individually against a standard alkali solution at a constant ionic strength or temperature. Either ionic strength or temperature may be varied for different sets of solutions. In all the cases, the change in the $\mathrm{pH}$ of the solution is measured after each addition of a known amount of alkali to the reaction cell which contains the reaction mixture. The titration curves are then drawn by plotting the measured $\mathrm{pH}$ values against the corresponding volume of alkali added and the stability constants of the complexes are determined from the titration curves by employing $\mathrm{pH}$-metric titration technique given by (Irving and Rossoti).

Metal-ligand stability constants ( $\log \mathrm{K}$ ) were determined by using the following relations:

$$
\bar{n}=\frac{\left(V_{3}-V_{2}\right)\left(E^{0}+N^{0}\right)}{\left(V^{0}+V_{2}\right) \bar{n}_{A} T_{m}^{0}}
$$

and

$$
P L=\log _{10}\left\{\frac{1+\beta_{n}^{H} \frac{1}{[\text { anti } \log \mathrm{pH}]^{\mathrm{n}}}}{\mathrm{T}_{\mathrm{L}}^{0}-n \bar{T}_{m}^{0}} \mathrm{X} \frac{\left(V^{0}+V_{3}\right)}{V^{0}}\right\}
$$


BAJOPAS Volume 14 Number 1,June, 2021

Where $T_{L}, T^{\circ}, E^{\circ}$, and $V^{\circ}$ havethe same significance as in equation (1) above, $T_{m}$ denotes the total concentration of metal present in solution, $V_{3}$ is the volume of metal ions present in solution and $\beta^{H}$ is the overall proton ligand stability constant. The metal-ligand stability constants (log K) were determined by employing point wise computational Method (eq. 5 and 6).

$\operatorname{LogK}_{1}=\log \left(\frac{n}{1-n}\right)+\mathrm{pL}$ .5

$\operatorname{LogK}_{2}=\log \left(\frac{1-n}{2-n}\right)+\mathrm{pL}$ ...6

Where: Log $\mathrm{K}$ is the metal-ligand stability constant, $\mathrm{pL}$ is the Free ligand exponent function, $\mathbf{n}$ is the Average number of ligand attached with metal ion (Janraoet al., 2014). The results obtained were analyzed by an ORIGIN 2016 program using titration data and then the proton-ligand stability constants (pKa) and Metal-ligand stability constant (LogK) calculated (Omar and Ali, 2015).

\section{RESULTS AND DISCUSSION}

Fourier transformed infrared (FT-IR) spectra of isolated humic acid from peat soils Figure 2 had distinct clear absorption bands indicating the presence of major humic acid structural elemental groups such as $\mathrm{H}$ bonded $\mathrm{OH}$ $\left(3680 \mathrm{~cm}^{-1}\right.$ peak $), C=0$ of carbonyl $\left(1721 \mathrm{~cm}^{-1}\right.$ peak), functional groups of aliphatic components $\mathrm{CH}_{2}\left(2918 \mathrm{~cm}^{-1}\right.$ peak) and $\mathrm{C}-\mathrm{O}$ stretching of polysaccharide $\left(1168 \mathrm{~cm}^{-1}\right.$ peak). The positions of the absorption bands of the spectra fell within typical major absorption bands of humic acid which is at frequencies 3680, 2918, 1721, 1168 $\mathrm{cm}^{-1}$. The first peak centred in the vicinity of $3680 \mathrm{~cm}^{-1}$ region is attributed to phenol $\mathrm{OH}$ group bounded by intermolecular $\mathrm{H}$ bonds. The $2918 \mathrm{~cm}^{-1}$ band usually has absorption maximum at $2918 \mathrm{~cm}^{-1}$ which is due to $\mathrm{C}-\mathrm{H}$ stretching of alkane group $\left(\mathrm{CH}_{2}\right)$. The next major absorption band is $1721 \mathrm{~cm}^{-1}$. This band has been commonly ascribed to $\mathrm{C}=\mathrm{O}$ stretching of mainly carboxyl group $(\mathrm{COOH})$ with trace amount of ketones. The last peak was observed at 1168 $\mathrm{cm}^{-1}$ due to $\mathrm{C}-\mathrm{O}$ stretching of polysaccharides and this peak appeared also in the spectra of humic acid from peat soil. The FTIR spectra of the isolated humic acid contained all major characteristic absorption peaks of humic acid. These absorption peaks indicated the presence of the major structural elements of humic acid namely $\mathrm{H}$ bonded $\mathrm{OH}, \mathrm{C}=\mathrm{C}$ of aromatic ring, $\mathrm{C}=\mathrm{O}$ of carbonyl group (both carboxyl and ketonic), $\mathrm{CH}_{2}$ group. This strongly supports the presence of humic acid.

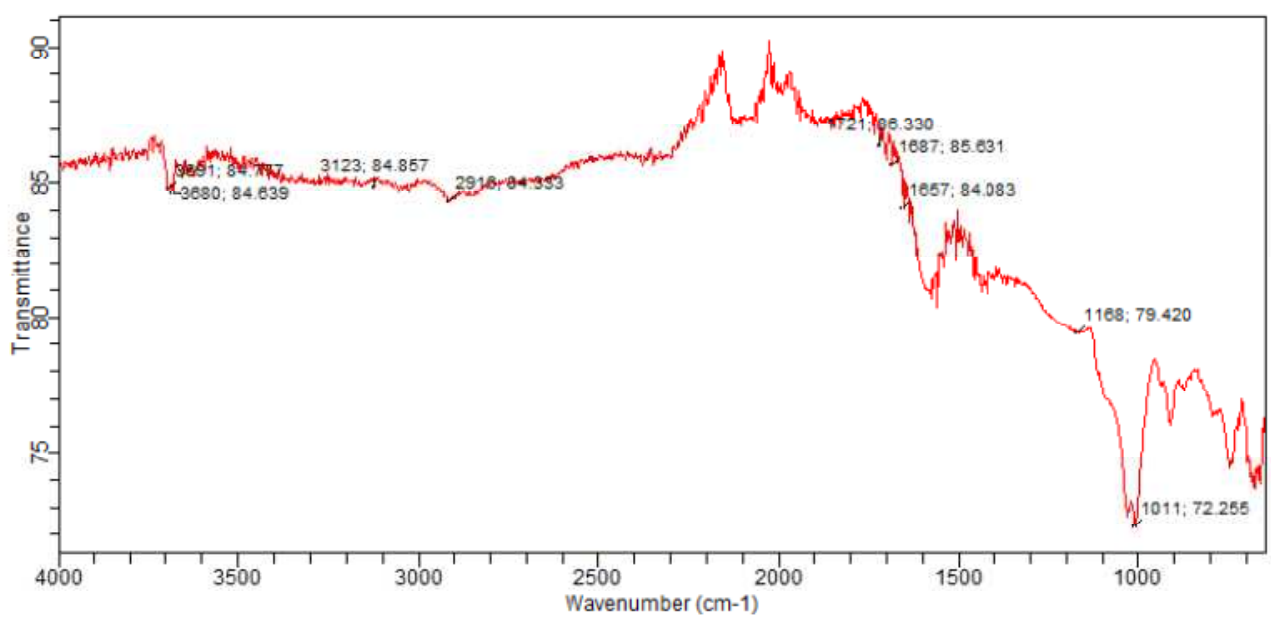

Fig. 2 : FT-IR spectraof peatsoilhumic acid (PSHA)

\section{Evaluation of acid dissociation constant (pka) of acid hydrolysed peat soil humicacid at phenolic group}

The value of the dissociation constant of the peat soil humic acid (PSHA) that underwent acidhydrolysis studied was found to be 8.9299 as shown Table 1, which is lower than the literaturevalues reported by Almeida and Szpoganics, (2015), Borges et al., (2005); Badr et al., (2012)and Fernandes et al,.(2009) of $9.73,9.47$ and 10.30. The difference between the obtained valuesand the reported values in this study might be probably as a result of acid hydrolysis of humicacid. 
BAJOPAS Volume 14 Number 1,June, 2021

Table 1: PKa of (Hydrolysed PSHA)

\begin{tabular}{|l|l|l|l|l|l|l|}
\hline $\mathrm{pH}$ & $\mathrm{BV}_{1}$ & $\mathrm{BV}_{2}$ & $\mathrm{~V}_{2}-\mathrm{V}_{1}$ & $\mathrm{nA}$ & $\log \left(\frac{n A}{1-n A}\right)$ & $\mathrm{pKa}$ \\
\hline 8.50 & 5.30 & 6.29 & 0.99 & 0.3594 & -0.2510 & 8.2490 \\
8.72 & 5.35 & 6.37 & 1.02 & 0.3400 & -0.2880 & 8.4320 \\
9.00 & 5.40 & 6.46 & 1.06 & 0.3141 & -0.3391 & 8.6609 \\
9.22 & 5.45 & 6.55 & 1.10 & 0.2882 & -0.3927 & 8.8273 \\
9.51 & 5.50 & 6.66 & 1.16 & 0.2494 & -0.4786 & 9.0314 \\
9.73 & 5.55 & 6.78 & 1.23 & 0.2041 & -0.5910 & 9.1390 \\
10.00 & 5.60 & 6.90 & 1.30 & 0.1589 & -0.7238 & 9.2762 \\
10.23 & 5.65 & 7.05 & 1.40 & 0.0941 & -0.9835 & 9.2465 \\
10.49 & 5.70 & 7.10 & 1.40 & 0.0941 & -0.9835 & 9.5065 \\
\hline
\end{tabular}

Average pKa $=8.9299 \pm 0.4186$

Table 2: PKa of (Unhydrolysed PSHA)

\begin{tabular}{|l|l|l|l|l|l|l|}
\hline $\mathrm{pH}$ & $\mathrm{BV}_{1}$ & $\mathrm{BV}_{2}$ & $\mathrm{~V}_{2}-\mathrm{V}_{1}$ & $\mathrm{nA}$ & $\log \left(\frac{\boldsymbol{n A}}{1-\boldsymbol{n}}\right)$ & $\mathrm{pKa}$ \\
\hline 8.50 & 5.30 & 5.81 & 0.51 & 0.6619 & 0.2919 & 8.7919 \\
8.72 & 5.35 & 5.90 & 0.55 & 0.6357 & 0.2418 & 8.9618 \\
9.00 & 5.40 & 6.00 & 0.60 & 0.6029 & 0.1813 & 9.1813 \\
9.22 & 5.45 & 6.10 & 0.65 & 0.5701 & 0.1226 & 9.3426 \\
9.51 & 5.50 & 6.20 & 0.70 & 0.5376 & 0.0654 & 9.5754 \\
9.73 & 5.55 & 6.33 & 0.78 & 0.4851 & -0.0259 & 9.7041 \\
10.00 & 5.60 & 6.47 & 0.87 & 0.4262 & -0.1291 & 9.8709 \\
10.23 & 5.65 & 6.62 & 0.99 & 0.3609 & -0.2481 & 9.9819 \\
10.49 & 5.70 & 6.80 & 1.10 & 0.2759 & -0.4690 & 10.0210 \\
\hline
\end{tabular}

Average pKa $=9.4923 \pm 0.4410$

Metal-ligand stability constant ( $\log \mathrm{K}$ )

The stabilityconstants require the accurate values of proton-ligand stability constants (Anil and Maroti, 2008). Metal titration curves crossed over ligand titration curve indicated the formation of complex upon proton release (Santosh, et al., 2011). If the values of n- are within range $0.2-0.8$ and $1.2-18$ this indicates the formation of $1: 1$ and 1:2 complexes (Sayyed and Mazahar, 2012).

The metal (II)-humate stepwise stability constants (log k) at phenolic group (Tables 318)

Table 3: Point-wise method, $\mathrm{Cu}$-(Hydrolysed PSHA)

\begin{tabular}{|l|l|l|l|l|l|l|l|l|}
\hline $\mathrm{pH}$ & $\mathrm{BV}_{1}$ & $\mathrm{BV}_{2}$ & $\mathrm{BV}_{3}$ & $\left(\mathrm{~V}_{3}-\mathrm{V}_{2}\right)$ & $\mathrm{n}$ & $\mathrm{pL}$ & $\log \left(\frac{n}{1-n}\right)$ & LogK $_{1}$ \\
\hline 8.50 & 5.30 & 6.29 & 6.33 & 0.04 & 0.5500 & 2.66 & 0.0871 & 2.7471 \\
8.72 & 5.35 & 6.37 & 6.41 & 0.04 & 0.5714 & 2.43 & 0.1249 & 2.5549 \\
9.00 & 5.40 & 6.46 & 6.50 & 0.04 & 0.6198 & 2.16 & 0.2122 & 2.3722 \\
9.22 & 5.45 & 6.55 & 6.59 & 0.04 & 0.6667 & 1.94 & 0.3010 & 2.2410 \\
\hline
\end{tabular}

LogK $_{1}$ (Average value) $=2.4788 \pm 0.2203$

Table 4: Point-wise method, $\mathrm{Cu}$-(Hydrolysed PSHA)

\begin{tabular}{|l|l|l|l|l|l|l|l|l|}
\hline $\mathrm{pH}$ & $\mathrm{BV}_{1}$ & $\mathrm{BV}_{2}$ & $\mathrm{BV}_{3}$ & $\left(\mathrm{~V}_{3}-\mathrm{V}_{2}\right)$ & $\mathrm{n}$ & $\mathrm{pL}$ & $\log \left(\frac{n-1}{2-n}\right)$ & LogK $_{2}$ \\
\hline 9.51 & 5.50 & 6.66 & 6.73 & 0.07 & 1.3509 & 1.70 & -0.2671 & 1.4329 \\
9.73 & 5.55 & 6.78 & 6.85 & 0.07 & 1.6383 & 1.51 & 0.2467 & 1.7567 \\
10.00 & 5.60 & 6.90 & 6.98 & 0.08 & 2.1783 & 1.31 & -0.2158 & 1.0942 \\
10.23 & 5.65 & 7.05 & 7.13 & 0.08 & 4.1904 & 1.27 & & \\
10.49 & 5.70 & 7.10 & 7.19 & 0.09 & 4.6920 & & & \\
\hline
\end{tabular}

Log $K_{2}($ Average value $)=1.4280 \pm 0.3312$ 
BAJOPAS Volume 14 Number 1,June, 2021

Table 5: Point-wise method, $\mathrm{Cu}$ (Unhydrolysed PSHA)

\begin{tabular}{|l|l|l|l|l|l|l|l|l|}
\hline $\mathrm{pH}$ & $\mathrm{BV}_{1}$ & $\mathrm{BV}_{2}$ & $\mathrm{BV}_{3}$ & $\left(\mathrm{~V}_{3}-\mathrm{V}_{2}\right)$ & $\mathrm{n}$ & $\mathrm{pL}$ & $\log \left(\frac{n}{n-1}\right)$ & Log $_{1}$ \\
\hline 8.50 & 5.30 & 5.81 & 5.85 & 0.04 & 0.2973 & 2.88 & -0.3736 & 2.5064 \\
8.72 & 5.35 & 5.90 & 5.95 & 0.05 & 0.3873 & 2.66 & -0.1992 & 2.4608 \\
9.00 & 5.40 & 6.00 & 6.05 & 0.05 & 0.4044 & 2.38 & -0.1681 & 2.2119 \\
9.22 & 5.45 & 6.10 & 6.15 & 0.06 & 0.5157 & 2.18 & -0.0272 & 2.2072 \\
9.51 & 5.50 & 6.20 & 6.27 & 0.07 & 0.6417 & 1.89 & 0.2530 & 1.1430 \\
\hline
\end{tabular}

$\operatorname{LogK}_{1}($ Average value $)=2.3059 \pm 0.6153$

Table 6:Point-wise method, $\mathrm{Cu}$ (Unhydrolysed PSHA)

\begin{tabular}{|l|l|l|l|l|l|l|l|l|}
\hline $\mathrm{pH}$ & $\mathrm{BV}_{1}$ & $\mathrm{BV}_{2}$ & $\mathrm{BV}_{3}$ & $\mathrm{~V}_{3}-\mathrm{V}_{2}$ & $\mathrm{n}$ & $\mathrm{pL}$ & $\log \left(\frac{n-1}{2-n}\right)$ & $\log \mathrm{K}_{2}$ \\
\hline 9.73 & 5.55 & 6.33 & 6.42 & 0.09 & 0.9000 & 1.69 & & \\
10.00 & 5.60 & 6.47 & 6.58 & 0.11 & 1.2578 & 1.44 & -0.4592 & 0.9808 \\
10.23 & 5.65 & 6.62 & 6.84 & 0.12 & 1.6137 & 1.26 & -0.2010 & 1.4610 \\
10.49 & 5.70 & 6.80 & 6.92 & 0.12 & 2.1052 & 1.03 & & \\
\hline
\end{tabular}

$\operatorname{LogK}_{2}$ (Average value) $=1.2209 \pm 0.3398$

Table 7:Point-wise method, Pb (Hydrolysed PSHA)

\begin{tabular}{|l|l|l|l|l|l|l|l|l|}
\hline $\mathrm{pH}$ & $\mathrm{BV}_{1}$ & $\mathrm{BV}_{2}$ & $\mathrm{BV}_{3}$ & $\left(\mathrm{~V}_{3}-\mathrm{V}_{2}\right)$ & $\mathrm{n}$ & $\mathrm{pL}$ & $\log \left(\frac{n}{1-n}\right)$ & LogK $_{1}$ \\
\hline 8.50 & 5.30 & 6.29 & 6.33 & 0.04 & 0.5500 & 2.66 & 0.0871 & 2.7471 \\
8.72 & 5.35 & 6.37 & 6.41 & 0.04 & 0.5714 & 2.43 & 0.1249 & 2.5549 \\
9.00 & 5.40 & 6.46 & 6.50 & 0.04 & 0.6198 & 2.16 & 0.2122 & 2.3722 \\
9.22 & 5.45 & 6.55 & 6.60 & 0.05 & 0.8333 & 1.96 & 0.6989 & 2.6589 \\
\hline
\end{tabular}

Log $_{\mathbf{1}}($ Average value $)=2.5832 \pm 0.1614$

Table 8:Point-wise method, Pb-(Hydrolysed PSHA)

\begin{tabular}{|l|l|l|l|l|l|l|l|l|}
\hline $\mathrm{pH}$ & $\mathrm{BV}_{1}$ & $\mathrm{BV}_{2}$ & $\mathrm{BV}_{3}$ & $\left(\mathrm{~V}_{3}-\mathrm{V}_{2}\right)$ & $\mathrm{n}$ & $\mathrm{pL}$ & $\log \left(\frac{n-1}{2-n}\right)$ & $\log \mathrm{K}_{2}$ \\
\hline 9.51 & 5.50 & 6.66 & 6.71 & 0.05 & 0.9650 & 1.67 & & \\
9.73 & 5.55 & 6.78 & 6.83 & 0.05 & 1.1702 & 1.44 & & \\
10.00 & 5.60 & 6.90 & 6.90 & 0.05 & 1.4864 & 1.22 & -0.0237 & 1.1963 \\
10.23 & 5.65 & 7.05 & 7.10 & 0.05 & 2.0190 & 1.09 & & \\
10.49 & 5.70 & 7.10 & 7.17 & 0.07 & 3.6492 & 1.00 & & \\
\hline
\end{tabular}

Log $K_{2}$ (Average value) $=1.1963$

Table 9: Point-wise method, Pb (Unhydrolysed PSHA)

\begin{tabular}{|l|l|l|l|l|l|l|l|l|}
\hline $\mathrm{pH}$ & $\mathrm{BV}_{1}$ & $\mathrm{BV}_{2}$ & $\mathrm{BV}_{3}$ & $\mathrm{~V}_{3}-\mathrm{V}_{2}$ & $\mathrm{n}$ & $\mathrm{pL}$ & $\begin{array}{l}\text { Log } \\
\left(\frac{n}{n-1}\right)\end{array}$ & Log $\mathrm{K}_{1}$ \\
\hline 8.50 & 5.30 & 5.81 & 5.85 & 0.04 & 0.2973 & 2.88 & -0.3736 & 2.5064 \\
8.72 & 5.35 & 5.90 & 5.94 & 0.04 & 0.3099 & 2.66 & -0.5477 & 2.3123 \\
9.00 & 5.40 & 6.00 & 6.05 & 0.05 & 0.4044 & 2.38 & -0.1681 & 2.2119 \\
9.22 & 5.45 & 6.10 & 6.15 & 0.06 & 0.5157 & 2.18 & 0.0272 & 2.2072 \\
9.51 & 5.50 & 6.20 & 6.26 & 0.07 & 0.6417 & 1.89 & 0.2530 & 2.1430 \\
9.73 & 5.55 & 6.40 & 6.40 & 0.07 & 0.7000 & 1.67 & 0.3680 & 2.0380 \\
\hline
\end{tabular}

LogK $_{1}$ (Average value) $=2.2364 \pm 0.1602$

Table 10: Point-wise method, Pb (Unhydrolysed PSHA)

\begin{tabular}{|l|l|l|l|l|l|l|l|l|}
\hline $\mathrm{pH}$ & $\mathrm{BV}_{1}$ & $\mathrm{BV}_{2}$ & $\mathrm{BV}_{3}$ & $\mathrm{~V}_{3}-\mathrm{V}_{2}$ & $\mathrm{n}$ & $\mathrm{pL}$ & $\log \left(\frac{n-1}{2-n}\right)$ & $\log \mathrm{K}_{2}$ \\
\hline 10.00 & 5.60 & 6.47 & 6.55 & 0.08 & 1.9503 & 1.41 & & \\
10.23 & 5.65 & 6.62 & 6.72 & 0.11 & 1.4792 & 1.26 & -0.0361 & 1.2239 \\
\hline
\end{tabular}

$\operatorname{LogK}_{2}$ (Average value) $=1.2239$

Table 11: Point-wise method, Mg (Hydrolysed PSHA)

\begin{tabular}{|l|l|l|l|l|l|l|l|l|}
\hline $\mathrm{pH}$ & $\mathrm{BV}_{1}$ & $\mathrm{BV}_{2}$ & $\mathrm{BV}_{3}$ & $\left(\mathrm{~V}_{3}-\mathrm{V}_{2}\right)$ & $\mathrm{n}$ & $\mathrm{pL}$ & $\log \left(\frac{n}{n-1}\right)$ & LogK $_{1}$ \\
\hline 8.50 & 5.30 & 6.29 & 6.31 & 0.02 & 0.2750 & 2.64 & -0.4290 & 2.2110 \\
8.72 & 5.35 & 6.37 & 6.39 & 0.02 & 0.2858 & 2.42 & -0.3978 & 2.0222 \\
9.00 & 5.40 & 6.46 & 6.49 & 0.03 & 0.4648 & 2.14 & -0.0612 & 2.0788 \\
9.22 & 5.45 & 6.55 & 6.59 & 0.04 & 0.6667 & 1.94 & 0.3010 & 2.2410 \\
\hline
\end{tabular}

$\log _{\mathbf{1}}($ Average value) $=2.1382 \pm 0.1046$ 
BAJOPAS Volume 14 Number 1,June, 2021

Table 12: Point-wise method, Mg (Hydrolysed PSHA)

\begin{tabular}{|l|l|l|l|l|l|l|l|l|}
\hline $\mathrm{pH}$ & $\mathrm{BV}_{1}$ & $\mathrm{BV}_{2}$ & $\mathrm{BV}_{3}$ & $\left(\mathrm{~V}_{3}-\mathrm{V}_{2}\right)$ & $\mathrm{n}$ & $\mathrm{pL}$ & $\log \left(\frac{n-1}{2-n}\right)$ & LogK $_{2}$ \\
\hline 9.51 & 5.55 & 6.66 & 6.71 & 0.05 & 0.9650 & 1.67 & & \\
9.73 & 5.55 & 6.78 & 6.84 & 0.06 & 1.4042 & 1.47 & -0.1686 & 1.3014 \\
10.00 & 5.60 & 6.90 & 6.93 & 0.06 & 1.7838 & 1.23 & 0.5593 & 1.7893 \\
10.23 & 5.65 & 7.05 & 7.10 & 0.06 & 3.1429 & 1.10 & & \\
10.49 & 5.70 & 7.10 & 7.18 & 0.07 & 3.6492 & 0.83 & & \\
\hline
\end{tabular}

LogK $_{2}($ Average value $)=1.5453 \pm 0.3450$

Table 13: Point-wise method, Mg (Unhydrolysed PSHA)

\begin{tabular}{|l|l|l|l|l|l|l|l|l|}
\hline $\mathrm{pH}$ & $\mathrm{BV}_{1}$ & $\mathrm{BV}_{2}$ & $\mathrm{BV}_{3}$ & $\mathrm{~V}_{3}-\mathrm{V}_{2}$ & $\mathrm{n}$ & $\mathrm{pL}$ & $\log \left(\frac{n}{n-1}\right)$ & $\operatorname{Log~}_{1}$ \\
\hline 8.50 & 5.30 & 5.81 & 5.85 & 0.04 & 0.2973 & 2.88 & -0.3736 & 2.5064 \\
8.72 & 5.35 & 5.90 & 5.94 & 0.04 & 0.3099 & 2.66 & -0.3477 & 2.3123 \\
9.00 & 5.40 & 6.00 & 6.04 & 0.04 & 0.3236 & 2.38 & -0.3202 & 2.0598 \\
9.22 & 5.45 & 6.10 & 6.15 & 0.05 & 0.4297 & 2.17 & -0.1230 & 2.0470 \\
9.51 & 5.50 & 6.20 & 6.26 & 0.06 & 0.5500 & 1.89 & 0.0871 & 1.9771 \\
9.73 & 5.55 & 6.33 & 6.40 & 0.07 & 0.7000 & 1.67 & 0.3680 & 2.0380 \\
\hline
\end{tabular}

LogK $_{1}$ (Average value) $=2.1568 \pm 0.2069$

Table 14: Point-wise method, Mg (Unhydrolysed PSHA)

\begin{tabular}{|l|l|l|l|l|l|l|l|l|}
\hline $\mathrm{pH}$ & $\mathrm{BV}_{1}$ & $\mathrm{BV}_{2}$ & $\mathrm{BV}_{3}$ & $\mathrm{~V}_{3}-\mathrm{V}_{2}$ & $\mathrm{n}$ & $\mathrm{pL}$ & $\log \left(\frac{n-1}{2-n}\right)$ & $\log \mathrm{K}_{2}$ \\
\hline 10.00 & 5.60 & 6.47 & 6.55 & 0.08 & 0.9148 & 1.41 & & \\
10.23 & 5.65 & 6.62 & 6.71 & 0.09 & 1.2102 & 1.20 & -0.5749 & 0.6251 \\
10.49 & 5.70 & 6.80 & 6.92 & 0.09 & 1.5968 & 1.03 & 0.1703 & 1.2003 \\
\hline
\end{tabular}

LogK $_{2}$ (Average value) $=0.9127 \pm 0.4070$

Table15:Point-wise method, Cd (Hydrolysed PSHA)

\begin{tabular}{|l|l|l|l|l|l|l|l|l|}
\hline $\mathrm{pH}$ & $\mathrm{BV}_{1}$ & $\mathrm{BV}_{2}$ & $\mathrm{BV}_{3}$ & $\left(\mathrm{~V}_{3}-\mathrm{V}_{2}\right)$ & $\mathrm{n}$ & $\mathrm{pL}$ & $\log \left(\frac{n}{1-n}\right)$ & LogK $_{1}$ \\
\hline 8.50 & 5.30 & 6.29 & 6.31 & 0.02 & 0.2750 & 2.64 & -0.4210 & 2.2190 \\
8.72 & 5.35 & 6.37 & 6.40 & 0.03 & 0.4286 & 2.42 & -0.1249 & 2.2951 \\
9.00 & 5.40 & 6.46 & 6.49 & 0.03 & 0.4648 & 2.14 & -0.0612 & 2.0788 \\
9.22 & 5.45 & 6.55 & 6.59 & 0.04 & 0.6667 & 1.96 & 0.3010 & 2.2610 \\
9.51 & 5.55 & 6.66 & 6.70 & 0.04 & 0.7720 & 1.67 & 0.5297 & 2.1997 \\
\hline
\end{tabular}

LogK $_{\mathbf{1}}$ (Average value) $=2.2108 \pm 0.0825$

Table 16: Point-wise method, Cd (Hydrolysed PSHA)

\begin{tabular}{|l|l|l|l|l|l|l|l|l|}
\hline $\mathrm{pH}$ & $\mathrm{BV}_{1}$ & $\mathrm{BV}_{2}$ & $\mathrm{BV}_{3}$ & $\left(\mathrm{~V}_{3}-\mathrm{V}_{2}\right)$ & $\mathrm{n}$ & $\mathrm{pL}$ & $\log \left(\frac{n-1}{2-n}\right)$ & Log $_{2}$ \\
\hline 9.73 & 5.55 & 6.78 & 6.83 & 0.06 & 1.4042 & 1.47 & -0.1686 & 1.3014 \\
10.00 & 5.60 & 6.90 & 6.95 & 0.06 & 1.7838 & 1.23 & 0.5593 & 1.7893 \\
10.23 & 5.65 & 7.05 & 7.10 & 0.06 & 3.1429 & 1.09 & & \\
10.49 & 5.70 & 7.10 & 7.16 & 0.06 & 3.1429 & 0.89 & & \\
& & & & & & & & \\
\hline
\end{tabular}

$\operatorname{LogK}_{2}$ (Average value) $=1.5453 \pm 0.3450$

Table 17: Point-wise method, Cd (Unhydrolysed PSHA)

\begin{tabular}{|l|l|l|l|l|l|l|l|l|}
\hline $\mathrm{pH}$ & $\mathrm{BV}_{1}$ & $\mathrm{BV}_{2}$ & $\mathrm{BV}_{3}$ & $\mathrm{~V}_{3}-\mathrm{V}_{2}$ & $\mathrm{n}$ & $\mathrm{pL}$ & $\log \left(\frac{n}{n-1}\right)$ & $\operatorname{Log~}_{1}$ \\
\hline 8.50 & 5.30 & 5.81 & 5.86 & 0.05 & 0.3717 & 2.88 & -0.2280 & 2.6520 \\
8.72 & 5.35 & 5.90 & 5.95 & 0.05 & 0.3873 & 2.66 & -0.1992 & 2.4608 \\
9.00 & 5.40 & 6.00 & 6.06 & 0.06 & 0.4853 & 2.38 & -0.0255 & 2.3545 \\
9.22 & 5.45 & 6.10 & 6.16 & 0.06 & 0.5157 & 2.18 & -0.0272 & 2.2072 \\
9.51 & 5.50 & 6.20 & 6.27 & 0.07 & 0.6417 & 1.89 & 0.2530 & 1.1430 \\
9.73 & 5.55 & 6.33 & 6.41 & 0.08 & 0.8000 & 1.69 & 0.6020 & 2.2920 \\
& & & & & & & & \\
\hline
\end{tabular}

$\operatorname{LogK}_{1}($ Average value $)=2.2516 \pm 0.5380$ 
BAJOPAS Volume 14 Number 1,June, 2021

Table 18: Point-wise method, Cd (Unhydrolysed PSHA)

\begin{tabular}{|l|l|l|l|l|l|l|l|l|}
\hline $\mathrm{pH}$ & $\mathrm{BV}_{1}$ & $\mathrm{BV}_{2}$ & $\mathrm{BV}_{3}$ & $\mathrm{~V}_{3}-\mathrm{V}_{2}$ & $\mathrm{n}$ & $\mathrm{pL}$ & $\log \left(\frac{n-1}{2-n}\right)$ & $\log \mathrm{K}_{2}$ \\
\hline 10.00 & 5.60 & 6.47 & 6.57 & 0.10 & 1.1434 & 1.43 & & \\
10.23 & 5.65 & 6.62 & 6.72 & 0.10 & 1.3448 & 1.23 & -0.2788 & 0.9512 \\
10.49 & 5.70 & 6.80 & 6.90 & 0.10 & 1.7742 & 1.03 & 0.5351 & 1.5651 \\
\hline
\end{tabular}

$\operatorname{LogK}_{2}($ Average value $)=1.2581 \pm 0.4340$

Table 19: Stepwise and overall Stability constants of thehydrolysed and unhydrolysed divalent metal (II) complexes

\begin{tabular}{|c|c|c|c|}
\hline Chelates & LogK $_{1}$ & $\log _{2}$ & Log $\beta$ \\
\hline [Cu (Hydrolysed PSHA-1) $\left.{ }_{2}\right]$ & 2.4788 & 1.4280 & 3.9068 \\
\hline$\left[\mathrm{Pb}(\text { Hydrolysed PSHA-1) })_{2}\right]$ & 2.5832 & 1.1963 & 3.7795 \\
\hline$\left[\mathrm{Cd}(\text { Hydrolysed PSHA-1 })_{2}\right]$ & 2.2108 & 1.5453 & 3.7561 \\
\hline$\left[\mathrm{Mg}(\text { Hydrolysed PSHA-1 })_{2}\right]$ & 2.1382 & 1.5453 & 3.6835 \\
\hline [Cu (Unhydrolysed PSHA-1) & 2.3059 & 1.2209 & 3.5268 \\
\hline$[\mathrm{Pb}$ (Unhydrolysed PSHA-1) 2$]$ & 2.2364 & 1.2239 & 3.4603 \\
\hline [Cd (Unhydrolysed PSHA-1) 2 ] & 2.2516 & 1.2581 & 3.5097 \\
\hline$[\mathrm{Mg}$ (Unydrolysed PSHA-1) & 2.1568 & 0.9127 & 3.0695 \\
\hline
\end{tabular}

The results obtained (Table19) shows the stepwise and overall stability constants to be not high indicating low stability of the complexes, because the solubility of most metal ions in the basic $\mathrm{pH}$ range is minimal due to metal hydroxide precipitation (Karimi, 2017). In general, the stepwise stability constants $\left(K_{1}\right.$ and $K_{2}$ ) follow the order $K_{1}>K_{2}$ for the copper, lead, magnesium and cadmium complexes respectively. The steady decrease of the values with increasing number of ligands is in agreement with the prediction made by researchers (Na'aliya, 2013). The decrease could be attributed to the fact that as the number of the ligands (Humate ions) that enters the coordination zone increases the aqua molecules available for replacement by the ligands become less. Thus, the metal ions become less electron loving with progressive intake of the ligand and this results in the decrease in the values of the constants (Na'aliya, 2013). Also the stability of the complexes is influenced by the size and number of the chelate rings(Mackay and Mackay,2002).All the complexes form rings in their structure as humate, a bidentate ligand, bond the metal ions in the ratio 1:2 (Boguta and Sokolowska, 2016) forming chelate rings. The values of the overall stability constants $(\log \beta)$ obtained for humate complexes are not high indicating low stability as the values are not high. LogK values for copper-humates (Table 3 to 6) obtained in this study are lower than those reported for the complexes of humic acids (Pandey et al., 2015; Dinu, 2013; Kaschl et al., 2010 and Gilbeto and Jorg, 2001). The values of LogK(Table 7 to 10 ) forlead-humates are lower than those reported for the lead in the literature (Dinu, 2013; Gilbeto and Jorg 2001). Log K values(Table 11 to 14 ) for magnesium-humates obtained in this study are close to those reported by (Pandey et al., 2015). Log K values of cadmium-humates (Table 15 to 18 ) obtained in this work near to the one reported by (Dinu, 2013 and Pandey et al., 2015).The difference between the reported values and the values obtained in this study might be probably as a result of acid hydrolysis of humic acid. The values of the overall stability constants $(\log \beta)$ of the copper humates complexes presented in Table 19 is high than that of other metal humate complexes, show relatively high stability of CuHA complexes, show the following order of stability: $\mathrm{Cu}>\mathrm{Pb}>\mathrm{Cd}>\mathrm{Mg}$; which are in close agreement to the findings of (Dinu, 2013 and Pandey et al., 2015).The high stability of Cuhumate chelate could be attributed to the existence of coordinate covalent bond between the complexing agents and the $\mathrm{Cu}^{2+}$ ions. Since, $\mathrm{Cu}^{2+}$ being a metal of the transitional series with $3 d^{9}$ electronic configurations can accept the electrons from the complexing agents. Similarly, the low stabilities of $\mathrm{Pb}, \mathrm{Cd}$ and $\mathrm{Mg}$ complexes could be explained by that $\mathrm{Pb}^{2+}$ with $6 s^{2}, \mathrm{Cd}^{2+}$ with $4 \mathrm{~d}^{10}$ and $\mathrm{Mg}^{2+}$ with $2 \mathrm{p}^{6}$ their electronic configuration has a completely filled $\mathrm{d}, \mathrm{p}$ and $\mathrm{s}$ orbitals. Moreover, the stabilities of metal ions with hydrolysed humic acid from peat soil were higher than those with unhydrolysed humic acid from peat soil; which is ascribed to the high content of acidity in hydrolysed humic acid than unhydrolysed humic acid. 
BAJOPAS Volume 14 Number 1,June, 2021 CONCLUSION

The values of logk for $\mathrm{Cu}(\mathrm{II})$ hydrolysed humic acid complex was higher followed by $\mathrm{Pb}$ (II), $\mathrm{Cd}(\mathrm{II})$ and $\mathrm{Mg}$ (II) hydrolysed humic acid complexes as compared with metal(II) unhydrolysed humic acid complexes. This indicates acid hydrolysis of humic acid can

\section{REFERENCES}

Almeida, V.R. and Szpoganicz, B. (2015). Humic Acid Potentiometric Response Patterns:Out- of Equilibrium Properties and Species Distribution Modelling. Chemical. Biol. Technol. Agric. 2: 17.

Anđelković, T., Nikolić, R., Bojić, A.,Anđelković, D., and Nikolic G.,(2010). Binding of Cadmium to Soil Humic Acid as A Function of Carboxyl Group Content. Macedonian Journal of Chemistry and Chemical Engineering.29(2): 215-224.

Anil, B. N. and Maroti, N. (2008). Studies on Influence of Die-Lectric Constants on Complex Equilibria between Substituted Py-Razalines and Lanthanide Metal Ions pH-Metrically. Amer.-Euras. scient. Res. 3(2): 212-216.

Ashok, K., Pandey, S. P. and Misra, V (2000). Stability Constants of Metal-Humic Acid Complexes and its Role in Environmental Detoxification. Journal of Ecotoxicology and Environmental Safety. 47(2):157-200.

Badr, M. H., El-Halafawi, M. H. and Abd El-al Zeid, E. R. (2012). Comparison Between the Effect of Ionic Strength on Acidity and Dissociation Constants of Humic Acids Extracted from Sewage Sludge and Nile Water Hyacinth Composts.Global Journal of Environmental Research 6 (1): 36-43.

Baruah, M.K., Borah, D., Saikia, P.P., Paul, S., Sharma, T. (2015). Evaluation of pKa Values of Soil Humic Acids and their Complexation Properties. International Journal of Plant \& Soil Science 6(4) : 218-228.

Boguta, P. Sokolowska, Z. (2016). Interactions of $\mathrm{Zn}$ (II) Ions with Humic Acids Isolated from Various Types of Soils. Effect of $\mathrm{pH}, \mathrm{Zn}$ Concentrations and Humic Acids Chemical Properties. Journal of Geochemical Explaration 168. 119-126.

Borges, F., Guimaraes, C., Lima, L.F.C., Pinto, I. and Reis, S.(2005). Potentiometric Studies on the Complexation of Copper(II) by Phenolic Acids as Discrete Ligand Models of enhance the complexation behavior of humic acid with metal (II) ions. However, the higher values of $\log \beta$ for $\mathrm{Cu}(\mathrm{II}), \mathrm{Pb}(\mathrm{II}), \mathrm{Cd}(\mathrm{II})$ and $\mathrm{Mg}(\mathrm{II})$ hydrolysed humic acid complexes indicates more stable stepwise complexes formed as compared with $\mathrm{Cu}(\mathrm{II}), \mathrm{Pb}$ (II), $\mathrm{Cd}$ (II) and $\mathrm{Mg}(\mathrm{II})$ unhydrolysed humic acid complexes.

Humic Substances Talanta 66 (2005) 670-673.

Chefetz, B., Salloum, M. J., Deshmulkin, A. P. and Hatcher, P. (2002). Structural Components of Humic Acids as Determined by Chemical Modifications and Carbon-13 NMR, Pyrolysis, and Thermochemolysis- Gas Chromatography/Mass Spectrometry. Soil Science Society of American Journal Abstract Division S-2- Soil Chemistry66. 1159-1171.

Dinu, M. I. (2013). Metals Complexation with Humic Acids in Surface Water of Different Environ. Sci. Technol. 31(1): 1-17.

Fernandes, A.N., Giacomelli, C., Giovanela, M. Vaz, D.V. Szpoganicz, B. and Maria M. D. (2009). Potentiometric Acidity Determination in Humic Substances Influenced by Different Analytical Procedures.J. Braz. Chem. Soc. 20 (9):14.

Gamal, A. H. (2015). Stability Constants of Rhenium (V) Metal Complexes with Selected Drugs. Pyrex Journal of Research in Environmental Studies. 2(2): 006-014.

Janrao, D. M., Pathan, J., Kayande, D.D., and Mulla, J.J. (2014). An Over View of Potentiometric Determination of Stability Constants of Metal Complexes. Sci. Revs. Chem. Commun.: 4(1), 2014, 11-24.

Karimi, H. (2017). Effect of pH and Initial Pb(II) Concentration on the Lead Removal Efficiency from Waste Water Using $\mathrm{Ca}(\mathrm{OH})_{2}$. International Journal of Water and Waste Water Treatment 3.2

Kaschl, A. Romheld, V. and Chen, Y. (2010). Binding of Cadmium, Copper and Zinc to Humic Substances Originating from Municipal Solid Waste Compost. Israel Journal of Chemistry Vol. 42(1): 89-98.

Kostic, I. S., Tatjana, P, A., Nikolic, R. S., Cvetkovic, T. P., Pavlovic, D. D., Aleksandar, L.J. and Bojic, A. (2012). Comparative Study of Binding Strengths of Heavy Metals with Humic Acid. J.serb. Chem. Soc. 76(9) pp 1-20. 
BAJOPAS Volume 14 Number 1,June, 2021

Na'aliya, J. (2013). Determination of Stepwise Stability Constants and Gibbs free Energy Change of Trisprolina to Complexes of some Divalent Transition Metal ions. Bayero Journal of Pure and Applied Sciences 6(2): 112-114.

Omar, A. A. and Ali, E. A. (2015). Potentiometric Studies on Complexes of $\mathrm{Cr}$ (III) and $\mathrm{Zr}$ (IV) with some Carboxylic Acids. International Journal of Advanced Chemistry, 3(1) 25-

37.

Pandey, A. K. Pandey, S. D. and Misr, V. (2015).Stability Constants of Metal- Humic Acid Complexes and Its Role in Environmental Detoxification. J. Ecotoxicology and Environmental Safety. 47(1):195-200.

Ram, N. and Raman, K.V. (1984). Stability Constants of Complexes of Metals with
Humicand Fuvic Acids under Non- acidConditions. Journal of Plant Nutrition and Soil Sciences.

147:171-176.

Santosh, D. D., Ashok, B. K., Vijay, J. T., Shivraj, G. W. and Vinay, V. W. (2011). Potentiometric Studies of Elec-Trolyte Effects on Complex Equilibria of Some Substituted 5-(2-hydroxy Phenyl) Pyrazoles. Der pharm. 3 (6): 75-83.

Sayyed, H. and Abdul Rahim, M. F. (2012). Studies of Binary Complexes of Metal Ions with Mandelic Acid by Potentiometry. Chem. J. 02 (6): 206209.

Shirvani, M. Moradian, E. Khalili, B. Bakhtiary, S. (2015). Interaction of $\mathrm{Cd}$ and $\mathrm{Pb}$ with Humate-Palygorskite and HumateSepiolite Complexes. Journal of water, air and pollution 3: 220-228. 


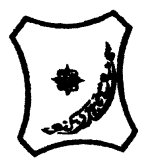

Bayero Journal of Pure and Applied Sciences, 14(1): 54 - 63

Received: November, 2020

Accepted: April, 2021

ISSN $2006-6996$

\title{
STABILITY CONSTANTS OF COMPLEXES OF METAL IONS WITH PEATSOIL HUMIC ACIDS UNDER NON-ACID-CONDITIONS
}

\author{
${ }^{* 1}$ Sabo, Yusuf ${ }^{2}$ Jimoh, W.L.O., ${ }^{3}$ Isa Baba Koki and ${ }^{4}$ Sholadoye, Q. 0. \\ ${ }^{1}$ Department of Pure and Industrial Chemistry, Bayero University, Kano \\ ${ }^{3}$ Department of Chemistry, Yusuf Maitama Sule University Kano. P.M.B. 3220 Kano, Nigeria. \\ ${ }^{4}$ Department of Chemistry, Nigerian Police Academy, Wudil, Kano-Nigeria
}

*Correspondence E-mail; saboyusuf18@yahoo.com

ABSTRACT

Stability constants of complexes of four divalent metal ions viz. $\mathrm{Cu}^{2+}, \mathrm{Pb}^{2+}, \mathrm{Mg}^{2+}$ and $\mathrm{Cd}^{2+}$ with humic acids (HA) were determined by potentiometric titration of humic acids with the corresponding salt of the divalent metals in aqueous media under non-acid-condition. The log $K$ (logarithm of the stability constant) ranged from 1.0942 to 2.7471 for metalhumic acid complexes were determined using point-wise computational method. The order of stability constants were obtained as follows: $\mathrm{Cu}>\mathrm{Pb}>\mathrm{Cd}>\mathrm{Mg}$ for metal $-\mathrm{HA}$ complexes respectively, indicating a higher degree of complexation with Cu metal ion.

Keywords: stability constant, humic acid, potentiometric titration, divalent metals, acid hydrolysis.

\section{NTRODUCTION}

The stability constant of a complex is the numerical expression of its stability and provides a quantitative measure of affinity of the metal ion to the complexing agent. An understanding of the relative stability of metal-complexes helps in predicting the behavior of metal ions in the soil (Ram and Raman, 1982). Extensive researches has been done to determine the stability constants of the complexes formed between humic acid (HA) with a number of metal ions. Ashok et al., (2000) reported that humic acid with hydroxyl, phenoxyl and carboxyl reactive groups can form coordination compound with metal ions at $\mathrm{pH}$ 3.5. The stability constants(Log K) for different metalhumic acid complexes indicated the following order of the stabilities of complexes formed between humic acid and metal ion, $\mathrm{Cu}>\mathrm{Fe}$ $>\mathrm{Pb}>\mathrm{Ni}>\mathrm{Co}>\mathrm{Ca}>\mathrm{Cd}>\mathrm{Zn}>\mathrm{Mn}>\mathrm{Mg}$. Andelkovic et al., (2010) investigated the binding of $\mathrm{Cd}$ (II) to soil humic acid at pH 6.5 and in $0.1 \mathrm{M} \mathrm{KNO}_{3}$ ionic medium. The stability constant for binding indicating greater stability in the case when carboxyl groups are involved in complexation reaction. Kostic et al.,(2012) investigated the complexation of humic acid with certain heavy metal ions (Co(II), $\mathrm{Ni}(\mathrm{II}), \mathrm{Cu}(\mathrm{II})$,
$\mathrm{Zn}(\mathrm{II})$, and $\mathrm{Pb}(\mathrm{II})$. The experiment was performed at $25^{\circ} \mathrm{C}$, at pH 4.0 and ionic strength of $0.01 \mathrm{M}$. Stability constant of complex between $\mathrm{Pb}$ (II) ions and humic acid is greater than stability constants of other investigated metalhumate complexes. Bogata and Sokolowska (2016) analyses the interaction between humic acids from different soils and $\mathrm{Zn}$ (II) ions at wide concentration ranges and at $\mathrm{pH} 5$. Studies have showed significant impact of $\mathrm{Zn}$ concentration, $\mathrm{pH}$ and some properties of humic acids with zinc.But all of these studies were limited to acidic $\mathrm{pH}$ range. Therefore, the present study was carried out to determine and compare the stability constants of complexes of metal ions with hydrolysed peat soil humic acid and unhydrolysed peat soil humic under non-acid conditions.

\section{MATERIALS AND METHODS}

Analytical grade chemicals used includes hydrochloric acid $(\mathrm{HCl})$, nitric acid $\left(\mathrm{HNO}_{3}\right)$, sodium hydroxide $(\mathrm{NaOH})$, lead nitrate $\mathrm{Pb}\left(\mathrm{NO}_{3}\right)_{2}$, copper nitrate $\mathrm{Cu}\left(\mathrm{NO}_{3}\right)_{2} \cdot 3 \mathrm{H}_{2} \mathrm{O}$, cadmium nitrate $\mathrm{Cd}\left(\mathrm{NO}_{3}\right)_{2} \cdot 4 \mathrm{H}_{2} \mathrm{O}$, magnesium nitrate $\mathrm{Mg}\left(\mathrm{NO}_{3}\right)_{2} \cdot 6 \mathrm{H}_{2} \mathrm{O}$, potassium nitrate $\left(\mathrm{KNO}_{3}\right)$, calcium chloride $\left(\mathrm{CaCl}_{2}\right)$, (sigma-Aldrich). Dowex 50WX8, (20-50 mesh) from Fluka. 


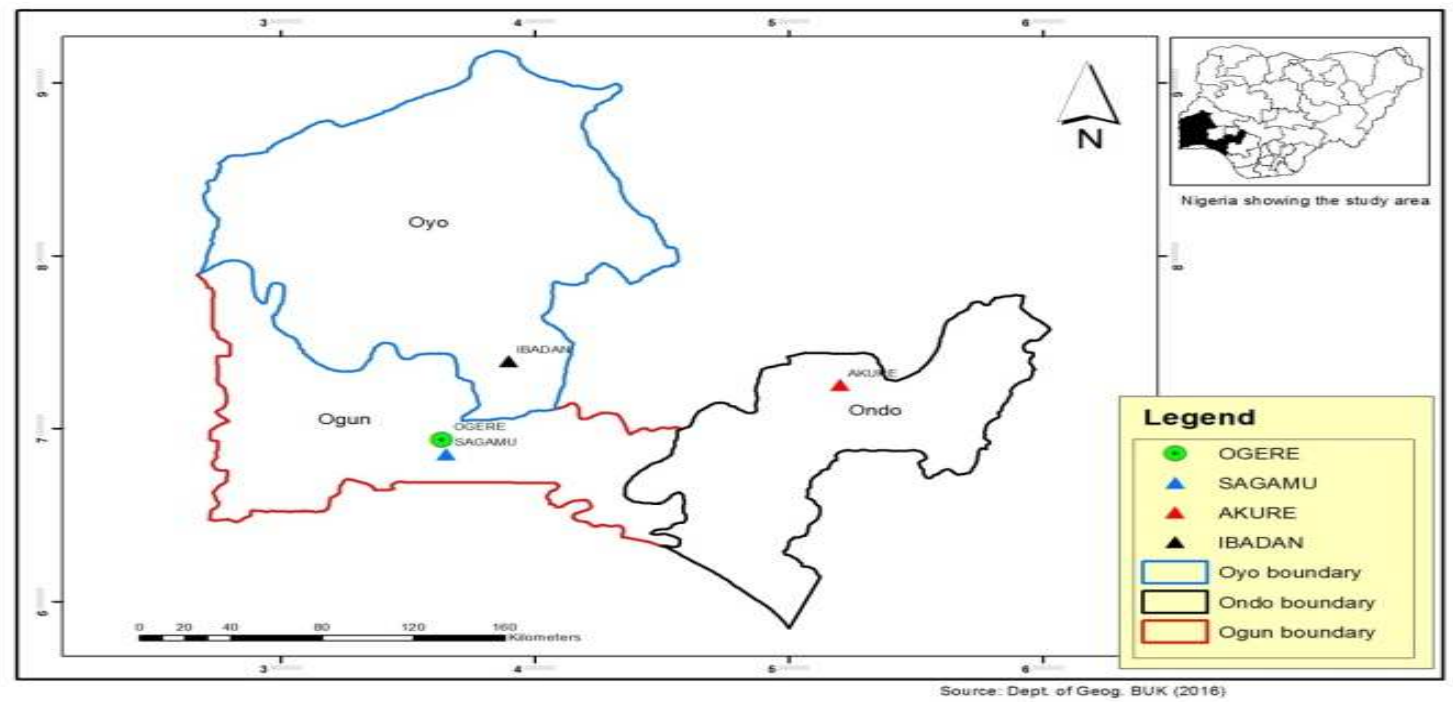

Figure 1: Map showing the sampling point at Sagamu Town, Ogun State.

\section{Description of Sampling Area}

Sagamu has geographical coordinates between $6^{\circ} 50^{\prime}$ north; $3^{\circ} 38^{\prime}$ east is located in south western region of Nigeria. The region has tropical wet and dry climate with a lengthy wet season and relatively constant temperatures throughout the course of the year. Wet season runs from March to October, November to December forms the region dry season. The vegetation type of the region is savannah which is really grassland with small bushes and occasional big trees. Grassland soils have substantially higher organic matter content than forest soils (Novackova, 2011).

\section{Sample Collection}

The Peatsoil samples were collected from four different sampling points $(0-10 \mathrm{~cm}$ depth) in Sagamu into polyethylene bag with plastic spoons. Samples were taken to the laboratory, extraneous materials were removed; the samples were air-dried, crushed and ground to a fine powder in a mortar passed through a $0.20 \mathrm{~mm}$ sieve. The samples were kept for analysis.

\section{Isolation and purification of humic acid from peat soil sample}

Peatsoil sample $(100 \mathrm{~g})$ was mixed with 1000 $\mathrm{cm}^{3}$ of $0.1 \mathrm{M} \mathrm{NaOH}$ solution, shaken for 3hours and left to stand overnight. Dark-coloured supernatant was obtained and decanted from solid residue. The dark-coloured supernatant was acidified to $(\mathrm{pH}=1.0)$ with $6 \mathrm{M} \mathrm{HCl}$ stirred and allowed to stand for 6 hours. Yellowish brown supernatant and dark-brown precipitate were obtained. The yellowish brown supernatant was decanted followed by centrifuge and discarded. The dark-brown precipitate was mixed with $500 \mathrm{~cm}^{3}$ of $0.1 \mathrm{M} \mathrm{NaOH}$ solution followed by passing through dowex resin. The dark-brown solution was acidified to $(\mathrm{pH}=1.0)$ with $6 \mathrm{M} \mathrm{HCl}$ stirred and allowed to stand for 3 hours. The dark-brown precipitate was washed several times with deionized water. The supernatant was treated with $\mathrm{AgNO}_{3}$ solution until no white precipitate observed. The humic acid was transferred to weighed crucible and dried at $60^{\circ} \mathrm{C}$ in an oven for 12 hours. The humic acid was cooled and dried in the desiccator, weighed and recorded. The obtained humic acid was dried again at $60^{\circ} \mathrm{C}$ for additional 6 hours cooled and dried in the desiccator, weighed and recorded constant weight was obtained (Baruah et al., 2015).

\section{FT-IR analysis}

FT-IR spectra of humic acid sample was analysed using Carry 630 FT-IR Agilent Technologies.

Unhydrolysed compost humic acid

The unhydrolysed humic acid was obtained after isolation and purification of compost humic acid and kept for investigation.

\section{Acid hydrolysis of Peatsoil acid}

Peatsoil humic acid sample (1g) was refluxed for 12 hours at $\left(160^{\circ} \mathrm{C}\right)$ with $50 \mathrm{~cm}^{3}$ of $6 \mathrm{M} \mathrm{HCl}$. The mixture was allowed to cool, decanted, and centrifuged after hydrolysis. The insoluble residues were washed with distilled water via centrifugation several times, and the supernatant was treated with $\mathrm{AgNO}_{3}$ solution until no white precipitate was observed. The residue was thoroughly dried over $\mathrm{CaCl}_{2}$ in a desiccator at room temperature (Chefetz et al., 2002). Finally, the obtained hydrolysed humic acid was kept for investigation. 
BAJOPAS Volume 14 Number 1,June, 2021 Potentiometric Titrations

Potentiometric measurements were carried out using a pH-meter Jenway (model 3510) with combine electrode, the sensitivity of the $\mathrm{pH}$ meter is 0.01 units. The $\mathrm{pH}$ meter was switched on half an hour before starting the titration for initial warm up of the instrument. The instrument was calibrated with an aqueous standard buffer solution of $\mathrm{pH} 4.00$ and 10.0 (borate buffer) prepared from a "Qualigens" buffer tablets.

The following sets of solutions were prepared in a $250 \mathrm{~cm}^{3}$ volumetric flask separately for $\mathrm{pH}$ metric titrations.

(i) $5 \mathrm{~cm}^{3} 0.1 \mathrm{M} \mathrm{HCl}+40 \mathrm{~cm}^{3}$ deionized water

(ii) $5 \mathrm{~cm}^{3} 0.1 \mathrm{M} \mathrm{HCl}+39 \mathrm{~cm}^{3}$ deionized water $+1 \mathrm{~cm}^{3} 0.15 \mathrm{gcm}^{-3}$ humic acid

(iii) $5 \mathrm{~cm}^{3} 0.1 \mathrm{M} \mathrm{HCl}+37 \mathrm{~cm}^{3}$ deionized water $+1 \mathrm{~cm}^{3} 0.15 \mathrm{gcm}^{-3}$ humic acid

$$
+2 \mathrm{~cm}^{3} \quad 0.01 \mathrm{M} \mathrm{Cu} \text { (II) }
$$

The solutions were titrated against standardized $0.110 \mathrm{MNaOH}$ separately. The total volume of each mixture was adjusted to $50 \mathrm{~cm}^{3}$ and the ionic strength of the solutions was maintained constant at by adding appropriate amount of stock solution of $1 \mathrm{M} \mathrm{KNO}_{3}$ (Gamal, 2015; Omar and Ali, 2015). A magnetic stirrer was used to achieve thorough mixing of the interacting solutions at $550 \mathrm{rpm}$. The same set of experimental conditions was applied for potentiometric titration of remaining samples.

\section{Evaluation of pKa of Hydrolysed peat soil Humic Acids}

The proton-ligand formation number $\mathrm{n}_{\mathbf{A}}$ were calculated by Irving and Rossotti expression (Omar and Ali, 2015).

$\mathrm{nA}=\mathrm{Y}-\frac{(\mathrm{V} 2-\mathrm{V1})(\mathrm{No}-\mathrm{Eo})}{(\mathrm{VO}+\mathrm{V1}) \mathrm{TCL}}$ 1

Where: $Y$ is number of dissociable proton, $\left(\mathrm{V}_{2^{-}}\right.$ $V_{1}$ ) is the measure of displacement of the ligand curve relative to acid curve, $\mathrm{N}^{\circ}$ and $\mathrm{E}^{\circ}$ are the resultant concentration of alkali solution, free acid solution, $\mathrm{T}_{\mathrm{cL}}{ }^{\circ}$ is the total ligand concentration, $\mathrm{V}^{\circ}$ is the total volume of titration solution, $V_{1}$ is the volume of alkali added to acid solution, $V_{2}$ is the volume of alkali added to acid solution + ligand solution, acid dissociation constants (pKa - values) of ligand were calculated by algebraic method point wise calculation (Tables 1 ). The dissociation constants (pKa) were calculated according to the following relation:

$\mathrm{pKa}=\mathrm{pH}+\log \left(\frac{n A}{1-n A}\right)$ 2

Where: pKa is the acid dissociation constant, $\mathrm{n}_{\mathrm{A}}$ is the Proton-ligand formation number and $\mathrm{pH}$ is the pH-values (Omar and Ali, 2015).

\section{Determination of metal-ligand stability constants $(\log K)$ of complexes}

The potentiometric measurement for the determination of stability constant of a complex in solution is based on the fact that the redox potential of the couple $\frac{M^{+(m-n)}}{M^{+m}}$ is shifted significantly on complexation of the metal ion with the ligand. This method involves change in hydrogen ion concentration $\left[\mathrm{H}^{+}\right]$due to the displacement or association of one or more protons taking place during complexation reaction. This change can be found out by titrating the solutions containing free acid, acid with ligand, and acid with ligand and metal ion, individually against a standard alkali solution at a constant ionic strength or temperature. Either ionic strength or temperature may be varied for different sets of solutions. In all the cases, the change in the $\mathrm{pH}$ of the solution is measured after each addition of a known amount of alkali to the reaction cell which contains the reaction mixture. The titration curves are then drawn by plotting the measured $\mathrm{pH}$ values against the corresponding volume of alkali added and the stability constants of the complexes are determined from the titration curves by employing $\mathrm{pH}$-metric titration technique given by (Irving and Rossoti).

Metal-ligand stability constants ( $\log \mathrm{K}$ ) were determined by using the following relations:

$$
\bar{n}=\frac{\left(V_{3}-V_{2}\right)\left(E^{0}+N^{0}\right)}{\left(V^{0}+V_{2}\right) \bar{n}_{A} T_{m}^{0}}
$$

and

$$
P L=\log _{10}\left\{\frac{1+\beta_{n}^{H} \frac{1}{[\text { anti } \log \mathrm{pH}]^{\mathrm{n}}}}{\mathrm{T}_{\mathrm{L}}^{0}-n \bar{T}_{m}^{0}} \mathrm{X} \frac{\left(V^{0}+V_{3}\right)}{V^{0}}\right\}
$$


BAJOPAS Volume 14 Number 1,June, 2021

Where $T_{L}, T^{\circ}, E^{\circ}$, and $V^{\circ}$ havethe same significance as in equation (1) above, $T_{m}$ denotes the total concentration of metal present in solution, $V_{3}$ is the volume of metal ions present in solution and $\beta^{H}$ is the overall proton ligand stability constant. The metal-ligand stability constants (log K) were determined by employing point wise computational Method (eq. 5 and 6).

$\operatorname{LogK}_{1}=\log \left(\frac{n}{1-n}\right)+\mathrm{pL}$ .5

$\operatorname{LogK}_{2}=\log \left(\frac{1-n}{2-n}\right)+\mathrm{pL}$ ...6

Where: Log $\mathrm{K}$ is the metal-ligand stability constant, $\mathrm{pL}$ is the Free ligand exponent function, $\mathbf{n}$ is the Average number of ligand attached with metal ion (Janraoet al., 2014). The results obtained were analyzed by an ORIGIN 2016 program using titration data and then the proton-ligand stability constants (pKa) and Metal-ligand stability constant (LogK) calculated (Omar and Ali, 2015).

\section{RESULTS AND DISCUSSION}

Fourier transformed infrared (FT-IR) spectra of isolated humic acid from peat soils Figure 2 had distinct clear absorption bands indicating the presence of major humic acid structural elemental groups such as $\mathrm{H}$ bonded $\mathrm{OH}$ $\left(3680 \mathrm{~cm}^{-1}\right.$ peak $), C=0$ of carbonyl $\left(1721 \mathrm{~cm}^{-1}\right.$ peak), functional groups of aliphatic components $\mathrm{CH}_{2}\left(2918 \mathrm{~cm}^{-1}\right.$ peak) and $\mathrm{C}-\mathrm{O}$ stretching of polysaccharide $\left(1168 \mathrm{~cm}^{-1}\right.$ peak). The positions of the absorption bands of the spectra fell within typical major absorption bands of humic acid which is at frequencies 3680, 2918, 1721, 1168 $\mathrm{cm}^{-1}$. The first peak centred in the vicinity of $3680 \mathrm{~cm}^{-1}$ region is attributed to phenol $\mathrm{OH}$ group bounded by intermolecular $\mathrm{H}$ bonds. The $2918 \mathrm{~cm}^{-1}$ band usually has absorption maximum at $2918 \mathrm{~cm}^{-1}$ which is due to $\mathrm{C}-\mathrm{H}$ stretching of alkane group $\left(\mathrm{CH}_{2}\right)$. The next major absorption band is $1721 \mathrm{~cm}^{-1}$. This band has been commonly ascribed to $\mathrm{C}=\mathrm{O}$ stretching of mainly carboxyl group $(\mathrm{COOH})$ with trace amount of ketones. The last peak was observed at 1168 $\mathrm{cm}^{-1}$ due to $\mathrm{C}-\mathrm{O}$ stretching of polysaccharides and this peak appeared also in the spectra of humic acid from peat soil. The FTIR spectra of the isolated humic acid contained all major characteristic absorption peaks of humic acid. These absorption peaks indicated the presence of the major structural elements of humic acid namely $\mathrm{H}$ bonded $\mathrm{OH}, \mathrm{C}=\mathrm{C}$ of aromatic ring, $\mathrm{C}=\mathrm{O}$ of carbonyl group (both carboxyl and ketonic), $\mathrm{CH}_{2}$ group. This strongly supports the presence of humic acid.

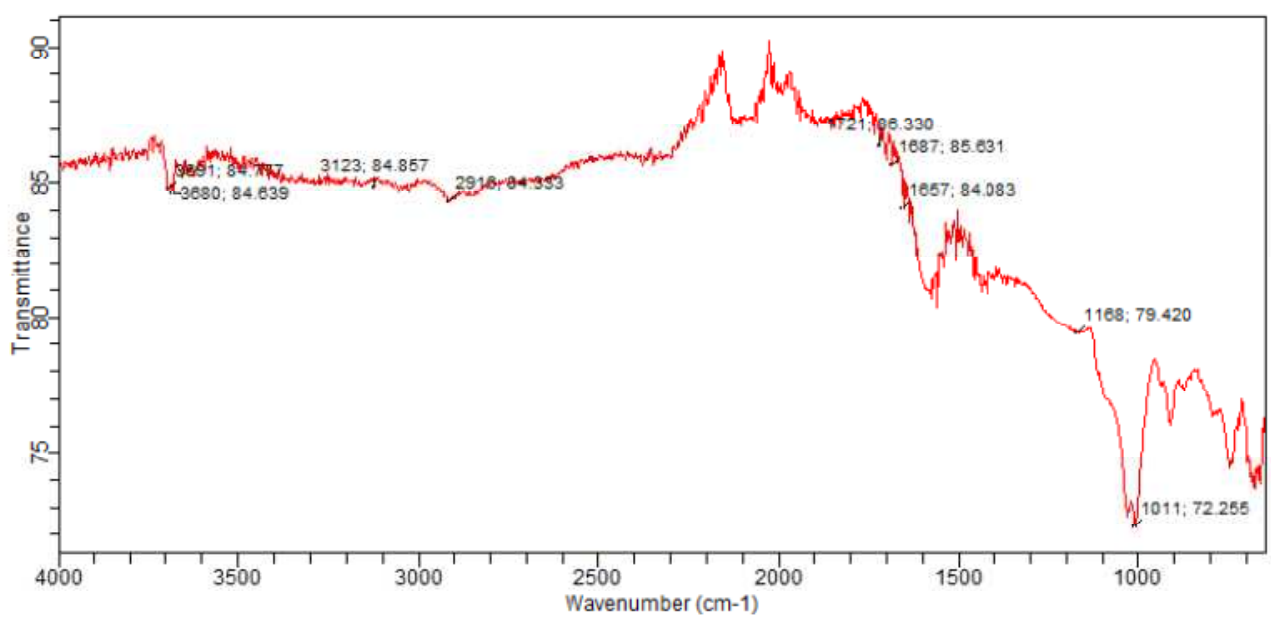

Fig. 2 : FT-IR spectraof peatsoilhumic acid (PSHA)

\section{Evaluation of acid dissociation constant (pka) of acid hydrolysed peat soil humicacid at phenolic group}

The value of the dissociation constant of the peat soil humic acid (PSHA) that underwent acidhydrolysis studied was found to be 8.9299 as shown Table 1, which is lower than the literaturevalues reported by Almeida and Szpoganics, (2015), Borges et al., (2005); Badr et al., (2012)and Fernandes et al,.(2009) of $9.73,9.47$ and 10.30. The difference between the obtained valuesand the reported values in this study might be probably as a result of acid hydrolysis of humicacid. 
BAJOPAS Volume 14 Number 1,June, 2021

Table 1: PKa of (Hydrolysed PSHA)

\begin{tabular}{|l|l|l|l|l|l|l|}
\hline $\mathrm{pH}$ & $\mathrm{BV}_{1}$ & $\mathrm{BV}_{2}$ & $\mathrm{~V}_{2}-\mathrm{V}_{1}$ & $\mathrm{nA}$ & $\log \left(\frac{n A}{1-n A}\right)$ & $\mathrm{pKa}$ \\
\hline 8.50 & 5.30 & 6.29 & 0.99 & 0.3594 & -0.2510 & 8.2490 \\
8.72 & 5.35 & 6.37 & 1.02 & 0.3400 & -0.2880 & 8.4320 \\
9.00 & 5.40 & 6.46 & 1.06 & 0.3141 & -0.3391 & 8.6609 \\
9.22 & 5.45 & 6.55 & 1.10 & 0.2882 & -0.3927 & 8.8273 \\
9.51 & 5.50 & 6.66 & 1.16 & 0.2494 & -0.4786 & 9.0314 \\
9.73 & 5.55 & 6.78 & 1.23 & 0.2041 & -0.5910 & 9.1390 \\
10.00 & 5.60 & 6.90 & 1.30 & 0.1589 & -0.7238 & 9.2762 \\
10.23 & 5.65 & 7.05 & 1.40 & 0.0941 & -0.9835 & 9.2465 \\
10.49 & 5.70 & 7.10 & 1.40 & 0.0941 & -0.9835 & 9.5065 \\
\hline
\end{tabular}

Average pKa $=8.9299 \pm 0.4186$

Table 2: PKa of (Unhydrolysed PSHA)

\begin{tabular}{|l|l|l|l|l|l|l|}
\hline $\mathrm{pH}$ & $\mathrm{BV}_{1}$ & $\mathrm{BV}_{2}$ & $\mathrm{~V}_{2}-\mathrm{V}_{1}$ & $\mathrm{nA}$ & $\log \left(\frac{\boldsymbol{n A}}{1-\boldsymbol{n}}\right)$ & $\mathrm{pKa}$ \\
\hline 8.50 & 5.30 & 5.81 & 0.51 & 0.6619 & 0.2919 & 8.7919 \\
8.72 & 5.35 & 5.90 & 0.55 & 0.6357 & 0.2418 & 8.9618 \\
9.00 & 5.40 & 6.00 & 0.60 & 0.6029 & 0.1813 & 9.1813 \\
9.22 & 5.45 & 6.10 & 0.65 & 0.5701 & 0.1226 & 9.3426 \\
9.51 & 5.50 & 6.20 & 0.70 & 0.5376 & 0.0654 & 9.5754 \\
9.73 & 5.55 & 6.33 & 0.78 & 0.4851 & -0.0259 & 9.7041 \\
10.00 & 5.60 & 6.47 & 0.87 & 0.4262 & -0.1291 & 9.8709 \\
10.23 & 5.65 & 6.62 & 0.99 & 0.3609 & -0.2481 & 9.9819 \\
10.49 & 5.70 & 6.80 & 1.10 & 0.2759 & -0.4690 & 10.0210 \\
\hline
\end{tabular}

Average pKa $=9.4923 \pm 0.4410$

Metal-ligand stability constant ( $\log \mathrm{K}$ )

The stabilityconstants require the accurate values of proton-ligand stability constants (Anil and Maroti, 2008). Metal titration curves crossed over ligand titration curve indicated the formation of complex upon proton release (Santosh, et al., 2011). If the values of n- are within range $0.2-0.8$ and $1.2-18$ this indicates the formation of $1: 1$ and 1:2 complexes (Sayyed and Mazahar, 2012).

The metal (II)-humate stepwise stability constants (log k) at phenolic group (Tables 318)

Table 3: Point-wise method, $\mathrm{Cu}$-(Hydrolysed PSHA)

\begin{tabular}{|l|l|l|l|l|l|l|l|l|}
\hline $\mathrm{pH}$ & $\mathrm{BV}_{1}$ & $\mathrm{BV}_{2}$ & $\mathrm{BV}_{3}$ & $\left(\mathrm{~V}_{3}-\mathrm{V}_{2}\right)$ & $\mathrm{n}$ & $\mathrm{pL}$ & $\log \left(\frac{n}{1-n}\right)$ & LogK $_{1}$ \\
\hline 8.50 & 5.30 & 6.29 & 6.33 & 0.04 & 0.5500 & 2.66 & 0.0871 & 2.7471 \\
8.72 & 5.35 & 6.37 & 6.41 & 0.04 & 0.5714 & 2.43 & 0.1249 & 2.5549 \\
9.00 & 5.40 & 6.46 & 6.50 & 0.04 & 0.6198 & 2.16 & 0.2122 & 2.3722 \\
9.22 & 5.45 & 6.55 & 6.59 & 0.04 & 0.6667 & 1.94 & 0.3010 & 2.2410 \\
\hline
\end{tabular}

LogK $_{1}$ (Average value) $=2.4788 \pm 0.2203$

Table 4: Point-wise method, $\mathrm{Cu}$-(Hydrolysed PSHA)

\begin{tabular}{|l|l|l|l|l|l|l|l|l|}
\hline $\mathrm{pH}$ & $\mathrm{BV}_{1}$ & $\mathrm{BV}_{2}$ & $\mathrm{BV}_{3}$ & $\left(\mathrm{~V}_{3}-\mathrm{V}_{2}\right)$ & $\mathrm{n}$ & $\mathrm{pL}$ & $\log \left(\frac{n-1}{2-n}\right)$ & LogK $_{2}$ \\
\hline 9.51 & 5.50 & 6.66 & 6.73 & 0.07 & 1.3509 & 1.70 & -0.2671 & 1.4329 \\
9.73 & 5.55 & 6.78 & 6.85 & 0.07 & 1.6383 & 1.51 & 0.2467 & 1.7567 \\
10.00 & 5.60 & 6.90 & 6.98 & 0.08 & 2.1783 & 1.31 & -0.2158 & 1.0942 \\
10.23 & 5.65 & 7.05 & 7.13 & 0.08 & 4.1904 & 1.27 & & \\
10.49 & 5.70 & 7.10 & 7.19 & 0.09 & 4.6920 & & & \\
\hline
\end{tabular}

Log $K_{2}($ Average value $)=1.4280 \pm 0.3312$ 
BAJOPAS Volume 14 Number 1,June, 2021

Table 5: Point-wise method, $\mathrm{Cu}$ (Unhydrolysed PSHA)

\begin{tabular}{|l|l|l|l|l|l|l|l|l|}
\hline $\mathrm{pH}$ & $\mathrm{BV}_{1}$ & $\mathrm{BV}_{2}$ & $\mathrm{BV}_{3}$ & $\left(\mathrm{~V}_{3}-\mathrm{V}_{2}\right)$ & $\mathrm{n}$ & $\mathrm{pL}$ & $\log \left(\frac{n}{n-1}\right)$ & Log $_{1}$ \\
\hline 8.50 & 5.30 & 5.81 & 5.85 & 0.04 & 0.2973 & 2.88 & -0.3736 & 2.5064 \\
8.72 & 5.35 & 5.90 & 5.95 & 0.05 & 0.3873 & 2.66 & -0.1992 & 2.4608 \\
9.00 & 5.40 & 6.00 & 6.05 & 0.05 & 0.4044 & 2.38 & -0.1681 & 2.2119 \\
9.22 & 5.45 & 6.10 & 6.15 & 0.06 & 0.5157 & 2.18 & -0.0272 & 2.2072 \\
9.51 & 5.50 & 6.20 & 6.27 & 0.07 & 0.6417 & 1.89 & 0.2530 & 1.1430 \\
\hline
\end{tabular}

$\operatorname{LogK}_{1}($ Average value $)=2.3059 \pm 0.6153$

Table 6:Point-wise method, $\mathrm{Cu}$ (Unhydrolysed PSHA)

\begin{tabular}{|l|l|l|l|l|l|l|l|l|}
\hline $\mathrm{pH}$ & $\mathrm{BV}_{1}$ & $\mathrm{BV}_{2}$ & $\mathrm{BV}_{3}$ & $\mathrm{~V}_{3}-\mathrm{V}_{2}$ & $\mathrm{n}$ & $\mathrm{pL}$ & $\log \left(\frac{n-1}{2-n}\right)$ & $\log \mathrm{K}_{2}$ \\
\hline 9.73 & 5.55 & 6.33 & 6.42 & 0.09 & 0.9000 & 1.69 & & \\
10.00 & 5.60 & 6.47 & 6.58 & 0.11 & 1.2578 & 1.44 & -0.4592 & 0.9808 \\
10.23 & 5.65 & 6.62 & 6.84 & 0.12 & 1.6137 & 1.26 & -0.2010 & 1.4610 \\
10.49 & 5.70 & 6.80 & 6.92 & 0.12 & 2.1052 & 1.03 & & \\
\hline
\end{tabular}

$\operatorname{LogK}_{2}$ (Average value) $=1.2209 \pm 0.3398$

Table 7:Point-wise method, Pb (Hydrolysed PSHA)

\begin{tabular}{|l|l|l|l|l|l|l|l|l|}
\hline $\mathrm{pH}$ & $\mathrm{BV}_{1}$ & $\mathrm{BV}_{2}$ & $\mathrm{BV}_{3}$ & $\left(\mathrm{~V}_{3}-\mathrm{V}_{2}\right)$ & $\mathrm{n}$ & $\mathrm{pL}$ & $\log \left(\frac{n}{1-n}\right)$ & LogK $_{1}$ \\
\hline 8.50 & 5.30 & 6.29 & 6.33 & 0.04 & 0.5500 & 2.66 & 0.0871 & 2.7471 \\
8.72 & 5.35 & 6.37 & 6.41 & 0.04 & 0.5714 & 2.43 & 0.1249 & 2.5549 \\
9.00 & 5.40 & 6.46 & 6.50 & 0.04 & 0.6198 & 2.16 & 0.2122 & 2.3722 \\
9.22 & 5.45 & 6.55 & 6.60 & 0.05 & 0.8333 & 1.96 & 0.6989 & 2.6589 \\
\hline
\end{tabular}

Log $_{\mathbf{1}}($ Average value $)=2.5832 \pm 0.1614$

Table 8:Point-wise method, Pb-(Hydrolysed PSHA)

\begin{tabular}{|l|l|l|l|l|l|l|l|l|}
\hline $\mathrm{pH}$ & $\mathrm{BV}_{1}$ & $\mathrm{BV}_{2}$ & $\mathrm{BV}_{3}$ & $\left(\mathrm{~V}_{3}-\mathrm{V}_{2}\right)$ & $\mathrm{n}$ & $\mathrm{pL}$ & $\log \left(\frac{n-1}{2-n}\right)$ & $\log \mathrm{K}_{2}$ \\
\hline 9.51 & 5.50 & 6.66 & 6.71 & 0.05 & 0.9650 & 1.67 & & \\
9.73 & 5.55 & 6.78 & 6.83 & 0.05 & 1.1702 & 1.44 & & \\
10.00 & 5.60 & 6.90 & 6.90 & 0.05 & 1.4864 & 1.22 & -0.0237 & 1.1963 \\
10.23 & 5.65 & 7.05 & 7.10 & 0.05 & 2.0190 & 1.09 & & \\
10.49 & 5.70 & 7.10 & 7.17 & 0.07 & 3.6492 & 1.00 & & \\
\hline
\end{tabular}

Log $K_{2}$ (Average value) $=1.1963$

Table 9: Point-wise method, Pb (Unhydrolysed PSHA)

\begin{tabular}{|l|l|l|l|l|l|l|l|l|}
\hline $\mathrm{pH}$ & $\mathrm{BV}_{1}$ & $\mathrm{BV}_{2}$ & $\mathrm{BV}_{3}$ & $\mathrm{~V}_{3}-\mathrm{V}_{2}$ & $\mathrm{n}$ & $\mathrm{pL}$ & $\begin{array}{l}\text { Log } \\
\left(\frac{n}{n-1}\right)\end{array}$ & Log $\mathrm{K}_{1}$ \\
\hline 8.50 & 5.30 & 5.81 & 5.85 & 0.04 & 0.2973 & 2.88 & -0.3736 & 2.5064 \\
8.72 & 5.35 & 5.90 & 5.94 & 0.04 & 0.3099 & 2.66 & -0.5477 & 2.3123 \\
9.00 & 5.40 & 6.00 & 6.05 & 0.05 & 0.4044 & 2.38 & -0.1681 & 2.2119 \\
9.22 & 5.45 & 6.10 & 6.15 & 0.06 & 0.5157 & 2.18 & 0.0272 & 2.2072 \\
9.51 & 5.50 & 6.20 & 6.26 & 0.07 & 0.6417 & 1.89 & 0.2530 & 2.1430 \\
9.73 & 5.55 & 6.40 & 6.40 & 0.07 & 0.7000 & 1.67 & 0.3680 & 2.0380 \\
\hline
\end{tabular}

LogK $_{1}$ (Average value) $=2.2364 \pm 0.1602$

Table 10: Point-wise method, Pb (Unhydrolysed PSHA)

\begin{tabular}{|l|l|l|l|l|l|l|l|l|}
\hline $\mathrm{pH}$ & $\mathrm{BV}_{1}$ & $\mathrm{BV}_{2}$ & $\mathrm{BV}_{3}$ & $\mathrm{~V}_{3}-\mathrm{V}_{2}$ & $\mathrm{n}$ & $\mathrm{pL}$ & $\log \left(\frac{n-1}{2-n}\right)$ & $\log \mathrm{K}_{2}$ \\
\hline 10.00 & 5.60 & 6.47 & 6.55 & 0.08 & 1.9503 & 1.41 & & \\
10.23 & 5.65 & 6.62 & 6.72 & 0.11 & 1.4792 & 1.26 & -0.0361 & 1.2239 \\
\hline
\end{tabular}

$\operatorname{LogK}_{2}$ (Average value) $=1.2239$

Table 11: Point-wise method, Mg (Hydrolysed PSHA)

\begin{tabular}{|l|l|l|l|l|l|l|l|l|}
\hline $\mathrm{pH}$ & $\mathrm{BV}_{1}$ & $\mathrm{BV}_{2}$ & $\mathrm{BV}_{3}$ & $\left(\mathrm{~V}_{3}-\mathrm{V}_{2}\right)$ & $\mathrm{n}$ & $\mathrm{pL}$ & $\log \left(\frac{n}{n-1}\right)$ & LogK $_{1}$ \\
\hline 8.50 & 5.30 & 6.29 & 6.31 & 0.02 & 0.2750 & 2.64 & -0.4290 & 2.2110 \\
8.72 & 5.35 & 6.37 & 6.39 & 0.02 & 0.2858 & 2.42 & -0.3978 & 2.0222 \\
9.00 & 5.40 & 6.46 & 6.49 & 0.03 & 0.4648 & 2.14 & -0.0612 & 2.0788 \\
9.22 & 5.45 & 6.55 & 6.59 & 0.04 & 0.6667 & 1.94 & 0.3010 & 2.2410 \\
\hline
\end{tabular}

$\log _{\mathbf{1}}($ Average value) $=2.1382 \pm 0.1046$ 
BAJOPAS Volume 14 Number 1,June, 2021

Table 12: Point-wise method, Mg (Hydrolysed PSHA)

\begin{tabular}{|l|l|l|l|l|l|l|l|l|}
\hline $\mathrm{pH}$ & $\mathrm{BV}_{1}$ & $\mathrm{BV}_{2}$ & $\mathrm{BV}_{3}$ & $\left(\mathrm{~V}_{3}-\mathrm{V}_{2}\right)$ & $\mathrm{n}$ & $\mathrm{pL}$ & $\log \left(\frac{n-1}{2-n}\right)$ & LogK $_{2}$ \\
\hline 9.51 & 5.55 & 6.66 & 6.71 & 0.05 & 0.9650 & 1.67 & & \\
9.73 & 5.55 & 6.78 & 6.84 & 0.06 & 1.4042 & 1.47 & -0.1686 & 1.3014 \\
10.00 & 5.60 & 6.90 & 6.93 & 0.06 & 1.7838 & 1.23 & 0.5593 & 1.7893 \\
10.23 & 5.65 & 7.05 & 7.10 & 0.06 & 3.1429 & 1.10 & & \\
10.49 & 5.70 & 7.10 & 7.18 & 0.07 & 3.6492 & 0.83 & & \\
\hline
\end{tabular}

LogK $_{2}($ Average value $)=1.5453 \pm 0.3450$

Table 13: Point-wise method, Mg (Unhydrolysed PSHA)

\begin{tabular}{|l|l|l|l|l|l|l|l|l|}
\hline $\mathrm{pH}$ & $\mathrm{BV}_{1}$ & $\mathrm{BV}_{2}$ & $\mathrm{BV}_{3}$ & $\mathrm{~V}_{3}-\mathrm{V}_{2}$ & $\mathrm{n}$ & $\mathrm{pL}$ & $\log \left(\frac{n}{n-1}\right)$ & $\operatorname{Log~}_{1}$ \\
\hline 8.50 & 5.30 & 5.81 & 5.85 & 0.04 & 0.2973 & 2.88 & -0.3736 & 2.5064 \\
8.72 & 5.35 & 5.90 & 5.94 & 0.04 & 0.3099 & 2.66 & -0.3477 & 2.3123 \\
9.00 & 5.40 & 6.00 & 6.04 & 0.04 & 0.3236 & 2.38 & -0.3202 & 2.0598 \\
9.22 & 5.45 & 6.10 & 6.15 & 0.05 & 0.4297 & 2.17 & -0.1230 & 2.0470 \\
9.51 & 5.50 & 6.20 & 6.26 & 0.06 & 0.5500 & 1.89 & 0.0871 & 1.9771 \\
9.73 & 5.55 & 6.33 & 6.40 & 0.07 & 0.7000 & 1.67 & 0.3680 & 2.0380 \\
\hline
\end{tabular}

LogK $_{1}$ (Average value) $=2.1568 \pm 0.2069$

Table 14: Point-wise method, Mg (Unhydrolysed PSHA)

\begin{tabular}{|l|l|l|l|l|l|l|l|l|}
\hline $\mathrm{pH}$ & $\mathrm{BV}_{1}$ & $\mathrm{BV}_{2}$ & $\mathrm{BV}_{3}$ & $\mathrm{~V}_{3}-\mathrm{V}_{2}$ & $\mathrm{n}$ & $\mathrm{pL}$ & $\log \left(\frac{n-1}{2-n}\right)$ & $\log \mathrm{K}_{2}$ \\
\hline 10.00 & 5.60 & 6.47 & 6.55 & 0.08 & 0.9148 & 1.41 & & \\
10.23 & 5.65 & 6.62 & 6.71 & 0.09 & 1.2102 & 1.20 & -0.5749 & 0.6251 \\
10.49 & 5.70 & 6.80 & 6.92 & 0.09 & 1.5968 & 1.03 & 0.1703 & 1.2003 \\
\hline
\end{tabular}

LogK $_{2}$ (Average value) $=0.9127 \pm 0.4070$

Table15:Point-wise method, Cd (Hydrolysed PSHA)

\begin{tabular}{|l|l|l|l|l|l|l|l|l|}
\hline $\mathrm{pH}$ & $\mathrm{BV}_{1}$ & $\mathrm{BV}_{2}$ & $\mathrm{BV}_{3}$ & $\left(\mathrm{~V}_{3}-\mathrm{V}_{2}\right)$ & $\mathrm{n}$ & $\mathrm{pL}$ & $\log \left(\frac{n}{1-n}\right)$ & LogK $_{1}$ \\
\hline 8.50 & 5.30 & 6.29 & 6.31 & 0.02 & 0.2750 & 2.64 & -0.4210 & 2.2190 \\
8.72 & 5.35 & 6.37 & 6.40 & 0.03 & 0.4286 & 2.42 & -0.1249 & 2.2951 \\
9.00 & 5.40 & 6.46 & 6.49 & 0.03 & 0.4648 & 2.14 & -0.0612 & 2.0788 \\
9.22 & 5.45 & 6.55 & 6.59 & 0.04 & 0.6667 & 1.96 & 0.3010 & 2.2610 \\
9.51 & 5.55 & 6.66 & 6.70 & 0.04 & 0.7720 & 1.67 & 0.5297 & 2.1997 \\
\hline
\end{tabular}

LogK $_{\mathbf{1}}$ (Average value) $=2.2108 \pm 0.0825$

Table 16: Point-wise method, Cd (Hydrolysed PSHA)

\begin{tabular}{|l|l|l|l|l|l|l|l|l|}
\hline $\mathrm{pH}$ & $\mathrm{BV}_{1}$ & $\mathrm{BV}_{2}$ & $\mathrm{BV}_{3}$ & $\left(\mathrm{~V}_{3}-\mathrm{V}_{2}\right)$ & $\mathrm{n}$ & $\mathrm{pL}$ & $\log \left(\frac{n-1}{2-n}\right)$ & Log $_{2}$ \\
\hline 9.73 & 5.55 & 6.78 & 6.83 & 0.06 & 1.4042 & 1.47 & -0.1686 & 1.3014 \\
10.00 & 5.60 & 6.90 & 6.95 & 0.06 & 1.7838 & 1.23 & 0.5593 & 1.7893 \\
10.23 & 5.65 & 7.05 & 7.10 & 0.06 & 3.1429 & 1.09 & & \\
10.49 & 5.70 & 7.10 & 7.16 & 0.06 & 3.1429 & 0.89 & & \\
& & & & & & & & \\
\hline
\end{tabular}

$\operatorname{LogK}_{2}$ (Average value) $=1.5453 \pm 0.3450$

Table 17: Point-wise method, Cd (Unhydrolysed PSHA)

\begin{tabular}{|l|l|l|l|l|l|l|l|l|}
\hline $\mathrm{pH}$ & $\mathrm{BV}_{1}$ & $\mathrm{BV}_{2}$ & $\mathrm{BV}_{3}$ & $\mathrm{~V}_{3}-\mathrm{V}_{2}$ & $\mathrm{n}$ & $\mathrm{pL}$ & $\log \left(\frac{n}{n-1}\right)$ & $\operatorname{Log~}_{1}$ \\
\hline 8.50 & 5.30 & 5.81 & 5.86 & 0.05 & 0.3717 & 2.88 & -0.2280 & 2.6520 \\
8.72 & 5.35 & 5.90 & 5.95 & 0.05 & 0.3873 & 2.66 & -0.1992 & 2.4608 \\
9.00 & 5.40 & 6.00 & 6.06 & 0.06 & 0.4853 & 2.38 & -0.0255 & 2.3545 \\
9.22 & 5.45 & 6.10 & 6.16 & 0.06 & 0.5157 & 2.18 & -0.0272 & 2.2072 \\
9.51 & 5.50 & 6.20 & 6.27 & 0.07 & 0.6417 & 1.89 & 0.2530 & 1.1430 \\
9.73 & 5.55 & 6.33 & 6.41 & 0.08 & 0.8000 & 1.69 & 0.6020 & 2.2920 \\
& & & & & & & & \\
\hline
\end{tabular}

$\operatorname{LogK}_{1}($ Average value $)=2.2516 \pm 0.5380$ 
BAJOPAS Volume 14 Number 1,June, 2021

Table 18: Point-wise method, Cd (Unhydrolysed PSHA)

\begin{tabular}{|l|l|l|l|l|l|l|l|l|}
\hline $\mathrm{pH}$ & $\mathrm{BV}_{1}$ & $\mathrm{BV}_{2}$ & $\mathrm{BV}_{3}$ & $\mathrm{~V}_{3}-\mathrm{V}_{2}$ & $\mathrm{n}$ & $\mathrm{pL}$ & $\log \left(\frac{n-1}{2-n}\right)$ & $\log \mathrm{K}_{2}$ \\
\hline 10.00 & 5.60 & 6.47 & 6.57 & 0.10 & 1.1434 & 1.43 & & \\
10.23 & 5.65 & 6.62 & 6.72 & 0.10 & 1.3448 & 1.23 & -0.2788 & 0.9512 \\
10.49 & 5.70 & 6.80 & 6.90 & 0.10 & 1.7742 & 1.03 & 0.5351 & 1.5651 \\
\hline
\end{tabular}

$\operatorname{LogK}_{2}($ Average value $)=1.2581 \pm 0.4340$

Table 19: Stepwise and overall Stability constants of thehydrolysed and unhydrolysed divalent metal (II) complexes

\begin{tabular}{|c|c|c|c|}
\hline Chelates & LogK $_{1}$ & $\log _{2}$ & Log $\beta$ \\
\hline [Cu (Hydrolysed PSHA-1) $\left.{ }_{2}\right]$ & 2.4788 & 1.4280 & 3.9068 \\
\hline$\left[\mathrm{Pb}(\text { Hydrolysed PSHA-1) })_{2}\right]$ & 2.5832 & 1.1963 & 3.7795 \\
\hline$\left[\mathrm{Cd}(\text { Hydrolysed PSHA-1 })_{2}\right]$ & 2.2108 & 1.5453 & 3.7561 \\
\hline$\left[\mathrm{Mg}(\text { Hydrolysed PSHA-1 })_{2}\right]$ & 2.1382 & 1.5453 & 3.6835 \\
\hline [Cu (Unhydrolysed PSHA-1) & 2.3059 & 1.2209 & 3.5268 \\
\hline$[\mathrm{Pb}$ (Unhydrolysed PSHA-1) 2$]$ & 2.2364 & 1.2239 & 3.4603 \\
\hline [Cd (Unhydrolysed PSHA-1) 2 ] & 2.2516 & 1.2581 & 3.5097 \\
\hline$[\mathrm{Mg}$ (Unydrolysed PSHA-1) & 2.1568 & 0.9127 & 3.0695 \\
\hline
\end{tabular}

The results obtained (Table19) shows the stepwise and overall stability constants to be not high indicating low stability of the complexes, because the solubility of most metal ions in the basic $\mathrm{pH}$ range is minimal due to metal hydroxide precipitation (Karimi, 2017). In general, the stepwise stability constants $\left(K_{1}\right.$ and $K_{2}$ ) follow the order $K_{1}>K_{2}$ for the copper, lead, magnesium and cadmium complexes respectively. The steady decrease of the values with increasing number of ligands is in agreement with the prediction made by researchers (Na'aliya, 2013). The decrease could be attributed to the fact that as the number of the ligands (Humate ions) that enters the coordination zone increases the aqua molecules available for replacement by the ligands become less. Thus, the metal ions become less electron loving with progressive intake of the ligand and this results in the decrease in the values of the constants (Na'aliya, 2013). Also the stability of the complexes is influenced by the size and number of the chelate rings(Mackay and Mackay,2002).All the complexes form rings in their structure as humate, a bidentate ligand, bond the metal ions in the ratio 1:2 (Boguta and Sokolowska, 2016) forming chelate rings. The values of the overall stability constants $(\log \beta)$ obtained for humate complexes are not high indicating low stability as the values are not high. LogK values for copper-humates (Table 3 to 6) obtained in this study are lower than those reported for the complexes of humic acids (Pandey et al., 2015; Dinu, 2013; Kaschl et al., 2010 and Gilbeto and Jorg, 2001). The values of LogK(Table 7 to 10 ) forlead-humates are lower than those reported for the lead in the literature (Dinu, 2013; Gilbeto and Jorg 2001). Log K values(Table 11 to 14 ) for magnesium-humates obtained in this study are close to those reported by (Pandey et al., 2015). Log K values of cadmium-humates (Table 15 to 18 ) obtained in this work near to the one reported by (Dinu, 2013 and Pandey et al., 2015).The difference between the reported values and the values obtained in this study might be probably as a result of acid hydrolysis of humic acid. The values of the overall stability constants $(\log \beta)$ of the copper humates complexes presented in Table 19 is high than that of other metal humate complexes, show relatively high stability of CuHA complexes, show the following order of stability: $\mathrm{Cu}>\mathrm{Pb}>\mathrm{Cd}>\mathrm{Mg}$; which are in close agreement to the findings of (Dinu, 2013 and Pandey et al., 2015).The high stability of Cuhumate chelate could be attributed to the existence of coordinate covalent bond between the complexing agents and the $\mathrm{Cu}^{2+}$ ions. Since, $\mathrm{Cu}^{2+}$ being a metal of the transitional series with $3 d^{9}$ electronic configurations can accept the electrons from the complexing agents. Similarly, the low stabilities of $\mathrm{Pb}, \mathrm{Cd}$ and $\mathrm{Mg}$ complexes could be explained by that $\mathrm{Pb}^{2+}$ with $6 s^{2}, \mathrm{Cd}^{2+}$ with $4 \mathrm{~d}^{10}$ and $\mathrm{Mg}^{2+}$ with $2 \mathrm{p}^{6}$ their electronic configuration has a completely filled $\mathrm{d}, \mathrm{p}$ and $\mathrm{s}$ orbitals. Moreover, the stabilities of metal ions with hydrolysed humic acid from peat soil were higher than those with unhydrolysed humic acid from peat soil; which is ascribed to the high content of acidity in hydrolysed humic acid than unhydrolysed humic acid. 
BAJOPAS Volume 14 Number 1,June, 2021 CONCLUSION

The values of logk for $\mathrm{Cu}(\mathrm{II})$ hydrolysed humic acid complex was higher followed by $\mathrm{Pb}$ (II), $\mathrm{Cd}(\mathrm{II})$ and $\mathrm{Mg}$ (II) hydrolysed humic acid complexes as compared with metal(II) unhydrolysed humic acid complexes. This indicates acid hydrolysis of humic acid can

\section{REFERENCES}

Almeida, V.R. and Szpoganicz, B. (2015). Humic Acid Potentiometric Response Patterns:Out- of Equilibrium Properties and Species Distribution Modelling. Chemical. Biol. Technol. Agric. 2: 17.

Anđelković, T., Nikolić, R., Bojić, A.,Anđelković, D., and Nikolic G.,(2010). Binding of Cadmium to Soil Humic Acid as A Function of Carboxyl Group Content. Macedonian Journal of Chemistry and Chemical Engineering.29(2): 215-224.

Anil, B. N. and Maroti, N. (2008). Studies on Influence of Die-Lectric Constants on Complex Equilibria between Substituted Py-Razalines and Lanthanide Metal Ions pH-Metrically. Amer.-Euras. scient. Res. 3(2): 212-216.

Ashok, K., Pandey, S. P. and Misra, V (2000). Stability Constants of Metal-Humic Acid Complexes and its Role in Environmental Detoxification. Journal of Ecotoxicology and Environmental Safety. 47(2):157-200.

Badr, M. H., El-Halafawi, M. H. and Abd El-al Zeid, E. R. (2012). Comparison Between the Effect of Ionic Strength on Acidity and Dissociation Constants of Humic Acids Extracted from Sewage Sludge and Nile Water Hyacinth Composts.Global Journal of Environmental Research 6 (1): 36-43.

Baruah, M.K., Borah, D., Saikia, P.P., Paul, S., Sharma, T. (2015). Evaluation of pKa Values of Soil Humic Acids and their Complexation Properties. International Journal of Plant \& Soil Science 6(4) : 218-228.

Boguta, P. Sokolowska, Z. (2016). Interactions of $\mathrm{Zn}$ (II) Ions with Humic Acids Isolated from Various Types of Soils. Effect of $\mathrm{pH}, \mathrm{Zn}$ Concentrations and Humic Acids Chemical Properties. Journal of Geochemical Explaration 168. 119-126.

Borges, F., Guimaraes, C., Lima, L.F.C., Pinto, I. and Reis, S.(2005). Potentiometric Studies on the Complexation of Copper(II) by Phenolic Acids as Discrete Ligand Models of enhance the complexation behavior of humic acid with metal (II) ions. However, the higher values of $\log \beta$ for $\mathrm{Cu}(\mathrm{II}), \mathrm{Pb}(\mathrm{II}), \mathrm{Cd}(\mathrm{II})$ and $\mathrm{Mg}(\mathrm{II})$ hydrolysed humic acid complexes indicates more stable stepwise complexes formed as compared with $\mathrm{Cu}(\mathrm{II}), \mathrm{Pb}$ (II), $\mathrm{Cd}$ (II) and $\mathrm{Mg}(\mathrm{II})$ unhydrolysed humic acid complexes.

Humic Substances Talanta 66 (2005) 670-673.

Chefetz, B., Salloum, M. J., Deshmulkin, A. P. and Hatcher, P. (2002). Structural Components of Humic Acids as Determined by Chemical Modifications and Carbon-13 NMR, Pyrolysis, and Thermochemolysis- Gas Chromatography/Mass Spectrometry. Soil Science Society of American Journal Abstract Division S-2- Soil Chemistry66. 1159-1171.

Dinu, M. I. (2013). Metals Complexation with Humic Acids in Surface Water of Different Environ. Sci. Technol. 31(1): 1-17.

Fernandes, A.N., Giacomelli, C., Giovanela, M. Vaz, D.V. Szpoganicz, B. and Maria M. D. (2009). Potentiometric Acidity Determination in Humic Substances Influenced by Different Analytical Procedures.J. Braz. Chem. Soc. 20 (9):14.

Gamal, A. H. (2015). Stability Constants of Rhenium (V) Metal Complexes with Selected Drugs. Pyrex Journal of Research in Environmental Studies. 2(2): 006-014.

Janrao, D. M., Pathan, J., Kayande, D.D., and Mulla, J.J. (2014). An Over View of Potentiometric Determination of Stability Constants of Metal Complexes. Sci. Revs. Chem. Commun.: 4(1), 2014, 11-24.

Karimi, H. (2017). Effect of pH and Initial Pb(II) Concentration on the Lead Removal Efficiency from Waste Water Using $\mathrm{Ca}(\mathrm{OH})_{2}$. International Journal of Water and Waste Water Treatment 3.2

Kaschl, A. Romheld, V. and Chen, Y. (2010). Binding of Cadmium, Copper and Zinc to Humic Substances Originating from Municipal Solid Waste Compost. Israel Journal of Chemistry Vol. 42(1): 89-98.

Kostic, I. S., Tatjana, P, A., Nikolic, R. S., Cvetkovic, T. P., Pavlovic, D. D., Aleksandar, L.J. and Bojic, A. (2012). Comparative Study of Binding Strengths of Heavy Metals with Humic Acid. J.serb. Chem. Soc. 76(9) pp 1-20. 
BAJOPAS Volume 14 Number 1,June, 2021

Na'aliya, J. (2013). Determination of Stepwise Stability Constants and Gibbs free Energy Change of Trisprolina to Complexes of some Divalent Transition Metal ions. Bayero Journal of Pure and Applied Sciences 6(2): 112-114.

Omar, A. A. and Ali, E. A. (2015). Potentiometric Studies on Complexes of $\mathrm{Cr}$ (III) and $\mathrm{Zr}$ (IV) with some Carboxylic Acids. International Journal of Advanced Chemistry, 3(1) 25-

37.

Pandey, A. K. Pandey, S. D. and Misr, V. (2015).Stability Constants of Metal- Humic Acid Complexes and Its Role in Environmental Detoxification. J. Ecotoxicology and Environmental Safety. 47(1):195-200.

Ram, N. and Raman, K.V. (1984). Stability Constants of Complexes of Metals with
Humicand Fuvic Acids under Non- acidConditions. Journal of Plant Nutrition and Soil Sciences.

147:171-176.

Santosh, D. D., Ashok, B. K., Vijay, J. T., Shivraj, G. W. and Vinay, V. W. (2011). Potentiometric Studies of Elec-Trolyte Effects on Complex Equilibria of Some Substituted 5-(2-hydroxy Phenyl) Pyrazoles. Der pharm. 3 (6): 75-83.

Sayyed, H. and Abdul Rahim, M. F. (2012). Studies of Binary Complexes of Metal Ions with Mandelic Acid by Potentiometry. Chem. J. 02 (6): 206209.

Shirvani, M. Moradian, E. Khalili, B. Bakhtiary, S. (2015). Interaction of $\mathrm{Cd}$ and $\mathrm{Pb}$ with Humate-Palygorskite and HumateSepiolite Complexes. Journal of water, air and pollution 3: 220-228. 


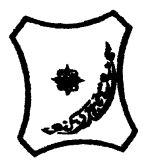

Bayero Journal of Pure and Applied Sciences, 14(1): 54 - 63

Received: November, 2020

Accepted: April, 2021

ISSN $2006-6996$

\title{
STABILITY CONSTANTS OF COMPLEXES OF METAL IONS WITH PEATSOIL HUMIC ACIDS UNDER NON-ACID-CONDITIONS
}

\author{
${ }^{* 1}$ Sabo, Yusuf ${ }^{2}$ Jimoh, W.L.O., ${ }^{3}$ Isa Baba Koki and ${ }^{4}$ Sholadoye, Q. 0. \\ ${ }^{1}$ Department of Pure and Industrial Chemistry, Bayero University, Kano \\ ${ }^{3}$ Department of Chemistry, Yusuf Maitama Sule University Kano. P.M.B. 3220 Kano, Nigeria. \\ ${ }^{4}$ Department of Chemistry, Nigerian Police Academy, Wudil, Kano-Nigeria
}

*Correspondence E-mail; saboyusuf18@yahoo.com

ABSTRACT

Stability constants of complexes of four divalent metal ions viz. $\mathrm{Cu}^{2+}, \mathrm{Pb}^{2+}, \mathrm{Mg}^{2+}$ and $\mathrm{Cd}^{2+}$ with humic acids (HA) were determined by potentiometric titration of humic acids with the corresponding salt of the divalent metals in aqueous media under non-acid-condition. The log $K$ (logarithm of the stability constant) ranged from 1.0942 to 2.7471 for metalhumic acid complexes were determined using point-wise computational method. The order of stability constants were obtained as follows: $\mathrm{Cu}>\mathrm{Pb}>\mathrm{Cd}>\mathrm{Mg}$ for metal $-\mathrm{HA}$ complexes respectively, indicating a higher degree of complexation with Cu metal ion.

Keywords: stability constant, humic acid, potentiometric titration, divalent metals, acid hydrolysis.

\section{NTRODUCTION}

The stability constant of a complex is the numerical expression of its stability and provides a quantitative measure of affinity of the metal ion to the complexing agent. An understanding of the relative stability of metal-complexes helps in predicting the behavior of metal ions in the soil (Ram and Raman, 1982). Extensive researches has been done to determine the stability constants of the complexes formed between humic acid (HA) with a number of metal ions. Ashok et al., (2000) reported that humic acid with hydroxyl, phenoxyl and carboxyl reactive groups can form coordination compound with metal ions at $\mathrm{pH}$ 3.5. The stability constants(Log K) for different metalhumic acid complexes indicated the following order of the stabilities of complexes formed between humic acid and metal ion, $\mathrm{Cu}>\mathrm{Fe}$ $>\mathrm{Pb}>\mathrm{Ni}>\mathrm{Co}>\mathrm{Ca}>\mathrm{Cd}>\mathrm{Zn}>\mathrm{Mn}>\mathrm{Mg}$. Andelkovic et al., (2010) investigated the binding of $\mathrm{Cd}$ (II) to soil humic acid at pH 6.5 and in $0.1 \mathrm{M} \mathrm{KNO}_{3}$ ionic medium. The stability constant for binding indicating greater stability in the case when carboxyl groups are involved in complexation reaction. Kostic et al.,(2012) investigated the complexation of humic acid with certain heavy metal ions (Co(II), $\mathrm{Ni}(\mathrm{II}), \mathrm{Cu}(\mathrm{II})$,
$\mathrm{Zn}(\mathrm{II})$, and $\mathrm{Pb}(\mathrm{II})$. The experiment was performed at $25^{\circ} \mathrm{C}$, at pH 4.0 and ionic strength of $0.01 \mathrm{M}$. Stability constant of complex between $\mathrm{Pb}$ (II) ions and humic acid is greater than stability constants of other investigated metalhumate complexes. Bogata and Sokolowska (2016) analyses the interaction between humic acids from different soils and $\mathrm{Zn}$ (II) ions at wide concentration ranges and at $\mathrm{pH} 5$. Studies have showed significant impact of $\mathrm{Zn}$ concentration, $\mathrm{pH}$ and some properties of humic acids with zinc.But all of these studies were limited to acidic $\mathrm{pH}$ range. Therefore, the present study was carried out to determine and compare the stability constants of complexes of metal ions with hydrolysed peat soil humic acid and unhydrolysed peat soil humic under non-acid conditions.

\section{MATERIALS AND METHODS}

Analytical grade chemicals used includes hydrochloric acid $(\mathrm{HCl})$, nitric acid $\left(\mathrm{HNO}_{3}\right)$, sodium hydroxide $(\mathrm{NaOH})$, lead nitrate $\mathrm{Pb}\left(\mathrm{NO}_{3}\right)_{2}$, copper nitrate $\mathrm{Cu}\left(\mathrm{NO}_{3}\right)_{2} \cdot 3 \mathrm{H}_{2} \mathrm{O}$, cadmium nitrate $\mathrm{Cd}\left(\mathrm{NO}_{3}\right)_{2} \cdot 4 \mathrm{H}_{2} \mathrm{O}$, magnesium nitrate $\mathrm{Mg}\left(\mathrm{NO}_{3}\right)_{2} \cdot 6 \mathrm{H}_{2} \mathrm{O}$, potassium nitrate $\left(\mathrm{KNO}_{3}\right)$, calcium chloride $\left(\mathrm{CaCl}_{2}\right)$, (sigma-Aldrich). Dowex 50WX8, (20-50 mesh) from Fluka. 


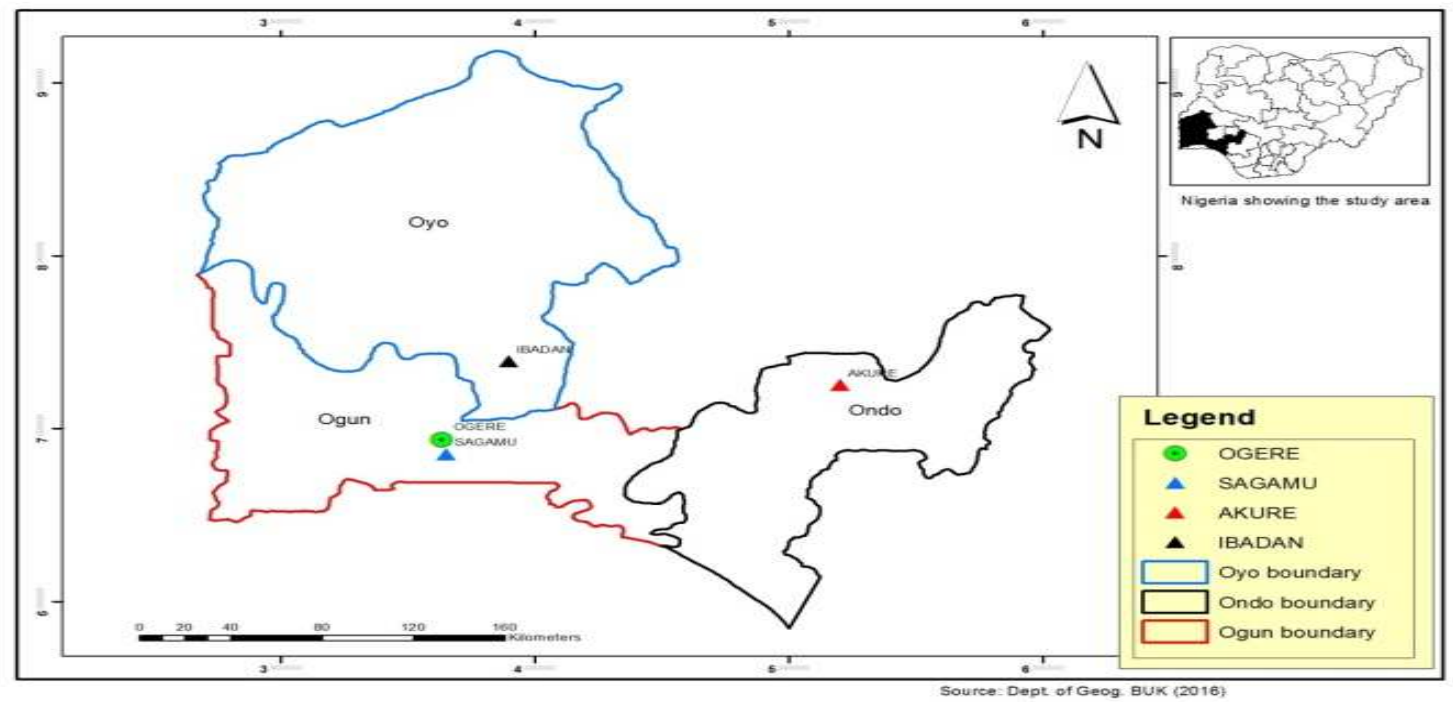

Figure 1: Map showing the sampling point at Sagamu Town, Ogun State.

\section{Description of Sampling Area}

Sagamu has geographical coordinates between $6^{\circ} 50^{\prime}$ north; $3^{\circ} 38^{\prime}$ east is located in south western region of Nigeria. The region has tropical wet and dry climate with a lengthy wet season and relatively constant temperatures throughout the course of the year. Wet season runs from March to October, November to December forms the region dry season. The vegetation type of the region is savannah which is really grassland with small bushes and occasional big trees. Grassland soils have substantially higher organic matter content than forest soils (Novackova, 2011).

\section{Sample Collection}

The Peatsoil samples were collected from four different sampling points $(0-10 \mathrm{~cm}$ depth) in Sagamu into polyethylene bag with plastic spoons. Samples were taken to the laboratory, extraneous materials were removed; the samples were air-dried, crushed and ground to a fine powder in a mortar passed through a $0.20 \mathrm{~mm}$ sieve. The samples were kept for analysis.

\section{Isolation and purification of humic acid from peat soil sample}

Peatsoil sample $(100 \mathrm{~g})$ was mixed with 1000 $\mathrm{cm}^{3}$ of $0.1 \mathrm{M} \mathrm{NaOH}$ solution, shaken for 3hours and left to stand overnight. Dark-coloured supernatant was obtained and decanted from solid residue. The dark-coloured supernatant was acidified to $(\mathrm{pH}=1.0)$ with $6 \mathrm{M} \mathrm{HCl}$ stirred and allowed to stand for 6 hours. Yellowish brown supernatant and dark-brown precipitate were obtained. The yellowish brown supernatant was decanted followed by centrifuge and discarded. The dark-brown precipitate was mixed with $500 \mathrm{~cm}^{3}$ of $0.1 \mathrm{M} \mathrm{NaOH}$ solution followed by passing through dowex resin. The dark-brown solution was acidified to $(\mathrm{pH}=1.0)$ with $6 \mathrm{M} \mathrm{HCl}$ stirred and allowed to stand for 3 hours. The dark-brown precipitate was washed several times with deionized water. The supernatant was treated with $\mathrm{AgNO}_{3}$ solution until no white precipitate observed. The humic acid was transferred to weighed crucible and dried at $60^{\circ} \mathrm{C}$ in an oven for 12 hours. The humic acid was cooled and dried in the desiccator, weighed and recorded. The obtained humic acid was dried again at $60^{\circ} \mathrm{C}$ for additional 6 hours cooled and dried in the desiccator, weighed and recorded constant weight was obtained (Baruah et al., 2015).

\section{FT-IR analysis}

FT-IR spectra of humic acid sample was analysed using Carry 630 FT-IR Agilent Technologies.

Unhydrolysed compost humic acid

The unhydrolysed humic acid was obtained after isolation and purification of compost humic acid and kept for investigation.

\section{Acid hydrolysis of Peatsoil acid}

Peatsoil humic acid sample (1g) was refluxed for 12 hours at $\left(160^{\circ} \mathrm{C}\right)$ with $50 \mathrm{~cm}^{3}$ of $6 \mathrm{M} \mathrm{HCl}$. The mixture was allowed to cool, decanted, and centrifuged after hydrolysis. The insoluble residues were washed with distilled water via centrifugation several times, and the supernatant was treated with $\mathrm{AgNO}_{3}$ solution until no white precipitate was observed. The residue was thoroughly dried over $\mathrm{CaCl}_{2}$ in a desiccator at room temperature (Chefetz et al., 2002). Finally, the obtained hydrolysed humic acid was kept for investigation. 
BAJOPAS Volume 14 Number 1,June, 2021 Potentiometric Titrations

Potentiometric measurements were carried out using a pH-meter Jenway (model 3510) with combine electrode, the sensitivity of the $\mathrm{pH}$ meter is 0.01 units. The $\mathrm{pH}$ meter was switched on half an hour before starting the titration for initial warm up of the instrument. The instrument was calibrated with an aqueous standard buffer solution of $\mathrm{pH} 4.00$ and 10.0 (borate buffer) prepared from a "Qualigens" buffer tablets.

The following sets of solutions were prepared in a $250 \mathrm{~cm}^{3}$ volumetric flask separately for $\mathrm{pH}$ metric titrations.

(i) $5 \mathrm{~cm}^{3} 0.1 \mathrm{M} \mathrm{HCl}+40 \mathrm{~cm}^{3}$ deionized water

(ii) $5 \mathrm{~cm}^{3} 0.1 \mathrm{M} \mathrm{HCl}+39 \mathrm{~cm}^{3}$ deionized water $+1 \mathrm{~cm}^{3} 0.15 \mathrm{gcm}^{-3}$ humic acid

(iii) $5 \mathrm{~cm}^{3} 0.1 \mathrm{M} \mathrm{HCl}+37 \mathrm{~cm}^{3}$ deionized water $+1 \mathrm{~cm}^{3} 0.15 \mathrm{gcm}^{-3}$ humic acid

$$
+2 \mathrm{~cm}^{3} \quad 0.01 \mathrm{M} \mathrm{Cu} \text { (II) }
$$

The solutions were titrated against standardized $0.110 \mathrm{MNaOH}$ separately. The total volume of each mixture was adjusted to $50 \mathrm{~cm}^{3}$ and the ionic strength of the solutions was maintained constant at by adding appropriate amount of stock solution of $1 \mathrm{M} \mathrm{KNO}_{3}$ (Gamal, 2015; Omar and Ali, 2015). A magnetic stirrer was used to achieve thorough mixing of the interacting solutions at $550 \mathrm{rpm}$. The same set of experimental conditions was applied for potentiometric titration of remaining samples.

\section{Evaluation of pKa of Hydrolysed peat soil Humic Acids}

The proton-ligand formation number $\mathrm{n}_{\mathbf{A}}$ were calculated by Irving and Rossotti expression (Omar and Ali, 2015).

$\mathrm{nA}=\mathrm{Y}-\frac{(\mathrm{V} 2-\mathrm{V1})(\mathrm{No}-\mathrm{Eo})}{(\mathrm{VO}+\mathrm{V1}) \mathrm{TCL}}$ 1

Where: $Y$ is number of dissociable proton, $\left(\mathrm{V}_{2^{-}}\right.$ $V_{1}$ ) is the measure of displacement of the ligand curve relative to acid curve, $\mathrm{N}^{\circ}$ and $\mathrm{E}^{\circ}$ are the resultant concentration of alkali solution, free acid solution, $\mathrm{T}_{\mathrm{cL}}{ }^{\circ}$ is the total ligand concentration, $\mathrm{V}^{\circ}$ is the total volume of titration solution, $V_{1}$ is the volume of alkali added to acid solution, $V_{2}$ is the volume of alkali added to acid solution + ligand solution, acid dissociation constants (pKa - values) of ligand were calculated by algebraic method point wise calculation (Tables 1 ). The dissociation constants (pKa) were calculated according to the following relation:

$\mathrm{pKa}=\mathrm{pH}+\log \left(\frac{n A}{1-n A}\right)$ 2

Where: pKa is the acid dissociation constant, $\mathrm{n}_{\mathrm{A}}$ is the Proton-ligand formation number and $\mathrm{pH}$ is the pH-values (Omar and Ali, 2015).

\section{Determination of metal-ligand stability constants $(\log K)$ of complexes}

The potentiometric measurement for the determination of stability constant of a complex in solution is based on the fact that the redox potential of the couple $\frac{M^{+(m-n)}}{M^{+m}}$ is shifted significantly on complexation of the metal ion with the ligand. This method involves change in hydrogen ion concentration $\left[\mathrm{H}^{+}\right]$due to the displacement or association of one or more protons taking place during complexation reaction. This change can be found out by titrating the solutions containing free acid, acid with ligand, and acid with ligand and metal ion, individually against a standard alkali solution at a constant ionic strength or temperature. Either ionic strength or temperature may be varied for different sets of solutions. In all the cases, the change in the $\mathrm{pH}$ of the solution is measured after each addition of a known amount of alkali to the reaction cell which contains the reaction mixture. The titration curves are then drawn by plotting the measured $\mathrm{pH}$ values against the corresponding volume of alkali added and the stability constants of the complexes are determined from the titration curves by employing $\mathrm{pH}$-metric titration technique given by (Irving and Rossoti).

Metal-ligand stability constants ( $\log \mathrm{K}$ ) were determined by using the following relations:

$$
\bar{n}=\frac{\left(V_{3}-V_{2}\right)\left(E^{0}+N^{0}\right)}{\left(V^{0}+V_{2}\right) \bar{n}_{A} T_{m}^{0}}
$$

and

$$
P L=\log _{10}\left\{\frac{1+\beta_{n}^{H} \frac{1}{[\text { anti } \log \mathrm{pH}]^{\mathrm{n}}}}{\mathrm{T}_{\mathrm{L}}^{0}-n \bar{T}_{m}^{0}} \mathrm{X} \frac{\left(V^{0}+V_{3}\right)}{V^{0}}\right\}
$$


BAJOPAS Volume 14 Number 1,June, 2021

Where $T_{L}, T^{\circ}, E^{\circ}$, and $V^{\circ}$ havethe same significance as in equation (1) above, $T_{m}$ denotes the total concentration of metal present in solution, $V_{3}$ is the volume of metal ions present in solution and $\beta^{H}$ is the overall proton ligand stability constant. The metal-ligand stability constants (log K) were determined by employing point wise computational Method (eq. 5 and 6).

$\operatorname{LogK}_{1}=\log \left(\frac{n}{1-n}\right)+\mathrm{pL}$ .5

$\operatorname{LogK}_{2}=\log \left(\frac{1-n}{2-n}\right)+\mathrm{pL}$ ...6

Where: Log $\mathrm{K}$ is the metal-ligand stability constant, $\mathrm{pL}$ is the Free ligand exponent function, $\mathbf{n}$ is the Average number of ligand attached with metal ion (Janraoet al., 2014). The results obtained were analyzed by an ORIGIN 2016 program using titration data and then the proton-ligand stability constants (pKa) and Metal-ligand stability constant (LogK) calculated (Omar and Ali, 2015).

\section{RESULTS AND DISCUSSION}

Fourier transformed infrared (FT-IR) spectra of isolated humic acid from peat soils Figure 2 had distinct clear absorption bands indicating the presence of major humic acid structural elemental groups such as $\mathrm{H}$ bonded $\mathrm{OH}$ $\left(3680 \mathrm{~cm}^{-1}\right.$ peak $), C=0$ of carbonyl $\left(1721 \mathrm{~cm}^{-1}\right.$ peak), functional groups of aliphatic components $\mathrm{CH}_{2}\left(2918 \mathrm{~cm}^{-1}\right.$ peak) and $\mathrm{C}-\mathrm{O}$ stretching of polysaccharide $\left(1168 \mathrm{~cm}^{-1}\right.$ peak). The positions of the absorption bands of the spectra fell within typical major absorption bands of humic acid which is at frequencies 3680, 2918, 1721, 1168 $\mathrm{cm}^{-1}$. The first peak centred in the vicinity of $3680 \mathrm{~cm}^{-1}$ region is attributed to phenol $\mathrm{OH}$ group bounded by intermolecular $\mathrm{H}$ bonds. The $2918 \mathrm{~cm}^{-1}$ band usually has absorption maximum at $2918 \mathrm{~cm}^{-1}$ which is due to $\mathrm{C}-\mathrm{H}$ stretching of alkane group $\left(\mathrm{CH}_{2}\right)$. The next major absorption band is $1721 \mathrm{~cm}^{-1}$. This band has been commonly ascribed to $\mathrm{C}=\mathrm{O}$ stretching of mainly carboxyl group $(\mathrm{COOH})$ with trace amount of ketones. The last peak was observed at 1168 $\mathrm{cm}^{-1}$ due to $\mathrm{C}-\mathrm{O}$ stretching of polysaccharides and this peak appeared also in the spectra of humic acid from peat soil. The FTIR spectra of the isolated humic acid contained all major characteristic absorption peaks of humic acid. These absorption peaks indicated the presence of the major structural elements of humic acid namely $\mathrm{H}$ bonded $\mathrm{OH}, \mathrm{C}=\mathrm{C}$ of aromatic ring, $\mathrm{C}=\mathrm{O}$ of carbonyl group (both carboxyl and ketonic), $\mathrm{CH}_{2}$ group. This strongly supports the presence of humic acid.

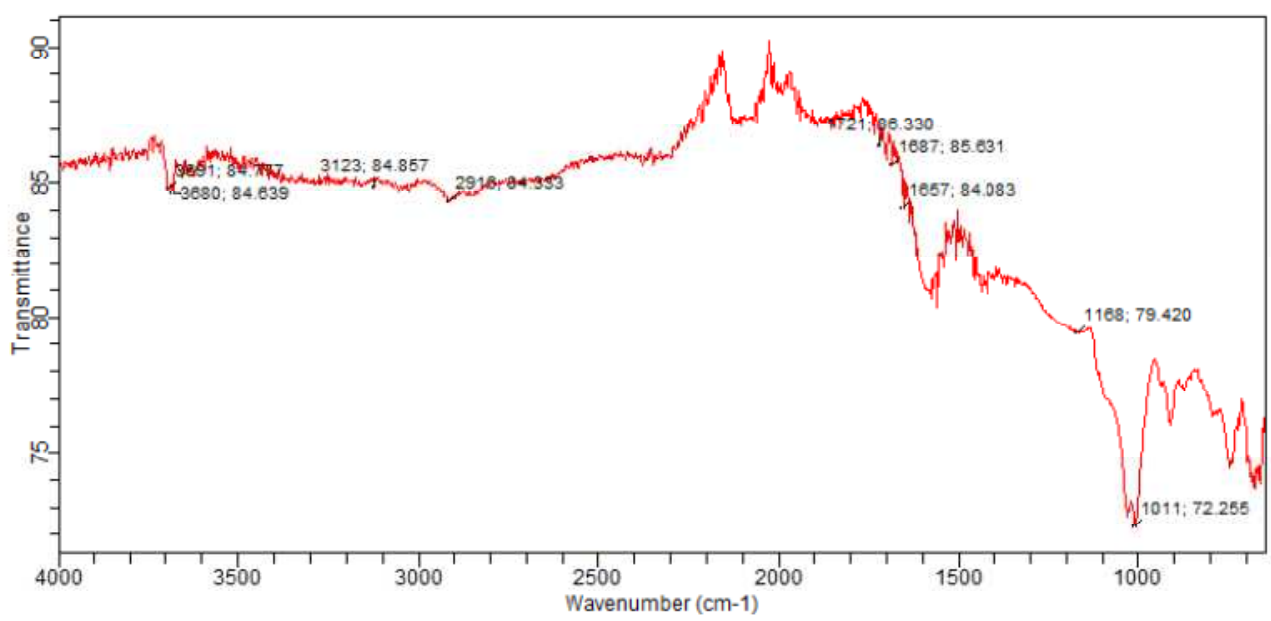

Fig. 2 : FT-IR spectraof peatsoilhumic acid (PSHA)

\section{Evaluation of acid dissociation constant (pka) of acid hydrolysed peat soil humicacid at phenolic group}

The value of the dissociation constant of the peat soil humic acid (PSHA) that underwent acidhydrolysis studied was found to be 8.9299 as shown Table 1, which is lower than the literaturevalues reported by Almeida and Szpoganics, (2015), Borges et al., (2005); Badr et al., (2012)and Fernandes et al,.(2009) of $9.73,9.47$ and 10.30. The difference between the obtained valuesand the reported values in this study might be probably as a result of acid hydrolysis of humicacid. 
BAJOPAS Volume 14 Number 1,June, 2021

Table 1: PKa of (Hydrolysed PSHA)

\begin{tabular}{|l|l|l|l|l|l|l|}
\hline $\mathrm{pH}$ & $\mathrm{BV}_{1}$ & $\mathrm{BV}_{2}$ & $\mathrm{~V}_{2}-\mathrm{V}_{1}$ & $\mathrm{nA}$ & $\log \left(\frac{n A}{1-n A}\right)$ & $\mathrm{pKa}$ \\
\hline 8.50 & 5.30 & 6.29 & 0.99 & 0.3594 & -0.2510 & 8.2490 \\
8.72 & 5.35 & 6.37 & 1.02 & 0.3400 & -0.2880 & 8.4320 \\
9.00 & 5.40 & 6.46 & 1.06 & 0.3141 & -0.3391 & 8.6609 \\
9.22 & 5.45 & 6.55 & 1.10 & 0.2882 & -0.3927 & 8.8273 \\
9.51 & 5.50 & 6.66 & 1.16 & 0.2494 & -0.4786 & 9.0314 \\
9.73 & 5.55 & 6.78 & 1.23 & 0.2041 & -0.5910 & 9.1390 \\
10.00 & 5.60 & 6.90 & 1.30 & 0.1589 & -0.7238 & 9.2762 \\
10.23 & 5.65 & 7.05 & 1.40 & 0.0941 & -0.9835 & 9.2465 \\
10.49 & 5.70 & 7.10 & 1.40 & 0.0941 & -0.9835 & 9.5065 \\
\hline
\end{tabular}

Average pKa $=8.9299 \pm 0.4186$

Table 2: PKa of (Unhydrolysed PSHA)

\begin{tabular}{|l|l|l|l|l|l|l|}
\hline $\mathrm{pH}$ & $\mathrm{BV}_{1}$ & $\mathrm{BV}_{2}$ & $\mathrm{~V}_{2}-\mathrm{V}_{1}$ & $\mathrm{nA}$ & $\log \left(\frac{\boldsymbol{n A}}{1-\boldsymbol{n}}\right)$ & $\mathrm{pKa}$ \\
\hline 8.50 & 5.30 & 5.81 & 0.51 & 0.6619 & 0.2919 & 8.7919 \\
8.72 & 5.35 & 5.90 & 0.55 & 0.6357 & 0.2418 & 8.9618 \\
9.00 & 5.40 & 6.00 & 0.60 & 0.6029 & 0.1813 & 9.1813 \\
9.22 & 5.45 & 6.10 & 0.65 & 0.5701 & 0.1226 & 9.3426 \\
9.51 & 5.50 & 6.20 & 0.70 & 0.5376 & 0.0654 & 9.5754 \\
9.73 & 5.55 & 6.33 & 0.78 & 0.4851 & -0.0259 & 9.7041 \\
10.00 & 5.60 & 6.47 & 0.87 & 0.4262 & -0.1291 & 9.8709 \\
10.23 & 5.65 & 6.62 & 0.99 & 0.3609 & -0.2481 & 9.9819 \\
10.49 & 5.70 & 6.80 & 1.10 & 0.2759 & -0.4690 & 10.0210 \\
\hline
\end{tabular}

Average pKa $=9.4923 \pm 0.4410$

Metal-ligand stability constant ( $\log \mathrm{K}$ )

The stabilityconstants require the accurate values of proton-ligand stability constants (Anil and Maroti, 2008). Metal titration curves crossed over ligand titration curve indicated the formation of complex upon proton release (Santosh, et al., 2011). If the values of n- are within range $0.2-0.8$ and $1.2-18$ this indicates the formation of $1: 1$ and 1:2 complexes (Sayyed and Mazahar, 2012).

The metal (II)-humate stepwise stability constants (log k) at phenolic group (Tables 318)

Table 3: Point-wise method, $\mathrm{Cu}$-(Hydrolysed PSHA)

\begin{tabular}{|l|l|l|l|l|l|l|l|l|}
\hline $\mathrm{pH}$ & $\mathrm{BV}_{1}$ & $\mathrm{BV}_{2}$ & $\mathrm{BV}_{3}$ & $\left(\mathrm{~V}_{3}-\mathrm{V}_{2}\right)$ & $\mathrm{n}$ & $\mathrm{pL}$ & $\log \left(\frac{n}{1-n}\right)$ & LogK $_{1}$ \\
\hline 8.50 & 5.30 & 6.29 & 6.33 & 0.04 & 0.5500 & 2.66 & 0.0871 & 2.7471 \\
8.72 & 5.35 & 6.37 & 6.41 & 0.04 & 0.5714 & 2.43 & 0.1249 & 2.5549 \\
9.00 & 5.40 & 6.46 & 6.50 & 0.04 & 0.6198 & 2.16 & 0.2122 & 2.3722 \\
9.22 & 5.45 & 6.55 & 6.59 & 0.04 & 0.6667 & 1.94 & 0.3010 & 2.2410 \\
\hline
\end{tabular}

LogK $_{1}$ (Average value) $=2.4788 \pm 0.2203$

Table 4: Point-wise method, $\mathrm{Cu}$-(Hydrolysed PSHA)

\begin{tabular}{|l|l|l|l|l|l|l|l|l|}
\hline $\mathrm{pH}$ & $\mathrm{BV}_{1}$ & $\mathrm{BV}_{2}$ & $\mathrm{BV}_{3}$ & $\left(\mathrm{~V}_{3}-\mathrm{V}_{2}\right)$ & $\mathrm{n}$ & $\mathrm{pL}$ & $\log \left(\frac{n-1}{2-n}\right)$ & LogK $_{2}$ \\
\hline 9.51 & 5.50 & 6.66 & 6.73 & 0.07 & 1.3509 & 1.70 & -0.2671 & 1.4329 \\
9.73 & 5.55 & 6.78 & 6.85 & 0.07 & 1.6383 & 1.51 & 0.2467 & 1.7567 \\
10.00 & 5.60 & 6.90 & 6.98 & 0.08 & 2.1783 & 1.31 & -0.2158 & 1.0942 \\
10.23 & 5.65 & 7.05 & 7.13 & 0.08 & 4.1904 & 1.27 & & \\
10.49 & 5.70 & 7.10 & 7.19 & 0.09 & 4.6920 & & & \\
\hline
\end{tabular}

Log $K_{2}($ Average value $)=1.4280 \pm 0.3312$ 
BAJOPAS Volume 14 Number 1,June, 2021

Table 5: Point-wise method, $\mathrm{Cu}$ (Unhydrolysed PSHA)

\begin{tabular}{|l|l|l|l|l|l|l|l|l|}
\hline $\mathrm{pH}$ & $\mathrm{BV}_{1}$ & $\mathrm{BV}_{2}$ & $\mathrm{BV}_{3}$ & $\left(\mathrm{~V}_{3}-\mathrm{V}_{2}\right)$ & $\mathrm{n}$ & $\mathrm{pL}$ & $\log \left(\frac{n}{n-1}\right)$ & Log $_{1}$ \\
\hline 8.50 & 5.30 & 5.81 & 5.85 & 0.04 & 0.2973 & 2.88 & -0.3736 & 2.5064 \\
8.72 & 5.35 & 5.90 & 5.95 & 0.05 & 0.3873 & 2.66 & -0.1992 & 2.4608 \\
9.00 & 5.40 & 6.00 & 6.05 & 0.05 & 0.4044 & 2.38 & -0.1681 & 2.2119 \\
9.22 & 5.45 & 6.10 & 6.15 & 0.06 & 0.5157 & 2.18 & -0.0272 & 2.2072 \\
9.51 & 5.50 & 6.20 & 6.27 & 0.07 & 0.6417 & 1.89 & 0.2530 & 1.1430 \\
\hline
\end{tabular}

$\operatorname{LogK}_{1}($ Average value $)=2.3059 \pm 0.6153$

Table 6:Point-wise method, $\mathrm{Cu}$ (Unhydrolysed PSHA)

\begin{tabular}{|l|l|l|l|l|l|l|l|l|}
\hline $\mathrm{pH}$ & $\mathrm{BV}_{1}$ & $\mathrm{BV}_{2}$ & $\mathrm{BV}_{3}$ & $\mathrm{~V}_{3}-\mathrm{V}_{2}$ & $\mathrm{n}$ & $\mathrm{pL}$ & $\log \left(\frac{n-1}{2-n}\right)$ & $\log \mathrm{K}_{2}$ \\
\hline 9.73 & 5.55 & 6.33 & 6.42 & 0.09 & 0.9000 & 1.69 & & \\
10.00 & 5.60 & 6.47 & 6.58 & 0.11 & 1.2578 & 1.44 & -0.4592 & 0.9808 \\
10.23 & 5.65 & 6.62 & 6.84 & 0.12 & 1.6137 & 1.26 & -0.2010 & 1.4610 \\
10.49 & 5.70 & 6.80 & 6.92 & 0.12 & 2.1052 & 1.03 & & \\
\hline
\end{tabular}

$\operatorname{LogK}_{2}$ (Average value) $=1.2209 \pm 0.3398$

Table 7:Point-wise method, Pb (Hydrolysed PSHA)

\begin{tabular}{|l|l|l|l|l|l|l|l|l|}
\hline $\mathrm{pH}$ & $\mathrm{BV}_{1}$ & $\mathrm{BV}_{2}$ & $\mathrm{BV}_{3}$ & $\left(\mathrm{~V}_{3}-\mathrm{V}_{2}\right)$ & $\mathrm{n}$ & $\mathrm{pL}$ & $\log \left(\frac{n}{1-n}\right)$ & LogK $_{1}$ \\
\hline 8.50 & 5.30 & 6.29 & 6.33 & 0.04 & 0.5500 & 2.66 & 0.0871 & 2.7471 \\
8.72 & 5.35 & 6.37 & 6.41 & 0.04 & 0.5714 & 2.43 & 0.1249 & 2.5549 \\
9.00 & 5.40 & 6.46 & 6.50 & 0.04 & 0.6198 & 2.16 & 0.2122 & 2.3722 \\
9.22 & 5.45 & 6.55 & 6.60 & 0.05 & 0.8333 & 1.96 & 0.6989 & 2.6589 \\
\hline
\end{tabular}

Log $_{\mathbf{1}}($ Average value $)=2.5832 \pm 0.1614$

Table 8:Point-wise method, Pb-(Hydrolysed PSHA)

\begin{tabular}{|l|l|l|l|l|l|l|l|l|}
\hline $\mathrm{pH}$ & $\mathrm{BV}_{1}$ & $\mathrm{BV}_{2}$ & $\mathrm{BV}_{3}$ & $\left(\mathrm{~V}_{3}-\mathrm{V}_{2}\right)$ & $\mathrm{n}$ & $\mathrm{pL}$ & $\log \left(\frac{n-1}{2-n}\right)$ & $\log \mathrm{K}_{2}$ \\
\hline 9.51 & 5.50 & 6.66 & 6.71 & 0.05 & 0.9650 & 1.67 & & \\
9.73 & 5.55 & 6.78 & 6.83 & 0.05 & 1.1702 & 1.44 & & \\
10.00 & 5.60 & 6.90 & 6.90 & 0.05 & 1.4864 & 1.22 & -0.0237 & 1.1963 \\
10.23 & 5.65 & 7.05 & 7.10 & 0.05 & 2.0190 & 1.09 & & \\
10.49 & 5.70 & 7.10 & 7.17 & 0.07 & 3.6492 & 1.00 & & \\
\hline
\end{tabular}

Log $K_{2}$ (Average value) $=1.1963$

Table 9: Point-wise method, Pb (Unhydrolysed PSHA)

\begin{tabular}{|l|l|l|l|l|l|l|l|l|}
\hline $\mathrm{pH}$ & $\mathrm{BV}_{1}$ & $\mathrm{BV}_{2}$ & $\mathrm{BV}_{3}$ & $\mathrm{~V}_{3}-\mathrm{V}_{2}$ & $\mathrm{n}$ & $\mathrm{pL}$ & $\begin{array}{l}\text { Log } \\
\left(\frac{n}{n-1}\right)\end{array}$ & Log $\mathrm{K}_{1}$ \\
\hline 8.50 & 5.30 & 5.81 & 5.85 & 0.04 & 0.2973 & 2.88 & -0.3736 & 2.5064 \\
8.72 & 5.35 & 5.90 & 5.94 & 0.04 & 0.3099 & 2.66 & -0.5477 & 2.3123 \\
9.00 & 5.40 & 6.00 & 6.05 & 0.05 & 0.4044 & 2.38 & -0.1681 & 2.2119 \\
9.22 & 5.45 & 6.10 & 6.15 & 0.06 & 0.5157 & 2.18 & 0.0272 & 2.2072 \\
9.51 & 5.50 & 6.20 & 6.26 & 0.07 & 0.6417 & 1.89 & 0.2530 & 2.1430 \\
9.73 & 5.55 & 6.40 & 6.40 & 0.07 & 0.7000 & 1.67 & 0.3680 & 2.0380 \\
\hline
\end{tabular}

LogK $_{1}$ (Average value) $=2.2364 \pm 0.1602$

Table 10: Point-wise method, Pb (Unhydrolysed PSHA)

\begin{tabular}{|l|l|l|l|l|l|l|l|l|}
\hline $\mathrm{pH}$ & $\mathrm{BV}_{1}$ & $\mathrm{BV}_{2}$ & $\mathrm{BV}_{3}$ & $\mathrm{~V}_{3}-\mathrm{V}_{2}$ & $\mathrm{n}$ & $\mathrm{pL}$ & $\log \left(\frac{n-1}{2-n}\right)$ & $\log \mathrm{K}_{2}$ \\
\hline 10.00 & 5.60 & 6.47 & 6.55 & 0.08 & 1.9503 & 1.41 & & \\
10.23 & 5.65 & 6.62 & 6.72 & 0.11 & 1.4792 & 1.26 & -0.0361 & 1.2239 \\
\hline
\end{tabular}

$\operatorname{LogK}_{2}$ (Average value) $=1.2239$

Table 11: Point-wise method, Mg (Hydrolysed PSHA)

\begin{tabular}{|l|l|l|l|l|l|l|l|l|}
\hline $\mathrm{pH}$ & $\mathrm{BV}_{1}$ & $\mathrm{BV}_{2}$ & $\mathrm{BV}_{3}$ & $\left(\mathrm{~V}_{3}-\mathrm{V}_{2}\right)$ & $\mathrm{n}$ & $\mathrm{pL}$ & $\log \left(\frac{n}{n-1}\right)$ & LogK $_{1}$ \\
\hline 8.50 & 5.30 & 6.29 & 6.31 & 0.02 & 0.2750 & 2.64 & -0.4290 & 2.2110 \\
8.72 & 5.35 & 6.37 & 6.39 & 0.02 & 0.2858 & 2.42 & -0.3978 & 2.0222 \\
9.00 & 5.40 & 6.46 & 6.49 & 0.03 & 0.4648 & 2.14 & -0.0612 & 2.0788 \\
9.22 & 5.45 & 6.55 & 6.59 & 0.04 & 0.6667 & 1.94 & 0.3010 & 2.2410 \\
\hline
\end{tabular}

$\log _{\mathbf{1}}($ Average value) $=2.1382 \pm 0.1046$ 
BAJOPAS Volume 14 Number 1,June, 2021

Table 12: Point-wise method, Mg (Hydrolysed PSHA)

\begin{tabular}{|l|l|l|l|l|l|l|l|l|}
\hline $\mathrm{pH}$ & $\mathrm{BV}_{1}$ & $\mathrm{BV}_{2}$ & $\mathrm{BV}_{3}$ & $\left(\mathrm{~V}_{3}-\mathrm{V}_{2}\right)$ & $\mathrm{n}$ & $\mathrm{pL}$ & $\log \left(\frac{n-1}{2-n}\right)$ & LogK $_{2}$ \\
\hline 9.51 & 5.55 & 6.66 & 6.71 & 0.05 & 0.9650 & 1.67 & & \\
9.73 & 5.55 & 6.78 & 6.84 & 0.06 & 1.4042 & 1.47 & -0.1686 & 1.3014 \\
10.00 & 5.60 & 6.90 & 6.93 & 0.06 & 1.7838 & 1.23 & 0.5593 & 1.7893 \\
10.23 & 5.65 & 7.05 & 7.10 & 0.06 & 3.1429 & 1.10 & & \\
10.49 & 5.70 & 7.10 & 7.18 & 0.07 & 3.6492 & 0.83 & & \\
\hline
\end{tabular}

LogK $_{2}($ Average value $)=1.5453 \pm 0.3450$

Table 13: Point-wise method, Mg (Unhydrolysed PSHA)

\begin{tabular}{|l|l|l|l|l|l|l|l|l|}
\hline $\mathrm{pH}$ & $\mathrm{BV}_{1}$ & $\mathrm{BV}_{2}$ & $\mathrm{BV}_{3}$ & $\mathrm{~V}_{3}-\mathrm{V}_{2}$ & $\mathrm{n}$ & $\mathrm{pL}$ & $\log \left(\frac{n}{n-1}\right)$ & $\operatorname{Log~}_{1}$ \\
\hline 8.50 & 5.30 & 5.81 & 5.85 & 0.04 & 0.2973 & 2.88 & -0.3736 & 2.5064 \\
8.72 & 5.35 & 5.90 & 5.94 & 0.04 & 0.3099 & 2.66 & -0.3477 & 2.3123 \\
9.00 & 5.40 & 6.00 & 6.04 & 0.04 & 0.3236 & 2.38 & -0.3202 & 2.0598 \\
9.22 & 5.45 & 6.10 & 6.15 & 0.05 & 0.4297 & 2.17 & -0.1230 & 2.0470 \\
9.51 & 5.50 & 6.20 & 6.26 & 0.06 & 0.5500 & 1.89 & 0.0871 & 1.9771 \\
9.73 & 5.55 & 6.33 & 6.40 & 0.07 & 0.7000 & 1.67 & 0.3680 & 2.0380 \\
\hline
\end{tabular}

LogK $_{1}$ (Average value) $=2.1568 \pm 0.2069$

Table 14: Point-wise method, Mg (Unhydrolysed PSHA)

\begin{tabular}{|l|l|l|l|l|l|l|l|l|}
\hline $\mathrm{pH}$ & $\mathrm{BV}_{1}$ & $\mathrm{BV}_{2}$ & $\mathrm{BV}_{3}$ & $\mathrm{~V}_{3}-\mathrm{V}_{2}$ & $\mathrm{n}$ & $\mathrm{pL}$ & $\log \left(\frac{n-1}{2-n}\right)$ & $\log \mathrm{K}_{2}$ \\
\hline 10.00 & 5.60 & 6.47 & 6.55 & 0.08 & 0.9148 & 1.41 & & \\
10.23 & 5.65 & 6.62 & 6.71 & 0.09 & 1.2102 & 1.20 & -0.5749 & 0.6251 \\
10.49 & 5.70 & 6.80 & 6.92 & 0.09 & 1.5968 & 1.03 & 0.1703 & 1.2003 \\
\hline
\end{tabular}

LogK $_{2}$ (Average value) $=0.9127 \pm 0.4070$

Table15:Point-wise method, Cd (Hydrolysed PSHA)

\begin{tabular}{|l|l|l|l|l|l|l|l|l|}
\hline $\mathrm{pH}$ & $\mathrm{BV}_{1}$ & $\mathrm{BV}_{2}$ & $\mathrm{BV}_{3}$ & $\left(\mathrm{~V}_{3}-\mathrm{V}_{2}\right)$ & $\mathrm{n}$ & $\mathrm{pL}$ & $\log \left(\frac{n}{1-n}\right)$ & LogK $_{1}$ \\
\hline 8.50 & 5.30 & 6.29 & 6.31 & 0.02 & 0.2750 & 2.64 & -0.4210 & 2.2190 \\
8.72 & 5.35 & 6.37 & 6.40 & 0.03 & 0.4286 & 2.42 & -0.1249 & 2.2951 \\
9.00 & 5.40 & 6.46 & 6.49 & 0.03 & 0.4648 & 2.14 & -0.0612 & 2.0788 \\
9.22 & 5.45 & 6.55 & 6.59 & 0.04 & 0.6667 & 1.96 & 0.3010 & 2.2610 \\
9.51 & 5.55 & 6.66 & 6.70 & 0.04 & 0.7720 & 1.67 & 0.5297 & 2.1997 \\
\hline
\end{tabular}

LogK $_{\mathbf{1}}$ (Average value) $=2.2108 \pm 0.0825$

Table 16: Point-wise method, Cd (Hydrolysed PSHA)

\begin{tabular}{|l|l|l|l|l|l|l|l|l|}
\hline $\mathrm{pH}$ & $\mathrm{BV}_{1}$ & $\mathrm{BV}_{2}$ & $\mathrm{BV}_{3}$ & $\left(\mathrm{~V}_{3}-\mathrm{V}_{2}\right)$ & $\mathrm{n}$ & $\mathrm{pL}$ & $\log \left(\frac{n-1}{2-n}\right)$ & Log $_{2}$ \\
\hline 9.73 & 5.55 & 6.78 & 6.83 & 0.06 & 1.4042 & 1.47 & -0.1686 & 1.3014 \\
10.00 & 5.60 & 6.90 & 6.95 & 0.06 & 1.7838 & 1.23 & 0.5593 & 1.7893 \\
10.23 & 5.65 & 7.05 & 7.10 & 0.06 & 3.1429 & 1.09 & & \\
10.49 & 5.70 & 7.10 & 7.16 & 0.06 & 3.1429 & 0.89 & & \\
& & & & & & & & \\
\hline
\end{tabular}

$\operatorname{LogK}_{2}$ (Average value) $=1.5453 \pm 0.3450$

Table 17: Point-wise method, Cd (Unhydrolysed PSHA)

\begin{tabular}{|l|l|l|l|l|l|l|l|l|}
\hline $\mathrm{pH}$ & $\mathrm{BV}_{1}$ & $\mathrm{BV}_{2}$ & $\mathrm{BV}_{3}$ & $\mathrm{~V}_{3}-\mathrm{V}_{2}$ & $\mathrm{n}$ & $\mathrm{pL}$ & $\log \left(\frac{n}{n-1}\right)$ & $\operatorname{Log~}_{1}$ \\
\hline 8.50 & 5.30 & 5.81 & 5.86 & 0.05 & 0.3717 & 2.88 & -0.2280 & 2.6520 \\
8.72 & 5.35 & 5.90 & 5.95 & 0.05 & 0.3873 & 2.66 & -0.1992 & 2.4608 \\
9.00 & 5.40 & 6.00 & 6.06 & 0.06 & 0.4853 & 2.38 & -0.0255 & 2.3545 \\
9.22 & 5.45 & 6.10 & 6.16 & 0.06 & 0.5157 & 2.18 & -0.0272 & 2.2072 \\
9.51 & 5.50 & 6.20 & 6.27 & 0.07 & 0.6417 & 1.89 & 0.2530 & 1.1430 \\
9.73 & 5.55 & 6.33 & 6.41 & 0.08 & 0.8000 & 1.69 & 0.6020 & 2.2920 \\
& & & & & & & & \\
\hline
\end{tabular}

$\operatorname{LogK}_{1}($ Average value $)=2.2516 \pm 0.5380$ 
BAJOPAS Volume 14 Number 1,June, 2021

Table 18: Point-wise method, Cd (Unhydrolysed PSHA)

\begin{tabular}{|l|l|l|l|l|l|l|l|l|}
\hline $\mathrm{pH}$ & $\mathrm{BV}_{1}$ & $\mathrm{BV}_{2}$ & $\mathrm{BV}_{3}$ & $\mathrm{~V}_{3}-\mathrm{V}_{2}$ & $\mathrm{n}$ & $\mathrm{pL}$ & $\log \left(\frac{n-1}{2-n}\right)$ & $\log \mathrm{K}_{2}$ \\
\hline 10.00 & 5.60 & 6.47 & 6.57 & 0.10 & 1.1434 & 1.43 & & \\
10.23 & 5.65 & 6.62 & 6.72 & 0.10 & 1.3448 & 1.23 & -0.2788 & 0.9512 \\
10.49 & 5.70 & 6.80 & 6.90 & 0.10 & 1.7742 & 1.03 & 0.5351 & 1.5651 \\
\hline
\end{tabular}

$\operatorname{LogK}_{2}($ Average value $)=1.2581 \pm 0.4340$

Table 19: Stepwise and overall Stability constants of thehydrolysed and unhydrolysed divalent metal (II) complexes

\begin{tabular}{|c|c|c|c|}
\hline Chelates & LogK $_{1}$ & $\log _{2}$ & Log $\beta$ \\
\hline [Cu (Hydrolysed PSHA-1) $\left.{ }_{2}\right]$ & 2.4788 & 1.4280 & 3.9068 \\
\hline$\left[\mathrm{Pb}(\text { Hydrolysed PSHA-1) })_{2}\right]$ & 2.5832 & 1.1963 & 3.7795 \\
\hline$\left[\mathrm{Cd}(\text { Hydrolysed PSHA-1 })_{2}\right]$ & 2.2108 & 1.5453 & 3.7561 \\
\hline$\left[\mathrm{Mg}(\text { Hydrolysed PSHA-1 })_{2}\right]$ & 2.1382 & 1.5453 & 3.6835 \\
\hline [Cu (Unhydrolysed PSHA-1) & 2.3059 & 1.2209 & 3.5268 \\
\hline$[\mathrm{Pb}$ (Unhydrolysed PSHA-1) 2$]$ & 2.2364 & 1.2239 & 3.4603 \\
\hline [Cd (Unhydrolysed PSHA-1) 2 ] & 2.2516 & 1.2581 & 3.5097 \\
\hline$[\mathrm{Mg}$ (Unydrolysed PSHA-1) & 2.1568 & 0.9127 & 3.0695 \\
\hline
\end{tabular}

The results obtained (Table19) shows the stepwise and overall stability constants to be not high indicating low stability of the complexes, because the solubility of most metal ions in the basic $\mathrm{pH}$ range is minimal due to metal hydroxide precipitation (Karimi, 2017). In general, the stepwise stability constants $\left(K_{1}\right.$ and $K_{2}$ ) follow the order $K_{1}>K_{2}$ for the copper, lead, magnesium and cadmium complexes respectively. The steady decrease of the values with increasing number of ligands is in agreement with the prediction made by researchers (Na'aliya, 2013). The decrease could be attributed to the fact that as the number of the ligands (Humate ions) that enters the coordination zone increases the aqua molecules available for replacement by the ligands become less. Thus, the metal ions become less electron loving with progressive intake of the ligand and this results in the decrease in the values of the constants (Na'aliya, 2013). Also the stability of the complexes is influenced by the size and number of the chelate rings(Mackay and Mackay,2002).All the complexes form rings in their structure as humate, a bidentate ligand, bond the metal ions in the ratio 1:2 (Boguta and Sokolowska, 2016) forming chelate rings. The values of the overall stability constants $(\log \beta)$ obtained for humate complexes are not high indicating low stability as the values are not high. LogK values for copper-humates (Table 3 to 6) obtained in this study are lower than those reported for the complexes of humic acids (Pandey et al., 2015; Dinu, 2013; Kaschl et al., 2010 and Gilbeto and Jorg, 2001). The values of LogK(Table 7 to 10 ) forlead-humates are lower than those reported for the lead in the literature (Dinu, 2013; Gilbeto and Jorg 2001). Log K values(Table 11 to 14 ) for magnesium-humates obtained in this study are close to those reported by (Pandey et al., 2015). Log K values of cadmium-humates (Table 15 to 18 ) obtained in this work near to the one reported by (Dinu, 2013 and Pandey et al., 2015).The difference between the reported values and the values obtained in this study might be probably as a result of acid hydrolysis of humic acid. The values of the overall stability constants $(\log \beta)$ of the copper humates complexes presented in Table 19 is high than that of other metal humate complexes, show relatively high stability of CuHA complexes, show the following order of stability: $\mathrm{Cu}>\mathrm{Pb}>\mathrm{Cd}>\mathrm{Mg}$; which are in close agreement to the findings of (Dinu, 2013 and Pandey et al., 2015).The high stability of Cuhumate chelate could be attributed to the existence of coordinate covalent bond between the complexing agents and the $\mathrm{Cu}^{2+}$ ions. Since, $\mathrm{Cu}^{2+}$ being a metal of the transitional series with $3 d^{9}$ electronic configurations can accept the electrons from the complexing agents. Similarly, the low stabilities of $\mathrm{Pb}, \mathrm{Cd}$ and $\mathrm{Mg}$ complexes could be explained by that $\mathrm{Pb}^{2+}$ with $6 s^{2}, \mathrm{Cd}^{2+}$ with $4 \mathrm{~d}^{10}$ and $\mathrm{Mg}^{2+}$ with $2 \mathrm{p}^{6}$ their electronic configuration has a completely filled $\mathrm{d}, \mathrm{p}$ and $\mathrm{s}$ orbitals. Moreover, the stabilities of metal ions with hydrolysed humic acid from peat soil were higher than those with unhydrolysed humic acid from peat soil; which is ascribed to the high content of acidity in hydrolysed humic acid than unhydrolysed humic acid. 
BAJOPAS Volume 14 Number 1,June, 2021 CONCLUSION

The values of logk for $\mathrm{Cu}(\mathrm{II})$ hydrolysed humic acid complex was higher followed by $\mathrm{Pb}$ (II), $\mathrm{Cd}(\mathrm{II})$ and $\mathrm{Mg}$ (II) hydrolysed humic acid complexes as compared with metal(II) unhydrolysed humic acid complexes. This indicates acid hydrolysis of humic acid can

\section{REFERENCES}

Almeida, V.R. and Szpoganicz, B. (2015). Humic Acid Potentiometric Response Patterns:Out- of Equilibrium Properties and Species Distribution Modelling. Chemical. Biol. Technol. Agric. 2: 17.

Anđelković, T., Nikolić, R., Bojić, A.,Anđelković, D., and Nikolic G.,(2010). Binding of Cadmium to Soil Humic Acid as A Function of Carboxyl Group Content. Macedonian Journal of Chemistry and Chemical Engineering.29(2): 215-224.

Anil, B. N. and Maroti, N. (2008). Studies on Influence of Die-Lectric Constants on Complex Equilibria between Substituted Py-Razalines and Lanthanide Metal Ions pH-Metrically. Amer.-Euras. scient. Res. 3(2): 212-216.

Ashok, K., Pandey, S. P. and Misra, V (2000). Stability Constants of Metal-Humic Acid Complexes and its Role in Environmental Detoxification. Journal of Ecotoxicology and Environmental Safety. 47(2):157-200.

Badr, M. H., El-Halafawi, M. H. and Abd El-al Zeid, E. R. (2012). Comparison Between the Effect of Ionic Strength on Acidity and Dissociation Constants of Humic Acids Extracted from Sewage Sludge and Nile Water Hyacinth Composts.Global Journal of Environmental Research 6 (1): 36-43.

Baruah, M.K., Borah, D., Saikia, P.P., Paul, S., Sharma, T. (2015). Evaluation of pKa Values of Soil Humic Acids and their Complexation Properties. International Journal of Plant \& Soil Science 6(4) : 218-228.

Boguta, P. Sokolowska, Z. (2016). Interactions of $\mathrm{Zn}$ (II) Ions with Humic Acids Isolated from Various Types of Soils. Effect of $\mathrm{pH}, \mathrm{Zn}$ Concentrations and Humic Acids Chemical Properties. Journal of Geochemical Explaration 168. 119-126.

Borges, F., Guimaraes, C., Lima, L.F.C., Pinto, I. and Reis, S.(2005). Potentiometric Studies on the Complexation of Copper(II) by Phenolic Acids as Discrete Ligand Models of enhance the complexation behavior of humic acid with metal (II) ions. However, the higher values of $\log \beta$ for $\mathrm{Cu}(\mathrm{II}), \mathrm{Pb}(\mathrm{II}), \mathrm{Cd}(\mathrm{II})$ and $\mathrm{Mg}(\mathrm{II})$ hydrolysed humic acid complexes indicates more stable stepwise complexes formed as compared with $\mathrm{Cu}(\mathrm{II}), \mathrm{Pb}$ (II), $\mathrm{Cd}$ (II) and $\mathrm{Mg}(\mathrm{II})$ unhydrolysed humic acid complexes.

Humic Substances Talanta 66 (2005) 670-673.

Chefetz, B., Salloum, M. J., Deshmulkin, A. P. and Hatcher, P. (2002). Structural Components of Humic Acids as Determined by Chemical Modifications and Carbon-13 NMR, Pyrolysis, and Thermochemolysis- Gas Chromatography/Mass Spectrometry. Soil Science Society of American Journal Abstract Division S-2- Soil Chemistry66. 1159-1171.

Dinu, M. I. (2013). Metals Complexation with Humic Acids in Surface Water of Different Environ. Sci. Technol. 31(1): 1-17.

Fernandes, A.N., Giacomelli, C., Giovanela, M. Vaz, D.V. Szpoganicz, B. and Maria M. D. (2009). Potentiometric Acidity Determination in Humic Substances Influenced by Different Analytical Procedures.J. Braz. Chem. Soc. 20 (9):14.

Gamal, A. H. (2015). Stability Constants of Rhenium (V) Metal Complexes with Selected Drugs. Pyrex Journal of Research in Environmental Studies. 2(2): 006-014.

Janrao, D. M., Pathan, J., Kayande, D.D., and Mulla, J.J. (2014). An Over View of Potentiometric Determination of Stability Constants of Metal Complexes. Sci. Revs. Chem. Commun.: 4(1), 2014, 11-24.

Karimi, H. (2017). Effect of pH and Initial Pb(II) Concentration on the Lead Removal Efficiency from Waste Water Using $\mathrm{Ca}(\mathrm{OH})_{2}$. International Journal of Water and Waste Water Treatment 3.2

Kaschl, A. Romheld, V. and Chen, Y. (2010). Binding of Cadmium, Copper and Zinc to Humic Substances Originating from Municipal Solid Waste Compost. Israel Journal of Chemistry Vol. 42(1): 89-98.

Kostic, I. S., Tatjana, P, A., Nikolic, R. S., Cvetkovic, T. P., Pavlovic, D. D., Aleksandar, L.J. and Bojic, A. (2012). Comparative Study of Binding Strengths of Heavy Metals with Humic Acid. J.serb. Chem. Soc. 76(9) pp 1-20. 
BAJOPAS Volume 14 Number 1,June, 2021

Na'aliya, J. (2013). Determination of Stepwise Stability Constants and Gibbs free Energy Change of Trisprolina to Complexes of some Divalent Transition Metal ions. Bayero Journal of Pure and Applied Sciences 6(2): 112-114.

Omar, A. A. and Ali, E. A. (2015). Potentiometric Studies on Complexes of $\mathrm{Cr}$ (III) and $\mathrm{Zr}$ (IV) with some Carboxylic Acids. International Journal of Advanced Chemistry, 3(1) 25-

37.

Pandey, A. K. Pandey, S. D. and Misr, V. (2015).Stability Constants of Metal- Humic Acid Complexes and Its Role in Environmental Detoxification. J. Ecotoxicology and Environmental Safety. 47(1):195-200.

Ram, N. and Raman, K.V. (1984). Stability Constants of Complexes of Metals with
Humicand Fuvic Acids under Non- acidConditions. Journal of Plant Nutrition and Soil Sciences.

147:171-176.

Santosh, D. D., Ashok, B. K., Vijay, J. T., Shivraj, G. W. and Vinay, V. W. (2011). Potentiometric Studies of Elec-Trolyte Effects on Complex Equilibria of Some Substituted 5-(2-hydroxy Phenyl) Pyrazoles. Der pharm. 3 (6): 75-83.

Sayyed, H. and Abdul Rahim, M. F. (2012). Studies of Binary Complexes of Metal Ions with Mandelic Acid by Potentiometry. Chem. J. 02 (6): 206209.

Shirvani, M. Moradian, E. Khalili, B. Bakhtiary, S. (2015). Interaction of $\mathrm{Cd}$ and $\mathrm{Pb}$ with Humate-Palygorskite and HumateSepiolite Complexes. Journal of water, air and pollution 3: 220-228. 


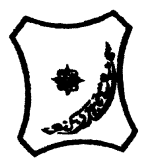

Bayero Journal of Pure and Applied Sciences, 14(1): 54 - 63

Received: November, 2020

Accepted: April, 2021

ISSN $2006-6996$

\title{
STABILITY CONSTANTS OF COMPLEXES OF METAL IONS WITH PEATSOIL HUMIC ACIDS UNDER NON-ACID-CONDITIONS
}

\author{
${ }^{* 1}$ Sabo, Yusuf ${ }^{2}$ Jimoh, W.L.O., ${ }^{3}$ Isa Baba Koki and ${ }^{4}$ Sholadoye, Q. 0. \\ ${ }^{1}$ Department of Pure and Industrial Chemistry, Bayero University, Kano \\ ${ }^{3}$ Department of Chemistry, Yusuf Maitama Sule University Kano. P.M.B. 3220 Kano, Nigeria. \\ ${ }^{4}$ Department of Chemistry, Nigerian Police Academy, Wudil, Kano-Nigeria
}

*Correspondence E-mail; saboyusuf18@yahoo.com

ABSTRACT

Stability constants of complexes of four divalent metal ions viz. $\mathrm{Cu}^{2+}, \mathrm{Pb}^{2+}, \mathrm{Mg}^{2+}$ and $\mathrm{Cd}^{2+}$ with humic acids (HA) were determined by potentiometric titration of humic acids with the corresponding salt of the divalent metals in aqueous media under non-acid-condition. The log $K$ (logarithm of the stability constant) ranged from 1.0942 to 2.7471 for metalhumic acid complexes were determined using point-wise computational method. The order of stability constants were obtained as follows: $\mathrm{Cu}>\mathrm{Pb}>\mathrm{Cd}>\mathrm{Mg}$ for metal $-\mathrm{HA}$ complexes respectively, indicating a higher degree of complexation with Cu metal ion.

Keywords: stability constant, humic acid, potentiometric titration, divalent metals, acid hydrolysis.

\section{NTRODUCTION}

The stability constant of a complex is the numerical expression of its stability and provides a quantitative measure of affinity of the metal ion to the complexing agent. An understanding of the relative stability of metal-complexes helps in predicting the behavior of metal ions in the soil (Ram and Raman, 1982). Extensive researches has been done to determine the stability constants of the complexes formed between humic acid (HA) with a number of metal ions. Ashok et al., (2000) reported that humic acid with hydroxyl, phenoxyl and carboxyl reactive groups can form coordination compound with metal ions at $\mathrm{pH}$ 3.5. The stability constants(Log K) for different metalhumic acid complexes indicated the following order of the stabilities of complexes formed between humic acid and metal ion, $\mathrm{Cu}>\mathrm{Fe}$ $>\mathrm{Pb}>\mathrm{Ni}>\mathrm{Co}>\mathrm{Ca}>\mathrm{Cd}>\mathrm{Zn}>\mathrm{Mn}>\mathrm{Mg}$. Andelkovic et al., (2010) investigated the binding of $\mathrm{Cd}$ (II) to soil humic acid at pH 6.5 and in $0.1 \mathrm{M} \mathrm{KNO}_{3}$ ionic medium. The stability constant for binding indicating greater stability in the case when carboxyl groups are involved in complexation reaction. Kostic et al.,(2012) investigated the complexation of humic acid with certain heavy metal ions (Co(II), $\mathrm{Ni}(\mathrm{II}), \mathrm{Cu}(\mathrm{II})$,
$\mathrm{Zn}(\mathrm{II})$, and $\mathrm{Pb}(\mathrm{II})$. The experiment was performed at $25^{\circ} \mathrm{C}$, at pH 4.0 and ionic strength of $0.01 \mathrm{M}$. Stability constant of complex between $\mathrm{Pb}$ (II) ions and humic acid is greater than stability constants of other investigated metalhumate complexes. Bogata and Sokolowska (2016) analyses the interaction between humic acids from different soils and $\mathrm{Zn}$ (II) ions at wide concentration ranges and at $\mathrm{pH} 5$. Studies have showed significant impact of $\mathrm{Zn}$ concentration, $\mathrm{pH}$ and some properties of humic acids with zinc.But all of these studies were limited to acidic $\mathrm{pH}$ range. Therefore, the present study was carried out to determine and compare the stability constants of complexes of metal ions with hydrolysed peat soil humic acid and unhydrolysed peat soil humic under non-acid conditions.

\section{MATERIALS AND METHODS}

Analytical grade chemicals used includes hydrochloric acid $(\mathrm{HCl})$, nitric acid $\left(\mathrm{HNO}_{3}\right)$, sodium hydroxide $(\mathrm{NaOH})$, lead nitrate $\mathrm{Pb}\left(\mathrm{NO}_{3}\right)_{2}$, copper nitrate $\mathrm{Cu}\left(\mathrm{NO}_{3}\right)_{2} \cdot 3 \mathrm{H}_{2} \mathrm{O}$, cadmium nitrate $\mathrm{Cd}\left(\mathrm{NO}_{3}\right)_{2} \cdot 4 \mathrm{H}_{2} \mathrm{O}$, magnesium nitrate $\mathrm{Mg}\left(\mathrm{NO}_{3}\right)_{2} \cdot 6 \mathrm{H}_{2} \mathrm{O}$, potassium nitrate $\left(\mathrm{KNO}_{3}\right)$, calcium chloride $\left(\mathrm{CaCl}_{2}\right)$, (sigma-Aldrich). Dowex 50WX8, (20-50 mesh) from Fluka. 


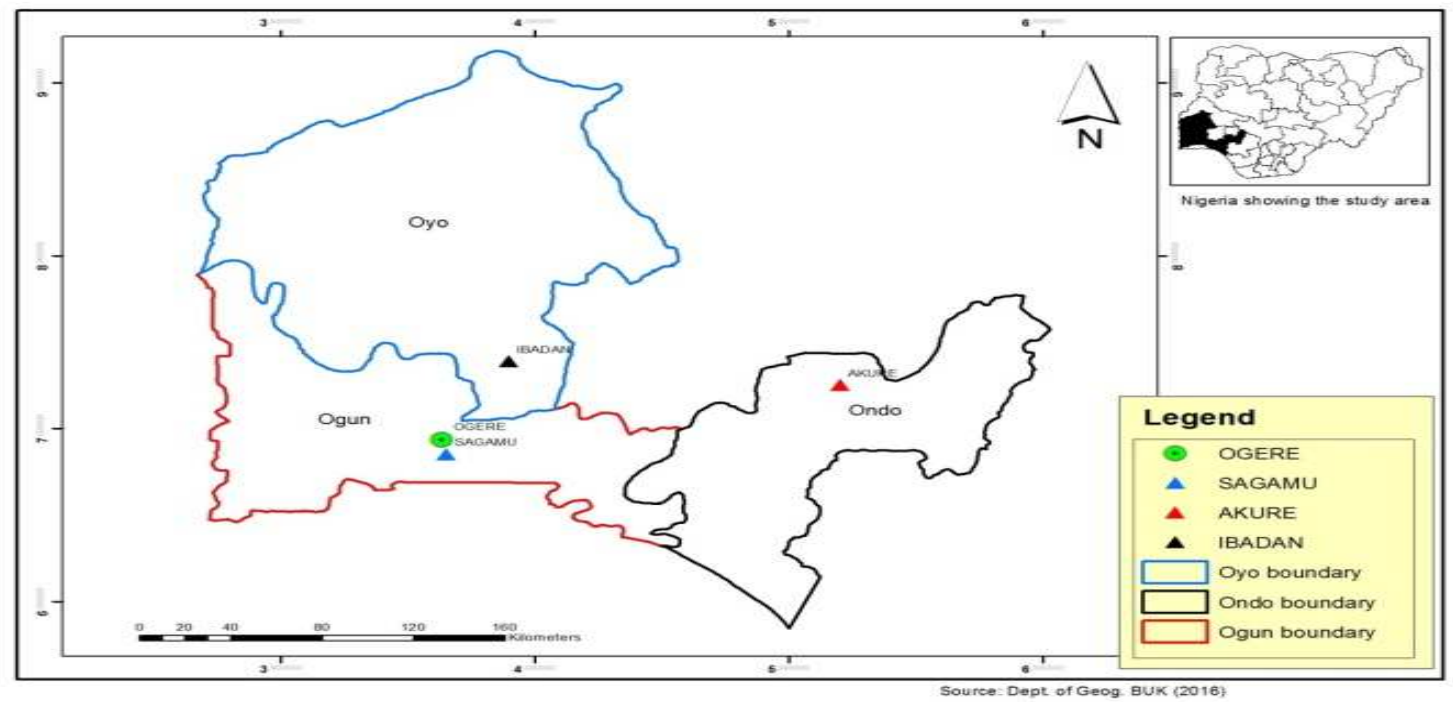

Figure 1: Map showing the sampling point at Sagamu Town, Ogun State.

\section{Description of Sampling Area}

Sagamu has geographical coordinates between $6^{\circ} 50^{\prime}$ north; $3^{\circ} 38^{\prime}$ east is located in south western region of Nigeria. The region has tropical wet and dry climate with a lengthy wet season and relatively constant temperatures throughout the course of the year. Wet season runs from March to October, November to December forms the region dry season. The vegetation type of the region is savannah which is really grassland with small bushes and occasional big trees. Grassland soils have substantially higher organic matter content than forest soils (Novackova, 2011).

\section{Sample Collection}

The Peatsoil samples were collected from four different sampling points $(0-10 \mathrm{~cm}$ depth) in Sagamu into polyethylene bag with plastic spoons. Samples were taken to the laboratory, extraneous materials were removed; the samples were air-dried, crushed and ground to a fine powder in a mortar passed through a $0.20 \mathrm{~mm}$ sieve. The samples were kept for analysis.

\section{Isolation and purification of humic acid from peat soil sample}

Peatsoil sample $(100 \mathrm{~g})$ was mixed with 1000 $\mathrm{cm}^{3}$ of $0.1 \mathrm{M} \mathrm{NaOH}$ solution, shaken for 3hours and left to stand overnight. Dark-coloured supernatant was obtained and decanted from solid residue. The dark-coloured supernatant was acidified to $(\mathrm{pH}=1.0)$ with $6 \mathrm{M} \mathrm{HCl}$ stirred and allowed to stand for 6 hours. Yellowish brown supernatant and dark-brown precipitate were obtained. The yellowish brown supernatant was decanted followed by centrifuge and discarded. The dark-brown precipitate was mixed with $500 \mathrm{~cm}^{3}$ of $0.1 \mathrm{M} \mathrm{NaOH}$ solution followed by passing through dowex resin. The dark-brown solution was acidified to $(\mathrm{pH}=1.0)$ with $6 \mathrm{M} \mathrm{HCl}$ stirred and allowed to stand for 3 hours. The dark-brown precipitate was washed several times with deionized water. The supernatant was treated with $\mathrm{AgNO}_{3}$ solution until no white precipitate observed. The humic acid was transferred to weighed crucible and dried at $60^{\circ} \mathrm{C}$ in an oven for 12 hours. The humic acid was cooled and dried in the desiccator, weighed and recorded. The obtained humic acid was dried again at $60^{\circ} \mathrm{C}$ for additional 6 hours cooled and dried in the desiccator, weighed and recorded constant weight was obtained (Baruah et al., 2015).

\section{FT-IR analysis}

FT-IR spectra of humic acid sample was analysed using Carry 630 FT-IR Agilent Technologies.

Unhydrolysed compost humic acid

The unhydrolysed humic acid was obtained after isolation and purification of compost humic acid and kept for investigation.

\section{Acid hydrolysis of Peatsoil acid}

Peatsoil humic acid sample (1g) was refluxed for 12 hours at $\left(160^{\circ} \mathrm{C}\right)$ with $50 \mathrm{~cm}^{3}$ of $6 \mathrm{M} \mathrm{HCl}$. The mixture was allowed to cool, decanted, and centrifuged after hydrolysis. The insoluble residues were washed with distilled water via centrifugation several times, and the supernatant was treated with $\mathrm{AgNO}_{3}$ solution until no white precipitate was observed. The residue was thoroughly dried over $\mathrm{CaCl}_{2}$ in a desiccator at room temperature (Chefetz et al., 2002). Finally, the obtained hydrolysed humic acid was kept for investigation. 
BAJOPAS Volume 14 Number 1,June, 2021 Potentiometric Titrations

Potentiometric measurements were carried out using a pH-meter Jenway (model 3510) with combine electrode, the sensitivity of the $\mathrm{pH}$ meter is 0.01 units. The $\mathrm{pH}$ meter was switched on half an hour before starting the titration for initial warm up of the instrument. The instrument was calibrated with an aqueous standard buffer solution of $\mathrm{pH} 4.00$ and 10.0 (borate buffer) prepared from a "Qualigens" buffer tablets.

The following sets of solutions were prepared in a $250 \mathrm{~cm}^{3}$ volumetric flask separately for $\mathrm{pH}$ metric titrations.

(i) $5 \mathrm{~cm}^{3} 0.1 \mathrm{M} \mathrm{HCl}+40 \mathrm{~cm}^{3}$ deionized water

(ii) $5 \mathrm{~cm}^{3} 0.1 \mathrm{M} \mathrm{HCl}+39 \mathrm{~cm}^{3}$ deionized water $+1 \mathrm{~cm}^{3} 0.15 \mathrm{gcm}^{-3}$ humic acid

(iii) $5 \mathrm{~cm}^{3} 0.1 \mathrm{M} \mathrm{HCl}+37 \mathrm{~cm}^{3}$ deionized water $+1 \mathrm{~cm}^{3} 0.15 \mathrm{gcm}^{-3}$ humic acid

$$
+2 \mathrm{~cm}^{3} \quad 0.01 \mathrm{M} \mathrm{Cu} \text { (II) }
$$

The solutions were titrated against standardized $0.110 \mathrm{MNaOH}$ separately. The total volume of each mixture was adjusted to $50 \mathrm{~cm}^{3}$ and the ionic strength of the solutions was maintained constant at by adding appropriate amount of stock solution of $1 \mathrm{M} \mathrm{KNO}_{3}$ (Gamal, 2015; Omar and Ali, 2015). A magnetic stirrer was used to achieve thorough mixing of the interacting solutions at $550 \mathrm{rpm}$. The same set of experimental conditions was applied for potentiometric titration of remaining samples.

\section{Evaluation of pKa of Hydrolysed peat soil Humic Acids}

The proton-ligand formation number $\mathrm{n}_{\mathbf{A}}$ were calculated by Irving and Rossotti expression (Omar and Ali, 2015).

$\mathrm{nA}=\mathrm{Y}-\frac{(\mathrm{V} 2-\mathrm{V1})(\mathrm{No}-\mathrm{Eo})}{(\mathrm{VO}+\mathrm{V1}) \mathrm{TCL}}$ 1

Where: $Y$ is number of dissociable proton, $\left(\mathrm{V}_{2^{-}}\right.$ $V_{1}$ ) is the measure of displacement of the ligand curve relative to acid curve, $\mathrm{N}^{\circ}$ and $\mathrm{E}^{\circ}$ are the resultant concentration of alkali solution, free acid solution, $\mathrm{T}_{\mathrm{cL}}{ }^{\circ}$ is the total ligand concentration, $\mathrm{V}^{\circ}$ is the total volume of titration solution, $V_{1}$ is the volume of alkali added to acid solution, $V_{2}$ is the volume of alkali added to acid solution + ligand solution, acid dissociation constants (pKa - values) of ligand were calculated by algebraic method point wise calculation (Tables 1 ). The dissociation constants (pKa) were calculated according to the following relation:

$\mathrm{pKa}=\mathrm{pH}+\log \left(\frac{n A}{1-n A}\right)$ 2

Where: pKa is the acid dissociation constant, $\mathrm{n}_{\mathrm{A}}$ is the Proton-ligand formation number and $\mathrm{pH}$ is the pH-values (Omar and Ali, 2015).

\section{Determination of metal-ligand stability constants $(\log K)$ of complexes}

The potentiometric measurement for the determination of stability constant of a complex in solution is based on the fact that the redox potential of the couple $\frac{M^{+(m-n)}}{M^{+m}}$ is shifted significantly on complexation of the metal ion with the ligand. This method involves change in hydrogen ion concentration $\left[\mathrm{H}^{+}\right]$due to the displacement or association of one or more protons taking place during complexation reaction. This change can be found out by titrating the solutions containing free acid, acid with ligand, and acid with ligand and metal ion, individually against a standard alkali solution at a constant ionic strength or temperature. Either ionic strength or temperature may be varied for different sets of solutions. In all the cases, the change in the $\mathrm{pH}$ of the solution is measured after each addition of a known amount of alkali to the reaction cell which contains the reaction mixture. The titration curves are then drawn by plotting the measured $\mathrm{pH}$ values against the corresponding volume of alkali added and the stability constants of the complexes are determined from the titration curves by employing $\mathrm{pH}$-metric titration technique given by (Irving and Rossoti).

Metal-ligand stability constants ( $\log \mathrm{K}$ ) were determined by using the following relations:

$$
\bar{n}=\frac{\left(V_{3}-V_{2}\right)\left(E^{0}+N^{0}\right)}{\left(V^{0}+V_{2}\right) \bar{n}_{A} T_{m}^{0}}
$$

and

$$
P L=\log _{10}\left\{\frac{1+\beta_{n}^{H} \frac{1}{[\text { anti } \log \mathrm{pH}]^{\mathrm{n}}}}{\mathrm{T}_{\mathrm{L}}^{0}-n \bar{T}_{m}^{0}} \mathrm{X} \frac{\left(V^{0}+V_{3}\right)}{V^{0}}\right\}
$$


BAJOPAS Volume 14 Number 1,June, 2021

Where $T_{L}, T^{\circ}, E^{\circ}$, and $V^{\circ}$ havethe same significance as in equation (1) above, $T_{m}$ denotes the total concentration of metal present in solution, $V_{3}$ is the volume of metal ions present in solution and $\beta^{H}$ is the overall proton ligand stability constant. The metal-ligand stability constants (log K) were determined by employing point wise computational Method (eq. 5 and 6).

$\operatorname{LogK}_{1}=\log \left(\frac{n}{1-n}\right)+\mathrm{pL}$ .5

$\operatorname{LogK}_{2}=\log \left(\frac{1-n}{2-n}\right)+\mathrm{pL}$ ...6

Where: Log $\mathrm{K}$ is the metal-ligand stability constant, $\mathrm{pL}$ is the Free ligand exponent function, $\mathbf{n}$ is the Average number of ligand attached with metal ion (Janraoet al., 2014). The results obtained were analyzed by an ORIGIN 2016 program using titration data and then the proton-ligand stability constants (pKa) and Metal-ligand stability constant (LogK) calculated (Omar and Ali, 2015).

\section{RESULTS AND DISCUSSION}

Fourier transformed infrared (FT-IR) spectra of isolated humic acid from peat soils Figure 2 had distinct clear absorption bands indicating the presence of major humic acid structural elemental groups such as $\mathrm{H}$ bonded $\mathrm{OH}$ $\left(3680 \mathrm{~cm}^{-1}\right.$ peak $), C=0$ of carbonyl $\left(1721 \mathrm{~cm}^{-1}\right.$ peak), functional groups of aliphatic components $\mathrm{CH}_{2}\left(2918 \mathrm{~cm}^{-1}\right.$ peak) and $\mathrm{C}-\mathrm{O}$ stretching of polysaccharide $\left(1168 \mathrm{~cm}^{-1}\right.$ peak). The positions of the absorption bands of the spectra fell within typical major absorption bands of humic acid which is at frequencies 3680, 2918, 1721, 1168 $\mathrm{cm}^{-1}$. The first peak centred in the vicinity of $3680 \mathrm{~cm}^{-1}$ region is attributed to phenol $\mathrm{OH}$ group bounded by intermolecular $\mathrm{H}$ bonds. The $2918 \mathrm{~cm}^{-1}$ band usually has absorption maximum at $2918 \mathrm{~cm}^{-1}$ which is due to $\mathrm{C}-\mathrm{H}$ stretching of alkane group $\left(\mathrm{CH}_{2}\right)$. The next major absorption band is $1721 \mathrm{~cm}^{-1}$. This band has been commonly ascribed to $\mathrm{C}=\mathrm{O}$ stretching of mainly carboxyl group $(\mathrm{COOH})$ with trace amount of ketones. The last peak was observed at 1168 $\mathrm{cm}^{-1}$ due to $\mathrm{C}-\mathrm{O}$ stretching of polysaccharides and this peak appeared also in the spectra of humic acid from peat soil. The FTIR spectra of the isolated humic acid contained all major characteristic absorption peaks of humic acid. These absorption peaks indicated the presence of the major structural elements of humic acid namely $\mathrm{H}$ bonded $\mathrm{OH}, \mathrm{C}=\mathrm{C}$ of aromatic ring, $\mathrm{C}=\mathrm{O}$ of carbonyl group (both carboxyl and ketonic), $\mathrm{CH}_{2}$ group. This strongly supports the presence of humic acid.

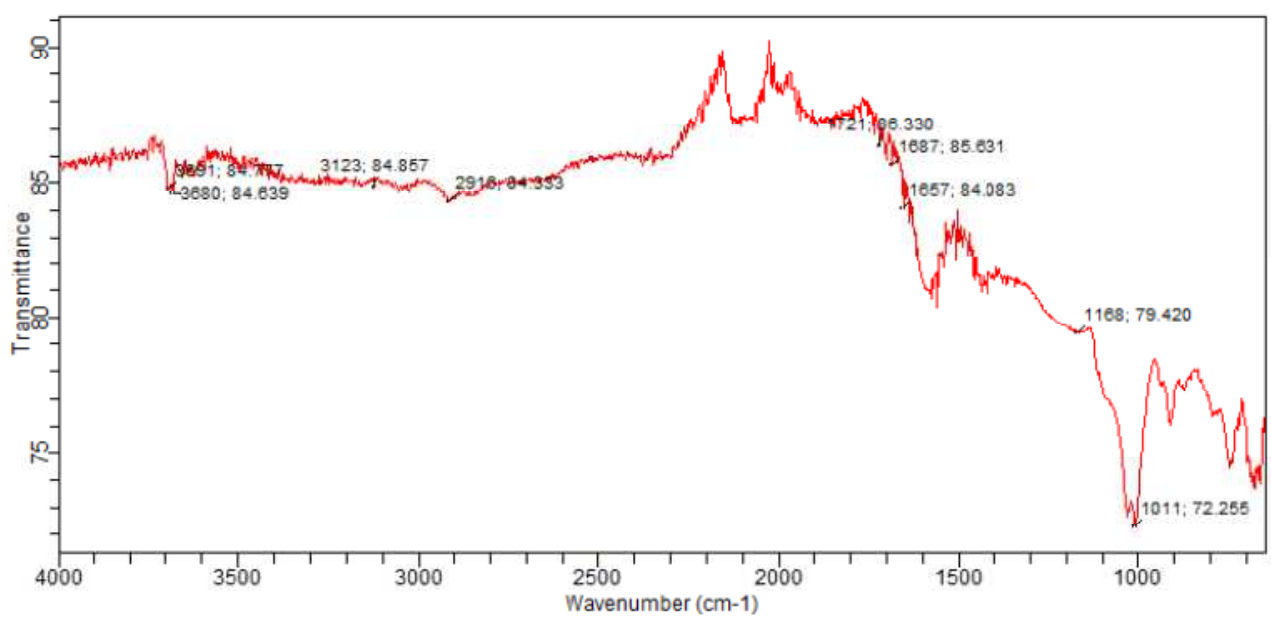

Fig. 2 : FT-IR spectraof peatsoilhumic acid (PSHA)

\section{Evaluation of acid dissociation constant (pka) of acid hydrolysed peat soil humicacid at phenolic group}

The value of the dissociation constant of the peat soil humic acid (PSHA) that underwent acidhydrolysis studied was found to be 8.9299 as shown Table 1, which is lower than the literaturevalues reported by Almeida and Szpoganics, (2015), Borges et al., (2005); Badr et al., (2012)and Fernandes et al,.(2009) of $9.73,9.47$ and 10.30. The difference between the obtained valuesand the reported values in this study might be probably as a result of acid hydrolysis of humicacid. 
BAJOPAS Volume 14 Number 1,June, 2021

Table 1: PKa of (Hydrolysed PSHA)

\begin{tabular}{|l|l|l|l|l|l|l|}
\hline $\mathrm{pH}$ & $\mathrm{BV}_{1}$ & $\mathrm{BV}_{2}$ & $\mathrm{~V}_{2}-\mathrm{V}_{1}$ & $\mathrm{nA}$ & $\log \left(\frac{n A}{1-n A}\right)$ & $\mathrm{pKa}$ \\
\hline 8.50 & 5.30 & 6.29 & 0.99 & 0.3594 & -0.2510 & 8.2490 \\
8.72 & 5.35 & 6.37 & 1.02 & 0.3400 & -0.2880 & 8.4320 \\
9.00 & 5.40 & 6.46 & 1.06 & 0.3141 & -0.3391 & 8.6609 \\
9.22 & 5.45 & 6.55 & 1.10 & 0.2882 & -0.3927 & 8.8273 \\
9.51 & 5.50 & 6.66 & 1.16 & 0.2494 & -0.4786 & 9.0314 \\
9.73 & 5.55 & 6.78 & 1.23 & 0.2041 & -0.5910 & 9.1390 \\
10.00 & 5.60 & 6.90 & 1.30 & 0.1589 & -0.7238 & 9.2762 \\
10.23 & 5.65 & 7.05 & 1.40 & 0.0941 & -0.9835 & 9.2465 \\
10.49 & 5.70 & 7.10 & 1.40 & 0.0941 & -0.9835 & 9.5065 \\
\hline
\end{tabular}

Average pKa $=8.9299 \pm 0.4186$

Table 2: PKa of (Unhydrolysed PSHA)

\begin{tabular}{|l|l|l|l|l|l|l|}
\hline $\mathrm{pH}$ & $\mathrm{BV}_{1}$ & $\mathrm{BV}_{2}$ & $\mathrm{~V}_{2}-\mathrm{V}_{1}$ & $\mathrm{nA}$ & $\log \left(\frac{\boldsymbol{n A}}{1-\boldsymbol{n}}\right)$ & $\mathrm{pKa}$ \\
\hline 8.50 & 5.30 & 5.81 & 0.51 & 0.6619 & 0.2919 & 8.7919 \\
8.72 & 5.35 & 5.90 & 0.55 & 0.6357 & 0.2418 & 8.9618 \\
9.00 & 5.40 & 6.00 & 0.60 & 0.6029 & 0.1813 & 9.1813 \\
9.22 & 5.45 & 6.10 & 0.65 & 0.5701 & 0.1226 & 9.3426 \\
9.51 & 5.50 & 6.20 & 0.70 & 0.5376 & 0.0654 & 9.5754 \\
9.73 & 5.55 & 6.33 & 0.78 & 0.4851 & -0.0259 & 9.7041 \\
10.00 & 5.60 & 6.47 & 0.87 & 0.4262 & -0.1291 & 9.8709 \\
10.23 & 5.65 & 6.62 & 0.99 & 0.3609 & -0.2481 & 9.9819 \\
10.49 & 5.70 & 6.80 & 1.10 & 0.2759 & -0.4690 & 10.0210 \\
\hline
\end{tabular}

Average pKa $=9.4923 \pm 0.4410$

Metal-ligand stability constant ( $\log \mathrm{K}$ )

The stabilityconstants require the accurate values of proton-ligand stability constants (Anil and Maroti, 2008). Metal titration curves crossed over ligand titration curve indicated the formation of complex upon proton release (Santosh, et al., 2011). If the values of n- are within range $0.2-0.8$ and $1.2-18$ this indicates the formation of $1: 1$ and 1:2 complexes (Sayyed and Mazahar, 2012).

The metal (II)-humate stepwise stability constants (log k) at phenolic group (Tables 318)

Table 3: Point-wise method, $\mathrm{Cu}$-(Hydrolysed PSHA)

\begin{tabular}{|l|l|l|l|l|l|l|l|l|}
\hline $\mathrm{pH}$ & $\mathrm{BV}_{1}$ & $\mathrm{BV}_{2}$ & $\mathrm{BV}_{3}$ & $\left(\mathrm{~V}_{3}-\mathrm{V}_{2}\right)$ & $\mathrm{n}$ & $\mathrm{pL}$ & $\log \left(\frac{n}{1-n}\right)$ & LogK $_{1}$ \\
\hline 8.50 & 5.30 & 6.29 & 6.33 & 0.04 & 0.5500 & 2.66 & 0.0871 & 2.7471 \\
8.72 & 5.35 & 6.37 & 6.41 & 0.04 & 0.5714 & 2.43 & 0.1249 & 2.5549 \\
9.00 & 5.40 & 6.46 & 6.50 & 0.04 & 0.6198 & 2.16 & 0.2122 & 2.3722 \\
9.22 & 5.45 & 6.55 & 6.59 & 0.04 & 0.6667 & 1.94 & 0.3010 & 2.2410 \\
\hline
\end{tabular}

LogK $_{1}$ (Average value) $=2.4788 \pm 0.2203$

Table 4: Point-wise method, $\mathrm{Cu}$-(Hydrolysed PSHA)

\begin{tabular}{|l|l|l|l|l|l|l|l|l|}
\hline $\mathrm{pH}$ & $\mathrm{BV}_{1}$ & $\mathrm{BV}_{2}$ & $\mathrm{BV}_{3}$ & $\left(\mathrm{~V}_{3}-\mathrm{V}_{2}\right)$ & $\mathrm{n}$ & $\mathrm{pL}$ & $\log \left(\frac{n-1}{2-n}\right)$ & LogK $_{2}$ \\
\hline 9.51 & 5.50 & 6.66 & 6.73 & 0.07 & 1.3509 & 1.70 & -0.2671 & 1.4329 \\
9.73 & 5.55 & 6.78 & 6.85 & 0.07 & 1.6383 & 1.51 & 0.2467 & 1.7567 \\
10.00 & 5.60 & 6.90 & 6.98 & 0.08 & 2.1783 & 1.31 & -0.2158 & 1.0942 \\
10.23 & 5.65 & 7.05 & 7.13 & 0.08 & 4.1904 & 1.27 & & \\
10.49 & 5.70 & 7.10 & 7.19 & 0.09 & 4.6920 & & & \\
\hline
\end{tabular}

Log $K_{2}($ Average value $)=1.4280 \pm 0.3312$ 
BAJOPAS Volume 14 Number 1,June, 2021

Table 5: Point-wise method, $\mathrm{Cu}$ (Unhydrolysed PSHA)

\begin{tabular}{|l|l|l|l|l|l|l|l|l|}
\hline $\mathrm{pH}$ & $\mathrm{BV}_{1}$ & $\mathrm{BV}_{2}$ & $\mathrm{BV}_{3}$ & $\left(\mathrm{~V}_{3}-\mathrm{V}_{2}\right)$ & $\mathrm{n}$ & $\mathrm{pL}$ & $\log \left(\frac{n}{n-1}\right)$ & Log $_{1}$ \\
\hline 8.50 & 5.30 & 5.81 & 5.85 & 0.04 & 0.2973 & 2.88 & -0.3736 & 2.5064 \\
8.72 & 5.35 & 5.90 & 5.95 & 0.05 & 0.3873 & 2.66 & -0.1992 & 2.4608 \\
9.00 & 5.40 & 6.00 & 6.05 & 0.05 & 0.4044 & 2.38 & -0.1681 & 2.2119 \\
9.22 & 5.45 & 6.10 & 6.15 & 0.06 & 0.5157 & 2.18 & -0.0272 & 2.2072 \\
9.51 & 5.50 & 6.20 & 6.27 & 0.07 & 0.6417 & 1.89 & 0.2530 & 1.1430 \\
\hline
\end{tabular}

$\operatorname{LogK}_{1}($ Average value $)=2.3059 \pm 0.6153$

Table 6:Point-wise method, $\mathrm{Cu}$ (Unhydrolysed PSHA)

\begin{tabular}{|l|l|l|l|l|l|l|l|l|}
\hline $\mathrm{pH}$ & $\mathrm{BV}_{1}$ & $\mathrm{BV}_{2}$ & $\mathrm{BV}_{3}$ & $\mathrm{~V}_{3}-\mathrm{V}_{2}$ & $\mathrm{n}$ & $\mathrm{pL}$ & $\log \left(\frac{n-1}{2-n}\right)$ & $\log \mathrm{K}_{2}$ \\
\hline 9.73 & 5.55 & 6.33 & 6.42 & 0.09 & 0.9000 & 1.69 & & \\
10.00 & 5.60 & 6.47 & 6.58 & 0.11 & 1.2578 & 1.44 & -0.4592 & 0.9808 \\
10.23 & 5.65 & 6.62 & 6.84 & 0.12 & 1.6137 & 1.26 & -0.2010 & 1.4610 \\
10.49 & 5.70 & 6.80 & 6.92 & 0.12 & 2.1052 & 1.03 & & \\
\hline
\end{tabular}

$\operatorname{LogK}_{2}$ (Average value) $=1.2209 \pm 0.3398$

Table 7:Point-wise method, Pb (Hydrolysed PSHA)

\begin{tabular}{|l|l|l|l|l|l|l|l|l|}
\hline $\mathrm{pH}$ & $\mathrm{BV}_{1}$ & $\mathrm{BV}_{2}$ & $\mathrm{BV}_{3}$ & $\left(\mathrm{~V}_{3}-\mathrm{V}_{2}\right)$ & $\mathrm{n}$ & $\mathrm{pL}$ & $\log \left(\frac{n}{1-n}\right)$ & LogK $_{1}$ \\
\hline 8.50 & 5.30 & 6.29 & 6.33 & 0.04 & 0.5500 & 2.66 & 0.0871 & 2.7471 \\
8.72 & 5.35 & 6.37 & 6.41 & 0.04 & 0.5714 & 2.43 & 0.1249 & 2.5549 \\
9.00 & 5.40 & 6.46 & 6.50 & 0.04 & 0.6198 & 2.16 & 0.2122 & 2.3722 \\
9.22 & 5.45 & 6.55 & 6.60 & 0.05 & 0.8333 & 1.96 & 0.6989 & 2.6589 \\
\hline
\end{tabular}

Log $_{\mathbf{1}}($ Average value $)=2.5832 \pm 0.1614$

Table 8:Point-wise method, Pb-(Hydrolysed PSHA)

\begin{tabular}{|l|l|l|l|l|l|l|l|l|}
\hline $\mathrm{pH}$ & $\mathrm{BV}_{1}$ & $\mathrm{BV}_{2}$ & $\mathrm{BV}_{3}$ & $\left(\mathrm{~V}_{3}-\mathrm{V}_{2}\right)$ & $\mathrm{n}$ & $\mathrm{pL}$ & $\log \left(\frac{n-1}{2-n}\right)$ & $\log \mathrm{K}_{2}$ \\
\hline 9.51 & 5.50 & 6.66 & 6.71 & 0.05 & 0.9650 & 1.67 & & \\
9.73 & 5.55 & 6.78 & 6.83 & 0.05 & 1.1702 & 1.44 & & \\
10.00 & 5.60 & 6.90 & 6.90 & 0.05 & 1.4864 & 1.22 & -0.0237 & 1.1963 \\
10.23 & 5.65 & 7.05 & 7.10 & 0.05 & 2.0190 & 1.09 & & \\
10.49 & 5.70 & 7.10 & 7.17 & 0.07 & 3.6492 & 1.00 & & \\
\hline
\end{tabular}

Log $K_{2}$ (Average value) $=1.1963$

Table 9: Point-wise method, Pb (Unhydrolysed PSHA)

\begin{tabular}{|l|l|l|l|l|l|l|l|l|}
\hline $\mathrm{pH}$ & $\mathrm{BV}_{1}$ & $\mathrm{BV}_{2}$ & $\mathrm{BV}_{3}$ & $\mathrm{~V}_{3}-\mathrm{V}_{2}$ & $\mathrm{n}$ & $\mathrm{pL}$ & $\begin{array}{l}\text { Log } \\
\left(\frac{n}{n-1}\right)\end{array}$ & Log $\mathrm{K}_{1}$ \\
\hline 8.50 & 5.30 & 5.81 & 5.85 & 0.04 & 0.2973 & 2.88 & -0.3736 & 2.5064 \\
8.72 & 5.35 & 5.90 & 5.94 & 0.04 & 0.3099 & 2.66 & -0.5477 & 2.3123 \\
9.00 & 5.40 & 6.00 & 6.05 & 0.05 & 0.4044 & 2.38 & -0.1681 & 2.2119 \\
9.22 & 5.45 & 6.10 & 6.15 & 0.06 & 0.5157 & 2.18 & 0.0272 & 2.2072 \\
9.51 & 5.50 & 6.20 & 6.26 & 0.07 & 0.6417 & 1.89 & 0.2530 & 2.1430 \\
9.73 & 5.55 & 6.40 & 6.40 & 0.07 & 0.7000 & 1.67 & 0.3680 & 2.0380 \\
\hline
\end{tabular}

LogK $_{1}$ (Average value) $=2.2364 \pm 0.1602$

Table 10: Point-wise method, Pb (Unhydrolysed PSHA)

\begin{tabular}{|l|l|l|l|l|l|l|l|l|}
\hline $\mathrm{pH}$ & $\mathrm{BV}_{1}$ & $\mathrm{BV}_{2}$ & $\mathrm{BV}_{3}$ & $\mathrm{~V}_{3}-\mathrm{V}_{2}$ & $\mathrm{n}$ & $\mathrm{pL}$ & $\log \left(\frac{n-1}{2-n}\right)$ & $\log \mathrm{K}_{2}$ \\
\hline 10.00 & 5.60 & 6.47 & 6.55 & 0.08 & 1.9503 & 1.41 & & \\
10.23 & 5.65 & 6.62 & 6.72 & 0.11 & 1.4792 & 1.26 & -0.0361 & 1.2239 \\
\hline
\end{tabular}

$\operatorname{LogK}_{2}$ (Average value) $=1.2239$

Table 11: Point-wise method, Mg (Hydrolysed PSHA)

\begin{tabular}{|l|l|l|l|l|l|l|l|l|}
\hline $\mathrm{pH}$ & $\mathrm{BV}_{1}$ & $\mathrm{BV}_{2}$ & $\mathrm{BV}_{3}$ & $\left(\mathrm{~V}_{3}-\mathrm{V}_{2}\right)$ & $\mathrm{n}$ & $\mathrm{pL}$ & $\log \left(\frac{n}{n-1}\right)$ & LogK $_{1}$ \\
\hline 8.50 & 5.30 & 6.29 & 6.31 & 0.02 & 0.2750 & 2.64 & -0.4290 & 2.2110 \\
8.72 & 5.35 & 6.37 & 6.39 & 0.02 & 0.2858 & 2.42 & -0.3978 & 2.0222 \\
9.00 & 5.40 & 6.46 & 6.49 & 0.03 & 0.4648 & 2.14 & -0.0612 & 2.0788 \\
9.22 & 5.45 & 6.55 & 6.59 & 0.04 & 0.6667 & 1.94 & 0.3010 & 2.2410 \\
\hline
\end{tabular}

$\log _{\mathbf{1}}($ Average value) $=2.1382 \pm 0.1046$ 
BAJOPAS Volume 14 Number 1,June, 2021

Table 12: Point-wise method, Mg (Hydrolysed PSHA)

\begin{tabular}{|l|l|l|l|l|l|l|l|l|}
\hline $\mathrm{pH}$ & $\mathrm{BV}_{1}$ & $\mathrm{BV}_{2}$ & $\mathrm{BV}_{3}$ & $\left(\mathrm{~V}_{3}-\mathrm{V}_{2}\right)$ & $\mathrm{n}$ & $\mathrm{pL}$ & $\log \left(\frac{n-1}{2-n}\right)$ & LogK $_{2}$ \\
\hline 9.51 & 5.55 & 6.66 & 6.71 & 0.05 & 0.9650 & 1.67 & & \\
9.73 & 5.55 & 6.78 & 6.84 & 0.06 & 1.4042 & 1.47 & -0.1686 & 1.3014 \\
10.00 & 5.60 & 6.90 & 6.93 & 0.06 & 1.7838 & 1.23 & 0.5593 & 1.7893 \\
10.23 & 5.65 & 7.05 & 7.10 & 0.06 & 3.1429 & 1.10 & & \\
10.49 & 5.70 & 7.10 & 7.18 & 0.07 & 3.6492 & 0.83 & & \\
\hline
\end{tabular}

LogK $_{2}($ Average value $)=1.5453 \pm 0.3450$

Table 13: Point-wise method, Mg (Unhydrolysed PSHA)

\begin{tabular}{|l|l|l|l|l|l|l|l|l|}
\hline $\mathrm{pH}$ & $\mathrm{BV}_{1}$ & $\mathrm{BV}_{2}$ & $\mathrm{BV}_{3}$ & $\mathrm{~V}_{3}-\mathrm{V}_{2}$ & $\mathrm{n}$ & $\mathrm{pL}$ & $\log \left(\frac{n}{n-1}\right)$ & $\operatorname{Log~}_{1}$ \\
\hline 8.50 & 5.30 & 5.81 & 5.85 & 0.04 & 0.2973 & 2.88 & -0.3736 & 2.5064 \\
8.72 & 5.35 & 5.90 & 5.94 & 0.04 & 0.3099 & 2.66 & -0.3477 & 2.3123 \\
9.00 & 5.40 & 6.00 & 6.04 & 0.04 & 0.3236 & 2.38 & -0.3202 & 2.0598 \\
9.22 & 5.45 & 6.10 & 6.15 & 0.05 & 0.4297 & 2.17 & -0.1230 & 2.0470 \\
9.51 & 5.50 & 6.20 & 6.26 & 0.06 & 0.5500 & 1.89 & 0.0871 & 1.9771 \\
9.73 & 5.55 & 6.33 & 6.40 & 0.07 & 0.7000 & 1.67 & 0.3680 & 2.0380 \\
\hline
\end{tabular}

LogK $_{1}$ (Average value) $=2.1568 \pm 0.2069$

Table 14: Point-wise method, Mg (Unhydrolysed PSHA)

\begin{tabular}{|l|l|l|l|l|l|l|l|l|}
\hline $\mathrm{pH}$ & $\mathrm{BV}_{1}$ & $\mathrm{BV}_{2}$ & $\mathrm{BV}_{3}$ & $\mathrm{~V}_{3}-\mathrm{V}_{2}$ & $\mathrm{n}$ & $\mathrm{pL}$ & $\log \left(\frac{n-1}{2-n}\right)$ & $\log \mathrm{K}_{2}$ \\
\hline 10.00 & 5.60 & 6.47 & 6.55 & 0.08 & 0.9148 & 1.41 & & \\
10.23 & 5.65 & 6.62 & 6.71 & 0.09 & 1.2102 & 1.20 & -0.5749 & 0.6251 \\
10.49 & 5.70 & 6.80 & 6.92 & 0.09 & 1.5968 & 1.03 & 0.1703 & 1.2003 \\
\hline
\end{tabular}

LogK $_{2}$ (Average value) $=0.9127 \pm 0.4070$

Table15:Point-wise method, Cd (Hydrolysed PSHA)

\begin{tabular}{|l|l|l|l|l|l|l|l|l|}
\hline $\mathrm{pH}$ & $\mathrm{BV}_{1}$ & $\mathrm{BV}_{2}$ & $\mathrm{BV}_{3}$ & $\left(\mathrm{~V}_{3}-\mathrm{V}_{2}\right)$ & $\mathrm{n}$ & $\mathrm{pL}$ & $\log \left(\frac{n}{1-n}\right)$ & LogK $_{1}$ \\
\hline 8.50 & 5.30 & 6.29 & 6.31 & 0.02 & 0.2750 & 2.64 & -0.4210 & 2.2190 \\
8.72 & 5.35 & 6.37 & 6.40 & 0.03 & 0.4286 & 2.42 & -0.1249 & 2.2951 \\
9.00 & 5.40 & 6.46 & 6.49 & 0.03 & 0.4648 & 2.14 & -0.0612 & 2.0788 \\
9.22 & 5.45 & 6.55 & 6.59 & 0.04 & 0.6667 & 1.96 & 0.3010 & 2.2610 \\
9.51 & 5.55 & 6.66 & 6.70 & 0.04 & 0.7720 & 1.67 & 0.5297 & 2.1997 \\
\hline
\end{tabular}

LogK $_{\mathbf{1}}$ (Average value) $=2.2108 \pm 0.0825$

Table 16: Point-wise method, Cd (Hydrolysed PSHA)

\begin{tabular}{|l|l|l|l|l|l|l|l|l|}
\hline $\mathrm{pH}$ & $\mathrm{BV}_{1}$ & $\mathrm{BV}_{2}$ & $\mathrm{BV}_{3}$ & $\left(\mathrm{~V}_{3}-\mathrm{V}_{2}\right)$ & $\mathrm{n}$ & $\mathrm{pL}$ & $\log \left(\frac{n-1}{2-n}\right)$ & Log $_{2}$ \\
\hline 9.73 & 5.55 & 6.78 & 6.83 & 0.06 & 1.4042 & 1.47 & -0.1686 & 1.3014 \\
10.00 & 5.60 & 6.90 & 6.95 & 0.06 & 1.7838 & 1.23 & 0.5593 & 1.7893 \\
10.23 & 5.65 & 7.05 & 7.10 & 0.06 & 3.1429 & 1.09 & & \\
10.49 & 5.70 & 7.10 & 7.16 & 0.06 & 3.1429 & 0.89 & & \\
& & & & & & & & \\
\hline
\end{tabular}

$\operatorname{LogK}_{2}$ (Average value) $=1.5453 \pm 0.3450$

Table 17: Point-wise method, Cd (Unhydrolysed PSHA)

\begin{tabular}{|l|l|l|l|l|l|l|l|l|}
\hline $\mathrm{pH}$ & $\mathrm{BV}_{1}$ & $\mathrm{BV}_{2}$ & $\mathrm{BV}_{3}$ & $\mathrm{~V}_{3}-\mathrm{V}_{2}$ & $\mathrm{n}$ & $\mathrm{pL}$ & $\log \left(\frac{n}{n-1}\right)$ & $\operatorname{Log~}_{1}$ \\
\hline 8.50 & 5.30 & 5.81 & 5.86 & 0.05 & 0.3717 & 2.88 & -0.2280 & 2.6520 \\
8.72 & 5.35 & 5.90 & 5.95 & 0.05 & 0.3873 & 2.66 & -0.1992 & 2.4608 \\
9.00 & 5.40 & 6.00 & 6.06 & 0.06 & 0.4853 & 2.38 & -0.0255 & 2.3545 \\
9.22 & 5.45 & 6.10 & 6.16 & 0.06 & 0.5157 & 2.18 & -0.0272 & 2.2072 \\
9.51 & 5.50 & 6.20 & 6.27 & 0.07 & 0.6417 & 1.89 & 0.2530 & 1.1430 \\
9.73 & 5.55 & 6.33 & 6.41 & 0.08 & 0.8000 & 1.69 & 0.6020 & 2.2920 \\
& & & & & & & & \\
\hline
\end{tabular}

$\operatorname{LogK}_{1}($ Average value $)=2.2516 \pm 0.5380$ 
BAJOPAS Volume 14 Number 1,June, 2021

Table 18: Point-wise method, Cd (Unhydrolysed PSHA)

\begin{tabular}{|l|l|l|l|l|l|l|l|l|}
\hline $\mathrm{pH}$ & $\mathrm{BV}_{1}$ & $\mathrm{BV}_{2}$ & $\mathrm{BV}_{3}$ & $\mathrm{~V}_{3}-\mathrm{V}_{2}$ & $\mathrm{n}$ & $\mathrm{pL}$ & $\log \left(\frac{n-1}{2-n}\right)$ & $\log \mathrm{K}_{2}$ \\
\hline 10.00 & 5.60 & 6.47 & 6.57 & 0.10 & 1.1434 & 1.43 & & \\
10.23 & 5.65 & 6.62 & 6.72 & 0.10 & 1.3448 & 1.23 & -0.2788 & 0.9512 \\
10.49 & 5.70 & 6.80 & 6.90 & 0.10 & 1.7742 & 1.03 & 0.5351 & 1.5651 \\
\hline
\end{tabular}

$\operatorname{LogK}_{2}($ Average value $)=1.2581 \pm 0.4340$

Table 19: Stepwise and overall Stability constants of thehydrolysed and unhydrolysed divalent metal (II) complexes

\begin{tabular}{|c|c|c|c|}
\hline Chelates & LogK $_{1}$ & $\log _{2}$ & Log $\beta$ \\
\hline [Cu (Hydrolysed PSHA-1) $\left.{ }_{2}\right]$ & 2.4788 & 1.4280 & 3.9068 \\
\hline$\left[\mathrm{Pb}(\text { Hydrolysed PSHA-1) })_{2}\right]$ & 2.5832 & 1.1963 & 3.7795 \\
\hline$\left[\mathrm{Cd}(\text { Hydrolysed PSHA-1 })_{2}\right]$ & 2.2108 & 1.5453 & 3.7561 \\
\hline$\left[\mathrm{Mg}(\text { Hydrolysed PSHA-1 })_{2}\right]$ & 2.1382 & 1.5453 & 3.6835 \\
\hline [Cu (Unhydrolysed PSHA-1) & 2.3059 & 1.2209 & 3.5268 \\
\hline$[\mathrm{Pb}$ (Unhydrolysed PSHA-1) 2$]$ & 2.2364 & 1.2239 & 3.4603 \\
\hline [Cd (Unhydrolysed PSHA-1) 2 ] & 2.2516 & 1.2581 & 3.5097 \\
\hline$[\mathrm{Mg}$ (Unydrolysed PSHA-1) & 2.1568 & 0.9127 & 3.0695 \\
\hline
\end{tabular}

The results obtained (Table19) shows the stepwise and overall stability constants to be not high indicating low stability of the complexes, because the solubility of most metal ions in the basic $\mathrm{pH}$ range is minimal due to metal hydroxide precipitation (Karimi, 2017). In general, the stepwise stability constants $\left(K_{1}\right.$ and $K_{2}$ ) follow the order $K_{1}>K_{2}$ for the copper, lead, magnesium and cadmium complexes respectively. The steady decrease of the values with increasing number of ligands is in agreement with the prediction made by researchers (Na'aliya, 2013). The decrease could be attributed to the fact that as the number of the ligands (Humate ions) that enters the coordination zone increases the aqua molecules available for replacement by the ligands become less. Thus, the metal ions become less electron loving with progressive intake of the ligand and this results in the decrease in the values of the constants (Na'aliya, 2013). Also the stability of the complexes is influenced by the size and number of the chelate rings(Mackay and Mackay,2002).All the complexes form rings in their structure as humate, a bidentate ligand, bond the metal ions in the ratio 1:2 (Boguta and Sokolowska, 2016) forming chelate rings. The values of the overall stability constants $(\log \beta)$ obtained for humate complexes are not high indicating low stability as the values are not high. LogK values for copper-humates (Table 3 to 6) obtained in this study are lower than those reported for the complexes of humic acids (Pandey et al., 2015; Dinu, 2013; Kaschl et al., 2010 and Gilbeto and Jorg, 2001). The values of LogK(Table 7 to 10 ) forlead-humates are lower than those reported for the lead in the literature (Dinu, 2013; Gilbeto and Jorg 2001). Log K values(Table 11 to 14 ) for magnesium-humates obtained in this study are close to those reported by (Pandey et al., 2015). Log K values of cadmium-humates (Table 15 to 18 ) obtained in this work near to the one reported by (Dinu, 2013 and Pandey et al., 2015).The difference between the reported values and the values obtained in this study might be probably as a result of acid hydrolysis of humic acid. The values of the overall stability constants $(\log \beta)$ of the copper humates complexes presented in Table 19 is high than that of other metal humate complexes, show relatively high stability of CuHA complexes, show the following order of stability: $\mathrm{Cu}>\mathrm{Pb}>\mathrm{Cd}>\mathrm{Mg}$; which are in close agreement to the findings of (Dinu, 2013 and Pandey et al., 2015).The high stability of Cuhumate chelate could be attributed to the existence of coordinate covalent bond between the complexing agents and the $\mathrm{Cu}^{2+}$ ions. Since, $\mathrm{Cu}^{2+}$ being a metal of the transitional series with $3 d^{9}$ electronic configurations can accept the electrons from the complexing agents. Similarly, the low stabilities of $\mathrm{Pb}, \mathrm{Cd}$ and $\mathrm{Mg}$ complexes could be explained by that $\mathrm{Pb}^{2+}$ with $6 s^{2}, \mathrm{Cd}^{2+}$ with $4 \mathrm{~d}^{10}$ and $\mathrm{Mg}^{2+}$ with $2 \mathrm{p}^{6}$ their electronic configuration has a completely filled $\mathrm{d}, \mathrm{p}$ and $\mathrm{s}$ orbitals. Moreover, the stabilities of metal ions with hydrolysed humic acid from peat soil were higher than those with unhydrolysed humic acid from peat soil; which is ascribed to the high content of acidity in hydrolysed humic acid than unhydrolysed humic acid. 
BAJOPAS Volume 14 Number 1,June, 2021 CONCLUSION

The values of logk for $\mathrm{Cu}(\mathrm{II})$ hydrolysed humic acid complex was higher followed by $\mathrm{Pb}$ (II), $\mathrm{Cd}(\mathrm{II})$ and $\mathrm{Mg}$ (II) hydrolysed humic acid complexes as compared with metal(II) unhydrolysed humic acid complexes. This indicates acid hydrolysis of humic acid can

\section{REFERENCES}

Almeida, V.R. and Szpoganicz, B. (2015). Humic Acid Potentiometric Response Patterns:Out- of Equilibrium Properties and Species Distribution Modelling. Chemical. Biol. Technol. Agric. 2: 17.

Anđelković, T., Nikolić, R., Bojić, A.,Anđelković, D., and Nikolic G.,(2010). Binding of Cadmium to Soil Humic Acid as A Function of Carboxyl Group Content. Macedonian Journal of Chemistry and Chemical Engineering.29(2): 215-224.

Anil, B. N. and Maroti, N. (2008). Studies on Influence of Die-Lectric Constants on Complex Equilibria between Substituted Py-Razalines and Lanthanide Metal Ions pH-Metrically. Amer.-Euras. scient. Res. 3(2): 212-216.

Ashok, K., Pandey, S. P. and Misra, V (2000). Stability Constants of Metal-Humic Acid Complexes and its Role in Environmental Detoxification. Journal of Ecotoxicology and Environmental Safety. 47(2):157-200.

Badr, M. H., El-Halafawi, M. H. and Abd El-al Zeid, E. R. (2012). Comparison Between the Effect of Ionic Strength on Acidity and Dissociation Constants of Humic Acids Extracted from Sewage Sludge and Nile Water Hyacinth Composts.Global Journal of Environmental Research 6 (1): 36-43.

Baruah, M.K., Borah, D., Saikia, P.P., Paul, S., Sharma, T. (2015). Evaluation of pKa Values of Soil Humic Acids and their Complexation Properties. International Journal of Plant \& Soil Science 6(4) : 218-228.

Boguta, P. Sokolowska, Z. (2016). Interactions of $\mathrm{Zn}$ (II) Ions with Humic Acids Isolated from Various Types of Soils. Effect of $\mathrm{pH}, \mathrm{Zn}$ Concentrations and Humic Acids Chemical Properties. Journal of Geochemical Explaration 168. 119-126.

Borges, F., Guimaraes, C., Lima, L.F.C., Pinto, I. and Reis, S.(2005). Potentiometric Studies on the Complexation of Copper(II) by Phenolic Acids as Discrete Ligand Models of enhance the complexation behavior of humic acid with metal (II) ions. However, the higher values of $\log \beta$ for $\mathrm{Cu}(\mathrm{II}), \mathrm{Pb}(\mathrm{II}), \mathrm{Cd}(\mathrm{II})$ and $\mathrm{Mg}(\mathrm{II})$ hydrolysed humic acid complexes indicates more stable stepwise complexes formed as compared with $\mathrm{Cu}(\mathrm{II}), \mathrm{Pb}$ (II), $\mathrm{Cd}$ (II) and $\mathrm{Mg}(\mathrm{II})$ unhydrolysed humic acid complexes.

Humic Substances Talanta 66 (2005) 670-673.

Chefetz, B., Salloum, M. J., Deshmulkin, A. P. and Hatcher, P. (2002). Structural Components of Humic Acids as Determined by Chemical Modifications and Carbon-13 NMR, Pyrolysis, and Thermochemolysis- Gas Chromatography/Mass Spectrometry. Soil Science Society of American Journal Abstract Division S-2- Soil Chemistry66. 1159-1171.

Dinu, M. I. (2013). Metals Complexation with Humic Acids in Surface Water of Different Environ. Sci. Technol. 31(1): 1-17.

Fernandes, A.N., Giacomelli, C., Giovanela, M. Vaz, D.V. Szpoganicz, B. and Maria M. D. (2009). Potentiometric Acidity Determination in Humic Substances Influenced by Different Analytical Procedures.J. Braz. Chem. Soc. 20 (9):14.

Gamal, A. H. (2015). Stability Constants of Rhenium (V) Metal Complexes with Selected Drugs. Pyrex Journal of Research in Environmental Studies. 2(2): 006-014.

Janrao, D. M., Pathan, J., Kayande, D.D., and Mulla, J.J. (2014). An Over View of Potentiometric Determination of Stability Constants of Metal Complexes. Sci. Revs. Chem. Commun.: 4(1), 2014, 11-24.

Karimi, H. (2017). Effect of pH and Initial Pb(II) Concentration on the Lead Removal Efficiency from Waste Water Using $\mathrm{Ca}(\mathrm{OH})_{2}$. International Journal of Water and Waste Water Treatment 3.2

Kaschl, A. Romheld, V. and Chen, Y. (2010). Binding of Cadmium, Copper and Zinc to Humic Substances Originating from Municipal Solid Waste Compost. Israel Journal of Chemistry Vol. 42(1): 89-98.

Kostic, I. S., Tatjana, P, A., Nikolic, R. S., Cvetkovic, T. P., Pavlovic, D. D., Aleksandar, L.J. and Bojic, A. (2012). Comparative Study of Binding Strengths of Heavy Metals with Humic Acid. J.serb. Chem. Soc. 76(9) pp 1-20. 
BAJOPAS Volume 14 Number 1,June, 2021

Na'aliya, J. (2013). Determination of Stepwise Stability Constants and Gibbs free Energy Change of Trisprolina to Complexes of some Divalent Transition Metal ions. Bayero Journal of Pure and Applied Sciences 6(2): 112-114.

Omar, A. A. and Ali, E. A. (2015). Potentiometric Studies on Complexes of $\mathrm{Cr}$ (III) and $\mathrm{Zr}$ (IV) with some Carboxylic Acids. International Journal of Advanced Chemistry, 3(1) 25-

37.

Pandey, A. K. Pandey, S. D. and Misr, V. (2015).Stability Constants of Metal- Humic Acid Complexes and Its Role in Environmental Detoxification. J. Ecotoxicology and Environmental Safety. 47(1):195-200.

Ram, N. and Raman, K.V. (1984). Stability Constants of Complexes of Metals with
Humicand Fuvic Acids under Non- acidConditions. Journal of Plant Nutrition and Soil Sciences.

147:171-176.

Santosh, D. D., Ashok, B. K., Vijay, J. T., Shivraj, G. W. and Vinay, V. W. (2011). Potentiometric Studies of Elec-Trolyte Effects on Complex Equilibria of Some Substituted 5-(2-hydroxy Phenyl) Pyrazoles. Der pharm. 3 (6): 75-83.

Sayyed, H. and Abdul Rahim, M. F. (2012). Studies of Binary Complexes of Metal Ions with Mandelic Acid by Potentiometry. Chem. J. 02 (6): 206209.

Shirvani, M. Moradian, E. Khalili, B. Bakhtiary, S. (2015). Interaction of $\mathrm{Cd}$ and $\mathrm{Pb}$ with Humate-Palygorskite and HumateSepiolite Complexes. Journal of water, air and pollution 3: 220-228. 


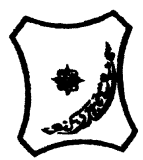

Bayero Journal of Pure and Applied Sciences, 14(1): 54 - 63

Received: November, 2020

Accepted: April, 2021

ISSN $2006-6996$

\title{
STABILITY CONSTANTS OF COMPLEXES OF METAL IONS WITH PEATSOIL HUMIC ACIDS UNDER NON-ACID-CONDITIONS
}

\author{
${ }^{* 1}$ Sabo, Yusuf ${ }^{2}$ Jimoh, W.L.O., ${ }^{3}$ Isa Baba Koki and ${ }^{4}$ Sholadoye, Q. 0. \\ ${ }^{1}$ Department of Pure and Industrial Chemistry, Bayero University, Kano \\ ${ }^{3}$ Department of Chemistry, Yusuf Maitama Sule University Kano. P.M.B. 3220 Kano, Nigeria. \\ ${ }^{4}$ Department of Chemistry, Nigerian Police Academy, Wudil, Kano-Nigeria
}

*Correspondence E-mail; saboyusuf18@yahoo.com

ABSTRACT

Stability constants of complexes of four divalent metal ions viz. $\mathrm{Cu}^{2+}, \mathrm{Pb}^{2+}, \mathrm{Mg}^{2+}$ and $\mathrm{Cd}^{2+}$ with humic acids (HA) were determined by potentiometric titration of humic acids with the corresponding salt of the divalent metals in aqueous media under non-acid-condition. The log $K$ (logarithm of the stability constant) ranged from 1.0942 to 2.7471 for metalhumic acid complexes were determined using point-wise computational method. The order of stability constants were obtained as follows: $\mathrm{Cu}>\mathrm{Pb}>\mathrm{Cd}>\mathrm{Mg}$ for metal $-\mathrm{HA}$ complexes respectively, indicating a higher degree of complexation with Cu metal ion.

Keywords: stability constant, humic acid, potentiometric titration, divalent metals, acid hydrolysis.

\section{NTRODUCTION}

The stability constant of a complex is the numerical expression of its stability and provides a quantitative measure of affinity of the metal ion to the complexing agent. An understanding of the relative stability of metal-complexes helps in predicting the behavior of metal ions in the soil (Ram and Raman, 1982). Extensive researches has been done to determine the stability constants of the complexes formed between humic acid (HA) with a number of metal ions. Ashok et al., (2000) reported that humic acid with hydroxyl, phenoxyl and carboxyl reactive groups can form coordination compound with metal ions at $\mathrm{pH}$ 3.5. The stability constants(Log K) for different metalhumic acid complexes indicated the following order of the stabilities of complexes formed between humic acid and metal ion, $\mathrm{Cu}>\mathrm{Fe}$ $>\mathrm{Pb}>\mathrm{Ni}>\mathrm{Co}>\mathrm{Ca}>\mathrm{Cd}>\mathrm{Zn}>\mathrm{Mn}>\mathrm{Mg}$. Andelkovic et al., (2010) investigated the binding of $\mathrm{Cd}$ (II) to soil humic acid at pH 6.5 and in $0.1 \mathrm{M} \mathrm{KNO}_{3}$ ionic medium. The stability constant for binding indicating greater stability in the case when carboxyl groups are involved in complexation reaction. Kostic et al.,(2012) investigated the complexation of humic acid with certain heavy metal ions (Co(II), $\mathrm{Ni}(\mathrm{II}), \mathrm{Cu}(\mathrm{II})$,
$\mathrm{Zn}(\mathrm{II})$, and $\mathrm{Pb}(\mathrm{II})$. The experiment was performed at $25^{\circ} \mathrm{C}$, at pH 4.0 and ionic strength of $0.01 \mathrm{M}$. Stability constant of complex between $\mathrm{Pb}$ (II) ions and humic acid is greater than stability constants of other investigated metalhumate complexes. Bogata and Sokolowska (2016) analyses the interaction between humic acids from different soils and $\mathrm{Zn}$ (II) ions at wide concentration ranges and at $\mathrm{pH} 5$. Studies have showed significant impact of $\mathrm{Zn}$ concentration, $\mathrm{pH}$ and some properties of humic acids with zinc.But all of these studies were limited to acidic $\mathrm{pH}$ range. Therefore, the present study was carried out to determine and compare the stability constants of complexes of metal ions with hydrolysed peat soil humic acid and unhydrolysed peat soil humic under non-acid conditions.

\section{MATERIALS AND METHODS}

Analytical grade chemicals used includes hydrochloric acid $(\mathrm{HCl})$, nitric acid $\left(\mathrm{HNO}_{3}\right)$, sodium hydroxide $(\mathrm{NaOH})$, lead nitrate $\mathrm{Pb}\left(\mathrm{NO}_{3}\right)_{2}$, copper nitrate $\mathrm{Cu}\left(\mathrm{NO}_{3}\right)_{2} \cdot 3 \mathrm{H}_{2} \mathrm{O}$, cadmium nitrate $\mathrm{Cd}\left(\mathrm{NO}_{3}\right)_{2} \cdot 4 \mathrm{H}_{2} \mathrm{O}$, magnesium nitrate $\mathrm{Mg}\left(\mathrm{NO}_{3}\right)_{2} \cdot 6 \mathrm{H}_{2} \mathrm{O}$, potassium nitrate $\left(\mathrm{KNO}_{3}\right)$, calcium chloride $\left(\mathrm{CaCl}_{2}\right)$, (sigma-Aldrich). Dowex 50WX8, (20-50 mesh) from Fluka. 


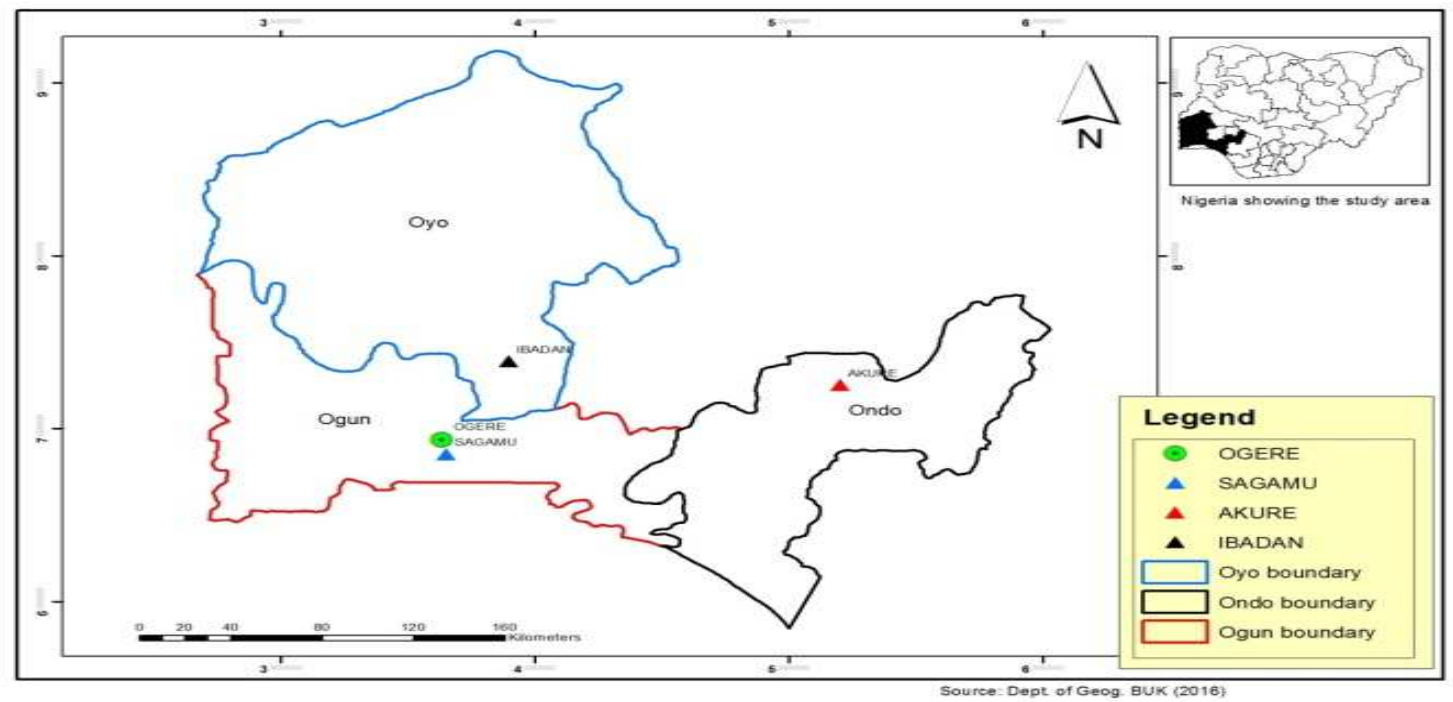

Figure 1: Map showing the sampling point at Sagamu Town, Ogun State.

\section{Description of Sampling Area}

Sagamu has geographical coordinates between $6^{\circ} 50^{\prime}$ north; $3^{\circ} 38^{\prime}$ east is located in south western region of Nigeria. The region has tropical wet and dry climate with a lengthy wet season and relatively constant temperatures throughout the course of the year. Wet season runs from March to October, November to December forms the region dry season. The vegetation type of the region is savannah which is really grassland with small bushes and occasional big trees. Grassland soils have substantially higher organic matter content than forest soils (Novackova, 2011).

\section{Sample Collection}

The Peatsoil samples were collected from four different sampling points $(0-10 \mathrm{~cm}$ depth) in Sagamu into polyethylene bag with plastic spoons. Samples were taken to the laboratory, extraneous materials were removed; the samples were air-dried, crushed and ground to a fine powder in a mortar passed through a $0.20 \mathrm{~mm}$ sieve. The samples were kept for analysis.

\section{Isolation and purification of humic acid from peat soil sample}

Peatsoil sample $(100 \mathrm{~g})$ was mixed with 1000 $\mathrm{cm}^{3}$ of $0.1 \mathrm{M} \mathrm{NaOH}$ solution, shaken for 3hours and left to stand overnight. Dark-coloured supernatant was obtained and decanted from solid residue. The dark-coloured supernatant was acidified to $(\mathrm{pH}=1.0)$ with $6 \mathrm{M} \mathrm{HCl}$ stirred and allowed to stand for 6 hours. Yellowish brown supernatant and dark-brown precipitate were obtained. The yellowish brown supernatant was decanted followed by centrifuge and discarded. The dark-brown precipitate was mixed with $500 \mathrm{~cm}^{3}$ of $0.1 \mathrm{M} \mathrm{NaOH}$ solution followed by passing through dowex resin. The dark-brown solution was acidified to $(\mathrm{pH}=1.0)$ with $6 \mathrm{M} \mathrm{HCl}$ stirred and allowed to stand for 3 hours. The dark-brown precipitate was washed several times with deionized water. The supernatant was treated with $\mathrm{AgNO}_{3}$ solution until no white precipitate observed. The humic acid was transferred to weighed crucible and dried at $60^{\circ} \mathrm{C}$ in an oven for 12 hours. The humic acid was cooled and dried in the desiccator, weighed and recorded. The obtained humic acid was dried again at $60^{\circ} \mathrm{C}$ for additional 6 hours cooled and dried in the desiccator, weighed and recorded constant weight was obtained (Baruah et al., 2015).

\section{FT-IR analysis}

FT-IR spectra of humic acid sample was analysed using Carry 630 FT-IR Agilent Technologies.

Unhydrolysed compost humic acid

The unhydrolysed humic acid was obtained after isolation and purification of compost humic acid and kept for investigation.

\section{Acid hydrolysis of Peatsoil acid}

Peatsoil humic acid sample (1g) was refluxed for 12 hours at $\left(160^{\circ} \mathrm{C}\right)$ with $50 \mathrm{~cm}^{3}$ of $6 \mathrm{M} \mathrm{HCl}$. The mixture was allowed to cool, decanted, and centrifuged after hydrolysis. The insoluble residues were washed with distilled water via centrifugation several times, and the supernatant was treated with $\mathrm{AgNO}_{3}$ solution until no white precipitate was observed. The residue was thoroughly dried over $\mathrm{CaCl}_{2}$ in a desiccator at room temperature (Chefetz et al., 2002). Finally, the obtained hydrolysed humic acid was kept for investigation. 
BAJOPAS Volume 14 Number 1,June, 2021 Potentiometric Titrations

Potentiometric measurements were carried out using a pH-meter Jenway (model 3510) with combine electrode, the sensitivity of the $\mathrm{pH}$ meter is 0.01 units. The $\mathrm{pH}$ meter was switched on half an hour before starting the titration for initial warm up of the instrument. The instrument was calibrated with an aqueous standard buffer solution of $\mathrm{pH} 4.00$ and 10.0 (borate buffer) prepared from a "Qualigens" buffer tablets.

The following sets of solutions were prepared in a $250 \mathrm{~cm}^{3}$ volumetric flask separately for $\mathrm{pH}$ metric titrations.

(i) $5 \mathrm{~cm}^{3} 0.1 \mathrm{M} \mathrm{HCl}+40 \mathrm{~cm}^{3}$ deionized water

(ii) $5 \mathrm{~cm}^{3} 0.1 \mathrm{M} \mathrm{HCl}+39 \mathrm{~cm}^{3}$ deionized water $+1 \mathrm{~cm}^{3} 0.15 \mathrm{gcm}^{-3}$ humic acid

(iii) $5 \mathrm{~cm}^{3} 0.1 \mathrm{M} \mathrm{HCl}+37 \mathrm{~cm}^{3}$ deionized water $+1 \mathrm{~cm}^{3} 0.15 \mathrm{gcm}^{-3}$ humic acid

$$
+2 \mathrm{~cm}^{3} \quad 0.01 \mathrm{M} \mathrm{Cu} \text { (II) }
$$

The solutions were titrated against standardized $0.110 \mathrm{MNaOH}$ separately. The total volume of each mixture was adjusted to $50 \mathrm{~cm}^{3}$ and the ionic strength of the solutions was maintained constant at by adding appropriate amount of stock solution of $1 \mathrm{M} \mathrm{KNO}_{3}$ (Gamal, 2015; Omar and Ali, 2015). A magnetic stirrer was used to achieve thorough mixing of the interacting solutions at $550 \mathrm{rpm}$. The same set of experimental conditions was applied for potentiometric titration of remaining samples.

\section{Evaluation of pKa of Hydrolysed peat soil Humic Acids}

The proton-ligand formation number $\mathrm{n}_{\mathbf{A}}$ were calculated by Irving and Rossotti expression (Omar and Ali, 2015).

$\mathrm{nA}=\mathrm{Y}-\frac{(\mathrm{V} 2-\mathrm{V1})(\mathrm{No}-\mathrm{Eo})}{(\mathrm{VO}+\mathrm{V1}) \mathrm{TCL}}$ 1

Where: $Y$ is number of dissociable proton, $\left(\mathrm{V}_{2^{-}}\right.$ $V_{1}$ ) is the measure of displacement of the ligand curve relative to acid curve, $\mathrm{N}^{\circ}$ and $\mathrm{E}^{\circ}$ are the resultant concentration of alkali solution, free acid solution, $\mathrm{T}_{\mathrm{cL}}{ }^{\circ}$ is the total ligand concentration, $\mathrm{V}^{\circ}$ is the total volume of titration solution, $V_{1}$ is the volume of alkali added to acid solution, $V_{2}$ is the volume of alkali added to acid solution + ligand solution, acid dissociation constants (pKa - values) of ligand were calculated by algebraic method point wise calculation (Tables 1 ). The dissociation constants (pKa) were calculated according to the following relation:

$\mathrm{pKa}=\mathrm{pH}+\log \left(\frac{n A}{1-n A}\right)$ 2

Where: pKa is the acid dissociation constant, $\mathrm{n}_{\mathrm{A}}$ is the Proton-ligand formation number and $\mathrm{pH}$ is the pH-values (Omar and Ali, 2015).

\section{Determination of metal-ligand stability constants $(\log K)$ of complexes}

The potentiometric measurement for the determination of stability constant of a complex in solution is based on the fact that the redox potential of the couple $\frac{M^{+(m-n)}}{M^{+m}}$ is shifted significantly on complexation of the metal ion with the ligand. This method involves change in hydrogen ion concentration $\left[\mathrm{H}^{+}\right]$due to the displacement or association of one or more protons taking place during complexation reaction. This change can be found out by titrating the solutions containing free acid, acid with ligand, and acid with ligand and metal ion, individually against a standard alkali solution at a constant ionic strength or temperature. Either ionic strength or temperature may be varied for different sets of solutions. In all the cases, the change in the $\mathrm{pH}$ of the solution is measured after each addition of a known amount of alkali to the reaction cell which contains the reaction mixture. The titration curves are then drawn by plotting the measured $\mathrm{pH}$ values against the corresponding volume of alkali added and the stability constants of the complexes are determined from the titration curves by employing $\mathrm{pH}$-metric titration technique given by (Irving and Rossoti).

Metal-ligand stability constants ( $\log \mathrm{K}$ ) were determined by using the following relations:

$$
\bar{n}=\frac{\left(V_{3}-V_{2}\right)\left(E^{0}+N^{0}\right)}{\left(V^{0}+V_{2}\right) \bar{n}_{A} T_{m}^{0}}
$$

and

$$
P L=\log _{10}\left\{\frac{1+\beta_{n}^{H} \frac{1}{[\text { anti } \log \mathrm{pH}]^{\mathrm{n}}}}{\mathrm{T}_{\mathrm{L}}^{0}-n \bar{T}_{m}^{0}} \mathrm{X} \frac{\left(V^{0}+V_{3}\right)}{V^{0}}\right\}
$$


BAJOPAS Volume 14 Number 1,June, 2021

Where $T_{L}, T^{\circ}, E^{\circ}$, and $V^{\circ}$ havethe same significance as in equation (1) above, $T_{m}$ denotes the total concentration of metal present in solution, $V_{3}$ is the volume of metal ions present in solution and $\beta^{H}$ is the overall proton ligand stability constant. The metal-ligand stability constants (log K) were determined by employing point wise computational Method (eq. 5 and 6).

$\operatorname{LogK}_{1}=\log \left(\frac{n}{1-n}\right)+\mathrm{pL}$ .5

$\operatorname{LogK}_{2}=\log \left(\frac{1-n}{2-n}\right)+\mathrm{pL}$ ...6

Where: Log $\mathrm{K}$ is the metal-ligand stability constant, $\mathrm{pL}$ is the Free ligand exponent function, $\mathbf{n}$ is the Average number of ligand attached with metal ion (Janraoet al., 2014). The results obtained were analyzed by an ORIGIN 2016 program using titration data and then the proton-ligand stability constants (pKa) and Metal-ligand stability constant (LogK) calculated (Omar and Ali, 2015).

\section{RESULTS AND DISCUSSION}

Fourier transformed infrared (FT-IR) spectra of isolated humic acid from peat soils Figure 2 had distinct clear absorption bands indicating the presence of major humic acid structural elemental groups such as $\mathrm{H}$ bonded $\mathrm{OH}$ $\left(3680 \mathrm{~cm}^{-1}\right.$ peak $), C=0$ of carbonyl $\left(1721 \mathrm{~cm}^{-1}\right.$ peak), functional groups of aliphatic components $\mathrm{CH}_{2}\left(2918 \mathrm{~cm}^{-1}\right.$ peak) and $\mathrm{C}-\mathrm{O}$ stretching of polysaccharide $\left(1168 \mathrm{~cm}^{-1}\right.$ peak). The positions of the absorption bands of the spectra fell within typical major absorption bands of humic acid which is at frequencies 3680, 2918, 1721, 1168 $\mathrm{cm}^{-1}$. The first peak centred in the vicinity of $3680 \mathrm{~cm}^{-1}$ region is attributed to phenol $\mathrm{OH}$ group bounded by intermolecular $\mathrm{H}$ bonds. The $2918 \mathrm{~cm}^{-1}$ band usually has absorption maximum at $2918 \mathrm{~cm}^{-1}$ which is due to $\mathrm{C}-\mathrm{H}$ stretching of alkane group $\left(\mathrm{CH}_{2}\right)$. The next major absorption band is $1721 \mathrm{~cm}^{-1}$. This band has been commonly ascribed to $\mathrm{C}=\mathrm{O}$ stretching of mainly carboxyl group $(\mathrm{COOH})$ with trace amount of ketones. The last peak was observed at 1168 $\mathrm{cm}^{-1}$ due to $\mathrm{C}-\mathrm{O}$ stretching of polysaccharides and this peak appeared also in the spectra of humic acid from peat soil. The FTIR spectra of the isolated humic acid contained all major characteristic absorption peaks of humic acid. These absorption peaks indicated the presence of the major structural elements of humic acid namely $\mathrm{H}$ bonded $\mathrm{OH}, \mathrm{C}=\mathrm{C}$ of aromatic ring, $\mathrm{C}=\mathrm{O}$ of carbonyl group (both carboxyl and ketonic), $\mathrm{CH}_{2}$ group. This strongly supports the presence of humic acid.

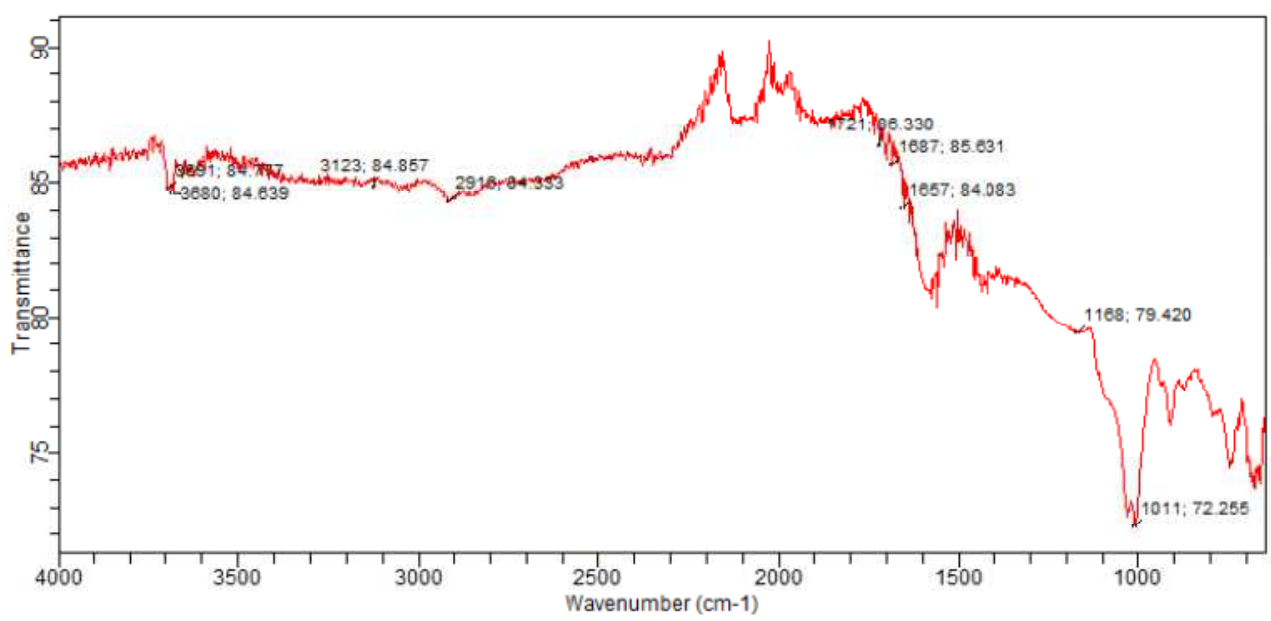

Fig. 2 : FT-IR spectraof peatsoilhumic acid (PSHA)

\section{Evaluation of acid dissociation constant (pka) of acid hydrolysed peat soil humicacid at phenolic group}

The value of the dissociation constant of the peat soil humic acid (PSHA) that underwent acidhydrolysis studied was found to be 8.9299 as shown Table 1, which is lower than the literaturevalues reported by Almeida and Szpoganics, (2015), Borges et al., (2005); Badr et al., (2012)and Fernandes et al,.(2009) of $9.73,9.47$ and 10.30. The difference between the obtained valuesand the reported values in this study might be probably as a result of acid hydrolysis of humicacid. 
BAJOPAS Volume 14 Number 1,June, 2021

Table 1: PKa of (Hydrolysed PSHA)

\begin{tabular}{|l|l|l|l|l|l|l|}
\hline $\mathrm{pH}$ & $\mathrm{BV}_{1}$ & $\mathrm{BV}_{2}$ & $\mathrm{~V}_{2}-\mathrm{V}_{1}$ & $\mathrm{nA}$ & $\log \left(\frac{n A}{1-n A}\right)$ & $\mathrm{pKa}$ \\
\hline 8.50 & 5.30 & 6.29 & 0.99 & 0.3594 & -0.2510 & 8.2490 \\
8.72 & 5.35 & 6.37 & 1.02 & 0.3400 & -0.2880 & 8.4320 \\
9.00 & 5.40 & 6.46 & 1.06 & 0.3141 & -0.3391 & 8.6609 \\
9.22 & 5.45 & 6.55 & 1.10 & 0.2882 & -0.3927 & 8.8273 \\
9.51 & 5.50 & 6.66 & 1.16 & 0.2494 & -0.4786 & 9.0314 \\
9.73 & 5.55 & 6.78 & 1.23 & 0.2041 & -0.5910 & 9.1390 \\
10.00 & 5.60 & 6.90 & 1.30 & 0.1589 & -0.7238 & 9.2762 \\
10.23 & 5.65 & 7.05 & 1.40 & 0.0941 & -0.9835 & 9.2465 \\
10.49 & 5.70 & 7.10 & 1.40 & 0.0941 & -0.9835 & 9.5065 \\
\hline
\end{tabular}

Average pKa $=8.9299 \pm 0.4186$

Table 2: PKa of (Unhydrolysed PSHA)

\begin{tabular}{|l|l|l|l|l|l|l|}
\hline $\mathrm{pH}$ & $\mathrm{BV}_{1}$ & $\mathrm{BV}_{2}$ & $\mathrm{~V}_{2}-\mathrm{V}_{1}$ & $\mathrm{nA}$ & $\log \left(\frac{\boldsymbol{n A}}{1-\boldsymbol{n}}\right)$ & $\mathrm{pKa}$ \\
\hline 8.50 & 5.30 & 5.81 & 0.51 & 0.6619 & 0.2919 & 8.7919 \\
8.72 & 5.35 & 5.90 & 0.55 & 0.6357 & 0.2418 & 8.9618 \\
9.00 & 5.40 & 6.00 & 0.60 & 0.6029 & 0.1813 & 9.1813 \\
9.22 & 5.45 & 6.10 & 0.65 & 0.5701 & 0.1226 & 9.3426 \\
9.51 & 5.50 & 6.20 & 0.70 & 0.5376 & 0.0654 & 9.5754 \\
9.73 & 5.55 & 6.33 & 0.78 & 0.4851 & -0.0259 & 9.7041 \\
10.00 & 5.60 & 6.47 & 0.87 & 0.4262 & -0.1291 & 9.8709 \\
10.23 & 5.65 & 6.62 & 0.99 & 0.3609 & -0.2481 & 9.9819 \\
10.49 & 5.70 & 6.80 & 1.10 & 0.2759 & -0.4690 & 10.0210 \\
\hline
\end{tabular}

Average pKa $=9.4923 \pm 0.4410$

Metal-ligand stability constant ( $\log \mathrm{K}$ )

The stabilityconstants require the accurate values of proton-ligand stability constants (Anil and Maroti, 2008). Metal titration curves crossed over ligand titration curve indicated the formation of complex upon proton release (Santosh, et al., 2011). If the values of n- are within range $0.2-0.8$ and $1.2-18$ this indicates the formation of $1: 1$ and 1:2 complexes (Sayyed and Mazahar, 2012).

The metal (II)-humate stepwise stability constants (log k) at phenolic group (Tables 318)

Table 3: Point-wise method, $\mathrm{Cu}$-(Hydrolysed PSHA)

\begin{tabular}{|l|l|l|l|l|l|l|l|l|}
\hline $\mathrm{pH}$ & $\mathrm{BV}_{1}$ & $\mathrm{BV}_{2}$ & $\mathrm{BV}_{3}$ & $\left(\mathrm{~V}_{3}-\mathrm{V}_{2}\right)$ & $\mathrm{n}$ & $\mathrm{pL}$ & $\log \left(\frac{n}{1-n}\right)$ & LogK $_{1}$ \\
\hline 8.50 & 5.30 & 6.29 & 6.33 & 0.04 & 0.5500 & 2.66 & 0.0871 & 2.7471 \\
8.72 & 5.35 & 6.37 & 6.41 & 0.04 & 0.5714 & 2.43 & 0.1249 & 2.5549 \\
9.00 & 5.40 & 6.46 & 6.50 & 0.04 & 0.6198 & 2.16 & 0.2122 & 2.3722 \\
9.22 & 5.45 & 6.55 & 6.59 & 0.04 & 0.6667 & 1.94 & 0.3010 & 2.2410 \\
\hline
\end{tabular}

LogK $_{1}$ (Average value) $=2.4788 \pm 0.2203$

Table 4: Point-wise method, $\mathrm{Cu}$-(Hydrolysed PSHA)

\begin{tabular}{|l|l|l|l|l|l|l|l|l|}
\hline $\mathrm{pH}$ & $\mathrm{BV}_{1}$ & $\mathrm{BV}_{2}$ & $\mathrm{BV}_{3}$ & $\left(\mathrm{~V}_{3}-\mathrm{V}_{2}\right)$ & $\mathrm{n}$ & $\mathrm{pL}$ & $\log \left(\frac{n-1}{2-n}\right)$ & LogK $_{2}$ \\
\hline 9.51 & 5.50 & 6.66 & 6.73 & 0.07 & 1.3509 & 1.70 & -0.2671 & 1.4329 \\
9.73 & 5.55 & 6.78 & 6.85 & 0.07 & 1.6383 & 1.51 & 0.2467 & 1.7567 \\
10.00 & 5.60 & 6.90 & 6.98 & 0.08 & 2.1783 & 1.31 & -0.2158 & 1.0942 \\
10.23 & 5.65 & 7.05 & 7.13 & 0.08 & 4.1904 & 1.27 & & \\
10.49 & 5.70 & 7.10 & 7.19 & 0.09 & 4.6920 & & & \\
\hline
\end{tabular}

Log $K_{2}($ Average value $)=1.4280 \pm 0.3312$ 
BAJOPAS Volume 14 Number 1,June, 2021

Table 5: Point-wise method, $\mathrm{Cu}$ (Unhydrolysed PSHA)

\begin{tabular}{|l|l|l|l|l|l|l|l|l|}
\hline $\mathrm{pH}$ & $\mathrm{BV}_{1}$ & $\mathrm{BV}_{2}$ & $\mathrm{BV}_{3}$ & $\left(\mathrm{~V}_{3}-\mathrm{V}_{2}\right)$ & $\mathrm{n}$ & $\mathrm{pL}$ & $\log \left(\frac{n}{n-1}\right)$ & Log $_{1}$ \\
\hline 8.50 & 5.30 & 5.81 & 5.85 & 0.04 & 0.2973 & 2.88 & -0.3736 & 2.5064 \\
8.72 & 5.35 & 5.90 & 5.95 & 0.05 & 0.3873 & 2.66 & -0.1992 & 2.4608 \\
9.00 & 5.40 & 6.00 & 6.05 & 0.05 & 0.4044 & 2.38 & -0.1681 & 2.2119 \\
9.22 & 5.45 & 6.10 & 6.15 & 0.06 & 0.5157 & 2.18 & -0.0272 & 2.2072 \\
9.51 & 5.50 & 6.20 & 6.27 & 0.07 & 0.6417 & 1.89 & 0.2530 & 1.1430 \\
\hline
\end{tabular}

$\operatorname{LogK}_{1}($ Average value $)=2.3059 \pm 0.6153$

Table 6:Point-wise method, $\mathrm{Cu}$ (Unhydrolysed PSHA)

\begin{tabular}{|l|l|l|l|l|l|l|l|l|}
\hline $\mathrm{pH}$ & $\mathrm{BV}_{1}$ & $\mathrm{BV}_{2}$ & $\mathrm{BV}_{3}$ & $\mathrm{~V}_{3}-\mathrm{V}_{2}$ & $\mathrm{n}$ & $\mathrm{pL}$ & $\log \left(\frac{n-1}{2-n}\right)$ & $\log \mathrm{K}_{2}$ \\
\hline 9.73 & 5.55 & 6.33 & 6.42 & 0.09 & 0.9000 & 1.69 & & \\
10.00 & 5.60 & 6.47 & 6.58 & 0.11 & 1.2578 & 1.44 & -0.4592 & 0.9808 \\
10.23 & 5.65 & 6.62 & 6.84 & 0.12 & 1.6137 & 1.26 & -0.2010 & 1.4610 \\
10.49 & 5.70 & 6.80 & 6.92 & 0.12 & 2.1052 & 1.03 & & \\
\hline
\end{tabular}

$\operatorname{LogK}_{2}$ (Average value) $=1.2209 \pm 0.3398$

Table 7:Point-wise method, Pb (Hydrolysed PSHA)

\begin{tabular}{|l|l|l|l|l|l|l|l|l|}
\hline $\mathrm{pH}$ & $\mathrm{BV}_{1}$ & $\mathrm{BV}_{2}$ & $\mathrm{BV}_{3}$ & $\left(\mathrm{~V}_{3}-\mathrm{V}_{2}\right)$ & $\mathrm{n}$ & $\mathrm{pL}$ & $\log \left(\frac{n}{1-n}\right)$ & LogK $_{1}$ \\
\hline 8.50 & 5.30 & 6.29 & 6.33 & 0.04 & 0.5500 & 2.66 & 0.0871 & 2.7471 \\
8.72 & 5.35 & 6.37 & 6.41 & 0.04 & 0.5714 & 2.43 & 0.1249 & 2.5549 \\
9.00 & 5.40 & 6.46 & 6.50 & 0.04 & 0.6198 & 2.16 & 0.2122 & 2.3722 \\
9.22 & 5.45 & 6.55 & 6.60 & 0.05 & 0.8333 & 1.96 & 0.6989 & 2.6589 \\
\hline
\end{tabular}

Log $_{\mathbf{1}}($ Average value $)=2.5832 \pm 0.1614$

Table 8:Point-wise method, Pb-(Hydrolysed PSHA)

\begin{tabular}{|l|l|l|l|l|l|l|l|l|}
\hline $\mathrm{pH}$ & $\mathrm{BV}_{1}$ & $\mathrm{BV}_{2}$ & $\mathrm{BV}_{3}$ & $\left(\mathrm{~V}_{3}-\mathrm{V}_{2}\right)$ & $\mathrm{n}$ & $\mathrm{pL}$ & $\log \left(\frac{n-1}{2-n}\right)$ & $\log \mathrm{K}_{2}$ \\
\hline 9.51 & 5.50 & 6.66 & 6.71 & 0.05 & 0.9650 & 1.67 & & \\
9.73 & 5.55 & 6.78 & 6.83 & 0.05 & 1.1702 & 1.44 & & \\
10.00 & 5.60 & 6.90 & 6.90 & 0.05 & 1.4864 & 1.22 & -0.0237 & 1.1963 \\
10.23 & 5.65 & 7.05 & 7.10 & 0.05 & 2.0190 & 1.09 & & \\
10.49 & 5.70 & 7.10 & 7.17 & 0.07 & 3.6492 & 1.00 & & \\
\hline
\end{tabular}

Log $K_{2}$ (Average value) $=1.1963$

Table 9: Point-wise method, Pb (Unhydrolysed PSHA)

\begin{tabular}{|l|l|l|l|l|l|l|l|l|}
\hline $\mathrm{pH}$ & $\mathrm{BV}_{1}$ & $\mathrm{BV}_{2}$ & $\mathrm{BV}_{3}$ & $\mathrm{~V}_{3}-\mathrm{V}_{2}$ & $\mathrm{n}$ & $\mathrm{pL}$ & $\begin{array}{l}\text { Log } \\
\left(\frac{n}{n-1}\right)\end{array}$ & Log $\mathrm{K}_{1}$ \\
\hline 8.50 & 5.30 & 5.81 & 5.85 & 0.04 & 0.2973 & 2.88 & -0.3736 & 2.5064 \\
8.72 & 5.35 & 5.90 & 5.94 & 0.04 & 0.3099 & 2.66 & -0.5477 & 2.3123 \\
9.00 & 5.40 & 6.00 & 6.05 & 0.05 & 0.4044 & 2.38 & -0.1681 & 2.2119 \\
9.22 & 5.45 & 6.10 & 6.15 & 0.06 & 0.5157 & 2.18 & 0.0272 & 2.2072 \\
9.51 & 5.50 & 6.20 & 6.26 & 0.07 & 0.6417 & 1.89 & 0.2530 & 2.1430 \\
9.73 & 5.55 & 6.40 & 6.40 & 0.07 & 0.7000 & 1.67 & 0.3680 & 2.0380 \\
\hline
\end{tabular}

LogK $_{1}$ (Average value) $=2.2364 \pm 0.1602$

Table 10: Point-wise method, Pb (Unhydrolysed PSHA)

\begin{tabular}{|l|l|l|l|l|l|l|l|l|}
\hline $\mathrm{pH}$ & $\mathrm{BV}_{1}$ & $\mathrm{BV}_{2}$ & $\mathrm{BV}_{3}$ & $\mathrm{~V}_{3}-\mathrm{V}_{2}$ & $\mathrm{n}$ & $\mathrm{pL}$ & $\log \left(\frac{n-1}{2-n}\right)$ & $\log \mathrm{K}_{2}$ \\
\hline 10.00 & 5.60 & 6.47 & 6.55 & 0.08 & 1.9503 & 1.41 & & \\
10.23 & 5.65 & 6.62 & 6.72 & 0.11 & 1.4792 & 1.26 & -0.0361 & 1.2239 \\
\hline
\end{tabular}

$\operatorname{LogK}_{2}$ (Average value) $=1.2239$

Table 11: Point-wise method, Mg (Hydrolysed PSHA)

\begin{tabular}{|l|l|l|l|l|l|l|l|l|}
\hline $\mathrm{pH}$ & $\mathrm{BV}_{1}$ & $\mathrm{BV}_{2}$ & $\mathrm{BV}_{3}$ & $\left(\mathrm{~V}_{3}-\mathrm{V}_{2}\right)$ & $\mathrm{n}$ & $\mathrm{pL}$ & $\log \left(\frac{n}{n-1}\right)$ & LogK $_{1}$ \\
\hline 8.50 & 5.30 & 6.29 & 6.31 & 0.02 & 0.2750 & 2.64 & -0.4290 & 2.2110 \\
8.72 & 5.35 & 6.37 & 6.39 & 0.02 & 0.2858 & 2.42 & -0.3978 & 2.0222 \\
9.00 & 5.40 & 6.46 & 6.49 & 0.03 & 0.4648 & 2.14 & -0.0612 & 2.0788 \\
9.22 & 5.45 & 6.55 & 6.59 & 0.04 & 0.6667 & 1.94 & 0.3010 & 2.2410 \\
\hline
\end{tabular}

$\log _{\mathbf{1}}($ Average value) $=2.1382 \pm 0.1046$ 
BAJOPAS Volume 14 Number 1,June, 2021

Table 12: Point-wise method, Mg (Hydrolysed PSHA)

\begin{tabular}{|l|l|l|l|l|l|l|l|l|}
\hline $\mathrm{pH}$ & $\mathrm{BV}_{1}$ & $\mathrm{BV}_{2}$ & $\mathrm{BV}_{3}$ & $\left(\mathrm{~V}_{3}-\mathrm{V}_{2}\right)$ & $\mathrm{n}$ & $\mathrm{pL}$ & $\log \left(\frac{n-1}{2-n}\right)$ & LogK $_{2}$ \\
\hline 9.51 & 5.55 & 6.66 & 6.71 & 0.05 & 0.9650 & 1.67 & & \\
9.73 & 5.55 & 6.78 & 6.84 & 0.06 & 1.4042 & 1.47 & -0.1686 & 1.3014 \\
10.00 & 5.60 & 6.90 & 6.93 & 0.06 & 1.7838 & 1.23 & 0.5593 & 1.7893 \\
10.23 & 5.65 & 7.05 & 7.10 & 0.06 & 3.1429 & 1.10 & & \\
10.49 & 5.70 & 7.10 & 7.18 & 0.07 & 3.6492 & 0.83 & & \\
\hline
\end{tabular}

LogK $_{2}($ Average value $)=1.5453 \pm 0.3450$

Table 13: Point-wise method, Mg (Unhydrolysed PSHA)

\begin{tabular}{|l|l|l|l|l|l|l|l|l|}
\hline $\mathrm{pH}$ & $\mathrm{BV}_{1}$ & $\mathrm{BV}_{2}$ & $\mathrm{BV}_{3}$ & $\mathrm{~V}_{3}-\mathrm{V}_{2}$ & $\mathrm{n}$ & $\mathrm{pL}$ & $\log \left(\frac{n}{n-1}\right)$ & $\operatorname{Log~}_{1}$ \\
\hline 8.50 & 5.30 & 5.81 & 5.85 & 0.04 & 0.2973 & 2.88 & -0.3736 & 2.5064 \\
8.72 & 5.35 & 5.90 & 5.94 & 0.04 & 0.3099 & 2.66 & -0.3477 & 2.3123 \\
9.00 & 5.40 & 6.00 & 6.04 & 0.04 & 0.3236 & 2.38 & -0.3202 & 2.0598 \\
9.22 & 5.45 & 6.10 & 6.15 & 0.05 & 0.4297 & 2.17 & -0.1230 & 2.0470 \\
9.51 & 5.50 & 6.20 & 6.26 & 0.06 & 0.5500 & 1.89 & 0.0871 & 1.9771 \\
9.73 & 5.55 & 6.33 & 6.40 & 0.07 & 0.7000 & 1.67 & 0.3680 & 2.0380 \\
\hline
\end{tabular}

LogK $_{1}$ (Average value) $=2.1568 \pm 0.2069$

Table 14: Point-wise method, Mg (Unhydrolysed PSHA)

\begin{tabular}{|l|l|l|l|l|l|l|l|l|}
\hline $\mathrm{pH}$ & $\mathrm{BV}_{1}$ & $\mathrm{BV}_{2}$ & $\mathrm{BV}_{3}$ & $\mathrm{~V}_{3}-\mathrm{V}_{2}$ & $\mathrm{n}$ & $\mathrm{pL}$ & $\log \left(\frac{n-1}{2-n}\right)$ & $\log \mathrm{K}_{2}$ \\
\hline 10.00 & 5.60 & 6.47 & 6.55 & 0.08 & 0.9148 & 1.41 & & \\
10.23 & 5.65 & 6.62 & 6.71 & 0.09 & 1.2102 & 1.20 & -0.5749 & 0.6251 \\
10.49 & 5.70 & 6.80 & 6.92 & 0.09 & 1.5968 & 1.03 & 0.1703 & 1.2003 \\
\hline
\end{tabular}

LogK $_{2}$ (Average value) $=0.9127 \pm 0.4070$

Table15:Point-wise method, Cd (Hydrolysed PSHA)

\begin{tabular}{|l|l|l|l|l|l|l|l|l|}
\hline $\mathrm{pH}$ & $\mathrm{BV}_{1}$ & $\mathrm{BV}_{2}$ & $\mathrm{BV}_{3}$ & $\left(\mathrm{~V}_{3}-\mathrm{V}_{2}\right)$ & $\mathrm{n}$ & $\mathrm{pL}$ & $\log \left(\frac{n}{1-n}\right)$ & LogK $_{1}$ \\
\hline 8.50 & 5.30 & 6.29 & 6.31 & 0.02 & 0.2750 & 2.64 & -0.4210 & 2.2190 \\
8.72 & 5.35 & 6.37 & 6.40 & 0.03 & 0.4286 & 2.42 & -0.1249 & 2.2951 \\
9.00 & 5.40 & 6.46 & 6.49 & 0.03 & 0.4648 & 2.14 & -0.0612 & 2.0788 \\
9.22 & 5.45 & 6.55 & 6.59 & 0.04 & 0.6667 & 1.96 & 0.3010 & 2.2610 \\
9.51 & 5.55 & 6.66 & 6.70 & 0.04 & 0.7720 & 1.67 & 0.5297 & 2.1997 \\
\hline
\end{tabular}

LogK $_{\mathbf{1}}$ (Average value) $=2.2108 \pm 0.0825$

Table 16: Point-wise method, Cd (Hydrolysed PSHA)

\begin{tabular}{|l|l|l|l|l|l|l|l|l|}
\hline $\mathrm{pH}$ & $\mathrm{BV}_{1}$ & $\mathrm{BV}_{2}$ & $\mathrm{BV}_{3}$ & $\left(\mathrm{~V}_{3}-\mathrm{V}_{2}\right)$ & $\mathrm{n}$ & $\mathrm{pL}$ & $\log \left(\frac{n-1}{2-n}\right)$ & Log $_{2}$ \\
\hline 9.73 & 5.55 & 6.78 & 6.83 & 0.06 & 1.4042 & 1.47 & -0.1686 & 1.3014 \\
10.00 & 5.60 & 6.90 & 6.95 & 0.06 & 1.7838 & 1.23 & 0.5593 & 1.7893 \\
10.23 & 5.65 & 7.05 & 7.10 & 0.06 & 3.1429 & 1.09 & & \\
10.49 & 5.70 & 7.10 & 7.16 & 0.06 & 3.1429 & 0.89 & & \\
& & & & & & & & \\
\hline
\end{tabular}

$\operatorname{LogK}_{2}$ (Average value) $=1.5453 \pm 0.3450$

Table 17: Point-wise method, Cd (Unhydrolysed PSHA)

\begin{tabular}{|l|l|l|l|l|l|l|l|l|}
\hline $\mathrm{pH}$ & $\mathrm{BV}_{1}$ & $\mathrm{BV}_{2}$ & $\mathrm{BV}_{3}$ & $\mathrm{~V}_{3}-\mathrm{V}_{2}$ & $\mathrm{n}$ & $\mathrm{pL}$ & $\log \left(\frac{n}{n-1}\right)$ & $\operatorname{Log~}_{1}$ \\
\hline 8.50 & 5.30 & 5.81 & 5.86 & 0.05 & 0.3717 & 2.88 & -0.2280 & 2.6520 \\
8.72 & 5.35 & 5.90 & 5.95 & 0.05 & 0.3873 & 2.66 & -0.1992 & 2.4608 \\
9.00 & 5.40 & 6.00 & 6.06 & 0.06 & 0.4853 & 2.38 & -0.0255 & 2.3545 \\
9.22 & 5.45 & 6.10 & 6.16 & 0.06 & 0.5157 & 2.18 & -0.0272 & 2.2072 \\
9.51 & 5.50 & 6.20 & 6.27 & 0.07 & 0.6417 & 1.89 & 0.2530 & 1.1430 \\
9.73 & 5.55 & 6.33 & 6.41 & 0.08 & 0.8000 & 1.69 & 0.6020 & 2.2920 \\
& & & & & & & & \\
\hline
\end{tabular}

$\operatorname{LogK}_{1}($ Average value $)=2.2516 \pm 0.5380$ 
BAJOPAS Volume 14 Number 1,June, 2021

Table 18: Point-wise method, Cd (Unhydrolysed PSHA)

\begin{tabular}{|l|l|l|l|l|l|l|l|l|}
\hline $\mathrm{pH}$ & $\mathrm{BV}_{1}$ & $\mathrm{BV}_{2}$ & $\mathrm{BV}_{3}$ & $\mathrm{~V}_{3}-\mathrm{V}_{2}$ & $\mathrm{n}$ & $\mathrm{pL}$ & $\log \left(\frac{n-1}{2-n}\right)$ & $\log \mathrm{K}_{2}$ \\
\hline 10.00 & 5.60 & 6.47 & 6.57 & 0.10 & 1.1434 & 1.43 & & \\
10.23 & 5.65 & 6.62 & 6.72 & 0.10 & 1.3448 & 1.23 & -0.2788 & 0.9512 \\
10.49 & 5.70 & 6.80 & 6.90 & 0.10 & 1.7742 & 1.03 & 0.5351 & 1.5651 \\
\hline
\end{tabular}

$\operatorname{LogK}_{2}($ Average value $)=1.2581 \pm 0.4340$

Table 19: Stepwise and overall Stability constants of thehydrolysed and unhydrolysed divalent metal (II) complexes

\begin{tabular}{|c|c|c|c|}
\hline Chelates & LogK $_{1}$ & $\log _{2}$ & Log $\beta$ \\
\hline [Cu (Hydrolysed PSHA-1) $\left.{ }_{2}\right]$ & 2.4788 & 1.4280 & 3.9068 \\
\hline$\left[\mathrm{Pb}(\text { Hydrolysed PSHA-1) })_{2}\right]$ & 2.5832 & 1.1963 & 3.7795 \\
\hline$\left[\mathrm{Cd}(\text { Hydrolysed PSHA-1 })_{2}\right]$ & 2.2108 & 1.5453 & 3.7561 \\
\hline$\left[\mathrm{Mg}(\text { Hydrolysed PSHA-1 })_{2}\right]$ & 2.1382 & 1.5453 & 3.6835 \\
\hline [Cu (Unhydrolysed PSHA-1) & 2.3059 & 1.2209 & 3.5268 \\
\hline$[\mathrm{Pb}$ (Unhydrolysed PSHA-1) 2$]$ & 2.2364 & 1.2239 & 3.4603 \\
\hline [Cd (Unhydrolysed PSHA-1) 2 ] & 2.2516 & 1.2581 & 3.5097 \\
\hline$[\mathrm{Mg}$ (Unydrolysed PSHA-1) & 2.1568 & 0.9127 & 3.0695 \\
\hline
\end{tabular}

The results obtained (Table19) shows the stepwise and overall stability constants to be not high indicating low stability of the complexes, because the solubility of most metal ions in the basic $\mathrm{pH}$ range is minimal due to metal hydroxide precipitation (Karimi, 2017). In general, the stepwise stability constants $\left(K_{1}\right.$ and $K_{2}$ ) follow the order $K_{1}>K_{2}$ for the copper, lead, magnesium and cadmium complexes respectively. The steady decrease of the values with increasing number of ligands is in agreement with the prediction made by researchers (Na'aliya, 2013). The decrease could be attributed to the fact that as the number of the ligands (Humate ions) that enters the coordination zone increases the aqua molecules available for replacement by the ligands become less. Thus, the metal ions become less electron loving with progressive intake of the ligand and this results in the decrease in the values of the constants (Na'aliya, 2013). Also the stability of the complexes is influenced by the size and number of the chelate rings(Mackay and Mackay,2002).All the complexes form rings in their structure as humate, a bidentate ligand, bond the metal ions in the ratio 1:2 (Boguta and Sokolowska, 2016) forming chelate rings. The values of the overall stability constants $(\log \beta)$ obtained for humate complexes are not high indicating low stability as the values are not high. LogK values for copper-humates (Table 3 to 6) obtained in this study are lower than those reported for the complexes of humic acids (Pandey et al., 2015; Dinu, 2013; Kaschl et al., 2010 and Gilbeto and Jorg, 2001). The values of LogK(Table 7 to 10 ) forlead-humates are lower than those reported for the lead in the literature (Dinu, 2013; Gilbeto and Jorg 2001). Log K values(Table 11 to 14 ) for magnesium-humates obtained in this study are close to those reported by (Pandey et al., 2015). Log K values of cadmium-humates (Table 15 to 18 ) obtained in this work near to the one reported by (Dinu, 2013 and Pandey et al., 2015).The difference between the reported values and the values obtained in this study might be probably as a result of acid hydrolysis of humic acid. The values of the overall stability constants $(\log \beta)$ of the copper humates complexes presented in Table 19 is high than that of other metal humate complexes, show relatively high stability of CuHA complexes, show the following order of stability: $\mathrm{Cu}>\mathrm{Pb}>\mathrm{Cd}>\mathrm{Mg}$; which are in close agreement to the findings of (Dinu, 2013 and Pandey et al., 2015).The high stability of Cuhumate chelate could be attributed to the existence of coordinate covalent bond between the complexing agents and the $\mathrm{Cu}^{2+}$ ions. Since, $\mathrm{Cu}^{2+}$ being a metal of the transitional series with $3 d^{9}$ electronic configurations can accept the electrons from the complexing agents. Similarly, the low stabilities of $\mathrm{Pb}, \mathrm{Cd}$ and $\mathrm{Mg}$ complexes could be explained by that $\mathrm{Pb}^{2+}$ with $6 s^{2}, \mathrm{Cd}^{2+}$ with $4 \mathrm{~d}^{10}$ and $\mathrm{Mg}^{2+}$ with $2 \mathrm{p}^{6}$ their electronic configuration has a completely filled $\mathrm{d}, \mathrm{p}$ and $\mathrm{s}$ orbitals. Moreover, the stabilities of metal ions with hydrolysed humic acid from peat soil were higher than those with unhydrolysed humic acid from peat soil; which is ascribed to the high content of acidity in hydrolysed humic acid than unhydrolysed humic acid. 
BAJOPAS Volume 14 Number 1,June, 2021 CONCLUSION

The values of logk for $\mathrm{Cu}(\mathrm{II})$ hydrolysed humic acid complex was higher followed by $\mathrm{Pb}$ (II), $\mathrm{Cd}(\mathrm{II})$ and $\mathrm{Mg}$ (II) hydrolysed humic acid complexes as compared with metal(II) unhydrolysed humic acid complexes. This indicates acid hydrolysis of humic acid can

\section{REFERENCES}

Almeida, V.R. and Szpoganicz, B. (2015). Humic Acid Potentiometric Response Patterns:Out- of Equilibrium Properties and Species Distribution Modelling. Chemical. Biol. Technol. Agric. 2: 17.

Anđelković, T., Nikolić, R., Bojić, A.,Anđelković, D., and Nikolic G.,(2010). Binding of Cadmium to Soil Humic Acid as A Function of Carboxyl Group Content. Macedonian Journal of Chemistry and Chemical Engineering.29(2): 215-224.

Anil, B. N. and Maroti, N. (2008). Studies on Influence of Die-Lectric Constants on Complex Equilibria between Substituted Py-Razalines and Lanthanide Metal Ions pH-Metrically. Amer.-Euras. scient. Res. 3(2): 212-216.

Ashok, K., Pandey, S. P. and Misra, V (2000). Stability Constants of Metal-Humic Acid Complexes and its Role in Environmental Detoxification. Journal of Ecotoxicology and Environmental Safety. 47(2):157-200.

Badr, M. H., El-Halafawi, M. H. and Abd El-al Zeid, E. R. (2012). Comparison Between the Effect of Ionic Strength on Acidity and Dissociation Constants of Humic Acids Extracted from Sewage Sludge and Nile Water Hyacinth Composts.Global Journal of Environmental Research 6 (1): 36-43.

Baruah, M.K., Borah, D., Saikia, P.P., Paul, S., Sharma, T. (2015). Evaluation of pKa Values of Soil Humic Acids and their Complexation Properties. International Journal of Plant \& Soil Science 6(4) : 218-228.

Boguta, P. Sokolowska, Z. (2016). Interactions of $\mathrm{Zn}$ (II) Ions with Humic Acids Isolated from Various Types of Soils. Effect of $\mathrm{pH}, \mathrm{Zn}$ Concentrations and Humic Acids Chemical Properties. Journal of Geochemical Explaration 168. 119-126.

Borges, F., Guimaraes, C., Lima, L.F.C., Pinto, I. and Reis, S.(2005). Potentiometric Studies on the Complexation of Copper(II) by Phenolic Acids as Discrete Ligand Models of enhance the complexation behavior of humic acid with metal (II) ions. However, the higher values of $\log \beta$ for $\mathrm{Cu}(\mathrm{II}), \mathrm{Pb}(\mathrm{II}), \mathrm{Cd}(\mathrm{II})$ and $\mathrm{Mg}(\mathrm{II})$ hydrolysed humic acid complexes indicates more stable stepwise complexes formed as compared with $\mathrm{Cu}(\mathrm{II}), \mathrm{Pb}$ (II), $\mathrm{Cd}$ (II) and $\mathrm{Mg}(\mathrm{II})$ unhydrolysed humic acid complexes.

Humic Substances Talanta 66 (2005) 670-673.

Chefetz, B., Salloum, M. J., Deshmulkin, A. P. and Hatcher, P. (2002). Structural Components of Humic Acids as Determined by Chemical Modifications and Carbon-13 NMR, Pyrolysis, and Thermochemolysis- Gas Chromatography/Mass Spectrometry. Soil Science Society of American Journal Abstract Division S-2- Soil Chemistry66. 1159-1171.

Dinu, M. I. (2013). Metals Complexation with Humic Acids in Surface Water of Different Environ. Sci. Technol. 31(1): 1-17.

Fernandes, A.N., Giacomelli, C., Giovanela, M. Vaz, D.V. Szpoganicz, B. and Maria M. D. (2009). Potentiometric Acidity Determination in Humic Substances Influenced by Different Analytical Procedures.J. Braz. Chem. Soc. 20 (9):14.

Gamal, A. H. (2015). Stability Constants of Rhenium (V) Metal Complexes with Selected Drugs. Pyrex Journal of Research in Environmental Studies. 2(2): 006-014.

Janrao, D. M., Pathan, J., Kayande, D.D., and Mulla, J.J. (2014). An Over View of Potentiometric Determination of Stability Constants of Metal Complexes. Sci. Revs. Chem. Commun.: 4(1), 2014, 11-24.

Karimi, H. (2017). Effect of pH and Initial Pb(II) Concentration on the Lead Removal Efficiency from Waste Water Using $\mathrm{Ca}(\mathrm{OH})_{2}$. International Journal of Water and Waste Water Treatment 3.2

Kaschl, A. Romheld, V. and Chen, Y. (2010). Binding of Cadmium, Copper and Zinc to Humic Substances Originating from Municipal Solid Waste Compost. Israel Journal of Chemistry Vol. 42(1): 89-98.

Kostic, I. S., Tatjana, P, A., Nikolic, R. S., Cvetkovic, T. P., Pavlovic, D. D., Aleksandar, L.J. and Bojic, A. (2012). Comparative Study of Binding Strengths of Heavy Metals with Humic Acid. J.serb. Chem. Soc. 76(9) pp 1-20. 
BAJOPAS Volume 14 Number 1,June, 2021

Na'aliya, J. (2013). Determination of Stepwise Stability Constants and Gibbs free Energy Change of Trisprolina to Complexes of some Divalent Transition Metal ions. Bayero Journal of Pure and Applied Sciences 6(2): 112-114.

Omar, A. A. and Ali, E. A. (2015). Potentiometric Studies on Complexes of $\mathrm{Cr}$ (III) and $\mathrm{Zr}$ (IV) with some Carboxylic Acids. International Journal of Advanced Chemistry, 3(1) 25-

37.

Pandey, A. K. Pandey, S. D. and Misr, V. (2015).Stability Constants of Metal- Humic Acid Complexes and Its Role in Environmental Detoxification. J. Ecotoxicology and Environmental Safety. 47(1):195-200.

Ram, N. and Raman, K.V. (1984). Stability Constants of Complexes of Metals with
Humicand Fuvic Acids under Non- acidConditions. Journal of Plant Nutrition and Soil Sciences.

147:171-176.

Santosh, D. D., Ashok, B. K., Vijay, J. T., Shivraj, G. W. and Vinay, V. W. (2011). Potentiometric Studies of Elec-Trolyte Effects on Complex Equilibria of Some Substituted 5-(2-hydroxy Phenyl) Pyrazoles. Der pharm. 3 (6): 75-83.

Sayyed, H. and Abdul Rahim, M. F. (2012). Studies of Binary Complexes of Metal Ions with Mandelic Acid by Potentiometry. Chem. J. 02 (6): 206209.

Shirvani, M. Moradian, E. Khalili, B. Bakhtiary, S. (2015). Interaction of $\mathrm{Cd}$ and $\mathrm{Pb}$ with Humate-Palygorskite and HumateSepiolite Complexes. Journal of water, air and pollution 3: 220-228. 


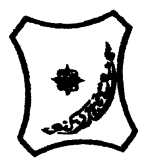

Bayero Journal of Pure and Applied Sciences, 14(1): 54 - 63

Received: November, 2020

Accepted: April, 2021

ISSN $2006-6996$

\title{
STABILITY CONSTANTS OF COMPLEXES OF METAL IONS WITH PEATSOIL HUMIC ACIDS UNDER NON-ACID-CONDITIONS
}

\author{
${ }^{* 1}$ Sabo, Yusuf ${ }^{2}$ Jimoh, W.L.O., ${ }^{3}$ Isa Baba Koki and ${ }^{4}$ Sholadoye, Q. 0. \\ ${ }^{1}$ Department of Pure and Industrial Chemistry, Bayero University, Kano \\ ${ }^{3}$ Department of Chemistry, Yusuf Maitama Sule University Kano. P.M.B. 3220 Kano, Nigeria. \\ ${ }^{4}$ Department of Chemistry, Nigerian Police Academy, Wudil, Kano-Nigeria
}

*Correspondence E-mail; saboyusuf18@yahoo.com

ABSTRACT

Stability constants of complexes of four divalent metal ions viz. $\mathrm{Cu}^{2+}, \mathrm{Pb}^{2+}, \mathrm{Mg}^{2+}$ and $\mathrm{Cd}^{2+}$ with humic acids (HA) were determined by potentiometric titration of humic acids with the corresponding salt of the divalent metals in aqueous media under non-acid-condition. The log $K$ (logarithm of the stability constant) ranged from 1.0942 to 2.7471 for metalhumic acid complexes were determined using point-wise computational method. The order of stability constants were obtained as follows: $\mathrm{Cu}>\mathrm{Pb}>\mathrm{Cd}>\mathrm{Mg}$ for metal $-\mathrm{HA}$ complexes respectively, indicating a higher degree of complexation with Cu metal ion.

Keywords: stability constant, humic acid, potentiometric titration, divalent metals, acid hydrolysis.

\section{NTRODUCTION}

The stability constant of a complex is the numerical expression of its stability and provides a quantitative measure of affinity of the metal ion to the complexing agent. An understanding of the relative stability of metal-complexes helps in predicting the behavior of metal ions in the soil (Ram and Raman, 1982). Extensive researches has been done to determine the stability constants of the complexes formed between humic acid (HA) with a number of metal ions. Ashok et al., (2000) reported that humic acid with hydroxyl, phenoxyl and carboxyl reactive groups can form coordination compound with metal ions at $\mathrm{pH}$ 3.5. The stability constants(Log K) for different metalhumic acid complexes indicated the following order of the stabilities of complexes formed between humic acid and metal ion, $\mathrm{Cu}>\mathrm{Fe}$ $>\mathrm{Pb}>\mathrm{Ni}>\mathrm{Co}>\mathrm{Ca}>\mathrm{Cd}>\mathrm{Zn}>\mathrm{Mn}>\mathrm{Mg}$. Andelkovic et al., (2010) investigated the binding of $\mathrm{Cd}$ (II) to soil humic acid at pH 6.5 and in $0.1 \mathrm{M} \mathrm{KNO}_{3}$ ionic medium. The stability constant for binding indicating greater stability in the case when carboxyl groups are involved in complexation reaction. Kostic et al.,(2012) investigated the complexation of humic acid with certain heavy metal ions (Co(II), $\mathrm{Ni}(\mathrm{II}), \mathrm{Cu}(\mathrm{II})$,
$\mathrm{Zn}(\mathrm{II})$, and $\mathrm{Pb}(\mathrm{II})$. The experiment was performed at $25^{\circ} \mathrm{C}$, at pH 4.0 and ionic strength of $0.01 \mathrm{M}$. Stability constant of complex between $\mathrm{Pb}$ (II) ions and humic acid is greater than stability constants of other investigated metalhumate complexes. Bogata and Sokolowska (2016) analyses the interaction between humic acids from different soils and $\mathrm{Zn}$ (II) ions at wide concentration ranges and at $\mathrm{pH} 5$. Studies have showed significant impact of $\mathrm{Zn}$ concentration, $\mathrm{pH}$ and some properties of humic acids with zinc.But all of these studies were limited to acidic $\mathrm{pH}$ range. Therefore, the present study was carried out to determine and compare the stability constants of complexes of metal ions with hydrolysed peat soil humic acid and unhydrolysed peat soil humic under non-acid conditions.

\section{MATERIALS AND METHODS}

Analytical grade chemicals used includes hydrochloric acid $(\mathrm{HCl})$, nitric acid $\left(\mathrm{HNO}_{3}\right)$, sodium hydroxide $(\mathrm{NaOH})$, lead nitrate $\mathrm{Pb}\left(\mathrm{NO}_{3}\right)_{2}$, copper nitrate $\mathrm{Cu}\left(\mathrm{NO}_{3}\right)_{2} \cdot 3 \mathrm{H}_{2} \mathrm{O}$, cadmium nitrate $\mathrm{Cd}\left(\mathrm{NO}_{3}\right)_{2} \cdot 4 \mathrm{H}_{2} \mathrm{O}$, magnesium nitrate $\mathrm{Mg}\left(\mathrm{NO}_{3}\right)_{2} \cdot 6 \mathrm{H}_{2} \mathrm{O}$, potassium nitrate $\left(\mathrm{KNO}_{3}\right)$, calcium chloride $\left(\mathrm{CaCl}_{2}\right)$, (sigma-Aldrich). Dowex 50WX8, (20-50 mesh) from Fluka. 


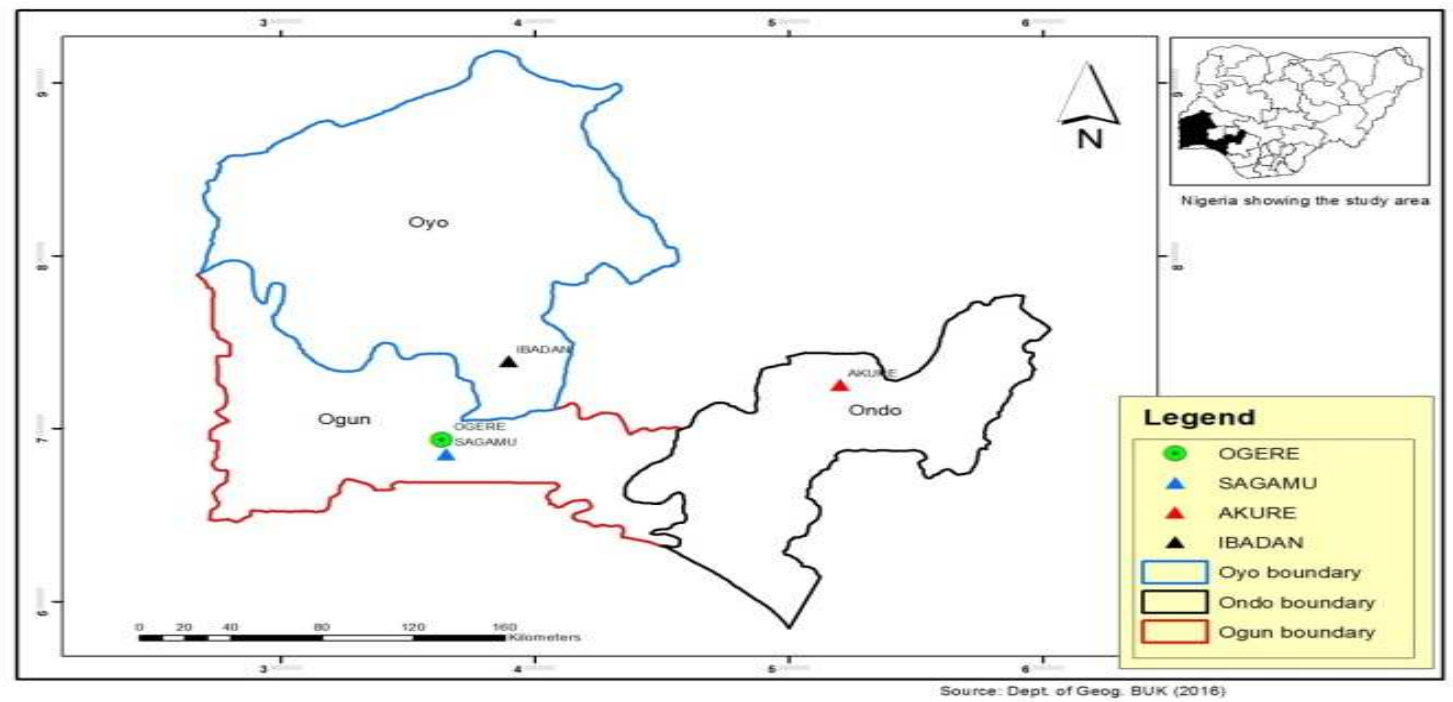

Figure 1: Map showing the sampling point at Sagamu Town, Ogun State.

\section{Description of Sampling Area}

Sagamu has geographical coordinates between $6^{\circ} 50^{\prime}$ north; $3^{\circ} 38^{\prime}$ east is located in south western region of Nigeria. The region has tropical wet and dry climate with a lengthy wet season and relatively constant temperatures throughout the course of the year. Wet season runs from March to October, November to December forms the region dry season. The vegetation type of the region is savannah which is really grassland with small bushes and occasional big trees. Grassland soils have substantially higher organic matter content than forest soils (Novackova, 2011).

\section{Sample Collection}

The Peatsoil samples were collected from four different sampling points $(0-10 \mathrm{~cm}$ depth) in Sagamu into polyethylene bag with plastic spoons. Samples were taken to the laboratory, extraneous materials were removed; the samples were air-dried, crushed and ground to a fine powder in a mortar passed through a $0.20 \mathrm{~mm}$ sieve. The samples were kept for analysis.

\section{Isolation and purification of humic acid from peat soil sample}

Peatsoil sample $(100 \mathrm{~g})$ was mixed with 1000 $\mathrm{cm}^{3}$ of $0.1 \mathrm{M} \mathrm{NaOH}$ solution, shaken for 3hours and left to stand overnight. Dark-coloured supernatant was obtained and decanted from solid residue. The dark-coloured supernatant was acidified to $(\mathrm{pH}=1.0)$ with $6 \mathrm{M} \mathrm{HCl}$ stirred and allowed to stand for 6 hours. Yellowish brown supernatant and dark-brown precipitate were obtained. The yellowish brown supernatant was decanted followed by centrifuge and discarded. The dark-brown precipitate was mixed with $500 \mathrm{~cm}^{3}$ of $0.1 \mathrm{M} \mathrm{NaOH}$ solution followed by passing through dowex resin. The dark-brown solution was acidified to $(\mathrm{pH}=1.0)$ with $6 \mathrm{M} \mathrm{HCl}$ stirred and allowed to stand for 3 hours. The dark-brown precipitate was washed several times with deionized water. The supernatant was treated with $\mathrm{AgNO}_{3}$ solution until no white precipitate observed. The humic acid was transferred to weighed crucible and dried at $60^{\circ} \mathrm{C}$ in an oven for 12 hours. The humic acid was cooled and dried in the desiccator, weighed and recorded. The obtained humic acid was dried again at $60^{\circ} \mathrm{C}$ for additional 6 hours cooled and dried in the desiccator, weighed and recorded constant weight was obtained (Baruah et al., 2015).

\section{FT-IR analysis}

FT-IR spectra of humic acid sample was analysed using Carry 630 FT-IR Agilent Technologies.

Unhydrolysed compost humic acid

The unhydrolysed humic acid was obtained after isolation and purification of compost humic acid and kept for investigation.

\section{Acid hydrolysis of Peatsoil acid}

Peatsoil humic acid sample (1g) was refluxed for 12 hours at $\left(160^{\circ} \mathrm{C}\right)$ with $50 \mathrm{~cm}^{3}$ of $6 \mathrm{M} \mathrm{HCl}$. The mixture was allowed to cool, decanted, and centrifuged after hydrolysis. The insoluble residues were washed with distilled water via centrifugation several times, and the supernatant was treated with $\mathrm{AgNO}_{3}$ solution until no white precipitate was observed. The residue was thoroughly dried over $\mathrm{CaCl}_{2}$ in a desiccator at room temperature (Chefetz et al., 2002). Finally, the obtained hydrolysed humic acid was kept for investigation. 
BAJOPAS Volume 14 Number 1,June, 2021 Potentiometric Titrations

Potentiometric measurements were carried out using a pH-meter Jenway (model 3510) with combine electrode, the sensitivity of the $\mathrm{pH}$ meter is 0.01 units. The $\mathrm{pH}$ meter was switched on half an hour before starting the titration for initial warm up of the instrument. The instrument was calibrated with an aqueous standard buffer solution of $\mathrm{pH} 4.00$ and 10.0 (borate buffer) prepared from a "Qualigens" buffer tablets.

The following sets of solutions were prepared in a $250 \mathrm{~cm}^{3}$ volumetric flask separately for $\mathrm{pH}$ metric titrations.

(i) $5 \mathrm{~cm}^{3} 0.1 \mathrm{M} \mathrm{HCl}+40 \mathrm{~cm}^{3}$ deionized water

(ii) $5 \mathrm{~cm}^{3} 0.1 \mathrm{M} \mathrm{HCl}+39 \mathrm{~cm}^{3}$ deionized water $+1 \mathrm{~cm}^{3} 0.15 \mathrm{gcm}^{-3}$ humic acid

(iii) $5 \mathrm{~cm}^{3} 0.1 \mathrm{M} \mathrm{HCl}+37 \mathrm{~cm}^{3}$ deionized water $+1 \mathrm{~cm}^{3} 0.15 \mathrm{gcm}^{-3}$ humic acid

$$
+2 \mathrm{~cm}^{3} \quad 0.01 \mathrm{M} \mathrm{Cu} \text { (II) }
$$

The solutions were titrated against standardized $0.110 \mathrm{MNaOH}$ separately. The total volume of each mixture was adjusted to $50 \mathrm{~cm}^{3}$ and the ionic strength of the solutions was maintained constant at by adding appropriate amount of stock solution of $1 \mathrm{M} \mathrm{KNO}_{3}$ (Gamal, 2015; Omar and Ali, 2015). A magnetic stirrer was used to achieve thorough mixing of the interacting solutions at $550 \mathrm{rpm}$. The same set of experimental conditions was applied for potentiometric titration of remaining samples.

\section{Evaluation of pKa of Hydrolysed peat soil Humic Acids}

The proton-ligand formation number $\mathrm{n}_{\mathbf{A}}$ were calculated by Irving and Rossotti expression (Omar and Ali, 2015).

$\mathrm{nA}=\mathrm{Y}-\frac{(\mathrm{V} 2-\mathrm{V1})(\mathrm{No}-\mathrm{Eo})}{(\mathrm{VO}+\mathrm{V1}) \mathrm{TCL}}$ 1

Where: $Y$ is number of dissociable proton, $\left(\mathrm{V}_{2^{-}}\right.$ $V_{1}$ ) is the measure of displacement of the ligand curve relative to acid curve, $\mathrm{N}^{\circ}$ and $\mathrm{E}^{\circ}$ are the resultant concentration of alkali solution, free acid solution, $\mathrm{T}_{\mathrm{cL}}{ }^{\circ}$ is the total ligand concentration, $\mathrm{V}^{\circ}$ is the total volume of titration solution, $V_{1}$ is the volume of alkali added to acid solution, $V_{2}$ is the volume of alkali added to acid solution + ligand solution, acid dissociation constants (pKa - values) of ligand were calculated by algebraic method point wise calculation (Tables 1 ). The dissociation constants (pKa) were calculated according to the following relation:

$\mathrm{pKa}=\mathrm{pH}+\log \left(\frac{n A}{1-n A}\right)$ 2

Where: pKa is the acid dissociation constant, $\mathrm{n}_{\mathrm{A}}$ is the Proton-ligand formation number and $\mathrm{pH}$ is the pH-values (Omar and Ali, 2015).

\section{Determination of metal-ligand stability constants $(\log K)$ of complexes}

The potentiometric measurement for the determination of stability constant of a complex in solution is based on the fact that the redox potential of the couple $\frac{M^{+(m-n)}}{M^{+m}}$ is shifted significantly on complexation of the metal ion with the ligand. This method involves change in hydrogen ion concentration $\left[\mathrm{H}^{+}\right]$due to the displacement or association of one or more protons taking place during complexation reaction. This change can be found out by titrating the solutions containing free acid, acid with ligand, and acid with ligand and metal ion, individually against a standard alkali solution at a constant ionic strength or temperature. Either ionic strength or temperature may be varied for different sets of solutions. In all the cases, the change in the $\mathrm{pH}$ of the solution is measured after each addition of a known amount of alkali to the reaction cell which contains the reaction mixture. The titration curves are then drawn by plotting the measured $\mathrm{pH}$ values against the corresponding volume of alkali added and the stability constants of the complexes are determined from the titration curves by employing $\mathrm{pH}$-metric titration technique given by (Irving and Rossoti).

Metal-ligand stability constants ( $\log \mathrm{K}$ ) were determined by using the following relations:

$$
\bar{n}=\frac{\left(V_{3}-V_{2}\right)\left(E^{0}+N^{0}\right)}{\left(V^{0}+V_{2}\right) \bar{n}_{A} T_{m}^{0}}
$$

and

$$
P L=\log _{10}\left\{\frac{1+\beta_{n}^{H} \frac{1}{[\text { anti } \log \mathrm{pH}]^{\mathrm{n}}}}{\mathrm{T}_{\mathrm{L}}^{0}-n \bar{T}_{m}^{0}} \mathrm{X} \frac{\left(V^{0}+V_{3}\right)}{V^{0}}\right\}
$$


BAJOPAS Volume 14 Number 1,June, 2021

Where $T_{L}, T^{\circ}, E^{\circ}$, and $V^{\circ}$ havethe same significance as in equation (1) above, $T_{m}$ denotes the total concentration of metal present in solution, $V_{3}$ is the volume of metal ions present in solution and $\beta^{H}$ is the overall proton ligand stability constant. The metal-ligand stability constants (log K) were determined by employing point wise computational Method (eq. 5 and 6).

$\operatorname{LogK}_{1}=\log \left(\frac{n}{1-n}\right)+\mathrm{pL}$ .5

$\operatorname{LogK}_{2}=\log \left(\frac{1-n}{2-n}\right)+\mathrm{pL}$ ...6

Where: Log $\mathrm{K}$ is the metal-ligand stability constant, $\mathrm{pL}$ is the Free ligand exponent function, $\mathbf{n}$ is the Average number of ligand attached with metal ion (Janraoet al., 2014). The results obtained were analyzed by an ORIGIN 2016 program using titration data and then the proton-ligand stability constants (pKa) and Metal-ligand stability constant (LogK) calculated (Omar and Ali, 2015).

\section{RESULTS AND DISCUSSION}

Fourier transformed infrared (FT-IR) spectra of isolated humic acid from peat soils Figure 2 had distinct clear absorption bands indicating the presence of major humic acid structural elemental groups such as $\mathrm{H}$ bonded $\mathrm{OH}$ $\left(3680 \mathrm{~cm}^{-1}\right.$ peak $), C=0$ of carbonyl $\left(1721 \mathrm{~cm}^{-1}\right.$ peak), functional groups of aliphatic components $\mathrm{CH}_{2}\left(2918 \mathrm{~cm}^{-1}\right.$ peak) and $\mathrm{C}-\mathrm{O}$ stretching of polysaccharide $\left(1168 \mathrm{~cm}^{-1}\right.$ peak). The positions of the absorption bands of the spectra fell within typical major absorption bands of humic acid which is at frequencies 3680, 2918, 1721, 1168 $\mathrm{cm}^{-1}$. The first peak centred in the vicinity of $3680 \mathrm{~cm}^{-1}$ region is attributed to phenol $\mathrm{OH}$ group bounded by intermolecular $\mathrm{H}$ bonds. The $2918 \mathrm{~cm}^{-1}$ band usually has absorption maximum at $2918 \mathrm{~cm}^{-1}$ which is due to $\mathrm{C}-\mathrm{H}$ stretching of alkane group $\left(\mathrm{CH}_{2}\right)$. The next major absorption band is $1721 \mathrm{~cm}^{-1}$. This band has been commonly ascribed to $\mathrm{C}=\mathrm{O}$ stretching of mainly carboxyl group $(\mathrm{COOH})$ with trace amount of ketones. The last peak was observed at 1168 $\mathrm{cm}^{-1}$ due to $\mathrm{C}-\mathrm{O}$ stretching of polysaccharides and this peak appeared also in the spectra of humic acid from peat soil. The FTIR spectra of the isolated humic acid contained all major characteristic absorption peaks of humic acid. These absorption peaks indicated the presence of the major structural elements of humic acid namely $\mathrm{H}$ bonded $\mathrm{OH}, \mathrm{C}=\mathrm{C}$ of aromatic ring, $\mathrm{C}=\mathrm{O}$ of carbonyl group (both carboxyl and ketonic), $\mathrm{CH}_{2}$ group. This strongly supports the presence of humic acid.

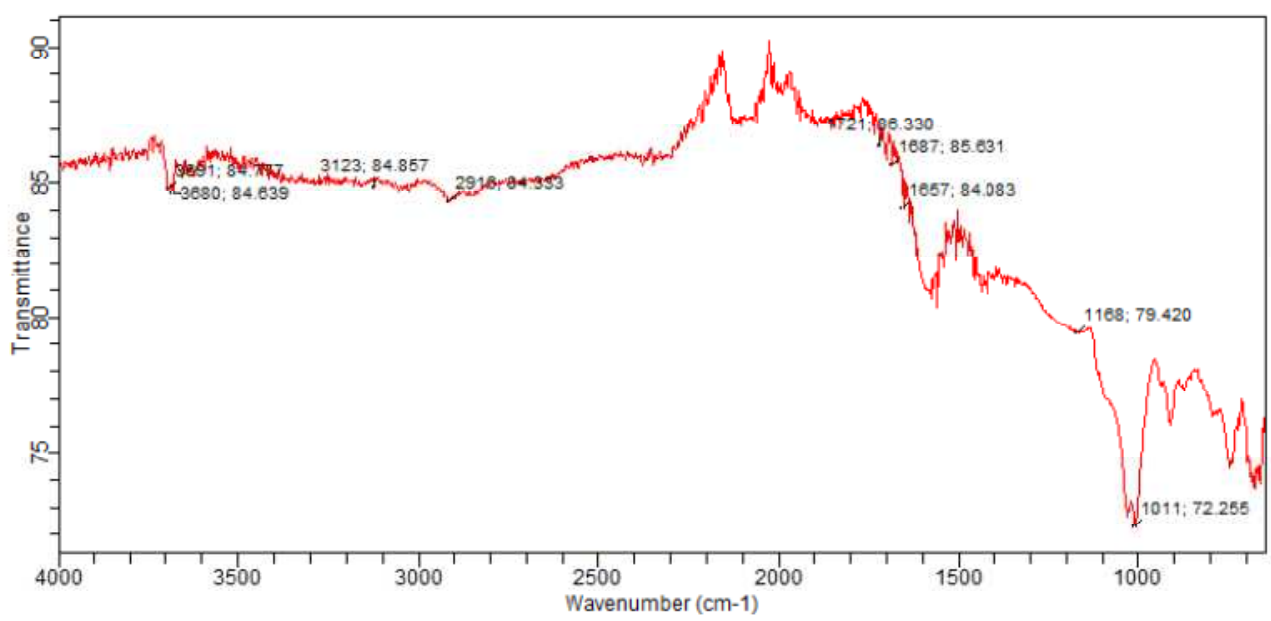

Fig. 2 : FT-IR spectraof peatsoilhumic acid (PSHA)

\section{Evaluation of acid dissociation constant (pka) of acid hydrolysed peat soil humicacid at phenolic group}

The value of the dissociation constant of the peat soil humic acid (PSHA) that underwent acidhydrolysis studied was found to be 8.9299 as shown Table 1, which is lower than the literaturevalues reported by Almeida and Szpoganics, (2015), Borges et al., (2005); Badr et al., (2012)and Fernandes et al,.(2009) of $9.73,9.47$ and 10.30. The difference between the obtained valuesand the reported values in this study might be probably as a result of acid hydrolysis of humicacid. 
BAJOPAS Volume 14 Number 1,June, 2021

Table 1: PKa of (Hydrolysed PSHA)

\begin{tabular}{|l|l|l|l|l|l|l|}
\hline $\mathrm{pH}$ & $\mathrm{BV}_{1}$ & $\mathrm{BV}_{2}$ & $\mathrm{~V}_{2}-\mathrm{V}_{1}$ & $\mathrm{nA}$ & $\log \left(\frac{n A}{1-n A}\right)$ & $\mathrm{pKa}$ \\
\hline 8.50 & 5.30 & 6.29 & 0.99 & 0.3594 & -0.2510 & 8.2490 \\
8.72 & 5.35 & 6.37 & 1.02 & 0.3400 & -0.2880 & 8.4320 \\
9.00 & 5.40 & 6.46 & 1.06 & 0.3141 & -0.3391 & 8.6609 \\
9.22 & 5.45 & 6.55 & 1.10 & 0.2882 & -0.3927 & 8.8273 \\
9.51 & 5.50 & 6.66 & 1.16 & 0.2494 & -0.4786 & 9.0314 \\
9.73 & 5.55 & 6.78 & 1.23 & 0.2041 & -0.5910 & 9.1390 \\
10.00 & 5.60 & 6.90 & 1.30 & 0.1589 & -0.7238 & 9.2762 \\
10.23 & 5.65 & 7.05 & 1.40 & 0.0941 & -0.9835 & 9.2465 \\
10.49 & 5.70 & 7.10 & 1.40 & 0.0941 & -0.9835 & 9.5065 \\
\hline
\end{tabular}

Average pKa $=8.9299 \pm 0.4186$

Table 2: PKa of (Unhydrolysed PSHA)

\begin{tabular}{|l|l|l|l|l|l|l|}
\hline $\mathrm{pH}$ & $\mathrm{BV}_{1}$ & $\mathrm{BV}_{2}$ & $\mathrm{~V}_{2}-\mathrm{V}_{1}$ & $\mathrm{nA}$ & $\log \left(\frac{\boldsymbol{n A}}{1-\boldsymbol{n}}\right)$ & $\mathrm{pKa}$ \\
\hline 8.50 & 5.30 & 5.81 & 0.51 & 0.6619 & 0.2919 & 8.7919 \\
8.72 & 5.35 & 5.90 & 0.55 & 0.6357 & 0.2418 & 8.9618 \\
9.00 & 5.40 & 6.00 & 0.60 & 0.6029 & 0.1813 & 9.1813 \\
9.22 & 5.45 & 6.10 & 0.65 & 0.5701 & 0.1226 & 9.3426 \\
9.51 & 5.50 & 6.20 & 0.70 & 0.5376 & 0.0654 & 9.5754 \\
9.73 & 5.55 & 6.33 & 0.78 & 0.4851 & -0.0259 & 9.7041 \\
10.00 & 5.60 & 6.47 & 0.87 & 0.4262 & -0.1291 & 9.8709 \\
10.23 & 5.65 & 6.62 & 0.99 & 0.3609 & -0.2481 & 9.9819 \\
10.49 & 5.70 & 6.80 & 1.10 & 0.2759 & -0.4690 & 10.0210 \\
\hline
\end{tabular}

Average pKa $=9.4923 \pm 0.4410$

Metal-ligand stability constant ( $\log \mathrm{K}$ )

The stabilityconstants require the accurate values of proton-ligand stability constants (Anil and Maroti, 2008). Metal titration curves crossed over ligand titration curve indicated the formation of complex upon proton release (Santosh, et al., 2011). If the values of n- are within range $0.2-0.8$ and $1.2-18$ this indicates the formation of $1: 1$ and 1:2 complexes (Sayyed and Mazahar, 2012).

The metal (II)-humate stepwise stability constants (log k) at phenolic group (Tables 318)

Table 3: Point-wise method, $\mathrm{Cu}$-(Hydrolysed PSHA)

\begin{tabular}{|l|l|l|l|l|l|l|l|l|}
\hline $\mathrm{pH}$ & $\mathrm{BV}_{1}$ & $\mathrm{BV}_{2}$ & $\mathrm{BV}_{3}$ & $\left(\mathrm{~V}_{3}-\mathrm{V}_{2}\right)$ & $\mathrm{n}$ & $\mathrm{pL}$ & $\log \left(\frac{n}{1-n}\right)$ & LogK $_{1}$ \\
\hline 8.50 & 5.30 & 6.29 & 6.33 & 0.04 & 0.5500 & 2.66 & 0.0871 & 2.7471 \\
8.72 & 5.35 & 6.37 & 6.41 & 0.04 & 0.5714 & 2.43 & 0.1249 & 2.5549 \\
9.00 & 5.40 & 6.46 & 6.50 & 0.04 & 0.6198 & 2.16 & 0.2122 & 2.3722 \\
9.22 & 5.45 & 6.55 & 6.59 & 0.04 & 0.6667 & 1.94 & 0.3010 & 2.2410 \\
\hline
\end{tabular}

LogK $_{1}$ (Average value) $=2.4788 \pm 0.2203$

Table 4: Point-wise method, $\mathrm{Cu}$-(Hydrolysed PSHA)

\begin{tabular}{|l|l|l|l|l|l|l|l|l|}
\hline $\mathrm{pH}$ & $\mathrm{BV}_{1}$ & $\mathrm{BV}_{2}$ & $\mathrm{BV}_{3}$ & $\left(\mathrm{~V}_{3}-\mathrm{V}_{2}\right)$ & $\mathrm{n}$ & $\mathrm{pL}$ & $\log \left(\frac{n-1}{2-n}\right)$ & LogK $_{2}$ \\
\hline 9.51 & 5.50 & 6.66 & 6.73 & 0.07 & 1.3509 & 1.70 & -0.2671 & 1.4329 \\
9.73 & 5.55 & 6.78 & 6.85 & 0.07 & 1.6383 & 1.51 & 0.2467 & 1.7567 \\
10.00 & 5.60 & 6.90 & 6.98 & 0.08 & 2.1783 & 1.31 & -0.2158 & 1.0942 \\
10.23 & 5.65 & 7.05 & 7.13 & 0.08 & 4.1904 & 1.27 & & \\
10.49 & 5.70 & 7.10 & 7.19 & 0.09 & 4.6920 & & & \\
\hline
\end{tabular}

Log $K_{2}($ Average value $)=1.4280 \pm 0.3312$ 
BAJOPAS Volume 14 Number 1,June, 2021

Table 5: Point-wise method, $\mathrm{Cu}$ (Unhydrolysed PSHA)

\begin{tabular}{|l|l|l|l|l|l|l|l|l|}
\hline $\mathrm{pH}$ & $\mathrm{BV}_{1}$ & $\mathrm{BV}_{2}$ & $\mathrm{BV}_{3}$ & $\left(\mathrm{~V}_{3}-\mathrm{V}_{2}\right)$ & $\mathrm{n}$ & $\mathrm{pL}$ & $\log \left(\frac{n}{n-1}\right)$ & Log $_{1}$ \\
\hline 8.50 & 5.30 & 5.81 & 5.85 & 0.04 & 0.2973 & 2.88 & -0.3736 & 2.5064 \\
8.72 & 5.35 & 5.90 & 5.95 & 0.05 & 0.3873 & 2.66 & -0.1992 & 2.4608 \\
9.00 & 5.40 & 6.00 & 6.05 & 0.05 & 0.4044 & 2.38 & -0.1681 & 2.2119 \\
9.22 & 5.45 & 6.10 & 6.15 & 0.06 & 0.5157 & 2.18 & -0.0272 & 2.2072 \\
9.51 & 5.50 & 6.20 & 6.27 & 0.07 & 0.6417 & 1.89 & 0.2530 & 1.1430 \\
\hline
\end{tabular}

$\operatorname{LogK}_{1}($ Average value $)=2.3059 \pm 0.6153$

Table 6:Point-wise method, $\mathrm{Cu}$ (Unhydrolysed PSHA)

\begin{tabular}{|l|l|l|l|l|l|l|l|l|}
\hline $\mathrm{pH}$ & $\mathrm{BV}_{1}$ & $\mathrm{BV}_{2}$ & $\mathrm{BV}_{3}$ & $\mathrm{~V}_{3}-\mathrm{V}_{2}$ & $\mathrm{n}$ & $\mathrm{pL}$ & $\log \left(\frac{n-1}{2-n}\right)$ & $\log \mathrm{K}_{2}$ \\
\hline 9.73 & 5.55 & 6.33 & 6.42 & 0.09 & 0.9000 & 1.69 & & \\
10.00 & 5.60 & 6.47 & 6.58 & 0.11 & 1.2578 & 1.44 & -0.4592 & 0.9808 \\
10.23 & 5.65 & 6.62 & 6.84 & 0.12 & 1.6137 & 1.26 & -0.2010 & 1.4610 \\
10.49 & 5.70 & 6.80 & 6.92 & 0.12 & 2.1052 & 1.03 & & \\
\hline
\end{tabular}

$\operatorname{LogK}_{2}$ (Average value) $=1.2209 \pm 0.3398$

Table 7:Point-wise method, Pb (Hydrolysed PSHA)

\begin{tabular}{|l|l|l|l|l|l|l|l|l|}
\hline $\mathrm{pH}$ & $\mathrm{BV}_{1}$ & $\mathrm{BV}_{2}$ & $\mathrm{BV}_{3}$ & $\left(\mathrm{~V}_{3}-\mathrm{V}_{2}\right)$ & $\mathrm{n}$ & $\mathrm{pL}$ & $\log \left(\frac{n}{1-n}\right)$ & LogK $_{1}$ \\
\hline 8.50 & 5.30 & 6.29 & 6.33 & 0.04 & 0.5500 & 2.66 & 0.0871 & 2.7471 \\
8.72 & 5.35 & 6.37 & 6.41 & 0.04 & 0.5714 & 2.43 & 0.1249 & 2.5549 \\
9.00 & 5.40 & 6.46 & 6.50 & 0.04 & 0.6198 & 2.16 & 0.2122 & 2.3722 \\
9.22 & 5.45 & 6.55 & 6.60 & 0.05 & 0.8333 & 1.96 & 0.6989 & 2.6589 \\
\hline
\end{tabular}

Log $_{\mathbf{1}}($ Average value $)=2.5832 \pm 0.1614$

Table 8:Point-wise method, Pb-(Hydrolysed PSHA)

\begin{tabular}{|l|l|l|l|l|l|l|l|l|}
\hline $\mathrm{pH}$ & $\mathrm{BV}_{1}$ & $\mathrm{BV}_{2}$ & $\mathrm{BV}_{3}$ & $\left(\mathrm{~V}_{3}-\mathrm{V}_{2}\right)$ & $\mathrm{n}$ & $\mathrm{pL}$ & $\log \left(\frac{n-1}{2-n}\right)$ & $\log \mathrm{K}_{2}$ \\
\hline 9.51 & 5.50 & 6.66 & 6.71 & 0.05 & 0.9650 & 1.67 & & \\
9.73 & 5.55 & 6.78 & 6.83 & 0.05 & 1.1702 & 1.44 & & \\
10.00 & 5.60 & 6.90 & 6.90 & 0.05 & 1.4864 & 1.22 & -0.0237 & 1.1963 \\
10.23 & 5.65 & 7.05 & 7.10 & 0.05 & 2.0190 & 1.09 & & \\
10.49 & 5.70 & 7.10 & 7.17 & 0.07 & 3.6492 & 1.00 & & \\
\hline
\end{tabular}

Log $K_{2}$ (Average value) $=1.1963$

Table 9: Point-wise method, Pb (Unhydrolysed PSHA)

\begin{tabular}{|l|l|l|l|l|l|l|l|l|}
\hline $\mathrm{pH}$ & $\mathrm{BV}_{1}$ & $\mathrm{BV}_{2}$ & $\mathrm{BV}_{3}$ & $\mathrm{~V}_{3}-\mathrm{V}_{2}$ & $\mathrm{n}$ & $\mathrm{pL}$ & $\begin{array}{l}\text { Log } \\
\left(\frac{n}{n-1}\right)\end{array}$ & Log $\mathrm{K}_{1}$ \\
\hline 8.50 & 5.30 & 5.81 & 5.85 & 0.04 & 0.2973 & 2.88 & -0.3736 & 2.5064 \\
8.72 & 5.35 & 5.90 & 5.94 & 0.04 & 0.3099 & 2.66 & -0.5477 & 2.3123 \\
9.00 & 5.40 & 6.00 & 6.05 & 0.05 & 0.4044 & 2.38 & -0.1681 & 2.2119 \\
9.22 & 5.45 & 6.10 & 6.15 & 0.06 & 0.5157 & 2.18 & 0.0272 & 2.2072 \\
9.51 & 5.50 & 6.20 & 6.26 & 0.07 & 0.6417 & 1.89 & 0.2530 & 2.1430 \\
9.73 & 5.55 & 6.40 & 6.40 & 0.07 & 0.7000 & 1.67 & 0.3680 & 2.0380 \\
\hline
\end{tabular}

LogK $_{1}$ (Average value) $=2.2364 \pm 0.1602$

Table 10: Point-wise method, Pb (Unhydrolysed PSHA)

\begin{tabular}{|l|l|l|l|l|l|l|l|l|}
\hline $\mathrm{pH}$ & $\mathrm{BV}_{1}$ & $\mathrm{BV}_{2}$ & $\mathrm{BV}_{3}$ & $\mathrm{~V}_{3}-\mathrm{V}_{2}$ & $\mathrm{n}$ & $\mathrm{pL}$ & $\log \left(\frac{n-1}{2-n}\right)$ & $\log \mathrm{K}_{2}$ \\
\hline 10.00 & 5.60 & 6.47 & 6.55 & 0.08 & 1.9503 & 1.41 & & \\
10.23 & 5.65 & 6.62 & 6.72 & 0.11 & 1.4792 & 1.26 & -0.0361 & 1.2239 \\
\hline
\end{tabular}

$\operatorname{LogK}_{2}$ (Average value) $=1.2239$

Table 11: Point-wise method, Mg (Hydrolysed PSHA)

\begin{tabular}{|l|l|l|l|l|l|l|l|l|}
\hline $\mathrm{pH}$ & $\mathrm{BV}_{1}$ & $\mathrm{BV}_{2}$ & $\mathrm{BV}_{3}$ & $\left(\mathrm{~V}_{3}-\mathrm{V}_{2}\right)$ & $\mathrm{n}$ & $\mathrm{pL}$ & $\log \left(\frac{n}{n-1}\right)$ & LogK $_{1}$ \\
\hline 8.50 & 5.30 & 6.29 & 6.31 & 0.02 & 0.2750 & 2.64 & -0.4290 & 2.2110 \\
8.72 & 5.35 & 6.37 & 6.39 & 0.02 & 0.2858 & 2.42 & -0.3978 & 2.0222 \\
9.00 & 5.40 & 6.46 & 6.49 & 0.03 & 0.4648 & 2.14 & -0.0612 & 2.0788 \\
9.22 & 5.45 & 6.55 & 6.59 & 0.04 & 0.6667 & 1.94 & 0.3010 & 2.2410 \\
\hline
\end{tabular}

$\log _{\mathbf{1}}($ Average value) $=2.1382 \pm 0.1046$ 
BAJOPAS Volume 14 Number 1,June, 2021

Table 12: Point-wise method, Mg (Hydrolysed PSHA)

\begin{tabular}{|l|l|l|l|l|l|l|l|l|}
\hline $\mathrm{pH}$ & $\mathrm{BV}_{1}$ & $\mathrm{BV}_{2}$ & $\mathrm{BV}_{3}$ & $\left(\mathrm{~V}_{3}-\mathrm{V}_{2}\right)$ & $\mathrm{n}$ & $\mathrm{pL}$ & $\log \left(\frac{n-1}{2-n}\right)$ & LogK $_{2}$ \\
\hline 9.51 & 5.55 & 6.66 & 6.71 & 0.05 & 0.9650 & 1.67 & & \\
9.73 & 5.55 & 6.78 & 6.84 & 0.06 & 1.4042 & 1.47 & -0.1686 & 1.3014 \\
10.00 & 5.60 & 6.90 & 6.93 & 0.06 & 1.7838 & 1.23 & 0.5593 & 1.7893 \\
10.23 & 5.65 & 7.05 & 7.10 & 0.06 & 3.1429 & 1.10 & & \\
10.49 & 5.70 & 7.10 & 7.18 & 0.07 & 3.6492 & 0.83 & & \\
\hline
\end{tabular}

LogK $_{2}($ Average value $)=1.5453 \pm 0.3450$

Table 13: Point-wise method, Mg (Unhydrolysed PSHA)

\begin{tabular}{|l|l|l|l|l|l|l|l|l|}
\hline $\mathrm{pH}$ & $\mathrm{BV}_{1}$ & $\mathrm{BV}_{2}$ & $\mathrm{BV}_{3}$ & $\mathrm{~V}_{3}-\mathrm{V}_{2}$ & $\mathrm{n}$ & $\mathrm{pL}$ & $\log \left(\frac{n}{n-1}\right)$ & $\operatorname{Log~}_{1}$ \\
\hline 8.50 & 5.30 & 5.81 & 5.85 & 0.04 & 0.2973 & 2.88 & -0.3736 & 2.5064 \\
8.72 & 5.35 & 5.90 & 5.94 & 0.04 & 0.3099 & 2.66 & -0.3477 & 2.3123 \\
9.00 & 5.40 & 6.00 & 6.04 & 0.04 & 0.3236 & 2.38 & -0.3202 & 2.0598 \\
9.22 & 5.45 & 6.10 & 6.15 & 0.05 & 0.4297 & 2.17 & -0.1230 & 2.0470 \\
9.51 & 5.50 & 6.20 & 6.26 & 0.06 & 0.5500 & 1.89 & 0.0871 & 1.9771 \\
9.73 & 5.55 & 6.33 & 6.40 & 0.07 & 0.7000 & 1.67 & 0.3680 & 2.0380 \\
\hline
\end{tabular}

LogK $_{1}$ (Average value) $=2.1568 \pm 0.2069$

Table 14: Point-wise method, Mg (Unhydrolysed PSHA)

\begin{tabular}{|l|l|l|l|l|l|l|l|l|}
\hline $\mathrm{pH}$ & $\mathrm{BV}_{1}$ & $\mathrm{BV}_{2}$ & $\mathrm{BV}_{3}$ & $\mathrm{~V}_{3}-\mathrm{V}_{2}$ & $\mathrm{n}$ & $\mathrm{pL}$ & $\log \left(\frac{n-1}{2-n}\right)$ & $\log \mathrm{K}_{2}$ \\
\hline 10.00 & 5.60 & 6.47 & 6.55 & 0.08 & 0.9148 & 1.41 & & \\
10.23 & 5.65 & 6.62 & 6.71 & 0.09 & 1.2102 & 1.20 & -0.5749 & 0.6251 \\
10.49 & 5.70 & 6.80 & 6.92 & 0.09 & 1.5968 & 1.03 & 0.1703 & 1.2003 \\
\hline
\end{tabular}

LogK $_{2}$ (Average value) $=0.9127 \pm 0.4070$

Table15:Point-wise method, Cd (Hydrolysed PSHA)

\begin{tabular}{|l|l|l|l|l|l|l|l|l|}
\hline $\mathrm{pH}$ & $\mathrm{BV}_{1}$ & $\mathrm{BV}_{2}$ & $\mathrm{BV}_{3}$ & $\left(\mathrm{~V}_{3}-\mathrm{V}_{2}\right)$ & $\mathrm{n}$ & $\mathrm{pL}$ & $\log \left(\frac{n}{1-n}\right)$ & LogK $_{1}$ \\
\hline 8.50 & 5.30 & 6.29 & 6.31 & 0.02 & 0.2750 & 2.64 & -0.4210 & 2.2190 \\
8.72 & 5.35 & 6.37 & 6.40 & 0.03 & 0.4286 & 2.42 & -0.1249 & 2.2951 \\
9.00 & 5.40 & 6.46 & 6.49 & 0.03 & 0.4648 & 2.14 & -0.0612 & 2.0788 \\
9.22 & 5.45 & 6.55 & 6.59 & 0.04 & 0.6667 & 1.96 & 0.3010 & 2.2610 \\
9.51 & 5.55 & 6.66 & 6.70 & 0.04 & 0.7720 & 1.67 & 0.5297 & 2.1997 \\
\hline
\end{tabular}

LogK $_{\mathbf{1}}$ (Average value) $=2.2108 \pm 0.0825$

Table 16: Point-wise method, Cd (Hydrolysed PSHA)

\begin{tabular}{|l|l|l|l|l|l|l|l|l|}
\hline $\mathrm{pH}$ & $\mathrm{BV}_{1}$ & $\mathrm{BV}_{2}$ & $\mathrm{BV}_{3}$ & $\left(\mathrm{~V}_{3}-\mathrm{V}_{2}\right)$ & $\mathrm{n}$ & $\mathrm{pL}$ & $\log \left(\frac{n-1}{2-n}\right)$ & Log $_{2}$ \\
\hline 9.73 & 5.55 & 6.78 & 6.83 & 0.06 & 1.4042 & 1.47 & -0.1686 & 1.3014 \\
10.00 & 5.60 & 6.90 & 6.95 & 0.06 & 1.7838 & 1.23 & 0.5593 & 1.7893 \\
10.23 & 5.65 & 7.05 & 7.10 & 0.06 & 3.1429 & 1.09 & & \\
10.49 & 5.70 & 7.10 & 7.16 & 0.06 & 3.1429 & 0.89 & & \\
& & & & & & & & \\
\hline
\end{tabular}

$\operatorname{LogK}_{2}$ (Average value) $=1.5453 \pm 0.3450$

Table 17: Point-wise method, Cd (Unhydrolysed PSHA)

\begin{tabular}{|l|l|l|l|l|l|l|l|l|}
\hline $\mathrm{pH}$ & $\mathrm{BV}_{1}$ & $\mathrm{BV}_{2}$ & $\mathrm{BV}_{3}$ & $\mathrm{~V}_{3}-\mathrm{V}_{2}$ & $\mathrm{n}$ & $\mathrm{pL}$ & $\log \left(\frac{n}{n-1}\right)$ & $\operatorname{Log~}_{1}$ \\
\hline 8.50 & 5.30 & 5.81 & 5.86 & 0.05 & 0.3717 & 2.88 & -0.2280 & 2.6520 \\
8.72 & 5.35 & 5.90 & 5.95 & 0.05 & 0.3873 & 2.66 & -0.1992 & 2.4608 \\
9.00 & 5.40 & 6.00 & 6.06 & 0.06 & 0.4853 & 2.38 & -0.0255 & 2.3545 \\
9.22 & 5.45 & 6.10 & 6.16 & 0.06 & 0.5157 & 2.18 & -0.0272 & 2.2072 \\
9.51 & 5.50 & 6.20 & 6.27 & 0.07 & 0.6417 & 1.89 & 0.2530 & 1.1430 \\
9.73 & 5.55 & 6.33 & 6.41 & 0.08 & 0.8000 & 1.69 & 0.6020 & 2.2920 \\
& & & & & & & & \\
\hline
\end{tabular}

$\operatorname{LogK}_{1}($ Average value $)=2.2516 \pm 0.5380$ 
BAJOPAS Volume 14 Number 1,June, 2021

Table 18: Point-wise method, Cd (Unhydrolysed PSHA)

\begin{tabular}{|l|l|l|l|l|l|l|l|l|}
\hline $\mathrm{pH}$ & $\mathrm{BV}_{1}$ & $\mathrm{BV}_{2}$ & $\mathrm{BV}_{3}$ & $\mathrm{~V}_{3}-\mathrm{V}_{2}$ & $\mathrm{n}$ & $\mathrm{pL}$ & $\log \left(\frac{n-1}{2-n}\right)$ & $\log \mathrm{K}_{2}$ \\
\hline 10.00 & 5.60 & 6.47 & 6.57 & 0.10 & 1.1434 & 1.43 & & \\
10.23 & 5.65 & 6.62 & 6.72 & 0.10 & 1.3448 & 1.23 & -0.2788 & 0.9512 \\
10.49 & 5.70 & 6.80 & 6.90 & 0.10 & 1.7742 & 1.03 & 0.5351 & 1.5651 \\
\hline
\end{tabular}

$\operatorname{LogK}_{2}($ Average value $)=1.2581 \pm 0.4340$

Table 19: Stepwise and overall Stability constants of thehydrolysed and unhydrolysed divalent metal (II) complexes

\begin{tabular}{|c|c|c|c|}
\hline Chelates & LogK $_{1}$ & $\log _{2}$ & Log $\beta$ \\
\hline [Cu (Hydrolysed PSHA-1) $\left.{ }_{2}\right]$ & 2.4788 & 1.4280 & 3.9068 \\
\hline$\left[\mathrm{Pb}(\text { Hydrolysed PSHA-1) })_{2}\right]$ & 2.5832 & 1.1963 & 3.7795 \\
\hline$\left[\mathrm{Cd}(\text { Hydrolysed PSHA-1 })_{2}\right]$ & 2.2108 & 1.5453 & 3.7561 \\
\hline$\left[\mathrm{Mg}(\text { Hydrolysed PSHA-1 })_{2}\right]$ & 2.1382 & 1.5453 & 3.6835 \\
\hline [Cu (Unhydrolysed PSHA-1) & 2.3059 & 1.2209 & 3.5268 \\
\hline$[\mathrm{Pb}$ (Unhydrolysed PSHA-1) 2$]$ & 2.2364 & 1.2239 & 3.4603 \\
\hline [Cd (Unhydrolysed PSHA-1) 2 ] & 2.2516 & 1.2581 & 3.5097 \\
\hline$[\mathrm{Mg}$ (Unydrolysed PSHA-1) & 2.1568 & 0.9127 & 3.0695 \\
\hline
\end{tabular}

The results obtained (Table19) shows the stepwise and overall stability constants to be not high indicating low stability of the complexes, because the solubility of most metal ions in the basic $\mathrm{pH}$ range is minimal due to metal hydroxide precipitation (Karimi, 2017). In general, the stepwise stability constants $\left(K_{1}\right.$ and $K_{2}$ ) follow the order $K_{1}>K_{2}$ for the copper, lead, magnesium and cadmium complexes respectively. The steady decrease of the values with increasing number of ligands is in agreement with the prediction made by researchers (Na'aliya, 2013). The decrease could be attributed to the fact that as the number of the ligands (Humate ions) that enters the coordination zone increases the aqua molecules available for replacement by the ligands become less. Thus, the metal ions become less electron loving with progressive intake of the ligand and this results in the decrease in the values of the constants (Na'aliya, 2013). Also the stability of the complexes is influenced by the size and number of the chelate rings(Mackay and Mackay,2002).All the complexes form rings in their structure as humate, a bidentate ligand, bond the metal ions in the ratio 1:2 (Boguta and Sokolowska, 2016) forming chelate rings. The values of the overall stability constants $(\log \beta)$ obtained for humate complexes are not high indicating low stability as the values are not high. LogK values for copper-humates (Table 3 to 6) obtained in this study are lower than those reported for the complexes of humic acids (Pandey et al., 2015; Dinu, 2013; Kaschl et al., 2010 and Gilbeto and Jorg, 2001). The values of LogK(Table 7 to 10 ) forlead-humates are lower than those reported for the lead in the literature (Dinu, 2013; Gilbeto and Jorg 2001). Log K values(Table 11 to 14 ) for magnesium-humates obtained in this study are close to those reported by (Pandey et al., 2015). Log K values of cadmium-humates (Table 15 to 18 ) obtained in this work near to the one reported by (Dinu, 2013 and Pandey et al., 2015).The difference between the reported values and the values obtained in this study might be probably as a result of acid hydrolysis of humic acid. The values of the overall stability constants $(\log \beta)$ of the copper humates complexes presented in Table 19 is high than that of other metal humate complexes, show relatively high stability of CuHA complexes, show the following order of stability: $\mathrm{Cu}>\mathrm{Pb}>\mathrm{Cd}>\mathrm{Mg}$; which are in close agreement to the findings of (Dinu, 2013 and Pandey et al., 2015).The high stability of Cuhumate chelate could be attributed to the existence of coordinate covalent bond between the complexing agents and the $\mathrm{Cu}^{2+}$ ions. Since, $\mathrm{Cu}^{2+}$ being a metal of the transitional series with $3 d^{9}$ electronic configurations can accept the electrons from the complexing agents. Similarly, the low stabilities of $\mathrm{Pb}, \mathrm{Cd}$ and $\mathrm{Mg}$ complexes could be explained by that $\mathrm{Pb}^{2+}$ with $6 s^{2}, \mathrm{Cd}^{2+}$ with $4 \mathrm{~d}^{10}$ and $\mathrm{Mg}^{2+}$ with $2 \mathrm{p}^{6}$ their electronic configuration has a completely filled $\mathrm{d}, \mathrm{p}$ and $\mathrm{s}$ orbitals. Moreover, the stabilities of metal ions with hydrolysed humic acid from peat soil were higher than those with unhydrolysed humic acid from peat soil; which is ascribed to the high content of acidity in hydrolysed humic acid than unhydrolysed humic acid. 
BAJOPAS Volume 14 Number 1,June, 2021 CONCLUSION

The values of logk for $\mathrm{Cu}(\mathrm{II})$ hydrolysed humic acid complex was higher followed by $\mathrm{Pb}$ (II), $\mathrm{Cd}(\mathrm{II})$ and $\mathrm{Mg}$ (II) hydrolysed humic acid complexes as compared with metal(II) unhydrolysed humic acid complexes. This indicates acid hydrolysis of humic acid can

\section{REFERENCES}

Almeida, V.R. and Szpoganicz, B. (2015). Humic Acid Potentiometric Response Patterns:Out- of Equilibrium Properties and Species Distribution Modelling. Chemical. Biol. Technol. Agric. 2: 17.

Anđelković, T., Nikolić, R., Bojić, A.,Anđelković, D., and Nikolic G.,(2010). Binding of Cadmium to Soil Humic Acid as A Function of Carboxyl Group Content. Macedonian Journal of Chemistry and Chemical Engineering.29(2): 215-224.

Anil, B. N. and Maroti, N. (2008). Studies on Influence of Die-Lectric Constants on Complex Equilibria between Substituted Py-Razalines and Lanthanide Metal Ions pH-Metrically. Amer.-Euras. scient. Res. 3(2): 212-216.

Ashok, K., Pandey, S. P. and Misra, V (2000). Stability Constants of Metal-Humic Acid Complexes and its Role in Environmental Detoxification. Journal of Ecotoxicology and Environmental Safety. 47(2):157-200.

Badr, M. H., El-Halafawi, M. H. and Abd El-al Zeid, E. R. (2012). Comparison Between the Effect of Ionic Strength on Acidity and Dissociation Constants of Humic Acids Extracted from Sewage Sludge and Nile Water Hyacinth Composts.Global Journal of Environmental Research 6 (1): 36-43.

Baruah, M.K., Borah, D., Saikia, P.P., Paul, S., Sharma, T. (2015). Evaluation of pKa Values of Soil Humic Acids and their Complexation Properties. International Journal of Plant \& Soil Science 6(4) : 218-228.

Boguta, P. Sokolowska, Z. (2016). Interactions of $\mathrm{Zn}$ (II) Ions with Humic Acids Isolated from Various Types of Soils. Effect of $\mathrm{pH}, \mathrm{Zn}$ Concentrations and Humic Acids Chemical Properties. Journal of Geochemical Explaration 168. 119-126.

Borges, F., Guimaraes, C., Lima, L.F.C., Pinto, I. and Reis, S.(2005). Potentiometric Studies on the Complexation of Copper(II) by Phenolic Acids as Discrete Ligand Models of enhance the complexation behavior of humic acid with metal (II) ions. However, the higher values of $\log \beta$ for $\mathrm{Cu}(\mathrm{II}), \mathrm{Pb}(\mathrm{II}), \mathrm{Cd}(\mathrm{II})$ and $\mathrm{Mg}(\mathrm{II})$ hydrolysed humic acid complexes indicates more stable stepwise complexes formed as compared with $\mathrm{Cu}(\mathrm{II}), \mathrm{Pb}$ (II), $\mathrm{Cd}$ (II) and $\mathrm{Mg}(\mathrm{II})$ unhydrolysed humic acid complexes.

Humic Substances Talanta 66 (2005) 670-673.

Chefetz, B., Salloum, M. J., Deshmulkin, A. P. and Hatcher, P. (2002). Structural Components of Humic Acids as Determined by Chemical Modifications and Carbon-13 NMR, Pyrolysis, and Thermochemolysis- Gas Chromatography/Mass Spectrometry. Soil Science Society of American Journal Abstract Division S-2- Soil Chemistry66. 1159-1171.

Dinu, M. I. (2013). Metals Complexation with Humic Acids in Surface Water of Different Environ. Sci. Technol. 31(1): 1-17.

Fernandes, A.N., Giacomelli, C., Giovanela, M. Vaz, D.V. Szpoganicz, B. and Maria M. D. (2009). Potentiometric Acidity Determination in Humic Substances Influenced by Different Analytical Procedures.J. Braz. Chem. Soc. 20 (9):14.

Gamal, A. H. (2015). Stability Constants of Rhenium (V) Metal Complexes with Selected Drugs. Pyrex Journal of Research in Environmental Studies. 2(2): 006-014.

Janrao, D. M., Pathan, J., Kayande, D.D., and Mulla, J.J. (2014). An Over View of Potentiometric Determination of Stability Constants of Metal Complexes. Sci. Revs. Chem. Commun.: 4(1), 2014, 11-24.

Karimi, H. (2017). Effect of pH and Initial Pb(II) Concentration on the Lead Removal Efficiency from Waste Water Using $\mathrm{Ca}(\mathrm{OH})_{2}$. International Journal of Water and Waste Water Treatment 3.2

Kaschl, A. Romheld, V. and Chen, Y. (2010). Binding of Cadmium, Copper and Zinc to Humic Substances Originating from Municipal Solid Waste Compost. Israel Journal of Chemistry Vol. 42(1): 89-98.

Kostic, I. S., Tatjana, P, A., Nikolic, R. S., Cvetkovic, T. P., Pavlovic, D. D., Aleksandar, L.J. and Bojic, A. (2012). Comparative Study of Binding Strengths of Heavy Metals with Humic Acid. J.serb. Chem. Soc. 76(9) pp 1-20. 
BAJOPAS Volume 14 Number 1,June, 2021

Na'aliya, J. (2013). Determination of Stepwise Stability Constants and Gibbs free Energy Change of Trisprolina to Complexes of some Divalent Transition Metal ions. Bayero Journal of Pure and Applied Sciences 6(2): 112-114.

Omar, A. A. and Ali, E. A. (2015). Potentiometric Studies on Complexes of $\mathrm{Cr}$ (III) and $\mathrm{Zr}$ (IV) with some Carboxylic Acids. International Journal of Advanced Chemistry, 3(1) 25-

37.

Pandey, A. K. Pandey, S. D. and Misr, V. (2015).Stability Constants of Metal- Humic Acid Complexes and Its Role in Environmental Detoxification. J. Ecotoxicology and Environmental Safety. 47(1):195-200.

Ram, N. and Raman, K.V. (1984). Stability Constants of Complexes of Metals with
Humicand Fuvic Acids under Non- acidConditions. Journal of Plant Nutrition and Soil Sciences.

147:171-176.

Santosh, D. D., Ashok, B. K., Vijay, J. T., Shivraj, G. W. and Vinay, V. W. (2011). Potentiometric Studies of Elec-Trolyte Effects on Complex Equilibria of Some Substituted 5-(2-hydroxy Phenyl) Pyrazoles. Der pharm. 3 (6): 75-83.

Sayyed, H. and Abdul Rahim, M. F. (2012). Studies of Binary Complexes of Metal Ions with Mandelic Acid by Potentiometry. Chem. J. 02 (6): 206209.

Shirvani, M. Moradian, E. Khalili, B. Bakhtiary, S. (2015). Interaction of $\mathrm{Cd}$ and $\mathrm{Pb}$ with Humate-Palygorskite and HumateSepiolite Complexes. Journal of water, air and pollution 3: 220-228. 


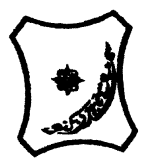

Bayero Journal of Pure and Applied Sciences, 14(1): 54 - 63

Received: November, 2020

Accepted: April, 2021

ISSN $2006-6996$

\title{
STABILITY CONSTANTS OF COMPLEXES OF METAL IONS WITH PEATSOIL HUMIC ACIDS UNDER NON-ACID-CONDITIONS
}

\author{
${ }^{* 1}$ Sabo, Yusuf ${ }^{2}$ Jimoh, W.L.O., ${ }^{3}$ Isa Baba Koki and ${ }^{4}$ Sholadoye, Q. 0. \\ ${ }^{1}$ Department of Pure and Industrial Chemistry, Bayero University, Kano \\ ${ }^{3}$ Department of Chemistry, Yusuf Maitama Sule University Kano. P.M.B. 3220 Kano, Nigeria. \\ ${ }^{4}$ Department of Chemistry, Nigerian Police Academy, Wudil, Kano-Nigeria
}

*Correspondence E-mail; saboyusuf18@yahoo.com

ABSTRACT

Stability constants of complexes of four divalent metal ions viz. $\mathrm{Cu}^{2+}, \mathrm{Pb}^{2+}, \mathrm{Mg}^{2+}$ and $\mathrm{Cd}^{2+}$ with humic acids (HA) were determined by potentiometric titration of humic acids with the corresponding salt of the divalent metals in aqueous media under non-acid-condition. The log $K$ (logarithm of the stability constant) ranged from 1.0942 to 2.7471 for metalhumic acid complexes were determined using point-wise computational method. The order of stability constants were obtained as follows: $\mathrm{Cu}>\mathrm{Pb}>\mathrm{Cd}>\mathrm{Mg}$ for metal $-\mathrm{HA}$ complexes respectively, indicating a higher degree of complexation with Cu metal ion.

Keywords: stability constant, humic acid, potentiometric titration, divalent metals, acid hydrolysis.

\section{NTRODUCTION}

The stability constant of a complex is the numerical expression of its stability and provides a quantitative measure of affinity of the metal ion to the complexing agent. An understanding of the relative stability of metal-complexes helps in predicting the behavior of metal ions in the soil (Ram and Raman, 1982). Extensive researches has been done to determine the stability constants of the complexes formed between humic acid (HA) with a number of metal ions. Ashok et al., (2000) reported that humic acid with hydroxyl, phenoxyl and carboxyl reactive groups can form coordination compound with metal ions at $\mathrm{pH}$ 3.5. The stability constants(Log K) for different metalhumic acid complexes indicated the following order of the stabilities of complexes formed between humic acid and metal ion, $\mathrm{Cu}>\mathrm{Fe}$ $>\mathrm{Pb}>\mathrm{Ni}>\mathrm{Co}>\mathrm{Ca}>\mathrm{Cd}>\mathrm{Zn}>\mathrm{Mn}>\mathrm{Mg}$. Andelkovic et al., (2010) investigated the binding of $\mathrm{Cd}$ (II) to soil humic acid at pH 6.5 and in $0.1 \mathrm{M} \mathrm{KNO}_{3}$ ionic medium. The stability constant for binding indicating greater stability in the case when carboxyl groups are involved in complexation reaction. Kostic et al.,(2012) investigated the complexation of humic acid with certain heavy metal ions (Co(II), $\mathrm{Ni}(\mathrm{II}), \mathrm{Cu}(\mathrm{II})$,
$\mathrm{Zn}(\mathrm{II})$, and $\mathrm{Pb}(\mathrm{II})$. The experiment was performed at $25^{\circ} \mathrm{C}$, at pH 4.0 and ionic strength of $0.01 \mathrm{M}$. Stability constant of complex between $\mathrm{Pb}$ (II) ions and humic acid is greater than stability constants of other investigated metalhumate complexes. Bogata and Sokolowska (2016) analyses the interaction between humic acids from different soils and $\mathrm{Zn}$ (II) ions at wide concentration ranges and at $\mathrm{pH} 5$. Studies have showed significant impact of $\mathrm{Zn}$ concentration, $\mathrm{pH}$ and some properties of humic acids with zinc.But all of these studies were limited to acidic $\mathrm{pH}$ range. Therefore, the present study was carried out to determine and compare the stability constants of complexes of metal ions with hydrolysed peat soil humic acid and unhydrolysed peat soil humic under non-acid conditions.

\section{MATERIALS AND METHODS}

Analytical grade chemicals used includes hydrochloric acid $(\mathrm{HCl})$, nitric acid $\left(\mathrm{HNO}_{3}\right)$, sodium hydroxide $(\mathrm{NaOH})$, lead nitrate $\mathrm{Pb}\left(\mathrm{NO}_{3}\right)_{2}$, copper nitrate $\mathrm{Cu}\left(\mathrm{NO}_{3}\right)_{2} \cdot 3 \mathrm{H}_{2} \mathrm{O}$, cadmium nitrate $\mathrm{Cd}\left(\mathrm{NO}_{3}\right)_{2} \cdot 4 \mathrm{H}_{2} \mathrm{O}$, magnesium nitrate $\mathrm{Mg}\left(\mathrm{NO}_{3}\right)_{2} \cdot 6 \mathrm{H}_{2} \mathrm{O}$, potassium nitrate $\left(\mathrm{KNO}_{3}\right)$, calcium chloride $\left(\mathrm{CaCl}_{2}\right)$, (sigma-Aldrich). Dowex 50WX8, (20-50 mesh) from Fluka. 


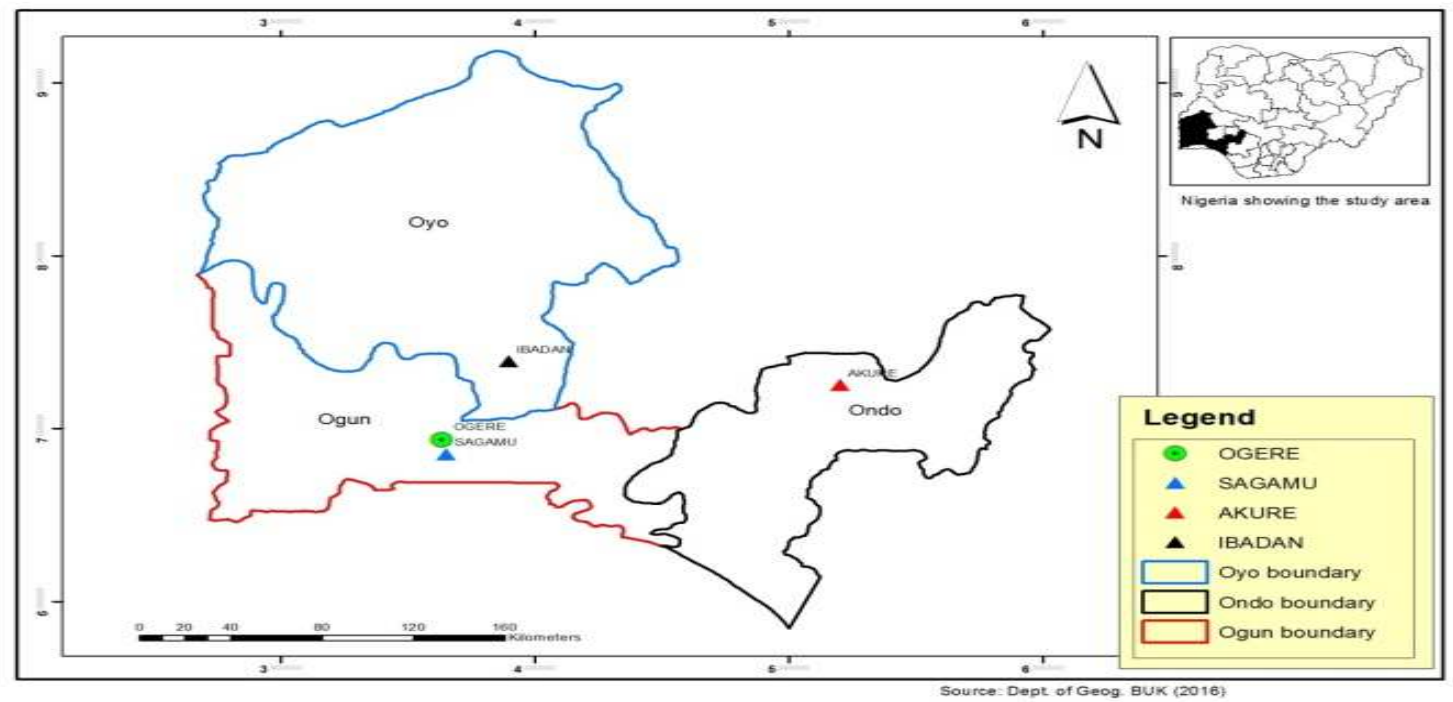

Figure 1: Map showing the sampling point at Sagamu Town, Ogun State.

\section{Description of Sampling Area}

Sagamu has geographical coordinates between $6^{\circ} 50^{\prime}$ north; $3^{\circ} 38^{\prime}$ east is located in south western region of Nigeria. The region has tropical wet and dry climate with a lengthy wet season and relatively constant temperatures throughout the course of the year. Wet season runs from March to October, November to December forms the region dry season. The vegetation type of the region is savannah which is really grassland with small bushes and occasional big trees. Grassland soils have substantially higher organic matter content than forest soils (Novackova, 2011).

\section{Sample Collection}

The Peatsoil samples were collected from four different sampling points $(0-10 \mathrm{~cm}$ depth) in Sagamu into polyethylene bag with plastic spoons. Samples were taken to the laboratory, extraneous materials were removed; the samples were air-dried, crushed and ground to a fine powder in a mortar passed through a $0.20 \mathrm{~mm}$ sieve. The samples were kept for analysis.

\section{Isolation and purification of humic acid from peat soil sample}

Peatsoil sample $(100 \mathrm{~g})$ was mixed with 1000 $\mathrm{cm}^{3}$ of $0.1 \mathrm{M} \mathrm{NaOH}$ solution, shaken for 3hours and left to stand overnight. Dark-coloured supernatant was obtained and decanted from solid residue. The dark-coloured supernatant was acidified to $(\mathrm{pH}=1.0)$ with $6 \mathrm{M} \mathrm{HCl}$ stirred and allowed to stand for 6 hours. Yellowish brown supernatant and dark-brown precipitate were obtained. The yellowish brown supernatant was decanted followed by centrifuge and discarded. The dark-brown precipitate was mixed with $500 \mathrm{~cm}^{3}$ of $0.1 \mathrm{M} \mathrm{NaOH}$ solution followed by passing through dowex resin. The dark-brown solution was acidified to $(\mathrm{pH}=1.0)$ with $6 \mathrm{M} \mathrm{HCl}$ stirred and allowed to stand for 3 hours. The dark-brown precipitate was washed several times with deionized water. The supernatant was treated with $\mathrm{AgNO}_{3}$ solution until no white precipitate observed. The humic acid was transferred to weighed crucible and dried at $60^{\circ} \mathrm{C}$ in an oven for 12 hours. The humic acid was cooled and dried in the desiccator, weighed and recorded. The obtained humic acid was dried again at $60^{\circ} \mathrm{C}$ for additional 6 hours cooled and dried in the desiccator, weighed and recorded constant weight was obtained (Baruah et al., 2015).

\section{FT-IR analysis}

FT-IR spectra of humic acid sample was analysed using Carry 630 FT-IR Agilent Technologies.

Unhydrolysed compost humic acid

The unhydrolysed humic acid was obtained after isolation and purification of compost humic acid and kept for investigation.

\section{Acid hydrolysis of Peatsoil acid}

Peatsoil humic acid sample (1g) was refluxed for 12 hours at $\left(160^{\circ} \mathrm{C}\right)$ with $50 \mathrm{~cm}^{3}$ of $6 \mathrm{M} \mathrm{HCl}$. The mixture was allowed to cool, decanted, and centrifuged after hydrolysis. The insoluble residues were washed with distilled water via centrifugation several times, and the supernatant was treated with $\mathrm{AgNO}_{3}$ solution until no white precipitate was observed. The residue was thoroughly dried over $\mathrm{CaCl}_{2}$ in a desiccator at room temperature (Chefetz et al., 2002). Finally, the obtained hydrolysed humic acid was kept for investigation. 
BAJOPAS Volume 14 Number 1,June, 2021 Potentiometric Titrations

Potentiometric measurements were carried out using a pH-meter Jenway (model 3510) with combine electrode, the sensitivity of the $\mathrm{pH}$ meter is 0.01 units. The $\mathrm{pH}$ meter was switched on half an hour before starting the titration for initial warm up of the instrument. The instrument was calibrated with an aqueous standard buffer solution of $\mathrm{pH} 4.00$ and 10.0 (borate buffer) prepared from a "Qualigens" buffer tablets.

The following sets of solutions were prepared in a $250 \mathrm{~cm}^{3}$ volumetric flask separately for $\mathrm{pH}$ metric titrations.

(i) $5 \mathrm{~cm}^{3} 0.1 \mathrm{M} \mathrm{HCl}+40 \mathrm{~cm}^{3}$ deionized water

(ii) $5 \mathrm{~cm}^{3} 0.1 \mathrm{M} \mathrm{HCl}+39 \mathrm{~cm}^{3}$ deionized water $+1 \mathrm{~cm}^{3} 0.15 \mathrm{gcm}^{-3}$ humic acid

(iii) $5 \mathrm{~cm}^{3} 0.1 \mathrm{M} \mathrm{HCl}+37 \mathrm{~cm}^{3}$ deionized water $+1 \mathrm{~cm}^{3} 0.15 \mathrm{gcm}^{-3}$ humic acid

$$
+2 \mathrm{~cm}^{3} \quad 0.01 \mathrm{M} \mathrm{Cu} \text { (II) }
$$

The solutions were titrated against standardized $0.110 \mathrm{MNaOH}$ separately. The total volume of each mixture was adjusted to $50 \mathrm{~cm}^{3}$ and the ionic strength of the solutions was maintained constant at by adding appropriate amount of stock solution of $1 \mathrm{M} \mathrm{KNO}_{3}$ (Gamal, 2015; Omar and Ali, 2015). A magnetic stirrer was used to achieve thorough mixing of the interacting solutions at $550 \mathrm{rpm}$. The same set of experimental conditions was applied for potentiometric titration of remaining samples.

\section{Evaluation of pKa of Hydrolysed peat soil Humic Acids}

The proton-ligand formation number $\mathrm{n}_{\mathbf{A}}$ were calculated by Irving and Rossotti expression (Omar and Ali, 2015).

$\mathrm{nA}=\mathrm{Y}-\frac{(\mathrm{V} 2-\mathrm{V1})(\mathrm{No}-\mathrm{Eo})}{(\mathrm{VO}+\mathrm{V1}) \mathrm{TCL}}$ 1

Where: $Y$ is number of dissociable proton, $\left(\mathrm{V}_{2^{-}}\right.$ $V_{1}$ ) is the measure of displacement of the ligand curve relative to acid curve, $\mathrm{N}^{\circ}$ and $\mathrm{E}^{\circ}$ are the resultant concentration of alkali solution, free acid solution, $\mathrm{T}_{\mathrm{cL}}{ }^{\circ}$ is the total ligand concentration, $\mathrm{V}^{\circ}$ is the total volume of titration solution, $V_{1}$ is the volume of alkali added to acid solution, $V_{2}$ is the volume of alkali added to acid solution + ligand solution, acid dissociation constants (pKa - values) of ligand were calculated by algebraic method point wise calculation (Tables 1 ). The dissociation constants (pKa) were calculated according to the following relation:

$\mathrm{pKa}=\mathrm{pH}+\log \left(\frac{n A}{1-n A}\right)$ 2

Where: pKa is the acid dissociation constant, $\mathrm{n}_{\mathrm{A}}$ is the Proton-ligand formation number and $\mathrm{pH}$ is the pH-values (Omar and Ali, 2015).

\section{Determination of metal-ligand stability constants $(\log K)$ of complexes}

The potentiometric measurement for the determination of stability constant of a complex in solution is based on the fact that the redox potential of the couple $\frac{M^{+(m-n)}}{M^{+m}}$ is shifted significantly on complexation of the metal ion with the ligand. This method involves change in hydrogen ion concentration $\left[\mathrm{H}^{+}\right]$due to the displacement or association of one or more protons taking place during complexation reaction. This change can be found out by titrating the solutions containing free acid, acid with ligand, and acid with ligand and metal ion, individually against a standard alkali solution at a constant ionic strength or temperature. Either ionic strength or temperature may be varied for different sets of solutions. In all the cases, the change in the $\mathrm{pH}$ of the solution is measured after each addition of a known amount of alkali to the reaction cell which contains the reaction mixture. The titration curves are then drawn by plotting the measured $\mathrm{pH}$ values against the corresponding volume of alkali added and the stability constants of the complexes are determined from the titration curves by employing $\mathrm{pH}$-metric titration technique given by (Irving and Rossoti).

Metal-ligand stability constants ( $\log \mathrm{K}$ ) were determined by using the following relations:

$$
\bar{n}=\frac{\left(V_{3}-V_{2}\right)\left(E^{0}+N^{0}\right)}{\left(V^{0}+V_{2}\right) \bar{n}_{A} T_{m}^{0}}
$$

and

$$
P L=\log _{10}\left\{\frac{1+\beta_{n}^{H} \frac{1}{[\text { anti } \log \mathrm{pH}]^{\mathrm{n}}}}{\mathrm{T}_{\mathrm{L}}^{0}-n \bar{T}_{m}^{0}} \mathrm{X} \frac{\left(V^{0}+V_{3}\right)}{V^{0}}\right\}
$$


BAJOPAS Volume 14 Number 1,June, 2021

Where $T_{L}, T^{\circ}, E^{\circ}$, and $V^{\circ}$ havethe same significance as in equation (1) above, $T_{m}$ denotes the total concentration of metal present in solution, $V_{3}$ is the volume of metal ions present in solution and $\beta^{H}$ is the overall proton ligand stability constant. The metal-ligand stability constants (log K) were determined by employing point wise computational Method (eq. 5 and 6).

$\operatorname{LogK}_{1}=\log \left(\frac{n}{1-n}\right)+\mathrm{pL}$ .5

$\operatorname{LogK}_{2}=\log \left(\frac{1-n}{2-n}\right)+\mathrm{pL}$ ...6

Where: Log $\mathrm{K}$ is the metal-ligand stability constant, $\mathrm{pL}$ is the Free ligand exponent function, $\mathbf{n}$ is the Average number of ligand attached with metal ion (Janraoet al., 2014). The results obtained were analyzed by an ORIGIN 2016 program using titration data and then the proton-ligand stability constants (pKa) and Metal-ligand stability constant (LogK) calculated (Omar and Ali, 2015).

\section{RESULTS AND DISCUSSION}

Fourier transformed infrared (FT-IR) spectra of isolated humic acid from peat soils Figure 2 had distinct clear absorption bands indicating the presence of major humic acid structural elemental groups such as $\mathrm{H}$ bonded $\mathrm{OH}$ $\left(3680 \mathrm{~cm}^{-1}\right.$ peak $), C=0$ of carbonyl $\left(1721 \mathrm{~cm}^{-1}\right.$ peak), functional groups of aliphatic components $\mathrm{CH}_{2}\left(2918 \mathrm{~cm}^{-1}\right.$ peak) and $\mathrm{C}-\mathrm{O}$ stretching of polysaccharide $\left(1168 \mathrm{~cm}^{-1}\right.$ peak). The positions of the absorption bands of the spectra fell within typical major absorption bands of humic acid which is at frequencies 3680, 2918, 1721, 1168 $\mathrm{cm}^{-1}$. The first peak centred in the vicinity of $3680 \mathrm{~cm}^{-1}$ region is attributed to phenol $\mathrm{OH}$ group bounded by intermolecular $\mathrm{H}$ bonds. The $2918 \mathrm{~cm}^{-1}$ band usually has absorption maximum at $2918 \mathrm{~cm}^{-1}$ which is due to $\mathrm{C}-\mathrm{H}$ stretching of alkane group $\left(\mathrm{CH}_{2}\right)$. The next major absorption band is $1721 \mathrm{~cm}^{-1}$. This band has been commonly ascribed to $\mathrm{C}=\mathrm{O}$ stretching of mainly carboxyl group $(\mathrm{COOH})$ with trace amount of ketones. The last peak was observed at 1168 $\mathrm{cm}^{-1}$ due to $\mathrm{C}-\mathrm{O}$ stretching of polysaccharides and this peak appeared also in the spectra of humic acid from peat soil. The FTIR spectra of the isolated humic acid contained all major characteristic absorption peaks of humic acid. These absorption peaks indicated the presence of the major structural elements of humic acid namely $\mathrm{H}$ bonded $\mathrm{OH}, \mathrm{C}=\mathrm{C}$ of aromatic ring, $\mathrm{C}=\mathrm{O}$ of carbonyl group (both carboxyl and ketonic), $\mathrm{CH}_{2}$ group. This strongly supports the presence of humic acid.

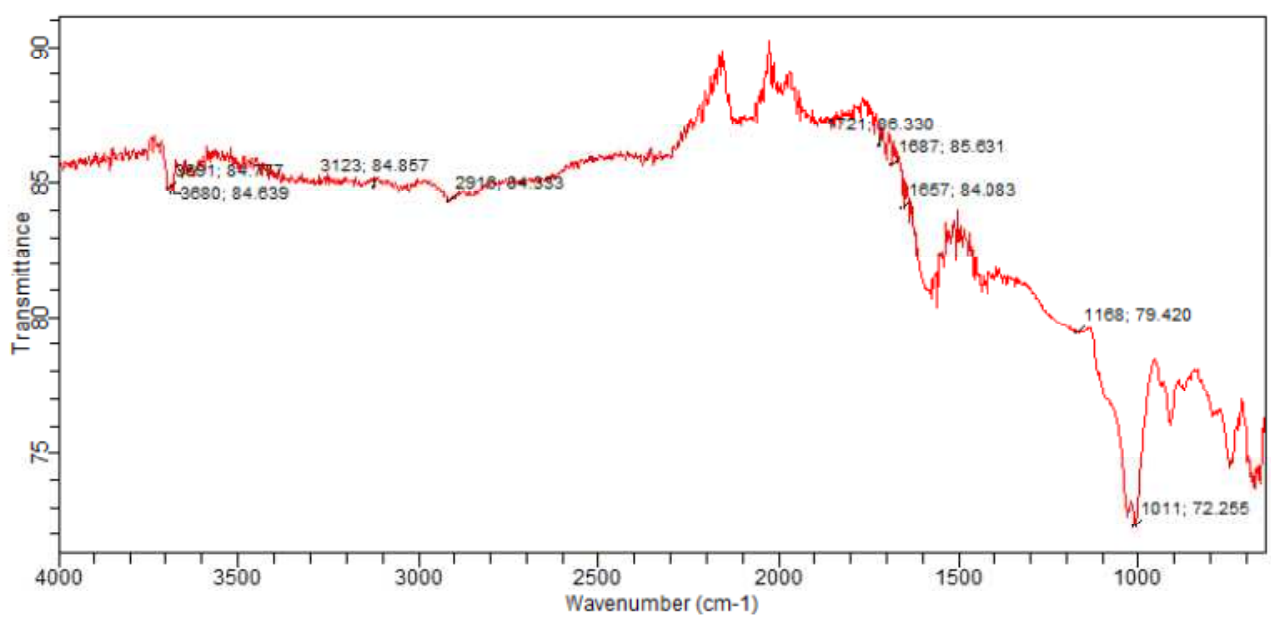

Fig. 2 : FT-IR spectraof peatsoilhumic acid (PSHA)

\section{Evaluation of acid dissociation constant (pka) of acid hydrolysed peat soil humicacid at phenolic group}

The value of the dissociation constant of the peat soil humic acid (PSHA) that underwent acidhydrolysis studied was found to be 8.9299 as shown Table 1, which is lower than the literaturevalues reported by Almeida and Szpoganics, (2015), Borges et al., (2005); Badr et al., (2012)and Fernandes et al,.(2009) of $9.73,9.47$ and 10.30. The difference between the obtained valuesand the reported values in this study might be probably as a result of acid hydrolysis of humicacid. 
BAJOPAS Volume 14 Number 1,June, 2021

Table 1: PKa of (Hydrolysed PSHA)

\begin{tabular}{|l|l|l|l|l|l|l|}
\hline $\mathrm{pH}$ & $\mathrm{BV}_{1}$ & $\mathrm{BV}_{2}$ & $\mathrm{~V}_{2}-\mathrm{V}_{1}$ & $\mathrm{nA}$ & $\log \left(\frac{n A}{1-n A}\right)$ & $\mathrm{pKa}$ \\
\hline 8.50 & 5.30 & 6.29 & 0.99 & 0.3594 & -0.2510 & 8.2490 \\
8.72 & 5.35 & 6.37 & 1.02 & 0.3400 & -0.2880 & 8.4320 \\
9.00 & 5.40 & 6.46 & 1.06 & 0.3141 & -0.3391 & 8.6609 \\
9.22 & 5.45 & 6.55 & 1.10 & 0.2882 & -0.3927 & 8.8273 \\
9.51 & 5.50 & 6.66 & 1.16 & 0.2494 & -0.4786 & 9.0314 \\
9.73 & 5.55 & 6.78 & 1.23 & 0.2041 & -0.5910 & 9.1390 \\
10.00 & 5.60 & 6.90 & 1.30 & 0.1589 & -0.7238 & 9.2762 \\
10.23 & 5.65 & 7.05 & 1.40 & 0.0941 & -0.9835 & 9.2465 \\
10.49 & 5.70 & 7.10 & 1.40 & 0.0941 & -0.9835 & 9.5065 \\
\hline
\end{tabular}

Average pKa $=8.9299 \pm 0.4186$

Table 2: PKa of (Unhydrolysed PSHA)

\begin{tabular}{|l|l|l|l|l|l|l|}
\hline $\mathrm{pH}$ & $\mathrm{BV}_{1}$ & $\mathrm{BV}_{2}$ & $\mathrm{~V}_{2}-\mathrm{V}_{1}$ & $\mathrm{nA}$ & $\log \left(\frac{\boldsymbol{n A}}{1-\boldsymbol{n}}\right)$ & $\mathrm{pKa}$ \\
\hline 8.50 & 5.30 & 5.81 & 0.51 & 0.6619 & 0.2919 & 8.7919 \\
8.72 & 5.35 & 5.90 & 0.55 & 0.6357 & 0.2418 & 8.9618 \\
9.00 & 5.40 & 6.00 & 0.60 & 0.6029 & 0.1813 & 9.1813 \\
9.22 & 5.45 & 6.10 & 0.65 & 0.5701 & 0.1226 & 9.3426 \\
9.51 & 5.50 & 6.20 & 0.70 & 0.5376 & 0.0654 & 9.5754 \\
9.73 & 5.55 & 6.33 & 0.78 & 0.4851 & -0.0259 & 9.7041 \\
10.00 & 5.60 & 6.47 & 0.87 & 0.4262 & -0.1291 & 9.8709 \\
10.23 & 5.65 & 6.62 & 0.99 & 0.3609 & -0.2481 & 9.9819 \\
10.49 & 5.70 & 6.80 & 1.10 & 0.2759 & -0.4690 & 10.0210 \\
\hline
\end{tabular}

Average pKa $=9.4923 \pm 0.4410$

Metal-ligand stability constant ( $\log \mathrm{K}$ )

The stabilityconstants require the accurate values of proton-ligand stability constants (Anil and Maroti, 2008). Metal titration curves crossed over ligand titration curve indicated the formation of complex upon proton release (Santosh, et al., 2011). If the values of n- are within range $0.2-0.8$ and $1.2-18$ this indicates the formation of $1: 1$ and 1:2 complexes (Sayyed and Mazahar, 2012).

The metal (II)-humate stepwise stability constants (log k) at phenolic group (Tables 318)

Table 3: Point-wise method, $\mathrm{Cu}$-(Hydrolysed PSHA)

\begin{tabular}{|l|l|l|l|l|l|l|l|l|}
\hline $\mathrm{pH}$ & $\mathrm{BV}_{1}$ & $\mathrm{BV}_{2}$ & $\mathrm{BV}_{3}$ & $\left(\mathrm{~V}_{3}-\mathrm{V}_{2}\right)$ & $\mathrm{n}$ & $\mathrm{pL}$ & $\log \left(\frac{n}{1-n}\right)$ & LogK $_{1}$ \\
\hline 8.50 & 5.30 & 6.29 & 6.33 & 0.04 & 0.5500 & 2.66 & 0.0871 & 2.7471 \\
8.72 & 5.35 & 6.37 & 6.41 & 0.04 & 0.5714 & 2.43 & 0.1249 & 2.5549 \\
9.00 & 5.40 & 6.46 & 6.50 & 0.04 & 0.6198 & 2.16 & 0.2122 & 2.3722 \\
9.22 & 5.45 & 6.55 & 6.59 & 0.04 & 0.6667 & 1.94 & 0.3010 & 2.2410 \\
\hline
\end{tabular}

LogK $_{1}$ (Average value) $=2.4788 \pm 0.2203$

Table 4: Point-wise method, $\mathrm{Cu}$-(Hydrolysed PSHA)

\begin{tabular}{|l|l|l|l|l|l|l|l|l|}
\hline $\mathrm{pH}$ & $\mathrm{BV}_{1}$ & $\mathrm{BV}_{2}$ & $\mathrm{BV}_{3}$ & $\left(\mathrm{~V}_{3}-\mathrm{V}_{2}\right)$ & $\mathrm{n}$ & $\mathrm{pL}$ & $\log \left(\frac{n-1}{2-n}\right)$ & LogK $_{2}$ \\
\hline 9.51 & 5.50 & 6.66 & 6.73 & 0.07 & 1.3509 & 1.70 & -0.2671 & 1.4329 \\
9.73 & 5.55 & 6.78 & 6.85 & 0.07 & 1.6383 & 1.51 & 0.2467 & 1.7567 \\
10.00 & 5.60 & 6.90 & 6.98 & 0.08 & 2.1783 & 1.31 & -0.2158 & 1.0942 \\
10.23 & 5.65 & 7.05 & 7.13 & 0.08 & 4.1904 & 1.27 & & \\
10.49 & 5.70 & 7.10 & 7.19 & 0.09 & 4.6920 & & & \\
\hline
\end{tabular}

Log $K_{2}($ Average value $)=1.4280 \pm 0.3312$ 
BAJOPAS Volume 14 Number 1,June, 2021

Table 5: Point-wise method, $\mathrm{Cu}$ (Unhydrolysed PSHA)

\begin{tabular}{|l|l|l|l|l|l|l|l|l|}
\hline $\mathrm{pH}$ & $\mathrm{BV}_{1}$ & $\mathrm{BV}_{2}$ & $\mathrm{BV}_{3}$ & $\left(\mathrm{~V}_{3}-\mathrm{V}_{2}\right)$ & $\mathrm{n}$ & $\mathrm{pL}$ & $\log \left(\frac{n}{n-1}\right)$ & Log $_{1}$ \\
\hline 8.50 & 5.30 & 5.81 & 5.85 & 0.04 & 0.2973 & 2.88 & -0.3736 & 2.5064 \\
8.72 & 5.35 & 5.90 & 5.95 & 0.05 & 0.3873 & 2.66 & -0.1992 & 2.4608 \\
9.00 & 5.40 & 6.00 & 6.05 & 0.05 & 0.4044 & 2.38 & -0.1681 & 2.2119 \\
9.22 & 5.45 & 6.10 & 6.15 & 0.06 & 0.5157 & 2.18 & -0.0272 & 2.2072 \\
9.51 & 5.50 & 6.20 & 6.27 & 0.07 & 0.6417 & 1.89 & 0.2530 & 1.1430 \\
\hline
\end{tabular}

$\operatorname{LogK}_{1}($ Average value $)=2.3059 \pm 0.6153$

Table 6:Point-wise method, $\mathrm{Cu}$ (Unhydrolysed PSHA)

\begin{tabular}{|l|l|l|l|l|l|l|l|l|}
\hline $\mathrm{pH}$ & $\mathrm{BV}_{1}$ & $\mathrm{BV}_{2}$ & $\mathrm{BV}_{3}$ & $\mathrm{~V}_{3}-\mathrm{V}_{2}$ & $\mathrm{n}$ & $\mathrm{pL}$ & $\log \left(\frac{n-1}{2-n}\right)$ & $\log \mathrm{K}_{2}$ \\
\hline 9.73 & 5.55 & 6.33 & 6.42 & 0.09 & 0.9000 & 1.69 & & \\
10.00 & 5.60 & 6.47 & 6.58 & 0.11 & 1.2578 & 1.44 & -0.4592 & 0.9808 \\
10.23 & 5.65 & 6.62 & 6.84 & 0.12 & 1.6137 & 1.26 & -0.2010 & 1.4610 \\
10.49 & 5.70 & 6.80 & 6.92 & 0.12 & 2.1052 & 1.03 & & \\
\hline
\end{tabular}

$\operatorname{LogK}_{2}$ (Average value) $=1.2209 \pm 0.3398$

Table 7:Point-wise method, Pb (Hydrolysed PSHA)

\begin{tabular}{|l|l|l|l|l|l|l|l|l|}
\hline $\mathrm{pH}$ & $\mathrm{BV}_{1}$ & $\mathrm{BV}_{2}$ & $\mathrm{BV}_{3}$ & $\left(\mathrm{~V}_{3}-\mathrm{V}_{2}\right)$ & $\mathrm{n}$ & $\mathrm{pL}$ & $\log \left(\frac{n}{1-n}\right)$ & LogK $_{1}$ \\
\hline 8.50 & 5.30 & 6.29 & 6.33 & 0.04 & 0.5500 & 2.66 & 0.0871 & 2.7471 \\
8.72 & 5.35 & 6.37 & 6.41 & 0.04 & 0.5714 & 2.43 & 0.1249 & 2.5549 \\
9.00 & 5.40 & 6.46 & 6.50 & 0.04 & 0.6198 & 2.16 & 0.2122 & 2.3722 \\
9.22 & 5.45 & 6.55 & 6.60 & 0.05 & 0.8333 & 1.96 & 0.6989 & 2.6589 \\
\hline
\end{tabular}

Log $_{\mathbf{1}}($ Average value $)=2.5832 \pm 0.1614$

Table 8:Point-wise method, Pb-(Hydrolysed PSHA)

\begin{tabular}{|l|l|l|l|l|l|l|l|l|}
\hline $\mathrm{pH}$ & $\mathrm{BV}_{1}$ & $\mathrm{BV}_{2}$ & $\mathrm{BV}_{3}$ & $\left(\mathrm{~V}_{3}-\mathrm{V}_{2}\right)$ & $\mathrm{n}$ & $\mathrm{pL}$ & $\log \left(\frac{n-1}{2-n}\right)$ & $\log \mathrm{K}_{2}$ \\
\hline 9.51 & 5.50 & 6.66 & 6.71 & 0.05 & 0.9650 & 1.67 & & \\
9.73 & 5.55 & 6.78 & 6.83 & 0.05 & 1.1702 & 1.44 & & \\
10.00 & 5.60 & 6.90 & 6.90 & 0.05 & 1.4864 & 1.22 & -0.0237 & 1.1963 \\
10.23 & 5.65 & 7.05 & 7.10 & 0.05 & 2.0190 & 1.09 & & \\
10.49 & 5.70 & 7.10 & 7.17 & 0.07 & 3.6492 & 1.00 & & \\
\hline
\end{tabular}

Log $K_{2}$ (Average value) $=1.1963$

Table 9: Point-wise method, Pb (Unhydrolysed PSHA)

\begin{tabular}{|l|l|l|l|l|l|l|l|l|}
\hline $\mathrm{pH}$ & $\mathrm{BV}_{1}$ & $\mathrm{BV}_{2}$ & $\mathrm{BV}_{3}$ & $\mathrm{~V}_{3}-\mathrm{V}_{2}$ & $\mathrm{n}$ & $\mathrm{pL}$ & $\begin{array}{l}\text { Log } \\
\left(\frac{n}{n-1}\right)\end{array}$ & Log $\mathrm{K}_{1}$ \\
\hline 8.50 & 5.30 & 5.81 & 5.85 & 0.04 & 0.2973 & 2.88 & -0.3736 & 2.5064 \\
8.72 & 5.35 & 5.90 & 5.94 & 0.04 & 0.3099 & 2.66 & -0.5477 & 2.3123 \\
9.00 & 5.40 & 6.00 & 6.05 & 0.05 & 0.4044 & 2.38 & -0.1681 & 2.2119 \\
9.22 & 5.45 & 6.10 & 6.15 & 0.06 & 0.5157 & 2.18 & 0.0272 & 2.2072 \\
9.51 & 5.50 & 6.20 & 6.26 & 0.07 & 0.6417 & 1.89 & 0.2530 & 2.1430 \\
9.73 & 5.55 & 6.40 & 6.40 & 0.07 & 0.7000 & 1.67 & 0.3680 & 2.0380 \\
\hline
\end{tabular}

LogK $_{1}$ (Average value) $=2.2364 \pm 0.1602$

Table 10: Point-wise method, Pb (Unhydrolysed PSHA)

\begin{tabular}{|l|l|l|l|l|l|l|l|l|}
\hline $\mathrm{pH}$ & $\mathrm{BV}_{1}$ & $\mathrm{BV}_{2}$ & $\mathrm{BV}_{3}$ & $\mathrm{~V}_{3}-\mathrm{V}_{2}$ & $\mathrm{n}$ & $\mathrm{pL}$ & $\log \left(\frac{n-1}{2-n}\right)$ & $\log \mathrm{K}_{2}$ \\
\hline 10.00 & 5.60 & 6.47 & 6.55 & 0.08 & 1.9503 & 1.41 & & \\
10.23 & 5.65 & 6.62 & 6.72 & 0.11 & 1.4792 & 1.26 & -0.0361 & 1.2239 \\
\hline
\end{tabular}

$\operatorname{LogK}_{2}$ (Average value) $=1.2239$

Table 11: Point-wise method, Mg (Hydrolysed PSHA)

\begin{tabular}{|l|l|l|l|l|l|l|l|l|}
\hline $\mathrm{pH}$ & $\mathrm{BV}_{1}$ & $\mathrm{BV}_{2}$ & $\mathrm{BV}_{3}$ & $\left(\mathrm{~V}_{3}-\mathrm{V}_{2}\right)$ & $\mathrm{n}$ & $\mathrm{pL}$ & $\log \left(\frac{n}{n-1}\right)$ & LogK $_{1}$ \\
\hline 8.50 & 5.30 & 6.29 & 6.31 & 0.02 & 0.2750 & 2.64 & -0.4290 & 2.2110 \\
8.72 & 5.35 & 6.37 & 6.39 & 0.02 & 0.2858 & 2.42 & -0.3978 & 2.0222 \\
9.00 & 5.40 & 6.46 & 6.49 & 0.03 & 0.4648 & 2.14 & -0.0612 & 2.0788 \\
9.22 & 5.45 & 6.55 & 6.59 & 0.04 & 0.6667 & 1.94 & 0.3010 & 2.2410 \\
\hline
\end{tabular}

$\log _{\mathbf{1}}($ Average value) $=2.1382 \pm 0.1046$ 
BAJOPAS Volume 14 Number 1,June, 2021

Table 12: Point-wise method, Mg (Hydrolysed PSHA)

\begin{tabular}{|l|l|l|l|l|l|l|l|l|}
\hline $\mathrm{pH}$ & $\mathrm{BV}_{1}$ & $\mathrm{BV}_{2}$ & $\mathrm{BV}_{3}$ & $\left(\mathrm{~V}_{3}-\mathrm{V}_{2}\right)$ & $\mathrm{n}$ & $\mathrm{pL}$ & $\log \left(\frac{n-1}{2-n}\right)$ & LogK $_{2}$ \\
\hline 9.51 & 5.55 & 6.66 & 6.71 & 0.05 & 0.9650 & 1.67 & & \\
9.73 & 5.55 & 6.78 & 6.84 & 0.06 & 1.4042 & 1.47 & -0.1686 & 1.3014 \\
10.00 & 5.60 & 6.90 & 6.93 & 0.06 & 1.7838 & 1.23 & 0.5593 & 1.7893 \\
10.23 & 5.65 & 7.05 & 7.10 & 0.06 & 3.1429 & 1.10 & & \\
10.49 & 5.70 & 7.10 & 7.18 & 0.07 & 3.6492 & 0.83 & & \\
\hline
\end{tabular}

LogK $_{2}($ Average value $)=1.5453 \pm 0.3450$

Table 13: Point-wise method, Mg (Unhydrolysed PSHA)

\begin{tabular}{|l|l|l|l|l|l|l|l|l|}
\hline $\mathrm{pH}$ & $\mathrm{BV}_{1}$ & $\mathrm{BV}_{2}$ & $\mathrm{BV}_{3}$ & $\mathrm{~V}_{3}-\mathrm{V}_{2}$ & $\mathrm{n}$ & $\mathrm{pL}$ & $\log \left(\frac{n}{n-1}\right)$ & $\operatorname{Log~}_{1}$ \\
\hline 8.50 & 5.30 & 5.81 & 5.85 & 0.04 & 0.2973 & 2.88 & -0.3736 & 2.5064 \\
8.72 & 5.35 & 5.90 & 5.94 & 0.04 & 0.3099 & 2.66 & -0.3477 & 2.3123 \\
9.00 & 5.40 & 6.00 & 6.04 & 0.04 & 0.3236 & 2.38 & -0.3202 & 2.0598 \\
9.22 & 5.45 & 6.10 & 6.15 & 0.05 & 0.4297 & 2.17 & -0.1230 & 2.0470 \\
9.51 & 5.50 & 6.20 & 6.26 & 0.06 & 0.5500 & 1.89 & 0.0871 & 1.9771 \\
9.73 & 5.55 & 6.33 & 6.40 & 0.07 & 0.7000 & 1.67 & 0.3680 & 2.0380 \\
\hline
\end{tabular}

LogK $_{1}$ (Average value) $=2.1568 \pm 0.2069$

Table 14: Point-wise method, Mg (Unhydrolysed PSHA)

\begin{tabular}{|l|l|l|l|l|l|l|l|l|}
\hline $\mathrm{pH}$ & $\mathrm{BV}_{1}$ & $\mathrm{BV}_{2}$ & $\mathrm{BV}_{3}$ & $\mathrm{~V}_{3}-\mathrm{V}_{2}$ & $\mathrm{n}$ & $\mathrm{pL}$ & $\log \left(\frac{n-1}{2-n}\right)$ & $\log \mathrm{K}_{2}$ \\
\hline 10.00 & 5.60 & 6.47 & 6.55 & 0.08 & 0.9148 & 1.41 & & \\
10.23 & 5.65 & 6.62 & 6.71 & 0.09 & 1.2102 & 1.20 & -0.5749 & 0.6251 \\
10.49 & 5.70 & 6.80 & 6.92 & 0.09 & 1.5968 & 1.03 & 0.1703 & 1.2003 \\
\hline
\end{tabular}

LogK $_{2}$ (Average value) $=0.9127 \pm 0.4070$

Table15:Point-wise method, Cd (Hydrolysed PSHA)

\begin{tabular}{|l|l|l|l|l|l|l|l|l|}
\hline $\mathrm{pH}$ & $\mathrm{BV}_{1}$ & $\mathrm{BV}_{2}$ & $\mathrm{BV}_{3}$ & $\left(\mathrm{~V}_{3}-\mathrm{V}_{2}\right)$ & $\mathrm{n}$ & $\mathrm{pL}$ & $\log \left(\frac{n}{1-n}\right)$ & LogK $_{1}$ \\
\hline 8.50 & 5.30 & 6.29 & 6.31 & 0.02 & 0.2750 & 2.64 & -0.4210 & 2.2190 \\
8.72 & 5.35 & 6.37 & 6.40 & 0.03 & 0.4286 & 2.42 & -0.1249 & 2.2951 \\
9.00 & 5.40 & 6.46 & 6.49 & 0.03 & 0.4648 & 2.14 & -0.0612 & 2.0788 \\
9.22 & 5.45 & 6.55 & 6.59 & 0.04 & 0.6667 & 1.96 & 0.3010 & 2.2610 \\
9.51 & 5.55 & 6.66 & 6.70 & 0.04 & 0.7720 & 1.67 & 0.5297 & 2.1997 \\
\hline
\end{tabular}

LogK $_{\mathbf{1}}$ (Average value) $=2.2108 \pm 0.0825$

Table 16: Point-wise method, Cd (Hydrolysed PSHA)

\begin{tabular}{|l|l|l|l|l|l|l|l|l|}
\hline $\mathrm{pH}$ & $\mathrm{BV}_{1}$ & $\mathrm{BV}_{2}$ & $\mathrm{BV}_{3}$ & $\left(\mathrm{~V}_{3}-\mathrm{V}_{2}\right)$ & $\mathrm{n}$ & $\mathrm{pL}$ & $\log \left(\frac{n-1}{2-n}\right)$ & Log $_{2}$ \\
\hline 9.73 & 5.55 & 6.78 & 6.83 & 0.06 & 1.4042 & 1.47 & -0.1686 & 1.3014 \\
10.00 & 5.60 & 6.90 & 6.95 & 0.06 & 1.7838 & 1.23 & 0.5593 & 1.7893 \\
10.23 & 5.65 & 7.05 & 7.10 & 0.06 & 3.1429 & 1.09 & & \\
10.49 & 5.70 & 7.10 & 7.16 & 0.06 & 3.1429 & 0.89 & & \\
& & & & & & & & \\
\hline
\end{tabular}

$\operatorname{LogK}_{2}$ (Average value) $=1.5453 \pm 0.3450$

Table 17: Point-wise method, Cd (Unhydrolysed PSHA)

\begin{tabular}{|l|l|l|l|l|l|l|l|l|}
\hline $\mathrm{pH}$ & $\mathrm{BV}_{1}$ & $\mathrm{BV}_{2}$ & $\mathrm{BV}_{3}$ & $\mathrm{~V}_{3}-\mathrm{V}_{2}$ & $\mathrm{n}$ & $\mathrm{pL}$ & $\log \left(\frac{n}{n-1}\right)$ & $\operatorname{Log~}_{1}$ \\
\hline 8.50 & 5.30 & 5.81 & 5.86 & 0.05 & 0.3717 & 2.88 & -0.2280 & 2.6520 \\
8.72 & 5.35 & 5.90 & 5.95 & 0.05 & 0.3873 & 2.66 & -0.1992 & 2.4608 \\
9.00 & 5.40 & 6.00 & 6.06 & 0.06 & 0.4853 & 2.38 & -0.0255 & 2.3545 \\
9.22 & 5.45 & 6.10 & 6.16 & 0.06 & 0.5157 & 2.18 & -0.0272 & 2.2072 \\
9.51 & 5.50 & 6.20 & 6.27 & 0.07 & 0.6417 & 1.89 & 0.2530 & 1.1430 \\
9.73 & 5.55 & 6.33 & 6.41 & 0.08 & 0.8000 & 1.69 & 0.6020 & 2.2920 \\
& & & & & & & & \\
\hline
\end{tabular}

$\operatorname{LogK}_{1}($ Average value $)=2.2516 \pm 0.5380$ 
BAJOPAS Volume 14 Number 1,June, 2021

Table 18: Point-wise method, Cd (Unhydrolysed PSHA)

\begin{tabular}{|l|l|l|l|l|l|l|l|l|}
\hline $\mathrm{pH}$ & $\mathrm{BV}_{1}$ & $\mathrm{BV}_{2}$ & $\mathrm{BV}_{3}$ & $\mathrm{~V}_{3}-\mathrm{V}_{2}$ & $\mathrm{n}$ & $\mathrm{pL}$ & $\log \left(\frac{n-1}{2-n}\right)$ & $\log \mathrm{K}_{2}$ \\
\hline 10.00 & 5.60 & 6.47 & 6.57 & 0.10 & 1.1434 & 1.43 & & \\
10.23 & 5.65 & 6.62 & 6.72 & 0.10 & 1.3448 & 1.23 & -0.2788 & 0.9512 \\
10.49 & 5.70 & 6.80 & 6.90 & 0.10 & 1.7742 & 1.03 & 0.5351 & 1.5651 \\
\hline
\end{tabular}

$\operatorname{LogK}_{2}($ Average value $)=1.2581 \pm 0.4340$

Table 19: Stepwise and overall Stability constants of thehydrolysed and unhydrolysed divalent metal (II) complexes

\begin{tabular}{|c|c|c|c|}
\hline Chelates & LogK $_{1}$ & $\log _{2}$ & Log $\beta$ \\
\hline [Cu (Hydrolysed PSHA-1) $\left.{ }_{2}\right]$ & 2.4788 & 1.4280 & 3.9068 \\
\hline$\left[\mathrm{Pb}(\text { Hydrolysed PSHA-1) })_{2}\right]$ & 2.5832 & 1.1963 & 3.7795 \\
\hline$\left[\mathrm{Cd}(\text { Hydrolysed PSHA-1 })_{2}\right]$ & 2.2108 & 1.5453 & 3.7561 \\
\hline$\left[\mathrm{Mg}(\text { Hydrolysed PSHA-1 })_{2}\right]$ & 2.1382 & 1.5453 & 3.6835 \\
\hline [Cu (Unhydrolysed PSHA-1) & 2.3059 & 1.2209 & 3.5268 \\
\hline$[\mathrm{Pb}$ (Unhydrolysed PSHA-1) 2$]$ & 2.2364 & 1.2239 & 3.4603 \\
\hline [Cd (Unhydrolysed PSHA-1) 2 ] & 2.2516 & 1.2581 & 3.5097 \\
\hline$[\mathrm{Mg}$ (Unydrolysed PSHA-1) & 2.1568 & 0.9127 & 3.0695 \\
\hline
\end{tabular}

The results obtained (Table19) shows the stepwise and overall stability constants to be not high indicating low stability of the complexes, because the solubility of most metal ions in the basic $\mathrm{pH}$ range is minimal due to metal hydroxide precipitation (Karimi, 2017). In general, the stepwise stability constants $\left(K_{1}\right.$ and $K_{2}$ ) follow the order $K_{1}>K_{2}$ for the copper, lead, magnesium and cadmium complexes respectively. The steady decrease of the values with increasing number of ligands is in agreement with the prediction made by researchers (Na'aliya, 2013). The decrease could be attributed to the fact that as the number of the ligands (Humate ions) that enters the coordination zone increases the aqua molecules available for replacement by the ligands become less. Thus, the metal ions become less electron loving with progressive intake of the ligand and this results in the decrease in the values of the constants (Na'aliya, 2013). Also the stability of the complexes is influenced by the size and number of the chelate rings(Mackay and Mackay,2002).All the complexes form rings in their structure as humate, a bidentate ligand, bond the metal ions in the ratio 1:2 (Boguta and Sokolowska, 2016) forming chelate rings. The values of the overall stability constants $(\log \beta)$ obtained for humate complexes are not high indicating low stability as the values are not high. LogK values for copper-humates (Table 3 to 6) obtained in this study are lower than those reported for the complexes of humic acids (Pandey et al., 2015; Dinu, 2013; Kaschl et al., 2010 and Gilbeto and Jorg, 2001). The values of LogK(Table 7 to 10 ) forlead-humates are lower than those reported for the lead in the literature (Dinu, 2013; Gilbeto and Jorg 2001). Log K values(Table 11 to 14 ) for magnesium-humates obtained in this study are close to those reported by (Pandey et al., 2015). Log K values of cadmium-humates (Table 15 to 18 ) obtained in this work near to the one reported by (Dinu, 2013 and Pandey et al., 2015).The difference between the reported values and the values obtained in this study might be probably as a result of acid hydrolysis of humic acid. The values of the overall stability constants $(\log \beta)$ of the copper humates complexes presented in Table 19 is high than that of other metal humate complexes, show relatively high stability of CuHA complexes, show the following order of stability: $\mathrm{Cu}>\mathrm{Pb}>\mathrm{Cd}>\mathrm{Mg}$; which are in close agreement to the findings of (Dinu, 2013 and Pandey et al., 2015).The high stability of Cuhumate chelate could be attributed to the existence of coordinate covalent bond between the complexing agents and the $\mathrm{Cu}^{2+}$ ions. Since, $\mathrm{Cu}^{2+}$ being a metal of the transitional series with $3 d^{9}$ electronic configurations can accept the electrons from the complexing agents. Similarly, the low stabilities of $\mathrm{Pb}, \mathrm{Cd}$ and $\mathrm{Mg}$ complexes could be explained by that $\mathrm{Pb}^{2+}$ with $6 s^{2}, \mathrm{Cd}^{2+}$ with $4 \mathrm{~d}^{10}$ and $\mathrm{Mg}^{2+}$ with $2 \mathrm{p}^{6}$ their electronic configuration has a completely filled $\mathrm{d}, \mathrm{p}$ and $\mathrm{s}$ orbitals. Moreover, the stabilities of metal ions with hydrolysed humic acid from peat soil were higher than those with unhydrolysed humic acid from peat soil; which is ascribed to the high content of acidity in hydrolysed humic acid than unhydrolysed humic acid. 
BAJOPAS Volume 14 Number 1,June, 2021 CONCLUSION

The values of logk for $\mathrm{Cu}(\mathrm{II})$ hydrolysed humic acid complex was higher followed by $\mathrm{Pb}$ (II), $\mathrm{Cd}(\mathrm{II})$ and $\mathrm{Mg}$ (II) hydrolysed humic acid complexes as compared with metal(II) unhydrolysed humic acid complexes. This indicates acid hydrolysis of humic acid can

\section{REFERENCES}

Almeida, V.R. and Szpoganicz, B. (2015). Humic Acid Potentiometric Response Patterns:Out- of Equilibrium Properties and Species Distribution Modelling. Chemical. Biol. Technol. Agric. 2: 17.

Anđelković, T., Nikolić, R., Bojić, A.,Anđelković, D., and Nikolic G.,(2010). Binding of Cadmium to Soil Humic Acid as A Function of Carboxyl Group Content. Macedonian Journal of Chemistry and Chemical Engineering.29(2): 215-224.

Anil, B. N. and Maroti, N. (2008). Studies on Influence of Die-Lectric Constants on Complex Equilibria between Substituted Py-Razalines and Lanthanide Metal Ions pH-Metrically. Amer.-Euras. scient. Res. 3(2): 212-216.

Ashok, K., Pandey, S. P. and Misra, V (2000). Stability Constants of Metal-Humic Acid Complexes and its Role in Environmental Detoxification. Journal of Ecotoxicology and Environmental Safety. 47(2):157-200.

Badr, M. H., El-Halafawi, M. H. and Abd El-al Zeid, E. R. (2012). Comparison Between the Effect of Ionic Strength on Acidity and Dissociation Constants of Humic Acids Extracted from Sewage Sludge and Nile Water Hyacinth Composts.Global Journal of Environmental Research 6 (1): 36-43.

Baruah, M.K., Borah, D., Saikia, P.P., Paul, S., Sharma, T. (2015). Evaluation of pKa Values of Soil Humic Acids and their Complexation Properties. International Journal of Plant \& Soil Science 6(4) : 218-228.

Boguta, P. Sokolowska, Z. (2016). Interactions of $\mathrm{Zn}$ (II) Ions with Humic Acids Isolated from Various Types of Soils. Effect of $\mathrm{pH}, \mathrm{Zn}$ Concentrations and Humic Acids Chemical Properties. Journal of Geochemical Explaration 168. 119-126.

Borges, F., Guimaraes, C., Lima, L.F.C., Pinto, I. and Reis, S.(2005). Potentiometric Studies on the Complexation of Copper(II) by Phenolic Acids as Discrete Ligand Models of enhance the complexation behavior of humic acid with metal (II) ions. However, the higher values of $\log \beta$ for $\mathrm{Cu}(\mathrm{II}), \mathrm{Pb}(\mathrm{II}), \mathrm{Cd}(\mathrm{II})$ and $\mathrm{Mg}(\mathrm{II})$ hydrolysed humic acid complexes indicates more stable stepwise complexes formed as compared with $\mathrm{Cu}(\mathrm{II}), \mathrm{Pb}$ (II), $\mathrm{Cd}$ (II) and $\mathrm{Mg}(\mathrm{II})$ unhydrolysed humic acid complexes.

Humic Substances Talanta 66 (2005) 670-673.

Chefetz, B., Salloum, M. J., Deshmulkin, A. P. and Hatcher, P. (2002). Structural Components of Humic Acids as Determined by Chemical Modifications and Carbon-13 NMR, Pyrolysis, and Thermochemolysis- Gas Chromatography/Mass Spectrometry. Soil Science Society of American Journal Abstract Division S-2- Soil Chemistry66. 1159-1171.

Dinu, M. I. (2013). Metals Complexation with Humic Acids in Surface Water of Different Environ. Sci. Technol. 31(1): 1-17.

Fernandes, A.N., Giacomelli, C., Giovanela, M. Vaz, D.V. Szpoganicz, B. and Maria M. D. (2009). Potentiometric Acidity Determination in Humic Substances Influenced by Different Analytical Procedures.J. Braz. Chem. Soc. 20 (9):14.

Gamal, A. H. (2015). Stability Constants of Rhenium (V) Metal Complexes with Selected Drugs. Pyrex Journal of Research in Environmental Studies. 2(2): 006-014.

Janrao, D. M., Pathan, J., Kayande, D.D., and Mulla, J.J. (2014). An Over View of Potentiometric Determination of Stability Constants of Metal Complexes. Sci. Revs. Chem. Commun.: 4(1), 2014, 11-24.

Karimi, H. (2017). Effect of pH and Initial Pb(II) Concentration on the Lead Removal Efficiency from Waste Water Using $\mathrm{Ca}(\mathrm{OH})_{2}$. International Journal of Water and Waste Water Treatment 3.2

Kaschl, A. Romheld, V. and Chen, Y. (2010). Binding of Cadmium, Copper and Zinc to Humic Substances Originating from Municipal Solid Waste Compost. Israel Journal of Chemistry Vol. 42(1): 89-98.

Kostic, I. S., Tatjana, P, A., Nikolic, R. S., Cvetkovic, T. P., Pavlovic, D. D., Aleksandar, L.J. and Bojic, A. (2012). Comparative Study of Binding Strengths of Heavy Metals with Humic Acid. J.serb. Chem. Soc. 76(9) pp 1-20. 
BAJOPAS Volume 14 Number 1,June, 2021

Na'aliya, J. (2013). Determination of Stepwise Stability Constants and Gibbs free Energy Change of Trisprolina to Complexes of some Divalent Transition Metal ions. Bayero Journal of Pure and Applied Sciences 6(2): 112-114.

Omar, A. A. and Ali, E. A. (2015). Potentiometric Studies on Complexes of $\mathrm{Cr}$ (III) and $\mathrm{Zr}$ (IV) with some Carboxylic Acids. International Journal of Advanced Chemistry, 3(1) 25-

37.

Pandey, A. K. Pandey, S. D. and Misr, V. (2015).Stability Constants of Metal- Humic Acid Complexes and Its Role in Environmental Detoxification. J. Ecotoxicology and Environmental Safety. 47(1):195-200.

Ram, N. and Raman, K.V. (1984). Stability Constants of Complexes of Metals with
Humicand Fuvic Acids under Non- acidConditions. Journal of Plant Nutrition and Soil Sciences.

147:171-176.

Santosh, D. D., Ashok, B. K., Vijay, J. T., Shivraj, G. W. and Vinay, V. W. (2011). Potentiometric Studies of Elec-Trolyte Effects on Complex Equilibria of Some Substituted 5-(2-hydroxy Phenyl) Pyrazoles. Der pharm. 3 (6): 75-83.

Sayyed, H. and Abdul Rahim, M. F. (2012). Studies of Binary Complexes of Metal Ions with Mandelic Acid by Potentiometry. Chem. J. 02 (6): 206209.

Shirvani, M. Moradian, E. Khalili, B. Bakhtiary, S. (2015). Interaction of $\mathrm{Cd}$ and $\mathrm{Pb}$ with Humate-Palygorskite and HumateSepiolite Complexes. Journal of water, air and pollution 3: 220-228. 


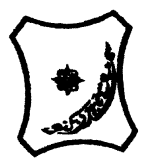

Bayero Journal of Pure and Applied Sciences, 14(1): 54 - 63

Received: November, 2020

Accepted: April, 2021

ISSN $2006-6996$

\title{
STABILITY CONSTANTS OF COMPLEXES OF METAL IONS WITH PEATSOIL HUMIC ACIDS UNDER NON-ACID-CONDITIONS
}

\author{
${ }^{* 1}$ Sabo, Yusuf ${ }^{2}$ Jimoh, W.L.O., ${ }^{3}$ Isa Baba Koki and ${ }^{4}$ Sholadoye, Q. 0. \\ ${ }^{1}$ Department of Pure and Industrial Chemistry, Bayero University, Kano \\ ${ }^{3}$ Department of Chemistry, Yusuf Maitama Sule University Kano. P.M.B. 3220 Kano, Nigeria. \\ ${ }^{4}$ Department of Chemistry, Nigerian Police Academy, Wudil, Kano-Nigeria
}

*Correspondence E-mail; saboyusuf18@yahoo.com

ABSTRACT

Stability constants of complexes of four divalent metal ions viz. $\mathrm{Cu}^{2+}, \mathrm{Pb}^{2+}, \mathrm{Mg}^{2+}$ and $\mathrm{Cd}^{2+}$ with humic acids (HA) were determined by potentiometric titration of humic acids with the corresponding salt of the divalent metals in aqueous media under non-acid-condition. The log $K$ (logarithm of the stability constant) ranged from 1.0942 to 2.7471 for metalhumic acid complexes were determined using point-wise computational method. The order of stability constants were obtained as follows: $\mathrm{Cu}>\mathrm{Pb}>\mathrm{Cd}>\mathrm{Mg}$ for metal $-\mathrm{HA}$ complexes respectively, indicating a higher degree of complexation with Cu metal ion.

Keywords: stability constant, humic acid, potentiometric titration, divalent metals, acid hydrolysis.

\section{NTRODUCTION}

The stability constant of a complex is the numerical expression of its stability and provides a quantitative measure of affinity of the metal ion to the complexing agent. An understanding of the relative stability of metal-complexes helps in predicting the behavior of metal ions in the soil (Ram and Raman, 1982). Extensive researches has been done to determine the stability constants of the complexes formed between humic acid (HA) with a number of metal ions. Ashok et al., (2000) reported that humic acid with hydroxyl, phenoxyl and carboxyl reactive groups can form coordination compound with metal ions at $\mathrm{pH}$ 3.5. The stability constants(Log K) for different metalhumic acid complexes indicated the following order of the stabilities of complexes formed between humic acid and metal ion, $\mathrm{Cu}>\mathrm{Fe}$ $>\mathrm{Pb}>\mathrm{Ni}>\mathrm{Co}>\mathrm{Ca}>\mathrm{Cd}>\mathrm{Zn}>\mathrm{Mn}>\mathrm{Mg}$. Andelkovic et al., (2010) investigated the binding of $\mathrm{Cd}$ (II) to soil humic acid at pH 6.5 and in $0.1 \mathrm{M} \mathrm{KNO}_{3}$ ionic medium. The stability constant for binding indicating greater stability in the case when carboxyl groups are involved in complexation reaction. Kostic et al.,(2012) investigated the complexation of humic acid with certain heavy metal ions (Co(II), $\mathrm{Ni}(\mathrm{II}), \mathrm{Cu}(\mathrm{II})$,
$\mathrm{Zn}(\mathrm{II})$, and $\mathrm{Pb}(\mathrm{II})$. The experiment was performed at $25^{\circ} \mathrm{C}$, at pH 4.0 and ionic strength of $0.01 \mathrm{M}$. Stability constant of complex between $\mathrm{Pb}$ (II) ions and humic acid is greater than stability constants of other investigated metalhumate complexes. Bogata and Sokolowska (2016) analyses the interaction between humic acids from different soils and $\mathrm{Zn}$ (II) ions at wide concentration ranges and at $\mathrm{pH} 5$. Studies have showed significant impact of $\mathrm{Zn}$ concentration, $\mathrm{pH}$ and some properties of humic acids with zinc.But all of these studies were limited to acidic $\mathrm{pH}$ range. Therefore, the present study was carried out to determine and compare the stability constants of complexes of metal ions with hydrolysed peat soil humic acid and unhydrolysed peat soil humic under non-acid conditions.

\section{MATERIALS AND METHODS}

Analytical grade chemicals used includes hydrochloric acid $(\mathrm{HCl})$, nitric acid $\left(\mathrm{HNO}_{3}\right)$, sodium hydroxide $(\mathrm{NaOH})$, lead nitrate $\mathrm{Pb}\left(\mathrm{NO}_{3}\right)_{2}$, copper nitrate $\mathrm{Cu}\left(\mathrm{NO}_{3}\right)_{2} \cdot 3 \mathrm{H}_{2} \mathrm{O}$, cadmium nitrate $\mathrm{Cd}\left(\mathrm{NO}_{3}\right)_{2} \cdot 4 \mathrm{H}_{2} \mathrm{O}$, magnesium nitrate $\mathrm{Mg}\left(\mathrm{NO}_{3}\right)_{2} \cdot 6 \mathrm{H}_{2} \mathrm{O}$, potassium nitrate $\left(\mathrm{KNO}_{3}\right)$, calcium chloride $\left(\mathrm{CaCl}_{2}\right)$, (sigma-Aldrich). Dowex 50WX8, (20-50 mesh) from Fluka. 


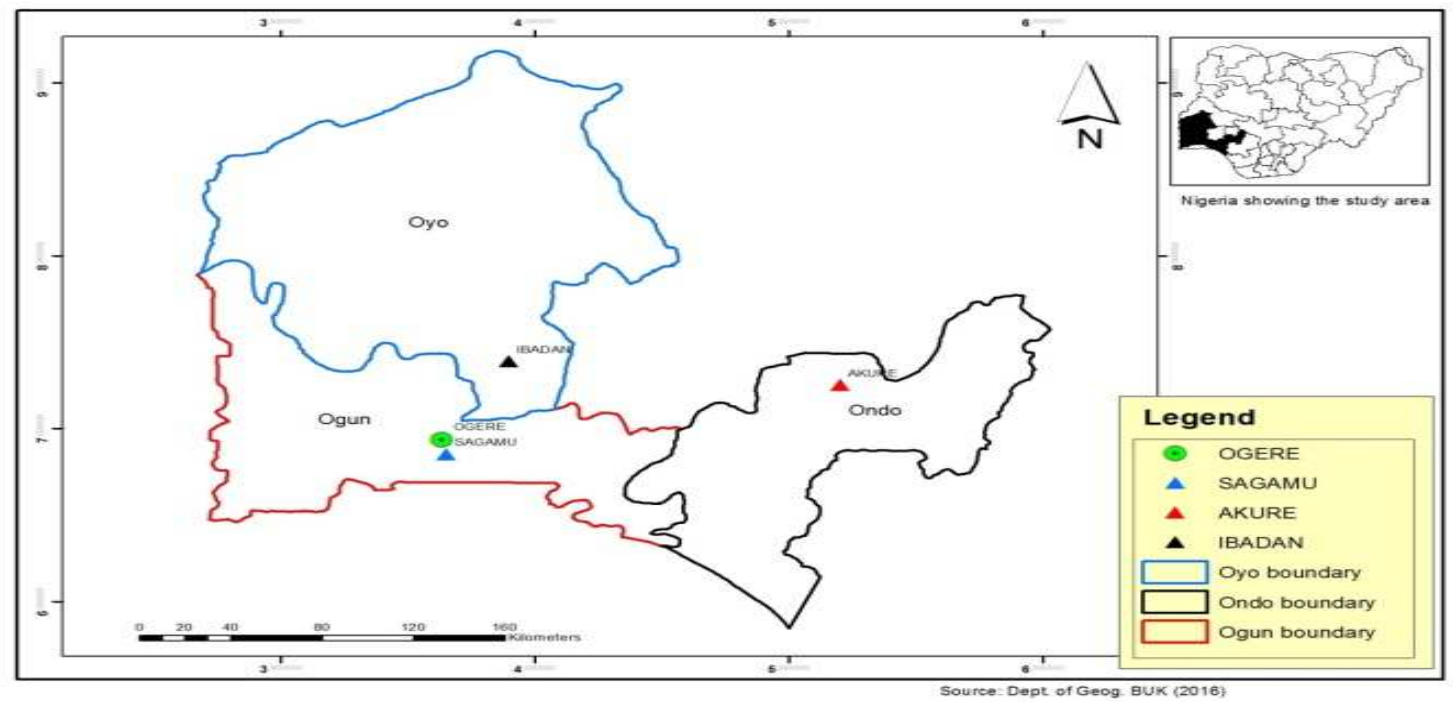

Figure 1: Map showing the sampling point at Sagamu Town, Ogun State.

\section{Description of Sampling Area}

Sagamu has geographical coordinates between $6^{\circ} 50^{\prime}$ north; $3^{\circ} 38^{\prime}$ east is located in south western region of Nigeria. The region has tropical wet and dry climate with a lengthy wet season and relatively constant temperatures throughout the course of the year. Wet season runs from March to October, November to December forms the region dry season. The vegetation type of the region is savannah which is really grassland with small bushes and occasional big trees. Grassland soils have substantially higher organic matter content than forest soils (Novackova, 2011).

\section{Sample Collection}

The Peatsoil samples were collected from four different sampling points $(0-10 \mathrm{~cm}$ depth) in Sagamu into polyethylene bag with plastic spoons. Samples were taken to the laboratory, extraneous materials were removed; the samples were air-dried, crushed and ground to a fine powder in a mortar passed through a $0.20 \mathrm{~mm}$ sieve. The samples were kept for analysis.

\section{Isolation and purification of humic acid from peat soil sample}

Peatsoil sample $(100 \mathrm{~g})$ was mixed with 1000 $\mathrm{cm}^{3}$ of $0.1 \mathrm{M} \mathrm{NaOH}$ solution, shaken for 3hours and left to stand overnight. Dark-coloured supernatant was obtained and decanted from solid residue. The dark-coloured supernatant was acidified to $(\mathrm{pH}=1.0)$ with $6 \mathrm{M} \mathrm{HCl}$ stirred and allowed to stand for 6 hours. Yellowish brown supernatant and dark-brown precipitate were obtained. The yellowish brown supernatant was decanted followed by centrifuge and discarded. The dark-brown precipitate was mixed with $500 \mathrm{~cm}^{3}$ of $0.1 \mathrm{M} \mathrm{NaOH}$ solution followed by passing through dowex resin. The dark-brown solution was acidified to $(\mathrm{pH}=1.0)$ with $6 \mathrm{M} \mathrm{HCl}$ stirred and allowed to stand for 3 hours. The dark-brown precipitate was washed several times with deionized water. The supernatant was treated with $\mathrm{AgNO}_{3}$ solution until no white precipitate observed. The humic acid was transferred to weighed crucible and dried at $60^{\circ} \mathrm{C}$ in an oven for 12 hours. The humic acid was cooled and dried in the desiccator, weighed and recorded. The obtained humic acid was dried again at $60^{\circ} \mathrm{C}$ for additional 6 hours cooled and dried in the desiccator, weighed and recorded constant weight was obtained (Baruah et al., 2015).

\section{FT-IR analysis}

FT-IR spectra of humic acid sample was analysed using Carry 630 FT-IR Agilent Technologies.

Unhydrolysed compost humic acid

The unhydrolysed humic acid was obtained after isolation and purification of compost humic acid and kept for investigation.

\section{Acid hydrolysis of Peatsoil acid}

Peatsoil humic acid sample (1g) was refluxed for 12 hours at $\left(160^{\circ} \mathrm{C}\right)$ with $50 \mathrm{~cm}^{3}$ of $6 \mathrm{M} \mathrm{HCl}$. The mixture was allowed to cool, decanted, and centrifuged after hydrolysis. The insoluble residues were washed with distilled water via centrifugation several times, and the supernatant was treated with $\mathrm{AgNO}_{3}$ solution until no white precipitate was observed. The residue was thoroughly dried over $\mathrm{CaCl}_{2}$ in a desiccator at room temperature (Chefetz et al., 2002). Finally, the obtained hydrolysed humic acid was kept for investigation. 
BAJOPAS Volume 14 Number 1,June, 2021 Potentiometric Titrations

Potentiometric measurements were carried out using a pH-meter Jenway (model 3510) with combine electrode, the sensitivity of the $\mathrm{pH}$ meter is 0.01 units. The $\mathrm{pH}$ meter was switched on half an hour before starting the titration for initial warm up of the instrument. The instrument was calibrated with an aqueous standard buffer solution of $\mathrm{pH} 4.00$ and 10.0 (borate buffer) prepared from a "Qualigens" buffer tablets.

The following sets of solutions were prepared in a $250 \mathrm{~cm}^{3}$ volumetric flask separately for $\mathrm{pH}$ metric titrations.

(i) $5 \mathrm{~cm}^{3} 0.1 \mathrm{M} \mathrm{HCl}+40 \mathrm{~cm}^{3}$ deionized water

(ii) $5 \mathrm{~cm}^{3} 0.1 \mathrm{M} \mathrm{HCl}+39 \mathrm{~cm}^{3}$ deionized water $+1 \mathrm{~cm}^{3} 0.15 \mathrm{gcm}^{-3}$ humic acid

(iii) $5 \mathrm{~cm}^{3} 0.1 \mathrm{M} \mathrm{HCl}+37 \mathrm{~cm}^{3}$ deionized water $+1 \mathrm{~cm}^{3} 0.15 \mathrm{gcm}^{-3}$ humic acid

$$
+2 \mathrm{~cm}^{3} \quad 0.01 \mathrm{M} \mathrm{Cu} \text { (II) }
$$

The solutions were titrated against standardized $0.110 \mathrm{MNaOH}$ separately. The total volume of each mixture was adjusted to $50 \mathrm{~cm}^{3}$ and the ionic strength of the solutions was maintained constant at by adding appropriate amount of stock solution of $1 \mathrm{M} \mathrm{KNO}_{3}$ (Gamal, 2015; Omar and Ali, 2015). A magnetic stirrer was used to achieve thorough mixing of the interacting solutions at $550 \mathrm{rpm}$. The same set of experimental conditions was applied for potentiometric titration of remaining samples.

\section{Evaluation of pKa of Hydrolysed peat soil Humic Acids}

The proton-ligand formation number $\mathrm{n}_{\mathbf{A}}$ were calculated by Irving and Rossotti expression (Omar and Ali, 2015).

$\mathrm{nA}=\mathrm{Y}-\frac{(\mathrm{V} 2-\mathrm{V1})(\mathrm{No}-\mathrm{Eo})}{(\mathrm{VO}+\mathrm{V1}) \mathrm{TCL}}$ 1

Where: $Y$ is number of dissociable proton, $\left(\mathrm{V}_{2^{-}}\right.$ $V_{1}$ ) is the measure of displacement of the ligand curve relative to acid curve, $\mathrm{N}^{\circ}$ and $\mathrm{E}^{\circ}$ are the resultant concentration of alkali solution, free acid solution, $\mathrm{T}_{\mathrm{cL}}{ }^{\circ}$ is the total ligand concentration, $\mathrm{V}^{\circ}$ is the total volume of titration solution, $V_{1}$ is the volume of alkali added to acid solution, $V_{2}$ is the volume of alkali added to acid solution + ligand solution, acid dissociation constants (pKa - values) of ligand were calculated by algebraic method point wise calculation (Tables 1 ). The dissociation constants (pKa) were calculated according to the following relation:

$\mathrm{pKa}=\mathrm{pH}+\log \left(\frac{n A}{1-n A}\right)$ 2

Where: pKa is the acid dissociation constant, $\mathrm{n}_{\mathrm{A}}$ is the Proton-ligand formation number and $\mathrm{pH}$ is the pH-values (Omar and Ali, 2015).

\section{Determination of metal-ligand stability constants $(\log K)$ of complexes}

The potentiometric measurement for the determination of stability constant of a complex in solution is based on the fact that the redox potential of the couple $\frac{M^{+(m-n)}}{M^{+m}}$ is shifted significantly on complexation of the metal ion with the ligand. This method involves change in hydrogen ion concentration $\left[\mathrm{H}^{+}\right]$due to the displacement or association of one or more protons taking place during complexation reaction. This change can be found out by titrating the solutions containing free acid, acid with ligand, and acid with ligand and metal ion, individually against a standard alkali solution at a constant ionic strength or temperature. Either ionic strength or temperature may be varied for different sets of solutions. In all the cases, the change in the $\mathrm{pH}$ of the solution is measured after each addition of a known amount of alkali to the reaction cell which contains the reaction mixture. The titration curves are then drawn by plotting the measured $\mathrm{pH}$ values against the corresponding volume of alkali added and the stability constants of the complexes are determined from the titration curves by employing $\mathrm{pH}$-metric titration technique given by (Irving and Rossoti).

Metal-ligand stability constants ( $\log \mathrm{K}$ ) were determined by using the following relations:

$$
\bar{n}=\frac{\left(V_{3}-V_{2}\right)\left(E^{0}+N^{0}\right)}{\left(V^{0}+V_{2}\right) \bar{n}_{A} T_{m}^{0}}
$$

and

$$
P L=\log _{10}\left\{\frac{1+\beta_{n}^{H} \frac{1}{[\text { anti } \log \mathrm{pH}]^{\mathrm{n}}}}{\mathrm{T}_{\mathrm{L}}^{0}-n \bar{T}_{m}^{0}} \mathrm{X} \frac{\left(V^{0}+V_{3}\right)}{V^{0}}\right\}
$$


BAJOPAS Volume 14 Number 1,June, 2021

Where $T_{L}, T^{\circ}, E^{\circ}$, and $V^{\circ}$ havethe same significance as in equation (1) above, $T_{m}$ denotes the total concentration of metal present in solution, $V_{3}$ is the volume of metal ions present in solution and $\beta^{H}$ is the overall proton ligand stability constant. The metal-ligand stability constants (log K) were determined by employing point wise computational Method (eq. 5 and 6).

$\operatorname{LogK}_{1}=\log \left(\frac{n}{1-n}\right)+\mathrm{pL}$ .5

$\operatorname{LogK}_{2}=\log \left(\frac{1-n}{2-n}\right)+\mathrm{pL}$ ...6

Where: Log $\mathrm{K}$ is the metal-ligand stability constant, $\mathrm{pL}$ is the Free ligand exponent function, $\mathbf{n}$ is the Average number of ligand attached with metal ion (Janraoet al., 2014). The results obtained were analyzed by an ORIGIN 2016 program using titration data and then the proton-ligand stability constants (pKa) and Metal-ligand stability constant (LogK) calculated (Omar and Ali, 2015).

\section{RESULTS AND DISCUSSION}

Fourier transformed infrared (FT-IR) spectra of isolated humic acid from peat soils Figure 2 had distinct clear absorption bands indicating the presence of major humic acid structural elemental groups such as $\mathrm{H}$ bonded $\mathrm{OH}$ $\left(3680 \mathrm{~cm}^{-1}\right.$ peak $), C=0$ of carbonyl $\left(1721 \mathrm{~cm}^{-1}\right.$ peak), functional groups of aliphatic components $\mathrm{CH}_{2}\left(2918 \mathrm{~cm}^{-1}\right.$ peak) and $\mathrm{C}-\mathrm{O}$ stretching of polysaccharide $\left(1168 \mathrm{~cm}^{-1}\right.$ peak). The positions of the absorption bands of the spectra fell within typical major absorption bands of humic acid which is at frequencies 3680, 2918, 1721, 1168 $\mathrm{cm}^{-1}$. The first peak centred in the vicinity of $3680 \mathrm{~cm}^{-1}$ region is attributed to phenol $\mathrm{OH}$ group bounded by intermolecular $\mathrm{H}$ bonds. The $2918 \mathrm{~cm}^{-1}$ band usually has absorption maximum at $2918 \mathrm{~cm}^{-1}$ which is due to $\mathrm{C}-\mathrm{H}$ stretching of alkane group $\left(\mathrm{CH}_{2}\right)$. The next major absorption band is $1721 \mathrm{~cm}^{-1}$. This band has been commonly ascribed to $\mathrm{C}=\mathrm{O}$ stretching of mainly carboxyl group $(\mathrm{COOH})$ with trace amount of ketones. The last peak was observed at 1168 $\mathrm{cm}^{-1}$ due to $\mathrm{C}-\mathrm{O}$ stretching of polysaccharides and this peak appeared also in the spectra of humic acid from peat soil. The FTIR spectra of the isolated humic acid contained all major characteristic absorption peaks of humic acid. These absorption peaks indicated the presence of the major structural elements of humic acid namely $\mathrm{H}$ bonded $\mathrm{OH}, \mathrm{C}=\mathrm{C}$ of aromatic ring, $\mathrm{C}=\mathrm{O}$ of carbonyl group (both carboxyl and ketonic), $\mathrm{CH}_{2}$ group. This strongly supports the presence of humic acid.

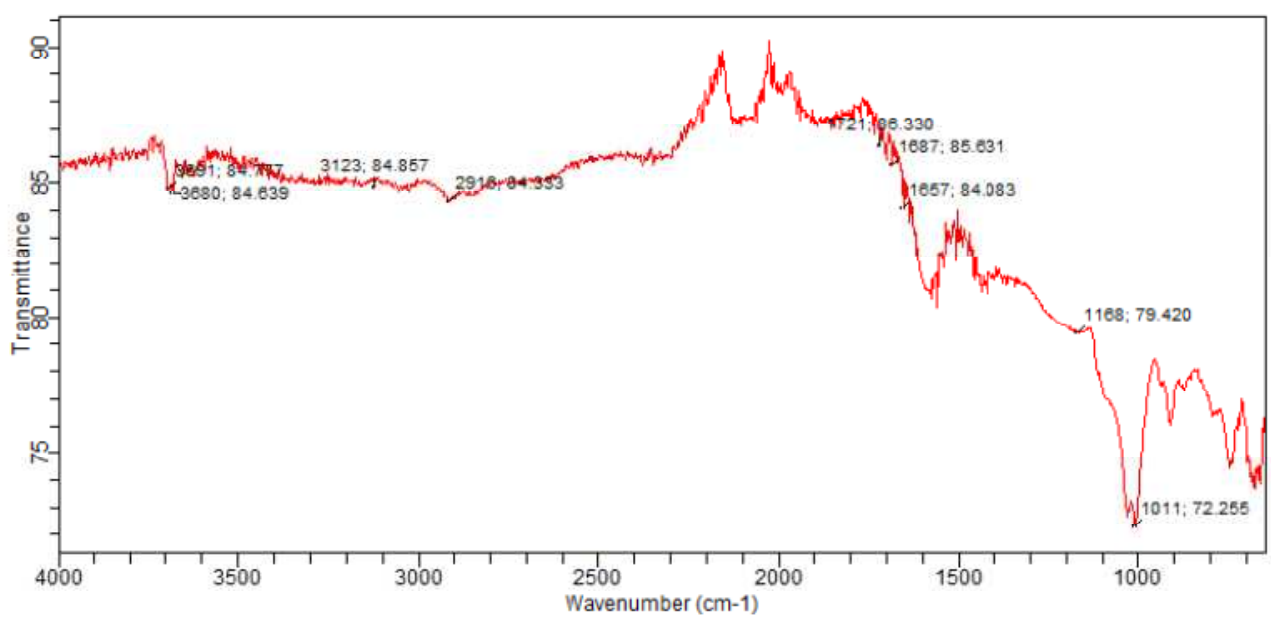

Fig. 2 : FT-IR spectraof peatsoilhumic acid (PSHA)

\section{Evaluation of acid dissociation constant (pka) of acid hydrolysed peat soil humicacid at phenolic group}

The value of the dissociation constant of the peat soil humic acid (PSHA) that underwent acidhydrolysis studied was found to be 8.9299 as shown Table 1, which is lower than the literaturevalues reported by Almeida and Szpoganics, (2015), Borges et al., (2005); Badr et al., (2012)and Fernandes et al,.(2009) of $9.73,9.47$ and 10.30. The difference between the obtained valuesand the reported values in this study might be probably as a result of acid hydrolysis of humicacid. 
BAJOPAS Volume 14 Number 1,June, 2021

Table 1: PKa of (Hydrolysed PSHA)

\begin{tabular}{|l|l|l|l|l|l|l|}
\hline $\mathrm{pH}$ & $\mathrm{BV}_{1}$ & $\mathrm{BV}_{2}$ & $\mathrm{~V}_{2}-\mathrm{V}_{1}$ & $\mathrm{nA}$ & $\log \left(\frac{n A}{1-n A}\right)$ & $\mathrm{pKa}$ \\
\hline 8.50 & 5.30 & 6.29 & 0.99 & 0.3594 & -0.2510 & 8.2490 \\
8.72 & 5.35 & 6.37 & 1.02 & 0.3400 & -0.2880 & 8.4320 \\
9.00 & 5.40 & 6.46 & 1.06 & 0.3141 & -0.3391 & 8.6609 \\
9.22 & 5.45 & 6.55 & 1.10 & 0.2882 & -0.3927 & 8.8273 \\
9.51 & 5.50 & 6.66 & 1.16 & 0.2494 & -0.4786 & 9.0314 \\
9.73 & 5.55 & 6.78 & 1.23 & 0.2041 & -0.5910 & 9.1390 \\
10.00 & 5.60 & 6.90 & 1.30 & 0.1589 & -0.7238 & 9.2762 \\
10.23 & 5.65 & 7.05 & 1.40 & 0.0941 & -0.9835 & 9.2465 \\
10.49 & 5.70 & 7.10 & 1.40 & 0.0941 & -0.9835 & 9.5065 \\
\hline
\end{tabular}

Average pKa $=8.9299 \pm 0.4186$

Table 2: PKa of (Unhydrolysed PSHA)

\begin{tabular}{|l|l|l|l|l|l|l|}
\hline $\mathrm{pH}$ & $\mathrm{BV}_{1}$ & $\mathrm{BV}_{2}$ & $\mathrm{~V}_{2}-\mathrm{V}_{1}$ & $\mathrm{nA}$ & $\log \left(\frac{\boldsymbol{n A}}{1-\boldsymbol{n}}\right)$ & $\mathrm{pKa}$ \\
\hline 8.50 & 5.30 & 5.81 & 0.51 & 0.6619 & 0.2919 & 8.7919 \\
8.72 & 5.35 & 5.90 & 0.55 & 0.6357 & 0.2418 & 8.9618 \\
9.00 & 5.40 & 6.00 & 0.60 & 0.6029 & 0.1813 & 9.1813 \\
9.22 & 5.45 & 6.10 & 0.65 & 0.5701 & 0.1226 & 9.3426 \\
9.51 & 5.50 & 6.20 & 0.70 & 0.5376 & 0.0654 & 9.5754 \\
9.73 & 5.55 & 6.33 & 0.78 & 0.4851 & -0.0259 & 9.7041 \\
10.00 & 5.60 & 6.47 & 0.87 & 0.4262 & -0.1291 & 9.8709 \\
10.23 & 5.65 & 6.62 & 0.99 & 0.3609 & -0.2481 & 9.9819 \\
10.49 & 5.70 & 6.80 & 1.10 & 0.2759 & -0.4690 & 10.0210 \\
\hline
\end{tabular}

Average pKa $=9.4923 \pm 0.4410$

Metal-ligand stability constant ( $\log \mathrm{K}$ )

The stabilityconstants require the accurate values of proton-ligand stability constants (Anil and Maroti, 2008). Metal titration curves crossed over ligand titration curve indicated the formation of complex upon proton release (Santosh, et al., 2011). If the values of n- are within range $0.2-0.8$ and $1.2-18$ this indicates the formation of $1: 1$ and 1:2 complexes (Sayyed and Mazahar, 2012).

The metal (II)-humate stepwise stability constants (log k) at phenolic group (Tables 318)

Table 3: Point-wise method, $\mathrm{Cu}$-(Hydrolysed PSHA)

\begin{tabular}{|l|l|l|l|l|l|l|l|l|}
\hline $\mathrm{pH}$ & $\mathrm{BV}_{1}$ & $\mathrm{BV}_{2}$ & $\mathrm{BV}_{3}$ & $\left(\mathrm{~V}_{3}-\mathrm{V}_{2}\right)$ & $\mathrm{n}$ & $\mathrm{pL}$ & $\log \left(\frac{n}{1-n}\right)$ & LogK $_{1}$ \\
\hline 8.50 & 5.30 & 6.29 & 6.33 & 0.04 & 0.5500 & 2.66 & 0.0871 & 2.7471 \\
8.72 & 5.35 & 6.37 & 6.41 & 0.04 & 0.5714 & 2.43 & 0.1249 & 2.5549 \\
9.00 & 5.40 & 6.46 & 6.50 & 0.04 & 0.6198 & 2.16 & 0.2122 & 2.3722 \\
9.22 & 5.45 & 6.55 & 6.59 & 0.04 & 0.6667 & 1.94 & 0.3010 & 2.2410 \\
\hline
\end{tabular}

LogK $_{1}$ (Average value) $=2.4788 \pm 0.2203$

Table 4: Point-wise method, $\mathrm{Cu}$-(Hydrolysed PSHA)

\begin{tabular}{|l|l|l|l|l|l|l|l|l|}
\hline $\mathrm{pH}$ & $\mathrm{BV}_{1}$ & $\mathrm{BV}_{2}$ & $\mathrm{BV}_{3}$ & $\left(\mathrm{~V}_{3}-\mathrm{V}_{2}\right)$ & $\mathrm{n}$ & $\mathrm{pL}$ & $\log \left(\frac{n-1}{2-n}\right)$ & LogK $_{2}$ \\
\hline 9.51 & 5.50 & 6.66 & 6.73 & 0.07 & 1.3509 & 1.70 & -0.2671 & 1.4329 \\
9.73 & 5.55 & 6.78 & 6.85 & 0.07 & 1.6383 & 1.51 & 0.2467 & 1.7567 \\
10.00 & 5.60 & 6.90 & 6.98 & 0.08 & 2.1783 & 1.31 & -0.2158 & 1.0942 \\
10.23 & 5.65 & 7.05 & 7.13 & 0.08 & 4.1904 & 1.27 & & \\
10.49 & 5.70 & 7.10 & 7.19 & 0.09 & 4.6920 & & & \\
\hline
\end{tabular}

Log $K_{2}($ Average value $)=1.4280 \pm 0.3312$ 
BAJOPAS Volume 14 Number 1,June, 2021

Table 5: Point-wise method, $\mathrm{Cu}$ (Unhydrolysed PSHA)

\begin{tabular}{|l|l|l|l|l|l|l|l|l|}
\hline $\mathrm{pH}$ & $\mathrm{BV}_{1}$ & $\mathrm{BV}_{2}$ & $\mathrm{BV}_{3}$ & $\left(\mathrm{~V}_{3}-\mathrm{V}_{2}\right)$ & $\mathrm{n}$ & $\mathrm{pL}$ & $\log \left(\frac{n}{n-1}\right)$ & Log $_{1}$ \\
\hline 8.50 & 5.30 & 5.81 & 5.85 & 0.04 & 0.2973 & 2.88 & -0.3736 & 2.5064 \\
8.72 & 5.35 & 5.90 & 5.95 & 0.05 & 0.3873 & 2.66 & -0.1992 & 2.4608 \\
9.00 & 5.40 & 6.00 & 6.05 & 0.05 & 0.4044 & 2.38 & -0.1681 & 2.2119 \\
9.22 & 5.45 & 6.10 & 6.15 & 0.06 & 0.5157 & 2.18 & -0.0272 & 2.2072 \\
9.51 & 5.50 & 6.20 & 6.27 & 0.07 & 0.6417 & 1.89 & 0.2530 & 1.1430 \\
\hline
\end{tabular}

$\operatorname{LogK}_{1}($ Average value $)=2.3059 \pm 0.6153$

Table 6:Point-wise method, $\mathrm{Cu}$ (Unhydrolysed PSHA)

\begin{tabular}{|l|l|l|l|l|l|l|l|l|}
\hline $\mathrm{pH}$ & $\mathrm{BV}_{1}$ & $\mathrm{BV}_{2}$ & $\mathrm{BV}_{3}$ & $\mathrm{~V}_{3}-\mathrm{V}_{2}$ & $\mathrm{n}$ & $\mathrm{pL}$ & $\log \left(\frac{n-1}{2-n}\right)$ & $\log \mathrm{K}_{2}$ \\
\hline 9.73 & 5.55 & 6.33 & 6.42 & 0.09 & 0.9000 & 1.69 & & \\
10.00 & 5.60 & 6.47 & 6.58 & 0.11 & 1.2578 & 1.44 & -0.4592 & 0.9808 \\
10.23 & 5.65 & 6.62 & 6.84 & 0.12 & 1.6137 & 1.26 & -0.2010 & 1.4610 \\
10.49 & 5.70 & 6.80 & 6.92 & 0.12 & 2.1052 & 1.03 & & \\
\hline
\end{tabular}

$\operatorname{LogK}_{2}$ (Average value) $=1.2209 \pm 0.3398$

Table 7:Point-wise method, Pb (Hydrolysed PSHA)

\begin{tabular}{|l|l|l|l|l|l|l|l|l|}
\hline $\mathrm{pH}$ & $\mathrm{BV}_{1}$ & $\mathrm{BV}_{2}$ & $\mathrm{BV}_{3}$ & $\left(\mathrm{~V}_{3}-\mathrm{V}_{2}\right)$ & $\mathrm{n}$ & $\mathrm{pL}$ & $\log \left(\frac{n}{1-n}\right)$ & LogK $_{1}$ \\
\hline 8.50 & 5.30 & 6.29 & 6.33 & 0.04 & 0.5500 & 2.66 & 0.0871 & 2.7471 \\
8.72 & 5.35 & 6.37 & 6.41 & 0.04 & 0.5714 & 2.43 & 0.1249 & 2.5549 \\
9.00 & 5.40 & 6.46 & 6.50 & 0.04 & 0.6198 & 2.16 & 0.2122 & 2.3722 \\
9.22 & 5.45 & 6.55 & 6.60 & 0.05 & 0.8333 & 1.96 & 0.6989 & 2.6589 \\
\hline
\end{tabular}

Log $_{\mathbf{1}}($ Average value $)=2.5832 \pm 0.1614$

Table 8:Point-wise method, Pb-(Hydrolysed PSHA)

\begin{tabular}{|l|l|l|l|l|l|l|l|l|}
\hline $\mathrm{pH}$ & $\mathrm{BV}_{1}$ & $\mathrm{BV}_{2}$ & $\mathrm{BV}_{3}$ & $\left(\mathrm{~V}_{3}-\mathrm{V}_{2}\right)$ & $\mathrm{n}$ & $\mathrm{pL}$ & $\log \left(\frac{n-1}{2-n}\right)$ & $\log \mathrm{K}_{2}$ \\
\hline 9.51 & 5.50 & 6.66 & 6.71 & 0.05 & 0.9650 & 1.67 & & \\
9.73 & 5.55 & 6.78 & 6.83 & 0.05 & 1.1702 & 1.44 & & \\
10.00 & 5.60 & 6.90 & 6.90 & 0.05 & 1.4864 & 1.22 & -0.0237 & 1.1963 \\
10.23 & 5.65 & 7.05 & 7.10 & 0.05 & 2.0190 & 1.09 & & \\
10.49 & 5.70 & 7.10 & 7.17 & 0.07 & 3.6492 & 1.00 & & \\
\hline
\end{tabular}

Log $K_{2}$ (Average value) $=1.1963$

Table 9: Point-wise method, Pb (Unhydrolysed PSHA)

\begin{tabular}{|l|l|l|l|l|l|l|l|l|}
\hline $\mathrm{pH}$ & $\mathrm{BV}_{1}$ & $\mathrm{BV}_{2}$ & $\mathrm{BV}_{3}$ & $\mathrm{~V}_{3}-\mathrm{V}_{2}$ & $\mathrm{n}$ & $\mathrm{pL}$ & $\begin{array}{l}\text { Log } \\
\left(\frac{n}{n-1}\right)\end{array}$ & Log $\mathrm{K}_{1}$ \\
\hline 8.50 & 5.30 & 5.81 & 5.85 & 0.04 & 0.2973 & 2.88 & -0.3736 & 2.5064 \\
8.72 & 5.35 & 5.90 & 5.94 & 0.04 & 0.3099 & 2.66 & -0.5477 & 2.3123 \\
9.00 & 5.40 & 6.00 & 6.05 & 0.05 & 0.4044 & 2.38 & -0.1681 & 2.2119 \\
9.22 & 5.45 & 6.10 & 6.15 & 0.06 & 0.5157 & 2.18 & 0.0272 & 2.2072 \\
9.51 & 5.50 & 6.20 & 6.26 & 0.07 & 0.6417 & 1.89 & 0.2530 & 2.1430 \\
9.73 & 5.55 & 6.40 & 6.40 & 0.07 & 0.7000 & 1.67 & 0.3680 & 2.0380 \\
\hline
\end{tabular}

LogK $_{1}$ (Average value) $=2.2364 \pm 0.1602$

Table 10: Point-wise method, Pb (Unhydrolysed PSHA)

\begin{tabular}{|l|l|l|l|l|l|l|l|l|}
\hline $\mathrm{pH}$ & $\mathrm{BV}_{1}$ & $\mathrm{BV}_{2}$ & $\mathrm{BV}_{3}$ & $\mathrm{~V}_{3}-\mathrm{V}_{2}$ & $\mathrm{n}$ & $\mathrm{pL}$ & $\log \left(\frac{n-1}{2-n}\right)$ & $\log \mathrm{K}_{2}$ \\
\hline 10.00 & 5.60 & 6.47 & 6.55 & 0.08 & 1.9503 & 1.41 & & \\
10.23 & 5.65 & 6.62 & 6.72 & 0.11 & 1.4792 & 1.26 & -0.0361 & 1.2239 \\
\hline
\end{tabular}

$\operatorname{LogK}_{2}$ (Average value) $=1.2239$

Table 11: Point-wise method, Mg (Hydrolysed PSHA)

\begin{tabular}{|l|l|l|l|l|l|l|l|l|}
\hline $\mathrm{pH}$ & $\mathrm{BV}_{1}$ & $\mathrm{BV}_{2}$ & $\mathrm{BV}_{3}$ & $\left(\mathrm{~V}_{3}-\mathrm{V}_{2}\right)$ & $\mathrm{n}$ & $\mathrm{pL}$ & $\log \left(\frac{n}{n-1}\right)$ & LogK $_{1}$ \\
\hline 8.50 & 5.30 & 6.29 & 6.31 & 0.02 & 0.2750 & 2.64 & -0.4290 & 2.2110 \\
8.72 & 5.35 & 6.37 & 6.39 & 0.02 & 0.2858 & 2.42 & -0.3978 & 2.0222 \\
9.00 & 5.40 & 6.46 & 6.49 & 0.03 & 0.4648 & 2.14 & -0.0612 & 2.0788 \\
9.22 & 5.45 & 6.55 & 6.59 & 0.04 & 0.6667 & 1.94 & 0.3010 & 2.2410 \\
\hline
\end{tabular}

$\log _{\mathbf{1}}($ Average value) $=2.1382 \pm 0.1046$ 
BAJOPAS Volume 14 Number 1,June, 2021

Table 12: Point-wise method, Mg (Hydrolysed PSHA)

\begin{tabular}{|l|l|l|l|l|l|l|l|l|}
\hline $\mathrm{pH}$ & $\mathrm{BV}_{1}$ & $\mathrm{BV}_{2}$ & $\mathrm{BV}_{3}$ & $\left(\mathrm{~V}_{3}-\mathrm{V}_{2}\right)$ & $\mathrm{n}$ & $\mathrm{pL}$ & $\log \left(\frac{n-1}{2-n}\right)$ & LogK $_{2}$ \\
\hline 9.51 & 5.55 & 6.66 & 6.71 & 0.05 & 0.9650 & 1.67 & & \\
9.73 & 5.55 & 6.78 & 6.84 & 0.06 & 1.4042 & 1.47 & -0.1686 & 1.3014 \\
10.00 & 5.60 & 6.90 & 6.93 & 0.06 & 1.7838 & 1.23 & 0.5593 & 1.7893 \\
10.23 & 5.65 & 7.05 & 7.10 & 0.06 & 3.1429 & 1.10 & & \\
10.49 & 5.70 & 7.10 & 7.18 & 0.07 & 3.6492 & 0.83 & & \\
\hline
\end{tabular}

LogK $_{2}($ Average value $)=1.5453 \pm 0.3450$

Table 13: Point-wise method, Mg (Unhydrolysed PSHA)

\begin{tabular}{|l|l|l|l|l|l|l|l|l|}
\hline $\mathrm{pH}$ & $\mathrm{BV}_{1}$ & $\mathrm{BV}_{2}$ & $\mathrm{BV}_{3}$ & $\mathrm{~V}_{3}-\mathrm{V}_{2}$ & $\mathrm{n}$ & $\mathrm{pL}$ & $\log \left(\frac{n}{n-1}\right)$ & $\operatorname{Log~}_{1}$ \\
\hline 8.50 & 5.30 & 5.81 & 5.85 & 0.04 & 0.2973 & 2.88 & -0.3736 & 2.5064 \\
8.72 & 5.35 & 5.90 & 5.94 & 0.04 & 0.3099 & 2.66 & -0.3477 & 2.3123 \\
9.00 & 5.40 & 6.00 & 6.04 & 0.04 & 0.3236 & 2.38 & -0.3202 & 2.0598 \\
9.22 & 5.45 & 6.10 & 6.15 & 0.05 & 0.4297 & 2.17 & -0.1230 & 2.0470 \\
9.51 & 5.50 & 6.20 & 6.26 & 0.06 & 0.5500 & 1.89 & 0.0871 & 1.9771 \\
9.73 & 5.55 & 6.33 & 6.40 & 0.07 & 0.7000 & 1.67 & 0.3680 & 2.0380 \\
\hline
\end{tabular}

LogK $_{1}$ (Average value) $=2.1568 \pm 0.2069$

Table 14: Point-wise method, Mg (Unhydrolysed PSHA)

\begin{tabular}{|l|l|l|l|l|l|l|l|l|}
\hline $\mathrm{pH}$ & $\mathrm{BV}_{1}$ & $\mathrm{BV}_{2}$ & $\mathrm{BV}_{3}$ & $\mathrm{~V}_{3}-\mathrm{V}_{2}$ & $\mathrm{n}$ & $\mathrm{pL}$ & $\log \left(\frac{n-1}{2-n}\right)$ & $\log \mathrm{K}_{2}$ \\
\hline 10.00 & 5.60 & 6.47 & 6.55 & 0.08 & 0.9148 & 1.41 & & \\
10.23 & 5.65 & 6.62 & 6.71 & 0.09 & 1.2102 & 1.20 & -0.5749 & 0.6251 \\
10.49 & 5.70 & 6.80 & 6.92 & 0.09 & 1.5968 & 1.03 & 0.1703 & 1.2003 \\
\hline
\end{tabular}

LogK $_{2}$ (Average value) $=0.9127 \pm 0.4070$

Table15:Point-wise method, Cd (Hydrolysed PSHA)

\begin{tabular}{|l|l|l|l|l|l|l|l|l|}
\hline $\mathrm{pH}$ & $\mathrm{BV}_{1}$ & $\mathrm{BV}_{2}$ & $\mathrm{BV}_{3}$ & $\left(\mathrm{~V}_{3}-\mathrm{V}_{2}\right)$ & $\mathrm{n}$ & $\mathrm{pL}$ & $\log \left(\frac{n}{1-n}\right)$ & LogK $_{1}$ \\
\hline 8.50 & 5.30 & 6.29 & 6.31 & 0.02 & 0.2750 & 2.64 & -0.4210 & 2.2190 \\
8.72 & 5.35 & 6.37 & 6.40 & 0.03 & 0.4286 & 2.42 & -0.1249 & 2.2951 \\
9.00 & 5.40 & 6.46 & 6.49 & 0.03 & 0.4648 & 2.14 & -0.0612 & 2.0788 \\
9.22 & 5.45 & 6.55 & 6.59 & 0.04 & 0.6667 & 1.96 & 0.3010 & 2.2610 \\
9.51 & 5.55 & 6.66 & 6.70 & 0.04 & 0.7720 & 1.67 & 0.5297 & 2.1997 \\
\hline
\end{tabular}

LogK $_{\mathbf{1}}$ (Average value) $=2.2108 \pm 0.0825$

Table 16: Point-wise method, Cd (Hydrolysed PSHA)

\begin{tabular}{|l|l|l|l|l|l|l|l|l|}
\hline $\mathrm{pH}$ & $\mathrm{BV}_{1}$ & $\mathrm{BV}_{2}$ & $\mathrm{BV}_{3}$ & $\left(\mathrm{~V}_{3}-\mathrm{V}_{2}\right)$ & $\mathrm{n}$ & $\mathrm{pL}$ & $\log \left(\frac{n-1}{2-n}\right)$ & Log $_{2}$ \\
\hline 9.73 & 5.55 & 6.78 & 6.83 & 0.06 & 1.4042 & 1.47 & -0.1686 & 1.3014 \\
10.00 & 5.60 & 6.90 & 6.95 & 0.06 & 1.7838 & 1.23 & 0.5593 & 1.7893 \\
10.23 & 5.65 & 7.05 & 7.10 & 0.06 & 3.1429 & 1.09 & & \\
10.49 & 5.70 & 7.10 & 7.16 & 0.06 & 3.1429 & 0.89 & & \\
& & & & & & & & \\
\hline
\end{tabular}

$\operatorname{LogK}_{2}$ (Average value) $=1.5453 \pm 0.3450$

Table 17: Point-wise method, Cd (Unhydrolysed PSHA)

\begin{tabular}{|l|l|l|l|l|l|l|l|l|}
\hline $\mathrm{pH}$ & $\mathrm{BV}_{1}$ & $\mathrm{BV}_{2}$ & $\mathrm{BV}_{3}$ & $\mathrm{~V}_{3}-\mathrm{V}_{2}$ & $\mathrm{n}$ & $\mathrm{pL}$ & $\log \left(\frac{n}{n-1}\right)$ & $\operatorname{Log~}_{1}$ \\
\hline 8.50 & 5.30 & 5.81 & 5.86 & 0.05 & 0.3717 & 2.88 & -0.2280 & 2.6520 \\
8.72 & 5.35 & 5.90 & 5.95 & 0.05 & 0.3873 & 2.66 & -0.1992 & 2.4608 \\
9.00 & 5.40 & 6.00 & 6.06 & 0.06 & 0.4853 & 2.38 & -0.0255 & 2.3545 \\
9.22 & 5.45 & 6.10 & 6.16 & 0.06 & 0.5157 & 2.18 & -0.0272 & 2.2072 \\
9.51 & 5.50 & 6.20 & 6.27 & 0.07 & 0.6417 & 1.89 & 0.2530 & 1.1430 \\
9.73 & 5.55 & 6.33 & 6.41 & 0.08 & 0.8000 & 1.69 & 0.6020 & 2.2920 \\
& & & & & & & & \\
\hline
\end{tabular}

$\operatorname{LogK}_{1}($ Average value $)=2.2516 \pm 0.5380$ 
BAJOPAS Volume 14 Number 1,June, 2021

Table 18: Point-wise method, Cd (Unhydrolysed PSHA)

\begin{tabular}{|l|l|l|l|l|l|l|l|l|}
\hline $\mathrm{pH}$ & $\mathrm{BV}_{1}$ & $\mathrm{BV}_{2}$ & $\mathrm{BV}_{3}$ & $\mathrm{~V}_{3}-\mathrm{V}_{2}$ & $\mathrm{n}$ & $\mathrm{pL}$ & $\log \left(\frac{n-1}{2-n}\right)$ & $\log \mathrm{K}_{2}$ \\
\hline 10.00 & 5.60 & 6.47 & 6.57 & 0.10 & 1.1434 & 1.43 & & \\
10.23 & 5.65 & 6.62 & 6.72 & 0.10 & 1.3448 & 1.23 & -0.2788 & 0.9512 \\
10.49 & 5.70 & 6.80 & 6.90 & 0.10 & 1.7742 & 1.03 & 0.5351 & 1.5651 \\
\hline
\end{tabular}

$\operatorname{LogK}_{2}($ Average value $)=1.2581 \pm 0.4340$

Table 19: Stepwise and overall Stability constants of thehydrolysed and unhydrolysed divalent metal (II) complexes

\begin{tabular}{|c|c|c|c|}
\hline Chelates & LogK $_{1}$ & $\log _{2}$ & Log $\beta$ \\
\hline [Cu (Hydrolysed PSHA-1) $\left.{ }_{2}\right]$ & 2.4788 & 1.4280 & 3.9068 \\
\hline$\left[\mathrm{Pb}(\text { Hydrolysed PSHA-1) })_{2}\right]$ & 2.5832 & 1.1963 & 3.7795 \\
\hline$\left[\mathrm{Cd}(\text { Hydrolysed PSHA-1 })_{2}\right]$ & 2.2108 & 1.5453 & 3.7561 \\
\hline$\left[\mathrm{Mg}(\text { Hydrolysed PSHA-1 })_{2}\right]$ & 2.1382 & 1.5453 & 3.6835 \\
\hline [Cu (Unhydrolysed PSHA-1) & 2.3059 & 1.2209 & 3.5268 \\
\hline$[\mathrm{Pb}$ (Unhydrolysed PSHA-1) 2$]$ & 2.2364 & 1.2239 & 3.4603 \\
\hline [Cd (Unhydrolysed PSHA-1) 2 ] & 2.2516 & 1.2581 & 3.5097 \\
\hline$[\mathrm{Mg}$ (Unydrolysed PSHA-1) & 2.1568 & 0.9127 & 3.0695 \\
\hline
\end{tabular}

The results obtained (Table19) shows the stepwise and overall stability constants to be not high indicating low stability of the complexes, because the solubility of most metal ions in the basic $\mathrm{pH}$ range is minimal due to metal hydroxide precipitation (Karimi, 2017). In general, the stepwise stability constants $\left(K_{1}\right.$ and $K_{2}$ ) follow the order $K_{1}>K_{2}$ for the copper, lead, magnesium and cadmium complexes respectively. The steady decrease of the values with increasing number of ligands is in agreement with the prediction made by researchers (Na'aliya, 2013). The decrease could be attributed to the fact that as the number of the ligands (Humate ions) that enters the coordination zone increases the aqua molecules available for replacement by the ligands become less. Thus, the metal ions become less electron loving with progressive intake of the ligand and this results in the decrease in the values of the constants (Na'aliya, 2013). Also the stability of the complexes is influenced by the size and number of the chelate rings(Mackay and Mackay,2002).All the complexes form rings in their structure as humate, a bidentate ligand, bond the metal ions in the ratio 1:2 (Boguta and Sokolowska, 2016) forming chelate rings. The values of the overall stability constants $(\log \beta)$ obtained for humate complexes are not high indicating low stability as the values are not high. LogK values for copper-humates (Table 3 to 6) obtained in this study are lower than those reported for the complexes of humic acids (Pandey et al., 2015; Dinu, 2013; Kaschl et al., 2010 and Gilbeto and Jorg, 2001). The values of LogK(Table 7 to 10 ) forlead-humates are lower than those reported for the lead in the literature (Dinu, 2013; Gilbeto and Jorg 2001). Log K values(Table 11 to 14 ) for magnesium-humates obtained in this study are close to those reported by (Pandey et al., 2015). Log K values of cadmium-humates (Table 15 to 18 ) obtained in this work near to the one reported by (Dinu, 2013 and Pandey et al., 2015).The difference between the reported values and the values obtained in this study might be probably as a result of acid hydrolysis of humic acid. The values of the overall stability constants $(\log \beta)$ of the copper humates complexes presented in Table 19 is high than that of other metal humate complexes, show relatively high stability of CuHA complexes, show the following order of stability: $\mathrm{Cu}>\mathrm{Pb}>\mathrm{Cd}>\mathrm{Mg}$; which are in close agreement to the findings of (Dinu, 2013 and Pandey et al., 2015).The high stability of Cuhumate chelate could be attributed to the existence of coordinate covalent bond between the complexing agents and the $\mathrm{Cu}^{2+}$ ions. Since, $\mathrm{Cu}^{2+}$ being a metal of the transitional series with $3 d^{9}$ electronic configurations can accept the electrons from the complexing agents. Similarly, the low stabilities of $\mathrm{Pb}, \mathrm{Cd}$ and $\mathrm{Mg}$ complexes could be explained by that $\mathrm{Pb}^{2+}$ with $6 s^{2}, \mathrm{Cd}^{2+}$ with $4 \mathrm{~d}^{10}$ and $\mathrm{Mg}^{2+}$ with $2 \mathrm{p}^{6}$ their electronic configuration has a completely filled $\mathrm{d}, \mathrm{p}$ and $\mathrm{s}$ orbitals. Moreover, the stabilities of metal ions with hydrolysed humic acid from peat soil were higher than those with unhydrolysed humic acid from peat soil; which is ascribed to the high content of acidity in hydrolysed humic acid than unhydrolysed humic acid. 
BAJOPAS Volume 14 Number 1,June, 2021 CONCLUSION

The values of logk for $\mathrm{Cu}(\mathrm{II})$ hydrolysed humic acid complex was higher followed by $\mathrm{Pb}$ (II), $\mathrm{Cd}(\mathrm{II})$ and $\mathrm{Mg}$ (II) hydrolysed humic acid complexes as compared with metal(II) unhydrolysed humic acid complexes. This indicates acid hydrolysis of humic acid can

\section{REFERENCES}

Almeida, V.R. and Szpoganicz, B. (2015). Humic Acid Potentiometric Response Patterns:Out- of Equilibrium Properties and Species Distribution Modelling. Chemical. Biol. Technol. Agric. 2: 17.

Anđelković, T., Nikolić, R., Bojić, A.,Anđelković, D., and Nikolic G.,(2010). Binding of Cadmium to Soil Humic Acid as A Function of Carboxyl Group Content. Macedonian Journal of Chemistry and Chemical Engineering.29(2): 215-224.

Anil, B. N. and Maroti, N. (2008). Studies on Influence of Die-Lectric Constants on Complex Equilibria between Substituted Py-Razalines and Lanthanide Metal Ions pH-Metrically. Amer.-Euras. scient. Res. 3(2): 212-216.

Ashok, K., Pandey, S. P. and Misra, V (2000). Stability Constants of Metal-Humic Acid Complexes and its Role in Environmental Detoxification. Journal of Ecotoxicology and Environmental Safety. 47(2):157-200.

Badr, M. H., El-Halafawi, M. H. and Abd El-al Zeid, E. R. (2012). Comparison Between the Effect of Ionic Strength on Acidity and Dissociation Constants of Humic Acids Extracted from Sewage Sludge and Nile Water Hyacinth Composts.Global Journal of Environmental Research 6 (1): 36-43.

Baruah, M.K., Borah, D., Saikia, P.P., Paul, S., Sharma, T. (2015). Evaluation of pKa Values of Soil Humic Acids and their Complexation Properties. International Journal of Plant \& Soil Science 6(4) : 218-228.

Boguta, P. Sokolowska, Z. (2016). Interactions of $\mathrm{Zn}$ (II) Ions with Humic Acids Isolated from Various Types of Soils. Effect of $\mathrm{pH}, \mathrm{Zn}$ Concentrations and Humic Acids Chemical Properties. Journal of Geochemical Explaration 168. 119-126.

Borges, F., Guimaraes, C., Lima, L.F.C., Pinto, I. and Reis, S.(2005). Potentiometric Studies on the Complexation of Copper(II) by Phenolic Acids as Discrete Ligand Models of enhance the complexation behavior of humic acid with metal (II) ions. However, the higher values of $\log \beta$ for $\mathrm{Cu}(\mathrm{II}), \mathrm{Pb}(\mathrm{II}), \mathrm{Cd}(\mathrm{II})$ and $\mathrm{Mg}(\mathrm{II})$ hydrolysed humic acid complexes indicates more stable stepwise complexes formed as compared with $\mathrm{Cu}(\mathrm{II}), \mathrm{Pb}$ (II), $\mathrm{Cd}$ (II) and $\mathrm{Mg}(\mathrm{II})$ unhydrolysed humic acid complexes.

Humic Substances Talanta 66 (2005) 670-673.

Chefetz, B., Salloum, M. J., Deshmulkin, A. P. and Hatcher, P. (2002). Structural Components of Humic Acids as Determined by Chemical Modifications and Carbon-13 NMR, Pyrolysis, and Thermochemolysis- Gas Chromatography/Mass Spectrometry. Soil Science Society of American Journal Abstract Division S-2- Soil Chemistry66. 1159-1171.

Dinu, M. I. (2013). Metals Complexation with Humic Acids in Surface Water of Different Environ. Sci. Technol. 31(1): 1-17.

Fernandes, A.N., Giacomelli, C., Giovanela, M. Vaz, D.V. Szpoganicz, B. and Maria M. D. (2009). Potentiometric Acidity Determination in Humic Substances Influenced by Different Analytical Procedures.J. Braz. Chem. Soc. 20 (9):14.

Gamal, A. H. (2015). Stability Constants of Rhenium (V) Metal Complexes with Selected Drugs. Pyrex Journal of Research in Environmental Studies. 2(2): 006-014.

Janrao, D. M., Pathan, J., Kayande, D.D., and Mulla, J.J. (2014). An Over View of Potentiometric Determination of Stability Constants of Metal Complexes. Sci. Revs. Chem. Commun.: 4(1), 2014, 11-24.

Karimi, H. (2017). Effect of pH and Initial Pb(II) Concentration on the Lead Removal Efficiency from Waste Water Using $\mathrm{Ca}(\mathrm{OH})_{2}$. International Journal of Water and Waste Water Treatment 3.2

Kaschl, A. Romheld, V. and Chen, Y. (2010). Binding of Cadmium, Copper and Zinc to Humic Substances Originating from Municipal Solid Waste Compost. Israel Journal of Chemistry Vol. 42(1): 89-98.

Kostic, I. S., Tatjana, P, A., Nikolic, R. S., Cvetkovic, T. P., Pavlovic, D. D., Aleksandar, L.J. and Bojic, A. (2012). Comparative Study of Binding Strengths of Heavy Metals with Humic Acid. J.serb. Chem. Soc. 76(9) pp 1-20. 
BAJOPAS Volume 14 Number 1,June, 2021

Na'aliya, J. (2013). Determination of Stepwise Stability Constants and Gibbs free Energy Change of Trisprolina to Complexes of some Divalent Transition Metal ions. Bayero Journal of Pure and Applied Sciences 6(2): 112-114.

Omar, A. A. and Ali, E. A. (2015). Potentiometric Studies on Complexes of $\mathrm{Cr}$ (III) and $\mathrm{Zr}$ (IV) with some Carboxylic Acids. International Journal of Advanced Chemistry, 3(1) 25-

37.

Pandey, A. K. Pandey, S. D. and Misr, V. (2015).Stability Constants of Metal- Humic Acid Complexes and Its Role in Environmental Detoxification. J. Ecotoxicology and Environmental Safety. 47(1):195-200.

Ram, N. and Raman, K.V. (1984). Stability Constants of Complexes of Metals with
Humicand Fuvic Acids under Non- acidConditions. Journal of Plant Nutrition and Soil Sciences.

147:171-176.

Santosh, D. D., Ashok, B. K., Vijay, J. T., Shivraj, G. W. and Vinay, V. W. (2011). Potentiometric Studies of Elec-Trolyte Effects on Complex Equilibria of Some Substituted 5-(2-hydroxy Phenyl) Pyrazoles. Der pharm. 3 (6): 75-83.

Sayyed, H. and Abdul Rahim, M. F. (2012). Studies of Binary Complexes of Metal Ions with Mandelic Acid by Potentiometry. Chem. J. 02 (6): 206209.

Shirvani, M. Moradian, E. Khalili, B. Bakhtiary, S. (2015). Interaction of $\mathrm{Cd}$ and $\mathrm{Pb}$ with Humate-Palygorskite and HumateSepiolite Complexes. Journal of water, air and pollution 3: 220-228. 


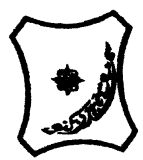

Bayero Journal of Pure and Applied Sciences, 14(1): 54 - 63

Received: November, 2020

Accepted: April, 2021

ISSN $2006-6996$

\title{
STABILITY CONSTANTS OF COMPLEXES OF METAL IONS WITH PEATSOIL HUMIC ACIDS UNDER NON-ACID-CONDITIONS
}

\author{
${ }^{* 1}$ Sabo, Yusuf ${ }^{2}$ Jimoh, W.L.O., ${ }^{3}$ Isa Baba Koki and ${ }^{4}$ Sholadoye, Q. 0. \\ ${ }^{1}$ Department of Pure and Industrial Chemistry, Bayero University, Kano \\ ${ }^{3}$ Department of Chemistry, Yusuf Maitama Sule University Kano. P.M.B. 3220 Kano, Nigeria. \\ ${ }^{4}$ Department of Chemistry, Nigerian Police Academy, Wudil, Kano-Nigeria
}

*Correspondence E-mail; saboyusuf18@yahoo.com

ABSTRACT

Stability constants of complexes of four divalent metal ions viz. $\mathrm{Cu}^{2+}, \mathrm{Pb}^{2+}, \mathrm{Mg}^{2+}$ and $\mathrm{Cd}^{2+}$ with humic acids (HA) were determined by potentiometric titration of humic acids with the corresponding salt of the divalent metals in aqueous media under non-acid-condition. The log $K$ (logarithm of the stability constant) ranged from 1.0942 to 2.7471 for metalhumic acid complexes were determined using point-wise computational method. The order of stability constants were obtained as follows: $\mathrm{Cu}>\mathrm{Pb}>\mathrm{Cd}>\mathrm{Mg}$ for metal $-\mathrm{HA}$ complexes respectively, indicating a higher degree of complexation with Cu metal ion.

Keywords: stability constant, humic acid, potentiometric titration, divalent metals, acid hydrolysis.

\section{NTRODUCTION}

The stability constant of a complex is the numerical expression of its stability and provides a quantitative measure of affinity of the metal ion to the complexing agent. An understanding of the relative stability of metal-complexes helps in predicting the behavior of metal ions in the soil (Ram and Raman, 1982). Extensive researches has been done to determine the stability constants of the complexes formed between humic acid (HA) with a number of metal ions. Ashok et al., (2000) reported that humic acid with hydroxyl, phenoxyl and carboxyl reactive groups can form coordination compound with metal ions at $\mathrm{pH}$ 3.5. The stability constants(Log K) for different metalhumic acid complexes indicated the following order of the stabilities of complexes formed between humic acid and metal ion, $\mathrm{Cu}>\mathrm{Fe}$ $>\mathrm{Pb}>\mathrm{Ni}>\mathrm{Co}>\mathrm{Ca}>\mathrm{Cd}>\mathrm{Zn}>\mathrm{Mn}>\mathrm{Mg}$. Andelkovic et al., (2010) investigated the binding of $\mathrm{Cd}$ (II) to soil humic acid at pH 6.5 and in $0.1 \mathrm{M} \mathrm{KNO}_{3}$ ionic medium. The stability constant for binding indicating greater stability in the case when carboxyl groups are involved in complexation reaction. Kostic et al.,(2012) investigated the complexation of humic acid with certain heavy metal ions (Co(II), $\mathrm{Ni}(\mathrm{II}), \mathrm{Cu}(\mathrm{II})$,
$\mathrm{Zn}(\mathrm{II})$, and $\mathrm{Pb}(\mathrm{II})$. The experiment was performed at $25^{\circ} \mathrm{C}$, at pH 4.0 and ionic strength of $0.01 \mathrm{M}$. Stability constant of complex between $\mathrm{Pb}$ (II) ions and humic acid is greater than stability constants of other investigated metalhumate complexes. Bogata and Sokolowska (2016) analyses the interaction between humic acids from different soils and $\mathrm{Zn}$ (II) ions at wide concentration ranges and at $\mathrm{pH} 5$. Studies have showed significant impact of $\mathrm{Zn}$ concentration, $\mathrm{pH}$ and some properties of humic acids with zinc.But all of these studies were limited to acidic $\mathrm{pH}$ range. Therefore, the present study was carried out to determine and compare the stability constants of complexes of metal ions with hydrolysed peat soil humic acid and unhydrolysed peat soil humic under non-acid conditions.

\section{MATERIALS AND METHODS}

Analytical grade chemicals used includes hydrochloric acid $(\mathrm{HCl})$, nitric acid $\left(\mathrm{HNO}_{3}\right)$, sodium hydroxide $(\mathrm{NaOH})$, lead nitrate $\mathrm{Pb}\left(\mathrm{NO}_{3}\right)_{2}$, copper nitrate $\mathrm{Cu}\left(\mathrm{NO}_{3}\right)_{2} \cdot 3 \mathrm{H}_{2} \mathrm{O}$, cadmium nitrate $\mathrm{Cd}\left(\mathrm{NO}_{3}\right)_{2} \cdot 4 \mathrm{H}_{2} \mathrm{O}$, magnesium nitrate $\mathrm{Mg}\left(\mathrm{NO}_{3}\right)_{2} \cdot 6 \mathrm{H}_{2} \mathrm{O}$, potassium nitrate $\left(\mathrm{KNO}_{3}\right)$, calcium chloride $\left(\mathrm{CaCl}_{2}\right)$, (sigma-Aldrich). Dowex 50WX8, (20-50 mesh) from Fluka. 


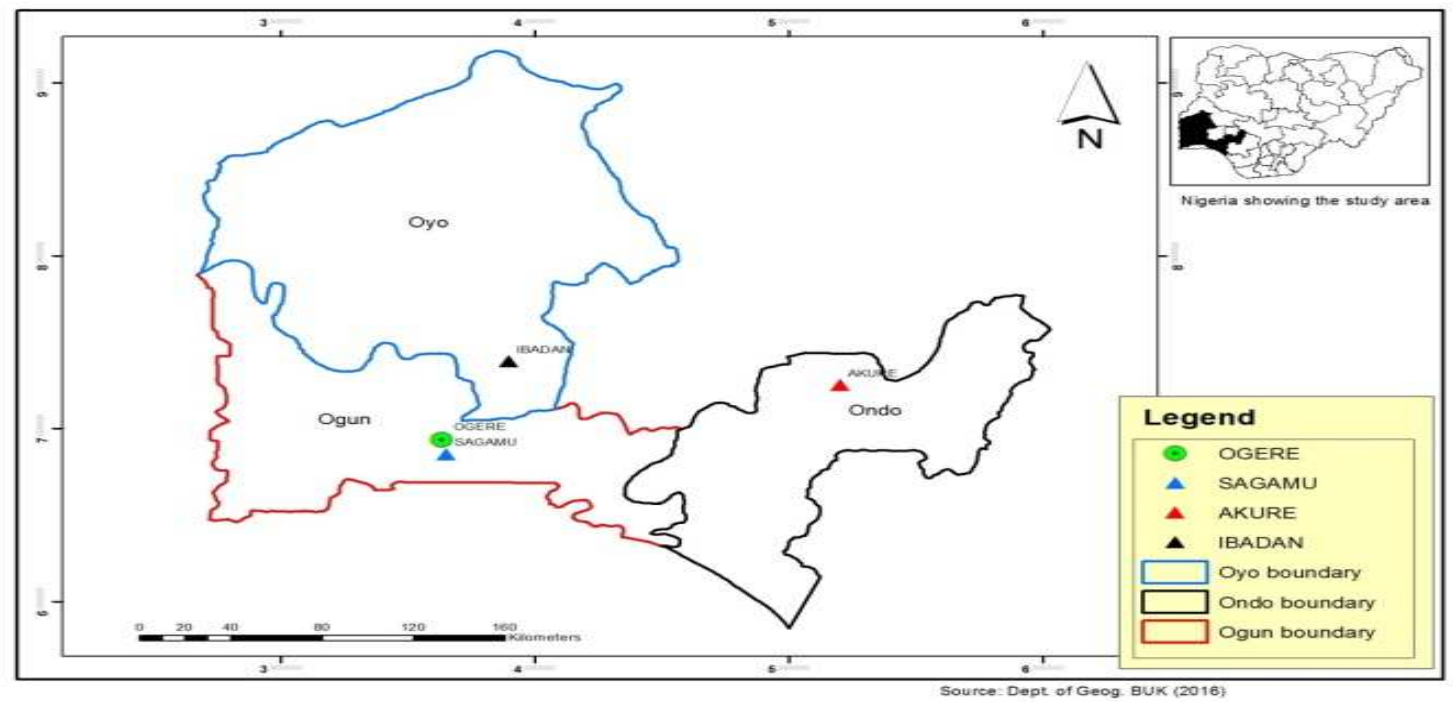

Figure 1: Map showing the sampling point at Sagamu Town, Ogun State.

\section{Description of Sampling Area}

Sagamu has geographical coordinates between $6^{\circ} 50^{\prime}$ north; $3^{\circ} 38^{\prime}$ east is located in south western region of Nigeria. The region has tropical wet and dry climate with a lengthy wet season and relatively constant temperatures throughout the course of the year. Wet season runs from March to October, November to December forms the region dry season. The vegetation type of the region is savannah which is really grassland with small bushes and occasional big trees. Grassland soils have substantially higher organic matter content than forest soils (Novackova, 2011).

\section{Sample Collection}

The Peatsoil samples were collected from four different sampling points $(0-10 \mathrm{~cm}$ depth) in Sagamu into polyethylene bag with plastic spoons. Samples were taken to the laboratory, extraneous materials were removed; the samples were air-dried, crushed and ground to a fine powder in a mortar passed through a $0.20 \mathrm{~mm}$ sieve. The samples were kept for analysis.

\section{Isolation and purification of humic acid from peat soil sample}

Peatsoil sample $(100 \mathrm{~g})$ was mixed with 1000 $\mathrm{cm}^{3}$ of $0.1 \mathrm{M} \mathrm{NaOH}$ solution, shaken for 3hours and left to stand overnight. Dark-coloured supernatant was obtained and decanted from solid residue. The dark-coloured supernatant was acidified to $(\mathrm{pH}=1.0)$ with $6 \mathrm{M} \mathrm{HCl}$ stirred and allowed to stand for 6 hours. Yellowish brown supernatant and dark-brown precipitate were obtained. The yellowish brown supernatant was decanted followed by centrifuge and discarded. The dark-brown precipitate was mixed with $500 \mathrm{~cm}^{3}$ of $0.1 \mathrm{M} \mathrm{NaOH}$ solution followed by passing through dowex resin. The dark-brown solution was acidified to $(\mathrm{pH}=1.0)$ with $6 \mathrm{M} \mathrm{HCl}$ stirred and allowed to stand for 3 hours. The dark-brown precipitate was washed several times with deionized water. The supernatant was treated with $\mathrm{AgNO}_{3}$ solution until no white precipitate observed. The humic acid was transferred to weighed crucible and dried at $60^{\circ} \mathrm{C}$ in an oven for 12 hours. The humic acid was cooled and dried in the desiccator, weighed and recorded. The obtained humic acid was dried again at $60^{\circ} \mathrm{C}$ for additional 6 hours cooled and dried in the desiccator, weighed and recorded constant weight was obtained (Baruah et al., 2015).

\section{FT-IR analysis}

FT-IR spectra of humic acid sample was analysed using Carry 630 FT-IR Agilent Technologies.

Unhydrolysed compost humic acid

The unhydrolysed humic acid was obtained after isolation and purification of compost humic acid and kept for investigation.

\section{Acid hydrolysis of Peatsoil acid}

Peatsoil humic acid sample (1g) was refluxed for 12 hours at $\left(160^{\circ} \mathrm{C}\right)$ with $50 \mathrm{~cm}^{3}$ of $6 \mathrm{M} \mathrm{HCl}$. The mixture was allowed to cool, decanted, and centrifuged after hydrolysis. The insoluble residues were washed with distilled water via centrifugation several times, and the supernatant was treated with $\mathrm{AgNO}_{3}$ solution until no white precipitate was observed. The residue was thoroughly dried over $\mathrm{CaCl}_{2}$ in a desiccator at room temperature (Chefetz et al., 2002). Finally, the obtained hydrolysed humic acid was kept for investigation. 
BAJOPAS Volume 14 Number 1,June, 2021 Potentiometric Titrations

Potentiometric measurements were carried out using a pH-meter Jenway (model 3510) with combine electrode, the sensitivity of the $\mathrm{pH}$ meter is 0.01 units. The $\mathrm{pH}$ meter was switched on half an hour before starting the titration for initial warm up of the instrument. The instrument was calibrated with an aqueous standard buffer solution of $\mathrm{pH} 4.00$ and 10.0 (borate buffer) prepared from a "Qualigens" buffer tablets.

The following sets of solutions were prepared in a $250 \mathrm{~cm}^{3}$ volumetric flask separately for $\mathrm{pH}$ metric titrations.

(i) $5 \mathrm{~cm}^{3} 0.1 \mathrm{M} \mathrm{HCl}+40 \mathrm{~cm}^{3}$ deionized water

(ii) $5 \mathrm{~cm}^{3} 0.1 \mathrm{M} \mathrm{HCl}+39 \mathrm{~cm}^{3}$ deionized water $+1 \mathrm{~cm}^{3} 0.15 \mathrm{gcm}^{-3}$ humic acid

(iii) $5 \mathrm{~cm}^{3} 0.1 \mathrm{M} \mathrm{HCl}+37 \mathrm{~cm}^{3}$ deionized water $+1 \mathrm{~cm}^{3} 0.15 \mathrm{gcm}^{-3}$ humic acid

$$
+2 \mathrm{~cm}^{3} \quad 0.01 \mathrm{M} \mathrm{Cu} \text { (II) }
$$

The solutions were titrated against standardized $0.110 \mathrm{MNaOH}$ separately. The total volume of each mixture was adjusted to $50 \mathrm{~cm}^{3}$ and the ionic strength of the solutions was maintained constant at by adding appropriate amount of stock solution of $1 \mathrm{M} \mathrm{KNO}_{3}$ (Gamal, 2015; Omar and Ali, 2015). A magnetic stirrer was used to achieve thorough mixing of the interacting solutions at $550 \mathrm{rpm}$. The same set of experimental conditions was applied for potentiometric titration of remaining samples.

\section{Evaluation of pKa of Hydrolysed peat soil Humic Acids}

The proton-ligand formation number $\mathrm{n}_{\mathbf{A}}$ were calculated by Irving and Rossotti expression (Omar and Ali, 2015).

$\mathrm{nA}=\mathrm{Y}-\frac{(\mathrm{V} 2-\mathrm{V1})(\mathrm{No}-\mathrm{Eo})}{(\mathrm{VO}+\mathrm{V1}) \mathrm{TCL}}$ 1

Where: $Y$ is number of dissociable proton, $\left(\mathrm{V}_{2^{-}}\right.$ $V_{1}$ ) is the measure of displacement of the ligand curve relative to acid curve, $\mathrm{N}^{\circ}$ and $\mathrm{E}^{\circ}$ are the resultant concentration of alkali solution, free acid solution, $\mathrm{T}_{\mathrm{cL}}{ }^{\circ}$ is the total ligand concentration, $\mathrm{V}^{\circ}$ is the total volume of titration solution, $V_{1}$ is the volume of alkali added to acid solution, $V_{2}$ is the volume of alkali added to acid solution + ligand solution, acid dissociation constants (pKa - values) of ligand were calculated by algebraic method point wise calculation (Tables 1 ). The dissociation constants (pKa) were calculated according to the following relation:

$\mathrm{pKa}=\mathrm{pH}+\log \left(\frac{n A}{1-n A}\right)$ 2

Where: pKa is the acid dissociation constant, $\mathrm{n}_{\mathrm{A}}$ is the Proton-ligand formation number and $\mathrm{pH}$ is the pH-values (Omar and Ali, 2015).

\section{Determination of metal-ligand stability constants $(\log K)$ of complexes}

The potentiometric measurement for the determination of stability constant of a complex in solution is based on the fact that the redox potential of the couple $\frac{M^{+(m-n)}}{M^{+m}}$ is shifted significantly on complexation of the metal ion with the ligand. This method involves change in hydrogen ion concentration $\left[\mathrm{H}^{+}\right]$due to the displacement or association of one or more protons taking place during complexation reaction. This change can be found out by titrating the solutions containing free acid, acid with ligand, and acid with ligand and metal ion, individually against a standard alkali solution at a constant ionic strength or temperature. Either ionic strength or temperature may be varied for different sets of solutions. In all the cases, the change in the $\mathrm{pH}$ of the solution is measured after each addition of a known amount of alkali to the reaction cell which contains the reaction mixture. The titration curves are then drawn by plotting the measured $\mathrm{pH}$ values against the corresponding volume of alkali added and the stability constants of the complexes are determined from the titration curves by employing $\mathrm{pH}$-metric titration technique given by (Irving and Rossoti).

Metal-ligand stability constants ( $\log \mathrm{K}$ ) were determined by using the following relations:

$$
\bar{n}=\frac{\left(V_{3}-V_{2}\right)\left(E^{0}+N^{0}\right)}{\left(V^{0}+V_{2}\right) \bar{n}_{A} T_{m}^{0}}
$$

and

$$
P L=\log _{10}\left\{\frac{1+\beta_{n}^{H} \frac{1}{[\text { anti } \log \mathrm{pH}]^{\mathrm{n}}}}{\mathrm{T}_{\mathrm{L}}^{0}-n \bar{T}_{m}^{0}} \mathrm{X} \frac{\left(V^{0}+V_{3}\right)}{V^{0}}\right\}
$$


BAJOPAS Volume 14 Number 1,June, 2021

Where $T_{L}, T^{\circ}, E^{\circ}$, and $V^{\circ}$ havethe same significance as in equation (1) above, $T_{m}$ denotes the total concentration of metal present in solution, $V_{3}$ is the volume of metal ions present in solution and $\beta^{H}$ is the overall proton ligand stability constant. The metal-ligand stability constants (log K) were determined by employing point wise computational Method (eq. 5 and 6).

$\operatorname{LogK}_{1}=\log \left(\frac{n}{1-n}\right)+\mathrm{pL}$ .5

$\operatorname{LogK}_{2}=\log \left(\frac{1-n}{2-n}\right)+\mathrm{pL}$ ...6

Where: Log $\mathrm{K}$ is the metal-ligand stability constant, $\mathrm{pL}$ is the Free ligand exponent function, $\mathbf{n}$ is the Average number of ligand attached with metal ion (Janraoet al., 2014). The results obtained were analyzed by an ORIGIN 2016 program using titration data and then the proton-ligand stability constants (pKa) and Metal-ligand stability constant (LogK) calculated (Omar and Ali, 2015).

\section{RESULTS AND DISCUSSION}

Fourier transformed infrared (FT-IR) spectra of isolated humic acid from peat soils Figure 2 had distinct clear absorption bands indicating the presence of major humic acid structural elemental groups such as $\mathrm{H}$ bonded $\mathrm{OH}$ $\left(3680 \mathrm{~cm}^{-1}\right.$ peak $), C=0$ of carbonyl $\left(1721 \mathrm{~cm}^{-1}\right.$ peak), functional groups of aliphatic components $\mathrm{CH}_{2}\left(2918 \mathrm{~cm}^{-1}\right.$ peak) and $\mathrm{C}-\mathrm{O}$ stretching of polysaccharide $\left(1168 \mathrm{~cm}^{-1}\right.$ peak). The positions of the absorption bands of the spectra fell within typical major absorption bands of humic acid which is at frequencies 3680, 2918, 1721, 1168 $\mathrm{cm}^{-1}$. The first peak centred in the vicinity of $3680 \mathrm{~cm}^{-1}$ region is attributed to phenol $\mathrm{OH}$ group bounded by intermolecular $\mathrm{H}$ bonds. The $2918 \mathrm{~cm}^{-1}$ band usually has absorption maximum at $2918 \mathrm{~cm}^{-1}$ which is due to $\mathrm{C}-\mathrm{H}$ stretching of alkane group $\left(\mathrm{CH}_{2}\right)$. The next major absorption band is $1721 \mathrm{~cm}^{-1}$. This band has been commonly ascribed to $\mathrm{C}=\mathrm{O}$ stretching of mainly carboxyl group $(\mathrm{COOH})$ with trace amount of ketones. The last peak was observed at 1168 $\mathrm{cm}^{-1}$ due to $\mathrm{C}-\mathrm{O}$ stretching of polysaccharides and this peak appeared also in the spectra of humic acid from peat soil. The FTIR spectra of the isolated humic acid contained all major characteristic absorption peaks of humic acid. These absorption peaks indicated the presence of the major structural elements of humic acid namely $\mathrm{H}$ bonded $\mathrm{OH}, \mathrm{C}=\mathrm{C}$ of aromatic ring, $\mathrm{C}=\mathrm{O}$ of carbonyl group (both carboxyl and ketonic), $\mathrm{CH}_{2}$ group. This strongly supports the presence of humic acid.

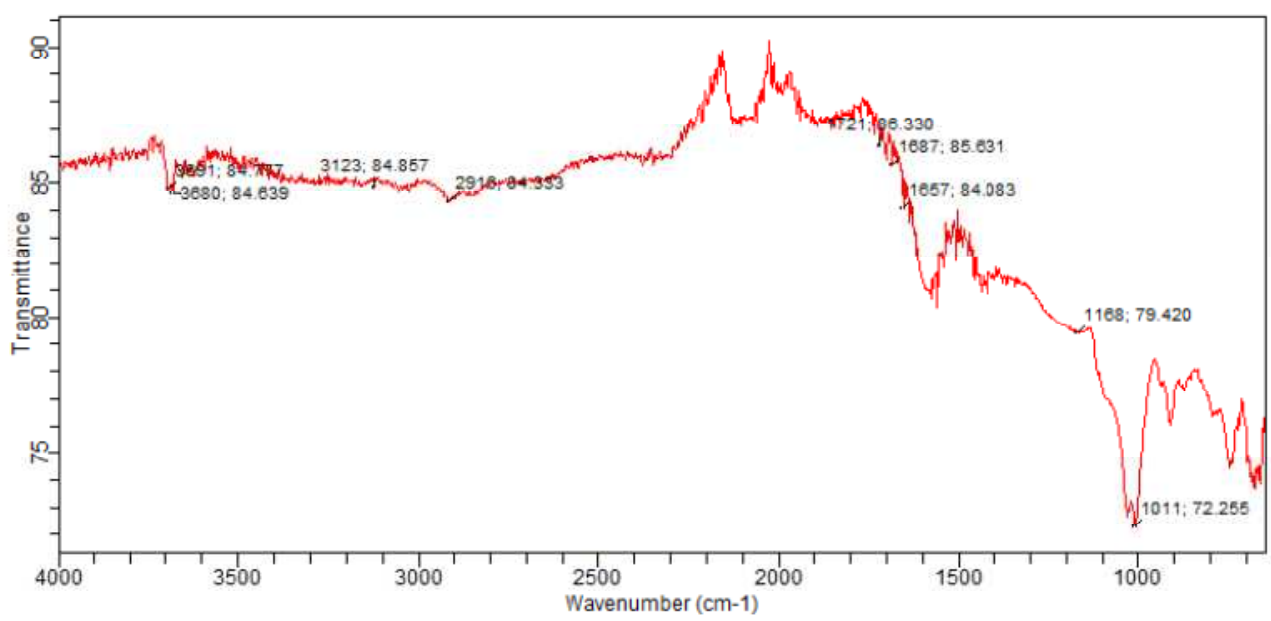

Fig. 2 : FT-IR spectraof peatsoilhumic acid (PSHA)

\section{Evaluation of acid dissociation constant (pka) of acid hydrolysed peat soil humicacid at phenolic group}

The value of the dissociation constant of the peat soil humic acid (PSHA) that underwent acidhydrolysis studied was found to be 8.9299 as shown Table 1, which is lower than the literaturevalues reported by Almeida and Szpoganics, (2015), Borges et al., (2005); Badr et al., (2012)and Fernandes et al,.(2009) of $9.73,9.47$ and 10.30. The difference between the obtained valuesand the reported values in this study might be probably as a result of acid hydrolysis of humicacid. 
BAJOPAS Volume 14 Number 1,June, 2021

Table 1: PKa of (Hydrolysed PSHA)

\begin{tabular}{|l|l|l|l|l|l|l|}
\hline $\mathrm{pH}$ & $\mathrm{BV}_{1}$ & $\mathrm{BV}_{2}$ & $\mathrm{~V}_{2}-\mathrm{V}_{1}$ & $\mathrm{nA}$ & $\log \left(\frac{n A}{1-n A}\right)$ & $\mathrm{pKa}$ \\
\hline 8.50 & 5.30 & 6.29 & 0.99 & 0.3594 & -0.2510 & 8.2490 \\
8.72 & 5.35 & 6.37 & 1.02 & 0.3400 & -0.2880 & 8.4320 \\
9.00 & 5.40 & 6.46 & 1.06 & 0.3141 & -0.3391 & 8.6609 \\
9.22 & 5.45 & 6.55 & 1.10 & 0.2882 & -0.3927 & 8.8273 \\
9.51 & 5.50 & 6.66 & 1.16 & 0.2494 & -0.4786 & 9.0314 \\
9.73 & 5.55 & 6.78 & 1.23 & 0.2041 & -0.5910 & 9.1390 \\
10.00 & 5.60 & 6.90 & 1.30 & 0.1589 & -0.7238 & 9.2762 \\
10.23 & 5.65 & 7.05 & 1.40 & 0.0941 & -0.9835 & 9.2465 \\
10.49 & 5.70 & 7.10 & 1.40 & 0.0941 & -0.9835 & 9.5065 \\
\hline
\end{tabular}

Average pKa $=8.9299 \pm 0.4186$

Table 2: PKa of (Unhydrolysed PSHA)

\begin{tabular}{|l|l|l|l|l|l|l|}
\hline $\mathrm{pH}$ & $\mathrm{BV}_{1}$ & $\mathrm{BV}_{2}$ & $\mathrm{~V}_{2}-\mathrm{V}_{1}$ & $\mathrm{nA}$ & $\log \left(\frac{\boldsymbol{n A}}{1-\boldsymbol{n}}\right)$ & $\mathrm{pKa}$ \\
\hline 8.50 & 5.30 & 5.81 & 0.51 & 0.6619 & 0.2919 & 8.7919 \\
8.72 & 5.35 & 5.90 & 0.55 & 0.6357 & 0.2418 & 8.9618 \\
9.00 & 5.40 & 6.00 & 0.60 & 0.6029 & 0.1813 & 9.1813 \\
9.22 & 5.45 & 6.10 & 0.65 & 0.5701 & 0.1226 & 9.3426 \\
9.51 & 5.50 & 6.20 & 0.70 & 0.5376 & 0.0654 & 9.5754 \\
9.73 & 5.55 & 6.33 & 0.78 & 0.4851 & -0.0259 & 9.7041 \\
10.00 & 5.60 & 6.47 & 0.87 & 0.4262 & -0.1291 & 9.8709 \\
10.23 & 5.65 & 6.62 & 0.99 & 0.3609 & -0.2481 & 9.9819 \\
10.49 & 5.70 & 6.80 & 1.10 & 0.2759 & -0.4690 & 10.0210 \\
\hline
\end{tabular}

Average pKa $=9.4923 \pm 0.4410$

Metal-ligand stability constant ( $\log \mathrm{K}$ )

The stabilityconstants require the accurate values of proton-ligand stability constants (Anil and Maroti, 2008). Metal titration curves crossed over ligand titration curve indicated the formation of complex upon proton release (Santosh, et al., 2011). If the values of n- are within range $0.2-0.8$ and $1.2-18$ this indicates the formation of $1: 1$ and 1:2 complexes (Sayyed and Mazahar, 2012).

The metal (II)-humate stepwise stability constants (log k) at phenolic group (Tables 318)

Table 3: Point-wise method, $\mathrm{Cu}$-(Hydrolysed PSHA)

\begin{tabular}{|l|l|l|l|l|l|l|l|l|}
\hline $\mathrm{pH}$ & $\mathrm{BV}_{1}$ & $\mathrm{BV}_{2}$ & $\mathrm{BV}_{3}$ & $\left(\mathrm{~V}_{3}-\mathrm{V}_{2}\right)$ & $\mathrm{n}$ & $\mathrm{pL}$ & $\log \left(\frac{n}{1-n}\right)$ & LogK $_{1}$ \\
\hline 8.50 & 5.30 & 6.29 & 6.33 & 0.04 & 0.5500 & 2.66 & 0.0871 & 2.7471 \\
8.72 & 5.35 & 6.37 & 6.41 & 0.04 & 0.5714 & 2.43 & 0.1249 & 2.5549 \\
9.00 & 5.40 & 6.46 & 6.50 & 0.04 & 0.6198 & 2.16 & 0.2122 & 2.3722 \\
9.22 & 5.45 & 6.55 & 6.59 & 0.04 & 0.6667 & 1.94 & 0.3010 & 2.2410 \\
\hline
\end{tabular}

LogK $_{1}$ (Average value) $=2.4788 \pm 0.2203$

Table 4: Point-wise method, $\mathrm{Cu}$-(Hydrolysed PSHA)

\begin{tabular}{|l|l|l|l|l|l|l|l|l|}
\hline $\mathrm{pH}$ & $\mathrm{BV}_{1}$ & $\mathrm{BV}_{2}$ & $\mathrm{BV}_{3}$ & $\left(\mathrm{~V}_{3}-\mathrm{V}_{2}\right)$ & $\mathrm{n}$ & $\mathrm{pL}$ & $\log \left(\frac{n-1}{2-n}\right)$ & LogK $_{2}$ \\
\hline 9.51 & 5.50 & 6.66 & 6.73 & 0.07 & 1.3509 & 1.70 & -0.2671 & 1.4329 \\
9.73 & 5.55 & 6.78 & 6.85 & 0.07 & 1.6383 & 1.51 & 0.2467 & 1.7567 \\
10.00 & 5.60 & 6.90 & 6.98 & 0.08 & 2.1783 & 1.31 & -0.2158 & 1.0942 \\
10.23 & 5.65 & 7.05 & 7.13 & 0.08 & 4.1904 & 1.27 & & \\
10.49 & 5.70 & 7.10 & 7.19 & 0.09 & 4.6920 & & & \\
\hline
\end{tabular}

Log $K_{2}($ Average value $)=1.4280 \pm 0.3312$ 
BAJOPAS Volume 14 Number 1,June, 2021

Table 5: Point-wise method, $\mathrm{Cu}$ (Unhydrolysed PSHA)

\begin{tabular}{|l|l|l|l|l|l|l|l|l|}
\hline $\mathrm{pH}$ & $\mathrm{BV}_{1}$ & $\mathrm{BV}_{2}$ & $\mathrm{BV}_{3}$ & $\left(\mathrm{~V}_{3}-\mathrm{V}_{2}\right)$ & $\mathrm{n}$ & $\mathrm{pL}$ & $\log \left(\frac{n}{n-1}\right)$ & Log $_{1}$ \\
\hline 8.50 & 5.30 & 5.81 & 5.85 & 0.04 & 0.2973 & 2.88 & -0.3736 & 2.5064 \\
8.72 & 5.35 & 5.90 & 5.95 & 0.05 & 0.3873 & 2.66 & -0.1992 & 2.4608 \\
9.00 & 5.40 & 6.00 & 6.05 & 0.05 & 0.4044 & 2.38 & -0.1681 & 2.2119 \\
9.22 & 5.45 & 6.10 & 6.15 & 0.06 & 0.5157 & 2.18 & -0.0272 & 2.2072 \\
9.51 & 5.50 & 6.20 & 6.27 & 0.07 & 0.6417 & 1.89 & 0.2530 & 1.1430 \\
\hline
\end{tabular}

$\operatorname{LogK}_{1}($ Average value $)=2.3059 \pm 0.6153$

Table 6:Point-wise method, $\mathrm{Cu}$ (Unhydrolysed PSHA)

\begin{tabular}{|l|l|l|l|l|l|l|l|l|}
\hline $\mathrm{pH}$ & $\mathrm{BV}_{1}$ & $\mathrm{BV}_{2}$ & $\mathrm{BV}_{3}$ & $\mathrm{~V}_{3}-\mathrm{V}_{2}$ & $\mathrm{n}$ & $\mathrm{pL}$ & $\log \left(\frac{n-1}{2-n}\right)$ & $\log \mathrm{K}_{2}$ \\
\hline 9.73 & 5.55 & 6.33 & 6.42 & 0.09 & 0.9000 & 1.69 & & \\
10.00 & 5.60 & 6.47 & 6.58 & 0.11 & 1.2578 & 1.44 & -0.4592 & 0.9808 \\
10.23 & 5.65 & 6.62 & 6.84 & 0.12 & 1.6137 & 1.26 & -0.2010 & 1.4610 \\
10.49 & 5.70 & 6.80 & 6.92 & 0.12 & 2.1052 & 1.03 & & \\
\hline
\end{tabular}

$\operatorname{LogK}_{2}$ (Average value) $=1.2209 \pm 0.3398$

Table 7:Point-wise method, Pb (Hydrolysed PSHA)

\begin{tabular}{|l|l|l|l|l|l|l|l|l|}
\hline $\mathrm{pH}$ & $\mathrm{BV}_{1}$ & $\mathrm{BV}_{2}$ & $\mathrm{BV}_{3}$ & $\left(\mathrm{~V}_{3}-\mathrm{V}_{2}\right)$ & $\mathrm{n}$ & $\mathrm{pL}$ & $\log \left(\frac{n}{1-n}\right)$ & LogK $_{1}$ \\
\hline 8.50 & 5.30 & 6.29 & 6.33 & 0.04 & 0.5500 & 2.66 & 0.0871 & 2.7471 \\
8.72 & 5.35 & 6.37 & 6.41 & 0.04 & 0.5714 & 2.43 & 0.1249 & 2.5549 \\
9.00 & 5.40 & 6.46 & 6.50 & 0.04 & 0.6198 & 2.16 & 0.2122 & 2.3722 \\
9.22 & 5.45 & 6.55 & 6.60 & 0.05 & 0.8333 & 1.96 & 0.6989 & 2.6589 \\
\hline
\end{tabular}

Log $_{\mathbf{1}}($ Average value $)=2.5832 \pm 0.1614$

Table 8:Point-wise method, Pb-(Hydrolysed PSHA)

\begin{tabular}{|l|l|l|l|l|l|l|l|l|}
\hline $\mathrm{pH}$ & $\mathrm{BV}_{1}$ & $\mathrm{BV}_{2}$ & $\mathrm{BV}_{3}$ & $\left(\mathrm{~V}_{3}-\mathrm{V}_{2}\right)$ & $\mathrm{n}$ & $\mathrm{pL}$ & $\log \left(\frac{n-1}{2-n}\right)$ & $\log \mathrm{K}_{2}$ \\
\hline 9.51 & 5.50 & 6.66 & 6.71 & 0.05 & 0.9650 & 1.67 & & \\
9.73 & 5.55 & 6.78 & 6.83 & 0.05 & 1.1702 & 1.44 & & \\
10.00 & 5.60 & 6.90 & 6.90 & 0.05 & 1.4864 & 1.22 & -0.0237 & 1.1963 \\
10.23 & 5.65 & 7.05 & 7.10 & 0.05 & 2.0190 & 1.09 & & \\
10.49 & 5.70 & 7.10 & 7.17 & 0.07 & 3.6492 & 1.00 & & \\
\hline
\end{tabular}

Log $K_{2}$ (Average value) $=1.1963$

Table 9: Point-wise method, Pb (Unhydrolysed PSHA)

\begin{tabular}{|l|l|l|l|l|l|l|l|l|}
\hline $\mathrm{pH}$ & $\mathrm{BV}_{1}$ & $\mathrm{BV}_{2}$ & $\mathrm{BV}_{3}$ & $\mathrm{~V}_{3}-\mathrm{V}_{2}$ & $\mathrm{n}$ & $\mathrm{pL}$ & $\begin{array}{l}\text { Log } \\
\left(\frac{n}{n-1}\right)\end{array}$ & Log $\mathrm{K}_{1}$ \\
\hline 8.50 & 5.30 & 5.81 & 5.85 & 0.04 & 0.2973 & 2.88 & -0.3736 & 2.5064 \\
8.72 & 5.35 & 5.90 & 5.94 & 0.04 & 0.3099 & 2.66 & -0.5477 & 2.3123 \\
9.00 & 5.40 & 6.00 & 6.05 & 0.05 & 0.4044 & 2.38 & -0.1681 & 2.2119 \\
9.22 & 5.45 & 6.10 & 6.15 & 0.06 & 0.5157 & 2.18 & 0.0272 & 2.2072 \\
9.51 & 5.50 & 6.20 & 6.26 & 0.07 & 0.6417 & 1.89 & 0.2530 & 2.1430 \\
9.73 & 5.55 & 6.40 & 6.40 & 0.07 & 0.7000 & 1.67 & 0.3680 & 2.0380 \\
\hline
\end{tabular}

LogK $_{1}$ (Average value) $=2.2364 \pm 0.1602$

Table 10: Point-wise method, Pb (Unhydrolysed PSHA)

\begin{tabular}{|l|l|l|l|l|l|l|l|l|}
\hline $\mathrm{pH}$ & $\mathrm{BV}_{1}$ & $\mathrm{BV}_{2}$ & $\mathrm{BV}_{3}$ & $\mathrm{~V}_{3}-\mathrm{V}_{2}$ & $\mathrm{n}$ & $\mathrm{pL}$ & $\log \left(\frac{n-1}{2-n}\right)$ & $\log \mathrm{K}_{2}$ \\
\hline 10.00 & 5.60 & 6.47 & 6.55 & 0.08 & 1.9503 & 1.41 & & \\
10.23 & 5.65 & 6.62 & 6.72 & 0.11 & 1.4792 & 1.26 & -0.0361 & 1.2239 \\
\hline
\end{tabular}

$\operatorname{LogK}_{2}$ (Average value) $=1.2239$

Table 11: Point-wise method, Mg (Hydrolysed PSHA)

\begin{tabular}{|l|l|l|l|l|l|l|l|l|}
\hline $\mathrm{pH}$ & $\mathrm{BV}_{1}$ & $\mathrm{BV}_{2}$ & $\mathrm{BV}_{3}$ & $\left(\mathrm{~V}_{3}-\mathrm{V}_{2}\right)$ & $\mathrm{n}$ & $\mathrm{pL}$ & $\log \left(\frac{n}{n-1}\right)$ & LogK $_{1}$ \\
\hline 8.50 & 5.30 & 6.29 & 6.31 & 0.02 & 0.2750 & 2.64 & -0.4290 & 2.2110 \\
8.72 & 5.35 & 6.37 & 6.39 & 0.02 & 0.2858 & 2.42 & -0.3978 & 2.0222 \\
9.00 & 5.40 & 6.46 & 6.49 & 0.03 & 0.4648 & 2.14 & -0.0612 & 2.0788 \\
9.22 & 5.45 & 6.55 & 6.59 & 0.04 & 0.6667 & 1.94 & 0.3010 & 2.2410 \\
\hline
\end{tabular}

$\log _{\mathbf{1}}($ Average value) $=2.1382 \pm 0.1046$ 
BAJOPAS Volume 14 Number 1,June, 2021

Table 12: Point-wise method, Mg (Hydrolysed PSHA)

\begin{tabular}{|l|l|l|l|l|l|l|l|l|}
\hline $\mathrm{pH}$ & $\mathrm{BV}_{1}$ & $\mathrm{BV}_{2}$ & $\mathrm{BV}_{3}$ & $\left(\mathrm{~V}_{3}-\mathrm{V}_{2}\right)$ & $\mathrm{n}$ & $\mathrm{pL}$ & $\log \left(\frac{n-1}{2-n}\right)$ & LogK $_{2}$ \\
\hline 9.51 & 5.55 & 6.66 & 6.71 & 0.05 & 0.9650 & 1.67 & & \\
9.73 & 5.55 & 6.78 & 6.84 & 0.06 & 1.4042 & 1.47 & -0.1686 & 1.3014 \\
10.00 & 5.60 & 6.90 & 6.93 & 0.06 & 1.7838 & 1.23 & 0.5593 & 1.7893 \\
10.23 & 5.65 & 7.05 & 7.10 & 0.06 & 3.1429 & 1.10 & & \\
10.49 & 5.70 & 7.10 & 7.18 & 0.07 & 3.6492 & 0.83 & & \\
\hline
\end{tabular}

LogK $_{2}($ Average value $)=1.5453 \pm 0.3450$

Table 13: Point-wise method, Mg (Unhydrolysed PSHA)

\begin{tabular}{|l|l|l|l|l|l|l|l|l|}
\hline $\mathrm{pH}$ & $\mathrm{BV}_{1}$ & $\mathrm{BV}_{2}$ & $\mathrm{BV}_{3}$ & $\mathrm{~V}_{3}-\mathrm{V}_{2}$ & $\mathrm{n}$ & $\mathrm{pL}$ & $\log \left(\frac{n}{n-1}\right)$ & $\operatorname{Log~}_{1}$ \\
\hline 8.50 & 5.30 & 5.81 & 5.85 & 0.04 & 0.2973 & 2.88 & -0.3736 & 2.5064 \\
8.72 & 5.35 & 5.90 & 5.94 & 0.04 & 0.3099 & 2.66 & -0.3477 & 2.3123 \\
9.00 & 5.40 & 6.00 & 6.04 & 0.04 & 0.3236 & 2.38 & -0.3202 & 2.0598 \\
9.22 & 5.45 & 6.10 & 6.15 & 0.05 & 0.4297 & 2.17 & -0.1230 & 2.0470 \\
9.51 & 5.50 & 6.20 & 6.26 & 0.06 & 0.5500 & 1.89 & 0.0871 & 1.9771 \\
9.73 & 5.55 & 6.33 & 6.40 & 0.07 & 0.7000 & 1.67 & 0.3680 & 2.0380 \\
\hline
\end{tabular}

LogK $_{1}$ (Average value) $=2.1568 \pm 0.2069$

Table 14: Point-wise method, Mg (Unhydrolysed PSHA)

\begin{tabular}{|l|l|l|l|l|l|l|l|l|}
\hline $\mathrm{pH}$ & $\mathrm{BV}_{1}$ & $\mathrm{BV}_{2}$ & $\mathrm{BV}_{3}$ & $\mathrm{~V}_{3}-\mathrm{V}_{2}$ & $\mathrm{n}$ & $\mathrm{pL}$ & $\log \left(\frac{n-1}{2-n}\right)$ & $\log \mathrm{K}_{2}$ \\
\hline 10.00 & 5.60 & 6.47 & 6.55 & 0.08 & 0.9148 & 1.41 & & \\
10.23 & 5.65 & 6.62 & 6.71 & 0.09 & 1.2102 & 1.20 & -0.5749 & 0.6251 \\
10.49 & 5.70 & 6.80 & 6.92 & 0.09 & 1.5968 & 1.03 & 0.1703 & 1.2003 \\
\hline
\end{tabular}

LogK $_{2}$ (Average value) $=0.9127 \pm 0.4070$

Table15:Point-wise method, Cd (Hydrolysed PSHA)

\begin{tabular}{|l|l|l|l|l|l|l|l|l|}
\hline $\mathrm{pH}$ & $\mathrm{BV}_{1}$ & $\mathrm{BV}_{2}$ & $\mathrm{BV}_{3}$ & $\left(\mathrm{~V}_{3}-\mathrm{V}_{2}\right)$ & $\mathrm{n}$ & $\mathrm{pL}$ & $\log \left(\frac{n}{1-n}\right)$ & LogK $_{1}$ \\
\hline 8.50 & 5.30 & 6.29 & 6.31 & 0.02 & 0.2750 & 2.64 & -0.4210 & 2.2190 \\
8.72 & 5.35 & 6.37 & 6.40 & 0.03 & 0.4286 & 2.42 & -0.1249 & 2.2951 \\
9.00 & 5.40 & 6.46 & 6.49 & 0.03 & 0.4648 & 2.14 & -0.0612 & 2.0788 \\
9.22 & 5.45 & 6.55 & 6.59 & 0.04 & 0.6667 & 1.96 & 0.3010 & 2.2610 \\
9.51 & 5.55 & 6.66 & 6.70 & 0.04 & 0.7720 & 1.67 & 0.5297 & 2.1997 \\
\hline
\end{tabular}

LogK $_{\mathbf{1}}$ (Average value) $=2.2108 \pm 0.0825$

Table 16: Point-wise method, Cd (Hydrolysed PSHA)

\begin{tabular}{|l|l|l|l|l|l|l|l|l|}
\hline $\mathrm{pH}$ & $\mathrm{BV}_{1}$ & $\mathrm{BV}_{2}$ & $\mathrm{BV}_{3}$ & $\left(\mathrm{~V}_{3}-\mathrm{V}_{2}\right)$ & $\mathrm{n}$ & $\mathrm{pL}$ & $\log \left(\frac{n-1}{2-n}\right)$ & Log $_{2}$ \\
\hline 9.73 & 5.55 & 6.78 & 6.83 & 0.06 & 1.4042 & 1.47 & -0.1686 & 1.3014 \\
10.00 & 5.60 & 6.90 & 6.95 & 0.06 & 1.7838 & 1.23 & 0.5593 & 1.7893 \\
10.23 & 5.65 & 7.05 & 7.10 & 0.06 & 3.1429 & 1.09 & & \\
10.49 & 5.70 & 7.10 & 7.16 & 0.06 & 3.1429 & 0.89 & & \\
& & & & & & & & \\
\hline
\end{tabular}

$\operatorname{LogK}_{2}$ (Average value) $=1.5453 \pm 0.3450$

Table 17: Point-wise method, Cd (Unhydrolysed PSHA)

\begin{tabular}{|l|l|l|l|l|l|l|l|l|}
\hline $\mathrm{pH}$ & $\mathrm{BV}_{1}$ & $\mathrm{BV}_{2}$ & $\mathrm{BV}_{3}$ & $\mathrm{~V}_{3}-\mathrm{V}_{2}$ & $\mathrm{n}$ & $\mathrm{pL}$ & $\log \left(\frac{n}{n-1}\right)$ & $\operatorname{Log~}_{1}$ \\
\hline 8.50 & 5.30 & 5.81 & 5.86 & 0.05 & 0.3717 & 2.88 & -0.2280 & 2.6520 \\
8.72 & 5.35 & 5.90 & 5.95 & 0.05 & 0.3873 & 2.66 & -0.1992 & 2.4608 \\
9.00 & 5.40 & 6.00 & 6.06 & 0.06 & 0.4853 & 2.38 & -0.0255 & 2.3545 \\
9.22 & 5.45 & 6.10 & 6.16 & 0.06 & 0.5157 & 2.18 & -0.0272 & 2.2072 \\
9.51 & 5.50 & 6.20 & 6.27 & 0.07 & 0.6417 & 1.89 & 0.2530 & 1.1430 \\
9.73 & 5.55 & 6.33 & 6.41 & 0.08 & 0.8000 & 1.69 & 0.6020 & 2.2920 \\
& & & & & & & & \\
\hline
\end{tabular}

$\operatorname{LogK}_{1}($ Average value $)=2.2516 \pm 0.5380$ 
BAJOPAS Volume 14 Number 1,June, 2021

Table 18: Point-wise method, Cd (Unhydrolysed PSHA)

\begin{tabular}{|l|l|l|l|l|l|l|l|l|}
\hline $\mathrm{pH}$ & $\mathrm{BV}_{1}$ & $\mathrm{BV}_{2}$ & $\mathrm{BV}_{3}$ & $\mathrm{~V}_{3}-\mathrm{V}_{2}$ & $\mathrm{n}$ & $\mathrm{pL}$ & $\log \left(\frac{n-1}{2-n}\right)$ & $\log \mathrm{K}_{2}$ \\
\hline 10.00 & 5.60 & 6.47 & 6.57 & 0.10 & 1.1434 & 1.43 & & \\
10.23 & 5.65 & 6.62 & 6.72 & 0.10 & 1.3448 & 1.23 & -0.2788 & 0.9512 \\
10.49 & 5.70 & 6.80 & 6.90 & 0.10 & 1.7742 & 1.03 & 0.5351 & 1.5651 \\
\hline
\end{tabular}

$\operatorname{LogK}_{2}($ Average value $)=1.2581 \pm 0.4340$

Table 19: Stepwise and overall Stability constants of thehydrolysed and unhydrolysed divalent metal (II) complexes

\begin{tabular}{|c|c|c|c|}
\hline Chelates & LogK $_{1}$ & $\log _{2}$ & Log $\beta$ \\
\hline [Cu (Hydrolysed PSHA-1) $\left.{ }_{2}\right]$ & 2.4788 & 1.4280 & 3.9068 \\
\hline$\left[\mathrm{Pb}(\text { Hydrolysed PSHA-1) })_{2}\right]$ & 2.5832 & 1.1963 & 3.7795 \\
\hline$\left[\mathrm{Cd}(\text { Hydrolysed PSHA-1 })_{2}\right]$ & 2.2108 & 1.5453 & 3.7561 \\
\hline$\left[\mathrm{Mg}(\text { Hydrolysed PSHA-1 })_{2}\right]$ & 2.1382 & 1.5453 & 3.6835 \\
\hline [Cu (Unhydrolysed PSHA-1) & 2.3059 & 1.2209 & 3.5268 \\
\hline$[\mathrm{Pb}$ (Unhydrolysed PSHA-1) 2$]$ & 2.2364 & 1.2239 & 3.4603 \\
\hline [Cd (Unhydrolysed PSHA-1) 2 ] & 2.2516 & 1.2581 & 3.5097 \\
\hline$[\mathrm{Mg}$ (Unydrolysed PSHA-1) & 2.1568 & 0.9127 & 3.0695 \\
\hline
\end{tabular}

The results obtained (Table19) shows the stepwise and overall stability constants to be not high indicating low stability of the complexes, because the solubility of most metal ions in the basic $\mathrm{pH}$ range is minimal due to metal hydroxide precipitation (Karimi, 2017). In general, the stepwise stability constants $\left(K_{1}\right.$ and $K_{2}$ ) follow the order $K_{1}>K_{2}$ for the copper, lead, magnesium and cadmium complexes respectively. The steady decrease of the values with increasing number of ligands is in agreement with the prediction made by researchers (Na'aliya, 2013). The decrease could be attributed to the fact that as the number of the ligands (Humate ions) that enters the coordination zone increases the aqua molecules available for replacement by the ligands become less. Thus, the metal ions become less electron loving with progressive intake of the ligand and this results in the decrease in the values of the constants (Na'aliya, 2013). Also the stability of the complexes is influenced by the size and number of the chelate rings(Mackay and Mackay,2002).All the complexes form rings in their structure as humate, a bidentate ligand, bond the metal ions in the ratio 1:2 (Boguta and Sokolowska, 2016) forming chelate rings. The values of the overall stability constants $(\log \beta)$ obtained for humate complexes are not high indicating low stability as the values are not high. LogK values for copper-humates (Table 3 to 6) obtained in this study are lower than those reported for the complexes of humic acids (Pandey et al., 2015; Dinu, 2013; Kaschl et al., 2010 and Gilbeto and Jorg, 2001). The values of LogK(Table 7 to 10 ) forlead-humates are lower than those reported for the lead in the literature (Dinu, 2013; Gilbeto and Jorg 2001). Log K values(Table 11 to 14 ) for magnesium-humates obtained in this study are close to those reported by (Pandey et al., 2015). Log K values of cadmium-humates (Table 15 to 18 ) obtained in this work near to the one reported by (Dinu, 2013 and Pandey et al., 2015).The difference between the reported values and the values obtained in this study might be probably as a result of acid hydrolysis of humic acid. The values of the overall stability constants $(\log \beta)$ of the copper humates complexes presented in Table 19 is high than that of other metal humate complexes, show relatively high stability of CuHA complexes, show the following order of stability: $\mathrm{Cu}>\mathrm{Pb}>\mathrm{Cd}>\mathrm{Mg}$; which are in close agreement to the findings of (Dinu, 2013 and Pandey et al., 2015).The high stability of Cuhumate chelate could be attributed to the existence of coordinate covalent bond between the complexing agents and the $\mathrm{Cu}^{2+}$ ions. Since, $\mathrm{Cu}^{2+}$ being a metal of the transitional series with $3 d^{9}$ electronic configurations can accept the electrons from the complexing agents. Similarly, the low stabilities of $\mathrm{Pb}, \mathrm{Cd}$ and $\mathrm{Mg}$ complexes could be explained by that $\mathrm{Pb}^{2+}$ with $6 s^{2}, \mathrm{Cd}^{2+}$ with $4 \mathrm{~d}^{10}$ and $\mathrm{Mg}^{2+}$ with $2 \mathrm{p}^{6}$ their electronic configuration has a completely filled $\mathrm{d}, \mathrm{p}$ and $\mathrm{s}$ orbitals. Moreover, the stabilities of metal ions with hydrolysed humic acid from peat soil were higher than those with unhydrolysed humic acid from peat soil; which is ascribed to the high content of acidity in hydrolysed humic acid than unhydrolysed humic acid. 
BAJOPAS Volume 14 Number 1,June, 2021 CONCLUSION

The values of logk for $\mathrm{Cu}(\mathrm{II})$ hydrolysed humic acid complex was higher followed by $\mathrm{Pb}$ (II), $\mathrm{Cd}(\mathrm{II})$ and $\mathrm{Mg}$ (II) hydrolysed humic acid complexes as compared with metal(II) unhydrolysed humic acid complexes. This indicates acid hydrolysis of humic acid can

\section{REFERENCES}

Almeida, V.R. and Szpoganicz, B. (2015). Humic Acid Potentiometric Response Patterns:Out- of Equilibrium Properties and Species Distribution Modelling. Chemical. Biol. Technol. Agric. 2: 17.

Anđelković, T., Nikolić, R., Bojić, A.,Anđelković, D., and Nikolic G.,(2010). Binding of Cadmium to Soil Humic Acid as A Function of Carboxyl Group Content. Macedonian Journal of Chemistry and Chemical Engineering.29(2): 215-224.

Anil, B. N. and Maroti, N. (2008). Studies on Influence of Die-Lectric Constants on Complex Equilibria between Substituted Py-Razalines and Lanthanide Metal Ions pH-Metrically. Amer.-Euras. scient. Res. 3(2): 212-216.

Ashok, K., Pandey, S. P. and Misra, V (2000). Stability Constants of Metal-Humic Acid Complexes and its Role in Environmental Detoxification. Journal of Ecotoxicology and Environmental Safety. 47(2):157-200.

Badr, M. H., El-Halafawi, M. H. and Abd El-al Zeid, E. R. (2012). Comparison Between the Effect of Ionic Strength on Acidity and Dissociation Constants of Humic Acids Extracted from Sewage Sludge and Nile Water Hyacinth Composts.Global Journal of Environmental Research 6 (1): 36-43.

Baruah, M.K., Borah, D., Saikia, P.P., Paul, S., Sharma, T. (2015). Evaluation of pKa Values of Soil Humic Acids and their Complexation Properties. International Journal of Plant \& Soil Science 6(4) : 218-228.

Boguta, P. Sokolowska, Z. (2016). Interactions of $\mathrm{Zn}$ (II) Ions with Humic Acids Isolated from Various Types of Soils. Effect of $\mathrm{pH}, \mathrm{Zn}$ Concentrations and Humic Acids Chemical Properties. Journal of Geochemical Explaration 168. 119-126.

Borges, F., Guimaraes, C., Lima, L.F.C., Pinto, I. and Reis, S.(2005). Potentiometric Studies on the Complexation of Copper(II) by Phenolic Acids as Discrete Ligand Models of enhance the complexation behavior of humic acid with metal (II) ions. However, the higher values of $\log \beta$ for $\mathrm{Cu}(\mathrm{II}), \mathrm{Pb}(\mathrm{II}), \mathrm{Cd}(\mathrm{II})$ and $\mathrm{Mg}(\mathrm{II})$ hydrolysed humic acid complexes indicates more stable stepwise complexes formed as compared with $\mathrm{Cu}(\mathrm{II}), \mathrm{Pb}$ (II), $\mathrm{Cd}$ (II) and $\mathrm{Mg}(\mathrm{II})$ unhydrolysed humic acid complexes.

Humic Substances Talanta 66 (2005) 670-673.

Chefetz, B., Salloum, M. J., Deshmulkin, A. P. and Hatcher, P. (2002). Structural Components of Humic Acids as Determined by Chemical Modifications and Carbon-13 NMR, Pyrolysis, and Thermochemolysis- Gas Chromatography/Mass Spectrometry. Soil Science Society of American Journal Abstract Division S-2- Soil Chemistry66. 1159-1171.

Dinu, M. I. (2013). Metals Complexation with Humic Acids in Surface Water of Different Environ. Sci. Technol. 31(1): 1-17.

Fernandes, A.N., Giacomelli, C., Giovanela, M. Vaz, D.V. Szpoganicz, B. and Maria M. D. (2009). Potentiometric Acidity Determination in Humic Substances Influenced by Different Analytical Procedures.J. Braz. Chem. Soc. 20 (9):14.

Gamal, A. H. (2015). Stability Constants of Rhenium (V) Metal Complexes with Selected Drugs. Pyrex Journal of Research in Environmental Studies. 2(2): 006-014.

Janrao, D. M., Pathan, J., Kayande, D.D., and Mulla, J.J. (2014). An Over View of Potentiometric Determination of Stability Constants of Metal Complexes. Sci. Revs. Chem. Commun.: 4(1), 2014, 11-24.

Karimi, H. (2017). Effect of pH and Initial Pb(II) Concentration on the Lead Removal Efficiency from Waste Water Using $\mathrm{Ca}(\mathrm{OH})_{2}$. International Journal of Water and Waste Water Treatment 3.2

Kaschl, A. Romheld, V. and Chen, Y. (2010). Binding of Cadmium, Copper and Zinc to Humic Substances Originating from Municipal Solid Waste Compost. Israel Journal of Chemistry Vol. 42(1): 89-98.

Kostic, I. S., Tatjana, P, A., Nikolic, R. S., Cvetkovic, T. P., Pavlovic, D. D., Aleksandar, L.J. and Bojic, A. (2012). Comparative Study of Binding Strengths of Heavy Metals with Humic Acid. J.serb. Chem. Soc. 76(9) pp 1-20. 
BAJOPAS Volume 14 Number 1,June, 2021

Na'aliya, J. (2013). Determination of Stepwise Stability Constants and Gibbs free Energy Change of Trisprolina to Complexes of some Divalent Transition Metal ions. Bayero Journal of Pure and Applied Sciences 6(2): 112-114.

Omar, A. A. and Ali, E. A. (2015). Potentiometric Studies on Complexes of $\mathrm{Cr}$ (III) and $\mathrm{Zr}$ (IV) with some Carboxylic Acids. International Journal of Advanced Chemistry, 3(1) 25-

37.

Pandey, A. K. Pandey, S. D. and Misr, V. (2015).Stability Constants of Metal- Humic Acid Complexes and Its Role in Environmental Detoxification. J. Ecotoxicology and Environmental Safety. 47(1):195-200.

Ram, N. and Raman, K.V. (1984). Stability Constants of Complexes of Metals with
Humicand Fuvic Acids under Non- acidConditions. Journal of Plant Nutrition and Soil Sciences.

147:171-176.

Santosh, D. D., Ashok, B. K., Vijay, J. T., Shivraj, G. W. and Vinay, V. W. (2011). Potentiometric Studies of Elec-Trolyte Effects on Complex Equilibria of Some Substituted 5-(2-hydroxy Phenyl) Pyrazoles. Der pharm. 3 (6): 75-83.

Sayyed, H. and Abdul Rahim, M. F. (2012). Studies of Binary Complexes of Metal Ions with Mandelic Acid by Potentiometry. Chem. J. 02 (6): 206209.

Shirvani, M. Moradian, E. Khalili, B. Bakhtiary, S. (2015). Interaction of $\mathrm{Cd}$ and $\mathrm{Pb}$ with Humate-Palygorskite and HumateSepiolite Complexes. Journal of water, air and pollution 3: 220-228. 


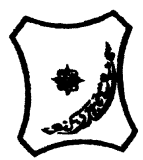

Bayero Journal of Pure and Applied Sciences, 14(1): 54 - 63

Received: November, 2020

Accepted: April, 2021

ISSN $2006-6996$

\title{
STABILITY CONSTANTS OF COMPLEXES OF METAL IONS WITH PEATSOIL HUMIC ACIDS UNDER NON-ACID-CONDITIONS
}

\author{
${ }^{* 1}$ Sabo, Yusuf ${ }^{2}$ Jimoh, W.L.O., ${ }^{3}$ Isa Baba Koki and ${ }^{4}$ Sholadoye, Q. 0. \\ ${ }^{1}$ Department of Pure and Industrial Chemistry, Bayero University, Kano \\ ${ }^{3}$ Department of Chemistry, Yusuf Maitama Sule University Kano. P.M.B. 3220 Kano, Nigeria. \\ ${ }^{4}$ Department of Chemistry, Nigerian Police Academy, Wudil, Kano-Nigeria
}

*Correspondence E-mail; saboyusuf18@yahoo.com

ABSTRACT

Stability constants of complexes of four divalent metal ions viz. $\mathrm{Cu}^{2+}, \mathrm{Pb}^{2+}, \mathrm{Mg}^{2+}$ and $\mathrm{Cd}^{2+}$ with humic acids (HA) were determined by potentiometric titration of humic acids with the corresponding salt of the divalent metals in aqueous media under non-acid-condition. The log $K$ (logarithm of the stability constant) ranged from 1.0942 to 2.7471 for metalhumic acid complexes were determined using point-wise computational method. The order of stability constants were obtained as follows: $\mathrm{Cu}>\mathrm{Pb}>\mathrm{Cd}>\mathrm{Mg}$ for metal $-\mathrm{HA}$ complexes respectively, indicating a higher degree of complexation with Cu metal ion.

Keywords: stability constant, humic acid, potentiometric titration, divalent metals, acid hydrolysis.

\section{NTRODUCTION}

The stability constant of a complex is the numerical expression of its stability and provides a quantitative measure of affinity of the metal ion to the complexing agent. An understanding of the relative stability of metal-complexes helps in predicting the behavior of metal ions in the soil (Ram and Raman, 1982). Extensive researches has been done to determine the stability constants of the complexes formed between humic acid (HA) with a number of metal ions. Ashok et al., (2000) reported that humic acid with hydroxyl, phenoxyl and carboxyl reactive groups can form coordination compound with metal ions at $\mathrm{pH}$ 3.5. The stability constants(Log K) for different metalhumic acid complexes indicated the following order of the stabilities of complexes formed between humic acid and metal ion, $\mathrm{Cu}>\mathrm{Fe}$ $>\mathrm{Pb}>\mathrm{Ni}>\mathrm{Co}>\mathrm{Ca}>\mathrm{Cd}>\mathrm{Zn}>\mathrm{Mn}>\mathrm{Mg}$. Andelkovic et al., (2010) investigated the binding of $\mathrm{Cd}$ (II) to soil humic acid at pH 6.5 and in $0.1 \mathrm{M} \mathrm{KNO}_{3}$ ionic medium. The stability constant for binding indicating greater stability in the case when carboxyl groups are involved in complexation reaction. Kostic et al.,(2012) investigated the complexation of humic acid with certain heavy metal ions (Co(II), $\mathrm{Ni}(\mathrm{II}), \mathrm{Cu}(\mathrm{II})$,
$\mathrm{Zn}(\mathrm{II})$, and $\mathrm{Pb}(\mathrm{II})$. The experiment was performed at $25^{\circ} \mathrm{C}$, at pH 4.0 and ionic strength of $0.01 \mathrm{M}$. Stability constant of complex between $\mathrm{Pb}$ (II) ions and humic acid is greater than stability constants of other investigated metalhumate complexes. Bogata and Sokolowska (2016) analyses the interaction between humic acids from different soils and $\mathrm{Zn}$ (II) ions at wide concentration ranges and at $\mathrm{pH} 5$. Studies have showed significant impact of $\mathrm{Zn}$ concentration, $\mathrm{pH}$ and some properties of humic acids with zinc.But all of these studies were limited to acidic $\mathrm{pH}$ range. Therefore, the present study was carried out to determine and compare the stability constants of complexes of metal ions with hydrolysed peat soil humic acid and unhydrolysed peat soil humic under non-acid conditions.

\section{MATERIALS AND METHODS}

Analytical grade chemicals used includes hydrochloric acid $(\mathrm{HCl})$, nitric acid $\left(\mathrm{HNO}_{3}\right)$, sodium hydroxide $(\mathrm{NaOH})$, lead nitrate $\mathrm{Pb}\left(\mathrm{NO}_{3}\right)_{2}$, copper nitrate $\mathrm{Cu}\left(\mathrm{NO}_{3}\right)_{2} \cdot 3 \mathrm{H}_{2} \mathrm{O}$, cadmium nitrate $\mathrm{Cd}\left(\mathrm{NO}_{3}\right)_{2} \cdot 4 \mathrm{H}_{2} \mathrm{O}$, magnesium nitrate $\mathrm{Mg}\left(\mathrm{NO}_{3}\right)_{2} \cdot 6 \mathrm{H}_{2} \mathrm{O}$, potassium nitrate $\left(\mathrm{KNO}_{3}\right)$, calcium chloride $\left(\mathrm{CaCl}_{2}\right)$, (sigma-Aldrich). Dowex 50WX8, (20-50 mesh) from Fluka. 


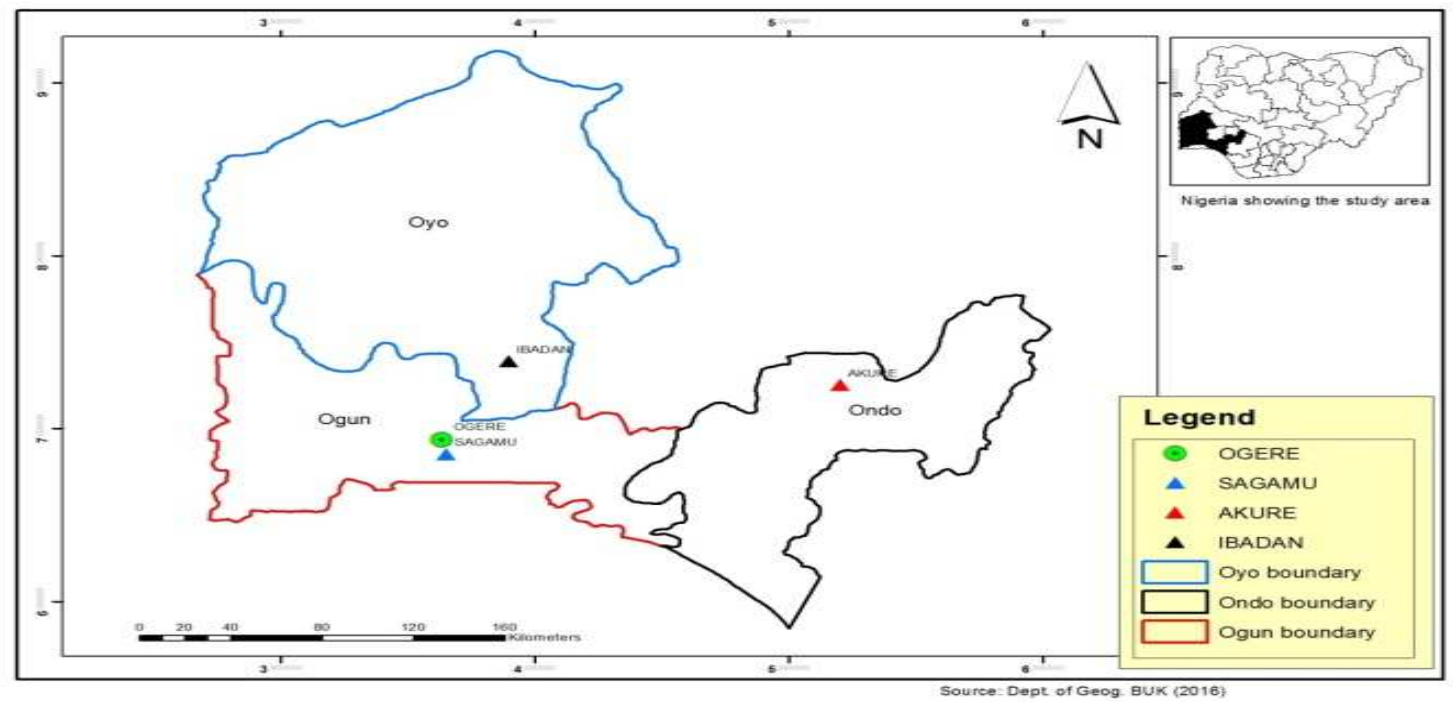

Figure 1: Map showing the sampling point at Sagamu Town, Ogun State.

\section{Description of Sampling Area}

Sagamu has geographical coordinates between $6^{\circ} 50^{\prime}$ north; $3^{\circ} 38^{\prime}$ east is located in south western region of Nigeria. The region has tropical wet and dry climate with a lengthy wet season and relatively constant temperatures throughout the course of the year. Wet season runs from March to October, November to December forms the region dry season. The vegetation type of the region is savannah which is really grassland with small bushes and occasional big trees. Grassland soils have substantially higher organic matter content than forest soils (Novackova, 2011).

\section{Sample Collection}

The Peatsoil samples were collected from four different sampling points $(0-10 \mathrm{~cm}$ depth) in Sagamu into polyethylene bag with plastic spoons. Samples were taken to the laboratory, extraneous materials were removed; the samples were air-dried, crushed and ground to a fine powder in a mortar passed through a $0.20 \mathrm{~mm}$ sieve. The samples were kept for analysis.

\section{Isolation and purification of humic acid from peat soil sample}

Peatsoil sample $(100 \mathrm{~g})$ was mixed with 1000 $\mathrm{cm}^{3}$ of $0.1 \mathrm{M} \mathrm{NaOH}$ solution, shaken for 3hours and left to stand overnight. Dark-coloured supernatant was obtained and decanted from solid residue. The dark-coloured supernatant was acidified to $(\mathrm{pH}=1.0)$ with $6 \mathrm{M} \mathrm{HCl}$ stirred and allowed to stand for 6 hours. Yellowish brown supernatant and dark-brown precipitate were obtained. The yellowish brown supernatant was decanted followed by centrifuge and discarded. The dark-brown precipitate was mixed with $500 \mathrm{~cm}^{3}$ of $0.1 \mathrm{M} \mathrm{NaOH}$ solution followed by passing through dowex resin. The dark-brown solution was acidified to $(\mathrm{pH}=1.0)$ with $6 \mathrm{M} \mathrm{HCl}$ stirred and allowed to stand for 3 hours. The dark-brown precipitate was washed several times with deionized water. The supernatant was treated with $\mathrm{AgNO}_{3}$ solution until no white precipitate observed. The humic acid was transferred to weighed crucible and dried at $60^{\circ} \mathrm{C}$ in an oven for 12 hours. The humic acid was cooled and dried in the desiccator, weighed and recorded. The obtained humic acid was dried again at $60^{\circ} \mathrm{C}$ for additional 6 hours cooled and dried in the desiccator, weighed and recorded constant weight was obtained (Baruah et al., 2015).

\section{FT-IR analysis}

FT-IR spectra of humic acid sample was analysed using Carry 630 FT-IR Agilent Technologies.

Unhydrolysed compost humic acid

The unhydrolysed humic acid was obtained after isolation and purification of compost humic acid and kept for investigation.

\section{Acid hydrolysis of Peatsoil acid}

Peatsoil humic acid sample (1g) was refluxed for 12 hours at $\left(160^{\circ} \mathrm{C}\right)$ with $50 \mathrm{~cm}^{3}$ of $6 \mathrm{M} \mathrm{HCl}$. The mixture was allowed to cool, decanted, and centrifuged after hydrolysis. The insoluble residues were washed with distilled water via centrifugation several times, and the supernatant was treated with $\mathrm{AgNO}_{3}$ solution until no white precipitate was observed. The residue was thoroughly dried over $\mathrm{CaCl}_{2}$ in a desiccator at room temperature (Chefetz et al., 2002). Finally, the obtained hydrolysed humic acid was kept for investigation. 
BAJOPAS Volume 14 Number 1,June, 2021 Potentiometric Titrations

Potentiometric measurements were carried out using a pH-meter Jenway (model 3510) with combine electrode, the sensitivity of the $\mathrm{pH}$ meter is 0.01 units. The $\mathrm{pH}$ meter was switched on half an hour before starting the titration for initial warm up of the instrument. The instrument was calibrated with an aqueous standard buffer solution of $\mathrm{pH} 4.00$ and 10.0 (borate buffer) prepared from a "Qualigens" buffer tablets.

The following sets of solutions were prepared in a $250 \mathrm{~cm}^{3}$ volumetric flask separately for $\mathrm{pH}$ metric titrations.

(i) $5 \mathrm{~cm}^{3} 0.1 \mathrm{M} \mathrm{HCl}+40 \mathrm{~cm}^{3}$ deionized water

(ii) $5 \mathrm{~cm}^{3} 0.1 \mathrm{M} \mathrm{HCl}+39 \mathrm{~cm}^{3}$ deionized water $+1 \mathrm{~cm}^{3} 0.15 \mathrm{gcm}^{-3}$ humic acid

(iii) $5 \mathrm{~cm}^{3} 0.1 \mathrm{M} \mathrm{HCl}+37 \mathrm{~cm}^{3}$ deionized water $+1 \mathrm{~cm}^{3} 0.15 \mathrm{gcm}^{-3}$ humic acid

$$
+2 \mathrm{~cm}^{3} \quad 0.01 \mathrm{M} \mathrm{Cu} \text { (II) }
$$

The solutions were titrated against standardized $0.110 \mathrm{MNaOH}$ separately. The total volume of each mixture was adjusted to $50 \mathrm{~cm}^{3}$ and the ionic strength of the solutions was maintained constant at by adding appropriate amount of stock solution of $1 \mathrm{M} \mathrm{KNO}_{3}$ (Gamal, 2015; Omar and Ali, 2015). A magnetic stirrer was used to achieve thorough mixing of the interacting solutions at $550 \mathrm{rpm}$. The same set of experimental conditions was applied for potentiometric titration of remaining samples.

\section{Evaluation of pKa of Hydrolysed peat soil Humic Acids}

The proton-ligand formation number $\mathrm{n}_{\mathbf{A}}$ were calculated by Irving and Rossotti expression (Omar and Ali, 2015).

$\mathrm{nA}=\mathrm{Y}-\frac{(\mathrm{V} 2-\mathrm{V1})(\mathrm{No}-\mathrm{Eo})}{(\mathrm{VO}+\mathrm{V1}) \mathrm{TCL}}$ 1

Where: $Y$ is number of dissociable proton, $\left(\mathrm{V}_{2^{-}}\right.$ $V_{1}$ ) is the measure of displacement of the ligand curve relative to acid curve, $\mathrm{N}^{\circ}$ and $\mathrm{E}^{\circ}$ are the resultant concentration of alkali solution, free acid solution, $\mathrm{T}_{\mathrm{cL}}{ }^{\circ}$ is the total ligand concentration, $\mathrm{V}^{\circ}$ is the total volume of titration solution, $V_{1}$ is the volume of alkali added to acid solution, $V_{2}$ is the volume of alkali added to acid solution + ligand solution, acid dissociation constants (pKa - values) of ligand were calculated by algebraic method point wise calculation (Tables 1 ). The dissociation constants (pKa) were calculated according to the following relation:

$\mathrm{pKa}=\mathrm{pH}+\log \left(\frac{n A}{1-n A}\right)$ 2

Where: pKa is the acid dissociation constant, $\mathrm{n}_{\mathrm{A}}$ is the Proton-ligand formation number and $\mathrm{pH}$ is the pH-values (Omar and Ali, 2015).

\section{Determination of metal-ligand stability constants $(\log K)$ of complexes}

The potentiometric measurement for the determination of stability constant of a complex in solution is based on the fact that the redox potential of the couple $\frac{M^{+(m-n)}}{M^{+m}}$ is shifted significantly on complexation of the metal ion with the ligand. This method involves change in hydrogen ion concentration $\left[\mathrm{H}^{+}\right]$due to the displacement or association of one or more protons taking place during complexation reaction. This change can be found out by titrating the solutions containing free acid, acid with ligand, and acid with ligand and metal ion, individually against a standard alkali solution at a constant ionic strength or temperature. Either ionic strength or temperature may be varied for different sets of solutions. In all the cases, the change in the $\mathrm{pH}$ of the solution is measured after each addition of a known amount of alkali to the reaction cell which contains the reaction mixture. The titration curves are then drawn by plotting the measured $\mathrm{pH}$ values against the corresponding volume of alkali added and the stability constants of the complexes are determined from the titration curves by employing $\mathrm{pH}$-metric titration technique given by (Irving and Rossoti).

Metal-ligand stability constants ( $\log \mathrm{K}$ ) were determined by using the following relations:

$$
\bar{n}=\frac{\left(V_{3}-V_{2}\right)\left(E^{0}+N^{0}\right)}{\left(V^{0}+V_{2}\right) \bar{n}_{A} T_{m}^{0}}
$$

and

$$
P L=\log _{10}\left\{\frac{1+\beta_{n}^{H} \frac{1}{[\text { anti } \log \mathrm{pH}]^{\mathrm{n}}}}{\mathrm{T}_{\mathrm{L}}^{0}-n \bar{T}_{m}^{0}} \mathrm{X} \frac{\left(V^{0}+V_{3}\right)}{V^{0}}\right\}
$$


BAJOPAS Volume 14 Number 1,June, 2021

Where $T_{L}, T^{\circ}, E^{\circ}$, and $V^{\circ}$ havethe same significance as in equation (1) above, $T_{m}$ denotes the total concentration of metal present in solution, $V_{3}$ is the volume of metal ions present in solution and $\beta^{H}$ is the overall proton ligand stability constant. The metal-ligand stability constants (log K) were determined by employing point wise computational Method (eq. 5 and 6).

$\operatorname{LogK}_{1}=\log \left(\frac{n}{1-n}\right)+\mathrm{pL}$ .5

$\operatorname{LogK}_{2}=\log \left(\frac{1-n}{2-n}\right)+\mathrm{pL}$ ...6

Where: Log $\mathrm{K}$ is the metal-ligand stability constant, $\mathrm{pL}$ is the Free ligand exponent function, $\mathbf{n}$ is the Average number of ligand attached with metal ion (Janraoet al., 2014). The results obtained were analyzed by an ORIGIN 2016 program using titration data and then the proton-ligand stability constants (pKa) and Metal-ligand stability constant (LogK) calculated (Omar and Ali, 2015).

\section{RESULTS AND DISCUSSION}

Fourier transformed infrared (FT-IR) spectra of isolated humic acid from peat soils Figure 2 had distinct clear absorption bands indicating the presence of major humic acid structural elemental groups such as $\mathrm{H}$ bonded $\mathrm{OH}$ $\left(3680 \mathrm{~cm}^{-1}\right.$ peak $), C=0$ of carbonyl $\left(1721 \mathrm{~cm}^{-1}\right.$ peak), functional groups of aliphatic components $\mathrm{CH}_{2}\left(2918 \mathrm{~cm}^{-1}\right.$ peak) and $\mathrm{C}-\mathrm{O}$ stretching of polysaccharide $\left(1168 \mathrm{~cm}^{-1}\right.$ peak). The positions of the absorption bands of the spectra fell within typical major absorption bands of humic acid which is at frequencies 3680, 2918, 1721, 1168 $\mathrm{cm}^{-1}$. The first peak centred in the vicinity of $3680 \mathrm{~cm}^{-1}$ region is attributed to phenol $\mathrm{OH}$ group bounded by intermolecular $\mathrm{H}$ bonds. The $2918 \mathrm{~cm}^{-1}$ band usually has absorption maximum at $2918 \mathrm{~cm}^{-1}$ which is due to $\mathrm{C}-\mathrm{H}$ stretching of alkane group $\left(\mathrm{CH}_{2}\right)$. The next major absorption band is $1721 \mathrm{~cm}^{-1}$. This band has been commonly ascribed to $\mathrm{C}=\mathrm{O}$ stretching of mainly carboxyl group $(\mathrm{COOH})$ with trace amount of ketones. The last peak was observed at 1168 $\mathrm{cm}^{-1}$ due to $\mathrm{C}-\mathrm{O}$ stretching of polysaccharides and this peak appeared also in the spectra of humic acid from peat soil. The FTIR spectra of the isolated humic acid contained all major characteristic absorption peaks of humic acid. These absorption peaks indicated the presence of the major structural elements of humic acid namely $\mathrm{H}$ bonded $\mathrm{OH}, \mathrm{C}=\mathrm{C}$ of aromatic ring, $\mathrm{C}=\mathrm{O}$ of carbonyl group (both carboxyl and ketonic), $\mathrm{CH}_{2}$ group. This strongly supports the presence of humic acid.

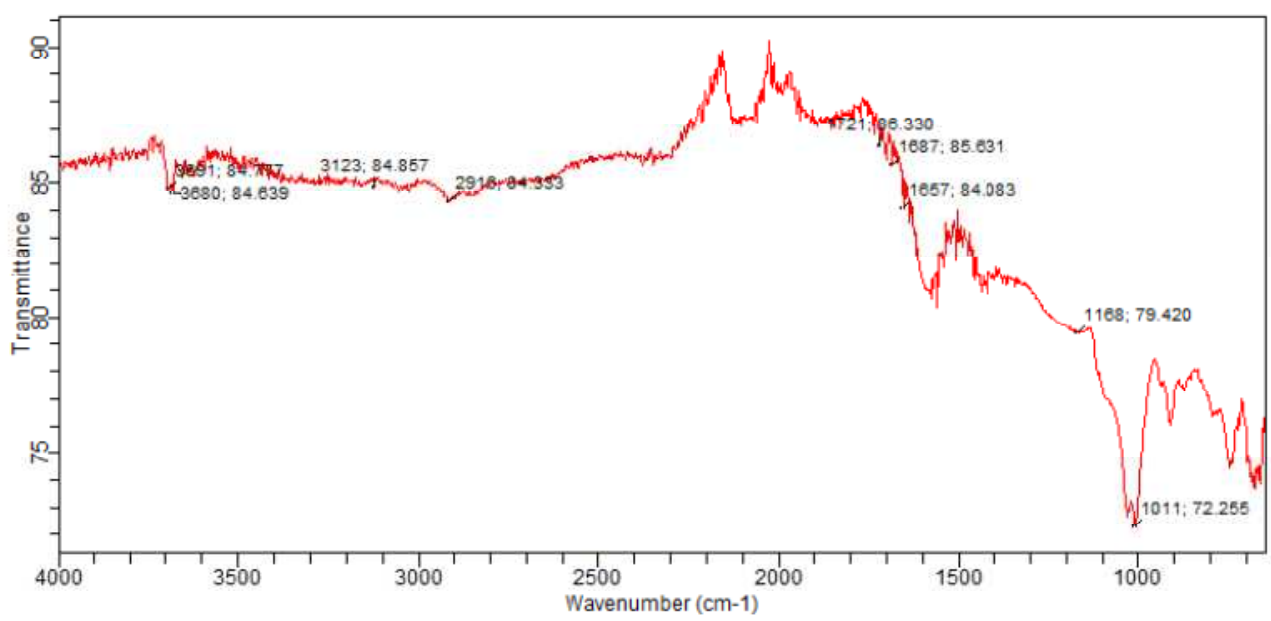

Fig. 2 : FT-IR spectraof peatsoilhumic acid (PSHA)

\section{Evaluation of acid dissociation constant (pka) of acid hydrolysed peat soil humicacid at phenolic group}

The value of the dissociation constant of the peat soil humic acid (PSHA) that underwent acidhydrolysis studied was found to be 8.9299 as shown Table 1, which is lower than the literaturevalues reported by Almeida and Szpoganics, (2015), Borges et al., (2005); Badr et al., (2012)and Fernandes et al,.(2009) of $9.73,9.47$ and 10.30. The difference between the obtained valuesand the reported values in this study might be probably as a result of acid hydrolysis of humicacid. 
BAJOPAS Volume 14 Number 1,June, 2021

Table 1: PKa of (Hydrolysed PSHA)

\begin{tabular}{|l|l|l|l|l|l|l|}
\hline $\mathrm{pH}$ & $\mathrm{BV}_{1}$ & $\mathrm{BV}_{2}$ & $\mathrm{~V}_{2}-\mathrm{V}_{1}$ & $\mathrm{nA}$ & $\log \left(\frac{n A}{1-n A}\right)$ & $\mathrm{pKa}$ \\
\hline 8.50 & 5.30 & 6.29 & 0.99 & 0.3594 & -0.2510 & 8.2490 \\
8.72 & 5.35 & 6.37 & 1.02 & 0.3400 & -0.2880 & 8.4320 \\
9.00 & 5.40 & 6.46 & 1.06 & 0.3141 & -0.3391 & 8.6609 \\
9.22 & 5.45 & 6.55 & 1.10 & 0.2882 & -0.3927 & 8.8273 \\
9.51 & 5.50 & 6.66 & 1.16 & 0.2494 & -0.4786 & 9.0314 \\
9.73 & 5.55 & 6.78 & 1.23 & 0.2041 & -0.5910 & 9.1390 \\
10.00 & 5.60 & 6.90 & 1.30 & 0.1589 & -0.7238 & 9.2762 \\
10.23 & 5.65 & 7.05 & 1.40 & 0.0941 & -0.9835 & 9.2465 \\
10.49 & 5.70 & 7.10 & 1.40 & 0.0941 & -0.9835 & 9.5065 \\
\hline
\end{tabular}

Average pKa $=8.9299 \pm 0.4186$

Table 2: PKa of (Unhydrolysed PSHA)

\begin{tabular}{|l|l|l|l|l|l|l|}
\hline $\mathrm{pH}$ & $\mathrm{BV}_{1}$ & $\mathrm{BV}_{2}$ & $\mathrm{~V}_{2}-\mathrm{V}_{1}$ & $\mathrm{nA}$ & $\log \left(\frac{\boldsymbol{n A}}{1-\boldsymbol{n}}\right)$ & $\mathrm{pKa}$ \\
\hline 8.50 & 5.30 & 5.81 & 0.51 & 0.6619 & 0.2919 & 8.7919 \\
8.72 & 5.35 & 5.90 & 0.55 & 0.6357 & 0.2418 & 8.9618 \\
9.00 & 5.40 & 6.00 & 0.60 & 0.6029 & 0.1813 & 9.1813 \\
9.22 & 5.45 & 6.10 & 0.65 & 0.5701 & 0.1226 & 9.3426 \\
9.51 & 5.50 & 6.20 & 0.70 & 0.5376 & 0.0654 & 9.5754 \\
9.73 & 5.55 & 6.33 & 0.78 & 0.4851 & -0.0259 & 9.7041 \\
10.00 & 5.60 & 6.47 & 0.87 & 0.4262 & -0.1291 & 9.8709 \\
10.23 & 5.65 & 6.62 & 0.99 & 0.3609 & -0.2481 & 9.9819 \\
10.49 & 5.70 & 6.80 & 1.10 & 0.2759 & -0.4690 & 10.0210 \\
\hline
\end{tabular}

Average pKa $=9.4923 \pm 0.4410$

Metal-ligand stability constant ( $\log \mathrm{K}$ )

The stabilityconstants require the accurate values of proton-ligand stability constants (Anil and Maroti, 2008). Metal titration curves crossed over ligand titration curve indicated the formation of complex upon proton release (Santosh, et al., 2011). If the values of n- are within range $0.2-0.8$ and $1.2-18$ this indicates the formation of $1: 1$ and 1:2 complexes (Sayyed and Mazahar, 2012).

The metal (II)-humate stepwise stability constants (log k) at phenolic group (Tables 318)

Table 3: Point-wise method, $\mathrm{Cu}$-(Hydrolysed PSHA)

\begin{tabular}{|l|l|l|l|l|l|l|l|l|}
\hline $\mathrm{pH}$ & $\mathrm{BV}_{1}$ & $\mathrm{BV}_{2}$ & $\mathrm{BV}_{3}$ & $\left(\mathrm{~V}_{3}-\mathrm{V}_{2}\right)$ & $\mathrm{n}$ & $\mathrm{pL}$ & $\log \left(\frac{n}{1-n}\right)$ & LogK $_{1}$ \\
\hline 8.50 & 5.30 & 6.29 & 6.33 & 0.04 & 0.5500 & 2.66 & 0.0871 & 2.7471 \\
8.72 & 5.35 & 6.37 & 6.41 & 0.04 & 0.5714 & 2.43 & 0.1249 & 2.5549 \\
9.00 & 5.40 & 6.46 & 6.50 & 0.04 & 0.6198 & 2.16 & 0.2122 & 2.3722 \\
9.22 & 5.45 & 6.55 & 6.59 & 0.04 & 0.6667 & 1.94 & 0.3010 & 2.2410 \\
\hline
\end{tabular}

LogK $_{1}$ (Average value) $=2.4788 \pm 0.2203$

Table 4: Point-wise method, $\mathrm{Cu}$-(Hydrolysed PSHA)

\begin{tabular}{|l|l|l|l|l|l|l|l|l|}
\hline $\mathrm{pH}$ & $\mathrm{BV}_{1}$ & $\mathrm{BV}_{2}$ & $\mathrm{BV}_{3}$ & $\left(\mathrm{~V}_{3}-\mathrm{V}_{2}\right)$ & $\mathrm{n}$ & $\mathrm{pL}$ & $\log \left(\frac{n-1}{2-n}\right)$ & LogK $_{2}$ \\
\hline 9.51 & 5.50 & 6.66 & 6.73 & 0.07 & 1.3509 & 1.70 & -0.2671 & 1.4329 \\
9.73 & 5.55 & 6.78 & 6.85 & 0.07 & 1.6383 & 1.51 & 0.2467 & 1.7567 \\
10.00 & 5.60 & 6.90 & 6.98 & 0.08 & 2.1783 & 1.31 & -0.2158 & 1.0942 \\
10.23 & 5.65 & 7.05 & 7.13 & 0.08 & 4.1904 & 1.27 & & \\
10.49 & 5.70 & 7.10 & 7.19 & 0.09 & 4.6920 & & & \\
\hline
\end{tabular}

Log $K_{2}($ Average value $)=1.4280 \pm 0.3312$ 
BAJOPAS Volume 14 Number 1,June, 2021

Table 5: Point-wise method, $\mathrm{Cu}$ (Unhydrolysed PSHA)

\begin{tabular}{|l|l|l|l|l|l|l|l|l|}
\hline $\mathrm{pH}$ & $\mathrm{BV}_{1}$ & $\mathrm{BV}_{2}$ & $\mathrm{BV}_{3}$ & $\left(\mathrm{~V}_{3}-\mathrm{V}_{2}\right)$ & $\mathrm{n}$ & $\mathrm{pL}$ & $\log \left(\frac{n}{n-1}\right)$ & Log $_{1}$ \\
\hline 8.50 & 5.30 & 5.81 & 5.85 & 0.04 & 0.2973 & 2.88 & -0.3736 & 2.5064 \\
8.72 & 5.35 & 5.90 & 5.95 & 0.05 & 0.3873 & 2.66 & -0.1992 & 2.4608 \\
9.00 & 5.40 & 6.00 & 6.05 & 0.05 & 0.4044 & 2.38 & -0.1681 & 2.2119 \\
9.22 & 5.45 & 6.10 & 6.15 & 0.06 & 0.5157 & 2.18 & -0.0272 & 2.2072 \\
9.51 & 5.50 & 6.20 & 6.27 & 0.07 & 0.6417 & 1.89 & 0.2530 & 1.1430 \\
\hline
\end{tabular}

$\operatorname{LogK}_{1}($ Average value $)=2.3059 \pm 0.6153$

Table 6:Point-wise method, $\mathrm{Cu}$ (Unhydrolysed PSHA)

\begin{tabular}{|l|l|l|l|l|l|l|l|l|}
\hline $\mathrm{pH}$ & $\mathrm{BV}_{1}$ & $\mathrm{BV}_{2}$ & $\mathrm{BV}_{3}$ & $\mathrm{~V}_{3}-\mathrm{V}_{2}$ & $\mathrm{n}$ & $\mathrm{pL}$ & $\log \left(\frac{n-1}{2-n}\right)$ & $\log \mathrm{K}_{2}$ \\
\hline 9.73 & 5.55 & 6.33 & 6.42 & 0.09 & 0.9000 & 1.69 & & \\
10.00 & 5.60 & 6.47 & 6.58 & 0.11 & 1.2578 & 1.44 & -0.4592 & 0.9808 \\
10.23 & 5.65 & 6.62 & 6.84 & 0.12 & 1.6137 & 1.26 & -0.2010 & 1.4610 \\
10.49 & 5.70 & 6.80 & 6.92 & 0.12 & 2.1052 & 1.03 & & \\
\hline
\end{tabular}

$\operatorname{LogK}_{2}$ (Average value) $=1.2209 \pm 0.3398$

Table 7:Point-wise method, Pb (Hydrolysed PSHA)

\begin{tabular}{|l|l|l|l|l|l|l|l|l|}
\hline $\mathrm{pH}$ & $\mathrm{BV}_{1}$ & $\mathrm{BV}_{2}$ & $\mathrm{BV}_{3}$ & $\left(\mathrm{~V}_{3}-\mathrm{V}_{2}\right)$ & $\mathrm{n}$ & $\mathrm{pL}$ & $\log \left(\frac{n}{1-n}\right)$ & LogK $_{1}$ \\
\hline 8.50 & 5.30 & 6.29 & 6.33 & 0.04 & 0.5500 & 2.66 & 0.0871 & 2.7471 \\
8.72 & 5.35 & 6.37 & 6.41 & 0.04 & 0.5714 & 2.43 & 0.1249 & 2.5549 \\
9.00 & 5.40 & 6.46 & 6.50 & 0.04 & 0.6198 & 2.16 & 0.2122 & 2.3722 \\
9.22 & 5.45 & 6.55 & 6.60 & 0.05 & 0.8333 & 1.96 & 0.6989 & 2.6589 \\
\hline
\end{tabular}

Log $_{\mathbf{1}}($ Average value $)=2.5832 \pm 0.1614$

Table 8:Point-wise method, Pb-(Hydrolysed PSHA)

\begin{tabular}{|l|l|l|l|l|l|l|l|l|}
\hline $\mathrm{pH}$ & $\mathrm{BV}_{1}$ & $\mathrm{BV}_{2}$ & $\mathrm{BV}_{3}$ & $\left(\mathrm{~V}_{3}-\mathrm{V}_{2}\right)$ & $\mathrm{n}$ & $\mathrm{pL}$ & $\log \left(\frac{n-1}{2-n}\right)$ & $\log \mathrm{K}_{2}$ \\
\hline 9.51 & 5.50 & 6.66 & 6.71 & 0.05 & 0.9650 & 1.67 & & \\
9.73 & 5.55 & 6.78 & 6.83 & 0.05 & 1.1702 & 1.44 & & \\
10.00 & 5.60 & 6.90 & 6.90 & 0.05 & 1.4864 & 1.22 & -0.0237 & 1.1963 \\
10.23 & 5.65 & 7.05 & 7.10 & 0.05 & 2.0190 & 1.09 & & \\
10.49 & 5.70 & 7.10 & 7.17 & 0.07 & 3.6492 & 1.00 & & \\
\hline
\end{tabular}

Log $K_{2}$ (Average value) $=1.1963$

Table 9: Point-wise method, Pb (Unhydrolysed PSHA)

\begin{tabular}{|l|l|l|l|l|l|l|l|l|}
\hline $\mathrm{pH}$ & $\mathrm{BV}_{1}$ & $\mathrm{BV}_{2}$ & $\mathrm{BV}_{3}$ & $\mathrm{~V}_{3}-\mathrm{V}_{2}$ & $\mathrm{n}$ & $\mathrm{pL}$ & $\begin{array}{l}\text { Log } \\
\left(\frac{n}{n-1}\right)\end{array}$ & Log $\mathrm{K}_{1}$ \\
\hline 8.50 & 5.30 & 5.81 & 5.85 & 0.04 & 0.2973 & 2.88 & -0.3736 & 2.5064 \\
8.72 & 5.35 & 5.90 & 5.94 & 0.04 & 0.3099 & 2.66 & -0.5477 & 2.3123 \\
9.00 & 5.40 & 6.00 & 6.05 & 0.05 & 0.4044 & 2.38 & -0.1681 & 2.2119 \\
9.22 & 5.45 & 6.10 & 6.15 & 0.06 & 0.5157 & 2.18 & 0.0272 & 2.2072 \\
9.51 & 5.50 & 6.20 & 6.26 & 0.07 & 0.6417 & 1.89 & 0.2530 & 2.1430 \\
9.73 & 5.55 & 6.40 & 6.40 & 0.07 & 0.7000 & 1.67 & 0.3680 & 2.0380 \\
\hline
\end{tabular}

LogK $_{1}$ (Average value) $=2.2364 \pm 0.1602$

Table 10: Point-wise method, Pb (Unhydrolysed PSHA)

\begin{tabular}{|l|l|l|l|l|l|l|l|l|}
\hline $\mathrm{pH}$ & $\mathrm{BV}_{1}$ & $\mathrm{BV}_{2}$ & $\mathrm{BV}_{3}$ & $\mathrm{~V}_{3}-\mathrm{V}_{2}$ & $\mathrm{n}$ & $\mathrm{pL}$ & $\log \left(\frac{n-1}{2-n}\right)$ & $\log \mathrm{K}_{2}$ \\
\hline 10.00 & 5.60 & 6.47 & 6.55 & 0.08 & 1.9503 & 1.41 & & \\
10.23 & 5.65 & 6.62 & 6.72 & 0.11 & 1.4792 & 1.26 & -0.0361 & 1.2239 \\
\hline
\end{tabular}

$\operatorname{LogK}_{2}$ (Average value) $=1.2239$

Table 11: Point-wise method, Mg (Hydrolysed PSHA)

\begin{tabular}{|l|l|l|l|l|l|l|l|l|}
\hline $\mathrm{pH}$ & $\mathrm{BV}_{1}$ & $\mathrm{BV}_{2}$ & $\mathrm{BV}_{3}$ & $\left(\mathrm{~V}_{3}-\mathrm{V}_{2}\right)$ & $\mathrm{n}$ & $\mathrm{pL}$ & $\log \left(\frac{n}{n-1}\right)$ & LogK $_{1}$ \\
\hline 8.50 & 5.30 & 6.29 & 6.31 & 0.02 & 0.2750 & 2.64 & -0.4290 & 2.2110 \\
8.72 & 5.35 & 6.37 & 6.39 & 0.02 & 0.2858 & 2.42 & -0.3978 & 2.0222 \\
9.00 & 5.40 & 6.46 & 6.49 & 0.03 & 0.4648 & 2.14 & -0.0612 & 2.0788 \\
9.22 & 5.45 & 6.55 & 6.59 & 0.04 & 0.6667 & 1.94 & 0.3010 & 2.2410 \\
\hline
\end{tabular}

$\log _{\mathbf{1}}($ Average value) $=2.1382 \pm 0.1046$ 
BAJOPAS Volume 14 Number 1,June, 2021

Table 12: Point-wise method, Mg (Hydrolysed PSHA)

\begin{tabular}{|l|l|l|l|l|l|l|l|l|}
\hline $\mathrm{pH}$ & $\mathrm{BV}_{1}$ & $\mathrm{BV}_{2}$ & $\mathrm{BV}_{3}$ & $\left(\mathrm{~V}_{3}-\mathrm{V}_{2}\right)$ & $\mathrm{n}$ & $\mathrm{pL}$ & $\log \left(\frac{n-1}{2-n}\right)$ & LogK $_{2}$ \\
\hline 9.51 & 5.55 & 6.66 & 6.71 & 0.05 & 0.9650 & 1.67 & & \\
9.73 & 5.55 & 6.78 & 6.84 & 0.06 & 1.4042 & 1.47 & -0.1686 & 1.3014 \\
10.00 & 5.60 & 6.90 & 6.93 & 0.06 & 1.7838 & 1.23 & 0.5593 & 1.7893 \\
10.23 & 5.65 & 7.05 & 7.10 & 0.06 & 3.1429 & 1.10 & & \\
10.49 & 5.70 & 7.10 & 7.18 & 0.07 & 3.6492 & 0.83 & & \\
\hline
\end{tabular}

LogK $_{2}($ Average value $)=1.5453 \pm 0.3450$

Table 13: Point-wise method, Mg (Unhydrolysed PSHA)

\begin{tabular}{|l|l|l|l|l|l|l|l|l|}
\hline $\mathrm{pH}$ & $\mathrm{BV}_{1}$ & $\mathrm{BV}_{2}$ & $\mathrm{BV}_{3}$ & $\mathrm{~V}_{3}-\mathrm{V}_{2}$ & $\mathrm{n}$ & $\mathrm{pL}$ & $\log \left(\frac{n}{n-1}\right)$ & $\operatorname{Log~}_{1}$ \\
\hline 8.50 & 5.30 & 5.81 & 5.85 & 0.04 & 0.2973 & 2.88 & -0.3736 & 2.5064 \\
8.72 & 5.35 & 5.90 & 5.94 & 0.04 & 0.3099 & 2.66 & -0.3477 & 2.3123 \\
9.00 & 5.40 & 6.00 & 6.04 & 0.04 & 0.3236 & 2.38 & -0.3202 & 2.0598 \\
9.22 & 5.45 & 6.10 & 6.15 & 0.05 & 0.4297 & 2.17 & -0.1230 & 2.0470 \\
9.51 & 5.50 & 6.20 & 6.26 & 0.06 & 0.5500 & 1.89 & 0.0871 & 1.9771 \\
9.73 & 5.55 & 6.33 & 6.40 & 0.07 & 0.7000 & 1.67 & 0.3680 & 2.0380 \\
\hline
\end{tabular}

LogK $_{1}$ (Average value) $=2.1568 \pm 0.2069$

Table 14: Point-wise method, Mg (Unhydrolysed PSHA)

\begin{tabular}{|l|l|l|l|l|l|l|l|l|}
\hline $\mathrm{pH}$ & $\mathrm{BV}_{1}$ & $\mathrm{BV}_{2}$ & $\mathrm{BV}_{3}$ & $\mathrm{~V}_{3}-\mathrm{V}_{2}$ & $\mathrm{n}$ & $\mathrm{pL}$ & $\log \left(\frac{n-1}{2-n}\right)$ & $\log \mathrm{K}_{2}$ \\
\hline 10.00 & 5.60 & 6.47 & 6.55 & 0.08 & 0.9148 & 1.41 & & \\
10.23 & 5.65 & 6.62 & 6.71 & 0.09 & 1.2102 & 1.20 & -0.5749 & 0.6251 \\
10.49 & 5.70 & 6.80 & 6.92 & 0.09 & 1.5968 & 1.03 & 0.1703 & 1.2003 \\
\hline
\end{tabular}

LogK $_{2}$ (Average value) $=0.9127 \pm 0.4070$

Table15:Point-wise method, Cd (Hydrolysed PSHA)

\begin{tabular}{|l|l|l|l|l|l|l|l|l|}
\hline $\mathrm{pH}$ & $\mathrm{BV}_{1}$ & $\mathrm{BV}_{2}$ & $\mathrm{BV}_{3}$ & $\left(\mathrm{~V}_{3}-\mathrm{V}_{2}\right)$ & $\mathrm{n}$ & $\mathrm{pL}$ & $\log \left(\frac{n}{1-n}\right)$ & LogK $_{1}$ \\
\hline 8.50 & 5.30 & 6.29 & 6.31 & 0.02 & 0.2750 & 2.64 & -0.4210 & 2.2190 \\
8.72 & 5.35 & 6.37 & 6.40 & 0.03 & 0.4286 & 2.42 & -0.1249 & 2.2951 \\
9.00 & 5.40 & 6.46 & 6.49 & 0.03 & 0.4648 & 2.14 & -0.0612 & 2.0788 \\
9.22 & 5.45 & 6.55 & 6.59 & 0.04 & 0.6667 & 1.96 & 0.3010 & 2.2610 \\
9.51 & 5.55 & 6.66 & 6.70 & 0.04 & 0.7720 & 1.67 & 0.5297 & 2.1997 \\
\hline
\end{tabular}

LogK $_{\mathbf{1}}$ (Average value) $=2.2108 \pm 0.0825$

Table 16: Point-wise method, Cd (Hydrolysed PSHA)

\begin{tabular}{|l|l|l|l|l|l|l|l|l|}
\hline $\mathrm{pH}$ & $\mathrm{BV}_{1}$ & $\mathrm{BV}_{2}$ & $\mathrm{BV}_{3}$ & $\left(\mathrm{~V}_{3}-\mathrm{V}_{2}\right)$ & $\mathrm{n}$ & $\mathrm{pL}$ & $\log \left(\frac{n-1}{2-n}\right)$ & Log $_{2}$ \\
\hline 9.73 & 5.55 & 6.78 & 6.83 & 0.06 & 1.4042 & 1.47 & -0.1686 & 1.3014 \\
10.00 & 5.60 & 6.90 & 6.95 & 0.06 & 1.7838 & 1.23 & 0.5593 & 1.7893 \\
10.23 & 5.65 & 7.05 & 7.10 & 0.06 & 3.1429 & 1.09 & & \\
10.49 & 5.70 & 7.10 & 7.16 & 0.06 & 3.1429 & 0.89 & & \\
& & & & & & & & \\
\hline
\end{tabular}

$\operatorname{LogK}_{2}$ (Average value) $=1.5453 \pm 0.3450$

Table 17: Point-wise method, Cd (Unhydrolysed PSHA)

\begin{tabular}{|l|l|l|l|l|l|l|l|l|}
\hline $\mathrm{pH}$ & $\mathrm{BV}_{1}$ & $\mathrm{BV}_{2}$ & $\mathrm{BV}_{3}$ & $\mathrm{~V}_{3}-\mathrm{V}_{2}$ & $\mathrm{n}$ & $\mathrm{pL}$ & $\log \left(\frac{n}{n-1}\right)$ & $\operatorname{Log~}_{1}$ \\
\hline 8.50 & 5.30 & 5.81 & 5.86 & 0.05 & 0.3717 & 2.88 & -0.2280 & 2.6520 \\
8.72 & 5.35 & 5.90 & 5.95 & 0.05 & 0.3873 & 2.66 & -0.1992 & 2.4608 \\
9.00 & 5.40 & 6.00 & 6.06 & 0.06 & 0.4853 & 2.38 & -0.0255 & 2.3545 \\
9.22 & 5.45 & 6.10 & 6.16 & 0.06 & 0.5157 & 2.18 & -0.0272 & 2.2072 \\
9.51 & 5.50 & 6.20 & 6.27 & 0.07 & 0.6417 & 1.89 & 0.2530 & 1.1430 \\
9.73 & 5.55 & 6.33 & 6.41 & 0.08 & 0.8000 & 1.69 & 0.6020 & 2.2920 \\
& & & & & & & & \\
\hline
\end{tabular}

$\operatorname{LogK}_{1}($ Average value $)=2.2516 \pm 0.5380$ 
BAJOPAS Volume 14 Number 1,June, 2021

Table 18: Point-wise method, Cd (Unhydrolysed PSHA)

\begin{tabular}{|l|l|l|l|l|l|l|l|l|}
\hline $\mathrm{pH}$ & $\mathrm{BV}_{1}$ & $\mathrm{BV}_{2}$ & $\mathrm{BV}_{3}$ & $\mathrm{~V}_{3}-\mathrm{V}_{2}$ & $\mathrm{n}$ & $\mathrm{pL}$ & $\log \left(\frac{n-1}{2-n}\right)$ & $\log \mathrm{K}_{2}$ \\
\hline 10.00 & 5.60 & 6.47 & 6.57 & 0.10 & 1.1434 & 1.43 & & \\
10.23 & 5.65 & 6.62 & 6.72 & 0.10 & 1.3448 & 1.23 & -0.2788 & 0.9512 \\
10.49 & 5.70 & 6.80 & 6.90 & 0.10 & 1.7742 & 1.03 & 0.5351 & 1.5651 \\
\hline
\end{tabular}

$\operatorname{LogK}_{2}($ Average value $)=1.2581 \pm 0.4340$

Table 19: Stepwise and overall Stability constants of thehydrolysed and unhydrolysed divalent metal (II) complexes

\begin{tabular}{|c|c|c|c|}
\hline Chelates & LogK $_{1}$ & $\log _{2}$ & Log $\beta$ \\
\hline [Cu (Hydrolysed PSHA-1) $\left.{ }_{2}\right]$ & 2.4788 & 1.4280 & 3.9068 \\
\hline$\left[\mathrm{Pb}(\text { Hydrolysed PSHA-1) })_{2}\right]$ & 2.5832 & 1.1963 & 3.7795 \\
\hline$\left[\mathrm{Cd}(\text { Hydrolysed PSHA-1 })_{2}\right]$ & 2.2108 & 1.5453 & 3.7561 \\
\hline$\left[\mathrm{Mg}(\text { Hydrolysed PSHA-1 })_{2}\right]$ & 2.1382 & 1.5453 & 3.6835 \\
\hline [Cu (Unhydrolysed PSHA-1) & 2.3059 & 1.2209 & 3.5268 \\
\hline$[\mathrm{Pb}$ (Unhydrolysed PSHA-1) 2$]$ & 2.2364 & 1.2239 & 3.4603 \\
\hline [Cd (Unhydrolysed PSHA-1) 2 ] & 2.2516 & 1.2581 & 3.5097 \\
\hline$[\mathrm{Mg}$ (Unydrolysed PSHA-1) & 2.1568 & 0.9127 & 3.0695 \\
\hline
\end{tabular}

The results obtained (Table19) shows the stepwise and overall stability constants to be not high indicating low stability of the complexes, because the solubility of most metal ions in the basic $\mathrm{pH}$ range is minimal due to metal hydroxide precipitation (Karimi, 2017). In general, the stepwise stability constants $\left(K_{1}\right.$ and $K_{2}$ ) follow the order $K_{1}>K_{2}$ for the copper, lead, magnesium and cadmium complexes respectively. The steady decrease of the values with increasing number of ligands is in agreement with the prediction made by researchers (Na'aliya, 2013). The decrease could be attributed to the fact that as the number of the ligands (Humate ions) that enters the coordination zone increases the aqua molecules available for replacement by the ligands become less. Thus, the metal ions become less electron loving with progressive intake of the ligand and this results in the decrease in the values of the constants (Na'aliya, 2013). Also the stability of the complexes is influenced by the size and number of the chelate rings(Mackay and Mackay,2002).All the complexes form rings in their structure as humate, a bidentate ligand, bond the metal ions in the ratio 1:2 (Boguta and Sokolowska, 2016) forming chelate rings. The values of the overall stability constants $(\log \beta)$ obtained for humate complexes are not high indicating low stability as the values are not high. LogK values for copper-humates (Table 3 to 6) obtained in this study are lower than those reported for the complexes of humic acids (Pandey et al., 2015; Dinu, 2013; Kaschl et al., 2010 and Gilbeto and Jorg, 2001). The values of LogK(Table 7 to 10 ) forlead-humates are lower than those reported for the lead in the literature (Dinu, 2013; Gilbeto and Jorg 2001). Log K values(Table 11 to 14 ) for magnesium-humates obtained in this study are close to those reported by (Pandey et al., 2015). Log K values of cadmium-humates (Table 15 to 18 ) obtained in this work near to the one reported by (Dinu, 2013 and Pandey et al., 2015).The difference between the reported values and the values obtained in this study might be probably as a result of acid hydrolysis of humic acid. The values of the overall stability constants $(\log \beta)$ of the copper humates complexes presented in Table 19 is high than that of other metal humate complexes, show relatively high stability of CuHA complexes, show the following order of stability: $\mathrm{Cu}>\mathrm{Pb}>\mathrm{Cd}>\mathrm{Mg}$; which are in close agreement to the findings of (Dinu, 2013 and Pandey et al., 2015).The high stability of Cuhumate chelate could be attributed to the existence of coordinate covalent bond between the complexing agents and the $\mathrm{Cu}^{2+}$ ions. Since, $\mathrm{Cu}^{2+}$ being a metal of the transitional series with $3 d^{9}$ electronic configurations can accept the electrons from the complexing agents. Similarly, the low stabilities of $\mathrm{Pb}, \mathrm{Cd}$ and $\mathrm{Mg}$ complexes could be explained by that $\mathrm{Pb}^{2+}$ with $6 s^{2}, \mathrm{Cd}^{2+}$ with $4 \mathrm{~d}^{10}$ and $\mathrm{Mg}^{2+}$ with $2 \mathrm{p}^{6}$ their electronic configuration has a completely filled $\mathrm{d}, \mathrm{p}$ and $\mathrm{s}$ orbitals. Moreover, the stabilities of metal ions with hydrolysed humic acid from peat soil were higher than those with unhydrolysed humic acid from peat soil; which is ascribed to the high content of acidity in hydrolysed humic acid than unhydrolysed humic acid. 
BAJOPAS Volume 14 Number 1,June, 2021 CONCLUSION

The values of logk for $\mathrm{Cu}(\mathrm{II})$ hydrolysed humic acid complex was higher followed by $\mathrm{Pb}$ (II), $\mathrm{Cd}(\mathrm{II})$ and $\mathrm{Mg}$ (II) hydrolysed humic acid complexes as compared with metal(II) unhydrolysed humic acid complexes. This indicates acid hydrolysis of humic acid can

\section{REFERENCES}

Almeida, V.R. and Szpoganicz, B. (2015). Humic Acid Potentiometric Response Patterns:Out- of Equilibrium Properties and Species Distribution Modelling. Chemical. Biol. Technol. Agric. 2: 17.

Anđelković, T., Nikolić, R., Bojić, A.,Anđelković, D., and Nikolic G.,(2010). Binding of Cadmium to Soil Humic Acid as A Function of Carboxyl Group Content. Macedonian Journal of Chemistry and Chemical Engineering.29(2): 215-224.

Anil, B. N. and Maroti, N. (2008). Studies on Influence of Die-Lectric Constants on Complex Equilibria between Substituted Py-Razalines and Lanthanide Metal Ions pH-Metrically. Amer.-Euras. scient. Res. 3(2): 212-216.

Ashok, K., Pandey, S. P. and Misra, V (2000). Stability Constants of Metal-Humic Acid Complexes and its Role in Environmental Detoxification. Journal of Ecotoxicology and Environmental Safety. 47(2):157-200.

Badr, M. H., El-Halafawi, M. H. and Abd El-al Zeid, E. R. (2012). Comparison Between the Effect of Ionic Strength on Acidity and Dissociation Constants of Humic Acids Extracted from Sewage Sludge and Nile Water Hyacinth Composts.Global Journal of Environmental Research 6 (1): 36-43.

Baruah, M.K., Borah, D., Saikia, P.P., Paul, S., Sharma, T. (2015). Evaluation of pKa Values of Soil Humic Acids and their Complexation Properties. International Journal of Plant \& Soil Science 6(4) : 218-228.

Boguta, P. Sokolowska, Z. (2016). Interactions of $\mathrm{Zn}$ (II) Ions with Humic Acids Isolated from Various Types of Soils. Effect of $\mathrm{pH}, \mathrm{Zn}$ Concentrations and Humic Acids Chemical Properties. Journal of Geochemical Explaration 168. 119-126.

Borges, F., Guimaraes, C., Lima, L.F.C., Pinto, I. and Reis, S.(2005). Potentiometric Studies on the Complexation of Copper(II) by Phenolic Acids as Discrete Ligand Models of enhance the complexation behavior of humic acid with metal (II) ions. However, the higher values of $\log \beta$ for $\mathrm{Cu}(\mathrm{II}), \mathrm{Pb}(\mathrm{II}), \mathrm{Cd}(\mathrm{II})$ and $\mathrm{Mg}(\mathrm{II})$ hydrolysed humic acid complexes indicates more stable stepwise complexes formed as compared with $\mathrm{Cu}(\mathrm{II}), \mathrm{Pb}$ (II), $\mathrm{Cd}$ (II) and $\mathrm{Mg}(\mathrm{II})$ unhydrolysed humic acid complexes.

Humic Substances Talanta 66 (2005) 670-673.

Chefetz, B., Salloum, M. J., Deshmulkin, A. P. and Hatcher, P. (2002). Structural Components of Humic Acids as Determined by Chemical Modifications and Carbon-13 NMR, Pyrolysis, and Thermochemolysis- Gas Chromatography/Mass Spectrometry. Soil Science Society of American Journal Abstract Division S-2- Soil Chemistry66. 1159-1171.

Dinu, M. I. (2013). Metals Complexation with Humic Acids in Surface Water of Different Environ. Sci. Technol. 31(1): 1-17.

Fernandes, A.N., Giacomelli, C., Giovanela, M. Vaz, D.V. Szpoganicz, B. and Maria M. D. (2009). Potentiometric Acidity Determination in Humic Substances Influenced by Different Analytical Procedures.J. Braz. Chem. Soc. 20 (9):14.

Gamal, A. H. (2015). Stability Constants of Rhenium (V) Metal Complexes with Selected Drugs. Pyrex Journal of Research in Environmental Studies. 2(2): 006-014.

Janrao, D. M., Pathan, J., Kayande, D.D., and Mulla, J.J. (2014). An Over View of Potentiometric Determination of Stability Constants of Metal Complexes. Sci. Revs. Chem. Commun.: 4(1), 2014, 11-24.

Karimi, H. (2017). Effect of pH and Initial Pb(II) Concentration on the Lead Removal Efficiency from Waste Water Using $\mathrm{Ca}(\mathrm{OH})_{2}$. International Journal of Water and Waste Water Treatment 3.2

Kaschl, A. Romheld, V. and Chen, Y. (2010). Binding of Cadmium, Copper and Zinc to Humic Substances Originating from Municipal Solid Waste Compost. Israel Journal of Chemistry Vol. 42(1): 89-98.

Kostic, I. S., Tatjana, P, A., Nikolic, R. S., Cvetkovic, T. P., Pavlovic, D. D., Aleksandar, L.J. and Bojic, A. (2012). Comparative Study of Binding Strengths of Heavy Metals with Humic Acid. J.serb. Chem. Soc. 76(9) pp 1-20. 
BAJOPAS Volume 14 Number 1,June, 2021

Na'aliya, J. (2013). Determination of Stepwise Stability Constants and Gibbs free Energy Change of Trisprolina to Complexes of some Divalent Transition Metal ions. Bayero Journal of Pure and Applied Sciences 6(2): 112-114.

Omar, A. A. and Ali, E. A. (2015). Potentiometric Studies on Complexes of $\mathrm{Cr}$ (III) and $\mathrm{Zr}$ (IV) with some Carboxylic Acids. International Journal of Advanced Chemistry, 3(1) 25-

37.

Pandey, A. K. Pandey, S. D. and Misr, V. (2015).Stability Constants of Metal- Humic Acid Complexes and Its Role in Environmental Detoxification. J. Ecotoxicology and Environmental Safety. 47(1):195-200.

Ram, N. and Raman, K.V. (1984). Stability Constants of Complexes of Metals with
Humicand Fuvic Acids under Non- acidConditions. Journal of Plant Nutrition and Soil Sciences.

147:171-176.

Santosh, D. D., Ashok, B. K., Vijay, J. T., Shivraj, G. W. and Vinay, V. W. (2011). Potentiometric Studies of Elec-Trolyte Effects on Complex Equilibria of Some Substituted 5-(2-hydroxy Phenyl) Pyrazoles. Der pharm. 3 (6): 75-83.

Sayyed, H. and Abdul Rahim, M. F. (2012). Studies of Binary Complexes of Metal Ions with Mandelic Acid by Potentiometry. Chem. J. 02 (6): 206209.

Shirvani, M. Moradian, E. Khalili, B. Bakhtiary, S. (2015). Interaction of $\mathrm{Cd}$ and $\mathrm{Pb}$ with Humate-Palygorskite and HumateSepiolite Complexes. Journal of water, air and pollution 3: 220-228. 


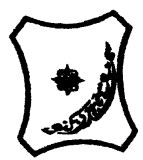

Bayero Journal of Pure and Applied Sciences, 14(1): 54 - 63

Received: November, 2020

Accepted: April, 2021

ISSN $2006-6996$

\title{
STABILITY CONSTANTS OF COMPLEXES OF METAL IONS WITH PEATSOIL HUMIC ACIDS UNDER NON-ACID-CONDITIONS
}

\author{
${ }^{* 1}$ Sabo, Yusuf ${ }^{2}$ Jimoh, W.L.O., ${ }^{3}$ Isa Baba Koki and ${ }^{4}$ Sholadoye, Q. 0. \\ ${ }^{1}$ Department of Pure and Industrial Chemistry, Bayero University, Kano \\ ${ }^{3}$ Department of Chemistry, Yusuf Maitama Sule University Kano. P.M.B. 3220 Kano, Nigeria. \\ ${ }^{4}$ Department of Chemistry, Nigerian Police Academy, Wudil, Kano-Nigeria
}

*Correspondence E-mail; saboyusuf18@yahoo.com

ABSTRACT

Stability constants of complexes of four divalent metal ions viz. $\mathrm{Cu}^{2+}, \mathrm{Pb}^{2+}, \mathrm{Mg}^{2+}$ and $\mathrm{Cd}^{2+}$ with humic acids (HA) were determined by potentiometric titration of humic acids with the corresponding salt of the divalent metals in aqueous media under non-acid-condition. The log $K$ (logarithm of the stability constant) ranged from 1.0942 to 2.7471 for metalhumic acid complexes were determined using point-wise computational method. The order of stability constants were obtained as follows: $\mathrm{Cu}>\mathrm{Pb}>\mathrm{Cd}>\mathrm{Mg}$ for metal $-\mathrm{HA}$ complexes respectively, indicating a higher degree of complexation with Cu metal ion.

Keywords: stability constant, humic acid, potentiometric titration, divalent metals, acid hydrolysis.

\section{NTRODUCTION}

The stability constant of a complex is the numerical expression of its stability and provides a quantitative measure of affinity of the metal ion to the complexing agent. An understanding of the relative stability of metal-complexes helps in predicting the behavior of metal ions in the soil (Ram and Raman, 1982). Extensive researches has been done to determine the stability constants of the complexes formed between humic acid (HA) with a number of metal ions. Ashok et al., (2000) reported that humic acid with hydroxyl, phenoxyl and carboxyl reactive groups can form coordination compound with metal ions at $\mathrm{pH}$ 3.5. The stability constants(Log K) for different metalhumic acid complexes indicated the following order of the stabilities of complexes formed between humic acid and metal ion, $\mathrm{Cu}>\mathrm{Fe}$ $>\mathrm{Pb}>\mathrm{Ni}>\mathrm{Co}>\mathrm{Ca}>\mathrm{Cd}>\mathrm{Zn}>\mathrm{Mn}>\mathrm{Mg}$. Andelkovic et al., (2010) investigated the binding of $\mathrm{Cd}$ (II) to soil humic acid at pH 6.5 and in $0.1 \mathrm{M} \mathrm{KNO}_{3}$ ionic medium. The stability constant for binding indicating greater stability in the case when carboxyl groups are involved in complexation reaction. Kostic et al.,(2012) investigated the complexation of humic acid with certain heavy metal ions (Co(II), $\mathrm{Ni}(\mathrm{II}), \mathrm{Cu}(\mathrm{II})$,
$\mathrm{Zn}(\mathrm{II})$, and $\mathrm{Pb}(\mathrm{II})$. The experiment was performed at $25^{\circ} \mathrm{C}$, at pH 4.0 and ionic strength of $0.01 \mathrm{M}$. Stability constant of complex between $\mathrm{Pb}$ (II) ions and humic acid is greater than stability constants of other investigated metalhumate complexes. Bogata and Sokolowska (2016) analyses the interaction between humic acids from different soils and $\mathrm{Zn}$ (II) ions at wide concentration ranges and at $\mathrm{pH} 5$. Studies have showed significant impact of $\mathrm{Zn}$ concentration, $\mathrm{pH}$ and some properties of humic acids with zinc.But all of these studies were limited to acidic $\mathrm{pH}$ range. Therefore, the present study was carried out to determine and compare the stability constants of complexes of metal ions with hydrolysed peat soil humic acid and unhydrolysed peat soil humic under non-acid conditions.

\section{MATERIALS AND METHODS}

Analytical grade chemicals used includes hydrochloric acid $(\mathrm{HCl})$, nitric acid $\left(\mathrm{HNO}_{3}\right)$, sodium hydroxide $(\mathrm{NaOH})$, lead nitrate $\mathrm{Pb}\left(\mathrm{NO}_{3}\right)_{2}$, copper nitrate $\mathrm{Cu}\left(\mathrm{NO}_{3}\right)_{2} \cdot 3 \mathrm{H}_{2} \mathrm{O}$, cadmium nitrate $\mathrm{Cd}\left(\mathrm{NO}_{3}\right)_{2} \cdot 4 \mathrm{H}_{2} \mathrm{O}$, magnesium nitrate $\mathrm{Mg}\left(\mathrm{NO}_{3}\right)_{2} \cdot 6 \mathrm{H}_{2} \mathrm{O}$, potassium nitrate $\left(\mathrm{KNO}_{3}\right)$, calcium chloride $\left(\mathrm{CaCl}_{2}\right)$, (sigma-Aldrich). Dowex 50WX8, (20-50 mesh) from Fluka. 


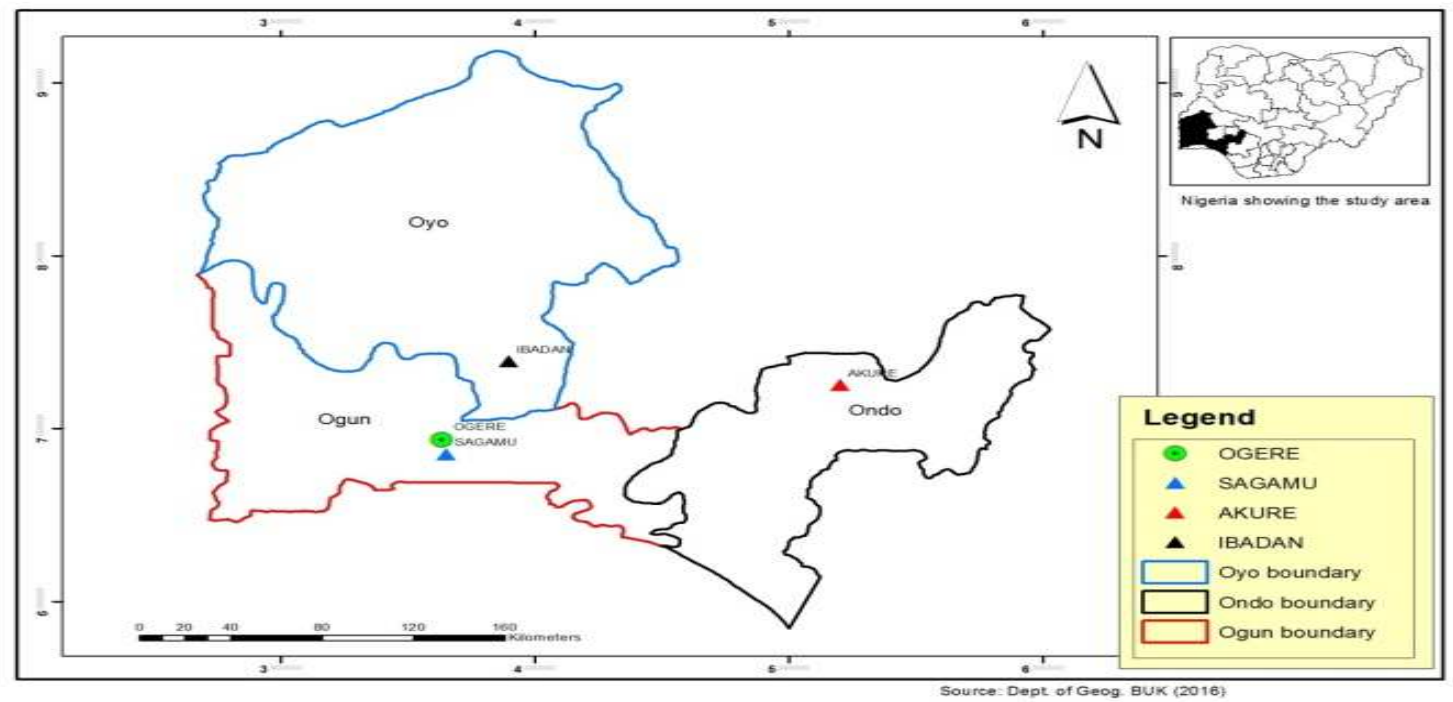

Figure 1: Map showing the sampling point at Sagamu Town, Ogun State.

\section{Description of Sampling Area}

Sagamu has geographical coordinates between $6^{\circ} 50^{\prime}$ north; $3^{\circ} 38^{\prime}$ east is located in south western region of Nigeria. The region has tropical wet and dry climate with a lengthy wet season and relatively constant temperatures throughout the course of the year. Wet season runs from March to October, November to December forms the region dry season. The vegetation type of the region is savannah which is really grassland with small bushes and occasional big trees. Grassland soils have substantially higher organic matter content than forest soils (Novackova, 2011).

\section{Sample Collection}

The Peatsoil samples were collected from four different sampling points $(0-10 \mathrm{~cm}$ depth) in Sagamu into polyethylene bag with plastic spoons. Samples were taken to the laboratory, extraneous materials were removed; the samples were air-dried, crushed and ground to a fine powder in a mortar passed through a $0.20 \mathrm{~mm}$ sieve. The samples were kept for analysis.

\section{Isolation and purification of humic acid from peat soil sample}

Peatsoil sample $(100 \mathrm{~g})$ was mixed with 1000 $\mathrm{cm}^{3}$ of $0.1 \mathrm{M} \mathrm{NaOH}$ solution, shaken for 3hours and left to stand overnight. Dark-coloured supernatant was obtained and decanted from solid residue. The dark-coloured supernatant was acidified to $(\mathrm{pH}=1.0)$ with $6 \mathrm{M} \mathrm{HCl}$ stirred and allowed to stand for 6 hours. Yellowish brown supernatant and dark-brown precipitate were obtained. The yellowish brown supernatant was decanted followed by centrifuge and discarded. The dark-brown precipitate was mixed with $500 \mathrm{~cm}^{3}$ of $0.1 \mathrm{M} \mathrm{NaOH}$ solution followed by passing through dowex resin. The dark-brown solution was acidified to $(\mathrm{pH}=1.0)$ with $6 \mathrm{M} \mathrm{HCl}$ stirred and allowed to stand for 3 hours. The dark-brown precipitate was washed several times with deionized water. The supernatant was treated with $\mathrm{AgNO}_{3}$ solution until no white precipitate observed. The humic acid was transferred to weighed crucible and dried at $60^{\circ} \mathrm{C}$ in an oven for 12 hours. The humic acid was cooled and dried in the desiccator, weighed and recorded. The obtained humic acid was dried again at $60^{\circ} \mathrm{C}$ for additional 6 hours cooled and dried in the desiccator, weighed and recorded constant weight was obtained (Baruah et al., 2015).

\section{FT-IR analysis}

FT-IR spectra of humic acid sample was analysed using Carry 630 FT-IR Agilent Technologies.

Unhydrolysed compost humic acid

The unhydrolysed humic acid was obtained after isolation and purification of compost humic acid and kept for investigation.

\section{Acid hydrolysis of Peatsoil acid}

Peatsoil humic acid sample (1g) was refluxed for 12 hours at $\left(160^{\circ} \mathrm{C}\right)$ with $50 \mathrm{~cm}^{3}$ of $6 \mathrm{M} \mathrm{HCl}$. The mixture was allowed to cool, decanted, and centrifuged after hydrolysis. The insoluble residues were washed with distilled water via centrifugation several times, and the supernatant was treated with $\mathrm{AgNO}_{3}$ solution until no white precipitate was observed. The residue was thoroughly dried over $\mathrm{CaCl}_{2}$ in a desiccator at room temperature (Chefetz et al., 2002). Finally, the obtained hydrolysed humic acid was kept for investigation. 
BAJOPAS Volume 14 Number 1,June, 2021 Potentiometric Titrations

Potentiometric measurements were carried out using a pH-meter Jenway (model 3510) with combine electrode, the sensitivity of the $\mathrm{pH}$ meter is 0.01 units. The $\mathrm{pH}$ meter was switched on half an hour before starting the titration for initial warm up of the instrument. The instrument was calibrated with an aqueous standard buffer solution of $\mathrm{pH} 4.00$ and 10.0 (borate buffer) prepared from a "Qualigens" buffer tablets.

The following sets of solutions were prepared in a $250 \mathrm{~cm}^{3}$ volumetric flask separately for $\mathrm{pH}$ metric titrations.

(i) $5 \mathrm{~cm}^{3} 0.1 \mathrm{M} \mathrm{HCl}+40 \mathrm{~cm}^{3}$ deionized water

(ii) $5 \mathrm{~cm}^{3} 0.1 \mathrm{M} \mathrm{HCl}+39 \mathrm{~cm}^{3}$ deionized water $+1 \mathrm{~cm}^{3} 0.15 \mathrm{gcm}^{-3}$ humic acid

(iii) $5 \mathrm{~cm}^{3} 0.1 \mathrm{M} \mathrm{HCl}+37 \mathrm{~cm}^{3}$ deionized water $+1 \mathrm{~cm}^{3} 0.15 \mathrm{gcm}^{-3}$ humic acid

$$
+2 \mathrm{~cm}^{3} \quad 0.01 \mathrm{M} \mathrm{Cu} \text { (II) }
$$

The solutions were titrated against standardized $0.110 \mathrm{MNaOH}$ separately. The total volume of each mixture was adjusted to $50 \mathrm{~cm}^{3}$ and the ionic strength of the solutions was maintained constant at by adding appropriate amount of stock solution of $1 \mathrm{M} \mathrm{KNO}_{3}$ (Gamal, 2015; Omar and Ali, 2015). A magnetic stirrer was used to achieve thorough mixing of the interacting solutions at $550 \mathrm{rpm}$. The same set of experimental conditions was applied for potentiometric titration of remaining samples.

\section{Evaluation of pKa of Hydrolysed peat soil Humic Acids}

The proton-ligand formation number $\mathrm{n}_{\mathbf{A}}$ were calculated by Irving and Rossotti expression (Omar and Ali, 2015).

$\mathrm{nA}=\mathrm{Y}-\frac{(\mathrm{V} 2-\mathrm{V1})(\mathrm{No}-\mathrm{Eo})}{(\mathrm{VO}+\mathrm{V1}) \mathrm{TCL}}$ 1

Where: $Y$ is number of dissociable proton, $\left(\mathrm{V}_{2^{-}}\right.$ $V_{1}$ ) is the measure of displacement of the ligand curve relative to acid curve, $\mathrm{N}^{\circ}$ and $\mathrm{E}^{\circ}$ are the resultant concentration of alkali solution, free acid solution, $\mathrm{T}_{\mathrm{cL}}{ }^{\circ}$ is the total ligand concentration, $\mathrm{V}^{\circ}$ is the total volume of titration solution, $V_{1}$ is the volume of alkali added to acid solution, $V_{2}$ is the volume of alkali added to acid solution + ligand solution, acid dissociation constants (pKa - values) of ligand were calculated by algebraic method point wise calculation (Tables 1 ). The dissociation constants (pKa) were calculated according to the following relation:

$\mathrm{pKa}=\mathrm{pH}+\log \left(\frac{n A}{1-n A}\right)$ 2

Where: pKa is the acid dissociation constant, $\mathrm{n}_{\mathrm{A}}$ is the Proton-ligand formation number and $\mathrm{pH}$ is the pH-values (Omar and Ali, 2015).

\section{Determination of metal-ligand stability constants $(\log K)$ of complexes}

The potentiometric measurement for the determination of stability constant of a complex in solution is based on the fact that the redox potential of the couple $\frac{M^{+(m-n)}}{M^{+m}}$ is shifted significantly on complexation of the metal ion with the ligand. This method involves change in hydrogen ion concentration $\left[\mathrm{H}^{+}\right]$due to the displacement or association of one or more protons taking place during complexation reaction. This change can be found out by titrating the solutions containing free acid, acid with ligand, and acid with ligand and metal ion, individually against a standard alkali solution at a constant ionic strength or temperature. Either ionic strength or temperature may be varied for different sets of solutions. In all the cases, the change in the $\mathrm{pH}$ of the solution is measured after each addition of a known amount of alkali to the reaction cell which contains the reaction mixture. The titration curves are then drawn by plotting the measured $\mathrm{pH}$ values against the corresponding volume of alkali added and the stability constants of the complexes are determined from the titration curves by employing $\mathrm{pH}$-metric titration technique given by (Irving and Rossoti).

Metal-ligand stability constants ( $\log \mathrm{K}$ ) were determined by using the following relations:

$$
\bar{n}=\frac{\left(V_{3}-V_{2}\right)\left(E^{0}+N^{0}\right)}{\left(V^{0}+V_{2}\right) \bar{n}_{A} T_{m}^{0}}
$$

and

$$
P L=\log _{10}\left\{\frac{1+\beta_{n}^{H} \frac{1}{[\text { anti } \log \mathrm{pH}]^{\mathrm{n}}}}{\mathrm{T}_{\mathrm{L}}^{0}-n \bar{T}_{m}^{0}} \mathrm{X} \frac{\left(V^{0}+V_{3}\right)}{V^{0}}\right\}
$$


BAJOPAS Volume 14 Number 1,June, 2021

Where $T_{L}, T^{\circ}, E^{\circ}$, and $V^{\circ}$ havethe same significance as in equation (1) above, $T_{m}$ denotes the total concentration of metal present in solution, $V_{3}$ is the volume of metal ions present in solution and $\beta^{H}$ is the overall proton ligand stability constant. The metal-ligand stability constants (log K) were determined by employing point wise computational Method (eq. 5 and 6).

$\operatorname{LogK}_{1}=\log \left(\frac{n}{1-n}\right)+\mathrm{pL}$ .5

$\operatorname{LogK}_{2}=\log \left(\frac{1-n}{2-n}\right)+\mathrm{pL}$ ...6

Where: Log $\mathrm{K}$ is the metal-ligand stability constant, $\mathrm{pL}$ is the Free ligand exponent function, $\mathbf{n}$ is the Average number of ligand attached with metal ion (Janraoet al., 2014). The results obtained were analyzed by an ORIGIN 2016 program using titration data and then the proton-ligand stability constants (pKa) and Metal-ligand stability constant (LogK) calculated (Omar and Ali, 2015).

\section{RESULTS AND DISCUSSION}

Fourier transformed infrared (FT-IR) spectra of isolated humic acid from peat soils Figure 2 had distinct clear absorption bands indicating the presence of major humic acid structural elemental groups such as $\mathrm{H}$ bonded $\mathrm{OH}$ $\left(3680 \mathrm{~cm}^{-1}\right.$ peak $), C=0$ of carbonyl $\left(1721 \mathrm{~cm}^{-1}\right.$ peak), functional groups of aliphatic components $\mathrm{CH}_{2}\left(2918 \mathrm{~cm}^{-1}\right.$ peak) and $\mathrm{C}-\mathrm{O}$ stretching of polysaccharide $\left(1168 \mathrm{~cm}^{-1}\right.$ peak). The positions of the absorption bands of the spectra fell within typical major absorption bands of humic acid which is at frequencies 3680, 2918, 1721, 1168 $\mathrm{cm}^{-1}$. The first peak centred in the vicinity of $3680 \mathrm{~cm}^{-1}$ region is attributed to phenol $\mathrm{OH}$ group bounded by intermolecular $\mathrm{H}$ bonds. The $2918 \mathrm{~cm}^{-1}$ band usually has absorption maximum at $2918 \mathrm{~cm}^{-1}$ which is due to $\mathrm{C}-\mathrm{H}$ stretching of alkane group $\left(\mathrm{CH}_{2}\right)$. The next major absorption band is $1721 \mathrm{~cm}^{-1}$. This band has been commonly ascribed to $\mathrm{C}=\mathrm{O}$ stretching of mainly carboxyl group $(\mathrm{COOH})$ with trace amount of ketones. The last peak was observed at 1168 $\mathrm{cm}^{-1}$ due to $\mathrm{C}-\mathrm{O}$ stretching of polysaccharides and this peak appeared also in the spectra of humic acid from peat soil. The FTIR spectra of the isolated humic acid contained all major characteristic absorption peaks of humic acid. These absorption peaks indicated the presence of the major structural elements of humic acid namely $\mathrm{H}$ bonded $\mathrm{OH}, \mathrm{C}=\mathrm{C}$ of aromatic ring, $\mathrm{C}=\mathrm{O}$ of carbonyl group (both carboxyl and ketonic), $\mathrm{CH}_{2}$ group. This strongly supports the presence of humic acid.

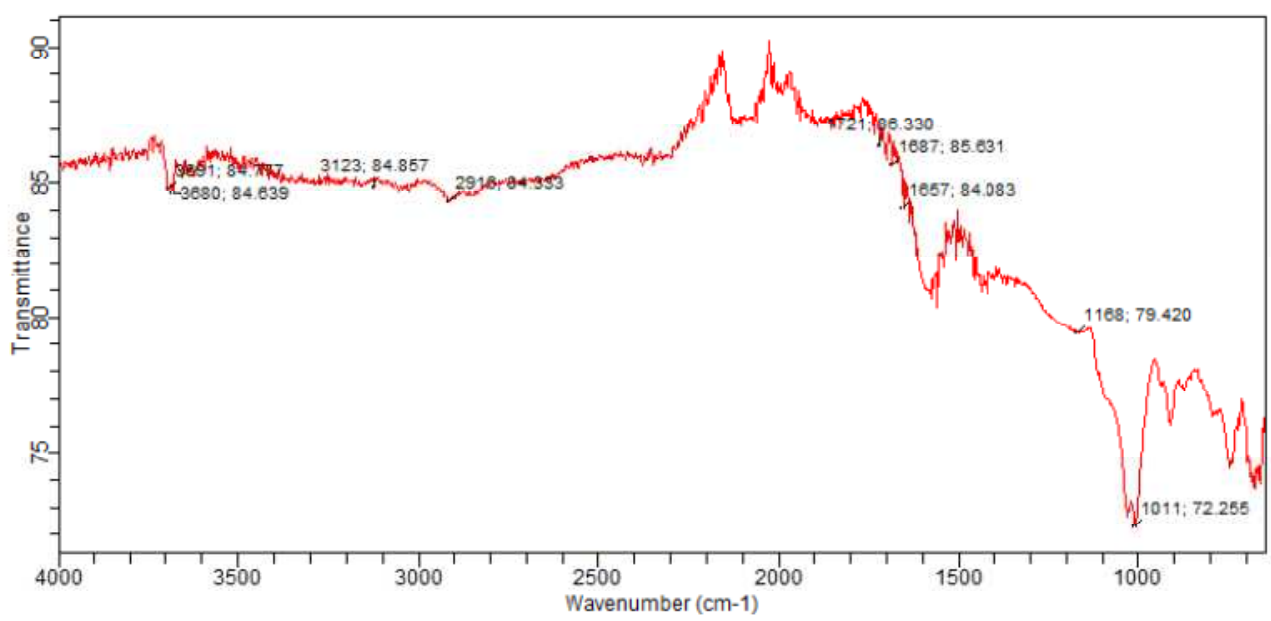

Fig. 2 : FT-IR spectraof peatsoilhumic acid (PSHA)

\section{Evaluation of acid dissociation constant (pka) of acid hydrolysed peat soil humicacid at phenolic group}

The value of the dissociation constant of the peat soil humic acid (PSHA) that underwent acidhydrolysis studied was found to be 8.9299 as shown Table 1, which is lower than the literaturevalues reported by Almeida and Szpoganics, (2015), Borges et al., (2005); Badr et al., (2012)and Fernandes et al,.(2009) of $9.73,9.47$ and 10.30. The difference between the obtained valuesand the reported values in this study might be probably as a result of acid hydrolysis of humicacid. 
BAJOPAS Volume 14 Number 1,June, 2021

Table 1: PKa of (Hydrolysed PSHA)

\begin{tabular}{|l|l|l|l|l|l|l|}
\hline $\mathrm{pH}$ & $\mathrm{BV}_{1}$ & $\mathrm{BV}_{2}$ & $\mathrm{~V}_{2}-\mathrm{V}_{1}$ & $\mathrm{nA}$ & $\log \left(\frac{n A}{1-n A}\right)$ & $\mathrm{pKa}$ \\
\hline 8.50 & 5.30 & 6.29 & 0.99 & 0.3594 & -0.2510 & 8.2490 \\
8.72 & 5.35 & 6.37 & 1.02 & 0.3400 & -0.2880 & 8.4320 \\
9.00 & 5.40 & 6.46 & 1.06 & 0.3141 & -0.3391 & 8.6609 \\
9.22 & 5.45 & 6.55 & 1.10 & 0.2882 & -0.3927 & 8.8273 \\
9.51 & 5.50 & 6.66 & 1.16 & 0.2494 & -0.4786 & 9.0314 \\
9.73 & 5.55 & 6.78 & 1.23 & 0.2041 & -0.5910 & 9.1390 \\
10.00 & 5.60 & 6.90 & 1.30 & 0.1589 & -0.7238 & 9.2762 \\
10.23 & 5.65 & 7.05 & 1.40 & 0.0941 & -0.9835 & 9.2465 \\
10.49 & 5.70 & 7.10 & 1.40 & 0.0941 & -0.9835 & 9.5065 \\
\hline
\end{tabular}

Average pKa $=8.9299 \pm 0.4186$

Table 2: PKa of (Unhydrolysed PSHA)

\begin{tabular}{|l|l|l|l|l|l|l|}
\hline $\mathrm{pH}$ & $\mathrm{BV}_{1}$ & $\mathrm{BV}_{2}$ & $\mathrm{~V}_{2}-\mathrm{V}_{1}$ & $\mathrm{nA}$ & $\log \left(\frac{\boldsymbol{n A}}{1-\boldsymbol{n}}\right)$ & $\mathrm{pKa}$ \\
\hline 8.50 & 5.30 & 5.81 & 0.51 & 0.6619 & 0.2919 & 8.7919 \\
8.72 & 5.35 & 5.90 & 0.55 & 0.6357 & 0.2418 & 8.9618 \\
9.00 & 5.40 & 6.00 & 0.60 & 0.6029 & 0.1813 & 9.1813 \\
9.22 & 5.45 & 6.10 & 0.65 & 0.5701 & 0.1226 & 9.3426 \\
9.51 & 5.50 & 6.20 & 0.70 & 0.5376 & 0.0654 & 9.5754 \\
9.73 & 5.55 & 6.33 & 0.78 & 0.4851 & -0.0259 & 9.7041 \\
10.00 & 5.60 & 6.47 & 0.87 & 0.4262 & -0.1291 & 9.8709 \\
10.23 & 5.65 & 6.62 & 0.99 & 0.3609 & -0.2481 & 9.9819 \\
10.49 & 5.70 & 6.80 & 1.10 & 0.2759 & -0.4690 & 10.0210 \\
\hline
\end{tabular}

Average pKa $=9.4923 \pm 0.4410$

Metal-ligand stability constant ( $\log \mathrm{K}$ )

The stabilityconstants require the accurate values of proton-ligand stability constants (Anil and Maroti, 2008). Metal titration curves crossed over ligand titration curve indicated the formation of complex upon proton release (Santosh, et al., 2011). If the values of n- are within range $0.2-0.8$ and $1.2-18$ this indicates the formation of $1: 1$ and 1:2 complexes (Sayyed and Mazahar, 2012).

The metal (II)-humate stepwise stability constants (log k) at phenolic group (Tables 318)

Table 3: Point-wise method, $\mathrm{Cu}$-(Hydrolysed PSHA)

\begin{tabular}{|l|l|l|l|l|l|l|l|l|}
\hline $\mathrm{pH}$ & $\mathrm{BV}_{1}$ & $\mathrm{BV}_{2}$ & $\mathrm{BV}_{3}$ & $\left(\mathrm{~V}_{3}-\mathrm{V}_{2}\right)$ & $\mathrm{n}$ & $\mathrm{pL}$ & $\log \left(\frac{n}{1-n}\right)$ & LogK $_{1}$ \\
\hline 8.50 & 5.30 & 6.29 & 6.33 & 0.04 & 0.5500 & 2.66 & 0.0871 & 2.7471 \\
8.72 & 5.35 & 6.37 & 6.41 & 0.04 & 0.5714 & 2.43 & 0.1249 & 2.5549 \\
9.00 & 5.40 & 6.46 & 6.50 & 0.04 & 0.6198 & 2.16 & 0.2122 & 2.3722 \\
9.22 & 5.45 & 6.55 & 6.59 & 0.04 & 0.6667 & 1.94 & 0.3010 & 2.2410 \\
\hline
\end{tabular}

LogK $_{1}$ (Average value) $=2.4788 \pm 0.2203$

Table 4: Point-wise method, $\mathrm{Cu}$-(Hydrolysed PSHA)

\begin{tabular}{|l|l|l|l|l|l|l|l|l|}
\hline $\mathrm{pH}$ & $\mathrm{BV}_{1}$ & $\mathrm{BV}_{2}$ & $\mathrm{BV}_{3}$ & $\left(\mathrm{~V}_{3}-\mathrm{V}_{2}\right)$ & $\mathrm{n}$ & $\mathrm{pL}$ & $\log \left(\frac{n-1}{2-n}\right)$ & LogK $_{2}$ \\
\hline 9.51 & 5.50 & 6.66 & 6.73 & 0.07 & 1.3509 & 1.70 & -0.2671 & 1.4329 \\
9.73 & 5.55 & 6.78 & 6.85 & 0.07 & 1.6383 & 1.51 & 0.2467 & 1.7567 \\
10.00 & 5.60 & 6.90 & 6.98 & 0.08 & 2.1783 & 1.31 & -0.2158 & 1.0942 \\
10.23 & 5.65 & 7.05 & 7.13 & 0.08 & 4.1904 & 1.27 & & \\
10.49 & 5.70 & 7.10 & 7.19 & 0.09 & 4.6920 & & & \\
\hline
\end{tabular}

Log $K_{2}($ Average value $)=1.4280 \pm 0.3312$ 
BAJOPAS Volume 14 Number 1,June, 2021

Table 5: Point-wise method, $\mathrm{Cu}$ (Unhydrolysed PSHA)

\begin{tabular}{|l|l|l|l|l|l|l|l|l|}
\hline $\mathrm{pH}$ & $\mathrm{BV}_{1}$ & $\mathrm{BV}_{2}$ & $\mathrm{BV}_{3}$ & $\left(\mathrm{~V}_{3}-\mathrm{V}_{2}\right)$ & $\mathrm{n}$ & $\mathrm{pL}$ & $\log \left(\frac{n}{n-1}\right)$ & Log $_{1}$ \\
\hline 8.50 & 5.30 & 5.81 & 5.85 & 0.04 & 0.2973 & 2.88 & -0.3736 & 2.5064 \\
8.72 & 5.35 & 5.90 & 5.95 & 0.05 & 0.3873 & 2.66 & -0.1992 & 2.4608 \\
9.00 & 5.40 & 6.00 & 6.05 & 0.05 & 0.4044 & 2.38 & -0.1681 & 2.2119 \\
9.22 & 5.45 & 6.10 & 6.15 & 0.06 & 0.5157 & 2.18 & -0.0272 & 2.2072 \\
9.51 & 5.50 & 6.20 & 6.27 & 0.07 & 0.6417 & 1.89 & 0.2530 & 1.1430 \\
\hline
\end{tabular}

$\operatorname{LogK}_{1}($ Average value $)=2.3059 \pm 0.6153$

Table 6:Point-wise method, $\mathrm{Cu}$ (Unhydrolysed PSHA)

\begin{tabular}{|l|l|l|l|l|l|l|l|l|}
\hline $\mathrm{pH}$ & $\mathrm{BV}_{1}$ & $\mathrm{BV}_{2}$ & $\mathrm{BV}_{3}$ & $\mathrm{~V}_{3}-\mathrm{V}_{2}$ & $\mathrm{n}$ & $\mathrm{pL}$ & $\log \left(\frac{n-1}{2-n}\right)$ & $\log \mathrm{K}_{2}$ \\
\hline 9.73 & 5.55 & 6.33 & 6.42 & 0.09 & 0.9000 & 1.69 & & \\
10.00 & 5.60 & 6.47 & 6.58 & 0.11 & 1.2578 & 1.44 & -0.4592 & 0.9808 \\
10.23 & 5.65 & 6.62 & 6.84 & 0.12 & 1.6137 & 1.26 & -0.2010 & 1.4610 \\
10.49 & 5.70 & 6.80 & 6.92 & 0.12 & 2.1052 & 1.03 & & \\
\hline
\end{tabular}

$\operatorname{LogK}_{2}$ (Average value) $=1.2209 \pm 0.3398$

Table 7:Point-wise method, Pb (Hydrolysed PSHA)

\begin{tabular}{|l|l|l|l|l|l|l|l|l|}
\hline $\mathrm{pH}$ & $\mathrm{BV}_{1}$ & $\mathrm{BV}_{2}$ & $\mathrm{BV}_{3}$ & $\left(\mathrm{~V}_{3}-\mathrm{V}_{2}\right)$ & $\mathrm{n}$ & $\mathrm{pL}$ & $\log \left(\frac{n}{1-n}\right)$ & LogK $_{1}$ \\
\hline 8.50 & 5.30 & 6.29 & 6.33 & 0.04 & 0.5500 & 2.66 & 0.0871 & 2.7471 \\
8.72 & 5.35 & 6.37 & 6.41 & 0.04 & 0.5714 & 2.43 & 0.1249 & 2.5549 \\
9.00 & 5.40 & 6.46 & 6.50 & 0.04 & 0.6198 & 2.16 & 0.2122 & 2.3722 \\
9.22 & 5.45 & 6.55 & 6.60 & 0.05 & 0.8333 & 1.96 & 0.6989 & 2.6589 \\
\hline
\end{tabular}

Log $_{\mathbf{1}}($ Average value $)=2.5832 \pm 0.1614$

Table 8:Point-wise method, Pb-(Hydrolysed PSHA)

\begin{tabular}{|l|l|l|l|l|l|l|l|l|}
\hline $\mathrm{pH}$ & $\mathrm{BV}_{1}$ & $\mathrm{BV}_{2}$ & $\mathrm{BV}_{3}$ & $\left(\mathrm{~V}_{3}-\mathrm{V}_{2}\right)$ & $\mathrm{n}$ & $\mathrm{pL}$ & $\log \left(\frac{n-1}{2-n}\right)$ & $\log \mathrm{K}_{2}$ \\
\hline 9.51 & 5.50 & 6.66 & 6.71 & 0.05 & 0.9650 & 1.67 & & \\
9.73 & 5.55 & 6.78 & 6.83 & 0.05 & 1.1702 & 1.44 & & \\
10.00 & 5.60 & 6.90 & 6.90 & 0.05 & 1.4864 & 1.22 & -0.0237 & 1.1963 \\
10.23 & 5.65 & 7.05 & 7.10 & 0.05 & 2.0190 & 1.09 & & \\
10.49 & 5.70 & 7.10 & 7.17 & 0.07 & 3.6492 & 1.00 & & \\
\hline
\end{tabular}

Log $K_{2}$ (Average value) $=1.1963$

Table 9: Point-wise method, Pb (Unhydrolysed PSHA)

\begin{tabular}{|l|l|l|l|l|l|l|l|l|}
\hline $\mathrm{pH}$ & $\mathrm{BV}_{1}$ & $\mathrm{BV}_{2}$ & $\mathrm{BV}_{3}$ & $\mathrm{~V}_{3}-\mathrm{V}_{2}$ & $\mathrm{n}$ & $\mathrm{pL}$ & $\begin{array}{l}\text { Log } \\
\left(\frac{n}{n-1}\right)\end{array}$ & Log $\mathrm{K}_{1}$ \\
\hline 8.50 & 5.30 & 5.81 & 5.85 & 0.04 & 0.2973 & 2.88 & -0.3736 & 2.5064 \\
8.72 & 5.35 & 5.90 & 5.94 & 0.04 & 0.3099 & 2.66 & -0.5477 & 2.3123 \\
9.00 & 5.40 & 6.00 & 6.05 & 0.05 & 0.4044 & 2.38 & -0.1681 & 2.2119 \\
9.22 & 5.45 & 6.10 & 6.15 & 0.06 & 0.5157 & 2.18 & 0.0272 & 2.2072 \\
9.51 & 5.50 & 6.20 & 6.26 & 0.07 & 0.6417 & 1.89 & 0.2530 & 2.1430 \\
9.73 & 5.55 & 6.40 & 6.40 & 0.07 & 0.7000 & 1.67 & 0.3680 & 2.0380 \\
\hline
\end{tabular}

LogK $_{1}$ (Average value) $=2.2364 \pm 0.1602$

Table 10: Point-wise method, Pb (Unhydrolysed PSHA)

\begin{tabular}{|l|l|l|l|l|l|l|l|l|}
\hline $\mathrm{pH}$ & $\mathrm{BV}_{1}$ & $\mathrm{BV}_{2}$ & $\mathrm{BV}_{3}$ & $\mathrm{~V}_{3}-\mathrm{V}_{2}$ & $\mathrm{n}$ & $\mathrm{pL}$ & $\log \left(\frac{n-1}{2-n}\right)$ & $\log \mathrm{K}_{2}$ \\
\hline 10.00 & 5.60 & 6.47 & 6.55 & 0.08 & 1.9503 & 1.41 & & \\
10.23 & 5.65 & 6.62 & 6.72 & 0.11 & 1.4792 & 1.26 & -0.0361 & 1.2239 \\
\hline
\end{tabular}

$\operatorname{LogK}_{2}$ (Average value) $=1.2239$

Table 11: Point-wise method, Mg (Hydrolysed PSHA)

\begin{tabular}{|l|l|l|l|l|l|l|l|l|}
\hline $\mathrm{pH}$ & $\mathrm{BV}_{1}$ & $\mathrm{BV}_{2}$ & $\mathrm{BV}_{3}$ & $\left(\mathrm{~V}_{3}-\mathrm{V}_{2}\right)$ & $\mathrm{n}$ & $\mathrm{pL}$ & $\log \left(\frac{n}{n-1}\right)$ & LogK $_{1}$ \\
\hline 8.50 & 5.30 & 6.29 & 6.31 & 0.02 & 0.2750 & 2.64 & -0.4290 & 2.2110 \\
8.72 & 5.35 & 6.37 & 6.39 & 0.02 & 0.2858 & 2.42 & -0.3978 & 2.0222 \\
9.00 & 5.40 & 6.46 & 6.49 & 0.03 & 0.4648 & 2.14 & -0.0612 & 2.0788 \\
9.22 & 5.45 & 6.55 & 6.59 & 0.04 & 0.6667 & 1.94 & 0.3010 & 2.2410 \\
\hline
\end{tabular}

$\log _{\mathbf{1}}($ Average value) $=2.1382 \pm 0.1046$ 
BAJOPAS Volume 14 Number 1,June, 2021

Table 12: Point-wise method, Mg (Hydrolysed PSHA)

\begin{tabular}{|l|l|l|l|l|l|l|l|l|}
\hline $\mathrm{pH}$ & $\mathrm{BV}_{1}$ & $\mathrm{BV}_{2}$ & $\mathrm{BV}_{3}$ & $\left(\mathrm{~V}_{3}-\mathrm{V}_{2}\right)$ & $\mathrm{n}$ & $\mathrm{pL}$ & $\log \left(\frac{n-1}{2-n}\right)$ & LogK $_{2}$ \\
\hline 9.51 & 5.55 & 6.66 & 6.71 & 0.05 & 0.9650 & 1.67 & & \\
9.73 & 5.55 & 6.78 & 6.84 & 0.06 & 1.4042 & 1.47 & -0.1686 & 1.3014 \\
10.00 & 5.60 & 6.90 & 6.93 & 0.06 & 1.7838 & 1.23 & 0.5593 & 1.7893 \\
10.23 & 5.65 & 7.05 & 7.10 & 0.06 & 3.1429 & 1.10 & & \\
10.49 & 5.70 & 7.10 & 7.18 & 0.07 & 3.6492 & 0.83 & & \\
\hline
\end{tabular}

LogK $_{2}($ Average value $)=1.5453 \pm 0.3450$

Table 13: Point-wise method, Mg (Unhydrolysed PSHA)

\begin{tabular}{|l|l|l|l|l|l|l|l|l|}
\hline $\mathrm{pH}$ & $\mathrm{BV}_{1}$ & $\mathrm{BV}_{2}$ & $\mathrm{BV}_{3}$ & $\mathrm{~V}_{3}-\mathrm{V}_{2}$ & $\mathrm{n}$ & $\mathrm{pL}$ & $\log \left(\frac{n}{n-1}\right)$ & $\operatorname{Log~}_{1}$ \\
\hline 8.50 & 5.30 & 5.81 & 5.85 & 0.04 & 0.2973 & 2.88 & -0.3736 & 2.5064 \\
8.72 & 5.35 & 5.90 & 5.94 & 0.04 & 0.3099 & 2.66 & -0.3477 & 2.3123 \\
9.00 & 5.40 & 6.00 & 6.04 & 0.04 & 0.3236 & 2.38 & -0.3202 & 2.0598 \\
9.22 & 5.45 & 6.10 & 6.15 & 0.05 & 0.4297 & 2.17 & -0.1230 & 2.0470 \\
9.51 & 5.50 & 6.20 & 6.26 & 0.06 & 0.5500 & 1.89 & 0.0871 & 1.9771 \\
9.73 & 5.55 & 6.33 & 6.40 & 0.07 & 0.7000 & 1.67 & 0.3680 & 2.0380 \\
\hline
\end{tabular}

LogK $_{1}$ (Average value) $=2.1568 \pm 0.2069$

Table 14: Point-wise method, Mg (Unhydrolysed PSHA)

\begin{tabular}{|l|l|l|l|l|l|l|l|l|}
\hline $\mathrm{pH}$ & $\mathrm{BV}_{1}$ & $\mathrm{BV}_{2}$ & $\mathrm{BV}_{3}$ & $\mathrm{~V}_{3}-\mathrm{V}_{2}$ & $\mathrm{n}$ & $\mathrm{pL}$ & $\log \left(\frac{n-1}{2-n}\right)$ & $\log \mathrm{K}_{2}$ \\
\hline 10.00 & 5.60 & 6.47 & 6.55 & 0.08 & 0.9148 & 1.41 & & \\
10.23 & 5.65 & 6.62 & 6.71 & 0.09 & 1.2102 & 1.20 & -0.5749 & 0.6251 \\
10.49 & 5.70 & 6.80 & 6.92 & 0.09 & 1.5968 & 1.03 & 0.1703 & 1.2003 \\
\hline
\end{tabular}

LogK $_{2}$ (Average value) $=0.9127 \pm 0.4070$

Table15:Point-wise method, Cd (Hydrolysed PSHA)

\begin{tabular}{|l|l|l|l|l|l|l|l|l|}
\hline $\mathrm{pH}$ & $\mathrm{BV}_{1}$ & $\mathrm{BV}_{2}$ & $\mathrm{BV}_{3}$ & $\left(\mathrm{~V}_{3}-\mathrm{V}_{2}\right)$ & $\mathrm{n}$ & $\mathrm{pL}$ & $\log \left(\frac{n}{1-n}\right)$ & LogK $_{1}$ \\
\hline 8.50 & 5.30 & 6.29 & 6.31 & 0.02 & 0.2750 & 2.64 & -0.4210 & 2.2190 \\
8.72 & 5.35 & 6.37 & 6.40 & 0.03 & 0.4286 & 2.42 & -0.1249 & 2.2951 \\
9.00 & 5.40 & 6.46 & 6.49 & 0.03 & 0.4648 & 2.14 & -0.0612 & 2.0788 \\
9.22 & 5.45 & 6.55 & 6.59 & 0.04 & 0.6667 & 1.96 & 0.3010 & 2.2610 \\
9.51 & 5.55 & 6.66 & 6.70 & 0.04 & 0.7720 & 1.67 & 0.5297 & 2.1997 \\
\hline
\end{tabular}

LogK $_{\mathbf{1}}$ (Average value) $=2.2108 \pm 0.0825$

Table 16: Point-wise method, Cd (Hydrolysed PSHA)

\begin{tabular}{|l|l|l|l|l|l|l|l|l|}
\hline $\mathrm{pH}$ & $\mathrm{BV}_{1}$ & $\mathrm{BV}_{2}$ & $\mathrm{BV}_{3}$ & $\left(\mathrm{~V}_{3}-\mathrm{V}_{2}\right)$ & $\mathrm{n}$ & $\mathrm{pL}$ & $\log \left(\frac{n-1}{2-n}\right)$ & Log $_{2}$ \\
\hline 9.73 & 5.55 & 6.78 & 6.83 & 0.06 & 1.4042 & 1.47 & -0.1686 & 1.3014 \\
10.00 & 5.60 & 6.90 & 6.95 & 0.06 & 1.7838 & 1.23 & 0.5593 & 1.7893 \\
10.23 & 5.65 & 7.05 & 7.10 & 0.06 & 3.1429 & 1.09 & & \\
10.49 & 5.70 & 7.10 & 7.16 & 0.06 & 3.1429 & 0.89 & & \\
& & & & & & & & \\
\hline
\end{tabular}

$\operatorname{LogK}_{2}$ (Average value) $=1.5453 \pm 0.3450$

Table 17: Point-wise method, Cd (Unhydrolysed PSHA)

\begin{tabular}{|l|l|l|l|l|l|l|l|l|}
\hline $\mathrm{pH}$ & $\mathrm{BV}_{1}$ & $\mathrm{BV}_{2}$ & $\mathrm{BV}_{3}$ & $\mathrm{~V}_{3}-\mathrm{V}_{2}$ & $\mathrm{n}$ & $\mathrm{pL}$ & $\log \left(\frac{n}{n-1}\right)$ & $\operatorname{Log~}_{1}$ \\
\hline 8.50 & 5.30 & 5.81 & 5.86 & 0.05 & 0.3717 & 2.88 & -0.2280 & 2.6520 \\
8.72 & 5.35 & 5.90 & 5.95 & 0.05 & 0.3873 & 2.66 & -0.1992 & 2.4608 \\
9.00 & 5.40 & 6.00 & 6.06 & 0.06 & 0.4853 & 2.38 & -0.0255 & 2.3545 \\
9.22 & 5.45 & 6.10 & 6.16 & 0.06 & 0.5157 & 2.18 & -0.0272 & 2.2072 \\
9.51 & 5.50 & 6.20 & 6.27 & 0.07 & 0.6417 & 1.89 & 0.2530 & 1.1430 \\
9.73 & 5.55 & 6.33 & 6.41 & 0.08 & 0.8000 & 1.69 & 0.6020 & 2.2920 \\
& & & & & & & & \\
\hline
\end{tabular}

$\operatorname{LogK}_{1}($ Average value $)=2.2516 \pm 0.5380$ 
BAJOPAS Volume 14 Number 1,June, 2021

Table 18: Point-wise method, Cd (Unhydrolysed PSHA)

\begin{tabular}{|l|l|l|l|l|l|l|l|l|}
\hline $\mathrm{pH}$ & $\mathrm{BV}_{1}$ & $\mathrm{BV}_{2}$ & $\mathrm{BV}_{3}$ & $\mathrm{~V}_{3}-\mathrm{V}_{2}$ & $\mathrm{n}$ & $\mathrm{pL}$ & $\log \left(\frac{n-1}{2-n}\right)$ & $\log \mathrm{K}_{2}$ \\
\hline 10.00 & 5.60 & 6.47 & 6.57 & 0.10 & 1.1434 & 1.43 & & \\
10.23 & 5.65 & 6.62 & 6.72 & 0.10 & 1.3448 & 1.23 & -0.2788 & 0.9512 \\
10.49 & 5.70 & 6.80 & 6.90 & 0.10 & 1.7742 & 1.03 & 0.5351 & 1.5651 \\
\hline
\end{tabular}

$\operatorname{LogK}_{2}($ Average value $)=1.2581 \pm 0.4340$

Table 19: Stepwise and overall Stability constants of thehydrolysed and unhydrolysed divalent metal (II) complexes

\begin{tabular}{|c|c|c|c|}
\hline Chelates & LogK $_{1}$ & $\log _{2}$ & Log $\beta$ \\
\hline [Cu (Hydrolysed PSHA-1) $\left.{ }_{2}\right]$ & 2.4788 & 1.4280 & 3.9068 \\
\hline$\left[\mathrm{Pb}(\text { Hydrolysed PSHA-1) })_{2}\right]$ & 2.5832 & 1.1963 & 3.7795 \\
\hline$\left[\mathrm{Cd}(\text { Hydrolysed PSHA-1 })_{2}\right]$ & 2.2108 & 1.5453 & 3.7561 \\
\hline$\left[\mathrm{Mg}(\text { Hydrolysed PSHA-1 })_{2}\right]$ & 2.1382 & 1.5453 & 3.6835 \\
\hline [Cu (Unhydrolysed PSHA-1) & 2.3059 & 1.2209 & 3.5268 \\
\hline$[\mathrm{Pb}$ (Unhydrolysed PSHA-1) 2$]$ & 2.2364 & 1.2239 & 3.4603 \\
\hline [Cd (Unhydrolysed PSHA-1) 2 ] & 2.2516 & 1.2581 & 3.5097 \\
\hline$[\mathrm{Mg}$ (Unydrolysed PSHA-1) & 2.1568 & 0.9127 & 3.0695 \\
\hline
\end{tabular}

The results obtained (Table19) shows the stepwise and overall stability constants to be not high indicating low stability of the complexes, because the solubility of most metal ions in the basic $\mathrm{pH}$ range is minimal due to metal hydroxide precipitation (Karimi, 2017). In general, the stepwise stability constants $\left(K_{1}\right.$ and $K_{2}$ ) follow the order $K_{1}>K_{2}$ for the copper, lead, magnesium and cadmium complexes respectively. The steady decrease of the values with increasing number of ligands is in agreement with the prediction made by researchers (Na'aliya, 2013). The decrease could be attributed to the fact that as the number of the ligands (Humate ions) that enters the coordination zone increases the aqua molecules available for replacement by the ligands become less. Thus, the metal ions become less electron loving with progressive intake of the ligand and this results in the decrease in the values of the constants (Na'aliya, 2013). Also the stability of the complexes is influenced by the size and number of the chelate rings(Mackay and Mackay,2002).All the complexes form rings in their structure as humate, a bidentate ligand, bond the metal ions in the ratio 1:2 (Boguta and Sokolowska, 2016) forming chelate rings. The values of the overall stability constants $(\log \beta)$ obtained for humate complexes are not high indicating low stability as the values are not high. LogK values for copper-humates (Table 3 to 6) obtained in this study are lower than those reported for the complexes of humic acids (Pandey et al., 2015; Dinu, 2013; Kaschl et al., 2010 and Gilbeto and Jorg, 2001). The values of LogK(Table 7 to 10 ) forlead-humates are lower than those reported for the lead in the literature (Dinu, 2013; Gilbeto and Jorg 2001). Log K values(Table 11 to 14 ) for magnesium-humates obtained in this study are close to those reported by (Pandey et al., 2015). Log K values of cadmium-humates (Table 15 to 18 ) obtained in this work near to the one reported by (Dinu, 2013 and Pandey et al., 2015).The difference between the reported values and the values obtained in this study might be probably as a result of acid hydrolysis of humic acid. The values of the overall stability constants $(\log \beta)$ of the copper humates complexes presented in Table 19 is high than that of other metal humate complexes, show relatively high stability of CuHA complexes, show the following order of stability: $\mathrm{Cu}>\mathrm{Pb}>\mathrm{Cd}>\mathrm{Mg}$; which are in close agreement to the findings of (Dinu, 2013 and Pandey et al., 2015).The high stability of Cuhumate chelate could be attributed to the existence of coordinate covalent bond between the complexing agents and the $\mathrm{Cu}^{2+}$ ions. Since, $\mathrm{Cu}^{2+}$ being a metal of the transitional series with $3 d^{9}$ electronic configurations can accept the electrons from the complexing agents. Similarly, the low stabilities of $\mathrm{Pb}, \mathrm{Cd}$ and $\mathrm{Mg}$ complexes could be explained by that $\mathrm{Pb}^{2+}$ with $6 s^{2}, \mathrm{Cd}^{2+}$ with $4 \mathrm{~d}^{10}$ and $\mathrm{Mg}^{2+}$ with $2 \mathrm{p}^{6}$ their electronic configuration has a completely filled $\mathrm{d}, \mathrm{p}$ and $\mathrm{s}$ orbitals. Moreover, the stabilities of metal ions with hydrolysed humic acid from peat soil were higher than those with unhydrolysed humic acid from peat soil; which is ascribed to the high content of acidity in hydrolysed humic acid than unhydrolysed humic acid. 
BAJOPAS Volume 14 Number 1,June, 2021 CONCLUSION

The values of logk for $\mathrm{Cu}(\mathrm{II})$ hydrolysed humic acid complex was higher followed by $\mathrm{Pb}$ (II), $\mathrm{Cd}(\mathrm{II})$ and $\mathrm{Mg}$ (II) hydrolysed humic acid complexes as compared with metal(II) unhydrolysed humic acid complexes. This indicates acid hydrolysis of humic acid can

\section{REFERENCES}

Almeida, V.R. and Szpoganicz, B. (2015). Humic Acid Potentiometric Response Patterns:Out- of Equilibrium Properties and Species Distribution Modelling. Chemical. Biol. Technol. Agric. 2: 17.

Anđelković, T., Nikolić, R., Bojić, A.,Anđelković, D., and Nikolic G.,(2010). Binding of Cadmium to Soil Humic Acid as A Function of Carboxyl Group Content. Macedonian Journal of Chemistry and Chemical Engineering.29(2): 215-224.

Anil, B. N. and Maroti, N. (2008). Studies on Influence of Die-Lectric Constants on Complex Equilibria between Substituted Py-Razalines and Lanthanide Metal Ions pH-Metrically. Amer.-Euras. scient. Res. 3(2): 212-216.

Ashok, K., Pandey, S. P. and Misra, V (2000). Stability Constants of Metal-Humic Acid Complexes and its Role in Environmental Detoxification. Journal of Ecotoxicology and Environmental Safety. 47(2):157-200.

Badr, M. H., El-Halafawi, M. H. and Abd El-al Zeid, E. R. (2012). Comparison Between the Effect of Ionic Strength on Acidity and Dissociation Constants of Humic Acids Extracted from Sewage Sludge and Nile Water Hyacinth Composts.Global Journal of Environmental Research 6 (1): 36-43.

Baruah, M.K., Borah, D., Saikia, P.P., Paul, S., Sharma, T. (2015). Evaluation of pKa Values of Soil Humic Acids and their Complexation Properties. International Journal of Plant \& Soil Science 6(4) : 218-228.

Boguta, P. Sokolowska, Z. (2016). Interactions of $\mathrm{Zn}$ (II) Ions with Humic Acids Isolated from Various Types of Soils. Effect of $\mathrm{pH}, \mathrm{Zn}$ Concentrations and Humic Acids Chemical Properties. Journal of Geochemical Explaration 168. 119-126.

Borges, F., Guimaraes, C., Lima, L.F.C., Pinto, I. and Reis, S.(2005). Potentiometric Studies on the Complexation of Copper(II) by Phenolic Acids as Discrete Ligand Models of enhance the complexation behavior of humic acid with metal (II) ions. However, the higher values of $\log \beta$ for $\mathrm{Cu}(\mathrm{II}), \mathrm{Pb}(\mathrm{II}), \mathrm{Cd}(\mathrm{II})$ and $\mathrm{Mg}(\mathrm{II})$ hydrolysed humic acid complexes indicates more stable stepwise complexes formed as compared with $\mathrm{Cu}(\mathrm{II}), \mathrm{Pb}$ (II), $\mathrm{Cd}$ (II) and $\mathrm{Mg}(\mathrm{II})$ unhydrolysed humic acid complexes.

Humic Substances Talanta 66 (2005) 670-673.

Chefetz, B., Salloum, M. J., Deshmulkin, A. P. and Hatcher, P. (2002). Structural Components of Humic Acids as Determined by Chemical Modifications and Carbon-13 NMR, Pyrolysis, and Thermochemolysis- Gas Chromatography/Mass Spectrometry. Soil Science Society of American Journal Abstract Division S-2- Soil Chemistry66. 1159-1171.

Dinu, M. I. (2013). Metals Complexation with Humic Acids in Surface Water of Different Environ. Sci. Technol. 31(1): 1-17.

Fernandes, A.N., Giacomelli, C., Giovanela, M. Vaz, D.V. Szpoganicz, B. and Maria M. D. (2009). Potentiometric Acidity Determination in Humic Substances Influenced by Different Analytical Procedures.J. Braz. Chem. Soc. 20 (9):14.

Gamal, A. H. (2015). Stability Constants of Rhenium (V) Metal Complexes with Selected Drugs. Pyrex Journal of Research in Environmental Studies. 2(2): 006-014.

Janrao, D. M., Pathan, J., Kayande, D.D., and Mulla, J.J. (2014). An Over View of Potentiometric Determination of Stability Constants of Metal Complexes. Sci. Revs. Chem. Commun.: 4(1), 2014, 11-24.

Karimi, H. (2017). Effect of pH and Initial Pb(II) Concentration on the Lead Removal Efficiency from Waste Water Using $\mathrm{Ca}(\mathrm{OH})_{2}$. International Journal of Water and Waste Water Treatment 3.2

Kaschl, A. Romheld, V. and Chen, Y. (2010). Binding of Cadmium, Copper and Zinc to Humic Substances Originating from Municipal Solid Waste Compost. Israel Journal of Chemistry Vol. 42(1): 89-98.

Kostic, I. S., Tatjana, P, A., Nikolic, R. S., Cvetkovic, T. P., Pavlovic, D. D., Aleksandar, L.J. and Bojic, A. (2012). Comparative Study of Binding Strengths of Heavy Metals with Humic Acid. J.serb. Chem. Soc. 76(9) pp 1-20. 
BAJOPAS Volume 14 Number 1,June, 2021

Na'aliya, J. (2013). Determination of Stepwise Stability Constants and Gibbs free Energy Change of Trisprolina to Complexes of some Divalent Transition Metal ions. Bayero Journal of Pure and Applied Sciences 6(2): 112-114.

Omar, A. A. and Ali, E. A. (2015). Potentiometric Studies on Complexes of $\mathrm{Cr}$ (III) and $\mathrm{Zr}$ (IV) with some Carboxylic Acids. International Journal of Advanced Chemistry, 3(1) 25-

37.

Pandey, A. K. Pandey, S. D. and Misr, V. (2015).Stability Constants of Metal- Humic Acid Complexes and Its Role in Environmental Detoxification. J. Ecotoxicology and Environmental Safety. 47(1):195-200.

Ram, N. and Raman, K.V. (1984). Stability Constants of Complexes of Metals with
Humicand Fuvic Acids under Non- acidConditions. Journal of Plant Nutrition and Soil Sciences.

147:171-176.

Santosh, D. D., Ashok, B. K., Vijay, J. T., Shivraj, G. W. and Vinay, V. W. (2011). Potentiometric Studies of Elec-Trolyte Effects on Complex Equilibria of Some Substituted 5-(2-hydroxy Phenyl) Pyrazoles. Der pharm. 3 (6): 75-83.

Sayyed, H. and Abdul Rahim, M. F. (2012). Studies of Binary Complexes of Metal Ions with Mandelic Acid by Potentiometry. Chem. J. 02 (6): 206209.

Shirvani, M. Moradian, E. Khalili, B. Bakhtiary, S. (2015). Interaction of $\mathrm{Cd}$ and $\mathrm{Pb}$ with Humate-Palygorskite and HumateSepiolite Complexes. Journal of water, air and pollution 3: 220-228. 


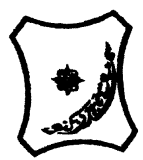

Bayero Journal of Pure and Applied Sciences, 14(1): 54 - 63

Received: November, 2020

Accepted: April, 2021

ISSN $2006-6996$

\title{
STABILITY CONSTANTS OF COMPLEXES OF METAL IONS WITH PEATSOIL HUMIC ACIDS UNDER NON-ACID-CONDITIONS
}

\author{
${ }^{* 1}$ Sabo, Yusuf ${ }^{2}$ Jimoh, W.L.O., ${ }^{3}$ Isa Baba Koki and ${ }^{4}$ Sholadoye, Q. 0. \\ ${ }^{1}$ Department of Pure and Industrial Chemistry, Bayero University, Kano \\ ${ }^{3}$ Department of Chemistry, Yusuf Maitama Sule University Kano. P.M.B. 3220 Kano, Nigeria. \\ ${ }^{4}$ Department of Chemistry, Nigerian Police Academy, Wudil, Kano-Nigeria
}

*Correspondence E-mail; saboyusuf18@yahoo.com

ABSTRACT

Stability constants of complexes of four divalent metal ions viz. $\mathrm{Cu}^{2+}, \mathrm{Pb}^{2+}, \mathrm{Mg}^{2+}$ and $\mathrm{Cd}^{2+}$ with humic acids (HA) were determined by potentiometric titration of humic acids with the corresponding salt of the divalent metals in aqueous media under non-acid-condition. The log $K$ (logarithm of the stability constant) ranged from 1.0942 to 2.7471 for metalhumic acid complexes were determined using point-wise computational method. The order of stability constants were obtained as follows: $\mathrm{Cu}>\mathrm{Pb}>\mathrm{Cd}>\mathrm{Mg}$ for metal $-\mathrm{HA}$ complexes respectively, indicating a higher degree of complexation with Cu metal ion.

Keywords: stability constant, humic acid, potentiometric titration, divalent metals, acid hydrolysis.

\section{NTRODUCTION}

The stability constant of a complex is the numerical expression of its stability and provides a quantitative measure of affinity of the metal ion to the complexing agent. An understanding of the relative stability of metal-complexes helps in predicting the behavior of metal ions in the soil (Ram and Raman, 1982). Extensive researches has been done to determine the stability constants of the complexes formed between humic acid (HA) with a number of metal ions. Ashok et al., (2000) reported that humic acid with hydroxyl, phenoxyl and carboxyl reactive groups can form coordination compound with metal ions at $\mathrm{pH}$ 3.5. The stability constants(Log K) for different metalhumic acid complexes indicated the following order of the stabilities of complexes formed between humic acid and metal ion, $\mathrm{Cu}>\mathrm{Fe}$ $>\mathrm{Pb}>\mathrm{Ni}>\mathrm{Co}>\mathrm{Ca}>\mathrm{Cd}>\mathrm{Zn}>\mathrm{Mn}>\mathrm{Mg}$. Andelkovic et al., (2010) investigated the binding of $\mathrm{Cd}$ (II) to soil humic acid at pH 6.5 and in $0.1 \mathrm{M} \mathrm{KNO}_{3}$ ionic medium. The stability constant for binding indicating greater stability in the case when carboxyl groups are involved in complexation reaction. Kostic et al.,(2012) investigated the complexation of humic acid with certain heavy metal ions (Co(II), $\mathrm{Ni}(\mathrm{II}), \mathrm{Cu}(\mathrm{II})$,
$\mathrm{Zn}(\mathrm{II})$, and $\mathrm{Pb}(\mathrm{II})$. The experiment was performed at $25^{\circ} \mathrm{C}$, at pH 4.0 and ionic strength of $0.01 \mathrm{M}$. Stability constant of complex between $\mathrm{Pb}$ (II) ions and humic acid is greater than stability constants of other investigated metalhumate complexes. Bogata and Sokolowska (2016) analyses the interaction between humic acids from different soils and $\mathrm{Zn}$ (II) ions at wide concentration ranges and at $\mathrm{pH} 5$. Studies have showed significant impact of $\mathrm{Zn}$ concentration, $\mathrm{pH}$ and some properties of humic acids with zinc.But all of these studies were limited to acidic $\mathrm{pH}$ range. Therefore, the present study was carried out to determine and compare the stability constants of complexes of metal ions with hydrolysed peat soil humic acid and unhydrolysed peat soil humic under non-acid conditions.

\section{MATERIALS AND METHODS}

Analytical grade chemicals used includes hydrochloric acid $(\mathrm{HCl})$, nitric acid $\left(\mathrm{HNO}_{3}\right)$, sodium hydroxide $(\mathrm{NaOH})$, lead nitrate $\mathrm{Pb}\left(\mathrm{NO}_{3}\right)_{2}$, copper nitrate $\mathrm{Cu}\left(\mathrm{NO}_{3}\right)_{2} \cdot 3 \mathrm{H}_{2} \mathrm{O}$, cadmium nitrate $\mathrm{Cd}\left(\mathrm{NO}_{3}\right)_{2} \cdot 4 \mathrm{H}_{2} \mathrm{O}$, magnesium nitrate $\mathrm{Mg}\left(\mathrm{NO}_{3}\right)_{2} \cdot 6 \mathrm{H}_{2} \mathrm{O}$, potassium nitrate $\left(\mathrm{KNO}_{3}\right)$, calcium chloride $\left(\mathrm{CaCl}_{2}\right)$, (sigma-Aldrich). Dowex 50WX8, (20-50 mesh) from Fluka. 


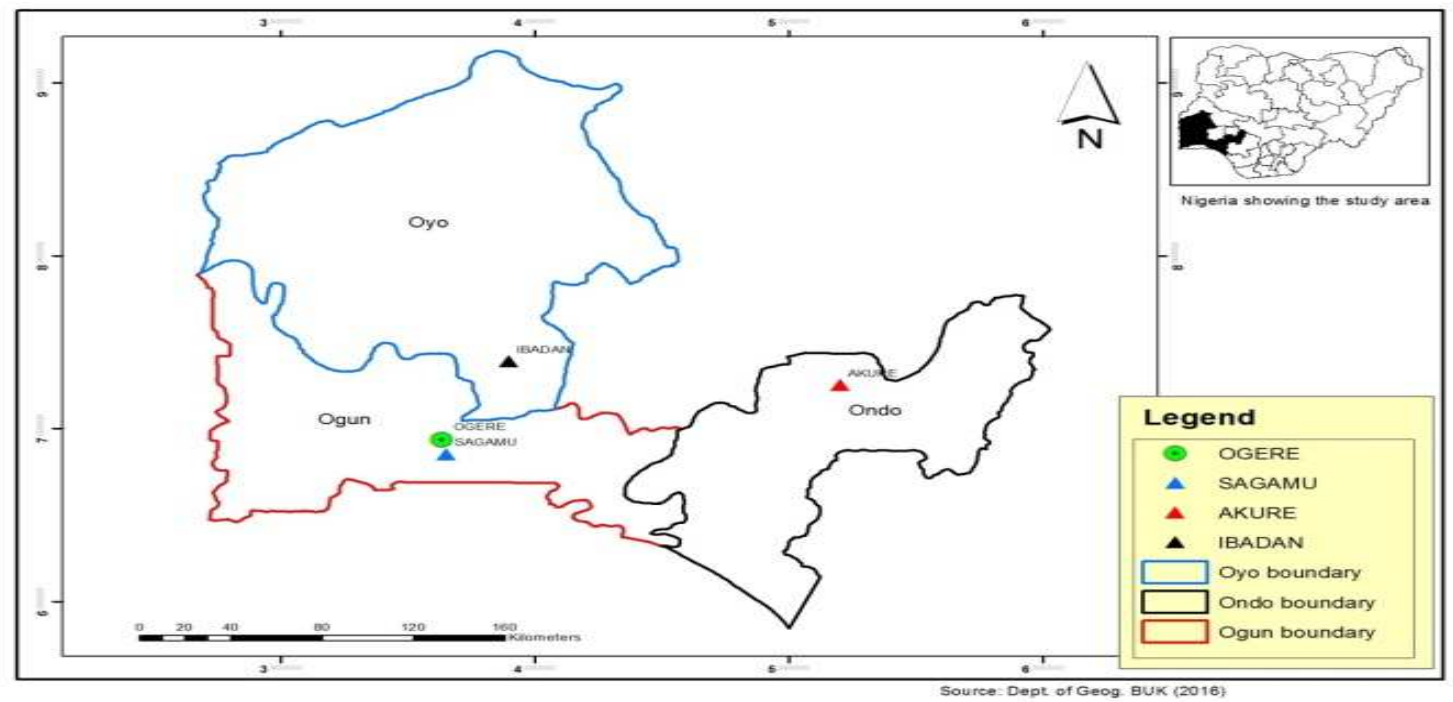

Figure 1: Map showing the sampling point at Sagamu Town, Ogun State.

\section{Description of Sampling Area}

Sagamu has geographical coordinates between $6^{\circ} 50^{\prime}$ north; $3^{\circ} 38^{\prime}$ east is located in south western region of Nigeria. The region has tropical wet and dry climate with a lengthy wet season and relatively constant temperatures throughout the course of the year. Wet season runs from March to October, November to December forms the region dry season. The vegetation type of the region is savannah which is really grassland with small bushes and occasional big trees. Grassland soils have substantially higher organic matter content than forest soils (Novackova, 2011).

\section{Sample Collection}

The Peatsoil samples were collected from four different sampling points $(0-10 \mathrm{~cm}$ depth) in Sagamu into polyethylene bag with plastic spoons. Samples were taken to the laboratory, extraneous materials were removed; the samples were air-dried, crushed and ground to a fine powder in a mortar passed through a $0.20 \mathrm{~mm}$ sieve. The samples were kept for analysis.

\section{Isolation and purification of humic acid from peat soil sample}

Peatsoil sample $(100 \mathrm{~g})$ was mixed with 1000 $\mathrm{cm}^{3}$ of $0.1 \mathrm{M} \mathrm{NaOH}$ solution, shaken for 3hours and left to stand overnight. Dark-coloured supernatant was obtained and decanted from solid residue. The dark-coloured supernatant was acidified to $(\mathrm{pH}=1.0)$ with $6 \mathrm{M} \mathrm{HCl}$ stirred and allowed to stand for 6 hours. Yellowish brown supernatant and dark-brown precipitate were obtained. The yellowish brown supernatant was decanted followed by centrifuge and discarded. The dark-brown precipitate was mixed with $500 \mathrm{~cm}^{3}$ of $0.1 \mathrm{M} \mathrm{NaOH}$ solution followed by passing through dowex resin. The dark-brown solution was acidified to $(\mathrm{pH}=1.0)$ with $6 \mathrm{M} \mathrm{HCl}$ stirred and allowed to stand for 3 hours. The dark-brown precipitate was washed several times with deionized water. The supernatant was treated with $\mathrm{AgNO}_{3}$ solution until no white precipitate observed. The humic acid was transferred to weighed crucible and dried at $60^{\circ} \mathrm{C}$ in an oven for 12 hours. The humic acid was cooled and dried in the desiccator, weighed and recorded. The obtained humic acid was dried again at $60^{\circ} \mathrm{C}$ for additional 6 hours cooled and dried in the desiccator, weighed and recorded constant weight was obtained (Baruah et al., 2015).

\section{FT-IR analysis}

FT-IR spectra of humic acid sample was analysed using Carry 630 FT-IR Agilent Technologies.

Unhydrolysed compost humic acid

The unhydrolysed humic acid was obtained after isolation and purification of compost humic acid and kept for investigation.

\section{Acid hydrolysis of Peatsoil acid}

Peatsoil humic acid sample (1g) was refluxed for 12 hours at $\left(160^{\circ} \mathrm{C}\right)$ with $50 \mathrm{~cm}^{3}$ of $6 \mathrm{M} \mathrm{HCl}$. The mixture was allowed to cool, decanted, and centrifuged after hydrolysis. The insoluble residues were washed with distilled water via centrifugation several times, and the supernatant was treated with $\mathrm{AgNO}_{3}$ solution until no white precipitate was observed. The residue was thoroughly dried over $\mathrm{CaCl}_{2}$ in a desiccator at room temperature (Chefetz et al., 2002). Finally, the obtained hydrolysed humic acid was kept for investigation. 
BAJOPAS Volume 14 Number 1,June, 2021 Potentiometric Titrations

Potentiometric measurements were carried out using a pH-meter Jenway (model 3510) with combine electrode, the sensitivity of the $\mathrm{pH}$ meter is 0.01 units. The $\mathrm{pH}$ meter was switched on half an hour before starting the titration for initial warm up of the instrument. The instrument was calibrated with an aqueous standard buffer solution of $\mathrm{pH} 4.00$ and 10.0 (borate buffer) prepared from a "Qualigens" buffer tablets.

The following sets of solutions were prepared in a $250 \mathrm{~cm}^{3}$ volumetric flask separately for $\mathrm{pH}$ metric titrations.

(i) $5 \mathrm{~cm}^{3} 0.1 \mathrm{M} \mathrm{HCl}+40 \mathrm{~cm}^{3}$ deionized water

(ii) $5 \mathrm{~cm}^{3} 0.1 \mathrm{M} \mathrm{HCl}+39 \mathrm{~cm}^{3}$ deionized water $+1 \mathrm{~cm}^{3} 0.15 \mathrm{gcm}^{-3}$ humic acid

(iii) $5 \mathrm{~cm}^{3} 0.1 \mathrm{M} \mathrm{HCl}+37 \mathrm{~cm}^{3}$ deionized water $+1 \mathrm{~cm}^{3} 0.15 \mathrm{gcm}^{-3}$ humic acid

$$
+2 \mathrm{~cm}^{3} \quad 0.01 \mathrm{M} \mathrm{Cu} \text { (II) }
$$

The solutions were titrated against standardized $0.110 \mathrm{MNaOH}$ separately. The total volume of each mixture was adjusted to $50 \mathrm{~cm}^{3}$ and the ionic strength of the solutions was maintained constant at by adding appropriate amount of stock solution of $1 \mathrm{M} \mathrm{KNO}_{3}$ (Gamal, 2015; Omar and Ali, 2015). A magnetic stirrer was used to achieve thorough mixing of the interacting solutions at $550 \mathrm{rpm}$. The same set of experimental conditions was applied for potentiometric titration of remaining samples.

\section{Evaluation of pKa of Hydrolysed peat soil Humic Acids}

The proton-ligand formation number $\mathrm{n}_{\mathbf{A}}$ were calculated by Irving and Rossotti expression (Omar and Ali, 2015).

$\mathrm{nA}=\mathrm{Y}-\frac{(\mathrm{V} 2-\mathrm{V1})(\mathrm{No}-\mathrm{Eo})}{(\mathrm{VO}+\mathrm{V1}) \mathrm{TCL}}$ 1

Where: $Y$ is number of dissociable proton, $\left(\mathrm{V}_{2^{-}}\right.$ $V_{1}$ ) is the measure of displacement of the ligand curve relative to acid curve, $\mathrm{N}^{\circ}$ and $\mathrm{E}^{\circ}$ are the resultant concentration of alkali solution, free acid solution, $\mathrm{T}_{\mathrm{cL}}{ }^{\circ}$ is the total ligand concentration, $\mathrm{V}^{\circ}$ is the total volume of titration solution, $V_{1}$ is the volume of alkali added to acid solution, $V_{2}$ is the volume of alkali added to acid solution + ligand solution, acid dissociation constants (pKa - values) of ligand were calculated by algebraic method point wise calculation (Tables 1 ). The dissociation constants (pKa) were calculated according to the following relation:

$\mathrm{pKa}=\mathrm{pH}+\log \left(\frac{n A}{1-n A}\right)$ 2

Where: pKa is the acid dissociation constant, $\mathrm{n}_{\mathrm{A}}$ is the Proton-ligand formation number and $\mathrm{pH}$ is the pH-values (Omar and Ali, 2015).

\section{Determination of metal-ligand stability constants $(\log K)$ of complexes}

The potentiometric measurement for the determination of stability constant of a complex in solution is based on the fact that the redox potential of the couple $\frac{M^{+(m-n)}}{M^{+m}}$ is shifted significantly on complexation of the metal ion with the ligand. This method involves change in hydrogen ion concentration $\left[\mathrm{H}^{+}\right]$due to the displacement or association of one or more protons taking place during complexation reaction. This change can be found out by titrating the solutions containing free acid, acid with ligand, and acid with ligand and metal ion, individually against a standard alkali solution at a constant ionic strength or temperature. Either ionic strength or temperature may be varied for different sets of solutions. In all the cases, the change in the $\mathrm{pH}$ of the solution is measured after each addition of a known amount of alkali to the reaction cell which contains the reaction mixture. The titration curves are then drawn by plotting the measured $\mathrm{pH}$ values against the corresponding volume of alkali added and the stability constants of the complexes are determined from the titration curves by employing $\mathrm{pH}$-metric titration technique given by (Irving and Rossoti).

Metal-ligand stability constants ( $\log \mathrm{K}$ ) were determined by using the following relations:

$$
\bar{n}=\frac{\left(V_{3}-V_{2}\right)\left(E^{0}+N^{0}\right)}{\left(V^{0}+V_{2}\right) \bar{n}_{A} T_{m}^{0}}
$$

and

$$
P L=\log _{10}\left\{\frac{1+\beta_{n}^{H} \frac{1}{[\text { anti } \log \mathrm{pH}]^{\mathrm{n}}}}{\mathrm{T}_{\mathrm{L}}^{0}-n \bar{T}_{m}^{0}} \mathrm{X} \frac{\left(V^{0}+V_{3}\right)}{V^{0}}\right\}
$$


BAJOPAS Volume 14 Number 1,June, 2021

Where $T_{L}, T^{\circ}, E^{\circ}$, and $V^{\circ}$ havethe same significance as in equation (1) above, $T_{m}$ denotes the total concentration of metal present in solution, $V_{3}$ is the volume of metal ions present in solution and $\beta^{H}$ is the overall proton ligand stability constant. The metal-ligand stability constants (log K) were determined by employing point wise computational Method (eq. 5 and 6).

$\operatorname{LogK}_{1}=\log \left(\frac{n}{1-n}\right)+\mathrm{pL}$ .5

$\operatorname{LogK}_{2}=\log \left(\frac{1-n}{2-n}\right)+\mathrm{pL}$ ...6

Where: Log $\mathrm{K}$ is the metal-ligand stability constant, $\mathrm{pL}$ is the Free ligand exponent function, $\mathbf{n}$ is the Average number of ligand attached with metal ion (Janraoet al., 2014). The results obtained were analyzed by an ORIGIN 2016 program using titration data and then the proton-ligand stability constants (pKa) and Metal-ligand stability constant (LogK) calculated (Omar and Ali, 2015).

\section{RESULTS AND DISCUSSION}

Fourier transformed infrared (FT-IR) spectra of isolated humic acid from peat soils Figure 2 had distinct clear absorption bands indicating the presence of major humic acid structural elemental groups such as $\mathrm{H}$ bonded $\mathrm{OH}$ $\left(3680 \mathrm{~cm}^{-1}\right.$ peak $), C=0$ of carbonyl $\left(1721 \mathrm{~cm}^{-1}\right.$ peak), functional groups of aliphatic components $\mathrm{CH}_{2}\left(2918 \mathrm{~cm}^{-1}\right.$ peak) and $\mathrm{C}-\mathrm{O}$ stretching of polysaccharide $\left(1168 \mathrm{~cm}^{-1}\right.$ peak). The positions of the absorption bands of the spectra fell within typical major absorption bands of humic acid which is at frequencies 3680, 2918, 1721, 1168 $\mathrm{cm}^{-1}$. The first peak centred in the vicinity of $3680 \mathrm{~cm}^{-1}$ region is attributed to phenol $\mathrm{OH}$ group bounded by intermolecular $\mathrm{H}$ bonds. The $2918 \mathrm{~cm}^{-1}$ band usually has absorption maximum at $2918 \mathrm{~cm}^{-1}$ which is due to $\mathrm{C}-\mathrm{H}$ stretching of alkane group $\left(\mathrm{CH}_{2}\right)$. The next major absorption band is $1721 \mathrm{~cm}^{-1}$. This band has been commonly ascribed to $\mathrm{C}=\mathrm{O}$ stretching of mainly carboxyl group $(\mathrm{COOH})$ with trace amount of ketones. The last peak was observed at 1168 $\mathrm{cm}^{-1}$ due to $\mathrm{C}-\mathrm{O}$ stretching of polysaccharides and this peak appeared also in the spectra of humic acid from peat soil. The FTIR spectra of the isolated humic acid contained all major characteristic absorption peaks of humic acid. These absorption peaks indicated the presence of the major structural elements of humic acid namely $\mathrm{H}$ bonded $\mathrm{OH}, \mathrm{C}=\mathrm{C}$ of aromatic ring, $\mathrm{C}=\mathrm{O}$ of carbonyl group (both carboxyl and ketonic), $\mathrm{CH}_{2}$ group. This strongly supports the presence of humic acid.

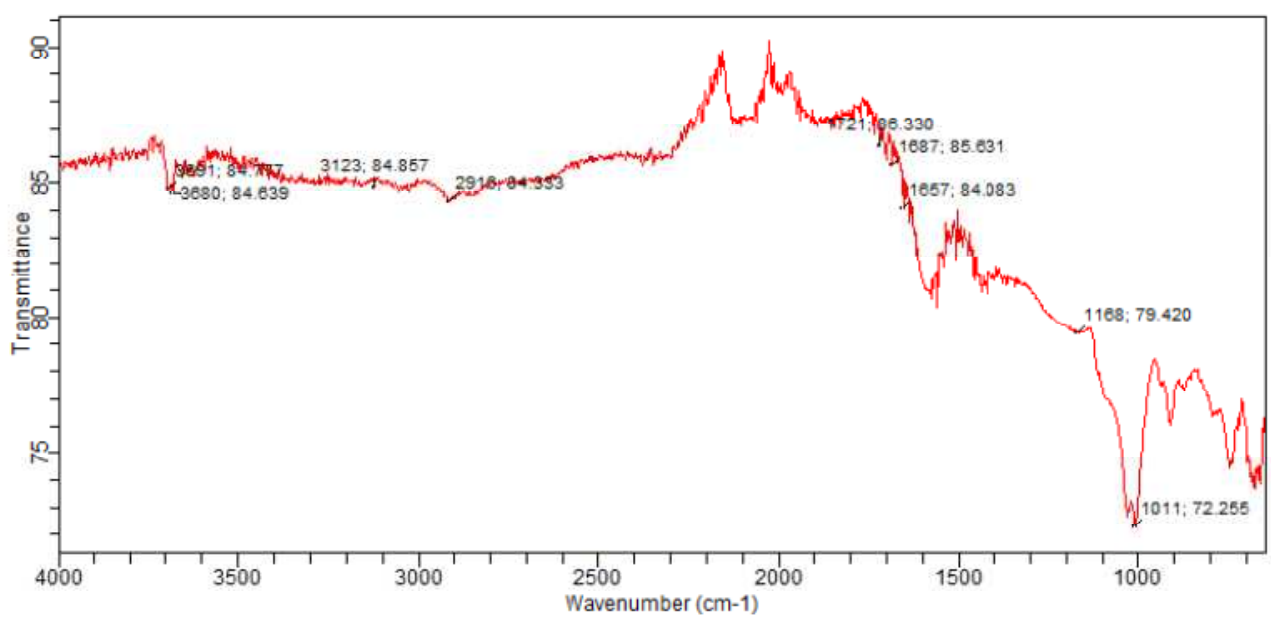

Fig. 2 : FT-IR spectraof peatsoilhumic acid (PSHA)

\section{Evaluation of acid dissociation constant (pka) of acid hydrolysed peat soil humicacid at phenolic group}

The value of the dissociation constant of the peat soil humic acid (PSHA) that underwent acidhydrolysis studied was found to be 8.9299 as shown Table 1, which is lower than the literaturevalues reported by Almeida and Szpoganics, (2015), Borges et al., (2005); Badr et al., (2012)and Fernandes et al,.(2009) of $9.73,9.47$ and 10.30. The difference between the obtained valuesand the reported values in this study might be probably as a result of acid hydrolysis of humicacid. 
BAJOPAS Volume 14 Number 1,June, 2021

Table 1: PKa of (Hydrolysed PSHA)

\begin{tabular}{|l|l|l|l|l|l|l|}
\hline $\mathrm{pH}$ & $\mathrm{BV}_{1}$ & $\mathrm{BV}_{2}$ & $\mathrm{~V}_{2}-\mathrm{V}_{1}$ & $\mathrm{nA}$ & $\log \left(\frac{n A}{1-n A}\right)$ & $\mathrm{pKa}$ \\
\hline 8.50 & 5.30 & 6.29 & 0.99 & 0.3594 & -0.2510 & 8.2490 \\
8.72 & 5.35 & 6.37 & 1.02 & 0.3400 & -0.2880 & 8.4320 \\
9.00 & 5.40 & 6.46 & 1.06 & 0.3141 & -0.3391 & 8.6609 \\
9.22 & 5.45 & 6.55 & 1.10 & 0.2882 & -0.3927 & 8.8273 \\
9.51 & 5.50 & 6.66 & 1.16 & 0.2494 & -0.4786 & 9.0314 \\
9.73 & 5.55 & 6.78 & 1.23 & 0.2041 & -0.5910 & 9.1390 \\
10.00 & 5.60 & 6.90 & 1.30 & 0.1589 & -0.7238 & 9.2762 \\
10.23 & 5.65 & 7.05 & 1.40 & 0.0941 & -0.9835 & 9.2465 \\
10.49 & 5.70 & 7.10 & 1.40 & 0.0941 & -0.9835 & 9.5065 \\
\hline
\end{tabular}

Average pKa $=8.9299 \pm 0.4186$

Table 2: PKa of (Unhydrolysed PSHA)

\begin{tabular}{|l|l|l|l|l|l|l|}
\hline $\mathrm{pH}$ & $\mathrm{BV}_{1}$ & $\mathrm{BV}_{2}$ & $\mathrm{~V}_{2}-\mathrm{V}_{1}$ & $\mathrm{nA}$ & $\log \left(\frac{\boldsymbol{n A}}{1-\boldsymbol{n}}\right)$ & $\mathrm{pKa}$ \\
\hline 8.50 & 5.30 & 5.81 & 0.51 & 0.6619 & 0.2919 & 8.7919 \\
8.72 & 5.35 & 5.90 & 0.55 & 0.6357 & 0.2418 & 8.9618 \\
9.00 & 5.40 & 6.00 & 0.60 & 0.6029 & 0.1813 & 9.1813 \\
9.22 & 5.45 & 6.10 & 0.65 & 0.5701 & 0.1226 & 9.3426 \\
9.51 & 5.50 & 6.20 & 0.70 & 0.5376 & 0.0654 & 9.5754 \\
9.73 & 5.55 & 6.33 & 0.78 & 0.4851 & -0.0259 & 9.7041 \\
10.00 & 5.60 & 6.47 & 0.87 & 0.4262 & -0.1291 & 9.8709 \\
10.23 & 5.65 & 6.62 & 0.99 & 0.3609 & -0.2481 & 9.9819 \\
10.49 & 5.70 & 6.80 & 1.10 & 0.2759 & -0.4690 & 10.0210 \\
\hline
\end{tabular}

Average pKa $=9.4923 \pm 0.4410$

Metal-ligand stability constant ( $\log \mathrm{K}$ )

The stabilityconstants require the accurate values of proton-ligand stability constants (Anil and Maroti, 2008). Metal titration curves crossed over ligand titration curve indicated the formation of complex upon proton release (Santosh, et al., 2011). If the values of n- are within range $0.2-0.8$ and $1.2-18$ this indicates the formation of $1: 1$ and 1:2 complexes (Sayyed and Mazahar, 2012).

The metal (II)-humate stepwise stability constants (log k) at phenolic group (Tables 318)

Table 3: Point-wise method, $\mathrm{Cu}$-(Hydrolysed PSHA)

\begin{tabular}{|l|l|l|l|l|l|l|l|l|}
\hline $\mathrm{pH}$ & $\mathrm{BV}_{1}$ & $\mathrm{BV}_{2}$ & $\mathrm{BV}_{3}$ & $\left(\mathrm{~V}_{3}-\mathrm{V}_{2}\right)$ & $\mathrm{n}$ & $\mathrm{pL}$ & $\log \left(\frac{n}{1-n}\right)$ & LogK $_{1}$ \\
\hline 8.50 & 5.30 & 6.29 & 6.33 & 0.04 & 0.5500 & 2.66 & 0.0871 & 2.7471 \\
8.72 & 5.35 & 6.37 & 6.41 & 0.04 & 0.5714 & 2.43 & 0.1249 & 2.5549 \\
9.00 & 5.40 & 6.46 & 6.50 & 0.04 & 0.6198 & 2.16 & 0.2122 & 2.3722 \\
9.22 & 5.45 & 6.55 & 6.59 & 0.04 & 0.6667 & 1.94 & 0.3010 & 2.2410 \\
\hline
\end{tabular}

LogK $_{1}$ (Average value) $=2.4788 \pm 0.2203$

Table 4: Point-wise method, $\mathrm{Cu}$-(Hydrolysed PSHA)

\begin{tabular}{|l|l|l|l|l|l|l|l|l|}
\hline $\mathrm{pH}$ & $\mathrm{BV}_{1}$ & $\mathrm{BV}_{2}$ & $\mathrm{BV}_{3}$ & $\left(\mathrm{~V}_{3}-\mathrm{V}_{2}\right)$ & $\mathrm{n}$ & $\mathrm{pL}$ & $\log \left(\frac{n-1}{2-n}\right)$ & LogK $_{2}$ \\
\hline 9.51 & 5.50 & 6.66 & 6.73 & 0.07 & 1.3509 & 1.70 & -0.2671 & 1.4329 \\
9.73 & 5.55 & 6.78 & 6.85 & 0.07 & 1.6383 & 1.51 & 0.2467 & 1.7567 \\
10.00 & 5.60 & 6.90 & 6.98 & 0.08 & 2.1783 & 1.31 & -0.2158 & 1.0942 \\
10.23 & 5.65 & 7.05 & 7.13 & 0.08 & 4.1904 & 1.27 & & \\
10.49 & 5.70 & 7.10 & 7.19 & 0.09 & 4.6920 & & & \\
\hline
\end{tabular}

Log $K_{2}($ Average value $)=1.4280 \pm 0.3312$ 
BAJOPAS Volume 14 Number 1,June, 2021

Table 5: Point-wise method, $\mathrm{Cu}$ (Unhydrolysed PSHA)

\begin{tabular}{|l|l|l|l|l|l|l|l|l|}
\hline $\mathrm{pH}$ & $\mathrm{BV}_{1}$ & $\mathrm{BV}_{2}$ & $\mathrm{BV}_{3}$ & $\left(\mathrm{~V}_{3}-\mathrm{V}_{2}\right)$ & $\mathrm{n}$ & $\mathrm{pL}$ & $\log \left(\frac{n}{n-1}\right)$ & Log $_{1}$ \\
\hline 8.50 & 5.30 & 5.81 & 5.85 & 0.04 & 0.2973 & 2.88 & -0.3736 & 2.5064 \\
8.72 & 5.35 & 5.90 & 5.95 & 0.05 & 0.3873 & 2.66 & -0.1992 & 2.4608 \\
9.00 & 5.40 & 6.00 & 6.05 & 0.05 & 0.4044 & 2.38 & -0.1681 & 2.2119 \\
9.22 & 5.45 & 6.10 & 6.15 & 0.06 & 0.5157 & 2.18 & -0.0272 & 2.2072 \\
9.51 & 5.50 & 6.20 & 6.27 & 0.07 & 0.6417 & 1.89 & 0.2530 & 1.1430 \\
\hline
\end{tabular}

$\operatorname{LogK}_{1}($ Average value $)=2.3059 \pm 0.6153$

Table 6:Point-wise method, $\mathrm{Cu}$ (Unhydrolysed PSHA)

\begin{tabular}{|l|l|l|l|l|l|l|l|l|}
\hline $\mathrm{pH}$ & $\mathrm{BV}_{1}$ & $\mathrm{BV}_{2}$ & $\mathrm{BV}_{3}$ & $\mathrm{~V}_{3}-\mathrm{V}_{2}$ & $\mathrm{n}$ & $\mathrm{pL}$ & $\log \left(\frac{n-1}{2-n}\right)$ & $\log \mathrm{K}_{2}$ \\
\hline 9.73 & 5.55 & 6.33 & 6.42 & 0.09 & 0.9000 & 1.69 & & \\
10.00 & 5.60 & 6.47 & 6.58 & 0.11 & 1.2578 & 1.44 & -0.4592 & 0.9808 \\
10.23 & 5.65 & 6.62 & 6.84 & 0.12 & 1.6137 & 1.26 & -0.2010 & 1.4610 \\
10.49 & 5.70 & 6.80 & 6.92 & 0.12 & 2.1052 & 1.03 & & \\
\hline
\end{tabular}

$\operatorname{LogK}_{2}$ (Average value) $=1.2209 \pm 0.3398$

Table 7:Point-wise method, Pb (Hydrolysed PSHA)

\begin{tabular}{|l|l|l|l|l|l|l|l|l|}
\hline $\mathrm{pH}$ & $\mathrm{BV}_{1}$ & $\mathrm{BV}_{2}$ & $\mathrm{BV}_{3}$ & $\left(\mathrm{~V}_{3}-\mathrm{V}_{2}\right)$ & $\mathrm{n}$ & $\mathrm{pL}$ & $\log \left(\frac{n}{1-n}\right)$ & LogK $_{1}$ \\
\hline 8.50 & 5.30 & 6.29 & 6.33 & 0.04 & 0.5500 & 2.66 & 0.0871 & 2.7471 \\
8.72 & 5.35 & 6.37 & 6.41 & 0.04 & 0.5714 & 2.43 & 0.1249 & 2.5549 \\
9.00 & 5.40 & 6.46 & 6.50 & 0.04 & 0.6198 & 2.16 & 0.2122 & 2.3722 \\
9.22 & 5.45 & 6.55 & 6.60 & 0.05 & 0.8333 & 1.96 & 0.6989 & 2.6589 \\
\hline
\end{tabular}

Log $_{\mathbf{1}}($ Average value $)=2.5832 \pm 0.1614$

Table 8:Point-wise method, Pb-(Hydrolysed PSHA)

\begin{tabular}{|l|l|l|l|l|l|l|l|l|}
\hline $\mathrm{pH}$ & $\mathrm{BV}_{1}$ & $\mathrm{BV}_{2}$ & $\mathrm{BV}_{3}$ & $\left(\mathrm{~V}_{3}-\mathrm{V}_{2}\right)$ & $\mathrm{n}$ & $\mathrm{pL}$ & $\log \left(\frac{n-1}{2-n}\right)$ & $\log \mathrm{K}_{2}$ \\
\hline 9.51 & 5.50 & 6.66 & 6.71 & 0.05 & 0.9650 & 1.67 & & \\
9.73 & 5.55 & 6.78 & 6.83 & 0.05 & 1.1702 & 1.44 & & \\
10.00 & 5.60 & 6.90 & 6.90 & 0.05 & 1.4864 & 1.22 & -0.0237 & 1.1963 \\
10.23 & 5.65 & 7.05 & 7.10 & 0.05 & 2.0190 & 1.09 & & \\
10.49 & 5.70 & 7.10 & 7.17 & 0.07 & 3.6492 & 1.00 & & \\
\hline
\end{tabular}

Log $K_{2}$ (Average value) $=1.1963$

Table 9: Point-wise method, Pb (Unhydrolysed PSHA)

\begin{tabular}{|l|l|l|l|l|l|l|l|l|}
\hline $\mathrm{pH}$ & $\mathrm{BV}_{1}$ & $\mathrm{BV}_{2}$ & $\mathrm{BV}_{3}$ & $\mathrm{~V}_{3}-\mathrm{V}_{2}$ & $\mathrm{n}$ & $\mathrm{pL}$ & $\begin{array}{l}\text { Log } \\
\left(\frac{n}{n-1}\right)\end{array}$ & Log $\mathrm{K}_{1}$ \\
\hline 8.50 & 5.30 & 5.81 & 5.85 & 0.04 & 0.2973 & 2.88 & -0.3736 & 2.5064 \\
8.72 & 5.35 & 5.90 & 5.94 & 0.04 & 0.3099 & 2.66 & -0.5477 & 2.3123 \\
9.00 & 5.40 & 6.00 & 6.05 & 0.05 & 0.4044 & 2.38 & -0.1681 & 2.2119 \\
9.22 & 5.45 & 6.10 & 6.15 & 0.06 & 0.5157 & 2.18 & 0.0272 & 2.2072 \\
9.51 & 5.50 & 6.20 & 6.26 & 0.07 & 0.6417 & 1.89 & 0.2530 & 2.1430 \\
9.73 & 5.55 & 6.40 & 6.40 & 0.07 & 0.7000 & 1.67 & 0.3680 & 2.0380 \\
\hline
\end{tabular}

LogK $_{1}$ (Average value) $=2.2364 \pm 0.1602$

Table 10: Point-wise method, Pb (Unhydrolysed PSHA)

\begin{tabular}{|l|l|l|l|l|l|l|l|l|}
\hline $\mathrm{pH}$ & $\mathrm{BV}_{1}$ & $\mathrm{BV}_{2}$ & $\mathrm{BV}_{3}$ & $\mathrm{~V}_{3}-\mathrm{V}_{2}$ & $\mathrm{n}$ & $\mathrm{pL}$ & $\log \left(\frac{n-1}{2-n}\right)$ & $\log \mathrm{K}_{2}$ \\
\hline 10.00 & 5.60 & 6.47 & 6.55 & 0.08 & 1.9503 & 1.41 & & \\
10.23 & 5.65 & 6.62 & 6.72 & 0.11 & 1.4792 & 1.26 & -0.0361 & 1.2239 \\
\hline
\end{tabular}

$\operatorname{LogK}_{2}$ (Average value) $=1.2239$

Table 11: Point-wise method, Mg (Hydrolysed PSHA)

\begin{tabular}{|l|l|l|l|l|l|l|l|l|}
\hline $\mathrm{pH}$ & $\mathrm{BV}_{1}$ & $\mathrm{BV}_{2}$ & $\mathrm{BV}_{3}$ & $\left(\mathrm{~V}_{3}-\mathrm{V}_{2}\right)$ & $\mathrm{n}$ & $\mathrm{pL}$ & $\log \left(\frac{n}{n-1}\right)$ & LogK $_{1}$ \\
\hline 8.50 & 5.30 & 6.29 & 6.31 & 0.02 & 0.2750 & 2.64 & -0.4290 & 2.2110 \\
8.72 & 5.35 & 6.37 & 6.39 & 0.02 & 0.2858 & 2.42 & -0.3978 & 2.0222 \\
9.00 & 5.40 & 6.46 & 6.49 & 0.03 & 0.4648 & 2.14 & -0.0612 & 2.0788 \\
9.22 & 5.45 & 6.55 & 6.59 & 0.04 & 0.6667 & 1.94 & 0.3010 & 2.2410 \\
\hline
\end{tabular}

$\log _{\mathbf{1}}($ Average value) $=2.1382 \pm 0.1046$ 
BAJOPAS Volume 14 Number 1,June, 2021

Table 12: Point-wise method, Mg (Hydrolysed PSHA)

\begin{tabular}{|l|l|l|l|l|l|l|l|l|}
\hline $\mathrm{pH}$ & $\mathrm{BV}_{1}$ & $\mathrm{BV}_{2}$ & $\mathrm{BV}_{3}$ & $\left(\mathrm{~V}_{3}-\mathrm{V}_{2}\right)$ & $\mathrm{n}$ & $\mathrm{pL}$ & $\log \left(\frac{n-1}{2-n}\right)$ & LogK $_{2}$ \\
\hline 9.51 & 5.55 & 6.66 & 6.71 & 0.05 & 0.9650 & 1.67 & & \\
9.73 & 5.55 & 6.78 & 6.84 & 0.06 & 1.4042 & 1.47 & -0.1686 & 1.3014 \\
10.00 & 5.60 & 6.90 & 6.93 & 0.06 & 1.7838 & 1.23 & 0.5593 & 1.7893 \\
10.23 & 5.65 & 7.05 & 7.10 & 0.06 & 3.1429 & 1.10 & & \\
10.49 & 5.70 & 7.10 & 7.18 & 0.07 & 3.6492 & 0.83 & & \\
\hline
\end{tabular}

LogK $_{2}($ Average value $)=1.5453 \pm 0.3450$

Table 13: Point-wise method, Mg (Unhydrolysed PSHA)

\begin{tabular}{|l|l|l|l|l|l|l|l|l|}
\hline $\mathrm{pH}$ & $\mathrm{BV}_{1}$ & $\mathrm{BV}_{2}$ & $\mathrm{BV}_{3}$ & $\mathrm{~V}_{3}-\mathrm{V}_{2}$ & $\mathrm{n}$ & $\mathrm{pL}$ & $\log \left(\frac{n}{n-1}\right)$ & $\operatorname{Log~}_{1}$ \\
\hline 8.50 & 5.30 & 5.81 & 5.85 & 0.04 & 0.2973 & 2.88 & -0.3736 & 2.5064 \\
8.72 & 5.35 & 5.90 & 5.94 & 0.04 & 0.3099 & 2.66 & -0.3477 & 2.3123 \\
9.00 & 5.40 & 6.00 & 6.04 & 0.04 & 0.3236 & 2.38 & -0.3202 & 2.0598 \\
9.22 & 5.45 & 6.10 & 6.15 & 0.05 & 0.4297 & 2.17 & -0.1230 & 2.0470 \\
9.51 & 5.50 & 6.20 & 6.26 & 0.06 & 0.5500 & 1.89 & 0.0871 & 1.9771 \\
9.73 & 5.55 & 6.33 & 6.40 & 0.07 & 0.7000 & 1.67 & 0.3680 & 2.0380 \\
\hline
\end{tabular}

LogK $_{1}$ (Average value) $=2.1568 \pm 0.2069$

Table 14: Point-wise method, Mg (Unhydrolysed PSHA)

\begin{tabular}{|l|l|l|l|l|l|l|l|l|}
\hline $\mathrm{pH}$ & $\mathrm{BV}_{1}$ & $\mathrm{BV}_{2}$ & $\mathrm{BV}_{3}$ & $\mathrm{~V}_{3}-\mathrm{V}_{2}$ & $\mathrm{n}$ & $\mathrm{pL}$ & $\log \left(\frac{n-1}{2-n}\right)$ & $\log \mathrm{K}_{2}$ \\
\hline 10.00 & 5.60 & 6.47 & 6.55 & 0.08 & 0.9148 & 1.41 & & \\
10.23 & 5.65 & 6.62 & 6.71 & 0.09 & 1.2102 & 1.20 & -0.5749 & 0.6251 \\
10.49 & 5.70 & 6.80 & 6.92 & 0.09 & 1.5968 & 1.03 & 0.1703 & 1.2003 \\
\hline
\end{tabular}

LogK $_{2}$ (Average value) $=0.9127 \pm 0.4070$

Table15:Point-wise method, Cd (Hydrolysed PSHA)

\begin{tabular}{|l|l|l|l|l|l|l|l|l|}
\hline $\mathrm{pH}$ & $\mathrm{BV}_{1}$ & $\mathrm{BV}_{2}$ & $\mathrm{BV}_{3}$ & $\left(\mathrm{~V}_{3}-\mathrm{V}_{2}\right)$ & $\mathrm{n}$ & $\mathrm{pL}$ & $\log \left(\frac{n}{1-n}\right)$ & LogK $_{1}$ \\
\hline 8.50 & 5.30 & 6.29 & 6.31 & 0.02 & 0.2750 & 2.64 & -0.4210 & 2.2190 \\
8.72 & 5.35 & 6.37 & 6.40 & 0.03 & 0.4286 & 2.42 & -0.1249 & 2.2951 \\
9.00 & 5.40 & 6.46 & 6.49 & 0.03 & 0.4648 & 2.14 & -0.0612 & 2.0788 \\
9.22 & 5.45 & 6.55 & 6.59 & 0.04 & 0.6667 & 1.96 & 0.3010 & 2.2610 \\
9.51 & 5.55 & 6.66 & 6.70 & 0.04 & 0.7720 & 1.67 & 0.5297 & 2.1997 \\
\hline
\end{tabular}

LogK $_{\mathbf{1}}$ (Average value) $=2.2108 \pm 0.0825$

Table 16: Point-wise method, Cd (Hydrolysed PSHA)

\begin{tabular}{|l|l|l|l|l|l|l|l|l|}
\hline $\mathrm{pH}$ & $\mathrm{BV}_{1}$ & $\mathrm{BV}_{2}$ & $\mathrm{BV}_{3}$ & $\left(\mathrm{~V}_{3}-\mathrm{V}_{2}\right)$ & $\mathrm{n}$ & $\mathrm{pL}$ & $\log \left(\frac{n-1}{2-n}\right)$ & Log $_{2}$ \\
\hline 9.73 & 5.55 & 6.78 & 6.83 & 0.06 & 1.4042 & 1.47 & -0.1686 & 1.3014 \\
10.00 & 5.60 & 6.90 & 6.95 & 0.06 & 1.7838 & 1.23 & 0.5593 & 1.7893 \\
10.23 & 5.65 & 7.05 & 7.10 & 0.06 & 3.1429 & 1.09 & & \\
10.49 & 5.70 & 7.10 & 7.16 & 0.06 & 3.1429 & 0.89 & & \\
& & & & & & & & \\
\hline
\end{tabular}

$\operatorname{LogK}_{2}$ (Average value) $=1.5453 \pm 0.3450$

Table 17: Point-wise method, Cd (Unhydrolysed PSHA)

\begin{tabular}{|l|l|l|l|l|l|l|l|l|}
\hline $\mathrm{pH}$ & $\mathrm{BV}_{1}$ & $\mathrm{BV}_{2}$ & $\mathrm{BV}_{3}$ & $\mathrm{~V}_{3}-\mathrm{V}_{2}$ & $\mathrm{n}$ & $\mathrm{pL}$ & $\log \left(\frac{n}{n-1}\right)$ & $\operatorname{Log~}_{1}$ \\
\hline 8.50 & 5.30 & 5.81 & 5.86 & 0.05 & 0.3717 & 2.88 & -0.2280 & 2.6520 \\
8.72 & 5.35 & 5.90 & 5.95 & 0.05 & 0.3873 & 2.66 & -0.1992 & 2.4608 \\
9.00 & 5.40 & 6.00 & 6.06 & 0.06 & 0.4853 & 2.38 & -0.0255 & 2.3545 \\
9.22 & 5.45 & 6.10 & 6.16 & 0.06 & 0.5157 & 2.18 & -0.0272 & 2.2072 \\
9.51 & 5.50 & 6.20 & 6.27 & 0.07 & 0.6417 & 1.89 & 0.2530 & 1.1430 \\
9.73 & 5.55 & 6.33 & 6.41 & 0.08 & 0.8000 & 1.69 & 0.6020 & 2.2920 \\
& & & & & & & & \\
\hline
\end{tabular}

$\operatorname{LogK}_{1}($ Average value $)=2.2516 \pm 0.5380$ 
BAJOPAS Volume 14 Number 1,June, 2021

Table 18: Point-wise method, Cd (Unhydrolysed PSHA)

\begin{tabular}{|l|l|l|l|l|l|l|l|l|}
\hline $\mathrm{pH}$ & $\mathrm{BV}_{1}$ & $\mathrm{BV}_{2}$ & $\mathrm{BV}_{3}$ & $\mathrm{~V}_{3}-\mathrm{V}_{2}$ & $\mathrm{n}$ & $\mathrm{pL}$ & $\log \left(\frac{n-1}{2-n}\right)$ & $\log \mathrm{K}_{2}$ \\
\hline 10.00 & 5.60 & 6.47 & 6.57 & 0.10 & 1.1434 & 1.43 & & \\
10.23 & 5.65 & 6.62 & 6.72 & 0.10 & 1.3448 & 1.23 & -0.2788 & 0.9512 \\
10.49 & 5.70 & 6.80 & 6.90 & 0.10 & 1.7742 & 1.03 & 0.5351 & 1.5651 \\
\hline
\end{tabular}

$\operatorname{LogK}_{2}($ Average value $)=1.2581 \pm 0.4340$

Table 19: Stepwise and overall Stability constants of thehydrolysed and unhydrolysed divalent metal (II) complexes

\begin{tabular}{|c|c|c|c|}
\hline Chelates & LogK $_{1}$ & $\log _{2}$ & Log $\beta$ \\
\hline [Cu (Hydrolysed PSHA-1) $\left.{ }_{2}\right]$ & 2.4788 & 1.4280 & 3.9068 \\
\hline$\left[\mathrm{Pb}(\text { Hydrolysed PSHA-1) })_{2}\right]$ & 2.5832 & 1.1963 & 3.7795 \\
\hline$\left[\mathrm{Cd}(\text { Hydrolysed PSHA-1 })_{2}\right]$ & 2.2108 & 1.5453 & 3.7561 \\
\hline$\left[\mathrm{Mg}(\text { Hydrolysed PSHA-1 })_{2}\right]$ & 2.1382 & 1.5453 & 3.6835 \\
\hline [Cu (Unhydrolysed PSHA-1) & 2.3059 & 1.2209 & 3.5268 \\
\hline$[\mathrm{Pb}$ (Unhydrolysed PSHA-1) 2$]$ & 2.2364 & 1.2239 & 3.4603 \\
\hline [Cd (Unhydrolysed PSHA-1) 2 ] & 2.2516 & 1.2581 & 3.5097 \\
\hline$[\mathrm{Mg}$ (Unydrolysed PSHA-1) & 2.1568 & 0.9127 & 3.0695 \\
\hline
\end{tabular}

The results obtained (Table19) shows the stepwise and overall stability constants to be not high indicating low stability of the complexes, because the solubility of most metal ions in the basic $\mathrm{pH}$ range is minimal due to metal hydroxide precipitation (Karimi, 2017). In general, the stepwise stability constants $\left(K_{1}\right.$ and $K_{2}$ ) follow the order $K_{1}>K_{2}$ for the copper, lead, magnesium and cadmium complexes respectively. The steady decrease of the values with increasing number of ligands is in agreement with the prediction made by researchers (Na'aliya, 2013). The decrease could be attributed to the fact that as the number of the ligands (Humate ions) that enters the coordination zone increases the aqua molecules available for replacement by the ligands become less. Thus, the metal ions become less electron loving with progressive intake of the ligand and this results in the decrease in the values of the constants (Na'aliya, 2013). Also the stability of the complexes is influenced by the size and number of the chelate rings(Mackay and Mackay,2002).All the complexes form rings in their structure as humate, a bidentate ligand, bond the metal ions in the ratio 1:2 (Boguta and Sokolowska, 2016) forming chelate rings. The values of the overall stability constants $(\log \beta)$ obtained for humate complexes are not high indicating low stability as the values are not high. LogK values for copper-humates (Table 3 to 6) obtained in this study are lower than those reported for the complexes of humic acids (Pandey et al., 2015; Dinu, 2013; Kaschl et al., 2010 and Gilbeto and Jorg, 2001). The values of LogK(Table 7 to 10 ) forlead-humates are lower than those reported for the lead in the literature (Dinu, 2013; Gilbeto and Jorg 2001). Log K values(Table 11 to 14 ) for magnesium-humates obtained in this study are close to those reported by (Pandey et al., 2015). Log K values of cadmium-humates (Table 15 to 18 ) obtained in this work near to the one reported by (Dinu, 2013 and Pandey et al., 2015).The difference between the reported values and the values obtained in this study might be probably as a result of acid hydrolysis of humic acid. The values of the overall stability constants $(\log \beta)$ of the copper humates complexes presented in Table 19 is high than that of other metal humate complexes, show relatively high stability of CuHA complexes, show the following order of stability: $\mathrm{Cu}>\mathrm{Pb}>\mathrm{Cd}>\mathrm{Mg}$; which are in close agreement to the findings of (Dinu, 2013 and Pandey et al., 2015).The high stability of Cuhumate chelate could be attributed to the existence of coordinate covalent bond between the complexing agents and the $\mathrm{Cu}^{2+}$ ions. Since, $\mathrm{Cu}^{2+}$ being a metal of the transitional series with $3 d^{9}$ electronic configurations can accept the electrons from the complexing agents. Similarly, the low stabilities of $\mathrm{Pb}, \mathrm{Cd}$ and $\mathrm{Mg}$ complexes could be explained by that $\mathrm{Pb}^{2+}$ with $6 s^{2}, \mathrm{Cd}^{2+}$ with $4 \mathrm{~d}^{10}$ and $\mathrm{Mg}^{2+}$ with $2 \mathrm{p}^{6}$ their electronic configuration has a completely filled $\mathrm{d}, \mathrm{p}$ and $\mathrm{s}$ orbitals. Moreover, the stabilities of metal ions with hydrolysed humic acid from peat soil were higher than those with unhydrolysed humic acid from peat soil; which is ascribed to the high content of acidity in hydrolysed humic acid than unhydrolysed humic acid. 
BAJOPAS Volume 14 Number 1,June, 2021 CONCLUSION

The values of logk for $\mathrm{Cu}(\mathrm{II})$ hydrolysed humic acid complex was higher followed by $\mathrm{Pb}$ (II), $\mathrm{Cd}(\mathrm{II})$ and $\mathrm{Mg}$ (II) hydrolysed humic acid complexes as compared with metal(II) unhydrolysed humic acid complexes. This indicates acid hydrolysis of humic acid can

\section{REFERENCES}

Almeida, V.R. and Szpoganicz, B. (2015). Humic Acid Potentiometric Response Patterns:Out- of Equilibrium Properties and Species Distribution Modelling. Chemical. Biol. Technol. Agric. 2: 17.

Anđelković, T., Nikolić, R., Bojić, A.,Anđelković, D., and Nikolic G.,(2010). Binding of Cadmium to Soil Humic Acid as A Function of Carboxyl Group Content. Macedonian Journal of Chemistry and Chemical Engineering.29(2): 215-224.

Anil, B. N. and Maroti, N. (2008). Studies on Influence of Die-Lectric Constants on Complex Equilibria between Substituted Py-Razalines and Lanthanide Metal Ions pH-Metrically. Amer.-Euras. scient. Res. 3(2): 212-216.

Ashok, K., Pandey, S. P. and Misra, V (2000). Stability Constants of Metal-Humic Acid Complexes and its Role in Environmental Detoxification. Journal of Ecotoxicology and Environmental Safety. 47(2):157-200.

Badr, M. H., El-Halafawi, M. H. and Abd El-al Zeid, E. R. (2012). Comparison Between the Effect of Ionic Strength on Acidity and Dissociation Constants of Humic Acids Extracted from Sewage Sludge and Nile Water Hyacinth Composts.Global Journal of Environmental Research 6 (1): 36-43.

Baruah, M.K., Borah, D., Saikia, P.P., Paul, S., Sharma, T. (2015). Evaluation of pKa Values of Soil Humic Acids and their Complexation Properties. International Journal of Plant \& Soil Science 6(4) : 218-228.

Boguta, P. Sokolowska, Z. (2016). Interactions of $\mathrm{Zn}$ (II) Ions with Humic Acids Isolated from Various Types of Soils. Effect of $\mathrm{pH}, \mathrm{Zn}$ Concentrations and Humic Acids Chemical Properties. Journal of Geochemical Explaration 168. 119-126.

Borges, F., Guimaraes, C., Lima, L.F.C., Pinto, I. and Reis, S.(2005). Potentiometric Studies on the Complexation of Copper(II) by Phenolic Acids as Discrete Ligand Models of enhance the complexation behavior of humic acid with metal (II) ions. However, the higher values of $\log \beta$ for $\mathrm{Cu}(\mathrm{II}), \mathrm{Pb}(\mathrm{II}), \mathrm{Cd}(\mathrm{II})$ and $\mathrm{Mg}(\mathrm{II})$ hydrolysed humic acid complexes indicates more stable stepwise complexes formed as compared with $\mathrm{Cu}(\mathrm{II}), \mathrm{Pb}$ (II), $\mathrm{Cd}$ (II) and $\mathrm{Mg}(\mathrm{II})$ unhydrolysed humic acid complexes.

Humic Substances Talanta 66 (2005) 670-673.

Chefetz, B., Salloum, M. J., Deshmulkin, A. P. and Hatcher, P. (2002). Structural Components of Humic Acids as Determined by Chemical Modifications and Carbon-13 NMR, Pyrolysis, and Thermochemolysis- Gas Chromatography/Mass Spectrometry. Soil Science Society of American Journal Abstract Division S-2- Soil Chemistry66. 1159-1171.

Dinu, M. I. (2013). Metals Complexation with Humic Acids in Surface Water of Different Environ. Sci. Technol. 31(1): 1-17.

Fernandes, A.N., Giacomelli, C., Giovanela, M. Vaz, D.V. Szpoganicz, B. and Maria M. D. (2009). Potentiometric Acidity Determination in Humic Substances Influenced by Different Analytical Procedures.J. Braz. Chem. Soc. 20 (9):14.

Gamal, A. H. (2015). Stability Constants of Rhenium (V) Metal Complexes with Selected Drugs. Pyrex Journal of Research in Environmental Studies. 2(2): 006-014.

Janrao, D. M., Pathan, J., Kayande, D.D., and Mulla, J.J. (2014). An Over View of Potentiometric Determination of Stability Constants of Metal Complexes. Sci. Revs. Chem. Commun.: 4(1), 2014, 11-24.

Karimi, H. (2017). Effect of pH and Initial Pb(II) Concentration on the Lead Removal Efficiency from Waste Water Using $\mathrm{Ca}(\mathrm{OH})_{2}$. International Journal of Water and Waste Water Treatment 3.2

Kaschl, A. Romheld, V. and Chen, Y. (2010). Binding of Cadmium, Copper and Zinc to Humic Substances Originating from Municipal Solid Waste Compost. Israel Journal of Chemistry Vol. 42(1): 89-98.

Kostic, I. S., Tatjana, P, A., Nikolic, R. S., Cvetkovic, T. P., Pavlovic, D. D., Aleksandar, L.J. and Bojic, A. (2012). Comparative Study of Binding Strengths of Heavy Metals with Humic Acid. J.serb. Chem. Soc. 76(9) pp 1-20. 
BAJOPAS Volume 14 Number 1,June, 2021

Na'aliya, J. (2013). Determination of Stepwise Stability Constants and Gibbs free Energy Change of Trisprolina to Complexes of some Divalent Transition Metal ions. Bayero Journal of Pure and Applied Sciences 6(2): 112-114.

Omar, A. A. and Ali, E. A. (2015). Potentiometric Studies on Complexes of $\mathrm{Cr}$ (III) and $\mathrm{Zr}$ (IV) with some Carboxylic Acids. International Journal of Advanced Chemistry, 3(1) 25-

37.

Pandey, A. K. Pandey, S. D. and Misr, V. (2015).Stability Constants of Metal- Humic Acid Complexes and Its Role in Environmental Detoxification. J. Ecotoxicology and Environmental Safety. 47(1):195-200.

Ram, N. and Raman, K.V. (1984). Stability Constants of Complexes of Metals with
Humicand Fuvic Acids under Non- acidConditions. Journal of Plant Nutrition and Soil Sciences.

147:171-176.

Santosh, D. D., Ashok, B. K., Vijay, J. T., Shivraj, G. W. and Vinay, V. W. (2011). Potentiometric Studies of Elec-Trolyte Effects on Complex Equilibria of Some Substituted 5-(2-hydroxy Phenyl) Pyrazoles. Der pharm. 3 (6): 75-83.

Sayyed, H. and Abdul Rahim, M. F. (2012). Studies of Binary Complexes of Metal Ions with Mandelic Acid by Potentiometry. Chem. J. 02 (6): 206209.

Shirvani, M. Moradian, E. Khalili, B. Bakhtiary, S. (2015). Interaction of $\mathrm{Cd}$ and $\mathrm{Pb}$ with Humate-Palygorskite and HumateSepiolite Complexes. Journal of water, air and pollution 3: 220-228. 


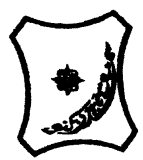

Bayero Journal of Pure and Applied Sciences, 14(1): 54 - 63

Received: November, 2020

Accepted: April, 2021

ISSN $2006-6996$

\title{
STABILITY CONSTANTS OF COMPLEXES OF METAL IONS WITH PEATSOIL HUMIC ACIDS UNDER NON-ACID-CONDITIONS
}

\author{
${ }^{* 1}$ Sabo, Yusuf ${ }^{2}$ Jimoh, W.L.O., ${ }^{3}$ Isa Baba Koki and ${ }^{4}$ Sholadoye, Q. 0. \\ ${ }^{1}$ Department of Pure and Industrial Chemistry, Bayero University, Kano \\ ${ }^{3}$ Department of Chemistry, Yusuf Maitama Sule University Kano. P.M.B. 3220 Kano, Nigeria. \\ ${ }^{4}$ Department of Chemistry, Nigerian Police Academy, Wudil, Kano-Nigeria
}

*Correspondence E-mail; saboyusuf18@yahoo.com

ABSTRACT

Stability constants of complexes of four divalent metal ions viz. $\mathrm{Cu}^{2+}, \mathrm{Pb}^{2+}, \mathrm{Mg}^{2+}$ and $\mathrm{Cd}^{2+}$ with humic acids (HA) were determined by potentiometric titration of humic acids with the corresponding salt of the divalent metals in aqueous media under non-acid-condition. The log $K$ (logarithm of the stability constant) ranged from 1.0942 to 2.7471 for metalhumic acid complexes were determined using point-wise computational method. The order of stability constants were obtained as follows: $\mathrm{Cu}>\mathrm{Pb}>\mathrm{Cd}>\mathrm{Mg}$ for metal $-\mathrm{HA}$ complexes respectively, indicating a higher degree of complexation with Cu metal ion.

Keywords: stability constant, humic acid, potentiometric titration, divalent metals, acid hydrolysis.

\section{NTRODUCTION}

The stability constant of a complex is the numerical expression of its stability and provides a quantitative measure of affinity of the metal ion to the complexing agent. An understanding of the relative stability of metal-complexes helps in predicting the behavior of metal ions in the soil (Ram and Raman, 1982). Extensive researches has been done to determine the stability constants of the complexes formed between humic acid (HA) with a number of metal ions. Ashok et al., (2000) reported that humic acid with hydroxyl, phenoxyl and carboxyl reactive groups can form coordination compound with metal ions at $\mathrm{pH}$ 3.5. The stability constants(Log K) for different metalhumic acid complexes indicated the following order of the stabilities of complexes formed between humic acid and metal ion, $\mathrm{Cu}>\mathrm{Fe}$ $>\mathrm{Pb}>\mathrm{Ni}>\mathrm{Co}>\mathrm{Ca}>\mathrm{Cd}>\mathrm{Zn}>\mathrm{Mn}>\mathrm{Mg}$. Andelkovic et al., (2010) investigated the binding of $\mathrm{Cd}$ (II) to soil humic acid at pH 6.5 and in $0.1 \mathrm{M} \mathrm{KNO}_{3}$ ionic medium. The stability constant for binding indicating greater stability in the case when carboxyl groups are involved in complexation reaction. Kostic et al.,(2012) investigated the complexation of humic acid with certain heavy metal ions (Co(II), $\mathrm{Ni}(\mathrm{II}), \mathrm{Cu}(\mathrm{II})$,
$\mathrm{Zn}(\mathrm{II})$, and $\mathrm{Pb}(\mathrm{II})$. The experiment was performed at $25^{\circ} \mathrm{C}$, at pH 4.0 and ionic strength of $0.01 \mathrm{M}$. Stability constant of complex between $\mathrm{Pb}$ (II) ions and humic acid is greater than stability constants of other investigated metalhumate complexes. Bogata and Sokolowska (2016) analyses the interaction between humic acids from different soils and $\mathrm{Zn}$ (II) ions at wide concentration ranges and at $\mathrm{pH} 5$. Studies have showed significant impact of $\mathrm{Zn}$ concentration, $\mathrm{pH}$ and some properties of humic acids with zinc.But all of these studies were limited to acidic $\mathrm{pH}$ range. Therefore, the present study was carried out to determine and compare the stability constants of complexes of metal ions with hydrolysed peat soil humic acid and unhydrolysed peat soil humic under non-acid conditions.

\section{MATERIALS AND METHODS}

Analytical grade chemicals used includes hydrochloric acid $(\mathrm{HCl})$, nitric acid $\left(\mathrm{HNO}_{3}\right)$, sodium hydroxide $(\mathrm{NaOH})$, lead nitrate $\mathrm{Pb}\left(\mathrm{NO}_{3}\right)_{2}$, copper nitrate $\mathrm{Cu}\left(\mathrm{NO}_{3}\right)_{2} \cdot 3 \mathrm{H}_{2} \mathrm{O}$, cadmium nitrate $\mathrm{Cd}\left(\mathrm{NO}_{3}\right)_{2} \cdot 4 \mathrm{H}_{2} \mathrm{O}$, magnesium nitrate $\mathrm{Mg}\left(\mathrm{NO}_{3}\right)_{2} \cdot 6 \mathrm{H}_{2} \mathrm{O}$, potassium nitrate $\left(\mathrm{KNO}_{3}\right)$, calcium chloride $\left(\mathrm{CaCl}_{2}\right)$, (sigma-Aldrich). Dowex 50WX8, (20-50 mesh) from Fluka. 


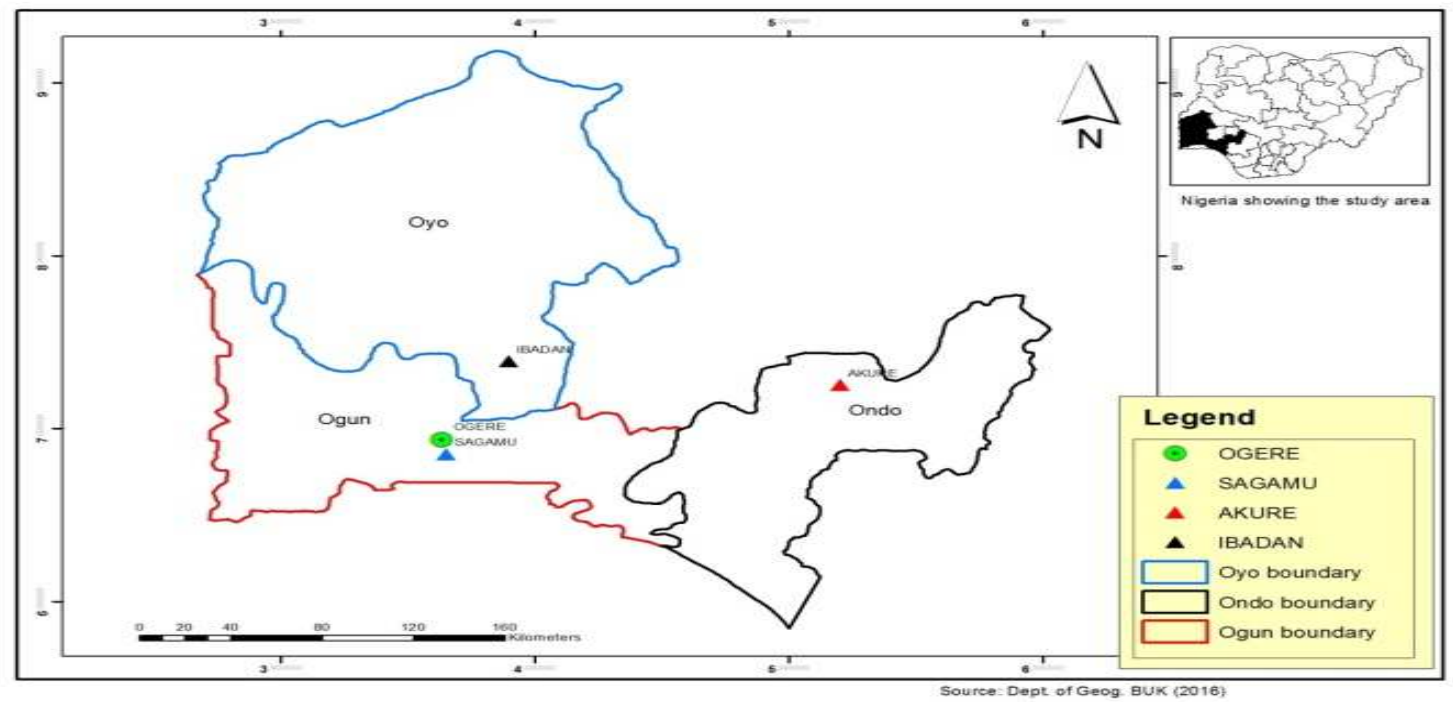

Figure 1: Map showing the sampling point at Sagamu Town, Ogun State.

\section{Description of Sampling Area}

Sagamu has geographical coordinates between $6^{\circ} 50^{\prime}$ north; $3^{\circ} 38^{\prime}$ east is located in south western region of Nigeria. The region has tropical wet and dry climate with a lengthy wet season and relatively constant temperatures throughout the course of the year. Wet season runs from March to October, November to December forms the region dry season. The vegetation type of the region is savannah which is really grassland with small bushes and occasional big trees. Grassland soils have substantially higher organic matter content than forest soils (Novackova, 2011).

\section{Sample Collection}

The Peatsoil samples were collected from four different sampling points $(0-10 \mathrm{~cm}$ depth) in Sagamu into polyethylene bag with plastic spoons. Samples were taken to the laboratory, extraneous materials were removed; the samples were air-dried, crushed and ground to a fine powder in a mortar passed through a $0.20 \mathrm{~mm}$ sieve. The samples were kept for analysis.

\section{Isolation and purification of humic acid from peat soil sample}

Peatsoil sample $(100 \mathrm{~g})$ was mixed with 1000 $\mathrm{cm}^{3}$ of $0.1 \mathrm{M} \mathrm{NaOH}$ solution, shaken for 3hours and left to stand overnight. Dark-coloured supernatant was obtained and decanted from solid residue. The dark-coloured supernatant was acidified to $(\mathrm{pH}=1.0)$ with $6 \mathrm{M} \mathrm{HCl}$ stirred and allowed to stand for 6 hours. Yellowish brown supernatant and dark-brown precipitate were obtained. The yellowish brown supernatant was decanted followed by centrifuge and discarded. The dark-brown precipitate was mixed with $500 \mathrm{~cm}^{3}$ of $0.1 \mathrm{M} \mathrm{NaOH}$ solution followed by passing through dowex resin. The dark-brown solution was acidified to $(\mathrm{pH}=1.0)$ with $6 \mathrm{M} \mathrm{HCl}$ stirred and allowed to stand for 3 hours. The dark-brown precipitate was washed several times with deionized water. The supernatant was treated with $\mathrm{AgNO}_{3}$ solution until no white precipitate observed. The humic acid was transferred to weighed crucible and dried at $60^{\circ} \mathrm{C}$ in an oven for 12 hours. The humic acid was cooled and dried in the desiccator, weighed and recorded. The obtained humic acid was dried again at $60^{\circ} \mathrm{C}$ for additional 6 hours cooled and dried in the desiccator, weighed and recorded constant weight was obtained (Baruah et al., 2015).

\section{FT-IR analysis}

FT-IR spectra of humic acid sample was analysed using Carry 630 FT-IR Agilent Technologies.

Unhydrolysed compost humic acid

The unhydrolysed humic acid was obtained after isolation and purification of compost humic acid and kept for investigation.

\section{Acid hydrolysis of Peatsoil acid}

Peatsoil humic acid sample (1g) was refluxed for 12 hours at $\left(160^{\circ} \mathrm{C}\right)$ with $50 \mathrm{~cm}^{3}$ of $6 \mathrm{M} \mathrm{HCl}$. The mixture was allowed to cool, decanted, and centrifuged after hydrolysis. The insoluble residues were washed with distilled water via centrifugation several times, and the supernatant was treated with $\mathrm{AgNO}_{3}$ solution until no white precipitate was observed. The residue was thoroughly dried over $\mathrm{CaCl}_{2}$ in a desiccator at room temperature (Chefetz et al., 2002). Finally, the obtained hydrolysed humic acid was kept for investigation. 
BAJOPAS Volume 14 Number 1,June, 2021 Potentiometric Titrations

Potentiometric measurements were carried out using a pH-meter Jenway (model 3510) with combine electrode, the sensitivity of the $\mathrm{pH}$ meter is 0.01 units. The $\mathrm{pH}$ meter was switched on half an hour before starting the titration for initial warm up of the instrument. The instrument was calibrated with an aqueous standard buffer solution of $\mathrm{pH} 4.00$ and 10.0 (borate buffer) prepared from a "Qualigens" buffer tablets.

The following sets of solutions were prepared in a $250 \mathrm{~cm}^{3}$ volumetric flask separately for $\mathrm{pH}$ metric titrations.

(i) $5 \mathrm{~cm}^{3} 0.1 \mathrm{M} \mathrm{HCl}+40 \mathrm{~cm}^{3}$ deionized water

(ii) $5 \mathrm{~cm}^{3} 0.1 \mathrm{M} \mathrm{HCl}+39 \mathrm{~cm}^{3}$ deionized water $+1 \mathrm{~cm}^{3} 0.15 \mathrm{gcm}^{-3}$ humic acid

(iii) $5 \mathrm{~cm}^{3} 0.1 \mathrm{M} \mathrm{HCl}+37 \mathrm{~cm}^{3}$ deionized water $+1 \mathrm{~cm}^{3} 0.15 \mathrm{gcm}^{-3}$ humic acid

$$
+2 \mathrm{~cm}^{3} \quad 0.01 \mathrm{M} \mathrm{Cu} \text { (II) }
$$

The solutions were titrated against standardized $0.110 \mathrm{MNaOH}$ separately. The total volume of each mixture was adjusted to $50 \mathrm{~cm}^{3}$ and the ionic strength of the solutions was maintained constant at by adding appropriate amount of stock solution of $1 \mathrm{M} \mathrm{KNO}_{3}$ (Gamal, 2015; Omar and Ali, 2015). A magnetic stirrer was used to achieve thorough mixing of the interacting solutions at $550 \mathrm{rpm}$. The same set of experimental conditions was applied for potentiometric titration of remaining samples.

\section{Evaluation of pKa of Hydrolysed peat soil Humic Acids}

The proton-ligand formation number $\mathrm{n}_{\mathbf{A}}$ were calculated by Irving and Rossotti expression (Omar and Ali, 2015).

$\mathrm{nA}=\mathrm{Y}-\frac{(\mathrm{V} 2-\mathrm{V1})(\mathrm{No}-\mathrm{Eo})}{(\mathrm{VO}+\mathrm{V1}) \mathrm{TCL}}$ 1

Where: $Y$ is number of dissociable proton, $\left(\mathrm{V}_{2^{-}}\right.$ $V_{1}$ ) is the measure of displacement of the ligand curve relative to acid curve, $\mathrm{N}^{\circ}$ and $\mathrm{E}^{\circ}$ are the resultant concentration of alkali solution, free acid solution, $\mathrm{T}_{\mathrm{cL}}{ }^{\circ}$ is the total ligand concentration, $\mathrm{V}^{\circ}$ is the total volume of titration solution, $V_{1}$ is the volume of alkali added to acid solution, $V_{2}$ is the volume of alkali added to acid solution + ligand solution, acid dissociation constants (pKa - values) of ligand were calculated by algebraic method point wise calculation (Tables 1 ). The dissociation constants (pKa) were calculated according to the following relation:

$\mathrm{pKa}=\mathrm{pH}+\log \left(\frac{n A}{1-n A}\right)$ 2

Where: pKa is the acid dissociation constant, $\mathrm{n}_{\mathrm{A}}$ is the Proton-ligand formation number and $\mathrm{pH}$ is the pH-values (Omar and Ali, 2015).

\section{Determination of metal-ligand stability constants $(\log K)$ of complexes}

The potentiometric measurement for the determination of stability constant of a complex in solution is based on the fact that the redox potential of the couple $\frac{M^{+(m-n)}}{M^{+m}}$ is shifted significantly on complexation of the metal ion with the ligand. This method involves change in hydrogen ion concentration $\left[\mathrm{H}^{+}\right]$due to the displacement or association of one or more protons taking place during complexation reaction. This change can be found out by titrating the solutions containing free acid, acid with ligand, and acid with ligand and metal ion, individually against a standard alkali solution at a constant ionic strength or temperature. Either ionic strength or temperature may be varied for different sets of solutions. In all the cases, the change in the $\mathrm{pH}$ of the solution is measured after each addition of a known amount of alkali to the reaction cell which contains the reaction mixture. The titration curves are then drawn by plotting the measured $\mathrm{pH}$ values against the corresponding volume of alkali added and the stability constants of the complexes are determined from the titration curves by employing $\mathrm{pH}$-metric titration technique given by (Irving and Rossoti).

Metal-ligand stability constants ( $\log \mathrm{K}$ ) were determined by using the following relations:

$$
\bar{n}=\frac{\left(V_{3}-V_{2}\right)\left(E^{0}+N^{0}\right)}{\left(V^{0}+V_{2}\right) \bar{n}_{A} T_{m}^{0}}
$$

and

$$
P L=\log _{10}\left\{\frac{1+\beta_{n}^{H} \frac{1}{[\text { anti } \log \mathrm{pH}]^{\mathrm{n}}}}{\mathrm{T}_{\mathrm{L}}^{0}-n \bar{T}_{m}^{0}} \mathrm{X} \frac{\left(V^{0}+V_{3}\right)}{V^{0}}\right\}
$$


BAJOPAS Volume 14 Number 1,June, 2021

Where $T_{L}, T^{\circ}, E^{\circ}$, and $V^{\circ}$ havethe same significance as in equation (1) above, $T_{m}$ denotes the total concentration of metal present in solution, $V_{3}$ is the volume of metal ions present in solution and $\beta^{H}$ is the overall proton ligand stability constant. The metal-ligand stability constants (log K) were determined by employing point wise computational Method (eq. 5 and 6).

$\operatorname{LogK}_{1}=\log \left(\frac{n}{1-n}\right)+\mathrm{pL}$ .5

$\operatorname{LogK}_{2}=\log \left(\frac{1-n}{2-n}\right)+\mathrm{pL}$ ...6

Where: Log $\mathrm{K}$ is the metal-ligand stability constant, $\mathrm{pL}$ is the Free ligand exponent function, $\mathbf{n}$ is the Average number of ligand attached with metal ion (Janraoet al., 2014). The results obtained were analyzed by an ORIGIN 2016 program using titration data and then the proton-ligand stability constants (pKa) and Metal-ligand stability constant (LogK) calculated (Omar and Ali, 2015).

\section{RESULTS AND DISCUSSION}

Fourier transformed infrared (FT-IR) spectra of isolated humic acid from peat soils Figure 2 had distinct clear absorption bands indicating the presence of major humic acid structural elemental groups such as $\mathrm{H}$ bonded $\mathrm{OH}$ $\left(3680 \mathrm{~cm}^{-1}\right.$ peak $), C=0$ of carbonyl $\left(1721 \mathrm{~cm}^{-1}\right.$ peak), functional groups of aliphatic components $\mathrm{CH}_{2}\left(2918 \mathrm{~cm}^{-1}\right.$ peak) and $\mathrm{C}-\mathrm{O}$ stretching of polysaccharide $\left(1168 \mathrm{~cm}^{-1}\right.$ peak). The positions of the absorption bands of the spectra fell within typical major absorption bands of humic acid which is at frequencies 3680, 2918, 1721, 1168 $\mathrm{cm}^{-1}$. The first peak centred in the vicinity of $3680 \mathrm{~cm}^{-1}$ region is attributed to phenol $\mathrm{OH}$ group bounded by intermolecular $\mathrm{H}$ bonds. The $2918 \mathrm{~cm}^{-1}$ band usually has absorption maximum at $2918 \mathrm{~cm}^{-1}$ which is due to $\mathrm{C}-\mathrm{H}$ stretching of alkane group $\left(\mathrm{CH}_{2}\right)$. The next major absorption band is $1721 \mathrm{~cm}^{-1}$. This band has been commonly ascribed to $\mathrm{C}=\mathrm{O}$ stretching of mainly carboxyl group $(\mathrm{COOH})$ with trace amount of ketones. The last peak was observed at 1168 $\mathrm{cm}^{-1}$ due to $\mathrm{C}-\mathrm{O}$ stretching of polysaccharides and this peak appeared also in the spectra of humic acid from peat soil. The FTIR spectra of the isolated humic acid contained all major characteristic absorption peaks of humic acid. These absorption peaks indicated the presence of the major structural elements of humic acid namely $\mathrm{H}$ bonded $\mathrm{OH}, \mathrm{C}=\mathrm{C}$ of aromatic ring, $\mathrm{C}=\mathrm{O}$ of carbonyl group (both carboxyl and ketonic), $\mathrm{CH}_{2}$ group. This strongly supports the presence of humic acid.

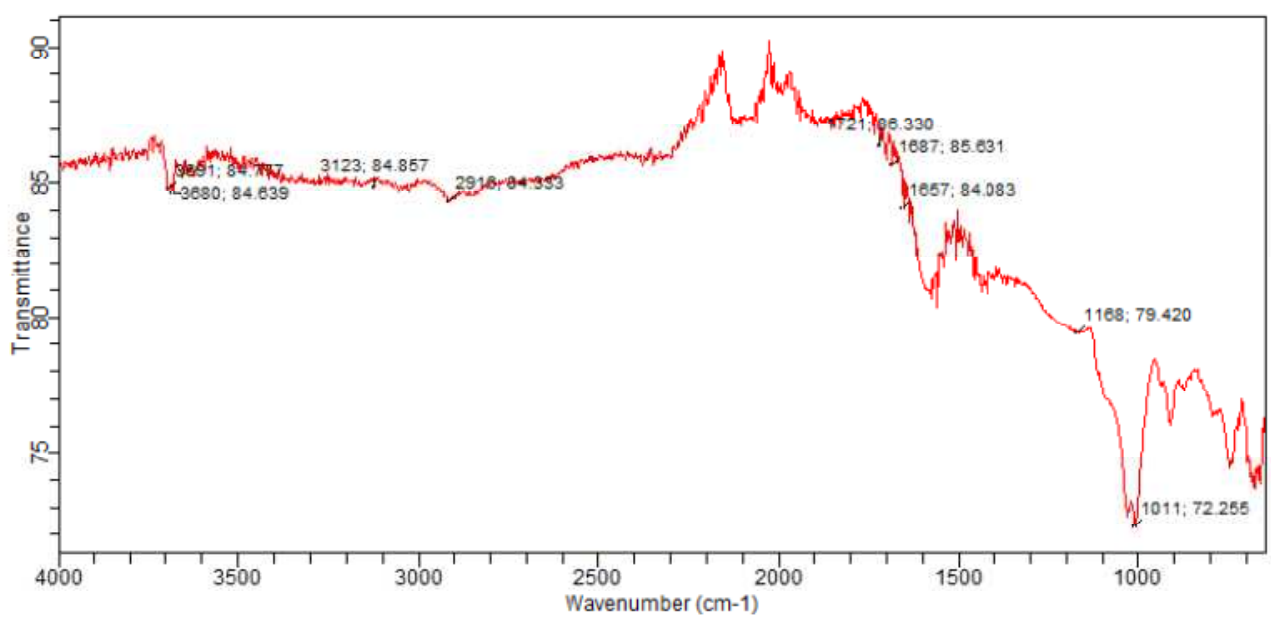

Fig. 2 : FT-IR spectraof peatsoilhumic acid (PSHA)

\section{Evaluation of acid dissociation constant (pka) of acid hydrolysed peat soil humicacid at phenolic group}

The value of the dissociation constant of the peat soil humic acid (PSHA) that underwent acidhydrolysis studied was found to be 8.9299 as shown Table 1, which is lower than the literaturevalues reported by Almeida and Szpoganics, (2015), Borges et al., (2005); Badr et al., (2012)and Fernandes et al,.(2009) of $9.73,9.47$ and 10.30. The difference between the obtained valuesand the reported values in this study might be probably as a result of acid hydrolysis of humicacid. 
BAJOPAS Volume 14 Number 1,June, 2021

Table 1: PKa of (Hydrolysed PSHA)

\begin{tabular}{|l|l|l|l|l|l|l|}
\hline $\mathrm{pH}$ & $\mathrm{BV}_{1}$ & $\mathrm{BV}_{2}$ & $\mathrm{~V}_{2}-\mathrm{V}_{1}$ & $\mathrm{nA}$ & $\log \left(\frac{n A}{1-n A}\right)$ & $\mathrm{pKa}$ \\
\hline 8.50 & 5.30 & 6.29 & 0.99 & 0.3594 & -0.2510 & 8.2490 \\
8.72 & 5.35 & 6.37 & 1.02 & 0.3400 & -0.2880 & 8.4320 \\
9.00 & 5.40 & 6.46 & 1.06 & 0.3141 & -0.3391 & 8.6609 \\
9.22 & 5.45 & 6.55 & 1.10 & 0.2882 & -0.3927 & 8.8273 \\
9.51 & 5.50 & 6.66 & 1.16 & 0.2494 & -0.4786 & 9.0314 \\
9.73 & 5.55 & 6.78 & 1.23 & 0.2041 & -0.5910 & 9.1390 \\
10.00 & 5.60 & 6.90 & 1.30 & 0.1589 & -0.7238 & 9.2762 \\
10.23 & 5.65 & 7.05 & 1.40 & 0.0941 & -0.9835 & 9.2465 \\
10.49 & 5.70 & 7.10 & 1.40 & 0.0941 & -0.9835 & 9.5065 \\
\hline
\end{tabular}

Average pKa $=8.9299 \pm 0.4186$

Table 2: PKa of (Unhydrolysed PSHA)

\begin{tabular}{|l|l|l|l|l|l|l|}
\hline $\mathrm{pH}$ & $\mathrm{BV}_{1}$ & $\mathrm{BV}_{2}$ & $\mathrm{~V}_{2}-\mathrm{V}_{1}$ & $\mathrm{nA}$ & $\log \left(\frac{\boldsymbol{n A}}{1-\boldsymbol{n}}\right)$ & $\mathrm{pKa}$ \\
\hline 8.50 & 5.30 & 5.81 & 0.51 & 0.6619 & 0.2919 & 8.7919 \\
8.72 & 5.35 & 5.90 & 0.55 & 0.6357 & 0.2418 & 8.9618 \\
9.00 & 5.40 & 6.00 & 0.60 & 0.6029 & 0.1813 & 9.1813 \\
9.22 & 5.45 & 6.10 & 0.65 & 0.5701 & 0.1226 & 9.3426 \\
9.51 & 5.50 & 6.20 & 0.70 & 0.5376 & 0.0654 & 9.5754 \\
9.73 & 5.55 & 6.33 & 0.78 & 0.4851 & -0.0259 & 9.7041 \\
10.00 & 5.60 & 6.47 & 0.87 & 0.4262 & -0.1291 & 9.8709 \\
10.23 & 5.65 & 6.62 & 0.99 & 0.3609 & -0.2481 & 9.9819 \\
10.49 & 5.70 & 6.80 & 1.10 & 0.2759 & -0.4690 & 10.0210 \\
\hline
\end{tabular}

Average pKa $=9.4923 \pm 0.4410$

Metal-ligand stability constant ( $\log \mathrm{K}$ )

The stabilityconstants require the accurate values of proton-ligand stability constants (Anil and Maroti, 2008). Metal titration curves crossed over ligand titration curve indicated the formation of complex upon proton release (Santosh, et al., 2011). If the values of n- are within range $0.2-0.8$ and $1.2-18$ this indicates the formation of $1: 1$ and 1:2 complexes (Sayyed and Mazahar, 2012).

The metal (II)-humate stepwise stability constants (log k) at phenolic group (Tables 318)

Table 3: Point-wise method, $\mathrm{Cu}$-(Hydrolysed PSHA)

\begin{tabular}{|l|l|l|l|l|l|l|l|l|}
\hline $\mathrm{pH}$ & $\mathrm{BV}_{1}$ & $\mathrm{BV}_{2}$ & $\mathrm{BV}_{3}$ & $\left(\mathrm{~V}_{3}-\mathrm{V}_{2}\right)$ & $\mathrm{n}$ & $\mathrm{pL}$ & $\log \left(\frac{n}{1-n}\right)$ & LogK $_{1}$ \\
\hline 8.50 & 5.30 & 6.29 & 6.33 & 0.04 & 0.5500 & 2.66 & 0.0871 & 2.7471 \\
8.72 & 5.35 & 6.37 & 6.41 & 0.04 & 0.5714 & 2.43 & 0.1249 & 2.5549 \\
9.00 & 5.40 & 6.46 & 6.50 & 0.04 & 0.6198 & 2.16 & 0.2122 & 2.3722 \\
9.22 & 5.45 & 6.55 & 6.59 & 0.04 & 0.6667 & 1.94 & 0.3010 & 2.2410 \\
\hline
\end{tabular}

LogK $_{1}$ (Average value) $=2.4788 \pm 0.2203$

Table 4: Point-wise method, $\mathrm{Cu}$-(Hydrolysed PSHA)

\begin{tabular}{|l|l|l|l|l|l|l|l|l|}
\hline $\mathrm{pH}$ & $\mathrm{BV}_{1}$ & $\mathrm{BV}_{2}$ & $\mathrm{BV}_{3}$ & $\left(\mathrm{~V}_{3}-\mathrm{V}_{2}\right)$ & $\mathrm{n}$ & $\mathrm{pL}$ & $\log \left(\frac{n-1}{2-n}\right)$ & LogK $_{2}$ \\
\hline 9.51 & 5.50 & 6.66 & 6.73 & 0.07 & 1.3509 & 1.70 & -0.2671 & 1.4329 \\
9.73 & 5.55 & 6.78 & 6.85 & 0.07 & 1.6383 & 1.51 & 0.2467 & 1.7567 \\
10.00 & 5.60 & 6.90 & 6.98 & 0.08 & 2.1783 & 1.31 & -0.2158 & 1.0942 \\
10.23 & 5.65 & 7.05 & 7.13 & 0.08 & 4.1904 & 1.27 & & \\
10.49 & 5.70 & 7.10 & 7.19 & 0.09 & 4.6920 & & & \\
\hline
\end{tabular}

Log $K_{2}($ Average value $)=1.4280 \pm 0.3312$ 
BAJOPAS Volume 14 Number 1,June, 2021

Table 5: Point-wise method, $\mathrm{Cu}$ (Unhydrolysed PSHA)

\begin{tabular}{|l|l|l|l|l|l|l|l|l|}
\hline $\mathrm{pH}$ & $\mathrm{BV}_{1}$ & $\mathrm{BV}_{2}$ & $\mathrm{BV}_{3}$ & $\left(\mathrm{~V}_{3}-\mathrm{V}_{2}\right)$ & $\mathrm{n}$ & $\mathrm{pL}$ & $\log \left(\frac{n}{n-1}\right)$ & Log $_{1}$ \\
\hline 8.50 & 5.30 & 5.81 & 5.85 & 0.04 & 0.2973 & 2.88 & -0.3736 & 2.5064 \\
8.72 & 5.35 & 5.90 & 5.95 & 0.05 & 0.3873 & 2.66 & -0.1992 & 2.4608 \\
9.00 & 5.40 & 6.00 & 6.05 & 0.05 & 0.4044 & 2.38 & -0.1681 & 2.2119 \\
9.22 & 5.45 & 6.10 & 6.15 & 0.06 & 0.5157 & 2.18 & -0.0272 & 2.2072 \\
9.51 & 5.50 & 6.20 & 6.27 & 0.07 & 0.6417 & 1.89 & 0.2530 & 1.1430 \\
\hline
\end{tabular}

$\operatorname{LogK}_{1}($ Average value $)=2.3059 \pm 0.6153$

Table 6:Point-wise method, $\mathrm{Cu}$ (Unhydrolysed PSHA)

\begin{tabular}{|l|l|l|l|l|l|l|l|l|}
\hline $\mathrm{pH}$ & $\mathrm{BV}_{1}$ & $\mathrm{BV}_{2}$ & $\mathrm{BV}_{3}$ & $\mathrm{~V}_{3}-\mathrm{V}_{2}$ & $\mathrm{n}$ & $\mathrm{pL}$ & $\log \left(\frac{n-1}{2-n}\right)$ & $\log \mathrm{K}_{2}$ \\
\hline 9.73 & 5.55 & 6.33 & 6.42 & 0.09 & 0.9000 & 1.69 & & \\
10.00 & 5.60 & 6.47 & 6.58 & 0.11 & 1.2578 & 1.44 & -0.4592 & 0.9808 \\
10.23 & 5.65 & 6.62 & 6.84 & 0.12 & 1.6137 & 1.26 & -0.2010 & 1.4610 \\
10.49 & 5.70 & 6.80 & 6.92 & 0.12 & 2.1052 & 1.03 & & \\
\hline
\end{tabular}

$\operatorname{LogK}_{2}$ (Average value) $=1.2209 \pm 0.3398$

Table 7:Point-wise method, Pb (Hydrolysed PSHA)

\begin{tabular}{|l|l|l|l|l|l|l|l|l|}
\hline $\mathrm{pH}$ & $\mathrm{BV}_{1}$ & $\mathrm{BV}_{2}$ & $\mathrm{BV}_{3}$ & $\left(\mathrm{~V}_{3}-\mathrm{V}_{2}\right)$ & $\mathrm{n}$ & $\mathrm{pL}$ & $\log \left(\frac{n}{1-n}\right)$ & LogK $_{1}$ \\
\hline 8.50 & 5.30 & 6.29 & 6.33 & 0.04 & 0.5500 & 2.66 & 0.0871 & 2.7471 \\
8.72 & 5.35 & 6.37 & 6.41 & 0.04 & 0.5714 & 2.43 & 0.1249 & 2.5549 \\
9.00 & 5.40 & 6.46 & 6.50 & 0.04 & 0.6198 & 2.16 & 0.2122 & 2.3722 \\
9.22 & 5.45 & 6.55 & 6.60 & 0.05 & 0.8333 & 1.96 & 0.6989 & 2.6589 \\
\hline
\end{tabular}

Log $_{\mathbf{1}}($ Average value $)=2.5832 \pm 0.1614$

Table 8:Point-wise method, Pb-(Hydrolysed PSHA)

\begin{tabular}{|l|l|l|l|l|l|l|l|l|}
\hline $\mathrm{pH}$ & $\mathrm{BV}_{1}$ & $\mathrm{BV}_{2}$ & $\mathrm{BV}_{3}$ & $\left(\mathrm{~V}_{3}-\mathrm{V}_{2}\right)$ & $\mathrm{n}$ & $\mathrm{pL}$ & $\log \left(\frac{n-1}{2-n}\right)$ & $\log \mathrm{K}_{2}$ \\
\hline 9.51 & 5.50 & 6.66 & 6.71 & 0.05 & 0.9650 & 1.67 & & \\
9.73 & 5.55 & 6.78 & 6.83 & 0.05 & 1.1702 & 1.44 & & \\
10.00 & 5.60 & 6.90 & 6.90 & 0.05 & 1.4864 & 1.22 & -0.0237 & 1.1963 \\
10.23 & 5.65 & 7.05 & 7.10 & 0.05 & 2.0190 & 1.09 & & \\
10.49 & 5.70 & 7.10 & 7.17 & 0.07 & 3.6492 & 1.00 & & \\
\hline
\end{tabular}

Log $K_{2}$ (Average value) $=1.1963$

Table 9: Point-wise method, Pb (Unhydrolysed PSHA)

\begin{tabular}{|l|l|l|l|l|l|l|l|l|}
\hline $\mathrm{pH}$ & $\mathrm{BV}_{1}$ & $\mathrm{BV}_{2}$ & $\mathrm{BV}_{3}$ & $\mathrm{~V}_{3}-\mathrm{V}_{2}$ & $\mathrm{n}$ & $\mathrm{pL}$ & $\begin{array}{l}\text { Log } \\
\left(\frac{n}{n-1}\right)\end{array}$ & Log $\mathrm{K}_{1}$ \\
\hline 8.50 & 5.30 & 5.81 & 5.85 & 0.04 & 0.2973 & 2.88 & -0.3736 & 2.5064 \\
8.72 & 5.35 & 5.90 & 5.94 & 0.04 & 0.3099 & 2.66 & -0.5477 & 2.3123 \\
9.00 & 5.40 & 6.00 & 6.05 & 0.05 & 0.4044 & 2.38 & -0.1681 & 2.2119 \\
9.22 & 5.45 & 6.10 & 6.15 & 0.06 & 0.5157 & 2.18 & 0.0272 & 2.2072 \\
9.51 & 5.50 & 6.20 & 6.26 & 0.07 & 0.6417 & 1.89 & 0.2530 & 2.1430 \\
9.73 & 5.55 & 6.40 & 6.40 & 0.07 & 0.7000 & 1.67 & 0.3680 & 2.0380 \\
\hline
\end{tabular}

LogK $_{1}$ (Average value) $=2.2364 \pm 0.1602$

Table 10: Point-wise method, Pb (Unhydrolysed PSHA)

\begin{tabular}{|l|l|l|l|l|l|l|l|l|}
\hline $\mathrm{pH}$ & $\mathrm{BV}_{1}$ & $\mathrm{BV}_{2}$ & $\mathrm{BV}_{3}$ & $\mathrm{~V}_{3}-\mathrm{V}_{2}$ & $\mathrm{n}$ & $\mathrm{pL}$ & $\log \left(\frac{n-1}{2-n}\right)$ & $\log \mathrm{K}_{2}$ \\
\hline 10.00 & 5.60 & 6.47 & 6.55 & 0.08 & 1.9503 & 1.41 & & \\
10.23 & 5.65 & 6.62 & 6.72 & 0.11 & 1.4792 & 1.26 & -0.0361 & 1.2239 \\
\hline
\end{tabular}

$\operatorname{LogK}_{2}$ (Average value) $=1.2239$

Table 11: Point-wise method, Mg (Hydrolysed PSHA)

\begin{tabular}{|l|l|l|l|l|l|l|l|l|}
\hline $\mathrm{pH}$ & $\mathrm{BV}_{1}$ & $\mathrm{BV}_{2}$ & $\mathrm{BV}_{3}$ & $\left(\mathrm{~V}_{3}-\mathrm{V}_{2}\right)$ & $\mathrm{n}$ & $\mathrm{pL}$ & $\log \left(\frac{n}{n-1}\right)$ & LogK $_{1}$ \\
\hline 8.50 & 5.30 & 6.29 & 6.31 & 0.02 & 0.2750 & 2.64 & -0.4290 & 2.2110 \\
8.72 & 5.35 & 6.37 & 6.39 & 0.02 & 0.2858 & 2.42 & -0.3978 & 2.0222 \\
9.00 & 5.40 & 6.46 & 6.49 & 0.03 & 0.4648 & 2.14 & -0.0612 & 2.0788 \\
9.22 & 5.45 & 6.55 & 6.59 & 0.04 & 0.6667 & 1.94 & 0.3010 & 2.2410 \\
\hline
\end{tabular}

$\log _{\mathbf{1}}($ Average value) $=2.1382 \pm 0.1046$ 
BAJOPAS Volume 14 Number 1,June, 2021

Table 12: Point-wise method, Mg (Hydrolysed PSHA)

\begin{tabular}{|l|l|l|l|l|l|l|l|l|}
\hline $\mathrm{pH}$ & $\mathrm{BV}_{1}$ & $\mathrm{BV}_{2}$ & $\mathrm{BV}_{3}$ & $\left(\mathrm{~V}_{3}-\mathrm{V}_{2}\right)$ & $\mathrm{n}$ & $\mathrm{pL}$ & $\log \left(\frac{n-1}{2-n}\right)$ & LogK $_{2}$ \\
\hline 9.51 & 5.55 & 6.66 & 6.71 & 0.05 & 0.9650 & 1.67 & & \\
9.73 & 5.55 & 6.78 & 6.84 & 0.06 & 1.4042 & 1.47 & -0.1686 & 1.3014 \\
10.00 & 5.60 & 6.90 & 6.93 & 0.06 & 1.7838 & 1.23 & 0.5593 & 1.7893 \\
10.23 & 5.65 & 7.05 & 7.10 & 0.06 & 3.1429 & 1.10 & & \\
10.49 & 5.70 & 7.10 & 7.18 & 0.07 & 3.6492 & 0.83 & & \\
\hline
\end{tabular}

LogK $_{2}($ Average value $)=1.5453 \pm 0.3450$

Table 13: Point-wise method, Mg (Unhydrolysed PSHA)

\begin{tabular}{|l|l|l|l|l|l|l|l|l|}
\hline $\mathrm{pH}$ & $\mathrm{BV}_{1}$ & $\mathrm{BV}_{2}$ & $\mathrm{BV}_{3}$ & $\mathrm{~V}_{3}-\mathrm{V}_{2}$ & $\mathrm{n}$ & $\mathrm{pL}$ & $\log \left(\frac{n}{n-1}\right)$ & $\operatorname{Log~}_{1}$ \\
\hline 8.50 & 5.30 & 5.81 & 5.85 & 0.04 & 0.2973 & 2.88 & -0.3736 & 2.5064 \\
8.72 & 5.35 & 5.90 & 5.94 & 0.04 & 0.3099 & 2.66 & -0.3477 & 2.3123 \\
9.00 & 5.40 & 6.00 & 6.04 & 0.04 & 0.3236 & 2.38 & -0.3202 & 2.0598 \\
9.22 & 5.45 & 6.10 & 6.15 & 0.05 & 0.4297 & 2.17 & -0.1230 & 2.0470 \\
9.51 & 5.50 & 6.20 & 6.26 & 0.06 & 0.5500 & 1.89 & 0.0871 & 1.9771 \\
9.73 & 5.55 & 6.33 & 6.40 & 0.07 & 0.7000 & 1.67 & 0.3680 & 2.0380 \\
\hline
\end{tabular}

LogK $_{1}$ (Average value) $=2.1568 \pm 0.2069$

Table 14: Point-wise method, Mg (Unhydrolysed PSHA)

\begin{tabular}{|l|l|l|l|l|l|l|l|l|}
\hline $\mathrm{pH}$ & $\mathrm{BV}_{1}$ & $\mathrm{BV}_{2}$ & $\mathrm{BV}_{3}$ & $\mathrm{~V}_{3}-\mathrm{V}_{2}$ & $\mathrm{n}$ & $\mathrm{pL}$ & $\log \left(\frac{n-1}{2-n}\right)$ & $\log \mathrm{K}_{2}$ \\
\hline 10.00 & 5.60 & 6.47 & 6.55 & 0.08 & 0.9148 & 1.41 & & \\
10.23 & 5.65 & 6.62 & 6.71 & 0.09 & 1.2102 & 1.20 & -0.5749 & 0.6251 \\
10.49 & 5.70 & 6.80 & 6.92 & 0.09 & 1.5968 & 1.03 & 0.1703 & 1.2003 \\
\hline
\end{tabular}

LogK $_{2}$ (Average value) $=0.9127 \pm 0.4070$

Table15:Point-wise method, Cd (Hydrolysed PSHA)

\begin{tabular}{|l|l|l|l|l|l|l|l|l|}
\hline $\mathrm{pH}$ & $\mathrm{BV}_{1}$ & $\mathrm{BV}_{2}$ & $\mathrm{BV}_{3}$ & $\left(\mathrm{~V}_{3}-\mathrm{V}_{2}\right)$ & $\mathrm{n}$ & $\mathrm{pL}$ & $\log \left(\frac{n}{1-n}\right)$ & LogK $_{1}$ \\
\hline 8.50 & 5.30 & 6.29 & 6.31 & 0.02 & 0.2750 & 2.64 & -0.4210 & 2.2190 \\
8.72 & 5.35 & 6.37 & 6.40 & 0.03 & 0.4286 & 2.42 & -0.1249 & 2.2951 \\
9.00 & 5.40 & 6.46 & 6.49 & 0.03 & 0.4648 & 2.14 & -0.0612 & 2.0788 \\
9.22 & 5.45 & 6.55 & 6.59 & 0.04 & 0.6667 & 1.96 & 0.3010 & 2.2610 \\
9.51 & 5.55 & 6.66 & 6.70 & 0.04 & 0.7720 & 1.67 & 0.5297 & 2.1997 \\
\hline
\end{tabular}

LogK $_{\mathbf{1}}$ (Average value) $=2.2108 \pm 0.0825$

Table 16: Point-wise method, Cd (Hydrolysed PSHA)

\begin{tabular}{|l|l|l|l|l|l|l|l|l|}
\hline $\mathrm{pH}$ & $\mathrm{BV}_{1}$ & $\mathrm{BV}_{2}$ & $\mathrm{BV}_{3}$ & $\left(\mathrm{~V}_{3}-\mathrm{V}_{2}\right)$ & $\mathrm{n}$ & $\mathrm{pL}$ & $\log \left(\frac{n-1}{2-n}\right)$ & Log $_{2}$ \\
\hline 9.73 & 5.55 & 6.78 & 6.83 & 0.06 & 1.4042 & 1.47 & -0.1686 & 1.3014 \\
10.00 & 5.60 & 6.90 & 6.95 & 0.06 & 1.7838 & 1.23 & 0.5593 & 1.7893 \\
10.23 & 5.65 & 7.05 & 7.10 & 0.06 & 3.1429 & 1.09 & & \\
10.49 & 5.70 & 7.10 & 7.16 & 0.06 & 3.1429 & 0.89 & & \\
& & & & & & & & \\
\hline
\end{tabular}

$\operatorname{LogK}_{2}$ (Average value) $=1.5453 \pm 0.3450$

Table 17: Point-wise method, Cd (Unhydrolysed PSHA)

\begin{tabular}{|l|l|l|l|l|l|l|l|l|}
\hline $\mathrm{pH}$ & $\mathrm{BV}_{1}$ & $\mathrm{BV}_{2}$ & $\mathrm{BV}_{3}$ & $\mathrm{~V}_{3}-\mathrm{V}_{2}$ & $\mathrm{n}$ & $\mathrm{pL}$ & $\log \left(\frac{n}{n-1}\right)$ & $\operatorname{Log~}_{1}$ \\
\hline 8.50 & 5.30 & 5.81 & 5.86 & 0.05 & 0.3717 & 2.88 & -0.2280 & 2.6520 \\
8.72 & 5.35 & 5.90 & 5.95 & 0.05 & 0.3873 & 2.66 & -0.1992 & 2.4608 \\
9.00 & 5.40 & 6.00 & 6.06 & 0.06 & 0.4853 & 2.38 & -0.0255 & 2.3545 \\
9.22 & 5.45 & 6.10 & 6.16 & 0.06 & 0.5157 & 2.18 & -0.0272 & 2.2072 \\
9.51 & 5.50 & 6.20 & 6.27 & 0.07 & 0.6417 & 1.89 & 0.2530 & 1.1430 \\
9.73 & 5.55 & 6.33 & 6.41 & 0.08 & 0.8000 & 1.69 & 0.6020 & 2.2920 \\
& & & & & & & & \\
\hline
\end{tabular}

$\operatorname{LogK}_{1}($ Average value $)=2.2516 \pm 0.5380$ 
BAJOPAS Volume 14 Number 1,June, 2021

Table 18: Point-wise method, Cd (Unhydrolysed PSHA)

\begin{tabular}{|l|l|l|l|l|l|l|l|l|}
\hline $\mathrm{pH}$ & $\mathrm{BV}_{1}$ & $\mathrm{BV}_{2}$ & $\mathrm{BV}_{3}$ & $\mathrm{~V}_{3}-\mathrm{V}_{2}$ & $\mathrm{n}$ & $\mathrm{pL}$ & $\log \left(\frac{n-1}{2-n}\right)$ & $\log \mathrm{K}_{2}$ \\
\hline 10.00 & 5.60 & 6.47 & 6.57 & 0.10 & 1.1434 & 1.43 & & \\
10.23 & 5.65 & 6.62 & 6.72 & 0.10 & 1.3448 & 1.23 & -0.2788 & 0.9512 \\
10.49 & 5.70 & 6.80 & 6.90 & 0.10 & 1.7742 & 1.03 & 0.5351 & 1.5651 \\
\hline
\end{tabular}

$\operatorname{LogK}_{2}($ Average value $)=1.2581 \pm 0.4340$

Table 19: Stepwise and overall Stability constants of thehydrolysed and unhydrolysed divalent metal (II) complexes

\begin{tabular}{|c|c|c|c|}
\hline Chelates & LogK $_{1}$ & $\log _{2}$ & Log $\beta$ \\
\hline [Cu (Hydrolysed PSHA-1) $\left.{ }_{2}\right]$ & 2.4788 & 1.4280 & 3.9068 \\
\hline$\left[\mathrm{Pb}(\text { Hydrolysed PSHA-1) })_{2}\right]$ & 2.5832 & 1.1963 & 3.7795 \\
\hline$\left[\mathrm{Cd}(\text { Hydrolysed PSHA-1 })_{2}\right]$ & 2.2108 & 1.5453 & 3.7561 \\
\hline$\left[\mathrm{Mg}(\text { Hydrolysed PSHA-1 })_{2}\right]$ & 2.1382 & 1.5453 & 3.6835 \\
\hline [Cu (Unhydrolysed PSHA-1) & 2.3059 & 1.2209 & 3.5268 \\
\hline$[\mathrm{Pb}$ (Unhydrolysed PSHA-1) 2$]$ & 2.2364 & 1.2239 & 3.4603 \\
\hline [Cd (Unhydrolysed PSHA-1) 2 ] & 2.2516 & 1.2581 & 3.5097 \\
\hline$[\mathrm{Mg}$ (Unydrolysed PSHA-1) & 2.1568 & 0.9127 & 3.0695 \\
\hline
\end{tabular}

The results obtained (Table19) shows the stepwise and overall stability constants to be not high indicating low stability of the complexes, because the solubility of most metal ions in the basic $\mathrm{pH}$ range is minimal due to metal hydroxide precipitation (Karimi, 2017). In general, the stepwise stability constants $\left(K_{1}\right.$ and $K_{2}$ ) follow the order $K_{1}>K_{2}$ for the copper, lead, magnesium and cadmium complexes respectively. The steady decrease of the values with increasing number of ligands is in agreement with the prediction made by researchers (Na'aliya, 2013). The decrease could be attributed to the fact that as the number of the ligands (Humate ions) that enters the coordination zone increases the aqua molecules available for replacement by the ligands become less. Thus, the metal ions become less electron loving with progressive intake of the ligand and this results in the decrease in the values of the constants (Na'aliya, 2013). Also the stability of the complexes is influenced by the size and number of the chelate rings(Mackay and Mackay,2002).All the complexes form rings in their structure as humate, a bidentate ligand, bond the metal ions in the ratio 1:2 (Boguta and Sokolowska, 2016) forming chelate rings. The values of the overall stability constants $(\log \beta)$ obtained for humate complexes are not high indicating low stability as the values are not high. LogK values for copper-humates (Table 3 to 6) obtained in this study are lower than those reported for the complexes of humic acids (Pandey et al., 2015; Dinu, 2013; Kaschl et al., 2010 and Gilbeto and Jorg, 2001). The values of LogK(Table 7 to 10 ) forlead-humates are lower than those reported for the lead in the literature (Dinu, 2013; Gilbeto and Jorg 2001). Log K values(Table 11 to 14 ) for magnesium-humates obtained in this study are close to those reported by (Pandey et al., 2015). Log K values of cadmium-humates (Table 15 to 18 ) obtained in this work near to the one reported by (Dinu, 2013 and Pandey et al., 2015).The difference between the reported values and the values obtained in this study might be probably as a result of acid hydrolysis of humic acid. The values of the overall stability constants $(\log \beta)$ of the copper humates complexes presented in Table 19 is high than that of other metal humate complexes, show relatively high stability of CuHA complexes, show the following order of stability: $\mathrm{Cu}>\mathrm{Pb}>\mathrm{Cd}>\mathrm{Mg}$; which are in close agreement to the findings of (Dinu, 2013 and Pandey et al., 2015).The high stability of Cuhumate chelate could be attributed to the existence of coordinate covalent bond between the complexing agents and the $\mathrm{Cu}^{2+}$ ions. Since, $\mathrm{Cu}^{2+}$ being a metal of the transitional series with $3 d^{9}$ electronic configurations can accept the electrons from the complexing agents. Similarly, the low stabilities of $\mathrm{Pb}, \mathrm{Cd}$ and $\mathrm{Mg}$ complexes could be explained by that $\mathrm{Pb}^{2+}$ with $6 s^{2}, \mathrm{Cd}^{2+}$ with $4 \mathrm{~d}^{10}$ and $\mathrm{Mg}^{2+}$ with $2 \mathrm{p}^{6}$ their electronic configuration has a completely filled $\mathrm{d}, \mathrm{p}$ and $\mathrm{s}$ orbitals. Moreover, the stabilities of metal ions with hydrolysed humic acid from peat soil were higher than those with unhydrolysed humic acid from peat soil; which is ascribed to the high content of acidity in hydrolysed humic acid than unhydrolysed humic acid. 
BAJOPAS Volume 14 Number 1,June, 2021 CONCLUSION

The values of logk for $\mathrm{Cu}(\mathrm{II})$ hydrolysed humic acid complex was higher followed by $\mathrm{Pb}$ (II), $\mathrm{Cd}(\mathrm{II})$ and $\mathrm{Mg}$ (II) hydrolysed humic acid complexes as compared with metal(II) unhydrolysed humic acid complexes. This indicates acid hydrolysis of humic acid can

\section{REFERENCES}

Almeida, V.R. and Szpoganicz, B. (2015). Humic Acid Potentiometric Response Patterns:Out- of Equilibrium Properties and Species Distribution Modelling. Chemical. Biol. Technol. Agric. 2: 17.

Anđelković, T., Nikolić, R., Bojić, A.,Anđelković, D., and Nikolic G.,(2010). Binding of Cadmium to Soil Humic Acid as A Function of Carboxyl Group Content. Macedonian Journal of Chemistry and Chemical Engineering.29(2): 215-224.

Anil, B. N. and Maroti, N. (2008). Studies on Influence of Die-Lectric Constants on Complex Equilibria between Substituted Py-Razalines and Lanthanide Metal Ions pH-Metrically. Amer.-Euras. scient. Res. 3(2): 212-216.

Ashok, K., Pandey, S. P. and Misra, V (2000). Stability Constants of Metal-Humic Acid Complexes and its Role in Environmental Detoxification. Journal of Ecotoxicology and Environmental Safety. 47(2):157-200.

Badr, M. H., El-Halafawi, M. H. and Abd El-al Zeid, E. R. (2012). Comparison Between the Effect of Ionic Strength on Acidity and Dissociation Constants of Humic Acids Extracted from Sewage Sludge and Nile Water Hyacinth Composts.Global Journal of Environmental Research 6 (1): 36-43.

Baruah, M.K., Borah, D., Saikia, P.P., Paul, S., Sharma, T. (2015). Evaluation of pKa Values of Soil Humic Acids and their Complexation Properties. International Journal of Plant \& Soil Science 6(4) : 218-228.

Boguta, P. Sokolowska, Z. (2016). Interactions of $\mathrm{Zn}$ (II) Ions with Humic Acids Isolated from Various Types of Soils. Effect of $\mathrm{pH}, \mathrm{Zn}$ Concentrations and Humic Acids Chemical Properties. Journal of Geochemical Explaration 168. 119-126.

Borges, F., Guimaraes, C., Lima, L.F.C., Pinto, I. and Reis, S.(2005). Potentiometric Studies on the Complexation of Copper(II) by Phenolic Acids as Discrete Ligand Models of enhance the complexation behavior of humic acid with metal (II) ions. However, the higher values of $\log \beta$ for $\mathrm{Cu}(\mathrm{II}), \mathrm{Pb}(\mathrm{II}), \mathrm{Cd}(\mathrm{II})$ and $\mathrm{Mg}(\mathrm{II})$ hydrolysed humic acid complexes indicates more stable stepwise complexes formed as compared with $\mathrm{Cu}(\mathrm{II}), \mathrm{Pb}$ (II), $\mathrm{Cd}$ (II) and $\mathrm{Mg}(\mathrm{II})$ unhydrolysed humic acid complexes.

Humic Substances Talanta 66 (2005) 670-673.

Chefetz, B., Salloum, M. J., Deshmulkin, A. P. and Hatcher, P. (2002). Structural Components of Humic Acids as Determined by Chemical Modifications and Carbon-13 NMR, Pyrolysis, and Thermochemolysis- Gas Chromatography/Mass Spectrometry. Soil Science Society of American Journal Abstract Division S-2- Soil Chemistry66. 1159-1171.

Dinu, M. I. (2013). Metals Complexation with Humic Acids in Surface Water of Different Environ. Sci. Technol. 31(1): 1-17.

Fernandes, A.N., Giacomelli, C., Giovanela, M. Vaz, D.V. Szpoganicz, B. and Maria M. D. (2009). Potentiometric Acidity Determination in Humic Substances Influenced by Different Analytical Procedures.J. Braz. Chem. Soc. 20 (9):14.

Gamal, A. H. (2015). Stability Constants of Rhenium (V) Metal Complexes with Selected Drugs. Pyrex Journal of Research in Environmental Studies. 2(2): 006-014.

Janrao, D. M., Pathan, J., Kayande, D.D., and Mulla, J.J. (2014). An Over View of Potentiometric Determination of Stability Constants of Metal Complexes. Sci. Revs. Chem. Commun.: 4(1), 2014, 11-24.

Karimi, H. (2017). Effect of pH and Initial Pb(II) Concentration on the Lead Removal Efficiency from Waste Water Using $\mathrm{Ca}(\mathrm{OH})_{2}$. International Journal of Water and Waste Water Treatment 3.2

Kaschl, A. Romheld, V. and Chen, Y. (2010). Binding of Cadmium, Copper and Zinc to Humic Substances Originating from Municipal Solid Waste Compost. Israel Journal of Chemistry Vol. 42(1): 89-98.

Kostic, I. S., Tatjana, P, A., Nikolic, R. S., Cvetkovic, T. P., Pavlovic, D. D., Aleksandar, L.J. and Bojic, A. (2012). Comparative Study of Binding Strengths of Heavy Metals with Humic Acid. J.serb. Chem. Soc. 76(9) pp 1-20. 
BAJOPAS Volume 14 Number 1,June, 2021

Na'aliya, J. (2013). Determination of Stepwise Stability Constants and Gibbs free Energy Change of Trisprolina to Complexes of some Divalent Transition Metal ions. Bayero Journal of Pure and Applied Sciences 6(2): 112-114.

Omar, A. A. and Ali, E. A. (2015). Potentiometric Studies on Complexes of $\mathrm{Cr}$ (III) and $\mathrm{Zr}$ (IV) with some Carboxylic Acids. International Journal of Advanced Chemistry, 3(1) 25-

37.

Pandey, A. K. Pandey, S. D. and Misr, V. (2015).Stability Constants of Metal- Humic Acid Complexes and Its Role in Environmental Detoxification. J. Ecotoxicology and Environmental Safety. 47(1):195-200.

Ram, N. and Raman, K.V. (1984). Stability Constants of Complexes of Metals with
Humicand Fuvic Acids under Non- acidConditions. Journal of Plant Nutrition and Soil Sciences.

147:171-176.

Santosh, D. D., Ashok, B. K., Vijay, J. T., Shivraj, G. W. and Vinay, V. W. (2011). Potentiometric Studies of Elec-Trolyte Effects on Complex Equilibria of Some Substituted 5-(2-hydroxy Phenyl) Pyrazoles. Der pharm. 3 (6): 75-83.

Sayyed, H. and Abdul Rahim, M. F. (2012). Studies of Binary Complexes of Metal Ions with Mandelic Acid by Potentiometry. Chem. J. 02 (6): 206209.

Shirvani, M. Moradian, E. Khalili, B. Bakhtiary, S. (2015). Interaction of $\mathrm{Cd}$ and $\mathrm{Pb}$ with Humate-Palygorskite and HumateSepiolite Complexes. Journal of water, air and pollution 3: 220-228. 


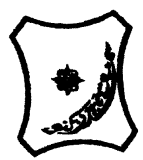

Bayero Journal of Pure and Applied Sciences, 14(1): 54 - 63

Received: November, 2020

Accepted: April, 2021

ISSN $2006-6996$

\title{
STABILITY CONSTANTS OF COMPLEXES OF METAL IONS WITH PEATSOIL HUMIC ACIDS UNDER NON-ACID-CONDITIONS
}

\author{
${ }^{* 1}$ Sabo, Yusuf ${ }^{2}$ Jimoh, W.L.O., ${ }^{3}$ Isa Baba Koki and ${ }^{4}$ Sholadoye, Q. 0. \\ ${ }^{1}$ Department of Pure and Industrial Chemistry, Bayero University, Kano \\ ${ }^{3}$ Department of Chemistry, Yusuf Maitama Sule University Kano. P.M.B. 3220 Kano, Nigeria. \\ ${ }^{4}$ Department of Chemistry, Nigerian Police Academy, Wudil, Kano-Nigeria
}

*Correspondence E-mail; saboyusuf18@yahoo.com

ABSTRACT

Stability constants of complexes of four divalent metal ions viz. $\mathrm{Cu}^{2+}, \mathrm{Pb}^{2+}, \mathrm{Mg}^{2+}$ and $\mathrm{Cd}^{2+}$ with humic acids (HA) were determined by potentiometric titration of humic acids with the corresponding salt of the divalent metals in aqueous media under non-acid-condition. The log $K$ (logarithm of the stability constant) ranged from 1.0942 to 2.7471 for metalhumic acid complexes were determined using point-wise computational method. The order of stability constants were obtained as follows: $\mathrm{Cu}>\mathrm{Pb}>\mathrm{Cd}>\mathrm{Mg}$ for metal $-\mathrm{HA}$ complexes respectively, indicating a higher degree of complexation with Cu metal ion.

Keywords: stability constant, humic acid, potentiometric titration, divalent metals, acid hydrolysis.

\section{NTRODUCTION}

The stability constant of a complex is the numerical expression of its stability and provides a quantitative measure of affinity of the metal ion to the complexing agent. An understanding of the relative stability of metal-complexes helps in predicting the behavior of metal ions in the soil (Ram and Raman, 1982). Extensive researches has been done to determine the stability constants of the complexes formed between humic acid (HA) with a number of metal ions. Ashok et al., (2000) reported that humic acid with hydroxyl, phenoxyl and carboxyl reactive groups can form coordination compound with metal ions at $\mathrm{pH}$ 3.5. The stability constants(Log K) for different metalhumic acid complexes indicated the following order of the stabilities of complexes formed between humic acid and metal ion, $\mathrm{Cu}>\mathrm{Fe}$ $>\mathrm{Pb}>\mathrm{Ni}>\mathrm{Co}>\mathrm{Ca}>\mathrm{Cd}>\mathrm{Zn}>\mathrm{Mn}>\mathrm{Mg}$. Andelkovic et al., (2010) investigated the binding of $\mathrm{Cd}$ (II) to soil humic acid at pH 6.5 and in $0.1 \mathrm{M} \mathrm{KNO}_{3}$ ionic medium. The stability constant for binding indicating greater stability in the case when carboxyl groups are involved in complexation reaction. Kostic et al.,(2012) investigated the complexation of humic acid with certain heavy metal ions (Co(II), $\mathrm{Ni}(\mathrm{II}), \mathrm{Cu}(\mathrm{II})$,
$\mathrm{Zn}(\mathrm{II})$, and $\mathrm{Pb}(\mathrm{II})$. The experiment was performed at $25^{\circ} \mathrm{C}$, at pH 4.0 and ionic strength of $0.01 \mathrm{M}$. Stability constant of complex between $\mathrm{Pb}$ (II) ions and humic acid is greater than stability constants of other investigated metalhumate complexes. Bogata and Sokolowska (2016) analyses the interaction between humic acids from different soils and $\mathrm{Zn}$ (II) ions at wide concentration ranges and at $\mathrm{pH} 5$. Studies have showed significant impact of $\mathrm{Zn}$ concentration, $\mathrm{pH}$ and some properties of humic acids with zinc.But all of these studies were limited to acidic $\mathrm{pH}$ range. Therefore, the present study was carried out to determine and compare the stability constants of complexes of metal ions with hydrolysed peat soil humic acid and unhydrolysed peat soil humic under non-acid conditions.

\section{MATERIALS AND METHODS}

Analytical grade chemicals used includes hydrochloric acid $(\mathrm{HCl})$, nitric acid $\left(\mathrm{HNO}_{3}\right)$, sodium hydroxide $(\mathrm{NaOH})$, lead nitrate $\mathrm{Pb}\left(\mathrm{NO}_{3}\right)_{2}$, copper nitrate $\mathrm{Cu}\left(\mathrm{NO}_{3}\right)_{2} \cdot 3 \mathrm{H}_{2} \mathrm{O}$, cadmium nitrate $\mathrm{Cd}\left(\mathrm{NO}_{3}\right)_{2} \cdot 4 \mathrm{H}_{2} \mathrm{O}$, magnesium nitrate $\mathrm{Mg}\left(\mathrm{NO}_{3}\right)_{2} \cdot 6 \mathrm{H}_{2} \mathrm{O}$, potassium nitrate $\left(\mathrm{KNO}_{3}\right)$, calcium chloride $\left(\mathrm{CaCl}_{2}\right)$, (sigma-Aldrich). Dowex 50WX8, (20-50 mesh) from Fluka. 


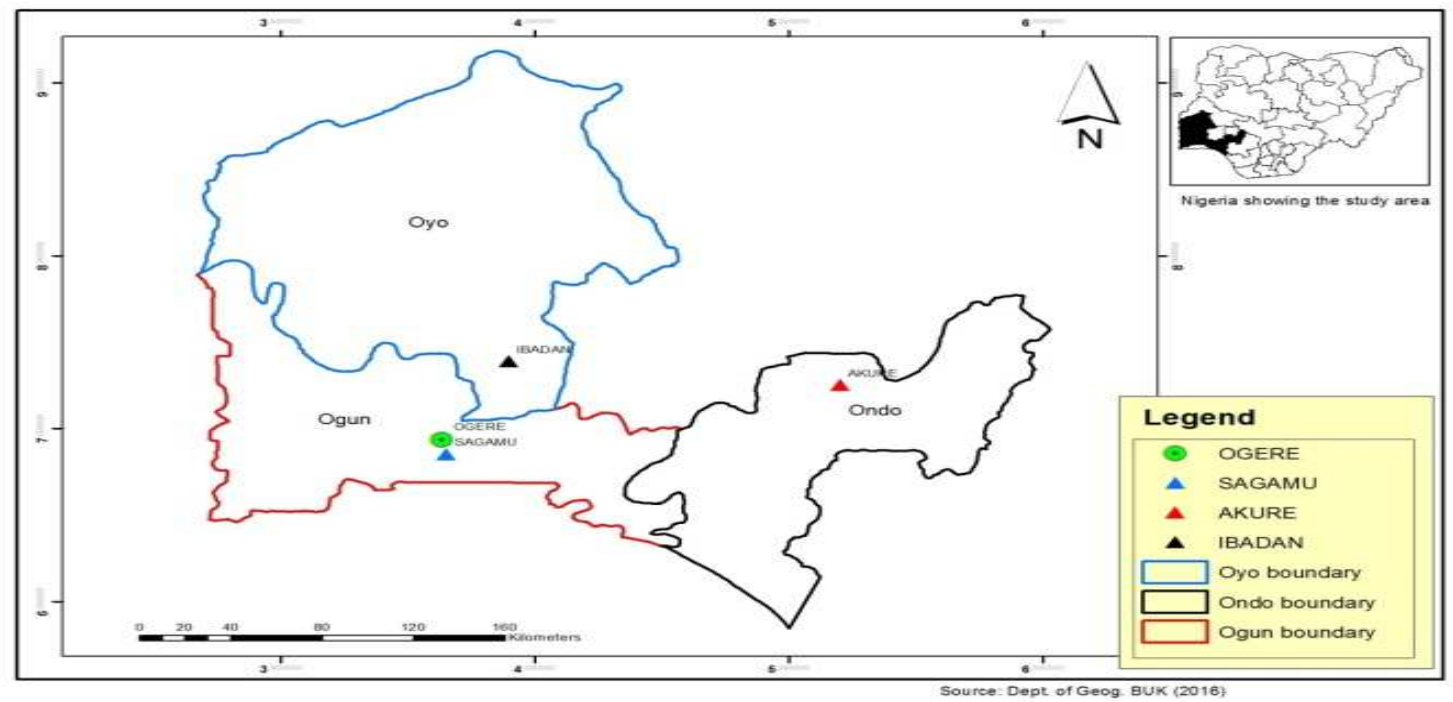

Figure 1: Map showing the sampling point at Sagamu Town, Ogun State.

\section{Description of Sampling Area}

Sagamu has geographical coordinates between $6^{\circ} 50^{\prime}$ north; $3^{\circ} 38^{\prime}$ east is located in south western region of Nigeria. The region has tropical wet and dry climate with a lengthy wet season and relatively constant temperatures throughout the course of the year. Wet season runs from March to October, November to December forms the region dry season. The vegetation type of the region is savannah which is really grassland with small bushes and occasional big trees. Grassland soils have substantially higher organic matter content than forest soils (Novackova, 2011).

\section{Sample Collection}

The Peatsoil samples were collected from four different sampling points $(0-10 \mathrm{~cm}$ depth) in Sagamu into polyethylene bag with plastic spoons. Samples were taken to the laboratory, extraneous materials were removed; the samples were air-dried, crushed and ground to a fine powder in a mortar passed through a $0.20 \mathrm{~mm}$ sieve. The samples were kept for analysis.

\section{Isolation and purification of humic acid from peat soil sample}

Peatsoil sample $(100 \mathrm{~g})$ was mixed with 1000 $\mathrm{cm}^{3}$ of $0.1 \mathrm{M} \mathrm{NaOH}$ solution, shaken for 3hours and left to stand overnight. Dark-coloured supernatant was obtained and decanted from solid residue. The dark-coloured supernatant was acidified to $(\mathrm{pH}=1.0)$ with $6 \mathrm{M} \mathrm{HCl}$ stirred and allowed to stand for 6 hours. Yellowish brown supernatant and dark-brown precipitate were obtained. The yellowish brown supernatant was decanted followed by centrifuge and discarded. The dark-brown precipitate was mixed with $500 \mathrm{~cm}^{3}$ of $0.1 \mathrm{M} \mathrm{NaOH}$ solution followed by passing through dowex resin. The dark-brown solution was acidified to $(\mathrm{pH}=1.0)$ with $6 \mathrm{M} \mathrm{HCl}$ stirred and allowed to stand for 3 hours. The dark-brown precipitate was washed several times with deionized water. The supernatant was treated with $\mathrm{AgNO}_{3}$ solution until no white precipitate observed. The humic acid was transferred to weighed crucible and dried at $60^{\circ} \mathrm{C}$ in an oven for 12 hours. The humic acid was cooled and dried in the desiccator, weighed and recorded. The obtained humic acid was dried again at $60^{\circ} \mathrm{C}$ for additional 6 hours cooled and dried in the desiccator, weighed and recorded constant weight was obtained (Baruah et al., 2015).

\section{FT-IR analysis}

FT-IR spectra of humic acid sample was analysed using Carry 630 FT-IR Agilent Technologies.

Unhydrolysed compost humic acid

The unhydrolysed humic acid was obtained after isolation and purification of compost humic acid and kept for investigation.

\section{Acid hydrolysis of Peatsoil acid}

Peatsoil humic acid sample (1g) was refluxed for 12 hours at $\left(160^{\circ} \mathrm{C}\right)$ with $50 \mathrm{~cm}^{3}$ of $6 \mathrm{M} \mathrm{HCl}$. The mixture was allowed to cool, decanted, and centrifuged after hydrolysis. The insoluble residues were washed with distilled water via centrifugation several times, and the supernatant was treated with $\mathrm{AgNO}_{3}$ solution until no white precipitate was observed. The residue was thoroughly dried over $\mathrm{CaCl}_{2}$ in a desiccator at room temperature (Chefetz et al., 2002). Finally, the obtained hydrolysed humic acid was kept for investigation. 
BAJOPAS Volume 14 Number 1,June, 2021 Potentiometric Titrations

Potentiometric measurements were carried out using a pH-meter Jenway (model 3510) with combine electrode, the sensitivity of the $\mathrm{pH}$ meter is 0.01 units. The $\mathrm{pH}$ meter was switched on half an hour before starting the titration for initial warm up of the instrument. The instrument was calibrated with an aqueous standard buffer solution of $\mathrm{pH} 4.00$ and 10.0 (borate buffer) prepared from a "Qualigens" buffer tablets.

The following sets of solutions were prepared in a $250 \mathrm{~cm}^{3}$ volumetric flask separately for $\mathrm{pH}$ metric titrations.

(i) $5 \mathrm{~cm}^{3} 0.1 \mathrm{M} \mathrm{HCl}+40 \mathrm{~cm}^{3}$ deionized water

(ii) $5 \mathrm{~cm}^{3} 0.1 \mathrm{M} \mathrm{HCl}+39 \mathrm{~cm}^{3}$ deionized water $+1 \mathrm{~cm}^{3} 0.15 \mathrm{gcm}^{-3}$ humic acid

(iii) $5 \mathrm{~cm}^{3} 0.1 \mathrm{M} \mathrm{HCl}+37 \mathrm{~cm}^{3}$ deionized water $+1 \mathrm{~cm}^{3} 0.15 \mathrm{gcm}^{-3}$ humic acid

$$
+2 \mathrm{~cm}^{3} \quad 0.01 \mathrm{M} \mathrm{Cu} \text { (II) }
$$

The solutions were titrated against standardized $0.110 \mathrm{MNaOH}$ separately. The total volume of each mixture was adjusted to $50 \mathrm{~cm}^{3}$ and the ionic strength of the solutions was maintained constant at by adding appropriate amount of stock solution of $1 \mathrm{M} \mathrm{KNO}_{3}$ (Gamal, 2015; Omar and Ali, 2015). A magnetic stirrer was used to achieve thorough mixing of the interacting solutions at $550 \mathrm{rpm}$. The same set of experimental conditions was applied for potentiometric titration of remaining samples.

\section{Evaluation of pKa of Hydrolysed peat soil Humic Acids}

The proton-ligand formation number $\mathrm{n}_{\mathbf{A}}$ were calculated by Irving and Rossotti expression (Omar and Ali, 2015).

$\mathrm{nA}=\mathrm{Y}-\frac{(\mathrm{V} 2-\mathrm{V1})(\mathrm{No}-\mathrm{Eo})}{(\mathrm{VO}+\mathrm{V1}) \mathrm{TCL}}$ 1

Where: $Y$ is number of dissociable proton, $\left(\mathrm{V}_{2^{-}}\right.$ $V_{1}$ ) is the measure of displacement of the ligand curve relative to acid curve, $\mathrm{N}^{\circ}$ and $\mathrm{E}^{\circ}$ are the resultant concentration of alkali solution, free acid solution, $\mathrm{T}_{\mathrm{cL}}{ }^{\circ}$ is the total ligand concentration, $\mathrm{V}^{\circ}$ is the total volume of titration solution, $V_{1}$ is the volume of alkali added to acid solution, $V_{2}$ is the volume of alkali added to acid solution + ligand solution, acid dissociation constants (pKa - values) of ligand were calculated by algebraic method point wise calculation (Tables 1 ). The dissociation constants (pKa) were calculated according to the following relation:

$\mathrm{pKa}=\mathrm{pH}+\log \left(\frac{n A}{1-n A}\right)$ 2

Where: pKa is the acid dissociation constant, $\mathrm{n}_{\mathrm{A}}$ is the Proton-ligand formation number and $\mathrm{pH}$ is the pH-values (Omar and Ali, 2015).

\section{Determination of metal-ligand stability constants $(\log K)$ of complexes}

The potentiometric measurement for the determination of stability constant of a complex in solution is based on the fact that the redox potential of the couple $\frac{M^{+(m-n)}}{M^{+m}}$ is shifted significantly on complexation of the metal ion with the ligand. This method involves change in hydrogen ion concentration $\left[\mathrm{H}^{+}\right]$due to the displacement or association of one or more protons taking place during complexation reaction. This change can be found out by titrating the solutions containing free acid, acid with ligand, and acid with ligand and metal ion, individually against a standard alkali solution at a constant ionic strength or temperature. Either ionic strength or temperature may be varied for different sets of solutions. In all the cases, the change in the $\mathrm{pH}$ of the solution is measured after each addition of a known amount of alkali to the reaction cell which contains the reaction mixture. The titration curves are then drawn by plotting the measured $\mathrm{pH}$ values against the corresponding volume of alkali added and the stability constants of the complexes are determined from the titration curves by employing $\mathrm{pH}$-metric titration technique given by (Irving and Rossoti).

Metal-ligand stability constants ( $\log \mathrm{K}$ ) were determined by using the following relations:

$$
\bar{n}=\frac{\left(V_{3}-V_{2}\right)\left(E^{0}+N^{0}\right)}{\left(V^{0}+V_{2}\right) \bar{n}_{A} T_{m}^{0}}
$$

and

$$
P L=\log _{10}\left\{\frac{1+\beta_{n}^{H} \frac{1}{[\text { anti } \log \mathrm{pH}]^{\mathrm{n}}}}{\mathrm{T}_{\mathrm{L}}^{0}-n \bar{T}_{m}^{0}} \mathrm{X} \frac{\left(V^{0}+V_{3}\right)}{V^{0}}\right\}
$$


BAJOPAS Volume 14 Number 1,June, 2021

Where $T_{L}, T^{\circ}, E^{\circ}$, and $V^{\circ}$ havethe same significance as in equation (1) above, $T_{m}$ denotes the total concentration of metal present in solution, $V_{3}$ is the volume of metal ions present in solution and $\beta^{H}$ is the overall proton ligand stability constant. The metal-ligand stability constants (log K) were determined by employing point wise computational Method (eq. 5 and 6).

$\operatorname{LogK}_{1}=\log \left(\frac{n}{1-n}\right)+\mathrm{pL}$ .5

$\operatorname{LogK}_{2}=\log \left(\frac{1-n}{2-n}\right)+\mathrm{pL}$ ...6

Where: Log $\mathrm{K}$ is the metal-ligand stability constant, $\mathrm{pL}$ is the Free ligand exponent function, $\mathbf{n}$ is the Average number of ligand attached with metal ion (Janraoet al., 2014). The results obtained were analyzed by an ORIGIN 2016 program using titration data and then the proton-ligand stability constants (pKa) and Metal-ligand stability constant (LogK) calculated (Omar and Ali, 2015).

\section{RESULTS AND DISCUSSION}

Fourier transformed infrared (FT-IR) spectra of isolated humic acid from peat soils Figure 2 had distinct clear absorption bands indicating the presence of major humic acid structural elemental groups such as $\mathrm{H}$ bonded $\mathrm{OH}$ $\left(3680 \mathrm{~cm}^{-1}\right.$ peak $), C=0$ of carbonyl $\left(1721 \mathrm{~cm}^{-1}\right.$ peak), functional groups of aliphatic components $\mathrm{CH}_{2}\left(2918 \mathrm{~cm}^{-1}\right.$ peak) and $\mathrm{C}-\mathrm{O}$ stretching of polysaccharide $\left(1168 \mathrm{~cm}^{-1}\right.$ peak). The positions of the absorption bands of the spectra fell within typical major absorption bands of humic acid which is at frequencies 3680, 2918, 1721, 1168 $\mathrm{cm}^{-1}$. The first peak centred in the vicinity of $3680 \mathrm{~cm}^{-1}$ region is attributed to phenol $\mathrm{OH}$ group bounded by intermolecular $\mathrm{H}$ bonds. The $2918 \mathrm{~cm}^{-1}$ band usually has absorption maximum at $2918 \mathrm{~cm}^{-1}$ which is due to $\mathrm{C}-\mathrm{H}$ stretching of alkane group $\left(\mathrm{CH}_{2}\right)$. The next major absorption band is $1721 \mathrm{~cm}^{-1}$. This band has been commonly ascribed to $\mathrm{C}=\mathrm{O}$ stretching of mainly carboxyl group $(\mathrm{COOH})$ with trace amount of ketones. The last peak was observed at 1168 $\mathrm{cm}^{-1}$ due to $\mathrm{C}-\mathrm{O}$ stretching of polysaccharides and this peak appeared also in the spectra of humic acid from peat soil. The FTIR spectra of the isolated humic acid contained all major characteristic absorption peaks of humic acid. These absorption peaks indicated the presence of the major structural elements of humic acid namely $\mathrm{H}$ bonded $\mathrm{OH}, \mathrm{C}=\mathrm{C}$ of aromatic ring, $\mathrm{C}=\mathrm{O}$ of carbonyl group (both carboxyl and ketonic), $\mathrm{CH}_{2}$ group. This strongly supports the presence of humic acid.

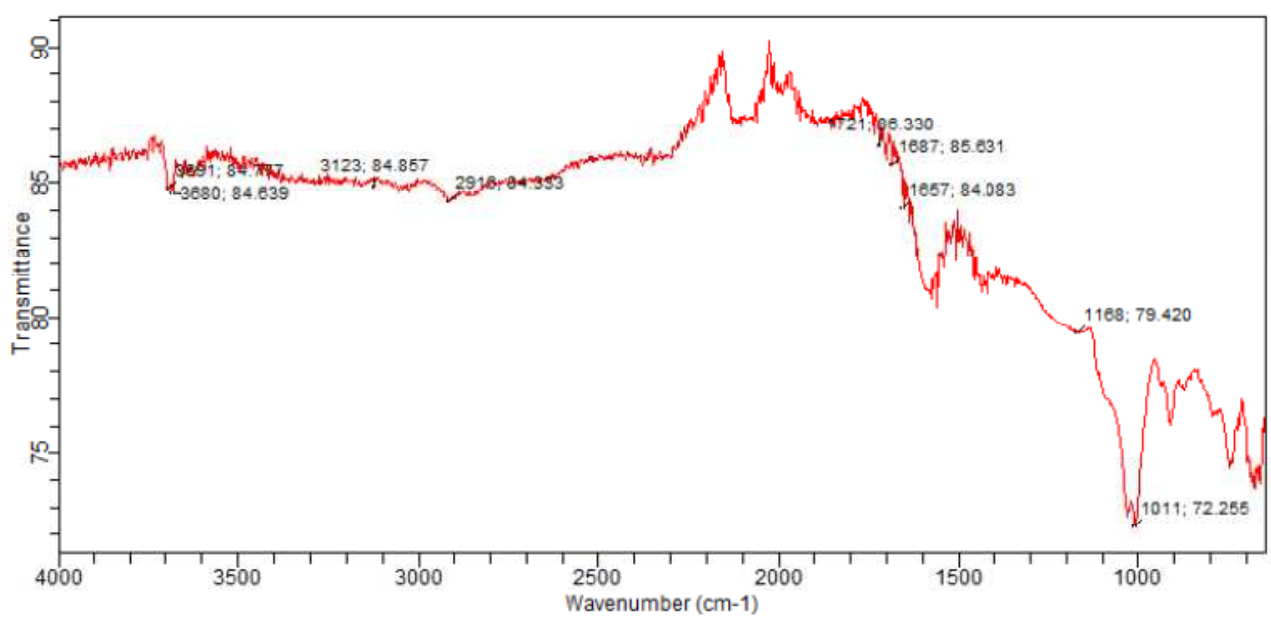

Fig. 2 : FT-IR spectraof peatsoilhumic acid (PSHA)

\section{Evaluation of acid dissociation constant (pka) of acid hydrolysed peat soil humicacid at phenolic group}

The value of the dissociation constant of the peat soil humic acid (PSHA) that underwent acidhydrolysis studied was found to be 8.9299 as shown Table 1, which is lower than the literaturevalues reported by Almeida and Szpoganics, (2015), Borges et al., (2005); Badr et al., (2012)and Fernandes et al,.(2009) of $9.73,9.47$ and 10.30. The difference between the obtained valuesand the reported values in this study might be probably as a result of acid hydrolysis of humicacid. 
BAJOPAS Volume 14 Number 1,June, 2021

Table 1: PKa of (Hydrolysed PSHA)

\begin{tabular}{|l|l|l|l|l|l|l|}
\hline $\mathrm{pH}$ & $\mathrm{BV}_{1}$ & $\mathrm{BV}_{2}$ & $\mathrm{~V}_{2}-\mathrm{V}_{1}$ & $\mathrm{nA}$ & $\log \left(\frac{n A}{1-n A}\right)$ & $\mathrm{pKa}$ \\
\hline 8.50 & 5.30 & 6.29 & 0.99 & 0.3594 & -0.2510 & 8.2490 \\
8.72 & 5.35 & 6.37 & 1.02 & 0.3400 & -0.2880 & 8.4320 \\
9.00 & 5.40 & 6.46 & 1.06 & 0.3141 & -0.3391 & 8.6609 \\
9.22 & 5.45 & 6.55 & 1.10 & 0.2882 & -0.3927 & 8.8273 \\
9.51 & 5.50 & 6.66 & 1.16 & 0.2494 & -0.4786 & 9.0314 \\
9.73 & 5.55 & 6.78 & 1.23 & 0.2041 & -0.5910 & 9.1390 \\
10.00 & 5.60 & 6.90 & 1.30 & 0.1589 & -0.7238 & 9.2762 \\
10.23 & 5.65 & 7.05 & 1.40 & 0.0941 & -0.9835 & 9.2465 \\
10.49 & 5.70 & 7.10 & 1.40 & 0.0941 & -0.9835 & 9.5065 \\
\hline
\end{tabular}

Average pKa $=8.9299 \pm 0.4186$

Table 2: PKa of (Unhydrolysed PSHA)

\begin{tabular}{|l|l|l|l|l|l|l|}
\hline $\mathrm{pH}$ & $\mathrm{BV}_{1}$ & $\mathrm{BV}_{2}$ & $\mathrm{~V}_{2}-\mathrm{V}_{1}$ & $\mathrm{nA}$ & $\log \left(\frac{\boldsymbol{n A}}{1-\boldsymbol{n}}\right)$ & $\mathrm{pKa}$ \\
\hline 8.50 & 5.30 & 5.81 & 0.51 & 0.6619 & 0.2919 & 8.7919 \\
8.72 & 5.35 & 5.90 & 0.55 & 0.6357 & 0.2418 & 8.9618 \\
9.00 & 5.40 & 6.00 & 0.60 & 0.6029 & 0.1813 & 9.1813 \\
9.22 & 5.45 & 6.10 & 0.65 & 0.5701 & 0.1226 & 9.3426 \\
9.51 & 5.50 & 6.20 & 0.70 & 0.5376 & 0.0654 & 9.5754 \\
9.73 & 5.55 & 6.33 & 0.78 & 0.4851 & -0.0259 & 9.7041 \\
10.00 & 5.60 & 6.47 & 0.87 & 0.4262 & -0.1291 & 9.8709 \\
10.23 & 5.65 & 6.62 & 0.99 & 0.3609 & -0.2481 & 9.9819 \\
10.49 & 5.70 & 6.80 & 1.10 & 0.2759 & -0.4690 & 10.0210 \\
\hline
\end{tabular}

Average pKa $=9.4923 \pm 0.4410$

Metal-ligand stability constant ( $\log \mathrm{K}$ )

The stabilityconstants require the accurate values of proton-ligand stability constants (Anil and Maroti, 2008). Metal titration curves crossed over ligand titration curve indicated the formation of complex upon proton release (Santosh, et al., 2011). If the values of n- are within range $0.2-0.8$ and $1.2-18$ this indicates the formation of $1: 1$ and 1:2 complexes (Sayyed and Mazahar, 2012).

The metal (II)-humate stepwise stability constants (log k) at phenolic group (Tables 318)

Table 3: Point-wise method, $\mathrm{Cu}$-(Hydrolysed PSHA)

\begin{tabular}{|l|l|l|l|l|l|l|l|l|}
\hline $\mathrm{pH}$ & $\mathrm{BV}_{1}$ & $\mathrm{BV}_{2}$ & $\mathrm{BV}_{3}$ & $\left(\mathrm{~V}_{3}-\mathrm{V}_{2}\right)$ & $\mathrm{n}$ & $\mathrm{pL}$ & $\log \left(\frac{n}{1-n}\right)$ & LogK $_{1}$ \\
\hline 8.50 & 5.30 & 6.29 & 6.33 & 0.04 & 0.5500 & 2.66 & 0.0871 & 2.7471 \\
8.72 & 5.35 & 6.37 & 6.41 & 0.04 & 0.5714 & 2.43 & 0.1249 & 2.5549 \\
9.00 & 5.40 & 6.46 & 6.50 & 0.04 & 0.6198 & 2.16 & 0.2122 & 2.3722 \\
9.22 & 5.45 & 6.55 & 6.59 & 0.04 & 0.6667 & 1.94 & 0.3010 & 2.2410 \\
\hline
\end{tabular}

LogK $_{1}$ (Average value) $=2.4788 \pm 0.2203$

Table 4: Point-wise method, $\mathrm{Cu}$-(Hydrolysed PSHA)

\begin{tabular}{|l|l|l|l|l|l|l|l|l|}
\hline $\mathrm{pH}$ & $\mathrm{BV}_{1}$ & $\mathrm{BV}_{2}$ & $\mathrm{BV}_{3}$ & $\left(\mathrm{~V}_{3}-\mathrm{V}_{2}\right)$ & $\mathrm{n}$ & $\mathrm{pL}$ & $\log \left(\frac{n-1}{2-n}\right)$ & LogK $_{2}$ \\
\hline 9.51 & 5.50 & 6.66 & 6.73 & 0.07 & 1.3509 & 1.70 & -0.2671 & 1.4329 \\
9.73 & 5.55 & 6.78 & 6.85 & 0.07 & 1.6383 & 1.51 & 0.2467 & 1.7567 \\
10.00 & 5.60 & 6.90 & 6.98 & 0.08 & 2.1783 & 1.31 & -0.2158 & 1.0942 \\
10.23 & 5.65 & 7.05 & 7.13 & 0.08 & 4.1904 & 1.27 & & \\
10.49 & 5.70 & 7.10 & 7.19 & 0.09 & 4.6920 & & & \\
\hline
\end{tabular}

Log $K_{2}($ Average value $)=1.4280 \pm 0.3312$ 
BAJOPAS Volume 14 Number 1,June, 2021

Table 5: Point-wise method, $\mathrm{Cu}$ (Unhydrolysed PSHA)

\begin{tabular}{|l|l|l|l|l|l|l|l|l|}
\hline $\mathrm{pH}$ & $\mathrm{BV}_{1}$ & $\mathrm{BV}_{2}$ & $\mathrm{BV}_{3}$ & $\left(\mathrm{~V}_{3}-\mathrm{V}_{2}\right)$ & $\mathrm{n}$ & $\mathrm{pL}$ & $\log \left(\frac{n}{n-1}\right)$ & Log $_{1}$ \\
\hline 8.50 & 5.30 & 5.81 & 5.85 & 0.04 & 0.2973 & 2.88 & -0.3736 & 2.5064 \\
8.72 & 5.35 & 5.90 & 5.95 & 0.05 & 0.3873 & 2.66 & -0.1992 & 2.4608 \\
9.00 & 5.40 & 6.00 & 6.05 & 0.05 & 0.4044 & 2.38 & -0.1681 & 2.2119 \\
9.22 & 5.45 & 6.10 & 6.15 & 0.06 & 0.5157 & 2.18 & -0.0272 & 2.2072 \\
9.51 & 5.50 & 6.20 & 6.27 & 0.07 & 0.6417 & 1.89 & 0.2530 & 1.1430 \\
\hline
\end{tabular}

$\operatorname{LogK}_{1}($ Average value $)=2.3059 \pm 0.6153$

Table 6:Point-wise method, $\mathrm{Cu}$ (Unhydrolysed PSHA)

\begin{tabular}{|l|l|l|l|l|l|l|l|l|}
\hline $\mathrm{pH}$ & $\mathrm{BV}_{1}$ & $\mathrm{BV}_{2}$ & $\mathrm{BV}_{3}$ & $\mathrm{~V}_{3}-\mathrm{V}_{2}$ & $\mathrm{n}$ & $\mathrm{pL}$ & $\log \left(\frac{n-1}{2-n}\right)$ & $\log \mathrm{K}_{2}$ \\
\hline 9.73 & 5.55 & 6.33 & 6.42 & 0.09 & 0.9000 & 1.69 & & \\
10.00 & 5.60 & 6.47 & 6.58 & 0.11 & 1.2578 & 1.44 & -0.4592 & 0.9808 \\
10.23 & 5.65 & 6.62 & 6.84 & 0.12 & 1.6137 & 1.26 & -0.2010 & 1.4610 \\
10.49 & 5.70 & 6.80 & 6.92 & 0.12 & 2.1052 & 1.03 & & \\
\hline
\end{tabular}

$\operatorname{LogK}_{2}$ (Average value) $=1.2209 \pm 0.3398$

Table 7:Point-wise method, Pb (Hydrolysed PSHA)

\begin{tabular}{|l|l|l|l|l|l|l|l|l|}
\hline $\mathrm{pH}$ & $\mathrm{BV}_{1}$ & $\mathrm{BV}_{2}$ & $\mathrm{BV}_{3}$ & $\left(\mathrm{~V}_{3}-\mathrm{V}_{2}\right)$ & $\mathrm{n}$ & $\mathrm{pL}$ & $\log \left(\frac{n}{1-n}\right)$ & LogK $_{1}$ \\
\hline 8.50 & 5.30 & 6.29 & 6.33 & 0.04 & 0.5500 & 2.66 & 0.0871 & 2.7471 \\
8.72 & 5.35 & 6.37 & 6.41 & 0.04 & 0.5714 & 2.43 & 0.1249 & 2.5549 \\
9.00 & 5.40 & 6.46 & 6.50 & 0.04 & 0.6198 & 2.16 & 0.2122 & 2.3722 \\
9.22 & 5.45 & 6.55 & 6.60 & 0.05 & 0.8333 & 1.96 & 0.6989 & 2.6589 \\
\hline
\end{tabular}

Log $_{\mathbf{1}}($ Average value $)=2.5832 \pm 0.1614$

Table 8:Point-wise method, Pb-(Hydrolysed PSHA)

\begin{tabular}{|l|l|l|l|l|l|l|l|l|}
\hline $\mathrm{pH}$ & $\mathrm{BV}_{1}$ & $\mathrm{BV}_{2}$ & $\mathrm{BV}_{3}$ & $\left(\mathrm{~V}_{3}-\mathrm{V}_{2}\right)$ & $\mathrm{n}$ & $\mathrm{pL}$ & $\log \left(\frac{n-1}{2-n}\right)$ & $\log \mathrm{K}_{2}$ \\
\hline 9.51 & 5.50 & 6.66 & 6.71 & 0.05 & 0.9650 & 1.67 & & \\
9.73 & 5.55 & 6.78 & 6.83 & 0.05 & 1.1702 & 1.44 & & \\
10.00 & 5.60 & 6.90 & 6.90 & 0.05 & 1.4864 & 1.22 & -0.0237 & 1.1963 \\
10.23 & 5.65 & 7.05 & 7.10 & 0.05 & 2.0190 & 1.09 & & \\
10.49 & 5.70 & 7.10 & 7.17 & 0.07 & 3.6492 & 1.00 & & \\
\hline
\end{tabular}

Log $K_{2}$ (Average value) $=1.1963$

Table 9: Point-wise method, Pb (Unhydrolysed PSHA)

\begin{tabular}{|l|l|l|l|l|l|l|l|l|}
\hline $\mathrm{pH}$ & $\mathrm{BV}_{1}$ & $\mathrm{BV}_{2}$ & $\mathrm{BV}_{3}$ & $\mathrm{~V}_{3}-\mathrm{V}_{2}$ & $\mathrm{n}$ & $\mathrm{pL}$ & $\begin{array}{l}\text { Log } \\
\left(\frac{n}{n-1}\right)\end{array}$ & Log $\mathrm{K}_{1}$ \\
\hline 8.50 & 5.30 & 5.81 & 5.85 & 0.04 & 0.2973 & 2.88 & -0.3736 & 2.5064 \\
8.72 & 5.35 & 5.90 & 5.94 & 0.04 & 0.3099 & 2.66 & -0.5477 & 2.3123 \\
9.00 & 5.40 & 6.00 & 6.05 & 0.05 & 0.4044 & 2.38 & -0.1681 & 2.2119 \\
9.22 & 5.45 & 6.10 & 6.15 & 0.06 & 0.5157 & 2.18 & 0.0272 & 2.2072 \\
9.51 & 5.50 & 6.20 & 6.26 & 0.07 & 0.6417 & 1.89 & 0.2530 & 2.1430 \\
9.73 & 5.55 & 6.40 & 6.40 & 0.07 & 0.7000 & 1.67 & 0.3680 & 2.0380 \\
\hline
\end{tabular}

LogK $_{1}$ (Average value) $=2.2364 \pm 0.1602$

Table 10: Point-wise method, Pb (Unhydrolysed PSHA)

\begin{tabular}{|l|l|l|l|l|l|l|l|l|}
\hline $\mathrm{pH}$ & $\mathrm{BV}_{1}$ & $\mathrm{BV}_{2}$ & $\mathrm{BV}_{3}$ & $\mathrm{~V}_{3}-\mathrm{V}_{2}$ & $\mathrm{n}$ & $\mathrm{pL}$ & $\log \left(\frac{n-1}{2-n}\right)$ & $\log \mathrm{K}_{2}$ \\
\hline 10.00 & 5.60 & 6.47 & 6.55 & 0.08 & 1.9503 & 1.41 & & \\
10.23 & 5.65 & 6.62 & 6.72 & 0.11 & 1.4792 & 1.26 & -0.0361 & 1.2239 \\
\hline
\end{tabular}

$\operatorname{LogK}_{2}$ (Average value) $=1.2239$

Table 11: Point-wise method, Mg (Hydrolysed PSHA)

\begin{tabular}{|l|l|l|l|l|l|l|l|l|}
\hline $\mathrm{pH}$ & $\mathrm{BV}_{1}$ & $\mathrm{BV}_{2}$ & $\mathrm{BV}_{3}$ & $\left(\mathrm{~V}_{3}-\mathrm{V}_{2}\right)$ & $\mathrm{n}$ & $\mathrm{pL}$ & $\log \left(\frac{n}{n-1}\right)$ & LogK $_{1}$ \\
\hline 8.50 & 5.30 & 6.29 & 6.31 & 0.02 & 0.2750 & 2.64 & -0.4290 & 2.2110 \\
8.72 & 5.35 & 6.37 & 6.39 & 0.02 & 0.2858 & 2.42 & -0.3978 & 2.0222 \\
9.00 & 5.40 & 6.46 & 6.49 & 0.03 & 0.4648 & 2.14 & -0.0612 & 2.0788 \\
9.22 & 5.45 & 6.55 & 6.59 & 0.04 & 0.6667 & 1.94 & 0.3010 & 2.2410 \\
\hline
\end{tabular}

$\log _{\mathbf{1}}($ Average value) $=2.1382 \pm 0.1046$ 
BAJOPAS Volume 14 Number 1,June, 2021

Table 12: Point-wise method, Mg (Hydrolysed PSHA)

\begin{tabular}{|l|l|l|l|l|l|l|l|l|}
\hline $\mathrm{pH}$ & $\mathrm{BV}_{1}$ & $\mathrm{BV}_{2}$ & $\mathrm{BV}_{3}$ & $\left(\mathrm{~V}_{3}-\mathrm{V}_{2}\right)$ & $\mathrm{n}$ & $\mathrm{pL}$ & $\log \left(\frac{n-1}{2-n}\right)$ & LogK $_{2}$ \\
\hline 9.51 & 5.55 & 6.66 & 6.71 & 0.05 & 0.9650 & 1.67 & & \\
9.73 & 5.55 & 6.78 & 6.84 & 0.06 & 1.4042 & 1.47 & -0.1686 & 1.3014 \\
10.00 & 5.60 & 6.90 & 6.93 & 0.06 & 1.7838 & 1.23 & 0.5593 & 1.7893 \\
10.23 & 5.65 & 7.05 & 7.10 & 0.06 & 3.1429 & 1.10 & & \\
10.49 & 5.70 & 7.10 & 7.18 & 0.07 & 3.6492 & 0.83 & & \\
\hline
\end{tabular}

LogK $_{2}($ Average value $)=1.5453 \pm 0.3450$

Table 13: Point-wise method, Mg (Unhydrolysed PSHA)

\begin{tabular}{|l|l|l|l|l|l|l|l|l|}
\hline $\mathrm{pH}$ & $\mathrm{BV}_{1}$ & $\mathrm{BV}_{2}$ & $\mathrm{BV}_{3}$ & $\mathrm{~V}_{3}-\mathrm{V}_{2}$ & $\mathrm{n}$ & $\mathrm{pL}$ & $\log \left(\frac{n}{n-1}\right)$ & $\operatorname{Log~}_{1}$ \\
\hline 8.50 & 5.30 & 5.81 & 5.85 & 0.04 & 0.2973 & 2.88 & -0.3736 & 2.5064 \\
8.72 & 5.35 & 5.90 & 5.94 & 0.04 & 0.3099 & 2.66 & -0.3477 & 2.3123 \\
9.00 & 5.40 & 6.00 & 6.04 & 0.04 & 0.3236 & 2.38 & -0.3202 & 2.0598 \\
9.22 & 5.45 & 6.10 & 6.15 & 0.05 & 0.4297 & 2.17 & -0.1230 & 2.0470 \\
9.51 & 5.50 & 6.20 & 6.26 & 0.06 & 0.5500 & 1.89 & 0.0871 & 1.9771 \\
9.73 & 5.55 & 6.33 & 6.40 & 0.07 & 0.7000 & 1.67 & 0.3680 & 2.0380 \\
\hline
\end{tabular}

LogK $_{1}$ (Average value) $=2.1568 \pm 0.2069$

Table 14: Point-wise method, Mg (Unhydrolysed PSHA)

\begin{tabular}{|l|l|l|l|l|l|l|l|l|}
\hline $\mathrm{pH}$ & $\mathrm{BV}_{1}$ & $\mathrm{BV}_{2}$ & $\mathrm{BV}_{3}$ & $\mathrm{~V}_{3}-\mathrm{V}_{2}$ & $\mathrm{n}$ & $\mathrm{pL}$ & $\log \left(\frac{n-1}{2-n}\right)$ & $\log \mathrm{K}_{2}$ \\
\hline 10.00 & 5.60 & 6.47 & 6.55 & 0.08 & 0.9148 & 1.41 & & \\
10.23 & 5.65 & 6.62 & 6.71 & 0.09 & 1.2102 & 1.20 & -0.5749 & 0.6251 \\
10.49 & 5.70 & 6.80 & 6.92 & 0.09 & 1.5968 & 1.03 & 0.1703 & 1.2003 \\
\hline
\end{tabular}

LogK $_{2}$ (Average value) $=0.9127 \pm 0.4070$

Table15:Point-wise method, Cd (Hydrolysed PSHA)

\begin{tabular}{|l|l|l|l|l|l|l|l|l|}
\hline $\mathrm{pH}$ & $\mathrm{BV}_{1}$ & $\mathrm{BV}_{2}$ & $\mathrm{BV}_{3}$ & $\left(\mathrm{~V}_{3}-\mathrm{V}_{2}\right)$ & $\mathrm{n}$ & $\mathrm{pL}$ & $\log \left(\frac{n}{1-n}\right)$ & LogK $_{1}$ \\
\hline 8.50 & 5.30 & 6.29 & 6.31 & 0.02 & 0.2750 & 2.64 & -0.4210 & 2.2190 \\
8.72 & 5.35 & 6.37 & 6.40 & 0.03 & 0.4286 & 2.42 & -0.1249 & 2.2951 \\
9.00 & 5.40 & 6.46 & 6.49 & 0.03 & 0.4648 & 2.14 & -0.0612 & 2.0788 \\
9.22 & 5.45 & 6.55 & 6.59 & 0.04 & 0.6667 & 1.96 & 0.3010 & 2.2610 \\
9.51 & 5.55 & 6.66 & 6.70 & 0.04 & 0.7720 & 1.67 & 0.5297 & 2.1997 \\
\hline
\end{tabular}

LogK $_{\mathbf{1}}$ (Average value) $=2.2108 \pm 0.0825$

Table 16: Point-wise method, Cd (Hydrolysed PSHA)

\begin{tabular}{|l|l|l|l|l|l|l|l|l|}
\hline $\mathrm{pH}$ & $\mathrm{BV}_{1}$ & $\mathrm{BV}_{2}$ & $\mathrm{BV}_{3}$ & $\left(\mathrm{~V}_{3}-\mathrm{V}_{2}\right)$ & $\mathrm{n}$ & $\mathrm{pL}$ & $\log \left(\frac{n-1}{2-n}\right)$ & Log $_{2}$ \\
\hline 9.73 & 5.55 & 6.78 & 6.83 & 0.06 & 1.4042 & 1.47 & -0.1686 & 1.3014 \\
10.00 & 5.60 & 6.90 & 6.95 & 0.06 & 1.7838 & 1.23 & 0.5593 & 1.7893 \\
10.23 & 5.65 & 7.05 & 7.10 & 0.06 & 3.1429 & 1.09 & & \\
10.49 & 5.70 & 7.10 & 7.16 & 0.06 & 3.1429 & 0.89 & & \\
& & & & & & & & \\
\hline
\end{tabular}

$\operatorname{LogK}_{2}$ (Average value) $=1.5453 \pm 0.3450$

Table 17: Point-wise method, Cd (Unhydrolysed PSHA)

\begin{tabular}{|l|l|l|l|l|l|l|l|l|}
\hline $\mathrm{pH}$ & $\mathrm{BV}_{1}$ & $\mathrm{BV}_{2}$ & $\mathrm{BV}_{3}$ & $\mathrm{~V}_{3}-\mathrm{V}_{2}$ & $\mathrm{n}$ & $\mathrm{pL}$ & $\log \left(\frac{n}{n-1}\right)$ & $\operatorname{Log~}_{1}$ \\
\hline 8.50 & 5.30 & 5.81 & 5.86 & 0.05 & 0.3717 & 2.88 & -0.2280 & 2.6520 \\
8.72 & 5.35 & 5.90 & 5.95 & 0.05 & 0.3873 & 2.66 & -0.1992 & 2.4608 \\
9.00 & 5.40 & 6.00 & 6.06 & 0.06 & 0.4853 & 2.38 & -0.0255 & 2.3545 \\
9.22 & 5.45 & 6.10 & 6.16 & 0.06 & 0.5157 & 2.18 & -0.0272 & 2.2072 \\
9.51 & 5.50 & 6.20 & 6.27 & 0.07 & 0.6417 & 1.89 & 0.2530 & 1.1430 \\
9.73 & 5.55 & 6.33 & 6.41 & 0.08 & 0.8000 & 1.69 & 0.6020 & 2.2920 \\
& & & & & & & & \\
\hline
\end{tabular}

$\operatorname{LogK}_{1}($ Average value $)=2.2516 \pm 0.5380$ 
BAJOPAS Volume 14 Number 1,June, 2021

Table 18: Point-wise method, Cd (Unhydrolysed PSHA)

\begin{tabular}{|l|l|l|l|l|l|l|l|l|}
\hline $\mathrm{pH}$ & $\mathrm{BV}_{1}$ & $\mathrm{BV}_{2}$ & $\mathrm{BV}_{3}$ & $\mathrm{~V}_{3}-\mathrm{V}_{2}$ & $\mathrm{n}$ & $\mathrm{pL}$ & $\log \left(\frac{n-1}{2-n}\right)$ & $\log \mathrm{K}_{2}$ \\
\hline 10.00 & 5.60 & 6.47 & 6.57 & 0.10 & 1.1434 & 1.43 & & \\
10.23 & 5.65 & 6.62 & 6.72 & 0.10 & 1.3448 & 1.23 & -0.2788 & 0.9512 \\
10.49 & 5.70 & 6.80 & 6.90 & 0.10 & 1.7742 & 1.03 & 0.5351 & 1.5651 \\
\hline
\end{tabular}

$\operatorname{LogK}_{2}($ Average value $)=1.2581 \pm 0.4340$

Table 19: Stepwise and overall Stability constants of thehydrolysed and unhydrolysed divalent metal (II) complexes

\begin{tabular}{|c|c|c|c|}
\hline Chelates & LogK $_{1}$ & $\log _{2}$ & Log $\beta$ \\
\hline [Cu (Hydrolysed PSHA-1) $\left.{ }_{2}\right]$ & 2.4788 & 1.4280 & 3.9068 \\
\hline$\left[\mathrm{Pb}(\text { Hydrolysed PSHA-1) })_{2}\right]$ & 2.5832 & 1.1963 & 3.7795 \\
\hline$\left[\mathrm{Cd}(\text { Hydrolysed PSHA-1 })_{2}\right]$ & 2.2108 & 1.5453 & 3.7561 \\
\hline$\left[\mathrm{Mg}(\text { Hydrolysed PSHA-1 })_{2}\right]$ & 2.1382 & 1.5453 & 3.6835 \\
\hline [Cu (Unhydrolysed PSHA-1) & 2.3059 & 1.2209 & 3.5268 \\
\hline$[\mathrm{Pb}$ (Unhydrolysed PSHA-1) 2$]$ & 2.2364 & 1.2239 & 3.4603 \\
\hline [Cd (Unhydrolysed PSHA-1) 2 ] & 2.2516 & 1.2581 & 3.5097 \\
\hline$[\mathrm{Mg}$ (Unydrolysed PSHA-1) & 2.1568 & 0.9127 & 3.0695 \\
\hline
\end{tabular}

The results obtained (Table19) shows the stepwise and overall stability constants to be not high indicating low stability of the complexes, because the solubility of most metal ions in the basic $\mathrm{pH}$ range is minimal due to metal hydroxide precipitation (Karimi, 2017). In general, the stepwise stability constants $\left(K_{1}\right.$ and $K_{2}$ ) follow the order $K_{1}>K_{2}$ for the copper, lead, magnesium and cadmium complexes respectively. The steady decrease of the values with increasing number of ligands is in agreement with the prediction made by researchers (Na'aliya, 2013). The decrease could be attributed to the fact that as the number of the ligands (Humate ions) that enters the coordination zone increases the aqua molecules available for replacement by the ligands become less. Thus, the metal ions become less electron loving with progressive intake of the ligand and this results in the decrease in the values of the constants (Na'aliya, 2013). Also the stability of the complexes is influenced by the size and number of the chelate rings(Mackay and Mackay,2002).All the complexes form rings in their structure as humate, a bidentate ligand, bond the metal ions in the ratio 1:2 (Boguta and Sokolowska, 2016) forming chelate rings. The values of the overall stability constants $(\log \beta)$ obtained for humate complexes are not high indicating low stability as the values are not high. LogK values for copper-humates (Table 3 to 6) obtained in this study are lower than those reported for the complexes of humic acids (Pandey et al., 2015; Dinu, 2013; Kaschl et al., 2010 and Gilbeto and Jorg, 2001). The values of LogK(Table 7 to 10 ) forlead-humates are lower than those reported for the lead in the literature (Dinu, 2013; Gilbeto and Jorg 2001). Log K values(Table 11 to 14 ) for magnesium-humates obtained in this study are close to those reported by (Pandey et al., 2015). Log K values of cadmium-humates (Table 15 to 18 ) obtained in this work near to the one reported by (Dinu, 2013 and Pandey et al., 2015).The difference between the reported values and the values obtained in this study might be probably as a result of acid hydrolysis of humic acid. The values of the overall stability constants $(\log \beta)$ of the copper humates complexes presented in Table 19 is high than that of other metal humate complexes, show relatively high stability of CuHA complexes, show the following order of stability: $\mathrm{Cu}>\mathrm{Pb}>\mathrm{Cd}>\mathrm{Mg}$; which are in close agreement to the findings of (Dinu, 2013 and Pandey et al., 2015).The high stability of Cuhumate chelate could be attributed to the existence of coordinate covalent bond between the complexing agents and the $\mathrm{Cu}^{2+}$ ions. Since, $\mathrm{Cu}^{2+}$ being a metal of the transitional series with $3 d^{9}$ electronic configurations can accept the electrons from the complexing agents. Similarly, the low stabilities of $\mathrm{Pb}, \mathrm{Cd}$ and $\mathrm{Mg}$ complexes could be explained by that $\mathrm{Pb}^{2+}$ with $6 s^{2}, \mathrm{Cd}^{2+}$ with $4 \mathrm{~d}^{10}$ and $\mathrm{Mg}^{2+}$ with $2 \mathrm{p}^{6}$ their electronic configuration has a completely filled $\mathrm{d}, \mathrm{p}$ and $\mathrm{s}$ orbitals. Moreover, the stabilities of metal ions with hydrolysed humic acid from peat soil were higher than those with unhydrolysed humic acid from peat soil; which is ascribed to the high content of acidity in hydrolysed humic acid than unhydrolysed humic acid. 
BAJOPAS Volume 14 Number 1,June, 2021 CONCLUSION

The values of logk for $\mathrm{Cu}(\mathrm{II})$ hydrolysed humic acid complex was higher followed by $\mathrm{Pb}$ (II), $\mathrm{Cd}(\mathrm{II})$ and $\mathrm{Mg}$ (II) hydrolysed humic acid complexes as compared with metal(II) unhydrolysed humic acid complexes. This indicates acid hydrolysis of humic acid can

\section{REFERENCES}

Almeida, V.R. and Szpoganicz, B. (2015). Humic Acid Potentiometric Response Patterns:Out- of Equilibrium Properties and Species Distribution Modelling. Chemical. Biol. Technol. Agric. 2: 17.

Anđelković, T., Nikolić, R., Bojić, A.,Anđelković, D., and Nikolic G.,(2010). Binding of Cadmium to Soil Humic Acid as A Function of Carboxyl Group Content. Macedonian Journal of Chemistry and Chemical Engineering.29(2): 215-224.

Anil, B. N. and Maroti, N. (2008). Studies on Influence of Die-Lectric Constants on Complex Equilibria between Substituted Py-Razalines and Lanthanide Metal Ions pH-Metrically. Amer.-Euras. scient. Res. 3(2): 212-216.

Ashok, K., Pandey, S. P. and Misra, V (2000). Stability Constants of Metal-Humic Acid Complexes and its Role in Environmental Detoxification. Journal of Ecotoxicology and Environmental Safety. 47(2):157-200.

Badr, M. H., El-Halafawi, M. H. and Abd El-al Zeid, E. R. (2012). Comparison Between the Effect of Ionic Strength on Acidity and Dissociation Constants of Humic Acids Extracted from Sewage Sludge and Nile Water Hyacinth Composts.Global Journal of Environmental Research 6 (1): 36-43.

Baruah, M.K., Borah, D., Saikia, P.P., Paul, S., Sharma, T. (2015). Evaluation of pKa Values of Soil Humic Acids and their Complexation Properties. International Journal of Plant \& Soil Science 6(4) : 218-228.

Boguta, P. Sokolowska, Z. (2016). Interactions of $\mathrm{Zn}$ (II) Ions with Humic Acids Isolated from Various Types of Soils. Effect of $\mathrm{pH}, \mathrm{Zn}$ Concentrations and Humic Acids Chemical Properties. Journal of Geochemical Explaration 168. 119-126.

Borges, F., Guimaraes, C., Lima, L.F.C., Pinto, I. and Reis, S.(2005). Potentiometric Studies on the Complexation of Copper(II) by Phenolic Acids as Discrete Ligand Models of enhance the complexation behavior of humic acid with metal (II) ions. However, the higher values of $\log \beta$ for $\mathrm{Cu}(\mathrm{II}), \mathrm{Pb}(\mathrm{II}), \mathrm{Cd}(\mathrm{II})$ and $\mathrm{Mg}(\mathrm{II})$ hydrolysed humic acid complexes indicates more stable stepwise complexes formed as compared with $\mathrm{Cu}(\mathrm{II}), \mathrm{Pb}$ (II), $\mathrm{Cd}$ (II) and $\mathrm{Mg}(\mathrm{II})$ unhydrolysed humic acid complexes.

Humic Substances Talanta 66 (2005) 670-673.

Chefetz, B., Salloum, M. J., Deshmulkin, A. P. and Hatcher, P. (2002). Structural Components of Humic Acids as Determined by Chemical Modifications and Carbon-13 NMR, Pyrolysis, and Thermochemolysis- Gas Chromatography/Mass Spectrometry. Soil Science Society of American Journal Abstract Division S-2- Soil Chemistry66. 1159-1171.

Dinu, M. I. (2013). Metals Complexation with Humic Acids in Surface Water of Different Environ. Sci. Technol. 31(1): 1-17.

Fernandes, A.N., Giacomelli, C., Giovanela, M. Vaz, D.V. Szpoganicz, B. and Maria M. D. (2009). Potentiometric Acidity Determination in Humic Substances Influenced by Different Analytical Procedures.J. Braz. Chem. Soc. 20 (9):14.

Gamal, A. H. (2015). Stability Constants of Rhenium (V) Metal Complexes with Selected Drugs. Pyrex Journal of Research in Environmental Studies. 2(2): 006-014.

Janrao, D. M., Pathan, J., Kayande, D.D., and Mulla, J.J. (2014). An Over View of Potentiometric Determination of Stability Constants of Metal Complexes. Sci. Revs. Chem. Commun.: 4(1), 2014, 11-24.

Karimi, H. (2017). Effect of pH and Initial Pb(II) Concentration on the Lead Removal Efficiency from Waste Water Using $\mathrm{Ca}(\mathrm{OH})_{2}$. International Journal of Water and Waste Water Treatment 3.2

Kaschl, A. Romheld, V. and Chen, Y. (2010). Binding of Cadmium, Copper and Zinc to Humic Substances Originating from Municipal Solid Waste Compost. Israel Journal of Chemistry Vol. 42(1): 89-98.

Kostic, I. S., Tatjana, P, A., Nikolic, R. S., Cvetkovic, T. P., Pavlovic, D. D., Aleksandar, L.J. and Bojic, A. (2012). Comparative Study of Binding Strengths of Heavy Metals with Humic Acid. J.serb. Chem. Soc. 76(9) pp 1-20. 
BAJOPAS Volume 14 Number 1,June, 2021

Na'aliya, J. (2013). Determination of Stepwise Stability Constants and Gibbs free Energy Change of Trisprolina to Complexes of some Divalent Transition Metal ions. Bayero Journal of Pure and Applied Sciences 6(2): 112-114.

Omar, A. A. and Ali, E. A. (2015). Potentiometric Studies on Complexes of $\mathrm{Cr}$ (III) and $\mathrm{Zr}$ (IV) with some Carboxylic Acids. International Journal of Advanced Chemistry, 3(1) 25-

37.

Pandey, A. K. Pandey, S. D. and Misr, V. (2015).Stability Constants of Metal- Humic Acid Complexes and Its Role in Environmental Detoxification. J. Ecotoxicology and Environmental Safety. 47(1):195-200.

Ram, N. and Raman, K.V. (1984). Stability Constants of Complexes of Metals with
Humicand Fuvic Acids under Non- acidConditions. Journal of Plant Nutrition and Soil Sciences.

147:171-176.

Santosh, D. D., Ashok, B. K., Vijay, J. T., Shivraj, G. W. and Vinay, V. W. (2011). Potentiometric Studies of Elec-Trolyte Effects on Complex Equilibria of Some Substituted 5-(2-hydroxy Phenyl) Pyrazoles. Der pharm. 3 (6): 75-83.

Sayyed, H. and Abdul Rahim, M. F. (2012). Studies of Binary Complexes of Metal Ions with Mandelic Acid by Potentiometry. Chem. J. 02 (6): 206209.

Shirvani, M. Moradian, E. Khalili, B. Bakhtiary, S. (2015). Interaction of $\mathrm{Cd}$ and $\mathrm{Pb}$ with Humate-Palygorskite and HumateSepiolite Complexes. Journal of water, air and pollution 3: 220-228. 


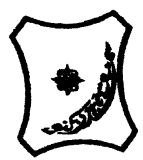

Bayero Journal of Pure and Applied Sciences, 14(1): 54 - 63

Received: November, 2020

Accepted: April, 2021

ISSN $2006-6996$

\title{
STABILITY CONSTANTS OF COMPLEXES OF METAL IONS WITH PEATSOIL HUMIC ACIDS UNDER NON-ACID-CONDITIONS
}

\author{
${ }^{* 1}$ Sabo, Yusuf ${ }^{2}$ Jimoh, W.L.O., ${ }^{3}$ Isa Baba Koki and ${ }^{4}$ Sholadoye, Q. 0. \\ ${ }^{1}$ Department of Pure and Industrial Chemistry, Bayero University, Kano \\ ${ }^{3}$ Department of Chemistry, Yusuf Maitama Sule University Kano. P.M.B. 3220 Kano, Nigeria. \\ ${ }^{4}$ Department of Chemistry, Nigerian Police Academy, Wudil, Kano-Nigeria
}

*Correspondence E-mail; saboyusuf18@yahoo.com

ABSTRACT

Stability constants of complexes of four divalent metal ions viz. $\mathrm{Cu}^{2+}, \mathrm{Pb}^{2+}, \mathrm{Mg}^{2+}$ and $\mathrm{Cd}^{2+}$ with humic acids (HA) were determined by potentiometric titration of humic acids with the corresponding salt of the divalent metals in aqueous media under non-acid-condition. The log $K$ (logarithm of the stability constant) ranged from 1.0942 to 2.7471 for metalhumic acid complexes were determined using point-wise computational method. The order of stability constants were obtained as follows: $\mathrm{Cu}>\mathrm{Pb}>\mathrm{Cd}>\mathrm{Mg}$ for metal $-\mathrm{HA}$ complexes respectively, indicating a higher degree of complexation with Cu metal ion.

Keywords: stability constant, humic acid, potentiometric titration, divalent metals, acid hydrolysis.

\section{NTRODUCTION}

The stability constant of a complex is the numerical expression of its stability and provides a quantitative measure of affinity of the metal ion to the complexing agent. An understanding of the relative stability of metal-complexes helps in predicting the behavior of metal ions in the soil (Ram and Raman, 1982). Extensive researches has been done to determine the stability constants of the complexes formed between humic acid (HA) with a number of metal ions. Ashok et al., (2000) reported that humic acid with hydroxyl, phenoxyl and carboxyl reactive groups can form coordination compound with metal ions at $\mathrm{pH}$ 3.5. The stability constants(Log K) for different metalhumic acid complexes indicated the following order of the stabilities of complexes formed between humic acid and metal ion, $\mathrm{Cu}>\mathrm{Fe}$ $>\mathrm{Pb}>\mathrm{Ni}>\mathrm{Co}>\mathrm{Ca}>\mathrm{Cd}>\mathrm{Zn}>\mathrm{Mn}>\mathrm{Mg}$. Andelkovic et al., (2010) investigated the binding of $\mathrm{Cd}$ (II) to soil humic acid at pH 6.5 and in $0.1 \mathrm{M} \mathrm{KNO}_{3}$ ionic medium. The stability constant for binding indicating greater stability in the case when carboxyl groups are involved in complexation reaction. Kostic et al.,(2012) investigated the complexation of humic acid with certain heavy metal ions (Co(II), $\mathrm{Ni}(\mathrm{II}), \mathrm{Cu}(\mathrm{II})$,
$\mathrm{Zn}(\mathrm{II})$, and $\mathrm{Pb}(\mathrm{II})$. The experiment was performed at $25^{\circ} \mathrm{C}$, at pH 4.0 and ionic strength of $0.01 \mathrm{M}$. Stability constant of complex between $\mathrm{Pb}$ (II) ions and humic acid is greater than stability constants of other investigated metalhumate complexes. Bogata and Sokolowska (2016) analyses the interaction between humic acids from different soils and $\mathrm{Zn}$ (II) ions at wide concentration ranges and at $\mathrm{pH} 5$. Studies have showed significant impact of $\mathrm{Zn}$ concentration, $\mathrm{pH}$ and some properties of humic acids with zinc.But all of these studies were limited to acidic $\mathrm{pH}$ range. Therefore, the present study was carried out to determine and compare the stability constants of complexes of metal ions with hydrolysed peat soil humic acid and unhydrolysed peat soil humic under non-acid conditions.

\section{MATERIALS AND METHODS}

Analytical grade chemicals used includes hydrochloric acid $(\mathrm{HCl})$, nitric acid $\left(\mathrm{HNO}_{3}\right)$, sodium hydroxide $(\mathrm{NaOH})$, lead nitrate $\mathrm{Pb}\left(\mathrm{NO}_{3}\right)_{2}$, copper nitrate $\mathrm{Cu}\left(\mathrm{NO}_{3}\right)_{2} \cdot 3 \mathrm{H}_{2} \mathrm{O}$, cadmium nitrate $\mathrm{Cd}\left(\mathrm{NO}_{3}\right)_{2} \cdot 4 \mathrm{H}_{2} \mathrm{O}$, magnesium nitrate $\mathrm{Mg}\left(\mathrm{NO}_{3}\right)_{2} \cdot 6 \mathrm{H}_{2} \mathrm{O}$, potassium nitrate $\left(\mathrm{KNO}_{3}\right)$, calcium chloride $\left(\mathrm{CaCl}_{2}\right)$, (sigma-Aldrich). Dowex 50WX8, (20-50 mesh) from Fluka. 


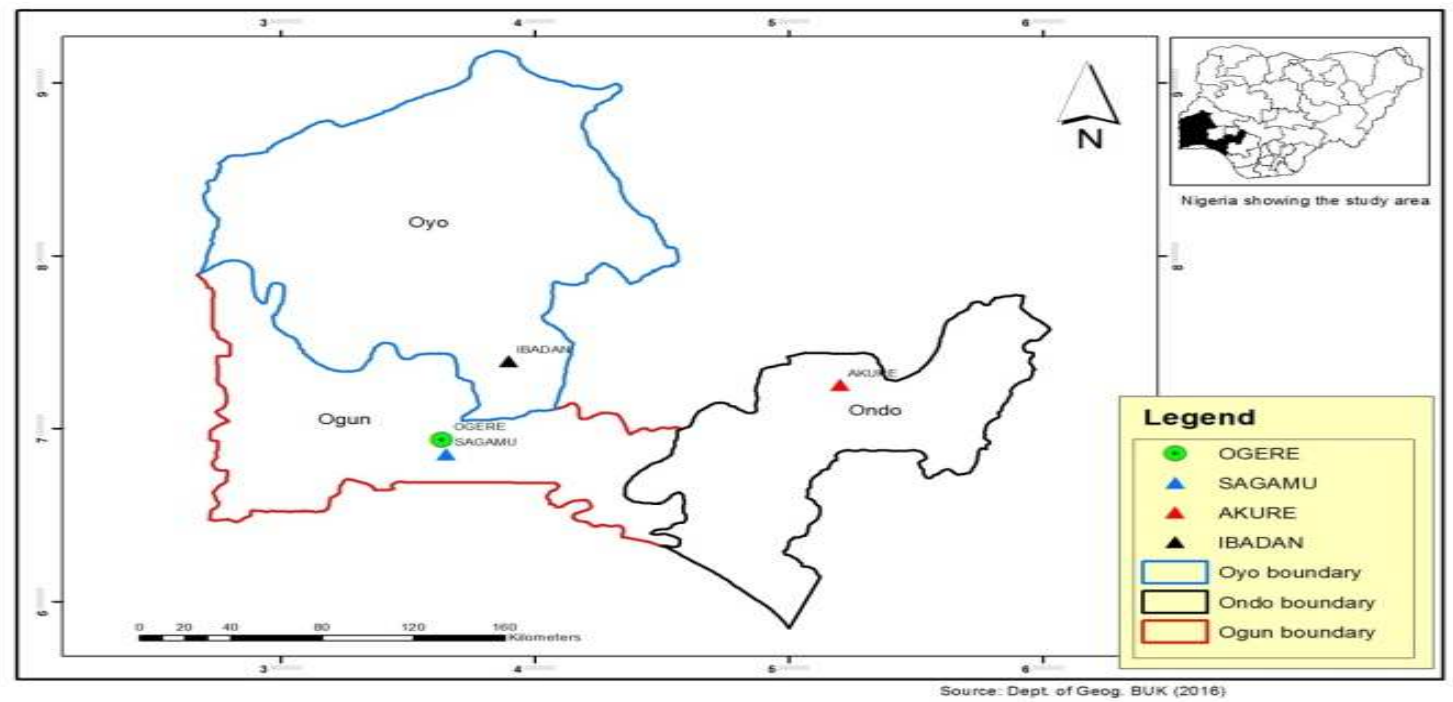

Figure 1: Map showing the sampling point at Sagamu Town, Ogun State.

\section{Description of Sampling Area}

Sagamu has geographical coordinates between $6^{\circ} 50^{\prime}$ north; $3^{\circ} 38^{\prime}$ east is located in south western region of Nigeria. The region has tropical wet and dry climate with a lengthy wet season and relatively constant temperatures throughout the course of the year. Wet season runs from March to October, November to December forms the region dry season. The vegetation type of the region is savannah which is really grassland with small bushes and occasional big trees. Grassland soils have substantially higher organic matter content than forest soils (Novackova, 2011).

\section{Sample Collection}

The Peatsoil samples were collected from four different sampling points $(0-10 \mathrm{~cm}$ depth) in Sagamu into polyethylene bag with plastic spoons. Samples were taken to the laboratory, extraneous materials were removed; the samples were air-dried, crushed and ground to a fine powder in a mortar passed through a $0.20 \mathrm{~mm}$ sieve. The samples were kept for analysis.

\section{Isolation and purification of humic acid from peat soil sample}

Peatsoil sample $(100 \mathrm{~g})$ was mixed with 1000 $\mathrm{cm}^{3}$ of $0.1 \mathrm{M} \mathrm{NaOH}$ solution, shaken for 3hours and left to stand overnight. Dark-coloured supernatant was obtained and decanted from solid residue. The dark-coloured supernatant was acidified to $(\mathrm{pH}=1.0)$ with $6 \mathrm{M} \mathrm{HCl}$ stirred and allowed to stand for 6 hours. Yellowish brown supernatant and dark-brown precipitate were obtained. The yellowish brown supernatant was decanted followed by centrifuge and discarded. The dark-brown precipitate was mixed with $500 \mathrm{~cm}^{3}$ of $0.1 \mathrm{M} \mathrm{NaOH}$ solution followed by passing through dowex resin. The dark-brown solution was acidified to $(\mathrm{pH}=1.0)$ with $6 \mathrm{M} \mathrm{HCl}$ stirred and allowed to stand for 3 hours. The dark-brown precipitate was washed several times with deionized water. The supernatant was treated with $\mathrm{AgNO}_{3}$ solution until no white precipitate observed. The humic acid was transferred to weighed crucible and dried at $60^{\circ} \mathrm{C}$ in an oven for 12 hours. The humic acid was cooled and dried in the desiccator, weighed and recorded. The obtained humic acid was dried again at $60^{\circ} \mathrm{C}$ for additional 6 hours cooled and dried in the desiccator, weighed and recorded constant weight was obtained (Baruah et al., 2015).

\section{FT-IR analysis}

FT-IR spectra of humic acid sample was analysed using Carry 630 FT-IR Agilent Technologies.

Unhydrolysed compost humic acid

The unhydrolysed humic acid was obtained after isolation and purification of compost humic acid and kept for investigation.

\section{Acid hydrolysis of Peatsoil acid}

Peatsoil humic acid sample (1g) was refluxed for 12 hours at $\left(160^{\circ} \mathrm{C}\right)$ with $50 \mathrm{~cm}^{3}$ of $6 \mathrm{M} \mathrm{HCl}$. The mixture was allowed to cool, decanted, and centrifuged after hydrolysis. The insoluble residues were washed with distilled water via centrifugation several times, and the supernatant was treated with $\mathrm{AgNO}_{3}$ solution until no white precipitate was observed. The residue was thoroughly dried over $\mathrm{CaCl}_{2}$ in a desiccator at room temperature (Chefetz et al., 2002). Finally, the obtained hydrolysed humic acid was kept for investigation. 
BAJOPAS Volume 14 Number 1,June, 2021 Potentiometric Titrations

Potentiometric measurements were carried out using a pH-meter Jenway (model 3510) with combine electrode, the sensitivity of the $\mathrm{pH}$ meter is 0.01 units. The $\mathrm{pH}$ meter was switched on half an hour before starting the titration for initial warm up of the instrument. The instrument was calibrated with an aqueous standard buffer solution of $\mathrm{pH} 4.00$ and 10.0 (borate buffer) prepared from a "Qualigens" buffer tablets.

The following sets of solutions were prepared in a $250 \mathrm{~cm}^{3}$ volumetric flask separately for $\mathrm{pH}$ metric titrations.

(i) $5 \mathrm{~cm}^{3} 0.1 \mathrm{M} \mathrm{HCl}+40 \mathrm{~cm}^{3}$ deionized water

(ii) $5 \mathrm{~cm}^{3} 0.1 \mathrm{M} \mathrm{HCl}+39 \mathrm{~cm}^{3}$ deionized water $+1 \mathrm{~cm}^{3} 0.15 \mathrm{gcm}^{-3}$ humic acid

(iii) $5 \mathrm{~cm}^{3} 0.1 \mathrm{M} \mathrm{HCl}+37 \mathrm{~cm}^{3}$ deionized water $+1 \mathrm{~cm}^{3} 0.15 \mathrm{gcm}^{-3}$ humic acid

$$
+2 \mathrm{~cm}^{3} \quad 0.01 \mathrm{M} \mathrm{Cu} \text { (II) }
$$

The solutions were titrated against standardized $0.110 \mathrm{MNaOH}$ separately. The total volume of each mixture was adjusted to $50 \mathrm{~cm}^{3}$ and the ionic strength of the solutions was maintained constant at by adding appropriate amount of stock solution of $1 \mathrm{M} \mathrm{KNO}_{3}$ (Gamal, 2015; Omar and Ali, 2015). A magnetic stirrer was used to achieve thorough mixing of the interacting solutions at $550 \mathrm{rpm}$. The same set of experimental conditions was applied for potentiometric titration of remaining samples.

\section{Evaluation of pKa of Hydrolysed peat soil Humic Acids}

The proton-ligand formation number $\mathrm{n}_{\mathbf{A}}$ were calculated by Irving and Rossotti expression (Omar and Ali, 2015).

$\mathrm{nA}=\mathrm{Y}-\frac{(\mathrm{V} 2-\mathrm{V1})(\mathrm{No}-\mathrm{Eo})}{(\mathrm{VO}+\mathrm{V1}) \mathrm{TCL}}$ 1

Where: $Y$ is number of dissociable proton, $\left(\mathrm{V}_{2^{-}}\right.$ $V_{1}$ ) is the measure of displacement of the ligand curve relative to acid curve, $\mathrm{N}^{\circ}$ and $\mathrm{E}^{\circ}$ are the resultant concentration of alkali solution, free acid solution, $\mathrm{T}_{\mathrm{cL}}{ }^{\circ}$ is the total ligand concentration, $\mathrm{V}^{\circ}$ is the total volume of titration solution, $V_{1}$ is the volume of alkali added to acid solution, $V_{2}$ is the volume of alkali added to acid solution + ligand solution, acid dissociation constants (pKa - values) of ligand were calculated by algebraic method point wise calculation (Tables 1 ). The dissociation constants (pKa) were calculated according to the following relation:

$\mathrm{pKa}=\mathrm{pH}+\log \left(\frac{n A}{1-n A}\right)$ 2

Where: pKa is the acid dissociation constant, $\mathrm{n}_{\mathrm{A}}$ is the Proton-ligand formation number and $\mathrm{pH}$ is the pH-values (Omar and Ali, 2015).

\section{Determination of metal-ligand stability constants $(\log K)$ of complexes}

The potentiometric measurement for the determination of stability constant of a complex in solution is based on the fact that the redox potential of the couple $\frac{M^{+(m-n)}}{M^{+m}}$ is shifted significantly on complexation of the metal ion with the ligand. This method involves change in hydrogen ion concentration $\left[\mathrm{H}^{+}\right]$due to the displacement or association of one or more protons taking place during complexation reaction. This change can be found out by titrating the solutions containing free acid, acid with ligand, and acid with ligand and metal ion, individually against a standard alkali solution at a constant ionic strength or temperature. Either ionic strength or temperature may be varied for different sets of solutions. In all the cases, the change in the $\mathrm{pH}$ of the solution is measured after each addition of a known amount of alkali to the reaction cell which contains the reaction mixture. The titration curves are then drawn by plotting the measured $\mathrm{pH}$ values against the corresponding volume of alkali added and the stability constants of the complexes are determined from the titration curves by employing $\mathrm{pH}$-metric titration technique given by (Irving and Rossoti).

Metal-ligand stability constants ( $\log \mathrm{K}$ ) were determined by using the following relations:

$$
\bar{n}=\frac{\left(V_{3}-V_{2}\right)\left(E^{0}+N^{0}\right)}{\left(V^{0}+V_{2}\right) \bar{n}_{A} T_{m}^{0}}
$$

and

$$
P L=\log _{10}\left\{\frac{1+\beta_{n}^{H} \frac{1}{[\text { anti } \log \mathrm{pH}]^{\mathrm{n}}}}{\mathrm{T}_{\mathrm{L}}^{0}-n \bar{T}_{m}^{0}} \mathrm{X} \frac{\left(V^{0}+V_{3}\right)}{V^{0}}\right\}
$$


BAJOPAS Volume 14 Number 1,June, 2021

Where $T_{L}, T^{\circ}, E^{\circ}$, and $V^{\circ}$ havethe same significance as in equation (1) above, $T_{m}$ denotes the total concentration of metal present in solution, $V_{3}$ is the volume of metal ions present in solution and $\beta^{H}$ is the overall proton ligand stability constant. The metal-ligand stability constants (log K) were determined by employing point wise computational Method (eq. 5 and 6).

$\operatorname{LogK}_{1}=\log \left(\frac{n}{1-n}\right)+\mathrm{pL}$ .5

$\operatorname{LogK}_{2}=\log \left(\frac{1-n}{2-n}\right)+\mathrm{pL}$ ...6

Where: Log $\mathrm{K}$ is the metal-ligand stability constant, $\mathrm{pL}$ is the Free ligand exponent function, $\mathbf{n}$ is the Average number of ligand attached with metal ion (Janraoet al., 2014). The results obtained were analyzed by an ORIGIN 2016 program using titration data and then the proton-ligand stability constants (pKa) and Metal-ligand stability constant (LogK) calculated (Omar and Ali, 2015).

\section{RESULTS AND DISCUSSION}

Fourier transformed infrared (FT-IR) spectra of isolated humic acid from peat soils Figure 2 had distinct clear absorption bands indicating the presence of major humic acid structural elemental groups such as $\mathrm{H}$ bonded $\mathrm{OH}$ $\left(3680 \mathrm{~cm}^{-1}\right.$ peak $), C=0$ of carbonyl $\left(1721 \mathrm{~cm}^{-1}\right.$ peak), functional groups of aliphatic components $\mathrm{CH}_{2}\left(2918 \mathrm{~cm}^{-1}\right.$ peak) and $\mathrm{C}-\mathrm{O}$ stretching of polysaccharide $\left(1168 \mathrm{~cm}^{-1}\right.$ peak). The positions of the absorption bands of the spectra fell within typical major absorption bands of humic acid which is at frequencies 3680, 2918, 1721, 1168 $\mathrm{cm}^{-1}$. The first peak centred in the vicinity of $3680 \mathrm{~cm}^{-1}$ region is attributed to phenol $\mathrm{OH}$ group bounded by intermolecular $\mathrm{H}$ bonds. The $2918 \mathrm{~cm}^{-1}$ band usually has absorption maximum at $2918 \mathrm{~cm}^{-1}$ which is due to $\mathrm{C}-\mathrm{H}$ stretching of alkane group $\left(\mathrm{CH}_{2}\right)$. The next major absorption band is $1721 \mathrm{~cm}^{-1}$. This band has been commonly ascribed to $\mathrm{C}=\mathrm{O}$ stretching of mainly carboxyl group $(\mathrm{COOH})$ with trace amount of ketones. The last peak was observed at 1168 $\mathrm{cm}^{-1}$ due to $\mathrm{C}-\mathrm{O}$ stretching of polysaccharides and this peak appeared also in the spectra of humic acid from peat soil. The FTIR spectra of the isolated humic acid contained all major characteristic absorption peaks of humic acid. These absorption peaks indicated the presence of the major structural elements of humic acid namely $\mathrm{H}$ bonded $\mathrm{OH}, \mathrm{C}=\mathrm{C}$ of aromatic ring, $\mathrm{C}=\mathrm{O}$ of carbonyl group (both carboxyl and ketonic), $\mathrm{CH}_{2}$ group. This strongly supports the presence of humic acid.

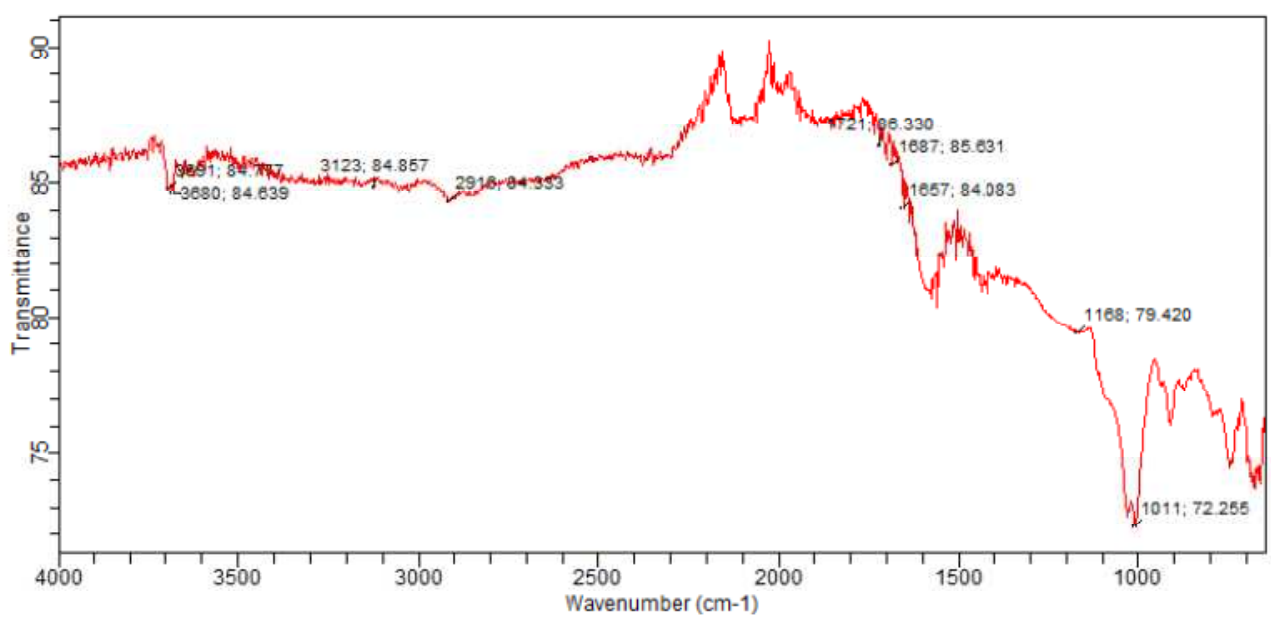

Fig. 2 : FT-IR spectraof peatsoilhumic acid (PSHA)

\section{Evaluation of acid dissociation constant (pka) of acid hydrolysed peat soil humicacid at phenolic group}

The value of the dissociation constant of the peat soil humic acid (PSHA) that underwent acidhydrolysis studied was found to be 8.9299 as shown Table 1, which is lower than the literaturevalues reported by Almeida and Szpoganics, (2015), Borges et al., (2005); Badr et al., (2012)and Fernandes et al,.(2009) of $9.73,9.47$ and 10.30. The difference between the obtained valuesand the reported values in this study might be probably as a result of acid hydrolysis of humicacid. 
BAJOPAS Volume 14 Number 1,June, 2021

Table 1: PKa of (Hydrolysed PSHA)

\begin{tabular}{|l|l|l|l|l|l|l|}
\hline $\mathrm{pH}$ & $\mathrm{BV}_{1}$ & $\mathrm{BV}_{2}$ & $\mathrm{~V}_{2}-\mathrm{V}_{1}$ & $\mathrm{nA}$ & $\log \left(\frac{n A}{1-n A}\right)$ & $\mathrm{pKa}$ \\
\hline 8.50 & 5.30 & 6.29 & 0.99 & 0.3594 & -0.2510 & 8.2490 \\
8.72 & 5.35 & 6.37 & 1.02 & 0.3400 & -0.2880 & 8.4320 \\
9.00 & 5.40 & 6.46 & 1.06 & 0.3141 & -0.3391 & 8.6609 \\
9.22 & 5.45 & 6.55 & 1.10 & 0.2882 & -0.3927 & 8.8273 \\
9.51 & 5.50 & 6.66 & 1.16 & 0.2494 & -0.4786 & 9.0314 \\
9.73 & 5.55 & 6.78 & 1.23 & 0.2041 & -0.5910 & 9.1390 \\
10.00 & 5.60 & 6.90 & 1.30 & 0.1589 & -0.7238 & 9.2762 \\
10.23 & 5.65 & 7.05 & 1.40 & 0.0941 & -0.9835 & 9.2465 \\
10.49 & 5.70 & 7.10 & 1.40 & 0.0941 & -0.9835 & 9.5065 \\
\hline
\end{tabular}

Average pKa $=8.9299 \pm 0.4186$

Table 2: PKa of (Unhydrolysed PSHA)

\begin{tabular}{|l|l|l|l|l|l|l|}
\hline $\mathrm{pH}$ & $\mathrm{BV}_{1}$ & $\mathrm{BV}_{2}$ & $\mathrm{~V}_{2}-\mathrm{V}_{1}$ & $\mathrm{nA}$ & $\log \left(\frac{\boldsymbol{n A}}{1-\boldsymbol{n}}\right)$ & $\mathrm{pKa}$ \\
\hline 8.50 & 5.30 & 5.81 & 0.51 & 0.6619 & 0.2919 & 8.7919 \\
8.72 & 5.35 & 5.90 & 0.55 & 0.6357 & 0.2418 & 8.9618 \\
9.00 & 5.40 & 6.00 & 0.60 & 0.6029 & 0.1813 & 9.1813 \\
9.22 & 5.45 & 6.10 & 0.65 & 0.5701 & 0.1226 & 9.3426 \\
9.51 & 5.50 & 6.20 & 0.70 & 0.5376 & 0.0654 & 9.5754 \\
9.73 & 5.55 & 6.33 & 0.78 & 0.4851 & -0.0259 & 9.7041 \\
10.00 & 5.60 & 6.47 & 0.87 & 0.4262 & -0.1291 & 9.8709 \\
10.23 & 5.65 & 6.62 & 0.99 & 0.3609 & -0.2481 & 9.9819 \\
10.49 & 5.70 & 6.80 & 1.10 & 0.2759 & -0.4690 & 10.0210 \\
\hline
\end{tabular}

Average pKa $=9.4923 \pm 0.4410$

Metal-ligand stability constant ( $\log \mathrm{K}$ )

The stabilityconstants require the accurate values of proton-ligand stability constants (Anil and Maroti, 2008). Metal titration curves crossed over ligand titration curve indicated the formation of complex upon proton release (Santosh, et al., 2011). If the values of n- are within range $0.2-0.8$ and $1.2-18$ this indicates the formation of $1: 1$ and 1:2 complexes (Sayyed and Mazahar, 2012).

The metal (II)-humate stepwise stability constants (log k) at phenolic group (Tables 318)

Table 3: Point-wise method, $\mathrm{Cu}$-(Hydrolysed PSHA)

\begin{tabular}{|l|l|l|l|l|l|l|l|l|}
\hline $\mathrm{pH}$ & $\mathrm{BV}_{1}$ & $\mathrm{BV}_{2}$ & $\mathrm{BV}_{3}$ & $\left(\mathrm{~V}_{3}-\mathrm{V}_{2}\right)$ & $\mathrm{n}$ & $\mathrm{pL}$ & $\log \left(\frac{n}{1-n}\right)$ & LogK $_{1}$ \\
\hline 8.50 & 5.30 & 6.29 & 6.33 & 0.04 & 0.5500 & 2.66 & 0.0871 & 2.7471 \\
8.72 & 5.35 & 6.37 & 6.41 & 0.04 & 0.5714 & 2.43 & 0.1249 & 2.5549 \\
9.00 & 5.40 & 6.46 & 6.50 & 0.04 & 0.6198 & 2.16 & 0.2122 & 2.3722 \\
9.22 & 5.45 & 6.55 & 6.59 & 0.04 & 0.6667 & 1.94 & 0.3010 & 2.2410 \\
\hline
\end{tabular}

LogK $_{1}$ (Average value) $=2.4788 \pm 0.2203$

Table 4: Point-wise method, $\mathrm{Cu}$-(Hydrolysed PSHA)

\begin{tabular}{|l|l|l|l|l|l|l|l|l|}
\hline $\mathrm{pH}$ & $\mathrm{BV}_{1}$ & $\mathrm{BV}_{2}$ & $\mathrm{BV}_{3}$ & $\left(\mathrm{~V}_{3}-\mathrm{V}_{2}\right)$ & $\mathrm{n}$ & $\mathrm{pL}$ & $\log \left(\frac{n-1}{2-n}\right)$ & LogK $_{2}$ \\
\hline 9.51 & 5.50 & 6.66 & 6.73 & 0.07 & 1.3509 & 1.70 & -0.2671 & 1.4329 \\
9.73 & 5.55 & 6.78 & 6.85 & 0.07 & 1.6383 & 1.51 & 0.2467 & 1.7567 \\
10.00 & 5.60 & 6.90 & 6.98 & 0.08 & 2.1783 & 1.31 & -0.2158 & 1.0942 \\
10.23 & 5.65 & 7.05 & 7.13 & 0.08 & 4.1904 & 1.27 & & \\
10.49 & 5.70 & 7.10 & 7.19 & 0.09 & 4.6920 & & & \\
\hline
\end{tabular}

Log $K_{2}($ Average value $)=1.4280 \pm 0.3312$ 
BAJOPAS Volume 14 Number 1,June, 2021

Table 5: Point-wise method, $\mathrm{Cu}$ (Unhydrolysed PSHA)

\begin{tabular}{|l|l|l|l|l|l|l|l|l|}
\hline $\mathrm{pH}$ & $\mathrm{BV}_{1}$ & $\mathrm{BV}_{2}$ & $\mathrm{BV}_{3}$ & $\left(\mathrm{~V}_{3}-\mathrm{V}_{2}\right)$ & $\mathrm{n}$ & $\mathrm{pL}$ & $\log \left(\frac{n}{n-1}\right)$ & Log $_{1}$ \\
\hline 8.50 & 5.30 & 5.81 & 5.85 & 0.04 & 0.2973 & 2.88 & -0.3736 & 2.5064 \\
8.72 & 5.35 & 5.90 & 5.95 & 0.05 & 0.3873 & 2.66 & -0.1992 & 2.4608 \\
9.00 & 5.40 & 6.00 & 6.05 & 0.05 & 0.4044 & 2.38 & -0.1681 & 2.2119 \\
9.22 & 5.45 & 6.10 & 6.15 & 0.06 & 0.5157 & 2.18 & -0.0272 & 2.2072 \\
9.51 & 5.50 & 6.20 & 6.27 & 0.07 & 0.6417 & 1.89 & 0.2530 & 1.1430 \\
\hline
\end{tabular}

$\operatorname{LogK}_{1}($ Average value $)=2.3059 \pm 0.6153$

Table 6:Point-wise method, $\mathrm{Cu}$ (Unhydrolysed PSHA)

\begin{tabular}{|l|l|l|l|l|l|l|l|l|}
\hline $\mathrm{pH}$ & $\mathrm{BV}_{1}$ & $\mathrm{BV}_{2}$ & $\mathrm{BV}_{3}$ & $\mathrm{~V}_{3}-\mathrm{V}_{2}$ & $\mathrm{n}$ & $\mathrm{pL}$ & $\log \left(\frac{n-1}{2-n}\right)$ & $\log \mathrm{K}_{2}$ \\
\hline 9.73 & 5.55 & 6.33 & 6.42 & 0.09 & 0.9000 & 1.69 & & \\
10.00 & 5.60 & 6.47 & 6.58 & 0.11 & 1.2578 & 1.44 & -0.4592 & 0.9808 \\
10.23 & 5.65 & 6.62 & 6.84 & 0.12 & 1.6137 & 1.26 & -0.2010 & 1.4610 \\
10.49 & 5.70 & 6.80 & 6.92 & 0.12 & 2.1052 & 1.03 & & \\
\hline
\end{tabular}

$\operatorname{LogK}_{2}$ (Average value) $=1.2209 \pm 0.3398$

Table 7:Point-wise method, Pb (Hydrolysed PSHA)

\begin{tabular}{|l|l|l|l|l|l|l|l|l|}
\hline $\mathrm{pH}$ & $\mathrm{BV}_{1}$ & $\mathrm{BV}_{2}$ & $\mathrm{BV}_{3}$ & $\left(\mathrm{~V}_{3}-\mathrm{V}_{2}\right)$ & $\mathrm{n}$ & $\mathrm{pL}$ & $\log \left(\frac{n}{1-n}\right)$ & LogK $_{1}$ \\
\hline 8.50 & 5.30 & 6.29 & 6.33 & 0.04 & 0.5500 & 2.66 & 0.0871 & 2.7471 \\
8.72 & 5.35 & 6.37 & 6.41 & 0.04 & 0.5714 & 2.43 & 0.1249 & 2.5549 \\
9.00 & 5.40 & 6.46 & 6.50 & 0.04 & 0.6198 & 2.16 & 0.2122 & 2.3722 \\
9.22 & 5.45 & 6.55 & 6.60 & 0.05 & 0.8333 & 1.96 & 0.6989 & 2.6589 \\
\hline
\end{tabular}

Log $_{\mathbf{1}}($ Average value $)=2.5832 \pm 0.1614$

Table 8:Point-wise method, Pb-(Hydrolysed PSHA)

\begin{tabular}{|l|l|l|l|l|l|l|l|l|}
\hline $\mathrm{pH}$ & $\mathrm{BV}_{1}$ & $\mathrm{BV}_{2}$ & $\mathrm{BV}_{3}$ & $\left(\mathrm{~V}_{3}-\mathrm{V}_{2}\right)$ & $\mathrm{n}$ & $\mathrm{pL}$ & $\log \left(\frac{n-1}{2-n}\right)$ & $\log \mathrm{K}_{2}$ \\
\hline 9.51 & 5.50 & 6.66 & 6.71 & 0.05 & 0.9650 & 1.67 & & \\
9.73 & 5.55 & 6.78 & 6.83 & 0.05 & 1.1702 & 1.44 & & \\
10.00 & 5.60 & 6.90 & 6.90 & 0.05 & 1.4864 & 1.22 & -0.0237 & 1.1963 \\
10.23 & 5.65 & 7.05 & 7.10 & 0.05 & 2.0190 & 1.09 & & \\
10.49 & 5.70 & 7.10 & 7.17 & 0.07 & 3.6492 & 1.00 & & \\
\hline
\end{tabular}

Log $K_{2}$ (Average value) $=1.1963$

Table 9: Point-wise method, Pb (Unhydrolysed PSHA)

\begin{tabular}{|l|l|l|l|l|l|l|l|l|}
\hline $\mathrm{pH}$ & $\mathrm{BV}_{1}$ & $\mathrm{BV}_{2}$ & $\mathrm{BV}_{3}$ & $\mathrm{~V}_{3}-\mathrm{V}_{2}$ & $\mathrm{n}$ & $\mathrm{pL}$ & $\begin{array}{l}\text { Log } \\
\left(\frac{n}{n-1}\right)\end{array}$ & Log $\mathrm{K}_{1}$ \\
\hline 8.50 & 5.30 & 5.81 & 5.85 & 0.04 & 0.2973 & 2.88 & -0.3736 & 2.5064 \\
8.72 & 5.35 & 5.90 & 5.94 & 0.04 & 0.3099 & 2.66 & -0.5477 & 2.3123 \\
9.00 & 5.40 & 6.00 & 6.05 & 0.05 & 0.4044 & 2.38 & -0.1681 & 2.2119 \\
9.22 & 5.45 & 6.10 & 6.15 & 0.06 & 0.5157 & 2.18 & 0.0272 & 2.2072 \\
9.51 & 5.50 & 6.20 & 6.26 & 0.07 & 0.6417 & 1.89 & 0.2530 & 2.1430 \\
9.73 & 5.55 & 6.40 & 6.40 & 0.07 & 0.7000 & 1.67 & 0.3680 & 2.0380 \\
\hline
\end{tabular}

LogK $_{1}$ (Average value) $=2.2364 \pm 0.1602$

Table 10: Point-wise method, Pb (Unhydrolysed PSHA)

\begin{tabular}{|l|l|l|l|l|l|l|l|l|}
\hline $\mathrm{pH}$ & $\mathrm{BV}_{1}$ & $\mathrm{BV}_{2}$ & $\mathrm{BV}_{3}$ & $\mathrm{~V}_{3}-\mathrm{V}_{2}$ & $\mathrm{n}$ & $\mathrm{pL}$ & $\log \left(\frac{n-1}{2-n}\right)$ & $\log \mathrm{K}_{2}$ \\
\hline 10.00 & 5.60 & 6.47 & 6.55 & 0.08 & 1.9503 & 1.41 & & \\
10.23 & 5.65 & 6.62 & 6.72 & 0.11 & 1.4792 & 1.26 & -0.0361 & 1.2239 \\
\hline
\end{tabular}

$\operatorname{LogK}_{2}$ (Average value) $=1.2239$

Table 11: Point-wise method, Mg (Hydrolysed PSHA)

\begin{tabular}{|l|l|l|l|l|l|l|l|l|}
\hline $\mathrm{pH}$ & $\mathrm{BV}_{1}$ & $\mathrm{BV}_{2}$ & $\mathrm{BV}_{3}$ & $\left(\mathrm{~V}_{3}-\mathrm{V}_{2}\right)$ & $\mathrm{n}$ & $\mathrm{pL}$ & $\log \left(\frac{n}{n-1}\right)$ & LogK $_{1}$ \\
\hline 8.50 & 5.30 & 6.29 & 6.31 & 0.02 & 0.2750 & 2.64 & -0.4290 & 2.2110 \\
8.72 & 5.35 & 6.37 & 6.39 & 0.02 & 0.2858 & 2.42 & -0.3978 & 2.0222 \\
9.00 & 5.40 & 6.46 & 6.49 & 0.03 & 0.4648 & 2.14 & -0.0612 & 2.0788 \\
9.22 & 5.45 & 6.55 & 6.59 & 0.04 & 0.6667 & 1.94 & 0.3010 & 2.2410 \\
\hline
\end{tabular}

$\log _{\mathbf{1}}($ Average value) $=2.1382 \pm 0.1046$ 
BAJOPAS Volume 14 Number 1,June, 2021

Table 12: Point-wise method, Mg (Hydrolysed PSHA)

\begin{tabular}{|l|l|l|l|l|l|l|l|l|}
\hline $\mathrm{pH}$ & $\mathrm{BV}_{1}$ & $\mathrm{BV}_{2}$ & $\mathrm{BV}_{3}$ & $\left(\mathrm{~V}_{3}-\mathrm{V}_{2}\right)$ & $\mathrm{n}$ & $\mathrm{pL}$ & $\log \left(\frac{n-1}{2-n}\right)$ & LogK $_{2}$ \\
\hline 9.51 & 5.55 & 6.66 & 6.71 & 0.05 & 0.9650 & 1.67 & & \\
9.73 & 5.55 & 6.78 & 6.84 & 0.06 & 1.4042 & 1.47 & -0.1686 & 1.3014 \\
10.00 & 5.60 & 6.90 & 6.93 & 0.06 & 1.7838 & 1.23 & 0.5593 & 1.7893 \\
10.23 & 5.65 & 7.05 & 7.10 & 0.06 & 3.1429 & 1.10 & & \\
10.49 & 5.70 & 7.10 & 7.18 & 0.07 & 3.6492 & 0.83 & & \\
\hline
\end{tabular}

LogK $_{2}($ Average value $)=1.5453 \pm 0.3450$

Table 13: Point-wise method, Mg (Unhydrolysed PSHA)

\begin{tabular}{|l|l|l|l|l|l|l|l|l|}
\hline $\mathrm{pH}$ & $\mathrm{BV}_{1}$ & $\mathrm{BV}_{2}$ & $\mathrm{BV}_{3}$ & $\mathrm{~V}_{3}-\mathrm{V}_{2}$ & $\mathrm{n}$ & $\mathrm{pL}$ & $\log \left(\frac{n}{n-1}\right)$ & $\operatorname{Log~}_{1}$ \\
\hline 8.50 & 5.30 & 5.81 & 5.85 & 0.04 & 0.2973 & 2.88 & -0.3736 & 2.5064 \\
8.72 & 5.35 & 5.90 & 5.94 & 0.04 & 0.3099 & 2.66 & -0.3477 & 2.3123 \\
9.00 & 5.40 & 6.00 & 6.04 & 0.04 & 0.3236 & 2.38 & -0.3202 & 2.0598 \\
9.22 & 5.45 & 6.10 & 6.15 & 0.05 & 0.4297 & 2.17 & -0.1230 & 2.0470 \\
9.51 & 5.50 & 6.20 & 6.26 & 0.06 & 0.5500 & 1.89 & 0.0871 & 1.9771 \\
9.73 & 5.55 & 6.33 & 6.40 & 0.07 & 0.7000 & 1.67 & 0.3680 & 2.0380 \\
\hline
\end{tabular}

LogK $_{1}$ (Average value) $=2.1568 \pm 0.2069$

Table 14: Point-wise method, Mg (Unhydrolysed PSHA)

\begin{tabular}{|l|l|l|l|l|l|l|l|l|}
\hline $\mathrm{pH}$ & $\mathrm{BV}_{1}$ & $\mathrm{BV}_{2}$ & $\mathrm{BV}_{3}$ & $\mathrm{~V}_{3}-\mathrm{V}_{2}$ & $\mathrm{n}$ & $\mathrm{pL}$ & $\log \left(\frac{n-1}{2-n}\right)$ & $\log \mathrm{K}_{2}$ \\
\hline 10.00 & 5.60 & 6.47 & 6.55 & 0.08 & 0.9148 & 1.41 & & \\
10.23 & 5.65 & 6.62 & 6.71 & 0.09 & 1.2102 & 1.20 & -0.5749 & 0.6251 \\
10.49 & 5.70 & 6.80 & 6.92 & 0.09 & 1.5968 & 1.03 & 0.1703 & 1.2003 \\
\hline
\end{tabular}

LogK $_{2}$ (Average value) $=0.9127 \pm 0.4070$

Table15:Point-wise method, Cd (Hydrolysed PSHA)

\begin{tabular}{|l|l|l|l|l|l|l|l|l|}
\hline $\mathrm{pH}$ & $\mathrm{BV}_{1}$ & $\mathrm{BV}_{2}$ & $\mathrm{BV}_{3}$ & $\left(\mathrm{~V}_{3}-\mathrm{V}_{2}\right)$ & $\mathrm{n}$ & $\mathrm{pL}$ & $\log \left(\frac{n}{1-n}\right)$ & LogK $_{1}$ \\
\hline 8.50 & 5.30 & 6.29 & 6.31 & 0.02 & 0.2750 & 2.64 & -0.4210 & 2.2190 \\
8.72 & 5.35 & 6.37 & 6.40 & 0.03 & 0.4286 & 2.42 & -0.1249 & 2.2951 \\
9.00 & 5.40 & 6.46 & 6.49 & 0.03 & 0.4648 & 2.14 & -0.0612 & 2.0788 \\
9.22 & 5.45 & 6.55 & 6.59 & 0.04 & 0.6667 & 1.96 & 0.3010 & 2.2610 \\
9.51 & 5.55 & 6.66 & 6.70 & 0.04 & 0.7720 & 1.67 & 0.5297 & 2.1997 \\
\hline
\end{tabular}

LogK $_{\mathbf{1}}$ (Average value) $=2.2108 \pm 0.0825$

Table 16: Point-wise method, Cd (Hydrolysed PSHA)

\begin{tabular}{|l|l|l|l|l|l|l|l|l|}
\hline $\mathrm{pH}$ & $\mathrm{BV}_{1}$ & $\mathrm{BV}_{2}$ & $\mathrm{BV}_{3}$ & $\left(\mathrm{~V}_{3}-\mathrm{V}_{2}\right)$ & $\mathrm{n}$ & $\mathrm{pL}$ & $\log \left(\frac{n-1}{2-n}\right)$ & Log $_{2}$ \\
\hline 9.73 & 5.55 & 6.78 & 6.83 & 0.06 & 1.4042 & 1.47 & -0.1686 & 1.3014 \\
10.00 & 5.60 & 6.90 & 6.95 & 0.06 & 1.7838 & 1.23 & 0.5593 & 1.7893 \\
10.23 & 5.65 & 7.05 & 7.10 & 0.06 & 3.1429 & 1.09 & & \\
10.49 & 5.70 & 7.10 & 7.16 & 0.06 & 3.1429 & 0.89 & & \\
& & & & & & & & \\
\hline
\end{tabular}

$\operatorname{LogK}_{2}$ (Average value) $=1.5453 \pm 0.3450$

Table 17: Point-wise method, Cd (Unhydrolysed PSHA)

\begin{tabular}{|l|l|l|l|l|l|l|l|l|}
\hline $\mathrm{pH}$ & $\mathrm{BV}_{1}$ & $\mathrm{BV}_{2}$ & $\mathrm{BV}_{3}$ & $\mathrm{~V}_{3}-\mathrm{V}_{2}$ & $\mathrm{n}$ & $\mathrm{pL}$ & $\log \left(\frac{n}{n-1}\right)$ & $\operatorname{Log~}_{1}$ \\
\hline 8.50 & 5.30 & 5.81 & 5.86 & 0.05 & 0.3717 & 2.88 & -0.2280 & 2.6520 \\
8.72 & 5.35 & 5.90 & 5.95 & 0.05 & 0.3873 & 2.66 & -0.1992 & 2.4608 \\
9.00 & 5.40 & 6.00 & 6.06 & 0.06 & 0.4853 & 2.38 & -0.0255 & 2.3545 \\
9.22 & 5.45 & 6.10 & 6.16 & 0.06 & 0.5157 & 2.18 & -0.0272 & 2.2072 \\
9.51 & 5.50 & 6.20 & 6.27 & 0.07 & 0.6417 & 1.89 & 0.2530 & 1.1430 \\
9.73 & 5.55 & 6.33 & 6.41 & 0.08 & 0.8000 & 1.69 & 0.6020 & 2.2920 \\
& & & & & & & & \\
\hline
\end{tabular}

$\operatorname{LogK}_{1}($ Average value $)=2.2516 \pm 0.5380$ 
BAJOPAS Volume 14 Number 1,June, 2021

Table 18: Point-wise method, Cd (Unhydrolysed PSHA)

\begin{tabular}{|l|l|l|l|l|l|l|l|l|}
\hline $\mathrm{pH}$ & $\mathrm{BV}_{1}$ & $\mathrm{BV}_{2}$ & $\mathrm{BV}_{3}$ & $\mathrm{~V}_{3}-\mathrm{V}_{2}$ & $\mathrm{n}$ & $\mathrm{pL}$ & $\log \left(\frac{n-1}{2-n}\right)$ & $\log \mathrm{K}_{2}$ \\
\hline 10.00 & 5.60 & 6.47 & 6.57 & 0.10 & 1.1434 & 1.43 & & \\
10.23 & 5.65 & 6.62 & 6.72 & 0.10 & 1.3448 & 1.23 & -0.2788 & 0.9512 \\
10.49 & 5.70 & 6.80 & 6.90 & 0.10 & 1.7742 & 1.03 & 0.5351 & 1.5651 \\
\hline
\end{tabular}

$\operatorname{LogK}_{2}($ Average value $)=1.2581 \pm 0.4340$

Table 19: Stepwise and overall Stability constants of thehydrolysed and unhydrolysed divalent metal (II) complexes

\begin{tabular}{|c|c|c|c|}
\hline Chelates & LogK $_{1}$ & $\log _{2}$ & Log $\beta$ \\
\hline [Cu (Hydrolysed PSHA-1) $\left.{ }_{2}\right]$ & 2.4788 & 1.4280 & 3.9068 \\
\hline$\left[\mathrm{Pb}(\text { Hydrolysed PSHA-1) })_{2}\right]$ & 2.5832 & 1.1963 & 3.7795 \\
\hline$\left[\mathrm{Cd}(\text { Hydrolysed PSHA-1 })_{2}\right]$ & 2.2108 & 1.5453 & 3.7561 \\
\hline$\left[\mathrm{Mg}(\text { Hydrolysed PSHA-1 })_{2}\right]$ & 2.1382 & 1.5453 & 3.6835 \\
\hline [Cu (Unhydrolysed PSHA-1) & 2.3059 & 1.2209 & 3.5268 \\
\hline$[\mathrm{Pb}$ (Unhydrolysed PSHA-1) 2$]$ & 2.2364 & 1.2239 & 3.4603 \\
\hline [Cd (Unhydrolysed PSHA-1) 2 ] & 2.2516 & 1.2581 & 3.5097 \\
\hline$[\mathrm{Mg}$ (Unydrolysed PSHA-1) & 2.1568 & 0.9127 & 3.0695 \\
\hline
\end{tabular}

The results obtained (Table19) shows the stepwise and overall stability constants to be not high indicating low stability of the complexes, because the solubility of most metal ions in the basic $\mathrm{pH}$ range is minimal due to metal hydroxide precipitation (Karimi, 2017). In general, the stepwise stability constants $\left(K_{1}\right.$ and $K_{2}$ ) follow the order $K_{1}>K_{2}$ for the copper, lead, magnesium and cadmium complexes respectively. The steady decrease of the values with increasing number of ligands is in agreement with the prediction made by researchers (Na'aliya, 2013). The decrease could be attributed to the fact that as the number of the ligands (Humate ions) that enters the coordination zone increases the aqua molecules available for replacement by the ligands become less. Thus, the metal ions become less electron loving with progressive intake of the ligand and this results in the decrease in the values of the constants (Na'aliya, 2013). Also the stability of the complexes is influenced by the size and number of the chelate rings(Mackay and Mackay,2002).All the complexes form rings in their structure as humate, a bidentate ligand, bond the metal ions in the ratio 1:2 (Boguta and Sokolowska, 2016) forming chelate rings. The values of the overall stability constants $(\log \beta)$ obtained for humate complexes are not high indicating low stability as the values are not high. LogK values for copper-humates (Table 3 to 6) obtained in this study are lower than those reported for the complexes of humic acids (Pandey et al., 2015; Dinu, 2013; Kaschl et al., 2010 and Gilbeto and Jorg, 2001). The values of LogK(Table 7 to 10 ) forlead-humates are lower than those reported for the lead in the literature (Dinu, 2013; Gilbeto and Jorg 2001). Log K values(Table 11 to 14 ) for magnesium-humates obtained in this study are close to those reported by (Pandey et al., 2015). Log K values of cadmium-humates (Table 15 to 18 ) obtained in this work near to the one reported by (Dinu, 2013 and Pandey et al., 2015).The difference between the reported values and the values obtained in this study might be probably as a result of acid hydrolysis of humic acid. The values of the overall stability constants $(\log \beta)$ of the copper humates complexes presented in Table 19 is high than that of other metal humate complexes, show relatively high stability of CuHA complexes, show the following order of stability: $\mathrm{Cu}>\mathrm{Pb}>\mathrm{Cd}>\mathrm{Mg}$; which are in close agreement to the findings of (Dinu, 2013 and Pandey et al., 2015).The high stability of Cuhumate chelate could be attributed to the existence of coordinate covalent bond between the complexing agents and the $\mathrm{Cu}^{2+}$ ions. Since, $\mathrm{Cu}^{2+}$ being a metal of the transitional series with $3 d^{9}$ electronic configurations can accept the electrons from the complexing agents. Similarly, the low stabilities of $\mathrm{Pb}, \mathrm{Cd}$ and $\mathrm{Mg}$ complexes could be explained by that $\mathrm{Pb}^{2+}$ with $6 s^{2}, \mathrm{Cd}^{2+}$ with $4 \mathrm{~d}^{10}$ and $\mathrm{Mg}^{2+}$ with $2 \mathrm{p}^{6}$ their electronic configuration has a completely filled $\mathrm{d}, \mathrm{p}$ and $\mathrm{s}$ orbitals. Moreover, the stabilities of metal ions with hydrolysed humic acid from peat soil were higher than those with unhydrolysed humic acid from peat soil; which is ascribed to the high content of acidity in hydrolysed humic acid than unhydrolysed humic acid. 
BAJOPAS Volume 14 Number 1,June, 2021 CONCLUSION

The values of logk for $\mathrm{Cu}(\mathrm{II})$ hydrolysed humic acid complex was higher followed by $\mathrm{Pb}$ (II), $\mathrm{Cd}(\mathrm{II})$ and $\mathrm{Mg}$ (II) hydrolysed humic acid complexes as compared with metal(II) unhydrolysed humic acid complexes. This indicates acid hydrolysis of humic acid can

\section{REFERENCES}

Almeida, V.R. and Szpoganicz, B. (2015). Humic Acid Potentiometric Response Patterns:Out- of Equilibrium Properties and Species Distribution Modelling. Chemical. Biol. Technol. Agric. 2: 17.

Anđelković, T., Nikolić, R., Bojić, A.,Anđelković, D., and Nikolic G.,(2010). Binding of Cadmium to Soil Humic Acid as A Function of Carboxyl Group Content. Macedonian Journal of Chemistry and Chemical Engineering.29(2): 215-224.

Anil, B. N. and Maroti, N. (2008). Studies on Influence of Die-Lectric Constants on Complex Equilibria between Substituted Py-Razalines and Lanthanide Metal Ions pH-Metrically. Amer.-Euras. scient. Res. 3(2): 212-216.

Ashok, K., Pandey, S. P. and Misra, V (2000). Stability Constants of Metal-Humic Acid Complexes and its Role in Environmental Detoxification. Journal of Ecotoxicology and Environmental Safety. 47(2):157-200.

Badr, M. H., El-Halafawi, M. H. and Abd El-al Zeid, E. R. (2012). Comparison Between the Effect of Ionic Strength on Acidity and Dissociation Constants of Humic Acids Extracted from Sewage Sludge and Nile Water Hyacinth Composts.Global Journal of Environmental Research 6 (1): 36-43.

Baruah, M.K., Borah, D., Saikia, P.P., Paul, S., Sharma, T. (2015). Evaluation of pKa Values of Soil Humic Acids and their Complexation Properties. International Journal of Plant \& Soil Science 6(4) : 218-228.

Boguta, P. Sokolowska, Z. (2016). Interactions of $\mathrm{Zn}$ (II) Ions with Humic Acids Isolated from Various Types of Soils. Effect of $\mathrm{pH}, \mathrm{Zn}$ Concentrations and Humic Acids Chemical Properties. Journal of Geochemical Explaration 168. 119-126.

Borges, F., Guimaraes, C., Lima, L.F.C., Pinto, I. and Reis, S.(2005). Potentiometric Studies on the Complexation of Copper(II) by Phenolic Acids as Discrete Ligand Models of enhance the complexation behavior of humic acid with metal (II) ions. However, the higher values of $\log \beta$ for $\mathrm{Cu}(\mathrm{II}), \mathrm{Pb}(\mathrm{II}), \mathrm{Cd}(\mathrm{II})$ and $\mathrm{Mg}(\mathrm{II})$ hydrolysed humic acid complexes indicates more stable stepwise complexes formed as compared with $\mathrm{Cu}(\mathrm{II}), \mathrm{Pb}$ (II), $\mathrm{Cd}$ (II) and $\mathrm{Mg}(\mathrm{II})$ unhydrolysed humic acid complexes.

Humic Substances Talanta 66 (2005) 670-673.

Chefetz, B., Salloum, M. J., Deshmulkin, A. P. and Hatcher, P. (2002). Structural Components of Humic Acids as Determined by Chemical Modifications and Carbon-13 NMR, Pyrolysis, and Thermochemolysis- Gas Chromatography/Mass Spectrometry. Soil Science Society of American Journal Abstract Division S-2- Soil Chemistry66. 1159-1171.

Dinu, M. I. (2013). Metals Complexation with Humic Acids in Surface Water of Different Environ. Sci. Technol. 31(1): 1-17.

Fernandes, A.N., Giacomelli, C., Giovanela, M. Vaz, D.V. Szpoganicz, B. and Maria M. D. (2009). Potentiometric Acidity Determination in Humic Substances Influenced by Different Analytical Procedures.J. Braz. Chem. Soc. 20 (9):14.

Gamal, A. H. (2015). Stability Constants of Rhenium (V) Metal Complexes with Selected Drugs. Pyrex Journal of Research in Environmental Studies. 2(2): 006-014.

Janrao, D. M., Pathan, J., Kayande, D.D., and Mulla, J.J. (2014). An Over View of Potentiometric Determination of Stability Constants of Metal Complexes. Sci. Revs. Chem. Commun.: 4(1), 2014, 11-24.

Karimi, H. (2017). Effect of pH and Initial Pb(II) Concentration on the Lead Removal Efficiency from Waste Water Using $\mathrm{Ca}(\mathrm{OH})_{2}$. International Journal of Water and Waste Water Treatment 3.2

Kaschl, A. Romheld, V. and Chen, Y. (2010). Binding of Cadmium, Copper and Zinc to Humic Substances Originating from Municipal Solid Waste Compost. Israel Journal of Chemistry Vol. 42(1): 89-98.

Kostic, I. S., Tatjana, P, A., Nikolic, R. S., Cvetkovic, T. P., Pavlovic, D. D., Aleksandar, L.J. and Bojic, A. (2012). Comparative Study of Binding Strengths of Heavy Metals with Humic Acid. J.serb. Chem. Soc. 76(9) pp 1-20. 
BAJOPAS Volume 14 Number 1,June, 2021

Na'aliya, J. (2013). Determination of Stepwise Stability Constants and Gibbs free Energy Change of Trisprolina to Complexes of some Divalent Transition Metal ions. Bayero Journal of Pure and Applied Sciences 6(2): 112-114.

Omar, A. A. and Ali, E. A. (2015). Potentiometric Studies on Complexes of $\mathrm{Cr}$ (III) and $\mathrm{Zr}$ (IV) with some Carboxylic Acids. International Journal of Advanced Chemistry, 3(1) 25-

37.

Pandey, A. K. Pandey, S. D. and Misr, V. (2015).Stability Constants of Metal- Humic Acid Complexes and Its Role in Environmental Detoxification. J. Ecotoxicology and Environmental Safety. 47(1):195-200.

Ram, N. and Raman, K.V. (1984). Stability Constants of Complexes of Metals with
Humicand Fuvic Acids under Non- acidConditions. Journal of Plant Nutrition and Soil Sciences.

147:171-176.

Santosh, D. D., Ashok, B. K., Vijay, J. T., Shivraj, G. W. and Vinay, V. W. (2011). Potentiometric Studies of Elec-Trolyte Effects on Complex Equilibria of Some Substituted 5-(2-hydroxy Phenyl) Pyrazoles. Der pharm. 3 (6): 75-83.

Sayyed, H. and Abdul Rahim, M. F. (2012). Studies of Binary Complexes of Metal Ions with Mandelic Acid by Potentiometry. Chem. J. 02 (6): 206209.

Shirvani, M. Moradian, E. Khalili, B. Bakhtiary, S. (2015). Interaction of $\mathrm{Cd}$ and $\mathrm{Pb}$ with Humate-Palygorskite and HumateSepiolite Complexes. Journal of water, air and pollution 3: 220-228. 


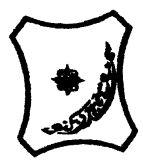

Bayero Journal of Pure and Applied Sciences, 14(1): 54 - 63

Received: November, 2020

Accepted: April, 2021

ISSN $2006-6996$

\title{
STABILITY CONSTANTS OF COMPLEXES OF METAL IONS WITH PEATSOIL HUMIC ACIDS UNDER NON-ACID-CONDITIONS
}

\author{
${ }^{* 1}$ Sabo, Yusuf ${ }^{2}$ Jimoh, W.L.O., ${ }^{3}$ Isa Baba Koki and ${ }^{4}$ Sholadoye, Q. 0. \\ ${ }^{1}$ Department of Pure and Industrial Chemistry, Bayero University, Kano \\ ${ }^{3}$ Department of Chemistry, Yusuf Maitama Sule University Kano. P.M.B. 3220 Kano, Nigeria. \\ ${ }^{4}$ Department of Chemistry, Nigerian Police Academy, Wudil, Kano-Nigeria
}

*Correspondence E-mail; saboyusuf18@yahoo.com

ABSTRACT

Stability constants of complexes of four divalent metal ions viz. $\mathrm{Cu}^{2+}, \mathrm{Pb}^{2+}, \mathrm{Mg}^{2+}$ and $\mathrm{Cd}^{2+}$ with humic acids (HA) were determined by potentiometric titration of humic acids with the corresponding salt of the divalent metals in aqueous media under non-acid-condition. The log $K$ (logarithm of the stability constant) ranged from 1.0942 to 2.7471 for metalhumic acid complexes were determined using point-wise computational method. The order of stability constants were obtained as follows: $\mathrm{Cu}>\mathrm{Pb}>\mathrm{Cd}>\mathrm{Mg}$ for metal $-\mathrm{HA}$ complexes respectively, indicating a higher degree of complexation with Cu metal ion.

Keywords: stability constant, humic acid, potentiometric titration, divalent metals, acid hydrolysis.

\section{NTRODUCTION}

The stability constant of a complex is the numerical expression of its stability and provides a quantitative measure of affinity of the metal ion to the complexing agent. An understanding of the relative stability of metal-complexes helps in predicting the behavior of metal ions in the soil (Ram and Raman, 1982). Extensive researches has been done to determine the stability constants of the complexes formed between humic acid (HA) with a number of metal ions. Ashok et al., (2000) reported that humic acid with hydroxyl, phenoxyl and carboxyl reactive groups can form coordination compound with metal ions at $\mathrm{pH}$ 3.5. The stability constants(Log K) for different metalhumic acid complexes indicated the following order of the stabilities of complexes formed between humic acid and metal ion, $\mathrm{Cu}>\mathrm{Fe}$ $>\mathrm{Pb}>\mathrm{Ni}>\mathrm{Co}>\mathrm{Ca}>\mathrm{Cd}>\mathrm{Zn}>\mathrm{Mn}>\mathrm{Mg}$. Andelkovic et al., (2010) investigated the binding of $\mathrm{Cd}$ (II) to soil humic acid at pH 6.5 and in $0.1 \mathrm{M} \mathrm{KNO}_{3}$ ionic medium. The stability constant for binding indicating greater stability in the case when carboxyl groups are involved in complexation reaction. Kostic et al.,(2012) investigated the complexation of humic acid with certain heavy metal ions (Co(II), $\mathrm{Ni}(\mathrm{II}), \mathrm{Cu}(\mathrm{II})$,
$\mathrm{Zn}(\mathrm{II})$, and $\mathrm{Pb}(\mathrm{II})$. The experiment was performed at $25^{\circ} \mathrm{C}$, at pH 4.0 and ionic strength of $0.01 \mathrm{M}$. Stability constant of complex between $\mathrm{Pb}$ (II) ions and humic acid is greater than stability constants of other investigated metalhumate complexes. Bogata and Sokolowska (2016) analyses the interaction between humic acids from different soils and $\mathrm{Zn}$ (II) ions at wide concentration ranges and at $\mathrm{pH} 5$. Studies have showed significant impact of $\mathrm{Zn}$ concentration, $\mathrm{pH}$ and some properties of humic acids with zinc.But all of these studies were limited to acidic $\mathrm{pH}$ range. Therefore, the present study was carried out to determine and compare the stability constants of complexes of metal ions with hydrolysed peat soil humic acid and unhydrolysed peat soil humic under non-acid conditions.

\section{MATERIALS AND METHODS}

Analytical grade chemicals used includes hydrochloric acid $(\mathrm{HCl})$, nitric acid $\left(\mathrm{HNO}_{3}\right)$, sodium hydroxide $(\mathrm{NaOH})$, lead nitrate $\mathrm{Pb}\left(\mathrm{NO}_{3}\right)_{2}$, copper nitrate $\mathrm{Cu}\left(\mathrm{NO}_{3}\right)_{2} \cdot 3 \mathrm{H}_{2} \mathrm{O}$, cadmium nitrate $\mathrm{Cd}\left(\mathrm{NO}_{3}\right)_{2} \cdot 4 \mathrm{H}_{2} \mathrm{O}$, magnesium nitrate $\mathrm{Mg}\left(\mathrm{NO}_{3}\right)_{2} \cdot 6 \mathrm{H}_{2} \mathrm{O}$, potassium nitrate $\left(\mathrm{KNO}_{3}\right)$, calcium chloride $\left(\mathrm{CaCl}_{2}\right)$, (sigma-Aldrich). Dowex 50WX8, (20-50 mesh) from Fluka. 


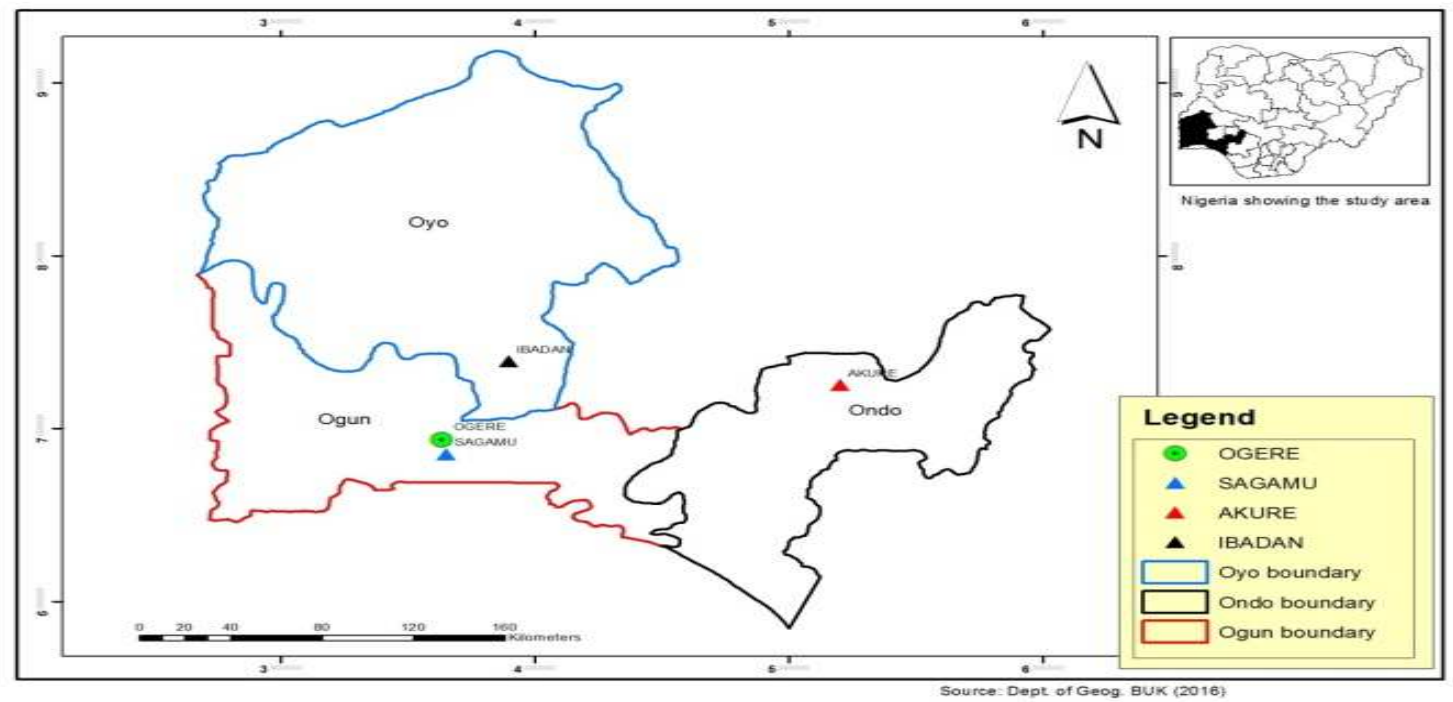

Figure 1: Map showing the sampling point at Sagamu Town, Ogun State.

\section{Description of Sampling Area}

Sagamu has geographical coordinates between $6^{\circ} 50^{\prime}$ north; $3^{\circ} 38^{\prime}$ east is located in south western region of Nigeria. The region has tropical wet and dry climate with a lengthy wet season and relatively constant temperatures throughout the course of the year. Wet season runs from March to October, November to December forms the region dry season. The vegetation type of the region is savannah which is really grassland with small bushes and occasional big trees. Grassland soils have substantially higher organic matter content than forest soils (Novackova, 2011).

\section{Sample Collection}

The Peatsoil samples were collected from four different sampling points $(0-10 \mathrm{~cm}$ depth) in Sagamu into polyethylene bag with plastic spoons. Samples were taken to the laboratory, extraneous materials were removed; the samples were air-dried, crushed and ground to a fine powder in a mortar passed through a $0.20 \mathrm{~mm}$ sieve. The samples were kept for analysis.

\section{Isolation and purification of humic acid from peat soil sample}

Peatsoil sample $(100 \mathrm{~g})$ was mixed with 1000 $\mathrm{cm}^{3}$ of $0.1 \mathrm{M} \mathrm{NaOH}$ solution, shaken for 3hours and left to stand overnight. Dark-coloured supernatant was obtained and decanted from solid residue. The dark-coloured supernatant was acidified to $(\mathrm{pH}=1.0)$ with $6 \mathrm{M} \mathrm{HCl}$ stirred and allowed to stand for 6 hours. Yellowish brown supernatant and dark-brown precipitate were obtained. The yellowish brown supernatant was decanted followed by centrifuge and discarded. The dark-brown precipitate was mixed with $500 \mathrm{~cm}^{3}$ of $0.1 \mathrm{M} \mathrm{NaOH}$ solution followed by passing through dowex resin. The dark-brown solution was acidified to $(\mathrm{pH}=1.0)$ with $6 \mathrm{M} \mathrm{HCl}$ stirred and allowed to stand for 3 hours. The dark-brown precipitate was washed several times with deionized water. The supernatant was treated with $\mathrm{AgNO}_{3}$ solution until no white precipitate observed. The humic acid was transferred to weighed crucible and dried at $60^{\circ} \mathrm{C}$ in an oven for 12 hours. The humic acid was cooled and dried in the desiccator, weighed and recorded. The obtained humic acid was dried again at $60^{\circ} \mathrm{C}$ for additional 6 hours cooled and dried in the desiccator, weighed and recorded constant weight was obtained (Baruah et al., 2015).

\section{FT-IR analysis}

FT-IR spectra of humic acid sample was analysed using Carry 630 FT-IR Agilent Technologies.

Unhydrolysed compost humic acid

The unhydrolysed humic acid was obtained after isolation and purification of compost humic acid and kept for investigation.

\section{Acid hydrolysis of Peatsoil acid}

Peatsoil humic acid sample (1g) was refluxed for 12 hours at $\left(160^{\circ} \mathrm{C}\right)$ with $50 \mathrm{~cm}^{3}$ of $6 \mathrm{M} \mathrm{HCl}$. The mixture was allowed to cool, decanted, and centrifuged after hydrolysis. The insoluble residues were washed with distilled water via centrifugation several times, and the supernatant was treated with $\mathrm{AgNO}_{3}$ solution until no white precipitate was observed. The residue was thoroughly dried over $\mathrm{CaCl}_{2}$ in a desiccator at room temperature (Chefetz et al., 2002). Finally, the obtained hydrolysed humic acid was kept for investigation. 
BAJOPAS Volume 14 Number 1,June, 2021 Potentiometric Titrations

Potentiometric measurements were carried out using a pH-meter Jenway (model 3510) with combine electrode, the sensitivity of the $\mathrm{pH}$ meter is 0.01 units. The $\mathrm{pH}$ meter was switched on half an hour before starting the titration for initial warm up of the instrument. The instrument was calibrated with an aqueous standard buffer solution of $\mathrm{pH} 4.00$ and 10.0 (borate buffer) prepared from a "Qualigens" buffer tablets.

The following sets of solutions were prepared in a $250 \mathrm{~cm}^{3}$ volumetric flask separately for $\mathrm{pH}$ metric titrations.

(i) $5 \mathrm{~cm}^{3} 0.1 \mathrm{M} \mathrm{HCl}+40 \mathrm{~cm}^{3}$ deionized water

(ii) $5 \mathrm{~cm}^{3} 0.1 \mathrm{M} \mathrm{HCl}+39 \mathrm{~cm}^{3}$ deionized water $+1 \mathrm{~cm}^{3} 0.15 \mathrm{gcm}^{-3}$ humic acid

(iii) $5 \mathrm{~cm}^{3} 0.1 \mathrm{M} \mathrm{HCl}+37 \mathrm{~cm}^{3}$ deionized water $+1 \mathrm{~cm}^{3} 0.15 \mathrm{gcm}^{-3}$ humic acid

$$
+2 \mathrm{~cm}^{3} \quad 0.01 \mathrm{M} \mathrm{Cu} \text { (II) }
$$

The solutions were titrated against standardized $0.110 \mathrm{MNaOH}$ separately. The total volume of each mixture was adjusted to $50 \mathrm{~cm}^{3}$ and the ionic strength of the solutions was maintained constant at by adding appropriate amount of stock solution of $1 \mathrm{M} \mathrm{KNO}_{3}$ (Gamal, 2015; Omar and Ali, 2015). A magnetic stirrer was used to achieve thorough mixing of the interacting solutions at $550 \mathrm{rpm}$. The same set of experimental conditions was applied for potentiometric titration of remaining samples.

\section{Evaluation of pKa of Hydrolysed peat soil Humic Acids}

The proton-ligand formation number $\mathrm{n}_{\mathbf{A}}$ were calculated by Irving and Rossotti expression (Omar and Ali, 2015).

$\mathrm{nA}=\mathrm{Y}-\frac{(\mathrm{V} 2-\mathrm{V1})(\mathrm{No}-\mathrm{Eo})}{(\mathrm{VO}+\mathrm{V1}) \mathrm{TCL}}$ 1

Where: $Y$ is number of dissociable proton, $\left(\mathrm{V}_{2^{-}}\right.$ $V_{1}$ ) is the measure of displacement of the ligand curve relative to acid curve, $\mathrm{N}^{\circ}$ and $\mathrm{E}^{\circ}$ are the resultant concentration of alkali solution, free acid solution, $\mathrm{T}_{\mathrm{cL}}{ }^{\circ}$ is the total ligand concentration, $\mathrm{V}^{\circ}$ is the total volume of titration solution, $V_{1}$ is the volume of alkali added to acid solution, $V_{2}$ is the volume of alkali added to acid solution + ligand solution, acid dissociation constants (pKa - values) of ligand were calculated by algebraic method point wise calculation (Tables 1 ). The dissociation constants (pKa) were calculated according to the following relation:

$\mathrm{pKa}=\mathrm{pH}+\log \left(\frac{n A}{1-n A}\right)$ 2

Where: pKa is the acid dissociation constant, $\mathrm{n}_{\mathrm{A}}$ is the Proton-ligand formation number and $\mathrm{pH}$ is the pH-values (Omar and Ali, 2015).

\section{Determination of metal-ligand stability constants $(\log K)$ of complexes}

The potentiometric measurement for the determination of stability constant of a complex in solution is based on the fact that the redox potential of the couple $\frac{M^{+(m-n)}}{M^{+m}}$ is shifted significantly on complexation of the metal ion with the ligand. This method involves change in hydrogen ion concentration $\left[\mathrm{H}^{+}\right]$due to the displacement or association of one or more protons taking place during complexation reaction. This change can be found out by titrating the solutions containing free acid, acid with ligand, and acid with ligand and metal ion, individually against a standard alkali solution at a constant ionic strength or temperature. Either ionic strength or temperature may be varied for different sets of solutions. In all the cases, the change in the $\mathrm{pH}$ of the solution is measured after each addition of a known amount of alkali to the reaction cell which contains the reaction mixture. The titration curves are then drawn by plotting the measured $\mathrm{pH}$ values against the corresponding volume of alkali added and the stability constants of the complexes are determined from the titration curves by employing $\mathrm{pH}$-metric titration technique given by (Irving and Rossoti).

Metal-ligand stability constants ( $\log \mathrm{K}$ ) were determined by using the following relations:

$$
\bar{n}=\frac{\left(V_{3}-V_{2}\right)\left(E^{0}+N^{0}\right)}{\left(V^{0}+V_{2}\right) \bar{n}_{A} T_{m}^{0}}
$$

and

$$
P L=\log _{10}\left\{\frac{1+\beta_{n}^{H} \frac{1}{[\text { anti } \log \mathrm{pH}]^{\mathrm{n}}}}{\mathrm{T}_{\mathrm{L}}^{0}-n \bar{T}_{m}^{0}} \mathrm{X} \frac{\left(V^{0}+V_{3}\right)}{V^{0}}\right\}
$$


BAJOPAS Volume 14 Number 1,June, 2021

Where $T_{L}, T^{\circ}, E^{\circ}$, and $V^{\circ}$ havethe same significance as in equation (1) above, $T_{m}$ denotes the total concentration of metal present in solution, $V_{3}$ is the volume of metal ions present in solution and $\beta^{H}$ is the overall proton ligand stability constant. The metal-ligand stability constants (log K) were determined by employing point wise computational Method (eq. 5 and 6).

$\operatorname{LogK}_{1}=\log \left(\frac{n}{1-n}\right)+\mathrm{pL}$ .5

$\operatorname{LogK}_{2}=\log \left(\frac{1-n}{2-n}\right)+\mathrm{pL}$ ...6

Where: Log $\mathrm{K}$ is the metal-ligand stability constant, $\mathrm{pL}$ is the Free ligand exponent function, $\mathbf{n}$ is the Average number of ligand attached with metal ion (Janraoet al., 2014). The results obtained were analyzed by an ORIGIN 2016 program using titration data and then the proton-ligand stability constants (pKa) and Metal-ligand stability constant (LogK) calculated (Omar and Ali, 2015).

\section{RESULTS AND DISCUSSION}

Fourier transformed infrared (FT-IR) spectra of isolated humic acid from peat soils Figure 2 had distinct clear absorption bands indicating the presence of major humic acid structural elemental groups such as $\mathrm{H}$ bonded $\mathrm{OH}$ $\left(3680 \mathrm{~cm}^{-1}\right.$ peak $), C=0$ of carbonyl $\left(1721 \mathrm{~cm}^{-1}\right.$ peak), functional groups of aliphatic components $\mathrm{CH}_{2}\left(2918 \mathrm{~cm}^{-1}\right.$ peak) and $\mathrm{C}-\mathrm{O}$ stretching of polysaccharide $\left(1168 \mathrm{~cm}^{-1}\right.$ peak). The positions of the absorption bands of the spectra fell within typical major absorption bands of humic acid which is at frequencies 3680, 2918, 1721, 1168 $\mathrm{cm}^{-1}$. The first peak centred in the vicinity of $3680 \mathrm{~cm}^{-1}$ region is attributed to phenol $\mathrm{OH}$ group bounded by intermolecular $\mathrm{H}$ bonds. The $2918 \mathrm{~cm}^{-1}$ band usually has absorption maximum at $2918 \mathrm{~cm}^{-1}$ which is due to $\mathrm{C}-\mathrm{H}$ stretching of alkane group $\left(\mathrm{CH}_{2}\right)$. The next major absorption band is $1721 \mathrm{~cm}^{-1}$. This band has been commonly ascribed to $\mathrm{C}=\mathrm{O}$ stretching of mainly carboxyl group $(\mathrm{COOH})$ with trace amount of ketones. The last peak was observed at 1168 $\mathrm{cm}^{-1}$ due to $\mathrm{C}-\mathrm{O}$ stretching of polysaccharides and this peak appeared also in the spectra of humic acid from peat soil. The FTIR spectra of the isolated humic acid contained all major characteristic absorption peaks of humic acid. These absorption peaks indicated the presence of the major structural elements of humic acid namely $\mathrm{H}$ bonded $\mathrm{OH}, \mathrm{C}=\mathrm{C}$ of aromatic ring, $\mathrm{C}=\mathrm{O}$ of carbonyl group (both carboxyl and ketonic), $\mathrm{CH}_{2}$ group. This strongly supports the presence of humic acid.

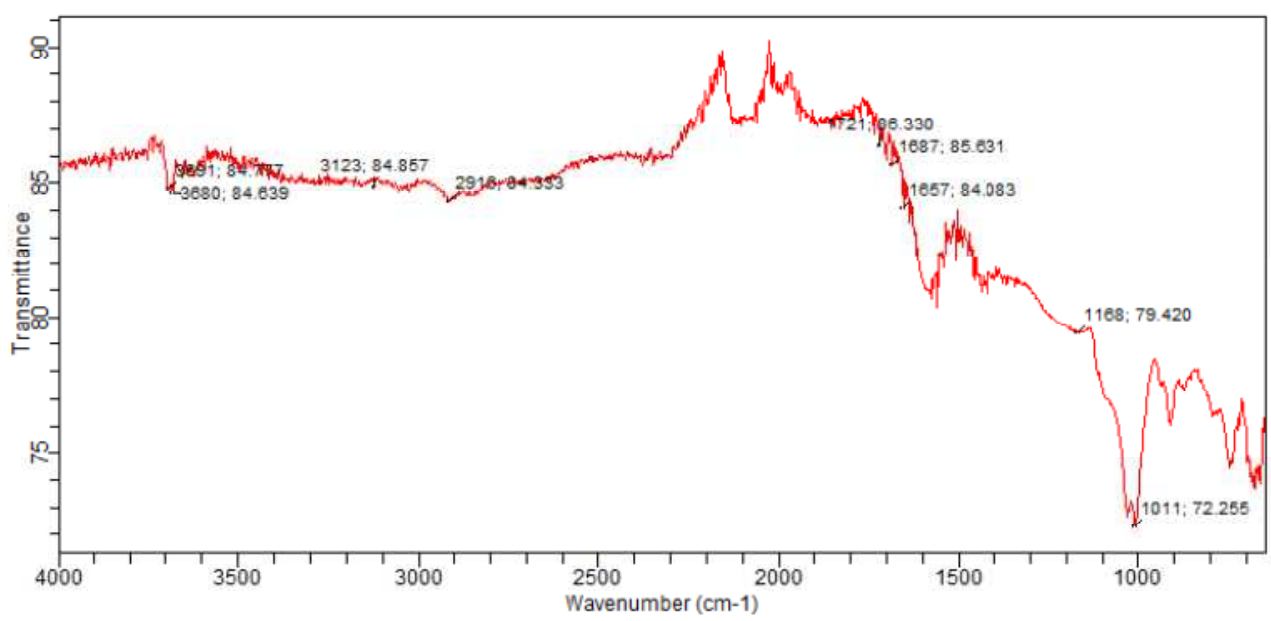

Fig. 2 : FT-IR spectraof peatsoilhumic acid (PSHA)

\section{Evaluation of acid dissociation constant (pka) of acid hydrolysed peat soil humicacid at phenolic group}

The value of the dissociation constant of the peat soil humic acid (PSHA) that underwent acidhydrolysis studied was found to be 8.9299 as shown Table 1, which is lower than the literaturevalues reported by Almeida and Szpoganics, (2015), Borges et al., (2005); Badr et al., (2012)and Fernandes et al,.(2009) of $9.73,9.47$ and 10.30. The difference between the obtained valuesand the reported values in this study might be probably as a result of acid hydrolysis of humicacid. 
BAJOPAS Volume 14 Number 1,June, 2021

Table 1: PKa of (Hydrolysed PSHA)

\begin{tabular}{|l|l|l|l|l|l|l|}
\hline $\mathrm{pH}$ & $\mathrm{BV}_{1}$ & $\mathrm{BV}_{2}$ & $\mathrm{~V}_{2}-\mathrm{V}_{1}$ & $\mathrm{nA}$ & $\log \left(\frac{n A}{1-n A}\right)$ & $\mathrm{pKa}$ \\
\hline 8.50 & 5.30 & 6.29 & 0.99 & 0.3594 & -0.2510 & 8.2490 \\
8.72 & 5.35 & 6.37 & 1.02 & 0.3400 & -0.2880 & 8.4320 \\
9.00 & 5.40 & 6.46 & 1.06 & 0.3141 & -0.3391 & 8.6609 \\
9.22 & 5.45 & 6.55 & 1.10 & 0.2882 & -0.3927 & 8.8273 \\
9.51 & 5.50 & 6.66 & 1.16 & 0.2494 & -0.4786 & 9.0314 \\
9.73 & 5.55 & 6.78 & 1.23 & 0.2041 & -0.5910 & 9.1390 \\
10.00 & 5.60 & 6.90 & 1.30 & 0.1589 & -0.7238 & 9.2762 \\
10.23 & 5.65 & 7.05 & 1.40 & 0.0941 & -0.9835 & 9.2465 \\
10.49 & 5.70 & 7.10 & 1.40 & 0.0941 & -0.9835 & 9.5065 \\
\hline
\end{tabular}

Average pKa $=8.9299 \pm 0.4186$

Table 2: PKa of (Unhydrolysed PSHA)

\begin{tabular}{|l|l|l|l|l|l|l|}
\hline $\mathrm{pH}$ & $\mathrm{BV}_{1}$ & $\mathrm{BV}_{2}$ & $\mathrm{~V}_{2}-\mathrm{V}_{1}$ & $\mathrm{nA}$ & $\log \left(\frac{\boldsymbol{n A}}{1-\boldsymbol{n}}\right)$ & $\mathrm{pKa}$ \\
\hline 8.50 & 5.30 & 5.81 & 0.51 & 0.6619 & 0.2919 & 8.7919 \\
8.72 & 5.35 & 5.90 & 0.55 & 0.6357 & 0.2418 & 8.9618 \\
9.00 & 5.40 & 6.00 & 0.60 & 0.6029 & 0.1813 & 9.1813 \\
9.22 & 5.45 & 6.10 & 0.65 & 0.5701 & 0.1226 & 9.3426 \\
9.51 & 5.50 & 6.20 & 0.70 & 0.5376 & 0.0654 & 9.5754 \\
9.73 & 5.55 & 6.33 & 0.78 & 0.4851 & -0.0259 & 9.7041 \\
10.00 & 5.60 & 6.47 & 0.87 & 0.4262 & -0.1291 & 9.8709 \\
10.23 & 5.65 & 6.62 & 0.99 & 0.3609 & -0.2481 & 9.9819 \\
10.49 & 5.70 & 6.80 & 1.10 & 0.2759 & -0.4690 & 10.0210 \\
\hline
\end{tabular}

Average pKa $=9.4923 \pm 0.4410$

Metal-ligand stability constant ( $\log \mathrm{K}$ )

The stabilityconstants require the accurate values of proton-ligand stability constants (Anil and Maroti, 2008). Metal titration curves crossed over ligand titration curve indicated the formation of complex upon proton release (Santosh, et al., 2011). If the values of n- are within range $0.2-0.8$ and $1.2-18$ this indicates the formation of $1: 1$ and 1:2 complexes (Sayyed and Mazahar, 2012).

The metal (II)-humate stepwise stability constants (log k) at phenolic group (Tables 318)

Table 3: Point-wise method, $\mathrm{Cu}$-(Hydrolysed PSHA)

\begin{tabular}{|l|l|l|l|l|l|l|l|l|}
\hline $\mathrm{pH}$ & $\mathrm{BV}_{1}$ & $\mathrm{BV}_{2}$ & $\mathrm{BV}_{3}$ & $\left(\mathrm{~V}_{3}-\mathrm{V}_{2}\right)$ & $\mathrm{n}$ & $\mathrm{pL}$ & $\log \left(\frac{n}{1-n}\right)$ & LogK $_{1}$ \\
\hline 8.50 & 5.30 & 6.29 & 6.33 & 0.04 & 0.5500 & 2.66 & 0.0871 & 2.7471 \\
8.72 & 5.35 & 6.37 & 6.41 & 0.04 & 0.5714 & 2.43 & 0.1249 & 2.5549 \\
9.00 & 5.40 & 6.46 & 6.50 & 0.04 & 0.6198 & 2.16 & 0.2122 & 2.3722 \\
9.22 & 5.45 & 6.55 & 6.59 & 0.04 & 0.6667 & 1.94 & 0.3010 & 2.2410 \\
\hline
\end{tabular}

LogK $_{1}$ (Average value) $=2.4788 \pm 0.2203$

Table 4: Point-wise method, $\mathrm{Cu}$-(Hydrolysed PSHA)

\begin{tabular}{|l|l|l|l|l|l|l|l|l|}
\hline $\mathrm{pH}$ & $\mathrm{BV}_{1}$ & $\mathrm{BV}_{2}$ & $\mathrm{BV}_{3}$ & $\left(\mathrm{~V}_{3}-\mathrm{V}_{2}\right)$ & $\mathrm{n}$ & $\mathrm{pL}$ & $\log \left(\frac{n-1}{2-n}\right)$ & LogK $_{2}$ \\
\hline 9.51 & 5.50 & 6.66 & 6.73 & 0.07 & 1.3509 & 1.70 & -0.2671 & 1.4329 \\
9.73 & 5.55 & 6.78 & 6.85 & 0.07 & 1.6383 & 1.51 & 0.2467 & 1.7567 \\
10.00 & 5.60 & 6.90 & 6.98 & 0.08 & 2.1783 & 1.31 & -0.2158 & 1.0942 \\
10.23 & 5.65 & 7.05 & 7.13 & 0.08 & 4.1904 & 1.27 & & \\
10.49 & 5.70 & 7.10 & 7.19 & 0.09 & 4.6920 & & & \\
\hline
\end{tabular}

Log $K_{2}($ Average value $)=1.4280 \pm 0.3312$ 
BAJOPAS Volume 14 Number 1,June, 2021

Table 5: Point-wise method, $\mathrm{Cu}$ (Unhydrolysed PSHA)

\begin{tabular}{|l|l|l|l|l|l|l|l|l|}
\hline $\mathrm{pH}$ & $\mathrm{BV}_{1}$ & $\mathrm{BV}_{2}$ & $\mathrm{BV}_{3}$ & $\left(\mathrm{~V}_{3}-\mathrm{V}_{2}\right)$ & $\mathrm{n}$ & $\mathrm{pL}$ & $\log \left(\frac{n}{n-1}\right)$ & Log $_{1}$ \\
\hline 8.50 & 5.30 & 5.81 & 5.85 & 0.04 & 0.2973 & 2.88 & -0.3736 & 2.5064 \\
8.72 & 5.35 & 5.90 & 5.95 & 0.05 & 0.3873 & 2.66 & -0.1992 & 2.4608 \\
9.00 & 5.40 & 6.00 & 6.05 & 0.05 & 0.4044 & 2.38 & -0.1681 & 2.2119 \\
9.22 & 5.45 & 6.10 & 6.15 & 0.06 & 0.5157 & 2.18 & -0.0272 & 2.2072 \\
9.51 & 5.50 & 6.20 & 6.27 & 0.07 & 0.6417 & 1.89 & 0.2530 & 1.1430 \\
\hline
\end{tabular}

$\operatorname{LogK}_{1}($ Average value $)=2.3059 \pm 0.6153$

Table 6:Point-wise method, $\mathrm{Cu}$ (Unhydrolysed PSHA)

\begin{tabular}{|l|l|l|l|l|l|l|l|l|}
\hline $\mathrm{pH}$ & $\mathrm{BV}_{1}$ & $\mathrm{BV}_{2}$ & $\mathrm{BV}_{3}$ & $\mathrm{~V}_{3}-\mathrm{V}_{2}$ & $\mathrm{n}$ & $\mathrm{pL}$ & $\log \left(\frac{n-1}{2-n}\right)$ & $\log \mathrm{K}_{2}$ \\
\hline 9.73 & 5.55 & 6.33 & 6.42 & 0.09 & 0.9000 & 1.69 & & \\
10.00 & 5.60 & 6.47 & 6.58 & 0.11 & 1.2578 & 1.44 & -0.4592 & 0.9808 \\
10.23 & 5.65 & 6.62 & 6.84 & 0.12 & 1.6137 & 1.26 & -0.2010 & 1.4610 \\
10.49 & 5.70 & 6.80 & 6.92 & 0.12 & 2.1052 & 1.03 & & \\
\hline
\end{tabular}

$\operatorname{LogK}_{2}$ (Average value) $=1.2209 \pm 0.3398$

Table 7:Point-wise method, Pb (Hydrolysed PSHA)

\begin{tabular}{|l|l|l|l|l|l|l|l|l|}
\hline $\mathrm{pH}$ & $\mathrm{BV}_{1}$ & $\mathrm{BV}_{2}$ & $\mathrm{BV}_{3}$ & $\left(\mathrm{~V}_{3}-\mathrm{V}_{2}\right)$ & $\mathrm{n}$ & $\mathrm{pL}$ & $\log \left(\frac{n}{1-n}\right)$ & LogK $_{1}$ \\
\hline 8.50 & 5.30 & 6.29 & 6.33 & 0.04 & 0.5500 & 2.66 & 0.0871 & 2.7471 \\
8.72 & 5.35 & 6.37 & 6.41 & 0.04 & 0.5714 & 2.43 & 0.1249 & 2.5549 \\
9.00 & 5.40 & 6.46 & 6.50 & 0.04 & 0.6198 & 2.16 & 0.2122 & 2.3722 \\
9.22 & 5.45 & 6.55 & 6.60 & 0.05 & 0.8333 & 1.96 & 0.6989 & 2.6589 \\
\hline
\end{tabular}

Log $_{\mathbf{1}}($ Average value $)=2.5832 \pm 0.1614$

Table 8:Point-wise method, Pb-(Hydrolysed PSHA)

\begin{tabular}{|l|l|l|l|l|l|l|l|l|}
\hline $\mathrm{pH}$ & $\mathrm{BV}_{1}$ & $\mathrm{BV}_{2}$ & $\mathrm{BV}_{3}$ & $\left(\mathrm{~V}_{3}-\mathrm{V}_{2}\right)$ & $\mathrm{n}$ & $\mathrm{pL}$ & $\log \left(\frac{n-1}{2-n}\right)$ & $\log \mathrm{K}_{2}$ \\
\hline 9.51 & 5.50 & 6.66 & 6.71 & 0.05 & 0.9650 & 1.67 & & \\
9.73 & 5.55 & 6.78 & 6.83 & 0.05 & 1.1702 & 1.44 & & \\
10.00 & 5.60 & 6.90 & 6.90 & 0.05 & 1.4864 & 1.22 & -0.0237 & 1.1963 \\
10.23 & 5.65 & 7.05 & 7.10 & 0.05 & 2.0190 & 1.09 & & \\
10.49 & 5.70 & 7.10 & 7.17 & 0.07 & 3.6492 & 1.00 & & \\
\hline
\end{tabular}

Log $K_{2}$ (Average value) $=1.1963$

Table 9: Point-wise method, Pb (Unhydrolysed PSHA)

\begin{tabular}{|l|l|l|l|l|l|l|l|l|}
\hline $\mathrm{pH}$ & $\mathrm{BV}_{1}$ & $\mathrm{BV}_{2}$ & $\mathrm{BV}_{3}$ & $\mathrm{~V}_{3}-\mathrm{V}_{2}$ & $\mathrm{n}$ & $\mathrm{pL}$ & $\begin{array}{l}\text { Log } \\
\left(\frac{n}{n-1}\right)\end{array}$ & Log $\mathrm{K}_{1}$ \\
\hline 8.50 & 5.30 & 5.81 & 5.85 & 0.04 & 0.2973 & 2.88 & -0.3736 & 2.5064 \\
8.72 & 5.35 & 5.90 & 5.94 & 0.04 & 0.3099 & 2.66 & -0.5477 & 2.3123 \\
9.00 & 5.40 & 6.00 & 6.05 & 0.05 & 0.4044 & 2.38 & -0.1681 & 2.2119 \\
9.22 & 5.45 & 6.10 & 6.15 & 0.06 & 0.5157 & 2.18 & 0.0272 & 2.2072 \\
9.51 & 5.50 & 6.20 & 6.26 & 0.07 & 0.6417 & 1.89 & 0.2530 & 2.1430 \\
9.73 & 5.55 & 6.40 & 6.40 & 0.07 & 0.7000 & 1.67 & 0.3680 & 2.0380 \\
\hline
\end{tabular}

LogK $_{1}$ (Average value) $=2.2364 \pm 0.1602$

Table 10: Point-wise method, Pb (Unhydrolysed PSHA)

\begin{tabular}{|l|l|l|l|l|l|l|l|l|}
\hline $\mathrm{pH}$ & $\mathrm{BV}_{1}$ & $\mathrm{BV}_{2}$ & $\mathrm{BV}_{3}$ & $\mathrm{~V}_{3}-\mathrm{V}_{2}$ & $\mathrm{n}$ & $\mathrm{pL}$ & $\log \left(\frac{n-1}{2-n}\right)$ & $\log \mathrm{K}_{2}$ \\
\hline 10.00 & 5.60 & 6.47 & 6.55 & 0.08 & 1.9503 & 1.41 & & \\
10.23 & 5.65 & 6.62 & 6.72 & 0.11 & 1.4792 & 1.26 & -0.0361 & 1.2239 \\
\hline
\end{tabular}

$\operatorname{LogK}_{2}$ (Average value) $=1.2239$

Table 11: Point-wise method, Mg (Hydrolysed PSHA)

\begin{tabular}{|l|l|l|l|l|l|l|l|l|}
\hline $\mathrm{pH}$ & $\mathrm{BV}_{1}$ & $\mathrm{BV}_{2}$ & $\mathrm{BV}_{3}$ & $\left(\mathrm{~V}_{3}-\mathrm{V}_{2}\right)$ & $\mathrm{n}$ & $\mathrm{pL}$ & $\log \left(\frac{n}{n-1}\right)$ & LogK $_{1}$ \\
\hline 8.50 & 5.30 & 6.29 & 6.31 & 0.02 & 0.2750 & 2.64 & -0.4290 & 2.2110 \\
8.72 & 5.35 & 6.37 & 6.39 & 0.02 & 0.2858 & 2.42 & -0.3978 & 2.0222 \\
9.00 & 5.40 & 6.46 & 6.49 & 0.03 & 0.4648 & 2.14 & -0.0612 & 2.0788 \\
9.22 & 5.45 & 6.55 & 6.59 & 0.04 & 0.6667 & 1.94 & 0.3010 & 2.2410 \\
\hline
\end{tabular}

$\log _{\mathbf{1}}($ Average value) $=2.1382 \pm 0.1046$ 
BAJOPAS Volume 14 Number 1,June, 2021

Table 12: Point-wise method, Mg (Hydrolysed PSHA)

\begin{tabular}{|l|l|l|l|l|l|l|l|l|}
\hline $\mathrm{pH}$ & $\mathrm{BV}_{1}$ & $\mathrm{BV}_{2}$ & $\mathrm{BV}_{3}$ & $\left(\mathrm{~V}_{3}-\mathrm{V}_{2}\right)$ & $\mathrm{n}$ & $\mathrm{pL}$ & $\log \left(\frac{n-1}{2-n}\right)$ & LogK $_{2}$ \\
\hline 9.51 & 5.55 & 6.66 & 6.71 & 0.05 & 0.9650 & 1.67 & & \\
9.73 & 5.55 & 6.78 & 6.84 & 0.06 & 1.4042 & 1.47 & -0.1686 & 1.3014 \\
10.00 & 5.60 & 6.90 & 6.93 & 0.06 & 1.7838 & 1.23 & 0.5593 & 1.7893 \\
10.23 & 5.65 & 7.05 & 7.10 & 0.06 & 3.1429 & 1.10 & & \\
10.49 & 5.70 & 7.10 & 7.18 & 0.07 & 3.6492 & 0.83 & & \\
\hline
\end{tabular}

LogK $_{2}($ Average value $)=1.5453 \pm 0.3450$

Table 13: Point-wise method, Mg (Unhydrolysed PSHA)

\begin{tabular}{|l|l|l|l|l|l|l|l|l|}
\hline $\mathrm{pH}$ & $\mathrm{BV}_{1}$ & $\mathrm{BV}_{2}$ & $\mathrm{BV}_{3}$ & $\mathrm{~V}_{3}-\mathrm{V}_{2}$ & $\mathrm{n}$ & $\mathrm{pL}$ & $\log \left(\frac{n}{n-1}\right)$ & $\operatorname{Log~}_{1}$ \\
\hline 8.50 & 5.30 & 5.81 & 5.85 & 0.04 & 0.2973 & 2.88 & -0.3736 & 2.5064 \\
8.72 & 5.35 & 5.90 & 5.94 & 0.04 & 0.3099 & 2.66 & -0.3477 & 2.3123 \\
9.00 & 5.40 & 6.00 & 6.04 & 0.04 & 0.3236 & 2.38 & -0.3202 & 2.0598 \\
9.22 & 5.45 & 6.10 & 6.15 & 0.05 & 0.4297 & 2.17 & -0.1230 & 2.0470 \\
9.51 & 5.50 & 6.20 & 6.26 & 0.06 & 0.5500 & 1.89 & 0.0871 & 1.9771 \\
9.73 & 5.55 & 6.33 & 6.40 & 0.07 & 0.7000 & 1.67 & 0.3680 & 2.0380 \\
\hline
\end{tabular}

LogK $_{1}$ (Average value) $=2.1568 \pm 0.2069$

Table 14: Point-wise method, Mg (Unhydrolysed PSHA)

\begin{tabular}{|l|l|l|l|l|l|l|l|l|}
\hline $\mathrm{pH}$ & $\mathrm{BV}_{1}$ & $\mathrm{BV}_{2}$ & $\mathrm{BV}_{3}$ & $\mathrm{~V}_{3}-\mathrm{V}_{2}$ & $\mathrm{n}$ & $\mathrm{pL}$ & $\log \left(\frac{n-1}{2-n}\right)$ & $\log \mathrm{K}_{2}$ \\
\hline 10.00 & 5.60 & 6.47 & 6.55 & 0.08 & 0.9148 & 1.41 & & \\
10.23 & 5.65 & 6.62 & 6.71 & 0.09 & 1.2102 & 1.20 & -0.5749 & 0.6251 \\
10.49 & 5.70 & 6.80 & 6.92 & 0.09 & 1.5968 & 1.03 & 0.1703 & 1.2003 \\
\hline
\end{tabular}

LogK $_{2}$ (Average value) $=0.9127 \pm 0.4070$

Table15:Point-wise method, Cd (Hydrolysed PSHA)

\begin{tabular}{|l|l|l|l|l|l|l|l|l|}
\hline $\mathrm{pH}$ & $\mathrm{BV}_{1}$ & $\mathrm{BV}_{2}$ & $\mathrm{BV}_{3}$ & $\left(\mathrm{~V}_{3}-\mathrm{V}_{2}\right)$ & $\mathrm{n}$ & $\mathrm{pL}$ & $\log \left(\frac{n}{1-n}\right)$ & LogK $_{1}$ \\
\hline 8.50 & 5.30 & 6.29 & 6.31 & 0.02 & 0.2750 & 2.64 & -0.4210 & 2.2190 \\
8.72 & 5.35 & 6.37 & 6.40 & 0.03 & 0.4286 & 2.42 & -0.1249 & 2.2951 \\
9.00 & 5.40 & 6.46 & 6.49 & 0.03 & 0.4648 & 2.14 & -0.0612 & 2.0788 \\
9.22 & 5.45 & 6.55 & 6.59 & 0.04 & 0.6667 & 1.96 & 0.3010 & 2.2610 \\
9.51 & 5.55 & 6.66 & 6.70 & 0.04 & 0.7720 & 1.67 & 0.5297 & 2.1997 \\
\hline
\end{tabular}

LogK $_{\mathbf{1}}$ (Average value) $=2.2108 \pm 0.0825$

Table 16: Point-wise method, Cd (Hydrolysed PSHA)

\begin{tabular}{|l|l|l|l|l|l|l|l|l|}
\hline $\mathrm{pH}$ & $\mathrm{BV}_{1}$ & $\mathrm{BV}_{2}$ & $\mathrm{BV}_{3}$ & $\left(\mathrm{~V}_{3}-\mathrm{V}_{2}\right)$ & $\mathrm{n}$ & $\mathrm{pL}$ & $\log \left(\frac{n-1}{2-n}\right)$ & Log $_{2}$ \\
\hline 9.73 & 5.55 & 6.78 & 6.83 & 0.06 & 1.4042 & 1.47 & -0.1686 & 1.3014 \\
10.00 & 5.60 & 6.90 & 6.95 & 0.06 & 1.7838 & 1.23 & 0.5593 & 1.7893 \\
10.23 & 5.65 & 7.05 & 7.10 & 0.06 & 3.1429 & 1.09 & & \\
10.49 & 5.70 & 7.10 & 7.16 & 0.06 & 3.1429 & 0.89 & & \\
& & & & & & & & \\
\hline
\end{tabular}

$\operatorname{LogK}_{2}$ (Average value) $=1.5453 \pm 0.3450$

Table 17: Point-wise method, Cd (Unhydrolysed PSHA)

\begin{tabular}{|l|l|l|l|l|l|l|l|l|}
\hline $\mathrm{pH}$ & $\mathrm{BV}_{1}$ & $\mathrm{BV}_{2}$ & $\mathrm{BV}_{3}$ & $\mathrm{~V}_{3}-\mathrm{V}_{2}$ & $\mathrm{n}$ & $\mathrm{pL}$ & $\log \left(\frac{n}{n-1}\right)$ & $\operatorname{Log~}_{1}$ \\
\hline 8.50 & 5.30 & 5.81 & 5.86 & 0.05 & 0.3717 & 2.88 & -0.2280 & 2.6520 \\
8.72 & 5.35 & 5.90 & 5.95 & 0.05 & 0.3873 & 2.66 & -0.1992 & 2.4608 \\
9.00 & 5.40 & 6.00 & 6.06 & 0.06 & 0.4853 & 2.38 & -0.0255 & 2.3545 \\
9.22 & 5.45 & 6.10 & 6.16 & 0.06 & 0.5157 & 2.18 & -0.0272 & 2.2072 \\
9.51 & 5.50 & 6.20 & 6.27 & 0.07 & 0.6417 & 1.89 & 0.2530 & 1.1430 \\
9.73 & 5.55 & 6.33 & 6.41 & 0.08 & 0.8000 & 1.69 & 0.6020 & 2.2920 \\
& & & & & & & & \\
\hline
\end{tabular}

$\operatorname{LogK}_{1}($ Average value $)=2.2516 \pm 0.5380$ 
BAJOPAS Volume 14 Number 1,June, 2021

Table 18: Point-wise method, Cd (Unhydrolysed PSHA)

\begin{tabular}{|l|l|l|l|l|l|l|l|l|}
\hline $\mathrm{pH}$ & $\mathrm{BV}_{1}$ & $\mathrm{BV}_{2}$ & $\mathrm{BV}_{3}$ & $\mathrm{~V}_{3}-\mathrm{V}_{2}$ & $\mathrm{n}$ & $\mathrm{pL}$ & $\log \left(\frac{n-1}{2-n}\right)$ & $\log \mathrm{K}_{2}$ \\
\hline 10.00 & 5.60 & 6.47 & 6.57 & 0.10 & 1.1434 & 1.43 & & \\
10.23 & 5.65 & 6.62 & 6.72 & 0.10 & 1.3448 & 1.23 & -0.2788 & 0.9512 \\
10.49 & 5.70 & 6.80 & 6.90 & 0.10 & 1.7742 & 1.03 & 0.5351 & 1.5651 \\
\hline
\end{tabular}

$\operatorname{LogK}_{2}($ Average value $)=1.2581 \pm 0.4340$

Table 19: Stepwise and overall Stability constants of thehydrolysed and unhydrolysed divalent metal (II) complexes

\begin{tabular}{|c|c|c|c|}
\hline Chelates & LogK $_{1}$ & $\log _{2}$ & Log $\beta$ \\
\hline [Cu (Hydrolysed PSHA-1) $\left.{ }_{2}\right]$ & 2.4788 & 1.4280 & 3.9068 \\
\hline$\left[\mathrm{Pb}(\text { Hydrolysed PSHA-1) })_{2}\right]$ & 2.5832 & 1.1963 & 3.7795 \\
\hline$\left[\mathrm{Cd}(\text { Hydrolysed PSHA-1 })_{2}\right]$ & 2.2108 & 1.5453 & 3.7561 \\
\hline$\left[\mathrm{Mg}(\text { Hydrolysed PSHA-1 })_{2}\right]$ & 2.1382 & 1.5453 & 3.6835 \\
\hline [Cu (Unhydrolysed PSHA-1) & 2.3059 & 1.2209 & 3.5268 \\
\hline$[\mathrm{Pb}$ (Unhydrolysed PSHA-1) 2$]$ & 2.2364 & 1.2239 & 3.4603 \\
\hline [Cd (Unhydrolysed PSHA-1) 2 ] & 2.2516 & 1.2581 & 3.5097 \\
\hline$[\mathrm{Mg}$ (Unydrolysed PSHA-1) & 2.1568 & 0.9127 & 3.0695 \\
\hline
\end{tabular}

The results obtained (Table19) shows the stepwise and overall stability constants to be not high indicating low stability of the complexes, because the solubility of most metal ions in the basic $\mathrm{pH}$ range is minimal due to metal hydroxide precipitation (Karimi, 2017). In general, the stepwise stability constants $\left(K_{1}\right.$ and $K_{2}$ ) follow the order $K_{1}>K_{2}$ for the copper, lead, magnesium and cadmium complexes respectively. The steady decrease of the values with increasing number of ligands is in agreement with the prediction made by researchers (Na'aliya, 2013). The decrease could be attributed to the fact that as the number of the ligands (Humate ions) that enters the coordination zone increases the aqua molecules available for replacement by the ligands become less. Thus, the metal ions become less electron loving with progressive intake of the ligand and this results in the decrease in the values of the constants (Na'aliya, 2013). Also the stability of the complexes is influenced by the size and number of the chelate rings(Mackay and Mackay,2002).All the complexes form rings in their structure as humate, a bidentate ligand, bond the metal ions in the ratio 1:2 (Boguta and Sokolowska, 2016) forming chelate rings. The values of the overall stability constants $(\log \beta)$ obtained for humate complexes are not high indicating low stability as the values are not high. LogK values for copper-humates (Table 3 to 6) obtained in this study are lower than those reported for the complexes of humic acids (Pandey et al., 2015; Dinu, 2013; Kaschl et al., 2010 and Gilbeto and Jorg, 2001). The values of LogK(Table 7 to 10 ) forlead-humates are lower than those reported for the lead in the literature (Dinu, 2013; Gilbeto and Jorg 2001). Log K values(Table 11 to 14 ) for magnesium-humates obtained in this study are close to those reported by (Pandey et al., 2015). Log K values of cadmium-humates (Table 15 to 18 ) obtained in this work near to the one reported by (Dinu, 2013 and Pandey et al., 2015).The difference between the reported values and the values obtained in this study might be probably as a result of acid hydrolysis of humic acid. The values of the overall stability constants $(\log \beta)$ of the copper humates complexes presented in Table 19 is high than that of other metal humate complexes, show relatively high stability of CuHA complexes, show the following order of stability: $\mathrm{Cu}>\mathrm{Pb}>\mathrm{Cd}>\mathrm{Mg}$; which are in close agreement to the findings of (Dinu, 2013 and Pandey et al., 2015).The high stability of Cuhumate chelate could be attributed to the existence of coordinate covalent bond between the complexing agents and the $\mathrm{Cu}^{2+}$ ions. Since, $\mathrm{Cu}^{2+}$ being a metal of the transitional series with $3 d^{9}$ electronic configurations can accept the electrons from the complexing agents. Similarly, the low stabilities of $\mathrm{Pb}, \mathrm{Cd}$ and $\mathrm{Mg}$ complexes could be explained by that $\mathrm{Pb}^{2+}$ with $6 s^{2}, \mathrm{Cd}^{2+}$ with $4 \mathrm{~d}^{10}$ and $\mathrm{Mg}^{2+}$ with $2 \mathrm{p}^{6}$ their electronic configuration has a completely filled $\mathrm{d}, \mathrm{p}$ and $\mathrm{s}$ orbitals. Moreover, the stabilities of metal ions with hydrolysed humic acid from peat soil were higher than those with unhydrolysed humic acid from peat soil; which is ascribed to the high content of acidity in hydrolysed humic acid than unhydrolysed humic acid. 
BAJOPAS Volume 14 Number 1,June, 2021 CONCLUSION

The values of logk for $\mathrm{Cu}(\mathrm{II})$ hydrolysed humic acid complex was higher followed by $\mathrm{Pb}$ (II), $\mathrm{Cd}(\mathrm{II})$ and $\mathrm{Mg}$ (II) hydrolysed humic acid complexes as compared with metal(II) unhydrolysed humic acid complexes. This indicates acid hydrolysis of humic acid can

\section{REFERENCES}

Almeida, V.R. and Szpoganicz, B. (2015). Humic Acid Potentiometric Response Patterns:Out- of Equilibrium Properties and Species Distribution Modelling. Chemical. Biol. Technol. Agric. 2: 17.

Anđelković, T., Nikolić, R., Bojić, A.,Anđelković, D., and Nikolic G.,(2010). Binding of Cadmium to Soil Humic Acid as A Function of Carboxyl Group Content. Macedonian Journal of Chemistry and Chemical Engineering.29(2): 215-224.

Anil, B. N. and Maroti, N. (2008). Studies on Influence of Die-Lectric Constants on Complex Equilibria between Substituted Py-Razalines and Lanthanide Metal Ions pH-Metrically. Amer.-Euras. scient. Res. 3(2): 212-216.

Ashok, K., Pandey, S. P. and Misra, V (2000). Stability Constants of Metal-Humic Acid Complexes and its Role in Environmental Detoxification. Journal of Ecotoxicology and Environmental Safety. 47(2):157-200.

Badr, M. H., El-Halafawi, M. H. and Abd El-al Zeid, E. R. (2012). Comparison Between the Effect of Ionic Strength on Acidity and Dissociation Constants of Humic Acids Extracted from Sewage Sludge and Nile Water Hyacinth Composts.Global Journal of Environmental Research 6 (1): 36-43.

Baruah, M.K., Borah, D., Saikia, P.P., Paul, S., Sharma, T. (2015). Evaluation of pKa Values of Soil Humic Acids and their Complexation Properties. International Journal of Plant \& Soil Science 6(4) : 218-228.

Boguta, P. Sokolowska, Z. (2016). Interactions of $\mathrm{Zn}$ (II) Ions with Humic Acids Isolated from Various Types of Soils. Effect of $\mathrm{pH}, \mathrm{Zn}$ Concentrations and Humic Acids Chemical Properties. Journal of Geochemical Explaration 168. 119-126.

Borges, F., Guimaraes, C., Lima, L.F.C., Pinto, I. and Reis, S.(2005). Potentiometric Studies on the Complexation of Copper(II) by Phenolic Acids as Discrete Ligand Models of enhance the complexation behavior of humic acid with metal (II) ions. However, the higher values of $\log \beta$ for $\mathrm{Cu}(\mathrm{II}), \mathrm{Pb}(\mathrm{II}), \mathrm{Cd}(\mathrm{II})$ and $\mathrm{Mg}(\mathrm{II})$ hydrolysed humic acid complexes indicates more stable stepwise complexes formed as compared with $\mathrm{Cu}(\mathrm{II}), \mathrm{Pb}$ (II), $\mathrm{Cd}$ (II) and $\mathrm{Mg}(\mathrm{II})$ unhydrolysed humic acid complexes.

Humic Substances Talanta 66 (2005) 670-673.

Chefetz, B., Salloum, M. J., Deshmulkin, A. P. and Hatcher, P. (2002). Structural Components of Humic Acids as Determined by Chemical Modifications and Carbon-13 NMR, Pyrolysis, and Thermochemolysis- Gas Chromatography/Mass Spectrometry. Soil Science Society of American Journal Abstract Division S-2- Soil Chemistry66. 1159-1171.

Dinu, M. I. (2013). Metals Complexation with Humic Acids in Surface Water of Different Environ. Sci. Technol. 31(1): 1-17.

Fernandes, A.N., Giacomelli, C., Giovanela, M. Vaz, D.V. Szpoganicz, B. and Maria M. D. (2009). Potentiometric Acidity Determination in Humic Substances Influenced by Different Analytical Procedures.J. Braz. Chem. Soc. 20 (9):14.

Gamal, A. H. (2015). Stability Constants of Rhenium (V) Metal Complexes with Selected Drugs. Pyrex Journal of Research in Environmental Studies. 2(2): 006-014.

Janrao, D. M., Pathan, J., Kayande, D.D., and Mulla, J.J. (2014). An Over View of Potentiometric Determination of Stability Constants of Metal Complexes. Sci. Revs. Chem. Commun.: 4(1), 2014, 11-24.

Karimi, H. (2017). Effect of pH and Initial Pb(II) Concentration on the Lead Removal Efficiency from Waste Water Using $\mathrm{Ca}(\mathrm{OH})_{2}$. International Journal of Water and Waste Water Treatment 3.2

Kaschl, A. Romheld, V. and Chen, Y. (2010). Binding of Cadmium, Copper and Zinc to Humic Substances Originating from Municipal Solid Waste Compost. Israel Journal of Chemistry Vol. 42(1): 89-98.

Kostic, I. S., Tatjana, P, A., Nikolic, R. S., Cvetkovic, T. P., Pavlovic, D. D., Aleksandar, L.J. and Bojic, A. (2012). Comparative Study of Binding Strengths of Heavy Metals with Humic Acid. J.serb. Chem. Soc. 76(9) pp 1-20. 
BAJOPAS Volume 14 Number 1,June, 2021

Na'aliya, J. (2013). Determination of Stepwise Stability Constants and Gibbs free Energy Change of Trisprolina to Complexes of some Divalent Transition Metal ions. Bayero Journal of Pure and Applied Sciences 6(2): 112-114.

Omar, A. A. and Ali, E. A. (2015). Potentiometric Studies on Complexes of $\mathrm{Cr}$ (III) and $\mathrm{Zr}$ (IV) with some Carboxylic Acids. International Journal of Advanced Chemistry, 3(1) 25-

37.

Pandey, A. K. Pandey, S. D. and Misr, V. (2015).Stability Constants of Metal- Humic Acid Complexes and Its Role in Environmental Detoxification. J. Ecotoxicology and Environmental Safety. 47(1):195-200.

Ram, N. and Raman, K.V. (1984). Stability Constants of Complexes of Metals with
Humicand Fuvic Acids under Non- acidConditions. Journal of Plant Nutrition and Soil Sciences.

147:171-176.

Santosh, D. D., Ashok, B. K., Vijay, J. T., Shivraj, G. W. and Vinay, V. W. (2011). Potentiometric Studies of Elec-Trolyte Effects on Complex Equilibria of Some Substituted 5-(2-hydroxy Phenyl) Pyrazoles. Der pharm. 3 (6): 75-83.

Sayyed, H. and Abdul Rahim, M. F. (2012). Studies of Binary Complexes of Metal Ions with Mandelic Acid by Potentiometry. Chem. J. 02 (6): 206209.

Shirvani, M. Moradian, E. Khalili, B. Bakhtiary, S. (2015). Interaction of $\mathrm{Cd}$ and $\mathrm{Pb}$ with Humate-Palygorskite and HumateSepiolite Complexes. Journal of water, air and pollution 3: 220-228. 


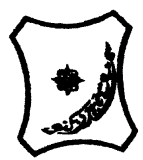

Bayero Journal of Pure and Applied Sciences, 14(1): 54 - 63

Received: November, 2020

Accepted: April, 2021

ISSN $2006-6996$

\title{
STABILITY CONSTANTS OF COMPLEXES OF METAL IONS WITH PEATSOIL HUMIC ACIDS UNDER NON-ACID-CONDITIONS
}

\author{
${ }^{* 1}$ Sabo, Yusuf ${ }^{2}$ Jimoh, W.L.O., ${ }^{3}$ Isa Baba Koki and ${ }^{4}$ Sholadoye, Q. 0. \\ ${ }^{1}$ Department of Pure and Industrial Chemistry, Bayero University, Kano \\ ${ }^{3}$ Department of Chemistry, Yusuf Maitama Sule University Kano. P.M.B. 3220 Kano, Nigeria. \\ ${ }^{4}$ Department of Chemistry, Nigerian Police Academy, Wudil, Kano-Nigeria
}

*Correspondence E-mail; saboyusuf18@yahoo.com

ABSTRACT

Stability constants of complexes of four divalent metal ions viz. $\mathrm{Cu}^{2+}, \mathrm{Pb}^{2+}, \mathrm{Mg}^{2+}$ and $\mathrm{Cd}^{2+}$ with humic acids (HA) were determined by potentiometric titration of humic acids with the corresponding salt of the divalent metals in aqueous media under non-acid-condition. The log $K$ (logarithm of the stability constant) ranged from 1.0942 to 2.7471 for metalhumic acid complexes were determined using point-wise computational method. The order of stability constants were obtained as follows: $\mathrm{Cu}>\mathrm{Pb}>\mathrm{Cd}>\mathrm{Mg}$ for metal $-\mathrm{HA}$ complexes respectively, indicating a higher degree of complexation with Cu metal ion.

Keywords: stability constant, humic acid, potentiometric titration, divalent metals, acid hydrolysis.

\section{NTRODUCTION}

The stability constant of a complex is the numerical expression of its stability and provides a quantitative measure of affinity of the metal ion to the complexing agent. An understanding of the relative stability of metal-complexes helps in predicting the behavior of metal ions in the soil (Ram and Raman, 1982). Extensive researches has been done to determine the stability constants of the complexes formed between humic acid (HA) with a number of metal ions. Ashok et al., (2000) reported that humic acid with hydroxyl, phenoxyl and carboxyl reactive groups can form coordination compound with metal ions at $\mathrm{pH}$ 3.5. The stability constants(Log K) for different metalhumic acid complexes indicated the following order of the stabilities of complexes formed between humic acid and metal ion, $\mathrm{Cu}>\mathrm{Fe}$ $>\mathrm{Pb}>\mathrm{Ni}>\mathrm{Co}>\mathrm{Ca}>\mathrm{Cd}>\mathrm{Zn}>\mathrm{Mn}>\mathrm{Mg}$. Andelkovic et al., (2010) investigated the binding of $\mathrm{Cd}$ (II) to soil humic acid at pH 6.5 and in $0.1 \mathrm{M} \mathrm{KNO}_{3}$ ionic medium. The stability constant for binding indicating greater stability in the case when carboxyl groups are involved in complexation reaction. Kostic et al.,(2012) investigated the complexation of humic acid with certain heavy metal ions (Co(II), $\mathrm{Ni}(\mathrm{II}), \mathrm{Cu}(\mathrm{II})$,
$\mathrm{Zn}(\mathrm{II})$, and $\mathrm{Pb}(\mathrm{II})$. The experiment was performed at $25^{\circ} \mathrm{C}$, at pH 4.0 and ionic strength of $0.01 \mathrm{M}$. Stability constant of complex between $\mathrm{Pb}$ (II) ions and humic acid is greater than stability constants of other investigated metalhumate complexes. Bogata and Sokolowska (2016) analyses the interaction between humic acids from different soils and $\mathrm{Zn}$ (II) ions at wide concentration ranges and at $\mathrm{pH} 5$. Studies have showed significant impact of $\mathrm{Zn}$ concentration, $\mathrm{pH}$ and some properties of humic acids with zinc.But all of these studies were limited to acidic $\mathrm{pH}$ range. Therefore, the present study was carried out to determine and compare the stability constants of complexes of metal ions with hydrolysed peat soil humic acid and unhydrolysed peat soil humic under non-acid conditions.

\section{MATERIALS AND METHODS}

Analytical grade chemicals used includes hydrochloric acid $(\mathrm{HCl})$, nitric acid $\left(\mathrm{HNO}_{3}\right)$, sodium hydroxide $(\mathrm{NaOH})$, lead nitrate $\mathrm{Pb}\left(\mathrm{NO}_{3}\right)_{2}$, copper nitrate $\mathrm{Cu}\left(\mathrm{NO}_{3}\right)_{2} \cdot 3 \mathrm{H}_{2} \mathrm{O}$, cadmium nitrate $\mathrm{Cd}\left(\mathrm{NO}_{3}\right)_{2} \cdot 4 \mathrm{H}_{2} \mathrm{O}$, magnesium nitrate $\mathrm{Mg}\left(\mathrm{NO}_{3}\right)_{2} \cdot 6 \mathrm{H}_{2} \mathrm{O}$, potassium nitrate $\left(\mathrm{KNO}_{3}\right)$, calcium chloride $\left(\mathrm{CaCl}_{2}\right)$, (sigma-Aldrich). Dowex 50WX8, (20-50 mesh) from Fluka. 


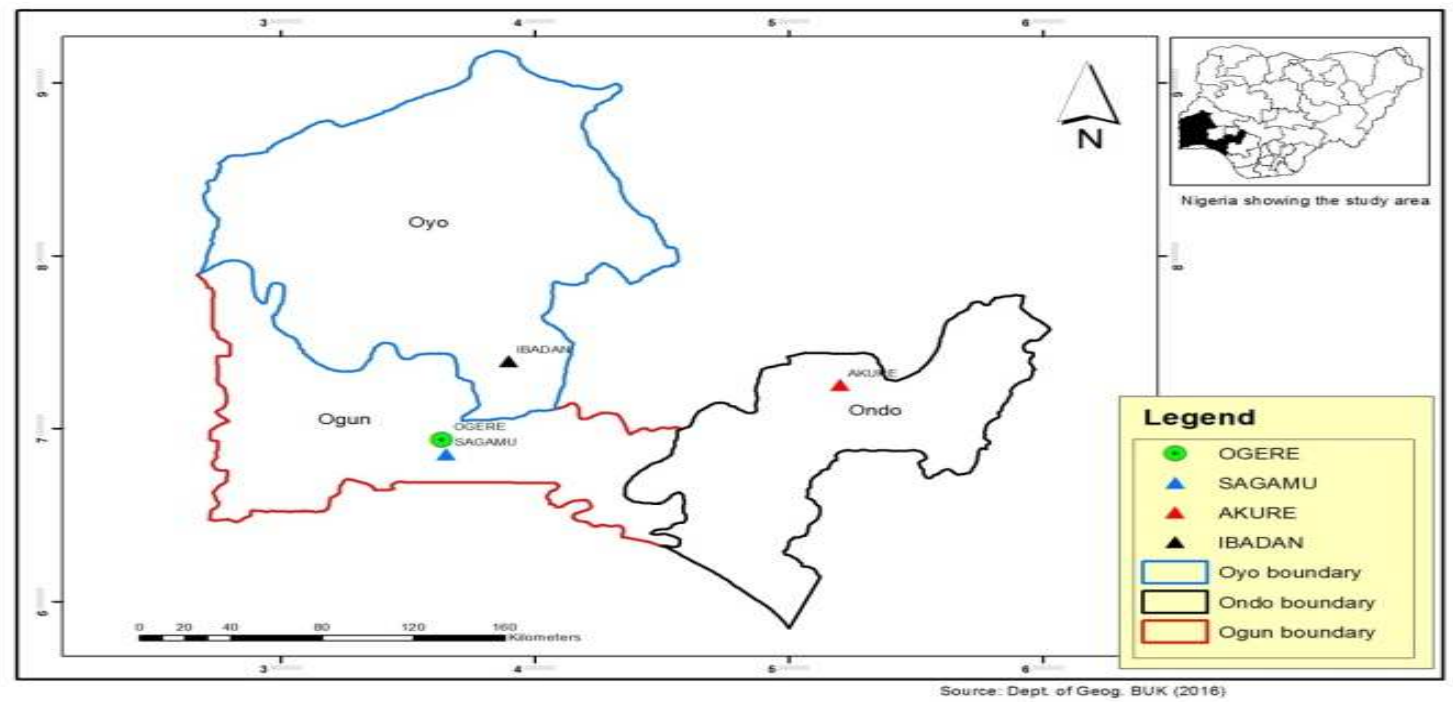

Figure 1: Map showing the sampling point at Sagamu Town, Ogun State.

\section{Description of Sampling Area}

Sagamu has geographical coordinates between $6^{\circ} 50^{\prime}$ north; $3^{\circ} 38^{\prime}$ east is located in south western region of Nigeria. The region has tropical wet and dry climate with a lengthy wet season and relatively constant temperatures throughout the course of the year. Wet season runs from March to October, November to December forms the region dry season. The vegetation type of the region is savannah which is really grassland with small bushes and occasional big trees. Grassland soils have substantially higher organic matter content than forest soils (Novackova, 2011).

\section{Sample Collection}

The Peatsoil samples were collected from four different sampling points $(0-10 \mathrm{~cm}$ depth) in Sagamu into polyethylene bag with plastic spoons. Samples were taken to the laboratory, extraneous materials were removed; the samples were air-dried, crushed and ground to a fine powder in a mortar passed through a $0.20 \mathrm{~mm}$ sieve. The samples were kept for analysis.

\section{Isolation and purification of humic acid from peat soil sample}

Peatsoil sample $(100 \mathrm{~g})$ was mixed with 1000 $\mathrm{cm}^{3}$ of $0.1 \mathrm{M} \mathrm{NaOH}$ solution, shaken for 3hours and left to stand overnight. Dark-coloured supernatant was obtained and decanted from solid residue. The dark-coloured supernatant was acidified to $(\mathrm{pH}=1.0)$ with $6 \mathrm{M} \mathrm{HCl}$ stirred and allowed to stand for 6 hours. Yellowish brown supernatant and dark-brown precipitate were obtained. The yellowish brown supernatant was decanted followed by centrifuge and discarded. The dark-brown precipitate was mixed with $500 \mathrm{~cm}^{3}$ of $0.1 \mathrm{M} \mathrm{NaOH}$ solution followed by passing through dowex resin. The dark-brown solution was acidified to $(\mathrm{pH}=1.0)$ with $6 \mathrm{M} \mathrm{HCl}$ stirred and allowed to stand for 3 hours. The dark-brown precipitate was washed several times with deionized water. The supernatant was treated with $\mathrm{AgNO}_{3}$ solution until no white precipitate observed. The humic acid was transferred to weighed crucible and dried at $60^{\circ} \mathrm{C}$ in an oven for 12 hours. The humic acid was cooled and dried in the desiccator, weighed and recorded. The obtained humic acid was dried again at $60^{\circ} \mathrm{C}$ for additional 6 hours cooled and dried in the desiccator, weighed and recorded constant weight was obtained (Baruah et al., 2015).

\section{FT-IR analysis}

FT-IR spectra of humic acid sample was analysed using Carry 630 FT-IR Agilent Technologies.

Unhydrolysed compost humic acid

The unhydrolysed humic acid was obtained after isolation and purification of compost humic acid and kept for investigation.

\section{Acid hydrolysis of Peatsoil acid}

Peatsoil humic acid sample (1g) was refluxed for 12 hours at $\left(160^{\circ} \mathrm{C}\right)$ with $50 \mathrm{~cm}^{3}$ of $6 \mathrm{M} \mathrm{HCl}$. The mixture was allowed to cool, decanted, and centrifuged after hydrolysis. The insoluble residues were washed with distilled water via centrifugation several times, and the supernatant was treated with $\mathrm{AgNO}_{3}$ solution until no white precipitate was observed. The residue was thoroughly dried over $\mathrm{CaCl}_{2}$ in a desiccator at room temperature (Chefetz et al., 2002). Finally, the obtained hydrolysed humic acid was kept for investigation. 
BAJOPAS Volume 14 Number 1,June, 2021 Potentiometric Titrations

Potentiometric measurements were carried out using a pH-meter Jenway (model 3510) with combine electrode, the sensitivity of the $\mathrm{pH}$ meter is 0.01 units. The $\mathrm{pH}$ meter was switched on half an hour before starting the titration for initial warm up of the instrument. The instrument was calibrated with an aqueous standard buffer solution of $\mathrm{pH} 4.00$ and 10.0 (borate buffer) prepared from a "Qualigens" buffer tablets.

The following sets of solutions were prepared in a $250 \mathrm{~cm}^{3}$ volumetric flask separately for $\mathrm{pH}$ metric titrations.

(i) $5 \mathrm{~cm}^{3} 0.1 \mathrm{M} \mathrm{HCl}+40 \mathrm{~cm}^{3}$ deionized water

(ii) $5 \mathrm{~cm}^{3} 0.1 \mathrm{M} \mathrm{HCl}+39 \mathrm{~cm}^{3}$ deionized water $+1 \mathrm{~cm}^{3} 0.15 \mathrm{gcm}^{-3}$ humic acid

(iii) $5 \mathrm{~cm}^{3} 0.1 \mathrm{M} \mathrm{HCl}+37 \mathrm{~cm}^{3}$ deionized water $+1 \mathrm{~cm}^{3} 0.15 \mathrm{gcm}^{-3}$ humic acid

$$
+2 \mathrm{~cm}^{3} \quad 0.01 \mathrm{M} \mathrm{Cu} \text { (II) }
$$

The solutions were titrated against standardized $0.110 \mathrm{MNaOH}$ separately. The total volume of each mixture was adjusted to $50 \mathrm{~cm}^{3}$ and the ionic strength of the solutions was maintained constant at by adding appropriate amount of stock solution of $1 \mathrm{M} \mathrm{KNO}_{3}$ (Gamal, 2015; Omar and Ali, 2015). A magnetic stirrer was used to achieve thorough mixing of the interacting solutions at $550 \mathrm{rpm}$. The same set of experimental conditions was applied for potentiometric titration of remaining samples.

\section{Evaluation of pKa of Hydrolysed peat soil Humic Acids}

The proton-ligand formation number $\mathrm{n}_{\mathbf{A}}$ were calculated by Irving and Rossotti expression (Omar and Ali, 2015).

$\mathrm{nA}=\mathrm{Y}-\frac{(\mathrm{V} 2-\mathrm{V1})(\mathrm{No}-\mathrm{Eo})}{(\mathrm{VO}+\mathrm{V1}) \mathrm{TCL}}$ 1

Where: $Y$ is number of dissociable proton, $\left(\mathrm{V}_{2^{-}}\right.$ $V_{1}$ ) is the measure of displacement of the ligand curve relative to acid curve, $\mathrm{N}^{\circ}$ and $\mathrm{E}^{\circ}$ are the resultant concentration of alkali solution, free acid solution, $\mathrm{T}_{\mathrm{cL}}{ }^{\circ}$ is the total ligand concentration, $\mathrm{V}^{\circ}$ is the total volume of titration solution, $V_{1}$ is the volume of alkali added to acid solution, $V_{2}$ is the volume of alkali added to acid solution + ligand solution, acid dissociation constants (pKa - values) of ligand were calculated by algebraic method point wise calculation (Tables 1 ). The dissociation constants (pKa) were calculated according to the following relation:

$\mathrm{pKa}=\mathrm{pH}+\log \left(\frac{n A}{1-n A}\right)$ 2

Where: pKa is the acid dissociation constant, $\mathrm{n}_{\mathrm{A}}$ is the Proton-ligand formation number and $\mathrm{pH}$ is the pH-values (Omar and Ali, 2015).

\section{Determination of metal-ligand stability constants $(\log K)$ of complexes}

The potentiometric measurement for the determination of stability constant of a complex in solution is based on the fact that the redox potential of the couple $\frac{M^{+(m-n)}}{M^{+m}}$ is shifted significantly on complexation of the metal ion with the ligand. This method involves change in hydrogen ion concentration $\left[\mathrm{H}^{+}\right]$due to the displacement or association of one or more protons taking place during complexation reaction. This change can be found out by titrating the solutions containing free acid, acid with ligand, and acid with ligand and metal ion, individually against a standard alkali solution at a constant ionic strength or temperature. Either ionic strength or temperature may be varied for different sets of solutions. In all the cases, the change in the $\mathrm{pH}$ of the solution is measured after each addition of a known amount of alkali to the reaction cell which contains the reaction mixture. The titration curves are then drawn by plotting the measured $\mathrm{pH}$ values against the corresponding volume of alkali added and the stability constants of the complexes are determined from the titration curves by employing $\mathrm{pH}$-metric titration technique given by (Irving and Rossoti).

Metal-ligand stability constants ( $\log \mathrm{K}$ ) were determined by using the following relations:

$$
\bar{n}=\frac{\left(V_{3}-V_{2}\right)\left(E^{0}+N^{0}\right)}{\left(V^{0}+V_{2}\right) \bar{n}_{A} T_{m}^{0}}
$$

and

$$
P L=\log _{10}\left\{\frac{1+\beta_{n}^{H} \frac{1}{[\text { anti } \log \mathrm{pH}]^{\mathrm{n}}}}{\mathrm{T}_{\mathrm{L}}^{0}-n \bar{T}_{m}^{0}} \mathrm{X} \frac{\left(V^{0}+V_{3}\right)}{V^{0}}\right\}
$$


BAJOPAS Volume 14 Number 1,June, 2021

Where $T_{L}, T^{\circ}, E^{\circ}$, and $V^{\circ}$ havethe same significance as in equation (1) above, $T_{m}$ denotes the total concentration of metal present in solution, $V_{3}$ is the volume of metal ions present in solution and $\beta^{H}$ is the overall proton ligand stability constant. The metal-ligand stability constants (log K) were determined by employing point wise computational Method (eq. 5 and 6).

$\operatorname{LogK}_{1}=\log \left(\frac{n}{1-n}\right)+\mathrm{pL}$ .5

$\operatorname{LogK}_{2}=\log \left(\frac{1-n}{2-n}\right)+\mathrm{pL}$ ...6

Where: Log $\mathrm{K}$ is the metal-ligand stability constant, $\mathrm{pL}$ is the Free ligand exponent function, $\mathbf{n}$ is the Average number of ligand attached with metal ion (Janraoet al., 2014). The results obtained were analyzed by an ORIGIN 2016 program using titration data and then the proton-ligand stability constants (pKa) and Metal-ligand stability constant (LogK) calculated (Omar and Ali, 2015).

\section{RESULTS AND DISCUSSION}

Fourier transformed infrared (FT-IR) spectra of isolated humic acid from peat soils Figure 2 had distinct clear absorption bands indicating the presence of major humic acid structural elemental groups such as $\mathrm{H}$ bonded $\mathrm{OH}$ $\left(3680 \mathrm{~cm}^{-1}\right.$ peak $), C=0$ of carbonyl $\left(1721 \mathrm{~cm}^{-1}\right.$ peak), functional groups of aliphatic components $\mathrm{CH}_{2}\left(2918 \mathrm{~cm}^{-1}\right.$ peak) and $\mathrm{C}-\mathrm{O}$ stretching of polysaccharide $\left(1168 \mathrm{~cm}^{-1}\right.$ peak). The positions of the absorption bands of the spectra fell within typical major absorption bands of humic acid which is at frequencies 3680, 2918, 1721, 1168 $\mathrm{cm}^{-1}$. The first peak centred in the vicinity of $3680 \mathrm{~cm}^{-1}$ region is attributed to phenol $\mathrm{OH}$ group bounded by intermolecular $\mathrm{H}$ bonds. The $2918 \mathrm{~cm}^{-1}$ band usually has absorption maximum at $2918 \mathrm{~cm}^{-1}$ which is due to $\mathrm{C}-\mathrm{H}$ stretching of alkane group $\left(\mathrm{CH}_{2}\right)$. The next major absorption band is $1721 \mathrm{~cm}^{-1}$. This band has been commonly ascribed to $\mathrm{C}=\mathrm{O}$ stretching of mainly carboxyl group $(\mathrm{COOH})$ with trace amount of ketones. The last peak was observed at 1168 $\mathrm{cm}^{-1}$ due to $\mathrm{C}-\mathrm{O}$ stretching of polysaccharides and this peak appeared also in the spectra of humic acid from peat soil. The FTIR spectra of the isolated humic acid contained all major characteristic absorption peaks of humic acid. These absorption peaks indicated the presence of the major structural elements of humic acid namely $\mathrm{H}$ bonded $\mathrm{OH}, \mathrm{C}=\mathrm{C}$ of aromatic ring, $\mathrm{C}=\mathrm{O}$ of carbonyl group (both carboxyl and ketonic), $\mathrm{CH}_{2}$ group. This strongly supports the presence of humic acid.

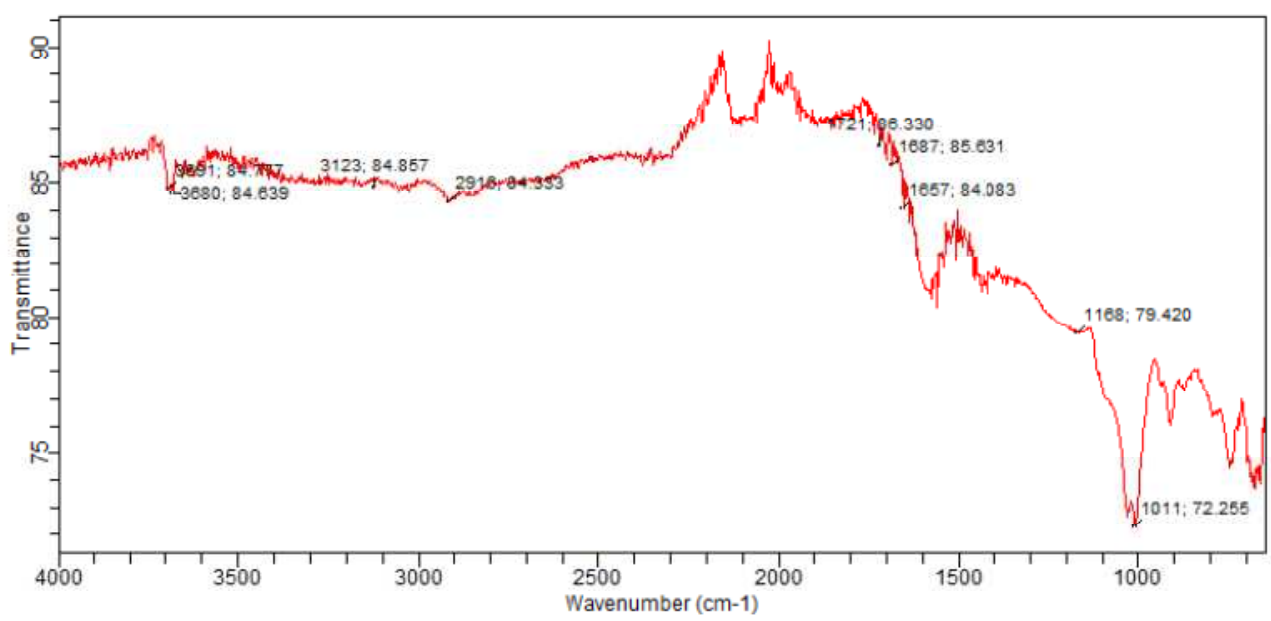

Fig. 2 : FT-IR spectraof peatsoilhumic acid (PSHA)

\section{Evaluation of acid dissociation constant (pka) of acid hydrolysed peat soil humicacid at phenolic group}

The value of the dissociation constant of the peat soil humic acid (PSHA) that underwent acidhydrolysis studied was found to be 8.9299 as shown Table 1, which is lower than the literaturevalues reported by Almeida and Szpoganics, (2015), Borges et al., (2005); Badr et al., (2012)and Fernandes et al,.(2009) of $9.73,9.47$ and 10.30. The difference between the obtained valuesand the reported values in this study might be probably as a result of acid hydrolysis of humicacid. 
BAJOPAS Volume 14 Number 1,June, 2021

Table 1: PKa of (Hydrolysed PSHA)

\begin{tabular}{|l|l|l|l|l|l|l|}
\hline $\mathrm{pH}$ & $\mathrm{BV}_{1}$ & $\mathrm{BV}_{2}$ & $\mathrm{~V}_{2}-\mathrm{V}_{1}$ & $\mathrm{nA}$ & $\log \left(\frac{n A}{1-n A}\right)$ & $\mathrm{pKa}$ \\
\hline 8.50 & 5.30 & 6.29 & 0.99 & 0.3594 & -0.2510 & 8.2490 \\
8.72 & 5.35 & 6.37 & 1.02 & 0.3400 & -0.2880 & 8.4320 \\
9.00 & 5.40 & 6.46 & 1.06 & 0.3141 & -0.3391 & 8.6609 \\
9.22 & 5.45 & 6.55 & 1.10 & 0.2882 & -0.3927 & 8.8273 \\
9.51 & 5.50 & 6.66 & 1.16 & 0.2494 & -0.4786 & 9.0314 \\
9.73 & 5.55 & 6.78 & 1.23 & 0.2041 & -0.5910 & 9.1390 \\
10.00 & 5.60 & 6.90 & 1.30 & 0.1589 & -0.7238 & 9.2762 \\
10.23 & 5.65 & 7.05 & 1.40 & 0.0941 & -0.9835 & 9.2465 \\
10.49 & 5.70 & 7.10 & 1.40 & 0.0941 & -0.9835 & 9.5065 \\
\hline
\end{tabular}

Average pKa $=8.9299 \pm 0.4186$

Table 2: PKa of (Unhydrolysed PSHA)

\begin{tabular}{|l|l|l|l|l|l|l|}
\hline $\mathrm{pH}$ & $\mathrm{BV}_{1}$ & $\mathrm{BV}_{2}$ & $\mathrm{~V}_{2}-\mathrm{V}_{1}$ & $\mathrm{nA}$ & $\log \left(\frac{\boldsymbol{n A}}{1-\boldsymbol{n}}\right)$ & $\mathrm{pKa}$ \\
\hline 8.50 & 5.30 & 5.81 & 0.51 & 0.6619 & 0.2919 & 8.7919 \\
8.72 & 5.35 & 5.90 & 0.55 & 0.6357 & 0.2418 & 8.9618 \\
9.00 & 5.40 & 6.00 & 0.60 & 0.6029 & 0.1813 & 9.1813 \\
9.22 & 5.45 & 6.10 & 0.65 & 0.5701 & 0.1226 & 9.3426 \\
9.51 & 5.50 & 6.20 & 0.70 & 0.5376 & 0.0654 & 9.5754 \\
9.73 & 5.55 & 6.33 & 0.78 & 0.4851 & -0.0259 & 9.7041 \\
10.00 & 5.60 & 6.47 & 0.87 & 0.4262 & -0.1291 & 9.8709 \\
10.23 & 5.65 & 6.62 & 0.99 & 0.3609 & -0.2481 & 9.9819 \\
10.49 & 5.70 & 6.80 & 1.10 & 0.2759 & -0.4690 & 10.0210 \\
\hline
\end{tabular}

Average pKa $=9.4923 \pm 0.4410$

Metal-ligand stability constant ( $\log \mathrm{K}$ )

The stabilityconstants require the accurate values of proton-ligand stability constants (Anil and Maroti, 2008). Metal titration curves crossed over ligand titration curve indicated the formation of complex upon proton release (Santosh, et al., 2011). If the values of n- are within range $0.2-0.8$ and $1.2-18$ this indicates the formation of $1: 1$ and 1:2 complexes (Sayyed and Mazahar, 2012).

The metal (II)-humate stepwise stability constants (log k) at phenolic group (Tables 318)

Table 3: Point-wise method, $\mathrm{Cu}$-(Hydrolysed PSHA)

\begin{tabular}{|l|l|l|l|l|l|l|l|l|}
\hline $\mathrm{pH}$ & $\mathrm{BV}_{1}$ & $\mathrm{BV}_{2}$ & $\mathrm{BV}_{3}$ & $\left(\mathrm{~V}_{3}-\mathrm{V}_{2}\right)$ & $\mathrm{n}$ & $\mathrm{pL}$ & $\log \left(\frac{n}{1-n}\right)$ & LogK $_{1}$ \\
\hline 8.50 & 5.30 & 6.29 & 6.33 & 0.04 & 0.5500 & 2.66 & 0.0871 & 2.7471 \\
8.72 & 5.35 & 6.37 & 6.41 & 0.04 & 0.5714 & 2.43 & 0.1249 & 2.5549 \\
9.00 & 5.40 & 6.46 & 6.50 & 0.04 & 0.6198 & 2.16 & 0.2122 & 2.3722 \\
9.22 & 5.45 & 6.55 & 6.59 & 0.04 & 0.6667 & 1.94 & 0.3010 & 2.2410 \\
\hline
\end{tabular}

LogK $_{1}$ (Average value) $=2.4788 \pm 0.2203$

Table 4: Point-wise method, $\mathrm{Cu}$-(Hydrolysed PSHA)

\begin{tabular}{|l|l|l|l|l|l|l|l|l|}
\hline $\mathrm{pH}$ & $\mathrm{BV}_{1}$ & $\mathrm{BV}_{2}$ & $\mathrm{BV}_{3}$ & $\left(\mathrm{~V}_{3}-\mathrm{V}_{2}\right)$ & $\mathrm{n}$ & $\mathrm{pL}$ & $\log \left(\frac{n-1}{2-n}\right)$ & LogK $_{2}$ \\
\hline 9.51 & 5.50 & 6.66 & 6.73 & 0.07 & 1.3509 & 1.70 & -0.2671 & 1.4329 \\
9.73 & 5.55 & 6.78 & 6.85 & 0.07 & 1.6383 & 1.51 & 0.2467 & 1.7567 \\
10.00 & 5.60 & 6.90 & 6.98 & 0.08 & 2.1783 & 1.31 & -0.2158 & 1.0942 \\
10.23 & 5.65 & 7.05 & 7.13 & 0.08 & 4.1904 & 1.27 & & \\
10.49 & 5.70 & 7.10 & 7.19 & 0.09 & 4.6920 & & & \\
\hline
\end{tabular}

Log $K_{2}($ Average value $)=1.4280 \pm 0.3312$ 
BAJOPAS Volume 14 Number 1,June, 2021

Table 5: Point-wise method, $\mathrm{Cu}$ (Unhydrolysed PSHA)

\begin{tabular}{|l|l|l|l|l|l|l|l|l|}
\hline $\mathrm{pH}$ & $\mathrm{BV}_{1}$ & $\mathrm{BV}_{2}$ & $\mathrm{BV}_{3}$ & $\left(\mathrm{~V}_{3}-\mathrm{V}_{2}\right)$ & $\mathrm{n}$ & $\mathrm{pL}$ & $\log \left(\frac{n}{n-1}\right)$ & Log $_{1}$ \\
\hline 8.50 & 5.30 & 5.81 & 5.85 & 0.04 & 0.2973 & 2.88 & -0.3736 & 2.5064 \\
8.72 & 5.35 & 5.90 & 5.95 & 0.05 & 0.3873 & 2.66 & -0.1992 & 2.4608 \\
9.00 & 5.40 & 6.00 & 6.05 & 0.05 & 0.4044 & 2.38 & -0.1681 & 2.2119 \\
9.22 & 5.45 & 6.10 & 6.15 & 0.06 & 0.5157 & 2.18 & -0.0272 & 2.2072 \\
9.51 & 5.50 & 6.20 & 6.27 & 0.07 & 0.6417 & 1.89 & 0.2530 & 1.1430 \\
\hline
\end{tabular}

$\operatorname{LogK}_{1}($ Average value $)=2.3059 \pm 0.6153$

Table 6:Point-wise method, $\mathrm{Cu}$ (Unhydrolysed PSHA)

\begin{tabular}{|l|l|l|l|l|l|l|l|l|}
\hline $\mathrm{pH}$ & $\mathrm{BV}_{1}$ & $\mathrm{BV}_{2}$ & $\mathrm{BV}_{3}$ & $\mathrm{~V}_{3}-\mathrm{V}_{2}$ & $\mathrm{n}$ & $\mathrm{pL}$ & $\log \left(\frac{n-1}{2-n}\right)$ & $\log \mathrm{K}_{2}$ \\
\hline 9.73 & 5.55 & 6.33 & 6.42 & 0.09 & 0.9000 & 1.69 & & \\
10.00 & 5.60 & 6.47 & 6.58 & 0.11 & 1.2578 & 1.44 & -0.4592 & 0.9808 \\
10.23 & 5.65 & 6.62 & 6.84 & 0.12 & 1.6137 & 1.26 & -0.2010 & 1.4610 \\
10.49 & 5.70 & 6.80 & 6.92 & 0.12 & 2.1052 & 1.03 & & \\
\hline
\end{tabular}

$\operatorname{LogK}_{2}$ (Average value) $=1.2209 \pm 0.3398$

Table 7:Point-wise method, Pb (Hydrolysed PSHA)

\begin{tabular}{|l|l|l|l|l|l|l|l|l|}
\hline $\mathrm{pH}$ & $\mathrm{BV}_{1}$ & $\mathrm{BV}_{2}$ & $\mathrm{BV}_{3}$ & $\left(\mathrm{~V}_{3}-\mathrm{V}_{2}\right)$ & $\mathrm{n}$ & $\mathrm{pL}$ & $\log \left(\frac{n}{1-n}\right)$ & LogK $_{1}$ \\
\hline 8.50 & 5.30 & 6.29 & 6.33 & 0.04 & 0.5500 & 2.66 & 0.0871 & 2.7471 \\
8.72 & 5.35 & 6.37 & 6.41 & 0.04 & 0.5714 & 2.43 & 0.1249 & 2.5549 \\
9.00 & 5.40 & 6.46 & 6.50 & 0.04 & 0.6198 & 2.16 & 0.2122 & 2.3722 \\
9.22 & 5.45 & 6.55 & 6.60 & 0.05 & 0.8333 & 1.96 & 0.6989 & 2.6589 \\
\hline
\end{tabular}

Log $_{\mathbf{1}}($ Average value $)=2.5832 \pm 0.1614$

Table 8:Point-wise method, Pb-(Hydrolysed PSHA)

\begin{tabular}{|l|l|l|l|l|l|l|l|l|}
\hline $\mathrm{pH}$ & $\mathrm{BV}_{1}$ & $\mathrm{BV}_{2}$ & $\mathrm{BV}_{3}$ & $\left(\mathrm{~V}_{3}-\mathrm{V}_{2}\right)$ & $\mathrm{n}$ & $\mathrm{pL}$ & $\log \left(\frac{n-1}{2-n}\right)$ & $\log \mathrm{K}_{2}$ \\
\hline 9.51 & 5.50 & 6.66 & 6.71 & 0.05 & 0.9650 & 1.67 & & \\
9.73 & 5.55 & 6.78 & 6.83 & 0.05 & 1.1702 & 1.44 & & \\
10.00 & 5.60 & 6.90 & 6.90 & 0.05 & 1.4864 & 1.22 & -0.0237 & 1.1963 \\
10.23 & 5.65 & 7.05 & 7.10 & 0.05 & 2.0190 & 1.09 & & \\
10.49 & 5.70 & 7.10 & 7.17 & 0.07 & 3.6492 & 1.00 & & \\
\hline
\end{tabular}

Log $K_{2}$ (Average value) $=1.1963$

Table 9: Point-wise method, Pb (Unhydrolysed PSHA)

\begin{tabular}{|l|l|l|l|l|l|l|l|l|}
\hline $\mathrm{pH}$ & $\mathrm{BV}_{1}$ & $\mathrm{BV}_{2}$ & $\mathrm{BV}_{3}$ & $\mathrm{~V}_{3}-\mathrm{V}_{2}$ & $\mathrm{n}$ & $\mathrm{pL}$ & $\begin{array}{l}\text { Log } \\
\left(\frac{n}{n-1}\right)\end{array}$ & Log $\mathrm{K}_{1}$ \\
\hline 8.50 & 5.30 & 5.81 & 5.85 & 0.04 & 0.2973 & 2.88 & -0.3736 & 2.5064 \\
8.72 & 5.35 & 5.90 & 5.94 & 0.04 & 0.3099 & 2.66 & -0.5477 & 2.3123 \\
9.00 & 5.40 & 6.00 & 6.05 & 0.05 & 0.4044 & 2.38 & -0.1681 & 2.2119 \\
9.22 & 5.45 & 6.10 & 6.15 & 0.06 & 0.5157 & 2.18 & 0.0272 & 2.2072 \\
9.51 & 5.50 & 6.20 & 6.26 & 0.07 & 0.6417 & 1.89 & 0.2530 & 2.1430 \\
9.73 & 5.55 & 6.40 & 6.40 & 0.07 & 0.7000 & 1.67 & 0.3680 & 2.0380 \\
\hline
\end{tabular}

LogK $_{1}$ (Average value) $=2.2364 \pm 0.1602$

Table 10: Point-wise method, Pb (Unhydrolysed PSHA)

\begin{tabular}{|l|l|l|l|l|l|l|l|l|}
\hline $\mathrm{pH}$ & $\mathrm{BV}_{1}$ & $\mathrm{BV}_{2}$ & $\mathrm{BV}_{3}$ & $\mathrm{~V}_{3}-\mathrm{V}_{2}$ & $\mathrm{n}$ & $\mathrm{pL}$ & $\log \left(\frac{n-1}{2-n}\right)$ & $\log \mathrm{K}_{2}$ \\
\hline 10.00 & 5.60 & 6.47 & 6.55 & 0.08 & 1.9503 & 1.41 & & \\
10.23 & 5.65 & 6.62 & 6.72 & 0.11 & 1.4792 & 1.26 & -0.0361 & 1.2239 \\
\hline
\end{tabular}

$\operatorname{LogK}_{2}$ (Average value) $=1.2239$

Table 11: Point-wise method, Mg (Hydrolysed PSHA)

\begin{tabular}{|l|l|l|l|l|l|l|l|l|}
\hline $\mathrm{pH}$ & $\mathrm{BV}_{1}$ & $\mathrm{BV}_{2}$ & $\mathrm{BV}_{3}$ & $\left(\mathrm{~V}_{3}-\mathrm{V}_{2}\right)$ & $\mathrm{n}$ & $\mathrm{pL}$ & $\log \left(\frac{n}{n-1}\right)$ & LogK $_{1}$ \\
\hline 8.50 & 5.30 & 6.29 & 6.31 & 0.02 & 0.2750 & 2.64 & -0.4290 & 2.2110 \\
8.72 & 5.35 & 6.37 & 6.39 & 0.02 & 0.2858 & 2.42 & -0.3978 & 2.0222 \\
9.00 & 5.40 & 6.46 & 6.49 & 0.03 & 0.4648 & 2.14 & -0.0612 & 2.0788 \\
9.22 & 5.45 & 6.55 & 6.59 & 0.04 & 0.6667 & 1.94 & 0.3010 & 2.2410 \\
\hline
\end{tabular}

$\log _{\mathbf{1}}($ Average value) $=2.1382 \pm 0.1046$ 
BAJOPAS Volume 14 Number 1,June, 2021

Table 12: Point-wise method, Mg (Hydrolysed PSHA)

\begin{tabular}{|l|l|l|l|l|l|l|l|l|}
\hline $\mathrm{pH}$ & $\mathrm{BV}_{1}$ & $\mathrm{BV}_{2}$ & $\mathrm{BV}_{3}$ & $\left(\mathrm{~V}_{3}-\mathrm{V}_{2}\right)$ & $\mathrm{n}$ & $\mathrm{pL}$ & $\log \left(\frac{n-1}{2-n}\right)$ & LogK $_{2}$ \\
\hline 9.51 & 5.55 & 6.66 & 6.71 & 0.05 & 0.9650 & 1.67 & & \\
9.73 & 5.55 & 6.78 & 6.84 & 0.06 & 1.4042 & 1.47 & -0.1686 & 1.3014 \\
10.00 & 5.60 & 6.90 & 6.93 & 0.06 & 1.7838 & 1.23 & 0.5593 & 1.7893 \\
10.23 & 5.65 & 7.05 & 7.10 & 0.06 & 3.1429 & 1.10 & & \\
10.49 & 5.70 & 7.10 & 7.18 & 0.07 & 3.6492 & 0.83 & & \\
\hline
\end{tabular}

LogK $_{2}($ Average value $)=1.5453 \pm 0.3450$

Table 13: Point-wise method, Mg (Unhydrolysed PSHA)

\begin{tabular}{|l|l|l|l|l|l|l|l|l|}
\hline $\mathrm{pH}$ & $\mathrm{BV}_{1}$ & $\mathrm{BV}_{2}$ & $\mathrm{BV}_{3}$ & $\mathrm{~V}_{3}-\mathrm{V}_{2}$ & $\mathrm{n}$ & $\mathrm{pL}$ & $\log \left(\frac{n}{n-1}\right)$ & $\operatorname{Log~}_{1}$ \\
\hline 8.50 & 5.30 & 5.81 & 5.85 & 0.04 & 0.2973 & 2.88 & -0.3736 & 2.5064 \\
8.72 & 5.35 & 5.90 & 5.94 & 0.04 & 0.3099 & 2.66 & -0.3477 & 2.3123 \\
9.00 & 5.40 & 6.00 & 6.04 & 0.04 & 0.3236 & 2.38 & -0.3202 & 2.0598 \\
9.22 & 5.45 & 6.10 & 6.15 & 0.05 & 0.4297 & 2.17 & -0.1230 & 2.0470 \\
9.51 & 5.50 & 6.20 & 6.26 & 0.06 & 0.5500 & 1.89 & 0.0871 & 1.9771 \\
9.73 & 5.55 & 6.33 & 6.40 & 0.07 & 0.7000 & 1.67 & 0.3680 & 2.0380 \\
\hline
\end{tabular}

LogK $_{1}$ (Average value) $=2.1568 \pm 0.2069$

Table 14: Point-wise method, Mg (Unhydrolysed PSHA)

\begin{tabular}{|l|l|l|l|l|l|l|l|l|}
\hline $\mathrm{pH}$ & $\mathrm{BV}_{1}$ & $\mathrm{BV}_{2}$ & $\mathrm{BV}_{3}$ & $\mathrm{~V}_{3}-\mathrm{V}_{2}$ & $\mathrm{n}$ & $\mathrm{pL}$ & $\log \left(\frac{n-1}{2-n}\right)$ & $\log \mathrm{K}_{2}$ \\
\hline 10.00 & 5.60 & 6.47 & 6.55 & 0.08 & 0.9148 & 1.41 & & \\
10.23 & 5.65 & 6.62 & 6.71 & 0.09 & 1.2102 & 1.20 & -0.5749 & 0.6251 \\
10.49 & 5.70 & 6.80 & 6.92 & 0.09 & 1.5968 & 1.03 & 0.1703 & 1.2003 \\
\hline
\end{tabular}

LogK $_{2}$ (Average value) $=0.9127 \pm 0.4070$

Table15:Point-wise method, Cd (Hydrolysed PSHA)

\begin{tabular}{|l|l|l|l|l|l|l|l|l|}
\hline $\mathrm{pH}$ & $\mathrm{BV}_{1}$ & $\mathrm{BV}_{2}$ & $\mathrm{BV}_{3}$ & $\left(\mathrm{~V}_{3}-\mathrm{V}_{2}\right)$ & $\mathrm{n}$ & $\mathrm{pL}$ & $\log \left(\frac{n}{1-n}\right)$ & LogK $_{1}$ \\
\hline 8.50 & 5.30 & 6.29 & 6.31 & 0.02 & 0.2750 & 2.64 & -0.4210 & 2.2190 \\
8.72 & 5.35 & 6.37 & 6.40 & 0.03 & 0.4286 & 2.42 & -0.1249 & 2.2951 \\
9.00 & 5.40 & 6.46 & 6.49 & 0.03 & 0.4648 & 2.14 & -0.0612 & 2.0788 \\
9.22 & 5.45 & 6.55 & 6.59 & 0.04 & 0.6667 & 1.96 & 0.3010 & 2.2610 \\
9.51 & 5.55 & 6.66 & 6.70 & 0.04 & 0.7720 & 1.67 & 0.5297 & 2.1997 \\
\hline
\end{tabular}

LogK $_{\mathbf{1}}$ (Average value) $=2.2108 \pm 0.0825$

Table 16: Point-wise method, Cd (Hydrolysed PSHA)

\begin{tabular}{|l|l|l|l|l|l|l|l|l|}
\hline $\mathrm{pH}$ & $\mathrm{BV}_{1}$ & $\mathrm{BV}_{2}$ & $\mathrm{BV}_{3}$ & $\left(\mathrm{~V}_{3}-\mathrm{V}_{2}\right)$ & $\mathrm{n}$ & $\mathrm{pL}$ & $\log \left(\frac{n-1}{2-n}\right)$ & Log $_{2}$ \\
\hline 9.73 & 5.55 & 6.78 & 6.83 & 0.06 & 1.4042 & 1.47 & -0.1686 & 1.3014 \\
10.00 & 5.60 & 6.90 & 6.95 & 0.06 & 1.7838 & 1.23 & 0.5593 & 1.7893 \\
10.23 & 5.65 & 7.05 & 7.10 & 0.06 & 3.1429 & 1.09 & & \\
10.49 & 5.70 & 7.10 & 7.16 & 0.06 & 3.1429 & 0.89 & & \\
& & & & & & & & \\
\hline
\end{tabular}

$\operatorname{LogK}_{2}$ (Average value) $=1.5453 \pm 0.3450$

Table 17: Point-wise method, Cd (Unhydrolysed PSHA)

\begin{tabular}{|l|l|l|l|l|l|l|l|l|}
\hline $\mathrm{pH}$ & $\mathrm{BV}_{1}$ & $\mathrm{BV}_{2}$ & $\mathrm{BV}_{3}$ & $\mathrm{~V}_{3}-\mathrm{V}_{2}$ & $\mathrm{n}$ & $\mathrm{pL}$ & $\log \left(\frac{n}{n-1}\right)$ & $\operatorname{Log~}_{1}$ \\
\hline 8.50 & 5.30 & 5.81 & 5.86 & 0.05 & 0.3717 & 2.88 & -0.2280 & 2.6520 \\
8.72 & 5.35 & 5.90 & 5.95 & 0.05 & 0.3873 & 2.66 & -0.1992 & 2.4608 \\
9.00 & 5.40 & 6.00 & 6.06 & 0.06 & 0.4853 & 2.38 & -0.0255 & 2.3545 \\
9.22 & 5.45 & 6.10 & 6.16 & 0.06 & 0.5157 & 2.18 & -0.0272 & 2.2072 \\
9.51 & 5.50 & 6.20 & 6.27 & 0.07 & 0.6417 & 1.89 & 0.2530 & 1.1430 \\
9.73 & 5.55 & 6.33 & 6.41 & 0.08 & 0.8000 & 1.69 & 0.6020 & 2.2920 \\
& & & & & & & & \\
\hline
\end{tabular}

$\operatorname{LogK}_{1}($ Average value $)=2.2516 \pm 0.5380$ 
BAJOPAS Volume 14 Number 1,June, 2021

Table 18: Point-wise method, Cd (Unhydrolysed PSHA)

\begin{tabular}{|l|l|l|l|l|l|l|l|l|}
\hline $\mathrm{pH}$ & $\mathrm{BV}_{1}$ & $\mathrm{BV}_{2}$ & $\mathrm{BV}_{3}$ & $\mathrm{~V}_{3}-\mathrm{V}_{2}$ & $\mathrm{n}$ & $\mathrm{pL}$ & $\log \left(\frac{n-1}{2-n}\right)$ & $\log \mathrm{K}_{2}$ \\
\hline 10.00 & 5.60 & 6.47 & 6.57 & 0.10 & 1.1434 & 1.43 & & \\
10.23 & 5.65 & 6.62 & 6.72 & 0.10 & 1.3448 & 1.23 & -0.2788 & 0.9512 \\
10.49 & 5.70 & 6.80 & 6.90 & 0.10 & 1.7742 & 1.03 & 0.5351 & 1.5651 \\
\hline
\end{tabular}

$\operatorname{LogK}_{2}($ Average value $)=1.2581 \pm 0.4340$

Table 19: Stepwise and overall Stability constants of thehydrolysed and unhydrolysed divalent metal (II) complexes

\begin{tabular}{|c|c|c|c|}
\hline Chelates & LogK $_{1}$ & $\log _{2}$ & Log $\beta$ \\
\hline [Cu (Hydrolysed PSHA-1) $\left.{ }_{2}\right]$ & 2.4788 & 1.4280 & 3.9068 \\
\hline$\left[\mathrm{Pb}(\text { Hydrolysed PSHA-1) })_{2}\right]$ & 2.5832 & 1.1963 & 3.7795 \\
\hline$\left[\mathrm{Cd}(\text { Hydrolysed PSHA-1 })_{2}\right]$ & 2.2108 & 1.5453 & 3.7561 \\
\hline$\left[\mathrm{Mg}(\text { Hydrolysed PSHA-1 })_{2}\right]$ & 2.1382 & 1.5453 & 3.6835 \\
\hline [Cu (Unhydrolysed PSHA-1) & 2.3059 & 1.2209 & 3.5268 \\
\hline$[\mathrm{Pb}$ (Unhydrolysed PSHA-1) 2$]$ & 2.2364 & 1.2239 & 3.4603 \\
\hline [Cd (Unhydrolysed PSHA-1) 2 ] & 2.2516 & 1.2581 & 3.5097 \\
\hline$[\mathrm{Mg}$ (Unydrolysed PSHA-1) & 2.1568 & 0.9127 & 3.0695 \\
\hline
\end{tabular}

The results obtained (Table19) shows the stepwise and overall stability constants to be not high indicating low stability of the complexes, because the solubility of most metal ions in the basic $\mathrm{pH}$ range is minimal due to metal hydroxide precipitation (Karimi, 2017). In general, the stepwise stability constants $\left(K_{1}\right.$ and $K_{2}$ ) follow the order $K_{1}>K_{2}$ for the copper, lead, magnesium and cadmium complexes respectively. The steady decrease of the values with increasing number of ligands is in agreement with the prediction made by researchers (Na'aliya, 2013). The decrease could be attributed to the fact that as the number of the ligands (Humate ions) that enters the coordination zone increases the aqua molecules available for replacement by the ligands become less. Thus, the metal ions become less electron loving with progressive intake of the ligand and this results in the decrease in the values of the constants (Na'aliya, 2013). Also the stability of the complexes is influenced by the size and number of the chelate rings(Mackay and Mackay,2002).All the complexes form rings in their structure as humate, a bidentate ligand, bond the metal ions in the ratio 1:2 (Boguta and Sokolowska, 2016) forming chelate rings. The values of the overall stability constants $(\log \beta)$ obtained for humate complexes are not high indicating low stability as the values are not high. LogK values for copper-humates (Table 3 to 6) obtained in this study are lower than those reported for the complexes of humic acids (Pandey et al., 2015; Dinu, 2013; Kaschl et al., 2010 and Gilbeto and Jorg, 2001). The values of LogK(Table 7 to 10 ) forlead-humates are lower than those reported for the lead in the literature (Dinu, 2013; Gilbeto and Jorg 2001). Log K values(Table 11 to 14 ) for magnesium-humates obtained in this study are close to those reported by (Pandey et al., 2015). Log K values of cadmium-humates (Table 15 to 18 ) obtained in this work near to the one reported by (Dinu, 2013 and Pandey et al., 2015).The difference between the reported values and the values obtained in this study might be probably as a result of acid hydrolysis of humic acid. The values of the overall stability constants $(\log \beta)$ of the copper humates complexes presented in Table 19 is high than that of other metal humate complexes, show relatively high stability of CuHA complexes, show the following order of stability: $\mathrm{Cu}>\mathrm{Pb}>\mathrm{Cd}>\mathrm{Mg}$; which are in close agreement to the findings of (Dinu, 2013 and Pandey et al., 2015).The high stability of Cuhumate chelate could be attributed to the existence of coordinate covalent bond between the complexing agents and the $\mathrm{Cu}^{2+}$ ions. Since, $\mathrm{Cu}^{2+}$ being a metal of the transitional series with $3 d^{9}$ electronic configurations can accept the electrons from the complexing agents. Similarly, the low stabilities of $\mathrm{Pb}, \mathrm{Cd}$ and $\mathrm{Mg}$ complexes could be explained by that $\mathrm{Pb}^{2+}$ with $6 s^{2}, \mathrm{Cd}^{2+}$ with $4 \mathrm{~d}^{10}$ and $\mathrm{Mg}^{2+}$ with $2 \mathrm{p}^{6}$ their electronic configuration has a completely filled $\mathrm{d}, \mathrm{p}$ and $\mathrm{s}$ orbitals. Moreover, the stabilities of metal ions with hydrolysed humic acid from peat soil were higher than those with unhydrolysed humic acid from peat soil; which is ascribed to the high content of acidity in hydrolysed humic acid than unhydrolysed humic acid. 
BAJOPAS Volume 14 Number 1,June, 2021 CONCLUSION

The values of logk for $\mathrm{Cu}(\mathrm{II})$ hydrolysed humic acid complex was higher followed by $\mathrm{Pb}$ (II), $\mathrm{Cd}(\mathrm{II})$ and $\mathrm{Mg}$ (II) hydrolysed humic acid complexes as compared with metal(II) unhydrolysed humic acid complexes. This indicates acid hydrolysis of humic acid can

\section{REFERENCES}

Almeida, V.R. and Szpoganicz, B. (2015). Humic Acid Potentiometric Response Patterns:Out- of Equilibrium Properties and Species Distribution Modelling. Chemical. Biol. Technol. Agric. 2: 17.

Anđelković, T., Nikolić, R., Bojić, A.,Anđelković, D., and Nikolic G.,(2010). Binding of Cadmium to Soil Humic Acid as A Function of Carboxyl Group Content. Macedonian Journal of Chemistry and Chemical Engineering.29(2): 215-224.

Anil, B. N. and Maroti, N. (2008). Studies on Influence of Die-Lectric Constants on Complex Equilibria between Substituted Py-Razalines and Lanthanide Metal Ions pH-Metrically. Amer.-Euras. scient. Res. 3(2): 212-216.

Ashok, K., Pandey, S. P. and Misra, V (2000). Stability Constants of Metal-Humic Acid Complexes and its Role in Environmental Detoxification. Journal of Ecotoxicology and Environmental Safety. 47(2):157-200.

Badr, M. H., El-Halafawi, M. H. and Abd El-al Zeid, E. R. (2012). Comparison Between the Effect of Ionic Strength on Acidity and Dissociation Constants of Humic Acids Extracted from Sewage Sludge and Nile Water Hyacinth Composts.Global Journal of Environmental Research 6 (1): 36-43.

Baruah, M.K., Borah, D., Saikia, P.P., Paul, S., Sharma, T. (2015). Evaluation of pKa Values of Soil Humic Acids and their Complexation Properties. International Journal of Plant \& Soil Science 6(4) : 218-228.

Boguta, P. Sokolowska, Z. (2016). Interactions of $\mathrm{Zn}$ (II) Ions with Humic Acids Isolated from Various Types of Soils. Effect of $\mathrm{pH}, \mathrm{Zn}$ Concentrations and Humic Acids Chemical Properties. Journal of Geochemical Explaration 168. 119-126.

Borges, F., Guimaraes, C., Lima, L.F.C., Pinto, I. and Reis, S.(2005). Potentiometric Studies on the Complexation of Copper(II) by Phenolic Acids as Discrete Ligand Models of enhance the complexation behavior of humic acid with metal (II) ions. However, the higher values of $\log \beta$ for $\mathrm{Cu}(\mathrm{II}), \mathrm{Pb}(\mathrm{II}), \mathrm{Cd}(\mathrm{II})$ and $\mathrm{Mg}(\mathrm{II})$ hydrolysed humic acid complexes indicates more stable stepwise complexes formed as compared with $\mathrm{Cu}(\mathrm{II}), \mathrm{Pb}$ (II), $\mathrm{Cd}$ (II) and $\mathrm{Mg}(\mathrm{II})$ unhydrolysed humic acid complexes.

Humic Substances Talanta 66 (2005) 670-673.

Chefetz, B., Salloum, M. J., Deshmulkin, A. P. and Hatcher, P. (2002). Structural Components of Humic Acids as Determined by Chemical Modifications and Carbon-13 NMR, Pyrolysis, and Thermochemolysis- Gas Chromatography/Mass Spectrometry. Soil Science Society of American Journal Abstract Division S-2- Soil Chemistry66. 1159-1171.

Dinu, M. I. (2013). Metals Complexation with Humic Acids in Surface Water of Different Environ. Sci. Technol. 31(1): 1-17.

Fernandes, A.N., Giacomelli, C., Giovanela, M. Vaz, D.V. Szpoganicz, B. and Maria M. D. (2009). Potentiometric Acidity Determination in Humic Substances Influenced by Different Analytical Procedures.J. Braz. Chem. Soc. 20 (9):14.

Gamal, A. H. (2015). Stability Constants of Rhenium (V) Metal Complexes with Selected Drugs. Pyrex Journal of Research in Environmental Studies. 2(2): 006-014.

Janrao, D. M., Pathan, J., Kayande, D.D., and Mulla, J.J. (2014). An Over View of Potentiometric Determination of Stability Constants of Metal Complexes. Sci. Revs. Chem. Commun.: 4(1), 2014, 11-24.

Karimi, H. (2017). Effect of pH and Initial Pb(II) Concentration on the Lead Removal Efficiency from Waste Water Using $\mathrm{Ca}(\mathrm{OH})_{2}$. International Journal of Water and Waste Water Treatment 3.2

Kaschl, A. Romheld, V. and Chen, Y. (2010). Binding of Cadmium, Copper and Zinc to Humic Substances Originating from Municipal Solid Waste Compost. Israel Journal of Chemistry Vol. 42(1): 89-98.

Kostic, I. S., Tatjana, P, A., Nikolic, R. S., Cvetkovic, T. P., Pavlovic, D. D., Aleksandar, L.J. and Bojic, A. (2012). Comparative Study of Binding Strengths of Heavy Metals with Humic Acid. J.serb. Chem. Soc. 76(9) pp 1-20. 
BAJOPAS Volume 14 Number 1,June, 2021

Na'aliya, J. (2013). Determination of Stepwise Stability Constants and Gibbs free Energy Change of Trisprolina to Complexes of some Divalent Transition Metal ions. Bayero Journal of Pure and Applied Sciences 6(2): 112-114.

Omar, A. A. and Ali, E. A. (2015). Potentiometric Studies on Complexes of $\mathrm{Cr}$ (III) and $\mathrm{Zr}$ (IV) with some Carboxylic Acids. International Journal of Advanced Chemistry, 3(1) 25-

37.

Pandey, A. K. Pandey, S. D. and Misr, V. (2015).Stability Constants of Metal- Humic Acid Complexes and Its Role in Environmental Detoxification. J. Ecotoxicology and Environmental Safety. 47(1):195-200.

Ram, N. and Raman, K.V. (1984). Stability Constants of Complexes of Metals with
Humicand Fuvic Acids under Non- acidConditions. Journal of Plant Nutrition and Soil Sciences.

147:171-176.

Santosh, D. D., Ashok, B. K., Vijay, J. T., Shivraj, G. W. and Vinay, V. W. (2011). Potentiometric Studies of Elec-Trolyte Effects on Complex Equilibria of Some Substituted 5-(2-hydroxy Phenyl) Pyrazoles. Der pharm. 3 (6): 75-83.

Sayyed, H. and Abdul Rahim, M. F. (2012). Studies of Binary Complexes of Metal Ions with Mandelic Acid by Potentiometry. Chem. J. 02 (6): 206209.

Shirvani, M. Moradian, E. Khalili, B. Bakhtiary, S. (2015). Interaction of $\mathrm{Cd}$ and $\mathrm{Pb}$ with Humate-Palygorskite and HumateSepiolite Complexes. Journal of water, air and pollution 3: 220-228. 


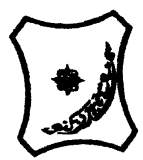

Bayero Journal of Pure and Applied Sciences, 14(1): 54 - 63

Received: November, 2020

Accepted: April, 2021

ISSN $2006-6996$

\title{
STABILITY CONSTANTS OF COMPLEXES OF METAL IONS WITH PEATSOIL HUMIC ACIDS UNDER NON-ACID-CONDITIONS
}

\author{
${ }^{* 1}$ Sabo, Yusuf ${ }^{2}$ Jimoh, W.L.O., ${ }^{3}$ Isa Baba Koki and ${ }^{4}$ Sholadoye, Q. 0. \\ ${ }^{1}$ Department of Pure and Industrial Chemistry, Bayero University, Kano \\ ${ }^{3}$ Department of Chemistry, Yusuf Maitama Sule University Kano. P.M.B. 3220 Kano, Nigeria. \\ ${ }^{4}$ Department of Chemistry, Nigerian Police Academy, Wudil, Kano-Nigeria
}

*Correspondence E-mail; saboyusuf18@yahoo.com

ABSTRACT

Stability constants of complexes of four divalent metal ions viz. $\mathrm{Cu}^{2+}, \mathrm{Pb}^{2+}, \mathrm{Mg}^{2+}$ and $\mathrm{Cd}^{2+}$ with humic acids (HA) were determined by potentiometric titration of humic acids with the corresponding salt of the divalent metals in aqueous media under non-acid-condition. The log $K$ (logarithm of the stability constant) ranged from 1.0942 to 2.7471 for metalhumic acid complexes were determined using point-wise computational method. The order of stability constants were obtained as follows: $\mathrm{Cu}>\mathrm{Pb}>\mathrm{Cd}>\mathrm{Mg}$ for metal $-\mathrm{HA}$ complexes respectively, indicating a higher degree of complexation with Cu metal ion.

Keywords: stability constant, humic acid, potentiometric titration, divalent metals, acid hydrolysis.

\section{NTRODUCTION}

The stability constant of a complex is the numerical expression of its stability and provides a quantitative measure of affinity of the metal ion to the complexing agent. An understanding of the relative stability of metal-complexes helps in predicting the behavior of metal ions in the soil (Ram and Raman, 1982). Extensive researches has been done to determine the stability constants of the complexes formed between humic acid (HA) with a number of metal ions. Ashok et al., (2000) reported that humic acid with hydroxyl, phenoxyl and carboxyl reactive groups can form coordination compound with metal ions at $\mathrm{pH}$ 3.5. The stability constants(Log K) for different metalhumic acid complexes indicated the following order of the stabilities of complexes formed between humic acid and metal ion, $\mathrm{Cu}>\mathrm{Fe}$ $>\mathrm{Pb}>\mathrm{Ni}>\mathrm{Co}>\mathrm{Ca}>\mathrm{Cd}>\mathrm{Zn}>\mathrm{Mn}>\mathrm{Mg}$. Andelkovic et al., (2010) investigated the binding of $\mathrm{Cd}$ (II) to soil humic acid at pH 6.5 and in $0.1 \mathrm{M} \mathrm{KNO}_{3}$ ionic medium. The stability constant for binding indicating greater stability in the case when carboxyl groups are involved in complexation reaction. Kostic et al.,(2012) investigated the complexation of humic acid with certain heavy metal ions (Co(II), $\mathrm{Ni}(\mathrm{II}), \mathrm{Cu}(\mathrm{II})$,
$\mathrm{Zn}(\mathrm{II})$, and $\mathrm{Pb}(\mathrm{II})$. The experiment was performed at $25^{\circ} \mathrm{C}$, at pH 4.0 and ionic strength of $0.01 \mathrm{M}$. Stability constant of complex between $\mathrm{Pb}$ (II) ions and humic acid is greater than stability constants of other investigated metalhumate complexes. Bogata and Sokolowska (2016) analyses the interaction between humic acids from different soils and $\mathrm{Zn}$ (II) ions at wide concentration ranges and at $\mathrm{pH} 5$. Studies have showed significant impact of $\mathrm{Zn}$ concentration, $\mathrm{pH}$ and some properties of humic acids with zinc.But all of these studies were limited to acidic $\mathrm{pH}$ range. Therefore, the present study was carried out to determine and compare the stability constants of complexes of metal ions with hydrolysed peat soil humic acid and unhydrolysed peat soil humic under non-acid conditions.

\section{MATERIALS AND METHODS}

Analytical grade chemicals used includes hydrochloric acid $(\mathrm{HCl})$, nitric acid $\left(\mathrm{HNO}_{3}\right)$, sodium hydroxide $(\mathrm{NaOH})$, lead nitrate $\mathrm{Pb}\left(\mathrm{NO}_{3}\right)_{2}$, copper nitrate $\mathrm{Cu}\left(\mathrm{NO}_{3}\right)_{2} \cdot 3 \mathrm{H}_{2} \mathrm{O}$, cadmium nitrate $\mathrm{Cd}\left(\mathrm{NO}_{3}\right)_{2} \cdot 4 \mathrm{H}_{2} \mathrm{O}$, magnesium nitrate $\mathrm{Mg}\left(\mathrm{NO}_{3}\right)_{2} \cdot 6 \mathrm{H}_{2} \mathrm{O}$, potassium nitrate $\left(\mathrm{KNO}_{3}\right)$, calcium chloride $\left(\mathrm{CaCl}_{2}\right)$, (sigma-Aldrich). Dowex 50WX8, (20-50 mesh) from Fluka. 


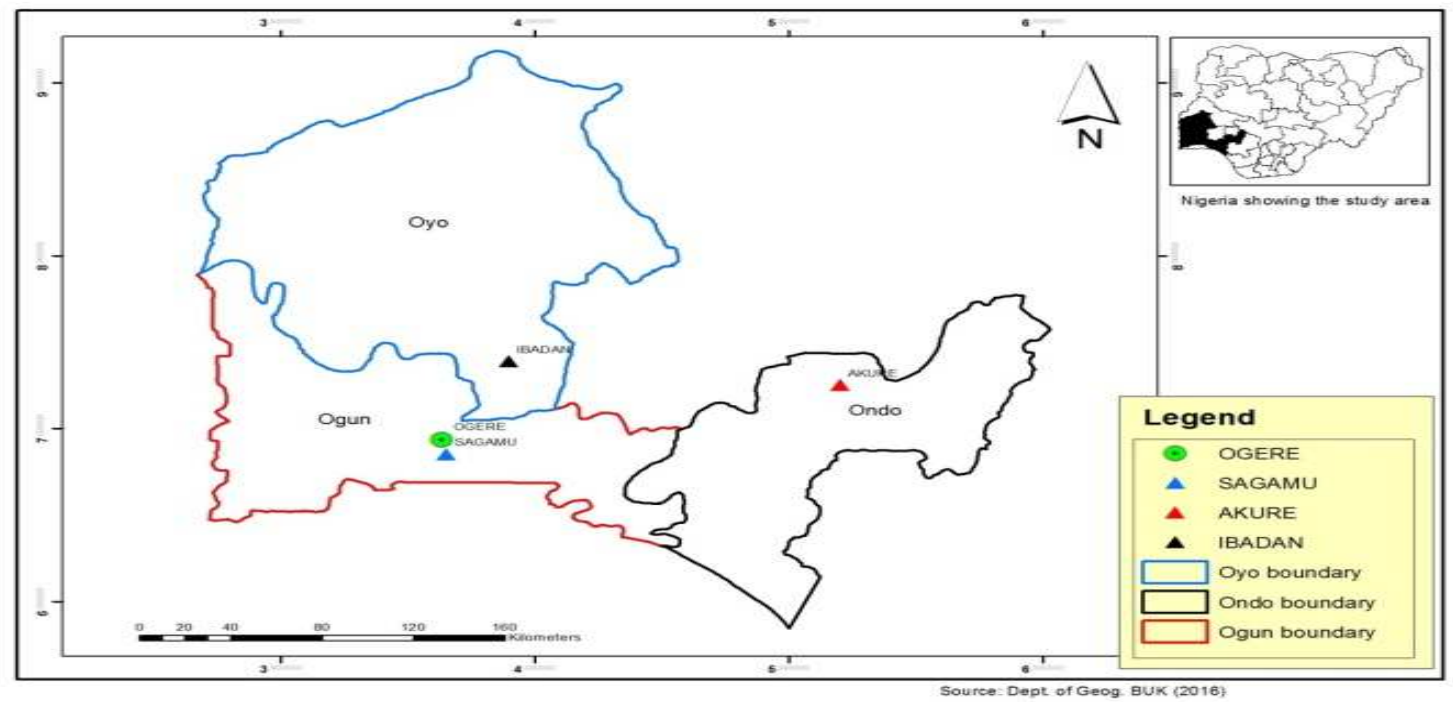

Figure 1: Map showing the sampling point at Sagamu Town, Ogun State.

\section{Description of Sampling Area}

Sagamu has geographical coordinates between $6^{\circ} 50^{\prime}$ north; $3^{\circ} 38^{\prime}$ east is located in south western region of Nigeria. The region has tropical wet and dry climate with a lengthy wet season and relatively constant temperatures throughout the course of the year. Wet season runs from March to October, November to December forms the region dry season. The vegetation type of the region is savannah which is really grassland with small bushes and occasional big trees. Grassland soils have substantially higher organic matter content than forest soils (Novackova, 2011).

\section{Sample Collection}

The Peatsoil samples were collected from four different sampling points $(0-10 \mathrm{~cm}$ depth) in Sagamu into polyethylene bag with plastic spoons. Samples were taken to the laboratory, extraneous materials were removed; the samples were air-dried, crushed and ground to a fine powder in a mortar passed through a $0.20 \mathrm{~mm}$ sieve. The samples were kept for analysis.

\section{Isolation and purification of humic acid from peat soil sample}

Peatsoil sample $(100 \mathrm{~g})$ was mixed with 1000 $\mathrm{cm}^{3}$ of $0.1 \mathrm{M} \mathrm{NaOH}$ solution, shaken for 3hours and left to stand overnight. Dark-coloured supernatant was obtained and decanted from solid residue. The dark-coloured supernatant was acidified to $(\mathrm{pH}=1.0)$ with $6 \mathrm{M} \mathrm{HCl}$ stirred and allowed to stand for 6 hours. Yellowish brown supernatant and dark-brown precipitate were obtained. The yellowish brown supernatant was decanted followed by centrifuge and discarded. The dark-brown precipitate was mixed with $500 \mathrm{~cm}^{3}$ of $0.1 \mathrm{M} \mathrm{NaOH}$ solution followed by passing through dowex resin. The dark-brown solution was acidified to $(\mathrm{pH}=1.0)$ with $6 \mathrm{M} \mathrm{HCl}$ stirred and allowed to stand for 3 hours. The dark-brown precipitate was washed several times with deionized water. The supernatant was treated with $\mathrm{AgNO}_{3}$ solution until no white precipitate observed. The humic acid was transferred to weighed crucible and dried at $60^{\circ} \mathrm{C}$ in an oven for 12 hours. The humic acid was cooled and dried in the desiccator, weighed and recorded. The obtained humic acid was dried again at $60^{\circ} \mathrm{C}$ for additional 6 hours cooled and dried in the desiccator, weighed and recorded constant weight was obtained (Baruah et al., 2015).

\section{FT-IR analysis}

FT-IR spectra of humic acid sample was analysed using Carry 630 FT-IR Agilent Technologies.

Unhydrolysed compost humic acid

The unhydrolysed humic acid was obtained after isolation and purification of compost humic acid and kept for investigation.

\section{Acid hydrolysis of Peatsoil acid}

Peatsoil humic acid sample (1g) was refluxed for 12 hours at $\left(160^{\circ} \mathrm{C}\right)$ with $50 \mathrm{~cm}^{3}$ of $6 \mathrm{M} \mathrm{HCl}$. The mixture was allowed to cool, decanted, and centrifuged after hydrolysis. The insoluble residues were washed with distilled water via centrifugation several times, and the supernatant was treated with $\mathrm{AgNO}_{3}$ solution until no white precipitate was observed. The residue was thoroughly dried over $\mathrm{CaCl}_{2}$ in a desiccator at room temperature (Chefetz et al., 2002). Finally, the obtained hydrolysed humic acid was kept for investigation. 
BAJOPAS Volume 14 Number 1,June, 2021 Potentiometric Titrations

Potentiometric measurements were carried out using a pH-meter Jenway (model 3510) with combine electrode, the sensitivity of the $\mathrm{pH}$ meter is 0.01 units. The $\mathrm{pH}$ meter was switched on half an hour before starting the titration for initial warm up of the instrument. The instrument was calibrated with an aqueous standard buffer solution of $\mathrm{pH} 4.00$ and 10.0 (borate buffer) prepared from a "Qualigens" buffer tablets.

The following sets of solutions were prepared in a $250 \mathrm{~cm}^{3}$ volumetric flask separately for $\mathrm{pH}$ metric titrations.

(i) $5 \mathrm{~cm}^{3} 0.1 \mathrm{M} \mathrm{HCl}+40 \mathrm{~cm}^{3}$ deionized water

(ii) $5 \mathrm{~cm}^{3} 0.1 \mathrm{M} \mathrm{HCl}+39 \mathrm{~cm}^{3}$ deionized water $+1 \mathrm{~cm}^{3} 0.15 \mathrm{gcm}^{-3}$ humic acid

(iii) $5 \mathrm{~cm}^{3} 0.1 \mathrm{M} \mathrm{HCl}+37 \mathrm{~cm}^{3}$ deionized water $+1 \mathrm{~cm}^{3} 0.15 \mathrm{gcm}^{-3}$ humic acid

$$
+2 \mathrm{~cm}^{3} \quad 0.01 \mathrm{M} \mathrm{Cu} \text { (II) }
$$

The solutions were titrated against standardized $0.110 \mathrm{MNaOH}$ separately. The total volume of each mixture was adjusted to $50 \mathrm{~cm}^{3}$ and the ionic strength of the solutions was maintained constant at by adding appropriate amount of stock solution of $1 \mathrm{M} \mathrm{KNO}_{3}$ (Gamal, 2015; Omar and Ali, 2015). A magnetic stirrer was used to achieve thorough mixing of the interacting solutions at $550 \mathrm{rpm}$. The same set of experimental conditions was applied for potentiometric titration of remaining samples.

\section{Evaluation of pKa of Hydrolysed peat soil Humic Acids}

The proton-ligand formation number $\mathrm{n}_{\mathbf{A}}$ were calculated by Irving and Rossotti expression (Omar and Ali, 2015).

$\mathrm{nA}=\mathrm{Y}-\frac{(\mathrm{V} 2-\mathrm{V1})(\mathrm{No}-\mathrm{Eo})}{(\mathrm{VO}+\mathrm{V1}) \mathrm{TCL}}$ 1

Where: $Y$ is number of dissociable proton, $\left(\mathrm{V}_{2^{-}}\right.$ $V_{1}$ ) is the measure of displacement of the ligand curve relative to acid curve, $\mathrm{N}^{\circ}$ and $\mathrm{E}^{\circ}$ are the resultant concentration of alkali solution, free acid solution, $\mathrm{T}_{\mathrm{cL}}{ }^{\circ}$ is the total ligand concentration, $\mathrm{V}^{\circ}$ is the total volume of titration solution, $V_{1}$ is the volume of alkali added to acid solution, $V_{2}$ is the volume of alkali added to acid solution + ligand solution, acid dissociation constants (pKa - values) of ligand were calculated by algebraic method point wise calculation (Tables 1 ). The dissociation constants (pKa) were calculated according to the following relation:

$\mathrm{pKa}=\mathrm{pH}+\log \left(\frac{n A}{1-n A}\right)$ 2

Where: pKa is the acid dissociation constant, $\mathrm{n}_{\mathrm{A}}$ is the Proton-ligand formation number and $\mathrm{pH}$ is the pH-values (Omar and Ali, 2015).

\section{Determination of metal-ligand stability constants $(\log K)$ of complexes}

The potentiometric measurement for the determination of stability constant of a complex in solution is based on the fact that the redox potential of the couple $\frac{M^{+(m-n)}}{M^{+m}}$ is shifted significantly on complexation of the metal ion with the ligand. This method involves change in hydrogen ion concentration $\left[\mathrm{H}^{+}\right]$due to the displacement or association of one or more protons taking place during complexation reaction. This change can be found out by titrating the solutions containing free acid, acid with ligand, and acid with ligand and metal ion, individually against a standard alkali solution at a constant ionic strength or temperature. Either ionic strength or temperature may be varied for different sets of solutions. In all the cases, the change in the $\mathrm{pH}$ of the solution is measured after each addition of a known amount of alkali to the reaction cell which contains the reaction mixture. The titration curves are then drawn by plotting the measured $\mathrm{pH}$ values against the corresponding volume of alkali added and the stability constants of the complexes are determined from the titration curves by employing $\mathrm{pH}$-metric titration technique given by (Irving and Rossoti).

Metal-ligand stability constants ( $\log \mathrm{K}$ ) were determined by using the following relations:

$$
\bar{n}=\frac{\left(V_{3}-V_{2}\right)\left(E^{0}+N^{0}\right)}{\left(V^{0}+V_{2}\right) \bar{n}_{A} T_{m}^{0}}
$$

and

$$
P L=\log _{10}\left\{\frac{1+\beta_{n}^{H} \frac{1}{[\text { anti } \log \mathrm{pH}]^{\mathrm{n}}}}{\mathrm{T}_{\mathrm{L}}^{0}-n \bar{T}_{m}^{0}} \mathrm{X} \frac{\left(V^{0}+V_{3}\right)}{V^{0}}\right\}
$$


BAJOPAS Volume 14 Number 1,June, 2021

Where $T_{L}, T^{\circ}, E^{\circ}$, and $V^{\circ}$ havethe same significance as in equation (1) above, $T_{m}$ denotes the total concentration of metal present in solution, $V_{3}$ is the volume of metal ions present in solution and $\beta^{H}$ is the overall proton ligand stability constant. The metal-ligand stability constants (log K) were determined by employing point wise computational Method (eq. 5 and 6).

$\operatorname{LogK}_{1}=\log \left(\frac{n}{1-n}\right)+\mathrm{pL}$ .5

$\operatorname{LogK}_{2}=\log \left(\frac{1-n}{2-n}\right)+\mathrm{pL}$ ...6

Where: Log $\mathrm{K}$ is the metal-ligand stability constant, $\mathrm{pL}$ is the Free ligand exponent function, $\mathbf{n}$ is the Average number of ligand attached with metal ion (Janraoet al., 2014). The results obtained were analyzed by an ORIGIN 2016 program using titration data and then the proton-ligand stability constants (pKa) and Metal-ligand stability constant (LogK) calculated (Omar and Ali, 2015).

\section{RESULTS AND DISCUSSION}

Fourier transformed infrared (FT-IR) spectra of isolated humic acid from peat soils Figure 2 had distinct clear absorption bands indicating the presence of major humic acid structural elemental groups such as $\mathrm{H}$ bonded $\mathrm{OH}$ $\left(3680 \mathrm{~cm}^{-1}\right.$ peak $), C=0$ of carbonyl $\left(1721 \mathrm{~cm}^{-1}\right.$ peak), functional groups of aliphatic components $\mathrm{CH}_{2}\left(2918 \mathrm{~cm}^{-1}\right.$ peak) and $\mathrm{C}-\mathrm{O}$ stretching of polysaccharide $\left(1168 \mathrm{~cm}^{-1}\right.$ peak). The positions of the absorption bands of the spectra fell within typical major absorption bands of humic acid which is at frequencies 3680, 2918, 1721, 1168 $\mathrm{cm}^{-1}$. The first peak centred in the vicinity of $3680 \mathrm{~cm}^{-1}$ region is attributed to phenol $\mathrm{OH}$ group bounded by intermolecular $\mathrm{H}$ bonds. The $2918 \mathrm{~cm}^{-1}$ band usually has absorption maximum at $2918 \mathrm{~cm}^{-1}$ which is due to $\mathrm{C}-\mathrm{H}$ stretching of alkane group $\left(\mathrm{CH}_{2}\right)$. The next major absorption band is $1721 \mathrm{~cm}^{-1}$. This band has been commonly ascribed to $\mathrm{C}=\mathrm{O}$ stretching of mainly carboxyl group $(\mathrm{COOH})$ with trace amount of ketones. The last peak was observed at 1168 $\mathrm{cm}^{-1}$ due to $\mathrm{C}-\mathrm{O}$ stretching of polysaccharides and this peak appeared also in the spectra of humic acid from peat soil. The FTIR spectra of the isolated humic acid contained all major characteristic absorption peaks of humic acid. These absorption peaks indicated the presence of the major structural elements of humic acid namely $\mathrm{H}$ bonded $\mathrm{OH}, \mathrm{C}=\mathrm{C}$ of aromatic ring, $\mathrm{C}=\mathrm{O}$ of carbonyl group (both carboxyl and ketonic), $\mathrm{CH}_{2}$ group. This strongly supports the presence of humic acid.

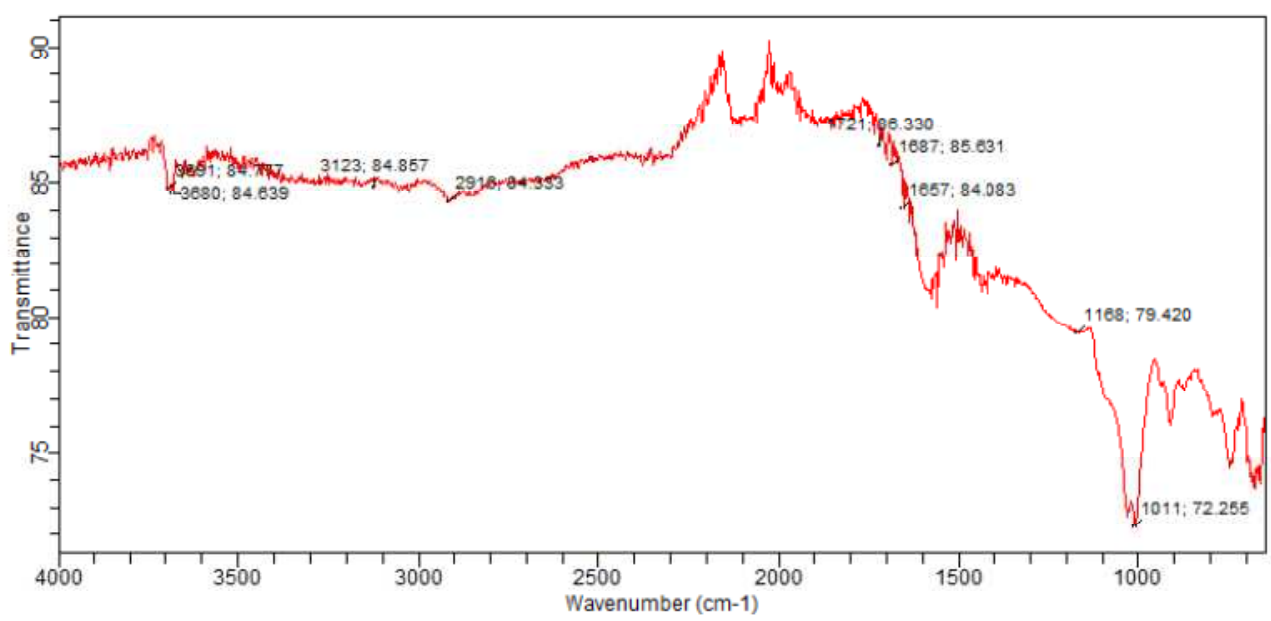

Fig. 2 : FT-IR spectraof peatsoilhumic acid (PSHA)

\section{Evaluation of acid dissociation constant (pka) of acid hydrolysed peat soil humicacid at phenolic group}

The value of the dissociation constant of the peat soil humic acid (PSHA) that underwent acidhydrolysis studied was found to be 8.9299 as shown Table 1, which is lower than the literaturevalues reported by Almeida and Szpoganics, (2015), Borges et al., (2005); Badr et al., (2012)and Fernandes et al,.(2009) of $9.73,9.47$ and 10.30. The difference between the obtained valuesand the reported values in this study might be probably as a result of acid hydrolysis of humicacid. 
BAJOPAS Volume 14 Number 1,June, 2021

Table 1: PKa of (Hydrolysed PSHA)

\begin{tabular}{|l|l|l|l|l|l|l|}
\hline $\mathrm{pH}$ & $\mathrm{BV}_{1}$ & $\mathrm{BV}_{2}$ & $\mathrm{~V}_{2}-\mathrm{V}_{1}$ & $\mathrm{nA}$ & $\log \left(\frac{n A}{1-n A}\right)$ & $\mathrm{pKa}$ \\
\hline 8.50 & 5.30 & 6.29 & 0.99 & 0.3594 & -0.2510 & 8.2490 \\
8.72 & 5.35 & 6.37 & 1.02 & 0.3400 & -0.2880 & 8.4320 \\
9.00 & 5.40 & 6.46 & 1.06 & 0.3141 & -0.3391 & 8.6609 \\
9.22 & 5.45 & 6.55 & 1.10 & 0.2882 & -0.3927 & 8.8273 \\
9.51 & 5.50 & 6.66 & 1.16 & 0.2494 & -0.4786 & 9.0314 \\
9.73 & 5.55 & 6.78 & 1.23 & 0.2041 & -0.5910 & 9.1390 \\
10.00 & 5.60 & 6.90 & 1.30 & 0.1589 & -0.7238 & 9.2762 \\
10.23 & 5.65 & 7.05 & 1.40 & 0.0941 & -0.9835 & 9.2465 \\
10.49 & 5.70 & 7.10 & 1.40 & 0.0941 & -0.9835 & 9.5065 \\
\hline
\end{tabular}

Average pKa $=8.9299 \pm 0.4186$

Table 2: PKa of (Unhydrolysed PSHA)

\begin{tabular}{|l|l|l|l|l|l|l|}
\hline $\mathrm{pH}$ & $\mathrm{BV}_{1}$ & $\mathrm{BV}_{2}$ & $\mathrm{~V}_{2}-\mathrm{V}_{1}$ & $\mathrm{nA}$ & $\log \left(\frac{\boldsymbol{n A}}{1-\boldsymbol{n}}\right)$ & $\mathrm{pKa}$ \\
\hline 8.50 & 5.30 & 5.81 & 0.51 & 0.6619 & 0.2919 & 8.7919 \\
8.72 & 5.35 & 5.90 & 0.55 & 0.6357 & 0.2418 & 8.9618 \\
9.00 & 5.40 & 6.00 & 0.60 & 0.6029 & 0.1813 & 9.1813 \\
9.22 & 5.45 & 6.10 & 0.65 & 0.5701 & 0.1226 & 9.3426 \\
9.51 & 5.50 & 6.20 & 0.70 & 0.5376 & 0.0654 & 9.5754 \\
9.73 & 5.55 & 6.33 & 0.78 & 0.4851 & -0.0259 & 9.7041 \\
10.00 & 5.60 & 6.47 & 0.87 & 0.4262 & -0.1291 & 9.8709 \\
10.23 & 5.65 & 6.62 & 0.99 & 0.3609 & -0.2481 & 9.9819 \\
10.49 & 5.70 & 6.80 & 1.10 & 0.2759 & -0.4690 & 10.0210 \\
\hline
\end{tabular}

Average pKa $=9.4923 \pm 0.4410$

Metal-ligand stability constant ( $\log \mathrm{K}$ )

The stabilityconstants require the accurate values of proton-ligand stability constants (Anil and Maroti, 2008). Metal titration curves crossed over ligand titration curve indicated the formation of complex upon proton release (Santosh, et al., 2011). If the values of n- are within range $0.2-0.8$ and $1.2-18$ this indicates the formation of $1: 1$ and 1:2 complexes (Sayyed and Mazahar, 2012).

The metal (II)-humate stepwise stability constants (log k) at phenolic group (Tables 318)

Table 3: Point-wise method, $\mathrm{Cu}$-(Hydrolysed PSHA)

\begin{tabular}{|l|l|l|l|l|l|l|l|l|}
\hline $\mathrm{pH}$ & $\mathrm{BV}_{1}$ & $\mathrm{BV}_{2}$ & $\mathrm{BV}_{3}$ & $\left(\mathrm{~V}_{3}-\mathrm{V}_{2}\right)$ & $\mathrm{n}$ & $\mathrm{pL}$ & $\log \left(\frac{n}{1-n}\right)$ & LogK $_{1}$ \\
\hline 8.50 & 5.30 & 6.29 & 6.33 & 0.04 & 0.5500 & 2.66 & 0.0871 & 2.7471 \\
8.72 & 5.35 & 6.37 & 6.41 & 0.04 & 0.5714 & 2.43 & 0.1249 & 2.5549 \\
9.00 & 5.40 & 6.46 & 6.50 & 0.04 & 0.6198 & 2.16 & 0.2122 & 2.3722 \\
9.22 & 5.45 & 6.55 & 6.59 & 0.04 & 0.6667 & 1.94 & 0.3010 & 2.2410 \\
\hline
\end{tabular}

LogK $_{1}$ (Average value) $=2.4788 \pm 0.2203$

Table 4: Point-wise method, $\mathrm{Cu}$-(Hydrolysed PSHA)

\begin{tabular}{|l|l|l|l|l|l|l|l|l|}
\hline $\mathrm{pH}$ & $\mathrm{BV}_{1}$ & $\mathrm{BV}_{2}$ & $\mathrm{BV}_{3}$ & $\left(\mathrm{~V}_{3}-\mathrm{V}_{2}\right)$ & $\mathrm{n}$ & $\mathrm{pL}$ & $\log \left(\frac{n-1}{2-n}\right)$ & LogK $_{2}$ \\
\hline 9.51 & 5.50 & 6.66 & 6.73 & 0.07 & 1.3509 & 1.70 & -0.2671 & 1.4329 \\
9.73 & 5.55 & 6.78 & 6.85 & 0.07 & 1.6383 & 1.51 & 0.2467 & 1.7567 \\
10.00 & 5.60 & 6.90 & 6.98 & 0.08 & 2.1783 & 1.31 & -0.2158 & 1.0942 \\
10.23 & 5.65 & 7.05 & 7.13 & 0.08 & 4.1904 & 1.27 & & \\
10.49 & 5.70 & 7.10 & 7.19 & 0.09 & 4.6920 & & & \\
\hline
\end{tabular}

Log $K_{2}($ Average value $)=1.4280 \pm 0.3312$ 
BAJOPAS Volume 14 Number 1,June, 2021

Table 5: Point-wise method, $\mathrm{Cu}$ (Unhydrolysed PSHA)

\begin{tabular}{|l|l|l|l|l|l|l|l|l|}
\hline $\mathrm{pH}$ & $\mathrm{BV}_{1}$ & $\mathrm{BV}_{2}$ & $\mathrm{BV}_{3}$ & $\left(\mathrm{~V}_{3}-\mathrm{V}_{2}\right)$ & $\mathrm{n}$ & $\mathrm{pL}$ & $\log \left(\frac{n}{n-1}\right)$ & Log $_{1}$ \\
\hline 8.50 & 5.30 & 5.81 & 5.85 & 0.04 & 0.2973 & 2.88 & -0.3736 & 2.5064 \\
8.72 & 5.35 & 5.90 & 5.95 & 0.05 & 0.3873 & 2.66 & -0.1992 & 2.4608 \\
9.00 & 5.40 & 6.00 & 6.05 & 0.05 & 0.4044 & 2.38 & -0.1681 & 2.2119 \\
9.22 & 5.45 & 6.10 & 6.15 & 0.06 & 0.5157 & 2.18 & -0.0272 & 2.2072 \\
9.51 & 5.50 & 6.20 & 6.27 & 0.07 & 0.6417 & 1.89 & 0.2530 & 1.1430 \\
\hline
\end{tabular}

$\operatorname{LogK}_{1}($ Average value $)=2.3059 \pm 0.6153$

Table 6:Point-wise method, $\mathrm{Cu}$ (Unhydrolysed PSHA)

\begin{tabular}{|l|l|l|l|l|l|l|l|l|}
\hline $\mathrm{pH}$ & $\mathrm{BV}_{1}$ & $\mathrm{BV}_{2}$ & $\mathrm{BV}_{3}$ & $\mathrm{~V}_{3}-\mathrm{V}_{2}$ & $\mathrm{n}$ & $\mathrm{pL}$ & $\log \left(\frac{n-1}{2-n}\right)$ & $\log \mathrm{K}_{2}$ \\
\hline 9.73 & 5.55 & 6.33 & 6.42 & 0.09 & 0.9000 & 1.69 & & \\
10.00 & 5.60 & 6.47 & 6.58 & 0.11 & 1.2578 & 1.44 & -0.4592 & 0.9808 \\
10.23 & 5.65 & 6.62 & 6.84 & 0.12 & 1.6137 & 1.26 & -0.2010 & 1.4610 \\
10.49 & 5.70 & 6.80 & 6.92 & 0.12 & 2.1052 & 1.03 & & \\
\hline
\end{tabular}

$\operatorname{LogK}_{2}$ (Average value) $=1.2209 \pm 0.3398$

Table 7:Point-wise method, Pb (Hydrolysed PSHA)

\begin{tabular}{|l|l|l|l|l|l|l|l|l|}
\hline $\mathrm{pH}$ & $\mathrm{BV}_{1}$ & $\mathrm{BV}_{2}$ & $\mathrm{BV}_{3}$ & $\left(\mathrm{~V}_{3}-\mathrm{V}_{2}\right)$ & $\mathrm{n}$ & $\mathrm{pL}$ & $\log \left(\frac{n}{1-n}\right)$ & LogK $_{1}$ \\
\hline 8.50 & 5.30 & 6.29 & 6.33 & 0.04 & 0.5500 & 2.66 & 0.0871 & 2.7471 \\
8.72 & 5.35 & 6.37 & 6.41 & 0.04 & 0.5714 & 2.43 & 0.1249 & 2.5549 \\
9.00 & 5.40 & 6.46 & 6.50 & 0.04 & 0.6198 & 2.16 & 0.2122 & 2.3722 \\
9.22 & 5.45 & 6.55 & 6.60 & 0.05 & 0.8333 & 1.96 & 0.6989 & 2.6589 \\
\hline
\end{tabular}

Log $_{\mathbf{1}}($ Average value $)=2.5832 \pm 0.1614$

Table 8:Point-wise method, Pb-(Hydrolysed PSHA)

\begin{tabular}{|l|l|l|l|l|l|l|l|l|}
\hline $\mathrm{pH}$ & $\mathrm{BV}_{1}$ & $\mathrm{BV}_{2}$ & $\mathrm{BV}_{3}$ & $\left(\mathrm{~V}_{3}-\mathrm{V}_{2}\right)$ & $\mathrm{n}$ & $\mathrm{pL}$ & $\log \left(\frac{n-1}{2-n}\right)$ & $\log \mathrm{K}_{2}$ \\
\hline 9.51 & 5.50 & 6.66 & 6.71 & 0.05 & 0.9650 & 1.67 & & \\
9.73 & 5.55 & 6.78 & 6.83 & 0.05 & 1.1702 & 1.44 & & \\
10.00 & 5.60 & 6.90 & 6.90 & 0.05 & 1.4864 & 1.22 & -0.0237 & 1.1963 \\
10.23 & 5.65 & 7.05 & 7.10 & 0.05 & 2.0190 & 1.09 & & \\
10.49 & 5.70 & 7.10 & 7.17 & 0.07 & 3.6492 & 1.00 & & \\
\hline
\end{tabular}

Log $K_{2}$ (Average value) $=1.1963$

Table 9: Point-wise method, Pb (Unhydrolysed PSHA)

\begin{tabular}{|l|l|l|l|l|l|l|l|l|}
\hline $\mathrm{pH}$ & $\mathrm{BV}_{1}$ & $\mathrm{BV}_{2}$ & $\mathrm{BV}_{3}$ & $\mathrm{~V}_{3}-\mathrm{V}_{2}$ & $\mathrm{n}$ & $\mathrm{pL}$ & $\begin{array}{l}\text { Log } \\
\left(\frac{n}{n-1}\right)\end{array}$ & Log $\mathrm{K}_{1}$ \\
\hline 8.50 & 5.30 & 5.81 & 5.85 & 0.04 & 0.2973 & 2.88 & -0.3736 & 2.5064 \\
8.72 & 5.35 & 5.90 & 5.94 & 0.04 & 0.3099 & 2.66 & -0.5477 & 2.3123 \\
9.00 & 5.40 & 6.00 & 6.05 & 0.05 & 0.4044 & 2.38 & -0.1681 & 2.2119 \\
9.22 & 5.45 & 6.10 & 6.15 & 0.06 & 0.5157 & 2.18 & 0.0272 & 2.2072 \\
9.51 & 5.50 & 6.20 & 6.26 & 0.07 & 0.6417 & 1.89 & 0.2530 & 2.1430 \\
9.73 & 5.55 & 6.40 & 6.40 & 0.07 & 0.7000 & 1.67 & 0.3680 & 2.0380 \\
\hline
\end{tabular}

LogK $_{1}$ (Average value) $=2.2364 \pm 0.1602$

Table 10: Point-wise method, Pb (Unhydrolysed PSHA)

\begin{tabular}{|l|l|l|l|l|l|l|l|l|}
\hline $\mathrm{pH}$ & $\mathrm{BV}_{1}$ & $\mathrm{BV}_{2}$ & $\mathrm{BV}_{3}$ & $\mathrm{~V}_{3}-\mathrm{V}_{2}$ & $\mathrm{n}$ & $\mathrm{pL}$ & $\log \left(\frac{n-1}{2-n}\right)$ & $\log \mathrm{K}_{2}$ \\
\hline 10.00 & 5.60 & 6.47 & 6.55 & 0.08 & 1.9503 & 1.41 & & \\
10.23 & 5.65 & 6.62 & 6.72 & 0.11 & 1.4792 & 1.26 & -0.0361 & 1.2239 \\
\hline
\end{tabular}

$\operatorname{LogK}_{2}$ (Average value) $=1.2239$

Table 11: Point-wise method, Mg (Hydrolysed PSHA)

\begin{tabular}{|l|l|l|l|l|l|l|l|l|}
\hline $\mathrm{pH}$ & $\mathrm{BV}_{1}$ & $\mathrm{BV}_{2}$ & $\mathrm{BV}_{3}$ & $\left(\mathrm{~V}_{3}-\mathrm{V}_{2}\right)$ & $\mathrm{n}$ & $\mathrm{pL}$ & $\log \left(\frac{n}{n-1}\right)$ & LogK $_{1}$ \\
\hline 8.50 & 5.30 & 6.29 & 6.31 & 0.02 & 0.2750 & 2.64 & -0.4290 & 2.2110 \\
8.72 & 5.35 & 6.37 & 6.39 & 0.02 & 0.2858 & 2.42 & -0.3978 & 2.0222 \\
9.00 & 5.40 & 6.46 & 6.49 & 0.03 & 0.4648 & 2.14 & -0.0612 & 2.0788 \\
9.22 & 5.45 & 6.55 & 6.59 & 0.04 & 0.6667 & 1.94 & 0.3010 & 2.2410 \\
\hline
\end{tabular}

$\log _{\mathbf{1}}($ Average value) $=2.1382 \pm 0.1046$ 
BAJOPAS Volume 14 Number 1,June, 2021

Table 12: Point-wise method, Mg (Hydrolysed PSHA)

\begin{tabular}{|l|l|l|l|l|l|l|l|l|}
\hline $\mathrm{pH}$ & $\mathrm{BV}_{1}$ & $\mathrm{BV}_{2}$ & $\mathrm{BV}_{3}$ & $\left(\mathrm{~V}_{3}-\mathrm{V}_{2}\right)$ & $\mathrm{n}$ & $\mathrm{pL}$ & $\log \left(\frac{n-1}{2-n}\right)$ & LogK $_{2}$ \\
\hline 9.51 & 5.55 & 6.66 & 6.71 & 0.05 & 0.9650 & 1.67 & & \\
9.73 & 5.55 & 6.78 & 6.84 & 0.06 & 1.4042 & 1.47 & -0.1686 & 1.3014 \\
10.00 & 5.60 & 6.90 & 6.93 & 0.06 & 1.7838 & 1.23 & 0.5593 & 1.7893 \\
10.23 & 5.65 & 7.05 & 7.10 & 0.06 & 3.1429 & 1.10 & & \\
10.49 & 5.70 & 7.10 & 7.18 & 0.07 & 3.6492 & 0.83 & & \\
\hline
\end{tabular}

LogK $_{2}($ Average value $)=1.5453 \pm 0.3450$

Table 13: Point-wise method, Mg (Unhydrolysed PSHA)

\begin{tabular}{|l|l|l|l|l|l|l|l|l|}
\hline $\mathrm{pH}$ & $\mathrm{BV}_{1}$ & $\mathrm{BV}_{2}$ & $\mathrm{BV}_{3}$ & $\mathrm{~V}_{3}-\mathrm{V}_{2}$ & $\mathrm{n}$ & $\mathrm{pL}$ & $\log \left(\frac{n}{n-1}\right)$ & $\operatorname{Log~}_{1}$ \\
\hline 8.50 & 5.30 & 5.81 & 5.85 & 0.04 & 0.2973 & 2.88 & -0.3736 & 2.5064 \\
8.72 & 5.35 & 5.90 & 5.94 & 0.04 & 0.3099 & 2.66 & -0.3477 & 2.3123 \\
9.00 & 5.40 & 6.00 & 6.04 & 0.04 & 0.3236 & 2.38 & -0.3202 & 2.0598 \\
9.22 & 5.45 & 6.10 & 6.15 & 0.05 & 0.4297 & 2.17 & -0.1230 & 2.0470 \\
9.51 & 5.50 & 6.20 & 6.26 & 0.06 & 0.5500 & 1.89 & 0.0871 & 1.9771 \\
9.73 & 5.55 & 6.33 & 6.40 & 0.07 & 0.7000 & 1.67 & 0.3680 & 2.0380 \\
\hline
\end{tabular}

LogK $_{1}$ (Average value) $=2.1568 \pm 0.2069$

Table 14: Point-wise method, Mg (Unhydrolysed PSHA)

\begin{tabular}{|l|l|l|l|l|l|l|l|l|}
\hline $\mathrm{pH}$ & $\mathrm{BV}_{1}$ & $\mathrm{BV}_{2}$ & $\mathrm{BV}_{3}$ & $\mathrm{~V}_{3}-\mathrm{V}_{2}$ & $\mathrm{n}$ & $\mathrm{pL}$ & $\log \left(\frac{n-1}{2-n}\right)$ & $\log \mathrm{K}_{2}$ \\
\hline 10.00 & 5.60 & 6.47 & 6.55 & 0.08 & 0.9148 & 1.41 & & \\
10.23 & 5.65 & 6.62 & 6.71 & 0.09 & 1.2102 & 1.20 & -0.5749 & 0.6251 \\
10.49 & 5.70 & 6.80 & 6.92 & 0.09 & 1.5968 & 1.03 & 0.1703 & 1.2003 \\
\hline
\end{tabular}

LogK $_{2}$ (Average value) $=0.9127 \pm 0.4070$

Table15:Point-wise method, Cd (Hydrolysed PSHA)

\begin{tabular}{|l|l|l|l|l|l|l|l|l|}
\hline $\mathrm{pH}$ & $\mathrm{BV}_{1}$ & $\mathrm{BV}_{2}$ & $\mathrm{BV}_{3}$ & $\left(\mathrm{~V}_{3}-\mathrm{V}_{2}\right)$ & $\mathrm{n}$ & $\mathrm{pL}$ & $\log \left(\frac{n}{1-n}\right)$ & LogK $_{1}$ \\
\hline 8.50 & 5.30 & 6.29 & 6.31 & 0.02 & 0.2750 & 2.64 & -0.4210 & 2.2190 \\
8.72 & 5.35 & 6.37 & 6.40 & 0.03 & 0.4286 & 2.42 & -0.1249 & 2.2951 \\
9.00 & 5.40 & 6.46 & 6.49 & 0.03 & 0.4648 & 2.14 & -0.0612 & 2.0788 \\
9.22 & 5.45 & 6.55 & 6.59 & 0.04 & 0.6667 & 1.96 & 0.3010 & 2.2610 \\
9.51 & 5.55 & 6.66 & 6.70 & 0.04 & 0.7720 & 1.67 & 0.5297 & 2.1997 \\
\hline
\end{tabular}

LogK $_{\mathbf{1}}$ (Average value) $=2.2108 \pm 0.0825$

Table 16: Point-wise method, Cd (Hydrolysed PSHA)

\begin{tabular}{|l|l|l|l|l|l|l|l|l|}
\hline $\mathrm{pH}$ & $\mathrm{BV}_{1}$ & $\mathrm{BV}_{2}$ & $\mathrm{BV}_{3}$ & $\left(\mathrm{~V}_{3}-\mathrm{V}_{2}\right)$ & $\mathrm{n}$ & $\mathrm{pL}$ & $\log \left(\frac{n-1}{2-n}\right)$ & Log $_{2}$ \\
\hline 9.73 & 5.55 & 6.78 & 6.83 & 0.06 & 1.4042 & 1.47 & -0.1686 & 1.3014 \\
10.00 & 5.60 & 6.90 & 6.95 & 0.06 & 1.7838 & 1.23 & 0.5593 & 1.7893 \\
10.23 & 5.65 & 7.05 & 7.10 & 0.06 & 3.1429 & 1.09 & & \\
10.49 & 5.70 & 7.10 & 7.16 & 0.06 & 3.1429 & 0.89 & & \\
& & & & & & & & \\
\hline
\end{tabular}

$\operatorname{LogK}_{2}$ (Average value) $=1.5453 \pm 0.3450$

Table 17: Point-wise method, Cd (Unhydrolysed PSHA)

\begin{tabular}{|l|l|l|l|l|l|l|l|l|}
\hline $\mathrm{pH}$ & $\mathrm{BV}_{1}$ & $\mathrm{BV}_{2}$ & $\mathrm{BV}_{3}$ & $\mathrm{~V}_{3}-\mathrm{V}_{2}$ & $\mathrm{n}$ & $\mathrm{pL}$ & $\log \left(\frac{n}{n-1}\right)$ & $\operatorname{Log~}_{1}$ \\
\hline 8.50 & 5.30 & 5.81 & 5.86 & 0.05 & 0.3717 & 2.88 & -0.2280 & 2.6520 \\
8.72 & 5.35 & 5.90 & 5.95 & 0.05 & 0.3873 & 2.66 & -0.1992 & 2.4608 \\
9.00 & 5.40 & 6.00 & 6.06 & 0.06 & 0.4853 & 2.38 & -0.0255 & 2.3545 \\
9.22 & 5.45 & 6.10 & 6.16 & 0.06 & 0.5157 & 2.18 & -0.0272 & 2.2072 \\
9.51 & 5.50 & 6.20 & 6.27 & 0.07 & 0.6417 & 1.89 & 0.2530 & 1.1430 \\
9.73 & 5.55 & 6.33 & 6.41 & 0.08 & 0.8000 & 1.69 & 0.6020 & 2.2920 \\
& & & & & & & & \\
\hline
\end{tabular}

$\operatorname{LogK}_{1}($ Average value $)=2.2516 \pm 0.5380$ 
BAJOPAS Volume 14 Number 1,June, 2021

Table 18: Point-wise method, Cd (Unhydrolysed PSHA)

\begin{tabular}{|l|l|l|l|l|l|l|l|l|}
\hline $\mathrm{pH}$ & $\mathrm{BV}_{1}$ & $\mathrm{BV}_{2}$ & $\mathrm{BV}_{3}$ & $\mathrm{~V}_{3}-\mathrm{V}_{2}$ & $\mathrm{n}$ & $\mathrm{pL}$ & $\log \left(\frac{n-1}{2-n}\right)$ & $\log \mathrm{K}_{2}$ \\
\hline 10.00 & 5.60 & 6.47 & 6.57 & 0.10 & 1.1434 & 1.43 & & \\
10.23 & 5.65 & 6.62 & 6.72 & 0.10 & 1.3448 & 1.23 & -0.2788 & 0.9512 \\
10.49 & 5.70 & 6.80 & 6.90 & 0.10 & 1.7742 & 1.03 & 0.5351 & 1.5651 \\
\hline
\end{tabular}

$\operatorname{LogK}_{2}($ Average value $)=1.2581 \pm 0.4340$

Table 19: Stepwise and overall Stability constants of thehydrolysed and unhydrolysed divalent metal (II) complexes

\begin{tabular}{|c|c|c|c|}
\hline Chelates & LogK $_{1}$ & $\log _{2}$ & Log $\beta$ \\
\hline [Cu (Hydrolysed PSHA-1) $\left.{ }_{2}\right]$ & 2.4788 & 1.4280 & 3.9068 \\
\hline$\left[\mathrm{Pb}(\text { Hydrolysed PSHA-1) })_{2}\right]$ & 2.5832 & 1.1963 & 3.7795 \\
\hline$\left[\mathrm{Cd}(\text { Hydrolysed PSHA-1 })_{2}\right]$ & 2.2108 & 1.5453 & 3.7561 \\
\hline$\left[\mathrm{Mg}(\text { Hydrolysed PSHA-1 })_{2}\right]$ & 2.1382 & 1.5453 & 3.6835 \\
\hline [Cu (Unhydrolysed PSHA-1) & 2.3059 & 1.2209 & 3.5268 \\
\hline$[\mathrm{Pb}$ (Unhydrolysed PSHA-1) 2$]$ & 2.2364 & 1.2239 & 3.4603 \\
\hline [Cd (Unhydrolysed PSHA-1) 2 ] & 2.2516 & 1.2581 & 3.5097 \\
\hline$[\mathrm{Mg}$ (Unydrolysed PSHA-1) & 2.1568 & 0.9127 & 3.0695 \\
\hline
\end{tabular}

The results obtained (Table19) shows the stepwise and overall stability constants to be not high indicating low stability of the complexes, because the solubility of most metal ions in the basic $\mathrm{pH}$ range is minimal due to metal hydroxide precipitation (Karimi, 2017). In general, the stepwise stability constants $\left(K_{1}\right.$ and $K_{2}$ ) follow the order $K_{1}>K_{2}$ for the copper, lead, magnesium and cadmium complexes respectively. The steady decrease of the values with increasing number of ligands is in agreement with the prediction made by researchers (Na'aliya, 2013). The decrease could be attributed to the fact that as the number of the ligands (Humate ions) that enters the coordination zone increases the aqua molecules available for replacement by the ligands become less. Thus, the metal ions become less electron loving with progressive intake of the ligand and this results in the decrease in the values of the constants (Na'aliya, 2013). Also the stability of the complexes is influenced by the size and number of the chelate rings(Mackay and Mackay,2002).All the complexes form rings in their structure as humate, a bidentate ligand, bond the metal ions in the ratio 1:2 (Boguta and Sokolowska, 2016) forming chelate rings. The values of the overall stability constants $(\log \beta)$ obtained for humate complexes are not high indicating low stability as the values are not high. LogK values for copper-humates (Table 3 to 6) obtained in this study are lower than those reported for the complexes of humic acids (Pandey et al., 2015; Dinu, 2013; Kaschl et al., 2010 and Gilbeto and Jorg, 2001). The values of LogK(Table 7 to 10 ) forlead-humates are lower than those reported for the lead in the literature (Dinu, 2013; Gilbeto and Jorg 2001). Log K values(Table 11 to 14 ) for magnesium-humates obtained in this study are close to those reported by (Pandey et al., 2015). Log K values of cadmium-humates (Table 15 to 18 ) obtained in this work near to the one reported by (Dinu, 2013 and Pandey et al., 2015).The difference between the reported values and the values obtained in this study might be probably as a result of acid hydrolysis of humic acid. The values of the overall stability constants $(\log \beta)$ of the copper humates complexes presented in Table 19 is high than that of other metal humate complexes, show relatively high stability of CuHA complexes, show the following order of stability: $\mathrm{Cu}>\mathrm{Pb}>\mathrm{Cd}>\mathrm{Mg}$; which are in close agreement to the findings of (Dinu, 2013 and Pandey et al., 2015).The high stability of Cuhumate chelate could be attributed to the existence of coordinate covalent bond between the complexing agents and the $\mathrm{Cu}^{2+}$ ions. Since, $\mathrm{Cu}^{2+}$ being a metal of the transitional series with $3 d^{9}$ electronic configurations can accept the electrons from the complexing agents. Similarly, the low stabilities of $\mathrm{Pb}, \mathrm{Cd}$ and $\mathrm{Mg}$ complexes could be explained by that $\mathrm{Pb}^{2+}$ with $6 s^{2}, \mathrm{Cd}^{2+}$ with $4 \mathrm{~d}^{10}$ and $\mathrm{Mg}^{2+}$ with $2 \mathrm{p}^{6}$ their electronic configuration has a completely filled $\mathrm{d}, \mathrm{p}$ and $\mathrm{s}$ orbitals. Moreover, the stabilities of metal ions with hydrolysed humic acid from peat soil were higher than those with unhydrolysed humic acid from peat soil; which is ascribed to the high content of acidity in hydrolysed humic acid than unhydrolysed humic acid. 
BAJOPAS Volume 14 Number 1,June, 2021 CONCLUSION

The values of logk for $\mathrm{Cu}(\mathrm{II})$ hydrolysed humic acid complex was higher followed by $\mathrm{Pb}$ (II), $\mathrm{Cd}(\mathrm{II})$ and $\mathrm{Mg}$ (II) hydrolysed humic acid complexes as compared with metal(II) unhydrolysed humic acid complexes. This indicates acid hydrolysis of humic acid can

\section{REFERENCES}

Almeida, V.R. and Szpoganicz, B. (2015). Humic Acid Potentiometric Response Patterns:Out- of Equilibrium Properties and Species Distribution Modelling. Chemical. Biol. Technol. Agric. 2: 17.

Anđelković, T., Nikolić, R., Bojić, A.,Anđelković, D., and Nikolic G.,(2010). Binding of Cadmium to Soil Humic Acid as A Function of Carboxyl Group Content. Macedonian Journal of Chemistry and Chemical Engineering.29(2): 215-224.

Anil, B. N. and Maroti, N. (2008). Studies on Influence of Die-Lectric Constants on Complex Equilibria between Substituted Py-Razalines and Lanthanide Metal Ions pH-Metrically. Amer.-Euras. scient. Res. 3(2): 212-216.

Ashok, K., Pandey, S. P. and Misra, V (2000). Stability Constants of Metal-Humic Acid Complexes and its Role in Environmental Detoxification. Journal of Ecotoxicology and Environmental Safety. 47(2):157-200.

Badr, M. H., El-Halafawi, M. H. and Abd El-al Zeid, E. R. (2012). Comparison Between the Effect of Ionic Strength on Acidity and Dissociation Constants of Humic Acids Extracted from Sewage Sludge and Nile Water Hyacinth Composts.Global Journal of Environmental Research 6 (1): 36-43.

Baruah, M.K., Borah, D., Saikia, P.P., Paul, S., Sharma, T. (2015). Evaluation of pKa Values of Soil Humic Acids and their Complexation Properties. International Journal of Plant \& Soil Science 6(4) : 218-228.

Boguta, P. Sokolowska, Z. (2016). Interactions of $\mathrm{Zn}$ (II) Ions with Humic Acids Isolated from Various Types of Soils. Effect of $\mathrm{pH}, \mathrm{Zn}$ Concentrations and Humic Acids Chemical Properties. Journal of Geochemical Explaration 168. 119-126.

Borges, F., Guimaraes, C., Lima, L.F.C., Pinto, I. and Reis, S.(2005). Potentiometric Studies on the Complexation of Copper(II) by Phenolic Acids as Discrete Ligand Models of enhance the complexation behavior of humic acid with metal (II) ions. However, the higher values of $\log \beta$ for $\mathrm{Cu}(\mathrm{II}), \mathrm{Pb}(\mathrm{II}), \mathrm{Cd}(\mathrm{II})$ and $\mathrm{Mg}(\mathrm{II})$ hydrolysed humic acid complexes indicates more stable stepwise complexes formed as compared with $\mathrm{Cu}(\mathrm{II}), \mathrm{Pb}$ (II), $\mathrm{Cd}$ (II) and $\mathrm{Mg}(\mathrm{II})$ unhydrolysed humic acid complexes.

Humic Substances Talanta 66 (2005) 670-673.

Chefetz, B., Salloum, M. J., Deshmulkin, A. P. and Hatcher, P. (2002). Structural Components of Humic Acids as Determined by Chemical Modifications and Carbon-13 NMR, Pyrolysis, and Thermochemolysis- Gas Chromatography/Mass Spectrometry. Soil Science Society of American Journal Abstract Division S-2- Soil Chemistry66. 1159-1171.

Dinu, M. I. (2013). Metals Complexation with Humic Acids in Surface Water of Different Environ. Sci. Technol. 31(1): 1-17.

Fernandes, A.N., Giacomelli, C., Giovanela, M. Vaz, D.V. Szpoganicz, B. and Maria M. D. (2009). Potentiometric Acidity Determination in Humic Substances Influenced by Different Analytical Procedures.J. Braz. Chem. Soc. 20 (9):14.

Gamal, A. H. (2015). Stability Constants of Rhenium (V) Metal Complexes with Selected Drugs. Pyrex Journal of Research in Environmental Studies. 2(2): 006-014.

Janrao, D. M., Pathan, J., Kayande, D.D., and Mulla, J.J. (2014). An Over View of Potentiometric Determination of Stability Constants of Metal Complexes. Sci. Revs. Chem. Commun.: 4(1), 2014, 11-24.

Karimi, H. (2017). Effect of pH and Initial Pb(II) Concentration on the Lead Removal Efficiency from Waste Water Using $\mathrm{Ca}(\mathrm{OH})_{2}$. International Journal of Water and Waste Water Treatment 3.2

Kaschl, A. Romheld, V. and Chen, Y. (2010). Binding of Cadmium, Copper and Zinc to Humic Substances Originating from Municipal Solid Waste Compost. Israel Journal of Chemistry Vol. 42(1): 89-98.

Kostic, I. S., Tatjana, P, A., Nikolic, R. S., Cvetkovic, T. P., Pavlovic, D. D., Aleksandar, L.J. and Bojic, A. (2012). Comparative Study of Binding Strengths of Heavy Metals with Humic Acid. J.serb. Chem. Soc. 76(9) pp 1-20. 
BAJOPAS Volume 14 Number 1,June, 2021

Na'aliya, J. (2013). Determination of Stepwise Stability Constants and Gibbs free Energy Change of Trisprolina to Complexes of some Divalent Transition Metal ions. Bayero Journal of Pure and Applied Sciences 6(2): 112-114.

Omar, A. A. and Ali, E. A. (2015). Potentiometric Studies on Complexes of $\mathrm{Cr}$ (III) and $\mathrm{Zr}$ (IV) with some Carboxylic Acids. International Journal of Advanced Chemistry, 3(1) 25-

37.

Pandey, A. K. Pandey, S. D. and Misr, V. (2015).Stability Constants of Metal- Humic Acid Complexes and Its Role in Environmental Detoxification. J. Ecotoxicology and Environmental Safety. 47(1):195-200.

Ram, N. and Raman, K.V. (1984). Stability Constants of Complexes of Metals with
Humicand Fuvic Acids under Non- acidConditions. Journal of Plant Nutrition and Soil Sciences.

147:171-176.

Santosh, D. D., Ashok, B. K., Vijay, J. T., Shivraj, G. W. and Vinay, V. W. (2011). Potentiometric Studies of Elec-Trolyte Effects on Complex Equilibria of Some Substituted 5-(2-hydroxy Phenyl) Pyrazoles. Der pharm. 3 (6): 75-83.

Sayyed, H. and Abdul Rahim, M. F. (2012). Studies of Binary Complexes of Metal Ions with Mandelic Acid by Potentiometry. Chem. J. 02 (6): 206209.

Shirvani, M. Moradian, E. Khalili, B. Bakhtiary, S. (2015). Interaction of $\mathrm{Cd}$ and $\mathrm{Pb}$ with Humate-Palygorskite and HumateSepiolite Complexes. Journal of water, air and pollution 3: 220-228. 


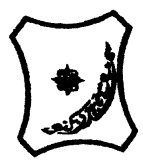

Bayero Journal of Pure and Applied Sciences, 14(1): 54 - 63

Received: November, 2020

Accepted: April, 2021

ISSN $2006-6996$

\title{
STABILITY CONSTANTS OF COMPLEXES OF METAL IONS WITH PEATSOIL HUMIC ACIDS UNDER NON-ACID-CONDITIONS
}

\author{
${ }^{* 1}$ Sabo, Yusuf ${ }^{2}$ Jimoh, W.L.O., ${ }^{3}$ Isa Baba Koki and ${ }^{4}$ Sholadoye, Q. 0. \\ ${ }^{1}$ Department of Pure and Industrial Chemistry, Bayero University, Kano \\ ${ }^{3}$ Department of Chemistry, Yusuf Maitama Sule University Kano. P.M.B. 3220 Kano, Nigeria. \\ ${ }^{4}$ Department of Chemistry, Nigerian Police Academy, Wudil, Kano-Nigeria
}

*Correspondence E-mail; saboyusuf18@yahoo.com

ABSTRACT

Stability constants of complexes of four divalent metal ions viz. $\mathrm{Cu}^{2+}, \mathrm{Pb}^{2+}, \mathrm{Mg}^{2+}$ and $\mathrm{Cd}^{2+}$ with humic acids (HA) were determined by potentiometric titration of humic acids with the corresponding salt of the divalent metals in aqueous media under non-acid-condition. The log $K$ (logarithm of the stability constant) ranged from 1.0942 to 2.7471 for metalhumic acid complexes were determined using point-wise computational method. The order of stability constants were obtained as follows: $\mathrm{Cu}>\mathrm{Pb}>\mathrm{Cd}>\mathrm{Mg}$ for metal $-\mathrm{HA}$ complexes respectively, indicating a higher degree of complexation with Cu metal ion.

Keywords: stability constant, humic acid, potentiometric titration, divalent metals, acid hydrolysis.

\section{NTRODUCTION}

The stability constant of a complex is the numerical expression of its stability and provides a quantitative measure of affinity of the metal ion to the complexing agent. An understanding of the relative stability of metal-complexes helps in predicting the behavior of metal ions in the soil (Ram and Raman, 1982). Extensive researches has been done to determine the stability constants of the complexes formed between humic acid (HA) with a number of metal ions. Ashok et al., (2000) reported that humic acid with hydroxyl, phenoxyl and carboxyl reactive groups can form coordination compound with metal ions at $\mathrm{pH}$ 3.5. The stability constants(Log K) for different metalhumic acid complexes indicated the following order of the stabilities of complexes formed between humic acid and metal ion, $\mathrm{Cu}>\mathrm{Fe}$ $>\mathrm{Pb}>\mathrm{Ni}>\mathrm{Co}>\mathrm{Ca}>\mathrm{Cd}>\mathrm{Zn}>\mathrm{Mn}>\mathrm{Mg}$. Andelkovic et al., (2010) investigated the binding of $\mathrm{Cd}$ (II) to soil humic acid at pH 6.5 and in $0.1 \mathrm{M} \mathrm{KNO}_{3}$ ionic medium. The stability constant for binding indicating greater stability in the case when carboxyl groups are involved in complexation reaction. Kostic et al.,(2012) investigated the complexation of humic acid with certain heavy metal ions (Co(II), $\mathrm{Ni}(\mathrm{II}), \mathrm{Cu}(\mathrm{II})$,
$\mathrm{Zn}(\mathrm{II})$, and $\mathrm{Pb}(\mathrm{II})$. The experiment was performed at $25^{\circ} \mathrm{C}$, at pH 4.0 and ionic strength of $0.01 \mathrm{M}$. Stability constant of complex between $\mathrm{Pb}$ (II) ions and humic acid is greater than stability constants of other investigated metalhumate complexes. Bogata and Sokolowska (2016) analyses the interaction between humic acids from different soils and $\mathrm{Zn}$ (II) ions at wide concentration ranges and at $\mathrm{pH} 5$. Studies have showed significant impact of $\mathrm{Zn}$ concentration, $\mathrm{pH}$ and some properties of humic acids with zinc.But all of these studies were limited to acidic $\mathrm{pH}$ range. Therefore, the present study was carried out to determine and compare the stability constants of complexes of metal ions with hydrolysed peat soil humic acid and unhydrolysed peat soil humic under non-acid conditions.

\section{MATERIALS AND METHODS}

Analytical grade chemicals used includes hydrochloric acid $(\mathrm{HCl})$, nitric acid $\left(\mathrm{HNO}_{3}\right)$, sodium hydroxide $(\mathrm{NaOH})$, lead nitrate $\mathrm{Pb}\left(\mathrm{NO}_{3}\right)_{2}$, copper nitrate $\mathrm{Cu}\left(\mathrm{NO}_{3}\right)_{2} \cdot 3 \mathrm{H}_{2} \mathrm{O}$, cadmium nitrate $\mathrm{Cd}\left(\mathrm{NO}_{3}\right)_{2} \cdot 4 \mathrm{H}_{2} \mathrm{O}$, magnesium nitrate $\mathrm{Mg}\left(\mathrm{NO}_{3}\right)_{2} \cdot 6 \mathrm{H}_{2} \mathrm{O}$, potassium nitrate $\left(\mathrm{KNO}_{3}\right)$, calcium chloride $\left(\mathrm{CaCl}_{2}\right)$, (sigma-Aldrich). Dowex 50WX8, (20-50 mesh) from Fluka. 


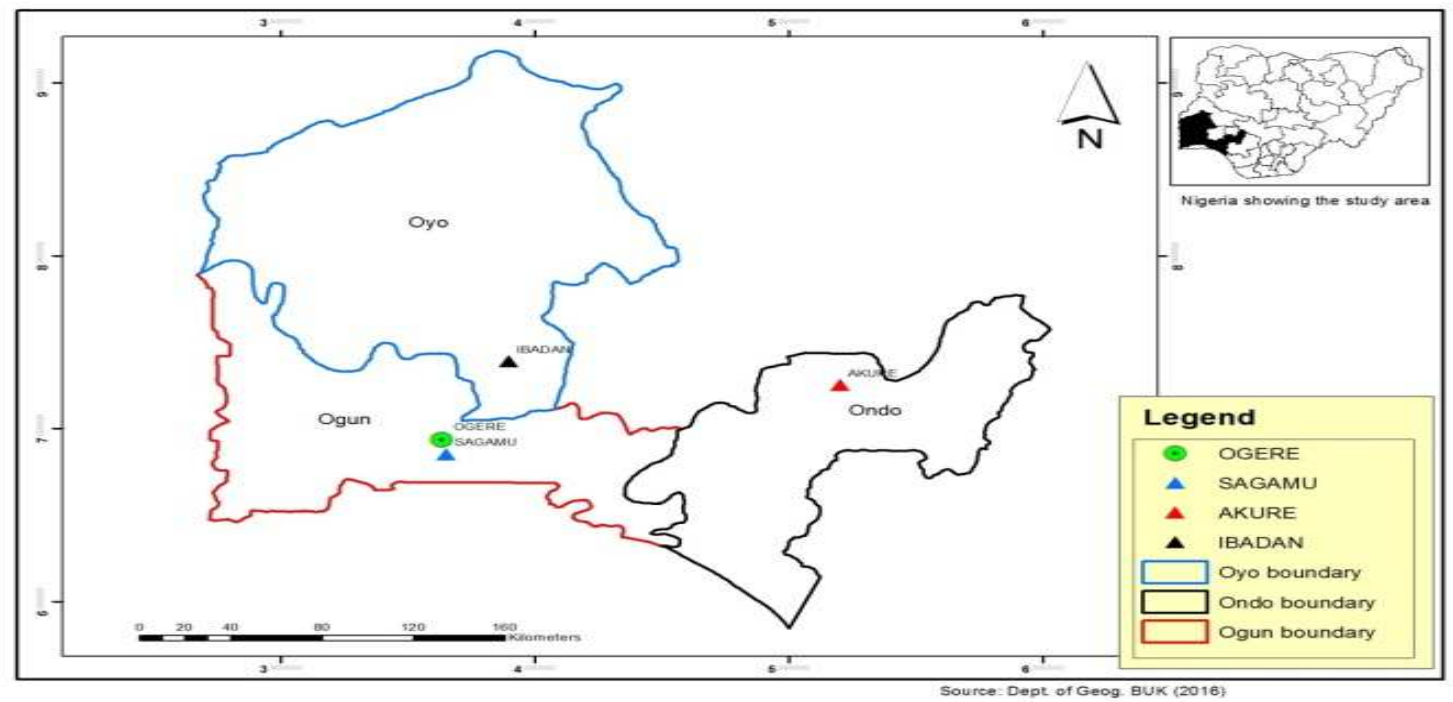

Figure 1: Map showing the sampling point at Sagamu Town, Ogun State.

\section{Description of Sampling Area}

Sagamu has geographical coordinates between $6^{\circ} 50^{\prime}$ north; $3^{\circ} 38^{\prime}$ east is located in south western region of Nigeria. The region has tropical wet and dry climate with a lengthy wet season and relatively constant temperatures throughout the course of the year. Wet season runs from March to October, November to December forms the region dry season. The vegetation type of the region is savannah which is really grassland with small bushes and occasional big trees. Grassland soils have substantially higher organic matter content than forest soils (Novackova, 2011).

\section{Sample Collection}

The Peatsoil samples were collected from four different sampling points $(0-10 \mathrm{~cm}$ depth) in Sagamu into polyethylene bag with plastic spoons. Samples were taken to the laboratory, extraneous materials were removed; the samples were air-dried, crushed and ground to a fine powder in a mortar passed through a $0.20 \mathrm{~mm}$ sieve. The samples were kept for analysis.

\section{Isolation and purification of humic acid from peat soil sample}

Peatsoil sample $(100 \mathrm{~g})$ was mixed with 1000 $\mathrm{cm}^{3}$ of $0.1 \mathrm{M} \mathrm{NaOH}$ solution, shaken for 3hours and left to stand overnight. Dark-coloured supernatant was obtained and decanted from solid residue. The dark-coloured supernatant was acidified to $(\mathrm{pH}=1.0)$ with $6 \mathrm{M} \mathrm{HCl}$ stirred and allowed to stand for 6 hours. Yellowish brown supernatant and dark-brown precipitate were obtained. The yellowish brown supernatant was decanted followed by centrifuge and discarded. The dark-brown precipitate was mixed with $500 \mathrm{~cm}^{3}$ of $0.1 \mathrm{M} \mathrm{NaOH}$ solution followed by passing through dowex resin. The dark-brown solution was acidified to $(\mathrm{pH}=1.0)$ with $6 \mathrm{M} \mathrm{HCl}$ stirred and allowed to stand for 3 hours. The dark-brown precipitate was washed several times with deionized water. The supernatant was treated with $\mathrm{AgNO}_{3}$ solution until no white precipitate observed. The humic acid was transferred to weighed crucible and dried at $60^{\circ} \mathrm{C}$ in an oven for 12 hours. The humic acid was cooled and dried in the desiccator, weighed and recorded. The obtained humic acid was dried again at $60^{\circ} \mathrm{C}$ for additional 6 hours cooled and dried in the desiccator, weighed and recorded constant weight was obtained (Baruah et al., 2015).

\section{FT-IR analysis}

FT-IR spectra of humic acid sample was analysed using Carry 630 FT-IR Agilent Technologies.

Unhydrolysed compost humic acid

The unhydrolysed humic acid was obtained after isolation and purification of compost humic acid and kept for investigation.

\section{Acid hydrolysis of Peatsoil acid}

Peatsoil humic acid sample (1g) was refluxed for 12 hours at $\left(160^{\circ} \mathrm{C}\right)$ with $50 \mathrm{~cm}^{3}$ of $6 \mathrm{M} \mathrm{HCl}$. The mixture was allowed to cool, decanted, and centrifuged after hydrolysis. The insoluble residues were washed with distilled water via centrifugation several times, and the supernatant was treated with $\mathrm{AgNO}_{3}$ solution until no white precipitate was observed. The residue was thoroughly dried over $\mathrm{CaCl}_{2}$ in a desiccator at room temperature (Chefetz et al., 2002). Finally, the obtained hydrolysed humic acid was kept for investigation. 
BAJOPAS Volume 14 Number 1,June, 2021 Potentiometric Titrations

Potentiometric measurements were carried out using a pH-meter Jenway (model 3510) with combine electrode, the sensitivity of the $\mathrm{pH}$ meter is 0.01 units. The $\mathrm{pH}$ meter was switched on half an hour before starting the titration for initial warm up of the instrument. The instrument was calibrated with an aqueous standard buffer solution of $\mathrm{pH} 4.00$ and 10.0 (borate buffer) prepared from a "Qualigens" buffer tablets.

The following sets of solutions were prepared in a $250 \mathrm{~cm}^{3}$ volumetric flask separately for $\mathrm{pH}$ metric titrations.

(i) $5 \mathrm{~cm}^{3} 0.1 \mathrm{M} \mathrm{HCl}+40 \mathrm{~cm}^{3}$ deionized water

(ii) $5 \mathrm{~cm}^{3} 0.1 \mathrm{M} \mathrm{HCl}+39 \mathrm{~cm}^{3}$ deionized water $+1 \mathrm{~cm}^{3} 0.15 \mathrm{gcm}^{-3}$ humic acid

(iii) $5 \mathrm{~cm}^{3} 0.1 \mathrm{M} \mathrm{HCl}+37 \mathrm{~cm}^{3}$ deionized water $+1 \mathrm{~cm}^{3} 0.15 \mathrm{gcm}^{-3}$ humic acid

$$
+2 \mathrm{~cm}^{3} \quad 0.01 \mathrm{M} \mathrm{Cu} \text { (II) }
$$

The solutions were titrated against standardized $0.110 \mathrm{MNaOH}$ separately. The total volume of each mixture was adjusted to $50 \mathrm{~cm}^{3}$ and the ionic strength of the solutions was maintained constant at by adding appropriate amount of stock solution of $1 \mathrm{M} \mathrm{KNO}_{3}$ (Gamal, 2015; Omar and Ali, 2015). A magnetic stirrer was used to achieve thorough mixing of the interacting solutions at $550 \mathrm{rpm}$. The same set of experimental conditions was applied for potentiometric titration of remaining samples.

\section{Evaluation of pKa of Hydrolysed peat soil Humic Acids}

The proton-ligand formation number $\mathrm{n}_{\mathbf{A}}$ were calculated by Irving and Rossotti expression (Omar and Ali, 2015).

$\mathrm{nA}=\mathrm{Y}-\frac{(\mathrm{V} 2-\mathrm{V1})(\mathrm{No}-\mathrm{Eo})}{(\mathrm{VO}+\mathrm{V1}) \mathrm{TCL}}$ 1

Where: $Y$ is number of dissociable proton, $\left(\mathrm{V}_{2^{-}}\right.$ $V_{1}$ ) is the measure of displacement of the ligand curve relative to acid curve, $\mathrm{N}^{\circ}$ and $\mathrm{E}^{\circ}$ are the resultant concentration of alkali solution, free acid solution, $\mathrm{T}_{\mathrm{cL}}{ }^{\circ}$ is the total ligand concentration, $\mathrm{V}^{\circ}$ is the total volume of titration solution, $V_{1}$ is the volume of alkali added to acid solution, $V_{2}$ is the volume of alkali added to acid solution + ligand solution, acid dissociation constants (pKa - values) of ligand were calculated by algebraic method point wise calculation (Tables 1 ). The dissociation constants (pKa) were calculated according to the following relation:

$\mathrm{pKa}=\mathrm{pH}+\log \left(\frac{n A}{1-n A}\right)$ 2

Where: pKa is the acid dissociation constant, $\mathrm{n}_{\mathrm{A}}$ is the Proton-ligand formation number and $\mathrm{pH}$ is the pH-values (Omar and Ali, 2015).

\section{Determination of metal-ligand stability constants $(\log K)$ of complexes}

The potentiometric measurement for the determination of stability constant of a complex in solution is based on the fact that the redox potential of the couple $\frac{M^{+(m-n)}}{M^{+m}}$ is shifted significantly on complexation of the metal ion with the ligand. This method involves change in hydrogen ion concentration $\left[\mathrm{H}^{+}\right]$due to the displacement or association of one or more protons taking place during complexation reaction. This change can be found out by titrating the solutions containing free acid, acid with ligand, and acid with ligand and metal ion, individually against a standard alkali solution at a constant ionic strength or temperature. Either ionic strength or temperature may be varied for different sets of solutions. In all the cases, the change in the $\mathrm{pH}$ of the solution is measured after each addition of a known amount of alkali to the reaction cell which contains the reaction mixture. The titration curves are then drawn by plotting the measured $\mathrm{pH}$ values against the corresponding volume of alkali added and the stability constants of the complexes are determined from the titration curves by employing $\mathrm{pH}$-metric titration technique given by (Irving and Rossoti).

Metal-ligand stability constants ( $\log \mathrm{K}$ ) were determined by using the following relations:

$$
\bar{n}=\frac{\left(V_{3}-V_{2}\right)\left(E^{0}+N^{0}\right)}{\left(V^{0}+V_{2}\right) \bar{n}_{A} T_{m}^{0}}
$$

and

$$
P L=\log _{10}\left\{\frac{1+\beta_{n}^{H} \frac{1}{[\text { anti } \log \mathrm{pH}]^{\mathrm{n}}}}{\mathrm{T}_{\mathrm{L}}^{0}-n \bar{T}_{m}^{0}} \mathrm{X} \frac{\left(V^{0}+V_{3}\right)}{V^{0}}\right\}
$$


BAJOPAS Volume 14 Number 1,June, 2021

Where $T_{L}, T^{\circ}, E^{\circ}$, and $V^{\circ}$ havethe same significance as in equation (1) above, $T_{m}$ denotes the total concentration of metal present in solution, $V_{3}$ is the volume of metal ions present in solution and $\beta^{H}$ is the overall proton ligand stability constant. The metal-ligand stability constants (log K) were determined by employing point wise computational Method (eq. 5 and 6).

$\operatorname{LogK}_{1}=\log \left(\frac{n}{1-n}\right)+\mathrm{pL}$ .5

$\operatorname{LogK}_{2}=\log \left(\frac{1-n}{2-n}\right)+\mathrm{pL}$ ...6

Where: Log $\mathrm{K}$ is the metal-ligand stability constant, $\mathrm{pL}$ is the Free ligand exponent function, $\mathbf{n}$ is the Average number of ligand attached with metal ion (Janraoet al., 2014). The results obtained were analyzed by an ORIGIN 2016 program using titration data and then the proton-ligand stability constants (pKa) and Metal-ligand stability constant (LogK) calculated (Omar and Ali, 2015).

\section{RESULTS AND DISCUSSION}

Fourier transformed infrared (FT-IR) spectra of isolated humic acid from peat soils Figure 2 had distinct clear absorption bands indicating the presence of major humic acid structural elemental groups such as $\mathrm{H}$ bonded $\mathrm{OH}$ $\left(3680 \mathrm{~cm}^{-1}\right.$ peak $), C=0$ of carbonyl $\left(1721 \mathrm{~cm}^{-1}\right.$ peak), functional groups of aliphatic components $\mathrm{CH}_{2}\left(2918 \mathrm{~cm}^{-1}\right.$ peak) and $\mathrm{C}-\mathrm{O}$ stretching of polysaccharide $\left(1168 \mathrm{~cm}^{-1}\right.$ peak). The positions of the absorption bands of the spectra fell within typical major absorption bands of humic acid which is at frequencies 3680, 2918, 1721, 1168 $\mathrm{cm}^{-1}$. The first peak centred in the vicinity of $3680 \mathrm{~cm}^{-1}$ region is attributed to phenol $\mathrm{OH}$ group bounded by intermolecular $\mathrm{H}$ bonds. The $2918 \mathrm{~cm}^{-1}$ band usually has absorption maximum at $2918 \mathrm{~cm}^{-1}$ which is due to $\mathrm{C}-\mathrm{H}$ stretching of alkane group $\left(\mathrm{CH}_{2}\right)$. The next major absorption band is $1721 \mathrm{~cm}^{-1}$. This band has been commonly ascribed to $\mathrm{C}=\mathrm{O}$ stretching of mainly carboxyl group $(\mathrm{COOH})$ with trace amount of ketones. The last peak was observed at 1168 $\mathrm{cm}^{-1}$ due to $\mathrm{C}-\mathrm{O}$ stretching of polysaccharides and this peak appeared also in the spectra of humic acid from peat soil. The FTIR spectra of the isolated humic acid contained all major characteristic absorption peaks of humic acid. These absorption peaks indicated the presence of the major structural elements of humic acid namely $\mathrm{H}$ bonded $\mathrm{OH}, \mathrm{C}=\mathrm{C}$ of aromatic ring, $\mathrm{C}=\mathrm{O}$ of carbonyl group (both carboxyl and ketonic), $\mathrm{CH}_{2}$ group. This strongly supports the presence of humic acid.

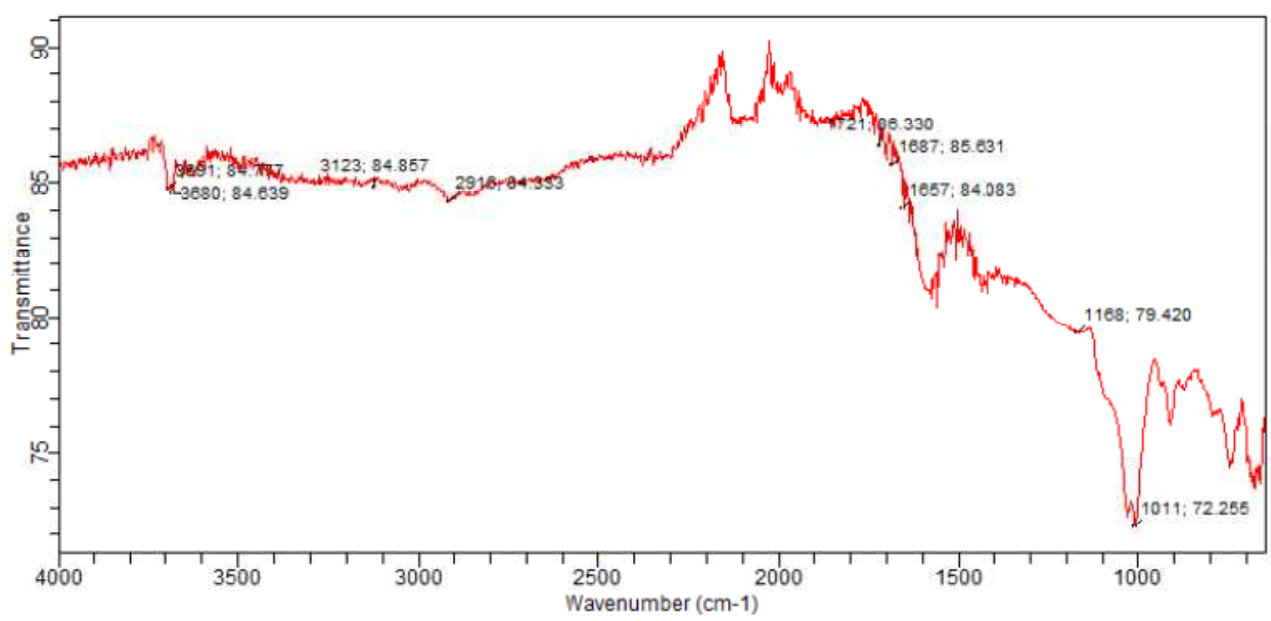

Fig. 2 : FT-IR spectraof peatsoilhumic acid (PSHA)

\section{Evaluation of acid dissociation constant (pka) of acid hydrolysed peat soil humicacid at phenolic group}

The value of the dissociation constant of the peat soil humic acid (PSHA) that underwent acidhydrolysis studied was found to be 8.9299 as shown Table 1, which is lower than the literaturevalues reported by Almeida and Szpoganics, (2015), Borges et al., (2005); Badr et al., (2012)and Fernandes et al,.(2009) of $9.73,9.47$ and 10.30. The difference between the obtained valuesand the reported values in this study might be probably as a result of acid hydrolysis of humicacid. 
BAJOPAS Volume 14 Number 1,June, 2021

Table 1: PKa of (Hydrolysed PSHA)

\begin{tabular}{|l|l|l|l|l|l|l|}
\hline $\mathrm{pH}$ & $\mathrm{BV}_{1}$ & $\mathrm{BV}_{2}$ & $\mathrm{~V}_{2}-\mathrm{V}_{1}$ & $\mathrm{nA}$ & $\log \left(\frac{n A}{1-n A}\right)$ & $\mathrm{pKa}$ \\
\hline 8.50 & 5.30 & 6.29 & 0.99 & 0.3594 & -0.2510 & 8.2490 \\
8.72 & 5.35 & 6.37 & 1.02 & 0.3400 & -0.2880 & 8.4320 \\
9.00 & 5.40 & 6.46 & 1.06 & 0.3141 & -0.3391 & 8.6609 \\
9.22 & 5.45 & 6.55 & 1.10 & 0.2882 & -0.3927 & 8.8273 \\
9.51 & 5.50 & 6.66 & 1.16 & 0.2494 & -0.4786 & 9.0314 \\
9.73 & 5.55 & 6.78 & 1.23 & 0.2041 & -0.5910 & 9.1390 \\
10.00 & 5.60 & 6.90 & 1.30 & 0.1589 & -0.7238 & 9.2762 \\
10.23 & 5.65 & 7.05 & 1.40 & 0.0941 & -0.9835 & 9.2465 \\
10.49 & 5.70 & 7.10 & 1.40 & 0.0941 & -0.9835 & 9.5065 \\
\hline
\end{tabular}

Average pKa $=8.9299 \pm 0.4186$

Table 2: PKa of (Unhydrolysed PSHA)

\begin{tabular}{|l|l|l|l|l|l|l|}
\hline $\mathrm{pH}$ & $\mathrm{BV}_{1}$ & $\mathrm{BV}_{2}$ & $\mathrm{~V}_{2}-\mathrm{V}_{1}$ & $\mathrm{nA}$ & $\log \left(\frac{\boldsymbol{n A}}{1-\boldsymbol{n}}\right)$ & $\mathrm{pKa}$ \\
\hline 8.50 & 5.30 & 5.81 & 0.51 & 0.6619 & 0.2919 & 8.7919 \\
8.72 & 5.35 & 5.90 & 0.55 & 0.6357 & 0.2418 & 8.9618 \\
9.00 & 5.40 & 6.00 & 0.60 & 0.6029 & 0.1813 & 9.1813 \\
9.22 & 5.45 & 6.10 & 0.65 & 0.5701 & 0.1226 & 9.3426 \\
9.51 & 5.50 & 6.20 & 0.70 & 0.5376 & 0.0654 & 9.5754 \\
9.73 & 5.55 & 6.33 & 0.78 & 0.4851 & -0.0259 & 9.7041 \\
10.00 & 5.60 & 6.47 & 0.87 & 0.4262 & -0.1291 & 9.8709 \\
10.23 & 5.65 & 6.62 & 0.99 & 0.3609 & -0.2481 & 9.9819 \\
10.49 & 5.70 & 6.80 & 1.10 & 0.2759 & -0.4690 & 10.0210 \\
\hline
\end{tabular}

Average pKa $=9.4923 \pm 0.4410$

Metal-ligand stability constant ( $\log \mathrm{K}$ )

The stabilityconstants require the accurate values of proton-ligand stability constants (Anil and Maroti, 2008). Metal titration curves crossed over ligand titration curve indicated the formation of complex upon proton release (Santosh, et al., 2011). If the values of n- are within range $0.2-0.8$ and $1.2-18$ this indicates the formation of $1: 1$ and 1:2 complexes (Sayyed and Mazahar, 2012).

The metal (II)-humate stepwise stability constants (log k) at phenolic group (Tables 318)

Table 3: Point-wise method, $\mathrm{Cu}$-(Hydrolysed PSHA)

\begin{tabular}{|l|l|l|l|l|l|l|l|l|}
\hline $\mathrm{pH}$ & $\mathrm{BV}_{1}$ & $\mathrm{BV}_{2}$ & $\mathrm{BV}_{3}$ & $\left(\mathrm{~V}_{3}-\mathrm{V}_{2}\right)$ & $\mathrm{n}$ & $\mathrm{pL}$ & $\log \left(\frac{n}{1-n}\right)$ & LogK $_{1}$ \\
\hline 8.50 & 5.30 & 6.29 & 6.33 & 0.04 & 0.5500 & 2.66 & 0.0871 & 2.7471 \\
8.72 & 5.35 & 6.37 & 6.41 & 0.04 & 0.5714 & 2.43 & 0.1249 & 2.5549 \\
9.00 & 5.40 & 6.46 & 6.50 & 0.04 & 0.6198 & 2.16 & 0.2122 & 2.3722 \\
9.22 & 5.45 & 6.55 & 6.59 & 0.04 & 0.6667 & 1.94 & 0.3010 & 2.2410 \\
\hline
\end{tabular}

LogK $_{1}$ (Average value) $=2.4788 \pm 0.2203$

Table 4: Point-wise method, $\mathrm{Cu}$-(Hydrolysed PSHA)

\begin{tabular}{|l|l|l|l|l|l|l|l|l|}
\hline $\mathrm{pH}$ & $\mathrm{BV}_{1}$ & $\mathrm{BV}_{2}$ & $\mathrm{BV}_{3}$ & $\left(\mathrm{~V}_{3}-\mathrm{V}_{2}\right)$ & $\mathrm{n}$ & $\mathrm{pL}$ & $\log \left(\frac{n-1}{2-n}\right)$ & LogK $_{2}$ \\
\hline 9.51 & 5.50 & 6.66 & 6.73 & 0.07 & 1.3509 & 1.70 & -0.2671 & 1.4329 \\
9.73 & 5.55 & 6.78 & 6.85 & 0.07 & 1.6383 & 1.51 & 0.2467 & 1.7567 \\
10.00 & 5.60 & 6.90 & 6.98 & 0.08 & 2.1783 & 1.31 & -0.2158 & 1.0942 \\
10.23 & 5.65 & 7.05 & 7.13 & 0.08 & 4.1904 & 1.27 & & \\
10.49 & 5.70 & 7.10 & 7.19 & 0.09 & 4.6920 & & & \\
\hline
\end{tabular}

Log $K_{2}($ Average value $)=1.4280 \pm 0.3312$ 
BAJOPAS Volume 14 Number 1,June, 2021

Table 5: Point-wise method, $\mathrm{Cu}$ (Unhydrolysed PSHA)

\begin{tabular}{|l|l|l|l|l|l|l|l|l|}
\hline $\mathrm{pH}$ & $\mathrm{BV}_{1}$ & $\mathrm{BV}_{2}$ & $\mathrm{BV}_{3}$ & $\left(\mathrm{~V}_{3}-\mathrm{V}_{2}\right)$ & $\mathrm{n}$ & $\mathrm{pL}$ & $\log \left(\frac{n}{n-1}\right)$ & Log $_{1}$ \\
\hline 8.50 & 5.30 & 5.81 & 5.85 & 0.04 & 0.2973 & 2.88 & -0.3736 & 2.5064 \\
8.72 & 5.35 & 5.90 & 5.95 & 0.05 & 0.3873 & 2.66 & -0.1992 & 2.4608 \\
9.00 & 5.40 & 6.00 & 6.05 & 0.05 & 0.4044 & 2.38 & -0.1681 & 2.2119 \\
9.22 & 5.45 & 6.10 & 6.15 & 0.06 & 0.5157 & 2.18 & -0.0272 & 2.2072 \\
9.51 & 5.50 & 6.20 & 6.27 & 0.07 & 0.6417 & 1.89 & 0.2530 & 1.1430 \\
\hline
\end{tabular}

$\operatorname{LogK}_{1}($ Average value $)=2.3059 \pm 0.6153$

Table 6:Point-wise method, $\mathrm{Cu}$ (Unhydrolysed PSHA)

\begin{tabular}{|l|l|l|l|l|l|l|l|l|}
\hline $\mathrm{pH}$ & $\mathrm{BV}_{1}$ & $\mathrm{BV}_{2}$ & $\mathrm{BV}_{3}$ & $\mathrm{~V}_{3}-\mathrm{V}_{2}$ & $\mathrm{n}$ & $\mathrm{pL}$ & $\log \left(\frac{n-1}{2-n}\right)$ & $\log \mathrm{K}_{2}$ \\
\hline 9.73 & 5.55 & 6.33 & 6.42 & 0.09 & 0.9000 & 1.69 & & \\
10.00 & 5.60 & 6.47 & 6.58 & 0.11 & 1.2578 & 1.44 & -0.4592 & 0.9808 \\
10.23 & 5.65 & 6.62 & 6.84 & 0.12 & 1.6137 & 1.26 & -0.2010 & 1.4610 \\
10.49 & 5.70 & 6.80 & 6.92 & 0.12 & 2.1052 & 1.03 & & \\
\hline
\end{tabular}

$\operatorname{LogK}_{2}$ (Average value) $=1.2209 \pm 0.3398$

Table 7:Point-wise method, Pb (Hydrolysed PSHA)

\begin{tabular}{|l|l|l|l|l|l|l|l|l|}
\hline $\mathrm{pH}$ & $\mathrm{BV}_{1}$ & $\mathrm{BV}_{2}$ & $\mathrm{BV}_{3}$ & $\left(\mathrm{~V}_{3}-\mathrm{V}_{2}\right)$ & $\mathrm{n}$ & $\mathrm{pL}$ & $\log \left(\frac{n}{1-n}\right)$ & LogK $_{1}$ \\
\hline 8.50 & 5.30 & 6.29 & 6.33 & 0.04 & 0.5500 & 2.66 & 0.0871 & 2.7471 \\
8.72 & 5.35 & 6.37 & 6.41 & 0.04 & 0.5714 & 2.43 & 0.1249 & 2.5549 \\
9.00 & 5.40 & 6.46 & 6.50 & 0.04 & 0.6198 & 2.16 & 0.2122 & 2.3722 \\
9.22 & 5.45 & 6.55 & 6.60 & 0.05 & 0.8333 & 1.96 & 0.6989 & 2.6589 \\
\hline
\end{tabular}

Log $_{\mathbf{1}}($ Average value $)=2.5832 \pm 0.1614$

Table 8:Point-wise method, Pb-(Hydrolysed PSHA)

\begin{tabular}{|l|l|l|l|l|l|l|l|l|}
\hline $\mathrm{pH}$ & $\mathrm{BV}_{1}$ & $\mathrm{BV}_{2}$ & $\mathrm{BV}_{3}$ & $\left(\mathrm{~V}_{3}-\mathrm{V}_{2}\right)$ & $\mathrm{n}$ & $\mathrm{pL}$ & $\log \left(\frac{n-1}{2-n}\right)$ & $\log \mathrm{K}_{2}$ \\
\hline 9.51 & 5.50 & 6.66 & 6.71 & 0.05 & 0.9650 & 1.67 & & \\
9.73 & 5.55 & 6.78 & 6.83 & 0.05 & 1.1702 & 1.44 & & \\
10.00 & 5.60 & 6.90 & 6.90 & 0.05 & 1.4864 & 1.22 & -0.0237 & 1.1963 \\
10.23 & 5.65 & 7.05 & 7.10 & 0.05 & 2.0190 & 1.09 & & \\
10.49 & 5.70 & 7.10 & 7.17 & 0.07 & 3.6492 & 1.00 & & \\
\hline
\end{tabular}

Log $K_{2}$ (Average value) $=1.1963$

Table 9: Point-wise method, Pb (Unhydrolysed PSHA)

\begin{tabular}{|l|l|l|l|l|l|l|l|l|}
\hline $\mathrm{pH}$ & $\mathrm{BV}_{1}$ & $\mathrm{BV}_{2}$ & $\mathrm{BV}_{3}$ & $\mathrm{~V}_{3}-\mathrm{V}_{2}$ & $\mathrm{n}$ & $\mathrm{pL}$ & $\begin{array}{l}\text { Log } \\
\left(\frac{n}{n-1}\right)\end{array}$ & Log $\mathrm{K}_{1}$ \\
\hline 8.50 & 5.30 & 5.81 & 5.85 & 0.04 & 0.2973 & 2.88 & -0.3736 & 2.5064 \\
8.72 & 5.35 & 5.90 & 5.94 & 0.04 & 0.3099 & 2.66 & -0.5477 & 2.3123 \\
9.00 & 5.40 & 6.00 & 6.05 & 0.05 & 0.4044 & 2.38 & -0.1681 & 2.2119 \\
9.22 & 5.45 & 6.10 & 6.15 & 0.06 & 0.5157 & 2.18 & 0.0272 & 2.2072 \\
9.51 & 5.50 & 6.20 & 6.26 & 0.07 & 0.6417 & 1.89 & 0.2530 & 2.1430 \\
9.73 & 5.55 & 6.40 & 6.40 & 0.07 & 0.7000 & 1.67 & 0.3680 & 2.0380 \\
\hline
\end{tabular}

LogK $_{1}$ (Average value) $=2.2364 \pm 0.1602$

Table 10: Point-wise method, Pb (Unhydrolysed PSHA)

\begin{tabular}{|l|l|l|l|l|l|l|l|l|}
\hline $\mathrm{pH}$ & $\mathrm{BV}_{1}$ & $\mathrm{BV}_{2}$ & $\mathrm{BV}_{3}$ & $\mathrm{~V}_{3}-\mathrm{V}_{2}$ & $\mathrm{n}$ & $\mathrm{pL}$ & $\log \left(\frac{n-1}{2-n}\right)$ & $\log \mathrm{K}_{2}$ \\
\hline 10.00 & 5.60 & 6.47 & 6.55 & 0.08 & 1.9503 & 1.41 & & \\
10.23 & 5.65 & 6.62 & 6.72 & 0.11 & 1.4792 & 1.26 & -0.0361 & 1.2239 \\
\hline
\end{tabular}

$\operatorname{LogK}_{2}$ (Average value) $=1.2239$

Table 11: Point-wise method, Mg (Hydrolysed PSHA)

\begin{tabular}{|l|l|l|l|l|l|l|l|l|}
\hline $\mathrm{pH}$ & $\mathrm{BV}_{1}$ & $\mathrm{BV}_{2}$ & $\mathrm{BV}_{3}$ & $\left(\mathrm{~V}_{3}-\mathrm{V}_{2}\right)$ & $\mathrm{n}$ & $\mathrm{pL}$ & $\log \left(\frac{n}{n-1}\right)$ & LogK $_{1}$ \\
\hline 8.50 & 5.30 & 6.29 & 6.31 & 0.02 & 0.2750 & 2.64 & -0.4290 & 2.2110 \\
8.72 & 5.35 & 6.37 & 6.39 & 0.02 & 0.2858 & 2.42 & -0.3978 & 2.0222 \\
9.00 & 5.40 & 6.46 & 6.49 & 0.03 & 0.4648 & 2.14 & -0.0612 & 2.0788 \\
9.22 & 5.45 & 6.55 & 6.59 & 0.04 & 0.6667 & 1.94 & 0.3010 & 2.2410 \\
\hline
\end{tabular}

$\log _{\mathbf{1}}($ Average value) $=2.1382 \pm 0.1046$ 
BAJOPAS Volume 14 Number 1,June, 2021

Table 12: Point-wise method, Mg (Hydrolysed PSHA)

\begin{tabular}{|l|l|l|l|l|l|l|l|l|}
\hline $\mathrm{pH}$ & $\mathrm{BV}_{1}$ & $\mathrm{BV}_{2}$ & $\mathrm{BV}_{3}$ & $\left(\mathrm{~V}_{3}-\mathrm{V}_{2}\right)$ & $\mathrm{n}$ & $\mathrm{pL}$ & $\log \left(\frac{n-1}{2-n}\right)$ & LogK $_{2}$ \\
\hline 9.51 & 5.55 & 6.66 & 6.71 & 0.05 & 0.9650 & 1.67 & & \\
9.73 & 5.55 & 6.78 & 6.84 & 0.06 & 1.4042 & 1.47 & -0.1686 & 1.3014 \\
10.00 & 5.60 & 6.90 & 6.93 & 0.06 & 1.7838 & 1.23 & 0.5593 & 1.7893 \\
10.23 & 5.65 & 7.05 & 7.10 & 0.06 & 3.1429 & 1.10 & & \\
10.49 & 5.70 & 7.10 & 7.18 & 0.07 & 3.6492 & 0.83 & & \\
\hline
\end{tabular}

LogK $_{2}($ Average value $)=1.5453 \pm 0.3450$

Table 13: Point-wise method, Mg (Unhydrolysed PSHA)

\begin{tabular}{|l|l|l|l|l|l|l|l|l|}
\hline $\mathrm{pH}$ & $\mathrm{BV}_{1}$ & $\mathrm{BV}_{2}$ & $\mathrm{BV}_{3}$ & $\mathrm{~V}_{3}-\mathrm{V}_{2}$ & $\mathrm{n}$ & $\mathrm{pL}$ & $\log \left(\frac{n}{n-1}\right)$ & $\operatorname{Log~}_{1}$ \\
\hline 8.50 & 5.30 & 5.81 & 5.85 & 0.04 & 0.2973 & 2.88 & -0.3736 & 2.5064 \\
8.72 & 5.35 & 5.90 & 5.94 & 0.04 & 0.3099 & 2.66 & -0.3477 & 2.3123 \\
9.00 & 5.40 & 6.00 & 6.04 & 0.04 & 0.3236 & 2.38 & -0.3202 & 2.0598 \\
9.22 & 5.45 & 6.10 & 6.15 & 0.05 & 0.4297 & 2.17 & -0.1230 & 2.0470 \\
9.51 & 5.50 & 6.20 & 6.26 & 0.06 & 0.5500 & 1.89 & 0.0871 & 1.9771 \\
9.73 & 5.55 & 6.33 & 6.40 & 0.07 & 0.7000 & 1.67 & 0.3680 & 2.0380 \\
\hline
\end{tabular}

LogK $_{1}$ (Average value) $=2.1568 \pm 0.2069$

Table 14: Point-wise method, Mg (Unhydrolysed PSHA)

\begin{tabular}{|l|l|l|l|l|l|l|l|l|}
\hline $\mathrm{pH}$ & $\mathrm{BV}_{1}$ & $\mathrm{BV}_{2}$ & $\mathrm{BV}_{3}$ & $\mathrm{~V}_{3}-\mathrm{V}_{2}$ & $\mathrm{n}$ & $\mathrm{pL}$ & $\log \left(\frac{n-1}{2-n}\right)$ & $\log \mathrm{K}_{2}$ \\
\hline 10.00 & 5.60 & 6.47 & 6.55 & 0.08 & 0.9148 & 1.41 & & \\
10.23 & 5.65 & 6.62 & 6.71 & 0.09 & 1.2102 & 1.20 & -0.5749 & 0.6251 \\
10.49 & 5.70 & 6.80 & 6.92 & 0.09 & 1.5968 & 1.03 & 0.1703 & 1.2003 \\
\hline
\end{tabular}

LogK $_{2}$ (Average value) $=0.9127 \pm 0.4070$

Table15:Point-wise method, Cd (Hydrolysed PSHA)

\begin{tabular}{|l|l|l|l|l|l|l|l|l|}
\hline $\mathrm{pH}$ & $\mathrm{BV}_{1}$ & $\mathrm{BV}_{2}$ & $\mathrm{BV}_{3}$ & $\left(\mathrm{~V}_{3}-\mathrm{V}_{2}\right)$ & $\mathrm{n}$ & $\mathrm{pL}$ & $\log \left(\frac{n}{1-n}\right)$ & LogK $_{1}$ \\
\hline 8.50 & 5.30 & 6.29 & 6.31 & 0.02 & 0.2750 & 2.64 & -0.4210 & 2.2190 \\
8.72 & 5.35 & 6.37 & 6.40 & 0.03 & 0.4286 & 2.42 & -0.1249 & 2.2951 \\
9.00 & 5.40 & 6.46 & 6.49 & 0.03 & 0.4648 & 2.14 & -0.0612 & 2.0788 \\
9.22 & 5.45 & 6.55 & 6.59 & 0.04 & 0.6667 & 1.96 & 0.3010 & 2.2610 \\
9.51 & 5.55 & 6.66 & 6.70 & 0.04 & 0.7720 & 1.67 & 0.5297 & 2.1997 \\
\hline
\end{tabular}

LogK $_{\mathbf{1}}$ (Average value) $=2.2108 \pm 0.0825$

Table 16: Point-wise method, Cd (Hydrolysed PSHA)

\begin{tabular}{|l|l|l|l|l|l|l|l|l|}
\hline $\mathrm{pH}$ & $\mathrm{BV}_{1}$ & $\mathrm{BV}_{2}$ & $\mathrm{BV}_{3}$ & $\left(\mathrm{~V}_{3}-\mathrm{V}_{2}\right)$ & $\mathrm{n}$ & $\mathrm{pL}$ & $\log \left(\frac{n-1}{2-n}\right)$ & Log $_{2}$ \\
\hline 9.73 & 5.55 & 6.78 & 6.83 & 0.06 & 1.4042 & 1.47 & -0.1686 & 1.3014 \\
10.00 & 5.60 & 6.90 & 6.95 & 0.06 & 1.7838 & 1.23 & 0.5593 & 1.7893 \\
10.23 & 5.65 & 7.05 & 7.10 & 0.06 & 3.1429 & 1.09 & & \\
10.49 & 5.70 & 7.10 & 7.16 & 0.06 & 3.1429 & 0.89 & & \\
& & & & & & & & \\
\hline
\end{tabular}

$\operatorname{LogK}_{2}$ (Average value) $=1.5453 \pm 0.3450$

Table 17: Point-wise method, Cd (Unhydrolysed PSHA)

\begin{tabular}{|l|l|l|l|l|l|l|l|l|}
\hline $\mathrm{pH}$ & $\mathrm{BV}_{1}$ & $\mathrm{BV}_{2}$ & $\mathrm{BV}_{3}$ & $\mathrm{~V}_{3}-\mathrm{V}_{2}$ & $\mathrm{n}$ & $\mathrm{pL}$ & $\log \left(\frac{n}{n-1}\right)$ & $\operatorname{Log~}_{1}$ \\
\hline 8.50 & 5.30 & 5.81 & 5.86 & 0.05 & 0.3717 & 2.88 & -0.2280 & 2.6520 \\
8.72 & 5.35 & 5.90 & 5.95 & 0.05 & 0.3873 & 2.66 & -0.1992 & 2.4608 \\
9.00 & 5.40 & 6.00 & 6.06 & 0.06 & 0.4853 & 2.38 & -0.0255 & 2.3545 \\
9.22 & 5.45 & 6.10 & 6.16 & 0.06 & 0.5157 & 2.18 & -0.0272 & 2.2072 \\
9.51 & 5.50 & 6.20 & 6.27 & 0.07 & 0.6417 & 1.89 & 0.2530 & 1.1430 \\
9.73 & 5.55 & 6.33 & 6.41 & 0.08 & 0.8000 & 1.69 & 0.6020 & 2.2920 \\
& & & & & & & & \\
\hline
\end{tabular}

$\operatorname{LogK}_{1}($ Average value $)=2.2516 \pm 0.5380$ 
BAJOPAS Volume 14 Number 1,June, 2021

Table 18: Point-wise method, Cd (Unhydrolysed PSHA)

\begin{tabular}{|l|l|l|l|l|l|l|l|l|}
\hline $\mathrm{pH}$ & $\mathrm{BV}_{1}$ & $\mathrm{BV}_{2}$ & $\mathrm{BV}_{3}$ & $\mathrm{~V}_{3}-\mathrm{V}_{2}$ & $\mathrm{n}$ & $\mathrm{pL}$ & $\log \left(\frac{n-1}{2-n}\right)$ & $\log \mathrm{K}_{2}$ \\
\hline 10.00 & 5.60 & 6.47 & 6.57 & 0.10 & 1.1434 & 1.43 & & \\
10.23 & 5.65 & 6.62 & 6.72 & 0.10 & 1.3448 & 1.23 & -0.2788 & 0.9512 \\
10.49 & 5.70 & 6.80 & 6.90 & 0.10 & 1.7742 & 1.03 & 0.5351 & 1.5651 \\
\hline
\end{tabular}

$\operatorname{LogK}_{2}($ Average value $)=1.2581 \pm 0.4340$

Table 19: Stepwise and overall Stability constants of thehydrolysed and unhydrolysed divalent metal (II) complexes

\begin{tabular}{|c|c|c|c|}
\hline Chelates & LogK $_{1}$ & $\log _{2}$ & Log $\beta$ \\
\hline [Cu (Hydrolysed PSHA-1) $\left.{ }_{2}\right]$ & 2.4788 & 1.4280 & 3.9068 \\
\hline$\left[\mathrm{Pb}(\text { Hydrolysed PSHA-1) })_{2}\right]$ & 2.5832 & 1.1963 & 3.7795 \\
\hline$\left[\mathrm{Cd}(\text { Hydrolysed PSHA-1 })_{2}\right]$ & 2.2108 & 1.5453 & 3.7561 \\
\hline$\left[\mathrm{Mg}(\text { Hydrolysed PSHA-1 })_{2}\right]$ & 2.1382 & 1.5453 & 3.6835 \\
\hline [Cu (Unhydrolysed PSHA-1) & 2.3059 & 1.2209 & 3.5268 \\
\hline$[\mathrm{Pb}$ (Unhydrolysed PSHA-1) 2$]$ & 2.2364 & 1.2239 & 3.4603 \\
\hline [Cd (Unhydrolysed PSHA-1) 2 ] & 2.2516 & 1.2581 & 3.5097 \\
\hline$[\mathrm{Mg}$ (Unydrolysed PSHA-1) & 2.1568 & 0.9127 & 3.0695 \\
\hline
\end{tabular}

The results obtained (Table19) shows the stepwise and overall stability constants to be not high indicating low stability of the complexes, because the solubility of most metal ions in the basic $\mathrm{pH}$ range is minimal due to metal hydroxide precipitation (Karimi, 2017). In general, the stepwise stability constants $\left(K_{1}\right.$ and $K_{2}$ ) follow the order $K_{1}>K_{2}$ for the copper, lead, magnesium and cadmium complexes respectively. The steady decrease of the values with increasing number of ligands is in agreement with the prediction made by researchers (Na'aliya, 2013). The decrease could be attributed to the fact that as the number of the ligands (Humate ions) that enters the coordination zone increases the aqua molecules available for replacement by the ligands become less. Thus, the metal ions become less electron loving with progressive intake of the ligand and this results in the decrease in the values of the constants (Na'aliya, 2013). Also the stability of the complexes is influenced by the size and number of the chelate rings(Mackay and Mackay,2002).All the complexes form rings in their structure as humate, a bidentate ligand, bond the metal ions in the ratio 1:2 (Boguta and Sokolowska, 2016) forming chelate rings. The values of the overall stability constants $(\log \beta)$ obtained for humate complexes are not high indicating low stability as the values are not high. LogK values for copper-humates (Table 3 to 6) obtained in this study are lower than those reported for the complexes of humic acids (Pandey et al., 2015; Dinu, 2013; Kaschl et al., 2010 and Gilbeto and Jorg, 2001). The values of LogK(Table 7 to 10 ) forlead-humates are lower than those reported for the lead in the literature (Dinu, 2013; Gilbeto and Jorg 2001). Log K values(Table 11 to 14 ) for magnesium-humates obtained in this study are close to those reported by (Pandey et al., 2015). Log K values of cadmium-humates (Table 15 to 18 ) obtained in this work near to the one reported by (Dinu, 2013 and Pandey et al., 2015).The difference between the reported values and the values obtained in this study might be probably as a result of acid hydrolysis of humic acid. The values of the overall stability constants $(\log \beta)$ of the copper humates complexes presented in Table 19 is high than that of other metal humate complexes, show relatively high stability of CuHA complexes, show the following order of stability: $\mathrm{Cu}>\mathrm{Pb}>\mathrm{Cd}>\mathrm{Mg}$; which are in close agreement to the findings of (Dinu, 2013 and Pandey et al., 2015).The high stability of Cuhumate chelate could be attributed to the existence of coordinate covalent bond between the complexing agents and the $\mathrm{Cu}^{2+}$ ions. Since, $\mathrm{Cu}^{2+}$ being a metal of the transitional series with $3 d^{9}$ electronic configurations can accept the electrons from the complexing agents. Similarly, the low stabilities of $\mathrm{Pb}, \mathrm{Cd}$ and $\mathrm{Mg}$ complexes could be explained by that $\mathrm{Pb}^{2+}$ with $6 s^{2}, \mathrm{Cd}^{2+}$ with $4 \mathrm{~d}^{10}$ and $\mathrm{Mg}^{2+}$ with $2 \mathrm{p}^{6}$ their electronic configuration has a completely filled $\mathrm{d}, \mathrm{p}$ and $\mathrm{s}$ orbitals. Moreover, the stabilities of metal ions with hydrolysed humic acid from peat soil were higher than those with unhydrolysed humic acid from peat soil; which is ascribed to the high content of acidity in hydrolysed humic acid than unhydrolysed humic acid. 
BAJOPAS Volume 14 Number 1,June, 2021 CONCLUSION

The values of logk for $\mathrm{Cu}(\mathrm{II})$ hydrolysed humic acid complex was higher followed by $\mathrm{Pb}$ (II), $\mathrm{Cd}(\mathrm{II})$ and $\mathrm{Mg}$ (II) hydrolysed humic acid complexes as compared with metal(II) unhydrolysed humic acid complexes. This indicates acid hydrolysis of humic acid can

\section{REFERENCES}

Almeida, V.R. and Szpoganicz, B. (2015). Humic Acid Potentiometric Response Patterns:Out- of Equilibrium Properties and Species Distribution Modelling. Chemical. Biol. Technol. Agric. 2: 17.

Anđelković, T., Nikolić, R., Bojić, A.,Anđelković, D., and Nikolic G.,(2010). Binding of Cadmium to Soil Humic Acid as A Function of Carboxyl Group Content. Macedonian Journal of Chemistry and Chemical Engineering.29(2): 215-224.

Anil, B. N. and Maroti, N. (2008). Studies on Influence of Die-Lectric Constants on Complex Equilibria between Substituted Py-Razalines and Lanthanide Metal Ions pH-Metrically. Amer.-Euras. scient. Res. 3(2): 212-216.

Ashok, K., Pandey, S. P. and Misra, V (2000). Stability Constants of Metal-Humic Acid Complexes and its Role in Environmental Detoxification. Journal of Ecotoxicology and Environmental Safety. 47(2):157-200.

Badr, M. H., El-Halafawi, M. H. and Abd El-al Zeid, E. R. (2012). Comparison Between the Effect of Ionic Strength on Acidity and Dissociation Constants of Humic Acids Extracted from Sewage Sludge and Nile Water Hyacinth Composts.Global Journal of Environmental Research 6 (1): 36-43.

Baruah, M.K., Borah, D., Saikia, P.P., Paul, S., Sharma, T. (2015). Evaluation of pKa Values of Soil Humic Acids and their Complexation Properties. International Journal of Plant \& Soil Science 6(4) : 218-228.

Boguta, P. Sokolowska, Z. (2016). Interactions of $\mathrm{Zn}$ (II) Ions with Humic Acids Isolated from Various Types of Soils. Effect of $\mathrm{pH}, \mathrm{Zn}$ Concentrations and Humic Acids Chemical Properties. Journal of Geochemical Explaration 168. 119-126.

Borges, F., Guimaraes, C., Lima, L.F.C., Pinto, I. and Reis, S.(2005). Potentiometric Studies on the Complexation of Copper(II) by Phenolic Acids as Discrete Ligand Models of enhance the complexation behavior of humic acid with metal (II) ions. However, the higher values of $\log \beta$ for $\mathrm{Cu}(\mathrm{II}), \mathrm{Pb}(\mathrm{II}), \mathrm{Cd}(\mathrm{II})$ and $\mathrm{Mg}(\mathrm{II})$ hydrolysed humic acid complexes indicates more stable stepwise complexes formed as compared with $\mathrm{Cu}(\mathrm{II}), \mathrm{Pb}$ (II), $\mathrm{Cd}$ (II) and $\mathrm{Mg}(\mathrm{II})$ unhydrolysed humic acid complexes.

Humic Substances Talanta 66 (2005) 670-673.

Chefetz, B., Salloum, M. J., Deshmulkin, A. P. and Hatcher, P. (2002). Structural Components of Humic Acids as Determined by Chemical Modifications and Carbon-13 NMR, Pyrolysis, and Thermochemolysis- Gas Chromatography/Mass Spectrometry. Soil Science Society of American Journal Abstract Division S-2- Soil Chemistry66. 1159-1171.

Dinu, M. I. (2013). Metals Complexation with Humic Acids in Surface Water of Different Environ. Sci. Technol. 31(1): 1-17.

Fernandes, A.N., Giacomelli, C., Giovanela, M. Vaz, D.V. Szpoganicz, B. and Maria M. D. (2009). Potentiometric Acidity Determination in Humic Substances Influenced by Different Analytical Procedures.J. Braz. Chem. Soc. 20 (9):14.

Gamal, A. H. (2015). Stability Constants of Rhenium (V) Metal Complexes with Selected Drugs. Pyrex Journal of Research in Environmental Studies. 2(2): 006-014.

Janrao, D. M., Pathan, J., Kayande, D.D., and Mulla, J.J. (2014). An Over View of Potentiometric Determination of Stability Constants of Metal Complexes. Sci. Revs. Chem. Commun.: 4(1), 2014, 11-24.

Karimi, H. (2017). Effect of pH and Initial Pb(II) Concentration on the Lead Removal Efficiency from Waste Water Using $\mathrm{Ca}(\mathrm{OH})_{2}$. International Journal of Water and Waste Water Treatment 3.2

Kaschl, A. Romheld, V. and Chen, Y. (2010). Binding of Cadmium, Copper and Zinc to Humic Substances Originating from Municipal Solid Waste Compost. Israel Journal of Chemistry Vol. 42(1): 89-98.

Kostic, I. S., Tatjana, P, A., Nikolic, R. S., Cvetkovic, T. P., Pavlovic, D. D., Aleksandar, L.J. and Bojic, A. (2012). Comparative Study of Binding Strengths of Heavy Metals with Humic Acid. J.serb. Chem. Soc. 76(9) pp 1-20. 
BAJOPAS Volume 14 Number 1,June, 2021

Na'aliya, J. (2013). Determination of Stepwise Stability Constants and Gibbs free Energy Change of Trisprolina to Complexes of some Divalent Transition Metal ions. Bayero Journal of Pure and Applied Sciences 6(2): 112-114.

Omar, A. A. and Ali, E. A. (2015). Potentiometric Studies on Complexes of $\mathrm{Cr}$ (III) and $\mathrm{Zr}$ (IV) with some Carboxylic Acids. International Journal of Advanced Chemistry, 3(1) 25-

37.

Pandey, A. K. Pandey, S. D. and Misr, V. (2015).Stability Constants of Metal- Humic Acid Complexes and Its Role in Environmental Detoxification. J. Ecotoxicology and Environmental Safety. 47(1):195-200.

Ram, N. and Raman, K.V. (1984). Stability Constants of Complexes of Metals with
Humicand Fuvic Acids under Non- acidConditions. Journal of Plant Nutrition and Soil Sciences.

147:171-176.

Santosh, D. D., Ashok, B. K., Vijay, J. T., Shivraj, G. W. and Vinay, V. W. (2011). Potentiometric Studies of Elec-Trolyte Effects on Complex Equilibria of Some Substituted 5-(2-hydroxy Phenyl) Pyrazoles. Der pharm. 3 (6): 75-83.

Sayyed, H. and Abdul Rahim, M. F. (2012). Studies of Binary Complexes of Metal Ions with Mandelic Acid by Potentiometry. Chem. J. 02 (6): 206209.

Shirvani, M. Moradian, E. Khalili, B. Bakhtiary, S. (2015). Interaction of $\mathrm{Cd}$ and $\mathrm{Pb}$ with Humate-Palygorskite and HumateSepiolite Complexes. Journal of water, air and pollution 3: 220-228. 


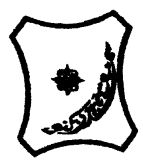

Bayero Journal of Pure and Applied Sciences, 14(1): 54 - 63

Received: November, 2020

Accepted: April, 2021

ISSN $2006-6996$

\title{
STABILITY CONSTANTS OF COMPLEXES OF METAL IONS WITH PEATSOIL HUMIC ACIDS UNDER NON-ACID-CONDITIONS
}

\author{
${ }^{* 1}$ Sabo, Yusuf ${ }^{2}$ Jimoh, W.L.O., ${ }^{3}$ Isa Baba Koki and ${ }^{4}$ Sholadoye, Q. 0. \\ ${ }^{1}$ Department of Pure and Industrial Chemistry, Bayero University, Kano \\ ${ }^{3}$ Department of Chemistry, Yusuf Maitama Sule University Kano. P.M.B. 3220 Kano, Nigeria. \\ ${ }^{4}$ Department of Chemistry, Nigerian Police Academy, Wudil, Kano-Nigeria
}

*Correspondence E-mail; saboyusuf18@yahoo.com

ABSTRACT

Stability constants of complexes of four divalent metal ions viz. $\mathrm{Cu}^{2+}, \mathrm{Pb}^{2+}, \mathrm{Mg}^{2+}$ and $\mathrm{Cd}^{2+}$ with humic acids (HA) were determined by potentiometric titration of humic acids with the corresponding salt of the divalent metals in aqueous media under non-acid-condition. The log $K$ (logarithm of the stability constant) ranged from 1.0942 to 2.7471 for metalhumic acid complexes were determined using point-wise computational method. The order of stability constants were obtained as follows: $\mathrm{Cu}>\mathrm{Pb}>\mathrm{Cd}>\mathrm{Mg}$ for metal $-\mathrm{HA}$ complexes respectively, indicating a higher degree of complexation with Cu metal ion.

Keywords: stability constant, humic acid, potentiometric titration, divalent metals, acid hydrolysis.

\section{NTRODUCTION}

The stability constant of a complex is the numerical expression of its stability and provides a quantitative measure of affinity of the metal ion to the complexing agent. An understanding of the relative stability of metal-complexes helps in predicting the behavior of metal ions in the soil (Ram and Raman, 1982). Extensive researches has been done to determine the stability constants of the complexes formed between humic acid (HA) with a number of metal ions. Ashok et al., (2000) reported that humic acid with hydroxyl, phenoxyl and carboxyl reactive groups can form coordination compound with metal ions at $\mathrm{pH}$ 3.5. The stability constants(Log K) for different metalhumic acid complexes indicated the following order of the stabilities of complexes formed between humic acid and metal ion, $\mathrm{Cu}>\mathrm{Fe}$ $>\mathrm{Pb}>\mathrm{Ni}>\mathrm{Co}>\mathrm{Ca}>\mathrm{Cd}>\mathrm{Zn}>\mathrm{Mn}>\mathrm{Mg}$. Andelkovic et al., (2010) investigated the binding of $\mathrm{Cd}$ (II) to soil humic acid at pH 6.5 and in $0.1 \mathrm{M} \mathrm{KNO}_{3}$ ionic medium. The stability constant for binding indicating greater stability in the case when carboxyl groups are involved in complexation reaction. Kostic et al.,(2012) investigated the complexation of humic acid with certain heavy metal ions (Co(II), $\mathrm{Ni}(\mathrm{II}), \mathrm{Cu}(\mathrm{II})$,
$\mathrm{Zn}(\mathrm{II})$, and $\mathrm{Pb}(\mathrm{II})$. The experiment was performed at $25^{\circ} \mathrm{C}$, at pH 4.0 and ionic strength of $0.01 \mathrm{M}$. Stability constant of complex between $\mathrm{Pb}$ (II) ions and humic acid is greater than stability constants of other investigated metalhumate complexes. Bogata and Sokolowska (2016) analyses the interaction between humic acids from different soils and $\mathrm{Zn}$ (II) ions at wide concentration ranges and at $\mathrm{pH} 5$. Studies have showed significant impact of $\mathrm{Zn}$ concentration, $\mathrm{pH}$ and some properties of humic acids with zinc.But all of these studies were limited to acidic $\mathrm{pH}$ range. Therefore, the present study was carried out to determine and compare the stability constants of complexes of metal ions with hydrolysed peat soil humic acid and unhydrolysed peat soil humic under non-acid conditions.

\section{MATERIALS AND METHODS}

Analytical grade chemicals used includes hydrochloric acid $(\mathrm{HCl})$, nitric acid $\left(\mathrm{HNO}_{3}\right)$, sodium hydroxide $(\mathrm{NaOH})$, lead nitrate $\mathrm{Pb}\left(\mathrm{NO}_{3}\right)_{2}$, copper nitrate $\mathrm{Cu}\left(\mathrm{NO}_{3}\right)_{2} \cdot 3 \mathrm{H}_{2} \mathrm{O}$, cadmium nitrate $\mathrm{Cd}\left(\mathrm{NO}_{3}\right)_{2} \cdot 4 \mathrm{H}_{2} \mathrm{O}$, magnesium nitrate $\mathrm{Mg}\left(\mathrm{NO}_{3}\right)_{2} \cdot 6 \mathrm{H}_{2} \mathrm{O}$, potassium nitrate $\left(\mathrm{KNO}_{3}\right)$, calcium chloride $\left(\mathrm{CaCl}_{2}\right)$, (sigma-Aldrich). Dowex 50WX8, (20-50 mesh) from Fluka. 


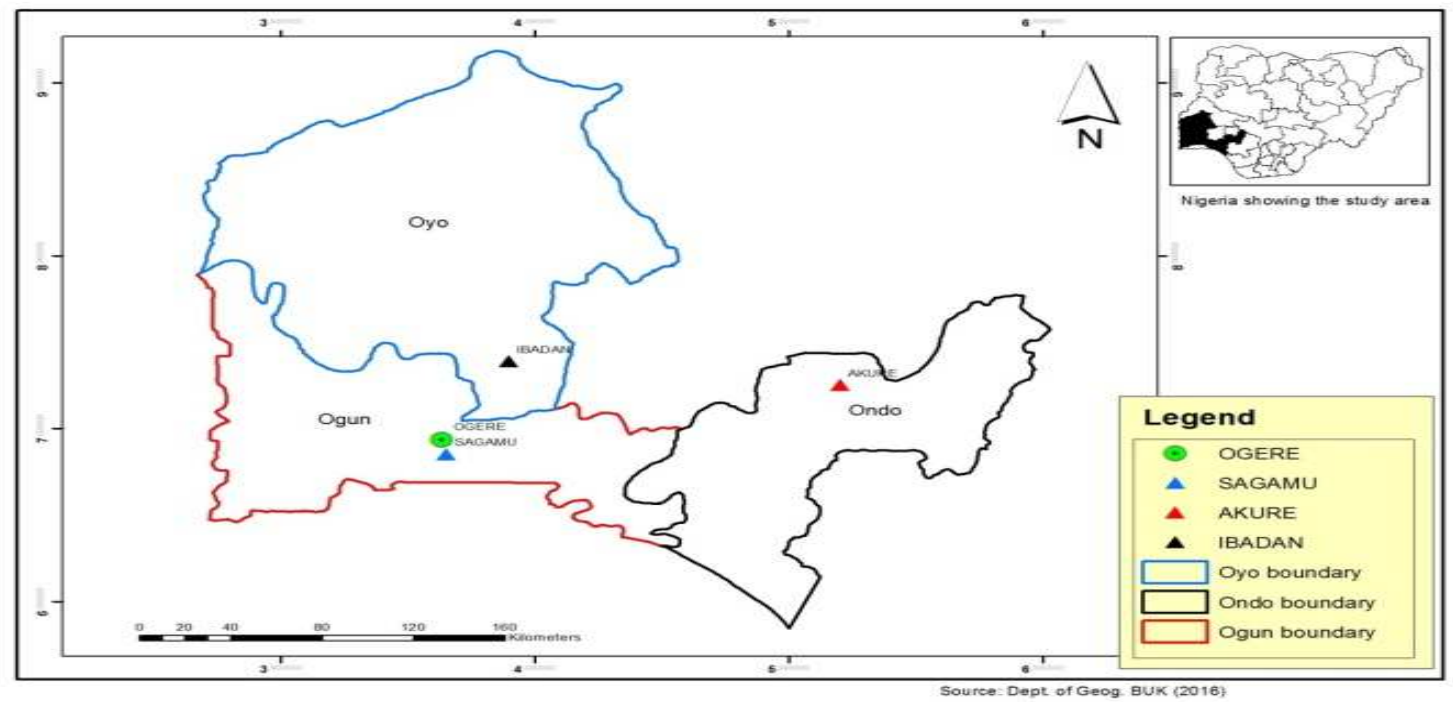

Figure 1: Map showing the sampling point at Sagamu Town, Ogun State.

\section{Description of Sampling Area}

Sagamu has geographical coordinates between $6^{\circ} 50^{\prime}$ north; $3^{\circ} 38^{\prime}$ east is located in south western region of Nigeria. The region has tropical wet and dry climate with a lengthy wet season and relatively constant temperatures throughout the course of the year. Wet season runs from March to October, November to December forms the region dry season. The vegetation type of the region is savannah which is really grassland with small bushes and occasional big trees. Grassland soils have substantially higher organic matter content than forest soils (Novackova, 2011).

\section{Sample Collection}

The Peatsoil samples were collected from four different sampling points $(0-10 \mathrm{~cm}$ depth) in Sagamu into polyethylene bag with plastic spoons. Samples were taken to the laboratory, extraneous materials were removed; the samples were air-dried, crushed and ground to a fine powder in a mortar passed through a $0.20 \mathrm{~mm}$ sieve. The samples were kept for analysis.

\section{Isolation and purification of humic acid from peat soil sample}

Peatsoil sample $(100 \mathrm{~g})$ was mixed with 1000 $\mathrm{cm}^{3}$ of $0.1 \mathrm{M} \mathrm{NaOH}$ solution, shaken for 3hours and left to stand overnight. Dark-coloured supernatant was obtained and decanted from solid residue. The dark-coloured supernatant was acidified to $(\mathrm{pH}=1.0)$ with $6 \mathrm{M} \mathrm{HCl}$ stirred and allowed to stand for 6 hours. Yellowish brown supernatant and dark-brown precipitate were obtained. The yellowish brown supernatant was decanted followed by centrifuge and discarded. The dark-brown precipitate was mixed with $500 \mathrm{~cm}^{3}$ of $0.1 \mathrm{M} \mathrm{NaOH}$ solution followed by passing through dowex resin. The dark-brown solution was acidified to $(\mathrm{pH}=1.0)$ with $6 \mathrm{M} \mathrm{HCl}$ stirred and allowed to stand for 3 hours. The dark-brown precipitate was washed several times with deionized water. The supernatant was treated with $\mathrm{AgNO}_{3}$ solution until no white precipitate observed. The humic acid was transferred to weighed crucible and dried at $60^{\circ} \mathrm{C}$ in an oven for 12 hours. The humic acid was cooled and dried in the desiccator, weighed and recorded. The obtained humic acid was dried again at $60^{\circ} \mathrm{C}$ for additional 6 hours cooled and dried in the desiccator, weighed and recorded constant weight was obtained (Baruah et al., 2015).

\section{FT-IR analysis}

FT-IR spectra of humic acid sample was analysed using Carry 630 FT-IR Agilent Technologies.

Unhydrolysed compost humic acid

The unhydrolysed humic acid was obtained after isolation and purification of compost humic acid and kept for investigation.

\section{Acid hydrolysis of Peatsoil acid}

Peatsoil humic acid sample (1g) was refluxed for 12 hours at $\left(160^{\circ} \mathrm{C}\right)$ with $50 \mathrm{~cm}^{3}$ of $6 \mathrm{M} \mathrm{HCl}$. The mixture was allowed to cool, decanted, and centrifuged after hydrolysis. The insoluble residues were washed with distilled water via centrifugation several times, and the supernatant was treated with $\mathrm{AgNO}_{3}$ solution until no white precipitate was observed. The residue was thoroughly dried over $\mathrm{CaCl}_{2}$ in a desiccator at room temperature (Chefetz et al., 2002). Finally, the obtained hydrolysed humic acid was kept for investigation. 
BAJOPAS Volume 14 Number 1,June, 2021 Potentiometric Titrations

Potentiometric measurements were carried out using a pH-meter Jenway (model 3510) with combine electrode, the sensitivity of the $\mathrm{pH}$ meter is 0.01 units. The $\mathrm{pH}$ meter was switched on half an hour before starting the titration for initial warm up of the instrument. The instrument was calibrated with an aqueous standard buffer solution of $\mathrm{pH} 4.00$ and 10.0 (borate buffer) prepared from a "Qualigens" buffer tablets.

The following sets of solutions were prepared in a $250 \mathrm{~cm}^{3}$ volumetric flask separately for $\mathrm{pH}$ metric titrations.

(i) $5 \mathrm{~cm}^{3} 0.1 \mathrm{M} \mathrm{HCl}+40 \mathrm{~cm}^{3}$ deionized water

(ii) $5 \mathrm{~cm}^{3} 0.1 \mathrm{M} \mathrm{HCl}+39 \mathrm{~cm}^{3}$ deionized water $+1 \mathrm{~cm}^{3} 0.15 \mathrm{gcm}^{-3}$ humic acid

(iii) $5 \mathrm{~cm}^{3} 0.1 \mathrm{M} \mathrm{HCl}+37 \mathrm{~cm}^{3}$ deionized water $+1 \mathrm{~cm}^{3} 0.15 \mathrm{gcm}^{-3}$ humic acid

$$
+2 \mathrm{~cm}^{3} \quad 0.01 \mathrm{M} \mathrm{Cu} \text { (II) }
$$

The solutions were titrated against standardized $0.110 \mathrm{MNaOH}$ separately. The total volume of each mixture was adjusted to $50 \mathrm{~cm}^{3}$ and the ionic strength of the solutions was maintained constant at by adding appropriate amount of stock solution of $1 \mathrm{M} \mathrm{KNO}_{3}$ (Gamal, 2015; Omar and Ali, 2015). A magnetic stirrer was used to achieve thorough mixing of the interacting solutions at $550 \mathrm{rpm}$. The same set of experimental conditions was applied for potentiometric titration of remaining samples.

\section{Evaluation of pKa of Hydrolysed peat soil Humic Acids}

The proton-ligand formation number $\mathrm{n}_{\mathbf{A}}$ were calculated by Irving and Rossotti expression (Omar and Ali, 2015).

$\mathrm{nA}=\mathrm{Y}-\frac{(\mathrm{V} 2-\mathrm{V1})(\mathrm{No}-\mathrm{Eo})}{(\mathrm{VO}+\mathrm{V1}) \mathrm{TCL}}$ 1

Where: $Y$ is number of dissociable proton, $\left(\mathrm{V}_{2^{-}}\right.$ $V_{1}$ ) is the measure of displacement of the ligand curve relative to acid curve, $\mathrm{N}^{\circ}$ and $\mathrm{E}^{\circ}$ are the resultant concentration of alkali solution, free acid solution, $\mathrm{T}_{\mathrm{cL}}{ }^{\circ}$ is the total ligand concentration, $\mathrm{V}^{\circ}$ is the total volume of titration solution, $V_{1}$ is the volume of alkali added to acid solution, $V_{2}$ is the volume of alkali added to acid solution + ligand solution, acid dissociation constants (pKa - values) of ligand were calculated by algebraic method point wise calculation (Tables 1 ). The dissociation constants (pKa) were calculated according to the following relation:

$\mathrm{pKa}=\mathrm{pH}+\log \left(\frac{n A}{1-n A}\right)$ 2

Where: pKa is the acid dissociation constant, $\mathrm{n}_{\mathrm{A}}$ is the Proton-ligand formation number and $\mathrm{pH}$ is the pH-values (Omar and Ali, 2015).

\section{Determination of metal-ligand stability constants $(\log K)$ of complexes}

The potentiometric measurement for the determination of stability constant of a complex in solution is based on the fact that the redox potential of the couple $\frac{M^{+(m-n)}}{M^{+m}}$ is shifted significantly on complexation of the metal ion with the ligand. This method involves change in hydrogen ion concentration $\left[\mathrm{H}^{+}\right]$due to the displacement or association of one or more protons taking place during complexation reaction. This change can be found out by titrating the solutions containing free acid, acid with ligand, and acid with ligand and metal ion, individually against a standard alkali solution at a constant ionic strength or temperature. Either ionic strength or temperature may be varied for different sets of solutions. In all the cases, the change in the $\mathrm{pH}$ of the solution is measured after each addition of a known amount of alkali to the reaction cell which contains the reaction mixture. The titration curves are then drawn by plotting the measured $\mathrm{pH}$ values against the corresponding volume of alkali added and the stability constants of the complexes are determined from the titration curves by employing $\mathrm{pH}$-metric titration technique given by (Irving and Rossoti).

Metal-ligand stability constants ( $\log \mathrm{K}$ ) were determined by using the following relations:

$$
\bar{n}=\frac{\left(V_{3}-V_{2}\right)\left(E^{0}+N^{0}\right)}{\left(V^{0}+V_{2}\right) \bar{n}_{A} T_{m}^{0}}
$$

and

$$
P L=\log _{10}\left\{\frac{1+\beta_{n}^{H} \frac{1}{[\text { anti } \log \mathrm{pH}]^{\mathrm{n}}}}{\mathrm{T}_{\mathrm{L}}^{0}-n \bar{T}_{m}^{0}} \mathrm{X} \frac{\left(V^{0}+V_{3}\right)}{V^{0}}\right\}
$$


BAJOPAS Volume 14 Number 1,June, 2021

Where $T_{L}, T^{\circ}, E^{\circ}$, and $V^{\circ}$ havethe same significance as in equation (1) above, $T_{m}$ denotes the total concentration of metal present in solution, $V_{3}$ is the volume of metal ions present in solution and $\beta^{H}$ is the overall proton ligand stability constant. The metal-ligand stability constants (log K) were determined by employing point wise computational Method (eq. 5 and 6).

$\operatorname{LogK}_{1}=\log \left(\frac{n}{1-n}\right)+\mathrm{pL}$ .5

$\operatorname{LogK}_{2}=\log \left(\frac{1-n}{2-n}\right)+\mathrm{pL}$ ...6

Where: Log $\mathrm{K}$ is the metal-ligand stability constant, $\mathrm{pL}$ is the Free ligand exponent function, $\mathbf{n}$ is the Average number of ligand attached with metal ion (Janraoet al., 2014). The results obtained were analyzed by an ORIGIN 2016 program using titration data and then the proton-ligand stability constants (pKa) and Metal-ligand stability constant (LogK) calculated (Omar and Ali, 2015).

\section{RESULTS AND DISCUSSION}

Fourier transformed infrared (FT-IR) spectra of isolated humic acid from peat soils Figure 2 had distinct clear absorption bands indicating the presence of major humic acid structural elemental groups such as $\mathrm{H}$ bonded $\mathrm{OH}$ $\left(3680 \mathrm{~cm}^{-1}\right.$ peak $), C=0$ of carbonyl $\left(1721 \mathrm{~cm}^{-1}\right.$ peak), functional groups of aliphatic components $\mathrm{CH}_{2}\left(2918 \mathrm{~cm}^{-1}\right.$ peak) and $\mathrm{C}-\mathrm{O}$ stretching of polysaccharide $\left(1168 \mathrm{~cm}^{-1}\right.$ peak). The positions of the absorption bands of the spectra fell within typical major absorption bands of humic acid which is at frequencies 3680, 2918, 1721, 1168 $\mathrm{cm}^{-1}$. The first peak centred in the vicinity of $3680 \mathrm{~cm}^{-1}$ region is attributed to phenol $\mathrm{OH}$ group bounded by intermolecular $\mathrm{H}$ bonds. The $2918 \mathrm{~cm}^{-1}$ band usually has absorption maximum at $2918 \mathrm{~cm}^{-1}$ which is due to $\mathrm{C}-\mathrm{H}$ stretching of alkane group $\left(\mathrm{CH}_{2}\right)$. The next major absorption band is $1721 \mathrm{~cm}^{-1}$. This band has been commonly ascribed to $\mathrm{C}=\mathrm{O}$ stretching of mainly carboxyl group $(\mathrm{COOH})$ with trace amount of ketones. The last peak was observed at 1168 $\mathrm{cm}^{-1}$ due to $\mathrm{C}-\mathrm{O}$ stretching of polysaccharides and this peak appeared also in the spectra of humic acid from peat soil. The FTIR spectra of the isolated humic acid contained all major characteristic absorption peaks of humic acid. These absorption peaks indicated the presence of the major structural elements of humic acid namely $\mathrm{H}$ bonded $\mathrm{OH}, \mathrm{C}=\mathrm{C}$ of aromatic ring, $\mathrm{C}=\mathrm{O}$ of carbonyl group (both carboxyl and ketonic), $\mathrm{CH}_{2}$ group. This strongly supports the presence of humic acid.

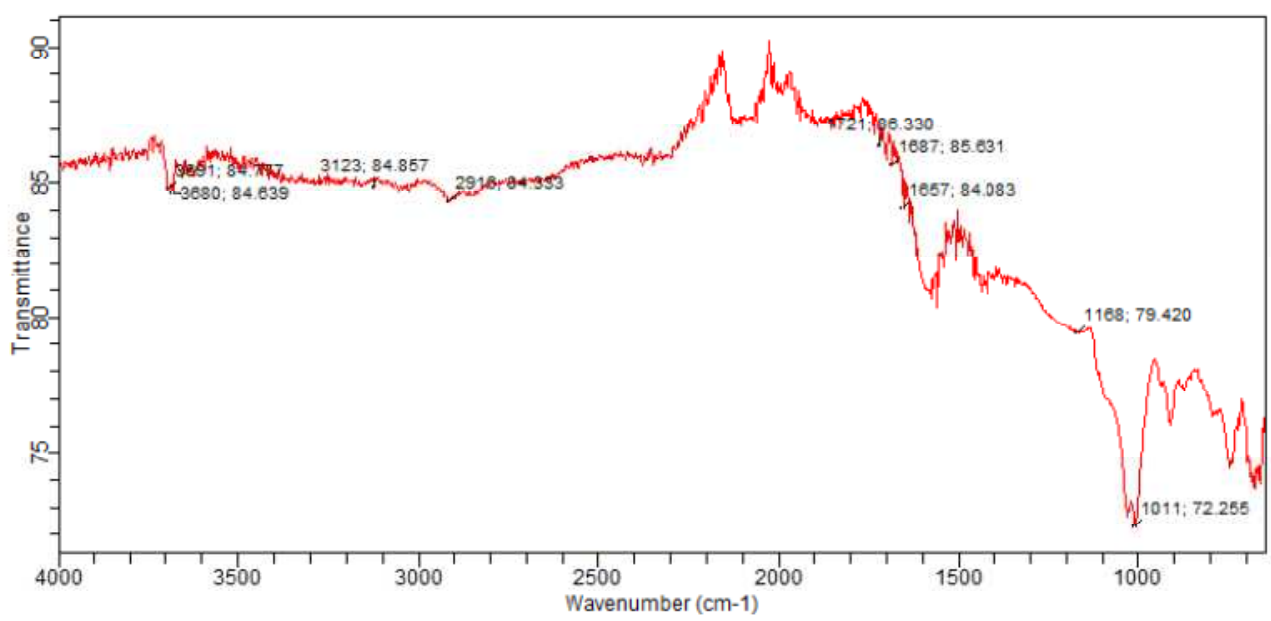

Fig. 2 : FT-IR spectraof peatsoilhumic acid (PSHA)

\section{Evaluation of acid dissociation constant (pka) of acid hydrolysed peat soil humicacid at phenolic group}

The value of the dissociation constant of the peat soil humic acid (PSHA) that underwent acidhydrolysis studied was found to be 8.9299 as shown Table 1, which is lower than the literaturevalues reported by Almeida and Szpoganics, (2015), Borges et al., (2005); Badr et al., (2012)and Fernandes et al,.(2009) of $9.73,9.47$ and 10.30. The difference between the obtained valuesand the reported values in this study might be probably as a result of acid hydrolysis of humicacid. 
BAJOPAS Volume 14 Number 1,June, 2021

Table 1: PKa of (Hydrolysed PSHA)

\begin{tabular}{|l|l|l|l|l|l|l|}
\hline $\mathrm{pH}$ & $\mathrm{BV}_{1}$ & $\mathrm{BV}_{2}$ & $\mathrm{~V}_{2}-\mathrm{V}_{1}$ & $\mathrm{nA}$ & $\log \left(\frac{n A}{1-n A}\right)$ & $\mathrm{pKa}$ \\
\hline 8.50 & 5.30 & 6.29 & 0.99 & 0.3594 & -0.2510 & 8.2490 \\
8.72 & 5.35 & 6.37 & 1.02 & 0.3400 & -0.2880 & 8.4320 \\
9.00 & 5.40 & 6.46 & 1.06 & 0.3141 & -0.3391 & 8.6609 \\
9.22 & 5.45 & 6.55 & 1.10 & 0.2882 & -0.3927 & 8.8273 \\
9.51 & 5.50 & 6.66 & 1.16 & 0.2494 & -0.4786 & 9.0314 \\
9.73 & 5.55 & 6.78 & 1.23 & 0.2041 & -0.5910 & 9.1390 \\
10.00 & 5.60 & 6.90 & 1.30 & 0.1589 & -0.7238 & 9.2762 \\
10.23 & 5.65 & 7.05 & 1.40 & 0.0941 & -0.9835 & 9.2465 \\
10.49 & 5.70 & 7.10 & 1.40 & 0.0941 & -0.9835 & 9.5065 \\
\hline
\end{tabular}

Average pKa $=8.9299 \pm 0.4186$

Table 2: PKa of (Unhydrolysed PSHA)

\begin{tabular}{|l|l|l|l|l|l|l|}
\hline $\mathrm{pH}$ & $\mathrm{BV}_{1}$ & $\mathrm{BV}_{2}$ & $\mathrm{~V}_{2}-\mathrm{V}_{1}$ & $\mathrm{nA}$ & $\log \left(\frac{\boldsymbol{n A}}{1-\boldsymbol{n}}\right)$ & $\mathrm{pKa}$ \\
\hline 8.50 & 5.30 & 5.81 & 0.51 & 0.6619 & 0.2919 & 8.7919 \\
8.72 & 5.35 & 5.90 & 0.55 & 0.6357 & 0.2418 & 8.9618 \\
9.00 & 5.40 & 6.00 & 0.60 & 0.6029 & 0.1813 & 9.1813 \\
9.22 & 5.45 & 6.10 & 0.65 & 0.5701 & 0.1226 & 9.3426 \\
9.51 & 5.50 & 6.20 & 0.70 & 0.5376 & 0.0654 & 9.5754 \\
9.73 & 5.55 & 6.33 & 0.78 & 0.4851 & -0.0259 & 9.7041 \\
10.00 & 5.60 & 6.47 & 0.87 & 0.4262 & -0.1291 & 9.8709 \\
10.23 & 5.65 & 6.62 & 0.99 & 0.3609 & -0.2481 & 9.9819 \\
10.49 & 5.70 & 6.80 & 1.10 & 0.2759 & -0.4690 & 10.0210 \\
\hline
\end{tabular}

Average pKa $=9.4923 \pm 0.4410$

Metal-ligand stability constant ( $\log \mathrm{K}$ )

The stabilityconstants require the accurate values of proton-ligand stability constants (Anil and Maroti, 2008). Metal titration curves crossed over ligand titration curve indicated the formation of complex upon proton release (Santosh, et al., 2011). If the values of n- are within range $0.2-0.8$ and $1.2-18$ this indicates the formation of $1: 1$ and 1:2 complexes (Sayyed and Mazahar, 2012).

The metal (II)-humate stepwise stability constants (log k) at phenolic group (Tables 318)

Table 3: Point-wise method, $\mathrm{Cu}$-(Hydrolysed PSHA)

\begin{tabular}{|l|l|l|l|l|l|l|l|l|}
\hline $\mathrm{pH}$ & $\mathrm{BV}_{1}$ & $\mathrm{BV}_{2}$ & $\mathrm{BV}_{3}$ & $\left(\mathrm{~V}_{3}-\mathrm{V}_{2}\right)$ & $\mathrm{n}$ & $\mathrm{pL}$ & $\log \left(\frac{n}{1-n}\right)$ & LogK $_{1}$ \\
\hline 8.50 & 5.30 & 6.29 & 6.33 & 0.04 & 0.5500 & 2.66 & 0.0871 & 2.7471 \\
8.72 & 5.35 & 6.37 & 6.41 & 0.04 & 0.5714 & 2.43 & 0.1249 & 2.5549 \\
9.00 & 5.40 & 6.46 & 6.50 & 0.04 & 0.6198 & 2.16 & 0.2122 & 2.3722 \\
9.22 & 5.45 & 6.55 & 6.59 & 0.04 & 0.6667 & 1.94 & 0.3010 & 2.2410 \\
\hline
\end{tabular}

LogK $_{1}$ (Average value) $=2.4788 \pm 0.2203$

Table 4: Point-wise method, $\mathrm{Cu}$-(Hydrolysed PSHA)

\begin{tabular}{|l|l|l|l|l|l|l|l|l|}
\hline $\mathrm{pH}$ & $\mathrm{BV}_{1}$ & $\mathrm{BV}_{2}$ & $\mathrm{BV}_{3}$ & $\left(\mathrm{~V}_{3}-\mathrm{V}_{2}\right)$ & $\mathrm{n}$ & $\mathrm{pL}$ & $\log \left(\frac{n-1}{2-n}\right)$ & LogK $_{2}$ \\
\hline 9.51 & 5.50 & 6.66 & 6.73 & 0.07 & 1.3509 & 1.70 & -0.2671 & 1.4329 \\
9.73 & 5.55 & 6.78 & 6.85 & 0.07 & 1.6383 & 1.51 & 0.2467 & 1.7567 \\
10.00 & 5.60 & 6.90 & 6.98 & 0.08 & 2.1783 & 1.31 & -0.2158 & 1.0942 \\
10.23 & 5.65 & 7.05 & 7.13 & 0.08 & 4.1904 & 1.27 & & \\
10.49 & 5.70 & 7.10 & 7.19 & 0.09 & 4.6920 & & & \\
\hline
\end{tabular}

Log $K_{2}($ Average value $)=1.4280 \pm 0.3312$ 
BAJOPAS Volume 14 Number 1,June, 2021

Table 5: Point-wise method, $\mathrm{Cu}$ (Unhydrolysed PSHA)

\begin{tabular}{|l|l|l|l|l|l|l|l|l|}
\hline $\mathrm{pH}$ & $\mathrm{BV}_{1}$ & $\mathrm{BV}_{2}$ & $\mathrm{BV}_{3}$ & $\left(\mathrm{~V}_{3}-\mathrm{V}_{2}\right)$ & $\mathrm{n}$ & $\mathrm{pL}$ & $\log \left(\frac{n}{n-1}\right)$ & Log $_{1}$ \\
\hline 8.50 & 5.30 & 5.81 & 5.85 & 0.04 & 0.2973 & 2.88 & -0.3736 & 2.5064 \\
8.72 & 5.35 & 5.90 & 5.95 & 0.05 & 0.3873 & 2.66 & -0.1992 & 2.4608 \\
9.00 & 5.40 & 6.00 & 6.05 & 0.05 & 0.4044 & 2.38 & -0.1681 & 2.2119 \\
9.22 & 5.45 & 6.10 & 6.15 & 0.06 & 0.5157 & 2.18 & -0.0272 & 2.2072 \\
9.51 & 5.50 & 6.20 & 6.27 & 0.07 & 0.6417 & 1.89 & 0.2530 & 1.1430 \\
\hline
\end{tabular}

$\operatorname{LogK}_{1}($ Average value $)=2.3059 \pm 0.6153$

Table 6:Point-wise method, $\mathrm{Cu}$ (Unhydrolysed PSHA)

\begin{tabular}{|l|l|l|l|l|l|l|l|l|}
\hline $\mathrm{pH}$ & $\mathrm{BV}_{1}$ & $\mathrm{BV}_{2}$ & $\mathrm{BV}_{3}$ & $\mathrm{~V}_{3}-\mathrm{V}_{2}$ & $\mathrm{n}$ & $\mathrm{pL}$ & $\log \left(\frac{n-1}{2-n}\right)$ & $\log \mathrm{K}_{2}$ \\
\hline 9.73 & 5.55 & 6.33 & 6.42 & 0.09 & 0.9000 & 1.69 & & \\
10.00 & 5.60 & 6.47 & 6.58 & 0.11 & 1.2578 & 1.44 & -0.4592 & 0.9808 \\
10.23 & 5.65 & 6.62 & 6.84 & 0.12 & 1.6137 & 1.26 & -0.2010 & 1.4610 \\
10.49 & 5.70 & 6.80 & 6.92 & 0.12 & 2.1052 & 1.03 & & \\
\hline
\end{tabular}

$\operatorname{LogK}_{2}$ (Average value) $=1.2209 \pm 0.3398$

Table 7:Point-wise method, Pb (Hydrolysed PSHA)

\begin{tabular}{|l|l|l|l|l|l|l|l|l|}
\hline $\mathrm{pH}$ & $\mathrm{BV}_{1}$ & $\mathrm{BV}_{2}$ & $\mathrm{BV}_{3}$ & $\left(\mathrm{~V}_{3}-\mathrm{V}_{2}\right)$ & $\mathrm{n}$ & $\mathrm{pL}$ & $\log \left(\frac{n}{1-n}\right)$ & LogK $_{1}$ \\
\hline 8.50 & 5.30 & 6.29 & 6.33 & 0.04 & 0.5500 & 2.66 & 0.0871 & 2.7471 \\
8.72 & 5.35 & 6.37 & 6.41 & 0.04 & 0.5714 & 2.43 & 0.1249 & 2.5549 \\
9.00 & 5.40 & 6.46 & 6.50 & 0.04 & 0.6198 & 2.16 & 0.2122 & 2.3722 \\
9.22 & 5.45 & 6.55 & 6.60 & 0.05 & 0.8333 & 1.96 & 0.6989 & 2.6589 \\
\hline
\end{tabular}

Log $_{\mathbf{1}}($ Average value $)=2.5832 \pm 0.1614$

Table 8:Point-wise method, Pb-(Hydrolysed PSHA)

\begin{tabular}{|l|l|l|l|l|l|l|l|l|}
\hline $\mathrm{pH}$ & $\mathrm{BV}_{1}$ & $\mathrm{BV}_{2}$ & $\mathrm{BV}_{3}$ & $\left(\mathrm{~V}_{3}-\mathrm{V}_{2}\right)$ & $\mathrm{n}$ & $\mathrm{pL}$ & $\log \left(\frac{n-1}{2-n}\right)$ & $\log \mathrm{K}_{2}$ \\
\hline 9.51 & 5.50 & 6.66 & 6.71 & 0.05 & 0.9650 & 1.67 & & \\
9.73 & 5.55 & 6.78 & 6.83 & 0.05 & 1.1702 & 1.44 & & \\
10.00 & 5.60 & 6.90 & 6.90 & 0.05 & 1.4864 & 1.22 & -0.0237 & 1.1963 \\
10.23 & 5.65 & 7.05 & 7.10 & 0.05 & 2.0190 & 1.09 & & \\
10.49 & 5.70 & 7.10 & 7.17 & 0.07 & 3.6492 & 1.00 & & \\
\hline
\end{tabular}

Log $K_{2}$ (Average value) $=1.1963$

Table 9: Point-wise method, Pb (Unhydrolysed PSHA)

\begin{tabular}{|l|l|l|l|l|l|l|l|l|}
\hline $\mathrm{pH}$ & $\mathrm{BV}_{1}$ & $\mathrm{BV}_{2}$ & $\mathrm{BV}_{3}$ & $\mathrm{~V}_{3}-\mathrm{V}_{2}$ & $\mathrm{n}$ & $\mathrm{pL}$ & $\begin{array}{l}\text { Log } \\
\left(\frac{n}{n-1}\right)\end{array}$ & Log $\mathrm{K}_{1}$ \\
\hline 8.50 & 5.30 & 5.81 & 5.85 & 0.04 & 0.2973 & 2.88 & -0.3736 & 2.5064 \\
8.72 & 5.35 & 5.90 & 5.94 & 0.04 & 0.3099 & 2.66 & -0.5477 & 2.3123 \\
9.00 & 5.40 & 6.00 & 6.05 & 0.05 & 0.4044 & 2.38 & -0.1681 & 2.2119 \\
9.22 & 5.45 & 6.10 & 6.15 & 0.06 & 0.5157 & 2.18 & 0.0272 & 2.2072 \\
9.51 & 5.50 & 6.20 & 6.26 & 0.07 & 0.6417 & 1.89 & 0.2530 & 2.1430 \\
9.73 & 5.55 & 6.40 & 6.40 & 0.07 & 0.7000 & 1.67 & 0.3680 & 2.0380 \\
\hline
\end{tabular}

LogK $_{1}$ (Average value) $=2.2364 \pm 0.1602$

Table 10: Point-wise method, Pb (Unhydrolysed PSHA)

\begin{tabular}{|l|l|l|l|l|l|l|l|l|}
\hline $\mathrm{pH}$ & $\mathrm{BV}_{1}$ & $\mathrm{BV}_{2}$ & $\mathrm{BV}_{3}$ & $\mathrm{~V}_{3}-\mathrm{V}_{2}$ & $\mathrm{n}$ & $\mathrm{pL}$ & $\log \left(\frac{n-1}{2-n}\right)$ & $\log \mathrm{K}_{2}$ \\
\hline 10.00 & 5.60 & 6.47 & 6.55 & 0.08 & 1.9503 & 1.41 & & \\
10.23 & 5.65 & 6.62 & 6.72 & 0.11 & 1.4792 & 1.26 & -0.0361 & 1.2239 \\
\hline
\end{tabular}

$\operatorname{LogK}_{2}$ (Average value) $=1.2239$

Table 11: Point-wise method, Mg (Hydrolysed PSHA)

\begin{tabular}{|l|l|l|l|l|l|l|l|l|}
\hline $\mathrm{pH}$ & $\mathrm{BV}_{1}$ & $\mathrm{BV}_{2}$ & $\mathrm{BV}_{3}$ & $\left(\mathrm{~V}_{3}-\mathrm{V}_{2}\right)$ & $\mathrm{n}$ & $\mathrm{pL}$ & $\log \left(\frac{n}{n-1}\right)$ & LogK $_{1}$ \\
\hline 8.50 & 5.30 & 6.29 & 6.31 & 0.02 & 0.2750 & 2.64 & -0.4290 & 2.2110 \\
8.72 & 5.35 & 6.37 & 6.39 & 0.02 & 0.2858 & 2.42 & -0.3978 & 2.0222 \\
9.00 & 5.40 & 6.46 & 6.49 & 0.03 & 0.4648 & 2.14 & -0.0612 & 2.0788 \\
9.22 & 5.45 & 6.55 & 6.59 & 0.04 & 0.6667 & 1.94 & 0.3010 & 2.2410 \\
\hline
\end{tabular}

$\log _{\mathbf{1}}($ Average value) $=2.1382 \pm 0.1046$ 
BAJOPAS Volume 14 Number 1,June, 2021

Table 12: Point-wise method, Mg (Hydrolysed PSHA)

\begin{tabular}{|l|l|l|l|l|l|l|l|l|}
\hline $\mathrm{pH}$ & $\mathrm{BV}_{1}$ & $\mathrm{BV}_{2}$ & $\mathrm{BV}_{3}$ & $\left(\mathrm{~V}_{3}-\mathrm{V}_{2}\right)$ & $\mathrm{n}$ & $\mathrm{pL}$ & $\log \left(\frac{n-1}{2-n}\right)$ & LogK $_{2}$ \\
\hline 9.51 & 5.55 & 6.66 & 6.71 & 0.05 & 0.9650 & 1.67 & & \\
9.73 & 5.55 & 6.78 & 6.84 & 0.06 & 1.4042 & 1.47 & -0.1686 & 1.3014 \\
10.00 & 5.60 & 6.90 & 6.93 & 0.06 & 1.7838 & 1.23 & 0.5593 & 1.7893 \\
10.23 & 5.65 & 7.05 & 7.10 & 0.06 & 3.1429 & 1.10 & & \\
10.49 & 5.70 & 7.10 & 7.18 & 0.07 & 3.6492 & 0.83 & & \\
\hline
\end{tabular}

LogK $_{2}($ Average value $)=1.5453 \pm 0.3450$

Table 13: Point-wise method, Mg (Unhydrolysed PSHA)

\begin{tabular}{|l|l|l|l|l|l|l|l|l|}
\hline $\mathrm{pH}$ & $\mathrm{BV}_{1}$ & $\mathrm{BV}_{2}$ & $\mathrm{BV}_{3}$ & $\mathrm{~V}_{3}-\mathrm{V}_{2}$ & $\mathrm{n}$ & $\mathrm{pL}$ & $\log \left(\frac{n}{n-1}\right)$ & $\operatorname{Log~}_{1}$ \\
\hline 8.50 & 5.30 & 5.81 & 5.85 & 0.04 & 0.2973 & 2.88 & -0.3736 & 2.5064 \\
8.72 & 5.35 & 5.90 & 5.94 & 0.04 & 0.3099 & 2.66 & -0.3477 & 2.3123 \\
9.00 & 5.40 & 6.00 & 6.04 & 0.04 & 0.3236 & 2.38 & -0.3202 & 2.0598 \\
9.22 & 5.45 & 6.10 & 6.15 & 0.05 & 0.4297 & 2.17 & -0.1230 & 2.0470 \\
9.51 & 5.50 & 6.20 & 6.26 & 0.06 & 0.5500 & 1.89 & 0.0871 & 1.9771 \\
9.73 & 5.55 & 6.33 & 6.40 & 0.07 & 0.7000 & 1.67 & 0.3680 & 2.0380 \\
\hline
\end{tabular}

LogK $_{1}$ (Average value) $=2.1568 \pm 0.2069$

Table 14: Point-wise method, Mg (Unhydrolysed PSHA)

\begin{tabular}{|l|l|l|l|l|l|l|l|l|}
\hline $\mathrm{pH}$ & $\mathrm{BV}_{1}$ & $\mathrm{BV}_{2}$ & $\mathrm{BV}_{3}$ & $\mathrm{~V}_{3}-\mathrm{V}_{2}$ & $\mathrm{n}$ & $\mathrm{pL}$ & $\log \left(\frac{n-1}{2-n}\right)$ & $\log \mathrm{K}_{2}$ \\
\hline 10.00 & 5.60 & 6.47 & 6.55 & 0.08 & 0.9148 & 1.41 & & \\
10.23 & 5.65 & 6.62 & 6.71 & 0.09 & 1.2102 & 1.20 & -0.5749 & 0.6251 \\
10.49 & 5.70 & 6.80 & 6.92 & 0.09 & 1.5968 & 1.03 & 0.1703 & 1.2003 \\
\hline
\end{tabular}

LogK $_{2}$ (Average value) $=0.9127 \pm 0.4070$

Table15:Point-wise method, Cd (Hydrolysed PSHA)

\begin{tabular}{|l|l|l|l|l|l|l|l|l|}
\hline $\mathrm{pH}$ & $\mathrm{BV}_{1}$ & $\mathrm{BV}_{2}$ & $\mathrm{BV}_{3}$ & $\left(\mathrm{~V}_{3}-\mathrm{V}_{2}\right)$ & $\mathrm{n}$ & $\mathrm{pL}$ & $\log \left(\frac{n}{1-n}\right)$ & LogK $_{1}$ \\
\hline 8.50 & 5.30 & 6.29 & 6.31 & 0.02 & 0.2750 & 2.64 & -0.4210 & 2.2190 \\
8.72 & 5.35 & 6.37 & 6.40 & 0.03 & 0.4286 & 2.42 & -0.1249 & 2.2951 \\
9.00 & 5.40 & 6.46 & 6.49 & 0.03 & 0.4648 & 2.14 & -0.0612 & 2.0788 \\
9.22 & 5.45 & 6.55 & 6.59 & 0.04 & 0.6667 & 1.96 & 0.3010 & 2.2610 \\
9.51 & 5.55 & 6.66 & 6.70 & 0.04 & 0.7720 & 1.67 & 0.5297 & 2.1997 \\
\hline
\end{tabular}

LogK $_{\mathbf{1}}$ (Average value) $=2.2108 \pm 0.0825$

Table 16: Point-wise method, Cd (Hydrolysed PSHA)

\begin{tabular}{|l|l|l|l|l|l|l|l|l|}
\hline $\mathrm{pH}$ & $\mathrm{BV}_{1}$ & $\mathrm{BV}_{2}$ & $\mathrm{BV}_{3}$ & $\left(\mathrm{~V}_{3}-\mathrm{V}_{2}\right)$ & $\mathrm{n}$ & $\mathrm{pL}$ & $\log \left(\frac{n-1}{2-n}\right)$ & Log $_{2}$ \\
\hline 9.73 & 5.55 & 6.78 & 6.83 & 0.06 & 1.4042 & 1.47 & -0.1686 & 1.3014 \\
10.00 & 5.60 & 6.90 & 6.95 & 0.06 & 1.7838 & 1.23 & 0.5593 & 1.7893 \\
10.23 & 5.65 & 7.05 & 7.10 & 0.06 & 3.1429 & 1.09 & & \\
10.49 & 5.70 & 7.10 & 7.16 & 0.06 & 3.1429 & 0.89 & & \\
& & & & & & & & \\
\hline
\end{tabular}

$\operatorname{LogK}_{2}$ (Average value) $=1.5453 \pm 0.3450$

Table 17: Point-wise method, Cd (Unhydrolysed PSHA)

\begin{tabular}{|l|l|l|l|l|l|l|l|l|}
\hline $\mathrm{pH}$ & $\mathrm{BV}_{1}$ & $\mathrm{BV}_{2}$ & $\mathrm{BV}_{3}$ & $\mathrm{~V}_{3}-\mathrm{V}_{2}$ & $\mathrm{n}$ & $\mathrm{pL}$ & $\log \left(\frac{n}{n-1}\right)$ & $\operatorname{Log~}_{1}$ \\
\hline 8.50 & 5.30 & 5.81 & 5.86 & 0.05 & 0.3717 & 2.88 & -0.2280 & 2.6520 \\
8.72 & 5.35 & 5.90 & 5.95 & 0.05 & 0.3873 & 2.66 & -0.1992 & 2.4608 \\
9.00 & 5.40 & 6.00 & 6.06 & 0.06 & 0.4853 & 2.38 & -0.0255 & 2.3545 \\
9.22 & 5.45 & 6.10 & 6.16 & 0.06 & 0.5157 & 2.18 & -0.0272 & 2.2072 \\
9.51 & 5.50 & 6.20 & 6.27 & 0.07 & 0.6417 & 1.89 & 0.2530 & 1.1430 \\
9.73 & 5.55 & 6.33 & 6.41 & 0.08 & 0.8000 & 1.69 & 0.6020 & 2.2920 \\
& & & & & & & & \\
\hline
\end{tabular}

$\operatorname{LogK}_{1}($ Average value $)=2.2516 \pm 0.5380$ 
BAJOPAS Volume 14 Number 1,June, 2021

Table 18: Point-wise method, Cd (Unhydrolysed PSHA)

\begin{tabular}{|l|l|l|l|l|l|l|l|l|}
\hline $\mathrm{pH}$ & $\mathrm{BV}_{1}$ & $\mathrm{BV}_{2}$ & $\mathrm{BV}_{3}$ & $\mathrm{~V}_{3}-\mathrm{V}_{2}$ & $\mathrm{n}$ & $\mathrm{pL}$ & $\log \left(\frac{n-1}{2-n}\right)$ & $\log \mathrm{K}_{2}$ \\
\hline 10.00 & 5.60 & 6.47 & 6.57 & 0.10 & 1.1434 & 1.43 & & \\
10.23 & 5.65 & 6.62 & 6.72 & 0.10 & 1.3448 & 1.23 & -0.2788 & 0.9512 \\
10.49 & 5.70 & 6.80 & 6.90 & 0.10 & 1.7742 & 1.03 & 0.5351 & 1.5651 \\
\hline
\end{tabular}

$\operatorname{LogK}_{2}($ Average value $)=1.2581 \pm 0.4340$

Table 19: Stepwise and overall Stability constants of thehydrolysed and unhydrolysed divalent metal (II) complexes

\begin{tabular}{|c|c|c|c|}
\hline Chelates & LogK $_{1}$ & $\log _{2}$ & Log $\beta$ \\
\hline [Cu (Hydrolysed PSHA-1) $\left.{ }_{2}\right]$ & 2.4788 & 1.4280 & 3.9068 \\
\hline$\left[\mathrm{Pb}(\text { Hydrolysed PSHA-1) })_{2}\right]$ & 2.5832 & 1.1963 & 3.7795 \\
\hline$\left[\mathrm{Cd}(\text { Hydrolysed PSHA-1 })_{2}\right]$ & 2.2108 & 1.5453 & 3.7561 \\
\hline$\left[\mathrm{Mg}(\text { Hydrolysed PSHA-1 })_{2}\right]$ & 2.1382 & 1.5453 & 3.6835 \\
\hline [Cu (Unhydrolysed PSHA-1) & 2.3059 & 1.2209 & 3.5268 \\
\hline$[\mathrm{Pb}$ (Unhydrolysed PSHA-1) 2$]$ & 2.2364 & 1.2239 & 3.4603 \\
\hline [Cd (Unhydrolysed PSHA-1) 2 ] & 2.2516 & 1.2581 & 3.5097 \\
\hline$[\mathrm{Mg}$ (Unydrolysed PSHA-1) & 2.1568 & 0.9127 & 3.0695 \\
\hline
\end{tabular}

The results obtained (Table19) shows the stepwise and overall stability constants to be not high indicating low stability of the complexes, because the solubility of most metal ions in the basic $\mathrm{pH}$ range is minimal due to metal hydroxide precipitation (Karimi, 2017). In general, the stepwise stability constants $\left(K_{1}\right.$ and $K_{2}$ ) follow the order $K_{1}>K_{2}$ for the copper, lead, magnesium and cadmium complexes respectively. The steady decrease of the values with increasing number of ligands is in agreement with the prediction made by researchers (Na'aliya, 2013). The decrease could be attributed to the fact that as the number of the ligands (Humate ions) that enters the coordination zone increases the aqua molecules available for replacement by the ligands become less. Thus, the metal ions become less electron loving with progressive intake of the ligand and this results in the decrease in the values of the constants (Na'aliya, 2013). Also the stability of the complexes is influenced by the size and number of the chelate rings(Mackay and Mackay,2002).All the complexes form rings in their structure as humate, a bidentate ligand, bond the metal ions in the ratio 1:2 (Boguta and Sokolowska, 2016) forming chelate rings. The values of the overall stability constants $(\log \beta)$ obtained for humate complexes are not high indicating low stability as the values are not high. LogK values for copper-humates (Table 3 to 6) obtained in this study are lower than those reported for the complexes of humic acids (Pandey et al., 2015; Dinu, 2013; Kaschl et al., 2010 and Gilbeto and Jorg, 2001). The values of LogK(Table 7 to 10 ) forlead-humates are lower than those reported for the lead in the literature (Dinu, 2013; Gilbeto and Jorg 2001). Log K values(Table 11 to 14 ) for magnesium-humates obtained in this study are close to those reported by (Pandey et al., 2015). Log K values of cadmium-humates (Table 15 to 18 ) obtained in this work near to the one reported by (Dinu, 2013 and Pandey et al., 2015).The difference between the reported values and the values obtained in this study might be probably as a result of acid hydrolysis of humic acid. The values of the overall stability constants $(\log \beta)$ of the copper humates complexes presented in Table 19 is high than that of other metal humate complexes, show relatively high stability of CuHA complexes, show the following order of stability: $\mathrm{Cu}>\mathrm{Pb}>\mathrm{Cd}>\mathrm{Mg}$; which are in close agreement to the findings of (Dinu, 2013 and Pandey et al., 2015).The high stability of Cuhumate chelate could be attributed to the existence of coordinate covalent bond between the complexing agents and the $\mathrm{Cu}^{2+}$ ions. Since, $\mathrm{Cu}^{2+}$ being a metal of the transitional series with $3 d^{9}$ electronic configurations can accept the electrons from the complexing agents. Similarly, the low stabilities of $\mathrm{Pb}, \mathrm{Cd}$ and $\mathrm{Mg}$ complexes could be explained by that $\mathrm{Pb}^{2+}$ with $6 s^{2}, \mathrm{Cd}^{2+}$ with $4 \mathrm{~d}^{10}$ and $\mathrm{Mg}^{2+}$ with $2 \mathrm{p}^{6}$ their electronic configuration has a completely filled $\mathrm{d}, \mathrm{p}$ and $\mathrm{s}$ orbitals. Moreover, the stabilities of metal ions with hydrolysed humic acid from peat soil were higher than those with unhydrolysed humic acid from peat soil; which is ascribed to the high content of acidity in hydrolysed humic acid than unhydrolysed humic acid. 
BAJOPAS Volume 14 Number 1,June, 2021 CONCLUSION

The values of logk for $\mathrm{Cu}(\mathrm{II})$ hydrolysed humic acid complex was higher followed by $\mathrm{Pb}$ (II), $\mathrm{Cd}(\mathrm{II})$ and $\mathrm{Mg}$ (II) hydrolysed humic acid complexes as compared with metal(II) unhydrolysed humic acid complexes. This indicates acid hydrolysis of humic acid can

\section{REFERENCES}

Almeida, V.R. and Szpoganicz, B. (2015). Humic Acid Potentiometric Response Patterns:Out- of Equilibrium Properties and Species Distribution Modelling. Chemical. Biol. Technol. Agric. 2: 17.

Anđelković, T., Nikolić, R., Bojić, A.,Anđelković, D., and Nikolic G.,(2010). Binding of Cadmium to Soil Humic Acid as A Function of Carboxyl Group Content. Macedonian Journal of Chemistry and Chemical Engineering.29(2): 215-224.

Anil, B. N. and Maroti, N. (2008). Studies on Influence of Die-Lectric Constants on Complex Equilibria between Substituted Py-Razalines and Lanthanide Metal Ions pH-Metrically. Amer.-Euras. scient. Res. 3(2): 212-216.

Ashok, K., Pandey, S. P. and Misra, V (2000). Stability Constants of Metal-Humic Acid Complexes and its Role in Environmental Detoxification. Journal of Ecotoxicology and Environmental Safety. 47(2):157-200.

Badr, M. H., El-Halafawi, M. H. and Abd El-al Zeid, E. R. (2012). Comparison Between the Effect of Ionic Strength on Acidity and Dissociation Constants of Humic Acids Extracted from Sewage Sludge and Nile Water Hyacinth Composts.Global Journal of Environmental Research 6 (1): 36-43.

Baruah, M.K., Borah, D., Saikia, P.P., Paul, S., Sharma, T. (2015). Evaluation of pKa Values of Soil Humic Acids and their Complexation Properties. International Journal of Plant \& Soil Science 6(4) : 218-228.

Boguta, P. Sokolowska, Z. (2016). Interactions of $\mathrm{Zn}$ (II) Ions with Humic Acids Isolated from Various Types of Soils. Effect of $\mathrm{pH}, \mathrm{Zn}$ Concentrations and Humic Acids Chemical Properties. Journal of Geochemical Explaration 168. 119-126.

Borges, F., Guimaraes, C., Lima, L.F.C., Pinto, I. and Reis, S.(2005). Potentiometric Studies on the Complexation of Copper(II) by Phenolic Acids as Discrete Ligand Models of enhance the complexation behavior of humic acid with metal (II) ions. However, the higher values of $\log \beta$ for $\mathrm{Cu}(\mathrm{II}), \mathrm{Pb}(\mathrm{II}), \mathrm{Cd}(\mathrm{II})$ and $\mathrm{Mg}(\mathrm{II})$ hydrolysed humic acid complexes indicates more stable stepwise complexes formed as compared with $\mathrm{Cu}(\mathrm{II}), \mathrm{Pb}$ (II), $\mathrm{Cd}$ (II) and $\mathrm{Mg}(\mathrm{II})$ unhydrolysed humic acid complexes.

Humic Substances Talanta 66 (2005) 670-673.

Chefetz, B., Salloum, M. J., Deshmulkin, A. P. and Hatcher, P. (2002). Structural Components of Humic Acids as Determined by Chemical Modifications and Carbon-13 NMR, Pyrolysis, and Thermochemolysis- Gas Chromatography/Mass Spectrometry. Soil Science Society of American Journal Abstract Division S-2- Soil Chemistry66. 1159-1171.

Dinu, M. I. (2013). Metals Complexation with Humic Acids in Surface Water of Different Environ. Sci. Technol. 31(1): 1-17.

Fernandes, A.N., Giacomelli, C., Giovanela, M. Vaz, D.V. Szpoganicz, B. and Maria M. D. (2009). Potentiometric Acidity Determination in Humic Substances Influenced by Different Analytical Procedures.J. Braz. Chem. Soc. 20 (9):14.

Gamal, A. H. (2015). Stability Constants of Rhenium (V) Metal Complexes with Selected Drugs. Pyrex Journal of Research in Environmental Studies. 2(2): 006-014.

Janrao, D. M., Pathan, J., Kayande, D.D., and Mulla, J.J. (2014). An Over View of Potentiometric Determination of Stability Constants of Metal Complexes. Sci. Revs. Chem. Commun.: 4(1), 2014, 11-24.

Karimi, H. (2017). Effect of pH and Initial Pb(II) Concentration on the Lead Removal Efficiency from Waste Water Using $\mathrm{Ca}(\mathrm{OH})_{2}$. International Journal of Water and Waste Water Treatment 3.2

Kaschl, A. Romheld, V. and Chen, Y. (2010). Binding of Cadmium, Copper and Zinc to Humic Substances Originating from Municipal Solid Waste Compost. Israel Journal of Chemistry Vol. 42(1): 89-98.

Kostic, I. S., Tatjana, P, A., Nikolic, R. S., Cvetkovic, T. P., Pavlovic, D. D., Aleksandar, L.J. and Bojic, A. (2012). Comparative Study of Binding Strengths of Heavy Metals with Humic Acid. J.serb. Chem. Soc. 76(9) pp 1-20. 
BAJOPAS Volume 14 Number 1,June, 2021

Na'aliya, J. (2013). Determination of Stepwise Stability Constants and Gibbs free Energy Change of Trisprolina to Complexes of some Divalent Transition Metal ions. Bayero Journal of Pure and Applied Sciences 6(2): 112-114.

Omar, A. A. and Ali, E. A. (2015). Potentiometric Studies on Complexes of $\mathrm{Cr}$ (III) and $\mathrm{Zr}$ (IV) with some Carboxylic Acids. International Journal of Advanced Chemistry, 3(1) 25-

37.

Pandey, A. K. Pandey, S. D. and Misr, V. (2015).Stability Constants of Metal- Humic Acid Complexes and Its Role in Environmental Detoxification. J. Ecotoxicology and Environmental Safety. 47(1):195-200.

Ram, N. and Raman, K.V. (1984). Stability Constants of Complexes of Metals with
Humicand Fuvic Acids under Non- acidConditions. Journal of Plant Nutrition and Soil Sciences.

147:171-176.

Santosh, D. D., Ashok, B. K., Vijay, J. T., Shivraj, G. W. and Vinay, V. W. (2011). Potentiometric Studies of Elec-Trolyte Effects on Complex Equilibria of Some Substituted 5-(2-hydroxy Phenyl) Pyrazoles. Der pharm. 3 (6): 75-83.

Sayyed, H. and Abdul Rahim, M. F. (2012). Studies of Binary Complexes of Metal Ions with Mandelic Acid by Potentiometry. Chem. J. 02 (6): 206209.

Shirvani, M. Moradian, E. Khalili, B. Bakhtiary, S. (2015). Interaction of $\mathrm{Cd}$ and $\mathrm{Pb}$ with Humate-Palygorskite and HumateSepiolite Complexes. Journal of water, air and pollution 3: 220-228. 


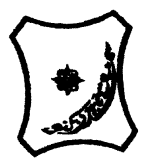

Bayero Journal of Pure and Applied Sciences, 14(1): 54 - 63

Received: November, 2020

Accepted: April, 2021

ISSN $2006-6996$

\title{
STABILITY CONSTANTS OF COMPLEXES OF METAL IONS WITH PEATSOIL HUMIC ACIDS UNDER NON-ACID-CONDITIONS
}

\author{
${ }^{* 1}$ Sabo, Yusuf ${ }^{2}$ Jimoh, W.L.O., ${ }^{3}$ Isa Baba Koki and ${ }^{4}$ Sholadoye, Q. 0. \\ ${ }^{1}$ Department of Pure and Industrial Chemistry, Bayero University, Kano \\ ${ }^{3}$ Department of Chemistry, Yusuf Maitama Sule University Kano. P.M.B. 3220 Kano, Nigeria. \\ ${ }^{4}$ Department of Chemistry, Nigerian Police Academy, Wudil, Kano-Nigeria
}

*Correspondence E-mail; saboyusuf18@yahoo.com

ABSTRACT

Stability constants of complexes of four divalent metal ions viz. $\mathrm{Cu}^{2+}, \mathrm{Pb}^{2+}, \mathrm{Mg}^{2+}$ and $\mathrm{Cd}^{2+}$ with humic acids (HA) were determined by potentiometric titration of humic acids with the corresponding salt of the divalent metals in aqueous media under non-acid-condition. The log $K$ (logarithm of the stability constant) ranged from 1.0942 to 2.7471 for metalhumic acid complexes were determined using point-wise computational method. The order of stability constants were obtained as follows: $\mathrm{Cu}>\mathrm{Pb}>\mathrm{Cd}>\mathrm{Mg}$ for metal $-\mathrm{HA}$ complexes respectively, indicating a higher degree of complexation with Cu metal ion.

Keywords: stability constant, humic acid, potentiometric titration, divalent metals, acid hydrolysis.

\section{NTRODUCTION}

The stability constant of a complex is the numerical expression of its stability and provides a quantitative measure of affinity of the metal ion to the complexing agent. An understanding of the relative stability of metal-complexes helps in predicting the behavior of metal ions in the soil (Ram and Raman, 1982). Extensive researches has been done to determine the stability constants of the complexes formed between humic acid (HA) with a number of metal ions. Ashok et al., (2000) reported that humic acid with hydroxyl, phenoxyl and carboxyl reactive groups can form coordination compound with metal ions at $\mathrm{pH}$ 3.5. The stability constants(Log K) for different metalhumic acid complexes indicated the following order of the stabilities of complexes formed between humic acid and metal ion, $\mathrm{Cu}>\mathrm{Fe}$ $>\mathrm{Pb}>\mathrm{Ni}>\mathrm{Co}>\mathrm{Ca}>\mathrm{Cd}>\mathrm{Zn}>\mathrm{Mn}>\mathrm{Mg}$. Andelkovic et al., (2010) investigated the binding of $\mathrm{Cd}$ (II) to soil humic acid at pH 6.5 and in $0.1 \mathrm{M} \mathrm{KNO}_{3}$ ionic medium. The stability constant for binding indicating greater stability in the case when carboxyl groups are involved in complexation reaction. Kostic et al.,(2012) investigated the complexation of humic acid with certain heavy metal ions (Co(II), $\mathrm{Ni}(\mathrm{II}), \mathrm{Cu}(\mathrm{II})$,
$\mathrm{Zn}(\mathrm{II})$, and $\mathrm{Pb}(\mathrm{II})$. The experiment was performed at $25^{\circ} \mathrm{C}$, at pH 4.0 and ionic strength of $0.01 \mathrm{M}$. Stability constant of complex between $\mathrm{Pb}$ (II) ions and humic acid is greater than stability constants of other investigated metalhumate complexes. Bogata and Sokolowska (2016) analyses the interaction between humic acids from different soils and $\mathrm{Zn}$ (II) ions at wide concentration ranges and at $\mathrm{pH} 5$. Studies have showed significant impact of $\mathrm{Zn}$ concentration, $\mathrm{pH}$ and some properties of humic acids with zinc.But all of these studies were limited to acidic $\mathrm{pH}$ range. Therefore, the present study was carried out to determine and compare the stability constants of complexes of metal ions with hydrolysed peat soil humic acid and unhydrolysed peat soil humic under non-acid conditions.

\section{MATERIALS AND METHODS}

Analytical grade chemicals used includes hydrochloric acid $(\mathrm{HCl})$, nitric acid $\left(\mathrm{HNO}_{3}\right)$, sodium hydroxide $(\mathrm{NaOH})$, lead nitrate $\mathrm{Pb}\left(\mathrm{NO}_{3}\right)_{2}$, copper nitrate $\mathrm{Cu}\left(\mathrm{NO}_{3}\right)_{2} \cdot 3 \mathrm{H}_{2} \mathrm{O}$, cadmium nitrate $\mathrm{Cd}\left(\mathrm{NO}_{3}\right)_{2} \cdot 4 \mathrm{H}_{2} \mathrm{O}$, magnesium nitrate $\mathrm{Mg}\left(\mathrm{NO}_{3}\right)_{2} \cdot 6 \mathrm{H}_{2} \mathrm{O}$, potassium nitrate $\left(\mathrm{KNO}_{3}\right)$, calcium chloride $\left(\mathrm{CaCl}_{2}\right)$, (sigma-Aldrich). Dowex 50WX8, (20-50 mesh) from Fluka. 


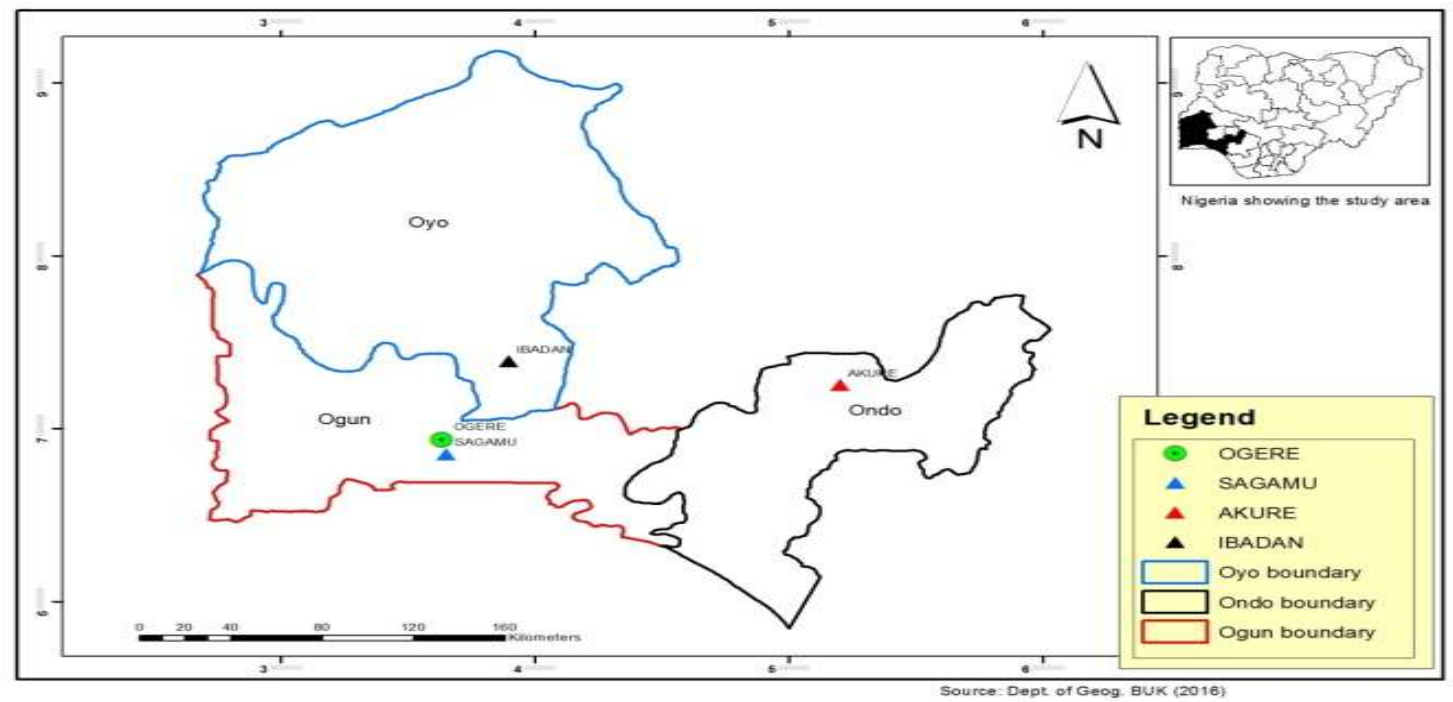

Figure 1: Map showing the sampling point at Sagamu Town, Ogun State.

\section{Description of Sampling Area}

Sagamu has geographical coordinates between $6^{\circ} 50^{\prime}$ north; $3^{\circ} 38^{\prime}$ east is located in south western region of Nigeria. The region has tropical wet and dry climate with a lengthy wet season and relatively constant temperatures throughout the course of the year. Wet season runs from March to October, November to December forms the region dry season. The vegetation type of the region is savannah which is really grassland with small bushes and occasional big trees. Grassland soils have substantially higher organic matter content than forest soils (Novackova, 2011).

\section{Sample Collection}

The Peatsoil samples were collected from four different sampling points $(0-10 \mathrm{~cm}$ depth) in Sagamu into polyethylene bag with plastic spoons. Samples were taken to the laboratory, extraneous materials were removed; the samples were air-dried, crushed and ground to a fine powder in a mortar passed through a $0.20 \mathrm{~mm}$ sieve. The samples were kept for analysis.

\section{Isolation and purification of humic acid from peat soil sample}

Peatsoil sample $(100 \mathrm{~g})$ was mixed with 1000 $\mathrm{cm}^{3}$ of $0.1 \mathrm{M} \mathrm{NaOH}$ solution, shaken for 3hours and left to stand overnight. Dark-coloured supernatant was obtained and decanted from solid residue. The dark-coloured supernatant was acidified to $(\mathrm{pH}=1.0)$ with $6 \mathrm{M} \mathrm{HCl}$ stirred and allowed to stand for 6 hours. Yellowish brown supernatant and dark-brown precipitate were obtained. The yellowish brown supernatant was decanted followed by centrifuge and discarded. The dark-brown precipitate was mixed with $500 \mathrm{~cm}^{3}$ of $0.1 \mathrm{M} \mathrm{NaOH}$ solution followed by passing through dowex resin. The dark-brown solution was acidified to $(\mathrm{pH}=1.0)$ with $6 \mathrm{M} \mathrm{HCl}$ stirred and allowed to stand for 3 hours. The dark-brown precipitate was washed several times with deionized water. The supernatant was treated with $\mathrm{AgNO}_{3}$ solution until no white precipitate observed. The humic acid was transferred to weighed crucible and dried at $60^{\circ} \mathrm{C}$ in an oven for 12 hours. The humic acid was cooled and dried in the desiccator, weighed and recorded. The obtained humic acid was dried again at $60^{\circ} \mathrm{C}$ for additional 6 hours cooled and dried in the desiccator, weighed and recorded constant weight was obtained (Baruah et al., 2015).

\section{FT-IR analysis}

FT-IR spectra of humic acid sample was analysed using Carry 630 FT-IR Agilent Technologies.

Unhydrolysed compost humic acid

The unhydrolysed humic acid was obtained after isolation and purification of compost humic acid and kept for investigation.

\section{Acid hydrolysis of Peatsoil acid}

Peatsoil humic acid sample (1g) was refluxed for 12 hours at $\left(160^{\circ} \mathrm{C}\right)$ with $50 \mathrm{~cm}^{3}$ of $6 \mathrm{M} \mathrm{HCl}$. The mixture was allowed to cool, decanted, and centrifuged after hydrolysis. The insoluble residues were washed with distilled water via centrifugation several times, and the supernatant was treated with $\mathrm{AgNO}_{3}$ solution until no white precipitate was observed. The residue was thoroughly dried over $\mathrm{CaCl}_{2}$ in a desiccator at room temperature (Chefetz et al., 2002). Finally, the obtained hydrolysed humic acid was kept for investigation. 
BAJOPAS Volume 14 Number 1,June, 2021 Potentiometric Titrations

Potentiometric measurements were carried out using a pH-meter Jenway (model 3510) with combine electrode, the sensitivity of the $\mathrm{pH}$ meter is 0.01 units. The $\mathrm{pH}$ meter was switched on half an hour before starting the titration for initial warm up of the instrument. The instrument was calibrated with an aqueous standard buffer solution of $\mathrm{pH} 4.00$ and 10.0 (borate buffer) prepared from a "Qualigens" buffer tablets.

The following sets of solutions were prepared in a $250 \mathrm{~cm}^{3}$ volumetric flask separately for $\mathrm{pH}$ metric titrations.

(i) $5 \mathrm{~cm}^{3} 0.1 \mathrm{M} \mathrm{HCl}+40 \mathrm{~cm}^{3}$ deionized water

(ii) $5 \mathrm{~cm}^{3} 0.1 \mathrm{M} \mathrm{HCl}+39 \mathrm{~cm}^{3}$ deionized water $+1 \mathrm{~cm}^{3} 0.15 \mathrm{gcm}^{-3}$ humic acid

(iii) $5 \mathrm{~cm}^{3} 0.1 \mathrm{M} \mathrm{HCl}+37 \mathrm{~cm}^{3}$ deionized water $+1 \mathrm{~cm}^{3} 0.15 \mathrm{gcm}^{-3}$ humic acid

$$
+2 \mathrm{~cm}^{3} \quad 0.01 \mathrm{M} \mathrm{Cu} \text { (II) }
$$

The solutions were titrated against standardized $0.110 \mathrm{MNaOH}$ separately. The total volume of each mixture was adjusted to $50 \mathrm{~cm}^{3}$ and the ionic strength of the solutions was maintained constant at by adding appropriate amount of stock solution of $1 \mathrm{M} \mathrm{KNO}_{3}$ (Gamal, 2015; Omar and Ali, 2015). A magnetic stirrer was used to achieve thorough mixing of the interacting solutions at $550 \mathrm{rpm}$. The same set of experimental conditions was applied for potentiometric titration of remaining samples.

\section{Evaluation of pKa of Hydrolysed peat soil Humic Acids}

The proton-ligand formation number $\mathrm{n}_{\mathbf{A}}$ were calculated by Irving and Rossotti expression (Omar and Ali, 2015).

$\mathrm{nA}=\mathrm{Y}-\frac{(\mathrm{V} 2-\mathrm{V1})(\mathrm{No}-\mathrm{Eo})}{(\mathrm{VO}+\mathrm{V1}) \mathrm{TCL}}$ 1

Where: $Y$ is number of dissociable proton, $\left(\mathrm{V}_{2^{-}}\right.$ $V_{1}$ ) is the measure of displacement of the ligand curve relative to acid curve, $\mathrm{N}^{\circ}$ and $\mathrm{E}^{\circ}$ are the resultant concentration of alkali solution, free acid solution, $\mathrm{T}_{\mathrm{cL}}{ }^{\circ}$ is the total ligand concentration, $\mathrm{V}^{\circ}$ is the total volume of titration solution, $V_{1}$ is the volume of alkali added to acid solution, $V_{2}$ is the volume of alkali added to acid solution + ligand solution, acid dissociation constants (pKa - values) of ligand were calculated by algebraic method point wise calculation (Tables 1 ). The dissociation constants (pKa) were calculated according to the following relation:

$\mathrm{pKa}=\mathrm{pH}+\log \left(\frac{n A}{1-n A}\right)$ 2

Where: pKa is the acid dissociation constant, $\mathrm{n}_{\mathrm{A}}$ is the Proton-ligand formation number and $\mathrm{pH}$ is the pH-values (Omar and Ali, 2015).

\section{Determination of metal-ligand stability constants $(\log K)$ of complexes}

The potentiometric measurement for the determination of stability constant of a complex in solution is based on the fact that the redox potential of the couple $\frac{M^{+(m-n)}}{M^{+m}}$ is shifted significantly on complexation of the metal ion with the ligand. This method involves change in hydrogen ion concentration $\left[\mathrm{H}^{+}\right]$due to the displacement or association of one or more protons taking place during complexation reaction. This change can be found out by titrating the solutions containing free acid, acid with ligand, and acid with ligand and metal ion, individually against a standard alkali solution at a constant ionic strength or temperature. Either ionic strength or temperature may be varied for different sets of solutions. In all the cases, the change in the $\mathrm{pH}$ of the solution is measured after each addition of a known amount of alkali to the reaction cell which contains the reaction mixture. The titration curves are then drawn by plotting the measured $\mathrm{pH}$ values against the corresponding volume of alkali added and the stability constants of the complexes are determined from the titration curves by employing $\mathrm{pH}$-metric titration technique given by (Irving and Rossoti).

Metal-ligand stability constants ( $\log \mathrm{K}$ ) were determined by using the following relations:

$$
\bar{n}=\frac{\left(V_{3}-V_{2}\right)\left(E^{0}+N^{0}\right)}{\left(V^{0}+V_{2}\right) \bar{n}_{A} T_{m}^{0}}
$$

and

$$
P L=\log _{10}\left\{\frac{1+\beta_{n}^{H} \frac{1}{[\text { anti } \log \mathrm{pH}]^{\mathrm{n}}}}{\mathrm{T}_{\mathrm{L}}^{0}-n \bar{T}_{m}^{0}} \mathrm{X} \frac{\left(V^{0}+V_{3}\right)}{V^{0}}\right\}
$$


BAJOPAS Volume 14 Number 1,June, 2021

Where $T_{L}, T^{\circ}, E^{\circ}$, and $V^{\circ}$ havethe same significance as in equation (1) above, $T_{m}$ denotes the total concentration of metal present in solution, $V_{3}$ is the volume of metal ions present in solution and $\beta^{H}$ is the overall proton ligand stability constant. The metal-ligand stability constants (log K) were determined by employing point wise computational Method (eq. 5 and 6).

$\operatorname{LogK}_{1}=\log \left(\frac{n}{1-n}\right)+\mathrm{pL}$ .5

$\operatorname{LogK}_{2}=\log \left(\frac{1-n}{2-n}\right)+\mathrm{pL}$ ...6

Where: Log $\mathrm{K}$ is the metal-ligand stability constant, $\mathrm{pL}$ is the Free ligand exponent function, $\mathbf{n}$ is the Average number of ligand attached with metal ion (Janraoet al., 2014). The results obtained were analyzed by an ORIGIN 2016 program using titration data and then the proton-ligand stability constants (pKa) and Metal-ligand stability constant (LogK) calculated (Omar and Ali, 2015).

\section{RESULTS AND DISCUSSION}

Fourier transformed infrared (FT-IR) spectra of isolated humic acid from peat soils Figure 2 had distinct clear absorption bands indicating the presence of major humic acid structural elemental groups such as $\mathrm{H}$ bonded $\mathrm{OH}$ $\left(3680 \mathrm{~cm}^{-1}\right.$ peak $), C=0$ of carbonyl $\left(1721 \mathrm{~cm}^{-1}\right.$ peak), functional groups of aliphatic components $\mathrm{CH}_{2}\left(2918 \mathrm{~cm}^{-1}\right.$ peak) and $\mathrm{C}-\mathrm{O}$ stretching of polysaccharide $\left(1168 \mathrm{~cm}^{-1}\right.$ peak). The positions of the absorption bands of the spectra fell within typical major absorption bands of humic acid which is at frequencies 3680, 2918, 1721, 1168 $\mathrm{cm}^{-1}$. The first peak centred in the vicinity of $3680 \mathrm{~cm}^{-1}$ region is attributed to phenol $\mathrm{OH}$ group bounded by intermolecular $\mathrm{H}$ bonds. The $2918 \mathrm{~cm}^{-1}$ band usually has absorption maximum at $2918 \mathrm{~cm}^{-1}$ which is due to $\mathrm{C}-\mathrm{H}$ stretching of alkane group $\left(\mathrm{CH}_{2}\right)$. The next major absorption band is $1721 \mathrm{~cm}^{-1}$. This band has been commonly ascribed to $\mathrm{C}=\mathrm{O}$ stretching of mainly carboxyl group $(\mathrm{COOH})$ with trace amount of ketones. The last peak was observed at 1168 $\mathrm{cm}^{-1}$ due to $\mathrm{C}-\mathrm{O}$ stretching of polysaccharides and this peak appeared also in the spectra of humic acid from peat soil. The FTIR spectra of the isolated humic acid contained all major characteristic absorption peaks of humic acid. These absorption peaks indicated the presence of the major structural elements of humic acid namely $\mathrm{H}$ bonded $\mathrm{OH}, \mathrm{C}=\mathrm{C}$ of aromatic ring, $\mathrm{C}=\mathrm{O}$ of carbonyl group (both carboxyl and ketonic), $\mathrm{CH}_{2}$ group. This strongly supports the presence of humic acid.

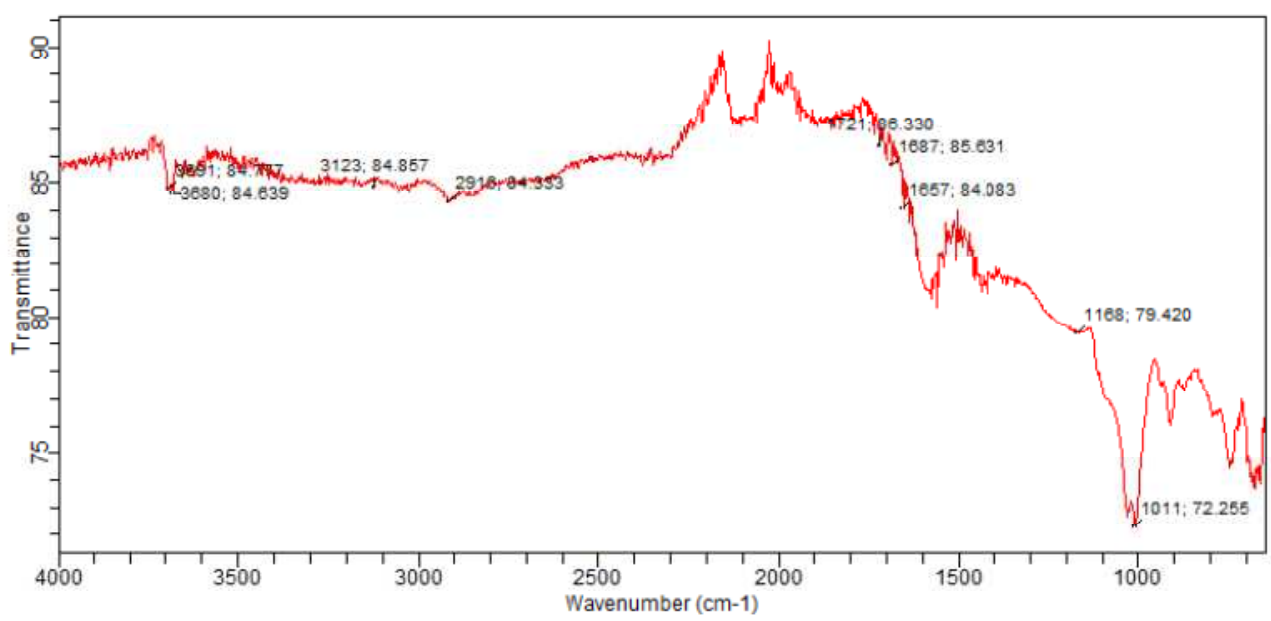

Fig. 2 : FT-IR spectraof peatsoilhumic acid (PSHA)

\section{Evaluation of acid dissociation constant (pka) of acid hydrolysed peat soil humicacid at phenolic group}

The value of the dissociation constant of the peat soil humic acid (PSHA) that underwent acidhydrolysis studied was found to be 8.9299 as shown Table 1, which is lower than the literaturevalues reported by Almeida and Szpoganics, (2015), Borges et al., (2005); Badr et al., (2012)and Fernandes et al,.(2009) of $9.73,9.47$ and 10.30. The difference between the obtained valuesand the reported values in this study might be probably as a result of acid hydrolysis of humicacid. 
BAJOPAS Volume 14 Number 1,June, 2021

Table 1: PKa of (Hydrolysed PSHA)

\begin{tabular}{|l|l|l|l|l|l|l|}
\hline $\mathrm{pH}$ & $\mathrm{BV}_{1}$ & $\mathrm{BV}_{2}$ & $\mathrm{~V}_{2}-\mathrm{V}_{1}$ & $\mathrm{nA}$ & $\log \left(\frac{n A}{1-n A}\right)$ & $\mathrm{pKa}$ \\
\hline 8.50 & 5.30 & 6.29 & 0.99 & 0.3594 & -0.2510 & 8.2490 \\
8.72 & 5.35 & 6.37 & 1.02 & 0.3400 & -0.2880 & 8.4320 \\
9.00 & 5.40 & 6.46 & 1.06 & 0.3141 & -0.3391 & 8.6609 \\
9.22 & 5.45 & 6.55 & 1.10 & 0.2882 & -0.3927 & 8.8273 \\
9.51 & 5.50 & 6.66 & 1.16 & 0.2494 & -0.4786 & 9.0314 \\
9.73 & 5.55 & 6.78 & 1.23 & 0.2041 & -0.5910 & 9.1390 \\
10.00 & 5.60 & 6.90 & 1.30 & 0.1589 & -0.7238 & 9.2762 \\
10.23 & 5.65 & 7.05 & 1.40 & 0.0941 & -0.9835 & 9.2465 \\
10.49 & 5.70 & 7.10 & 1.40 & 0.0941 & -0.9835 & 9.5065 \\
\hline
\end{tabular}

Average pKa $=8.9299 \pm 0.4186$

Table 2: PKa of (Unhydrolysed PSHA)

\begin{tabular}{|l|l|l|l|l|l|l|}
\hline $\mathrm{pH}$ & $\mathrm{BV}_{1}$ & $\mathrm{BV}_{2}$ & $\mathrm{~V}_{2}-\mathrm{V}_{1}$ & $\mathrm{nA}$ & $\log \left(\frac{\boldsymbol{n A}}{1-\boldsymbol{n}}\right)$ & $\mathrm{pKa}$ \\
\hline 8.50 & 5.30 & 5.81 & 0.51 & 0.6619 & 0.2919 & 8.7919 \\
8.72 & 5.35 & 5.90 & 0.55 & 0.6357 & 0.2418 & 8.9618 \\
9.00 & 5.40 & 6.00 & 0.60 & 0.6029 & 0.1813 & 9.1813 \\
9.22 & 5.45 & 6.10 & 0.65 & 0.5701 & 0.1226 & 9.3426 \\
9.51 & 5.50 & 6.20 & 0.70 & 0.5376 & 0.0654 & 9.5754 \\
9.73 & 5.55 & 6.33 & 0.78 & 0.4851 & -0.0259 & 9.7041 \\
10.00 & 5.60 & 6.47 & 0.87 & 0.4262 & -0.1291 & 9.8709 \\
10.23 & 5.65 & 6.62 & 0.99 & 0.3609 & -0.2481 & 9.9819 \\
10.49 & 5.70 & 6.80 & 1.10 & 0.2759 & -0.4690 & 10.0210 \\
\hline
\end{tabular}

Average pKa $=9.4923 \pm 0.4410$

Metal-ligand stability constant ( $\log \mathrm{K}$ )

The stabilityconstants require the accurate values of proton-ligand stability constants (Anil and Maroti, 2008). Metal titration curves crossed over ligand titration curve indicated the formation of complex upon proton release (Santosh, et al., 2011). If the values of n- are within range $0.2-0.8$ and $1.2-18$ this indicates the formation of $1: 1$ and 1:2 complexes (Sayyed and Mazahar, 2012).

The metal (II)-humate stepwise stability constants (log k) at phenolic group (Tables 318)

Table 3: Point-wise method, $\mathrm{Cu}$-(Hydrolysed PSHA)

\begin{tabular}{|l|l|l|l|l|l|l|l|l|}
\hline $\mathrm{pH}$ & $\mathrm{BV}_{1}$ & $\mathrm{BV}_{2}$ & $\mathrm{BV}_{3}$ & $\left(\mathrm{~V}_{3}-\mathrm{V}_{2}\right)$ & $\mathrm{n}$ & $\mathrm{pL}$ & $\log \left(\frac{n}{1-n}\right)$ & LogK $_{1}$ \\
\hline 8.50 & 5.30 & 6.29 & 6.33 & 0.04 & 0.5500 & 2.66 & 0.0871 & 2.7471 \\
8.72 & 5.35 & 6.37 & 6.41 & 0.04 & 0.5714 & 2.43 & 0.1249 & 2.5549 \\
9.00 & 5.40 & 6.46 & 6.50 & 0.04 & 0.6198 & 2.16 & 0.2122 & 2.3722 \\
9.22 & 5.45 & 6.55 & 6.59 & 0.04 & 0.6667 & 1.94 & 0.3010 & 2.2410 \\
\hline
\end{tabular}

LogK $_{1}$ (Average value) $=2.4788 \pm 0.2203$

Table 4: Point-wise method, $\mathrm{Cu}$-(Hydrolysed PSHA)

\begin{tabular}{|l|l|l|l|l|l|l|l|l|}
\hline $\mathrm{pH}$ & $\mathrm{BV}_{1}$ & $\mathrm{BV}_{2}$ & $\mathrm{BV}_{3}$ & $\left(\mathrm{~V}_{3}-\mathrm{V}_{2}\right)$ & $\mathrm{n}$ & $\mathrm{pL}$ & $\log \left(\frac{n-1}{2-n}\right)$ & LogK $_{2}$ \\
\hline 9.51 & 5.50 & 6.66 & 6.73 & 0.07 & 1.3509 & 1.70 & -0.2671 & 1.4329 \\
9.73 & 5.55 & 6.78 & 6.85 & 0.07 & 1.6383 & 1.51 & 0.2467 & 1.7567 \\
10.00 & 5.60 & 6.90 & 6.98 & 0.08 & 2.1783 & 1.31 & -0.2158 & 1.0942 \\
10.23 & 5.65 & 7.05 & 7.13 & 0.08 & 4.1904 & 1.27 & & \\
10.49 & 5.70 & 7.10 & 7.19 & 0.09 & 4.6920 & & & \\
\hline
\end{tabular}

Log $K_{2}($ Average value $)=1.4280 \pm 0.3312$ 
BAJOPAS Volume 14 Number 1,June, 2021

Table 5: Point-wise method, $\mathrm{Cu}$ (Unhydrolysed PSHA)

\begin{tabular}{|l|l|l|l|l|l|l|l|l|}
\hline $\mathrm{pH}$ & $\mathrm{BV}_{1}$ & $\mathrm{BV}_{2}$ & $\mathrm{BV}_{3}$ & $\left(\mathrm{~V}_{3}-\mathrm{V}_{2}\right)$ & $\mathrm{n}$ & $\mathrm{pL}$ & $\log \left(\frac{n}{n-1}\right)$ & Log $_{1}$ \\
\hline 8.50 & 5.30 & 5.81 & 5.85 & 0.04 & 0.2973 & 2.88 & -0.3736 & 2.5064 \\
8.72 & 5.35 & 5.90 & 5.95 & 0.05 & 0.3873 & 2.66 & -0.1992 & 2.4608 \\
9.00 & 5.40 & 6.00 & 6.05 & 0.05 & 0.4044 & 2.38 & -0.1681 & 2.2119 \\
9.22 & 5.45 & 6.10 & 6.15 & 0.06 & 0.5157 & 2.18 & -0.0272 & 2.2072 \\
9.51 & 5.50 & 6.20 & 6.27 & 0.07 & 0.6417 & 1.89 & 0.2530 & 1.1430 \\
\hline
\end{tabular}

$\operatorname{LogK}_{1}($ Average value $)=2.3059 \pm 0.6153$

Table 6:Point-wise method, $\mathrm{Cu}$ (Unhydrolysed PSHA)

\begin{tabular}{|l|l|l|l|l|l|l|l|l|}
\hline $\mathrm{pH}$ & $\mathrm{BV}_{1}$ & $\mathrm{BV}_{2}$ & $\mathrm{BV}_{3}$ & $\mathrm{~V}_{3}-\mathrm{V}_{2}$ & $\mathrm{n}$ & $\mathrm{pL}$ & $\log \left(\frac{n-1}{2-n}\right)$ & $\log \mathrm{K}_{2}$ \\
\hline 9.73 & 5.55 & 6.33 & 6.42 & 0.09 & 0.9000 & 1.69 & & \\
10.00 & 5.60 & 6.47 & 6.58 & 0.11 & 1.2578 & 1.44 & -0.4592 & 0.9808 \\
10.23 & 5.65 & 6.62 & 6.84 & 0.12 & 1.6137 & 1.26 & -0.2010 & 1.4610 \\
10.49 & 5.70 & 6.80 & 6.92 & 0.12 & 2.1052 & 1.03 & & \\
\hline
\end{tabular}

$\operatorname{LogK}_{2}$ (Average value) $=1.2209 \pm 0.3398$

Table 7:Point-wise method, Pb (Hydrolysed PSHA)

\begin{tabular}{|l|l|l|l|l|l|l|l|l|}
\hline $\mathrm{pH}$ & $\mathrm{BV}_{1}$ & $\mathrm{BV}_{2}$ & $\mathrm{BV}_{3}$ & $\left(\mathrm{~V}_{3}-\mathrm{V}_{2}\right)$ & $\mathrm{n}$ & $\mathrm{pL}$ & $\log \left(\frac{n}{1-n}\right)$ & LogK $_{1}$ \\
\hline 8.50 & 5.30 & 6.29 & 6.33 & 0.04 & 0.5500 & 2.66 & 0.0871 & 2.7471 \\
8.72 & 5.35 & 6.37 & 6.41 & 0.04 & 0.5714 & 2.43 & 0.1249 & 2.5549 \\
9.00 & 5.40 & 6.46 & 6.50 & 0.04 & 0.6198 & 2.16 & 0.2122 & 2.3722 \\
9.22 & 5.45 & 6.55 & 6.60 & 0.05 & 0.8333 & 1.96 & 0.6989 & 2.6589 \\
\hline
\end{tabular}

Log $_{\mathbf{1}}($ Average value $)=2.5832 \pm 0.1614$

Table 8:Point-wise method, Pb-(Hydrolysed PSHA)

\begin{tabular}{|l|l|l|l|l|l|l|l|l|}
\hline $\mathrm{pH}$ & $\mathrm{BV}_{1}$ & $\mathrm{BV}_{2}$ & $\mathrm{BV}_{3}$ & $\left(\mathrm{~V}_{3}-\mathrm{V}_{2}\right)$ & $\mathrm{n}$ & $\mathrm{pL}$ & $\log \left(\frac{n-1}{2-n}\right)$ & $\log \mathrm{K}_{2}$ \\
\hline 9.51 & 5.50 & 6.66 & 6.71 & 0.05 & 0.9650 & 1.67 & & \\
9.73 & 5.55 & 6.78 & 6.83 & 0.05 & 1.1702 & 1.44 & & \\
10.00 & 5.60 & 6.90 & 6.90 & 0.05 & 1.4864 & 1.22 & -0.0237 & 1.1963 \\
10.23 & 5.65 & 7.05 & 7.10 & 0.05 & 2.0190 & 1.09 & & \\
10.49 & 5.70 & 7.10 & 7.17 & 0.07 & 3.6492 & 1.00 & & \\
\hline
\end{tabular}

Log $K_{2}$ (Average value) $=1.1963$

Table 9: Point-wise method, Pb (Unhydrolysed PSHA)

\begin{tabular}{|l|l|l|l|l|l|l|l|l|}
\hline $\mathrm{pH}$ & $\mathrm{BV}_{1}$ & $\mathrm{BV}_{2}$ & $\mathrm{BV}_{3}$ & $\mathrm{~V}_{3}-\mathrm{V}_{2}$ & $\mathrm{n}$ & $\mathrm{pL}$ & $\begin{array}{l}\text { Log } \\
\left(\frac{n}{n-1}\right)\end{array}$ & Log $\mathrm{K}_{1}$ \\
\hline 8.50 & 5.30 & 5.81 & 5.85 & 0.04 & 0.2973 & 2.88 & -0.3736 & 2.5064 \\
8.72 & 5.35 & 5.90 & 5.94 & 0.04 & 0.3099 & 2.66 & -0.5477 & 2.3123 \\
9.00 & 5.40 & 6.00 & 6.05 & 0.05 & 0.4044 & 2.38 & -0.1681 & 2.2119 \\
9.22 & 5.45 & 6.10 & 6.15 & 0.06 & 0.5157 & 2.18 & 0.0272 & 2.2072 \\
9.51 & 5.50 & 6.20 & 6.26 & 0.07 & 0.6417 & 1.89 & 0.2530 & 2.1430 \\
9.73 & 5.55 & 6.40 & 6.40 & 0.07 & 0.7000 & 1.67 & 0.3680 & 2.0380 \\
\hline
\end{tabular}

LogK $_{1}$ (Average value) $=2.2364 \pm 0.1602$

Table 10: Point-wise method, Pb (Unhydrolysed PSHA)

\begin{tabular}{|l|l|l|l|l|l|l|l|l|}
\hline $\mathrm{pH}$ & $\mathrm{BV}_{1}$ & $\mathrm{BV}_{2}$ & $\mathrm{BV}_{3}$ & $\mathrm{~V}_{3}-\mathrm{V}_{2}$ & $\mathrm{n}$ & $\mathrm{pL}$ & $\log \left(\frac{n-1}{2-n}\right)$ & $\log \mathrm{K}_{2}$ \\
\hline 10.00 & 5.60 & 6.47 & 6.55 & 0.08 & 1.9503 & 1.41 & & \\
10.23 & 5.65 & 6.62 & 6.72 & 0.11 & 1.4792 & 1.26 & -0.0361 & 1.2239 \\
\hline
\end{tabular}

$\operatorname{LogK}_{2}$ (Average value) $=1.2239$

Table 11: Point-wise method, Mg (Hydrolysed PSHA)

\begin{tabular}{|l|l|l|l|l|l|l|l|l|}
\hline $\mathrm{pH}$ & $\mathrm{BV}_{1}$ & $\mathrm{BV}_{2}$ & $\mathrm{BV}_{3}$ & $\left(\mathrm{~V}_{3}-\mathrm{V}_{2}\right)$ & $\mathrm{n}$ & $\mathrm{pL}$ & $\log \left(\frac{n}{n-1}\right)$ & LogK $_{1}$ \\
\hline 8.50 & 5.30 & 6.29 & 6.31 & 0.02 & 0.2750 & 2.64 & -0.4290 & 2.2110 \\
8.72 & 5.35 & 6.37 & 6.39 & 0.02 & 0.2858 & 2.42 & -0.3978 & 2.0222 \\
9.00 & 5.40 & 6.46 & 6.49 & 0.03 & 0.4648 & 2.14 & -0.0612 & 2.0788 \\
9.22 & 5.45 & 6.55 & 6.59 & 0.04 & 0.6667 & 1.94 & 0.3010 & 2.2410 \\
\hline
\end{tabular}

$\log _{\mathbf{1}}($ Average value) $=2.1382 \pm 0.1046$ 
BAJOPAS Volume 14 Number 1,June, 2021

Table 12: Point-wise method, Mg (Hydrolysed PSHA)

\begin{tabular}{|l|l|l|l|l|l|l|l|l|}
\hline $\mathrm{pH}$ & $\mathrm{BV}_{1}$ & $\mathrm{BV}_{2}$ & $\mathrm{BV}_{3}$ & $\left(\mathrm{~V}_{3}-\mathrm{V}_{2}\right)$ & $\mathrm{n}$ & $\mathrm{pL}$ & $\log \left(\frac{n-1}{2-n}\right)$ & LogK $_{2}$ \\
\hline 9.51 & 5.55 & 6.66 & 6.71 & 0.05 & 0.9650 & 1.67 & & \\
9.73 & 5.55 & 6.78 & 6.84 & 0.06 & 1.4042 & 1.47 & -0.1686 & 1.3014 \\
10.00 & 5.60 & 6.90 & 6.93 & 0.06 & 1.7838 & 1.23 & 0.5593 & 1.7893 \\
10.23 & 5.65 & 7.05 & 7.10 & 0.06 & 3.1429 & 1.10 & & \\
10.49 & 5.70 & 7.10 & 7.18 & 0.07 & 3.6492 & 0.83 & & \\
\hline
\end{tabular}

LogK $_{2}($ Average value $)=1.5453 \pm 0.3450$

Table 13: Point-wise method, Mg (Unhydrolysed PSHA)

\begin{tabular}{|l|l|l|l|l|l|l|l|l|}
\hline $\mathrm{pH}$ & $\mathrm{BV}_{1}$ & $\mathrm{BV}_{2}$ & $\mathrm{BV}_{3}$ & $\mathrm{~V}_{3}-\mathrm{V}_{2}$ & $\mathrm{n}$ & $\mathrm{pL}$ & $\log \left(\frac{n}{n-1}\right)$ & $\operatorname{Log~}_{1}$ \\
\hline 8.50 & 5.30 & 5.81 & 5.85 & 0.04 & 0.2973 & 2.88 & -0.3736 & 2.5064 \\
8.72 & 5.35 & 5.90 & 5.94 & 0.04 & 0.3099 & 2.66 & -0.3477 & 2.3123 \\
9.00 & 5.40 & 6.00 & 6.04 & 0.04 & 0.3236 & 2.38 & -0.3202 & 2.0598 \\
9.22 & 5.45 & 6.10 & 6.15 & 0.05 & 0.4297 & 2.17 & -0.1230 & 2.0470 \\
9.51 & 5.50 & 6.20 & 6.26 & 0.06 & 0.5500 & 1.89 & 0.0871 & 1.9771 \\
9.73 & 5.55 & 6.33 & 6.40 & 0.07 & 0.7000 & 1.67 & 0.3680 & 2.0380 \\
\hline
\end{tabular}

LogK $_{1}$ (Average value) $=2.1568 \pm 0.2069$

Table 14: Point-wise method, Mg (Unhydrolysed PSHA)

\begin{tabular}{|l|l|l|l|l|l|l|l|l|}
\hline $\mathrm{pH}$ & $\mathrm{BV}_{1}$ & $\mathrm{BV}_{2}$ & $\mathrm{BV}_{3}$ & $\mathrm{~V}_{3}-\mathrm{V}_{2}$ & $\mathrm{n}$ & $\mathrm{pL}$ & $\log \left(\frac{n-1}{2-n}\right)$ & $\log \mathrm{K}_{2}$ \\
\hline 10.00 & 5.60 & 6.47 & 6.55 & 0.08 & 0.9148 & 1.41 & & \\
10.23 & 5.65 & 6.62 & 6.71 & 0.09 & 1.2102 & 1.20 & -0.5749 & 0.6251 \\
10.49 & 5.70 & 6.80 & 6.92 & 0.09 & 1.5968 & 1.03 & 0.1703 & 1.2003 \\
\hline
\end{tabular}

LogK $_{2}$ (Average value) $=0.9127 \pm 0.4070$

Table15:Point-wise method, Cd (Hydrolysed PSHA)

\begin{tabular}{|l|l|l|l|l|l|l|l|l|}
\hline $\mathrm{pH}$ & $\mathrm{BV}_{1}$ & $\mathrm{BV}_{2}$ & $\mathrm{BV}_{3}$ & $\left(\mathrm{~V}_{3}-\mathrm{V}_{2}\right)$ & $\mathrm{n}$ & $\mathrm{pL}$ & $\log \left(\frac{n}{1-n}\right)$ & LogK $_{1}$ \\
\hline 8.50 & 5.30 & 6.29 & 6.31 & 0.02 & 0.2750 & 2.64 & -0.4210 & 2.2190 \\
8.72 & 5.35 & 6.37 & 6.40 & 0.03 & 0.4286 & 2.42 & -0.1249 & 2.2951 \\
9.00 & 5.40 & 6.46 & 6.49 & 0.03 & 0.4648 & 2.14 & -0.0612 & 2.0788 \\
9.22 & 5.45 & 6.55 & 6.59 & 0.04 & 0.6667 & 1.96 & 0.3010 & 2.2610 \\
9.51 & 5.55 & 6.66 & 6.70 & 0.04 & 0.7720 & 1.67 & 0.5297 & 2.1997 \\
\hline
\end{tabular}

LogK $_{\mathbf{1}}$ (Average value) $=2.2108 \pm 0.0825$

Table 16: Point-wise method, Cd (Hydrolysed PSHA)

\begin{tabular}{|l|l|l|l|l|l|l|l|l|}
\hline $\mathrm{pH}$ & $\mathrm{BV}_{1}$ & $\mathrm{BV}_{2}$ & $\mathrm{BV}_{3}$ & $\left(\mathrm{~V}_{3}-\mathrm{V}_{2}\right)$ & $\mathrm{n}$ & $\mathrm{pL}$ & $\log \left(\frac{n-1}{2-n}\right)$ & Log $_{2}$ \\
\hline 9.73 & 5.55 & 6.78 & 6.83 & 0.06 & 1.4042 & 1.47 & -0.1686 & 1.3014 \\
10.00 & 5.60 & 6.90 & 6.95 & 0.06 & 1.7838 & 1.23 & 0.5593 & 1.7893 \\
10.23 & 5.65 & 7.05 & 7.10 & 0.06 & 3.1429 & 1.09 & & \\
10.49 & 5.70 & 7.10 & 7.16 & 0.06 & 3.1429 & 0.89 & & \\
& & & & & & & & \\
\hline
\end{tabular}

$\operatorname{LogK}_{2}$ (Average value) $=1.5453 \pm 0.3450$

Table 17: Point-wise method, Cd (Unhydrolysed PSHA)

\begin{tabular}{|l|l|l|l|l|l|l|l|l|}
\hline $\mathrm{pH}$ & $\mathrm{BV}_{1}$ & $\mathrm{BV}_{2}$ & $\mathrm{BV}_{3}$ & $\mathrm{~V}_{3}-\mathrm{V}_{2}$ & $\mathrm{n}$ & $\mathrm{pL}$ & $\log \left(\frac{n}{n-1}\right)$ & $\operatorname{Log~}_{1}$ \\
\hline 8.50 & 5.30 & 5.81 & 5.86 & 0.05 & 0.3717 & 2.88 & -0.2280 & 2.6520 \\
8.72 & 5.35 & 5.90 & 5.95 & 0.05 & 0.3873 & 2.66 & -0.1992 & 2.4608 \\
9.00 & 5.40 & 6.00 & 6.06 & 0.06 & 0.4853 & 2.38 & -0.0255 & 2.3545 \\
9.22 & 5.45 & 6.10 & 6.16 & 0.06 & 0.5157 & 2.18 & -0.0272 & 2.2072 \\
9.51 & 5.50 & 6.20 & 6.27 & 0.07 & 0.6417 & 1.89 & 0.2530 & 1.1430 \\
9.73 & 5.55 & 6.33 & 6.41 & 0.08 & 0.8000 & 1.69 & 0.6020 & 2.2920 \\
& & & & & & & & \\
\hline
\end{tabular}

$\operatorname{LogK}_{1}($ Average value $)=2.2516 \pm 0.5380$ 
BAJOPAS Volume 14 Number 1,June, 2021

Table 18: Point-wise method, Cd (Unhydrolysed PSHA)

\begin{tabular}{|l|l|l|l|l|l|l|l|l|}
\hline $\mathrm{pH}$ & $\mathrm{BV}_{1}$ & $\mathrm{BV}_{2}$ & $\mathrm{BV}_{3}$ & $\mathrm{~V}_{3}-\mathrm{V}_{2}$ & $\mathrm{n}$ & $\mathrm{pL}$ & $\log \left(\frac{n-1}{2-n}\right)$ & $\log \mathrm{K}_{2}$ \\
\hline 10.00 & 5.60 & 6.47 & 6.57 & 0.10 & 1.1434 & 1.43 & & \\
10.23 & 5.65 & 6.62 & 6.72 & 0.10 & 1.3448 & 1.23 & -0.2788 & 0.9512 \\
10.49 & 5.70 & 6.80 & 6.90 & 0.10 & 1.7742 & 1.03 & 0.5351 & 1.5651 \\
\hline
\end{tabular}

$\operatorname{LogK}_{2}($ Average value $)=1.2581 \pm 0.4340$

Table 19: Stepwise and overall Stability constants of thehydrolysed and unhydrolysed divalent metal (II) complexes

\begin{tabular}{|c|c|c|c|}
\hline Chelates & LogK $_{1}$ & $\log _{2}$ & Log $\beta$ \\
\hline [Cu (Hydrolysed PSHA-1) $\left.{ }_{2}\right]$ & 2.4788 & 1.4280 & 3.9068 \\
\hline$\left[\mathrm{Pb}(\text { Hydrolysed PSHA-1) })_{2}\right]$ & 2.5832 & 1.1963 & 3.7795 \\
\hline$\left[\mathrm{Cd}(\text { Hydrolysed PSHA-1 })_{2}\right]$ & 2.2108 & 1.5453 & 3.7561 \\
\hline$\left[\mathrm{Mg}(\text { Hydrolysed PSHA-1 })_{2}\right]$ & 2.1382 & 1.5453 & 3.6835 \\
\hline [Cu (Unhydrolysed PSHA-1) & 2.3059 & 1.2209 & 3.5268 \\
\hline$[\mathrm{Pb}$ (Unhydrolysed PSHA-1) 2$]$ & 2.2364 & 1.2239 & 3.4603 \\
\hline [Cd (Unhydrolysed PSHA-1) 2 ] & 2.2516 & 1.2581 & 3.5097 \\
\hline$[\mathrm{Mg}$ (Unydrolysed PSHA-1) & 2.1568 & 0.9127 & 3.0695 \\
\hline
\end{tabular}

The results obtained (Table19) shows the stepwise and overall stability constants to be not high indicating low stability of the complexes, because the solubility of most metal ions in the basic $\mathrm{pH}$ range is minimal due to metal hydroxide precipitation (Karimi, 2017). In general, the stepwise stability constants $\left(K_{1}\right.$ and $K_{2}$ ) follow the order $K_{1}>K_{2}$ for the copper, lead, magnesium and cadmium complexes respectively. The steady decrease of the values with increasing number of ligands is in agreement with the prediction made by researchers (Na'aliya, 2013). The decrease could be attributed to the fact that as the number of the ligands (Humate ions) that enters the coordination zone increases the aqua molecules available for replacement by the ligands become less. Thus, the metal ions become less electron loving with progressive intake of the ligand and this results in the decrease in the values of the constants (Na'aliya, 2013). Also the stability of the complexes is influenced by the size and number of the chelate rings(Mackay and Mackay,2002).All the complexes form rings in their structure as humate, a bidentate ligand, bond the metal ions in the ratio 1:2 (Boguta and Sokolowska, 2016) forming chelate rings. The values of the overall stability constants $(\log \beta)$ obtained for humate complexes are not high indicating low stability as the values are not high. LogK values for copper-humates (Table 3 to 6) obtained in this study are lower than those reported for the complexes of humic acids (Pandey et al., 2015; Dinu, 2013; Kaschl et al., 2010 and Gilbeto and Jorg, 2001). The values of LogK(Table 7 to 10 ) forlead-humates are lower than those reported for the lead in the literature (Dinu, 2013; Gilbeto and Jorg 2001). Log K values(Table 11 to 14 ) for magnesium-humates obtained in this study are close to those reported by (Pandey et al., 2015). Log K values of cadmium-humates (Table 15 to 18 ) obtained in this work near to the one reported by (Dinu, 2013 and Pandey et al., 2015).The difference between the reported values and the values obtained in this study might be probably as a result of acid hydrolysis of humic acid. The values of the overall stability constants $(\log \beta)$ of the copper humates complexes presented in Table 19 is high than that of other metal humate complexes, show relatively high stability of CuHA complexes, show the following order of stability: $\mathrm{Cu}>\mathrm{Pb}>\mathrm{Cd}>\mathrm{Mg}$; which are in close agreement to the findings of (Dinu, 2013 and Pandey et al., 2015).The high stability of Cuhumate chelate could be attributed to the existence of coordinate covalent bond between the complexing agents and the $\mathrm{Cu}^{2+}$ ions. Since, $\mathrm{Cu}^{2+}$ being a metal of the transitional series with $3 d^{9}$ electronic configurations can accept the electrons from the complexing agents. Similarly, the low stabilities of $\mathrm{Pb}, \mathrm{Cd}$ and $\mathrm{Mg}$ complexes could be explained by that $\mathrm{Pb}^{2+}$ with $6 s^{2}, \mathrm{Cd}^{2+}$ with $4 \mathrm{~d}^{10}$ and $\mathrm{Mg}^{2+}$ with $2 \mathrm{p}^{6}$ their electronic configuration has a completely filled $\mathrm{d}, \mathrm{p}$ and $\mathrm{s}$ orbitals. Moreover, the stabilities of metal ions with hydrolysed humic acid from peat soil were higher than those with unhydrolysed humic acid from peat soil; which is ascribed to the high content of acidity in hydrolysed humic acid than unhydrolysed humic acid. 
BAJOPAS Volume 14 Number 1,June, 2021 CONCLUSION

The values of logk for $\mathrm{Cu}(\mathrm{II})$ hydrolysed humic acid complex was higher followed by $\mathrm{Pb}$ (II), $\mathrm{Cd}(\mathrm{II})$ and $\mathrm{Mg}$ (II) hydrolysed humic acid complexes as compared with metal(II) unhydrolysed humic acid complexes. This indicates acid hydrolysis of humic acid can

\section{REFERENCES}

Almeida, V.R. and Szpoganicz, B. (2015). Humic Acid Potentiometric Response Patterns:Out- of Equilibrium Properties and Species Distribution Modelling. Chemical. Biol. Technol. Agric. 2: 17.

Anđelković, T., Nikolić, R., Bojić, A.,Anđelković, D., and Nikolic G.,(2010). Binding of Cadmium to Soil Humic Acid as A Function of Carboxyl Group Content. Macedonian Journal of Chemistry and Chemical Engineering.29(2): 215-224.

Anil, B. N. and Maroti, N. (2008). Studies on Influence of Die-Lectric Constants on Complex Equilibria between Substituted Py-Razalines and Lanthanide Metal Ions pH-Metrically. Amer.-Euras. scient. Res. 3(2): 212-216.

Ashok, K., Pandey, S. P. and Misra, V (2000). Stability Constants of Metal-Humic Acid Complexes and its Role in Environmental Detoxification. Journal of Ecotoxicology and Environmental Safety. 47(2):157-200.

Badr, M. H., El-Halafawi, M. H. and Abd El-al Zeid, E. R. (2012). Comparison Between the Effect of Ionic Strength on Acidity and Dissociation Constants of Humic Acids Extracted from Sewage Sludge and Nile Water Hyacinth Composts.Global Journal of Environmental Research 6 (1): 36-43.

Baruah, M.K., Borah, D., Saikia, P.P., Paul, S., Sharma, T. (2015). Evaluation of pKa Values of Soil Humic Acids and their Complexation Properties. International Journal of Plant \& Soil Science 6(4) : 218-228.

Boguta, P. Sokolowska, Z. (2016). Interactions of $\mathrm{Zn}$ (II) Ions with Humic Acids Isolated from Various Types of Soils. Effect of $\mathrm{pH}, \mathrm{Zn}$ Concentrations and Humic Acids Chemical Properties. Journal of Geochemical Explaration 168. 119-126.

Borges, F., Guimaraes, C., Lima, L.F.C., Pinto, I. and Reis, S.(2005). Potentiometric Studies on the Complexation of Copper(II) by Phenolic Acids as Discrete Ligand Models of enhance the complexation behavior of humic acid with metal (II) ions. However, the higher values of $\log \beta$ for $\mathrm{Cu}(\mathrm{II}), \mathrm{Pb}(\mathrm{II}), \mathrm{Cd}(\mathrm{II})$ and $\mathrm{Mg}(\mathrm{II})$ hydrolysed humic acid complexes indicates more stable stepwise complexes formed as compared with $\mathrm{Cu}(\mathrm{II}), \mathrm{Pb}$ (II), $\mathrm{Cd}$ (II) and $\mathrm{Mg}(\mathrm{II})$ unhydrolysed humic acid complexes.

Humic Substances Talanta 66 (2005) 670-673.

Chefetz, B., Salloum, M. J., Deshmulkin, A. P. and Hatcher, P. (2002). Structural Components of Humic Acids as Determined by Chemical Modifications and Carbon-13 NMR, Pyrolysis, and Thermochemolysis- Gas Chromatography/Mass Spectrometry. Soil Science Society of American Journal Abstract Division S-2- Soil Chemistry66. 1159-1171.

Dinu, M. I. (2013). Metals Complexation with Humic Acids in Surface Water of Different Environ. Sci. Technol. 31(1): 1-17.

Fernandes, A.N., Giacomelli, C., Giovanela, M. Vaz, D.V. Szpoganicz, B. and Maria M. D. (2009). Potentiometric Acidity Determination in Humic Substances Influenced by Different Analytical Procedures.J. Braz. Chem. Soc. 20 (9):14.

Gamal, A. H. (2015). Stability Constants of Rhenium (V) Metal Complexes with Selected Drugs. Pyrex Journal of Research in Environmental Studies. 2(2): 006-014.

Janrao, D. M., Pathan, J., Kayande, D.D., and Mulla, J.J. (2014). An Over View of Potentiometric Determination of Stability Constants of Metal Complexes. Sci. Revs. Chem. Commun.: 4(1), 2014, 11-24.

Karimi, H. (2017). Effect of pH and Initial Pb(II) Concentration on the Lead Removal Efficiency from Waste Water Using $\mathrm{Ca}(\mathrm{OH})_{2}$. International Journal of Water and Waste Water Treatment 3.2

Kaschl, A. Romheld, V. and Chen, Y. (2010). Binding of Cadmium, Copper and Zinc to Humic Substances Originating from Municipal Solid Waste Compost. Israel Journal of Chemistry Vol. 42(1): 89-98.

Kostic, I. S., Tatjana, P, A., Nikolic, R. S., Cvetkovic, T. P., Pavlovic, D. D., Aleksandar, L.J. and Bojic, A. (2012). Comparative Study of Binding Strengths of Heavy Metals with Humic Acid. J.serb. Chem. Soc. 76(9) pp 1-20. 
BAJOPAS Volume 14 Number 1,June, 2021

Na'aliya, J. (2013). Determination of Stepwise Stability Constants and Gibbs free Energy Change of Trisprolina to Complexes of some Divalent Transition Metal ions. Bayero Journal of Pure and Applied Sciences 6(2): 112-114.

Omar, A. A. and Ali, E. A. (2015). Potentiometric Studies on Complexes of $\mathrm{Cr}$ (III) and $\mathrm{Zr}$ (IV) with some Carboxylic Acids. International Journal of Advanced Chemistry, 3(1) 25-

37.

Pandey, A. K. Pandey, S. D. and Misr, V. (2015).Stability Constants of Metal- Humic Acid Complexes and Its Role in Environmental Detoxification. J. Ecotoxicology and Environmental Safety. 47(1):195-200.

Ram, N. and Raman, K.V. (1984). Stability Constants of Complexes of Metals with
Humicand Fuvic Acids under Non- acidConditions. Journal of Plant Nutrition and Soil Sciences.

147:171-176.

Santosh, D. D., Ashok, B. K., Vijay, J. T., Shivraj, G. W. and Vinay, V. W. (2011). Potentiometric Studies of Elec-Trolyte Effects on Complex Equilibria of Some Substituted 5-(2-hydroxy Phenyl) Pyrazoles. Der pharm. 3 (6): 75-83.

Sayyed, H. and Abdul Rahim, M. F. (2012). Studies of Binary Complexes of Metal Ions with Mandelic Acid by Potentiometry. Chem. J. 02 (6): 206209.

Shirvani, M. Moradian, E. Khalili, B. Bakhtiary, S. (2015). Interaction of $\mathrm{Cd}$ and $\mathrm{Pb}$ with Humate-Palygorskite and HumateSepiolite Complexes. Journal of water, air and pollution 3: 220-228. 


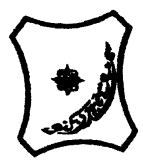

Bayero Journal of Pure and Applied Sciences, 14(1): 54 - 63

Received: November, 2020

Accepted: April, 2021

ISSN $2006-6996$

\title{
STABILITY CONSTANTS OF COMPLEXES OF METAL IONS WITH PEATSOIL HUMIC ACIDS UNDER NON-ACID-CONDITIONS
}

\author{
${ }^{* 1}$ Sabo, Yusuf ${ }^{2}$ Jimoh, W.L.O., ${ }^{3}$ Isa Baba Koki and ${ }^{4}$ Sholadoye, Q. 0. \\ ${ }^{1}$ Department of Pure and Industrial Chemistry, Bayero University, Kano \\ ${ }^{3}$ Department of Chemistry, Yusuf Maitama Sule University Kano. P.M.B. 3220 Kano, Nigeria. \\ ${ }^{4}$ Department of Chemistry, Nigerian Police Academy, Wudil, Kano-Nigeria
}

*Correspondence E-mail; saboyusuf18@yahoo.com

ABSTRACT

Stability constants of complexes of four divalent metal ions viz. $\mathrm{Cu}^{2+}, \mathrm{Pb}^{2+}, \mathrm{Mg}^{2+}$ and $\mathrm{Cd}^{2+}$ with humic acids (HA) were determined by potentiometric titration of humic acids with the corresponding salt of the divalent metals in aqueous media under non-acid-condition. The log $K$ (logarithm of the stability constant) ranged from 1.0942 to 2.7471 for metalhumic acid complexes were determined using point-wise computational method. The order of stability constants were obtained as follows: $\mathrm{Cu}>\mathrm{Pb}>\mathrm{Cd}>\mathrm{Mg}$ for metal $-\mathrm{HA}$ complexes respectively, indicating a higher degree of complexation with Cu metal ion.

Keywords: stability constant, humic acid, potentiometric titration, divalent metals, acid hydrolysis.

\section{NTRODUCTION}

The stability constant of a complex is the numerical expression of its stability and provides a quantitative measure of affinity of the metal ion to the complexing agent. An understanding of the relative stability of metal-complexes helps in predicting the behavior of metal ions in the soil (Ram and Raman, 1982). Extensive researches has been done to determine the stability constants of the complexes formed between humic acid (HA) with a number of metal ions. Ashok et al., (2000) reported that humic acid with hydroxyl, phenoxyl and carboxyl reactive groups can form coordination compound with metal ions at $\mathrm{pH}$ 3.5. The stability constants(Log K) for different metalhumic acid complexes indicated the following order of the stabilities of complexes formed between humic acid and metal ion, $\mathrm{Cu}>\mathrm{Fe}$ $>\mathrm{Pb}>\mathrm{Ni}>\mathrm{Co}>\mathrm{Ca}>\mathrm{Cd}>\mathrm{Zn}>\mathrm{Mn}>\mathrm{Mg}$. Andelkovic et al., (2010) investigated the binding of $\mathrm{Cd}$ (II) to soil humic acid at pH 6.5 and in $0.1 \mathrm{M} \mathrm{KNO}_{3}$ ionic medium. The stability constant for binding indicating greater stability in the case when carboxyl groups are involved in complexation reaction. Kostic et al.,(2012) investigated the complexation of humic acid with certain heavy metal ions (Co(II), $\mathrm{Ni}(\mathrm{II}), \mathrm{Cu}(\mathrm{II})$,
$\mathrm{Zn}(\mathrm{II})$, and $\mathrm{Pb}(\mathrm{II})$. The experiment was performed at $25^{\circ} \mathrm{C}$, at pH 4.0 and ionic strength of $0.01 \mathrm{M}$. Stability constant of complex between $\mathrm{Pb}$ (II) ions and humic acid is greater than stability constants of other investigated metalhumate complexes. Bogata and Sokolowska (2016) analyses the interaction between humic acids from different soils and $\mathrm{Zn}$ (II) ions at wide concentration ranges and at $\mathrm{pH} 5$. Studies have showed significant impact of $\mathrm{Zn}$ concentration, $\mathrm{pH}$ and some properties of humic acids with zinc.But all of these studies were limited to acidic $\mathrm{pH}$ range. Therefore, the present study was carried out to determine and compare the stability constants of complexes of metal ions with hydrolysed peat soil humic acid and unhydrolysed peat soil humic under non-acid conditions.

\section{MATERIALS AND METHODS}

Analytical grade chemicals used includes hydrochloric acid $(\mathrm{HCl})$, nitric acid $\left(\mathrm{HNO}_{3}\right)$, sodium hydroxide $(\mathrm{NaOH})$, lead nitrate $\mathrm{Pb}\left(\mathrm{NO}_{3}\right)_{2}$, copper nitrate $\mathrm{Cu}\left(\mathrm{NO}_{3}\right)_{2} \cdot 3 \mathrm{H}_{2} \mathrm{O}$, cadmium nitrate $\mathrm{Cd}\left(\mathrm{NO}_{3}\right)_{2} \cdot 4 \mathrm{H}_{2} \mathrm{O}$, magnesium nitrate $\mathrm{Mg}\left(\mathrm{NO}_{3}\right)_{2} \cdot 6 \mathrm{H}_{2} \mathrm{O}$, potassium nitrate $\left(\mathrm{KNO}_{3}\right)$, calcium chloride $\left(\mathrm{CaCl}_{2}\right)$, (sigma-Aldrich). Dowex 50WX8, (20-50 mesh) from Fluka. 


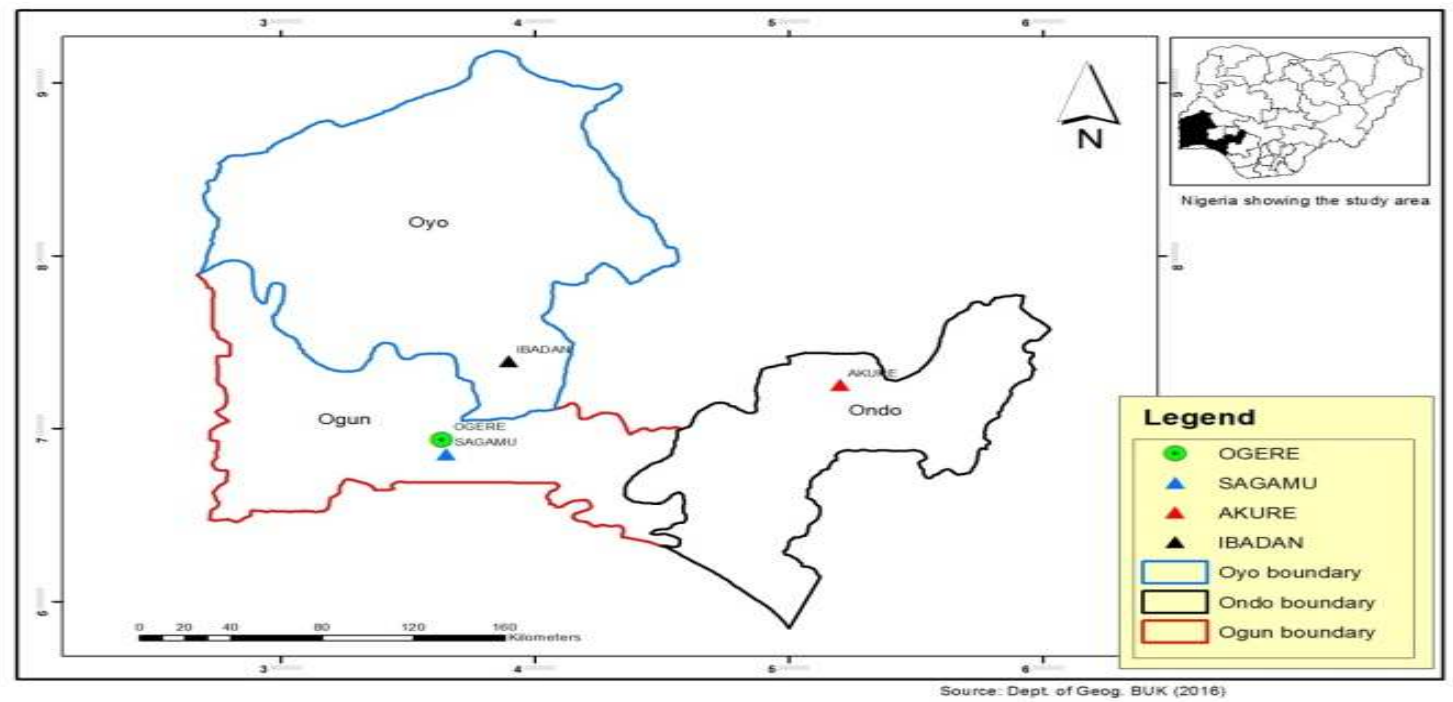

Figure 1: Map showing the sampling point at Sagamu Town, Ogun State.

\section{Description of Sampling Area}

Sagamu has geographical coordinates between $6^{\circ} 50^{\prime}$ north; $3^{\circ} 38^{\prime}$ east is located in south western region of Nigeria. The region has tropical wet and dry climate with a lengthy wet season and relatively constant temperatures throughout the course of the year. Wet season runs from March to October, November to December forms the region dry season. The vegetation type of the region is savannah which is really grassland with small bushes and occasional big trees. Grassland soils have substantially higher organic matter content than forest soils (Novackova, 2011).

\section{Sample Collection}

The Peatsoil samples were collected from four different sampling points $(0-10 \mathrm{~cm}$ depth) in Sagamu into polyethylene bag with plastic spoons. Samples were taken to the laboratory, extraneous materials were removed; the samples were air-dried, crushed and ground to a fine powder in a mortar passed through a $0.20 \mathrm{~mm}$ sieve. The samples were kept for analysis.

\section{Isolation and purification of humic acid from peat soil sample}

Peatsoil sample $(100 \mathrm{~g})$ was mixed with 1000 $\mathrm{cm}^{3}$ of $0.1 \mathrm{M} \mathrm{NaOH}$ solution, shaken for 3hours and left to stand overnight. Dark-coloured supernatant was obtained and decanted from solid residue. The dark-coloured supernatant was acidified to $(\mathrm{pH}=1.0)$ with $6 \mathrm{M} \mathrm{HCl}$ stirred and allowed to stand for 6 hours. Yellowish brown supernatant and dark-brown precipitate were obtained. The yellowish brown supernatant was decanted followed by centrifuge and discarded. The dark-brown precipitate was mixed with $500 \mathrm{~cm}^{3}$ of $0.1 \mathrm{M} \mathrm{NaOH}$ solution followed by passing through dowex resin. The dark-brown solution was acidified to $(\mathrm{pH}=1.0)$ with $6 \mathrm{M} \mathrm{HCl}$ stirred and allowed to stand for 3 hours. The dark-brown precipitate was washed several times with deionized water. The supernatant was treated with $\mathrm{AgNO}_{3}$ solution until no white precipitate observed. The humic acid was transferred to weighed crucible and dried at $60^{\circ} \mathrm{C}$ in an oven for 12 hours. The humic acid was cooled and dried in the desiccator, weighed and recorded. The obtained humic acid was dried again at $60^{\circ} \mathrm{C}$ for additional 6 hours cooled and dried in the desiccator, weighed and recorded constant weight was obtained (Baruah et al., 2015).

\section{FT-IR analysis}

FT-IR spectra of humic acid sample was analysed using Carry 630 FT-IR Agilent Technologies.

Unhydrolysed compost humic acid

The unhydrolysed humic acid was obtained after isolation and purification of compost humic acid and kept for investigation.

\section{Acid hydrolysis of Peatsoil acid}

Peatsoil humic acid sample (1g) was refluxed for 12 hours at $\left(160^{\circ} \mathrm{C}\right)$ with $50 \mathrm{~cm}^{3}$ of $6 \mathrm{M} \mathrm{HCl}$. The mixture was allowed to cool, decanted, and centrifuged after hydrolysis. The insoluble residues were washed with distilled water via centrifugation several times, and the supernatant was treated with $\mathrm{AgNO}_{3}$ solution until no white precipitate was observed. The residue was thoroughly dried over $\mathrm{CaCl}_{2}$ in a desiccator at room temperature (Chefetz et al., 2002). Finally, the obtained hydrolysed humic acid was kept for investigation. 
BAJOPAS Volume 14 Number 1,June, 2021 Potentiometric Titrations

Potentiometric measurements were carried out using a pH-meter Jenway (model 3510) with combine electrode, the sensitivity of the $\mathrm{pH}$ meter is 0.01 units. The $\mathrm{pH}$ meter was switched on half an hour before starting the titration for initial warm up of the instrument. The instrument was calibrated with an aqueous standard buffer solution of $\mathrm{pH} 4.00$ and 10.0 (borate buffer) prepared from a "Qualigens" buffer tablets.

The following sets of solutions were prepared in a $250 \mathrm{~cm}^{3}$ volumetric flask separately for $\mathrm{pH}$ metric titrations.

(i) $5 \mathrm{~cm}^{3} 0.1 \mathrm{M} \mathrm{HCl}+40 \mathrm{~cm}^{3}$ deionized water

(ii) $5 \mathrm{~cm}^{3} 0.1 \mathrm{M} \mathrm{HCl}+39 \mathrm{~cm}^{3}$ deionized water $+1 \mathrm{~cm}^{3} 0.15 \mathrm{gcm}^{-3}$ humic acid

(iii) $5 \mathrm{~cm}^{3} 0.1 \mathrm{M} \mathrm{HCl}+37 \mathrm{~cm}^{3}$ deionized water $+1 \mathrm{~cm}^{3} 0.15 \mathrm{gcm}^{-3}$ humic acid

$$
+2 \mathrm{~cm}^{3} \quad 0.01 \mathrm{M} \mathrm{Cu} \text { (II) }
$$

The solutions were titrated against standardized $0.110 \mathrm{MNaOH}$ separately. The total volume of each mixture was adjusted to $50 \mathrm{~cm}^{3}$ and the ionic strength of the solutions was maintained constant at by adding appropriate amount of stock solution of $1 \mathrm{M} \mathrm{KNO}_{3}$ (Gamal, 2015; Omar and Ali, 2015). A magnetic stirrer was used to achieve thorough mixing of the interacting solutions at $550 \mathrm{rpm}$. The same set of experimental conditions was applied for potentiometric titration of remaining samples.

\section{Evaluation of pKa of Hydrolysed peat soil Humic Acids}

The proton-ligand formation number $\mathrm{n}_{\mathbf{A}}$ were calculated by Irving and Rossotti expression (Omar and Ali, 2015).

$\mathrm{nA}=\mathrm{Y}-\frac{(\mathrm{V} 2-\mathrm{V1})(\mathrm{No}-\mathrm{Eo})}{(\mathrm{VO}+\mathrm{V1}) \mathrm{TCL}}$ 1

Where: $Y$ is number of dissociable proton, $\left(\mathrm{V}_{2^{-}}\right.$ $V_{1}$ ) is the measure of displacement of the ligand curve relative to acid curve, $\mathrm{N}^{\circ}$ and $\mathrm{E}^{\circ}$ are the resultant concentration of alkali solution, free acid solution, $\mathrm{T}_{\mathrm{cL}}{ }^{\circ}$ is the total ligand concentration, $\mathrm{V}^{\circ}$ is the total volume of titration solution, $V_{1}$ is the volume of alkali added to acid solution, $V_{2}$ is the volume of alkali added to acid solution + ligand solution, acid dissociation constants (pKa - values) of ligand were calculated by algebraic method point wise calculation (Tables 1 ). The dissociation constants (pKa) were calculated according to the following relation:

$\mathrm{pKa}=\mathrm{pH}+\log \left(\frac{n A}{1-n A}\right)$ 2

Where: pKa is the acid dissociation constant, $\mathrm{n}_{\mathrm{A}}$ is the Proton-ligand formation number and $\mathrm{pH}$ is the pH-values (Omar and Ali, 2015).

\section{Determination of metal-ligand stability constants $(\log K)$ of complexes}

The potentiometric measurement for the determination of stability constant of a complex in solution is based on the fact that the redox potential of the couple $\frac{M^{+(m-n)}}{M^{+m}}$ is shifted significantly on complexation of the metal ion with the ligand. This method involves change in hydrogen ion concentration $\left[\mathrm{H}^{+}\right]$due to the displacement or association of one or more protons taking place during complexation reaction. This change can be found out by titrating the solutions containing free acid, acid with ligand, and acid with ligand and metal ion, individually against a standard alkali solution at a constant ionic strength or temperature. Either ionic strength or temperature may be varied for different sets of solutions. In all the cases, the change in the $\mathrm{pH}$ of the solution is measured after each addition of a known amount of alkali to the reaction cell which contains the reaction mixture. The titration curves are then drawn by plotting the measured $\mathrm{pH}$ values against the corresponding volume of alkali added and the stability constants of the complexes are determined from the titration curves by employing $\mathrm{pH}$-metric titration technique given by (Irving and Rossoti).

Metal-ligand stability constants ( $\log \mathrm{K}$ ) were determined by using the following relations:

$$
\bar{n}=\frac{\left(V_{3}-V_{2}\right)\left(E^{0}+N^{0}\right)}{\left(V^{0}+V_{2}\right) \bar{n}_{A} T_{m}^{0}}
$$

and

$$
P L=\log _{10}\left\{\frac{1+\beta_{n}^{H} \frac{1}{[\text { anti } \log \mathrm{pH}]^{\mathrm{n}}}}{\mathrm{T}_{\mathrm{L}}^{0}-n \bar{T}_{m}^{0}} \mathrm{X} \frac{\left(V^{0}+V_{3}\right)}{V^{0}}\right\}
$$


BAJOPAS Volume 14 Number 1,June, 2021

Where $T_{L}, T^{\circ}, E^{\circ}$, and $V^{\circ}$ havethe same significance as in equation (1) above, $T_{m}$ denotes the total concentration of metal present in solution, $V_{3}$ is the volume of metal ions present in solution and $\beta^{H}$ is the overall proton ligand stability constant. The metal-ligand stability constants (log K) were determined by employing point wise computational Method (eq. 5 and 6).

$\operatorname{LogK}_{1}=\log \left(\frac{n}{1-n}\right)+\mathrm{pL}$ .5

$\operatorname{LogK}_{2}=\log \left(\frac{1-n}{2-n}\right)+\mathrm{pL}$ ...6

Where: Log $\mathrm{K}$ is the metal-ligand stability constant, $\mathrm{pL}$ is the Free ligand exponent function, $\mathbf{n}$ is the Average number of ligand attached with metal ion (Janraoet al., 2014). The results obtained were analyzed by an ORIGIN 2016 program using titration data and then the proton-ligand stability constants (pKa) and Metal-ligand stability constant (LogK) calculated (Omar and Ali, 2015).

\section{RESULTS AND DISCUSSION}

Fourier transformed infrared (FT-IR) spectra of isolated humic acid from peat soils Figure 2 had distinct clear absorption bands indicating the presence of major humic acid structural elemental groups such as $\mathrm{H}$ bonded $\mathrm{OH}$ $\left(3680 \mathrm{~cm}^{-1}\right.$ peak $), C=0$ of carbonyl $\left(1721 \mathrm{~cm}^{-1}\right.$ peak), functional groups of aliphatic components $\mathrm{CH}_{2}\left(2918 \mathrm{~cm}^{-1}\right.$ peak) and $\mathrm{C}-\mathrm{O}$ stretching of polysaccharide $\left(1168 \mathrm{~cm}^{-1}\right.$ peak). The positions of the absorption bands of the spectra fell within typical major absorption bands of humic acid which is at frequencies 3680, 2918, 1721, 1168 $\mathrm{cm}^{-1}$. The first peak centred in the vicinity of $3680 \mathrm{~cm}^{-1}$ region is attributed to phenol $\mathrm{OH}$ group bounded by intermolecular $\mathrm{H}$ bonds. The $2918 \mathrm{~cm}^{-1}$ band usually has absorption maximum at $2918 \mathrm{~cm}^{-1}$ which is due to $\mathrm{C}-\mathrm{H}$ stretching of alkane group $\left(\mathrm{CH}_{2}\right)$. The next major absorption band is $1721 \mathrm{~cm}^{-1}$. This band has been commonly ascribed to $\mathrm{C}=\mathrm{O}$ stretching of mainly carboxyl group $(\mathrm{COOH})$ with trace amount of ketones. The last peak was observed at 1168 $\mathrm{cm}^{-1}$ due to $\mathrm{C}-\mathrm{O}$ stretching of polysaccharides and this peak appeared also in the spectra of humic acid from peat soil. The FTIR spectra of the isolated humic acid contained all major characteristic absorption peaks of humic acid. These absorption peaks indicated the presence of the major structural elements of humic acid namely $\mathrm{H}$ bonded $\mathrm{OH}, \mathrm{C}=\mathrm{C}$ of aromatic ring, $\mathrm{C}=\mathrm{O}$ of carbonyl group (both carboxyl and ketonic), $\mathrm{CH}_{2}$ group. This strongly supports the presence of humic acid.

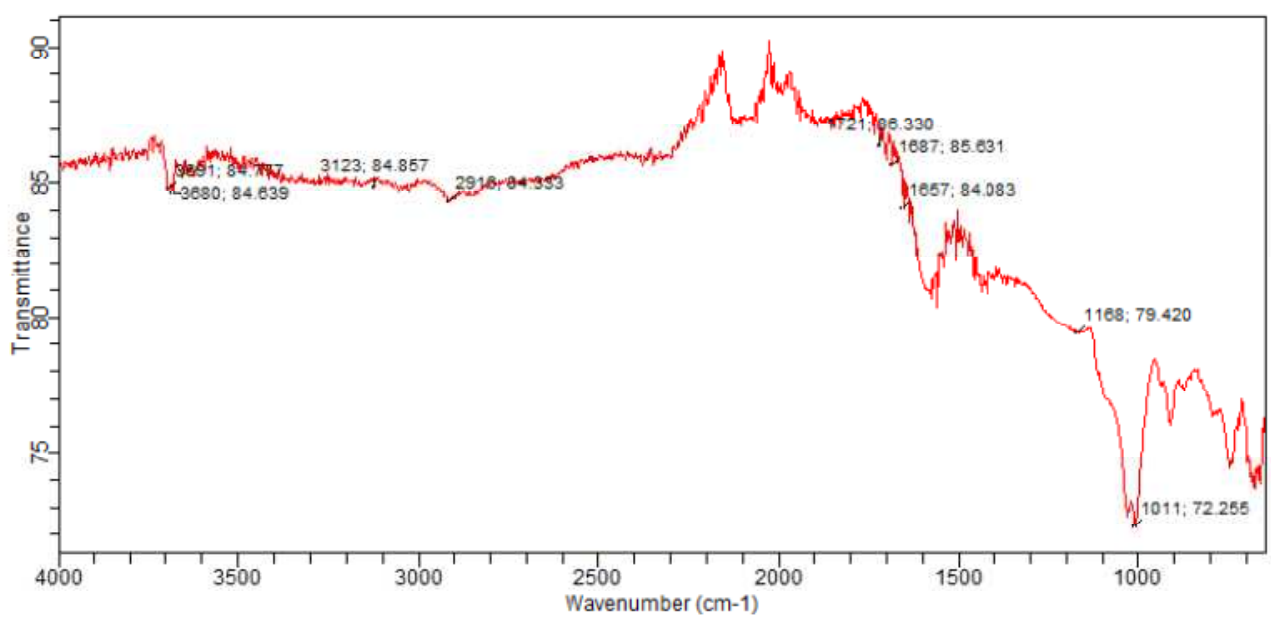

Fig. 2 : FT-IR spectraof peatsoilhumic acid (PSHA)

\section{Evaluation of acid dissociation constant (pka) of acid hydrolysed peat soil humicacid at phenolic group}

The value of the dissociation constant of the peat soil humic acid (PSHA) that underwent acidhydrolysis studied was found to be 8.9299 as shown Table 1, which is lower than the literaturevalues reported by Almeida and Szpoganics, (2015), Borges et al., (2005); Badr et al., (2012)and Fernandes et al,.(2009) of $9.73,9.47$ and 10.30. The difference between the obtained valuesand the reported values in this study might be probably as a result of acid hydrolysis of humicacid. 
BAJOPAS Volume 14 Number 1,June, 2021

Table 1: PKa of (Hydrolysed PSHA)

\begin{tabular}{|l|l|l|l|l|l|l|}
\hline $\mathrm{pH}$ & $\mathrm{BV}_{1}$ & $\mathrm{BV}_{2}$ & $\mathrm{~V}_{2}-\mathrm{V}_{1}$ & $\mathrm{nA}$ & $\log \left(\frac{n A}{1-n A}\right)$ & $\mathrm{pKa}$ \\
\hline 8.50 & 5.30 & 6.29 & 0.99 & 0.3594 & -0.2510 & 8.2490 \\
8.72 & 5.35 & 6.37 & 1.02 & 0.3400 & -0.2880 & 8.4320 \\
9.00 & 5.40 & 6.46 & 1.06 & 0.3141 & -0.3391 & 8.6609 \\
9.22 & 5.45 & 6.55 & 1.10 & 0.2882 & -0.3927 & 8.8273 \\
9.51 & 5.50 & 6.66 & 1.16 & 0.2494 & -0.4786 & 9.0314 \\
9.73 & 5.55 & 6.78 & 1.23 & 0.2041 & -0.5910 & 9.1390 \\
10.00 & 5.60 & 6.90 & 1.30 & 0.1589 & -0.7238 & 9.2762 \\
10.23 & 5.65 & 7.05 & 1.40 & 0.0941 & -0.9835 & 9.2465 \\
10.49 & 5.70 & 7.10 & 1.40 & 0.0941 & -0.9835 & 9.5065 \\
\hline
\end{tabular}

Average pKa $=8.9299 \pm 0.4186$

Table 2: PKa of (Unhydrolysed PSHA)

\begin{tabular}{|l|l|l|l|l|l|l|}
\hline $\mathrm{pH}$ & $\mathrm{BV}_{1}$ & $\mathrm{BV}_{2}$ & $\mathrm{~V}_{2}-\mathrm{V}_{1}$ & $\mathrm{nA}$ & $\log \left(\frac{\boldsymbol{n A}}{1-\boldsymbol{n}}\right)$ & $\mathrm{pKa}$ \\
\hline 8.50 & 5.30 & 5.81 & 0.51 & 0.6619 & 0.2919 & 8.7919 \\
8.72 & 5.35 & 5.90 & 0.55 & 0.6357 & 0.2418 & 8.9618 \\
9.00 & 5.40 & 6.00 & 0.60 & 0.6029 & 0.1813 & 9.1813 \\
9.22 & 5.45 & 6.10 & 0.65 & 0.5701 & 0.1226 & 9.3426 \\
9.51 & 5.50 & 6.20 & 0.70 & 0.5376 & 0.0654 & 9.5754 \\
9.73 & 5.55 & 6.33 & 0.78 & 0.4851 & -0.0259 & 9.7041 \\
10.00 & 5.60 & 6.47 & 0.87 & 0.4262 & -0.1291 & 9.8709 \\
10.23 & 5.65 & 6.62 & 0.99 & 0.3609 & -0.2481 & 9.9819 \\
10.49 & 5.70 & 6.80 & 1.10 & 0.2759 & -0.4690 & 10.0210 \\
\hline
\end{tabular}

Average pKa $=9.4923 \pm 0.4410$

Metal-ligand stability constant ( $\log \mathrm{K}$ )

The stabilityconstants require the accurate values of proton-ligand stability constants (Anil and Maroti, 2008). Metal titration curves crossed over ligand titration curve indicated the formation of complex upon proton release (Santosh, et al., 2011). If the values of n- are within range $0.2-0.8$ and $1.2-18$ this indicates the formation of $1: 1$ and 1:2 complexes (Sayyed and Mazahar, 2012).

The metal (II)-humate stepwise stability constants (log k) at phenolic group (Tables 318)

Table 3: Point-wise method, $\mathrm{Cu}$-(Hydrolysed PSHA)

\begin{tabular}{|l|l|l|l|l|l|l|l|l|}
\hline $\mathrm{pH}$ & $\mathrm{BV}_{1}$ & $\mathrm{BV}_{2}$ & $\mathrm{BV}_{3}$ & $\left(\mathrm{~V}_{3}-\mathrm{V}_{2}\right)$ & $\mathrm{n}$ & $\mathrm{pL}$ & $\log \left(\frac{n}{1-n}\right)$ & LogK $_{1}$ \\
\hline 8.50 & 5.30 & 6.29 & 6.33 & 0.04 & 0.5500 & 2.66 & 0.0871 & 2.7471 \\
8.72 & 5.35 & 6.37 & 6.41 & 0.04 & 0.5714 & 2.43 & 0.1249 & 2.5549 \\
9.00 & 5.40 & 6.46 & 6.50 & 0.04 & 0.6198 & 2.16 & 0.2122 & 2.3722 \\
9.22 & 5.45 & 6.55 & 6.59 & 0.04 & 0.6667 & 1.94 & 0.3010 & 2.2410 \\
\hline
\end{tabular}

LogK $_{1}$ (Average value) $=2.4788 \pm 0.2203$

Table 4: Point-wise method, $\mathrm{Cu}$-(Hydrolysed PSHA)

\begin{tabular}{|l|l|l|l|l|l|l|l|l|}
\hline $\mathrm{pH}$ & $\mathrm{BV}_{1}$ & $\mathrm{BV}_{2}$ & $\mathrm{BV}_{3}$ & $\left(\mathrm{~V}_{3}-\mathrm{V}_{2}\right)$ & $\mathrm{n}$ & $\mathrm{pL}$ & $\log \left(\frac{n-1}{2-n}\right)$ & LogK $_{2}$ \\
\hline 9.51 & 5.50 & 6.66 & 6.73 & 0.07 & 1.3509 & 1.70 & -0.2671 & 1.4329 \\
9.73 & 5.55 & 6.78 & 6.85 & 0.07 & 1.6383 & 1.51 & 0.2467 & 1.7567 \\
10.00 & 5.60 & 6.90 & 6.98 & 0.08 & 2.1783 & 1.31 & -0.2158 & 1.0942 \\
10.23 & 5.65 & 7.05 & 7.13 & 0.08 & 4.1904 & 1.27 & & \\
10.49 & 5.70 & 7.10 & 7.19 & 0.09 & 4.6920 & & & \\
\hline
\end{tabular}

Log $K_{2}($ Average value $)=1.4280 \pm 0.3312$ 
BAJOPAS Volume 14 Number 1,June, 2021

Table 5: Point-wise method, $\mathrm{Cu}$ (Unhydrolysed PSHA)

\begin{tabular}{|l|l|l|l|l|l|l|l|l|}
\hline $\mathrm{pH}$ & $\mathrm{BV}_{1}$ & $\mathrm{BV}_{2}$ & $\mathrm{BV}_{3}$ & $\left(\mathrm{~V}_{3}-\mathrm{V}_{2}\right)$ & $\mathrm{n}$ & $\mathrm{pL}$ & $\log \left(\frac{n}{n-1}\right)$ & Log $_{1}$ \\
\hline 8.50 & 5.30 & 5.81 & 5.85 & 0.04 & 0.2973 & 2.88 & -0.3736 & 2.5064 \\
8.72 & 5.35 & 5.90 & 5.95 & 0.05 & 0.3873 & 2.66 & -0.1992 & 2.4608 \\
9.00 & 5.40 & 6.00 & 6.05 & 0.05 & 0.4044 & 2.38 & -0.1681 & 2.2119 \\
9.22 & 5.45 & 6.10 & 6.15 & 0.06 & 0.5157 & 2.18 & -0.0272 & 2.2072 \\
9.51 & 5.50 & 6.20 & 6.27 & 0.07 & 0.6417 & 1.89 & 0.2530 & 1.1430 \\
\hline
\end{tabular}

$\operatorname{LogK}_{1}($ Average value $)=2.3059 \pm 0.6153$

Table 6:Point-wise method, $\mathrm{Cu}$ (Unhydrolysed PSHA)

\begin{tabular}{|l|l|l|l|l|l|l|l|l|}
\hline $\mathrm{pH}$ & $\mathrm{BV}_{1}$ & $\mathrm{BV}_{2}$ & $\mathrm{BV}_{3}$ & $\mathrm{~V}_{3}-\mathrm{V}_{2}$ & $\mathrm{n}$ & $\mathrm{pL}$ & $\log \left(\frac{n-1}{2-n}\right)$ & $\log \mathrm{K}_{2}$ \\
\hline 9.73 & 5.55 & 6.33 & 6.42 & 0.09 & 0.9000 & 1.69 & & \\
10.00 & 5.60 & 6.47 & 6.58 & 0.11 & 1.2578 & 1.44 & -0.4592 & 0.9808 \\
10.23 & 5.65 & 6.62 & 6.84 & 0.12 & 1.6137 & 1.26 & -0.2010 & 1.4610 \\
10.49 & 5.70 & 6.80 & 6.92 & 0.12 & 2.1052 & 1.03 & & \\
\hline
\end{tabular}

$\operatorname{LogK}_{2}$ (Average value) $=1.2209 \pm 0.3398$

Table 7:Point-wise method, Pb (Hydrolysed PSHA)

\begin{tabular}{|l|l|l|l|l|l|l|l|l|}
\hline $\mathrm{pH}$ & $\mathrm{BV}_{1}$ & $\mathrm{BV}_{2}$ & $\mathrm{BV}_{3}$ & $\left(\mathrm{~V}_{3}-\mathrm{V}_{2}\right)$ & $\mathrm{n}$ & $\mathrm{pL}$ & $\log \left(\frac{n}{1-n}\right)$ & LogK $_{1}$ \\
\hline 8.50 & 5.30 & 6.29 & 6.33 & 0.04 & 0.5500 & 2.66 & 0.0871 & 2.7471 \\
8.72 & 5.35 & 6.37 & 6.41 & 0.04 & 0.5714 & 2.43 & 0.1249 & 2.5549 \\
9.00 & 5.40 & 6.46 & 6.50 & 0.04 & 0.6198 & 2.16 & 0.2122 & 2.3722 \\
9.22 & 5.45 & 6.55 & 6.60 & 0.05 & 0.8333 & 1.96 & 0.6989 & 2.6589 \\
\hline
\end{tabular}

Log $_{\mathbf{1}}($ Average value $)=2.5832 \pm 0.1614$

Table 8:Point-wise method, Pb-(Hydrolysed PSHA)

\begin{tabular}{|l|l|l|l|l|l|l|l|l|}
\hline $\mathrm{pH}$ & $\mathrm{BV}_{1}$ & $\mathrm{BV}_{2}$ & $\mathrm{BV}_{3}$ & $\left(\mathrm{~V}_{3}-\mathrm{V}_{2}\right)$ & $\mathrm{n}$ & $\mathrm{pL}$ & $\log \left(\frac{n-1}{2-n}\right)$ & $\log \mathrm{K}_{2}$ \\
\hline 9.51 & 5.50 & 6.66 & 6.71 & 0.05 & 0.9650 & 1.67 & & \\
9.73 & 5.55 & 6.78 & 6.83 & 0.05 & 1.1702 & 1.44 & & \\
10.00 & 5.60 & 6.90 & 6.90 & 0.05 & 1.4864 & 1.22 & -0.0237 & 1.1963 \\
10.23 & 5.65 & 7.05 & 7.10 & 0.05 & 2.0190 & 1.09 & & \\
10.49 & 5.70 & 7.10 & 7.17 & 0.07 & 3.6492 & 1.00 & & \\
\hline
\end{tabular}

Log $K_{2}$ (Average value) $=1.1963$

Table 9: Point-wise method, Pb (Unhydrolysed PSHA)

\begin{tabular}{|l|l|l|l|l|l|l|l|l|}
\hline $\mathrm{pH}$ & $\mathrm{BV}_{1}$ & $\mathrm{BV}_{2}$ & $\mathrm{BV}_{3}$ & $\mathrm{~V}_{3}-\mathrm{V}_{2}$ & $\mathrm{n}$ & $\mathrm{pL}$ & $\begin{array}{l}\text { Log } \\
\left(\frac{n}{n-1}\right)\end{array}$ & Log $\mathrm{K}_{1}$ \\
\hline 8.50 & 5.30 & 5.81 & 5.85 & 0.04 & 0.2973 & 2.88 & -0.3736 & 2.5064 \\
8.72 & 5.35 & 5.90 & 5.94 & 0.04 & 0.3099 & 2.66 & -0.5477 & 2.3123 \\
9.00 & 5.40 & 6.00 & 6.05 & 0.05 & 0.4044 & 2.38 & -0.1681 & 2.2119 \\
9.22 & 5.45 & 6.10 & 6.15 & 0.06 & 0.5157 & 2.18 & 0.0272 & 2.2072 \\
9.51 & 5.50 & 6.20 & 6.26 & 0.07 & 0.6417 & 1.89 & 0.2530 & 2.1430 \\
9.73 & 5.55 & 6.40 & 6.40 & 0.07 & 0.7000 & 1.67 & 0.3680 & 2.0380 \\
\hline
\end{tabular}

LogK $_{1}$ (Average value) $=2.2364 \pm 0.1602$

Table 10: Point-wise method, Pb (Unhydrolysed PSHA)

\begin{tabular}{|l|l|l|l|l|l|l|l|l|}
\hline $\mathrm{pH}$ & $\mathrm{BV}_{1}$ & $\mathrm{BV}_{2}$ & $\mathrm{BV}_{3}$ & $\mathrm{~V}_{3}-\mathrm{V}_{2}$ & $\mathrm{n}$ & $\mathrm{pL}$ & $\log \left(\frac{n-1}{2-n}\right)$ & $\log \mathrm{K}_{2}$ \\
\hline 10.00 & 5.60 & 6.47 & 6.55 & 0.08 & 1.9503 & 1.41 & & \\
10.23 & 5.65 & 6.62 & 6.72 & 0.11 & 1.4792 & 1.26 & -0.0361 & 1.2239 \\
\hline
\end{tabular}

$\operatorname{LogK}_{2}$ (Average value) $=1.2239$

Table 11: Point-wise method, Mg (Hydrolysed PSHA)

\begin{tabular}{|l|l|l|l|l|l|l|l|l|}
\hline $\mathrm{pH}$ & $\mathrm{BV}_{1}$ & $\mathrm{BV}_{2}$ & $\mathrm{BV}_{3}$ & $\left(\mathrm{~V}_{3}-\mathrm{V}_{2}\right)$ & $\mathrm{n}$ & $\mathrm{pL}$ & $\log \left(\frac{n}{n-1}\right)$ & LogK $_{1}$ \\
\hline 8.50 & 5.30 & 6.29 & 6.31 & 0.02 & 0.2750 & 2.64 & -0.4290 & 2.2110 \\
8.72 & 5.35 & 6.37 & 6.39 & 0.02 & 0.2858 & 2.42 & -0.3978 & 2.0222 \\
9.00 & 5.40 & 6.46 & 6.49 & 0.03 & 0.4648 & 2.14 & -0.0612 & 2.0788 \\
9.22 & 5.45 & 6.55 & 6.59 & 0.04 & 0.6667 & 1.94 & 0.3010 & 2.2410 \\
\hline
\end{tabular}

$\log _{\mathbf{1}}($ Average value) $=2.1382 \pm 0.1046$ 
BAJOPAS Volume 14 Number 1,June, 2021

Table 12: Point-wise method, Mg (Hydrolysed PSHA)

\begin{tabular}{|l|l|l|l|l|l|l|l|l|}
\hline $\mathrm{pH}$ & $\mathrm{BV}_{1}$ & $\mathrm{BV}_{2}$ & $\mathrm{BV}_{3}$ & $\left(\mathrm{~V}_{3}-\mathrm{V}_{2}\right)$ & $\mathrm{n}$ & $\mathrm{pL}$ & $\log \left(\frac{n-1}{2-n}\right)$ & LogK $_{2}$ \\
\hline 9.51 & 5.55 & 6.66 & 6.71 & 0.05 & 0.9650 & 1.67 & & \\
9.73 & 5.55 & 6.78 & 6.84 & 0.06 & 1.4042 & 1.47 & -0.1686 & 1.3014 \\
10.00 & 5.60 & 6.90 & 6.93 & 0.06 & 1.7838 & 1.23 & 0.5593 & 1.7893 \\
10.23 & 5.65 & 7.05 & 7.10 & 0.06 & 3.1429 & 1.10 & & \\
10.49 & 5.70 & 7.10 & 7.18 & 0.07 & 3.6492 & 0.83 & & \\
\hline
\end{tabular}

LogK $_{2}($ Average value $)=1.5453 \pm 0.3450$

Table 13: Point-wise method, Mg (Unhydrolysed PSHA)

\begin{tabular}{|l|l|l|l|l|l|l|l|l|}
\hline $\mathrm{pH}$ & $\mathrm{BV}_{1}$ & $\mathrm{BV}_{2}$ & $\mathrm{BV}_{3}$ & $\mathrm{~V}_{3}-\mathrm{V}_{2}$ & $\mathrm{n}$ & $\mathrm{pL}$ & $\log \left(\frac{n}{n-1}\right)$ & $\operatorname{Log~}_{1}$ \\
\hline 8.50 & 5.30 & 5.81 & 5.85 & 0.04 & 0.2973 & 2.88 & -0.3736 & 2.5064 \\
8.72 & 5.35 & 5.90 & 5.94 & 0.04 & 0.3099 & 2.66 & -0.3477 & 2.3123 \\
9.00 & 5.40 & 6.00 & 6.04 & 0.04 & 0.3236 & 2.38 & -0.3202 & 2.0598 \\
9.22 & 5.45 & 6.10 & 6.15 & 0.05 & 0.4297 & 2.17 & -0.1230 & 2.0470 \\
9.51 & 5.50 & 6.20 & 6.26 & 0.06 & 0.5500 & 1.89 & 0.0871 & 1.9771 \\
9.73 & 5.55 & 6.33 & 6.40 & 0.07 & 0.7000 & 1.67 & 0.3680 & 2.0380 \\
\hline
\end{tabular}

LogK $_{1}$ (Average value) $=2.1568 \pm 0.2069$

Table 14: Point-wise method, Mg (Unhydrolysed PSHA)

\begin{tabular}{|l|l|l|l|l|l|l|l|l|}
\hline $\mathrm{pH}$ & $\mathrm{BV}_{1}$ & $\mathrm{BV}_{2}$ & $\mathrm{BV}_{3}$ & $\mathrm{~V}_{3}-\mathrm{V}_{2}$ & $\mathrm{n}$ & $\mathrm{pL}$ & $\log \left(\frac{n-1}{2-n}\right)$ & $\log \mathrm{K}_{2}$ \\
\hline 10.00 & 5.60 & 6.47 & 6.55 & 0.08 & 0.9148 & 1.41 & & \\
10.23 & 5.65 & 6.62 & 6.71 & 0.09 & 1.2102 & 1.20 & -0.5749 & 0.6251 \\
10.49 & 5.70 & 6.80 & 6.92 & 0.09 & 1.5968 & 1.03 & 0.1703 & 1.2003 \\
\hline
\end{tabular}

LogK $_{2}$ (Average value) $=0.9127 \pm 0.4070$

Table15:Point-wise method, Cd (Hydrolysed PSHA)

\begin{tabular}{|l|l|l|l|l|l|l|l|l|}
\hline $\mathrm{pH}$ & $\mathrm{BV}_{1}$ & $\mathrm{BV}_{2}$ & $\mathrm{BV}_{3}$ & $\left(\mathrm{~V}_{3}-\mathrm{V}_{2}\right)$ & $\mathrm{n}$ & $\mathrm{pL}$ & $\log \left(\frac{n}{1-n}\right)$ & LogK $_{1}$ \\
\hline 8.50 & 5.30 & 6.29 & 6.31 & 0.02 & 0.2750 & 2.64 & -0.4210 & 2.2190 \\
8.72 & 5.35 & 6.37 & 6.40 & 0.03 & 0.4286 & 2.42 & -0.1249 & 2.2951 \\
9.00 & 5.40 & 6.46 & 6.49 & 0.03 & 0.4648 & 2.14 & -0.0612 & 2.0788 \\
9.22 & 5.45 & 6.55 & 6.59 & 0.04 & 0.6667 & 1.96 & 0.3010 & 2.2610 \\
9.51 & 5.55 & 6.66 & 6.70 & 0.04 & 0.7720 & 1.67 & 0.5297 & 2.1997 \\
\hline
\end{tabular}

LogK $_{\mathbf{1}}$ (Average value) $=2.2108 \pm 0.0825$

Table 16: Point-wise method, Cd (Hydrolysed PSHA)

\begin{tabular}{|l|l|l|l|l|l|l|l|l|}
\hline $\mathrm{pH}$ & $\mathrm{BV}_{1}$ & $\mathrm{BV}_{2}$ & $\mathrm{BV}_{3}$ & $\left(\mathrm{~V}_{3}-\mathrm{V}_{2}\right)$ & $\mathrm{n}$ & $\mathrm{pL}$ & $\log \left(\frac{n-1}{2-n}\right)$ & Log $_{2}$ \\
\hline 9.73 & 5.55 & 6.78 & 6.83 & 0.06 & 1.4042 & 1.47 & -0.1686 & 1.3014 \\
10.00 & 5.60 & 6.90 & 6.95 & 0.06 & 1.7838 & 1.23 & 0.5593 & 1.7893 \\
10.23 & 5.65 & 7.05 & 7.10 & 0.06 & 3.1429 & 1.09 & & \\
10.49 & 5.70 & 7.10 & 7.16 & 0.06 & 3.1429 & 0.89 & & \\
& & & & & & & & \\
\hline
\end{tabular}

$\operatorname{LogK}_{2}$ (Average value) $=1.5453 \pm 0.3450$

Table 17: Point-wise method, Cd (Unhydrolysed PSHA)

\begin{tabular}{|l|l|l|l|l|l|l|l|l|}
\hline $\mathrm{pH}$ & $\mathrm{BV}_{1}$ & $\mathrm{BV}_{2}$ & $\mathrm{BV}_{3}$ & $\mathrm{~V}_{3}-\mathrm{V}_{2}$ & $\mathrm{n}$ & $\mathrm{pL}$ & $\log \left(\frac{n}{n-1}\right)$ & $\operatorname{Log~}_{1}$ \\
\hline 8.50 & 5.30 & 5.81 & 5.86 & 0.05 & 0.3717 & 2.88 & -0.2280 & 2.6520 \\
8.72 & 5.35 & 5.90 & 5.95 & 0.05 & 0.3873 & 2.66 & -0.1992 & 2.4608 \\
9.00 & 5.40 & 6.00 & 6.06 & 0.06 & 0.4853 & 2.38 & -0.0255 & 2.3545 \\
9.22 & 5.45 & 6.10 & 6.16 & 0.06 & 0.5157 & 2.18 & -0.0272 & 2.2072 \\
9.51 & 5.50 & 6.20 & 6.27 & 0.07 & 0.6417 & 1.89 & 0.2530 & 1.1430 \\
9.73 & 5.55 & 6.33 & 6.41 & 0.08 & 0.8000 & 1.69 & 0.6020 & 2.2920 \\
& & & & & & & & \\
\hline
\end{tabular}

$\operatorname{LogK}_{1}($ Average value $)=2.2516 \pm 0.5380$ 
BAJOPAS Volume 14 Number 1,June, 2021

Table 18: Point-wise method, Cd (Unhydrolysed PSHA)

\begin{tabular}{|l|l|l|l|l|l|l|l|l|}
\hline $\mathrm{pH}$ & $\mathrm{BV}_{1}$ & $\mathrm{BV}_{2}$ & $\mathrm{BV}_{3}$ & $\mathrm{~V}_{3}-\mathrm{V}_{2}$ & $\mathrm{n}$ & $\mathrm{pL}$ & $\log \left(\frac{n-1}{2-n}\right)$ & $\log \mathrm{K}_{2}$ \\
\hline 10.00 & 5.60 & 6.47 & 6.57 & 0.10 & 1.1434 & 1.43 & & \\
10.23 & 5.65 & 6.62 & 6.72 & 0.10 & 1.3448 & 1.23 & -0.2788 & 0.9512 \\
10.49 & 5.70 & 6.80 & 6.90 & 0.10 & 1.7742 & 1.03 & 0.5351 & 1.5651 \\
\hline
\end{tabular}

$\operatorname{LogK}_{2}($ Average value $)=1.2581 \pm 0.4340$

Table 19: Stepwise and overall Stability constants of thehydrolysed and unhydrolysed divalent metal (II) complexes

\begin{tabular}{|c|c|c|c|}
\hline Chelates & LogK $_{1}$ & $\log _{2}$ & Log $\beta$ \\
\hline [Cu (Hydrolysed PSHA-1) $\left.{ }_{2}\right]$ & 2.4788 & 1.4280 & 3.9068 \\
\hline$\left[\mathrm{Pb}(\text { Hydrolysed PSHA-1) })_{2}\right]$ & 2.5832 & 1.1963 & 3.7795 \\
\hline$\left[\mathrm{Cd}(\text { Hydrolysed PSHA-1 })_{2}\right]$ & 2.2108 & 1.5453 & 3.7561 \\
\hline$\left[\mathrm{Mg}(\text { Hydrolysed PSHA-1 })_{2}\right]$ & 2.1382 & 1.5453 & 3.6835 \\
\hline [Cu (Unhydrolysed PSHA-1) & 2.3059 & 1.2209 & 3.5268 \\
\hline$[\mathrm{Pb}$ (Unhydrolysed PSHA-1) 2$]$ & 2.2364 & 1.2239 & 3.4603 \\
\hline [Cd (Unhydrolysed PSHA-1) 2 ] & 2.2516 & 1.2581 & 3.5097 \\
\hline$[\mathrm{Mg}$ (Unydrolysed PSHA-1) & 2.1568 & 0.9127 & 3.0695 \\
\hline
\end{tabular}

The results obtained (Table19) shows the stepwise and overall stability constants to be not high indicating low stability of the complexes, because the solubility of most metal ions in the basic $\mathrm{pH}$ range is minimal due to metal hydroxide precipitation (Karimi, 2017). In general, the stepwise stability constants $\left(K_{1}\right.$ and $K_{2}$ ) follow the order $K_{1}>K_{2}$ for the copper, lead, magnesium and cadmium complexes respectively. The steady decrease of the values with increasing number of ligands is in agreement with the prediction made by researchers (Na'aliya, 2013). The decrease could be attributed to the fact that as the number of the ligands (Humate ions) that enters the coordination zone increases the aqua molecules available for replacement by the ligands become less. Thus, the metal ions become less electron loving with progressive intake of the ligand and this results in the decrease in the values of the constants (Na'aliya, 2013). Also the stability of the complexes is influenced by the size and number of the chelate rings(Mackay and Mackay,2002).All the complexes form rings in their structure as humate, a bidentate ligand, bond the metal ions in the ratio 1:2 (Boguta and Sokolowska, 2016) forming chelate rings. The values of the overall stability constants $(\log \beta)$ obtained for humate complexes are not high indicating low stability as the values are not high. LogK values for copper-humates (Table 3 to 6) obtained in this study are lower than those reported for the complexes of humic acids (Pandey et al., 2015; Dinu, 2013; Kaschl et al., 2010 and Gilbeto and Jorg, 2001). The values of LogK(Table 7 to 10 ) forlead-humates are lower than those reported for the lead in the literature (Dinu, 2013; Gilbeto and Jorg 2001). Log K values(Table 11 to 14 ) for magnesium-humates obtained in this study are close to those reported by (Pandey et al., 2015). Log K values of cadmium-humates (Table 15 to 18 ) obtained in this work near to the one reported by (Dinu, 2013 and Pandey et al., 2015).The difference between the reported values and the values obtained in this study might be probably as a result of acid hydrolysis of humic acid. The values of the overall stability constants $(\log \beta)$ of the copper humates complexes presented in Table 19 is high than that of other metal humate complexes, show relatively high stability of CuHA complexes, show the following order of stability: $\mathrm{Cu}>\mathrm{Pb}>\mathrm{Cd}>\mathrm{Mg}$; which are in close agreement to the findings of (Dinu, 2013 and Pandey et al., 2015).The high stability of Cuhumate chelate could be attributed to the existence of coordinate covalent bond between the complexing agents and the $\mathrm{Cu}^{2+}$ ions. Since, $\mathrm{Cu}^{2+}$ being a metal of the transitional series with $3 d^{9}$ electronic configurations can accept the electrons from the complexing agents. Similarly, the low stabilities of $\mathrm{Pb}, \mathrm{Cd}$ and $\mathrm{Mg}$ complexes could be explained by that $\mathrm{Pb}^{2+}$ with $6 s^{2}, \mathrm{Cd}^{2+}$ with $4 \mathrm{~d}^{10}$ and $\mathrm{Mg}^{2+}$ with $2 \mathrm{p}^{6}$ their electronic configuration has a completely filled $\mathrm{d}, \mathrm{p}$ and $\mathrm{s}$ orbitals. Moreover, the stabilities of metal ions with hydrolysed humic acid from peat soil were higher than those with unhydrolysed humic acid from peat soil; which is ascribed to the high content of acidity in hydrolysed humic acid than unhydrolysed humic acid. 
BAJOPAS Volume 14 Number 1,June, 2021 CONCLUSION

The values of logk for $\mathrm{Cu}(\mathrm{II})$ hydrolysed humic acid complex was higher followed by $\mathrm{Pb}$ (II), $\mathrm{Cd}(\mathrm{II})$ and $\mathrm{Mg}$ (II) hydrolysed humic acid complexes as compared with metal(II) unhydrolysed humic acid complexes. This indicates acid hydrolysis of humic acid can

\section{REFERENCES}

Almeida, V.R. and Szpoganicz, B. (2015). Humic Acid Potentiometric Response Patterns:Out- of Equilibrium Properties and Species Distribution Modelling. Chemical. Biol. Technol. Agric. 2: 17.

Anđelković, T., Nikolić, R., Bojić, A.,Anđelković, D., and Nikolic G.,(2010). Binding of Cadmium to Soil Humic Acid as A Function of Carboxyl Group Content. Macedonian Journal of Chemistry and Chemical Engineering.29(2): 215-224.

Anil, B. N. and Maroti, N. (2008). Studies on Influence of Die-Lectric Constants on Complex Equilibria between Substituted Py-Razalines and Lanthanide Metal Ions pH-Metrically. Amer.-Euras. scient. Res. 3(2): 212-216.

Ashok, K., Pandey, S. P. and Misra, V (2000). Stability Constants of Metal-Humic Acid Complexes and its Role in Environmental Detoxification. Journal of Ecotoxicology and Environmental Safety. 47(2):157-200.

Badr, M. H., El-Halafawi, M. H. and Abd El-al Zeid, E. R. (2012). Comparison Between the Effect of Ionic Strength on Acidity and Dissociation Constants of Humic Acids Extracted from Sewage Sludge and Nile Water Hyacinth Composts.Global Journal of Environmental Research 6 (1): 36-43.

Baruah, M.K., Borah, D., Saikia, P.P., Paul, S., Sharma, T. (2015). Evaluation of pKa Values of Soil Humic Acids and their Complexation Properties. International Journal of Plant \& Soil Science 6(4) : 218-228.

Boguta, P. Sokolowska, Z. (2016). Interactions of $\mathrm{Zn}$ (II) Ions with Humic Acids Isolated from Various Types of Soils. Effect of $\mathrm{pH}, \mathrm{Zn}$ Concentrations and Humic Acids Chemical Properties. Journal of Geochemical Explaration 168. 119-126.

Borges, F., Guimaraes, C., Lima, L.F.C., Pinto, I. and Reis, S.(2005). Potentiometric Studies on the Complexation of Copper(II) by Phenolic Acids as Discrete Ligand Models of enhance the complexation behavior of humic acid with metal (II) ions. However, the higher values of $\log \beta$ for $\mathrm{Cu}(\mathrm{II}), \mathrm{Pb}(\mathrm{II}), \mathrm{Cd}(\mathrm{II})$ and $\mathrm{Mg}(\mathrm{II})$ hydrolysed humic acid complexes indicates more stable stepwise complexes formed as compared with $\mathrm{Cu}(\mathrm{II}), \mathrm{Pb}$ (II), $\mathrm{Cd}$ (II) and $\mathrm{Mg}(\mathrm{II})$ unhydrolysed humic acid complexes.

Humic Substances Talanta 66 (2005) 670-673.

Chefetz, B., Salloum, M. J., Deshmulkin, A. P. and Hatcher, P. (2002). Structural Components of Humic Acids as Determined by Chemical Modifications and Carbon-13 NMR, Pyrolysis, and Thermochemolysis- Gas Chromatography/Mass Spectrometry. Soil Science Society of American Journal Abstract Division S-2- Soil Chemistry66. 1159-1171.

Dinu, M. I. (2013). Metals Complexation with Humic Acids in Surface Water of Different Environ. Sci. Technol. 31(1): 1-17.

Fernandes, A.N., Giacomelli, C., Giovanela, M. Vaz, D.V. Szpoganicz, B. and Maria M. D. (2009). Potentiometric Acidity Determination in Humic Substances Influenced by Different Analytical Procedures.J. Braz. Chem. Soc. 20 (9):14.

Gamal, A. H. (2015). Stability Constants of Rhenium (V) Metal Complexes with Selected Drugs. Pyrex Journal of Research in Environmental Studies. 2(2): 006-014.

Janrao, D. M., Pathan, J., Kayande, D.D., and Mulla, J.J. (2014). An Over View of Potentiometric Determination of Stability Constants of Metal Complexes. Sci. Revs. Chem. Commun.: 4(1), 2014, 11-24.

Karimi, H. (2017). Effect of pH and Initial Pb(II) Concentration on the Lead Removal Efficiency from Waste Water Using $\mathrm{Ca}(\mathrm{OH})_{2}$. International Journal of Water and Waste Water Treatment 3.2

Kaschl, A. Romheld, V. and Chen, Y. (2010). Binding of Cadmium, Copper and Zinc to Humic Substances Originating from Municipal Solid Waste Compost. Israel Journal of Chemistry Vol. 42(1): 89-98.

Kostic, I. S., Tatjana, P, A., Nikolic, R. S., Cvetkovic, T. P., Pavlovic, D. D., Aleksandar, L.J. and Bojic, A. (2012). Comparative Study of Binding Strengths of Heavy Metals with Humic Acid. J.serb. Chem. Soc. 76(9) pp 1-20. 
BAJOPAS Volume 14 Number 1,June, 2021

Na'aliya, J. (2013). Determination of Stepwise Stability Constants and Gibbs free Energy Change of Trisprolina to Complexes of some Divalent Transition Metal ions. Bayero Journal of Pure and Applied Sciences 6(2): 112-114.

Omar, A. A. and Ali, E. A. (2015). Potentiometric Studies on Complexes of $\mathrm{Cr}$ (III) and $\mathrm{Zr}$ (IV) with some Carboxylic Acids. International Journal of Advanced Chemistry, 3(1) 25-

37.

Pandey, A. K. Pandey, S. D. and Misr, V. (2015).Stability Constants of Metal- Humic Acid Complexes and Its Role in Environmental Detoxification. J. Ecotoxicology and Environmental Safety. 47(1):195-200.

Ram, N. and Raman, K.V. (1984). Stability Constants of Complexes of Metals with
Humicand Fuvic Acids under Non- acidConditions. Journal of Plant Nutrition and Soil Sciences.

147:171-176.

Santosh, D. D., Ashok, B. K., Vijay, J. T., Shivraj, G. W. and Vinay, V. W. (2011). Potentiometric Studies of Elec-Trolyte Effects on Complex Equilibria of Some Substituted 5-(2-hydroxy Phenyl) Pyrazoles. Der pharm. 3 (6): 75-83.

Sayyed, H. and Abdul Rahim, M. F. (2012). Studies of Binary Complexes of Metal Ions with Mandelic Acid by Potentiometry. Chem. J. 02 (6): 206209.

Shirvani, M. Moradian, E. Khalili, B. Bakhtiary, S. (2015). Interaction of $\mathrm{Cd}$ and $\mathrm{Pb}$ with Humate-Palygorskite and HumateSepiolite Complexes. Journal of water, air and pollution 3: 220-228. 


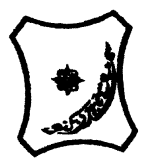

Bayero Journal of Pure and Applied Sciences, 14(1): 54 - 63

Received: November, 2020

Accepted: April, 2021

ISSN $2006-6996$

\title{
STABILITY CONSTANTS OF COMPLEXES OF METAL IONS WITH PEATSOIL HUMIC ACIDS UNDER NON-ACID-CONDITIONS
}

\author{
${ }^{* 1}$ Sabo, Yusuf ${ }^{2}$ Jimoh, W.L.O., ${ }^{3}$ Isa Baba Koki and ${ }^{4}$ Sholadoye, Q. 0. \\ ${ }^{1}$ Department of Pure and Industrial Chemistry, Bayero University, Kano \\ ${ }^{3}$ Department of Chemistry, Yusuf Maitama Sule University Kano. P.M.B. 3220 Kano, Nigeria. \\ ${ }^{4}$ Department of Chemistry, Nigerian Police Academy, Wudil, Kano-Nigeria
}

*Correspondence E-mail; saboyusuf18@yahoo.com

ABSTRACT

Stability constants of complexes of four divalent metal ions viz. $\mathrm{Cu}^{2+}, \mathrm{Pb}^{2+}, \mathrm{Mg}^{2+}$ and $\mathrm{Cd}^{2+}$ with humic acids (HA) were determined by potentiometric titration of humic acids with the corresponding salt of the divalent metals in aqueous media under non-acid-condition. The log $K$ (logarithm of the stability constant) ranged from 1.0942 to 2.7471 for metalhumic acid complexes were determined using point-wise computational method. The order of stability constants were obtained as follows: $\mathrm{Cu}>\mathrm{Pb}>\mathrm{Cd}>\mathrm{Mg}$ for metal $-\mathrm{HA}$ complexes respectively, indicating a higher degree of complexation with Cu metal ion.

Keywords: stability constant, humic acid, potentiometric titration, divalent metals, acid hydrolysis.

\section{NTRODUCTION}

The stability constant of a complex is the numerical expression of its stability and provides a quantitative measure of affinity of the metal ion to the complexing agent. An understanding of the relative stability of metal-complexes helps in predicting the behavior of metal ions in the soil (Ram and Raman, 1982). Extensive researches has been done to determine the stability constants of the complexes formed between humic acid (HA) with a number of metal ions. Ashok et al., (2000) reported that humic acid with hydroxyl, phenoxyl and carboxyl reactive groups can form coordination compound with metal ions at $\mathrm{pH}$ 3.5. The stability constants(Log K) for different metalhumic acid complexes indicated the following order of the stabilities of complexes formed between humic acid and metal ion, $\mathrm{Cu}>\mathrm{Fe}$ $>\mathrm{Pb}>\mathrm{Ni}>\mathrm{Co}>\mathrm{Ca}>\mathrm{Cd}>\mathrm{Zn}>\mathrm{Mn}>\mathrm{Mg}$. Andelkovic et al., (2010) investigated the binding of $\mathrm{Cd}$ (II) to soil humic acid at pH 6.5 and in $0.1 \mathrm{M} \mathrm{KNO}_{3}$ ionic medium. The stability constant for binding indicating greater stability in the case when carboxyl groups are involved in complexation reaction. Kostic et al.,(2012) investigated the complexation of humic acid with certain heavy metal ions (Co(II), $\mathrm{Ni}(\mathrm{II}), \mathrm{Cu}(\mathrm{II})$,
$\mathrm{Zn}(\mathrm{II})$, and $\mathrm{Pb}(\mathrm{II})$. The experiment was performed at $25^{\circ} \mathrm{C}$, at pH 4.0 and ionic strength of $0.01 \mathrm{M}$. Stability constant of complex between $\mathrm{Pb}$ (II) ions and humic acid is greater than stability constants of other investigated metalhumate complexes. Bogata and Sokolowska (2016) analyses the interaction between humic acids from different soils and $\mathrm{Zn}$ (II) ions at wide concentration ranges and at $\mathrm{pH} 5$. Studies have showed significant impact of $\mathrm{Zn}$ concentration, $\mathrm{pH}$ and some properties of humic acids with zinc.But all of these studies were limited to acidic $\mathrm{pH}$ range. Therefore, the present study was carried out to determine and compare the stability constants of complexes of metal ions with hydrolysed peat soil humic acid and unhydrolysed peat soil humic under non-acid conditions.

\section{MATERIALS AND METHODS}

Analytical grade chemicals used includes hydrochloric acid $(\mathrm{HCl})$, nitric acid $\left(\mathrm{HNO}_{3}\right)$, sodium hydroxide $(\mathrm{NaOH})$, lead nitrate $\mathrm{Pb}\left(\mathrm{NO}_{3}\right)_{2}$, copper nitrate $\mathrm{Cu}\left(\mathrm{NO}_{3}\right)_{2} \cdot 3 \mathrm{H}_{2} \mathrm{O}$, cadmium nitrate $\mathrm{Cd}\left(\mathrm{NO}_{3}\right)_{2} \cdot 4 \mathrm{H}_{2} \mathrm{O}$, magnesium nitrate $\mathrm{Mg}\left(\mathrm{NO}_{3}\right)_{2} \cdot 6 \mathrm{H}_{2} \mathrm{O}$, potassium nitrate $\left(\mathrm{KNO}_{3}\right)$, calcium chloride $\left(\mathrm{CaCl}_{2}\right)$, (sigma-Aldrich). Dowex 50WX8, (20-50 mesh) from Fluka. 


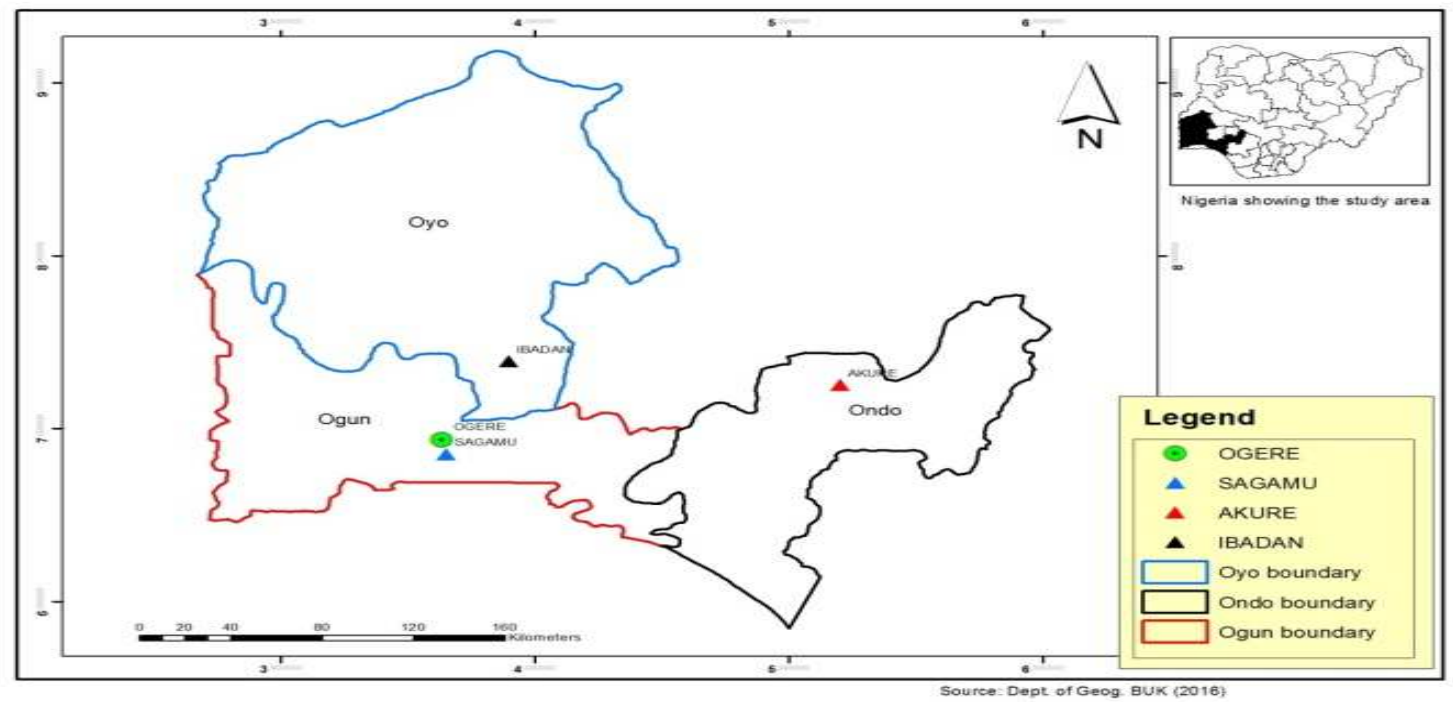

Figure 1: Map showing the sampling point at Sagamu Town, Ogun State.

\section{Description of Sampling Area}

Sagamu has geographical coordinates between $6^{\circ} 50^{\prime}$ north; $3^{\circ} 38^{\prime}$ east is located in south western region of Nigeria. The region has tropical wet and dry climate with a lengthy wet season and relatively constant temperatures throughout the course of the year. Wet season runs from March to October, November to December forms the region dry season. The vegetation type of the region is savannah which is really grassland with small bushes and occasional big trees. Grassland soils have substantially higher organic matter content than forest soils (Novackova, 2011).

\section{Sample Collection}

The Peatsoil samples were collected from four different sampling points $(0-10 \mathrm{~cm}$ depth) in Sagamu into polyethylene bag with plastic spoons. Samples were taken to the laboratory, extraneous materials were removed; the samples were air-dried, crushed and ground to a fine powder in a mortar passed through a $0.20 \mathrm{~mm}$ sieve. The samples were kept for analysis.

\section{Isolation and purification of humic acid from peat soil sample}

Peatsoil sample $(100 \mathrm{~g})$ was mixed with 1000 $\mathrm{cm}^{3}$ of $0.1 \mathrm{M} \mathrm{NaOH}$ solution, shaken for 3hours and left to stand overnight. Dark-coloured supernatant was obtained and decanted from solid residue. The dark-coloured supernatant was acidified to $(\mathrm{pH}=1.0)$ with $6 \mathrm{M} \mathrm{HCl}$ stirred and allowed to stand for 6 hours. Yellowish brown supernatant and dark-brown precipitate were obtained. The yellowish brown supernatant was decanted followed by centrifuge and discarded. The dark-brown precipitate was mixed with $500 \mathrm{~cm}^{3}$ of $0.1 \mathrm{M} \mathrm{NaOH}$ solution followed by passing through dowex resin. The dark-brown solution was acidified to $(\mathrm{pH}=1.0)$ with $6 \mathrm{M} \mathrm{HCl}$ stirred and allowed to stand for 3 hours. The dark-brown precipitate was washed several times with deionized water. The supernatant was treated with $\mathrm{AgNO}_{3}$ solution until no white precipitate observed. The humic acid was transferred to weighed crucible and dried at $60^{\circ} \mathrm{C}$ in an oven for 12 hours. The humic acid was cooled and dried in the desiccator, weighed and recorded. The obtained humic acid was dried again at $60^{\circ} \mathrm{C}$ for additional 6 hours cooled and dried in the desiccator, weighed and recorded constant weight was obtained (Baruah et al., 2015).

\section{FT-IR analysis}

FT-IR spectra of humic acid sample was analysed using Carry 630 FT-IR Agilent Technologies.

Unhydrolysed compost humic acid

The unhydrolysed humic acid was obtained after isolation and purification of compost humic acid and kept for investigation.

\section{Acid hydrolysis of Peatsoil acid}

Peatsoil humic acid sample (1g) was refluxed for 12 hours at $\left(160^{\circ} \mathrm{C}\right)$ with $50 \mathrm{~cm}^{3}$ of $6 \mathrm{M} \mathrm{HCl}$. The mixture was allowed to cool, decanted, and centrifuged after hydrolysis. The insoluble residues were washed with distilled water via centrifugation several times, and the supernatant was treated with $\mathrm{AgNO}_{3}$ solution until no white precipitate was observed. The residue was thoroughly dried over $\mathrm{CaCl}_{2}$ in a desiccator at room temperature (Chefetz et al., 2002). Finally, the obtained hydrolysed humic acid was kept for investigation. 
BAJOPAS Volume 14 Number 1,June, 2021 Potentiometric Titrations

Potentiometric measurements were carried out using a pH-meter Jenway (model 3510) with combine electrode, the sensitivity of the $\mathrm{pH}$ meter is 0.01 units. The $\mathrm{pH}$ meter was switched on half an hour before starting the titration for initial warm up of the instrument. The instrument was calibrated with an aqueous standard buffer solution of $\mathrm{pH} 4.00$ and 10.0 (borate buffer) prepared from a "Qualigens" buffer tablets.

The following sets of solutions were prepared in a $250 \mathrm{~cm}^{3}$ volumetric flask separately for $\mathrm{pH}$ metric titrations.

(i) $5 \mathrm{~cm}^{3} 0.1 \mathrm{M} \mathrm{HCl}+40 \mathrm{~cm}^{3}$ deionized water

(ii) $5 \mathrm{~cm}^{3} 0.1 \mathrm{M} \mathrm{HCl}+39 \mathrm{~cm}^{3}$ deionized water $+1 \mathrm{~cm}^{3} 0.15 \mathrm{gcm}^{-3}$ humic acid

(iii) $5 \mathrm{~cm}^{3} 0.1 \mathrm{M} \mathrm{HCl}+37 \mathrm{~cm}^{3}$ deionized water $+1 \mathrm{~cm}^{3} 0.15 \mathrm{gcm}^{-3}$ humic acid

$$
+2 \mathrm{~cm}^{3} \quad 0.01 \mathrm{M} \mathrm{Cu} \text { (II) }
$$

The solutions were titrated against standardized $0.110 \mathrm{MNaOH}$ separately. The total volume of each mixture was adjusted to $50 \mathrm{~cm}^{3}$ and the ionic strength of the solutions was maintained constant at by adding appropriate amount of stock solution of $1 \mathrm{M} \mathrm{KNO}_{3}$ (Gamal, 2015; Omar and Ali, 2015). A magnetic stirrer was used to achieve thorough mixing of the interacting solutions at $550 \mathrm{rpm}$. The same set of experimental conditions was applied for potentiometric titration of remaining samples.

\section{Evaluation of pKa of Hydrolysed peat soil Humic Acids}

The proton-ligand formation number $\mathrm{n}_{\mathbf{A}}$ were calculated by Irving and Rossotti expression (Omar and Ali, 2015).

$\mathrm{nA}=\mathrm{Y}-\frac{(\mathrm{V} 2-\mathrm{V1})(\mathrm{No}-\mathrm{Eo})}{(\mathrm{VO}+\mathrm{V1}) \mathrm{TCL}}$ 1

Where: $Y$ is number of dissociable proton, $\left(\mathrm{V}_{2^{-}}\right.$ $V_{1}$ ) is the measure of displacement of the ligand curve relative to acid curve, $\mathrm{N}^{\circ}$ and $\mathrm{E}^{\circ}$ are the resultant concentration of alkali solution, free acid solution, $\mathrm{T}_{\mathrm{cL}}{ }^{\circ}$ is the total ligand concentration, $\mathrm{V}^{\circ}$ is the total volume of titration solution, $V_{1}$ is the volume of alkali added to acid solution, $V_{2}$ is the volume of alkali added to acid solution + ligand solution, acid dissociation constants (pKa - values) of ligand were calculated by algebraic method point wise calculation (Tables 1 ). The dissociation constants (pKa) were calculated according to the following relation:

$\mathrm{pKa}=\mathrm{pH}+\log \left(\frac{n A}{1-n A}\right)$ 2

Where: pKa is the acid dissociation constant, $\mathrm{n}_{\mathrm{A}}$ is the Proton-ligand formation number and $\mathrm{pH}$ is the pH-values (Omar and Ali, 2015).

\section{Determination of metal-ligand stability constants $(\log K)$ of complexes}

The potentiometric measurement for the determination of stability constant of a complex in solution is based on the fact that the redox potential of the couple $\frac{M^{+(m-n)}}{M^{+m}}$ is shifted significantly on complexation of the metal ion with the ligand. This method involves change in hydrogen ion concentration $\left[\mathrm{H}^{+}\right]$due to the displacement or association of one or more protons taking place during complexation reaction. This change can be found out by titrating the solutions containing free acid, acid with ligand, and acid with ligand and metal ion, individually against a standard alkali solution at a constant ionic strength or temperature. Either ionic strength or temperature may be varied for different sets of solutions. In all the cases, the change in the $\mathrm{pH}$ of the solution is measured after each addition of a known amount of alkali to the reaction cell which contains the reaction mixture. The titration curves are then drawn by plotting the measured $\mathrm{pH}$ values against the corresponding volume of alkali added and the stability constants of the complexes are determined from the titration curves by employing $\mathrm{pH}$-metric titration technique given by (Irving and Rossoti).

Metal-ligand stability constants ( $\log \mathrm{K}$ ) were determined by using the following relations:

$$
\bar{n}=\frac{\left(V_{3}-V_{2}\right)\left(E^{0}+N^{0}\right)}{\left(V^{0}+V_{2}\right) \bar{n}_{A} T_{m}^{0}}
$$

and

$$
P L=\log _{10}\left\{\frac{1+\beta_{n}^{H} \frac{1}{[\text { anti } \log \mathrm{pH}]^{\mathrm{n}}}}{\mathrm{T}_{\mathrm{L}}^{0}-n \bar{T}_{m}^{0}} \mathrm{X} \frac{\left(V^{0}+V_{3}\right)}{V^{0}}\right\}
$$


BAJOPAS Volume 14 Number 1,June, 2021

Where $T_{L}, T^{\circ}, E^{\circ}$, and $V^{\circ}$ havethe same significance as in equation (1) above, $T_{m}$ denotes the total concentration of metal present in solution, $V_{3}$ is the volume of metal ions present in solution and $\beta^{H}$ is the overall proton ligand stability constant. The metal-ligand stability constants (log K) were determined by employing point wise computational Method (eq. 5 and 6).

$\operatorname{LogK}_{1}=\log \left(\frac{n}{1-n}\right)+\mathrm{pL}$ .5

$\operatorname{LogK}_{2}=\log \left(\frac{1-n}{2-n}\right)+\mathrm{pL}$ ...6

Where: Log $\mathrm{K}$ is the metal-ligand stability constant, $\mathrm{pL}$ is the Free ligand exponent function, $\mathbf{n}$ is the Average number of ligand attached with metal ion (Janraoet al., 2014). The results obtained were analyzed by an ORIGIN 2016 program using titration data and then the proton-ligand stability constants (pKa) and Metal-ligand stability constant (LogK) calculated (Omar and Ali, 2015).

\section{RESULTS AND DISCUSSION}

Fourier transformed infrared (FT-IR) spectra of isolated humic acid from peat soils Figure 2 had distinct clear absorption bands indicating the presence of major humic acid structural elemental groups such as $\mathrm{H}$ bonded $\mathrm{OH}$ $\left(3680 \mathrm{~cm}^{-1}\right.$ peak $), C=0$ of carbonyl $\left(1721 \mathrm{~cm}^{-1}\right.$ peak), functional groups of aliphatic components $\mathrm{CH}_{2}\left(2918 \mathrm{~cm}^{-1}\right.$ peak) and $\mathrm{C}-\mathrm{O}$ stretching of polysaccharide $\left(1168 \mathrm{~cm}^{-1}\right.$ peak). The positions of the absorption bands of the spectra fell within typical major absorption bands of humic acid which is at frequencies 3680, 2918, 1721, 1168 $\mathrm{cm}^{-1}$. The first peak centred in the vicinity of $3680 \mathrm{~cm}^{-1}$ region is attributed to phenol $\mathrm{OH}$ group bounded by intermolecular $\mathrm{H}$ bonds. The $2918 \mathrm{~cm}^{-1}$ band usually has absorption maximum at $2918 \mathrm{~cm}^{-1}$ which is due to $\mathrm{C}-\mathrm{H}$ stretching of alkane group $\left(\mathrm{CH}_{2}\right)$. The next major absorption band is $1721 \mathrm{~cm}^{-1}$. This band has been commonly ascribed to $\mathrm{C}=\mathrm{O}$ stretching of mainly carboxyl group $(\mathrm{COOH})$ with trace amount of ketones. The last peak was observed at 1168 $\mathrm{cm}^{-1}$ due to $\mathrm{C}-\mathrm{O}$ stretching of polysaccharides and this peak appeared also in the spectra of humic acid from peat soil. The FTIR spectra of the isolated humic acid contained all major characteristic absorption peaks of humic acid. These absorption peaks indicated the presence of the major structural elements of humic acid namely $\mathrm{H}$ bonded $\mathrm{OH}, \mathrm{C}=\mathrm{C}$ of aromatic ring, $\mathrm{C}=\mathrm{O}$ of carbonyl group (both carboxyl and ketonic), $\mathrm{CH}_{2}$ group. This strongly supports the presence of humic acid.

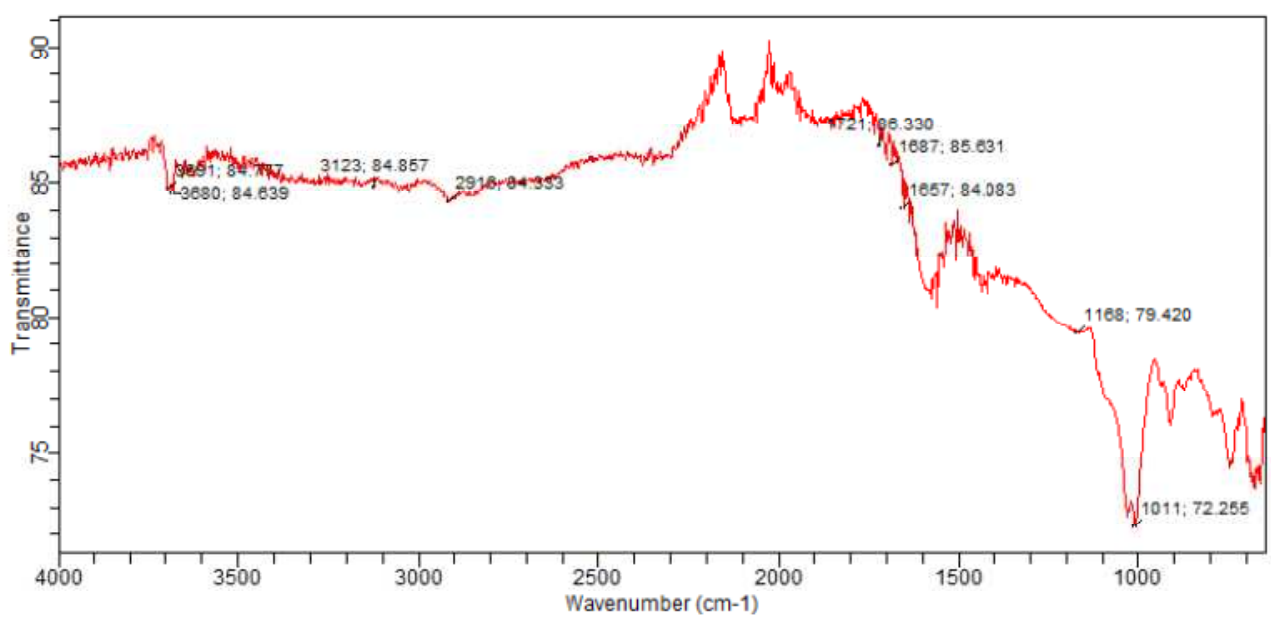

Fig. 2 : FT-IR spectraof peatsoilhumic acid (PSHA)

\section{Evaluation of acid dissociation constant (pka) of acid hydrolysed peat soil humicacid at phenolic group}

The value of the dissociation constant of the peat soil humic acid (PSHA) that underwent acidhydrolysis studied was found to be 8.9299 as shown Table 1, which is lower than the literaturevalues reported by Almeida and Szpoganics, (2015), Borges et al., (2005); Badr et al., (2012)and Fernandes et al,.(2009) of $9.73,9.47$ and 10.30. The difference between the obtained valuesand the reported values in this study might be probably as a result of acid hydrolysis of humicacid. 
BAJOPAS Volume 14 Number 1,June, 2021

Table 1: PKa of (Hydrolysed PSHA)

\begin{tabular}{|l|l|l|l|l|l|l|}
\hline $\mathrm{pH}$ & $\mathrm{BV}_{1}$ & $\mathrm{BV}_{2}$ & $\mathrm{~V}_{2}-\mathrm{V}_{1}$ & $\mathrm{nA}$ & $\log \left(\frac{n A}{1-n A}\right)$ & $\mathrm{pKa}$ \\
\hline 8.50 & 5.30 & 6.29 & 0.99 & 0.3594 & -0.2510 & 8.2490 \\
8.72 & 5.35 & 6.37 & 1.02 & 0.3400 & -0.2880 & 8.4320 \\
9.00 & 5.40 & 6.46 & 1.06 & 0.3141 & -0.3391 & 8.6609 \\
9.22 & 5.45 & 6.55 & 1.10 & 0.2882 & -0.3927 & 8.8273 \\
9.51 & 5.50 & 6.66 & 1.16 & 0.2494 & -0.4786 & 9.0314 \\
9.73 & 5.55 & 6.78 & 1.23 & 0.2041 & -0.5910 & 9.1390 \\
10.00 & 5.60 & 6.90 & 1.30 & 0.1589 & -0.7238 & 9.2762 \\
10.23 & 5.65 & 7.05 & 1.40 & 0.0941 & -0.9835 & 9.2465 \\
10.49 & 5.70 & 7.10 & 1.40 & 0.0941 & -0.9835 & 9.5065 \\
\hline
\end{tabular}

Average pKa $=8.9299 \pm 0.4186$

Table 2: PKa of (Unhydrolysed PSHA)

\begin{tabular}{|l|l|l|l|l|l|l|}
\hline $\mathrm{pH}$ & $\mathrm{BV}_{1}$ & $\mathrm{BV}_{2}$ & $\mathrm{~V}_{2}-\mathrm{V}_{1}$ & $\mathrm{nA}$ & $\log \left(\frac{\boldsymbol{n A}}{1-\boldsymbol{n}}\right)$ & $\mathrm{pKa}$ \\
\hline 8.50 & 5.30 & 5.81 & 0.51 & 0.6619 & 0.2919 & 8.7919 \\
8.72 & 5.35 & 5.90 & 0.55 & 0.6357 & 0.2418 & 8.9618 \\
9.00 & 5.40 & 6.00 & 0.60 & 0.6029 & 0.1813 & 9.1813 \\
9.22 & 5.45 & 6.10 & 0.65 & 0.5701 & 0.1226 & 9.3426 \\
9.51 & 5.50 & 6.20 & 0.70 & 0.5376 & 0.0654 & 9.5754 \\
9.73 & 5.55 & 6.33 & 0.78 & 0.4851 & -0.0259 & 9.7041 \\
10.00 & 5.60 & 6.47 & 0.87 & 0.4262 & -0.1291 & 9.8709 \\
10.23 & 5.65 & 6.62 & 0.99 & 0.3609 & -0.2481 & 9.9819 \\
10.49 & 5.70 & 6.80 & 1.10 & 0.2759 & -0.4690 & 10.0210 \\
\hline
\end{tabular}

Average pKa $=9.4923 \pm 0.4410$

Metal-ligand stability constant ( $\log \mathrm{K}$ )

The stabilityconstants require the accurate values of proton-ligand stability constants (Anil and Maroti, 2008). Metal titration curves crossed over ligand titration curve indicated the formation of complex upon proton release (Santosh, et al., 2011). If the values of n- are within range $0.2-0.8$ and $1.2-18$ this indicates the formation of $1: 1$ and 1:2 complexes (Sayyed and Mazahar, 2012).

The metal (II)-humate stepwise stability constants (log k) at phenolic group (Tables 318)

Table 3: Point-wise method, $\mathrm{Cu}$-(Hydrolysed PSHA)

\begin{tabular}{|l|l|l|l|l|l|l|l|l|}
\hline $\mathrm{pH}$ & $\mathrm{BV}_{1}$ & $\mathrm{BV}_{2}$ & $\mathrm{BV}_{3}$ & $\left(\mathrm{~V}_{3}-\mathrm{V}_{2}\right)$ & $\mathrm{n}$ & $\mathrm{pL}$ & $\log \left(\frac{n}{1-n}\right)$ & LogK $_{1}$ \\
\hline 8.50 & 5.30 & 6.29 & 6.33 & 0.04 & 0.5500 & 2.66 & 0.0871 & 2.7471 \\
8.72 & 5.35 & 6.37 & 6.41 & 0.04 & 0.5714 & 2.43 & 0.1249 & 2.5549 \\
9.00 & 5.40 & 6.46 & 6.50 & 0.04 & 0.6198 & 2.16 & 0.2122 & 2.3722 \\
9.22 & 5.45 & 6.55 & 6.59 & 0.04 & 0.6667 & 1.94 & 0.3010 & 2.2410 \\
\hline
\end{tabular}

LogK $_{1}$ (Average value) $=2.4788 \pm 0.2203$

Table 4: Point-wise method, $\mathrm{Cu}$-(Hydrolysed PSHA)

\begin{tabular}{|l|l|l|l|l|l|l|l|l|}
\hline $\mathrm{pH}$ & $\mathrm{BV}_{1}$ & $\mathrm{BV}_{2}$ & $\mathrm{BV}_{3}$ & $\left(\mathrm{~V}_{3}-\mathrm{V}_{2}\right)$ & $\mathrm{n}$ & $\mathrm{pL}$ & $\log \left(\frac{n-1}{2-n}\right)$ & LogK $_{2}$ \\
\hline 9.51 & 5.50 & 6.66 & 6.73 & 0.07 & 1.3509 & 1.70 & -0.2671 & 1.4329 \\
9.73 & 5.55 & 6.78 & 6.85 & 0.07 & 1.6383 & 1.51 & 0.2467 & 1.7567 \\
10.00 & 5.60 & 6.90 & 6.98 & 0.08 & 2.1783 & 1.31 & -0.2158 & 1.0942 \\
10.23 & 5.65 & 7.05 & 7.13 & 0.08 & 4.1904 & 1.27 & & \\
10.49 & 5.70 & 7.10 & 7.19 & 0.09 & 4.6920 & & & \\
\hline
\end{tabular}

Log $K_{2}($ Average value $)=1.4280 \pm 0.3312$ 
BAJOPAS Volume 14 Number 1,June, 2021

Table 5: Point-wise method, $\mathrm{Cu}$ (Unhydrolysed PSHA)

\begin{tabular}{|l|l|l|l|l|l|l|l|l|}
\hline $\mathrm{pH}$ & $\mathrm{BV}_{1}$ & $\mathrm{BV}_{2}$ & $\mathrm{BV}_{3}$ & $\left(\mathrm{~V}_{3}-\mathrm{V}_{2}\right)$ & $\mathrm{n}$ & $\mathrm{pL}$ & $\log \left(\frac{n}{n-1}\right)$ & Log $_{1}$ \\
\hline 8.50 & 5.30 & 5.81 & 5.85 & 0.04 & 0.2973 & 2.88 & -0.3736 & 2.5064 \\
8.72 & 5.35 & 5.90 & 5.95 & 0.05 & 0.3873 & 2.66 & -0.1992 & 2.4608 \\
9.00 & 5.40 & 6.00 & 6.05 & 0.05 & 0.4044 & 2.38 & -0.1681 & 2.2119 \\
9.22 & 5.45 & 6.10 & 6.15 & 0.06 & 0.5157 & 2.18 & -0.0272 & 2.2072 \\
9.51 & 5.50 & 6.20 & 6.27 & 0.07 & 0.6417 & 1.89 & 0.2530 & 1.1430 \\
\hline
\end{tabular}

$\operatorname{LogK}_{1}($ Average value $)=2.3059 \pm 0.6153$

Table 6:Point-wise method, $\mathrm{Cu}$ (Unhydrolysed PSHA)

\begin{tabular}{|l|l|l|l|l|l|l|l|l|}
\hline $\mathrm{pH}$ & $\mathrm{BV}_{1}$ & $\mathrm{BV}_{2}$ & $\mathrm{BV}_{3}$ & $\mathrm{~V}_{3}-\mathrm{V}_{2}$ & $\mathrm{n}$ & $\mathrm{pL}$ & $\log \left(\frac{n-1}{2-n}\right)$ & $\log \mathrm{K}_{2}$ \\
\hline 9.73 & 5.55 & 6.33 & 6.42 & 0.09 & 0.9000 & 1.69 & & \\
10.00 & 5.60 & 6.47 & 6.58 & 0.11 & 1.2578 & 1.44 & -0.4592 & 0.9808 \\
10.23 & 5.65 & 6.62 & 6.84 & 0.12 & 1.6137 & 1.26 & -0.2010 & 1.4610 \\
10.49 & 5.70 & 6.80 & 6.92 & 0.12 & 2.1052 & 1.03 & & \\
\hline
\end{tabular}

$\operatorname{LogK}_{2}$ (Average value) $=1.2209 \pm 0.3398$

Table 7:Point-wise method, Pb (Hydrolysed PSHA)

\begin{tabular}{|l|l|l|l|l|l|l|l|l|}
\hline $\mathrm{pH}$ & $\mathrm{BV}_{1}$ & $\mathrm{BV}_{2}$ & $\mathrm{BV}_{3}$ & $\left(\mathrm{~V}_{3}-\mathrm{V}_{2}\right)$ & $\mathrm{n}$ & $\mathrm{pL}$ & $\log \left(\frac{n}{1-n}\right)$ & LogK $_{1}$ \\
\hline 8.50 & 5.30 & 6.29 & 6.33 & 0.04 & 0.5500 & 2.66 & 0.0871 & 2.7471 \\
8.72 & 5.35 & 6.37 & 6.41 & 0.04 & 0.5714 & 2.43 & 0.1249 & 2.5549 \\
9.00 & 5.40 & 6.46 & 6.50 & 0.04 & 0.6198 & 2.16 & 0.2122 & 2.3722 \\
9.22 & 5.45 & 6.55 & 6.60 & 0.05 & 0.8333 & 1.96 & 0.6989 & 2.6589 \\
\hline
\end{tabular}

Log $_{\mathbf{1}}($ Average value $)=2.5832 \pm 0.1614$

Table 8:Point-wise method, Pb-(Hydrolysed PSHA)

\begin{tabular}{|l|l|l|l|l|l|l|l|l|}
\hline $\mathrm{pH}$ & $\mathrm{BV}_{1}$ & $\mathrm{BV}_{2}$ & $\mathrm{BV}_{3}$ & $\left(\mathrm{~V}_{3}-\mathrm{V}_{2}\right)$ & $\mathrm{n}$ & $\mathrm{pL}$ & $\log \left(\frac{n-1}{2-n}\right)$ & $\log \mathrm{K}_{2}$ \\
\hline 9.51 & 5.50 & 6.66 & 6.71 & 0.05 & 0.9650 & 1.67 & & \\
9.73 & 5.55 & 6.78 & 6.83 & 0.05 & 1.1702 & 1.44 & & \\
10.00 & 5.60 & 6.90 & 6.90 & 0.05 & 1.4864 & 1.22 & -0.0237 & 1.1963 \\
10.23 & 5.65 & 7.05 & 7.10 & 0.05 & 2.0190 & 1.09 & & \\
10.49 & 5.70 & 7.10 & 7.17 & 0.07 & 3.6492 & 1.00 & & \\
\hline
\end{tabular}

Log $K_{2}$ (Average value) $=1.1963$

Table 9: Point-wise method, Pb (Unhydrolysed PSHA)

\begin{tabular}{|l|l|l|l|l|l|l|l|l|}
\hline $\mathrm{pH}$ & $\mathrm{BV}_{1}$ & $\mathrm{BV}_{2}$ & $\mathrm{BV}_{3}$ & $\mathrm{~V}_{3}-\mathrm{V}_{2}$ & $\mathrm{n}$ & $\mathrm{pL}$ & $\begin{array}{l}\text { Log } \\
\left(\frac{n}{n-1}\right)\end{array}$ & Log $\mathrm{K}_{1}$ \\
\hline 8.50 & 5.30 & 5.81 & 5.85 & 0.04 & 0.2973 & 2.88 & -0.3736 & 2.5064 \\
8.72 & 5.35 & 5.90 & 5.94 & 0.04 & 0.3099 & 2.66 & -0.5477 & 2.3123 \\
9.00 & 5.40 & 6.00 & 6.05 & 0.05 & 0.4044 & 2.38 & -0.1681 & 2.2119 \\
9.22 & 5.45 & 6.10 & 6.15 & 0.06 & 0.5157 & 2.18 & 0.0272 & 2.2072 \\
9.51 & 5.50 & 6.20 & 6.26 & 0.07 & 0.6417 & 1.89 & 0.2530 & 2.1430 \\
9.73 & 5.55 & 6.40 & 6.40 & 0.07 & 0.7000 & 1.67 & 0.3680 & 2.0380 \\
\hline
\end{tabular}

LogK $_{1}$ (Average value) $=2.2364 \pm 0.1602$

Table 10: Point-wise method, Pb (Unhydrolysed PSHA)

\begin{tabular}{|l|l|l|l|l|l|l|l|l|}
\hline $\mathrm{pH}$ & $\mathrm{BV}_{1}$ & $\mathrm{BV}_{2}$ & $\mathrm{BV}_{3}$ & $\mathrm{~V}_{3}-\mathrm{V}_{2}$ & $\mathrm{n}$ & $\mathrm{pL}$ & $\log \left(\frac{n-1}{2-n}\right)$ & $\log \mathrm{K}_{2}$ \\
\hline 10.00 & 5.60 & 6.47 & 6.55 & 0.08 & 1.9503 & 1.41 & & \\
10.23 & 5.65 & 6.62 & 6.72 & 0.11 & 1.4792 & 1.26 & -0.0361 & 1.2239 \\
\hline
\end{tabular}

$\operatorname{LogK}_{2}$ (Average value) $=1.2239$

Table 11: Point-wise method, Mg (Hydrolysed PSHA)

\begin{tabular}{|l|l|l|l|l|l|l|l|l|}
\hline $\mathrm{pH}$ & $\mathrm{BV}_{1}$ & $\mathrm{BV}_{2}$ & $\mathrm{BV}_{3}$ & $\left(\mathrm{~V}_{3}-\mathrm{V}_{2}\right)$ & $\mathrm{n}$ & $\mathrm{pL}$ & $\log \left(\frac{n}{n-1}\right)$ & LogK $_{1}$ \\
\hline 8.50 & 5.30 & 6.29 & 6.31 & 0.02 & 0.2750 & 2.64 & -0.4290 & 2.2110 \\
8.72 & 5.35 & 6.37 & 6.39 & 0.02 & 0.2858 & 2.42 & -0.3978 & 2.0222 \\
9.00 & 5.40 & 6.46 & 6.49 & 0.03 & 0.4648 & 2.14 & -0.0612 & 2.0788 \\
9.22 & 5.45 & 6.55 & 6.59 & 0.04 & 0.6667 & 1.94 & 0.3010 & 2.2410 \\
\hline
\end{tabular}

$\log _{\mathbf{1}}($ Average value) $=2.1382 \pm 0.1046$ 
BAJOPAS Volume 14 Number 1,June, 2021

Table 12: Point-wise method, Mg (Hydrolysed PSHA)

\begin{tabular}{|l|l|l|l|l|l|l|l|l|}
\hline $\mathrm{pH}$ & $\mathrm{BV}_{1}$ & $\mathrm{BV}_{2}$ & $\mathrm{BV}_{3}$ & $\left(\mathrm{~V}_{3}-\mathrm{V}_{2}\right)$ & $\mathrm{n}$ & $\mathrm{pL}$ & $\log \left(\frac{n-1}{2-n}\right)$ & LogK $_{2}$ \\
\hline 9.51 & 5.55 & 6.66 & 6.71 & 0.05 & 0.9650 & 1.67 & & \\
9.73 & 5.55 & 6.78 & 6.84 & 0.06 & 1.4042 & 1.47 & -0.1686 & 1.3014 \\
10.00 & 5.60 & 6.90 & 6.93 & 0.06 & 1.7838 & 1.23 & 0.5593 & 1.7893 \\
10.23 & 5.65 & 7.05 & 7.10 & 0.06 & 3.1429 & 1.10 & & \\
10.49 & 5.70 & 7.10 & 7.18 & 0.07 & 3.6492 & 0.83 & & \\
\hline
\end{tabular}

LogK $_{2}($ Average value $)=1.5453 \pm 0.3450$

Table 13: Point-wise method, Mg (Unhydrolysed PSHA)

\begin{tabular}{|l|l|l|l|l|l|l|l|l|}
\hline $\mathrm{pH}$ & $\mathrm{BV}_{1}$ & $\mathrm{BV}_{2}$ & $\mathrm{BV}_{3}$ & $\mathrm{~V}_{3}-\mathrm{V}_{2}$ & $\mathrm{n}$ & $\mathrm{pL}$ & $\log \left(\frac{n}{n-1}\right)$ & $\operatorname{Log~}_{1}$ \\
\hline 8.50 & 5.30 & 5.81 & 5.85 & 0.04 & 0.2973 & 2.88 & -0.3736 & 2.5064 \\
8.72 & 5.35 & 5.90 & 5.94 & 0.04 & 0.3099 & 2.66 & -0.3477 & 2.3123 \\
9.00 & 5.40 & 6.00 & 6.04 & 0.04 & 0.3236 & 2.38 & -0.3202 & 2.0598 \\
9.22 & 5.45 & 6.10 & 6.15 & 0.05 & 0.4297 & 2.17 & -0.1230 & 2.0470 \\
9.51 & 5.50 & 6.20 & 6.26 & 0.06 & 0.5500 & 1.89 & 0.0871 & 1.9771 \\
9.73 & 5.55 & 6.33 & 6.40 & 0.07 & 0.7000 & 1.67 & 0.3680 & 2.0380 \\
\hline
\end{tabular}

LogK $_{1}$ (Average value) $=2.1568 \pm 0.2069$

Table 14: Point-wise method, Mg (Unhydrolysed PSHA)

\begin{tabular}{|l|l|l|l|l|l|l|l|l|}
\hline $\mathrm{pH}$ & $\mathrm{BV}_{1}$ & $\mathrm{BV}_{2}$ & $\mathrm{BV}_{3}$ & $\mathrm{~V}_{3}-\mathrm{V}_{2}$ & $\mathrm{n}$ & $\mathrm{pL}$ & $\log \left(\frac{n-1}{2-n}\right)$ & $\log \mathrm{K}_{2}$ \\
\hline 10.00 & 5.60 & 6.47 & 6.55 & 0.08 & 0.9148 & 1.41 & & \\
10.23 & 5.65 & 6.62 & 6.71 & 0.09 & 1.2102 & 1.20 & -0.5749 & 0.6251 \\
10.49 & 5.70 & 6.80 & 6.92 & 0.09 & 1.5968 & 1.03 & 0.1703 & 1.2003 \\
\hline
\end{tabular}

LogK $_{2}$ (Average value) $=0.9127 \pm 0.4070$

Table15:Point-wise method, Cd (Hydrolysed PSHA)

\begin{tabular}{|l|l|l|l|l|l|l|l|l|}
\hline $\mathrm{pH}$ & $\mathrm{BV}_{1}$ & $\mathrm{BV}_{2}$ & $\mathrm{BV}_{3}$ & $\left(\mathrm{~V}_{3}-\mathrm{V}_{2}\right)$ & $\mathrm{n}$ & $\mathrm{pL}$ & $\log \left(\frac{n}{1-n}\right)$ & LogK $_{1}$ \\
\hline 8.50 & 5.30 & 6.29 & 6.31 & 0.02 & 0.2750 & 2.64 & -0.4210 & 2.2190 \\
8.72 & 5.35 & 6.37 & 6.40 & 0.03 & 0.4286 & 2.42 & -0.1249 & 2.2951 \\
9.00 & 5.40 & 6.46 & 6.49 & 0.03 & 0.4648 & 2.14 & -0.0612 & 2.0788 \\
9.22 & 5.45 & 6.55 & 6.59 & 0.04 & 0.6667 & 1.96 & 0.3010 & 2.2610 \\
9.51 & 5.55 & 6.66 & 6.70 & 0.04 & 0.7720 & 1.67 & 0.5297 & 2.1997 \\
\hline
\end{tabular}

LogK $_{\mathbf{1}}$ (Average value) $=2.2108 \pm 0.0825$

Table 16: Point-wise method, Cd (Hydrolysed PSHA)

\begin{tabular}{|l|l|l|l|l|l|l|l|l|}
\hline $\mathrm{pH}$ & $\mathrm{BV}_{1}$ & $\mathrm{BV}_{2}$ & $\mathrm{BV}_{3}$ & $\left(\mathrm{~V}_{3}-\mathrm{V}_{2}\right)$ & $\mathrm{n}$ & $\mathrm{pL}$ & $\log \left(\frac{n-1}{2-n}\right)$ & Log $_{2}$ \\
\hline 9.73 & 5.55 & 6.78 & 6.83 & 0.06 & 1.4042 & 1.47 & -0.1686 & 1.3014 \\
10.00 & 5.60 & 6.90 & 6.95 & 0.06 & 1.7838 & 1.23 & 0.5593 & 1.7893 \\
10.23 & 5.65 & 7.05 & 7.10 & 0.06 & 3.1429 & 1.09 & & \\
10.49 & 5.70 & 7.10 & 7.16 & 0.06 & 3.1429 & 0.89 & & \\
& & & & & & & & \\
\hline
\end{tabular}

$\operatorname{LogK}_{2}$ (Average value) $=1.5453 \pm 0.3450$

Table 17: Point-wise method, Cd (Unhydrolysed PSHA)

\begin{tabular}{|l|l|l|l|l|l|l|l|l|}
\hline $\mathrm{pH}$ & $\mathrm{BV}_{1}$ & $\mathrm{BV}_{2}$ & $\mathrm{BV}_{3}$ & $\mathrm{~V}_{3}-\mathrm{V}_{2}$ & $\mathrm{n}$ & $\mathrm{pL}$ & $\log \left(\frac{n}{n-1}\right)$ & $\operatorname{Log~}_{1}$ \\
\hline 8.50 & 5.30 & 5.81 & 5.86 & 0.05 & 0.3717 & 2.88 & -0.2280 & 2.6520 \\
8.72 & 5.35 & 5.90 & 5.95 & 0.05 & 0.3873 & 2.66 & -0.1992 & 2.4608 \\
9.00 & 5.40 & 6.00 & 6.06 & 0.06 & 0.4853 & 2.38 & -0.0255 & 2.3545 \\
9.22 & 5.45 & 6.10 & 6.16 & 0.06 & 0.5157 & 2.18 & -0.0272 & 2.2072 \\
9.51 & 5.50 & 6.20 & 6.27 & 0.07 & 0.6417 & 1.89 & 0.2530 & 1.1430 \\
9.73 & 5.55 & 6.33 & 6.41 & 0.08 & 0.8000 & 1.69 & 0.6020 & 2.2920 \\
& & & & & & & & \\
\hline
\end{tabular}

$\operatorname{LogK}_{1}($ Average value $)=2.2516 \pm 0.5380$ 
BAJOPAS Volume 14 Number 1,June, 2021

Table 18: Point-wise method, Cd (Unhydrolysed PSHA)

\begin{tabular}{|l|l|l|l|l|l|l|l|l|}
\hline $\mathrm{pH}$ & $\mathrm{BV}_{1}$ & $\mathrm{BV}_{2}$ & $\mathrm{BV}_{3}$ & $\mathrm{~V}_{3}-\mathrm{V}_{2}$ & $\mathrm{n}$ & $\mathrm{pL}$ & $\log \left(\frac{n-1}{2-n}\right)$ & $\log \mathrm{K}_{2}$ \\
\hline 10.00 & 5.60 & 6.47 & 6.57 & 0.10 & 1.1434 & 1.43 & & \\
10.23 & 5.65 & 6.62 & 6.72 & 0.10 & 1.3448 & 1.23 & -0.2788 & 0.9512 \\
10.49 & 5.70 & 6.80 & 6.90 & 0.10 & 1.7742 & 1.03 & 0.5351 & 1.5651 \\
\hline
\end{tabular}

$\operatorname{LogK}_{2}($ Average value $)=1.2581 \pm 0.4340$

Table 19: Stepwise and overall Stability constants of thehydrolysed and unhydrolysed divalent metal (II) complexes

\begin{tabular}{|c|c|c|c|}
\hline Chelates & LogK $_{1}$ & $\log _{2}$ & Log $\beta$ \\
\hline [Cu (Hydrolysed PSHA-1) $\left.{ }_{2}\right]$ & 2.4788 & 1.4280 & 3.9068 \\
\hline$\left[\mathrm{Pb}(\text { Hydrolysed PSHA-1) })_{2}\right]$ & 2.5832 & 1.1963 & 3.7795 \\
\hline$\left[\mathrm{Cd}(\text { Hydrolysed PSHA-1 })_{2}\right]$ & 2.2108 & 1.5453 & 3.7561 \\
\hline$\left[\mathrm{Mg}(\text { Hydrolysed PSHA-1 })_{2}\right]$ & 2.1382 & 1.5453 & 3.6835 \\
\hline [Cu (Unhydrolysed PSHA-1) & 2.3059 & 1.2209 & 3.5268 \\
\hline$[\mathrm{Pb}$ (Unhydrolysed PSHA-1) 2$]$ & 2.2364 & 1.2239 & 3.4603 \\
\hline [Cd (Unhydrolysed PSHA-1) 2 ] & 2.2516 & 1.2581 & 3.5097 \\
\hline$[\mathrm{Mg}$ (Unydrolysed PSHA-1) & 2.1568 & 0.9127 & 3.0695 \\
\hline
\end{tabular}

The results obtained (Table19) shows the stepwise and overall stability constants to be not high indicating low stability of the complexes, because the solubility of most metal ions in the basic $\mathrm{pH}$ range is minimal due to metal hydroxide precipitation (Karimi, 2017). In general, the stepwise stability constants $\left(K_{1}\right.$ and $K_{2}$ ) follow the order $K_{1}>K_{2}$ for the copper, lead, magnesium and cadmium complexes respectively. The steady decrease of the values with increasing number of ligands is in agreement with the prediction made by researchers (Na'aliya, 2013). The decrease could be attributed to the fact that as the number of the ligands (Humate ions) that enters the coordination zone increases the aqua molecules available for replacement by the ligands become less. Thus, the metal ions become less electron loving with progressive intake of the ligand and this results in the decrease in the values of the constants (Na'aliya, 2013). Also the stability of the complexes is influenced by the size and number of the chelate rings(Mackay and Mackay,2002).All the complexes form rings in their structure as humate, a bidentate ligand, bond the metal ions in the ratio 1:2 (Boguta and Sokolowska, 2016) forming chelate rings. The values of the overall stability constants $(\log \beta)$ obtained for humate complexes are not high indicating low stability as the values are not high. LogK values for copper-humates (Table 3 to 6) obtained in this study are lower than those reported for the complexes of humic acids (Pandey et al., 2015; Dinu, 2013; Kaschl et al., 2010 and Gilbeto and Jorg, 2001). The values of LogK(Table 7 to 10 ) forlead-humates are lower than those reported for the lead in the literature (Dinu, 2013; Gilbeto and Jorg 2001). Log K values(Table 11 to 14 ) for magnesium-humates obtained in this study are close to those reported by (Pandey et al., 2015). Log K values of cadmium-humates (Table 15 to 18 ) obtained in this work near to the one reported by (Dinu, 2013 and Pandey et al., 2015).The difference between the reported values and the values obtained in this study might be probably as a result of acid hydrolysis of humic acid. The values of the overall stability constants $(\log \beta)$ of the copper humates complexes presented in Table 19 is high than that of other metal humate complexes, show relatively high stability of CuHA complexes, show the following order of stability: $\mathrm{Cu}>\mathrm{Pb}>\mathrm{Cd}>\mathrm{Mg}$; which are in close agreement to the findings of (Dinu, 2013 and Pandey et al., 2015).The high stability of Cuhumate chelate could be attributed to the existence of coordinate covalent bond between the complexing agents and the $\mathrm{Cu}^{2+}$ ions. Since, $\mathrm{Cu}^{2+}$ being a metal of the transitional series with $3 d^{9}$ electronic configurations can accept the electrons from the complexing agents. Similarly, the low stabilities of $\mathrm{Pb}, \mathrm{Cd}$ and $\mathrm{Mg}$ complexes could be explained by that $\mathrm{Pb}^{2+}$ with $6 s^{2}, \mathrm{Cd}^{2+}$ with $4 \mathrm{~d}^{10}$ and $\mathrm{Mg}^{2+}$ with $2 \mathrm{p}^{6}$ their electronic configuration has a completely filled $\mathrm{d}, \mathrm{p}$ and $\mathrm{s}$ orbitals. Moreover, the stabilities of metal ions with hydrolysed humic acid from peat soil were higher than those with unhydrolysed humic acid from peat soil; which is ascribed to the high content of acidity in hydrolysed humic acid than unhydrolysed humic acid. 
BAJOPAS Volume 14 Number 1,June, 2021 CONCLUSION

The values of logk for $\mathrm{Cu}(\mathrm{II})$ hydrolysed humic acid complex was higher followed by $\mathrm{Pb}$ (II), $\mathrm{Cd}(\mathrm{II})$ and $\mathrm{Mg}$ (II) hydrolysed humic acid complexes as compared with metal(II) unhydrolysed humic acid complexes. This indicates acid hydrolysis of humic acid can

\section{REFERENCES}

Almeida, V.R. and Szpoganicz, B. (2015). Humic Acid Potentiometric Response Patterns:Out- of Equilibrium Properties and Species Distribution Modelling. Chemical. Biol. Technol. Agric. 2: 17.

Anđelković, T., Nikolić, R., Bojić, A.,Anđelković, D., and Nikolic G.,(2010). Binding of Cadmium to Soil Humic Acid as A Function of Carboxyl Group Content. Macedonian Journal of Chemistry and Chemical Engineering.29(2): 215-224.

Anil, B. N. and Maroti, N. (2008). Studies on Influence of Die-Lectric Constants on Complex Equilibria between Substituted Py-Razalines and Lanthanide Metal Ions pH-Metrically. Amer.-Euras. scient. Res. 3(2): 212-216.

Ashok, K., Pandey, S. P. and Misra, V (2000). Stability Constants of Metal-Humic Acid Complexes and its Role in Environmental Detoxification. Journal of Ecotoxicology and Environmental Safety. 47(2):157-200.

Badr, M. H., El-Halafawi, M. H. and Abd El-al Zeid, E. R. (2012). Comparison Between the Effect of Ionic Strength on Acidity and Dissociation Constants of Humic Acids Extracted from Sewage Sludge and Nile Water Hyacinth Composts.Global Journal of Environmental Research 6 (1): 36-43.

Baruah, M.K., Borah, D., Saikia, P.P., Paul, S., Sharma, T. (2015). Evaluation of pKa Values of Soil Humic Acids and their Complexation Properties. International Journal of Plant \& Soil Science 6(4) : 218-228.

Boguta, P. Sokolowska, Z. (2016). Interactions of $\mathrm{Zn}$ (II) Ions with Humic Acids Isolated from Various Types of Soils. Effect of $\mathrm{pH}, \mathrm{Zn}$ Concentrations and Humic Acids Chemical Properties. Journal of Geochemical Explaration 168. 119-126.

Borges, F., Guimaraes, C., Lima, L.F.C., Pinto, I. and Reis, S.(2005). Potentiometric Studies on the Complexation of Copper(II) by Phenolic Acids as Discrete Ligand Models of enhance the complexation behavior of humic acid with metal (II) ions. However, the higher values of $\log \beta$ for $\mathrm{Cu}(\mathrm{II}), \mathrm{Pb}(\mathrm{II}), \mathrm{Cd}(\mathrm{II})$ and $\mathrm{Mg}(\mathrm{II})$ hydrolysed humic acid complexes indicates more stable stepwise complexes formed as compared with $\mathrm{Cu}(\mathrm{II}), \mathrm{Pb}$ (II), $\mathrm{Cd}$ (II) and $\mathrm{Mg}(\mathrm{II})$ unhydrolysed humic acid complexes.

Humic Substances Talanta 66 (2005) 670-673.

Chefetz, B., Salloum, M. J., Deshmulkin, A. P. and Hatcher, P. (2002). Structural Components of Humic Acids as Determined by Chemical Modifications and Carbon-13 NMR, Pyrolysis, and Thermochemolysis- Gas Chromatography/Mass Spectrometry. Soil Science Society of American Journal Abstract Division S-2- Soil Chemistry66. 1159-1171.

Dinu, M. I. (2013). Metals Complexation with Humic Acids in Surface Water of Different Environ. Sci. Technol. 31(1): 1-17.

Fernandes, A.N., Giacomelli, C., Giovanela, M. Vaz, D.V. Szpoganicz, B. and Maria M. D. (2009). Potentiometric Acidity Determination in Humic Substances Influenced by Different Analytical Procedures.J. Braz. Chem. Soc. 20 (9):14.

Gamal, A. H. (2015). Stability Constants of Rhenium (V) Metal Complexes with Selected Drugs. Pyrex Journal of Research in Environmental Studies. 2(2): 006-014.

Janrao, D. M., Pathan, J., Kayande, D.D., and Mulla, J.J. (2014). An Over View of Potentiometric Determination of Stability Constants of Metal Complexes. Sci. Revs. Chem. Commun.: 4(1), 2014, 11-24.

Karimi, H. (2017). Effect of pH and Initial Pb(II) Concentration on the Lead Removal Efficiency from Waste Water Using $\mathrm{Ca}(\mathrm{OH})_{2}$. International Journal of Water and Waste Water Treatment 3.2

Kaschl, A. Romheld, V. and Chen, Y. (2010). Binding of Cadmium, Copper and Zinc to Humic Substances Originating from Municipal Solid Waste Compost. Israel Journal of Chemistry Vol. 42(1): 89-98.

Kostic, I. S., Tatjana, P, A., Nikolic, R. S., Cvetkovic, T. P., Pavlovic, D. D., Aleksandar, L.J. and Bojic, A. (2012). Comparative Study of Binding Strengths of Heavy Metals with Humic Acid. J.serb. Chem. Soc. 76(9) pp 1-20. 
BAJOPAS Volume 14 Number 1,June, 2021

Na'aliya, J. (2013). Determination of Stepwise Stability Constants and Gibbs free Energy Change of Trisprolina to Complexes of some Divalent Transition Metal ions. Bayero Journal of Pure and Applied Sciences 6(2): 112-114.

Omar, A. A. and Ali, E. A. (2015). Potentiometric Studies on Complexes of $\mathrm{Cr}$ (III) and $\mathrm{Zr}$ (IV) with some Carboxylic Acids. International Journal of Advanced Chemistry, 3(1) 25-

37.

Pandey, A. K. Pandey, S. D. and Misr, V. (2015).Stability Constants of Metal- Humic Acid Complexes and Its Role in Environmental Detoxification. J. Ecotoxicology and Environmental Safety. 47(1):195-200.

Ram, N. and Raman, K.V. (1984). Stability Constants of Complexes of Metals with
Humicand Fuvic Acids under Non- acidConditions. Journal of Plant Nutrition and Soil Sciences.

147:171-176.

Santosh, D. D., Ashok, B. K., Vijay, J. T., Shivraj, G. W. and Vinay, V. W. (2011). Potentiometric Studies of Elec-Trolyte Effects on Complex Equilibria of Some Substituted 5-(2-hydroxy Phenyl) Pyrazoles. Der pharm. 3 (6): 75-83.

Sayyed, H. and Abdul Rahim, M. F. (2012). Studies of Binary Complexes of Metal Ions with Mandelic Acid by Potentiometry. Chem. J. 02 (6): 206209.

Shirvani, M. Moradian, E. Khalili, B. Bakhtiary, S. (2015). Interaction of $\mathrm{Cd}$ and $\mathrm{Pb}$ with Humate-Palygorskite and HumateSepiolite Complexes. Journal of water, air and pollution 3: 220-228. 


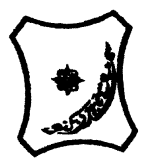

Bayero Journal of Pure and Applied Sciences, 14(1): 54 - 63

Received: November, 2020

Accepted: April, 2021

ISSN $2006-6996$

\title{
STABILITY CONSTANTS OF COMPLEXES OF METAL IONS WITH PEATSOIL HUMIC ACIDS UNDER NON-ACID-CONDITIONS
}

\author{
${ }^{* 1}$ Sabo, Yusuf ${ }^{2}$ Jimoh, W.L.O., ${ }^{3}$ Isa Baba Koki and ${ }^{4}$ Sholadoye, Q. 0. \\ ${ }^{1}$ Department of Pure and Industrial Chemistry, Bayero University, Kano \\ ${ }^{3}$ Department of Chemistry, Yusuf Maitama Sule University Kano. P.M.B. 3220 Kano, Nigeria. \\ ${ }^{4}$ Department of Chemistry, Nigerian Police Academy, Wudil, Kano-Nigeria
}

*Correspondence E-mail; saboyusuf18@yahoo.com

ABSTRACT

Stability constants of complexes of four divalent metal ions viz. $\mathrm{Cu}^{2+}, \mathrm{Pb}^{2+}, \mathrm{Mg}^{2+}$ and $\mathrm{Cd}^{2+}$ with humic acids (HA) were determined by potentiometric titration of humic acids with the corresponding salt of the divalent metals in aqueous media under non-acid-condition. The log $K$ (logarithm of the stability constant) ranged from 1.0942 to 2.7471 for metalhumic acid complexes were determined using point-wise computational method. The order of stability constants were obtained as follows: $\mathrm{Cu}>\mathrm{Pb}>\mathrm{Cd}>\mathrm{Mg}$ for metal $-\mathrm{HA}$ complexes respectively, indicating a higher degree of complexation with Cu metal ion.

Keywords: stability constant, humic acid, potentiometric titration, divalent metals, acid hydrolysis.

\section{NTRODUCTION}

The stability constant of a complex is the numerical expression of its stability and provides a quantitative measure of affinity of the metal ion to the complexing agent. An understanding of the relative stability of metal-complexes helps in predicting the behavior of metal ions in the soil (Ram and Raman, 1982). Extensive researches has been done to determine the stability constants of the complexes formed between humic acid (HA) with a number of metal ions. Ashok et al., (2000) reported that humic acid with hydroxyl, phenoxyl and carboxyl reactive groups can form coordination compound with metal ions at $\mathrm{pH}$ 3.5. The stability constants(Log K) for different metalhumic acid complexes indicated the following order of the stabilities of complexes formed between humic acid and metal ion, $\mathrm{Cu}>\mathrm{Fe}$ $>\mathrm{Pb}>\mathrm{Ni}>\mathrm{Co}>\mathrm{Ca}>\mathrm{Cd}>\mathrm{Zn}>\mathrm{Mn}>\mathrm{Mg}$. Andelkovic et al., (2010) investigated the binding of $\mathrm{Cd}$ (II) to soil humic acid at pH 6.5 and in $0.1 \mathrm{M} \mathrm{KNO}_{3}$ ionic medium. The stability constant for binding indicating greater stability in the case when carboxyl groups are involved in complexation reaction. Kostic et al.,(2012) investigated the complexation of humic acid with certain heavy metal ions (Co(II), $\mathrm{Ni}(\mathrm{II}), \mathrm{Cu}(\mathrm{II})$,
$\mathrm{Zn}(\mathrm{II})$, and $\mathrm{Pb}(\mathrm{II})$. The experiment was performed at $25^{\circ} \mathrm{C}$, at pH 4.0 and ionic strength of $0.01 \mathrm{M}$. Stability constant of complex between $\mathrm{Pb}$ (II) ions and humic acid is greater than stability constants of other investigated metalhumate complexes. Bogata and Sokolowska (2016) analyses the interaction between humic acids from different soils and $\mathrm{Zn}$ (II) ions at wide concentration ranges and at $\mathrm{pH} 5$. Studies have showed significant impact of $\mathrm{Zn}$ concentration, $\mathrm{pH}$ and some properties of humic acids with zinc.But all of these studies were limited to acidic $\mathrm{pH}$ range. Therefore, the present study was carried out to determine and compare the stability constants of complexes of metal ions with hydrolysed peat soil humic acid and unhydrolysed peat soil humic under non-acid conditions.

\section{MATERIALS AND METHODS}

Analytical grade chemicals used includes hydrochloric acid $(\mathrm{HCl})$, nitric acid $\left(\mathrm{HNO}_{3}\right)$, sodium hydroxide $(\mathrm{NaOH})$, lead nitrate $\mathrm{Pb}\left(\mathrm{NO}_{3}\right)_{2}$, copper nitrate $\mathrm{Cu}\left(\mathrm{NO}_{3}\right)_{2} \cdot 3 \mathrm{H}_{2} \mathrm{O}$, cadmium nitrate $\mathrm{Cd}\left(\mathrm{NO}_{3}\right)_{2} \cdot 4 \mathrm{H}_{2} \mathrm{O}$, magnesium nitrate $\mathrm{Mg}\left(\mathrm{NO}_{3}\right)_{2} \cdot 6 \mathrm{H}_{2} \mathrm{O}$, potassium nitrate $\left(\mathrm{KNO}_{3}\right)$, calcium chloride $\left(\mathrm{CaCl}_{2}\right)$, (sigma-Aldrich). Dowex 50WX8, (20-50 mesh) from Fluka. 


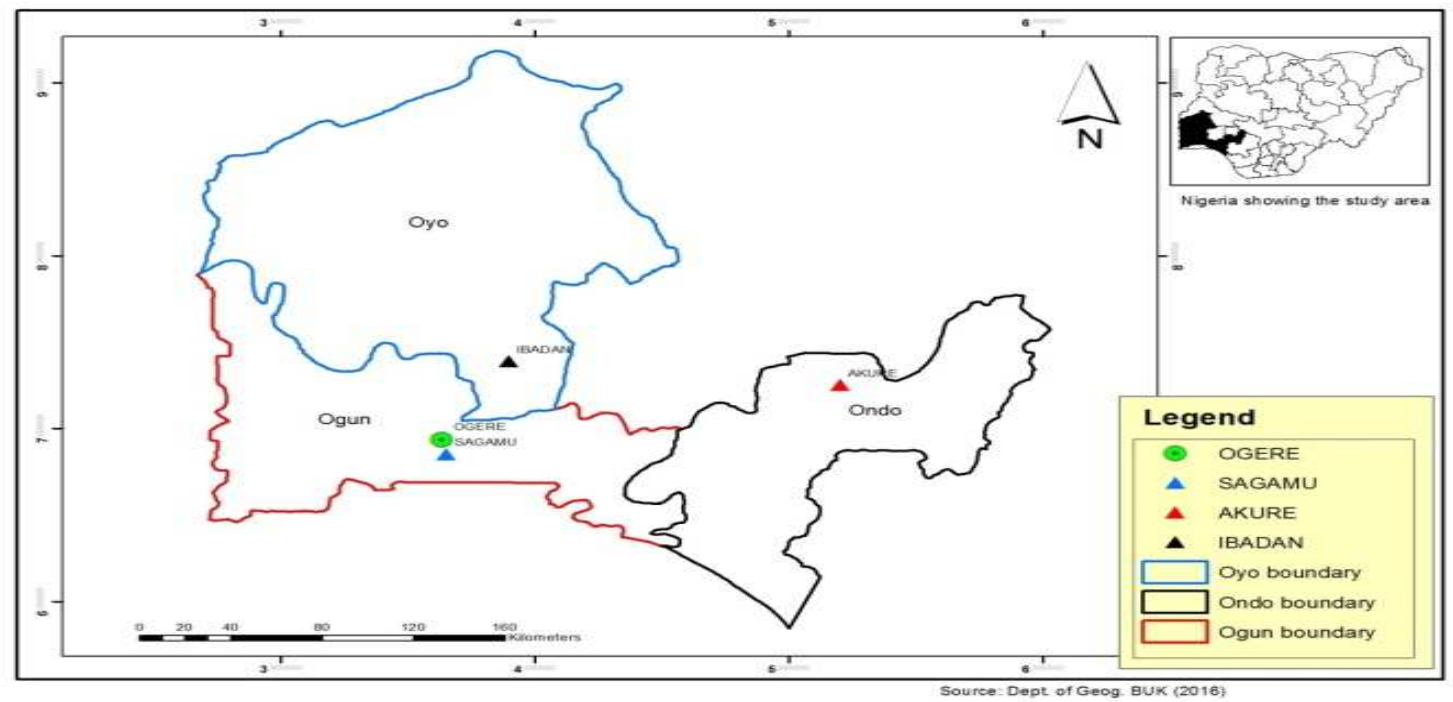

Figure 1: Map showing the sampling point at Sagamu Town, Ogun State.

\section{Description of Sampling Area}

Sagamu has geographical coordinates between $6^{\circ} 50^{\prime}$ north; $3^{\circ} 38^{\prime}$ east is located in south western region of Nigeria. The region has tropical wet and dry climate with a lengthy wet season and relatively constant temperatures throughout the course of the year. Wet season runs from March to October, November to December forms the region dry season. The vegetation type of the region is savannah which is really grassland with small bushes and occasional big trees. Grassland soils have substantially higher organic matter content than forest soils (Novackova, 2011).

\section{Sample Collection}

The Peatsoil samples were collected from four different sampling points $(0-10 \mathrm{~cm}$ depth) in Sagamu into polyethylene bag with plastic spoons. Samples were taken to the laboratory, extraneous materials were removed; the samples were air-dried, crushed and ground to a fine powder in a mortar passed through a $0.20 \mathrm{~mm}$ sieve. The samples were kept for analysis.

\section{Isolation and purification of humic acid from peat soil sample}

Peatsoil sample $(100 \mathrm{~g})$ was mixed with 1000 $\mathrm{cm}^{3}$ of $0.1 \mathrm{M} \mathrm{NaOH}$ solution, shaken for 3hours and left to stand overnight. Dark-coloured supernatant was obtained and decanted from solid residue. The dark-coloured supernatant was acidified to $(\mathrm{pH}=1.0)$ with $6 \mathrm{M} \mathrm{HCl}$ stirred and allowed to stand for 6 hours. Yellowish brown supernatant and dark-brown precipitate were obtained. The yellowish brown supernatant was decanted followed by centrifuge and discarded. The dark-brown precipitate was mixed with $500 \mathrm{~cm}^{3}$ of $0.1 \mathrm{M} \mathrm{NaOH}$ solution followed by passing through dowex resin. The dark-brown solution was acidified to $(\mathrm{pH}=1.0)$ with $6 \mathrm{M} \mathrm{HCl}$ stirred and allowed to stand for 3 hours. The dark-brown precipitate was washed several times with deionized water. The supernatant was treated with $\mathrm{AgNO}_{3}$ solution until no white precipitate observed. The humic acid was transferred to weighed crucible and dried at $60^{\circ} \mathrm{C}$ in an oven for 12 hours. The humic acid was cooled and dried in the desiccator, weighed and recorded. The obtained humic acid was dried again at $60^{\circ} \mathrm{C}$ for additional 6 hours cooled and dried in the desiccator, weighed and recorded constant weight was obtained (Baruah et al., 2015).

\section{FT-IR analysis}

FT-IR spectra of humic acid sample was analysed using Carry 630 FT-IR Agilent Technologies.

Unhydrolysed compost humic acid

The unhydrolysed humic acid was obtained after isolation and purification of compost humic acid and kept for investigation.

\section{Acid hydrolysis of Peatsoil acid}

Peatsoil humic acid sample (1g) was refluxed for 12 hours at $\left(160^{\circ} \mathrm{C}\right)$ with $50 \mathrm{~cm}^{3}$ of $6 \mathrm{M} \mathrm{HCl}$. The mixture was allowed to cool, decanted, and centrifuged after hydrolysis. The insoluble residues were washed with distilled water via centrifugation several times, and the supernatant was treated with $\mathrm{AgNO}_{3}$ solution until no white precipitate was observed. The residue was thoroughly dried over $\mathrm{CaCl}_{2}$ in a desiccator at room temperature (Chefetz et al., 2002). Finally, the obtained hydrolysed humic acid was kept for investigation. 
BAJOPAS Volume 14 Number 1,June, 2021 Potentiometric Titrations

Potentiometric measurements were carried out using a pH-meter Jenway (model 3510) with combine electrode, the sensitivity of the $\mathrm{pH}$ meter is 0.01 units. The $\mathrm{pH}$ meter was switched on half an hour before starting the titration for initial warm up of the instrument. The instrument was calibrated with an aqueous standard buffer solution of $\mathrm{pH} 4.00$ and 10.0 (borate buffer) prepared from a "Qualigens" buffer tablets.

The following sets of solutions were prepared in a $250 \mathrm{~cm}^{3}$ volumetric flask separately for $\mathrm{pH}$ metric titrations.

(i) $5 \mathrm{~cm}^{3} 0.1 \mathrm{M} \mathrm{HCl}+40 \mathrm{~cm}^{3}$ deionized water

(ii) $5 \mathrm{~cm}^{3} 0.1 \mathrm{M} \mathrm{HCl}+39 \mathrm{~cm}^{3}$ deionized water $+1 \mathrm{~cm}^{3} 0.15 \mathrm{gcm}^{-3}$ humic acid

(iii) $5 \mathrm{~cm}^{3} 0.1 \mathrm{M} \mathrm{HCl}+37 \mathrm{~cm}^{3}$ deionized water $+1 \mathrm{~cm}^{3} 0.15 \mathrm{gcm}^{-3}$ humic acid

$$
+2 \mathrm{~cm}^{3} \quad 0.01 \mathrm{M} \mathrm{Cu} \text { (II) }
$$

The solutions were titrated against standardized $0.110 \mathrm{MNaOH}$ separately. The total volume of each mixture was adjusted to $50 \mathrm{~cm}^{3}$ and the ionic strength of the solutions was maintained constant at by adding appropriate amount of stock solution of $1 \mathrm{M} \mathrm{KNO}_{3}$ (Gamal, 2015; Omar and Ali, 2015). A magnetic stirrer was used to achieve thorough mixing of the interacting solutions at $550 \mathrm{rpm}$. The same set of experimental conditions was applied for potentiometric titration of remaining samples.

\section{Evaluation of pKa of Hydrolysed peat soil Humic Acids}

The proton-ligand formation number $\mathrm{n}_{\mathbf{A}}$ were calculated by Irving and Rossotti expression (Omar and Ali, 2015).

$\mathrm{nA}=\mathrm{Y}-\frac{(\mathrm{V} 2-\mathrm{V1})(\mathrm{No}-\mathrm{Eo})}{(\mathrm{VO}+\mathrm{V1}) \mathrm{TCL}}$ 1

Where: $Y$ is number of dissociable proton, $\left(\mathrm{V}_{2^{-}}\right.$ $V_{1}$ ) is the measure of displacement of the ligand curve relative to acid curve, $\mathrm{N}^{\circ}$ and $\mathrm{E}^{\circ}$ are the resultant concentration of alkali solution, free acid solution, $\mathrm{T}_{\mathrm{cL}}{ }^{\circ}$ is the total ligand concentration, $\mathrm{V}^{\circ}$ is the total volume of titration solution, $V_{1}$ is the volume of alkali added to acid solution, $V_{2}$ is the volume of alkali added to acid solution + ligand solution, acid dissociation constants (pKa - values) of ligand were calculated by algebraic method point wise calculation (Tables 1 ). The dissociation constants (pKa) were calculated according to the following relation:

$\mathrm{pKa}=\mathrm{pH}+\log \left(\frac{n A}{1-n A}\right)$ 2

Where: pKa is the acid dissociation constant, $\mathrm{n}_{\mathrm{A}}$ is the Proton-ligand formation number and $\mathrm{pH}$ is the pH-values (Omar and Ali, 2015).

\section{Determination of metal-ligand stability constants $(\log K)$ of complexes}

The potentiometric measurement for the determination of stability constant of a complex in solution is based on the fact that the redox potential of the couple $\frac{M^{+(m-n)}}{M^{+m}}$ is shifted significantly on complexation of the metal ion with the ligand. This method involves change in hydrogen ion concentration $\left[\mathrm{H}^{+}\right]$due to the displacement or association of one or more protons taking place during complexation reaction. This change can be found out by titrating the solutions containing free acid, acid with ligand, and acid with ligand and metal ion, individually against a standard alkali solution at a constant ionic strength or temperature. Either ionic strength or temperature may be varied for different sets of solutions. In all the cases, the change in the $\mathrm{pH}$ of the solution is measured after each addition of a known amount of alkali to the reaction cell which contains the reaction mixture. The titration curves are then drawn by plotting the measured $\mathrm{pH}$ values against the corresponding volume of alkali added and the stability constants of the complexes are determined from the titration curves by employing $\mathrm{pH}$-metric titration technique given by (Irving and Rossoti).

Metal-ligand stability constants ( $\log \mathrm{K}$ ) were determined by using the following relations:

$$
\bar{n}=\frac{\left(V_{3}-V_{2}\right)\left(E^{0}+N^{0}\right)}{\left(V^{0}+V_{2}\right) \bar{n}_{A} T_{m}^{0}}
$$

and

$$
P L=\log _{10}\left\{\frac{1+\beta_{n}^{H} \frac{1}{[\text { anti } \log \mathrm{pH}]^{\mathrm{n}}}}{\mathrm{T}_{\mathrm{L}}^{0}-n \bar{T}_{m}^{0}} \mathrm{X} \frac{\left(V^{0}+V_{3}\right)}{V^{0}}\right\}
$$


BAJOPAS Volume 14 Number 1,June, 2021

Where $T_{L}, T^{\circ}, E^{\circ}$, and $V^{\circ}$ havethe same significance as in equation (1) above, $T_{m}$ denotes the total concentration of metal present in solution, $V_{3}$ is the volume of metal ions present in solution and $\beta^{H}$ is the overall proton ligand stability constant. The metal-ligand stability constants (log K) were determined by employing point wise computational Method (eq. 5 and 6).

$\operatorname{LogK}_{1}=\log \left(\frac{n}{1-n}\right)+\mathrm{pL}$ .5

$\operatorname{LogK}_{2}=\log \left(\frac{1-n}{2-n}\right)+\mathrm{pL}$ ...6

Where: Log $\mathrm{K}$ is the metal-ligand stability constant, $\mathrm{pL}$ is the Free ligand exponent function, $\mathbf{n}$ is the Average number of ligand attached with metal ion (Janraoet al., 2014). The results obtained were analyzed by an ORIGIN 2016 program using titration data and then the proton-ligand stability constants (pKa) and Metal-ligand stability constant (LogK) calculated (Omar and Ali, 2015).

\section{RESULTS AND DISCUSSION}

Fourier transformed infrared (FT-IR) spectra of isolated humic acid from peat soils Figure 2 had distinct clear absorption bands indicating the presence of major humic acid structural elemental groups such as $\mathrm{H}$ bonded $\mathrm{OH}$ $\left(3680 \mathrm{~cm}^{-1}\right.$ peak $), C=0$ of carbonyl $\left(1721 \mathrm{~cm}^{-1}\right.$ peak), functional groups of aliphatic components $\mathrm{CH}_{2}\left(2918 \mathrm{~cm}^{-1}\right.$ peak) and $\mathrm{C}-\mathrm{O}$ stretching of polysaccharide $\left(1168 \mathrm{~cm}^{-1}\right.$ peak). The positions of the absorption bands of the spectra fell within typical major absorption bands of humic acid which is at frequencies 3680, 2918, 1721, 1168 $\mathrm{cm}^{-1}$. The first peak centred in the vicinity of $3680 \mathrm{~cm}^{-1}$ region is attributed to phenol $\mathrm{OH}$ group bounded by intermolecular $\mathrm{H}$ bonds. The $2918 \mathrm{~cm}^{-1}$ band usually has absorption maximum at $2918 \mathrm{~cm}^{-1}$ which is due to $\mathrm{C}-\mathrm{H}$ stretching of alkane group $\left(\mathrm{CH}_{2}\right)$. The next major absorption band is $1721 \mathrm{~cm}^{-1}$. This band has been commonly ascribed to $\mathrm{C}=\mathrm{O}$ stretching of mainly carboxyl group $(\mathrm{COOH})$ with trace amount of ketones. The last peak was observed at 1168 $\mathrm{cm}^{-1}$ due to $\mathrm{C}-\mathrm{O}$ stretching of polysaccharides and this peak appeared also in the spectra of humic acid from peat soil. The FTIR spectra of the isolated humic acid contained all major characteristic absorption peaks of humic acid. These absorption peaks indicated the presence of the major structural elements of humic acid namely $\mathrm{H}$ bonded $\mathrm{OH}, \mathrm{C}=\mathrm{C}$ of aromatic ring, $\mathrm{C}=\mathrm{O}$ of carbonyl group (both carboxyl and ketonic), $\mathrm{CH}_{2}$ group. This strongly supports the presence of humic acid.

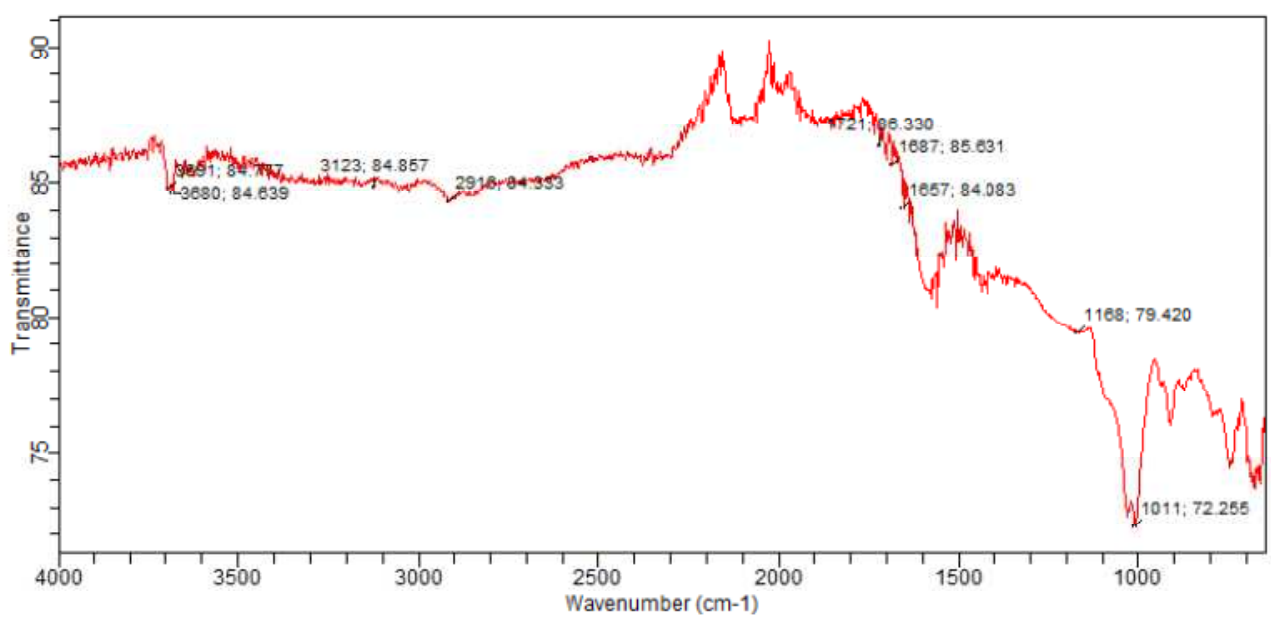

Fig. 2 : FT-IR spectraof peatsoilhumic acid (PSHA)

\section{Evaluation of acid dissociation constant (pka) of acid hydrolysed peat soil humicacid at phenolic group}

The value of the dissociation constant of the peat soil humic acid (PSHA) that underwent acidhydrolysis studied was found to be 8.9299 as shown Table 1, which is lower than the literaturevalues reported by Almeida and Szpoganics, (2015), Borges et al., (2005); Badr et al., (2012)and Fernandes et al,.(2009) of $9.73,9.47$ and 10.30. The difference between the obtained valuesand the reported values in this study might be probably as a result of acid hydrolysis of humicacid. 
BAJOPAS Volume 14 Number 1,June, 2021

Table 1: PKa of (Hydrolysed PSHA)

\begin{tabular}{|l|l|l|l|l|l|l|}
\hline $\mathrm{pH}$ & $\mathrm{BV}_{1}$ & $\mathrm{BV}_{2}$ & $\mathrm{~V}_{2}-\mathrm{V}_{1}$ & $\mathrm{nA}$ & $\log \left(\frac{n A}{1-n A}\right)$ & $\mathrm{pKa}$ \\
\hline 8.50 & 5.30 & 6.29 & 0.99 & 0.3594 & -0.2510 & 8.2490 \\
8.72 & 5.35 & 6.37 & 1.02 & 0.3400 & -0.2880 & 8.4320 \\
9.00 & 5.40 & 6.46 & 1.06 & 0.3141 & -0.3391 & 8.6609 \\
9.22 & 5.45 & 6.55 & 1.10 & 0.2882 & -0.3927 & 8.8273 \\
9.51 & 5.50 & 6.66 & 1.16 & 0.2494 & -0.4786 & 9.0314 \\
9.73 & 5.55 & 6.78 & 1.23 & 0.2041 & -0.5910 & 9.1390 \\
10.00 & 5.60 & 6.90 & 1.30 & 0.1589 & -0.7238 & 9.2762 \\
10.23 & 5.65 & 7.05 & 1.40 & 0.0941 & -0.9835 & 9.2465 \\
10.49 & 5.70 & 7.10 & 1.40 & 0.0941 & -0.9835 & 9.5065 \\
\hline
\end{tabular}

Average pKa $=8.9299 \pm 0.4186$

Table 2: PKa of (Unhydrolysed PSHA)

\begin{tabular}{|l|l|l|l|l|l|l|}
\hline $\mathrm{pH}$ & $\mathrm{BV}_{1}$ & $\mathrm{BV}_{2}$ & $\mathrm{~V}_{2}-\mathrm{V}_{1}$ & $\mathrm{nA}$ & $\log \left(\frac{\boldsymbol{n A}}{1-\boldsymbol{n}}\right)$ & $\mathrm{pKa}$ \\
\hline 8.50 & 5.30 & 5.81 & 0.51 & 0.6619 & 0.2919 & 8.7919 \\
8.72 & 5.35 & 5.90 & 0.55 & 0.6357 & 0.2418 & 8.9618 \\
9.00 & 5.40 & 6.00 & 0.60 & 0.6029 & 0.1813 & 9.1813 \\
9.22 & 5.45 & 6.10 & 0.65 & 0.5701 & 0.1226 & 9.3426 \\
9.51 & 5.50 & 6.20 & 0.70 & 0.5376 & 0.0654 & 9.5754 \\
9.73 & 5.55 & 6.33 & 0.78 & 0.4851 & -0.0259 & 9.7041 \\
10.00 & 5.60 & 6.47 & 0.87 & 0.4262 & -0.1291 & 9.8709 \\
10.23 & 5.65 & 6.62 & 0.99 & 0.3609 & -0.2481 & 9.9819 \\
10.49 & 5.70 & 6.80 & 1.10 & 0.2759 & -0.4690 & 10.0210 \\
\hline
\end{tabular}

Average pKa $=9.4923 \pm 0.4410$

Metal-ligand stability constant ( $\log \mathrm{K}$ )

The stabilityconstants require the accurate values of proton-ligand stability constants (Anil and Maroti, 2008). Metal titration curves crossed over ligand titration curve indicated the formation of complex upon proton release (Santosh, et al., 2011). If the values of n- are within range $0.2-0.8$ and $1.2-18$ this indicates the formation of $1: 1$ and 1:2 complexes (Sayyed and Mazahar, 2012).

The metal (II)-humate stepwise stability constants (log k) at phenolic group (Tables 318)

Table 3: Point-wise method, $\mathrm{Cu}$-(Hydrolysed PSHA)

\begin{tabular}{|l|l|l|l|l|l|l|l|l|}
\hline $\mathrm{pH}$ & $\mathrm{BV}_{1}$ & $\mathrm{BV}_{2}$ & $\mathrm{BV}_{3}$ & $\left(\mathrm{~V}_{3}-\mathrm{V}_{2}\right)$ & $\mathrm{n}$ & $\mathrm{pL}$ & $\log \left(\frac{n}{1-n}\right)$ & LogK $_{1}$ \\
\hline 8.50 & 5.30 & 6.29 & 6.33 & 0.04 & 0.5500 & 2.66 & 0.0871 & 2.7471 \\
8.72 & 5.35 & 6.37 & 6.41 & 0.04 & 0.5714 & 2.43 & 0.1249 & 2.5549 \\
9.00 & 5.40 & 6.46 & 6.50 & 0.04 & 0.6198 & 2.16 & 0.2122 & 2.3722 \\
9.22 & 5.45 & 6.55 & 6.59 & 0.04 & 0.6667 & 1.94 & 0.3010 & 2.2410 \\
\hline
\end{tabular}

LogK $_{1}$ (Average value) $=2.4788 \pm 0.2203$

Table 4: Point-wise method, $\mathrm{Cu}$-(Hydrolysed PSHA)

\begin{tabular}{|l|l|l|l|l|l|l|l|l|}
\hline $\mathrm{pH}$ & $\mathrm{BV}_{1}$ & $\mathrm{BV}_{2}$ & $\mathrm{BV}_{3}$ & $\left(\mathrm{~V}_{3}-\mathrm{V}_{2}\right)$ & $\mathrm{n}$ & $\mathrm{pL}$ & $\log \left(\frac{n-1}{2-n}\right)$ & LogK $_{2}$ \\
\hline 9.51 & 5.50 & 6.66 & 6.73 & 0.07 & 1.3509 & 1.70 & -0.2671 & 1.4329 \\
9.73 & 5.55 & 6.78 & 6.85 & 0.07 & 1.6383 & 1.51 & 0.2467 & 1.7567 \\
10.00 & 5.60 & 6.90 & 6.98 & 0.08 & 2.1783 & 1.31 & -0.2158 & 1.0942 \\
10.23 & 5.65 & 7.05 & 7.13 & 0.08 & 4.1904 & 1.27 & & \\
10.49 & 5.70 & 7.10 & 7.19 & 0.09 & 4.6920 & & & \\
\hline
\end{tabular}

Log $K_{2}($ Average value $)=1.4280 \pm 0.3312$ 
BAJOPAS Volume 14 Number 1,June, 2021

Table 5: Point-wise method, $\mathrm{Cu}$ (Unhydrolysed PSHA)

\begin{tabular}{|l|l|l|l|l|l|l|l|l|}
\hline $\mathrm{pH}$ & $\mathrm{BV}_{1}$ & $\mathrm{BV}_{2}$ & $\mathrm{BV}_{3}$ & $\left(\mathrm{~V}_{3}-\mathrm{V}_{2}\right)$ & $\mathrm{n}$ & $\mathrm{pL}$ & $\log \left(\frac{n}{n-1}\right)$ & Log $_{1}$ \\
\hline 8.50 & 5.30 & 5.81 & 5.85 & 0.04 & 0.2973 & 2.88 & -0.3736 & 2.5064 \\
8.72 & 5.35 & 5.90 & 5.95 & 0.05 & 0.3873 & 2.66 & -0.1992 & 2.4608 \\
9.00 & 5.40 & 6.00 & 6.05 & 0.05 & 0.4044 & 2.38 & -0.1681 & 2.2119 \\
9.22 & 5.45 & 6.10 & 6.15 & 0.06 & 0.5157 & 2.18 & -0.0272 & 2.2072 \\
9.51 & 5.50 & 6.20 & 6.27 & 0.07 & 0.6417 & 1.89 & 0.2530 & 1.1430 \\
\hline
\end{tabular}

$\operatorname{LogK}_{1}($ Average value $)=2.3059 \pm 0.6153$

Table 6:Point-wise method, $\mathrm{Cu}$ (Unhydrolysed PSHA)

\begin{tabular}{|l|l|l|l|l|l|l|l|l|}
\hline $\mathrm{pH}$ & $\mathrm{BV}_{1}$ & $\mathrm{BV}_{2}$ & $\mathrm{BV}_{3}$ & $\mathrm{~V}_{3}-\mathrm{V}_{2}$ & $\mathrm{n}$ & $\mathrm{pL}$ & $\log \left(\frac{n-1}{2-n}\right)$ & $\log \mathrm{K}_{2}$ \\
\hline 9.73 & 5.55 & 6.33 & 6.42 & 0.09 & 0.9000 & 1.69 & & \\
10.00 & 5.60 & 6.47 & 6.58 & 0.11 & 1.2578 & 1.44 & -0.4592 & 0.9808 \\
10.23 & 5.65 & 6.62 & 6.84 & 0.12 & 1.6137 & 1.26 & -0.2010 & 1.4610 \\
10.49 & 5.70 & 6.80 & 6.92 & 0.12 & 2.1052 & 1.03 & & \\
\hline
\end{tabular}

$\operatorname{LogK}_{2}$ (Average value) $=1.2209 \pm 0.3398$

Table 7:Point-wise method, Pb (Hydrolysed PSHA)

\begin{tabular}{|l|l|l|l|l|l|l|l|l|}
\hline $\mathrm{pH}$ & $\mathrm{BV}_{1}$ & $\mathrm{BV}_{2}$ & $\mathrm{BV}_{3}$ & $\left(\mathrm{~V}_{3}-\mathrm{V}_{2}\right)$ & $\mathrm{n}$ & $\mathrm{pL}$ & $\log \left(\frac{n}{1-n}\right)$ & LogK $_{1}$ \\
\hline 8.50 & 5.30 & 6.29 & 6.33 & 0.04 & 0.5500 & 2.66 & 0.0871 & 2.7471 \\
8.72 & 5.35 & 6.37 & 6.41 & 0.04 & 0.5714 & 2.43 & 0.1249 & 2.5549 \\
9.00 & 5.40 & 6.46 & 6.50 & 0.04 & 0.6198 & 2.16 & 0.2122 & 2.3722 \\
9.22 & 5.45 & 6.55 & 6.60 & 0.05 & 0.8333 & 1.96 & 0.6989 & 2.6589 \\
\hline
\end{tabular}

Log $_{\mathbf{1}}($ Average value $)=2.5832 \pm 0.1614$

Table 8:Point-wise method, Pb-(Hydrolysed PSHA)

\begin{tabular}{|l|l|l|l|l|l|l|l|l|}
\hline $\mathrm{pH}$ & $\mathrm{BV}_{1}$ & $\mathrm{BV}_{2}$ & $\mathrm{BV}_{3}$ & $\left(\mathrm{~V}_{3}-\mathrm{V}_{2}\right)$ & $\mathrm{n}$ & $\mathrm{pL}$ & $\log \left(\frac{n-1}{2-n}\right)$ & $\log \mathrm{K}_{2}$ \\
\hline 9.51 & 5.50 & 6.66 & 6.71 & 0.05 & 0.9650 & 1.67 & & \\
9.73 & 5.55 & 6.78 & 6.83 & 0.05 & 1.1702 & 1.44 & & \\
10.00 & 5.60 & 6.90 & 6.90 & 0.05 & 1.4864 & 1.22 & -0.0237 & 1.1963 \\
10.23 & 5.65 & 7.05 & 7.10 & 0.05 & 2.0190 & 1.09 & & \\
10.49 & 5.70 & 7.10 & 7.17 & 0.07 & 3.6492 & 1.00 & & \\
\hline
\end{tabular}

Log $K_{2}$ (Average value) $=1.1963$

Table 9: Point-wise method, Pb (Unhydrolysed PSHA)

\begin{tabular}{|l|l|l|l|l|l|l|l|l|}
\hline $\mathrm{pH}$ & $\mathrm{BV}_{1}$ & $\mathrm{BV}_{2}$ & $\mathrm{BV}_{3}$ & $\mathrm{~V}_{3}-\mathrm{V}_{2}$ & $\mathrm{n}$ & $\mathrm{pL}$ & $\begin{array}{l}\text { Log } \\
\left(\frac{n}{n-1}\right)\end{array}$ & Log $\mathrm{K}_{1}$ \\
\hline 8.50 & 5.30 & 5.81 & 5.85 & 0.04 & 0.2973 & 2.88 & -0.3736 & 2.5064 \\
8.72 & 5.35 & 5.90 & 5.94 & 0.04 & 0.3099 & 2.66 & -0.5477 & 2.3123 \\
9.00 & 5.40 & 6.00 & 6.05 & 0.05 & 0.4044 & 2.38 & -0.1681 & 2.2119 \\
9.22 & 5.45 & 6.10 & 6.15 & 0.06 & 0.5157 & 2.18 & 0.0272 & 2.2072 \\
9.51 & 5.50 & 6.20 & 6.26 & 0.07 & 0.6417 & 1.89 & 0.2530 & 2.1430 \\
9.73 & 5.55 & 6.40 & 6.40 & 0.07 & 0.7000 & 1.67 & 0.3680 & 2.0380 \\
\hline
\end{tabular}

LogK $_{1}$ (Average value) $=2.2364 \pm 0.1602$

Table 10: Point-wise method, Pb (Unhydrolysed PSHA)

\begin{tabular}{|l|l|l|l|l|l|l|l|l|}
\hline $\mathrm{pH}$ & $\mathrm{BV}_{1}$ & $\mathrm{BV}_{2}$ & $\mathrm{BV}_{3}$ & $\mathrm{~V}_{3}-\mathrm{V}_{2}$ & $\mathrm{n}$ & $\mathrm{pL}$ & $\log \left(\frac{n-1}{2-n}\right)$ & $\log \mathrm{K}_{2}$ \\
\hline 10.00 & 5.60 & 6.47 & 6.55 & 0.08 & 1.9503 & 1.41 & & \\
10.23 & 5.65 & 6.62 & 6.72 & 0.11 & 1.4792 & 1.26 & -0.0361 & 1.2239 \\
\hline
\end{tabular}

$\operatorname{LogK}_{2}$ (Average value) $=1.2239$

Table 11: Point-wise method, Mg (Hydrolysed PSHA)

\begin{tabular}{|l|l|l|l|l|l|l|l|l|}
\hline $\mathrm{pH}$ & $\mathrm{BV}_{1}$ & $\mathrm{BV}_{2}$ & $\mathrm{BV}_{3}$ & $\left(\mathrm{~V}_{3}-\mathrm{V}_{2}\right)$ & $\mathrm{n}$ & $\mathrm{pL}$ & $\log \left(\frac{n}{n-1}\right)$ & LogK $_{1}$ \\
\hline 8.50 & 5.30 & 6.29 & 6.31 & 0.02 & 0.2750 & 2.64 & -0.4290 & 2.2110 \\
8.72 & 5.35 & 6.37 & 6.39 & 0.02 & 0.2858 & 2.42 & -0.3978 & 2.0222 \\
9.00 & 5.40 & 6.46 & 6.49 & 0.03 & 0.4648 & 2.14 & -0.0612 & 2.0788 \\
9.22 & 5.45 & 6.55 & 6.59 & 0.04 & 0.6667 & 1.94 & 0.3010 & 2.2410 \\
\hline
\end{tabular}

$\log _{\mathbf{1}}($ Average value) $=2.1382 \pm 0.1046$ 
BAJOPAS Volume 14 Number 1,June, 2021

Table 12: Point-wise method, Mg (Hydrolysed PSHA)

\begin{tabular}{|l|l|l|l|l|l|l|l|l|}
\hline $\mathrm{pH}$ & $\mathrm{BV}_{1}$ & $\mathrm{BV}_{2}$ & $\mathrm{BV}_{3}$ & $\left(\mathrm{~V}_{3}-\mathrm{V}_{2}\right)$ & $\mathrm{n}$ & $\mathrm{pL}$ & $\log \left(\frac{n-1}{2-n}\right)$ & LogK $_{2}$ \\
\hline 9.51 & 5.55 & 6.66 & 6.71 & 0.05 & 0.9650 & 1.67 & & \\
9.73 & 5.55 & 6.78 & 6.84 & 0.06 & 1.4042 & 1.47 & -0.1686 & 1.3014 \\
10.00 & 5.60 & 6.90 & 6.93 & 0.06 & 1.7838 & 1.23 & 0.5593 & 1.7893 \\
10.23 & 5.65 & 7.05 & 7.10 & 0.06 & 3.1429 & 1.10 & & \\
10.49 & 5.70 & 7.10 & 7.18 & 0.07 & 3.6492 & 0.83 & & \\
\hline
\end{tabular}

LogK $_{2}($ Average value $)=1.5453 \pm 0.3450$

Table 13: Point-wise method, Mg (Unhydrolysed PSHA)

\begin{tabular}{|l|l|l|l|l|l|l|l|l|}
\hline $\mathrm{pH}$ & $\mathrm{BV}_{1}$ & $\mathrm{BV}_{2}$ & $\mathrm{BV}_{3}$ & $\mathrm{~V}_{3}-\mathrm{V}_{2}$ & $\mathrm{n}$ & $\mathrm{pL}$ & $\log \left(\frac{n}{n-1}\right)$ & $\operatorname{Log~}_{1}$ \\
\hline 8.50 & 5.30 & 5.81 & 5.85 & 0.04 & 0.2973 & 2.88 & -0.3736 & 2.5064 \\
8.72 & 5.35 & 5.90 & 5.94 & 0.04 & 0.3099 & 2.66 & -0.3477 & 2.3123 \\
9.00 & 5.40 & 6.00 & 6.04 & 0.04 & 0.3236 & 2.38 & -0.3202 & 2.0598 \\
9.22 & 5.45 & 6.10 & 6.15 & 0.05 & 0.4297 & 2.17 & -0.1230 & 2.0470 \\
9.51 & 5.50 & 6.20 & 6.26 & 0.06 & 0.5500 & 1.89 & 0.0871 & 1.9771 \\
9.73 & 5.55 & 6.33 & 6.40 & 0.07 & 0.7000 & 1.67 & 0.3680 & 2.0380 \\
\hline
\end{tabular}

LogK $_{1}$ (Average value) $=2.1568 \pm 0.2069$

Table 14: Point-wise method, Mg (Unhydrolysed PSHA)

\begin{tabular}{|l|l|l|l|l|l|l|l|l|}
\hline $\mathrm{pH}$ & $\mathrm{BV}_{1}$ & $\mathrm{BV}_{2}$ & $\mathrm{BV}_{3}$ & $\mathrm{~V}_{3}-\mathrm{V}_{2}$ & $\mathrm{n}$ & $\mathrm{pL}$ & $\log \left(\frac{n-1}{2-n}\right)$ & $\log \mathrm{K}_{2}$ \\
\hline 10.00 & 5.60 & 6.47 & 6.55 & 0.08 & 0.9148 & 1.41 & & \\
10.23 & 5.65 & 6.62 & 6.71 & 0.09 & 1.2102 & 1.20 & -0.5749 & 0.6251 \\
10.49 & 5.70 & 6.80 & 6.92 & 0.09 & 1.5968 & 1.03 & 0.1703 & 1.2003 \\
\hline
\end{tabular}

LogK $_{2}$ (Average value) $=0.9127 \pm 0.4070$

Table15:Point-wise method, Cd (Hydrolysed PSHA)

\begin{tabular}{|l|l|l|l|l|l|l|l|l|}
\hline $\mathrm{pH}$ & $\mathrm{BV}_{1}$ & $\mathrm{BV}_{2}$ & $\mathrm{BV}_{3}$ & $\left(\mathrm{~V}_{3}-\mathrm{V}_{2}\right)$ & $\mathrm{n}$ & $\mathrm{pL}$ & $\log \left(\frac{n}{1-n}\right)$ & LogK $_{1}$ \\
\hline 8.50 & 5.30 & 6.29 & 6.31 & 0.02 & 0.2750 & 2.64 & -0.4210 & 2.2190 \\
8.72 & 5.35 & 6.37 & 6.40 & 0.03 & 0.4286 & 2.42 & -0.1249 & 2.2951 \\
9.00 & 5.40 & 6.46 & 6.49 & 0.03 & 0.4648 & 2.14 & -0.0612 & 2.0788 \\
9.22 & 5.45 & 6.55 & 6.59 & 0.04 & 0.6667 & 1.96 & 0.3010 & 2.2610 \\
9.51 & 5.55 & 6.66 & 6.70 & 0.04 & 0.7720 & 1.67 & 0.5297 & 2.1997 \\
\hline
\end{tabular}

LogK $_{\mathbf{1}}$ (Average value) $=2.2108 \pm 0.0825$

Table 16: Point-wise method, Cd (Hydrolysed PSHA)

\begin{tabular}{|l|l|l|l|l|l|l|l|l|}
\hline $\mathrm{pH}$ & $\mathrm{BV}_{1}$ & $\mathrm{BV}_{2}$ & $\mathrm{BV}_{3}$ & $\left(\mathrm{~V}_{3}-\mathrm{V}_{2}\right)$ & $\mathrm{n}$ & $\mathrm{pL}$ & $\log \left(\frac{n-1}{2-n}\right)$ & Log $_{2}$ \\
\hline 9.73 & 5.55 & 6.78 & 6.83 & 0.06 & 1.4042 & 1.47 & -0.1686 & 1.3014 \\
10.00 & 5.60 & 6.90 & 6.95 & 0.06 & 1.7838 & 1.23 & 0.5593 & 1.7893 \\
10.23 & 5.65 & 7.05 & 7.10 & 0.06 & 3.1429 & 1.09 & & \\
10.49 & 5.70 & 7.10 & 7.16 & 0.06 & 3.1429 & 0.89 & & \\
& & & & & & & & \\
\hline
\end{tabular}

$\operatorname{LogK}_{2}$ (Average value) $=1.5453 \pm 0.3450$

Table 17: Point-wise method, Cd (Unhydrolysed PSHA)

\begin{tabular}{|l|l|l|l|l|l|l|l|l|}
\hline $\mathrm{pH}$ & $\mathrm{BV}_{1}$ & $\mathrm{BV}_{2}$ & $\mathrm{BV}_{3}$ & $\mathrm{~V}_{3}-\mathrm{V}_{2}$ & $\mathrm{n}$ & $\mathrm{pL}$ & $\log \left(\frac{n}{n-1}\right)$ & $\operatorname{Log~}_{1}$ \\
\hline 8.50 & 5.30 & 5.81 & 5.86 & 0.05 & 0.3717 & 2.88 & -0.2280 & 2.6520 \\
8.72 & 5.35 & 5.90 & 5.95 & 0.05 & 0.3873 & 2.66 & -0.1992 & 2.4608 \\
9.00 & 5.40 & 6.00 & 6.06 & 0.06 & 0.4853 & 2.38 & -0.0255 & 2.3545 \\
9.22 & 5.45 & 6.10 & 6.16 & 0.06 & 0.5157 & 2.18 & -0.0272 & 2.2072 \\
9.51 & 5.50 & 6.20 & 6.27 & 0.07 & 0.6417 & 1.89 & 0.2530 & 1.1430 \\
9.73 & 5.55 & 6.33 & 6.41 & 0.08 & 0.8000 & 1.69 & 0.6020 & 2.2920 \\
& & & & & & & & \\
\hline
\end{tabular}

$\operatorname{LogK}_{1}($ Average value $)=2.2516 \pm 0.5380$ 
BAJOPAS Volume 14 Number 1,June, 2021

Table 18: Point-wise method, Cd (Unhydrolysed PSHA)

\begin{tabular}{|l|l|l|l|l|l|l|l|l|}
\hline $\mathrm{pH}$ & $\mathrm{BV}_{1}$ & $\mathrm{BV}_{2}$ & $\mathrm{BV}_{3}$ & $\mathrm{~V}_{3}-\mathrm{V}_{2}$ & $\mathrm{n}$ & $\mathrm{pL}$ & $\log \left(\frac{n-1}{2-n}\right)$ & $\log \mathrm{K}_{2}$ \\
\hline 10.00 & 5.60 & 6.47 & 6.57 & 0.10 & 1.1434 & 1.43 & & \\
10.23 & 5.65 & 6.62 & 6.72 & 0.10 & 1.3448 & 1.23 & -0.2788 & 0.9512 \\
10.49 & 5.70 & 6.80 & 6.90 & 0.10 & 1.7742 & 1.03 & 0.5351 & 1.5651 \\
\hline
\end{tabular}

$\operatorname{LogK}_{2}($ Average value $)=1.2581 \pm 0.4340$

Table 19: Stepwise and overall Stability constants of thehydrolysed and unhydrolysed divalent metal (II) complexes

\begin{tabular}{|c|c|c|c|}
\hline Chelates & LogK $_{1}$ & $\log _{2}$ & Log $\beta$ \\
\hline [Cu (Hydrolysed PSHA-1) $\left.{ }_{2}\right]$ & 2.4788 & 1.4280 & 3.9068 \\
\hline$\left[\mathrm{Pb}(\text { Hydrolysed PSHA-1) })_{2}\right]$ & 2.5832 & 1.1963 & 3.7795 \\
\hline$\left[\mathrm{Cd}(\text { Hydrolysed PSHA-1 })_{2}\right]$ & 2.2108 & 1.5453 & 3.7561 \\
\hline$\left[\mathrm{Mg}(\text { Hydrolysed PSHA-1 })_{2}\right]$ & 2.1382 & 1.5453 & 3.6835 \\
\hline [Cu (Unhydrolysed PSHA-1) & 2.3059 & 1.2209 & 3.5268 \\
\hline$[\mathrm{Pb}$ (Unhydrolysed PSHA-1) 2$]$ & 2.2364 & 1.2239 & 3.4603 \\
\hline [Cd (Unhydrolysed PSHA-1) 2 ] & 2.2516 & 1.2581 & 3.5097 \\
\hline$[\mathrm{Mg}$ (Unydrolysed PSHA-1) & 2.1568 & 0.9127 & 3.0695 \\
\hline
\end{tabular}

The results obtained (Table19) shows the stepwise and overall stability constants to be not high indicating low stability of the complexes, because the solubility of most metal ions in the basic $\mathrm{pH}$ range is minimal due to metal hydroxide precipitation (Karimi, 2017). In general, the stepwise stability constants $\left(K_{1}\right.$ and $K_{2}$ ) follow the order $K_{1}>K_{2}$ for the copper, lead, magnesium and cadmium complexes respectively. The steady decrease of the values with increasing number of ligands is in agreement with the prediction made by researchers (Na'aliya, 2013). The decrease could be attributed to the fact that as the number of the ligands (Humate ions) that enters the coordination zone increases the aqua molecules available for replacement by the ligands become less. Thus, the metal ions become less electron loving with progressive intake of the ligand and this results in the decrease in the values of the constants (Na'aliya, 2013). Also the stability of the complexes is influenced by the size and number of the chelate rings(Mackay and Mackay,2002).All the complexes form rings in their structure as humate, a bidentate ligand, bond the metal ions in the ratio 1:2 (Boguta and Sokolowska, 2016) forming chelate rings. The values of the overall stability constants $(\log \beta)$ obtained for humate complexes are not high indicating low stability as the values are not high. LogK values for copper-humates (Table 3 to 6) obtained in this study are lower than those reported for the complexes of humic acids (Pandey et al., 2015; Dinu, 2013; Kaschl et al., 2010 and Gilbeto and Jorg, 2001). The values of LogK(Table 7 to 10 ) forlead-humates are lower than those reported for the lead in the literature (Dinu, 2013; Gilbeto and Jorg 2001). Log K values(Table 11 to 14 ) for magnesium-humates obtained in this study are close to those reported by (Pandey et al., 2015). Log K values of cadmium-humates (Table 15 to 18 ) obtained in this work near to the one reported by (Dinu, 2013 and Pandey et al., 2015).The difference between the reported values and the values obtained in this study might be probably as a result of acid hydrolysis of humic acid. The values of the overall stability constants $(\log \beta)$ of the copper humates complexes presented in Table 19 is high than that of other metal humate complexes, show relatively high stability of CuHA complexes, show the following order of stability: $\mathrm{Cu}>\mathrm{Pb}>\mathrm{Cd}>\mathrm{Mg}$; which are in close agreement to the findings of (Dinu, 2013 and Pandey et al., 2015).The high stability of Cuhumate chelate could be attributed to the existence of coordinate covalent bond between the complexing agents and the $\mathrm{Cu}^{2+}$ ions. Since, $\mathrm{Cu}^{2+}$ being a metal of the transitional series with $3 d^{9}$ electronic configurations can accept the electrons from the complexing agents. Similarly, the low stabilities of $\mathrm{Pb}, \mathrm{Cd}$ and $\mathrm{Mg}$ complexes could be explained by that $\mathrm{Pb}^{2+}$ with $6 s^{2}, \mathrm{Cd}^{2+}$ with $4 \mathrm{~d}^{10}$ and $\mathrm{Mg}^{2+}$ with $2 \mathrm{p}^{6}$ their electronic configuration has a completely filled $\mathrm{d}, \mathrm{p}$ and $\mathrm{s}$ orbitals. Moreover, the stabilities of metal ions with hydrolysed humic acid from peat soil were higher than those with unhydrolysed humic acid from peat soil; which is ascribed to the high content of acidity in hydrolysed humic acid than unhydrolysed humic acid. 
BAJOPAS Volume 14 Number 1,June, 2021 CONCLUSION

The values of logk for $\mathrm{Cu}(\mathrm{II})$ hydrolysed humic acid complex was higher followed by $\mathrm{Pb}$ (II), $\mathrm{Cd}(\mathrm{II})$ and $\mathrm{Mg}$ (II) hydrolysed humic acid complexes as compared with metal(II) unhydrolysed humic acid complexes. This indicates acid hydrolysis of humic acid can

\section{REFERENCES}

Almeida, V.R. and Szpoganicz, B. (2015). Humic Acid Potentiometric Response Patterns:Out- of Equilibrium Properties and Species Distribution Modelling. Chemical. Biol. Technol. Agric. 2: 17.

Anđelković, T., Nikolić, R., Bojić, A.,Anđelković, D., and Nikolic G.,(2010). Binding of Cadmium to Soil Humic Acid as A Function of Carboxyl Group Content. Macedonian Journal of Chemistry and Chemical Engineering.29(2): 215-224.

Anil, B. N. and Maroti, N. (2008). Studies on Influence of Die-Lectric Constants on Complex Equilibria between Substituted Py-Razalines and Lanthanide Metal Ions pH-Metrically. Amer.-Euras. scient. Res. 3(2): 212-216.

Ashok, K., Pandey, S. P. and Misra, V (2000). Stability Constants of Metal-Humic Acid Complexes and its Role in Environmental Detoxification. Journal of Ecotoxicology and Environmental Safety. 47(2):157-200.

Badr, M. H., El-Halafawi, M. H. and Abd El-al Zeid, E. R. (2012). Comparison Between the Effect of Ionic Strength on Acidity and Dissociation Constants of Humic Acids Extracted from Sewage Sludge and Nile Water Hyacinth Composts.Global Journal of Environmental Research 6 (1): 36-43.

Baruah, M.K., Borah, D., Saikia, P.P., Paul, S., Sharma, T. (2015). Evaluation of pKa Values of Soil Humic Acids and their Complexation Properties. International Journal of Plant \& Soil Science 6(4) : 218-228.

Boguta, P. Sokolowska, Z. (2016). Interactions of $\mathrm{Zn}$ (II) Ions with Humic Acids Isolated from Various Types of Soils. Effect of $\mathrm{pH}, \mathrm{Zn}$ Concentrations and Humic Acids Chemical Properties. Journal of Geochemical Explaration 168. 119-126.

Borges, F., Guimaraes, C., Lima, L.F.C., Pinto, I. and Reis, S.(2005). Potentiometric Studies on the Complexation of Copper(II) by Phenolic Acids as Discrete Ligand Models of enhance the complexation behavior of humic acid with metal (II) ions. However, the higher values of $\log \beta$ for $\mathrm{Cu}(\mathrm{II}), \mathrm{Pb}(\mathrm{II}), \mathrm{Cd}(\mathrm{II})$ and $\mathrm{Mg}(\mathrm{II})$ hydrolysed humic acid complexes indicates more stable stepwise complexes formed as compared with $\mathrm{Cu}(\mathrm{II}), \mathrm{Pb}$ (II), $\mathrm{Cd}$ (II) and $\mathrm{Mg}(\mathrm{II})$ unhydrolysed humic acid complexes.

Humic Substances Talanta 66 (2005) 670-673.

Chefetz, B., Salloum, M. J., Deshmulkin, A. P. and Hatcher, P. (2002). Structural Components of Humic Acids as Determined by Chemical Modifications and Carbon-13 NMR, Pyrolysis, and Thermochemolysis- Gas Chromatography/Mass Spectrometry. Soil Science Society of American Journal Abstract Division S-2- Soil Chemistry66. 1159-1171.

Dinu, M. I. (2013). Metals Complexation with Humic Acids in Surface Water of Different Environ. Sci. Technol. 31(1): 1-17.

Fernandes, A.N., Giacomelli, C., Giovanela, M. Vaz, D.V. Szpoganicz, B. and Maria M. D. (2009). Potentiometric Acidity Determination in Humic Substances Influenced by Different Analytical Procedures.J. Braz. Chem. Soc. 20 (9):14.

Gamal, A. H. (2015). Stability Constants of Rhenium (V) Metal Complexes with Selected Drugs. Pyrex Journal of Research in Environmental Studies. 2(2): 006-014.

Janrao, D. M., Pathan, J., Kayande, D.D., and Mulla, J.J. (2014). An Over View of Potentiometric Determination of Stability Constants of Metal Complexes. Sci. Revs. Chem. Commun.: 4(1), 2014, 11-24.

Karimi, H. (2017). Effect of pH and Initial Pb(II) Concentration on the Lead Removal Efficiency from Waste Water Using $\mathrm{Ca}(\mathrm{OH})_{2}$. International Journal of Water and Waste Water Treatment 3.2

Kaschl, A. Romheld, V. and Chen, Y. (2010). Binding of Cadmium, Copper and Zinc to Humic Substances Originating from Municipal Solid Waste Compost. Israel Journal of Chemistry Vol. 42(1): 89-98.

Kostic, I. S., Tatjana, P, A., Nikolic, R. S., Cvetkovic, T. P., Pavlovic, D. D., Aleksandar, L.J. and Bojic, A. (2012). Comparative Study of Binding Strengths of Heavy Metals with Humic Acid. J.serb. Chem. Soc. 76(9) pp 1-20. 
BAJOPAS Volume 14 Number 1,June, 2021

Na'aliya, J. (2013). Determination of Stepwise Stability Constants and Gibbs free Energy Change of Trisprolina to Complexes of some Divalent Transition Metal ions. Bayero Journal of Pure and Applied Sciences 6(2): 112-114.

Omar, A. A. and Ali, E. A. (2015). Potentiometric Studies on Complexes of $\mathrm{Cr}$ (III) and $\mathrm{Zr}$ (IV) with some Carboxylic Acids. International Journal of Advanced Chemistry, 3(1) 25-

37.

Pandey, A. K. Pandey, S. D. and Misr, V. (2015).Stability Constants of Metal- Humic Acid Complexes and Its Role in Environmental Detoxification. J. Ecotoxicology and Environmental Safety. 47(1):195-200.

Ram, N. and Raman, K.V. (1984). Stability Constants of Complexes of Metals with
Humicand Fuvic Acids under Non- acidConditions. Journal of Plant Nutrition and Soil Sciences.

147:171-176.

Santosh, D. D., Ashok, B. K., Vijay, J. T., Shivraj, G. W. and Vinay, V. W. (2011). Potentiometric Studies of Elec-Trolyte Effects on Complex Equilibria of Some Substituted 5-(2-hydroxy Phenyl) Pyrazoles. Der pharm. 3 (6): 75-83.

Sayyed, H. and Abdul Rahim, M. F. (2012). Studies of Binary Complexes of Metal Ions with Mandelic Acid by Potentiometry. Chem. J. 02 (6): 206209.

Shirvani, M. Moradian, E. Khalili, B. Bakhtiary, S. (2015). Interaction of $\mathrm{Cd}$ and $\mathrm{Pb}$ with Humate-Palygorskite and HumateSepiolite Complexes. Journal of water, air and pollution 3: 220-228. 


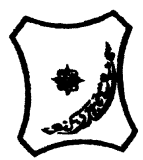

Bayero Journal of Pure and Applied Sciences, 14(1): 54 - 63

Received: November, 2020

Accepted: April, 2021

ISSN $2006-6996$

\title{
STABILITY CONSTANTS OF COMPLEXES OF METAL IONS WITH PEATSOIL HUMIC ACIDS UNDER NON-ACID-CONDITIONS
}

\author{
${ }^{* 1}$ Sabo, Yusuf ${ }^{2}$ Jimoh, W.L.O., ${ }^{3}$ Isa Baba Koki and ${ }^{4}$ Sholadoye, Q. 0. \\ ${ }^{1}$ Department of Pure and Industrial Chemistry, Bayero University, Kano \\ ${ }^{3}$ Department of Chemistry, Yusuf Maitama Sule University Kano. P.M.B. 3220 Kano, Nigeria. \\ ${ }^{4}$ Department of Chemistry, Nigerian Police Academy, Wudil, Kano-Nigeria
}

*Correspondence E-mail; saboyusuf18@yahoo.com

ABSTRACT

Stability constants of complexes of four divalent metal ions viz. $\mathrm{Cu}^{2+}, \mathrm{Pb}^{2+}, \mathrm{Mg}^{2+}$ and $\mathrm{Cd}^{2+}$ with humic acids (HA) were determined by potentiometric titration of humic acids with the corresponding salt of the divalent metals in aqueous media under non-acid-condition. The log $K$ (logarithm of the stability constant) ranged from 1.0942 to 2.7471 for metalhumic acid complexes were determined using point-wise computational method. The order of stability constants were obtained as follows: $\mathrm{Cu}>\mathrm{Pb}>\mathrm{Cd}>\mathrm{Mg}$ for metal $-\mathrm{HA}$ complexes respectively, indicating a higher degree of complexation with Cu metal ion.

Keywords: stability constant, humic acid, potentiometric titration, divalent metals, acid hydrolysis.

\section{NTRODUCTION}

The stability constant of a complex is the numerical expression of its stability and provides a quantitative measure of affinity of the metal ion to the complexing agent. An understanding of the relative stability of metal-complexes helps in predicting the behavior of metal ions in the soil (Ram and Raman, 1982). Extensive researches has been done to determine the stability constants of the complexes formed between humic acid (HA) with a number of metal ions. Ashok et al., (2000) reported that humic acid with hydroxyl, phenoxyl and carboxyl reactive groups can form coordination compound with metal ions at $\mathrm{pH}$ 3.5. The stability constants(Log K) for different metalhumic acid complexes indicated the following order of the stabilities of complexes formed between humic acid and metal ion, $\mathrm{Cu}>\mathrm{Fe}$ $>\mathrm{Pb}>\mathrm{Ni}>\mathrm{Co}>\mathrm{Ca}>\mathrm{Cd}>\mathrm{Zn}>\mathrm{Mn}>\mathrm{Mg}$. Andelkovic et al., (2010) investigated the binding of $\mathrm{Cd}$ (II) to soil humic acid at pH 6.5 and in $0.1 \mathrm{M} \mathrm{KNO}_{3}$ ionic medium. The stability constant for binding indicating greater stability in the case when carboxyl groups are involved in complexation reaction. Kostic et al.,(2012) investigated the complexation of humic acid with certain heavy metal ions (Co(II), $\mathrm{Ni}(\mathrm{II}), \mathrm{Cu}(\mathrm{II})$,
$\mathrm{Zn}(\mathrm{II})$, and $\mathrm{Pb}(\mathrm{II})$. The experiment was performed at $25^{\circ} \mathrm{C}$, at pH 4.0 and ionic strength of $0.01 \mathrm{M}$. Stability constant of complex between $\mathrm{Pb}$ (II) ions and humic acid is greater than stability constants of other investigated metalhumate complexes. Bogata and Sokolowska (2016) analyses the interaction between humic acids from different soils and $\mathrm{Zn}$ (II) ions at wide concentration ranges and at $\mathrm{pH} 5$. Studies have showed significant impact of $\mathrm{Zn}$ concentration, $\mathrm{pH}$ and some properties of humic acids with zinc.But all of these studies were limited to acidic $\mathrm{pH}$ range. Therefore, the present study was carried out to determine and compare the stability constants of complexes of metal ions with hydrolysed peat soil humic acid and unhydrolysed peat soil humic under non-acid conditions.

\section{MATERIALS AND METHODS}

Analytical grade chemicals used includes hydrochloric acid $(\mathrm{HCl})$, nitric acid $\left(\mathrm{HNO}_{3}\right)$, sodium hydroxide $(\mathrm{NaOH})$, lead nitrate $\mathrm{Pb}\left(\mathrm{NO}_{3}\right)_{2}$, copper nitrate $\mathrm{Cu}\left(\mathrm{NO}_{3}\right)_{2} \cdot 3 \mathrm{H}_{2} \mathrm{O}$, cadmium nitrate $\mathrm{Cd}\left(\mathrm{NO}_{3}\right)_{2} \cdot 4 \mathrm{H}_{2} \mathrm{O}$, magnesium nitrate $\mathrm{Mg}\left(\mathrm{NO}_{3}\right)_{2} \cdot 6 \mathrm{H}_{2} \mathrm{O}$, potassium nitrate $\left(\mathrm{KNO}_{3}\right)$, calcium chloride $\left(\mathrm{CaCl}_{2}\right)$, (sigma-Aldrich). Dowex 50WX8, (20-50 mesh) from Fluka. 


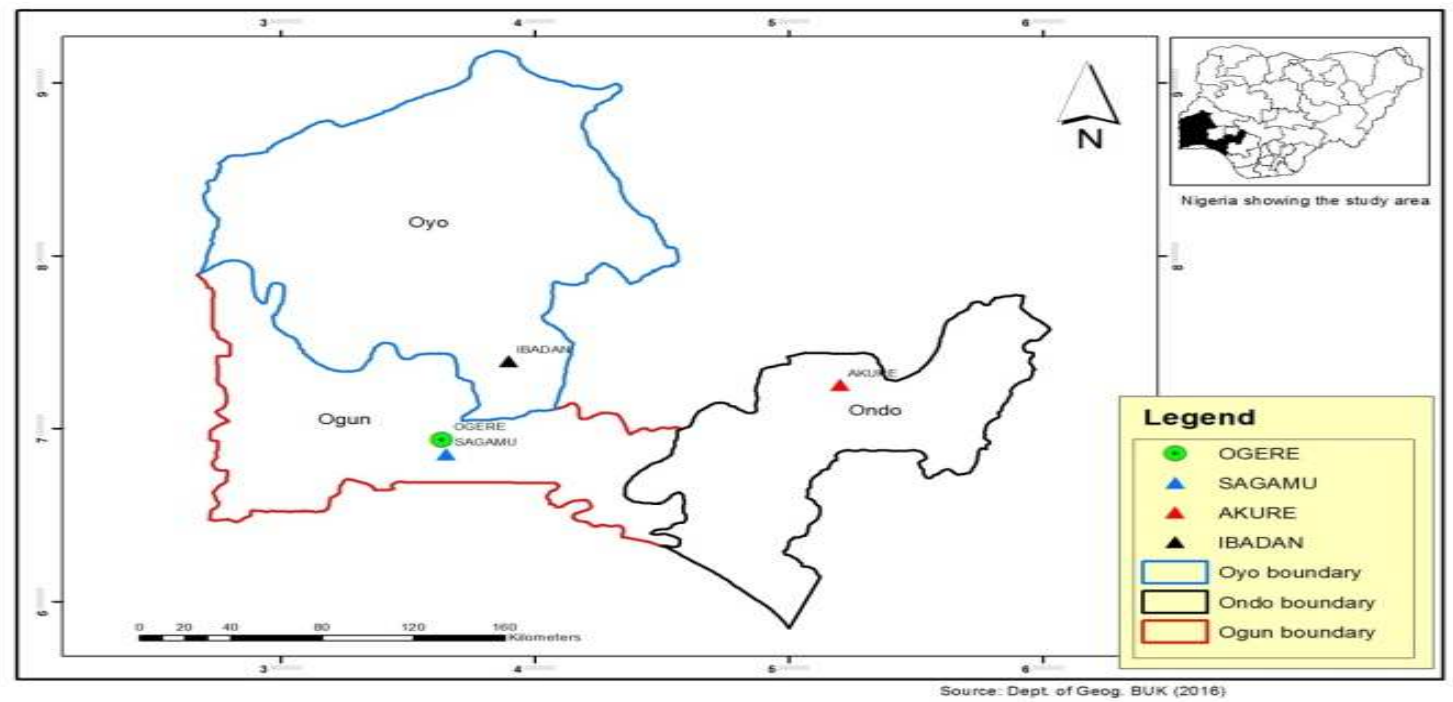

Figure 1: Map showing the sampling point at Sagamu Town, Ogun State.

\section{Description of Sampling Area}

Sagamu has geographical coordinates between $6^{\circ} 50^{\prime}$ north; $3^{\circ} 38^{\prime}$ east is located in south western region of Nigeria. The region has tropical wet and dry climate with a lengthy wet season and relatively constant temperatures throughout the course of the year. Wet season runs from March to October, November to December forms the region dry season. The vegetation type of the region is savannah which is really grassland with small bushes and occasional big trees. Grassland soils have substantially higher organic matter content than forest soils (Novackova, 2011).

\section{Sample Collection}

The Peatsoil samples were collected from four different sampling points $(0-10 \mathrm{~cm}$ depth) in Sagamu into polyethylene bag with plastic spoons. Samples were taken to the laboratory, extraneous materials were removed; the samples were air-dried, crushed and ground to a fine powder in a mortar passed through a $0.20 \mathrm{~mm}$ sieve. The samples were kept for analysis.

\section{Isolation and purification of humic acid from peat soil sample}

Peatsoil sample $(100 \mathrm{~g})$ was mixed with 1000 $\mathrm{cm}^{3}$ of $0.1 \mathrm{M} \mathrm{NaOH}$ solution, shaken for 3hours and left to stand overnight. Dark-coloured supernatant was obtained and decanted from solid residue. The dark-coloured supernatant was acidified to $(\mathrm{pH}=1.0)$ with $6 \mathrm{M} \mathrm{HCl}$ stirred and allowed to stand for 6 hours. Yellowish brown supernatant and dark-brown precipitate were obtained. The yellowish brown supernatant was decanted followed by centrifuge and discarded. The dark-brown precipitate was mixed with $500 \mathrm{~cm}^{3}$ of $0.1 \mathrm{M} \mathrm{NaOH}$ solution followed by passing through dowex resin. The dark-brown solution was acidified to $(\mathrm{pH}=1.0)$ with $6 \mathrm{M} \mathrm{HCl}$ stirred and allowed to stand for 3 hours. The dark-brown precipitate was washed several times with deionized water. The supernatant was treated with $\mathrm{AgNO}_{3}$ solution until no white precipitate observed. The humic acid was transferred to weighed crucible and dried at $60^{\circ} \mathrm{C}$ in an oven for 12 hours. The humic acid was cooled and dried in the desiccator, weighed and recorded. The obtained humic acid was dried again at $60^{\circ} \mathrm{C}$ for additional 6 hours cooled and dried in the desiccator, weighed and recorded constant weight was obtained (Baruah et al., 2015).

\section{FT-IR analysis}

FT-IR spectra of humic acid sample was analysed using Carry 630 FT-IR Agilent Technologies.

Unhydrolysed compost humic acid

The unhydrolysed humic acid was obtained after isolation and purification of compost humic acid and kept for investigation.

\section{Acid hydrolysis of Peatsoil acid}

Peatsoil humic acid sample (1g) was refluxed for 12 hours at $\left(160^{\circ} \mathrm{C}\right)$ with $50 \mathrm{~cm}^{3}$ of $6 \mathrm{M} \mathrm{HCl}$. The mixture was allowed to cool, decanted, and centrifuged after hydrolysis. The insoluble residues were washed with distilled water via centrifugation several times, and the supernatant was treated with $\mathrm{AgNO}_{3}$ solution until no white precipitate was observed. The residue was thoroughly dried over $\mathrm{CaCl}_{2}$ in a desiccator at room temperature (Chefetz et al., 2002). Finally, the obtained hydrolysed humic acid was kept for investigation. 
BAJOPAS Volume 14 Number 1,June, 2021 Potentiometric Titrations

Potentiometric measurements were carried out using a pH-meter Jenway (model 3510) with combine electrode, the sensitivity of the $\mathrm{pH}$ meter is 0.01 units. The $\mathrm{pH}$ meter was switched on half an hour before starting the titration for initial warm up of the instrument. The instrument was calibrated with an aqueous standard buffer solution of $\mathrm{pH} 4.00$ and 10.0 (borate buffer) prepared from a "Qualigens" buffer tablets.

The following sets of solutions were prepared in a $250 \mathrm{~cm}^{3}$ volumetric flask separately for $\mathrm{pH}$ metric titrations.

(i) $5 \mathrm{~cm}^{3} 0.1 \mathrm{M} \mathrm{HCl}+40 \mathrm{~cm}^{3}$ deionized water

(ii) $5 \mathrm{~cm}^{3} 0.1 \mathrm{M} \mathrm{HCl}+39 \mathrm{~cm}^{3}$ deionized water $+1 \mathrm{~cm}^{3} 0.15 \mathrm{gcm}^{-3}$ humic acid

(iii) $5 \mathrm{~cm}^{3} 0.1 \mathrm{M} \mathrm{HCl}+37 \mathrm{~cm}^{3}$ deionized water $+1 \mathrm{~cm}^{3} 0.15 \mathrm{gcm}^{-3}$ humic acid

$$
+2 \mathrm{~cm}^{3} \quad 0.01 \mathrm{M} \mathrm{Cu} \text { (II) }
$$

The solutions were titrated against standardized $0.110 \mathrm{MNaOH}$ separately. The total volume of each mixture was adjusted to $50 \mathrm{~cm}^{3}$ and the ionic strength of the solutions was maintained constant at by adding appropriate amount of stock solution of $1 \mathrm{M} \mathrm{KNO}_{3}$ (Gamal, 2015; Omar and Ali, 2015). A magnetic stirrer was used to achieve thorough mixing of the interacting solutions at $550 \mathrm{rpm}$. The same set of experimental conditions was applied for potentiometric titration of remaining samples.

\section{Evaluation of pKa of Hydrolysed peat soil Humic Acids}

The proton-ligand formation number $\mathrm{n}_{\mathbf{A}}$ were calculated by Irving and Rossotti expression (Omar and Ali, 2015).

$\mathrm{nA}=\mathrm{Y}-\frac{(\mathrm{V} 2-\mathrm{V1})(\mathrm{No}-\mathrm{Eo})}{(\mathrm{VO}+\mathrm{V1}) \mathrm{TCL}}$ 1

Where: $Y$ is number of dissociable proton, $\left(\mathrm{V}_{2^{-}}\right.$ $V_{1}$ ) is the measure of displacement of the ligand curve relative to acid curve, $\mathrm{N}^{\circ}$ and $\mathrm{E}^{\circ}$ are the resultant concentration of alkali solution, free acid solution, $\mathrm{T}_{\mathrm{cL}}{ }^{\circ}$ is the total ligand concentration, $\mathrm{V}^{\circ}$ is the total volume of titration solution, $V_{1}$ is the volume of alkali added to acid solution, $V_{2}$ is the volume of alkali added to acid solution + ligand solution, acid dissociation constants (pKa - values) of ligand were calculated by algebraic method point wise calculation (Tables 1 ). The dissociation constants (pKa) were calculated according to the following relation:

$\mathrm{pKa}=\mathrm{pH}+\log \left(\frac{n A}{1-n A}\right)$ 2

Where: pKa is the acid dissociation constant, $\mathrm{n}_{\mathrm{A}}$ is the Proton-ligand formation number and $\mathrm{pH}$ is the pH-values (Omar and Ali, 2015).

\section{Determination of metal-ligand stability constants $(\log K)$ of complexes}

The potentiometric measurement for the determination of stability constant of a complex in solution is based on the fact that the redox potential of the couple $\frac{M^{+(m-n)}}{M^{+m}}$ is shifted significantly on complexation of the metal ion with the ligand. This method involves change in hydrogen ion concentration $\left[\mathrm{H}^{+}\right]$due to the displacement or association of one or more protons taking place during complexation reaction. This change can be found out by titrating the solutions containing free acid, acid with ligand, and acid with ligand and metal ion, individually against a standard alkali solution at a constant ionic strength or temperature. Either ionic strength or temperature may be varied for different sets of solutions. In all the cases, the change in the $\mathrm{pH}$ of the solution is measured after each addition of a known amount of alkali to the reaction cell which contains the reaction mixture. The titration curves are then drawn by plotting the measured $\mathrm{pH}$ values against the corresponding volume of alkali added and the stability constants of the complexes are determined from the titration curves by employing $\mathrm{pH}$-metric titration technique given by (Irving and Rossoti).

Metal-ligand stability constants ( $\log \mathrm{K}$ ) were determined by using the following relations:

$$
\bar{n}=\frac{\left(V_{3}-V_{2}\right)\left(E^{0}+N^{0}\right)}{\left(V^{0}+V_{2}\right) \bar{n}_{A} T_{m}^{0}}
$$

and

$$
P L=\log _{10}\left\{\frac{1+\beta_{n}^{H} \frac{1}{[\text { anti } \log \mathrm{pH}]^{\mathrm{n}}}}{\mathrm{T}_{\mathrm{L}}^{0}-n \bar{T}_{m}^{0}} \mathrm{X} \frac{\left(V^{0}+V_{3}\right)}{V^{0}}\right\}
$$


BAJOPAS Volume 14 Number 1,June, 2021

Where $T_{L}, T^{\circ}, E^{\circ}$, and $V^{\circ}$ havethe same significance as in equation (1) above, $T_{m}$ denotes the total concentration of metal present in solution, $V_{3}$ is the volume of metal ions present in solution and $\beta^{H}$ is the overall proton ligand stability constant. The metal-ligand stability constants (log K) were determined by employing point wise computational Method (eq. 5 and 6).

$\operatorname{LogK}_{1}=\log \left(\frac{n}{1-n}\right)+\mathrm{pL}$ .5

$\operatorname{LogK}_{2}=\log \left(\frac{1-n}{2-n}\right)+\mathrm{pL}$ ...6

Where: Log $\mathrm{K}$ is the metal-ligand stability constant, $\mathrm{pL}$ is the Free ligand exponent function, $\mathbf{n}$ is the Average number of ligand attached with metal ion (Janraoet al., 2014). The results obtained were analyzed by an ORIGIN 2016 program using titration data and then the proton-ligand stability constants (pKa) and Metal-ligand stability constant (LogK) calculated (Omar and Ali, 2015).

\section{RESULTS AND DISCUSSION}

Fourier transformed infrared (FT-IR) spectra of isolated humic acid from peat soils Figure 2 had distinct clear absorption bands indicating the presence of major humic acid structural elemental groups such as $\mathrm{H}$ bonded $\mathrm{OH}$ $\left(3680 \mathrm{~cm}^{-1}\right.$ peak $), C=0$ of carbonyl $\left(1721 \mathrm{~cm}^{-1}\right.$ peak), functional groups of aliphatic components $\mathrm{CH}_{2}\left(2918 \mathrm{~cm}^{-1}\right.$ peak) and $\mathrm{C}-\mathrm{O}$ stretching of polysaccharide $\left(1168 \mathrm{~cm}^{-1}\right.$ peak). The positions of the absorption bands of the spectra fell within typical major absorption bands of humic acid which is at frequencies 3680, 2918, 1721, 1168 $\mathrm{cm}^{-1}$. The first peak centred in the vicinity of $3680 \mathrm{~cm}^{-1}$ region is attributed to phenol $\mathrm{OH}$ group bounded by intermolecular $\mathrm{H}$ bonds. The $2918 \mathrm{~cm}^{-1}$ band usually has absorption maximum at $2918 \mathrm{~cm}^{-1}$ which is due to $\mathrm{C}-\mathrm{H}$ stretching of alkane group $\left(\mathrm{CH}_{2}\right)$. The next major absorption band is $1721 \mathrm{~cm}^{-1}$. This band has been commonly ascribed to $\mathrm{C}=\mathrm{O}$ stretching of mainly carboxyl group $(\mathrm{COOH})$ with trace amount of ketones. The last peak was observed at 1168 $\mathrm{cm}^{-1}$ due to $\mathrm{C}-\mathrm{O}$ stretching of polysaccharides and this peak appeared also in the spectra of humic acid from peat soil. The FTIR spectra of the isolated humic acid contained all major characteristic absorption peaks of humic acid. These absorption peaks indicated the presence of the major structural elements of humic acid namely $\mathrm{H}$ bonded $\mathrm{OH}, \mathrm{C}=\mathrm{C}$ of aromatic ring, $\mathrm{C}=\mathrm{O}$ of carbonyl group (both carboxyl and ketonic), $\mathrm{CH}_{2}$ group. This strongly supports the presence of humic acid.

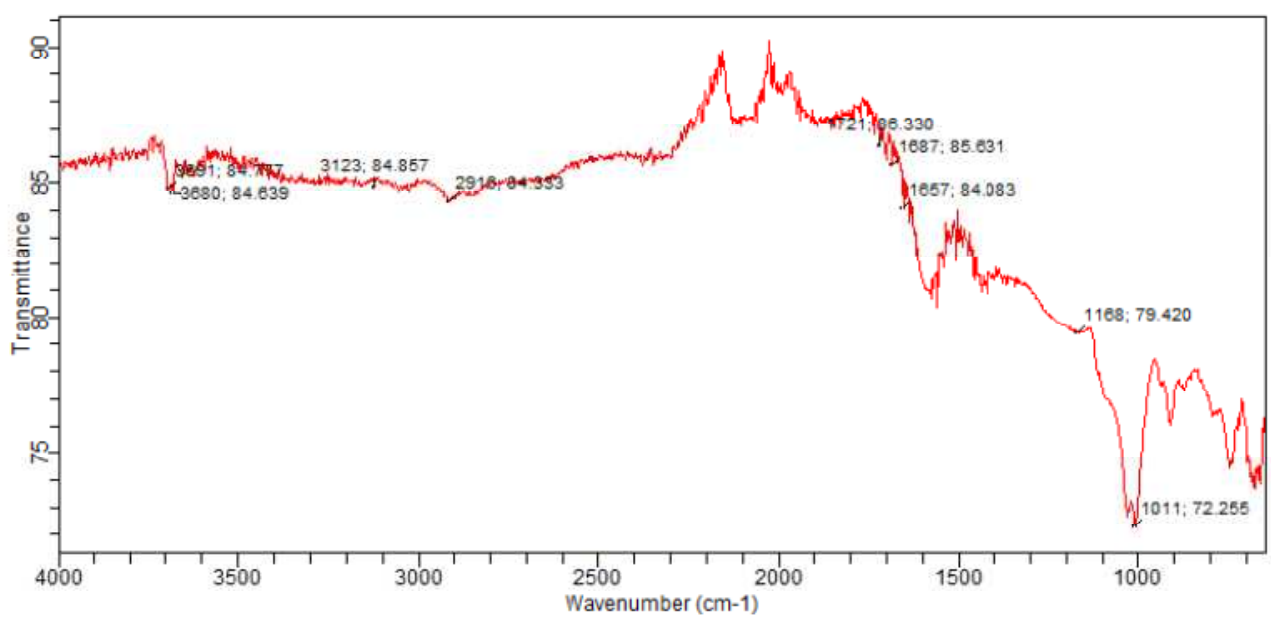

Fig. 2 : FT-IR spectraof peatsoilhumic acid (PSHA)

\section{Evaluation of acid dissociation constant (pka) of acid hydrolysed peat soil humicacid at phenolic group}

The value of the dissociation constant of the peat soil humic acid (PSHA) that underwent acidhydrolysis studied was found to be 8.9299 as shown Table 1, which is lower than the literaturevalues reported by Almeida and Szpoganics, (2015), Borges et al., (2005); Badr et al., (2012)and Fernandes et al,.(2009) of $9.73,9.47$ and 10.30. The difference between the obtained valuesand the reported values in this study might be probably as a result of acid hydrolysis of humicacid. 
BAJOPAS Volume 14 Number 1,June, 2021

Table 1: PKa of (Hydrolysed PSHA)

\begin{tabular}{|l|l|l|l|l|l|l|}
\hline $\mathrm{pH}$ & $\mathrm{BV}_{1}$ & $\mathrm{BV}_{2}$ & $\mathrm{~V}_{2}-\mathrm{V}_{1}$ & $\mathrm{nA}$ & $\log \left(\frac{n A}{1-n A}\right)$ & $\mathrm{pKa}$ \\
\hline 8.50 & 5.30 & 6.29 & 0.99 & 0.3594 & -0.2510 & 8.2490 \\
8.72 & 5.35 & 6.37 & 1.02 & 0.3400 & -0.2880 & 8.4320 \\
9.00 & 5.40 & 6.46 & 1.06 & 0.3141 & -0.3391 & 8.6609 \\
9.22 & 5.45 & 6.55 & 1.10 & 0.2882 & -0.3927 & 8.8273 \\
9.51 & 5.50 & 6.66 & 1.16 & 0.2494 & -0.4786 & 9.0314 \\
9.73 & 5.55 & 6.78 & 1.23 & 0.2041 & -0.5910 & 9.1390 \\
10.00 & 5.60 & 6.90 & 1.30 & 0.1589 & -0.7238 & 9.2762 \\
10.23 & 5.65 & 7.05 & 1.40 & 0.0941 & -0.9835 & 9.2465 \\
10.49 & 5.70 & 7.10 & 1.40 & 0.0941 & -0.9835 & 9.5065 \\
\hline
\end{tabular}

Average pKa $=8.9299 \pm 0.4186$

Table 2: PKa of (Unhydrolysed PSHA)

\begin{tabular}{|l|l|l|l|l|l|l|}
\hline $\mathrm{pH}$ & $\mathrm{BV}_{1}$ & $\mathrm{BV}_{2}$ & $\mathrm{~V}_{2}-\mathrm{V}_{1}$ & $\mathrm{nA}$ & $\log \left(\frac{\boldsymbol{n A}}{1-\boldsymbol{n}}\right)$ & $\mathrm{pKa}$ \\
\hline 8.50 & 5.30 & 5.81 & 0.51 & 0.6619 & 0.2919 & 8.7919 \\
8.72 & 5.35 & 5.90 & 0.55 & 0.6357 & 0.2418 & 8.9618 \\
9.00 & 5.40 & 6.00 & 0.60 & 0.6029 & 0.1813 & 9.1813 \\
9.22 & 5.45 & 6.10 & 0.65 & 0.5701 & 0.1226 & 9.3426 \\
9.51 & 5.50 & 6.20 & 0.70 & 0.5376 & 0.0654 & 9.5754 \\
9.73 & 5.55 & 6.33 & 0.78 & 0.4851 & -0.0259 & 9.7041 \\
10.00 & 5.60 & 6.47 & 0.87 & 0.4262 & -0.1291 & 9.8709 \\
10.23 & 5.65 & 6.62 & 0.99 & 0.3609 & -0.2481 & 9.9819 \\
10.49 & 5.70 & 6.80 & 1.10 & 0.2759 & -0.4690 & 10.0210 \\
\hline
\end{tabular}

Average pKa $=9.4923 \pm 0.4410$

Metal-ligand stability constant ( $\log \mathrm{K}$ )

The stabilityconstants require the accurate values of proton-ligand stability constants (Anil and Maroti, 2008). Metal titration curves crossed over ligand titration curve indicated the formation of complex upon proton release (Santosh, et al., 2011). If the values of n- are within range $0.2-0.8$ and $1.2-18$ this indicates the formation of $1: 1$ and 1:2 complexes (Sayyed and Mazahar, 2012).

The metal (II)-humate stepwise stability constants (log k) at phenolic group (Tables 318)

Table 3: Point-wise method, $\mathrm{Cu}$-(Hydrolysed PSHA)

\begin{tabular}{|l|l|l|l|l|l|l|l|l|}
\hline $\mathrm{pH}$ & $\mathrm{BV}_{1}$ & $\mathrm{BV}_{2}$ & $\mathrm{BV}_{3}$ & $\left(\mathrm{~V}_{3}-\mathrm{V}_{2}\right)$ & $\mathrm{n}$ & $\mathrm{pL}$ & $\log \left(\frac{n}{1-n}\right)$ & LogK $_{1}$ \\
\hline 8.50 & 5.30 & 6.29 & 6.33 & 0.04 & 0.5500 & 2.66 & 0.0871 & 2.7471 \\
8.72 & 5.35 & 6.37 & 6.41 & 0.04 & 0.5714 & 2.43 & 0.1249 & 2.5549 \\
9.00 & 5.40 & 6.46 & 6.50 & 0.04 & 0.6198 & 2.16 & 0.2122 & 2.3722 \\
9.22 & 5.45 & 6.55 & 6.59 & 0.04 & 0.6667 & 1.94 & 0.3010 & 2.2410 \\
\hline
\end{tabular}

LogK $_{1}$ (Average value) $=2.4788 \pm 0.2203$

Table 4: Point-wise method, $\mathrm{Cu}$-(Hydrolysed PSHA)

\begin{tabular}{|l|l|l|l|l|l|l|l|l|}
\hline $\mathrm{pH}$ & $\mathrm{BV}_{1}$ & $\mathrm{BV}_{2}$ & $\mathrm{BV}_{3}$ & $\left(\mathrm{~V}_{3}-\mathrm{V}_{2}\right)$ & $\mathrm{n}$ & $\mathrm{pL}$ & $\log \left(\frac{n-1}{2-n}\right)$ & LogK $_{2}$ \\
\hline 9.51 & 5.50 & 6.66 & 6.73 & 0.07 & 1.3509 & 1.70 & -0.2671 & 1.4329 \\
9.73 & 5.55 & 6.78 & 6.85 & 0.07 & 1.6383 & 1.51 & 0.2467 & 1.7567 \\
10.00 & 5.60 & 6.90 & 6.98 & 0.08 & 2.1783 & 1.31 & -0.2158 & 1.0942 \\
10.23 & 5.65 & 7.05 & 7.13 & 0.08 & 4.1904 & 1.27 & & \\
10.49 & 5.70 & 7.10 & 7.19 & 0.09 & 4.6920 & & & \\
\hline
\end{tabular}

Log $K_{2}($ Average value $)=1.4280 \pm 0.3312$ 
BAJOPAS Volume 14 Number 1,June, 2021

Table 5: Point-wise method, $\mathrm{Cu}$ (Unhydrolysed PSHA)

\begin{tabular}{|l|l|l|l|l|l|l|l|l|}
\hline $\mathrm{pH}$ & $\mathrm{BV}_{1}$ & $\mathrm{BV}_{2}$ & $\mathrm{BV}_{3}$ & $\left(\mathrm{~V}_{3}-\mathrm{V}_{2}\right)$ & $\mathrm{n}$ & $\mathrm{pL}$ & $\log \left(\frac{n}{n-1}\right)$ & Log $_{1}$ \\
\hline 8.50 & 5.30 & 5.81 & 5.85 & 0.04 & 0.2973 & 2.88 & -0.3736 & 2.5064 \\
8.72 & 5.35 & 5.90 & 5.95 & 0.05 & 0.3873 & 2.66 & -0.1992 & 2.4608 \\
9.00 & 5.40 & 6.00 & 6.05 & 0.05 & 0.4044 & 2.38 & -0.1681 & 2.2119 \\
9.22 & 5.45 & 6.10 & 6.15 & 0.06 & 0.5157 & 2.18 & -0.0272 & 2.2072 \\
9.51 & 5.50 & 6.20 & 6.27 & 0.07 & 0.6417 & 1.89 & 0.2530 & 1.1430 \\
\hline
\end{tabular}

$\operatorname{LogK}_{1}($ Average value $)=2.3059 \pm 0.6153$

Table 6:Point-wise method, $\mathrm{Cu}$ (Unhydrolysed PSHA)

\begin{tabular}{|l|l|l|l|l|l|l|l|l|}
\hline $\mathrm{pH}$ & $\mathrm{BV}_{1}$ & $\mathrm{BV}_{2}$ & $\mathrm{BV}_{3}$ & $\mathrm{~V}_{3}-\mathrm{V}_{2}$ & $\mathrm{n}$ & $\mathrm{pL}$ & $\log \left(\frac{n-1}{2-n}\right)$ & $\log \mathrm{K}_{2}$ \\
\hline 9.73 & 5.55 & 6.33 & 6.42 & 0.09 & 0.9000 & 1.69 & & \\
10.00 & 5.60 & 6.47 & 6.58 & 0.11 & 1.2578 & 1.44 & -0.4592 & 0.9808 \\
10.23 & 5.65 & 6.62 & 6.84 & 0.12 & 1.6137 & 1.26 & -0.2010 & 1.4610 \\
10.49 & 5.70 & 6.80 & 6.92 & 0.12 & 2.1052 & 1.03 & & \\
\hline
\end{tabular}

$\operatorname{LogK}_{2}$ (Average value) $=1.2209 \pm 0.3398$

Table 7:Point-wise method, Pb (Hydrolysed PSHA)

\begin{tabular}{|l|l|l|l|l|l|l|l|l|}
\hline $\mathrm{pH}$ & $\mathrm{BV}_{1}$ & $\mathrm{BV}_{2}$ & $\mathrm{BV}_{3}$ & $\left(\mathrm{~V}_{3}-\mathrm{V}_{2}\right)$ & $\mathrm{n}$ & $\mathrm{pL}$ & $\log \left(\frac{n}{1-n}\right)$ & LogK $_{1}$ \\
\hline 8.50 & 5.30 & 6.29 & 6.33 & 0.04 & 0.5500 & 2.66 & 0.0871 & 2.7471 \\
8.72 & 5.35 & 6.37 & 6.41 & 0.04 & 0.5714 & 2.43 & 0.1249 & 2.5549 \\
9.00 & 5.40 & 6.46 & 6.50 & 0.04 & 0.6198 & 2.16 & 0.2122 & 2.3722 \\
9.22 & 5.45 & 6.55 & 6.60 & 0.05 & 0.8333 & 1.96 & 0.6989 & 2.6589 \\
\hline
\end{tabular}

Log $_{\mathbf{1}}($ Average value $)=2.5832 \pm 0.1614$

Table 8:Point-wise method, Pb-(Hydrolysed PSHA)

\begin{tabular}{|l|l|l|l|l|l|l|l|l|}
\hline $\mathrm{pH}$ & $\mathrm{BV}_{1}$ & $\mathrm{BV}_{2}$ & $\mathrm{BV}_{3}$ & $\left(\mathrm{~V}_{3}-\mathrm{V}_{2}\right)$ & $\mathrm{n}$ & $\mathrm{pL}$ & $\log \left(\frac{n-1}{2-n}\right)$ & $\log \mathrm{K}_{2}$ \\
\hline 9.51 & 5.50 & 6.66 & 6.71 & 0.05 & 0.9650 & 1.67 & & \\
9.73 & 5.55 & 6.78 & 6.83 & 0.05 & 1.1702 & 1.44 & & \\
10.00 & 5.60 & 6.90 & 6.90 & 0.05 & 1.4864 & 1.22 & -0.0237 & 1.1963 \\
10.23 & 5.65 & 7.05 & 7.10 & 0.05 & 2.0190 & 1.09 & & \\
10.49 & 5.70 & 7.10 & 7.17 & 0.07 & 3.6492 & 1.00 & & \\
\hline
\end{tabular}

Log $K_{2}$ (Average value) $=1.1963$

Table 9: Point-wise method, Pb (Unhydrolysed PSHA)

\begin{tabular}{|l|l|l|l|l|l|l|l|l|}
\hline $\mathrm{pH}$ & $\mathrm{BV}_{1}$ & $\mathrm{BV}_{2}$ & $\mathrm{BV}_{3}$ & $\mathrm{~V}_{3}-\mathrm{V}_{2}$ & $\mathrm{n}$ & $\mathrm{pL}$ & $\begin{array}{l}\text { Log } \\
\left(\frac{n}{n-1}\right)\end{array}$ & Log $\mathrm{K}_{1}$ \\
\hline 8.50 & 5.30 & 5.81 & 5.85 & 0.04 & 0.2973 & 2.88 & -0.3736 & 2.5064 \\
8.72 & 5.35 & 5.90 & 5.94 & 0.04 & 0.3099 & 2.66 & -0.5477 & 2.3123 \\
9.00 & 5.40 & 6.00 & 6.05 & 0.05 & 0.4044 & 2.38 & -0.1681 & 2.2119 \\
9.22 & 5.45 & 6.10 & 6.15 & 0.06 & 0.5157 & 2.18 & 0.0272 & 2.2072 \\
9.51 & 5.50 & 6.20 & 6.26 & 0.07 & 0.6417 & 1.89 & 0.2530 & 2.1430 \\
9.73 & 5.55 & 6.40 & 6.40 & 0.07 & 0.7000 & 1.67 & 0.3680 & 2.0380 \\
\hline
\end{tabular}

LogK $_{1}$ (Average value) $=2.2364 \pm 0.1602$

Table 10: Point-wise method, Pb (Unhydrolysed PSHA)

\begin{tabular}{|l|l|l|l|l|l|l|l|l|}
\hline $\mathrm{pH}$ & $\mathrm{BV}_{1}$ & $\mathrm{BV}_{2}$ & $\mathrm{BV}_{3}$ & $\mathrm{~V}_{3}-\mathrm{V}_{2}$ & $\mathrm{n}$ & $\mathrm{pL}$ & $\log \left(\frac{n-1}{2-n}\right)$ & $\log \mathrm{K}_{2}$ \\
\hline 10.00 & 5.60 & 6.47 & 6.55 & 0.08 & 1.9503 & 1.41 & & \\
10.23 & 5.65 & 6.62 & 6.72 & 0.11 & 1.4792 & 1.26 & -0.0361 & 1.2239 \\
\hline
\end{tabular}

$\operatorname{LogK}_{2}$ (Average value) $=1.2239$

Table 11: Point-wise method, Mg (Hydrolysed PSHA)

\begin{tabular}{|l|l|l|l|l|l|l|l|l|}
\hline $\mathrm{pH}$ & $\mathrm{BV}_{1}$ & $\mathrm{BV}_{2}$ & $\mathrm{BV}_{3}$ & $\left(\mathrm{~V}_{3}-\mathrm{V}_{2}\right)$ & $\mathrm{n}$ & $\mathrm{pL}$ & $\log \left(\frac{n}{n-1}\right)$ & LogK $_{1}$ \\
\hline 8.50 & 5.30 & 6.29 & 6.31 & 0.02 & 0.2750 & 2.64 & -0.4290 & 2.2110 \\
8.72 & 5.35 & 6.37 & 6.39 & 0.02 & 0.2858 & 2.42 & -0.3978 & 2.0222 \\
9.00 & 5.40 & 6.46 & 6.49 & 0.03 & 0.4648 & 2.14 & -0.0612 & 2.0788 \\
9.22 & 5.45 & 6.55 & 6.59 & 0.04 & 0.6667 & 1.94 & 0.3010 & 2.2410 \\
\hline
\end{tabular}

$\log _{\mathbf{1}}($ Average value) $=2.1382 \pm 0.1046$ 
BAJOPAS Volume 14 Number 1,June, 2021

Table 12: Point-wise method, Mg (Hydrolysed PSHA)

\begin{tabular}{|l|l|l|l|l|l|l|l|l|}
\hline $\mathrm{pH}$ & $\mathrm{BV}_{1}$ & $\mathrm{BV}_{2}$ & $\mathrm{BV}_{3}$ & $\left(\mathrm{~V}_{3}-\mathrm{V}_{2}\right)$ & $\mathrm{n}$ & $\mathrm{pL}$ & $\log \left(\frac{n-1}{2-n}\right)$ & LogK $_{2}$ \\
\hline 9.51 & 5.55 & 6.66 & 6.71 & 0.05 & 0.9650 & 1.67 & & \\
9.73 & 5.55 & 6.78 & 6.84 & 0.06 & 1.4042 & 1.47 & -0.1686 & 1.3014 \\
10.00 & 5.60 & 6.90 & 6.93 & 0.06 & 1.7838 & 1.23 & 0.5593 & 1.7893 \\
10.23 & 5.65 & 7.05 & 7.10 & 0.06 & 3.1429 & 1.10 & & \\
10.49 & 5.70 & 7.10 & 7.18 & 0.07 & 3.6492 & 0.83 & & \\
\hline
\end{tabular}

LogK $_{2}($ Average value $)=1.5453 \pm 0.3450$

Table 13: Point-wise method, Mg (Unhydrolysed PSHA)

\begin{tabular}{|l|l|l|l|l|l|l|l|l|}
\hline $\mathrm{pH}$ & $\mathrm{BV}_{1}$ & $\mathrm{BV}_{2}$ & $\mathrm{BV}_{3}$ & $\mathrm{~V}_{3}-\mathrm{V}_{2}$ & $\mathrm{n}$ & $\mathrm{pL}$ & $\log \left(\frac{n}{n-1}\right)$ & $\operatorname{Log~}_{1}$ \\
\hline 8.50 & 5.30 & 5.81 & 5.85 & 0.04 & 0.2973 & 2.88 & -0.3736 & 2.5064 \\
8.72 & 5.35 & 5.90 & 5.94 & 0.04 & 0.3099 & 2.66 & -0.3477 & 2.3123 \\
9.00 & 5.40 & 6.00 & 6.04 & 0.04 & 0.3236 & 2.38 & -0.3202 & 2.0598 \\
9.22 & 5.45 & 6.10 & 6.15 & 0.05 & 0.4297 & 2.17 & -0.1230 & 2.0470 \\
9.51 & 5.50 & 6.20 & 6.26 & 0.06 & 0.5500 & 1.89 & 0.0871 & 1.9771 \\
9.73 & 5.55 & 6.33 & 6.40 & 0.07 & 0.7000 & 1.67 & 0.3680 & 2.0380 \\
\hline
\end{tabular}

LogK $_{1}$ (Average value) $=2.1568 \pm 0.2069$

Table 14: Point-wise method, Mg (Unhydrolysed PSHA)

\begin{tabular}{|l|l|l|l|l|l|l|l|l|}
\hline $\mathrm{pH}$ & $\mathrm{BV}_{1}$ & $\mathrm{BV}_{2}$ & $\mathrm{BV}_{3}$ & $\mathrm{~V}_{3}-\mathrm{V}_{2}$ & $\mathrm{n}$ & $\mathrm{pL}$ & $\log \left(\frac{n-1}{2-n}\right)$ & $\log \mathrm{K}_{2}$ \\
\hline 10.00 & 5.60 & 6.47 & 6.55 & 0.08 & 0.9148 & 1.41 & & \\
10.23 & 5.65 & 6.62 & 6.71 & 0.09 & 1.2102 & 1.20 & -0.5749 & 0.6251 \\
10.49 & 5.70 & 6.80 & 6.92 & 0.09 & 1.5968 & 1.03 & 0.1703 & 1.2003 \\
\hline
\end{tabular}

LogK $_{2}$ (Average value) $=0.9127 \pm 0.4070$

Table15:Point-wise method, Cd (Hydrolysed PSHA)

\begin{tabular}{|l|l|l|l|l|l|l|l|l|}
\hline $\mathrm{pH}$ & $\mathrm{BV}_{1}$ & $\mathrm{BV}_{2}$ & $\mathrm{BV}_{3}$ & $\left(\mathrm{~V}_{3}-\mathrm{V}_{2}\right)$ & $\mathrm{n}$ & $\mathrm{pL}$ & $\log \left(\frac{n}{1-n}\right)$ & LogK $_{1}$ \\
\hline 8.50 & 5.30 & 6.29 & 6.31 & 0.02 & 0.2750 & 2.64 & -0.4210 & 2.2190 \\
8.72 & 5.35 & 6.37 & 6.40 & 0.03 & 0.4286 & 2.42 & -0.1249 & 2.2951 \\
9.00 & 5.40 & 6.46 & 6.49 & 0.03 & 0.4648 & 2.14 & -0.0612 & 2.0788 \\
9.22 & 5.45 & 6.55 & 6.59 & 0.04 & 0.6667 & 1.96 & 0.3010 & 2.2610 \\
9.51 & 5.55 & 6.66 & 6.70 & 0.04 & 0.7720 & 1.67 & 0.5297 & 2.1997 \\
\hline
\end{tabular}

LogK $_{\mathbf{1}}$ (Average value) $=2.2108 \pm 0.0825$

Table 16: Point-wise method, Cd (Hydrolysed PSHA)

\begin{tabular}{|l|l|l|l|l|l|l|l|l|}
\hline $\mathrm{pH}$ & $\mathrm{BV}_{1}$ & $\mathrm{BV}_{2}$ & $\mathrm{BV}_{3}$ & $\left(\mathrm{~V}_{3}-\mathrm{V}_{2}\right)$ & $\mathrm{n}$ & $\mathrm{pL}$ & $\log \left(\frac{n-1}{2-n}\right)$ & Log $_{2}$ \\
\hline 9.73 & 5.55 & 6.78 & 6.83 & 0.06 & 1.4042 & 1.47 & -0.1686 & 1.3014 \\
10.00 & 5.60 & 6.90 & 6.95 & 0.06 & 1.7838 & 1.23 & 0.5593 & 1.7893 \\
10.23 & 5.65 & 7.05 & 7.10 & 0.06 & 3.1429 & 1.09 & & \\
10.49 & 5.70 & 7.10 & 7.16 & 0.06 & 3.1429 & 0.89 & & \\
& & & & & & & & \\
\hline
\end{tabular}

$\operatorname{LogK}_{2}$ (Average value) $=1.5453 \pm 0.3450$

Table 17: Point-wise method, Cd (Unhydrolysed PSHA)

\begin{tabular}{|l|l|l|l|l|l|l|l|l|}
\hline $\mathrm{pH}$ & $\mathrm{BV}_{1}$ & $\mathrm{BV}_{2}$ & $\mathrm{BV}_{3}$ & $\mathrm{~V}_{3}-\mathrm{V}_{2}$ & $\mathrm{n}$ & $\mathrm{pL}$ & $\log \left(\frac{n}{n-1}\right)$ & $\operatorname{Log~}_{1}$ \\
\hline 8.50 & 5.30 & 5.81 & 5.86 & 0.05 & 0.3717 & 2.88 & -0.2280 & 2.6520 \\
8.72 & 5.35 & 5.90 & 5.95 & 0.05 & 0.3873 & 2.66 & -0.1992 & 2.4608 \\
9.00 & 5.40 & 6.00 & 6.06 & 0.06 & 0.4853 & 2.38 & -0.0255 & 2.3545 \\
9.22 & 5.45 & 6.10 & 6.16 & 0.06 & 0.5157 & 2.18 & -0.0272 & 2.2072 \\
9.51 & 5.50 & 6.20 & 6.27 & 0.07 & 0.6417 & 1.89 & 0.2530 & 1.1430 \\
9.73 & 5.55 & 6.33 & 6.41 & 0.08 & 0.8000 & 1.69 & 0.6020 & 2.2920 \\
& & & & & & & & \\
\hline
\end{tabular}

$\operatorname{LogK}_{1}($ Average value $)=2.2516 \pm 0.5380$ 
BAJOPAS Volume 14 Number 1,June, 2021

Table 18: Point-wise method, Cd (Unhydrolysed PSHA)

\begin{tabular}{|l|l|l|l|l|l|l|l|l|}
\hline $\mathrm{pH}$ & $\mathrm{BV}_{1}$ & $\mathrm{BV}_{2}$ & $\mathrm{BV}_{3}$ & $\mathrm{~V}_{3}-\mathrm{V}_{2}$ & $\mathrm{n}$ & $\mathrm{pL}$ & $\log \left(\frac{n-1}{2-n}\right)$ & $\log \mathrm{K}_{2}$ \\
\hline 10.00 & 5.60 & 6.47 & 6.57 & 0.10 & 1.1434 & 1.43 & & \\
10.23 & 5.65 & 6.62 & 6.72 & 0.10 & 1.3448 & 1.23 & -0.2788 & 0.9512 \\
10.49 & 5.70 & 6.80 & 6.90 & 0.10 & 1.7742 & 1.03 & 0.5351 & 1.5651 \\
\hline
\end{tabular}

$\operatorname{LogK}_{2}($ Average value $)=1.2581 \pm 0.4340$

Table 19: Stepwise and overall Stability constants of thehydrolysed and unhydrolysed divalent metal (II) complexes

\begin{tabular}{|c|c|c|c|}
\hline Chelates & LogK $_{1}$ & $\log _{2}$ & Log $\beta$ \\
\hline [Cu (Hydrolysed PSHA-1) $\left.{ }_{2}\right]$ & 2.4788 & 1.4280 & 3.9068 \\
\hline$\left[\mathrm{Pb}(\text { Hydrolysed PSHA-1) })_{2}\right]$ & 2.5832 & 1.1963 & 3.7795 \\
\hline$\left[\mathrm{Cd}(\text { Hydrolysed PSHA-1 })_{2}\right]$ & 2.2108 & 1.5453 & 3.7561 \\
\hline$\left[\mathrm{Mg}(\text { Hydrolysed PSHA-1 })_{2}\right]$ & 2.1382 & 1.5453 & 3.6835 \\
\hline [Cu (Unhydrolysed PSHA-1) & 2.3059 & 1.2209 & 3.5268 \\
\hline$[\mathrm{Pb}$ (Unhydrolysed PSHA-1) 2$]$ & 2.2364 & 1.2239 & 3.4603 \\
\hline [Cd (Unhydrolysed PSHA-1) 2 ] & 2.2516 & 1.2581 & 3.5097 \\
\hline$[\mathrm{Mg}$ (Unydrolysed PSHA-1) & 2.1568 & 0.9127 & 3.0695 \\
\hline
\end{tabular}

The results obtained (Table19) shows the stepwise and overall stability constants to be not high indicating low stability of the complexes, because the solubility of most metal ions in the basic $\mathrm{pH}$ range is minimal due to metal hydroxide precipitation (Karimi, 2017). In general, the stepwise stability constants $\left(K_{1}\right.$ and $K_{2}$ ) follow the order $K_{1}>K_{2}$ for the copper, lead, magnesium and cadmium complexes respectively. The steady decrease of the values with increasing number of ligands is in agreement with the prediction made by researchers (Na'aliya, 2013). The decrease could be attributed to the fact that as the number of the ligands (Humate ions) that enters the coordination zone increases the aqua molecules available for replacement by the ligands become less. Thus, the metal ions become less electron loving with progressive intake of the ligand and this results in the decrease in the values of the constants (Na'aliya, 2013). Also the stability of the complexes is influenced by the size and number of the chelate rings(Mackay and Mackay,2002).All the complexes form rings in their structure as humate, a bidentate ligand, bond the metal ions in the ratio 1:2 (Boguta and Sokolowska, 2016) forming chelate rings. The values of the overall stability constants $(\log \beta)$ obtained for humate complexes are not high indicating low stability as the values are not high. LogK values for copper-humates (Table 3 to 6) obtained in this study are lower than those reported for the complexes of humic acids (Pandey et al., 2015; Dinu, 2013; Kaschl et al., 2010 and Gilbeto and Jorg, 2001). The values of LogK(Table 7 to 10 ) forlead-humates are lower than those reported for the lead in the literature (Dinu, 2013; Gilbeto and Jorg 2001). Log K values(Table 11 to 14 ) for magnesium-humates obtained in this study are close to those reported by (Pandey et al., 2015). Log K values of cadmium-humates (Table 15 to 18 ) obtained in this work near to the one reported by (Dinu, 2013 and Pandey et al., 2015).The difference between the reported values and the values obtained in this study might be probably as a result of acid hydrolysis of humic acid. The values of the overall stability constants $(\log \beta)$ of the copper humates complexes presented in Table 19 is high than that of other metal humate complexes, show relatively high stability of CuHA complexes, show the following order of stability: $\mathrm{Cu}>\mathrm{Pb}>\mathrm{Cd}>\mathrm{Mg}$; which are in close agreement to the findings of (Dinu, 2013 and Pandey et al., 2015).The high stability of Cuhumate chelate could be attributed to the existence of coordinate covalent bond between the complexing agents and the $\mathrm{Cu}^{2+}$ ions. Since, $\mathrm{Cu}^{2+}$ being a metal of the transitional series with $3 d^{9}$ electronic configurations can accept the electrons from the complexing agents. Similarly, the low stabilities of $\mathrm{Pb}, \mathrm{Cd}$ and $\mathrm{Mg}$ complexes could be explained by that $\mathrm{Pb}^{2+}$ with $6 s^{2}, \mathrm{Cd}^{2+}$ with $4 \mathrm{~d}^{10}$ and $\mathrm{Mg}^{2+}$ with $2 \mathrm{p}^{6}$ their electronic configuration has a completely filled $\mathrm{d}, \mathrm{p}$ and $\mathrm{s}$ orbitals. Moreover, the stabilities of metal ions with hydrolysed humic acid from peat soil were higher than those with unhydrolysed humic acid from peat soil; which is ascribed to the high content of acidity in hydrolysed humic acid than unhydrolysed humic acid. 
BAJOPAS Volume 14 Number 1,June, 2021 CONCLUSION

The values of logk for $\mathrm{Cu}(\mathrm{II})$ hydrolysed humic acid complex was higher followed by $\mathrm{Pb}$ (II), $\mathrm{Cd}(\mathrm{II})$ and $\mathrm{Mg}$ (II) hydrolysed humic acid complexes as compared with metal(II) unhydrolysed humic acid complexes. This indicates acid hydrolysis of humic acid can

\section{REFERENCES}

Almeida, V.R. and Szpoganicz, B. (2015). Humic Acid Potentiometric Response Patterns:Out- of Equilibrium Properties and Species Distribution Modelling. Chemical. Biol. Technol. Agric. 2: 17.

Anđelković, T., Nikolić, R., Bojić, A.,Anđelković, D., and Nikolic G.,(2010). Binding of Cadmium to Soil Humic Acid as A Function of Carboxyl Group Content. Macedonian Journal of Chemistry and Chemical Engineering.29(2): 215-224.

Anil, B. N. and Maroti, N. (2008). Studies on Influence of Die-Lectric Constants on Complex Equilibria between Substituted Py-Razalines and Lanthanide Metal Ions pH-Metrically. Amer.-Euras. scient. Res. 3(2): 212-216.

Ashok, K., Pandey, S. P. and Misra, V (2000). Stability Constants of Metal-Humic Acid Complexes and its Role in Environmental Detoxification. Journal of Ecotoxicology and Environmental Safety. 47(2):157-200.

Badr, M. H., El-Halafawi, M. H. and Abd El-al Zeid, E. R. (2012). Comparison Between the Effect of Ionic Strength on Acidity and Dissociation Constants of Humic Acids Extracted from Sewage Sludge and Nile Water Hyacinth Composts.Global Journal of Environmental Research 6 (1): 36-43.

Baruah, M.K., Borah, D., Saikia, P.P., Paul, S., Sharma, T. (2015). Evaluation of pKa Values of Soil Humic Acids and their Complexation Properties. International Journal of Plant \& Soil Science 6(4) : 218-228.

Boguta, P. Sokolowska, Z. (2016). Interactions of $\mathrm{Zn}$ (II) Ions with Humic Acids Isolated from Various Types of Soils. Effect of $\mathrm{pH}, \mathrm{Zn}$ Concentrations and Humic Acids Chemical Properties. Journal of Geochemical Explaration 168. 119-126.

Borges, F., Guimaraes, C., Lima, L.F.C., Pinto, I. and Reis, S.(2005). Potentiometric Studies on the Complexation of Copper(II) by Phenolic Acids as Discrete Ligand Models of enhance the complexation behavior of humic acid with metal (II) ions. However, the higher values of $\log \beta$ for $\mathrm{Cu}(\mathrm{II}), \mathrm{Pb}(\mathrm{II}), \mathrm{Cd}(\mathrm{II})$ and $\mathrm{Mg}(\mathrm{II})$ hydrolysed humic acid complexes indicates more stable stepwise complexes formed as compared with $\mathrm{Cu}(\mathrm{II}), \mathrm{Pb}$ (II), $\mathrm{Cd}$ (II) and $\mathrm{Mg}(\mathrm{II})$ unhydrolysed humic acid complexes.

Humic Substances Talanta 66 (2005) 670-673.

Chefetz, B., Salloum, M. J., Deshmulkin, A. P. and Hatcher, P. (2002). Structural Components of Humic Acids as Determined by Chemical Modifications and Carbon-13 NMR, Pyrolysis, and Thermochemolysis- Gas Chromatography/Mass Spectrometry. Soil Science Society of American Journal Abstract Division S-2- Soil Chemistry66. 1159-1171.

Dinu, M. I. (2013). Metals Complexation with Humic Acids in Surface Water of Different Environ. Sci. Technol. 31(1): 1-17.

Fernandes, A.N., Giacomelli, C., Giovanela, M. Vaz, D.V. Szpoganicz, B. and Maria M. D. (2009). Potentiometric Acidity Determination in Humic Substances Influenced by Different Analytical Procedures.J. Braz. Chem. Soc. 20 (9):14.

Gamal, A. H. (2015). Stability Constants of Rhenium (V) Metal Complexes with Selected Drugs. Pyrex Journal of Research in Environmental Studies. 2(2): 006-014.

Janrao, D. M., Pathan, J., Kayande, D.D., and Mulla, J.J. (2014). An Over View of Potentiometric Determination of Stability Constants of Metal Complexes. Sci. Revs. Chem. Commun.: 4(1), 2014, 11-24.

Karimi, H. (2017). Effect of pH and Initial Pb(II) Concentration on the Lead Removal Efficiency from Waste Water Using $\mathrm{Ca}(\mathrm{OH})_{2}$. International Journal of Water and Waste Water Treatment 3.2

Kaschl, A. Romheld, V. and Chen, Y. (2010). Binding of Cadmium, Copper and Zinc to Humic Substances Originating from Municipal Solid Waste Compost. Israel Journal of Chemistry Vol. 42(1): 89-98.

Kostic, I. S., Tatjana, P, A., Nikolic, R. S., Cvetkovic, T. P., Pavlovic, D. D., Aleksandar, L.J. and Bojic, A. (2012). Comparative Study of Binding Strengths of Heavy Metals with Humic Acid. J.serb. Chem. Soc. 76(9) pp 1-20. 
BAJOPAS Volume 14 Number 1,June, 2021

Na'aliya, J. (2013). Determination of Stepwise Stability Constants and Gibbs free Energy Change of Trisprolina to Complexes of some Divalent Transition Metal ions. Bayero Journal of Pure and Applied Sciences 6(2): 112-114.

Omar, A. A. and Ali, E. A. (2015). Potentiometric Studies on Complexes of $\mathrm{Cr}$ (III) and $\mathrm{Zr}$ (IV) with some Carboxylic Acids. International Journal of Advanced Chemistry, 3(1) 25-

37.

Pandey, A. K. Pandey, S. D. and Misr, V. (2015).Stability Constants of Metal- Humic Acid Complexes and Its Role in Environmental Detoxification. J. Ecotoxicology and Environmental Safety. 47(1):195-200.

Ram, N. and Raman, K.V. (1984). Stability Constants of Complexes of Metals with
Humicand Fuvic Acids under Non- acidConditions. Journal of Plant Nutrition and Soil Sciences.

147:171-176.

Santosh, D. D., Ashok, B. K., Vijay, J. T., Shivraj, G. W. and Vinay, V. W. (2011). Potentiometric Studies of Elec-Trolyte Effects on Complex Equilibria of Some Substituted 5-(2-hydroxy Phenyl) Pyrazoles. Der pharm. 3 (6): 75-83.

Sayyed, H. and Abdul Rahim, M. F. (2012). Studies of Binary Complexes of Metal Ions with Mandelic Acid by Potentiometry. Chem. J. 02 (6): 206209.

Shirvani, M. Moradian, E. Khalili, B. Bakhtiary, S. (2015). Interaction of $\mathrm{Cd}$ and $\mathrm{Pb}$ with Humate-Palygorskite and HumateSepiolite Complexes. Journal of water, air and pollution 3: 220-228. 


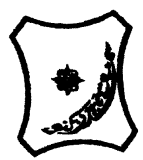

Bayero Journal of Pure and Applied Sciences, 14(1): 54 - 63

Received: November, 2020

Accepted: April, 2021

ISSN $2006-6996$

\title{
STABILITY CONSTANTS OF COMPLEXES OF METAL IONS WITH PEATSOIL HUMIC ACIDS UNDER NON-ACID-CONDITIONS
}

\author{
${ }^{* 1}$ Sabo, Yusuf ${ }^{2}$ Jimoh, W.L.O., ${ }^{3}$ Isa Baba Koki and ${ }^{4}$ Sholadoye, Q. 0. \\ ${ }^{1}$ Department of Pure and Industrial Chemistry, Bayero University, Kano \\ ${ }^{3}$ Department of Chemistry, Yusuf Maitama Sule University Kano. P.M.B. 3220 Kano, Nigeria. \\ ${ }^{4}$ Department of Chemistry, Nigerian Police Academy, Wudil, Kano-Nigeria
}

*Correspondence E-mail; saboyusuf18@yahoo.com

ABSTRACT

Stability constants of complexes of four divalent metal ions viz. $\mathrm{Cu}^{2+}, \mathrm{Pb}^{2+}, \mathrm{Mg}^{2+}$ and $\mathrm{Cd}^{2+}$ with humic acids (HA) were determined by potentiometric titration of humic acids with the corresponding salt of the divalent metals in aqueous media under non-acid-condition. The log $K$ (logarithm of the stability constant) ranged from 1.0942 to 2.7471 for metalhumic acid complexes were determined using point-wise computational method. The order of stability constants were obtained as follows: $\mathrm{Cu}>\mathrm{Pb}>\mathrm{Cd}>\mathrm{Mg}$ for metal $-\mathrm{HA}$ complexes respectively, indicating a higher degree of complexation with Cu metal ion.

Keywords: stability constant, humic acid, potentiometric titration, divalent metals, acid hydrolysis.

\section{NTRODUCTION}

The stability constant of a complex is the numerical expression of its stability and provides a quantitative measure of affinity of the metal ion to the complexing agent. An understanding of the relative stability of metal-complexes helps in predicting the behavior of metal ions in the soil (Ram and Raman, 1982). Extensive researches has been done to determine the stability constants of the complexes formed between humic acid (HA) with a number of metal ions. Ashok et al., (2000) reported that humic acid with hydroxyl, phenoxyl and carboxyl reactive groups can form coordination compound with metal ions at $\mathrm{pH}$ 3.5. The stability constants(Log K) for different metalhumic acid complexes indicated the following order of the stabilities of complexes formed between humic acid and metal ion, $\mathrm{Cu}>\mathrm{Fe}$ $>\mathrm{Pb}>\mathrm{Ni}>\mathrm{Co}>\mathrm{Ca}>\mathrm{Cd}>\mathrm{Zn}>\mathrm{Mn}>\mathrm{Mg}$. Andelkovic et al., (2010) investigated the binding of $\mathrm{Cd}$ (II) to soil humic acid at pH 6.5 and in $0.1 \mathrm{M} \mathrm{KNO}_{3}$ ionic medium. The stability constant for binding indicating greater stability in the case when carboxyl groups are involved in complexation reaction. Kostic et al.,(2012) investigated the complexation of humic acid with certain heavy metal ions (Co(II), $\mathrm{Ni}(\mathrm{II}), \mathrm{Cu}(\mathrm{II})$,
$\mathrm{Zn}(\mathrm{II})$, and $\mathrm{Pb}(\mathrm{II})$. The experiment was performed at $25^{\circ} \mathrm{C}$, at pH 4.0 and ionic strength of $0.01 \mathrm{M}$. Stability constant of complex between $\mathrm{Pb}$ (II) ions and humic acid is greater than stability constants of other investigated metalhumate complexes. Bogata and Sokolowska (2016) analyses the interaction between humic acids from different soils and $\mathrm{Zn}$ (II) ions at wide concentration ranges and at $\mathrm{pH} 5$. Studies have showed significant impact of $\mathrm{Zn}$ concentration, $\mathrm{pH}$ and some properties of humic acids with zinc.But all of these studies were limited to acidic $\mathrm{pH}$ range. Therefore, the present study was carried out to determine and compare the stability constants of complexes of metal ions with hydrolysed peat soil humic acid and unhydrolysed peat soil humic under non-acid conditions.

\section{MATERIALS AND METHODS}

Analytical grade chemicals used includes hydrochloric acid $(\mathrm{HCl})$, nitric acid $\left(\mathrm{HNO}_{3}\right)$, sodium hydroxide $(\mathrm{NaOH})$, lead nitrate $\mathrm{Pb}\left(\mathrm{NO}_{3}\right)_{2}$, copper nitrate $\mathrm{Cu}\left(\mathrm{NO}_{3}\right)_{2} \cdot 3 \mathrm{H}_{2} \mathrm{O}$, cadmium nitrate $\mathrm{Cd}\left(\mathrm{NO}_{3}\right)_{2} \cdot 4 \mathrm{H}_{2} \mathrm{O}$, magnesium nitrate $\mathrm{Mg}\left(\mathrm{NO}_{3}\right)_{2} \cdot 6 \mathrm{H}_{2} \mathrm{O}$, potassium nitrate $\left(\mathrm{KNO}_{3}\right)$, calcium chloride $\left(\mathrm{CaCl}_{2}\right)$, (sigma-Aldrich). Dowex 50WX8, (20-50 mesh) from Fluka. 


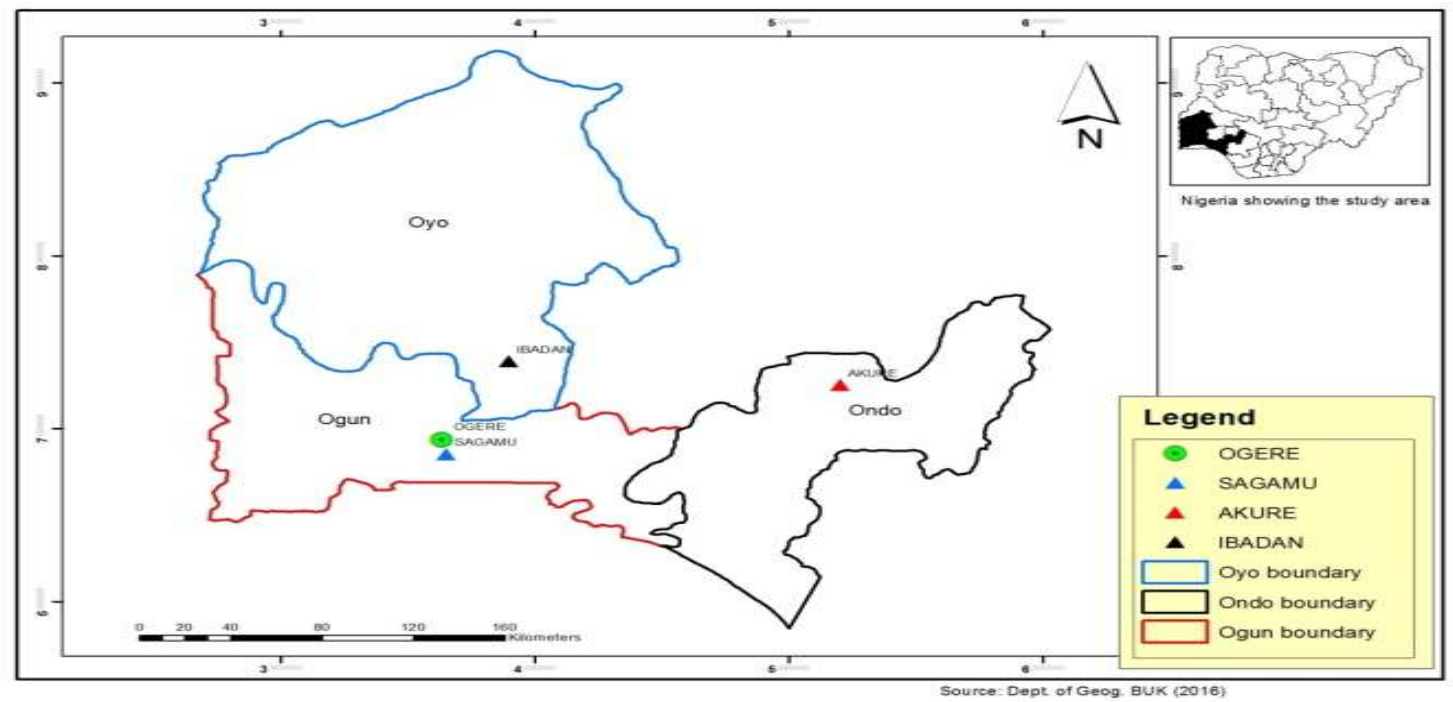

Figure 1: Map showing the sampling point at Sagamu Town, Ogun State.

\section{Description of Sampling Area}

Sagamu has geographical coordinates between $6^{\circ} 50^{\prime}$ north; $3^{\circ} 38^{\prime}$ east is located in south western region of Nigeria. The region has tropical wet and dry climate with a lengthy wet season and relatively constant temperatures throughout the course of the year. Wet season runs from March to October, November to December forms the region dry season. The vegetation type of the region is savannah which is really grassland with small bushes and occasional big trees. Grassland soils have substantially higher organic matter content than forest soils (Novackova, 2011).

\section{Sample Collection}

The Peatsoil samples were collected from four different sampling points $(0-10 \mathrm{~cm}$ depth) in Sagamu into polyethylene bag with plastic spoons. Samples were taken to the laboratory, extraneous materials were removed; the samples were air-dried, crushed and ground to a fine powder in a mortar passed through a $0.20 \mathrm{~mm}$ sieve. The samples were kept for analysis.

\section{Isolation and purification of humic acid from peat soil sample}

Peatsoil sample $(100 \mathrm{~g})$ was mixed with 1000 $\mathrm{cm}^{3}$ of $0.1 \mathrm{M} \mathrm{NaOH}$ solution, shaken for 3hours and left to stand overnight. Dark-coloured supernatant was obtained and decanted from solid residue. The dark-coloured supernatant was acidified to $(\mathrm{pH}=1.0)$ with $6 \mathrm{M} \mathrm{HCl}$ stirred and allowed to stand for 6 hours. Yellowish brown supernatant and dark-brown precipitate were obtained. The yellowish brown supernatant was decanted followed by centrifuge and discarded. The dark-brown precipitate was mixed with $500 \mathrm{~cm}^{3}$ of $0.1 \mathrm{M} \mathrm{NaOH}$ solution followed by passing through dowex resin. The dark-brown solution was acidified to $(\mathrm{pH}=1.0)$ with $6 \mathrm{M} \mathrm{HCl}$ stirred and allowed to stand for 3 hours. The dark-brown precipitate was washed several times with deionized water. The supernatant was treated with $\mathrm{AgNO}_{3}$ solution until no white precipitate observed. The humic acid was transferred to weighed crucible and dried at $60^{\circ} \mathrm{C}$ in an oven for 12 hours. The humic acid was cooled and dried in the desiccator, weighed and recorded. The obtained humic acid was dried again at $60^{\circ} \mathrm{C}$ for additional 6 hours cooled and dried in the desiccator, weighed and recorded constant weight was obtained (Baruah et al., 2015).

\section{FT-IR analysis}

FT-IR spectra of humic acid sample was analysed using Carry 630 FT-IR Agilent Technologies.

Unhydrolysed compost humic acid

The unhydrolysed humic acid was obtained after isolation and purification of compost humic acid and kept for investigation.

\section{Acid hydrolysis of Peatsoil acid}

Peatsoil humic acid sample (1g) was refluxed for 12 hours at $\left(160^{\circ} \mathrm{C}\right)$ with $50 \mathrm{~cm}^{3}$ of $6 \mathrm{M} \mathrm{HCl}$. The mixture was allowed to cool, decanted, and centrifuged after hydrolysis. The insoluble residues were washed with distilled water via centrifugation several times, and the supernatant was treated with $\mathrm{AgNO}_{3}$ solution until no white precipitate was observed. The residue was thoroughly dried over $\mathrm{CaCl}_{2}$ in a desiccator at room temperature (Chefetz et al., 2002). Finally, the obtained hydrolysed humic acid was kept for investigation. 
BAJOPAS Volume 14 Number 1,June, 2021 Potentiometric Titrations

Potentiometric measurements were carried out using a pH-meter Jenway (model 3510) with combine electrode, the sensitivity of the $\mathrm{pH}$ meter is 0.01 units. The $\mathrm{pH}$ meter was switched on half an hour before starting the titration for initial warm up of the instrument. The instrument was calibrated with an aqueous standard buffer solution of $\mathrm{pH} 4.00$ and 10.0 (borate buffer) prepared from a "Qualigens" buffer tablets.

The following sets of solutions were prepared in a $250 \mathrm{~cm}^{3}$ volumetric flask separately for $\mathrm{pH}$ metric titrations.

(i) $5 \mathrm{~cm}^{3} 0.1 \mathrm{M} \mathrm{HCl}+40 \mathrm{~cm}^{3}$ deionized water

(ii) $5 \mathrm{~cm}^{3} 0.1 \mathrm{M} \mathrm{HCl}+39 \mathrm{~cm}^{3}$ deionized water $+1 \mathrm{~cm}^{3} 0.15 \mathrm{gcm}^{-3}$ humic acid

(iii) $5 \mathrm{~cm}^{3} 0.1 \mathrm{M} \mathrm{HCl}+37 \mathrm{~cm}^{3}$ deionized water $+1 \mathrm{~cm}^{3} 0.15 \mathrm{gcm}^{-3}$ humic acid

$$
+2 \mathrm{~cm}^{3} \quad 0.01 \mathrm{M} \mathrm{Cu} \text { (II) }
$$

The solutions were titrated against standardized $0.110 \mathrm{MNaOH}$ separately. The total volume of each mixture was adjusted to $50 \mathrm{~cm}^{3}$ and the ionic strength of the solutions was maintained constant at by adding appropriate amount of stock solution of $1 \mathrm{M} \mathrm{KNO}_{3}$ (Gamal, 2015; Omar and Ali, 2015). A magnetic stirrer was used to achieve thorough mixing of the interacting solutions at $550 \mathrm{rpm}$. The same set of experimental conditions was applied for potentiometric titration of remaining samples.

\section{Evaluation of pKa of Hydrolysed peat soil Humic Acids}

The proton-ligand formation number $\mathrm{n}_{\mathbf{A}}$ were calculated by Irving and Rossotti expression (Omar and Ali, 2015).

$\mathrm{nA}=\mathrm{Y}-\frac{(\mathrm{V} 2-\mathrm{V1})(\mathrm{No}-\mathrm{Eo})}{(\mathrm{VO}+\mathrm{V1}) \mathrm{TCL}}$ 1

Where: $Y$ is number of dissociable proton, $\left(\mathrm{V}_{2^{-}}\right.$ $V_{1}$ ) is the measure of displacement of the ligand curve relative to acid curve, $\mathrm{N}^{\circ}$ and $\mathrm{E}^{\circ}$ are the resultant concentration of alkali solution, free acid solution, $\mathrm{T}_{\mathrm{cL}}{ }^{\circ}$ is the total ligand concentration, $\mathrm{V}^{\circ}$ is the total volume of titration solution, $V_{1}$ is the volume of alkali added to acid solution, $V_{2}$ is the volume of alkali added to acid solution + ligand solution, acid dissociation constants (pKa - values) of ligand were calculated by algebraic method point wise calculation (Tables 1 ). The dissociation constants (pKa) were calculated according to the following relation:

$\mathrm{pKa}=\mathrm{pH}+\log \left(\frac{n A}{1-n A}\right)$ 2

Where: pKa is the acid dissociation constant, $\mathrm{n}_{\mathrm{A}}$ is the Proton-ligand formation number and $\mathrm{pH}$ is the pH-values (Omar and Ali, 2015).

\section{Determination of metal-ligand stability constants $(\log K)$ of complexes}

The potentiometric measurement for the determination of stability constant of a complex in solution is based on the fact that the redox potential of the couple $\frac{M^{+(m-n)}}{M^{+m}}$ is shifted significantly on complexation of the metal ion with the ligand. This method involves change in hydrogen ion concentration $\left[\mathrm{H}^{+}\right]$due to the displacement or association of one or more protons taking place during complexation reaction. This change can be found out by titrating the solutions containing free acid, acid with ligand, and acid with ligand and metal ion, individually against a standard alkali solution at a constant ionic strength or temperature. Either ionic strength or temperature may be varied for different sets of solutions. In all the cases, the change in the $\mathrm{pH}$ of the solution is measured after each addition of a known amount of alkali to the reaction cell which contains the reaction mixture. The titration curves are then drawn by plotting the measured $\mathrm{pH}$ values against the corresponding volume of alkali added and the stability constants of the complexes are determined from the titration curves by employing $\mathrm{pH}$-metric titration technique given by (Irving and Rossoti).

Metal-ligand stability constants ( $\log \mathrm{K}$ ) were determined by using the following relations:

$$
\bar{n}=\frac{\left(V_{3}-V_{2}\right)\left(E^{0}+N^{0}\right)}{\left(V^{0}+V_{2}\right) \bar{n}_{A} T_{m}^{0}}
$$

and

$$
P L=\log _{10}\left\{\frac{1+\beta_{n}^{H} \frac{1}{[\text { anti } \log \mathrm{pH}]^{\mathrm{n}}}}{\mathrm{T}_{\mathrm{L}}^{0}-n \bar{T}_{m}^{0}} \mathrm{X} \frac{\left(V^{0}+V_{3}\right)}{V^{0}}\right\}
$$


BAJOPAS Volume 14 Number 1,June, 2021

Where $T_{L}, T^{\circ}, E^{\circ}$, and $V^{\circ}$ havethe same significance as in equation (1) above, $T_{m}$ denotes the total concentration of metal present in solution, $V_{3}$ is the volume of metal ions present in solution and $\beta^{H}$ is the overall proton ligand stability constant. The metal-ligand stability constants (log K) were determined by employing point wise computational Method (eq. 5 and 6).

$\operatorname{LogK}_{1}=\log \left(\frac{n}{1-n}\right)+\mathrm{pL}$ .5

$\operatorname{LogK}_{2}=\log \left(\frac{1-n}{2-n}\right)+\mathrm{pL}$ ...6

Where: Log $\mathrm{K}$ is the metal-ligand stability constant, $\mathrm{pL}$ is the Free ligand exponent function, $\mathbf{n}$ is the Average number of ligand attached with metal ion (Janraoet al., 2014). The results obtained were analyzed by an ORIGIN 2016 program using titration data and then the proton-ligand stability constants (pKa) and Metal-ligand stability constant (LogK) calculated (Omar and Ali, 2015).

\section{RESULTS AND DISCUSSION}

Fourier transformed infrared (FT-IR) spectra of isolated humic acid from peat soils Figure 2 had distinct clear absorption bands indicating the presence of major humic acid structural elemental groups such as $\mathrm{H}$ bonded $\mathrm{OH}$ $\left(3680 \mathrm{~cm}^{-1}\right.$ peak $), C=0$ of carbonyl $\left(1721 \mathrm{~cm}^{-1}\right.$ peak), functional groups of aliphatic components $\mathrm{CH}_{2}\left(2918 \mathrm{~cm}^{-1}\right.$ peak) and $\mathrm{C}-\mathrm{O}$ stretching of polysaccharide $\left(1168 \mathrm{~cm}^{-1}\right.$ peak). The positions of the absorption bands of the spectra fell within typical major absorption bands of humic acid which is at frequencies 3680, 2918, 1721, 1168 $\mathrm{cm}^{-1}$. The first peak centred in the vicinity of $3680 \mathrm{~cm}^{-1}$ region is attributed to phenol $\mathrm{OH}$ group bounded by intermolecular $\mathrm{H}$ bonds. The $2918 \mathrm{~cm}^{-1}$ band usually has absorption maximum at $2918 \mathrm{~cm}^{-1}$ which is due to $\mathrm{C}-\mathrm{H}$ stretching of alkane group $\left(\mathrm{CH}_{2}\right)$. The next major absorption band is $1721 \mathrm{~cm}^{-1}$. This band has been commonly ascribed to $\mathrm{C}=\mathrm{O}$ stretching of mainly carboxyl group $(\mathrm{COOH})$ with trace amount of ketones. The last peak was observed at 1168 $\mathrm{cm}^{-1}$ due to $\mathrm{C}-\mathrm{O}$ stretching of polysaccharides and this peak appeared also in the spectra of humic acid from peat soil. The FTIR spectra of the isolated humic acid contained all major characteristic absorption peaks of humic acid. These absorption peaks indicated the presence of the major structural elements of humic acid namely $\mathrm{H}$ bonded $\mathrm{OH}, \mathrm{C}=\mathrm{C}$ of aromatic ring, $\mathrm{C}=\mathrm{O}$ of carbonyl group (both carboxyl and ketonic), $\mathrm{CH}_{2}$ group. This strongly supports the presence of humic acid.

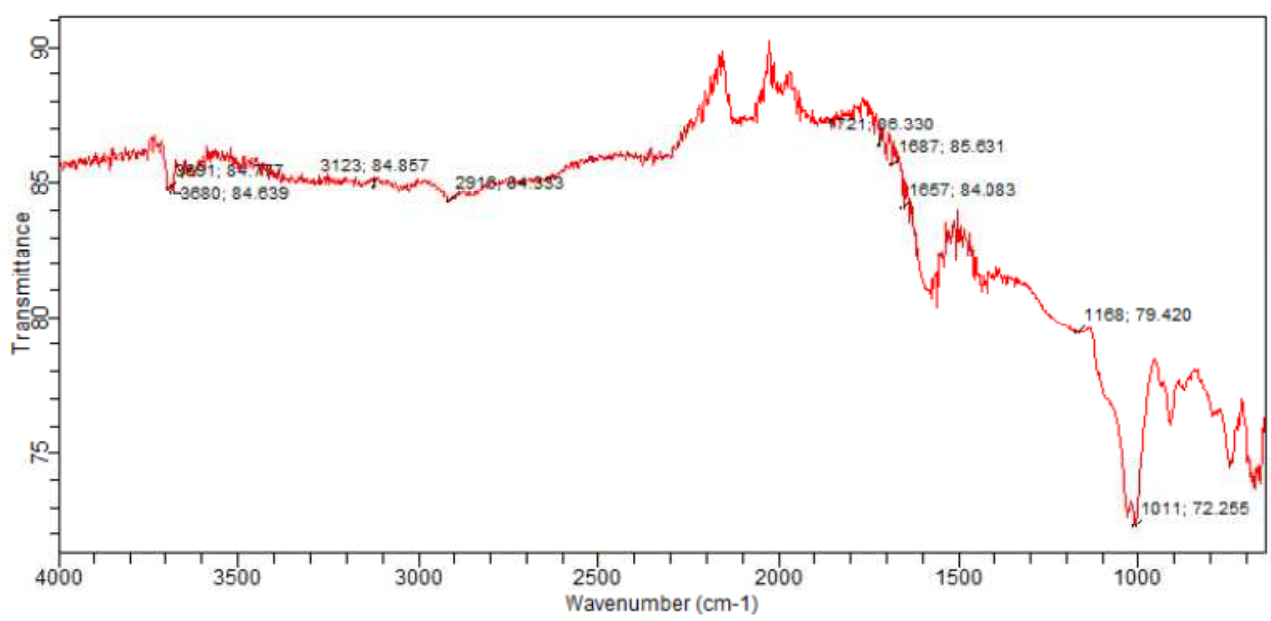

Fig. 2 : FT-IR spectraof peatsoilhumic acid (PSHA)

\section{Evaluation of acid dissociation constant (pka) of acid hydrolysed peat soil humicacid at phenolic group}

The value of the dissociation constant of the peat soil humic acid (PSHA) that underwent acidhydrolysis studied was found to be 8.9299 as shown Table 1, which is lower than the literaturevalues reported by Almeida and Szpoganics, (2015), Borges et al., (2005); Badr et al., (2012)and Fernandes et al,.(2009) of $9.73,9.47$ and 10.30. The difference between the obtained valuesand the reported values in this study might be probably as a result of acid hydrolysis of humicacid. 
BAJOPAS Volume 14 Number 1,June, 2021

Table 1: PKa of (Hydrolysed PSHA)

\begin{tabular}{|l|l|l|l|l|l|l|}
\hline $\mathrm{pH}$ & $\mathrm{BV}_{1}$ & $\mathrm{BV}_{2}$ & $\mathrm{~V}_{2}-\mathrm{V}_{1}$ & $\mathrm{nA}$ & $\log \left(\frac{n A}{1-n A}\right)$ & $\mathrm{pKa}$ \\
\hline 8.50 & 5.30 & 6.29 & 0.99 & 0.3594 & -0.2510 & 8.2490 \\
8.72 & 5.35 & 6.37 & 1.02 & 0.3400 & -0.2880 & 8.4320 \\
9.00 & 5.40 & 6.46 & 1.06 & 0.3141 & -0.3391 & 8.6609 \\
9.22 & 5.45 & 6.55 & 1.10 & 0.2882 & -0.3927 & 8.8273 \\
9.51 & 5.50 & 6.66 & 1.16 & 0.2494 & -0.4786 & 9.0314 \\
9.73 & 5.55 & 6.78 & 1.23 & 0.2041 & -0.5910 & 9.1390 \\
10.00 & 5.60 & 6.90 & 1.30 & 0.1589 & -0.7238 & 9.2762 \\
10.23 & 5.65 & 7.05 & 1.40 & 0.0941 & -0.9835 & 9.2465 \\
10.49 & 5.70 & 7.10 & 1.40 & 0.0941 & -0.9835 & 9.5065 \\
\hline
\end{tabular}

Average pKa $=8.9299 \pm 0.4186$

Table 2: PKa of (Unhydrolysed PSHA)

\begin{tabular}{|l|l|l|l|l|l|l|}
\hline $\mathrm{pH}$ & $\mathrm{BV}_{1}$ & $\mathrm{BV}_{2}$ & $\mathrm{~V}_{2}-\mathrm{V}_{1}$ & $\mathrm{nA}$ & $\log \left(\frac{\boldsymbol{n A}}{1-\boldsymbol{n}}\right)$ & $\mathrm{pKa}$ \\
\hline 8.50 & 5.30 & 5.81 & 0.51 & 0.6619 & 0.2919 & 8.7919 \\
8.72 & 5.35 & 5.90 & 0.55 & 0.6357 & 0.2418 & 8.9618 \\
9.00 & 5.40 & 6.00 & 0.60 & 0.6029 & 0.1813 & 9.1813 \\
9.22 & 5.45 & 6.10 & 0.65 & 0.5701 & 0.1226 & 9.3426 \\
9.51 & 5.50 & 6.20 & 0.70 & 0.5376 & 0.0654 & 9.5754 \\
9.73 & 5.55 & 6.33 & 0.78 & 0.4851 & -0.0259 & 9.7041 \\
10.00 & 5.60 & 6.47 & 0.87 & 0.4262 & -0.1291 & 9.8709 \\
10.23 & 5.65 & 6.62 & 0.99 & 0.3609 & -0.2481 & 9.9819 \\
10.49 & 5.70 & 6.80 & 1.10 & 0.2759 & -0.4690 & 10.0210 \\
\hline
\end{tabular}

Average pKa $=9.4923 \pm 0.4410$

Metal-ligand stability constant ( $\log \mathrm{K}$ )

The stabilityconstants require the accurate values of proton-ligand stability constants (Anil and Maroti, 2008). Metal titration curves crossed over ligand titration curve indicated the formation of complex upon proton release (Santosh, et al., 2011). If the values of n- are within range $0.2-0.8$ and $1.2-18$ this indicates the formation of $1: 1$ and 1:2 complexes (Sayyed and Mazahar, 2012).

The metal (II)-humate stepwise stability constants (log k) at phenolic group (Tables 318)

Table 3: Point-wise method, $\mathrm{Cu}$-(Hydrolysed PSHA)

\begin{tabular}{|l|l|l|l|l|l|l|l|l|}
\hline $\mathrm{pH}$ & $\mathrm{BV}_{1}$ & $\mathrm{BV}_{2}$ & $\mathrm{BV}_{3}$ & $\left(\mathrm{~V}_{3}-\mathrm{V}_{2}\right)$ & $\mathrm{n}$ & $\mathrm{pL}$ & $\log \left(\frac{n}{1-n}\right)$ & LogK $_{1}$ \\
\hline 8.50 & 5.30 & 6.29 & 6.33 & 0.04 & 0.5500 & 2.66 & 0.0871 & 2.7471 \\
8.72 & 5.35 & 6.37 & 6.41 & 0.04 & 0.5714 & 2.43 & 0.1249 & 2.5549 \\
9.00 & 5.40 & 6.46 & 6.50 & 0.04 & 0.6198 & 2.16 & 0.2122 & 2.3722 \\
9.22 & 5.45 & 6.55 & 6.59 & 0.04 & 0.6667 & 1.94 & 0.3010 & 2.2410 \\
\hline
\end{tabular}

LogK $_{1}$ (Average value) $=2.4788 \pm 0.2203$

Table 4: Point-wise method, $\mathrm{Cu}$-(Hydrolysed PSHA)

\begin{tabular}{|l|l|l|l|l|l|l|l|l|}
\hline $\mathrm{pH}$ & $\mathrm{BV}_{1}$ & $\mathrm{BV}_{2}$ & $\mathrm{BV}_{3}$ & $\left(\mathrm{~V}_{3}-\mathrm{V}_{2}\right)$ & $\mathrm{n}$ & $\mathrm{pL}$ & $\log \left(\frac{n-1}{2-n}\right)$ & LogK $_{2}$ \\
\hline 9.51 & 5.50 & 6.66 & 6.73 & 0.07 & 1.3509 & 1.70 & -0.2671 & 1.4329 \\
9.73 & 5.55 & 6.78 & 6.85 & 0.07 & 1.6383 & 1.51 & 0.2467 & 1.7567 \\
10.00 & 5.60 & 6.90 & 6.98 & 0.08 & 2.1783 & 1.31 & -0.2158 & 1.0942 \\
10.23 & 5.65 & 7.05 & 7.13 & 0.08 & 4.1904 & 1.27 & & \\
10.49 & 5.70 & 7.10 & 7.19 & 0.09 & 4.6920 & & & \\
\hline
\end{tabular}

Log $K_{2}($ Average value $)=1.4280 \pm 0.3312$ 
BAJOPAS Volume 14 Number 1,June, 2021

Table 5: Point-wise method, $\mathrm{Cu}$ (Unhydrolysed PSHA)

\begin{tabular}{|l|l|l|l|l|l|l|l|l|}
\hline $\mathrm{pH}$ & $\mathrm{BV}_{1}$ & $\mathrm{BV}_{2}$ & $\mathrm{BV}_{3}$ & $\left(\mathrm{~V}_{3}-\mathrm{V}_{2}\right)$ & $\mathrm{n}$ & $\mathrm{pL}$ & $\log \left(\frac{n}{n-1}\right)$ & Log $_{1}$ \\
\hline 8.50 & 5.30 & 5.81 & 5.85 & 0.04 & 0.2973 & 2.88 & -0.3736 & 2.5064 \\
8.72 & 5.35 & 5.90 & 5.95 & 0.05 & 0.3873 & 2.66 & -0.1992 & 2.4608 \\
9.00 & 5.40 & 6.00 & 6.05 & 0.05 & 0.4044 & 2.38 & -0.1681 & 2.2119 \\
9.22 & 5.45 & 6.10 & 6.15 & 0.06 & 0.5157 & 2.18 & -0.0272 & 2.2072 \\
9.51 & 5.50 & 6.20 & 6.27 & 0.07 & 0.6417 & 1.89 & 0.2530 & 1.1430 \\
\hline
\end{tabular}

$\operatorname{LogK}_{1}($ Average value $)=2.3059 \pm 0.6153$

Table 6:Point-wise method, $\mathrm{Cu}$ (Unhydrolysed PSHA)

\begin{tabular}{|l|l|l|l|l|l|l|l|l|}
\hline $\mathrm{pH}$ & $\mathrm{BV}_{1}$ & $\mathrm{BV}_{2}$ & $\mathrm{BV}_{3}$ & $\mathrm{~V}_{3}-\mathrm{V}_{2}$ & $\mathrm{n}$ & $\mathrm{pL}$ & $\log \left(\frac{n-1}{2-n}\right)$ & $\log \mathrm{K}_{2}$ \\
\hline 9.73 & 5.55 & 6.33 & 6.42 & 0.09 & 0.9000 & 1.69 & & \\
10.00 & 5.60 & 6.47 & 6.58 & 0.11 & 1.2578 & 1.44 & -0.4592 & 0.9808 \\
10.23 & 5.65 & 6.62 & 6.84 & 0.12 & 1.6137 & 1.26 & -0.2010 & 1.4610 \\
10.49 & 5.70 & 6.80 & 6.92 & 0.12 & 2.1052 & 1.03 & & \\
\hline
\end{tabular}

$\operatorname{LogK}_{2}$ (Average value) $=1.2209 \pm 0.3398$

Table 7:Point-wise method, Pb (Hydrolysed PSHA)

\begin{tabular}{|l|l|l|l|l|l|l|l|l|}
\hline $\mathrm{pH}$ & $\mathrm{BV}_{1}$ & $\mathrm{BV}_{2}$ & $\mathrm{BV}_{3}$ & $\left(\mathrm{~V}_{3}-\mathrm{V}_{2}\right)$ & $\mathrm{n}$ & $\mathrm{pL}$ & $\log \left(\frac{n}{1-n}\right)$ & LogK $_{1}$ \\
\hline 8.50 & 5.30 & 6.29 & 6.33 & 0.04 & 0.5500 & 2.66 & 0.0871 & 2.7471 \\
8.72 & 5.35 & 6.37 & 6.41 & 0.04 & 0.5714 & 2.43 & 0.1249 & 2.5549 \\
9.00 & 5.40 & 6.46 & 6.50 & 0.04 & 0.6198 & 2.16 & 0.2122 & 2.3722 \\
9.22 & 5.45 & 6.55 & 6.60 & 0.05 & 0.8333 & 1.96 & 0.6989 & 2.6589 \\
\hline
\end{tabular}

Log $_{\mathbf{1}}($ Average value $)=2.5832 \pm 0.1614$

Table 8:Point-wise method, Pb-(Hydrolysed PSHA)

\begin{tabular}{|l|l|l|l|l|l|l|l|l|}
\hline $\mathrm{pH}$ & $\mathrm{BV}_{1}$ & $\mathrm{BV}_{2}$ & $\mathrm{BV}_{3}$ & $\left(\mathrm{~V}_{3}-\mathrm{V}_{2}\right)$ & $\mathrm{n}$ & $\mathrm{pL}$ & $\log \left(\frac{n-1}{2-n}\right)$ & $\log \mathrm{K}_{2}$ \\
\hline 9.51 & 5.50 & 6.66 & 6.71 & 0.05 & 0.9650 & 1.67 & & \\
9.73 & 5.55 & 6.78 & 6.83 & 0.05 & 1.1702 & 1.44 & & \\
10.00 & 5.60 & 6.90 & 6.90 & 0.05 & 1.4864 & 1.22 & -0.0237 & 1.1963 \\
10.23 & 5.65 & 7.05 & 7.10 & 0.05 & 2.0190 & 1.09 & & \\
10.49 & 5.70 & 7.10 & 7.17 & 0.07 & 3.6492 & 1.00 & & \\
\hline
\end{tabular}

Log $K_{2}$ (Average value) $=1.1963$

Table 9: Point-wise method, Pb (Unhydrolysed PSHA)

\begin{tabular}{|l|l|l|l|l|l|l|l|l|}
\hline $\mathrm{pH}$ & $\mathrm{BV}_{1}$ & $\mathrm{BV}_{2}$ & $\mathrm{BV}_{3}$ & $\mathrm{~V}_{3}-\mathrm{V}_{2}$ & $\mathrm{n}$ & $\mathrm{pL}$ & $\begin{array}{l}\text { Log } \\
\left(\frac{n}{n-1}\right)\end{array}$ & Log $\mathrm{K}_{1}$ \\
\hline 8.50 & 5.30 & 5.81 & 5.85 & 0.04 & 0.2973 & 2.88 & -0.3736 & 2.5064 \\
8.72 & 5.35 & 5.90 & 5.94 & 0.04 & 0.3099 & 2.66 & -0.5477 & 2.3123 \\
9.00 & 5.40 & 6.00 & 6.05 & 0.05 & 0.4044 & 2.38 & -0.1681 & 2.2119 \\
9.22 & 5.45 & 6.10 & 6.15 & 0.06 & 0.5157 & 2.18 & 0.0272 & 2.2072 \\
9.51 & 5.50 & 6.20 & 6.26 & 0.07 & 0.6417 & 1.89 & 0.2530 & 2.1430 \\
9.73 & 5.55 & 6.40 & 6.40 & 0.07 & 0.7000 & 1.67 & 0.3680 & 2.0380 \\
\hline
\end{tabular}

LogK $_{1}$ (Average value) $=2.2364 \pm 0.1602$

Table 10: Point-wise method, Pb (Unhydrolysed PSHA)

\begin{tabular}{|l|l|l|l|l|l|l|l|l|}
\hline $\mathrm{pH}$ & $\mathrm{BV}_{1}$ & $\mathrm{BV}_{2}$ & $\mathrm{BV}_{3}$ & $\mathrm{~V}_{3}-\mathrm{V}_{2}$ & $\mathrm{n}$ & $\mathrm{pL}$ & $\log \left(\frac{n-1}{2-n}\right)$ & $\log \mathrm{K}_{2}$ \\
\hline 10.00 & 5.60 & 6.47 & 6.55 & 0.08 & 1.9503 & 1.41 & & \\
10.23 & 5.65 & 6.62 & 6.72 & 0.11 & 1.4792 & 1.26 & -0.0361 & 1.2239 \\
\hline
\end{tabular}

$\operatorname{LogK}_{2}$ (Average value) $=1.2239$

Table 11: Point-wise method, Mg (Hydrolysed PSHA)

\begin{tabular}{|l|l|l|l|l|l|l|l|l|}
\hline $\mathrm{pH}$ & $\mathrm{BV}_{1}$ & $\mathrm{BV}_{2}$ & $\mathrm{BV}_{3}$ & $\left(\mathrm{~V}_{3}-\mathrm{V}_{2}\right)$ & $\mathrm{n}$ & $\mathrm{pL}$ & $\log \left(\frac{n}{n-1}\right)$ & LogK $_{1}$ \\
\hline 8.50 & 5.30 & 6.29 & 6.31 & 0.02 & 0.2750 & 2.64 & -0.4290 & 2.2110 \\
8.72 & 5.35 & 6.37 & 6.39 & 0.02 & 0.2858 & 2.42 & -0.3978 & 2.0222 \\
9.00 & 5.40 & 6.46 & 6.49 & 0.03 & 0.4648 & 2.14 & -0.0612 & 2.0788 \\
9.22 & 5.45 & 6.55 & 6.59 & 0.04 & 0.6667 & 1.94 & 0.3010 & 2.2410 \\
\hline
\end{tabular}

$\log _{\mathbf{1}}($ Average value) $=2.1382 \pm 0.1046$ 
BAJOPAS Volume 14 Number 1,June, 2021

Table 12: Point-wise method, Mg (Hydrolysed PSHA)

\begin{tabular}{|l|l|l|l|l|l|l|l|l|}
\hline $\mathrm{pH}$ & $\mathrm{BV}_{1}$ & $\mathrm{BV}_{2}$ & $\mathrm{BV}_{3}$ & $\left(\mathrm{~V}_{3}-\mathrm{V}_{2}\right)$ & $\mathrm{n}$ & $\mathrm{pL}$ & $\log \left(\frac{n-1}{2-n}\right)$ & LogK $_{2}$ \\
\hline 9.51 & 5.55 & 6.66 & 6.71 & 0.05 & 0.9650 & 1.67 & & \\
9.73 & 5.55 & 6.78 & 6.84 & 0.06 & 1.4042 & 1.47 & -0.1686 & 1.3014 \\
10.00 & 5.60 & 6.90 & 6.93 & 0.06 & 1.7838 & 1.23 & 0.5593 & 1.7893 \\
10.23 & 5.65 & 7.05 & 7.10 & 0.06 & 3.1429 & 1.10 & & \\
10.49 & 5.70 & 7.10 & 7.18 & 0.07 & 3.6492 & 0.83 & & \\
\hline
\end{tabular}

LogK $_{2}($ Average value $)=1.5453 \pm 0.3450$

Table 13: Point-wise method, Mg (Unhydrolysed PSHA)

\begin{tabular}{|l|l|l|l|l|l|l|l|l|}
\hline $\mathrm{pH}$ & $\mathrm{BV}_{1}$ & $\mathrm{BV}_{2}$ & $\mathrm{BV}_{3}$ & $\mathrm{~V}_{3}-\mathrm{V}_{2}$ & $\mathrm{n}$ & $\mathrm{pL}$ & $\log \left(\frac{n}{n-1}\right)$ & $\operatorname{Log~}_{1}$ \\
\hline 8.50 & 5.30 & 5.81 & 5.85 & 0.04 & 0.2973 & 2.88 & -0.3736 & 2.5064 \\
8.72 & 5.35 & 5.90 & 5.94 & 0.04 & 0.3099 & 2.66 & -0.3477 & 2.3123 \\
9.00 & 5.40 & 6.00 & 6.04 & 0.04 & 0.3236 & 2.38 & -0.3202 & 2.0598 \\
9.22 & 5.45 & 6.10 & 6.15 & 0.05 & 0.4297 & 2.17 & -0.1230 & 2.0470 \\
9.51 & 5.50 & 6.20 & 6.26 & 0.06 & 0.5500 & 1.89 & 0.0871 & 1.9771 \\
9.73 & 5.55 & 6.33 & 6.40 & 0.07 & 0.7000 & 1.67 & 0.3680 & 2.0380 \\
\hline
\end{tabular}

LogK $_{1}$ (Average value) $=2.1568 \pm 0.2069$

Table 14: Point-wise method, Mg (Unhydrolysed PSHA)

\begin{tabular}{|l|l|l|l|l|l|l|l|l|}
\hline $\mathrm{pH}$ & $\mathrm{BV}_{1}$ & $\mathrm{BV}_{2}$ & $\mathrm{BV}_{3}$ & $\mathrm{~V}_{3}-\mathrm{V}_{2}$ & $\mathrm{n}$ & $\mathrm{pL}$ & $\log \left(\frac{n-1}{2-n}\right)$ & $\log \mathrm{K}_{2}$ \\
\hline 10.00 & 5.60 & 6.47 & 6.55 & 0.08 & 0.9148 & 1.41 & & \\
10.23 & 5.65 & 6.62 & 6.71 & 0.09 & 1.2102 & 1.20 & -0.5749 & 0.6251 \\
10.49 & 5.70 & 6.80 & 6.92 & 0.09 & 1.5968 & 1.03 & 0.1703 & 1.2003 \\
\hline
\end{tabular}

LogK $_{2}$ (Average value) $=0.9127 \pm 0.4070$

Table15:Point-wise method, Cd (Hydrolysed PSHA)

\begin{tabular}{|l|l|l|l|l|l|l|l|l|}
\hline $\mathrm{pH}$ & $\mathrm{BV}_{1}$ & $\mathrm{BV}_{2}$ & $\mathrm{BV}_{3}$ & $\left(\mathrm{~V}_{3}-\mathrm{V}_{2}\right)$ & $\mathrm{n}$ & $\mathrm{pL}$ & $\log \left(\frac{n}{1-n}\right)$ & LogK $_{1}$ \\
\hline 8.50 & 5.30 & 6.29 & 6.31 & 0.02 & 0.2750 & 2.64 & -0.4210 & 2.2190 \\
8.72 & 5.35 & 6.37 & 6.40 & 0.03 & 0.4286 & 2.42 & -0.1249 & 2.2951 \\
9.00 & 5.40 & 6.46 & 6.49 & 0.03 & 0.4648 & 2.14 & -0.0612 & 2.0788 \\
9.22 & 5.45 & 6.55 & 6.59 & 0.04 & 0.6667 & 1.96 & 0.3010 & 2.2610 \\
9.51 & 5.55 & 6.66 & 6.70 & 0.04 & 0.7720 & 1.67 & 0.5297 & 2.1997 \\
\hline
\end{tabular}

LogK $_{\mathbf{1}}$ (Average value) $=2.2108 \pm 0.0825$

Table 16: Point-wise method, Cd (Hydrolysed PSHA)

\begin{tabular}{|l|l|l|l|l|l|l|l|l|}
\hline $\mathrm{pH}$ & $\mathrm{BV}_{1}$ & $\mathrm{BV}_{2}$ & $\mathrm{BV}_{3}$ & $\left(\mathrm{~V}_{3}-\mathrm{V}_{2}\right)$ & $\mathrm{n}$ & $\mathrm{pL}$ & $\log \left(\frac{n-1}{2-n}\right)$ & Log $_{2}$ \\
\hline 9.73 & 5.55 & 6.78 & 6.83 & 0.06 & 1.4042 & 1.47 & -0.1686 & 1.3014 \\
10.00 & 5.60 & 6.90 & 6.95 & 0.06 & 1.7838 & 1.23 & 0.5593 & 1.7893 \\
10.23 & 5.65 & 7.05 & 7.10 & 0.06 & 3.1429 & 1.09 & & \\
10.49 & 5.70 & 7.10 & 7.16 & 0.06 & 3.1429 & 0.89 & & \\
& & & & & & & & \\
\hline
\end{tabular}

$\operatorname{LogK}_{2}$ (Average value) $=1.5453 \pm 0.3450$

Table 17: Point-wise method, Cd (Unhydrolysed PSHA)

\begin{tabular}{|l|l|l|l|l|l|l|l|l|}
\hline $\mathrm{pH}$ & $\mathrm{BV}_{1}$ & $\mathrm{BV}_{2}$ & $\mathrm{BV}_{3}$ & $\mathrm{~V}_{3}-\mathrm{V}_{2}$ & $\mathrm{n}$ & $\mathrm{pL}$ & $\log \left(\frac{n}{n-1}\right)$ & $\operatorname{Log~}_{1}$ \\
\hline 8.50 & 5.30 & 5.81 & 5.86 & 0.05 & 0.3717 & 2.88 & -0.2280 & 2.6520 \\
8.72 & 5.35 & 5.90 & 5.95 & 0.05 & 0.3873 & 2.66 & -0.1992 & 2.4608 \\
9.00 & 5.40 & 6.00 & 6.06 & 0.06 & 0.4853 & 2.38 & -0.0255 & 2.3545 \\
9.22 & 5.45 & 6.10 & 6.16 & 0.06 & 0.5157 & 2.18 & -0.0272 & 2.2072 \\
9.51 & 5.50 & 6.20 & 6.27 & 0.07 & 0.6417 & 1.89 & 0.2530 & 1.1430 \\
9.73 & 5.55 & 6.33 & 6.41 & 0.08 & 0.8000 & 1.69 & 0.6020 & 2.2920 \\
& & & & & & & & \\
\hline
\end{tabular}

$\operatorname{LogK}_{1}($ Average value $)=2.2516 \pm 0.5380$ 
BAJOPAS Volume 14 Number 1,June, 2021

Table 18: Point-wise method, Cd (Unhydrolysed PSHA)

\begin{tabular}{|l|l|l|l|l|l|l|l|l|}
\hline $\mathrm{pH}$ & $\mathrm{BV}_{1}$ & $\mathrm{BV}_{2}$ & $\mathrm{BV}_{3}$ & $\mathrm{~V}_{3}-\mathrm{V}_{2}$ & $\mathrm{n}$ & $\mathrm{pL}$ & $\log \left(\frac{n-1}{2-n}\right)$ & $\log \mathrm{K}_{2}$ \\
\hline 10.00 & 5.60 & 6.47 & 6.57 & 0.10 & 1.1434 & 1.43 & & \\
10.23 & 5.65 & 6.62 & 6.72 & 0.10 & 1.3448 & 1.23 & -0.2788 & 0.9512 \\
10.49 & 5.70 & 6.80 & 6.90 & 0.10 & 1.7742 & 1.03 & 0.5351 & 1.5651 \\
\hline
\end{tabular}

$\operatorname{LogK}_{2}($ Average value $)=1.2581 \pm 0.4340$

Table 19: Stepwise and overall Stability constants of thehydrolysed and unhydrolysed divalent metal (II) complexes

\begin{tabular}{|c|c|c|c|}
\hline Chelates & LogK $_{1}$ & $\log _{2}$ & Log $\beta$ \\
\hline [Cu (Hydrolysed PSHA-1) $\left.{ }_{2}\right]$ & 2.4788 & 1.4280 & 3.9068 \\
\hline$\left[\mathrm{Pb}(\text { Hydrolysed PSHA-1) })_{2}\right]$ & 2.5832 & 1.1963 & 3.7795 \\
\hline$\left[\mathrm{Cd}(\text { Hydrolysed PSHA-1 })_{2}\right]$ & 2.2108 & 1.5453 & 3.7561 \\
\hline$\left[\mathrm{Mg}(\text { Hydrolysed PSHA-1 })_{2}\right]$ & 2.1382 & 1.5453 & 3.6835 \\
\hline [Cu (Unhydrolysed PSHA-1) & 2.3059 & 1.2209 & 3.5268 \\
\hline$[\mathrm{Pb}$ (Unhydrolysed PSHA-1) 2$]$ & 2.2364 & 1.2239 & 3.4603 \\
\hline [Cd (Unhydrolysed PSHA-1) 2 ] & 2.2516 & 1.2581 & 3.5097 \\
\hline$[\mathrm{Mg}$ (Unydrolysed PSHA-1) & 2.1568 & 0.9127 & 3.0695 \\
\hline
\end{tabular}

The results obtained (Table19) shows the stepwise and overall stability constants to be not high indicating low stability of the complexes, because the solubility of most metal ions in the basic $\mathrm{pH}$ range is minimal due to metal hydroxide precipitation (Karimi, 2017). In general, the stepwise stability constants $\left(K_{1}\right.$ and $K_{2}$ ) follow the order $K_{1}>K_{2}$ for the copper, lead, magnesium and cadmium complexes respectively. The steady decrease of the values with increasing number of ligands is in agreement with the prediction made by researchers (Na'aliya, 2013). The decrease could be attributed to the fact that as the number of the ligands (Humate ions) that enters the coordination zone increases the aqua molecules available for replacement by the ligands become less. Thus, the metal ions become less electron loving with progressive intake of the ligand and this results in the decrease in the values of the constants (Na'aliya, 2013). Also the stability of the complexes is influenced by the size and number of the chelate rings(Mackay and Mackay,2002).All the complexes form rings in their structure as humate, a bidentate ligand, bond the metal ions in the ratio 1:2 (Boguta and Sokolowska, 2016) forming chelate rings. The values of the overall stability constants $(\log \beta)$ obtained for humate complexes are not high indicating low stability as the values are not high. LogK values for copper-humates (Table 3 to 6) obtained in this study are lower than those reported for the complexes of humic acids (Pandey et al., 2015; Dinu, 2013; Kaschl et al., 2010 and Gilbeto and Jorg, 2001). The values of LogK(Table 7 to 10 ) forlead-humates are lower than those reported for the lead in the literature (Dinu, 2013; Gilbeto and Jorg 2001). Log K values(Table 11 to 14 ) for magnesium-humates obtained in this study are close to those reported by (Pandey et al., 2015). Log K values of cadmium-humates (Table 15 to 18 ) obtained in this work near to the one reported by (Dinu, 2013 and Pandey et al., 2015).The difference between the reported values and the values obtained in this study might be probably as a result of acid hydrolysis of humic acid. The values of the overall stability constants $(\log \beta)$ of the copper humates complexes presented in Table 19 is high than that of other metal humate complexes, show relatively high stability of CuHA complexes, show the following order of stability: $\mathrm{Cu}>\mathrm{Pb}>\mathrm{Cd}>\mathrm{Mg}$; which are in close agreement to the findings of (Dinu, 2013 and Pandey et al., 2015).The high stability of Cuhumate chelate could be attributed to the existence of coordinate covalent bond between the complexing agents and the $\mathrm{Cu}^{2+}$ ions. Since, $\mathrm{Cu}^{2+}$ being a metal of the transitional series with $3 d^{9}$ electronic configurations can accept the electrons from the complexing agents. Similarly, the low stabilities of $\mathrm{Pb}, \mathrm{Cd}$ and $\mathrm{Mg}$ complexes could be explained by that $\mathrm{Pb}^{2+}$ with $6 s^{2}, \mathrm{Cd}^{2+}$ with $4 \mathrm{~d}^{10}$ and $\mathrm{Mg}^{2+}$ with $2 \mathrm{p}^{6}$ their electronic configuration has a completely filled $\mathrm{d}, \mathrm{p}$ and $\mathrm{s}$ orbitals. Moreover, the stabilities of metal ions with hydrolysed humic acid from peat soil were higher than those with unhydrolysed humic acid from peat soil; which is ascribed to the high content of acidity in hydrolysed humic acid than unhydrolysed humic acid. 
BAJOPAS Volume 14 Number 1,June, 2021 CONCLUSION

The values of logk for $\mathrm{Cu}(\mathrm{II})$ hydrolysed humic acid complex was higher followed by $\mathrm{Pb}$ (II), $\mathrm{Cd}(\mathrm{II})$ and $\mathrm{Mg}$ (II) hydrolysed humic acid complexes as compared with metal(II) unhydrolysed humic acid complexes. This indicates acid hydrolysis of humic acid can

\section{REFERENCES}

Almeida, V.R. and Szpoganicz, B. (2015). Humic Acid Potentiometric Response Patterns:Out- of Equilibrium Properties and Species Distribution Modelling. Chemical. Biol. Technol. Agric. 2: 17.

Anđelković, T., Nikolić, R., Bojić, A.,Anđelković, D., and Nikolic G.,(2010). Binding of Cadmium to Soil Humic Acid as A Function of Carboxyl Group Content. Macedonian Journal of Chemistry and Chemical Engineering.29(2): 215-224.

Anil, B. N. and Maroti, N. (2008). Studies on Influence of Die-Lectric Constants on Complex Equilibria between Substituted Py-Razalines and Lanthanide Metal Ions pH-Metrically. Amer.-Euras. scient. Res. 3(2): 212-216.

Ashok, K., Pandey, S. P. and Misra, V (2000). Stability Constants of Metal-Humic Acid Complexes and its Role in Environmental Detoxification. Journal of Ecotoxicology and Environmental Safety. 47(2):157-200.

Badr, M. H., El-Halafawi, M. H. and Abd El-al Zeid, E. R. (2012). Comparison Between the Effect of Ionic Strength on Acidity and Dissociation Constants of Humic Acids Extracted from Sewage Sludge and Nile Water Hyacinth Composts.Global Journal of Environmental Research 6 (1): 36-43.

Baruah, M.K., Borah, D., Saikia, P.P., Paul, S., Sharma, T. (2015). Evaluation of pKa Values of Soil Humic Acids and their Complexation Properties. International Journal of Plant \& Soil Science 6(4) : 218-228.

Boguta, P. Sokolowska, Z. (2016). Interactions of $\mathrm{Zn}$ (II) Ions with Humic Acids Isolated from Various Types of Soils. Effect of $\mathrm{pH}, \mathrm{Zn}$ Concentrations and Humic Acids Chemical Properties. Journal of Geochemical Explaration 168. 119-126.

Borges, F., Guimaraes, C., Lima, L.F.C., Pinto, I. and Reis, S.(2005). Potentiometric Studies on the Complexation of Copper(II) by Phenolic Acids as Discrete Ligand Models of enhance the complexation behavior of humic acid with metal (II) ions. However, the higher values of $\log \beta$ for $\mathrm{Cu}(\mathrm{II}), \mathrm{Pb}(\mathrm{II}), \mathrm{Cd}(\mathrm{II})$ and $\mathrm{Mg}(\mathrm{II})$ hydrolysed humic acid complexes indicates more stable stepwise complexes formed as compared with $\mathrm{Cu}(\mathrm{II}), \mathrm{Pb}$ (II), $\mathrm{Cd}$ (II) and $\mathrm{Mg}(\mathrm{II})$ unhydrolysed humic acid complexes.

Humic Substances Talanta 66 (2005) 670-673.

Chefetz, B., Salloum, M. J., Deshmulkin, A. P. and Hatcher, P. (2002). Structural Components of Humic Acids as Determined by Chemical Modifications and Carbon-13 NMR, Pyrolysis, and Thermochemolysis- Gas Chromatography/Mass Spectrometry. Soil Science Society of American Journal Abstract Division S-2- Soil Chemistry66. 1159-1171.

Dinu, M. I. (2013). Metals Complexation with Humic Acids in Surface Water of Different Environ. Sci. Technol. 31(1): 1-17.

Fernandes, A.N., Giacomelli, C., Giovanela, M. Vaz, D.V. Szpoganicz, B. and Maria M. D. (2009). Potentiometric Acidity Determination in Humic Substances Influenced by Different Analytical Procedures.J. Braz. Chem. Soc. 20 (9):14.

Gamal, A. H. (2015). Stability Constants of Rhenium (V) Metal Complexes with Selected Drugs. Pyrex Journal of Research in Environmental Studies. 2(2): 006-014.

Janrao, D. M., Pathan, J., Kayande, D.D., and Mulla, J.J. (2014). An Over View of Potentiometric Determination of Stability Constants of Metal Complexes. Sci. Revs. Chem. Commun.: 4(1), 2014, 11-24.

Karimi, H. (2017). Effect of pH and Initial Pb(II) Concentration on the Lead Removal Efficiency from Waste Water Using $\mathrm{Ca}(\mathrm{OH})_{2}$. International Journal of Water and Waste Water Treatment 3.2

Kaschl, A. Romheld, V. and Chen, Y. (2010). Binding of Cadmium, Copper and Zinc to Humic Substances Originating from Municipal Solid Waste Compost. Israel Journal of Chemistry Vol. 42(1): 89-98.

Kostic, I. S., Tatjana, P, A., Nikolic, R. S., Cvetkovic, T. P., Pavlovic, D. D., Aleksandar, L.J. and Bojic, A. (2012). Comparative Study of Binding Strengths of Heavy Metals with Humic Acid. J.serb. Chem. Soc. 76(9) pp 1-20. 
BAJOPAS Volume 14 Number 1,June, 2021

Na'aliya, J. (2013). Determination of Stepwise Stability Constants and Gibbs free Energy Change of Trisprolina to Complexes of some Divalent Transition Metal ions. Bayero Journal of Pure and Applied Sciences 6(2): 112-114.

Omar, A. A. and Ali, E. A. (2015). Potentiometric Studies on Complexes of $\mathrm{Cr}$ (III) and $\mathrm{Zr}$ (IV) with some Carboxylic Acids. International Journal of Advanced Chemistry, 3(1) 25-

37.

Pandey, A. K. Pandey, S. D. and Misr, V. (2015).Stability Constants of Metal- Humic Acid Complexes and Its Role in Environmental Detoxification. J. Ecotoxicology and Environmental Safety. 47(1):195-200.

Ram, N. and Raman, K.V. (1984). Stability Constants of Complexes of Metals with
Humicand Fuvic Acids under Non- acidConditions. Journal of Plant Nutrition and Soil Sciences.

147:171-176.

Santosh, D. D., Ashok, B. K., Vijay, J. T., Shivraj, G. W. and Vinay, V. W. (2011). Potentiometric Studies of Elec-Trolyte Effects on Complex Equilibria of Some Substituted 5-(2-hydroxy Phenyl) Pyrazoles. Der pharm. 3 (6): 75-83.

Sayyed, H. and Abdul Rahim, M. F. (2012). Studies of Binary Complexes of Metal Ions with Mandelic Acid by Potentiometry. Chem. J. 02 (6): 206209.

Shirvani, M. Moradian, E. Khalili, B. Bakhtiary, S. (2015). Interaction of $\mathrm{Cd}$ and $\mathrm{Pb}$ with Humate-Palygorskite and HumateSepiolite Complexes. Journal of water, air and pollution 3: 220-228. 


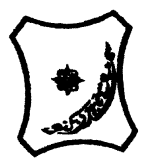

Bayero Journal of Pure and Applied Sciences, 14(1): 54 - 63

Received: November, 2020

Accepted: April, 2021

ISSN $2006-6996$

\title{
STABILITY CONSTANTS OF COMPLEXES OF METAL IONS WITH PEATSOIL HUMIC ACIDS UNDER NON-ACID-CONDITIONS
}

\author{
${ }^{* 1}$ Sabo, Yusuf ${ }^{2}$ Jimoh, W.L.O., ${ }^{3}$ Isa Baba Koki and ${ }^{4}$ Sholadoye, Q. 0. \\ ${ }^{1}$ Department of Pure and Industrial Chemistry, Bayero University, Kano \\ ${ }^{3}$ Department of Chemistry, Yusuf Maitama Sule University Kano. P.M.B. 3220 Kano, Nigeria. \\ ${ }^{4}$ Department of Chemistry, Nigerian Police Academy, Wudil, Kano-Nigeria
}

*Correspondence E-mail; saboyusuf18@yahoo.com

ABSTRACT

Stability constants of complexes of four divalent metal ions viz. $\mathrm{Cu}^{2+}, \mathrm{Pb}^{2+}, \mathrm{Mg}^{2+}$ and $\mathrm{Cd}^{2+}$ with humic acids (HA) were determined by potentiometric titration of humic acids with the corresponding salt of the divalent metals in aqueous media under non-acid-condition. The log $K$ (logarithm of the stability constant) ranged from 1.0942 to 2.7471 for metalhumic acid complexes were determined using point-wise computational method. The order of stability constants were obtained as follows: $\mathrm{Cu}>\mathrm{Pb}>\mathrm{Cd}>\mathrm{Mg}$ for metal $-\mathrm{HA}$ complexes respectively, indicating a higher degree of complexation with Cu metal ion.

Keywords: stability constant, humic acid, potentiometric titration, divalent metals, acid hydrolysis.

\section{NTRODUCTION}

The stability constant of a complex is the numerical expression of its stability and provides a quantitative measure of affinity of the metal ion to the complexing agent. An understanding of the relative stability of metal-complexes helps in predicting the behavior of metal ions in the soil (Ram and Raman, 1982). Extensive researches has been done to determine the stability constants of the complexes formed between humic acid (HA) with a number of metal ions. Ashok et al., (2000) reported that humic acid with hydroxyl, phenoxyl and carboxyl reactive groups can form coordination compound with metal ions at $\mathrm{pH}$ 3.5. The stability constants(Log K) for different metalhumic acid complexes indicated the following order of the stabilities of complexes formed between humic acid and metal ion, $\mathrm{Cu}>\mathrm{Fe}$ $>\mathrm{Pb}>\mathrm{Ni}>\mathrm{Co}>\mathrm{Ca}>\mathrm{Cd}>\mathrm{Zn}>\mathrm{Mn}>\mathrm{Mg}$. Andelkovic et al., (2010) investigated the binding of $\mathrm{Cd}$ (II) to soil humic acid at pH 6.5 and in $0.1 \mathrm{M} \mathrm{KNO}_{3}$ ionic medium. The stability constant for binding indicating greater stability in the case when carboxyl groups are involved in complexation reaction. Kostic et al.,(2012) investigated the complexation of humic acid with certain heavy metal ions (Co(II), $\mathrm{Ni}(\mathrm{II}), \mathrm{Cu}(\mathrm{II})$,
$\mathrm{Zn}(\mathrm{II})$, and $\mathrm{Pb}(\mathrm{II})$. The experiment was performed at $25^{\circ} \mathrm{C}$, at pH 4.0 and ionic strength of $0.01 \mathrm{M}$. Stability constant of complex between $\mathrm{Pb}$ (II) ions and humic acid is greater than stability constants of other investigated metalhumate complexes. Bogata and Sokolowska (2016) analyses the interaction between humic acids from different soils and $\mathrm{Zn}$ (II) ions at wide concentration ranges and at $\mathrm{pH} 5$. Studies have showed significant impact of $\mathrm{Zn}$ concentration, $\mathrm{pH}$ and some properties of humic acids with zinc.But all of these studies were limited to acidic $\mathrm{pH}$ range. Therefore, the present study was carried out to determine and compare the stability constants of complexes of metal ions with hydrolysed peat soil humic acid and unhydrolysed peat soil humic under non-acid conditions.

\section{MATERIALS AND METHODS}

Analytical grade chemicals used includes hydrochloric acid $(\mathrm{HCl})$, nitric acid $\left(\mathrm{HNO}_{3}\right)$, sodium hydroxide $(\mathrm{NaOH})$, lead nitrate $\mathrm{Pb}\left(\mathrm{NO}_{3}\right)_{2}$, copper nitrate $\mathrm{Cu}\left(\mathrm{NO}_{3}\right)_{2} \cdot 3 \mathrm{H}_{2} \mathrm{O}$, cadmium nitrate $\mathrm{Cd}\left(\mathrm{NO}_{3}\right)_{2} \cdot 4 \mathrm{H}_{2} \mathrm{O}$, magnesium nitrate $\mathrm{Mg}\left(\mathrm{NO}_{3}\right)_{2} \cdot 6 \mathrm{H}_{2} \mathrm{O}$, potassium nitrate $\left(\mathrm{KNO}_{3}\right)$, calcium chloride $\left(\mathrm{CaCl}_{2}\right)$, (sigma-Aldrich). Dowex 50WX8, (20-50 mesh) from Fluka. 


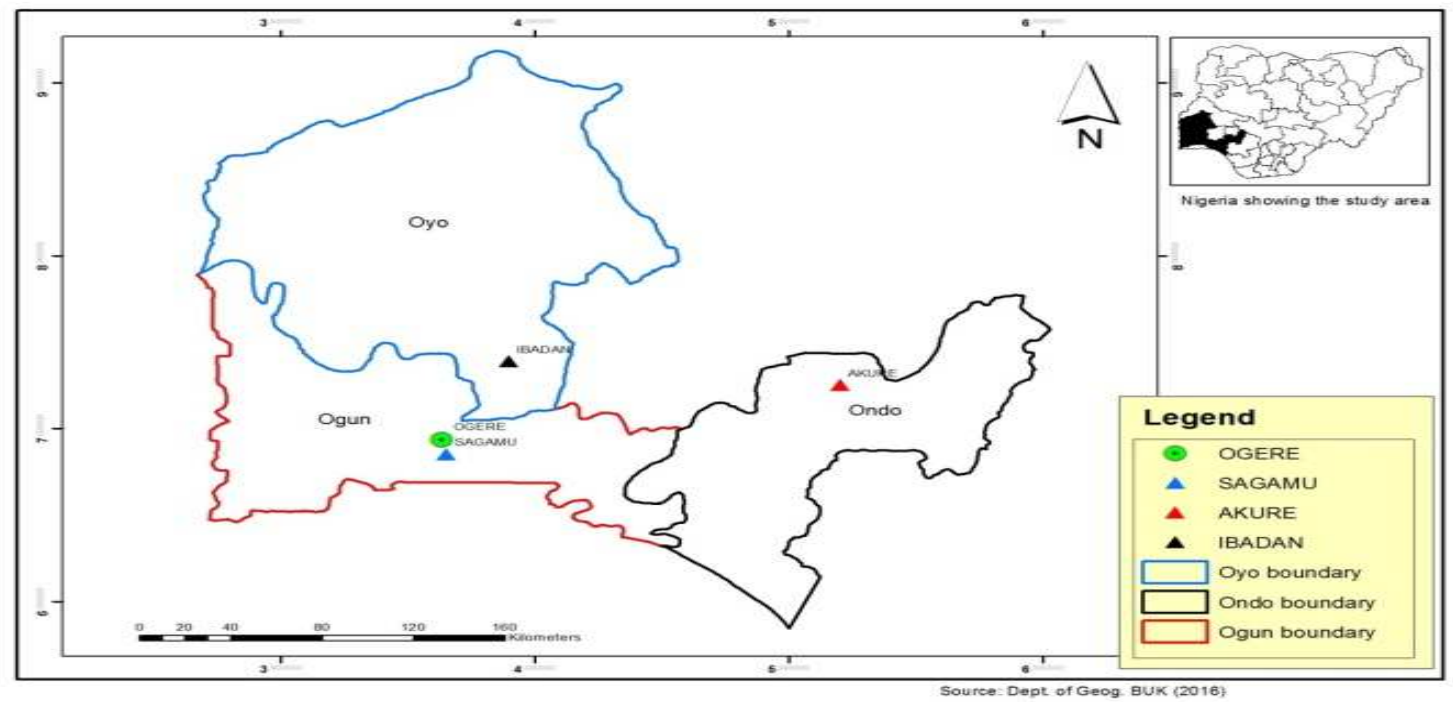

Figure 1: Map showing the sampling point at Sagamu Town, Ogun State.

\section{Description of Sampling Area}

Sagamu has geographical coordinates between $6^{\circ} 50^{\prime}$ north; $3^{\circ} 38^{\prime}$ east is located in south western region of Nigeria. The region has tropical wet and dry climate with a lengthy wet season and relatively constant temperatures throughout the course of the year. Wet season runs from March to October, November to December forms the region dry season. The vegetation type of the region is savannah which is really grassland with small bushes and occasional big trees. Grassland soils have substantially higher organic matter content than forest soils (Novackova, 2011).

\section{Sample Collection}

The Peatsoil samples were collected from four different sampling points $(0-10 \mathrm{~cm}$ depth) in Sagamu into polyethylene bag with plastic spoons. Samples were taken to the laboratory, extraneous materials were removed; the samples were air-dried, crushed and ground to a fine powder in a mortar passed through a $0.20 \mathrm{~mm}$ sieve. The samples were kept for analysis.

\section{Isolation and purification of humic acid from peat soil sample}

Peatsoil sample $(100 \mathrm{~g})$ was mixed with 1000 $\mathrm{cm}^{3}$ of $0.1 \mathrm{M} \mathrm{NaOH}$ solution, shaken for 3hours and left to stand overnight. Dark-coloured supernatant was obtained and decanted from solid residue. The dark-coloured supernatant was acidified to $(\mathrm{pH}=1.0)$ with $6 \mathrm{M} \mathrm{HCl}$ stirred and allowed to stand for 6 hours. Yellowish brown supernatant and dark-brown precipitate were obtained. The yellowish brown supernatant was decanted followed by centrifuge and discarded. The dark-brown precipitate was mixed with $500 \mathrm{~cm}^{3}$ of $0.1 \mathrm{M} \mathrm{NaOH}$ solution followed by passing through dowex resin. The dark-brown solution was acidified to $(\mathrm{pH}=1.0)$ with $6 \mathrm{M} \mathrm{HCl}$ stirred and allowed to stand for 3 hours. The dark-brown precipitate was washed several times with deionized water. The supernatant was treated with $\mathrm{AgNO}_{3}$ solution until no white precipitate observed. The humic acid was transferred to weighed crucible and dried at $60^{\circ} \mathrm{C}$ in an oven for 12 hours. The humic acid was cooled and dried in the desiccator, weighed and recorded. The obtained humic acid was dried again at $60^{\circ} \mathrm{C}$ for additional 6 hours cooled and dried in the desiccator, weighed and recorded constant weight was obtained (Baruah et al., 2015).

\section{FT-IR analysis}

FT-IR spectra of humic acid sample was analysed using Carry 630 FT-IR Agilent Technologies.

Unhydrolysed compost humic acid

The unhydrolysed humic acid was obtained after isolation and purification of compost humic acid and kept for investigation.

\section{Acid hydrolysis of Peatsoil acid}

Peatsoil humic acid sample (1g) was refluxed for 12 hours at $\left(160^{\circ} \mathrm{C}\right)$ with $50 \mathrm{~cm}^{3}$ of $6 \mathrm{M} \mathrm{HCl}$. The mixture was allowed to cool, decanted, and centrifuged after hydrolysis. The insoluble residues were washed with distilled water via centrifugation several times, and the supernatant was treated with $\mathrm{AgNO}_{3}$ solution until no white precipitate was observed. The residue was thoroughly dried over $\mathrm{CaCl}_{2}$ in a desiccator at room temperature (Chefetz et al., 2002). Finally, the obtained hydrolysed humic acid was kept for investigation. 
BAJOPAS Volume 14 Number 1,June, 2021 Potentiometric Titrations

Potentiometric measurements were carried out using a pH-meter Jenway (model 3510) with combine electrode, the sensitivity of the $\mathrm{pH}$ meter is 0.01 units. The $\mathrm{pH}$ meter was switched on half an hour before starting the titration for initial warm up of the instrument. The instrument was calibrated with an aqueous standard buffer solution of $\mathrm{pH} 4.00$ and 10.0 (borate buffer) prepared from a "Qualigens" buffer tablets.

The following sets of solutions were prepared in a $250 \mathrm{~cm}^{3}$ volumetric flask separately for $\mathrm{pH}$ metric titrations.

(i) $5 \mathrm{~cm}^{3} 0.1 \mathrm{M} \mathrm{HCl}+40 \mathrm{~cm}^{3}$ deionized water

(ii) $5 \mathrm{~cm}^{3} 0.1 \mathrm{M} \mathrm{HCl}+39 \mathrm{~cm}^{3}$ deionized water $+1 \mathrm{~cm}^{3} 0.15 \mathrm{gcm}^{-3}$ humic acid

(iii) $5 \mathrm{~cm}^{3} 0.1 \mathrm{M} \mathrm{HCl}+37 \mathrm{~cm}^{3}$ deionized water $+1 \mathrm{~cm}^{3} 0.15 \mathrm{gcm}^{-3}$ humic acid

$$
+2 \mathrm{~cm}^{3} \quad 0.01 \mathrm{M} \mathrm{Cu} \text { (II) }
$$

The solutions were titrated against standardized $0.110 \mathrm{MNaOH}$ separately. The total volume of each mixture was adjusted to $50 \mathrm{~cm}^{3}$ and the ionic strength of the solutions was maintained constant at by adding appropriate amount of stock solution of $1 \mathrm{M} \mathrm{KNO}_{3}$ (Gamal, 2015; Omar and Ali, 2015). A magnetic stirrer was used to achieve thorough mixing of the interacting solutions at $550 \mathrm{rpm}$. The same set of experimental conditions was applied for potentiometric titration of remaining samples.

\section{Evaluation of pKa of Hydrolysed peat soil Humic Acids}

The proton-ligand formation number $\mathrm{n}_{\mathbf{A}}$ were calculated by Irving and Rossotti expression (Omar and Ali, 2015).

$\mathrm{nA}=\mathrm{Y}-\frac{(\mathrm{V} 2-\mathrm{V1})(\mathrm{No}-\mathrm{Eo})}{(\mathrm{VO}+\mathrm{V1}) \mathrm{TCL}}$ 1

Where: $Y$ is number of dissociable proton, $\left(\mathrm{V}_{2^{-}}\right.$ $V_{1}$ ) is the measure of displacement of the ligand curve relative to acid curve, $\mathrm{N}^{\circ}$ and $\mathrm{E}^{\circ}$ are the resultant concentration of alkali solution, free acid solution, $\mathrm{T}_{\mathrm{cL}}{ }^{\circ}$ is the total ligand concentration, $\mathrm{V}^{\circ}$ is the total volume of titration solution, $V_{1}$ is the volume of alkali added to acid solution, $V_{2}$ is the volume of alkali added to acid solution + ligand solution, acid dissociation constants (pKa - values) of ligand were calculated by algebraic method point wise calculation (Tables 1 ). The dissociation constants (pKa) were calculated according to the following relation:

$\mathrm{pKa}=\mathrm{pH}+\log \left(\frac{n A}{1-n A}\right)$ 2

Where: pKa is the acid dissociation constant, $\mathrm{n}_{\mathrm{A}}$ is the Proton-ligand formation number and $\mathrm{pH}$ is the pH-values (Omar and Ali, 2015).

\section{Determination of metal-ligand stability constants $(\log K)$ of complexes}

The potentiometric measurement for the determination of stability constant of a complex in solution is based on the fact that the redox potential of the couple $\frac{M^{+(m-n)}}{M^{+m}}$ is shifted significantly on complexation of the metal ion with the ligand. This method involves change in hydrogen ion concentration $\left[\mathrm{H}^{+}\right]$due to the displacement or association of one or more protons taking place during complexation reaction. This change can be found out by titrating the solutions containing free acid, acid with ligand, and acid with ligand and metal ion, individually against a standard alkali solution at a constant ionic strength or temperature. Either ionic strength or temperature may be varied for different sets of solutions. In all the cases, the change in the $\mathrm{pH}$ of the solution is measured after each addition of a known amount of alkali to the reaction cell which contains the reaction mixture. The titration curves are then drawn by plotting the measured $\mathrm{pH}$ values against the corresponding volume of alkali added and the stability constants of the complexes are determined from the titration curves by employing $\mathrm{pH}$-metric titration technique given by (Irving and Rossoti).

Metal-ligand stability constants ( $\log \mathrm{K}$ ) were determined by using the following relations:

$$
\bar{n}=\frac{\left(V_{3}-V_{2}\right)\left(E^{0}+N^{0}\right)}{\left(V^{0}+V_{2}\right) \bar{n}_{A} T_{m}^{0}}
$$

and

$$
P L=\log _{10}\left\{\frac{1+\beta_{n}^{H} \frac{1}{[\text { anti } \log \mathrm{pH}]^{\mathrm{n}}}}{\mathrm{T}_{\mathrm{L}}^{0}-n \bar{T}_{m}^{0}} \mathrm{X} \frac{\left(V^{0}+V_{3}\right)}{V^{0}}\right\}
$$


BAJOPAS Volume 14 Number 1,June, 2021

Where $T_{L}, T^{\circ}, E^{\circ}$, and $V^{\circ}$ havethe same significance as in equation (1) above, $T_{m}$ denotes the total concentration of metal present in solution, $V_{3}$ is the volume of metal ions present in solution and $\beta^{H}$ is the overall proton ligand stability constant. The metal-ligand stability constants (log K) were determined by employing point wise computational Method (eq. 5 and 6).

$\operatorname{LogK}_{1}=\log \left(\frac{n}{1-n}\right)+\mathrm{pL}$ .5

$\operatorname{LogK}_{2}=\log \left(\frac{1-n}{2-n}\right)+\mathrm{pL}$ ...6

Where: Log $\mathrm{K}$ is the metal-ligand stability constant, $\mathrm{pL}$ is the Free ligand exponent function, $\mathbf{n}$ is the Average number of ligand attached with metal ion (Janraoet al., 2014). The results obtained were analyzed by an ORIGIN 2016 program using titration data and then the proton-ligand stability constants (pKa) and Metal-ligand stability constant (LogK) calculated (Omar and Ali, 2015).

\section{RESULTS AND DISCUSSION}

Fourier transformed infrared (FT-IR) spectra of isolated humic acid from peat soils Figure 2 had distinct clear absorption bands indicating the presence of major humic acid structural elemental groups such as $\mathrm{H}$ bonded $\mathrm{OH}$ $\left(3680 \mathrm{~cm}^{-1}\right.$ peak $), C=0$ of carbonyl $\left(1721 \mathrm{~cm}^{-1}\right.$ peak), functional groups of aliphatic components $\mathrm{CH}_{2}\left(2918 \mathrm{~cm}^{-1}\right.$ peak) and $\mathrm{C}-\mathrm{O}$ stretching of polysaccharide $\left(1168 \mathrm{~cm}^{-1}\right.$ peak). The positions of the absorption bands of the spectra fell within typical major absorption bands of humic acid which is at frequencies 3680, 2918, 1721, 1168 $\mathrm{cm}^{-1}$. The first peak centred in the vicinity of $3680 \mathrm{~cm}^{-1}$ region is attributed to phenol $\mathrm{OH}$ group bounded by intermolecular $\mathrm{H}$ bonds. The $2918 \mathrm{~cm}^{-1}$ band usually has absorption maximum at $2918 \mathrm{~cm}^{-1}$ which is due to $\mathrm{C}-\mathrm{H}$ stretching of alkane group $\left(\mathrm{CH}_{2}\right)$. The next major absorption band is $1721 \mathrm{~cm}^{-1}$. This band has been commonly ascribed to $\mathrm{C}=\mathrm{O}$ stretching of mainly carboxyl group $(\mathrm{COOH})$ with trace amount of ketones. The last peak was observed at 1168 $\mathrm{cm}^{-1}$ due to $\mathrm{C}-\mathrm{O}$ stretching of polysaccharides and this peak appeared also in the spectra of humic acid from peat soil. The FTIR spectra of the isolated humic acid contained all major characteristic absorption peaks of humic acid. These absorption peaks indicated the presence of the major structural elements of humic acid namely $\mathrm{H}$ bonded $\mathrm{OH}, \mathrm{C}=\mathrm{C}$ of aromatic ring, $\mathrm{C}=\mathrm{O}$ of carbonyl group (both carboxyl and ketonic), $\mathrm{CH}_{2}$ group. This strongly supports the presence of humic acid.

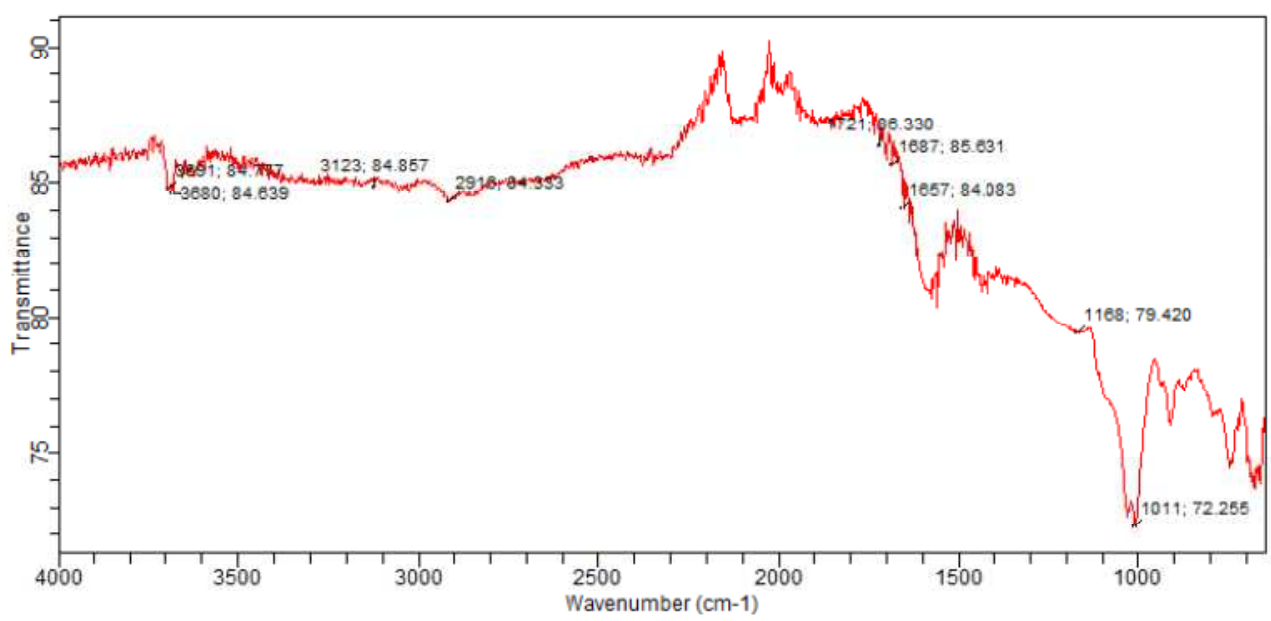

Fig. 2 : FT-IR spectraof peatsoilhumic acid (PSHA)

\section{Evaluation of acid dissociation constant (pka) of acid hydrolysed peat soil humicacid at phenolic group}

The value of the dissociation constant of the peat soil humic acid (PSHA) that underwent acidhydrolysis studied was found to be 8.9299 as shown Table 1, which is lower than the literaturevalues reported by Almeida and Szpoganics, (2015), Borges et al., (2005); Badr et al., (2012)and Fernandes et al,.(2009) of $9.73,9.47$ and 10.30. The difference between the obtained valuesand the reported values in this study might be probably as a result of acid hydrolysis of humicacid. 
BAJOPAS Volume 14 Number 1,June, 2021

Table 1: PKa of (Hydrolysed PSHA)

\begin{tabular}{|l|l|l|l|l|l|l|}
\hline $\mathrm{pH}$ & $\mathrm{BV}_{1}$ & $\mathrm{BV}_{2}$ & $\mathrm{~V}_{2}-\mathrm{V}_{1}$ & $\mathrm{nA}$ & $\log \left(\frac{n A}{1-n A}\right)$ & $\mathrm{pKa}$ \\
\hline 8.50 & 5.30 & 6.29 & 0.99 & 0.3594 & -0.2510 & 8.2490 \\
8.72 & 5.35 & 6.37 & 1.02 & 0.3400 & -0.2880 & 8.4320 \\
9.00 & 5.40 & 6.46 & 1.06 & 0.3141 & -0.3391 & 8.6609 \\
9.22 & 5.45 & 6.55 & 1.10 & 0.2882 & -0.3927 & 8.8273 \\
9.51 & 5.50 & 6.66 & 1.16 & 0.2494 & -0.4786 & 9.0314 \\
9.73 & 5.55 & 6.78 & 1.23 & 0.2041 & -0.5910 & 9.1390 \\
10.00 & 5.60 & 6.90 & 1.30 & 0.1589 & -0.7238 & 9.2762 \\
10.23 & 5.65 & 7.05 & 1.40 & 0.0941 & -0.9835 & 9.2465 \\
10.49 & 5.70 & 7.10 & 1.40 & 0.0941 & -0.9835 & 9.5065 \\
\hline
\end{tabular}

Average pKa $=8.9299 \pm 0.4186$

Table 2: PKa of (Unhydrolysed PSHA)

\begin{tabular}{|l|l|l|l|l|l|l|}
\hline $\mathrm{pH}$ & $\mathrm{BV}_{1}$ & $\mathrm{BV}_{2}$ & $\mathrm{~V}_{2}-\mathrm{V}_{1}$ & $\mathrm{nA}$ & $\log \left(\frac{\boldsymbol{n A}}{1-\boldsymbol{n}}\right)$ & $\mathrm{pKa}$ \\
\hline 8.50 & 5.30 & 5.81 & 0.51 & 0.6619 & 0.2919 & 8.7919 \\
8.72 & 5.35 & 5.90 & 0.55 & 0.6357 & 0.2418 & 8.9618 \\
9.00 & 5.40 & 6.00 & 0.60 & 0.6029 & 0.1813 & 9.1813 \\
9.22 & 5.45 & 6.10 & 0.65 & 0.5701 & 0.1226 & 9.3426 \\
9.51 & 5.50 & 6.20 & 0.70 & 0.5376 & 0.0654 & 9.5754 \\
9.73 & 5.55 & 6.33 & 0.78 & 0.4851 & -0.0259 & 9.7041 \\
10.00 & 5.60 & 6.47 & 0.87 & 0.4262 & -0.1291 & 9.8709 \\
10.23 & 5.65 & 6.62 & 0.99 & 0.3609 & -0.2481 & 9.9819 \\
10.49 & 5.70 & 6.80 & 1.10 & 0.2759 & -0.4690 & 10.0210 \\
\hline
\end{tabular}

Average pKa $=9.4923 \pm 0.4410$

Metal-ligand stability constant ( $\log \mathrm{K}$ )

The stabilityconstants require the accurate values of proton-ligand stability constants (Anil and Maroti, 2008). Metal titration curves crossed over ligand titration curve indicated the formation of complex upon proton release (Santosh, et al., 2011). If the values of n- are within range $0.2-0.8$ and $1.2-18$ this indicates the formation of $1: 1$ and 1:2 complexes (Sayyed and Mazahar, 2012).

The metal (II)-humate stepwise stability constants (log k) at phenolic group (Tables 318)

Table 3: Point-wise method, $\mathrm{Cu}$-(Hydrolysed PSHA)

\begin{tabular}{|l|l|l|l|l|l|l|l|l|}
\hline $\mathrm{pH}$ & $\mathrm{BV}_{1}$ & $\mathrm{BV}_{2}$ & $\mathrm{BV}_{3}$ & $\left(\mathrm{~V}_{3}-\mathrm{V}_{2}\right)$ & $\mathrm{n}$ & $\mathrm{pL}$ & $\log \left(\frac{n}{1-n}\right)$ & LogK $_{1}$ \\
\hline 8.50 & 5.30 & 6.29 & 6.33 & 0.04 & 0.5500 & 2.66 & 0.0871 & 2.7471 \\
8.72 & 5.35 & 6.37 & 6.41 & 0.04 & 0.5714 & 2.43 & 0.1249 & 2.5549 \\
9.00 & 5.40 & 6.46 & 6.50 & 0.04 & 0.6198 & 2.16 & 0.2122 & 2.3722 \\
9.22 & 5.45 & 6.55 & 6.59 & 0.04 & 0.6667 & 1.94 & 0.3010 & 2.2410 \\
\hline
\end{tabular}

LogK $_{1}$ (Average value) $=2.4788 \pm 0.2203$

Table 4: Point-wise method, $\mathrm{Cu}$-(Hydrolysed PSHA)

\begin{tabular}{|l|l|l|l|l|l|l|l|l|}
\hline $\mathrm{pH}$ & $\mathrm{BV}_{1}$ & $\mathrm{BV}_{2}$ & $\mathrm{BV}_{3}$ & $\left(\mathrm{~V}_{3}-\mathrm{V}_{2}\right)$ & $\mathrm{n}$ & $\mathrm{pL}$ & $\log \left(\frac{n-1}{2-n}\right)$ & LogK $_{2}$ \\
\hline 9.51 & 5.50 & 6.66 & 6.73 & 0.07 & 1.3509 & 1.70 & -0.2671 & 1.4329 \\
9.73 & 5.55 & 6.78 & 6.85 & 0.07 & 1.6383 & 1.51 & 0.2467 & 1.7567 \\
10.00 & 5.60 & 6.90 & 6.98 & 0.08 & 2.1783 & 1.31 & -0.2158 & 1.0942 \\
10.23 & 5.65 & 7.05 & 7.13 & 0.08 & 4.1904 & 1.27 & & \\
10.49 & 5.70 & 7.10 & 7.19 & 0.09 & 4.6920 & & & \\
\hline
\end{tabular}

Log $K_{2}($ Average value $)=1.4280 \pm 0.3312$ 
BAJOPAS Volume 14 Number 1,June, 2021

Table 5: Point-wise method, $\mathrm{Cu}$ (Unhydrolysed PSHA)

\begin{tabular}{|l|l|l|l|l|l|l|l|l|}
\hline $\mathrm{pH}$ & $\mathrm{BV}_{1}$ & $\mathrm{BV}_{2}$ & $\mathrm{BV}_{3}$ & $\left(\mathrm{~V}_{3}-\mathrm{V}_{2}\right)$ & $\mathrm{n}$ & $\mathrm{pL}$ & $\log \left(\frac{n}{n-1}\right)$ & Log $_{1}$ \\
\hline 8.50 & 5.30 & 5.81 & 5.85 & 0.04 & 0.2973 & 2.88 & -0.3736 & 2.5064 \\
8.72 & 5.35 & 5.90 & 5.95 & 0.05 & 0.3873 & 2.66 & -0.1992 & 2.4608 \\
9.00 & 5.40 & 6.00 & 6.05 & 0.05 & 0.4044 & 2.38 & -0.1681 & 2.2119 \\
9.22 & 5.45 & 6.10 & 6.15 & 0.06 & 0.5157 & 2.18 & -0.0272 & 2.2072 \\
9.51 & 5.50 & 6.20 & 6.27 & 0.07 & 0.6417 & 1.89 & 0.2530 & 1.1430 \\
\hline
\end{tabular}

$\operatorname{LogK}_{1}($ Average value $)=2.3059 \pm 0.6153$

Table 6:Point-wise method, $\mathrm{Cu}$ (Unhydrolysed PSHA)

\begin{tabular}{|l|l|l|l|l|l|l|l|l|}
\hline $\mathrm{pH}$ & $\mathrm{BV}_{1}$ & $\mathrm{BV}_{2}$ & $\mathrm{BV}_{3}$ & $\mathrm{~V}_{3}-\mathrm{V}_{2}$ & $\mathrm{n}$ & $\mathrm{pL}$ & $\log \left(\frac{n-1}{2-n}\right)$ & $\log \mathrm{K}_{2}$ \\
\hline 9.73 & 5.55 & 6.33 & 6.42 & 0.09 & 0.9000 & 1.69 & & \\
10.00 & 5.60 & 6.47 & 6.58 & 0.11 & 1.2578 & 1.44 & -0.4592 & 0.9808 \\
10.23 & 5.65 & 6.62 & 6.84 & 0.12 & 1.6137 & 1.26 & -0.2010 & 1.4610 \\
10.49 & 5.70 & 6.80 & 6.92 & 0.12 & 2.1052 & 1.03 & & \\
\hline
\end{tabular}

$\operatorname{LogK}_{2}$ (Average value) $=1.2209 \pm 0.3398$

Table 7:Point-wise method, Pb (Hydrolysed PSHA)

\begin{tabular}{|l|l|l|l|l|l|l|l|l|}
\hline $\mathrm{pH}$ & $\mathrm{BV}_{1}$ & $\mathrm{BV}_{2}$ & $\mathrm{BV}_{3}$ & $\left(\mathrm{~V}_{3}-\mathrm{V}_{2}\right)$ & $\mathrm{n}$ & $\mathrm{pL}$ & $\log \left(\frac{n}{1-n}\right)$ & LogK $_{1}$ \\
\hline 8.50 & 5.30 & 6.29 & 6.33 & 0.04 & 0.5500 & 2.66 & 0.0871 & 2.7471 \\
8.72 & 5.35 & 6.37 & 6.41 & 0.04 & 0.5714 & 2.43 & 0.1249 & 2.5549 \\
9.00 & 5.40 & 6.46 & 6.50 & 0.04 & 0.6198 & 2.16 & 0.2122 & 2.3722 \\
9.22 & 5.45 & 6.55 & 6.60 & 0.05 & 0.8333 & 1.96 & 0.6989 & 2.6589 \\
\hline
\end{tabular}

Log $_{\mathbf{1}}($ Average value $)=2.5832 \pm 0.1614$

Table 8:Point-wise method, Pb-(Hydrolysed PSHA)

\begin{tabular}{|l|l|l|l|l|l|l|l|l|}
\hline $\mathrm{pH}$ & $\mathrm{BV}_{1}$ & $\mathrm{BV}_{2}$ & $\mathrm{BV}_{3}$ & $\left(\mathrm{~V}_{3}-\mathrm{V}_{2}\right)$ & $\mathrm{n}$ & $\mathrm{pL}$ & $\log \left(\frac{n-1}{2-n}\right)$ & $\log \mathrm{K}_{2}$ \\
\hline 9.51 & 5.50 & 6.66 & 6.71 & 0.05 & 0.9650 & 1.67 & & \\
9.73 & 5.55 & 6.78 & 6.83 & 0.05 & 1.1702 & 1.44 & & \\
10.00 & 5.60 & 6.90 & 6.90 & 0.05 & 1.4864 & 1.22 & -0.0237 & 1.1963 \\
10.23 & 5.65 & 7.05 & 7.10 & 0.05 & 2.0190 & 1.09 & & \\
10.49 & 5.70 & 7.10 & 7.17 & 0.07 & 3.6492 & 1.00 & & \\
\hline
\end{tabular}

Log $K_{2}$ (Average value) $=1.1963$

Table 9: Point-wise method, Pb (Unhydrolysed PSHA)

\begin{tabular}{|l|l|l|l|l|l|l|l|l|}
\hline $\mathrm{pH}$ & $\mathrm{BV}_{1}$ & $\mathrm{BV}_{2}$ & $\mathrm{BV}_{3}$ & $\mathrm{~V}_{3}-\mathrm{V}_{2}$ & $\mathrm{n}$ & $\mathrm{pL}$ & $\begin{array}{l}\text { Log } \\
\left(\frac{n}{n-1}\right)\end{array}$ & Log $\mathrm{K}_{1}$ \\
\hline 8.50 & 5.30 & 5.81 & 5.85 & 0.04 & 0.2973 & 2.88 & -0.3736 & 2.5064 \\
8.72 & 5.35 & 5.90 & 5.94 & 0.04 & 0.3099 & 2.66 & -0.5477 & 2.3123 \\
9.00 & 5.40 & 6.00 & 6.05 & 0.05 & 0.4044 & 2.38 & -0.1681 & 2.2119 \\
9.22 & 5.45 & 6.10 & 6.15 & 0.06 & 0.5157 & 2.18 & 0.0272 & 2.2072 \\
9.51 & 5.50 & 6.20 & 6.26 & 0.07 & 0.6417 & 1.89 & 0.2530 & 2.1430 \\
9.73 & 5.55 & 6.40 & 6.40 & 0.07 & 0.7000 & 1.67 & 0.3680 & 2.0380 \\
\hline
\end{tabular}

LogK $_{1}$ (Average value) $=2.2364 \pm 0.1602$

Table 10: Point-wise method, Pb (Unhydrolysed PSHA)

\begin{tabular}{|l|l|l|l|l|l|l|l|l|}
\hline $\mathrm{pH}$ & $\mathrm{BV}_{1}$ & $\mathrm{BV}_{2}$ & $\mathrm{BV}_{3}$ & $\mathrm{~V}_{3}-\mathrm{V}_{2}$ & $\mathrm{n}$ & $\mathrm{pL}$ & $\log \left(\frac{n-1}{2-n}\right)$ & $\log \mathrm{K}_{2}$ \\
\hline 10.00 & 5.60 & 6.47 & 6.55 & 0.08 & 1.9503 & 1.41 & & \\
10.23 & 5.65 & 6.62 & 6.72 & 0.11 & 1.4792 & 1.26 & -0.0361 & 1.2239 \\
\hline
\end{tabular}

$\operatorname{LogK}_{2}$ (Average value) $=1.2239$

Table 11: Point-wise method, Mg (Hydrolysed PSHA)

\begin{tabular}{|l|l|l|l|l|l|l|l|l|}
\hline $\mathrm{pH}$ & $\mathrm{BV}_{1}$ & $\mathrm{BV}_{2}$ & $\mathrm{BV}_{3}$ & $\left(\mathrm{~V}_{3}-\mathrm{V}_{2}\right)$ & $\mathrm{n}$ & $\mathrm{pL}$ & $\log \left(\frac{n}{n-1}\right)$ & LogK $_{1}$ \\
\hline 8.50 & 5.30 & 6.29 & 6.31 & 0.02 & 0.2750 & 2.64 & -0.4290 & 2.2110 \\
8.72 & 5.35 & 6.37 & 6.39 & 0.02 & 0.2858 & 2.42 & -0.3978 & 2.0222 \\
9.00 & 5.40 & 6.46 & 6.49 & 0.03 & 0.4648 & 2.14 & -0.0612 & 2.0788 \\
9.22 & 5.45 & 6.55 & 6.59 & 0.04 & 0.6667 & 1.94 & 0.3010 & 2.2410 \\
\hline
\end{tabular}

$\log _{\mathbf{1}}($ Average value) $=2.1382 \pm 0.1046$ 
BAJOPAS Volume 14 Number 1,June, 2021

Table 12: Point-wise method, Mg (Hydrolysed PSHA)

\begin{tabular}{|l|l|l|l|l|l|l|l|l|}
\hline $\mathrm{pH}$ & $\mathrm{BV}_{1}$ & $\mathrm{BV}_{2}$ & $\mathrm{BV}_{3}$ & $\left(\mathrm{~V}_{3}-\mathrm{V}_{2}\right)$ & $\mathrm{n}$ & $\mathrm{pL}$ & $\log \left(\frac{n-1}{2-n}\right)$ & LogK $_{2}$ \\
\hline 9.51 & 5.55 & 6.66 & 6.71 & 0.05 & 0.9650 & 1.67 & & \\
9.73 & 5.55 & 6.78 & 6.84 & 0.06 & 1.4042 & 1.47 & -0.1686 & 1.3014 \\
10.00 & 5.60 & 6.90 & 6.93 & 0.06 & 1.7838 & 1.23 & 0.5593 & 1.7893 \\
10.23 & 5.65 & 7.05 & 7.10 & 0.06 & 3.1429 & 1.10 & & \\
10.49 & 5.70 & 7.10 & 7.18 & 0.07 & 3.6492 & 0.83 & & \\
\hline
\end{tabular}

LogK $_{2}($ Average value $)=1.5453 \pm 0.3450$

Table 13: Point-wise method, Mg (Unhydrolysed PSHA)

\begin{tabular}{|l|l|l|l|l|l|l|l|l|}
\hline $\mathrm{pH}$ & $\mathrm{BV}_{1}$ & $\mathrm{BV}_{2}$ & $\mathrm{BV}_{3}$ & $\mathrm{~V}_{3}-\mathrm{V}_{2}$ & $\mathrm{n}$ & $\mathrm{pL}$ & $\log \left(\frac{n}{n-1}\right)$ & $\operatorname{Log~}_{1}$ \\
\hline 8.50 & 5.30 & 5.81 & 5.85 & 0.04 & 0.2973 & 2.88 & -0.3736 & 2.5064 \\
8.72 & 5.35 & 5.90 & 5.94 & 0.04 & 0.3099 & 2.66 & -0.3477 & 2.3123 \\
9.00 & 5.40 & 6.00 & 6.04 & 0.04 & 0.3236 & 2.38 & -0.3202 & 2.0598 \\
9.22 & 5.45 & 6.10 & 6.15 & 0.05 & 0.4297 & 2.17 & -0.1230 & 2.0470 \\
9.51 & 5.50 & 6.20 & 6.26 & 0.06 & 0.5500 & 1.89 & 0.0871 & 1.9771 \\
9.73 & 5.55 & 6.33 & 6.40 & 0.07 & 0.7000 & 1.67 & 0.3680 & 2.0380 \\
\hline
\end{tabular}

LogK $_{1}$ (Average value) $=2.1568 \pm 0.2069$

Table 14: Point-wise method, Mg (Unhydrolysed PSHA)

\begin{tabular}{|l|l|l|l|l|l|l|l|l|}
\hline $\mathrm{pH}$ & $\mathrm{BV}_{1}$ & $\mathrm{BV}_{2}$ & $\mathrm{BV}_{3}$ & $\mathrm{~V}_{3}-\mathrm{V}_{2}$ & $\mathrm{n}$ & $\mathrm{pL}$ & $\log \left(\frac{n-1}{2-n}\right)$ & $\log \mathrm{K}_{2}$ \\
\hline 10.00 & 5.60 & 6.47 & 6.55 & 0.08 & 0.9148 & 1.41 & & \\
10.23 & 5.65 & 6.62 & 6.71 & 0.09 & 1.2102 & 1.20 & -0.5749 & 0.6251 \\
10.49 & 5.70 & 6.80 & 6.92 & 0.09 & 1.5968 & 1.03 & 0.1703 & 1.2003 \\
\hline
\end{tabular}

LogK $_{2}$ (Average value) $=0.9127 \pm 0.4070$

Table15:Point-wise method, Cd (Hydrolysed PSHA)

\begin{tabular}{|l|l|l|l|l|l|l|l|l|}
\hline $\mathrm{pH}$ & $\mathrm{BV}_{1}$ & $\mathrm{BV}_{2}$ & $\mathrm{BV}_{3}$ & $\left(\mathrm{~V}_{3}-\mathrm{V}_{2}\right)$ & $\mathrm{n}$ & $\mathrm{pL}$ & $\log \left(\frac{n}{1-n}\right)$ & LogK $_{1}$ \\
\hline 8.50 & 5.30 & 6.29 & 6.31 & 0.02 & 0.2750 & 2.64 & -0.4210 & 2.2190 \\
8.72 & 5.35 & 6.37 & 6.40 & 0.03 & 0.4286 & 2.42 & -0.1249 & 2.2951 \\
9.00 & 5.40 & 6.46 & 6.49 & 0.03 & 0.4648 & 2.14 & -0.0612 & 2.0788 \\
9.22 & 5.45 & 6.55 & 6.59 & 0.04 & 0.6667 & 1.96 & 0.3010 & 2.2610 \\
9.51 & 5.55 & 6.66 & 6.70 & 0.04 & 0.7720 & 1.67 & 0.5297 & 2.1997 \\
\hline
\end{tabular}

LogK $_{\mathbf{1}}$ (Average value) $=2.2108 \pm 0.0825$

Table 16: Point-wise method, Cd (Hydrolysed PSHA)

\begin{tabular}{|l|l|l|l|l|l|l|l|l|}
\hline $\mathrm{pH}$ & $\mathrm{BV}_{1}$ & $\mathrm{BV}_{2}$ & $\mathrm{BV}_{3}$ & $\left(\mathrm{~V}_{3}-\mathrm{V}_{2}\right)$ & $\mathrm{n}$ & $\mathrm{pL}$ & $\log \left(\frac{n-1}{2-n}\right)$ & Log $_{2}$ \\
\hline 9.73 & 5.55 & 6.78 & 6.83 & 0.06 & 1.4042 & 1.47 & -0.1686 & 1.3014 \\
10.00 & 5.60 & 6.90 & 6.95 & 0.06 & 1.7838 & 1.23 & 0.5593 & 1.7893 \\
10.23 & 5.65 & 7.05 & 7.10 & 0.06 & 3.1429 & 1.09 & & \\
10.49 & 5.70 & 7.10 & 7.16 & 0.06 & 3.1429 & 0.89 & & \\
& & & & & & & & \\
\hline
\end{tabular}

$\operatorname{LogK}_{2}$ (Average value) $=1.5453 \pm 0.3450$

Table 17: Point-wise method, Cd (Unhydrolysed PSHA)

\begin{tabular}{|l|l|l|l|l|l|l|l|l|}
\hline $\mathrm{pH}$ & $\mathrm{BV}_{1}$ & $\mathrm{BV}_{2}$ & $\mathrm{BV}_{3}$ & $\mathrm{~V}_{3}-\mathrm{V}_{2}$ & $\mathrm{n}$ & $\mathrm{pL}$ & $\log \left(\frac{n}{n-1}\right)$ & $\operatorname{Log~}_{1}$ \\
\hline 8.50 & 5.30 & 5.81 & 5.86 & 0.05 & 0.3717 & 2.88 & -0.2280 & 2.6520 \\
8.72 & 5.35 & 5.90 & 5.95 & 0.05 & 0.3873 & 2.66 & -0.1992 & 2.4608 \\
9.00 & 5.40 & 6.00 & 6.06 & 0.06 & 0.4853 & 2.38 & -0.0255 & 2.3545 \\
9.22 & 5.45 & 6.10 & 6.16 & 0.06 & 0.5157 & 2.18 & -0.0272 & 2.2072 \\
9.51 & 5.50 & 6.20 & 6.27 & 0.07 & 0.6417 & 1.89 & 0.2530 & 1.1430 \\
9.73 & 5.55 & 6.33 & 6.41 & 0.08 & 0.8000 & 1.69 & 0.6020 & 2.2920 \\
& & & & & & & & \\
\hline
\end{tabular}

$\operatorname{LogK}_{1}($ Average value $)=2.2516 \pm 0.5380$ 
BAJOPAS Volume 14 Number 1,June, 2021

Table 18: Point-wise method, Cd (Unhydrolysed PSHA)

\begin{tabular}{|l|l|l|l|l|l|l|l|l|}
\hline $\mathrm{pH}$ & $\mathrm{BV}_{1}$ & $\mathrm{BV}_{2}$ & $\mathrm{BV}_{3}$ & $\mathrm{~V}_{3}-\mathrm{V}_{2}$ & $\mathrm{n}$ & $\mathrm{pL}$ & $\log \left(\frac{n-1}{2-n}\right)$ & $\log \mathrm{K}_{2}$ \\
\hline 10.00 & 5.60 & 6.47 & 6.57 & 0.10 & 1.1434 & 1.43 & & \\
10.23 & 5.65 & 6.62 & 6.72 & 0.10 & 1.3448 & 1.23 & -0.2788 & 0.9512 \\
10.49 & 5.70 & 6.80 & 6.90 & 0.10 & 1.7742 & 1.03 & 0.5351 & 1.5651 \\
\hline
\end{tabular}

$\operatorname{LogK}_{2}($ Average value $)=1.2581 \pm 0.4340$

Table 19: Stepwise and overall Stability constants of thehydrolysed and unhydrolysed divalent metal (II) complexes

\begin{tabular}{|c|c|c|c|}
\hline Chelates & LogK $_{1}$ & $\log _{2}$ & Log $\beta$ \\
\hline [Cu (Hydrolysed PSHA-1) $\left.{ }_{2}\right]$ & 2.4788 & 1.4280 & 3.9068 \\
\hline$\left[\mathrm{Pb}(\text { Hydrolysed PSHA-1) })_{2}\right]$ & 2.5832 & 1.1963 & 3.7795 \\
\hline$\left[\mathrm{Cd}(\text { Hydrolysed PSHA-1 })_{2}\right]$ & 2.2108 & 1.5453 & 3.7561 \\
\hline$\left[\mathrm{Mg}(\text { Hydrolysed PSHA-1 })_{2}\right]$ & 2.1382 & 1.5453 & 3.6835 \\
\hline [Cu (Unhydrolysed PSHA-1) & 2.3059 & 1.2209 & 3.5268 \\
\hline$[\mathrm{Pb}$ (Unhydrolysed PSHA-1) 2$]$ & 2.2364 & 1.2239 & 3.4603 \\
\hline [Cd (Unhydrolysed PSHA-1) 2 ] & 2.2516 & 1.2581 & 3.5097 \\
\hline$[\mathrm{Mg}$ (Unydrolysed PSHA-1) & 2.1568 & 0.9127 & 3.0695 \\
\hline
\end{tabular}

The results obtained (Table19) shows the stepwise and overall stability constants to be not high indicating low stability of the complexes, because the solubility of most metal ions in the basic $\mathrm{pH}$ range is minimal due to metal hydroxide precipitation (Karimi, 2017). In general, the stepwise stability constants $\left(K_{1}\right.$ and $K_{2}$ ) follow the order $K_{1}>K_{2}$ for the copper, lead, magnesium and cadmium complexes respectively. The steady decrease of the values with increasing number of ligands is in agreement with the prediction made by researchers (Na'aliya, 2013). The decrease could be attributed to the fact that as the number of the ligands (Humate ions) that enters the coordination zone increases the aqua molecules available for replacement by the ligands become less. Thus, the metal ions become less electron loving with progressive intake of the ligand and this results in the decrease in the values of the constants (Na'aliya, 2013). Also the stability of the complexes is influenced by the size and number of the chelate rings(Mackay and Mackay,2002).All the complexes form rings in their structure as humate, a bidentate ligand, bond the metal ions in the ratio 1:2 (Boguta and Sokolowska, 2016) forming chelate rings. The values of the overall stability constants $(\log \beta)$ obtained for humate complexes are not high indicating low stability as the values are not high. LogK values for copper-humates (Table 3 to 6) obtained in this study are lower than those reported for the complexes of humic acids (Pandey et al., 2015; Dinu, 2013; Kaschl et al., 2010 and Gilbeto and Jorg, 2001). The values of LogK(Table 7 to 10 ) forlead-humates are lower than those reported for the lead in the literature (Dinu, 2013; Gilbeto and Jorg 2001). Log K values(Table 11 to 14 ) for magnesium-humates obtained in this study are close to those reported by (Pandey et al., 2015). Log K values of cadmium-humates (Table 15 to 18 ) obtained in this work near to the one reported by (Dinu, 2013 and Pandey et al., 2015).The difference between the reported values and the values obtained in this study might be probably as a result of acid hydrolysis of humic acid. The values of the overall stability constants $(\log \beta)$ of the copper humates complexes presented in Table 19 is high than that of other metal humate complexes, show relatively high stability of CuHA complexes, show the following order of stability: $\mathrm{Cu}>\mathrm{Pb}>\mathrm{Cd}>\mathrm{Mg}$; which are in close agreement to the findings of (Dinu, 2013 and Pandey et al., 2015).The high stability of Cuhumate chelate could be attributed to the existence of coordinate covalent bond between the complexing agents and the $\mathrm{Cu}^{2+}$ ions. Since, $\mathrm{Cu}^{2+}$ being a metal of the transitional series with $3 d^{9}$ electronic configurations can accept the electrons from the complexing agents. Similarly, the low stabilities of $\mathrm{Pb}, \mathrm{Cd}$ and $\mathrm{Mg}$ complexes could be explained by that $\mathrm{Pb}^{2+}$ with $6 s^{2}, \mathrm{Cd}^{2+}$ with $4 \mathrm{~d}^{10}$ and $\mathrm{Mg}^{2+}$ with $2 \mathrm{p}^{6}$ their electronic configuration has a completely filled $\mathrm{d}, \mathrm{p}$ and $\mathrm{s}$ orbitals. Moreover, the stabilities of metal ions with hydrolysed humic acid from peat soil were higher than those with unhydrolysed humic acid from peat soil; which is ascribed to the high content of acidity in hydrolysed humic acid than unhydrolysed humic acid. 
BAJOPAS Volume 14 Number 1,June, 2021 CONCLUSION

The values of logk for $\mathrm{Cu}(\mathrm{II})$ hydrolysed humic acid complex was higher followed by $\mathrm{Pb}$ (II), $\mathrm{Cd}(\mathrm{II})$ and $\mathrm{Mg}$ (II) hydrolysed humic acid complexes as compared with metal(II) unhydrolysed humic acid complexes. This indicates acid hydrolysis of humic acid can

\section{REFERENCES}

Almeida, V.R. and Szpoganicz, B. (2015). Humic Acid Potentiometric Response Patterns:Out- of Equilibrium Properties and Species Distribution Modelling. Chemical. Biol. Technol. Agric. 2: 17.

Anđelković, T., Nikolić, R., Bojić, A.,Anđelković, D., and Nikolic G.,(2010). Binding of Cadmium to Soil Humic Acid as A Function of Carboxyl Group Content. Macedonian Journal of Chemistry and Chemical Engineering.29(2): 215-224.

Anil, B. N. and Maroti, N. (2008). Studies on Influence of Die-Lectric Constants on Complex Equilibria between Substituted Py-Razalines and Lanthanide Metal Ions pH-Metrically. Amer.-Euras. scient. Res. 3(2): 212-216.

Ashok, K., Pandey, S. P. and Misra, V (2000). Stability Constants of Metal-Humic Acid Complexes and its Role in Environmental Detoxification. Journal of Ecotoxicology and Environmental Safety. 47(2):157-200.

Badr, M. H., El-Halafawi, M. H. and Abd El-al Zeid, E. R. (2012). Comparison Between the Effect of Ionic Strength on Acidity and Dissociation Constants of Humic Acids Extracted from Sewage Sludge and Nile Water Hyacinth Composts.Global Journal of Environmental Research 6 (1): 36-43.

Baruah, M.K., Borah, D., Saikia, P.P., Paul, S., Sharma, T. (2015). Evaluation of pKa Values of Soil Humic Acids and their Complexation Properties. International Journal of Plant \& Soil Science 6(4) : 218-228.

Boguta, P. Sokolowska, Z. (2016). Interactions of $\mathrm{Zn}$ (II) Ions with Humic Acids Isolated from Various Types of Soils. Effect of $\mathrm{pH}, \mathrm{Zn}$ Concentrations and Humic Acids Chemical Properties. Journal of Geochemical Explaration 168. 119-126.

Borges, F., Guimaraes, C., Lima, L.F.C., Pinto, I. and Reis, S.(2005). Potentiometric Studies on the Complexation of Copper(II) by Phenolic Acids as Discrete Ligand Models of enhance the complexation behavior of humic acid with metal (II) ions. However, the higher values of $\log \beta$ for $\mathrm{Cu}(\mathrm{II}), \mathrm{Pb}(\mathrm{II}), \mathrm{Cd}(\mathrm{II})$ and $\mathrm{Mg}(\mathrm{II})$ hydrolysed humic acid complexes indicates more stable stepwise complexes formed as compared with $\mathrm{Cu}(\mathrm{II}), \mathrm{Pb}$ (II), $\mathrm{Cd}$ (II) and $\mathrm{Mg}(\mathrm{II})$ unhydrolysed humic acid complexes.

Humic Substances Talanta 66 (2005) 670-673.

Chefetz, B., Salloum, M. J., Deshmulkin, A. P. and Hatcher, P. (2002). Structural Components of Humic Acids as Determined by Chemical Modifications and Carbon-13 NMR, Pyrolysis, and Thermochemolysis- Gas Chromatography/Mass Spectrometry. Soil Science Society of American Journal Abstract Division S-2- Soil Chemistry66. 1159-1171.

Dinu, M. I. (2013). Metals Complexation with Humic Acids in Surface Water of Different Environ. Sci. Technol. 31(1): 1-17.

Fernandes, A.N., Giacomelli, C., Giovanela, M. Vaz, D.V. Szpoganicz, B. and Maria M. D. (2009). Potentiometric Acidity Determination in Humic Substances Influenced by Different Analytical Procedures.J. Braz. Chem. Soc. 20 (9):14.

Gamal, A. H. (2015). Stability Constants of Rhenium (V) Metal Complexes with Selected Drugs. Pyrex Journal of Research in Environmental Studies. 2(2): 006-014.

Janrao, D. M., Pathan, J., Kayande, D.D., and Mulla, J.J. (2014). An Over View of Potentiometric Determination of Stability Constants of Metal Complexes. Sci. Revs. Chem. Commun.: 4(1), 2014, 11-24.

Karimi, H. (2017). Effect of pH and Initial Pb(II) Concentration on the Lead Removal Efficiency from Waste Water Using $\mathrm{Ca}(\mathrm{OH})_{2}$. International Journal of Water and Waste Water Treatment 3.2

Kaschl, A. Romheld, V. and Chen, Y. (2010). Binding of Cadmium, Copper and Zinc to Humic Substances Originating from Municipal Solid Waste Compost. Israel Journal of Chemistry Vol. 42(1): 89-98.

Kostic, I. S., Tatjana, P, A., Nikolic, R. S., Cvetkovic, T. P., Pavlovic, D. D., Aleksandar, L.J. and Bojic, A. (2012). Comparative Study of Binding Strengths of Heavy Metals with Humic Acid. J.serb. Chem. Soc. 76(9) pp 1-20. 
BAJOPAS Volume 14 Number 1,June, 2021

Na'aliya, J. (2013). Determination of Stepwise Stability Constants and Gibbs free Energy Change of Trisprolina to Complexes of some Divalent Transition Metal ions. Bayero Journal of Pure and Applied Sciences 6(2): 112-114.

Omar, A. A. and Ali, E. A. (2015). Potentiometric Studies on Complexes of $\mathrm{Cr}$ (III) and $\mathrm{Zr}$ (IV) with some Carboxylic Acids. International Journal of Advanced Chemistry, 3(1) 25-

37.

Pandey, A. K. Pandey, S. D. and Misr, V. (2015).Stability Constants of Metal- Humic Acid Complexes and Its Role in Environmental Detoxification. J. Ecotoxicology and Environmental Safety. 47(1):195-200.

Ram, N. and Raman, K.V. (1984). Stability Constants of Complexes of Metals with
Humicand Fuvic Acids under Non- acidConditions. Journal of Plant Nutrition and Soil Sciences.

147:171-176.

Santosh, D. D., Ashok, B. K., Vijay, J. T., Shivraj, G. W. and Vinay, V. W. (2011). Potentiometric Studies of Elec-Trolyte Effects on Complex Equilibria of Some Substituted 5-(2-hydroxy Phenyl) Pyrazoles. Der pharm. 3 (6): 75-83.

Sayyed, H. and Abdul Rahim, M. F. (2012). Studies of Binary Complexes of Metal Ions with Mandelic Acid by Potentiometry. Chem. J. 02 (6): 206209.

Shirvani, M. Moradian, E. Khalili, B. Bakhtiary, S. (2015). Interaction of $\mathrm{Cd}$ and $\mathrm{Pb}$ with Humate-Palygorskite and HumateSepiolite Complexes. Journal of water, air and pollution 3: 220-228. 


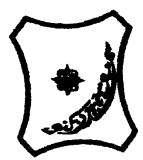

Bayero Journal of Pure and Applied Sciences, 14(1): 54 - 63

Received: November, 2020

Accepted: April, 2021

ISSN $2006-6996$

\title{
STABILITY CONSTANTS OF COMPLEXES OF METAL IONS WITH PEATSOIL HUMIC ACIDS UNDER NON-ACID-CONDITIONS
}

\author{
${ }^{* 1}$ Sabo, Yusuf ${ }^{2}$ Jimoh, W.L.O., ${ }^{3}$ Isa Baba Koki and ${ }^{4}$ Sholadoye, Q. 0. \\ ${ }^{1}$ Department of Pure and Industrial Chemistry, Bayero University, Kano \\ ${ }^{3}$ Department of Chemistry, Yusuf Maitama Sule University Kano. P.M.B. 3220 Kano, Nigeria. \\ ${ }^{4}$ Department of Chemistry, Nigerian Police Academy, Wudil, Kano-Nigeria
}

*Correspondence E-mail; saboyusuf18@yahoo.com

ABSTRACT

Stability constants of complexes of four divalent metal ions viz. $\mathrm{Cu}^{2+}, \mathrm{Pb}^{2+}, \mathrm{Mg}^{2+}$ and $\mathrm{Cd}^{2+}$ with humic acids (HA) were determined by potentiometric titration of humic acids with the corresponding salt of the divalent metals in aqueous media under non-acid-condition. The log $K$ (logarithm of the stability constant) ranged from 1.0942 to 2.7471 for metalhumic acid complexes were determined using point-wise computational method. The order of stability constants were obtained as follows: $\mathrm{Cu}>\mathrm{Pb}>\mathrm{Cd}>\mathrm{Mg}$ for metal $-\mathrm{HA}$ complexes respectively, indicating a higher degree of complexation with Cu metal ion.

Keywords: stability constant, humic acid, potentiometric titration, divalent metals, acid hydrolysis.

\section{NTRODUCTION}

The stability constant of a complex is the numerical expression of its stability and provides a quantitative measure of affinity of the metal ion to the complexing agent. An understanding of the relative stability of metal-complexes helps in predicting the behavior of metal ions in the soil (Ram and Raman, 1982). Extensive researches has been done to determine the stability constants of the complexes formed between humic acid (HA) with a number of metal ions. Ashok et al., (2000) reported that humic acid with hydroxyl, phenoxyl and carboxyl reactive groups can form coordination compound with metal ions at $\mathrm{pH}$ 3.5. The stability constants(Log K) for different metalhumic acid complexes indicated the following order of the stabilities of complexes formed between humic acid and metal ion, $\mathrm{Cu}>\mathrm{Fe}$ $>\mathrm{Pb}>\mathrm{Ni}>\mathrm{Co}>\mathrm{Ca}>\mathrm{Cd}>\mathrm{Zn}>\mathrm{Mn}>\mathrm{Mg}$. Andelkovic et al., (2010) investigated the binding of $\mathrm{Cd}$ (II) to soil humic acid at pH 6.5 and in $0.1 \mathrm{M} \mathrm{KNO}_{3}$ ionic medium. The stability constant for binding indicating greater stability in the case when carboxyl groups are involved in complexation reaction. Kostic et al.,(2012) investigated the complexation of humic acid with certain heavy metal ions (Co(II), $\mathrm{Ni}(\mathrm{II}), \mathrm{Cu}(\mathrm{II})$,
$\mathrm{Zn}(\mathrm{II})$, and $\mathrm{Pb}(\mathrm{II})$. The experiment was performed at $25^{\circ} \mathrm{C}$, at pH 4.0 and ionic strength of $0.01 \mathrm{M}$. Stability constant of complex between $\mathrm{Pb}$ (II) ions and humic acid is greater than stability constants of other investigated metalhumate complexes. Bogata and Sokolowska (2016) analyses the interaction between humic acids from different soils and $\mathrm{Zn}$ (II) ions at wide concentration ranges and at $\mathrm{pH} 5$. Studies have showed significant impact of $\mathrm{Zn}$ concentration, $\mathrm{pH}$ and some properties of humic acids with zinc.But all of these studies were limited to acidic $\mathrm{pH}$ range. Therefore, the present study was carried out to determine and compare the stability constants of complexes of metal ions with hydrolysed peat soil humic acid and unhydrolysed peat soil humic under non-acid conditions.

\section{MATERIALS AND METHODS}

Analytical grade chemicals used includes hydrochloric acid $(\mathrm{HCl})$, nitric acid $\left(\mathrm{HNO}_{3}\right)$, sodium hydroxide $(\mathrm{NaOH})$, lead nitrate $\mathrm{Pb}\left(\mathrm{NO}_{3}\right)_{2}$, copper nitrate $\mathrm{Cu}\left(\mathrm{NO}_{3}\right)_{2} \cdot 3 \mathrm{H}_{2} \mathrm{O}$, cadmium nitrate $\mathrm{Cd}\left(\mathrm{NO}_{3}\right)_{2} \cdot 4 \mathrm{H}_{2} \mathrm{O}$, magnesium nitrate $\mathrm{Mg}\left(\mathrm{NO}_{3}\right)_{2} \cdot 6 \mathrm{H}_{2} \mathrm{O}$, potassium nitrate $\left(\mathrm{KNO}_{3}\right)$, calcium chloride $\left(\mathrm{CaCl}_{2}\right)$, (sigma-Aldrich). Dowex 50WX8, (20-50 mesh) from Fluka. 


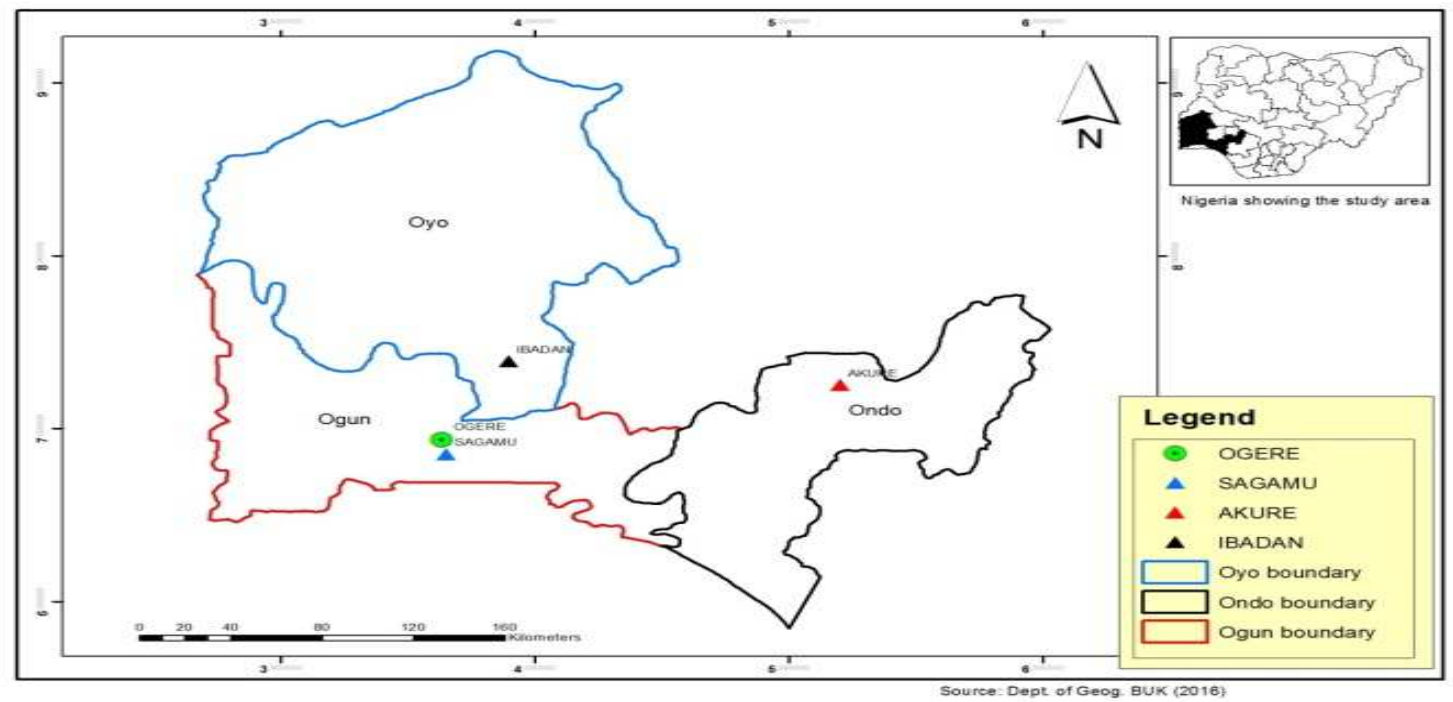

Figure 1: Map showing the sampling point at Sagamu Town, Ogun State.

\section{Description of Sampling Area}

Sagamu has geographical coordinates between $6^{\circ} 50^{\prime}$ north; $3^{\circ} 38^{\prime}$ east is located in south western region of Nigeria. The region has tropical wet and dry climate with a lengthy wet season and relatively constant temperatures throughout the course of the year. Wet season runs from March to October, November to December forms the region dry season. The vegetation type of the region is savannah which is really grassland with small bushes and occasional big trees. Grassland soils have substantially higher organic matter content than forest soils (Novackova, 2011).

\section{Sample Collection}

The Peatsoil samples were collected from four different sampling points $(0-10 \mathrm{~cm}$ depth) in Sagamu into polyethylene bag with plastic spoons. Samples were taken to the laboratory, extraneous materials were removed; the samples were air-dried, crushed and ground to a fine powder in a mortar passed through a $0.20 \mathrm{~mm}$ sieve. The samples were kept for analysis.

\section{Isolation and purification of humic acid from peat soil sample}

Peatsoil sample $(100 \mathrm{~g})$ was mixed with 1000 $\mathrm{cm}^{3}$ of $0.1 \mathrm{M} \mathrm{NaOH}$ solution, shaken for 3hours and left to stand overnight. Dark-coloured supernatant was obtained and decanted from solid residue. The dark-coloured supernatant was acidified to $(\mathrm{pH}=1.0)$ with $6 \mathrm{M} \mathrm{HCl}$ stirred and allowed to stand for 6 hours. Yellowish brown supernatant and dark-brown precipitate were obtained. The yellowish brown supernatant was decanted followed by centrifuge and discarded. The dark-brown precipitate was mixed with $500 \mathrm{~cm}^{3}$ of $0.1 \mathrm{M} \mathrm{NaOH}$ solution followed by passing through dowex resin. The dark-brown solution was acidified to $(\mathrm{pH}=1.0)$ with $6 \mathrm{M} \mathrm{HCl}$ stirred and allowed to stand for 3 hours. The dark-brown precipitate was washed several times with deionized water. The supernatant was treated with $\mathrm{AgNO}_{3}$ solution until no white precipitate observed. The humic acid was transferred to weighed crucible and dried at $60^{\circ} \mathrm{C}$ in an oven for 12 hours. The humic acid was cooled and dried in the desiccator, weighed and recorded. The obtained humic acid was dried again at $60^{\circ} \mathrm{C}$ for additional 6 hours cooled and dried in the desiccator, weighed and recorded constant weight was obtained (Baruah et al., 2015).

\section{FT-IR analysis}

FT-IR spectra of humic acid sample was analysed using Carry 630 FT-IR Agilent Technologies.

Unhydrolysed compost humic acid

The unhydrolysed humic acid was obtained after isolation and purification of compost humic acid and kept for investigation.

\section{Acid hydrolysis of Peatsoil acid}

Peatsoil humic acid sample (1g) was refluxed for 12 hours at $\left(160^{\circ} \mathrm{C}\right)$ with $50 \mathrm{~cm}^{3}$ of $6 \mathrm{M} \mathrm{HCl}$. The mixture was allowed to cool, decanted, and centrifuged after hydrolysis. The insoluble residues were washed with distilled water via centrifugation several times, and the supernatant was treated with $\mathrm{AgNO}_{3}$ solution until no white precipitate was observed. The residue was thoroughly dried over $\mathrm{CaCl}_{2}$ in a desiccator at room temperature (Chefetz et al., 2002). Finally, the obtained hydrolysed humic acid was kept for investigation. 
BAJOPAS Volume 14 Number 1,June, 2021 Potentiometric Titrations

Potentiometric measurements were carried out using a pH-meter Jenway (model 3510) with combine electrode, the sensitivity of the $\mathrm{pH}$ meter is 0.01 units. The $\mathrm{pH}$ meter was switched on half an hour before starting the titration for initial warm up of the instrument. The instrument was calibrated with an aqueous standard buffer solution of $\mathrm{pH} 4.00$ and 10.0 (borate buffer) prepared from a "Qualigens" buffer tablets.

The following sets of solutions were prepared in a $250 \mathrm{~cm}^{3}$ volumetric flask separately for $\mathrm{pH}$ metric titrations.

(i) $5 \mathrm{~cm}^{3} 0.1 \mathrm{M} \mathrm{HCl}+40 \mathrm{~cm}^{3}$ deionized water

(ii) $5 \mathrm{~cm}^{3} 0.1 \mathrm{M} \mathrm{HCl}+39 \mathrm{~cm}^{3}$ deionized water $+1 \mathrm{~cm}^{3} 0.15 \mathrm{gcm}^{-3}$ humic acid

(iii) $5 \mathrm{~cm}^{3} 0.1 \mathrm{M} \mathrm{HCl}+37 \mathrm{~cm}^{3}$ deionized water $+1 \mathrm{~cm}^{3} 0.15 \mathrm{gcm}^{-3}$ humic acid

$$
+2 \mathrm{~cm}^{3} \quad 0.01 \mathrm{M} \mathrm{Cu} \text { (II) }
$$

The solutions were titrated against standardized $0.110 \mathrm{MNaOH}$ separately. The total volume of each mixture was adjusted to $50 \mathrm{~cm}^{3}$ and the ionic strength of the solutions was maintained constant at by adding appropriate amount of stock solution of $1 \mathrm{M} \mathrm{KNO}_{3}$ (Gamal, 2015; Omar and Ali, 2015). A magnetic stirrer was used to achieve thorough mixing of the interacting solutions at $550 \mathrm{rpm}$. The same set of experimental conditions was applied for potentiometric titration of remaining samples.

\section{Evaluation of pKa of Hydrolysed peat soil Humic Acids}

The proton-ligand formation number $\mathrm{n}_{\mathbf{A}}$ were calculated by Irving and Rossotti expression (Omar and Ali, 2015).

$\mathrm{nA}=\mathrm{Y}-\frac{(\mathrm{V} 2-\mathrm{V1})(\mathrm{No}-\mathrm{Eo})}{(\mathrm{VO}+\mathrm{V1}) \mathrm{TCL}}$ 1

Where: $Y$ is number of dissociable proton, $\left(\mathrm{V}_{2^{-}}\right.$ $V_{1}$ ) is the measure of displacement of the ligand curve relative to acid curve, $\mathrm{N}^{\circ}$ and $\mathrm{E}^{\circ}$ are the resultant concentration of alkali solution, free acid solution, $\mathrm{T}_{\mathrm{cL}}{ }^{\circ}$ is the total ligand concentration, $\mathrm{V}^{\circ}$ is the total volume of titration solution, $V_{1}$ is the volume of alkali added to acid solution, $V_{2}$ is the volume of alkali added to acid solution + ligand solution, acid dissociation constants (pKa - values) of ligand were calculated by algebraic method point wise calculation (Tables 1 ). The dissociation constants (pKa) were calculated according to the following relation:

$\mathrm{pKa}=\mathrm{pH}+\log \left(\frac{n A}{1-n A}\right)$ 2

Where: pKa is the acid dissociation constant, $\mathrm{n}_{\mathrm{A}}$ is the Proton-ligand formation number and $\mathrm{pH}$ is the pH-values (Omar and Ali, 2015).

\section{Determination of metal-ligand stability constants $(\log K)$ of complexes}

The potentiometric measurement for the determination of stability constant of a complex in solution is based on the fact that the redox potential of the couple $\frac{M^{+(m-n)}}{M^{+m}}$ is shifted significantly on complexation of the metal ion with the ligand. This method involves change in hydrogen ion concentration $\left[\mathrm{H}^{+}\right]$due to the displacement or association of one or more protons taking place during complexation reaction. This change can be found out by titrating the solutions containing free acid, acid with ligand, and acid with ligand and metal ion, individually against a standard alkali solution at a constant ionic strength or temperature. Either ionic strength or temperature may be varied for different sets of solutions. In all the cases, the change in the $\mathrm{pH}$ of the solution is measured after each addition of a known amount of alkali to the reaction cell which contains the reaction mixture. The titration curves are then drawn by plotting the measured $\mathrm{pH}$ values against the corresponding volume of alkali added and the stability constants of the complexes are determined from the titration curves by employing $\mathrm{pH}$-metric titration technique given by (Irving and Rossoti).

Metal-ligand stability constants ( $\log \mathrm{K}$ ) were determined by using the following relations:

$$
\bar{n}=\frac{\left(V_{3}-V_{2}\right)\left(E^{0}+N^{0}\right)}{\left(V^{0}+V_{2}\right) \bar{n}_{A} T_{m}^{0}}
$$

and

$$
P L=\log _{10}\left\{\frac{1+\beta_{n}^{H} \frac{1}{[\text { anti } \log \mathrm{pH}]^{\mathrm{n}}}}{\mathrm{T}_{\mathrm{L}}^{0}-n \bar{T}_{m}^{0}} \mathrm{X} \frac{\left(V^{0}+V_{3}\right)}{V^{0}}\right\}
$$


BAJOPAS Volume 14 Number 1,June, 2021

Where $T_{L}, T^{\circ}, E^{\circ}$, and $V^{\circ}$ havethe same significance as in equation (1) above, $T_{m}$ denotes the total concentration of metal present in solution, $V_{3}$ is the volume of metal ions present in solution and $\beta^{H}$ is the overall proton ligand stability constant. The metal-ligand stability constants (log K) were determined by employing point wise computational Method (eq. 5 and 6).

$\operatorname{LogK}_{1}=\log \left(\frac{n}{1-n}\right)+\mathrm{pL}$ .5

$\operatorname{LogK}_{2}=\log \left(\frac{1-n}{2-n}\right)+\mathrm{pL}$ ...6

Where: Log $\mathrm{K}$ is the metal-ligand stability constant, $\mathrm{pL}$ is the Free ligand exponent function, $\mathbf{n}$ is the Average number of ligand attached with metal ion (Janraoet al., 2014). The results obtained were analyzed by an ORIGIN 2016 program using titration data and then the proton-ligand stability constants (pKa) and Metal-ligand stability constant (LogK) calculated (Omar and Ali, 2015).

\section{RESULTS AND DISCUSSION}

Fourier transformed infrared (FT-IR) spectra of isolated humic acid from peat soils Figure 2 had distinct clear absorption bands indicating the presence of major humic acid structural elemental groups such as $\mathrm{H}$ bonded $\mathrm{OH}$ $\left(3680 \mathrm{~cm}^{-1}\right.$ peak $), C=0$ of carbonyl $\left(1721 \mathrm{~cm}^{-1}\right.$ peak), functional groups of aliphatic components $\mathrm{CH}_{2}\left(2918 \mathrm{~cm}^{-1}\right.$ peak) and $\mathrm{C}-\mathrm{O}$ stretching of polysaccharide $\left(1168 \mathrm{~cm}^{-1}\right.$ peak). The positions of the absorption bands of the spectra fell within typical major absorption bands of humic acid which is at frequencies 3680, 2918, 1721, 1168 $\mathrm{cm}^{-1}$. The first peak centred in the vicinity of $3680 \mathrm{~cm}^{-1}$ region is attributed to phenol $\mathrm{OH}$ group bounded by intermolecular $\mathrm{H}$ bonds. The $2918 \mathrm{~cm}^{-1}$ band usually has absorption maximum at $2918 \mathrm{~cm}^{-1}$ which is due to $\mathrm{C}-\mathrm{H}$ stretching of alkane group $\left(\mathrm{CH}_{2}\right)$. The next major absorption band is $1721 \mathrm{~cm}^{-1}$. This band has been commonly ascribed to $\mathrm{C}=\mathrm{O}$ stretching of mainly carboxyl group $(\mathrm{COOH})$ with trace amount of ketones. The last peak was observed at 1168 $\mathrm{cm}^{-1}$ due to $\mathrm{C}-\mathrm{O}$ stretching of polysaccharides and this peak appeared also in the spectra of humic acid from peat soil. The FTIR spectra of the isolated humic acid contained all major characteristic absorption peaks of humic acid. These absorption peaks indicated the presence of the major structural elements of humic acid namely $\mathrm{H}$ bonded $\mathrm{OH}, \mathrm{C}=\mathrm{C}$ of aromatic ring, $\mathrm{C}=\mathrm{O}$ of carbonyl group (both carboxyl and ketonic), $\mathrm{CH}_{2}$ group. This strongly supports the presence of humic acid.

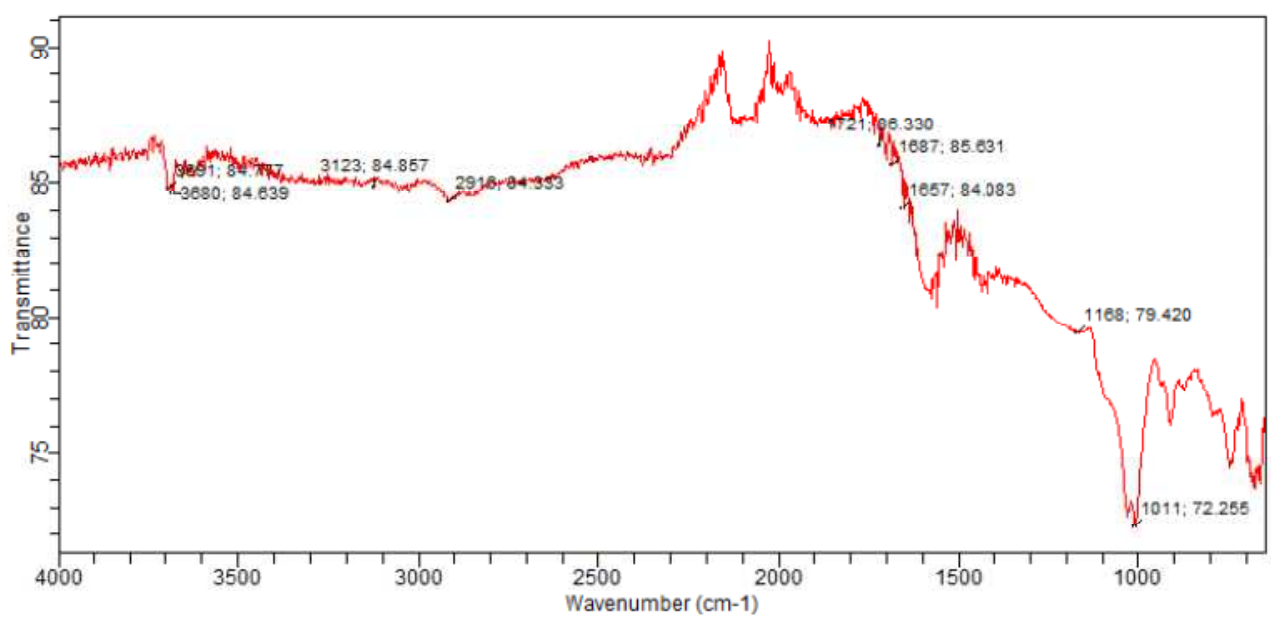

Fig. 2 : FT-IR spectraof peatsoilhumic acid (PSHA)

\section{Evaluation of acid dissociation constant (pka) of acid hydrolysed peat soil humicacid at phenolic group}

The value of the dissociation constant of the peat soil humic acid (PSHA) that underwent acidhydrolysis studied was found to be 8.9299 as shown Table 1, which is lower than the literaturevalues reported by Almeida and Szpoganics, (2015), Borges et al., (2005); Badr et al., (2012)and Fernandes et al,.(2009) of $9.73,9.47$ and 10.30. The difference between the obtained valuesand the reported values in this study might be probably as a result of acid hydrolysis of humicacid. 
BAJOPAS Volume 14 Number 1,June, 2021

Table 1: PKa of (Hydrolysed PSHA)

\begin{tabular}{|l|l|l|l|l|l|l|}
\hline $\mathrm{pH}$ & $\mathrm{BV}_{1}$ & $\mathrm{BV}_{2}$ & $\mathrm{~V}_{2}-\mathrm{V}_{1}$ & $\mathrm{nA}$ & $\log \left(\frac{n A}{1-n A}\right)$ & $\mathrm{pKa}$ \\
\hline 8.50 & 5.30 & 6.29 & 0.99 & 0.3594 & -0.2510 & 8.2490 \\
8.72 & 5.35 & 6.37 & 1.02 & 0.3400 & -0.2880 & 8.4320 \\
9.00 & 5.40 & 6.46 & 1.06 & 0.3141 & -0.3391 & 8.6609 \\
9.22 & 5.45 & 6.55 & 1.10 & 0.2882 & -0.3927 & 8.8273 \\
9.51 & 5.50 & 6.66 & 1.16 & 0.2494 & -0.4786 & 9.0314 \\
9.73 & 5.55 & 6.78 & 1.23 & 0.2041 & -0.5910 & 9.1390 \\
10.00 & 5.60 & 6.90 & 1.30 & 0.1589 & -0.7238 & 9.2762 \\
10.23 & 5.65 & 7.05 & 1.40 & 0.0941 & -0.9835 & 9.2465 \\
10.49 & 5.70 & 7.10 & 1.40 & 0.0941 & -0.9835 & 9.5065 \\
\hline
\end{tabular}

Average pKa $=8.9299 \pm 0.4186$

Table 2: PKa of (Unhydrolysed PSHA)

\begin{tabular}{|l|l|l|l|l|l|l|}
\hline $\mathrm{pH}$ & $\mathrm{BV}_{1}$ & $\mathrm{BV}_{2}$ & $\mathrm{~V}_{2}-\mathrm{V}_{1}$ & $\mathrm{nA}$ & $\log \left(\frac{\boldsymbol{n A}}{1-\boldsymbol{n}}\right)$ & $\mathrm{pKa}$ \\
\hline 8.50 & 5.30 & 5.81 & 0.51 & 0.6619 & 0.2919 & 8.7919 \\
8.72 & 5.35 & 5.90 & 0.55 & 0.6357 & 0.2418 & 8.9618 \\
9.00 & 5.40 & 6.00 & 0.60 & 0.6029 & 0.1813 & 9.1813 \\
9.22 & 5.45 & 6.10 & 0.65 & 0.5701 & 0.1226 & 9.3426 \\
9.51 & 5.50 & 6.20 & 0.70 & 0.5376 & 0.0654 & 9.5754 \\
9.73 & 5.55 & 6.33 & 0.78 & 0.4851 & -0.0259 & 9.7041 \\
10.00 & 5.60 & 6.47 & 0.87 & 0.4262 & -0.1291 & 9.8709 \\
10.23 & 5.65 & 6.62 & 0.99 & 0.3609 & -0.2481 & 9.9819 \\
10.49 & 5.70 & 6.80 & 1.10 & 0.2759 & -0.4690 & 10.0210 \\
\hline
\end{tabular}

Average pKa $=9.4923 \pm 0.4410$

Metal-ligand stability constant ( $\log \mathrm{K}$ )

The stabilityconstants require the accurate values of proton-ligand stability constants (Anil and Maroti, 2008). Metal titration curves crossed over ligand titration curve indicated the formation of complex upon proton release (Santosh, et al., 2011). If the values of n- are within range $0.2-0.8$ and $1.2-18$ this indicates the formation of $1: 1$ and 1:2 complexes (Sayyed and Mazahar, 2012).

The metal (II)-humate stepwise stability constants (log k) at phenolic group (Tables 318)

Table 3: Point-wise method, $\mathrm{Cu}$-(Hydrolysed PSHA)

\begin{tabular}{|l|l|l|l|l|l|l|l|l|}
\hline $\mathrm{pH}$ & $\mathrm{BV}_{1}$ & $\mathrm{BV}_{2}$ & $\mathrm{BV}_{3}$ & $\left(\mathrm{~V}_{3}-\mathrm{V}_{2}\right)$ & $\mathrm{n}$ & $\mathrm{pL}$ & $\log \left(\frac{n}{1-n}\right)$ & LogK $_{1}$ \\
\hline 8.50 & 5.30 & 6.29 & 6.33 & 0.04 & 0.5500 & 2.66 & 0.0871 & 2.7471 \\
8.72 & 5.35 & 6.37 & 6.41 & 0.04 & 0.5714 & 2.43 & 0.1249 & 2.5549 \\
9.00 & 5.40 & 6.46 & 6.50 & 0.04 & 0.6198 & 2.16 & 0.2122 & 2.3722 \\
9.22 & 5.45 & 6.55 & 6.59 & 0.04 & 0.6667 & 1.94 & 0.3010 & 2.2410 \\
\hline
\end{tabular}

LogK $_{1}$ (Average value) $=2.4788 \pm 0.2203$

Table 4: Point-wise method, $\mathrm{Cu}$-(Hydrolysed PSHA)

\begin{tabular}{|l|l|l|l|l|l|l|l|l|}
\hline $\mathrm{pH}$ & $\mathrm{BV}_{1}$ & $\mathrm{BV}_{2}$ & $\mathrm{BV}_{3}$ & $\left(\mathrm{~V}_{3}-\mathrm{V}_{2}\right)$ & $\mathrm{n}$ & $\mathrm{pL}$ & $\log \left(\frac{n-1}{2-n}\right)$ & LogK $_{2}$ \\
\hline 9.51 & 5.50 & 6.66 & 6.73 & 0.07 & 1.3509 & 1.70 & -0.2671 & 1.4329 \\
9.73 & 5.55 & 6.78 & 6.85 & 0.07 & 1.6383 & 1.51 & 0.2467 & 1.7567 \\
10.00 & 5.60 & 6.90 & 6.98 & 0.08 & 2.1783 & 1.31 & -0.2158 & 1.0942 \\
10.23 & 5.65 & 7.05 & 7.13 & 0.08 & 4.1904 & 1.27 & & \\
10.49 & 5.70 & 7.10 & 7.19 & 0.09 & 4.6920 & & & \\
\hline
\end{tabular}

Log $K_{2}($ Average value $)=1.4280 \pm 0.3312$ 
BAJOPAS Volume 14 Number 1,June, 2021

Table 5: Point-wise method, $\mathrm{Cu}$ (Unhydrolysed PSHA)

\begin{tabular}{|l|l|l|l|l|l|l|l|l|}
\hline $\mathrm{pH}$ & $\mathrm{BV}_{1}$ & $\mathrm{BV}_{2}$ & $\mathrm{BV}_{3}$ & $\left(\mathrm{~V}_{3}-\mathrm{V}_{2}\right)$ & $\mathrm{n}$ & $\mathrm{pL}$ & $\log \left(\frac{n}{n-1}\right)$ & Log $_{1}$ \\
\hline 8.50 & 5.30 & 5.81 & 5.85 & 0.04 & 0.2973 & 2.88 & -0.3736 & 2.5064 \\
8.72 & 5.35 & 5.90 & 5.95 & 0.05 & 0.3873 & 2.66 & -0.1992 & 2.4608 \\
9.00 & 5.40 & 6.00 & 6.05 & 0.05 & 0.4044 & 2.38 & -0.1681 & 2.2119 \\
9.22 & 5.45 & 6.10 & 6.15 & 0.06 & 0.5157 & 2.18 & -0.0272 & 2.2072 \\
9.51 & 5.50 & 6.20 & 6.27 & 0.07 & 0.6417 & 1.89 & 0.2530 & 1.1430 \\
\hline
\end{tabular}

$\operatorname{LogK}_{1}($ Average value $)=2.3059 \pm 0.6153$

Table 6:Point-wise method, $\mathrm{Cu}$ (Unhydrolysed PSHA)

\begin{tabular}{|l|l|l|l|l|l|l|l|l|}
\hline $\mathrm{pH}$ & $\mathrm{BV}_{1}$ & $\mathrm{BV}_{2}$ & $\mathrm{BV}_{3}$ & $\mathrm{~V}_{3}-\mathrm{V}_{2}$ & $\mathrm{n}$ & $\mathrm{pL}$ & $\log \left(\frac{n-1}{2-n}\right)$ & $\log \mathrm{K}_{2}$ \\
\hline 9.73 & 5.55 & 6.33 & 6.42 & 0.09 & 0.9000 & 1.69 & & \\
10.00 & 5.60 & 6.47 & 6.58 & 0.11 & 1.2578 & 1.44 & -0.4592 & 0.9808 \\
10.23 & 5.65 & 6.62 & 6.84 & 0.12 & 1.6137 & 1.26 & -0.2010 & 1.4610 \\
10.49 & 5.70 & 6.80 & 6.92 & 0.12 & 2.1052 & 1.03 & & \\
\hline
\end{tabular}

$\operatorname{LogK}_{2}$ (Average value) $=1.2209 \pm 0.3398$

Table 7:Point-wise method, Pb (Hydrolysed PSHA)

\begin{tabular}{|l|l|l|l|l|l|l|l|l|}
\hline $\mathrm{pH}$ & $\mathrm{BV}_{1}$ & $\mathrm{BV}_{2}$ & $\mathrm{BV}_{3}$ & $\left(\mathrm{~V}_{3}-\mathrm{V}_{2}\right)$ & $\mathrm{n}$ & $\mathrm{pL}$ & $\log \left(\frac{n}{1-n}\right)$ & LogK $_{1}$ \\
\hline 8.50 & 5.30 & 6.29 & 6.33 & 0.04 & 0.5500 & 2.66 & 0.0871 & 2.7471 \\
8.72 & 5.35 & 6.37 & 6.41 & 0.04 & 0.5714 & 2.43 & 0.1249 & 2.5549 \\
9.00 & 5.40 & 6.46 & 6.50 & 0.04 & 0.6198 & 2.16 & 0.2122 & 2.3722 \\
9.22 & 5.45 & 6.55 & 6.60 & 0.05 & 0.8333 & 1.96 & 0.6989 & 2.6589 \\
\hline
\end{tabular}

Log $_{\mathbf{1}}($ Average value $)=2.5832 \pm 0.1614$

Table 8:Point-wise method, Pb-(Hydrolysed PSHA)

\begin{tabular}{|l|l|l|l|l|l|l|l|l|}
\hline $\mathrm{pH}$ & $\mathrm{BV}_{1}$ & $\mathrm{BV}_{2}$ & $\mathrm{BV}_{3}$ & $\left(\mathrm{~V}_{3}-\mathrm{V}_{2}\right)$ & $\mathrm{n}$ & $\mathrm{pL}$ & $\log \left(\frac{n-1}{2-n}\right)$ & $\log \mathrm{K}_{2}$ \\
\hline 9.51 & 5.50 & 6.66 & 6.71 & 0.05 & 0.9650 & 1.67 & & \\
9.73 & 5.55 & 6.78 & 6.83 & 0.05 & 1.1702 & 1.44 & & \\
10.00 & 5.60 & 6.90 & 6.90 & 0.05 & 1.4864 & 1.22 & -0.0237 & 1.1963 \\
10.23 & 5.65 & 7.05 & 7.10 & 0.05 & 2.0190 & 1.09 & & \\
10.49 & 5.70 & 7.10 & 7.17 & 0.07 & 3.6492 & 1.00 & & \\
\hline
\end{tabular}

Log $K_{2}$ (Average value) $=1.1963$

Table 9: Point-wise method, Pb (Unhydrolysed PSHA)

\begin{tabular}{|l|l|l|l|l|l|l|l|l|}
\hline $\mathrm{pH}$ & $\mathrm{BV}_{1}$ & $\mathrm{BV}_{2}$ & $\mathrm{BV}_{3}$ & $\mathrm{~V}_{3}-\mathrm{V}_{2}$ & $\mathrm{n}$ & $\mathrm{pL}$ & $\begin{array}{l}\text { Log } \\
\left(\frac{n}{n-1}\right)\end{array}$ & Log $\mathrm{K}_{1}$ \\
\hline 8.50 & 5.30 & 5.81 & 5.85 & 0.04 & 0.2973 & 2.88 & -0.3736 & 2.5064 \\
8.72 & 5.35 & 5.90 & 5.94 & 0.04 & 0.3099 & 2.66 & -0.5477 & 2.3123 \\
9.00 & 5.40 & 6.00 & 6.05 & 0.05 & 0.4044 & 2.38 & -0.1681 & 2.2119 \\
9.22 & 5.45 & 6.10 & 6.15 & 0.06 & 0.5157 & 2.18 & 0.0272 & 2.2072 \\
9.51 & 5.50 & 6.20 & 6.26 & 0.07 & 0.6417 & 1.89 & 0.2530 & 2.1430 \\
9.73 & 5.55 & 6.40 & 6.40 & 0.07 & 0.7000 & 1.67 & 0.3680 & 2.0380 \\
\hline
\end{tabular}

LogK $_{1}$ (Average value) $=2.2364 \pm 0.1602$

Table 10: Point-wise method, Pb (Unhydrolysed PSHA)

\begin{tabular}{|l|l|l|l|l|l|l|l|l|}
\hline $\mathrm{pH}$ & $\mathrm{BV}_{1}$ & $\mathrm{BV}_{2}$ & $\mathrm{BV}_{3}$ & $\mathrm{~V}_{3}-\mathrm{V}_{2}$ & $\mathrm{n}$ & $\mathrm{pL}$ & $\log \left(\frac{n-1}{2-n}\right)$ & $\log \mathrm{K}_{2}$ \\
\hline 10.00 & 5.60 & 6.47 & 6.55 & 0.08 & 1.9503 & 1.41 & & \\
10.23 & 5.65 & 6.62 & 6.72 & 0.11 & 1.4792 & 1.26 & -0.0361 & 1.2239 \\
\hline
\end{tabular}

$\operatorname{LogK}_{2}$ (Average value) $=1.2239$

Table 11: Point-wise method, Mg (Hydrolysed PSHA)

\begin{tabular}{|l|l|l|l|l|l|l|l|l|}
\hline $\mathrm{pH}$ & $\mathrm{BV}_{1}$ & $\mathrm{BV}_{2}$ & $\mathrm{BV}_{3}$ & $\left(\mathrm{~V}_{3}-\mathrm{V}_{2}\right)$ & $\mathrm{n}$ & $\mathrm{pL}$ & $\log \left(\frac{n}{n-1}\right)$ & LogK $_{1}$ \\
\hline 8.50 & 5.30 & 6.29 & 6.31 & 0.02 & 0.2750 & 2.64 & -0.4290 & 2.2110 \\
8.72 & 5.35 & 6.37 & 6.39 & 0.02 & 0.2858 & 2.42 & -0.3978 & 2.0222 \\
9.00 & 5.40 & 6.46 & 6.49 & 0.03 & 0.4648 & 2.14 & -0.0612 & 2.0788 \\
9.22 & 5.45 & 6.55 & 6.59 & 0.04 & 0.6667 & 1.94 & 0.3010 & 2.2410 \\
\hline
\end{tabular}

$\log _{\mathbf{1}}($ Average value) $=2.1382 \pm 0.1046$ 
BAJOPAS Volume 14 Number 1,June, 2021

Table 12: Point-wise method, Mg (Hydrolysed PSHA)

\begin{tabular}{|l|l|l|l|l|l|l|l|l|}
\hline $\mathrm{pH}$ & $\mathrm{BV}_{1}$ & $\mathrm{BV}_{2}$ & $\mathrm{BV}_{3}$ & $\left(\mathrm{~V}_{3}-\mathrm{V}_{2}\right)$ & $\mathrm{n}$ & $\mathrm{pL}$ & $\log \left(\frac{n-1}{2-n}\right)$ & LogK $_{2}$ \\
\hline 9.51 & 5.55 & 6.66 & 6.71 & 0.05 & 0.9650 & 1.67 & & \\
9.73 & 5.55 & 6.78 & 6.84 & 0.06 & 1.4042 & 1.47 & -0.1686 & 1.3014 \\
10.00 & 5.60 & 6.90 & 6.93 & 0.06 & 1.7838 & 1.23 & 0.5593 & 1.7893 \\
10.23 & 5.65 & 7.05 & 7.10 & 0.06 & 3.1429 & 1.10 & & \\
10.49 & 5.70 & 7.10 & 7.18 & 0.07 & 3.6492 & 0.83 & & \\
\hline
\end{tabular}

LogK $_{2}($ Average value $)=1.5453 \pm 0.3450$

Table 13: Point-wise method, Mg (Unhydrolysed PSHA)

\begin{tabular}{|l|l|l|l|l|l|l|l|l|}
\hline $\mathrm{pH}$ & $\mathrm{BV}_{1}$ & $\mathrm{BV}_{2}$ & $\mathrm{BV}_{3}$ & $\mathrm{~V}_{3}-\mathrm{V}_{2}$ & $\mathrm{n}$ & $\mathrm{pL}$ & $\log \left(\frac{n}{n-1}\right)$ & $\operatorname{Log~}_{1}$ \\
\hline 8.50 & 5.30 & 5.81 & 5.85 & 0.04 & 0.2973 & 2.88 & -0.3736 & 2.5064 \\
8.72 & 5.35 & 5.90 & 5.94 & 0.04 & 0.3099 & 2.66 & -0.3477 & 2.3123 \\
9.00 & 5.40 & 6.00 & 6.04 & 0.04 & 0.3236 & 2.38 & -0.3202 & 2.0598 \\
9.22 & 5.45 & 6.10 & 6.15 & 0.05 & 0.4297 & 2.17 & -0.1230 & 2.0470 \\
9.51 & 5.50 & 6.20 & 6.26 & 0.06 & 0.5500 & 1.89 & 0.0871 & 1.9771 \\
9.73 & 5.55 & 6.33 & 6.40 & 0.07 & 0.7000 & 1.67 & 0.3680 & 2.0380 \\
\hline
\end{tabular}

LogK $_{1}$ (Average value) $=2.1568 \pm 0.2069$

Table 14: Point-wise method, Mg (Unhydrolysed PSHA)

\begin{tabular}{|l|l|l|l|l|l|l|l|l|}
\hline $\mathrm{pH}$ & $\mathrm{BV}_{1}$ & $\mathrm{BV}_{2}$ & $\mathrm{BV}_{3}$ & $\mathrm{~V}_{3}-\mathrm{V}_{2}$ & $\mathrm{n}$ & $\mathrm{pL}$ & $\log \left(\frac{n-1}{2-n}\right)$ & $\log \mathrm{K}_{2}$ \\
\hline 10.00 & 5.60 & 6.47 & 6.55 & 0.08 & 0.9148 & 1.41 & & \\
10.23 & 5.65 & 6.62 & 6.71 & 0.09 & 1.2102 & 1.20 & -0.5749 & 0.6251 \\
10.49 & 5.70 & 6.80 & 6.92 & 0.09 & 1.5968 & 1.03 & 0.1703 & 1.2003 \\
\hline
\end{tabular}

LogK $_{2}$ (Average value) $=0.9127 \pm 0.4070$

Table15:Point-wise method, Cd (Hydrolysed PSHA)

\begin{tabular}{|l|l|l|l|l|l|l|l|l|}
\hline $\mathrm{pH}$ & $\mathrm{BV}_{1}$ & $\mathrm{BV}_{2}$ & $\mathrm{BV}_{3}$ & $\left(\mathrm{~V}_{3}-\mathrm{V}_{2}\right)$ & $\mathrm{n}$ & $\mathrm{pL}$ & $\log \left(\frac{n}{1-n}\right)$ & LogK $_{1}$ \\
\hline 8.50 & 5.30 & 6.29 & 6.31 & 0.02 & 0.2750 & 2.64 & -0.4210 & 2.2190 \\
8.72 & 5.35 & 6.37 & 6.40 & 0.03 & 0.4286 & 2.42 & -0.1249 & 2.2951 \\
9.00 & 5.40 & 6.46 & 6.49 & 0.03 & 0.4648 & 2.14 & -0.0612 & 2.0788 \\
9.22 & 5.45 & 6.55 & 6.59 & 0.04 & 0.6667 & 1.96 & 0.3010 & 2.2610 \\
9.51 & 5.55 & 6.66 & 6.70 & 0.04 & 0.7720 & 1.67 & 0.5297 & 2.1997 \\
\hline
\end{tabular}

LogK $_{\mathbf{1}}$ (Average value) $=2.2108 \pm 0.0825$

Table 16: Point-wise method, Cd (Hydrolysed PSHA)

\begin{tabular}{|l|l|l|l|l|l|l|l|l|}
\hline $\mathrm{pH}$ & $\mathrm{BV}_{1}$ & $\mathrm{BV}_{2}$ & $\mathrm{BV}_{3}$ & $\left(\mathrm{~V}_{3}-\mathrm{V}_{2}\right)$ & $\mathrm{n}$ & $\mathrm{pL}$ & $\log \left(\frac{n-1}{2-n}\right)$ & Log $_{2}$ \\
\hline 9.73 & 5.55 & 6.78 & 6.83 & 0.06 & 1.4042 & 1.47 & -0.1686 & 1.3014 \\
10.00 & 5.60 & 6.90 & 6.95 & 0.06 & 1.7838 & 1.23 & 0.5593 & 1.7893 \\
10.23 & 5.65 & 7.05 & 7.10 & 0.06 & 3.1429 & 1.09 & & \\
10.49 & 5.70 & 7.10 & 7.16 & 0.06 & 3.1429 & 0.89 & & \\
& & & & & & & & \\
\hline
\end{tabular}

$\operatorname{LogK}_{2}$ (Average value) $=1.5453 \pm 0.3450$

Table 17: Point-wise method, Cd (Unhydrolysed PSHA)

\begin{tabular}{|l|l|l|l|l|l|l|l|l|}
\hline $\mathrm{pH}$ & $\mathrm{BV}_{1}$ & $\mathrm{BV}_{2}$ & $\mathrm{BV}_{3}$ & $\mathrm{~V}_{3}-\mathrm{V}_{2}$ & $\mathrm{n}$ & $\mathrm{pL}$ & $\log \left(\frac{n}{n-1}\right)$ & $\operatorname{Log~}_{1}$ \\
\hline 8.50 & 5.30 & 5.81 & 5.86 & 0.05 & 0.3717 & 2.88 & -0.2280 & 2.6520 \\
8.72 & 5.35 & 5.90 & 5.95 & 0.05 & 0.3873 & 2.66 & -0.1992 & 2.4608 \\
9.00 & 5.40 & 6.00 & 6.06 & 0.06 & 0.4853 & 2.38 & -0.0255 & 2.3545 \\
9.22 & 5.45 & 6.10 & 6.16 & 0.06 & 0.5157 & 2.18 & -0.0272 & 2.2072 \\
9.51 & 5.50 & 6.20 & 6.27 & 0.07 & 0.6417 & 1.89 & 0.2530 & 1.1430 \\
9.73 & 5.55 & 6.33 & 6.41 & 0.08 & 0.8000 & 1.69 & 0.6020 & 2.2920 \\
& & & & & & & & \\
\hline
\end{tabular}

$\operatorname{LogK}_{1}($ Average value $)=2.2516 \pm 0.5380$ 
BAJOPAS Volume 14 Number 1,June, 2021

Table 18: Point-wise method, Cd (Unhydrolysed PSHA)

\begin{tabular}{|l|l|l|l|l|l|l|l|l|}
\hline $\mathrm{pH}$ & $\mathrm{BV}_{1}$ & $\mathrm{BV}_{2}$ & $\mathrm{BV}_{3}$ & $\mathrm{~V}_{3}-\mathrm{V}_{2}$ & $\mathrm{n}$ & $\mathrm{pL}$ & $\log \left(\frac{n-1}{2-n}\right)$ & $\log \mathrm{K}_{2}$ \\
\hline 10.00 & 5.60 & 6.47 & 6.57 & 0.10 & 1.1434 & 1.43 & & \\
10.23 & 5.65 & 6.62 & 6.72 & 0.10 & 1.3448 & 1.23 & -0.2788 & 0.9512 \\
10.49 & 5.70 & 6.80 & 6.90 & 0.10 & 1.7742 & 1.03 & 0.5351 & 1.5651 \\
\hline
\end{tabular}

$\operatorname{LogK}_{2}($ Average value $)=1.2581 \pm 0.4340$

Table 19: Stepwise and overall Stability constants of thehydrolysed and unhydrolysed divalent metal (II) complexes

\begin{tabular}{|c|c|c|c|}
\hline Chelates & LogK $_{1}$ & $\log _{2}$ & Log $\beta$ \\
\hline [Cu (Hydrolysed PSHA-1) $\left.{ }_{2}\right]$ & 2.4788 & 1.4280 & 3.9068 \\
\hline$\left[\mathrm{Pb}(\text { Hydrolysed PSHA-1) })_{2}\right]$ & 2.5832 & 1.1963 & 3.7795 \\
\hline$\left[\mathrm{Cd}(\text { Hydrolysed PSHA-1 })_{2}\right]$ & 2.2108 & 1.5453 & 3.7561 \\
\hline$\left[\mathrm{Mg}(\text { Hydrolysed PSHA-1 })_{2}\right]$ & 2.1382 & 1.5453 & 3.6835 \\
\hline [Cu (Unhydrolysed PSHA-1) & 2.3059 & 1.2209 & 3.5268 \\
\hline$[\mathrm{Pb}$ (Unhydrolysed PSHA-1) 2$]$ & 2.2364 & 1.2239 & 3.4603 \\
\hline [Cd (Unhydrolysed PSHA-1) 2 ] & 2.2516 & 1.2581 & 3.5097 \\
\hline$[\mathrm{Mg}$ (Unydrolysed PSHA-1) & 2.1568 & 0.9127 & 3.0695 \\
\hline
\end{tabular}

The results obtained (Table19) shows the stepwise and overall stability constants to be not high indicating low stability of the complexes, because the solubility of most metal ions in the basic $\mathrm{pH}$ range is minimal due to metal hydroxide precipitation (Karimi, 2017). In general, the stepwise stability constants $\left(K_{1}\right.$ and $K_{2}$ ) follow the order $K_{1}>K_{2}$ for the copper, lead, magnesium and cadmium complexes respectively. The steady decrease of the values with increasing number of ligands is in agreement with the prediction made by researchers (Na'aliya, 2013). The decrease could be attributed to the fact that as the number of the ligands (Humate ions) that enters the coordination zone increases the aqua molecules available for replacement by the ligands become less. Thus, the metal ions become less electron loving with progressive intake of the ligand and this results in the decrease in the values of the constants (Na'aliya, 2013). Also the stability of the complexes is influenced by the size and number of the chelate rings(Mackay and Mackay,2002).All the complexes form rings in their structure as humate, a bidentate ligand, bond the metal ions in the ratio 1:2 (Boguta and Sokolowska, 2016) forming chelate rings. The values of the overall stability constants $(\log \beta)$ obtained for humate complexes are not high indicating low stability as the values are not high. LogK values for copper-humates (Table 3 to 6) obtained in this study are lower than those reported for the complexes of humic acids (Pandey et al., 2015; Dinu, 2013; Kaschl et al., 2010 and Gilbeto and Jorg, 2001). The values of LogK(Table 7 to 10 ) forlead-humates are lower than those reported for the lead in the literature (Dinu, 2013; Gilbeto and Jorg 2001). Log K values(Table 11 to 14 ) for magnesium-humates obtained in this study are close to those reported by (Pandey et al., 2015). Log K values of cadmium-humates (Table 15 to 18 ) obtained in this work near to the one reported by (Dinu, 2013 and Pandey et al., 2015).The difference between the reported values and the values obtained in this study might be probably as a result of acid hydrolysis of humic acid. The values of the overall stability constants $(\log \beta)$ of the copper humates complexes presented in Table 19 is high than that of other metal humate complexes, show relatively high stability of CuHA complexes, show the following order of stability: $\mathrm{Cu}>\mathrm{Pb}>\mathrm{Cd}>\mathrm{Mg}$; which are in close agreement to the findings of (Dinu, 2013 and Pandey et al., 2015).The high stability of Cuhumate chelate could be attributed to the existence of coordinate covalent bond between the complexing agents and the $\mathrm{Cu}^{2+}$ ions. Since, $\mathrm{Cu}^{2+}$ being a metal of the transitional series with $3 d^{9}$ electronic configurations can accept the electrons from the complexing agents. Similarly, the low stabilities of $\mathrm{Pb}, \mathrm{Cd}$ and $\mathrm{Mg}$ complexes could be explained by that $\mathrm{Pb}^{2+}$ with $6 s^{2}, \mathrm{Cd}^{2+}$ with $4 \mathrm{~d}^{10}$ and $\mathrm{Mg}^{2+}$ with $2 \mathrm{p}^{6}$ their electronic configuration has a completely filled $\mathrm{d}, \mathrm{p}$ and $\mathrm{s}$ orbitals. Moreover, the stabilities of metal ions with hydrolysed humic acid from peat soil were higher than those with unhydrolysed humic acid from peat soil; which is ascribed to the high content of acidity in hydrolysed humic acid than unhydrolysed humic acid. 
BAJOPAS Volume 14 Number 1,June, 2021 CONCLUSION

The values of logk for $\mathrm{Cu}(\mathrm{II})$ hydrolysed humic acid complex was higher followed by $\mathrm{Pb}$ (II), $\mathrm{Cd}(\mathrm{II})$ and $\mathrm{Mg}$ (II) hydrolysed humic acid complexes as compared with metal(II) unhydrolysed humic acid complexes. This indicates acid hydrolysis of humic acid can

\section{REFERENCES}

Almeida, V.R. and Szpoganicz, B. (2015). Humic Acid Potentiometric Response Patterns:Out- of Equilibrium Properties and Species Distribution Modelling. Chemical. Biol. Technol. Agric. 2: 17.

Anđelković, T., Nikolić, R., Bojić, A.,Anđelković, D., and Nikolic G.,(2010). Binding of Cadmium to Soil Humic Acid as A Function of Carboxyl Group Content. Macedonian Journal of Chemistry and Chemical Engineering.29(2): 215-224.

Anil, B. N. and Maroti, N. (2008). Studies on Influence of Die-Lectric Constants on Complex Equilibria between Substituted Py-Razalines and Lanthanide Metal Ions pH-Metrically. Amer.-Euras. scient. Res. 3(2): 212-216.

Ashok, K., Pandey, S. P. and Misra, V (2000). Stability Constants of Metal-Humic Acid Complexes and its Role in Environmental Detoxification. Journal of Ecotoxicology and Environmental Safety. 47(2):157-200.

Badr, M. H., El-Halafawi, M. H. and Abd El-al Zeid, E. R. (2012). Comparison Between the Effect of Ionic Strength on Acidity and Dissociation Constants of Humic Acids Extracted from Sewage Sludge and Nile Water Hyacinth Composts.Global Journal of Environmental Research 6 (1): 36-43.

Baruah, M.K., Borah, D., Saikia, P.P., Paul, S., Sharma, T. (2015). Evaluation of pKa Values of Soil Humic Acids and their Complexation Properties. International Journal of Plant \& Soil Science 6(4) : 218-228.

Boguta, P. Sokolowska, Z. (2016). Interactions of $\mathrm{Zn}$ (II) Ions with Humic Acids Isolated from Various Types of Soils. Effect of $\mathrm{pH}, \mathrm{Zn}$ Concentrations and Humic Acids Chemical Properties. Journal of Geochemical Explaration 168. 119-126.

Borges, F., Guimaraes, C., Lima, L.F.C., Pinto, I. and Reis, S.(2005). Potentiometric Studies on the Complexation of Copper(II) by Phenolic Acids as Discrete Ligand Models of enhance the complexation behavior of humic acid with metal (II) ions. However, the higher values of $\log \beta$ for $\mathrm{Cu}(\mathrm{II}), \mathrm{Pb}(\mathrm{II}), \mathrm{Cd}(\mathrm{II})$ and $\mathrm{Mg}(\mathrm{II})$ hydrolysed humic acid complexes indicates more stable stepwise complexes formed as compared with $\mathrm{Cu}(\mathrm{II}), \mathrm{Pb}$ (II), $\mathrm{Cd}$ (II) and $\mathrm{Mg}(\mathrm{II})$ unhydrolysed humic acid complexes.

Humic Substances Talanta 66 (2005) 670-673.

Chefetz, B., Salloum, M. J., Deshmulkin, A. P. and Hatcher, P. (2002). Structural Components of Humic Acids as Determined by Chemical Modifications and Carbon-13 NMR, Pyrolysis, and Thermochemolysis- Gas Chromatography/Mass Spectrometry. Soil Science Society of American Journal Abstract Division S-2- Soil Chemistry66. 1159-1171.

Dinu, M. I. (2013). Metals Complexation with Humic Acids in Surface Water of Different Environ. Sci. Technol. 31(1): 1-17.

Fernandes, A.N., Giacomelli, C., Giovanela, M. Vaz, D.V. Szpoganicz, B. and Maria M. D. (2009). Potentiometric Acidity Determination in Humic Substances Influenced by Different Analytical Procedures.J. Braz. Chem. Soc. 20 (9):14.

Gamal, A. H. (2015). Stability Constants of Rhenium (V) Metal Complexes with Selected Drugs. Pyrex Journal of Research in Environmental Studies. 2(2): 006-014.

Janrao, D. M., Pathan, J., Kayande, D.D., and Mulla, J.J. (2014). An Over View of Potentiometric Determination of Stability Constants of Metal Complexes. Sci. Revs. Chem. Commun.: 4(1), 2014, 11-24.

Karimi, H. (2017). Effect of pH and Initial Pb(II) Concentration on the Lead Removal Efficiency from Waste Water Using $\mathrm{Ca}(\mathrm{OH})_{2}$. International Journal of Water and Waste Water Treatment 3.2

Kaschl, A. Romheld, V. and Chen, Y. (2010). Binding of Cadmium, Copper and Zinc to Humic Substances Originating from Municipal Solid Waste Compost. Israel Journal of Chemistry Vol. 42(1): 89-98.

Kostic, I. S., Tatjana, P, A., Nikolic, R. S., Cvetkovic, T. P., Pavlovic, D. D., Aleksandar, L.J. and Bojic, A. (2012). Comparative Study of Binding Strengths of Heavy Metals with Humic Acid. J.serb. Chem. Soc. 76(9) pp 1-20. 
BAJOPAS Volume 14 Number 1,June, 2021

Na'aliya, J. (2013). Determination of Stepwise Stability Constants and Gibbs free Energy Change of Trisprolina to Complexes of some Divalent Transition Metal ions. Bayero Journal of Pure and Applied Sciences 6(2): 112-114.

Omar, A. A. and Ali, E. A. (2015). Potentiometric Studies on Complexes of $\mathrm{Cr}$ (III) and $\mathrm{Zr}$ (IV) with some Carboxylic Acids. International Journal of Advanced Chemistry, 3(1) 25-

37.

Pandey, A. K. Pandey, S. D. and Misr, V. (2015).Stability Constants of Metal- Humic Acid Complexes and Its Role in Environmental Detoxification. J. Ecotoxicology and Environmental Safety. 47(1):195-200.

Ram, N. and Raman, K.V. (1984). Stability Constants of Complexes of Metals with
Humicand Fuvic Acids under Non- acidConditions. Journal of Plant Nutrition and Soil Sciences.

147:171-176.

Santosh, D. D., Ashok, B. K., Vijay, J. T., Shivraj, G. W. and Vinay, V. W. (2011). Potentiometric Studies of Elec-Trolyte Effects on Complex Equilibria of Some Substituted 5-(2-hydroxy Phenyl) Pyrazoles. Der pharm. 3 (6): 75-83.

Sayyed, H. and Abdul Rahim, M. F. (2012). Studies of Binary Complexes of Metal Ions with Mandelic Acid by Potentiometry. Chem. J. 02 (6): 206209.

Shirvani, M. Moradian, E. Khalili, B. Bakhtiary, S. (2015). Interaction of $\mathrm{Cd}$ and $\mathrm{Pb}$ with Humate-Palygorskite and HumateSepiolite Complexes. Journal of water, air and pollution 3: 220-228. 


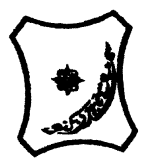

Bayero Journal of Pure and Applied Sciences, 14(1): 54 - 63

Received: November, 2020

Accepted: April, 2021

ISSN $2006-6996$

\title{
STABILITY CONSTANTS OF COMPLEXES OF METAL IONS WITH PEATSOIL HUMIC ACIDS UNDER NON-ACID-CONDITIONS
}

\author{
${ }^{* 1}$ Sabo, Yusuf ${ }^{2}$ Jimoh, W.L.O., ${ }^{3}$ Isa Baba Koki and ${ }^{4}$ Sholadoye, Q. 0. \\ ${ }^{1}$ Department of Pure and Industrial Chemistry, Bayero University, Kano \\ ${ }^{3}$ Department of Chemistry, Yusuf Maitama Sule University Kano. P.M.B. 3220 Kano, Nigeria. \\ ${ }^{4}$ Department of Chemistry, Nigerian Police Academy, Wudil, Kano-Nigeria
}

*Correspondence E-mail; saboyusuf18@yahoo.com

ABSTRACT

Stability constants of complexes of four divalent metal ions viz. $\mathrm{Cu}^{2+}, \mathrm{Pb}^{2+}, \mathrm{Mg}^{2+}$ and $\mathrm{Cd}^{2+}$ with humic acids (HA) were determined by potentiometric titration of humic acids with the corresponding salt of the divalent metals in aqueous media under non-acid-condition. The log $K$ (logarithm of the stability constant) ranged from 1.0942 to 2.7471 for metalhumic acid complexes were determined using point-wise computational method. The order of stability constants were obtained as follows: $\mathrm{Cu}>\mathrm{Pb}>\mathrm{Cd}>\mathrm{Mg}$ for metal $-\mathrm{HA}$ complexes respectively, indicating a higher degree of complexation with Cu metal ion.

Keywords: stability constant, humic acid, potentiometric titration, divalent metals, acid hydrolysis.

\section{NTRODUCTION}

The stability constant of a complex is the numerical expression of its stability and provides a quantitative measure of affinity of the metal ion to the complexing agent. An understanding of the relative stability of metal-complexes helps in predicting the behavior of metal ions in the soil (Ram and Raman, 1982). Extensive researches has been done to determine the stability constants of the complexes formed between humic acid (HA) with a number of metal ions. Ashok et al., (2000) reported that humic acid with hydroxyl, phenoxyl and carboxyl reactive groups can form coordination compound with metal ions at $\mathrm{pH}$ 3.5. The stability constants(Log K) for different metalhumic acid complexes indicated the following order of the stabilities of complexes formed between humic acid and metal ion, $\mathrm{Cu}>\mathrm{Fe}$ $>\mathrm{Pb}>\mathrm{Ni}>\mathrm{Co}>\mathrm{Ca}>\mathrm{Cd}>\mathrm{Zn}>\mathrm{Mn}>\mathrm{Mg}$. Andelkovic et al., (2010) investigated the binding of $\mathrm{Cd}$ (II) to soil humic acid at pH 6.5 and in $0.1 \mathrm{M} \mathrm{KNO}_{3}$ ionic medium. The stability constant for binding indicating greater stability in the case when carboxyl groups are involved in complexation reaction. Kostic et al.,(2012) investigated the complexation of humic acid with certain heavy metal ions (Co(II), $\mathrm{Ni}(\mathrm{II}), \mathrm{Cu}(\mathrm{II})$,
$\mathrm{Zn}(\mathrm{II})$, and $\mathrm{Pb}(\mathrm{II})$. The experiment was performed at $25^{\circ} \mathrm{C}$, at pH 4.0 and ionic strength of $0.01 \mathrm{M}$. Stability constant of complex between $\mathrm{Pb}$ (II) ions and humic acid is greater than stability constants of other investigated metalhumate complexes. Bogata and Sokolowska (2016) analyses the interaction between humic acids from different soils and $\mathrm{Zn}$ (II) ions at wide concentration ranges and at $\mathrm{pH} 5$. Studies have showed significant impact of $\mathrm{Zn}$ concentration, $\mathrm{pH}$ and some properties of humic acids with zinc.But all of these studies were limited to acidic $\mathrm{pH}$ range. Therefore, the present study was carried out to determine and compare the stability constants of complexes of metal ions with hydrolysed peat soil humic acid and unhydrolysed peat soil humic under non-acid conditions.

\section{MATERIALS AND METHODS}

Analytical grade chemicals used includes hydrochloric acid $(\mathrm{HCl})$, nitric acid $\left(\mathrm{HNO}_{3}\right)$, sodium hydroxide $(\mathrm{NaOH})$, lead nitrate $\mathrm{Pb}\left(\mathrm{NO}_{3}\right)_{2}$, copper nitrate $\mathrm{Cu}\left(\mathrm{NO}_{3}\right)_{2} \cdot 3 \mathrm{H}_{2} \mathrm{O}$, cadmium nitrate $\mathrm{Cd}\left(\mathrm{NO}_{3}\right)_{2} \cdot 4 \mathrm{H}_{2} \mathrm{O}$, magnesium nitrate $\mathrm{Mg}\left(\mathrm{NO}_{3}\right)_{2} \cdot 6 \mathrm{H}_{2} \mathrm{O}$, potassium nitrate $\left(\mathrm{KNO}_{3}\right)$, calcium chloride $\left(\mathrm{CaCl}_{2}\right)$, (sigma-Aldrich). Dowex 50WX8, (20-50 mesh) from Fluka. 


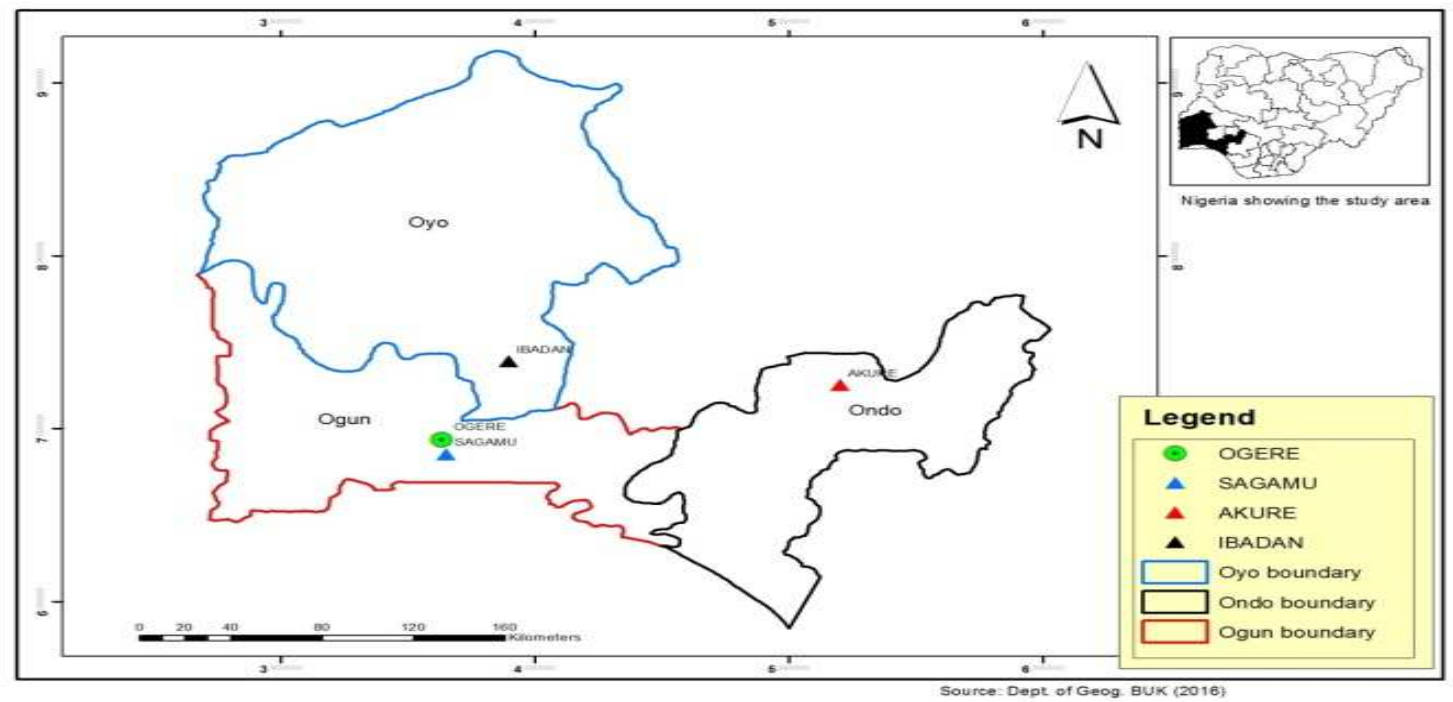

Figure 1: Map showing the sampling point at Sagamu Town, Ogun State.

\section{Description of Sampling Area}

Sagamu has geographical coordinates between $6^{\circ} 50^{\prime}$ north; $3^{\circ} 38^{\prime}$ east is located in south western region of Nigeria. The region has tropical wet and dry climate with a lengthy wet season and relatively constant temperatures throughout the course of the year. Wet season runs from March to October, November to December forms the region dry season. The vegetation type of the region is savannah which is really grassland with small bushes and occasional big trees. Grassland soils have substantially higher organic matter content than forest soils (Novackova, 2011).

\section{Sample Collection}

The Peatsoil samples were collected from four different sampling points $(0-10 \mathrm{~cm}$ depth) in Sagamu into polyethylene bag with plastic spoons. Samples were taken to the laboratory, extraneous materials were removed; the samples were air-dried, crushed and ground to a fine powder in a mortar passed through a $0.20 \mathrm{~mm}$ sieve. The samples were kept for analysis.

\section{Isolation and purification of humic acid from peat soil sample}

Peatsoil sample $(100 \mathrm{~g})$ was mixed with 1000 $\mathrm{cm}^{3}$ of $0.1 \mathrm{M} \mathrm{NaOH}$ solution, shaken for 3hours and left to stand overnight. Dark-coloured supernatant was obtained and decanted from solid residue. The dark-coloured supernatant was acidified to $(\mathrm{pH}=1.0)$ with $6 \mathrm{M} \mathrm{HCl}$ stirred and allowed to stand for 6 hours. Yellowish brown supernatant and dark-brown precipitate were obtained. The yellowish brown supernatant was decanted followed by centrifuge and discarded. The dark-brown precipitate was mixed with $500 \mathrm{~cm}^{3}$ of $0.1 \mathrm{M} \mathrm{NaOH}$ solution followed by passing through dowex resin. The dark-brown solution was acidified to $(\mathrm{pH}=1.0)$ with $6 \mathrm{M} \mathrm{HCl}$ stirred and allowed to stand for 3 hours. The dark-brown precipitate was washed several times with deionized water. The supernatant was treated with $\mathrm{AgNO}_{3}$ solution until no white precipitate observed. The humic acid was transferred to weighed crucible and dried at $60^{\circ} \mathrm{C}$ in an oven for 12 hours. The humic acid was cooled and dried in the desiccator, weighed and recorded. The obtained humic acid was dried again at $60^{\circ} \mathrm{C}$ for additional 6 hours cooled and dried in the desiccator, weighed and recorded constant weight was obtained (Baruah et al., 2015).

\section{FT-IR analysis}

FT-IR spectra of humic acid sample was analysed using Carry 630 FT-IR Agilent Technologies.

Unhydrolysed compost humic acid

The unhydrolysed humic acid was obtained after isolation and purification of compost humic acid and kept for investigation.

\section{Acid hydrolysis of Peatsoil acid}

Peatsoil humic acid sample (1g) was refluxed for 12 hours at $\left(160^{\circ} \mathrm{C}\right)$ with $50 \mathrm{~cm}^{3}$ of $6 \mathrm{M} \mathrm{HCl}$. The mixture was allowed to cool, decanted, and centrifuged after hydrolysis. The insoluble residues were washed with distilled water via centrifugation several times, and the supernatant was treated with $\mathrm{AgNO}_{3}$ solution until no white precipitate was observed. The residue was thoroughly dried over $\mathrm{CaCl}_{2}$ in a desiccator at room temperature (Chefetz et al., 2002). Finally, the obtained hydrolysed humic acid was kept for investigation. 
BAJOPAS Volume 14 Number 1,June, 2021 Potentiometric Titrations

Potentiometric measurements were carried out using a pH-meter Jenway (model 3510) with combine electrode, the sensitivity of the $\mathrm{pH}$ meter is 0.01 units. The $\mathrm{pH}$ meter was switched on half an hour before starting the titration for initial warm up of the instrument. The instrument was calibrated with an aqueous standard buffer solution of $\mathrm{pH} 4.00$ and 10.0 (borate buffer) prepared from a "Qualigens" buffer tablets.

The following sets of solutions were prepared in a $250 \mathrm{~cm}^{3}$ volumetric flask separately for $\mathrm{pH}$ metric titrations.

(i) $5 \mathrm{~cm}^{3} 0.1 \mathrm{M} \mathrm{HCl}+40 \mathrm{~cm}^{3}$ deionized water

(ii) $5 \mathrm{~cm}^{3} 0.1 \mathrm{M} \mathrm{HCl}+39 \mathrm{~cm}^{3}$ deionized water $+1 \mathrm{~cm}^{3} 0.15 \mathrm{gcm}^{-3}$ humic acid

(iii) $5 \mathrm{~cm}^{3} 0.1 \mathrm{M} \mathrm{HCl}+37 \mathrm{~cm}^{3}$ deionized water $+1 \mathrm{~cm}^{3} 0.15 \mathrm{gcm}^{-3}$ humic acid

$$
+2 \mathrm{~cm}^{3} \quad 0.01 \mathrm{M} \mathrm{Cu} \text { (II) }
$$

The solutions were titrated against standardized $0.110 \mathrm{MNaOH}$ separately. The total volume of each mixture was adjusted to $50 \mathrm{~cm}^{3}$ and the ionic strength of the solutions was maintained constant at by adding appropriate amount of stock solution of $1 \mathrm{M} \mathrm{KNO}_{3}$ (Gamal, 2015; Omar and Ali, 2015). A magnetic stirrer was used to achieve thorough mixing of the interacting solutions at $550 \mathrm{rpm}$. The same set of experimental conditions was applied for potentiometric titration of remaining samples.

\section{Evaluation of pKa of Hydrolysed peat soil Humic Acids}

The proton-ligand formation number $\mathrm{n}_{\mathbf{A}}$ were calculated by Irving and Rossotti expression (Omar and Ali, 2015).

$\mathrm{nA}=\mathrm{Y}-\frac{(\mathrm{V} 2-\mathrm{V1})(\mathrm{No}-\mathrm{Eo})}{(\mathrm{VO}+\mathrm{V1}) \mathrm{TCL}}$ 1

Where: $Y$ is number of dissociable proton, $\left(\mathrm{V}_{2^{-}}\right.$ $V_{1}$ ) is the measure of displacement of the ligand curve relative to acid curve, $\mathrm{N}^{\circ}$ and $\mathrm{E}^{\circ}$ are the resultant concentration of alkali solution, free acid solution, $\mathrm{T}_{\mathrm{cL}}{ }^{\circ}$ is the total ligand concentration, $\mathrm{V}^{\circ}$ is the total volume of titration solution, $V_{1}$ is the volume of alkali added to acid solution, $V_{2}$ is the volume of alkali added to acid solution + ligand solution, acid dissociation constants (pKa - values) of ligand were calculated by algebraic method point wise calculation (Tables 1 ). The dissociation constants (pKa) were calculated according to the following relation:

$\mathrm{pKa}=\mathrm{pH}+\log \left(\frac{n A}{1-n A}\right)$ 2

Where: pKa is the acid dissociation constant, $\mathrm{n}_{\mathrm{A}}$ is the Proton-ligand formation number and $\mathrm{pH}$ is the pH-values (Omar and Ali, 2015).

\section{Determination of metal-ligand stability constants $(\log K)$ of complexes}

The potentiometric measurement for the determination of stability constant of a complex in solution is based on the fact that the redox potential of the couple $\frac{M^{+(m-n)}}{M^{+m}}$ is shifted significantly on complexation of the metal ion with the ligand. This method involves change in hydrogen ion concentration $\left[\mathrm{H}^{+}\right]$due to the displacement or association of one or more protons taking place during complexation reaction. This change can be found out by titrating the solutions containing free acid, acid with ligand, and acid with ligand and metal ion, individually against a standard alkali solution at a constant ionic strength or temperature. Either ionic strength or temperature may be varied for different sets of solutions. In all the cases, the change in the $\mathrm{pH}$ of the solution is measured after each addition of a known amount of alkali to the reaction cell which contains the reaction mixture. The titration curves are then drawn by plotting the measured $\mathrm{pH}$ values against the corresponding volume of alkali added and the stability constants of the complexes are determined from the titration curves by employing $\mathrm{pH}$-metric titration technique given by (Irving and Rossoti).

Metal-ligand stability constants ( $\log \mathrm{K}$ ) were determined by using the following relations:

$$
\bar{n}=\frac{\left(V_{3}-V_{2}\right)\left(E^{0}+N^{0}\right)}{\left(V^{0}+V_{2}\right) \bar{n}_{A} T_{m}^{0}}
$$

and

$$
P L=\log _{10}\left\{\frac{1+\beta_{n}^{H} \frac{1}{[\text { anti } \log \mathrm{pH}]^{\mathrm{n}}}}{\mathrm{T}_{\mathrm{L}}^{0}-n \bar{T}_{m}^{0}} \mathrm{X} \frac{\left(V^{0}+V_{3}\right)}{V^{0}}\right\}
$$


BAJOPAS Volume 14 Number 1,June, 2021

Where $T_{L}, T^{\circ}, E^{\circ}$, and $V^{\circ}$ havethe same significance as in equation (1) above, $T_{m}$ denotes the total concentration of metal present in solution, $V_{3}$ is the volume of metal ions present in solution and $\beta^{H}$ is the overall proton ligand stability constant. The metal-ligand stability constants (log K) were determined by employing point wise computational Method (eq. 5 and 6).

$\operatorname{LogK}_{1}=\log \left(\frac{n}{1-n}\right)+\mathrm{pL}$ .5

$\operatorname{LogK}_{2}=\log \left(\frac{1-n}{2-n}\right)+\mathrm{pL}$ ...6

Where: Log $\mathrm{K}$ is the metal-ligand stability constant, $\mathrm{pL}$ is the Free ligand exponent function, $\mathbf{n}$ is the Average number of ligand attached with metal ion (Janraoet al., 2014). The results obtained were analyzed by an ORIGIN 2016 program using titration data and then the proton-ligand stability constants (pKa) and Metal-ligand stability constant (LogK) calculated (Omar and Ali, 2015).

\section{RESULTS AND DISCUSSION}

Fourier transformed infrared (FT-IR) spectra of isolated humic acid from peat soils Figure 2 had distinct clear absorption bands indicating the presence of major humic acid structural elemental groups such as $\mathrm{H}$ bonded $\mathrm{OH}$ $\left(3680 \mathrm{~cm}^{-1}\right.$ peak $), C=0$ of carbonyl $\left(1721 \mathrm{~cm}^{-1}\right.$ peak), functional groups of aliphatic components $\mathrm{CH}_{2}\left(2918 \mathrm{~cm}^{-1}\right.$ peak) and $\mathrm{C}-\mathrm{O}$ stretching of polysaccharide $\left(1168 \mathrm{~cm}^{-1}\right.$ peak). The positions of the absorption bands of the spectra fell within typical major absorption bands of humic acid which is at frequencies 3680, 2918, 1721, 1168 $\mathrm{cm}^{-1}$. The first peak centred in the vicinity of $3680 \mathrm{~cm}^{-1}$ region is attributed to phenol $\mathrm{OH}$ group bounded by intermolecular $\mathrm{H}$ bonds. The $2918 \mathrm{~cm}^{-1}$ band usually has absorption maximum at $2918 \mathrm{~cm}^{-1}$ which is due to $\mathrm{C}-\mathrm{H}$ stretching of alkane group $\left(\mathrm{CH}_{2}\right)$. The next major absorption band is $1721 \mathrm{~cm}^{-1}$. This band has been commonly ascribed to $\mathrm{C}=\mathrm{O}$ stretching of mainly carboxyl group $(\mathrm{COOH})$ with trace amount of ketones. The last peak was observed at 1168 $\mathrm{cm}^{-1}$ due to $\mathrm{C}-\mathrm{O}$ stretching of polysaccharides and this peak appeared also in the spectra of humic acid from peat soil. The FTIR spectra of the isolated humic acid contained all major characteristic absorption peaks of humic acid. These absorption peaks indicated the presence of the major structural elements of humic acid namely $\mathrm{H}$ bonded $\mathrm{OH}, \mathrm{C}=\mathrm{C}$ of aromatic ring, $\mathrm{C}=\mathrm{O}$ of carbonyl group (both carboxyl and ketonic), $\mathrm{CH}_{2}$ group. This strongly supports the presence of humic acid.

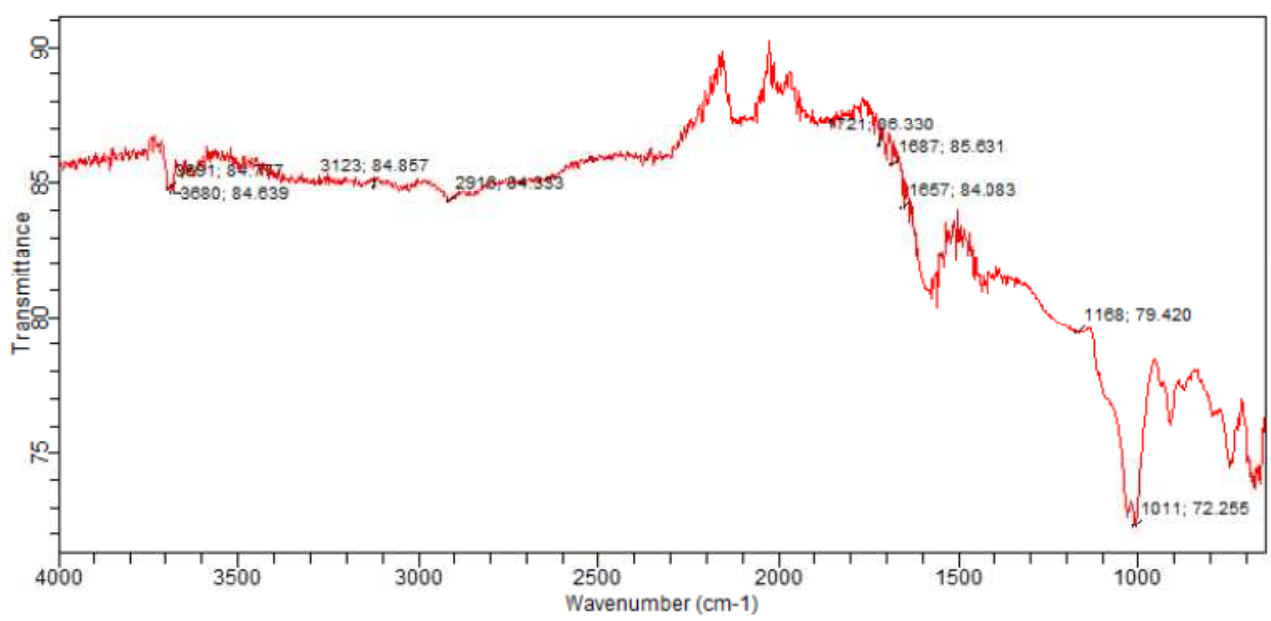

Fig. 2 : FT-IR spectraof peatsoilhumic acid (PSHA)

\section{Evaluation of acid dissociation constant (pka) of acid hydrolysed peat soil humicacid at phenolic group}

The value of the dissociation constant of the peat soil humic acid (PSHA) that underwent acidhydrolysis studied was found to be 8.9299 as shown Table 1, which is lower than the literaturevalues reported by Almeida and Szpoganics, (2015), Borges et al., (2005); Badr et al., (2012)and Fernandes et al,.(2009) of $9.73,9.47$ and 10.30. The difference between the obtained valuesand the reported values in this study might be probably as a result of acid hydrolysis of humicacid. 
BAJOPAS Volume 14 Number 1,June, 2021

Table 1: PKa of (Hydrolysed PSHA)

\begin{tabular}{|l|l|l|l|l|l|l|}
\hline $\mathrm{pH}$ & $\mathrm{BV}_{1}$ & $\mathrm{BV}_{2}$ & $\mathrm{~V}_{2}-\mathrm{V}_{1}$ & $\mathrm{nA}$ & $\log \left(\frac{n A}{1-n A}\right)$ & $\mathrm{pKa}$ \\
\hline 8.50 & 5.30 & 6.29 & 0.99 & 0.3594 & -0.2510 & 8.2490 \\
8.72 & 5.35 & 6.37 & 1.02 & 0.3400 & -0.2880 & 8.4320 \\
9.00 & 5.40 & 6.46 & 1.06 & 0.3141 & -0.3391 & 8.6609 \\
9.22 & 5.45 & 6.55 & 1.10 & 0.2882 & -0.3927 & 8.8273 \\
9.51 & 5.50 & 6.66 & 1.16 & 0.2494 & -0.4786 & 9.0314 \\
9.73 & 5.55 & 6.78 & 1.23 & 0.2041 & -0.5910 & 9.1390 \\
10.00 & 5.60 & 6.90 & 1.30 & 0.1589 & -0.7238 & 9.2762 \\
10.23 & 5.65 & 7.05 & 1.40 & 0.0941 & -0.9835 & 9.2465 \\
10.49 & 5.70 & 7.10 & 1.40 & 0.0941 & -0.9835 & 9.5065 \\
\hline
\end{tabular}

Average pKa $=8.9299 \pm 0.4186$

Table 2: PKa of (Unhydrolysed PSHA)

\begin{tabular}{|l|l|l|l|l|l|l|}
\hline $\mathrm{pH}$ & $\mathrm{BV}_{1}$ & $\mathrm{BV}_{2}$ & $\mathrm{~V}_{2}-\mathrm{V}_{1}$ & $\mathrm{nA}$ & $\log \left(\frac{\boldsymbol{n A}}{1-\boldsymbol{n}}\right)$ & $\mathrm{pKa}$ \\
\hline 8.50 & 5.30 & 5.81 & 0.51 & 0.6619 & 0.2919 & 8.7919 \\
8.72 & 5.35 & 5.90 & 0.55 & 0.6357 & 0.2418 & 8.9618 \\
9.00 & 5.40 & 6.00 & 0.60 & 0.6029 & 0.1813 & 9.1813 \\
9.22 & 5.45 & 6.10 & 0.65 & 0.5701 & 0.1226 & 9.3426 \\
9.51 & 5.50 & 6.20 & 0.70 & 0.5376 & 0.0654 & 9.5754 \\
9.73 & 5.55 & 6.33 & 0.78 & 0.4851 & -0.0259 & 9.7041 \\
10.00 & 5.60 & 6.47 & 0.87 & 0.4262 & -0.1291 & 9.8709 \\
10.23 & 5.65 & 6.62 & 0.99 & 0.3609 & -0.2481 & 9.9819 \\
10.49 & 5.70 & 6.80 & 1.10 & 0.2759 & -0.4690 & 10.0210 \\
\hline
\end{tabular}

Average pKa $=9.4923 \pm 0.4410$

Metal-ligand stability constant ( $\log \mathrm{K}$ )

The stabilityconstants require the accurate values of proton-ligand stability constants (Anil and Maroti, 2008). Metal titration curves crossed over ligand titration curve indicated the formation of complex upon proton release (Santosh, et al., 2011). If the values of n- are within range $0.2-0.8$ and $1.2-18$ this indicates the formation of $1: 1$ and 1:2 complexes (Sayyed and Mazahar, 2012).

The metal (II)-humate stepwise stability constants (log k) at phenolic group (Tables 318)

Table 3: Point-wise method, $\mathrm{Cu}$-(Hydrolysed PSHA)

\begin{tabular}{|l|l|l|l|l|l|l|l|l|}
\hline $\mathrm{pH}$ & $\mathrm{BV}_{1}$ & $\mathrm{BV}_{2}$ & $\mathrm{BV}_{3}$ & $\left(\mathrm{~V}_{3}-\mathrm{V}_{2}\right)$ & $\mathrm{n}$ & $\mathrm{pL}$ & $\log \left(\frac{n}{1-n}\right)$ & LogK $_{1}$ \\
\hline 8.50 & 5.30 & 6.29 & 6.33 & 0.04 & 0.5500 & 2.66 & 0.0871 & 2.7471 \\
8.72 & 5.35 & 6.37 & 6.41 & 0.04 & 0.5714 & 2.43 & 0.1249 & 2.5549 \\
9.00 & 5.40 & 6.46 & 6.50 & 0.04 & 0.6198 & 2.16 & 0.2122 & 2.3722 \\
9.22 & 5.45 & 6.55 & 6.59 & 0.04 & 0.6667 & 1.94 & 0.3010 & 2.2410 \\
\hline
\end{tabular}

LogK $_{1}$ (Average value) $=2.4788 \pm 0.2203$

Table 4: Point-wise method, $\mathrm{Cu}$-(Hydrolysed PSHA)

\begin{tabular}{|l|l|l|l|l|l|l|l|l|}
\hline $\mathrm{pH}$ & $\mathrm{BV}_{1}$ & $\mathrm{BV}_{2}$ & $\mathrm{BV}_{3}$ & $\left(\mathrm{~V}_{3}-\mathrm{V}_{2}\right)$ & $\mathrm{n}$ & $\mathrm{pL}$ & $\log \left(\frac{n-1}{2-n}\right)$ & LogK $_{2}$ \\
\hline 9.51 & 5.50 & 6.66 & 6.73 & 0.07 & 1.3509 & 1.70 & -0.2671 & 1.4329 \\
9.73 & 5.55 & 6.78 & 6.85 & 0.07 & 1.6383 & 1.51 & 0.2467 & 1.7567 \\
10.00 & 5.60 & 6.90 & 6.98 & 0.08 & 2.1783 & 1.31 & -0.2158 & 1.0942 \\
10.23 & 5.65 & 7.05 & 7.13 & 0.08 & 4.1904 & 1.27 & & \\
10.49 & 5.70 & 7.10 & 7.19 & 0.09 & 4.6920 & & & \\
\hline
\end{tabular}

Log $K_{2}($ Average value $)=1.4280 \pm 0.3312$ 
BAJOPAS Volume 14 Number 1,June, 2021

Table 5: Point-wise method, $\mathrm{Cu}$ (Unhydrolysed PSHA)

\begin{tabular}{|l|l|l|l|l|l|l|l|l|}
\hline $\mathrm{pH}$ & $\mathrm{BV}_{1}$ & $\mathrm{BV}_{2}$ & $\mathrm{BV}_{3}$ & $\left(\mathrm{~V}_{3}-\mathrm{V}_{2}\right)$ & $\mathrm{n}$ & $\mathrm{pL}$ & $\log \left(\frac{n}{n-1}\right)$ & Log $_{1}$ \\
\hline 8.50 & 5.30 & 5.81 & 5.85 & 0.04 & 0.2973 & 2.88 & -0.3736 & 2.5064 \\
8.72 & 5.35 & 5.90 & 5.95 & 0.05 & 0.3873 & 2.66 & -0.1992 & 2.4608 \\
9.00 & 5.40 & 6.00 & 6.05 & 0.05 & 0.4044 & 2.38 & -0.1681 & 2.2119 \\
9.22 & 5.45 & 6.10 & 6.15 & 0.06 & 0.5157 & 2.18 & -0.0272 & 2.2072 \\
9.51 & 5.50 & 6.20 & 6.27 & 0.07 & 0.6417 & 1.89 & 0.2530 & 1.1430 \\
\hline
\end{tabular}

$\operatorname{LogK}_{1}($ Average value $)=2.3059 \pm 0.6153$

Table 6:Point-wise method, $\mathrm{Cu}$ (Unhydrolysed PSHA)

\begin{tabular}{|l|l|l|l|l|l|l|l|l|}
\hline $\mathrm{pH}$ & $\mathrm{BV}_{1}$ & $\mathrm{BV}_{2}$ & $\mathrm{BV}_{3}$ & $\mathrm{~V}_{3}-\mathrm{V}_{2}$ & $\mathrm{n}$ & $\mathrm{pL}$ & $\log \left(\frac{n-1}{2-n}\right)$ & $\log \mathrm{K}_{2}$ \\
\hline 9.73 & 5.55 & 6.33 & 6.42 & 0.09 & 0.9000 & 1.69 & & \\
10.00 & 5.60 & 6.47 & 6.58 & 0.11 & 1.2578 & 1.44 & -0.4592 & 0.9808 \\
10.23 & 5.65 & 6.62 & 6.84 & 0.12 & 1.6137 & 1.26 & -0.2010 & 1.4610 \\
10.49 & 5.70 & 6.80 & 6.92 & 0.12 & 2.1052 & 1.03 & & \\
\hline
\end{tabular}

$\operatorname{LogK}_{2}$ (Average value) $=1.2209 \pm 0.3398$

Table 7:Point-wise method, Pb (Hydrolysed PSHA)

\begin{tabular}{|l|l|l|l|l|l|l|l|l|}
\hline $\mathrm{pH}$ & $\mathrm{BV}_{1}$ & $\mathrm{BV}_{2}$ & $\mathrm{BV}_{3}$ & $\left(\mathrm{~V}_{3}-\mathrm{V}_{2}\right)$ & $\mathrm{n}$ & $\mathrm{pL}$ & $\log \left(\frac{n}{1-n}\right)$ & LogK $_{1}$ \\
\hline 8.50 & 5.30 & 6.29 & 6.33 & 0.04 & 0.5500 & 2.66 & 0.0871 & 2.7471 \\
8.72 & 5.35 & 6.37 & 6.41 & 0.04 & 0.5714 & 2.43 & 0.1249 & 2.5549 \\
9.00 & 5.40 & 6.46 & 6.50 & 0.04 & 0.6198 & 2.16 & 0.2122 & 2.3722 \\
9.22 & 5.45 & 6.55 & 6.60 & 0.05 & 0.8333 & 1.96 & 0.6989 & 2.6589 \\
\hline
\end{tabular}

Log $_{\mathbf{1}}($ Average value $)=2.5832 \pm 0.1614$

Table 8:Point-wise method, Pb-(Hydrolysed PSHA)

\begin{tabular}{|l|l|l|l|l|l|l|l|l|}
\hline $\mathrm{pH}$ & $\mathrm{BV}_{1}$ & $\mathrm{BV}_{2}$ & $\mathrm{BV}_{3}$ & $\left(\mathrm{~V}_{3}-\mathrm{V}_{2}\right)$ & $\mathrm{n}$ & $\mathrm{pL}$ & $\log \left(\frac{n-1}{2-n}\right)$ & $\log \mathrm{K}_{2}$ \\
\hline 9.51 & 5.50 & 6.66 & 6.71 & 0.05 & 0.9650 & 1.67 & & \\
9.73 & 5.55 & 6.78 & 6.83 & 0.05 & 1.1702 & 1.44 & & \\
10.00 & 5.60 & 6.90 & 6.90 & 0.05 & 1.4864 & 1.22 & -0.0237 & 1.1963 \\
10.23 & 5.65 & 7.05 & 7.10 & 0.05 & 2.0190 & 1.09 & & \\
10.49 & 5.70 & 7.10 & 7.17 & 0.07 & 3.6492 & 1.00 & & \\
\hline
\end{tabular}

Log $K_{2}$ (Average value) $=1.1963$

Table 9: Point-wise method, Pb (Unhydrolysed PSHA)

\begin{tabular}{|l|l|l|l|l|l|l|l|l|}
\hline $\mathrm{pH}$ & $\mathrm{BV}_{1}$ & $\mathrm{BV}_{2}$ & $\mathrm{BV}_{3}$ & $\mathrm{~V}_{3}-\mathrm{V}_{2}$ & $\mathrm{n}$ & $\mathrm{pL}$ & $\begin{array}{l}\text { Log } \\
\left(\frac{n}{n-1}\right)\end{array}$ & Log $\mathrm{K}_{1}$ \\
\hline 8.50 & 5.30 & 5.81 & 5.85 & 0.04 & 0.2973 & 2.88 & -0.3736 & 2.5064 \\
8.72 & 5.35 & 5.90 & 5.94 & 0.04 & 0.3099 & 2.66 & -0.5477 & 2.3123 \\
9.00 & 5.40 & 6.00 & 6.05 & 0.05 & 0.4044 & 2.38 & -0.1681 & 2.2119 \\
9.22 & 5.45 & 6.10 & 6.15 & 0.06 & 0.5157 & 2.18 & 0.0272 & 2.2072 \\
9.51 & 5.50 & 6.20 & 6.26 & 0.07 & 0.6417 & 1.89 & 0.2530 & 2.1430 \\
9.73 & 5.55 & 6.40 & 6.40 & 0.07 & 0.7000 & 1.67 & 0.3680 & 2.0380 \\
\hline
\end{tabular}

LogK $_{1}$ (Average value) $=2.2364 \pm 0.1602$

Table 10: Point-wise method, Pb (Unhydrolysed PSHA)

\begin{tabular}{|l|l|l|l|l|l|l|l|l|}
\hline $\mathrm{pH}$ & $\mathrm{BV}_{1}$ & $\mathrm{BV}_{2}$ & $\mathrm{BV}_{3}$ & $\mathrm{~V}_{3}-\mathrm{V}_{2}$ & $\mathrm{n}$ & $\mathrm{pL}$ & $\log \left(\frac{n-1}{2-n}\right)$ & $\log \mathrm{K}_{2}$ \\
\hline 10.00 & 5.60 & 6.47 & 6.55 & 0.08 & 1.9503 & 1.41 & & \\
10.23 & 5.65 & 6.62 & 6.72 & 0.11 & 1.4792 & 1.26 & -0.0361 & 1.2239 \\
\hline
\end{tabular}

$\operatorname{LogK}_{2}$ (Average value) $=1.2239$

Table 11: Point-wise method, Mg (Hydrolysed PSHA)

\begin{tabular}{|l|l|l|l|l|l|l|l|l|}
\hline $\mathrm{pH}$ & $\mathrm{BV}_{1}$ & $\mathrm{BV}_{2}$ & $\mathrm{BV}_{3}$ & $\left(\mathrm{~V}_{3}-\mathrm{V}_{2}\right)$ & $\mathrm{n}$ & $\mathrm{pL}$ & $\log \left(\frac{n}{n-1}\right)$ & LogK $_{1}$ \\
\hline 8.50 & 5.30 & 6.29 & 6.31 & 0.02 & 0.2750 & 2.64 & -0.4290 & 2.2110 \\
8.72 & 5.35 & 6.37 & 6.39 & 0.02 & 0.2858 & 2.42 & -0.3978 & 2.0222 \\
9.00 & 5.40 & 6.46 & 6.49 & 0.03 & 0.4648 & 2.14 & -0.0612 & 2.0788 \\
9.22 & 5.45 & 6.55 & 6.59 & 0.04 & 0.6667 & 1.94 & 0.3010 & 2.2410 \\
\hline
\end{tabular}

$\log _{\mathbf{1}}($ Average value) $=2.1382 \pm 0.1046$ 
BAJOPAS Volume 14 Number 1,June, 2021

Table 12: Point-wise method, Mg (Hydrolysed PSHA)

\begin{tabular}{|l|l|l|l|l|l|l|l|l|}
\hline $\mathrm{pH}$ & $\mathrm{BV}_{1}$ & $\mathrm{BV}_{2}$ & $\mathrm{BV}_{3}$ & $\left(\mathrm{~V}_{3}-\mathrm{V}_{2}\right)$ & $\mathrm{n}$ & $\mathrm{pL}$ & $\log \left(\frac{n-1}{2-n}\right)$ & LogK $_{2}$ \\
\hline 9.51 & 5.55 & 6.66 & 6.71 & 0.05 & 0.9650 & 1.67 & & \\
9.73 & 5.55 & 6.78 & 6.84 & 0.06 & 1.4042 & 1.47 & -0.1686 & 1.3014 \\
10.00 & 5.60 & 6.90 & 6.93 & 0.06 & 1.7838 & 1.23 & 0.5593 & 1.7893 \\
10.23 & 5.65 & 7.05 & 7.10 & 0.06 & 3.1429 & 1.10 & & \\
10.49 & 5.70 & 7.10 & 7.18 & 0.07 & 3.6492 & 0.83 & & \\
\hline
\end{tabular}

LogK $_{2}($ Average value $)=1.5453 \pm 0.3450$

Table 13: Point-wise method, Mg (Unhydrolysed PSHA)

\begin{tabular}{|l|l|l|l|l|l|l|l|l|}
\hline $\mathrm{pH}$ & $\mathrm{BV}_{1}$ & $\mathrm{BV}_{2}$ & $\mathrm{BV}_{3}$ & $\mathrm{~V}_{3}-\mathrm{V}_{2}$ & $\mathrm{n}$ & $\mathrm{pL}$ & $\log \left(\frac{n}{n-1}\right)$ & $\operatorname{Log~}_{1}$ \\
\hline 8.50 & 5.30 & 5.81 & 5.85 & 0.04 & 0.2973 & 2.88 & -0.3736 & 2.5064 \\
8.72 & 5.35 & 5.90 & 5.94 & 0.04 & 0.3099 & 2.66 & -0.3477 & 2.3123 \\
9.00 & 5.40 & 6.00 & 6.04 & 0.04 & 0.3236 & 2.38 & -0.3202 & 2.0598 \\
9.22 & 5.45 & 6.10 & 6.15 & 0.05 & 0.4297 & 2.17 & -0.1230 & 2.0470 \\
9.51 & 5.50 & 6.20 & 6.26 & 0.06 & 0.5500 & 1.89 & 0.0871 & 1.9771 \\
9.73 & 5.55 & 6.33 & 6.40 & 0.07 & 0.7000 & 1.67 & 0.3680 & 2.0380 \\
\hline
\end{tabular}

LogK $_{1}$ (Average value) $=2.1568 \pm 0.2069$

Table 14: Point-wise method, Mg (Unhydrolysed PSHA)

\begin{tabular}{|l|l|l|l|l|l|l|l|l|}
\hline $\mathrm{pH}$ & $\mathrm{BV}_{1}$ & $\mathrm{BV}_{2}$ & $\mathrm{BV}_{3}$ & $\mathrm{~V}_{3}-\mathrm{V}_{2}$ & $\mathrm{n}$ & $\mathrm{pL}$ & $\log \left(\frac{n-1}{2-n}\right)$ & $\log \mathrm{K}_{2}$ \\
\hline 10.00 & 5.60 & 6.47 & 6.55 & 0.08 & 0.9148 & 1.41 & & \\
10.23 & 5.65 & 6.62 & 6.71 & 0.09 & 1.2102 & 1.20 & -0.5749 & 0.6251 \\
10.49 & 5.70 & 6.80 & 6.92 & 0.09 & 1.5968 & 1.03 & 0.1703 & 1.2003 \\
\hline
\end{tabular}

LogK $_{2}$ (Average value) $=0.9127 \pm 0.4070$

Table15:Point-wise method, Cd (Hydrolysed PSHA)

\begin{tabular}{|l|l|l|l|l|l|l|l|l|}
\hline $\mathrm{pH}$ & $\mathrm{BV}_{1}$ & $\mathrm{BV}_{2}$ & $\mathrm{BV}_{3}$ & $\left(\mathrm{~V}_{3}-\mathrm{V}_{2}\right)$ & $\mathrm{n}$ & $\mathrm{pL}$ & $\log \left(\frac{n}{1-n}\right)$ & LogK $_{1}$ \\
\hline 8.50 & 5.30 & 6.29 & 6.31 & 0.02 & 0.2750 & 2.64 & -0.4210 & 2.2190 \\
8.72 & 5.35 & 6.37 & 6.40 & 0.03 & 0.4286 & 2.42 & -0.1249 & 2.2951 \\
9.00 & 5.40 & 6.46 & 6.49 & 0.03 & 0.4648 & 2.14 & -0.0612 & 2.0788 \\
9.22 & 5.45 & 6.55 & 6.59 & 0.04 & 0.6667 & 1.96 & 0.3010 & 2.2610 \\
9.51 & 5.55 & 6.66 & 6.70 & 0.04 & 0.7720 & 1.67 & 0.5297 & 2.1997 \\
\hline
\end{tabular}

LogK $_{\mathbf{1}}$ (Average value) $=2.2108 \pm 0.0825$

Table 16: Point-wise method, Cd (Hydrolysed PSHA)

\begin{tabular}{|l|l|l|l|l|l|l|l|l|}
\hline $\mathrm{pH}$ & $\mathrm{BV}_{1}$ & $\mathrm{BV}_{2}$ & $\mathrm{BV}_{3}$ & $\left(\mathrm{~V}_{3}-\mathrm{V}_{2}\right)$ & $\mathrm{n}$ & $\mathrm{pL}$ & $\log \left(\frac{n-1}{2-n}\right)$ & Log $_{2}$ \\
\hline 9.73 & 5.55 & 6.78 & 6.83 & 0.06 & 1.4042 & 1.47 & -0.1686 & 1.3014 \\
10.00 & 5.60 & 6.90 & 6.95 & 0.06 & 1.7838 & 1.23 & 0.5593 & 1.7893 \\
10.23 & 5.65 & 7.05 & 7.10 & 0.06 & 3.1429 & 1.09 & & \\
10.49 & 5.70 & 7.10 & 7.16 & 0.06 & 3.1429 & 0.89 & & \\
& & & & & & & & \\
\hline
\end{tabular}

$\operatorname{LogK}_{2}$ (Average value) $=1.5453 \pm 0.3450$

Table 17: Point-wise method, Cd (Unhydrolysed PSHA)

\begin{tabular}{|l|l|l|l|l|l|l|l|l|}
\hline $\mathrm{pH}$ & $\mathrm{BV}_{1}$ & $\mathrm{BV}_{2}$ & $\mathrm{BV}_{3}$ & $\mathrm{~V}_{3}-\mathrm{V}_{2}$ & $\mathrm{n}$ & $\mathrm{pL}$ & $\log \left(\frac{n}{n-1}\right)$ & $\operatorname{Log~}_{1}$ \\
\hline 8.50 & 5.30 & 5.81 & 5.86 & 0.05 & 0.3717 & 2.88 & -0.2280 & 2.6520 \\
8.72 & 5.35 & 5.90 & 5.95 & 0.05 & 0.3873 & 2.66 & -0.1992 & 2.4608 \\
9.00 & 5.40 & 6.00 & 6.06 & 0.06 & 0.4853 & 2.38 & -0.0255 & 2.3545 \\
9.22 & 5.45 & 6.10 & 6.16 & 0.06 & 0.5157 & 2.18 & -0.0272 & 2.2072 \\
9.51 & 5.50 & 6.20 & 6.27 & 0.07 & 0.6417 & 1.89 & 0.2530 & 1.1430 \\
9.73 & 5.55 & 6.33 & 6.41 & 0.08 & 0.8000 & 1.69 & 0.6020 & 2.2920 \\
& & & & & & & & \\
\hline
\end{tabular}

$\operatorname{LogK}_{1}($ Average value $)=2.2516 \pm 0.5380$ 
BAJOPAS Volume 14 Number 1,June, 2021

Table 18: Point-wise method, Cd (Unhydrolysed PSHA)

\begin{tabular}{|l|l|l|l|l|l|l|l|l|}
\hline $\mathrm{pH}$ & $\mathrm{BV}_{1}$ & $\mathrm{BV}_{2}$ & $\mathrm{BV}_{3}$ & $\mathrm{~V}_{3}-\mathrm{V}_{2}$ & $\mathrm{n}$ & $\mathrm{pL}$ & $\log \left(\frac{n-1}{2-n}\right)$ & $\log \mathrm{K}_{2}$ \\
\hline 10.00 & 5.60 & 6.47 & 6.57 & 0.10 & 1.1434 & 1.43 & & \\
10.23 & 5.65 & 6.62 & 6.72 & 0.10 & 1.3448 & 1.23 & -0.2788 & 0.9512 \\
10.49 & 5.70 & 6.80 & 6.90 & 0.10 & 1.7742 & 1.03 & 0.5351 & 1.5651 \\
\hline
\end{tabular}

$\operatorname{LogK}_{2}($ Average value $)=1.2581 \pm 0.4340$

Table 19: Stepwise and overall Stability constants of thehydrolysed and unhydrolysed divalent metal (II) complexes

\begin{tabular}{|c|c|c|c|}
\hline Chelates & LogK $_{1}$ & $\log _{2}$ & Log $\beta$ \\
\hline [Cu (Hydrolysed PSHA-1) $\left.{ }_{2}\right]$ & 2.4788 & 1.4280 & 3.9068 \\
\hline$\left[\mathrm{Pb}(\text { Hydrolysed PSHA-1) })_{2}\right]$ & 2.5832 & 1.1963 & 3.7795 \\
\hline$\left[\mathrm{Cd}(\text { Hydrolysed PSHA-1 })_{2}\right]$ & 2.2108 & 1.5453 & 3.7561 \\
\hline$\left[\mathrm{Mg}(\text { Hydrolysed PSHA-1 })_{2}\right]$ & 2.1382 & 1.5453 & 3.6835 \\
\hline [Cu (Unhydrolysed PSHA-1) & 2.3059 & 1.2209 & 3.5268 \\
\hline$[\mathrm{Pb}$ (Unhydrolysed PSHA-1) 2$]$ & 2.2364 & 1.2239 & 3.4603 \\
\hline [Cd (Unhydrolysed PSHA-1) 2 ] & 2.2516 & 1.2581 & 3.5097 \\
\hline$[\mathrm{Mg}$ (Unydrolysed PSHA-1) & 2.1568 & 0.9127 & 3.0695 \\
\hline
\end{tabular}

The results obtained (Table19) shows the stepwise and overall stability constants to be not high indicating low stability of the complexes, because the solubility of most metal ions in the basic $\mathrm{pH}$ range is minimal due to metal hydroxide precipitation (Karimi, 2017). In general, the stepwise stability constants $\left(K_{1}\right.$ and $K_{2}$ ) follow the order $K_{1}>K_{2}$ for the copper, lead, magnesium and cadmium complexes respectively. The steady decrease of the values with increasing number of ligands is in agreement with the prediction made by researchers (Na'aliya, 2013). The decrease could be attributed to the fact that as the number of the ligands (Humate ions) that enters the coordination zone increases the aqua molecules available for replacement by the ligands become less. Thus, the metal ions become less electron loving with progressive intake of the ligand and this results in the decrease in the values of the constants (Na'aliya, 2013). Also the stability of the complexes is influenced by the size and number of the chelate rings(Mackay and Mackay,2002).All the complexes form rings in their structure as humate, a bidentate ligand, bond the metal ions in the ratio 1:2 (Boguta and Sokolowska, 2016) forming chelate rings. The values of the overall stability constants $(\log \beta)$ obtained for humate complexes are not high indicating low stability as the values are not high. LogK values for copper-humates (Table 3 to 6) obtained in this study are lower than those reported for the complexes of humic acids (Pandey et al., 2015; Dinu, 2013; Kaschl et al., 2010 and Gilbeto and Jorg, 2001). The values of LogK(Table 7 to 10 ) forlead-humates are lower than those reported for the lead in the literature (Dinu, 2013; Gilbeto and Jorg 2001). Log K values(Table 11 to 14 ) for magnesium-humates obtained in this study are close to those reported by (Pandey et al., 2015). Log K values of cadmium-humates (Table 15 to 18 ) obtained in this work near to the one reported by (Dinu, 2013 and Pandey et al., 2015).The difference between the reported values and the values obtained in this study might be probably as a result of acid hydrolysis of humic acid. The values of the overall stability constants $(\log \beta)$ of the copper humates complexes presented in Table 19 is high than that of other metal humate complexes, show relatively high stability of CuHA complexes, show the following order of stability: $\mathrm{Cu}>\mathrm{Pb}>\mathrm{Cd}>\mathrm{Mg}$; which are in close agreement to the findings of (Dinu, 2013 and Pandey et al., 2015).The high stability of Cuhumate chelate could be attributed to the existence of coordinate covalent bond between the complexing agents and the $\mathrm{Cu}^{2+}$ ions. Since, $\mathrm{Cu}^{2+}$ being a metal of the transitional series with $3 d^{9}$ electronic configurations can accept the electrons from the complexing agents. Similarly, the low stabilities of $\mathrm{Pb}, \mathrm{Cd}$ and $\mathrm{Mg}$ complexes could be explained by that $\mathrm{Pb}^{2+}$ with $6 s^{2}, \mathrm{Cd}^{2+}$ with $4 \mathrm{~d}^{10}$ and $\mathrm{Mg}^{2+}$ with $2 \mathrm{p}^{6}$ their electronic configuration has a completely filled $\mathrm{d}, \mathrm{p}$ and $\mathrm{s}$ orbitals. Moreover, the stabilities of metal ions with hydrolysed humic acid from peat soil were higher than those with unhydrolysed humic acid from peat soil; which is ascribed to the high content of acidity in hydrolysed humic acid than unhydrolysed humic acid. 
BAJOPAS Volume 14 Number 1,June, 2021 CONCLUSION

The values of logk for $\mathrm{Cu}(\mathrm{II})$ hydrolysed humic acid complex was higher followed by $\mathrm{Pb}$ (II), $\mathrm{Cd}(\mathrm{II})$ and $\mathrm{Mg}$ (II) hydrolysed humic acid complexes as compared with metal(II) unhydrolysed humic acid complexes. This indicates acid hydrolysis of humic acid can

\section{REFERENCES}

Almeida, V.R. and Szpoganicz, B. (2015). Humic Acid Potentiometric Response Patterns:Out- of Equilibrium Properties and Species Distribution Modelling. Chemical. Biol. Technol. Agric. 2: 17.

Anđelković, T., Nikolić, R., Bojić, A.,Anđelković, D., and Nikolic G.,(2010). Binding of Cadmium to Soil Humic Acid as A Function of Carboxyl Group Content. Macedonian Journal of Chemistry and Chemical Engineering.29(2): 215-224.

Anil, B. N. and Maroti, N. (2008). Studies on Influence of Die-Lectric Constants on Complex Equilibria between Substituted Py-Razalines and Lanthanide Metal Ions pH-Metrically. Amer.-Euras. scient. Res. 3(2): 212-216.

Ashok, K., Pandey, S. P. and Misra, V (2000). Stability Constants of Metal-Humic Acid Complexes and its Role in Environmental Detoxification. Journal of Ecotoxicology and Environmental Safety. 47(2):157-200.

Badr, M. H., El-Halafawi, M. H. and Abd El-al Zeid, E. R. (2012). Comparison Between the Effect of Ionic Strength on Acidity and Dissociation Constants of Humic Acids Extracted from Sewage Sludge and Nile Water Hyacinth Composts.Global Journal of Environmental Research 6 (1): 36-43.

Baruah, M.K., Borah, D., Saikia, P.P., Paul, S., Sharma, T. (2015). Evaluation of pKa Values of Soil Humic Acids and their Complexation Properties. International Journal of Plant \& Soil Science 6(4) : 218-228.

Boguta, P. Sokolowska, Z. (2016). Interactions of $\mathrm{Zn}$ (II) Ions with Humic Acids Isolated from Various Types of Soils. Effect of $\mathrm{pH}, \mathrm{Zn}$ Concentrations and Humic Acids Chemical Properties. Journal of Geochemical Explaration 168. 119-126.

Borges, F., Guimaraes, C., Lima, L.F.C., Pinto, I. and Reis, S.(2005). Potentiometric Studies on the Complexation of Copper(II) by Phenolic Acids as Discrete Ligand Models of enhance the complexation behavior of humic acid with metal (II) ions. However, the higher values of $\log \beta$ for $\mathrm{Cu}(\mathrm{II}), \mathrm{Pb}(\mathrm{II}), \mathrm{Cd}(\mathrm{II})$ and $\mathrm{Mg}(\mathrm{II})$ hydrolysed humic acid complexes indicates more stable stepwise complexes formed as compared with $\mathrm{Cu}(\mathrm{II}), \mathrm{Pb}$ (II), $\mathrm{Cd}$ (II) and $\mathrm{Mg}(\mathrm{II})$ unhydrolysed humic acid complexes.

Humic Substances Talanta 66 (2005) 670-673.

Chefetz, B., Salloum, M. J., Deshmulkin, A. P. and Hatcher, P. (2002). Structural Components of Humic Acids as Determined by Chemical Modifications and Carbon-13 NMR, Pyrolysis, and Thermochemolysis- Gas Chromatography/Mass Spectrometry. Soil Science Society of American Journal Abstract Division S-2- Soil Chemistry66. 1159-1171.

Dinu, M. I. (2013). Metals Complexation with Humic Acids in Surface Water of Different Environ. Sci. Technol. 31(1): 1-17.

Fernandes, A.N., Giacomelli, C., Giovanela, M. Vaz, D.V. Szpoganicz, B. and Maria M. D. (2009). Potentiometric Acidity Determination in Humic Substances Influenced by Different Analytical Procedures.J. Braz. Chem. Soc. 20 (9):14.

Gamal, A. H. (2015). Stability Constants of Rhenium (V) Metal Complexes with Selected Drugs. Pyrex Journal of Research in Environmental Studies. 2(2): 006-014.

Janrao, D. M., Pathan, J., Kayande, D.D., and Mulla, J.J. (2014). An Over View of Potentiometric Determination of Stability Constants of Metal Complexes. Sci. Revs. Chem. Commun.: 4(1), 2014, 11-24.

Karimi, H. (2017). Effect of pH and Initial Pb(II) Concentration on the Lead Removal Efficiency from Waste Water Using $\mathrm{Ca}(\mathrm{OH})_{2}$. International Journal of Water and Waste Water Treatment 3.2

Kaschl, A. Romheld, V. and Chen, Y. (2010). Binding of Cadmium, Copper and Zinc to Humic Substances Originating from Municipal Solid Waste Compost. Israel Journal of Chemistry Vol. 42(1): 89-98.

Kostic, I. S., Tatjana, P, A., Nikolic, R. S., Cvetkovic, T. P., Pavlovic, D. D., Aleksandar, L.J. and Bojic, A. (2012). Comparative Study of Binding Strengths of Heavy Metals with Humic Acid. J.serb. Chem. Soc. 76(9) pp 1-20. 
BAJOPAS Volume 14 Number 1,June, 2021

Na'aliya, J. (2013). Determination of Stepwise Stability Constants and Gibbs free Energy Change of Trisprolina to Complexes of some Divalent Transition Metal ions. Bayero Journal of Pure and Applied Sciences 6(2): 112-114.

Omar, A. A. and Ali, E. A. (2015). Potentiometric Studies on Complexes of $\mathrm{Cr}$ (III) and $\mathrm{Zr}$ (IV) with some Carboxylic Acids. International Journal of Advanced Chemistry, 3(1) 25-

37.

Pandey, A. K. Pandey, S. D. and Misr, V. (2015).Stability Constants of Metal- Humic Acid Complexes and Its Role in Environmental Detoxification. J. Ecotoxicology and Environmental Safety. 47(1):195-200.

Ram, N. and Raman, K.V. (1984). Stability Constants of Complexes of Metals with
Humicand Fuvic Acids under Non- acidConditions. Journal of Plant Nutrition and Soil Sciences.

147:171-176.

Santosh, D. D., Ashok, B. K., Vijay, J. T., Shivraj, G. W. and Vinay, V. W. (2011). Potentiometric Studies of Elec-Trolyte Effects on Complex Equilibria of Some Substituted 5-(2-hydroxy Phenyl) Pyrazoles. Der pharm. 3 (6): 75-83.

Sayyed, H. and Abdul Rahim, M. F. (2012). Studies of Binary Complexes of Metal Ions with Mandelic Acid by Potentiometry. Chem. J. 02 (6): 206209.

Shirvani, M. Moradian, E. Khalili, B. Bakhtiary, S. (2015). Interaction of $\mathrm{Cd}$ and $\mathrm{Pb}$ with Humate-Palygorskite and HumateSepiolite Complexes. Journal of water, air and pollution 3: 220-228. 


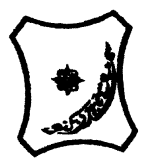

Bayero Journal of Pure and Applied Sciences, 14(1): 54 - 63

Received: November, 2020

Accepted: April, 2021

ISSN $2006-6996$

\title{
STABILITY CONSTANTS OF COMPLEXES OF METAL IONS WITH PEATSOIL HUMIC ACIDS UNDER NON-ACID-CONDITIONS
}

\author{
${ }^{* 1}$ Sabo, Yusuf ${ }^{2}$ Jimoh, W.L.O., ${ }^{3}$ Isa Baba Koki and ${ }^{4}$ Sholadoye, Q. 0. \\ ${ }^{1}$ Department of Pure and Industrial Chemistry, Bayero University, Kano \\ ${ }^{3}$ Department of Chemistry, Yusuf Maitama Sule University Kano. P.M.B. 3220 Kano, Nigeria. \\ ${ }^{4}$ Department of Chemistry, Nigerian Police Academy, Wudil, Kano-Nigeria
}

*Correspondence E-mail; saboyusuf18@yahoo.com

ABSTRACT

Stability constants of complexes of four divalent metal ions viz. $\mathrm{Cu}^{2+}, \mathrm{Pb}^{2+}, \mathrm{Mg}^{2+}$ and $\mathrm{Cd}^{2+}$ with humic acids (HA) were determined by potentiometric titration of humic acids with the corresponding salt of the divalent metals in aqueous media under non-acid-condition. The log $K$ (logarithm of the stability constant) ranged from 1.0942 to 2.7471 for metalhumic acid complexes were determined using point-wise computational method. The order of stability constants were obtained as follows: $\mathrm{Cu}>\mathrm{Pb}>\mathrm{Cd}>\mathrm{Mg}$ for metal $-\mathrm{HA}$ complexes respectively, indicating a higher degree of complexation with Cu metal ion.

Keywords: stability constant, humic acid, potentiometric titration, divalent metals, acid hydrolysis.

\section{NTRODUCTION}

The stability constant of a complex is the numerical expression of its stability and provides a quantitative measure of affinity of the metal ion to the complexing agent. An understanding of the relative stability of metal-complexes helps in predicting the behavior of metal ions in the soil (Ram and Raman, 1982). Extensive researches has been done to determine the stability constants of the complexes formed between humic acid (HA) with a number of metal ions. Ashok et al., (2000) reported that humic acid with hydroxyl, phenoxyl and carboxyl reactive groups can form coordination compound with metal ions at $\mathrm{pH}$ 3.5. The stability constants(Log K) for different metalhumic acid complexes indicated the following order of the stabilities of complexes formed between humic acid and metal ion, $\mathrm{Cu}>\mathrm{Fe}$ $>\mathrm{Pb}>\mathrm{Ni}>\mathrm{Co}>\mathrm{Ca}>\mathrm{Cd}>\mathrm{Zn}>\mathrm{Mn}>\mathrm{Mg}$. Andelkovic et al., (2010) investigated the binding of $\mathrm{Cd}$ (II) to soil humic acid at pH 6.5 and in $0.1 \mathrm{M} \mathrm{KNO}_{3}$ ionic medium. The stability constant for binding indicating greater stability in the case when carboxyl groups are involved in complexation reaction. Kostic et al.,(2012) investigated the complexation of humic acid with certain heavy metal ions (Co(II), $\mathrm{Ni}(\mathrm{II}), \mathrm{Cu}(\mathrm{II})$,
$\mathrm{Zn}(\mathrm{II})$, and $\mathrm{Pb}(\mathrm{II})$. The experiment was performed at $25^{\circ} \mathrm{C}$, at pH 4.0 and ionic strength of $0.01 \mathrm{M}$. Stability constant of complex between $\mathrm{Pb}$ (II) ions and humic acid is greater than stability constants of other investigated metalhumate complexes. Bogata and Sokolowska (2016) analyses the interaction between humic acids from different soils and $\mathrm{Zn}$ (II) ions at wide concentration ranges and at $\mathrm{pH} 5$. Studies have showed significant impact of $\mathrm{Zn}$ concentration, $\mathrm{pH}$ and some properties of humic acids with zinc.But all of these studies were limited to acidic $\mathrm{pH}$ range. Therefore, the present study was carried out to determine and compare the stability constants of complexes of metal ions with hydrolysed peat soil humic acid and unhydrolysed peat soil humic under non-acid conditions.

\section{MATERIALS AND METHODS}

Analytical grade chemicals used includes hydrochloric acid $(\mathrm{HCl})$, nitric acid $\left(\mathrm{HNO}_{3}\right)$, sodium hydroxide $(\mathrm{NaOH})$, lead nitrate $\mathrm{Pb}\left(\mathrm{NO}_{3}\right)_{2}$, copper nitrate $\mathrm{Cu}\left(\mathrm{NO}_{3}\right)_{2} \cdot 3 \mathrm{H}_{2} \mathrm{O}$, cadmium nitrate $\mathrm{Cd}\left(\mathrm{NO}_{3}\right)_{2} \cdot 4 \mathrm{H}_{2} \mathrm{O}$, magnesium nitrate $\mathrm{Mg}\left(\mathrm{NO}_{3}\right)_{2} \cdot 6 \mathrm{H}_{2} \mathrm{O}$, potassium nitrate $\left(\mathrm{KNO}_{3}\right)$, calcium chloride $\left(\mathrm{CaCl}_{2}\right)$, (sigma-Aldrich). Dowex 50WX8, (20-50 mesh) from Fluka. 


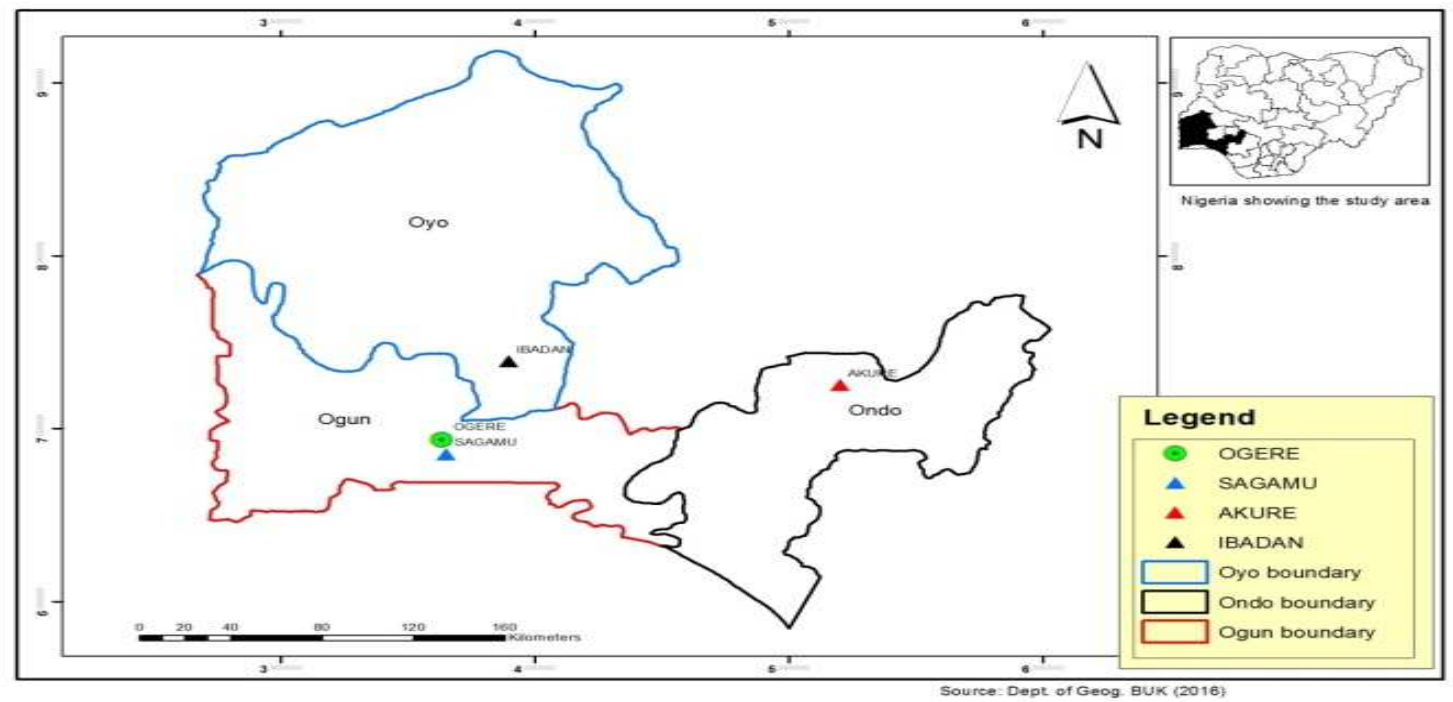

Figure 1: Map showing the sampling point at Sagamu Town, Ogun State.

\section{Description of Sampling Area}

Sagamu has geographical coordinates between $6^{\circ} 50^{\prime}$ north; $3^{\circ} 38^{\prime}$ east is located in south western region of Nigeria. The region has tropical wet and dry climate with a lengthy wet season and relatively constant temperatures throughout the course of the year. Wet season runs from March to October, November to December forms the region dry season. The vegetation type of the region is savannah which is really grassland with small bushes and occasional big trees. Grassland soils have substantially higher organic matter content than forest soils (Novackova, 2011).

\section{Sample Collection}

The Peatsoil samples were collected from four different sampling points $(0-10 \mathrm{~cm}$ depth) in Sagamu into polyethylene bag with plastic spoons. Samples were taken to the laboratory, extraneous materials were removed; the samples were air-dried, crushed and ground to a fine powder in a mortar passed through a $0.20 \mathrm{~mm}$ sieve. The samples were kept for analysis.

\section{Isolation and purification of humic acid from peat soil sample}

Peatsoil sample $(100 \mathrm{~g})$ was mixed with 1000 $\mathrm{cm}^{3}$ of $0.1 \mathrm{M} \mathrm{NaOH}$ solution, shaken for 3hours and left to stand overnight. Dark-coloured supernatant was obtained and decanted from solid residue. The dark-coloured supernatant was acidified to $(\mathrm{pH}=1.0)$ with $6 \mathrm{M} \mathrm{HCl}$ stirred and allowed to stand for 6 hours. Yellowish brown supernatant and dark-brown precipitate were obtained. The yellowish brown supernatant was decanted followed by centrifuge and discarded. The dark-brown precipitate was mixed with $500 \mathrm{~cm}^{3}$ of $0.1 \mathrm{M} \mathrm{NaOH}$ solution followed by passing through dowex resin. The dark-brown solution was acidified to $(\mathrm{pH}=1.0)$ with $6 \mathrm{M} \mathrm{HCl}$ stirred and allowed to stand for 3 hours. The dark-brown precipitate was washed several times with deionized water. The supernatant was treated with $\mathrm{AgNO}_{3}$ solution until no white precipitate observed. The humic acid was transferred to weighed crucible and dried at $60^{\circ} \mathrm{C}$ in an oven for 12 hours. The humic acid was cooled and dried in the desiccator, weighed and recorded. The obtained humic acid was dried again at $60^{\circ} \mathrm{C}$ for additional 6 hours cooled and dried in the desiccator, weighed and recorded constant weight was obtained (Baruah et al., 2015).

\section{FT-IR analysis}

FT-IR spectra of humic acid sample was analysed using Carry 630 FT-IR Agilent Technologies.

Unhydrolysed compost humic acid

The unhydrolysed humic acid was obtained after isolation and purification of compost humic acid and kept for investigation.

\section{Acid hydrolysis of Peatsoil acid}

Peatsoil humic acid sample (1g) was refluxed for 12 hours at $\left(160^{\circ} \mathrm{C}\right)$ with $50 \mathrm{~cm}^{3}$ of $6 \mathrm{M} \mathrm{HCl}$. The mixture was allowed to cool, decanted, and centrifuged after hydrolysis. The insoluble residues were washed with distilled water via centrifugation several times, and the supernatant was treated with $\mathrm{AgNO}_{3}$ solution until no white precipitate was observed. The residue was thoroughly dried over $\mathrm{CaCl}_{2}$ in a desiccator at room temperature (Chefetz et al., 2002). Finally, the obtained hydrolysed humic acid was kept for investigation. 
BAJOPAS Volume 14 Number 1,June, 2021 Potentiometric Titrations

Potentiometric measurements were carried out using a pH-meter Jenway (model 3510) with combine electrode, the sensitivity of the $\mathrm{pH}$ meter is 0.01 units. The $\mathrm{pH}$ meter was switched on half an hour before starting the titration for initial warm up of the instrument. The instrument was calibrated with an aqueous standard buffer solution of $\mathrm{pH} 4.00$ and 10.0 (borate buffer) prepared from a "Qualigens" buffer tablets.

The following sets of solutions were prepared in a $250 \mathrm{~cm}^{3}$ volumetric flask separately for $\mathrm{pH}$ metric titrations.

(i) $5 \mathrm{~cm}^{3} 0.1 \mathrm{M} \mathrm{HCl}+40 \mathrm{~cm}^{3}$ deionized water

(ii) $5 \mathrm{~cm}^{3} 0.1 \mathrm{M} \mathrm{HCl}+39 \mathrm{~cm}^{3}$ deionized water $+1 \mathrm{~cm}^{3} 0.15 \mathrm{gcm}^{-3}$ humic acid

(iii) $5 \mathrm{~cm}^{3} 0.1 \mathrm{M} \mathrm{HCl}+37 \mathrm{~cm}^{3}$ deionized water $+1 \mathrm{~cm}^{3} 0.15 \mathrm{gcm}^{-3}$ humic acid

$$
+2 \mathrm{~cm}^{3} \quad 0.01 \mathrm{M} \mathrm{Cu} \text { (II) }
$$

The solutions were titrated against standardized $0.110 \mathrm{MNaOH}$ separately. The total volume of each mixture was adjusted to $50 \mathrm{~cm}^{3}$ and the ionic strength of the solutions was maintained constant at by adding appropriate amount of stock solution of $1 \mathrm{M} \mathrm{KNO}_{3}$ (Gamal, 2015; Omar and Ali, 2015). A magnetic stirrer was used to achieve thorough mixing of the interacting solutions at $550 \mathrm{rpm}$. The same set of experimental conditions was applied for potentiometric titration of remaining samples.

\section{Evaluation of pKa of Hydrolysed peat soil Humic Acids}

The proton-ligand formation number $\mathrm{n}_{\mathbf{A}}$ were calculated by Irving and Rossotti expression (Omar and Ali, 2015).

$\mathrm{nA}=\mathrm{Y}-\frac{(\mathrm{V} 2-\mathrm{V1})(\mathrm{No}-\mathrm{Eo})}{(\mathrm{VO}+\mathrm{V1}) \mathrm{TCL}}$ 1

Where: $Y$ is number of dissociable proton, $\left(\mathrm{V}_{2^{-}}\right.$ $V_{1}$ ) is the measure of displacement of the ligand curve relative to acid curve, $\mathrm{N}^{\circ}$ and $\mathrm{E}^{\circ}$ are the resultant concentration of alkali solution, free acid solution, $\mathrm{T}_{\mathrm{cL}}{ }^{\circ}$ is the total ligand concentration, $\mathrm{V}^{\circ}$ is the total volume of titration solution, $V_{1}$ is the volume of alkali added to acid solution, $V_{2}$ is the volume of alkali added to acid solution + ligand solution, acid dissociation constants (pKa - values) of ligand were calculated by algebraic method point wise calculation (Tables 1 ). The dissociation constants (pKa) were calculated according to the following relation:

$\mathrm{pKa}=\mathrm{pH}+\log \left(\frac{n A}{1-n A}\right)$ 2

Where: pKa is the acid dissociation constant, $\mathrm{n}_{\mathrm{A}}$ is the Proton-ligand formation number and $\mathrm{pH}$ is the pH-values (Omar and Ali, 2015).

\section{Determination of metal-ligand stability constants $(\log K)$ of complexes}

The potentiometric measurement for the determination of stability constant of a complex in solution is based on the fact that the redox potential of the couple $\frac{M^{+(m-n)}}{M^{+m}}$ is shifted significantly on complexation of the metal ion with the ligand. This method involves change in hydrogen ion concentration $\left[\mathrm{H}^{+}\right]$due to the displacement or association of one or more protons taking place during complexation reaction. This change can be found out by titrating the solutions containing free acid, acid with ligand, and acid with ligand and metal ion, individually against a standard alkali solution at a constant ionic strength or temperature. Either ionic strength or temperature may be varied for different sets of solutions. In all the cases, the change in the $\mathrm{pH}$ of the solution is measured after each addition of a known amount of alkali to the reaction cell which contains the reaction mixture. The titration curves are then drawn by plotting the measured $\mathrm{pH}$ values against the corresponding volume of alkali added and the stability constants of the complexes are determined from the titration curves by employing $\mathrm{pH}$-metric titration technique given by (Irving and Rossoti).

Metal-ligand stability constants ( $\log \mathrm{K}$ ) were determined by using the following relations:

$$
\bar{n}=\frac{\left(V_{3}-V_{2}\right)\left(E^{0}+N^{0}\right)}{\left(V^{0}+V_{2}\right) \bar{n}_{A} T_{m}^{0}}
$$

and

$$
P L=\log _{10}\left\{\frac{1+\beta_{n}^{H} \frac{1}{[\text { anti } \log \mathrm{pH}]^{\mathrm{n}}}}{\mathrm{T}_{\mathrm{L}}^{0}-n \bar{T}_{m}^{0}} \mathrm{X} \frac{\left(V^{0}+V_{3}\right)}{V^{0}}\right\}
$$


BAJOPAS Volume 14 Number 1,June, 2021

Where $T_{L}, T^{\circ}, E^{\circ}$, and $V^{\circ}$ havethe same significance as in equation (1) above, $T_{m}$ denotes the total concentration of metal present in solution, $V_{3}$ is the volume of metal ions present in solution and $\beta^{H}$ is the overall proton ligand stability constant. The metal-ligand stability constants (log K) were determined by employing point wise computational Method (eq. 5 and 6).

$\operatorname{LogK}_{1}=\log \left(\frac{n}{1-n}\right)+\mathrm{pL}$ .5

$\operatorname{LogK}_{2}=\log \left(\frac{1-n}{2-n}\right)+\mathrm{pL}$ ...6

Where: Log $\mathrm{K}$ is the metal-ligand stability constant, $\mathrm{pL}$ is the Free ligand exponent function, $\mathbf{n}$ is the Average number of ligand attached with metal ion (Janraoet al., 2014). The results obtained were analyzed by an ORIGIN 2016 program using titration data and then the proton-ligand stability constants (pKa) and Metal-ligand stability constant (LogK) calculated (Omar and Ali, 2015).

\section{RESULTS AND DISCUSSION}

Fourier transformed infrared (FT-IR) spectra of isolated humic acid from peat soils Figure 2 had distinct clear absorption bands indicating the presence of major humic acid structural elemental groups such as $\mathrm{H}$ bonded $\mathrm{OH}$ $\left(3680 \mathrm{~cm}^{-1}\right.$ peak $), C=0$ of carbonyl $\left(1721 \mathrm{~cm}^{-1}\right.$ peak), functional groups of aliphatic components $\mathrm{CH}_{2}\left(2918 \mathrm{~cm}^{-1}\right.$ peak) and $\mathrm{C}-\mathrm{O}$ stretching of polysaccharide $\left(1168 \mathrm{~cm}^{-1}\right.$ peak). The positions of the absorption bands of the spectra fell within typical major absorption bands of humic acid which is at frequencies 3680, 2918, 1721, 1168 $\mathrm{cm}^{-1}$. The first peak centred in the vicinity of $3680 \mathrm{~cm}^{-1}$ region is attributed to phenol $\mathrm{OH}$ group bounded by intermolecular $\mathrm{H}$ bonds. The $2918 \mathrm{~cm}^{-1}$ band usually has absorption maximum at $2918 \mathrm{~cm}^{-1}$ which is due to $\mathrm{C}-\mathrm{H}$ stretching of alkane group $\left(\mathrm{CH}_{2}\right)$. The next major absorption band is $1721 \mathrm{~cm}^{-1}$. This band has been commonly ascribed to $\mathrm{C}=\mathrm{O}$ stretching of mainly carboxyl group $(\mathrm{COOH})$ with trace amount of ketones. The last peak was observed at 1168 $\mathrm{cm}^{-1}$ due to $\mathrm{C}-\mathrm{O}$ stretching of polysaccharides and this peak appeared also in the spectra of humic acid from peat soil. The FTIR spectra of the isolated humic acid contained all major characteristic absorption peaks of humic acid. These absorption peaks indicated the presence of the major structural elements of humic acid namely $\mathrm{H}$ bonded $\mathrm{OH}, \mathrm{C}=\mathrm{C}$ of aromatic ring, $\mathrm{C}=\mathrm{O}$ of carbonyl group (both carboxyl and ketonic), $\mathrm{CH}_{2}$ group. This strongly supports the presence of humic acid.

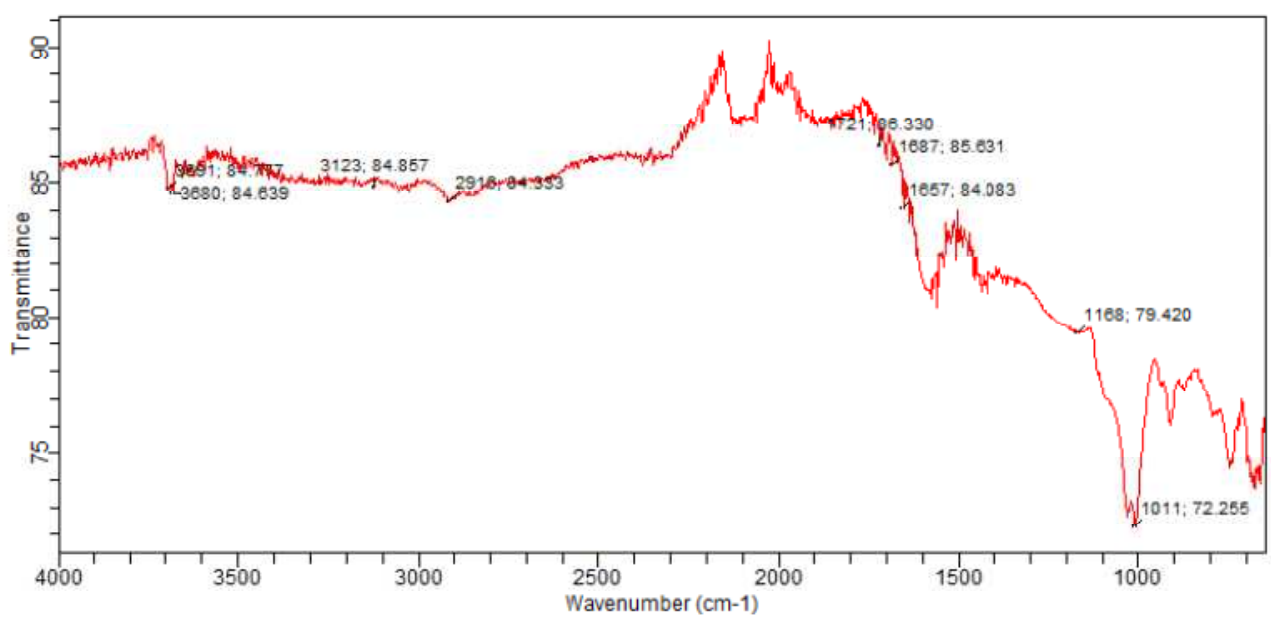

Fig. 2 : FT-IR spectraof peatsoilhumic acid (PSHA)

\section{Evaluation of acid dissociation constant (pka) of acid hydrolysed peat soil humicacid at phenolic group}

The value of the dissociation constant of the peat soil humic acid (PSHA) that underwent acidhydrolysis studied was found to be 8.9299 as shown Table 1, which is lower than the literaturevalues reported by Almeida and Szpoganics, (2015), Borges et al., (2005); Badr et al., (2012)and Fernandes et al,.(2009) of $9.73,9.47$ and 10.30. The difference between the obtained valuesand the reported values in this study might be probably as a result of acid hydrolysis of humicacid. 
BAJOPAS Volume 14 Number 1,June, 2021

Table 1: PKa of (Hydrolysed PSHA)

\begin{tabular}{|l|l|l|l|l|l|l|}
\hline $\mathrm{pH}$ & $\mathrm{BV}_{1}$ & $\mathrm{BV}_{2}$ & $\mathrm{~V}_{2}-\mathrm{V}_{1}$ & $\mathrm{nA}$ & $\log \left(\frac{n A}{1-n A}\right)$ & $\mathrm{pKa}$ \\
\hline 8.50 & 5.30 & 6.29 & 0.99 & 0.3594 & -0.2510 & 8.2490 \\
8.72 & 5.35 & 6.37 & 1.02 & 0.3400 & -0.2880 & 8.4320 \\
9.00 & 5.40 & 6.46 & 1.06 & 0.3141 & -0.3391 & 8.6609 \\
9.22 & 5.45 & 6.55 & 1.10 & 0.2882 & -0.3927 & 8.8273 \\
9.51 & 5.50 & 6.66 & 1.16 & 0.2494 & -0.4786 & 9.0314 \\
9.73 & 5.55 & 6.78 & 1.23 & 0.2041 & -0.5910 & 9.1390 \\
10.00 & 5.60 & 6.90 & 1.30 & 0.1589 & -0.7238 & 9.2762 \\
10.23 & 5.65 & 7.05 & 1.40 & 0.0941 & -0.9835 & 9.2465 \\
10.49 & 5.70 & 7.10 & 1.40 & 0.0941 & -0.9835 & 9.5065 \\
\hline
\end{tabular}

Average pKa $=8.9299 \pm 0.4186$

Table 2: PKa of (Unhydrolysed PSHA)

\begin{tabular}{|l|l|l|l|l|l|l|}
\hline $\mathrm{pH}$ & $\mathrm{BV}_{1}$ & $\mathrm{BV}_{2}$ & $\mathrm{~V}_{2}-\mathrm{V}_{1}$ & $\mathrm{nA}$ & $\log \left(\frac{\boldsymbol{n A}}{1-\boldsymbol{n}}\right)$ & $\mathrm{pKa}$ \\
\hline 8.50 & 5.30 & 5.81 & 0.51 & 0.6619 & 0.2919 & 8.7919 \\
8.72 & 5.35 & 5.90 & 0.55 & 0.6357 & 0.2418 & 8.9618 \\
9.00 & 5.40 & 6.00 & 0.60 & 0.6029 & 0.1813 & 9.1813 \\
9.22 & 5.45 & 6.10 & 0.65 & 0.5701 & 0.1226 & 9.3426 \\
9.51 & 5.50 & 6.20 & 0.70 & 0.5376 & 0.0654 & 9.5754 \\
9.73 & 5.55 & 6.33 & 0.78 & 0.4851 & -0.0259 & 9.7041 \\
10.00 & 5.60 & 6.47 & 0.87 & 0.4262 & -0.1291 & 9.8709 \\
10.23 & 5.65 & 6.62 & 0.99 & 0.3609 & -0.2481 & 9.9819 \\
10.49 & 5.70 & 6.80 & 1.10 & 0.2759 & -0.4690 & 10.0210 \\
\hline
\end{tabular}

Average pKa $=9.4923 \pm 0.4410$

Metal-ligand stability constant ( $\log \mathrm{K}$ )

The stabilityconstants require the accurate values of proton-ligand stability constants (Anil and Maroti, 2008). Metal titration curves crossed over ligand titration curve indicated the formation of complex upon proton release (Santosh, et al., 2011). If the values of n- are within range $0.2-0.8$ and $1.2-18$ this indicates the formation of $1: 1$ and 1:2 complexes (Sayyed and Mazahar, 2012).

The metal (II)-humate stepwise stability constants (log k) at phenolic group (Tables 318)

Table 3: Point-wise method, $\mathrm{Cu}$-(Hydrolysed PSHA)

\begin{tabular}{|l|l|l|l|l|l|l|l|l|}
\hline $\mathrm{pH}$ & $\mathrm{BV}_{1}$ & $\mathrm{BV}_{2}$ & $\mathrm{BV}_{3}$ & $\left(\mathrm{~V}_{3}-\mathrm{V}_{2}\right)$ & $\mathrm{n}$ & $\mathrm{pL}$ & $\log \left(\frac{n}{1-n}\right)$ & LogK $_{1}$ \\
\hline 8.50 & 5.30 & 6.29 & 6.33 & 0.04 & 0.5500 & 2.66 & 0.0871 & 2.7471 \\
8.72 & 5.35 & 6.37 & 6.41 & 0.04 & 0.5714 & 2.43 & 0.1249 & 2.5549 \\
9.00 & 5.40 & 6.46 & 6.50 & 0.04 & 0.6198 & 2.16 & 0.2122 & 2.3722 \\
9.22 & 5.45 & 6.55 & 6.59 & 0.04 & 0.6667 & 1.94 & 0.3010 & 2.2410 \\
\hline
\end{tabular}

LogK $_{1}$ (Average value) $=2.4788 \pm 0.2203$

Table 4: Point-wise method, $\mathrm{Cu}$-(Hydrolysed PSHA)

\begin{tabular}{|l|l|l|l|l|l|l|l|l|}
\hline $\mathrm{pH}$ & $\mathrm{BV}_{1}$ & $\mathrm{BV}_{2}$ & $\mathrm{BV}_{3}$ & $\left(\mathrm{~V}_{3}-\mathrm{V}_{2}\right)$ & $\mathrm{n}$ & $\mathrm{pL}$ & $\log \left(\frac{n-1}{2-n}\right)$ & LogK $_{2}$ \\
\hline 9.51 & 5.50 & 6.66 & 6.73 & 0.07 & 1.3509 & 1.70 & -0.2671 & 1.4329 \\
9.73 & 5.55 & 6.78 & 6.85 & 0.07 & 1.6383 & 1.51 & 0.2467 & 1.7567 \\
10.00 & 5.60 & 6.90 & 6.98 & 0.08 & 2.1783 & 1.31 & -0.2158 & 1.0942 \\
10.23 & 5.65 & 7.05 & 7.13 & 0.08 & 4.1904 & 1.27 & & \\
10.49 & 5.70 & 7.10 & 7.19 & 0.09 & 4.6920 & & & \\
\hline
\end{tabular}

Log $K_{2}($ Average value $)=1.4280 \pm 0.3312$ 
BAJOPAS Volume 14 Number 1,June, 2021

Table 5: Point-wise method, $\mathrm{Cu}$ (Unhydrolysed PSHA)

\begin{tabular}{|l|l|l|l|l|l|l|l|l|}
\hline $\mathrm{pH}$ & $\mathrm{BV}_{1}$ & $\mathrm{BV}_{2}$ & $\mathrm{BV}_{3}$ & $\left(\mathrm{~V}_{3}-\mathrm{V}_{2}\right)$ & $\mathrm{n}$ & $\mathrm{pL}$ & $\log \left(\frac{n}{n-1}\right)$ & Log $_{1}$ \\
\hline 8.50 & 5.30 & 5.81 & 5.85 & 0.04 & 0.2973 & 2.88 & -0.3736 & 2.5064 \\
8.72 & 5.35 & 5.90 & 5.95 & 0.05 & 0.3873 & 2.66 & -0.1992 & 2.4608 \\
9.00 & 5.40 & 6.00 & 6.05 & 0.05 & 0.4044 & 2.38 & -0.1681 & 2.2119 \\
9.22 & 5.45 & 6.10 & 6.15 & 0.06 & 0.5157 & 2.18 & -0.0272 & 2.2072 \\
9.51 & 5.50 & 6.20 & 6.27 & 0.07 & 0.6417 & 1.89 & 0.2530 & 1.1430 \\
\hline
\end{tabular}

$\operatorname{LogK}_{1}($ Average value $)=2.3059 \pm 0.6153$

Table 6:Point-wise method, $\mathrm{Cu}$ (Unhydrolysed PSHA)

\begin{tabular}{|l|l|l|l|l|l|l|l|l|}
\hline $\mathrm{pH}$ & $\mathrm{BV}_{1}$ & $\mathrm{BV}_{2}$ & $\mathrm{BV}_{3}$ & $\mathrm{~V}_{3}-\mathrm{V}_{2}$ & $\mathrm{n}$ & $\mathrm{pL}$ & $\log \left(\frac{n-1}{2-n}\right)$ & $\log \mathrm{K}_{2}$ \\
\hline 9.73 & 5.55 & 6.33 & 6.42 & 0.09 & 0.9000 & 1.69 & & \\
10.00 & 5.60 & 6.47 & 6.58 & 0.11 & 1.2578 & 1.44 & -0.4592 & 0.9808 \\
10.23 & 5.65 & 6.62 & 6.84 & 0.12 & 1.6137 & 1.26 & -0.2010 & 1.4610 \\
10.49 & 5.70 & 6.80 & 6.92 & 0.12 & 2.1052 & 1.03 & & \\
\hline
\end{tabular}

$\operatorname{LogK}_{2}$ (Average value) $=1.2209 \pm 0.3398$

Table 7:Point-wise method, Pb (Hydrolysed PSHA)

\begin{tabular}{|l|l|l|l|l|l|l|l|l|}
\hline $\mathrm{pH}$ & $\mathrm{BV}_{1}$ & $\mathrm{BV}_{2}$ & $\mathrm{BV}_{3}$ & $\left(\mathrm{~V}_{3}-\mathrm{V}_{2}\right)$ & $\mathrm{n}$ & $\mathrm{pL}$ & $\log \left(\frac{n}{1-n}\right)$ & LogK $_{1}$ \\
\hline 8.50 & 5.30 & 6.29 & 6.33 & 0.04 & 0.5500 & 2.66 & 0.0871 & 2.7471 \\
8.72 & 5.35 & 6.37 & 6.41 & 0.04 & 0.5714 & 2.43 & 0.1249 & 2.5549 \\
9.00 & 5.40 & 6.46 & 6.50 & 0.04 & 0.6198 & 2.16 & 0.2122 & 2.3722 \\
9.22 & 5.45 & 6.55 & 6.60 & 0.05 & 0.8333 & 1.96 & 0.6989 & 2.6589 \\
\hline
\end{tabular}

Log $_{\mathbf{1}}($ Average value $)=2.5832 \pm 0.1614$

Table 8:Point-wise method, Pb-(Hydrolysed PSHA)

\begin{tabular}{|l|l|l|l|l|l|l|l|l|}
\hline $\mathrm{pH}$ & $\mathrm{BV}_{1}$ & $\mathrm{BV}_{2}$ & $\mathrm{BV}_{3}$ & $\left(\mathrm{~V}_{3}-\mathrm{V}_{2}\right)$ & $\mathrm{n}$ & $\mathrm{pL}$ & $\log \left(\frac{n-1}{2-n}\right)$ & $\log \mathrm{K}_{2}$ \\
\hline 9.51 & 5.50 & 6.66 & 6.71 & 0.05 & 0.9650 & 1.67 & & \\
9.73 & 5.55 & 6.78 & 6.83 & 0.05 & 1.1702 & 1.44 & & \\
10.00 & 5.60 & 6.90 & 6.90 & 0.05 & 1.4864 & 1.22 & -0.0237 & 1.1963 \\
10.23 & 5.65 & 7.05 & 7.10 & 0.05 & 2.0190 & 1.09 & & \\
10.49 & 5.70 & 7.10 & 7.17 & 0.07 & 3.6492 & 1.00 & & \\
\hline
\end{tabular}

Log $K_{2}$ (Average value) $=1.1963$

Table 9: Point-wise method, Pb (Unhydrolysed PSHA)

\begin{tabular}{|l|l|l|l|l|l|l|l|l|}
\hline $\mathrm{pH}$ & $\mathrm{BV}_{1}$ & $\mathrm{BV}_{2}$ & $\mathrm{BV}_{3}$ & $\mathrm{~V}_{3}-\mathrm{V}_{2}$ & $\mathrm{n}$ & $\mathrm{pL}$ & $\begin{array}{l}\text { Log } \\
\left(\frac{n}{n-1}\right)\end{array}$ & Log $\mathrm{K}_{1}$ \\
\hline 8.50 & 5.30 & 5.81 & 5.85 & 0.04 & 0.2973 & 2.88 & -0.3736 & 2.5064 \\
8.72 & 5.35 & 5.90 & 5.94 & 0.04 & 0.3099 & 2.66 & -0.5477 & 2.3123 \\
9.00 & 5.40 & 6.00 & 6.05 & 0.05 & 0.4044 & 2.38 & -0.1681 & 2.2119 \\
9.22 & 5.45 & 6.10 & 6.15 & 0.06 & 0.5157 & 2.18 & 0.0272 & 2.2072 \\
9.51 & 5.50 & 6.20 & 6.26 & 0.07 & 0.6417 & 1.89 & 0.2530 & 2.1430 \\
9.73 & 5.55 & 6.40 & 6.40 & 0.07 & 0.7000 & 1.67 & 0.3680 & 2.0380 \\
\hline
\end{tabular}

LogK $_{1}$ (Average value) $=2.2364 \pm 0.1602$

Table 10: Point-wise method, Pb (Unhydrolysed PSHA)

\begin{tabular}{|l|l|l|l|l|l|l|l|l|}
\hline $\mathrm{pH}$ & $\mathrm{BV}_{1}$ & $\mathrm{BV}_{2}$ & $\mathrm{BV}_{3}$ & $\mathrm{~V}_{3}-\mathrm{V}_{2}$ & $\mathrm{n}$ & $\mathrm{pL}$ & $\log \left(\frac{n-1}{2-n}\right)$ & $\log \mathrm{K}_{2}$ \\
\hline 10.00 & 5.60 & 6.47 & 6.55 & 0.08 & 1.9503 & 1.41 & & \\
10.23 & 5.65 & 6.62 & 6.72 & 0.11 & 1.4792 & 1.26 & -0.0361 & 1.2239 \\
\hline
\end{tabular}

$\operatorname{LogK}_{2}$ (Average value) $=1.2239$

Table 11: Point-wise method, Mg (Hydrolysed PSHA)

\begin{tabular}{|l|l|l|l|l|l|l|l|l|}
\hline $\mathrm{pH}$ & $\mathrm{BV}_{1}$ & $\mathrm{BV}_{2}$ & $\mathrm{BV}_{3}$ & $\left(\mathrm{~V}_{3}-\mathrm{V}_{2}\right)$ & $\mathrm{n}$ & $\mathrm{pL}$ & $\log \left(\frac{n}{n-1}\right)$ & LogK $_{1}$ \\
\hline 8.50 & 5.30 & 6.29 & 6.31 & 0.02 & 0.2750 & 2.64 & -0.4290 & 2.2110 \\
8.72 & 5.35 & 6.37 & 6.39 & 0.02 & 0.2858 & 2.42 & -0.3978 & 2.0222 \\
9.00 & 5.40 & 6.46 & 6.49 & 0.03 & 0.4648 & 2.14 & -0.0612 & 2.0788 \\
9.22 & 5.45 & 6.55 & 6.59 & 0.04 & 0.6667 & 1.94 & 0.3010 & 2.2410 \\
\hline
\end{tabular}

$\log _{\mathbf{1}}($ Average value) $=2.1382 \pm 0.1046$ 
BAJOPAS Volume 14 Number 1,June, 2021

Table 12: Point-wise method, Mg (Hydrolysed PSHA)

\begin{tabular}{|l|l|l|l|l|l|l|l|l|}
\hline $\mathrm{pH}$ & $\mathrm{BV}_{1}$ & $\mathrm{BV}_{2}$ & $\mathrm{BV}_{3}$ & $\left(\mathrm{~V}_{3}-\mathrm{V}_{2}\right)$ & $\mathrm{n}$ & $\mathrm{pL}$ & $\log \left(\frac{n-1}{2-n}\right)$ & LogK $_{2}$ \\
\hline 9.51 & 5.55 & 6.66 & 6.71 & 0.05 & 0.9650 & 1.67 & & \\
9.73 & 5.55 & 6.78 & 6.84 & 0.06 & 1.4042 & 1.47 & -0.1686 & 1.3014 \\
10.00 & 5.60 & 6.90 & 6.93 & 0.06 & 1.7838 & 1.23 & 0.5593 & 1.7893 \\
10.23 & 5.65 & 7.05 & 7.10 & 0.06 & 3.1429 & 1.10 & & \\
10.49 & 5.70 & 7.10 & 7.18 & 0.07 & 3.6492 & 0.83 & & \\
\hline
\end{tabular}

LogK $_{2}($ Average value $)=1.5453 \pm 0.3450$

Table 13: Point-wise method, Mg (Unhydrolysed PSHA)

\begin{tabular}{|l|l|l|l|l|l|l|l|l|}
\hline $\mathrm{pH}$ & $\mathrm{BV}_{1}$ & $\mathrm{BV}_{2}$ & $\mathrm{BV}_{3}$ & $\mathrm{~V}_{3}-\mathrm{V}_{2}$ & $\mathrm{n}$ & $\mathrm{pL}$ & $\log \left(\frac{n}{n-1}\right)$ & $\operatorname{Log~}_{1}$ \\
\hline 8.50 & 5.30 & 5.81 & 5.85 & 0.04 & 0.2973 & 2.88 & -0.3736 & 2.5064 \\
8.72 & 5.35 & 5.90 & 5.94 & 0.04 & 0.3099 & 2.66 & -0.3477 & 2.3123 \\
9.00 & 5.40 & 6.00 & 6.04 & 0.04 & 0.3236 & 2.38 & -0.3202 & 2.0598 \\
9.22 & 5.45 & 6.10 & 6.15 & 0.05 & 0.4297 & 2.17 & -0.1230 & 2.0470 \\
9.51 & 5.50 & 6.20 & 6.26 & 0.06 & 0.5500 & 1.89 & 0.0871 & 1.9771 \\
9.73 & 5.55 & 6.33 & 6.40 & 0.07 & 0.7000 & 1.67 & 0.3680 & 2.0380 \\
\hline
\end{tabular}

LogK $_{1}$ (Average value) $=2.1568 \pm 0.2069$

Table 14: Point-wise method, Mg (Unhydrolysed PSHA)

\begin{tabular}{|l|l|l|l|l|l|l|l|l|}
\hline $\mathrm{pH}$ & $\mathrm{BV}_{1}$ & $\mathrm{BV}_{2}$ & $\mathrm{BV}_{3}$ & $\mathrm{~V}_{3}-\mathrm{V}_{2}$ & $\mathrm{n}$ & $\mathrm{pL}$ & $\log \left(\frac{n-1}{2-n}\right)$ & $\log \mathrm{K}_{2}$ \\
\hline 10.00 & 5.60 & 6.47 & 6.55 & 0.08 & 0.9148 & 1.41 & & \\
10.23 & 5.65 & 6.62 & 6.71 & 0.09 & 1.2102 & 1.20 & -0.5749 & 0.6251 \\
10.49 & 5.70 & 6.80 & 6.92 & 0.09 & 1.5968 & 1.03 & 0.1703 & 1.2003 \\
\hline
\end{tabular}

LogK $_{2}$ (Average value) $=0.9127 \pm 0.4070$

Table15:Point-wise method, Cd (Hydrolysed PSHA)

\begin{tabular}{|l|l|l|l|l|l|l|l|l|}
\hline $\mathrm{pH}$ & $\mathrm{BV}_{1}$ & $\mathrm{BV}_{2}$ & $\mathrm{BV}_{3}$ & $\left(\mathrm{~V}_{3}-\mathrm{V}_{2}\right)$ & $\mathrm{n}$ & $\mathrm{pL}$ & $\log \left(\frac{n}{1-n}\right)$ & LogK $_{1}$ \\
\hline 8.50 & 5.30 & 6.29 & 6.31 & 0.02 & 0.2750 & 2.64 & -0.4210 & 2.2190 \\
8.72 & 5.35 & 6.37 & 6.40 & 0.03 & 0.4286 & 2.42 & -0.1249 & 2.2951 \\
9.00 & 5.40 & 6.46 & 6.49 & 0.03 & 0.4648 & 2.14 & -0.0612 & 2.0788 \\
9.22 & 5.45 & 6.55 & 6.59 & 0.04 & 0.6667 & 1.96 & 0.3010 & 2.2610 \\
9.51 & 5.55 & 6.66 & 6.70 & 0.04 & 0.7720 & 1.67 & 0.5297 & 2.1997 \\
\hline
\end{tabular}

LogK $_{\mathbf{1}}$ (Average value) $=2.2108 \pm 0.0825$

Table 16: Point-wise method, Cd (Hydrolysed PSHA)

\begin{tabular}{|l|l|l|l|l|l|l|l|l|}
\hline $\mathrm{pH}$ & $\mathrm{BV}_{1}$ & $\mathrm{BV}_{2}$ & $\mathrm{BV}_{3}$ & $\left(\mathrm{~V}_{3}-\mathrm{V}_{2}\right)$ & $\mathrm{n}$ & $\mathrm{pL}$ & $\log \left(\frac{n-1}{2-n}\right)$ & Log $_{2}$ \\
\hline 9.73 & 5.55 & 6.78 & 6.83 & 0.06 & 1.4042 & 1.47 & -0.1686 & 1.3014 \\
10.00 & 5.60 & 6.90 & 6.95 & 0.06 & 1.7838 & 1.23 & 0.5593 & 1.7893 \\
10.23 & 5.65 & 7.05 & 7.10 & 0.06 & 3.1429 & 1.09 & & \\
10.49 & 5.70 & 7.10 & 7.16 & 0.06 & 3.1429 & 0.89 & & \\
& & & & & & & & \\
\hline
\end{tabular}

$\operatorname{LogK}_{2}$ (Average value) $=1.5453 \pm 0.3450$

Table 17: Point-wise method, Cd (Unhydrolysed PSHA)

\begin{tabular}{|l|l|l|l|l|l|l|l|l|}
\hline $\mathrm{pH}$ & $\mathrm{BV}_{1}$ & $\mathrm{BV}_{2}$ & $\mathrm{BV}_{3}$ & $\mathrm{~V}_{3}-\mathrm{V}_{2}$ & $\mathrm{n}$ & $\mathrm{pL}$ & $\log \left(\frac{n}{n-1}\right)$ & $\operatorname{Log~}_{1}$ \\
\hline 8.50 & 5.30 & 5.81 & 5.86 & 0.05 & 0.3717 & 2.88 & -0.2280 & 2.6520 \\
8.72 & 5.35 & 5.90 & 5.95 & 0.05 & 0.3873 & 2.66 & -0.1992 & 2.4608 \\
9.00 & 5.40 & 6.00 & 6.06 & 0.06 & 0.4853 & 2.38 & -0.0255 & 2.3545 \\
9.22 & 5.45 & 6.10 & 6.16 & 0.06 & 0.5157 & 2.18 & -0.0272 & 2.2072 \\
9.51 & 5.50 & 6.20 & 6.27 & 0.07 & 0.6417 & 1.89 & 0.2530 & 1.1430 \\
9.73 & 5.55 & 6.33 & 6.41 & 0.08 & 0.8000 & 1.69 & 0.6020 & 2.2920 \\
& & & & & & & & \\
\hline
\end{tabular}

$\operatorname{LogK}_{1}($ Average value $)=2.2516 \pm 0.5380$ 
BAJOPAS Volume 14 Number 1,June, 2021

Table 18: Point-wise method, Cd (Unhydrolysed PSHA)

\begin{tabular}{|l|l|l|l|l|l|l|l|l|}
\hline $\mathrm{pH}$ & $\mathrm{BV}_{1}$ & $\mathrm{BV}_{2}$ & $\mathrm{BV}_{3}$ & $\mathrm{~V}_{3}-\mathrm{V}_{2}$ & $\mathrm{n}$ & $\mathrm{pL}$ & $\log \left(\frac{n-1}{2-n}\right)$ & $\log \mathrm{K}_{2}$ \\
\hline 10.00 & 5.60 & 6.47 & 6.57 & 0.10 & 1.1434 & 1.43 & & \\
10.23 & 5.65 & 6.62 & 6.72 & 0.10 & 1.3448 & 1.23 & -0.2788 & 0.9512 \\
10.49 & 5.70 & 6.80 & 6.90 & 0.10 & 1.7742 & 1.03 & 0.5351 & 1.5651 \\
\hline
\end{tabular}

$\operatorname{LogK}_{2}($ Average value $)=1.2581 \pm 0.4340$

Table 19: Stepwise and overall Stability constants of thehydrolysed and unhydrolysed divalent metal (II) complexes

\begin{tabular}{|c|c|c|c|}
\hline Chelates & LogK $_{1}$ & $\log _{2}$ & Log $\beta$ \\
\hline [Cu (Hydrolysed PSHA-1) $\left.{ }_{2}\right]$ & 2.4788 & 1.4280 & 3.9068 \\
\hline$\left[\mathrm{Pb}(\text { Hydrolysed PSHA-1) })_{2}\right]$ & 2.5832 & 1.1963 & 3.7795 \\
\hline$\left[\mathrm{Cd}(\text { Hydrolysed PSHA-1 })_{2}\right]$ & 2.2108 & 1.5453 & 3.7561 \\
\hline$\left[\mathrm{Mg}(\text { Hydrolysed PSHA-1 })_{2}\right]$ & 2.1382 & 1.5453 & 3.6835 \\
\hline [Cu (Unhydrolysed PSHA-1) & 2.3059 & 1.2209 & 3.5268 \\
\hline$[\mathrm{Pb}$ (Unhydrolysed PSHA-1) 2$]$ & 2.2364 & 1.2239 & 3.4603 \\
\hline [Cd (Unhydrolysed PSHA-1) 2 ] & 2.2516 & 1.2581 & 3.5097 \\
\hline$[\mathrm{Mg}$ (Unydrolysed PSHA-1) & 2.1568 & 0.9127 & 3.0695 \\
\hline
\end{tabular}

The results obtained (Table19) shows the stepwise and overall stability constants to be not high indicating low stability of the complexes, because the solubility of most metal ions in the basic $\mathrm{pH}$ range is minimal due to metal hydroxide precipitation (Karimi, 2017). In general, the stepwise stability constants $\left(K_{1}\right.$ and $K_{2}$ ) follow the order $K_{1}>K_{2}$ for the copper, lead, magnesium and cadmium complexes respectively. The steady decrease of the values with increasing number of ligands is in agreement with the prediction made by researchers (Na'aliya, 2013). The decrease could be attributed to the fact that as the number of the ligands (Humate ions) that enters the coordination zone increases the aqua molecules available for replacement by the ligands become less. Thus, the metal ions become less electron loving with progressive intake of the ligand and this results in the decrease in the values of the constants (Na'aliya, 2013). Also the stability of the complexes is influenced by the size and number of the chelate rings(Mackay and Mackay,2002).All the complexes form rings in their structure as humate, a bidentate ligand, bond the metal ions in the ratio 1:2 (Boguta and Sokolowska, 2016) forming chelate rings. The values of the overall stability constants $(\log \beta)$ obtained for humate complexes are not high indicating low stability as the values are not high. LogK values for copper-humates (Table 3 to 6) obtained in this study are lower than those reported for the complexes of humic acids (Pandey et al., 2015; Dinu, 2013; Kaschl et al., 2010 and Gilbeto and Jorg, 2001). The values of LogK(Table 7 to 10 ) forlead-humates are lower than those reported for the lead in the literature (Dinu, 2013; Gilbeto and Jorg 2001). Log K values(Table 11 to 14 ) for magnesium-humates obtained in this study are close to those reported by (Pandey et al., 2015). Log K values of cadmium-humates (Table 15 to 18 ) obtained in this work near to the one reported by (Dinu, 2013 and Pandey et al., 2015).The difference between the reported values and the values obtained in this study might be probably as a result of acid hydrolysis of humic acid. The values of the overall stability constants $(\log \beta)$ of the copper humates complexes presented in Table 19 is high than that of other metal humate complexes, show relatively high stability of CuHA complexes, show the following order of stability: $\mathrm{Cu}>\mathrm{Pb}>\mathrm{Cd}>\mathrm{Mg}$; which are in close agreement to the findings of (Dinu, 2013 and Pandey et al., 2015).The high stability of Cuhumate chelate could be attributed to the existence of coordinate covalent bond between the complexing agents and the $\mathrm{Cu}^{2+}$ ions. Since, $\mathrm{Cu}^{2+}$ being a metal of the transitional series with $3 d^{9}$ electronic configurations can accept the electrons from the complexing agents. Similarly, the low stabilities of $\mathrm{Pb}, \mathrm{Cd}$ and $\mathrm{Mg}$ complexes could be explained by that $\mathrm{Pb}^{2+}$ with $6 s^{2}, \mathrm{Cd}^{2+}$ with $4 \mathrm{~d}^{10}$ and $\mathrm{Mg}^{2+}$ with $2 \mathrm{p}^{6}$ their electronic configuration has a completely filled $\mathrm{d}, \mathrm{p}$ and $\mathrm{s}$ orbitals. Moreover, the stabilities of metal ions with hydrolysed humic acid from peat soil were higher than those with unhydrolysed humic acid from peat soil; which is ascribed to the high content of acidity in hydrolysed humic acid than unhydrolysed humic acid. 
BAJOPAS Volume 14 Number 1,June, 2021 CONCLUSION

The values of logk for $\mathrm{Cu}(\mathrm{II})$ hydrolysed humic acid complex was higher followed by $\mathrm{Pb}$ (II), $\mathrm{Cd}(\mathrm{II})$ and $\mathrm{Mg}$ (II) hydrolysed humic acid complexes as compared with metal(II) unhydrolysed humic acid complexes. This indicates acid hydrolysis of humic acid can

\section{REFERENCES}

Almeida, V.R. and Szpoganicz, B. (2015). Humic Acid Potentiometric Response Patterns:Out- of Equilibrium Properties and Species Distribution Modelling. Chemical. Biol. Technol. Agric. 2: 17.

Anđelković, T., Nikolić, R., Bojić, A.,Anđelković, D., and Nikolic G.,(2010). Binding of Cadmium to Soil Humic Acid as A Function of Carboxyl Group Content. Macedonian Journal of Chemistry and Chemical Engineering.29(2): 215-224.

Anil, B. N. and Maroti, N. (2008). Studies on Influence of Die-Lectric Constants on Complex Equilibria between Substituted Py-Razalines and Lanthanide Metal Ions pH-Metrically. Amer.-Euras. scient. Res. 3(2): 212-216.

Ashok, K., Pandey, S. P. and Misra, V (2000). Stability Constants of Metal-Humic Acid Complexes and its Role in Environmental Detoxification. Journal of Ecotoxicology and Environmental Safety. 47(2):157-200.

Badr, M. H., El-Halafawi, M. H. and Abd El-al Zeid, E. R. (2012). Comparison Between the Effect of Ionic Strength on Acidity and Dissociation Constants of Humic Acids Extracted from Sewage Sludge and Nile Water Hyacinth Composts.Global Journal of Environmental Research 6 (1): 36-43.

Baruah, M.K., Borah, D., Saikia, P.P., Paul, S., Sharma, T. (2015). Evaluation of pKa Values of Soil Humic Acids and their Complexation Properties. International Journal of Plant \& Soil Science 6(4) : 218-228.

Boguta, P. Sokolowska, Z. (2016). Interactions of $\mathrm{Zn}$ (II) Ions with Humic Acids Isolated from Various Types of Soils. Effect of $\mathrm{pH}, \mathrm{Zn}$ Concentrations and Humic Acids Chemical Properties. Journal of Geochemical Explaration 168. 119-126.

Borges, F., Guimaraes, C., Lima, L.F.C., Pinto, I. and Reis, S.(2005). Potentiometric Studies on the Complexation of Copper(II) by Phenolic Acids as Discrete Ligand Models of enhance the complexation behavior of humic acid with metal (II) ions. However, the higher values of $\log \beta$ for $\mathrm{Cu}(\mathrm{II}), \mathrm{Pb}(\mathrm{II}), \mathrm{Cd}(\mathrm{II})$ and $\mathrm{Mg}(\mathrm{II})$ hydrolysed humic acid complexes indicates more stable stepwise complexes formed as compared with $\mathrm{Cu}(\mathrm{II}), \mathrm{Pb}$ (II), $\mathrm{Cd}$ (II) and $\mathrm{Mg}(\mathrm{II})$ unhydrolysed humic acid complexes.

Humic Substances Talanta 66 (2005) 670-673.

Chefetz, B., Salloum, M. J., Deshmulkin, A. P. and Hatcher, P. (2002). Structural Components of Humic Acids as Determined by Chemical Modifications and Carbon-13 NMR, Pyrolysis, and Thermochemolysis- Gas Chromatography/Mass Spectrometry. Soil Science Society of American Journal Abstract Division S-2- Soil Chemistry66. 1159-1171.

Dinu, M. I. (2013). Metals Complexation with Humic Acids in Surface Water of Different Environ. Sci. Technol. 31(1): 1-17.

Fernandes, A.N., Giacomelli, C., Giovanela, M. Vaz, D.V. Szpoganicz, B. and Maria M. D. (2009). Potentiometric Acidity Determination in Humic Substances Influenced by Different Analytical Procedures.J. Braz. Chem. Soc. 20 (9):14.

Gamal, A. H. (2015). Stability Constants of Rhenium (V) Metal Complexes with Selected Drugs. Pyrex Journal of Research in Environmental Studies. 2(2): 006-014.

Janrao, D. M., Pathan, J., Kayande, D.D., and Mulla, J.J. (2014). An Over View of Potentiometric Determination of Stability Constants of Metal Complexes. Sci. Revs. Chem. Commun.: 4(1), 2014, 11-24.

Karimi, H. (2017). Effect of pH and Initial Pb(II) Concentration on the Lead Removal Efficiency from Waste Water Using $\mathrm{Ca}(\mathrm{OH})_{2}$. International Journal of Water and Waste Water Treatment 3.2

Kaschl, A. Romheld, V. and Chen, Y. (2010). Binding of Cadmium, Copper and Zinc to Humic Substances Originating from Municipal Solid Waste Compost. Israel Journal of Chemistry Vol. 42(1): 89-98.

Kostic, I. S., Tatjana, P, A., Nikolic, R. S., Cvetkovic, T. P., Pavlovic, D. D., Aleksandar, L.J. and Bojic, A. (2012). Comparative Study of Binding Strengths of Heavy Metals with Humic Acid. J.serb. Chem. Soc. 76(9) pp 1-20. 
BAJOPAS Volume 14 Number 1,June, 2021

Na'aliya, J. (2013). Determination of Stepwise Stability Constants and Gibbs free Energy Change of Trisprolina to Complexes of some Divalent Transition Metal ions. Bayero Journal of Pure and Applied Sciences 6(2): 112-114.

Omar, A. A. and Ali, E. A. (2015). Potentiometric Studies on Complexes of $\mathrm{Cr}$ (III) and $\mathrm{Zr}$ (IV) with some Carboxylic Acids. International Journal of Advanced Chemistry, 3(1) 25-

37.

Pandey, A. K. Pandey, S. D. and Misr, V. (2015).Stability Constants of Metal- Humic Acid Complexes and Its Role in Environmental Detoxification. J. Ecotoxicology and Environmental Safety. 47(1):195-200.

Ram, N. and Raman, K.V. (1984). Stability Constants of Complexes of Metals with
Humicand Fuvic Acids under Non- acidConditions. Journal of Plant Nutrition and Soil Sciences.

147:171-176.

Santosh, D. D., Ashok, B. K., Vijay, J. T., Shivraj, G. W. and Vinay, V. W. (2011). Potentiometric Studies of Elec-Trolyte Effects on Complex Equilibria of Some Substituted 5-(2-hydroxy Phenyl) Pyrazoles. Der pharm. 3 (6): 75-83.

Sayyed, H. and Abdul Rahim, M. F. (2012). Studies of Binary Complexes of Metal Ions with Mandelic Acid by Potentiometry. Chem. J. 02 (6): 206209.

Shirvani, M. Moradian, E. Khalili, B. Bakhtiary, S. (2015). Interaction of $\mathrm{Cd}$ and $\mathrm{Pb}$ with Humate-Palygorskite and HumateSepiolite Complexes. Journal of water, air and pollution 3: 220-228. 


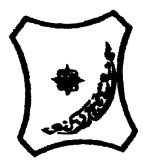

Bayero Journal of Pure and Applied Sciences, 14(1): 54 - 63

Received: November, 2020

Accepted: April, 2021

ISSN $2006-6996$

\title{
STABILITY CONSTANTS OF COMPLEXES OF METAL IONS WITH PEATSOIL HUMIC ACIDS UNDER NON-ACID-CONDITIONS
}

\author{
${ }^{* 1}$ Sabo, Yusuf ${ }^{2}$ Jimoh, W.L.O., ${ }^{3}$ Isa Baba Koki and ${ }^{4}$ Sholadoye, Q. 0. \\ ${ }^{1}$ Department of Pure and Industrial Chemistry, Bayero University, Kano \\ ${ }^{3}$ Department of Chemistry, Yusuf Maitama Sule University Kano. P.M.B. 3220 Kano, Nigeria. \\ ${ }^{4}$ Department of Chemistry, Nigerian Police Academy, Wudil, Kano-Nigeria
}

*Correspondence E-mail; saboyusuf18@yahoo.com

ABSTRACT

Stability constants of complexes of four divalent metal ions viz. $\mathrm{Cu}^{2+}, \mathrm{Pb}^{2+}, \mathrm{Mg}^{2+}$ and $\mathrm{Cd}^{2+}$ with humic acids (HA) were determined by potentiometric titration of humic acids with the corresponding salt of the divalent metals in aqueous media under non-acid-condition. The log $K$ (logarithm of the stability constant) ranged from 1.0942 to 2.7471 for metalhumic acid complexes were determined using point-wise computational method. The order of stability constants were obtained as follows: $\mathrm{Cu}>\mathrm{Pb}>\mathrm{Cd}>\mathrm{Mg}$ for metal $-\mathrm{HA}$ complexes respectively, indicating a higher degree of complexation with Cu metal ion.

Keywords: stability constant, humic acid, potentiometric titration, divalent metals, acid hydrolysis.

\section{NTRODUCTION}

The stability constant of a complex is the numerical expression of its stability and provides a quantitative measure of affinity of the metal ion to the complexing agent. An understanding of the relative stability of metal-complexes helps in predicting the behavior of metal ions in the soil (Ram and Raman, 1982). Extensive researches has been done to determine the stability constants of the complexes formed between humic acid (HA) with a number of metal ions. Ashok et al., (2000) reported that humic acid with hydroxyl, phenoxyl and carboxyl reactive groups can form coordination compound with metal ions at $\mathrm{pH}$ 3.5. The stability constants(Log K) for different metalhumic acid complexes indicated the following order of the stabilities of complexes formed between humic acid and metal ion, $\mathrm{Cu}>\mathrm{Fe}$ $>\mathrm{Pb}>\mathrm{Ni}>\mathrm{Co}>\mathrm{Ca}>\mathrm{Cd}>\mathrm{Zn}>\mathrm{Mn}>\mathrm{Mg}$. Andelkovic et al., (2010) investigated the binding of $\mathrm{Cd}$ (II) to soil humic acid at pH 6.5 and in $0.1 \mathrm{M} \mathrm{KNO}_{3}$ ionic medium. The stability constant for binding indicating greater stability in the case when carboxyl groups are involved in complexation reaction. Kostic et al.,(2012) investigated the complexation of humic acid with certain heavy metal ions (Co(II), $\mathrm{Ni}(\mathrm{II}), \mathrm{Cu}(\mathrm{II})$,
$\mathrm{Zn}(\mathrm{II})$, and $\mathrm{Pb}(\mathrm{II})$. The experiment was performed at $25^{\circ} \mathrm{C}$, at pH 4.0 and ionic strength of $0.01 \mathrm{M}$. Stability constant of complex between $\mathrm{Pb}$ (II) ions and humic acid is greater than stability constants of other investigated metalhumate complexes. Bogata and Sokolowska (2016) analyses the interaction between humic acids from different soils and $\mathrm{Zn}$ (II) ions at wide concentration ranges and at $\mathrm{pH} 5$. Studies have showed significant impact of $\mathrm{Zn}$ concentration, $\mathrm{pH}$ and some properties of humic acids with zinc.But all of these studies were limited to acidic $\mathrm{pH}$ range. Therefore, the present study was carried out to determine and compare the stability constants of complexes of metal ions with hydrolysed peat soil humic acid and unhydrolysed peat soil humic under non-acid conditions.

\section{MATERIALS AND METHODS}

Analytical grade chemicals used includes hydrochloric acid $(\mathrm{HCl})$, nitric acid $\left(\mathrm{HNO}_{3}\right)$, sodium hydroxide $(\mathrm{NaOH})$, lead nitrate $\mathrm{Pb}\left(\mathrm{NO}_{3}\right)_{2}$, copper nitrate $\mathrm{Cu}\left(\mathrm{NO}_{3}\right)_{2} \cdot 3 \mathrm{H}_{2} \mathrm{O}$, cadmium nitrate $\mathrm{Cd}\left(\mathrm{NO}_{3}\right)_{2} \cdot 4 \mathrm{H}_{2} \mathrm{O}$, magnesium nitrate $\mathrm{Mg}\left(\mathrm{NO}_{3}\right)_{2} \cdot 6 \mathrm{H}_{2} \mathrm{O}$, potassium nitrate $\left(\mathrm{KNO}_{3}\right)$, calcium chloride $\left(\mathrm{CaCl}_{2}\right)$, (sigma-Aldrich). Dowex 50WX8, (20-50 mesh) from Fluka. 


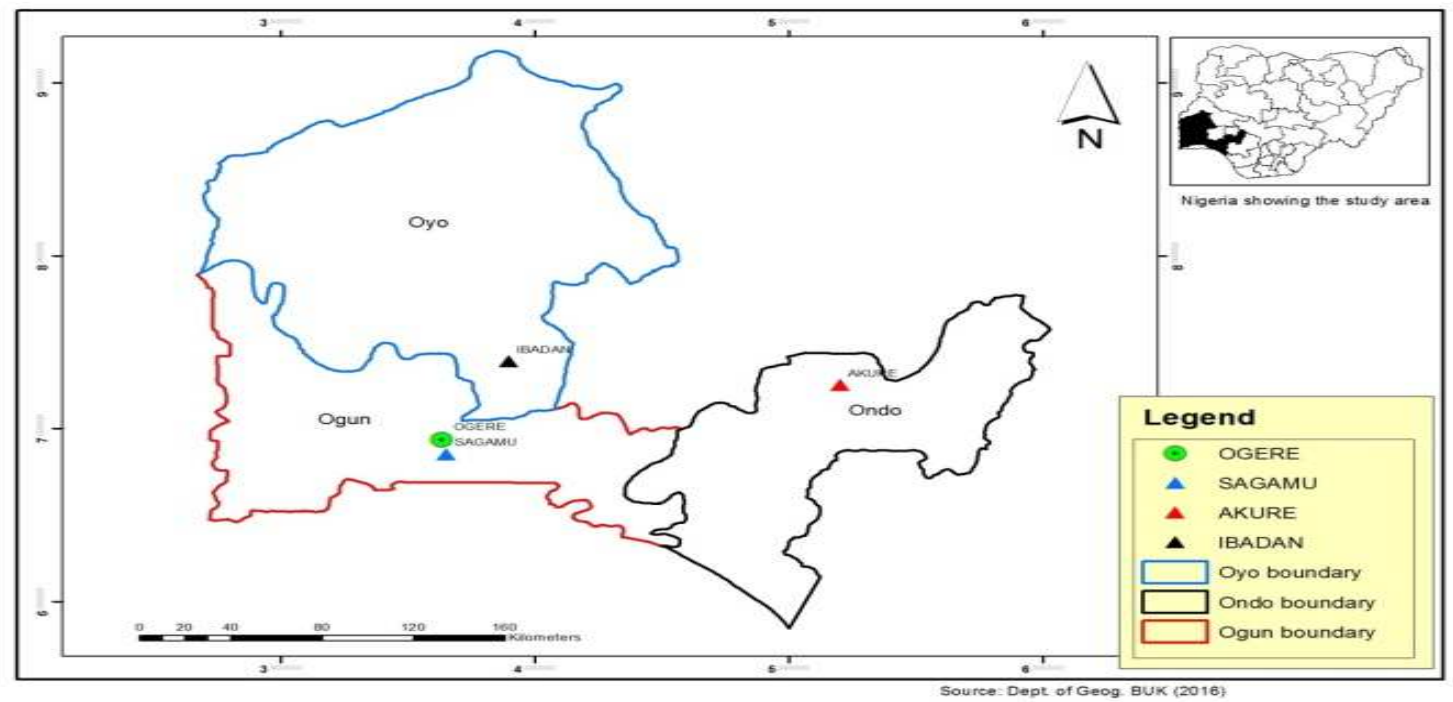

Figure 1: Map showing the sampling point at Sagamu Town, Ogun State.

\section{Description of Sampling Area}

Sagamu has geographical coordinates between $6^{\circ} 50^{\prime}$ north; $3^{\circ} 38^{\prime}$ east is located in south western region of Nigeria. The region has tropical wet and dry climate with a lengthy wet season and relatively constant temperatures throughout the course of the year. Wet season runs from March to October, November to December forms the region dry season. The vegetation type of the region is savannah which is really grassland with small bushes and occasional big trees. Grassland soils have substantially higher organic matter content than forest soils (Novackova, 2011).

\section{Sample Collection}

The Peatsoil samples were collected from four different sampling points $(0-10 \mathrm{~cm}$ depth) in Sagamu into polyethylene bag with plastic spoons. Samples were taken to the laboratory, extraneous materials were removed; the samples were air-dried, crushed and ground to a fine powder in a mortar passed through a $0.20 \mathrm{~mm}$ sieve. The samples were kept for analysis.

\section{Isolation and purification of humic acid from peat soil sample}

Peatsoil sample $(100 \mathrm{~g})$ was mixed with 1000 $\mathrm{cm}^{3}$ of $0.1 \mathrm{M} \mathrm{NaOH}$ solution, shaken for 3hours and left to stand overnight. Dark-coloured supernatant was obtained and decanted from solid residue. The dark-coloured supernatant was acidified to $(\mathrm{pH}=1.0)$ with $6 \mathrm{M} \mathrm{HCl}$ stirred and allowed to stand for 6 hours. Yellowish brown supernatant and dark-brown precipitate were obtained. The yellowish brown supernatant was decanted followed by centrifuge and discarded. The dark-brown precipitate was mixed with $500 \mathrm{~cm}^{3}$ of $0.1 \mathrm{M} \mathrm{NaOH}$ solution followed by passing through dowex resin. The dark-brown solution was acidified to $(\mathrm{pH}=1.0)$ with $6 \mathrm{M} \mathrm{HCl}$ stirred and allowed to stand for 3 hours. The dark-brown precipitate was washed several times with deionized water. The supernatant was treated with $\mathrm{AgNO}_{3}$ solution until no white precipitate observed. The humic acid was transferred to weighed crucible and dried at $60^{\circ} \mathrm{C}$ in an oven for 12 hours. The humic acid was cooled and dried in the desiccator, weighed and recorded. The obtained humic acid was dried again at $60^{\circ} \mathrm{C}$ for additional 6 hours cooled and dried in the desiccator, weighed and recorded constant weight was obtained (Baruah et al., 2015).

\section{FT-IR analysis}

FT-IR spectra of humic acid sample was analysed using Carry 630 FT-IR Agilent Technologies.

Unhydrolysed compost humic acid

The unhydrolysed humic acid was obtained after isolation and purification of compost humic acid and kept for investigation.

\section{Acid hydrolysis of Peatsoil acid}

Peatsoil humic acid sample (1g) was refluxed for 12 hours at $\left(160^{\circ} \mathrm{C}\right)$ with $50 \mathrm{~cm}^{3}$ of $6 \mathrm{M} \mathrm{HCl}$. The mixture was allowed to cool, decanted, and centrifuged after hydrolysis. The insoluble residues were washed with distilled water via centrifugation several times, and the supernatant was treated with $\mathrm{AgNO}_{3}$ solution until no white precipitate was observed. The residue was thoroughly dried over $\mathrm{CaCl}_{2}$ in a desiccator at room temperature (Chefetz et al., 2002). Finally, the obtained hydrolysed humic acid was kept for investigation. 
BAJOPAS Volume 14 Number 1,June, 2021 Potentiometric Titrations

Potentiometric measurements were carried out using a pH-meter Jenway (model 3510) with combine electrode, the sensitivity of the $\mathrm{pH}$ meter is 0.01 units. The $\mathrm{pH}$ meter was switched on half an hour before starting the titration for initial warm up of the instrument. The instrument was calibrated with an aqueous standard buffer solution of $\mathrm{pH} 4.00$ and 10.0 (borate buffer) prepared from a "Qualigens" buffer tablets.

The following sets of solutions were prepared in a $250 \mathrm{~cm}^{3}$ volumetric flask separately for $\mathrm{pH}$ metric titrations.

(i) $5 \mathrm{~cm}^{3} 0.1 \mathrm{M} \mathrm{HCl}+40 \mathrm{~cm}^{3}$ deionized water

(ii) $5 \mathrm{~cm}^{3} 0.1 \mathrm{M} \mathrm{HCl}+39 \mathrm{~cm}^{3}$ deionized water $+1 \mathrm{~cm}^{3} 0.15 \mathrm{gcm}^{-3}$ humic acid

(iii) $5 \mathrm{~cm}^{3} 0.1 \mathrm{M} \mathrm{HCl}+37 \mathrm{~cm}^{3}$ deionized water $+1 \mathrm{~cm}^{3} 0.15 \mathrm{gcm}^{-3}$ humic acid

$$
+2 \mathrm{~cm}^{3} \quad 0.01 \mathrm{M} \mathrm{Cu} \text { (II) }
$$

The solutions were titrated against standardized $0.110 \mathrm{MNaOH}$ separately. The total volume of each mixture was adjusted to $50 \mathrm{~cm}^{3}$ and the ionic strength of the solutions was maintained constant at by adding appropriate amount of stock solution of $1 \mathrm{M} \mathrm{KNO}_{3}$ (Gamal, 2015; Omar and Ali, 2015). A magnetic stirrer was used to achieve thorough mixing of the interacting solutions at $550 \mathrm{rpm}$. The same set of experimental conditions was applied for potentiometric titration of remaining samples.

\section{Evaluation of pKa of Hydrolysed peat soil Humic Acids}

The proton-ligand formation number $\mathrm{n}_{\mathbf{A}}$ were calculated by Irving and Rossotti expression (Omar and Ali, 2015).

$\mathrm{nA}=\mathrm{Y}-\frac{(\mathrm{V} 2-\mathrm{V1})(\mathrm{No}-\mathrm{Eo})}{(\mathrm{VO}+\mathrm{V1}) \mathrm{TCL}}$ 1

Where: $Y$ is number of dissociable proton, $\left(\mathrm{V}_{2^{-}}\right.$ $V_{1}$ ) is the measure of displacement of the ligand curve relative to acid curve, $\mathrm{N}^{\circ}$ and $\mathrm{E}^{\circ}$ are the resultant concentration of alkali solution, free acid solution, $\mathrm{T}_{\mathrm{cL}}{ }^{\circ}$ is the total ligand concentration, $\mathrm{V}^{\circ}$ is the total volume of titration solution, $V_{1}$ is the volume of alkali added to acid solution, $V_{2}$ is the volume of alkali added to acid solution + ligand solution, acid dissociation constants (pKa - values) of ligand were calculated by algebraic method point wise calculation (Tables 1 ). The dissociation constants (pKa) were calculated according to the following relation:

$\mathrm{pKa}=\mathrm{pH}+\log \left(\frac{n A}{1-n A}\right)$ 2

Where: pKa is the acid dissociation constant, $\mathrm{n}_{\mathrm{A}}$ is the Proton-ligand formation number and $\mathrm{pH}$ is the pH-values (Omar and Ali, 2015).

\section{Determination of metal-ligand stability constants $(\log K)$ of complexes}

The potentiometric measurement for the determination of stability constant of a complex in solution is based on the fact that the redox potential of the couple $\frac{M^{+(m-n)}}{M^{+m}}$ is shifted significantly on complexation of the metal ion with the ligand. This method involves change in hydrogen ion concentration $\left[\mathrm{H}^{+}\right]$due to the displacement or association of one or more protons taking place during complexation reaction. This change can be found out by titrating the solutions containing free acid, acid with ligand, and acid with ligand and metal ion, individually against a standard alkali solution at a constant ionic strength or temperature. Either ionic strength or temperature may be varied for different sets of solutions. In all the cases, the change in the $\mathrm{pH}$ of the solution is measured after each addition of a known amount of alkali to the reaction cell which contains the reaction mixture. The titration curves are then drawn by plotting the measured $\mathrm{pH}$ values against the corresponding volume of alkali added and the stability constants of the complexes are determined from the titration curves by employing $\mathrm{pH}$-metric titration technique given by (Irving and Rossoti).

Metal-ligand stability constants ( $\log \mathrm{K}$ ) were determined by using the following relations:

$$
\bar{n}=\frac{\left(V_{3}-V_{2}\right)\left(E^{0}+N^{0}\right)}{\left(V^{0}+V_{2}\right) \bar{n}_{A} T_{m}^{0}}
$$

and

$$
P L=\log _{10}\left\{\frac{1+\beta_{n}^{H} \frac{1}{[\text { anti } \log \mathrm{pH}]^{\mathrm{n}}}}{\mathrm{T}_{\mathrm{L}}^{0}-n \bar{T}_{m}^{0}} \mathrm{X} \frac{\left(V^{0}+V_{3}\right)}{V^{0}}\right\}
$$


BAJOPAS Volume 14 Number 1,June, 2021

Where $T_{L}, T^{\circ}, E^{\circ}$, and $V^{\circ}$ havethe same significance as in equation (1) above, $T_{m}$ denotes the total concentration of metal present in solution, $V_{3}$ is the volume of metal ions present in solution and $\beta^{H}$ is the overall proton ligand stability constant. The metal-ligand stability constants (log K) were determined by employing point wise computational Method (eq. 5 and 6).

$\operatorname{LogK}_{1}=\log \left(\frac{n}{1-n}\right)+\mathrm{pL}$ .5

$\operatorname{LogK}_{2}=\log \left(\frac{1-n}{2-n}\right)+\mathrm{pL}$ ...6

Where: Log $\mathrm{K}$ is the metal-ligand stability constant, $\mathrm{pL}$ is the Free ligand exponent function, $\mathbf{n}$ is the Average number of ligand attached with metal ion (Janraoet al., 2014). The results obtained were analyzed by an ORIGIN 2016 program using titration data and then the proton-ligand stability constants (pKa) and Metal-ligand stability constant (LogK) calculated (Omar and Ali, 2015).

\section{RESULTS AND DISCUSSION}

Fourier transformed infrared (FT-IR) spectra of isolated humic acid from peat soils Figure 2 had distinct clear absorption bands indicating the presence of major humic acid structural elemental groups such as $\mathrm{H}$ bonded $\mathrm{OH}$ $\left(3680 \mathrm{~cm}^{-1}\right.$ peak $), C=0$ of carbonyl $\left(1721 \mathrm{~cm}^{-1}\right.$ peak), functional groups of aliphatic components $\mathrm{CH}_{2}\left(2918 \mathrm{~cm}^{-1}\right.$ peak) and $\mathrm{C}-\mathrm{O}$ stretching of polysaccharide $\left(1168 \mathrm{~cm}^{-1}\right.$ peak). The positions of the absorption bands of the spectra fell within typical major absorption bands of humic acid which is at frequencies 3680, 2918, 1721, 1168 $\mathrm{cm}^{-1}$. The first peak centred in the vicinity of $3680 \mathrm{~cm}^{-1}$ region is attributed to phenol $\mathrm{OH}$ group bounded by intermolecular $\mathrm{H}$ bonds. The $2918 \mathrm{~cm}^{-1}$ band usually has absorption maximum at $2918 \mathrm{~cm}^{-1}$ which is due to $\mathrm{C}-\mathrm{H}$ stretching of alkane group $\left(\mathrm{CH}_{2}\right)$. The next major absorption band is $1721 \mathrm{~cm}^{-1}$. This band has been commonly ascribed to $\mathrm{C}=\mathrm{O}$ stretching of mainly carboxyl group $(\mathrm{COOH})$ with trace amount of ketones. The last peak was observed at 1168 $\mathrm{cm}^{-1}$ due to $\mathrm{C}-\mathrm{O}$ stretching of polysaccharides and this peak appeared also in the spectra of humic acid from peat soil. The FTIR spectra of the isolated humic acid contained all major characteristic absorption peaks of humic acid. These absorption peaks indicated the presence of the major structural elements of humic acid namely $\mathrm{H}$ bonded $\mathrm{OH}, \mathrm{C}=\mathrm{C}$ of aromatic ring, $\mathrm{C}=\mathrm{O}$ of carbonyl group (both carboxyl and ketonic), $\mathrm{CH}_{2}$ group. This strongly supports the presence of humic acid.

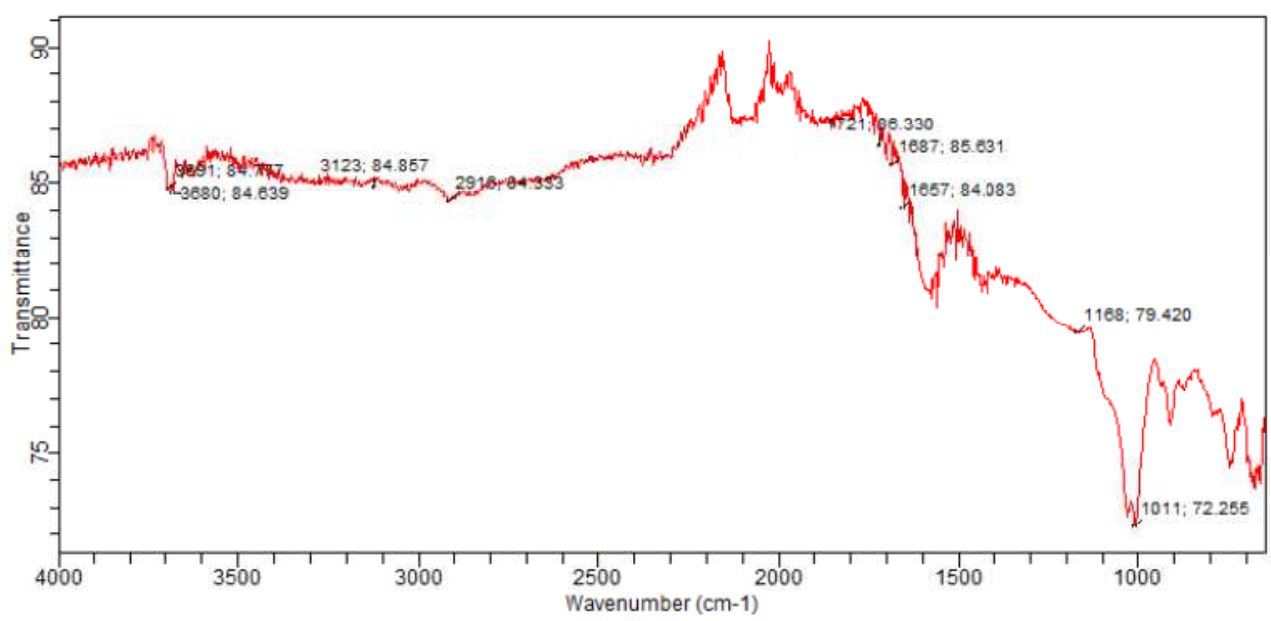

Fig. 2 : FT-IR spectraof peatsoilhumic acid (PSHA)

\section{Evaluation of acid dissociation constant (pka) of acid hydrolysed peat soil humicacid at phenolic group}

The value of the dissociation constant of the peat soil humic acid (PSHA) that underwent acidhydrolysis studied was found to be 8.9299 as shown Table 1, which is lower than the literaturevalues reported by Almeida and Szpoganics, (2015), Borges et al., (2005); Badr et al., (2012)and Fernandes et al,.(2009) of $9.73,9.47$ and 10.30. The difference between the obtained valuesand the reported values in this study might be probably as a result of acid hydrolysis of humicacid. 
BAJOPAS Volume 14 Number 1,June, 2021

Table 1: PKa of (Hydrolysed PSHA)

\begin{tabular}{|l|l|l|l|l|l|l|}
\hline $\mathrm{pH}$ & $\mathrm{BV}_{1}$ & $\mathrm{BV}_{2}$ & $\mathrm{~V}_{2}-\mathrm{V}_{1}$ & $\mathrm{nA}$ & $\log \left(\frac{n A}{1-n A}\right)$ & $\mathrm{pKa}$ \\
\hline 8.50 & 5.30 & 6.29 & 0.99 & 0.3594 & -0.2510 & 8.2490 \\
8.72 & 5.35 & 6.37 & 1.02 & 0.3400 & -0.2880 & 8.4320 \\
9.00 & 5.40 & 6.46 & 1.06 & 0.3141 & -0.3391 & 8.6609 \\
9.22 & 5.45 & 6.55 & 1.10 & 0.2882 & -0.3927 & 8.8273 \\
9.51 & 5.50 & 6.66 & 1.16 & 0.2494 & -0.4786 & 9.0314 \\
9.73 & 5.55 & 6.78 & 1.23 & 0.2041 & -0.5910 & 9.1390 \\
10.00 & 5.60 & 6.90 & 1.30 & 0.1589 & -0.7238 & 9.2762 \\
10.23 & 5.65 & 7.05 & 1.40 & 0.0941 & -0.9835 & 9.2465 \\
10.49 & 5.70 & 7.10 & 1.40 & 0.0941 & -0.9835 & 9.5065 \\
\hline
\end{tabular}

Average pKa $=8.9299 \pm 0.4186$

Table 2: PKa of (Unhydrolysed PSHA)

\begin{tabular}{|l|l|l|l|l|l|l|}
\hline $\mathrm{pH}$ & $\mathrm{BV}_{1}$ & $\mathrm{BV}_{2}$ & $\mathrm{~V}_{2}-\mathrm{V}_{1}$ & $\mathrm{nA}$ & $\log \left(\frac{\boldsymbol{n A}}{1-\boldsymbol{n}}\right)$ & $\mathrm{pKa}$ \\
\hline 8.50 & 5.30 & 5.81 & 0.51 & 0.6619 & 0.2919 & 8.7919 \\
8.72 & 5.35 & 5.90 & 0.55 & 0.6357 & 0.2418 & 8.9618 \\
9.00 & 5.40 & 6.00 & 0.60 & 0.6029 & 0.1813 & 9.1813 \\
9.22 & 5.45 & 6.10 & 0.65 & 0.5701 & 0.1226 & 9.3426 \\
9.51 & 5.50 & 6.20 & 0.70 & 0.5376 & 0.0654 & 9.5754 \\
9.73 & 5.55 & 6.33 & 0.78 & 0.4851 & -0.0259 & 9.7041 \\
10.00 & 5.60 & 6.47 & 0.87 & 0.4262 & -0.1291 & 9.8709 \\
10.23 & 5.65 & 6.62 & 0.99 & 0.3609 & -0.2481 & 9.9819 \\
10.49 & 5.70 & 6.80 & 1.10 & 0.2759 & -0.4690 & 10.0210 \\
\hline
\end{tabular}

Average pKa $=9.4923 \pm 0.4410$

Metal-ligand stability constant ( $\log \mathrm{K}$ )

The stabilityconstants require the accurate values of proton-ligand stability constants (Anil and Maroti, 2008). Metal titration curves crossed over ligand titration curve indicated the formation of complex upon proton release (Santosh, et al., 2011). If the values of n- are within range $0.2-0.8$ and $1.2-18$ this indicates the formation of $1: 1$ and 1:2 complexes (Sayyed and Mazahar, 2012).

The metal (II)-humate stepwise stability constants (log k) at phenolic group (Tables 318)

Table 3: Point-wise method, $\mathrm{Cu}$-(Hydrolysed PSHA)

\begin{tabular}{|l|l|l|l|l|l|l|l|l|}
\hline $\mathrm{pH}$ & $\mathrm{BV}_{1}$ & $\mathrm{BV}_{2}$ & $\mathrm{BV}_{3}$ & $\left(\mathrm{~V}_{3}-\mathrm{V}_{2}\right)$ & $\mathrm{n}$ & $\mathrm{pL}$ & $\log \left(\frac{n}{1-n}\right)$ & LogK $_{1}$ \\
\hline 8.50 & 5.30 & 6.29 & 6.33 & 0.04 & 0.5500 & 2.66 & 0.0871 & 2.7471 \\
8.72 & 5.35 & 6.37 & 6.41 & 0.04 & 0.5714 & 2.43 & 0.1249 & 2.5549 \\
9.00 & 5.40 & 6.46 & 6.50 & 0.04 & 0.6198 & 2.16 & 0.2122 & 2.3722 \\
9.22 & 5.45 & 6.55 & 6.59 & 0.04 & 0.6667 & 1.94 & 0.3010 & 2.2410 \\
\hline
\end{tabular}

LogK $_{1}$ (Average value) $=2.4788 \pm 0.2203$

Table 4: Point-wise method, $\mathrm{Cu}$-(Hydrolysed PSHA)

\begin{tabular}{|l|l|l|l|l|l|l|l|l|}
\hline $\mathrm{pH}$ & $\mathrm{BV}_{1}$ & $\mathrm{BV}_{2}$ & $\mathrm{BV}_{3}$ & $\left(\mathrm{~V}_{3}-\mathrm{V}_{2}\right)$ & $\mathrm{n}$ & $\mathrm{pL}$ & $\log \left(\frac{n-1}{2-n}\right)$ & LogK $_{2}$ \\
\hline 9.51 & 5.50 & 6.66 & 6.73 & 0.07 & 1.3509 & 1.70 & -0.2671 & 1.4329 \\
9.73 & 5.55 & 6.78 & 6.85 & 0.07 & 1.6383 & 1.51 & 0.2467 & 1.7567 \\
10.00 & 5.60 & 6.90 & 6.98 & 0.08 & 2.1783 & 1.31 & -0.2158 & 1.0942 \\
10.23 & 5.65 & 7.05 & 7.13 & 0.08 & 4.1904 & 1.27 & & \\
10.49 & 5.70 & 7.10 & 7.19 & 0.09 & 4.6920 & & & \\
\hline
\end{tabular}

Log $K_{2}($ Average value $)=1.4280 \pm 0.3312$ 
BAJOPAS Volume 14 Number 1,June, 2021

Table 5: Point-wise method, $\mathrm{Cu}$ (Unhydrolysed PSHA)

\begin{tabular}{|l|l|l|l|l|l|l|l|l|}
\hline $\mathrm{pH}$ & $\mathrm{BV}_{1}$ & $\mathrm{BV}_{2}$ & $\mathrm{BV}_{3}$ & $\left(\mathrm{~V}_{3}-\mathrm{V}_{2}\right)$ & $\mathrm{n}$ & $\mathrm{pL}$ & $\log \left(\frac{n}{n-1}\right)$ & Log $_{1}$ \\
\hline 8.50 & 5.30 & 5.81 & 5.85 & 0.04 & 0.2973 & 2.88 & -0.3736 & 2.5064 \\
8.72 & 5.35 & 5.90 & 5.95 & 0.05 & 0.3873 & 2.66 & -0.1992 & 2.4608 \\
9.00 & 5.40 & 6.00 & 6.05 & 0.05 & 0.4044 & 2.38 & -0.1681 & 2.2119 \\
9.22 & 5.45 & 6.10 & 6.15 & 0.06 & 0.5157 & 2.18 & -0.0272 & 2.2072 \\
9.51 & 5.50 & 6.20 & 6.27 & 0.07 & 0.6417 & 1.89 & 0.2530 & 1.1430 \\
\hline
\end{tabular}

$\operatorname{LogK}_{1}($ Average value $)=2.3059 \pm 0.6153$

Table 6:Point-wise method, $\mathrm{Cu}$ (Unhydrolysed PSHA)

\begin{tabular}{|l|l|l|l|l|l|l|l|l|}
\hline $\mathrm{pH}$ & $\mathrm{BV}_{1}$ & $\mathrm{BV}_{2}$ & $\mathrm{BV}_{3}$ & $\mathrm{~V}_{3}-\mathrm{V}_{2}$ & $\mathrm{n}$ & $\mathrm{pL}$ & $\log \left(\frac{n-1}{2-n}\right)$ & $\log \mathrm{K}_{2}$ \\
\hline 9.73 & 5.55 & 6.33 & 6.42 & 0.09 & 0.9000 & 1.69 & & \\
10.00 & 5.60 & 6.47 & 6.58 & 0.11 & 1.2578 & 1.44 & -0.4592 & 0.9808 \\
10.23 & 5.65 & 6.62 & 6.84 & 0.12 & 1.6137 & 1.26 & -0.2010 & 1.4610 \\
10.49 & 5.70 & 6.80 & 6.92 & 0.12 & 2.1052 & 1.03 & & \\
\hline
\end{tabular}

$\operatorname{LogK}_{2}$ (Average value) $=1.2209 \pm 0.3398$

Table 7:Point-wise method, Pb (Hydrolysed PSHA)

\begin{tabular}{|l|l|l|l|l|l|l|l|l|}
\hline $\mathrm{pH}$ & $\mathrm{BV}_{1}$ & $\mathrm{BV}_{2}$ & $\mathrm{BV}_{3}$ & $\left(\mathrm{~V}_{3}-\mathrm{V}_{2}\right)$ & $\mathrm{n}$ & $\mathrm{pL}$ & $\log \left(\frac{n}{1-n}\right)$ & LogK $_{1}$ \\
\hline 8.50 & 5.30 & 6.29 & 6.33 & 0.04 & 0.5500 & 2.66 & 0.0871 & 2.7471 \\
8.72 & 5.35 & 6.37 & 6.41 & 0.04 & 0.5714 & 2.43 & 0.1249 & 2.5549 \\
9.00 & 5.40 & 6.46 & 6.50 & 0.04 & 0.6198 & 2.16 & 0.2122 & 2.3722 \\
9.22 & 5.45 & 6.55 & 6.60 & 0.05 & 0.8333 & 1.96 & 0.6989 & 2.6589 \\
\hline
\end{tabular}

Log $_{\mathbf{1}}($ Average value $)=2.5832 \pm 0.1614$

Table 8:Point-wise method, Pb-(Hydrolysed PSHA)

\begin{tabular}{|l|l|l|l|l|l|l|l|l|}
\hline $\mathrm{pH}$ & $\mathrm{BV}_{1}$ & $\mathrm{BV}_{2}$ & $\mathrm{BV}_{3}$ & $\left(\mathrm{~V}_{3}-\mathrm{V}_{2}\right)$ & $\mathrm{n}$ & $\mathrm{pL}$ & $\log \left(\frac{n-1}{2-n}\right)$ & $\log \mathrm{K}_{2}$ \\
\hline 9.51 & 5.50 & 6.66 & 6.71 & 0.05 & 0.9650 & 1.67 & & \\
9.73 & 5.55 & 6.78 & 6.83 & 0.05 & 1.1702 & 1.44 & & \\
10.00 & 5.60 & 6.90 & 6.90 & 0.05 & 1.4864 & 1.22 & -0.0237 & 1.1963 \\
10.23 & 5.65 & 7.05 & 7.10 & 0.05 & 2.0190 & 1.09 & & \\
10.49 & 5.70 & 7.10 & 7.17 & 0.07 & 3.6492 & 1.00 & & \\
\hline
\end{tabular}

Log $K_{2}$ (Average value) $=1.1963$

Table 9: Point-wise method, Pb (Unhydrolysed PSHA)

\begin{tabular}{|l|l|l|l|l|l|l|l|l|}
\hline $\mathrm{pH}$ & $\mathrm{BV}_{1}$ & $\mathrm{BV}_{2}$ & $\mathrm{BV}_{3}$ & $\mathrm{~V}_{3}-\mathrm{V}_{2}$ & $\mathrm{n}$ & $\mathrm{pL}$ & $\begin{array}{l}\text { Log } \\
\left(\frac{n}{n-1}\right)\end{array}$ & Log $\mathrm{K}_{1}$ \\
\hline 8.50 & 5.30 & 5.81 & 5.85 & 0.04 & 0.2973 & 2.88 & -0.3736 & 2.5064 \\
8.72 & 5.35 & 5.90 & 5.94 & 0.04 & 0.3099 & 2.66 & -0.5477 & 2.3123 \\
9.00 & 5.40 & 6.00 & 6.05 & 0.05 & 0.4044 & 2.38 & -0.1681 & 2.2119 \\
9.22 & 5.45 & 6.10 & 6.15 & 0.06 & 0.5157 & 2.18 & 0.0272 & 2.2072 \\
9.51 & 5.50 & 6.20 & 6.26 & 0.07 & 0.6417 & 1.89 & 0.2530 & 2.1430 \\
9.73 & 5.55 & 6.40 & 6.40 & 0.07 & 0.7000 & 1.67 & 0.3680 & 2.0380 \\
\hline
\end{tabular}

LogK $_{1}$ (Average value) $=2.2364 \pm 0.1602$

Table 10: Point-wise method, Pb (Unhydrolysed PSHA)

\begin{tabular}{|l|l|l|l|l|l|l|l|l|}
\hline $\mathrm{pH}$ & $\mathrm{BV}_{1}$ & $\mathrm{BV}_{2}$ & $\mathrm{BV}_{3}$ & $\mathrm{~V}_{3}-\mathrm{V}_{2}$ & $\mathrm{n}$ & $\mathrm{pL}$ & $\log \left(\frac{n-1}{2-n}\right)$ & $\log \mathrm{K}_{2}$ \\
\hline 10.00 & 5.60 & 6.47 & 6.55 & 0.08 & 1.9503 & 1.41 & & \\
10.23 & 5.65 & 6.62 & 6.72 & 0.11 & 1.4792 & 1.26 & -0.0361 & 1.2239 \\
\hline
\end{tabular}

$\operatorname{LogK}_{2}$ (Average value) $=1.2239$

Table 11: Point-wise method, Mg (Hydrolysed PSHA)

\begin{tabular}{|l|l|l|l|l|l|l|l|l|}
\hline $\mathrm{pH}$ & $\mathrm{BV}_{1}$ & $\mathrm{BV}_{2}$ & $\mathrm{BV}_{3}$ & $\left(\mathrm{~V}_{3}-\mathrm{V}_{2}\right)$ & $\mathrm{n}$ & $\mathrm{pL}$ & $\log \left(\frac{n}{n-1}\right)$ & LogK $_{1}$ \\
\hline 8.50 & 5.30 & 6.29 & 6.31 & 0.02 & 0.2750 & 2.64 & -0.4290 & 2.2110 \\
8.72 & 5.35 & 6.37 & 6.39 & 0.02 & 0.2858 & 2.42 & -0.3978 & 2.0222 \\
9.00 & 5.40 & 6.46 & 6.49 & 0.03 & 0.4648 & 2.14 & -0.0612 & 2.0788 \\
9.22 & 5.45 & 6.55 & 6.59 & 0.04 & 0.6667 & 1.94 & 0.3010 & 2.2410 \\
\hline
\end{tabular}

$\log _{\mathbf{1}}($ Average value) $=2.1382 \pm 0.1046$ 
BAJOPAS Volume 14 Number 1,June, 2021

Table 12: Point-wise method, Mg (Hydrolysed PSHA)

\begin{tabular}{|l|l|l|l|l|l|l|l|l|}
\hline $\mathrm{pH}$ & $\mathrm{BV}_{1}$ & $\mathrm{BV}_{2}$ & $\mathrm{BV}_{3}$ & $\left(\mathrm{~V}_{3}-\mathrm{V}_{2}\right)$ & $\mathrm{n}$ & $\mathrm{pL}$ & $\log \left(\frac{n-1}{2-n}\right)$ & LogK $_{2}$ \\
\hline 9.51 & 5.55 & 6.66 & 6.71 & 0.05 & 0.9650 & 1.67 & & \\
9.73 & 5.55 & 6.78 & 6.84 & 0.06 & 1.4042 & 1.47 & -0.1686 & 1.3014 \\
10.00 & 5.60 & 6.90 & 6.93 & 0.06 & 1.7838 & 1.23 & 0.5593 & 1.7893 \\
10.23 & 5.65 & 7.05 & 7.10 & 0.06 & 3.1429 & 1.10 & & \\
10.49 & 5.70 & 7.10 & 7.18 & 0.07 & 3.6492 & 0.83 & & \\
\hline
\end{tabular}

LogK $_{2}($ Average value $)=1.5453 \pm 0.3450$

Table 13: Point-wise method, Mg (Unhydrolysed PSHA)

\begin{tabular}{|l|l|l|l|l|l|l|l|l|}
\hline $\mathrm{pH}$ & $\mathrm{BV}_{1}$ & $\mathrm{BV}_{2}$ & $\mathrm{BV}_{3}$ & $\mathrm{~V}_{3}-\mathrm{V}_{2}$ & $\mathrm{n}$ & $\mathrm{pL}$ & $\log \left(\frac{n}{n-1}\right)$ & $\operatorname{Log~}_{1}$ \\
\hline 8.50 & 5.30 & 5.81 & 5.85 & 0.04 & 0.2973 & 2.88 & -0.3736 & 2.5064 \\
8.72 & 5.35 & 5.90 & 5.94 & 0.04 & 0.3099 & 2.66 & -0.3477 & 2.3123 \\
9.00 & 5.40 & 6.00 & 6.04 & 0.04 & 0.3236 & 2.38 & -0.3202 & 2.0598 \\
9.22 & 5.45 & 6.10 & 6.15 & 0.05 & 0.4297 & 2.17 & -0.1230 & 2.0470 \\
9.51 & 5.50 & 6.20 & 6.26 & 0.06 & 0.5500 & 1.89 & 0.0871 & 1.9771 \\
9.73 & 5.55 & 6.33 & 6.40 & 0.07 & 0.7000 & 1.67 & 0.3680 & 2.0380 \\
\hline
\end{tabular}

LogK $_{1}$ (Average value) $=2.1568 \pm 0.2069$

Table 14: Point-wise method, Mg (Unhydrolysed PSHA)

\begin{tabular}{|l|l|l|l|l|l|l|l|l|}
\hline $\mathrm{pH}$ & $\mathrm{BV}_{1}$ & $\mathrm{BV}_{2}$ & $\mathrm{BV}_{3}$ & $\mathrm{~V}_{3}-\mathrm{V}_{2}$ & $\mathrm{n}$ & $\mathrm{pL}$ & $\log \left(\frac{n-1}{2-n}\right)$ & $\log \mathrm{K}_{2}$ \\
\hline 10.00 & 5.60 & 6.47 & 6.55 & 0.08 & 0.9148 & 1.41 & & \\
10.23 & 5.65 & 6.62 & 6.71 & 0.09 & 1.2102 & 1.20 & -0.5749 & 0.6251 \\
10.49 & 5.70 & 6.80 & 6.92 & 0.09 & 1.5968 & 1.03 & 0.1703 & 1.2003 \\
\hline
\end{tabular}

LogK $_{2}$ (Average value) $=0.9127 \pm 0.4070$

Table15:Point-wise method, Cd (Hydrolysed PSHA)

\begin{tabular}{|l|l|l|l|l|l|l|l|l|}
\hline $\mathrm{pH}$ & $\mathrm{BV}_{1}$ & $\mathrm{BV}_{2}$ & $\mathrm{BV}_{3}$ & $\left(\mathrm{~V}_{3}-\mathrm{V}_{2}\right)$ & $\mathrm{n}$ & $\mathrm{pL}$ & $\log \left(\frac{n}{1-n}\right)$ & LogK $_{1}$ \\
\hline 8.50 & 5.30 & 6.29 & 6.31 & 0.02 & 0.2750 & 2.64 & -0.4210 & 2.2190 \\
8.72 & 5.35 & 6.37 & 6.40 & 0.03 & 0.4286 & 2.42 & -0.1249 & 2.2951 \\
9.00 & 5.40 & 6.46 & 6.49 & 0.03 & 0.4648 & 2.14 & -0.0612 & 2.0788 \\
9.22 & 5.45 & 6.55 & 6.59 & 0.04 & 0.6667 & 1.96 & 0.3010 & 2.2610 \\
9.51 & 5.55 & 6.66 & 6.70 & 0.04 & 0.7720 & 1.67 & 0.5297 & 2.1997 \\
\hline
\end{tabular}

LogK $_{\mathbf{1}}$ (Average value) $=2.2108 \pm 0.0825$

Table 16: Point-wise method, Cd (Hydrolysed PSHA)

\begin{tabular}{|l|l|l|l|l|l|l|l|l|}
\hline $\mathrm{pH}$ & $\mathrm{BV}_{1}$ & $\mathrm{BV}_{2}$ & $\mathrm{BV}_{3}$ & $\left(\mathrm{~V}_{3}-\mathrm{V}_{2}\right)$ & $\mathrm{n}$ & $\mathrm{pL}$ & $\log \left(\frac{n-1}{2-n}\right)$ & Log $_{2}$ \\
\hline 9.73 & 5.55 & 6.78 & 6.83 & 0.06 & 1.4042 & 1.47 & -0.1686 & 1.3014 \\
10.00 & 5.60 & 6.90 & 6.95 & 0.06 & 1.7838 & 1.23 & 0.5593 & 1.7893 \\
10.23 & 5.65 & 7.05 & 7.10 & 0.06 & 3.1429 & 1.09 & & \\
10.49 & 5.70 & 7.10 & 7.16 & 0.06 & 3.1429 & 0.89 & & \\
& & & & & & & & \\
\hline
\end{tabular}

$\operatorname{LogK}_{2}$ (Average value) $=1.5453 \pm 0.3450$

Table 17: Point-wise method, Cd (Unhydrolysed PSHA)

\begin{tabular}{|l|l|l|l|l|l|l|l|l|}
\hline $\mathrm{pH}$ & $\mathrm{BV}_{1}$ & $\mathrm{BV}_{2}$ & $\mathrm{BV}_{3}$ & $\mathrm{~V}_{3}-\mathrm{V}_{2}$ & $\mathrm{n}$ & $\mathrm{pL}$ & $\log \left(\frac{n}{n-1}\right)$ & $\operatorname{Log~}_{1}$ \\
\hline 8.50 & 5.30 & 5.81 & 5.86 & 0.05 & 0.3717 & 2.88 & -0.2280 & 2.6520 \\
8.72 & 5.35 & 5.90 & 5.95 & 0.05 & 0.3873 & 2.66 & -0.1992 & 2.4608 \\
9.00 & 5.40 & 6.00 & 6.06 & 0.06 & 0.4853 & 2.38 & -0.0255 & 2.3545 \\
9.22 & 5.45 & 6.10 & 6.16 & 0.06 & 0.5157 & 2.18 & -0.0272 & 2.2072 \\
9.51 & 5.50 & 6.20 & 6.27 & 0.07 & 0.6417 & 1.89 & 0.2530 & 1.1430 \\
9.73 & 5.55 & 6.33 & 6.41 & 0.08 & 0.8000 & 1.69 & 0.6020 & 2.2920 \\
& & & & & & & & \\
\hline
\end{tabular}

$\operatorname{LogK}_{1}($ Average value $)=2.2516 \pm 0.5380$ 
BAJOPAS Volume 14 Number 1,June, 2021

Table 18: Point-wise method, Cd (Unhydrolysed PSHA)

\begin{tabular}{|l|l|l|l|l|l|l|l|l|}
\hline $\mathrm{pH}$ & $\mathrm{BV}_{1}$ & $\mathrm{BV}_{2}$ & $\mathrm{BV}_{3}$ & $\mathrm{~V}_{3}-\mathrm{V}_{2}$ & $\mathrm{n}$ & $\mathrm{pL}$ & $\log \left(\frac{n-1}{2-n}\right)$ & $\log \mathrm{K}_{2}$ \\
\hline 10.00 & 5.60 & 6.47 & 6.57 & 0.10 & 1.1434 & 1.43 & & \\
10.23 & 5.65 & 6.62 & 6.72 & 0.10 & 1.3448 & 1.23 & -0.2788 & 0.9512 \\
10.49 & 5.70 & 6.80 & 6.90 & 0.10 & 1.7742 & 1.03 & 0.5351 & 1.5651 \\
\hline
\end{tabular}

$\operatorname{LogK}_{2}($ Average value $)=1.2581 \pm 0.4340$

Table 19: Stepwise and overall Stability constants of thehydrolysed and unhydrolysed divalent metal (II) complexes

\begin{tabular}{|c|c|c|c|}
\hline Chelates & LogK $_{1}$ & $\log _{2}$ & Log $\beta$ \\
\hline [Cu (Hydrolysed PSHA-1) $\left.{ }_{2}\right]$ & 2.4788 & 1.4280 & 3.9068 \\
\hline$\left[\mathrm{Pb}(\text { Hydrolysed PSHA-1) })_{2}\right]$ & 2.5832 & 1.1963 & 3.7795 \\
\hline$\left[\mathrm{Cd}(\text { Hydrolysed PSHA-1 })_{2}\right]$ & 2.2108 & 1.5453 & 3.7561 \\
\hline$\left[\mathrm{Mg}(\text { Hydrolysed PSHA-1 })_{2}\right]$ & 2.1382 & 1.5453 & 3.6835 \\
\hline [Cu (Unhydrolysed PSHA-1) & 2.3059 & 1.2209 & 3.5268 \\
\hline$[\mathrm{Pb}$ (Unhydrolysed PSHA-1) 2$]$ & 2.2364 & 1.2239 & 3.4603 \\
\hline [Cd (Unhydrolysed PSHA-1) 2 ] & 2.2516 & 1.2581 & 3.5097 \\
\hline$[\mathrm{Mg}$ (Unydrolysed PSHA-1) & 2.1568 & 0.9127 & 3.0695 \\
\hline
\end{tabular}

The results obtained (Table19) shows the stepwise and overall stability constants to be not high indicating low stability of the complexes, because the solubility of most metal ions in the basic $\mathrm{pH}$ range is minimal due to metal hydroxide precipitation (Karimi, 2017). In general, the stepwise stability constants $\left(K_{1}\right.$ and $K_{2}$ ) follow the order $K_{1}>K_{2}$ for the copper, lead, magnesium and cadmium complexes respectively. The steady decrease of the values with increasing number of ligands is in agreement with the prediction made by researchers (Na'aliya, 2013). The decrease could be attributed to the fact that as the number of the ligands (Humate ions) that enters the coordination zone increases the aqua molecules available for replacement by the ligands become less. Thus, the metal ions become less electron loving with progressive intake of the ligand and this results in the decrease in the values of the constants (Na'aliya, 2013). Also the stability of the complexes is influenced by the size and number of the chelate rings(Mackay and Mackay,2002).All the complexes form rings in their structure as humate, a bidentate ligand, bond the metal ions in the ratio 1:2 (Boguta and Sokolowska, 2016) forming chelate rings. The values of the overall stability constants $(\log \beta)$ obtained for humate complexes are not high indicating low stability as the values are not high. LogK values for copper-humates (Table 3 to 6) obtained in this study are lower than those reported for the complexes of humic acids (Pandey et al., 2015; Dinu, 2013; Kaschl et al., 2010 and Gilbeto and Jorg, 2001). The values of LogK(Table 7 to 10 ) forlead-humates are lower than those reported for the lead in the literature (Dinu, 2013; Gilbeto and Jorg 2001). Log K values(Table 11 to 14 ) for magnesium-humates obtained in this study are close to those reported by (Pandey et al., 2015). Log K values of cadmium-humates (Table 15 to 18 ) obtained in this work near to the one reported by (Dinu, 2013 and Pandey et al., 2015).The difference between the reported values and the values obtained in this study might be probably as a result of acid hydrolysis of humic acid. The values of the overall stability constants $(\log \beta)$ of the copper humates complexes presented in Table 19 is high than that of other metal humate complexes, show relatively high stability of CuHA complexes, show the following order of stability: $\mathrm{Cu}>\mathrm{Pb}>\mathrm{Cd}>\mathrm{Mg}$; which are in close agreement to the findings of (Dinu, 2013 and Pandey et al., 2015).The high stability of Cuhumate chelate could be attributed to the existence of coordinate covalent bond between the complexing agents and the $\mathrm{Cu}^{2+}$ ions. Since, $\mathrm{Cu}^{2+}$ being a metal of the transitional series with $3 d^{9}$ electronic configurations can accept the electrons from the complexing agents. Similarly, the low stabilities of $\mathrm{Pb}, \mathrm{Cd}$ and $\mathrm{Mg}$ complexes could be explained by that $\mathrm{Pb}^{2+}$ with $6 s^{2}, \mathrm{Cd}^{2+}$ with $4 \mathrm{~d}^{10}$ and $\mathrm{Mg}^{2+}$ with $2 \mathrm{p}^{6}$ their electronic configuration has a completely filled $\mathrm{d}, \mathrm{p}$ and $\mathrm{s}$ orbitals. Moreover, the stabilities of metal ions with hydrolysed humic acid from peat soil were higher than those with unhydrolysed humic acid from peat soil; which is ascribed to the high content of acidity in hydrolysed humic acid than unhydrolysed humic acid. 
BAJOPAS Volume 14 Number 1,June, 2021 CONCLUSION

The values of logk for $\mathrm{Cu}(\mathrm{II})$ hydrolysed humic acid complex was higher followed by $\mathrm{Pb}$ (II), $\mathrm{Cd}(\mathrm{II})$ and $\mathrm{Mg}$ (II) hydrolysed humic acid complexes as compared with metal(II) unhydrolysed humic acid complexes. This indicates acid hydrolysis of humic acid can

\section{REFERENCES}

Almeida, V.R. and Szpoganicz, B. (2015). Humic Acid Potentiometric Response Patterns:Out- of Equilibrium Properties and Species Distribution Modelling. Chemical. Biol. Technol. Agric. 2: 17.

Anđelković, T., Nikolić, R., Bojić, A.,Anđelković, D., and Nikolic G.,(2010). Binding of Cadmium to Soil Humic Acid as A Function of Carboxyl Group Content. Macedonian Journal of Chemistry and Chemical Engineering.29(2): 215-224.

Anil, B. N. and Maroti, N. (2008). Studies on Influence of Die-Lectric Constants on Complex Equilibria between Substituted Py-Razalines and Lanthanide Metal Ions pH-Metrically. Amer.-Euras. scient. Res. 3(2): 212-216.

Ashok, K., Pandey, S. P. and Misra, V (2000). Stability Constants of Metal-Humic Acid Complexes and its Role in Environmental Detoxification. Journal of Ecotoxicology and Environmental Safety. 47(2):157-200.

Badr, M. H., El-Halafawi, M. H. and Abd El-al Zeid, E. R. (2012). Comparison Between the Effect of Ionic Strength on Acidity and Dissociation Constants of Humic Acids Extracted from Sewage Sludge and Nile Water Hyacinth Composts.Global Journal of Environmental Research 6 (1): 36-43.

Baruah, M.K., Borah, D., Saikia, P.P., Paul, S., Sharma, T. (2015). Evaluation of pKa Values of Soil Humic Acids and their Complexation Properties. International Journal of Plant \& Soil Science 6(4) : 218-228.

Boguta, P. Sokolowska, Z. (2016). Interactions of $\mathrm{Zn}$ (II) Ions with Humic Acids Isolated from Various Types of Soils. Effect of $\mathrm{pH}, \mathrm{Zn}$ Concentrations and Humic Acids Chemical Properties. Journal of Geochemical Explaration 168. 119-126.

Borges, F., Guimaraes, C., Lima, L.F.C., Pinto, I. and Reis, S.(2005). Potentiometric Studies on the Complexation of Copper(II) by Phenolic Acids as Discrete Ligand Models of enhance the complexation behavior of humic acid with metal (II) ions. However, the higher values of $\log \beta$ for $\mathrm{Cu}(\mathrm{II}), \mathrm{Pb}(\mathrm{II}), \mathrm{Cd}(\mathrm{II})$ and $\mathrm{Mg}(\mathrm{II})$ hydrolysed humic acid complexes indicates more stable stepwise complexes formed as compared with $\mathrm{Cu}(\mathrm{II}), \mathrm{Pb}$ (II), $\mathrm{Cd}$ (II) and $\mathrm{Mg}(\mathrm{II})$ unhydrolysed humic acid complexes.

Humic Substances Talanta 66 (2005) 670-673.

Chefetz, B., Salloum, M. J., Deshmulkin, A. P. and Hatcher, P. (2002). Structural Components of Humic Acids as Determined by Chemical Modifications and Carbon-13 NMR, Pyrolysis, and Thermochemolysis- Gas Chromatography/Mass Spectrometry. Soil Science Society of American Journal Abstract Division S-2- Soil Chemistry66. 1159-1171.

Dinu, M. I. (2013). Metals Complexation with Humic Acids in Surface Water of Different Environ. Sci. Technol. 31(1): 1-17.

Fernandes, A.N., Giacomelli, C., Giovanela, M. Vaz, D.V. Szpoganicz, B. and Maria M. D. (2009). Potentiometric Acidity Determination in Humic Substances Influenced by Different Analytical Procedures.J. Braz. Chem. Soc. 20 (9):14.

Gamal, A. H. (2015). Stability Constants of Rhenium (V) Metal Complexes with Selected Drugs. Pyrex Journal of Research in Environmental Studies. 2(2): 006-014.

Janrao, D. M., Pathan, J., Kayande, D.D., and Mulla, J.J. (2014). An Over View of Potentiometric Determination of Stability Constants of Metal Complexes. Sci. Revs. Chem. Commun.: 4(1), 2014, 11-24.

Karimi, H. (2017). Effect of pH and Initial Pb(II) Concentration on the Lead Removal Efficiency from Waste Water Using $\mathrm{Ca}(\mathrm{OH})_{2}$. International Journal of Water and Waste Water Treatment 3.2

Kaschl, A. Romheld, V. and Chen, Y. (2010). Binding of Cadmium, Copper and Zinc to Humic Substances Originating from Municipal Solid Waste Compost. Israel Journal of Chemistry Vol. 42(1): 89-98.

Kostic, I. S., Tatjana, P, A., Nikolic, R. S., Cvetkovic, T. P., Pavlovic, D. D., Aleksandar, L.J. and Bojic, A. (2012). Comparative Study of Binding Strengths of Heavy Metals with Humic Acid. J.serb. Chem. Soc. 76(9) pp 1-20. 
BAJOPAS Volume 14 Number 1,June, 2021

Na'aliya, J. (2013). Determination of Stepwise Stability Constants and Gibbs free Energy Change of Trisprolina to Complexes of some Divalent Transition Metal ions. Bayero Journal of Pure and Applied Sciences 6(2): 112-114.

Omar, A. A. and Ali, E. A. (2015). Potentiometric Studies on Complexes of $\mathrm{Cr}$ (III) and $\mathrm{Zr}$ (IV) with some Carboxylic Acids. International Journal of Advanced Chemistry, 3(1) 25-

37.

Pandey, A. K. Pandey, S. D. and Misr, V. (2015).Stability Constants of Metal- Humic Acid Complexes and Its Role in Environmental Detoxification. J. Ecotoxicology and Environmental Safety. 47(1):195-200.

Ram, N. and Raman, K.V. (1984). Stability Constants of Complexes of Metals with
Humicand Fuvic Acids under Non- acidConditions. Journal of Plant Nutrition and Soil Sciences.

147:171-176.

Santosh, D. D., Ashok, B. K., Vijay, J. T., Shivraj, G. W. and Vinay, V. W. (2011). Potentiometric Studies of Elec-Trolyte Effects on Complex Equilibria of Some Substituted 5-(2-hydroxy Phenyl) Pyrazoles. Der pharm. 3 (6): 75-83.

Sayyed, H. and Abdul Rahim, M. F. (2012). Studies of Binary Complexes of Metal Ions with Mandelic Acid by Potentiometry. Chem. J. 02 (6): 206209.

Shirvani, M. Moradian, E. Khalili, B. Bakhtiary, S. (2015). Interaction of $\mathrm{Cd}$ and $\mathrm{Pb}$ with Humate-Palygorskite and HumateSepiolite Complexes. Journal of water, air and pollution 3: 220-228. 


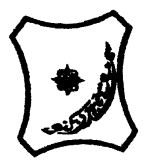

Bayero Journal of Pure and Applied Sciences, 14(1): 54 - 63

Received: November, 2020

Accepted: April, 2021

ISSN $2006-6996$

\title{
STABILITY CONSTANTS OF COMPLEXES OF METAL IONS WITH PEATSOIL HUMIC ACIDS UNDER NON-ACID-CONDITIONS
}

\author{
${ }^{* 1}$ Sabo, Yusuf ${ }^{2}$ Jimoh, W.L.O., ${ }^{3}$ Isa Baba Koki and ${ }^{4}$ Sholadoye, Q. 0. \\ ${ }^{1}$ Department of Pure and Industrial Chemistry, Bayero University, Kano \\ ${ }^{3}$ Department of Chemistry, Yusuf Maitama Sule University Kano. P.M.B. 3220 Kano, Nigeria. \\ ${ }^{4}$ Department of Chemistry, Nigerian Police Academy, Wudil, Kano-Nigeria
}

*Correspondence E-mail; saboyusuf18@yahoo.com

ABSTRACT

Stability constants of complexes of four divalent metal ions viz. $\mathrm{Cu}^{2+}, \mathrm{Pb}^{2+}, \mathrm{Mg}^{2+}$ and $\mathrm{Cd}^{2+}$ with humic acids (HA) were determined by potentiometric titration of humic acids with the corresponding salt of the divalent metals in aqueous media under non-acid-condition. The log $K$ (logarithm of the stability constant) ranged from 1.0942 to 2.7471 for metalhumic acid complexes were determined using point-wise computational method. The order of stability constants were obtained as follows: $\mathrm{Cu}>\mathrm{Pb}>\mathrm{Cd}>\mathrm{Mg}$ for metal $-\mathrm{HA}$ complexes respectively, indicating a higher degree of complexation with Cu metal ion.

Keywords: stability constant, humic acid, potentiometric titration, divalent metals, acid hydrolysis.

\section{NTRODUCTION}

The stability constant of a complex is the numerical expression of its stability and provides a quantitative measure of affinity of the metal ion to the complexing agent. An understanding of the relative stability of metal-complexes helps in predicting the behavior of metal ions in the soil (Ram and Raman, 1982). Extensive researches has been done to determine the stability constants of the complexes formed between humic acid (HA) with a number of metal ions. Ashok et al., (2000) reported that humic acid with hydroxyl, phenoxyl and carboxyl reactive groups can form coordination compound with metal ions at $\mathrm{pH}$ 3.5. The stability constants(Log K) for different metalhumic acid complexes indicated the following order of the stabilities of complexes formed between humic acid and metal ion, $\mathrm{Cu}>\mathrm{Fe}$ $>\mathrm{Pb}>\mathrm{Ni}>\mathrm{Co}>\mathrm{Ca}>\mathrm{Cd}>\mathrm{Zn}>\mathrm{Mn}>\mathrm{Mg}$. Andelkovic et al., (2010) investigated the binding of $\mathrm{Cd}$ (II) to soil humic acid at pH 6.5 and in $0.1 \mathrm{M} \mathrm{KNO}_{3}$ ionic medium. The stability constant for binding indicating greater stability in the case when carboxyl groups are involved in complexation reaction. Kostic et al.,(2012) investigated the complexation of humic acid with certain heavy metal ions (Co(II), $\mathrm{Ni}(\mathrm{II}), \mathrm{Cu}(\mathrm{II})$,
$\mathrm{Zn}(\mathrm{II})$, and $\mathrm{Pb}(\mathrm{II})$. The experiment was performed at $25^{\circ} \mathrm{C}$, at pH 4.0 and ionic strength of $0.01 \mathrm{M}$. Stability constant of complex between $\mathrm{Pb}$ (II) ions and humic acid is greater than stability constants of other investigated metalhumate complexes. Bogata and Sokolowska (2016) analyses the interaction between humic acids from different soils and $\mathrm{Zn}$ (II) ions at wide concentration ranges and at $\mathrm{pH} 5$. Studies have showed significant impact of $\mathrm{Zn}$ concentration, $\mathrm{pH}$ and some properties of humic acids with zinc.But all of these studies were limited to acidic $\mathrm{pH}$ range. Therefore, the present study was carried out to determine and compare the stability constants of complexes of metal ions with hydrolysed peat soil humic acid and unhydrolysed peat soil humic under non-acid conditions.

\section{MATERIALS AND METHODS}

Analytical grade chemicals used includes hydrochloric acid $(\mathrm{HCl})$, nitric acid $\left(\mathrm{HNO}_{3}\right)$, sodium hydroxide $(\mathrm{NaOH})$, lead nitrate $\mathrm{Pb}\left(\mathrm{NO}_{3}\right)_{2}$, copper nitrate $\mathrm{Cu}\left(\mathrm{NO}_{3}\right)_{2} \cdot 3 \mathrm{H}_{2} \mathrm{O}$, cadmium nitrate $\mathrm{Cd}\left(\mathrm{NO}_{3}\right)_{2} \cdot 4 \mathrm{H}_{2} \mathrm{O}$, magnesium nitrate $\mathrm{Mg}\left(\mathrm{NO}_{3}\right)_{2} \cdot 6 \mathrm{H}_{2} \mathrm{O}$, potassium nitrate $\left(\mathrm{KNO}_{3}\right)$, calcium chloride $\left(\mathrm{CaCl}_{2}\right)$, (sigma-Aldrich). Dowex 50WX8, (20-50 mesh) from Fluka. 


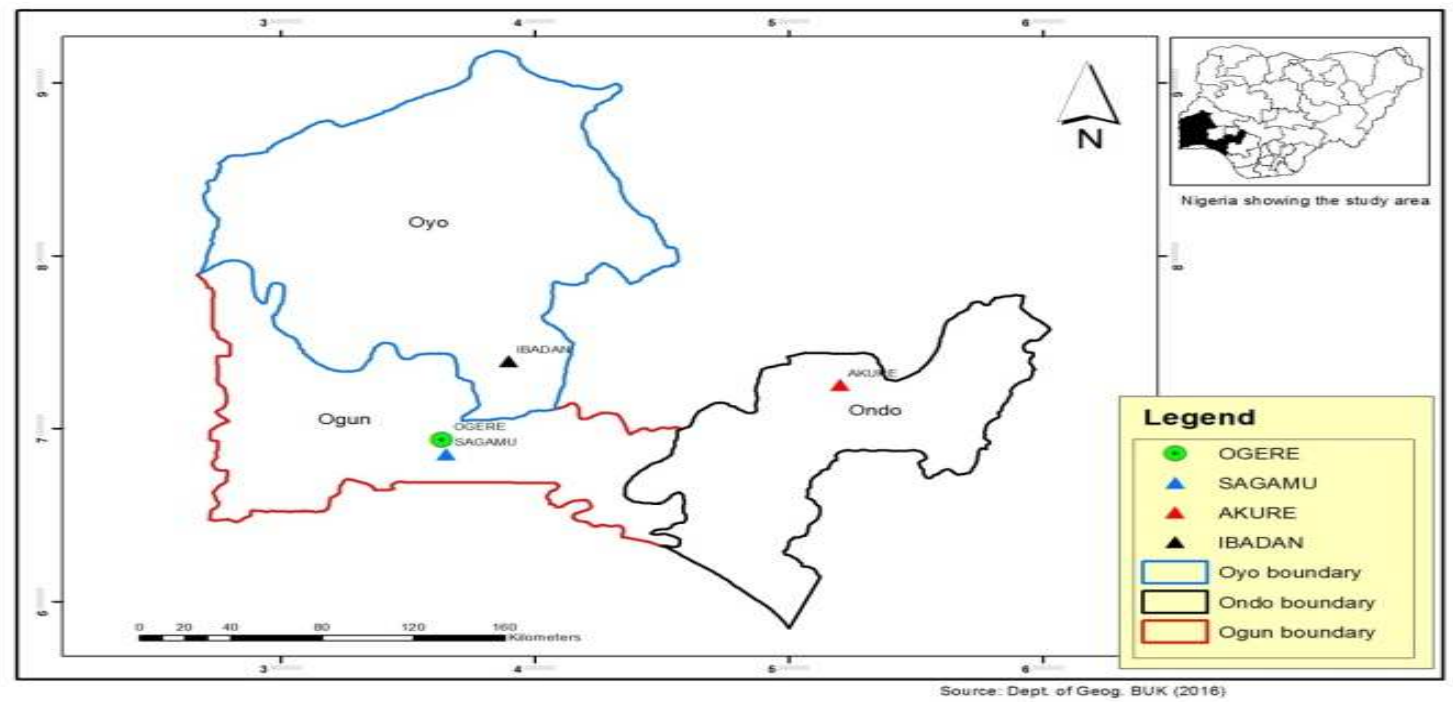

Figure 1: Map showing the sampling point at Sagamu Town, Ogun State.

\section{Description of Sampling Area}

Sagamu has geographical coordinates between $6^{\circ} 50^{\prime}$ north; $3^{\circ} 38^{\prime}$ east is located in south western region of Nigeria. The region has tropical wet and dry climate with a lengthy wet season and relatively constant temperatures throughout the course of the year. Wet season runs from March to October, November to December forms the region dry season. The vegetation type of the region is savannah which is really grassland with small bushes and occasional big trees. Grassland soils have substantially higher organic matter content than forest soils (Novackova, 2011).

\section{Sample Collection}

The Peatsoil samples were collected from four different sampling points $(0-10 \mathrm{~cm}$ depth) in Sagamu into polyethylene bag with plastic spoons. Samples were taken to the laboratory, extraneous materials were removed; the samples were air-dried, crushed and ground to a fine powder in a mortar passed through a $0.20 \mathrm{~mm}$ sieve. The samples were kept for analysis.

\section{Isolation and purification of humic acid from peat soil sample}

Peatsoil sample $(100 \mathrm{~g})$ was mixed with 1000 $\mathrm{cm}^{3}$ of $0.1 \mathrm{M} \mathrm{NaOH}$ solution, shaken for 3hours and left to stand overnight. Dark-coloured supernatant was obtained and decanted from solid residue. The dark-coloured supernatant was acidified to $(\mathrm{pH}=1.0)$ with $6 \mathrm{M} \mathrm{HCl}$ stirred and allowed to stand for 6 hours. Yellowish brown supernatant and dark-brown precipitate were obtained. The yellowish brown supernatant was decanted followed by centrifuge and discarded. The dark-brown precipitate was mixed with $500 \mathrm{~cm}^{3}$ of $0.1 \mathrm{M} \mathrm{NaOH}$ solution followed by passing through dowex resin. The dark-brown solution was acidified to $(\mathrm{pH}=1.0)$ with $6 \mathrm{M} \mathrm{HCl}$ stirred and allowed to stand for 3 hours. The dark-brown precipitate was washed several times with deionized water. The supernatant was treated with $\mathrm{AgNO}_{3}$ solution until no white precipitate observed. The humic acid was transferred to weighed crucible and dried at $60^{\circ} \mathrm{C}$ in an oven for 12 hours. The humic acid was cooled and dried in the desiccator, weighed and recorded. The obtained humic acid was dried again at $60^{\circ} \mathrm{C}$ for additional 6 hours cooled and dried in the desiccator, weighed and recorded constant weight was obtained (Baruah et al., 2015).

\section{FT-IR analysis}

FT-IR spectra of humic acid sample was analysed using Carry 630 FT-IR Agilent Technologies.

Unhydrolysed compost humic acid

The unhydrolysed humic acid was obtained after isolation and purification of compost humic acid and kept for investigation.

\section{Acid hydrolysis of Peatsoil acid}

Peatsoil humic acid sample (1g) was refluxed for 12 hours at $\left(160^{\circ} \mathrm{C}\right)$ with $50 \mathrm{~cm}^{3}$ of $6 \mathrm{M} \mathrm{HCl}$. The mixture was allowed to cool, decanted, and centrifuged after hydrolysis. The insoluble residues were washed with distilled water via centrifugation several times, and the supernatant was treated with $\mathrm{AgNO}_{3}$ solution until no white precipitate was observed. The residue was thoroughly dried over $\mathrm{CaCl}_{2}$ in a desiccator at room temperature (Chefetz et al., 2002). Finally, the obtained hydrolysed humic acid was kept for investigation. 
BAJOPAS Volume 14 Number 1,June, 2021 Potentiometric Titrations

Potentiometric measurements were carried out using a pH-meter Jenway (model 3510) with combine electrode, the sensitivity of the $\mathrm{pH}$ meter is 0.01 units. The $\mathrm{pH}$ meter was switched on half an hour before starting the titration for initial warm up of the instrument. The instrument was calibrated with an aqueous standard buffer solution of $\mathrm{pH} 4.00$ and 10.0 (borate buffer) prepared from a "Qualigens" buffer tablets.

The following sets of solutions were prepared in a $250 \mathrm{~cm}^{3}$ volumetric flask separately for $\mathrm{pH}$ metric titrations.

(i) $5 \mathrm{~cm}^{3} 0.1 \mathrm{M} \mathrm{HCl}+40 \mathrm{~cm}^{3}$ deionized water

(ii) $5 \mathrm{~cm}^{3} 0.1 \mathrm{M} \mathrm{HCl}+39 \mathrm{~cm}^{3}$ deionized water $+1 \mathrm{~cm}^{3} 0.15 \mathrm{gcm}^{-3}$ humic acid

(iii) $5 \mathrm{~cm}^{3} 0.1 \mathrm{M} \mathrm{HCl}+37 \mathrm{~cm}^{3}$ deionized water $+1 \mathrm{~cm}^{3} 0.15 \mathrm{gcm}^{-3}$ humic acid

$$
+2 \mathrm{~cm}^{3} \quad 0.01 \mathrm{M} \mathrm{Cu} \text { (II) }
$$

The solutions were titrated against standardized $0.110 \mathrm{MNaOH}$ separately. The total volume of each mixture was adjusted to $50 \mathrm{~cm}^{3}$ and the ionic strength of the solutions was maintained constant at by adding appropriate amount of stock solution of $1 \mathrm{M} \mathrm{KNO}_{3}$ (Gamal, 2015; Omar and Ali, 2015). A magnetic stirrer was used to achieve thorough mixing of the interacting solutions at $550 \mathrm{rpm}$. The same set of experimental conditions was applied for potentiometric titration of remaining samples.

\section{Evaluation of pKa of Hydrolysed peat soil Humic Acids}

The proton-ligand formation number $\mathrm{n}_{\mathbf{A}}$ were calculated by Irving and Rossotti expression (Omar and Ali, 2015).

$\mathrm{nA}=\mathrm{Y}-\frac{(\mathrm{V} 2-\mathrm{V1})(\mathrm{No}-\mathrm{Eo})}{(\mathrm{VO}+\mathrm{V1}) \mathrm{TCL}}$ 1

Where: $Y$ is number of dissociable proton, $\left(\mathrm{V}_{2^{-}}\right.$ $V_{1}$ ) is the measure of displacement of the ligand curve relative to acid curve, $\mathrm{N}^{\circ}$ and $\mathrm{E}^{\circ}$ are the resultant concentration of alkali solution, free acid solution, $\mathrm{T}_{\mathrm{cL}}{ }^{\circ}$ is the total ligand concentration, $\mathrm{V}^{\circ}$ is the total volume of titration solution, $V_{1}$ is the volume of alkali added to acid solution, $V_{2}$ is the volume of alkali added to acid solution + ligand solution, acid dissociation constants (pKa - values) of ligand were calculated by algebraic method point wise calculation (Tables 1 ). The dissociation constants (pKa) were calculated according to the following relation:

$\mathrm{pKa}=\mathrm{pH}+\log \left(\frac{n A}{1-n A}\right)$ 2

Where: pKa is the acid dissociation constant, $\mathrm{n}_{\mathrm{A}}$ is the Proton-ligand formation number and $\mathrm{pH}$ is the pH-values (Omar and Ali, 2015).

\section{Determination of metal-ligand stability constants $(\log K)$ of complexes}

The potentiometric measurement for the determination of stability constant of a complex in solution is based on the fact that the redox potential of the couple $\frac{M^{+(m-n)}}{M^{+m}}$ is shifted significantly on complexation of the metal ion with the ligand. This method involves change in hydrogen ion concentration $\left[\mathrm{H}^{+}\right]$due to the displacement or association of one or more protons taking place during complexation reaction. This change can be found out by titrating the solutions containing free acid, acid with ligand, and acid with ligand and metal ion, individually against a standard alkali solution at a constant ionic strength or temperature. Either ionic strength or temperature may be varied for different sets of solutions. In all the cases, the change in the $\mathrm{pH}$ of the solution is measured after each addition of a known amount of alkali to the reaction cell which contains the reaction mixture. The titration curves are then drawn by plotting the measured $\mathrm{pH}$ values against the corresponding volume of alkali added and the stability constants of the complexes are determined from the titration curves by employing $\mathrm{pH}$-metric titration technique given by (Irving and Rossoti).

Metal-ligand stability constants ( $\log \mathrm{K}$ ) were determined by using the following relations:

$$
\bar{n}=\frac{\left(V_{3}-V_{2}\right)\left(E^{0}+N^{0}\right)}{\left(V^{0}+V_{2}\right) \bar{n}_{A} T_{m}^{0}}
$$

and

$$
P L=\log _{10}\left\{\frac{1+\beta_{n}^{H} \frac{1}{[\text { anti } \log \mathrm{pH}]^{\mathrm{n}}}}{\mathrm{T}_{\mathrm{L}}^{0}-n \bar{T}_{m}^{0}} \mathrm{X} \frac{\left(V^{0}+V_{3}\right)}{V^{0}}\right\}
$$


BAJOPAS Volume 14 Number 1,June, 2021

Where $T_{L}, T^{\circ}, E^{\circ}$, and $V^{\circ}$ havethe same significance as in equation (1) above, $T_{m}$ denotes the total concentration of metal present in solution, $V_{3}$ is the volume of metal ions present in solution and $\beta^{H}$ is the overall proton ligand stability constant. The metal-ligand stability constants (log K) were determined by employing point wise computational Method (eq. 5 and 6).

$\operatorname{LogK}_{1}=\log \left(\frac{n}{1-n}\right)+\mathrm{pL}$ .5

$\operatorname{LogK}_{2}=\log \left(\frac{1-n}{2-n}\right)+\mathrm{pL}$ ...6

Where: Log $\mathrm{K}$ is the metal-ligand stability constant, $\mathrm{pL}$ is the Free ligand exponent function, $\mathbf{n}$ is the Average number of ligand attached with metal ion (Janraoet al., 2014). The results obtained were analyzed by an ORIGIN 2016 program using titration data and then the proton-ligand stability constants (pKa) and Metal-ligand stability constant (LogK) calculated (Omar and Ali, 2015).

\section{RESULTS AND DISCUSSION}

Fourier transformed infrared (FT-IR) spectra of isolated humic acid from peat soils Figure 2 had distinct clear absorption bands indicating the presence of major humic acid structural elemental groups such as $\mathrm{H}$ bonded $\mathrm{OH}$ $\left(3680 \mathrm{~cm}^{-1}\right.$ peak $), C=0$ of carbonyl $\left(1721 \mathrm{~cm}^{-1}\right.$ peak), functional groups of aliphatic components $\mathrm{CH}_{2}\left(2918 \mathrm{~cm}^{-1}\right.$ peak) and $\mathrm{C}-\mathrm{O}$ stretching of polysaccharide $\left(1168 \mathrm{~cm}^{-1}\right.$ peak). The positions of the absorption bands of the spectra fell within typical major absorption bands of humic acid which is at frequencies 3680, 2918, 1721, 1168 $\mathrm{cm}^{-1}$. The first peak centred in the vicinity of $3680 \mathrm{~cm}^{-1}$ region is attributed to phenol $\mathrm{OH}$ group bounded by intermolecular $\mathrm{H}$ bonds. The $2918 \mathrm{~cm}^{-1}$ band usually has absorption maximum at $2918 \mathrm{~cm}^{-1}$ which is due to $\mathrm{C}-\mathrm{H}$ stretching of alkane group $\left(\mathrm{CH}_{2}\right)$. The next major absorption band is $1721 \mathrm{~cm}^{-1}$. This band has been commonly ascribed to $\mathrm{C}=\mathrm{O}$ stretching of mainly carboxyl group $(\mathrm{COOH})$ with trace amount of ketones. The last peak was observed at 1168 $\mathrm{cm}^{-1}$ due to $\mathrm{C}-\mathrm{O}$ stretching of polysaccharides and this peak appeared also in the spectra of humic acid from peat soil. The FTIR spectra of the isolated humic acid contained all major characteristic absorption peaks of humic acid. These absorption peaks indicated the presence of the major structural elements of humic acid namely $\mathrm{H}$ bonded $\mathrm{OH}, \mathrm{C}=\mathrm{C}$ of aromatic ring, $\mathrm{C}=\mathrm{O}$ of carbonyl group (both carboxyl and ketonic), $\mathrm{CH}_{2}$ group. This strongly supports the presence of humic acid.

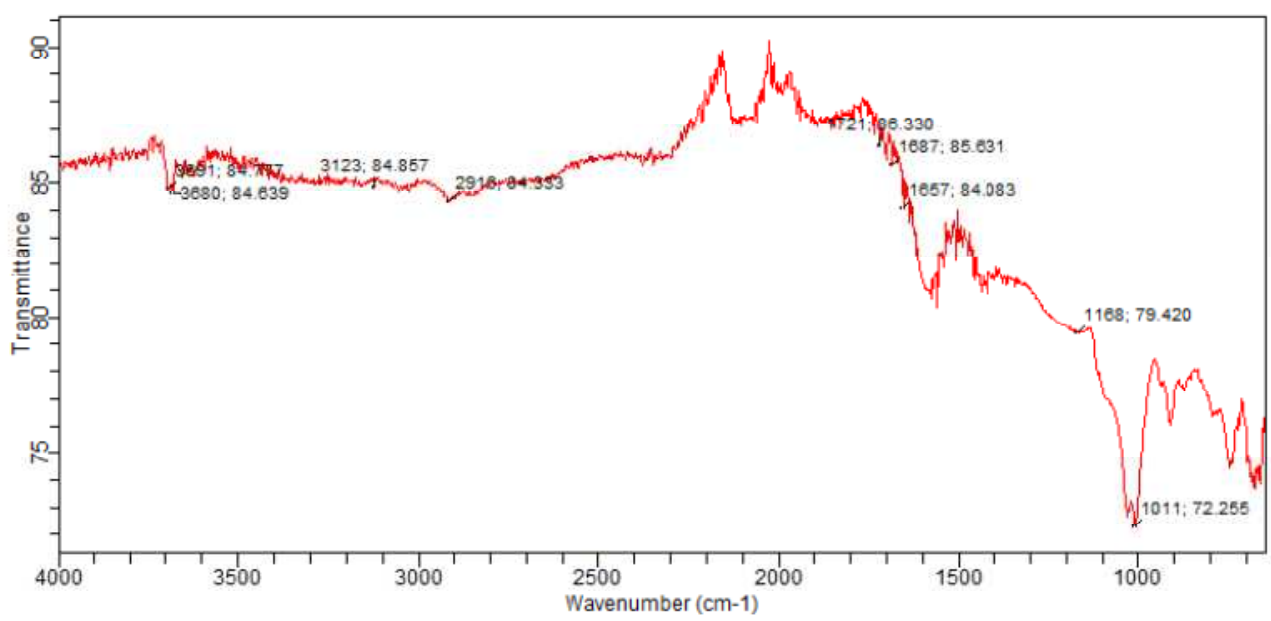

Fig. 2 : FT-IR spectraof peatsoilhumic acid (PSHA)

\section{Evaluation of acid dissociation constant (pka) of acid hydrolysed peat soil humicacid at phenolic group}

The value of the dissociation constant of the peat soil humic acid (PSHA) that underwent acidhydrolysis studied was found to be 8.9299 as shown Table 1, which is lower than the literaturevalues reported by Almeida and Szpoganics, (2015), Borges et al., (2005); Badr et al., (2012)and Fernandes et al,.(2009) of $9.73,9.47$ and 10.30. The difference between the obtained valuesand the reported values in this study might be probably as a result of acid hydrolysis of humicacid. 
BAJOPAS Volume 14 Number 1,June, 2021

Table 1: PKa of (Hydrolysed PSHA)

\begin{tabular}{|l|l|l|l|l|l|l|}
\hline $\mathrm{pH}$ & $\mathrm{BV}_{1}$ & $\mathrm{BV}_{2}$ & $\mathrm{~V}_{2}-\mathrm{V}_{1}$ & $\mathrm{nA}$ & $\log \left(\frac{n A}{1-n A}\right)$ & $\mathrm{pKa}$ \\
\hline 8.50 & 5.30 & 6.29 & 0.99 & 0.3594 & -0.2510 & 8.2490 \\
8.72 & 5.35 & 6.37 & 1.02 & 0.3400 & -0.2880 & 8.4320 \\
9.00 & 5.40 & 6.46 & 1.06 & 0.3141 & -0.3391 & 8.6609 \\
9.22 & 5.45 & 6.55 & 1.10 & 0.2882 & -0.3927 & 8.8273 \\
9.51 & 5.50 & 6.66 & 1.16 & 0.2494 & -0.4786 & 9.0314 \\
9.73 & 5.55 & 6.78 & 1.23 & 0.2041 & -0.5910 & 9.1390 \\
10.00 & 5.60 & 6.90 & 1.30 & 0.1589 & -0.7238 & 9.2762 \\
10.23 & 5.65 & 7.05 & 1.40 & 0.0941 & -0.9835 & 9.2465 \\
10.49 & 5.70 & 7.10 & 1.40 & 0.0941 & -0.9835 & 9.5065 \\
\hline
\end{tabular}

Average pKa $=8.9299 \pm 0.4186$

Table 2: PKa of (Unhydrolysed PSHA)

\begin{tabular}{|l|l|l|l|l|l|l|}
\hline $\mathrm{pH}$ & $\mathrm{BV}_{1}$ & $\mathrm{BV}_{2}$ & $\mathrm{~V}_{2}-\mathrm{V}_{1}$ & $\mathrm{nA}$ & $\log \left(\frac{\boldsymbol{n A}}{1-\boldsymbol{n}}\right)$ & $\mathrm{pKa}$ \\
\hline 8.50 & 5.30 & 5.81 & 0.51 & 0.6619 & 0.2919 & 8.7919 \\
8.72 & 5.35 & 5.90 & 0.55 & 0.6357 & 0.2418 & 8.9618 \\
9.00 & 5.40 & 6.00 & 0.60 & 0.6029 & 0.1813 & 9.1813 \\
9.22 & 5.45 & 6.10 & 0.65 & 0.5701 & 0.1226 & 9.3426 \\
9.51 & 5.50 & 6.20 & 0.70 & 0.5376 & 0.0654 & 9.5754 \\
9.73 & 5.55 & 6.33 & 0.78 & 0.4851 & -0.0259 & 9.7041 \\
10.00 & 5.60 & 6.47 & 0.87 & 0.4262 & -0.1291 & 9.8709 \\
10.23 & 5.65 & 6.62 & 0.99 & 0.3609 & -0.2481 & 9.9819 \\
10.49 & 5.70 & 6.80 & 1.10 & 0.2759 & -0.4690 & 10.0210 \\
\hline
\end{tabular}

Average pKa $=9.4923 \pm 0.4410$

Metal-ligand stability constant ( $\log \mathrm{K}$ )

The stabilityconstants require the accurate values of proton-ligand stability constants (Anil and Maroti, 2008). Metal titration curves crossed over ligand titration curve indicated the formation of complex upon proton release (Santosh, et al., 2011). If the values of n- are within range $0.2-0.8$ and $1.2-18$ this indicates the formation of $1: 1$ and 1:2 complexes (Sayyed and Mazahar, 2012).

The metal (II)-humate stepwise stability constants (log k) at phenolic group (Tables 318)

Table 3: Point-wise method, $\mathrm{Cu}$-(Hydrolysed PSHA)

\begin{tabular}{|l|l|l|l|l|l|l|l|l|}
\hline $\mathrm{pH}$ & $\mathrm{BV}_{1}$ & $\mathrm{BV}_{2}$ & $\mathrm{BV}_{3}$ & $\left(\mathrm{~V}_{3}-\mathrm{V}_{2}\right)$ & $\mathrm{n}$ & $\mathrm{pL}$ & $\log \left(\frac{n}{1-n}\right)$ & LogK $_{1}$ \\
\hline 8.50 & 5.30 & 6.29 & 6.33 & 0.04 & 0.5500 & 2.66 & 0.0871 & 2.7471 \\
8.72 & 5.35 & 6.37 & 6.41 & 0.04 & 0.5714 & 2.43 & 0.1249 & 2.5549 \\
9.00 & 5.40 & 6.46 & 6.50 & 0.04 & 0.6198 & 2.16 & 0.2122 & 2.3722 \\
9.22 & 5.45 & 6.55 & 6.59 & 0.04 & 0.6667 & 1.94 & 0.3010 & 2.2410 \\
\hline
\end{tabular}

LogK $_{1}$ (Average value) $=2.4788 \pm 0.2203$

Table 4: Point-wise method, $\mathrm{Cu}$-(Hydrolysed PSHA)

\begin{tabular}{|l|l|l|l|l|l|l|l|l|}
\hline $\mathrm{pH}$ & $\mathrm{BV}_{1}$ & $\mathrm{BV}_{2}$ & $\mathrm{BV}_{3}$ & $\left(\mathrm{~V}_{3}-\mathrm{V}_{2}\right)$ & $\mathrm{n}$ & $\mathrm{pL}$ & $\log \left(\frac{n-1}{2-n}\right)$ & LogK $_{2}$ \\
\hline 9.51 & 5.50 & 6.66 & 6.73 & 0.07 & 1.3509 & 1.70 & -0.2671 & 1.4329 \\
9.73 & 5.55 & 6.78 & 6.85 & 0.07 & 1.6383 & 1.51 & 0.2467 & 1.7567 \\
10.00 & 5.60 & 6.90 & 6.98 & 0.08 & 2.1783 & 1.31 & -0.2158 & 1.0942 \\
10.23 & 5.65 & 7.05 & 7.13 & 0.08 & 4.1904 & 1.27 & & \\
10.49 & 5.70 & 7.10 & 7.19 & 0.09 & 4.6920 & & & \\
\hline
\end{tabular}

Log $K_{2}($ Average value $)=1.4280 \pm 0.3312$ 
BAJOPAS Volume 14 Number 1,June, 2021

Table 5: Point-wise method, $\mathrm{Cu}$ (Unhydrolysed PSHA)

\begin{tabular}{|l|l|l|l|l|l|l|l|l|}
\hline $\mathrm{pH}$ & $\mathrm{BV}_{1}$ & $\mathrm{BV}_{2}$ & $\mathrm{BV}_{3}$ & $\left(\mathrm{~V}_{3}-\mathrm{V}_{2}\right)$ & $\mathrm{n}$ & $\mathrm{pL}$ & $\log \left(\frac{n}{n-1}\right)$ & Log $_{1}$ \\
\hline 8.50 & 5.30 & 5.81 & 5.85 & 0.04 & 0.2973 & 2.88 & -0.3736 & 2.5064 \\
8.72 & 5.35 & 5.90 & 5.95 & 0.05 & 0.3873 & 2.66 & -0.1992 & 2.4608 \\
9.00 & 5.40 & 6.00 & 6.05 & 0.05 & 0.4044 & 2.38 & -0.1681 & 2.2119 \\
9.22 & 5.45 & 6.10 & 6.15 & 0.06 & 0.5157 & 2.18 & -0.0272 & 2.2072 \\
9.51 & 5.50 & 6.20 & 6.27 & 0.07 & 0.6417 & 1.89 & 0.2530 & 1.1430 \\
\hline
\end{tabular}

$\operatorname{LogK}_{1}($ Average value $)=2.3059 \pm 0.6153$

Table 6:Point-wise method, $\mathrm{Cu}$ (Unhydrolysed PSHA)

\begin{tabular}{|l|l|l|l|l|l|l|l|l|}
\hline $\mathrm{pH}$ & $\mathrm{BV}_{1}$ & $\mathrm{BV}_{2}$ & $\mathrm{BV}_{3}$ & $\mathrm{~V}_{3}-\mathrm{V}_{2}$ & $\mathrm{n}$ & $\mathrm{pL}$ & $\log \left(\frac{n-1}{2-n}\right)$ & $\log \mathrm{K}_{2}$ \\
\hline 9.73 & 5.55 & 6.33 & 6.42 & 0.09 & 0.9000 & 1.69 & & \\
10.00 & 5.60 & 6.47 & 6.58 & 0.11 & 1.2578 & 1.44 & -0.4592 & 0.9808 \\
10.23 & 5.65 & 6.62 & 6.84 & 0.12 & 1.6137 & 1.26 & -0.2010 & 1.4610 \\
10.49 & 5.70 & 6.80 & 6.92 & 0.12 & 2.1052 & 1.03 & & \\
\hline
\end{tabular}

$\operatorname{LogK}_{2}$ (Average value) $=1.2209 \pm 0.3398$

Table 7:Point-wise method, Pb (Hydrolysed PSHA)

\begin{tabular}{|l|l|l|l|l|l|l|l|l|}
\hline $\mathrm{pH}$ & $\mathrm{BV}_{1}$ & $\mathrm{BV}_{2}$ & $\mathrm{BV}_{3}$ & $\left(\mathrm{~V}_{3}-\mathrm{V}_{2}\right)$ & $\mathrm{n}$ & $\mathrm{pL}$ & $\log \left(\frac{n}{1-n}\right)$ & LogK $_{1}$ \\
\hline 8.50 & 5.30 & 6.29 & 6.33 & 0.04 & 0.5500 & 2.66 & 0.0871 & 2.7471 \\
8.72 & 5.35 & 6.37 & 6.41 & 0.04 & 0.5714 & 2.43 & 0.1249 & 2.5549 \\
9.00 & 5.40 & 6.46 & 6.50 & 0.04 & 0.6198 & 2.16 & 0.2122 & 2.3722 \\
9.22 & 5.45 & 6.55 & 6.60 & 0.05 & 0.8333 & 1.96 & 0.6989 & 2.6589 \\
\hline
\end{tabular}

Log $_{\mathbf{1}}($ Average value $)=2.5832 \pm 0.1614$

Table 8:Point-wise method, Pb-(Hydrolysed PSHA)

\begin{tabular}{|l|l|l|l|l|l|l|l|l|}
\hline $\mathrm{pH}$ & $\mathrm{BV}_{1}$ & $\mathrm{BV}_{2}$ & $\mathrm{BV}_{3}$ & $\left(\mathrm{~V}_{3}-\mathrm{V}_{2}\right)$ & $\mathrm{n}$ & $\mathrm{pL}$ & $\log \left(\frac{n-1}{2-n}\right)$ & $\log \mathrm{K}_{2}$ \\
\hline 9.51 & 5.50 & 6.66 & 6.71 & 0.05 & 0.9650 & 1.67 & & \\
9.73 & 5.55 & 6.78 & 6.83 & 0.05 & 1.1702 & 1.44 & & \\
10.00 & 5.60 & 6.90 & 6.90 & 0.05 & 1.4864 & 1.22 & -0.0237 & 1.1963 \\
10.23 & 5.65 & 7.05 & 7.10 & 0.05 & 2.0190 & 1.09 & & \\
10.49 & 5.70 & 7.10 & 7.17 & 0.07 & 3.6492 & 1.00 & & \\
\hline
\end{tabular}

Log $K_{2}$ (Average value) $=1.1963$

Table 9: Point-wise method, Pb (Unhydrolysed PSHA)

\begin{tabular}{|l|l|l|l|l|l|l|l|l|}
\hline $\mathrm{pH}$ & $\mathrm{BV}_{1}$ & $\mathrm{BV}_{2}$ & $\mathrm{BV}_{3}$ & $\mathrm{~V}_{3}-\mathrm{V}_{2}$ & $\mathrm{n}$ & $\mathrm{pL}$ & $\begin{array}{l}\text { Log } \\
\left(\frac{n}{n-1}\right)\end{array}$ & Log $\mathrm{K}_{1}$ \\
\hline 8.50 & 5.30 & 5.81 & 5.85 & 0.04 & 0.2973 & 2.88 & -0.3736 & 2.5064 \\
8.72 & 5.35 & 5.90 & 5.94 & 0.04 & 0.3099 & 2.66 & -0.5477 & 2.3123 \\
9.00 & 5.40 & 6.00 & 6.05 & 0.05 & 0.4044 & 2.38 & -0.1681 & 2.2119 \\
9.22 & 5.45 & 6.10 & 6.15 & 0.06 & 0.5157 & 2.18 & 0.0272 & 2.2072 \\
9.51 & 5.50 & 6.20 & 6.26 & 0.07 & 0.6417 & 1.89 & 0.2530 & 2.1430 \\
9.73 & 5.55 & 6.40 & 6.40 & 0.07 & 0.7000 & 1.67 & 0.3680 & 2.0380 \\
\hline
\end{tabular}

LogK $_{1}$ (Average value) $=2.2364 \pm 0.1602$

Table 10: Point-wise method, Pb (Unhydrolysed PSHA)

\begin{tabular}{|l|l|l|l|l|l|l|l|l|}
\hline $\mathrm{pH}$ & $\mathrm{BV}_{1}$ & $\mathrm{BV}_{2}$ & $\mathrm{BV}_{3}$ & $\mathrm{~V}_{3}-\mathrm{V}_{2}$ & $\mathrm{n}$ & $\mathrm{pL}$ & $\log \left(\frac{n-1}{2-n}\right)$ & $\log \mathrm{K}_{2}$ \\
\hline 10.00 & 5.60 & 6.47 & 6.55 & 0.08 & 1.9503 & 1.41 & & \\
10.23 & 5.65 & 6.62 & 6.72 & 0.11 & 1.4792 & 1.26 & -0.0361 & 1.2239 \\
\hline
\end{tabular}

$\operatorname{LogK}_{2}$ (Average value) $=1.2239$

Table 11: Point-wise method, Mg (Hydrolysed PSHA)

\begin{tabular}{|l|l|l|l|l|l|l|l|l|}
\hline $\mathrm{pH}$ & $\mathrm{BV}_{1}$ & $\mathrm{BV}_{2}$ & $\mathrm{BV}_{3}$ & $\left(\mathrm{~V}_{3}-\mathrm{V}_{2}\right)$ & $\mathrm{n}$ & $\mathrm{pL}$ & $\log \left(\frac{n}{n-1}\right)$ & LogK $_{1}$ \\
\hline 8.50 & 5.30 & 6.29 & 6.31 & 0.02 & 0.2750 & 2.64 & -0.4290 & 2.2110 \\
8.72 & 5.35 & 6.37 & 6.39 & 0.02 & 0.2858 & 2.42 & -0.3978 & 2.0222 \\
9.00 & 5.40 & 6.46 & 6.49 & 0.03 & 0.4648 & 2.14 & -0.0612 & 2.0788 \\
9.22 & 5.45 & 6.55 & 6.59 & 0.04 & 0.6667 & 1.94 & 0.3010 & 2.2410 \\
\hline
\end{tabular}

$\log _{\mathbf{1}}($ Average value) $=2.1382 \pm 0.1046$ 
BAJOPAS Volume 14 Number 1,June, 2021

Table 12: Point-wise method, Mg (Hydrolysed PSHA)

\begin{tabular}{|l|l|l|l|l|l|l|l|l|}
\hline $\mathrm{pH}$ & $\mathrm{BV}_{1}$ & $\mathrm{BV}_{2}$ & $\mathrm{BV}_{3}$ & $\left(\mathrm{~V}_{3}-\mathrm{V}_{2}\right)$ & $\mathrm{n}$ & $\mathrm{pL}$ & $\log \left(\frac{n-1}{2-n}\right)$ & LogK $_{2}$ \\
\hline 9.51 & 5.55 & 6.66 & 6.71 & 0.05 & 0.9650 & 1.67 & & \\
9.73 & 5.55 & 6.78 & 6.84 & 0.06 & 1.4042 & 1.47 & -0.1686 & 1.3014 \\
10.00 & 5.60 & 6.90 & 6.93 & 0.06 & 1.7838 & 1.23 & 0.5593 & 1.7893 \\
10.23 & 5.65 & 7.05 & 7.10 & 0.06 & 3.1429 & 1.10 & & \\
10.49 & 5.70 & 7.10 & 7.18 & 0.07 & 3.6492 & 0.83 & & \\
\hline
\end{tabular}

LogK $_{2}($ Average value $)=1.5453 \pm 0.3450$

Table 13: Point-wise method, Mg (Unhydrolysed PSHA)

\begin{tabular}{|l|l|l|l|l|l|l|l|l|}
\hline $\mathrm{pH}$ & $\mathrm{BV}_{1}$ & $\mathrm{BV}_{2}$ & $\mathrm{BV}_{3}$ & $\mathrm{~V}_{3}-\mathrm{V}_{2}$ & $\mathrm{n}$ & $\mathrm{pL}$ & $\log \left(\frac{n}{n-1}\right)$ & $\operatorname{Log~}_{1}$ \\
\hline 8.50 & 5.30 & 5.81 & 5.85 & 0.04 & 0.2973 & 2.88 & -0.3736 & 2.5064 \\
8.72 & 5.35 & 5.90 & 5.94 & 0.04 & 0.3099 & 2.66 & -0.3477 & 2.3123 \\
9.00 & 5.40 & 6.00 & 6.04 & 0.04 & 0.3236 & 2.38 & -0.3202 & 2.0598 \\
9.22 & 5.45 & 6.10 & 6.15 & 0.05 & 0.4297 & 2.17 & -0.1230 & 2.0470 \\
9.51 & 5.50 & 6.20 & 6.26 & 0.06 & 0.5500 & 1.89 & 0.0871 & 1.9771 \\
9.73 & 5.55 & 6.33 & 6.40 & 0.07 & 0.7000 & 1.67 & 0.3680 & 2.0380 \\
\hline
\end{tabular}

LogK $_{1}$ (Average value) $=2.1568 \pm 0.2069$

Table 14: Point-wise method, Mg (Unhydrolysed PSHA)

\begin{tabular}{|l|l|l|l|l|l|l|l|l|}
\hline $\mathrm{pH}$ & $\mathrm{BV}_{1}$ & $\mathrm{BV}_{2}$ & $\mathrm{BV}_{3}$ & $\mathrm{~V}_{3}-\mathrm{V}_{2}$ & $\mathrm{n}$ & $\mathrm{pL}$ & $\log \left(\frac{n-1}{2-n}\right)$ & $\log \mathrm{K}_{2}$ \\
\hline 10.00 & 5.60 & 6.47 & 6.55 & 0.08 & 0.9148 & 1.41 & & \\
10.23 & 5.65 & 6.62 & 6.71 & 0.09 & 1.2102 & 1.20 & -0.5749 & 0.6251 \\
10.49 & 5.70 & 6.80 & 6.92 & 0.09 & 1.5968 & 1.03 & 0.1703 & 1.2003 \\
\hline
\end{tabular}

LogK $_{2}$ (Average value) $=0.9127 \pm 0.4070$

Table15:Point-wise method, Cd (Hydrolysed PSHA)

\begin{tabular}{|l|l|l|l|l|l|l|l|l|}
\hline $\mathrm{pH}$ & $\mathrm{BV}_{1}$ & $\mathrm{BV}_{2}$ & $\mathrm{BV}_{3}$ & $\left(\mathrm{~V}_{3}-\mathrm{V}_{2}\right)$ & $\mathrm{n}$ & $\mathrm{pL}$ & $\log \left(\frac{n}{1-n}\right)$ & LogK $_{1}$ \\
\hline 8.50 & 5.30 & 6.29 & 6.31 & 0.02 & 0.2750 & 2.64 & -0.4210 & 2.2190 \\
8.72 & 5.35 & 6.37 & 6.40 & 0.03 & 0.4286 & 2.42 & -0.1249 & 2.2951 \\
9.00 & 5.40 & 6.46 & 6.49 & 0.03 & 0.4648 & 2.14 & -0.0612 & 2.0788 \\
9.22 & 5.45 & 6.55 & 6.59 & 0.04 & 0.6667 & 1.96 & 0.3010 & 2.2610 \\
9.51 & 5.55 & 6.66 & 6.70 & 0.04 & 0.7720 & 1.67 & 0.5297 & 2.1997 \\
\hline
\end{tabular}

LogK $_{\mathbf{1}}$ (Average value) $=2.2108 \pm 0.0825$

Table 16: Point-wise method, Cd (Hydrolysed PSHA)

\begin{tabular}{|l|l|l|l|l|l|l|l|l|}
\hline $\mathrm{pH}$ & $\mathrm{BV}_{1}$ & $\mathrm{BV}_{2}$ & $\mathrm{BV}_{3}$ & $\left(\mathrm{~V}_{3}-\mathrm{V}_{2}\right)$ & $\mathrm{n}$ & $\mathrm{pL}$ & $\log \left(\frac{n-1}{2-n}\right)$ & Log $_{2}$ \\
\hline 9.73 & 5.55 & 6.78 & 6.83 & 0.06 & 1.4042 & 1.47 & -0.1686 & 1.3014 \\
10.00 & 5.60 & 6.90 & 6.95 & 0.06 & 1.7838 & 1.23 & 0.5593 & 1.7893 \\
10.23 & 5.65 & 7.05 & 7.10 & 0.06 & 3.1429 & 1.09 & & \\
10.49 & 5.70 & 7.10 & 7.16 & 0.06 & 3.1429 & 0.89 & & \\
& & & & & & & & \\
\hline
\end{tabular}

$\operatorname{LogK}_{2}$ (Average value) $=1.5453 \pm 0.3450$

Table 17: Point-wise method, Cd (Unhydrolysed PSHA)

\begin{tabular}{|l|l|l|l|l|l|l|l|l|}
\hline $\mathrm{pH}$ & $\mathrm{BV}_{1}$ & $\mathrm{BV}_{2}$ & $\mathrm{BV}_{3}$ & $\mathrm{~V}_{3}-\mathrm{V}_{2}$ & $\mathrm{n}$ & $\mathrm{pL}$ & $\log \left(\frac{n}{n-1}\right)$ & $\operatorname{Log~}_{1}$ \\
\hline 8.50 & 5.30 & 5.81 & 5.86 & 0.05 & 0.3717 & 2.88 & -0.2280 & 2.6520 \\
8.72 & 5.35 & 5.90 & 5.95 & 0.05 & 0.3873 & 2.66 & -0.1992 & 2.4608 \\
9.00 & 5.40 & 6.00 & 6.06 & 0.06 & 0.4853 & 2.38 & -0.0255 & 2.3545 \\
9.22 & 5.45 & 6.10 & 6.16 & 0.06 & 0.5157 & 2.18 & -0.0272 & 2.2072 \\
9.51 & 5.50 & 6.20 & 6.27 & 0.07 & 0.6417 & 1.89 & 0.2530 & 1.1430 \\
9.73 & 5.55 & 6.33 & 6.41 & 0.08 & 0.8000 & 1.69 & 0.6020 & 2.2920 \\
& & & & & & & & \\
\hline
\end{tabular}

$\operatorname{LogK}_{1}($ Average value $)=2.2516 \pm 0.5380$ 
BAJOPAS Volume 14 Number 1,June, 2021

Table 18: Point-wise method, Cd (Unhydrolysed PSHA)

\begin{tabular}{|l|l|l|l|l|l|l|l|l|}
\hline $\mathrm{pH}$ & $\mathrm{BV}_{1}$ & $\mathrm{BV}_{2}$ & $\mathrm{BV}_{3}$ & $\mathrm{~V}_{3}-\mathrm{V}_{2}$ & $\mathrm{n}$ & $\mathrm{pL}$ & $\log \left(\frac{n-1}{2-n}\right)$ & $\log \mathrm{K}_{2}$ \\
\hline 10.00 & 5.60 & 6.47 & 6.57 & 0.10 & 1.1434 & 1.43 & & \\
10.23 & 5.65 & 6.62 & 6.72 & 0.10 & 1.3448 & 1.23 & -0.2788 & 0.9512 \\
10.49 & 5.70 & 6.80 & 6.90 & 0.10 & 1.7742 & 1.03 & 0.5351 & 1.5651 \\
\hline
\end{tabular}

$\operatorname{LogK}_{2}($ Average value $)=1.2581 \pm 0.4340$

Table 19: Stepwise and overall Stability constants of thehydrolysed and unhydrolysed divalent metal (II) complexes

\begin{tabular}{|c|c|c|c|}
\hline Chelates & LogK $_{1}$ & $\log _{2}$ & Log $\beta$ \\
\hline [Cu (Hydrolysed PSHA-1) $\left.{ }_{2}\right]$ & 2.4788 & 1.4280 & 3.9068 \\
\hline$\left[\mathrm{Pb}(\text { Hydrolysed PSHA-1) })_{2}\right]$ & 2.5832 & 1.1963 & 3.7795 \\
\hline$\left[\mathrm{Cd}(\text { Hydrolysed PSHA-1 })_{2}\right]$ & 2.2108 & 1.5453 & 3.7561 \\
\hline$\left[\mathrm{Mg}(\text { Hydrolysed PSHA-1 })_{2}\right]$ & 2.1382 & 1.5453 & 3.6835 \\
\hline [Cu (Unhydrolysed PSHA-1) & 2.3059 & 1.2209 & 3.5268 \\
\hline$[\mathrm{Pb}$ (Unhydrolysed PSHA-1) 2$]$ & 2.2364 & 1.2239 & 3.4603 \\
\hline [Cd (Unhydrolysed PSHA-1) 2 ] & 2.2516 & 1.2581 & 3.5097 \\
\hline$[\mathrm{Mg}$ (Unydrolysed PSHA-1) & 2.1568 & 0.9127 & 3.0695 \\
\hline
\end{tabular}

The results obtained (Table19) shows the stepwise and overall stability constants to be not high indicating low stability of the complexes, because the solubility of most metal ions in the basic $\mathrm{pH}$ range is minimal due to metal hydroxide precipitation (Karimi, 2017). In general, the stepwise stability constants $\left(K_{1}\right.$ and $K_{2}$ ) follow the order $K_{1}>K_{2}$ for the copper, lead, magnesium and cadmium complexes respectively. The steady decrease of the values with increasing number of ligands is in agreement with the prediction made by researchers (Na'aliya, 2013). The decrease could be attributed to the fact that as the number of the ligands (Humate ions) that enters the coordination zone increases the aqua molecules available for replacement by the ligands become less. Thus, the metal ions become less electron loving with progressive intake of the ligand and this results in the decrease in the values of the constants (Na'aliya, 2013). Also the stability of the complexes is influenced by the size and number of the chelate rings(Mackay and Mackay,2002).All the complexes form rings in their structure as humate, a bidentate ligand, bond the metal ions in the ratio 1:2 (Boguta and Sokolowska, 2016) forming chelate rings. The values of the overall stability constants $(\log \beta)$ obtained for humate complexes are not high indicating low stability as the values are not high. LogK values for copper-humates (Table 3 to 6) obtained in this study are lower than those reported for the complexes of humic acids (Pandey et al., 2015; Dinu, 2013; Kaschl et al., 2010 and Gilbeto and Jorg, 2001). The values of LogK(Table 7 to 10 ) forlead-humates are lower than those reported for the lead in the literature (Dinu, 2013; Gilbeto and Jorg 2001). Log K values(Table 11 to 14 ) for magnesium-humates obtained in this study are close to those reported by (Pandey et al., 2015). Log K values of cadmium-humates (Table 15 to 18 ) obtained in this work near to the one reported by (Dinu, 2013 and Pandey et al., 2015).The difference between the reported values and the values obtained in this study might be probably as a result of acid hydrolysis of humic acid. The values of the overall stability constants $(\log \beta)$ of the copper humates complexes presented in Table 19 is high than that of other metal humate complexes, show relatively high stability of CuHA complexes, show the following order of stability: $\mathrm{Cu}>\mathrm{Pb}>\mathrm{Cd}>\mathrm{Mg}$; which are in close agreement to the findings of (Dinu, 2013 and Pandey et al., 2015).The high stability of Cuhumate chelate could be attributed to the existence of coordinate covalent bond between the complexing agents and the $\mathrm{Cu}^{2+}$ ions. Since, $\mathrm{Cu}^{2+}$ being a metal of the transitional series with $3 d^{9}$ electronic configurations can accept the electrons from the complexing agents. Similarly, the low stabilities of $\mathrm{Pb}, \mathrm{Cd}$ and $\mathrm{Mg}$ complexes could be explained by that $\mathrm{Pb}^{2+}$ with $6 s^{2}, \mathrm{Cd}^{2+}$ with $4 \mathrm{~d}^{10}$ and $\mathrm{Mg}^{2+}$ with $2 \mathrm{p}^{6}$ their electronic configuration has a completely filled $\mathrm{d}, \mathrm{p}$ and $\mathrm{s}$ orbitals. Moreover, the stabilities of metal ions with hydrolysed humic acid from peat soil were higher than those with unhydrolysed humic acid from peat soil; which is ascribed to the high content of acidity in hydrolysed humic acid than unhydrolysed humic acid. 
BAJOPAS Volume 14 Number 1,June, 2021 CONCLUSION

The values of logk for $\mathrm{Cu}(\mathrm{II})$ hydrolysed humic acid complex was higher followed by $\mathrm{Pb}$ (II), $\mathrm{Cd}(\mathrm{II})$ and $\mathrm{Mg}$ (II) hydrolysed humic acid complexes as compared with metal(II) unhydrolysed humic acid complexes. This indicates acid hydrolysis of humic acid can

\section{REFERENCES}

Almeida, V.R. and Szpoganicz, B. (2015). Humic Acid Potentiometric Response Patterns:Out- of Equilibrium Properties and Species Distribution Modelling. Chemical. Biol. Technol. Agric. 2: 17.

Anđelković, T., Nikolić, R., Bojić, A.,Anđelković, D., and Nikolic G.,(2010). Binding of Cadmium to Soil Humic Acid as A Function of Carboxyl Group Content. Macedonian Journal of Chemistry and Chemical Engineering.29(2): 215-224.

Anil, B. N. and Maroti, N. (2008). Studies on Influence of Die-Lectric Constants on Complex Equilibria between Substituted Py-Razalines and Lanthanide Metal Ions pH-Metrically. Amer.-Euras. scient. Res. 3(2): 212-216.

Ashok, K., Pandey, S. P. and Misra, V (2000). Stability Constants of Metal-Humic Acid Complexes and its Role in Environmental Detoxification. Journal of Ecotoxicology and Environmental Safety. 47(2):157-200.

Badr, M. H., El-Halafawi, M. H. and Abd El-al Zeid, E. R. (2012). Comparison Between the Effect of Ionic Strength on Acidity and Dissociation Constants of Humic Acids Extracted from Sewage Sludge and Nile Water Hyacinth Composts.Global Journal of Environmental Research 6 (1): 36-43.

Baruah, M.K., Borah, D., Saikia, P.P., Paul, S., Sharma, T. (2015). Evaluation of pKa Values of Soil Humic Acids and their Complexation Properties. International Journal of Plant \& Soil Science 6(4) : 218-228.

Boguta, P. Sokolowska, Z. (2016). Interactions of $\mathrm{Zn}$ (II) Ions with Humic Acids Isolated from Various Types of Soils. Effect of $\mathrm{pH}, \mathrm{Zn}$ Concentrations and Humic Acids Chemical Properties. Journal of Geochemical Explaration 168. 119-126.

Borges, F., Guimaraes, C., Lima, L.F.C., Pinto, I. and Reis, S.(2005). Potentiometric Studies on the Complexation of Copper(II) by Phenolic Acids as Discrete Ligand Models of enhance the complexation behavior of humic acid with metal (II) ions. However, the higher values of $\log \beta$ for $\mathrm{Cu}(\mathrm{II}), \mathrm{Pb}(\mathrm{II}), \mathrm{Cd}(\mathrm{II})$ and $\mathrm{Mg}(\mathrm{II})$ hydrolysed humic acid complexes indicates more stable stepwise complexes formed as compared with $\mathrm{Cu}(\mathrm{II}), \mathrm{Pb}$ (II), $\mathrm{Cd}$ (II) and $\mathrm{Mg}(\mathrm{II})$ unhydrolysed humic acid complexes.

Humic Substances Talanta 66 (2005) 670-673.

Chefetz, B., Salloum, M. J., Deshmulkin, A. P. and Hatcher, P. (2002). Structural Components of Humic Acids as Determined by Chemical Modifications and Carbon-13 NMR, Pyrolysis, and Thermochemolysis- Gas Chromatography/Mass Spectrometry. Soil Science Society of American Journal Abstract Division S-2- Soil Chemistry66. 1159-1171.

Dinu, M. I. (2013). Metals Complexation with Humic Acids in Surface Water of Different Environ. Sci. Technol. 31(1): 1-17.

Fernandes, A.N., Giacomelli, C., Giovanela, M. Vaz, D.V. Szpoganicz, B. and Maria M. D. (2009). Potentiometric Acidity Determination in Humic Substances Influenced by Different Analytical Procedures.J. Braz. Chem. Soc. 20 (9):14.

Gamal, A. H. (2015). Stability Constants of Rhenium (V) Metal Complexes with Selected Drugs. Pyrex Journal of Research in Environmental Studies. 2(2): 006-014.

Janrao, D. M., Pathan, J., Kayande, D.D., and Mulla, J.J. (2014). An Over View of Potentiometric Determination of Stability Constants of Metal Complexes. Sci. Revs. Chem. Commun.: 4(1), 2014, 11-24.

Karimi, H. (2017). Effect of pH and Initial Pb(II) Concentration on the Lead Removal Efficiency from Waste Water Using $\mathrm{Ca}(\mathrm{OH})_{2}$. International Journal of Water and Waste Water Treatment 3.2

Kaschl, A. Romheld, V. and Chen, Y. (2010). Binding of Cadmium, Copper and Zinc to Humic Substances Originating from Municipal Solid Waste Compost. Israel Journal of Chemistry Vol. 42(1): 89-98.

Kostic, I. S., Tatjana, P, A., Nikolic, R. S., Cvetkovic, T. P., Pavlovic, D. D., Aleksandar, L.J. and Bojic, A. (2012). Comparative Study of Binding Strengths of Heavy Metals with Humic Acid. J.serb. Chem. Soc. 76(9) pp 1-20. 
BAJOPAS Volume 14 Number 1,June, 2021

Na'aliya, J. (2013). Determination of Stepwise Stability Constants and Gibbs free Energy Change of Trisprolina to Complexes of some Divalent Transition Metal ions. Bayero Journal of Pure and Applied Sciences 6(2): 112-114.

Omar, A. A. and Ali, E. A. (2015). Potentiometric Studies on Complexes of $\mathrm{Cr}$ (III) and $\mathrm{Zr}$ (IV) with some Carboxylic Acids. International Journal of Advanced Chemistry, 3(1) 25-

37.

Pandey, A. K. Pandey, S. D. and Misr, V. (2015).Stability Constants of Metal- Humic Acid Complexes and Its Role in Environmental Detoxification. J. Ecotoxicology and Environmental Safety. 47(1):195-200.

Ram, N. and Raman, K.V. (1984). Stability Constants of Complexes of Metals with
Humicand Fuvic Acids under Non- acidConditions. Journal of Plant Nutrition and Soil Sciences.

147:171-176.

Santosh, D. D., Ashok, B. K., Vijay, J. T., Shivraj, G. W. and Vinay, V. W. (2011). Potentiometric Studies of Elec-Trolyte Effects on Complex Equilibria of Some Substituted 5-(2-hydroxy Phenyl) Pyrazoles. Der pharm. 3 (6): 75-83.

Sayyed, H. and Abdul Rahim, M. F. (2012). Studies of Binary Complexes of Metal Ions with Mandelic Acid by Potentiometry. Chem. J. 02 (6): 206209.

Shirvani, M. Moradian, E. Khalili, B. Bakhtiary, S. (2015). Interaction of $\mathrm{Cd}$ and $\mathrm{Pb}$ with Humate-Palygorskite and HumateSepiolite Complexes. Journal of water, air and pollution 3: 220-228. 


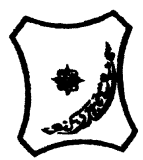

Bayero Journal of Pure and Applied Sciences, 14(1): 54 - 63

Received: November, 2020

Accepted: April, 2021

ISSN $2006-6996$

\title{
STABILITY CONSTANTS OF COMPLEXES OF METAL IONS WITH PEATSOIL HUMIC ACIDS UNDER NON-ACID-CONDITIONS
}

\author{
${ }^{* 1}$ Sabo, Yusuf ${ }^{2}$ Jimoh, W.L.O., ${ }^{3}$ Isa Baba Koki and ${ }^{4}$ Sholadoye, Q. 0. \\ ${ }^{1}$ Department of Pure and Industrial Chemistry, Bayero University, Kano \\ ${ }^{3}$ Department of Chemistry, Yusuf Maitama Sule University Kano. P.M.B. 3220 Kano, Nigeria. \\ ${ }^{4}$ Department of Chemistry, Nigerian Police Academy, Wudil, Kano-Nigeria
}

*Correspondence E-mail; saboyusuf18@yahoo.com

ABSTRACT

Stability constants of complexes of four divalent metal ions viz. $\mathrm{Cu}^{2+}, \mathrm{Pb}^{2+}, \mathrm{Mg}^{2+}$ and $\mathrm{Cd}^{2+}$ with humic acids (HA) were determined by potentiometric titration of humic acids with the corresponding salt of the divalent metals in aqueous media under non-acid-condition. The log $K$ (logarithm of the stability constant) ranged from 1.0942 to 2.7471 for metalhumic acid complexes were determined using point-wise computational method. The order of stability constants were obtained as follows: $\mathrm{Cu}>\mathrm{Pb}>\mathrm{Cd}>\mathrm{Mg}$ for metal $-\mathrm{HA}$ complexes respectively, indicating a higher degree of complexation with Cu metal ion.

Keywords: stability constant, humic acid, potentiometric titration, divalent metals, acid hydrolysis.

\section{NTRODUCTION}

The stability constant of a complex is the numerical expression of its stability and provides a quantitative measure of affinity of the metal ion to the complexing agent. An understanding of the relative stability of metal-complexes helps in predicting the behavior of metal ions in the soil (Ram and Raman, 1982). Extensive researches has been done to determine the stability constants of the complexes formed between humic acid (HA) with a number of metal ions. Ashok et al., (2000) reported that humic acid with hydroxyl, phenoxyl and carboxyl reactive groups can form coordination compound with metal ions at $\mathrm{pH}$ 3.5. The stability constants(Log K) for different metalhumic acid complexes indicated the following order of the stabilities of complexes formed between humic acid and metal ion, $\mathrm{Cu}>\mathrm{Fe}$ $>\mathrm{Pb}>\mathrm{Ni}>\mathrm{Co}>\mathrm{Ca}>\mathrm{Cd}>\mathrm{Zn}>\mathrm{Mn}>\mathrm{Mg}$. Andelkovic et al., (2010) investigated the binding of $\mathrm{Cd}$ (II) to soil humic acid at pH 6.5 and in $0.1 \mathrm{M} \mathrm{KNO}_{3}$ ionic medium. The stability constant for binding indicating greater stability in the case when carboxyl groups are involved in complexation reaction. Kostic et al.,(2012) investigated the complexation of humic acid with certain heavy metal ions (Co(II), $\mathrm{Ni}(\mathrm{II}), \mathrm{Cu}(\mathrm{II})$,
$\mathrm{Zn}(\mathrm{II})$, and $\mathrm{Pb}(\mathrm{II})$. The experiment was performed at $25^{\circ} \mathrm{C}$, at pH 4.0 and ionic strength of $0.01 \mathrm{M}$. Stability constant of complex between $\mathrm{Pb}$ (II) ions and humic acid is greater than stability constants of other investigated metalhumate complexes. Bogata and Sokolowska (2016) analyses the interaction between humic acids from different soils and $\mathrm{Zn}$ (II) ions at wide concentration ranges and at $\mathrm{pH} 5$. Studies have showed significant impact of $\mathrm{Zn}$ concentration, $\mathrm{pH}$ and some properties of humic acids with zinc.But all of these studies were limited to acidic $\mathrm{pH}$ range. Therefore, the present study was carried out to determine and compare the stability constants of complexes of metal ions with hydrolysed peat soil humic acid and unhydrolysed peat soil humic under non-acid conditions.

\section{MATERIALS AND METHODS}

Analytical grade chemicals used includes hydrochloric acid $(\mathrm{HCl})$, nitric acid $\left(\mathrm{HNO}_{3}\right)$, sodium hydroxide $(\mathrm{NaOH})$, lead nitrate $\mathrm{Pb}\left(\mathrm{NO}_{3}\right)_{2}$, copper nitrate $\mathrm{Cu}\left(\mathrm{NO}_{3}\right)_{2} \cdot 3 \mathrm{H}_{2} \mathrm{O}$, cadmium nitrate $\mathrm{Cd}\left(\mathrm{NO}_{3}\right)_{2} \cdot 4 \mathrm{H}_{2} \mathrm{O}$, magnesium nitrate $\mathrm{Mg}\left(\mathrm{NO}_{3}\right)_{2} \cdot 6 \mathrm{H}_{2} \mathrm{O}$, potassium nitrate $\left(\mathrm{KNO}_{3}\right)$, calcium chloride $\left(\mathrm{CaCl}_{2}\right)$, (sigma-Aldrich). Dowex 50WX8, (20-50 mesh) from Fluka. 


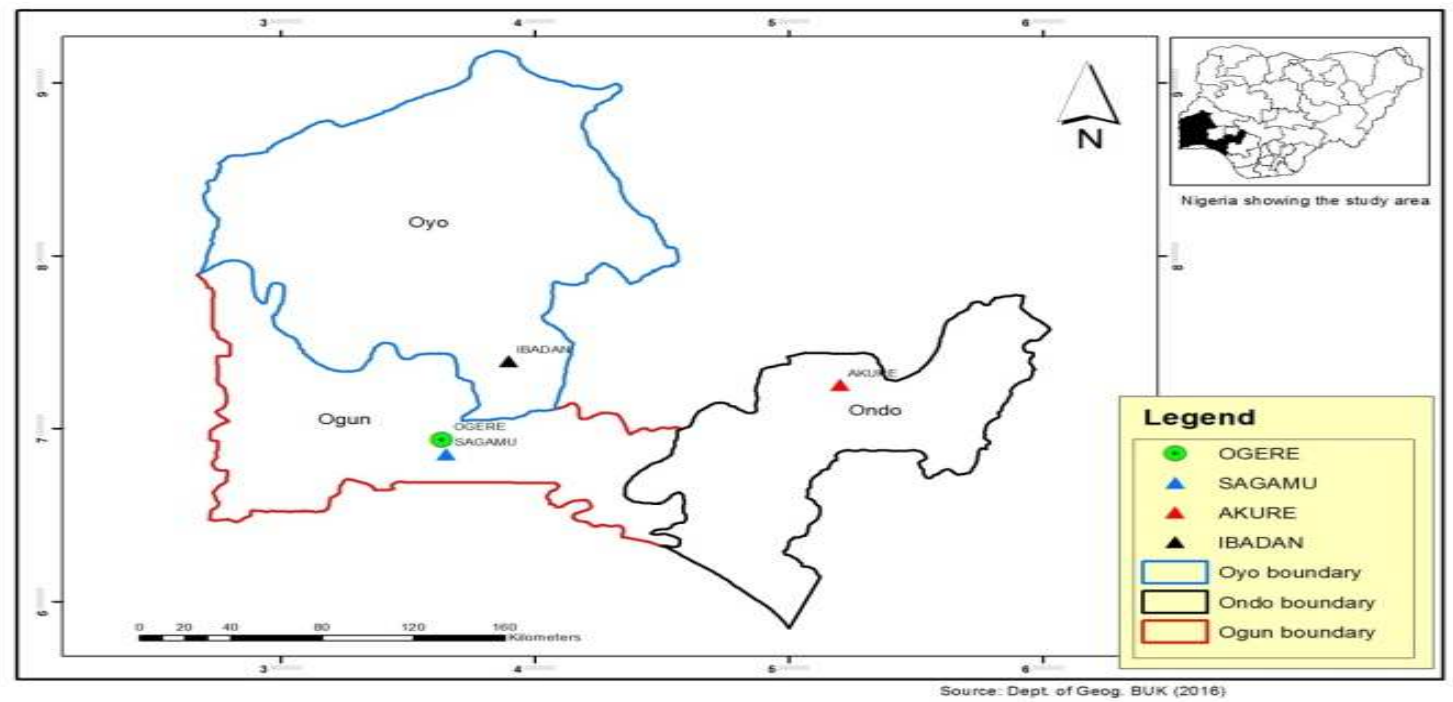

Figure 1: Map showing the sampling point at Sagamu Town, Ogun State.

\section{Description of Sampling Area}

Sagamu has geographical coordinates between $6^{\circ} 50^{\prime}$ north; $3^{\circ} 38^{\prime}$ east is located in south western region of Nigeria. The region has tropical wet and dry climate with a lengthy wet season and relatively constant temperatures throughout the course of the year. Wet season runs from March to October, November to December forms the region dry season. The vegetation type of the region is savannah which is really grassland with small bushes and occasional big trees. Grassland soils have substantially higher organic matter content than forest soils (Novackova, 2011).

\section{Sample Collection}

The Peatsoil samples were collected from four different sampling points $(0-10 \mathrm{~cm}$ depth) in Sagamu into polyethylene bag with plastic spoons. Samples were taken to the laboratory, extraneous materials were removed; the samples were air-dried, crushed and ground to a fine powder in a mortar passed through a $0.20 \mathrm{~mm}$ sieve. The samples were kept for analysis.

\section{Isolation and purification of humic acid from peat soil sample}

Peatsoil sample $(100 \mathrm{~g})$ was mixed with 1000 $\mathrm{cm}^{3}$ of $0.1 \mathrm{M} \mathrm{NaOH}$ solution, shaken for 3hours and left to stand overnight. Dark-coloured supernatant was obtained and decanted from solid residue. The dark-coloured supernatant was acidified to $(\mathrm{pH}=1.0)$ with $6 \mathrm{M} \mathrm{HCl}$ stirred and allowed to stand for 6 hours. Yellowish brown supernatant and dark-brown precipitate were obtained. The yellowish brown supernatant was decanted followed by centrifuge and discarded. The dark-brown precipitate was mixed with $500 \mathrm{~cm}^{3}$ of $0.1 \mathrm{M} \mathrm{NaOH}$ solution followed by passing through dowex resin. The dark-brown solution was acidified to $(\mathrm{pH}=1.0)$ with $6 \mathrm{M} \mathrm{HCl}$ stirred and allowed to stand for 3 hours. The dark-brown precipitate was washed several times with deionized water. The supernatant was treated with $\mathrm{AgNO}_{3}$ solution until no white precipitate observed. The humic acid was transferred to weighed crucible and dried at $60^{\circ} \mathrm{C}$ in an oven for 12 hours. The humic acid was cooled and dried in the desiccator, weighed and recorded. The obtained humic acid was dried again at $60^{\circ} \mathrm{C}$ for additional 6 hours cooled and dried in the desiccator, weighed and recorded constant weight was obtained (Baruah et al., 2015).

\section{FT-IR analysis}

FT-IR spectra of humic acid sample was analysed using Carry 630 FT-IR Agilent Technologies.

Unhydrolysed compost humic acid

The unhydrolysed humic acid was obtained after isolation and purification of compost humic acid and kept for investigation.

\section{Acid hydrolysis of Peatsoil acid}

Peatsoil humic acid sample (1g) was refluxed for 12 hours at $\left(160^{\circ} \mathrm{C}\right)$ with $50 \mathrm{~cm}^{3}$ of $6 \mathrm{M} \mathrm{HCl}$. The mixture was allowed to cool, decanted, and centrifuged after hydrolysis. The insoluble residues were washed with distilled water via centrifugation several times, and the supernatant was treated with $\mathrm{AgNO}_{3}$ solution until no white precipitate was observed. The residue was thoroughly dried over $\mathrm{CaCl}_{2}$ in a desiccator at room temperature (Chefetz et al., 2002). Finally, the obtained hydrolysed humic acid was kept for investigation. 
BAJOPAS Volume 14 Number 1,June, 2021 Potentiometric Titrations

Potentiometric measurements were carried out using a pH-meter Jenway (model 3510) with combine electrode, the sensitivity of the $\mathrm{pH}$ meter is 0.01 units. The $\mathrm{pH}$ meter was switched on half an hour before starting the titration for initial warm up of the instrument. The instrument was calibrated with an aqueous standard buffer solution of $\mathrm{pH} 4.00$ and 10.0 (borate buffer) prepared from a "Qualigens" buffer tablets.

The following sets of solutions were prepared in a $250 \mathrm{~cm}^{3}$ volumetric flask separately for $\mathrm{pH}$ metric titrations.

(i) $5 \mathrm{~cm}^{3} 0.1 \mathrm{M} \mathrm{HCl}+40 \mathrm{~cm}^{3}$ deionized water

(ii) $5 \mathrm{~cm}^{3} 0.1 \mathrm{M} \mathrm{HCl}+39 \mathrm{~cm}^{3}$ deionized water $+1 \mathrm{~cm}^{3} 0.15 \mathrm{gcm}^{-3}$ humic acid

(iii) $5 \mathrm{~cm}^{3} 0.1 \mathrm{M} \mathrm{HCl}+37 \mathrm{~cm}^{3}$ deionized water $+1 \mathrm{~cm}^{3} 0.15 \mathrm{gcm}^{-3}$ humic acid

$$
+2 \mathrm{~cm}^{3} \quad 0.01 \mathrm{M} \mathrm{Cu} \text { (II) }
$$

The solutions were titrated against standardized $0.110 \mathrm{MNaOH}$ separately. The total volume of each mixture was adjusted to $50 \mathrm{~cm}^{3}$ and the ionic strength of the solutions was maintained constant at by adding appropriate amount of stock solution of $1 \mathrm{M} \mathrm{KNO}_{3}$ (Gamal, 2015; Omar and Ali, 2015). A magnetic stirrer was used to achieve thorough mixing of the interacting solutions at $550 \mathrm{rpm}$. The same set of experimental conditions was applied for potentiometric titration of remaining samples.

\section{Evaluation of pKa of Hydrolysed peat soil Humic Acids}

The proton-ligand formation number $\mathrm{n}_{\mathbf{A}}$ were calculated by Irving and Rossotti expression (Omar and Ali, 2015).

$\mathrm{nA}=\mathrm{Y}-\frac{(\mathrm{V} 2-\mathrm{V1})(\mathrm{No}-\mathrm{Eo})}{(\mathrm{VO}+\mathrm{V1}) \mathrm{TCL}}$ 1

Where: $Y$ is number of dissociable proton, $\left(\mathrm{V}_{2^{-}}\right.$ $V_{1}$ ) is the measure of displacement of the ligand curve relative to acid curve, $\mathrm{N}^{\circ}$ and $\mathrm{E}^{\circ}$ are the resultant concentration of alkali solution, free acid solution, $\mathrm{T}_{\mathrm{cL}}{ }^{\circ}$ is the total ligand concentration, $\mathrm{V}^{\circ}$ is the total volume of titration solution, $V_{1}$ is the volume of alkali added to acid solution, $V_{2}$ is the volume of alkali added to acid solution + ligand solution, acid dissociation constants (pKa - values) of ligand were calculated by algebraic method point wise calculation (Tables 1 ). The dissociation constants (pKa) were calculated according to the following relation:

$\mathrm{pKa}=\mathrm{pH}+\log \left(\frac{n A}{1-n A}\right)$ 2

Where: pKa is the acid dissociation constant, $\mathrm{n}_{\mathrm{A}}$ is the Proton-ligand formation number and $\mathrm{pH}$ is the pH-values (Omar and Ali, 2015).

\section{Determination of metal-ligand stability constants $(\log K)$ of complexes}

The potentiometric measurement for the determination of stability constant of a complex in solution is based on the fact that the redox potential of the couple $\frac{M^{+(m-n)}}{M^{+m}}$ is shifted significantly on complexation of the metal ion with the ligand. This method involves change in hydrogen ion concentration $\left[\mathrm{H}^{+}\right]$due to the displacement or association of one or more protons taking place during complexation reaction. This change can be found out by titrating the solutions containing free acid, acid with ligand, and acid with ligand and metal ion, individually against a standard alkali solution at a constant ionic strength or temperature. Either ionic strength or temperature may be varied for different sets of solutions. In all the cases, the change in the $\mathrm{pH}$ of the solution is measured after each addition of a known amount of alkali to the reaction cell which contains the reaction mixture. The titration curves are then drawn by plotting the measured $\mathrm{pH}$ values against the corresponding volume of alkali added and the stability constants of the complexes are determined from the titration curves by employing $\mathrm{pH}$-metric titration technique given by (Irving and Rossoti).

Metal-ligand stability constants ( $\log \mathrm{K}$ ) were determined by using the following relations:

$$
\bar{n}=\frac{\left(V_{3}-V_{2}\right)\left(E^{0}+N^{0}\right)}{\left(V^{0}+V_{2}\right) \bar{n}_{A} T_{m}^{0}}
$$

and

$$
P L=\log _{10}\left\{\frac{1+\beta_{n}^{H} \frac{1}{[\text { anti } \log \mathrm{pH}]^{\mathrm{n}}}}{\mathrm{T}_{\mathrm{L}}^{0}-n \bar{T}_{m}^{0}} \mathrm{X} \frac{\left(V^{0}+V_{3}\right)}{V^{0}}\right\}
$$


BAJOPAS Volume 14 Number 1,June, 2021

Where $T_{L}, T^{\circ}, E^{\circ}$, and $V^{\circ}$ havethe same significance as in equation (1) above, $T_{m}$ denotes the total concentration of metal present in solution, $V_{3}$ is the volume of metal ions present in solution and $\beta^{H}$ is the overall proton ligand stability constant. The metal-ligand stability constants (log K) were determined by employing point wise computational Method (eq. 5 and 6).

$\operatorname{LogK}_{1}=\log \left(\frac{n}{1-n}\right)+\mathrm{pL}$ .5

$\operatorname{LogK}_{2}=\log \left(\frac{1-n}{2-n}\right)+\mathrm{pL}$ ...6

Where: Log $\mathrm{K}$ is the metal-ligand stability constant, $\mathrm{pL}$ is the Free ligand exponent function, $\mathbf{n}$ is the Average number of ligand attached with metal ion (Janraoet al., 2014). The results obtained were analyzed by an ORIGIN 2016 program using titration data and then the proton-ligand stability constants (pKa) and Metal-ligand stability constant (LogK) calculated (Omar and Ali, 2015).

\section{RESULTS AND DISCUSSION}

Fourier transformed infrared (FT-IR) spectra of isolated humic acid from peat soils Figure 2 had distinct clear absorption bands indicating the presence of major humic acid structural elemental groups such as $\mathrm{H}$ bonded $\mathrm{OH}$ $\left(3680 \mathrm{~cm}^{-1}\right.$ peak $), C=0$ of carbonyl $\left(1721 \mathrm{~cm}^{-1}\right.$ peak), functional groups of aliphatic components $\mathrm{CH}_{2}\left(2918 \mathrm{~cm}^{-1}\right.$ peak) and $\mathrm{C}-\mathrm{O}$ stretching of polysaccharide $\left(1168 \mathrm{~cm}^{-1}\right.$ peak). The positions of the absorption bands of the spectra fell within typical major absorption bands of humic acid which is at frequencies 3680, 2918, 1721, 1168 $\mathrm{cm}^{-1}$. The first peak centred in the vicinity of $3680 \mathrm{~cm}^{-1}$ region is attributed to phenol $\mathrm{OH}$ group bounded by intermolecular $\mathrm{H}$ bonds. The $2918 \mathrm{~cm}^{-1}$ band usually has absorption maximum at $2918 \mathrm{~cm}^{-1}$ which is due to $\mathrm{C}-\mathrm{H}$ stretching of alkane group $\left(\mathrm{CH}_{2}\right)$. The next major absorption band is $1721 \mathrm{~cm}^{-1}$. This band has been commonly ascribed to $\mathrm{C}=\mathrm{O}$ stretching of mainly carboxyl group $(\mathrm{COOH})$ with trace amount of ketones. The last peak was observed at 1168 $\mathrm{cm}^{-1}$ due to $\mathrm{C}-\mathrm{O}$ stretching of polysaccharides and this peak appeared also in the spectra of humic acid from peat soil. The FTIR spectra of the isolated humic acid contained all major characteristic absorption peaks of humic acid. These absorption peaks indicated the presence of the major structural elements of humic acid namely $\mathrm{H}$ bonded $\mathrm{OH}, \mathrm{C}=\mathrm{C}$ of aromatic ring, $\mathrm{C}=\mathrm{O}$ of carbonyl group (both carboxyl and ketonic), $\mathrm{CH}_{2}$ group. This strongly supports the presence of humic acid.

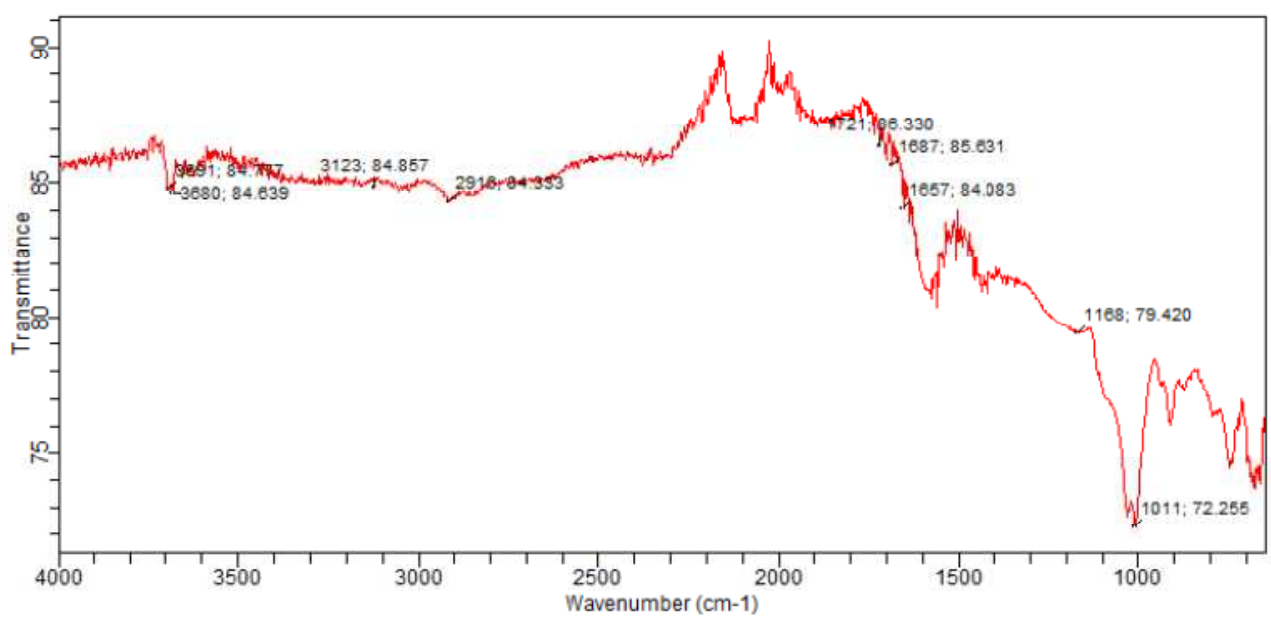

Fig. 2 : FT-IR spectraof peatsoilhumic acid (PSHA)

\section{Evaluation of acid dissociation constant (pka) of acid hydrolysed peat soil humicacid at phenolic group}

The value of the dissociation constant of the peat soil humic acid (PSHA) that underwent acidhydrolysis studied was found to be 8.9299 as shown Table 1, which is lower than the literaturevalues reported by Almeida and Szpoganics, (2015), Borges et al., (2005); Badr et al., (2012)and Fernandes et al,.(2009) of $9.73,9.47$ and 10.30. The difference between the obtained valuesand the reported values in this study might be probably as a result of acid hydrolysis of humicacid. 
BAJOPAS Volume 14 Number 1,June, 2021

Table 1: PKa of (Hydrolysed PSHA)

\begin{tabular}{|l|l|l|l|l|l|l|}
\hline $\mathrm{pH}$ & $\mathrm{BV}_{1}$ & $\mathrm{BV}_{2}$ & $\mathrm{~V}_{2}-\mathrm{V}_{1}$ & $\mathrm{nA}$ & $\log \left(\frac{n A}{1-n A}\right)$ & $\mathrm{pKa}$ \\
\hline 8.50 & 5.30 & 6.29 & 0.99 & 0.3594 & -0.2510 & 8.2490 \\
8.72 & 5.35 & 6.37 & 1.02 & 0.3400 & -0.2880 & 8.4320 \\
9.00 & 5.40 & 6.46 & 1.06 & 0.3141 & -0.3391 & 8.6609 \\
9.22 & 5.45 & 6.55 & 1.10 & 0.2882 & -0.3927 & 8.8273 \\
9.51 & 5.50 & 6.66 & 1.16 & 0.2494 & -0.4786 & 9.0314 \\
9.73 & 5.55 & 6.78 & 1.23 & 0.2041 & -0.5910 & 9.1390 \\
10.00 & 5.60 & 6.90 & 1.30 & 0.1589 & -0.7238 & 9.2762 \\
10.23 & 5.65 & 7.05 & 1.40 & 0.0941 & -0.9835 & 9.2465 \\
10.49 & 5.70 & 7.10 & 1.40 & 0.0941 & -0.9835 & 9.5065 \\
\hline
\end{tabular}

Average pKa $=8.9299 \pm 0.4186$

Table 2: PKa of (Unhydrolysed PSHA)

\begin{tabular}{|l|l|l|l|l|l|l|}
\hline $\mathrm{pH}$ & $\mathrm{BV}_{1}$ & $\mathrm{BV}_{2}$ & $\mathrm{~V}_{2}-\mathrm{V}_{1}$ & $\mathrm{nA}$ & $\log \left(\frac{\boldsymbol{n A}}{1-\boldsymbol{n}}\right)$ & $\mathrm{pKa}$ \\
\hline 8.50 & 5.30 & 5.81 & 0.51 & 0.6619 & 0.2919 & 8.7919 \\
8.72 & 5.35 & 5.90 & 0.55 & 0.6357 & 0.2418 & 8.9618 \\
9.00 & 5.40 & 6.00 & 0.60 & 0.6029 & 0.1813 & 9.1813 \\
9.22 & 5.45 & 6.10 & 0.65 & 0.5701 & 0.1226 & 9.3426 \\
9.51 & 5.50 & 6.20 & 0.70 & 0.5376 & 0.0654 & 9.5754 \\
9.73 & 5.55 & 6.33 & 0.78 & 0.4851 & -0.0259 & 9.7041 \\
10.00 & 5.60 & 6.47 & 0.87 & 0.4262 & -0.1291 & 9.8709 \\
10.23 & 5.65 & 6.62 & 0.99 & 0.3609 & -0.2481 & 9.9819 \\
10.49 & 5.70 & 6.80 & 1.10 & 0.2759 & -0.4690 & 10.0210 \\
\hline
\end{tabular}

Average pKa $=9.4923 \pm 0.4410$

Metal-ligand stability constant ( $\log \mathrm{K}$ )

The stabilityconstants require the accurate values of proton-ligand stability constants (Anil and Maroti, 2008). Metal titration curves crossed over ligand titration curve indicated the formation of complex upon proton release (Santosh, et al., 2011). If the values of n- are within range $0.2-0.8$ and $1.2-18$ this indicates the formation of $1: 1$ and 1:2 complexes (Sayyed and Mazahar, 2012).

The metal (II)-humate stepwise stability constants (log k) at phenolic group (Tables 318)

Table 3: Point-wise method, $\mathrm{Cu}$-(Hydrolysed PSHA)

\begin{tabular}{|l|l|l|l|l|l|l|l|l|}
\hline $\mathrm{pH}$ & $\mathrm{BV}_{1}$ & $\mathrm{BV}_{2}$ & $\mathrm{BV}_{3}$ & $\left(\mathrm{~V}_{3}-\mathrm{V}_{2}\right)$ & $\mathrm{n}$ & $\mathrm{pL}$ & $\log \left(\frac{n}{1-n}\right)$ & LogK $_{1}$ \\
\hline 8.50 & 5.30 & 6.29 & 6.33 & 0.04 & 0.5500 & 2.66 & 0.0871 & 2.7471 \\
8.72 & 5.35 & 6.37 & 6.41 & 0.04 & 0.5714 & 2.43 & 0.1249 & 2.5549 \\
9.00 & 5.40 & 6.46 & 6.50 & 0.04 & 0.6198 & 2.16 & 0.2122 & 2.3722 \\
9.22 & 5.45 & 6.55 & 6.59 & 0.04 & 0.6667 & 1.94 & 0.3010 & 2.2410 \\
\hline
\end{tabular}

LogK $_{1}$ (Average value) $=2.4788 \pm 0.2203$

Table 4: Point-wise method, $\mathrm{Cu}$-(Hydrolysed PSHA)

\begin{tabular}{|l|l|l|l|l|l|l|l|l|}
\hline $\mathrm{pH}$ & $\mathrm{BV}_{1}$ & $\mathrm{BV}_{2}$ & $\mathrm{BV}_{3}$ & $\left(\mathrm{~V}_{3}-\mathrm{V}_{2}\right)$ & $\mathrm{n}$ & $\mathrm{pL}$ & $\log \left(\frac{n-1}{2-n}\right)$ & LogK $_{2}$ \\
\hline 9.51 & 5.50 & 6.66 & 6.73 & 0.07 & 1.3509 & 1.70 & -0.2671 & 1.4329 \\
9.73 & 5.55 & 6.78 & 6.85 & 0.07 & 1.6383 & 1.51 & 0.2467 & 1.7567 \\
10.00 & 5.60 & 6.90 & 6.98 & 0.08 & 2.1783 & 1.31 & -0.2158 & 1.0942 \\
10.23 & 5.65 & 7.05 & 7.13 & 0.08 & 4.1904 & 1.27 & & \\
10.49 & 5.70 & 7.10 & 7.19 & 0.09 & 4.6920 & & & \\
\hline
\end{tabular}

Log $K_{2}($ Average value $)=1.4280 \pm 0.3312$ 
BAJOPAS Volume 14 Number 1,June, 2021

Table 5: Point-wise method, $\mathrm{Cu}$ (Unhydrolysed PSHA)

\begin{tabular}{|l|l|l|l|l|l|l|l|l|}
\hline $\mathrm{pH}$ & $\mathrm{BV}_{1}$ & $\mathrm{BV}_{2}$ & $\mathrm{BV}_{3}$ & $\left(\mathrm{~V}_{3}-\mathrm{V}_{2}\right)$ & $\mathrm{n}$ & $\mathrm{pL}$ & $\log \left(\frac{n}{n-1}\right)$ & Log $_{1}$ \\
\hline 8.50 & 5.30 & 5.81 & 5.85 & 0.04 & 0.2973 & 2.88 & -0.3736 & 2.5064 \\
8.72 & 5.35 & 5.90 & 5.95 & 0.05 & 0.3873 & 2.66 & -0.1992 & 2.4608 \\
9.00 & 5.40 & 6.00 & 6.05 & 0.05 & 0.4044 & 2.38 & -0.1681 & 2.2119 \\
9.22 & 5.45 & 6.10 & 6.15 & 0.06 & 0.5157 & 2.18 & -0.0272 & 2.2072 \\
9.51 & 5.50 & 6.20 & 6.27 & 0.07 & 0.6417 & 1.89 & 0.2530 & 1.1430 \\
\hline
\end{tabular}

$\operatorname{LogK}_{1}($ Average value $)=2.3059 \pm 0.6153$

Table 6:Point-wise method, $\mathrm{Cu}$ (Unhydrolysed PSHA)

\begin{tabular}{|l|l|l|l|l|l|l|l|l|}
\hline $\mathrm{pH}$ & $\mathrm{BV}_{1}$ & $\mathrm{BV}_{2}$ & $\mathrm{BV}_{3}$ & $\mathrm{~V}_{3}-\mathrm{V}_{2}$ & $\mathrm{n}$ & $\mathrm{pL}$ & $\log \left(\frac{n-1}{2-n}\right)$ & $\log \mathrm{K}_{2}$ \\
\hline 9.73 & 5.55 & 6.33 & 6.42 & 0.09 & 0.9000 & 1.69 & & \\
10.00 & 5.60 & 6.47 & 6.58 & 0.11 & 1.2578 & 1.44 & -0.4592 & 0.9808 \\
10.23 & 5.65 & 6.62 & 6.84 & 0.12 & 1.6137 & 1.26 & -0.2010 & 1.4610 \\
10.49 & 5.70 & 6.80 & 6.92 & 0.12 & 2.1052 & 1.03 & & \\
\hline
\end{tabular}

$\operatorname{LogK}_{2}$ (Average value) $=1.2209 \pm 0.3398$

Table 7:Point-wise method, Pb (Hydrolysed PSHA)

\begin{tabular}{|l|l|l|l|l|l|l|l|l|}
\hline $\mathrm{pH}$ & $\mathrm{BV}_{1}$ & $\mathrm{BV}_{2}$ & $\mathrm{BV}_{3}$ & $\left(\mathrm{~V}_{3}-\mathrm{V}_{2}\right)$ & $\mathrm{n}$ & $\mathrm{pL}$ & $\log \left(\frac{n}{1-n}\right)$ & LogK $_{1}$ \\
\hline 8.50 & 5.30 & 6.29 & 6.33 & 0.04 & 0.5500 & 2.66 & 0.0871 & 2.7471 \\
8.72 & 5.35 & 6.37 & 6.41 & 0.04 & 0.5714 & 2.43 & 0.1249 & 2.5549 \\
9.00 & 5.40 & 6.46 & 6.50 & 0.04 & 0.6198 & 2.16 & 0.2122 & 2.3722 \\
9.22 & 5.45 & 6.55 & 6.60 & 0.05 & 0.8333 & 1.96 & 0.6989 & 2.6589 \\
\hline
\end{tabular}

Log $_{\mathbf{1}}($ Average value $)=2.5832 \pm 0.1614$

Table 8:Point-wise method, Pb-(Hydrolysed PSHA)

\begin{tabular}{|l|l|l|l|l|l|l|l|l|}
\hline $\mathrm{pH}$ & $\mathrm{BV}_{1}$ & $\mathrm{BV}_{2}$ & $\mathrm{BV}_{3}$ & $\left(\mathrm{~V}_{3}-\mathrm{V}_{2}\right)$ & $\mathrm{n}$ & $\mathrm{pL}$ & $\log \left(\frac{n-1}{2-n}\right)$ & $\log \mathrm{K}_{2}$ \\
\hline 9.51 & 5.50 & 6.66 & 6.71 & 0.05 & 0.9650 & 1.67 & & \\
9.73 & 5.55 & 6.78 & 6.83 & 0.05 & 1.1702 & 1.44 & & \\
10.00 & 5.60 & 6.90 & 6.90 & 0.05 & 1.4864 & 1.22 & -0.0237 & 1.1963 \\
10.23 & 5.65 & 7.05 & 7.10 & 0.05 & 2.0190 & 1.09 & & \\
10.49 & 5.70 & 7.10 & 7.17 & 0.07 & 3.6492 & 1.00 & & \\
\hline
\end{tabular}

Log $K_{2}$ (Average value) $=1.1963$

Table 9: Point-wise method, Pb (Unhydrolysed PSHA)

\begin{tabular}{|l|l|l|l|l|l|l|l|l|}
\hline $\mathrm{pH}$ & $\mathrm{BV}_{1}$ & $\mathrm{BV}_{2}$ & $\mathrm{BV}_{3}$ & $\mathrm{~V}_{3}-\mathrm{V}_{2}$ & $\mathrm{n}$ & $\mathrm{pL}$ & $\begin{array}{l}\text { Log } \\
\left(\frac{n}{n-1}\right)\end{array}$ & Log $\mathrm{K}_{1}$ \\
\hline 8.50 & 5.30 & 5.81 & 5.85 & 0.04 & 0.2973 & 2.88 & -0.3736 & 2.5064 \\
8.72 & 5.35 & 5.90 & 5.94 & 0.04 & 0.3099 & 2.66 & -0.5477 & 2.3123 \\
9.00 & 5.40 & 6.00 & 6.05 & 0.05 & 0.4044 & 2.38 & -0.1681 & 2.2119 \\
9.22 & 5.45 & 6.10 & 6.15 & 0.06 & 0.5157 & 2.18 & 0.0272 & 2.2072 \\
9.51 & 5.50 & 6.20 & 6.26 & 0.07 & 0.6417 & 1.89 & 0.2530 & 2.1430 \\
9.73 & 5.55 & 6.40 & 6.40 & 0.07 & 0.7000 & 1.67 & 0.3680 & 2.0380 \\
\hline
\end{tabular}

LogK $_{1}$ (Average value) $=2.2364 \pm 0.1602$

Table 10: Point-wise method, Pb (Unhydrolysed PSHA)

\begin{tabular}{|l|l|l|l|l|l|l|l|l|}
\hline $\mathrm{pH}$ & $\mathrm{BV}_{1}$ & $\mathrm{BV}_{2}$ & $\mathrm{BV}_{3}$ & $\mathrm{~V}_{3}-\mathrm{V}_{2}$ & $\mathrm{n}$ & $\mathrm{pL}$ & $\log \left(\frac{n-1}{2-n}\right)$ & $\log \mathrm{K}_{2}$ \\
\hline 10.00 & 5.60 & 6.47 & 6.55 & 0.08 & 1.9503 & 1.41 & & \\
10.23 & 5.65 & 6.62 & 6.72 & 0.11 & 1.4792 & 1.26 & -0.0361 & 1.2239 \\
\hline
\end{tabular}

$\operatorname{LogK}_{2}$ (Average value) $=1.2239$

Table 11: Point-wise method, Mg (Hydrolysed PSHA)

\begin{tabular}{|l|l|l|l|l|l|l|l|l|}
\hline $\mathrm{pH}$ & $\mathrm{BV}_{1}$ & $\mathrm{BV}_{2}$ & $\mathrm{BV}_{3}$ & $\left(\mathrm{~V}_{3}-\mathrm{V}_{2}\right)$ & $\mathrm{n}$ & $\mathrm{pL}$ & $\log \left(\frac{n}{n-1}\right)$ & LogK $_{1}$ \\
\hline 8.50 & 5.30 & 6.29 & 6.31 & 0.02 & 0.2750 & 2.64 & -0.4290 & 2.2110 \\
8.72 & 5.35 & 6.37 & 6.39 & 0.02 & 0.2858 & 2.42 & -0.3978 & 2.0222 \\
9.00 & 5.40 & 6.46 & 6.49 & 0.03 & 0.4648 & 2.14 & -0.0612 & 2.0788 \\
9.22 & 5.45 & 6.55 & 6.59 & 0.04 & 0.6667 & 1.94 & 0.3010 & 2.2410 \\
\hline
\end{tabular}

$\log _{\mathbf{1}}($ Average value) $=2.1382 \pm 0.1046$ 
BAJOPAS Volume 14 Number 1,June, 2021

Table 12: Point-wise method, Mg (Hydrolysed PSHA)

\begin{tabular}{|l|l|l|l|l|l|l|l|l|}
\hline $\mathrm{pH}$ & $\mathrm{BV}_{1}$ & $\mathrm{BV}_{2}$ & $\mathrm{BV}_{3}$ & $\left(\mathrm{~V}_{3}-\mathrm{V}_{2}\right)$ & $\mathrm{n}$ & $\mathrm{pL}$ & $\log \left(\frac{n-1}{2-n}\right)$ & LogK $_{2}$ \\
\hline 9.51 & 5.55 & 6.66 & 6.71 & 0.05 & 0.9650 & 1.67 & & \\
9.73 & 5.55 & 6.78 & 6.84 & 0.06 & 1.4042 & 1.47 & -0.1686 & 1.3014 \\
10.00 & 5.60 & 6.90 & 6.93 & 0.06 & 1.7838 & 1.23 & 0.5593 & 1.7893 \\
10.23 & 5.65 & 7.05 & 7.10 & 0.06 & 3.1429 & 1.10 & & \\
10.49 & 5.70 & 7.10 & 7.18 & 0.07 & 3.6492 & 0.83 & & \\
\hline
\end{tabular}

LogK $_{2}($ Average value $)=1.5453 \pm 0.3450$

Table 13: Point-wise method, Mg (Unhydrolysed PSHA)

\begin{tabular}{|l|l|l|l|l|l|l|l|l|}
\hline $\mathrm{pH}$ & $\mathrm{BV}_{1}$ & $\mathrm{BV}_{2}$ & $\mathrm{BV}_{3}$ & $\mathrm{~V}_{3}-\mathrm{V}_{2}$ & $\mathrm{n}$ & $\mathrm{pL}$ & $\log \left(\frac{n}{n-1}\right)$ & $\operatorname{Log~}_{1}$ \\
\hline 8.50 & 5.30 & 5.81 & 5.85 & 0.04 & 0.2973 & 2.88 & -0.3736 & 2.5064 \\
8.72 & 5.35 & 5.90 & 5.94 & 0.04 & 0.3099 & 2.66 & -0.3477 & 2.3123 \\
9.00 & 5.40 & 6.00 & 6.04 & 0.04 & 0.3236 & 2.38 & -0.3202 & 2.0598 \\
9.22 & 5.45 & 6.10 & 6.15 & 0.05 & 0.4297 & 2.17 & -0.1230 & 2.0470 \\
9.51 & 5.50 & 6.20 & 6.26 & 0.06 & 0.5500 & 1.89 & 0.0871 & 1.9771 \\
9.73 & 5.55 & 6.33 & 6.40 & 0.07 & 0.7000 & 1.67 & 0.3680 & 2.0380 \\
\hline
\end{tabular}

LogK $_{1}$ (Average value) $=2.1568 \pm 0.2069$

Table 14: Point-wise method, Mg (Unhydrolysed PSHA)

\begin{tabular}{|l|l|l|l|l|l|l|l|l|}
\hline $\mathrm{pH}$ & $\mathrm{BV}_{1}$ & $\mathrm{BV}_{2}$ & $\mathrm{BV}_{3}$ & $\mathrm{~V}_{3}-\mathrm{V}_{2}$ & $\mathrm{n}$ & $\mathrm{pL}$ & $\log \left(\frac{n-1}{2-n}\right)$ & $\log \mathrm{K}_{2}$ \\
\hline 10.00 & 5.60 & 6.47 & 6.55 & 0.08 & 0.9148 & 1.41 & & \\
10.23 & 5.65 & 6.62 & 6.71 & 0.09 & 1.2102 & 1.20 & -0.5749 & 0.6251 \\
10.49 & 5.70 & 6.80 & 6.92 & 0.09 & 1.5968 & 1.03 & 0.1703 & 1.2003 \\
\hline
\end{tabular}

LogK $_{2}$ (Average value) $=0.9127 \pm 0.4070$

Table15:Point-wise method, Cd (Hydrolysed PSHA)

\begin{tabular}{|l|l|l|l|l|l|l|l|l|}
\hline $\mathrm{pH}$ & $\mathrm{BV}_{1}$ & $\mathrm{BV}_{2}$ & $\mathrm{BV}_{3}$ & $\left(\mathrm{~V}_{3}-\mathrm{V}_{2}\right)$ & $\mathrm{n}$ & $\mathrm{pL}$ & $\log \left(\frac{n}{1-n}\right)$ & LogK $_{1}$ \\
\hline 8.50 & 5.30 & 6.29 & 6.31 & 0.02 & 0.2750 & 2.64 & -0.4210 & 2.2190 \\
8.72 & 5.35 & 6.37 & 6.40 & 0.03 & 0.4286 & 2.42 & -0.1249 & 2.2951 \\
9.00 & 5.40 & 6.46 & 6.49 & 0.03 & 0.4648 & 2.14 & -0.0612 & 2.0788 \\
9.22 & 5.45 & 6.55 & 6.59 & 0.04 & 0.6667 & 1.96 & 0.3010 & 2.2610 \\
9.51 & 5.55 & 6.66 & 6.70 & 0.04 & 0.7720 & 1.67 & 0.5297 & 2.1997 \\
\hline
\end{tabular}

LogK $_{\mathbf{1}}$ (Average value) $=2.2108 \pm 0.0825$

Table 16: Point-wise method, Cd (Hydrolysed PSHA)

\begin{tabular}{|l|l|l|l|l|l|l|l|l|}
\hline $\mathrm{pH}$ & $\mathrm{BV}_{1}$ & $\mathrm{BV}_{2}$ & $\mathrm{BV}_{3}$ & $\left(\mathrm{~V}_{3}-\mathrm{V}_{2}\right)$ & $\mathrm{n}$ & $\mathrm{pL}$ & $\log \left(\frac{n-1}{2-n}\right)$ & Log $_{2}$ \\
\hline 9.73 & 5.55 & 6.78 & 6.83 & 0.06 & 1.4042 & 1.47 & -0.1686 & 1.3014 \\
10.00 & 5.60 & 6.90 & 6.95 & 0.06 & 1.7838 & 1.23 & 0.5593 & 1.7893 \\
10.23 & 5.65 & 7.05 & 7.10 & 0.06 & 3.1429 & 1.09 & & \\
10.49 & 5.70 & 7.10 & 7.16 & 0.06 & 3.1429 & 0.89 & & \\
& & & & & & & & \\
\hline
\end{tabular}

$\operatorname{LogK}_{2}$ (Average value) $=1.5453 \pm 0.3450$

Table 17: Point-wise method, Cd (Unhydrolysed PSHA)

\begin{tabular}{|l|l|l|l|l|l|l|l|l|}
\hline $\mathrm{pH}$ & $\mathrm{BV}_{1}$ & $\mathrm{BV}_{2}$ & $\mathrm{BV}_{3}$ & $\mathrm{~V}_{3}-\mathrm{V}_{2}$ & $\mathrm{n}$ & $\mathrm{pL}$ & $\log \left(\frac{n}{n-1}\right)$ & $\operatorname{Log~}_{1}$ \\
\hline 8.50 & 5.30 & 5.81 & 5.86 & 0.05 & 0.3717 & 2.88 & -0.2280 & 2.6520 \\
8.72 & 5.35 & 5.90 & 5.95 & 0.05 & 0.3873 & 2.66 & -0.1992 & 2.4608 \\
9.00 & 5.40 & 6.00 & 6.06 & 0.06 & 0.4853 & 2.38 & -0.0255 & 2.3545 \\
9.22 & 5.45 & 6.10 & 6.16 & 0.06 & 0.5157 & 2.18 & -0.0272 & 2.2072 \\
9.51 & 5.50 & 6.20 & 6.27 & 0.07 & 0.6417 & 1.89 & 0.2530 & 1.1430 \\
9.73 & 5.55 & 6.33 & 6.41 & 0.08 & 0.8000 & 1.69 & 0.6020 & 2.2920 \\
& & & & & & & & \\
\hline
\end{tabular}

$\operatorname{LogK}_{1}($ Average value $)=2.2516 \pm 0.5380$ 
BAJOPAS Volume 14 Number 1,June, 2021

Table 18: Point-wise method, Cd (Unhydrolysed PSHA)

\begin{tabular}{|l|l|l|l|l|l|l|l|l|}
\hline $\mathrm{pH}$ & $\mathrm{BV}_{1}$ & $\mathrm{BV}_{2}$ & $\mathrm{BV}_{3}$ & $\mathrm{~V}_{3}-\mathrm{V}_{2}$ & $\mathrm{n}$ & $\mathrm{pL}$ & $\log \left(\frac{n-1}{2-n}\right)$ & $\log \mathrm{K}_{2}$ \\
\hline 10.00 & 5.60 & 6.47 & 6.57 & 0.10 & 1.1434 & 1.43 & & \\
10.23 & 5.65 & 6.62 & 6.72 & 0.10 & 1.3448 & 1.23 & -0.2788 & 0.9512 \\
10.49 & 5.70 & 6.80 & 6.90 & 0.10 & 1.7742 & 1.03 & 0.5351 & 1.5651 \\
\hline
\end{tabular}

$\operatorname{LogK}_{2}($ Average value $)=1.2581 \pm 0.4340$

Table 19: Stepwise and overall Stability constants of thehydrolysed and unhydrolysed divalent metal (II) complexes

\begin{tabular}{|c|c|c|c|}
\hline Chelates & LogK $_{1}$ & $\log _{2}$ & Log $\beta$ \\
\hline [Cu (Hydrolysed PSHA-1) $\left.{ }_{2}\right]$ & 2.4788 & 1.4280 & 3.9068 \\
\hline$\left[\mathrm{Pb}(\text { Hydrolysed PSHA-1) })_{2}\right]$ & 2.5832 & 1.1963 & 3.7795 \\
\hline$\left[\mathrm{Cd}(\text { Hydrolysed PSHA-1 })_{2}\right]$ & 2.2108 & 1.5453 & 3.7561 \\
\hline$\left[\mathrm{Mg}(\text { Hydrolysed PSHA-1 })_{2}\right]$ & 2.1382 & 1.5453 & 3.6835 \\
\hline [Cu (Unhydrolysed PSHA-1) & 2.3059 & 1.2209 & 3.5268 \\
\hline$[\mathrm{Pb}$ (Unhydrolysed PSHA-1) 2$]$ & 2.2364 & 1.2239 & 3.4603 \\
\hline [Cd (Unhydrolysed PSHA-1) 2 ] & 2.2516 & 1.2581 & 3.5097 \\
\hline$[\mathrm{Mg}$ (Unydrolysed PSHA-1) & 2.1568 & 0.9127 & 3.0695 \\
\hline
\end{tabular}

The results obtained (Table19) shows the stepwise and overall stability constants to be not high indicating low stability of the complexes, because the solubility of most metal ions in the basic $\mathrm{pH}$ range is minimal due to metal hydroxide precipitation (Karimi, 2017). In general, the stepwise stability constants $\left(K_{1}\right.$ and $K_{2}$ ) follow the order $K_{1}>K_{2}$ for the copper, lead, magnesium and cadmium complexes respectively. The steady decrease of the values with increasing number of ligands is in agreement with the prediction made by researchers (Na'aliya, 2013). The decrease could be attributed to the fact that as the number of the ligands (Humate ions) that enters the coordination zone increases the aqua molecules available for replacement by the ligands become less. Thus, the metal ions become less electron loving with progressive intake of the ligand and this results in the decrease in the values of the constants (Na'aliya, 2013). Also the stability of the complexes is influenced by the size and number of the chelate rings(Mackay and Mackay,2002).All the complexes form rings in their structure as humate, a bidentate ligand, bond the metal ions in the ratio 1:2 (Boguta and Sokolowska, 2016) forming chelate rings. The values of the overall stability constants $(\log \beta)$ obtained for humate complexes are not high indicating low stability as the values are not high. LogK values for copper-humates (Table 3 to 6) obtained in this study are lower than those reported for the complexes of humic acids (Pandey et al., 2015; Dinu, 2013; Kaschl et al., 2010 and Gilbeto and Jorg, 2001). The values of LogK(Table 7 to 10 ) forlead-humates are lower than those reported for the lead in the literature (Dinu, 2013; Gilbeto and Jorg 2001). Log K values(Table 11 to 14 ) for magnesium-humates obtained in this study are close to those reported by (Pandey et al., 2015). Log K values of cadmium-humates (Table 15 to 18 ) obtained in this work near to the one reported by (Dinu, 2013 and Pandey et al., 2015).The difference between the reported values and the values obtained in this study might be probably as a result of acid hydrolysis of humic acid. The values of the overall stability constants $(\log \beta)$ of the copper humates complexes presented in Table 19 is high than that of other metal humate complexes, show relatively high stability of CuHA complexes, show the following order of stability: $\mathrm{Cu}>\mathrm{Pb}>\mathrm{Cd}>\mathrm{Mg}$; which are in close agreement to the findings of (Dinu, 2013 and Pandey et al., 2015).The high stability of Cuhumate chelate could be attributed to the existence of coordinate covalent bond between the complexing agents and the $\mathrm{Cu}^{2+}$ ions. Since, $\mathrm{Cu}^{2+}$ being a metal of the transitional series with $3 d^{9}$ electronic configurations can accept the electrons from the complexing agents. Similarly, the low stabilities of $\mathrm{Pb}, \mathrm{Cd}$ and $\mathrm{Mg}$ complexes could be explained by that $\mathrm{Pb}^{2+}$ with $6 s^{2}, \mathrm{Cd}^{2+}$ with $4 \mathrm{~d}^{10}$ and $\mathrm{Mg}^{2+}$ with $2 \mathrm{p}^{6}$ their electronic configuration has a completely filled $\mathrm{d}, \mathrm{p}$ and $\mathrm{s}$ orbitals. Moreover, the stabilities of metal ions with hydrolysed humic acid from peat soil were higher than those with unhydrolysed humic acid from peat soil; which is ascribed to the high content of acidity in hydrolysed humic acid than unhydrolysed humic acid. 
BAJOPAS Volume 14 Number 1,June, 2021 CONCLUSION

The values of logk for $\mathrm{Cu}(\mathrm{II})$ hydrolysed humic acid complex was higher followed by $\mathrm{Pb}$ (II), $\mathrm{Cd}(\mathrm{II})$ and $\mathrm{Mg}$ (II) hydrolysed humic acid complexes as compared with metal(II) unhydrolysed humic acid complexes. This indicates acid hydrolysis of humic acid can

\section{REFERENCES}

Almeida, V.R. and Szpoganicz, B. (2015). Humic Acid Potentiometric Response Patterns:Out- of Equilibrium Properties and Species Distribution Modelling. Chemical. Biol. Technol. Agric. 2: 17.

Anđelković, T., Nikolić, R., Bojić, A.,Anđelković, D., and Nikolic G.,(2010). Binding of Cadmium to Soil Humic Acid as A Function of Carboxyl Group Content. Macedonian Journal of Chemistry and Chemical Engineering.29(2): 215-224.

Anil, B. N. and Maroti, N. (2008). Studies on Influence of Die-Lectric Constants on Complex Equilibria between Substituted Py-Razalines and Lanthanide Metal Ions pH-Metrically. Amer.-Euras. scient. Res. 3(2): 212-216.

Ashok, K., Pandey, S. P. and Misra, V (2000). Stability Constants of Metal-Humic Acid Complexes and its Role in Environmental Detoxification. Journal of Ecotoxicology and Environmental Safety. 47(2):157-200.

Badr, M. H., El-Halafawi, M. H. and Abd El-al Zeid, E. R. (2012). Comparison Between the Effect of Ionic Strength on Acidity and Dissociation Constants of Humic Acids Extracted from Sewage Sludge and Nile Water Hyacinth Composts.Global Journal of Environmental Research 6 (1): 36-43.

Baruah, M.K., Borah, D., Saikia, P.P., Paul, S., Sharma, T. (2015). Evaluation of pKa Values of Soil Humic Acids and their Complexation Properties. International Journal of Plant \& Soil Science 6(4) : 218-228.

Boguta, P. Sokolowska, Z. (2016). Interactions of $\mathrm{Zn}$ (II) Ions with Humic Acids Isolated from Various Types of Soils. Effect of $\mathrm{pH}, \mathrm{Zn}$ Concentrations and Humic Acids Chemical Properties. Journal of Geochemical Explaration 168. 119-126.

Borges, F., Guimaraes, C., Lima, L.F.C., Pinto, I. and Reis, S.(2005). Potentiometric Studies on the Complexation of Copper(II) by Phenolic Acids as Discrete Ligand Models of enhance the complexation behavior of humic acid with metal (II) ions. However, the higher values of $\log \beta$ for $\mathrm{Cu}(\mathrm{II}), \mathrm{Pb}(\mathrm{II}), \mathrm{Cd}(\mathrm{II})$ and $\mathrm{Mg}(\mathrm{II})$ hydrolysed humic acid complexes indicates more stable stepwise complexes formed as compared with $\mathrm{Cu}(\mathrm{II}), \mathrm{Pb}$ (II), $\mathrm{Cd}$ (II) and $\mathrm{Mg}(\mathrm{II})$ unhydrolysed humic acid complexes.

Humic Substances Talanta 66 (2005) 670-673.

Chefetz, B., Salloum, M. J., Deshmulkin, A. P. and Hatcher, P. (2002). Structural Components of Humic Acids as Determined by Chemical Modifications and Carbon-13 NMR, Pyrolysis, and Thermochemolysis- Gas Chromatography/Mass Spectrometry. Soil Science Society of American Journal Abstract Division S-2- Soil Chemistry66. 1159-1171.

Dinu, M. I. (2013). Metals Complexation with Humic Acids in Surface Water of Different Environ. Sci. Technol. 31(1): 1-17.

Fernandes, A.N., Giacomelli, C., Giovanela, M. Vaz, D.V. Szpoganicz, B. and Maria M. D. (2009). Potentiometric Acidity Determination in Humic Substances Influenced by Different Analytical Procedures.J. Braz. Chem. Soc. 20 (9):14.

Gamal, A. H. (2015). Stability Constants of Rhenium (V) Metal Complexes with Selected Drugs. Pyrex Journal of Research in Environmental Studies. 2(2): 006-014.

Janrao, D. M., Pathan, J., Kayande, D.D., and Mulla, J.J. (2014). An Over View of Potentiometric Determination of Stability Constants of Metal Complexes. Sci. Revs. Chem. Commun.: 4(1), 2014, 11-24.

Karimi, H. (2017). Effect of pH and Initial Pb(II) Concentration on the Lead Removal Efficiency from Waste Water Using $\mathrm{Ca}(\mathrm{OH})_{2}$. International Journal of Water and Waste Water Treatment 3.2

Kaschl, A. Romheld, V. and Chen, Y. (2010). Binding of Cadmium, Copper and Zinc to Humic Substances Originating from Municipal Solid Waste Compost. Israel Journal of Chemistry Vol. 42(1): 89-98.

Kostic, I. S., Tatjana, P, A., Nikolic, R. S., Cvetkovic, T. P., Pavlovic, D. D., Aleksandar, L.J. and Bojic, A. (2012). Comparative Study of Binding Strengths of Heavy Metals with Humic Acid. J.serb. Chem. Soc. 76(9) pp 1-20. 
BAJOPAS Volume 14 Number 1,June, 2021

Na'aliya, J. (2013). Determination of Stepwise Stability Constants and Gibbs free Energy Change of Trisprolina to Complexes of some Divalent Transition Metal ions. Bayero Journal of Pure and Applied Sciences 6(2): 112-114.

Omar, A. A. and Ali, E. A. (2015). Potentiometric Studies on Complexes of $\mathrm{Cr}$ (III) and $\mathrm{Zr}$ (IV) with some Carboxylic Acids. International Journal of Advanced Chemistry, 3(1) 25-

37.

Pandey, A. K. Pandey, S. D. and Misr, V. (2015).Stability Constants of Metal- Humic Acid Complexes and Its Role in Environmental Detoxification. J. Ecotoxicology and Environmental Safety. 47(1):195-200.

Ram, N. and Raman, K.V. (1984). Stability Constants of Complexes of Metals with
Humicand Fuvic Acids under Non- acidConditions. Journal of Plant Nutrition and Soil Sciences.

147:171-176.

Santosh, D. D., Ashok, B. K., Vijay, J. T., Shivraj, G. W. and Vinay, V. W. (2011). Potentiometric Studies of Elec-Trolyte Effects on Complex Equilibria of Some Substituted 5-(2-hydroxy Phenyl) Pyrazoles. Der pharm. 3 (6): 75-83.

Sayyed, H. and Abdul Rahim, M. F. (2012). Studies of Binary Complexes of Metal Ions with Mandelic Acid by Potentiometry. Chem. J. 02 (6): 206209.

Shirvani, M. Moradian, E. Khalili, B. Bakhtiary, S. (2015). Interaction of $\mathrm{Cd}$ and $\mathrm{Pb}$ with Humate-Palygorskite and HumateSepiolite Complexes. Journal of water, air and pollution 3: 220-228. 


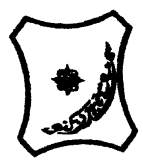

Bayero Journal of Pure and Applied Sciences, 14(1): 54 - 63

Received: November, 2020

Accepted: April, 2021

ISSN $2006-6996$

\title{
STABILITY CONSTANTS OF COMPLEXES OF METAL IONS WITH PEATSOIL HUMIC ACIDS UNDER NON-ACID-CONDITIONS
}

\author{
${ }^{* 1}$ Sabo, Yusuf ${ }^{2}$ Jimoh, W.L.O., ${ }^{3}$ Isa Baba Koki and ${ }^{4}$ Sholadoye, Q. 0. \\ ${ }^{1}$ Department of Pure and Industrial Chemistry, Bayero University, Kano \\ ${ }^{3}$ Department of Chemistry, Yusuf Maitama Sule University Kano. P.M.B. 3220 Kano, Nigeria. \\ ${ }^{4}$ Department of Chemistry, Nigerian Police Academy, Wudil, Kano-Nigeria
}

*Correspondence E-mail; saboyusuf18@yahoo.com

ABSTRACT

Stability constants of complexes of four divalent metal ions viz. $\mathrm{Cu}^{2+}, \mathrm{Pb}^{2+}, \mathrm{Mg}^{2+}$ and $\mathrm{Cd}^{2+}$ with humic acids (HA) were determined by potentiometric titration of humic acids with the corresponding salt of the divalent metals in aqueous media under non-acid-condition. The log $K$ (logarithm of the stability constant) ranged from 1.0942 to 2.7471 for metalhumic acid complexes were determined using point-wise computational method. The order of stability constants were obtained as follows: $\mathrm{Cu}>\mathrm{Pb}>\mathrm{Cd}>\mathrm{Mg}$ for metal $-\mathrm{HA}$ complexes respectively, indicating a higher degree of complexation with Cu metal ion.

Keywords: stability constant, humic acid, potentiometric titration, divalent metals, acid hydrolysis.

\section{NTRODUCTION}

The stability constant of a complex is the numerical expression of its stability and provides a quantitative measure of affinity of the metal ion to the complexing agent. An understanding of the relative stability of metal-complexes helps in predicting the behavior of metal ions in the soil (Ram and Raman, 1982). Extensive researches has been done to determine the stability constants of the complexes formed between humic acid (HA) with a number of metal ions. Ashok et al., (2000) reported that humic acid with hydroxyl, phenoxyl and carboxyl reactive groups can form coordination compound with metal ions at $\mathrm{pH}$ 3.5. The stability constants(Log K) for different metalhumic acid complexes indicated the following order of the stabilities of complexes formed between humic acid and metal ion, $\mathrm{Cu}>\mathrm{Fe}$ $>\mathrm{Pb}>\mathrm{Ni}>\mathrm{Co}>\mathrm{Ca}>\mathrm{Cd}>\mathrm{Zn}>\mathrm{Mn}>\mathrm{Mg}$. Andelkovic et al., (2010) investigated the binding of $\mathrm{Cd}$ (II) to soil humic acid at pH 6.5 and in $0.1 \mathrm{M} \mathrm{KNO}_{3}$ ionic medium. The stability constant for binding indicating greater stability in the case when carboxyl groups are involved in complexation reaction. Kostic et al.,(2012) investigated the complexation of humic acid with certain heavy metal ions (Co(II), $\mathrm{Ni}(\mathrm{II}), \mathrm{Cu}(\mathrm{II})$,
$\mathrm{Zn}(\mathrm{II})$, and $\mathrm{Pb}(\mathrm{II})$. The experiment was performed at $25^{\circ} \mathrm{C}$, at pH 4.0 and ionic strength of $0.01 \mathrm{M}$. Stability constant of complex between $\mathrm{Pb}$ (II) ions and humic acid is greater than stability constants of other investigated metalhumate complexes. Bogata and Sokolowska (2016) analyses the interaction between humic acids from different soils and $\mathrm{Zn}$ (II) ions at wide concentration ranges and at $\mathrm{pH} 5$. Studies have showed significant impact of $\mathrm{Zn}$ concentration, $\mathrm{pH}$ and some properties of humic acids with zinc.But all of these studies were limited to acidic $\mathrm{pH}$ range. Therefore, the present study was carried out to determine and compare the stability constants of complexes of metal ions with hydrolysed peat soil humic acid and unhydrolysed peat soil humic under non-acid conditions.

\section{MATERIALS AND METHODS}

Analytical grade chemicals used includes hydrochloric acid $(\mathrm{HCl})$, nitric acid $\left(\mathrm{HNO}_{3}\right)$, sodium hydroxide $(\mathrm{NaOH})$, lead nitrate $\mathrm{Pb}\left(\mathrm{NO}_{3}\right)_{2}$, copper nitrate $\mathrm{Cu}\left(\mathrm{NO}_{3}\right)_{2} \cdot 3 \mathrm{H}_{2} \mathrm{O}$, cadmium nitrate $\mathrm{Cd}\left(\mathrm{NO}_{3}\right)_{2} \cdot 4 \mathrm{H}_{2} \mathrm{O}$, magnesium nitrate $\mathrm{Mg}\left(\mathrm{NO}_{3}\right)_{2} \cdot 6 \mathrm{H}_{2} \mathrm{O}$, potassium nitrate $\left(\mathrm{KNO}_{3}\right)$, calcium chloride $\left(\mathrm{CaCl}_{2}\right)$, (sigma-Aldrich). Dowex 50WX8, (20-50 mesh) from Fluka. 


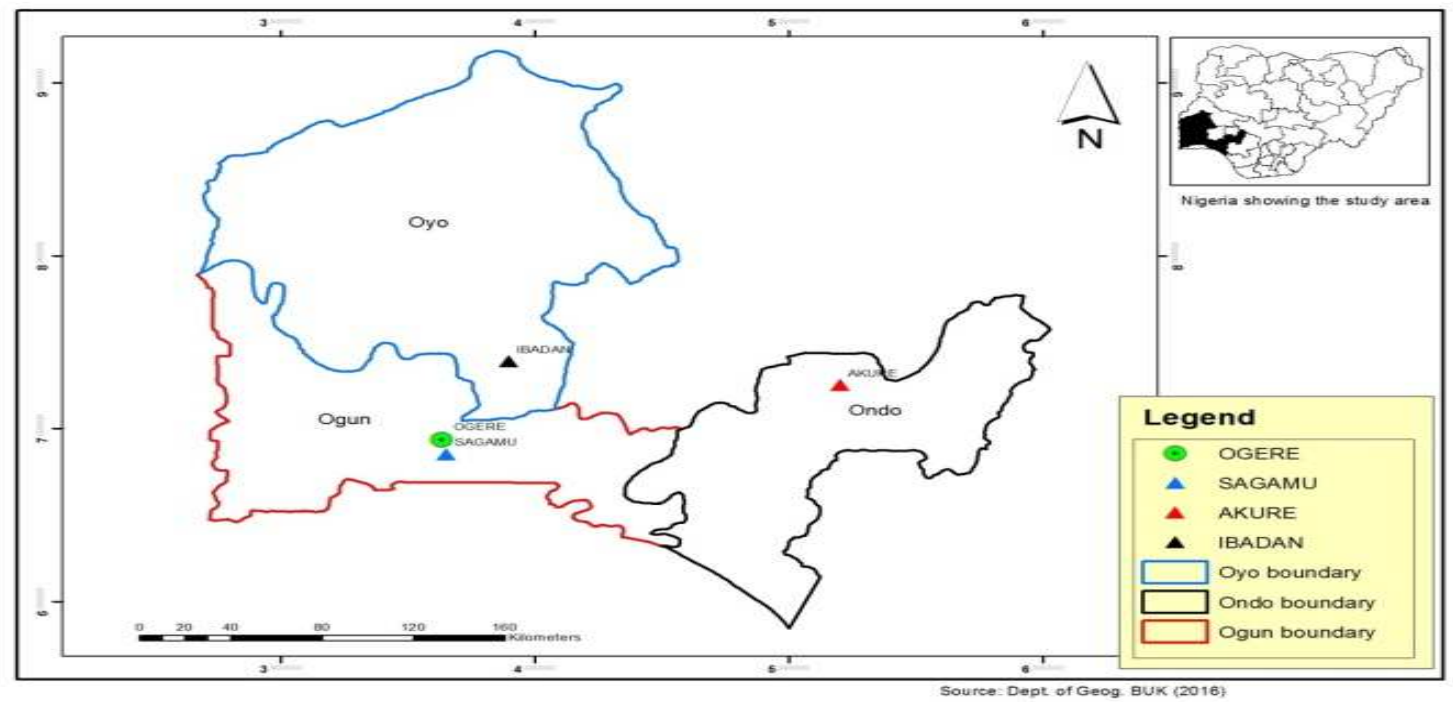

Figure 1: Map showing the sampling point at Sagamu Town, Ogun State.

\section{Description of Sampling Area}

Sagamu has geographical coordinates between $6^{\circ} 50^{\prime}$ north; $3^{\circ} 38^{\prime}$ east is located in south western region of Nigeria. The region has tropical wet and dry climate with a lengthy wet season and relatively constant temperatures throughout the course of the year. Wet season runs from March to October, November to December forms the region dry season. The vegetation type of the region is savannah which is really grassland with small bushes and occasional big trees. Grassland soils have substantially higher organic matter content than forest soils (Novackova, 2011).

\section{Sample Collection}

The Peatsoil samples were collected from four different sampling points $(0-10 \mathrm{~cm}$ depth) in Sagamu into polyethylene bag with plastic spoons. Samples were taken to the laboratory, extraneous materials were removed; the samples were air-dried, crushed and ground to a fine powder in a mortar passed through a $0.20 \mathrm{~mm}$ sieve. The samples were kept for analysis.

\section{Isolation and purification of humic acid from peat soil sample}

Peatsoil sample $(100 \mathrm{~g})$ was mixed with 1000 $\mathrm{cm}^{3}$ of $0.1 \mathrm{M} \mathrm{NaOH}$ solution, shaken for 3hours and left to stand overnight. Dark-coloured supernatant was obtained and decanted from solid residue. The dark-coloured supernatant was acidified to $(\mathrm{pH}=1.0)$ with $6 \mathrm{M} \mathrm{HCl}$ stirred and allowed to stand for 6 hours. Yellowish brown supernatant and dark-brown precipitate were obtained. The yellowish brown supernatant was decanted followed by centrifuge and discarded. The dark-brown precipitate was mixed with $500 \mathrm{~cm}^{3}$ of $0.1 \mathrm{M} \mathrm{NaOH}$ solution followed by passing through dowex resin. The dark-brown solution was acidified to $(\mathrm{pH}=1.0)$ with $6 \mathrm{M} \mathrm{HCl}$ stirred and allowed to stand for 3 hours. The dark-brown precipitate was washed several times with deionized water. The supernatant was treated with $\mathrm{AgNO}_{3}$ solution until no white precipitate observed. The humic acid was transferred to weighed crucible and dried at $60^{\circ} \mathrm{C}$ in an oven for 12 hours. The humic acid was cooled and dried in the desiccator, weighed and recorded. The obtained humic acid was dried again at $60^{\circ} \mathrm{C}$ for additional 6 hours cooled and dried in the desiccator, weighed and recorded constant weight was obtained (Baruah et al., 2015).

\section{FT-IR analysis}

FT-IR spectra of humic acid sample was analysed using Carry 630 FT-IR Agilent Technologies.

Unhydrolysed compost humic acid

The unhydrolysed humic acid was obtained after isolation and purification of compost humic acid and kept for investigation.

\section{Acid hydrolysis of Peatsoil acid}

Peatsoil humic acid sample (1g) was refluxed for 12 hours at $\left(160^{\circ} \mathrm{C}\right)$ with $50 \mathrm{~cm}^{3}$ of $6 \mathrm{M} \mathrm{HCl}$. The mixture was allowed to cool, decanted, and centrifuged after hydrolysis. The insoluble residues were washed with distilled water via centrifugation several times, and the supernatant was treated with $\mathrm{AgNO}_{3}$ solution until no white precipitate was observed. The residue was thoroughly dried over $\mathrm{CaCl}_{2}$ in a desiccator at room temperature (Chefetz et al., 2002). Finally, the obtained hydrolysed humic acid was kept for investigation. 
BAJOPAS Volume 14 Number 1,June, 2021 Potentiometric Titrations

Potentiometric measurements were carried out using a pH-meter Jenway (model 3510) with combine electrode, the sensitivity of the $\mathrm{pH}$ meter is 0.01 units. The $\mathrm{pH}$ meter was switched on half an hour before starting the titration for initial warm up of the instrument. The instrument was calibrated with an aqueous standard buffer solution of $\mathrm{pH} 4.00$ and 10.0 (borate buffer) prepared from a "Qualigens" buffer tablets.

The following sets of solutions were prepared in a $250 \mathrm{~cm}^{3}$ volumetric flask separately for $\mathrm{pH}$ metric titrations.

(i) $5 \mathrm{~cm}^{3} 0.1 \mathrm{M} \mathrm{HCl}+40 \mathrm{~cm}^{3}$ deionized water

(ii) $5 \mathrm{~cm}^{3} 0.1 \mathrm{M} \mathrm{HCl}+39 \mathrm{~cm}^{3}$ deionized water $+1 \mathrm{~cm}^{3} 0.15 \mathrm{gcm}^{-3}$ humic acid

(iii) $5 \mathrm{~cm}^{3} 0.1 \mathrm{M} \mathrm{HCl}+37 \mathrm{~cm}^{3}$ deionized water $+1 \mathrm{~cm}^{3} 0.15 \mathrm{gcm}^{-3}$ humic acid

$$
+2 \mathrm{~cm}^{3} \quad 0.01 \mathrm{M} \mathrm{Cu} \text { (II) }
$$

The solutions were titrated against standardized $0.110 \mathrm{MNaOH}$ separately. The total volume of each mixture was adjusted to $50 \mathrm{~cm}^{3}$ and the ionic strength of the solutions was maintained constant at by adding appropriate amount of stock solution of $1 \mathrm{M} \mathrm{KNO}_{3}$ (Gamal, 2015; Omar and Ali, 2015). A magnetic stirrer was used to achieve thorough mixing of the interacting solutions at $550 \mathrm{rpm}$. The same set of experimental conditions was applied for potentiometric titration of remaining samples.

\section{Evaluation of pKa of Hydrolysed peat soil Humic Acids}

The proton-ligand formation number $\mathrm{n}_{\mathbf{A}}$ were calculated by Irving and Rossotti expression (Omar and Ali, 2015).

$\mathrm{nA}=\mathrm{Y}-\frac{(\mathrm{V} 2-\mathrm{V1})(\mathrm{No}-\mathrm{Eo})}{(\mathrm{VO}+\mathrm{V1}) \mathrm{TCL}}$ 1

Where: $Y$ is number of dissociable proton, $\left(\mathrm{V}_{2^{-}}\right.$ $V_{1}$ ) is the measure of displacement of the ligand curve relative to acid curve, $\mathrm{N}^{\circ}$ and $\mathrm{E}^{\circ}$ are the resultant concentration of alkali solution, free acid solution, $\mathrm{T}_{\mathrm{cL}}{ }^{\circ}$ is the total ligand concentration, $\mathrm{V}^{\circ}$ is the total volume of titration solution, $V_{1}$ is the volume of alkali added to acid solution, $V_{2}$ is the volume of alkali added to acid solution + ligand solution, acid dissociation constants (pKa - values) of ligand were calculated by algebraic method point wise calculation (Tables 1 ). The dissociation constants (pKa) were calculated according to the following relation:

$\mathrm{pKa}=\mathrm{pH}+\log \left(\frac{n A}{1-n A}\right)$ 2

Where: pKa is the acid dissociation constant, $\mathrm{n}_{\mathrm{A}}$ is the Proton-ligand formation number and $\mathrm{pH}$ is the pH-values (Omar and Ali, 2015).

\section{Determination of metal-ligand stability constants $(\log K)$ of complexes}

The potentiometric measurement for the determination of stability constant of a complex in solution is based on the fact that the redox potential of the couple $\frac{M^{+(m-n)}}{M^{+m}}$ is shifted significantly on complexation of the metal ion with the ligand. This method involves change in hydrogen ion concentration $\left[\mathrm{H}^{+}\right]$due to the displacement or association of one or more protons taking place during complexation reaction. This change can be found out by titrating the solutions containing free acid, acid with ligand, and acid with ligand and metal ion, individually against a standard alkali solution at a constant ionic strength or temperature. Either ionic strength or temperature may be varied for different sets of solutions. In all the cases, the change in the $\mathrm{pH}$ of the solution is measured after each addition of a known amount of alkali to the reaction cell which contains the reaction mixture. The titration curves are then drawn by plotting the measured $\mathrm{pH}$ values against the corresponding volume of alkali added and the stability constants of the complexes are determined from the titration curves by employing $\mathrm{pH}$-metric titration technique given by (Irving and Rossoti).

Metal-ligand stability constants ( $\log \mathrm{K}$ ) were determined by using the following relations:

$$
\bar{n}=\frac{\left(V_{3}-V_{2}\right)\left(E^{0}+N^{0}\right)}{\left(V^{0}+V_{2}\right) \bar{n}_{A} T_{m}^{0}}
$$

and

$$
P L=\log _{10}\left\{\frac{1+\beta_{n}^{H} \frac{1}{[\text { anti } \log \mathrm{pH}]^{\mathrm{n}}}}{\mathrm{T}_{\mathrm{L}}^{0}-n \bar{T}_{m}^{0}} \mathrm{X} \frac{\left(V^{0}+V_{3}\right)}{V^{0}}\right\}
$$


BAJOPAS Volume 14 Number 1,June, 2021

Where $T_{L}, T^{\circ}, E^{\circ}$, and $V^{\circ}$ havethe same significance as in equation (1) above, $T_{m}$ denotes the total concentration of metal present in solution, $V_{3}$ is the volume of metal ions present in solution and $\beta^{H}$ is the overall proton ligand stability constant. The metal-ligand stability constants (log K) were determined by employing point wise computational Method (eq. 5 and 6).

$\operatorname{LogK}_{1}=\log \left(\frac{n}{1-n}\right)+\mathrm{pL}$ .5

$\operatorname{LogK}_{2}=\log \left(\frac{1-n}{2-n}\right)+\mathrm{pL}$ ...6

Where: Log $\mathrm{K}$ is the metal-ligand stability constant, $\mathrm{pL}$ is the Free ligand exponent function, $\mathbf{n}$ is the Average number of ligand attached with metal ion (Janraoet al., 2014). The results obtained were analyzed by an ORIGIN 2016 program using titration data and then the proton-ligand stability constants (pKa) and Metal-ligand stability constant (LogK) calculated (Omar and Ali, 2015).

\section{RESULTS AND DISCUSSION}

Fourier transformed infrared (FT-IR) spectra of isolated humic acid from peat soils Figure 2 had distinct clear absorption bands indicating the presence of major humic acid structural elemental groups such as $\mathrm{H}$ bonded $\mathrm{OH}$ $\left(3680 \mathrm{~cm}^{-1}\right.$ peak $), C=0$ of carbonyl $\left(1721 \mathrm{~cm}^{-1}\right.$ peak), functional groups of aliphatic components $\mathrm{CH}_{2}\left(2918 \mathrm{~cm}^{-1}\right.$ peak) and $\mathrm{C}-\mathrm{O}$ stretching of polysaccharide $\left(1168 \mathrm{~cm}^{-1}\right.$ peak). The positions of the absorption bands of the spectra fell within typical major absorption bands of humic acid which is at frequencies 3680, 2918, 1721, 1168 $\mathrm{cm}^{-1}$. The first peak centred in the vicinity of $3680 \mathrm{~cm}^{-1}$ region is attributed to phenol $\mathrm{OH}$ group bounded by intermolecular $\mathrm{H}$ bonds. The $2918 \mathrm{~cm}^{-1}$ band usually has absorption maximum at $2918 \mathrm{~cm}^{-1}$ which is due to $\mathrm{C}-\mathrm{H}$ stretching of alkane group $\left(\mathrm{CH}_{2}\right)$. The next major absorption band is $1721 \mathrm{~cm}^{-1}$. This band has been commonly ascribed to $\mathrm{C}=\mathrm{O}$ stretching of mainly carboxyl group $(\mathrm{COOH})$ with trace amount of ketones. The last peak was observed at 1168 $\mathrm{cm}^{-1}$ due to $\mathrm{C}-\mathrm{O}$ stretching of polysaccharides and this peak appeared also in the spectra of humic acid from peat soil. The FTIR spectra of the isolated humic acid contained all major characteristic absorption peaks of humic acid. These absorption peaks indicated the presence of the major structural elements of humic acid namely $\mathrm{H}$ bonded $\mathrm{OH}, \mathrm{C}=\mathrm{C}$ of aromatic ring, $\mathrm{C}=\mathrm{O}$ of carbonyl group (both carboxyl and ketonic), $\mathrm{CH}_{2}$ group. This strongly supports the presence of humic acid.

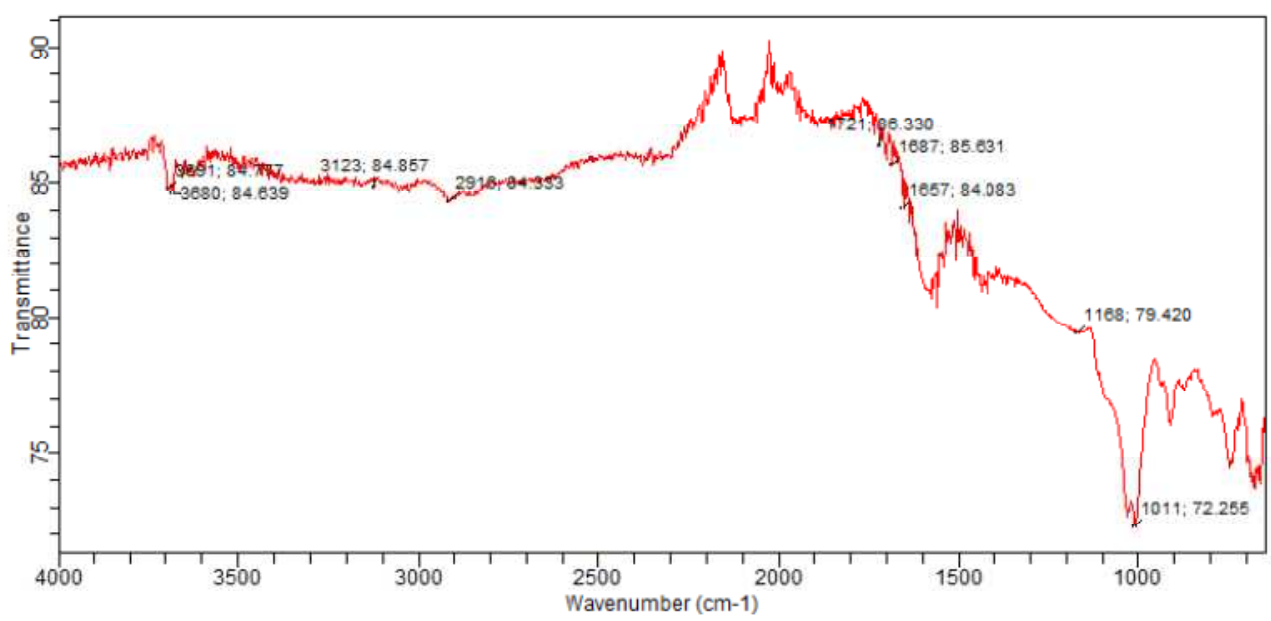

Fig. 2 : FT-IR spectraof peatsoilhumic acid (PSHA)

\section{Evaluation of acid dissociation constant (pka) of acid hydrolysed peat soil humicacid at phenolic group}

The value of the dissociation constant of the peat soil humic acid (PSHA) that underwent acidhydrolysis studied was found to be 8.9299 as shown Table 1, which is lower than the literaturevalues reported by Almeida and Szpoganics, (2015), Borges et al., (2005); Badr et al., (2012)and Fernandes et al,.(2009) of $9.73,9.47$ and 10.30. The difference between the obtained valuesand the reported values in this study might be probably as a result of acid hydrolysis of humicacid. 
BAJOPAS Volume 14 Number 1,June, 2021

Table 1: PKa of (Hydrolysed PSHA)

\begin{tabular}{|l|l|l|l|l|l|l|}
\hline $\mathrm{pH}$ & $\mathrm{BV}_{1}$ & $\mathrm{BV}_{2}$ & $\mathrm{~V}_{2}-\mathrm{V}_{1}$ & $\mathrm{nA}$ & $\log \left(\frac{n A}{1-n A}\right)$ & $\mathrm{pKa}$ \\
\hline 8.50 & 5.30 & 6.29 & 0.99 & 0.3594 & -0.2510 & 8.2490 \\
8.72 & 5.35 & 6.37 & 1.02 & 0.3400 & -0.2880 & 8.4320 \\
9.00 & 5.40 & 6.46 & 1.06 & 0.3141 & -0.3391 & 8.6609 \\
9.22 & 5.45 & 6.55 & 1.10 & 0.2882 & -0.3927 & 8.8273 \\
9.51 & 5.50 & 6.66 & 1.16 & 0.2494 & -0.4786 & 9.0314 \\
9.73 & 5.55 & 6.78 & 1.23 & 0.2041 & -0.5910 & 9.1390 \\
10.00 & 5.60 & 6.90 & 1.30 & 0.1589 & -0.7238 & 9.2762 \\
10.23 & 5.65 & 7.05 & 1.40 & 0.0941 & -0.9835 & 9.2465 \\
10.49 & 5.70 & 7.10 & 1.40 & 0.0941 & -0.9835 & 9.5065 \\
\hline
\end{tabular}

Average pKa $=8.9299 \pm 0.4186$

Table 2: PKa of (Unhydrolysed PSHA)

\begin{tabular}{|l|l|l|l|l|l|l|}
\hline $\mathrm{pH}$ & $\mathrm{BV}_{1}$ & $\mathrm{BV}_{2}$ & $\mathrm{~V}_{2}-\mathrm{V}_{1}$ & $\mathrm{nA}$ & $\log \left(\frac{\boldsymbol{n A}}{1-\boldsymbol{n}}\right)$ & $\mathrm{pKa}$ \\
\hline 8.50 & 5.30 & 5.81 & 0.51 & 0.6619 & 0.2919 & 8.7919 \\
8.72 & 5.35 & 5.90 & 0.55 & 0.6357 & 0.2418 & 8.9618 \\
9.00 & 5.40 & 6.00 & 0.60 & 0.6029 & 0.1813 & 9.1813 \\
9.22 & 5.45 & 6.10 & 0.65 & 0.5701 & 0.1226 & 9.3426 \\
9.51 & 5.50 & 6.20 & 0.70 & 0.5376 & 0.0654 & 9.5754 \\
9.73 & 5.55 & 6.33 & 0.78 & 0.4851 & -0.0259 & 9.7041 \\
10.00 & 5.60 & 6.47 & 0.87 & 0.4262 & -0.1291 & 9.8709 \\
10.23 & 5.65 & 6.62 & 0.99 & 0.3609 & -0.2481 & 9.9819 \\
10.49 & 5.70 & 6.80 & 1.10 & 0.2759 & -0.4690 & 10.0210 \\
\hline
\end{tabular}

Average pKa $=9.4923 \pm 0.4410$

Metal-ligand stability constant ( $\log \mathrm{K}$ )

The stabilityconstants require the accurate values of proton-ligand stability constants (Anil and Maroti, 2008). Metal titration curves crossed over ligand titration curve indicated the formation of complex upon proton release (Santosh, et al., 2011). If the values of n- are within range $0.2-0.8$ and $1.2-18$ this indicates the formation of $1: 1$ and 1:2 complexes (Sayyed and Mazahar, 2012).

The metal (II)-humate stepwise stability constants (log k) at phenolic group (Tables 318)

Table 3: Point-wise method, $\mathrm{Cu}$-(Hydrolysed PSHA)

\begin{tabular}{|l|l|l|l|l|l|l|l|l|}
\hline $\mathrm{pH}$ & $\mathrm{BV}_{1}$ & $\mathrm{BV}_{2}$ & $\mathrm{BV}_{3}$ & $\left(\mathrm{~V}_{3}-\mathrm{V}_{2}\right)$ & $\mathrm{n}$ & $\mathrm{pL}$ & $\log \left(\frac{n}{1-n}\right)$ & LogK $_{1}$ \\
\hline 8.50 & 5.30 & 6.29 & 6.33 & 0.04 & 0.5500 & 2.66 & 0.0871 & 2.7471 \\
8.72 & 5.35 & 6.37 & 6.41 & 0.04 & 0.5714 & 2.43 & 0.1249 & 2.5549 \\
9.00 & 5.40 & 6.46 & 6.50 & 0.04 & 0.6198 & 2.16 & 0.2122 & 2.3722 \\
9.22 & 5.45 & 6.55 & 6.59 & 0.04 & 0.6667 & 1.94 & 0.3010 & 2.2410 \\
\hline
\end{tabular}

LogK $_{1}$ (Average value) $=2.4788 \pm 0.2203$

Table 4: Point-wise method, $\mathrm{Cu}$-(Hydrolysed PSHA)

\begin{tabular}{|l|l|l|l|l|l|l|l|l|}
\hline $\mathrm{pH}$ & $\mathrm{BV}_{1}$ & $\mathrm{BV}_{2}$ & $\mathrm{BV}_{3}$ & $\left(\mathrm{~V}_{3}-\mathrm{V}_{2}\right)$ & $\mathrm{n}$ & $\mathrm{pL}$ & $\log \left(\frac{n-1}{2-n}\right)$ & LogK $_{2}$ \\
\hline 9.51 & 5.50 & 6.66 & 6.73 & 0.07 & 1.3509 & 1.70 & -0.2671 & 1.4329 \\
9.73 & 5.55 & 6.78 & 6.85 & 0.07 & 1.6383 & 1.51 & 0.2467 & 1.7567 \\
10.00 & 5.60 & 6.90 & 6.98 & 0.08 & 2.1783 & 1.31 & -0.2158 & 1.0942 \\
10.23 & 5.65 & 7.05 & 7.13 & 0.08 & 4.1904 & 1.27 & & \\
10.49 & 5.70 & 7.10 & 7.19 & 0.09 & 4.6920 & & & \\
\hline
\end{tabular}

Log $K_{2}($ Average value $)=1.4280 \pm 0.3312$ 
BAJOPAS Volume 14 Number 1,June, 2021

Table 5: Point-wise method, $\mathrm{Cu}$ (Unhydrolysed PSHA)

\begin{tabular}{|l|l|l|l|l|l|l|l|l|}
\hline $\mathrm{pH}$ & $\mathrm{BV}_{1}$ & $\mathrm{BV}_{2}$ & $\mathrm{BV}_{3}$ & $\left(\mathrm{~V}_{3}-\mathrm{V}_{2}\right)$ & $\mathrm{n}$ & $\mathrm{pL}$ & $\log \left(\frac{n}{n-1}\right)$ & Log $_{1}$ \\
\hline 8.50 & 5.30 & 5.81 & 5.85 & 0.04 & 0.2973 & 2.88 & -0.3736 & 2.5064 \\
8.72 & 5.35 & 5.90 & 5.95 & 0.05 & 0.3873 & 2.66 & -0.1992 & 2.4608 \\
9.00 & 5.40 & 6.00 & 6.05 & 0.05 & 0.4044 & 2.38 & -0.1681 & 2.2119 \\
9.22 & 5.45 & 6.10 & 6.15 & 0.06 & 0.5157 & 2.18 & -0.0272 & 2.2072 \\
9.51 & 5.50 & 6.20 & 6.27 & 0.07 & 0.6417 & 1.89 & 0.2530 & 1.1430 \\
\hline
\end{tabular}

$\operatorname{LogK}_{1}($ Average value $)=2.3059 \pm 0.6153$

Table 6:Point-wise method, $\mathrm{Cu}$ (Unhydrolysed PSHA)

\begin{tabular}{|l|l|l|l|l|l|l|l|l|}
\hline $\mathrm{pH}$ & $\mathrm{BV}_{1}$ & $\mathrm{BV}_{2}$ & $\mathrm{BV}_{3}$ & $\mathrm{~V}_{3}-\mathrm{V}_{2}$ & $\mathrm{n}$ & $\mathrm{pL}$ & $\log \left(\frac{n-1}{2-n}\right)$ & $\log \mathrm{K}_{2}$ \\
\hline 9.73 & 5.55 & 6.33 & 6.42 & 0.09 & 0.9000 & 1.69 & & \\
10.00 & 5.60 & 6.47 & 6.58 & 0.11 & 1.2578 & 1.44 & -0.4592 & 0.9808 \\
10.23 & 5.65 & 6.62 & 6.84 & 0.12 & 1.6137 & 1.26 & -0.2010 & 1.4610 \\
10.49 & 5.70 & 6.80 & 6.92 & 0.12 & 2.1052 & 1.03 & & \\
\hline
\end{tabular}

$\operatorname{LogK}_{2}$ (Average value) $=1.2209 \pm 0.3398$

Table 7:Point-wise method, Pb (Hydrolysed PSHA)

\begin{tabular}{|l|l|l|l|l|l|l|l|l|}
\hline $\mathrm{pH}$ & $\mathrm{BV}_{1}$ & $\mathrm{BV}_{2}$ & $\mathrm{BV}_{3}$ & $\left(\mathrm{~V}_{3}-\mathrm{V}_{2}\right)$ & $\mathrm{n}$ & $\mathrm{pL}$ & $\log \left(\frac{n}{1-n}\right)$ & LogK $_{1}$ \\
\hline 8.50 & 5.30 & 6.29 & 6.33 & 0.04 & 0.5500 & 2.66 & 0.0871 & 2.7471 \\
8.72 & 5.35 & 6.37 & 6.41 & 0.04 & 0.5714 & 2.43 & 0.1249 & 2.5549 \\
9.00 & 5.40 & 6.46 & 6.50 & 0.04 & 0.6198 & 2.16 & 0.2122 & 2.3722 \\
9.22 & 5.45 & 6.55 & 6.60 & 0.05 & 0.8333 & 1.96 & 0.6989 & 2.6589 \\
\hline
\end{tabular}

Log $_{\mathbf{1}}($ Average value $)=2.5832 \pm 0.1614$

Table 8:Point-wise method, Pb-(Hydrolysed PSHA)

\begin{tabular}{|l|l|l|l|l|l|l|l|l|}
\hline $\mathrm{pH}$ & $\mathrm{BV}_{1}$ & $\mathrm{BV}_{2}$ & $\mathrm{BV}_{3}$ & $\left(\mathrm{~V}_{3}-\mathrm{V}_{2}\right)$ & $\mathrm{n}$ & $\mathrm{pL}$ & $\log \left(\frac{n-1}{2-n}\right)$ & $\log \mathrm{K}_{2}$ \\
\hline 9.51 & 5.50 & 6.66 & 6.71 & 0.05 & 0.9650 & 1.67 & & \\
9.73 & 5.55 & 6.78 & 6.83 & 0.05 & 1.1702 & 1.44 & & \\
10.00 & 5.60 & 6.90 & 6.90 & 0.05 & 1.4864 & 1.22 & -0.0237 & 1.1963 \\
10.23 & 5.65 & 7.05 & 7.10 & 0.05 & 2.0190 & 1.09 & & \\
10.49 & 5.70 & 7.10 & 7.17 & 0.07 & 3.6492 & 1.00 & & \\
\hline
\end{tabular}

Log $K_{2}$ (Average value) $=1.1963$

Table 9: Point-wise method, Pb (Unhydrolysed PSHA)

\begin{tabular}{|l|l|l|l|l|l|l|l|l|}
\hline $\mathrm{pH}$ & $\mathrm{BV}_{1}$ & $\mathrm{BV}_{2}$ & $\mathrm{BV}_{3}$ & $\mathrm{~V}_{3}-\mathrm{V}_{2}$ & $\mathrm{n}$ & $\mathrm{pL}$ & $\begin{array}{l}\text { Log } \\
\left(\frac{n}{n-1}\right)\end{array}$ & Log $\mathrm{K}_{1}$ \\
\hline 8.50 & 5.30 & 5.81 & 5.85 & 0.04 & 0.2973 & 2.88 & -0.3736 & 2.5064 \\
8.72 & 5.35 & 5.90 & 5.94 & 0.04 & 0.3099 & 2.66 & -0.5477 & 2.3123 \\
9.00 & 5.40 & 6.00 & 6.05 & 0.05 & 0.4044 & 2.38 & -0.1681 & 2.2119 \\
9.22 & 5.45 & 6.10 & 6.15 & 0.06 & 0.5157 & 2.18 & 0.0272 & 2.2072 \\
9.51 & 5.50 & 6.20 & 6.26 & 0.07 & 0.6417 & 1.89 & 0.2530 & 2.1430 \\
9.73 & 5.55 & 6.40 & 6.40 & 0.07 & 0.7000 & 1.67 & 0.3680 & 2.0380 \\
\hline
\end{tabular}

LogK $_{1}$ (Average value) $=2.2364 \pm 0.1602$

Table 10: Point-wise method, Pb (Unhydrolysed PSHA)

\begin{tabular}{|l|l|l|l|l|l|l|l|l|}
\hline $\mathrm{pH}$ & $\mathrm{BV}_{1}$ & $\mathrm{BV}_{2}$ & $\mathrm{BV}_{3}$ & $\mathrm{~V}_{3}-\mathrm{V}_{2}$ & $\mathrm{n}$ & $\mathrm{pL}$ & $\log \left(\frac{n-1}{2-n}\right)$ & $\log \mathrm{K}_{2}$ \\
\hline 10.00 & 5.60 & 6.47 & 6.55 & 0.08 & 1.9503 & 1.41 & & \\
10.23 & 5.65 & 6.62 & 6.72 & 0.11 & 1.4792 & 1.26 & -0.0361 & 1.2239 \\
\hline
\end{tabular}

$\operatorname{LogK}_{2}$ (Average value) $=1.2239$

Table 11: Point-wise method, Mg (Hydrolysed PSHA)

\begin{tabular}{|l|l|l|l|l|l|l|l|l|}
\hline $\mathrm{pH}$ & $\mathrm{BV}_{1}$ & $\mathrm{BV}_{2}$ & $\mathrm{BV}_{3}$ & $\left(\mathrm{~V}_{3}-\mathrm{V}_{2}\right)$ & $\mathrm{n}$ & $\mathrm{pL}$ & $\log \left(\frac{n}{n-1}\right)$ & LogK $_{1}$ \\
\hline 8.50 & 5.30 & 6.29 & 6.31 & 0.02 & 0.2750 & 2.64 & -0.4290 & 2.2110 \\
8.72 & 5.35 & 6.37 & 6.39 & 0.02 & 0.2858 & 2.42 & -0.3978 & 2.0222 \\
9.00 & 5.40 & 6.46 & 6.49 & 0.03 & 0.4648 & 2.14 & -0.0612 & 2.0788 \\
9.22 & 5.45 & 6.55 & 6.59 & 0.04 & 0.6667 & 1.94 & 0.3010 & 2.2410 \\
\hline
\end{tabular}

$\log _{\mathbf{1}}($ Average value) $=2.1382 \pm 0.1046$ 
BAJOPAS Volume 14 Number 1,June, 2021

Table 12: Point-wise method, Mg (Hydrolysed PSHA)

\begin{tabular}{|l|l|l|l|l|l|l|l|l|}
\hline $\mathrm{pH}$ & $\mathrm{BV}_{1}$ & $\mathrm{BV}_{2}$ & $\mathrm{BV}_{3}$ & $\left(\mathrm{~V}_{3}-\mathrm{V}_{2}\right)$ & $\mathrm{n}$ & $\mathrm{pL}$ & $\log \left(\frac{n-1}{2-n}\right)$ & LogK $_{2}$ \\
\hline 9.51 & 5.55 & 6.66 & 6.71 & 0.05 & 0.9650 & 1.67 & & \\
9.73 & 5.55 & 6.78 & 6.84 & 0.06 & 1.4042 & 1.47 & -0.1686 & 1.3014 \\
10.00 & 5.60 & 6.90 & 6.93 & 0.06 & 1.7838 & 1.23 & 0.5593 & 1.7893 \\
10.23 & 5.65 & 7.05 & 7.10 & 0.06 & 3.1429 & 1.10 & & \\
10.49 & 5.70 & 7.10 & 7.18 & 0.07 & 3.6492 & 0.83 & & \\
\hline
\end{tabular}

LogK $_{2}($ Average value $)=1.5453 \pm 0.3450$

Table 13: Point-wise method, Mg (Unhydrolysed PSHA)

\begin{tabular}{|l|l|l|l|l|l|l|l|l|}
\hline $\mathrm{pH}$ & $\mathrm{BV}_{1}$ & $\mathrm{BV}_{2}$ & $\mathrm{BV}_{3}$ & $\mathrm{~V}_{3}-\mathrm{V}_{2}$ & $\mathrm{n}$ & $\mathrm{pL}$ & $\log \left(\frac{n}{n-1}\right)$ & $\operatorname{Log~}_{1}$ \\
\hline 8.50 & 5.30 & 5.81 & 5.85 & 0.04 & 0.2973 & 2.88 & -0.3736 & 2.5064 \\
8.72 & 5.35 & 5.90 & 5.94 & 0.04 & 0.3099 & 2.66 & -0.3477 & 2.3123 \\
9.00 & 5.40 & 6.00 & 6.04 & 0.04 & 0.3236 & 2.38 & -0.3202 & 2.0598 \\
9.22 & 5.45 & 6.10 & 6.15 & 0.05 & 0.4297 & 2.17 & -0.1230 & 2.0470 \\
9.51 & 5.50 & 6.20 & 6.26 & 0.06 & 0.5500 & 1.89 & 0.0871 & 1.9771 \\
9.73 & 5.55 & 6.33 & 6.40 & 0.07 & 0.7000 & 1.67 & 0.3680 & 2.0380 \\
\hline
\end{tabular}

LogK $_{1}$ (Average value) $=2.1568 \pm 0.2069$

Table 14: Point-wise method, Mg (Unhydrolysed PSHA)

\begin{tabular}{|l|l|l|l|l|l|l|l|l|}
\hline $\mathrm{pH}$ & $\mathrm{BV}_{1}$ & $\mathrm{BV}_{2}$ & $\mathrm{BV}_{3}$ & $\mathrm{~V}_{3}-\mathrm{V}_{2}$ & $\mathrm{n}$ & $\mathrm{pL}$ & $\log \left(\frac{n-1}{2-n}\right)$ & $\log \mathrm{K}_{2}$ \\
\hline 10.00 & 5.60 & 6.47 & 6.55 & 0.08 & 0.9148 & 1.41 & & \\
10.23 & 5.65 & 6.62 & 6.71 & 0.09 & 1.2102 & 1.20 & -0.5749 & 0.6251 \\
10.49 & 5.70 & 6.80 & 6.92 & 0.09 & 1.5968 & 1.03 & 0.1703 & 1.2003 \\
\hline
\end{tabular}

LogK $_{2}$ (Average value) $=0.9127 \pm 0.4070$

Table15:Point-wise method, Cd (Hydrolysed PSHA)

\begin{tabular}{|l|l|l|l|l|l|l|l|l|}
\hline $\mathrm{pH}$ & $\mathrm{BV}_{1}$ & $\mathrm{BV}_{2}$ & $\mathrm{BV}_{3}$ & $\left(\mathrm{~V}_{3}-\mathrm{V}_{2}\right)$ & $\mathrm{n}$ & $\mathrm{pL}$ & $\log \left(\frac{n}{1-n}\right)$ & LogK $_{1}$ \\
\hline 8.50 & 5.30 & 6.29 & 6.31 & 0.02 & 0.2750 & 2.64 & -0.4210 & 2.2190 \\
8.72 & 5.35 & 6.37 & 6.40 & 0.03 & 0.4286 & 2.42 & -0.1249 & 2.2951 \\
9.00 & 5.40 & 6.46 & 6.49 & 0.03 & 0.4648 & 2.14 & -0.0612 & 2.0788 \\
9.22 & 5.45 & 6.55 & 6.59 & 0.04 & 0.6667 & 1.96 & 0.3010 & 2.2610 \\
9.51 & 5.55 & 6.66 & 6.70 & 0.04 & 0.7720 & 1.67 & 0.5297 & 2.1997 \\
\hline
\end{tabular}

LogK $_{\mathbf{1}}$ (Average value) $=2.2108 \pm 0.0825$

Table 16: Point-wise method, Cd (Hydrolysed PSHA)

\begin{tabular}{|l|l|l|l|l|l|l|l|l|}
\hline $\mathrm{pH}$ & $\mathrm{BV}_{1}$ & $\mathrm{BV}_{2}$ & $\mathrm{BV}_{3}$ & $\left(\mathrm{~V}_{3}-\mathrm{V}_{2}\right)$ & $\mathrm{n}$ & $\mathrm{pL}$ & $\log \left(\frac{n-1}{2-n}\right)$ & Log $_{2}$ \\
\hline 9.73 & 5.55 & 6.78 & 6.83 & 0.06 & 1.4042 & 1.47 & -0.1686 & 1.3014 \\
10.00 & 5.60 & 6.90 & 6.95 & 0.06 & 1.7838 & 1.23 & 0.5593 & 1.7893 \\
10.23 & 5.65 & 7.05 & 7.10 & 0.06 & 3.1429 & 1.09 & & \\
10.49 & 5.70 & 7.10 & 7.16 & 0.06 & 3.1429 & 0.89 & & \\
& & & & & & & & \\
\hline
\end{tabular}

$\operatorname{LogK}_{2}$ (Average value) $=1.5453 \pm 0.3450$

Table 17: Point-wise method, Cd (Unhydrolysed PSHA)

\begin{tabular}{|l|l|l|l|l|l|l|l|l|}
\hline $\mathrm{pH}$ & $\mathrm{BV}_{1}$ & $\mathrm{BV}_{2}$ & $\mathrm{BV}_{3}$ & $\mathrm{~V}_{3}-\mathrm{V}_{2}$ & $\mathrm{n}$ & $\mathrm{pL}$ & $\log \left(\frac{n}{n-1}\right)$ & $\operatorname{Log~}_{1}$ \\
\hline 8.50 & 5.30 & 5.81 & 5.86 & 0.05 & 0.3717 & 2.88 & -0.2280 & 2.6520 \\
8.72 & 5.35 & 5.90 & 5.95 & 0.05 & 0.3873 & 2.66 & -0.1992 & 2.4608 \\
9.00 & 5.40 & 6.00 & 6.06 & 0.06 & 0.4853 & 2.38 & -0.0255 & 2.3545 \\
9.22 & 5.45 & 6.10 & 6.16 & 0.06 & 0.5157 & 2.18 & -0.0272 & 2.2072 \\
9.51 & 5.50 & 6.20 & 6.27 & 0.07 & 0.6417 & 1.89 & 0.2530 & 1.1430 \\
9.73 & 5.55 & 6.33 & 6.41 & 0.08 & 0.8000 & 1.69 & 0.6020 & 2.2920 \\
& & & & & & & & \\
\hline
\end{tabular}

$\operatorname{LogK}_{1}($ Average value $)=2.2516 \pm 0.5380$ 
BAJOPAS Volume 14 Number 1,June, 2021

Table 18: Point-wise method, Cd (Unhydrolysed PSHA)

\begin{tabular}{|l|l|l|l|l|l|l|l|l|}
\hline $\mathrm{pH}$ & $\mathrm{BV}_{1}$ & $\mathrm{BV}_{2}$ & $\mathrm{BV}_{3}$ & $\mathrm{~V}_{3}-\mathrm{V}_{2}$ & $\mathrm{n}$ & $\mathrm{pL}$ & $\log \left(\frac{n-1}{2-n}\right)$ & $\log \mathrm{K}_{2}$ \\
\hline 10.00 & 5.60 & 6.47 & 6.57 & 0.10 & 1.1434 & 1.43 & & \\
10.23 & 5.65 & 6.62 & 6.72 & 0.10 & 1.3448 & 1.23 & -0.2788 & 0.9512 \\
10.49 & 5.70 & 6.80 & 6.90 & 0.10 & 1.7742 & 1.03 & 0.5351 & 1.5651 \\
\hline
\end{tabular}

$\operatorname{LogK}_{2}($ Average value $)=1.2581 \pm 0.4340$

Table 19: Stepwise and overall Stability constants of thehydrolysed and unhydrolysed divalent metal (II) complexes

\begin{tabular}{|c|c|c|c|}
\hline Chelates & LogK $_{1}$ & $\log _{2}$ & Log $\beta$ \\
\hline [Cu (Hydrolysed PSHA-1) $\left.{ }_{2}\right]$ & 2.4788 & 1.4280 & 3.9068 \\
\hline$\left[\mathrm{Pb}(\text { Hydrolysed PSHA-1) })_{2}\right]$ & 2.5832 & 1.1963 & 3.7795 \\
\hline$\left[\mathrm{Cd}(\text { Hydrolysed PSHA-1 })_{2}\right]$ & 2.2108 & 1.5453 & 3.7561 \\
\hline$\left[\mathrm{Mg}(\text { Hydrolysed PSHA-1 })_{2}\right]$ & 2.1382 & 1.5453 & 3.6835 \\
\hline [Cu (Unhydrolysed PSHA-1) & 2.3059 & 1.2209 & 3.5268 \\
\hline$[\mathrm{Pb}$ (Unhydrolysed PSHA-1) 2$]$ & 2.2364 & 1.2239 & 3.4603 \\
\hline [Cd (Unhydrolysed PSHA-1) 2 ] & 2.2516 & 1.2581 & 3.5097 \\
\hline$[\mathrm{Mg}$ (Unydrolysed PSHA-1) & 2.1568 & 0.9127 & 3.0695 \\
\hline
\end{tabular}

The results obtained (Table19) shows the stepwise and overall stability constants to be not high indicating low stability of the complexes, because the solubility of most metal ions in the basic $\mathrm{pH}$ range is minimal due to metal hydroxide precipitation (Karimi, 2017). In general, the stepwise stability constants $\left(K_{1}\right.$ and $K_{2}$ ) follow the order $K_{1}>K_{2}$ for the copper, lead, magnesium and cadmium complexes respectively. The steady decrease of the values with increasing number of ligands is in agreement with the prediction made by researchers (Na'aliya, 2013). The decrease could be attributed to the fact that as the number of the ligands (Humate ions) that enters the coordination zone increases the aqua molecules available for replacement by the ligands become less. Thus, the metal ions become less electron loving with progressive intake of the ligand and this results in the decrease in the values of the constants (Na'aliya, 2013). Also the stability of the complexes is influenced by the size and number of the chelate rings(Mackay and Mackay,2002).All the complexes form rings in their structure as humate, a bidentate ligand, bond the metal ions in the ratio 1:2 (Boguta and Sokolowska, 2016) forming chelate rings. The values of the overall stability constants $(\log \beta)$ obtained for humate complexes are not high indicating low stability as the values are not high. LogK values for copper-humates (Table 3 to 6) obtained in this study are lower than those reported for the complexes of humic acids (Pandey et al., 2015; Dinu, 2013; Kaschl et al., 2010 and Gilbeto and Jorg, 2001). The values of LogK(Table 7 to 10 ) forlead-humates are lower than those reported for the lead in the literature (Dinu, 2013; Gilbeto and Jorg 2001). Log K values(Table 11 to 14 ) for magnesium-humates obtained in this study are close to those reported by (Pandey et al., 2015). Log K values of cadmium-humates (Table 15 to 18 ) obtained in this work near to the one reported by (Dinu, 2013 and Pandey et al., 2015).The difference between the reported values and the values obtained in this study might be probably as a result of acid hydrolysis of humic acid. The values of the overall stability constants $(\log \beta)$ of the copper humates complexes presented in Table 19 is high than that of other metal humate complexes, show relatively high stability of CuHA complexes, show the following order of stability: $\mathrm{Cu}>\mathrm{Pb}>\mathrm{Cd}>\mathrm{Mg}$; which are in close agreement to the findings of (Dinu, 2013 and Pandey et al., 2015).The high stability of Cuhumate chelate could be attributed to the existence of coordinate covalent bond between the complexing agents and the $\mathrm{Cu}^{2+}$ ions. Since, $\mathrm{Cu}^{2+}$ being a metal of the transitional series with $3 d^{9}$ electronic configurations can accept the electrons from the complexing agents. Similarly, the low stabilities of $\mathrm{Pb}, \mathrm{Cd}$ and $\mathrm{Mg}$ complexes could be explained by that $\mathrm{Pb}^{2+}$ with $6 s^{2}, \mathrm{Cd}^{2+}$ with $4 \mathrm{~d}^{10}$ and $\mathrm{Mg}^{2+}$ with $2 \mathrm{p}^{6}$ their electronic configuration has a completely filled $\mathrm{d}, \mathrm{p}$ and $\mathrm{s}$ orbitals. Moreover, the stabilities of metal ions with hydrolysed humic acid from peat soil were higher than those with unhydrolysed humic acid from peat soil; which is ascribed to the high content of acidity in hydrolysed humic acid than unhydrolysed humic acid. 
BAJOPAS Volume 14 Number 1,June, 2021 CONCLUSION

The values of logk for $\mathrm{Cu}(\mathrm{II})$ hydrolysed humic acid complex was higher followed by $\mathrm{Pb}$ (II), $\mathrm{Cd}(\mathrm{II})$ and $\mathrm{Mg}$ (II) hydrolysed humic acid complexes as compared with metal(II) unhydrolysed humic acid complexes. This indicates acid hydrolysis of humic acid can

\section{REFERENCES}

Almeida, V.R. and Szpoganicz, B. (2015). Humic Acid Potentiometric Response Patterns:Out- of Equilibrium Properties and Species Distribution Modelling. Chemical. Biol. Technol. Agric. 2: 17.

Anđelković, T., Nikolić, R., Bojić, A.,Anđelković, D., and Nikolic G.,(2010). Binding of Cadmium to Soil Humic Acid as A Function of Carboxyl Group Content. Macedonian Journal of Chemistry and Chemical Engineering.29(2): 215-224.

Anil, B. N. and Maroti, N. (2008). Studies on Influence of Die-Lectric Constants on Complex Equilibria between Substituted Py-Razalines and Lanthanide Metal Ions pH-Metrically. Amer.-Euras. scient. Res. 3(2): 212-216.

Ashok, K., Pandey, S. P. and Misra, V (2000). Stability Constants of Metal-Humic Acid Complexes and its Role in Environmental Detoxification. Journal of Ecotoxicology and Environmental Safety. 47(2):157-200.

Badr, M. H., El-Halafawi, M. H. and Abd El-al Zeid, E. R. (2012). Comparison Between the Effect of Ionic Strength on Acidity and Dissociation Constants of Humic Acids Extracted from Sewage Sludge and Nile Water Hyacinth Composts.Global Journal of Environmental Research 6 (1): 36-43.

Baruah, M.K., Borah, D., Saikia, P.P., Paul, S., Sharma, T. (2015). Evaluation of pKa Values of Soil Humic Acids and their Complexation Properties. International Journal of Plant \& Soil Science 6(4) : 218-228.

Boguta, P. Sokolowska, Z. (2016). Interactions of $\mathrm{Zn}$ (II) Ions with Humic Acids Isolated from Various Types of Soils. Effect of $\mathrm{pH}, \mathrm{Zn}$ Concentrations and Humic Acids Chemical Properties. Journal of Geochemical Explaration 168. 119-126.

Borges, F., Guimaraes, C., Lima, L.F.C., Pinto, I. and Reis, S.(2005). Potentiometric Studies on the Complexation of Copper(II) by Phenolic Acids as Discrete Ligand Models of enhance the complexation behavior of humic acid with metal (II) ions. However, the higher values of $\log \beta$ for $\mathrm{Cu}(\mathrm{II}), \mathrm{Pb}(\mathrm{II}), \mathrm{Cd}(\mathrm{II})$ and $\mathrm{Mg}(\mathrm{II})$ hydrolysed humic acid complexes indicates more stable stepwise complexes formed as compared with $\mathrm{Cu}(\mathrm{II}), \mathrm{Pb}$ (II), $\mathrm{Cd}$ (II) and $\mathrm{Mg}(\mathrm{II})$ unhydrolysed humic acid complexes.

Humic Substances Talanta 66 (2005) 670-673.

Chefetz, B., Salloum, M. J., Deshmulkin, A. P. and Hatcher, P. (2002). Structural Components of Humic Acids as Determined by Chemical Modifications and Carbon-13 NMR, Pyrolysis, and Thermochemolysis- Gas Chromatography/Mass Spectrometry. Soil Science Society of American Journal Abstract Division S-2- Soil Chemistry66. 1159-1171.

Dinu, M. I. (2013). Metals Complexation with Humic Acids in Surface Water of Different Environ. Sci. Technol. 31(1): 1-17.

Fernandes, A.N., Giacomelli, C., Giovanela, M. Vaz, D.V. Szpoganicz, B. and Maria M. D. (2009). Potentiometric Acidity Determination in Humic Substances Influenced by Different Analytical Procedures.J. Braz. Chem. Soc. 20 (9):14.

Gamal, A. H. (2015). Stability Constants of Rhenium (V) Metal Complexes with Selected Drugs. Pyrex Journal of Research in Environmental Studies. 2(2): 006-014.

Janrao, D. M., Pathan, J., Kayande, D.D., and Mulla, J.J. (2014). An Over View of Potentiometric Determination of Stability Constants of Metal Complexes. Sci. Revs. Chem. Commun.: 4(1), 2014, 11-24.

Karimi, H. (2017). Effect of pH and Initial Pb(II) Concentration on the Lead Removal Efficiency from Waste Water Using $\mathrm{Ca}(\mathrm{OH})_{2}$. International Journal of Water and Waste Water Treatment 3.2

Kaschl, A. Romheld, V. and Chen, Y. (2010). Binding of Cadmium, Copper and Zinc to Humic Substances Originating from Municipal Solid Waste Compost. Israel Journal of Chemistry Vol. 42(1): 89-98.

Kostic, I. S., Tatjana, P, A., Nikolic, R. S., Cvetkovic, T. P., Pavlovic, D. D., Aleksandar, L.J. and Bojic, A. (2012). Comparative Study of Binding Strengths of Heavy Metals with Humic Acid. J.serb. Chem. Soc. 76(9) pp 1-20. 
BAJOPAS Volume 14 Number 1,June, 2021

Na'aliya, J. (2013). Determination of Stepwise Stability Constants and Gibbs free Energy Change of Trisprolina to Complexes of some Divalent Transition Metal ions. Bayero Journal of Pure and Applied Sciences 6(2): 112-114.

Omar, A. A. and Ali, E. A. (2015). Potentiometric Studies on Complexes of $\mathrm{Cr}$ (III) and $\mathrm{Zr}$ (IV) with some Carboxylic Acids. International Journal of Advanced Chemistry, 3(1) 25-

37.

Pandey, A. K. Pandey, S. D. and Misr, V. (2015).Stability Constants of Metal- Humic Acid Complexes and Its Role in Environmental Detoxification. J. Ecotoxicology and Environmental Safety. 47(1):195-200.

Ram, N. and Raman, K.V. (1984). Stability Constants of Complexes of Metals with
Humicand Fuvic Acids under Non- acidConditions. Journal of Plant Nutrition and Soil Sciences.

147:171-176.

Santosh, D. D., Ashok, B. K., Vijay, J. T., Shivraj, G. W. and Vinay, V. W. (2011). Potentiometric Studies of Elec-Trolyte Effects on Complex Equilibria of Some Substituted 5-(2-hydroxy Phenyl) Pyrazoles. Der pharm. 3 (6): 75-83.

Sayyed, H. and Abdul Rahim, M. F. (2012). Studies of Binary Complexes of Metal Ions with Mandelic Acid by Potentiometry. Chem. J. 02 (6): 206209.

Shirvani, M. Moradian, E. Khalili, B. Bakhtiary, S. (2015). Interaction of $\mathrm{Cd}$ and $\mathrm{Pb}$ with Humate-Palygorskite and HumateSepiolite Complexes. Journal of water, air and pollution 3: 220-228. 


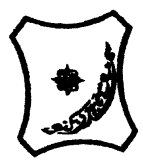

Bayero Journal of Pure and Applied Sciences, 14(1): 54 - 63

Received: November, 2020

Accepted: April, 2021

ISSN $2006-6996$

\title{
STABILITY CONSTANTS OF COMPLEXES OF METAL IONS WITH PEATSOIL HUMIC ACIDS UNDER NON-ACID-CONDITIONS
}

\author{
${ }^{* 1}$ Sabo, Yusuf ${ }^{2}$ Jimoh, W.L.O., ${ }^{3}$ Isa Baba Koki and ${ }^{4}$ Sholadoye, Q. 0. \\ ${ }^{1}$ Department of Pure and Industrial Chemistry, Bayero University, Kano \\ ${ }^{3}$ Department of Chemistry, Yusuf Maitama Sule University Kano. P.M.B. 3220 Kano, Nigeria. \\ ${ }^{4}$ Department of Chemistry, Nigerian Police Academy, Wudil, Kano-Nigeria
}

*Correspondence E-mail; saboyusuf18@yahoo.com

ABSTRACT

Stability constants of complexes of four divalent metal ions viz. $\mathrm{Cu}^{2+}, \mathrm{Pb}^{2+}, \mathrm{Mg}^{2+}$ and $\mathrm{Cd}^{2+}$ with humic acids (HA) were determined by potentiometric titration of humic acids with the corresponding salt of the divalent metals in aqueous media under non-acid-condition. The log $K$ (logarithm of the stability constant) ranged from 1.0942 to 2.7471 for metalhumic acid complexes were determined using point-wise computational method. The order of stability constants were obtained as follows: $\mathrm{Cu}>\mathrm{Pb}>\mathrm{Cd}>\mathrm{Mg}$ for metal $-\mathrm{HA}$ complexes respectively, indicating a higher degree of complexation with Cu metal ion.

Keywords: stability constant, humic acid, potentiometric titration, divalent metals, acid hydrolysis.

\section{NTRODUCTION}

The stability constant of a complex is the numerical expression of its stability and provides a quantitative measure of affinity of the metal ion to the complexing agent. An understanding of the relative stability of metal-complexes helps in predicting the behavior of metal ions in the soil (Ram and Raman, 1982). Extensive researches has been done to determine the stability constants of the complexes formed between humic acid (HA) with a number of metal ions. Ashok et al., (2000) reported that humic acid with hydroxyl, phenoxyl and carboxyl reactive groups can form coordination compound with metal ions at $\mathrm{pH}$ 3.5. The stability constants(Log K) for different metalhumic acid complexes indicated the following order of the stabilities of complexes formed between humic acid and metal ion, $\mathrm{Cu}>\mathrm{Fe}$ $>\mathrm{Pb}>\mathrm{Ni}>\mathrm{Co}>\mathrm{Ca}>\mathrm{Cd}>\mathrm{Zn}>\mathrm{Mn}>\mathrm{Mg}$. Andelkovic et al., (2010) investigated the binding of $\mathrm{Cd}$ (II) to soil humic acid at pH 6.5 and in $0.1 \mathrm{M} \mathrm{KNO}_{3}$ ionic medium. The stability constant for binding indicating greater stability in the case when carboxyl groups are involved in complexation reaction. Kostic et al.,(2012) investigated the complexation of humic acid with certain heavy metal ions (Co(II), $\mathrm{Ni}(\mathrm{II}), \mathrm{Cu}(\mathrm{II})$,
$\mathrm{Zn}(\mathrm{II})$, and $\mathrm{Pb}(\mathrm{II})$. The experiment was performed at $25^{\circ} \mathrm{C}$, at pH 4.0 and ionic strength of $0.01 \mathrm{M}$. Stability constant of complex between $\mathrm{Pb}$ (II) ions and humic acid is greater than stability constants of other investigated metalhumate complexes. Bogata and Sokolowska (2016) analyses the interaction between humic acids from different soils and $\mathrm{Zn}$ (II) ions at wide concentration ranges and at $\mathrm{pH} 5$. Studies have showed significant impact of $\mathrm{Zn}$ concentration, $\mathrm{pH}$ and some properties of humic acids with zinc.But all of these studies were limited to acidic $\mathrm{pH}$ range. Therefore, the present study was carried out to determine and compare the stability constants of complexes of metal ions with hydrolysed peat soil humic acid and unhydrolysed peat soil humic under non-acid conditions.

\section{MATERIALS AND METHODS}

Analytical grade chemicals used includes hydrochloric acid $(\mathrm{HCl})$, nitric acid $\left(\mathrm{HNO}_{3}\right)$, sodium hydroxide $(\mathrm{NaOH})$, lead nitrate $\mathrm{Pb}\left(\mathrm{NO}_{3}\right)_{2}$, copper nitrate $\mathrm{Cu}\left(\mathrm{NO}_{3}\right)_{2} \cdot 3 \mathrm{H}_{2} \mathrm{O}$, cadmium nitrate $\mathrm{Cd}\left(\mathrm{NO}_{3}\right)_{2} \cdot 4 \mathrm{H}_{2} \mathrm{O}$, magnesium nitrate $\mathrm{Mg}\left(\mathrm{NO}_{3}\right)_{2} \cdot 6 \mathrm{H}_{2} \mathrm{O}$, potassium nitrate $\left(\mathrm{KNO}_{3}\right)$, calcium chloride $\left(\mathrm{CaCl}_{2}\right)$, (sigma-Aldrich). Dowex 50WX8, (20-50 mesh) from Fluka. 


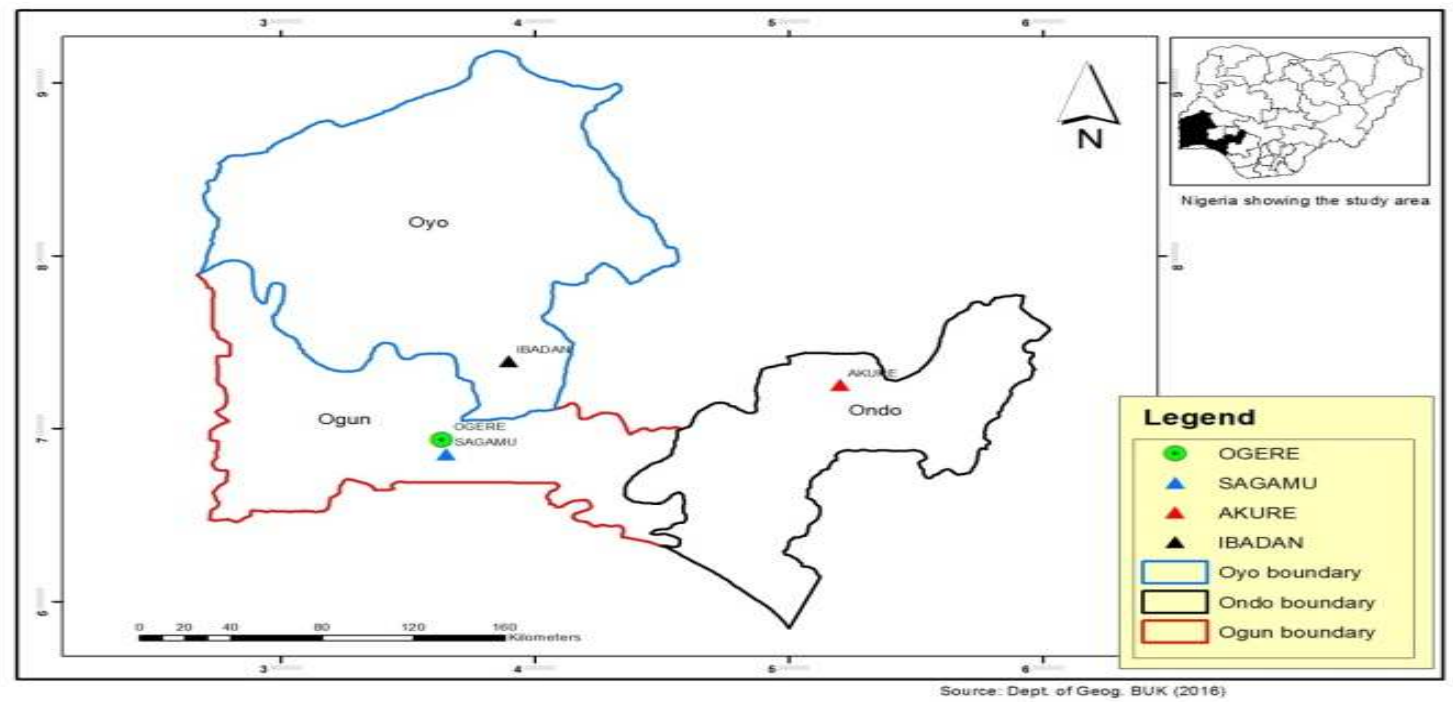

Figure 1: Map showing the sampling point at Sagamu Town, Ogun State.

\section{Description of Sampling Area}

Sagamu has geographical coordinates between $6^{\circ} 50^{\prime}$ north; $3^{\circ} 38^{\prime}$ east is located in south western region of Nigeria. The region has tropical wet and dry climate with a lengthy wet season and relatively constant temperatures throughout the course of the year. Wet season runs from March to October, November to December forms the region dry season. The vegetation type of the region is savannah which is really grassland with small bushes and occasional big trees. Grassland soils have substantially higher organic matter content than forest soils (Novackova, 2011).

\section{Sample Collection}

The Peatsoil samples were collected from four different sampling points $(0-10 \mathrm{~cm}$ depth) in Sagamu into polyethylene bag with plastic spoons. Samples were taken to the laboratory, extraneous materials were removed; the samples were air-dried, crushed and ground to a fine powder in a mortar passed through a $0.20 \mathrm{~mm}$ sieve. The samples were kept for analysis.

\section{Isolation and purification of humic acid from peat soil sample}

Peatsoil sample $(100 \mathrm{~g})$ was mixed with 1000 $\mathrm{cm}^{3}$ of $0.1 \mathrm{M} \mathrm{NaOH}$ solution, shaken for 3hours and left to stand overnight. Dark-coloured supernatant was obtained and decanted from solid residue. The dark-coloured supernatant was acidified to $(\mathrm{pH}=1.0)$ with $6 \mathrm{M} \mathrm{HCl}$ stirred and allowed to stand for 6 hours. Yellowish brown supernatant and dark-brown precipitate were obtained. The yellowish brown supernatant was decanted followed by centrifuge and discarded. The dark-brown precipitate was mixed with $500 \mathrm{~cm}^{3}$ of $0.1 \mathrm{M} \mathrm{NaOH}$ solution followed by passing through dowex resin. The dark-brown solution was acidified to $(\mathrm{pH}=1.0)$ with $6 \mathrm{M} \mathrm{HCl}$ stirred and allowed to stand for 3 hours. The dark-brown precipitate was washed several times with deionized water. The supernatant was treated with $\mathrm{AgNO}_{3}$ solution until no white precipitate observed. The humic acid was transferred to weighed crucible and dried at $60^{\circ} \mathrm{C}$ in an oven for 12 hours. The humic acid was cooled and dried in the desiccator, weighed and recorded. The obtained humic acid was dried again at $60^{\circ} \mathrm{C}$ for additional 6 hours cooled and dried in the desiccator, weighed and recorded constant weight was obtained (Baruah et al., 2015).

\section{FT-IR analysis}

FT-IR spectra of humic acid sample was analysed using Carry 630 FT-IR Agilent Technologies.

Unhydrolysed compost humic acid

The unhydrolysed humic acid was obtained after isolation and purification of compost humic acid and kept for investigation.

\section{Acid hydrolysis of Peatsoil acid}

Peatsoil humic acid sample (1g) was refluxed for 12 hours at $\left(160^{\circ} \mathrm{C}\right)$ with $50 \mathrm{~cm}^{3}$ of $6 \mathrm{M} \mathrm{HCl}$. The mixture was allowed to cool, decanted, and centrifuged after hydrolysis. The insoluble residues were washed with distilled water via centrifugation several times, and the supernatant was treated with $\mathrm{AgNO}_{3}$ solution until no white precipitate was observed. The residue was thoroughly dried over $\mathrm{CaCl}_{2}$ in a desiccator at room temperature (Chefetz et al., 2002). Finally, the obtained hydrolysed humic acid was kept for investigation. 
BAJOPAS Volume 14 Number 1,June, 2021 Potentiometric Titrations

Potentiometric measurements were carried out using a pH-meter Jenway (model 3510) with combine electrode, the sensitivity of the $\mathrm{pH}$ meter is 0.01 units. The $\mathrm{pH}$ meter was switched on half an hour before starting the titration for initial warm up of the instrument. The instrument was calibrated with an aqueous standard buffer solution of $\mathrm{pH} 4.00$ and 10.0 (borate buffer) prepared from a "Qualigens" buffer tablets.

The following sets of solutions were prepared in a $250 \mathrm{~cm}^{3}$ volumetric flask separately for $\mathrm{pH}$ metric titrations.

(i) $5 \mathrm{~cm}^{3} 0.1 \mathrm{M} \mathrm{HCl}+40 \mathrm{~cm}^{3}$ deionized water

(ii) $5 \mathrm{~cm}^{3} 0.1 \mathrm{M} \mathrm{HCl}+39 \mathrm{~cm}^{3}$ deionized water $+1 \mathrm{~cm}^{3} 0.15 \mathrm{gcm}^{-3}$ humic acid

(iii) $5 \mathrm{~cm}^{3} 0.1 \mathrm{M} \mathrm{HCl}+37 \mathrm{~cm}^{3}$ deionized water $+1 \mathrm{~cm}^{3} 0.15 \mathrm{gcm}^{-3}$ humic acid

$$
+2 \mathrm{~cm}^{3} \quad 0.01 \mathrm{M} \mathrm{Cu} \text { (II) }
$$

The solutions were titrated against standardized $0.110 \mathrm{MNaOH}$ separately. The total volume of each mixture was adjusted to $50 \mathrm{~cm}^{3}$ and the ionic strength of the solutions was maintained constant at by adding appropriate amount of stock solution of $1 \mathrm{M} \mathrm{KNO}_{3}$ (Gamal, 2015; Omar and Ali, 2015). A magnetic stirrer was used to achieve thorough mixing of the interacting solutions at $550 \mathrm{rpm}$. The same set of experimental conditions was applied for potentiometric titration of remaining samples.

\section{Evaluation of pKa of Hydrolysed peat soil Humic Acids}

The proton-ligand formation number $\mathrm{n}_{\mathbf{A}}$ were calculated by Irving and Rossotti expression (Omar and Ali, 2015).

$\mathrm{nA}=\mathrm{Y}-\frac{(\mathrm{V} 2-\mathrm{V1})(\mathrm{No}-\mathrm{Eo})}{(\mathrm{VO}+\mathrm{V1}) \mathrm{TCL}}$ 1

Where: $Y$ is number of dissociable proton, $\left(\mathrm{V}_{2^{-}}\right.$ $V_{1}$ ) is the measure of displacement of the ligand curve relative to acid curve, $\mathrm{N}^{\circ}$ and $\mathrm{E}^{\circ}$ are the resultant concentration of alkali solution, free acid solution, $\mathrm{T}_{\mathrm{cL}}{ }^{\circ}$ is the total ligand concentration, $\mathrm{V}^{\circ}$ is the total volume of titration solution, $V_{1}$ is the volume of alkali added to acid solution, $V_{2}$ is the volume of alkali added to acid solution + ligand solution, acid dissociation constants (pKa - values) of ligand were calculated by algebraic method point wise calculation (Tables 1 ). The dissociation constants (pKa) were calculated according to the following relation:

$\mathrm{pKa}=\mathrm{pH}+\log \left(\frac{n A}{1-n A}\right)$ 2

Where: pKa is the acid dissociation constant, $\mathrm{n}_{\mathrm{A}}$ is the Proton-ligand formation number and $\mathrm{pH}$ is the pH-values (Omar and Ali, 2015).

\section{Determination of metal-ligand stability constants $(\log K)$ of complexes}

The potentiometric measurement for the determination of stability constant of a complex in solution is based on the fact that the redox potential of the couple $\frac{M^{+(m-n)}}{M^{+m}}$ is shifted significantly on complexation of the metal ion with the ligand. This method involves change in hydrogen ion concentration $\left[\mathrm{H}^{+}\right]$due to the displacement or association of one or more protons taking place during complexation reaction. This change can be found out by titrating the solutions containing free acid, acid with ligand, and acid with ligand and metal ion, individually against a standard alkali solution at a constant ionic strength or temperature. Either ionic strength or temperature may be varied for different sets of solutions. In all the cases, the change in the $\mathrm{pH}$ of the solution is measured after each addition of a known amount of alkali to the reaction cell which contains the reaction mixture. The titration curves are then drawn by plotting the measured $\mathrm{pH}$ values against the corresponding volume of alkali added and the stability constants of the complexes are determined from the titration curves by employing $\mathrm{pH}$-metric titration technique given by (Irving and Rossoti).

Metal-ligand stability constants ( $\log \mathrm{K}$ ) were determined by using the following relations:

$$
\bar{n}=\frac{\left(V_{3}-V_{2}\right)\left(E^{0}+N^{0}\right)}{\left(V^{0}+V_{2}\right) \bar{n}_{A} T_{m}^{0}}
$$

and

$$
P L=\log _{10}\left\{\frac{1+\beta_{n}^{H} \frac{1}{[\text { anti } \log \mathrm{pH}]^{\mathrm{n}}}}{\mathrm{T}_{\mathrm{L}}^{0}-n \bar{T}_{m}^{0}} \mathrm{X} \frac{\left(V^{0}+V_{3}\right)}{V^{0}}\right\}
$$


BAJOPAS Volume 14 Number 1,June, 2021

Where $T_{L}, T^{\circ}, E^{\circ}$, and $V^{\circ}$ havethe same significance as in equation (1) above, $T_{m}$ denotes the total concentration of metal present in solution, $V_{3}$ is the volume of metal ions present in solution and $\beta^{H}$ is the overall proton ligand stability constant. The metal-ligand stability constants (log K) were determined by employing point wise computational Method (eq. 5 and 6).

$\operatorname{LogK}_{1}=\log \left(\frac{n}{1-n}\right)+\mathrm{pL}$ .5

$\operatorname{LogK}_{2}=\log \left(\frac{1-n}{2-n}\right)+\mathrm{pL}$ ...6

Where: Log $\mathrm{K}$ is the metal-ligand stability constant, $\mathrm{pL}$ is the Free ligand exponent function, $\mathbf{n}$ is the Average number of ligand attached with metal ion (Janraoet al., 2014). The results obtained were analyzed by an ORIGIN 2016 program using titration data and then the proton-ligand stability constants (pKa) and Metal-ligand stability constant (LogK) calculated (Omar and Ali, 2015).

\section{RESULTS AND DISCUSSION}

Fourier transformed infrared (FT-IR) spectra of isolated humic acid from peat soils Figure 2 had distinct clear absorption bands indicating the presence of major humic acid structural elemental groups such as $\mathrm{H}$ bonded $\mathrm{OH}$ $\left(3680 \mathrm{~cm}^{-1}\right.$ peak $), C=0$ of carbonyl $\left(1721 \mathrm{~cm}^{-1}\right.$ peak), functional groups of aliphatic components $\mathrm{CH}_{2}\left(2918 \mathrm{~cm}^{-1}\right.$ peak) and $\mathrm{C}-\mathrm{O}$ stretching of polysaccharide $\left(1168 \mathrm{~cm}^{-1}\right.$ peak). The positions of the absorption bands of the spectra fell within typical major absorption bands of humic acid which is at frequencies 3680, 2918, 1721, 1168 $\mathrm{cm}^{-1}$. The first peak centred in the vicinity of $3680 \mathrm{~cm}^{-1}$ region is attributed to phenol $\mathrm{OH}$ group bounded by intermolecular $\mathrm{H}$ bonds. The $2918 \mathrm{~cm}^{-1}$ band usually has absorption maximum at $2918 \mathrm{~cm}^{-1}$ which is due to $\mathrm{C}-\mathrm{H}$ stretching of alkane group $\left(\mathrm{CH}_{2}\right)$. The next major absorption band is $1721 \mathrm{~cm}^{-1}$. This band has been commonly ascribed to $\mathrm{C}=\mathrm{O}$ stretching of mainly carboxyl group $(\mathrm{COOH})$ with trace amount of ketones. The last peak was observed at 1168 $\mathrm{cm}^{-1}$ due to $\mathrm{C}-\mathrm{O}$ stretching of polysaccharides and this peak appeared also in the spectra of humic acid from peat soil. The FTIR spectra of the isolated humic acid contained all major characteristic absorption peaks of humic acid. These absorption peaks indicated the presence of the major structural elements of humic acid namely $\mathrm{H}$ bonded $\mathrm{OH}, \mathrm{C}=\mathrm{C}$ of aromatic ring, $\mathrm{C}=\mathrm{O}$ of carbonyl group (both carboxyl and ketonic), $\mathrm{CH}_{2}$ group. This strongly supports the presence of humic acid.

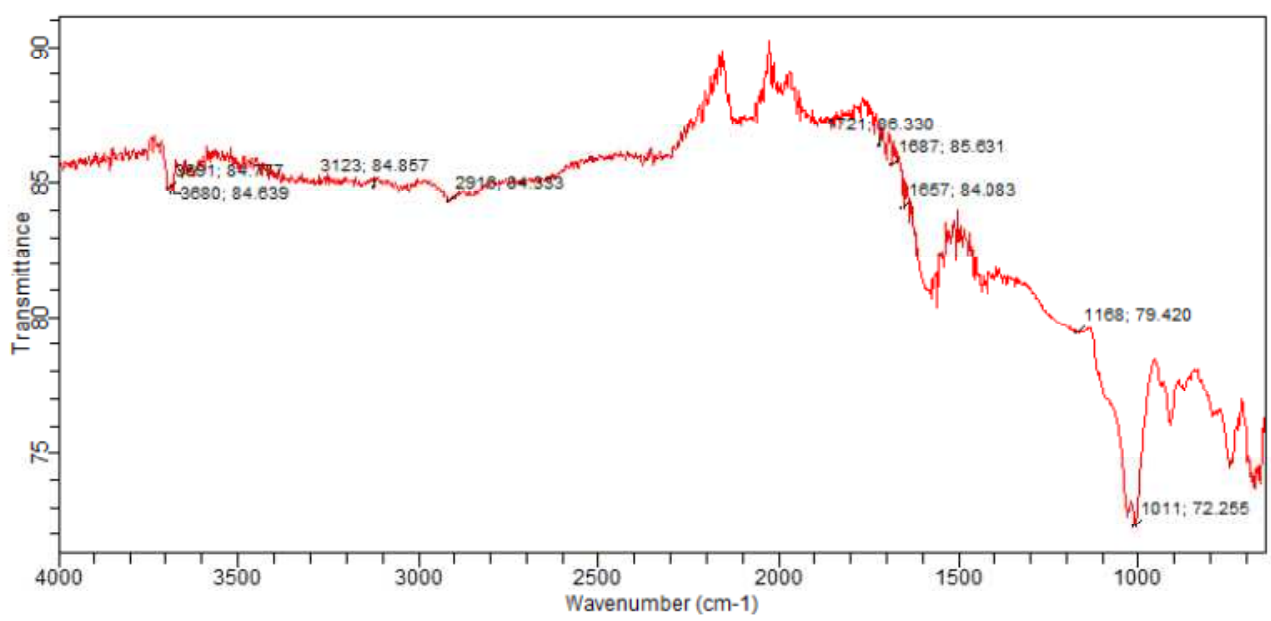

Fig. 2 : FT-IR spectraof peatsoilhumic acid (PSHA)

\section{Evaluation of acid dissociation constant (pka) of acid hydrolysed peat soil humicacid at phenolic group}

The value of the dissociation constant of the peat soil humic acid (PSHA) that underwent acidhydrolysis studied was found to be 8.9299 as shown Table 1, which is lower than the literaturevalues reported by Almeida and Szpoganics, (2015), Borges et al., (2005); Badr et al., (2012)and Fernandes et al,.(2009) of $9.73,9.47$ and 10.30. The difference between the obtained valuesand the reported values in this study might be probably as a result of acid hydrolysis of humicacid. 
BAJOPAS Volume 14 Number 1,June, 2021

Table 1: PKa of (Hydrolysed PSHA)

\begin{tabular}{|l|l|l|l|l|l|l|}
\hline $\mathrm{pH}$ & $\mathrm{BV}_{1}$ & $\mathrm{BV}_{2}$ & $\mathrm{~V}_{2}-\mathrm{V}_{1}$ & $\mathrm{nA}$ & $\log \left(\frac{n A}{1-n A}\right)$ & $\mathrm{pKa}$ \\
\hline 8.50 & 5.30 & 6.29 & 0.99 & 0.3594 & -0.2510 & 8.2490 \\
8.72 & 5.35 & 6.37 & 1.02 & 0.3400 & -0.2880 & 8.4320 \\
9.00 & 5.40 & 6.46 & 1.06 & 0.3141 & -0.3391 & 8.6609 \\
9.22 & 5.45 & 6.55 & 1.10 & 0.2882 & -0.3927 & 8.8273 \\
9.51 & 5.50 & 6.66 & 1.16 & 0.2494 & -0.4786 & 9.0314 \\
9.73 & 5.55 & 6.78 & 1.23 & 0.2041 & -0.5910 & 9.1390 \\
10.00 & 5.60 & 6.90 & 1.30 & 0.1589 & -0.7238 & 9.2762 \\
10.23 & 5.65 & 7.05 & 1.40 & 0.0941 & -0.9835 & 9.2465 \\
10.49 & 5.70 & 7.10 & 1.40 & 0.0941 & -0.9835 & 9.5065 \\
\hline
\end{tabular}

Average pKa $=8.9299 \pm 0.4186$

Table 2: PKa of (Unhydrolysed PSHA)

\begin{tabular}{|l|l|l|l|l|l|l|}
\hline $\mathrm{pH}$ & $\mathrm{BV}_{1}$ & $\mathrm{BV}_{2}$ & $\mathrm{~V}_{2}-\mathrm{V}_{1}$ & $\mathrm{nA}$ & $\log \left(\frac{\boldsymbol{n A}}{1-\boldsymbol{n}}\right)$ & $\mathrm{pKa}$ \\
\hline 8.50 & 5.30 & 5.81 & 0.51 & 0.6619 & 0.2919 & 8.7919 \\
8.72 & 5.35 & 5.90 & 0.55 & 0.6357 & 0.2418 & 8.9618 \\
9.00 & 5.40 & 6.00 & 0.60 & 0.6029 & 0.1813 & 9.1813 \\
9.22 & 5.45 & 6.10 & 0.65 & 0.5701 & 0.1226 & 9.3426 \\
9.51 & 5.50 & 6.20 & 0.70 & 0.5376 & 0.0654 & 9.5754 \\
9.73 & 5.55 & 6.33 & 0.78 & 0.4851 & -0.0259 & 9.7041 \\
10.00 & 5.60 & 6.47 & 0.87 & 0.4262 & -0.1291 & 9.8709 \\
10.23 & 5.65 & 6.62 & 0.99 & 0.3609 & -0.2481 & 9.9819 \\
10.49 & 5.70 & 6.80 & 1.10 & 0.2759 & -0.4690 & 10.0210 \\
\hline
\end{tabular}

Average pKa $=9.4923 \pm 0.4410$

Metal-ligand stability constant ( $\log \mathrm{K}$ )

The stabilityconstants require the accurate values of proton-ligand stability constants (Anil and Maroti, 2008). Metal titration curves crossed over ligand titration curve indicated the formation of complex upon proton release (Santosh, et al., 2011). If the values of n- are within range $0.2-0.8$ and $1.2-18$ this indicates the formation of $1: 1$ and 1:2 complexes (Sayyed and Mazahar, 2012).

The metal (II)-humate stepwise stability constants (log k) at phenolic group (Tables 318)

Table 3: Point-wise method, $\mathrm{Cu}$-(Hydrolysed PSHA)

\begin{tabular}{|l|l|l|l|l|l|l|l|l|}
\hline $\mathrm{pH}$ & $\mathrm{BV}_{1}$ & $\mathrm{BV}_{2}$ & $\mathrm{BV}_{3}$ & $\left(\mathrm{~V}_{3}-\mathrm{V}_{2}\right)$ & $\mathrm{n}$ & $\mathrm{pL}$ & $\log \left(\frac{n}{1-n}\right)$ & LogK $_{1}$ \\
\hline 8.50 & 5.30 & 6.29 & 6.33 & 0.04 & 0.5500 & 2.66 & 0.0871 & 2.7471 \\
8.72 & 5.35 & 6.37 & 6.41 & 0.04 & 0.5714 & 2.43 & 0.1249 & 2.5549 \\
9.00 & 5.40 & 6.46 & 6.50 & 0.04 & 0.6198 & 2.16 & 0.2122 & 2.3722 \\
9.22 & 5.45 & 6.55 & 6.59 & 0.04 & 0.6667 & 1.94 & 0.3010 & 2.2410 \\
\hline
\end{tabular}

LogK $_{1}$ (Average value) $=2.4788 \pm 0.2203$

Table 4: Point-wise method, $\mathrm{Cu}$-(Hydrolysed PSHA)

\begin{tabular}{|l|l|l|l|l|l|l|l|l|}
\hline $\mathrm{pH}$ & $\mathrm{BV}_{1}$ & $\mathrm{BV}_{2}$ & $\mathrm{BV}_{3}$ & $\left(\mathrm{~V}_{3}-\mathrm{V}_{2}\right)$ & $\mathrm{n}$ & $\mathrm{pL}$ & $\log \left(\frac{n-1}{2-n}\right)$ & LogK $_{2}$ \\
\hline 9.51 & 5.50 & 6.66 & 6.73 & 0.07 & 1.3509 & 1.70 & -0.2671 & 1.4329 \\
9.73 & 5.55 & 6.78 & 6.85 & 0.07 & 1.6383 & 1.51 & 0.2467 & 1.7567 \\
10.00 & 5.60 & 6.90 & 6.98 & 0.08 & 2.1783 & 1.31 & -0.2158 & 1.0942 \\
10.23 & 5.65 & 7.05 & 7.13 & 0.08 & 4.1904 & 1.27 & & \\
10.49 & 5.70 & 7.10 & 7.19 & 0.09 & 4.6920 & & & \\
\hline
\end{tabular}

Log $K_{2}($ Average value $)=1.4280 \pm 0.3312$ 
BAJOPAS Volume 14 Number 1,June, 2021

Table 5: Point-wise method, $\mathrm{Cu}$ (Unhydrolysed PSHA)

\begin{tabular}{|l|l|l|l|l|l|l|l|l|}
\hline $\mathrm{pH}$ & $\mathrm{BV}_{1}$ & $\mathrm{BV}_{2}$ & $\mathrm{BV}_{3}$ & $\left(\mathrm{~V}_{3}-\mathrm{V}_{2}\right)$ & $\mathrm{n}$ & $\mathrm{pL}$ & $\log \left(\frac{n}{n-1}\right)$ & Log $_{1}$ \\
\hline 8.50 & 5.30 & 5.81 & 5.85 & 0.04 & 0.2973 & 2.88 & -0.3736 & 2.5064 \\
8.72 & 5.35 & 5.90 & 5.95 & 0.05 & 0.3873 & 2.66 & -0.1992 & 2.4608 \\
9.00 & 5.40 & 6.00 & 6.05 & 0.05 & 0.4044 & 2.38 & -0.1681 & 2.2119 \\
9.22 & 5.45 & 6.10 & 6.15 & 0.06 & 0.5157 & 2.18 & -0.0272 & 2.2072 \\
9.51 & 5.50 & 6.20 & 6.27 & 0.07 & 0.6417 & 1.89 & 0.2530 & 1.1430 \\
\hline
\end{tabular}

$\operatorname{LogK}_{1}($ Average value $)=2.3059 \pm 0.6153$

Table 6:Point-wise method, $\mathrm{Cu}$ (Unhydrolysed PSHA)

\begin{tabular}{|l|l|l|l|l|l|l|l|l|}
\hline $\mathrm{pH}$ & $\mathrm{BV}_{1}$ & $\mathrm{BV}_{2}$ & $\mathrm{BV}_{3}$ & $\mathrm{~V}_{3}-\mathrm{V}_{2}$ & $\mathrm{n}$ & $\mathrm{pL}$ & $\log \left(\frac{n-1}{2-n}\right)$ & $\log \mathrm{K}_{2}$ \\
\hline 9.73 & 5.55 & 6.33 & 6.42 & 0.09 & 0.9000 & 1.69 & & \\
10.00 & 5.60 & 6.47 & 6.58 & 0.11 & 1.2578 & 1.44 & -0.4592 & 0.9808 \\
10.23 & 5.65 & 6.62 & 6.84 & 0.12 & 1.6137 & 1.26 & -0.2010 & 1.4610 \\
10.49 & 5.70 & 6.80 & 6.92 & 0.12 & 2.1052 & 1.03 & & \\
\hline
\end{tabular}

$\operatorname{LogK}_{2}$ (Average value) $=1.2209 \pm 0.3398$

Table 7:Point-wise method, Pb (Hydrolysed PSHA)

\begin{tabular}{|l|l|l|l|l|l|l|l|l|}
\hline $\mathrm{pH}$ & $\mathrm{BV}_{1}$ & $\mathrm{BV}_{2}$ & $\mathrm{BV}_{3}$ & $\left(\mathrm{~V}_{3}-\mathrm{V}_{2}\right)$ & $\mathrm{n}$ & $\mathrm{pL}$ & $\log \left(\frac{n}{1-n}\right)$ & LogK $_{1}$ \\
\hline 8.50 & 5.30 & 6.29 & 6.33 & 0.04 & 0.5500 & 2.66 & 0.0871 & 2.7471 \\
8.72 & 5.35 & 6.37 & 6.41 & 0.04 & 0.5714 & 2.43 & 0.1249 & 2.5549 \\
9.00 & 5.40 & 6.46 & 6.50 & 0.04 & 0.6198 & 2.16 & 0.2122 & 2.3722 \\
9.22 & 5.45 & 6.55 & 6.60 & 0.05 & 0.8333 & 1.96 & 0.6989 & 2.6589 \\
\hline
\end{tabular}

Log $_{\mathbf{1}}($ Average value $)=2.5832 \pm 0.1614$

Table 8:Point-wise method, Pb-(Hydrolysed PSHA)

\begin{tabular}{|l|l|l|l|l|l|l|l|l|}
\hline $\mathrm{pH}$ & $\mathrm{BV}_{1}$ & $\mathrm{BV}_{2}$ & $\mathrm{BV}_{3}$ & $\left(\mathrm{~V}_{3}-\mathrm{V}_{2}\right)$ & $\mathrm{n}$ & $\mathrm{pL}$ & $\log \left(\frac{n-1}{2-n}\right)$ & $\log \mathrm{K}_{2}$ \\
\hline 9.51 & 5.50 & 6.66 & 6.71 & 0.05 & 0.9650 & 1.67 & & \\
9.73 & 5.55 & 6.78 & 6.83 & 0.05 & 1.1702 & 1.44 & & \\
10.00 & 5.60 & 6.90 & 6.90 & 0.05 & 1.4864 & 1.22 & -0.0237 & 1.1963 \\
10.23 & 5.65 & 7.05 & 7.10 & 0.05 & 2.0190 & 1.09 & & \\
10.49 & 5.70 & 7.10 & 7.17 & 0.07 & 3.6492 & 1.00 & & \\
\hline
\end{tabular}

Log $K_{2}$ (Average value) $=1.1963$

Table 9: Point-wise method, Pb (Unhydrolysed PSHA)

\begin{tabular}{|l|l|l|l|l|l|l|l|l|}
\hline $\mathrm{pH}$ & $\mathrm{BV}_{1}$ & $\mathrm{BV}_{2}$ & $\mathrm{BV}_{3}$ & $\mathrm{~V}_{3}-\mathrm{V}_{2}$ & $\mathrm{n}$ & $\mathrm{pL}$ & $\begin{array}{l}\text { Log } \\
\left(\frac{n}{n-1}\right)\end{array}$ & Log $\mathrm{K}_{1}$ \\
\hline 8.50 & 5.30 & 5.81 & 5.85 & 0.04 & 0.2973 & 2.88 & -0.3736 & 2.5064 \\
8.72 & 5.35 & 5.90 & 5.94 & 0.04 & 0.3099 & 2.66 & -0.5477 & 2.3123 \\
9.00 & 5.40 & 6.00 & 6.05 & 0.05 & 0.4044 & 2.38 & -0.1681 & 2.2119 \\
9.22 & 5.45 & 6.10 & 6.15 & 0.06 & 0.5157 & 2.18 & 0.0272 & 2.2072 \\
9.51 & 5.50 & 6.20 & 6.26 & 0.07 & 0.6417 & 1.89 & 0.2530 & 2.1430 \\
9.73 & 5.55 & 6.40 & 6.40 & 0.07 & 0.7000 & 1.67 & 0.3680 & 2.0380 \\
\hline
\end{tabular}

LogK $_{1}$ (Average value) $=2.2364 \pm 0.1602$

Table 10: Point-wise method, Pb (Unhydrolysed PSHA)

\begin{tabular}{|l|l|l|l|l|l|l|l|l|}
\hline $\mathrm{pH}$ & $\mathrm{BV}_{1}$ & $\mathrm{BV}_{2}$ & $\mathrm{BV}_{3}$ & $\mathrm{~V}_{3}-\mathrm{V}_{2}$ & $\mathrm{n}$ & $\mathrm{pL}$ & $\log \left(\frac{n-1}{2-n}\right)$ & $\log \mathrm{K}_{2}$ \\
\hline 10.00 & 5.60 & 6.47 & 6.55 & 0.08 & 1.9503 & 1.41 & & \\
10.23 & 5.65 & 6.62 & 6.72 & 0.11 & 1.4792 & 1.26 & -0.0361 & 1.2239 \\
\hline
\end{tabular}

$\operatorname{LogK}_{2}$ (Average value) $=1.2239$

Table 11: Point-wise method, Mg (Hydrolysed PSHA)

\begin{tabular}{|l|l|l|l|l|l|l|l|l|}
\hline $\mathrm{pH}$ & $\mathrm{BV}_{1}$ & $\mathrm{BV}_{2}$ & $\mathrm{BV}_{3}$ & $\left(\mathrm{~V}_{3}-\mathrm{V}_{2}\right)$ & $\mathrm{n}$ & $\mathrm{pL}$ & $\log \left(\frac{n}{n-1}\right)$ & LogK $_{1}$ \\
\hline 8.50 & 5.30 & 6.29 & 6.31 & 0.02 & 0.2750 & 2.64 & -0.4290 & 2.2110 \\
8.72 & 5.35 & 6.37 & 6.39 & 0.02 & 0.2858 & 2.42 & -0.3978 & 2.0222 \\
9.00 & 5.40 & 6.46 & 6.49 & 0.03 & 0.4648 & 2.14 & -0.0612 & 2.0788 \\
9.22 & 5.45 & 6.55 & 6.59 & 0.04 & 0.6667 & 1.94 & 0.3010 & 2.2410 \\
\hline
\end{tabular}

$\log _{\mathbf{1}}($ Average value) $=2.1382 \pm 0.1046$ 
BAJOPAS Volume 14 Number 1,June, 2021

Table 12: Point-wise method, Mg (Hydrolysed PSHA)

\begin{tabular}{|l|l|l|l|l|l|l|l|l|}
\hline $\mathrm{pH}$ & $\mathrm{BV}_{1}$ & $\mathrm{BV}_{2}$ & $\mathrm{BV}_{3}$ & $\left(\mathrm{~V}_{3}-\mathrm{V}_{2}\right)$ & $\mathrm{n}$ & $\mathrm{pL}$ & $\log \left(\frac{n-1}{2-n}\right)$ & LogK $_{2}$ \\
\hline 9.51 & 5.55 & 6.66 & 6.71 & 0.05 & 0.9650 & 1.67 & & \\
9.73 & 5.55 & 6.78 & 6.84 & 0.06 & 1.4042 & 1.47 & -0.1686 & 1.3014 \\
10.00 & 5.60 & 6.90 & 6.93 & 0.06 & 1.7838 & 1.23 & 0.5593 & 1.7893 \\
10.23 & 5.65 & 7.05 & 7.10 & 0.06 & 3.1429 & 1.10 & & \\
10.49 & 5.70 & 7.10 & 7.18 & 0.07 & 3.6492 & 0.83 & & \\
\hline
\end{tabular}

LogK $_{2}($ Average value $)=1.5453 \pm 0.3450$

Table 13: Point-wise method, Mg (Unhydrolysed PSHA)

\begin{tabular}{|l|l|l|l|l|l|l|l|l|}
\hline $\mathrm{pH}$ & $\mathrm{BV}_{1}$ & $\mathrm{BV}_{2}$ & $\mathrm{BV}_{3}$ & $\mathrm{~V}_{3}-\mathrm{V}_{2}$ & $\mathrm{n}$ & $\mathrm{pL}$ & $\log \left(\frac{n}{n-1}\right)$ & $\operatorname{Log~}_{1}$ \\
\hline 8.50 & 5.30 & 5.81 & 5.85 & 0.04 & 0.2973 & 2.88 & -0.3736 & 2.5064 \\
8.72 & 5.35 & 5.90 & 5.94 & 0.04 & 0.3099 & 2.66 & -0.3477 & 2.3123 \\
9.00 & 5.40 & 6.00 & 6.04 & 0.04 & 0.3236 & 2.38 & -0.3202 & 2.0598 \\
9.22 & 5.45 & 6.10 & 6.15 & 0.05 & 0.4297 & 2.17 & -0.1230 & 2.0470 \\
9.51 & 5.50 & 6.20 & 6.26 & 0.06 & 0.5500 & 1.89 & 0.0871 & 1.9771 \\
9.73 & 5.55 & 6.33 & 6.40 & 0.07 & 0.7000 & 1.67 & 0.3680 & 2.0380 \\
\hline
\end{tabular}

LogK $_{1}$ (Average value) $=2.1568 \pm 0.2069$

Table 14: Point-wise method, Mg (Unhydrolysed PSHA)

\begin{tabular}{|l|l|l|l|l|l|l|l|l|}
\hline $\mathrm{pH}$ & $\mathrm{BV}_{1}$ & $\mathrm{BV}_{2}$ & $\mathrm{BV}_{3}$ & $\mathrm{~V}_{3}-\mathrm{V}_{2}$ & $\mathrm{n}$ & $\mathrm{pL}$ & $\log \left(\frac{n-1}{2-n}\right)$ & $\log \mathrm{K}_{2}$ \\
\hline 10.00 & 5.60 & 6.47 & 6.55 & 0.08 & 0.9148 & 1.41 & & \\
10.23 & 5.65 & 6.62 & 6.71 & 0.09 & 1.2102 & 1.20 & -0.5749 & 0.6251 \\
10.49 & 5.70 & 6.80 & 6.92 & 0.09 & 1.5968 & 1.03 & 0.1703 & 1.2003 \\
\hline
\end{tabular}

LogK $_{2}$ (Average value) $=0.9127 \pm 0.4070$

Table15:Point-wise method, Cd (Hydrolysed PSHA)

\begin{tabular}{|l|l|l|l|l|l|l|l|l|}
\hline $\mathrm{pH}$ & $\mathrm{BV}_{1}$ & $\mathrm{BV}_{2}$ & $\mathrm{BV}_{3}$ & $\left(\mathrm{~V}_{3}-\mathrm{V}_{2}\right)$ & $\mathrm{n}$ & $\mathrm{pL}$ & $\log \left(\frac{n}{1-n}\right)$ & LogK $_{1}$ \\
\hline 8.50 & 5.30 & 6.29 & 6.31 & 0.02 & 0.2750 & 2.64 & -0.4210 & 2.2190 \\
8.72 & 5.35 & 6.37 & 6.40 & 0.03 & 0.4286 & 2.42 & -0.1249 & 2.2951 \\
9.00 & 5.40 & 6.46 & 6.49 & 0.03 & 0.4648 & 2.14 & -0.0612 & 2.0788 \\
9.22 & 5.45 & 6.55 & 6.59 & 0.04 & 0.6667 & 1.96 & 0.3010 & 2.2610 \\
9.51 & 5.55 & 6.66 & 6.70 & 0.04 & 0.7720 & 1.67 & 0.5297 & 2.1997 \\
\hline
\end{tabular}

LogK $_{\mathbf{1}}$ (Average value) $=2.2108 \pm 0.0825$

Table 16: Point-wise method, Cd (Hydrolysed PSHA)

\begin{tabular}{|l|l|l|l|l|l|l|l|l|}
\hline $\mathrm{pH}$ & $\mathrm{BV}_{1}$ & $\mathrm{BV}_{2}$ & $\mathrm{BV}_{3}$ & $\left(\mathrm{~V}_{3}-\mathrm{V}_{2}\right)$ & $\mathrm{n}$ & $\mathrm{pL}$ & $\log \left(\frac{n-1}{2-n}\right)$ & Log $_{2}$ \\
\hline 9.73 & 5.55 & 6.78 & 6.83 & 0.06 & 1.4042 & 1.47 & -0.1686 & 1.3014 \\
10.00 & 5.60 & 6.90 & 6.95 & 0.06 & 1.7838 & 1.23 & 0.5593 & 1.7893 \\
10.23 & 5.65 & 7.05 & 7.10 & 0.06 & 3.1429 & 1.09 & & \\
10.49 & 5.70 & 7.10 & 7.16 & 0.06 & 3.1429 & 0.89 & & \\
& & & & & & & & \\
\hline
\end{tabular}

$\operatorname{LogK}_{2}$ (Average value) $=1.5453 \pm 0.3450$

Table 17: Point-wise method, Cd (Unhydrolysed PSHA)

\begin{tabular}{|l|l|l|l|l|l|l|l|l|}
\hline $\mathrm{pH}$ & $\mathrm{BV}_{1}$ & $\mathrm{BV}_{2}$ & $\mathrm{BV}_{3}$ & $\mathrm{~V}_{3}-\mathrm{V}_{2}$ & $\mathrm{n}$ & $\mathrm{pL}$ & $\log \left(\frac{n}{n-1}\right)$ & $\operatorname{Log~}_{1}$ \\
\hline 8.50 & 5.30 & 5.81 & 5.86 & 0.05 & 0.3717 & 2.88 & -0.2280 & 2.6520 \\
8.72 & 5.35 & 5.90 & 5.95 & 0.05 & 0.3873 & 2.66 & -0.1992 & 2.4608 \\
9.00 & 5.40 & 6.00 & 6.06 & 0.06 & 0.4853 & 2.38 & -0.0255 & 2.3545 \\
9.22 & 5.45 & 6.10 & 6.16 & 0.06 & 0.5157 & 2.18 & -0.0272 & 2.2072 \\
9.51 & 5.50 & 6.20 & 6.27 & 0.07 & 0.6417 & 1.89 & 0.2530 & 1.1430 \\
9.73 & 5.55 & 6.33 & 6.41 & 0.08 & 0.8000 & 1.69 & 0.6020 & 2.2920 \\
& & & & & & & & \\
\hline
\end{tabular}

$\operatorname{LogK}_{1}($ Average value $)=2.2516 \pm 0.5380$ 
BAJOPAS Volume 14 Number 1,June, 2021

Table 18: Point-wise method, Cd (Unhydrolysed PSHA)

\begin{tabular}{|l|l|l|l|l|l|l|l|l|}
\hline $\mathrm{pH}$ & $\mathrm{BV}_{1}$ & $\mathrm{BV}_{2}$ & $\mathrm{BV}_{3}$ & $\mathrm{~V}_{3}-\mathrm{V}_{2}$ & $\mathrm{n}$ & $\mathrm{pL}$ & $\log \left(\frac{n-1}{2-n}\right)$ & $\log \mathrm{K}_{2}$ \\
\hline 10.00 & 5.60 & 6.47 & 6.57 & 0.10 & 1.1434 & 1.43 & & \\
10.23 & 5.65 & 6.62 & 6.72 & 0.10 & 1.3448 & 1.23 & -0.2788 & 0.9512 \\
10.49 & 5.70 & 6.80 & 6.90 & 0.10 & 1.7742 & 1.03 & 0.5351 & 1.5651 \\
\hline
\end{tabular}

$\operatorname{LogK}_{2}($ Average value $)=1.2581 \pm 0.4340$

Table 19: Stepwise and overall Stability constants of thehydrolysed and unhydrolysed divalent metal (II) complexes

\begin{tabular}{|c|c|c|c|}
\hline Chelates & LogK $_{1}$ & $\log _{2}$ & Log $\beta$ \\
\hline [Cu (Hydrolysed PSHA-1) $\left.{ }_{2}\right]$ & 2.4788 & 1.4280 & 3.9068 \\
\hline$\left[\mathrm{Pb}(\text { Hydrolysed PSHA-1) })_{2}\right]$ & 2.5832 & 1.1963 & 3.7795 \\
\hline$\left[\mathrm{Cd}(\text { Hydrolysed PSHA-1 })_{2}\right]$ & 2.2108 & 1.5453 & 3.7561 \\
\hline$\left[\mathrm{Mg}(\text { Hydrolysed PSHA-1 })_{2}\right]$ & 2.1382 & 1.5453 & 3.6835 \\
\hline [Cu (Unhydrolysed PSHA-1) & 2.3059 & 1.2209 & 3.5268 \\
\hline$[\mathrm{Pb}$ (Unhydrolysed PSHA-1) 2$]$ & 2.2364 & 1.2239 & 3.4603 \\
\hline [Cd (Unhydrolysed PSHA-1) 2 ] & 2.2516 & 1.2581 & 3.5097 \\
\hline$[\mathrm{Mg}$ (Unydrolysed PSHA-1) & 2.1568 & 0.9127 & 3.0695 \\
\hline
\end{tabular}

The results obtained (Table19) shows the stepwise and overall stability constants to be not high indicating low stability of the complexes, because the solubility of most metal ions in the basic $\mathrm{pH}$ range is minimal due to metal hydroxide precipitation (Karimi, 2017). In general, the stepwise stability constants $\left(K_{1}\right.$ and $K_{2}$ ) follow the order $K_{1}>K_{2}$ for the copper, lead, magnesium and cadmium complexes respectively. The steady decrease of the values with increasing number of ligands is in agreement with the prediction made by researchers (Na'aliya, 2013). The decrease could be attributed to the fact that as the number of the ligands (Humate ions) that enters the coordination zone increases the aqua molecules available for replacement by the ligands become less. Thus, the metal ions become less electron loving with progressive intake of the ligand and this results in the decrease in the values of the constants (Na'aliya, 2013). Also the stability of the complexes is influenced by the size and number of the chelate rings(Mackay and Mackay,2002).All the complexes form rings in their structure as humate, a bidentate ligand, bond the metal ions in the ratio 1:2 (Boguta and Sokolowska, 2016) forming chelate rings. The values of the overall stability constants $(\log \beta)$ obtained for humate complexes are not high indicating low stability as the values are not high. LogK values for copper-humates (Table 3 to 6) obtained in this study are lower than those reported for the complexes of humic acids (Pandey et al., 2015; Dinu, 2013; Kaschl et al., 2010 and Gilbeto and Jorg, 2001). The values of LogK(Table 7 to 10 ) forlead-humates are lower than those reported for the lead in the literature (Dinu, 2013; Gilbeto and Jorg 2001). Log K values(Table 11 to 14 ) for magnesium-humates obtained in this study are close to those reported by (Pandey et al., 2015). Log K values of cadmium-humates (Table 15 to 18 ) obtained in this work near to the one reported by (Dinu, 2013 and Pandey et al., 2015).The difference between the reported values and the values obtained in this study might be probably as a result of acid hydrolysis of humic acid. The values of the overall stability constants $(\log \beta)$ of the copper humates complexes presented in Table 19 is high than that of other metal humate complexes, show relatively high stability of CuHA complexes, show the following order of stability: $\mathrm{Cu}>\mathrm{Pb}>\mathrm{Cd}>\mathrm{Mg}$; which are in close agreement to the findings of (Dinu, 2013 and Pandey et al., 2015).The high stability of Cuhumate chelate could be attributed to the existence of coordinate covalent bond between the complexing agents and the $\mathrm{Cu}^{2+}$ ions. Since, $\mathrm{Cu}^{2+}$ being a metal of the transitional series with $3 d^{9}$ electronic configurations can accept the electrons from the complexing agents. Similarly, the low stabilities of $\mathrm{Pb}, \mathrm{Cd}$ and $\mathrm{Mg}$ complexes could be explained by that $\mathrm{Pb}^{2+}$ with $6 s^{2}, \mathrm{Cd}^{2+}$ with $4 \mathrm{~d}^{10}$ and $\mathrm{Mg}^{2+}$ with $2 \mathrm{p}^{6}$ their electronic configuration has a completely filled $\mathrm{d}, \mathrm{p}$ and $\mathrm{s}$ orbitals. Moreover, the stabilities of metal ions with hydrolysed humic acid from peat soil were higher than those with unhydrolysed humic acid from peat soil; which is ascribed to the high content of acidity in hydrolysed humic acid than unhydrolysed humic acid. 
BAJOPAS Volume 14 Number 1,June, 2021 CONCLUSION

The values of logk for $\mathrm{Cu}(\mathrm{II})$ hydrolysed humic acid complex was higher followed by $\mathrm{Pb}$ (II), $\mathrm{Cd}(\mathrm{II})$ and $\mathrm{Mg}$ (II) hydrolysed humic acid complexes as compared with metal(II) unhydrolysed humic acid complexes. This indicates acid hydrolysis of humic acid can

\section{REFERENCES}

Almeida, V.R. and Szpoganicz, B. (2015). Humic Acid Potentiometric Response Patterns:Out- of Equilibrium Properties and Species Distribution Modelling. Chemical. Biol. Technol. Agric. 2: 17.

Anđelković, T., Nikolić, R., Bojić, A.,Anđelković, D., and Nikolic G.,(2010). Binding of Cadmium to Soil Humic Acid as A Function of Carboxyl Group Content. Macedonian Journal of Chemistry and Chemical Engineering.29(2): 215-224.

Anil, B. N. and Maroti, N. (2008). Studies on Influence of Die-Lectric Constants on Complex Equilibria between Substituted Py-Razalines and Lanthanide Metal Ions pH-Metrically. Amer.-Euras. scient. Res. 3(2): 212-216.

Ashok, K., Pandey, S. P. and Misra, V (2000). Stability Constants of Metal-Humic Acid Complexes and its Role in Environmental Detoxification. Journal of Ecotoxicology and Environmental Safety. 47(2):157-200.

Badr, M. H., El-Halafawi, M. H. and Abd El-al Zeid, E. R. (2012). Comparison Between the Effect of Ionic Strength on Acidity and Dissociation Constants of Humic Acids Extracted from Sewage Sludge and Nile Water Hyacinth Composts.Global Journal of Environmental Research 6 (1): 36-43.

Baruah, M.K., Borah, D., Saikia, P.P., Paul, S., Sharma, T. (2015). Evaluation of pKa Values of Soil Humic Acids and their Complexation Properties. International Journal of Plant \& Soil Science 6(4) : 218-228.

Boguta, P. Sokolowska, Z. (2016). Interactions of $\mathrm{Zn}$ (II) Ions with Humic Acids Isolated from Various Types of Soils. Effect of $\mathrm{pH}, \mathrm{Zn}$ Concentrations and Humic Acids Chemical Properties. Journal of Geochemical Explaration 168. 119-126.

Borges, F., Guimaraes, C., Lima, L.F.C., Pinto, I. and Reis, S.(2005). Potentiometric Studies on the Complexation of Copper(II) by Phenolic Acids as Discrete Ligand Models of enhance the complexation behavior of humic acid with metal (II) ions. However, the higher values of $\log \beta$ for $\mathrm{Cu}(\mathrm{II}), \mathrm{Pb}(\mathrm{II}), \mathrm{Cd}(\mathrm{II})$ and $\mathrm{Mg}(\mathrm{II})$ hydrolysed humic acid complexes indicates more stable stepwise complexes formed as compared with $\mathrm{Cu}(\mathrm{II}), \mathrm{Pb}$ (II), $\mathrm{Cd}$ (II) and $\mathrm{Mg}(\mathrm{II})$ unhydrolysed humic acid complexes.

Humic Substances Talanta 66 (2005) 670-673.

Chefetz, B., Salloum, M. J., Deshmulkin, A. P. and Hatcher, P. (2002). Structural Components of Humic Acids as Determined by Chemical Modifications and Carbon-13 NMR, Pyrolysis, and Thermochemolysis- Gas Chromatography/Mass Spectrometry. Soil Science Society of American Journal Abstract Division S-2- Soil Chemistry66. 1159-1171.

Dinu, M. I. (2013). Metals Complexation with Humic Acids in Surface Water of Different Environ. Sci. Technol. 31(1): 1-17.

Fernandes, A.N., Giacomelli, C., Giovanela, M. Vaz, D.V. Szpoganicz, B. and Maria M. D. (2009). Potentiometric Acidity Determination in Humic Substances Influenced by Different Analytical Procedures.J. Braz. Chem. Soc. 20 (9):14.

Gamal, A. H. (2015). Stability Constants of Rhenium (V) Metal Complexes with Selected Drugs. Pyrex Journal of Research in Environmental Studies. 2(2): 006-014.

Janrao, D. M., Pathan, J., Kayande, D.D., and Mulla, J.J. (2014). An Over View of Potentiometric Determination of Stability Constants of Metal Complexes. Sci. Revs. Chem. Commun.: 4(1), 2014, 11-24.

Karimi, H. (2017). Effect of pH and Initial Pb(II) Concentration on the Lead Removal Efficiency from Waste Water Using $\mathrm{Ca}(\mathrm{OH})_{2}$. International Journal of Water and Waste Water Treatment 3.2

Kaschl, A. Romheld, V. and Chen, Y. (2010). Binding of Cadmium, Copper and Zinc to Humic Substances Originating from Municipal Solid Waste Compost. Israel Journal of Chemistry Vol. 42(1): 89-98.

Kostic, I. S., Tatjana, P, A., Nikolic, R. S., Cvetkovic, T. P., Pavlovic, D. D., Aleksandar, L.J. and Bojic, A. (2012). Comparative Study of Binding Strengths of Heavy Metals with Humic Acid. J.serb. Chem. Soc. 76(9) pp 1-20. 
BAJOPAS Volume 14 Number 1,June, 2021

Na'aliya, J. (2013). Determination of Stepwise Stability Constants and Gibbs free Energy Change of Trisprolina to Complexes of some Divalent Transition Metal ions. Bayero Journal of Pure and Applied Sciences 6(2): 112-114.

Omar, A. A. and Ali, E. A. (2015). Potentiometric Studies on Complexes of $\mathrm{Cr}$ (III) and $\mathrm{Zr}$ (IV) with some Carboxylic Acids. International Journal of Advanced Chemistry, 3(1) 25-

37.

Pandey, A. K. Pandey, S. D. and Misr, V. (2015).Stability Constants of Metal- Humic Acid Complexes and Its Role in Environmental Detoxification. J. Ecotoxicology and Environmental Safety. 47(1):195-200.

Ram, N. and Raman, K.V. (1984). Stability Constants of Complexes of Metals with
Humicand Fuvic Acids under Non- acidConditions. Journal of Plant Nutrition and Soil Sciences.

147:171-176.

Santosh, D. D., Ashok, B. K., Vijay, J. T., Shivraj, G. W. and Vinay, V. W. (2011). Potentiometric Studies of Elec-Trolyte Effects on Complex Equilibria of Some Substituted 5-(2-hydroxy Phenyl) Pyrazoles. Der pharm. 3 (6): 75-83.

Sayyed, H. and Abdul Rahim, M. F. (2012). Studies of Binary Complexes of Metal Ions with Mandelic Acid by Potentiometry. Chem. J. 02 (6): 206209.

Shirvani, M. Moradian, E. Khalili, B. Bakhtiary, S. (2015). Interaction of $\mathrm{Cd}$ and $\mathrm{Pb}$ with Humate-Palygorskite and HumateSepiolite Complexes. Journal of water, air and pollution 3: 220-228. 


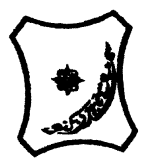

Bayero Journal of Pure and Applied Sciences, 14(1): 54 - 63

Received: November, 2020

Accepted: April, 2021

ISSN $2006-6996$

\title{
STABILITY CONSTANTS OF COMPLEXES OF METAL IONS WITH PEATSOIL HUMIC ACIDS UNDER NON-ACID-CONDITIONS
}

\author{
${ }^{* 1}$ Sabo, Yusuf ${ }^{2}$ Jimoh, W.L.O., ${ }^{3}$ Isa Baba Koki and ${ }^{4}$ Sholadoye, Q. 0. \\ ${ }^{1}$ Department of Pure and Industrial Chemistry, Bayero University, Kano \\ ${ }^{3}$ Department of Chemistry, Yusuf Maitama Sule University Kano. P.M.B. 3220 Kano, Nigeria. \\ ${ }^{4}$ Department of Chemistry, Nigerian Police Academy, Wudil, Kano-Nigeria
}

*Correspondence E-mail; saboyusuf18@yahoo.com

ABSTRACT

Stability constants of complexes of four divalent metal ions viz. $\mathrm{Cu}^{2+}, \mathrm{Pb}^{2+}, \mathrm{Mg}^{2+}$ and $\mathrm{Cd}^{2+}$ with humic acids (HA) were determined by potentiometric titration of humic acids with the corresponding salt of the divalent metals in aqueous media under non-acid-condition. The log $K$ (logarithm of the stability constant) ranged from 1.0942 to 2.7471 for metalhumic acid complexes were determined using point-wise computational method. The order of stability constants were obtained as follows: $\mathrm{Cu}>\mathrm{Pb}>\mathrm{Cd}>\mathrm{Mg}$ for metal $-\mathrm{HA}$ complexes respectively, indicating a higher degree of complexation with Cu metal ion.

Keywords: stability constant, humic acid, potentiometric titration, divalent metals, acid hydrolysis.

\section{NTRODUCTION}

The stability constant of a complex is the numerical expression of its stability and provides a quantitative measure of affinity of the metal ion to the complexing agent. An understanding of the relative stability of metal-complexes helps in predicting the behavior of metal ions in the soil (Ram and Raman, 1982). Extensive researches has been done to determine the stability constants of the complexes formed between humic acid (HA) with a number of metal ions. Ashok et al., (2000) reported that humic acid with hydroxyl, phenoxyl and carboxyl reactive groups can form coordination compound with metal ions at $\mathrm{pH}$ 3.5. The stability constants(Log K) for different metalhumic acid complexes indicated the following order of the stabilities of complexes formed between humic acid and metal ion, $\mathrm{Cu}>\mathrm{Fe}$ $>\mathrm{Pb}>\mathrm{Ni}>\mathrm{Co}>\mathrm{Ca}>\mathrm{Cd}>\mathrm{Zn}>\mathrm{Mn}>\mathrm{Mg}$. Andelkovic et al., (2010) investigated the binding of $\mathrm{Cd}$ (II) to soil humic acid at pH 6.5 and in $0.1 \mathrm{M} \mathrm{KNO}_{3}$ ionic medium. The stability constant for binding indicating greater stability in the case when carboxyl groups are involved in complexation reaction. Kostic et al.,(2012) investigated the complexation of humic acid with certain heavy metal ions (Co(II), $\mathrm{Ni}(\mathrm{II}), \mathrm{Cu}(\mathrm{II})$,
$\mathrm{Zn}(\mathrm{II})$, and $\mathrm{Pb}(\mathrm{II})$. The experiment was performed at $25^{\circ} \mathrm{C}$, at pH 4.0 and ionic strength of $0.01 \mathrm{M}$. Stability constant of complex between $\mathrm{Pb}$ (II) ions and humic acid is greater than stability constants of other investigated metalhumate complexes. Bogata and Sokolowska (2016) analyses the interaction between humic acids from different soils and $\mathrm{Zn}$ (II) ions at wide concentration ranges and at $\mathrm{pH} 5$. Studies have showed significant impact of $\mathrm{Zn}$ concentration, $\mathrm{pH}$ and some properties of humic acids with zinc.But all of these studies were limited to acidic $\mathrm{pH}$ range. Therefore, the present study was carried out to determine and compare the stability constants of complexes of metal ions with hydrolysed peat soil humic acid and unhydrolysed peat soil humic under non-acid conditions.

\section{MATERIALS AND METHODS}

Analytical grade chemicals used includes hydrochloric acid $(\mathrm{HCl})$, nitric acid $\left(\mathrm{HNO}_{3}\right)$, sodium hydroxide $(\mathrm{NaOH})$, lead nitrate $\mathrm{Pb}\left(\mathrm{NO}_{3}\right)_{2}$, copper nitrate $\mathrm{Cu}\left(\mathrm{NO}_{3}\right)_{2} \cdot 3 \mathrm{H}_{2} \mathrm{O}$, cadmium nitrate $\mathrm{Cd}\left(\mathrm{NO}_{3}\right)_{2} \cdot 4 \mathrm{H}_{2} \mathrm{O}$, magnesium nitrate $\mathrm{Mg}\left(\mathrm{NO}_{3}\right)_{2} \cdot 6 \mathrm{H}_{2} \mathrm{O}$, potassium nitrate $\left(\mathrm{KNO}_{3}\right)$, calcium chloride $\left(\mathrm{CaCl}_{2}\right)$, (sigma-Aldrich). Dowex 50WX8, (20-50 mesh) from Fluka. 


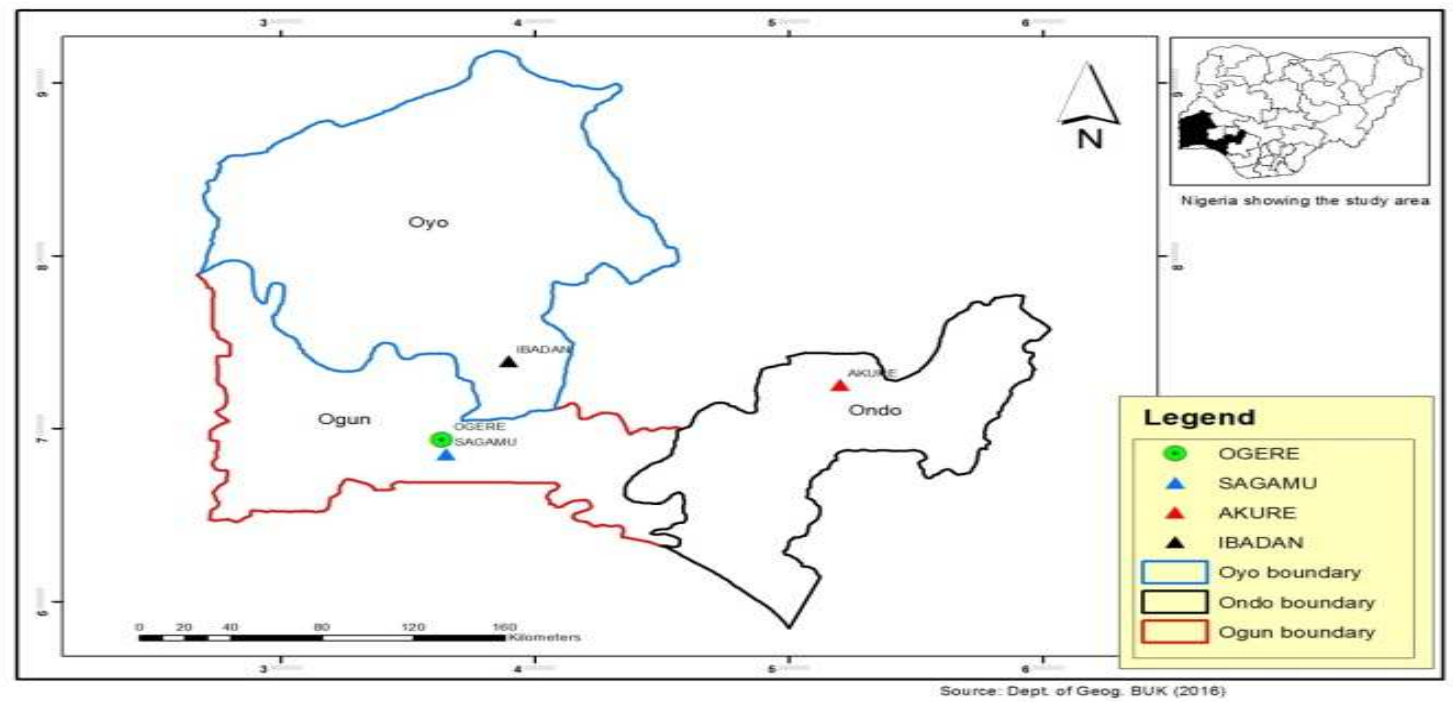

Figure 1: Map showing the sampling point at Sagamu Town, Ogun State.

\section{Description of Sampling Area}

Sagamu has geographical coordinates between $6^{\circ} 50^{\prime}$ north; $3^{\circ} 38^{\prime}$ east is located in south western region of Nigeria. The region has tropical wet and dry climate with a lengthy wet season and relatively constant temperatures throughout the course of the year. Wet season runs from March to October, November to December forms the region dry season. The vegetation type of the region is savannah which is really grassland with small bushes and occasional big trees. Grassland soils have substantially higher organic matter content than forest soils (Novackova, 2011).

\section{Sample Collection}

The Peatsoil samples were collected from four different sampling points $(0-10 \mathrm{~cm}$ depth) in Sagamu into polyethylene bag with plastic spoons. Samples were taken to the laboratory, extraneous materials were removed; the samples were air-dried, crushed and ground to a fine powder in a mortar passed through a $0.20 \mathrm{~mm}$ sieve. The samples were kept for analysis.

\section{Isolation and purification of humic acid from peat soil sample}

Peatsoil sample $(100 \mathrm{~g})$ was mixed with 1000 $\mathrm{cm}^{3}$ of $0.1 \mathrm{M} \mathrm{NaOH}$ solution, shaken for 3hours and left to stand overnight. Dark-coloured supernatant was obtained and decanted from solid residue. The dark-coloured supernatant was acidified to $(\mathrm{pH}=1.0)$ with $6 \mathrm{M} \mathrm{HCl}$ stirred and allowed to stand for 6 hours. Yellowish brown supernatant and dark-brown precipitate were obtained. The yellowish brown supernatant was decanted followed by centrifuge and discarded. The dark-brown precipitate was mixed with $500 \mathrm{~cm}^{3}$ of $0.1 \mathrm{M} \mathrm{NaOH}$ solution followed by passing through dowex resin. The dark-brown solution was acidified to $(\mathrm{pH}=1.0)$ with $6 \mathrm{M} \mathrm{HCl}$ stirred and allowed to stand for 3 hours. The dark-brown precipitate was washed several times with deionized water. The supernatant was treated with $\mathrm{AgNO}_{3}$ solution until no white precipitate observed. The humic acid was transferred to weighed crucible and dried at $60^{\circ} \mathrm{C}$ in an oven for 12 hours. The humic acid was cooled and dried in the desiccator, weighed and recorded. The obtained humic acid was dried again at $60^{\circ} \mathrm{C}$ for additional 6 hours cooled and dried in the desiccator, weighed and recorded constant weight was obtained (Baruah et al., 2015).

\section{FT-IR analysis}

FT-IR spectra of humic acid sample was analysed using Carry 630 FT-IR Agilent Technologies.

Unhydrolysed compost humic acid

The unhydrolysed humic acid was obtained after isolation and purification of compost humic acid and kept for investigation.

\section{Acid hydrolysis of Peatsoil acid}

Peatsoil humic acid sample (1g) was refluxed for 12 hours at $\left(160^{\circ} \mathrm{C}\right)$ with $50 \mathrm{~cm}^{3}$ of $6 \mathrm{M} \mathrm{HCl}$. The mixture was allowed to cool, decanted, and centrifuged after hydrolysis. The insoluble residues were washed with distilled water via centrifugation several times, and the supernatant was treated with $\mathrm{AgNO}_{3}$ solution until no white precipitate was observed. The residue was thoroughly dried over $\mathrm{CaCl}_{2}$ in a desiccator at room temperature (Chefetz et al., 2002). Finally, the obtained hydrolysed humic acid was kept for investigation. 
BAJOPAS Volume 14 Number 1,June, 2021 Potentiometric Titrations

Potentiometric measurements were carried out using a pH-meter Jenway (model 3510) with combine electrode, the sensitivity of the $\mathrm{pH}$ meter is 0.01 units. The $\mathrm{pH}$ meter was switched on half an hour before starting the titration for initial warm up of the instrument. The instrument was calibrated with an aqueous standard buffer solution of $\mathrm{pH} 4.00$ and 10.0 (borate buffer) prepared from a "Qualigens" buffer tablets.

The following sets of solutions were prepared in a $250 \mathrm{~cm}^{3}$ volumetric flask separately for $\mathrm{pH}$ metric titrations.

(i) $5 \mathrm{~cm}^{3} 0.1 \mathrm{M} \mathrm{HCl}+40 \mathrm{~cm}^{3}$ deionized water

(ii) $5 \mathrm{~cm}^{3} 0.1 \mathrm{M} \mathrm{HCl}+39 \mathrm{~cm}^{3}$ deionized water $+1 \mathrm{~cm}^{3} 0.15 \mathrm{gcm}^{-3}$ humic acid

(iii) $5 \mathrm{~cm}^{3} 0.1 \mathrm{M} \mathrm{HCl}+37 \mathrm{~cm}^{3}$ deionized water $+1 \mathrm{~cm}^{3} 0.15 \mathrm{gcm}^{-3}$ humic acid

$$
+2 \mathrm{~cm}^{3} \quad 0.01 \mathrm{M} \mathrm{Cu} \text { (II) }
$$

The solutions were titrated against standardized $0.110 \mathrm{MNaOH}$ separately. The total volume of each mixture was adjusted to $50 \mathrm{~cm}^{3}$ and the ionic strength of the solutions was maintained constant at by adding appropriate amount of stock solution of $1 \mathrm{M} \mathrm{KNO}_{3}$ (Gamal, 2015; Omar and Ali, 2015). A magnetic stirrer was used to achieve thorough mixing of the interacting solutions at $550 \mathrm{rpm}$. The same set of experimental conditions was applied for potentiometric titration of remaining samples.

\section{Evaluation of pKa of Hydrolysed peat soil Humic Acids}

The proton-ligand formation number $\mathrm{n}_{\mathbf{A}}$ were calculated by Irving and Rossotti expression (Omar and Ali, 2015).

$\mathrm{nA}=\mathrm{Y}-\frac{(\mathrm{V} 2-\mathrm{V1})(\mathrm{No}-\mathrm{Eo})}{(\mathrm{VO}+\mathrm{V1}) \mathrm{TCL}}$ 1

Where: $Y$ is number of dissociable proton, $\left(\mathrm{V}_{2^{-}}\right.$ $V_{1}$ ) is the measure of displacement of the ligand curve relative to acid curve, $\mathrm{N}^{\circ}$ and $\mathrm{E}^{\circ}$ are the resultant concentration of alkali solution, free acid solution, $\mathrm{T}_{\mathrm{cL}}{ }^{\circ}$ is the total ligand concentration, $\mathrm{V}^{\circ}$ is the total volume of titration solution, $V_{1}$ is the volume of alkali added to acid solution, $V_{2}$ is the volume of alkali added to acid solution + ligand solution, acid dissociation constants (pKa - values) of ligand were calculated by algebraic method point wise calculation (Tables 1 ). The dissociation constants (pKa) were calculated according to the following relation:

$\mathrm{pKa}=\mathrm{pH}+\log \left(\frac{n A}{1-n A}\right)$ 2

Where: pKa is the acid dissociation constant, $\mathrm{n}_{\mathrm{A}}$ is the Proton-ligand formation number and $\mathrm{pH}$ is the pH-values (Omar and Ali, 2015).

\section{Determination of metal-ligand stability constants $(\log K)$ of complexes}

The potentiometric measurement for the determination of stability constant of a complex in solution is based on the fact that the redox potential of the couple $\frac{M^{+(m-n)}}{M^{+m}}$ is shifted significantly on complexation of the metal ion with the ligand. This method involves change in hydrogen ion concentration $\left[\mathrm{H}^{+}\right]$due to the displacement or association of one or more protons taking place during complexation reaction. This change can be found out by titrating the solutions containing free acid, acid with ligand, and acid with ligand and metal ion, individually against a standard alkali solution at a constant ionic strength or temperature. Either ionic strength or temperature may be varied for different sets of solutions. In all the cases, the change in the $\mathrm{pH}$ of the solution is measured after each addition of a known amount of alkali to the reaction cell which contains the reaction mixture. The titration curves are then drawn by plotting the measured $\mathrm{pH}$ values against the corresponding volume of alkali added and the stability constants of the complexes are determined from the titration curves by employing $\mathrm{pH}$-metric titration technique given by (Irving and Rossoti).

Metal-ligand stability constants ( $\log \mathrm{K}$ ) were determined by using the following relations:

$$
\bar{n}=\frac{\left(V_{3}-V_{2}\right)\left(E^{0}+N^{0}\right)}{\left(V^{0}+V_{2}\right) \bar{n}_{A} T_{m}^{0}}
$$

and

$$
P L=\log _{10}\left\{\frac{1+\beta_{n}^{H} \frac{1}{[\text { anti } \log \mathrm{pH}]^{\mathrm{n}}}}{\mathrm{T}_{\mathrm{L}}^{0}-n \bar{T}_{m}^{0}} \mathrm{X} \frac{\left(V^{0}+V_{3}\right)}{V^{0}}\right\}
$$


BAJOPAS Volume 14 Number 1,June, 2021

Where $T_{L}, T^{\circ}, E^{\circ}$, and $V^{\circ}$ havethe same significance as in equation (1) above, $T_{m}$ denotes the total concentration of metal present in solution, $V_{3}$ is the volume of metal ions present in solution and $\beta^{H}$ is the overall proton ligand stability constant. The metal-ligand stability constants (log K) were determined by employing point wise computational Method (eq. 5 and 6).

$\operatorname{LogK}_{1}=\log \left(\frac{n}{1-n}\right)+\mathrm{pL}$ .5

$\operatorname{LogK}_{2}=\log \left(\frac{1-n}{2-n}\right)+\mathrm{pL}$ ...6

Where: Log $\mathrm{K}$ is the metal-ligand stability constant, $\mathrm{pL}$ is the Free ligand exponent function, $\mathbf{n}$ is the Average number of ligand attached with metal ion (Janraoet al., 2014). The results obtained were analyzed by an ORIGIN 2016 program using titration data and then the proton-ligand stability constants (pKa) and Metal-ligand stability constant (LogK) calculated (Omar and Ali, 2015).

\section{RESULTS AND DISCUSSION}

Fourier transformed infrared (FT-IR) spectra of isolated humic acid from peat soils Figure 2 had distinct clear absorption bands indicating the presence of major humic acid structural elemental groups such as $\mathrm{H}$ bonded $\mathrm{OH}$ $\left(3680 \mathrm{~cm}^{-1}\right.$ peak $), C=0$ of carbonyl $\left(1721 \mathrm{~cm}^{-1}\right.$ peak), functional groups of aliphatic components $\mathrm{CH}_{2}\left(2918 \mathrm{~cm}^{-1}\right.$ peak) and $\mathrm{C}-\mathrm{O}$ stretching of polysaccharide $\left(1168 \mathrm{~cm}^{-1}\right.$ peak). The positions of the absorption bands of the spectra fell within typical major absorption bands of humic acid which is at frequencies 3680, 2918, 1721, 1168 $\mathrm{cm}^{-1}$. The first peak centred in the vicinity of $3680 \mathrm{~cm}^{-1}$ region is attributed to phenol $\mathrm{OH}$ group bounded by intermolecular $\mathrm{H}$ bonds. The $2918 \mathrm{~cm}^{-1}$ band usually has absorption maximum at $2918 \mathrm{~cm}^{-1}$ which is due to $\mathrm{C}-\mathrm{H}$ stretching of alkane group $\left(\mathrm{CH}_{2}\right)$. The next major absorption band is $1721 \mathrm{~cm}^{-1}$. This band has been commonly ascribed to $\mathrm{C}=\mathrm{O}$ stretching of mainly carboxyl group $(\mathrm{COOH})$ with trace amount of ketones. The last peak was observed at 1168 $\mathrm{cm}^{-1}$ due to $\mathrm{C}-\mathrm{O}$ stretching of polysaccharides and this peak appeared also in the spectra of humic acid from peat soil. The FTIR spectra of the isolated humic acid contained all major characteristic absorption peaks of humic acid. These absorption peaks indicated the presence of the major structural elements of humic acid namely $\mathrm{H}$ bonded $\mathrm{OH}, \mathrm{C}=\mathrm{C}$ of aromatic ring, $\mathrm{C}=\mathrm{O}$ of carbonyl group (both carboxyl and ketonic), $\mathrm{CH}_{2}$ group. This strongly supports the presence of humic acid.

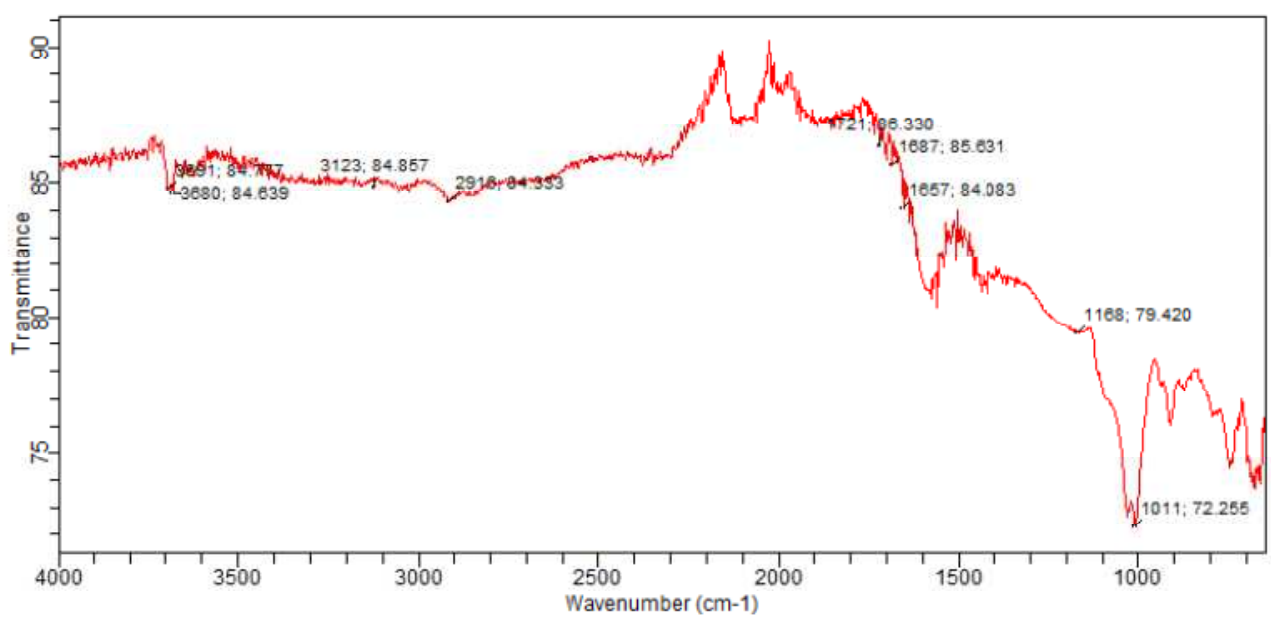

Fig. 2 : FT-IR spectraof peatsoilhumic acid (PSHA)

\section{Evaluation of acid dissociation constant (pka) of acid hydrolysed peat soil humicacid at phenolic group}

The value of the dissociation constant of the peat soil humic acid (PSHA) that underwent acidhydrolysis studied was found to be 8.9299 as shown Table 1, which is lower than the literaturevalues reported by Almeida and Szpoganics, (2015), Borges et al., (2005); Badr et al., (2012)and Fernandes et al,.(2009) of $9.73,9.47$ and 10.30. The difference between the obtained valuesand the reported values in this study might be probably as a result of acid hydrolysis of humicacid. 
BAJOPAS Volume 14 Number 1,June, 2021

Table 1: PKa of (Hydrolysed PSHA)

\begin{tabular}{|l|l|l|l|l|l|l|}
\hline $\mathrm{pH}$ & $\mathrm{BV}_{1}$ & $\mathrm{BV}_{2}$ & $\mathrm{~V}_{2}-\mathrm{V}_{1}$ & $\mathrm{nA}$ & $\log \left(\frac{n A}{1-n A}\right)$ & $\mathrm{pKa}$ \\
\hline 8.50 & 5.30 & 6.29 & 0.99 & 0.3594 & -0.2510 & 8.2490 \\
8.72 & 5.35 & 6.37 & 1.02 & 0.3400 & -0.2880 & 8.4320 \\
9.00 & 5.40 & 6.46 & 1.06 & 0.3141 & -0.3391 & 8.6609 \\
9.22 & 5.45 & 6.55 & 1.10 & 0.2882 & -0.3927 & 8.8273 \\
9.51 & 5.50 & 6.66 & 1.16 & 0.2494 & -0.4786 & 9.0314 \\
9.73 & 5.55 & 6.78 & 1.23 & 0.2041 & -0.5910 & 9.1390 \\
10.00 & 5.60 & 6.90 & 1.30 & 0.1589 & -0.7238 & 9.2762 \\
10.23 & 5.65 & 7.05 & 1.40 & 0.0941 & -0.9835 & 9.2465 \\
10.49 & 5.70 & 7.10 & 1.40 & 0.0941 & -0.9835 & 9.5065 \\
\hline
\end{tabular}

Average pKa $=8.9299 \pm 0.4186$

Table 2: PKa of (Unhydrolysed PSHA)

\begin{tabular}{|l|l|l|l|l|l|l|}
\hline $\mathrm{pH}$ & $\mathrm{BV}_{1}$ & $\mathrm{BV}_{2}$ & $\mathrm{~V}_{2}-\mathrm{V}_{1}$ & $\mathrm{nA}$ & $\log \left(\frac{\boldsymbol{n A}}{1-\boldsymbol{n}}\right)$ & $\mathrm{pKa}$ \\
\hline 8.50 & 5.30 & 5.81 & 0.51 & 0.6619 & 0.2919 & 8.7919 \\
8.72 & 5.35 & 5.90 & 0.55 & 0.6357 & 0.2418 & 8.9618 \\
9.00 & 5.40 & 6.00 & 0.60 & 0.6029 & 0.1813 & 9.1813 \\
9.22 & 5.45 & 6.10 & 0.65 & 0.5701 & 0.1226 & 9.3426 \\
9.51 & 5.50 & 6.20 & 0.70 & 0.5376 & 0.0654 & 9.5754 \\
9.73 & 5.55 & 6.33 & 0.78 & 0.4851 & -0.0259 & 9.7041 \\
10.00 & 5.60 & 6.47 & 0.87 & 0.4262 & -0.1291 & 9.8709 \\
10.23 & 5.65 & 6.62 & 0.99 & 0.3609 & -0.2481 & 9.9819 \\
10.49 & 5.70 & 6.80 & 1.10 & 0.2759 & -0.4690 & 10.0210 \\
\hline
\end{tabular}

Average pKa $=9.4923 \pm 0.4410$

Metal-ligand stability constant ( $\log \mathrm{K}$ )

The stabilityconstants require the accurate values of proton-ligand stability constants (Anil and Maroti, 2008). Metal titration curves crossed over ligand titration curve indicated the formation of complex upon proton release (Santosh, et al., 2011). If the values of n- are within range $0.2-0.8$ and $1.2-18$ this indicates the formation of $1: 1$ and 1:2 complexes (Sayyed and Mazahar, 2012).

The metal (II)-humate stepwise stability constants (log k) at phenolic group (Tables 318)

Table 3: Point-wise method, $\mathrm{Cu}$-(Hydrolysed PSHA)

\begin{tabular}{|l|l|l|l|l|l|l|l|l|}
\hline $\mathrm{pH}$ & $\mathrm{BV}_{1}$ & $\mathrm{BV}_{2}$ & $\mathrm{BV}_{3}$ & $\left(\mathrm{~V}_{3}-\mathrm{V}_{2}\right)$ & $\mathrm{n}$ & $\mathrm{pL}$ & $\log \left(\frac{n}{1-n}\right)$ & LogK $_{1}$ \\
\hline 8.50 & 5.30 & 6.29 & 6.33 & 0.04 & 0.5500 & 2.66 & 0.0871 & 2.7471 \\
8.72 & 5.35 & 6.37 & 6.41 & 0.04 & 0.5714 & 2.43 & 0.1249 & 2.5549 \\
9.00 & 5.40 & 6.46 & 6.50 & 0.04 & 0.6198 & 2.16 & 0.2122 & 2.3722 \\
9.22 & 5.45 & 6.55 & 6.59 & 0.04 & 0.6667 & 1.94 & 0.3010 & 2.2410 \\
\hline
\end{tabular}

LogK $_{1}$ (Average value) $=2.4788 \pm 0.2203$

Table 4: Point-wise method, $\mathrm{Cu}$-(Hydrolysed PSHA)

\begin{tabular}{|l|l|l|l|l|l|l|l|l|}
\hline $\mathrm{pH}$ & $\mathrm{BV}_{1}$ & $\mathrm{BV}_{2}$ & $\mathrm{BV}_{3}$ & $\left(\mathrm{~V}_{3}-\mathrm{V}_{2}\right)$ & $\mathrm{n}$ & $\mathrm{pL}$ & $\log \left(\frac{n-1}{2-n}\right)$ & LogK $_{2}$ \\
\hline 9.51 & 5.50 & 6.66 & 6.73 & 0.07 & 1.3509 & 1.70 & -0.2671 & 1.4329 \\
9.73 & 5.55 & 6.78 & 6.85 & 0.07 & 1.6383 & 1.51 & 0.2467 & 1.7567 \\
10.00 & 5.60 & 6.90 & 6.98 & 0.08 & 2.1783 & 1.31 & -0.2158 & 1.0942 \\
10.23 & 5.65 & 7.05 & 7.13 & 0.08 & 4.1904 & 1.27 & & \\
10.49 & 5.70 & 7.10 & 7.19 & 0.09 & 4.6920 & & & \\
\hline
\end{tabular}

Log $K_{2}($ Average value $)=1.4280 \pm 0.3312$ 
BAJOPAS Volume 14 Number 1,June, 2021

Table 5: Point-wise method, $\mathrm{Cu}$ (Unhydrolysed PSHA)

\begin{tabular}{|l|l|l|l|l|l|l|l|l|}
\hline $\mathrm{pH}$ & $\mathrm{BV}_{1}$ & $\mathrm{BV}_{2}$ & $\mathrm{BV}_{3}$ & $\left(\mathrm{~V}_{3}-\mathrm{V}_{2}\right)$ & $\mathrm{n}$ & $\mathrm{pL}$ & $\log \left(\frac{n}{n-1}\right)$ & Log $_{1}$ \\
\hline 8.50 & 5.30 & 5.81 & 5.85 & 0.04 & 0.2973 & 2.88 & -0.3736 & 2.5064 \\
8.72 & 5.35 & 5.90 & 5.95 & 0.05 & 0.3873 & 2.66 & -0.1992 & 2.4608 \\
9.00 & 5.40 & 6.00 & 6.05 & 0.05 & 0.4044 & 2.38 & -0.1681 & 2.2119 \\
9.22 & 5.45 & 6.10 & 6.15 & 0.06 & 0.5157 & 2.18 & -0.0272 & 2.2072 \\
9.51 & 5.50 & 6.20 & 6.27 & 0.07 & 0.6417 & 1.89 & 0.2530 & 1.1430 \\
\hline
\end{tabular}

$\operatorname{LogK}_{1}($ Average value $)=2.3059 \pm 0.6153$

Table 6:Point-wise method, $\mathrm{Cu}$ (Unhydrolysed PSHA)

\begin{tabular}{|l|l|l|l|l|l|l|l|l|}
\hline $\mathrm{pH}$ & $\mathrm{BV}_{1}$ & $\mathrm{BV}_{2}$ & $\mathrm{BV}_{3}$ & $\mathrm{~V}_{3}-\mathrm{V}_{2}$ & $\mathrm{n}$ & $\mathrm{pL}$ & $\log \left(\frac{n-1}{2-n}\right)$ & $\log \mathrm{K}_{2}$ \\
\hline 9.73 & 5.55 & 6.33 & 6.42 & 0.09 & 0.9000 & 1.69 & & \\
10.00 & 5.60 & 6.47 & 6.58 & 0.11 & 1.2578 & 1.44 & -0.4592 & 0.9808 \\
10.23 & 5.65 & 6.62 & 6.84 & 0.12 & 1.6137 & 1.26 & -0.2010 & 1.4610 \\
10.49 & 5.70 & 6.80 & 6.92 & 0.12 & 2.1052 & 1.03 & & \\
\hline
\end{tabular}

$\operatorname{LogK}_{2}$ (Average value) $=1.2209 \pm 0.3398$

Table 7:Point-wise method, Pb (Hydrolysed PSHA)

\begin{tabular}{|l|l|l|l|l|l|l|l|l|}
\hline $\mathrm{pH}$ & $\mathrm{BV}_{1}$ & $\mathrm{BV}_{2}$ & $\mathrm{BV}_{3}$ & $\left(\mathrm{~V}_{3}-\mathrm{V}_{2}\right)$ & $\mathrm{n}$ & $\mathrm{pL}$ & $\log \left(\frac{n}{1-n}\right)$ & LogK $_{1}$ \\
\hline 8.50 & 5.30 & 6.29 & 6.33 & 0.04 & 0.5500 & 2.66 & 0.0871 & 2.7471 \\
8.72 & 5.35 & 6.37 & 6.41 & 0.04 & 0.5714 & 2.43 & 0.1249 & 2.5549 \\
9.00 & 5.40 & 6.46 & 6.50 & 0.04 & 0.6198 & 2.16 & 0.2122 & 2.3722 \\
9.22 & 5.45 & 6.55 & 6.60 & 0.05 & 0.8333 & 1.96 & 0.6989 & 2.6589 \\
\hline
\end{tabular}

Log $_{\mathbf{1}}($ Average value $)=2.5832 \pm 0.1614$

Table 8:Point-wise method, Pb-(Hydrolysed PSHA)

\begin{tabular}{|l|l|l|l|l|l|l|l|l|}
\hline $\mathrm{pH}$ & $\mathrm{BV}_{1}$ & $\mathrm{BV}_{2}$ & $\mathrm{BV}_{3}$ & $\left(\mathrm{~V}_{3}-\mathrm{V}_{2}\right)$ & $\mathrm{n}$ & $\mathrm{pL}$ & $\log \left(\frac{n-1}{2-n}\right)$ & $\log \mathrm{K}_{2}$ \\
\hline 9.51 & 5.50 & 6.66 & 6.71 & 0.05 & 0.9650 & 1.67 & & \\
9.73 & 5.55 & 6.78 & 6.83 & 0.05 & 1.1702 & 1.44 & & \\
10.00 & 5.60 & 6.90 & 6.90 & 0.05 & 1.4864 & 1.22 & -0.0237 & 1.1963 \\
10.23 & 5.65 & 7.05 & 7.10 & 0.05 & 2.0190 & 1.09 & & \\
10.49 & 5.70 & 7.10 & 7.17 & 0.07 & 3.6492 & 1.00 & & \\
\hline
\end{tabular}

Log $K_{2}$ (Average value) $=1.1963$

Table 9: Point-wise method, Pb (Unhydrolysed PSHA)

\begin{tabular}{|l|l|l|l|l|l|l|l|l|}
\hline $\mathrm{pH}$ & $\mathrm{BV}_{1}$ & $\mathrm{BV}_{2}$ & $\mathrm{BV}_{3}$ & $\mathrm{~V}_{3}-\mathrm{V}_{2}$ & $\mathrm{n}$ & $\mathrm{pL}$ & $\begin{array}{l}\text { Log } \\
\left(\frac{n}{n-1}\right)\end{array}$ & Log $\mathrm{K}_{1}$ \\
\hline 8.50 & 5.30 & 5.81 & 5.85 & 0.04 & 0.2973 & 2.88 & -0.3736 & 2.5064 \\
8.72 & 5.35 & 5.90 & 5.94 & 0.04 & 0.3099 & 2.66 & -0.5477 & 2.3123 \\
9.00 & 5.40 & 6.00 & 6.05 & 0.05 & 0.4044 & 2.38 & -0.1681 & 2.2119 \\
9.22 & 5.45 & 6.10 & 6.15 & 0.06 & 0.5157 & 2.18 & 0.0272 & 2.2072 \\
9.51 & 5.50 & 6.20 & 6.26 & 0.07 & 0.6417 & 1.89 & 0.2530 & 2.1430 \\
9.73 & 5.55 & 6.40 & 6.40 & 0.07 & 0.7000 & 1.67 & 0.3680 & 2.0380 \\
\hline
\end{tabular}

LogK $_{1}$ (Average value) $=2.2364 \pm 0.1602$

Table 10: Point-wise method, Pb (Unhydrolysed PSHA)

\begin{tabular}{|l|l|l|l|l|l|l|l|l|}
\hline $\mathrm{pH}$ & $\mathrm{BV}_{1}$ & $\mathrm{BV}_{2}$ & $\mathrm{BV}_{3}$ & $\mathrm{~V}_{3}-\mathrm{V}_{2}$ & $\mathrm{n}$ & $\mathrm{pL}$ & $\log \left(\frac{n-1}{2-n}\right)$ & $\log \mathrm{K}_{2}$ \\
\hline 10.00 & 5.60 & 6.47 & 6.55 & 0.08 & 1.9503 & 1.41 & & \\
10.23 & 5.65 & 6.62 & 6.72 & 0.11 & 1.4792 & 1.26 & -0.0361 & 1.2239 \\
\hline
\end{tabular}

$\operatorname{LogK}_{2}$ (Average value) $=1.2239$

Table 11: Point-wise method, Mg (Hydrolysed PSHA)

\begin{tabular}{|l|l|l|l|l|l|l|l|l|}
\hline $\mathrm{pH}$ & $\mathrm{BV}_{1}$ & $\mathrm{BV}_{2}$ & $\mathrm{BV}_{3}$ & $\left(\mathrm{~V}_{3}-\mathrm{V}_{2}\right)$ & $\mathrm{n}$ & $\mathrm{pL}$ & $\log \left(\frac{n}{n-1}\right)$ & LogK $_{1}$ \\
\hline 8.50 & 5.30 & 6.29 & 6.31 & 0.02 & 0.2750 & 2.64 & -0.4290 & 2.2110 \\
8.72 & 5.35 & 6.37 & 6.39 & 0.02 & 0.2858 & 2.42 & -0.3978 & 2.0222 \\
9.00 & 5.40 & 6.46 & 6.49 & 0.03 & 0.4648 & 2.14 & -0.0612 & 2.0788 \\
9.22 & 5.45 & 6.55 & 6.59 & 0.04 & 0.6667 & 1.94 & 0.3010 & 2.2410 \\
\hline
\end{tabular}

$\log _{\mathbf{1}}($ Average value) $=2.1382 \pm 0.1046$ 
BAJOPAS Volume 14 Number 1,June, 2021

Table 12: Point-wise method, Mg (Hydrolysed PSHA)

\begin{tabular}{|l|l|l|l|l|l|l|l|l|}
\hline $\mathrm{pH}$ & $\mathrm{BV}_{1}$ & $\mathrm{BV}_{2}$ & $\mathrm{BV}_{3}$ & $\left(\mathrm{~V}_{3}-\mathrm{V}_{2}\right)$ & $\mathrm{n}$ & $\mathrm{pL}$ & $\log \left(\frac{n-1}{2-n}\right)$ & LogK $_{2}$ \\
\hline 9.51 & 5.55 & 6.66 & 6.71 & 0.05 & 0.9650 & 1.67 & & \\
9.73 & 5.55 & 6.78 & 6.84 & 0.06 & 1.4042 & 1.47 & -0.1686 & 1.3014 \\
10.00 & 5.60 & 6.90 & 6.93 & 0.06 & 1.7838 & 1.23 & 0.5593 & 1.7893 \\
10.23 & 5.65 & 7.05 & 7.10 & 0.06 & 3.1429 & 1.10 & & \\
10.49 & 5.70 & 7.10 & 7.18 & 0.07 & 3.6492 & 0.83 & & \\
\hline
\end{tabular}

LogK $_{2}($ Average value $)=1.5453 \pm 0.3450$

Table 13: Point-wise method, Mg (Unhydrolysed PSHA)

\begin{tabular}{|l|l|l|l|l|l|l|l|l|}
\hline $\mathrm{pH}$ & $\mathrm{BV}_{1}$ & $\mathrm{BV}_{2}$ & $\mathrm{BV}_{3}$ & $\mathrm{~V}_{3}-\mathrm{V}_{2}$ & $\mathrm{n}$ & $\mathrm{pL}$ & $\log \left(\frac{n}{n-1}\right)$ & $\operatorname{Log~}_{1}$ \\
\hline 8.50 & 5.30 & 5.81 & 5.85 & 0.04 & 0.2973 & 2.88 & -0.3736 & 2.5064 \\
8.72 & 5.35 & 5.90 & 5.94 & 0.04 & 0.3099 & 2.66 & -0.3477 & 2.3123 \\
9.00 & 5.40 & 6.00 & 6.04 & 0.04 & 0.3236 & 2.38 & -0.3202 & 2.0598 \\
9.22 & 5.45 & 6.10 & 6.15 & 0.05 & 0.4297 & 2.17 & -0.1230 & 2.0470 \\
9.51 & 5.50 & 6.20 & 6.26 & 0.06 & 0.5500 & 1.89 & 0.0871 & 1.9771 \\
9.73 & 5.55 & 6.33 & 6.40 & 0.07 & 0.7000 & 1.67 & 0.3680 & 2.0380 \\
\hline
\end{tabular}

LogK $_{1}$ (Average value) $=2.1568 \pm 0.2069$

Table 14: Point-wise method, Mg (Unhydrolysed PSHA)

\begin{tabular}{|l|l|l|l|l|l|l|l|l|}
\hline $\mathrm{pH}$ & $\mathrm{BV}_{1}$ & $\mathrm{BV}_{2}$ & $\mathrm{BV}_{3}$ & $\mathrm{~V}_{3}-\mathrm{V}_{2}$ & $\mathrm{n}$ & $\mathrm{pL}$ & $\log \left(\frac{n-1}{2-n}\right)$ & $\log \mathrm{K}_{2}$ \\
\hline 10.00 & 5.60 & 6.47 & 6.55 & 0.08 & 0.9148 & 1.41 & & \\
10.23 & 5.65 & 6.62 & 6.71 & 0.09 & 1.2102 & 1.20 & -0.5749 & 0.6251 \\
10.49 & 5.70 & 6.80 & 6.92 & 0.09 & 1.5968 & 1.03 & 0.1703 & 1.2003 \\
\hline
\end{tabular}

LogK $_{2}$ (Average value) $=0.9127 \pm 0.4070$

Table15:Point-wise method, Cd (Hydrolysed PSHA)

\begin{tabular}{|l|l|l|l|l|l|l|l|l|}
\hline $\mathrm{pH}$ & $\mathrm{BV}_{1}$ & $\mathrm{BV}_{2}$ & $\mathrm{BV}_{3}$ & $\left(\mathrm{~V}_{3}-\mathrm{V}_{2}\right)$ & $\mathrm{n}$ & $\mathrm{pL}$ & $\log \left(\frac{n}{1-n}\right)$ & LogK $_{1}$ \\
\hline 8.50 & 5.30 & 6.29 & 6.31 & 0.02 & 0.2750 & 2.64 & -0.4210 & 2.2190 \\
8.72 & 5.35 & 6.37 & 6.40 & 0.03 & 0.4286 & 2.42 & -0.1249 & 2.2951 \\
9.00 & 5.40 & 6.46 & 6.49 & 0.03 & 0.4648 & 2.14 & -0.0612 & 2.0788 \\
9.22 & 5.45 & 6.55 & 6.59 & 0.04 & 0.6667 & 1.96 & 0.3010 & 2.2610 \\
9.51 & 5.55 & 6.66 & 6.70 & 0.04 & 0.7720 & 1.67 & 0.5297 & 2.1997 \\
\hline
\end{tabular}

LogK $_{\mathbf{1}}$ (Average value) $=2.2108 \pm 0.0825$

Table 16: Point-wise method, Cd (Hydrolysed PSHA)

\begin{tabular}{|l|l|l|l|l|l|l|l|l|}
\hline $\mathrm{pH}$ & $\mathrm{BV}_{1}$ & $\mathrm{BV}_{2}$ & $\mathrm{BV}_{3}$ & $\left(\mathrm{~V}_{3}-\mathrm{V}_{2}\right)$ & $\mathrm{n}$ & $\mathrm{pL}$ & $\log \left(\frac{n-1}{2-n}\right)$ & Log $_{2}$ \\
\hline 9.73 & 5.55 & 6.78 & 6.83 & 0.06 & 1.4042 & 1.47 & -0.1686 & 1.3014 \\
10.00 & 5.60 & 6.90 & 6.95 & 0.06 & 1.7838 & 1.23 & 0.5593 & 1.7893 \\
10.23 & 5.65 & 7.05 & 7.10 & 0.06 & 3.1429 & 1.09 & & \\
10.49 & 5.70 & 7.10 & 7.16 & 0.06 & 3.1429 & 0.89 & & \\
& & & & & & & & \\
\hline
\end{tabular}

$\operatorname{LogK}_{2}$ (Average value) $=1.5453 \pm 0.3450$

Table 17: Point-wise method, Cd (Unhydrolysed PSHA)

\begin{tabular}{|l|l|l|l|l|l|l|l|l|}
\hline $\mathrm{pH}$ & $\mathrm{BV}_{1}$ & $\mathrm{BV}_{2}$ & $\mathrm{BV}_{3}$ & $\mathrm{~V}_{3}-\mathrm{V}_{2}$ & $\mathrm{n}$ & $\mathrm{pL}$ & $\log \left(\frac{n}{n-1}\right)$ & $\operatorname{Log~}_{1}$ \\
\hline 8.50 & 5.30 & 5.81 & 5.86 & 0.05 & 0.3717 & 2.88 & -0.2280 & 2.6520 \\
8.72 & 5.35 & 5.90 & 5.95 & 0.05 & 0.3873 & 2.66 & -0.1992 & 2.4608 \\
9.00 & 5.40 & 6.00 & 6.06 & 0.06 & 0.4853 & 2.38 & -0.0255 & 2.3545 \\
9.22 & 5.45 & 6.10 & 6.16 & 0.06 & 0.5157 & 2.18 & -0.0272 & 2.2072 \\
9.51 & 5.50 & 6.20 & 6.27 & 0.07 & 0.6417 & 1.89 & 0.2530 & 1.1430 \\
9.73 & 5.55 & 6.33 & 6.41 & 0.08 & 0.8000 & 1.69 & 0.6020 & 2.2920 \\
& & & & & & & & \\
\hline
\end{tabular}

$\operatorname{LogK}_{1}($ Average value $)=2.2516 \pm 0.5380$ 
BAJOPAS Volume 14 Number 1,June, 2021

Table 18: Point-wise method, Cd (Unhydrolysed PSHA)

\begin{tabular}{|l|l|l|l|l|l|l|l|l|}
\hline $\mathrm{pH}$ & $\mathrm{BV}_{1}$ & $\mathrm{BV}_{2}$ & $\mathrm{BV}_{3}$ & $\mathrm{~V}_{3}-\mathrm{V}_{2}$ & $\mathrm{n}$ & $\mathrm{pL}$ & $\log \left(\frac{n-1}{2-n}\right)$ & $\log \mathrm{K}_{2}$ \\
\hline 10.00 & 5.60 & 6.47 & 6.57 & 0.10 & 1.1434 & 1.43 & & \\
10.23 & 5.65 & 6.62 & 6.72 & 0.10 & 1.3448 & 1.23 & -0.2788 & 0.9512 \\
10.49 & 5.70 & 6.80 & 6.90 & 0.10 & 1.7742 & 1.03 & 0.5351 & 1.5651 \\
\hline
\end{tabular}

$\operatorname{LogK}_{2}($ Average value $)=1.2581 \pm 0.4340$

Table 19: Stepwise and overall Stability constants of thehydrolysed and unhydrolysed divalent metal (II) complexes

\begin{tabular}{|c|c|c|c|}
\hline Chelates & LogK $_{1}$ & $\log _{2}$ & Log $\beta$ \\
\hline [Cu (Hydrolysed PSHA-1) $\left.{ }_{2}\right]$ & 2.4788 & 1.4280 & 3.9068 \\
\hline$\left[\mathrm{Pb}(\text { Hydrolysed PSHA-1) })_{2}\right]$ & 2.5832 & 1.1963 & 3.7795 \\
\hline$\left[\mathrm{Cd}(\text { Hydrolysed PSHA-1 })_{2}\right]$ & 2.2108 & 1.5453 & 3.7561 \\
\hline$\left[\mathrm{Mg}(\text { Hydrolysed PSHA-1 })_{2}\right]$ & 2.1382 & 1.5453 & 3.6835 \\
\hline [Cu (Unhydrolysed PSHA-1) & 2.3059 & 1.2209 & 3.5268 \\
\hline$[\mathrm{Pb}$ (Unhydrolysed PSHA-1) 2$]$ & 2.2364 & 1.2239 & 3.4603 \\
\hline [Cd (Unhydrolysed PSHA-1) 2 ] & 2.2516 & 1.2581 & 3.5097 \\
\hline$[\mathrm{Mg}$ (Unydrolysed PSHA-1) & 2.1568 & 0.9127 & 3.0695 \\
\hline
\end{tabular}

The results obtained (Table19) shows the stepwise and overall stability constants to be not high indicating low stability of the complexes, because the solubility of most metal ions in the basic $\mathrm{pH}$ range is minimal due to metal hydroxide precipitation (Karimi, 2017). In general, the stepwise stability constants $\left(K_{1}\right.$ and $K_{2}$ ) follow the order $K_{1}>K_{2}$ for the copper, lead, magnesium and cadmium complexes respectively. The steady decrease of the values with increasing number of ligands is in agreement with the prediction made by researchers (Na'aliya, 2013). The decrease could be attributed to the fact that as the number of the ligands (Humate ions) that enters the coordination zone increases the aqua molecules available for replacement by the ligands become less. Thus, the metal ions become less electron loving with progressive intake of the ligand and this results in the decrease in the values of the constants (Na'aliya, 2013). Also the stability of the complexes is influenced by the size and number of the chelate rings(Mackay and Mackay,2002).All the complexes form rings in their structure as humate, a bidentate ligand, bond the metal ions in the ratio 1:2 (Boguta and Sokolowska, 2016) forming chelate rings. The values of the overall stability constants $(\log \beta)$ obtained for humate complexes are not high indicating low stability as the values are not high. LogK values for copper-humates (Table 3 to 6) obtained in this study are lower than those reported for the complexes of humic acids (Pandey et al., 2015; Dinu, 2013; Kaschl et al., 2010 and Gilbeto and Jorg, 2001). The values of LogK(Table 7 to 10 ) forlead-humates are lower than those reported for the lead in the literature (Dinu, 2013; Gilbeto and Jorg 2001). Log K values(Table 11 to 14 ) for magnesium-humates obtained in this study are close to those reported by (Pandey et al., 2015). Log K values of cadmium-humates (Table 15 to 18 ) obtained in this work near to the one reported by (Dinu, 2013 and Pandey et al., 2015).The difference between the reported values and the values obtained in this study might be probably as a result of acid hydrolysis of humic acid. The values of the overall stability constants $(\log \beta)$ of the copper humates complexes presented in Table 19 is high than that of other metal humate complexes, show relatively high stability of CuHA complexes, show the following order of stability: $\mathrm{Cu}>\mathrm{Pb}>\mathrm{Cd}>\mathrm{Mg}$; which are in close agreement to the findings of (Dinu, 2013 and Pandey et al., 2015).The high stability of Cuhumate chelate could be attributed to the existence of coordinate covalent bond between the complexing agents and the $\mathrm{Cu}^{2+}$ ions. Since, $\mathrm{Cu}^{2+}$ being a metal of the transitional series with $3 d^{9}$ electronic configurations can accept the electrons from the complexing agents. Similarly, the low stabilities of $\mathrm{Pb}, \mathrm{Cd}$ and $\mathrm{Mg}$ complexes could be explained by that $\mathrm{Pb}^{2+}$ with $6 s^{2}, \mathrm{Cd}^{2+}$ with $4 \mathrm{~d}^{10}$ and $\mathrm{Mg}^{2+}$ with $2 \mathrm{p}^{6}$ their electronic configuration has a completely filled $\mathrm{d}, \mathrm{p}$ and $\mathrm{s}$ orbitals. Moreover, the stabilities of metal ions with hydrolysed humic acid from peat soil were higher than those with unhydrolysed humic acid from peat soil; which is ascribed to the high content of acidity in hydrolysed humic acid than unhydrolysed humic acid. 
BAJOPAS Volume 14 Number 1,June, 2021 CONCLUSION

The values of logk for $\mathrm{Cu}(\mathrm{II})$ hydrolysed humic acid complex was higher followed by $\mathrm{Pb}$ (II), $\mathrm{Cd}(\mathrm{II})$ and $\mathrm{Mg}$ (II) hydrolysed humic acid complexes as compared with metal(II) unhydrolysed humic acid complexes. This indicates acid hydrolysis of humic acid can

\section{REFERENCES}

Almeida, V.R. and Szpoganicz, B. (2015). Humic Acid Potentiometric Response Patterns:Out- of Equilibrium Properties and Species Distribution Modelling. Chemical. Biol. Technol. Agric. 2: 17.

Anđelković, T., Nikolić, R., Bojić, A.,Anđelković, D., and Nikolic G.,(2010). Binding of Cadmium to Soil Humic Acid as A Function of Carboxyl Group Content. Macedonian Journal of Chemistry and Chemical Engineering.29(2): 215-224.

Anil, B. N. and Maroti, N. (2008). Studies on Influence of Die-Lectric Constants on Complex Equilibria between Substituted Py-Razalines and Lanthanide Metal Ions pH-Metrically. Amer.-Euras. scient. Res. 3(2): 212-216.

Ashok, K., Pandey, S. P. and Misra, V (2000). Stability Constants of Metal-Humic Acid Complexes and its Role in Environmental Detoxification. Journal of Ecotoxicology and Environmental Safety. 47(2):157-200.

Badr, M. H., El-Halafawi, M. H. and Abd El-al Zeid, E. R. (2012). Comparison Between the Effect of Ionic Strength on Acidity and Dissociation Constants of Humic Acids Extracted from Sewage Sludge and Nile Water Hyacinth Composts.Global Journal of Environmental Research 6 (1): 36-43.

Baruah, M.K., Borah, D., Saikia, P.P., Paul, S., Sharma, T. (2015). Evaluation of pKa Values of Soil Humic Acids and their Complexation Properties. International Journal of Plant \& Soil Science 6(4) : 218-228.

Boguta, P. Sokolowska, Z. (2016). Interactions of $\mathrm{Zn}$ (II) Ions with Humic Acids Isolated from Various Types of Soils. Effect of $\mathrm{pH}, \mathrm{Zn}$ Concentrations and Humic Acids Chemical Properties. Journal of Geochemical Explaration 168. 119-126.

Borges, F., Guimaraes, C., Lima, L.F.C., Pinto, I. and Reis, S.(2005). Potentiometric Studies on the Complexation of Copper(II) by Phenolic Acids as Discrete Ligand Models of enhance the complexation behavior of humic acid with metal (II) ions. However, the higher values of $\log \beta$ for $\mathrm{Cu}(\mathrm{II}), \mathrm{Pb}(\mathrm{II}), \mathrm{Cd}(\mathrm{II})$ and $\mathrm{Mg}(\mathrm{II})$ hydrolysed humic acid complexes indicates more stable stepwise complexes formed as compared with $\mathrm{Cu}(\mathrm{II}), \mathrm{Pb}$ (II), $\mathrm{Cd}$ (II) and $\mathrm{Mg}(\mathrm{II})$ unhydrolysed humic acid complexes.

Humic Substances Talanta 66 (2005) 670-673.

Chefetz, B., Salloum, M. J., Deshmulkin, A. P. and Hatcher, P. (2002). Structural Components of Humic Acids as Determined by Chemical Modifications and Carbon-13 NMR, Pyrolysis, and Thermochemolysis- Gas Chromatography/Mass Spectrometry. Soil Science Society of American Journal Abstract Division S-2- Soil Chemistry66. 1159-1171.

Dinu, M. I. (2013). Metals Complexation with Humic Acids in Surface Water of Different Environ. Sci. Technol. 31(1): 1-17.

Fernandes, A.N., Giacomelli, C., Giovanela, M. Vaz, D.V. Szpoganicz, B. and Maria M. D. (2009). Potentiometric Acidity Determination in Humic Substances Influenced by Different Analytical Procedures.J. Braz. Chem. Soc. 20 (9):14.

Gamal, A. H. (2015). Stability Constants of Rhenium (V) Metal Complexes with Selected Drugs. Pyrex Journal of Research in Environmental Studies. 2(2): 006-014.

Janrao, D. M., Pathan, J., Kayande, D.D., and Mulla, J.J. (2014). An Over View of Potentiometric Determination of Stability Constants of Metal Complexes. Sci. Revs. Chem. Commun.: 4(1), 2014, 11-24.

Karimi, H. (2017). Effect of pH and Initial Pb(II) Concentration on the Lead Removal Efficiency from Waste Water Using $\mathrm{Ca}(\mathrm{OH})_{2}$. International Journal of Water and Waste Water Treatment 3.2

Kaschl, A. Romheld, V. and Chen, Y. (2010). Binding of Cadmium, Copper and Zinc to Humic Substances Originating from Municipal Solid Waste Compost. Israel Journal of Chemistry Vol. 42(1): 89-98.

Kostic, I. S., Tatjana, P, A., Nikolic, R. S., Cvetkovic, T. P., Pavlovic, D. D., Aleksandar, L.J. and Bojic, A. (2012). Comparative Study of Binding Strengths of Heavy Metals with Humic Acid. J.serb. Chem. Soc. 76(9) pp 1-20. 
BAJOPAS Volume 14 Number 1,June, 2021

Na'aliya, J. (2013). Determination of Stepwise Stability Constants and Gibbs free Energy Change of Trisprolina to Complexes of some Divalent Transition Metal ions. Bayero Journal of Pure and Applied Sciences 6(2): 112-114.

Omar, A. A. and Ali, E. A. (2015). Potentiometric Studies on Complexes of $\mathrm{Cr}$ (III) and $\mathrm{Zr}$ (IV) with some Carboxylic Acids. International Journal of Advanced Chemistry, 3(1) 25-

37.

Pandey, A. K. Pandey, S. D. and Misr, V. (2015).Stability Constants of Metal- Humic Acid Complexes and Its Role in Environmental Detoxification. J. Ecotoxicology and Environmental Safety. 47(1):195-200.

Ram, N. and Raman, K.V. (1984). Stability Constants of Complexes of Metals with
Humicand Fuvic Acids under Non- acidConditions. Journal of Plant Nutrition and Soil Sciences.

147:171-176.

Santosh, D. D., Ashok, B. K., Vijay, J. T., Shivraj, G. W. and Vinay, V. W. (2011). Potentiometric Studies of Elec-Trolyte Effects on Complex Equilibria of Some Substituted 5-(2-hydroxy Phenyl) Pyrazoles. Der pharm. 3 (6): 75-83.

Sayyed, H. and Abdul Rahim, M. F. (2012). Studies of Binary Complexes of Metal Ions with Mandelic Acid by Potentiometry. Chem. J. 02 (6): 206209.

Shirvani, M. Moradian, E. Khalili, B. Bakhtiary, S. (2015). Interaction of $\mathrm{Cd}$ and $\mathrm{Pb}$ with Humate-Palygorskite and HumateSepiolite Complexes. Journal of water, air and pollution 3: 220-228. 


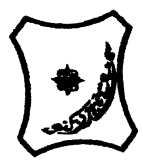

Bayero Journal of Pure and Applied Sciences, 14(1): 54 - 63

Received: November, 2020

Accepted: April, 2021

ISSN $2006-6996$

\title{
STABILITY CONSTANTS OF COMPLEXES OF METAL IONS WITH PEATSOIL HUMIC ACIDS UNDER NON-ACID-CONDITIONS
}

\author{
${ }^{* 1}$ Sabo, Yusuf ${ }^{2}$ Jimoh, W.L.O., ${ }^{3}$ Isa Baba Koki and ${ }^{4}$ Sholadoye, Q. 0. \\ ${ }^{1}$ Department of Pure and Industrial Chemistry, Bayero University, Kano \\ ${ }^{3}$ Department of Chemistry, Yusuf Maitama Sule University Kano. P.M.B. 3220 Kano, Nigeria. \\ ${ }^{4}$ Department of Chemistry, Nigerian Police Academy, Wudil, Kano-Nigeria
}

*Correspondence E-mail; saboyusuf18@yahoo.com

ABSTRACT

Stability constants of complexes of four divalent metal ions viz. $\mathrm{Cu}^{2+}, \mathrm{Pb}^{2+}, \mathrm{Mg}^{2+}$ and $\mathrm{Cd}^{2+}$ with humic acids (HA) were determined by potentiometric titration of humic acids with the corresponding salt of the divalent metals in aqueous media under non-acid-condition. The log $K$ (logarithm of the stability constant) ranged from 1.0942 to 2.7471 for metalhumic acid complexes were determined using point-wise computational method. The order of stability constants were obtained as follows: $\mathrm{Cu}>\mathrm{Pb}>\mathrm{Cd}>\mathrm{Mg}$ for metal $-\mathrm{HA}$ complexes respectively, indicating a higher degree of complexation with Cu metal ion.

Keywords: stability constant, humic acid, potentiometric titration, divalent metals, acid hydrolysis.

\section{NTRODUCTION}

The stability constant of a complex is the numerical expression of its stability and provides a quantitative measure of affinity of the metal ion to the complexing agent. An understanding of the relative stability of metal-complexes helps in predicting the behavior of metal ions in the soil (Ram and Raman, 1982). Extensive researches has been done to determine the stability constants of the complexes formed between humic acid (HA) with a number of metal ions. Ashok et al., (2000) reported that humic acid with hydroxyl, phenoxyl and carboxyl reactive groups can form coordination compound with metal ions at $\mathrm{pH}$ 3.5. The stability constants(Log K) for different metalhumic acid complexes indicated the following order of the stabilities of complexes formed between humic acid and metal ion, $\mathrm{Cu}>\mathrm{Fe}$ $>\mathrm{Pb}>\mathrm{Ni}>\mathrm{Co}>\mathrm{Ca}>\mathrm{Cd}>\mathrm{Zn}>\mathrm{Mn}>\mathrm{Mg}$. Andelkovic et al., (2010) investigated the binding of $\mathrm{Cd}$ (II) to soil humic acid at pH 6.5 and in $0.1 \mathrm{M} \mathrm{KNO}_{3}$ ionic medium. The stability constant for binding indicating greater stability in the case when carboxyl groups are involved in complexation reaction. Kostic et al.,(2012) investigated the complexation of humic acid with certain heavy metal ions (Co(II), $\mathrm{Ni}(\mathrm{II}), \mathrm{Cu}(\mathrm{II})$,
$\mathrm{Zn}(\mathrm{II})$, and $\mathrm{Pb}(\mathrm{II})$. The experiment was performed at $25^{\circ} \mathrm{C}$, at pH 4.0 and ionic strength of $0.01 \mathrm{M}$. Stability constant of complex between $\mathrm{Pb}$ (II) ions and humic acid is greater than stability constants of other investigated metalhumate complexes. Bogata and Sokolowska (2016) analyses the interaction between humic acids from different soils and $\mathrm{Zn}$ (II) ions at wide concentration ranges and at $\mathrm{pH} 5$. Studies have showed significant impact of $\mathrm{Zn}$ concentration, $\mathrm{pH}$ and some properties of humic acids with zinc.But all of these studies were limited to acidic $\mathrm{pH}$ range. Therefore, the present study was carried out to determine and compare the stability constants of complexes of metal ions with hydrolysed peat soil humic acid and unhydrolysed peat soil humic under non-acid conditions.

\section{MATERIALS AND METHODS}

Analytical grade chemicals used includes hydrochloric acid $(\mathrm{HCl})$, nitric acid $\left(\mathrm{HNO}_{3}\right)$, sodium hydroxide $(\mathrm{NaOH})$, lead nitrate $\mathrm{Pb}\left(\mathrm{NO}_{3}\right)_{2}$, copper nitrate $\mathrm{Cu}\left(\mathrm{NO}_{3}\right)_{2} \cdot 3 \mathrm{H}_{2} \mathrm{O}$, cadmium nitrate $\mathrm{Cd}\left(\mathrm{NO}_{3}\right)_{2} \cdot 4 \mathrm{H}_{2} \mathrm{O}$, magnesium nitrate $\mathrm{Mg}\left(\mathrm{NO}_{3}\right)_{2} \cdot 6 \mathrm{H}_{2} \mathrm{O}$, potassium nitrate $\left(\mathrm{KNO}_{3}\right)$, calcium chloride $\left(\mathrm{CaCl}_{2}\right)$, (sigma-Aldrich). Dowex 50WX8, (20-50 mesh) from Fluka. 


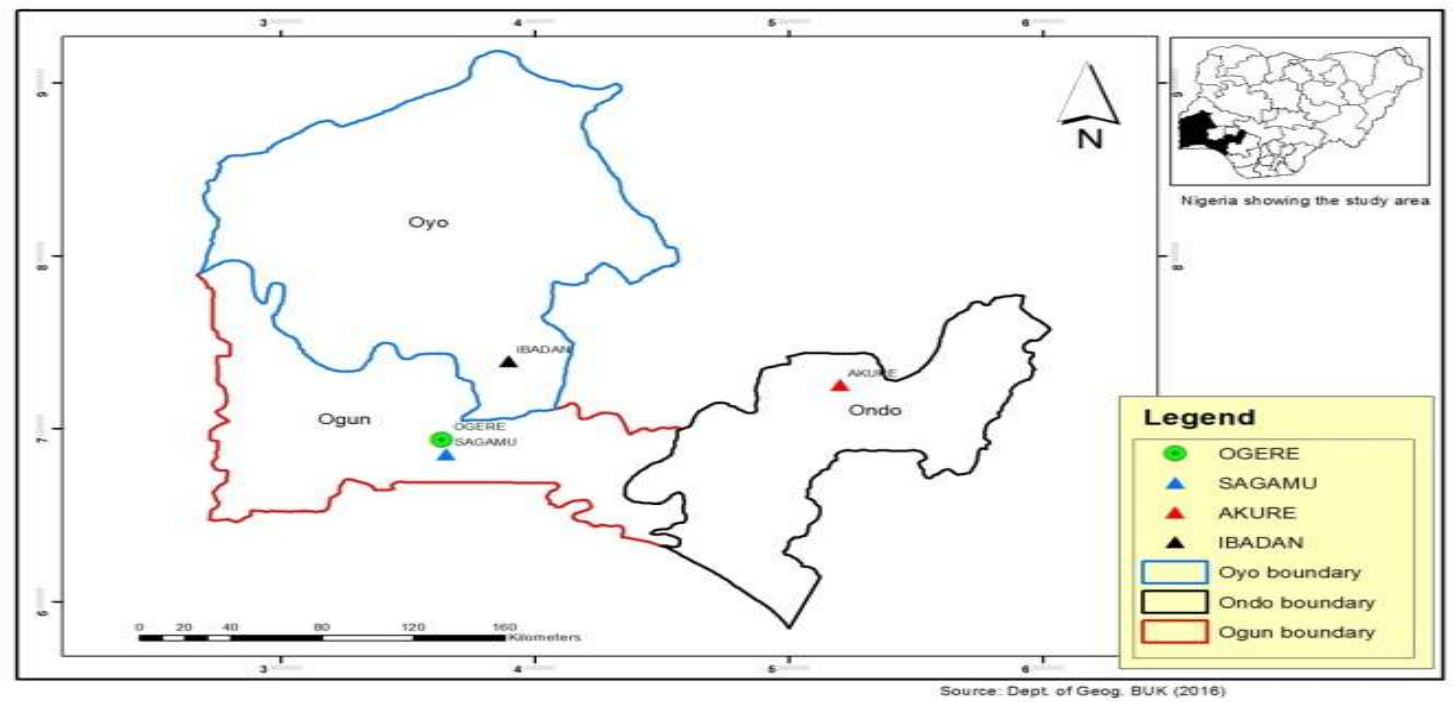

Figure 1: Map showing the sampling point at Sagamu Town, Ogun State.

\section{Description of Sampling Area}

Sagamu has geographical coordinates between $6^{\circ} 50^{\prime}$ north; $3^{\circ} 38^{\prime}$ east is located in south western region of Nigeria. The region has tropical wet and dry climate with a lengthy wet season and relatively constant temperatures throughout the course of the year. Wet season runs from March to October, November to December forms the region dry season. The vegetation type of the region is savannah which is really grassland with small bushes and occasional big trees. Grassland soils have substantially higher organic matter content than forest soils (Novackova, 2011).

\section{Sample Collection}

The Peatsoil samples were collected from four different sampling points $(0-10 \mathrm{~cm}$ depth) in Sagamu into polyethylene bag with plastic spoons. Samples were taken to the laboratory, extraneous materials were removed; the samples were air-dried, crushed and ground to a fine powder in a mortar passed through a $0.20 \mathrm{~mm}$ sieve. The samples were kept for analysis.

\section{Isolation and purification of humic acid from peat soil sample}

Peatsoil sample $(100 \mathrm{~g})$ was mixed with 1000 $\mathrm{cm}^{3}$ of $0.1 \mathrm{M} \mathrm{NaOH}$ solution, shaken for 3hours and left to stand overnight. Dark-coloured supernatant was obtained and decanted from solid residue. The dark-coloured supernatant was acidified to $(\mathrm{pH}=1.0)$ with $6 \mathrm{M} \mathrm{HCl}$ stirred and allowed to stand for 6 hours. Yellowish brown supernatant and dark-brown precipitate were obtained. The yellowish brown supernatant was decanted followed by centrifuge and discarded. The dark-brown precipitate was mixed with $500 \mathrm{~cm}^{3}$ of $0.1 \mathrm{M} \mathrm{NaOH}$ solution followed by passing through dowex resin. The dark-brown solution was acidified to $(\mathrm{pH}=1.0)$ with $6 \mathrm{M} \mathrm{HCl}$ stirred and allowed to stand for 3 hours. The dark-brown precipitate was washed several times with deionized water. The supernatant was treated with $\mathrm{AgNO}_{3}$ solution until no white precipitate observed. The humic acid was transferred to weighed crucible and dried at $60^{\circ} \mathrm{C}$ in an oven for 12 hours. The humic acid was cooled and dried in the desiccator, weighed and recorded. The obtained humic acid was dried again at $60^{\circ} \mathrm{C}$ for additional 6 hours cooled and dried in the desiccator, weighed and recorded constant weight was obtained (Baruah et al., 2015).

\section{FT-IR analysis}

FT-IR spectra of humic acid sample was analysed using Carry 630 FT-IR Agilent Technologies.

Unhydrolysed compost humic acid

The unhydrolysed humic acid was obtained after isolation and purification of compost humic acid and kept for investigation.

\section{Acid hydrolysis of Peatsoil acid}

Peatsoil humic acid sample (1g) was refluxed for 12 hours at $\left(160^{\circ} \mathrm{C}\right)$ with $50 \mathrm{~cm}^{3}$ of $6 \mathrm{M} \mathrm{HCl}$. The mixture was allowed to cool, decanted, and centrifuged after hydrolysis. The insoluble residues were washed with distilled water via centrifugation several times, and the supernatant was treated with $\mathrm{AgNO}_{3}$ solution until no white precipitate was observed. The residue was thoroughly dried over $\mathrm{CaCl}_{2}$ in a desiccator at room temperature (Chefetz et al., 2002). Finally, the obtained hydrolysed humic acid was kept for investigation. 
BAJOPAS Volume 14 Number 1,June, 2021 Potentiometric Titrations

Potentiometric measurements were carried out using a pH-meter Jenway (model 3510) with combine electrode, the sensitivity of the $\mathrm{pH}$ meter is 0.01 units. The $\mathrm{pH}$ meter was switched on half an hour before starting the titration for initial warm up of the instrument. The instrument was calibrated with an aqueous standard buffer solution of $\mathrm{pH} 4.00$ and 10.0 (borate buffer) prepared from a "Qualigens" buffer tablets.

The following sets of solutions were prepared in a $250 \mathrm{~cm}^{3}$ volumetric flask separately for $\mathrm{pH}$ metric titrations.

(i) $5 \mathrm{~cm}^{3} 0.1 \mathrm{M} \mathrm{HCl}+40 \mathrm{~cm}^{3}$ deionized water

(ii) $5 \mathrm{~cm}^{3} 0.1 \mathrm{M} \mathrm{HCl}+39 \mathrm{~cm}^{3}$ deionized water $+1 \mathrm{~cm}^{3} 0.15 \mathrm{gcm}^{-3}$ humic acid

(iii) $5 \mathrm{~cm}^{3} 0.1 \mathrm{M} \mathrm{HCl}+37 \mathrm{~cm}^{3}$ deionized water $+1 \mathrm{~cm}^{3} 0.15 \mathrm{gcm}^{-3}$ humic acid

$$
+2 \mathrm{~cm}^{3} \quad 0.01 \mathrm{M} \mathrm{Cu} \text { (II) }
$$

The solutions were titrated against standardized $0.110 \mathrm{MNaOH}$ separately. The total volume of each mixture was adjusted to $50 \mathrm{~cm}^{3}$ and the ionic strength of the solutions was maintained constant at by adding appropriate amount of stock solution of $1 \mathrm{M} \mathrm{KNO}_{3}$ (Gamal, 2015; Omar and Ali, 2015). A magnetic stirrer was used to achieve thorough mixing of the interacting solutions at $550 \mathrm{rpm}$. The same set of experimental conditions was applied for potentiometric titration of remaining samples.

\section{Evaluation of pKa of Hydrolysed peat soil Humic Acids}

The proton-ligand formation number $\mathrm{n}_{\mathbf{A}}$ were calculated by Irving and Rossotti expression (Omar and Ali, 2015).

$\mathrm{nA}=\mathrm{Y}-\frac{(\mathrm{V} 2-\mathrm{V1})(\mathrm{No}-\mathrm{Eo})}{(\mathrm{VO}+\mathrm{V1}) \mathrm{TCL}}$ 1

Where: $Y$ is number of dissociable proton, $\left(\mathrm{V}_{2^{-}}\right.$ $V_{1}$ ) is the measure of displacement of the ligand curve relative to acid curve, $\mathrm{N}^{\circ}$ and $\mathrm{E}^{\circ}$ are the resultant concentration of alkali solution, free acid solution, $\mathrm{T}_{\mathrm{cL}}{ }^{\circ}$ is the total ligand concentration, $\mathrm{V}^{\circ}$ is the total volume of titration solution, $V_{1}$ is the volume of alkali added to acid solution, $V_{2}$ is the volume of alkali added to acid solution + ligand solution, acid dissociation constants (pKa - values) of ligand were calculated by algebraic method point wise calculation (Tables 1 ). The dissociation constants (pKa) were calculated according to the following relation:

$\mathrm{pKa}=\mathrm{pH}+\log \left(\frac{n A}{1-n A}\right)$ 2

Where: pKa is the acid dissociation constant, $\mathrm{n}_{\mathrm{A}}$ is the Proton-ligand formation number and $\mathrm{pH}$ is the pH-values (Omar and Ali, 2015).

\section{Determination of metal-ligand stability constants $(\log K)$ of complexes}

The potentiometric measurement for the determination of stability constant of a complex in solution is based on the fact that the redox potential of the couple $\frac{M^{+(m-n)}}{M^{+m}}$ is shifted significantly on complexation of the metal ion with the ligand. This method involves change in hydrogen ion concentration $\left[\mathrm{H}^{+}\right]$due to the displacement or association of one or more protons taking place during complexation reaction. This change can be found out by titrating the solutions containing free acid, acid with ligand, and acid with ligand and metal ion, individually against a standard alkali solution at a constant ionic strength or temperature. Either ionic strength or temperature may be varied for different sets of solutions. In all the cases, the change in the $\mathrm{pH}$ of the solution is measured after each addition of a known amount of alkali to the reaction cell which contains the reaction mixture. The titration curves are then drawn by plotting the measured $\mathrm{pH}$ values against the corresponding volume of alkali added and the stability constants of the complexes are determined from the titration curves by employing $\mathrm{pH}$-metric titration technique given by (Irving and Rossoti).

Metal-ligand stability constants ( $\log \mathrm{K}$ ) were determined by using the following relations:

$$
\bar{n}=\frac{\left(V_{3}-V_{2}\right)\left(E^{0}+N^{0}\right)}{\left(V^{0}+V_{2}\right) \bar{n}_{A} T_{m}^{0}}
$$

and

$$
P L=\log _{10}\left\{\frac{1+\beta_{n}^{H} \frac{1}{[\text { anti } \log \mathrm{pH}]^{\mathrm{n}}}}{\mathrm{T}_{\mathrm{L}}^{0}-n \bar{T}_{m}^{0}} \mathrm{X} \frac{\left(V^{0}+V_{3}\right)}{V^{0}}\right\}
$$


BAJOPAS Volume 14 Number 1,June, 2021

Where $T_{L}, T^{\circ}, E^{\circ}$, and $V^{\circ}$ havethe same significance as in equation (1) above, $T_{m}$ denotes the total concentration of metal present in solution, $V_{3}$ is the volume of metal ions present in solution and $\beta^{H}$ is the overall proton ligand stability constant. The metal-ligand stability constants (log K) were determined by employing point wise computational Method (eq. 5 and 6).

$\operatorname{LogK}_{1}=\log \left(\frac{n}{1-n}\right)+\mathrm{pL}$ .5

$\operatorname{LogK}_{2}=\log \left(\frac{1-n}{2-n}\right)+\mathrm{pL}$ ...6

Where: Log $\mathrm{K}$ is the metal-ligand stability constant, $\mathrm{pL}$ is the Free ligand exponent function, $\mathbf{n}$ is the Average number of ligand attached with metal ion (Janraoet al., 2014). The results obtained were analyzed by an ORIGIN 2016 program using titration data and then the proton-ligand stability constants (pKa) and Metal-ligand stability constant (LogK) calculated (Omar and Ali, 2015).

\section{RESULTS AND DISCUSSION}

Fourier transformed infrared (FT-IR) spectra of isolated humic acid from peat soils Figure 2 had distinct clear absorption bands indicating the presence of major humic acid structural elemental groups such as $\mathrm{H}$ bonded $\mathrm{OH}$ $\left(3680 \mathrm{~cm}^{-1}\right.$ peak $), C=0$ of carbonyl $\left(1721 \mathrm{~cm}^{-1}\right.$ peak), functional groups of aliphatic components $\mathrm{CH}_{2}\left(2918 \mathrm{~cm}^{-1}\right.$ peak) and $\mathrm{C}-\mathrm{O}$ stretching of polysaccharide $\left(1168 \mathrm{~cm}^{-1}\right.$ peak). The positions of the absorption bands of the spectra fell within typical major absorption bands of humic acid which is at frequencies 3680, 2918, 1721, 1168 $\mathrm{cm}^{-1}$. The first peak centred in the vicinity of $3680 \mathrm{~cm}^{-1}$ region is attributed to phenol $\mathrm{OH}$ group bounded by intermolecular $\mathrm{H}$ bonds. The $2918 \mathrm{~cm}^{-1}$ band usually has absorption maximum at $2918 \mathrm{~cm}^{-1}$ which is due to $\mathrm{C}-\mathrm{H}$ stretching of alkane group $\left(\mathrm{CH}_{2}\right)$. The next major absorption band is $1721 \mathrm{~cm}^{-1}$. This band has been commonly ascribed to $\mathrm{C}=\mathrm{O}$ stretching of mainly carboxyl group $(\mathrm{COOH})$ with trace amount of ketones. The last peak was observed at 1168 $\mathrm{cm}^{-1}$ due to $\mathrm{C}-\mathrm{O}$ stretching of polysaccharides and this peak appeared also in the spectra of humic acid from peat soil. The FTIR spectra of the isolated humic acid contained all major characteristic absorption peaks of humic acid. These absorption peaks indicated the presence of the major structural elements of humic acid namely $\mathrm{H}$ bonded $\mathrm{OH}, \mathrm{C}=\mathrm{C}$ of aromatic ring, $\mathrm{C}=\mathrm{O}$ of carbonyl group (both carboxyl and ketonic), $\mathrm{CH}_{2}$ group. This strongly supports the presence of humic acid.

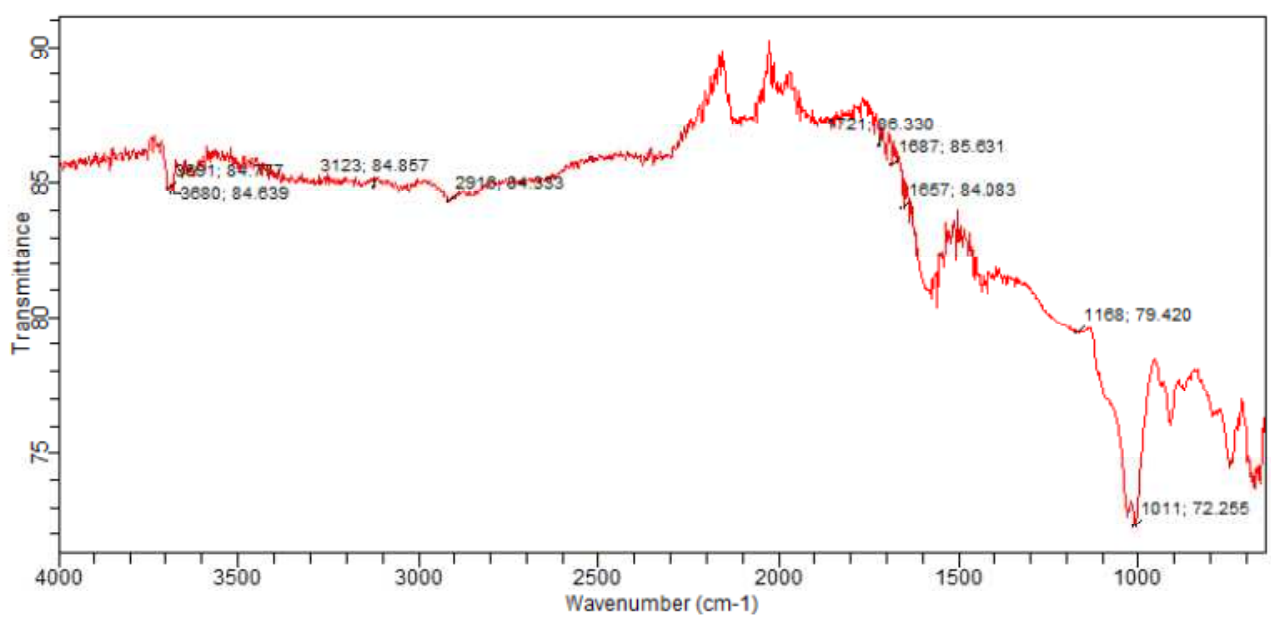

Fig. 2 : FT-IR spectraof peatsoilhumic acid (PSHA)

\section{Evaluation of acid dissociation constant (pka) of acid hydrolysed peat soil humicacid at phenolic group}

The value of the dissociation constant of the peat soil humic acid (PSHA) that underwent acidhydrolysis studied was found to be 8.9299 as shown Table 1, which is lower than the literaturevalues reported by Almeida and Szpoganics, (2015), Borges et al., (2005); Badr et al., (2012)and Fernandes et al,.(2009) of $9.73,9.47$ and 10.30. The difference between the obtained valuesand the reported values in this study might be probably as a result of acid hydrolysis of humicacid. 
BAJOPAS Volume 14 Number 1,June, 2021

Table 1: PKa of (Hydrolysed PSHA)

\begin{tabular}{|l|l|l|l|l|l|l|}
\hline $\mathrm{pH}$ & $\mathrm{BV}_{1}$ & $\mathrm{BV}_{2}$ & $\mathrm{~V}_{2}-\mathrm{V}_{1}$ & $\mathrm{nA}$ & $\log \left(\frac{n A}{1-n A}\right)$ & $\mathrm{pKa}$ \\
\hline 8.50 & 5.30 & 6.29 & 0.99 & 0.3594 & -0.2510 & 8.2490 \\
8.72 & 5.35 & 6.37 & 1.02 & 0.3400 & -0.2880 & 8.4320 \\
9.00 & 5.40 & 6.46 & 1.06 & 0.3141 & -0.3391 & 8.6609 \\
9.22 & 5.45 & 6.55 & 1.10 & 0.2882 & -0.3927 & 8.8273 \\
9.51 & 5.50 & 6.66 & 1.16 & 0.2494 & -0.4786 & 9.0314 \\
9.73 & 5.55 & 6.78 & 1.23 & 0.2041 & -0.5910 & 9.1390 \\
10.00 & 5.60 & 6.90 & 1.30 & 0.1589 & -0.7238 & 9.2762 \\
10.23 & 5.65 & 7.05 & 1.40 & 0.0941 & -0.9835 & 9.2465 \\
10.49 & 5.70 & 7.10 & 1.40 & 0.0941 & -0.9835 & 9.5065 \\
\hline
\end{tabular}

Average pKa $=8.9299 \pm 0.4186$

Table 2: PKa of (Unhydrolysed PSHA)

\begin{tabular}{|l|l|l|l|l|l|l|}
\hline $\mathrm{pH}$ & $\mathrm{BV}_{1}$ & $\mathrm{BV}_{2}$ & $\mathrm{~V}_{2}-\mathrm{V}_{1}$ & $\mathrm{nA}$ & $\log \left(\frac{\boldsymbol{n A}}{1-\boldsymbol{n}}\right)$ & $\mathrm{pKa}$ \\
\hline 8.50 & 5.30 & 5.81 & 0.51 & 0.6619 & 0.2919 & 8.7919 \\
8.72 & 5.35 & 5.90 & 0.55 & 0.6357 & 0.2418 & 8.9618 \\
9.00 & 5.40 & 6.00 & 0.60 & 0.6029 & 0.1813 & 9.1813 \\
9.22 & 5.45 & 6.10 & 0.65 & 0.5701 & 0.1226 & 9.3426 \\
9.51 & 5.50 & 6.20 & 0.70 & 0.5376 & 0.0654 & 9.5754 \\
9.73 & 5.55 & 6.33 & 0.78 & 0.4851 & -0.0259 & 9.7041 \\
10.00 & 5.60 & 6.47 & 0.87 & 0.4262 & -0.1291 & 9.8709 \\
10.23 & 5.65 & 6.62 & 0.99 & 0.3609 & -0.2481 & 9.9819 \\
10.49 & 5.70 & 6.80 & 1.10 & 0.2759 & -0.4690 & 10.0210 \\
\hline
\end{tabular}

Average pKa $=9.4923 \pm 0.4410$

Metal-ligand stability constant ( $\log \mathrm{K}$ )

The stabilityconstants require the accurate values of proton-ligand stability constants (Anil and Maroti, 2008). Metal titration curves crossed over ligand titration curve indicated the formation of complex upon proton release (Santosh, et al., 2011). If the values of n- are within range $0.2-0.8$ and $1.2-18$ this indicates the formation of $1: 1$ and 1:2 complexes (Sayyed and Mazahar, 2012).

The metal (II)-humate stepwise stability constants (log k) at phenolic group (Tables 318)

Table 3: Point-wise method, $\mathrm{Cu}$-(Hydrolysed PSHA)

\begin{tabular}{|l|l|l|l|l|l|l|l|l|}
\hline $\mathrm{pH}$ & $\mathrm{BV}_{1}$ & $\mathrm{BV}_{2}$ & $\mathrm{BV}_{3}$ & $\left(\mathrm{~V}_{3}-\mathrm{V}_{2}\right)$ & $\mathrm{n}$ & $\mathrm{pL}$ & $\log \left(\frac{n}{1-n}\right)$ & LogK $_{1}$ \\
\hline 8.50 & 5.30 & 6.29 & 6.33 & 0.04 & 0.5500 & 2.66 & 0.0871 & 2.7471 \\
8.72 & 5.35 & 6.37 & 6.41 & 0.04 & 0.5714 & 2.43 & 0.1249 & 2.5549 \\
9.00 & 5.40 & 6.46 & 6.50 & 0.04 & 0.6198 & 2.16 & 0.2122 & 2.3722 \\
9.22 & 5.45 & 6.55 & 6.59 & 0.04 & 0.6667 & 1.94 & 0.3010 & 2.2410 \\
\hline
\end{tabular}

LogK $_{1}$ (Average value) $=2.4788 \pm 0.2203$

Table 4: Point-wise method, $\mathrm{Cu}$-(Hydrolysed PSHA)

\begin{tabular}{|l|l|l|l|l|l|l|l|l|}
\hline $\mathrm{pH}$ & $\mathrm{BV}_{1}$ & $\mathrm{BV}_{2}$ & $\mathrm{BV}_{3}$ & $\left(\mathrm{~V}_{3}-\mathrm{V}_{2}\right)$ & $\mathrm{n}$ & $\mathrm{pL}$ & $\log \left(\frac{n-1}{2-n}\right)$ & LogK $_{2}$ \\
\hline 9.51 & 5.50 & 6.66 & 6.73 & 0.07 & 1.3509 & 1.70 & -0.2671 & 1.4329 \\
9.73 & 5.55 & 6.78 & 6.85 & 0.07 & 1.6383 & 1.51 & 0.2467 & 1.7567 \\
10.00 & 5.60 & 6.90 & 6.98 & 0.08 & 2.1783 & 1.31 & -0.2158 & 1.0942 \\
10.23 & 5.65 & 7.05 & 7.13 & 0.08 & 4.1904 & 1.27 & & \\
10.49 & 5.70 & 7.10 & 7.19 & 0.09 & 4.6920 & & & \\
\hline
\end{tabular}

Log $K_{2}($ Average value $)=1.4280 \pm 0.3312$ 
BAJOPAS Volume 14 Number 1,June, 2021

Table 5: Point-wise method, $\mathrm{Cu}$ (Unhydrolysed PSHA)

\begin{tabular}{|l|l|l|l|l|l|l|l|l|}
\hline $\mathrm{pH}$ & $\mathrm{BV}_{1}$ & $\mathrm{BV}_{2}$ & $\mathrm{BV}_{3}$ & $\left(\mathrm{~V}_{3}-\mathrm{V}_{2}\right)$ & $\mathrm{n}$ & $\mathrm{pL}$ & $\log \left(\frac{n}{n-1}\right)$ & Log $_{1}$ \\
\hline 8.50 & 5.30 & 5.81 & 5.85 & 0.04 & 0.2973 & 2.88 & -0.3736 & 2.5064 \\
8.72 & 5.35 & 5.90 & 5.95 & 0.05 & 0.3873 & 2.66 & -0.1992 & 2.4608 \\
9.00 & 5.40 & 6.00 & 6.05 & 0.05 & 0.4044 & 2.38 & -0.1681 & 2.2119 \\
9.22 & 5.45 & 6.10 & 6.15 & 0.06 & 0.5157 & 2.18 & -0.0272 & 2.2072 \\
9.51 & 5.50 & 6.20 & 6.27 & 0.07 & 0.6417 & 1.89 & 0.2530 & 1.1430 \\
\hline
\end{tabular}

$\operatorname{LogK}_{1}($ Average value $)=2.3059 \pm 0.6153$

Table 6:Point-wise method, $\mathrm{Cu}$ (Unhydrolysed PSHA)

\begin{tabular}{|l|l|l|l|l|l|l|l|l|}
\hline $\mathrm{pH}$ & $\mathrm{BV}_{1}$ & $\mathrm{BV}_{2}$ & $\mathrm{BV}_{3}$ & $\mathrm{~V}_{3}-\mathrm{V}_{2}$ & $\mathrm{n}$ & $\mathrm{pL}$ & $\log \left(\frac{n-1}{2-n}\right)$ & $\log \mathrm{K}_{2}$ \\
\hline 9.73 & 5.55 & 6.33 & 6.42 & 0.09 & 0.9000 & 1.69 & & \\
10.00 & 5.60 & 6.47 & 6.58 & 0.11 & 1.2578 & 1.44 & -0.4592 & 0.9808 \\
10.23 & 5.65 & 6.62 & 6.84 & 0.12 & 1.6137 & 1.26 & -0.2010 & 1.4610 \\
10.49 & 5.70 & 6.80 & 6.92 & 0.12 & 2.1052 & 1.03 & & \\
\hline
\end{tabular}

$\operatorname{LogK}_{2}$ (Average value) $=1.2209 \pm 0.3398$

Table 7:Point-wise method, Pb (Hydrolysed PSHA)

\begin{tabular}{|l|l|l|l|l|l|l|l|l|}
\hline $\mathrm{pH}$ & $\mathrm{BV}_{1}$ & $\mathrm{BV}_{2}$ & $\mathrm{BV}_{3}$ & $\left(\mathrm{~V}_{3}-\mathrm{V}_{2}\right)$ & $\mathrm{n}$ & $\mathrm{pL}$ & $\log \left(\frac{n}{1-n}\right)$ & LogK $_{1}$ \\
\hline 8.50 & 5.30 & 6.29 & 6.33 & 0.04 & 0.5500 & 2.66 & 0.0871 & 2.7471 \\
8.72 & 5.35 & 6.37 & 6.41 & 0.04 & 0.5714 & 2.43 & 0.1249 & 2.5549 \\
9.00 & 5.40 & 6.46 & 6.50 & 0.04 & 0.6198 & 2.16 & 0.2122 & 2.3722 \\
9.22 & 5.45 & 6.55 & 6.60 & 0.05 & 0.8333 & 1.96 & 0.6989 & 2.6589 \\
\hline
\end{tabular}

Log $_{\mathbf{1}}($ Average value $)=2.5832 \pm 0.1614$

Table 8:Point-wise method, Pb-(Hydrolysed PSHA)

\begin{tabular}{|l|l|l|l|l|l|l|l|l|}
\hline $\mathrm{pH}$ & $\mathrm{BV}_{1}$ & $\mathrm{BV}_{2}$ & $\mathrm{BV}_{3}$ & $\left(\mathrm{~V}_{3}-\mathrm{V}_{2}\right)$ & $\mathrm{n}$ & $\mathrm{pL}$ & $\log \left(\frac{n-1}{2-n}\right)$ & $\log \mathrm{K}_{2}$ \\
\hline 9.51 & 5.50 & 6.66 & 6.71 & 0.05 & 0.9650 & 1.67 & & \\
9.73 & 5.55 & 6.78 & 6.83 & 0.05 & 1.1702 & 1.44 & & \\
10.00 & 5.60 & 6.90 & 6.90 & 0.05 & 1.4864 & 1.22 & -0.0237 & 1.1963 \\
10.23 & 5.65 & 7.05 & 7.10 & 0.05 & 2.0190 & 1.09 & & \\
10.49 & 5.70 & 7.10 & 7.17 & 0.07 & 3.6492 & 1.00 & & \\
\hline
\end{tabular}

Log $K_{2}$ (Average value) $=1.1963$

Table 9: Point-wise method, Pb (Unhydrolysed PSHA)

\begin{tabular}{|l|l|l|l|l|l|l|l|l|}
\hline $\mathrm{pH}$ & $\mathrm{BV}_{1}$ & $\mathrm{BV}_{2}$ & $\mathrm{BV}_{3}$ & $\mathrm{~V}_{3}-\mathrm{V}_{2}$ & $\mathrm{n}$ & $\mathrm{pL}$ & $\begin{array}{l}\text { Log } \\
\left(\frac{n}{n-1}\right)\end{array}$ & Log $\mathrm{K}_{1}$ \\
\hline 8.50 & 5.30 & 5.81 & 5.85 & 0.04 & 0.2973 & 2.88 & -0.3736 & 2.5064 \\
8.72 & 5.35 & 5.90 & 5.94 & 0.04 & 0.3099 & 2.66 & -0.5477 & 2.3123 \\
9.00 & 5.40 & 6.00 & 6.05 & 0.05 & 0.4044 & 2.38 & -0.1681 & 2.2119 \\
9.22 & 5.45 & 6.10 & 6.15 & 0.06 & 0.5157 & 2.18 & 0.0272 & 2.2072 \\
9.51 & 5.50 & 6.20 & 6.26 & 0.07 & 0.6417 & 1.89 & 0.2530 & 2.1430 \\
9.73 & 5.55 & 6.40 & 6.40 & 0.07 & 0.7000 & 1.67 & 0.3680 & 2.0380 \\
\hline
\end{tabular}

LogK $_{1}$ (Average value) $=2.2364 \pm 0.1602$

Table 10: Point-wise method, Pb (Unhydrolysed PSHA)

\begin{tabular}{|l|l|l|l|l|l|l|l|l|}
\hline $\mathrm{pH}$ & $\mathrm{BV}_{1}$ & $\mathrm{BV}_{2}$ & $\mathrm{BV}_{3}$ & $\mathrm{~V}_{3}-\mathrm{V}_{2}$ & $\mathrm{n}$ & $\mathrm{pL}$ & $\log \left(\frac{n-1}{2-n}\right)$ & $\log \mathrm{K}_{2}$ \\
\hline 10.00 & 5.60 & 6.47 & 6.55 & 0.08 & 1.9503 & 1.41 & & \\
10.23 & 5.65 & 6.62 & 6.72 & 0.11 & 1.4792 & 1.26 & -0.0361 & 1.2239 \\
\hline
\end{tabular}

$\operatorname{LogK}_{2}$ (Average value) $=1.2239$

Table 11: Point-wise method, Mg (Hydrolysed PSHA)

\begin{tabular}{|l|l|l|l|l|l|l|l|l|}
\hline $\mathrm{pH}$ & $\mathrm{BV}_{1}$ & $\mathrm{BV}_{2}$ & $\mathrm{BV}_{3}$ & $\left(\mathrm{~V}_{3}-\mathrm{V}_{2}\right)$ & $\mathrm{n}$ & $\mathrm{pL}$ & $\log \left(\frac{n}{n-1}\right)$ & LogK $_{1}$ \\
\hline 8.50 & 5.30 & 6.29 & 6.31 & 0.02 & 0.2750 & 2.64 & -0.4290 & 2.2110 \\
8.72 & 5.35 & 6.37 & 6.39 & 0.02 & 0.2858 & 2.42 & -0.3978 & 2.0222 \\
9.00 & 5.40 & 6.46 & 6.49 & 0.03 & 0.4648 & 2.14 & -0.0612 & 2.0788 \\
9.22 & 5.45 & 6.55 & 6.59 & 0.04 & 0.6667 & 1.94 & 0.3010 & 2.2410 \\
\hline
\end{tabular}

$\log _{\mathbf{1}}($ Average value) $=2.1382 \pm 0.1046$ 
BAJOPAS Volume 14 Number 1,June, 2021

Table 12: Point-wise method, Mg (Hydrolysed PSHA)

\begin{tabular}{|l|l|l|l|l|l|l|l|l|}
\hline $\mathrm{pH}$ & $\mathrm{BV}_{1}$ & $\mathrm{BV}_{2}$ & $\mathrm{BV}_{3}$ & $\left(\mathrm{~V}_{3}-\mathrm{V}_{2}\right)$ & $\mathrm{n}$ & $\mathrm{pL}$ & $\log \left(\frac{n-1}{2-n}\right)$ & LogK $_{2}$ \\
\hline 9.51 & 5.55 & 6.66 & 6.71 & 0.05 & 0.9650 & 1.67 & & \\
9.73 & 5.55 & 6.78 & 6.84 & 0.06 & 1.4042 & 1.47 & -0.1686 & 1.3014 \\
10.00 & 5.60 & 6.90 & 6.93 & 0.06 & 1.7838 & 1.23 & 0.5593 & 1.7893 \\
10.23 & 5.65 & 7.05 & 7.10 & 0.06 & 3.1429 & 1.10 & & \\
10.49 & 5.70 & 7.10 & 7.18 & 0.07 & 3.6492 & 0.83 & & \\
\hline
\end{tabular}

LogK $_{2}($ Average value $)=1.5453 \pm 0.3450$

Table 13: Point-wise method, Mg (Unhydrolysed PSHA)

\begin{tabular}{|l|l|l|l|l|l|l|l|l|}
\hline $\mathrm{pH}$ & $\mathrm{BV}_{1}$ & $\mathrm{BV}_{2}$ & $\mathrm{BV}_{3}$ & $\mathrm{~V}_{3}-\mathrm{V}_{2}$ & $\mathrm{n}$ & $\mathrm{pL}$ & $\log \left(\frac{n}{n-1}\right)$ & $\operatorname{Log~}_{1}$ \\
\hline 8.50 & 5.30 & 5.81 & 5.85 & 0.04 & 0.2973 & 2.88 & -0.3736 & 2.5064 \\
8.72 & 5.35 & 5.90 & 5.94 & 0.04 & 0.3099 & 2.66 & -0.3477 & 2.3123 \\
9.00 & 5.40 & 6.00 & 6.04 & 0.04 & 0.3236 & 2.38 & -0.3202 & 2.0598 \\
9.22 & 5.45 & 6.10 & 6.15 & 0.05 & 0.4297 & 2.17 & -0.1230 & 2.0470 \\
9.51 & 5.50 & 6.20 & 6.26 & 0.06 & 0.5500 & 1.89 & 0.0871 & 1.9771 \\
9.73 & 5.55 & 6.33 & 6.40 & 0.07 & 0.7000 & 1.67 & 0.3680 & 2.0380 \\
\hline
\end{tabular}

LogK $_{1}$ (Average value) $=2.1568 \pm 0.2069$

Table 14: Point-wise method, Mg (Unhydrolysed PSHA)

\begin{tabular}{|l|l|l|l|l|l|l|l|l|}
\hline $\mathrm{pH}$ & $\mathrm{BV}_{1}$ & $\mathrm{BV}_{2}$ & $\mathrm{BV}_{3}$ & $\mathrm{~V}_{3}-\mathrm{V}_{2}$ & $\mathrm{n}$ & $\mathrm{pL}$ & $\log \left(\frac{n-1}{2-n}\right)$ & $\log \mathrm{K}_{2}$ \\
\hline 10.00 & 5.60 & 6.47 & 6.55 & 0.08 & 0.9148 & 1.41 & & \\
10.23 & 5.65 & 6.62 & 6.71 & 0.09 & 1.2102 & 1.20 & -0.5749 & 0.6251 \\
10.49 & 5.70 & 6.80 & 6.92 & 0.09 & 1.5968 & 1.03 & 0.1703 & 1.2003 \\
\hline
\end{tabular}

LogK $_{2}$ (Average value) $=0.9127 \pm 0.4070$

Table15:Point-wise method, Cd (Hydrolysed PSHA)

\begin{tabular}{|l|l|l|l|l|l|l|l|l|}
\hline $\mathrm{pH}$ & $\mathrm{BV}_{1}$ & $\mathrm{BV}_{2}$ & $\mathrm{BV}_{3}$ & $\left(\mathrm{~V}_{3}-\mathrm{V}_{2}\right)$ & $\mathrm{n}$ & $\mathrm{pL}$ & $\log \left(\frac{n}{1-n}\right)$ & LogK $_{1}$ \\
\hline 8.50 & 5.30 & 6.29 & 6.31 & 0.02 & 0.2750 & 2.64 & -0.4210 & 2.2190 \\
8.72 & 5.35 & 6.37 & 6.40 & 0.03 & 0.4286 & 2.42 & -0.1249 & 2.2951 \\
9.00 & 5.40 & 6.46 & 6.49 & 0.03 & 0.4648 & 2.14 & -0.0612 & 2.0788 \\
9.22 & 5.45 & 6.55 & 6.59 & 0.04 & 0.6667 & 1.96 & 0.3010 & 2.2610 \\
9.51 & 5.55 & 6.66 & 6.70 & 0.04 & 0.7720 & 1.67 & 0.5297 & 2.1997 \\
\hline
\end{tabular}

LogK $_{\mathbf{1}}$ (Average value) $=2.2108 \pm 0.0825$

Table 16: Point-wise method, Cd (Hydrolysed PSHA)

\begin{tabular}{|l|l|l|l|l|l|l|l|l|}
\hline $\mathrm{pH}$ & $\mathrm{BV}_{1}$ & $\mathrm{BV}_{2}$ & $\mathrm{BV}_{3}$ & $\left(\mathrm{~V}_{3}-\mathrm{V}_{2}\right)$ & $\mathrm{n}$ & $\mathrm{pL}$ & $\log \left(\frac{n-1}{2-n}\right)$ & Log $_{2}$ \\
\hline 9.73 & 5.55 & 6.78 & 6.83 & 0.06 & 1.4042 & 1.47 & -0.1686 & 1.3014 \\
10.00 & 5.60 & 6.90 & 6.95 & 0.06 & 1.7838 & 1.23 & 0.5593 & 1.7893 \\
10.23 & 5.65 & 7.05 & 7.10 & 0.06 & 3.1429 & 1.09 & & \\
10.49 & 5.70 & 7.10 & 7.16 & 0.06 & 3.1429 & 0.89 & & \\
& & & & & & & & \\
\hline
\end{tabular}

$\operatorname{LogK}_{2}$ (Average value) $=1.5453 \pm 0.3450$

Table 17: Point-wise method, Cd (Unhydrolysed PSHA)

\begin{tabular}{|l|l|l|l|l|l|l|l|l|}
\hline $\mathrm{pH}$ & $\mathrm{BV}_{1}$ & $\mathrm{BV}_{2}$ & $\mathrm{BV}_{3}$ & $\mathrm{~V}_{3}-\mathrm{V}_{2}$ & $\mathrm{n}$ & $\mathrm{pL}$ & $\log \left(\frac{n}{n-1}\right)$ & $\operatorname{Log~}_{1}$ \\
\hline 8.50 & 5.30 & 5.81 & 5.86 & 0.05 & 0.3717 & 2.88 & -0.2280 & 2.6520 \\
8.72 & 5.35 & 5.90 & 5.95 & 0.05 & 0.3873 & 2.66 & -0.1992 & 2.4608 \\
9.00 & 5.40 & 6.00 & 6.06 & 0.06 & 0.4853 & 2.38 & -0.0255 & 2.3545 \\
9.22 & 5.45 & 6.10 & 6.16 & 0.06 & 0.5157 & 2.18 & -0.0272 & 2.2072 \\
9.51 & 5.50 & 6.20 & 6.27 & 0.07 & 0.6417 & 1.89 & 0.2530 & 1.1430 \\
9.73 & 5.55 & 6.33 & 6.41 & 0.08 & 0.8000 & 1.69 & 0.6020 & 2.2920 \\
& & & & & & & & \\
\hline
\end{tabular}

$\operatorname{LogK}_{1}($ Average value $)=2.2516 \pm 0.5380$ 
BAJOPAS Volume 14 Number 1,June, 2021

Table 18: Point-wise method, Cd (Unhydrolysed PSHA)

\begin{tabular}{|l|l|l|l|l|l|l|l|l|}
\hline $\mathrm{pH}$ & $\mathrm{BV}_{1}$ & $\mathrm{BV}_{2}$ & $\mathrm{BV}_{3}$ & $\mathrm{~V}_{3}-\mathrm{V}_{2}$ & $\mathrm{n}$ & $\mathrm{pL}$ & $\log \left(\frac{n-1}{2-n}\right)$ & $\log \mathrm{K}_{2}$ \\
\hline 10.00 & 5.60 & 6.47 & 6.57 & 0.10 & 1.1434 & 1.43 & & \\
10.23 & 5.65 & 6.62 & 6.72 & 0.10 & 1.3448 & 1.23 & -0.2788 & 0.9512 \\
10.49 & 5.70 & 6.80 & 6.90 & 0.10 & 1.7742 & 1.03 & 0.5351 & 1.5651 \\
\hline
\end{tabular}

$\operatorname{LogK}_{2}($ Average value $)=1.2581 \pm 0.4340$

Table 19: Stepwise and overall Stability constants of thehydrolysed and unhydrolysed divalent metal (II) complexes

\begin{tabular}{|c|c|c|c|}
\hline Chelates & LogK $_{1}$ & $\log _{2}$ & Log $\beta$ \\
\hline [Cu (Hydrolysed PSHA-1) $\left.{ }_{2}\right]$ & 2.4788 & 1.4280 & 3.9068 \\
\hline$\left[\mathrm{Pb}(\text { Hydrolysed PSHA-1) })_{2}\right]$ & 2.5832 & 1.1963 & 3.7795 \\
\hline$\left[\mathrm{Cd}(\text { Hydrolysed PSHA-1 })_{2}\right]$ & 2.2108 & 1.5453 & 3.7561 \\
\hline$\left[\mathrm{Mg}(\text { Hydrolysed PSHA-1 })_{2}\right]$ & 2.1382 & 1.5453 & 3.6835 \\
\hline [Cu (Unhydrolysed PSHA-1) & 2.3059 & 1.2209 & 3.5268 \\
\hline$[\mathrm{Pb}$ (Unhydrolysed PSHA-1) 2$]$ & 2.2364 & 1.2239 & 3.4603 \\
\hline [Cd (Unhydrolysed PSHA-1) 2 ] & 2.2516 & 1.2581 & 3.5097 \\
\hline$[\mathrm{Mg}$ (Unydrolysed PSHA-1) & 2.1568 & 0.9127 & 3.0695 \\
\hline
\end{tabular}

The results obtained (Table19) shows the stepwise and overall stability constants to be not high indicating low stability of the complexes, because the solubility of most metal ions in the basic $\mathrm{pH}$ range is minimal due to metal hydroxide precipitation (Karimi, 2017). In general, the stepwise stability constants $\left(K_{1}\right.$ and $K_{2}$ ) follow the order $K_{1}>K_{2}$ for the copper, lead, magnesium and cadmium complexes respectively. The steady decrease of the values with increasing number of ligands is in agreement with the prediction made by researchers (Na'aliya, 2013). The decrease could be attributed to the fact that as the number of the ligands (Humate ions) that enters the coordination zone increases the aqua molecules available for replacement by the ligands become less. Thus, the metal ions become less electron loving with progressive intake of the ligand and this results in the decrease in the values of the constants (Na'aliya, 2013). Also the stability of the complexes is influenced by the size and number of the chelate rings(Mackay and Mackay,2002).All the complexes form rings in their structure as humate, a bidentate ligand, bond the metal ions in the ratio 1:2 (Boguta and Sokolowska, 2016) forming chelate rings. The values of the overall stability constants $(\log \beta)$ obtained for humate complexes are not high indicating low stability as the values are not high. LogK values for copper-humates (Table 3 to 6) obtained in this study are lower than those reported for the complexes of humic acids (Pandey et al., 2015; Dinu, 2013; Kaschl et al., 2010 and Gilbeto and Jorg, 2001). The values of LogK(Table 7 to 10 ) forlead-humates are lower than those reported for the lead in the literature (Dinu, 2013; Gilbeto and Jorg 2001). Log K values(Table 11 to 14 ) for magnesium-humates obtained in this study are close to those reported by (Pandey et al., 2015). Log K values of cadmium-humates (Table 15 to 18 ) obtained in this work near to the one reported by (Dinu, 2013 and Pandey et al., 2015).The difference between the reported values and the values obtained in this study might be probably as a result of acid hydrolysis of humic acid. The values of the overall stability constants $(\log \beta)$ of the copper humates complexes presented in Table 19 is high than that of other metal humate complexes, show relatively high stability of CuHA complexes, show the following order of stability: $\mathrm{Cu}>\mathrm{Pb}>\mathrm{Cd}>\mathrm{Mg}$; which are in close agreement to the findings of (Dinu, 2013 and Pandey et al., 2015).The high stability of Cuhumate chelate could be attributed to the existence of coordinate covalent bond between the complexing agents and the $\mathrm{Cu}^{2+}$ ions. Since, $\mathrm{Cu}^{2+}$ being a metal of the transitional series with $3 d^{9}$ electronic configurations can accept the electrons from the complexing agents. Similarly, the low stabilities of $\mathrm{Pb}, \mathrm{Cd}$ and $\mathrm{Mg}$ complexes could be explained by that $\mathrm{Pb}^{2+}$ with $6 s^{2}, \mathrm{Cd}^{2+}$ with $4 \mathrm{~d}^{10}$ and $\mathrm{Mg}^{2+}$ with $2 \mathrm{p}^{6}$ their electronic configuration has a completely filled $\mathrm{d}, \mathrm{p}$ and $\mathrm{s}$ orbitals. Moreover, the stabilities of metal ions with hydrolysed humic acid from peat soil were higher than those with unhydrolysed humic acid from peat soil; which is ascribed to the high content of acidity in hydrolysed humic acid than unhydrolysed humic acid. 
BAJOPAS Volume 14 Number 1,June, 2021 CONCLUSION

The values of logk for $\mathrm{Cu}(\mathrm{II})$ hydrolysed humic acid complex was higher followed by $\mathrm{Pb}$ (II), $\mathrm{Cd}(\mathrm{II})$ and $\mathrm{Mg}$ (II) hydrolysed humic acid complexes as compared with metal(II) unhydrolysed humic acid complexes. This indicates acid hydrolysis of humic acid can

\section{REFERENCES}

Almeida, V.R. and Szpoganicz, B. (2015). Humic Acid Potentiometric Response Patterns:Out- of Equilibrium Properties and Species Distribution Modelling. Chemical. Biol. Technol. Agric. 2: 17.

Anđelković, T., Nikolić, R., Bojić, A.,Anđelković, D., and Nikolic G.,(2010). Binding of Cadmium to Soil Humic Acid as A Function of Carboxyl Group Content. Macedonian Journal of Chemistry and Chemical Engineering.29(2): 215-224.

Anil, B. N. and Maroti, N. (2008). Studies on Influence of Die-Lectric Constants on Complex Equilibria between Substituted Py-Razalines and Lanthanide Metal Ions pH-Metrically. Amer.-Euras. scient. Res. 3(2): 212-216.

Ashok, K., Pandey, S. P. and Misra, V (2000). Stability Constants of Metal-Humic Acid Complexes and its Role in Environmental Detoxification. Journal of Ecotoxicology and Environmental Safety. 47(2):157-200.

Badr, M. H., El-Halafawi, M. H. and Abd El-al Zeid, E. R. (2012). Comparison Between the Effect of Ionic Strength on Acidity and Dissociation Constants of Humic Acids Extracted from Sewage Sludge and Nile Water Hyacinth Composts.Global Journal of Environmental Research 6 (1): 36-43.

Baruah, M.K., Borah, D., Saikia, P.P., Paul, S., Sharma, T. (2015). Evaluation of pKa Values of Soil Humic Acids and their Complexation Properties. International Journal of Plant \& Soil Science 6(4) : 218-228.

Boguta, P. Sokolowska, Z. (2016). Interactions of $\mathrm{Zn}$ (II) Ions with Humic Acids Isolated from Various Types of Soils. Effect of $\mathrm{pH}, \mathrm{Zn}$ Concentrations and Humic Acids Chemical Properties. Journal of Geochemical Explaration 168. 119-126.

Borges, F., Guimaraes, C., Lima, L.F.C., Pinto, I. and Reis, S.(2005). Potentiometric Studies on the Complexation of Copper(II) by Phenolic Acids as Discrete Ligand Models of enhance the complexation behavior of humic acid with metal (II) ions. However, the higher values of $\log \beta$ for $\mathrm{Cu}(\mathrm{II}), \mathrm{Pb}(\mathrm{II}), \mathrm{Cd}(\mathrm{II})$ and $\mathrm{Mg}(\mathrm{II})$ hydrolysed humic acid complexes indicates more stable stepwise complexes formed as compared with $\mathrm{Cu}(\mathrm{II}), \mathrm{Pb}$ (II), $\mathrm{Cd}$ (II) and $\mathrm{Mg}(\mathrm{II})$ unhydrolysed humic acid complexes.

Humic Substances Talanta 66 (2005) 670-673.

Chefetz, B., Salloum, M. J., Deshmulkin, A. P. and Hatcher, P. (2002). Structural Components of Humic Acids as Determined by Chemical Modifications and Carbon-13 NMR, Pyrolysis, and Thermochemolysis- Gas Chromatography/Mass Spectrometry. Soil Science Society of American Journal Abstract Division S-2- Soil Chemistry66. 1159-1171.

Dinu, M. I. (2013). Metals Complexation with Humic Acids in Surface Water of Different Environ. Sci. Technol. 31(1): 1-17.

Fernandes, A.N., Giacomelli, C., Giovanela, M. Vaz, D.V. Szpoganicz, B. and Maria M. D. (2009). Potentiometric Acidity Determination in Humic Substances Influenced by Different Analytical Procedures.J. Braz. Chem. Soc. 20 (9):14.

Gamal, A. H. (2015). Stability Constants of Rhenium (V) Metal Complexes with Selected Drugs. Pyrex Journal of Research in Environmental Studies. 2(2): 006-014.

Janrao, D. M., Pathan, J., Kayande, D.D., and Mulla, J.J. (2014). An Over View of Potentiometric Determination of Stability Constants of Metal Complexes. Sci. Revs. Chem. Commun.: 4(1), 2014, 11-24.

Karimi, H. (2017). Effect of pH and Initial Pb(II) Concentration on the Lead Removal Efficiency from Waste Water Using $\mathrm{Ca}(\mathrm{OH})_{2}$. International Journal of Water and Waste Water Treatment 3.2

Kaschl, A. Romheld, V. and Chen, Y. (2010). Binding of Cadmium, Copper and Zinc to Humic Substances Originating from Municipal Solid Waste Compost. Israel Journal of Chemistry Vol. 42(1): 89-98.

Kostic, I. S., Tatjana, P, A., Nikolic, R. S., Cvetkovic, T. P., Pavlovic, D. D., Aleksandar, L.J. and Bojic, A. (2012). Comparative Study of Binding Strengths of Heavy Metals with Humic Acid. J.serb. Chem. Soc. 76(9) pp 1-20. 
BAJOPAS Volume 14 Number 1,June, 2021

Na'aliya, J. (2013). Determination of Stepwise Stability Constants and Gibbs free Energy Change of Trisprolina to Complexes of some Divalent Transition Metal ions. Bayero Journal of Pure and Applied Sciences 6(2): 112-114.

Omar, A. A. and Ali, E. A. (2015). Potentiometric Studies on Complexes of $\mathrm{Cr}$ (III) and $\mathrm{Zr}$ (IV) with some Carboxylic Acids. International Journal of Advanced Chemistry, 3(1) 25-

37.

Pandey, A. K. Pandey, S. D. and Misr, V. (2015).Stability Constants of Metal- Humic Acid Complexes and Its Role in Environmental Detoxification. J. Ecotoxicology and Environmental Safety. 47(1):195-200.

Ram, N. and Raman, K.V. (1984). Stability Constants of Complexes of Metals with
Humicand Fuvic Acids under Non- acidConditions. Journal of Plant Nutrition and Soil Sciences.

147:171-176.

Santosh, D. D., Ashok, B. K., Vijay, J. T., Shivraj, G. W. and Vinay, V. W. (2011). Potentiometric Studies of Elec-Trolyte Effects on Complex Equilibria of Some Substituted 5-(2-hydroxy Phenyl) Pyrazoles. Der pharm. 3 (6): 75-83.

Sayyed, H. and Abdul Rahim, M. F. (2012). Studies of Binary Complexes of Metal Ions with Mandelic Acid by Potentiometry. Chem. J. 02 (6): 206209.

Shirvani, M. Moradian, E. Khalili, B. Bakhtiary, S. (2015). Interaction of $\mathrm{Cd}$ and $\mathrm{Pb}$ with Humate-Palygorskite and HumateSepiolite Complexes. Journal of water, air and pollution 3: 220-228. 


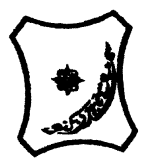

Bayero Journal of Pure and Applied Sciences, 14(1): 54 - 63

Received: November, 2020

Accepted: April, 2021

ISSN $2006-6996$

\title{
STABILITY CONSTANTS OF COMPLEXES OF METAL IONS WITH PEATSOIL HUMIC ACIDS UNDER NON-ACID-CONDITIONS
}

\author{
${ }^{* 1}$ Sabo, Yusuf ${ }^{2}$ Jimoh, W.L.O., ${ }^{3}$ Isa Baba Koki and ${ }^{4}$ Sholadoye, Q. 0. \\ ${ }^{1}$ Department of Pure and Industrial Chemistry, Bayero University, Kano \\ ${ }^{3}$ Department of Chemistry, Yusuf Maitama Sule University Kano. P.M.B. 3220 Kano, Nigeria. \\ ${ }^{4}$ Department of Chemistry, Nigerian Police Academy, Wudil, Kano-Nigeria
}

*Correspondence E-mail; saboyusuf18@yahoo.com

ABSTRACT

Stability constants of complexes of four divalent metal ions viz. $\mathrm{Cu}^{2+}, \mathrm{Pb}^{2+}, \mathrm{Mg}^{2+}$ and $\mathrm{Cd}^{2+}$ with humic acids (HA) were determined by potentiometric titration of humic acids with the corresponding salt of the divalent metals in aqueous media under non-acid-condition. The log $K$ (logarithm of the stability constant) ranged from 1.0942 to 2.7471 for metalhumic acid complexes were determined using point-wise computational method. The order of stability constants were obtained as follows: $\mathrm{Cu}>\mathrm{Pb}>\mathrm{Cd}>\mathrm{Mg}$ for metal $-\mathrm{HA}$ complexes respectively, indicating a higher degree of complexation with Cu metal ion.

Keywords: stability constant, humic acid, potentiometric titration, divalent metals, acid hydrolysis.

\section{NTRODUCTION}

The stability constant of a complex is the numerical expression of its stability and provides a quantitative measure of affinity of the metal ion to the complexing agent. An understanding of the relative stability of metal-complexes helps in predicting the behavior of metal ions in the soil (Ram and Raman, 1982). Extensive researches has been done to determine the stability constants of the complexes formed between humic acid (HA) with a number of metal ions. Ashok et al., (2000) reported that humic acid with hydroxyl, phenoxyl and carboxyl reactive groups can form coordination compound with metal ions at $\mathrm{pH}$ 3.5. The stability constants(Log K) for different metalhumic acid complexes indicated the following order of the stabilities of complexes formed between humic acid and metal ion, $\mathrm{Cu}>\mathrm{Fe}$ $>\mathrm{Pb}>\mathrm{Ni}>\mathrm{Co}>\mathrm{Ca}>\mathrm{Cd}>\mathrm{Zn}>\mathrm{Mn}>\mathrm{Mg}$. Andelkovic et al., (2010) investigated the binding of $\mathrm{Cd}$ (II) to soil humic acid at pH 6.5 and in $0.1 \mathrm{M} \mathrm{KNO}_{3}$ ionic medium. The stability constant for binding indicating greater stability in the case when carboxyl groups are involved in complexation reaction. Kostic et al.,(2012) investigated the complexation of humic acid with certain heavy metal ions (Co(II), $\mathrm{Ni}(\mathrm{II}), \mathrm{Cu}(\mathrm{II})$,
$\mathrm{Zn}(\mathrm{II})$, and $\mathrm{Pb}(\mathrm{II})$. The experiment was performed at $25^{\circ} \mathrm{C}$, at pH 4.0 and ionic strength of $0.01 \mathrm{M}$. Stability constant of complex between $\mathrm{Pb}$ (II) ions and humic acid is greater than stability constants of other investigated metalhumate complexes. Bogata and Sokolowska (2016) analyses the interaction between humic acids from different soils and $\mathrm{Zn}$ (II) ions at wide concentration ranges and at $\mathrm{pH} 5$. Studies have showed significant impact of $\mathrm{Zn}$ concentration, $\mathrm{pH}$ and some properties of humic acids with zinc.But all of these studies were limited to acidic $\mathrm{pH}$ range. Therefore, the present study was carried out to determine and compare the stability constants of complexes of metal ions with hydrolysed peat soil humic acid and unhydrolysed peat soil humic under non-acid conditions.

\section{MATERIALS AND METHODS}

Analytical grade chemicals used includes hydrochloric acid $(\mathrm{HCl})$, nitric acid $\left(\mathrm{HNO}_{3}\right)$, sodium hydroxide $(\mathrm{NaOH})$, lead nitrate $\mathrm{Pb}\left(\mathrm{NO}_{3}\right)_{2}$, copper nitrate $\mathrm{Cu}\left(\mathrm{NO}_{3}\right)_{2} \cdot 3 \mathrm{H}_{2} \mathrm{O}$, cadmium nitrate $\mathrm{Cd}\left(\mathrm{NO}_{3}\right)_{2} \cdot 4 \mathrm{H}_{2} \mathrm{O}$, magnesium nitrate $\mathrm{Mg}\left(\mathrm{NO}_{3}\right)_{2} \cdot 6 \mathrm{H}_{2} \mathrm{O}$, potassium nitrate $\left(\mathrm{KNO}_{3}\right)$, calcium chloride $\left(\mathrm{CaCl}_{2}\right)$, (sigma-Aldrich). Dowex 50WX8, (20-50 mesh) from Fluka. 


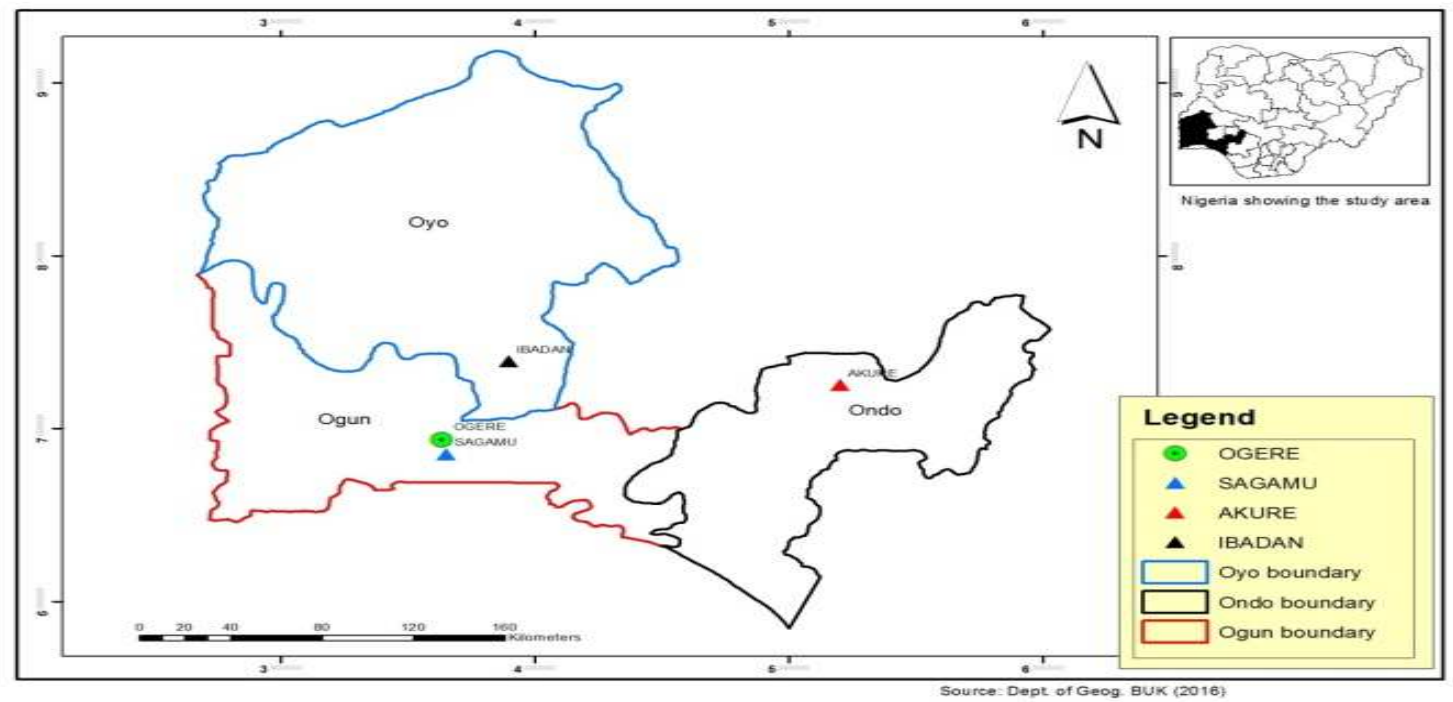

Figure 1: Map showing the sampling point at Sagamu Town, Ogun State.

\section{Description of Sampling Area}

Sagamu has geographical coordinates between $6^{\circ} 50^{\prime}$ north; $3^{\circ} 38^{\prime}$ east is located in south western region of Nigeria. The region has tropical wet and dry climate with a lengthy wet season and relatively constant temperatures throughout the course of the year. Wet season runs from March to October, November to December forms the region dry season. The vegetation type of the region is savannah which is really grassland with small bushes and occasional big trees. Grassland soils have substantially higher organic matter content than forest soils (Novackova, 2011).

\section{Sample Collection}

The Peatsoil samples were collected from four different sampling points $(0-10 \mathrm{~cm}$ depth) in Sagamu into polyethylene bag with plastic spoons. Samples were taken to the laboratory, extraneous materials were removed; the samples were air-dried, crushed and ground to a fine powder in a mortar passed through a $0.20 \mathrm{~mm}$ sieve. The samples were kept for analysis.

\section{Isolation and purification of humic acid from peat soil sample}

Peatsoil sample $(100 \mathrm{~g})$ was mixed with 1000 $\mathrm{cm}^{3}$ of $0.1 \mathrm{M} \mathrm{NaOH}$ solution, shaken for 3hours and left to stand overnight. Dark-coloured supernatant was obtained and decanted from solid residue. The dark-coloured supernatant was acidified to $(\mathrm{pH}=1.0)$ with $6 \mathrm{M} \mathrm{HCl}$ stirred and allowed to stand for 6 hours. Yellowish brown supernatant and dark-brown precipitate were obtained. The yellowish brown supernatant was decanted followed by centrifuge and discarded. The dark-brown precipitate was mixed with $500 \mathrm{~cm}^{3}$ of $0.1 \mathrm{M} \mathrm{NaOH}$ solution followed by passing through dowex resin. The dark-brown solution was acidified to $(\mathrm{pH}=1.0)$ with $6 \mathrm{M} \mathrm{HCl}$ stirred and allowed to stand for 3 hours. The dark-brown precipitate was washed several times with deionized water. The supernatant was treated with $\mathrm{AgNO}_{3}$ solution until no white precipitate observed. The humic acid was transferred to weighed crucible and dried at $60^{\circ} \mathrm{C}$ in an oven for 12 hours. The humic acid was cooled and dried in the desiccator, weighed and recorded. The obtained humic acid was dried again at $60^{\circ} \mathrm{C}$ for additional 6 hours cooled and dried in the desiccator, weighed and recorded constant weight was obtained (Baruah et al., 2015).

\section{FT-IR analysis}

FT-IR spectra of humic acid sample was analysed using Carry 630 FT-IR Agilent Technologies.

Unhydrolysed compost humic acid

The unhydrolysed humic acid was obtained after isolation and purification of compost humic acid and kept for investigation.

\section{Acid hydrolysis of Peatsoil acid}

Peatsoil humic acid sample (1g) was refluxed for 12 hours at $\left(160^{\circ} \mathrm{C}\right)$ with $50 \mathrm{~cm}^{3}$ of $6 \mathrm{M} \mathrm{HCl}$. The mixture was allowed to cool, decanted, and centrifuged after hydrolysis. The insoluble residues were washed with distilled water via centrifugation several times, and the supernatant was treated with $\mathrm{AgNO}_{3}$ solution until no white precipitate was observed. The residue was thoroughly dried over $\mathrm{CaCl}_{2}$ in a desiccator at room temperature (Chefetz et al., 2002). Finally, the obtained hydrolysed humic acid was kept for investigation. 
BAJOPAS Volume 14 Number 1,June, 2021 Potentiometric Titrations

Potentiometric measurements were carried out using a pH-meter Jenway (model 3510) with combine electrode, the sensitivity of the $\mathrm{pH}$ meter is 0.01 units. The $\mathrm{pH}$ meter was switched on half an hour before starting the titration for initial warm up of the instrument. The instrument was calibrated with an aqueous standard buffer solution of $\mathrm{pH} 4.00$ and 10.0 (borate buffer) prepared from a "Qualigens" buffer tablets.

The following sets of solutions were prepared in a $250 \mathrm{~cm}^{3}$ volumetric flask separately for $\mathrm{pH}$ metric titrations.

(i) $5 \mathrm{~cm}^{3} 0.1 \mathrm{M} \mathrm{HCl}+40 \mathrm{~cm}^{3}$ deionized water

(ii) $5 \mathrm{~cm}^{3} 0.1 \mathrm{M} \mathrm{HCl}+39 \mathrm{~cm}^{3}$ deionized water $+1 \mathrm{~cm}^{3} 0.15 \mathrm{gcm}^{-3}$ humic acid

(iii) $5 \mathrm{~cm}^{3} 0.1 \mathrm{M} \mathrm{HCl}+37 \mathrm{~cm}^{3}$ deionized water $+1 \mathrm{~cm}^{3} 0.15 \mathrm{gcm}^{-3}$ humic acid

$$
+2 \mathrm{~cm}^{3} \quad 0.01 \mathrm{M} \mathrm{Cu} \text { (II) }
$$

The solutions were titrated against standardized $0.110 \mathrm{MNaOH}$ separately. The total volume of each mixture was adjusted to $50 \mathrm{~cm}^{3}$ and the ionic strength of the solutions was maintained constant at by adding appropriate amount of stock solution of $1 \mathrm{M} \mathrm{KNO}_{3}$ (Gamal, 2015; Omar and Ali, 2015). A magnetic stirrer was used to achieve thorough mixing of the interacting solutions at $550 \mathrm{rpm}$. The same set of experimental conditions was applied for potentiometric titration of remaining samples.

\section{Evaluation of pKa of Hydrolysed peat soil Humic Acids}

The proton-ligand formation number $\mathrm{n}_{\mathbf{A}}$ were calculated by Irving and Rossotti expression (Omar and Ali, 2015).

$\mathrm{nA}=\mathrm{Y}-\frac{(\mathrm{V} 2-\mathrm{V1})(\mathrm{No}-\mathrm{Eo})}{(\mathrm{VO}+\mathrm{V1}) \mathrm{TCL}}$ 1

Where: $Y$ is number of dissociable proton, $\left(\mathrm{V}_{2^{-}}\right.$ $V_{1}$ ) is the measure of displacement of the ligand curve relative to acid curve, $\mathrm{N}^{\circ}$ and $\mathrm{E}^{\circ}$ are the resultant concentration of alkali solution, free acid solution, $\mathrm{T}_{\mathrm{cL}}{ }^{\circ}$ is the total ligand concentration, $\mathrm{V}^{\circ}$ is the total volume of titration solution, $V_{1}$ is the volume of alkali added to acid solution, $V_{2}$ is the volume of alkali added to acid solution + ligand solution, acid dissociation constants (pKa - values) of ligand were calculated by algebraic method point wise calculation (Tables 1 ). The dissociation constants (pKa) were calculated according to the following relation:

$\mathrm{pKa}=\mathrm{pH}+\log \left(\frac{n A}{1-n A}\right)$ 2

Where: pKa is the acid dissociation constant, $\mathrm{n}_{\mathrm{A}}$ is the Proton-ligand formation number and $\mathrm{pH}$ is the pH-values (Omar and Ali, 2015).

\section{Determination of metal-ligand stability constants $(\log K)$ of complexes}

The potentiometric measurement for the determination of stability constant of a complex in solution is based on the fact that the redox potential of the couple $\frac{M^{+(m-n)}}{M^{+m}}$ is shifted significantly on complexation of the metal ion with the ligand. This method involves change in hydrogen ion concentration $\left[\mathrm{H}^{+}\right]$due to the displacement or association of one or more protons taking place during complexation reaction. This change can be found out by titrating the solutions containing free acid, acid with ligand, and acid with ligand and metal ion, individually against a standard alkali solution at a constant ionic strength or temperature. Either ionic strength or temperature may be varied for different sets of solutions. In all the cases, the change in the $\mathrm{pH}$ of the solution is measured after each addition of a known amount of alkali to the reaction cell which contains the reaction mixture. The titration curves are then drawn by plotting the measured $\mathrm{pH}$ values against the corresponding volume of alkali added and the stability constants of the complexes are determined from the titration curves by employing $\mathrm{pH}$-metric titration technique given by (Irving and Rossoti).

Metal-ligand stability constants ( $\log \mathrm{K}$ ) were determined by using the following relations:

$$
\bar{n}=\frac{\left(V_{3}-V_{2}\right)\left(E^{0}+N^{0}\right)}{\left(V^{0}+V_{2}\right) \bar{n}_{A} T_{m}^{0}}
$$

and

$$
P L=\log _{10}\left\{\frac{1+\beta_{n}^{H} \frac{1}{[\text { anti } \log \mathrm{pH}]^{\mathrm{n}}}}{\mathrm{T}_{\mathrm{L}}^{0}-n \bar{T}_{m}^{0}} \mathrm{X} \frac{\left(V^{0}+V_{3}\right)}{V^{0}}\right\}
$$


BAJOPAS Volume 14 Number 1,June, 2021

Where $T_{L}, T^{\circ}, E^{\circ}$, and $V^{\circ}$ havethe same significance as in equation (1) above, $T_{m}$ denotes the total concentration of metal present in solution, $V_{3}$ is the volume of metal ions present in solution and $\beta^{H}$ is the overall proton ligand stability constant. The metal-ligand stability constants (log K) were determined by employing point wise computational Method (eq. 5 and 6).

$\operatorname{LogK}_{1}=\log \left(\frac{n}{1-n}\right)+\mathrm{pL}$ .5

$\operatorname{LogK}_{2}=\log \left(\frac{1-n}{2-n}\right)+\mathrm{pL}$ ...6

Where: Log $\mathrm{K}$ is the metal-ligand stability constant, $\mathrm{pL}$ is the Free ligand exponent function, $\mathbf{n}$ is the Average number of ligand attached with metal ion (Janraoet al., 2014). The results obtained were analyzed by an ORIGIN 2016 program using titration data and then the proton-ligand stability constants (pKa) and Metal-ligand stability constant (LogK) calculated (Omar and Ali, 2015).

\section{RESULTS AND DISCUSSION}

Fourier transformed infrared (FT-IR) spectra of isolated humic acid from peat soils Figure 2 had distinct clear absorption bands indicating the presence of major humic acid structural elemental groups such as $\mathrm{H}$ bonded $\mathrm{OH}$ $\left(3680 \mathrm{~cm}^{-1}\right.$ peak $), C=0$ of carbonyl $\left(1721 \mathrm{~cm}^{-1}\right.$ peak), functional groups of aliphatic components $\mathrm{CH}_{2}\left(2918 \mathrm{~cm}^{-1}\right.$ peak) and $\mathrm{C}-\mathrm{O}$ stretching of polysaccharide $\left(1168 \mathrm{~cm}^{-1}\right.$ peak). The positions of the absorption bands of the spectra fell within typical major absorption bands of humic acid which is at frequencies 3680, 2918, 1721, 1168 $\mathrm{cm}^{-1}$. The first peak centred in the vicinity of $3680 \mathrm{~cm}^{-1}$ region is attributed to phenol $\mathrm{OH}$ group bounded by intermolecular $\mathrm{H}$ bonds. The $2918 \mathrm{~cm}^{-1}$ band usually has absorption maximum at $2918 \mathrm{~cm}^{-1}$ which is due to $\mathrm{C}-\mathrm{H}$ stretching of alkane group $\left(\mathrm{CH}_{2}\right)$. The next major absorption band is $1721 \mathrm{~cm}^{-1}$. This band has been commonly ascribed to $\mathrm{C}=\mathrm{O}$ stretching of mainly carboxyl group $(\mathrm{COOH})$ with trace amount of ketones. The last peak was observed at 1168 $\mathrm{cm}^{-1}$ due to $\mathrm{C}-\mathrm{O}$ stretching of polysaccharides and this peak appeared also in the spectra of humic acid from peat soil. The FTIR spectra of the isolated humic acid contained all major characteristic absorption peaks of humic acid. These absorption peaks indicated the presence of the major structural elements of humic acid namely $\mathrm{H}$ bonded $\mathrm{OH}, \mathrm{C}=\mathrm{C}$ of aromatic ring, $\mathrm{C}=\mathrm{O}$ of carbonyl group (both carboxyl and ketonic), $\mathrm{CH}_{2}$ group. This strongly supports the presence of humic acid.

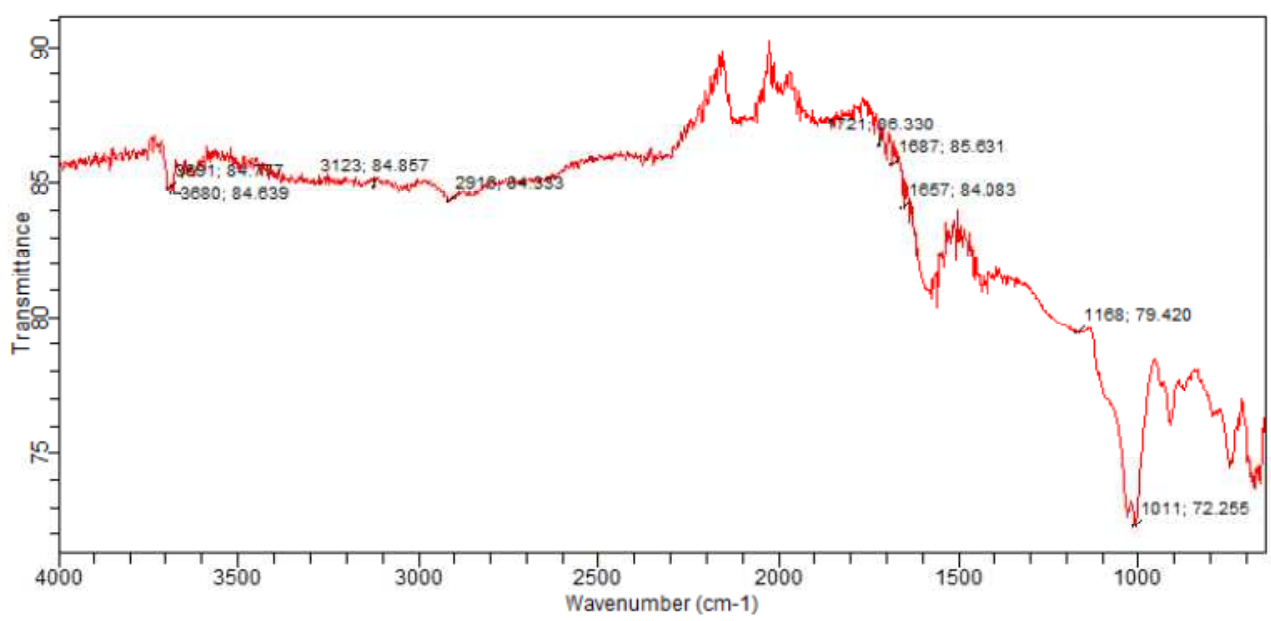

Fig. 2 : FT-IR spectraof peatsoilhumic acid (PSHA)

\section{Evaluation of acid dissociation constant (pka) of acid hydrolysed peat soil humicacid at phenolic group}

The value of the dissociation constant of the peat soil humic acid (PSHA) that underwent acidhydrolysis studied was found to be 8.9299 as shown Table 1, which is lower than the literaturevalues reported by Almeida and Szpoganics, (2015), Borges et al., (2005); Badr et al., (2012)and Fernandes et al,.(2009) of $9.73,9.47$ and 10.30. The difference between the obtained valuesand the reported values in this study might be probably as a result of acid hydrolysis of humicacid. 
BAJOPAS Volume 14 Number 1,June, 2021

Table 1: PKa of (Hydrolysed PSHA)

\begin{tabular}{|l|l|l|l|l|l|l|}
\hline $\mathrm{pH}$ & $\mathrm{BV}_{1}$ & $\mathrm{BV}_{2}$ & $\mathrm{~V}_{2}-\mathrm{V}_{1}$ & $\mathrm{nA}$ & $\log \left(\frac{n A}{1-n A}\right)$ & $\mathrm{pKa}$ \\
\hline 8.50 & 5.30 & 6.29 & 0.99 & 0.3594 & -0.2510 & 8.2490 \\
8.72 & 5.35 & 6.37 & 1.02 & 0.3400 & -0.2880 & 8.4320 \\
9.00 & 5.40 & 6.46 & 1.06 & 0.3141 & -0.3391 & 8.6609 \\
9.22 & 5.45 & 6.55 & 1.10 & 0.2882 & -0.3927 & 8.8273 \\
9.51 & 5.50 & 6.66 & 1.16 & 0.2494 & -0.4786 & 9.0314 \\
9.73 & 5.55 & 6.78 & 1.23 & 0.2041 & -0.5910 & 9.1390 \\
10.00 & 5.60 & 6.90 & 1.30 & 0.1589 & -0.7238 & 9.2762 \\
10.23 & 5.65 & 7.05 & 1.40 & 0.0941 & -0.9835 & 9.2465 \\
10.49 & 5.70 & 7.10 & 1.40 & 0.0941 & -0.9835 & 9.5065 \\
\hline
\end{tabular}

Average pKa $=8.9299 \pm 0.4186$

Table 2: PKa of (Unhydrolysed PSHA)

\begin{tabular}{|l|l|l|l|l|l|l|}
\hline $\mathrm{pH}$ & $\mathrm{BV}_{1}$ & $\mathrm{BV}_{2}$ & $\mathrm{~V}_{2}-\mathrm{V}_{1}$ & $\mathrm{nA}$ & $\log \left(\frac{\boldsymbol{n A}}{1-\boldsymbol{n}}\right)$ & $\mathrm{pKa}$ \\
\hline 8.50 & 5.30 & 5.81 & 0.51 & 0.6619 & 0.2919 & 8.7919 \\
8.72 & 5.35 & 5.90 & 0.55 & 0.6357 & 0.2418 & 8.9618 \\
9.00 & 5.40 & 6.00 & 0.60 & 0.6029 & 0.1813 & 9.1813 \\
9.22 & 5.45 & 6.10 & 0.65 & 0.5701 & 0.1226 & 9.3426 \\
9.51 & 5.50 & 6.20 & 0.70 & 0.5376 & 0.0654 & 9.5754 \\
9.73 & 5.55 & 6.33 & 0.78 & 0.4851 & -0.0259 & 9.7041 \\
10.00 & 5.60 & 6.47 & 0.87 & 0.4262 & -0.1291 & 9.8709 \\
10.23 & 5.65 & 6.62 & 0.99 & 0.3609 & -0.2481 & 9.9819 \\
10.49 & 5.70 & 6.80 & 1.10 & 0.2759 & -0.4690 & 10.0210 \\
\hline
\end{tabular}

Average pKa $=9.4923 \pm 0.4410$

Metal-ligand stability constant ( $\log \mathrm{K}$ )

The stabilityconstants require the accurate values of proton-ligand stability constants (Anil and Maroti, 2008). Metal titration curves crossed over ligand titration curve indicated the formation of complex upon proton release (Santosh, et al., 2011). If the values of n- are within range $0.2-0.8$ and $1.2-18$ this indicates the formation of $1: 1$ and 1:2 complexes (Sayyed and Mazahar, 2012).

The metal (II)-humate stepwise stability constants (log k) at phenolic group (Tables 318)

Table 3: Point-wise method, $\mathrm{Cu}$-(Hydrolysed PSHA)

\begin{tabular}{|l|l|l|l|l|l|l|l|l|}
\hline $\mathrm{pH}$ & $\mathrm{BV}_{1}$ & $\mathrm{BV}_{2}$ & $\mathrm{BV}_{3}$ & $\left(\mathrm{~V}_{3}-\mathrm{V}_{2}\right)$ & $\mathrm{n}$ & $\mathrm{pL}$ & $\log \left(\frac{n}{1-n}\right)$ & LogK $_{1}$ \\
\hline 8.50 & 5.30 & 6.29 & 6.33 & 0.04 & 0.5500 & 2.66 & 0.0871 & 2.7471 \\
8.72 & 5.35 & 6.37 & 6.41 & 0.04 & 0.5714 & 2.43 & 0.1249 & 2.5549 \\
9.00 & 5.40 & 6.46 & 6.50 & 0.04 & 0.6198 & 2.16 & 0.2122 & 2.3722 \\
9.22 & 5.45 & 6.55 & 6.59 & 0.04 & 0.6667 & 1.94 & 0.3010 & 2.2410 \\
\hline
\end{tabular}

LogK $_{1}$ (Average value) $=2.4788 \pm 0.2203$

Table 4: Point-wise method, $\mathrm{Cu}$-(Hydrolysed PSHA)

\begin{tabular}{|l|l|l|l|l|l|l|l|l|}
\hline $\mathrm{pH}$ & $\mathrm{BV}_{1}$ & $\mathrm{BV}_{2}$ & $\mathrm{BV}_{3}$ & $\left(\mathrm{~V}_{3}-\mathrm{V}_{2}\right)$ & $\mathrm{n}$ & $\mathrm{pL}$ & $\log \left(\frac{n-1}{2-n}\right)$ & LogK $_{2}$ \\
\hline 9.51 & 5.50 & 6.66 & 6.73 & 0.07 & 1.3509 & 1.70 & -0.2671 & 1.4329 \\
9.73 & 5.55 & 6.78 & 6.85 & 0.07 & 1.6383 & 1.51 & 0.2467 & 1.7567 \\
10.00 & 5.60 & 6.90 & 6.98 & 0.08 & 2.1783 & 1.31 & -0.2158 & 1.0942 \\
10.23 & 5.65 & 7.05 & 7.13 & 0.08 & 4.1904 & 1.27 & & \\
10.49 & 5.70 & 7.10 & 7.19 & 0.09 & 4.6920 & & & \\
\hline
\end{tabular}

Log $K_{2}($ Average value $)=1.4280 \pm 0.3312$ 
BAJOPAS Volume 14 Number 1,June, 2021

Table 5: Point-wise method, $\mathrm{Cu}$ (Unhydrolysed PSHA)

\begin{tabular}{|l|l|l|l|l|l|l|l|l|}
\hline $\mathrm{pH}$ & $\mathrm{BV}_{1}$ & $\mathrm{BV}_{2}$ & $\mathrm{BV}_{3}$ & $\left(\mathrm{~V}_{3}-\mathrm{V}_{2}\right)$ & $\mathrm{n}$ & $\mathrm{pL}$ & $\log \left(\frac{n}{n-1}\right)$ & Log $_{1}$ \\
\hline 8.50 & 5.30 & 5.81 & 5.85 & 0.04 & 0.2973 & 2.88 & -0.3736 & 2.5064 \\
8.72 & 5.35 & 5.90 & 5.95 & 0.05 & 0.3873 & 2.66 & -0.1992 & 2.4608 \\
9.00 & 5.40 & 6.00 & 6.05 & 0.05 & 0.4044 & 2.38 & -0.1681 & 2.2119 \\
9.22 & 5.45 & 6.10 & 6.15 & 0.06 & 0.5157 & 2.18 & -0.0272 & 2.2072 \\
9.51 & 5.50 & 6.20 & 6.27 & 0.07 & 0.6417 & 1.89 & 0.2530 & 1.1430 \\
\hline
\end{tabular}

$\operatorname{LogK}_{1}($ Average value $)=2.3059 \pm 0.6153$

Table 6:Point-wise method, $\mathrm{Cu}$ (Unhydrolysed PSHA)

\begin{tabular}{|l|l|l|l|l|l|l|l|l|}
\hline $\mathrm{pH}$ & $\mathrm{BV}_{1}$ & $\mathrm{BV}_{2}$ & $\mathrm{BV}_{3}$ & $\mathrm{~V}_{3}-\mathrm{V}_{2}$ & $\mathrm{n}$ & $\mathrm{pL}$ & $\log \left(\frac{n-1}{2-n}\right)$ & $\log \mathrm{K}_{2}$ \\
\hline 9.73 & 5.55 & 6.33 & 6.42 & 0.09 & 0.9000 & 1.69 & & \\
10.00 & 5.60 & 6.47 & 6.58 & 0.11 & 1.2578 & 1.44 & -0.4592 & 0.9808 \\
10.23 & 5.65 & 6.62 & 6.84 & 0.12 & 1.6137 & 1.26 & -0.2010 & 1.4610 \\
10.49 & 5.70 & 6.80 & 6.92 & 0.12 & 2.1052 & 1.03 & & \\
\hline
\end{tabular}

$\operatorname{LogK}_{2}$ (Average value) $=1.2209 \pm 0.3398$

Table 7:Point-wise method, Pb (Hydrolysed PSHA)

\begin{tabular}{|l|l|l|l|l|l|l|l|l|}
\hline $\mathrm{pH}$ & $\mathrm{BV}_{1}$ & $\mathrm{BV}_{2}$ & $\mathrm{BV}_{3}$ & $\left(\mathrm{~V}_{3}-\mathrm{V}_{2}\right)$ & $\mathrm{n}$ & $\mathrm{pL}$ & $\log \left(\frac{n}{1-n}\right)$ & LogK $_{1}$ \\
\hline 8.50 & 5.30 & 6.29 & 6.33 & 0.04 & 0.5500 & 2.66 & 0.0871 & 2.7471 \\
8.72 & 5.35 & 6.37 & 6.41 & 0.04 & 0.5714 & 2.43 & 0.1249 & 2.5549 \\
9.00 & 5.40 & 6.46 & 6.50 & 0.04 & 0.6198 & 2.16 & 0.2122 & 2.3722 \\
9.22 & 5.45 & 6.55 & 6.60 & 0.05 & 0.8333 & 1.96 & 0.6989 & 2.6589 \\
\hline
\end{tabular}

Log $_{\mathbf{1}}($ Average value $)=2.5832 \pm 0.1614$

Table 8:Point-wise method, Pb-(Hydrolysed PSHA)

\begin{tabular}{|l|l|l|l|l|l|l|l|l|}
\hline $\mathrm{pH}$ & $\mathrm{BV}_{1}$ & $\mathrm{BV}_{2}$ & $\mathrm{BV}_{3}$ & $\left(\mathrm{~V}_{3}-\mathrm{V}_{2}\right)$ & $\mathrm{n}$ & $\mathrm{pL}$ & $\log \left(\frac{n-1}{2-n}\right)$ & $\log \mathrm{K}_{2}$ \\
\hline 9.51 & 5.50 & 6.66 & 6.71 & 0.05 & 0.9650 & 1.67 & & \\
9.73 & 5.55 & 6.78 & 6.83 & 0.05 & 1.1702 & 1.44 & & \\
10.00 & 5.60 & 6.90 & 6.90 & 0.05 & 1.4864 & 1.22 & -0.0237 & 1.1963 \\
10.23 & 5.65 & 7.05 & 7.10 & 0.05 & 2.0190 & 1.09 & & \\
10.49 & 5.70 & 7.10 & 7.17 & 0.07 & 3.6492 & 1.00 & & \\
\hline
\end{tabular}

Log $K_{2}$ (Average value) $=1.1963$

Table 9: Point-wise method, Pb (Unhydrolysed PSHA)

\begin{tabular}{|l|l|l|l|l|l|l|l|l|}
\hline $\mathrm{pH}$ & $\mathrm{BV}_{1}$ & $\mathrm{BV}_{2}$ & $\mathrm{BV}_{3}$ & $\mathrm{~V}_{3}-\mathrm{V}_{2}$ & $\mathrm{n}$ & $\mathrm{pL}$ & $\begin{array}{l}\text { Log } \\
\left(\frac{n}{n-1}\right)\end{array}$ & Log $\mathrm{K}_{1}$ \\
\hline 8.50 & 5.30 & 5.81 & 5.85 & 0.04 & 0.2973 & 2.88 & -0.3736 & 2.5064 \\
8.72 & 5.35 & 5.90 & 5.94 & 0.04 & 0.3099 & 2.66 & -0.5477 & 2.3123 \\
9.00 & 5.40 & 6.00 & 6.05 & 0.05 & 0.4044 & 2.38 & -0.1681 & 2.2119 \\
9.22 & 5.45 & 6.10 & 6.15 & 0.06 & 0.5157 & 2.18 & 0.0272 & 2.2072 \\
9.51 & 5.50 & 6.20 & 6.26 & 0.07 & 0.6417 & 1.89 & 0.2530 & 2.1430 \\
9.73 & 5.55 & 6.40 & 6.40 & 0.07 & 0.7000 & 1.67 & 0.3680 & 2.0380 \\
\hline
\end{tabular}

LogK $_{1}$ (Average value) $=2.2364 \pm 0.1602$

Table 10: Point-wise method, Pb (Unhydrolysed PSHA)

\begin{tabular}{|l|l|l|l|l|l|l|l|l|}
\hline $\mathrm{pH}$ & $\mathrm{BV}_{1}$ & $\mathrm{BV}_{2}$ & $\mathrm{BV}_{3}$ & $\mathrm{~V}_{3}-\mathrm{V}_{2}$ & $\mathrm{n}$ & $\mathrm{pL}$ & $\log \left(\frac{n-1}{2-n}\right)$ & $\log \mathrm{K}_{2}$ \\
\hline 10.00 & 5.60 & 6.47 & 6.55 & 0.08 & 1.9503 & 1.41 & & \\
10.23 & 5.65 & 6.62 & 6.72 & 0.11 & 1.4792 & 1.26 & -0.0361 & 1.2239 \\
\hline
\end{tabular}

$\operatorname{LogK}_{2}$ (Average value) $=1.2239$

Table 11: Point-wise method, Mg (Hydrolysed PSHA)

\begin{tabular}{|l|l|l|l|l|l|l|l|l|}
\hline $\mathrm{pH}$ & $\mathrm{BV}_{1}$ & $\mathrm{BV}_{2}$ & $\mathrm{BV}_{3}$ & $\left(\mathrm{~V}_{3}-\mathrm{V}_{2}\right)$ & $\mathrm{n}$ & $\mathrm{pL}$ & $\log \left(\frac{n}{n-1}\right)$ & LogK $_{1}$ \\
\hline 8.50 & 5.30 & 6.29 & 6.31 & 0.02 & 0.2750 & 2.64 & -0.4290 & 2.2110 \\
8.72 & 5.35 & 6.37 & 6.39 & 0.02 & 0.2858 & 2.42 & -0.3978 & 2.0222 \\
9.00 & 5.40 & 6.46 & 6.49 & 0.03 & 0.4648 & 2.14 & -0.0612 & 2.0788 \\
9.22 & 5.45 & 6.55 & 6.59 & 0.04 & 0.6667 & 1.94 & 0.3010 & 2.2410 \\
\hline
\end{tabular}

$\log _{\mathbf{1}}($ Average value) $=2.1382 \pm 0.1046$ 
BAJOPAS Volume 14 Number 1,June, 2021

Table 12: Point-wise method, Mg (Hydrolysed PSHA)

\begin{tabular}{|l|l|l|l|l|l|l|l|l|}
\hline $\mathrm{pH}$ & $\mathrm{BV}_{1}$ & $\mathrm{BV}_{2}$ & $\mathrm{BV}_{3}$ & $\left(\mathrm{~V}_{3}-\mathrm{V}_{2}\right)$ & $\mathrm{n}$ & $\mathrm{pL}$ & $\log \left(\frac{n-1}{2-n}\right)$ & LogK $_{2}$ \\
\hline 9.51 & 5.55 & 6.66 & 6.71 & 0.05 & 0.9650 & 1.67 & & \\
9.73 & 5.55 & 6.78 & 6.84 & 0.06 & 1.4042 & 1.47 & -0.1686 & 1.3014 \\
10.00 & 5.60 & 6.90 & 6.93 & 0.06 & 1.7838 & 1.23 & 0.5593 & 1.7893 \\
10.23 & 5.65 & 7.05 & 7.10 & 0.06 & 3.1429 & 1.10 & & \\
10.49 & 5.70 & 7.10 & 7.18 & 0.07 & 3.6492 & 0.83 & & \\
\hline
\end{tabular}

LogK $_{2}($ Average value $)=1.5453 \pm 0.3450$

Table 13: Point-wise method, Mg (Unhydrolysed PSHA)

\begin{tabular}{|l|l|l|l|l|l|l|l|l|}
\hline $\mathrm{pH}$ & $\mathrm{BV}_{1}$ & $\mathrm{BV}_{2}$ & $\mathrm{BV}_{3}$ & $\mathrm{~V}_{3}-\mathrm{V}_{2}$ & $\mathrm{n}$ & $\mathrm{pL}$ & $\log \left(\frac{n}{n-1}\right)$ & $\operatorname{Log~}_{1}$ \\
\hline 8.50 & 5.30 & 5.81 & 5.85 & 0.04 & 0.2973 & 2.88 & -0.3736 & 2.5064 \\
8.72 & 5.35 & 5.90 & 5.94 & 0.04 & 0.3099 & 2.66 & -0.3477 & 2.3123 \\
9.00 & 5.40 & 6.00 & 6.04 & 0.04 & 0.3236 & 2.38 & -0.3202 & 2.0598 \\
9.22 & 5.45 & 6.10 & 6.15 & 0.05 & 0.4297 & 2.17 & -0.1230 & 2.0470 \\
9.51 & 5.50 & 6.20 & 6.26 & 0.06 & 0.5500 & 1.89 & 0.0871 & 1.9771 \\
9.73 & 5.55 & 6.33 & 6.40 & 0.07 & 0.7000 & 1.67 & 0.3680 & 2.0380 \\
\hline
\end{tabular}

LogK $_{1}$ (Average value) $=2.1568 \pm 0.2069$

Table 14: Point-wise method, Mg (Unhydrolysed PSHA)

\begin{tabular}{|l|l|l|l|l|l|l|l|l|}
\hline $\mathrm{pH}$ & $\mathrm{BV}_{1}$ & $\mathrm{BV}_{2}$ & $\mathrm{BV}_{3}$ & $\mathrm{~V}_{3}-\mathrm{V}_{2}$ & $\mathrm{n}$ & $\mathrm{pL}$ & $\log \left(\frac{n-1}{2-n}\right)$ & $\log \mathrm{K}_{2}$ \\
\hline 10.00 & 5.60 & 6.47 & 6.55 & 0.08 & 0.9148 & 1.41 & & \\
10.23 & 5.65 & 6.62 & 6.71 & 0.09 & 1.2102 & 1.20 & -0.5749 & 0.6251 \\
10.49 & 5.70 & 6.80 & 6.92 & 0.09 & 1.5968 & 1.03 & 0.1703 & 1.2003 \\
\hline
\end{tabular}

LogK $_{2}$ (Average value) $=0.9127 \pm 0.4070$

Table15:Point-wise method, Cd (Hydrolysed PSHA)

\begin{tabular}{|l|l|l|l|l|l|l|l|l|}
\hline $\mathrm{pH}$ & $\mathrm{BV}_{1}$ & $\mathrm{BV}_{2}$ & $\mathrm{BV}_{3}$ & $\left(\mathrm{~V}_{3}-\mathrm{V}_{2}\right)$ & $\mathrm{n}$ & $\mathrm{pL}$ & $\log \left(\frac{n}{1-n}\right)$ & LogK $_{1}$ \\
\hline 8.50 & 5.30 & 6.29 & 6.31 & 0.02 & 0.2750 & 2.64 & -0.4210 & 2.2190 \\
8.72 & 5.35 & 6.37 & 6.40 & 0.03 & 0.4286 & 2.42 & -0.1249 & 2.2951 \\
9.00 & 5.40 & 6.46 & 6.49 & 0.03 & 0.4648 & 2.14 & -0.0612 & 2.0788 \\
9.22 & 5.45 & 6.55 & 6.59 & 0.04 & 0.6667 & 1.96 & 0.3010 & 2.2610 \\
9.51 & 5.55 & 6.66 & 6.70 & 0.04 & 0.7720 & 1.67 & 0.5297 & 2.1997 \\
\hline
\end{tabular}

LogK $_{\mathbf{1}}$ (Average value) $=2.2108 \pm 0.0825$

Table 16: Point-wise method, Cd (Hydrolysed PSHA)

\begin{tabular}{|l|l|l|l|l|l|l|l|l|}
\hline $\mathrm{pH}$ & $\mathrm{BV}_{1}$ & $\mathrm{BV}_{2}$ & $\mathrm{BV}_{3}$ & $\left(\mathrm{~V}_{3}-\mathrm{V}_{2}\right)$ & $\mathrm{n}$ & $\mathrm{pL}$ & $\log \left(\frac{n-1}{2-n}\right)$ & Log $_{2}$ \\
\hline 9.73 & 5.55 & 6.78 & 6.83 & 0.06 & 1.4042 & 1.47 & -0.1686 & 1.3014 \\
10.00 & 5.60 & 6.90 & 6.95 & 0.06 & 1.7838 & 1.23 & 0.5593 & 1.7893 \\
10.23 & 5.65 & 7.05 & 7.10 & 0.06 & 3.1429 & 1.09 & & \\
10.49 & 5.70 & 7.10 & 7.16 & 0.06 & 3.1429 & 0.89 & & \\
& & & & & & & & \\
\hline
\end{tabular}

$\operatorname{LogK}_{2}$ (Average value) $=1.5453 \pm 0.3450$

Table 17: Point-wise method, Cd (Unhydrolysed PSHA)

\begin{tabular}{|l|l|l|l|l|l|l|l|l|}
\hline $\mathrm{pH}$ & $\mathrm{BV}_{1}$ & $\mathrm{BV}_{2}$ & $\mathrm{BV}_{3}$ & $\mathrm{~V}_{3}-\mathrm{V}_{2}$ & $\mathrm{n}$ & $\mathrm{pL}$ & $\log \left(\frac{n}{n-1}\right)$ & $\operatorname{Log~}_{1}$ \\
\hline 8.50 & 5.30 & 5.81 & 5.86 & 0.05 & 0.3717 & 2.88 & -0.2280 & 2.6520 \\
8.72 & 5.35 & 5.90 & 5.95 & 0.05 & 0.3873 & 2.66 & -0.1992 & 2.4608 \\
9.00 & 5.40 & 6.00 & 6.06 & 0.06 & 0.4853 & 2.38 & -0.0255 & 2.3545 \\
9.22 & 5.45 & 6.10 & 6.16 & 0.06 & 0.5157 & 2.18 & -0.0272 & 2.2072 \\
9.51 & 5.50 & 6.20 & 6.27 & 0.07 & 0.6417 & 1.89 & 0.2530 & 1.1430 \\
9.73 & 5.55 & 6.33 & 6.41 & 0.08 & 0.8000 & 1.69 & 0.6020 & 2.2920 \\
& & & & & & & & \\
\hline
\end{tabular}

$\operatorname{LogK}_{1}($ Average value $)=2.2516 \pm 0.5380$ 
BAJOPAS Volume 14 Number 1,June, 2021

Table 18: Point-wise method, Cd (Unhydrolysed PSHA)

\begin{tabular}{|l|l|l|l|l|l|l|l|l|}
\hline $\mathrm{pH}$ & $\mathrm{BV}_{1}$ & $\mathrm{BV}_{2}$ & $\mathrm{BV}_{3}$ & $\mathrm{~V}_{3}-\mathrm{V}_{2}$ & $\mathrm{n}$ & $\mathrm{pL}$ & $\log \left(\frac{n-1}{2-n}\right)$ & $\log \mathrm{K}_{2}$ \\
\hline 10.00 & 5.60 & 6.47 & 6.57 & 0.10 & 1.1434 & 1.43 & & \\
10.23 & 5.65 & 6.62 & 6.72 & 0.10 & 1.3448 & 1.23 & -0.2788 & 0.9512 \\
10.49 & 5.70 & 6.80 & 6.90 & 0.10 & 1.7742 & 1.03 & 0.5351 & 1.5651 \\
\hline
\end{tabular}

$\operatorname{LogK}_{2}($ Average value $)=1.2581 \pm 0.4340$

Table 19: Stepwise and overall Stability constants of thehydrolysed and unhydrolysed divalent metal (II) complexes

\begin{tabular}{|c|c|c|c|}
\hline Chelates & LogK $_{1}$ & $\log _{2}$ & Log $\beta$ \\
\hline [Cu (Hydrolysed PSHA-1) $\left.{ }_{2}\right]$ & 2.4788 & 1.4280 & 3.9068 \\
\hline$\left[\mathrm{Pb}(\text { Hydrolysed PSHA-1) })_{2}\right]$ & 2.5832 & 1.1963 & 3.7795 \\
\hline$\left[\mathrm{Cd}(\text { Hydrolysed PSHA-1 })_{2}\right]$ & 2.2108 & 1.5453 & 3.7561 \\
\hline$\left[\mathrm{Mg}(\text { Hydrolysed PSHA-1 })_{2}\right]$ & 2.1382 & 1.5453 & 3.6835 \\
\hline [Cu (Unhydrolysed PSHA-1) & 2.3059 & 1.2209 & 3.5268 \\
\hline$[\mathrm{Pb}$ (Unhydrolysed PSHA-1) 2$]$ & 2.2364 & 1.2239 & 3.4603 \\
\hline [Cd (Unhydrolysed PSHA-1) 2 ] & 2.2516 & 1.2581 & 3.5097 \\
\hline$[\mathrm{Mg}$ (Unydrolysed PSHA-1) & 2.1568 & 0.9127 & 3.0695 \\
\hline
\end{tabular}

The results obtained (Table19) shows the stepwise and overall stability constants to be not high indicating low stability of the complexes, because the solubility of most metal ions in the basic $\mathrm{pH}$ range is minimal due to metal hydroxide precipitation (Karimi, 2017). In general, the stepwise stability constants $\left(K_{1}\right.$ and $K_{2}$ ) follow the order $K_{1}>K_{2}$ for the copper, lead, magnesium and cadmium complexes respectively. The steady decrease of the values with increasing number of ligands is in agreement with the prediction made by researchers (Na'aliya, 2013). The decrease could be attributed to the fact that as the number of the ligands (Humate ions) that enters the coordination zone increases the aqua molecules available for replacement by the ligands become less. Thus, the metal ions become less electron loving with progressive intake of the ligand and this results in the decrease in the values of the constants (Na'aliya, 2013). Also the stability of the complexes is influenced by the size and number of the chelate rings(Mackay and Mackay,2002).All the complexes form rings in their structure as humate, a bidentate ligand, bond the metal ions in the ratio 1:2 (Boguta and Sokolowska, 2016) forming chelate rings. The values of the overall stability constants $(\log \beta)$ obtained for humate complexes are not high indicating low stability as the values are not high. LogK values for copper-humates (Table 3 to 6) obtained in this study are lower than those reported for the complexes of humic acids (Pandey et al., 2015; Dinu, 2013; Kaschl et al., 2010 and Gilbeto and Jorg, 2001). The values of LogK(Table 7 to 10 ) forlead-humates are lower than those reported for the lead in the literature (Dinu, 2013; Gilbeto and Jorg 2001). Log K values(Table 11 to 14 ) for magnesium-humates obtained in this study are close to those reported by (Pandey et al., 2015). Log K values of cadmium-humates (Table 15 to 18 ) obtained in this work near to the one reported by (Dinu, 2013 and Pandey et al., 2015).The difference between the reported values and the values obtained in this study might be probably as a result of acid hydrolysis of humic acid. The values of the overall stability constants $(\log \beta)$ of the copper humates complexes presented in Table 19 is high than that of other metal humate complexes, show relatively high stability of CuHA complexes, show the following order of stability: $\mathrm{Cu}>\mathrm{Pb}>\mathrm{Cd}>\mathrm{Mg}$; which are in close agreement to the findings of (Dinu, 2013 and Pandey et al., 2015).The high stability of Cuhumate chelate could be attributed to the existence of coordinate covalent bond between the complexing agents and the $\mathrm{Cu}^{2+}$ ions. Since, $\mathrm{Cu}^{2+}$ being a metal of the transitional series with $3 d^{9}$ electronic configurations can accept the electrons from the complexing agents. Similarly, the low stabilities of $\mathrm{Pb}, \mathrm{Cd}$ and $\mathrm{Mg}$ complexes could be explained by that $\mathrm{Pb}^{2+}$ with $6 s^{2}, \mathrm{Cd}^{2+}$ with $4 \mathrm{~d}^{10}$ and $\mathrm{Mg}^{2+}$ with $2 \mathrm{p}^{6}$ their electronic configuration has a completely filled $\mathrm{d}, \mathrm{p}$ and $\mathrm{s}$ orbitals. Moreover, the stabilities of metal ions with hydrolysed humic acid from peat soil were higher than those with unhydrolysed humic acid from peat soil; which is ascribed to the high content of acidity in hydrolysed humic acid than unhydrolysed humic acid. 
BAJOPAS Volume 14 Number 1,June, 2021 CONCLUSION

The values of logk for $\mathrm{Cu}(\mathrm{II})$ hydrolysed humic acid complex was higher followed by $\mathrm{Pb}$ (II), $\mathrm{Cd}(\mathrm{II})$ and $\mathrm{Mg}$ (II) hydrolysed humic acid complexes as compared with metal(II) unhydrolysed humic acid complexes. This indicates acid hydrolysis of humic acid can

\section{REFERENCES}

Almeida, V.R. and Szpoganicz, B. (2015). Humic Acid Potentiometric Response Patterns:Out- of Equilibrium Properties and Species Distribution Modelling. Chemical. Biol. Technol. Agric. 2: 17.

Anđelković, T., Nikolić, R., Bojić, A.,Anđelković, D., and Nikolic G.,(2010). Binding of Cadmium to Soil Humic Acid as A Function of Carboxyl Group Content. Macedonian Journal of Chemistry and Chemical Engineering.29(2): 215-224.

Anil, B. N. and Maroti, N. (2008). Studies on Influence of Die-Lectric Constants on Complex Equilibria between Substituted Py-Razalines and Lanthanide Metal Ions pH-Metrically. Amer.-Euras. scient. Res. 3(2): 212-216.

Ashok, K., Pandey, S. P. and Misra, V (2000). Stability Constants of Metal-Humic Acid Complexes and its Role in Environmental Detoxification. Journal of Ecotoxicology and Environmental Safety. 47(2):157-200.

Badr, M. H., El-Halafawi, M. H. and Abd El-al Zeid, E. R. (2012). Comparison Between the Effect of Ionic Strength on Acidity and Dissociation Constants of Humic Acids Extracted from Sewage Sludge and Nile Water Hyacinth Composts.Global Journal of Environmental Research 6 (1): 36-43.

Baruah, M.K., Borah, D., Saikia, P.P., Paul, S., Sharma, T. (2015). Evaluation of pKa Values of Soil Humic Acids and their Complexation Properties. International Journal of Plant \& Soil Science 6(4) : 218-228.

Boguta, P. Sokolowska, Z. (2016). Interactions of $\mathrm{Zn}$ (II) Ions with Humic Acids Isolated from Various Types of Soils. Effect of $\mathrm{pH}, \mathrm{Zn}$ Concentrations and Humic Acids Chemical Properties. Journal of Geochemical Explaration 168. 119-126.

Borges, F., Guimaraes, C., Lima, L.F.C., Pinto, I. and Reis, S.(2005). Potentiometric Studies on the Complexation of Copper(II) by Phenolic Acids as Discrete Ligand Models of enhance the complexation behavior of humic acid with metal (II) ions. However, the higher values of $\log \beta$ for $\mathrm{Cu}(\mathrm{II}), \mathrm{Pb}(\mathrm{II}), \mathrm{Cd}(\mathrm{II})$ and $\mathrm{Mg}(\mathrm{II})$ hydrolysed humic acid complexes indicates more stable stepwise complexes formed as compared with $\mathrm{Cu}(\mathrm{II}), \mathrm{Pb}$ (II), $\mathrm{Cd}$ (II) and $\mathrm{Mg}(\mathrm{II})$ unhydrolysed humic acid complexes.

Humic Substances Talanta 66 (2005) 670-673.

Chefetz, B., Salloum, M. J., Deshmulkin, A. P. and Hatcher, P. (2002). Structural Components of Humic Acids as Determined by Chemical Modifications and Carbon-13 NMR, Pyrolysis, and Thermochemolysis- Gas Chromatography/Mass Spectrometry. Soil Science Society of American Journal Abstract Division S-2- Soil Chemistry66. 1159-1171.

Dinu, M. I. (2013). Metals Complexation with Humic Acids in Surface Water of Different Environ. Sci. Technol. 31(1): 1-17.

Fernandes, A.N., Giacomelli, C., Giovanela, M. Vaz, D.V. Szpoganicz, B. and Maria M. D. (2009). Potentiometric Acidity Determination in Humic Substances Influenced by Different Analytical Procedures.J. Braz. Chem. Soc. 20 (9):14.

Gamal, A. H. (2015). Stability Constants of Rhenium (V) Metal Complexes with Selected Drugs. Pyrex Journal of Research in Environmental Studies. 2(2): 006-014.

Janrao, D. M., Pathan, J., Kayande, D.D., and Mulla, J.J. (2014). An Over View of Potentiometric Determination of Stability Constants of Metal Complexes. Sci. Revs. Chem. Commun.: 4(1), 2014, 11-24.

Karimi, H. (2017). Effect of pH and Initial Pb(II) Concentration on the Lead Removal Efficiency from Waste Water Using $\mathrm{Ca}(\mathrm{OH})_{2}$. International Journal of Water and Waste Water Treatment 3.2

Kaschl, A. Romheld, V. and Chen, Y. (2010). Binding of Cadmium, Copper and Zinc to Humic Substances Originating from Municipal Solid Waste Compost. Israel Journal of Chemistry Vol. 42(1): 89-98.

Kostic, I. S., Tatjana, P, A., Nikolic, R. S., Cvetkovic, T. P., Pavlovic, D. D., Aleksandar, L.J. and Bojic, A. (2012). Comparative Study of Binding Strengths of Heavy Metals with Humic Acid. J.serb. Chem. Soc. 76(9) pp 1-20. 
BAJOPAS Volume 14 Number 1,June, 2021

Na'aliya, J. (2013). Determination of Stepwise Stability Constants and Gibbs free Energy Change of Trisprolina to Complexes of some Divalent Transition Metal ions. Bayero Journal of Pure and Applied Sciences 6(2): 112-114.

Omar, A. A. and Ali, E. A. (2015). Potentiometric Studies on Complexes of $\mathrm{Cr}$ (III) and $\mathrm{Zr}$ (IV) with some Carboxylic Acids. International Journal of Advanced Chemistry, 3(1) 25-

37.

Pandey, A. K. Pandey, S. D. and Misr, V. (2015).Stability Constants of Metal- Humic Acid Complexes and Its Role in Environmental Detoxification. J. Ecotoxicology and Environmental Safety. 47(1):195-200.

Ram, N. and Raman, K.V. (1984). Stability Constants of Complexes of Metals with
Humicand Fuvic Acids under Non- acidConditions. Journal of Plant Nutrition and Soil Sciences.

147:171-176.

Santosh, D. D., Ashok, B. K., Vijay, J. T., Shivraj, G. W. and Vinay, V. W. (2011). Potentiometric Studies of Elec-Trolyte Effects on Complex Equilibria of Some Substituted 5-(2-hydroxy Phenyl) Pyrazoles. Der pharm. 3 (6): 75-83.

Sayyed, H. and Abdul Rahim, M. F. (2012). Studies of Binary Complexes of Metal Ions with Mandelic Acid by Potentiometry. Chem. J. 02 (6): 206209.

Shirvani, M. Moradian, E. Khalili, B. Bakhtiary, S. (2015). Interaction of $\mathrm{Cd}$ and $\mathrm{Pb}$ with Humate-Palygorskite and HumateSepiolite Complexes. Journal of water, air and pollution 3: 220-228. 


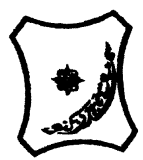

Bayero Journal of Pure and Applied Sciences, 14(1): 54 - 63

Received: November, 2020

Accepted: April, 2021

ISSN $2006-6996$

\title{
STABILITY CONSTANTS OF COMPLEXES OF METAL IONS WITH PEATSOIL HUMIC ACIDS UNDER NON-ACID-CONDITIONS
}

\author{
${ }^{* 1}$ Sabo, Yusuf ${ }^{2}$ Jimoh, W.L.O., ${ }^{3}$ Isa Baba Koki and ${ }^{4}$ Sholadoye, Q. 0. \\ ${ }^{1}$ Department of Pure and Industrial Chemistry, Bayero University, Kano \\ ${ }^{3}$ Department of Chemistry, Yusuf Maitama Sule University Kano. P.M.B. 3220 Kano, Nigeria. \\ ${ }^{4}$ Department of Chemistry, Nigerian Police Academy, Wudil, Kano-Nigeria
}

*Correspondence E-mail; saboyusuf18@yahoo.com

ABSTRACT

Stability constants of complexes of four divalent metal ions viz. $\mathrm{Cu}^{2+}, \mathrm{Pb}^{2+}, \mathrm{Mg}^{2+}$ and $\mathrm{Cd}^{2+}$ with humic acids (HA) were determined by potentiometric titration of humic acids with the corresponding salt of the divalent metals in aqueous media under non-acid-condition. The log $K$ (logarithm of the stability constant) ranged from 1.0942 to 2.7471 for metalhumic acid complexes were determined using point-wise computational method. The order of stability constants were obtained as follows: $\mathrm{Cu}>\mathrm{Pb}>\mathrm{Cd}>\mathrm{Mg}$ for metal $-\mathrm{HA}$ complexes respectively, indicating a higher degree of complexation with Cu metal ion.

Keywords: stability constant, humic acid, potentiometric titration, divalent metals, acid hydrolysis.

\section{NTRODUCTION}

The stability constant of a complex is the numerical expression of its stability and provides a quantitative measure of affinity of the metal ion to the complexing agent. An understanding of the relative stability of metal-complexes helps in predicting the behavior of metal ions in the soil (Ram and Raman, 1982). Extensive researches has been done to determine the stability constants of the complexes formed between humic acid (HA) with a number of metal ions. Ashok et al., (2000) reported that humic acid with hydroxyl, phenoxyl and carboxyl reactive groups can form coordination compound with metal ions at $\mathrm{pH}$ 3.5. The stability constants(Log K) for different metalhumic acid complexes indicated the following order of the stabilities of complexes formed between humic acid and metal ion, $\mathrm{Cu}>\mathrm{Fe}$ $>\mathrm{Pb}>\mathrm{Ni}>\mathrm{Co}>\mathrm{Ca}>\mathrm{Cd}>\mathrm{Zn}>\mathrm{Mn}>\mathrm{Mg}$. Andelkovic et al., (2010) investigated the binding of $\mathrm{Cd}$ (II) to soil humic acid at pH 6.5 and in $0.1 \mathrm{M} \mathrm{KNO}_{3}$ ionic medium. The stability constant for binding indicating greater stability in the case when carboxyl groups are involved in complexation reaction. Kostic et al.,(2012) investigated the complexation of humic acid with certain heavy metal ions (Co(II), $\mathrm{Ni}(\mathrm{II}), \mathrm{Cu}(\mathrm{II})$,
$\mathrm{Zn}(\mathrm{II})$, and $\mathrm{Pb}(\mathrm{II})$. The experiment was performed at $25^{\circ} \mathrm{C}$, at pH 4.0 and ionic strength of $0.01 \mathrm{M}$. Stability constant of complex between $\mathrm{Pb}$ (II) ions and humic acid is greater than stability constants of other investigated metalhumate complexes. Bogata and Sokolowska (2016) analyses the interaction between humic acids from different soils and $\mathrm{Zn}$ (II) ions at wide concentration ranges and at $\mathrm{pH} 5$. Studies have showed significant impact of $\mathrm{Zn}$ concentration, $\mathrm{pH}$ and some properties of humic acids with zinc.But all of these studies were limited to acidic $\mathrm{pH}$ range. Therefore, the present study was carried out to determine and compare the stability constants of complexes of metal ions with hydrolysed peat soil humic acid and unhydrolysed peat soil humic under non-acid conditions.

\section{MATERIALS AND METHODS}

Analytical grade chemicals used includes hydrochloric acid $(\mathrm{HCl})$, nitric acid $\left(\mathrm{HNO}_{3}\right)$, sodium hydroxide $(\mathrm{NaOH})$, lead nitrate $\mathrm{Pb}\left(\mathrm{NO}_{3}\right)_{2}$, copper nitrate $\mathrm{Cu}\left(\mathrm{NO}_{3}\right)_{2} \cdot 3 \mathrm{H}_{2} \mathrm{O}$, cadmium nitrate $\mathrm{Cd}\left(\mathrm{NO}_{3}\right)_{2} \cdot 4 \mathrm{H}_{2} \mathrm{O}$, magnesium nitrate $\mathrm{Mg}\left(\mathrm{NO}_{3}\right)_{2} \cdot 6 \mathrm{H}_{2} \mathrm{O}$, potassium nitrate $\left(\mathrm{KNO}_{3}\right)$, calcium chloride $\left(\mathrm{CaCl}_{2}\right)$, (sigma-Aldrich). Dowex 50WX8, (20-50 mesh) from Fluka. 


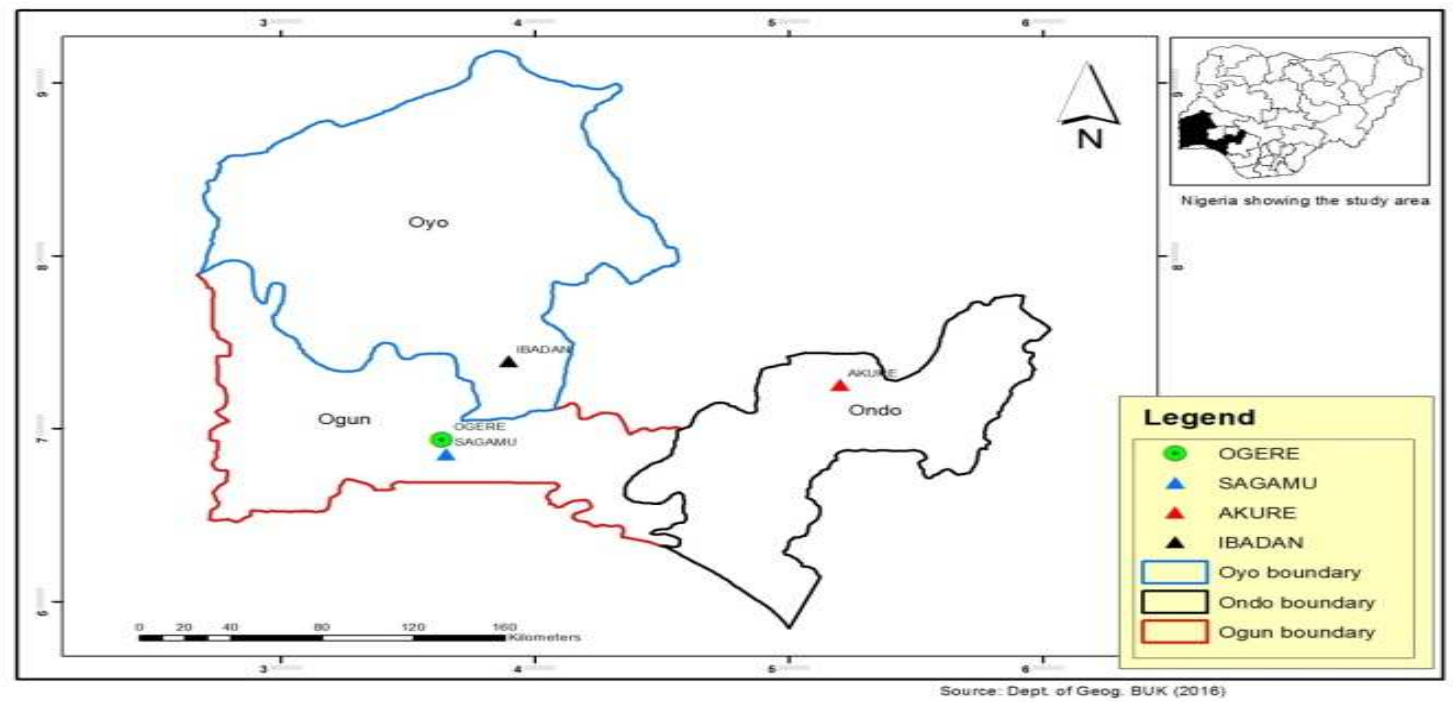

Figure 1: Map showing the sampling point at Sagamu Town, Ogun State.

\section{Description of Sampling Area}

Sagamu has geographical coordinates between $6^{\circ} 50^{\prime}$ north; $3^{\circ} 38^{\prime}$ east is located in south western region of Nigeria. The region has tropical wet and dry climate with a lengthy wet season and relatively constant temperatures throughout the course of the year. Wet season runs from March to October, November to December forms the region dry season. The vegetation type of the region is savannah which is really grassland with small bushes and occasional big trees. Grassland soils have substantially higher organic matter content than forest soils (Novackova, 2011).

\section{Sample Collection}

The Peatsoil samples were collected from four different sampling points $(0-10 \mathrm{~cm}$ depth) in Sagamu into polyethylene bag with plastic spoons. Samples were taken to the laboratory, extraneous materials were removed; the samples were air-dried, crushed and ground to a fine powder in a mortar passed through a $0.20 \mathrm{~mm}$ sieve. The samples were kept for analysis.

\section{Isolation and purification of humic acid from peat soil sample}

Peatsoil sample $(100 \mathrm{~g})$ was mixed with 1000 $\mathrm{cm}^{3}$ of $0.1 \mathrm{M} \mathrm{NaOH}$ solution, shaken for 3hours and left to stand overnight. Dark-coloured supernatant was obtained and decanted from solid residue. The dark-coloured supernatant was acidified to $(\mathrm{pH}=1.0)$ with $6 \mathrm{M} \mathrm{HCl}$ stirred and allowed to stand for 6 hours. Yellowish brown supernatant and dark-brown precipitate were obtained. The yellowish brown supernatant was decanted followed by centrifuge and discarded. The dark-brown precipitate was mixed with $500 \mathrm{~cm}^{3}$ of $0.1 \mathrm{M} \mathrm{NaOH}$ solution followed by passing through dowex resin. The dark-brown solution was acidified to $(\mathrm{pH}=1.0)$ with $6 \mathrm{M} \mathrm{HCl}$ stirred and allowed to stand for 3 hours. The dark-brown precipitate was washed several times with deionized water. The supernatant was treated with $\mathrm{AgNO}_{3}$ solution until no white precipitate observed. The humic acid was transferred to weighed crucible and dried at $60^{\circ} \mathrm{C}$ in an oven for 12 hours. The humic acid was cooled and dried in the desiccator, weighed and recorded. The obtained humic acid was dried again at $60^{\circ} \mathrm{C}$ for additional 6 hours cooled and dried in the desiccator, weighed and recorded constant weight was obtained (Baruah et al., 2015).

\section{FT-IR analysis}

FT-IR spectra of humic acid sample was analysed using Carry 630 FT-IR Agilent Technologies.

Unhydrolysed compost humic acid

The unhydrolysed humic acid was obtained after isolation and purification of compost humic acid and kept for investigation.

\section{Acid hydrolysis of Peatsoil acid}

Peatsoil humic acid sample (1g) was refluxed for 12 hours at $\left(160^{\circ} \mathrm{C}\right)$ with $50 \mathrm{~cm}^{3}$ of $6 \mathrm{M} \mathrm{HCl}$. The mixture was allowed to cool, decanted, and centrifuged after hydrolysis. The insoluble residues were washed with distilled water via centrifugation several times, and the supernatant was treated with $\mathrm{AgNO}_{3}$ solution until no white precipitate was observed. The residue was thoroughly dried over $\mathrm{CaCl}_{2}$ in a desiccator at room temperature (Chefetz et al., 2002). Finally, the obtained hydrolysed humic acid was kept for investigation. 
BAJOPAS Volume 14 Number 1,June, 2021 Potentiometric Titrations

Potentiometric measurements were carried out using a pH-meter Jenway (model 3510) with combine electrode, the sensitivity of the $\mathrm{pH}$ meter is 0.01 units. The $\mathrm{pH}$ meter was switched on half an hour before starting the titration for initial warm up of the instrument. The instrument was calibrated with an aqueous standard buffer solution of $\mathrm{pH} 4.00$ and 10.0 (borate buffer) prepared from a "Qualigens" buffer tablets.

The following sets of solutions were prepared in a $250 \mathrm{~cm}^{3}$ volumetric flask separately for $\mathrm{pH}$ metric titrations.

(i) $5 \mathrm{~cm}^{3} 0.1 \mathrm{M} \mathrm{HCl}+40 \mathrm{~cm}^{3}$ deionized water

(ii) $5 \mathrm{~cm}^{3} 0.1 \mathrm{M} \mathrm{HCl}+39 \mathrm{~cm}^{3}$ deionized water $+1 \mathrm{~cm}^{3} 0.15 \mathrm{gcm}^{-3}$ humic acid

(iii) $5 \mathrm{~cm}^{3} 0.1 \mathrm{M} \mathrm{HCl}+37 \mathrm{~cm}^{3}$ deionized water $+1 \mathrm{~cm}^{3} 0.15 \mathrm{gcm}^{-3}$ humic acid

$$
+2 \mathrm{~cm}^{3} \quad 0.01 \mathrm{M} \mathrm{Cu} \text { (II) }
$$

The solutions were titrated against standardized $0.110 \mathrm{MNaOH}$ separately. The total volume of each mixture was adjusted to $50 \mathrm{~cm}^{3}$ and the ionic strength of the solutions was maintained constant at by adding appropriate amount of stock solution of $1 \mathrm{M} \mathrm{KNO}_{3}$ (Gamal, 2015; Omar and Ali, 2015). A magnetic stirrer was used to achieve thorough mixing of the interacting solutions at $550 \mathrm{rpm}$. The same set of experimental conditions was applied for potentiometric titration of remaining samples.

\section{Evaluation of pKa of Hydrolysed peat soil Humic Acids}

The proton-ligand formation number $\mathrm{n}_{\mathbf{A}}$ were calculated by Irving and Rossotti expression (Omar and Ali, 2015).

$\mathrm{nA}=\mathrm{Y}-\frac{(\mathrm{V} 2-\mathrm{V1})(\mathrm{No}-\mathrm{Eo})}{(\mathrm{VO}+\mathrm{V1}) \mathrm{TCL}}$ 1

Where: $Y$ is number of dissociable proton, $\left(\mathrm{V}_{2^{-}}\right.$ $V_{1}$ ) is the measure of displacement of the ligand curve relative to acid curve, $\mathrm{N}^{\circ}$ and $\mathrm{E}^{\circ}$ are the resultant concentration of alkali solution, free acid solution, $\mathrm{T}_{\mathrm{cL}}{ }^{\circ}$ is the total ligand concentration, $\mathrm{V}^{\circ}$ is the total volume of titration solution, $V_{1}$ is the volume of alkali added to acid solution, $V_{2}$ is the volume of alkali added to acid solution + ligand solution, acid dissociation constants (pKa - values) of ligand were calculated by algebraic method point wise calculation (Tables 1 ). The dissociation constants (pKa) were calculated according to the following relation:

$\mathrm{pKa}=\mathrm{pH}+\log \left(\frac{n A}{1-n A}\right)$ 2

Where: pKa is the acid dissociation constant, $\mathrm{n}_{\mathrm{A}}$ is the Proton-ligand formation number and $\mathrm{pH}$ is the pH-values (Omar and Ali, 2015).

\section{Determination of metal-ligand stability constants $(\log K)$ of complexes}

The potentiometric measurement for the determination of stability constant of a complex in solution is based on the fact that the redox potential of the couple $\frac{M^{+(m-n)}}{M^{+m}}$ is shifted significantly on complexation of the metal ion with the ligand. This method involves change in hydrogen ion concentration $\left[\mathrm{H}^{+}\right]$due to the displacement or association of one or more protons taking place during complexation reaction. This change can be found out by titrating the solutions containing free acid, acid with ligand, and acid with ligand and metal ion, individually against a standard alkali solution at a constant ionic strength or temperature. Either ionic strength or temperature may be varied for different sets of solutions. In all the cases, the change in the $\mathrm{pH}$ of the solution is measured after each addition of a known amount of alkali to the reaction cell which contains the reaction mixture. The titration curves are then drawn by plotting the measured $\mathrm{pH}$ values against the corresponding volume of alkali added and the stability constants of the complexes are determined from the titration curves by employing $\mathrm{pH}$-metric titration technique given by (Irving and Rossoti).

Metal-ligand stability constants ( $\log \mathrm{K}$ ) were determined by using the following relations:

$$
\bar{n}=\frac{\left(V_{3}-V_{2}\right)\left(E^{0}+N^{0}\right)}{\left(V^{0}+V_{2}\right) \bar{n}_{A} T_{m}^{0}}
$$

and

$$
P L=\log _{10}\left\{\frac{1+\beta_{n}^{H} \frac{1}{[\text { anti } \log \mathrm{pH}]^{\mathrm{n}}}}{\mathrm{T}_{\mathrm{L}}^{0}-n \bar{T}_{m}^{0}} \mathrm{X} \frac{\left(V^{0}+V_{3}\right)}{V^{0}}\right\}
$$


BAJOPAS Volume 14 Number 1,June, 2021

Where $T_{L}, T^{\circ}, E^{\circ}$, and $V^{\circ}$ havethe same significance as in equation (1) above, $T_{m}$ denotes the total concentration of metal present in solution, $V_{3}$ is the volume of metal ions present in solution and $\beta^{H}$ is the overall proton ligand stability constant. The metal-ligand stability constants (log K) were determined by employing point wise computational Method (eq. 5 and 6).

$\operatorname{LogK}_{1}=\log \left(\frac{n}{1-n}\right)+\mathrm{pL}$ .5

$\operatorname{LogK}_{2}=\log \left(\frac{1-n}{2-n}\right)+\mathrm{pL}$ ...6

Where: Log $\mathrm{K}$ is the metal-ligand stability constant, $\mathrm{pL}$ is the Free ligand exponent function, $\mathbf{n}$ is the Average number of ligand attached with metal ion (Janraoet al., 2014). The results obtained were analyzed by an ORIGIN 2016 program using titration data and then the proton-ligand stability constants (pKa) and Metal-ligand stability constant (LogK) calculated (Omar and Ali, 2015).

\section{RESULTS AND DISCUSSION}

Fourier transformed infrared (FT-IR) spectra of isolated humic acid from peat soils Figure 2 had distinct clear absorption bands indicating the presence of major humic acid structural elemental groups such as $\mathrm{H}$ bonded $\mathrm{OH}$ $\left(3680 \mathrm{~cm}^{-1}\right.$ peak $), C=0$ of carbonyl $\left(1721 \mathrm{~cm}^{-1}\right.$ peak), functional groups of aliphatic components $\mathrm{CH}_{2}\left(2918 \mathrm{~cm}^{-1}\right.$ peak) and $\mathrm{C}-\mathrm{O}$ stretching of polysaccharide $\left(1168 \mathrm{~cm}^{-1}\right.$ peak). The positions of the absorption bands of the spectra fell within typical major absorption bands of humic acid which is at frequencies 3680, 2918, 1721, 1168 $\mathrm{cm}^{-1}$. The first peak centred in the vicinity of $3680 \mathrm{~cm}^{-1}$ region is attributed to phenol $\mathrm{OH}$ group bounded by intermolecular $\mathrm{H}$ bonds. The $2918 \mathrm{~cm}^{-1}$ band usually has absorption maximum at $2918 \mathrm{~cm}^{-1}$ which is due to $\mathrm{C}-\mathrm{H}$ stretching of alkane group $\left(\mathrm{CH}_{2}\right)$. The next major absorption band is $1721 \mathrm{~cm}^{-1}$. This band has been commonly ascribed to $\mathrm{C}=\mathrm{O}$ stretching of mainly carboxyl group $(\mathrm{COOH})$ with trace amount of ketones. The last peak was observed at 1168 $\mathrm{cm}^{-1}$ due to $\mathrm{C}-\mathrm{O}$ stretching of polysaccharides and this peak appeared also in the spectra of humic acid from peat soil. The FTIR spectra of the isolated humic acid contained all major characteristic absorption peaks of humic acid. These absorption peaks indicated the presence of the major structural elements of humic acid namely $\mathrm{H}$ bonded $\mathrm{OH}, \mathrm{C}=\mathrm{C}$ of aromatic ring, $\mathrm{C}=\mathrm{O}$ of carbonyl group (both carboxyl and ketonic), $\mathrm{CH}_{2}$ group. This strongly supports the presence of humic acid.

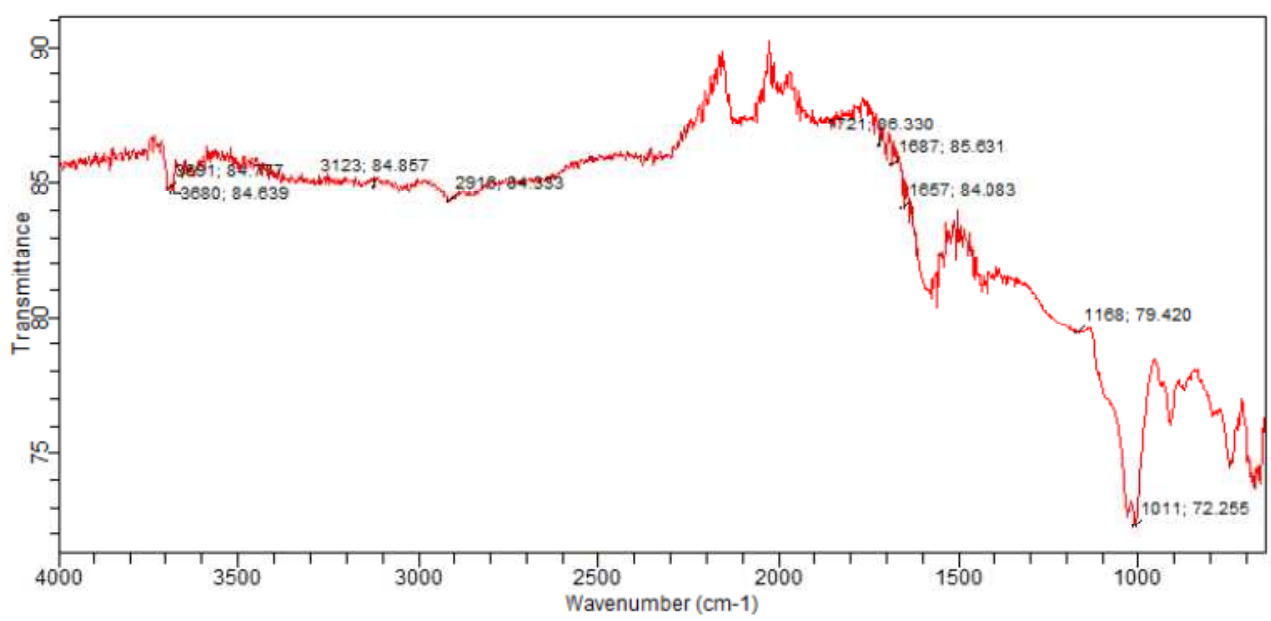

Fig. 2 : FT-IR spectraof peatsoilhumic acid (PSHA)

\section{Evaluation of acid dissociation constant (pka) of acid hydrolysed peat soil humicacid at phenolic group}

The value of the dissociation constant of the peat soil humic acid (PSHA) that underwent acidhydrolysis studied was found to be 8.9299 as shown Table 1, which is lower than the literaturevalues reported by Almeida and Szpoganics, (2015), Borges et al., (2005); Badr et al., (2012)and Fernandes et al,.(2009) of $9.73,9.47$ and 10.30. The difference between the obtained valuesand the reported values in this study might be probably as a result of acid hydrolysis of humicacid. 
BAJOPAS Volume 14 Number 1,June, 2021

Table 1: PKa of (Hydrolysed PSHA)

\begin{tabular}{|l|l|l|l|l|l|l|}
\hline $\mathrm{pH}$ & $\mathrm{BV}_{1}$ & $\mathrm{BV}_{2}$ & $\mathrm{~V}_{2}-\mathrm{V}_{1}$ & $\mathrm{nA}$ & $\log \left(\frac{n A}{1-n A}\right)$ & $\mathrm{pKa}$ \\
\hline 8.50 & 5.30 & 6.29 & 0.99 & 0.3594 & -0.2510 & 8.2490 \\
8.72 & 5.35 & 6.37 & 1.02 & 0.3400 & -0.2880 & 8.4320 \\
9.00 & 5.40 & 6.46 & 1.06 & 0.3141 & -0.3391 & 8.6609 \\
9.22 & 5.45 & 6.55 & 1.10 & 0.2882 & -0.3927 & 8.8273 \\
9.51 & 5.50 & 6.66 & 1.16 & 0.2494 & -0.4786 & 9.0314 \\
9.73 & 5.55 & 6.78 & 1.23 & 0.2041 & -0.5910 & 9.1390 \\
10.00 & 5.60 & 6.90 & 1.30 & 0.1589 & -0.7238 & 9.2762 \\
10.23 & 5.65 & 7.05 & 1.40 & 0.0941 & -0.9835 & 9.2465 \\
10.49 & 5.70 & 7.10 & 1.40 & 0.0941 & -0.9835 & 9.5065 \\
\hline
\end{tabular}

Average pKa $=8.9299 \pm 0.4186$

Table 2: PKa of (Unhydrolysed PSHA)

\begin{tabular}{|l|l|l|l|l|l|l|}
\hline $\mathrm{pH}$ & $\mathrm{BV}_{1}$ & $\mathrm{BV}_{2}$ & $\mathrm{~V}_{2}-\mathrm{V}_{1}$ & $\mathrm{nA}$ & $\log \left(\frac{\boldsymbol{n A}}{1-\boldsymbol{n}}\right)$ & $\mathrm{pKa}$ \\
\hline 8.50 & 5.30 & 5.81 & 0.51 & 0.6619 & 0.2919 & 8.7919 \\
8.72 & 5.35 & 5.90 & 0.55 & 0.6357 & 0.2418 & 8.9618 \\
9.00 & 5.40 & 6.00 & 0.60 & 0.6029 & 0.1813 & 9.1813 \\
9.22 & 5.45 & 6.10 & 0.65 & 0.5701 & 0.1226 & 9.3426 \\
9.51 & 5.50 & 6.20 & 0.70 & 0.5376 & 0.0654 & 9.5754 \\
9.73 & 5.55 & 6.33 & 0.78 & 0.4851 & -0.0259 & 9.7041 \\
10.00 & 5.60 & 6.47 & 0.87 & 0.4262 & -0.1291 & 9.8709 \\
10.23 & 5.65 & 6.62 & 0.99 & 0.3609 & -0.2481 & 9.9819 \\
10.49 & 5.70 & 6.80 & 1.10 & 0.2759 & -0.4690 & 10.0210 \\
\hline
\end{tabular}

Average pKa $=9.4923 \pm 0.4410$

Metal-ligand stability constant ( $\log \mathrm{K}$ )

The stabilityconstants require the accurate values of proton-ligand stability constants (Anil and Maroti, 2008). Metal titration curves crossed over ligand titration curve indicated the formation of complex upon proton release (Santosh, et al., 2011). If the values of n- are within range $0.2-0.8$ and $1.2-18$ this indicates the formation of $1: 1$ and 1:2 complexes (Sayyed and Mazahar, 2012).

The metal (II)-humate stepwise stability constants (log k) at phenolic group (Tables 318)

Table 3: Point-wise method, $\mathrm{Cu}$-(Hydrolysed PSHA)

\begin{tabular}{|l|l|l|l|l|l|l|l|l|}
\hline $\mathrm{pH}$ & $\mathrm{BV}_{1}$ & $\mathrm{BV}_{2}$ & $\mathrm{BV}_{3}$ & $\left(\mathrm{~V}_{3}-\mathrm{V}_{2}\right)$ & $\mathrm{n}$ & $\mathrm{pL}$ & $\log \left(\frac{n}{1-n}\right)$ & LogK $_{1}$ \\
\hline 8.50 & 5.30 & 6.29 & 6.33 & 0.04 & 0.5500 & 2.66 & 0.0871 & 2.7471 \\
8.72 & 5.35 & 6.37 & 6.41 & 0.04 & 0.5714 & 2.43 & 0.1249 & 2.5549 \\
9.00 & 5.40 & 6.46 & 6.50 & 0.04 & 0.6198 & 2.16 & 0.2122 & 2.3722 \\
9.22 & 5.45 & 6.55 & 6.59 & 0.04 & 0.6667 & 1.94 & 0.3010 & 2.2410 \\
\hline
\end{tabular}

LogK $_{1}$ (Average value) $=2.4788 \pm 0.2203$

Table 4: Point-wise method, $\mathrm{Cu}$-(Hydrolysed PSHA)

\begin{tabular}{|l|l|l|l|l|l|l|l|l|}
\hline $\mathrm{pH}$ & $\mathrm{BV}_{1}$ & $\mathrm{BV}_{2}$ & $\mathrm{BV}_{3}$ & $\left(\mathrm{~V}_{3}-\mathrm{V}_{2}\right)$ & $\mathrm{n}$ & $\mathrm{pL}$ & $\log \left(\frac{n-1}{2-n}\right)$ & LogK $_{2}$ \\
\hline 9.51 & 5.50 & 6.66 & 6.73 & 0.07 & 1.3509 & 1.70 & -0.2671 & 1.4329 \\
9.73 & 5.55 & 6.78 & 6.85 & 0.07 & 1.6383 & 1.51 & 0.2467 & 1.7567 \\
10.00 & 5.60 & 6.90 & 6.98 & 0.08 & 2.1783 & 1.31 & -0.2158 & 1.0942 \\
10.23 & 5.65 & 7.05 & 7.13 & 0.08 & 4.1904 & 1.27 & & \\
10.49 & 5.70 & 7.10 & 7.19 & 0.09 & 4.6920 & & & \\
\hline
\end{tabular}

Log $K_{2}($ Average value $)=1.4280 \pm 0.3312$ 
BAJOPAS Volume 14 Number 1,June, 2021

Table 5: Point-wise method, $\mathrm{Cu}$ (Unhydrolysed PSHA)

\begin{tabular}{|l|l|l|l|l|l|l|l|l|}
\hline $\mathrm{pH}$ & $\mathrm{BV}_{1}$ & $\mathrm{BV}_{2}$ & $\mathrm{BV}_{3}$ & $\left(\mathrm{~V}_{3}-\mathrm{V}_{2}\right)$ & $\mathrm{n}$ & $\mathrm{pL}$ & $\log \left(\frac{n}{n-1}\right)$ & Log $_{1}$ \\
\hline 8.50 & 5.30 & 5.81 & 5.85 & 0.04 & 0.2973 & 2.88 & -0.3736 & 2.5064 \\
8.72 & 5.35 & 5.90 & 5.95 & 0.05 & 0.3873 & 2.66 & -0.1992 & 2.4608 \\
9.00 & 5.40 & 6.00 & 6.05 & 0.05 & 0.4044 & 2.38 & -0.1681 & 2.2119 \\
9.22 & 5.45 & 6.10 & 6.15 & 0.06 & 0.5157 & 2.18 & -0.0272 & 2.2072 \\
9.51 & 5.50 & 6.20 & 6.27 & 0.07 & 0.6417 & 1.89 & 0.2530 & 1.1430 \\
\hline
\end{tabular}

$\operatorname{LogK}_{1}($ Average value $)=2.3059 \pm 0.6153$

Table 6:Point-wise method, $\mathrm{Cu}$ (Unhydrolysed PSHA)

\begin{tabular}{|l|l|l|l|l|l|l|l|l|}
\hline $\mathrm{pH}$ & $\mathrm{BV}_{1}$ & $\mathrm{BV}_{2}$ & $\mathrm{BV}_{3}$ & $\mathrm{~V}_{3}-\mathrm{V}_{2}$ & $\mathrm{n}$ & $\mathrm{pL}$ & $\log \left(\frac{n-1}{2-n}\right)$ & $\log \mathrm{K}_{2}$ \\
\hline 9.73 & 5.55 & 6.33 & 6.42 & 0.09 & 0.9000 & 1.69 & & \\
10.00 & 5.60 & 6.47 & 6.58 & 0.11 & 1.2578 & 1.44 & -0.4592 & 0.9808 \\
10.23 & 5.65 & 6.62 & 6.84 & 0.12 & 1.6137 & 1.26 & -0.2010 & 1.4610 \\
10.49 & 5.70 & 6.80 & 6.92 & 0.12 & 2.1052 & 1.03 & & \\
\hline
\end{tabular}

$\operatorname{LogK}_{2}$ (Average value) $=1.2209 \pm 0.3398$

Table 7:Point-wise method, Pb (Hydrolysed PSHA)

\begin{tabular}{|l|l|l|l|l|l|l|l|l|}
\hline $\mathrm{pH}$ & $\mathrm{BV}_{1}$ & $\mathrm{BV}_{2}$ & $\mathrm{BV}_{3}$ & $\left(\mathrm{~V}_{3}-\mathrm{V}_{2}\right)$ & $\mathrm{n}$ & $\mathrm{pL}$ & $\log \left(\frac{n}{1-n}\right)$ & LogK $_{1}$ \\
\hline 8.50 & 5.30 & 6.29 & 6.33 & 0.04 & 0.5500 & 2.66 & 0.0871 & 2.7471 \\
8.72 & 5.35 & 6.37 & 6.41 & 0.04 & 0.5714 & 2.43 & 0.1249 & 2.5549 \\
9.00 & 5.40 & 6.46 & 6.50 & 0.04 & 0.6198 & 2.16 & 0.2122 & 2.3722 \\
9.22 & 5.45 & 6.55 & 6.60 & 0.05 & 0.8333 & 1.96 & 0.6989 & 2.6589 \\
\hline
\end{tabular}

Log $_{\mathbf{1}}($ Average value $)=2.5832 \pm 0.1614$

Table 8:Point-wise method, Pb-(Hydrolysed PSHA)

\begin{tabular}{|l|l|l|l|l|l|l|l|l|}
\hline $\mathrm{pH}$ & $\mathrm{BV}_{1}$ & $\mathrm{BV}_{2}$ & $\mathrm{BV}_{3}$ & $\left(\mathrm{~V}_{3}-\mathrm{V}_{2}\right)$ & $\mathrm{n}$ & $\mathrm{pL}$ & $\log \left(\frac{n-1}{2-n}\right)$ & $\log \mathrm{K}_{2}$ \\
\hline 9.51 & 5.50 & 6.66 & 6.71 & 0.05 & 0.9650 & 1.67 & & \\
9.73 & 5.55 & 6.78 & 6.83 & 0.05 & 1.1702 & 1.44 & & \\
10.00 & 5.60 & 6.90 & 6.90 & 0.05 & 1.4864 & 1.22 & -0.0237 & 1.1963 \\
10.23 & 5.65 & 7.05 & 7.10 & 0.05 & 2.0190 & 1.09 & & \\
10.49 & 5.70 & 7.10 & 7.17 & 0.07 & 3.6492 & 1.00 & & \\
\hline
\end{tabular}

Log $K_{2}$ (Average value) $=1.1963$

Table 9: Point-wise method, Pb (Unhydrolysed PSHA)

\begin{tabular}{|l|l|l|l|l|l|l|l|l|}
\hline $\mathrm{pH}$ & $\mathrm{BV}_{1}$ & $\mathrm{BV}_{2}$ & $\mathrm{BV}_{3}$ & $\mathrm{~V}_{3}-\mathrm{V}_{2}$ & $\mathrm{n}$ & $\mathrm{pL}$ & $\begin{array}{l}\text { Log } \\
\left(\frac{n}{n-1}\right)\end{array}$ & Log $\mathrm{K}_{1}$ \\
\hline 8.50 & 5.30 & 5.81 & 5.85 & 0.04 & 0.2973 & 2.88 & -0.3736 & 2.5064 \\
8.72 & 5.35 & 5.90 & 5.94 & 0.04 & 0.3099 & 2.66 & -0.5477 & 2.3123 \\
9.00 & 5.40 & 6.00 & 6.05 & 0.05 & 0.4044 & 2.38 & -0.1681 & 2.2119 \\
9.22 & 5.45 & 6.10 & 6.15 & 0.06 & 0.5157 & 2.18 & 0.0272 & 2.2072 \\
9.51 & 5.50 & 6.20 & 6.26 & 0.07 & 0.6417 & 1.89 & 0.2530 & 2.1430 \\
9.73 & 5.55 & 6.40 & 6.40 & 0.07 & 0.7000 & 1.67 & 0.3680 & 2.0380 \\
\hline
\end{tabular}

LogK $_{1}$ (Average value) $=2.2364 \pm 0.1602$

Table 10: Point-wise method, Pb (Unhydrolysed PSHA)

\begin{tabular}{|l|l|l|l|l|l|l|l|l|}
\hline $\mathrm{pH}$ & $\mathrm{BV}_{1}$ & $\mathrm{BV}_{2}$ & $\mathrm{BV}_{3}$ & $\mathrm{~V}_{3}-\mathrm{V}_{2}$ & $\mathrm{n}$ & $\mathrm{pL}$ & $\log \left(\frac{n-1}{2-n}\right)$ & $\log \mathrm{K}_{2}$ \\
\hline 10.00 & 5.60 & 6.47 & 6.55 & 0.08 & 1.9503 & 1.41 & & \\
10.23 & 5.65 & 6.62 & 6.72 & 0.11 & 1.4792 & 1.26 & -0.0361 & 1.2239 \\
\hline
\end{tabular}

$\operatorname{LogK}_{2}$ (Average value) $=1.2239$

Table 11: Point-wise method, Mg (Hydrolysed PSHA)

\begin{tabular}{|l|l|l|l|l|l|l|l|l|}
\hline $\mathrm{pH}$ & $\mathrm{BV}_{1}$ & $\mathrm{BV}_{2}$ & $\mathrm{BV}_{3}$ & $\left(\mathrm{~V}_{3}-\mathrm{V}_{2}\right)$ & $\mathrm{n}$ & $\mathrm{pL}$ & $\log \left(\frac{n}{n-1}\right)$ & LogK $_{1}$ \\
\hline 8.50 & 5.30 & 6.29 & 6.31 & 0.02 & 0.2750 & 2.64 & -0.4290 & 2.2110 \\
8.72 & 5.35 & 6.37 & 6.39 & 0.02 & 0.2858 & 2.42 & -0.3978 & 2.0222 \\
9.00 & 5.40 & 6.46 & 6.49 & 0.03 & 0.4648 & 2.14 & -0.0612 & 2.0788 \\
9.22 & 5.45 & 6.55 & 6.59 & 0.04 & 0.6667 & 1.94 & 0.3010 & 2.2410 \\
\hline
\end{tabular}

$\log _{\mathbf{1}}($ Average value) $=2.1382 \pm 0.1046$ 
BAJOPAS Volume 14 Number 1,June, 2021

Table 12: Point-wise method, Mg (Hydrolysed PSHA)

\begin{tabular}{|l|l|l|l|l|l|l|l|l|}
\hline $\mathrm{pH}$ & $\mathrm{BV}_{1}$ & $\mathrm{BV}_{2}$ & $\mathrm{BV}_{3}$ & $\left(\mathrm{~V}_{3}-\mathrm{V}_{2}\right)$ & $\mathrm{n}$ & $\mathrm{pL}$ & $\log \left(\frac{n-1}{2-n}\right)$ & LogK $_{2}$ \\
\hline 9.51 & 5.55 & 6.66 & 6.71 & 0.05 & 0.9650 & 1.67 & & \\
9.73 & 5.55 & 6.78 & 6.84 & 0.06 & 1.4042 & 1.47 & -0.1686 & 1.3014 \\
10.00 & 5.60 & 6.90 & 6.93 & 0.06 & 1.7838 & 1.23 & 0.5593 & 1.7893 \\
10.23 & 5.65 & 7.05 & 7.10 & 0.06 & 3.1429 & 1.10 & & \\
10.49 & 5.70 & 7.10 & 7.18 & 0.07 & 3.6492 & 0.83 & & \\
\hline
\end{tabular}

LogK $_{2}($ Average value $)=1.5453 \pm 0.3450$

Table 13: Point-wise method, Mg (Unhydrolysed PSHA)

\begin{tabular}{|l|l|l|l|l|l|l|l|l|}
\hline $\mathrm{pH}$ & $\mathrm{BV}_{1}$ & $\mathrm{BV}_{2}$ & $\mathrm{BV}_{3}$ & $\mathrm{~V}_{3}-\mathrm{V}_{2}$ & $\mathrm{n}$ & $\mathrm{pL}$ & $\log \left(\frac{n}{n-1}\right)$ & $\operatorname{Log~}_{1}$ \\
\hline 8.50 & 5.30 & 5.81 & 5.85 & 0.04 & 0.2973 & 2.88 & -0.3736 & 2.5064 \\
8.72 & 5.35 & 5.90 & 5.94 & 0.04 & 0.3099 & 2.66 & -0.3477 & 2.3123 \\
9.00 & 5.40 & 6.00 & 6.04 & 0.04 & 0.3236 & 2.38 & -0.3202 & 2.0598 \\
9.22 & 5.45 & 6.10 & 6.15 & 0.05 & 0.4297 & 2.17 & -0.1230 & 2.0470 \\
9.51 & 5.50 & 6.20 & 6.26 & 0.06 & 0.5500 & 1.89 & 0.0871 & 1.9771 \\
9.73 & 5.55 & 6.33 & 6.40 & 0.07 & 0.7000 & 1.67 & 0.3680 & 2.0380 \\
\hline
\end{tabular}

LogK $_{1}$ (Average value) $=2.1568 \pm 0.2069$

Table 14: Point-wise method, Mg (Unhydrolysed PSHA)

\begin{tabular}{|l|l|l|l|l|l|l|l|l|}
\hline $\mathrm{pH}$ & $\mathrm{BV}_{1}$ & $\mathrm{BV}_{2}$ & $\mathrm{BV}_{3}$ & $\mathrm{~V}_{3}-\mathrm{V}_{2}$ & $\mathrm{n}$ & $\mathrm{pL}$ & $\log \left(\frac{n-1}{2-n}\right)$ & $\log \mathrm{K}_{2}$ \\
\hline 10.00 & 5.60 & 6.47 & 6.55 & 0.08 & 0.9148 & 1.41 & & \\
10.23 & 5.65 & 6.62 & 6.71 & 0.09 & 1.2102 & 1.20 & -0.5749 & 0.6251 \\
10.49 & 5.70 & 6.80 & 6.92 & 0.09 & 1.5968 & 1.03 & 0.1703 & 1.2003 \\
\hline
\end{tabular}

LogK $_{2}$ (Average value) $=0.9127 \pm 0.4070$

Table15:Point-wise method, Cd (Hydrolysed PSHA)

\begin{tabular}{|l|l|l|l|l|l|l|l|l|}
\hline $\mathrm{pH}$ & $\mathrm{BV}_{1}$ & $\mathrm{BV}_{2}$ & $\mathrm{BV}_{3}$ & $\left(\mathrm{~V}_{3}-\mathrm{V}_{2}\right)$ & $\mathrm{n}$ & $\mathrm{pL}$ & $\log \left(\frac{n}{1-n}\right)$ & LogK $_{1}$ \\
\hline 8.50 & 5.30 & 6.29 & 6.31 & 0.02 & 0.2750 & 2.64 & -0.4210 & 2.2190 \\
8.72 & 5.35 & 6.37 & 6.40 & 0.03 & 0.4286 & 2.42 & -0.1249 & 2.2951 \\
9.00 & 5.40 & 6.46 & 6.49 & 0.03 & 0.4648 & 2.14 & -0.0612 & 2.0788 \\
9.22 & 5.45 & 6.55 & 6.59 & 0.04 & 0.6667 & 1.96 & 0.3010 & 2.2610 \\
9.51 & 5.55 & 6.66 & 6.70 & 0.04 & 0.7720 & 1.67 & 0.5297 & 2.1997 \\
\hline
\end{tabular}

LogK $_{\mathbf{1}}$ (Average value) $=2.2108 \pm 0.0825$

Table 16: Point-wise method, Cd (Hydrolysed PSHA)

\begin{tabular}{|l|l|l|l|l|l|l|l|l|}
\hline $\mathrm{pH}$ & $\mathrm{BV}_{1}$ & $\mathrm{BV}_{2}$ & $\mathrm{BV}_{3}$ & $\left(\mathrm{~V}_{3}-\mathrm{V}_{2}\right)$ & $\mathrm{n}$ & $\mathrm{pL}$ & $\log \left(\frac{n-1}{2-n}\right)$ & Log $_{2}$ \\
\hline 9.73 & 5.55 & 6.78 & 6.83 & 0.06 & 1.4042 & 1.47 & -0.1686 & 1.3014 \\
10.00 & 5.60 & 6.90 & 6.95 & 0.06 & 1.7838 & 1.23 & 0.5593 & 1.7893 \\
10.23 & 5.65 & 7.05 & 7.10 & 0.06 & 3.1429 & 1.09 & & \\
10.49 & 5.70 & 7.10 & 7.16 & 0.06 & 3.1429 & 0.89 & & \\
& & & & & & & & \\
\hline
\end{tabular}

$\operatorname{LogK}_{2}$ (Average value) $=1.5453 \pm 0.3450$

Table 17: Point-wise method, Cd (Unhydrolysed PSHA)

\begin{tabular}{|l|l|l|l|l|l|l|l|l|}
\hline $\mathrm{pH}$ & $\mathrm{BV}_{1}$ & $\mathrm{BV}_{2}$ & $\mathrm{BV}_{3}$ & $\mathrm{~V}_{3}-\mathrm{V}_{2}$ & $\mathrm{n}$ & $\mathrm{pL}$ & $\log \left(\frac{n}{n-1}\right)$ & $\operatorname{Log~}_{1}$ \\
\hline 8.50 & 5.30 & 5.81 & 5.86 & 0.05 & 0.3717 & 2.88 & -0.2280 & 2.6520 \\
8.72 & 5.35 & 5.90 & 5.95 & 0.05 & 0.3873 & 2.66 & -0.1992 & 2.4608 \\
9.00 & 5.40 & 6.00 & 6.06 & 0.06 & 0.4853 & 2.38 & -0.0255 & 2.3545 \\
9.22 & 5.45 & 6.10 & 6.16 & 0.06 & 0.5157 & 2.18 & -0.0272 & 2.2072 \\
9.51 & 5.50 & 6.20 & 6.27 & 0.07 & 0.6417 & 1.89 & 0.2530 & 1.1430 \\
9.73 & 5.55 & 6.33 & 6.41 & 0.08 & 0.8000 & 1.69 & 0.6020 & 2.2920 \\
& & & & & & & & \\
\hline
\end{tabular}

$\operatorname{LogK}_{1}($ Average value $)=2.2516 \pm 0.5380$ 
BAJOPAS Volume 14 Number 1,June, 2021

Table 18: Point-wise method, Cd (Unhydrolysed PSHA)

\begin{tabular}{|l|l|l|l|l|l|l|l|l|}
\hline $\mathrm{pH}$ & $\mathrm{BV}_{1}$ & $\mathrm{BV}_{2}$ & $\mathrm{BV}_{3}$ & $\mathrm{~V}_{3}-\mathrm{V}_{2}$ & $\mathrm{n}$ & $\mathrm{pL}$ & $\log \left(\frac{n-1}{2-n}\right)$ & $\log \mathrm{K}_{2}$ \\
\hline 10.00 & 5.60 & 6.47 & 6.57 & 0.10 & 1.1434 & 1.43 & & \\
10.23 & 5.65 & 6.62 & 6.72 & 0.10 & 1.3448 & 1.23 & -0.2788 & 0.9512 \\
10.49 & 5.70 & 6.80 & 6.90 & 0.10 & 1.7742 & 1.03 & 0.5351 & 1.5651 \\
\hline
\end{tabular}

$\operatorname{LogK}_{2}($ Average value $)=1.2581 \pm 0.4340$

Table 19: Stepwise and overall Stability constants of thehydrolysed and unhydrolysed divalent metal (II) complexes

\begin{tabular}{|c|c|c|c|}
\hline Chelates & LogK $_{1}$ & $\log _{2}$ & Log $\beta$ \\
\hline [Cu (Hydrolysed PSHA-1) $\left.{ }_{2}\right]$ & 2.4788 & 1.4280 & 3.9068 \\
\hline$\left[\mathrm{Pb}(\text { Hydrolysed PSHA-1) })_{2}\right]$ & 2.5832 & 1.1963 & 3.7795 \\
\hline$\left[\mathrm{Cd}(\text { Hydrolysed PSHA-1 })_{2}\right]$ & 2.2108 & 1.5453 & 3.7561 \\
\hline$\left[\mathrm{Mg}(\text { Hydrolysed PSHA-1 })_{2}\right]$ & 2.1382 & 1.5453 & 3.6835 \\
\hline [Cu (Unhydrolysed PSHA-1) & 2.3059 & 1.2209 & 3.5268 \\
\hline$[\mathrm{Pb}$ (Unhydrolysed PSHA-1) 2$]$ & 2.2364 & 1.2239 & 3.4603 \\
\hline [Cd (Unhydrolysed PSHA-1) 2 ] & 2.2516 & 1.2581 & 3.5097 \\
\hline$[\mathrm{Mg}$ (Unydrolysed PSHA-1) & 2.1568 & 0.9127 & 3.0695 \\
\hline
\end{tabular}

The results obtained (Table19) shows the stepwise and overall stability constants to be not high indicating low stability of the complexes, because the solubility of most metal ions in the basic $\mathrm{pH}$ range is minimal due to metal hydroxide precipitation (Karimi, 2017). In general, the stepwise stability constants $\left(K_{1}\right.$ and $K_{2}$ ) follow the order $K_{1}>K_{2}$ for the copper, lead, magnesium and cadmium complexes respectively. The steady decrease of the values with increasing number of ligands is in agreement with the prediction made by researchers (Na'aliya, 2013). The decrease could be attributed to the fact that as the number of the ligands (Humate ions) that enters the coordination zone increases the aqua molecules available for replacement by the ligands become less. Thus, the metal ions become less electron loving with progressive intake of the ligand and this results in the decrease in the values of the constants (Na'aliya, 2013). Also the stability of the complexes is influenced by the size and number of the chelate rings(Mackay and Mackay,2002).All the complexes form rings in their structure as humate, a bidentate ligand, bond the metal ions in the ratio 1:2 (Boguta and Sokolowska, 2016) forming chelate rings. The values of the overall stability constants $(\log \beta)$ obtained for humate complexes are not high indicating low stability as the values are not high. LogK values for copper-humates (Table 3 to 6) obtained in this study are lower than those reported for the complexes of humic acids (Pandey et al., 2015; Dinu, 2013; Kaschl et al., 2010 and Gilbeto and Jorg, 2001). The values of LogK(Table 7 to 10 ) forlead-humates are lower than those reported for the lead in the literature (Dinu, 2013; Gilbeto and Jorg 2001). Log K values(Table 11 to 14 ) for magnesium-humates obtained in this study are close to those reported by (Pandey et al., 2015). Log K values of cadmium-humates (Table 15 to 18 ) obtained in this work near to the one reported by (Dinu, 2013 and Pandey et al., 2015).The difference between the reported values and the values obtained in this study might be probably as a result of acid hydrolysis of humic acid. The values of the overall stability constants $(\log \beta)$ of the copper humates complexes presented in Table 19 is high than that of other metal humate complexes, show relatively high stability of CuHA complexes, show the following order of stability: $\mathrm{Cu}>\mathrm{Pb}>\mathrm{Cd}>\mathrm{Mg}$; which are in close agreement to the findings of (Dinu, 2013 and Pandey et al., 2015).The high stability of Cuhumate chelate could be attributed to the existence of coordinate covalent bond between the complexing agents and the $\mathrm{Cu}^{2+}$ ions. Since, $\mathrm{Cu}^{2+}$ being a metal of the transitional series with $3 d^{9}$ electronic configurations can accept the electrons from the complexing agents. Similarly, the low stabilities of $\mathrm{Pb}, \mathrm{Cd}$ and $\mathrm{Mg}$ complexes could be explained by that $\mathrm{Pb}^{2+}$ with $6 s^{2}, \mathrm{Cd}^{2+}$ with $4 \mathrm{~d}^{10}$ and $\mathrm{Mg}^{2+}$ with $2 \mathrm{p}^{6}$ their electronic configuration has a completely filled $\mathrm{d}, \mathrm{p}$ and $\mathrm{s}$ orbitals. Moreover, the stabilities of metal ions with hydrolysed humic acid from peat soil were higher than those with unhydrolysed humic acid from peat soil; which is ascribed to the high content of acidity in hydrolysed humic acid than unhydrolysed humic acid. 
BAJOPAS Volume 14 Number 1,June, 2021 CONCLUSION

The values of logk for $\mathrm{Cu}(\mathrm{II})$ hydrolysed humic acid complex was higher followed by $\mathrm{Pb}$ (II), $\mathrm{Cd}(\mathrm{II})$ and $\mathrm{Mg}$ (II) hydrolysed humic acid complexes as compared with metal(II) unhydrolysed humic acid complexes. This indicates acid hydrolysis of humic acid can

\section{REFERENCES}

Almeida, V.R. and Szpoganicz, B. (2015). Humic Acid Potentiometric Response Patterns:Out- of Equilibrium Properties and Species Distribution Modelling. Chemical. Biol. Technol. Agric. 2: 17.

Anđelković, T., Nikolić, R., Bojić, A.,Anđelković, D., and Nikolic G.,(2010). Binding of Cadmium to Soil Humic Acid as A Function of Carboxyl Group Content. Macedonian Journal of Chemistry and Chemical Engineering.29(2): 215-224.

Anil, B. N. and Maroti, N. (2008). Studies on Influence of Die-Lectric Constants on Complex Equilibria between Substituted Py-Razalines and Lanthanide Metal Ions pH-Metrically. Amer.-Euras. scient. Res. 3(2): 212-216.

Ashok, K., Pandey, S. P. and Misra, V (2000). Stability Constants of Metal-Humic Acid Complexes and its Role in Environmental Detoxification. Journal of Ecotoxicology and Environmental Safety. 47(2):157-200.

Badr, M. H., El-Halafawi, M. H. and Abd El-al Zeid, E. R. (2012). Comparison Between the Effect of Ionic Strength on Acidity and Dissociation Constants of Humic Acids Extracted from Sewage Sludge and Nile Water Hyacinth Composts.Global Journal of Environmental Research 6 (1): 36-43.

Baruah, M.K., Borah, D., Saikia, P.P., Paul, S., Sharma, T. (2015). Evaluation of pKa Values of Soil Humic Acids and their Complexation Properties. International Journal of Plant \& Soil Science 6(4) : 218-228.

Boguta, P. Sokolowska, Z. (2016). Interactions of $\mathrm{Zn}$ (II) Ions with Humic Acids Isolated from Various Types of Soils. Effect of $\mathrm{pH}, \mathrm{Zn}$ Concentrations and Humic Acids Chemical Properties. Journal of Geochemical Explaration 168. 119-126.

Borges, F., Guimaraes, C., Lima, L.F.C., Pinto, I. and Reis, S.(2005). Potentiometric Studies on the Complexation of Copper(II) by Phenolic Acids as Discrete Ligand Models of enhance the complexation behavior of humic acid with metal (II) ions. However, the higher values of $\log \beta$ for $\mathrm{Cu}(\mathrm{II}), \mathrm{Pb}(\mathrm{II}), \mathrm{Cd}(\mathrm{II})$ and $\mathrm{Mg}(\mathrm{II})$ hydrolysed humic acid complexes indicates more stable stepwise complexes formed as compared with $\mathrm{Cu}(\mathrm{II}), \mathrm{Pb}$ (II), $\mathrm{Cd}$ (II) and $\mathrm{Mg}(\mathrm{II})$ unhydrolysed humic acid complexes.

Humic Substances Talanta 66 (2005) 670-673.

Chefetz, B., Salloum, M. J., Deshmulkin, A. P. and Hatcher, P. (2002). Structural Components of Humic Acids as Determined by Chemical Modifications and Carbon-13 NMR, Pyrolysis, and Thermochemolysis- Gas Chromatography/Mass Spectrometry. Soil Science Society of American Journal Abstract Division S-2- Soil Chemistry66. 1159-1171.

Dinu, M. I. (2013). Metals Complexation with Humic Acids in Surface Water of Different Environ. Sci. Technol. 31(1): 1-17.

Fernandes, A.N., Giacomelli, C., Giovanela, M. Vaz, D.V. Szpoganicz, B. and Maria M. D. (2009). Potentiometric Acidity Determination in Humic Substances Influenced by Different Analytical Procedures.J. Braz. Chem. Soc. 20 (9):14.

Gamal, A. H. (2015). Stability Constants of Rhenium (V) Metal Complexes with Selected Drugs. Pyrex Journal of Research in Environmental Studies. 2(2): 006-014.

Janrao, D. M., Pathan, J., Kayande, D.D., and Mulla, J.J. (2014). An Over View of Potentiometric Determination of Stability Constants of Metal Complexes. Sci. Revs. Chem. Commun.: 4(1), 2014, 11-24.

Karimi, H. (2017). Effect of pH and Initial Pb(II) Concentration on the Lead Removal Efficiency from Waste Water Using $\mathrm{Ca}(\mathrm{OH})_{2}$. International Journal of Water and Waste Water Treatment 3.2

Kaschl, A. Romheld, V. and Chen, Y. (2010). Binding of Cadmium, Copper and Zinc to Humic Substances Originating from Municipal Solid Waste Compost. Israel Journal of Chemistry Vol. 42(1): 89-98.

Kostic, I. S., Tatjana, P, A., Nikolic, R. S., Cvetkovic, T. P., Pavlovic, D. D., Aleksandar, L.J. and Bojic, A. (2012). Comparative Study of Binding Strengths of Heavy Metals with Humic Acid. J.serb. Chem. Soc. 76(9) pp 1-20. 
BAJOPAS Volume 14 Number 1,June, 2021

Na'aliya, J. (2013). Determination of Stepwise Stability Constants and Gibbs free Energy Change of Trisprolina to Complexes of some Divalent Transition Metal ions. Bayero Journal of Pure and Applied Sciences 6(2): 112-114.

Omar, A. A. and Ali, E. A. (2015). Potentiometric Studies on Complexes of $\mathrm{Cr}$ (III) and $\mathrm{Zr}$ (IV) with some Carboxylic Acids. International Journal of Advanced Chemistry, 3(1) 25-

37.

Pandey, A. K. Pandey, S. D. and Misr, V. (2015).Stability Constants of Metal- Humic Acid Complexes and Its Role in Environmental Detoxification. J. Ecotoxicology and Environmental Safety. 47(1):195-200.

Ram, N. and Raman, K.V. (1984). Stability Constants of Complexes of Metals with
Humicand Fuvic Acids under Non- acidConditions. Journal of Plant Nutrition and Soil Sciences.

147:171-176.

Santosh, D. D., Ashok, B. K., Vijay, J. T., Shivraj, G. W. and Vinay, V. W. (2011). Potentiometric Studies of Elec-Trolyte Effects on Complex Equilibria of Some Substituted 5-(2-hydroxy Phenyl) Pyrazoles. Der pharm. 3 (6): 75-83.

Sayyed, H. and Abdul Rahim, M. F. (2012). Studies of Binary Complexes of Metal Ions with Mandelic Acid by Potentiometry. Chem. J. 02 (6): 206209.

Shirvani, M. Moradian, E. Khalili, B. Bakhtiary, S. (2015). Interaction of $\mathrm{Cd}$ and $\mathrm{Pb}$ with Humate-Palygorskite and HumateSepiolite Complexes. Journal of water, air and pollution 3: 220-228. 


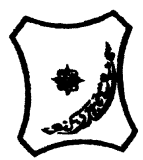

Bayero Journal of Pure and Applied Sciences, 14(1): 54 - 63

Received: November, 2020

Accepted: April, 2021

ISSN $2006-6996$

\title{
STABILITY CONSTANTS OF COMPLEXES OF METAL IONS WITH PEATSOIL HUMIC ACIDS UNDER NON-ACID-CONDITIONS
}

\author{
${ }^{* 1}$ Sabo, Yusuf ${ }^{2}$ Jimoh, W.L.O., ${ }^{3}$ Isa Baba Koki and ${ }^{4}$ Sholadoye, Q. 0. \\ ${ }^{1}$ Department of Pure and Industrial Chemistry, Bayero University, Kano \\ ${ }^{3}$ Department of Chemistry, Yusuf Maitama Sule University Kano. P.M.B. 3220 Kano, Nigeria. \\ ${ }^{4}$ Department of Chemistry, Nigerian Police Academy, Wudil, Kano-Nigeria
}

*Correspondence E-mail; saboyusuf18@yahoo.com

ABSTRACT

Stability constants of complexes of four divalent metal ions viz. $\mathrm{Cu}^{2+}, \mathrm{Pb}^{2+}, \mathrm{Mg}^{2+}$ and $\mathrm{Cd}^{2+}$ with humic acids (HA) were determined by potentiometric titration of humic acids with the corresponding salt of the divalent metals in aqueous media under non-acid-condition. The log $K$ (logarithm of the stability constant) ranged from 1.0942 to 2.7471 for metalhumic acid complexes were determined using point-wise computational method. The order of stability constants were obtained as follows: $\mathrm{Cu}>\mathrm{Pb}>\mathrm{Cd}>\mathrm{Mg}$ for metal $-\mathrm{HA}$ complexes respectively, indicating a higher degree of complexation with Cu metal ion.

Keywords: stability constant, humic acid, potentiometric titration, divalent metals, acid hydrolysis.

\section{NTRODUCTION}

The stability constant of a complex is the numerical expression of its stability and provides a quantitative measure of affinity of the metal ion to the complexing agent. An understanding of the relative stability of metal-complexes helps in predicting the behavior of metal ions in the soil (Ram and Raman, 1982). Extensive researches has been done to determine the stability constants of the complexes formed between humic acid (HA) with a number of metal ions. Ashok et al., (2000) reported that humic acid with hydroxyl, phenoxyl and carboxyl reactive groups can form coordination compound with metal ions at $\mathrm{pH}$ 3.5. The stability constants(Log K) for different metalhumic acid complexes indicated the following order of the stabilities of complexes formed between humic acid and metal ion, $\mathrm{Cu}>\mathrm{Fe}$ $>\mathrm{Pb}>\mathrm{Ni}>\mathrm{Co}>\mathrm{Ca}>\mathrm{Cd}>\mathrm{Zn}>\mathrm{Mn}>\mathrm{Mg}$. Andelkovic et al., (2010) investigated the binding of $\mathrm{Cd}$ (II) to soil humic acid at pH 6.5 and in $0.1 \mathrm{M} \mathrm{KNO}_{3}$ ionic medium. The stability constant for binding indicating greater stability in the case when carboxyl groups are involved in complexation reaction. Kostic et al.,(2012) investigated the complexation of humic acid with certain heavy metal ions (Co(II), $\mathrm{Ni}(\mathrm{II}), \mathrm{Cu}(\mathrm{II})$,
$\mathrm{Zn}(\mathrm{II})$, and $\mathrm{Pb}(\mathrm{II})$. The experiment was performed at $25^{\circ} \mathrm{C}$, at pH 4.0 and ionic strength of $0.01 \mathrm{M}$. Stability constant of complex between $\mathrm{Pb}$ (II) ions and humic acid is greater than stability constants of other investigated metalhumate complexes. Bogata and Sokolowska (2016) analyses the interaction between humic acids from different soils and $\mathrm{Zn}$ (II) ions at wide concentration ranges and at $\mathrm{pH} 5$. Studies have showed significant impact of $\mathrm{Zn}$ concentration, $\mathrm{pH}$ and some properties of humic acids with zinc.But all of these studies were limited to acidic $\mathrm{pH}$ range. Therefore, the present study was carried out to determine and compare the stability constants of complexes of metal ions with hydrolysed peat soil humic acid and unhydrolysed peat soil humic under non-acid conditions.

\section{MATERIALS AND METHODS}

Analytical grade chemicals used includes hydrochloric acid $(\mathrm{HCl})$, nitric acid $\left(\mathrm{HNO}_{3}\right)$, sodium hydroxide $(\mathrm{NaOH})$, lead nitrate $\mathrm{Pb}\left(\mathrm{NO}_{3}\right)_{2}$, copper nitrate $\mathrm{Cu}\left(\mathrm{NO}_{3}\right)_{2} \cdot 3 \mathrm{H}_{2} \mathrm{O}$, cadmium nitrate $\mathrm{Cd}\left(\mathrm{NO}_{3}\right)_{2} \cdot 4 \mathrm{H}_{2} \mathrm{O}$, magnesium nitrate $\mathrm{Mg}\left(\mathrm{NO}_{3}\right)_{2} \cdot 6 \mathrm{H}_{2} \mathrm{O}$, potassium nitrate $\left(\mathrm{KNO}_{3}\right)$, calcium chloride $\left(\mathrm{CaCl}_{2}\right)$, (sigma-Aldrich). Dowex 50WX8, (20-50 mesh) from Fluka. 


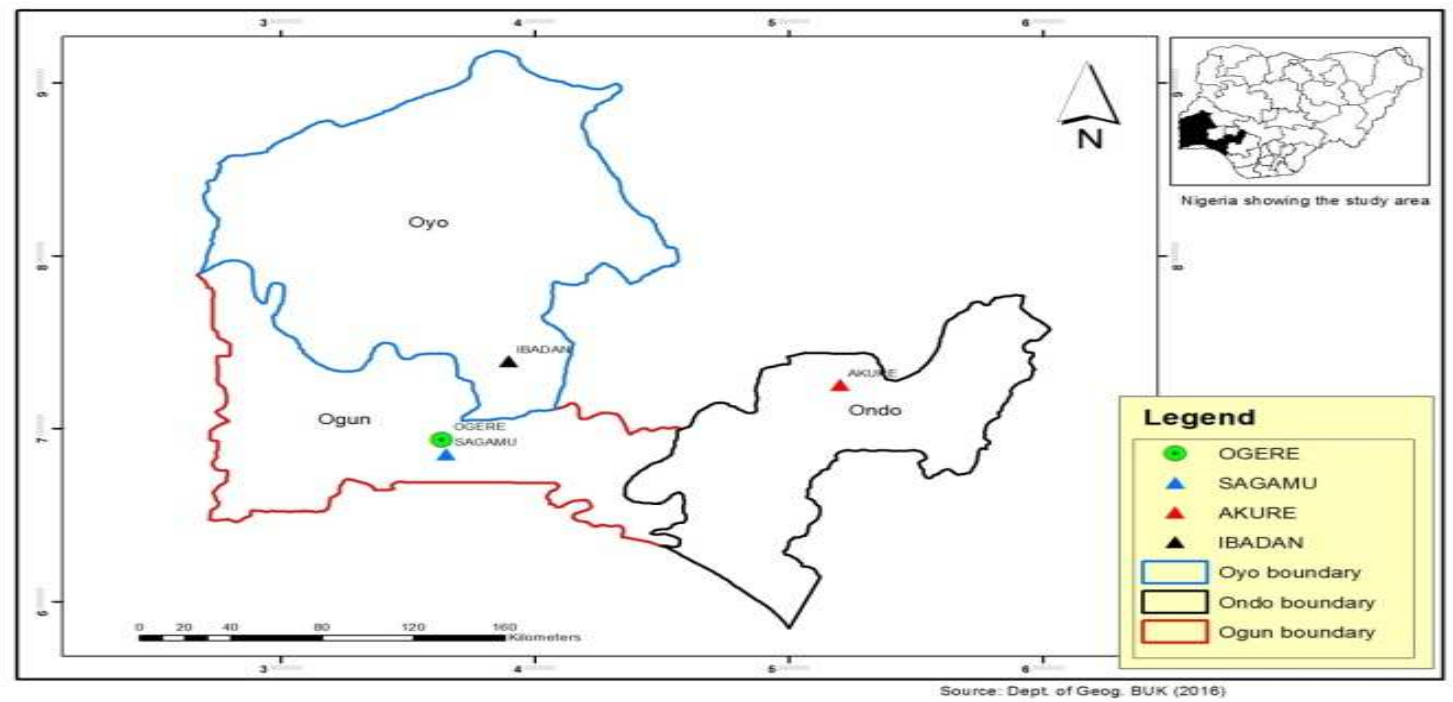

Figure 1: Map showing the sampling point at Sagamu Town, Ogun State.

\section{Description of Sampling Area}

Sagamu has geographical coordinates between $6^{\circ} 50^{\prime}$ north; $3^{\circ} 38^{\prime}$ east is located in south western region of Nigeria. The region has tropical wet and dry climate with a lengthy wet season and relatively constant temperatures throughout the course of the year. Wet season runs from March to October, November to December forms the region dry season. The vegetation type of the region is savannah which is really grassland with small bushes and occasional big trees. Grassland soils have substantially higher organic matter content than forest soils (Novackova, 2011).

\section{Sample Collection}

The Peatsoil samples were collected from four different sampling points $(0-10 \mathrm{~cm}$ depth) in Sagamu into polyethylene bag with plastic spoons. Samples were taken to the laboratory, extraneous materials were removed; the samples were air-dried, crushed and ground to a fine powder in a mortar passed through a $0.20 \mathrm{~mm}$ sieve. The samples were kept for analysis.

\section{Isolation and purification of humic acid from peat soil sample}

Peatsoil sample $(100 \mathrm{~g})$ was mixed with 1000 $\mathrm{cm}^{3}$ of $0.1 \mathrm{M} \mathrm{NaOH}$ solution, shaken for 3hours and left to stand overnight. Dark-coloured supernatant was obtained and decanted from solid residue. The dark-coloured supernatant was acidified to $(\mathrm{pH}=1.0)$ with $6 \mathrm{M} \mathrm{HCl}$ stirred and allowed to stand for 6 hours. Yellowish brown supernatant and dark-brown precipitate were obtained. The yellowish brown supernatant was decanted followed by centrifuge and discarded. The dark-brown precipitate was mixed with $500 \mathrm{~cm}^{3}$ of $0.1 \mathrm{M} \mathrm{NaOH}$ solution followed by passing through dowex resin. The dark-brown solution was acidified to $(\mathrm{pH}=1.0)$ with $6 \mathrm{M} \mathrm{HCl}$ stirred and allowed to stand for 3 hours. The dark-brown precipitate was washed several times with deionized water. The supernatant was treated with $\mathrm{AgNO}_{3}$ solution until no white precipitate observed. The humic acid was transferred to weighed crucible and dried at $60^{\circ} \mathrm{C}$ in an oven for 12 hours. The humic acid was cooled and dried in the desiccator, weighed and recorded. The obtained humic acid was dried again at $60^{\circ} \mathrm{C}$ for additional 6 hours cooled and dried in the desiccator, weighed and recorded constant weight was obtained (Baruah et al., 2015).

\section{FT-IR analysis}

FT-IR spectra of humic acid sample was analysed using Carry 630 FT-IR Agilent Technologies.

Unhydrolysed compost humic acid

The unhydrolysed humic acid was obtained after isolation and purification of compost humic acid and kept for investigation.

\section{Acid hydrolysis of Peatsoil acid}

Peatsoil humic acid sample (1g) was refluxed for 12 hours at $\left(160^{\circ} \mathrm{C}\right)$ with $50 \mathrm{~cm}^{3}$ of $6 \mathrm{M} \mathrm{HCl}$. The mixture was allowed to cool, decanted, and centrifuged after hydrolysis. The insoluble residues were washed with distilled water via centrifugation several times, and the supernatant was treated with $\mathrm{AgNO}_{3}$ solution until no white precipitate was observed. The residue was thoroughly dried over $\mathrm{CaCl}_{2}$ in a desiccator at room temperature (Chefetz et al., 2002). Finally, the obtained hydrolysed humic acid was kept for investigation. 
BAJOPAS Volume 14 Number 1,June, 2021 Potentiometric Titrations

Potentiometric measurements were carried out using a pH-meter Jenway (model 3510) with combine electrode, the sensitivity of the $\mathrm{pH}$ meter is 0.01 units. The $\mathrm{pH}$ meter was switched on half an hour before starting the titration for initial warm up of the instrument. The instrument was calibrated with an aqueous standard buffer solution of $\mathrm{pH} 4.00$ and 10.0 (borate buffer) prepared from a "Qualigens" buffer tablets.

The following sets of solutions were prepared in a $250 \mathrm{~cm}^{3}$ volumetric flask separately for $\mathrm{pH}$ metric titrations.

(i) $5 \mathrm{~cm}^{3} 0.1 \mathrm{M} \mathrm{HCl}+40 \mathrm{~cm}^{3}$ deionized water

(ii) $5 \mathrm{~cm}^{3} 0.1 \mathrm{M} \mathrm{HCl}+39 \mathrm{~cm}^{3}$ deionized water $+1 \mathrm{~cm}^{3} 0.15 \mathrm{gcm}^{-3}$ humic acid

(iii) $5 \mathrm{~cm}^{3} 0.1 \mathrm{M} \mathrm{HCl}+37 \mathrm{~cm}^{3}$ deionized water $+1 \mathrm{~cm}^{3} 0.15 \mathrm{gcm}^{-3}$ humic acid

$$
+2 \mathrm{~cm}^{3} \quad 0.01 \mathrm{M} \mathrm{Cu} \text { (II) }
$$

The solutions were titrated against standardized $0.110 \mathrm{MNaOH}$ separately. The total volume of each mixture was adjusted to $50 \mathrm{~cm}^{3}$ and the ionic strength of the solutions was maintained constant at by adding appropriate amount of stock solution of $1 \mathrm{M} \mathrm{KNO}_{3}$ (Gamal, 2015; Omar and Ali, 2015). A magnetic stirrer was used to achieve thorough mixing of the interacting solutions at $550 \mathrm{rpm}$. The same set of experimental conditions was applied for potentiometric titration of remaining samples.

\section{Evaluation of pKa of Hydrolysed peat soil Humic Acids}

The proton-ligand formation number $\mathrm{n}_{\mathbf{A}}$ were calculated by Irving and Rossotti expression (Omar and Ali, 2015).

$\mathrm{nA}=\mathrm{Y}-\frac{(\mathrm{V} 2-\mathrm{V1})(\mathrm{No}-\mathrm{Eo})}{(\mathrm{VO}+\mathrm{V1}) \mathrm{TCL}}$ 1

Where: $Y$ is number of dissociable proton, $\left(\mathrm{V}_{2^{-}}\right.$ $V_{1}$ ) is the measure of displacement of the ligand curve relative to acid curve, $\mathrm{N}^{\circ}$ and $\mathrm{E}^{\circ}$ are the resultant concentration of alkali solution, free acid solution, $\mathrm{T}_{\mathrm{cL}}{ }^{\circ}$ is the total ligand concentration, $\mathrm{V}^{\circ}$ is the total volume of titration solution, $V_{1}$ is the volume of alkali added to acid solution, $V_{2}$ is the volume of alkali added to acid solution + ligand solution, acid dissociation constants (pKa - values) of ligand were calculated by algebraic method point wise calculation (Tables 1 ). The dissociation constants (pKa) were calculated according to the following relation:

$\mathrm{pKa}=\mathrm{pH}+\log \left(\frac{n A}{1-n A}\right)$ 2

Where: pKa is the acid dissociation constant, $\mathrm{n}_{\mathrm{A}}$ is the Proton-ligand formation number and $\mathrm{pH}$ is the pH-values (Omar and Ali, 2015).

\section{Determination of metal-ligand stability constants $(\log K)$ of complexes}

The potentiometric measurement for the determination of stability constant of a complex in solution is based on the fact that the redox potential of the couple $\frac{M^{+(m-n)}}{M^{+m}}$ is shifted significantly on complexation of the metal ion with the ligand. This method involves change in hydrogen ion concentration $\left[\mathrm{H}^{+}\right]$due to the displacement or association of one or more protons taking place during complexation reaction. This change can be found out by titrating the solutions containing free acid, acid with ligand, and acid with ligand and metal ion, individually against a standard alkali solution at a constant ionic strength or temperature. Either ionic strength or temperature may be varied for different sets of solutions. In all the cases, the change in the $\mathrm{pH}$ of the solution is measured after each addition of a known amount of alkali to the reaction cell which contains the reaction mixture. The titration curves are then drawn by plotting the measured $\mathrm{pH}$ values against the corresponding volume of alkali added and the stability constants of the complexes are determined from the titration curves by employing $\mathrm{pH}$-metric titration technique given by (Irving and Rossoti).

Metal-ligand stability constants ( $\log \mathrm{K}$ ) were determined by using the following relations:

$$
\bar{n}=\frac{\left(V_{3}-V_{2}\right)\left(E^{0}+N^{0}\right)}{\left(V^{0}+V_{2}\right) \bar{n}_{A} T_{m}^{0}}
$$

and

$$
P L=\log _{10}\left\{\frac{1+\beta_{n}^{H} \frac{1}{[\text { anti } \log \mathrm{pH}]^{\mathrm{n}}}}{\mathrm{T}_{\mathrm{L}}^{0}-n \bar{T}_{m}^{0}} \mathrm{X} \frac{\left(V^{0}+V_{3}\right)}{V^{0}}\right\}
$$


BAJOPAS Volume 14 Number 1,June, 2021

Where $T_{L}, T^{\circ}, E^{\circ}$, and $V^{\circ}$ havethe same significance as in equation (1) above, $T_{m}$ denotes the total concentration of metal present in solution, $V_{3}$ is the volume of metal ions present in solution and $\beta^{H}$ is the overall proton ligand stability constant. The metal-ligand stability constants (log K) were determined by employing point wise computational Method (eq. 5 and 6).

$\operatorname{LogK}_{1}=\log \left(\frac{n}{1-n}\right)+\mathrm{pL}$ .5

$\operatorname{LogK}_{2}=\log \left(\frac{1-n}{2-n}\right)+\mathrm{pL}$ ...6

Where: Log $\mathrm{K}$ is the metal-ligand stability constant, $\mathrm{pL}$ is the Free ligand exponent function, $\mathbf{n}$ is the Average number of ligand attached with metal ion (Janraoet al., 2014). The results obtained were analyzed by an ORIGIN 2016 program using titration data and then the proton-ligand stability constants (pKa) and Metal-ligand stability constant (LogK) calculated (Omar and Ali, 2015).

\section{RESULTS AND DISCUSSION}

Fourier transformed infrared (FT-IR) spectra of isolated humic acid from peat soils Figure 2 had distinct clear absorption bands indicating the presence of major humic acid structural elemental groups such as $\mathrm{H}$ bonded $\mathrm{OH}$ $\left(3680 \mathrm{~cm}^{-1}\right.$ peak $), C=0$ of carbonyl $\left(1721 \mathrm{~cm}^{-1}\right.$ peak), functional groups of aliphatic components $\mathrm{CH}_{2}\left(2918 \mathrm{~cm}^{-1}\right.$ peak) and $\mathrm{C}-\mathrm{O}$ stretching of polysaccharide $\left(1168 \mathrm{~cm}^{-1}\right.$ peak). The positions of the absorption bands of the spectra fell within typical major absorption bands of humic acid which is at frequencies 3680, 2918, 1721, 1168 $\mathrm{cm}^{-1}$. The first peak centred in the vicinity of $3680 \mathrm{~cm}^{-1}$ region is attributed to phenol $\mathrm{OH}$ group bounded by intermolecular $\mathrm{H}$ bonds. The $2918 \mathrm{~cm}^{-1}$ band usually has absorption maximum at $2918 \mathrm{~cm}^{-1}$ which is due to $\mathrm{C}-\mathrm{H}$ stretching of alkane group $\left(\mathrm{CH}_{2}\right)$. The next major absorption band is $1721 \mathrm{~cm}^{-1}$. This band has been commonly ascribed to $\mathrm{C}=\mathrm{O}$ stretching of mainly carboxyl group $(\mathrm{COOH})$ with trace amount of ketones. The last peak was observed at 1168 $\mathrm{cm}^{-1}$ due to $\mathrm{C}-\mathrm{O}$ stretching of polysaccharides and this peak appeared also in the spectra of humic acid from peat soil. The FTIR spectra of the isolated humic acid contained all major characteristic absorption peaks of humic acid. These absorption peaks indicated the presence of the major structural elements of humic acid namely $\mathrm{H}$ bonded $\mathrm{OH}, \mathrm{C}=\mathrm{C}$ of aromatic ring, $\mathrm{C}=\mathrm{O}$ of carbonyl group (both carboxyl and ketonic), $\mathrm{CH}_{2}$ group. This strongly supports the presence of humic acid.

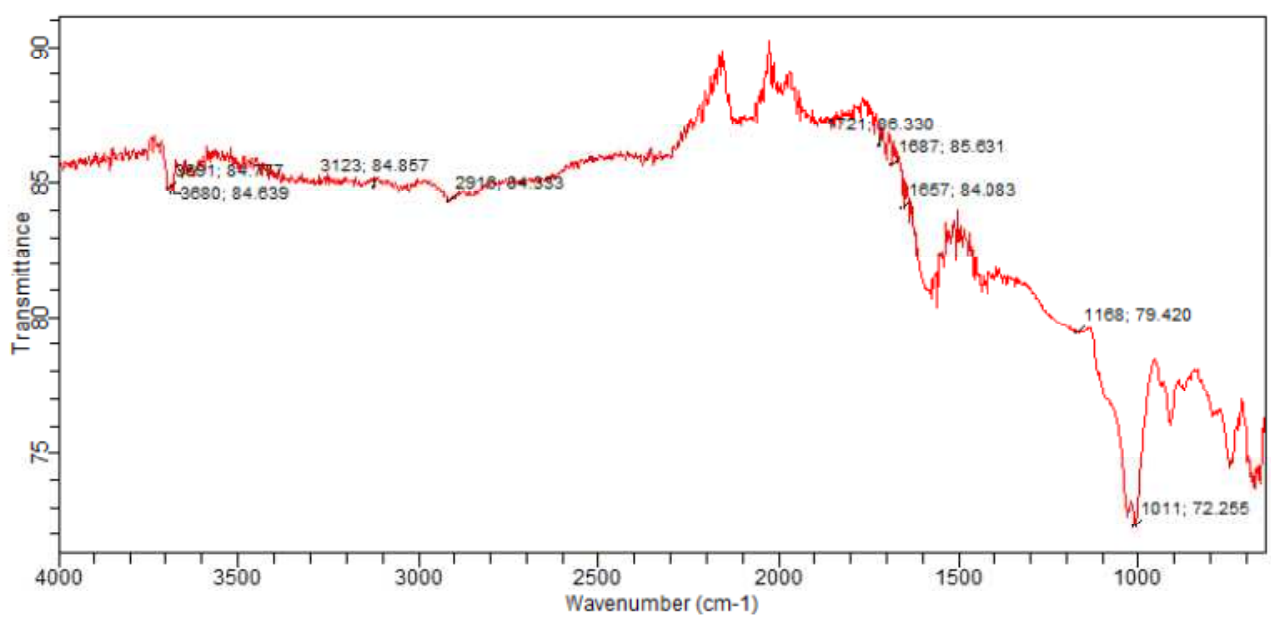

Fig. 2 : FT-IR spectraof peatsoilhumic acid (PSHA)

\section{Evaluation of acid dissociation constant (pka) of acid hydrolysed peat soil humicacid at phenolic group}

The value of the dissociation constant of the peat soil humic acid (PSHA) that underwent acidhydrolysis studied was found to be 8.9299 as shown Table 1, which is lower than the literaturevalues reported by Almeida and Szpoganics, (2015), Borges et al., (2005); Badr et al., (2012)and Fernandes et al,.(2009) of $9.73,9.47$ and 10.30. The difference between the obtained valuesand the reported values in this study might be probably as a result of acid hydrolysis of humicacid. 
BAJOPAS Volume 14 Number 1,June, 2021

Table 1: PKa of (Hydrolysed PSHA)

\begin{tabular}{|l|l|l|l|l|l|l|}
\hline $\mathrm{pH}$ & $\mathrm{BV}_{1}$ & $\mathrm{BV}_{2}$ & $\mathrm{~V}_{2}-\mathrm{V}_{1}$ & $\mathrm{nA}$ & $\log \left(\frac{n A}{1-n A}\right)$ & $\mathrm{pKa}$ \\
\hline 8.50 & 5.30 & 6.29 & 0.99 & 0.3594 & -0.2510 & 8.2490 \\
8.72 & 5.35 & 6.37 & 1.02 & 0.3400 & -0.2880 & 8.4320 \\
9.00 & 5.40 & 6.46 & 1.06 & 0.3141 & -0.3391 & 8.6609 \\
9.22 & 5.45 & 6.55 & 1.10 & 0.2882 & -0.3927 & 8.8273 \\
9.51 & 5.50 & 6.66 & 1.16 & 0.2494 & -0.4786 & 9.0314 \\
9.73 & 5.55 & 6.78 & 1.23 & 0.2041 & -0.5910 & 9.1390 \\
10.00 & 5.60 & 6.90 & 1.30 & 0.1589 & -0.7238 & 9.2762 \\
10.23 & 5.65 & 7.05 & 1.40 & 0.0941 & -0.9835 & 9.2465 \\
10.49 & 5.70 & 7.10 & 1.40 & 0.0941 & -0.9835 & 9.5065 \\
\hline
\end{tabular}

Average pKa $=8.9299 \pm 0.4186$

Table 2: PKa of (Unhydrolysed PSHA)

\begin{tabular}{|l|l|l|l|l|l|l|}
\hline $\mathrm{pH}$ & $\mathrm{BV}_{1}$ & $\mathrm{BV}_{2}$ & $\mathrm{~V}_{2}-\mathrm{V}_{1}$ & $\mathrm{nA}$ & $\log \left(\frac{\boldsymbol{n A}}{1-\boldsymbol{n}}\right)$ & $\mathrm{pKa}$ \\
\hline 8.50 & 5.30 & 5.81 & 0.51 & 0.6619 & 0.2919 & 8.7919 \\
8.72 & 5.35 & 5.90 & 0.55 & 0.6357 & 0.2418 & 8.9618 \\
9.00 & 5.40 & 6.00 & 0.60 & 0.6029 & 0.1813 & 9.1813 \\
9.22 & 5.45 & 6.10 & 0.65 & 0.5701 & 0.1226 & 9.3426 \\
9.51 & 5.50 & 6.20 & 0.70 & 0.5376 & 0.0654 & 9.5754 \\
9.73 & 5.55 & 6.33 & 0.78 & 0.4851 & -0.0259 & 9.7041 \\
10.00 & 5.60 & 6.47 & 0.87 & 0.4262 & -0.1291 & 9.8709 \\
10.23 & 5.65 & 6.62 & 0.99 & 0.3609 & -0.2481 & 9.9819 \\
10.49 & 5.70 & 6.80 & 1.10 & 0.2759 & -0.4690 & 10.0210 \\
\hline
\end{tabular}

Average pKa $=9.4923 \pm 0.4410$

Metal-ligand stability constant ( $\log \mathrm{K}$ )

The stabilityconstants require the accurate values of proton-ligand stability constants (Anil and Maroti, 2008). Metal titration curves crossed over ligand titration curve indicated the formation of complex upon proton release (Santosh, et al., 2011). If the values of n- are within range $0.2-0.8$ and $1.2-18$ this indicates the formation of $1: 1$ and 1:2 complexes (Sayyed and Mazahar, 2012).

The metal (II)-humate stepwise stability constants (log k) at phenolic group (Tables 318)

Table 3: Point-wise method, $\mathrm{Cu}$-(Hydrolysed PSHA)

\begin{tabular}{|l|l|l|l|l|l|l|l|l|}
\hline $\mathrm{pH}$ & $\mathrm{BV}_{1}$ & $\mathrm{BV}_{2}$ & $\mathrm{BV}_{3}$ & $\left(\mathrm{~V}_{3}-\mathrm{V}_{2}\right)$ & $\mathrm{n}$ & $\mathrm{pL}$ & $\log \left(\frac{n}{1-n}\right)$ & LogK $_{1}$ \\
\hline 8.50 & 5.30 & 6.29 & 6.33 & 0.04 & 0.5500 & 2.66 & 0.0871 & 2.7471 \\
8.72 & 5.35 & 6.37 & 6.41 & 0.04 & 0.5714 & 2.43 & 0.1249 & 2.5549 \\
9.00 & 5.40 & 6.46 & 6.50 & 0.04 & 0.6198 & 2.16 & 0.2122 & 2.3722 \\
9.22 & 5.45 & 6.55 & 6.59 & 0.04 & 0.6667 & 1.94 & 0.3010 & 2.2410 \\
\hline
\end{tabular}

LogK $_{1}$ (Average value) $=2.4788 \pm 0.2203$

Table 4: Point-wise method, $\mathrm{Cu}$-(Hydrolysed PSHA)

\begin{tabular}{|l|l|l|l|l|l|l|l|l|}
\hline $\mathrm{pH}$ & $\mathrm{BV}_{1}$ & $\mathrm{BV}_{2}$ & $\mathrm{BV}_{3}$ & $\left(\mathrm{~V}_{3}-\mathrm{V}_{2}\right)$ & $\mathrm{n}$ & $\mathrm{pL}$ & $\log \left(\frac{n-1}{2-n}\right)$ & LogK $_{2}$ \\
\hline 9.51 & 5.50 & 6.66 & 6.73 & 0.07 & 1.3509 & 1.70 & -0.2671 & 1.4329 \\
9.73 & 5.55 & 6.78 & 6.85 & 0.07 & 1.6383 & 1.51 & 0.2467 & 1.7567 \\
10.00 & 5.60 & 6.90 & 6.98 & 0.08 & 2.1783 & 1.31 & -0.2158 & 1.0942 \\
10.23 & 5.65 & 7.05 & 7.13 & 0.08 & 4.1904 & 1.27 & & \\
10.49 & 5.70 & 7.10 & 7.19 & 0.09 & 4.6920 & & & \\
\hline
\end{tabular}

Log $K_{2}($ Average value $)=1.4280 \pm 0.3312$ 
BAJOPAS Volume 14 Number 1,June, 2021

Table 5: Point-wise method, $\mathrm{Cu}$ (Unhydrolysed PSHA)

\begin{tabular}{|l|l|l|l|l|l|l|l|l|}
\hline $\mathrm{pH}$ & $\mathrm{BV}_{1}$ & $\mathrm{BV}_{2}$ & $\mathrm{BV}_{3}$ & $\left(\mathrm{~V}_{3}-\mathrm{V}_{2}\right)$ & $\mathrm{n}$ & $\mathrm{pL}$ & $\log \left(\frac{n}{n-1}\right)$ & Log $_{1}$ \\
\hline 8.50 & 5.30 & 5.81 & 5.85 & 0.04 & 0.2973 & 2.88 & -0.3736 & 2.5064 \\
8.72 & 5.35 & 5.90 & 5.95 & 0.05 & 0.3873 & 2.66 & -0.1992 & 2.4608 \\
9.00 & 5.40 & 6.00 & 6.05 & 0.05 & 0.4044 & 2.38 & -0.1681 & 2.2119 \\
9.22 & 5.45 & 6.10 & 6.15 & 0.06 & 0.5157 & 2.18 & -0.0272 & 2.2072 \\
9.51 & 5.50 & 6.20 & 6.27 & 0.07 & 0.6417 & 1.89 & 0.2530 & 1.1430 \\
\hline
\end{tabular}

$\operatorname{LogK}_{1}($ Average value $)=2.3059 \pm 0.6153$

Table 6:Point-wise method, $\mathrm{Cu}$ (Unhydrolysed PSHA)

\begin{tabular}{|l|l|l|l|l|l|l|l|l|}
\hline $\mathrm{pH}$ & $\mathrm{BV}_{1}$ & $\mathrm{BV}_{2}$ & $\mathrm{BV}_{3}$ & $\mathrm{~V}_{3}-\mathrm{V}_{2}$ & $\mathrm{n}$ & $\mathrm{pL}$ & $\log \left(\frac{n-1}{2-n}\right)$ & $\log \mathrm{K}_{2}$ \\
\hline 9.73 & 5.55 & 6.33 & 6.42 & 0.09 & 0.9000 & 1.69 & & \\
10.00 & 5.60 & 6.47 & 6.58 & 0.11 & 1.2578 & 1.44 & -0.4592 & 0.9808 \\
10.23 & 5.65 & 6.62 & 6.84 & 0.12 & 1.6137 & 1.26 & -0.2010 & 1.4610 \\
10.49 & 5.70 & 6.80 & 6.92 & 0.12 & 2.1052 & 1.03 & & \\
\hline
\end{tabular}

$\operatorname{LogK}_{2}$ (Average value) $=1.2209 \pm 0.3398$

Table 7:Point-wise method, Pb (Hydrolysed PSHA)

\begin{tabular}{|l|l|l|l|l|l|l|l|l|}
\hline $\mathrm{pH}$ & $\mathrm{BV}_{1}$ & $\mathrm{BV}_{2}$ & $\mathrm{BV}_{3}$ & $\left(\mathrm{~V}_{3}-\mathrm{V}_{2}\right)$ & $\mathrm{n}$ & $\mathrm{pL}$ & $\log \left(\frac{n}{1-n}\right)$ & LogK $_{1}$ \\
\hline 8.50 & 5.30 & 6.29 & 6.33 & 0.04 & 0.5500 & 2.66 & 0.0871 & 2.7471 \\
8.72 & 5.35 & 6.37 & 6.41 & 0.04 & 0.5714 & 2.43 & 0.1249 & 2.5549 \\
9.00 & 5.40 & 6.46 & 6.50 & 0.04 & 0.6198 & 2.16 & 0.2122 & 2.3722 \\
9.22 & 5.45 & 6.55 & 6.60 & 0.05 & 0.8333 & 1.96 & 0.6989 & 2.6589 \\
\hline
\end{tabular}

Log $_{\mathbf{1}}($ Average value $)=2.5832 \pm 0.1614$

Table 8:Point-wise method, Pb-(Hydrolysed PSHA)

\begin{tabular}{|l|l|l|l|l|l|l|l|l|}
\hline $\mathrm{pH}$ & $\mathrm{BV}_{1}$ & $\mathrm{BV}_{2}$ & $\mathrm{BV}_{3}$ & $\left(\mathrm{~V}_{3}-\mathrm{V}_{2}\right)$ & $\mathrm{n}$ & $\mathrm{pL}$ & $\log \left(\frac{n-1}{2-n}\right)$ & $\log \mathrm{K}_{2}$ \\
\hline 9.51 & 5.50 & 6.66 & 6.71 & 0.05 & 0.9650 & 1.67 & & \\
9.73 & 5.55 & 6.78 & 6.83 & 0.05 & 1.1702 & 1.44 & & \\
10.00 & 5.60 & 6.90 & 6.90 & 0.05 & 1.4864 & 1.22 & -0.0237 & 1.1963 \\
10.23 & 5.65 & 7.05 & 7.10 & 0.05 & 2.0190 & 1.09 & & \\
10.49 & 5.70 & 7.10 & 7.17 & 0.07 & 3.6492 & 1.00 & & \\
\hline
\end{tabular}

Log $K_{2}$ (Average value) $=1.1963$

Table 9: Point-wise method, Pb (Unhydrolysed PSHA)

\begin{tabular}{|l|l|l|l|l|l|l|l|l|}
\hline $\mathrm{pH}$ & $\mathrm{BV}_{1}$ & $\mathrm{BV}_{2}$ & $\mathrm{BV}_{3}$ & $\mathrm{~V}_{3}-\mathrm{V}_{2}$ & $\mathrm{n}$ & $\mathrm{pL}$ & $\begin{array}{l}\text { Log } \\
\left(\frac{n}{n-1}\right)\end{array}$ & Log $\mathrm{K}_{1}$ \\
\hline 8.50 & 5.30 & 5.81 & 5.85 & 0.04 & 0.2973 & 2.88 & -0.3736 & 2.5064 \\
8.72 & 5.35 & 5.90 & 5.94 & 0.04 & 0.3099 & 2.66 & -0.5477 & 2.3123 \\
9.00 & 5.40 & 6.00 & 6.05 & 0.05 & 0.4044 & 2.38 & -0.1681 & 2.2119 \\
9.22 & 5.45 & 6.10 & 6.15 & 0.06 & 0.5157 & 2.18 & 0.0272 & 2.2072 \\
9.51 & 5.50 & 6.20 & 6.26 & 0.07 & 0.6417 & 1.89 & 0.2530 & 2.1430 \\
9.73 & 5.55 & 6.40 & 6.40 & 0.07 & 0.7000 & 1.67 & 0.3680 & 2.0380 \\
\hline
\end{tabular}

LogK $_{1}$ (Average value) $=2.2364 \pm 0.1602$

Table 10: Point-wise method, Pb (Unhydrolysed PSHA)

\begin{tabular}{|l|l|l|l|l|l|l|l|l|}
\hline $\mathrm{pH}$ & $\mathrm{BV}_{1}$ & $\mathrm{BV}_{2}$ & $\mathrm{BV}_{3}$ & $\mathrm{~V}_{3}-\mathrm{V}_{2}$ & $\mathrm{n}$ & $\mathrm{pL}$ & $\log \left(\frac{n-1}{2-n}\right)$ & $\log \mathrm{K}_{2}$ \\
\hline 10.00 & 5.60 & 6.47 & 6.55 & 0.08 & 1.9503 & 1.41 & & \\
10.23 & 5.65 & 6.62 & 6.72 & 0.11 & 1.4792 & 1.26 & -0.0361 & 1.2239 \\
\hline
\end{tabular}

$\operatorname{LogK}_{2}$ (Average value) $=1.2239$

Table 11: Point-wise method, Mg (Hydrolysed PSHA)

\begin{tabular}{|l|l|l|l|l|l|l|l|l|}
\hline $\mathrm{pH}$ & $\mathrm{BV}_{1}$ & $\mathrm{BV}_{2}$ & $\mathrm{BV}_{3}$ & $\left(\mathrm{~V}_{3}-\mathrm{V}_{2}\right)$ & $\mathrm{n}$ & $\mathrm{pL}$ & $\log \left(\frac{n}{n-1}\right)$ & LogK $_{1}$ \\
\hline 8.50 & 5.30 & 6.29 & 6.31 & 0.02 & 0.2750 & 2.64 & -0.4290 & 2.2110 \\
8.72 & 5.35 & 6.37 & 6.39 & 0.02 & 0.2858 & 2.42 & -0.3978 & 2.0222 \\
9.00 & 5.40 & 6.46 & 6.49 & 0.03 & 0.4648 & 2.14 & -0.0612 & 2.0788 \\
9.22 & 5.45 & 6.55 & 6.59 & 0.04 & 0.6667 & 1.94 & 0.3010 & 2.2410 \\
\hline
\end{tabular}

$\log _{\mathbf{1}}($ Average value) $=2.1382 \pm 0.1046$ 
BAJOPAS Volume 14 Number 1,June, 2021

Table 12: Point-wise method, Mg (Hydrolysed PSHA)

\begin{tabular}{|l|l|l|l|l|l|l|l|l|}
\hline $\mathrm{pH}$ & $\mathrm{BV}_{1}$ & $\mathrm{BV}_{2}$ & $\mathrm{BV}_{3}$ & $\left(\mathrm{~V}_{3}-\mathrm{V}_{2}\right)$ & $\mathrm{n}$ & $\mathrm{pL}$ & $\log \left(\frac{n-1}{2-n}\right)$ & LogK $_{2}$ \\
\hline 9.51 & 5.55 & 6.66 & 6.71 & 0.05 & 0.9650 & 1.67 & & \\
9.73 & 5.55 & 6.78 & 6.84 & 0.06 & 1.4042 & 1.47 & -0.1686 & 1.3014 \\
10.00 & 5.60 & 6.90 & 6.93 & 0.06 & 1.7838 & 1.23 & 0.5593 & 1.7893 \\
10.23 & 5.65 & 7.05 & 7.10 & 0.06 & 3.1429 & 1.10 & & \\
10.49 & 5.70 & 7.10 & 7.18 & 0.07 & 3.6492 & 0.83 & & \\
\hline
\end{tabular}

LogK $_{2}($ Average value $)=1.5453 \pm 0.3450$

Table 13: Point-wise method, Mg (Unhydrolysed PSHA)

\begin{tabular}{|l|l|l|l|l|l|l|l|l|}
\hline $\mathrm{pH}$ & $\mathrm{BV}_{1}$ & $\mathrm{BV}_{2}$ & $\mathrm{BV}_{3}$ & $\mathrm{~V}_{3}-\mathrm{V}_{2}$ & $\mathrm{n}$ & $\mathrm{pL}$ & $\log \left(\frac{n}{n-1}\right)$ & $\operatorname{Log~}_{1}$ \\
\hline 8.50 & 5.30 & 5.81 & 5.85 & 0.04 & 0.2973 & 2.88 & -0.3736 & 2.5064 \\
8.72 & 5.35 & 5.90 & 5.94 & 0.04 & 0.3099 & 2.66 & -0.3477 & 2.3123 \\
9.00 & 5.40 & 6.00 & 6.04 & 0.04 & 0.3236 & 2.38 & -0.3202 & 2.0598 \\
9.22 & 5.45 & 6.10 & 6.15 & 0.05 & 0.4297 & 2.17 & -0.1230 & 2.0470 \\
9.51 & 5.50 & 6.20 & 6.26 & 0.06 & 0.5500 & 1.89 & 0.0871 & 1.9771 \\
9.73 & 5.55 & 6.33 & 6.40 & 0.07 & 0.7000 & 1.67 & 0.3680 & 2.0380 \\
\hline
\end{tabular}

LogK $_{1}$ (Average value) $=2.1568 \pm 0.2069$

Table 14: Point-wise method, Mg (Unhydrolysed PSHA)

\begin{tabular}{|l|l|l|l|l|l|l|l|l|}
\hline $\mathrm{pH}$ & $\mathrm{BV}_{1}$ & $\mathrm{BV}_{2}$ & $\mathrm{BV}_{3}$ & $\mathrm{~V}_{3}-\mathrm{V}_{2}$ & $\mathrm{n}$ & $\mathrm{pL}$ & $\log \left(\frac{n-1}{2-n}\right)$ & $\log \mathrm{K}_{2}$ \\
\hline 10.00 & 5.60 & 6.47 & 6.55 & 0.08 & 0.9148 & 1.41 & & \\
10.23 & 5.65 & 6.62 & 6.71 & 0.09 & 1.2102 & 1.20 & -0.5749 & 0.6251 \\
10.49 & 5.70 & 6.80 & 6.92 & 0.09 & 1.5968 & 1.03 & 0.1703 & 1.2003 \\
\hline
\end{tabular}

LogK $_{2}$ (Average value) $=0.9127 \pm 0.4070$

Table15:Point-wise method, Cd (Hydrolysed PSHA)

\begin{tabular}{|l|l|l|l|l|l|l|l|l|}
\hline $\mathrm{pH}$ & $\mathrm{BV}_{1}$ & $\mathrm{BV}_{2}$ & $\mathrm{BV}_{3}$ & $\left(\mathrm{~V}_{3}-\mathrm{V}_{2}\right)$ & $\mathrm{n}$ & $\mathrm{pL}$ & $\log \left(\frac{n}{1-n}\right)$ & LogK $_{1}$ \\
\hline 8.50 & 5.30 & 6.29 & 6.31 & 0.02 & 0.2750 & 2.64 & -0.4210 & 2.2190 \\
8.72 & 5.35 & 6.37 & 6.40 & 0.03 & 0.4286 & 2.42 & -0.1249 & 2.2951 \\
9.00 & 5.40 & 6.46 & 6.49 & 0.03 & 0.4648 & 2.14 & -0.0612 & 2.0788 \\
9.22 & 5.45 & 6.55 & 6.59 & 0.04 & 0.6667 & 1.96 & 0.3010 & 2.2610 \\
9.51 & 5.55 & 6.66 & 6.70 & 0.04 & 0.7720 & 1.67 & 0.5297 & 2.1997 \\
\hline
\end{tabular}

LogK $_{\mathbf{1}}$ (Average value) $=2.2108 \pm 0.0825$

Table 16: Point-wise method, Cd (Hydrolysed PSHA)

\begin{tabular}{|l|l|l|l|l|l|l|l|l|}
\hline $\mathrm{pH}$ & $\mathrm{BV}_{1}$ & $\mathrm{BV}_{2}$ & $\mathrm{BV}_{3}$ & $\left(\mathrm{~V}_{3}-\mathrm{V}_{2}\right)$ & $\mathrm{n}$ & $\mathrm{pL}$ & $\log \left(\frac{n-1}{2-n}\right)$ & Log $_{2}$ \\
\hline 9.73 & 5.55 & 6.78 & 6.83 & 0.06 & 1.4042 & 1.47 & -0.1686 & 1.3014 \\
10.00 & 5.60 & 6.90 & 6.95 & 0.06 & 1.7838 & 1.23 & 0.5593 & 1.7893 \\
10.23 & 5.65 & 7.05 & 7.10 & 0.06 & 3.1429 & 1.09 & & \\
10.49 & 5.70 & 7.10 & 7.16 & 0.06 & 3.1429 & 0.89 & & \\
& & & & & & & & \\
\hline
\end{tabular}

$\operatorname{LogK}_{2}$ (Average value) $=1.5453 \pm 0.3450$

Table 17: Point-wise method, Cd (Unhydrolysed PSHA)

\begin{tabular}{|l|l|l|l|l|l|l|l|l|}
\hline $\mathrm{pH}$ & $\mathrm{BV}_{1}$ & $\mathrm{BV}_{2}$ & $\mathrm{BV}_{3}$ & $\mathrm{~V}_{3}-\mathrm{V}_{2}$ & $\mathrm{n}$ & $\mathrm{pL}$ & $\log \left(\frac{n}{n-1}\right)$ & $\operatorname{Log~}_{1}$ \\
\hline 8.50 & 5.30 & 5.81 & 5.86 & 0.05 & 0.3717 & 2.88 & -0.2280 & 2.6520 \\
8.72 & 5.35 & 5.90 & 5.95 & 0.05 & 0.3873 & 2.66 & -0.1992 & 2.4608 \\
9.00 & 5.40 & 6.00 & 6.06 & 0.06 & 0.4853 & 2.38 & -0.0255 & 2.3545 \\
9.22 & 5.45 & 6.10 & 6.16 & 0.06 & 0.5157 & 2.18 & -0.0272 & 2.2072 \\
9.51 & 5.50 & 6.20 & 6.27 & 0.07 & 0.6417 & 1.89 & 0.2530 & 1.1430 \\
9.73 & 5.55 & 6.33 & 6.41 & 0.08 & 0.8000 & 1.69 & 0.6020 & 2.2920 \\
& & & & & & & & \\
\hline
\end{tabular}

$\operatorname{LogK}_{1}($ Average value $)=2.2516 \pm 0.5380$ 
BAJOPAS Volume 14 Number 1,June, 2021

Table 18: Point-wise method, Cd (Unhydrolysed PSHA)

\begin{tabular}{|l|l|l|l|l|l|l|l|l|}
\hline $\mathrm{pH}$ & $\mathrm{BV}_{1}$ & $\mathrm{BV}_{2}$ & $\mathrm{BV}_{3}$ & $\mathrm{~V}_{3}-\mathrm{V}_{2}$ & $\mathrm{n}$ & $\mathrm{pL}$ & $\log \left(\frac{n-1}{2-n}\right)$ & $\log \mathrm{K}_{2}$ \\
\hline 10.00 & 5.60 & 6.47 & 6.57 & 0.10 & 1.1434 & 1.43 & & \\
10.23 & 5.65 & 6.62 & 6.72 & 0.10 & 1.3448 & 1.23 & -0.2788 & 0.9512 \\
10.49 & 5.70 & 6.80 & 6.90 & 0.10 & 1.7742 & 1.03 & 0.5351 & 1.5651 \\
\hline
\end{tabular}

$\operatorname{LogK}_{2}($ Average value $)=1.2581 \pm 0.4340$

Table 19: Stepwise and overall Stability constants of thehydrolysed and unhydrolysed divalent metal (II) complexes

\begin{tabular}{|c|c|c|c|}
\hline Chelates & LogK $_{1}$ & $\log _{2}$ & Log $\beta$ \\
\hline [Cu (Hydrolysed PSHA-1) $\left.{ }_{2}\right]$ & 2.4788 & 1.4280 & 3.9068 \\
\hline$\left[\mathrm{Pb}(\text { Hydrolysed PSHA-1) })_{2}\right]$ & 2.5832 & 1.1963 & 3.7795 \\
\hline$\left[\mathrm{Cd}(\text { Hydrolysed PSHA-1 })_{2}\right]$ & 2.2108 & 1.5453 & 3.7561 \\
\hline$\left[\mathrm{Mg}(\text { Hydrolysed PSHA-1 })_{2}\right]$ & 2.1382 & 1.5453 & 3.6835 \\
\hline [Cu (Unhydrolysed PSHA-1) & 2.3059 & 1.2209 & 3.5268 \\
\hline$[\mathrm{Pb}$ (Unhydrolysed PSHA-1) 2$]$ & 2.2364 & 1.2239 & 3.4603 \\
\hline [Cd (Unhydrolysed PSHA-1) 2 ] & 2.2516 & 1.2581 & 3.5097 \\
\hline$[\mathrm{Mg}$ (Unydrolysed PSHA-1) & 2.1568 & 0.9127 & 3.0695 \\
\hline
\end{tabular}

The results obtained (Table19) shows the stepwise and overall stability constants to be not high indicating low stability of the complexes, because the solubility of most metal ions in the basic $\mathrm{pH}$ range is minimal due to metal hydroxide precipitation (Karimi, 2017). In general, the stepwise stability constants $\left(K_{1}\right.$ and $K_{2}$ ) follow the order $K_{1}>K_{2}$ for the copper, lead, magnesium and cadmium complexes respectively. The steady decrease of the values with increasing number of ligands is in agreement with the prediction made by researchers (Na'aliya, 2013). The decrease could be attributed to the fact that as the number of the ligands (Humate ions) that enters the coordination zone increases the aqua molecules available for replacement by the ligands become less. Thus, the metal ions become less electron loving with progressive intake of the ligand and this results in the decrease in the values of the constants (Na'aliya, 2013). Also the stability of the complexes is influenced by the size and number of the chelate rings(Mackay and Mackay,2002).All the complexes form rings in their structure as humate, a bidentate ligand, bond the metal ions in the ratio 1:2 (Boguta and Sokolowska, 2016) forming chelate rings. The values of the overall stability constants $(\log \beta)$ obtained for humate complexes are not high indicating low stability as the values are not high. LogK values for copper-humates (Table 3 to 6) obtained in this study are lower than those reported for the complexes of humic acids (Pandey et al., 2015; Dinu, 2013; Kaschl et al., 2010 and Gilbeto and Jorg, 2001). The values of LogK(Table 7 to 10 ) forlead-humates are lower than those reported for the lead in the literature (Dinu, 2013; Gilbeto and Jorg 2001). Log K values(Table 11 to 14 ) for magnesium-humates obtained in this study are close to those reported by (Pandey et al., 2015). Log K values of cadmium-humates (Table 15 to 18 ) obtained in this work near to the one reported by (Dinu, 2013 and Pandey et al., 2015).The difference between the reported values and the values obtained in this study might be probably as a result of acid hydrolysis of humic acid. The values of the overall stability constants $(\log \beta)$ of the copper humates complexes presented in Table 19 is high than that of other metal humate complexes, show relatively high stability of CuHA complexes, show the following order of stability: $\mathrm{Cu}>\mathrm{Pb}>\mathrm{Cd}>\mathrm{Mg}$; which are in close agreement to the findings of (Dinu, 2013 and Pandey et al., 2015).The high stability of Cuhumate chelate could be attributed to the existence of coordinate covalent bond between the complexing agents and the $\mathrm{Cu}^{2+}$ ions. Since, $\mathrm{Cu}^{2+}$ being a metal of the transitional series with $3 d^{9}$ electronic configurations can accept the electrons from the complexing agents. Similarly, the low stabilities of $\mathrm{Pb}, \mathrm{Cd}$ and $\mathrm{Mg}$ complexes could be explained by that $\mathrm{Pb}^{2+}$ with $6 s^{2}, \mathrm{Cd}^{2+}$ with $4 \mathrm{~d}^{10}$ and $\mathrm{Mg}^{2+}$ with $2 \mathrm{p}^{6}$ their electronic configuration has a completely filled $\mathrm{d}, \mathrm{p}$ and $\mathrm{s}$ orbitals. Moreover, the stabilities of metal ions with hydrolysed humic acid from peat soil were higher than those with unhydrolysed humic acid from peat soil; which is ascribed to the high content of acidity in hydrolysed humic acid than unhydrolysed humic acid. 
BAJOPAS Volume 14 Number 1,June, 2021 CONCLUSION

The values of logk for $\mathrm{Cu}(\mathrm{II})$ hydrolysed humic acid complex was higher followed by $\mathrm{Pb}$ (II), $\mathrm{Cd}(\mathrm{II})$ and $\mathrm{Mg}$ (II) hydrolysed humic acid complexes as compared with metal(II) unhydrolysed humic acid complexes. This indicates acid hydrolysis of humic acid can

\section{REFERENCES}

Almeida, V.R. and Szpoganicz, B. (2015). Humic Acid Potentiometric Response Patterns:Out- of Equilibrium Properties and Species Distribution Modelling. Chemical. Biol. Technol. Agric. 2: 17.

Anđelković, T., Nikolić, R., Bojić, A.,Anđelković, D., and Nikolic G.,(2010). Binding of Cadmium to Soil Humic Acid as A Function of Carboxyl Group Content. Macedonian Journal of Chemistry and Chemical Engineering.29(2): 215-224.

Anil, B. N. and Maroti, N. (2008). Studies on Influence of Die-Lectric Constants on Complex Equilibria between Substituted Py-Razalines and Lanthanide Metal Ions pH-Metrically. Amer.-Euras. scient. Res. 3(2): 212-216.

Ashok, K., Pandey, S. P. and Misra, V (2000). Stability Constants of Metal-Humic Acid Complexes and its Role in Environmental Detoxification. Journal of Ecotoxicology and Environmental Safety. 47(2):157-200.

Badr, M. H., El-Halafawi, M. H. and Abd El-al Zeid, E. R. (2012). Comparison Between the Effect of Ionic Strength on Acidity and Dissociation Constants of Humic Acids Extracted from Sewage Sludge and Nile Water Hyacinth Composts.Global Journal of Environmental Research 6 (1): 36-43.

Baruah, M.K., Borah, D., Saikia, P.P., Paul, S., Sharma, T. (2015). Evaluation of pKa Values of Soil Humic Acids and their Complexation Properties. International Journal of Plant \& Soil Science 6(4) : 218-228.

Boguta, P. Sokolowska, Z. (2016). Interactions of $\mathrm{Zn}$ (II) Ions with Humic Acids Isolated from Various Types of Soils. Effect of $\mathrm{pH}, \mathrm{Zn}$ Concentrations and Humic Acids Chemical Properties. Journal of Geochemical Explaration 168. 119-126.

Borges, F., Guimaraes, C., Lima, L.F.C., Pinto, I. and Reis, S.(2005). Potentiometric Studies on the Complexation of Copper(II) by Phenolic Acids as Discrete Ligand Models of enhance the complexation behavior of humic acid with metal (II) ions. However, the higher values of $\log \beta$ for $\mathrm{Cu}(\mathrm{II}), \mathrm{Pb}(\mathrm{II}), \mathrm{Cd}(\mathrm{II})$ and $\mathrm{Mg}(\mathrm{II})$ hydrolysed humic acid complexes indicates more stable stepwise complexes formed as compared with $\mathrm{Cu}(\mathrm{II}), \mathrm{Pb}$ (II), $\mathrm{Cd}$ (II) and $\mathrm{Mg}(\mathrm{II})$ unhydrolysed humic acid complexes.

Humic Substances Talanta 66 (2005) 670-673.

Chefetz, B., Salloum, M. J., Deshmulkin, A. P. and Hatcher, P. (2002). Structural Components of Humic Acids as Determined by Chemical Modifications and Carbon-13 NMR, Pyrolysis, and Thermochemolysis- Gas Chromatography/Mass Spectrometry. Soil Science Society of American Journal Abstract Division S-2- Soil Chemistry66. 1159-1171.

Dinu, M. I. (2013). Metals Complexation with Humic Acids in Surface Water of Different Environ. Sci. Technol. 31(1): 1-17.

Fernandes, A.N., Giacomelli, C., Giovanela, M. Vaz, D.V. Szpoganicz, B. and Maria M. D. (2009). Potentiometric Acidity Determination in Humic Substances Influenced by Different Analytical Procedures.J. Braz. Chem. Soc. 20 (9):14.

Gamal, A. H. (2015). Stability Constants of Rhenium (V) Metal Complexes with Selected Drugs. Pyrex Journal of Research in Environmental Studies. 2(2): 006-014.

Janrao, D. M., Pathan, J., Kayande, D.D., and Mulla, J.J. (2014). An Over View of Potentiometric Determination of Stability Constants of Metal Complexes. Sci. Revs. Chem. Commun.: 4(1), 2014, 11-24.

Karimi, H. (2017). Effect of pH and Initial Pb(II) Concentration on the Lead Removal Efficiency from Waste Water Using $\mathrm{Ca}(\mathrm{OH})_{2}$. International Journal of Water and Waste Water Treatment 3.2

Kaschl, A. Romheld, V. and Chen, Y. (2010). Binding of Cadmium, Copper and Zinc to Humic Substances Originating from Municipal Solid Waste Compost. Israel Journal of Chemistry Vol. 42(1): 89-98.

Kostic, I. S., Tatjana, P, A., Nikolic, R. S., Cvetkovic, T. P., Pavlovic, D. D., Aleksandar, L.J. and Bojic, A. (2012). Comparative Study of Binding Strengths of Heavy Metals with Humic Acid. J.serb. Chem. Soc. 76(9) pp 1-20. 
BAJOPAS Volume 14 Number 1,June, 2021

Na'aliya, J. (2013). Determination of Stepwise Stability Constants and Gibbs free Energy Change of Trisprolina to Complexes of some Divalent Transition Metal ions. Bayero Journal of Pure and Applied Sciences 6(2): 112-114.

Omar, A. A. and Ali, E. A. (2015). Potentiometric Studies on Complexes of $\mathrm{Cr}$ (III) and $\mathrm{Zr}$ (IV) with some Carboxylic Acids. International Journal of Advanced Chemistry, 3(1) 25-

37.

Pandey, A. K. Pandey, S. D. and Misr, V. (2015).Stability Constants of Metal- Humic Acid Complexes and Its Role in Environmental Detoxification. J. Ecotoxicology and Environmental Safety. 47(1):195-200.

Ram, N. and Raman, K.V. (1984). Stability Constants of Complexes of Metals with
Humicand Fuvic Acids under Non- acidConditions. Journal of Plant Nutrition and Soil Sciences.

147:171-176.

Santosh, D. D., Ashok, B. K., Vijay, J. T., Shivraj, G. W. and Vinay, V. W. (2011). Potentiometric Studies of Elec-Trolyte Effects on Complex Equilibria of Some Substituted 5-(2-hydroxy Phenyl) Pyrazoles. Der pharm. 3 (6): 75-83.

Sayyed, H. and Abdul Rahim, M. F. (2012). Studies of Binary Complexes of Metal Ions with Mandelic Acid by Potentiometry. Chem. J. 02 (6): 206209.

Shirvani, M. Moradian, E. Khalili, B. Bakhtiary, S. (2015). Interaction of $\mathrm{Cd}$ and $\mathrm{Pb}$ with Humate-Palygorskite and HumateSepiolite Complexes. Journal of water, air and pollution 3: 220-228. 


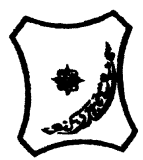

Bayero Journal of Pure and Applied Sciences, 14(1): 54 - 63

Received: November, 2020

Accepted: April, 2021

ISSN $2006-6996$

\title{
STABILITY CONSTANTS OF COMPLEXES OF METAL IONS WITH PEATSOIL HUMIC ACIDS UNDER NON-ACID-CONDITIONS
}

\author{
${ }^{* 1}$ Sabo, Yusuf ${ }^{2}$ Jimoh, W.L.O., ${ }^{3}$ Isa Baba Koki and ${ }^{4}$ Sholadoye, Q. 0. \\ ${ }^{1}$ Department of Pure and Industrial Chemistry, Bayero University, Kano \\ ${ }^{3}$ Department of Chemistry, Yusuf Maitama Sule University Kano. P.M.B. 3220 Kano, Nigeria. \\ ${ }^{4}$ Department of Chemistry, Nigerian Police Academy, Wudil, Kano-Nigeria
}

*Correspondence E-mail; saboyusuf18@yahoo.com

ABSTRACT

Stability constants of complexes of four divalent metal ions viz. $\mathrm{Cu}^{2+}, \mathrm{Pb}^{2+}, \mathrm{Mg}^{2+}$ and $\mathrm{Cd}^{2+}$ with humic acids (HA) were determined by potentiometric titration of humic acids with the corresponding salt of the divalent metals in aqueous media under non-acid-condition. The log $K$ (logarithm of the stability constant) ranged from 1.0942 to 2.7471 for metalhumic acid complexes were determined using point-wise computational method. The order of stability constants were obtained as follows: $\mathrm{Cu}>\mathrm{Pb}>\mathrm{Cd}>\mathrm{Mg}$ for metal $-\mathrm{HA}$ complexes respectively, indicating a higher degree of complexation with Cu metal ion.

Keywords: stability constant, humic acid, potentiometric titration, divalent metals, acid hydrolysis.

\section{NTRODUCTION}

The stability constant of a complex is the numerical expression of its stability and provides a quantitative measure of affinity of the metal ion to the complexing agent. An understanding of the relative stability of metal-complexes helps in predicting the behavior of metal ions in the soil (Ram and Raman, 1982). Extensive researches has been done to determine the stability constants of the complexes formed between humic acid (HA) with a number of metal ions. Ashok et al., (2000) reported that humic acid with hydroxyl, phenoxyl and carboxyl reactive groups can form coordination compound with metal ions at $\mathrm{pH}$ 3.5. The stability constants(Log K) for different metalhumic acid complexes indicated the following order of the stabilities of complexes formed between humic acid and metal ion, $\mathrm{Cu}>\mathrm{Fe}$ $>\mathrm{Pb}>\mathrm{Ni}>\mathrm{Co}>\mathrm{Ca}>\mathrm{Cd}>\mathrm{Zn}>\mathrm{Mn}>\mathrm{Mg}$. Andelkovic et al., (2010) investigated the binding of $\mathrm{Cd}$ (II) to soil humic acid at pH 6.5 and in $0.1 \mathrm{M} \mathrm{KNO}_{3}$ ionic medium. The stability constant for binding indicating greater stability in the case when carboxyl groups are involved in complexation reaction. Kostic et al.,(2012) investigated the complexation of humic acid with certain heavy metal ions (Co(II), $\mathrm{Ni}(\mathrm{II}), \mathrm{Cu}(\mathrm{II})$,
$\mathrm{Zn}(\mathrm{II})$, and $\mathrm{Pb}(\mathrm{II})$. The experiment was performed at $25^{\circ} \mathrm{C}$, at pH 4.0 and ionic strength of $0.01 \mathrm{M}$. Stability constant of complex between $\mathrm{Pb}$ (II) ions and humic acid is greater than stability constants of other investigated metalhumate complexes. Bogata and Sokolowska (2016) analyses the interaction between humic acids from different soils and $\mathrm{Zn}$ (II) ions at wide concentration ranges and at $\mathrm{pH} 5$. Studies have showed significant impact of $\mathrm{Zn}$ concentration, $\mathrm{pH}$ and some properties of humic acids with zinc.But all of these studies were limited to acidic $\mathrm{pH}$ range. Therefore, the present study was carried out to determine and compare the stability constants of complexes of metal ions with hydrolysed peat soil humic acid and unhydrolysed peat soil humic under non-acid conditions.

\section{MATERIALS AND METHODS}

Analytical grade chemicals used includes hydrochloric acid $(\mathrm{HCl})$, nitric acid $\left(\mathrm{HNO}_{3}\right)$, sodium hydroxide $(\mathrm{NaOH})$, lead nitrate $\mathrm{Pb}\left(\mathrm{NO}_{3}\right)_{2}$, copper nitrate $\mathrm{Cu}\left(\mathrm{NO}_{3}\right)_{2} \cdot 3 \mathrm{H}_{2} \mathrm{O}$, cadmium nitrate $\mathrm{Cd}\left(\mathrm{NO}_{3}\right)_{2} \cdot 4 \mathrm{H}_{2} \mathrm{O}$, magnesium nitrate $\mathrm{Mg}\left(\mathrm{NO}_{3}\right)_{2} \cdot 6 \mathrm{H}_{2} \mathrm{O}$, potassium nitrate $\left(\mathrm{KNO}_{3}\right)$, calcium chloride $\left(\mathrm{CaCl}_{2}\right)$, (sigma-Aldrich). Dowex 50WX8, (20-50 mesh) from Fluka. 


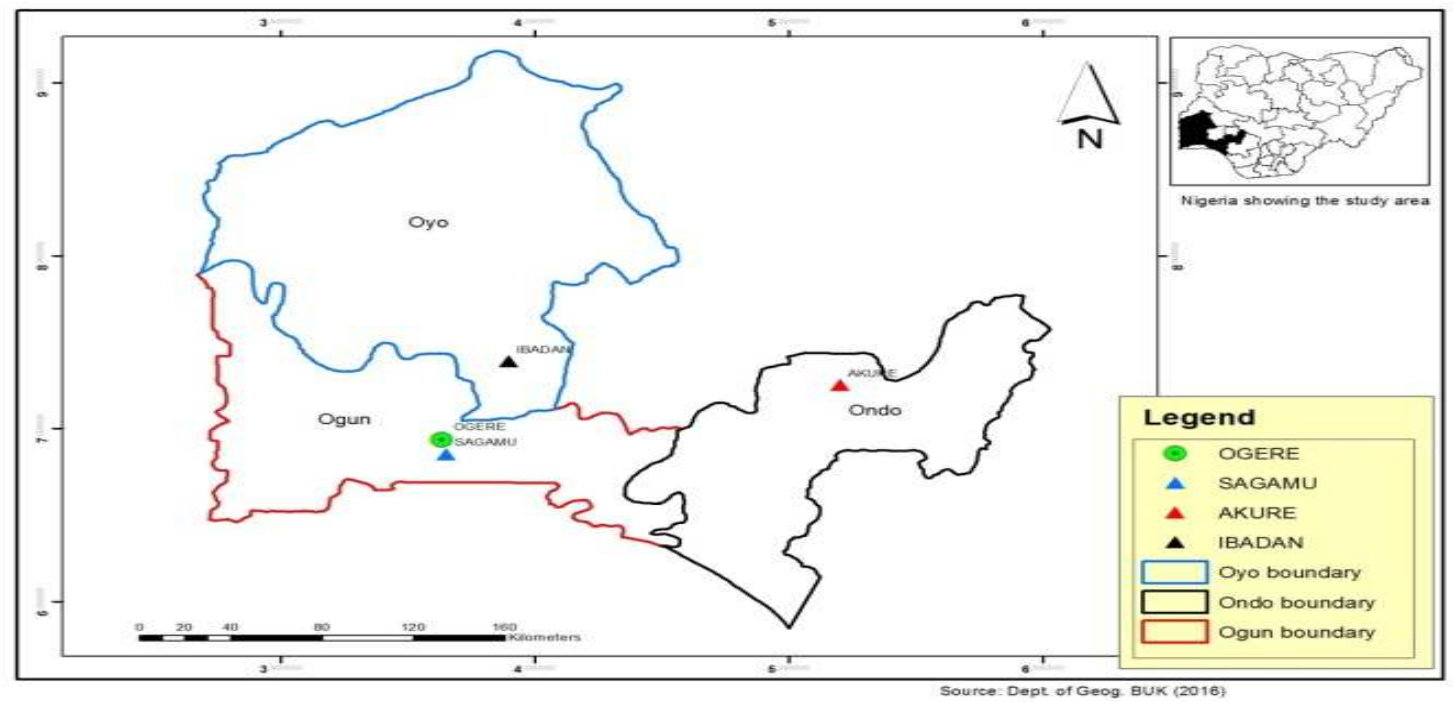

Figure 1: Map showing the sampling point at Sagamu Town, Ogun State.

\section{Description of Sampling Area}

Sagamu has geographical coordinates between $6^{\circ} 50^{\prime}$ north; $3^{\circ} 38^{\prime}$ east is located in south western region of Nigeria. The region has tropical wet and dry climate with a lengthy wet season and relatively constant temperatures throughout the course of the year. Wet season runs from March to October, November to December forms the region dry season. The vegetation type of the region is savannah which is really grassland with small bushes and occasional big trees. Grassland soils have substantially higher organic matter content than forest soils (Novackova, 2011).

\section{Sample Collection}

The Peatsoil samples were collected from four different sampling points $(0-10 \mathrm{~cm}$ depth) in Sagamu into polyethylene bag with plastic spoons. Samples were taken to the laboratory, extraneous materials were removed; the samples were air-dried, crushed and ground to a fine powder in a mortar passed through a $0.20 \mathrm{~mm}$ sieve. The samples were kept for analysis.

\section{Isolation and purification of humic acid from peat soil sample}

Peatsoil sample $(100 \mathrm{~g})$ was mixed with 1000 $\mathrm{cm}^{3}$ of $0.1 \mathrm{M} \mathrm{NaOH}$ solution, shaken for 3hours and left to stand overnight. Dark-coloured supernatant was obtained and decanted from solid residue. The dark-coloured supernatant was acidified to $(\mathrm{pH}=1.0)$ with $6 \mathrm{M} \mathrm{HCl}$ stirred and allowed to stand for 6 hours. Yellowish brown supernatant and dark-brown precipitate were obtained. The yellowish brown supernatant was decanted followed by centrifuge and discarded. The dark-brown precipitate was mixed with $500 \mathrm{~cm}^{3}$ of $0.1 \mathrm{M} \mathrm{NaOH}$ solution followed by passing through dowex resin. The dark-brown solution was acidified to $(\mathrm{pH}=1.0)$ with $6 \mathrm{M} \mathrm{HCl}$ stirred and allowed to stand for 3 hours. The dark-brown precipitate was washed several times with deionized water. The supernatant was treated with $\mathrm{AgNO}_{3}$ solution until no white precipitate observed. The humic acid was transferred to weighed crucible and dried at $60^{\circ} \mathrm{C}$ in an oven for 12 hours. The humic acid was cooled and dried in the desiccator, weighed and recorded. The obtained humic acid was dried again at $60^{\circ} \mathrm{C}$ for additional 6 hours cooled and dried in the desiccator, weighed and recorded constant weight was obtained (Baruah et al., 2015).

\section{FT-IR analysis}

FT-IR spectra of humic acid sample was analysed using Carry 630 FT-IR Agilent Technologies.

Unhydrolysed compost humic acid

The unhydrolysed humic acid was obtained after isolation and purification of compost humic acid and kept for investigation.

\section{Acid hydrolysis of Peatsoil acid}

Peatsoil humic acid sample (1g) was refluxed for 12 hours at $\left(160^{\circ} \mathrm{C}\right)$ with $50 \mathrm{~cm}^{3}$ of $6 \mathrm{M} \mathrm{HCl}$. The mixture was allowed to cool, decanted, and centrifuged after hydrolysis. The insoluble residues were washed with distilled water via centrifugation several times, and the supernatant was treated with $\mathrm{AgNO}_{3}$ solution until no white precipitate was observed. The residue was thoroughly dried over $\mathrm{CaCl}_{2}$ in a desiccator at room temperature (Chefetz et al., 2002). Finally, the obtained hydrolysed humic acid was kept for investigation. 
BAJOPAS Volume 14 Number 1,June, 2021 Potentiometric Titrations

Potentiometric measurements were carried out using a pH-meter Jenway (model 3510) with combine electrode, the sensitivity of the $\mathrm{pH}$ meter is 0.01 units. The $\mathrm{pH}$ meter was switched on half an hour before starting the titration for initial warm up of the instrument. The instrument was calibrated with an aqueous standard buffer solution of $\mathrm{pH} 4.00$ and 10.0 (borate buffer) prepared from a "Qualigens" buffer tablets.

The following sets of solutions were prepared in a $250 \mathrm{~cm}^{3}$ volumetric flask separately for $\mathrm{pH}$ metric titrations.

(i) $5 \mathrm{~cm}^{3} 0.1 \mathrm{M} \mathrm{HCl}+40 \mathrm{~cm}^{3}$ deionized water

(ii) $5 \mathrm{~cm}^{3} 0.1 \mathrm{M} \mathrm{HCl}+39 \mathrm{~cm}^{3}$ deionized water $+1 \mathrm{~cm}^{3} 0.15 \mathrm{gcm}^{-3}$ humic acid

(iii) $5 \mathrm{~cm}^{3} 0.1 \mathrm{M} \mathrm{HCl}+37 \mathrm{~cm}^{3}$ deionized water $+1 \mathrm{~cm}^{3} 0.15 \mathrm{gcm}^{-3}$ humic acid

$$
+2 \mathrm{~cm}^{3} \quad 0.01 \mathrm{M} \mathrm{Cu} \text { (II) }
$$

The solutions were titrated against standardized $0.110 \mathrm{MNaOH}$ separately. The total volume of each mixture was adjusted to $50 \mathrm{~cm}^{3}$ and the ionic strength of the solutions was maintained constant at by adding appropriate amount of stock solution of $1 \mathrm{M} \mathrm{KNO}_{3}$ (Gamal, 2015; Omar and Ali, 2015). A magnetic stirrer was used to achieve thorough mixing of the interacting solutions at $550 \mathrm{rpm}$. The same set of experimental conditions was applied for potentiometric titration of remaining samples.

\section{Evaluation of pKa of Hydrolysed peat soil Humic Acids}

The proton-ligand formation number $\mathrm{n}_{\mathbf{A}}$ were calculated by Irving and Rossotti expression (Omar and Ali, 2015).

$\mathrm{nA}=\mathrm{Y}-\frac{(\mathrm{V} 2-\mathrm{V1})(\mathrm{No}-\mathrm{Eo})}{(\mathrm{VO}+\mathrm{V1}) \mathrm{TCL}}$ 1

Where: $Y$ is number of dissociable proton, $\left(\mathrm{V}_{2^{-}}\right.$ $V_{1}$ ) is the measure of displacement of the ligand curve relative to acid curve, $\mathrm{N}^{\circ}$ and $\mathrm{E}^{\circ}$ are the resultant concentration of alkali solution, free acid solution, $\mathrm{T}_{\mathrm{cL}}{ }^{\circ}$ is the total ligand concentration, $\mathrm{V}^{\circ}$ is the total volume of titration solution, $V_{1}$ is the volume of alkali added to acid solution, $V_{2}$ is the volume of alkali added to acid solution + ligand solution, acid dissociation constants (pKa - values) of ligand were calculated by algebraic method point wise calculation (Tables 1 ). The dissociation constants (pKa) were calculated according to the following relation:

$\mathrm{pKa}=\mathrm{pH}+\log \left(\frac{n A}{1-n A}\right)$ 2

Where: pKa is the acid dissociation constant, $\mathrm{n}_{\mathrm{A}}$ is the Proton-ligand formation number and $\mathrm{pH}$ is the pH-values (Omar and Ali, 2015).

\section{Determination of metal-ligand stability constants $(\log K)$ of complexes}

The potentiometric measurement for the determination of stability constant of a complex in solution is based on the fact that the redox potential of the couple $\frac{M^{+(m-n)}}{M^{+m}}$ is shifted significantly on complexation of the metal ion with the ligand. This method involves change in hydrogen ion concentration $\left[\mathrm{H}^{+}\right]$due to the displacement or association of one or more protons taking place during complexation reaction. This change can be found out by titrating the solutions containing free acid, acid with ligand, and acid with ligand and metal ion, individually against a standard alkali solution at a constant ionic strength or temperature. Either ionic strength or temperature may be varied for different sets of solutions. In all the cases, the change in the $\mathrm{pH}$ of the solution is measured after each addition of a known amount of alkali to the reaction cell which contains the reaction mixture. The titration curves are then drawn by plotting the measured $\mathrm{pH}$ values against the corresponding volume of alkali added and the stability constants of the complexes are determined from the titration curves by employing $\mathrm{pH}$-metric titration technique given by (Irving and Rossoti).

Metal-ligand stability constants ( $\log \mathrm{K}$ ) were determined by using the following relations:

$$
\bar{n}=\frac{\left(V_{3}-V_{2}\right)\left(E^{0}+N^{0}\right)}{\left(V^{0}+V_{2}\right) \bar{n}_{A} T_{m}^{0}}
$$

and

$$
P L=\log _{10}\left\{\frac{1+\beta_{n}^{H} \frac{1}{[\text { anti } \log \mathrm{pH}]^{\mathrm{n}}}}{\mathrm{T}_{\mathrm{L}}^{0}-n \bar{T}_{m}^{0}} \mathrm{X} \frac{\left(V^{0}+V_{3}\right)}{V^{0}}\right\}
$$


BAJOPAS Volume 14 Number 1,June, 2021

Where $T_{L}, T^{\circ}, E^{\circ}$, and $V^{\circ}$ havethe same significance as in equation (1) above, $T_{m}$ denotes the total concentration of metal present in solution, $V_{3}$ is the volume of metal ions present in solution and $\beta^{H}$ is the overall proton ligand stability constant. The metal-ligand stability constants (log K) were determined by employing point wise computational Method (eq. 5 and 6).

$\operatorname{LogK}_{1}=\log \left(\frac{n}{1-n}\right)+\mathrm{pL}$ .5

$\operatorname{LogK}_{2}=\log \left(\frac{1-n}{2-n}\right)+\mathrm{pL}$ ...6

Where: Log $\mathrm{K}$ is the metal-ligand stability constant, $\mathrm{pL}$ is the Free ligand exponent function, $\mathbf{n}$ is the Average number of ligand attached with metal ion (Janraoet al., 2014). The results obtained were analyzed by an ORIGIN 2016 program using titration data and then the proton-ligand stability constants (pKa) and Metal-ligand stability constant (LogK) calculated (Omar and Ali, 2015).

\section{RESULTS AND DISCUSSION}

Fourier transformed infrared (FT-IR) spectra of isolated humic acid from peat soils Figure 2 had distinct clear absorption bands indicating the presence of major humic acid structural elemental groups such as $\mathrm{H}$ bonded $\mathrm{OH}$ $\left(3680 \mathrm{~cm}^{-1}\right.$ peak $), C=0$ of carbonyl $\left(1721 \mathrm{~cm}^{-1}\right.$ peak), functional groups of aliphatic components $\mathrm{CH}_{2}\left(2918 \mathrm{~cm}^{-1}\right.$ peak) and $\mathrm{C}-\mathrm{O}$ stretching of polysaccharide $\left(1168 \mathrm{~cm}^{-1}\right.$ peak). The positions of the absorption bands of the spectra fell within typical major absorption bands of humic acid which is at frequencies 3680, 2918, 1721, 1168 $\mathrm{cm}^{-1}$. The first peak centred in the vicinity of $3680 \mathrm{~cm}^{-1}$ region is attributed to phenol $\mathrm{OH}$ group bounded by intermolecular $\mathrm{H}$ bonds. The $2918 \mathrm{~cm}^{-1}$ band usually has absorption maximum at $2918 \mathrm{~cm}^{-1}$ which is due to $\mathrm{C}-\mathrm{H}$ stretching of alkane group $\left(\mathrm{CH}_{2}\right)$. The next major absorption band is $1721 \mathrm{~cm}^{-1}$. This band has been commonly ascribed to $\mathrm{C}=\mathrm{O}$ stretching of mainly carboxyl group $(\mathrm{COOH})$ with trace amount of ketones. The last peak was observed at 1168 $\mathrm{cm}^{-1}$ due to $\mathrm{C}-\mathrm{O}$ stretching of polysaccharides and this peak appeared also in the spectra of humic acid from peat soil. The FTIR spectra of the isolated humic acid contained all major characteristic absorption peaks of humic acid. These absorption peaks indicated the presence of the major structural elements of humic acid namely $\mathrm{H}$ bonded $\mathrm{OH}, \mathrm{C}=\mathrm{C}$ of aromatic ring, $\mathrm{C}=\mathrm{O}$ of carbonyl group (both carboxyl and ketonic), $\mathrm{CH}_{2}$ group. This strongly supports the presence of humic acid.

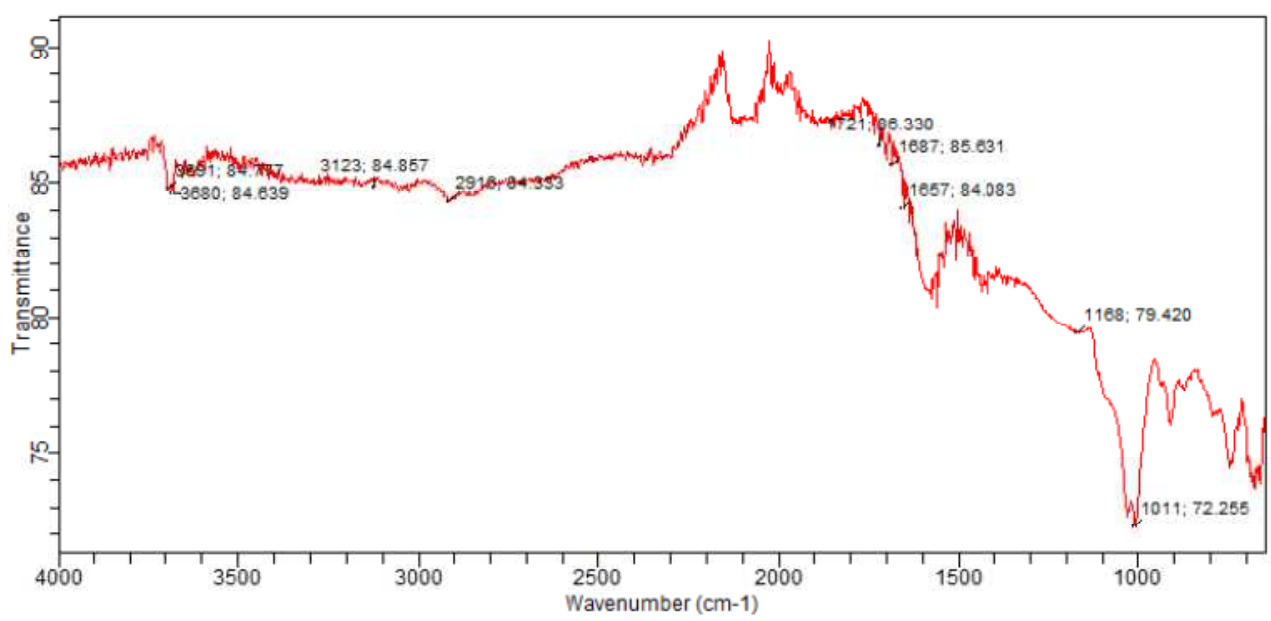

Fig. 2 : FT-IR spectraof peatsoilhumic acid (PSHA)

\section{Evaluation of acid dissociation constant (pka) of acid hydrolysed peat soil humicacid at phenolic group}

The value of the dissociation constant of the peat soil humic acid (PSHA) that underwent acidhydrolysis studied was found to be 8.9299 as shown Table 1, which is lower than the literaturevalues reported by Almeida and Szpoganics, (2015), Borges et al., (2005); Badr et al., (2012)and Fernandes et al,.(2009) of $9.73,9.47$ and 10.30. The difference between the obtained valuesand the reported values in this study might be probably as a result of acid hydrolysis of humicacid. 
BAJOPAS Volume 14 Number 1,June, 2021

Table 1: PKa of (Hydrolysed PSHA)

\begin{tabular}{|l|l|l|l|l|l|l|}
\hline $\mathrm{pH}$ & $\mathrm{BV}_{1}$ & $\mathrm{BV}_{2}$ & $\mathrm{~V}_{2}-\mathrm{V}_{1}$ & $\mathrm{nA}$ & $\log \left(\frac{n A}{1-n A}\right)$ & $\mathrm{pKa}$ \\
\hline 8.50 & 5.30 & 6.29 & 0.99 & 0.3594 & -0.2510 & 8.2490 \\
8.72 & 5.35 & 6.37 & 1.02 & 0.3400 & -0.2880 & 8.4320 \\
9.00 & 5.40 & 6.46 & 1.06 & 0.3141 & -0.3391 & 8.6609 \\
9.22 & 5.45 & 6.55 & 1.10 & 0.2882 & -0.3927 & 8.8273 \\
9.51 & 5.50 & 6.66 & 1.16 & 0.2494 & -0.4786 & 9.0314 \\
9.73 & 5.55 & 6.78 & 1.23 & 0.2041 & -0.5910 & 9.1390 \\
10.00 & 5.60 & 6.90 & 1.30 & 0.1589 & -0.7238 & 9.2762 \\
10.23 & 5.65 & 7.05 & 1.40 & 0.0941 & -0.9835 & 9.2465 \\
10.49 & 5.70 & 7.10 & 1.40 & 0.0941 & -0.9835 & 9.5065 \\
\hline
\end{tabular}

Average pKa $=8.9299 \pm 0.4186$

Table 2: PKa of (Unhydrolysed PSHA)

\begin{tabular}{|l|l|l|l|l|l|l|}
\hline $\mathrm{pH}$ & $\mathrm{BV}_{1}$ & $\mathrm{BV}_{2}$ & $\mathrm{~V}_{2}-\mathrm{V}_{1}$ & $\mathrm{nA}$ & $\log \left(\frac{\boldsymbol{n A}}{1-\boldsymbol{n}}\right)$ & $\mathrm{pKa}$ \\
\hline 8.50 & 5.30 & 5.81 & 0.51 & 0.6619 & 0.2919 & 8.7919 \\
8.72 & 5.35 & 5.90 & 0.55 & 0.6357 & 0.2418 & 8.9618 \\
9.00 & 5.40 & 6.00 & 0.60 & 0.6029 & 0.1813 & 9.1813 \\
9.22 & 5.45 & 6.10 & 0.65 & 0.5701 & 0.1226 & 9.3426 \\
9.51 & 5.50 & 6.20 & 0.70 & 0.5376 & 0.0654 & 9.5754 \\
9.73 & 5.55 & 6.33 & 0.78 & 0.4851 & -0.0259 & 9.7041 \\
10.00 & 5.60 & 6.47 & 0.87 & 0.4262 & -0.1291 & 9.8709 \\
10.23 & 5.65 & 6.62 & 0.99 & 0.3609 & -0.2481 & 9.9819 \\
10.49 & 5.70 & 6.80 & 1.10 & 0.2759 & -0.4690 & 10.0210 \\
\hline
\end{tabular}

Average pKa $=9.4923 \pm 0.4410$

Metal-ligand stability constant ( $\log \mathrm{K}$ )

The stabilityconstants require the accurate values of proton-ligand stability constants (Anil and Maroti, 2008). Metal titration curves crossed over ligand titration curve indicated the formation of complex upon proton release (Santosh, et al., 2011). If the values of n- are within range $0.2-0.8$ and $1.2-18$ this indicates the formation of $1: 1$ and 1:2 complexes (Sayyed and Mazahar, 2012).

The metal (II)-humate stepwise stability constants (log k) at phenolic group (Tables 318)

Table 3: Point-wise method, $\mathrm{Cu}$-(Hydrolysed PSHA)

\begin{tabular}{|l|l|l|l|l|l|l|l|l|}
\hline $\mathrm{pH}$ & $\mathrm{BV}_{1}$ & $\mathrm{BV}_{2}$ & $\mathrm{BV}_{3}$ & $\left(\mathrm{~V}_{3}-\mathrm{V}_{2}\right)$ & $\mathrm{n}$ & $\mathrm{pL}$ & $\log \left(\frac{n}{1-n}\right)$ & LogK $_{1}$ \\
\hline 8.50 & 5.30 & 6.29 & 6.33 & 0.04 & 0.5500 & 2.66 & 0.0871 & 2.7471 \\
8.72 & 5.35 & 6.37 & 6.41 & 0.04 & 0.5714 & 2.43 & 0.1249 & 2.5549 \\
9.00 & 5.40 & 6.46 & 6.50 & 0.04 & 0.6198 & 2.16 & 0.2122 & 2.3722 \\
9.22 & 5.45 & 6.55 & 6.59 & 0.04 & 0.6667 & 1.94 & 0.3010 & 2.2410 \\
\hline
\end{tabular}

LogK $_{1}$ (Average value) $=2.4788 \pm 0.2203$

Table 4: Point-wise method, $\mathrm{Cu}$-(Hydrolysed PSHA)

\begin{tabular}{|l|l|l|l|l|l|l|l|l|}
\hline $\mathrm{pH}$ & $\mathrm{BV}_{1}$ & $\mathrm{BV}_{2}$ & $\mathrm{BV}_{3}$ & $\left(\mathrm{~V}_{3}-\mathrm{V}_{2}\right)$ & $\mathrm{n}$ & $\mathrm{pL}$ & $\log \left(\frac{n-1}{2-n}\right)$ & LogK $_{2}$ \\
\hline 9.51 & 5.50 & 6.66 & 6.73 & 0.07 & 1.3509 & 1.70 & -0.2671 & 1.4329 \\
9.73 & 5.55 & 6.78 & 6.85 & 0.07 & 1.6383 & 1.51 & 0.2467 & 1.7567 \\
10.00 & 5.60 & 6.90 & 6.98 & 0.08 & 2.1783 & 1.31 & -0.2158 & 1.0942 \\
10.23 & 5.65 & 7.05 & 7.13 & 0.08 & 4.1904 & 1.27 & & \\
10.49 & 5.70 & 7.10 & 7.19 & 0.09 & 4.6920 & & & \\
\hline
\end{tabular}

Log $K_{2}($ Average value $)=1.4280 \pm 0.3312$ 
BAJOPAS Volume 14 Number 1,June, 2021

Table 5: Point-wise method, $\mathrm{Cu}$ (Unhydrolysed PSHA)

\begin{tabular}{|l|l|l|l|l|l|l|l|l|}
\hline $\mathrm{pH}$ & $\mathrm{BV}_{1}$ & $\mathrm{BV}_{2}$ & $\mathrm{BV}_{3}$ & $\left(\mathrm{~V}_{3}-\mathrm{V}_{2}\right)$ & $\mathrm{n}$ & $\mathrm{pL}$ & $\log \left(\frac{n}{n-1}\right)$ & Log $_{1}$ \\
\hline 8.50 & 5.30 & 5.81 & 5.85 & 0.04 & 0.2973 & 2.88 & -0.3736 & 2.5064 \\
8.72 & 5.35 & 5.90 & 5.95 & 0.05 & 0.3873 & 2.66 & -0.1992 & 2.4608 \\
9.00 & 5.40 & 6.00 & 6.05 & 0.05 & 0.4044 & 2.38 & -0.1681 & 2.2119 \\
9.22 & 5.45 & 6.10 & 6.15 & 0.06 & 0.5157 & 2.18 & -0.0272 & 2.2072 \\
9.51 & 5.50 & 6.20 & 6.27 & 0.07 & 0.6417 & 1.89 & 0.2530 & 1.1430 \\
\hline
\end{tabular}

$\operatorname{LogK}_{1}($ Average value $)=2.3059 \pm 0.6153$

Table 6:Point-wise method, $\mathrm{Cu}$ (Unhydrolysed PSHA)

\begin{tabular}{|l|l|l|l|l|l|l|l|l|}
\hline $\mathrm{pH}$ & $\mathrm{BV}_{1}$ & $\mathrm{BV}_{2}$ & $\mathrm{BV}_{3}$ & $\mathrm{~V}_{3}-\mathrm{V}_{2}$ & $\mathrm{n}$ & $\mathrm{pL}$ & $\log \left(\frac{n-1}{2-n}\right)$ & $\log \mathrm{K}_{2}$ \\
\hline 9.73 & 5.55 & 6.33 & 6.42 & 0.09 & 0.9000 & 1.69 & & \\
10.00 & 5.60 & 6.47 & 6.58 & 0.11 & 1.2578 & 1.44 & -0.4592 & 0.9808 \\
10.23 & 5.65 & 6.62 & 6.84 & 0.12 & 1.6137 & 1.26 & -0.2010 & 1.4610 \\
10.49 & 5.70 & 6.80 & 6.92 & 0.12 & 2.1052 & 1.03 & & \\
\hline
\end{tabular}

$\operatorname{LogK}_{2}$ (Average value) $=1.2209 \pm 0.3398$

Table 7:Point-wise method, Pb (Hydrolysed PSHA)

\begin{tabular}{|l|l|l|l|l|l|l|l|l|}
\hline $\mathrm{pH}$ & $\mathrm{BV}_{1}$ & $\mathrm{BV}_{2}$ & $\mathrm{BV}_{3}$ & $\left(\mathrm{~V}_{3}-\mathrm{V}_{2}\right)$ & $\mathrm{n}$ & $\mathrm{pL}$ & $\log \left(\frac{n}{1-n}\right)$ & LogK $_{1}$ \\
\hline 8.50 & 5.30 & 6.29 & 6.33 & 0.04 & 0.5500 & 2.66 & 0.0871 & 2.7471 \\
8.72 & 5.35 & 6.37 & 6.41 & 0.04 & 0.5714 & 2.43 & 0.1249 & 2.5549 \\
9.00 & 5.40 & 6.46 & 6.50 & 0.04 & 0.6198 & 2.16 & 0.2122 & 2.3722 \\
9.22 & 5.45 & 6.55 & 6.60 & 0.05 & 0.8333 & 1.96 & 0.6989 & 2.6589 \\
\hline
\end{tabular}

Log $_{\mathbf{1}}($ Average value $)=2.5832 \pm 0.1614$

Table 8:Point-wise method, Pb-(Hydrolysed PSHA)

\begin{tabular}{|l|l|l|l|l|l|l|l|l|}
\hline $\mathrm{pH}$ & $\mathrm{BV}_{1}$ & $\mathrm{BV}_{2}$ & $\mathrm{BV}_{3}$ & $\left(\mathrm{~V}_{3}-\mathrm{V}_{2}\right)$ & $\mathrm{n}$ & $\mathrm{pL}$ & $\log \left(\frac{n-1}{2-n}\right)$ & $\log \mathrm{K}_{2}$ \\
\hline 9.51 & 5.50 & 6.66 & 6.71 & 0.05 & 0.9650 & 1.67 & & \\
9.73 & 5.55 & 6.78 & 6.83 & 0.05 & 1.1702 & 1.44 & & \\
10.00 & 5.60 & 6.90 & 6.90 & 0.05 & 1.4864 & 1.22 & -0.0237 & 1.1963 \\
10.23 & 5.65 & 7.05 & 7.10 & 0.05 & 2.0190 & 1.09 & & \\
10.49 & 5.70 & 7.10 & 7.17 & 0.07 & 3.6492 & 1.00 & & \\
\hline
\end{tabular}

Log $K_{2}$ (Average value) $=1.1963$

Table 9: Point-wise method, Pb (Unhydrolysed PSHA)

\begin{tabular}{|l|l|l|l|l|l|l|l|l|}
\hline $\mathrm{pH}$ & $\mathrm{BV}_{1}$ & $\mathrm{BV}_{2}$ & $\mathrm{BV}_{3}$ & $\mathrm{~V}_{3}-\mathrm{V}_{2}$ & $\mathrm{n}$ & $\mathrm{pL}$ & $\begin{array}{l}\text { Log } \\
\left(\frac{n}{n-1}\right)\end{array}$ & Log $\mathrm{K}_{1}$ \\
\hline 8.50 & 5.30 & 5.81 & 5.85 & 0.04 & 0.2973 & 2.88 & -0.3736 & 2.5064 \\
8.72 & 5.35 & 5.90 & 5.94 & 0.04 & 0.3099 & 2.66 & -0.5477 & 2.3123 \\
9.00 & 5.40 & 6.00 & 6.05 & 0.05 & 0.4044 & 2.38 & -0.1681 & 2.2119 \\
9.22 & 5.45 & 6.10 & 6.15 & 0.06 & 0.5157 & 2.18 & 0.0272 & 2.2072 \\
9.51 & 5.50 & 6.20 & 6.26 & 0.07 & 0.6417 & 1.89 & 0.2530 & 2.1430 \\
9.73 & 5.55 & 6.40 & 6.40 & 0.07 & 0.7000 & 1.67 & 0.3680 & 2.0380 \\
\hline
\end{tabular}

LogK $_{1}$ (Average value) $=2.2364 \pm 0.1602$

Table 10: Point-wise method, Pb (Unhydrolysed PSHA)

\begin{tabular}{|l|l|l|l|l|l|l|l|l|}
\hline $\mathrm{pH}$ & $\mathrm{BV}_{1}$ & $\mathrm{BV}_{2}$ & $\mathrm{BV}_{3}$ & $\mathrm{~V}_{3}-\mathrm{V}_{2}$ & $\mathrm{n}$ & $\mathrm{pL}$ & $\log \left(\frac{n-1}{2-n}\right)$ & $\log \mathrm{K}_{2}$ \\
\hline 10.00 & 5.60 & 6.47 & 6.55 & 0.08 & 1.9503 & 1.41 & & \\
10.23 & 5.65 & 6.62 & 6.72 & 0.11 & 1.4792 & 1.26 & -0.0361 & 1.2239 \\
\hline
\end{tabular}

$\operatorname{LogK}_{2}$ (Average value) $=1.2239$

Table 11: Point-wise method, Mg (Hydrolysed PSHA)

\begin{tabular}{|l|l|l|l|l|l|l|l|l|}
\hline $\mathrm{pH}$ & $\mathrm{BV}_{1}$ & $\mathrm{BV}_{2}$ & $\mathrm{BV}_{3}$ & $\left(\mathrm{~V}_{3}-\mathrm{V}_{2}\right)$ & $\mathrm{n}$ & $\mathrm{pL}$ & $\log \left(\frac{n}{n-1}\right)$ & LogK $_{1}$ \\
\hline 8.50 & 5.30 & 6.29 & 6.31 & 0.02 & 0.2750 & 2.64 & -0.4290 & 2.2110 \\
8.72 & 5.35 & 6.37 & 6.39 & 0.02 & 0.2858 & 2.42 & -0.3978 & 2.0222 \\
9.00 & 5.40 & 6.46 & 6.49 & 0.03 & 0.4648 & 2.14 & -0.0612 & 2.0788 \\
9.22 & 5.45 & 6.55 & 6.59 & 0.04 & 0.6667 & 1.94 & 0.3010 & 2.2410 \\
\hline
\end{tabular}

$\log _{\mathbf{1}}($ Average value) $=2.1382 \pm 0.1046$ 
BAJOPAS Volume 14 Number 1,June, 2021

Table 12: Point-wise method, Mg (Hydrolysed PSHA)

\begin{tabular}{|l|l|l|l|l|l|l|l|l|}
\hline $\mathrm{pH}$ & $\mathrm{BV}_{1}$ & $\mathrm{BV}_{2}$ & $\mathrm{BV}_{3}$ & $\left(\mathrm{~V}_{3}-\mathrm{V}_{2}\right)$ & $\mathrm{n}$ & $\mathrm{pL}$ & $\log \left(\frac{n-1}{2-n}\right)$ & LogK $_{2}$ \\
\hline 9.51 & 5.55 & 6.66 & 6.71 & 0.05 & 0.9650 & 1.67 & & \\
9.73 & 5.55 & 6.78 & 6.84 & 0.06 & 1.4042 & 1.47 & -0.1686 & 1.3014 \\
10.00 & 5.60 & 6.90 & 6.93 & 0.06 & 1.7838 & 1.23 & 0.5593 & 1.7893 \\
10.23 & 5.65 & 7.05 & 7.10 & 0.06 & 3.1429 & 1.10 & & \\
10.49 & 5.70 & 7.10 & 7.18 & 0.07 & 3.6492 & 0.83 & & \\
\hline
\end{tabular}

LogK $_{2}($ Average value $)=1.5453 \pm 0.3450$

Table 13: Point-wise method, Mg (Unhydrolysed PSHA)

\begin{tabular}{|l|l|l|l|l|l|l|l|l|}
\hline $\mathrm{pH}$ & $\mathrm{BV}_{1}$ & $\mathrm{BV}_{2}$ & $\mathrm{BV}_{3}$ & $\mathrm{~V}_{3}-\mathrm{V}_{2}$ & $\mathrm{n}$ & $\mathrm{pL}$ & $\log \left(\frac{n}{n-1}\right)$ & $\operatorname{Log~}_{1}$ \\
\hline 8.50 & 5.30 & 5.81 & 5.85 & 0.04 & 0.2973 & 2.88 & -0.3736 & 2.5064 \\
8.72 & 5.35 & 5.90 & 5.94 & 0.04 & 0.3099 & 2.66 & -0.3477 & 2.3123 \\
9.00 & 5.40 & 6.00 & 6.04 & 0.04 & 0.3236 & 2.38 & -0.3202 & 2.0598 \\
9.22 & 5.45 & 6.10 & 6.15 & 0.05 & 0.4297 & 2.17 & -0.1230 & 2.0470 \\
9.51 & 5.50 & 6.20 & 6.26 & 0.06 & 0.5500 & 1.89 & 0.0871 & 1.9771 \\
9.73 & 5.55 & 6.33 & 6.40 & 0.07 & 0.7000 & 1.67 & 0.3680 & 2.0380 \\
\hline
\end{tabular}

LogK $_{1}$ (Average value) $=2.1568 \pm 0.2069$

Table 14: Point-wise method, Mg (Unhydrolysed PSHA)

\begin{tabular}{|l|l|l|l|l|l|l|l|l|}
\hline $\mathrm{pH}$ & $\mathrm{BV}_{1}$ & $\mathrm{BV}_{2}$ & $\mathrm{BV}_{3}$ & $\mathrm{~V}_{3}-\mathrm{V}_{2}$ & $\mathrm{n}$ & $\mathrm{pL}$ & $\log \left(\frac{n-1}{2-n}\right)$ & $\log \mathrm{K}_{2}$ \\
\hline 10.00 & 5.60 & 6.47 & 6.55 & 0.08 & 0.9148 & 1.41 & & \\
10.23 & 5.65 & 6.62 & 6.71 & 0.09 & 1.2102 & 1.20 & -0.5749 & 0.6251 \\
10.49 & 5.70 & 6.80 & 6.92 & 0.09 & 1.5968 & 1.03 & 0.1703 & 1.2003 \\
\hline
\end{tabular}

LogK $_{2}$ (Average value) $=0.9127 \pm 0.4070$

Table15:Point-wise method, Cd (Hydrolysed PSHA)

\begin{tabular}{|l|l|l|l|l|l|l|l|l|}
\hline $\mathrm{pH}$ & $\mathrm{BV}_{1}$ & $\mathrm{BV}_{2}$ & $\mathrm{BV}_{3}$ & $\left(\mathrm{~V}_{3}-\mathrm{V}_{2}\right)$ & $\mathrm{n}$ & $\mathrm{pL}$ & $\log \left(\frac{n}{1-n}\right)$ & LogK $_{1}$ \\
\hline 8.50 & 5.30 & 6.29 & 6.31 & 0.02 & 0.2750 & 2.64 & -0.4210 & 2.2190 \\
8.72 & 5.35 & 6.37 & 6.40 & 0.03 & 0.4286 & 2.42 & -0.1249 & 2.2951 \\
9.00 & 5.40 & 6.46 & 6.49 & 0.03 & 0.4648 & 2.14 & -0.0612 & 2.0788 \\
9.22 & 5.45 & 6.55 & 6.59 & 0.04 & 0.6667 & 1.96 & 0.3010 & 2.2610 \\
9.51 & 5.55 & 6.66 & 6.70 & 0.04 & 0.7720 & 1.67 & 0.5297 & 2.1997 \\
\hline
\end{tabular}

LogK $_{\mathbf{1}}$ (Average value) $=2.2108 \pm 0.0825$

Table 16: Point-wise method, Cd (Hydrolysed PSHA)

\begin{tabular}{|l|l|l|l|l|l|l|l|l|}
\hline $\mathrm{pH}$ & $\mathrm{BV}_{1}$ & $\mathrm{BV}_{2}$ & $\mathrm{BV}_{3}$ & $\left(\mathrm{~V}_{3}-\mathrm{V}_{2}\right)$ & $\mathrm{n}$ & $\mathrm{pL}$ & $\log \left(\frac{n-1}{2-n}\right)$ & Log $_{2}$ \\
\hline 9.73 & 5.55 & 6.78 & 6.83 & 0.06 & 1.4042 & 1.47 & -0.1686 & 1.3014 \\
10.00 & 5.60 & 6.90 & 6.95 & 0.06 & 1.7838 & 1.23 & 0.5593 & 1.7893 \\
10.23 & 5.65 & 7.05 & 7.10 & 0.06 & 3.1429 & 1.09 & & \\
10.49 & 5.70 & 7.10 & 7.16 & 0.06 & 3.1429 & 0.89 & & \\
& & & & & & & & \\
\hline
\end{tabular}

$\operatorname{LogK}_{2}$ (Average value) $=1.5453 \pm 0.3450$

Table 17: Point-wise method, Cd (Unhydrolysed PSHA)

\begin{tabular}{|l|l|l|l|l|l|l|l|l|}
\hline $\mathrm{pH}$ & $\mathrm{BV}_{1}$ & $\mathrm{BV}_{2}$ & $\mathrm{BV}_{3}$ & $\mathrm{~V}_{3}-\mathrm{V}_{2}$ & $\mathrm{n}$ & $\mathrm{pL}$ & $\log \left(\frac{n}{n-1}\right)$ & $\operatorname{Log~}_{1}$ \\
\hline 8.50 & 5.30 & 5.81 & 5.86 & 0.05 & 0.3717 & 2.88 & -0.2280 & 2.6520 \\
8.72 & 5.35 & 5.90 & 5.95 & 0.05 & 0.3873 & 2.66 & -0.1992 & 2.4608 \\
9.00 & 5.40 & 6.00 & 6.06 & 0.06 & 0.4853 & 2.38 & -0.0255 & 2.3545 \\
9.22 & 5.45 & 6.10 & 6.16 & 0.06 & 0.5157 & 2.18 & -0.0272 & 2.2072 \\
9.51 & 5.50 & 6.20 & 6.27 & 0.07 & 0.6417 & 1.89 & 0.2530 & 1.1430 \\
9.73 & 5.55 & 6.33 & 6.41 & 0.08 & 0.8000 & 1.69 & 0.6020 & 2.2920 \\
& & & & & & & & \\
\hline
\end{tabular}

$\operatorname{LogK}_{1}($ Average value $)=2.2516 \pm 0.5380$ 
BAJOPAS Volume 14 Number 1,June, 2021

Table 18: Point-wise method, Cd (Unhydrolysed PSHA)

\begin{tabular}{|l|l|l|l|l|l|l|l|l|}
\hline $\mathrm{pH}$ & $\mathrm{BV}_{1}$ & $\mathrm{BV}_{2}$ & $\mathrm{BV}_{3}$ & $\mathrm{~V}_{3}-\mathrm{V}_{2}$ & $\mathrm{n}$ & $\mathrm{pL}$ & $\log \left(\frac{n-1}{2-n}\right)$ & $\log \mathrm{K}_{2}$ \\
\hline 10.00 & 5.60 & 6.47 & 6.57 & 0.10 & 1.1434 & 1.43 & & \\
10.23 & 5.65 & 6.62 & 6.72 & 0.10 & 1.3448 & 1.23 & -0.2788 & 0.9512 \\
10.49 & 5.70 & 6.80 & 6.90 & 0.10 & 1.7742 & 1.03 & 0.5351 & 1.5651 \\
\hline
\end{tabular}

$\operatorname{LogK}_{2}($ Average value $)=1.2581 \pm 0.4340$

Table 19: Stepwise and overall Stability constants of thehydrolysed and unhydrolysed divalent metal (II) complexes

\begin{tabular}{|c|c|c|c|}
\hline Chelates & LogK $_{1}$ & $\log _{2}$ & Log $\beta$ \\
\hline [Cu (Hydrolysed PSHA-1) $\left.{ }_{2}\right]$ & 2.4788 & 1.4280 & 3.9068 \\
\hline$\left[\mathrm{Pb}(\text { Hydrolysed PSHA-1) })_{2}\right]$ & 2.5832 & 1.1963 & 3.7795 \\
\hline$\left[\mathrm{Cd}(\text { Hydrolysed PSHA-1 })_{2}\right]$ & 2.2108 & 1.5453 & 3.7561 \\
\hline$\left[\mathrm{Mg}(\text { Hydrolysed PSHA-1 })_{2}\right]$ & 2.1382 & 1.5453 & 3.6835 \\
\hline [Cu (Unhydrolysed PSHA-1) & 2.3059 & 1.2209 & 3.5268 \\
\hline$[\mathrm{Pb}$ (Unhydrolysed PSHA-1) 2$]$ & 2.2364 & 1.2239 & 3.4603 \\
\hline [Cd (Unhydrolysed PSHA-1) 2 ] & 2.2516 & 1.2581 & 3.5097 \\
\hline$[\mathrm{Mg}$ (Unydrolysed PSHA-1) & 2.1568 & 0.9127 & 3.0695 \\
\hline
\end{tabular}

The results obtained (Table19) shows the stepwise and overall stability constants to be not high indicating low stability of the complexes, because the solubility of most metal ions in the basic $\mathrm{pH}$ range is minimal due to metal hydroxide precipitation (Karimi, 2017). In general, the stepwise stability constants $\left(K_{1}\right.$ and $K_{2}$ ) follow the order $K_{1}>K_{2}$ for the copper, lead, magnesium and cadmium complexes respectively. The steady decrease of the values with increasing number of ligands is in agreement with the prediction made by researchers (Na'aliya, 2013). The decrease could be attributed to the fact that as the number of the ligands (Humate ions) that enters the coordination zone increases the aqua molecules available for replacement by the ligands become less. Thus, the metal ions become less electron loving with progressive intake of the ligand and this results in the decrease in the values of the constants (Na'aliya, 2013). Also the stability of the complexes is influenced by the size and number of the chelate rings(Mackay and Mackay,2002).All the complexes form rings in their structure as humate, a bidentate ligand, bond the metal ions in the ratio 1:2 (Boguta and Sokolowska, 2016) forming chelate rings. The values of the overall stability constants $(\log \beta)$ obtained for humate complexes are not high indicating low stability as the values are not high. LogK values for copper-humates (Table 3 to 6) obtained in this study are lower than those reported for the complexes of humic acids (Pandey et al., 2015; Dinu, 2013; Kaschl et al., 2010 and Gilbeto and Jorg, 2001). The values of LogK(Table 7 to 10 ) forlead-humates are lower than those reported for the lead in the literature (Dinu, 2013; Gilbeto and Jorg 2001). Log K values(Table 11 to 14 ) for magnesium-humates obtained in this study are close to those reported by (Pandey et al., 2015). Log K values of cadmium-humates (Table 15 to 18 ) obtained in this work near to the one reported by (Dinu, 2013 and Pandey et al., 2015).The difference between the reported values and the values obtained in this study might be probably as a result of acid hydrolysis of humic acid. The values of the overall stability constants $(\log \beta)$ of the copper humates complexes presented in Table 19 is high than that of other metal humate complexes, show relatively high stability of CuHA complexes, show the following order of stability: $\mathrm{Cu}>\mathrm{Pb}>\mathrm{Cd}>\mathrm{Mg}$; which are in close agreement to the findings of (Dinu, 2013 and Pandey et al., 2015).The high stability of Cuhumate chelate could be attributed to the existence of coordinate covalent bond between the complexing agents and the $\mathrm{Cu}^{2+}$ ions. Since, $\mathrm{Cu}^{2+}$ being a metal of the transitional series with $3 d^{9}$ electronic configurations can accept the electrons from the complexing agents. Similarly, the low stabilities of $\mathrm{Pb}, \mathrm{Cd}$ and $\mathrm{Mg}$ complexes could be explained by that $\mathrm{Pb}^{2+}$ with $6 s^{2}, \mathrm{Cd}^{2+}$ with $4 \mathrm{~d}^{10}$ and $\mathrm{Mg}^{2+}$ with $2 \mathrm{p}^{6}$ their electronic configuration has a completely filled $\mathrm{d}, \mathrm{p}$ and $\mathrm{s}$ orbitals. Moreover, the stabilities of metal ions with hydrolysed humic acid from peat soil were higher than those with unhydrolysed humic acid from peat soil; which is ascribed to the high content of acidity in hydrolysed humic acid than unhydrolysed humic acid. 
BAJOPAS Volume 14 Number 1,June, 2021 CONCLUSION

The values of logk for $\mathrm{Cu}(\mathrm{II})$ hydrolysed humic acid complex was higher followed by $\mathrm{Pb}$ (II), $\mathrm{Cd}(\mathrm{II})$ and $\mathrm{Mg}$ (II) hydrolysed humic acid complexes as compared with metal(II) unhydrolysed humic acid complexes. This indicates acid hydrolysis of humic acid can

\section{REFERENCES}

Almeida, V.R. and Szpoganicz, B. (2015). Humic Acid Potentiometric Response Patterns:Out- of Equilibrium Properties and Species Distribution Modelling. Chemical. Biol. Technol. Agric. 2: 17.

Anđelković, T., Nikolić, R., Bojić, A.,Anđelković, D., and Nikolic G.,(2010). Binding of Cadmium to Soil Humic Acid as A Function of Carboxyl Group Content. Macedonian Journal of Chemistry and Chemical Engineering.29(2): 215-224.

Anil, B. N. and Maroti, N. (2008). Studies on Influence of Die-Lectric Constants on Complex Equilibria between Substituted Py-Razalines and Lanthanide Metal Ions pH-Metrically. Amer.-Euras. scient. Res. 3(2): 212-216.

Ashok, K., Pandey, S. P. and Misra, V (2000). Stability Constants of Metal-Humic Acid Complexes and its Role in Environmental Detoxification. Journal of Ecotoxicology and Environmental Safety. 47(2):157-200.

Badr, M. H., El-Halafawi, M. H. and Abd El-al Zeid, E. R. (2012). Comparison Between the Effect of Ionic Strength on Acidity and Dissociation Constants of Humic Acids Extracted from Sewage Sludge and Nile Water Hyacinth Composts.Global Journal of Environmental Research 6 (1): 36-43.

Baruah, M.K., Borah, D., Saikia, P.P., Paul, S., Sharma, T. (2015). Evaluation of pKa Values of Soil Humic Acids and their Complexation Properties. International Journal of Plant \& Soil Science 6(4) : 218-228.

Boguta, P. Sokolowska, Z. (2016). Interactions of $\mathrm{Zn}$ (II) Ions with Humic Acids Isolated from Various Types of Soils. Effect of $\mathrm{pH}, \mathrm{Zn}$ Concentrations and Humic Acids Chemical Properties. Journal of Geochemical Explaration 168. 119-126.

Borges, F., Guimaraes, C., Lima, L.F.C., Pinto, I. and Reis, S.(2005). Potentiometric Studies on the Complexation of Copper(II) by Phenolic Acids as Discrete Ligand Models of enhance the complexation behavior of humic acid with metal (II) ions. However, the higher values of $\log \beta$ for $\mathrm{Cu}(\mathrm{II}), \mathrm{Pb}(\mathrm{II}), \mathrm{Cd}(\mathrm{II})$ and $\mathrm{Mg}(\mathrm{II})$ hydrolysed humic acid complexes indicates more stable stepwise complexes formed as compared with $\mathrm{Cu}(\mathrm{II}), \mathrm{Pb}$ (II), $\mathrm{Cd}$ (II) and $\mathrm{Mg}(\mathrm{II})$ unhydrolysed humic acid complexes.

Humic Substances Talanta 66 (2005) 670-673.

Chefetz, B., Salloum, M. J., Deshmulkin, A. P. and Hatcher, P. (2002). Structural Components of Humic Acids as Determined by Chemical Modifications and Carbon-13 NMR, Pyrolysis, and Thermochemolysis- Gas Chromatography/Mass Spectrometry. Soil Science Society of American Journal Abstract Division S-2- Soil Chemistry66. 1159-1171.

Dinu, M. I. (2013). Metals Complexation with Humic Acids in Surface Water of Different Environ. Sci. Technol. 31(1): 1-17.

Fernandes, A.N., Giacomelli, C., Giovanela, M. Vaz, D.V. Szpoganicz, B. and Maria M. D. (2009). Potentiometric Acidity Determination in Humic Substances Influenced by Different Analytical Procedures.J. Braz. Chem. Soc. 20 (9):14.

Gamal, A. H. (2015). Stability Constants of Rhenium (V) Metal Complexes with Selected Drugs. Pyrex Journal of Research in Environmental Studies. 2(2): 006-014.

Janrao, D. M., Pathan, J., Kayande, D.D., and Mulla, J.J. (2014). An Over View of Potentiometric Determination of Stability Constants of Metal Complexes. Sci. Revs. Chem. Commun.: 4(1), 2014, 11-24.

Karimi, H. (2017). Effect of pH and Initial Pb(II) Concentration on the Lead Removal Efficiency from Waste Water Using $\mathrm{Ca}(\mathrm{OH})_{2}$. International Journal of Water and Waste Water Treatment 3.2

Kaschl, A. Romheld, V. and Chen, Y. (2010). Binding of Cadmium, Copper and Zinc to Humic Substances Originating from Municipal Solid Waste Compost. Israel Journal of Chemistry Vol. 42(1): 89-98.

Kostic, I. S., Tatjana, P, A., Nikolic, R. S., Cvetkovic, T. P., Pavlovic, D. D., Aleksandar, L.J. and Bojic, A. (2012). Comparative Study of Binding Strengths of Heavy Metals with Humic Acid. J.serb. Chem. Soc. 76(9) pp 1-20. 
BAJOPAS Volume 14 Number 1,June, 2021

Na'aliya, J. (2013). Determination of Stepwise Stability Constants and Gibbs free Energy Change of Trisprolina to Complexes of some Divalent Transition Metal ions. Bayero Journal of Pure and Applied Sciences 6(2): 112-114.

Omar, A. A. and Ali, E. A. (2015). Potentiometric Studies on Complexes of $\mathrm{Cr}$ (III) and $\mathrm{Zr}$ (IV) with some Carboxylic Acids. International Journal of Advanced Chemistry, 3(1) 25-

37.

Pandey, A. K. Pandey, S. D. and Misr, V. (2015).Stability Constants of Metal- Humic Acid Complexes and Its Role in Environmental Detoxification. J. Ecotoxicology and Environmental Safety. 47(1):195-200.

Ram, N. and Raman, K.V. (1984). Stability Constants of Complexes of Metals with
Humicand Fuvic Acids under Non- acidConditions. Journal of Plant Nutrition and Soil Sciences.

147:171-176.

Santosh, D. D., Ashok, B. K., Vijay, J. T., Shivraj, G. W. and Vinay, V. W. (2011). Potentiometric Studies of Elec-Trolyte Effects on Complex Equilibria of Some Substituted 5-(2-hydroxy Phenyl) Pyrazoles. Der pharm. 3 (6): 75-83.

Sayyed, H. and Abdul Rahim, M. F. (2012). Studies of Binary Complexes of Metal Ions with Mandelic Acid by Potentiometry. Chem. J. 02 (6): 206209.

Shirvani, M. Moradian, E. Khalili, B. Bakhtiary, S. (2015). Interaction of $\mathrm{Cd}$ and $\mathrm{Pb}$ with Humate-Palygorskite and HumateSepiolite Complexes. Journal of water, air and pollution 3: 220-228. 


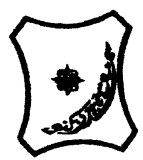

Bayero Journal of Pure and Applied Sciences, 14(1): 54 - 63

Received: November, 2020

Accepted: April, 2021

ISSN $2006-6996$

\title{
STABILITY CONSTANTS OF COMPLEXES OF METAL IONS WITH PEATSOIL HUMIC ACIDS UNDER NON-ACID-CONDITIONS
}

\author{
${ }^{* 1}$ Sabo, Yusuf ${ }^{2}$ Jimoh, W.L.O., ${ }^{3}$ Isa Baba Koki and ${ }^{4}$ Sholadoye, Q. 0. \\ ${ }^{1}$ Department of Pure and Industrial Chemistry, Bayero University, Kano \\ ${ }^{3}$ Department of Chemistry, Yusuf Maitama Sule University Kano. P.M.B. 3220 Kano, Nigeria. \\ ${ }^{4}$ Department of Chemistry, Nigerian Police Academy, Wudil, Kano-Nigeria
}

*Correspondence E-mail; saboyusuf18@yahoo.com

ABSTRACT

Stability constants of complexes of four divalent metal ions viz. $\mathrm{Cu}^{2+}, \mathrm{Pb}^{2+}, \mathrm{Mg}^{2+}$ and $\mathrm{Cd}^{2+}$ with humic acids (HA) were determined by potentiometric titration of humic acids with the corresponding salt of the divalent metals in aqueous media under non-acid-condition. The log $K$ (logarithm of the stability constant) ranged from 1.0942 to 2.7471 for metalhumic acid complexes were determined using point-wise computational method. The order of stability constants were obtained as follows: $\mathrm{Cu}>\mathrm{Pb}>\mathrm{Cd}>\mathrm{Mg}$ for metal $-\mathrm{HA}$ complexes respectively, indicating a higher degree of complexation with Cu metal ion.

Keywords: stability constant, humic acid, potentiometric titration, divalent metals, acid hydrolysis.

\section{NTRODUCTION}

The stability constant of a complex is the numerical expression of its stability and provides a quantitative measure of affinity of the metal ion to the complexing agent. An understanding of the relative stability of metal-complexes helps in predicting the behavior of metal ions in the soil (Ram and Raman, 1982). Extensive researches has been done to determine the stability constants of the complexes formed between humic acid (HA) with a number of metal ions. Ashok et al., (2000) reported that humic acid with hydroxyl, phenoxyl and carboxyl reactive groups can form coordination compound with metal ions at $\mathrm{pH}$ 3.5. The stability constants(Log K) for different metalhumic acid complexes indicated the following order of the stabilities of complexes formed between humic acid and metal ion, $\mathrm{Cu}>\mathrm{Fe}$ $>\mathrm{Pb}>\mathrm{Ni}>\mathrm{Co}>\mathrm{Ca}>\mathrm{Cd}>\mathrm{Zn}>\mathrm{Mn}>\mathrm{Mg}$. Andelkovic et al., (2010) investigated the binding of $\mathrm{Cd}$ (II) to soil humic acid at pH 6.5 and in $0.1 \mathrm{M} \mathrm{KNO}_{3}$ ionic medium. The stability constant for binding indicating greater stability in the case when carboxyl groups are involved in complexation reaction. Kostic et al.,(2012) investigated the complexation of humic acid with certain heavy metal ions (Co(II), $\mathrm{Ni}(\mathrm{II}), \mathrm{Cu}(\mathrm{II})$,
$\mathrm{Zn}(\mathrm{II})$, and $\mathrm{Pb}(\mathrm{II})$. The experiment was performed at $25^{\circ} \mathrm{C}$, at pH 4.0 and ionic strength of $0.01 \mathrm{M}$. Stability constant of complex between $\mathrm{Pb}$ (II) ions and humic acid is greater than stability constants of other investigated metalhumate complexes. Bogata and Sokolowska (2016) analyses the interaction between humic acids from different soils and $\mathrm{Zn}$ (II) ions at wide concentration ranges and at $\mathrm{pH} 5$. Studies have showed significant impact of $\mathrm{Zn}$ concentration, $\mathrm{pH}$ and some properties of humic acids with zinc.But all of these studies were limited to acidic $\mathrm{pH}$ range. Therefore, the present study was carried out to determine and compare the stability constants of complexes of metal ions with hydrolysed peat soil humic acid and unhydrolysed peat soil humic under non-acid conditions.

\section{MATERIALS AND METHODS}

Analytical grade chemicals used includes hydrochloric acid $(\mathrm{HCl})$, nitric acid $\left(\mathrm{HNO}_{3}\right)$, sodium hydroxide $(\mathrm{NaOH})$, lead nitrate $\mathrm{Pb}\left(\mathrm{NO}_{3}\right)_{2}$, copper nitrate $\mathrm{Cu}\left(\mathrm{NO}_{3}\right)_{2} \cdot 3 \mathrm{H}_{2} \mathrm{O}$, cadmium nitrate $\mathrm{Cd}\left(\mathrm{NO}_{3}\right)_{2} \cdot 4 \mathrm{H}_{2} \mathrm{O}$, magnesium nitrate $\mathrm{Mg}\left(\mathrm{NO}_{3}\right)_{2} \cdot 6 \mathrm{H}_{2} \mathrm{O}$, potassium nitrate $\left(\mathrm{KNO}_{3}\right)$, calcium chloride $\left(\mathrm{CaCl}_{2}\right)$, (sigma-Aldrich). Dowex 50WX8, (20-50 mesh) from Fluka. 


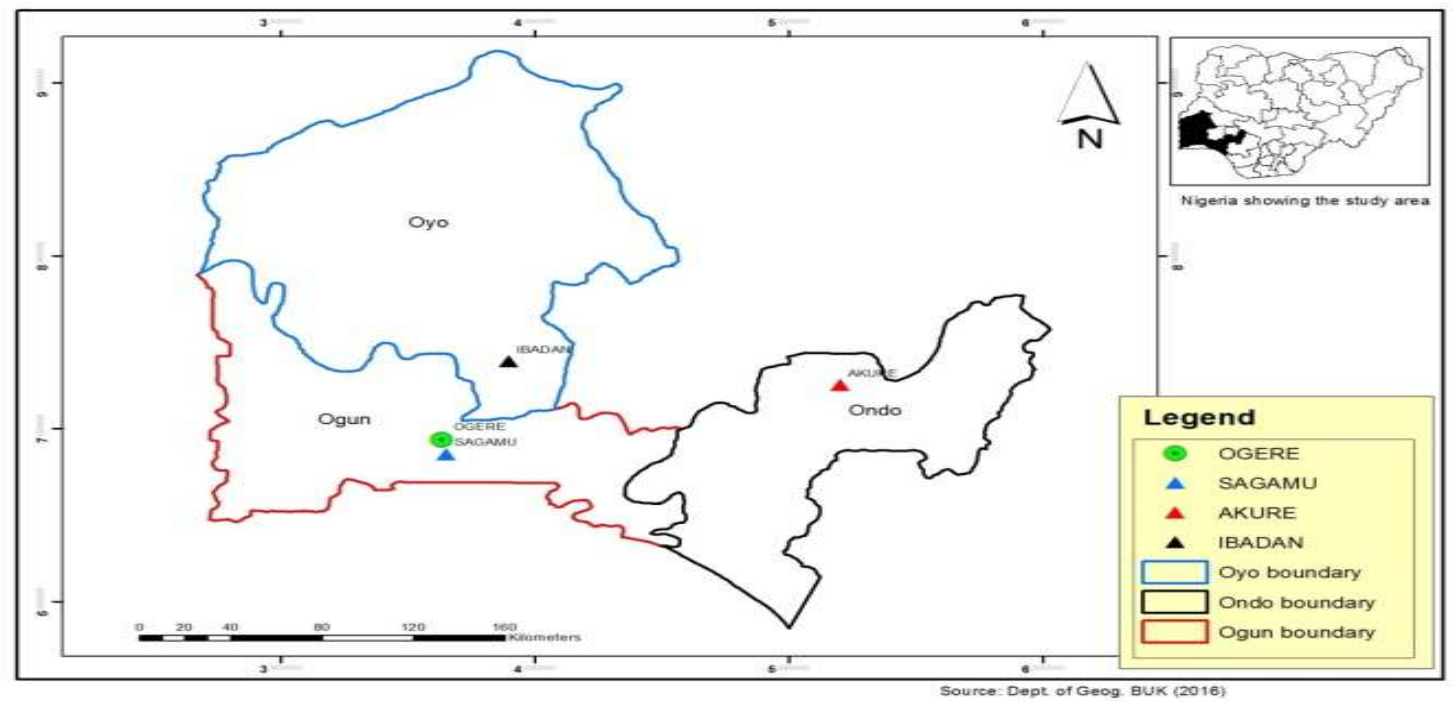

Figure 1: Map showing the sampling point at Sagamu Town, Ogun State.

\section{Description of Sampling Area}

Sagamu has geographical coordinates between $6^{\circ} 50^{\prime}$ north; $3^{\circ} 38^{\prime}$ east is located in south western region of Nigeria. The region has tropical wet and dry climate with a lengthy wet season and relatively constant temperatures throughout the course of the year. Wet season runs from March to October, November to December forms the region dry season. The vegetation type of the region is savannah which is really grassland with small bushes and occasional big trees. Grassland soils have substantially higher organic matter content than forest soils (Novackova, 2011).

\section{Sample Collection}

The Peatsoil samples were collected from four different sampling points $(0-10 \mathrm{~cm}$ depth) in Sagamu into polyethylene bag with plastic spoons. Samples were taken to the laboratory, extraneous materials were removed; the samples were air-dried, crushed and ground to a fine powder in a mortar passed through a $0.20 \mathrm{~mm}$ sieve. The samples were kept for analysis.

\section{Isolation and purification of humic acid from peat soil sample}

Peatsoil sample $(100 \mathrm{~g})$ was mixed with 1000 $\mathrm{cm}^{3}$ of $0.1 \mathrm{M} \mathrm{NaOH}$ solution, shaken for 3hours and left to stand overnight. Dark-coloured supernatant was obtained and decanted from solid residue. The dark-coloured supernatant was acidified to $(\mathrm{pH}=1.0)$ with $6 \mathrm{M} \mathrm{HCl}$ stirred and allowed to stand for 6 hours. Yellowish brown supernatant and dark-brown precipitate were obtained. The yellowish brown supernatant was decanted followed by centrifuge and discarded. The dark-brown precipitate was mixed with $500 \mathrm{~cm}^{3}$ of $0.1 \mathrm{M} \mathrm{NaOH}$ solution followed by passing through dowex resin. The dark-brown solution was acidified to $(\mathrm{pH}=1.0)$ with $6 \mathrm{M} \mathrm{HCl}$ stirred and allowed to stand for 3 hours. The dark-brown precipitate was washed several times with deionized water. The supernatant was treated with $\mathrm{AgNO}_{3}$ solution until no white precipitate observed. The humic acid was transferred to weighed crucible and dried at $60^{\circ} \mathrm{C}$ in an oven for 12 hours. The humic acid was cooled and dried in the desiccator, weighed and recorded. The obtained humic acid was dried again at $60^{\circ} \mathrm{C}$ for additional 6 hours cooled and dried in the desiccator, weighed and recorded constant weight was obtained (Baruah et al., 2015).

\section{FT-IR analysis}

FT-IR spectra of humic acid sample was analysed using Carry 630 FT-IR Agilent Technologies.

Unhydrolysed compost humic acid

The unhydrolysed humic acid was obtained after isolation and purification of compost humic acid and kept for investigation.

\section{Acid hydrolysis of Peatsoil acid}

Peatsoil humic acid sample (1g) was refluxed for 12 hours at $\left(160^{\circ} \mathrm{C}\right)$ with $50 \mathrm{~cm}^{3}$ of $6 \mathrm{M} \mathrm{HCl}$. The mixture was allowed to cool, decanted, and centrifuged after hydrolysis. The insoluble residues were washed with distilled water via centrifugation several times, and the supernatant was treated with $\mathrm{AgNO}_{3}$ solution until no white precipitate was observed. The residue was thoroughly dried over $\mathrm{CaCl}_{2}$ in a desiccator at room temperature (Chefetz et al., 2002). Finally, the obtained hydrolysed humic acid was kept for investigation. 
BAJOPAS Volume 14 Number 1,June, 2021 Potentiometric Titrations

Potentiometric measurements were carried out using a pH-meter Jenway (model 3510) with combine electrode, the sensitivity of the $\mathrm{pH}$ meter is 0.01 units. The $\mathrm{pH}$ meter was switched on half an hour before starting the titration for initial warm up of the instrument. The instrument was calibrated with an aqueous standard buffer solution of $\mathrm{pH} 4.00$ and 10.0 (borate buffer) prepared from a "Qualigens" buffer tablets.

The following sets of solutions were prepared in a $250 \mathrm{~cm}^{3}$ volumetric flask separately for $\mathrm{pH}$ metric titrations.

(i) $5 \mathrm{~cm}^{3} 0.1 \mathrm{M} \mathrm{HCl}+40 \mathrm{~cm}^{3}$ deionized water

(ii) $5 \mathrm{~cm}^{3} 0.1 \mathrm{M} \mathrm{HCl}+39 \mathrm{~cm}^{3}$ deionized water $+1 \mathrm{~cm}^{3} 0.15 \mathrm{gcm}^{-3}$ humic acid

(iii) $5 \mathrm{~cm}^{3} 0.1 \mathrm{M} \mathrm{HCl}+37 \mathrm{~cm}^{3}$ deionized water $+1 \mathrm{~cm}^{3} 0.15 \mathrm{gcm}^{-3}$ humic acid

$$
+2 \mathrm{~cm}^{3} \quad 0.01 \mathrm{M} \mathrm{Cu} \text { (II) }
$$

The solutions were titrated against standardized $0.110 \mathrm{MNaOH}$ separately. The total volume of each mixture was adjusted to $50 \mathrm{~cm}^{3}$ and the ionic strength of the solutions was maintained constant at by adding appropriate amount of stock solution of $1 \mathrm{M} \mathrm{KNO}_{3}$ (Gamal, 2015; Omar and Ali, 2015). A magnetic stirrer was used to achieve thorough mixing of the interacting solutions at $550 \mathrm{rpm}$. The same set of experimental conditions was applied for potentiometric titration of remaining samples.

\section{Evaluation of pKa of Hydrolysed peat soil Humic Acids}

The proton-ligand formation number $\mathrm{n}_{\mathbf{A}}$ were calculated by Irving and Rossotti expression (Omar and Ali, 2015).

$\mathrm{nA}=\mathrm{Y}-\frac{(\mathrm{V} 2-\mathrm{V1})(\mathrm{No}-\mathrm{Eo})}{(\mathrm{VO}+\mathrm{V1}) \mathrm{TCL}}$ 1

Where: $Y$ is number of dissociable proton, $\left(\mathrm{V}_{2^{-}}\right.$ $V_{1}$ ) is the measure of displacement of the ligand curve relative to acid curve, $\mathrm{N}^{\circ}$ and $\mathrm{E}^{\circ}$ are the resultant concentration of alkali solution, free acid solution, $\mathrm{T}_{\mathrm{cL}}{ }^{\circ}$ is the total ligand concentration, $\mathrm{V}^{\circ}$ is the total volume of titration solution, $V_{1}$ is the volume of alkali added to acid solution, $V_{2}$ is the volume of alkali added to acid solution + ligand solution, acid dissociation constants (pKa - values) of ligand were calculated by algebraic method point wise calculation (Tables 1 ). The dissociation constants (pKa) were calculated according to the following relation:

$\mathrm{pKa}=\mathrm{pH}+\log \left(\frac{n A}{1-n A}\right)$ 2

Where: pKa is the acid dissociation constant, $\mathrm{n}_{\mathrm{A}}$ is the Proton-ligand formation number and $\mathrm{pH}$ is the pH-values (Omar and Ali, 2015).

\section{Determination of metal-ligand stability constants $(\log K)$ of complexes}

The potentiometric measurement for the determination of stability constant of a complex in solution is based on the fact that the redox potential of the couple $\frac{M^{+(m-n)}}{M^{+m}}$ is shifted significantly on complexation of the metal ion with the ligand. This method involves change in hydrogen ion concentration $\left[\mathrm{H}^{+}\right]$due to the displacement or association of one or more protons taking place during complexation reaction. This change can be found out by titrating the solutions containing free acid, acid with ligand, and acid with ligand and metal ion, individually against a standard alkali solution at a constant ionic strength or temperature. Either ionic strength or temperature may be varied for different sets of solutions. In all the cases, the change in the $\mathrm{pH}$ of the solution is measured after each addition of a known amount of alkali to the reaction cell which contains the reaction mixture. The titration curves are then drawn by plotting the measured $\mathrm{pH}$ values against the corresponding volume of alkali added and the stability constants of the complexes are determined from the titration curves by employing $\mathrm{pH}$-metric titration technique given by (Irving and Rossoti).

Metal-ligand stability constants ( $\log \mathrm{K}$ ) were determined by using the following relations:

$$
\bar{n}=\frac{\left(V_{3}-V_{2}\right)\left(E^{0}+N^{0}\right)}{\left(V^{0}+V_{2}\right) \bar{n}_{A} T_{m}^{0}}
$$

and

$$
P L=\log _{10}\left\{\frac{1+\beta_{n}^{H} \frac{1}{[\text { anti } \log \mathrm{pH}]^{\mathrm{n}}}}{\mathrm{T}_{\mathrm{L}}^{0}-n \bar{T}_{m}^{0}} \mathrm{X} \frac{\left(V^{0}+V_{3}\right)}{V^{0}}\right\}
$$


BAJOPAS Volume 14 Number 1,June, 2021

Where $T_{L}, T^{\circ}, E^{\circ}$, and $V^{\circ}$ havethe same significance as in equation (1) above, $T_{m}$ denotes the total concentration of metal present in solution, $V_{3}$ is the volume of metal ions present in solution and $\beta^{H}$ is the overall proton ligand stability constant. The metal-ligand stability constants (log K) were determined by employing point wise computational Method (eq. 5 and 6).

$\operatorname{LogK}_{1}=\log \left(\frac{n}{1-n}\right)+\mathrm{pL}$ .5

$\operatorname{LogK}_{2}=\log \left(\frac{1-n}{2-n}\right)+\mathrm{pL}$ ...6

Where: Log $\mathrm{K}$ is the metal-ligand stability constant, $\mathrm{pL}$ is the Free ligand exponent function, $\mathbf{n}$ is the Average number of ligand attached with metal ion (Janraoet al., 2014). The results obtained were analyzed by an ORIGIN 2016 program using titration data and then the proton-ligand stability constants (pKa) and Metal-ligand stability constant (LogK) calculated (Omar and Ali, 2015).

\section{RESULTS AND DISCUSSION}

Fourier transformed infrared (FT-IR) spectra of isolated humic acid from peat soils Figure 2 had distinct clear absorption bands indicating the presence of major humic acid structural elemental groups such as $\mathrm{H}$ bonded $\mathrm{OH}$ $\left(3680 \mathrm{~cm}^{-1}\right.$ peak $), C=0$ of carbonyl $\left(1721 \mathrm{~cm}^{-1}\right.$ peak), functional groups of aliphatic components $\mathrm{CH}_{2}\left(2918 \mathrm{~cm}^{-1}\right.$ peak) and $\mathrm{C}-\mathrm{O}$ stretching of polysaccharide $\left(1168 \mathrm{~cm}^{-1}\right.$ peak). The positions of the absorption bands of the spectra fell within typical major absorption bands of humic acid which is at frequencies 3680, 2918, 1721, 1168 $\mathrm{cm}^{-1}$. The first peak centred in the vicinity of $3680 \mathrm{~cm}^{-1}$ region is attributed to phenol $\mathrm{OH}$ group bounded by intermolecular $\mathrm{H}$ bonds. The $2918 \mathrm{~cm}^{-1}$ band usually has absorption maximum at $2918 \mathrm{~cm}^{-1}$ which is due to $\mathrm{C}-\mathrm{H}$ stretching of alkane group $\left(\mathrm{CH}_{2}\right)$. The next major absorption band is $1721 \mathrm{~cm}^{-1}$. This band has been commonly ascribed to $\mathrm{C}=\mathrm{O}$ stretching of mainly carboxyl group $(\mathrm{COOH})$ with trace amount of ketones. The last peak was observed at 1168 $\mathrm{cm}^{-1}$ due to $\mathrm{C}-\mathrm{O}$ stretching of polysaccharides and this peak appeared also in the spectra of humic acid from peat soil. The FTIR spectra of the isolated humic acid contained all major characteristic absorption peaks of humic acid. These absorption peaks indicated the presence of the major structural elements of humic acid namely $\mathrm{H}$ bonded $\mathrm{OH}, \mathrm{C}=\mathrm{C}$ of aromatic ring, $\mathrm{C}=\mathrm{O}$ of carbonyl group (both carboxyl and ketonic), $\mathrm{CH}_{2}$ group. This strongly supports the presence of humic acid.

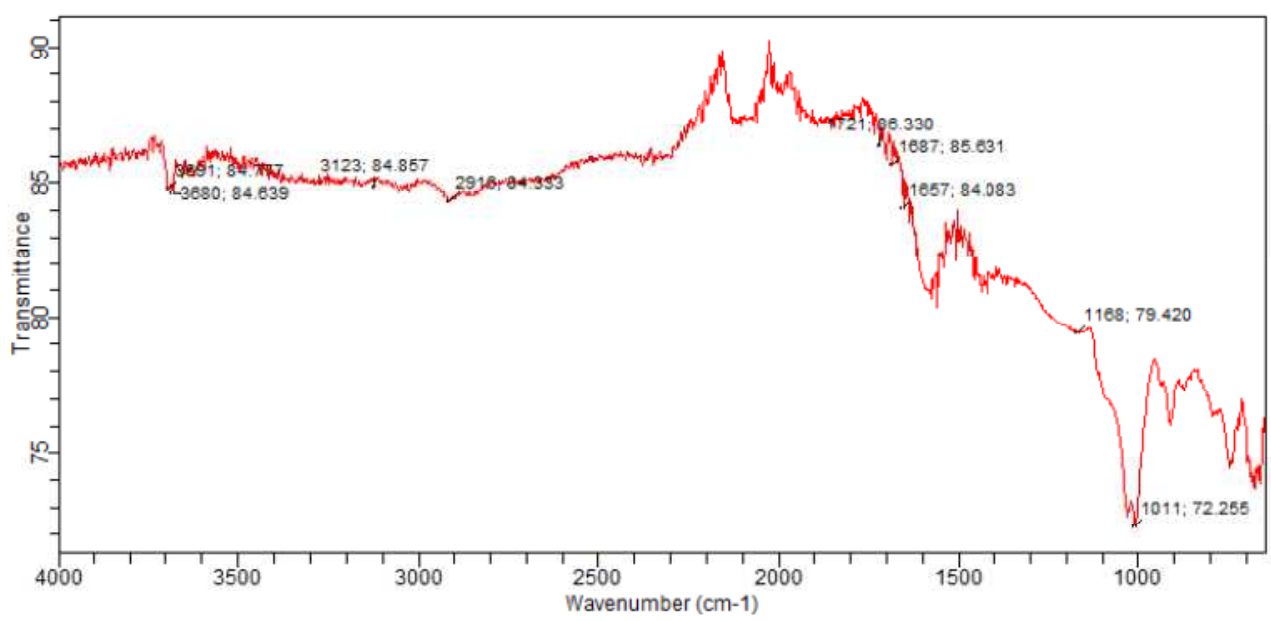

Fig. 2 : FT-IR spectraof peatsoilhumic acid (PSHA)

\section{Evaluation of acid dissociation constant (pka) of acid hydrolysed peat soil humicacid at phenolic group}

The value of the dissociation constant of the peat soil humic acid (PSHA) that underwent acidhydrolysis studied was found to be 8.9299 as shown Table 1, which is lower than the literaturevalues reported by Almeida and Szpoganics, (2015), Borges et al., (2005); Badr et al., (2012)and Fernandes et al,.(2009) of $9.73,9.47$ and 10.30. The difference between the obtained valuesand the reported values in this study might be probably as a result of acid hydrolysis of humicacid. 
BAJOPAS Volume 14 Number 1,June, 2021

Table 1: PKa of (Hydrolysed PSHA)

\begin{tabular}{|l|l|l|l|l|l|l|}
\hline $\mathrm{pH}$ & $\mathrm{BV}_{1}$ & $\mathrm{BV}_{2}$ & $\mathrm{~V}_{2}-\mathrm{V}_{1}$ & $\mathrm{nA}$ & $\log \left(\frac{n A}{1-n A}\right)$ & $\mathrm{pKa}$ \\
\hline 8.50 & 5.30 & 6.29 & 0.99 & 0.3594 & -0.2510 & 8.2490 \\
8.72 & 5.35 & 6.37 & 1.02 & 0.3400 & -0.2880 & 8.4320 \\
9.00 & 5.40 & 6.46 & 1.06 & 0.3141 & -0.3391 & 8.6609 \\
9.22 & 5.45 & 6.55 & 1.10 & 0.2882 & -0.3927 & 8.8273 \\
9.51 & 5.50 & 6.66 & 1.16 & 0.2494 & -0.4786 & 9.0314 \\
9.73 & 5.55 & 6.78 & 1.23 & 0.2041 & -0.5910 & 9.1390 \\
10.00 & 5.60 & 6.90 & 1.30 & 0.1589 & -0.7238 & 9.2762 \\
10.23 & 5.65 & 7.05 & 1.40 & 0.0941 & -0.9835 & 9.2465 \\
10.49 & 5.70 & 7.10 & 1.40 & 0.0941 & -0.9835 & 9.5065 \\
\hline
\end{tabular}

Average pKa $=8.9299 \pm 0.4186$

Table 2: PKa of (Unhydrolysed PSHA)

\begin{tabular}{|l|l|l|l|l|l|l|}
\hline $\mathrm{pH}$ & $\mathrm{BV}_{1}$ & $\mathrm{BV}_{2}$ & $\mathrm{~V}_{2}-\mathrm{V}_{1}$ & $\mathrm{nA}$ & $\log \left(\frac{\boldsymbol{n A}}{1-\boldsymbol{n}}\right)$ & $\mathrm{pKa}$ \\
\hline 8.50 & 5.30 & 5.81 & 0.51 & 0.6619 & 0.2919 & 8.7919 \\
8.72 & 5.35 & 5.90 & 0.55 & 0.6357 & 0.2418 & 8.9618 \\
9.00 & 5.40 & 6.00 & 0.60 & 0.6029 & 0.1813 & 9.1813 \\
9.22 & 5.45 & 6.10 & 0.65 & 0.5701 & 0.1226 & 9.3426 \\
9.51 & 5.50 & 6.20 & 0.70 & 0.5376 & 0.0654 & 9.5754 \\
9.73 & 5.55 & 6.33 & 0.78 & 0.4851 & -0.0259 & 9.7041 \\
10.00 & 5.60 & 6.47 & 0.87 & 0.4262 & -0.1291 & 9.8709 \\
10.23 & 5.65 & 6.62 & 0.99 & 0.3609 & -0.2481 & 9.9819 \\
10.49 & 5.70 & 6.80 & 1.10 & 0.2759 & -0.4690 & 10.0210 \\
\hline
\end{tabular}

Average pKa $=9.4923 \pm 0.4410$

Metal-ligand stability constant ( $\log \mathrm{K}$ )

The stabilityconstants require the accurate values of proton-ligand stability constants (Anil and Maroti, 2008). Metal titration curves crossed over ligand titration curve indicated the formation of complex upon proton release (Santosh, et al., 2011). If the values of n- are within range $0.2-0.8$ and $1.2-18$ this indicates the formation of $1: 1$ and 1:2 complexes (Sayyed and Mazahar, 2012).

The metal (II)-humate stepwise stability constants (log k) at phenolic group (Tables 318)

Table 3: Point-wise method, $\mathrm{Cu}$-(Hydrolysed PSHA)

\begin{tabular}{|l|l|l|l|l|l|l|l|l|}
\hline $\mathrm{pH}$ & $\mathrm{BV}_{1}$ & $\mathrm{BV}_{2}$ & $\mathrm{BV}_{3}$ & $\left(\mathrm{~V}_{3}-\mathrm{V}_{2}\right)$ & $\mathrm{n}$ & $\mathrm{pL}$ & $\log \left(\frac{n}{1-n}\right)$ & LogK $_{1}$ \\
\hline 8.50 & 5.30 & 6.29 & 6.33 & 0.04 & 0.5500 & 2.66 & 0.0871 & 2.7471 \\
8.72 & 5.35 & 6.37 & 6.41 & 0.04 & 0.5714 & 2.43 & 0.1249 & 2.5549 \\
9.00 & 5.40 & 6.46 & 6.50 & 0.04 & 0.6198 & 2.16 & 0.2122 & 2.3722 \\
9.22 & 5.45 & 6.55 & 6.59 & 0.04 & 0.6667 & 1.94 & 0.3010 & 2.2410 \\
\hline
\end{tabular}

LogK $_{1}$ (Average value) $=2.4788 \pm 0.2203$

Table 4: Point-wise method, $\mathrm{Cu}$-(Hydrolysed PSHA)

\begin{tabular}{|l|l|l|l|l|l|l|l|l|}
\hline $\mathrm{pH}$ & $\mathrm{BV}_{1}$ & $\mathrm{BV}_{2}$ & $\mathrm{BV}_{3}$ & $\left(\mathrm{~V}_{3}-\mathrm{V}_{2}\right)$ & $\mathrm{n}$ & $\mathrm{pL}$ & $\log \left(\frac{n-1}{2-n}\right)$ & LogK $_{2}$ \\
\hline 9.51 & 5.50 & 6.66 & 6.73 & 0.07 & 1.3509 & 1.70 & -0.2671 & 1.4329 \\
9.73 & 5.55 & 6.78 & 6.85 & 0.07 & 1.6383 & 1.51 & 0.2467 & 1.7567 \\
10.00 & 5.60 & 6.90 & 6.98 & 0.08 & 2.1783 & 1.31 & -0.2158 & 1.0942 \\
10.23 & 5.65 & 7.05 & 7.13 & 0.08 & 4.1904 & 1.27 & & \\
10.49 & 5.70 & 7.10 & 7.19 & 0.09 & 4.6920 & & & \\
\hline
\end{tabular}

Log $K_{2}($ Average value $)=1.4280 \pm 0.3312$ 
BAJOPAS Volume 14 Number 1,June, 2021

Table 5: Point-wise method, $\mathrm{Cu}$ (Unhydrolysed PSHA)

\begin{tabular}{|l|l|l|l|l|l|l|l|l|}
\hline $\mathrm{pH}$ & $\mathrm{BV}_{1}$ & $\mathrm{BV}_{2}$ & $\mathrm{BV}_{3}$ & $\left(\mathrm{~V}_{3}-\mathrm{V}_{2}\right)$ & $\mathrm{n}$ & $\mathrm{pL}$ & $\log \left(\frac{n}{n-1}\right)$ & Log $_{1}$ \\
\hline 8.50 & 5.30 & 5.81 & 5.85 & 0.04 & 0.2973 & 2.88 & -0.3736 & 2.5064 \\
8.72 & 5.35 & 5.90 & 5.95 & 0.05 & 0.3873 & 2.66 & -0.1992 & 2.4608 \\
9.00 & 5.40 & 6.00 & 6.05 & 0.05 & 0.4044 & 2.38 & -0.1681 & 2.2119 \\
9.22 & 5.45 & 6.10 & 6.15 & 0.06 & 0.5157 & 2.18 & -0.0272 & 2.2072 \\
9.51 & 5.50 & 6.20 & 6.27 & 0.07 & 0.6417 & 1.89 & 0.2530 & 1.1430 \\
\hline
\end{tabular}

$\operatorname{LogK}_{1}($ Average value $)=2.3059 \pm 0.6153$

Table 6:Point-wise method, $\mathrm{Cu}$ (Unhydrolysed PSHA)

\begin{tabular}{|l|l|l|l|l|l|l|l|l|}
\hline $\mathrm{pH}$ & $\mathrm{BV}_{1}$ & $\mathrm{BV}_{2}$ & $\mathrm{BV}_{3}$ & $\mathrm{~V}_{3}-\mathrm{V}_{2}$ & $\mathrm{n}$ & $\mathrm{pL}$ & $\log \left(\frac{n-1}{2-n}\right)$ & $\log \mathrm{K}_{2}$ \\
\hline 9.73 & 5.55 & 6.33 & 6.42 & 0.09 & 0.9000 & 1.69 & & \\
10.00 & 5.60 & 6.47 & 6.58 & 0.11 & 1.2578 & 1.44 & -0.4592 & 0.9808 \\
10.23 & 5.65 & 6.62 & 6.84 & 0.12 & 1.6137 & 1.26 & -0.2010 & 1.4610 \\
10.49 & 5.70 & 6.80 & 6.92 & 0.12 & 2.1052 & 1.03 & & \\
\hline
\end{tabular}

$\operatorname{LogK}_{2}$ (Average value) $=1.2209 \pm 0.3398$

Table 7:Point-wise method, Pb (Hydrolysed PSHA)

\begin{tabular}{|l|l|l|l|l|l|l|l|l|}
\hline $\mathrm{pH}$ & $\mathrm{BV}_{1}$ & $\mathrm{BV}_{2}$ & $\mathrm{BV}_{3}$ & $\left(\mathrm{~V}_{3}-\mathrm{V}_{2}\right)$ & $\mathrm{n}$ & $\mathrm{pL}$ & $\log \left(\frac{n}{1-n}\right)$ & LogK $_{1}$ \\
\hline 8.50 & 5.30 & 6.29 & 6.33 & 0.04 & 0.5500 & 2.66 & 0.0871 & 2.7471 \\
8.72 & 5.35 & 6.37 & 6.41 & 0.04 & 0.5714 & 2.43 & 0.1249 & 2.5549 \\
9.00 & 5.40 & 6.46 & 6.50 & 0.04 & 0.6198 & 2.16 & 0.2122 & 2.3722 \\
9.22 & 5.45 & 6.55 & 6.60 & 0.05 & 0.8333 & 1.96 & 0.6989 & 2.6589 \\
\hline
\end{tabular}

Log $_{\mathbf{1}}($ Average value $)=2.5832 \pm 0.1614$

Table 8:Point-wise method, Pb-(Hydrolysed PSHA)

\begin{tabular}{|l|l|l|l|l|l|l|l|l|}
\hline $\mathrm{pH}$ & $\mathrm{BV}_{1}$ & $\mathrm{BV}_{2}$ & $\mathrm{BV}_{3}$ & $\left(\mathrm{~V}_{3}-\mathrm{V}_{2}\right)$ & $\mathrm{n}$ & $\mathrm{pL}$ & $\log \left(\frac{n-1}{2-n}\right)$ & $\log \mathrm{K}_{2}$ \\
\hline 9.51 & 5.50 & 6.66 & 6.71 & 0.05 & 0.9650 & 1.67 & & \\
9.73 & 5.55 & 6.78 & 6.83 & 0.05 & 1.1702 & 1.44 & & \\
10.00 & 5.60 & 6.90 & 6.90 & 0.05 & 1.4864 & 1.22 & -0.0237 & 1.1963 \\
10.23 & 5.65 & 7.05 & 7.10 & 0.05 & 2.0190 & 1.09 & & \\
10.49 & 5.70 & 7.10 & 7.17 & 0.07 & 3.6492 & 1.00 & & \\
\hline
\end{tabular}

Log $K_{2}$ (Average value) $=1.1963$

Table 9: Point-wise method, Pb (Unhydrolysed PSHA)

\begin{tabular}{|l|l|l|l|l|l|l|l|l|}
\hline $\mathrm{pH}$ & $\mathrm{BV}_{1}$ & $\mathrm{BV}_{2}$ & $\mathrm{BV}_{3}$ & $\mathrm{~V}_{3}-\mathrm{V}_{2}$ & $\mathrm{n}$ & $\mathrm{pL}$ & $\begin{array}{l}\text { Log } \\
\left(\frac{n}{n-1}\right)\end{array}$ & Log $\mathrm{K}_{1}$ \\
\hline 8.50 & 5.30 & 5.81 & 5.85 & 0.04 & 0.2973 & 2.88 & -0.3736 & 2.5064 \\
8.72 & 5.35 & 5.90 & 5.94 & 0.04 & 0.3099 & 2.66 & -0.5477 & 2.3123 \\
9.00 & 5.40 & 6.00 & 6.05 & 0.05 & 0.4044 & 2.38 & -0.1681 & 2.2119 \\
9.22 & 5.45 & 6.10 & 6.15 & 0.06 & 0.5157 & 2.18 & 0.0272 & 2.2072 \\
9.51 & 5.50 & 6.20 & 6.26 & 0.07 & 0.6417 & 1.89 & 0.2530 & 2.1430 \\
9.73 & 5.55 & 6.40 & 6.40 & 0.07 & 0.7000 & 1.67 & 0.3680 & 2.0380 \\
\hline
\end{tabular}

LogK $_{1}$ (Average value) $=2.2364 \pm 0.1602$

Table 10: Point-wise method, Pb (Unhydrolysed PSHA)

\begin{tabular}{|l|l|l|l|l|l|l|l|l|}
\hline $\mathrm{pH}$ & $\mathrm{BV}_{1}$ & $\mathrm{BV}_{2}$ & $\mathrm{BV}_{3}$ & $\mathrm{~V}_{3}-\mathrm{V}_{2}$ & $\mathrm{n}$ & $\mathrm{pL}$ & $\log \left(\frac{n-1}{2-n}\right)$ & $\log \mathrm{K}_{2}$ \\
\hline 10.00 & 5.60 & 6.47 & 6.55 & 0.08 & 1.9503 & 1.41 & & \\
10.23 & 5.65 & 6.62 & 6.72 & 0.11 & 1.4792 & 1.26 & -0.0361 & 1.2239 \\
\hline
\end{tabular}

$\operatorname{LogK}_{2}$ (Average value) $=1.2239$

Table 11: Point-wise method, Mg (Hydrolysed PSHA)

\begin{tabular}{|l|l|l|l|l|l|l|l|l|}
\hline $\mathrm{pH}$ & $\mathrm{BV}_{1}$ & $\mathrm{BV}_{2}$ & $\mathrm{BV}_{3}$ & $\left(\mathrm{~V}_{3}-\mathrm{V}_{2}\right)$ & $\mathrm{n}$ & $\mathrm{pL}$ & $\log \left(\frac{n}{n-1}\right)$ & LogK $_{1}$ \\
\hline 8.50 & 5.30 & 6.29 & 6.31 & 0.02 & 0.2750 & 2.64 & -0.4290 & 2.2110 \\
8.72 & 5.35 & 6.37 & 6.39 & 0.02 & 0.2858 & 2.42 & -0.3978 & 2.0222 \\
9.00 & 5.40 & 6.46 & 6.49 & 0.03 & 0.4648 & 2.14 & -0.0612 & 2.0788 \\
9.22 & 5.45 & 6.55 & 6.59 & 0.04 & 0.6667 & 1.94 & 0.3010 & 2.2410 \\
\hline
\end{tabular}

$\log _{\mathbf{1}}($ Average value) $=2.1382 \pm 0.1046$ 
BAJOPAS Volume 14 Number 1,June, 2021

Table 12: Point-wise method, Mg (Hydrolysed PSHA)

\begin{tabular}{|l|l|l|l|l|l|l|l|l|}
\hline $\mathrm{pH}$ & $\mathrm{BV}_{1}$ & $\mathrm{BV}_{2}$ & $\mathrm{BV}_{3}$ & $\left(\mathrm{~V}_{3}-\mathrm{V}_{2}\right)$ & $\mathrm{n}$ & $\mathrm{pL}$ & $\log \left(\frac{n-1}{2-n}\right)$ & LogK $_{2}$ \\
\hline 9.51 & 5.55 & 6.66 & 6.71 & 0.05 & 0.9650 & 1.67 & & \\
9.73 & 5.55 & 6.78 & 6.84 & 0.06 & 1.4042 & 1.47 & -0.1686 & 1.3014 \\
10.00 & 5.60 & 6.90 & 6.93 & 0.06 & 1.7838 & 1.23 & 0.5593 & 1.7893 \\
10.23 & 5.65 & 7.05 & 7.10 & 0.06 & 3.1429 & 1.10 & & \\
10.49 & 5.70 & 7.10 & 7.18 & 0.07 & 3.6492 & 0.83 & & \\
\hline
\end{tabular}

LogK $_{2}($ Average value $)=1.5453 \pm 0.3450$

Table 13: Point-wise method, Mg (Unhydrolysed PSHA)

\begin{tabular}{|l|l|l|l|l|l|l|l|l|}
\hline $\mathrm{pH}$ & $\mathrm{BV}_{1}$ & $\mathrm{BV}_{2}$ & $\mathrm{BV}_{3}$ & $\mathrm{~V}_{3}-\mathrm{V}_{2}$ & $\mathrm{n}$ & $\mathrm{pL}$ & $\log \left(\frac{n}{n-1}\right)$ & $\operatorname{Log~}_{1}$ \\
\hline 8.50 & 5.30 & 5.81 & 5.85 & 0.04 & 0.2973 & 2.88 & -0.3736 & 2.5064 \\
8.72 & 5.35 & 5.90 & 5.94 & 0.04 & 0.3099 & 2.66 & -0.3477 & 2.3123 \\
9.00 & 5.40 & 6.00 & 6.04 & 0.04 & 0.3236 & 2.38 & -0.3202 & 2.0598 \\
9.22 & 5.45 & 6.10 & 6.15 & 0.05 & 0.4297 & 2.17 & -0.1230 & 2.0470 \\
9.51 & 5.50 & 6.20 & 6.26 & 0.06 & 0.5500 & 1.89 & 0.0871 & 1.9771 \\
9.73 & 5.55 & 6.33 & 6.40 & 0.07 & 0.7000 & 1.67 & 0.3680 & 2.0380 \\
\hline
\end{tabular}

LogK $_{1}$ (Average value) $=2.1568 \pm 0.2069$

Table 14: Point-wise method, Mg (Unhydrolysed PSHA)

\begin{tabular}{|l|l|l|l|l|l|l|l|l|}
\hline $\mathrm{pH}$ & $\mathrm{BV}_{1}$ & $\mathrm{BV}_{2}$ & $\mathrm{BV}_{3}$ & $\mathrm{~V}_{3}-\mathrm{V}_{2}$ & $\mathrm{n}$ & $\mathrm{pL}$ & $\log \left(\frac{n-1}{2-n}\right)$ & $\log \mathrm{K}_{2}$ \\
\hline 10.00 & 5.60 & 6.47 & 6.55 & 0.08 & 0.9148 & 1.41 & & \\
10.23 & 5.65 & 6.62 & 6.71 & 0.09 & 1.2102 & 1.20 & -0.5749 & 0.6251 \\
10.49 & 5.70 & 6.80 & 6.92 & 0.09 & 1.5968 & 1.03 & 0.1703 & 1.2003 \\
\hline
\end{tabular}

LogK $_{2}$ (Average value) $=0.9127 \pm 0.4070$

Table15:Point-wise method, Cd (Hydrolysed PSHA)

\begin{tabular}{|l|l|l|l|l|l|l|l|l|}
\hline $\mathrm{pH}$ & $\mathrm{BV}_{1}$ & $\mathrm{BV}_{2}$ & $\mathrm{BV}_{3}$ & $\left(\mathrm{~V}_{3}-\mathrm{V}_{2}\right)$ & $\mathrm{n}$ & $\mathrm{pL}$ & $\log \left(\frac{n}{1-n}\right)$ & LogK $_{1}$ \\
\hline 8.50 & 5.30 & 6.29 & 6.31 & 0.02 & 0.2750 & 2.64 & -0.4210 & 2.2190 \\
8.72 & 5.35 & 6.37 & 6.40 & 0.03 & 0.4286 & 2.42 & -0.1249 & 2.2951 \\
9.00 & 5.40 & 6.46 & 6.49 & 0.03 & 0.4648 & 2.14 & -0.0612 & 2.0788 \\
9.22 & 5.45 & 6.55 & 6.59 & 0.04 & 0.6667 & 1.96 & 0.3010 & 2.2610 \\
9.51 & 5.55 & 6.66 & 6.70 & 0.04 & 0.7720 & 1.67 & 0.5297 & 2.1997 \\
\hline
\end{tabular}

LogK $_{\mathbf{1}}$ (Average value) $=2.2108 \pm 0.0825$

Table 16: Point-wise method, Cd (Hydrolysed PSHA)

\begin{tabular}{|l|l|l|l|l|l|l|l|l|}
\hline $\mathrm{pH}$ & $\mathrm{BV}_{1}$ & $\mathrm{BV}_{2}$ & $\mathrm{BV}_{3}$ & $\left(\mathrm{~V}_{3}-\mathrm{V}_{2}\right)$ & $\mathrm{n}$ & $\mathrm{pL}$ & $\log \left(\frac{n-1}{2-n}\right)$ & Log $_{2}$ \\
\hline 9.73 & 5.55 & 6.78 & 6.83 & 0.06 & 1.4042 & 1.47 & -0.1686 & 1.3014 \\
10.00 & 5.60 & 6.90 & 6.95 & 0.06 & 1.7838 & 1.23 & 0.5593 & 1.7893 \\
10.23 & 5.65 & 7.05 & 7.10 & 0.06 & 3.1429 & 1.09 & & \\
10.49 & 5.70 & 7.10 & 7.16 & 0.06 & 3.1429 & 0.89 & & \\
& & & & & & & & \\
\hline
\end{tabular}

$\operatorname{LogK}_{2}$ (Average value) $=1.5453 \pm 0.3450$

Table 17: Point-wise method, Cd (Unhydrolysed PSHA)

\begin{tabular}{|l|l|l|l|l|l|l|l|l|}
\hline $\mathrm{pH}$ & $\mathrm{BV}_{1}$ & $\mathrm{BV}_{2}$ & $\mathrm{BV}_{3}$ & $\mathrm{~V}_{3}-\mathrm{V}_{2}$ & $\mathrm{n}$ & $\mathrm{pL}$ & $\log \left(\frac{n}{n-1}\right)$ & $\operatorname{Log~}_{1}$ \\
\hline 8.50 & 5.30 & 5.81 & 5.86 & 0.05 & 0.3717 & 2.88 & -0.2280 & 2.6520 \\
8.72 & 5.35 & 5.90 & 5.95 & 0.05 & 0.3873 & 2.66 & -0.1992 & 2.4608 \\
9.00 & 5.40 & 6.00 & 6.06 & 0.06 & 0.4853 & 2.38 & -0.0255 & 2.3545 \\
9.22 & 5.45 & 6.10 & 6.16 & 0.06 & 0.5157 & 2.18 & -0.0272 & 2.2072 \\
9.51 & 5.50 & 6.20 & 6.27 & 0.07 & 0.6417 & 1.89 & 0.2530 & 1.1430 \\
9.73 & 5.55 & 6.33 & 6.41 & 0.08 & 0.8000 & 1.69 & 0.6020 & 2.2920 \\
& & & & & & & & \\
\hline
\end{tabular}

$\operatorname{LogK}_{1}($ Average value $)=2.2516 \pm 0.5380$ 
BAJOPAS Volume 14 Number 1,June, 2021

Table 18: Point-wise method, Cd (Unhydrolysed PSHA)

\begin{tabular}{|l|l|l|l|l|l|l|l|l|}
\hline $\mathrm{pH}$ & $\mathrm{BV}_{1}$ & $\mathrm{BV}_{2}$ & $\mathrm{BV}_{3}$ & $\mathrm{~V}_{3}-\mathrm{V}_{2}$ & $\mathrm{n}$ & $\mathrm{pL}$ & $\log \left(\frac{n-1}{2-n}\right)$ & $\log \mathrm{K}_{2}$ \\
\hline 10.00 & 5.60 & 6.47 & 6.57 & 0.10 & 1.1434 & 1.43 & & \\
10.23 & 5.65 & 6.62 & 6.72 & 0.10 & 1.3448 & 1.23 & -0.2788 & 0.9512 \\
10.49 & 5.70 & 6.80 & 6.90 & 0.10 & 1.7742 & 1.03 & 0.5351 & 1.5651 \\
\hline
\end{tabular}

$\operatorname{LogK}_{2}($ Average value $)=1.2581 \pm 0.4340$

Table 19: Stepwise and overall Stability constants of thehydrolysed and unhydrolysed divalent metal (II) complexes

\begin{tabular}{|c|c|c|c|}
\hline Chelates & LogK $_{1}$ & $\log _{2}$ & Log $\beta$ \\
\hline [Cu (Hydrolysed PSHA-1) $\left.{ }_{2}\right]$ & 2.4788 & 1.4280 & 3.9068 \\
\hline$\left[\mathrm{Pb}(\text { Hydrolysed PSHA-1) })_{2}\right]$ & 2.5832 & 1.1963 & 3.7795 \\
\hline$\left[\mathrm{Cd}(\text { Hydrolysed PSHA-1 })_{2}\right]$ & 2.2108 & 1.5453 & 3.7561 \\
\hline$\left[\mathrm{Mg}(\text { Hydrolysed PSHA-1 })_{2}\right]$ & 2.1382 & 1.5453 & 3.6835 \\
\hline [Cu (Unhydrolysed PSHA-1) & 2.3059 & 1.2209 & 3.5268 \\
\hline$[\mathrm{Pb}$ (Unhydrolysed PSHA-1) 2$]$ & 2.2364 & 1.2239 & 3.4603 \\
\hline [Cd (Unhydrolysed PSHA-1) 2 ] & 2.2516 & 1.2581 & 3.5097 \\
\hline$[\mathrm{Mg}$ (Unydrolysed PSHA-1) & 2.1568 & 0.9127 & 3.0695 \\
\hline
\end{tabular}

The results obtained (Table19) shows the stepwise and overall stability constants to be not high indicating low stability of the complexes, because the solubility of most metal ions in the basic $\mathrm{pH}$ range is minimal due to metal hydroxide precipitation (Karimi, 2017). In general, the stepwise stability constants $\left(K_{1}\right.$ and $K_{2}$ ) follow the order $K_{1}>K_{2}$ for the copper, lead, magnesium and cadmium complexes respectively. The steady decrease of the values with increasing number of ligands is in agreement with the prediction made by researchers (Na'aliya, 2013). The decrease could be attributed to the fact that as the number of the ligands (Humate ions) that enters the coordination zone increases the aqua molecules available for replacement by the ligands become less. Thus, the metal ions become less electron loving with progressive intake of the ligand and this results in the decrease in the values of the constants (Na'aliya, 2013). Also the stability of the complexes is influenced by the size and number of the chelate rings(Mackay and Mackay,2002).All the complexes form rings in their structure as humate, a bidentate ligand, bond the metal ions in the ratio 1:2 (Boguta and Sokolowska, 2016) forming chelate rings. The values of the overall stability constants $(\log \beta)$ obtained for humate complexes are not high indicating low stability as the values are not high. LogK values for copper-humates (Table 3 to 6) obtained in this study are lower than those reported for the complexes of humic acids (Pandey et al., 2015; Dinu, 2013; Kaschl et al., 2010 and Gilbeto and Jorg, 2001). The values of LogK(Table 7 to 10 ) forlead-humates are lower than those reported for the lead in the literature (Dinu, 2013; Gilbeto and Jorg 2001). Log K values(Table 11 to 14 ) for magnesium-humates obtained in this study are close to those reported by (Pandey et al., 2015). Log K values of cadmium-humates (Table 15 to 18 ) obtained in this work near to the one reported by (Dinu, 2013 and Pandey et al., 2015).The difference between the reported values and the values obtained in this study might be probably as a result of acid hydrolysis of humic acid. The values of the overall stability constants $(\log \beta)$ of the copper humates complexes presented in Table 19 is high than that of other metal humate complexes, show relatively high stability of CuHA complexes, show the following order of stability: $\mathrm{Cu}>\mathrm{Pb}>\mathrm{Cd}>\mathrm{Mg}$; which are in close agreement to the findings of (Dinu, 2013 and Pandey et al., 2015).The high stability of Cuhumate chelate could be attributed to the existence of coordinate covalent bond between the complexing agents and the $\mathrm{Cu}^{2+}$ ions. Since, $\mathrm{Cu}^{2+}$ being a metal of the transitional series with $3 d^{9}$ electronic configurations can accept the electrons from the complexing agents. Similarly, the low stabilities of $\mathrm{Pb}, \mathrm{Cd}$ and $\mathrm{Mg}$ complexes could be explained by that $\mathrm{Pb}^{2+}$ with $6 s^{2}, \mathrm{Cd}^{2+}$ with $4 \mathrm{~d}^{10}$ and $\mathrm{Mg}^{2+}$ with $2 \mathrm{p}^{6}$ their electronic configuration has a completely filled $\mathrm{d}, \mathrm{p}$ and $\mathrm{s}$ orbitals. Moreover, the stabilities of metal ions with hydrolysed humic acid from peat soil were higher than those with unhydrolysed humic acid from peat soil; which is ascribed to the high content of acidity in hydrolysed humic acid than unhydrolysed humic acid. 
BAJOPAS Volume 14 Number 1,June, 2021 CONCLUSION

The values of logk for $\mathrm{Cu}(\mathrm{II})$ hydrolysed humic acid complex was higher followed by $\mathrm{Pb}$ (II), $\mathrm{Cd}(\mathrm{II})$ and $\mathrm{Mg}$ (II) hydrolysed humic acid complexes as compared with metal(II) unhydrolysed humic acid complexes. This indicates acid hydrolysis of humic acid can

\section{REFERENCES}

Almeida, V.R. and Szpoganicz, B. (2015). Humic Acid Potentiometric Response Patterns:Out- of Equilibrium Properties and Species Distribution Modelling. Chemical. Biol. Technol. Agric. 2: 17.

Anđelković, T., Nikolić, R., Bojić, A.,Anđelković, D., and Nikolic G.,(2010). Binding of Cadmium to Soil Humic Acid as A Function of Carboxyl Group Content. Macedonian Journal of Chemistry and Chemical Engineering.29(2): 215-224.

Anil, B. N. and Maroti, N. (2008). Studies on Influence of Die-Lectric Constants on Complex Equilibria between Substituted Py-Razalines and Lanthanide Metal Ions pH-Metrically. Amer.-Euras. scient. Res. 3(2): 212-216.

Ashok, K., Pandey, S. P. and Misra, V (2000). Stability Constants of Metal-Humic Acid Complexes and its Role in Environmental Detoxification. Journal of Ecotoxicology and Environmental Safety. 47(2):157-200.

Badr, M. H., El-Halafawi, M. H. and Abd El-al Zeid, E. R. (2012). Comparison Between the Effect of Ionic Strength on Acidity and Dissociation Constants of Humic Acids Extracted from Sewage Sludge and Nile Water Hyacinth Composts.Global Journal of Environmental Research 6 (1): 36-43.

Baruah, M.K., Borah, D., Saikia, P.P., Paul, S., Sharma, T. (2015). Evaluation of pKa Values of Soil Humic Acids and their Complexation Properties. International Journal of Plant \& Soil Science 6(4) : 218-228.

Boguta, P. Sokolowska, Z. (2016). Interactions of $\mathrm{Zn}$ (II) Ions with Humic Acids Isolated from Various Types of Soils. Effect of $\mathrm{pH}, \mathrm{Zn}$ Concentrations and Humic Acids Chemical Properties. Journal of Geochemical Explaration 168. 119-126.

Borges, F., Guimaraes, C., Lima, L.F.C., Pinto, I. and Reis, S.(2005). Potentiometric Studies on the Complexation of Copper(II) by Phenolic Acids as Discrete Ligand Models of enhance the complexation behavior of humic acid with metal (II) ions. However, the higher values of $\log \beta$ for $\mathrm{Cu}(\mathrm{II}), \mathrm{Pb}(\mathrm{II}), \mathrm{Cd}(\mathrm{II})$ and $\mathrm{Mg}(\mathrm{II})$ hydrolysed humic acid complexes indicates more stable stepwise complexes formed as compared with $\mathrm{Cu}(\mathrm{II}), \mathrm{Pb}$ (II), $\mathrm{Cd}$ (II) and $\mathrm{Mg}(\mathrm{II})$ unhydrolysed humic acid complexes.

Humic Substances Talanta 66 (2005) 670-673.

Chefetz, B., Salloum, M. J., Deshmulkin, A. P. and Hatcher, P. (2002). Structural Components of Humic Acids as Determined by Chemical Modifications and Carbon-13 NMR, Pyrolysis, and Thermochemolysis- Gas Chromatography/Mass Spectrometry. Soil Science Society of American Journal Abstract Division S-2- Soil Chemistry66. 1159-1171.

Dinu, M. I. (2013). Metals Complexation with Humic Acids in Surface Water of Different Environ. Sci. Technol. 31(1): 1-17.

Fernandes, A.N., Giacomelli, C., Giovanela, M. Vaz, D.V. Szpoganicz, B. and Maria M. D. (2009). Potentiometric Acidity Determination in Humic Substances Influenced by Different Analytical Procedures.J. Braz. Chem. Soc. 20 (9):14.

Gamal, A. H. (2015). Stability Constants of Rhenium (V) Metal Complexes with Selected Drugs. Pyrex Journal of Research in Environmental Studies. 2(2): 006-014.

Janrao, D. M., Pathan, J., Kayande, D.D., and Mulla, J.J. (2014). An Over View of Potentiometric Determination of Stability Constants of Metal Complexes. Sci. Revs. Chem. Commun.: 4(1), 2014, 11-24.

Karimi, H. (2017). Effect of pH and Initial Pb(II) Concentration on the Lead Removal Efficiency from Waste Water Using $\mathrm{Ca}(\mathrm{OH})_{2}$. International Journal of Water and Waste Water Treatment 3.2

Kaschl, A. Romheld, V. and Chen, Y. (2010). Binding of Cadmium, Copper and Zinc to Humic Substances Originating from Municipal Solid Waste Compost. Israel Journal of Chemistry Vol. 42(1): 89-98.

Kostic, I. S., Tatjana, P, A., Nikolic, R. S., Cvetkovic, T. P., Pavlovic, D. D., Aleksandar, L.J. and Bojic, A. (2012). Comparative Study of Binding Strengths of Heavy Metals with Humic Acid. J.serb. Chem. Soc. 76(9) pp 1-20. 
BAJOPAS Volume 14 Number 1,June, 2021

Na'aliya, J. (2013). Determination of Stepwise Stability Constants and Gibbs free Energy Change of Trisprolina to Complexes of some Divalent Transition Metal ions. Bayero Journal of Pure and Applied Sciences 6(2): 112-114.

Omar, A. A. and Ali, E. A. (2015). Potentiometric Studies on Complexes of $\mathrm{Cr}$ (III) and $\mathrm{Zr}$ (IV) with some Carboxylic Acids. International Journal of Advanced Chemistry, 3(1) 25-

37.

Pandey, A. K. Pandey, S. D. and Misr, V. (2015).Stability Constants of Metal- Humic Acid Complexes and Its Role in Environmental Detoxification. J. Ecotoxicology and Environmental Safety. 47(1):195-200.

Ram, N. and Raman, K.V. (1984). Stability Constants of Complexes of Metals with
Humicand Fuvic Acids under Non- acidConditions. Journal of Plant Nutrition and Soil Sciences.

147:171-176.

Santosh, D. D., Ashok, B. K., Vijay, J. T., Shivraj, G. W. and Vinay, V. W. (2011). Potentiometric Studies of Elec-Trolyte Effects on Complex Equilibria of Some Substituted 5-(2-hydroxy Phenyl) Pyrazoles. Der pharm. 3 (6): 75-83.

Sayyed, H. and Abdul Rahim, M. F. (2012). Studies of Binary Complexes of Metal Ions with Mandelic Acid by Potentiometry. Chem. J. 02 (6): 206209.

Shirvani, M. Moradian, E. Khalili, B. Bakhtiary, S. (2015). Interaction of $\mathrm{Cd}$ and $\mathrm{Pb}$ with Humate-Palygorskite and HumateSepiolite Complexes. Journal of water, air and pollution 3: 220-228. 


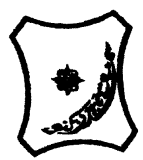

Bayero Journal of Pure and Applied Sciences, 14(1): 54 - 63

Received: November, 2020

Accepted: April, 2021

ISSN $2006-6996$

\title{
STABILITY CONSTANTS OF COMPLEXES OF METAL IONS WITH PEATSOIL HUMIC ACIDS UNDER NON-ACID-CONDITIONS
}

\author{
${ }^{* 1}$ Sabo, Yusuf ${ }^{2}$ Jimoh, W.L.O., ${ }^{3}$ Isa Baba Koki and ${ }^{4}$ Sholadoye, Q. 0. \\ ${ }^{1}$ Department of Pure and Industrial Chemistry, Bayero University, Kano \\ ${ }^{3}$ Department of Chemistry, Yusuf Maitama Sule University Kano. P.M.B. 3220 Kano, Nigeria. \\ ${ }^{4}$ Department of Chemistry, Nigerian Police Academy, Wudil, Kano-Nigeria
}

*Correspondence E-mail; saboyusuf18@yahoo.com

ABSTRACT

Stability constants of complexes of four divalent metal ions viz. $\mathrm{Cu}^{2+}, \mathrm{Pb}^{2+}, \mathrm{Mg}^{2+}$ and $\mathrm{Cd}^{2+}$ with humic acids (HA) were determined by potentiometric titration of humic acids with the corresponding salt of the divalent metals in aqueous media under non-acid-condition. The log $K$ (logarithm of the stability constant) ranged from 1.0942 to 2.7471 for metalhumic acid complexes were determined using point-wise computational method. The order of stability constants were obtained as follows: $\mathrm{Cu}>\mathrm{Pb}>\mathrm{Cd}>\mathrm{Mg}$ for metal $-\mathrm{HA}$ complexes respectively, indicating a higher degree of complexation with Cu metal ion.

Keywords: stability constant, humic acid, potentiometric titration, divalent metals, acid hydrolysis.

\section{NTRODUCTION}

The stability constant of a complex is the numerical expression of its stability and provides a quantitative measure of affinity of the metal ion to the complexing agent. An understanding of the relative stability of metal-complexes helps in predicting the behavior of metal ions in the soil (Ram and Raman, 1982). Extensive researches has been done to determine the stability constants of the complexes formed between humic acid (HA) with a number of metal ions. Ashok et al., (2000) reported that humic acid with hydroxyl, phenoxyl and carboxyl reactive groups can form coordination compound with metal ions at $\mathrm{pH}$ 3.5. The stability constants(Log K) for different metalhumic acid complexes indicated the following order of the stabilities of complexes formed between humic acid and metal ion, $\mathrm{Cu}>\mathrm{Fe}$ $>\mathrm{Pb}>\mathrm{Ni}>\mathrm{Co}>\mathrm{Ca}>\mathrm{Cd}>\mathrm{Zn}>\mathrm{Mn}>\mathrm{Mg}$. Andelkovic et al., (2010) investigated the binding of $\mathrm{Cd}$ (II) to soil humic acid at pH 6.5 and in $0.1 \mathrm{M} \mathrm{KNO}_{3}$ ionic medium. The stability constant for binding indicating greater stability in the case when carboxyl groups are involved in complexation reaction. Kostic et al.,(2012) investigated the complexation of humic acid with certain heavy metal ions (Co(II), $\mathrm{Ni}(\mathrm{II}), \mathrm{Cu}(\mathrm{II})$,
$\mathrm{Zn}(\mathrm{II})$, and $\mathrm{Pb}(\mathrm{II})$. The experiment was performed at $25^{\circ} \mathrm{C}$, at pH 4.0 and ionic strength of $0.01 \mathrm{M}$. Stability constant of complex between $\mathrm{Pb}$ (II) ions and humic acid is greater than stability constants of other investigated metalhumate complexes. Bogata and Sokolowska (2016) analyses the interaction between humic acids from different soils and $\mathrm{Zn}$ (II) ions at wide concentration ranges and at $\mathrm{pH} 5$. Studies have showed significant impact of $\mathrm{Zn}$ concentration, $\mathrm{pH}$ and some properties of humic acids with zinc.But all of these studies were limited to acidic $\mathrm{pH}$ range. Therefore, the present study was carried out to determine and compare the stability constants of complexes of metal ions with hydrolysed peat soil humic acid and unhydrolysed peat soil humic under non-acid conditions.

\section{MATERIALS AND METHODS}

Analytical grade chemicals used includes hydrochloric acid $(\mathrm{HCl})$, nitric acid $\left(\mathrm{HNO}_{3}\right)$, sodium hydroxide $(\mathrm{NaOH})$, lead nitrate $\mathrm{Pb}\left(\mathrm{NO}_{3}\right)_{2}$, copper nitrate $\mathrm{Cu}\left(\mathrm{NO}_{3}\right)_{2} \cdot 3 \mathrm{H}_{2} \mathrm{O}$, cadmium nitrate $\mathrm{Cd}\left(\mathrm{NO}_{3}\right)_{2} \cdot 4 \mathrm{H}_{2} \mathrm{O}$, magnesium nitrate $\mathrm{Mg}\left(\mathrm{NO}_{3}\right)_{2} \cdot 6 \mathrm{H}_{2} \mathrm{O}$, potassium nitrate $\left(\mathrm{KNO}_{3}\right)$, calcium chloride $\left(\mathrm{CaCl}_{2}\right)$, (sigma-Aldrich). Dowex 50WX8, (20-50 mesh) from Fluka. 


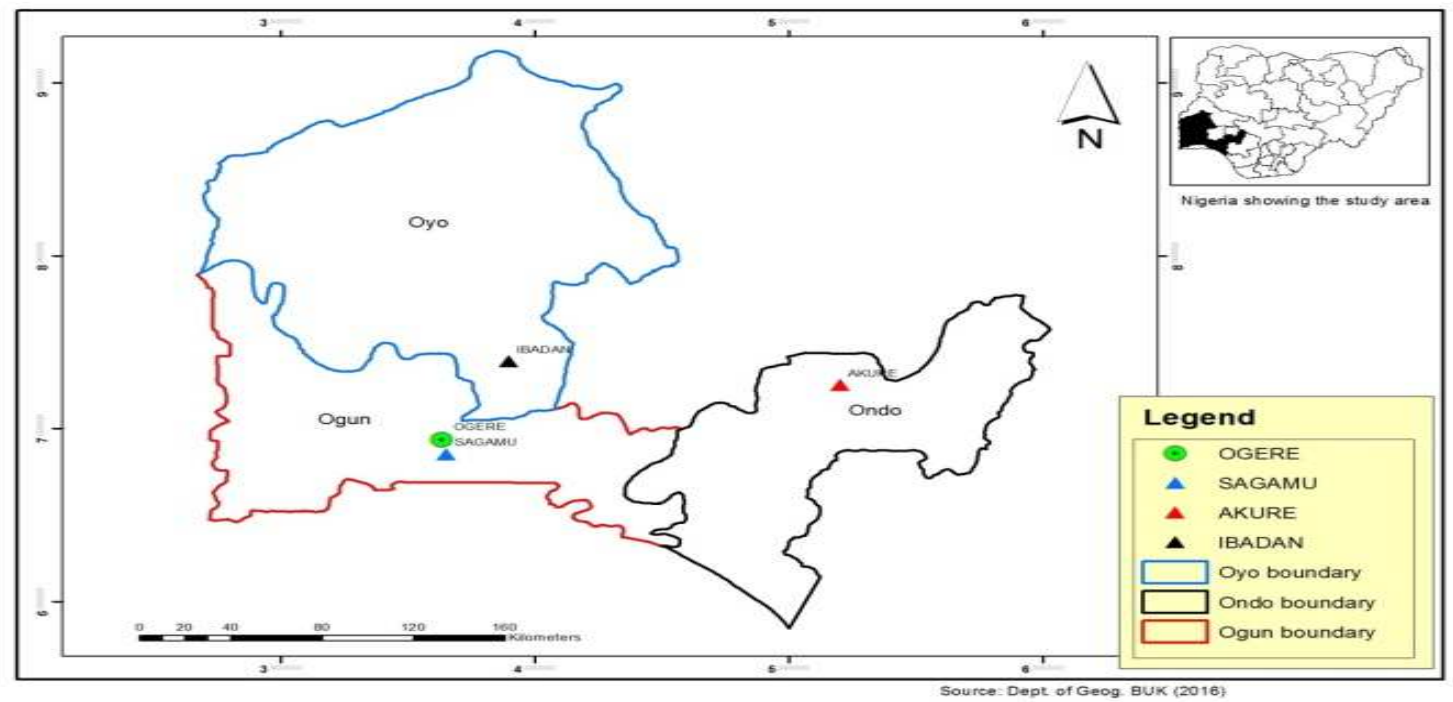

Figure 1: Map showing the sampling point at Sagamu Town, Ogun State.

\section{Description of Sampling Area}

Sagamu has geographical coordinates between $6^{\circ} 50^{\prime}$ north; $3^{\circ} 38^{\prime}$ east is located in south western region of Nigeria. The region has tropical wet and dry climate with a lengthy wet season and relatively constant temperatures throughout the course of the year. Wet season runs from March to October, November to December forms the region dry season. The vegetation type of the region is savannah which is really grassland with small bushes and occasional big trees. Grassland soils have substantially higher organic matter content than forest soils (Novackova, 2011).

\section{Sample Collection}

The Peatsoil samples were collected from four different sampling points $(0-10 \mathrm{~cm}$ depth) in Sagamu into polyethylene bag with plastic spoons. Samples were taken to the laboratory, extraneous materials were removed; the samples were air-dried, crushed and ground to a fine powder in a mortar passed through a $0.20 \mathrm{~mm}$ sieve. The samples were kept for analysis.

\section{Isolation and purification of humic acid from peat soil sample}

Peatsoil sample $(100 \mathrm{~g})$ was mixed with 1000 $\mathrm{cm}^{3}$ of $0.1 \mathrm{M} \mathrm{NaOH}$ solution, shaken for 3hours and left to stand overnight. Dark-coloured supernatant was obtained and decanted from solid residue. The dark-coloured supernatant was acidified to $(\mathrm{pH}=1.0)$ with $6 \mathrm{M} \mathrm{HCl}$ stirred and allowed to stand for 6 hours. Yellowish brown supernatant and dark-brown precipitate were obtained. The yellowish brown supernatant was decanted followed by centrifuge and discarded. The dark-brown precipitate was mixed with $500 \mathrm{~cm}^{3}$ of $0.1 \mathrm{M} \mathrm{NaOH}$ solution followed by passing through dowex resin. The dark-brown solution was acidified to $(\mathrm{pH}=1.0)$ with $6 \mathrm{M} \mathrm{HCl}$ stirred and allowed to stand for 3 hours. The dark-brown precipitate was washed several times with deionized water. The supernatant was treated with $\mathrm{AgNO}_{3}$ solution until no white precipitate observed. The humic acid was transferred to weighed crucible and dried at $60^{\circ} \mathrm{C}$ in an oven for 12 hours. The humic acid was cooled and dried in the desiccator, weighed and recorded. The obtained humic acid was dried again at $60^{\circ} \mathrm{C}$ for additional 6 hours cooled and dried in the desiccator, weighed and recorded constant weight was obtained (Baruah et al., 2015).

\section{FT-IR analysis}

FT-IR spectra of humic acid sample was analysed using Carry 630 FT-IR Agilent Technologies.

Unhydrolysed compost humic acid

The unhydrolysed humic acid was obtained after isolation and purification of compost humic acid and kept for investigation.

\section{Acid hydrolysis of Peatsoil acid}

Peatsoil humic acid sample (1g) was refluxed for 12 hours at $\left(160^{\circ} \mathrm{C}\right)$ with $50 \mathrm{~cm}^{3}$ of $6 \mathrm{M} \mathrm{HCl}$. The mixture was allowed to cool, decanted, and centrifuged after hydrolysis. The insoluble residues were washed with distilled water via centrifugation several times, and the supernatant was treated with $\mathrm{AgNO}_{3}$ solution until no white precipitate was observed. The residue was thoroughly dried over $\mathrm{CaCl}_{2}$ in a desiccator at room temperature (Chefetz et al., 2002). Finally, the obtained hydrolysed humic acid was kept for investigation. 
BAJOPAS Volume 14 Number 1,June, 2021 Potentiometric Titrations

Potentiometric measurements were carried out using a pH-meter Jenway (model 3510) with combine electrode, the sensitivity of the $\mathrm{pH}$ meter is 0.01 units. The $\mathrm{pH}$ meter was switched on half an hour before starting the titration for initial warm up of the instrument. The instrument was calibrated with an aqueous standard buffer solution of $\mathrm{pH} 4.00$ and 10.0 (borate buffer) prepared from a "Qualigens" buffer tablets.

The following sets of solutions were prepared in a $250 \mathrm{~cm}^{3}$ volumetric flask separately for $\mathrm{pH}$ metric titrations.

(i) $5 \mathrm{~cm}^{3} 0.1 \mathrm{M} \mathrm{HCl}+40 \mathrm{~cm}^{3}$ deionized water

(ii) $5 \mathrm{~cm}^{3} 0.1 \mathrm{M} \mathrm{HCl}+39 \mathrm{~cm}^{3}$ deionized water $+1 \mathrm{~cm}^{3} 0.15 \mathrm{gcm}^{-3}$ humic acid

(iii) $5 \mathrm{~cm}^{3} 0.1 \mathrm{M} \mathrm{HCl}+37 \mathrm{~cm}^{3}$ deionized water $+1 \mathrm{~cm}^{3} 0.15 \mathrm{gcm}^{-3}$ humic acid

$$
+2 \mathrm{~cm}^{3} \quad 0.01 \mathrm{M} \mathrm{Cu} \text { (II) }
$$

The solutions were titrated against standardized $0.110 \mathrm{MNaOH}$ separately. The total volume of each mixture was adjusted to $50 \mathrm{~cm}^{3}$ and the ionic strength of the solutions was maintained constant at by adding appropriate amount of stock solution of $1 \mathrm{M} \mathrm{KNO}_{3}$ (Gamal, 2015; Omar and Ali, 2015). A magnetic stirrer was used to achieve thorough mixing of the interacting solutions at $550 \mathrm{rpm}$. The same set of experimental conditions was applied for potentiometric titration of remaining samples.

\section{Evaluation of pKa of Hydrolysed peat soil Humic Acids}

The proton-ligand formation number $\mathrm{n}_{\mathbf{A}}$ were calculated by Irving and Rossotti expression (Omar and Ali, 2015).

$\mathrm{nA}=\mathrm{Y}-\frac{(\mathrm{V} 2-\mathrm{V1})(\mathrm{No}-\mathrm{Eo})}{(\mathrm{VO}+\mathrm{V1}) \mathrm{TCL}}$ 1

Where: $Y$ is number of dissociable proton, $\left(\mathrm{V}_{2^{-}}\right.$ $V_{1}$ ) is the measure of displacement of the ligand curve relative to acid curve, $\mathrm{N}^{\circ}$ and $\mathrm{E}^{\circ}$ are the resultant concentration of alkali solution, free acid solution, $\mathrm{T}_{\mathrm{cL}}{ }^{\circ}$ is the total ligand concentration, $\mathrm{V}^{\circ}$ is the total volume of titration solution, $V_{1}$ is the volume of alkali added to acid solution, $V_{2}$ is the volume of alkali added to acid solution + ligand solution, acid dissociation constants (pKa - values) of ligand were calculated by algebraic method point wise calculation (Tables 1 ). The dissociation constants (pKa) were calculated according to the following relation:

$\mathrm{pKa}=\mathrm{pH}+\log \left(\frac{n A}{1-n A}\right)$ 2

Where: pKa is the acid dissociation constant, $\mathrm{n}_{\mathrm{A}}$ is the Proton-ligand formation number and $\mathrm{pH}$ is the pH-values (Omar and Ali, 2015).

\section{Determination of metal-ligand stability constants $(\log K)$ of complexes}

The potentiometric measurement for the determination of stability constant of a complex in solution is based on the fact that the redox potential of the couple $\frac{M^{+(m-n)}}{M^{+m}}$ is shifted significantly on complexation of the metal ion with the ligand. This method involves change in hydrogen ion concentration $\left[\mathrm{H}^{+}\right]$due to the displacement or association of one or more protons taking place during complexation reaction. This change can be found out by titrating the solutions containing free acid, acid with ligand, and acid with ligand and metal ion, individually against a standard alkali solution at a constant ionic strength or temperature. Either ionic strength or temperature may be varied for different sets of solutions. In all the cases, the change in the $\mathrm{pH}$ of the solution is measured after each addition of a known amount of alkali to the reaction cell which contains the reaction mixture. The titration curves are then drawn by plotting the measured $\mathrm{pH}$ values against the corresponding volume of alkali added and the stability constants of the complexes are determined from the titration curves by employing $\mathrm{pH}$-metric titration technique given by (Irving and Rossoti).

Metal-ligand stability constants ( $\log \mathrm{K}$ ) were determined by using the following relations:

$$
\bar{n}=\frac{\left(V_{3}-V_{2}\right)\left(E^{0}+N^{0}\right)}{\left(V^{0}+V_{2}\right) \bar{n}_{A} T_{m}^{0}}
$$

and

$$
P L=\log _{10}\left\{\frac{1+\beta_{n}^{H} \frac{1}{[\text { anti } \log \mathrm{pH}]^{\mathrm{n}}}}{\mathrm{T}_{\mathrm{L}}^{0}-n \bar{T}_{m}^{0}} \mathrm{X} \frac{\left(V^{0}+V_{3}\right)}{V^{0}}\right\}
$$


BAJOPAS Volume 14 Number 1,June, 2021

Where $T_{L}, T^{\circ}, E^{\circ}$, and $V^{\circ}$ havethe same significance as in equation (1) above, $T_{m}$ denotes the total concentration of metal present in solution, $V_{3}$ is the volume of metal ions present in solution and $\beta^{H}$ is the overall proton ligand stability constant. The metal-ligand stability constants (log K) were determined by employing point wise computational Method (eq. 5 and 6).

$\operatorname{LogK}_{1}=\log \left(\frac{n}{1-n}\right)+\mathrm{pL}$ .5

$\operatorname{LogK}_{2}=\log \left(\frac{1-n}{2-n}\right)+\mathrm{pL}$ ...6

Where: Log $\mathrm{K}$ is the metal-ligand stability constant, $\mathrm{pL}$ is the Free ligand exponent function, $\mathbf{n}$ is the Average number of ligand attached with metal ion (Janraoet al., 2014). The results obtained were analyzed by an ORIGIN 2016 program using titration data and then the proton-ligand stability constants (pKa) and Metal-ligand stability constant (LogK) calculated (Omar and Ali, 2015).

\section{RESULTS AND DISCUSSION}

Fourier transformed infrared (FT-IR) spectra of isolated humic acid from peat soils Figure 2 had distinct clear absorption bands indicating the presence of major humic acid structural elemental groups such as $\mathrm{H}$ bonded $\mathrm{OH}$ $\left(3680 \mathrm{~cm}^{-1}\right.$ peak $), C=0$ of carbonyl $\left(1721 \mathrm{~cm}^{-1}\right.$ peak), functional groups of aliphatic components $\mathrm{CH}_{2}\left(2918 \mathrm{~cm}^{-1}\right.$ peak) and $\mathrm{C}-\mathrm{O}$ stretching of polysaccharide $\left(1168 \mathrm{~cm}^{-1}\right.$ peak). The positions of the absorption bands of the spectra fell within typical major absorption bands of humic acid which is at frequencies 3680, 2918, 1721, 1168 $\mathrm{cm}^{-1}$. The first peak centred in the vicinity of $3680 \mathrm{~cm}^{-1}$ region is attributed to phenol $\mathrm{OH}$ group bounded by intermolecular $\mathrm{H}$ bonds. The $2918 \mathrm{~cm}^{-1}$ band usually has absorption maximum at $2918 \mathrm{~cm}^{-1}$ which is due to $\mathrm{C}-\mathrm{H}$ stretching of alkane group $\left(\mathrm{CH}_{2}\right)$. The next major absorption band is $1721 \mathrm{~cm}^{-1}$. This band has been commonly ascribed to $\mathrm{C}=\mathrm{O}$ stretching of mainly carboxyl group $(\mathrm{COOH})$ with trace amount of ketones. The last peak was observed at 1168 $\mathrm{cm}^{-1}$ due to $\mathrm{C}-\mathrm{O}$ stretching of polysaccharides and this peak appeared also in the spectra of humic acid from peat soil. The FTIR spectra of the isolated humic acid contained all major characteristic absorption peaks of humic acid. These absorption peaks indicated the presence of the major structural elements of humic acid namely $\mathrm{H}$ bonded $\mathrm{OH}, \mathrm{C}=\mathrm{C}$ of aromatic ring, $\mathrm{C}=\mathrm{O}$ of carbonyl group (both carboxyl and ketonic), $\mathrm{CH}_{2}$ group. This strongly supports the presence of humic acid.

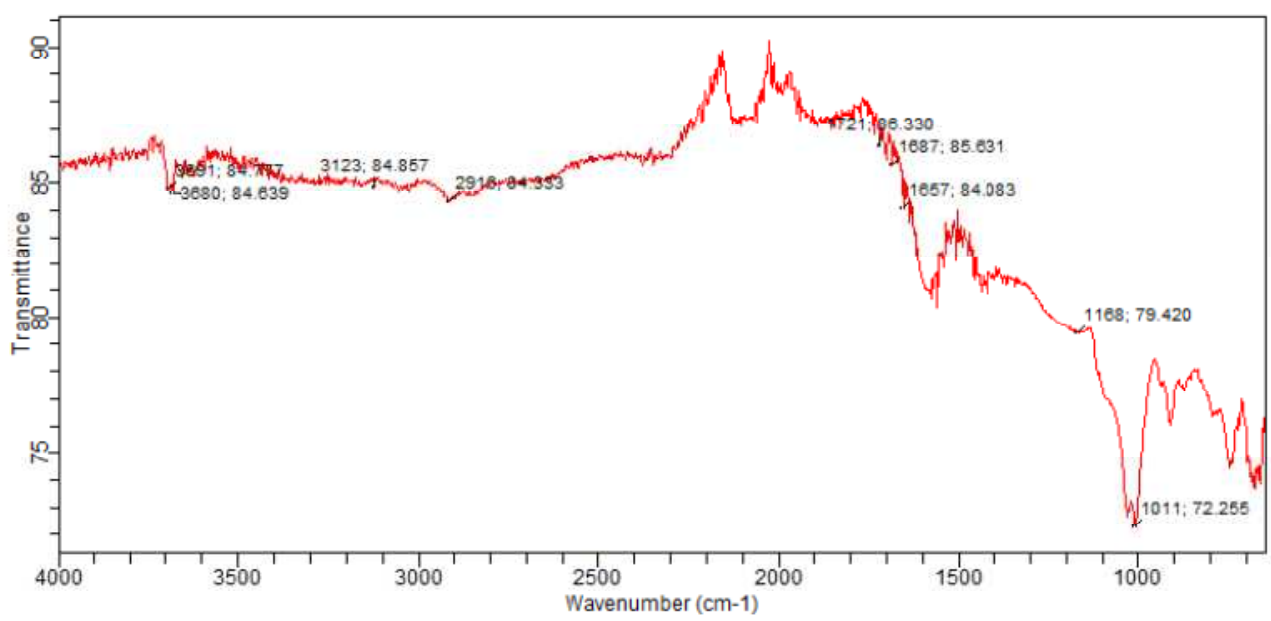

Fig. 2 : FT-IR spectraof peatsoilhumic acid (PSHA)

\section{Evaluation of acid dissociation constant (pka) of acid hydrolysed peat soil humicacid at phenolic group}

The value of the dissociation constant of the peat soil humic acid (PSHA) that underwent acidhydrolysis studied was found to be 8.9299 as shown Table 1, which is lower than the literaturevalues reported by Almeida and Szpoganics, (2015), Borges et al., (2005); Badr et al., (2012)and Fernandes et al,.(2009) of $9.73,9.47$ and 10.30. The difference between the obtained valuesand the reported values in this study might be probably as a result of acid hydrolysis of humicacid. 
BAJOPAS Volume 14 Number 1,June, 2021

Table 1: PKa of (Hydrolysed PSHA)

\begin{tabular}{|l|l|l|l|l|l|l|}
\hline $\mathrm{pH}$ & $\mathrm{BV}_{1}$ & $\mathrm{BV}_{2}$ & $\mathrm{~V}_{2}-\mathrm{V}_{1}$ & $\mathrm{nA}$ & $\log \left(\frac{n A}{1-n A}\right)$ & $\mathrm{pKa}$ \\
\hline 8.50 & 5.30 & 6.29 & 0.99 & 0.3594 & -0.2510 & 8.2490 \\
8.72 & 5.35 & 6.37 & 1.02 & 0.3400 & -0.2880 & 8.4320 \\
9.00 & 5.40 & 6.46 & 1.06 & 0.3141 & -0.3391 & 8.6609 \\
9.22 & 5.45 & 6.55 & 1.10 & 0.2882 & -0.3927 & 8.8273 \\
9.51 & 5.50 & 6.66 & 1.16 & 0.2494 & -0.4786 & 9.0314 \\
9.73 & 5.55 & 6.78 & 1.23 & 0.2041 & -0.5910 & 9.1390 \\
10.00 & 5.60 & 6.90 & 1.30 & 0.1589 & -0.7238 & 9.2762 \\
10.23 & 5.65 & 7.05 & 1.40 & 0.0941 & -0.9835 & 9.2465 \\
10.49 & 5.70 & 7.10 & 1.40 & 0.0941 & -0.9835 & 9.5065 \\
\hline
\end{tabular}

Average pKa $=8.9299 \pm 0.4186$

Table 2: PKa of (Unhydrolysed PSHA)

\begin{tabular}{|l|l|l|l|l|l|l|}
\hline $\mathrm{pH}$ & $\mathrm{BV}_{1}$ & $\mathrm{BV}_{2}$ & $\mathrm{~V}_{2}-\mathrm{V}_{1}$ & $\mathrm{nA}$ & $\log \left(\frac{\boldsymbol{n A}}{1-\boldsymbol{n}}\right)$ & $\mathrm{pKa}$ \\
\hline 8.50 & 5.30 & 5.81 & 0.51 & 0.6619 & 0.2919 & 8.7919 \\
8.72 & 5.35 & 5.90 & 0.55 & 0.6357 & 0.2418 & 8.9618 \\
9.00 & 5.40 & 6.00 & 0.60 & 0.6029 & 0.1813 & 9.1813 \\
9.22 & 5.45 & 6.10 & 0.65 & 0.5701 & 0.1226 & 9.3426 \\
9.51 & 5.50 & 6.20 & 0.70 & 0.5376 & 0.0654 & 9.5754 \\
9.73 & 5.55 & 6.33 & 0.78 & 0.4851 & -0.0259 & 9.7041 \\
10.00 & 5.60 & 6.47 & 0.87 & 0.4262 & -0.1291 & 9.8709 \\
10.23 & 5.65 & 6.62 & 0.99 & 0.3609 & -0.2481 & 9.9819 \\
10.49 & 5.70 & 6.80 & 1.10 & 0.2759 & -0.4690 & 10.0210 \\
\hline
\end{tabular}

Average pKa $=9.4923 \pm 0.4410$

Metal-ligand stability constant ( $\log \mathrm{K}$ )

The stabilityconstants require the accurate values of proton-ligand stability constants (Anil and Maroti, 2008). Metal titration curves crossed over ligand titration curve indicated the formation of complex upon proton release (Santosh, et al., 2011). If the values of n- are within range $0.2-0.8$ and $1.2-18$ this indicates the formation of $1: 1$ and 1:2 complexes (Sayyed and Mazahar, 2012).

The metal (II)-humate stepwise stability constants (log k) at phenolic group (Tables 318)

Table 3: Point-wise method, $\mathrm{Cu}$-(Hydrolysed PSHA)

\begin{tabular}{|l|l|l|l|l|l|l|l|l|}
\hline $\mathrm{pH}$ & $\mathrm{BV}_{1}$ & $\mathrm{BV}_{2}$ & $\mathrm{BV}_{3}$ & $\left(\mathrm{~V}_{3}-\mathrm{V}_{2}\right)$ & $\mathrm{n}$ & $\mathrm{pL}$ & $\log \left(\frac{n}{1-n}\right)$ & LogK $_{1}$ \\
\hline 8.50 & 5.30 & 6.29 & 6.33 & 0.04 & 0.5500 & 2.66 & 0.0871 & 2.7471 \\
8.72 & 5.35 & 6.37 & 6.41 & 0.04 & 0.5714 & 2.43 & 0.1249 & 2.5549 \\
9.00 & 5.40 & 6.46 & 6.50 & 0.04 & 0.6198 & 2.16 & 0.2122 & 2.3722 \\
9.22 & 5.45 & 6.55 & 6.59 & 0.04 & 0.6667 & 1.94 & 0.3010 & 2.2410 \\
\hline
\end{tabular}

LogK $_{1}$ (Average value) $=2.4788 \pm 0.2203$

Table 4: Point-wise method, $\mathrm{Cu}$-(Hydrolysed PSHA)

\begin{tabular}{|l|l|l|l|l|l|l|l|l|}
\hline $\mathrm{pH}$ & $\mathrm{BV}_{1}$ & $\mathrm{BV}_{2}$ & $\mathrm{BV}_{3}$ & $\left(\mathrm{~V}_{3}-\mathrm{V}_{2}\right)$ & $\mathrm{n}$ & $\mathrm{pL}$ & $\log \left(\frac{n-1}{2-n}\right)$ & LogK $_{2}$ \\
\hline 9.51 & 5.50 & 6.66 & 6.73 & 0.07 & 1.3509 & 1.70 & -0.2671 & 1.4329 \\
9.73 & 5.55 & 6.78 & 6.85 & 0.07 & 1.6383 & 1.51 & 0.2467 & 1.7567 \\
10.00 & 5.60 & 6.90 & 6.98 & 0.08 & 2.1783 & 1.31 & -0.2158 & 1.0942 \\
10.23 & 5.65 & 7.05 & 7.13 & 0.08 & 4.1904 & 1.27 & & \\
10.49 & 5.70 & 7.10 & 7.19 & 0.09 & 4.6920 & & & \\
\hline
\end{tabular}

Log $K_{2}($ Average value $)=1.4280 \pm 0.3312$ 
BAJOPAS Volume 14 Number 1,June, 2021

Table 5: Point-wise method, $\mathrm{Cu}$ (Unhydrolysed PSHA)

\begin{tabular}{|l|l|l|l|l|l|l|l|l|}
\hline $\mathrm{pH}$ & $\mathrm{BV}_{1}$ & $\mathrm{BV}_{2}$ & $\mathrm{BV}_{3}$ & $\left(\mathrm{~V}_{3}-\mathrm{V}_{2}\right)$ & $\mathrm{n}$ & $\mathrm{pL}$ & $\log \left(\frac{n}{n-1}\right)$ & Log $_{1}$ \\
\hline 8.50 & 5.30 & 5.81 & 5.85 & 0.04 & 0.2973 & 2.88 & -0.3736 & 2.5064 \\
8.72 & 5.35 & 5.90 & 5.95 & 0.05 & 0.3873 & 2.66 & -0.1992 & 2.4608 \\
9.00 & 5.40 & 6.00 & 6.05 & 0.05 & 0.4044 & 2.38 & -0.1681 & 2.2119 \\
9.22 & 5.45 & 6.10 & 6.15 & 0.06 & 0.5157 & 2.18 & -0.0272 & 2.2072 \\
9.51 & 5.50 & 6.20 & 6.27 & 0.07 & 0.6417 & 1.89 & 0.2530 & 1.1430 \\
\hline
\end{tabular}

$\operatorname{LogK}_{1}($ Average value $)=2.3059 \pm 0.6153$

Table 6:Point-wise method, $\mathrm{Cu}$ (Unhydrolysed PSHA)

\begin{tabular}{|l|l|l|l|l|l|l|l|l|}
\hline $\mathrm{pH}$ & $\mathrm{BV}_{1}$ & $\mathrm{BV}_{2}$ & $\mathrm{BV}_{3}$ & $\mathrm{~V}_{3}-\mathrm{V}_{2}$ & $\mathrm{n}$ & $\mathrm{pL}$ & $\log \left(\frac{n-1}{2-n}\right)$ & $\log \mathrm{K}_{2}$ \\
\hline 9.73 & 5.55 & 6.33 & 6.42 & 0.09 & 0.9000 & 1.69 & & \\
10.00 & 5.60 & 6.47 & 6.58 & 0.11 & 1.2578 & 1.44 & -0.4592 & 0.9808 \\
10.23 & 5.65 & 6.62 & 6.84 & 0.12 & 1.6137 & 1.26 & -0.2010 & 1.4610 \\
10.49 & 5.70 & 6.80 & 6.92 & 0.12 & 2.1052 & 1.03 & & \\
\hline
\end{tabular}

$\operatorname{LogK}_{2}$ (Average value) $=1.2209 \pm 0.3398$

Table 7:Point-wise method, Pb (Hydrolysed PSHA)

\begin{tabular}{|l|l|l|l|l|l|l|l|l|}
\hline $\mathrm{pH}$ & $\mathrm{BV}_{1}$ & $\mathrm{BV}_{2}$ & $\mathrm{BV}_{3}$ & $\left(\mathrm{~V}_{3}-\mathrm{V}_{2}\right)$ & $\mathrm{n}$ & $\mathrm{pL}$ & $\log \left(\frac{n}{1-n}\right)$ & LogK $_{1}$ \\
\hline 8.50 & 5.30 & 6.29 & 6.33 & 0.04 & 0.5500 & 2.66 & 0.0871 & 2.7471 \\
8.72 & 5.35 & 6.37 & 6.41 & 0.04 & 0.5714 & 2.43 & 0.1249 & 2.5549 \\
9.00 & 5.40 & 6.46 & 6.50 & 0.04 & 0.6198 & 2.16 & 0.2122 & 2.3722 \\
9.22 & 5.45 & 6.55 & 6.60 & 0.05 & 0.8333 & 1.96 & 0.6989 & 2.6589 \\
\hline
\end{tabular}

Log $_{\mathbf{1}}($ Average value $)=2.5832 \pm 0.1614$

Table 8:Point-wise method, Pb-(Hydrolysed PSHA)

\begin{tabular}{|l|l|l|l|l|l|l|l|l|}
\hline $\mathrm{pH}$ & $\mathrm{BV}_{1}$ & $\mathrm{BV}_{2}$ & $\mathrm{BV}_{3}$ & $\left(\mathrm{~V}_{3}-\mathrm{V}_{2}\right)$ & $\mathrm{n}$ & $\mathrm{pL}$ & $\log \left(\frac{n-1}{2-n}\right)$ & $\log \mathrm{K}_{2}$ \\
\hline 9.51 & 5.50 & 6.66 & 6.71 & 0.05 & 0.9650 & 1.67 & & \\
9.73 & 5.55 & 6.78 & 6.83 & 0.05 & 1.1702 & 1.44 & & \\
10.00 & 5.60 & 6.90 & 6.90 & 0.05 & 1.4864 & 1.22 & -0.0237 & 1.1963 \\
10.23 & 5.65 & 7.05 & 7.10 & 0.05 & 2.0190 & 1.09 & & \\
10.49 & 5.70 & 7.10 & 7.17 & 0.07 & 3.6492 & 1.00 & & \\
\hline
\end{tabular}

Log $K_{2}$ (Average value) $=1.1963$

Table 9: Point-wise method, Pb (Unhydrolysed PSHA)

\begin{tabular}{|l|l|l|l|l|l|l|l|l|}
\hline $\mathrm{pH}$ & $\mathrm{BV}_{1}$ & $\mathrm{BV}_{2}$ & $\mathrm{BV}_{3}$ & $\mathrm{~V}_{3}-\mathrm{V}_{2}$ & $\mathrm{n}$ & $\mathrm{pL}$ & $\begin{array}{l}\text { Log } \\
\left(\frac{n}{n-1}\right)\end{array}$ & Log $\mathrm{K}_{1}$ \\
\hline 8.50 & 5.30 & 5.81 & 5.85 & 0.04 & 0.2973 & 2.88 & -0.3736 & 2.5064 \\
8.72 & 5.35 & 5.90 & 5.94 & 0.04 & 0.3099 & 2.66 & -0.5477 & 2.3123 \\
9.00 & 5.40 & 6.00 & 6.05 & 0.05 & 0.4044 & 2.38 & -0.1681 & 2.2119 \\
9.22 & 5.45 & 6.10 & 6.15 & 0.06 & 0.5157 & 2.18 & 0.0272 & 2.2072 \\
9.51 & 5.50 & 6.20 & 6.26 & 0.07 & 0.6417 & 1.89 & 0.2530 & 2.1430 \\
9.73 & 5.55 & 6.40 & 6.40 & 0.07 & 0.7000 & 1.67 & 0.3680 & 2.0380 \\
\hline
\end{tabular}

LogK $_{1}$ (Average value) $=2.2364 \pm 0.1602$

Table 10: Point-wise method, Pb (Unhydrolysed PSHA)

\begin{tabular}{|l|l|l|l|l|l|l|l|l|}
\hline $\mathrm{pH}$ & $\mathrm{BV}_{1}$ & $\mathrm{BV}_{2}$ & $\mathrm{BV}_{3}$ & $\mathrm{~V}_{3}-\mathrm{V}_{2}$ & $\mathrm{n}$ & $\mathrm{pL}$ & $\log \left(\frac{n-1}{2-n}\right)$ & $\log \mathrm{K}_{2}$ \\
\hline 10.00 & 5.60 & 6.47 & 6.55 & 0.08 & 1.9503 & 1.41 & & \\
10.23 & 5.65 & 6.62 & 6.72 & 0.11 & 1.4792 & 1.26 & -0.0361 & 1.2239 \\
\hline
\end{tabular}

$\operatorname{LogK}_{2}$ (Average value) $=1.2239$

Table 11: Point-wise method, Mg (Hydrolysed PSHA)

\begin{tabular}{|l|l|l|l|l|l|l|l|l|}
\hline $\mathrm{pH}$ & $\mathrm{BV}_{1}$ & $\mathrm{BV}_{2}$ & $\mathrm{BV}_{3}$ & $\left(\mathrm{~V}_{3}-\mathrm{V}_{2}\right)$ & $\mathrm{n}$ & $\mathrm{pL}$ & $\log \left(\frac{n}{n-1}\right)$ & LogK $_{1}$ \\
\hline 8.50 & 5.30 & 6.29 & 6.31 & 0.02 & 0.2750 & 2.64 & -0.4290 & 2.2110 \\
8.72 & 5.35 & 6.37 & 6.39 & 0.02 & 0.2858 & 2.42 & -0.3978 & 2.0222 \\
9.00 & 5.40 & 6.46 & 6.49 & 0.03 & 0.4648 & 2.14 & -0.0612 & 2.0788 \\
9.22 & 5.45 & 6.55 & 6.59 & 0.04 & 0.6667 & 1.94 & 0.3010 & 2.2410 \\
\hline
\end{tabular}

$\log _{\mathbf{1}}($ Average value) $=2.1382 \pm 0.1046$ 
BAJOPAS Volume 14 Number 1,June, 2021

Table 12: Point-wise method, Mg (Hydrolysed PSHA)

\begin{tabular}{|l|l|l|l|l|l|l|l|l|}
\hline $\mathrm{pH}$ & $\mathrm{BV}_{1}$ & $\mathrm{BV}_{2}$ & $\mathrm{BV}_{3}$ & $\left(\mathrm{~V}_{3}-\mathrm{V}_{2}\right)$ & $\mathrm{n}$ & $\mathrm{pL}$ & $\log \left(\frac{n-1}{2-n}\right)$ & LogK $_{2}$ \\
\hline 9.51 & 5.55 & 6.66 & 6.71 & 0.05 & 0.9650 & 1.67 & & \\
9.73 & 5.55 & 6.78 & 6.84 & 0.06 & 1.4042 & 1.47 & -0.1686 & 1.3014 \\
10.00 & 5.60 & 6.90 & 6.93 & 0.06 & 1.7838 & 1.23 & 0.5593 & 1.7893 \\
10.23 & 5.65 & 7.05 & 7.10 & 0.06 & 3.1429 & 1.10 & & \\
10.49 & 5.70 & 7.10 & 7.18 & 0.07 & 3.6492 & 0.83 & & \\
\hline
\end{tabular}

LogK $_{2}($ Average value $)=1.5453 \pm 0.3450$

Table 13: Point-wise method, Mg (Unhydrolysed PSHA)

\begin{tabular}{|l|l|l|l|l|l|l|l|l|}
\hline $\mathrm{pH}$ & $\mathrm{BV}_{1}$ & $\mathrm{BV}_{2}$ & $\mathrm{BV}_{3}$ & $\mathrm{~V}_{3}-\mathrm{V}_{2}$ & $\mathrm{n}$ & $\mathrm{pL}$ & $\log \left(\frac{n}{n-1}\right)$ & $\operatorname{Log~}_{1}$ \\
\hline 8.50 & 5.30 & 5.81 & 5.85 & 0.04 & 0.2973 & 2.88 & -0.3736 & 2.5064 \\
8.72 & 5.35 & 5.90 & 5.94 & 0.04 & 0.3099 & 2.66 & -0.3477 & 2.3123 \\
9.00 & 5.40 & 6.00 & 6.04 & 0.04 & 0.3236 & 2.38 & -0.3202 & 2.0598 \\
9.22 & 5.45 & 6.10 & 6.15 & 0.05 & 0.4297 & 2.17 & -0.1230 & 2.0470 \\
9.51 & 5.50 & 6.20 & 6.26 & 0.06 & 0.5500 & 1.89 & 0.0871 & 1.9771 \\
9.73 & 5.55 & 6.33 & 6.40 & 0.07 & 0.7000 & 1.67 & 0.3680 & 2.0380 \\
\hline
\end{tabular}

LogK $_{1}$ (Average value) $=2.1568 \pm 0.2069$

Table 14: Point-wise method, Mg (Unhydrolysed PSHA)

\begin{tabular}{|l|l|l|l|l|l|l|l|l|}
\hline $\mathrm{pH}$ & $\mathrm{BV}_{1}$ & $\mathrm{BV}_{2}$ & $\mathrm{BV}_{3}$ & $\mathrm{~V}_{3}-\mathrm{V}_{2}$ & $\mathrm{n}$ & $\mathrm{pL}$ & $\log \left(\frac{n-1}{2-n}\right)$ & $\log \mathrm{K}_{2}$ \\
\hline 10.00 & 5.60 & 6.47 & 6.55 & 0.08 & 0.9148 & 1.41 & & \\
10.23 & 5.65 & 6.62 & 6.71 & 0.09 & 1.2102 & 1.20 & -0.5749 & 0.6251 \\
10.49 & 5.70 & 6.80 & 6.92 & 0.09 & 1.5968 & 1.03 & 0.1703 & 1.2003 \\
\hline
\end{tabular}

LogK $_{2}$ (Average value) $=0.9127 \pm 0.4070$

Table15:Point-wise method, Cd (Hydrolysed PSHA)

\begin{tabular}{|l|l|l|l|l|l|l|l|l|}
\hline $\mathrm{pH}$ & $\mathrm{BV}_{1}$ & $\mathrm{BV}_{2}$ & $\mathrm{BV}_{3}$ & $\left(\mathrm{~V}_{3}-\mathrm{V}_{2}\right)$ & $\mathrm{n}$ & $\mathrm{pL}$ & $\log \left(\frac{n}{1-n}\right)$ & LogK $_{1}$ \\
\hline 8.50 & 5.30 & 6.29 & 6.31 & 0.02 & 0.2750 & 2.64 & -0.4210 & 2.2190 \\
8.72 & 5.35 & 6.37 & 6.40 & 0.03 & 0.4286 & 2.42 & -0.1249 & 2.2951 \\
9.00 & 5.40 & 6.46 & 6.49 & 0.03 & 0.4648 & 2.14 & -0.0612 & 2.0788 \\
9.22 & 5.45 & 6.55 & 6.59 & 0.04 & 0.6667 & 1.96 & 0.3010 & 2.2610 \\
9.51 & 5.55 & 6.66 & 6.70 & 0.04 & 0.7720 & 1.67 & 0.5297 & 2.1997 \\
\hline
\end{tabular}

LogK $_{\mathbf{1}}$ (Average value) $=2.2108 \pm 0.0825$

Table 16: Point-wise method, Cd (Hydrolysed PSHA)

\begin{tabular}{|l|l|l|l|l|l|l|l|l|}
\hline $\mathrm{pH}$ & $\mathrm{BV}_{1}$ & $\mathrm{BV}_{2}$ & $\mathrm{BV}_{3}$ & $\left(\mathrm{~V}_{3}-\mathrm{V}_{2}\right)$ & $\mathrm{n}$ & $\mathrm{pL}$ & $\log \left(\frac{n-1}{2-n}\right)$ & Log $_{2}$ \\
\hline 9.73 & 5.55 & 6.78 & 6.83 & 0.06 & 1.4042 & 1.47 & -0.1686 & 1.3014 \\
10.00 & 5.60 & 6.90 & 6.95 & 0.06 & 1.7838 & 1.23 & 0.5593 & 1.7893 \\
10.23 & 5.65 & 7.05 & 7.10 & 0.06 & 3.1429 & 1.09 & & \\
10.49 & 5.70 & 7.10 & 7.16 & 0.06 & 3.1429 & 0.89 & & \\
& & & & & & & & \\
\hline
\end{tabular}

$\operatorname{LogK}_{2}$ (Average value) $=1.5453 \pm 0.3450$

Table 17: Point-wise method, Cd (Unhydrolysed PSHA)

\begin{tabular}{|l|l|l|l|l|l|l|l|l|}
\hline $\mathrm{pH}$ & $\mathrm{BV}_{1}$ & $\mathrm{BV}_{2}$ & $\mathrm{BV}_{3}$ & $\mathrm{~V}_{3}-\mathrm{V}_{2}$ & $\mathrm{n}$ & $\mathrm{pL}$ & $\log \left(\frac{n}{n-1}\right)$ & $\operatorname{Log~}_{1}$ \\
\hline 8.50 & 5.30 & 5.81 & 5.86 & 0.05 & 0.3717 & 2.88 & -0.2280 & 2.6520 \\
8.72 & 5.35 & 5.90 & 5.95 & 0.05 & 0.3873 & 2.66 & -0.1992 & 2.4608 \\
9.00 & 5.40 & 6.00 & 6.06 & 0.06 & 0.4853 & 2.38 & -0.0255 & 2.3545 \\
9.22 & 5.45 & 6.10 & 6.16 & 0.06 & 0.5157 & 2.18 & -0.0272 & 2.2072 \\
9.51 & 5.50 & 6.20 & 6.27 & 0.07 & 0.6417 & 1.89 & 0.2530 & 1.1430 \\
9.73 & 5.55 & 6.33 & 6.41 & 0.08 & 0.8000 & 1.69 & 0.6020 & 2.2920 \\
& & & & & & & & \\
\hline
\end{tabular}

$\operatorname{LogK}_{1}($ Average value $)=2.2516 \pm 0.5380$ 
BAJOPAS Volume 14 Number 1,June, 2021

Table 18: Point-wise method, Cd (Unhydrolysed PSHA)

\begin{tabular}{|l|l|l|l|l|l|l|l|l|}
\hline $\mathrm{pH}$ & $\mathrm{BV}_{1}$ & $\mathrm{BV}_{2}$ & $\mathrm{BV}_{3}$ & $\mathrm{~V}_{3}-\mathrm{V}_{2}$ & $\mathrm{n}$ & $\mathrm{pL}$ & $\log \left(\frac{n-1}{2-n}\right)$ & $\log \mathrm{K}_{2}$ \\
\hline 10.00 & 5.60 & 6.47 & 6.57 & 0.10 & 1.1434 & 1.43 & & \\
10.23 & 5.65 & 6.62 & 6.72 & 0.10 & 1.3448 & 1.23 & -0.2788 & 0.9512 \\
10.49 & 5.70 & 6.80 & 6.90 & 0.10 & 1.7742 & 1.03 & 0.5351 & 1.5651 \\
\hline
\end{tabular}

$\operatorname{LogK}_{2}($ Average value $)=1.2581 \pm 0.4340$

Table 19: Stepwise and overall Stability constants of thehydrolysed and unhydrolysed divalent metal (II) complexes

\begin{tabular}{|c|c|c|c|}
\hline Chelates & LogK $_{1}$ & $\log _{2}$ & Log $\beta$ \\
\hline [Cu (Hydrolysed PSHA-1) $\left.{ }_{2}\right]$ & 2.4788 & 1.4280 & 3.9068 \\
\hline$\left[\mathrm{Pb}(\text { Hydrolysed PSHA-1) })_{2}\right]$ & 2.5832 & 1.1963 & 3.7795 \\
\hline$\left[\mathrm{Cd}(\text { Hydrolysed PSHA-1 })_{2}\right]$ & 2.2108 & 1.5453 & 3.7561 \\
\hline$\left[\mathrm{Mg}(\text { Hydrolysed PSHA-1 })_{2}\right]$ & 2.1382 & 1.5453 & 3.6835 \\
\hline [Cu (Unhydrolysed PSHA-1) & 2.3059 & 1.2209 & 3.5268 \\
\hline$[\mathrm{Pb}$ (Unhydrolysed PSHA-1) 2$]$ & 2.2364 & 1.2239 & 3.4603 \\
\hline [Cd (Unhydrolysed PSHA-1) 2 ] & 2.2516 & 1.2581 & 3.5097 \\
\hline$[\mathrm{Mg}$ (Unydrolysed PSHA-1) & 2.1568 & 0.9127 & 3.0695 \\
\hline
\end{tabular}

The results obtained (Table19) shows the stepwise and overall stability constants to be not high indicating low stability of the complexes, because the solubility of most metal ions in the basic $\mathrm{pH}$ range is minimal due to metal hydroxide precipitation (Karimi, 2017). In general, the stepwise stability constants $\left(K_{1}\right.$ and $K_{2}$ ) follow the order $K_{1}>K_{2}$ for the copper, lead, magnesium and cadmium complexes respectively. The steady decrease of the values with increasing number of ligands is in agreement with the prediction made by researchers (Na'aliya, 2013). The decrease could be attributed to the fact that as the number of the ligands (Humate ions) that enters the coordination zone increases the aqua molecules available for replacement by the ligands become less. Thus, the metal ions become less electron loving with progressive intake of the ligand and this results in the decrease in the values of the constants (Na'aliya, 2013). Also the stability of the complexes is influenced by the size and number of the chelate rings(Mackay and Mackay,2002).All the complexes form rings in their structure as humate, a bidentate ligand, bond the metal ions in the ratio 1:2 (Boguta and Sokolowska, 2016) forming chelate rings. The values of the overall stability constants $(\log \beta)$ obtained for humate complexes are not high indicating low stability as the values are not high. LogK values for copper-humates (Table 3 to 6) obtained in this study are lower than those reported for the complexes of humic acids (Pandey et al., 2015; Dinu, 2013; Kaschl et al., 2010 and Gilbeto and Jorg, 2001). The values of LogK(Table 7 to 10 ) forlead-humates are lower than those reported for the lead in the literature (Dinu, 2013; Gilbeto and Jorg 2001). Log K values(Table 11 to 14 ) for magnesium-humates obtained in this study are close to those reported by (Pandey et al., 2015). Log K values of cadmium-humates (Table 15 to 18 ) obtained in this work near to the one reported by (Dinu, 2013 and Pandey et al., 2015).The difference between the reported values and the values obtained in this study might be probably as a result of acid hydrolysis of humic acid. The values of the overall stability constants $(\log \beta)$ of the copper humates complexes presented in Table 19 is high than that of other metal humate complexes, show relatively high stability of CuHA complexes, show the following order of stability: $\mathrm{Cu}>\mathrm{Pb}>\mathrm{Cd}>\mathrm{Mg}$; which are in close agreement to the findings of (Dinu, 2013 and Pandey et al., 2015).The high stability of Cuhumate chelate could be attributed to the existence of coordinate covalent bond between the complexing agents and the $\mathrm{Cu}^{2+}$ ions. Since, $\mathrm{Cu}^{2+}$ being a metal of the transitional series with $3 d^{9}$ electronic configurations can accept the electrons from the complexing agents. Similarly, the low stabilities of $\mathrm{Pb}, \mathrm{Cd}$ and $\mathrm{Mg}$ complexes could be explained by that $\mathrm{Pb}^{2+}$ with $6 s^{2}, \mathrm{Cd}^{2+}$ with $4 \mathrm{~d}^{10}$ and $\mathrm{Mg}^{2+}$ with $2 \mathrm{p}^{6}$ their electronic configuration has a completely filled $\mathrm{d}, \mathrm{p}$ and $\mathrm{s}$ orbitals. Moreover, the stabilities of metal ions with hydrolysed humic acid from peat soil were higher than those with unhydrolysed humic acid from peat soil; which is ascribed to the high content of acidity in hydrolysed humic acid than unhydrolysed humic acid. 
BAJOPAS Volume 14 Number 1,June, 2021 CONCLUSION

The values of logk for $\mathrm{Cu}(\mathrm{II})$ hydrolysed humic acid complex was higher followed by $\mathrm{Pb}$ (II), $\mathrm{Cd}(\mathrm{II})$ and $\mathrm{Mg}$ (II) hydrolysed humic acid complexes as compared with metal(II) unhydrolysed humic acid complexes. This indicates acid hydrolysis of humic acid can

\section{REFERENCES}

Almeida, V.R. and Szpoganicz, B. (2015). Humic Acid Potentiometric Response Patterns:Out- of Equilibrium Properties and Species Distribution Modelling. Chemical. Biol. Technol. Agric. 2: 17.

Anđelković, T., Nikolić, R., Bojić, A.,Anđelković, D., and Nikolic G.,(2010). Binding of Cadmium to Soil Humic Acid as A Function of Carboxyl Group Content. Macedonian Journal of Chemistry and Chemical Engineering.29(2): 215-224.

Anil, B. N. and Maroti, N. (2008). Studies on Influence of Die-Lectric Constants on Complex Equilibria between Substituted Py-Razalines and Lanthanide Metal Ions pH-Metrically. Amer.-Euras. scient. Res. 3(2): 212-216.

Ashok, K., Pandey, S. P. and Misra, V (2000). Stability Constants of Metal-Humic Acid Complexes and its Role in Environmental Detoxification. Journal of Ecotoxicology and Environmental Safety. 47(2):157-200.

Badr, M. H., El-Halafawi, M. H. and Abd El-al Zeid, E. R. (2012). Comparison Between the Effect of Ionic Strength on Acidity and Dissociation Constants of Humic Acids Extracted from Sewage Sludge and Nile Water Hyacinth Composts.Global Journal of Environmental Research 6 (1): 36-43.

Baruah, M.K., Borah, D., Saikia, P.P., Paul, S., Sharma, T. (2015). Evaluation of pKa Values of Soil Humic Acids and their Complexation Properties. International Journal of Plant \& Soil Science 6(4) : 218-228.

Boguta, P. Sokolowska, Z. (2016). Interactions of $\mathrm{Zn}$ (II) Ions with Humic Acids Isolated from Various Types of Soils. Effect of $\mathrm{pH}, \mathrm{Zn}$ Concentrations and Humic Acids Chemical Properties. Journal of Geochemical Explaration 168. 119-126.

Borges, F., Guimaraes, C., Lima, L.F.C., Pinto, I. and Reis, S.(2005). Potentiometric Studies on the Complexation of Copper(II) by Phenolic Acids as Discrete Ligand Models of enhance the complexation behavior of humic acid with metal (II) ions. However, the higher values of $\log \beta$ for $\mathrm{Cu}(\mathrm{II}), \mathrm{Pb}(\mathrm{II}), \mathrm{Cd}(\mathrm{II})$ and $\mathrm{Mg}(\mathrm{II})$ hydrolysed humic acid complexes indicates more stable stepwise complexes formed as compared with $\mathrm{Cu}(\mathrm{II}), \mathrm{Pb}$ (II), $\mathrm{Cd}$ (II) and $\mathrm{Mg}(\mathrm{II})$ unhydrolysed humic acid complexes.

Humic Substances Talanta 66 (2005) 670-673.

Chefetz, B., Salloum, M. J., Deshmulkin, A. P. and Hatcher, P. (2002). Structural Components of Humic Acids as Determined by Chemical Modifications and Carbon-13 NMR, Pyrolysis, and Thermochemolysis- Gas Chromatography/Mass Spectrometry. Soil Science Society of American Journal Abstract Division S-2- Soil Chemistry66. 1159-1171.

Dinu, M. I. (2013). Metals Complexation with Humic Acids in Surface Water of Different Environ. Sci. Technol. 31(1): 1-17.

Fernandes, A.N., Giacomelli, C., Giovanela, M. Vaz, D.V. Szpoganicz, B. and Maria M. D. (2009). Potentiometric Acidity Determination in Humic Substances Influenced by Different Analytical Procedures.J. Braz. Chem. Soc. 20 (9):14.

Gamal, A. H. (2015). Stability Constants of Rhenium (V) Metal Complexes with Selected Drugs. Pyrex Journal of Research in Environmental Studies. 2(2): 006-014.

Janrao, D. M., Pathan, J., Kayande, D.D., and Mulla, J.J. (2014). An Over View of Potentiometric Determination of Stability Constants of Metal Complexes. Sci. Revs. Chem. Commun.: 4(1), 2014, 11-24.

Karimi, H. (2017). Effect of pH and Initial Pb(II) Concentration on the Lead Removal Efficiency from Waste Water Using $\mathrm{Ca}(\mathrm{OH})_{2}$. International Journal of Water and Waste Water Treatment 3.2

Kaschl, A. Romheld, V. and Chen, Y. (2010). Binding of Cadmium, Copper and Zinc to Humic Substances Originating from Municipal Solid Waste Compost. Israel Journal of Chemistry Vol. 42(1): 89-98.

Kostic, I. S., Tatjana, P, A., Nikolic, R. S., Cvetkovic, T. P., Pavlovic, D. D., Aleksandar, L.J. and Bojic, A. (2012). Comparative Study of Binding Strengths of Heavy Metals with Humic Acid. J.serb. Chem. Soc. 76(9) pp 1-20. 
BAJOPAS Volume 14 Number 1,June, 2021

Na'aliya, J. (2013). Determination of Stepwise Stability Constants and Gibbs free Energy Change of Trisprolina to Complexes of some Divalent Transition Metal ions. Bayero Journal of Pure and Applied Sciences 6(2): 112-114.

Omar, A. A. and Ali, E. A. (2015). Potentiometric Studies on Complexes of $\mathrm{Cr}$ (III) and $\mathrm{Zr}$ (IV) with some Carboxylic Acids. International Journal of Advanced Chemistry, 3(1) 25-

37.

Pandey, A. K. Pandey, S. D. and Misr, V. (2015).Stability Constants of Metal- Humic Acid Complexes and Its Role in Environmental Detoxification. J. Ecotoxicology and Environmental Safety. 47(1):195-200.

Ram, N. and Raman, K.V. (1984). Stability Constants of Complexes of Metals with
Humicand Fuvic Acids under Non- acidConditions. Journal of Plant Nutrition and Soil Sciences.

147:171-176.

Santosh, D. D., Ashok, B. K., Vijay, J. T., Shivraj, G. W. and Vinay, V. W. (2011). Potentiometric Studies of Elec-Trolyte Effects on Complex Equilibria of Some Substituted 5-(2-hydroxy Phenyl) Pyrazoles. Der pharm. 3 (6): 75-83.

Sayyed, H. and Abdul Rahim, M. F. (2012). Studies of Binary Complexes of Metal Ions with Mandelic Acid by Potentiometry. Chem. J. 02 (6): 206209.

Shirvani, M. Moradian, E. Khalili, B. Bakhtiary, S. (2015). Interaction of $\mathrm{Cd}$ and $\mathrm{Pb}$ with Humate-Palygorskite and HumateSepiolite Complexes. Journal of water, air and pollution 3: 220-228. 


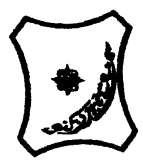

Bayero Journal of Pure and Applied Sciences, 14(1): 54 - 63

Received: November, 2020

Accepted: April, 2021

ISSN $2006-6996$

\title{
STABILITY CONSTANTS OF COMPLEXES OF METAL IONS WITH PEATSOIL HUMIC ACIDS UNDER NON-ACID-CONDITIONS
}

\author{
${ }^{* 1}$ Sabo, Yusuf ${ }^{2}$ Jimoh, W.L.O., ${ }^{3}$ Isa Baba Koki and ${ }^{4}$ Sholadoye, Q. 0. \\ ${ }^{1}$ Department of Pure and Industrial Chemistry, Bayero University, Kano \\ ${ }^{3}$ Department of Chemistry, Yusuf Maitama Sule University Kano. P.M.B. 3220 Kano, Nigeria. \\ ${ }^{4}$ Department of Chemistry, Nigerian Police Academy, Wudil, Kano-Nigeria
}

*Correspondence E-mail; saboyusuf18@yahoo.com

ABSTRACT

Stability constants of complexes of four divalent metal ions viz. $\mathrm{Cu}^{2+}, \mathrm{Pb}^{2+}, \mathrm{Mg}^{2+}$ and $\mathrm{Cd}^{2+}$ with humic acids (HA) were determined by potentiometric titration of humic acids with the corresponding salt of the divalent metals in aqueous media under non-acid-condition. The log $K$ (logarithm of the stability constant) ranged from 1.0942 to 2.7471 for metalhumic acid complexes were determined using point-wise computational method. The order of stability constants were obtained as follows: $\mathrm{Cu}>\mathrm{Pb}>\mathrm{Cd}>\mathrm{Mg}$ for metal $-\mathrm{HA}$ complexes respectively, indicating a higher degree of complexation with Cu metal ion.

Keywords: stability constant, humic acid, potentiometric titration, divalent metals, acid hydrolysis.

\section{NTRODUCTION}

The stability constant of a complex is the numerical expression of its stability and provides a quantitative measure of affinity of the metal ion to the complexing agent. An understanding of the relative stability of metal-complexes helps in predicting the behavior of metal ions in the soil (Ram and Raman, 1982). Extensive researches has been done to determine the stability constants of the complexes formed between humic acid (HA) with a number of metal ions. Ashok et al., (2000) reported that humic acid with hydroxyl, phenoxyl and carboxyl reactive groups can form coordination compound with metal ions at $\mathrm{pH}$ 3.5. The stability constants(Log K) for different metalhumic acid complexes indicated the following order of the stabilities of complexes formed between humic acid and metal ion, $\mathrm{Cu}>\mathrm{Fe}$ $>\mathrm{Pb}>\mathrm{Ni}>\mathrm{Co}>\mathrm{Ca}>\mathrm{Cd}>\mathrm{Zn}>\mathrm{Mn}>\mathrm{Mg}$. Andelkovic et al., (2010) investigated the binding of $\mathrm{Cd}$ (II) to soil humic acid at pH 6.5 and in $0.1 \mathrm{M} \mathrm{KNO}_{3}$ ionic medium. The stability constant for binding indicating greater stability in the case when carboxyl groups are involved in complexation reaction. Kostic et al.,(2012) investigated the complexation of humic acid with certain heavy metal ions (Co(II), $\mathrm{Ni}(\mathrm{II}), \mathrm{Cu}(\mathrm{II})$,
$\mathrm{Zn}(\mathrm{II})$, and $\mathrm{Pb}(\mathrm{II})$. The experiment was performed at $25^{\circ} \mathrm{C}$, at pH 4.0 and ionic strength of $0.01 \mathrm{M}$. Stability constant of complex between $\mathrm{Pb}$ (II) ions and humic acid is greater than stability constants of other investigated metalhumate complexes. Bogata and Sokolowska (2016) analyses the interaction between humic acids from different soils and $\mathrm{Zn}$ (II) ions at wide concentration ranges and at $\mathrm{pH} 5$. Studies have showed significant impact of $\mathrm{Zn}$ concentration, $\mathrm{pH}$ and some properties of humic acids with zinc.But all of these studies were limited to acidic $\mathrm{pH}$ range. Therefore, the present study was carried out to determine and compare the stability constants of complexes of metal ions with hydrolysed peat soil humic acid and unhydrolysed peat soil humic under non-acid conditions.

\section{MATERIALS AND METHODS}

Analytical grade chemicals used includes hydrochloric acid $(\mathrm{HCl})$, nitric acid $\left(\mathrm{HNO}_{3}\right)$, sodium hydroxide $(\mathrm{NaOH})$, lead nitrate $\mathrm{Pb}\left(\mathrm{NO}_{3}\right)_{2}$, copper nitrate $\mathrm{Cu}\left(\mathrm{NO}_{3}\right)_{2} \cdot 3 \mathrm{H}_{2} \mathrm{O}$, cadmium nitrate $\mathrm{Cd}\left(\mathrm{NO}_{3}\right)_{2} \cdot 4 \mathrm{H}_{2} \mathrm{O}$, magnesium nitrate $\mathrm{Mg}\left(\mathrm{NO}_{3}\right)_{2} \cdot 6 \mathrm{H}_{2} \mathrm{O}$, potassium nitrate $\left(\mathrm{KNO}_{3}\right)$, calcium chloride $\left(\mathrm{CaCl}_{2}\right)$, (sigma-Aldrich). Dowex 50WX8, (20-50 mesh) from Fluka. 


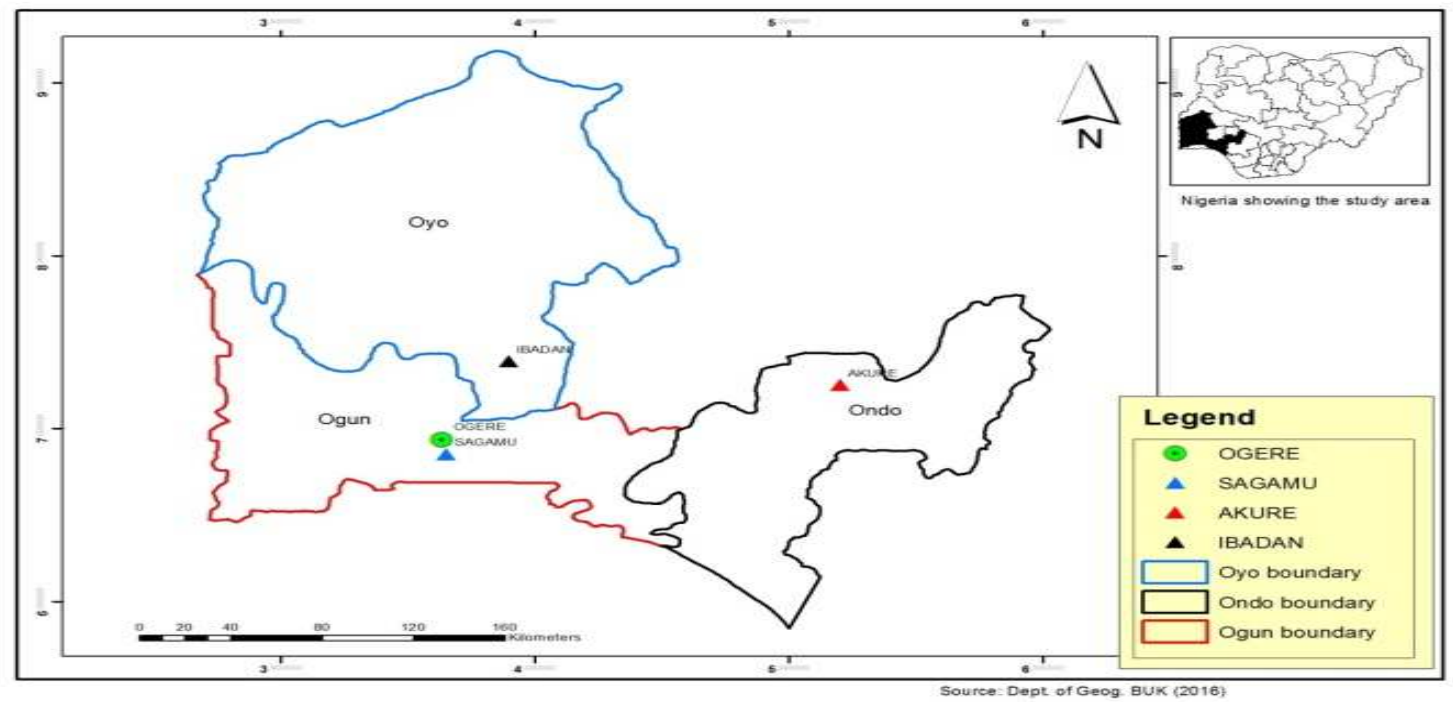

Figure 1: Map showing the sampling point at Sagamu Town, Ogun State.

\section{Description of Sampling Area}

Sagamu has geographical coordinates between $6^{\circ} 50^{\prime}$ north; $3^{\circ} 38^{\prime}$ east is located in south western region of Nigeria. The region has tropical wet and dry climate with a lengthy wet season and relatively constant temperatures throughout the course of the year. Wet season runs from March to October, November to December forms the region dry season. The vegetation type of the region is savannah which is really grassland with small bushes and occasional big trees. Grassland soils have substantially higher organic matter content than forest soils (Novackova, 2011).

\section{Sample Collection}

The Peatsoil samples were collected from four different sampling points $(0-10 \mathrm{~cm}$ depth) in Sagamu into polyethylene bag with plastic spoons. Samples were taken to the laboratory, extraneous materials were removed; the samples were air-dried, crushed and ground to a fine powder in a mortar passed through a $0.20 \mathrm{~mm}$ sieve. The samples were kept for analysis.

\section{Isolation and purification of humic acid from peat soil sample}

Peatsoil sample $(100 \mathrm{~g})$ was mixed with 1000 $\mathrm{cm}^{3}$ of $0.1 \mathrm{M} \mathrm{NaOH}$ solution, shaken for 3hours and left to stand overnight. Dark-coloured supernatant was obtained and decanted from solid residue. The dark-coloured supernatant was acidified to $(\mathrm{pH}=1.0)$ with $6 \mathrm{M} \mathrm{HCl}$ stirred and allowed to stand for 6 hours. Yellowish brown supernatant and dark-brown precipitate were obtained. The yellowish brown supernatant was decanted followed by centrifuge and discarded. The dark-brown precipitate was mixed with $500 \mathrm{~cm}^{3}$ of $0.1 \mathrm{M} \mathrm{NaOH}$ solution followed by passing through dowex resin. The dark-brown solution was acidified to $(\mathrm{pH}=1.0)$ with $6 \mathrm{M} \mathrm{HCl}$ stirred and allowed to stand for 3 hours. The dark-brown precipitate was washed several times with deionized water. The supernatant was treated with $\mathrm{AgNO}_{3}$ solution until no white precipitate observed. The humic acid was transferred to weighed crucible and dried at $60^{\circ} \mathrm{C}$ in an oven for 12 hours. The humic acid was cooled and dried in the desiccator, weighed and recorded. The obtained humic acid was dried again at $60^{\circ} \mathrm{C}$ for additional 6 hours cooled and dried in the desiccator, weighed and recorded constant weight was obtained (Baruah et al., 2015).

\section{FT-IR analysis}

FT-IR spectra of humic acid sample was analysed using Carry 630 FT-IR Agilent Technologies.

Unhydrolysed compost humic acid

The unhydrolysed humic acid was obtained after isolation and purification of compost humic acid and kept for investigation.

\section{Acid hydrolysis of Peatsoil acid}

Peatsoil humic acid sample (1g) was refluxed for 12 hours at $\left(160^{\circ} \mathrm{C}\right)$ with $50 \mathrm{~cm}^{3}$ of $6 \mathrm{M} \mathrm{HCl}$. The mixture was allowed to cool, decanted, and centrifuged after hydrolysis. The insoluble residues were washed with distilled water via centrifugation several times, and the supernatant was treated with $\mathrm{AgNO}_{3}$ solution until no white precipitate was observed. The residue was thoroughly dried over $\mathrm{CaCl}_{2}$ in a desiccator at room temperature (Chefetz et al., 2002). Finally, the obtained hydrolysed humic acid was kept for investigation. 
BAJOPAS Volume 14 Number 1,June, 2021 Potentiometric Titrations

Potentiometric measurements were carried out using a pH-meter Jenway (model 3510) with combine electrode, the sensitivity of the $\mathrm{pH}$ meter is 0.01 units. The $\mathrm{pH}$ meter was switched on half an hour before starting the titration for initial warm up of the instrument. The instrument was calibrated with an aqueous standard buffer solution of $\mathrm{pH} 4.00$ and 10.0 (borate buffer) prepared from a "Qualigens" buffer tablets.

The following sets of solutions were prepared in a $250 \mathrm{~cm}^{3}$ volumetric flask separately for $\mathrm{pH}$ metric titrations.

(i) $5 \mathrm{~cm}^{3} 0.1 \mathrm{M} \mathrm{HCl}+40 \mathrm{~cm}^{3}$ deionized water

(ii) $5 \mathrm{~cm}^{3} 0.1 \mathrm{M} \mathrm{HCl}+39 \mathrm{~cm}^{3}$ deionized water $+1 \mathrm{~cm}^{3} 0.15 \mathrm{gcm}^{-3}$ humic acid

(iii) $5 \mathrm{~cm}^{3} 0.1 \mathrm{M} \mathrm{HCl}+37 \mathrm{~cm}^{3}$ deionized water $+1 \mathrm{~cm}^{3} 0.15 \mathrm{gcm}^{-3}$ humic acid

$$
+2 \mathrm{~cm}^{3} \quad 0.01 \mathrm{M} \mathrm{Cu} \text { (II) }
$$

The solutions were titrated against standardized $0.110 \mathrm{MNaOH}$ separately. The total volume of each mixture was adjusted to $50 \mathrm{~cm}^{3}$ and the ionic strength of the solutions was maintained constant at by adding appropriate amount of stock solution of $1 \mathrm{M} \mathrm{KNO}_{3}$ (Gamal, 2015; Omar and Ali, 2015). A magnetic stirrer was used to achieve thorough mixing of the interacting solutions at $550 \mathrm{rpm}$. The same set of experimental conditions was applied for potentiometric titration of remaining samples.

\section{Evaluation of pKa of Hydrolysed peat soil Humic Acids}

The proton-ligand formation number $\mathrm{n}_{\mathbf{A}}$ were calculated by Irving and Rossotti expression (Omar and Ali, 2015).

$\mathrm{nA}=\mathrm{Y}-\frac{(\mathrm{V} 2-\mathrm{V1})(\mathrm{No}-\mathrm{Eo})}{(\mathrm{VO}+\mathrm{V1}) \mathrm{TCL}}$ 1

Where: $Y$ is number of dissociable proton, $\left(\mathrm{V}_{2^{-}}\right.$ $V_{1}$ ) is the measure of displacement of the ligand curve relative to acid curve, $\mathrm{N}^{\circ}$ and $\mathrm{E}^{\circ}$ are the resultant concentration of alkali solution, free acid solution, $\mathrm{T}_{\mathrm{cL}}{ }^{\circ}$ is the total ligand concentration, $\mathrm{V}^{\circ}$ is the total volume of titration solution, $V_{1}$ is the volume of alkali added to acid solution, $V_{2}$ is the volume of alkali added to acid solution + ligand solution, acid dissociation constants (pKa - values) of ligand were calculated by algebraic method point wise calculation (Tables 1 ). The dissociation constants (pKa) were calculated according to the following relation:

$\mathrm{pKa}=\mathrm{pH}+\log \left(\frac{n A}{1-n A}\right)$ 2

Where: pKa is the acid dissociation constant, $\mathrm{n}_{\mathrm{A}}$ is the Proton-ligand formation number and $\mathrm{pH}$ is the pH-values (Omar and Ali, 2015).

\section{Determination of metal-ligand stability constants $(\log K)$ of complexes}

The potentiometric measurement for the determination of stability constant of a complex in solution is based on the fact that the redox potential of the couple $\frac{M^{+(m-n)}}{M^{+m}}$ is shifted significantly on complexation of the metal ion with the ligand. This method involves change in hydrogen ion concentration $\left[\mathrm{H}^{+}\right]$due to the displacement or association of one or more protons taking place during complexation reaction. This change can be found out by titrating the solutions containing free acid, acid with ligand, and acid with ligand and metal ion, individually against a standard alkali solution at a constant ionic strength or temperature. Either ionic strength or temperature may be varied for different sets of solutions. In all the cases, the change in the $\mathrm{pH}$ of the solution is measured after each addition of a known amount of alkali to the reaction cell which contains the reaction mixture. The titration curves are then drawn by plotting the measured $\mathrm{pH}$ values against the corresponding volume of alkali added and the stability constants of the complexes are determined from the titration curves by employing $\mathrm{pH}$-metric titration technique given by (Irving and Rossoti).

Metal-ligand stability constants ( $\log \mathrm{K}$ ) were determined by using the following relations:

$$
\bar{n}=\frac{\left(V_{3}-V_{2}\right)\left(E^{0}+N^{0}\right)}{\left(V^{0}+V_{2}\right) \bar{n}_{A} T_{m}^{0}}
$$

and

$$
P L=\log _{10}\left\{\frac{1+\beta_{n}^{H} \frac{1}{[\text { anti } \log \mathrm{pH}]^{\mathrm{n}}}}{\mathrm{T}_{\mathrm{L}}^{0}-n \bar{T}_{m}^{0}} \mathrm{X} \frac{\left(V^{0}+V_{3}\right)}{V^{0}}\right\}
$$


BAJOPAS Volume 14 Number 1,June, 2021

Where $T_{L}, T^{\circ}, E^{\circ}$, and $V^{\circ}$ havethe same significance as in equation (1) above, $T_{m}$ denotes the total concentration of metal present in solution, $V_{3}$ is the volume of metal ions present in solution and $\beta^{H}$ is the overall proton ligand stability constant. The metal-ligand stability constants (log K) were determined by employing point wise computational Method (eq. 5 and 6).

$\operatorname{LogK}_{1}=\log \left(\frac{n}{1-n}\right)+\mathrm{pL}$ .5

$\operatorname{LogK}_{2}=\log \left(\frac{1-n}{2-n}\right)+\mathrm{pL}$ ...6

Where: Log $\mathrm{K}$ is the metal-ligand stability constant, $\mathrm{pL}$ is the Free ligand exponent function, $\mathbf{n}$ is the Average number of ligand attached with metal ion (Janraoet al., 2014). The results obtained were analyzed by an ORIGIN 2016 program using titration data and then the proton-ligand stability constants (pKa) and Metal-ligand stability constant (LogK) calculated (Omar and Ali, 2015).

\section{RESULTS AND DISCUSSION}

Fourier transformed infrared (FT-IR) spectra of isolated humic acid from peat soils Figure 2 had distinct clear absorption bands indicating the presence of major humic acid structural elemental groups such as $\mathrm{H}$ bonded $\mathrm{OH}$ $\left(3680 \mathrm{~cm}^{-1}\right.$ peak $), C=0$ of carbonyl $\left(1721 \mathrm{~cm}^{-1}\right.$ peak), functional groups of aliphatic components $\mathrm{CH}_{2}\left(2918 \mathrm{~cm}^{-1}\right.$ peak) and $\mathrm{C}-\mathrm{O}$ stretching of polysaccharide $\left(1168 \mathrm{~cm}^{-1}\right.$ peak). The positions of the absorption bands of the spectra fell within typical major absorption bands of humic acid which is at frequencies 3680, 2918, 1721, 1168 $\mathrm{cm}^{-1}$. The first peak centred in the vicinity of $3680 \mathrm{~cm}^{-1}$ region is attributed to phenol $\mathrm{OH}$ group bounded by intermolecular $\mathrm{H}$ bonds. The $2918 \mathrm{~cm}^{-1}$ band usually has absorption maximum at $2918 \mathrm{~cm}^{-1}$ which is due to $\mathrm{C}-\mathrm{H}$ stretching of alkane group $\left(\mathrm{CH}_{2}\right)$. The next major absorption band is $1721 \mathrm{~cm}^{-1}$. This band has been commonly ascribed to $\mathrm{C}=\mathrm{O}$ stretching of mainly carboxyl group $(\mathrm{COOH})$ with trace amount of ketones. The last peak was observed at 1168 $\mathrm{cm}^{-1}$ due to $\mathrm{C}-\mathrm{O}$ stretching of polysaccharides and this peak appeared also in the spectra of humic acid from peat soil. The FTIR spectra of the isolated humic acid contained all major characteristic absorption peaks of humic acid. These absorption peaks indicated the presence of the major structural elements of humic acid namely $\mathrm{H}$ bonded $\mathrm{OH}, \mathrm{C}=\mathrm{C}$ of aromatic ring, $\mathrm{C}=\mathrm{O}$ of carbonyl group (both carboxyl and ketonic), $\mathrm{CH}_{2}$ group. This strongly supports the presence of humic acid.

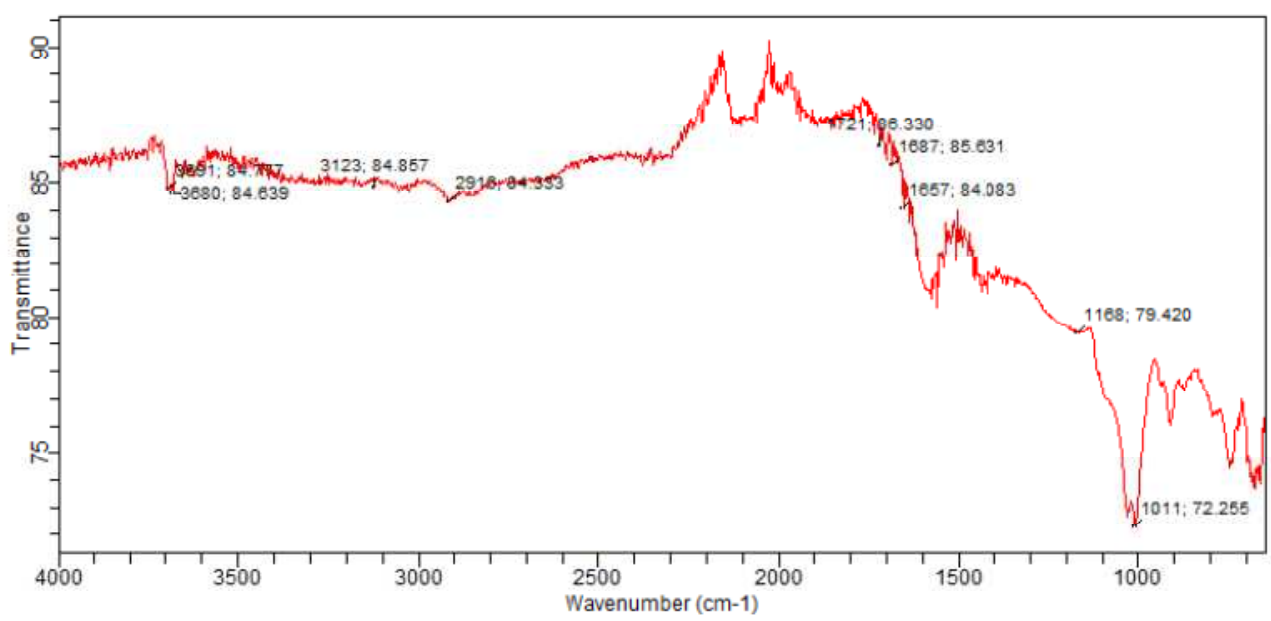

Fig. 2 : FT-IR spectraof peatsoilhumic acid (PSHA)

\section{Evaluation of acid dissociation constant (pka) of acid hydrolysed peat soil humicacid at phenolic group}

The value of the dissociation constant of the peat soil humic acid (PSHA) that underwent acidhydrolysis studied was found to be 8.9299 as shown Table 1, which is lower than the literaturevalues reported by Almeida and Szpoganics, (2015), Borges et al., (2005); Badr et al., (2012)and Fernandes et al,.(2009) of $9.73,9.47$ and 10.30. The difference between the obtained valuesand the reported values in this study might be probably as a result of acid hydrolysis of humicacid. 
BAJOPAS Volume 14 Number 1,June, 2021

Table 1: PKa of (Hydrolysed PSHA)

\begin{tabular}{|l|l|l|l|l|l|l|}
\hline $\mathrm{pH}$ & $\mathrm{BV}_{1}$ & $\mathrm{BV}_{2}$ & $\mathrm{~V}_{2}-\mathrm{V}_{1}$ & $\mathrm{nA}$ & $\log \left(\frac{n A}{1-n A}\right)$ & $\mathrm{pKa}$ \\
\hline 8.50 & 5.30 & 6.29 & 0.99 & 0.3594 & -0.2510 & 8.2490 \\
8.72 & 5.35 & 6.37 & 1.02 & 0.3400 & -0.2880 & 8.4320 \\
9.00 & 5.40 & 6.46 & 1.06 & 0.3141 & -0.3391 & 8.6609 \\
9.22 & 5.45 & 6.55 & 1.10 & 0.2882 & -0.3927 & 8.8273 \\
9.51 & 5.50 & 6.66 & 1.16 & 0.2494 & -0.4786 & 9.0314 \\
9.73 & 5.55 & 6.78 & 1.23 & 0.2041 & -0.5910 & 9.1390 \\
10.00 & 5.60 & 6.90 & 1.30 & 0.1589 & -0.7238 & 9.2762 \\
10.23 & 5.65 & 7.05 & 1.40 & 0.0941 & -0.9835 & 9.2465 \\
10.49 & 5.70 & 7.10 & 1.40 & 0.0941 & -0.9835 & 9.5065 \\
\hline
\end{tabular}

Average pKa $=8.9299 \pm 0.4186$

Table 2: PKa of (Unhydrolysed PSHA)

\begin{tabular}{|l|l|l|l|l|l|l|}
\hline $\mathrm{pH}$ & $\mathrm{BV}_{1}$ & $\mathrm{BV}_{2}$ & $\mathrm{~V}_{2}-\mathrm{V}_{1}$ & $\mathrm{nA}$ & $\log \left(\frac{\boldsymbol{n A}}{1-\boldsymbol{n}}\right)$ & $\mathrm{pKa}$ \\
\hline 8.50 & 5.30 & 5.81 & 0.51 & 0.6619 & 0.2919 & 8.7919 \\
8.72 & 5.35 & 5.90 & 0.55 & 0.6357 & 0.2418 & 8.9618 \\
9.00 & 5.40 & 6.00 & 0.60 & 0.6029 & 0.1813 & 9.1813 \\
9.22 & 5.45 & 6.10 & 0.65 & 0.5701 & 0.1226 & 9.3426 \\
9.51 & 5.50 & 6.20 & 0.70 & 0.5376 & 0.0654 & 9.5754 \\
9.73 & 5.55 & 6.33 & 0.78 & 0.4851 & -0.0259 & 9.7041 \\
10.00 & 5.60 & 6.47 & 0.87 & 0.4262 & -0.1291 & 9.8709 \\
10.23 & 5.65 & 6.62 & 0.99 & 0.3609 & -0.2481 & 9.9819 \\
10.49 & 5.70 & 6.80 & 1.10 & 0.2759 & -0.4690 & 10.0210 \\
\hline
\end{tabular}

Average pKa $=9.4923 \pm 0.4410$

Metal-ligand stability constant ( $\log \mathrm{K}$ )

The stabilityconstants require the accurate values of proton-ligand stability constants (Anil and Maroti, 2008). Metal titration curves crossed over ligand titration curve indicated the formation of complex upon proton release (Santosh, et al., 2011). If the values of n- are within range $0.2-0.8$ and $1.2-18$ this indicates the formation of $1: 1$ and 1:2 complexes (Sayyed and Mazahar, 2012).

The metal (II)-humate stepwise stability constants (log k) at phenolic group (Tables 318)

Table 3: Point-wise method, $\mathrm{Cu}$-(Hydrolysed PSHA)

\begin{tabular}{|l|l|l|l|l|l|l|l|l|}
\hline $\mathrm{pH}$ & $\mathrm{BV}_{1}$ & $\mathrm{BV}_{2}$ & $\mathrm{BV}_{3}$ & $\left(\mathrm{~V}_{3}-\mathrm{V}_{2}\right)$ & $\mathrm{n}$ & $\mathrm{pL}$ & $\log \left(\frac{n}{1-n}\right)$ & LogK $_{1}$ \\
\hline 8.50 & 5.30 & 6.29 & 6.33 & 0.04 & 0.5500 & 2.66 & 0.0871 & 2.7471 \\
8.72 & 5.35 & 6.37 & 6.41 & 0.04 & 0.5714 & 2.43 & 0.1249 & 2.5549 \\
9.00 & 5.40 & 6.46 & 6.50 & 0.04 & 0.6198 & 2.16 & 0.2122 & 2.3722 \\
9.22 & 5.45 & 6.55 & 6.59 & 0.04 & 0.6667 & 1.94 & 0.3010 & 2.2410 \\
\hline
\end{tabular}

LogK $_{1}$ (Average value) $=2.4788 \pm 0.2203$

Table 4: Point-wise method, $\mathrm{Cu}$-(Hydrolysed PSHA)

\begin{tabular}{|l|l|l|l|l|l|l|l|l|}
\hline $\mathrm{pH}$ & $\mathrm{BV}_{1}$ & $\mathrm{BV}_{2}$ & $\mathrm{BV}_{3}$ & $\left(\mathrm{~V}_{3}-\mathrm{V}_{2}\right)$ & $\mathrm{n}$ & $\mathrm{pL}$ & $\log \left(\frac{n-1}{2-n}\right)$ & LogK $_{2}$ \\
\hline 9.51 & 5.50 & 6.66 & 6.73 & 0.07 & 1.3509 & 1.70 & -0.2671 & 1.4329 \\
9.73 & 5.55 & 6.78 & 6.85 & 0.07 & 1.6383 & 1.51 & 0.2467 & 1.7567 \\
10.00 & 5.60 & 6.90 & 6.98 & 0.08 & 2.1783 & 1.31 & -0.2158 & 1.0942 \\
10.23 & 5.65 & 7.05 & 7.13 & 0.08 & 4.1904 & 1.27 & & \\
10.49 & 5.70 & 7.10 & 7.19 & 0.09 & 4.6920 & & & \\
\hline
\end{tabular}

Log $K_{2}($ Average value $)=1.4280 \pm 0.3312$ 
BAJOPAS Volume 14 Number 1,June, 2021

Table 5: Point-wise method, $\mathrm{Cu}$ (Unhydrolysed PSHA)

\begin{tabular}{|l|l|l|l|l|l|l|l|l|}
\hline $\mathrm{pH}$ & $\mathrm{BV}_{1}$ & $\mathrm{BV}_{2}$ & $\mathrm{BV}_{3}$ & $\left(\mathrm{~V}_{3}-\mathrm{V}_{2}\right)$ & $\mathrm{n}$ & $\mathrm{pL}$ & $\log \left(\frac{n}{n-1}\right)$ & Log $_{1}$ \\
\hline 8.50 & 5.30 & 5.81 & 5.85 & 0.04 & 0.2973 & 2.88 & -0.3736 & 2.5064 \\
8.72 & 5.35 & 5.90 & 5.95 & 0.05 & 0.3873 & 2.66 & -0.1992 & 2.4608 \\
9.00 & 5.40 & 6.00 & 6.05 & 0.05 & 0.4044 & 2.38 & -0.1681 & 2.2119 \\
9.22 & 5.45 & 6.10 & 6.15 & 0.06 & 0.5157 & 2.18 & -0.0272 & 2.2072 \\
9.51 & 5.50 & 6.20 & 6.27 & 0.07 & 0.6417 & 1.89 & 0.2530 & 1.1430 \\
\hline
\end{tabular}

$\operatorname{LogK}_{1}($ Average value $)=2.3059 \pm 0.6153$

Table 6:Point-wise method, $\mathrm{Cu}$ (Unhydrolysed PSHA)

\begin{tabular}{|l|l|l|l|l|l|l|l|l|}
\hline $\mathrm{pH}$ & $\mathrm{BV}_{1}$ & $\mathrm{BV}_{2}$ & $\mathrm{BV}_{3}$ & $\mathrm{~V}_{3}-\mathrm{V}_{2}$ & $\mathrm{n}$ & $\mathrm{pL}$ & $\log \left(\frac{n-1}{2-n}\right)$ & $\log \mathrm{K}_{2}$ \\
\hline 9.73 & 5.55 & 6.33 & 6.42 & 0.09 & 0.9000 & 1.69 & & \\
10.00 & 5.60 & 6.47 & 6.58 & 0.11 & 1.2578 & 1.44 & -0.4592 & 0.9808 \\
10.23 & 5.65 & 6.62 & 6.84 & 0.12 & 1.6137 & 1.26 & -0.2010 & 1.4610 \\
10.49 & 5.70 & 6.80 & 6.92 & 0.12 & 2.1052 & 1.03 & & \\
\hline
\end{tabular}

$\operatorname{LogK}_{2}$ (Average value) $=1.2209 \pm 0.3398$

Table 7:Point-wise method, Pb (Hydrolysed PSHA)

\begin{tabular}{|l|l|l|l|l|l|l|l|l|}
\hline $\mathrm{pH}$ & $\mathrm{BV}_{1}$ & $\mathrm{BV}_{2}$ & $\mathrm{BV}_{3}$ & $\left(\mathrm{~V}_{3}-\mathrm{V}_{2}\right)$ & $\mathrm{n}$ & $\mathrm{pL}$ & $\log \left(\frac{n}{1-n}\right)$ & LogK $_{1}$ \\
\hline 8.50 & 5.30 & 6.29 & 6.33 & 0.04 & 0.5500 & 2.66 & 0.0871 & 2.7471 \\
8.72 & 5.35 & 6.37 & 6.41 & 0.04 & 0.5714 & 2.43 & 0.1249 & 2.5549 \\
9.00 & 5.40 & 6.46 & 6.50 & 0.04 & 0.6198 & 2.16 & 0.2122 & 2.3722 \\
9.22 & 5.45 & 6.55 & 6.60 & 0.05 & 0.8333 & 1.96 & 0.6989 & 2.6589 \\
\hline
\end{tabular}

Log $_{\mathbf{1}}($ Average value $)=2.5832 \pm 0.1614$

Table 8:Point-wise method, Pb-(Hydrolysed PSHA)

\begin{tabular}{|l|l|l|l|l|l|l|l|l|}
\hline $\mathrm{pH}$ & $\mathrm{BV}_{1}$ & $\mathrm{BV}_{2}$ & $\mathrm{BV}_{3}$ & $\left(\mathrm{~V}_{3}-\mathrm{V}_{2}\right)$ & $\mathrm{n}$ & $\mathrm{pL}$ & $\log \left(\frac{n-1}{2-n}\right)$ & $\log \mathrm{K}_{2}$ \\
\hline 9.51 & 5.50 & 6.66 & 6.71 & 0.05 & 0.9650 & 1.67 & & \\
9.73 & 5.55 & 6.78 & 6.83 & 0.05 & 1.1702 & 1.44 & & \\
10.00 & 5.60 & 6.90 & 6.90 & 0.05 & 1.4864 & 1.22 & -0.0237 & 1.1963 \\
10.23 & 5.65 & 7.05 & 7.10 & 0.05 & 2.0190 & 1.09 & & \\
10.49 & 5.70 & 7.10 & 7.17 & 0.07 & 3.6492 & 1.00 & & \\
\hline
\end{tabular}

Log $K_{2}$ (Average value) $=1.1963$

Table 9: Point-wise method, Pb (Unhydrolysed PSHA)

\begin{tabular}{|l|l|l|l|l|l|l|l|l|}
\hline $\mathrm{pH}$ & $\mathrm{BV}_{1}$ & $\mathrm{BV}_{2}$ & $\mathrm{BV}_{3}$ & $\mathrm{~V}_{3}-\mathrm{V}_{2}$ & $\mathrm{n}$ & $\mathrm{pL}$ & $\begin{array}{l}\text { Log } \\
\left(\frac{n}{n-1}\right)\end{array}$ & Log $\mathrm{K}_{1}$ \\
\hline 8.50 & 5.30 & 5.81 & 5.85 & 0.04 & 0.2973 & 2.88 & -0.3736 & 2.5064 \\
8.72 & 5.35 & 5.90 & 5.94 & 0.04 & 0.3099 & 2.66 & -0.5477 & 2.3123 \\
9.00 & 5.40 & 6.00 & 6.05 & 0.05 & 0.4044 & 2.38 & -0.1681 & 2.2119 \\
9.22 & 5.45 & 6.10 & 6.15 & 0.06 & 0.5157 & 2.18 & 0.0272 & 2.2072 \\
9.51 & 5.50 & 6.20 & 6.26 & 0.07 & 0.6417 & 1.89 & 0.2530 & 2.1430 \\
9.73 & 5.55 & 6.40 & 6.40 & 0.07 & 0.7000 & 1.67 & 0.3680 & 2.0380 \\
\hline
\end{tabular}

LogK $_{1}$ (Average value) $=2.2364 \pm 0.1602$

Table 10: Point-wise method, Pb (Unhydrolysed PSHA)

\begin{tabular}{|l|l|l|l|l|l|l|l|l|}
\hline $\mathrm{pH}$ & $\mathrm{BV}_{1}$ & $\mathrm{BV}_{2}$ & $\mathrm{BV}_{3}$ & $\mathrm{~V}_{3}-\mathrm{V}_{2}$ & $\mathrm{n}$ & $\mathrm{pL}$ & $\log \left(\frac{n-1}{2-n}\right)$ & $\log \mathrm{K}_{2}$ \\
\hline 10.00 & 5.60 & 6.47 & 6.55 & 0.08 & 1.9503 & 1.41 & & \\
10.23 & 5.65 & 6.62 & 6.72 & 0.11 & 1.4792 & 1.26 & -0.0361 & 1.2239 \\
\hline
\end{tabular}

$\operatorname{LogK}_{2}$ (Average value) $=1.2239$

Table 11: Point-wise method, Mg (Hydrolysed PSHA)

\begin{tabular}{|l|l|l|l|l|l|l|l|l|}
\hline $\mathrm{pH}$ & $\mathrm{BV}_{1}$ & $\mathrm{BV}_{2}$ & $\mathrm{BV}_{3}$ & $\left(\mathrm{~V}_{3}-\mathrm{V}_{2}\right)$ & $\mathrm{n}$ & $\mathrm{pL}$ & $\log \left(\frac{n}{n-1}\right)$ & LogK $_{1}$ \\
\hline 8.50 & 5.30 & 6.29 & 6.31 & 0.02 & 0.2750 & 2.64 & -0.4290 & 2.2110 \\
8.72 & 5.35 & 6.37 & 6.39 & 0.02 & 0.2858 & 2.42 & -0.3978 & 2.0222 \\
9.00 & 5.40 & 6.46 & 6.49 & 0.03 & 0.4648 & 2.14 & -0.0612 & 2.0788 \\
9.22 & 5.45 & 6.55 & 6.59 & 0.04 & 0.6667 & 1.94 & 0.3010 & 2.2410 \\
\hline
\end{tabular}

$\log _{\mathbf{1}}($ Average value) $=2.1382 \pm 0.1046$ 
BAJOPAS Volume 14 Number 1,June, 2021

Table 12: Point-wise method, Mg (Hydrolysed PSHA)

\begin{tabular}{|l|l|l|l|l|l|l|l|l|}
\hline $\mathrm{pH}$ & $\mathrm{BV}_{1}$ & $\mathrm{BV}_{2}$ & $\mathrm{BV}_{3}$ & $\left(\mathrm{~V}_{3}-\mathrm{V}_{2}\right)$ & $\mathrm{n}$ & $\mathrm{pL}$ & $\log \left(\frac{n-1}{2-n}\right)$ & LogK $_{2}$ \\
\hline 9.51 & 5.55 & 6.66 & 6.71 & 0.05 & 0.9650 & 1.67 & & \\
9.73 & 5.55 & 6.78 & 6.84 & 0.06 & 1.4042 & 1.47 & -0.1686 & 1.3014 \\
10.00 & 5.60 & 6.90 & 6.93 & 0.06 & 1.7838 & 1.23 & 0.5593 & 1.7893 \\
10.23 & 5.65 & 7.05 & 7.10 & 0.06 & 3.1429 & 1.10 & & \\
10.49 & 5.70 & 7.10 & 7.18 & 0.07 & 3.6492 & 0.83 & & \\
\hline
\end{tabular}

LogK $_{2}($ Average value $)=1.5453 \pm 0.3450$

Table 13: Point-wise method, Mg (Unhydrolysed PSHA)

\begin{tabular}{|l|l|l|l|l|l|l|l|l|}
\hline $\mathrm{pH}$ & $\mathrm{BV}_{1}$ & $\mathrm{BV}_{2}$ & $\mathrm{BV}_{3}$ & $\mathrm{~V}_{3}-\mathrm{V}_{2}$ & $\mathrm{n}$ & $\mathrm{pL}$ & $\log \left(\frac{n}{n-1}\right)$ & $\operatorname{Log~}_{1}$ \\
\hline 8.50 & 5.30 & 5.81 & 5.85 & 0.04 & 0.2973 & 2.88 & -0.3736 & 2.5064 \\
8.72 & 5.35 & 5.90 & 5.94 & 0.04 & 0.3099 & 2.66 & -0.3477 & 2.3123 \\
9.00 & 5.40 & 6.00 & 6.04 & 0.04 & 0.3236 & 2.38 & -0.3202 & 2.0598 \\
9.22 & 5.45 & 6.10 & 6.15 & 0.05 & 0.4297 & 2.17 & -0.1230 & 2.0470 \\
9.51 & 5.50 & 6.20 & 6.26 & 0.06 & 0.5500 & 1.89 & 0.0871 & 1.9771 \\
9.73 & 5.55 & 6.33 & 6.40 & 0.07 & 0.7000 & 1.67 & 0.3680 & 2.0380 \\
\hline
\end{tabular}

LogK $_{1}$ (Average value) $=2.1568 \pm 0.2069$

Table 14: Point-wise method, Mg (Unhydrolysed PSHA)

\begin{tabular}{|l|l|l|l|l|l|l|l|l|}
\hline $\mathrm{pH}$ & $\mathrm{BV}_{1}$ & $\mathrm{BV}_{2}$ & $\mathrm{BV}_{3}$ & $\mathrm{~V}_{3}-\mathrm{V}_{2}$ & $\mathrm{n}$ & $\mathrm{pL}$ & $\log \left(\frac{n-1}{2-n}\right)$ & $\log \mathrm{K}_{2}$ \\
\hline 10.00 & 5.60 & 6.47 & 6.55 & 0.08 & 0.9148 & 1.41 & & \\
10.23 & 5.65 & 6.62 & 6.71 & 0.09 & 1.2102 & 1.20 & -0.5749 & 0.6251 \\
10.49 & 5.70 & 6.80 & 6.92 & 0.09 & 1.5968 & 1.03 & 0.1703 & 1.2003 \\
\hline
\end{tabular}

LogK $_{2}$ (Average value) $=0.9127 \pm 0.4070$

Table15:Point-wise method, Cd (Hydrolysed PSHA)

\begin{tabular}{|l|l|l|l|l|l|l|l|l|}
\hline $\mathrm{pH}$ & $\mathrm{BV}_{1}$ & $\mathrm{BV}_{2}$ & $\mathrm{BV}_{3}$ & $\left(\mathrm{~V}_{3}-\mathrm{V}_{2}\right)$ & $\mathrm{n}$ & $\mathrm{pL}$ & $\log \left(\frac{n}{1-n}\right)$ & LogK $_{1}$ \\
\hline 8.50 & 5.30 & 6.29 & 6.31 & 0.02 & 0.2750 & 2.64 & -0.4210 & 2.2190 \\
8.72 & 5.35 & 6.37 & 6.40 & 0.03 & 0.4286 & 2.42 & -0.1249 & 2.2951 \\
9.00 & 5.40 & 6.46 & 6.49 & 0.03 & 0.4648 & 2.14 & -0.0612 & 2.0788 \\
9.22 & 5.45 & 6.55 & 6.59 & 0.04 & 0.6667 & 1.96 & 0.3010 & 2.2610 \\
9.51 & 5.55 & 6.66 & 6.70 & 0.04 & 0.7720 & 1.67 & 0.5297 & 2.1997 \\
\hline
\end{tabular}

LogK $_{\mathbf{1}}$ (Average value) $=2.2108 \pm 0.0825$

Table 16: Point-wise method, Cd (Hydrolysed PSHA)

\begin{tabular}{|l|l|l|l|l|l|l|l|l|}
\hline $\mathrm{pH}$ & $\mathrm{BV}_{1}$ & $\mathrm{BV}_{2}$ & $\mathrm{BV}_{3}$ & $\left(\mathrm{~V}_{3}-\mathrm{V}_{2}\right)$ & $\mathrm{n}$ & $\mathrm{pL}$ & $\log \left(\frac{n-1}{2-n}\right)$ & Log $_{2}$ \\
\hline 9.73 & 5.55 & 6.78 & 6.83 & 0.06 & 1.4042 & 1.47 & -0.1686 & 1.3014 \\
10.00 & 5.60 & 6.90 & 6.95 & 0.06 & 1.7838 & 1.23 & 0.5593 & 1.7893 \\
10.23 & 5.65 & 7.05 & 7.10 & 0.06 & 3.1429 & 1.09 & & \\
10.49 & 5.70 & 7.10 & 7.16 & 0.06 & 3.1429 & 0.89 & & \\
& & & & & & & & \\
\hline
\end{tabular}

$\operatorname{LogK}_{2}$ (Average value) $=1.5453 \pm 0.3450$

Table 17: Point-wise method, Cd (Unhydrolysed PSHA)

\begin{tabular}{|l|l|l|l|l|l|l|l|l|}
\hline $\mathrm{pH}$ & $\mathrm{BV}_{1}$ & $\mathrm{BV}_{2}$ & $\mathrm{BV}_{3}$ & $\mathrm{~V}_{3}-\mathrm{V}_{2}$ & $\mathrm{n}$ & $\mathrm{pL}$ & $\log \left(\frac{n}{n-1}\right)$ & $\operatorname{Log~}_{1}$ \\
\hline 8.50 & 5.30 & 5.81 & 5.86 & 0.05 & 0.3717 & 2.88 & -0.2280 & 2.6520 \\
8.72 & 5.35 & 5.90 & 5.95 & 0.05 & 0.3873 & 2.66 & -0.1992 & 2.4608 \\
9.00 & 5.40 & 6.00 & 6.06 & 0.06 & 0.4853 & 2.38 & -0.0255 & 2.3545 \\
9.22 & 5.45 & 6.10 & 6.16 & 0.06 & 0.5157 & 2.18 & -0.0272 & 2.2072 \\
9.51 & 5.50 & 6.20 & 6.27 & 0.07 & 0.6417 & 1.89 & 0.2530 & 1.1430 \\
9.73 & 5.55 & 6.33 & 6.41 & 0.08 & 0.8000 & 1.69 & 0.6020 & 2.2920 \\
& & & & & & & & \\
\hline
\end{tabular}

$\operatorname{LogK}_{1}($ Average value $)=2.2516 \pm 0.5380$ 
BAJOPAS Volume 14 Number 1,June, 2021

Table 18: Point-wise method, Cd (Unhydrolysed PSHA)

\begin{tabular}{|l|l|l|l|l|l|l|l|l|}
\hline $\mathrm{pH}$ & $\mathrm{BV}_{1}$ & $\mathrm{BV}_{2}$ & $\mathrm{BV}_{3}$ & $\mathrm{~V}_{3}-\mathrm{V}_{2}$ & $\mathrm{n}$ & $\mathrm{pL}$ & $\log \left(\frac{n-1}{2-n}\right)$ & $\log \mathrm{K}_{2}$ \\
\hline 10.00 & 5.60 & 6.47 & 6.57 & 0.10 & 1.1434 & 1.43 & & \\
10.23 & 5.65 & 6.62 & 6.72 & 0.10 & 1.3448 & 1.23 & -0.2788 & 0.9512 \\
10.49 & 5.70 & 6.80 & 6.90 & 0.10 & 1.7742 & 1.03 & 0.5351 & 1.5651 \\
\hline
\end{tabular}

$\operatorname{LogK}_{2}($ Average value $)=1.2581 \pm 0.4340$

Table 19: Stepwise and overall Stability constants of thehydrolysed and unhydrolysed divalent metal (II) complexes

\begin{tabular}{|c|c|c|c|}
\hline Chelates & LogK $_{1}$ & $\log _{2}$ & Log $\beta$ \\
\hline [Cu (Hydrolysed PSHA-1) $\left.{ }_{2}\right]$ & 2.4788 & 1.4280 & 3.9068 \\
\hline$\left[\mathrm{Pb}(\text { Hydrolysed PSHA-1) })_{2}\right]$ & 2.5832 & 1.1963 & 3.7795 \\
\hline$\left[\mathrm{Cd}(\text { Hydrolysed PSHA-1 })_{2}\right]$ & 2.2108 & 1.5453 & 3.7561 \\
\hline$\left[\mathrm{Mg}(\text { Hydrolysed PSHA-1 })_{2}\right]$ & 2.1382 & 1.5453 & 3.6835 \\
\hline [Cu (Unhydrolysed PSHA-1) & 2.3059 & 1.2209 & 3.5268 \\
\hline$[\mathrm{Pb}$ (Unhydrolysed PSHA-1) 2$]$ & 2.2364 & 1.2239 & 3.4603 \\
\hline [Cd (Unhydrolysed PSHA-1) 2 ] & 2.2516 & 1.2581 & 3.5097 \\
\hline$[\mathrm{Mg}$ (Unydrolysed PSHA-1) & 2.1568 & 0.9127 & 3.0695 \\
\hline
\end{tabular}

The results obtained (Table19) shows the stepwise and overall stability constants to be not high indicating low stability of the complexes, because the solubility of most metal ions in the basic $\mathrm{pH}$ range is minimal due to metal hydroxide precipitation (Karimi, 2017). In general, the stepwise stability constants $\left(K_{1}\right.$ and $K_{2}$ ) follow the order $K_{1}>K_{2}$ for the copper, lead, magnesium and cadmium complexes respectively. The steady decrease of the values with increasing number of ligands is in agreement with the prediction made by researchers (Na'aliya, 2013). The decrease could be attributed to the fact that as the number of the ligands (Humate ions) that enters the coordination zone increases the aqua molecules available for replacement by the ligands become less. Thus, the metal ions become less electron loving with progressive intake of the ligand and this results in the decrease in the values of the constants (Na'aliya, 2013). Also the stability of the complexes is influenced by the size and number of the chelate rings(Mackay and Mackay,2002).All the complexes form rings in their structure as humate, a bidentate ligand, bond the metal ions in the ratio 1:2 (Boguta and Sokolowska, 2016) forming chelate rings. The values of the overall stability constants $(\log \beta)$ obtained for humate complexes are not high indicating low stability as the values are not high. LogK values for copper-humates (Table 3 to 6) obtained in this study are lower than those reported for the complexes of humic acids (Pandey et al., 2015; Dinu, 2013; Kaschl et al., 2010 and Gilbeto and Jorg, 2001). The values of LogK(Table 7 to 10 ) forlead-humates are lower than those reported for the lead in the literature (Dinu, 2013; Gilbeto and Jorg 2001). Log K values(Table 11 to 14 ) for magnesium-humates obtained in this study are close to those reported by (Pandey et al., 2015). Log K values of cadmium-humates (Table 15 to 18 ) obtained in this work near to the one reported by (Dinu, 2013 and Pandey et al., 2015).The difference between the reported values and the values obtained in this study might be probably as a result of acid hydrolysis of humic acid. The values of the overall stability constants $(\log \beta)$ of the copper humates complexes presented in Table 19 is high than that of other metal humate complexes, show relatively high stability of CuHA complexes, show the following order of stability: $\mathrm{Cu}>\mathrm{Pb}>\mathrm{Cd}>\mathrm{Mg}$; which are in close agreement to the findings of (Dinu, 2013 and Pandey et al., 2015).The high stability of Cuhumate chelate could be attributed to the existence of coordinate covalent bond between the complexing agents and the $\mathrm{Cu}^{2+}$ ions. Since, $\mathrm{Cu}^{2+}$ being a metal of the transitional series with $3 d^{9}$ electronic configurations can accept the electrons from the complexing agents. Similarly, the low stabilities of $\mathrm{Pb}, \mathrm{Cd}$ and $\mathrm{Mg}$ complexes could be explained by that $\mathrm{Pb}^{2+}$ with $6 s^{2}, \mathrm{Cd}^{2+}$ with $4 \mathrm{~d}^{10}$ and $\mathrm{Mg}^{2+}$ with $2 \mathrm{p}^{6}$ their electronic configuration has a completely filled $\mathrm{d}, \mathrm{p}$ and $\mathrm{s}$ orbitals. Moreover, the stabilities of metal ions with hydrolysed humic acid from peat soil were higher than those with unhydrolysed humic acid from peat soil; which is ascribed to the high content of acidity in hydrolysed humic acid than unhydrolysed humic acid. 
BAJOPAS Volume 14 Number 1,June, 2021 CONCLUSION

The values of logk for $\mathrm{Cu}(\mathrm{II})$ hydrolysed humic acid complex was higher followed by $\mathrm{Pb}$ (II), $\mathrm{Cd}(\mathrm{II})$ and $\mathrm{Mg}$ (II) hydrolysed humic acid complexes as compared with metal(II) unhydrolysed humic acid complexes. This indicates acid hydrolysis of humic acid can

\section{REFERENCES}

Almeida, V.R. and Szpoganicz, B. (2015). Humic Acid Potentiometric Response Patterns:Out- of Equilibrium Properties and Species Distribution Modelling. Chemical. Biol. Technol. Agric. 2: 17.

Anđelković, T., Nikolić, R., Bojić, A.,Anđelković, D., and Nikolic G.,(2010). Binding of Cadmium to Soil Humic Acid as A Function of Carboxyl Group Content. Macedonian Journal of Chemistry and Chemical Engineering.29(2): 215-224.

Anil, B. N. and Maroti, N. (2008). Studies on Influence of Die-Lectric Constants on Complex Equilibria between Substituted Py-Razalines and Lanthanide Metal Ions pH-Metrically. Amer.-Euras. scient. Res. 3(2): 212-216.

Ashok, K., Pandey, S. P. and Misra, V (2000). Stability Constants of Metal-Humic Acid Complexes and its Role in Environmental Detoxification. Journal of Ecotoxicology and Environmental Safety. 47(2):157-200.

Badr, M. H., El-Halafawi, M. H. and Abd El-al Zeid, E. R. (2012). Comparison Between the Effect of Ionic Strength on Acidity and Dissociation Constants of Humic Acids Extracted from Sewage Sludge and Nile Water Hyacinth Composts.Global Journal of Environmental Research 6 (1): 36-43.

Baruah, M.K., Borah, D., Saikia, P.P., Paul, S., Sharma, T. (2015). Evaluation of pKa Values of Soil Humic Acids and their Complexation Properties. International Journal of Plant \& Soil Science 6(4) : 218-228.

Boguta, P. Sokolowska, Z. (2016). Interactions of $\mathrm{Zn}$ (II) Ions with Humic Acids Isolated from Various Types of Soils. Effect of $\mathrm{pH}, \mathrm{Zn}$ Concentrations and Humic Acids Chemical Properties. Journal of Geochemical Explaration 168. 119-126.

Borges, F., Guimaraes, C., Lima, L.F.C., Pinto, I. and Reis, S.(2005). Potentiometric Studies on the Complexation of Copper(II) by Phenolic Acids as Discrete Ligand Models of enhance the complexation behavior of humic acid with metal (II) ions. However, the higher values of $\log \beta$ for $\mathrm{Cu}(\mathrm{II}), \mathrm{Pb}(\mathrm{II}), \mathrm{Cd}(\mathrm{II})$ and $\mathrm{Mg}(\mathrm{II})$ hydrolysed humic acid complexes indicates more stable stepwise complexes formed as compared with $\mathrm{Cu}(\mathrm{II}), \mathrm{Pb}$ (II), $\mathrm{Cd}$ (II) and $\mathrm{Mg}(\mathrm{II})$ unhydrolysed humic acid complexes.

Humic Substances Talanta 66 (2005) 670-673.

Chefetz, B., Salloum, M. J., Deshmulkin, A. P. and Hatcher, P. (2002). Structural Components of Humic Acids as Determined by Chemical Modifications and Carbon-13 NMR, Pyrolysis, and Thermochemolysis- Gas Chromatography/Mass Spectrometry. Soil Science Society of American Journal Abstract Division S-2- Soil Chemistry66. 1159-1171.

Dinu, M. I. (2013). Metals Complexation with Humic Acids in Surface Water of Different Environ. Sci. Technol. 31(1): 1-17.

Fernandes, A.N., Giacomelli, C., Giovanela, M. Vaz, D.V. Szpoganicz, B. and Maria M. D. (2009). Potentiometric Acidity Determination in Humic Substances Influenced by Different Analytical Procedures.J. Braz. Chem. Soc. 20 (9):14.

Gamal, A. H. (2015). Stability Constants of Rhenium (V) Metal Complexes with Selected Drugs. Pyrex Journal of Research in Environmental Studies. 2(2): 006-014.

Janrao, D. M., Pathan, J., Kayande, D.D., and Mulla, J.J. (2014). An Over View of Potentiometric Determination of Stability Constants of Metal Complexes. Sci. Revs. Chem. Commun.: 4(1), 2014, 11-24.

Karimi, H. (2017). Effect of pH and Initial Pb(II) Concentration on the Lead Removal Efficiency from Waste Water Using $\mathrm{Ca}(\mathrm{OH})_{2}$. International Journal of Water and Waste Water Treatment 3.2

Kaschl, A. Romheld, V. and Chen, Y. (2010). Binding of Cadmium, Copper and Zinc to Humic Substances Originating from Municipal Solid Waste Compost. Israel Journal of Chemistry Vol. 42(1): 89-98.

Kostic, I. S., Tatjana, P, A., Nikolic, R. S., Cvetkovic, T. P., Pavlovic, D. D., Aleksandar, L.J. and Bojic, A. (2012). Comparative Study of Binding Strengths of Heavy Metals with Humic Acid. J.serb. Chem. Soc. 76(9) pp 1-20. 
BAJOPAS Volume 14 Number 1,June, 2021

Na'aliya, J. (2013). Determination of Stepwise Stability Constants and Gibbs free Energy Change of Trisprolina to Complexes of some Divalent Transition Metal ions. Bayero Journal of Pure and Applied Sciences 6(2): 112-114.

Omar, A. A. and Ali, E. A. (2015). Potentiometric Studies on Complexes of $\mathrm{Cr}$ (III) and $\mathrm{Zr}$ (IV) with some Carboxylic Acids. International Journal of Advanced Chemistry, 3(1) 25-

37.

Pandey, A. K. Pandey, S. D. and Misr, V. (2015).Stability Constants of Metal- Humic Acid Complexes and Its Role in Environmental Detoxification. J. Ecotoxicology and Environmental Safety. 47(1):195-200.

Ram, N. and Raman, K.V. (1984). Stability Constants of Complexes of Metals with
Humicand Fuvic Acids under Non- acidConditions. Journal of Plant Nutrition and Soil Sciences.

147:171-176.

Santosh, D. D., Ashok, B. K., Vijay, J. T., Shivraj, G. W. and Vinay, V. W. (2011). Potentiometric Studies of Elec-Trolyte Effects on Complex Equilibria of Some Substituted 5-(2-hydroxy Phenyl) Pyrazoles. Der pharm. 3 (6): 75-83.

Sayyed, H. and Abdul Rahim, M. F. (2012). Studies of Binary Complexes of Metal Ions with Mandelic Acid by Potentiometry. Chem. J. 02 (6): 206209.

Shirvani, M. Moradian, E. Khalili, B. Bakhtiary, S. (2015). Interaction of $\mathrm{Cd}$ and $\mathrm{Pb}$ with Humate-Palygorskite and HumateSepiolite Complexes. Journal of water, air and pollution 3: 220-228. 


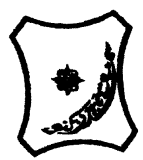

Bayero Journal of Pure and Applied Sciences, 14(1): 54 - 63

Received: November, 2020

Accepted: April, 2021

ISSN $2006-6996$

\title{
STABILITY CONSTANTS OF COMPLEXES OF METAL IONS WITH PEATSOIL HUMIC ACIDS UNDER NON-ACID-CONDITIONS
}

\author{
${ }^{* 1}$ Sabo, Yusuf ${ }^{2}$ Jimoh, W.L.O., ${ }^{3}$ Isa Baba Koki and ${ }^{4}$ Sholadoye, Q. 0. \\ ${ }^{1}$ Department of Pure and Industrial Chemistry, Bayero University, Kano \\ ${ }^{3}$ Department of Chemistry, Yusuf Maitama Sule University Kano. P.M.B. 3220 Kano, Nigeria. \\ ${ }^{4}$ Department of Chemistry, Nigerian Police Academy, Wudil, Kano-Nigeria
}

*Correspondence E-mail; saboyusuf18@yahoo.com

ABSTRACT

Stability constants of complexes of four divalent metal ions viz. $\mathrm{Cu}^{2+}, \mathrm{Pb}^{2+}, \mathrm{Mg}^{2+}$ and $\mathrm{Cd}^{2+}$ with humic acids (HA) were determined by potentiometric titration of humic acids with the corresponding salt of the divalent metals in aqueous media under non-acid-condition. The log $K$ (logarithm of the stability constant) ranged from 1.0942 to 2.7471 for metalhumic acid complexes were determined using point-wise computational method. The order of stability constants were obtained as follows: $\mathrm{Cu}>\mathrm{Pb}>\mathrm{Cd}>\mathrm{Mg}$ for metal $-\mathrm{HA}$ complexes respectively, indicating a higher degree of complexation with Cu metal ion.

Keywords: stability constant, humic acid, potentiometric titration, divalent metals, acid hydrolysis.

\section{NTRODUCTION}

The stability constant of a complex is the numerical expression of its stability and provides a quantitative measure of affinity of the metal ion to the complexing agent. An understanding of the relative stability of metal-complexes helps in predicting the behavior of metal ions in the soil (Ram and Raman, 1982). Extensive researches has been done to determine the stability constants of the complexes formed between humic acid (HA) with a number of metal ions. Ashok et al., (2000) reported that humic acid with hydroxyl, phenoxyl and carboxyl reactive groups can form coordination compound with metal ions at $\mathrm{pH}$ 3.5. The stability constants(Log K) for different metalhumic acid complexes indicated the following order of the stabilities of complexes formed between humic acid and metal ion, $\mathrm{Cu}>\mathrm{Fe}$ $>\mathrm{Pb}>\mathrm{Ni}>\mathrm{Co}>\mathrm{Ca}>\mathrm{Cd}>\mathrm{Zn}>\mathrm{Mn}>\mathrm{Mg}$. Andelkovic et al., (2010) investigated the binding of $\mathrm{Cd}$ (II) to soil humic acid at pH 6.5 and in $0.1 \mathrm{M} \mathrm{KNO}_{3}$ ionic medium. The stability constant for binding indicating greater stability in the case when carboxyl groups are involved in complexation reaction. Kostic et al.,(2012) investigated the complexation of humic acid with certain heavy metal ions (Co(II), $\mathrm{Ni}(\mathrm{II}), \mathrm{Cu}(\mathrm{II})$,
$\mathrm{Zn}(\mathrm{II})$, and $\mathrm{Pb}(\mathrm{II})$. The experiment was performed at $25^{\circ} \mathrm{C}$, at pH 4.0 and ionic strength of $0.01 \mathrm{M}$. Stability constant of complex between $\mathrm{Pb}$ (II) ions and humic acid is greater than stability constants of other investigated metalhumate complexes. Bogata and Sokolowska (2016) analyses the interaction between humic acids from different soils and $\mathrm{Zn}$ (II) ions at wide concentration ranges and at $\mathrm{pH} 5$. Studies have showed significant impact of $\mathrm{Zn}$ concentration, $\mathrm{pH}$ and some properties of humic acids with zinc.But all of these studies were limited to acidic $\mathrm{pH}$ range. Therefore, the present study was carried out to determine and compare the stability constants of complexes of metal ions with hydrolysed peat soil humic acid and unhydrolysed peat soil humic under non-acid conditions.

\section{MATERIALS AND METHODS}

Analytical grade chemicals used includes hydrochloric acid $(\mathrm{HCl})$, nitric acid $\left(\mathrm{HNO}_{3}\right)$, sodium hydroxide $(\mathrm{NaOH})$, lead nitrate $\mathrm{Pb}\left(\mathrm{NO}_{3}\right)_{2}$, copper nitrate $\mathrm{Cu}\left(\mathrm{NO}_{3}\right)_{2} \cdot 3 \mathrm{H}_{2} \mathrm{O}$, cadmium nitrate $\mathrm{Cd}\left(\mathrm{NO}_{3}\right)_{2} \cdot 4 \mathrm{H}_{2} \mathrm{O}$, magnesium nitrate $\mathrm{Mg}\left(\mathrm{NO}_{3}\right)_{2} \cdot 6 \mathrm{H}_{2} \mathrm{O}$, potassium nitrate $\left(\mathrm{KNO}_{3}\right)$, calcium chloride $\left(\mathrm{CaCl}_{2}\right)$, (sigma-Aldrich). Dowex 50WX8, (20-50 mesh) from Fluka. 


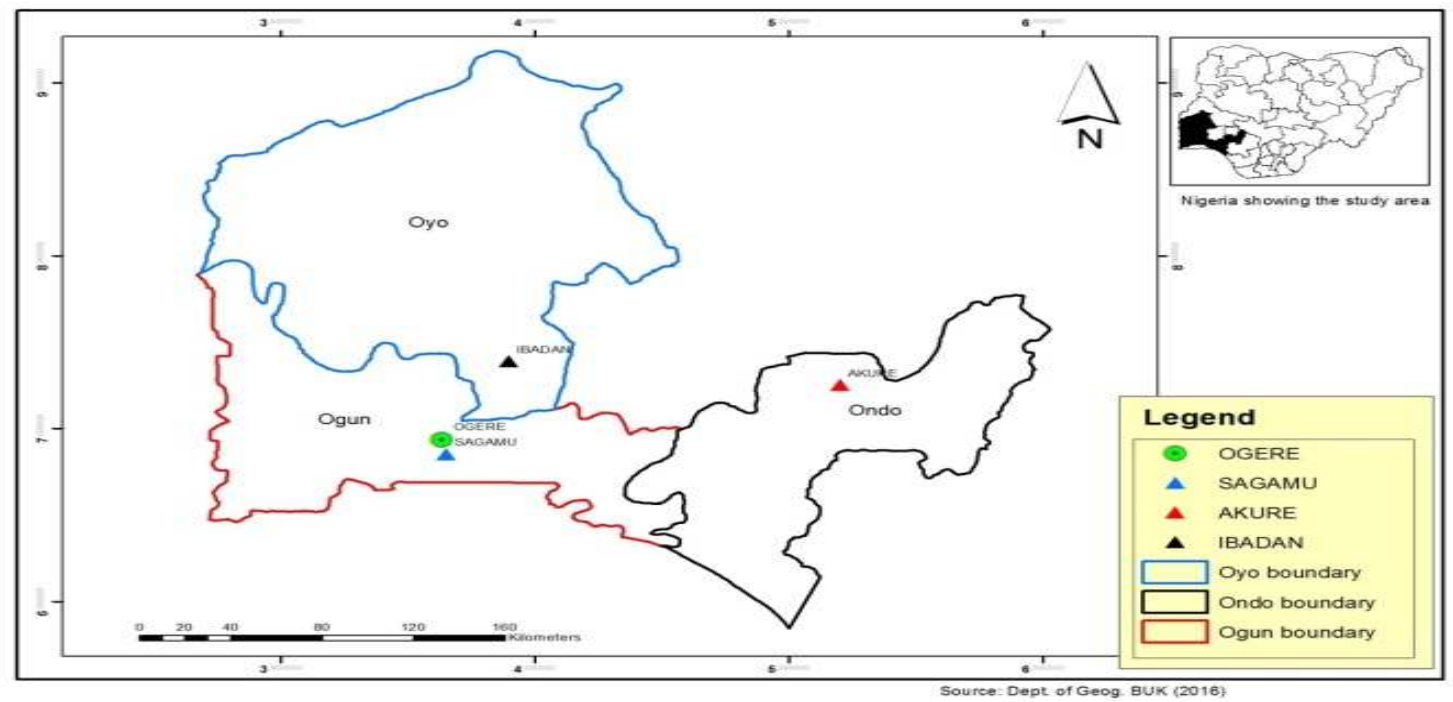

Figure 1: Map showing the sampling point at Sagamu Town, Ogun State.

\section{Description of Sampling Area}

Sagamu has geographical coordinates between $6^{\circ} 50^{\prime}$ north; $3^{\circ} 38^{\prime}$ east is located in south western region of Nigeria. The region has tropical wet and dry climate with a lengthy wet season and relatively constant temperatures throughout the course of the year. Wet season runs from March to October, November to December forms the region dry season. The vegetation type of the region is savannah which is really grassland with small bushes and occasional big trees. Grassland soils have substantially higher organic matter content than forest soils (Novackova, 2011).

\section{Sample Collection}

The Peatsoil samples were collected from four different sampling points $(0-10 \mathrm{~cm}$ depth) in Sagamu into polyethylene bag with plastic spoons. Samples were taken to the laboratory, extraneous materials were removed; the samples were air-dried, crushed and ground to a fine powder in a mortar passed through a $0.20 \mathrm{~mm}$ sieve. The samples were kept for analysis.

\section{Isolation and purification of humic acid from peat soil sample}

Peatsoil sample $(100 \mathrm{~g})$ was mixed with 1000 $\mathrm{cm}^{3}$ of $0.1 \mathrm{M} \mathrm{NaOH}$ solution, shaken for 3hours and left to stand overnight. Dark-coloured supernatant was obtained and decanted from solid residue. The dark-coloured supernatant was acidified to $(\mathrm{pH}=1.0)$ with $6 \mathrm{M} \mathrm{HCl}$ stirred and allowed to stand for 6 hours. Yellowish brown supernatant and dark-brown precipitate were obtained. The yellowish brown supernatant was decanted followed by centrifuge and discarded. The dark-brown precipitate was mixed with $500 \mathrm{~cm}^{3}$ of $0.1 \mathrm{M} \mathrm{NaOH}$ solution followed by passing through dowex resin. The dark-brown solution was acidified to $(\mathrm{pH}=1.0)$ with $6 \mathrm{M} \mathrm{HCl}$ stirred and allowed to stand for 3 hours. The dark-brown precipitate was washed several times with deionized water. The supernatant was treated with $\mathrm{AgNO}_{3}$ solution until no white precipitate observed. The humic acid was transferred to weighed crucible and dried at $60^{\circ} \mathrm{C}$ in an oven for 12 hours. The humic acid was cooled and dried in the desiccator, weighed and recorded. The obtained humic acid was dried again at $60^{\circ} \mathrm{C}$ for additional 6 hours cooled and dried in the desiccator, weighed and recorded constant weight was obtained (Baruah et al., 2015).

\section{FT-IR analysis}

FT-IR spectra of humic acid sample was analysed using Carry 630 FT-IR Agilent Technologies.

Unhydrolysed compost humic acid

The unhydrolysed humic acid was obtained after isolation and purification of compost humic acid and kept for investigation.

\section{Acid hydrolysis of Peatsoil acid}

Peatsoil humic acid sample (1g) was refluxed for 12 hours at $\left(160^{\circ} \mathrm{C}\right)$ with $50 \mathrm{~cm}^{3}$ of $6 \mathrm{M} \mathrm{HCl}$. The mixture was allowed to cool, decanted, and centrifuged after hydrolysis. The insoluble residues were washed with distilled water via centrifugation several times, and the supernatant was treated with $\mathrm{AgNO}_{3}$ solution until no white precipitate was observed. The residue was thoroughly dried over $\mathrm{CaCl}_{2}$ in a desiccator at room temperature (Chefetz et al., 2002). Finally, the obtained hydrolysed humic acid was kept for investigation. 
BAJOPAS Volume 14 Number 1,June, 2021 Potentiometric Titrations

Potentiometric measurements were carried out using a pH-meter Jenway (model 3510) with combine electrode, the sensitivity of the $\mathrm{pH}$ meter is 0.01 units. The $\mathrm{pH}$ meter was switched on half an hour before starting the titration for initial warm up of the instrument. The instrument was calibrated with an aqueous standard buffer solution of $\mathrm{pH} 4.00$ and 10.0 (borate buffer) prepared from a "Qualigens" buffer tablets.

The following sets of solutions were prepared in a $250 \mathrm{~cm}^{3}$ volumetric flask separately for $\mathrm{pH}$ metric titrations.

(i) $5 \mathrm{~cm}^{3} 0.1 \mathrm{M} \mathrm{HCl}+40 \mathrm{~cm}^{3}$ deionized water

(ii) $5 \mathrm{~cm}^{3} 0.1 \mathrm{M} \mathrm{HCl}+39 \mathrm{~cm}^{3}$ deionized water $+1 \mathrm{~cm}^{3} 0.15 \mathrm{gcm}^{-3}$ humic acid

(iii) $5 \mathrm{~cm}^{3} 0.1 \mathrm{M} \mathrm{HCl}+37 \mathrm{~cm}^{3}$ deionized water $+1 \mathrm{~cm}^{3} 0.15 \mathrm{gcm}^{-3}$ humic acid

$$
+2 \mathrm{~cm}^{3} \quad 0.01 \mathrm{M} \mathrm{Cu} \text { (II) }
$$

The solutions were titrated against standardized $0.110 \mathrm{MNaOH}$ separately. The total volume of each mixture was adjusted to $50 \mathrm{~cm}^{3}$ and the ionic strength of the solutions was maintained constant at by adding appropriate amount of stock solution of $1 \mathrm{M} \mathrm{KNO}_{3}$ (Gamal, 2015; Omar and Ali, 2015). A magnetic stirrer was used to achieve thorough mixing of the interacting solutions at $550 \mathrm{rpm}$. The same set of experimental conditions was applied for potentiometric titration of remaining samples.

\section{Evaluation of pKa of Hydrolysed peat soil Humic Acids}

The proton-ligand formation number $\mathrm{n}_{\mathbf{A}}$ were calculated by Irving and Rossotti expression (Omar and Ali, 2015).

$\mathrm{nA}=\mathrm{Y}-\frac{(\mathrm{V} 2-\mathrm{V1})(\mathrm{No}-\mathrm{Eo})}{(\mathrm{VO}+\mathrm{V1}) \mathrm{TCL}}$ 1

Where: $Y$ is number of dissociable proton, $\left(\mathrm{V}_{2^{-}}\right.$ $V_{1}$ ) is the measure of displacement of the ligand curve relative to acid curve, $\mathrm{N}^{\circ}$ and $\mathrm{E}^{\circ}$ are the resultant concentration of alkali solution, free acid solution, $\mathrm{T}_{\mathrm{cL}}{ }^{\circ}$ is the total ligand concentration, $\mathrm{V}^{\circ}$ is the total volume of titration solution, $V_{1}$ is the volume of alkali added to acid solution, $V_{2}$ is the volume of alkali added to acid solution + ligand solution, acid dissociation constants (pKa - values) of ligand were calculated by algebraic method point wise calculation (Tables 1 ). The dissociation constants (pKa) were calculated according to the following relation:

$\mathrm{pKa}=\mathrm{pH}+\log \left(\frac{n A}{1-n A}\right)$ 2

Where: pKa is the acid dissociation constant, $\mathrm{n}_{\mathrm{A}}$ is the Proton-ligand formation number and $\mathrm{pH}$ is the pH-values (Omar and Ali, 2015).

\section{Determination of metal-ligand stability constants $(\log K)$ of complexes}

The potentiometric measurement for the determination of stability constant of a complex in solution is based on the fact that the redox potential of the couple $\frac{M^{+(m-n)}}{M^{+m}}$ is shifted significantly on complexation of the metal ion with the ligand. This method involves change in hydrogen ion concentration $\left[\mathrm{H}^{+}\right]$due to the displacement or association of one or more protons taking place during complexation reaction. This change can be found out by titrating the solutions containing free acid, acid with ligand, and acid with ligand and metal ion, individually against a standard alkali solution at a constant ionic strength or temperature. Either ionic strength or temperature may be varied for different sets of solutions. In all the cases, the change in the $\mathrm{pH}$ of the solution is measured after each addition of a known amount of alkali to the reaction cell which contains the reaction mixture. The titration curves are then drawn by plotting the measured $\mathrm{pH}$ values against the corresponding volume of alkali added and the stability constants of the complexes are determined from the titration curves by employing $\mathrm{pH}$-metric titration technique given by (Irving and Rossoti).

Metal-ligand stability constants ( $\log \mathrm{K}$ ) were determined by using the following relations:

$$
\bar{n}=\frac{\left(V_{3}-V_{2}\right)\left(E^{0}+N^{0}\right)}{\left(V^{0}+V_{2}\right) \bar{n}_{A} T_{m}^{0}}
$$

and

$$
P L=\log _{10}\left\{\frac{1+\beta_{n}^{H} \frac{1}{[\text { anti } \log \mathrm{pH}]^{\mathrm{n}}}}{\mathrm{T}_{\mathrm{L}}^{0}-n \bar{T}_{m}^{0}} \mathrm{X} \frac{\left(V^{0}+V_{3}\right)}{V^{0}}\right\}
$$


BAJOPAS Volume 14 Number 1,June, 2021

Where $T_{L}, T^{\circ}, E^{\circ}$, and $V^{\circ}$ havethe same significance as in equation (1) above, $T_{m}$ denotes the total concentration of metal present in solution, $V_{3}$ is the volume of metal ions present in solution and $\beta^{H}$ is the overall proton ligand stability constant. The metal-ligand stability constants (log K) were determined by employing point wise computational Method (eq. 5 and 6).

$\operatorname{LogK}_{1}=\log \left(\frac{n}{1-n}\right)+\mathrm{pL}$ .5

$\operatorname{LogK}_{2}=\log \left(\frac{1-n}{2-n}\right)+\mathrm{pL}$ ...6

Where: Log $\mathrm{K}$ is the metal-ligand stability constant, $\mathrm{pL}$ is the Free ligand exponent function, $\mathbf{n}$ is the Average number of ligand attached with metal ion (Janraoet al., 2014). The results obtained were analyzed by an ORIGIN 2016 program using titration data and then the proton-ligand stability constants (pKa) and Metal-ligand stability constant (LogK) calculated (Omar and Ali, 2015).

\section{RESULTS AND DISCUSSION}

Fourier transformed infrared (FT-IR) spectra of isolated humic acid from peat soils Figure 2 had distinct clear absorption bands indicating the presence of major humic acid structural elemental groups such as $\mathrm{H}$ bonded $\mathrm{OH}$ $\left(3680 \mathrm{~cm}^{-1}\right.$ peak $), C=0$ of carbonyl $\left(1721 \mathrm{~cm}^{-1}\right.$ peak), functional groups of aliphatic components $\mathrm{CH}_{2}\left(2918 \mathrm{~cm}^{-1}\right.$ peak) and $\mathrm{C}-\mathrm{O}$ stretching of polysaccharide $\left(1168 \mathrm{~cm}^{-1}\right.$ peak). The positions of the absorption bands of the spectra fell within typical major absorption bands of humic acid which is at frequencies 3680, 2918, 1721, 1168 $\mathrm{cm}^{-1}$. The first peak centred in the vicinity of $3680 \mathrm{~cm}^{-1}$ region is attributed to phenol $\mathrm{OH}$ group bounded by intermolecular $\mathrm{H}$ bonds. The $2918 \mathrm{~cm}^{-1}$ band usually has absorption maximum at $2918 \mathrm{~cm}^{-1}$ which is due to $\mathrm{C}-\mathrm{H}$ stretching of alkane group $\left(\mathrm{CH}_{2}\right)$. The next major absorption band is $1721 \mathrm{~cm}^{-1}$. This band has been commonly ascribed to $\mathrm{C}=\mathrm{O}$ stretching of mainly carboxyl group $(\mathrm{COOH})$ with trace amount of ketones. The last peak was observed at 1168 $\mathrm{cm}^{-1}$ due to $\mathrm{C}-\mathrm{O}$ stretching of polysaccharides and this peak appeared also in the spectra of humic acid from peat soil. The FTIR spectra of the isolated humic acid contained all major characteristic absorption peaks of humic acid. These absorption peaks indicated the presence of the major structural elements of humic acid namely $\mathrm{H}$ bonded $\mathrm{OH}, \mathrm{C}=\mathrm{C}$ of aromatic ring, $\mathrm{C}=\mathrm{O}$ of carbonyl group (both carboxyl and ketonic), $\mathrm{CH}_{2}$ group. This strongly supports the presence of humic acid.

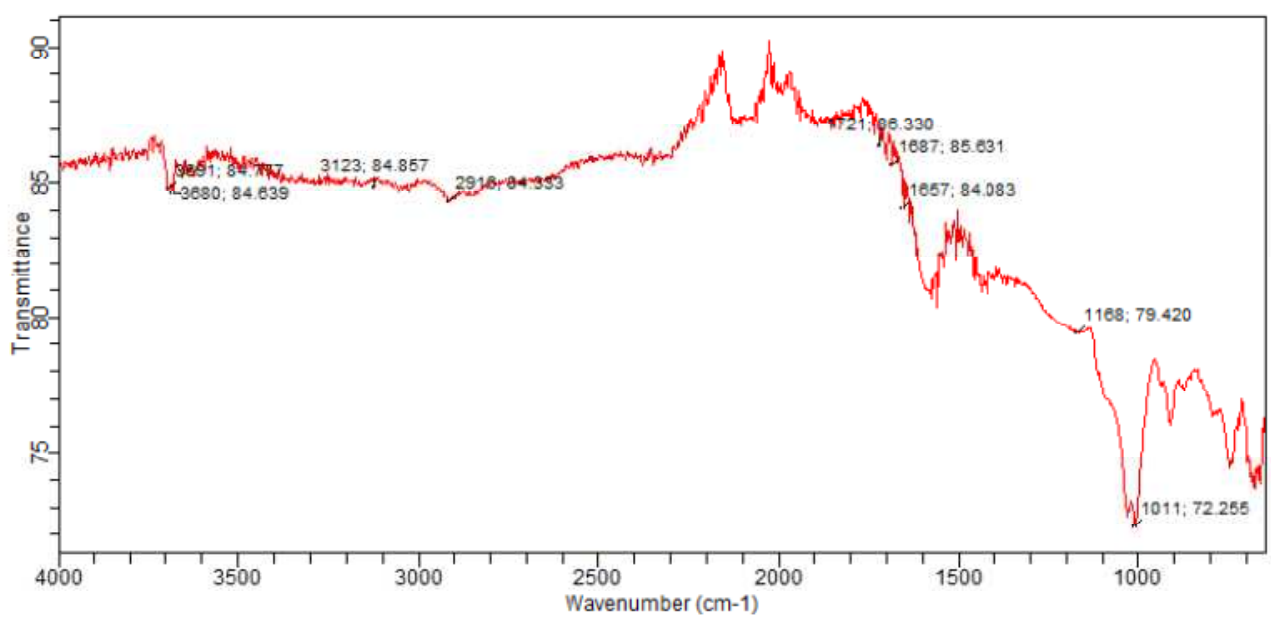

Fig. 2 : FT-IR spectraof peatsoilhumic acid (PSHA)

\section{Evaluation of acid dissociation constant (pka) of acid hydrolysed peat soil humicacid at phenolic group}

The value of the dissociation constant of the peat soil humic acid (PSHA) that underwent acidhydrolysis studied was found to be 8.9299 as shown Table 1, which is lower than the literaturevalues reported by Almeida and Szpoganics, (2015), Borges et al., (2005); Badr et al., (2012)and Fernandes et al,.(2009) of $9.73,9.47$ and 10.30. The difference between the obtained valuesand the reported values in this study might be probably as a result of acid hydrolysis of humicacid. 
BAJOPAS Volume 14 Number 1,June, 2021

Table 1: PKa of (Hydrolysed PSHA)

\begin{tabular}{|l|l|l|l|l|l|l|}
\hline $\mathrm{pH}$ & $\mathrm{BV}_{1}$ & $\mathrm{BV}_{2}$ & $\mathrm{~V}_{2}-\mathrm{V}_{1}$ & $\mathrm{nA}$ & $\log \left(\frac{n A}{1-n A}\right)$ & $\mathrm{pKa}$ \\
\hline 8.50 & 5.30 & 6.29 & 0.99 & 0.3594 & -0.2510 & 8.2490 \\
8.72 & 5.35 & 6.37 & 1.02 & 0.3400 & -0.2880 & 8.4320 \\
9.00 & 5.40 & 6.46 & 1.06 & 0.3141 & -0.3391 & 8.6609 \\
9.22 & 5.45 & 6.55 & 1.10 & 0.2882 & -0.3927 & 8.8273 \\
9.51 & 5.50 & 6.66 & 1.16 & 0.2494 & -0.4786 & 9.0314 \\
9.73 & 5.55 & 6.78 & 1.23 & 0.2041 & -0.5910 & 9.1390 \\
10.00 & 5.60 & 6.90 & 1.30 & 0.1589 & -0.7238 & 9.2762 \\
10.23 & 5.65 & 7.05 & 1.40 & 0.0941 & -0.9835 & 9.2465 \\
10.49 & 5.70 & 7.10 & 1.40 & 0.0941 & -0.9835 & 9.5065 \\
\hline
\end{tabular}

Average pKa $=8.9299 \pm 0.4186$

Table 2: PKa of (Unhydrolysed PSHA)

\begin{tabular}{|l|l|l|l|l|l|l|}
\hline $\mathrm{pH}$ & $\mathrm{BV}_{1}$ & $\mathrm{BV}_{2}$ & $\mathrm{~V}_{2}-\mathrm{V}_{1}$ & $\mathrm{nA}$ & $\log \left(\frac{\boldsymbol{n A}}{1-\boldsymbol{n}}\right)$ & $\mathrm{pKa}$ \\
\hline 8.50 & 5.30 & 5.81 & 0.51 & 0.6619 & 0.2919 & 8.7919 \\
8.72 & 5.35 & 5.90 & 0.55 & 0.6357 & 0.2418 & 8.9618 \\
9.00 & 5.40 & 6.00 & 0.60 & 0.6029 & 0.1813 & 9.1813 \\
9.22 & 5.45 & 6.10 & 0.65 & 0.5701 & 0.1226 & 9.3426 \\
9.51 & 5.50 & 6.20 & 0.70 & 0.5376 & 0.0654 & 9.5754 \\
9.73 & 5.55 & 6.33 & 0.78 & 0.4851 & -0.0259 & 9.7041 \\
10.00 & 5.60 & 6.47 & 0.87 & 0.4262 & -0.1291 & 9.8709 \\
10.23 & 5.65 & 6.62 & 0.99 & 0.3609 & -0.2481 & 9.9819 \\
10.49 & 5.70 & 6.80 & 1.10 & 0.2759 & -0.4690 & 10.0210 \\
\hline
\end{tabular}

Average pKa $=9.4923 \pm 0.4410$

Metal-ligand stability constant ( $\log \mathrm{K}$ )

The stabilityconstants require the accurate values of proton-ligand stability constants (Anil and Maroti, 2008). Metal titration curves crossed over ligand titration curve indicated the formation of complex upon proton release (Santosh, et al., 2011). If the values of n- are within range $0.2-0.8$ and $1.2-18$ this indicates the formation of $1: 1$ and 1:2 complexes (Sayyed and Mazahar, 2012).

The metal (II)-humate stepwise stability constants (log k) at phenolic group (Tables 318)

Table 3: Point-wise method, $\mathrm{Cu}$-(Hydrolysed PSHA)

\begin{tabular}{|l|l|l|l|l|l|l|l|l|}
\hline $\mathrm{pH}$ & $\mathrm{BV}_{1}$ & $\mathrm{BV}_{2}$ & $\mathrm{BV}_{3}$ & $\left(\mathrm{~V}_{3}-\mathrm{V}_{2}\right)$ & $\mathrm{n}$ & $\mathrm{pL}$ & $\log \left(\frac{n}{1-n}\right)$ & LogK $_{1}$ \\
\hline 8.50 & 5.30 & 6.29 & 6.33 & 0.04 & 0.5500 & 2.66 & 0.0871 & 2.7471 \\
8.72 & 5.35 & 6.37 & 6.41 & 0.04 & 0.5714 & 2.43 & 0.1249 & 2.5549 \\
9.00 & 5.40 & 6.46 & 6.50 & 0.04 & 0.6198 & 2.16 & 0.2122 & 2.3722 \\
9.22 & 5.45 & 6.55 & 6.59 & 0.04 & 0.6667 & 1.94 & 0.3010 & 2.2410 \\
\hline
\end{tabular}

LogK $_{1}$ (Average value) $=2.4788 \pm 0.2203$

Table 4: Point-wise method, $\mathrm{Cu}$-(Hydrolysed PSHA)

\begin{tabular}{|l|l|l|l|l|l|l|l|l|}
\hline $\mathrm{pH}$ & $\mathrm{BV}_{1}$ & $\mathrm{BV}_{2}$ & $\mathrm{BV}_{3}$ & $\left(\mathrm{~V}_{3}-\mathrm{V}_{2}\right)$ & $\mathrm{n}$ & $\mathrm{pL}$ & $\log \left(\frac{n-1}{2-n}\right)$ & LogK $_{2}$ \\
\hline 9.51 & 5.50 & 6.66 & 6.73 & 0.07 & 1.3509 & 1.70 & -0.2671 & 1.4329 \\
9.73 & 5.55 & 6.78 & 6.85 & 0.07 & 1.6383 & 1.51 & 0.2467 & 1.7567 \\
10.00 & 5.60 & 6.90 & 6.98 & 0.08 & 2.1783 & 1.31 & -0.2158 & 1.0942 \\
10.23 & 5.65 & 7.05 & 7.13 & 0.08 & 4.1904 & 1.27 & & \\
10.49 & 5.70 & 7.10 & 7.19 & 0.09 & 4.6920 & & & \\
\hline
\end{tabular}

Log $K_{2}($ Average value $)=1.4280 \pm 0.3312$ 
BAJOPAS Volume 14 Number 1,June, 2021

Table 5: Point-wise method, $\mathrm{Cu}$ (Unhydrolysed PSHA)

\begin{tabular}{|l|l|l|l|l|l|l|l|l|}
\hline $\mathrm{pH}$ & $\mathrm{BV}_{1}$ & $\mathrm{BV}_{2}$ & $\mathrm{BV}_{3}$ & $\left(\mathrm{~V}_{3}-\mathrm{V}_{2}\right)$ & $\mathrm{n}$ & $\mathrm{pL}$ & $\log \left(\frac{n}{n-1}\right)$ & Log $_{1}$ \\
\hline 8.50 & 5.30 & 5.81 & 5.85 & 0.04 & 0.2973 & 2.88 & -0.3736 & 2.5064 \\
8.72 & 5.35 & 5.90 & 5.95 & 0.05 & 0.3873 & 2.66 & -0.1992 & 2.4608 \\
9.00 & 5.40 & 6.00 & 6.05 & 0.05 & 0.4044 & 2.38 & -0.1681 & 2.2119 \\
9.22 & 5.45 & 6.10 & 6.15 & 0.06 & 0.5157 & 2.18 & -0.0272 & 2.2072 \\
9.51 & 5.50 & 6.20 & 6.27 & 0.07 & 0.6417 & 1.89 & 0.2530 & 1.1430 \\
\hline
\end{tabular}

$\operatorname{LogK}_{1}($ Average value $)=2.3059 \pm 0.6153$

Table 6:Point-wise method, $\mathrm{Cu}$ (Unhydrolysed PSHA)

\begin{tabular}{|l|l|l|l|l|l|l|l|l|}
\hline $\mathrm{pH}$ & $\mathrm{BV}_{1}$ & $\mathrm{BV}_{2}$ & $\mathrm{BV}_{3}$ & $\mathrm{~V}_{3}-\mathrm{V}_{2}$ & $\mathrm{n}$ & $\mathrm{pL}$ & $\log \left(\frac{n-1}{2-n}\right)$ & $\log \mathrm{K}_{2}$ \\
\hline 9.73 & 5.55 & 6.33 & 6.42 & 0.09 & 0.9000 & 1.69 & & \\
10.00 & 5.60 & 6.47 & 6.58 & 0.11 & 1.2578 & 1.44 & -0.4592 & 0.9808 \\
10.23 & 5.65 & 6.62 & 6.84 & 0.12 & 1.6137 & 1.26 & -0.2010 & 1.4610 \\
10.49 & 5.70 & 6.80 & 6.92 & 0.12 & 2.1052 & 1.03 & & \\
\hline
\end{tabular}

$\operatorname{LogK}_{2}$ (Average value) $=1.2209 \pm 0.3398$

Table 7:Point-wise method, Pb (Hydrolysed PSHA)

\begin{tabular}{|l|l|l|l|l|l|l|l|l|}
\hline $\mathrm{pH}$ & $\mathrm{BV}_{1}$ & $\mathrm{BV}_{2}$ & $\mathrm{BV}_{3}$ & $\left(\mathrm{~V}_{3}-\mathrm{V}_{2}\right)$ & $\mathrm{n}$ & $\mathrm{pL}$ & $\log \left(\frac{n}{1-n}\right)$ & LogK $_{1}$ \\
\hline 8.50 & 5.30 & 6.29 & 6.33 & 0.04 & 0.5500 & 2.66 & 0.0871 & 2.7471 \\
8.72 & 5.35 & 6.37 & 6.41 & 0.04 & 0.5714 & 2.43 & 0.1249 & 2.5549 \\
9.00 & 5.40 & 6.46 & 6.50 & 0.04 & 0.6198 & 2.16 & 0.2122 & 2.3722 \\
9.22 & 5.45 & 6.55 & 6.60 & 0.05 & 0.8333 & 1.96 & 0.6989 & 2.6589 \\
\hline
\end{tabular}

Log $_{\mathbf{1}}($ Average value $)=2.5832 \pm 0.1614$

Table 8:Point-wise method, Pb-(Hydrolysed PSHA)

\begin{tabular}{|l|l|l|l|l|l|l|l|l|}
\hline $\mathrm{pH}$ & $\mathrm{BV}_{1}$ & $\mathrm{BV}_{2}$ & $\mathrm{BV}_{3}$ & $\left(\mathrm{~V}_{3}-\mathrm{V}_{2}\right)$ & $\mathrm{n}$ & $\mathrm{pL}$ & $\log \left(\frac{n-1}{2-n}\right)$ & $\log \mathrm{K}_{2}$ \\
\hline 9.51 & 5.50 & 6.66 & 6.71 & 0.05 & 0.9650 & 1.67 & & \\
9.73 & 5.55 & 6.78 & 6.83 & 0.05 & 1.1702 & 1.44 & & \\
10.00 & 5.60 & 6.90 & 6.90 & 0.05 & 1.4864 & 1.22 & -0.0237 & 1.1963 \\
10.23 & 5.65 & 7.05 & 7.10 & 0.05 & 2.0190 & 1.09 & & \\
10.49 & 5.70 & 7.10 & 7.17 & 0.07 & 3.6492 & 1.00 & & \\
\hline
\end{tabular}

Log $K_{2}$ (Average value) $=1.1963$

Table 9: Point-wise method, Pb (Unhydrolysed PSHA)

\begin{tabular}{|l|l|l|l|l|l|l|l|l|}
\hline $\mathrm{pH}$ & $\mathrm{BV}_{1}$ & $\mathrm{BV}_{2}$ & $\mathrm{BV}_{3}$ & $\mathrm{~V}_{3}-\mathrm{V}_{2}$ & $\mathrm{n}$ & $\mathrm{pL}$ & $\begin{array}{l}\text { Log } \\
\left(\frac{n}{n-1}\right)\end{array}$ & Log $\mathrm{K}_{1}$ \\
\hline 8.50 & 5.30 & 5.81 & 5.85 & 0.04 & 0.2973 & 2.88 & -0.3736 & 2.5064 \\
8.72 & 5.35 & 5.90 & 5.94 & 0.04 & 0.3099 & 2.66 & -0.5477 & 2.3123 \\
9.00 & 5.40 & 6.00 & 6.05 & 0.05 & 0.4044 & 2.38 & -0.1681 & 2.2119 \\
9.22 & 5.45 & 6.10 & 6.15 & 0.06 & 0.5157 & 2.18 & 0.0272 & 2.2072 \\
9.51 & 5.50 & 6.20 & 6.26 & 0.07 & 0.6417 & 1.89 & 0.2530 & 2.1430 \\
9.73 & 5.55 & 6.40 & 6.40 & 0.07 & 0.7000 & 1.67 & 0.3680 & 2.0380 \\
\hline
\end{tabular}

LogK $_{1}$ (Average value) $=2.2364 \pm 0.1602$

Table 10: Point-wise method, Pb (Unhydrolysed PSHA)

\begin{tabular}{|l|l|l|l|l|l|l|l|l|}
\hline $\mathrm{pH}$ & $\mathrm{BV}_{1}$ & $\mathrm{BV}_{2}$ & $\mathrm{BV}_{3}$ & $\mathrm{~V}_{3}-\mathrm{V}_{2}$ & $\mathrm{n}$ & $\mathrm{pL}$ & $\log \left(\frac{n-1}{2-n}\right)$ & $\log \mathrm{K}_{2}$ \\
\hline 10.00 & 5.60 & 6.47 & 6.55 & 0.08 & 1.9503 & 1.41 & & \\
10.23 & 5.65 & 6.62 & 6.72 & 0.11 & 1.4792 & 1.26 & -0.0361 & 1.2239 \\
\hline
\end{tabular}

$\operatorname{LogK}_{2}$ (Average value) $=1.2239$

Table 11: Point-wise method, Mg (Hydrolysed PSHA)

\begin{tabular}{|l|l|l|l|l|l|l|l|l|}
\hline $\mathrm{pH}$ & $\mathrm{BV}_{1}$ & $\mathrm{BV}_{2}$ & $\mathrm{BV}_{3}$ & $\left(\mathrm{~V}_{3}-\mathrm{V}_{2}\right)$ & $\mathrm{n}$ & $\mathrm{pL}$ & $\log \left(\frac{n}{n-1}\right)$ & LogK $_{1}$ \\
\hline 8.50 & 5.30 & 6.29 & 6.31 & 0.02 & 0.2750 & 2.64 & -0.4290 & 2.2110 \\
8.72 & 5.35 & 6.37 & 6.39 & 0.02 & 0.2858 & 2.42 & -0.3978 & 2.0222 \\
9.00 & 5.40 & 6.46 & 6.49 & 0.03 & 0.4648 & 2.14 & -0.0612 & 2.0788 \\
9.22 & 5.45 & 6.55 & 6.59 & 0.04 & 0.6667 & 1.94 & 0.3010 & 2.2410 \\
\hline
\end{tabular}

$\log _{\mathbf{1}}($ Average value) $=2.1382 \pm 0.1046$ 
BAJOPAS Volume 14 Number 1,June, 2021

Table 12: Point-wise method, Mg (Hydrolysed PSHA)

\begin{tabular}{|l|l|l|l|l|l|l|l|l|}
\hline $\mathrm{pH}$ & $\mathrm{BV}_{1}$ & $\mathrm{BV}_{2}$ & $\mathrm{BV}_{3}$ & $\left(\mathrm{~V}_{3}-\mathrm{V}_{2}\right)$ & $\mathrm{n}$ & $\mathrm{pL}$ & $\log \left(\frac{n-1}{2-n}\right)$ & LogK $_{2}$ \\
\hline 9.51 & 5.55 & 6.66 & 6.71 & 0.05 & 0.9650 & 1.67 & & \\
9.73 & 5.55 & 6.78 & 6.84 & 0.06 & 1.4042 & 1.47 & -0.1686 & 1.3014 \\
10.00 & 5.60 & 6.90 & 6.93 & 0.06 & 1.7838 & 1.23 & 0.5593 & 1.7893 \\
10.23 & 5.65 & 7.05 & 7.10 & 0.06 & 3.1429 & 1.10 & & \\
10.49 & 5.70 & 7.10 & 7.18 & 0.07 & 3.6492 & 0.83 & & \\
\hline
\end{tabular}

LogK $_{2}($ Average value $)=1.5453 \pm 0.3450$

Table 13: Point-wise method, Mg (Unhydrolysed PSHA)

\begin{tabular}{|l|l|l|l|l|l|l|l|l|}
\hline $\mathrm{pH}$ & $\mathrm{BV}_{1}$ & $\mathrm{BV}_{2}$ & $\mathrm{BV}_{3}$ & $\mathrm{~V}_{3}-\mathrm{V}_{2}$ & $\mathrm{n}$ & $\mathrm{pL}$ & $\log \left(\frac{n}{n-1}\right)$ & $\operatorname{Log~}_{1}$ \\
\hline 8.50 & 5.30 & 5.81 & 5.85 & 0.04 & 0.2973 & 2.88 & -0.3736 & 2.5064 \\
8.72 & 5.35 & 5.90 & 5.94 & 0.04 & 0.3099 & 2.66 & -0.3477 & 2.3123 \\
9.00 & 5.40 & 6.00 & 6.04 & 0.04 & 0.3236 & 2.38 & -0.3202 & 2.0598 \\
9.22 & 5.45 & 6.10 & 6.15 & 0.05 & 0.4297 & 2.17 & -0.1230 & 2.0470 \\
9.51 & 5.50 & 6.20 & 6.26 & 0.06 & 0.5500 & 1.89 & 0.0871 & 1.9771 \\
9.73 & 5.55 & 6.33 & 6.40 & 0.07 & 0.7000 & 1.67 & 0.3680 & 2.0380 \\
\hline
\end{tabular}

LogK $_{1}$ (Average value) $=2.1568 \pm 0.2069$

Table 14: Point-wise method, Mg (Unhydrolysed PSHA)

\begin{tabular}{|l|l|l|l|l|l|l|l|l|}
\hline $\mathrm{pH}$ & $\mathrm{BV}_{1}$ & $\mathrm{BV}_{2}$ & $\mathrm{BV}_{3}$ & $\mathrm{~V}_{3}-\mathrm{V}_{2}$ & $\mathrm{n}$ & $\mathrm{pL}$ & $\log \left(\frac{n-1}{2-n}\right)$ & $\log \mathrm{K}_{2}$ \\
\hline 10.00 & 5.60 & 6.47 & 6.55 & 0.08 & 0.9148 & 1.41 & & \\
10.23 & 5.65 & 6.62 & 6.71 & 0.09 & 1.2102 & 1.20 & -0.5749 & 0.6251 \\
10.49 & 5.70 & 6.80 & 6.92 & 0.09 & 1.5968 & 1.03 & 0.1703 & 1.2003 \\
\hline
\end{tabular}

LogK $_{2}$ (Average value) $=0.9127 \pm 0.4070$

Table15:Point-wise method, Cd (Hydrolysed PSHA)

\begin{tabular}{|l|l|l|l|l|l|l|l|l|}
\hline $\mathrm{pH}$ & $\mathrm{BV}_{1}$ & $\mathrm{BV}_{2}$ & $\mathrm{BV}_{3}$ & $\left(\mathrm{~V}_{3}-\mathrm{V}_{2}\right)$ & $\mathrm{n}$ & $\mathrm{pL}$ & $\log \left(\frac{n}{1-n}\right)$ & LogK $_{1}$ \\
\hline 8.50 & 5.30 & 6.29 & 6.31 & 0.02 & 0.2750 & 2.64 & -0.4210 & 2.2190 \\
8.72 & 5.35 & 6.37 & 6.40 & 0.03 & 0.4286 & 2.42 & -0.1249 & 2.2951 \\
9.00 & 5.40 & 6.46 & 6.49 & 0.03 & 0.4648 & 2.14 & -0.0612 & 2.0788 \\
9.22 & 5.45 & 6.55 & 6.59 & 0.04 & 0.6667 & 1.96 & 0.3010 & 2.2610 \\
9.51 & 5.55 & 6.66 & 6.70 & 0.04 & 0.7720 & 1.67 & 0.5297 & 2.1997 \\
\hline
\end{tabular}

LogK $_{\mathbf{1}}$ (Average value) $=2.2108 \pm 0.0825$

Table 16: Point-wise method, Cd (Hydrolysed PSHA)

\begin{tabular}{|l|l|l|l|l|l|l|l|l|}
\hline $\mathrm{pH}$ & $\mathrm{BV}_{1}$ & $\mathrm{BV}_{2}$ & $\mathrm{BV}_{3}$ & $\left(\mathrm{~V}_{3}-\mathrm{V}_{2}\right)$ & $\mathrm{n}$ & $\mathrm{pL}$ & $\log \left(\frac{n-1}{2-n}\right)$ & Log $_{2}$ \\
\hline 9.73 & 5.55 & 6.78 & 6.83 & 0.06 & 1.4042 & 1.47 & -0.1686 & 1.3014 \\
10.00 & 5.60 & 6.90 & 6.95 & 0.06 & 1.7838 & 1.23 & 0.5593 & 1.7893 \\
10.23 & 5.65 & 7.05 & 7.10 & 0.06 & 3.1429 & 1.09 & & \\
10.49 & 5.70 & 7.10 & 7.16 & 0.06 & 3.1429 & 0.89 & & \\
& & & & & & & & \\
\hline
\end{tabular}

$\operatorname{LogK}_{2}$ (Average value) $=1.5453 \pm 0.3450$

Table 17: Point-wise method, Cd (Unhydrolysed PSHA)

\begin{tabular}{|l|l|l|l|l|l|l|l|l|}
\hline $\mathrm{pH}$ & $\mathrm{BV}_{1}$ & $\mathrm{BV}_{2}$ & $\mathrm{BV}_{3}$ & $\mathrm{~V}_{3}-\mathrm{V}_{2}$ & $\mathrm{n}$ & $\mathrm{pL}$ & $\log \left(\frac{n}{n-1}\right)$ & $\operatorname{Log~}_{1}$ \\
\hline 8.50 & 5.30 & 5.81 & 5.86 & 0.05 & 0.3717 & 2.88 & -0.2280 & 2.6520 \\
8.72 & 5.35 & 5.90 & 5.95 & 0.05 & 0.3873 & 2.66 & -0.1992 & 2.4608 \\
9.00 & 5.40 & 6.00 & 6.06 & 0.06 & 0.4853 & 2.38 & -0.0255 & 2.3545 \\
9.22 & 5.45 & 6.10 & 6.16 & 0.06 & 0.5157 & 2.18 & -0.0272 & 2.2072 \\
9.51 & 5.50 & 6.20 & 6.27 & 0.07 & 0.6417 & 1.89 & 0.2530 & 1.1430 \\
9.73 & 5.55 & 6.33 & 6.41 & 0.08 & 0.8000 & 1.69 & 0.6020 & 2.2920 \\
& & & & & & & & \\
\hline
\end{tabular}

$\operatorname{LogK}_{1}($ Average value $)=2.2516 \pm 0.5380$ 
BAJOPAS Volume 14 Number 1,June, 2021

Table 18: Point-wise method, Cd (Unhydrolysed PSHA)

\begin{tabular}{|l|l|l|l|l|l|l|l|l|}
\hline $\mathrm{pH}$ & $\mathrm{BV}_{1}$ & $\mathrm{BV}_{2}$ & $\mathrm{BV}_{3}$ & $\mathrm{~V}_{3}-\mathrm{V}_{2}$ & $\mathrm{n}$ & $\mathrm{pL}$ & $\log \left(\frac{n-1}{2-n}\right)$ & $\log \mathrm{K}_{2}$ \\
\hline 10.00 & 5.60 & 6.47 & 6.57 & 0.10 & 1.1434 & 1.43 & & \\
10.23 & 5.65 & 6.62 & 6.72 & 0.10 & 1.3448 & 1.23 & -0.2788 & 0.9512 \\
10.49 & 5.70 & 6.80 & 6.90 & 0.10 & 1.7742 & 1.03 & 0.5351 & 1.5651 \\
\hline
\end{tabular}

$\operatorname{LogK}_{2}($ Average value $)=1.2581 \pm 0.4340$

Table 19: Stepwise and overall Stability constants of thehydrolysed and unhydrolysed divalent metal (II) complexes

\begin{tabular}{|c|c|c|c|}
\hline Chelates & LogK $_{1}$ & $\log _{2}$ & Log $\beta$ \\
\hline [Cu (Hydrolysed PSHA-1) $\left.{ }_{2}\right]$ & 2.4788 & 1.4280 & 3.9068 \\
\hline$\left[\mathrm{Pb}(\text { Hydrolysed PSHA-1) })_{2}\right]$ & 2.5832 & 1.1963 & 3.7795 \\
\hline$\left[\mathrm{Cd}(\text { Hydrolysed PSHA-1 })_{2}\right]$ & 2.2108 & 1.5453 & 3.7561 \\
\hline$\left[\mathrm{Mg}(\text { Hydrolysed PSHA-1 })_{2}\right]$ & 2.1382 & 1.5453 & 3.6835 \\
\hline [Cu (Unhydrolysed PSHA-1) & 2.3059 & 1.2209 & 3.5268 \\
\hline$[\mathrm{Pb}$ (Unhydrolysed PSHA-1) 2$]$ & 2.2364 & 1.2239 & 3.4603 \\
\hline [Cd (Unhydrolysed PSHA-1) 2 ] & 2.2516 & 1.2581 & 3.5097 \\
\hline$[\mathrm{Mg}$ (Unydrolysed PSHA-1) & 2.1568 & 0.9127 & 3.0695 \\
\hline
\end{tabular}

The results obtained (Table19) shows the stepwise and overall stability constants to be not high indicating low stability of the complexes, because the solubility of most metal ions in the basic $\mathrm{pH}$ range is minimal due to metal hydroxide precipitation (Karimi, 2017). In general, the stepwise stability constants $\left(K_{1}\right.$ and $K_{2}$ ) follow the order $K_{1}>K_{2}$ for the copper, lead, magnesium and cadmium complexes respectively. The steady decrease of the values with increasing number of ligands is in agreement with the prediction made by researchers (Na'aliya, 2013). The decrease could be attributed to the fact that as the number of the ligands (Humate ions) that enters the coordination zone increases the aqua molecules available for replacement by the ligands become less. Thus, the metal ions become less electron loving with progressive intake of the ligand and this results in the decrease in the values of the constants (Na'aliya, 2013). Also the stability of the complexes is influenced by the size and number of the chelate rings(Mackay and Mackay,2002).All the complexes form rings in their structure as humate, a bidentate ligand, bond the metal ions in the ratio 1:2 (Boguta and Sokolowska, 2016) forming chelate rings. The values of the overall stability constants $(\log \beta)$ obtained for humate complexes are not high indicating low stability as the values are not high. LogK values for copper-humates (Table 3 to 6) obtained in this study are lower than those reported for the complexes of humic acids (Pandey et al., 2015; Dinu, 2013; Kaschl et al., 2010 and Gilbeto and Jorg, 2001). The values of LogK(Table 7 to 10 ) forlead-humates are lower than those reported for the lead in the literature (Dinu, 2013; Gilbeto and Jorg 2001). Log K values(Table 11 to 14 ) for magnesium-humates obtained in this study are close to those reported by (Pandey et al., 2015). Log K values of cadmium-humates (Table 15 to 18 ) obtained in this work near to the one reported by (Dinu, 2013 and Pandey et al., 2015).The difference between the reported values and the values obtained in this study might be probably as a result of acid hydrolysis of humic acid. The values of the overall stability constants $(\log \beta)$ of the copper humates complexes presented in Table 19 is high than that of other metal humate complexes, show relatively high stability of CuHA complexes, show the following order of stability: $\mathrm{Cu}>\mathrm{Pb}>\mathrm{Cd}>\mathrm{Mg}$; which are in close agreement to the findings of (Dinu, 2013 and Pandey et al., 2015).The high stability of Cuhumate chelate could be attributed to the existence of coordinate covalent bond between the complexing agents and the $\mathrm{Cu}^{2+}$ ions. Since, $\mathrm{Cu}^{2+}$ being a metal of the transitional series with $3 d^{9}$ electronic configurations can accept the electrons from the complexing agents. Similarly, the low stabilities of $\mathrm{Pb}, \mathrm{Cd}$ and $\mathrm{Mg}$ complexes could be explained by that $\mathrm{Pb}^{2+}$ with $6 s^{2}, \mathrm{Cd}^{2+}$ with $4 \mathrm{~d}^{10}$ and $\mathrm{Mg}^{2+}$ with $2 \mathrm{p}^{6}$ their electronic configuration has a completely filled $\mathrm{d}, \mathrm{p}$ and $\mathrm{s}$ orbitals. Moreover, the stabilities of metal ions with hydrolysed humic acid from peat soil were higher than those with unhydrolysed humic acid from peat soil; which is ascribed to the high content of acidity in hydrolysed humic acid than unhydrolysed humic acid. 
BAJOPAS Volume 14 Number 1,June, 2021 CONCLUSION

The values of logk for $\mathrm{Cu}(\mathrm{II})$ hydrolysed humic acid complex was higher followed by $\mathrm{Pb}$ (II), $\mathrm{Cd}(\mathrm{II})$ and $\mathrm{Mg}$ (II) hydrolysed humic acid complexes as compared with metal(II) unhydrolysed humic acid complexes. This indicates acid hydrolysis of humic acid can

\section{REFERENCES}

Almeida, V.R. and Szpoganicz, B. (2015). Humic Acid Potentiometric Response Patterns:Out- of Equilibrium Properties and Species Distribution Modelling. Chemical. Biol. Technol. Agric. 2: 17.

Anđelković, T., Nikolić, R., Bojić, A.,Anđelković, D., and Nikolic G.,(2010). Binding of Cadmium to Soil Humic Acid as A Function of Carboxyl Group Content. Macedonian Journal of Chemistry and Chemical Engineering.29(2): 215-224.

Anil, B. N. and Maroti, N. (2008). Studies on Influence of Die-Lectric Constants on Complex Equilibria between Substituted Py-Razalines and Lanthanide Metal Ions pH-Metrically. Amer.-Euras. scient. Res. 3(2): 212-216.

Ashok, K., Pandey, S. P. and Misra, V (2000). Stability Constants of Metal-Humic Acid Complexes and its Role in Environmental Detoxification. Journal of Ecotoxicology and Environmental Safety. 47(2):157-200.

Badr, M. H., El-Halafawi, M. H. and Abd El-al Zeid, E. R. (2012). Comparison Between the Effect of Ionic Strength on Acidity and Dissociation Constants of Humic Acids Extracted from Sewage Sludge and Nile Water Hyacinth Composts.Global Journal of Environmental Research 6 (1): 36-43.

Baruah, M.K., Borah, D., Saikia, P.P., Paul, S., Sharma, T. (2015). Evaluation of pKa Values of Soil Humic Acids and their Complexation Properties. International Journal of Plant \& Soil Science 6(4) : 218-228.

Boguta, P. Sokolowska, Z. (2016). Interactions of $\mathrm{Zn}$ (II) Ions with Humic Acids Isolated from Various Types of Soils. Effect of $\mathrm{pH}, \mathrm{Zn}$ Concentrations and Humic Acids Chemical Properties. Journal of Geochemical Explaration 168. 119-126.

Borges, F., Guimaraes, C., Lima, L.F.C., Pinto, I. and Reis, S.(2005). Potentiometric Studies on the Complexation of Copper(II) by Phenolic Acids as Discrete Ligand Models of enhance the complexation behavior of humic acid with metal (II) ions. However, the higher values of $\log \beta$ for $\mathrm{Cu}(\mathrm{II}), \mathrm{Pb}(\mathrm{II}), \mathrm{Cd}(\mathrm{II})$ and $\mathrm{Mg}(\mathrm{II})$ hydrolysed humic acid complexes indicates more stable stepwise complexes formed as compared with $\mathrm{Cu}(\mathrm{II}), \mathrm{Pb}$ (II), $\mathrm{Cd}$ (II) and $\mathrm{Mg}(\mathrm{II})$ unhydrolysed humic acid complexes.

Humic Substances Talanta 66 (2005) 670-673.

Chefetz, B., Salloum, M. J., Deshmulkin, A. P. and Hatcher, P. (2002). Structural Components of Humic Acids as Determined by Chemical Modifications and Carbon-13 NMR, Pyrolysis, and Thermochemolysis- Gas Chromatography/Mass Spectrometry. Soil Science Society of American Journal Abstract Division S-2- Soil Chemistry66. 1159-1171.

Dinu, M. I. (2013). Metals Complexation with Humic Acids in Surface Water of Different Environ. Sci. Technol. 31(1): 1-17.

Fernandes, A.N., Giacomelli, C., Giovanela, M. Vaz, D.V. Szpoganicz, B. and Maria M. D. (2009). Potentiometric Acidity Determination in Humic Substances Influenced by Different Analytical Procedures.J. Braz. Chem. Soc. 20 (9):14.

Gamal, A. H. (2015). Stability Constants of Rhenium (V) Metal Complexes with Selected Drugs. Pyrex Journal of Research in Environmental Studies. 2(2): 006-014.

Janrao, D. M., Pathan, J., Kayande, D.D., and Mulla, J.J. (2014). An Over View of Potentiometric Determination of Stability Constants of Metal Complexes. Sci. Revs. Chem. Commun.: 4(1), 2014, 11-24.

Karimi, H. (2017). Effect of pH and Initial Pb(II) Concentration on the Lead Removal Efficiency from Waste Water Using $\mathrm{Ca}(\mathrm{OH})_{2}$. International Journal of Water and Waste Water Treatment 3.2

Kaschl, A. Romheld, V. and Chen, Y. (2010). Binding of Cadmium, Copper and Zinc to Humic Substances Originating from Municipal Solid Waste Compost. Israel Journal of Chemistry Vol. 42(1): 89-98.

Kostic, I. S., Tatjana, P, A., Nikolic, R. S., Cvetkovic, T. P., Pavlovic, D. D., Aleksandar, L.J. and Bojic, A. (2012). Comparative Study of Binding Strengths of Heavy Metals with Humic Acid. J.serb. Chem. Soc. 76(9) pp 1-20. 
BAJOPAS Volume 14 Number 1,June, 2021

Na'aliya, J. (2013). Determination of Stepwise Stability Constants and Gibbs free Energy Change of Trisprolina to Complexes of some Divalent Transition Metal ions. Bayero Journal of Pure and Applied Sciences 6(2): 112-114.

Omar, A. A. and Ali, E. A. (2015). Potentiometric Studies on Complexes of $\mathrm{Cr}$ (III) and $\mathrm{Zr}$ (IV) with some Carboxylic Acids. International Journal of Advanced Chemistry, 3(1) 25-

37.

Pandey, A. K. Pandey, S. D. and Misr, V. (2015).Stability Constants of Metal- Humic Acid Complexes and Its Role in Environmental Detoxification. J. Ecotoxicology and Environmental Safety. 47(1):195-200.

Ram, N. and Raman, K.V. (1984). Stability Constants of Complexes of Metals with
Humicand Fuvic Acids under Non- acidConditions. Journal of Plant Nutrition and Soil Sciences.

147:171-176.

Santosh, D. D., Ashok, B. K., Vijay, J. T., Shivraj, G. W. and Vinay, V. W. (2011). Potentiometric Studies of Elec-Trolyte Effects on Complex Equilibria of Some Substituted 5-(2-hydroxy Phenyl) Pyrazoles. Der pharm. 3 (6): 75-83.

Sayyed, H. and Abdul Rahim, M. F. (2012). Studies of Binary Complexes of Metal Ions with Mandelic Acid by Potentiometry. Chem. J. 02 (6): 206209.

Shirvani, M. Moradian, E. Khalili, B. Bakhtiary, S. (2015). Interaction of $\mathrm{Cd}$ and $\mathrm{Pb}$ with Humate-Palygorskite and HumateSepiolite Complexes. Journal of water, air and pollution 3: 220-228. 


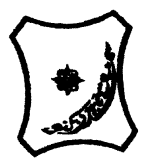

Bayero Journal of Pure and Applied Sciences, 14(1): 54 - 63

Received: November, 2020

Accepted: April, 2021

ISSN $2006-6996$

\title{
STABILITY CONSTANTS OF COMPLEXES OF METAL IONS WITH PEATSOIL HUMIC ACIDS UNDER NON-ACID-CONDITIONS
}

\author{
${ }^{* 1}$ Sabo, Yusuf ${ }^{2}$ Jimoh, W.L.O., ${ }^{3}$ Isa Baba Koki and ${ }^{4}$ Sholadoye, Q. 0. \\ ${ }^{1}$ Department of Pure and Industrial Chemistry, Bayero University, Kano \\ ${ }^{3}$ Department of Chemistry, Yusuf Maitama Sule University Kano. P.M.B. 3220 Kano, Nigeria. \\ ${ }^{4}$ Department of Chemistry, Nigerian Police Academy, Wudil, Kano-Nigeria
}

*Correspondence E-mail; saboyusuf18@yahoo.com

ABSTRACT

Stability constants of complexes of four divalent metal ions viz. $\mathrm{Cu}^{2+}, \mathrm{Pb}^{2+}, \mathrm{Mg}^{2+}$ and $\mathrm{Cd}^{2+}$ with humic acids (HA) were determined by potentiometric titration of humic acids with the corresponding salt of the divalent metals in aqueous media under non-acid-condition. The log $K$ (logarithm of the stability constant) ranged from 1.0942 to 2.7471 for metalhumic acid complexes were determined using point-wise computational method. The order of stability constants were obtained as follows: $\mathrm{Cu}>\mathrm{Pb}>\mathrm{Cd}>\mathrm{Mg}$ for metal $-\mathrm{HA}$ complexes respectively, indicating a higher degree of complexation with Cu metal ion.

Keywords: stability constant, humic acid, potentiometric titration, divalent metals, acid hydrolysis.

\section{NTRODUCTION}

The stability constant of a complex is the numerical expression of its stability and provides a quantitative measure of affinity of the metal ion to the complexing agent. An understanding of the relative stability of metal-complexes helps in predicting the behavior of metal ions in the soil (Ram and Raman, 1982). Extensive researches has been done to determine the stability constants of the complexes formed between humic acid (HA) with a number of metal ions. Ashok et al., (2000) reported that humic acid with hydroxyl, phenoxyl and carboxyl reactive groups can form coordination compound with metal ions at $\mathrm{pH}$ 3.5. The stability constants(Log K) for different metalhumic acid complexes indicated the following order of the stabilities of complexes formed between humic acid and metal ion, $\mathrm{Cu}>\mathrm{Fe}$ $>\mathrm{Pb}>\mathrm{Ni}>\mathrm{Co}>\mathrm{Ca}>\mathrm{Cd}>\mathrm{Zn}>\mathrm{Mn}>\mathrm{Mg}$. Andelkovic et al., (2010) investigated the binding of $\mathrm{Cd}$ (II) to soil humic acid at pH 6.5 and in $0.1 \mathrm{M} \mathrm{KNO}_{3}$ ionic medium. The stability constant for binding indicating greater stability in the case when carboxyl groups are involved in complexation reaction. Kostic et al.,(2012) investigated the complexation of humic acid with certain heavy metal ions (Co(II), $\mathrm{Ni}(\mathrm{II}), \mathrm{Cu}(\mathrm{II})$,
$\mathrm{Zn}(\mathrm{II})$, and $\mathrm{Pb}(\mathrm{II})$. The experiment was performed at $25^{\circ} \mathrm{C}$, at pH 4.0 and ionic strength of $0.01 \mathrm{M}$. Stability constant of complex between $\mathrm{Pb}$ (II) ions and humic acid is greater than stability constants of other investigated metalhumate complexes. Bogata and Sokolowska (2016) analyses the interaction between humic acids from different soils and $\mathrm{Zn}$ (II) ions at wide concentration ranges and at $\mathrm{pH} 5$. Studies have showed significant impact of $\mathrm{Zn}$ concentration, $\mathrm{pH}$ and some properties of humic acids with zinc.But all of these studies were limited to acidic $\mathrm{pH}$ range. Therefore, the present study was carried out to determine and compare the stability constants of complexes of metal ions with hydrolysed peat soil humic acid and unhydrolysed peat soil humic under non-acid conditions.

\section{MATERIALS AND METHODS}

Analytical grade chemicals used includes hydrochloric acid $(\mathrm{HCl})$, nitric acid $\left(\mathrm{HNO}_{3}\right)$, sodium hydroxide $(\mathrm{NaOH})$, lead nitrate $\mathrm{Pb}\left(\mathrm{NO}_{3}\right)_{2}$, copper nitrate $\mathrm{Cu}\left(\mathrm{NO}_{3}\right)_{2} \cdot 3 \mathrm{H}_{2} \mathrm{O}$, cadmium nitrate $\mathrm{Cd}\left(\mathrm{NO}_{3}\right)_{2} \cdot 4 \mathrm{H}_{2} \mathrm{O}$, magnesium nitrate $\mathrm{Mg}\left(\mathrm{NO}_{3}\right)_{2} \cdot 6 \mathrm{H}_{2} \mathrm{O}$, potassium nitrate $\left(\mathrm{KNO}_{3}\right)$, calcium chloride $\left(\mathrm{CaCl}_{2}\right)$, (sigma-Aldrich). Dowex 50WX8, (20-50 mesh) from Fluka. 


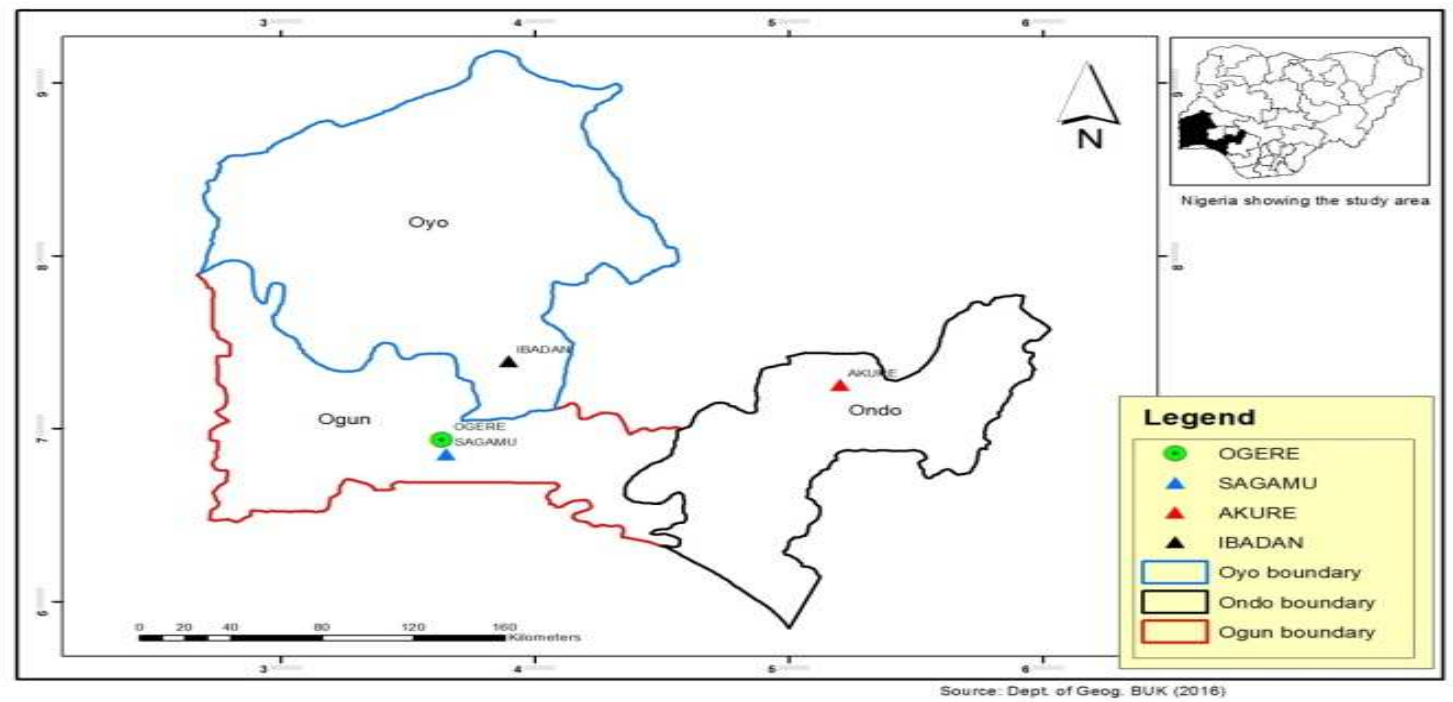

Figure 1: Map showing the sampling point at Sagamu Town, Ogun State.

\section{Description of Sampling Area}

Sagamu has geographical coordinates between $6^{\circ} 50^{\prime}$ north; $3^{\circ} 38^{\prime}$ east is located in south western region of Nigeria. The region has tropical wet and dry climate with a lengthy wet season and relatively constant temperatures throughout the course of the year. Wet season runs from March to October, November to December forms the region dry season. The vegetation type of the region is savannah which is really grassland with small bushes and occasional big trees. Grassland soils have substantially higher organic matter content than forest soils (Novackova, 2011).

\section{Sample Collection}

The Peatsoil samples were collected from four different sampling points $(0-10 \mathrm{~cm}$ depth) in Sagamu into polyethylene bag with plastic spoons. Samples were taken to the laboratory, extraneous materials were removed; the samples were air-dried, crushed and ground to a fine powder in a mortar passed through a $0.20 \mathrm{~mm}$ sieve. The samples were kept for analysis.

\section{Isolation and purification of humic acid from peat soil sample}

Peatsoil sample $(100 \mathrm{~g})$ was mixed with 1000 $\mathrm{cm}^{3}$ of $0.1 \mathrm{M} \mathrm{NaOH}$ solution, shaken for 3hours and left to stand overnight. Dark-coloured supernatant was obtained and decanted from solid residue. The dark-coloured supernatant was acidified to $(\mathrm{pH}=1.0)$ with $6 \mathrm{M} \mathrm{HCl}$ stirred and allowed to stand for 6 hours. Yellowish brown supernatant and dark-brown precipitate were obtained. The yellowish brown supernatant was decanted followed by centrifuge and discarded. The dark-brown precipitate was mixed with $500 \mathrm{~cm}^{3}$ of $0.1 \mathrm{M} \mathrm{NaOH}$ solution followed by passing through dowex resin. The dark-brown solution was acidified to $(\mathrm{pH}=1.0)$ with $6 \mathrm{M} \mathrm{HCl}$ stirred and allowed to stand for 3 hours. The dark-brown precipitate was washed several times with deionized water. The supernatant was treated with $\mathrm{AgNO}_{3}$ solution until no white precipitate observed. The humic acid was transferred to weighed crucible and dried at $60^{\circ} \mathrm{C}$ in an oven for 12 hours. The humic acid was cooled and dried in the desiccator, weighed and recorded. The obtained humic acid was dried again at $60^{\circ} \mathrm{C}$ for additional 6 hours cooled and dried in the desiccator, weighed and recorded constant weight was obtained (Baruah et al., 2015).

\section{FT-IR analysis}

FT-IR spectra of humic acid sample was analysed using Carry 630 FT-IR Agilent Technologies.

Unhydrolysed compost humic acid

The unhydrolysed humic acid was obtained after isolation and purification of compost humic acid and kept for investigation.

\section{Acid hydrolysis of Peatsoil acid}

Peatsoil humic acid sample (1g) was refluxed for 12 hours at $\left(160^{\circ} \mathrm{C}\right)$ with $50 \mathrm{~cm}^{3}$ of $6 \mathrm{M} \mathrm{HCl}$. The mixture was allowed to cool, decanted, and centrifuged after hydrolysis. The insoluble residues were washed with distilled water via centrifugation several times, and the supernatant was treated with $\mathrm{AgNO}_{3}$ solution until no white precipitate was observed. The residue was thoroughly dried over $\mathrm{CaCl}_{2}$ in a desiccator at room temperature (Chefetz et al., 2002). Finally, the obtained hydrolysed humic acid was kept for investigation. 
BAJOPAS Volume 14 Number 1,June, 2021 Potentiometric Titrations

Potentiometric measurements were carried out using a pH-meter Jenway (model 3510) with combine electrode, the sensitivity of the $\mathrm{pH}$ meter is 0.01 units. The $\mathrm{pH}$ meter was switched on half an hour before starting the titration for initial warm up of the instrument. The instrument was calibrated with an aqueous standard buffer solution of $\mathrm{pH} 4.00$ and 10.0 (borate buffer) prepared from a "Qualigens" buffer tablets.

The following sets of solutions were prepared in a $250 \mathrm{~cm}^{3}$ volumetric flask separately for $\mathrm{pH}$ metric titrations.

(i) $5 \mathrm{~cm}^{3} 0.1 \mathrm{M} \mathrm{HCl}+40 \mathrm{~cm}^{3}$ deionized water

(ii) $5 \mathrm{~cm}^{3} 0.1 \mathrm{M} \mathrm{HCl}+39 \mathrm{~cm}^{3}$ deionized water $+1 \mathrm{~cm}^{3} 0.15 \mathrm{gcm}^{-3}$ humic acid

(iii) $5 \mathrm{~cm}^{3} 0.1 \mathrm{M} \mathrm{HCl}+37 \mathrm{~cm}^{3}$ deionized water $+1 \mathrm{~cm}^{3} 0.15 \mathrm{gcm}^{-3}$ humic acid

$$
+2 \mathrm{~cm}^{3} \quad 0.01 \mathrm{M} \mathrm{Cu} \text { (II) }
$$

The solutions were titrated against standardized $0.110 \mathrm{MNaOH}$ separately. The total volume of each mixture was adjusted to $50 \mathrm{~cm}^{3}$ and the ionic strength of the solutions was maintained constant at by adding appropriate amount of stock solution of $1 \mathrm{M} \mathrm{KNO}_{3}$ (Gamal, 2015; Omar and Ali, 2015). A magnetic stirrer was used to achieve thorough mixing of the interacting solutions at $550 \mathrm{rpm}$. The same set of experimental conditions was applied for potentiometric titration of remaining samples.

\section{Evaluation of pKa of Hydrolysed peat soil Humic Acids}

The proton-ligand formation number $\mathrm{n}_{\mathbf{A}}$ were calculated by Irving and Rossotti expression (Omar and Ali, 2015).

$\mathrm{nA}=\mathrm{Y}-\frac{(\mathrm{V} 2-\mathrm{V1})(\mathrm{No}-\mathrm{Eo})}{(\mathrm{VO}+\mathrm{V1}) \mathrm{TCL}}$ 1

Where: $Y$ is number of dissociable proton, $\left(\mathrm{V}_{2^{-}}\right.$ $V_{1}$ ) is the measure of displacement of the ligand curve relative to acid curve, $\mathrm{N}^{\circ}$ and $\mathrm{E}^{\circ}$ are the resultant concentration of alkali solution, free acid solution, $\mathrm{T}_{\mathrm{cL}}{ }^{\circ}$ is the total ligand concentration, $\mathrm{V}^{\circ}$ is the total volume of titration solution, $V_{1}$ is the volume of alkali added to acid solution, $V_{2}$ is the volume of alkali added to acid solution + ligand solution, acid dissociation constants (pKa - values) of ligand were calculated by algebraic method point wise calculation (Tables 1 ). The dissociation constants (pKa) were calculated according to the following relation:

$\mathrm{pKa}=\mathrm{pH}+\log \left(\frac{n A}{1-n A}\right)$ 2

Where: pKa is the acid dissociation constant, $\mathrm{n}_{\mathrm{A}}$ is the Proton-ligand formation number and $\mathrm{pH}$ is the pH-values (Omar and Ali, 2015).

\section{Determination of metal-ligand stability constants $(\log K)$ of complexes}

The potentiometric measurement for the determination of stability constant of a complex in solution is based on the fact that the redox potential of the couple $\frac{M^{+(m-n)}}{M^{+m}}$ is shifted significantly on complexation of the metal ion with the ligand. This method involves change in hydrogen ion concentration $\left[\mathrm{H}^{+}\right]$due to the displacement or association of one or more protons taking place during complexation reaction. This change can be found out by titrating the solutions containing free acid, acid with ligand, and acid with ligand and metal ion, individually against a standard alkali solution at a constant ionic strength or temperature. Either ionic strength or temperature may be varied for different sets of solutions. In all the cases, the change in the $\mathrm{pH}$ of the solution is measured after each addition of a known amount of alkali to the reaction cell which contains the reaction mixture. The titration curves are then drawn by plotting the measured $\mathrm{pH}$ values against the corresponding volume of alkali added and the stability constants of the complexes are determined from the titration curves by employing $\mathrm{pH}$-metric titration technique given by (Irving and Rossoti).

Metal-ligand stability constants ( $\log \mathrm{K}$ ) were determined by using the following relations:

$$
\bar{n}=\frac{\left(V_{3}-V_{2}\right)\left(E^{0}+N^{0}\right)}{\left(V^{0}+V_{2}\right) \bar{n}_{A} T_{m}^{0}}
$$

and

$$
P L=\log _{10}\left\{\frac{1+\beta_{n}^{H} \frac{1}{[\text { anti } \log \mathrm{pH}]^{\mathrm{n}}}}{\mathrm{T}_{\mathrm{L}}^{0}-n \bar{T}_{m}^{0}} \mathrm{X} \frac{\left(V^{0}+V_{3}\right)}{V^{0}}\right\}
$$


BAJOPAS Volume 14 Number 1,June, 2021

Where $T_{L}, T^{\circ}, E^{\circ}$, and $V^{\circ}$ havethe same significance as in equation (1) above, $T_{m}$ denotes the total concentration of metal present in solution, $V_{3}$ is the volume of metal ions present in solution and $\beta^{H}$ is the overall proton ligand stability constant. The metal-ligand stability constants (log K) were determined by employing point wise computational Method (eq. 5 and 6).

$\operatorname{LogK}_{1}=\log \left(\frac{n}{1-n}\right)+\mathrm{pL}$ .5

$\operatorname{LogK}_{2}=\log \left(\frac{1-n}{2-n}\right)+\mathrm{pL}$ ...6

Where: Log $\mathrm{K}$ is the metal-ligand stability constant, $\mathrm{pL}$ is the Free ligand exponent function, $\mathbf{n}$ is the Average number of ligand attached with metal ion (Janraoet al., 2014). The results obtained were analyzed by an ORIGIN 2016 program using titration data and then the proton-ligand stability constants (pKa) and Metal-ligand stability constant (LogK) calculated (Omar and Ali, 2015).

\section{RESULTS AND DISCUSSION}

Fourier transformed infrared (FT-IR) spectra of isolated humic acid from peat soils Figure 2 had distinct clear absorption bands indicating the presence of major humic acid structural elemental groups such as $\mathrm{H}$ bonded $\mathrm{OH}$ $\left(3680 \mathrm{~cm}^{-1}\right.$ peak $), C=0$ of carbonyl $\left(1721 \mathrm{~cm}^{-1}\right.$ peak), functional groups of aliphatic components $\mathrm{CH}_{2}\left(2918 \mathrm{~cm}^{-1}\right.$ peak) and $\mathrm{C}-\mathrm{O}$ stretching of polysaccharide $\left(1168 \mathrm{~cm}^{-1}\right.$ peak). The positions of the absorption bands of the spectra fell within typical major absorption bands of humic acid which is at frequencies 3680, 2918, 1721, 1168 $\mathrm{cm}^{-1}$. The first peak centred in the vicinity of $3680 \mathrm{~cm}^{-1}$ region is attributed to phenol $\mathrm{OH}$ group bounded by intermolecular $\mathrm{H}$ bonds. The $2918 \mathrm{~cm}^{-1}$ band usually has absorption maximum at $2918 \mathrm{~cm}^{-1}$ which is due to $\mathrm{C}-\mathrm{H}$ stretching of alkane group $\left(\mathrm{CH}_{2}\right)$. The next major absorption band is $1721 \mathrm{~cm}^{-1}$. This band has been commonly ascribed to $\mathrm{C}=\mathrm{O}$ stretching of mainly carboxyl group $(\mathrm{COOH})$ with trace amount of ketones. The last peak was observed at 1168 $\mathrm{cm}^{-1}$ due to $\mathrm{C}-\mathrm{O}$ stretching of polysaccharides and this peak appeared also in the spectra of humic acid from peat soil. The FTIR spectra of the isolated humic acid contained all major characteristic absorption peaks of humic acid. These absorption peaks indicated the presence of the major structural elements of humic acid namely $\mathrm{H}$ bonded $\mathrm{OH}, \mathrm{C}=\mathrm{C}$ of aromatic ring, $\mathrm{C}=\mathrm{O}$ of carbonyl group (both carboxyl and ketonic), $\mathrm{CH}_{2}$ group. This strongly supports the presence of humic acid.

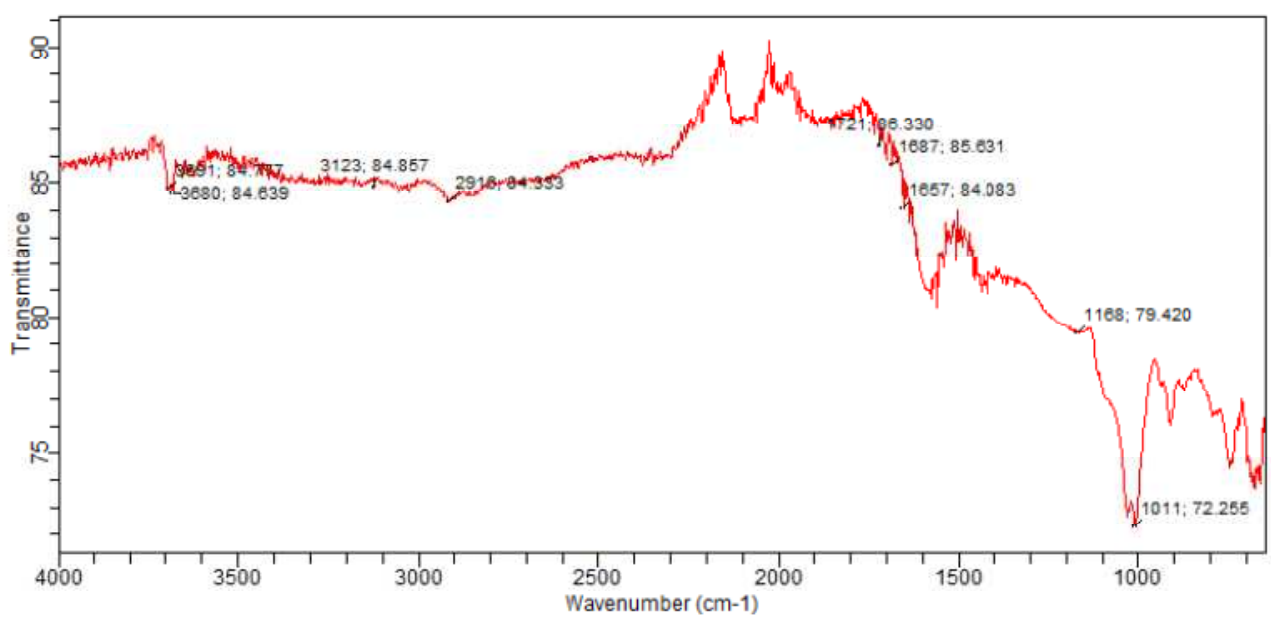

Fig. 2 : FT-IR spectraof peatsoilhumic acid (PSHA)

\section{Evaluation of acid dissociation constant (pka) of acid hydrolysed peat soil humicacid at phenolic group}

The value of the dissociation constant of the peat soil humic acid (PSHA) that underwent acidhydrolysis studied was found to be 8.9299 as shown Table 1, which is lower than the literaturevalues reported by Almeida and Szpoganics, (2015), Borges et al., (2005); Badr et al., (2012)and Fernandes et al,.(2009) of $9.73,9.47$ and 10.30. The difference between the obtained valuesand the reported values in this study might be probably as a result of acid hydrolysis of humicacid. 
BAJOPAS Volume 14 Number 1,June, 2021

Table 1: PKa of (Hydrolysed PSHA)

\begin{tabular}{|l|l|l|l|l|l|l|}
\hline $\mathrm{pH}$ & $\mathrm{BV}_{1}$ & $\mathrm{BV}_{2}$ & $\mathrm{~V}_{2}-\mathrm{V}_{1}$ & $\mathrm{nA}$ & $\log \left(\frac{n A}{1-n A}\right)$ & $\mathrm{pKa}$ \\
\hline 8.50 & 5.30 & 6.29 & 0.99 & 0.3594 & -0.2510 & 8.2490 \\
8.72 & 5.35 & 6.37 & 1.02 & 0.3400 & -0.2880 & 8.4320 \\
9.00 & 5.40 & 6.46 & 1.06 & 0.3141 & -0.3391 & 8.6609 \\
9.22 & 5.45 & 6.55 & 1.10 & 0.2882 & -0.3927 & 8.8273 \\
9.51 & 5.50 & 6.66 & 1.16 & 0.2494 & -0.4786 & 9.0314 \\
9.73 & 5.55 & 6.78 & 1.23 & 0.2041 & -0.5910 & 9.1390 \\
10.00 & 5.60 & 6.90 & 1.30 & 0.1589 & -0.7238 & 9.2762 \\
10.23 & 5.65 & 7.05 & 1.40 & 0.0941 & -0.9835 & 9.2465 \\
10.49 & 5.70 & 7.10 & 1.40 & 0.0941 & -0.9835 & 9.5065 \\
\hline
\end{tabular}

Average pKa $=8.9299 \pm 0.4186$

Table 2: PKa of (Unhydrolysed PSHA)

\begin{tabular}{|l|l|l|l|l|l|l|}
\hline $\mathrm{pH}$ & $\mathrm{BV}_{1}$ & $\mathrm{BV}_{2}$ & $\mathrm{~V}_{2}-\mathrm{V}_{1}$ & $\mathrm{nA}$ & $\log \left(\frac{\boldsymbol{n A}}{1-\boldsymbol{n}}\right)$ & $\mathrm{pKa}$ \\
\hline 8.50 & 5.30 & 5.81 & 0.51 & 0.6619 & 0.2919 & 8.7919 \\
8.72 & 5.35 & 5.90 & 0.55 & 0.6357 & 0.2418 & 8.9618 \\
9.00 & 5.40 & 6.00 & 0.60 & 0.6029 & 0.1813 & 9.1813 \\
9.22 & 5.45 & 6.10 & 0.65 & 0.5701 & 0.1226 & 9.3426 \\
9.51 & 5.50 & 6.20 & 0.70 & 0.5376 & 0.0654 & 9.5754 \\
9.73 & 5.55 & 6.33 & 0.78 & 0.4851 & -0.0259 & 9.7041 \\
10.00 & 5.60 & 6.47 & 0.87 & 0.4262 & -0.1291 & 9.8709 \\
10.23 & 5.65 & 6.62 & 0.99 & 0.3609 & -0.2481 & 9.9819 \\
10.49 & 5.70 & 6.80 & 1.10 & 0.2759 & -0.4690 & 10.0210 \\
\hline
\end{tabular}

Average pKa $=9.4923 \pm 0.4410$

Metal-ligand stability constant ( $\log \mathrm{K}$ )

The stabilityconstants require the accurate values of proton-ligand stability constants (Anil and Maroti, 2008). Metal titration curves crossed over ligand titration curve indicated the formation of complex upon proton release (Santosh, et al., 2011). If the values of n- are within range $0.2-0.8$ and $1.2-18$ this indicates the formation of $1: 1$ and 1:2 complexes (Sayyed and Mazahar, 2012).

The metal (II)-humate stepwise stability constants (log k) at phenolic group (Tables 318)

Table 3: Point-wise method, $\mathrm{Cu}$-(Hydrolysed PSHA)

\begin{tabular}{|l|l|l|l|l|l|l|l|l|}
\hline $\mathrm{pH}$ & $\mathrm{BV}_{1}$ & $\mathrm{BV}_{2}$ & $\mathrm{BV}_{3}$ & $\left(\mathrm{~V}_{3}-\mathrm{V}_{2}\right)$ & $\mathrm{n}$ & $\mathrm{pL}$ & $\log \left(\frac{n}{1-n}\right)$ & LogK $_{1}$ \\
\hline 8.50 & 5.30 & 6.29 & 6.33 & 0.04 & 0.5500 & 2.66 & 0.0871 & 2.7471 \\
8.72 & 5.35 & 6.37 & 6.41 & 0.04 & 0.5714 & 2.43 & 0.1249 & 2.5549 \\
9.00 & 5.40 & 6.46 & 6.50 & 0.04 & 0.6198 & 2.16 & 0.2122 & 2.3722 \\
9.22 & 5.45 & 6.55 & 6.59 & 0.04 & 0.6667 & 1.94 & 0.3010 & 2.2410 \\
\hline
\end{tabular}

LogK $_{1}$ (Average value) $=2.4788 \pm 0.2203$

Table 4: Point-wise method, $\mathrm{Cu}$-(Hydrolysed PSHA)

\begin{tabular}{|l|l|l|l|l|l|l|l|l|}
\hline $\mathrm{pH}$ & $\mathrm{BV}_{1}$ & $\mathrm{BV}_{2}$ & $\mathrm{BV}_{3}$ & $\left(\mathrm{~V}_{3}-\mathrm{V}_{2}\right)$ & $\mathrm{n}$ & $\mathrm{pL}$ & $\log \left(\frac{n-1}{2-n}\right)$ & LogK $_{2}$ \\
\hline 9.51 & 5.50 & 6.66 & 6.73 & 0.07 & 1.3509 & 1.70 & -0.2671 & 1.4329 \\
9.73 & 5.55 & 6.78 & 6.85 & 0.07 & 1.6383 & 1.51 & 0.2467 & 1.7567 \\
10.00 & 5.60 & 6.90 & 6.98 & 0.08 & 2.1783 & 1.31 & -0.2158 & 1.0942 \\
10.23 & 5.65 & 7.05 & 7.13 & 0.08 & 4.1904 & 1.27 & & \\
10.49 & 5.70 & 7.10 & 7.19 & 0.09 & 4.6920 & & & \\
\hline
\end{tabular}

Log $K_{2}($ Average value $)=1.4280 \pm 0.3312$ 
BAJOPAS Volume 14 Number 1,June, 2021

Table 5: Point-wise method, $\mathrm{Cu}$ (Unhydrolysed PSHA)

\begin{tabular}{|l|l|l|l|l|l|l|l|l|}
\hline $\mathrm{pH}$ & $\mathrm{BV}_{1}$ & $\mathrm{BV}_{2}$ & $\mathrm{BV}_{3}$ & $\left(\mathrm{~V}_{3}-\mathrm{V}_{2}\right)$ & $\mathrm{n}$ & $\mathrm{pL}$ & $\log \left(\frac{n}{n-1}\right)$ & Log $_{1}$ \\
\hline 8.50 & 5.30 & 5.81 & 5.85 & 0.04 & 0.2973 & 2.88 & -0.3736 & 2.5064 \\
8.72 & 5.35 & 5.90 & 5.95 & 0.05 & 0.3873 & 2.66 & -0.1992 & 2.4608 \\
9.00 & 5.40 & 6.00 & 6.05 & 0.05 & 0.4044 & 2.38 & -0.1681 & 2.2119 \\
9.22 & 5.45 & 6.10 & 6.15 & 0.06 & 0.5157 & 2.18 & -0.0272 & 2.2072 \\
9.51 & 5.50 & 6.20 & 6.27 & 0.07 & 0.6417 & 1.89 & 0.2530 & 1.1430 \\
\hline
\end{tabular}

$\operatorname{LogK}_{1}($ Average value $)=2.3059 \pm 0.6153$

Table 6:Point-wise method, $\mathrm{Cu}$ (Unhydrolysed PSHA)

\begin{tabular}{|l|l|l|l|l|l|l|l|l|}
\hline $\mathrm{pH}$ & $\mathrm{BV}_{1}$ & $\mathrm{BV}_{2}$ & $\mathrm{BV}_{3}$ & $\mathrm{~V}_{3}-\mathrm{V}_{2}$ & $\mathrm{n}$ & $\mathrm{pL}$ & $\log \left(\frac{n-1}{2-n}\right)$ & $\log \mathrm{K}_{2}$ \\
\hline 9.73 & 5.55 & 6.33 & 6.42 & 0.09 & 0.9000 & 1.69 & & \\
10.00 & 5.60 & 6.47 & 6.58 & 0.11 & 1.2578 & 1.44 & -0.4592 & 0.9808 \\
10.23 & 5.65 & 6.62 & 6.84 & 0.12 & 1.6137 & 1.26 & -0.2010 & 1.4610 \\
10.49 & 5.70 & 6.80 & 6.92 & 0.12 & 2.1052 & 1.03 & & \\
\hline
\end{tabular}

$\operatorname{LogK}_{2}$ (Average value) $=1.2209 \pm 0.3398$

Table 7:Point-wise method, Pb (Hydrolysed PSHA)

\begin{tabular}{|l|l|l|l|l|l|l|l|l|}
\hline $\mathrm{pH}$ & $\mathrm{BV}_{1}$ & $\mathrm{BV}_{2}$ & $\mathrm{BV}_{3}$ & $\left(\mathrm{~V}_{3}-\mathrm{V}_{2}\right)$ & $\mathrm{n}$ & $\mathrm{pL}$ & $\log \left(\frac{n}{1-n}\right)$ & LogK $_{1}$ \\
\hline 8.50 & 5.30 & 6.29 & 6.33 & 0.04 & 0.5500 & 2.66 & 0.0871 & 2.7471 \\
8.72 & 5.35 & 6.37 & 6.41 & 0.04 & 0.5714 & 2.43 & 0.1249 & 2.5549 \\
9.00 & 5.40 & 6.46 & 6.50 & 0.04 & 0.6198 & 2.16 & 0.2122 & 2.3722 \\
9.22 & 5.45 & 6.55 & 6.60 & 0.05 & 0.8333 & 1.96 & 0.6989 & 2.6589 \\
\hline
\end{tabular}

Log $_{\mathbf{1}}($ Average value $)=2.5832 \pm 0.1614$

Table 8:Point-wise method, Pb-(Hydrolysed PSHA)

\begin{tabular}{|l|l|l|l|l|l|l|l|l|}
\hline $\mathrm{pH}$ & $\mathrm{BV}_{1}$ & $\mathrm{BV}_{2}$ & $\mathrm{BV}_{3}$ & $\left(\mathrm{~V}_{3}-\mathrm{V}_{2}\right)$ & $\mathrm{n}$ & $\mathrm{pL}$ & $\log \left(\frac{n-1}{2-n}\right)$ & $\log \mathrm{K}_{2}$ \\
\hline 9.51 & 5.50 & 6.66 & 6.71 & 0.05 & 0.9650 & 1.67 & & \\
9.73 & 5.55 & 6.78 & 6.83 & 0.05 & 1.1702 & 1.44 & & \\
10.00 & 5.60 & 6.90 & 6.90 & 0.05 & 1.4864 & 1.22 & -0.0237 & 1.1963 \\
10.23 & 5.65 & 7.05 & 7.10 & 0.05 & 2.0190 & 1.09 & & \\
10.49 & 5.70 & 7.10 & 7.17 & 0.07 & 3.6492 & 1.00 & & \\
\hline
\end{tabular}

Log $K_{2}$ (Average value) $=1.1963$

Table 9: Point-wise method, Pb (Unhydrolysed PSHA)

\begin{tabular}{|l|l|l|l|l|l|l|l|l|}
\hline $\mathrm{pH}$ & $\mathrm{BV}_{1}$ & $\mathrm{BV}_{2}$ & $\mathrm{BV}_{3}$ & $\mathrm{~V}_{3}-\mathrm{V}_{2}$ & $\mathrm{n}$ & $\mathrm{pL}$ & $\begin{array}{l}\text { Log } \\
\left(\frac{n}{n-1}\right)\end{array}$ & Log $\mathrm{K}_{1}$ \\
\hline 8.50 & 5.30 & 5.81 & 5.85 & 0.04 & 0.2973 & 2.88 & -0.3736 & 2.5064 \\
8.72 & 5.35 & 5.90 & 5.94 & 0.04 & 0.3099 & 2.66 & -0.5477 & 2.3123 \\
9.00 & 5.40 & 6.00 & 6.05 & 0.05 & 0.4044 & 2.38 & -0.1681 & 2.2119 \\
9.22 & 5.45 & 6.10 & 6.15 & 0.06 & 0.5157 & 2.18 & 0.0272 & 2.2072 \\
9.51 & 5.50 & 6.20 & 6.26 & 0.07 & 0.6417 & 1.89 & 0.2530 & 2.1430 \\
9.73 & 5.55 & 6.40 & 6.40 & 0.07 & 0.7000 & 1.67 & 0.3680 & 2.0380 \\
\hline
\end{tabular}

LogK $_{1}$ (Average value) $=2.2364 \pm 0.1602$

Table 10: Point-wise method, Pb (Unhydrolysed PSHA)

\begin{tabular}{|l|l|l|l|l|l|l|l|l|}
\hline $\mathrm{pH}$ & $\mathrm{BV}_{1}$ & $\mathrm{BV}_{2}$ & $\mathrm{BV}_{3}$ & $\mathrm{~V}_{3}-\mathrm{V}_{2}$ & $\mathrm{n}$ & $\mathrm{pL}$ & $\log \left(\frac{n-1}{2-n}\right)$ & $\log \mathrm{K}_{2}$ \\
\hline 10.00 & 5.60 & 6.47 & 6.55 & 0.08 & 1.9503 & 1.41 & & \\
10.23 & 5.65 & 6.62 & 6.72 & 0.11 & 1.4792 & 1.26 & -0.0361 & 1.2239 \\
\hline
\end{tabular}

$\operatorname{LogK}_{2}$ (Average value) $=1.2239$

Table 11: Point-wise method, Mg (Hydrolysed PSHA)

\begin{tabular}{|l|l|l|l|l|l|l|l|l|}
\hline $\mathrm{pH}$ & $\mathrm{BV}_{1}$ & $\mathrm{BV}_{2}$ & $\mathrm{BV}_{3}$ & $\left(\mathrm{~V}_{3}-\mathrm{V}_{2}\right)$ & $\mathrm{n}$ & $\mathrm{pL}$ & $\log \left(\frac{n}{n-1}\right)$ & LogK $_{1}$ \\
\hline 8.50 & 5.30 & 6.29 & 6.31 & 0.02 & 0.2750 & 2.64 & -0.4290 & 2.2110 \\
8.72 & 5.35 & 6.37 & 6.39 & 0.02 & 0.2858 & 2.42 & -0.3978 & 2.0222 \\
9.00 & 5.40 & 6.46 & 6.49 & 0.03 & 0.4648 & 2.14 & -0.0612 & 2.0788 \\
9.22 & 5.45 & 6.55 & 6.59 & 0.04 & 0.6667 & 1.94 & 0.3010 & 2.2410 \\
\hline
\end{tabular}

$\log _{\mathbf{1}}($ Average value) $=2.1382 \pm 0.1046$ 
BAJOPAS Volume 14 Number 1,June, 2021

Table 12: Point-wise method, Mg (Hydrolysed PSHA)

\begin{tabular}{|l|l|l|l|l|l|l|l|l|}
\hline $\mathrm{pH}$ & $\mathrm{BV}_{1}$ & $\mathrm{BV}_{2}$ & $\mathrm{BV}_{3}$ & $\left(\mathrm{~V}_{3}-\mathrm{V}_{2}\right)$ & $\mathrm{n}$ & $\mathrm{pL}$ & $\log \left(\frac{n-1}{2-n}\right)$ & LogK $_{2}$ \\
\hline 9.51 & 5.55 & 6.66 & 6.71 & 0.05 & 0.9650 & 1.67 & & \\
9.73 & 5.55 & 6.78 & 6.84 & 0.06 & 1.4042 & 1.47 & -0.1686 & 1.3014 \\
10.00 & 5.60 & 6.90 & 6.93 & 0.06 & 1.7838 & 1.23 & 0.5593 & 1.7893 \\
10.23 & 5.65 & 7.05 & 7.10 & 0.06 & 3.1429 & 1.10 & & \\
10.49 & 5.70 & 7.10 & 7.18 & 0.07 & 3.6492 & 0.83 & & \\
\hline
\end{tabular}

LogK $_{2}($ Average value $)=1.5453 \pm 0.3450$

Table 13: Point-wise method, Mg (Unhydrolysed PSHA)

\begin{tabular}{|l|l|l|l|l|l|l|l|l|}
\hline $\mathrm{pH}$ & $\mathrm{BV}_{1}$ & $\mathrm{BV}_{2}$ & $\mathrm{BV}_{3}$ & $\mathrm{~V}_{3}-\mathrm{V}_{2}$ & $\mathrm{n}$ & $\mathrm{pL}$ & $\log \left(\frac{n}{n-1}\right)$ & $\operatorname{Log~}_{1}$ \\
\hline 8.50 & 5.30 & 5.81 & 5.85 & 0.04 & 0.2973 & 2.88 & -0.3736 & 2.5064 \\
8.72 & 5.35 & 5.90 & 5.94 & 0.04 & 0.3099 & 2.66 & -0.3477 & 2.3123 \\
9.00 & 5.40 & 6.00 & 6.04 & 0.04 & 0.3236 & 2.38 & -0.3202 & 2.0598 \\
9.22 & 5.45 & 6.10 & 6.15 & 0.05 & 0.4297 & 2.17 & -0.1230 & 2.0470 \\
9.51 & 5.50 & 6.20 & 6.26 & 0.06 & 0.5500 & 1.89 & 0.0871 & 1.9771 \\
9.73 & 5.55 & 6.33 & 6.40 & 0.07 & 0.7000 & 1.67 & 0.3680 & 2.0380 \\
\hline
\end{tabular}

LogK $_{1}$ (Average value) $=2.1568 \pm 0.2069$

Table 14: Point-wise method, Mg (Unhydrolysed PSHA)

\begin{tabular}{|l|l|l|l|l|l|l|l|l|}
\hline $\mathrm{pH}$ & $\mathrm{BV}_{1}$ & $\mathrm{BV}_{2}$ & $\mathrm{BV}_{3}$ & $\mathrm{~V}_{3}-\mathrm{V}_{2}$ & $\mathrm{n}$ & $\mathrm{pL}$ & $\log \left(\frac{n-1}{2-n}\right)$ & $\log \mathrm{K}_{2}$ \\
\hline 10.00 & 5.60 & 6.47 & 6.55 & 0.08 & 0.9148 & 1.41 & & \\
10.23 & 5.65 & 6.62 & 6.71 & 0.09 & 1.2102 & 1.20 & -0.5749 & 0.6251 \\
10.49 & 5.70 & 6.80 & 6.92 & 0.09 & 1.5968 & 1.03 & 0.1703 & 1.2003 \\
\hline
\end{tabular}

LogK $_{2}$ (Average value) $=0.9127 \pm 0.4070$

Table15:Point-wise method, Cd (Hydrolysed PSHA)

\begin{tabular}{|l|l|l|l|l|l|l|l|l|}
\hline $\mathrm{pH}$ & $\mathrm{BV}_{1}$ & $\mathrm{BV}_{2}$ & $\mathrm{BV}_{3}$ & $\left(\mathrm{~V}_{3}-\mathrm{V}_{2}\right)$ & $\mathrm{n}$ & $\mathrm{pL}$ & $\log \left(\frac{n}{1-n}\right)$ & LogK $_{1}$ \\
\hline 8.50 & 5.30 & 6.29 & 6.31 & 0.02 & 0.2750 & 2.64 & -0.4210 & 2.2190 \\
8.72 & 5.35 & 6.37 & 6.40 & 0.03 & 0.4286 & 2.42 & -0.1249 & 2.2951 \\
9.00 & 5.40 & 6.46 & 6.49 & 0.03 & 0.4648 & 2.14 & -0.0612 & 2.0788 \\
9.22 & 5.45 & 6.55 & 6.59 & 0.04 & 0.6667 & 1.96 & 0.3010 & 2.2610 \\
9.51 & 5.55 & 6.66 & 6.70 & 0.04 & 0.7720 & 1.67 & 0.5297 & 2.1997 \\
\hline
\end{tabular}

LogK $_{\mathbf{1}}$ (Average value) $=2.2108 \pm 0.0825$

Table 16: Point-wise method, Cd (Hydrolysed PSHA)

\begin{tabular}{|l|l|l|l|l|l|l|l|l|}
\hline $\mathrm{pH}$ & $\mathrm{BV}_{1}$ & $\mathrm{BV}_{2}$ & $\mathrm{BV}_{3}$ & $\left(\mathrm{~V}_{3}-\mathrm{V}_{2}\right)$ & $\mathrm{n}$ & $\mathrm{pL}$ & $\log \left(\frac{n-1}{2-n}\right)$ & Log $_{2}$ \\
\hline 9.73 & 5.55 & 6.78 & 6.83 & 0.06 & 1.4042 & 1.47 & -0.1686 & 1.3014 \\
10.00 & 5.60 & 6.90 & 6.95 & 0.06 & 1.7838 & 1.23 & 0.5593 & 1.7893 \\
10.23 & 5.65 & 7.05 & 7.10 & 0.06 & 3.1429 & 1.09 & & \\
10.49 & 5.70 & 7.10 & 7.16 & 0.06 & 3.1429 & 0.89 & & \\
& & & & & & & & \\
\hline
\end{tabular}

$\operatorname{LogK}_{2}$ (Average value) $=1.5453 \pm 0.3450$

Table 17: Point-wise method, Cd (Unhydrolysed PSHA)

\begin{tabular}{|l|l|l|l|l|l|l|l|l|}
\hline $\mathrm{pH}$ & $\mathrm{BV}_{1}$ & $\mathrm{BV}_{2}$ & $\mathrm{BV}_{3}$ & $\mathrm{~V}_{3}-\mathrm{V}_{2}$ & $\mathrm{n}$ & $\mathrm{pL}$ & $\log \left(\frac{n}{n-1}\right)$ & $\operatorname{Log~}_{1}$ \\
\hline 8.50 & 5.30 & 5.81 & 5.86 & 0.05 & 0.3717 & 2.88 & -0.2280 & 2.6520 \\
8.72 & 5.35 & 5.90 & 5.95 & 0.05 & 0.3873 & 2.66 & -0.1992 & 2.4608 \\
9.00 & 5.40 & 6.00 & 6.06 & 0.06 & 0.4853 & 2.38 & -0.0255 & 2.3545 \\
9.22 & 5.45 & 6.10 & 6.16 & 0.06 & 0.5157 & 2.18 & -0.0272 & 2.2072 \\
9.51 & 5.50 & 6.20 & 6.27 & 0.07 & 0.6417 & 1.89 & 0.2530 & 1.1430 \\
9.73 & 5.55 & 6.33 & 6.41 & 0.08 & 0.8000 & 1.69 & 0.6020 & 2.2920 \\
& & & & & & & & \\
\hline
\end{tabular}

$\operatorname{LogK}_{1}($ Average value $)=2.2516 \pm 0.5380$ 
BAJOPAS Volume 14 Number 1,June, 2021

Table 18: Point-wise method, Cd (Unhydrolysed PSHA)

\begin{tabular}{|l|l|l|l|l|l|l|l|l|}
\hline $\mathrm{pH}$ & $\mathrm{BV}_{1}$ & $\mathrm{BV}_{2}$ & $\mathrm{BV}_{3}$ & $\mathrm{~V}_{3}-\mathrm{V}_{2}$ & $\mathrm{n}$ & $\mathrm{pL}$ & $\log \left(\frac{n-1}{2-n}\right)$ & $\log \mathrm{K}_{2}$ \\
\hline 10.00 & 5.60 & 6.47 & 6.57 & 0.10 & 1.1434 & 1.43 & & \\
10.23 & 5.65 & 6.62 & 6.72 & 0.10 & 1.3448 & 1.23 & -0.2788 & 0.9512 \\
10.49 & 5.70 & 6.80 & 6.90 & 0.10 & 1.7742 & 1.03 & 0.5351 & 1.5651 \\
\hline
\end{tabular}

$\operatorname{LogK}_{2}($ Average value $)=1.2581 \pm 0.4340$

Table 19: Stepwise and overall Stability constants of thehydrolysed and unhydrolysed divalent metal (II) complexes

\begin{tabular}{|c|c|c|c|}
\hline Chelates & LogK $_{1}$ & $\log _{2}$ & Log $\beta$ \\
\hline [Cu (Hydrolysed PSHA-1) $\left.{ }_{2}\right]$ & 2.4788 & 1.4280 & 3.9068 \\
\hline$\left[\mathrm{Pb}(\text { Hydrolysed PSHA-1) })_{2}\right]$ & 2.5832 & 1.1963 & 3.7795 \\
\hline$\left[\mathrm{Cd}(\text { Hydrolysed PSHA-1 })_{2}\right]$ & 2.2108 & 1.5453 & 3.7561 \\
\hline$\left[\mathrm{Mg}(\text { Hydrolysed PSHA-1 })_{2}\right]$ & 2.1382 & 1.5453 & 3.6835 \\
\hline [Cu (Unhydrolysed PSHA-1) & 2.3059 & 1.2209 & 3.5268 \\
\hline$[\mathrm{Pb}$ (Unhydrolysed PSHA-1) 2$]$ & 2.2364 & 1.2239 & 3.4603 \\
\hline [Cd (Unhydrolysed PSHA-1) 2 ] & 2.2516 & 1.2581 & 3.5097 \\
\hline$[\mathrm{Mg}$ (Unydrolysed PSHA-1) & 2.1568 & 0.9127 & 3.0695 \\
\hline
\end{tabular}

The results obtained (Table19) shows the stepwise and overall stability constants to be not high indicating low stability of the complexes, because the solubility of most metal ions in the basic $\mathrm{pH}$ range is minimal due to metal hydroxide precipitation (Karimi, 2017). In general, the stepwise stability constants $\left(K_{1}\right.$ and $K_{2}$ ) follow the order $K_{1}>K_{2}$ for the copper, lead, magnesium and cadmium complexes respectively. The steady decrease of the values with increasing number of ligands is in agreement with the prediction made by researchers (Na'aliya, 2013). The decrease could be attributed to the fact that as the number of the ligands (Humate ions) that enters the coordination zone increases the aqua molecules available for replacement by the ligands become less. Thus, the metal ions become less electron loving with progressive intake of the ligand and this results in the decrease in the values of the constants (Na'aliya, 2013). Also the stability of the complexes is influenced by the size and number of the chelate rings(Mackay and Mackay,2002).All the complexes form rings in their structure as humate, a bidentate ligand, bond the metal ions in the ratio 1:2 (Boguta and Sokolowska, 2016) forming chelate rings. The values of the overall stability constants $(\log \beta)$ obtained for humate complexes are not high indicating low stability as the values are not high. LogK values for copper-humates (Table 3 to 6) obtained in this study are lower than those reported for the complexes of humic acids (Pandey et al., 2015; Dinu, 2013; Kaschl et al., 2010 and Gilbeto and Jorg, 2001). The values of LogK(Table 7 to 10 ) forlead-humates are lower than those reported for the lead in the literature (Dinu, 2013; Gilbeto and Jorg 2001). Log K values(Table 11 to 14 ) for magnesium-humates obtained in this study are close to those reported by (Pandey et al., 2015). Log K values of cadmium-humates (Table 15 to 18 ) obtained in this work near to the one reported by (Dinu, 2013 and Pandey et al., 2015).The difference between the reported values and the values obtained in this study might be probably as a result of acid hydrolysis of humic acid. The values of the overall stability constants $(\log \beta)$ of the copper humates complexes presented in Table 19 is high than that of other metal humate complexes, show relatively high stability of CuHA complexes, show the following order of stability: $\mathrm{Cu}>\mathrm{Pb}>\mathrm{Cd}>\mathrm{Mg}$; which are in close agreement to the findings of (Dinu, 2013 and Pandey et al., 2015).The high stability of Cuhumate chelate could be attributed to the existence of coordinate covalent bond between the complexing agents and the $\mathrm{Cu}^{2+}$ ions. Since, $\mathrm{Cu}^{2+}$ being a metal of the transitional series with $3 d^{9}$ electronic configurations can accept the electrons from the complexing agents. Similarly, the low stabilities of $\mathrm{Pb}, \mathrm{Cd}$ and $\mathrm{Mg}$ complexes could be explained by that $\mathrm{Pb}^{2+}$ with $6 s^{2}, \mathrm{Cd}^{2+}$ with $4 \mathrm{~d}^{10}$ and $\mathrm{Mg}^{2+}$ with $2 \mathrm{p}^{6}$ their electronic configuration has a completely filled $\mathrm{d}, \mathrm{p}$ and $\mathrm{s}$ orbitals. Moreover, the stabilities of metal ions with hydrolysed humic acid from peat soil were higher than those with unhydrolysed humic acid from peat soil; which is ascribed to the high content of acidity in hydrolysed humic acid than unhydrolysed humic acid. 
BAJOPAS Volume 14 Number 1,June, 2021 CONCLUSION

The values of logk for $\mathrm{Cu}(\mathrm{II})$ hydrolysed humic acid complex was higher followed by $\mathrm{Pb}$ (II), $\mathrm{Cd}(\mathrm{II})$ and $\mathrm{Mg}$ (II) hydrolysed humic acid complexes as compared with metal(II) unhydrolysed humic acid complexes. This indicates acid hydrolysis of humic acid can

\section{REFERENCES}

Almeida, V.R. and Szpoganicz, B. (2015). Humic Acid Potentiometric Response Patterns:Out- of Equilibrium Properties and Species Distribution Modelling. Chemical. Biol. Technol. Agric. 2: 17.

Anđelković, T., Nikolić, R., Bojić, A.,Anđelković, D., and Nikolic G.,(2010). Binding of Cadmium to Soil Humic Acid as A Function of Carboxyl Group Content. Macedonian Journal of Chemistry and Chemical Engineering.29(2): 215-224.

Anil, B. N. and Maroti, N. (2008). Studies on Influence of Die-Lectric Constants on Complex Equilibria between Substituted Py-Razalines and Lanthanide Metal Ions pH-Metrically. Amer.-Euras. scient. Res. 3(2): 212-216.

Ashok, K., Pandey, S. P. and Misra, V (2000). Stability Constants of Metal-Humic Acid Complexes and its Role in Environmental Detoxification. Journal of Ecotoxicology and Environmental Safety. 47(2):157-200.

Badr, M. H., El-Halafawi, M. H. and Abd El-al Zeid, E. R. (2012). Comparison Between the Effect of Ionic Strength on Acidity and Dissociation Constants of Humic Acids Extracted from Sewage Sludge and Nile Water Hyacinth Composts.Global Journal of Environmental Research 6 (1): 36-43.

Baruah, M.K., Borah, D., Saikia, P.P., Paul, S., Sharma, T. (2015). Evaluation of pKa Values of Soil Humic Acids and their Complexation Properties. International Journal of Plant \& Soil Science 6(4) : 218-228.

Boguta, P. Sokolowska, Z. (2016). Interactions of $\mathrm{Zn}$ (II) Ions with Humic Acids Isolated from Various Types of Soils. Effect of $\mathrm{pH}, \mathrm{Zn}$ Concentrations and Humic Acids Chemical Properties. Journal of Geochemical Explaration 168. 119-126.

Borges, F., Guimaraes, C., Lima, L.F.C., Pinto, I. and Reis, S.(2005). Potentiometric Studies on the Complexation of Copper(II) by Phenolic Acids as Discrete Ligand Models of enhance the complexation behavior of humic acid with metal (II) ions. However, the higher values of $\log \beta$ for $\mathrm{Cu}(\mathrm{II}), \mathrm{Pb}(\mathrm{II}), \mathrm{Cd}(\mathrm{II})$ and $\mathrm{Mg}(\mathrm{II})$ hydrolysed humic acid complexes indicates more stable stepwise complexes formed as compared with $\mathrm{Cu}(\mathrm{II}), \mathrm{Pb}$ (II), $\mathrm{Cd}$ (II) and $\mathrm{Mg}(\mathrm{II})$ unhydrolysed humic acid complexes.

Humic Substances Talanta 66 (2005) 670-673.

Chefetz, B., Salloum, M. J., Deshmulkin, A. P. and Hatcher, P. (2002). Structural Components of Humic Acids as Determined by Chemical Modifications and Carbon-13 NMR, Pyrolysis, and Thermochemolysis- Gas Chromatography/Mass Spectrometry. Soil Science Society of American Journal Abstract Division S-2- Soil Chemistry66. 1159-1171.

Dinu, M. I. (2013). Metals Complexation with Humic Acids in Surface Water of Different Environ. Sci. Technol. 31(1): 1-17.

Fernandes, A.N., Giacomelli, C., Giovanela, M. Vaz, D.V. Szpoganicz, B. and Maria M. D. (2009). Potentiometric Acidity Determination in Humic Substances Influenced by Different Analytical Procedures.J. Braz. Chem. Soc. 20 (9):14.

Gamal, A. H. (2015). Stability Constants of Rhenium (V) Metal Complexes with Selected Drugs. Pyrex Journal of Research in Environmental Studies. 2(2): 006-014.

Janrao, D. M., Pathan, J., Kayande, D.D., and Mulla, J.J. (2014). An Over View of Potentiometric Determination of Stability Constants of Metal Complexes. Sci. Revs. Chem. Commun.: 4(1), 2014, 11-24.

Karimi, H. (2017). Effect of pH and Initial Pb(II) Concentration on the Lead Removal Efficiency from Waste Water Using $\mathrm{Ca}(\mathrm{OH})_{2}$. International Journal of Water and Waste Water Treatment 3.2

Kaschl, A. Romheld, V. and Chen, Y. (2010). Binding of Cadmium, Copper and Zinc to Humic Substances Originating from Municipal Solid Waste Compost. Israel Journal of Chemistry Vol. 42(1): 89-98.

Kostic, I. S., Tatjana, P, A., Nikolic, R. S., Cvetkovic, T. P., Pavlovic, D. D., Aleksandar, L.J. and Bojic, A. (2012). Comparative Study of Binding Strengths of Heavy Metals with Humic Acid. J.serb. Chem. Soc. 76(9) pp 1-20. 
BAJOPAS Volume 14 Number 1,June, 2021

Na'aliya, J. (2013). Determination of Stepwise Stability Constants and Gibbs free Energy Change of Trisprolina to Complexes of some Divalent Transition Metal ions. Bayero Journal of Pure and Applied Sciences 6(2): 112-114.

Omar, A. A. and Ali, E. A. (2015). Potentiometric Studies on Complexes of $\mathrm{Cr}$ (III) and $\mathrm{Zr}$ (IV) with some Carboxylic Acids. International Journal of Advanced Chemistry, 3(1) 25-

37.

Pandey, A. K. Pandey, S. D. and Misr, V. (2015).Stability Constants of Metal- Humic Acid Complexes and Its Role in Environmental Detoxification. J. Ecotoxicology and Environmental Safety. 47(1):195-200.

Ram, N. and Raman, K.V. (1984). Stability Constants of Complexes of Metals with
Humicand Fuvic Acids under Non- acidConditions. Journal of Plant Nutrition and Soil Sciences.

147:171-176.

Santosh, D. D., Ashok, B. K., Vijay, J. T., Shivraj, G. W. and Vinay, V. W. (2011). Potentiometric Studies of Elec-Trolyte Effects on Complex Equilibria of Some Substituted 5-(2-hydroxy Phenyl) Pyrazoles. Der pharm. 3 (6): 75-83.

Sayyed, H. and Abdul Rahim, M. F. (2012). Studies of Binary Complexes of Metal Ions with Mandelic Acid by Potentiometry. Chem. J. 02 (6): 206209.

Shirvani, M. Moradian, E. Khalili, B. Bakhtiary, S. (2015). Interaction of $\mathrm{Cd}$ and $\mathrm{Pb}$ with Humate-Palygorskite and HumateSepiolite Complexes. Journal of water, air and pollution 3: 220-228. 


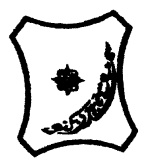

Bayero Journal of Pure and Applied Sciences, 14(1): 54 - 63

Received: November, 2020

Accepted: April, 2021

ISSN $2006-6996$

\title{
STABILITY CONSTANTS OF COMPLEXES OF METAL IONS WITH PEATSOIL HUMIC ACIDS UNDER NON-ACID-CONDITIONS
}

\author{
${ }^{* 1}$ Sabo, Yusuf ${ }^{2}$ Jimoh, W.L.O., ${ }^{3}$ Isa Baba Koki and ${ }^{4}$ Sholadoye, Q. 0. \\ ${ }^{1}$ Department of Pure and Industrial Chemistry, Bayero University, Kano \\ ${ }^{3}$ Department of Chemistry, Yusuf Maitama Sule University Kano. P.M.B. 3220 Kano, Nigeria. \\ ${ }^{4}$ Department of Chemistry, Nigerian Police Academy, Wudil, Kano-Nigeria
}

*Correspondence E-mail; saboyusuf18@yahoo.com

ABSTRACT

Stability constants of complexes of four divalent metal ions viz. $\mathrm{Cu}^{2+}, \mathrm{Pb}^{2+}, \mathrm{Mg}^{2+}$ and $\mathrm{Cd}^{2+}$ with humic acids (HA) were determined by potentiometric titration of humic acids with the corresponding salt of the divalent metals in aqueous media under non-acid-condition. The log $K$ (logarithm of the stability constant) ranged from 1.0942 to 2.7471 for metalhumic acid complexes were determined using point-wise computational method. The order of stability constants were obtained as follows: $\mathrm{Cu}>\mathrm{Pb}>\mathrm{Cd}>\mathrm{Mg}$ for metal $-\mathrm{HA}$ complexes respectively, indicating a higher degree of complexation with Cu metal ion.

Keywords: stability constant, humic acid, potentiometric titration, divalent metals, acid hydrolysis.

\section{NTRODUCTION}

The stability constant of a complex is the numerical expression of its stability and provides a quantitative measure of affinity of the metal ion to the complexing agent. An understanding of the relative stability of metal-complexes helps in predicting the behavior of metal ions in the soil (Ram and Raman, 1982). Extensive researches has been done to determine the stability constants of the complexes formed between humic acid (HA) with a number of metal ions. Ashok et al., (2000) reported that humic acid with hydroxyl, phenoxyl and carboxyl reactive groups can form coordination compound with metal ions at $\mathrm{pH}$ 3.5. The stability constants(Log K) for different metalhumic acid complexes indicated the following order of the stabilities of complexes formed between humic acid and metal ion, $\mathrm{Cu}>\mathrm{Fe}$ $>\mathrm{Pb}>\mathrm{Ni}>\mathrm{Co}>\mathrm{Ca}>\mathrm{Cd}>\mathrm{Zn}>\mathrm{Mn}>\mathrm{Mg}$. Andelkovic et al., (2010) investigated the binding of $\mathrm{Cd}$ (II) to soil humic acid at pH 6.5 and in $0.1 \mathrm{M} \mathrm{KNO}_{3}$ ionic medium. The stability constant for binding indicating greater stability in the case when carboxyl groups are involved in complexation reaction. Kostic et al.,(2012) investigated the complexation of humic acid with certain heavy metal ions (Co(II), $\mathrm{Ni}(\mathrm{II}), \mathrm{Cu}(\mathrm{II})$,
$\mathrm{Zn}(\mathrm{II})$, and $\mathrm{Pb}(\mathrm{II})$. The experiment was performed at $25^{\circ} \mathrm{C}$, at pH 4.0 and ionic strength of $0.01 \mathrm{M}$. Stability constant of complex between $\mathrm{Pb}$ (II) ions and humic acid is greater than stability constants of other investigated metalhumate complexes. Bogata and Sokolowska (2016) analyses the interaction between humic acids from different soils and $\mathrm{Zn}$ (II) ions at wide concentration ranges and at $\mathrm{pH} 5$. Studies have showed significant impact of $\mathrm{Zn}$ concentration, $\mathrm{pH}$ and some properties of humic acids with zinc.But all of these studies were limited to acidic $\mathrm{pH}$ range. Therefore, the present study was carried out to determine and compare the stability constants of complexes of metal ions with hydrolysed peat soil humic acid and unhydrolysed peat soil humic under non-acid conditions.

\section{MATERIALS AND METHODS}

Analytical grade chemicals used includes hydrochloric acid $(\mathrm{HCl})$, nitric acid $\left(\mathrm{HNO}_{3}\right)$, sodium hydroxide $(\mathrm{NaOH})$, lead nitrate $\mathrm{Pb}\left(\mathrm{NO}_{3}\right)_{2}$, copper nitrate $\mathrm{Cu}\left(\mathrm{NO}_{3}\right)_{2} \cdot 3 \mathrm{H}_{2} \mathrm{O}$, cadmium nitrate $\mathrm{Cd}\left(\mathrm{NO}_{3}\right)_{2} \cdot 4 \mathrm{H}_{2} \mathrm{O}$, magnesium nitrate $\mathrm{Mg}\left(\mathrm{NO}_{3}\right)_{2} \cdot 6 \mathrm{H}_{2} \mathrm{O}$, potassium nitrate $\left(\mathrm{KNO}_{3}\right)$, calcium chloride $\left(\mathrm{CaCl}_{2}\right)$, (sigma-Aldrich). Dowex 50WX8, (20-50 mesh) from Fluka. 


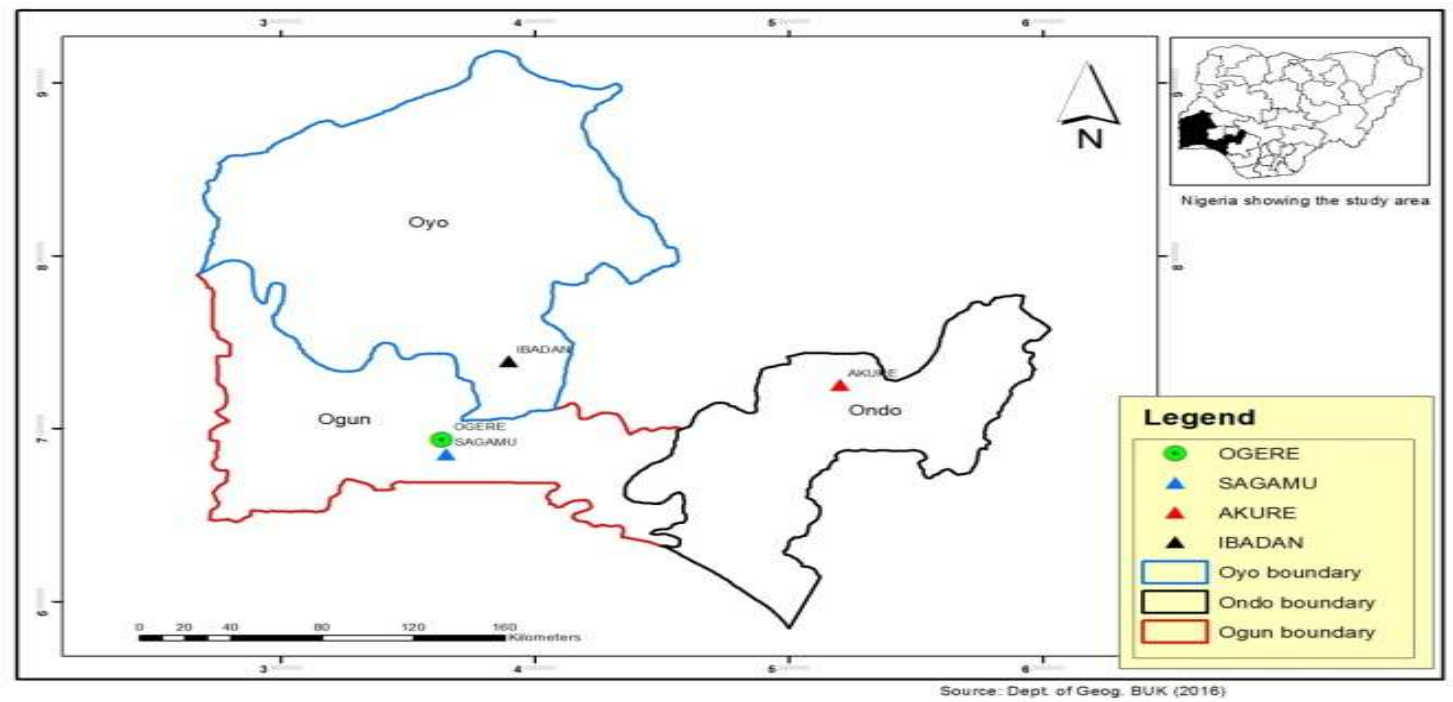

Figure 1: Map showing the sampling point at Sagamu Town, Ogun State.

\section{Description of Sampling Area}

Sagamu has geographical coordinates between $6^{\circ} 50^{\prime}$ north; $3^{\circ} 38^{\prime}$ east is located in south western region of Nigeria. The region has tropical wet and dry climate with a lengthy wet season and relatively constant temperatures throughout the course of the year. Wet season runs from March to October, November to December forms the region dry season. The vegetation type of the region is savannah which is really grassland with small bushes and occasional big trees. Grassland soils have substantially higher organic matter content than forest soils (Novackova, 2011).

\section{Sample Collection}

The Peatsoil samples were collected from four different sampling points $(0-10 \mathrm{~cm}$ depth) in Sagamu into polyethylene bag with plastic spoons. Samples were taken to the laboratory, extraneous materials were removed; the samples were air-dried, crushed and ground to a fine powder in a mortar passed through a $0.20 \mathrm{~mm}$ sieve. The samples were kept for analysis.

\section{Isolation and purification of humic acid from peat soil sample}

Peatsoil sample $(100 \mathrm{~g})$ was mixed with 1000 $\mathrm{cm}^{3}$ of $0.1 \mathrm{M} \mathrm{NaOH}$ solution, shaken for 3hours and left to stand overnight. Dark-coloured supernatant was obtained and decanted from solid residue. The dark-coloured supernatant was acidified to $(\mathrm{pH}=1.0)$ with $6 \mathrm{M} \mathrm{HCl}$ stirred and allowed to stand for 6 hours. Yellowish brown supernatant and dark-brown precipitate were obtained. The yellowish brown supernatant was decanted followed by centrifuge and discarded. The dark-brown precipitate was mixed with $500 \mathrm{~cm}^{3}$ of $0.1 \mathrm{M} \mathrm{NaOH}$ solution followed by passing through dowex resin. The dark-brown solution was acidified to $(\mathrm{pH}=1.0)$ with $6 \mathrm{M} \mathrm{HCl}$ stirred and allowed to stand for 3 hours. The dark-brown precipitate was washed several times with deionized water. The supernatant was treated with $\mathrm{AgNO}_{3}$ solution until no white precipitate observed. The humic acid was transferred to weighed crucible and dried at $60^{\circ} \mathrm{C}$ in an oven for 12 hours. The humic acid was cooled and dried in the desiccator, weighed and recorded. The obtained humic acid was dried again at $60^{\circ} \mathrm{C}$ for additional 6 hours cooled and dried in the desiccator, weighed and recorded constant weight was obtained (Baruah et al., 2015).

\section{FT-IR analysis}

FT-IR spectra of humic acid sample was analysed using Carry 630 FT-IR Agilent Technologies.

Unhydrolysed compost humic acid

The unhydrolysed humic acid was obtained after isolation and purification of compost humic acid and kept for investigation.

\section{Acid hydrolysis of Peatsoil acid}

Peatsoil humic acid sample (1g) was refluxed for 12 hours at $\left(160^{\circ} \mathrm{C}\right)$ with $50 \mathrm{~cm}^{3}$ of $6 \mathrm{M} \mathrm{HCl}$. The mixture was allowed to cool, decanted, and centrifuged after hydrolysis. The insoluble residues were washed with distilled water via centrifugation several times, and the supernatant was treated with $\mathrm{AgNO}_{3}$ solution until no white precipitate was observed. The residue was thoroughly dried over $\mathrm{CaCl}_{2}$ in a desiccator at room temperature (Chefetz et al., 2002). Finally, the obtained hydrolysed humic acid was kept for investigation. 
BAJOPAS Volume 14 Number 1,June, 2021 Potentiometric Titrations

Potentiometric measurements were carried out using a pH-meter Jenway (model 3510) with combine electrode, the sensitivity of the $\mathrm{pH}$ meter is 0.01 units. The $\mathrm{pH}$ meter was switched on half an hour before starting the titration for initial warm up of the instrument. The instrument was calibrated with an aqueous standard buffer solution of $\mathrm{pH} 4.00$ and 10.0 (borate buffer) prepared from a "Qualigens" buffer tablets.

The following sets of solutions were prepared in a $250 \mathrm{~cm}^{3}$ volumetric flask separately for $\mathrm{pH}$ metric titrations.

(i) $5 \mathrm{~cm}^{3} 0.1 \mathrm{M} \mathrm{HCl}+40 \mathrm{~cm}^{3}$ deionized water

(ii) $5 \mathrm{~cm}^{3} 0.1 \mathrm{M} \mathrm{HCl}+39 \mathrm{~cm}^{3}$ deionized water $+1 \mathrm{~cm}^{3} 0.15 \mathrm{gcm}^{-3}$ humic acid

(iii) $5 \mathrm{~cm}^{3} 0.1 \mathrm{M} \mathrm{HCl}+37 \mathrm{~cm}^{3}$ deionized water $+1 \mathrm{~cm}^{3} 0.15 \mathrm{gcm}^{-3}$ humic acid

$$
+2 \mathrm{~cm}^{3} \quad 0.01 \mathrm{M} \mathrm{Cu} \text { (II) }
$$

The solutions were titrated against standardized $0.110 \mathrm{MNaOH}$ separately. The total volume of each mixture was adjusted to $50 \mathrm{~cm}^{3}$ and the ionic strength of the solutions was maintained constant at by adding appropriate amount of stock solution of $1 \mathrm{M} \mathrm{KNO}_{3}$ (Gamal, 2015; Omar and Ali, 2015). A magnetic stirrer was used to achieve thorough mixing of the interacting solutions at $550 \mathrm{rpm}$. The same set of experimental conditions was applied for potentiometric titration of remaining samples.

\section{Evaluation of pKa of Hydrolysed peat soil Humic Acids}

The proton-ligand formation number $\mathrm{n}_{\mathbf{A}}$ were calculated by Irving and Rossotti expression (Omar and Ali, 2015).

$\mathrm{nA}=\mathrm{Y}-\frac{(\mathrm{V} 2-\mathrm{V1})(\mathrm{No}-\mathrm{Eo})}{(\mathrm{VO}+\mathrm{V1}) \mathrm{TCL}}$ 1

Where: $Y$ is number of dissociable proton, $\left(\mathrm{V}_{2^{-}}\right.$ $V_{1}$ ) is the measure of displacement of the ligand curve relative to acid curve, $\mathrm{N}^{\circ}$ and $\mathrm{E}^{\circ}$ are the resultant concentration of alkali solution, free acid solution, $\mathrm{T}_{\mathrm{cL}}{ }^{\circ}$ is the total ligand concentration, $\mathrm{V}^{\circ}$ is the total volume of titration solution, $V_{1}$ is the volume of alkali added to acid solution, $V_{2}$ is the volume of alkali added to acid solution + ligand solution, acid dissociation constants (pKa - values) of ligand were calculated by algebraic method point wise calculation (Tables 1 ). The dissociation constants (pKa) were calculated according to the following relation:

$\mathrm{pKa}=\mathrm{pH}+\log \left(\frac{n A}{1-n A}\right)$ 2

Where: pKa is the acid dissociation constant, $\mathrm{n}_{\mathrm{A}}$ is the Proton-ligand formation number and $\mathrm{pH}$ is the pH-values (Omar and Ali, 2015).

\section{Determination of metal-ligand stability constants $(\log K)$ of complexes}

The potentiometric measurement for the determination of stability constant of a complex in solution is based on the fact that the redox potential of the couple $\frac{M^{+(m-n)}}{M^{+m}}$ is shifted significantly on complexation of the metal ion with the ligand. This method involves change in hydrogen ion concentration $\left[\mathrm{H}^{+}\right]$due to the displacement or association of one or more protons taking place during complexation reaction. This change can be found out by titrating the solutions containing free acid, acid with ligand, and acid with ligand and metal ion, individually against a standard alkali solution at a constant ionic strength or temperature. Either ionic strength or temperature may be varied for different sets of solutions. In all the cases, the change in the $\mathrm{pH}$ of the solution is measured after each addition of a known amount of alkali to the reaction cell which contains the reaction mixture. The titration curves are then drawn by plotting the measured $\mathrm{pH}$ values against the corresponding volume of alkali added and the stability constants of the complexes are determined from the titration curves by employing $\mathrm{pH}$-metric titration technique given by (Irving and Rossoti).

Metal-ligand stability constants ( $\log \mathrm{K}$ ) were determined by using the following relations:

$$
\bar{n}=\frac{\left(V_{3}-V_{2}\right)\left(E^{0}+N^{0}\right)}{\left(V^{0}+V_{2}\right) \bar{n}_{A} T_{m}^{0}}
$$

and

$$
P L=\log _{10}\left\{\frac{1+\beta_{n}^{H} \frac{1}{[\text { anti } \log \mathrm{pH}]^{\mathrm{n}}}}{\mathrm{T}_{\mathrm{L}}^{0}-n \bar{T}_{m}^{0}} \mathrm{X} \frac{\left(V^{0}+V_{3}\right)}{V^{0}}\right\}
$$


BAJOPAS Volume 14 Number 1,June, 2021

Where $T_{L}, T^{\circ}, E^{\circ}$, and $V^{\circ}$ havethe same significance as in equation (1) above, $T_{m}$ denotes the total concentration of metal present in solution, $V_{3}$ is the volume of metal ions present in solution and $\beta^{H}$ is the overall proton ligand stability constant. The metal-ligand stability constants (log K) were determined by employing point wise computational Method (eq. 5 and 6).

$\operatorname{LogK}_{1}=\log \left(\frac{n}{1-n}\right)+\mathrm{pL}$ .5

$\operatorname{LogK}_{2}=\log \left(\frac{1-n}{2-n}\right)+\mathrm{pL}$ ...6

Where: Log $\mathrm{K}$ is the metal-ligand stability constant, $\mathrm{pL}$ is the Free ligand exponent function, $\mathbf{n}$ is the Average number of ligand attached with metal ion (Janraoet al., 2014). The results obtained were analyzed by an ORIGIN 2016 program using titration data and then the proton-ligand stability constants (pKa) and Metal-ligand stability constant (LogK) calculated (Omar and Ali, 2015).

\section{RESULTS AND DISCUSSION}

Fourier transformed infrared (FT-IR) spectra of isolated humic acid from peat soils Figure 2 had distinct clear absorption bands indicating the presence of major humic acid structural elemental groups such as $\mathrm{H}$ bonded $\mathrm{OH}$ $\left(3680 \mathrm{~cm}^{-1}\right.$ peak $), C=0$ of carbonyl $\left(1721 \mathrm{~cm}^{-1}\right.$ peak), functional groups of aliphatic components $\mathrm{CH}_{2}\left(2918 \mathrm{~cm}^{-1}\right.$ peak) and $\mathrm{C}-\mathrm{O}$ stretching of polysaccharide $\left(1168 \mathrm{~cm}^{-1}\right.$ peak). The positions of the absorption bands of the spectra fell within typical major absorption bands of humic acid which is at frequencies 3680, 2918, 1721, 1168 $\mathrm{cm}^{-1}$. The first peak centred in the vicinity of $3680 \mathrm{~cm}^{-1}$ region is attributed to phenol $\mathrm{OH}$ group bounded by intermolecular $\mathrm{H}$ bonds. The $2918 \mathrm{~cm}^{-1}$ band usually has absorption maximum at $2918 \mathrm{~cm}^{-1}$ which is due to $\mathrm{C}-\mathrm{H}$ stretching of alkane group $\left(\mathrm{CH}_{2}\right)$. The next major absorption band is $1721 \mathrm{~cm}^{-1}$. This band has been commonly ascribed to $\mathrm{C}=\mathrm{O}$ stretching of mainly carboxyl group $(\mathrm{COOH})$ with trace amount of ketones. The last peak was observed at 1168 $\mathrm{cm}^{-1}$ due to $\mathrm{C}-\mathrm{O}$ stretching of polysaccharides and this peak appeared also in the spectra of humic acid from peat soil. The FTIR spectra of the isolated humic acid contained all major characteristic absorption peaks of humic acid. These absorption peaks indicated the presence of the major structural elements of humic acid namely $\mathrm{H}$ bonded $\mathrm{OH}, \mathrm{C}=\mathrm{C}$ of aromatic ring, $\mathrm{C}=\mathrm{O}$ of carbonyl group (both carboxyl and ketonic), $\mathrm{CH}_{2}$ group. This strongly supports the presence of humic acid.

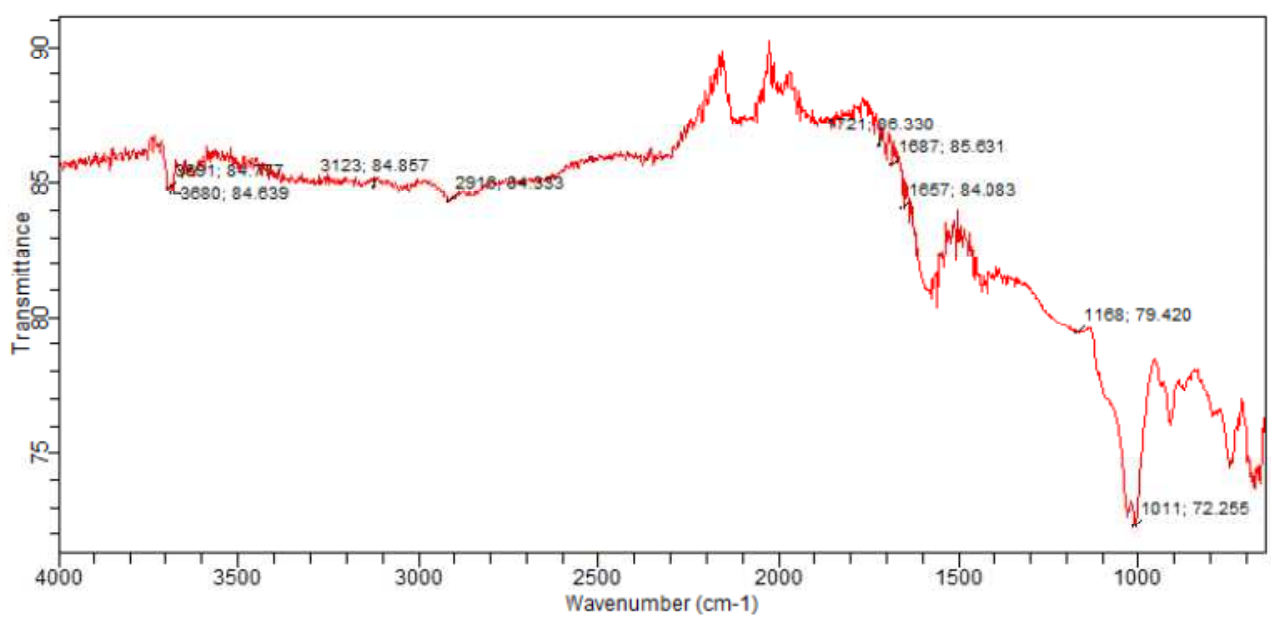

Fig. 2 : FT-IR spectraof peatsoilhumic acid (PSHA)

\section{Evaluation of acid dissociation constant (pka) of acid hydrolysed peat soil humicacid at phenolic group}

The value of the dissociation constant of the peat soil humic acid (PSHA) that underwent acidhydrolysis studied was found to be 8.9299 as shown Table 1, which is lower than the literaturevalues reported by Almeida and Szpoganics, (2015), Borges et al., (2005); Badr et al., (2012)and Fernandes et al,.(2009) of $9.73,9.47$ and 10.30. The difference between the obtained valuesand the reported values in this study might be probably as a result of acid hydrolysis of humicacid. 
BAJOPAS Volume 14 Number 1,June, 2021

Table 1: PKa of (Hydrolysed PSHA)

\begin{tabular}{|l|l|l|l|l|l|l|}
\hline $\mathrm{pH}$ & $\mathrm{BV}_{1}$ & $\mathrm{BV}_{2}$ & $\mathrm{~V}_{2}-\mathrm{V}_{1}$ & $\mathrm{nA}$ & $\log \left(\frac{n A}{1-n A}\right)$ & $\mathrm{pKa}$ \\
\hline 8.50 & 5.30 & 6.29 & 0.99 & 0.3594 & -0.2510 & 8.2490 \\
8.72 & 5.35 & 6.37 & 1.02 & 0.3400 & -0.2880 & 8.4320 \\
9.00 & 5.40 & 6.46 & 1.06 & 0.3141 & -0.3391 & 8.6609 \\
9.22 & 5.45 & 6.55 & 1.10 & 0.2882 & -0.3927 & 8.8273 \\
9.51 & 5.50 & 6.66 & 1.16 & 0.2494 & -0.4786 & 9.0314 \\
9.73 & 5.55 & 6.78 & 1.23 & 0.2041 & -0.5910 & 9.1390 \\
10.00 & 5.60 & 6.90 & 1.30 & 0.1589 & -0.7238 & 9.2762 \\
10.23 & 5.65 & 7.05 & 1.40 & 0.0941 & -0.9835 & 9.2465 \\
10.49 & 5.70 & 7.10 & 1.40 & 0.0941 & -0.9835 & 9.5065 \\
\hline
\end{tabular}

Average pKa $=8.9299 \pm 0.4186$

Table 2: PKa of (Unhydrolysed PSHA)

\begin{tabular}{|l|l|l|l|l|l|l|}
\hline $\mathrm{pH}$ & $\mathrm{BV}_{1}$ & $\mathrm{BV}_{2}$ & $\mathrm{~V}_{2}-\mathrm{V}_{1}$ & $\mathrm{nA}$ & $\log \left(\frac{\boldsymbol{n A}}{1-\boldsymbol{n}}\right)$ & $\mathrm{pKa}$ \\
\hline 8.50 & 5.30 & 5.81 & 0.51 & 0.6619 & 0.2919 & 8.7919 \\
8.72 & 5.35 & 5.90 & 0.55 & 0.6357 & 0.2418 & 8.9618 \\
9.00 & 5.40 & 6.00 & 0.60 & 0.6029 & 0.1813 & 9.1813 \\
9.22 & 5.45 & 6.10 & 0.65 & 0.5701 & 0.1226 & 9.3426 \\
9.51 & 5.50 & 6.20 & 0.70 & 0.5376 & 0.0654 & 9.5754 \\
9.73 & 5.55 & 6.33 & 0.78 & 0.4851 & -0.0259 & 9.7041 \\
10.00 & 5.60 & 6.47 & 0.87 & 0.4262 & -0.1291 & 9.8709 \\
10.23 & 5.65 & 6.62 & 0.99 & 0.3609 & -0.2481 & 9.9819 \\
10.49 & 5.70 & 6.80 & 1.10 & 0.2759 & -0.4690 & 10.0210 \\
\hline
\end{tabular}

Average pKa $=9.4923 \pm 0.4410$

Metal-ligand stability constant ( $\log \mathrm{K}$ )

The stabilityconstants require the accurate values of proton-ligand stability constants (Anil and Maroti, 2008). Metal titration curves crossed over ligand titration curve indicated the formation of complex upon proton release (Santosh, et al., 2011). If the values of n- are within range $0.2-0.8$ and $1.2-18$ this indicates the formation of $1: 1$ and 1:2 complexes (Sayyed and Mazahar, 2012).

The metal (II)-humate stepwise stability constants (log k) at phenolic group (Tables 318)

Table 3: Point-wise method, $\mathrm{Cu}$-(Hydrolysed PSHA)

\begin{tabular}{|l|l|l|l|l|l|l|l|l|}
\hline $\mathrm{pH}$ & $\mathrm{BV}_{1}$ & $\mathrm{BV}_{2}$ & $\mathrm{BV}_{3}$ & $\left(\mathrm{~V}_{3}-\mathrm{V}_{2}\right)$ & $\mathrm{n}$ & $\mathrm{pL}$ & $\log \left(\frac{n}{1-n}\right)$ & LogK $_{1}$ \\
\hline 8.50 & 5.30 & 6.29 & 6.33 & 0.04 & 0.5500 & 2.66 & 0.0871 & 2.7471 \\
8.72 & 5.35 & 6.37 & 6.41 & 0.04 & 0.5714 & 2.43 & 0.1249 & 2.5549 \\
9.00 & 5.40 & 6.46 & 6.50 & 0.04 & 0.6198 & 2.16 & 0.2122 & 2.3722 \\
9.22 & 5.45 & 6.55 & 6.59 & 0.04 & 0.6667 & 1.94 & 0.3010 & 2.2410 \\
\hline
\end{tabular}

LogK $_{1}$ (Average value) $=2.4788 \pm 0.2203$

Table 4: Point-wise method, $\mathrm{Cu}$-(Hydrolysed PSHA)

\begin{tabular}{|l|l|l|l|l|l|l|l|l|}
\hline $\mathrm{pH}$ & $\mathrm{BV}_{1}$ & $\mathrm{BV}_{2}$ & $\mathrm{BV}_{3}$ & $\left(\mathrm{~V}_{3}-\mathrm{V}_{2}\right)$ & $\mathrm{n}$ & $\mathrm{pL}$ & $\log \left(\frac{n-1}{2-n}\right)$ & LogK $_{2}$ \\
\hline 9.51 & 5.50 & 6.66 & 6.73 & 0.07 & 1.3509 & 1.70 & -0.2671 & 1.4329 \\
9.73 & 5.55 & 6.78 & 6.85 & 0.07 & 1.6383 & 1.51 & 0.2467 & 1.7567 \\
10.00 & 5.60 & 6.90 & 6.98 & 0.08 & 2.1783 & 1.31 & -0.2158 & 1.0942 \\
10.23 & 5.65 & 7.05 & 7.13 & 0.08 & 4.1904 & 1.27 & & \\
10.49 & 5.70 & 7.10 & 7.19 & 0.09 & 4.6920 & & & \\
\hline
\end{tabular}

Log $K_{2}($ Average value $)=1.4280 \pm 0.3312$ 
BAJOPAS Volume 14 Number 1,June, 2021

Table 5: Point-wise method, $\mathrm{Cu}$ (Unhydrolysed PSHA)

\begin{tabular}{|l|l|l|l|l|l|l|l|l|}
\hline $\mathrm{pH}$ & $\mathrm{BV}_{1}$ & $\mathrm{BV}_{2}$ & $\mathrm{BV}_{3}$ & $\left(\mathrm{~V}_{3}-\mathrm{V}_{2}\right)$ & $\mathrm{n}$ & $\mathrm{pL}$ & $\log \left(\frac{n}{n-1}\right)$ & Log $_{1}$ \\
\hline 8.50 & 5.30 & 5.81 & 5.85 & 0.04 & 0.2973 & 2.88 & -0.3736 & 2.5064 \\
8.72 & 5.35 & 5.90 & 5.95 & 0.05 & 0.3873 & 2.66 & -0.1992 & 2.4608 \\
9.00 & 5.40 & 6.00 & 6.05 & 0.05 & 0.4044 & 2.38 & -0.1681 & 2.2119 \\
9.22 & 5.45 & 6.10 & 6.15 & 0.06 & 0.5157 & 2.18 & -0.0272 & 2.2072 \\
9.51 & 5.50 & 6.20 & 6.27 & 0.07 & 0.6417 & 1.89 & 0.2530 & 1.1430 \\
\hline
\end{tabular}

$\operatorname{LogK}_{1}($ Average value $)=2.3059 \pm 0.6153$

Table 6:Point-wise method, $\mathrm{Cu}$ (Unhydrolysed PSHA)

\begin{tabular}{|l|l|l|l|l|l|l|l|l|}
\hline $\mathrm{pH}$ & $\mathrm{BV}_{1}$ & $\mathrm{BV}_{2}$ & $\mathrm{BV}_{3}$ & $\mathrm{~V}_{3}-\mathrm{V}_{2}$ & $\mathrm{n}$ & $\mathrm{pL}$ & $\log \left(\frac{n-1}{2-n}\right)$ & $\log \mathrm{K}_{2}$ \\
\hline 9.73 & 5.55 & 6.33 & 6.42 & 0.09 & 0.9000 & 1.69 & & \\
10.00 & 5.60 & 6.47 & 6.58 & 0.11 & 1.2578 & 1.44 & -0.4592 & 0.9808 \\
10.23 & 5.65 & 6.62 & 6.84 & 0.12 & 1.6137 & 1.26 & -0.2010 & 1.4610 \\
10.49 & 5.70 & 6.80 & 6.92 & 0.12 & 2.1052 & 1.03 & & \\
\hline
\end{tabular}

$\operatorname{LogK}_{2}$ (Average value) $=1.2209 \pm 0.3398$

Table 7:Point-wise method, Pb (Hydrolysed PSHA)

\begin{tabular}{|l|l|l|l|l|l|l|l|l|}
\hline $\mathrm{pH}$ & $\mathrm{BV}_{1}$ & $\mathrm{BV}_{2}$ & $\mathrm{BV}_{3}$ & $\left(\mathrm{~V}_{3}-\mathrm{V}_{2}\right)$ & $\mathrm{n}$ & $\mathrm{pL}$ & $\log \left(\frac{n}{1-n}\right)$ & LogK $_{1}$ \\
\hline 8.50 & 5.30 & 6.29 & 6.33 & 0.04 & 0.5500 & 2.66 & 0.0871 & 2.7471 \\
8.72 & 5.35 & 6.37 & 6.41 & 0.04 & 0.5714 & 2.43 & 0.1249 & 2.5549 \\
9.00 & 5.40 & 6.46 & 6.50 & 0.04 & 0.6198 & 2.16 & 0.2122 & 2.3722 \\
9.22 & 5.45 & 6.55 & 6.60 & 0.05 & 0.8333 & 1.96 & 0.6989 & 2.6589 \\
\hline
\end{tabular}

Log $_{\mathbf{1}}($ Average value $)=2.5832 \pm 0.1614$

Table 8:Point-wise method, Pb-(Hydrolysed PSHA)

\begin{tabular}{|l|l|l|l|l|l|l|l|l|}
\hline $\mathrm{pH}$ & $\mathrm{BV}_{1}$ & $\mathrm{BV}_{2}$ & $\mathrm{BV}_{3}$ & $\left(\mathrm{~V}_{3}-\mathrm{V}_{2}\right)$ & $\mathrm{n}$ & $\mathrm{pL}$ & $\log \left(\frac{n-1}{2-n}\right)$ & $\log \mathrm{K}_{2}$ \\
\hline 9.51 & 5.50 & 6.66 & 6.71 & 0.05 & 0.9650 & 1.67 & & \\
9.73 & 5.55 & 6.78 & 6.83 & 0.05 & 1.1702 & 1.44 & & \\
10.00 & 5.60 & 6.90 & 6.90 & 0.05 & 1.4864 & 1.22 & -0.0237 & 1.1963 \\
10.23 & 5.65 & 7.05 & 7.10 & 0.05 & 2.0190 & 1.09 & & \\
10.49 & 5.70 & 7.10 & 7.17 & 0.07 & 3.6492 & 1.00 & & \\
\hline
\end{tabular}

Log $K_{2}$ (Average value) $=1.1963$

Table 9: Point-wise method, Pb (Unhydrolysed PSHA)

\begin{tabular}{|l|l|l|l|l|l|l|l|l|}
\hline $\mathrm{pH}$ & $\mathrm{BV}_{1}$ & $\mathrm{BV}_{2}$ & $\mathrm{BV}_{3}$ & $\mathrm{~V}_{3}-\mathrm{V}_{2}$ & $\mathrm{n}$ & $\mathrm{pL}$ & $\begin{array}{l}\text { Log } \\
\left(\frac{n}{n-1}\right)\end{array}$ & Log $\mathrm{K}_{1}$ \\
\hline 8.50 & 5.30 & 5.81 & 5.85 & 0.04 & 0.2973 & 2.88 & -0.3736 & 2.5064 \\
8.72 & 5.35 & 5.90 & 5.94 & 0.04 & 0.3099 & 2.66 & -0.5477 & 2.3123 \\
9.00 & 5.40 & 6.00 & 6.05 & 0.05 & 0.4044 & 2.38 & -0.1681 & 2.2119 \\
9.22 & 5.45 & 6.10 & 6.15 & 0.06 & 0.5157 & 2.18 & 0.0272 & 2.2072 \\
9.51 & 5.50 & 6.20 & 6.26 & 0.07 & 0.6417 & 1.89 & 0.2530 & 2.1430 \\
9.73 & 5.55 & 6.40 & 6.40 & 0.07 & 0.7000 & 1.67 & 0.3680 & 2.0380 \\
\hline
\end{tabular}

LogK $_{1}$ (Average value) $=2.2364 \pm 0.1602$

Table 10: Point-wise method, Pb (Unhydrolysed PSHA)

\begin{tabular}{|l|l|l|l|l|l|l|l|l|}
\hline $\mathrm{pH}$ & $\mathrm{BV}_{1}$ & $\mathrm{BV}_{2}$ & $\mathrm{BV}_{3}$ & $\mathrm{~V}_{3}-\mathrm{V}_{2}$ & $\mathrm{n}$ & $\mathrm{pL}$ & $\log \left(\frac{n-1}{2-n}\right)$ & $\log \mathrm{K}_{2}$ \\
\hline 10.00 & 5.60 & 6.47 & 6.55 & 0.08 & 1.9503 & 1.41 & & \\
10.23 & 5.65 & 6.62 & 6.72 & 0.11 & 1.4792 & 1.26 & -0.0361 & 1.2239 \\
\hline
\end{tabular}

$\operatorname{LogK}_{2}$ (Average value) $=1.2239$

Table 11: Point-wise method, Mg (Hydrolysed PSHA)

\begin{tabular}{|l|l|l|l|l|l|l|l|l|}
\hline $\mathrm{pH}$ & $\mathrm{BV}_{1}$ & $\mathrm{BV}_{2}$ & $\mathrm{BV}_{3}$ & $\left(\mathrm{~V}_{3}-\mathrm{V}_{2}\right)$ & $\mathrm{n}$ & $\mathrm{pL}$ & $\log \left(\frac{n}{n-1}\right)$ & LogK $_{1}$ \\
\hline 8.50 & 5.30 & 6.29 & 6.31 & 0.02 & 0.2750 & 2.64 & -0.4290 & 2.2110 \\
8.72 & 5.35 & 6.37 & 6.39 & 0.02 & 0.2858 & 2.42 & -0.3978 & 2.0222 \\
9.00 & 5.40 & 6.46 & 6.49 & 0.03 & 0.4648 & 2.14 & -0.0612 & 2.0788 \\
9.22 & 5.45 & 6.55 & 6.59 & 0.04 & 0.6667 & 1.94 & 0.3010 & 2.2410 \\
\hline
\end{tabular}

$\log _{\mathbf{1}}($ Average value) $=2.1382 \pm 0.1046$ 
BAJOPAS Volume 14 Number 1,June, 2021

Table 12: Point-wise method, Mg (Hydrolysed PSHA)

\begin{tabular}{|l|l|l|l|l|l|l|l|l|}
\hline $\mathrm{pH}$ & $\mathrm{BV}_{1}$ & $\mathrm{BV}_{2}$ & $\mathrm{BV}_{3}$ & $\left(\mathrm{~V}_{3}-\mathrm{V}_{2}\right)$ & $\mathrm{n}$ & $\mathrm{pL}$ & $\log \left(\frac{n-1}{2-n}\right)$ & LogK $_{2}$ \\
\hline 9.51 & 5.55 & 6.66 & 6.71 & 0.05 & 0.9650 & 1.67 & & \\
9.73 & 5.55 & 6.78 & 6.84 & 0.06 & 1.4042 & 1.47 & -0.1686 & 1.3014 \\
10.00 & 5.60 & 6.90 & 6.93 & 0.06 & 1.7838 & 1.23 & 0.5593 & 1.7893 \\
10.23 & 5.65 & 7.05 & 7.10 & 0.06 & 3.1429 & 1.10 & & \\
10.49 & 5.70 & 7.10 & 7.18 & 0.07 & 3.6492 & 0.83 & & \\
\hline
\end{tabular}

LogK $_{2}($ Average value $)=1.5453 \pm 0.3450$

Table 13: Point-wise method, Mg (Unhydrolysed PSHA)

\begin{tabular}{|l|l|l|l|l|l|l|l|l|}
\hline $\mathrm{pH}$ & $\mathrm{BV}_{1}$ & $\mathrm{BV}_{2}$ & $\mathrm{BV}_{3}$ & $\mathrm{~V}_{3}-\mathrm{V}_{2}$ & $\mathrm{n}$ & $\mathrm{pL}$ & $\log \left(\frac{n}{n-1}\right)$ & $\operatorname{Log~}_{1}$ \\
\hline 8.50 & 5.30 & 5.81 & 5.85 & 0.04 & 0.2973 & 2.88 & -0.3736 & 2.5064 \\
8.72 & 5.35 & 5.90 & 5.94 & 0.04 & 0.3099 & 2.66 & -0.3477 & 2.3123 \\
9.00 & 5.40 & 6.00 & 6.04 & 0.04 & 0.3236 & 2.38 & -0.3202 & 2.0598 \\
9.22 & 5.45 & 6.10 & 6.15 & 0.05 & 0.4297 & 2.17 & -0.1230 & 2.0470 \\
9.51 & 5.50 & 6.20 & 6.26 & 0.06 & 0.5500 & 1.89 & 0.0871 & 1.9771 \\
9.73 & 5.55 & 6.33 & 6.40 & 0.07 & 0.7000 & 1.67 & 0.3680 & 2.0380 \\
\hline
\end{tabular}

LogK $_{1}$ (Average value) $=2.1568 \pm 0.2069$

Table 14: Point-wise method, Mg (Unhydrolysed PSHA)

\begin{tabular}{|l|l|l|l|l|l|l|l|l|}
\hline $\mathrm{pH}$ & $\mathrm{BV}_{1}$ & $\mathrm{BV}_{2}$ & $\mathrm{BV}_{3}$ & $\mathrm{~V}_{3}-\mathrm{V}_{2}$ & $\mathrm{n}$ & $\mathrm{pL}$ & $\log \left(\frac{n-1}{2-n}\right)$ & $\log \mathrm{K}_{2}$ \\
\hline 10.00 & 5.60 & 6.47 & 6.55 & 0.08 & 0.9148 & 1.41 & & \\
10.23 & 5.65 & 6.62 & 6.71 & 0.09 & 1.2102 & 1.20 & -0.5749 & 0.6251 \\
10.49 & 5.70 & 6.80 & 6.92 & 0.09 & 1.5968 & 1.03 & 0.1703 & 1.2003 \\
\hline
\end{tabular}

LogK $_{2}$ (Average value) $=0.9127 \pm 0.4070$

Table15:Point-wise method, Cd (Hydrolysed PSHA)

\begin{tabular}{|l|l|l|l|l|l|l|l|l|}
\hline $\mathrm{pH}$ & $\mathrm{BV}_{1}$ & $\mathrm{BV}_{2}$ & $\mathrm{BV}_{3}$ & $\left(\mathrm{~V}_{3}-\mathrm{V}_{2}\right)$ & $\mathrm{n}$ & $\mathrm{pL}$ & $\log \left(\frac{n}{1-n}\right)$ & LogK $_{1}$ \\
\hline 8.50 & 5.30 & 6.29 & 6.31 & 0.02 & 0.2750 & 2.64 & -0.4210 & 2.2190 \\
8.72 & 5.35 & 6.37 & 6.40 & 0.03 & 0.4286 & 2.42 & -0.1249 & 2.2951 \\
9.00 & 5.40 & 6.46 & 6.49 & 0.03 & 0.4648 & 2.14 & -0.0612 & 2.0788 \\
9.22 & 5.45 & 6.55 & 6.59 & 0.04 & 0.6667 & 1.96 & 0.3010 & 2.2610 \\
9.51 & 5.55 & 6.66 & 6.70 & 0.04 & 0.7720 & 1.67 & 0.5297 & 2.1997 \\
\hline
\end{tabular}

LogK $_{\mathbf{1}}$ (Average value) $=2.2108 \pm 0.0825$

Table 16: Point-wise method, Cd (Hydrolysed PSHA)

\begin{tabular}{|l|l|l|l|l|l|l|l|l|}
\hline $\mathrm{pH}$ & $\mathrm{BV}_{1}$ & $\mathrm{BV}_{2}$ & $\mathrm{BV}_{3}$ & $\left(\mathrm{~V}_{3}-\mathrm{V}_{2}\right)$ & $\mathrm{n}$ & $\mathrm{pL}$ & $\log \left(\frac{n-1}{2-n}\right)$ & Log $_{2}$ \\
\hline 9.73 & 5.55 & 6.78 & 6.83 & 0.06 & 1.4042 & 1.47 & -0.1686 & 1.3014 \\
10.00 & 5.60 & 6.90 & 6.95 & 0.06 & 1.7838 & 1.23 & 0.5593 & 1.7893 \\
10.23 & 5.65 & 7.05 & 7.10 & 0.06 & 3.1429 & 1.09 & & \\
10.49 & 5.70 & 7.10 & 7.16 & 0.06 & 3.1429 & 0.89 & & \\
& & & & & & & & \\
\hline
\end{tabular}

$\operatorname{LogK}_{2}$ (Average value) $=1.5453 \pm 0.3450$

Table 17: Point-wise method, Cd (Unhydrolysed PSHA)

\begin{tabular}{|l|l|l|l|l|l|l|l|l|}
\hline $\mathrm{pH}$ & $\mathrm{BV}_{1}$ & $\mathrm{BV}_{2}$ & $\mathrm{BV}_{3}$ & $\mathrm{~V}_{3}-\mathrm{V}_{2}$ & $\mathrm{n}$ & $\mathrm{pL}$ & $\log \left(\frac{n}{n-1}\right)$ & $\operatorname{Log~}_{1}$ \\
\hline 8.50 & 5.30 & 5.81 & 5.86 & 0.05 & 0.3717 & 2.88 & -0.2280 & 2.6520 \\
8.72 & 5.35 & 5.90 & 5.95 & 0.05 & 0.3873 & 2.66 & -0.1992 & 2.4608 \\
9.00 & 5.40 & 6.00 & 6.06 & 0.06 & 0.4853 & 2.38 & -0.0255 & 2.3545 \\
9.22 & 5.45 & 6.10 & 6.16 & 0.06 & 0.5157 & 2.18 & -0.0272 & 2.2072 \\
9.51 & 5.50 & 6.20 & 6.27 & 0.07 & 0.6417 & 1.89 & 0.2530 & 1.1430 \\
9.73 & 5.55 & 6.33 & 6.41 & 0.08 & 0.8000 & 1.69 & 0.6020 & 2.2920 \\
& & & & & & & & \\
\hline
\end{tabular}

$\operatorname{LogK}_{1}($ Average value $)=2.2516 \pm 0.5380$ 
BAJOPAS Volume 14 Number 1,June, 2021

Table 18: Point-wise method, Cd (Unhydrolysed PSHA)

\begin{tabular}{|l|l|l|l|l|l|l|l|l|}
\hline $\mathrm{pH}$ & $\mathrm{BV}_{1}$ & $\mathrm{BV}_{2}$ & $\mathrm{BV}_{3}$ & $\mathrm{~V}_{3}-\mathrm{V}_{2}$ & $\mathrm{n}$ & $\mathrm{pL}$ & $\log \left(\frac{n-1}{2-n}\right)$ & $\log \mathrm{K}_{2}$ \\
\hline 10.00 & 5.60 & 6.47 & 6.57 & 0.10 & 1.1434 & 1.43 & & \\
10.23 & 5.65 & 6.62 & 6.72 & 0.10 & 1.3448 & 1.23 & -0.2788 & 0.9512 \\
10.49 & 5.70 & 6.80 & 6.90 & 0.10 & 1.7742 & 1.03 & 0.5351 & 1.5651 \\
\hline
\end{tabular}

$\operatorname{LogK}_{2}($ Average value $)=1.2581 \pm 0.4340$

Table 19: Stepwise and overall Stability constants of thehydrolysed and unhydrolysed divalent metal (II) complexes

\begin{tabular}{|c|c|c|c|}
\hline Chelates & LogK $_{1}$ & $\log _{2}$ & Log $\beta$ \\
\hline [Cu (Hydrolysed PSHA-1) $\left.{ }_{2}\right]$ & 2.4788 & 1.4280 & 3.9068 \\
\hline$\left[\mathrm{Pb}(\text { Hydrolysed PSHA-1) })_{2}\right]$ & 2.5832 & 1.1963 & 3.7795 \\
\hline$\left[\mathrm{Cd}(\text { Hydrolysed PSHA-1 })_{2}\right]$ & 2.2108 & 1.5453 & 3.7561 \\
\hline$\left[\mathrm{Mg}(\text { Hydrolysed PSHA-1 })_{2}\right]$ & 2.1382 & 1.5453 & 3.6835 \\
\hline [Cu (Unhydrolysed PSHA-1) & 2.3059 & 1.2209 & 3.5268 \\
\hline$[\mathrm{Pb}$ (Unhydrolysed PSHA-1) 2$]$ & 2.2364 & 1.2239 & 3.4603 \\
\hline [Cd (Unhydrolysed PSHA-1) 2 ] & 2.2516 & 1.2581 & 3.5097 \\
\hline$[\mathrm{Mg}$ (Unydrolysed PSHA-1) & 2.1568 & 0.9127 & 3.0695 \\
\hline
\end{tabular}

The results obtained (Table19) shows the stepwise and overall stability constants to be not high indicating low stability of the complexes, because the solubility of most metal ions in the basic $\mathrm{pH}$ range is minimal due to metal hydroxide precipitation (Karimi, 2017). In general, the stepwise stability constants $\left(K_{1}\right.$ and $K_{2}$ ) follow the order $K_{1}>K_{2}$ for the copper, lead, magnesium and cadmium complexes respectively. The steady decrease of the values with increasing number of ligands is in agreement with the prediction made by researchers (Na'aliya, 2013). The decrease could be attributed to the fact that as the number of the ligands (Humate ions) that enters the coordination zone increases the aqua molecules available for replacement by the ligands become less. Thus, the metal ions become less electron loving with progressive intake of the ligand and this results in the decrease in the values of the constants (Na'aliya, 2013). Also the stability of the complexes is influenced by the size and number of the chelate rings(Mackay and Mackay,2002).All the complexes form rings in their structure as humate, a bidentate ligand, bond the metal ions in the ratio 1:2 (Boguta and Sokolowska, 2016) forming chelate rings. The values of the overall stability constants $(\log \beta)$ obtained for humate complexes are not high indicating low stability as the values are not high. LogK values for copper-humates (Table 3 to 6) obtained in this study are lower than those reported for the complexes of humic acids (Pandey et al., 2015; Dinu, 2013; Kaschl et al., 2010 and Gilbeto and Jorg, 2001). The values of LogK(Table 7 to 10 ) forlead-humates are lower than those reported for the lead in the literature (Dinu, 2013; Gilbeto and Jorg 2001). Log K values(Table 11 to 14 ) for magnesium-humates obtained in this study are close to those reported by (Pandey et al., 2015). Log K values of cadmium-humates (Table 15 to 18 ) obtained in this work near to the one reported by (Dinu, 2013 and Pandey et al., 2015).The difference between the reported values and the values obtained in this study might be probably as a result of acid hydrolysis of humic acid. The values of the overall stability constants $(\log \beta)$ of the copper humates complexes presented in Table 19 is high than that of other metal humate complexes, show relatively high stability of CuHA complexes, show the following order of stability: $\mathrm{Cu}>\mathrm{Pb}>\mathrm{Cd}>\mathrm{Mg}$; which are in close agreement to the findings of (Dinu, 2013 and Pandey et al., 2015).The high stability of Cuhumate chelate could be attributed to the existence of coordinate covalent bond between the complexing agents and the $\mathrm{Cu}^{2+}$ ions. Since, $\mathrm{Cu}^{2+}$ being a metal of the transitional series with $3 d^{9}$ electronic configurations can accept the electrons from the complexing agents. Similarly, the low stabilities of $\mathrm{Pb}, \mathrm{Cd}$ and $\mathrm{Mg}$ complexes could be explained by that $\mathrm{Pb}^{2+}$ with $6 s^{2}, \mathrm{Cd}^{2+}$ with $4 \mathrm{~d}^{10}$ and $\mathrm{Mg}^{2+}$ with $2 \mathrm{p}^{6}$ their electronic configuration has a completely filled $\mathrm{d}, \mathrm{p}$ and $\mathrm{s}$ orbitals. Moreover, the stabilities of metal ions with hydrolysed humic acid from peat soil were higher than those with unhydrolysed humic acid from peat soil; which is ascribed to the high content of acidity in hydrolysed humic acid than unhydrolysed humic acid. 
BAJOPAS Volume 14 Number 1,June, 2021 CONCLUSION

The values of logk for $\mathrm{Cu}(\mathrm{II})$ hydrolysed humic acid complex was higher followed by $\mathrm{Pb}$ (II), $\mathrm{Cd}(\mathrm{II})$ and $\mathrm{Mg}$ (II) hydrolysed humic acid complexes as compared with metal(II) unhydrolysed humic acid complexes. This indicates acid hydrolysis of humic acid can

\section{REFERENCES}

Almeida, V.R. and Szpoganicz, B. (2015). Humic Acid Potentiometric Response Patterns:Out- of Equilibrium Properties and Species Distribution Modelling. Chemical. Biol. Technol. Agric. 2: 17.

Anđelković, T., Nikolić, R., Bojić, A.,Anđelković, D., and Nikolic G.,(2010). Binding of Cadmium to Soil Humic Acid as A Function of Carboxyl Group Content. Macedonian Journal of Chemistry and Chemical Engineering.29(2): 215-224.

Anil, B. N. and Maroti, N. (2008). Studies on Influence of Die-Lectric Constants on Complex Equilibria between Substituted Py-Razalines and Lanthanide Metal Ions pH-Metrically. Amer.-Euras. scient. Res. 3(2): 212-216.

Ashok, K., Pandey, S. P. and Misra, V (2000). Stability Constants of Metal-Humic Acid Complexes and its Role in Environmental Detoxification. Journal of Ecotoxicology and Environmental Safety. 47(2):157-200.

Badr, M. H., El-Halafawi, M. H. and Abd El-al Zeid, E. R. (2012). Comparison Between the Effect of Ionic Strength on Acidity and Dissociation Constants of Humic Acids Extracted from Sewage Sludge and Nile Water Hyacinth Composts.Global Journal of Environmental Research 6 (1): 36-43.

Baruah, M.K., Borah, D., Saikia, P.P., Paul, S., Sharma, T. (2015). Evaluation of pKa Values of Soil Humic Acids and their Complexation Properties. International Journal of Plant \& Soil Science 6(4) : 218-228.

Boguta, P. Sokolowska, Z. (2016). Interactions of $\mathrm{Zn}$ (II) Ions with Humic Acids Isolated from Various Types of Soils. Effect of $\mathrm{pH}, \mathrm{Zn}$ Concentrations and Humic Acids Chemical Properties. Journal of Geochemical Explaration 168. 119-126.

Borges, F., Guimaraes, C., Lima, L.F.C., Pinto, I. and Reis, S.(2005). Potentiometric Studies on the Complexation of Copper(II) by Phenolic Acids as Discrete Ligand Models of enhance the complexation behavior of humic acid with metal (II) ions. However, the higher values of $\log \beta$ for $\mathrm{Cu}(\mathrm{II}), \mathrm{Pb}(\mathrm{II}), \mathrm{Cd}(\mathrm{II})$ and $\mathrm{Mg}(\mathrm{II})$ hydrolysed humic acid complexes indicates more stable stepwise complexes formed as compared with $\mathrm{Cu}(\mathrm{II}), \mathrm{Pb}$ (II), $\mathrm{Cd}$ (II) and $\mathrm{Mg}(\mathrm{II})$ unhydrolysed humic acid complexes.

Humic Substances Talanta 66 (2005) 670-673.

Chefetz, B., Salloum, M. J., Deshmulkin, A. P. and Hatcher, P. (2002). Structural Components of Humic Acids as Determined by Chemical Modifications and Carbon-13 NMR, Pyrolysis, and Thermochemolysis- Gas Chromatography/Mass Spectrometry. Soil Science Society of American Journal Abstract Division S-2- Soil Chemistry66. 1159-1171.

Dinu, M. I. (2013). Metals Complexation with Humic Acids in Surface Water of Different Environ. Sci. Technol. 31(1): 1-17.

Fernandes, A.N., Giacomelli, C., Giovanela, M. Vaz, D.V. Szpoganicz, B. and Maria M. D. (2009). Potentiometric Acidity Determination in Humic Substances Influenced by Different Analytical Procedures.J. Braz. Chem. Soc. 20 (9):14.

Gamal, A. H. (2015). Stability Constants of Rhenium (V) Metal Complexes with Selected Drugs. Pyrex Journal of Research in Environmental Studies. 2(2): 006-014.

Janrao, D. M., Pathan, J., Kayande, D.D., and Mulla, J.J. (2014). An Over View of Potentiometric Determination of Stability Constants of Metal Complexes. Sci. Revs. Chem. Commun.: 4(1), 2014, 11-24.

Karimi, H. (2017). Effect of pH and Initial Pb(II) Concentration on the Lead Removal Efficiency from Waste Water Using $\mathrm{Ca}(\mathrm{OH})_{2}$. International Journal of Water and Waste Water Treatment 3.2

Kaschl, A. Romheld, V. and Chen, Y. (2010). Binding of Cadmium, Copper and Zinc to Humic Substances Originating from Municipal Solid Waste Compost. Israel Journal of Chemistry Vol. 42(1): 89-98.

Kostic, I. S., Tatjana, P, A., Nikolic, R. S., Cvetkovic, T. P., Pavlovic, D. D., Aleksandar, L.J. and Bojic, A. (2012). Comparative Study of Binding Strengths of Heavy Metals with Humic Acid. J.serb. Chem. Soc. 76(9) pp 1-20. 
BAJOPAS Volume 14 Number 1,June, 2021

Na'aliya, J. (2013). Determination of Stepwise Stability Constants and Gibbs free Energy Change of Trisprolina to Complexes of some Divalent Transition Metal ions. Bayero Journal of Pure and Applied Sciences 6(2): 112-114.

Omar, A. A. and Ali, E. A. (2015). Potentiometric Studies on Complexes of $\mathrm{Cr}$ (III) and $\mathrm{Zr}$ (IV) with some Carboxylic Acids. International Journal of Advanced Chemistry, 3(1) 25-

37.

Pandey, A. K. Pandey, S. D. and Misr, V. (2015).Stability Constants of Metal- Humic Acid Complexes and Its Role in Environmental Detoxification. J. Ecotoxicology and Environmental Safety. 47(1):195-200.

Ram, N. and Raman, K.V. (1984). Stability Constants of Complexes of Metals with
Humicand Fuvic Acids under Non- acidConditions. Journal of Plant Nutrition and Soil Sciences.

147:171-176.

Santosh, D. D., Ashok, B. K., Vijay, J. T., Shivraj, G. W. and Vinay, V. W. (2011). Potentiometric Studies of Elec-Trolyte Effects on Complex Equilibria of Some Substituted 5-(2-hydroxy Phenyl) Pyrazoles. Der pharm. 3 (6): 75-83.

Sayyed, H. and Abdul Rahim, M. F. (2012). Studies of Binary Complexes of Metal Ions with Mandelic Acid by Potentiometry. Chem. J. 02 (6): 206209.

Shirvani, M. Moradian, E. Khalili, B. Bakhtiary, S. (2015). Interaction of $\mathrm{Cd}$ and $\mathrm{Pb}$ with Humate-Palygorskite and HumateSepiolite Complexes. Journal of water, air and pollution 3: 220-228. 


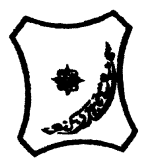

Bayero Journal of Pure and Applied Sciences, 14(1): 54 - 63

Received: November, 2020

Accepted: April, 2021

ISSN $2006-6996$

\title{
STABILITY CONSTANTS OF COMPLEXES OF METAL IONS WITH PEATSOIL HUMIC ACIDS UNDER NON-ACID-CONDITIONS
}

\author{
${ }^{* 1}$ Sabo, Yusuf ${ }^{2}$ Jimoh, W.L.O., ${ }^{3}$ Isa Baba Koki and ${ }^{4}$ Sholadoye, Q. 0. \\ ${ }^{1}$ Department of Pure and Industrial Chemistry, Bayero University, Kano \\ ${ }^{3}$ Department of Chemistry, Yusuf Maitama Sule University Kano. P.M.B. 3220 Kano, Nigeria. \\ ${ }^{4}$ Department of Chemistry, Nigerian Police Academy, Wudil, Kano-Nigeria
}

*Correspondence E-mail; saboyusuf18@yahoo.com

ABSTRACT

Stability constants of complexes of four divalent metal ions viz. $\mathrm{Cu}^{2+}, \mathrm{Pb}^{2+}, \mathrm{Mg}^{2+}$ and $\mathrm{Cd}^{2+}$ with humic acids (HA) were determined by potentiometric titration of humic acids with the corresponding salt of the divalent metals in aqueous media under non-acid-condition. The log $K$ (logarithm of the stability constant) ranged from 1.0942 to 2.7471 for metalhumic acid complexes were determined using point-wise computational method. The order of stability constants were obtained as follows: $\mathrm{Cu}>\mathrm{Pb}>\mathrm{Cd}>\mathrm{Mg}$ for metal $-\mathrm{HA}$ complexes respectively, indicating a higher degree of complexation with Cu metal ion.

Keywords: stability constant, humic acid, potentiometric titration, divalent metals, acid hydrolysis.

\section{NTRODUCTION}

The stability constant of a complex is the numerical expression of its stability and provides a quantitative measure of affinity of the metal ion to the complexing agent. An understanding of the relative stability of metal-complexes helps in predicting the behavior of metal ions in the soil (Ram and Raman, 1982). Extensive researches has been done to determine the stability constants of the complexes formed between humic acid (HA) with a number of metal ions. Ashok et al., (2000) reported that humic acid with hydroxyl, phenoxyl and carboxyl reactive groups can form coordination compound with metal ions at $\mathrm{pH}$ 3.5. The stability constants(Log K) for different metalhumic acid complexes indicated the following order of the stabilities of complexes formed between humic acid and metal ion, $\mathrm{Cu}>\mathrm{Fe}$ $>\mathrm{Pb}>\mathrm{Ni}>\mathrm{Co}>\mathrm{Ca}>\mathrm{Cd}>\mathrm{Zn}>\mathrm{Mn}>\mathrm{Mg}$. Andelkovic et al., (2010) investigated the binding of $\mathrm{Cd}$ (II) to soil humic acid at pH 6.5 and in $0.1 \mathrm{M} \mathrm{KNO}_{3}$ ionic medium. The stability constant for binding indicating greater stability in the case when carboxyl groups are involved in complexation reaction. Kostic et al.,(2012) investigated the complexation of humic acid with certain heavy metal ions (Co(II), $\mathrm{Ni}(\mathrm{II}), \mathrm{Cu}(\mathrm{II})$,
$\mathrm{Zn}(\mathrm{II})$, and $\mathrm{Pb}(\mathrm{II})$. The experiment was performed at $25^{\circ} \mathrm{C}$, at pH 4.0 and ionic strength of $0.01 \mathrm{M}$. Stability constant of complex between $\mathrm{Pb}$ (II) ions and humic acid is greater than stability constants of other investigated metalhumate complexes. Bogata and Sokolowska (2016) analyses the interaction between humic acids from different soils and $\mathrm{Zn}$ (II) ions at wide concentration ranges and at $\mathrm{pH} 5$. Studies have showed significant impact of $\mathrm{Zn}$ concentration, $\mathrm{pH}$ and some properties of humic acids with zinc.But all of these studies were limited to acidic $\mathrm{pH}$ range. Therefore, the present study was carried out to determine and compare the stability constants of complexes of metal ions with hydrolysed peat soil humic acid and unhydrolysed peat soil humic under non-acid conditions.

\section{MATERIALS AND METHODS}

Analytical grade chemicals used includes hydrochloric acid $(\mathrm{HCl})$, nitric acid $\left(\mathrm{HNO}_{3}\right)$, sodium hydroxide $(\mathrm{NaOH})$, lead nitrate $\mathrm{Pb}\left(\mathrm{NO}_{3}\right)_{2}$, copper nitrate $\mathrm{Cu}\left(\mathrm{NO}_{3}\right)_{2} \cdot 3 \mathrm{H}_{2} \mathrm{O}$, cadmium nitrate $\mathrm{Cd}\left(\mathrm{NO}_{3}\right)_{2} \cdot 4 \mathrm{H}_{2} \mathrm{O}$, magnesium nitrate $\mathrm{Mg}\left(\mathrm{NO}_{3}\right)_{2} \cdot 6 \mathrm{H}_{2} \mathrm{O}$, potassium nitrate $\left(\mathrm{KNO}_{3}\right)$, calcium chloride $\left(\mathrm{CaCl}_{2}\right)$, (sigma-Aldrich). Dowex 50WX8, (20-50 mesh) from Fluka. 


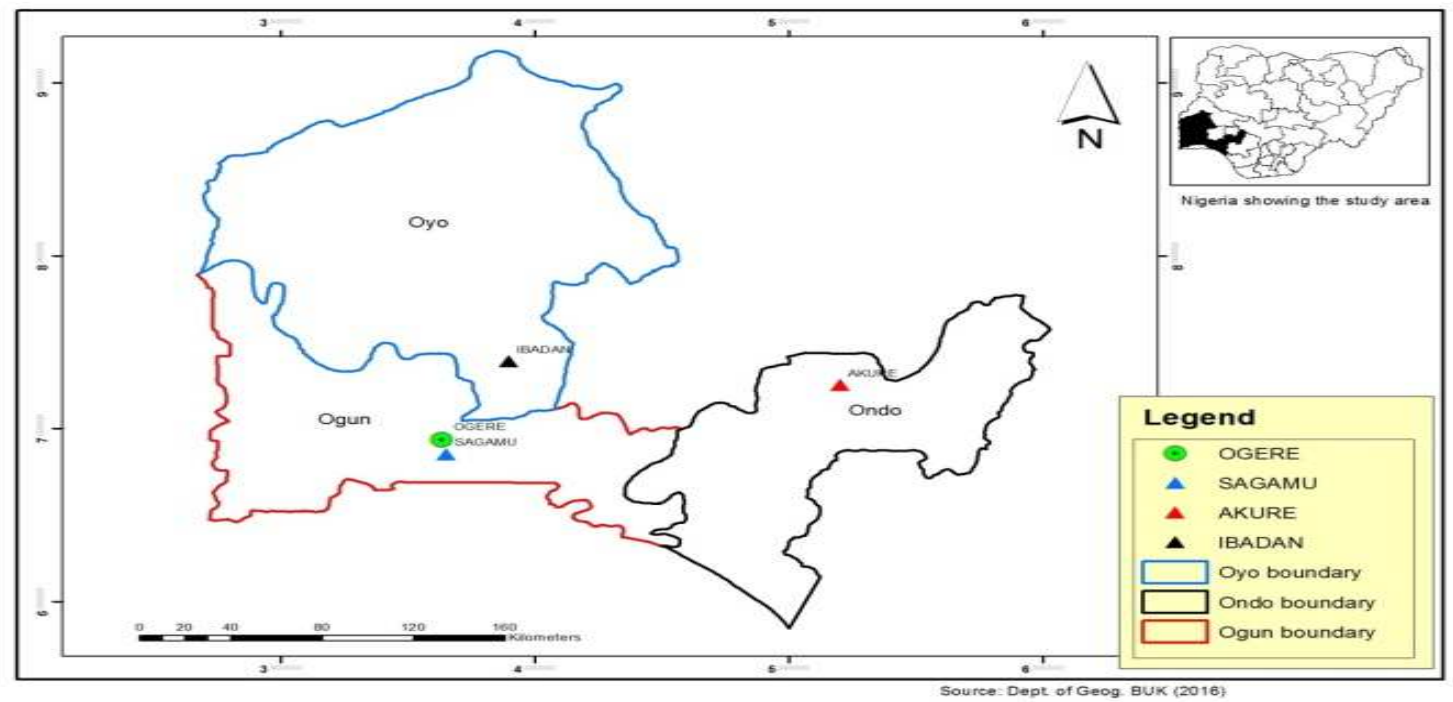

Figure 1: Map showing the sampling point at Sagamu Town, Ogun State.

\section{Description of Sampling Area}

Sagamu has geographical coordinates between $6^{\circ} 50^{\prime}$ north; $3^{\circ} 38^{\prime}$ east is located in south western region of Nigeria. The region has tropical wet and dry climate with a lengthy wet season and relatively constant temperatures throughout the course of the year. Wet season runs from March to October, November to December forms the region dry season. The vegetation type of the region is savannah which is really grassland with small bushes and occasional big trees. Grassland soils have substantially higher organic matter content than forest soils (Novackova, 2011).

\section{Sample Collection}

The Peatsoil samples were collected from four different sampling points $(0-10 \mathrm{~cm}$ depth) in Sagamu into polyethylene bag with plastic spoons. Samples were taken to the laboratory, extraneous materials were removed; the samples were air-dried, crushed and ground to a fine powder in a mortar passed through a $0.20 \mathrm{~mm}$ sieve. The samples were kept for analysis.

\section{Isolation and purification of humic acid from peat soil sample}

Peatsoil sample $(100 \mathrm{~g})$ was mixed with 1000 $\mathrm{cm}^{3}$ of $0.1 \mathrm{M} \mathrm{NaOH}$ solution, shaken for 3hours and left to stand overnight. Dark-coloured supernatant was obtained and decanted from solid residue. The dark-coloured supernatant was acidified to $(\mathrm{pH}=1.0)$ with $6 \mathrm{M} \mathrm{HCl}$ stirred and allowed to stand for 6 hours. Yellowish brown supernatant and dark-brown precipitate were obtained. The yellowish brown supernatant was decanted followed by centrifuge and discarded. The dark-brown precipitate was mixed with $500 \mathrm{~cm}^{3}$ of $0.1 \mathrm{M} \mathrm{NaOH}$ solution followed by passing through dowex resin. The dark-brown solution was acidified to $(\mathrm{pH}=1.0)$ with $6 \mathrm{M} \mathrm{HCl}$ stirred and allowed to stand for 3 hours. The dark-brown precipitate was washed several times with deionized water. The supernatant was treated with $\mathrm{AgNO}_{3}$ solution until no white precipitate observed. The humic acid was transferred to weighed crucible and dried at $60^{\circ} \mathrm{C}$ in an oven for 12 hours. The humic acid was cooled and dried in the desiccator, weighed and recorded. The obtained humic acid was dried again at $60^{\circ} \mathrm{C}$ for additional 6 hours cooled and dried in the desiccator, weighed and recorded constant weight was obtained (Baruah et al., 2015).

\section{FT-IR analysis}

FT-IR spectra of humic acid sample was analysed using Carry 630 FT-IR Agilent Technologies.

Unhydrolysed compost humic acid

The unhydrolysed humic acid was obtained after isolation and purification of compost humic acid and kept for investigation.

\section{Acid hydrolysis of Peatsoil acid}

Peatsoil humic acid sample (1g) was refluxed for 12 hours at $\left(160^{\circ} \mathrm{C}\right)$ with $50 \mathrm{~cm}^{3}$ of $6 \mathrm{M} \mathrm{HCl}$. The mixture was allowed to cool, decanted, and centrifuged after hydrolysis. The insoluble residues were washed with distilled water via centrifugation several times, and the supernatant was treated with $\mathrm{AgNO}_{3}$ solution until no white precipitate was observed. The residue was thoroughly dried over $\mathrm{CaCl}_{2}$ in a desiccator at room temperature (Chefetz et al., 2002). Finally, the obtained hydrolysed humic acid was kept for investigation. 
BAJOPAS Volume 14 Number 1,June, 2021 Potentiometric Titrations

Potentiometric measurements were carried out using a pH-meter Jenway (model 3510) with combine electrode, the sensitivity of the $\mathrm{pH}$ meter is 0.01 units. The $\mathrm{pH}$ meter was switched on half an hour before starting the titration for initial warm up of the instrument. The instrument was calibrated with an aqueous standard buffer solution of $\mathrm{pH} 4.00$ and 10.0 (borate buffer) prepared from a "Qualigens" buffer tablets.

The following sets of solutions were prepared in a $250 \mathrm{~cm}^{3}$ volumetric flask separately for $\mathrm{pH}$ metric titrations.

(i) $5 \mathrm{~cm}^{3} 0.1 \mathrm{M} \mathrm{HCl}+40 \mathrm{~cm}^{3}$ deionized water

(ii) $5 \mathrm{~cm}^{3} 0.1 \mathrm{M} \mathrm{HCl}+39 \mathrm{~cm}^{3}$ deionized water $+1 \mathrm{~cm}^{3} 0.15 \mathrm{gcm}^{-3}$ humic acid

(iii) $5 \mathrm{~cm}^{3} 0.1 \mathrm{M} \mathrm{HCl}+37 \mathrm{~cm}^{3}$ deionized water $+1 \mathrm{~cm}^{3} 0.15 \mathrm{gcm}^{-3}$ humic acid

$$
+2 \mathrm{~cm}^{3} \quad 0.01 \mathrm{M} \mathrm{Cu} \text { (II) }
$$

The solutions were titrated against standardized $0.110 \mathrm{MNaOH}$ separately. The total volume of each mixture was adjusted to $50 \mathrm{~cm}^{3}$ and the ionic strength of the solutions was maintained constant at by adding appropriate amount of stock solution of $1 \mathrm{M} \mathrm{KNO}_{3}$ (Gamal, 2015; Omar and Ali, 2015). A magnetic stirrer was used to achieve thorough mixing of the interacting solutions at $550 \mathrm{rpm}$. The same set of experimental conditions was applied for potentiometric titration of remaining samples.

\section{Evaluation of pKa of Hydrolysed peat soil Humic Acids}

The proton-ligand formation number $\mathrm{n}_{\mathbf{A}}$ were calculated by Irving and Rossotti expression (Omar and Ali, 2015).

$\mathrm{nA}=\mathrm{Y}-\frac{(\mathrm{V} 2-\mathrm{V1})(\mathrm{No}-\mathrm{Eo})}{(\mathrm{VO}+\mathrm{V1}) \mathrm{TCL}}$ 1

Where: $Y$ is number of dissociable proton, $\left(\mathrm{V}_{2^{-}}\right.$ $V_{1}$ ) is the measure of displacement of the ligand curve relative to acid curve, $\mathrm{N}^{\circ}$ and $\mathrm{E}^{\circ}$ are the resultant concentration of alkali solution, free acid solution, $\mathrm{T}_{\mathrm{cL}}{ }^{\circ}$ is the total ligand concentration, $\mathrm{V}^{\circ}$ is the total volume of titration solution, $V_{1}$ is the volume of alkali added to acid solution, $V_{2}$ is the volume of alkali added to acid solution + ligand solution, acid dissociation constants (pKa - values) of ligand were calculated by algebraic method point wise calculation (Tables 1 ). The dissociation constants (pKa) were calculated according to the following relation:

$\mathrm{pKa}=\mathrm{pH}+\log \left(\frac{n A}{1-n A}\right)$ 2

Where: pKa is the acid dissociation constant, $\mathrm{n}_{\mathrm{A}}$ is the Proton-ligand formation number and $\mathrm{pH}$ is the pH-values (Omar and Ali, 2015).

\section{Determination of metal-ligand stability constants $(\log K)$ of complexes}

The potentiometric measurement for the determination of stability constant of a complex in solution is based on the fact that the redox potential of the couple $\frac{M^{+(m-n)}}{M^{+m}}$ is shifted significantly on complexation of the metal ion with the ligand. This method involves change in hydrogen ion concentration $\left[\mathrm{H}^{+}\right]$due to the displacement or association of one or more protons taking place during complexation reaction. This change can be found out by titrating the solutions containing free acid, acid with ligand, and acid with ligand and metal ion, individually against a standard alkali solution at a constant ionic strength or temperature. Either ionic strength or temperature may be varied for different sets of solutions. In all the cases, the change in the $\mathrm{pH}$ of the solution is measured after each addition of a known amount of alkali to the reaction cell which contains the reaction mixture. The titration curves are then drawn by plotting the measured $\mathrm{pH}$ values against the corresponding volume of alkali added and the stability constants of the complexes are determined from the titration curves by employing $\mathrm{pH}$-metric titration technique given by (Irving and Rossoti).

Metal-ligand stability constants ( $\log \mathrm{K}$ ) were determined by using the following relations:

$$
\bar{n}=\frac{\left(V_{3}-V_{2}\right)\left(E^{0}+N^{0}\right)}{\left(V^{0}+V_{2}\right) \bar{n}_{A} T_{m}^{0}}
$$

and

$$
P L=\log _{10}\left\{\frac{1+\beta_{n}^{H} \frac{1}{[\text { anti } \log \mathrm{pH}]^{\mathrm{n}}}}{\mathrm{T}_{\mathrm{L}}^{0}-n \bar{T}_{m}^{0}} \mathrm{X} \frac{\left(V^{0}+V_{3}\right)}{V^{0}}\right\}
$$


BAJOPAS Volume 14 Number 1,June, 2021

Where $T_{L}, T^{\circ}, E^{\circ}$, and $V^{\circ}$ havethe same significance as in equation (1) above, $T_{m}$ denotes the total concentration of metal present in solution, $V_{3}$ is the volume of metal ions present in solution and $\beta^{H}$ is the overall proton ligand stability constant. The metal-ligand stability constants (log K) were determined by employing point wise computational Method (eq. 5 and 6).

$\operatorname{LogK}_{1}=\log \left(\frac{n}{1-n}\right)+\mathrm{pL}$ .5

$\operatorname{LogK}_{2}=\log \left(\frac{1-n}{2-n}\right)+\mathrm{pL}$ ...6

Where: Log $\mathrm{K}$ is the metal-ligand stability constant, $\mathrm{pL}$ is the Free ligand exponent function, $\mathbf{n}$ is the Average number of ligand attached with metal ion (Janraoet al., 2014). The results obtained were analyzed by an ORIGIN 2016 program using titration data and then the proton-ligand stability constants (pKa) and Metal-ligand stability constant (LogK) calculated (Omar and Ali, 2015).

\section{RESULTS AND DISCUSSION}

Fourier transformed infrared (FT-IR) spectra of isolated humic acid from peat soils Figure 2 had distinct clear absorption bands indicating the presence of major humic acid structural elemental groups such as $\mathrm{H}$ bonded $\mathrm{OH}$ $\left(3680 \mathrm{~cm}^{-1}\right.$ peak $), C=0$ of carbonyl $\left(1721 \mathrm{~cm}^{-1}\right.$ peak), functional groups of aliphatic components $\mathrm{CH}_{2}\left(2918 \mathrm{~cm}^{-1}\right.$ peak) and $\mathrm{C}-\mathrm{O}$ stretching of polysaccharide $\left(1168 \mathrm{~cm}^{-1}\right.$ peak). The positions of the absorption bands of the spectra fell within typical major absorption bands of humic acid which is at frequencies 3680, 2918, 1721, 1168 $\mathrm{cm}^{-1}$. The first peak centred in the vicinity of $3680 \mathrm{~cm}^{-1}$ region is attributed to phenol $\mathrm{OH}$ group bounded by intermolecular $\mathrm{H}$ bonds. The $2918 \mathrm{~cm}^{-1}$ band usually has absorption maximum at $2918 \mathrm{~cm}^{-1}$ which is due to $\mathrm{C}-\mathrm{H}$ stretching of alkane group $\left(\mathrm{CH}_{2}\right)$. The next major absorption band is $1721 \mathrm{~cm}^{-1}$. This band has been commonly ascribed to $\mathrm{C}=\mathrm{O}$ stretching of mainly carboxyl group $(\mathrm{COOH})$ with trace amount of ketones. The last peak was observed at 1168 $\mathrm{cm}^{-1}$ due to $\mathrm{C}-\mathrm{O}$ stretching of polysaccharides and this peak appeared also in the spectra of humic acid from peat soil. The FTIR spectra of the isolated humic acid contained all major characteristic absorption peaks of humic acid. These absorption peaks indicated the presence of the major structural elements of humic acid namely $\mathrm{H}$ bonded $\mathrm{OH}, \mathrm{C}=\mathrm{C}$ of aromatic ring, $\mathrm{C}=\mathrm{O}$ of carbonyl group (both carboxyl and ketonic), $\mathrm{CH}_{2}$ group. This strongly supports the presence of humic acid.

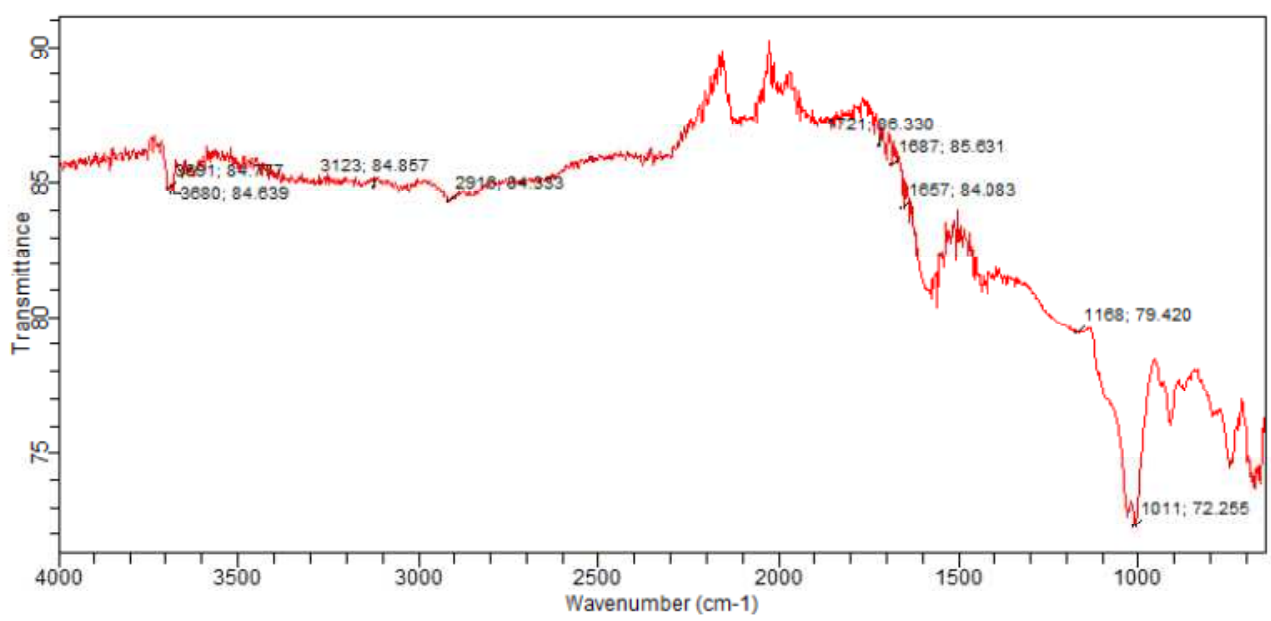

Fig. 2 : FT-IR spectraof peatsoilhumic acid (PSHA)

\section{Evaluation of acid dissociation constant (pka) of acid hydrolysed peat soil humicacid at phenolic group}

The value of the dissociation constant of the peat soil humic acid (PSHA) that underwent acidhydrolysis studied was found to be 8.9299 as shown Table 1, which is lower than the literaturevalues reported by Almeida and Szpoganics, (2015), Borges et al., (2005); Badr et al., (2012)and Fernandes et al,.(2009) of $9.73,9.47$ and 10.30. The difference between the obtained valuesand the reported values in this study might be probably as a result of acid hydrolysis of humicacid. 
BAJOPAS Volume 14 Number 1,June, 2021

Table 1: PKa of (Hydrolysed PSHA)

\begin{tabular}{|l|l|l|l|l|l|l|}
\hline $\mathrm{pH}$ & $\mathrm{BV}_{1}$ & $\mathrm{BV}_{2}$ & $\mathrm{~V}_{2}-\mathrm{V}_{1}$ & $\mathrm{nA}$ & $\log \left(\frac{n A}{1-n A}\right)$ & $\mathrm{pKa}$ \\
\hline 8.50 & 5.30 & 6.29 & 0.99 & 0.3594 & -0.2510 & 8.2490 \\
8.72 & 5.35 & 6.37 & 1.02 & 0.3400 & -0.2880 & 8.4320 \\
9.00 & 5.40 & 6.46 & 1.06 & 0.3141 & -0.3391 & 8.6609 \\
9.22 & 5.45 & 6.55 & 1.10 & 0.2882 & -0.3927 & 8.8273 \\
9.51 & 5.50 & 6.66 & 1.16 & 0.2494 & -0.4786 & 9.0314 \\
9.73 & 5.55 & 6.78 & 1.23 & 0.2041 & -0.5910 & 9.1390 \\
10.00 & 5.60 & 6.90 & 1.30 & 0.1589 & -0.7238 & 9.2762 \\
10.23 & 5.65 & 7.05 & 1.40 & 0.0941 & -0.9835 & 9.2465 \\
10.49 & 5.70 & 7.10 & 1.40 & 0.0941 & -0.9835 & 9.5065 \\
\hline
\end{tabular}

Average pKa $=8.9299 \pm 0.4186$

Table 2: PKa of (Unhydrolysed PSHA)

\begin{tabular}{|l|l|l|l|l|l|l|}
\hline $\mathrm{pH}$ & $\mathrm{BV}_{1}$ & $\mathrm{BV}_{2}$ & $\mathrm{~V}_{2}-\mathrm{V}_{1}$ & $\mathrm{nA}$ & $\log \left(\frac{\boldsymbol{n A}}{1-\boldsymbol{n}}\right)$ & $\mathrm{pKa}$ \\
\hline 8.50 & 5.30 & 5.81 & 0.51 & 0.6619 & 0.2919 & 8.7919 \\
8.72 & 5.35 & 5.90 & 0.55 & 0.6357 & 0.2418 & 8.9618 \\
9.00 & 5.40 & 6.00 & 0.60 & 0.6029 & 0.1813 & 9.1813 \\
9.22 & 5.45 & 6.10 & 0.65 & 0.5701 & 0.1226 & 9.3426 \\
9.51 & 5.50 & 6.20 & 0.70 & 0.5376 & 0.0654 & 9.5754 \\
9.73 & 5.55 & 6.33 & 0.78 & 0.4851 & -0.0259 & 9.7041 \\
10.00 & 5.60 & 6.47 & 0.87 & 0.4262 & -0.1291 & 9.8709 \\
10.23 & 5.65 & 6.62 & 0.99 & 0.3609 & -0.2481 & 9.9819 \\
10.49 & 5.70 & 6.80 & 1.10 & 0.2759 & -0.4690 & 10.0210 \\
\hline
\end{tabular}

Average pKa $=9.4923 \pm 0.4410$

Metal-ligand stability constant ( $\log \mathrm{K}$ )

The stabilityconstants require the accurate values of proton-ligand stability constants (Anil and Maroti, 2008). Metal titration curves crossed over ligand titration curve indicated the formation of complex upon proton release (Santosh, et al., 2011). If the values of n- are within range $0.2-0.8$ and $1.2-18$ this indicates the formation of $1: 1$ and 1:2 complexes (Sayyed and Mazahar, 2012).

The metal (II)-humate stepwise stability constants (log k) at phenolic group (Tables 318)

Table 3: Point-wise method, $\mathrm{Cu}$-(Hydrolysed PSHA)

\begin{tabular}{|l|l|l|l|l|l|l|l|l|}
\hline $\mathrm{pH}$ & $\mathrm{BV}_{1}$ & $\mathrm{BV}_{2}$ & $\mathrm{BV}_{3}$ & $\left(\mathrm{~V}_{3}-\mathrm{V}_{2}\right)$ & $\mathrm{n}$ & $\mathrm{pL}$ & $\log \left(\frac{n}{1-n}\right)$ & LogK $_{1}$ \\
\hline 8.50 & 5.30 & 6.29 & 6.33 & 0.04 & 0.5500 & 2.66 & 0.0871 & 2.7471 \\
8.72 & 5.35 & 6.37 & 6.41 & 0.04 & 0.5714 & 2.43 & 0.1249 & 2.5549 \\
9.00 & 5.40 & 6.46 & 6.50 & 0.04 & 0.6198 & 2.16 & 0.2122 & 2.3722 \\
9.22 & 5.45 & 6.55 & 6.59 & 0.04 & 0.6667 & 1.94 & 0.3010 & 2.2410 \\
\hline
\end{tabular}

LogK $_{1}$ (Average value) $=2.4788 \pm 0.2203$

Table 4: Point-wise method, $\mathrm{Cu}$-(Hydrolysed PSHA)

\begin{tabular}{|l|l|l|l|l|l|l|l|l|}
\hline $\mathrm{pH}$ & $\mathrm{BV}_{1}$ & $\mathrm{BV}_{2}$ & $\mathrm{BV}_{3}$ & $\left(\mathrm{~V}_{3}-\mathrm{V}_{2}\right)$ & $\mathrm{n}$ & $\mathrm{pL}$ & $\log \left(\frac{n-1}{2-n}\right)$ & LogK $_{2}$ \\
\hline 9.51 & 5.50 & 6.66 & 6.73 & 0.07 & 1.3509 & 1.70 & -0.2671 & 1.4329 \\
9.73 & 5.55 & 6.78 & 6.85 & 0.07 & 1.6383 & 1.51 & 0.2467 & 1.7567 \\
10.00 & 5.60 & 6.90 & 6.98 & 0.08 & 2.1783 & 1.31 & -0.2158 & 1.0942 \\
10.23 & 5.65 & 7.05 & 7.13 & 0.08 & 4.1904 & 1.27 & & \\
10.49 & 5.70 & 7.10 & 7.19 & 0.09 & 4.6920 & & & \\
\hline
\end{tabular}

Log $K_{2}($ Average value $)=1.4280 \pm 0.3312$ 
BAJOPAS Volume 14 Number 1,June, 2021

Table 5: Point-wise method, $\mathrm{Cu}$ (Unhydrolysed PSHA)

\begin{tabular}{|l|l|l|l|l|l|l|l|l|}
\hline $\mathrm{pH}$ & $\mathrm{BV}_{1}$ & $\mathrm{BV}_{2}$ & $\mathrm{BV}_{3}$ & $\left(\mathrm{~V}_{3}-\mathrm{V}_{2}\right)$ & $\mathrm{n}$ & $\mathrm{pL}$ & $\log \left(\frac{n}{n-1}\right)$ & Log $_{1}$ \\
\hline 8.50 & 5.30 & 5.81 & 5.85 & 0.04 & 0.2973 & 2.88 & -0.3736 & 2.5064 \\
8.72 & 5.35 & 5.90 & 5.95 & 0.05 & 0.3873 & 2.66 & -0.1992 & 2.4608 \\
9.00 & 5.40 & 6.00 & 6.05 & 0.05 & 0.4044 & 2.38 & -0.1681 & 2.2119 \\
9.22 & 5.45 & 6.10 & 6.15 & 0.06 & 0.5157 & 2.18 & -0.0272 & 2.2072 \\
9.51 & 5.50 & 6.20 & 6.27 & 0.07 & 0.6417 & 1.89 & 0.2530 & 1.1430 \\
\hline
\end{tabular}

$\operatorname{LogK}_{1}($ Average value $)=2.3059 \pm 0.6153$

Table 6:Point-wise method, $\mathrm{Cu}$ (Unhydrolysed PSHA)

\begin{tabular}{|l|l|l|l|l|l|l|l|l|}
\hline $\mathrm{pH}$ & $\mathrm{BV}_{1}$ & $\mathrm{BV}_{2}$ & $\mathrm{BV}_{3}$ & $\mathrm{~V}_{3}-\mathrm{V}_{2}$ & $\mathrm{n}$ & $\mathrm{pL}$ & $\log \left(\frac{n-1}{2-n}\right)$ & $\log \mathrm{K}_{2}$ \\
\hline 9.73 & 5.55 & 6.33 & 6.42 & 0.09 & 0.9000 & 1.69 & & \\
10.00 & 5.60 & 6.47 & 6.58 & 0.11 & 1.2578 & 1.44 & -0.4592 & 0.9808 \\
10.23 & 5.65 & 6.62 & 6.84 & 0.12 & 1.6137 & 1.26 & -0.2010 & 1.4610 \\
10.49 & 5.70 & 6.80 & 6.92 & 0.12 & 2.1052 & 1.03 & & \\
\hline
\end{tabular}

$\operatorname{LogK}_{2}$ (Average value) $=1.2209 \pm 0.3398$

Table 7:Point-wise method, Pb (Hydrolysed PSHA)

\begin{tabular}{|l|l|l|l|l|l|l|l|l|}
\hline $\mathrm{pH}$ & $\mathrm{BV}_{1}$ & $\mathrm{BV}_{2}$ & $\mathrm{BV}_{3}$ & $\left(\mathrm{~V}_{3}-\mathrm{V}_{2}\right)$ & $\mathrm{n}$ & $\mathrm{pL}$ & $\log \left(\frac{n}{1-n}\right)$ & LogK $_{1}$ \\
\hline 8.50 & 5.30 & 6.29 & 6.33 & 0.04 & 0.5500 & 2.66 & 0.0871 & 2.7471 \\
8.72 & 5.35 & 6.37 & 6.41 & 0.04 & 0.5714 & 2.43 & 0.1249 & 2.5549 \\
9.00 & 5.40 & 6.46 & 6.50 & 0.04 & 0.6198 & 2.16 & 0.2122 & 2.3722 \\
9.22 & 5.45 & 6.55 & 6.60 & 0.05 & 0.8333 & 1.96 & 0.6989 & 2.6589 \\
\hline
\end{tabular}

Log $_{\mathbf{1}}($ Average value $)=2.5832 \pm 0.1614$

Table 8:Point-wise method, Pb-(Hydrolysed PSHA)

\begin{tabular}{|l|l|l|l|l|l|l|l|l|}
\hline $\mathrm{pH}$ & $\mathrm{BV}_{1}$ & $\mathrm{BV}_{2}$ & $\mathrm{BV}_{3}$ & $\left(\mathrm{~V}_{3}-\mathrm{V}_{2}\right)$ & $\mathrm{n}$ & $\mathrm{pL}$ & $\log \left(\frac{n-1}{2-n}\right)$ & $\log \mathrm{K}_{2}$ \\
\hline 9.51 & 5.50 & 6.66 & 6.71 & 0.05 & 0.9650 & 1.67 & & \\
9.73 & 5.55 & 6.78 & 6.83 & 0.05 & 1.1702 & 1.44 & & \\
10.00 & 5.60 & 6.90 & 6.90 & 0.05 & 1.4864 & 1.22 & -0.0237 & 1.1963 \\
10.23 & 5.65 & 7.05 & 7.10 & 0.05 & 2.0190 & 1.09 & & \\
10.49 & 5.70 & 7.10 & 7.17 & 0.07 & 3.6492 & 1.00 & & \\
\hline
\end{tabular}

Log $K_{2}$ (Average value) $=1.1963$

Table 9: Point-wise method, Pb (Unhydrolysed PSHA)

\begin{tabular}{|l|l|l|l|l|l|l|l|l|}
\hline $\mathrm{pH}$ & $\mathrm{BV}_{1}$ & $\mathrm{BV}_{2}$ & $\mathrm{BV}_{3}$ & $\mathrm{~V}_{3}-\mathrm{V}_{2}$ & $\mathrm{n}$ & $\mathrm{pL}$ & $\begin{array}{l}\text { Log } \\
\left(\frac{n}{n-1}\right)\end{array}$ & Log $\mathrm{K}_{1}$ \\
\hline 8.50 & 5.30 & 5.81 & 5.85 & 0.04 & 0.2973 & 2.88 & -0.3736 & 2.5064 \\
8.72 & 5.35 & 5.90 & 5.94 & 0.04 & 0.3099 & 2.66 & -0.5477 & 2.3123 \\
9.00 & 5.40 & 6.00 & 6.05 & 0.05 & 0.4044 & 2.38 & -0.1681 & 2.2119 \\
9.22 & 5.45 & 6.10 & 6.15 & 0.06 & 0.5157 & 2.18 & 0.0272 & 2.2072 \\
9.51 & 5.50 & 6.20 & 6.26 & 0.07 & 0.6417 & 1.89 & 0.2530 & 2.1430 \\
9.73 & 5.55 & 6.40 & 6.40 & 0.07 & 0.7000 & 1.67 & 0.3680 & 2.0380 \\
\hline
\end{tabular}

LogK $_{1}$ (Average value) $=2.2364 \pm 0.1602$

Table 10: Point-wise method, Pb (Unhydrolysed PSHA)

\begin{tabular}{|l|l|l|l|l|l|l|l|l|}
\hline $\mathrm{pH}$ & $\mathrm{BV}_{1}$ & $\mathrm{BV}_{2}$ & $\mathrm{BV}_{3}$ & $\mathrm{~V}_{3}-\mathrm{V}_{2}$ & $\mathrm{n}$ & $\mathrm{pL}$ & $\log \left(\frac{n-1}{2-n}\right)$ & $\log \mathrm{K}_{2}$ \\
\hline 10.00 & 5.60 & 6.47 & 6.55 & 0.08 & 1.9503 & 1.41 & & \\
10.23 & 5.65 & 6.62 & 6.72 & 0.11 & 1.4792 & 1.26 & -0.0361 & 1.2239 \\
\hline
\end{tabular}

$\operatorname{LogK}_{2}$ (Average value) $=1.2239$

Table 11: Point-wise method, Mg (Hydrolysed PSHA)

\begin{tabular}{|l|l|l|l|l|l|l|l|l|}
\hline $\mathrm{pH}$ & $\mathrm{BV}_{1}$ & $\mathrm{BV}_{2}$ & $\mathrm{BV}_{3}$ & $\left(\mathrm{~V}_{3}-\mathrm{V}_{2}\right)$ & $\mathrm{n}$ & $\mathrm{pL}$ & $\log \left(\frac{n}{n-1}\right)$ & LogK $_{1}$ \\
\hline 8.50 & 5.30 & 6.29 & 6.31 & 0.02 & 0.2750 & 2.64 & -0.4290 & 2.2110 \\
8.72 & 5.35 & 6.37 & 6.39 & 0.02 & 0.2858 & 2.42 & -0.3978 & 2.0222 \\
9.00 & 5.40 & 6.46 & 6.49 & 0.03 & 0.4648 & 2.14 & -0.0612 & 2.0788 \\
9.22 & 5.45 & 6.55 & 6.59 & 0.04 & 0.6667 & 1.94 & 0.3010 & 2.2410 \\
\hline
\end{tabular}

$\log _{\mathbf{1}}($ Average value) $=2.1382 \pm 0.1046$ 
BAJOPAS Volume 14 Number 1,June, 2021

Table 12: Point-wise method, Mg (Hydrolysed PSHA)

\begin{tabular}{|l|l|l|l|l|l|l|l|l|}
\hline $\mathrm{pH}$ & $\mathrm{BV}_{1}$ & $\mathrm{BV}_{2}$ & $\mathrm{BV}_{3}$ & $\left(\mathrm{~V}_{3}-\mathrm{V}_{2}\right)$ & $\mathrm{n}$ & $\mathrm{pL}$ & $\log \left(\frac{n-1}{2-n}\right)$ & LogK $_{2}$ \\
\hline 9.51 & 5.55 & 6.66 & 6.71 & 0.05 & 0.9650 & 1.67 & & \\
9.73 & 5.55 & 6.78 & 6.84 & 0.06 & 1.4042 & 1.47 & -0.1686 & 1.3014 \\
10.00 & 5.60 & 6.90 & 6.93 & 0.06 & 1.7838 & 1.23 & 0.5593 & 1.7893 \\
10.23 & 5.65 & 7.05 & 7.10 & 0.06 & 3.1429 & 1.10 & & \\
10.49 & 5.70 & 7.10 & 7.18 & 0.07 & 3.6492 & 0.83 & & \\
\hline
\end{tabular}

LogK $_{2}($ Average value $)=1.5453 \pm 0.3450$

Table 13: Point-wise method, Mg (Unhydrolysed PSHA)

\begin{tabular}{|l|l|l|l|l|l|l|l|l|}
\hline $\mathrm{pH}$ & $\mathrm{BV}_{1}$ & $\mathrm{BV}_{2}$ & $\mathrm{BV}_{3}$ & $\mathrm{~V}_{3}-\mathrm{V}_{2}$ & $\mathrm{n}$ & $\mathrm{pL}$ & $\log \left(\frac{n}{n-1}\right)$ & $\operatorname{Log~}_{1}$ \\
\hline 8.50 & 5.30 & 5.81 & 5.85 & 0.04 & 0.2973 & 2.88 & -0.3736 & 2.5064 \\
8.72 & 5.35 & 5.90 & 5.94 & 0.04 & 0.3099 & 2.66 & -0.3477 & 2.3123 \\
9.00 & 5.40 & 6.00 & 6.04 & 0.04 & 0.3236 & 2.38 & -0.3202 & 2.0598 \\
9.22 & 5.45 & 6.10 & 6.15 & 0.05 & 0.4297 & 2.17 & -0.1230 & 2.0470 \\
9.51 & 5.50 & 6.20 & 6.26 & 0.06 & 0.5500 & 1.89 & 0.0871 & 1.9771 \\
9.73 & 5.55 & 6.33 & 6.40 & 0.07 & 0.7000 & 1.67 & 0.3680 & 2.0380 \\
\hline
\end{tabular}

LogK $_{1}$ (Average value) $=2.1568 \pm 0.2069$

Table 14: Point-wise method, Mg (Unhydrolysed PSHA)

\begin{tabular}{|l|l|l|l|l|l|l|l|l|}
\hline $\mathrm{pH}$ & $\mathrm{BV}_{1}$ & $\mathrm{BV}_{2}$ & $\mathrm{BV}_{3}$ & $\mathrm{~V}_{3}-\mathrm{V}_{2}$ & $\mathrm{n}$ & $\mathrm{pL}$ & $\log \left(\frac{n-1}{2-n}\right)$ & $\log \mathrm{K}_{2}$ \\
\hline 10.00 & 5.60 & 6.47 & 6.55 & 0.08 & 0.9148 & 1.41 & & \\
10.23 & 5.65 & 6.62 & 6.71 & 0.09 & 1.2102 & 1.20 & -0.5749 & 0.6251 \\
10.49 & 5.70 & 6.80 & 6.92 & 0.09 & 1.5968 & 1.03 & 0.1703 & 1.2003 \\
\hline
\end{tabular}

LogK $_{2}$ (Average value) $=0.9127 \pm 0.4070$

Table15:Point-wise method, Cd (Hydrolysed PSHA)

\begin{tabular}{|l|l|l|l|l|l|l|l|l|}
\hline $\mathrm{pH}$ & $\mathrm{BV}_{1}$ & $\mathrm{BV}_{2}$ & $\mathrm{BV}_{3}$ & $\left(\mathrm{~V}_{3}-\mathrm{V}_{2}\right)$ & $\mathrm{n}$ & $\mathrm{pL}$ & $\log \left(\frac{n}{1-n}\right)$ & LogK $_{1}$ \\
\hline 8.50 & 5.30 & 6.29 & 6.31 & 0.02 & 0.2750 & 2.64 & -0.4210 & 2.2190 \\
8.72 & 5.35 & 6.37 & 6.40 & 0.03 & 0.4286 & 2.42 & -0.1249 & 2.2951 \\
9.00 & 5.40 & 6.46 & 6.49 & 0.03 & 0.4648 & 2.14 & -0.0612 & 2.0788 \\
9.22 & 5.45 & 6.55 & 6.59 & 0.04 & 0.6667 & 1.96 & 0.3010 & 2.2610 \\
9.51 & 5.55 & 6.66 & 6.70 & 0.04 & 0.7720 & 1.67 & 0.5297 & 2.1997 \\
\hline
\end{tabular}

LogK $_{\mathbf{1}}$ (Average value) $=2.2108 \pm 0.0825$

Table 16: Point-wise method, Cd (Hydrolysed PSHA)

\begin{tabular}{|l|l|l|l|l|l|l|l|l|}
\hline $\mathrm{pH}$ & $\mathrm{BV}_{1}$ & $\mathrm{BV}_{2}$ & $\mathrm{BV}_{3}$ & $\left(\mathrm{~V}_{3}-\mathrm{V}_{2}\right)$ & $\mathrm{n}$ & $\mathrm{pL}$ & $\log \left(\frac{n-1}{2-n}\right)$ & Log $_{2}$ \\
\hline 9.73 & 5.55 & 6.78 & 6.83 & 0.06 & 1.4042 & 1.47 & -0.1686 & 1.3014 \\
10.00 & 5.60 & 6.90 & 6.95 & 0.06 & 1.7838 & 1.23 & 0.5593 & 1.7893 \\
10.23 & 5.65 & 7.05 & 7.10 & 0.06 & 3.1429 & 1.09 & & \\
10.49 & 5.70 & 7.10 & 7.16 & 0.06 & 3.1429 & 0.89 & & \\
& & & & & & & & \\
\hline
\end{tabular}

$\operatorname{LogK}_{2}$ (Average value) $=1.5453 \pm 0.3450$

Table 17: Point-wise method, Cd (Unhydrolysed PSHA)

\begin{tabular}{|l|l|l|l|l|l|l|l|l|}
\hline $\mathrm{pH}$ & $\mathrm{BV}_{1}$ & $\mathrm{BV}_{2}$ & $\mathrm{BV}_{3}$ & $\mathrm{~V}_{3}-\mathrm{V}_{2}$ & $\mathrm{n}$ & $\mathrm{pL}$ & $\log \left(\frac{n}{n-1}\right)$ & $\operatorname{Log~}_{1}$ \\
\hline 8.50 & 5.30 & 5.81 & 5.86 & 0.05 & 0.3717 & 2.88 & -0.2280 & 2.6520 \\
8.72 & 5.35 & 5.90 & 5.95 & 0.05 & 0.3873 & 2.66 & -0.1992 & 2.4608 \\
9.00 & 5.40 & 6.00 & 6.06 & 0.06 & 0.4853 & 2.38 & -0.0255 & 2.3545 \\
9.22 & 5.45 & 6.10 & 6.16 & 0.06 & 0.5157 & 2.18 & -0.0272 & 2.2072 \\
9.51 & 5.50 & 6.20 & 6.27 & 0.07 & 0.6417 & 1.89 & 0.2530 & 1.1430 \\
9.73 & 5.55 & 6.33 & 6.41 & 0.08 & 0.8000 & 1.69 & 0.6020 & 2.2920 \\
& & & & & & & & \\
\hline
\end{tabular}

$\operatorname{LogK}_{1}($ Average value $)=2.2516 \pm 0.5380$ 
BAJOPAS Volume 14 Number 1,June, 2021

Table 18: Point-wise method, Cd (Unhydrolysed PSHA)

\begin{tabular}{|l|l|l|l|l|l|l|l|l|}
\hline $\mathrm{pH}$ & $\mathrm{BV}_{1}$ & $\mathrm{BV}_{2}$ & $\mathrm{BV}_{3}$ & $\mathrm{~V}_{3}-\mathrm{V}_{2}$ & $\mathrm{n}$ & $\mathrm{pL}$ & $\log \left(\frac{n-1}{2-n}\right)$ & $\log \mathrm{K}_{2}$ \\
\hline 10.00 & 5.60 & 6.47 & 6.57 & 0.10 & 1.1434 & 1.43 & & \\
10.23 & 5.65 & 6.62 & 6.72 & 0.10 & 1.3448 & 1.23 & -0.2788 & 0.9512 \\
10.49 & 5.70 & 6.80 & 6.90 & 0.10 & 1.7742 & 1.03 & 0.5351 & 1.5651 \\
\hline
\end{tabular}

$\operatorname{LogK}_{2}($ Average value $)=1.2581 \pm 0.4340$

Table 19: Stepwise and overall Stability constants of thehydrolysed and unhydrolysed divalent metal (II) complexes

\begin{tabular}{|c|c|c|c|}
\hline Chelates & LogK $_{1}$ & $\log _{2}$ & Log $\beta$ \\
\hline [Cu (Hydrolysed PSHA-1) $\left.{ }_{2}\right]$ & 2.4788 & 1.4280 & 3.9068 \\
\hline$\left[\mathrm{Pb}(\text { Hydrolysed PSHA-1) })_{2}\right]$ & 2.5832 & 1.1963 & 3.7795 \\
\hline$\left[\mathrm{Cd}(\text { Hydrolysed PSHA-1 })_{2}\right]$ & 2.2108 & 1.5453 & 3.7561 \\
\hline$\left[\mathrm{Mg}(\text { Hydrolysed PSHA-1 })_{2}\right]$ & 2.1382 & 1.5453 & 3.6835 \\
\hline [Cu (Unhydrolysed PSHA-1) & 2.3059 & 1.2209 & 3.5268 \\
\hline$[\mathrm{Pb}$ (Unhydrolysed PSHA-1) 2$]$ & 2.2364 & 1.2239 & 3.4603 \\
\hline [Cd (Unhydrolysed PSHA-1) 2 ] & 2.2516 & 1.2581 & 3.5097 \\
\hline$[\mathrm{Mg}$ (Unydrolysed PSHA-1) & 2.1568 & 0.9127 & 3.0695 \\
\hline
\end{tabular}

The results obtained (Table19) shows the stepwise and overall stability constants to be not high indicating low stability of the complexes, because the solubility of most metal ions in the basic $\mathrm{pH}$ range is minimal due to metal hydroxide precipitation (Karimi, 2017). In general, the stepwise stability constants $\left(K_{1}\right.$ and $K_{2}$ ) follow the order $K_{1}>K_{2}$ for the copper, lead, magnesium and cadmium complexes respectively. The steady decrease of the values with increasing number of ligands is in agreement with the prediction made by researchers (Na'aliya, 2013). The decrease could be attributed to the fact that as the number of the ligands (Humate ions) that enters the coordination zone increases the aqua molecules available for replacement by the ligands become less. Thus, the metal ions become less electron loving with progressive intake of the ligand and this results in the decrease in the values of the constants (Na'aliya, 2013). Also the stability of the complexes is influenced by the size and number of the chelate rings(Mackay and Mackay,2002).All the complexes form rings in their structure as humate, a bidentate ligand, bond the metal ions in the ratio 1:2 (Boguta and Sokolowska, 2016) forming chelate rings. The values of the overall stability constants $(\log \beta)$ obtained for humate complexes are not high indicating low stability as the values are not high. LogK values for copper-humates (Table 3 to 6) obtained in this study are lower than those reported for the complexes of humic acids (Pandey et al., 2015; Dinu, 2013; Kaschl et al., 2010 and Gilbeto and Jorg, 2001). The values of LogK(Table 7 to 10 ) forlead-humates are lower than those reported for the lead in the literature (Dinu, 2013; Gilbeto and Jorg 2001). Log K values(Table 11 to 14 ) for magnesium-humates obtained in this study are close to those reported by (Pandey et al., 2015). Log K values of cadmium-humates (Table 15 to 18 ) obtained in this work near to the one reported by (Dinu, 2013 and Pandey et al., 2015).The difference between the reported values and the values obtained in this study might be probably as a result of acid hydrolysis of humic acid. The values of the overall stability constants $(\log \beta)$ of the copper humates complexes presented in Table 19 is high than that of other metal humate complexes, show relatively high stability of CuHA complexes, show the following order of stability: $\mathrm{Cu}>\mathrm{Pb}>\mathrm{Cd}>\mathrm{Mg}$; which are in close agreement to the findings of (Dinu, 2013 and Pandey et al., 2015).The high stability of Cuhumate chelate could be attributed to the existence of coordinate covalent bond between the complexing agents and the $\mathrm{Cu}^{2+}$ ions. Since, $\mathrm{Cu}^{2+}$ being a metal of the transitional series with $3 d^{9}$ electronic configurations can accept the electrons from the complexing agents. Similarly, the low stabilities of $\mathrm{Pb}, \mathrm{Cd}$ and $\mathrm{Mg}$ complexes could be explained by that $\mathrm{Pb}^{2+}$ with $6 s^{2}, \mathrm{Cd}^{2+}$ with $4 \mathrm{~d}^{10}$ and $\mathrm{Mg}^{2+}$ with $2 \mathrm{p}^{6}$ their electronic configuration has a completely filled $\mathrm{d}, \mathrm{p}$ and $\mathrm{s}$ orbitals. Moreover, the stabilities of metal ions with hydrolysed humic acid from peat soil were higher than those with unhydrolysed humic acid from peat soil; which is ascribed to the high content of acidity in hydrolysed humic acid than unhydrolysed humic acid. 
BAJOPAS Volume 14 Number 1,June, 2021 CONCLUSION

The values of logk for $\mathrm{Cu}(\mathrm{II})$ hydrolysed humic acid complex was higher followed by $\mathrm{Pb}$ (II), $\mathrm{Cd}(\mathrm{II})$ and $\mathrm{Mg}$ (II) hydrolysed humic acid complexes as compared with metal(II) unhydrolysed humic acid complexes. This indicates acid hydrolysis of humic acid can

\section{REFERENCES}

Almeida, V.R. and Szpoganicz, B. (2015). Humic Acid Potentiometric Response Patterns:Out- of Equilibrium Properties and Species Distribution Modelling. Chemical. Biol. Technol. Agric. 2: 17.

Anđelković, T., Nikolić, R., Bojić, A.,Anđelković, D., and Nikolic G.,(2010). Binding of Cadmium to Soil Humic Acid as A Function of Carboxyl Group Content. Macedonian Journal of Chemistry and Chemical Engineering.29(2): 215-224.

Anil, B. N. and Maroti, N. (2008). Studies on Influence of Die-Lectric Constants on Complex Equilibria between Substituted Py-Razalines and Lanthanide Metal Ions pH-Metrically. Amer.-Euras. scient. Res. 3(2): 212-216.

Ashok, K., Pandey, S. P. and Misra, V (2000). Stability Constants of Metal-Humic Acid Complexes and its Role in Environmental Detoxification. Journal of Ecotoxicology and Environmental Safety. 47(2):157-200.

Badr, M. H., El-Halafawi, M. H. and Abd El-al Zeid, E. R. (2012). Comparison Between the Effect of Ionic Strength on Acidity and Dissociation Constants of Humic Acids Extracted from Sewage Sludge and Nile Water Hyacinth Composts.Global Journal of Environmental Research 6 (1): 36-43.

Baruah, M.K., Borah, D., Saikia, P.P., Paul, S., Sharma, T. (2015). Evaluation of pKa Values of Soil Humic Acids and their Complexation Properties. International Journal of Plant \& Soil Science 6(4) : 218-228.

Boguta, P. Sokolowska, Z. (2016). Interactions of $\mathrm{Zn}$ (II) Ions with Humic Acids Isolated from Various Types of Soils. Effect of $\mathrm{pH}, \mathrm{Zn}$ Concentrations and Humic Acids Chemical Properties. Journal of Geochemical Explaration 168. 119-126.

Borges, F., Guimaraes, C., Lima, L.F.C., Pinto, I. and Reis, S.(2005). Potentiometric Studies on the Complexation of Copper(II) by Phenolic Acids as Discrete Ligand Models of enhance the complexation behavior of humic acid with metal (II) ions. However, the higher values of $\log \beta$ for $\mathrm{Cu}(\mathrm{II}), \mathrm{Pb}(\mathrm{II}), \mathrm{Cd}(\mathrm{II})$ and $\mathrm{Mg}(\mathrm{II})$ hydrolysed humic acid complexes indicates more stable stepwise complexes formed as compared with $\mathrm{Cu}(\mathrm{II}), \mathrm{Pb}$ (II), $\mathrm{Cd}$ (II) and $\mathrm{Mg}(\mathrm{II})$ unhydrolysed humic acid complexes.

Humic Substances Talanta 66 (2005) 670-673.

Chefetz, B., Salloum, M. J., Deshmulkin, A. P. and Hatcher, P. (2002). Structural Components of Humic Acids as Determined by Chemical Modifications and Carbon-13 NMR, Pyrolysis, and Thermochemolysis- Gas Chromatography/Mass Spectrometry. Soil Science Society of American Journal Abstract Division S-2- Soil Chemistry66. 1159-1171.

Dinu, M. I. (2013). Metals Complexation with Humic Acids in Surface Water of Different Environ. Sci. Technol. 31(1): 1-17.

Fernandes, A.N., Giacomelli, C., Giovanela, M. Vaz, D.V. Szpoganicz, B. and Maria M. D. (2009). Potentiometric Acidity Determination in Humic Substances Influenced by Different Analytical Procedures.J. Braz. Chem. Soc. 20 (9):14.

Gamal, A. H. (2015). Stability Constants of Rhenium (V) Metal Complexes with Selected Drugs. Pyrex Journal of Research in Environmental Studies. 2(2): 006-014.

Janrao, D. M., Pathan, J., Kayande, D.D., and Mulla, J.J. (2014). An Over View of Potentiometric Determination of Stability Constants of Metal Complexes. Sci. Revs. Chem. Commun.: 4(1), 2014, 11-24.

Karimi, H. (2017). Effect of pH and Initial Pb(II) Concentration on the Lead Removal Efficiency from Waste Water Using $\mathrm{Ca}(\mathrm{OH})_{2}$. International Journal of Water and Waste Water Treatment 3.2

Kaschl, A. Romheld, V. and Chen, Y. (2010). Binding of Cadmium, Copper and Zinc to Humic Substances Originating from Municipal Solid Waste Compost. Israel Journal of Chemistry Vol. 42(1): 89-98.

Kostic, I. S., Tatjana, P, A., Nikolic, R. S., Cvetkovic, T. P., Pavlovic, D. D., Aleksandar, L.J. and Bojic, A. (2012). Comparative Study of Binding Strengths of Heavy Metals with Humic Acid. J.serb. Chem. Soc. 76(9) pp 1-20. 
BAJOPAS Volume 14 Number 1,June, 2021

Na'aliya, J. (2013). Determination of Stepwise Stability Constants and Gibbs free Energy Change of Trisprolina to Complexes of some Divalent Transition Metal ions. Bayero Journal of Pure and Applied Sciences 6(2): 112-114.

Omar, A. A. and Ali, E. A. (2015). Potentiometric Studies on Complexes of $\mathrm{Cr}$ (III) and $\mathrm{Zr}$ (IV) with some Carboxylic Acids. International Journal of Advanced Chemistry, 3(1) 25-

37.

Pandey, A. K. Pandey, S. D. and Misr, V. (2015).Stability Constants of Metal- Humic Acid Complexes and Its Role in Environmental Detoxification. J. Ecotoxicology and Environmental Safety. 47(1):195-200.

Ram, N. and Raman, K.V. (1984). Stability Constants of Complexes of Metals with
Humicand Fuvic Acids under Non- acidConditions. Journal of Plant Nutrition and Soil Sciences.

147:171-176.

Santosh, D. D., Ashok, B. K., Vijay, J. T., Shivraj, G. W. and Vinay, V. W. (2011). Potentiometric Studies of Elec-Trolyte Effects on Complex Equilibria of Some Substituted 5-(2-hydroxy Phenyl) Pyrazoles. Der pharm. 3 (6): 75-83.

Sayyed, H. and Abdul Rahim, M. F. (2012). Studies of Binary Complexes of Metal Ions with Mandelic Acid by Potentiometry. Chem. J. 02 (6): 206209.

Shirvani, M. Moradian, E. Khalili, B. Bakhtiary, S. (2015). Interaction of $\mathrm{Cd}$ and $\mathrm{Pb}$ with Humate-Palygorskite and HumateSepiolite Complexes. Journal of water, air and pollution 3: 220-228. 


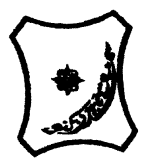

Bayero Journal of Pure and Applied Sciences, 14(1): 54 - 63

Received: November, 2020

Accepted: April, 2021

ISSN $2006-6996$

\title{
STABILITY CONSTANTS OF COMPLEXES OF METAL IONS WITH PEATSOIL HUMIC ACIDS UNDER NON-ACID-CONDITIONS
}

\author{
${ }^{* 1}$ Sabo, Yusuf ${ }^{2}$ Jimoh, W.L.O., ${ }^{3}$ Isa Baba Koki and ${ }^{4}$ Sholadoye, Q. 0. \\ ${ }^{1}$ Department of Pure and Industrial Chemistry, Bayero University, Kano \\ ${ }^{3}$ Department of Chemistry, Yusuf Maitama Sule University Kano. P.M.B. 3220 Kano, Nigeria. \\ ${ }^{4}$ Department of Chemistry, Nigerian Police Academy, Wudil, Kano-Nigeria
}

*Correspondence E-mail; saboyusuf18@yahoo.com

ABSTRACT

Stability constants of complexes of four divalent metal ions viz. $\mathrm{Cu}^{2+}, \mathrm{Pb}^{2+}, \mathrm{Mg}^{2+}$ and $\mathrm{Cd}^{2+}$ with humic acids (HA) were determined by potentiometric titration of humic acids with the corresponding salt of the divalent metals in aqueous media under non-acid-condition. The log $K$ (logarithm of the stability constant) ranged from 1.0942 to 2.7471 for metalhumic acid complexes were determined using point-wise computational method. The order of stability constants were obtained as follows: $\mathrm{Cu}>\mathrm{Pb}>\mathrm{Cd}>\mathrm{Mg}$ for metal $-\mathrm{HA}$ complexes respectively, indicating a higher degree of complexation with Cu metal ion.

Keywords: stability constant, humic acid, potentiometric titration, divalent metals, acid hydrolysis.

\section{NTRODUCTION}

The stability constant of a complex is the numerical expression of its stability and provides a quantitative measure of affinity of the metal ion to the complexing agent. An understanding of the relative stability of metal-complexes helps in predicting the behavior of metal ions in the soil (Ram and Raman, 1982). Extensive researches has been done to determine the stability constants of the complexes formed between humic acid (HA) with a number of metal ions. Ashok et al., (2000) reported that humic acid with hydroxyl, phenoxyl and carboxyl reactive groups can form coordination compound with metal ions at $\mathrm{pH}$ 3.5. The stability constants(Log K) for different metalhumic acid complexes indicated the following order of the stabilities of complexes formed between humic acid and metal ion, $\mathrm{Cu}>\mathrm{Fe}$ $>\mathrm{Pb}>\mathrm{Ni}>\mathrm{Co}>\mathrm{Ca}>\mathrm{Cd}>\mathrm{Zn}>\mathrm{Mn}>\mathrm{Mg}$. Andelkovic et al., (2010) investigated the binding of $\mathrm{Cd}$ (II) to soil humic acid at pH 6.5 and in $0.1 \mathrm{M} \mathrm{KNO}_{3}$ ionic medium. The stability constant for binding indicating greater stability in the case when carboxyl groups are involved in complexation reaction. Kostic et al.,(2012) investigated the complexation of humic acid with certain heavy metal ions (Co(II), $\mathrm{Ni}(\mathrm{II}), \mathrm{Cu}(\mathrm{II})$,
$\mathrm{Zn}(\mathrm{II})$, and $\mathrm{Pb}(\mathrm{II})$. The experiment was performed at $25^{\circ} \mathrm{C}$, at pH 4.0 and ionic strength of $0.01 \mathrm{M}$. Stability constant of complex between $\mathrm{Pb}$ (II) ions and humic acid is greater than stability constants of other investigated metalhumate complexes. Bogata and Sokolowska (2016) analyses the interaction between humic acids from different soils and $\mathrm{Zn}$ (II) ions at wide concentration ranges and at $\mathrm{pH} 5$. Studies have showed significant impact of $\mathrm{Zn}$ concentration, $\mathrm{pH}$ and some properties of humic acids with zinc.But all of these studies were limited to acidic $\mathrm{pH}$ range. Therefore, the present study was carried out to determine and compare the stability constants of complexes of metal ions with hydrolysed peat soil humic acid and unhydrolysed peat soil humic under non-acid conditions.

\section{MATERIALS AND METHODS}

Analytical grade chemicals used includes hydrochloric acid $(\mathrm{HCl})$, nitric acid $\left(\mathrm{HNO}_{3}\right)$, sodium hydroxide $(\mathrm{NaOH})$, lead nitrate $\mathrm{Pb}\left(\mathrm{NO}_{3}\right)_{2}$, copper nitrate $\mathrm{Cu}\left(\mathrm{NO}_{3}\right)_{2} \cdot 3 \mathrm{H}_{2} \mathrm{O}$, cadmium nitrate $\mathrm{Cd}\left(\mathrm{NO}_{3}\right)_{2} \cdot 4 \mathrm{H}_{2} \mathrm{O}$, magnesium nitrate $\mathrm{Mg}\left(\mathrm{NO}_{3}\right)_{2} \cdot 6 \mathrm{H}_{2} \mathrm{O}$, potassium nitrate $\left(\mathrm{KNO}_{3}\right)$, calcium chloride $\left(\mathrm{CaCl}_{2}\right)$, (sigma-Aldrich). Dowex 50WX8, (20-50 mesh) from Fluka. 


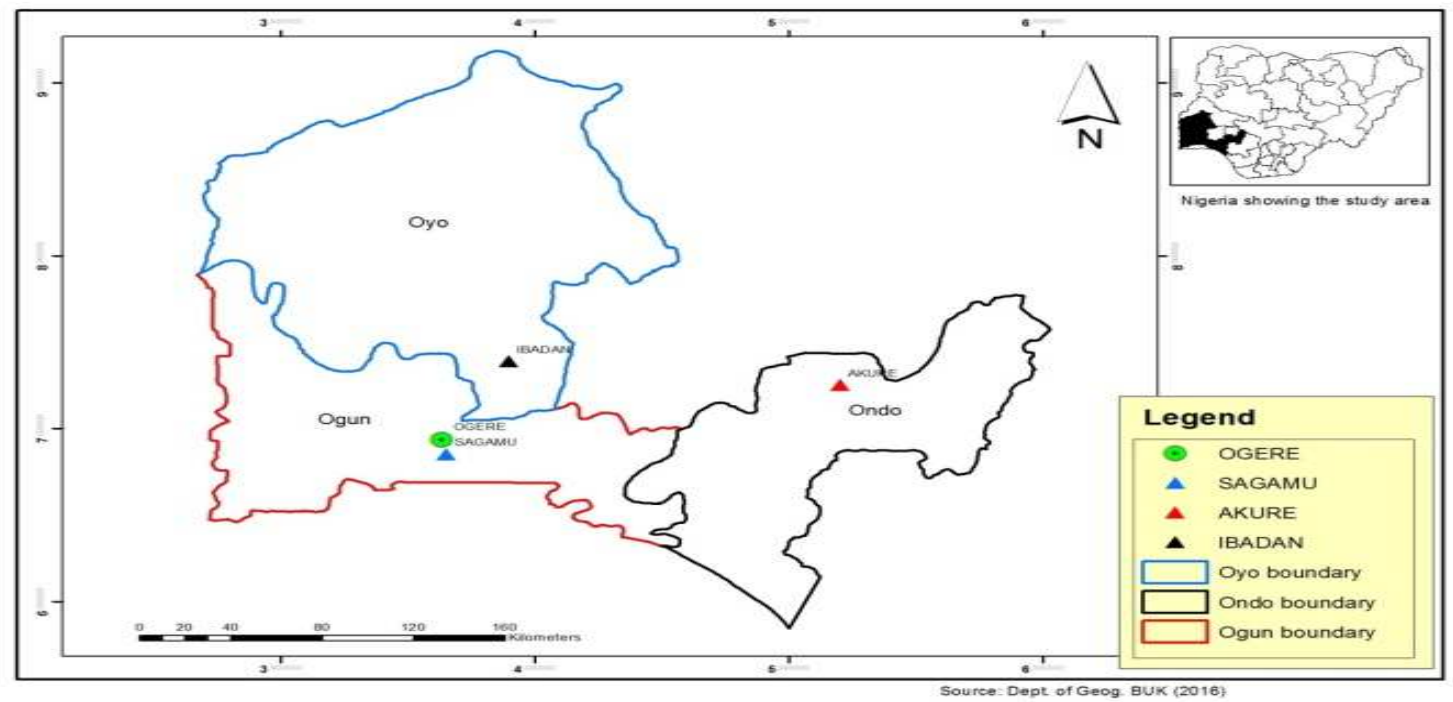

Figure 1: Map showing the sampling point at Sagamu Town, Ogun State.

\section{Description of Sampling Area}

Sagamu has geographical coordinates between $6^{\circ} 50^{\prime}$ north; $3^{\circ} 38^{\prime}$ east is located in south western region of Nigeria. The region has tropical wet and dry climate with a lengthy wet season and relatively constant temperatures throughout the course of the year. Wet season runs from March to October, November to December forms the region dry season. The vegetation type of the region is savannah which is really grassland with small bushes and occasional big trees. Grassland soils have substantially higher organic matter content than forest soils (Novackova, 2011).

\section{Sample Collection}

The Peatsoil samples were collected from four different sampling points $(0-10 \mathrm{~cm}$ depth) in Sagamu into polyethylene bag with plastic spoons. Samples were taken to the laboratory, extraneous materials were removed; the samples were air-dried, crushed and ground to a fine powder in a mortar passed through a $0.20 \mathrm{~mm}$ sieve. The samples were kept for analysis.

\section{Isolation and purification of humic acid from peat soil sample}

Peatsoil sample $(100 \mathrm{~g})$ was mixed with 1000 $\mathrm{cm}^{3}$ of $0.1 \mathrm{M} \mathrm{NaOH}$ solution, shaken for 3hours and left to stand overnight. Dark-coloured supernatant was obtained and decanted from solid residue. The dark-coloured supernatant was acidified to $(\mathrm{pH}=1.0)$ with $6 \mathrm{M} \mathrm{HCl}$ stirred and allowed to stand for 6 hours. Yellowish brown supernatant and dark-brown precipitate were obtained. The yellowish brown supernatant was decanted followed by centrifuge and discarded. The dark-brown precipitate was mixed with $500 \mathrm{~cm}^{3}$ of $0.1 \mathrm{M} \mathrm{NaOH}$ solution followed by passing through dowex resin. The dark-brown solution was acidified to $(\mathrm{pH}=1.0)$ with $6 \mathrm{M} \mathrm{HCl}$ stirred and allowed to stand for 3 hours. The dark-brown precipitate was washed several times with deionized water. The supernatant was treated with $\mathrm{AgNO}_{3}$ solution until no white precipitate observed. The humic acid was transferred to weighed crucible and dried at $60^{\circ} \mathrm{C}$ in an oven for 12 hours. The humic acid was cooled and dried in the desiccator, weighed and recorded. The obtained humic acid was dried again at $60^{\circ} \mathrm{C}$ for additional 6 hours cooled and dried in the desiccator, weighed and recorded constant weight was obtained (Baruah et al., 2015).

\section{FT-IR analysis}

FT-IR spectra of humic acid sample was analysed using Carry 630 FT-IR Agilent Technologies.

Unhydrolysed compost humic acid

The unhydrolysed humic acid was obtained after isolation and purification of compost humic acid and kept for investigation.

\section{Acid hydrolysis of Peatsoil acid}

Peatsoil humic acid sample (1g) was refluxed for 12 hours at $\left(160^{\circ} \mathrm{C}\right)$ with $50 \mathrm{~cm}^{3}$ of $6 \mathrm{M} \mathrm{HCl}$. The mixture was allowed to cool, decanted, and centrifuged after hydrolysis. The insoluble residues were washed with distilled water via centrifugation several times, and the supernatant was treated with $\mathrm{AgNO}_{3}$ solution until no white precipitate was observed. The residue was thoroughly dried over $\mathrm{CaCl}_{2}$ in a desiccator at room temperature (Chefetz et al., 2002). Finally, the obtained hydrolysed humic acid was kept for investigation. 
BAJOPAS Volume 14 Number 1,June, 2021 Potentiometric Titrations

Potentiometric measurements were carried out using a pH-meter Jenway (model 3510) with combine electrode, the sensitivity of the $\mathrm{pH}$ meter is 0.01 units. The $\mathrm{pH}$ meter was switched on half an hour before starting the titration for initial warm up of the instrument. The instrument was calibrated with an aqueous standard buffer solution of $\mathrm{pH} 4.00$ and 10.0 (borate buffer) prepared from a "Qualigens" buffer tablets.

The following sets of solutions were prepared in a $250 \mathrm{~cm}^{3}$ volumetric flask separately for $\mathrm{pH}$ metric titrations.

(i) $5 \mathrm{~cm}^{3} 0.1 \mathrm{M} \mathrm{HCl}+40 \mathrm{~cm}^{3}$ deionized water

(ii) $5 \mathrm{~cm}^{3} 0.1 \mathrm{M} \mathrm{HCl}+39 \mathrm{~cm}^{3}$ deionized water $+1 \mathrm{~cm}^{3} 0.15 \mathrm{gcm}^{-3}$ humic acid

(iii) $5 \mathrm{~cm}^{3} 0.1 \mathrm{M} \mathrm{HCl}+37 \mathrm{~cm}^{3}$ deionized water $+1 \mathrm{~cm}^{3} 0.15 \mathrm{gcm}^{-3}$ humic acid

$$
+2 \mathrm{~cm}^{3} \quad 0.01 \mathrm{M} \mathrm{Cu} \text { (II) }
$$

The solutions were titrated against standardized $0.110 \mathrm{MNaOH}$ separately. The total volume of each mixture was adjusted to $50 \mathrm{~cm}^{3}$ and the ionic strength of the solutions was maintained constant at by adding appropriate amount of stock solution of $1 \mathrm{M} \mathrm{KNO}_{3}$ (Gamal, 2015; Omar and Ali, 2015). A magnetic stirrer was used to achieve thorough mixing of the interacting solutions at $550 \mathrm{rpm}$. The same set of experimental conditions was applied for potentiometric titration of remaining samples.

\section{Evaluation of pKa of Hydrolysed peat soil Humic Acids}

The proton-ligand formation number $\mathrm{n}_{\mathbf{A}}$ were calculated by Irving and Rossotti expression (Omar and Ali, 2015).

$\mathrm{nA}=\mathrm{Y}-\frac{(\mathrm{V} 2-\mathrm{V1})(\mathrm{No}-\mathrm{Eo})}{(\mathrm{VO}+\mathrm{V1}) \mathrm{TCL}}$ 1

Where: $Y$ is number of dissociable proton, $\left(\mathrm{V}_{2^{-}}\right.$ $V_{1}$ ) is the measure of displacement of the ligand curve relative to acid curve, $\mathrm{N}^{\circ}$ and $\mathrm{E}^{\circ}$ are the resultant concentration of alkali solution, free acid solution, $\mathrm{T}_{\mathrm{cL}}{ }^{\circ}$ is the total ligand concentration, $\mathrm{V}^{\circ}$ is the total volume of titration solution, $V_{1}$ is the volume of alkali added to acid solution, $V_{2}$ is the volume of alkali added to acid solution + ligand solution, acid dissociation constants (pKa - values) of ligand were calculated by algebraic method point wise calculation (Tables 1 ). The dissociation constants (pKa) were calculated according to the following relation:

$\mathrm{pKa}=\mathrm{pH}+\log \left(\frac{n A}{1-n A}\right)$ 2

Where: pKa is the acid dissociation constant, $\mathrm{n}_{\mathrm{A}}$ is the Proton-ligand formation number and $\mathrm{pH}$ is the pH-values (Omar and Ali, 2015).

\section{Determination of metal-ligand stability constants $(\log K)$ of complexes}

The potentiometric measurement for the determination of stability constant of a complex in solution is based on the fact that the redox potential of the couple $\frac{M^{+(m-n)}}{M^{+m}}$ is shifted significantly on complexation of the metal ion with the ligand. This method involves change in hydrogen ion concentration $\left[\mathrm{H}^{+}\right]$due to the displacement or association of one or more protons taking place during complexation reaction. This change can be found out by titrating the solutions containing free acid, acid with ligand, and acid with ligand and metal ion, individually against a standard alkali solution at a constant ionic strength or temperature. Either ionic strength or temperature may be varied for different sets of solutions. In all the cases, the change in the $\mathrm{pH}$ of the solution is measured after each addition of a known amount of alkali to the reaction cell which contains the reaction mixture. The titration curves are then drawn by plotting the measured $\mathrm{pH}$ values against the corresponding volume of alkali added and the stability constants of the complexes are determined from the titration curves by employing $\mathrm{pH}$-metric titration technique given by (Irving and Rossoti).

Metal-ligand stability constants ( $\log \mathrm{K}$ ) were determined by using the following relations:

$$
\bar{n}=\frac{\left(V_{3}-V_{2}\right)\left(E^{0}+N^{0}\right)}{\left(V^{0}+V_{2}\right) \bar{n}_{A} T_{m}^{0}}
$$

and

$$
P L=\log _{10}\left\{\frac{1+\beta_{n}^{H} \frac{1}{[\text { anti } \log \mathrm{pH}]^{\mathrm{n}}}}{\mathrm{T}_{\mathrm{L}}^{0}-n \bar{T}_{m}^{0}} \mathrm{X} \frac{\left(V^{0}+V_{3}\right)}{V^{0}}\right\}
$$


BAJOPAS Volume 14 Number 1,June, 2021

Where $T_{L}, T^{\circ}, E^{\circ}$, and $V^{\circ}$ havethe same significance as in equation (1) above, $T_{m}$ denotes the total concentration of metal present in solution, $V_{3}$ is the volume of metal ions present in solution and $\beta^{H}$ is the overall proton ligand stability constant. The metal-ligand stability constants (log K) were determined by employing point wise computational Method (eq. 5 and 6).

$\operatorname{LogK}_{1}=\log \left(\frac{n}{1-n}\right)+\mathrm{pL}$ .5

$\operatorname{LogK}_{2}=\log \left(\frac{1-n}{2-n}\right)+\mathrm{pL}$ ...6

Where: Log $\mathrm{K}$ is the metal-ligand stability constant, $\mathrm{pL}$ is the Free ligand exponent function, $\mathbf{n}$ is the Average number of ligand attached with metal ion (Janraoet al., 2014). The results obtained were analyzed by an ORIGIN 2016 program using titration data and then the proton-ligand stability constants (pKa) and Metal-ligand stability constant (LogK) calculated (Omar and Ali, 2015).

\section{RESULTS AND DISCUSSION}

Fourier transformed infrared (FT-IR) spectra of isolated humic acid from peat soils Figure 2 had distinct clear absorption bands indicating the presence of major humic acid structural elemental groups such as $\mathrm{H}$ bonded $\mathrm{OH}$ $\left(3680 \mathrm{~cm}^{-1}\right.$ peak $), C=0$ of carbonyl $\left(1721 \mathrm{~cm}^{-1}\right.$ peak), functional groups of aliphatic components $\mathrm{CH}_{2}\left(2918 \mathrm{~cm}^{-1}\right.$ peak) and $\mathrm{C}-\mathrm{O}$ stretching of polysaccharide $\left(1168 \mathrm{~cm}^{-1}\right.$ peak). The positions of the absorption bands of the spectra fell within typical major absorption bands of humic acid which is at frequencies 3680, 2918, 1721, 1168 $\mathrm{cm}^{-1}$. The first peak centred in the vicinity of $3680 \mathrm{~cm}^{-1}$ region is attributed to phenol $\mathrm{OH}$ group bounded by intermolecular $\mathrm{H}$ bonds. The $2918 \mathrm{~cm}^{-1}$ band usually has absorption maximum at $2918 \mathrm{~cm}^{-1}$ which is due to $\mathrm{C}-\mathrm{H}$ stretching of alkane group $\left(\mathrm{CH}_{2}\right)$. The next major absorption band is $1721 \mathrm{~cm}^{-1}$. This band has been commonly ascribed to $\mathrm{C}=\mathrm{O}$ stretching of mainly carboxyl group $(\mathrm{COOH})$ with trace amount of ketones. The last peak was observed at 1168 $\mathrm{cm}^{-1}$ due to $\mathrm{C}-\mathrm{O}$ stretching of polysaccharides and this peak appeared also in the spectra of humic acid from peat soil. The FTIR spectra of the isolated humic acid contained all major characteristic absorption peaks of humic acid. These absorption peaks indicated the presence of the major structural elements of humic acid namely $\mathrm{H}$ bonded $\mathrm{OH}, \mathrm{C}=\mathrm{C}$ of aromatic ring, $\mathrm{C}=\mathrm{O}$ of carbonyl group (both carboxyl and ketonic), $\mathrm{CH}_{2}$ group. This strongly supports the presence of humic acid.

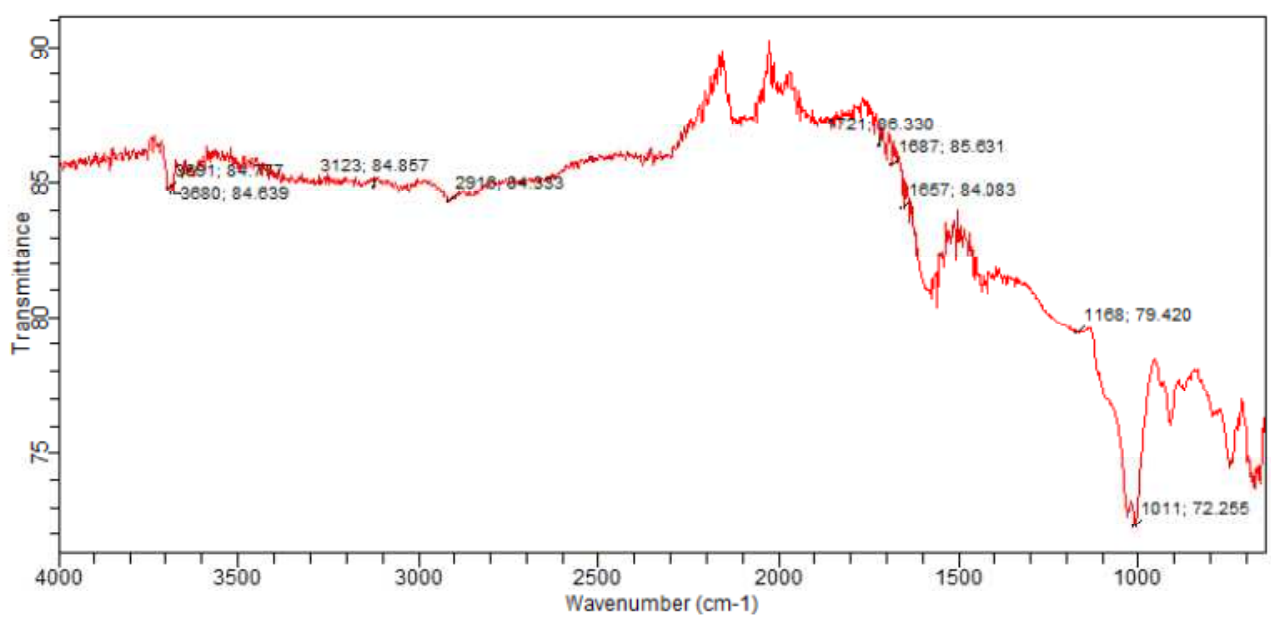

Fig. 2 : FT-IR spectraof peatsoilhumic acid (PSHA)

\section{Evaluation of acid dissociation constant (pka) of acid hydrolysed peat soil humicacid at phenolic group}

The value of the dissociation constant of the peat soil humic acid (PSHA) that underwent acidhydrolysis studied was found to be 8.9299 as shown Table 1, which is lower than the literaturevalues reported by Almeida and Szpoganics, (2015), Borges et al., (2005); Badr et al., (2012)and Fernandes et al,.(2009) of $9.73,9.47$ and 10.30. The difference between the obtained valuesand the reported values in this study might be probably as a result of acid hydrolysis of humicacid. 
BAJOPAS Volume 14 Number 1,June, 2021

Table 1: PKa of (Hydrolysed PSHA)

\begin{tabular}{|l|l|l|l|l|l|l|}
\hline $\mathrm{pH}$ & $\mathrm{BV}_{1}$ & $\mathrm{BV}_{2}$ & $\mathrm{~V}_{2}-\mathrm{V}_{1}$ & $\mathrm{nA}$ & $\log \left(\frac{n A}{1-n A}\right)$ & $\mathrm{pKa}$ \\
\hline 8.50 & 5.30 & 6.29 & 0.99 & 0.3594 & -0.2510 & 8.2490 \\
8.72 & 5.35 & 6.37 & 1.02 & 0.3400 & -0.2880 & 8.4320 \\
9.00 & 5.40 & 6.46 & 1.06 & 0.3141 & -0.3391 & 8.6609 \\
9.22 & 5.45 & 6.55 & 1.10 & 0.2882 & -0.3927 & 8.8273 \\
9.51 & 5.50 & 6.66 & 1.16 & 0.2494 & -0.4786 & 9.0314 \\
9.73 & 5.55 & 6.78 & 1.23 & 0.2041 & -0.5910 & 9.1390 \\
10.00 & 5.60 & 6.90 & 1.30 & 0.1589 & -0.7238 & 9.2762 \\
10.23 & 5.65 & 7.05 & 1.40 & 0.0941 & -0.9835 & 9.2465 \\
10.49 & 5.70 & 7.10 & 1.40 & 0.0941 & -0.9835 & 9.5065 \\
\hline
\end{tabular}

Average pKa $=8.9299 \pm 0.4186$

Table 2: PKa of (Unhydrolysed PSHA)

\begin{tabular}{|l|l|l|l|l|l|l|}
\hline $\mathrm{pH}$ & $\mathrm{BV}_{1}$ & $\mathrm{BV}_{2}$ & $\mathrm{~V}_{2}-\mathrm{V}_{1}$ & $\mathrm{nA}$ & $\log \left(\frac{\boldsymbol{n A}}{1-\boldsymbol{n}}\right)$ & $\mathrm{pKa}$ \\
\hline 8.50 & 5.30 & 5.81 & 0.51 & 0.6619 & 0.2919 & 8.7919 \\
8.72 & 5.35 & 5.90 & 0.55 & 0.6357 & 0.2418 & 8.9618 \\
9.00 & 5.40 & 6.00 & 0.60 & 0.6029 & 0.1813 & 9.1813 \\
9.22 & 5.45 & 6.10 & 0.65 & 0.5701 & 0.1226 & 9.3426 \\
9.51 & 5.50 & 6.20 & 0.70 & 0.5376 & 0.0654 & 9.5754 \\
9.73 & 5.55 & 6.33 & 0.78 & 0.4851 & -0.0259 & 9.7041 \\
10.00 & 5.60 & 6.47 & 0.87 & 0.4262 & -0.1291 & 9.8709 \\
10.23 & 5.65 & 6.62 & 0.99 & 0.3609 & -0.2481 & 9.9819 \\
10.49 & 5.70 & 6.80 & 1.10 & 0.2759 & -0.4690 & 10.0210 \\
\hline
\end{tabular}

Average pKa $=9.4923 \pm 0.4410$

Metal-ligand stability constant ( $\log \mathrm{K}$ )

The stabilityconstants require the accurate values of proton-ligand stability constants (Anil and Maroti, 2008). Metal titration curves crossed over ligand titration curve indicated the formation of complex upon proton release (Santosh, et al., 2011). If the values of n- are within range $0.2-0.8$ and $1.2-18$ this indicates the formation of $1: 1$ and 1:2 complexes (Sayyed and Mazahar, 2012).

The metal (II)-humate stepwise stability constants (log k) at phenolic group (Tables 318)

Table 3: Point-wise method, $\mathrm{Cu}$-(Hydrolysed PSHA)

\begin{tabular}{|l|l|l|l|l|l|l|l|l|}
\hline $\mathrm{pH}$ & $\mathrm{BV}_{1}$ & $\mathrm{BV}_{2}$ & $\mathrm{BV}_{3}$ & $\left(\mathrm{~V}_{3}-\mathrm{V}_{2}\right)$ & $\mathrm{n}$ & $\mathrm{pL}$ & $\log \left(\frac{n}{1-n}\right)$ & LogK $_{1}$ \\
\hline 8.50 & 5.30 & 6.29 & 6.33 & 0.04 & 0.5500 & 2.66 & 0.0871 & 2.7471 \\
8.72 & 5.35 & 6.37 & 6.41 & 0.04 & 0.5714 & 2.43 & 0.1249 & 2.5549 \\
9.00 & 5.40 & 6.46 & 6.50 & 0.04 & 0.6198 & 2.16 & 0.2122 & 2.3722 \\
9.22 & 5.45 & 6.55 & 6.59 & 0.04 & 0.6667 & 1.94 & 0.3010 & 2.2410 \\
\hline
\end{tabular}

LogK $_{1}$ (Average value) $=2.4788 \pm 0.2203$

Table 4: Point-wise method, $\mathrm{Cu}$-(Hydrolysed PSHA)

\begin{tabular}{|l|l|l|l|l|l|l|l|l|}
\hline $\mathrm{pH}$ & $\mathrm{BV}_{1}$ & $\mathrm{BV}_{2}$ & $\mathrm{BV}_{3}$ & $\left(\mathrm{~V}_{3}-\mathrm{V}_{2}\right)$ & $\mathrm{n}$ & $\mathrm{pL}$ & $\log \left(\frac{n-1}{2-n}\right)$ & LogK $_{2}$ \\
\hline 9.51 & 5.50 & 6.66 & 6.73 & 0.07 & 1.3509 & 1.70 & -0.2671 & 1.4329 \\
9.73 & 5.55 & 6.78 & 6.85 & 0.07 & 1.6383 & 1.51 & 0.2467 & 1.7567 \\
10.00 & 5.60 & 6.90 & 6.98 & 0.08 & 2.1783 & 1.31 & -0.2158 & 1.0942 \\
10.23 & 5.65 & 7.05 & 7.13 & 0.08 & 4.1904 & 1.27 & & \\
10.49 & 5.70 & 7.10 & 7.19 & 0.09 & 4.6920 & & & \\
\hline
\end{tabular}

Log $K_{2}($ Average value $)=1.4280 \pm 0.3312$ 
BAJOPAS Volume 14 Number 1,June, 2021

Table 5: Point-wise method, $\mathrm{Cu}$ (Unhydrolysed PSHA)

\begin{tabular}{|l|l|l|l|l|l|l|l|l|}
\hline $\mathrm{pH}$ & $\mathrm{BV}_{1}$ & $\mathrm{BV}_{2}$ & $\mathrm{BV}_{3}$ & $\left(\mathrm{~V}_{3}-\mathrm{V}_{2}\right)$ & $\mathrm{n}$ & $\mathrm{pL}$ & $\log \left(\frac{n}{n-1}\right)$ & Log $_{1}$ \\
\hline 8.50 & 5.30 & 5.81 & 5.85 & 0.04 & 0.2973 & 2.88 & -0.3736 & 2.5064 \\
8.72 & 5.35 & 5.90 & 5.95 & 0.05 & 0.3873 & 2.66 & -0.1992 & 2.4608 \\
9.00 & 5.40 & 6.00 & 6.05 & 0.05 & 0.4044 & 2.38 & -0.1681 & 2.2119 \\
9.22 & 5.45 & 6.10 & 6.15 & 0.06 & 0.5157 & 2.18 & -0.0272 & 2.2072 \\
9.51 & 5.50 & 6.20 & 6.27 & 0.07 & 0.6417 & 1.89 & 0.2530 & 1.1430 \\
\hline
\end{tabular}

$\operatorname{LogK}_{1}($ Average value $)=2.3059 \pm 0.6153$

Table 6:Point-wise method, $\mathrm{Cu}$ (Unhydrolysed PSHA)

\begin{tabular}{|l|l|l|l|l|l|l|l|l|}
\hline $\mathrm{pH}$ & $\mathrm{BV}_{1}$ & $\mathrm{BV}_{2}$ & $\mathrm{BV}_{3}$ & $\mathrm{~V}_{3}-\mathrm{V}_{2}$ & $\mathrm{n}$ & $\mathrm{pL}$ & $\log \left(\frac{n-1}{2-n}\right)$ & $\log \mathrm{K}_{2}$ \\
\hline 9.73 & 5.55 & 6.33 & 6.42 & 0.09 & 0.9000 & 1.69 & & \\
10.00 & 5.60 & 6.47 & 6.58 & 0.11 & 1.2578 & 1.44 & -0.4592 & 0.9808 \\
10.23 & 5.65 & 6.62 & 6.84 & 0.12 & 1.6137 & 1.26 & -0.2010 & 1.4610 \\
10.49 & 5.70 & 6.80 & 6.92 & 0.12 & 2.1052 & 1.03 & & \\
\hline
\end{tabular}

$\operatorname{LogK}_{2}$ (Average value) $=1.2209 \pm 0.3398$

Table 7:Point-wise method, Pb (Hydrolysed PSHA)

\begin{tabular}{|l|l|l|l|l|l|l|l|l|}
\hline $\mathrm{pH}$ & $\mathrm{BV}_{1}$ & $\mathrm{BV}_{2}$ & $\mathrm{BV}_{3}$ & $\left(\mathrm{~V}_{3}-\mathrm{V}_{2}\right)$ & $\mathrm{n}$ & $\mathrm{pL}$ & $\log \left(\frac{n}{1-n}\right)$ & LogK $_{1}$ \\
\hline 8.50 & 5.30 & 6.29 & 6.33 & 0.04 & 0.5500 & 2.66 & 0.0871 & 2.7471 \\
8.72 & 5.35 & 6.37 & 6.41 & 0.04 & 0.5714 & 2.43 & 0.1249 & 2.5549 \\
9.00 & 5.40 & 6.46 & 6.50 & 0.04 & 0.6198 & 2.16 & 0.2122 & 2.3722 \\
9.22 & 5.45 & 6.55 & 6.60 & 0.05 & 0.8333 & 1.96 & 0.6989 & 2.6589 \\
\hline
\end{tabular}

Log $_{\mathbf{1}}($ Average value $)=2.5832 \pm 0.1614$

Table 8:Point-wise method, Pb-(Hydrolysed PSHA)

\begin{tabular}{|l|l|l|l|l|l|l|l|l|}
\hline $\mathrm{pH}$ & $\mathrm{BV}_{1}$ & $\mathrm{BV}_{2}$ & $\mathrm{BV}_{3}$ & $\left(\mathrm{~V}_{3}-\mathrm{V}_{2}\right)$ & $\mathrm{n}$ & $\mathrm{pL}$ & $\log \left(\frac{n-1}{2-n}\right)$ & $\log \mathrm{K}_{2}$ \\
\hline 9.51 & 5.50 & 6.66 & 6.71 & 0.05 & 0.9650 & 1.67 & & \\
9.73 & 5.55 & 6.78 & 6.83 & 0.05 & 1.1702 & 1.44 & & \\
10.00 & 5.60 & 6.90 & 6.90 & 0.05 & 1.4864 & 1.22 & -0.0237 & 1.1963 \\
10.23 & 5.65 & 7.05 & 7.10 & 0.05 & 2.0190 & 1.09 & & \\
10.49 & 5.70 & 7.10 & 7.17 & 0.07 & 3.6492 & 1.00 & & \\
\hline
\end{tabular}

Log $K_{2}$ (Average value) $=1.1963$

Table 9: Point-wise method, Pb (Unhydrolysed PSHA)

\begin{tabular}{|l|l|l|l|l|l|l|l|l|}
\hline $\mathrm{pH}$ & $\mathrm{BV}_{1}$ & $\mathrm{BV}_{2}$ & $\mathrm{BV}_{3}$ & $\mathrm{~V}_{3}-\mathrm{V}_{2}$ & $\mathrm{n}$ & $\mathrm{pL}$ & $\begin{array}{l}\text { Log } \\
\left(\frac{n}{n-1}\right)\end{array}$ & Log $\mathrm{K}_{1}$ \\
\hline 8.50 & 5.30 & 5.81 & 5.85 & 0.04 & 0.2973 & 2.88 & -0.3736 & 2.5064 \\
8.72 & 5.35 & 5.90 & 5.94 & 0.04 & 0.3099 & 2.66 & -0.5477 & 2.3123 \\
9.00 & 5.40 & 6.00 & 6.05 & 0.05 & 0.4044 & 2.38 & -0.1681 & 2.2119 \\
9.22 & 5.45 & 6.10 & 6.15 & 0.06 & 0.5157 & 2.18 & 0.0272 & 2.2072 \\
9.51 & 5.50 & 6.20 & 6.26 & 0.07 & 0.6417 & 1.89 & 0.2530 & 2.1430 \\
9.73 & 5.55 & 6.40 & 6.40 & 0.07 & 0.7000 & 1.67 & 0.3680 & 2.0380 \\
\hline
\end{tabular}

LogK $_{1}$ (Average value) $=2.2364 \pm 0.1602$

Table 10: Point-wise method, Pb (Unhydrolysed PSHA)

\begin{tabular}{|l|l|l|l|l|l|l|l|l|}
\hline $\mathrm{pH}$ & $\mathrm{BV}_{1}$ & $\mathrm{BV}_{2}$ & $\mathrm{BV}_{3}$ & $\mathrm{~V}_{3}-\mathrm{V}_{2}$ & $\mathrm{n}$ & $\mathrm{pL}$ & $\log \left(\frac{n-1}{2-n}\right)$ & $\log \mathrm{K}_{2}$ \\
\hline 10.00 & 5.60 & 6.47 & 6.55 & 0.08 & 1.9503 & 1.41 & & \\
10.23 & 5.65 & 6.62 & 6.72 & 0.11 & 1.4792 & 1.26 & -0.0361 & 1.2239 \\
\hline
\end{tabular}

$\operatorname{LogK}_{2}$ (Average value) $=1.2239$

Table 11: Point-wise method, Mg (Hydrolysed PSHA)

\begin{tabular}{|l|l|l|l|l|l|l|l|l|}
\hline $\mathrm{pH}$ & $\mathrm{BV}_{1}$ & $\mathrm{BV}_{2}$ & $\mathrm{BV}_{3}$ & $\left(\mathrm{~V}_{3}-\mathrm{V}_{2}\right)$ & $\mathrm{n}$ & $\mathrm{pL}$ & $\log \left(\frac{n}{n-1}\right)$ & LogK $_{1}$ \\
\hline 8.50 & 5.30 & 6.29 & 6.31 & 0.02 & 0.2750 & 2.64 & -0.4290 & 2.2110 \\
8.72 & 5.35 & 6.37 & 6.39 & 0.02 & 0.2858 & 2.42 & -0.3978 & 2.0222 \\
9.00 & 5.40 & 6.46 & 6.49 & 0.03 & 0.4648 & 2.14 & -0.0612 & 2.0788 \\
9.22 & 5.45 & 6.55 & 6.59 & 0.04 & 0.6667 & 1.94 & 0.3010 & 2.2410 \\
\hline
\end{tabular}

$\log _{\mathbf{1}}($ Average value) $=2.1382 \pm 0.1046$ 
BAJOPAS Volume 14 Number 1,June, 2021

Table 12: Point-wise method, Mg (Hydrolysed PSHA)

\begin{tabular}{|l|l|l|l|l|l|l|l|l|}
\hline $\mathrm{pH}$ & $\mathrm{BV}_{1}$ & $\mathrm{BV}_{2}$ & $\mathrm{BV}_{3}$ & $\left(\mathrm{~V}_{3}-\mathrm{V}_{2}\right)$ & $\mathrm{n}$ & $\mathrm{pL}$ & $\log \left(\frac{n-1}{2-n}\right)$ & LogK $_{2}$ \\
\hline 9.51 & 5.55 & 6.66 & 6.71 & 0.05 & 0.9650 & 1.67 & & \\
9.73 & 5.55 & 6.78 & 6.84 & 0.06 & 1.4042 & 1.47 & -0.1686 & 1.3014 \\
10.00 & 5.60 & 6.90 & 6.93 & 0.06 & 1.7838 & 1.23 & 0.5593 & 1.7893 \\
10.23 & 5.65 & 7.05 & 7.10 & 0.06 & 3.1429 & 1.10 & & \\
10.49 & 5.70 & 7.10 & 7.18 & 0.07 & 3.6492 & 0.83 & & \\
\hline
\end{tabular}

LogK $_{2}($ Average value $)=1.5453 \pm 0.3450$

Table 13: Point-wise method, Mg (Unhydrolysed PSHA)

\begin{tabular}{|l|l|l|l|l|l|l|l|l|}
\hline $\mathrm{pH}$ & $\mathrm{BV}_{1}$ & $\mathrm{BV}_{2}$ & $\mathrm{BV}_{3}$ & $\mathrm{~V}_{3}-\mathrm{V}_{2}$ & $\mathrm{n}$ & $\mathrm{pL}$ & $\log \left(\frac{n}{n-1}\right)$ & $\operatorname{Log~}_{1}$ \\
\hline 8.50 & 5.30 & 5.81 & 5.85 & 0.04 & 0.2973 & 2.88 & -0.3736 & 2.5064 \\
8.72 & 5.35 & 5.90 & 5.94 & 0.04 & 0.3099 & 2.66 & -0.3477 & 2.3123 \\
9.00 & 5.40 & 6.00 & 6.04 & 0.04 & 0.3236 & 2.38 & -0.3202 & 2.0598 \\
9.22 & 5.45 & 6.10 & 6.15 & 0.05 & 0.4297 & 2.17 & -0.1230 & 2.0470 \\
9.51 & 5.50 & 6.20 & 6.26 & 0.06 & 0.5500 & 1.89 & 0.0871 & 1.9771 \\
9.73 & 5.55 & 6.33 & 6.40 & 0.07 & 0.7000 & 1.67 & 0.3680 & 2.0380 \\
\hline
\end{tabular}

LogK $_{1}$ (Average value) $=2.1568 \pm 0.2069$

Table 14: Point-wise method, Mg (Unhydrolysed PSHA)

\begin{tabular}{|l|l|l|l|l|l|l|l|l|}
\hline $\mathrm{pH}$ & $\mathrm{BV}_{1}$ & $\mathrm{BV}_{2}$ & $\mathrm{BV}_{3}$ & $\mathrm{~V}_{3}-\mathrm{V}_{2}$ & $\mathrm{n}$ & $\mathrm{pL}$ & $\log \left(\frac{n-1}{2-n}\right)$ & $\log \mathrm{K}_{2}$ \\
\hline 10.00 & 5.60 & 6.47 & 6.55 & 0.08 & 0.9148 & 1.41 & & \\
10.23 & 5.65 & 6.62 & 6.71 & 0.09 & 1.2102 & 1.20 & -0.5749 & 0.6251 \\
10.49 & 5.70 & 6.80 & 6.92 & 0.09 & 1.5968 & 1.03 & 0.1703 & 1.2003 \\
\hline
\end{tabular}

LogK $_{2}$ (Average value) $=0.9127 \pm 0.4070$

Table15:Point-wise method, Cd (Hydrolysed PSHA)

\begin{tabular}{|l|l|l|l|l|l|l|l|l|}
\hline $\mathrm{pH}$ & $\mathrm{BV}_{1}$ & $\mathrm{BV}_{2}$ & $\mathrm{BV}_{3}$ & $\left(\mathrm{~V}_{3}-\mathrm{V}_{2}\right)$ & $\mathrm{n}$ & $\mathrm{pL}$ & $\log \left(\frac{n}{1-n}\right)$ & LogK $_{1}$ \\
\hline 8.50 & 5.30 & 6.29 & 6.31 & 0.02 & 0.2750 & 2.64 & -0.4210 & 2.2190 \\
8.72 & 5.35 & 6.37 & 6.40 & 0.03 & 0.4286 & 2.42 & -0.1249 & 2.2951 \\
9.00 & 5.40 & 6.46 & 6.49 & 0.03 & 0.4648 & 2.14 & -0.0612 & 2.0788 \\
9.22 & 5.45 & 6.55 & 6.59 & 0.04 & 0.6667 & 1.96 & 0.3010 & 2.2610 \\
9.51 & 5.55 & 6.66 & 6.70 & 0.04 & 0.7720 & 1.67 & 0.5297 & 2.1997 \\
\hline
\end{tabular}

LogK $_{\mathbf{1}}$ (Average value) $=2.2108 \pm 0.0825$

Table 16: Point-wise method, Cd (Hydrolysed PSHA)

\begin{tabular}{|l|l|l|l|l|l|l|l|l|}
\hline $\mathrm{pH}$ & $\mathrm{BV}_{1}$ & $\mathrm{BV}_{2}$ & $\mathrm{BV}_{3}$ & $\left(\mathrm{~V}_{3}-\mathrm{V}_{2}\right)$ & $\mathrm{n}$ & $\mathrm{pL}$ & $\log \left(\frac{n-1}{2-n}\right)$ & Log $_{2}$ \\
\hline 9.73 & 5.55 & 6.78 & 6.83 & 0.06 & 1.4042 & 1.47 & -0.1686 & 1.3014 \\
10.00 & 5.60 & 6.90 & 6.95 & 0.06 & 1.7838 & 1.23 & 0.5593 & 1.7893 \\
10.23 & 5.65 & 7.05 & 7.10 & 0.06 & 3.1429 & 1.09 & & \\
10.49 & 5.70 & 7.10 & 7.16 & 0.06 & 3.1429 & 0.89 & & \\
& & & & & & & & \\
\hline
\end{tabular}

$\operatorname{LogK}_{2}$ (Average value) $=1.5453 \pm 0.3450$

Table 17: Point-wise method, Cd (Unhydrolysed PSHA)

\begin{tabular}{|l|l|l|l|l|l|l|l|l|}
\hline $\mathrm{pH}$ & $\mathrm{BV}_{1}$ & $\mathrm{BV}_{2}$ & $\mathrm{BV}_{3}$ & $\mathrm{~V}_{3}-\mathrm{V}_{2}$ & $\mathrm{n}$ & $\mathrm{pL}$ & $\log \left(\frac{n}{n-1}\right)$ & $\operatorname{Log~}_{1}$ \\
\hline 8.50 & 5.30 & 5.81 & 5.86 & 0.05 & 0.3717 & 2.88 & -0.2280 & 2.6520 \\
8.72 & 5.35 & 5.90 & 5.95 & 0.05 & 0.3873 & 2.66 & -0.1992 & 2.4608 \\
9.00 & 5.40 & 6.00 & 6.06 & 0.06 & 0.4853 & 2.38 & -0.0255 & 2.3545 \\
9.22 & 5.45 & 6.10 & 6.16 & 0.06 & 0.5157 & 2.18 & -0.0272 & 2.2072 \\
9.51 & 5.50 & 6.20 & 6.27 & 0.07 & 0.6417 & 1.89 & 0.2530 & 1.1430 \\
9.73 & 5.55 & 6.33 & 6.41 & 0.08 & 0.8000 & 1.69 & 0.6020 & 2.2920 \\
& & & & & & & & \\
\hline
\end{tabular}

$\operatorname{LogK}_{1}($ Average value $)=2.2516 \pm 0.5380$ 
BAJOPAS Volume 14 Number 1,June, 2021

Table 18: Point-wise method, Cd (Unhydrolysed PSHA)

\begin{tabular}{|l|l|l|l|l|l|l|l|l|}
\hline $\mathrm{pH}$ & $\mathrm{BV}_{1}$ & $\mathrm{BV}_{2}$ & $\mathrm{BV}_{3}$ & $\mathrm{~V}_{3}-\mathrm{V}_{2}$ & $\mathrm{n}$ & $\mathrm{pL}$ & $\log \left(\frac{n-1}{2-n}\right)$ & $\log \mathrm{K}_{2}$ \\
\hline 10.00 & 5.60 & 6.47 & 6.57 & 0.10 & 1.1434 & 1.43 & & \\
10.23 & 5.65 & 6.62 & 6.72 & 0.10 & 1.3448 & 1.23 & -0.2788 & 0.9512 \\
10.49 & 5.70 & 6.80 & 6.90 & 0.10 & 1.7742 & 1.03 & 0.5351 & 1.5651 \\
\hline
\end{tabular}

$\operatorname{LogK}_{2}($ Average value $)=1.2581 \pm 0.4340$

Table 19: Stepwise and overall Stability constants of thehydrolysed and unhydrolysed divalent metal (II) complexes

\begin{tabular}{|c|c|c|c|}
\hline Chelates & LogK $_{1}$ & $\log _{2}$ & Log $\beta$ \\
\hline [Cu (Hydrolysed PSHA-1) $\left.{ }_{2}\right]$ & 2.4788 & 1.4280 & 3.9068 \\
\hline$\left[\mathrm{Pb}(\text { Hydrolysed PSHA-1) })_{2}\right]$ & 2.5832 & 1.1963 & 3.7795 \\
\hline$\left[\mathrm{Cd}(\text { Hydrolysed PSHA-1 })_{2}\right]$ & 2.2108 & 1.5453 & 3.7561 \\
\hline$\left[\mathrm{Mg}(\text { Hydrolysed PSHA-1 })_{2}\right]$ & 2.1382 & 1.5453 & 3.6835 \\
\hline [Cu (Unhydrolysed PSHA-1) & 2.3059 & 1.2209 & 3.5268 \\
\hline$[\mathrm{Pb}$ (Unhydrolysed PSHA-1) 2$]$ & 2.2364 & 1.2239 & 3.4603 \\
\hline [Cd (Unhydrolysed PSHA-1) 2 ] & 2.2516 & 1.2581 & 3.5097 \\
\hline$[\mathrm{Mg}$ (Unydrolysed PSHA-1) & 2.1568 & 0.9127 & 3.0695 \\
\hline
\end{tabular}

The results obtained (Table19) shows the stepwise and overall stability constants to be not high indicating low stability of the complexes, because the solubility of most metal ions in the basic $\mathrm{pH}$ range is minimal due to metal hydroxide precipitation (Karimi, 2017). In general, the stepwise stability constants $\left(K_{1}\right.$ and $K_{2}$ ) follow the order $K_{1}>K_{2}$ for the copper, lead, magnesium and cadmium complexes respectively. The steady decrease of the values with increasing number of ligands is in agreement with the prediction made by researchers (Na'aliya, 2013). The decrease could be attributed to the fact that as the number of the ligands (Humate ions) that enters the coordination zone increases the aqua molecules available for replacement by the ligands become less. Thus, the metal ions become less electron loving with progressive intake of the ligand and this results in the decrease in the values of the constants (Na'aliya, 2013). Also the stability of the complexes is influenced by the size and number of the chelate rings(Mackay and Mackay,2002).All the complexes form rings in their structure as humate, a bidentate ligand, bond the metal ions in the ratio 1:2 (Boguta and Sokolowska, 2016) forming chelate rings. The values of the overall stability constants $(\log \beta)$ obtained for humate complexes are not high indicating low stability as the values are not high. LogK values for copper-humates (Table 3 to 6) obtained in this study are lower than those reported for the complexes of humic acids (Pandey et al., 2015; Dinu, 2013; Kaschl et al., 2010 and Gilbeto and Jorg, 2001). The values of LogK(Table 7 to 10 ) forlead-humates are lower than those reported for the lead in the literature (Dinu, 2013; Gilbeto and Jorg 2001). Log K values(Table 11 to 14 ) for magnesium-humates obtained in this study are close to those reported by (Pandey et al., 2015). Log K values of cadmium-humates (Table 15 to 18 ) obtained in this work near to the one reported by (Dinu, 2013 and Pandey et al., 2015).The difference between the reported values and the values obtained in this study might be probably as a result of acid hydrolysis of humic acid. The values of the overall stability constants $(\log \beta)$ of the copper humates complexes presented in Table 19 is high than that of other metal humate complexes, show relatively high stability of CuHA complexes, show the following order of stability: $\mathrm{Cu}>\mathrm{Pb}>\mathrm{Cd}>\mathrm{Mg}$; which are in close agreement to the findings of (Dinu, 2013 and Pandey et al., 2015).The high stability of Cuhumate chelate could be attributed to the existence of coordinate covalent bond between the complexing agents and the $\mathrm{Cu}^{2+}$ ions. Since, $\mathrm{Cu}^{2+}$ being a metal of the transitional series with $3 d^{9}$ electronic configurations can accept the electrons from the complexing agents. Similarly, the low stabilities of $\mathrm{Pb}, \mathrm{Cd}$ and $\mathrm{Mg}$ complexes could be explained by that $\mathrm{Pb}^{2+}$ with $6 s^{2}, \mathrm{Cd}^{2+}$ with $4 \mathrm{~d}^{10}$ and $\mathrm{Mg}^{2+}$ with $2 \mathrm{p}^{6}$ their electronic configuration has a completely filled $\mathrm{d}, \mathrm{p}$ and $\mathrm{s}$ orbitals. Moreover, the stabilities of metal ions with hydrolysed humic acid from peat soil were higher than those with unhydrolysed humic acid from peat soil; which is ascribed to the high content of acidity in hydrolysed humic acid than unhydrolysed humic acid. 
BAJOPAS Volume 14 Number 1,June, 2021 CONCLUSION

The values of logk for $\mathrm{Cu}(\mathrm{II})$ hydrolysed humic acid complex was higher followed by $\mathrm{Pb}$ (II), $\mathrm{Cd}(\mathrm{II})$ and $\mathrm{Mg}$ (II) hydrolysed humic acid complexes as compared with metal(II) unhydrolysed humic acid complexes. This indicates acid hydrolysis of humic acid can

\section{REFERENCES}

Almeida, V.R. and Szpoganicz, B. (2015). Humic Acid Potentiometric Response Patterns:Out- of Equilibrium Properties and Species Distribution Modelling. Chemical. Biol. Technol. Agric. 2: 17.

Anđelković, T., Nikolić, R., Bojić, A.,Anđelković, D., and Nikolic G.,(2010). Binding of Cadmium to Soil Humic Acid as A Function of Carboxyl Group Content. Macedonian Journal of Chemistry and Chemical Engineering.29(2): 215-224.

Anil, B. N. and Maroti, N. (2008). Studies on Influence of Die-Lectric Constants on Complex Equilibria between Substituted Py-Razalines and Lanthanide Metal Ions pH-Metrically. Amer.-Euras. scient. Res. 3(2): 212-216.

Ashok, K., Pandey, S. P. and Misra, V (2000). Stability Constants of Metal-Humic Acid Complexes and its Role in Environmental Detoxification. Journal of Ecotoxicology and Environmental Safety. 47(2):157-200.

Badr, M. H., El-Halafawi, M. H. and Abd El-al Zeid, E. R. (2012). Comparison Between the Effect of Ionic Strength on Acidity and Dissociation Constants of Humic Acids Extracted from Sewage Sludge and Nile Water Hyacinth Composts.Global Journal of Environmental Research 6 (1): 36-43.

Baruah, M.K., Borah, D., Saikia, P.P., Paul, S., Sharma, T. (2015). Evaluation of pKa Values of Soil Humic Acids and their Complexation Properties. International Journal of Plant \& Soil Science 6(4) : 218-228.

Boguta, P. Sokolowska, Z. (2016). Interactions of $\mathrm{Zn}$ (II) Ions with Humic Acids Isolated from Various Types of Soils. Effect of $\mathrm{pH}, \mathrm{Zn}$ Concentrations and Humic Acids Chemical Properties. Journal of Geochemical Explaration 168. 119-126.

Borges, F., Guimaraes, C., Lima, L.F.C., Pinto, I. and Reis, S.(2005). Potentiometric Studies on the Complexation of Copper(II) by Phenolic Acids as Discrete Ligand Models of enhance the complexation behavior of humic acid with metal (II) ions. However, the higher values of $\log \beta$ for $\mathrm{Cu}(\mathrm{II}), \mathrm{Pb}(\mathrm{II}), \mathrm{Cd}(\mathrm{II})$ and $\mathrm{Mg}(\mathrm{II})$ hydrolysed humic acid complexes indicates more stable stepwise complexes formed as compared with $\mathrm{Cu}(\mathrm{II}), \mathrm{Pb}$ (II), $\mathrm{Cd}$ (II) and $\mathrm{Mg}(\mathrm{II})$ unhydrolysed humic acid complexes.

Humic Substances Talanta 66 (2005) 670-673.

Chefetz, B., Salloum, M. J., Deshmulkin, A. P. and Hatcher, P. (2002). Structural Components of Humic Acids as Determined by Chemical Modifications and Carbon-13 NMR, Pyrolysis, and Thermochemolysis- Gas Chromatography/Mass Spectrometry. Soil Science Society of American Journal Abstract Division S-2- Soil Chemistry66. 1159-1171.

Dinu, M. I. (2013). Metals Complexation with Humic Acids in Surface Water of Different Environ. Sci. Technol. 31(1): 1-17.

Fernandes, A.N., Giacomelli, C., Giovanela, M. Vaz, D.V. Szpoganicz, B. and Maria M. D. (2009). Potentiometric Acidity Determination in Humic Substances Influenced by Different Analytical Procedures.J. Braz. Chem. Soc. 20 (9):14.

Gamal, A. H. (2015). Stability Constants of Rhenium (V) Metal Complexes with Selected Drugs. Pyrex Journal of Research in Environmental Studies. 2(2): 006-014.

Janrao, D. M., Pathan, J., Kayande, D.D., and Mulla, J.J. (2014). An Over View of Potentiometric Determination of Stability Constants of Metal Complexes. Sci. Revs. Chem. Commun.: 4(1), 2014, 11-24.

Karimi, H. (2017). Effect of pH and Initial Pb(II) Concentration on the Lead Removal Efficiency from Waste Water Using $\mathrm{Ca}(\mathrm{OH})_{2}$. International Journal of Water and Waste Water Treatment 3.2

Kaschl, A. Romheld, V. and Chen, Y. (2010). Binding of Cadmium, Copper and Zinc to Humic Substances Originating from Municipal Solid Waste Compost. Israel Journal of Chemistry Vol. 42(1): 89-98.

Kostic, I. S., Tatjana, P, A., Nikolic, R. S., Cvetkovic, T. P., Pavlovic, D. D., Aleksandar, L.J. and Bojic, A. (2012). Comparative Study of Binding Strengths of Heavy Metals with Humic Acid. J.serb. Chem. Soc. 76(9) pp 1-20. 
BAJOPAS Volume 14 Number 1,June, 2021

Na'aliya, J. (2013). Determination of Stepwise Stability Constants and Gibbs free Energy Change of Trisprolina to Complexes of some Divalent Transition Metal ions. Bayero Journal of Pure and Applied Sciences 6(2): 112-114.

Omar, A. A. and Ali, E. A. (2015). Potentiometric Studies on Complexes of $\mathrm{Cr}$ (III) and $\mathrm{Zr}$ (IV) with some Carboxylic Acids. International Journal of Advanced Chemistry, 3(1) 25-

37.

Pandey, A. K. Pandey, S. D. and Misr, V. (2015).Stability Constants of Metal- Humic Acid Complexes and Its Role in Environmental Detoxification. J. Ecotoxicology and Environmental Safety. 47(1):195-200.

Ram, N. and Raman, K.V. (1984). Stability Constants of Complexes of Metals with
Humicand Fuvic Acids under Non- acidConditions. Journal of Plant Nutrition and Soil Sciences.

147:171-176.

Santosh, D. D., Ashok, B. K., Vijay, J. T., Shivraj, G. W. and Vinay, V. W. (2011). Potentiometric Studies of Elec-Trolyte Effects on Complex Equilibria of Some Substituted 5-(2-hydroxy Phenyl) Pyrazoles. Der pharm. 3 (6): 75-83.

Sayyed, H. and Abdul Rahim, M. F. (2012). Studies of Binary Complexes of Metal Ions with Mandelic Acid by Potentiometry. Chem. J. 02 (6): 206209.

Shirvani, M. Moradian, E. Khalili, B. Bakhtiary, S. (2015). Interaction of $\mathrm{Cd}$ and $\mathrm{Pb}$ with Humate-Palygorskite and HumateSepiolite Complexes. Journal of water, air and pollution 3: 220-228. 


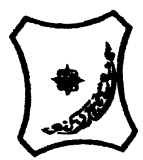

Bayero Journal of Pure and Applied Sciences, 14(1): 54 - 63

Received: November, 2020

Accepted: April, 2021

ISSN $2006-6996$

\title{
STABILITY CONSTANTS OF COMPLEXES OF METAL IONS WITH PEATSOIL HUMIC ACIDS UNDER NON-ACID-CONDITIONS
}

\author{
${ }^{* 1}$ Sabo, Yusuf ${ }^{2}$ Jimoh, W.L.O., ${ }^{3}$ Isa Baba Koki and ${ }^{4}$ Sholadoye, Q. 0. \\ ${ }^{1}$ Department of Pure and Industrial Chemistry, Bayero University, Kano \\ ${ }^{3}$ Department of Chemistry, Yusuf Maitama Sule University Kano. P.M.B. 3220 Kano, Nigeria. \\ ${ }^{4}$ Department of Chemistry, Nigerian Police Academy, Wudil, Kano-Nigeria
}

*Correspondence E-mail; saboyusuf18@yahoo.com

ABSTRACT

Stability constants of complexes of four divalent metal ions viz. $\mathrm{Cu}^{2+}, \mathrm{Pb}^{2+}, \mathrm{Mg}^{2+}$ and $\mathrm{Cd}^{2+}$ with humic acids (HA) were determined by potentiometric titration of humic acids with the corresponding salt of the divalent metals in aqueous media under non-acid-condition. The log $K$ (logarithm of the stability constant) ranged from 1.0942 to 2.7471 for metalhumic acid complexes were determined using point-wise computational method. The order of stability constants were obtained as follows: $\mathrm{Cu}>\mathrm{Pb}>\mathrm{Cd}>\mathrm{Mg}$ for metal $-\mathrm{HA}$ complexes respectively, indicating a higher degree of complexation with Cu metal ion.

Keywords: stability constant, humic acid, potentiometric titration, divalent metals, acid hydrolysis.

\section{NTRODUCTION}

The stability constant of a complex is the numerical expression of its stability and provides a quantitative measure of affinity of the metal ion to the complexing agent. An understanding of the relative stability of metal-complexes helps in predicting the behavior of metal ions in the soil (Ram and Raman, 1982). Extensive researches has been done to determine the stability constants of the complexes formed between humic acid (HA) with a number of metal ions. Ashok et al., (2000) reported that humic acid with hydroxyl, phenoxyl and carboxyl reactive groups can form coordination compound with metal ions at $\mathrm{pH}$ 3.5. The stability constants(Log K) for different metalhumic acid complexes indicated the following order of the stabilities of complexes formed between humic acid and metal ion, $\mathrm{Cu}>\mathrm{Fe}$ $>\mathrm{Pb}>\mathrm{Ni}>\mathrm{Co}>\mathrm{Ca}>\mathrm{Cd}>\mathrm{Zn}>\mathrm{Mn}>\mathrm{Mg}$. Andelkovic et al., (2010) investigated the binding of $\mathrm{Cd}$ (II) to soil humic acid at pH 6.5 and in $0.1 \mathrm{M} \mathrm{KNO}_{3}$ ionic medium. The stability constant for binding indicating greater stability in the case when carboxyl groups are involved in complexation reaction. Kostic et al.,(2012) investigated the complexation of humic acid with certain heavy metal ions (Co(II), $\mathrm{Ni}(\mathrm{II}), \mathrm{Cu}(\mathrm{II})$,
$\mathrm{Zn}(\mathrm{II})$, and $\mathrm{Pb}(\mathrm{II})$. The experiment was performed at $25^{\circ} \mathrm{C}$, at pH 4.0 and ionic strength of $0.01 \mathrm{M}$. Stability constant of complex between $\mathrm{Pb}$ (II) ions and humic acid is greater than stability constants of other investigated metalhumate complexes. Bogata and Sokolowska (2016) analyses the interaction between humic acids from different soils and $\mathrm{Zn}$ (II) ions at wide concentration ranges and at $\mathrm{pH} 5$. Studies have showed significant impact of $\mathrm{Zn}$ concentration, $\mathrm{pH}$ and some properties of humic acids with zinc.But all of these studies were limited to acidic $\mathrm{pH}$ range. Therefore, the present study was carried out to determine and compare the stability constants of complexes of metal ions with hydrolysed peat soil humic acid and unhydrolysed peat soil humic under non-acid conditions.

\section{MATERIALS AND METHODS}

Analytical grade chemicals used includes hydrochloric acid $(\mathrm{HCl})$, nitric acid $\left(\mathrm{HNO}_{3}\right)$, sodium hydroxide $(\mathrm{NaOH})$, lead nitrate $\mathrm{Pb}\left(\mathrm{NO}_{3}\right)_{2}$, copper nitrate $\mathrm{Cu}\left(\mathrm{NO}_{3}\right)_{2} \cdot 3 \mathrm{H}_{2} \mathrm{O}$, cadmium nitrate $\mathrm{Cd}\left(\mathrm{NO}_{3}\right)_{2} \cdot 4 \mathrm{H}_{2} \mathrm{O}$, magnesium nitrate $\mathrm{Mg}\left(\mathrm{NO}_{3}\right)_{2} \cdot 6 \mathrm{H}_{2} \mathrm{O}$, potassium nitrate $\left(\mathrm{KNO}_{3}\right)$, calcium chloride $\left(\mathrm{CaCl}_{2}\right)$, (sigma-Aldrich). Dowex 50WX8, (20-50 mesh) from Fluka. 


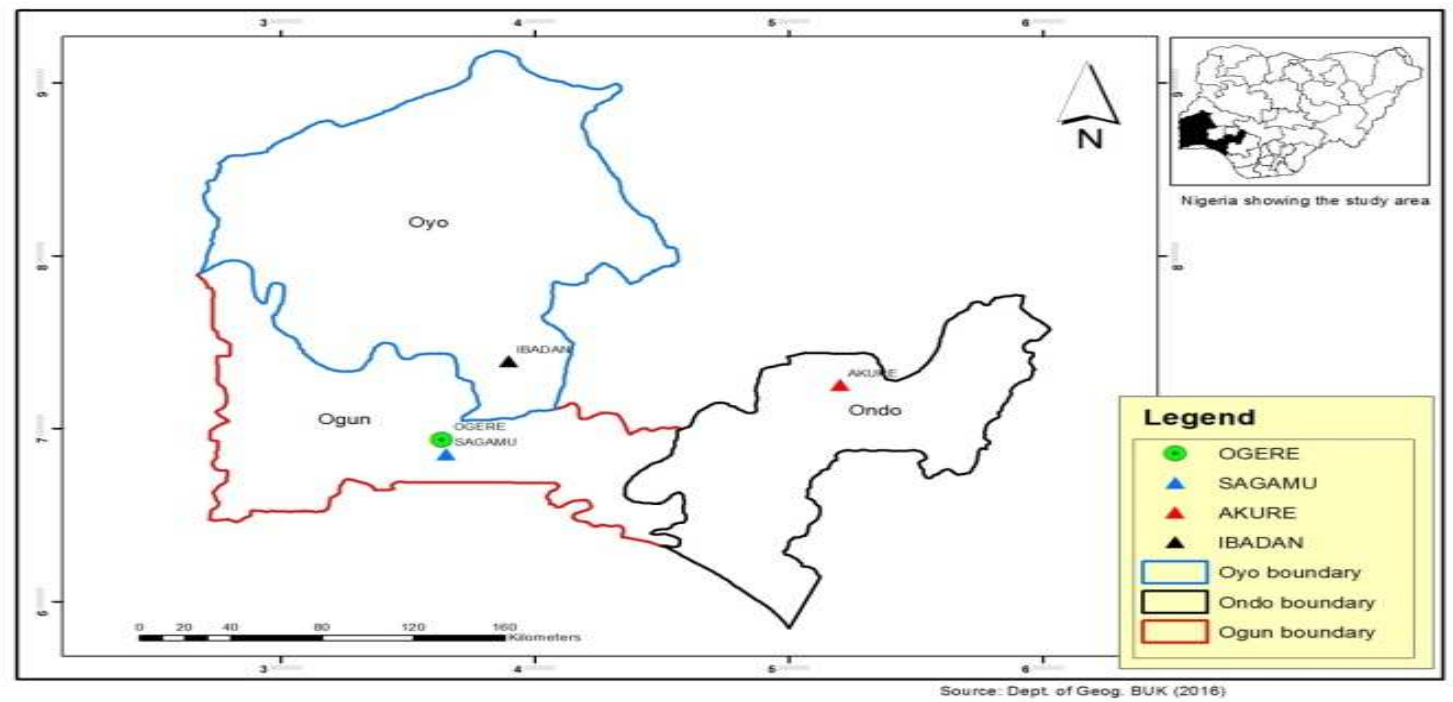

Figure 1: Map showing the sampling point at Sagamu Town, Ogun State.

\section{Description of Sampling Area}

Sagamu has geographical coordinates between $6^{\circ} 50^{\prime}$ north; $3^{\circ} 38^{\prime}$ east is located in south western region of Nigeria. The region has tropical wet and dry climate with a lengthy wet season and relatively constant temperatures throughout the course of the year. Wet season runs from March to October, November to December forms the region dry season. The vegetation type of the region is savannah which is really grassland with small bushes and occasional big trees. Grassland soils have substantially higher organic matter content than forest soils (Novackova, 2011).

\section{Sample Collection}

The Peatsoil samples were collected from four different sampling points $(0-10 \mathrm{~cm}$ depth) in Sagamu into polyethylene bag with plastic spoons. Samples were taken to the laboratory, extraneous materials were removed; the samples were air-dried, crushed and ground to a fine powder in a mortar passed through a $0.20 \mathrm{~mm}$ sieve. The samples were kept for analysis.

\section{Isolation and purification of humic acid from peat soil sample}

Peatsoil sample $(100 \mathrm{~g})$ was mixed with 1000 $\mathrm{cm}^{3}$ of $0.1 \mathrm{M} \mathrm{NaOH}$ solution, shaken for 3hours and left to stand overnight. Dark-coloured supernatant was obtained and decanted from solid residue. The dark-coloured supernatant was acidified to $(\mathrm{pH}=1.0)$ with $6 \mathrm{M} \mathrm{HCl}$ stirred and allowed to stand for 6 hours. Yellowish brown supernatant and dark-brown precipitate were obtained. The yellowish brown supernatant was decanted followed by centrifuge and discarded. The dark-brown precipitate was mixed with $500 \mathrm{~cm}^{3}$ of $0.1 \mathrm{M} \mathrm{NaOH}$ solution followed by passing through dowex resin. The dark-brown solution was acidified to $(\mathrm{pH}=1.0)$ with $6 \mathrm{M} \mathrm{HCl}$ stirred and allowed to stand for 3 hours. The dark-brown precipitate was washed several times with deionized water. The supernatant was treated with $\mathrm{AgNO}_{3}$ solution until no white precipitate observed. The humic acid was transferred to weighed crucible and dried at $60^{\circ} \mathrm{C}$ in an oven for 12 hours. The humic acid was cooled and dried in the desiccator, weighed and recorded. The obtained humic acid was dried again at $60^{\circ} \mathrm{C}$ for additional 6 hours cooled and dried in the desiccator, weighed and recorded constant weight was obtained (Baruah et al., 2015).

\section{FT-IR analysis}

FT-IR spectra of humic acid sample was analysed using Carry 630 FT-IR Agilent Technologies.

Unhydrolysed compost humic acid

The unhydrolysed humic acid was obtained after isolation and purification of compost humic acid and kept for investigation.

\section{Acid hydrolysis of Peatsoil acid}

Peatsoil humic acid sample (1g) was refluxed for 12 hours at $\left(160^{\circ} \mathrm{C}\right)$ with $50 \mathrm{~cm}^{3}$ of $6 \mathrm{M} \mathrm{HCl}$. The mixture was allowed to cool, decanted, and centrifuged after hydrolysis. The insoluble residues were washed with distilled water via centrifugation several times, and the supernatant was treated with $\mathrm{AgNO}_{3}$ solution until no white precipitate was observed. The residue was thoroughly dried over $\mathrm{CaCl}_{2}$ in a desiccator at room temperature (Chefetz et al., 2002). Finally, the obtained hydrolysed humic acid was kept for investigation. 
BAJOPAS Volume 14 Number 1,June, 2021 Potentiometric Titrations

Potentiometric measurements were carried out using a pH-meter Jenway (model 3510) with combine electrode, the sensitivity of the $\mathrm{pH}$ meter is 0.01 units. The $\mathrm{pH}$ meter was switched on half an hour before starting the titration for initial warm up of the instrument. The instrument was calibrated with an aqueous standard buffer solution of $\mathrm{pH} 4.00$ and 10.0 (borate buffer) prepared from a "Qualigens" buffer tablets.

The following sets of solutions were prepared in a $250 \mathrm{~cm}^{3}$ volumetric flask separately for $\mathrm{pH}$ metric titrations.

(i) $5 \mathrm{~cm}^{3} 0.1 \mathrm{M} \mathrm{HCl}+40 \mathrm{~cm}^{3}$ deionized water

(ii) $5 \mathrm{~cm}^{3} 0.1 \mathrm{M} \mathrm{HCl}+39 \mathrm{~cm}^{3}$ deionized water $+1 \mathrm{~cm}^{3} 0.15 \mathrm{gcm}^{-3}$ humic acid

(iii) $5 \mathrm{~cm}^{3} 0.1 \mathrm{M} \mathrm{HCl}+37 \mathrm{~cm}^{3}$ deionized water $+1 \mathrm{~cm}^{3} 0.15 \mathrm{gcm}^{-3}$ humic acid

$$
+2 \mathrm{~cm}^{3} \quad 0.01 \mathrm{M} \mathrm{Cu} \text { (II) }
$$

The solutions were titrated against standardized $0.110 \mathrm{MNaOH}$ separately. The total volume of each mixture was adjusted to $50 \mathrm{~cm}^{3}$ and the ionic strength of the solutions was maintained constant at by adding appropriate amount of stock solution of $1 \mathrm{M} \mathrm{KNO}_{3}$ (Gamal, 2015; Omar and Ali, 2015). A magnetic stirrer was used to achieve thorough mixing of the interacting solutions at $550 \mathrm{rpm}$. The same set of experimental conditions was applied for potentiometric titration of remaining samples.

\section{Evaluation of pKa of Hydrolysed peat soil Humic Acids}

The proton-ligand formation number $\mathrm{n}_{\mathbf{A}}$ were calculated by Irving and Rossotti expression (Omar and Ali, 2015).

$\mathrm{nA}=\mathrm{Y}-\frac{(\mathrm{V} 2-\mathrm{V1})(\mathrm{No}-\mathrm{Eo})}{(\mathrm{VO}+\mathrm{V1}) \mathrm{TCL}}$ 1

Where: $Y$ is number of dissociable proton, $\left(\mathrm{V}_{2^{-}}\right.$ $V_{1}$ ) is the measure of displacement of the ligand curve relative to acid curve, $\mathrm{N}^{\circ}$ and $\mathrm{E}^{\circ}$ are the resultant concentration of alkali solution, free acid solution, $\mathrm{T}_{\mathrm{cL}}{ }^{\circ}$ is the total ligand concentration, $\mathrm{V}^{\circ}$ is the total volume of titration solution, $V_{1}$ is the volume of alkali added to acid solution, $V_{2}$ is the volume of alkali added to acid solution + ligand solution, acid dissociation constants (pKa - values) of ligand were calculated by algebraic method point wise calculation (Tables 1 ). The dissociation constants (pKa) were calculated according to the following relation:

$\mathrm{pKa}=\mathrm{pH}+\log \left(\frac{n A}{1-n A}\right)$ 2

Where: pKa is the acid dissociation constant, $\mathrm{n}_{\mathrm{A}}$ is the Proton-ligand formation number and $\mathrm{pH}$ is the pH-values (Omar and Ali, 2015).

\section{Determination of metal-ligand stability constants $(\log K)$ of complexes}

The potentiometric measurement for the determination of stability constant of a complex in solution is based on the fact that the redox potential of the couple $\frac{M^{+(m-n)}}{M^{+m}}$ is shifted significantly on complexation of the metal ion with the ligand. This method involves change in hydrogen ion concentration $\left[\mathrm{H}^{+}\right]$due to the displacement or association of one or more protons taking place during complexation reaction. This change can be found out by titrating the solutions containing free acid, acid with ligand, and acid with ligand and metal ion, individually against a standard alkali solution at a constant ionic strength or temperature. Either ionic strength or temperature may be varied for different sets of solutions. In all the cases, the change in the $\mathrm{pH}$ of the solution is measured after each addition of a known amount of alkali to the reaction cell which contains the reaction mixture. The titration curves are then drawn by plotting the measured $\mathrm{pH}$ values against the corresponding volume of alkali added and the stability constants of the complexes are determined from the titration curves by employing $\mathrm{pH}$-metric titration technique given by (Irving and Rossoti).

Metal-ligand stability constants ( $\log \mathrm{K}$ ) were determined by using the following relations:

$$
\bar{n}=\frac{\left(V_{3}-V_{2}\right)\left(E^{0}+N^{0}\right)}{\left(V^{0}+V_{2}\right) \bar{n}_{A} T_{m}^{0}}
$$

and

$$
P L=\log _{10}\left\{\frac{1+\beta_{n}^{H} \frac{1}{[\text { anti } \log \mathrm{pH}]^{\mathrm{n}}}}{\mathrm{T}_{\mathrm{L}}^{0}-n \bar{T}_{m}^{0}} \mathrm{X} \frac{\left(V^{0}+V_{3}\right)}{V^{0}}\right\}
$$


BAJOPAS Volume 14 Number 1,June, 2021

Where $T_{L}, T^{\circ}, E^{\circ}$, and $V^{\circ}$ havethe same significance as in equation (1) above, $T_{m}$ denotes the total concentration of metal present in solution, $V_{3}$ is the volume of metal ions present in solution and $\beta^{H}$ is the overall proton ligand stability constant. The metal-ligand stability constants (log K) were determined by employing point wise computational Method (eq. 5 and 6).

$\operatorname{LogK}_{1}=\log \left(\frac{n}{1-n}\right)+\mathrm{pL}$ .5

$\operatorname{LogK}_{2}=\log \left(\frac{1-n}{2-n}\right)+\mathrm{pL}$ ...6

Where: Log $\mathrm{K}$ is the metal-ligand stability constant, $\mathrm{pL}$ is the Free ligand exponent function, $\mathbf{n}$ is the Average number of ligand attached with metal ion (Janraoet al., 2014). The results obtained were analyzed by an ORIGIN 2016 program using titration data and then the proton-ligand stability constants (pKa) and Metal-ligand stability constant (LogK) calculated (Omar and Ali, 2015).

\section{RESULTS AND DISCUSSION}

Fourier transformed infrared (FT-IR) spectra of isolated humic acid from peat soils Figure 2 had distinct clear absorption bands indicating the presence of major humic acid structural elemental groups such as $\mathrm{H}$ bonded $\mathrm{OH}$ $\left(3680 \mathrm{~cm}^{-1}\right.$ peak $), C=0$ of carbonyl $\left(1721 \mathrm{~cm}^{-1}\right.$ peak), functional groups of aliphatic components $\mathrm{CH}_{2}\left(2918 \mathrm{~cm}^{-1}\right.$ peak) and $\mathrm{C}-\mathrm{O}$ stretching of polysaccharide $\left(1168 \mathrm{~cm}^{-1}\right.$ peak). The positions of the absorption bands of the spectra fell within typical major absorption bands of humic acid which is at frequencies 3680, 2918, 1721, 1168 $\mathrm{cm}^{-1}$. The first peak centred in the vicinity of $3680 \mathrm{~cm}^{-1}$ region is attributed to phenol $\mathrm{OH}$ group bounded by intermolecular $\mathrm{H}$ bonds. The $2918 \mathrm{~cm}^{-1}$ band usually has absorption maximum at $2918 \mathrm{~cm}^{-1}$ which is due to $\mathrm{C}-\mathrm{H}$ stretching of alkane group $\left(\mathrm{CH}_{2}\right)$. The next major absorption band is $1721 \mathrm{~cm}^{-1}$. This band has been commonly ascribed to $\mathrm{C}=\mathrm{O}$ stretching of mainly carboxyl group $(\mathrm{COOH})$ with trace amount of ketones. The last peak was observed at 1168 $\mathrm{cm}^{-1}$ due to $\mathrm{C}-\mathrm{O}$ stretching of polysaccharides and this peak appeared also in the spectra of humic acid from peat soil. The FTIR spectra of the isolated humic acid contained all major characteristic absorption peaks of humic acid. These absorption peaks indicated the presence of the major structural elements of humic acid namely $\mathrm{H}$ bonded $\mathrm{OH}, \mathrm{C}=\mathrm{C}$ of aromatic ring, $\mathrm{C}=\mathrm{O}$ of carbonyl group (both carboxyl and ketonic), $\mathrm{CH}_{2}$ group. This strongly supports the presence of humic acid.

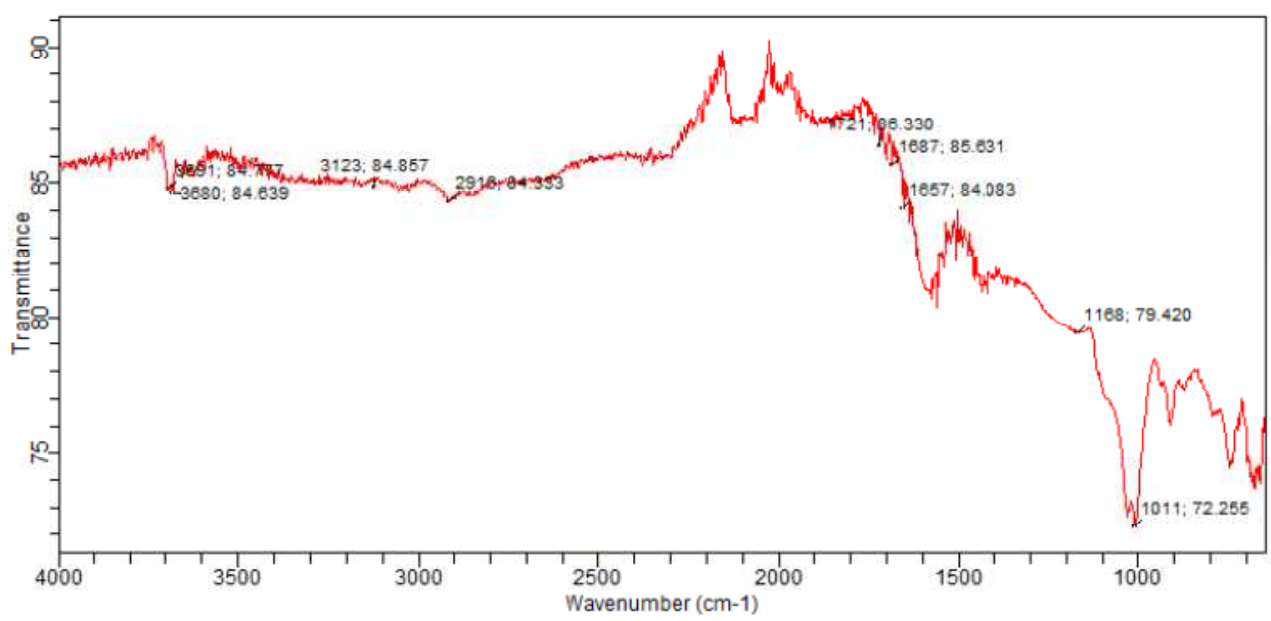

Fig. 2 : FT-IR spectraof peatsoilhumic acid (PSHA)

\section{Evaluation of acid dissociation constant (pka) of acid hydrolysed peat soil humicacid at phenolic group}

The value of the dissociation constant of the peat soil humic acid (PSHA) that underwent acidhydrolysis studied was found to be 8.9299 as shown Table 1, which is lower than the literaturevalues reported by Almeida and Szpoganics, (2015), Borges et al., (2005); Badr et al., (2012)and Fernandes et al,.(2009) of $9.73,9.47$ and 10.30. The difference between the obtained valuesand the reported values in this study might be probably as a result of acid hydrolysis of humicacid. 
BAJOPAS Volume 14 Number 1,June, 2021

Table 1: PKa of (Hydrolysed PSHA)

\begin{tabular}{|l|l|l|l|l|l|l|}
\hline $\mathrm{pH}$ & $\mathrm{BV}_{1}$ & $\mathrm{BV}_{2}$ & $\mathrm{~V}_{2}-\mathrm{V}_{1}$ & $\mathrm{nA}$ & $\log \left(\frac{n A}{1-n A}\right)$ & $\mathrm{pKa}$ \\
\hline 8.50 & 5.30 & 6.29 & 0.99 & 0.3594 & -0.2510 & 8.2490 \\
8.72 & 5.35 & 6.37 & 1.02 & 0.3400 & -0.2880 & 8.4320 \\
9.00 & 5.40 & 6.46 & 1.06 & 0.3141 & -0.3391 & 8.6609 \\
9.22 & 5.45 & 6.55 & 1.10 & 0.2882 & -0.3927 & 8.8273 \\
9.51 & 5.50 & 6.66 & 1.16 & 0.2494 & -0.4786 & 9.0314 \\
9.73 & 5.55 & 6.78 & 1.23 & 0.2041 & -0.5910 & 9.1390 \\
10.00 & 5.60 & 6.90 & 1.30 & 0.1589 & -0.7238 & 9.2762 \\
10.23 & 5.65 & 7.05 & 1.40 & 0.0941 & -0.9835 & 9.2465 \\
10.49 & 5.70 & 7.10 & 1.40 & 0.0941 & -0.9835 & 9.5065 \\
\hline
\end{tabular}

Average pKa $=8.9299 \pm 0.4186$

Table 2: PKa of (Unhydrolysed PSHA)

\begin{tabular}{|l|l|l|l|l|l|l|}
\hline $\mathrm{pH}$ & $\mathrm{BV}_{1}$ & $\mathrm{BV}_{2}$ & $\mathrm{~V}_{2}-\mathrm{V}_{1}$ & $\mathrm{nA}$ & $\log \left(\frac{\boldsymbol{n A}}{1-\boldsymbol{n}}\right)$ & $\mathrm{pKa}$ \\
\hline 8.50 & 5.30 & 5.81 & 0.51 & 0.6619 & 0.2919 & 8.7919 \\
8.72 & 5.35 & 5.90 & 0.55 & 0.6357 & 0.2418 & 8.9618 \\
9.00 & 5.40 & 6.00 & 0.60 & 0.6029 & 0.1813 & 9.1813 \\
9.22 & 5.45 & 6.10 & 0.65 & 0.5701 & 0.1226 & 9.3426 \\
9.51 & 5.50 & 6.20 & 0.70 & 0.5376 & 0.0654 & 9.5754 \\
9.73 & 5.55 & 6.33 & 0.78 & 0.4851 & -0.0259 & 9.7041 \\
10.00 & 5.60 & 6.47 & 0.87 & 0.4262 & -0.1291 & 9.8709 \\
10.23 & 5.65 & 6.62 & 0.99 & 0.3609 & -0.2481 & 9.9819 \\
10.49 & 5.70 & 6.80 & 1.10 & 0.2759 & -0.4690 & 10.0210 \\
\hline
\end{tabular}

Average pKa $=9.4923 \pm 0.4410$

Metal-ligand stability constant ( $\log \mathrm{K}$ )

The stabilityconstants require the accurate values of proton-ligand stability constants (Anil and Maroti, 2008). Metal titration curves crossed over ligand titration curve indicated the formation of complex upon proton release (Santosh, et al., 2011). If the values of n- are within range $0.2-0.8$ and $1.2-18$ this indicates the formation of $1: 1$ and 1:2 complexes (Sayyed and Mazahar, 2012).

The metal (II)-humate stepwise stability constants (log k) at phenolic group (Tables 318)

Table 3: Point-wise method, $\mathrm{Cu}$-(Hydrolysed PSHA)

\begin{tabular}{|l|l|l|l|l|l|l|l|l|}
\hline $\mathrm{pH}$ & $\mathrm{BV}_{1}$ & $\mathrm{BV}_{2}$ & $\mathrm{BV}_{3}$ & $\left(\mathrm{~V}_{3}-\mathrm{V}_{2}\right)$ & $\mathrm{n}$ & $\mathrm{pL}$ & $\log \left(\frac{n}{1-n}\right)$ & LogK $_{1}$ \\
\hline 8.50 & 5.30 & 6.29 & 6.33 & 0.04 & 0.5500 & 2.66 & 0.0871 & 2.7471 \\
8.72 & 5.35 & 6.37 & 6.41 & 0.04 & 0.5714 & 2.43 & 0.1249 & 2.5549 \\
9.00 & 5.40 & 6.46 & 6.50 & 0.04 & 0.6198 & 2.16 & 0.2122 & 2.3722 \\
9.22 & 5.45 & 6.55 & 6.59 & 0.04 & 0.6667 & 1.94 & 0.3010 & 2.2410 \\
\hline
\end{tabular}

LogK $_{1}$ (Average value) $=2.4788 \pm 0.2203$

Table 4: Point-wise method, $\mathrm{Cu}$-(Hydrolysed PSHA)

\begin{tabular}{|l|l|l|l|l|l|l|l|l|}
\hline $\mathrm{pH}$ & $\mathrm{BV}_{1}$ & $\mathrm{BV}_{2}$ & $\mathrm{BV}_{3}$ & $\left(\mathrm{~V}_{3}-\mathrm{V}_{2}\right)$ & $\mathrm{n}$ & $\mathrm{pL}$ & $\log \left(\frac{n-1}{2-n}\right)$ & LogK $_{2}$ \\
\hline 9.51 & 5.50 & 6.66 & 6.73 & 0.07 & 1.3509 & 1.70 & -0.2671 & 1.4329 \\
9.73 & 5.55 & 6.78 & 6.85 & 0.07 & 1.6383 & 1.51 & 0.2467 & 1.7567 \\
10.00 & 5.60 & 6.90 & 6.98 & 0.08 & 2.1783 & 1.31 & -0.2158 & 1.0942 \\
10.23 & 5.65 & 7.05 & 7.13 & 0.08 & 4.1904 & 1.27 & & \\
10.49 & 5.70 & 7.10 & 7.19 & 0.09 & 4.6920 & & & \\
\hline
\end{tabular}

Log $K_{2}($ Average value $)=1.4280 \pm 0.3312$ 
BAJOPAS Volume 14 Number 1,June, 2021

Table 5: Point-wise method, $\mathrm{Cu}$ (Unhydrolysed PSHA)

\begin{tabular}{|l|l|l|l|l|l|l|l|l|}
\hline $\mathrm{pH}$ & $\mathrm{BV}_{1}$ & $\mathrm{BV}_{2}$ & $\mathrm{BV}_{3}$ & $\left(\mathrm{~V}_{3}-\mathrm{V}_{2}\right)$ & $\mathrm{n}$ & $\mathrm{pL}$ & $\log \left(\frac{n}{n-1}\right)$ & Log $_{1}$ \\
\hline 8.50 & 5.30 & 5.81 & 5.85 & 0.04 & 0.2973 & 2.88 & -0.3736 & 2.5064 \\
8.72 & 5.35 & 5.90 & 5.95 & 0.05 & 0.3873 & 2.66 & -0.1992 & 2.4608 \\
9.00 & 5.40 & 6.00 & 6.05 & 0.05 & 0.4044 & 2.38 & -0.1681 & 2.2119 \\
9.22 & 5.45 & 6.10 & 6.15 & 0.06 & 0.5157 & 2.18 & -0.0272 & 2.2072 \\
9.51 & 5.50 & 6.20 & 6.27 & 0.07 & 0.6417 & 1.89 & 0.2530 & 1.1430 \\
\hline
\end{tabular}

$\operatorname{LogK}_{1}($ Average value $)=2.3059 \pm 0.6153$

Table 6:Point-wise method, $\mathrm{Cu}$ (Unhydrolysed PSHA)

\begin{tabular}{|l|l|l|l|l|l|l|l|l|}
\hline $\mathrm{pH}$ & $\mathrm{BV}_{1}$ & $\mathrm{BV}_{2}$ & $\mathrm{BV}_{3}$ & $\mathrm{~V}_{3}-\mathrm{V}_{2}$ & $\mathrm{n}$ & $\mathrm{pL}$ & $\log \left(\frac{n-1}{2-n}\right)$ & $\log \mathrm{K}_{2}$ \\
\hline 9.73 & 5.55 & 6.33 & 6.42 & 0.09 & 0.9000 & 1.69 & & \\
10.00 & 5.60 & 6.47 & 6.58 & 0.11 & 1.2578 & 1.44 & -0.4592 & 0.9808 \\
10.23 & 5.65 & 6.62 & 6.84 & 0.12 & 1.6137 & 1.26 & -0.2010 & 1.4610 \\
10.49 & 5.70 & 6.80 & 6.92 & 0.12 & 2.1052 & 1.03 & & \\
\hline
\end{tabular}

$\operatorname{LogK}_{2}$ (Average value) $=1.2209 \pm 0.3398$

Table 7:Point-wise method, Pb (Hydrolysed PSHA)

\begin{tabular}{|l|l|l|l|l|l|l|l|l|}
\hline $\mathrm{pH}$ & $\mathrm{BV}_{1}$ & $\mathrm{BV}_{2}$ & $\mathrm{BV}_{3}$ & $\left(\mathrm{~V}_{3}-\mathrm{V}_{2}\right)$ & $\mathrm{n}$ & $\mathrm{pL}$ & $\log \left(\frac{n}{1-n}\right)$ & LogK $_{1}$ \\
\hline 8.50 & 5.30 & 6.29 & 6.33 & 0.04 & 0.5500 & 2.66 & 0.0871 & 2.7471 \\
8.72 & 5.35 & 6.37 & 6.41 & 0.04 & 0.5714 & 2.43 & 0.1249 & 2.5549 \\
9.00 & 5.40 & 6.46 & 6.50 & 0.04 & 0.6198 & 2.16 & 0.2122 & 2.3722 \\
9.22 & 5.45 & 6.55 & 6.60 & 0.05 & 0.8333 & 1.96 & 0.6989 & 2.6589 \\
\hline
\end{tabular}

Log $_{\mathbf{1}}($ Average value $)=2.5832 \pm 0.1614$

Table 8:Point-wise method, Pb-(Hydrolysed PSHA)

\begin{tabular}{|l|l|l|l|l|l|l|l|l|}
\hline $\mathrm{pH}$ & $\mathrm{BV}_{1}$ & $\mathrm{BV}_{2}$ & $\mathrm{BV}_{3}$ & $\left(\mathrm{~V}_{3}-\mathrm{V}_{2}\right)$ & $\mathrm{n}$ & $\mathrm{pL}$ & $\log \left(\frac{n-1}{2-n}\right)$ & $\log \mathrm{K}_{2}$ \\
\hline 9.51 & 5.50 & 6.66 & 6.71 & 0.05 & 0.9650 & 1.67 & & \\
9.73 & 5.55 & 6.78 & 6.83 & 0.05 & 1.1702 & 1.44 & & \\
10.00 & 5.60 & 6.90 & 6.90 & 0.05 & 1.4864 & 1.22 & -0.0237 & 1.1963 \\
10.23 & 5.65 & 7.05 & 7.10 & 0.05 & 2.0190 & 1.09 & & \\
10.49 & 5.70 & 7.10 & 7.17 & 0.07 & 3.6492 & 1.00 & & \\
\hline
\end{tabular}

Log $K_{2}$ (Average value) $=1.1963$

Table 9: Point-wise method, Pb (Unhydrolysed PSHA)

\begin{tabular}{|l|l|l|l|l|l|l|l|l|}
\hline $\mathrm{pH}$ & $\mathrm{BV}_{1}$ & $\mathrm{BV}_{2}$ & $\mathrm{BV}_{3}$ & $\mathrm{~V}_{3}-\mathrm{V}_{2}$ & $\mathrm{n}$ & $\mathrm{pL}$ & $\begin{array}{l}\text { Log } \\
\left(\frac{n}{n-1}\right)\end{array}$ & Log $\mathrm{K}_{1}$ \\
\hline 8.50 & 5.30 & 5.81 & 5.85 & 0.04 & 0.2973 & 2.88 & -0.3736 & 2.5064 \\
8.72 & 5.35 & 5.90 & 5.94 & 0.04 & 0.3099 & 2.66 & -0.5477 & 2.3123 \\
9.00 & 5.40 & 6.00 & 6.05 & 0.05 & 0.4044 & 2.38 & -0.1681 & 2.2119 \\
9.22 & 5.45 & 6.10 & 6.15 & 0.06 & 0.5157 & 2.18 & 0.0272 & 2.2072 \\
9.51 & 5.50 & 6.20 & 6.26 & 0.07 & 0.6417 & 1.89 & 0.2530 & 2.1430 \\
9.73 & 5.55 & 6.40 & 6.40 & 0.07 & 0.7000 & 1.67 & 0.3680 & 2.0380 \\
\hline
\end{tabular}

LogK $_{1}$ (Average value) $=2.2364 \pm 0.1602$

Table 10: Point-wise method, Pb (Unhydrolysed PSHA)

\begin{tabular}{|l|l|l|l|l|l|l|l|l|}
\hline $\mathrm{pH}$ & $\mathrm{BV}_{1}$ & $\mathrm{BV}_{2}$ & $\mathrm{BV}_{3}$ & $\mathrm{~V}_{3}-\mathrm{V}_{2}$ & $\mathrm{n}$ & $\mathrm{pL}$ & $\log \left(\frac{n-1}{2-n}\right)$ & $\log \mathrm{K}_{2}$ \\
\hline 10.00 & 5.60 & 6.47 & 6.55 & 0.08 & 1.9503 & 1.41 & & \\
10.23 & 5.65 & 6.62 & 6.72 & 0.11 & 1.4792 & 1.26 & -0.0361 & 1.2239 \\
\hline
\end{tabular}

$\operatorname{LogK}_{2}$ (Average value) $=1.2239$

Table 11: Point-wise method, Mg (Hydrolysed PSHA)

\begin{tabular}{|l|l|l|l|l|l|l|l|l|}
\hline $\mathrm{pH}$ & $\mathrm{BV}_{1}$ & $\mathrm{BV}_{2}$ & $\mathrm{BV}_{3}$ & $\left(\mathrm{~V}_{3}-\mathrm{V}_{2}\right)$ & $\mathrm{n}$ & $\mathrm{pL}$ & $\log \left(\frac{n}{n-1}\right)$ & LogK $_{1}$ \\
\hline 8.50 & 5.30 & 6.29 & 6.31 & 0.02 & 0.2750 & 2.64 & -0.4290 & 2.2110 \\
8.72 & 5.35 & 6.37 & 6.39 & 0.02 & 0.2858 & 2.42 & -0.3978 & 2.0222 \\
9.00 & 5.40 & 6.46 & 6.49 & 0.03 & 0.4648 & 2.14 & -0.0612 & 2.0788 \\
9.22 & 5.45 & 6.55 & 6.59 & 0.04 & 0.6667 & 1.94 & 0.3010 & 2.2410 \\
\hline
\end{tabular}

$\log _{\mathbf{1}}($ Average value) $=2.1382 \pm 0.1046$ 
BAJOPAS Volume 14 Number 1,June, 2021

Table 12: Point-wise method, Mg (Hydrolysed PSHA)

\begin{tabular}{|l|l|l|l|l|l|l|l|l|}
\hline $\mathrm{pH}$ & $\mathrm{BV}_{1}$ & $\mathrm{BV}_{2}$ & $\mathrm{BV}_{3}$ & $\left(\mathrm{~V}_{3}-\mathrm{V}_{2}\right)$ & $\mathrm{n}$ & $\mathrm{pL}$ & $\log \left(\frac{n-1}{2-n}\right)$ & LogK $_{2}$ \\
\hline 9.51 & 5.55 & 6.66 & 6.71 & 0.05 & 0.9650 & 1.67 & & \\
9.73 & 5.55 & 6.78 & 6.84 & 0.06 & 1.4042 & 1.47 & -0.1686 & 1.3014 \\
10.00 & 5.60 & 6.90 & 6.93 & 0.06 & 1.7838 & 1.23 & 0.5593 & 1.7893 \\
10.23 & 5.65 & 7.05 & 7.10 & 0.06 & 3.1429 & 1.10 & & \\
10.49 & 5.70 & 7.10 & 7.18 & 0.07 & 3.6492 & 0.83 & & \\
\hline
\end{tabular}

LogK $_{2}($ Average value $)=1.5453 \pm 0.3450$

Table 13: Point-wise method, Mg (Unhydrolysed PSHA)

\begin{tabular}{|l|l|l|l|l|l|l|l|l|}
\hline $\mathrm{pH}$ & $\mathrm{BV}_{1}$ & $\mathrm{BV}_{2}$ & $\mathrm{BV}_{3}$ & $\mathrm{~V}_{3}-\mathrm{V}_{2}$ & $\mathrm{n}$ & $\mathrm{pL}$ & $\log \left(\frac{n}{n-1}\right)$ & $\operatorname{Log~}_{1}$ \\
\hline 8.50 & 5.30 & 5.81 & 5.85 & 0.04 & 0.2973 & 2.88 & -0.3736 & 2.5064 \\
8.72 & 5.35 & 5.90 & 5.94 & 0.04 & 0.3099 & 2.66 & -0.3477 & 2.3123 \\
9.00 & 5.40 & 6.00 & 6.04 & 0.04 & 0.3236 & 2.38 & -0.3202 & 2.0598 \\
9.22 & 5.45 & 6.10 & 6.15 & 0.05 & 0.4297 & 2.17 & -0.1230 & 2.0470 \\
9.51 & 5.50 & 6.20 & 6.26 & 0.06 & 0.5500 & 1.89 & 0.0871 & 1.9771 \\
9.73 & 5.55 & 6.33 & 6.40 & 0.07 & 0.7000 & 1.67 & 0.3680 & 2.0380 \\
\hline
\end{tabular}

LogK $_{1}$ (Average value) $=2.1568 \pm 0.2069$

Table 14: Point-wise method, Mg (Unhydrolysed PSHA)

\begin{tabular}{|l|l|l|l|l|l|l|l|l|}
\hline $\mathrm{pH}$ & $\mathrm{BV}_{1}$ & $\mathrm{BV}_{2}$ & $\mathrm{BV}_{3}$ & $\mathrm{~V}_{3}-\mathrm{V}_{2}$ & $\mathrm{n}$ & $\mathrm{pL}$ & $\log \left(\frac{n-1}{2-n}\right)$ & $\log \mathrm{K}_{2}$ \\
\hline 10.00 & 5.60 & 6.47 & 6.55 & 0.08 & 0.9148 & 1.41 & & \\
10.23 & 5.65 & 6.62 & 6.71 & 0.09 & 1.2102 & 1.20 & -0.5749 & 0.6251 \\
10.49 & 5.70 & 6.80 & 6.92 & 0.09 & 1.5968 & 1.03 & 0.1703 & 1.2003 \\
\hline
\end{tabular}

LogK $_{2}$ (Average value) $=0.9127 \pm 0.4070$

Table15:Point-wise method, Cd (Hydrolysed PSHA)

\begin{tabular}{|l|l|l|l|l|l|l|l|l|}
\hline $\mathrm{pH}$ & $\mathrm{BV}_{1}$ & $\mathrm{BV}_{2}$ & $\mathrm{BV}_{3}$ & $\left(\mathrm{~V}_{3}-\mathrm{V}_{2}\right)$ & $\mathrm{n}$ & $\mathrm{pL}$ & $\log \left(\frac{n}{1-n}\right)$ & LogK $_{1}$ \\
\hline 8.50 & 5.30 & 6.29 & 6.31 & 0.02 & 0.2750 & 2.64 & -0.4210 & 2.2190 \\
8.72 & 5.35 & 6.37 & 6.40 & 0.03 & 0.4286 & 2.42 & -0.1249 & 2.2951 \\
9.00 & 5.40 & 6.46 & 6.49 & 0.03 & 0.4648 & 2.14 & -0.0612 & 2.0788 \\
9.22 & 5.45 & 6.55 & 6.59 & 0.04 & 0.6667 & 1.96 & 0.3010 & 2.2610 \\
9.51 & 5.55 & 6.66 & 6.70 & 0.04 & 0.7720 & 1.67 & 0.5297 & 2.1997 \\
\hline
\end{tabular}

LogK $_{\mathbf{1}}$ (Average value) $=2.2108 \pm 0.0825$

Table 16: Point-wise method, Cd (Hydrolysed PSHA)

\begin{tabular}{|l|l|l|l|l|l|l|l|l|}
\hline $\mathrm{pH}$ & $\mathrm{BV}_{1}$ & $\mathrm{BV}_{2}$ & $\mathrm{BV}_{3}$ & $\left(\mathrm{~V}_{3}-\mathrm{V}_{2}\right)$ & $\mathrm{n}$ & $\mathrm{pL}$ & $\log \left(\frac{n-1}{2-n}\right)$ & Log $_{2}$ \\
\hline 9.73 & 5.55 & 6.78 & 6.83 & 0.06 & 1.4042 & 1.47 & -0.1686 & 1.3014 \\
10.00 & 5.60 & 6.90 & 6.95 & 0.06 & 1.7838 & 1.23 & 0.5593 & 1.7893 \\
10.23 & 5.65 & 7.05 & 7.10 & 0.06 & 3.1429 & 1.09 & & \\
10.49 & 5.70 & 7.10 & 7.16 & 0.06 & 3.1429 & 0.89 & & \\
& & & & & & & & \\
\hline
\end{tabular}

$\operatorname{LogK}_{2}$ (Average value) $=1.5453 \pm 0.3450$

Table 17: Point-wise method, Cd (Unhydrolysed PSHA)

\begin{tabular}{|l|l|l|l|l|l|l|l|l|}
\hline $\mathrm{pH}$ & $\mathrm{BV}_{1}$ & $\mathrm{BV}_{2}$ & $\mathrm{BV}_{3}$ & $\mathrm{~V}_{3}-\mathrm{V}_{2}$ & $\mathrm{n}$ & $\mathrm{pL}$ & $\log \left(\frac{n}{n-1}\right)$ & $\operatorname{Log~}_{1}$ \\
\hline 8.50 & 5.30 & 5.81 & 5.86 & 0.05 & 0.3717 & 2.88 & -0.2280 & 2.6520 \\
8.72 & 5.35 & 5.90 & 5.95 & 0.05 & 0.3873 & 2.66 & -0.1992 & 2.4608 \\
9.00 & 5.40 & 6.00 & 6.06 & 0.06 & 0.4853 & 2.38 & -0.0255 & 2.3545 \\
9.22 & 5.45 & 6.10 & 6.16 & 0.06 & 0.5157 & 2.18 & -0.0272 & 2.2072 \\
9.51 & 5.50 & 6.20 & 6.27 & 0.07 & 0.6417 & 1.89 & 0.2530 & 1.1430 \\
9.73 & 5.55 & 6.33 & 6.41 & 0.08 & 0.8000 & 1.69 & 0.6020 & 2.2920 \\
& & & & & & & & \\
\hline
\end{tabular}

$\operatorname{LogK}_{1}($ Average value $)=2.2516 \pm 0.5380$ 
BAJOPAS Volume 14 Number 1,June, 2021

Table 18: Point-wise method, Cd (Unhydrolysed PSHA)

\begin{tabular}{|l|l|l|l|l|l|l|l|l|}
\hline $\mathrm{pH}$ & $\mathrm{BV}_{1}$ & $\mathrm{BV}_{2}$ & $\mathrm{BV}_{3}$ & $\mathrm{~V}_{3}-\mathrm{V}_{2}$ & $\mathrm{n}$ & $\mathrm{pL}$ & $\log \left(\frac{n-1}{2-n}\right)$ & $\log \mathrm{K}_{2}$ \\
\hline 10.00 & 5.60 & 6.47 & 6.57 & 0.10 & 1.1434 & 1.43 & & \\
10.23 & 5.65 & 6.62 & 6.72 & 0.10 & 1.3448 & 1.23 & -0.2788 & 0.9512 \\
10.49 & 5.70 & 6.80 & 6.90 & 0.10 & 1.7742 & 1.03 & 0.5351 & 1.5651 \\
\hline
\end{tabular}

$\operatorname{LogK}_{2}($ Average value $)=1.2581 \pm 0.4340$

Table 19: Stepwise and overall Stability constants of thehydrolysed and unhydrolysed divalent metal (II) complexes

\begin{tabular}{|c|c|c|c|}
\hline Chelates & LogK $_{1}$ & $\log _{2}$ & Log $\beta$ \\
\hline [Cu (Hydrolysed PSHA-1) $\left.{ }_{2}\right]$ & 2.4788 & 1.4280 & 3.9068 \\
\hline$\left[\mathrm{Pb}(\text { Hydrolysed PSHA-1) })_{2}\right]$ & 2.5832 & 1.1963 & 3.7795 \\
\hline$\left[\mathrm{Cd}(\text { Hydrolysed PSHA-1 })_{2}\right]$ & 2.2108 & 1.5453 & 3.7561 \\
\hline$\left[\mathrm{Mg}(\text { Hydrolysed PSHA-1 })_{2}\right]$ & 2.1382 & 1.5453 & 3.6835 \\
\hline [Cu (Unhydrolysed PSHA-1) & 2.3059 & 1.2209 & 3.5268 \\
\hline$[\mathrm{Pb}$ (Unhydrolysed PSHA-1) 2$]$ & 2.2364 & 1.2239 & 3.4603 \\
\hline [Cd (Unhydrolysed PSHA-1) 2 ] & 2.2516 & 1.2581 & 3.5097 \\
\hline$[\mathrm{Mg}$ (Unydrolysed PSHA-1) & 2.1568 & 0.9127 & 3.0695 \\
\hline
\end{tabular}

The results obtained (Table19) shows the stepwise and overall stability constants to be not high indicating low stability of the complexes, because the solubility of most metal ions in the basic $\mathrm{pH}$ range is minimal due to metal hydroxide precipitation (Karimi, 2017). In general, the stepwise stability constants $\left(K_{1}\right.$ and $K_{2}$ ) follow the order $K_{1}>K_{2}$ for the copper, lead, magnesium and cadmium complexes respectively. The steady decrease of the values with increasing number of ligands is in agreement with the prediction made by researchers (Na'aliya, 2013). The decrease could be attributed to the fact that as the number of the ligands (Humate ions) that enters the coordination zone increases the aqua molecules available for replacement by the ligands become less. Thus, the metal ions become less electron loving with progressive intake of the ligand and this results in the decrease in the values of the constants (Na'aliya, 2013). Also the stability of the complexes is influenced by the size and number of the chelate rings(Mackay and Mackay,2002).All the complexes form rings in their structure as humate, a bidentate ligand, bond the metal ions in the ratio 1:2 (Boguta and Sokolowska, 2016) forming chelate rings. The values of the overall stability constants $(\log \beta)$ obtained for humate complexes are not high indicating low stability as the values are not high. LogK values for copper-humates (Table 3 to 6) obtained in this study are lower than those reported for the complexes of humic acids (Pandey et al., 2015; Dinu, 2013; Kaschl et al., 2010 and Gilbeto and Jorg, 2001). The values of LogK(Table 7 to 10 ) forlead-humates are lower than those reported for the lead in the literature (Dinu, 2013; Gilbeto and Jorg 2001). Log K values(Table 11 to 14 ) for magnesium-humates obtained in this study are close to those reported by (Pandey et al., 2015). Log K values of cadmium-humates (Table 15 to 18 ) obtained in this work near to the one reported by (Dinu, 2013 and Pandey et al., 2015).The difference between the reported values and the values obtained in this study might be probably as a result of acid hydrolysis of humic acid. The values of the overall stability constants $(\log \beta)$ of the copper humates complexes presented in Table 19 is high than that of other metal humate complexes, show relatively high stability of CuHA complexes, show the following order of stability: $\mathrm{Cu}>\mathrm{Pb}>\mathrm{Cd}>\mathrm{Mg}$; which are in close agreement to the findings of (Dinu, 2013 and Pandey et al., 2015).The high stability of Cuhumate chelate could be attributed to the existence of coordinate covalent bond between the complexing agents and the $\mathrm{Cu}^{2+}$ ions. Since, $\mathrm{Cu}^{2+}$ being a metal of the transitional series with $3 d^{9}$ electronic configurations can accept the electrons from the complexing agents. Similarly, the low stabilities of $\mathrm{Pb}, \mathrm{Cd}$ and $\mathrm{Mg}$ complexes could be explained by that $\mathrm{Pb}^{2+}$ with $6 s^{2}, \mathrm{Cd}^{2+}$ with $4 \mathrm{~d}^{10}$ and $\mathrm{Mg}^{2+}$ with $2 \mathrm{p}^{6}$ their electronic configuration has a completely filled $\mathrm{d}, \mathrm{p}$ and $\mathrm{s}$ orbitals. Moreover, the stabilities of metal ions with hydrolysed humic acid from peat soil were higher than those with unhydrolysed humic acid from peat soil; which is ascribed to the high content of acidity in hydrolysed humic acid than unhydrolysed humic acid. 
BAJOPAS Volume 14 Number 1,June, 2021 CONCLUSION

The values of logk for $\mathrm{Cu}(\mathrm{II})$ hydrolysed humic acid complex was higher followed by $\mathrm{Pb}$ (II), $\mathrm{Cd}(\mathrm{II})$ and $\mathrm{Mg}$ (II) hydrolysed humic acid complexes as compared with metal(II) unhydrolysed humic acid complexes. This indicates acid hydrolysis of humic acid can

\section{REFERENCES}

Almeida, V.R. and Szpoganicz, B. (2015). Humic Acid Potentiometric Response Patterns:Out- of Equilibrium Properties and Species Distribution Modelling. Chemical. Biol. Technol. Agric. 2: 17.

Anđelković, T., Nikolić, R., Bojić, A.,Anđelković, D., and Nikolic G.,(2010). Binding of Cadmium to Soil Humic Acid as A Function of Carboxyl Group Content. Macedonian Journal of Chemistry and Chemical Engineering.29(2): 215-224.

Anil, B. N. and Maroti, N. (2008). Studies on Influence of Die-Lectric Constants on Complex Equilibria between Substituted Py-Razalines and Lanthanide Metal Ions pH-Metrically. Amer.-Euras. scient. Res. 3(2): 212-216.

Ashok, K., Pandey, S. P. and Misra, V (2000). Stability Constants of Metal-Humic Acid Complexes and its Role in Environmental Detoxification. Journal of Ecotoxicology and Environmental Safety. 47(2):157-200.

Badr, M. H., El-Halafawi, M. H. and Abd El-al Zeid, E. R. (2012). Comparison Between the Effect of Ionic Strength on Acidity and Dissociation Constants of Humic Acids Extracted from Sewage Sludge and Nile Water Hyacinth Composts.Global Journal of Environmental Research 6 (1): 36-43.

Baruah, M.K., Borah, D., Saikia, P.P., Paul, S., Sharma, T. (2015). Evaluation of pKa Values of Soil Humic Acids and their Complexation Properties. International Journal of Plant \& Soil Science 6(4) : 218-228.

Boguta, P. Sokolowska, Z. (2016). Interactions of $\mathrm{Zn}$ (II) Ions with Humic Acids Isolated from Various Types of Soils. Effect of $\mathrm{pH}, \mathrm{Zn}$ Concentrations and Humic Acids Chemical Properties. Journal of Geochemical Explaration 168. 119-126.

Borges, F., Guimaraes, C., Lima, L.F.C., Pinto, I. and Reis, S.(2005). Potentiometric Studies on the Complexation of Copper(II) by Phenolic Acids as Discrete Ligand Models of enhance the complexation behavior of humic acid with metal (II) ions. However, the higher values of $\log \beta$ for $\mathrm{Cu}(\mathrm{II}), \mathrm{Pb}(\mathrm{II}), \mathrm{Cd}(\mathrm{II})$ and $\mathrm{Mg}(\mathrm{II})$ hydrolysed humic acid complexes indicates more stable stepwise complexes formed as compared with $\mathrm{Cu}(\mathrm{II}), \mathrm{Pb}$ (II), $\mathrm{Cd}$ (II) and $\mathrm{Mg}(\mathrm{II})$ unhydrolysed humic acid complexes.

Humic Substances Talanta 66 (2005) 670-673.

Chefetz, B., Salloum, M. J., Deshmulkin, A. P. and Hatcher, P. (2002). Structural Components of Humic Acids as Determined by Chemical Modifications and Carbon-13 NMR, Pyrolysis, and Thermochemolysis- Gas Chromatography/Mass Spectrometry. Soil Science Society of American Journal Abstract Division S-2- Soil Chemistry66. 1159-1171.

Dinu, M. I. (2013). Metals Complexation with Humic Acids in Surface Water of Different Environ. Sci. Technol. 31(1): 1-17.

Fernandes, A.N., Giacomelli, C., Giovanela, M. Vaz, D.V. Szpoganicz, B. and Maria M. D. (2009). Potentiometric Acidity Determination in Humic Substances Influenced by Different Analytical Procedures.J. Braz. Chem. Soc. 20 (9):14.

Gamal, A. H. (2015). Stability Constants of Rhenium (V) Metal Complexes with Selected Drugs. Pyrex Journal of Research in Environmental Studies. 2(2): 006-014.

Janrao, D. M., Pathan, J., Kayande, D.D., and Mulla, J.J. (2014). An Over View of Potentiometric Determination of Stability Constants of Metal Complexes. Sci. Revs. Chem. Commun.: 4(1), 2014, 11-24.

Karimi, H. (2017). Effect of pH and Initial Pb(II) Concentration on the Lead Removal Efficiency from Waste Water Using $\mathrm{Ca}(\mathrm{OH})_{2}$. International Journal of Water and Waste Water Treatment 3.2

Kaschl, A. Romheld, V. and Chen, Y. (2010). Binding of Cadmium, Copper and Zinc to Humic Substances Originating from Municipal Solid Waste Compost. Israel Journal of Chemistry Vol. 42(1): 89-98.

Kostic, I. S., Tatjana, P, A., Nikolic, R. S., Cvetkovic, T. P., Pavlovic, D. D., Aleksandar, L.J. and Bojic, A. (2012). Comparative Study of Binding Strengths of Heavy Metals with Humic Acid. J.serb. Chem. Soc. 76(9) pp 1-20. 
BAJOPAS Volume 14 Number 1,June, 2021

Na'aliya, J. (2013). Determination of Stepwise Stability Constants and Gibbs free Energy Change of Trisprolina to Complexes of some Divalent Transition Metal ions. Bayero Journal of Pure and Applied Sciences 6(2): 112-114.

Omar, A. A. and Ali, E. A. (2015). Potentiometric Studies on Complexes of $\mathrm{Cr}$ (III) and $\mathrm{Zr}$ (IV) with some Carboxylic Acids. International Journal of Advanced Chemistry, 3(1) 25-

37.

Pandey, A. K. Pandey, S. D. and Misr, V. (2015).Stability Constants of Metal- Humic Acid Complexes and Its Role in Environmental Detoxification. J. Ecotoxicology and Environmental Safety. 47(1):195-200.

Ram, N. and Raman, K.V. (1984). Stability Constants of Complexes of Metals with
Humicand Fuvic Acids under Non- acidConditions. Journal of Plant Nutrition and Soil Sciences.

147:171-176.

Santosh, D. D., Ashok, B. K., Vijay, J. T., Shivraj, G. W. and Vinay, V. W. (2011). Potentiometric Studies of Elec-Trolyte Effects on Complex Equilibria of Some Substituted 5-(2-hydroxy Phenyl) Pyrazoles. Der pharm. 3 (6): 75-83.

Sayyed, H. and Abdul Rahim, M. F. (2012). Studies of Binary Complexes of Metal Ions with Mandelic Acid by Potentiometry. Chem. J. 02 (6): 206209.

Shirvani, M. Moradian, E. Khalili, B. Bakhtiary, S. (2015). Interaction of $\mathrm{Cd}$ and $\mathrm{Pb}$ with Humate-Palygorskite and HumateSepiolite Complexes. Journal of water, air and pollution 3: 220-228. 


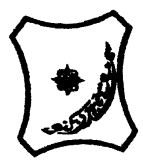

Bayero Journal of Pure and Applied Sciences, 14(1): 54 - 63

Received: November, 2020

Accepted: April, 2021

ISSN $2006-6996$

\title{
STABILITY CONSTANTS OF COMPLEXES OF METAL IONS WITH PEATSOIL HUMIC ACIDS UNDER NON-ACID-CONDITIONS
}

\author{
${ }^{* 1}$ Sabo, Yusuf ${ }^{2}$ Jimoh, W.L.O., ${ }^{3}$ Isa Baba Koki and ${ }^{4}$ Sholadoye, Q. 0. \\ ${ }^{1}$ Department of Pure and Industrial Chemistry, Bayero University, Kano \\ ${ }^{3}$ Department of Chemistry, Yusuf Maitama Sule University Kano. P.M.B. 3220 Kano, Nigeria. \\ ${ }^{4}$ Department of Chemistry, Nigerian Police Academy, Wudil, Kano-Nigeria
}

*Correspondence E-mail; saboyusuf18@yahoo.com

ABSTRACT

Stability constants of complexes of four divalent metal ions viz. $\mathrm{Cu}^{2+}, \mathrm{Pb}^{2+}, \mathrm{Mg}^{2+}$ and $\mathrm{Cd}^{2+}$ with humic acids (HA) were determined by potentiometric titration of humic acids with the corresponding salt of the divalent metals in aqueous media under non-acid-condition. The log $K$ (logarithm of the stability constant) ranged from 1.0942 to 2.7471 for metalhumic acid complexes were determined using point-wise computational method. The order of stability constants were obtained as follows: $\mathrm{Cu}>\mathrm{Pb}>\mathrm{Cd}>\mathrm{Mg}$ for metal $-\mathrm{HA}$ complexes respectively, indicating a higher degree of complexation with Cu metal ion.

Keywords: stability constant, humic acid, potentiometric titration, divalent metals, acid hydrolysis.

\section{NTRODUCTION}

The stability constant of a complex is the numerical expression of its stability and provides a quantitative measure of affinity of the metal ion to the complexing agent. An understanding of the relative stability of metal-complexes helps in predicting the behavior of metal ions in the soil (Ram and Raman, 1982). Extensive researches has been done to determine the stability constants of the complexes formed between humic acid (HA) with a number of metal ions. Ashok et al., (2000) reported that humic acid with hydroxyl, phenoxyl and carboxyl reactive groups can form coordination compound with metal ions at $\mathrm{pH}$ 3.5. The stability constants(Log K) for different metalhumic acid complexes indicated the following order of the stabilities of complexes formed between humic acid and metal ion, $\mathrm{Cu}>\mathrm{Fe}$ $>\mathrm{Pb}>\mathrm{Ni}>\mathrm{Co}>\mathrm{Ca}>\mathrm{Cd}>\mathrm{Zn}>\mathrm{Mn}>\mathrm{Mg}$. Andelkovic et al., (2010) investigated the binding of $\mathrm{Cd}$ (II) to soil humic acid at pH 6.5 and in $0.1 \mathrm{M} \mathrm{KNO}_{3}$ ionic medium. The stability constant for binding indicating greater stability in the case when carboxyl groups are involved in complexation reaction. Kostic et al.,(2012) investigated the complexation of humic acid with certain heavy metal ions (Co(II), $\mathrm{Ni}(\mathrm{II}), \mathrm{Cu}(\mathrm{II})$,
$\mathrm{Zn}(\mathrm{II})$, and $\mathrm{Pb}(\mathrm{II})$. The experiment was performed at $25^{\circ} \mathrm{C}$, at pH 4.0 and ionic strength of $0.01 \mathrm{M}$. Stability constant of complex between $\mathrm{Pb}$ (II) ions and humic acid is greater than stability constants of other investigated metalhumate complexes. Bogata and Sokolowska (2016) analyses the interaction between humic acids from different soils and $\mathrm{Zn}$ (II) ions at wide concentration ranges and at $\mathrm{pH} 5$. Studies have showed significant impact of $\mathrm{Zn}$ concentration, $\mathrm{pH}$ and some properties of humic acids with zinc.But all of these studies were limited to acidic $\mathrm{pH}$ range. Therefore, the present study was carried out to determine and compare the stability constants of complexes of metal ions with hydrolysed peat soil humic acid and unhydrolysed peat soil humic under non-acid conditions.

\section{MATERIALS AND METHODS}

Analytical grade chemicals used includes hydrochloric acid $(\mathrm{HCl})$, nitric acid $\left(\mathrm{HNO}_{3}\right)$, sodium hydroxide $(\mathrm{NaOH})$, lead nitrate $\mathrm{Pb}\left(\mathrm{NO}_{3}\right)_{2}$, copper nitrate $\mathrm{Cu}\left(\mathrm{NO}_{3}\right)_{2} \cdot 3 \mathrm{H}_{2} \mathrm{O}$, cadmium nitrate $\mathrm{Cd}\left(\mathrm{NO}_{3}\right)_{2} \cdot 4 \mathrm{H}_{2} \mathrm{O}$, magnesium nitrate $\mathrm{Mg}\left(\mathrm{NO}_{3}\right)_{2} \cdot 6 \mathrm{H}_{2} \mathrm{O}$, potassium nitrate $\left(\mathrm{KNO}_{3}\right)$, calcium chloride $\left(\mathrm{CaCl}_{2}\right)$, (sigma-Aldrich). Dowex 50WX8, (20-50 mesh) from Fluka. 


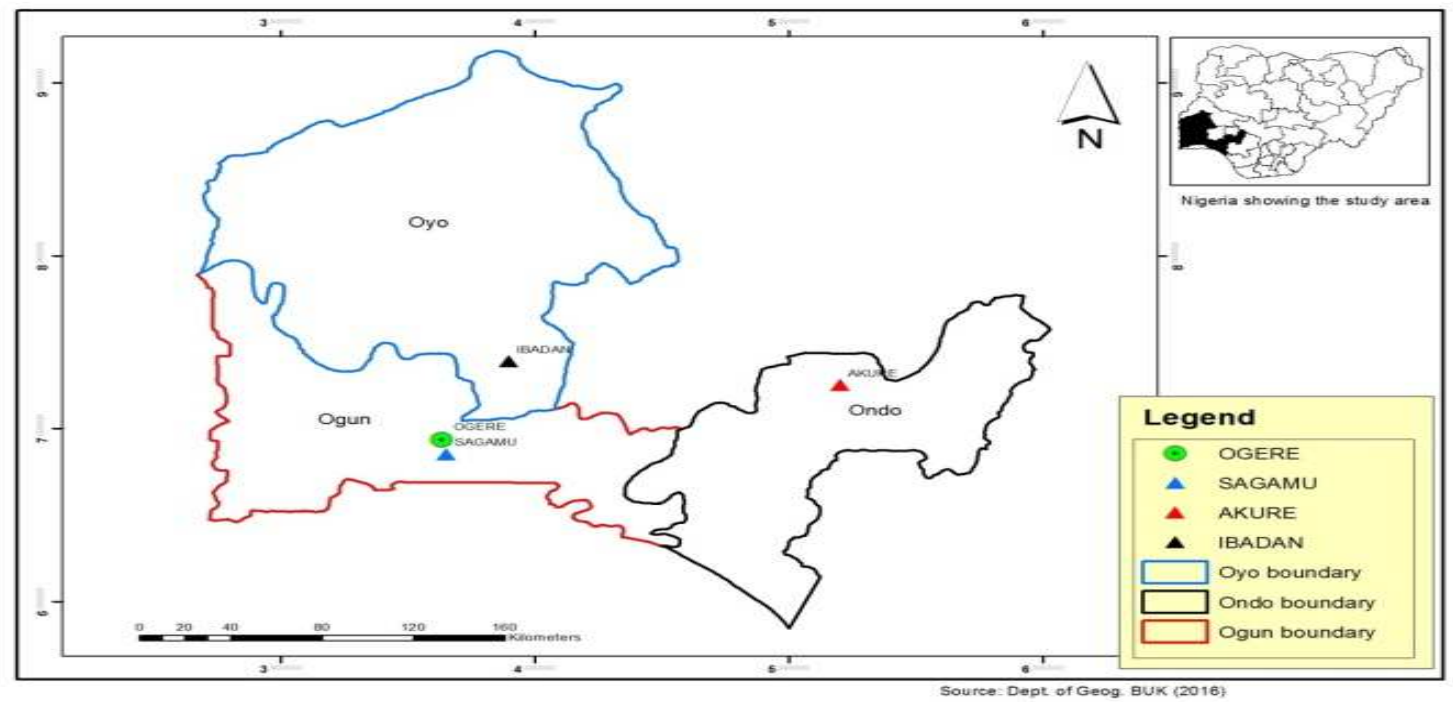

Figure 1: Map showing the sampling point at Sagamu Town, Ogun State.

\section{Description of Sampling Area}

Sagamu has geographical coordinates between $6^{\circ} 50^{\prime}$ north; $3^{\circ} 38^{\prime}$ east is located in south western region of Nigeria. The region has tropical wet and dry climate with a lengthy wet season and relatively constant temperatures throughout the course of the year. Wet season runs from March to October, November to December forms the region dry season. The vegetation type of the region is savannah which is really grassland with small bushes and occasional big trees. Grassland soils have substantially higher organic matter content than forest soils (Novackova, 2011).

\section{Sample Collection}

The Peatsoil samples were collected from four different sampling points $(0-10 \mathrm{~cm}$ depth) in Sagamu into polyethylene bag with plastic spoons. Samples were taken to the laboratory, extraneous materials were removed; the samples were air-dried, crushed and ground to a fine powder in a mortar passed through a $0.20 \mathrm{~mm}$ sieve. The samples were kept for analysis.

\section{Isolation and purification of humic acid from peat soil sample}

Peatsoil sample $(100 \mathrm{~g})$ was mixed with 1000 $\mathrm{cm}^{3}$ of $0.1 \mathrm{M} \mathrm{NaOH}$ solution, shaken for 3hours and left to stand overnight. Dark-coloured supernatant was obtained and decanted from solid residue. The dark-coloured supernatant was acidified to $(\mathrm{pH}=1.0)$ with $6 \mathrm{M} \mathrm{HCl}$ stirred and allowed to stand for 6 hours. Yellowish brown supernatant and dark-brown precipitate were obtained. The yellowish brown supernatant was decanted followed by centrifuge and discarded. The dark-brown precipitate was mixed with $500 \mathrm{~cm}^{3}$ of $0.1 \mathrm{M} \mathrm{NaOH}$ solution followed by passing through dowex resin. The dark-brown solution was acidified to $(\mathrm{pH}=1.0)$ with $6 \mathrm{M} \mathrm{HCl}$ stirred and allowed to stand for 3 hours. The dark-brown precipitate was washed several times with deionized water. The supernatant was treated with $\mathrm{AgNO}_{3}$ solution until no white precipitate observed. The humic acid was transferred to weighed crucible and dried at $60^{\circ} \mathrm{C}$ in an oven for 12 hours. The humic acid was cooled and dried in the desiccator, weighed and recorded. The obtained humic acid was dried again at $60^{\circ} \mathrm{C}$ for additional 6 hours cooled and dried in the desiccator, weighed and recorded constant weight was obtained (Baruah et al., 2015).

\section{FT-IR analysis}

FT-IR spectra of humic acid sample was analysed using Carry 630 FT-IR Agilent Technologies.

Unhydrolysed compost humic acid

The unhydrolysed humic acid was obtained after isolation and purification of compost humic acid and kept for investigation.

\section{Acid hydrolysis of Peatsoil acid}

Peatsoil humic acid sample (1g) was refluxed for 12 hours at $\left(160^{\circ} \mathrm{C}\right)$ with $50 \mathrm{~cm}^{3}$ of $6 \mathrm{M} \mathrm{HCl}$. The mixture was allowed to cool, decanted, and centrifuged after hydrolysis. The insoluble residues were washed with distilled water via centrifugation several times, and the supernatant was treated with $\mathrm{AgNO}_{3}$ solution until no white precipitate was observed. The residue was thoroughly dried over $\mathrm{CaCl}_{2}$ in a desiccator at room temperature (Chefetz et al., 2002). Finally, the obtained hydrolysed humic acid was kept for investigation. 
BAJOPAS Volume 14 Number 1,June, 2021 Potentiometric Titrations

Potentiometric measurements were carried out using a pH-meter Jenway (model 3510) with combine electrode, the sensitivity of the $\mathrm{pH}$ meter is 0.01 units. The $\mathrm{pH}$ meter was switched on half an hour before starting the titration for initial warm up of the instrument. The instrument was calibrated with an aqueous standard buffer solution of $\mathrm{pH} 4.00$ and 10.0 (borate buffer) prepared from a "Qualigens" buffer tablets.

The following sets of solutions were prepared in a $250 \mathrm{~cm}^{3}$ volumetric flask separately for $\mathrm{pH}$ metric titrations.

(i) $5 \mathrm{~cm}^{3} 0.1 \mathrm{M} \mathrm{HCl}+40 \mathrm{~cm}^{3}$ deionized water

(ii) $5 \mathrm{~cm}^{3} 0.1 \mathrm{M} \mathrm{HCl}+39 \mathrm{~cm}^{3}$ deionized water $+1 \mathrm{~cm}^{3} 0.15 \mathrm{gcm}^{-3}$ humic acid

(iii) $5 \mathrm{~cm}^{3} 0.1 \mathrm{M} \mathrm{HCl}+37 \mathrm{~cm}^{3}$ deionized water $+1 \mathrm{~cm}^{3} 0.15 \mathrm{gcm}^{-3}$ humic acid

$$
+2 \mathrm{~cm}^{3} \quad 0.01 \mathrm{M} \mathrm{Cu} \text { (II) }
$$

The solutions were titrated against standardized $0.110 \mathrm{MNaOH}$ separately. The total volume of each mixture was adjusted to $50 \mathrm{~cm}^{3}$ and the ionic strength of the solutions was maintained constant at by adding appropriate amount of stock solution of $1 \mathrm{M} \mathrm{KNO}_{3}$ (Gamal, 2015; Omar and Ali, 2015). A magnetic stirrer was used to achieve thorough mixing of the interacting solutions at $550 \mathrm{rpm}$. The same set of experimental conditions was applied for potentiometric titration of remaining samples.

\section{Evaluation of pKa of Hydrolysed peat soil Humic Acids}

The proton-ligand formation number $\mathrm{n}_{\mathbf{A}}$ were calculated by Irving and Rossotti expression (Omar and Ali, 2015).

$\mathrm{nA}=\mathrm{Y}-\frac{(\mathrm{V} 2-\mathrm{V1})(\mathrm{No}-\mathrm{Eo})}{(\mathrm{VO}+\mathrm{V1}) \mathrm{TCL}}$ 1

Where: $Y$ is number of dissociable proton, $\left(\mathrm{V}_{2^{-}}\right.$ $V_{1}$ ) is the measure of displacement of the ligand curve relative to acid curve, $\mathrm{N}^{\circ}$ and $\mathrm{E}^{\circ}$ are the resultant concentration of alkali solution, free acid solution, $\mathrm{T}_{\mathrm{cL}}{ }^{\circ}$ is the total ligand concentration, $\mathrm{V}^{\circ}$ is the total volume of titration solution, $V_{1}$ is the volume of alkali added to acid solution, $V_{2}$ is the volume of alkali added to acid solution + ligand solution, acid dissociation constants (pKa - values) of ligand were calculated by algebraic method point wise calculation (Tables 1 ). The dissociation constants (pKa) were calculated according to the following relation:

$\mathrm{pKa}=\mathrm{pH}+\log \left(\frac{n A}{1-n A}\right)$ 2

Where: pKa is the acid dissociation constant, $\mathrm{n}_{\mathrm{A}}$ is the Proton-ligand formation number and $\mathrm{pH}$ is the pH-values (Omar and Ali, 2015).

\section{Determination of metal-ligand stability constants $(\log K)$ of complexes}

The potentiometric measurement for the determination of stability constant of a complex in solution is based on the fact that the redox potential of the couple $\frac{M^{+(m-n)}}{M^{+m}}$ is shifted significantly on complexation of the metal ion with the ligand. This method involves change in hydrogen ion concentration $\left[\mathrm{H}^{+}\right]$due to the displacement or association of one or more protons taking place during complexation reaction. This change can be found out by titrating the solutions containing free acid, acid with ligand, and acid with ligand and metal ion, individually against a standard alkali solution at a constant ionic strength or temperature. Either ionic strength or temperature may be varied for different sets of solutions. In all the cases, the change in the $\mathrm{pH}$ of the solution is measured after each addition of a known amount of alkali to the reaction cell which contains the reaction mixture. The titration curves are then drawn by plotting the measured $\mathrm{pH}$ values against the corresponding volume of alkali added and the stability constants of the complexes are determined from the titration curves by employing $\mathrm{pH}$-metric titration technique given by (Irving and Rossoti).

Metal-ligand stability constants ( $\log \mathrm{K}$ ) were determined by using the following relations:

$$
\bar{n}=\frac{\left(V_{3}-V_{2}\right)\left(E^{0}+N^{0}\right)}{\left(V^{0}+V_{2}\right) \bar{n}_{A} T_{m}^{0}}
$$

and

$$
P L=\log _{10}\left\{\frac{1+\beta_{n}^{H} \frac{1}{[\text { anti } \log \mathrm{pH}]^{\mathrm{n}}}}{\mathrm{T}_{\mathrm{L}}^{0}-n \bar{T}_{m}^{0}} \mathrm{X} \frac{\left(V^{0}+V_{3}\right)}{V^{0}}\right\}
$$


BAJOPAS Volume 14 Number 1,June, 2021

Where $T_{L}, T^{\circ}, E^{\circ}$, and $V^{\circ}$ havethe same significance as in equation (1) above, $T_{m}$ denotes the total concentration of metal present in solution, $V_{3}$ is the volume of metal ions present in solution and $\beta^{H}$ is the overall proton ligand stability constant. The metal-ligand stability constants (log K) were determined by employing point wise computational Method (eq. 5 and 6).

$\operatorname{LogK}_{1}=\log \left(\frac{n}{1-n}\right)+\mathrm{pL}$ .5

$\operatorname{LogK}_{2}=\log \left(\frac{1-n}{2-n}\right)+\mathrm{pL}$ ...6

Where: Log $\mathrm{K}$ is the metal-ligand stability constant, $\mathrm{pL}$ is the Free ligand exponent function, $\mathbf{n}$ is the Average number of ligand attached with metal ion (Janraoet al., 2014). The results obtained were analyzed by an ORIGIN 2016 program using titration data and then the proton-ligand stability constants (pKa) and Metal-ligand stability constant (LogK) calculated (Omar and Ali, 2015).

\section{RESULTS AND DISCUSSION}

Fourier transformed infrared (FT-IR) spectra of isolated humic acid from peat soils Figure 2 had distinct clear absorption bands indicating the presence of major humic acid structural elemental groups such as $\mathrm{H}$ bonded $\mathrm{OH}$ $\left(3680 \mathrm{~cm}^{-1}\right.$ peak $), C=0$ of carbonyl $\left(1721 \mathrm{~cm}^{-1}\right.$ peak), functional groups of aliphatic components $\mathrm{CH}_{2}\left(2918 \mathrm{~cm}^{-1}\right.$ peak) and $\mathrm{C}-\mathrm{O}$ stretching of polysaccharide $\left(1168 \mathrm{~cm}^{-1}\right.$ peak). The positions of the absorption bands of the spectra fell within typical major absorption bands of humic acid which is at frequencies 3680, 2918, 1721, 1168 $\mathrm{cm}^{-1}$. The first peak centred in the vicinity of $3680 \mathrm{~cm}^{-1}$ region is attributed to phenol $\mathrm{OH}$ group bounded by intermolecular $\mathrm{H}$ bonds. The $2918 \mathrm{~cm}^{-1}$ band usually has absorption maximum at $2918 \mathrm{~cm}^{-1}$ which is due to $\mathrm{C}-\mathrm{H}$ stretching of alkane group $\left(\mathrm{CH}_{2}\right)$. The next major absorption band is $1721 \mathrm{~cm}^{-1}$. This band has been commonly ascribed to $\mathrm{C}=\mathrm{O}$ stretching of mainly carboxyl group $(\mathrm{COOH})$ with trace amount of ketones. The last peak was observed at 1168 $\mathrm{cm}^{-1}$ due to $\mathrm{C}-\mathrm{O}$ stretching of polysaccharides and this peak appeared also in the spectra of humic acid from peat soil. The FTIR spectra of the isolated humic acid contained all major characteristic absorption peaks of humic acid. These absorption peaks indicated the presence of the major structural elements of humic acid namely $\mathrm{H}$ bonded $\mathrm{OH}, \mathrm{C}=\mathrm{C}$ of aromatic ring, $\mathrm{C}=\mathrm{O}$ of carbonyl group (both carboxyl and ketonic), $\mathrm{CH}_{2}$ group. This strongly supports the presence of humic acid.

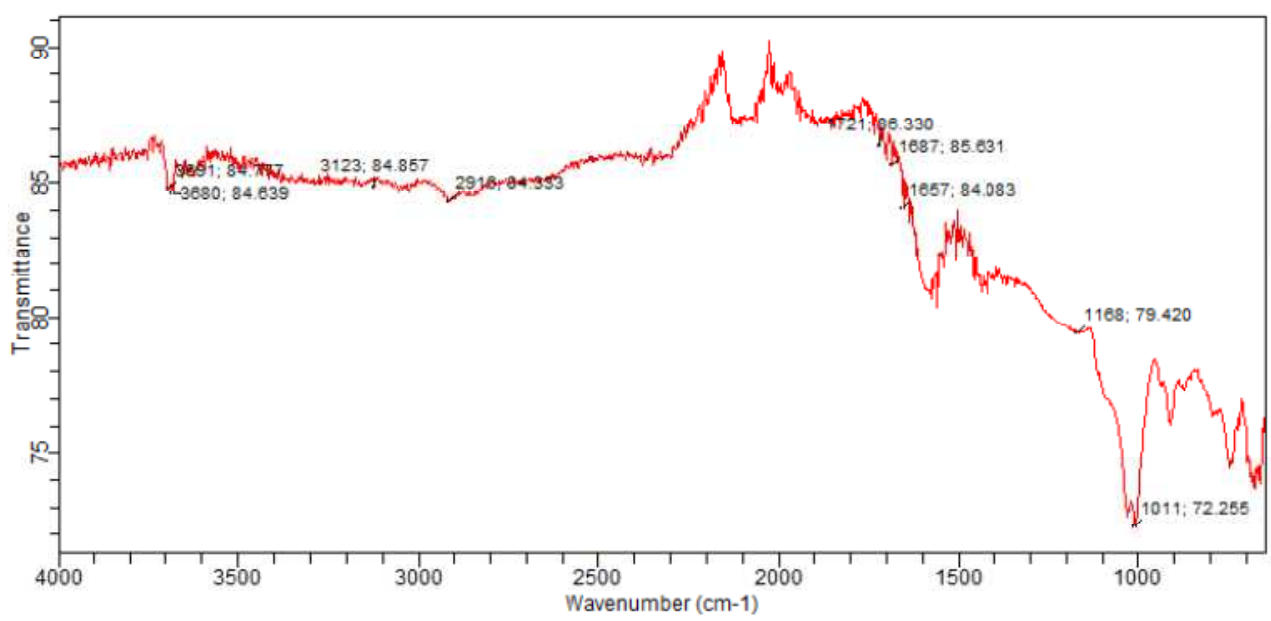

Fig. 2 : FT-IR spectraof peatsoilhumic acid (PSHA)

\section{Evaluation of acid dissociation constant (pka) of acid hydrolysed peat soil humicacid at phenolic group}

The value of the dissociation constant of the peat soil humic acid (PSHA) that underwent acidhydrolysis studied was found to be 8.9299 as shown Table 1, which is lower than the literaturevalues reported by Almeida and Szpoganics, (2015), Borges et al., (2005); Badr et al., (2012)and Fernandes et al,.(2009) of $9.73,9.47$ and 10.30. The difference between the obtained valuesand the reported values in this study might be probably as a result of acid hydrolysis of humicacid. 
BAJOPAS Volume 14 Number 1,June, 2021

Table 1: PKa of (Hydrolysed PSHA)

\begin{tabular}{|l|l|l|l|l|l|l|}
\hline $\mathrm{pH}$ & $\mathrm{BV}_{1}$ & $\mathrm{BV}_{2}$ & $\mathrm{~V}_{2}-\mathrm{V}_{1}$ & $\mathrm{nA}$ & $\log \left(\frac{n A}{1-n A}\right)$ & $\mathrm{pKa}$ \\
\hline 8.50 & 5.30 & 6.29 & 0.99 & 0.3594 & -0.2510 & 8.2490 \\
8.72 & 5.35 & 6.37 & 1.02 & 0.3400 & -0.2880 & 8.4320 \\
9.00 & 5.40 & 6.46 & 1.06 & 0.3141 & -0.3391 & 8.6609 \\
9.22 & 5.45 & 6.55 & 1.10 & 0.2882 & -0.3927 & 8.8273 \\
9.51 & 5.50 & 6.66 & 1.16 & 0.2494 & -0.4786 & 9.0314 \\
9.73 & 5.55 & 6.78 & 1.23 & 0.2041 & -0.5910 & 9.1390 \\
10.00 & 5.60 & 6.90 & 1.30 & 0.1589 & -0.7238 & 9.2762 \\
10.23 & 5.65 & 7.05 & 1.40 & 0.0941 & -0.9835 & 9.2465 \\
10.49 & 5.70 & 7.10 & 1.40 & 0.0941 & -0.9835 & 9.5065 \\
\hline
\end{tabular}

Average pKa $=8.9299 \pm 0.4186$

Table 2: PKa of (Unhydrolysed PSHA)

\begin{tabular}{|l|l|l|l|l|l|l|}
\hline $\mathrm{pH}$ & $\mathrm{BV}_{1}$ & $\mathrm{BV}_{2}$ & $\mathrm{~V}_{2}-\mathrm{V}_{1}$ & $\mathrm{nA}$ & $\log \left(\frac{\boldsymbol{n A}}{1-\boldsymbol{n}}\right)$ & $\mathrm{pKa}$ \\
\hline 8.50 & 5.30 & 5.81 & 0.51 & 0.6619 & 0.2919 & 8.7919 \\
8.72 & 5.35 & 5.90 & 0.55 & 0.6357 & 0.2418 & 8.9618 \\
9.00 & 5.40 & 6.00 & 0.60 & 0.6029 & 0.1813 & 9.1813 \\
9.22 & 5.45 & 6.10 & 0.65 & 0.5701 & 0.1226 & 9.3426 \\
9.51 & 5.50 & 6.20 & 0.70 & 0.5376 & 0.0654 & 9.5754 \\
9.73 & 5.55 & 6.33 & 0.78 & 0.4851 & -0.0259 & 9.7041 \\
10.00 & 5.60 & 6.47 & 0.87 & 0.4262 & -0.1291 & 9.8709 \\
10.23 & 5.65 & 6.62 & 0.99 & 0.3609 & -0.2481 & 9.9819 \\
10.49 & 5.70 & 6.80 & 1.10 & 0.2759 & -0.4690 & 10.0210 \\
\hline
\end{tabular}

Average pKa $=9.4923 \pm 0.4410$

Metal-ligand stability constant ( $\log \mathrm{K}$ )

The stabilityconstants require the accurate values of proton-ligand stability constants (Anil and Maroti, 2008). Metal titration curves crossed over ligand titration curve indicated the formation of complex upon proton release (Santosh, et al., 2011). If the values of n- are within range $0.2-0.8$ and $1.2-18$ this indicates the formation of $1: 1$ and 1:2 complexes (Sayyed and Mazahar, 2012).

The metal (II)-humate stepwise stability constants (log k) at phenolic group (Tables 318)

Table 3: Point-wise method, $\mathrm{Cu}$-(Hydrolysed PSHA)

\begin{tabular}{|l|l|l|l|l|l|l|l|l|}
\hline $\mathrm{pH}$ & $\mathrm{BV}_{1}$ & $\mathrm{BV}_{2}$ & $\mathrm{BV}_{3}$ & $\left(\mathrm{~V}_{3}-\mathrm{V}_{2}\right)$ & $\mathrm{n}$ & $\mathrm{pL}$ & $\log \left(\frac{n}{1-n}\right)$ & LogK $_{1}$ \\
\hline 8.50 & 5.30 & 6.29 & 6.33 & 0.04 & 0.5500 & 2.66 & 0.0871 & 2.7471 \\
8.72 & 5.35 & 6.37 & 6.41 & 0.04 & 0.5714 & 2.43 & 0.1249 & 2.5549 \\
9.00 & 5.40 & 6.46 & 6.50 & 0.04 & 0.6198 & 2.16 & 0.2122 & 2.3722 \\
9.22 & 5.45 & 6.55 & 6.59 & 0.04 & 0.6667 & 1.94 & 0.3010 & 2.2410 \\
\hline
\end{tabular}

LogK $_{1}$ (Average value) $=2.4788 \pm 0.2203$

Table 4: Point-wise method, $\mathrm{Cu}$-(Hydrolysed PSHA)

\begin{tabular}{|l|l|l|l|l|l|l|l|l|}
\hline $\mathrm{pH}$ & $\mathrm{BV}_{1}$ & $\mathrm{BV}_{2}$ & $\mathrm{BV}_{3}$ & $\left(\mathrm{~V}_{3}-\mathrm{V}_{2}\right)$ & $\mathrm{n}$ & $\mathrm{pL}$ & $\log \left(\frac{n-1}{2-n}\right)$ & LogK $_{2}$ \\
\hline 9.51 & 5.50 & 6.66 & 6.73 & 0.07 & 1.3509 & 1.70 & -0.2671 & 1.4329 \\
9.73 & 5.55 & 6.78 & 6.85 & 0.07 & 1.6383 & 1.51 & 0.2467 & 1.7567 \\
10.00 & 5.60 & 6.90 & 6.98 & 0.08 & 2.1783 & 1.31 & -0.2158 & 1.0942 \\
10.23 & 5.65 & 7.05 & 7.13 & 0.08 & 4.1904 & 1.27 & & \\
10.49 & 5.70 & 7.10 & 7.19 & 0.09 & 4.6920 & & & \\
\hline
\end{tabular}

Log $K_{2}($ Average value $)=1.4280 \pm 0.3312$ 
BAJOPAS Volume 14 Number 1,June, 2021

Table 5: Point-wise method, $\mathrm{Cu}$ (Unhydrolysed PSHA)

\begin{tabular}{|l|l|l|l|l|l|l|l|l|}
\hline $\mathrm{pH}$ & $\mathrm{BV}_{1}$ & $\mathrm{BV}_{2}$ & $\mathrm{BV}_{3}$ & $\left(\mathrm{~V}_{3}-\mathrm{V}_{2}\right)$ & $\mathrm{n}$ & $\mathrm{pL}$ & $\log \left(\frac{n}{n-1}\right)$ & Log $_{1}$ \\
\hline 8.50 & 5.30 & 5.81 & 5.85 & 0.04 & 0.2973 & 2.88 & -0.3736 & 2.5064 \\
8.72 & 5.35 & 5.90 & 5.95 & 0.05 & 0.3873 & 2.66 & -0.1992 & 2.4608 \\
9.00 & 5.40 & 6.00 & 6.05 & 0.05 & 0.4044 & 2.38 & -0.1681 & 2.2119 \\
9.22 & 5.45 & 6.10 & 6.15 & 0.06 & 0.5157 & 2.18 & -0.0272 & 2.2072 \\
9.51 & 5.50 & 6.20 & 6.27 & 0.07 & 0.6417 & 1.89 & 0.2530 & 1.1430 \\
\hline
\end{tabular}

$\operatorname{LogK}_{1}($ Average value $)=2.3059 \pm 0.6153$

Table 6:Point-wise method, $\mathrm{Cu}$ (Unhydrolysed PSHA)

\begin{tabular}{|l|l|l|l|l|l|l|l|l|}
\hline $\mathrm{pH}$ & $\mathrm{BV}_{1}$ & $\mathrm{BV}_{2}$ & $\mathrm{BV}_{3}$ & $\mathrm{~V}_{3}-\mathrm{V}_{2}$ & $\mathrm{n}$ & $\mathrm{pL}$ & $\log \left(\frac{n-1}{2-n}\right)$ & $\log \mathrm{K}_{2}$ \\
\hline 9.73 & 5.55 & 6.33 & 6.42 & 0.09 & 0.9000 & 1.69 & & \\
10.00 & 5.60 & 6.47 & 6.58 & 0.11 & 1.2578 & 1.44 & -0.4592 & 0.9808 \\
10.23 & 5.65 & 6.62 & 6.84 & 0.12 & 1.6137 & 1.26 & -0.2010 & 1.4610 \\
10.49 & 5.70 & 6.80 & 6.92 & 0.12 & 2.1052 & 1.03 & & \\
\hline
\end{tabular}

$\operatorname{LogK}_{2}$ (Average value) $=1.2209 \pm 0.3398$

Table 7:Point-wise method, Pb (Hydrolysed PSHA)

\begin{tabular}{|l|l|l|l|l|l|l|l|l|}
\hline $\mathrm{pH}$ & $\mathrm{BV}_{1}$ & $\mathrm{BV}_{2}$ & $\mathrm{BV}_{3}$ & $\left(\mathrm{~V}_{3}-\mathrm{V}_{2}\right)$ & $\mathrm{n}$ & $\mathrm{pL}$ & $\log \left(\frac{n}{1-n}\right)$ & LogK $_{1}$ \\
\hline 8.50 & 5.30 & 6.29 & 6.33 & 0.04 & 0.5500 & 2.66 & 0.0871 & 2.7471 \\
8.72 & 5.35 & 6.37 & 6.41 & 0.04 & 0.5714 & 2.43 & 0.1249 & 2.5549 \\
9.00 & 5.40 & 6.46 & 6.50 & 0.04 & 0.6198 & 2.16 & 0.2122 & 2.3722 \\
9.22 & 5.45 & 6.55 & 6.60 & 0.05 & 0.8333 & 1.96 & 0.6989 & 2.6589 \\
\hline
\end{tabular}

Log $_{\mathbf{1}}($ Average value $)=2.5832 \pm 0.1614$

Table 8:Point-wise method, Pb-(Hydrolysed PSHA)

\begin{tabular}{|l|l|l|l|l|l|l|l|l|}
\hline $\mathrm{pH}$ & $\mathrm{BV}_{1}$ & $\mathrm{BV}_{2}$ & $\mathrm{BV}_{3}$ & $\left(\mathrm{~V}_{3}-\mathrm{V}_{2}\right)$ & $\mathrm{n}$ & $\mathrm{pL}$ & $\log \left(\frac{n-1}{2-n}\right)$ & $\log \mathrm{K}_{2}$ \\
\hline 9.51 & 5.50 & 6.66 & 6.71 & 0.05 & 0.9650 & 1.67 & & \\
9.73 & 5.55 & 6.78 & 6.83 & 0.05 & 1.1702 & 1.44 & & \\
10.00 & 5.60 & 6.90 & 6.90 & 0.05 & 1.4864 & 1.22 & -0.0237 & 1.1963 \\
10.23 & 5.65 & 7.05 & 7.10 & 0.05 & 2.0190 & 1.09 & & \\
10.49 & 5.70 & 7.10 & 7.17 & 0.07 & 3.6492 & 1.00 & & \\
\hline
\end{tabular}

Log $K_{2}$ (Average value) $=1.1963$

Table 9: Point-wise method, Pb (Unhydrolysed PSHA)

\begin{tabular}{|l|l|l|l|l|l|l|l|l|}
\hline $\mathrm{pH}$ & $\mathrm{BV}_{1}$ & $\mathrm{BV}_{2}$ & $\mathrm{BV}_{3}$ & $\mathrm{~V}_{3}-\mathrm{V}_{2}$ & $\mathrm{n}$ & $\mathrm{pL}$ & $\begin{array}{l}\text { Log } \\
\left(\frac{n}{n-1}\right)\end{array}$ & Log $\mathrm{K}_{1}$ \\
\hline 8.50 & 5.30 & 5.81 & 5.85 & 0.04 & 0.2973 & 2.88 & -0.3736 & 2.5064 \\
8.72 & 5.35 & 5.90 & 5.94 & 0.04 & 0.3099 & 2.66 & -0.5477 & 2.3123 \\
9.00 & 5.40 & 6.00 & 6.05 & 0.05 & 0.4044 & 2.38 & -0.1681 & 2.2119 \\
9.22 & 5.45 & 6.10 & 6.15 & 0.06 & 0.5157 & 2.18 & 0.0272 & 2.2072 \\
9.51 & 5.50 & 6.20 & 6.26 & 0.07 & 0.6417 & 1.89 & 0.2530 & 2.1430 \\
9.73 & 5.55 & 6.40 & 6.40 & 0.07 & 0.7000 & 1.67 & 0.3680 & 2.0380 \\
\hline
\end{tabular}

LogK $_{1}$ (Average value) $=2.2364 \pm 0.1602$

Table 10: Point-wise method, Pb (Unhydrolysed PSHA)

\begin{tabular}{|l|l|l|l|l|l|l|l|l|}
\hline $\mathrm{pH}$ & $\mathrm{BV}_{1}$ & $\mathrm{BV}_{2}$ & $\mathrm{BV}_{3}$ & $\mathrm{~V}_{3}-\mathrm{V}_{2}$ & $\mathrm{n}$ & $\mathrm{pL}$ & $\log \left(\frac{n-1}{2-n}\right)$ & $\log \mathrm{K}_{2}$ \\
\hline 10.00 & 5.60 & 6.47 & 6.55 & 0.08 & 1.9503 & 1.41 & & \\
10.23 & 5.65 & 6.62 & 6.72 & 0.11 & 1.4792 & 1.26 & -0.0361 & 1.2239 \\
\hline
\end{tabular}

$\operatorname{LogK}_{2}$ (Average value) $=1.2239$

Table 11: Point-wise method, Mg (Hydrolysed PSHA)

\begin{tabular}{|l|l|l|l|l|l|l|l|l|}
\hline $\mathrm{pH}$ & $\mathrm{BV}_{1}$ & $\mathrm{BV}_{2}$ & $\mathrm{BV}_{3}$ & $\left(\mathrm{~V}_{3}-\mathrm{V}_{2}\right)$ & $\mathrm{n}$ & $\mathrm{pL}$ & $\log \left(\frac{n}{n-1}\right)$ & LogK $_{1}$ \\
\hline 8.50 & 5.30 & 6.29 & 6.31 & 0.02 & 0.2750 & 2.64 & -0.4290 & 2.2110 \\
8.72 & 5.35 & 6.37 & 6.39 & 0.02 & 0.2858 & 2.42 & -0.3978 & 2.0222 \\
9.00 & 5.40 & 6.46 & 6.49 & 0.03 & 0.4648 & 2.14 & -0.0612 & 2.0788 \\
9.22 & 5.45 & 6.55 & 6.59 & 0.04 & 0.6667 & 1.94 & 0.3010 & 2.2410 \\
\hline
\end{tabular}

$\log _{\mathbf{1}}($ Average value) $=2.1382 \pm 0.1046$ 
BAJOPAS Volume 14 Number 1,June, 2021

Table 12: Point-wise method, Mg (Hydrolysed PSHA)

\begin{tabular}{|l|l|l|l|l|l|l|l|l|}
\hline $\mathrm{pH}$ & $\mathrm{BV}_{1}$ & $\mathrm{BV}_{2}$ & $\mathrm{BV}_{3}$ & $\left(\mathrm{~V}_{3}-\mathrm{V}_{2}\right)$ & $\mathrm{n}$ & $\mathrm{pL}$ & $\log \left(\frac{n-1}{2-n}\right)$ & LogK $_{2}$ \\
\hline 9.51 & 5.55 & 6.66 & 6.71 & 0.05 & 0.9650 & 1.67 & & \\
9.73 & 5.55 & 6.78 & 6.84 & 0.06 & 1.4042 & 1.47 & -0.1686 & 1.3014 \\
10.00 & 5.60 & 6.90 & 6.93 & 0.06 & 1.7838 & 1.23 & 0.5593 & 1.7893 \\
10.23 & 5.65 & 7.05 & 7.10 & 0.06 & 3.1429 & 1.10 & & \\
10.49 & 5.70 & 7.10 & 7.18 & 0.07 & 3.6492 & 0.83 & & \\
\hline
\end{tabular}

LogK $_{2}($ Average value $)=1.5453 \pm 0.3450$

Table 13: Point-wise method, Mg (Unhydrolysed PSHA)

\begin{tabular}{|l|l|l|l|l|l|l|l|l|}
\hline $\mathrm{pH}$ & $\mathrm{BV}_{1}$ & $\mathrm{BV}_{2}$ & $\mathrm{BV}_{3}$ & $\mathrm{~V}_{3}-\mathrm{V}_{2}$ & $\mathrm{n}$ & $\mathrm{pL}$ & $\log \left(\frac{n}{n-1}\right)$ & $\operatorname{Log~}_{1}$ \\
\hline 8.50 & 5.30 & 5.81 & 5.85 & 0.04 & 0.2973 & 2.88 & -0.3736 & 2.5064 \\
8.72 & 5.35 & 5.90 & 5.94 & 0.04 & 0.3099 & 2.66 & -0.3477 & 2.3123 \\
9.00 & 5.40 & 6.00 & 6.04 & 0.04 & 0.3236 & 2.38 & -0.3202 & 2.0598 \\
9.22 & 5.45 & 6.10 & 6.15 & 0.05 & 0.4297 & 2.17 & -0.1230 & 2.0470 \\
9.51 & 5.50 & 6.20 & 6.26 & 0.06 & 0.5500 & 1.89 & 0.0871 & 1.9771 \\
9.73 & 5.55 & 6.33 & 6.40 & 0.07 & 0.7000 & 1.67 & 0.3680 & 2.0380 \\
\hline
\end{tabular}

LogK $_{1}$ (Average value) $=2.1568 \pm 0.2069$

Table 14: Point-wise method, Mg (Unhydrolysed PSHA)

\begin{tabular}{|l|l|l|l|l|l|l|l|l|}
\hline $\mathrm{pH}$ & $\mathrm{BV}_{1}$ & $\mathrm{BV}_{2}$ & $\mathrm{BV}_{3}$ & $\mathrm{~V}_{3}-\mathrm{V}_{2}$ & $\mathrm{n}$ & $\mathrm{pL}$ & $\log \left(\frac{n-1}{2-n}\right)$ & $\log \mathrm{K}_{2}$ \\
\hline 10.00 & 5.60 & 6.47 & 6.55 & 0.08 & 0.9148 & 1.41 & & \\
10.23 & 5.65 & 6.62 & 6.71 & 0.09 & 1.2102 & 1.20 & -0.5749 & 0.6251 \\
10.49 & 5.70 & 6.80 & 6.92 & 0.09 & 1.5968 & 1.03 & 0.1703 & 1.2003 \\
\hline
\end{tabular}

LogK $_{2}$ (Average value) $=0.9127 \pm 0.4070$

Table15:Point-wise method, Cd (Hydrolysed PSHA)

\begin{tabular}{|l|l|l|l|l|l|l|l|l|}
\hline $\mathrm{pH}$ & $\mathrm{BV}_{1}$ & $\mathrm{BV}_{2}$ & $\mathrm{BV}_{3}$ & $\left(\mathrm{~V}_{3}-\mathrm{V}_{2}\right)$ & $\mathrm{n}$ & $\mathrm{pL}$ & $\log \left(\frac{n}{1-n}\right)$ & LogK $_{1}$ \\
\hline 8.50 & 5.30 & 6.29 & 6.31 & 0.02 & 0.2750 & 2.64 & -0.4210 & 2.2190 \\
8.72 & 5.35 & 6.37 & 6.40 & 0.03 & 0.4286 & 2.42 & -0.1249 & 2.2951 \\
9.00 & 5.40 & 6.46 & 6.49 & 0.03 & 0.4648 & 2.14 & -0.0612 & 2.0788 \\
9.22 & 5.45 & 6.55 & 6.59 & 0.04 & 0.6667 & 1.96 & 0.3010 & 2.2610 \\
9.51 & 5.55 & 6.66 & 6.70 & 0.04 & 0.7720 & 1.67 & 0.5297 & 2.1997 \\
\hline
\end{tabular}

LogK $_{\mathbf{1}}$ (Average value) $=2.2108 \pm 0.0825$

Table 16: Point-wise method, Cd (Hydrolysed PSHA)

\begin{tabular}{|l|l|l|l|l|l|l|l|l|}
\hline $\mathrm{pH}$ & $\mathrm{BV}_{1}$ & $\mathrm{BV}_{2}$ & $\mathrm{BV}_{3}$ & $\left(\mathrm{~V}_{3}-\mathrm{V}_{2}\right)$ & $\mathrm{n}$ & $\mathrm{pL}$ & $\log \left(\frac{n-1}{2-n}\right)$ & Log $_{2}$ \\
\hline 9.73 & 5.55 & 6.78 & 6.83 & 0.06 & 1.4042 & 1.47 & -0.1686 & 1.3014 \\
10.00 & 5.60 & 6.90 & 6.95 & 0.06 & 1.7838 & 1.23 & 0.5593 & 1.7893 \\
10.23 & 5.65 & 7.05 & 7.10 & 0.06 & 3.1429 & 1.09 & & \\
10.49 & 5.70 & 7.10 & 7.16 & 0.06 & 3.1429 & 0.89 & & \\
& & & & & & & & \\
\hline
\end{tabular}

$\operatorname{LogK}_{2}$ (Average value) $=1.5453 \pm 0.3450$

Table 17: Point-wise method, Cd (Unhydrolysed PSHA)

\begin{tabular}{|l|l|l|l|l|l|l|l|l|}
\hline $\mathrm{pH}$ & $\mathrm{BV}_{1}$ & $\mathrm{BV}_{2}$ & $\mathrm{BV}_{3}$ & $\mathrm{~V}_{3}-\mathrm{V}_{2}$ & $\mathrm{n}$ & $\mathrm{pL}$ & $\log \left(\frac{n}{n-1}\right)$ & $\operatorname{Log~}_{1}$ \\
\hline 8.50 & 5.30 & 5.81 & 5.86 & 0.05 & 0.3717 & 2.88 & -0.2280 & 2.6520 \\
8.72 & 5.35 & 5.90 & 5.95 & 0.05 & 0.3873 & 2.66 & -0.1992 & 2.4608 \\
9.00 & 5.40 & 6.00 & 6.06 & 0.06 & 0.4853 & 2.38 & -0.0255 & 2.3545 \\
9.22 & 5.45 & 6.10 & 6.16 & 0.06 & 0.5157 & 2.18 & -0.0272 & 2.2072 \\
9.51 & 5.50 & 6.20 & 6.27 & 0.07 & 0.6417 & 1.89 & 0.2530 & 1.1430 \\
9.73 & 5.55 & 6.33 & 6.41 & 0.08 & 0.8000 & 1.69 & 0.6020 & 2.2920 \\
& & & & & & & & \\
\hline
\end{tabular}

$\operatorname{LogK}_{1}($ Average value $)=2.2516 \pm 0.5380$ 
BAJOPAS Volume 14 Number 1,June, 2021

Table 18: Point-wise method, Cd (Unhydrolysed PSHA)

\begin{tabular}{|l|l|l|l|l|l|l|l|l|}
\hline $\mathrm{pH}$ & $\mathrm{BV}_{1}$ & $\mathrm{BV}_{2}$ & $\mathrm{BV}_{3}$ & $\mathrm{~V}_{3}-\mathrm{V}_{2}$ & $\mathrm{n}$ & $\mathrm{pL}$ & $\log \left(\frac{n-1}{2-n}\right)$ & $\log \mathrm{K}_{2}$ \\
\hline 10.00 & 5.60 & 6.47 & 6.57 & 0.10 & 1.1434 & 1.43 & & \\
10.23 & 5.65 & 6.62 & 6.72 & 0.10 & 1.3448 & 1.23 & -0.2788 & 0.9512 \\
10.49 & 5.70 & 6.80 & 6.90 & 0.10 & 1.7742 & 1.03 & 0.5351 & 1.5651 \\
\hline
\end{tabular}

$\operatorname{LogK}_{2}($ Average value $)=1.2581 \pm 0.4340$

Table 19: Stepwise and overall Stability constants of thehydrolysed and unhydrolysed divalent metal (II) complexes

\begin{tabular}{|c|c|c|c|}
\hline Chelates & LogK $_{1}$ & $\log _{2}$ & Log $\beta$ \\
\hline [Cu (Hydrolysed PSHA-1) $\left.{ }_{2}\right]$ & 2.4788 & 1.4280 & 3.9068 \\
\hline$\left[\mathrm{Pb}(\text { Hydrolysed PSHA-1) })_{2}\right]$ & 2.5832 & 1.1963 & 3.7795 \\
\hline$\left[\mathrm{Cd}(\text { Hydrolysed PSHA-1 })_{2}\right]$ & 2.2108 & 1.5453 & 3.7561 \\
\hline$\left[\mathrm{Mg}(\text { Hydrolysed PSHA-1 })_{2}\right]$ & 2.1382 & 1.5453 & 3.6835 \\
\hline [Cu (Unhydrolysed PSHA-1) & 2.3059 & 1.2209 & 3.5268 \\
\hline$[\mathrm{Pb}$ (Unhydrolysed PSHA-1) 2$]$ & 2.2364 & 1.2239 & 3.4603 \\
\hline [Cd (Unhydrolysed PSHA-1) 2 ] & 2.2516 & 1.2581 & 3.5097 \\
\hline$[\mathrm{Mg}$ (Unydrolysed PSHA-1) & 2.1568 & 0.9127 & 3.0695 \\
\hline
\end{tabular}

The results obtained (Table19) shows the stepwise and overall stability constants to be not high indicating low stability of the complexes, because the solubility of most metal ions in the basic $\mathrm{pH}$ range is minimal due to metal hydroxide precipitation (Karimi, 2017). In general, the stepwise stability constants $\left(K_{1}\right.$ and $K_{2}$ ) follow the order $K_{1}>K_{2}$ for the copper, lead, magnesium and cadmium complexes respectively. The steady decrease of the values with increasing number of ligands is in agreement with the prediction made by researchers (Na'aliya, 2013). The decrease could be attributed to the fact that as the number of the ligands (Humate ions) that enters the coordination zone increases the aqua molecules available for replacement by the ligands become less. Thus, the metal ions become less electron loving with progressive intake of the ligand and this results in the decrease in the values of the constants (Na'aliya, 2013). Also the stability of the complexes is influenced by the size and number of the chelate rings(Mackay and Mackay,2002).All the complexes form rings in their structure as humate, a bidentate ligand, bond the metal ions in the ratio 1:2 (Boguta and Sokolowska, 2016) forming chelate rings. The values of the overall stability constants $(\log \beta)$ obtained for humate complexes are not high indicating low stability as the values are not high. LogK values for copper-humates (Table 3 to 6) obtained in this study are lower than those reported for the complexes of humic acids (Pandey et al., 2015; Dinu, 2013; Kaschl et al., 2010 and Gilbeto and Jorg, 2001). The values of LogK(Table 7 to 10 ) forlead-humates are lower than those reported for the lead in the literature (Dinu, 2013; Gilbeto and Jorg 2001). Log K values(Table 11 to 14 ) for magnesium-humates obtained in this study are close to those reported by (Pandey et al., 2015). Log K values of cadmium-humates (Table 15 to 18 ) obtained in this work near to the one reported by (Dinu, 2013 and Pandey et al., 2015).The difference between the reported values and the values obtained in this study might be probably as a result of acid hydrolysis of humic acid. The values of the overall stability constants $(\log \beta)$ of the copper humates complexes presented in Table 19 is high than that of other metal humate complexes, show relatively high stability of CuHA complexes, show the following order of stability: $\mathrm{Cu}>\mathrm{Pb}>\mathrm{Cd}>\mathrm{Mg}$; which are in close agreement to the findings of (Dinu, 2013 and Pandey et al., 2015).The high stability of Cuhumate chelate could be attributed to the existence of coordinate covalent bond between the complexing agents and the $\mathrm{Cu}^{2+}$ ions. Since, $\mathrm{Cu}^{2+}$ being a metal of the transitional series with $3 d^{9}$ electronic configurations can accept the electrons from the complexing agents. Similarly, the low stabilities of $\mathrm{Pb}, \mathrm{Cd}$ and $\mathrm{Mg}$ complexes could be explained by that $\mathrm{Pb}^{2+}$ with $6 s^{2}, \mathrm{Cd}^{2+}$ with $4 \mathrm{~d}^{10}$ and $\mathrm{Mg}^{2+}$ with $2 \mathrm{p}^{6}$ their electronic configuration has a completely filled $\mathrm{d}, \mathrm{p}$ and $\mathrm{s}$ orbitals. Moreover, the stabilities of metal ions with hydrolysed humic acid from peat soil were higher than those with unhydrolysed humic acid from peat soil; which is ascribed to the high content of acidity in hydrolysed humic acid than unhydrolysed humic acid. 
BAJOPAS Volume 14 Number 1,June, 2021 CONCLUSION

The values of logk for $\mathrm{Cu}(\mathrm{II})$ hydrolysed humic acid complex was higher followed by $\mathrm{Pb}$ (II), $\mathrm{Cd}(\mathrm{II})$ and $\mathrm{Mg}$ (II) hydrolysed humic acid complexes as compared with metal(II) unhydrolysed humic acid complexes. This indicates acid hydrolysis of humic acid can

\section{REFERENCES}

Almeida, V.R. and Szpoganicz, B. (2015). Humic Acid Potentiometric Response Patterns:Out- of Equilibrium Properties and Species Distribution Modelling. Chemical. Biol. Technol. Agric. 2: 17.

Anđelković, T., Nikolić, R., Bojić, A.,Anđelković, D., and Nikolic G.,(2010). Binding of Cadmium to Soil Humic Acid as A Function of Carboxyl Group Content. Macedonian Journal of Chemistry and Chemical Engineering.29(2): 215-224.

Anil, B. N. and Maroti, N. (2008). Studies on Influence of Die-Lectric Constants on Complex Equilibria between Substituted Py-Razalines and Lanthanide Metal Ions pH-Metrically. Amer.-Euras. scient. Res. 3(2): 212-216.

Ashok, K., Pandey, S. P. and Misra, V (2000). Stability Constants of Metal-Humic Acid Complexes and its Role in Environmental Detoxification. Journal of Ecotoxicology and Environmental Safety. 47(2):157-200.

Badr, M. H., El-Halafawi, M. H. and Abd El-al Zeid, E. R. (2012). Comparison Between the Effect of Ionic Strength on Acidity and Dissociation Constants of Humic Acids Extracted from Sewage Sludge and Nile Water Hyacinth Composts.Global Journal of Environmental Research 6 (1): 36-43.

Baruah, M.K., Borah, D., Saikia, P.P., Paul, S., Sharma, T. (2015). Evaluation of pKa Values of Soil Humic Acids and their Complexation Properties. International Journal of Plant \& Soil Science 6(4) : 218-228.

Boguta, P. Sokolowska, Z. (2016). Interactions of $\mathrm{Zn}$ (II) Ions with Humic Acids Isolated from Various Types of Soils. Effect of $\mathrm{pH}, \mathrm{Zn}$ Concentrations and Humic Acids Chemical Properties. Journal of Geochemical Explaration 168. 119-126.

Borges, F., Guimaraes, C., Lima, L.F.C., Pinto, I. and Reis, S.(2005). Potentiometric Studies on the Complexation of Copper(II) by Phenolic Acids as Discrete Ligand Models of enhance the complexation behavior of humic acid with metal (II) ions. However, the higher values of $\log \beta$ for $\mathrm{Cu}(\mathrm{II}), \mathrm{Pb}(\mathrm{II}), \mathrm{Cd}(\mathrm{II})$ and $\mathrm{Mg}(\mathrm{II})$ hydrolysed humic acid complexes indicates more stable stepwise complexes formed as compared with $\mathrm{Cu}(\mathrm{II}), \mathrm{Pb}$ (II), $\mathrm{Cd}$ (II) and $\mathrm{Mg}(\mathrm{II})$ unhydrolysed humic acid complexes.

Humic Substances Talanta 66 (2005) 670-673.

Chefetz, B., Salloum, M. J., Deshmulkin, A. P. and Hatcher, P. (2002). Structural Components of Humic Acids as Determined by Chemical Modifications and Carbon-13 NMR, Pyrolysis, and Thermochemolysis- Gas Chromatography/Mass Spectrometry. Soil Science Society of American Journal Abstract Division S-2- Soil Chemistry66. 1159-1171.

Dinu, M. I. (2013). Metals Complexation with Humic Acids in Surface Water of Different Environ. Sci. Technol. 31(1): 1-17.

Fernandes, A.N., Giacomelli, C., Giovanela, M. Vaz, D.V. Szpoganicz, B. and Maria M. D. (2009). Potentiometric Acidity Determination in Humic Substances Influenced by Different Analytical Procedures.J. Braz. Chem. Soc. 20 (9):14.

Gamal, A. H. (2015). Stability Constants of Rhenium (V) Metal Complexes with Selected Drugs. Pyrex Journal of Research in Environmental Studies. 2(2): 006-014.

Janrao, D. M., Pathan, J., Kayande, D.D., and Mulla, J.J. (2014). An Over View of Potentiometric Determination of Stability Constants of Metal Complexes. Sci. Revs. Chem. Commun.: 4(1), 2014, 11-24.

Karimi, H. (2017). Effect of pH and Initial Pb(II) Concentration on the Lead Removal Efficiency from Waste Water Using $\mathrm{Ca}(\mathrm{OH})_{2}$. International Journal of Water and Waste Water Treatment 3.2

Kaschl, A. Romheld, V. and Chen, Y. (2010). Binding of Cadmium, Copper and Zinc to Humic Substances Originating from Municipal Solid Waste Compost. Israel Journal of Chemistry Vol. 42(1): 89-98.

Kostic, I. S., Tatjana, P, A., Nikolic, R. S., Cvetkovic, T. P., Pavlovic, D. D., Aleksandar, L.J. and Bojic, A. (2012). Comparative Study of Binding Strengths of Heavy Metals with Humic Acid. J.serb. Chem. Soc. 76(9) pp 1-20. 
BAJOPAS Volume 14 Number 1,June, 2021

Na'aliya, J. (2013). Determination of Stepwise Stability Constants and Gibbs free Energy Change of Trisprolina to Complexes of some Divalent Transition Metal ions. Bayero Journal of Pure and Applied Sciences 6(2): 112-114.

Omar, A. A. and Ali, E. A. (2015). Potentiometric Studies on Complexes of $\mathrm{Cr}$ (III) and $\mathrm{Zr}$ (IV) with some Carboxylic Acids. International Journal of Advanced Chemistry, 3(1) 25-

37.

Pandey, A. K. Pandey, S. D. and Misr, V. (2015).Stability Constants of Metal- Humic Acid Complexes and Its Role in Environmental Detoxification. J. Ecotoxicology and Environmental Safety. 47(1):195-200.

Ram, N. and Raman, K.V. (1984). Stability Constants of Complexes of Metals with
Humicand Fuvic Acids under Non- acidConditions. Journal of Plant Nutrition and Soil Sciences.

147:171-176.

Santosh, D. D., Ashok, B. K., Vijay, J. T., Shivraj, G. W. and Vinay, V. W. (2011). Potentiometric Studies of Elec-Trolyte Effects on Complex Equilibria of Some Substituted 5-(2-hydroxy Phenyl) Pyrazoles. Der pharm. 3 (6): 75-83.

Sayyed, H. and Abdul Rahim, M. F. (2012). Studies of Binary Complexes of Metal Ions with Mandelic Acid by Potentiometry. Chem. J. 02 (6): 206209.

Shirvani, M. Moradian, E. Khalili, B. Bakhtiary, S. (2015). Interaction of $\mathrm{Cd}$ and $\mathrm{Pb}$ with Humate-Palygorskite and HumateSepiolite Complexes. Journal of water, air and pollution 3: 220-228. 


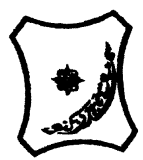

Bayero Journal of Pure and Applied Sciences, 14(1): 54 - 63

Received: November, 2020

Accepted: April, 2021

ISSN $2006-6996$

\title{
STABILITY CONSTANTS OF COMPLEXES OF METAL IONS WITH PEATSOIL HUMIC ACIDS UNDER NON-ACID-CONDITIONS
}

\author{
${ }^{* 1}$ Sabo, Yusuf ${ }^{2}$ Jimoh, W.L.O., ${ }^{3}$ Isa Baba Koki and ${ }^{4}$ Sholadoye, Q. 0. \\ ${ }^{1}$ Department of Pure and Industrial Chemistry, Bayero University, Kano \\ ${ }^{3}$ Department of Chemistry, Yusuf Maitama Sule University Kano. P.M.B. 3220 Kano, Nigeria. \\ ${ }^{4}$ Department of Chemistry, Nigerian Police Academy, Wudil, Kano-Nigeria
}

*Correspondence E-mail; saboyusuf18@yahoo.com

ABSTRACT

Stability constants of complexes of four divalent metal ions viz. $\mathrm{Cu}^{2+}, \mathrm{Pb}^{2+}, \mathrm{Mg}^{2+}$ and $\mathrm{Cd}^{2+}$ with humic acids (HA) were determined by potentiometric titration of humic acids with the corresponding salt of the divalent metals in aqueous media under non-acid-condition. The log $K$ (logarithm of the stability constant) ranged from 1.0942 to 2.7471 for metalhumic acid complexes were determined using point-wise computational method. The order of stability constants were obtained as follows: $\mathrm{Cu}>\mathrm{Pb}>\mathrm{Cd}>\mathrm{Mg}$ for metal $-\mathrm{HA}$ complexes respectively, indicating a higher degree of complexation with Cu metal ion.

Keywords: stability constant, humic acid, potentiometric titration, divalent metals, acid hydrolysis.

\section{NTRODUCTION}

The stability constant of a complex is the numerical expression of its stability and provides a quantitative measure of affinity of the metal ion to the complexing agent. An understanding of the relative stability of metal-complexes helps in predicting the behavior of metal ions in the soil (Ram and Raman, 1982). Extensive researches has been done to determine the stability constants of the complexes formed between humic acid (HA) with a number of metal ions. Ashok et al., (2000) reported that humic acid with hydroxyl, phenoxyl and carboxyl reactive groups can form coordination compound with metal ions at $\mathrm{pH}$ 3.5. The stability constants(Log K) for different metalhumic acid complexes indicated the following order of the stabilities of complexes formed between humic acid and metal ion, $\mathrm{Cu}>\mathrm{Fe}$ $>\mathrm{Pb}>\mathrm{Ni}>\mathrm{Co}>\mathrm{Ca}>\mathrm{Cd}>\mathrm{Zn}>\mathrm{Mn}>\mathrm{Mg}$. Andelkovic et al., (2010) investigated the binding of $\mathrm{Cd}$ (II) to soil humic acid at pH 6.5 and in $0.1 \mathrm{M} \mathrm{KNO}_{3}$ ionic medium. The stability constant for binding indicating greater stability in the case when carboxyl groups are involved in complexation reaction. Kostic et al.,(2012) investigated the complexation of humic acid with certain heavy metal ions (Co(II), $\mathrm{Ni}(\mathrm{II}), \mathrm{Cu}(\mathrm{II})$,
$\mathrm{Zn}(\mathrm{II})$, and $\mathrm{Pb}(\mathrm{II})$. The experiment was performed at $25^{\circ} \mathrm{C}$, at pH 4.0 and ionic strength of $0.01 \mathrm{M}$. Stability constant of complex between $\mathrm{Pb}$ (II) ions and humic acid is greater than stability constants of other investigated metalhumate complexes. Bogata and Sokolowska (2016) analyses the interaction between humic acids from different soils and $\mathrm{Zn}$ (II) ions at wide concentration ranges and at $\mathrm{pH} 5$. Studies have showed significant impact of $\mathrm{Zn}$ concentration, $\mathrm{pH}$ and some properties of humic acids with zinc.But all of these studies were limited to acidic $\mathrm{pH}$ range. Therefore, the present study was carried out to determine and compare the stability constants of complexes of metal ions with hydrolysed peat soil humic acid and unhydrolysed peat soil humic under non-acid conditions.

\section{MATERIALS AND METHODS}

Analytical grade chemicals used includes hydrochloric acid $(\mathrm{HCl})$, nitric acid $\left(\mathrm{HNO}_{3}\right)$, sodium hydroxide $(\mathrm{NaOH})$, lead nitrate $\mathrm{Pb}\left(\mathrm{NO}_{3}\right)_{2}$, copper nitrate $\mathrm{Cu}\left(\mathrm{NO}_{3}\right)_{2} \cdot 3 \mathrm{H}_{2} \mathrm{O}$, cadmium nitrate $\mathrm{Cd}\left(\mathrm{NO}_{3}\right)_{2} \cdot 4 \mathrm{H}_{2} \mathrm{O}$, magnesium nitrate $\mathrm{Mg}\left(\mathrm{NO}_{3}\right)_{2} \cdot 6 \mathrm{H}_{2} \mathrm{O}$, potassium nitrate $\left(\mathrm{KNO}_{3}\right)$, calcium chloride $\left(\mathrm{CaCl}_{2}\right)$, (sigma-Aldrich). Dowex 50WX8, (20-50 mesh) from Fluka. 


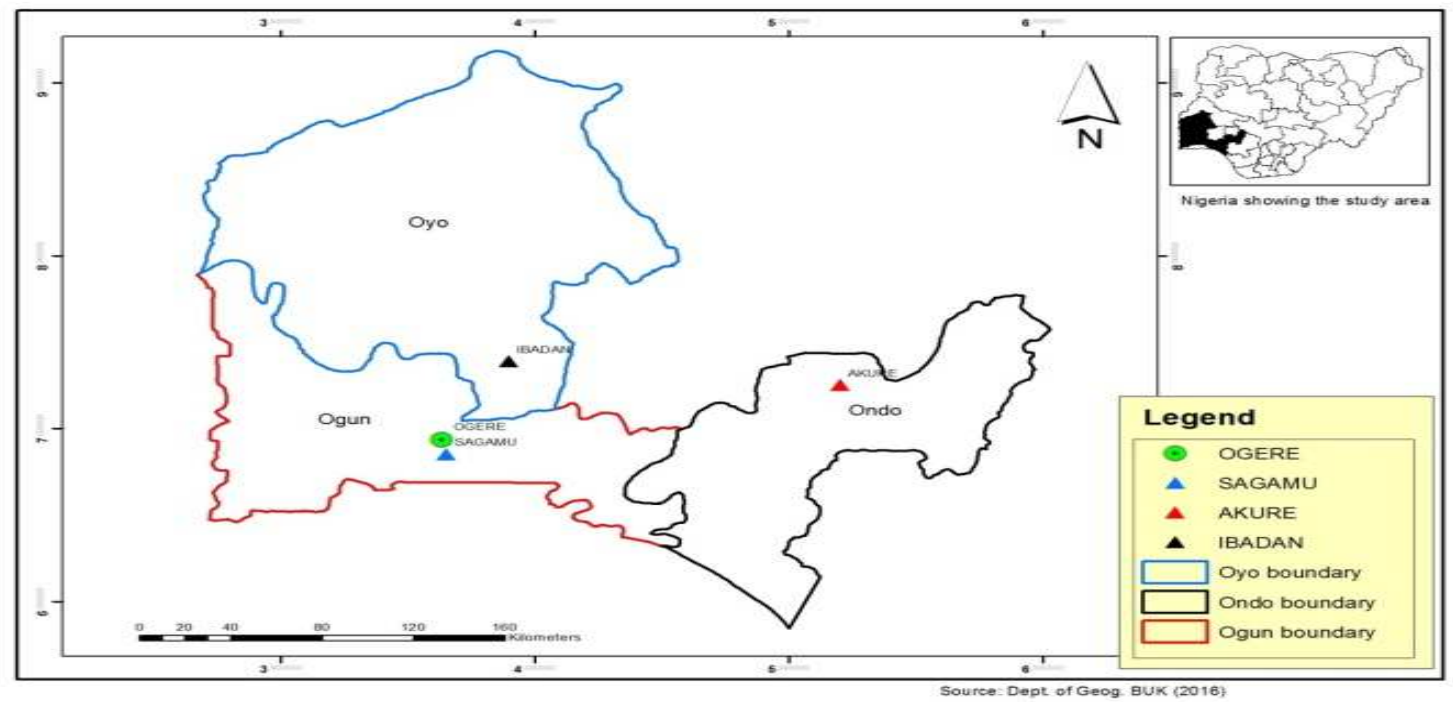

Figure 1: Map showing the sampling point at Sagamu Town, Ogun State.

\section{Description of Sampling Area}

Sagamu has geographical coordinates between $6^{\circ} 50^{\prime}$ north; $3^{\circ} 38^{\prime}$ east is located in south western region of Nigeria. The region has tropical wet and dry climate with a lengthy wet season and relatively constant temperatures throughout the course of the year. Wet season runs from March to October, November to December forms the region dry season. The vegetation type of the region is savannah which is really grassland with small bushes and occasional big trees. Grassland soils have substantially higher organic matter content than forest soils (Novackova, 2011).

\section{Sample Collection}

The Peatsoil samples were collected from four different sampling points $(0-10 \mathrm{~cm}$ depth) in Sagamu into polyethylene bag with plastic spoons. Samples were taken to the laboratory, extraneous materials were removed; the samples were air-dried, crushed and ground to a fine powder in a mortar passed through a $0.20 \mathrm{~mm}$ sieve. The samples were kept for analysis.

\section{Isolation and purification of humic acid from peat soil sample}

Peatsoil sample $(100 \mathrm{~g})$ was mixed with 1000 $\mathrm{cm}^{3}$ of $0.1 \mathrm{M} \mathrm{NaOH}$ solution, shaken for 3hours and left to stand overnight. Dark-coloured supernatant was obtained and decanted from solid residue. The dark-coloured supernatant was acidified to $(\mathrm{pH}=1.0)$ with $6 \mathrm{M} \mathrm{HCl}$ stirred and allowed to stand for 6 hours. Yellowish brown supernatant and dark-brown precipitate were obtained. The yellowish brown supernatant was decanted followed by centrifuge and discarded. The dark-brown precipitate was mixed with $500 \mathrm{~cm}^{3}$ of $0.1 \mathrm{M} \mathrm{NaOH}$ solution followed by passing through dowex resin. The dark-brown solution was acidified to $(\mathrm{pH}=1.0)$ with $6 \mathrm{M} \mathrm{HCl}$ stirred and allowed to stand for 3 hours. The dark-brown precipitate was washed several times with deionized water. The supernatant was treated with $\mathrm{AgNO}_{3}$ solution until no white precipitate observed. The humic acid was transferred to weighed crucible and dried at $60^{\circ} \mathrm{C}$ in an oven for 12 hours. The humic acid was cooled and dried in the desiccator, weighed and recorded. The obtained humic acid was dried again at $60^{\circ} \mathrm{C}$ for additional 6 hours cooled and dried in the desiccator, weighed and recorded constant weight was obtained (Baruah et al., 2015).

\section{FT-IR analysis}

FT-IR spectra of humic acid sample was analysed using Carry 630 FT-IR Agilent Technologies.

Unhydrolysed compost humic acid

The unhydrolysed humic acid was obtained after isolation and purification of compost humic acid and kept for investigation.

\section{Acid hydrolysis of Peatsoil acid}

Peatsoil humic acid sample (1g) was refluxed for 12 hours at $\left(160^{\circ} \mathrm{C}\right)$ with $50 \mathrm{~cm}^{3}$ of $6 \mathrm{M} \mathrm{HCl}$. The mixture was allowed to cool, decanted, and centrifuged after hydrolysis. The insoluble residues were washed with distilled water via centrifugation several times, and the supernatant was treated with $\mathrm{AgNO}_{3}$ solution until no white precipitate was observed. The residue was thoroughly dried over $\mathrm{CaCl}_{2}$ in a desiccator at room temperature (Chefetz et al., 2002). Finally, the obtained hydrolysed humic acid was kept for investigation. 
BAJOPAS Volume 14 Number 1,June, 2021 Potentiometric Titrations

Potentiometric measurements were carried out using a pH-meter Jenway (model 3510) with combine electrode, the sensitivity of the $\mathrm{pH}$ meter is 0.01 units. The $\mathrm{pH}$ meter was switched on half an hour before starting the titration for initial warm up of the instrument. The instrument was calibrated with an aqueous standard buffer solution of $\mathrm{pH} 4.00$ and 10.0 (borate buffer) prepared from a "Qualigens" buffer tablets.

The following sets of solutions were prepared in a $250 \mathrm{~cm}^{3}$ volumetric flask separately for $\mathrm{pH}$ metric titrations.

(i) $5 \mathrm{~cm}^{3} 0.1 \mathrm{M} \mathrm{HCl}+40 \mathrm{~cm}^{3}$ deionized water

(ii) $5 \mathrm{~cm}^{3} 0.1 \mathrm{M} \mathrm{HCl}+39 \mathrm{~cm}^{3}$ deionized water $+1 \mathrm{~cm}^{3} 0.15 \mathrm{gcm}^{-3}$ humic acid

(iii) $5 \mathrm{~cm}^{3} 0.1 \mathrm{M} \mathrm{HCl}+37 \mathrm{~cm}^{3}$ deionized water $+1 \mathrm{~cm}^{3} 0.15 \mathrm{gcm}^{-3}$ humic acid

$$
+2 \mathrm{~cm}^{3} \quad 0.01 \mathrm{M} \mathrm{Cu} \text { (II) }
$$

The solutions were titrated against standardized $0.110 \mathrm{MNaOH}$ separately. The total volume of each mixture was adjusted to $50 \mathrm{~cm}^{3}$ and the ionic strength of the solutions was maintained constant at by adding appropriate amount of stock solution of $1 \mathrm{M} \mathrm{KNO}_{3}$ (Gamal, 2015; Omar and Ali, 2015). A magnetic stirrer was used to achieve thorough mixing of the interacting solutions at $550 \mathrm{rpm}$. The same set of experimental conditions was applied for potentiometric titration of remaining samples.

\section{Evaluation of pKa of Hydrolysed peat soil Humic Acids}

The proton-ligand formation number $\mathrm{n}_{\mathbf{A}}$ were calculated by Irving and Rossotti expression (Omar and Ali, 2015).

$\mathrm{nA}=\mathrm{Y}-\frac{(\mathrm{V} 2-\mathrm{V1})(\mathrm{No}-\mathrm{Eo})}{(\mathrm{VO}+\mathrm{V1}) \mathrm{TCL}}$ 1

Where: $Y$ is number of dissociable proton, $\left(\mathrm{V}_{2^{-}}\right.$ $V_{1}$ ) is the measure of displacement of the ligand curve relative to acid curve, $\mathrm{N}^{\circ}$ and $\mathrm{E}^{\circ}$ are the resultant concentration of alkali solution, free acid solution, $\mathrm{T}_{\mathrm{cL}}{ }^{\circ}$ is the total ligand concentration, $\mathrm{V}^{\circ}$ is the total volume of titration solution, $V_{1}$ is the volume of alkali added to acid solution, $V_{2}$ is the volume of alkali added to acid solution + ligand solution, acid dissociation constants (pKa - values) of ligand were calculated by algebraic method point wise calculation (Tables 1 ). The dissociation constants (pKa) were calculated according to the following relation:

$\mathrm{pKa}=\mathrm{pH}+\log \left(\frac{n A}{1-n A}\right)$ 2

Where: pKa is the acid dissociation constant, $\mathrm{n}_{\mathrm{A}}$ is the Proton-ligand formation number and $\mathrm{pH}$ is the pH-values (Omar and Ali, 2015).

\section{Determination of metal-ligand stability constants $(\log K)$ of complexes}

The potentiometric measurement for the determination of stability constant of a complex in solution is based on the fact that the redox potential of the couple $\frac{M^{+(m-n)}}{M^{+m}}$ is shifted significantly on complexation of the metal ion with the ligand. This method involves change in hydrogen ion concentration $\left[\mathrm{H}^{+}\right]$due to the displacement or association of one or more protons taking place during complexation reaction. This change can be found out by titrating the solutions containing free acid, acid with ligand, and acid with ligand and metal ion, individually against a standard alkali solution at a constant ionic strength or temperature. Either ionic strength or temperature may be varied for different sets of solutions. In all the cases, the change in the $\mathrm{pH}$ of the solution is measured after each addition of a known amount of alkali to the reaction cell which contains the reaction mixture. The titration curves are then drawn by plotting the measured $\mathrm{pH}$ values against the corresponding volume of alkali added and the stability constants of the complexes are determined from the titration curves by employing $\mathrm{pH}$-metric titration technique given by (Irving and Rossoti).

Metal-ligand stability constants ( $\log \mathrm{K}$ ) were determined by using the following relations:

$$
\bar{n}=\frac{\left(V_{3}-V_{2}\right)\left(E^{0}+N^{0}\right)}{\left(V^{0}+V_{2}\right) \bar{n}_{A} T_{m}^{0}}
$$

and

$$
P L=\log _{10}\left\{\frac{1+\beta_{n}^{H} \frac{1}{[\text { anti } \log \mathrm{pH}]^{\mathrm{n}}}}{\mathrm{T}_{\mathrm{L}}^{0}-n \bar{T}_{m}^{0}} \mathrm{X} \frac{\left(V^{0}+V_{3}\right)}{V^{0}}\right\}
$$


BAJOPAS Volume 14 Number 1,June, 2021

Where $T_{L}, T^{\circ}, E^{\circ}$, and $V^{\circ}$ havethe same significance as in equation (1) above, $T_{m}$ denotes the total concentration of metal present in solution, $V_{3}$ is the volume of metal ions present in solution and $\beta^{H}$ is the overall proton ligand stability constant. The metal-ligand stability constants (log K) were determined by employing point wise computational Method (eq. 5 and 6).

$\operatorname{LogK}_{1}=\log \left(\frac{n}{1-n}\right)+\mathrm{pL}$ .5

$\operatorname{LogK}_{2}=\log \left(\frac{1-n}{2-n}\right)+\mathrm{pL}$ ...6

Where: Log $\mathrm{K}$ is the metal-ligand stability constant, $\mathrm{pL}$ is the Free ligand exponent function, $\mathbf{n}$ is the Average number of ligand attached with metal ion (Janraoet al., 2014). The results obtained were analyzed by an ORIGIN 2016 program using titration data and then the proton-ligand stability constants (pKa) and Metal-ligand stability constant (LogK) calculated (Omar and Ali, 2015).

\section{RESULTS AND DISCUSSION}

Fourier transformed infrared (FT-IR) spectra of isolated humic acid from peat soils Figure 2 had distinct clear absorption bands indicating the presence of major humic acid structural elemental groups such as $\mathrm{H}$ bonded $\mathrm{OH}$ $\left(3680 \mathrm{~cm}^{-1}\right.$ peak $), C=0$ of carbonyl $\left(1721 \mathrm{~cm}^{-1}\right.$ peak), functional groups of aliphatic components $\mathrm{CH}_{2}\left(2918 \mathrm{~cm}^{-1}\right.$ peak) and $\mathrm{C}-\mathrm{O}$ stretching of polysaccharide $\left(1168 \mathrm{~cm}^{-1}\right.$ peak). The positions of the absorption bands of the spectra fell within typical major absorption bands of humic acid which is at frequencies 3680, 2918, 1721, 1168 $\mathrm{cm}^{-1}$. The first peak centred in the vicinity of $3680 \mathrm{~cm}^{-1}$ region is attributed to phenol $\mathrm{OH}$ group bounded by intermolecular $\mathrm{H}$ bonds. The $2918 \mathrm{~cm}^{-1}$ band usually has absorption maximum at $2918 \mathrm{~cm}^{-1}$ which is due to $\mathrm{C}-\mathrm{H}$ stretching of alkane group $\left(\mathrm{CH}_{2}\right)$. The next major absorption band is $1721 \mathrm{~cm}^{-1}$. This band has been commonly ascribed to $\mathrm{C}=\mathrm{O}$ stretching of mainly carboxyl group $(\mathrm{COOH})$ with trace amount of ketones. The last peak was observed at 1168 $\mathrm{cm}^{-1}$ due to $\mathrm{C}-\mathrm{O}$ stretching of polysaccharides and this peak appeared also in the spectra of humic acid from peat soil. The FTIR spectra of the isolated humic acid contained all major characteristic absorption peaks of humic acid. These absorption peaks indicated the presence of the major structural elements of humic acid namely $\mathrm{H}$ bonded $\mathrm{OH}, \mathrm{C}=\mathrm{C}$ of aromatic ring, $\mathrm{C}=\mathrm{O}$ of carbonyl group (both carboxyl and ketonic), $\mathrm{CH}_{2}$ group. This strongly supports the presence of humic acid.

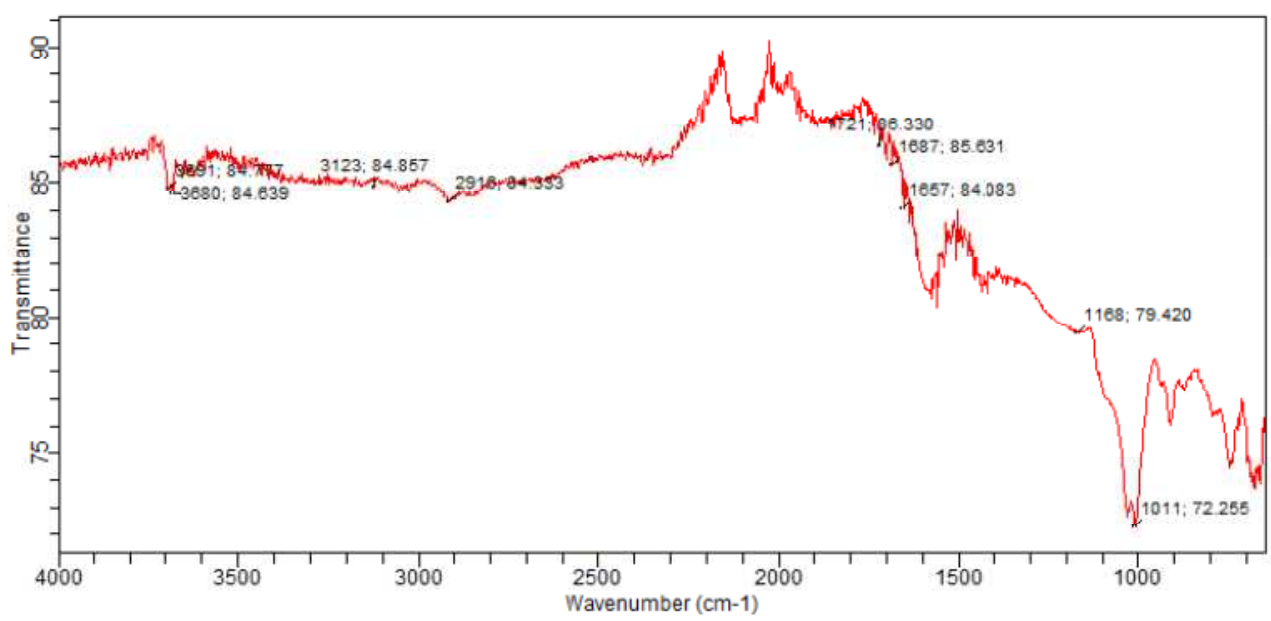

Fig. 2 : FT-IR spectraof peatsoilhumic acid (PSHA)

\section{Evaluation of acid dissociation constant (pka) of acid hydrolysed peat soil humicacid at phenolic group}

The value of the dissociation constant of the peat soil humic acid (PSHA) that underwent acidhydrolysis studied was found to be 8.9299 as shown Table 1, which is lower than the literaturevalues reported by Almeida and Szpoganics, (2015), Borges et al., (2005); Badr et al., (2012)and Fernandes et al,.(2009) of $9.73,9.47$ and 10.30. The difference between the obtained valuesand the reported values in this study might be probably as a result of acid hydrolysis of humicacid. 
BAJOPAS Volume 14 Number 1,June, 2021

Table 1: PKa of (Hydrolysed PSHA)

\begin{tabular}{|l|l|l|l|l|l|l|}
\hline $\mathrm{pH}$ & $\mathrm{BV}_{1}$ & $\mathrm{BV}_{2}$ & $\mathrm{~V}_{2}-\mathrm{V}_{1}$ & $\mathrm{nA}$ & $\log \left(\frac{n A}{1-n A}\right)$ & $\mathrm{pKa}$ \\
\hline 8.50 & 5.30 & 6.29 & 0.99 & 0.3594 & -0.2510 & 8.2490 \\
8.72 & 5.35 & 6.37 & 1.02 & 0.3400 & -0.2880 & 8.4320 \\
9.00 & 5.40 & 6.46 & 1.06 & 0.3141 & -0.3391 & 8.6609 \\
9.22 & 5.45 & 6.55 & 1.10 & 0.2882 & -0.3927 & 8.8273 \\
9.51 & 5.50 & 6.66 & 1.16 & 0.2494 & -0.4786 & 9.0314 \\
9.73 & 5.55 & 6.78 & 1.23 & 0.2041 & -0.5910 & 9.1390 \\
10.00 & 5.60 & 6.90 & 1.30 & 0.1589 & -0.7238 & 9.2762 \\
10.23 & 5.65 & 7.05 & 1.40 & 0.0941 & -0.9835 & 9.2465 \\
10.49 & 5.70 & 7.10 & 1.40 & 0.0941 & -0.9835 & 9.5065 \\
\hline
\end{tabular}

Average pKa $=8.9299 \pm 0.4186$

Table 2: PKa of (Unhydrolysed PSHA)

\begin{tabular}{|l|l|l|l|l|l|l|}
\hline $\mathrm{pH}$ & $\mathrm{BV}_{1}$ & $\mathrm{BV}_{2}$ & $\mathrm{~V}_{2}-\mathrm{V}_{1}$ & $\mathrm{nA}$ & $\log \left(\frac{\boldsymbol{n A}}{1-\boldsymbol{n}}\right)$ & $\mathrm{pKa}$ \\
\hline 8.50 & 5.30 & 5.81 & 0.51 & 0.6619 & 0.2919 & 8.7919 \\
8.72 & 5.35 & 5.90 & 0.55 & 0.6357 & 0.2418 & 8.9618 \\
9.00 & 5.40 & 6.00 & 0.60 & 0.6029 & 0.1813 & 9.1813 \\
9.22 & 5.45 & 6.10 & 0.65 & 0.5701 & 0.1226 & 9.3426 \\
9.51 & 5.50 & 6.20 & 0.70 & 0.5376 & 0.0654 & 9.5754 \\
9.73 & 5.55 & 6.33 & 0.78 & 0.4851 & -0.0259 & 9.7041 \\
10.00 & 5.60 & 6.47 & 0.87 & 0.4262 & -0.1291 & 9.8709 \\
10.23 & 5.65 & 6.62 & 0.99 & 0.3609 & -0.2481 & 9.9819 \\
10.49 & 5.70 & 6.80 & 1.10 & 0.2759 & -0.4690 & 10.0210 \\
\hline
\end{tabular}

Average pKa $=9.4923 \pm 0.4410$

Metal-ligand stability constant ( $\log \mathrm{K}$ )

The stabilityconstants require the accurate values of proton-ligand stability constants (Anil and Maroti, 2008). Metal titration curves crossed over ligand titration curve indicated the formation of complex upon proton release (Santosh, et al., 2011). If the values of n- are within range $0.2-0.8$ and $1.2-18$ this indicates the formation of $1: 1$ and 1:2 complexes (Sayyed and Mazahar, 2012).

The metal (II)-humate stepwise stability constants (log k) at phenolic group (Tables 318)

Table 3: Point-wise method, $\mathrm{Cu}$-(Hydrolysed PSHA)

\begin{tabular}{|l|l|l|l|l|l|l|l|l|}
\hline $\mathrm{pH}$ & $\mathrm{BV}_{1}$ & $\mathrm{BV}_{2}$ & $\mathrm{BV}_{3}$ & $\left(\mathrm{~V}_{3}-\mathrm{V}_{2}\right)$ & $\mathrm{n}$ & $\mathrm{pL}$ & $\log \left(\frac{n}{1-n}\right)$ & LogK $_{1}$ \\
\hline 8.50 & 5.30 & 6.29 & 6.33 & 0.04 & 0.5500 & 2.66 & 0.0871 & 2.7471 \\
8.72 & 5.35 & 6.37 & 6.41 & 0.04 & 0.5714 & 2.43 & 0.1249 & 2.5549 \\
9.00 & 5.40 & 6.46 & 6.50 & 0.04 & 0.6198 & 2.16 & 0.2122 & 2.3722 \\
9.22 & 5.45 & 6.55 & 6.59 & 0.04 & 0.6667 & 1.94 & 0.3010 & 2.2410 \\
\hline
\end{tabular}

LogK $_{1}$ (Average value) $=2.4788 \pm 0.2203$

Table 4: Point-wise method, $\mathrm{Cu}$-(Hydrolysed PSHA)

\begin{tabular}{|l|l|l|l|l|l|l|l|l|}
\hline $\mathrm{pH}$ & $\mathrm{BV}_{1}$ & $\mathrm{BV}_{2}$ & $\mathrm{BV}_{3}$ & $\left(\mathrm{~V}_{3}-\mathrm{V}_{2}\right)$ & $\mathrm{n}$ & $\mathrm{pL}$ & $\log \left(\frac{n-1}{2-n}\right)$ & LogK $_{2}$ \\
\hline 9.51 & 5.50 & 6.66 & 6.73 & 0.07 & 1.3509 & 1.70 & -0.2671 & 1.4329 \\
9.73 & 5.55 & 6.78 & 6.85 & 0.07 & 1.6383 & 1.51 & 0.2467 & 1.7567 \\
10.00 & 5.60 & 6.90 & 6.98 & 0.08 & 2.1783 & 1.31 & -0.2158 & 1.0942 \\
10.23 & 5.65 & 7.05 & 7.13 & 0.08 & 4.1904 & 1.27 & & \\
10.49 & 5.70 & 7.10 & 7.19 & 0.09 & 4.6920 & & & \\
\hline
\end{tabular}

Log $K_{2}($ Average value $)=1.4280 \pm 0.3312$ 
BAJOPAS Volume 14 Number 1,June, 2021

Table 5: Point-wise method, $\mathrm{Cu}$ (Unhydrolysed PSHA)

\begin{tabular}{|l|l|l|l|l|l|l|l|l|}
\hline $\mathrm{pH}$ & $\mathrm{BV}_{1}$ & $\mathrm{BV}_{2}$ & $\mathrm{BV}_{3}$ & $\left(\mathrm{~V}_{3}-\mathrm{V}_{2}\right)$ & $\mathrm{n}$ & $\mathrm{pL}$ & $\log \left(\frac{n}{n-1}\right)$ & Log $_{1}$ \\
\hline 8.50 & 5.30 & 5.81 & 5.85 & 0.04 & 0.2973 & 2.88 & -0.3736 & 2.5064 \\
8.72 & 5.35 & 5.90 & 5.95 & 0.05 & 0.3873 & 2.66 & -0.1992 & 2.4608 \\
9.00 & 5.40 & 6.00 & 6.05 & 0.05 & 0.4044 & 2.38 & -0.1681 & 2.2119 \\
9.22 & 5.45 & 6.10 & 6.15 & 0.06 & 0.5157 & 2.18 & -0.0272 & 2.2072 \\
9.51 & 5.50 & 6.20 & 6.27 & 0.07 & 0.6417 & 1.89 & 0.2530 & 1.1430 \\
\hline
\end{tabular}

$\operatorname{LogK}_{1}($ Average value $)=2.3059 \pm 0.6153$

Table 6:Point-wise method, $\mathrm{Cu}$ (Unhydrolysed PSHA)

\begin{tabular}{|l|l|l|l|l|l|l|l|l|}
\hline $\mathrm{pH}$ & $\mathrm{BV}_{1}$ & $\mathrm{BV}_{2}$ & $\mathrm{BV}_{3}$ & $\mathrm{~V}_{3}-\mathrm{V}_{2}$ & $\mathrm{n}$ & $\mathrm{pL}$ & $\log \left(\frac{n-1}{2-n}\right)$ & $\log \mathrm{K}_{2}$ \\
\hline 9.73 & 5.55 & 6.33 & 6.42 & 0.09 & 0.9000 & 1.69 & & \\
10.00 & 5.60 & 6.47 & 6.58 & 0.11 & 1.2578 & 1.44 & -0.4592 & 0.9808 \\
10.23 & 5.65 & 6.62 & 6.84 & 0.12 & 1.6137 & 1.26 & -0.2010 & 1.4610 \\
10.49 & 5.70 & 6.80 & 6.92 & 0.12 & 2.1052 & 1.03 & & \\
\hline
\end{tabular}

$\operatorname{LogK}_{2}$ (Average value) $=1.2209 \pm 0.3398$

Table 7:Point-wise method, Pb (Hydrolysed PSHA)

\begin{tabular}{|l|l|l|l|l|l|l|l|l|}
\hline $\mathrm{pH}$ & $\mathrm{BV}_{1}$ & $\mathrm{BV}_{2}$ & $\mathrm{BV}_{3}$ & $\left(\mathrm{~V}_{3}-\mathrm{V}_{2}\right)$ & $\mathrm{n}$ & $\mathrm{pL}$ & $\log \left(\frac{n}{1-n}\right)$ & LogK $_{1}$ \\
\hline 8.50 & 5.30 & 6.29 & 6.33 & 0.04 & 0.5500 & 2.66 & 0.0871 & 2.7471 \\
8.72 & 5.35 & 6.37 & 6.41 & 0.04 & 0.5714 & 2.43 & 0.1249 & 2.5549 \\
9.00 & 5.40 & 6.46 & 6.50 & 0.04 & 0.6198 & 2.16 & 0.2122 & 2.3722 \\
9.22 & 5.45 & 6.55 & 6.60 & 0.05 & 0.8333 & 1.96 & 0.6989 & 2.6589 \\
\hline
\end{tabular}

Log $_{\mathbf{1}}($ Average value $)=2.5832 \pm 0.1614$

Table 8:Point-wise method, Pb-(Hydrolysed PSHA)

\begin{tabular}{|l|l|l|l|l|l|l|l|l|}
\hline $\mathrm{pH}$ & $\mathrm{BV}_{1}$ & $\mathrm{BV}_{2}$ & $\mathrm{BV}_{3}$ & $\left(\mathrm{~V}_{3}-\mathrm{V}_{2}\right)$ & $\mathrm{n}$ & $\mathrm{pL}$ & $\log \left(\frac{n-1}{2-n}\right)$ & $\log \mathrm{K}_{2}$ \\
\hline 9.51 & 5.50 & 6.66 & 6.71 & 0.05 & 0.9650 & 1.67 & & \\
9.73 & 5.55 & 6.78 & 6.83 & 0.05 & 1.1702 & 1.44 & & \\
10.00 & 5.60 & 6.90 & 6.90 & 0.05 & 1.4864 & 1.22 & -0.0237 & 1.1963 \\
10.23 & 5.65 & 7.05 & 7.10 & 0.05 & 2.0190 & 1.09 & & \\
10.49 & 5.70 & 7.10 & 7.17 & 0.07 & 3.6492 & 1.00 & & \\
\hline
\end{tabular}

Log $K_{2}$ (Average value) $=1.1963$

Table 9: Point-wise method, Pb (Unhydrolysed PSHA)

\begin{tabular}{|l|l|l|l|l|l|l|l|l|}
\hline $\mathrm{pH}$ & $\mathrm{BV}_{1}$ & $\mathrm{BV}_{2}$ & $\mathrm{BV}_{3}$ & $\mathrm{~V}_{3}-\mathrm{V}_{2}$ & $\mathrm{n}$ & $\mathrm{pL}$ & $\begin{array}{l}\text { Log } \\
\left(\frac{n}{n-1}\right)\end{array}$ & Log $\mathrm{K}_{1}$ \\
\hline 8.50 & 5.30 & 5.81 & 5.85 & 0.04 & 0.2973 & 2.88 & -0.3736 & 2.5064 \\
8.72 & 5.35 & 5.90 & 5.94 & 0.04 & 0.3099 & 2.66 & -0.5477 & 2.3123 \\
9.00 & 5.40 & 6.00 & 6.05 & 0.05 & 0.4044 & 2.38 & -0.1681 & 2.2119 \\
9.22 & 5.45 & 6.10 & 6.15 & 0.06 & 0.5157 & 2.18 & 0.0272 & 2.2072 \\
9.51 & 5.50 & 6.20 & 6.26 & 0.07 & 0.6417 & 1.89 & 0.2530 & 2.1430 \\
9.73 & 5.55 & 6.40 & 6.40 & 0.07 & 0.7000 & 1.67 & 0.3680 & 2.0380 \\
\hline
\end{tabular}

LogK $_{1}$ (Average value) $=2.2364 \pm 0.1602$

Table 10: Point-wise method, Pb (Unhydrolysed PSHA)

\begin{tabular}{|l|l|l|l|l|l|l|l|l|}
\hline $\mathrm{pH}$ & $\mathrm{BV}_{1}$ & $\mathrm{BV}_{2}$ & $\mathrm{BV}_{3}$ & $\mathrm{~V}_{3}-\mathrm{V}_{2}$ & $\mathrm{n}$ & $\mathrm{pL}$ & $\log \left(\frac{n-1}{2-n}\right)$ & $\log \mathrm{K}_{2}$ \\
\hline 10.00 & 5.60 & 6.47 & 6.55 & 0.08 & 1.9503 & 1.41 & & \\
10.23 & 5.65 & 6.62 & 6.72 & 0.11 & 1.4792 & 1.26 & -0.0361 & 1.2239 \\
\hline
\end{tabular}

$\operatorname{LogK}_{2}$ (Average value) $=1.2239$

Table 11: Point-wise method, Mg (Hydrolysed PSHA)

\begin{tabular}{|l|l|l|l|l|l|l|l|l|}
\hline $\mathrm{pH}$ & $\mathrm{BV}_{1}$ & $\mathrm{BV}_{2}$ & $\mathrm{BV}_{3}$ & $\left(\mathrm{~V}_{3}-\mathrm{V}_{2}\right)$ & $\mathrm{n}$ & $\mathrm{pL}$ & $\log \left(\frac{n}{n-1}\right)$ & LogK $_{1}$ \\
\hline 8.50 & 5.30 & 6.29 & 6.31 & 0.02 & 0.2750 & 2.64 & -0.4290 & 2.2110 \\
8.72 & 5.35 & 6.37 & 6.39 & 0.02 & 0.2858 & 2.42 & -0.3978 & 2.0222 \\
9.00 & 5.40 & 6.46 & 6.49 & 0.03 & 0.4648 & 2.14 & -0.0612 & 2.0788 \\
9.22 & 5.45 & 6.55 & 6.59 & 0.04 & 0.6667 & 1.94 & 0.3010 & 2.2410 \\
\hline
\end{tabular}

$\log _{\mathbf{1}}($ Average value) $=2.1382 \pm 0.1046$ 
BAJOPAS Volume 14 Number 1,June, 2021

Table 12: Point-wise method, Mg (Hydrolysed PSHA)

\begin{tabular}{|l|l|l|l|l|l|l|l|l|}
\hline $\mathrm{pH}$ & $\mathrm{BV}_{1}$ & $\mathrm{BV}_{2}$ & $\mathrm{BV}_{3}$ & $\left(\mathrm{~V}_{3}-\mathrm{V}_{2}\right)$ & $\mathrm{n}$ & $\mathrm{pL}$ & $\log \left(\frac{n-1}{2-n}\right)$ & LogK $_{2}$ \\
\hline 9.51 & 5.55 & 6.66 & 6.71 & 0.05 & 0.9650 & 1.67 & & \\
9.73 & 5.55 & 6.78 & 6.84 & 0.06 & 1.4042 & 1.47 & -0.1686 & 1.3014 \\
10.00 & 5.60 & 6.90 & 6.93 & 0.06 & 1.7838 & 1.23 & 0.5593 & 1.7893 \\
10.23 & 5.65 & 7.05 & 7.10 & 0.06 & 3.1429 & 1.10 & & \\
10.49 & 5.70 & 7.10 & 7.18 & 0.07 & 3.6492 & 0.83 & & \\
\hline
\end{tabular}

LogK $_{2}($ Average value $)=1.5453 \pm 0.3450$

Table 13: Point-wise method, Mg (Unhydrolysed PSHA)

\begin{tabular}{|l|l|l|l|l|l|l|l|l|}
\hline $\mathrm{pH}$ & $\mathrm{BV}_{1}$ & $\mathrm{BV}_{2}$ & $\mathrm{BV}_{3}$ & $\mathrm{~V}_{3}-\mathrm{V}_{2}$ & $\mathrm{n}$ & $\mathrm{pL}$ & $\log \left(\frac{n}{n-1}\right)$ & $\operatorname{Log~}_{1}$ \\
\hline 8.50 & 5.30 & 5.81 & 5.85 & 0.04 & 0.2973 & 2.88 & -0.3736 & 2.5064 \\
8.72 & 5.35 & 5.90 & 5.94 & 0.04 & 0.3099 & 2.66 & -0.3477 & 2.3123 \\
9.00 & 5.40 & 6.00 & 6.04 & 0.04 & 0.3236 & 2.38 & -0.3202 & 2.0598 \\
9.22 & 5.45 & 6.10 & 6.15 & 0.05 & 0.4297 & 2.17 & -0.1230 & 2.0470 \\
9.51 & 5.50 & 6.20 & 6.26 & 0.06 & 0.5500 & 1.89 & 0.0871 & 1.9771 \\
9.73 & 5.55 & 6.33 & 6.40 & 0.07 & 0.7000 & 1.67 & 0.3680 & 2.0380 \\
\hline
\end{tabular}

LogK $_{1}$ (Average value) $=2.1568 \pm 0.2069$

Table 14: Point-wise method, Mg (Unhydrolysed PSHA)

\begin{tabular}{|l|l|l|l|l|l|l|l|l|}
\hline $\mathrm{pH}$ & $\mathrm{BV}_{1}$ & $\mathrm{BV}_{2}$ & $\mathrm{BV}_{3}$ & $\mathrm{~V}_{3}-\mathrm{V}_{2}$ & $\mathrm{n}$ & $\mathrm{pL}$ & $\log \left(\frac{n-1}{2-n}\right)$ & $\log \mathrm{K}_{2}$ \\
\hline 10.00 & 5.60 & 6.47 & 6.55 & 0.08 & 0.9148 & 1.41 & & \\
10.23 & 5.65 & 6.62 & 6.71 & 0.09 & 1.2102 & 1.20 & -0.5749 & 0.6251 \\
10.49 & 5.70 & 6.80 & 6.92 & 0.09 & 1.5968 & 1.03 & 0.1703 & 1.2003 \\
\hline
\end{tabular}

LogK $_{2}$ (Average value) $=0.9127 \pm 0.4070$

Table15:Point-wise method, Cd (Hydrolysed PSHA)

\begin{tabular}{|l|l|l|l|l|l|l|l|l|}
\hline $\mathrm{pH}$ & $\mathrm{BV}_{1}$ & $\mathrm{BV}_{2}$ & $\mathrm{BV}_{3}$ & $\left(\mathrm{~V}_{3}-\mathrm{V}_{2}\right)$ & $\mathrm{n}$ & $\mathrm{pL}$ & $\log \left(\frac{n}{1-n}\right)$ & LogK $_{1}$ \\
\hline 8.50 & 5.30 & 6.29 & 6.31 & 0.02 & 0.2750 & 2.64 & -0.4210 & 2.2190 \\
8.72 & 5.35 & 6.37 & 6.40 & 0.03 & 0.4286 & 2.42 & -0.1249 & 2.2951 \\
9.00 & 5.40 & 6.46 & 6.49 & 0.03 & 0.4648 & 2.14 & -0.0612 & 2.0788 \\
9.22 & 5.45 & 6.55 & 6.59 & 0.04 & 0.6667 & 1.96 & 0.3010 & 2.2610 \\
9.51 & 5.55 & 6.66 & 6.70 & 0.04 & 0.7720 & 1.67 & 0.5297 & 2.1997 \\
\hline
\end{tabular}

LogK $_{\mathbf{1}}$ (Average value) $=2.2108 \pm 0.0825$

Table 16: Point-wise method, Cd (Hydrolysed PSHA)

\begin{tabular}{|l|l|l|l|l|l|l|l|l|}
\hline $\mathrm{pH}$ & $\mathrm{BV}_{1}$ & $\mathrm{BV}_{2}$ & $\mathrm{BV}_{3}$ & $\left(\mathrm{~V}_{3}-\mathrm{V}_{2}\right)$ & $\mathrm{n}$ & $\mathrm{pL}$ & $\log \left(\frac{n-1}{2-n}\right)$ & Log $_{2}$ \\
\hline 9.73 & 5.55 & 6.78 & 6.83 & 0.06 & 1.4042 & 1.47 & -0.1686 & 1.3014 \\
10.00 & 5.60 & 6.90 & 6.95 & 0.06 & 1.7838 & 1.23 & 0.5593 & 1.7893 \\
10.23 & 5.65 & 7.05 & 7.10 & 0.06 & 3.1429 & 1.09 & & \\
10.49 & 5.70 & 7.10 & 7.16 & 0.06 & 3.1429 & 0.89 & & \\
& & & & & & & & \\
\hline
\end{tabular}

$\operatorname{LogK}_{2}$ (Average value) $=1.5453 \pm 0.3450$

Table 17: Point-wise method, Cd (Unhydrolysed PSHA)

\begin{tabular}{|l|l|l|l|l|l|l|l|l|}
\hline $\mathrm{pH}$ & $\mathrm{BV}_{1}$ & $\mathrm{BV}_{2}$ & $\mathrm{BV}_{3}$ & $\mathrm{~V}_{3}-\mathrm{V}_{2}$ & $\mathrm{n}$ & $\mathrm{pL}$ & $\log \left(\frac{n}{n-1}\right)$ & $\operatorname{Log~}_{1}$ \\
\hline 8.50 & 5.30 & 5.81 & 5.86 & 0.05 & 0.3717 & 2.88 & -0.2280 & 2.6520 \\
8.72 & 5.35 & 5.90 & 5.95 & 0.05 & 0.3873 & 2.66 & -0.1992 & 2.4608 \\
9.00 & 5.40 & 6.00 & 6.06 & 0.06 & 0.4853 & 2.38 & -0.0255 & 2.3545 \\
9.22 & 5.45 & 6.10 & 6.16 & 0.06 & 0.5157 & 2.18 & -0.0272 & 2.2072 \\
9.51 & 5.50 & 6.20 & 6.27 & 0.07 & 0.6417 & 1.89 & 0.2530 & 1.1430 \\
9.73 & 5.55 & 6.33 & 6.41 & 0.08 & 0.8000 & 1.69 & 0.6020 & 2.2920 \\
& & & & & & & & \\
\hline
\end{tabular}

$\operatorname{LogK}_{1}($ Average value $)=2.2516 \pm 0.5380$ 
BAJOPAS Volume 14 Number 1,June, 2021

Table 18: Point-wise method, Cd (Unhydrolysed PSHA)

\begin{tabular}{|l|l|l|l|l|l|l|l|l|}
\hline $\mathrm{pH}$ & $\mathrm{BV}_{1}$ & $\mathrm{BV}_{2}$ & $\mathrm{BV}_{3}$ & $\mathrm{~V}_{3}-\mathrm{V}_{2}$ & $\mathrm{n}$ & $\mathrm{pL}$ & $\log \left(\frac{n-1}{2-n}\right)$ & $\log \mathrm{K}_{2}$ \\
\hline 10.00 & 5.60 & 6.47 & 6.57 & 0.10 & 1.1434 & 1.43 & & \\
10.23 & 5.65 & 6.62 & 6.72 & 0.10 & 1.3448 & 1.23 & -0.2788 & 0.9512 \\
10.49 & 5.70 & 6.80 & 6.90 & 0.10 & 1.7742 & 1.03 & 0.5351 & 1.5651 \\
\hline
\end{tabular}

$\operatorname{LogK}_{2}($ Average value $)=1.2581 \pm 0.4340$

Table 19: Stepwise and overall Stability constants of thehydrolysed and unhydrolysed divalent metal (II) complexes

\begin{tabular}{|c|c|c|c|}
\hline Chelates & LogK $_{1}$ & $\log _{2}$ & Log $\beta$ \\
\hline [Cu (Hydrolysed PSHA-1) $\left.{ }_{2}\right]$ & 2.4788 & 1.4280 & 3.9068 \\
\hline$\left[\mathrm{Pb}(\text { Hydrolysed PSHA-1) })_{2}\right]$ & 2.5832 & 1.1963 & 3.7795 \\
\hline$\left[\mathrm{Cd}(\text { Hydrolysed PSHA-1 })_{2}\right]$ & 2.2108 & 1.5453 & 3.7561 \\
\hline$\left[\mathrm{Mg}(\text { Hydrolysed PSHA-1 })_{2}\right]$ & 2.1382 & 1.5453 & 3.6835 \\
\hline [Cu (Unhydrolysed PSHA-1) & 2.3059 & 1.2209 & 3.5268 \\
\hline$[\mathrm{Pb}$ (Unhydrolysed PSHA-1) 2$]$ & 2.2364 & 1.2239 & 3.4603 \\
\hline [Cd (Unhydrolysed PSHA-1) 2 ] & 2.2516 & 1.2581 & 3.5097 \\
\hline$[\mathrm{Mg}$ (Unydrolysed PSHA-1) & 2.1568 & 0.9127 & 3.0695 \\
\hline
\end{tabular}

The results obtained (Table19) shows the stepwise and overall stability constants to be not high indicating low stability of the complexes, because the solubility of most metal ions in the basic $\mathrm{pH}$ range is minimal due to metal hydroxide precipitation (Karimi, 2017). In general, the stepwise stability constants $\left(K_{1}\right.$ and $K_{2}$ ) follow the order $K_{1}>K_{2}$ for the copper, lead, magnesium and cadmium complexes respectively. The steady decrease of the values with increasing number of ligands is in agreement with the prediction made by researchers (Na'aliya, 2013). The decrease could be attributed to the fact that as the number of the ligands (Humate ions) that enters the coordination zone increases the aqua molecules available for replacement by the ligands become less. Thus, the metal ions become less electron loving with progressive intake of the ligand and this results in the decrease in the values of the constants (Na'aliya, 2013). Also the stability of the complexes is influenced by the size and number of the chelate rings(Mackay and Mackay,2002).All the complexes form rings in their structure as humate, a bidentate ligand, bond the metal ions in the ratio 1:2 (Boguta and Sokolowska, 2016) forming chelate rings. The values of the overall stability constants $(\log \beta)$ obtained for humate complexes are not high indicating low stability as the values are not high. LogK values for copper-humates (Table 3 to 6) obtained in this study are lower than those reported for the complexes of humic acids (Pandey et al., 2015; Dinu, 2013; Kaschl et al., 2010 and Gilbeto and Jorg, 2001). The values of LogK(Table 7 to 10 ) forlead-humates are lower than those reported for the lead in the literature (Dinu, 2013; Gilbeto and Jorg 2001). Log K values(Table 11 to 14 ) for magnesium-humates obtained in this study are close to those reported by (Pandey et al., 2015). Log K values of cadmium-humates (Table 15 to 18 ) obtained in this work near to the one reported by (Dinu, 2013 and Pandey et al., 2015).The difference between the reported values and the values obtained in this study might be probably as a result of acid hydrolysis of humic acid. The values of the overall stability constants $(\log \beta)$ of the copper humates complexes presented in Table 19 is high than that of other metal humate complexes, show relatively high stability of CuHA complexes, show the following order of stability: $\mathrm{Cu}>\mathrm{Pb}>\mathrm{Cd}>\mathrm{Mg}$; which are in close agreement to the findings of (Dinu, 2013 and Pandey et al., 2015).The high stability of Cuhumate chelate could be attributed to the existence of coordinate covalent bond between the complexing agents and the $\mathrm{Cu}^{2+}$ ions. Since, $\mathrm{Cu}^{2+}$ being a metal of the transitional series with $3 d^{9}$ electronic configurations can accept the electrons from the complexing agents. Similarly, the low stabilities of $\mathrm{Pb}, \mathrm{Cd}$ and $\mathrm{Mg}$ complexes could be explained by that $\mathrm{Pb}^{2+}$ with $6 s^{2}, \mathrm{Cd}^{2+}$ with $4 \mathrm{~d}^{10}$ and $\mathrm{Mg}^{2+}$ with $2 \mathrm{p}^{6}$ their electronic configuration has a completely filled $\mathrm{d}, \mathrm{p}$ and $\mathrm{s}$ orbitals. Moreover, the stabilities of metal ions with hydrolysed humic acid from peat soil were higher than those with unhydrolysed humic acid from peat soil; which is ascribed to the high content of acidity in hydrolysed humic acid than unhydrolysed humic acid. 
BAJOPAS Volume 14 Number 1,June, 2021 CONCLUSION

The values of logk for $\mathrm{Cu}(\mathrm{II})$ hydrolysed humic acid complex was higher followed by $\mathrm{Pb}$ (II), $\mathrm{Cd}(\mathrm{II})$ and $\mathrm{Mg}$ (II) hydrolysed humic acid complexes as compared with metal(II) unhydrolysed humic acid complexes. This indicates acid hydrolysis of humic acid can

\section{REFERENCES}

Almeida, V.R. and Szpoganicz, B. (2015). Humic Acid Potentiometric Response Patterns:Out- of Equilibrium Properties and Species Distribution Modelling. Chemical. Biol. Technol. Agric. 2: 17.

Anđelković, T., Nikolić, R., Bojić, A.,Anđelković, D., and Nikolic G.,(2010). Binding of Cadmium to Soil Humic Acid as A Function of Carboxyl Group Content. Macedonian Journal of Chemistry and Chemical Engineering.29(2): 215-224.

Anil, B. N. and Maroti, N. (2008). Studies on Influence of Die-Lectric Constants on Complex Equilibria between Substituted Py-Razalines and Lanthanide Metal Ions pH-Metrically. Amer.-Euras. scient. Res. 3(2): 212-216.

Ashok, K., Pandey, S. P. and Misra, V (2000). Stability Constants of Metal-Humic Acid Complexes and its Role in Environmental Detoxification. Journal of Ecotoxicology and Environmental Safety. 47(2):157-200.

Badr, M. H., El-Halafawi, M. H. and Abd El-al Zeid, E. R. (2012). Comparison Between the Effect of Ionic Strength on Acidity and Dissociation Constants of Humic Acids Extracted from Sewage Sludge and Nile Water Hyacinth Composts.Global Journal of Environmental Research 6 (1): 36-43.

Baruah, M.K., Borah, D., Saikia, P.P., Paul, S., Sharma, T. (2015). Evaluation of pKa Values of Soil Humic Acids and their Complexation Properties. International Journal of Plant \& Soil Science 6(4) : 218-228.

Boguta, P. Sokolowska, Z. (2016). Interactions of $\mathrm{Zn}$ (II) Ions with Humic Acids Isolated from Various Types of Soils. Effect of $\mathrm{pH}, \mathrm{Zn}$ Concentrations and Humic Acids Chemical Properties. Journal of Geochemical Explaration 168. 119-126.

Borges, F., Guimaraes, C., Lima, L.F.C., Pinto, I. and Reis, S.(2005). Potentiometric Studies on the Complexation of Copper(II) by Phenolic Acids as Discrete Ligand Models of enhance the complexation behavior of humic acid with metal (II) ions. However, the higher values of $\log \beta$ for $\mathrm{Cu}(\mathrm{II}), \mathrm{Pb}(\mathrm{II}), \mathrm{Cd}(\mathrm{II})$ and $\mathrm{Mg}(\mathrm{II})$ hydrolysed humic acid complexes indicates more stable stepwise complexes formed as compared with $\mathrm{Cu}(\mathrm{II}), \mathrm{Pb}$ (II), $\mathrm{Cd}$ (II) and $\mathrm{Mg}(\mathrm{II})$ unhydrolysed humic acid complexes.

Humic Substances Talanta 66 (2005) 670-673.

Chefetz, B., Salloum, M. J., Deshmulkin, A. P. and Hatcher, P. (2002). Structural Components of Humic Acids as Determined by Chemical Modifications and Carbon-13 NMR, Pyrolysis, and Thermochemolysis- Gas Chromatography/Mass Spectrometry. Soil Science Society of American Journal Abstract Division S-2- Soil Chemistry66. 1159-1171.

Dinu, M. I. (2013). Metals Complexation with Humic Acids in Surface Water of Different Environ. Sci. Technol. 31(1): 1-17.

Fernandes, A.N., Giacomelli, C., Giovanela, M. Vaz, D.V. Szpoganicz, B. and Maria M. D. (2009). Potentiometric Acidity Determination in Humic Substances Influenced by Different Analytical Procedures.J. Braz. Chem. Soc. 20 (9):14.

Gamal, A. H. (2015). Stability Constants of Rhenium (V) Metal Complexes with Selected Drugs. Pyrex Journal of Research in Environmental Studies. 2(2): 006-014.

Janrao, D. M., Pathan, J., Kayande, D.D., and Mulla, J.J. (2014). An Over View of Potentiometric Determination of Stability Constants of Metal Complexes. Sci. Revs. Chem. Commun.: 4(1), 2014, 11-24.

Karimi, H. (2017). Effect of pH and Initial Pb(II) Concentration on the Lead Removal Efficiency from Waste Water Using $\mathrm{Ca}(\mathrm{OH})_{2}$. International Journal of Water and Waste Water Treatment 3.2

Kaschl, A. Romheld, V. and Chen, Y. (2010). Binding of Cadmium, Copper and Zinc to Humic Substances Originating from Municipal Solid Waste Compost. Israel Journal of Chemistry Vol. 42(1): 89-98.

Kostic, I. S., Tatjana, P, A., Nikolic, R. S., Cvetkovic, T. P., Pavlovic, D. D., Aleksandar, L.J. and Bojic, A. (2012). Comparative Study of Binding Strengths of Heavy Metals with Humic Acid. J.serb. Chem. Soc. 76(9) pp 1-20. 
BAJOPAS Volume 14 Number 1,June, 2021

Na'aliya, J. (2013). Determination of Stepwise Stability Constants and Gibbs free Energy Change of Trisprolina to Complexes of some Divalent Transition Metal ions. Bayero Journal of Pure and Applied Sciences 6(2): 112-114.

Omar, A. A. and Ali, E. A. (2015). Potentiometric Studies on Complexes of $\mathrm{Cr}$ (III) and $\mathrm{Zr}$ (IV) with some Carboxylic Acids. International Journal of Advanced Chemistry, 3(1) 25-

37.

Pandey, A. K. Pandey, S. D. and Misr, V. (2015).Stability Constants of Metal- Humic Acid Complexes and Its Role in Environmental Detoxification. J. Ecotoxicology and Environmental Safety. 47(1):195-200.

Ram, N. and Raman, K.V. (1984). Stability Constants of Complexes of Metals with
Humicand Fuvic Acids under Non- acidConditions. Journal of Plant Nutrition and Soil Sciences.

147:171-176.

Santosh, D. D., Ashok, B. K., Vijay, J. T., Shivraj, G. W. and Vinay, V. W. (2011). Potentiometric Studies of Elec-Trolyte Effects on Complex Equilibria of Some Substituted 5-(2-hydroxy Phenyl) Pyrazoles. Der pharm. 3 (6): 75-83.

Sayyed, H. and Abdul Rahim, M. F. (2012). Studies of Binary Complexes of Metal Ions with Mandelic Acid by Potentiometry. Chem. J. 02 (6): 206209.

Shirvani, M. Moradian, E. Khalili, B. Bakhtiary, S. (2015). Interaction of $\mathrm{Cd}$ and $\mathrm{Pb}$ with Humate-Palygorskite and HumateSepiolite Complexes. Journal of water, air and pollution 3: 220-228. 


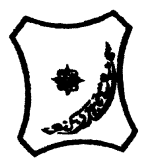

Bayero Journal of Pure and Applied Sciences, 14(1): 54 - 63

Received: November, 2020

Accepted: April, 2021

ISSN $2006-6996$

\title{
STABILITY CONSTANTS OF COMPLEXES OF METAL IONS WITH PEATSOIL HUMIC ACIDS UNDER NON-ACID-CONDITIONS
}

\author{
${ }^{* 1}$ Sabo, Yusuf ${ }^{2}$ Jimoh, W.L.O., ${ }^{3}$ Isa Baba Koki and ${ }^{4}$ Sholadoye, Q. 0. \\ ${ }^{1}$ Department of Pure and Industrial Chemistry, Bayero University, Kano \\ ${ }^{3}$ Department of Chemistry, Yusuf Maitama Sule University Kano. P.M.B. 3220 Kano, Nigeria. \\ ${ }^{4}$ Department of Chemistry, Nigerian Police Academy, Wudil, Kano-Nigeria
}

*Correspondence E-mail; saboyusuf18@yahoo.com

ABSTRACT

Stability constants of complexes of four divalent metal ions viz. $\mathrm{Cu}^{2+}, \mathrm{Pb}^{2+}, \mathrm{Mg}^{2+}$ and $\mathrm{Cd}^{2+}$ with humic acids (HA) were determined by potentiometric titration of humic acids with the corresponding salt of the divalent metals in aqueous media under non-acid-condition. The log $K$ (logarithm of the stability constant) ranged from 1.0942 to 2.7471 for metalhumic acid complexes were determined using point-wise computational method. The order of stability constants were obtained as follows: $\mathrm{Cu}>\mathrm{Pb}>\mathrm{Cd}>\mathrm{Mg}$ for metal $-\mathrm{HA}$ complexes respectively, indicating a higher degree of complexation with Cu metal ion.

Keywords: stability constant, humic acid, potentiometric titration, divalent metals, acid hydrolysis.

\section{NTRODUCTION}

The stability constant of a complex is the numerical expression of its stability and provides a quantitative measure of affinity of the metal ion to the complexing agent. An understanding of the relative stability of metal-complexes helps in predicting the behavior of metal ions in the soil (Ram and Raman, 1982). Extensive researches has been done to determine the stability constants of the complexes formed between humic acid (HA) with a number of metal ions. Ashok et al., (2000) reported that humic acid with hydroxyl, phenoxyl and carboxyl reactive groups can form coordination compound with metal ions at $\mathrm{pH}$ 3.5. The stability constants(Log K) for different metalhumic acid complexes indicated the following order of the stabilities of complexes formed between humic acid and metal ion, $\mathrm{Cu}>\mathrm{Fe}$ $>\mathrm{Pb}>\mathrm{Ni}>\mathrm{Co}>\mathrm{Ca}>\mathrm{Cd}>\mathrm{Zn}>\mathrm{Mn}>\mathrm{Mg}$. Andelkovic et al., (2010) investigated the binding of $\mathrm{Cd}$ (II) to soil humic acid at pH 6.5 and in $0.1 \mathrm{M} \mathrm{KNO}_{3}$ ionic medium. The stability constant for binding indicating greater stability in the case when carboxyl groups are involved in complexation reaction. Kostic et al.,(2012) investigated the complexation of humic acid with certain heavy metal ions (Co(II), $\mathrm{Ni}(\mathrm{II}), \mathrm{Cu}(\mathrm{II})$,
$\mathrm{Zn}(\mathrm{II})$, and $\mathrm{Pb}(\mathrm{II})$. The experiment was performed at $25^{\circ} \mathrm{C}$, at pH 4.0 and ionic strength of $0.01 \mathrm{M}$. Stability constant of complex between $\mathrm{Pb}$ (II) ions and humic acid is greater than stability constants of other investigated metalhumate complexes. Bogata and Sokolowska (2016) analyses the interaction between humic acids from different soils and $\mathrm{Zn}$ (II) ions at wide concentration ranges and at $\mathrm{pH} 5$. Studies have showed significant impact of $\mathrm{Zn}$ concentration, $\mathrm{pH}$ and some properties of humic acids with zinc.But all of these studies were limited to acidic $\mathrm{pH}$ range. Therefore, the present study was carried out to determine and compare the stability constants of complexes of metal ions with hydrolysed peat soil humic acid and unhydrolysed peat soil humic under non-acid conditions.

\section{MATERIALS AND METHODS}

Analytical grade chemicals used includes hydrochloric acid $(\mathrm{HCl})$, nitric acid $\left(\mathrm{HNO}_{3}\right)$, sodium hydroxide $(\mathrm{NaOH})$, lead nitrate $\mathrm{Pb}\left(\mathrm{NO}_{3}\right)_{2}$, copper nitrate $\mathrm{Cu}\left(\mathrm{NO}_{3}\right)_{2} \cdot 3 \mathrm{H}_{2} \mathrm{O}$, cadmium nitrate $\mathrm{Cd}\left(\mathrm{NO}_{3}\right)_{2} \cdot 4 \mathrm{H}_{2} \mathrm{O}$, magnesium nitrate $\mathrm{Mg}\left(\mathrm{NO}_{3}\right)_{2} \cdot 6 \mathrm{H}_{2} \mathrm{O}$, potassium nitrate $\left(\mathrm{KNO}_{3}\right)$, calcium chloride $\left(\mathrm{CaCl}_{2}\right)$, (sigma-Aldrich). Dowex 50WX8, (20-50 mesh) from Fluka. 


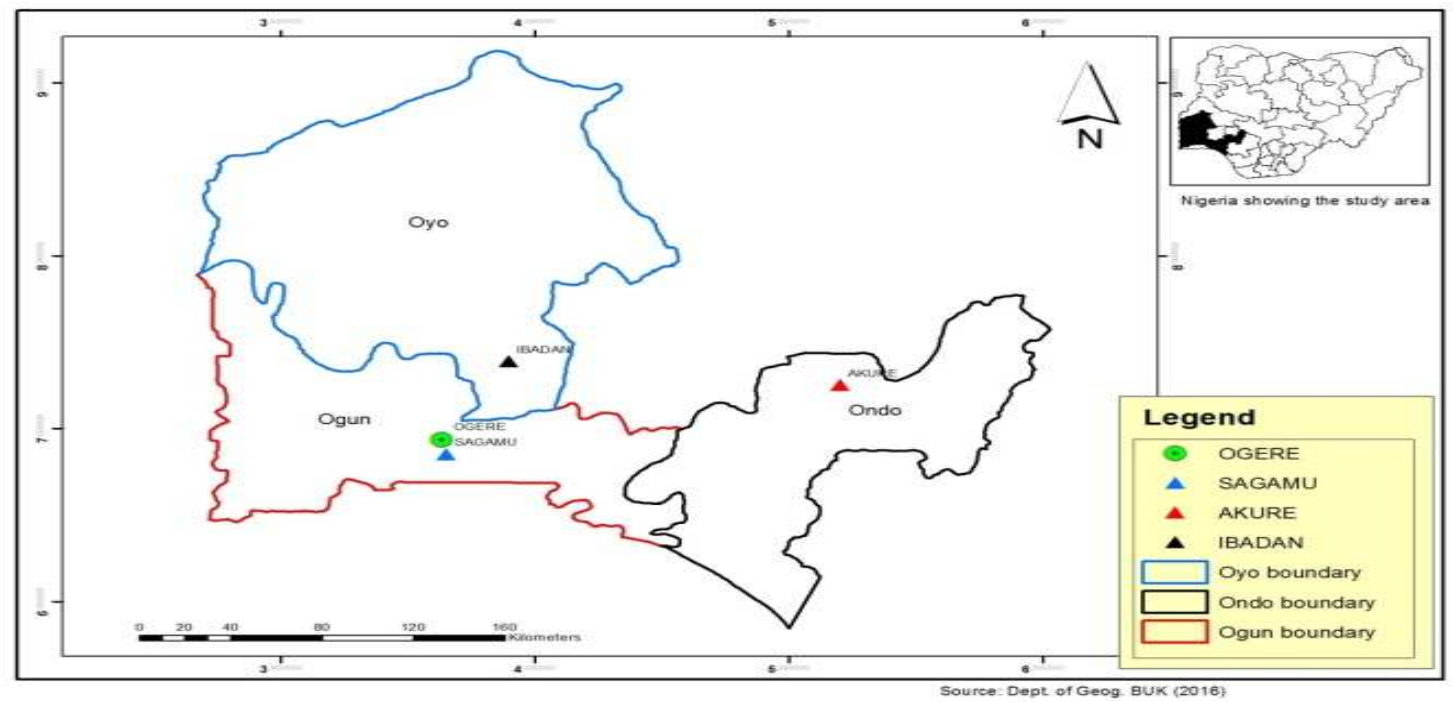

Figure 1: Map showing the sampling point at Sagamu Town, Ogun State.

\section{Description of Sampling Area}

Sagamu has geographical coordinates between $6^{\circ} 50^{\prime}$ north; $3^{\circ} 38^{\prime}$ east is located in south western region of Nigeria. The region has tropical wet and dry climate with a lengthy wet season and relatively constant temperatures throughout the course of the year. Wet season runs from March to October, November to December forms the region dry season. The vegetation type of the region is savannah which is really grassland with small bushes and occasional big trees. Grassland soils have substantially higher organic matter content than forest soils (Novackova, 2011).

\section{Sample Collection}

The Peatsoil samples were collected from four different sampling points $(0-10 \mathrm{~cm}$ depth) in Sagamu into polyethylene bag with plastic spoons. Samples were taken to the laboratory, extraneous materials were removed; the samples were air-dried, crushed and ground to a fine powder in a mortar passed through a $0.20 \mathrm{~mm}$ sieve. The samples were kept for analysis.

\section{Isolation and purification of humic acid from peat soil sample}

Peatsoil sample $(100 \mathrm{~g})$ was mixed with 1000 $\mathrm{cm}^{3}$ of $0.1 \mathrm{M} \mathrm{NaOH}$ solution, shaken for 3hours and left to stand overnight. Dark-coloured supernatant was obtained and decanted from solid residue. The dark-coloured supernatant was acidified to $(\mathrm{pH}=1.0)$ with $6 \mathrm{M} \mathrm{HCl}$ stirred and allowed to stand for 6 hours. Yellowish brown supernatant and dark-brown precipitate were obtained. The yellowish brown supernatant was decanted followed by centrifuge and discarded. The dark-brown precipitate was mixed with $500 \mathrm{~cm}^{3}$ of $0.1 \mathrm{M} \mathrm{NaOH}$ solution followed by passing through dowex resin. The dark-brown solution was acidified to $(\mathrm{pH}=1.0)$ with $6 \mathrm{M} \mathrm{HCl}$ stirred and allowed to stand for 3 hours. The dark-brown precipitate was washed several times with deionized water. The supernatant was treated with $\mathrm{AgNO}_{3}$ solution until no white precipitate observed. The humic acid was transferred to weighed crucible and dried at $60^{\circ} \mathrm{C}$ in an oven for 12 hours. The humic acid was cooled and dried in the desiccator, weighed and recorded. The obtained humic acid was dried again at $60^{\circ} \mathrm{C}$ for additional 6 hours cooled and dried in the desiccator, weighed and recorded constant weight was obtained (Baruah et al., 2015).

\section{FT-IR analysis}

FT-IR spectra of humic acid sample was analysed using Carry 630 FT-IR Agilent Technologies.

Unhydrolysed compost humic acid

The unhydrolysed humic acid was obtained after isolation and purification of compost humic acid and kept for investigation.

\section{Acid hydrolysis of Peatsoil acid}

Peatsoil humic acid sample (1g) was refluxed for 12 hours at $\left(160^{\circ} \mathrm{C}\right)$ with $50 \mathrm{~cm}^{3}$ of $6 \mathrm{M} \mathrm{HCl}$. The mixture was allowed to cool, decanted, and centrifuged after hydrolysis. The insoluble residues were washed with distilled water via centrifugation several times, and the supernatant was treated with $\mathrm{AgNO}_{3}$ solution until no white precipitate was observed. The residue was thoroughly dried over $\mathrm{CaCl}_{2}$ in a desiccator at room temperature (Chefetz et al., 2002). Finally, the obtained hydrolysed humic acid was kept for investigation. 
BAJOPAS Volume 14 Number 1,June, 2021 Potentiometric Titrations

Potentiometric measurements were carried out using a pH-meter Jenway (model 3510) with combine electrode, the sensitivity of the $\mathrm{pH}$ meter is 0.01 units. The $\mathrm{pH}$ meter was switched on half an hour before starting the titration for initial warm up of the instrument. The instrument was calibrated with an aqueous standard buffer solution of $\mathrm{pH} 4.00$ and 10.0 (borate buffer) prepared from a "Qualigens" buffer tablets.

The following sets of solutions were prepared in a $250 \mathrm{~cm}^{3}$ volumetric flask separately for $\mathrm{pH}$ metric titrations.

(i) $5 \mathrm{~cm}^{3} 0.1 \mathrm{M} \mathrm{HCl}+40 \mathrm{~cm}^{3}$ deionized water

(ii) $5 \mathrm{~cm}^{3} 0.1 \mathrm{M} \mathrm{HCl}+39 \mathrm{~cm}^{3}$ deionized water $+1 \mathrm{~cm}^{3} 0.15 \mathrm{gcm}^{-3}$ humic acid

(iii) $5 \mathrm{~cm}^{3} 0.1 \mathrm{M} \mathrm{HCl}+37 \mathrm{~cm}^{3}$ deionized water $+1 \mathrm{~cm}^{3} 0.15 \mathrm{gcm}^{-3}$ humic acid

$$
+2 \mathrm{~cm}^{3} \quad 0.01 \mathrm{M} \mathrm{Cu} \text { (II) }
$$

The solutions were titrated against standardized $0.110 \mathrm{MNaOH}$ separately. The total volume of each mixture was adjusted to $50 \mathrm{~cm}^{3}$ and the ionic strength of the solutions was maintained constant at by adding appropriate amount of stock solution of $1 \mathrm{M} \mathrm{KNO}_{3}$ (Gamal, 2015; Omar and Ali, 2015). A magnetic stirrer was used to achieve thorough mixing of the interacting solutions at $550 \mathrm{rpm}$. The same set of experimental conditions was applied for potentiometric titration of remaining samples.

\section{Evaluation of pKa of Hydrolysed peat soil Humic Acids}

The proton-ligand formation number $\mathrm{n}_{\mathbf{A}}$ were calculated by Irving and Rossotti expression (Omar and Ali, 2015).

$\mathrm{nA}=\mathrm{Y}-\frac{(\mathrm{V} 2-\mathrm{V1})(\mathrm{No}-\mathrm{Eo})}{(\mathrm{VO}+\mathrm{V1}) \mathrm{TCL}}$ 1

Where: $Y$ is number of dissociable proton, $\left(\mathrm{V}_{2^{-}}\right.$ $V_{1}$ ) is the measure of displacement of the ligand curve relative to acid curve, $\mathrm{N}^{\circ}$ and $\mathrm{E}^{\circ}$ are the resultant concentration of alkali solution, free acid solution, $\mathrm{T}_{\mathrm{cL}}{ }^{\circ}$ is the total ligand concentration, $\mathrm{V}^{\circ}$ is the total volume of titration solution, $V_{1}$ is the volume of alkali added to acid solution, $V_{2}$ is the volume of alkali added to acid solution + ligand solution, acid dissociation constants (pKa - values) of ligand were calculated by algebraic method point wise calculation (Tables 1 ). The dissociation constants (pKa) were calculated according to the following relation:

$\mathrm{pKa}=\mathrm{pH}+\log \left(\frac{n A}{1-n A}\right)$ 2

Where: pKa is the acid dissociation constant, $\mathrm{n}_{\mathrm{A}}$ is the Proton-ligand formation number and $\mathrm{pH}$ is the pH-values (Omar and Ali, 2015).

\section{Determination of metal-ligand stability constants $(\log K)$ of complexes}

The potentiometric measurement for the determination of stability constant of a complex in solution is based on the fact that the redox potential of the couple $\frac{M^{+(m-n)}}{M^{+m}}$ is shifted significantly on complexation of the metal ion with the ligand. This method involves change in hydrogen ion concentration $\left[\mathrm{H}^{+}\right]$due to the displacement or association of one or more protons taking place during complexation reaction. This change can be found out by titrating the solutions containing free acid, acid with ligand, and acid with ligand and metal ion, individually against a standard alkali solution at a constant ionic strength or temperature. Either ionic strength or temperature may be varied for different sets of solutions. In all the cases, the change in the $\mathrm{pH}$ of the solution is measured after each addition of a known amount of alkali to the reaction cell which contains the reaction mixture. The titration curves are then drawn by plotting the measured $\mathrm{pH}$ values against the corresponding volume of alkali added and the stability constants of the complexes are determined from the titration curves by employing $\mathrm{pH}$-metric titration technique given by (Irving and Rossoti).

Metal-ligand stability constants ( $\log \mathrm{K}$ ) were determined by using the following relations:

$$
\bar{n}=\frac{\left(V_{3}-V_{2}\right)\left(E^{0}+N^{0}\right)}{\left(V^{0}+V_{2}\right) \bar{n}_{A} T_{m}^{0}}
$$

and

$$
P L=\log _{10}\left\{\frac{1+\beta_{n}^{H} \frac{1}{[\text { anti } \log \mathrm{pH}]^{\mathrm{n}}}}{\mathrm{T}_{\mathrm{L}}^{0}-n \bar{T}_{m}^{0}} \mathrm{X} \frac{\left(V^{0}+V_{3}\right)}{V^{0}}\right\}
$$


BAJOPAS Volume 14 Number 1,June, 2021

Where $T_{L}, T^{\circ}, E^{\circ}$, and $V^{\circ}$ havethe same significance as in equation (1) above, $T_{m}$ denotes the total concentration of metal present in solution, $V_{3}$ is the volume of metal ions present in solution and $\beta^{H}$ is the overall proton ligand stability constant. The metal-ligand stability constants (log K) were determined by employing point wise computational Method (eq. 5 and 6).

$\operatorname{LogK}_{1}=\log \left(\frac{n}{1-n}\right)+\mathrm{pL}$ .5

$\operatorname{LogK}_{2}=\log \left(\frac{1-n}{2-n}\right)+\mathrm{pL}$ ...6

Where: Log $\mathrm{K}$ is the metal-ligand stability constant, $\mathrm{pL}$ is the Free ligand exponent function, $\mathbf{n}$ is the Average number of ligand attached with metal ion (Janraoet al., 2014). The results obtained were analyzed by an ORIGIN 2016 program using titration data and then the proton-ligand stability constants (pKa) and Metal-ligand stability constant (LogK) calculated (Omar and Ali, 2015).

\section{RESULTS AND DISCUSSION}

Fourier transformed infrared (FT-IR) spectra of isolated humic acid from peat soils Figure 2 had distinct clear absorption bands indicating the presence of major humic acid structural elemental groups such as $\mathrm{H}$ bonded $\mathrm{OH}$ $\left(3680 \mathrm{~cm}^{-1}\right.$ peak $), C=0$ of carbonyl $\left(1721 \mathrm{~cm}^{-1}\right.$ peak), functional groups of aliphatic components $\mathrm{CH}_{2}\left(2918 \mathrm{~cm}^{-1}\right.$ peak) and $\mathrm{C}-\mathrm{O}$ stretching of polysaccharide $\left(1168 \mathrm{~cm}^{-1}\right.$ peak). The positions of the absorption bands of the spectra fell within typical major absorption bands of humic acid which is at frequencies 3680, 2918, 1721, 1168 $\mathrm{cm}^{-1}$. The first peak centred in the vicinity of $3680 \mathrm{~cm}^{-1}$ region is attributed to phenol $\mathrm{OH}$ group bounded by intermolecular $\mathrm{H}$ bonds. The $2918 \mathrm{~cm}^{-1}$ band usually has absorption maximum at $2918 \mathrm{~cm}^{-1}$ which is due to $\mathrm{C}-\mathrm{H}$ stretching of alkane group $\left(\mathrm{CH}_{2}\right)$. The next major absorption band is $1721 \mathrm{~cm}^{-1}$. This band has been commonly ascribed to $\mathrm{C}=\mathrm{O}$ stretching of mainly carboxyl group $(\mathrm{COOH})$ with trace amount of ketones. The last peak was observed at 1168 $\mathrm{cm}^{-1}$ due to $\mathrm{C}-\mathrm{O}$ stretching of polysaccharides and this peak appeared also in the spectra of humic acid from peat soil. The FTIR spectra of the isolated humic acid contained all major characteristic absorption peaks of humic acid. These absorption peaks indicated the presence of the major structural elements of humic acid namely $\mathrm{H}$ bonded $\mathrm{OH}, \mathrm{C}=\mathrm{C}$ of aromatic ring, $\mathrm{C}=\mathrm{O}$ of carbonyl group (both carboxyl and ketonic), $\mathrm{CH}_{2}$ group. This strongly supports the presence of humic acid.

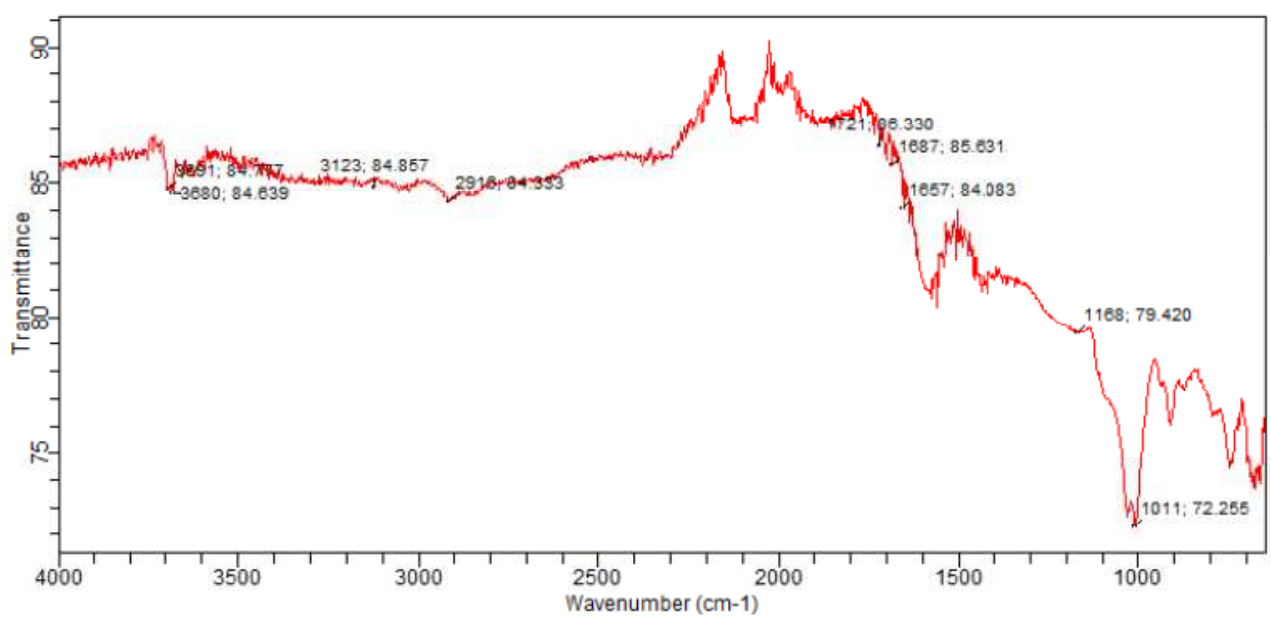

Fig. 2 : FT-IR spectraof peatsoilhumic acid (PSHA)

\section{Evaluation of acid dissociation constant (pka) of acid hydrolysed peat soil humicacid at phenolic group}

The value of the dissociation constant of the peat soil humic acid (PSHA) that underwent acidhydrolysis studied was found to be 8.9299 as shown Table 1, which is lower than the literaturevalues reported by Almeida and Szpoganics, (2015), Borges et al., (2005); Badr et al., (2012)and Fernandes et al,.(2009) of $9.73,9.47$ and 10.30. The difference between the obtained valuesand the reported values in this study might be probably as a result of acid hydrolysis of humicacid. 
BAJOPAS Volume 14 Number 1,June, 2021

Table 1: PKa of (Hydrolysed PSHA)

\begin{tabular}{|l|l|l|l|l|l|l|}
\hline $\mathrm{pH}$ & $\mathrm{BV}_{1}$ & $\mathrm{BV}_{2}$ & $\mathrm{~V}_{2}-\mathrm{V}_{1}$ & $\mathrm{nA}$ & $\log \left(\frac{n A}{1-n A}\right)$ & $\mathrm{pKa}$ \\
\hline 8.50 & 5.30 & 6.29 & 0.99 & 0.3594 & -0.2510 & 8.2490 \\
8.72 & 5.35 & 6.37 & 1.02 & 0.3400 & -0.2880 & 8.4320 \\
9.00 & 5.40 & 6.46 & 1.06 & 0.3141 & -0.3391 & 8.6609 \\
9.22 & 5.45 & 6.55 & 1.10 & 0.2882 & -0.3927 & 8.8273 \\
9.51 & 5.50 & 6.66 & 1.16 & 0.2494 & -0.4786 & 9.0314 \\
9.73 & 5.55 & 6.78 & 1.23 & 0.2041 & -0.5910 & 9.1390 \\
10.00 & 5.60 & 6.90 & 1.30 & 0.1589 & -0.7238 & 9.2762 \\
10.23 & 5.65 & 7.05 & 1.40 & 0.0941 & -0.9835 & 9.2465 \\
10.49 & 5.70 & 7.10 & 1.40 & 0.0941 & -0.9835 & 9.5065 \\
\hline
\end{tabular}

Average pKa $=8.9299 \pm 0.4186$

Table 2: PKa of (Unhydrolysed PSHA)

\begin{tabular}{|l|l|l|l|l|l|l|}
\hline $\mathrm{pH}$ & $\mathrm{BV}_{1}$ & $\mathrm{BV}_{2}$ & $\mathrm{~V}_{2}-\mathrm{V}_{1}$ & $\mathrm{nA}$ & $\log \left(\frac{\boldsymbol{n A}}{1-\boldsymbol{n}}\right)$ & $\mathrm{pKa}$ \\
\hline 8.50 & 5.30 & 5.81 & 0.51 & 0.6619 & 0.2919 & 8.7919 \\
8.72 & 5.35 & 5.90 & 0.55 & 0.6357 & 0.2418 & 8.9618 \\
9.00 & 5.40 & 6.00 & 0.60 & 0.6029 & 0.1813 & 9.1813 \\
9.22 & 5.45 & 6.10 & 0.65 & 0.5701 & 0.1226 & 9.3426 \\
9.51 & 5.50 & 6.20 & 0.70 & 0.5376 & 0.0654 & 9.5754 \\
9.73 & 5.55 & 6.33 & 0.78 & 0.4851 & -0.0259 & 9.7041 \\
10.00 & 5.60 & 6.47 & 0.87 & 0.4262 & -0.1291 & 9.8709 \\
10.23 & 5.65 & 6.62 & 0.99 & 0.3609 & -0.2481 & 9.9819 \\
10.49 & 5.70 & 6.80 & 1.10 & 0.2759 & -0.4690 & 10.0210 \\
\hline
\end{tabular}

Average pKa $=9.4923 \pm 0.4410$

Metal-ligand stability constant ( $\log \mathrm{K}$ )

The stabilityconstants require the accurate values of proton-ligand stability constants (Anil and Maroti, 2008). Metal titration curves crossed over ligand titration curve indicated the formation of complex upon proton release (Santosh, et al., 2011). If the values of n- are within range $0.2-0.8$ and $1.2-18$ this indicates the formation of $1: 1$ and 1:2 complexes (Sayyed and Mazahar, 2012).

The metal (II)-humate stepwise stability constants (log k) at phenolic group (Tables 318)

Table 3: Point-wise method, $\mathrm{Cu}$-(Hydrolysed PSHA)

\begin{tabular}{|l|l|l|l|l|l|l|l|l|}
\hline $\mathrm{pH}$ & $\mathrm{BV}_{1}$ & $\mathrm{BV}_{2}$ & $\mathrm{BV}_{3}$ & $\left(\mathrm{~V}_{3}-\mathrm{V}_{2}\right)$ & $\mathrm{n}$ & $\mathrm{pL}$ & $\log \left(\frac{n}{1-n}\right)$ & LogK $_{1}$ \\
\hline 8.50 & 5.30 & 6.29 & 6.33 & 0.04 & 0.5500 & 2.66 & 0.0871 & 2.7471 \\
8.72 & 5.35 & 6.37 & 6.41 & 0.04 & 0.5714 & 2.43 & 0.1249 & 2.5549 \\
9.00 & 5.40 & 6.46 & 6.50 & 0.04 & 0.6198 & 2.16 & 0.2122 & 2.3722 \\
9.22 & 5.45 & 6.55 & 6.59 & 0.04 & 0.6667 & 1.94 & 0.3010 & 2.2410 \\
\hline
\end{tabular}

LogK $_{1}$ (Average value) $=2.4788 \pm 0.2203$

Table 4: Point-wise method, $\mathrm{Cu}$-(Hydrolysed PSHA)

\begin{tabular}{|l|l|l|l|l|l|l|l|l|}
\hline $\mathrm{pH}$ & $\mathrm{BV}_{1}$ & $\mathrm{BV}_{2}$ & $\mathrm{BV}_{3}$ & $\left(\mathrm{~V}_{3}-\mathrm{V}_{2}\right)$ & $\mathrm{n}$ & $\mathrm{pL}$ & $\log \left(\frac{n-1}{2-n}\right)$ & LogK $_{2}$ \\
\hline 9.51 & 5.50 & 6.66 & 6.73 & 0.07 & 1.3509 & 1.70 & -0.2671 & 1.4329 \\
9.73 & 5.55 & 6.78 & 6.85 & 0.07 & 1.6383 & 1.51 & 0.2467 & 1.7567 \\
10.00 & 5.60 & 6.90 & 6.98 & 0.08 & 2.1783 & 1.31 & -0.2158 & 1.0942 \\
10.23 & 5.65 & 7.05 & 7.13 & 0.08 & 4.1904 & 1.27 & & \\
10.49 & 5.70 & 7.10 & 7.19 & 0.09 & 4.6920 & & & \\
\hline
\end{tabular}

Log $K_{2}($ Average value $)=1.4280 \pm 0.3312$ 
BAJOPAS Volume 14 Number 1,June, 2021

Table 5: Point-wise method, $\mathrm{Cu}$ (Unhydrolysed PSHA)

\begin{tabular}{|l|l|l|l|l|l|l|l|l|}
\hline $\mathrm{pH}$ & $\mathrm{BV}_{1}$ & $\mathrm{BV}_{2}$ & $\mathrm{BV}_{3}$ & $\left(\mathrm{~V}_{3}-\mathrm{V}_{2}\right)$ & $\mathrm{n}$ & $\mathrm{pL}$ & $\log \left(\frac{n}{n-1}\right)$ & Log $_{1}$ \\
\hline 8.50 & 5.30 & 5.81 & 5.85 & 0.04 & 0.2973 & 2.88 & -0.3736 & 2.5064 \\
8.72 & 5.35 & 5.90 & 5.95 & 0.05 & 0.3873 & 2.66 & -0.1992 & 2.4608 \\
9.00 & 5.40 & 6.00 & 6.05 & 0.05 & 0.4044 & 2.38 & -0.1681 & 2.2119 \\
9.22 & 5.45 & 6.10 & 6.15 & 0.06 & 0.5157 & 2.18 & -0.0272 & 2.2072 \\
9.51 & 5.50 & 6.20 & 6.27 & 0.07 & 0.6417 & 1.89 & 0.2530 & 1.1430 \\
\hline
\end{tabular}

$\operatorname{LogK}_{1}($ Average value $)=2.3059 \pm 0.6153$

Table 6:Point-wise method, $\mathrm{Cu}$ (Unhydrolysed PSHA)

\begin{tabular}{|l|l|l|l|l|l|l|l|l|}
\hline $\mathrm{pH}$ & $\mathrm{BV}_{1}$ & $\mathrm{BV}_{2}$ & $\mathrm{BV}_{3}$ & $\mathrm{~V}_{3}-\mathrm{V}_{2}$ & $\mathrm{n}$ & $\mathrm{pL}$ & $\log \left(\frac{n-1}{2-n}\right)$ & $\log \mathrm{K}_{2}$ \\
\hline 9.73 & 5.55 & 6.33 & 6.42 & 0.09 & 0.9000 & 1.69 & & \\
10.00 & 5.60 & 6.47 & 6.58 & 0.11 & 1.2578 & 1.44 & -0.4592 & 0.9808 \\
10.23 & 5.65 & 6.62 & 6.84 & 0.12 & 1.6137 & 1.26 & -0.2010 & 1.4610 \\
10.49 & 5.70 & 6.80 & 6.92 & 0.12 & 2.1052 & 1.03 & & \\
\hline
\end{tabular}

$\operatorname{LogK}_{2}$ (Average value) $=1.2209 \pm 0.3398$

Table 7:Point-wise method, Pb (Hydrolysed PSHA)

\begin{tabular}{|l|l|l|l|l|l|l|l|l|}
\hline $\mathrm{pH}$ & $\mathrm{BV}_{1}$ & $\mathrm{BV}_{2}$ & $\mathrm{BV}_{3}$ & $\left(\mathrm{~V}_{3}-\mathrm{V}_{2}\right)$ & $\mathrm{n}$ & $\mathrm{pL}$ & $\log \left(\frac{n}{1-n}\right)$ & LogK $_{1}$ \\
\hline 8.50 & 5.30 & 6.29 & 6.33 & 0.04 & 0.5500 & 2.66 & 0.0871 & 2.7471 \\
8.72 & 5.35 & 6.37 & 6.41 & 0.04 & 0.5714 & 2.43 & 0.1249 & 2.5549 \\
9.00 & 5.40 & 6.46 & 6.50 & 0.04 & 0.6198 & 2.16 & 0.2122 & 2.3722 \\
9.22 & 5.45 & 6.55 & 6.60 & 0.05 & 0.8333 & 1.96 & 0.6989 & 2.6589 \\
\hline
\end{tabular}

Log $_{\mathbf{1}}($ Average value $)=2.5832 \pm 0.1614$

Table 8:Point-wise method, Pb-(Hydrolysed PSHA)

\begin{tabular}{|l|l|l|l|l|l|l|l|l|}
\hline $\mathrm{pH}$ & $\mathrm{BV}_{1}$ & $\mathrm{BV}_{2}$ & $\mathrm{BV}_{3}$ & $\left(\mathrm{~V}_{3}-\mathrm{V}_{2}\right)$ & $\mathrm{n}$ & $\mathrm{pL}$ & $\log \left(\frac{n-1}{2-n}\right)$ & $\log \mathrm{K}_{2}$ \\
\hline 9.51 & 5.50 & 6.66 & 6.71 & 0.05 & 0.9650 & 1.67 & & \\
9.73 & 5.55 & 6.78 & 6.83 & 0.05 & 1.1702 & 1.44 & & \\
10.00 & 5.60 & 6.90 & 6.90 & 0.05 & 1.4864 & 1.22 & -0.0237 & 1.1963 \\
10.23 & 5.65 & 7.05 & 7.10 & 0.05 & 2.0190 & 1.09 & & \\
10.49 & 5.70 & 7.10 & 7.17 & 0.07 & 3.6492 & 1.00 & & \\
\hline
\end{tabular}

Log $K_{2}$ (Average value) $=1.1963$

Table 9: Point-wise method, Pb (Unhydrolysed PSHA)

\begin{tabular}{|l|l|l|l|l|l|l|l|l|}
\hline $\mathrm{pH}$ & $\mathrm{BV}_{1}$ & $\mathrm{BV}_{2}$ & $\mathrm{BV}_{3}$ & $\mathrm{~V}_{3}-\mathrm{V}_{2}$ & $\mathrm{n}$ & $\mathrm{pL}$ & $\begin{array}{l}\text { Log } \\
\left(\frac{n}{n-1}\right)\end{array}$ & Log $\mathrm{K}_{1}$ \\
\hline 8.50 & 5.30 & 5.81 & 5.85 & 0.04 & 0.2973 & 2.88 & -0.3736 & 2.5064 \\
8.72 & 5.35 & 5.90 & 5.94 & 0.04 & 0.3099 & 2.66 & -0.5477 & 2.3123 \\
9.00 & 5.40 & 6.00 & 6.05 & 0.05 & 0.4044 & 2.38 & -0.1681 & 2.2119 \\
9.22 & 5.45 & 6.10 & 6.15 & 0.06 & 0.5157 & 2.18 & 0.0272 & 2.2072 \\
9.51 & 5.50 & 6.20 & 6.26 & 0.07 & 0.6417 & 1.89 & 0.2530 & 2.1430 \\
9.73 & 5.55 & 6.40 & 6.40 & 0.07 & 0.7000 & 1.67 & 0.3680 & 2.0380 \\
\hline
\end{tabular}

LogK $_{1}$ (Average value) $=2.2364 \pm 0.1602$

Table 10: Point-wise method, Pb (Unhydrolysed PSHA)

\begin{tabular}{|l|l|l|l|l|l|l|l|l|}
\hline $\mathrm{pH}$ & $\mathrm{BV}_{1}$ & $\mathrm{BV}_{2}$ & $\mathrm{BV}_{3}$ & $\mathrm{~V}_{3}-\mathrm{V}_{2}$ & $\mathrm{n}$ & $\mathrm{pL}$ & $\log \left(\frac{n-1}{2-n}\right)$ & $\log \mathrm{K}_{2}$ \\
\hline 10.00 & 5.60 & 6.47 & 6.55 & 0.08 & 1.9503 & 1.41 & & \\
10.23 & 5.65 & 6.62 & 6.72 & 0.11 & 1.4792 & 1.26 & -0.0361 & 1.2239 \\
\hline
\end{tabular}

$\operatorname{LogK}_{2}$ (Average value) $=1.2239$

Table 11: Point-wise method, Mg (Hydrolysed PSHA)

\begin{tabular}{|l|l|l|l|l|l|l|l|l|}
\hline $\mathrm{pH}$ & $\mathrm{BV}_{1}$ & $\mathrm{BV}_{2}$ & $\mathrm{BV}_{3}$ & $\left(\mathrm{~V}_{3}-\mathrm{V}_{2}\right)$ & $\mathrm{n}$ & $\mathrm{pL}$ & $\log \left(\frac{n}{n-1}\right)$ & LogK $_{1}$ \\
\hline 8.50 & 5.30 & 6.29 & 6.31 & 0.02 & 0.2750 & 2.64 & -0.4290 & 2.2110 \\
8.72 & 5.35 & 6.37 & 6.39 & 0.02 & 0.2858 & 2.42 & -0.3978 & 2.0222 \\
9.00 & 5.40 & 6.46 & 6.49 & 0.03 & 0.4648 & 2.14 & -0.0612 & 2.0788 \\
9.22 & 5.45 & 6.55 & 6.59 & 0.04 & 0.6667 & 1.94 & 0.3010 & 2.2410 \\
\hline
\end{tabular}

$\log _{\mathbf{1}}($ Average value) $=2.1382 \pm 0.1046$ 
BAJOPAS Volume 14 Number 1,June, 2021

Table 12: Point-wise method, Mg (Hydrolysed PSHA)

\begin{tabular}{|l|l|l|l|l|l|l|l|l|}
\hline $\mathrm{pH}$ & $\mathrm{BV}_{1}$ & $\mathrm{BV}_{2}$ & $\mathrm{BV}_{3}$ & $\left(\mathrm{~V}_{3}-\mathrm{V}_{2}\right)$ & $\mathrm{n}$ & $\mathrm{pL}$ & $\log \left(\frac{n-1}{2-n}\right)$ & LogK $_{2}$ \\
\hline 9.51 & 5.55 & 6.66 & 6.71 & 0.05 & 0.9650 & 1.67 & & \\
9.73 & 5.55 & 6.78 & 6.84 & 0.06 & 1.4042 & 1.47 & -0.1686 & 1.3014 \\
10.00 & 5.60 & 6.90 & 6.93 & 0.06 & 1.7838 & 1.23 & 0.5593 & 1.7893 \\
10.23 & 5.65 & 7.05 & 7.10 & 0.06 & 3.1429 & 1.10 & & \\
10.49 & 5.70 & 7.10 & 7.18 & 0.07 & 3.6492 & 0.83 & & \\
\hline
\end{tabular}

LogK $_{2}($ Average value $)=1.5453 \pm 0.3450$

Table 13: Point-wise method, Mg (Unhydrolysed PSHA)

\begin{tabular}{|l|l|l|l|l|l|l|l|l|}
\hline $\mathrm{pH}$ & $\mathrm{BV}_{1}$ & $\mathrm{BV}_{2}$ & $\mathrm{BV}_{3}$ & $\mathrm{~V}_{3}-\mathrm{V}_{2}$ & $\mathrm{n}$ & $\mathrm{pL}$ & $\log \left(\frac{n}{n-1}\right)$ & $\operatorname{Log~}_{1}$ \\
\hline 8.50 & 5.30 & 5.81 & 5.85 & 0.04 & 0.2973 & 2.88 & -0.3736 & 2.5064 \\
8.72 & 5.35 & 5.90 & 5.94 & 0.04 & 0.3099 & 2.66 & -0.3477 & 2.3123 \\
9.00 & 5.40 & 6.00 & 6.04 & 0.04 & 0.3236 & 2.38 & -0.3202 & 2.0598 \\
9.22 & 5.45 & 6.10 & 6.15 & 0.05 & 0.4297 & 2.17 & -0.1230 & 2.0470 \\
9.51 & 5.50 & 6.20 & 6.26 & 0.06 & 0.5500 & 1.89 & 0.0871 & 1.9771 \\
9.73 & 5.55 & 6.33 & 6.40 & 0.07 & 0.7000 & 1.67 & 0.3680 & 2.0380 \\
\hline
\end{tabular}

LogK $_{1}$ (Average value) $=2.1568 \pm 0.2069$

Table 14: Point-wise method, Mg (Unhydrolysed PSHA)

\begin{tabular}{|l|l|l|l|l|l|l|l|l|}
\hline $\mathrm{pH}$ & $\mathrm{BV}_{1}$ & $\mathrm{BV}_{2}$ & $\mathrm{BV}_{3}$ & $\mathrm{~V}_{3}-\mathrm{V}_{2}$ & $\mathrm{n}$ & $\mathrm{pL}$ & $\log \left(\frac{n-1}{2-n}\right)$ & $\log \mathrm{K}_{2}$ \\
\hline 10.00 & 5.60 & 6.47 & 6.55 & 0.08 & 0.9148 & 1.41 & & \\
10.23 & 5.65 & 6.62 & 6.71 & 0.09 & 1.2102 & 1.20 & -0.5749 & 0.6251 \\
10.49 & 5.70 & 6.80 & 6.92 & 0.09 & 1.5968 & 1.03 & 0.1703 & 1.2003 \\
\hline
\end{tabular}

LogK $_{2}$ (Average value) $=0.9127 \pm 0.4070$

Table15:Point-wise method, Cd (Hydrolysed PSHA)

\begin{tabular}{|l|l|l|l|l|l|l|l|l|}
\hline $\mathrm{pH}$ & $\mathrm{BV}_{1}$ & $\mathrm{BV}_{2}$ & $\mathrm{BV}_{3}$ & $\left(\mathrm{~V}_{3}-\mathrm{V}_{2}\right)$ & $\mathrm{n}$ & $\mathrm{pL}$ & $\log \left(\frac{n}{1-n}\right)$ & LogK $_{1}$ \\
\hline 8.50 & 5.30 & 6.29 & 6.31 & 0.02 & 0.2750 & 2.64 & -0.4210 & 2.2190 \\
8.72 & 5.35 & 6.37 & 6.40 & 0.03 & 0.4286 & 2.42 & -0.1249 & 2.2951 \\
9.00 & 5.40 & 6.46 & 6.49 & 0.03 & 0.4648 & 2.14 & -0.0612 & 2.0788 \\
9.22 & 5.45 & 6.55 & 6.59 & 0.04 & 0.6667 & 1.96 & 0.3010 & 2.2610 \\
9.51 & 5.55 & 6.66 & 6.70 & 0.04 & 0.7720 & 1.67 & 0.5297 & 2.1997 \\
\hline
\end{tabular}

LogK $_{\mathbf{1}}$ (Average value) $=2.2108 \pm 0.0825$

Table 16: Point-wise method, Cd (Hydrolysed PSHA)

\begin{tabular}{|l|l|l|l|l|l|l|l|l|}
\hline $\mathrm{pH}$ & $\mathrm{BV}_{1}$ & $\mathrm{BV}_{2}$ & $\mathrm{BV}_{3}$ & $\left(\mathrm{~V}_{3}-\mathrm{V}_{2}\right)$ & $\mathrm{n}$ & $\mathrm{pL}$ & $\log \left(\frac{n-1}{2-n}\right)$ & Log $_{2}$ \\
\hline 9.73 & 5.55 & 6.78 & 6.83 & 0.06 & 1.4042 & 1.47 & -0.1686 & 1.3014 \\
10.00 & 5.60 & 6.90 & 6.95 & 0.06 & 1.7838 & 1.23 & 0.5593 & 1.7893 \\
10.23 & 5.65 & 7.05 & 7.10 & 0.06 & 3.1429 & 1.09 & & \\
10.49 & 5.70 & 7.10 & 7.16 & 0.06 & 3.1429 & 0.89 & & \\
& & & & & & & & \\
\hline
\end{tabular}

$\operatorname{LogK}_{2}$ (Average value) $=1.5453 \pm 0.3450$

Table 17: Point-wise method, Cd (Unhydrolysed PSHA)

\begin{tabular}{|l|l|l|l|l|l|l|l|l|}
\hline $\mathrm{pH}$ & $\mathrm{BV}_{1}$ & $\mathrm{BV}_{2}$ & $\mathrm{BV}_{3}$ & $\mathrm{~V}_{3}-\mathrm{V}_{2}$ & $\mathrm{n}$ & $\mathrm{pL}$ & $\log \left(\frac{n}{n-1}\right)$ & $\operatorname{Log~}_{1}$ \\
\hline 8.50 & 5.30 & 5.81 & 5.86 & 0.05 & 0.3717 & 2.88 & -0.2280 & 2.6520 \\
8.72 & 5.35 & 5.90 & 5.95 & 0.05 & 0.3873 & 2.66 & -0.1992 & 2.4608 \\
9.00 & 5.40 & 6.00 & 6.06 & 0.06 & 0.4853 & 2.38 & -0.0255 & 2.3545 \\
9.22 & 5.45 & 6.10 & 6.16 & 0.06 & 0.5157 & 2.18 & -0.0272 & 2.2072 \\
9.51 & 5.50 & 6.20 & 6.27 & 0.07 & 0.6417 & 1.89 & 0.2530 & 1.1430 \\
9.73 & 5.55 & 6.33 & 6.41 & 0.08 & 0.8000 & 1.69 & 0.6020 & 2.2920 \\
& & & & & & & & \\
\hline
\end{tabular}

$\operatorname{LogK}_{1}($ Average value $)=2.2516 \pm 0.5380$ 
BAJOPAS Volume 14 Number 1,June, 2021

Table 18: Point-wise method, Cd (Unhydrolysed PSHA)

\begin{tabular}{|l|l|l|l|l|l|l|l|l|}
\hline $\mathrm{pH}$ & $\mathrm{BV}_{1}$ & $\mathrm{BV}_{2}$ & $\mathrm{BV}_{3}$ & $\mathrm{~V}_{3}-\mathrm{V}_{2}$ & $\mathrm{n}$ & $\mathrm{pL}$ & $\log \left(\frac{n-1}{2-n}\right)$ & $\log \mathrm{K}_{2}$ \\
\hline 10.00 & 5.60 & 6.47 & 6.57 & 0.10 & 1.1434 & 1.43 & & \\
10.23 & 5.65 & 6.62 & 6.72 & 0.10 & 1.3448 & 1.23 & -0.2788 & 0.9512 \\
10.49 & 5.70 & 6.80 & 6.90 & 0.10 & 1.7742 & 1.03 & 0.5351 & 1.5651 \\
\hline
\end{tabular}

$\operatorname{LogK}_{2}($ Average value $)=1.2581 \pm 0.4340$

Table 19: Stepwise and overall Stability constants of thehydrolysed and unhydrolysed divalent metal (II) complexes

\begin{tabular}{|c|c|c|c|}
\hline Chelates & LogK $_{1}$ & $\log _{2}$ & Log $\beta$ \\
\hline [Cu (Hydrolysed PSHA-1) $\left.{ }_{2}\right]$ & 2.4788 & 1.4280 & 3.9068 \\
\hline$\left[\mathrm{Pb}(\text { Hydrolysed PSHA-1) })_{2}\right]$ & 2.5832 & 1.1963 & 3.7795 \\
\hline$\left[\mathrm{Cd}(\text { Hydrolysed PSHA-1 })_{2}\right]$ & 2.2108 & 1.5453 & 3.7561 \\
\hline$\left[\mathrm{Mg}(\text { Hydrolysed PSHA-1 })_{2}\right]$ & 2.1382 & 1.5453 & 3.6835 \\
\hline [Cu (Unhydrolysed PSHA-1) & 2.3059 & 1.2209 & 3.5268 \\
\hline$[\mathrm{Pb}$ (Unhydrolysed PSHA-1) 2$]$ & 2.2364 & 1.2239 & 3.4603 \\
\hline [Cd (Unhydrolysed PSHA-1) 2 ] & 2.2516 & 1.2581 & 3.5097 \\
\hline$[\mathrm{Mg}$ (Unydrolysed PSHA-1) & 2.1568 & 0.9127 & 3.0695 \\
\hline
\end{tabular}

The results obtained (Table19) shows the stepwise and overall stability constants to be not high indicating low stability of the complexes, because the solubility of most metal ions in the basic $\mathrm{pH}$ range is minimal due to metal hydroxide precipitation (Karimi, 2017). In general, the stepwise stability constants $\left(K_{1}\right.$ and $K_{2}$ ) follow the order $K_{1}>K_{2}$ for the copper, lead, magnesium and cadmium complexes respectively. The steady decrease of the values with increasing number of ligands is in agreement with the prediction made by researchers (Na'aliya, 2013). The decrease could be attributed to the fact that as the number of the ligands (Humate ions) that enters the coordination zone increases the aqua molecules available for replacement by the ligands become less. Thus, the metal ions become less electron loving with progressive intake of the ligand and this results in the decrease in the values of the constants (Na'aliya, 2013). Also the stability of the complexes is influenced by the size and number of the chelate rings(Mackay and Mackay,2002).All the complexes form rings in their structure as humate, a bidentate ligand, bond the metal ions in the ratio 1:2 (Boguta and Sokolowska, 2016) forming chelate rings. The values of the overall stability constants $(\log \beta)$ obtained for humate complexes are not high indicating low stability as the values are not high. LogK values for copper-humates (Table 3 to 6) obtained in this study are lower than those reported for the complexes of humic acids (Pandey et al., 2015; Dinu, 2013; Kaschl et al., 2010 and Gilbeto and Jorg, 2001). The values of LogK(Table 7 to 10 ) forlead-humates are lower than those reported for the lead in the literature (Dinu, 2013; Gilbeto and Jorg 2001). Log K values(Table 11 to 14 ) for magnesium-humates obtained in this study are close to those reported by (Pandey et al., 2015). Log K values of cadmium-humates (Table 15 to 18 ) obtained in this work near to the one reported by (Dinu, 2013 and Pandey et al., 2015).The difference between the reported values and the values obtained in this study might be probably as a result of acid hydrolysis of humic acid. The values of the overall stability constants $(\log \beta)$ of the copper humates complexes presented in Table 19 is high than that of other metal humate complexes, show relatively high stability of CuHA complexes, show the following order of stability: $\mathrm{Cu}>\mathrm{Pb}>\mathrm{Cd}>\mathrm{Mg}$; which are in close agreement to the findings of (Dinu, 2013 and Pandey et al., 2015).The high stability of Cuhumate chelate could be attributed to the existence of coordinate covalent bond between the complexing agents and the $\mathrm{Cu}^{2+}$ ions. Since, $\mathrm{Cu}^{2+}$ being a metal of the transitional series with $3 d^{9}$ electronic configurations can accept the electrons from the complexing agents. Similarly, the low stabilities of $\mathrm{Pb}, \mathrm{Cd}$ and $\mathrm{Mg}$ complexes could be explained by that $\mathrm{Pb}^{2+}$ with $6 s^{2}, \mathrm{Cd}^{2+}$ with $4 \mathrm{~d}^{10}$ and $\mathrm{Mg}^{2+}$ with $2 \mathrm{p}^{6}$ their electronic configuration has a completely filled $\mathrm{d}, \mathrm{p}$ and $\mathrm{s}$ orbitals. Moreover, the stabilities of metal ions with hydrolysed humic acid from peat soil were higher than those with unhydrolysed humic acid from peat soil; which is ascribed to the high content of acidity in hydrolysed humic acid than unhydrolysed humic acid. 
BAJOPAS Volume 14 Number 1,June, 2021 CONCLUSION

The values of logk for $\mathrm{Cu}(\mathrm{II})$ hydrolysed humic acid complex was higher followed by $\mathrm{Pb}$ (II), $\mathrm{Cd}(\mathrm{II})$ and $\mathrm{Mg}$ (II) hydrolysed humic acid complexes as compared with metal(II) unhydrolysed humic acid complexes. This indicates acid hydrolysis of humic acid can

\section{REFERENCES}

Almeida, V.R. and Szpoganicz, B. (2015). Humic Acid Potentiometric Response Patterns:Out- of Equilibrium Properties and Species Distribution Modelling. Chemical. Biol. Technol. Agric. 2: 17.

Anđelković, T., Nikolić, R., Bojić, A.,Anđelković, D., and Nikolic G.,(2010). Binding of Cadmium to Soil Humic Acid as A Function of Carboxyl Group Content. Macedonian Journal of Chemistry and Chemical Engineering.29(2): 215-224.

Anil, B. N. and Maroti, N. (2008). Studies on Influence of Die-Lectric Constants on Complex Equilibria between Substituted Py-Razalines and Lanthanide Metal Ions pH-Metrically. Amer.-Euras. scient. Res. 3(2): 212-216.

Ashok, K., Pandey, S. P. and Misra, V (2000). Stability Constants of Metal-Humic Acid Complexes and its Role in Environmental Detoxification. Journal of Ecotoxicology and Environmental Safety. 47(2):157-200.

Badr, M. H., El-Halafawi, M. H. and Abd El-al Zeid, E. R. (2012). Comparison Between the Effect of Ionic Strength on Acidity and Dissociation Constants of Humic Acids Extracted from Sewage Sludge and Nile Water Hyacinth Composts.Global Journal of Environmental Research 6 (1): 36-43.

Baruah, M.K., Borah, D., Saikia, P.P., Paul, S., Sharma, T. (2015). Evaluation of pKa Values of Soil Humic Acids and their Complexation Properties. International Journal of Plant \& Soil Science 6(4) : 218-228.

Boguta, P. Sokolowska, Z. (2016). Interactions of $\mathrm{Zn}$ (II) Ions with Humic Acids Isolated from Various Types of Soils. Effect of $\mathrm{pH}, \mathrm{Zn}$ Concentrations and Humic Acids Chemical Properties. Journal of Geochemical Explaration 168. 119-126.

Borges, F., Guimaraes, C., Lima, L.F.C., Pinto, I. and Reis, S.(2005). Potentiometric Studies on the Complexation of Copper(II) by Phenolic Acids as Discrete Ligand Models of enhance the complexation behavior of humic acid with metal (II) ions. However, the higher values of $\log \beta$ for $\mathrm{Cu}(\mathrm{II}), \mathrm{Pb}(\mathrm{II}), \mathrm{Cd}(\mathrm{II})$ and $\mathrm{Mg}(\mathrm{II})$ hydrolysed humic acid complexes indicates more stable stepwise complexes formed as compared with $\mathrm{Cu}(\mathrm{II}), \mathrm{Pb}$ (II), $\mathrm{Cd}$ (II) and $\mathrm{Mg}(\mathrm{II})$ unhydrolysed humic acid complexes.

Humic Substances Talanta 66 (2005) 670-673.

Chefetz, B., Salloum, M. J., Deshmulkin, A. P. and Hatcher, P. (2002). Structural Components of Humic Acids as Determined by Chemical Modifications and Carbon-13 NMR, Pyrolysis, and Thermochemolysis- Gas Chromatography/Mass Spectrometry. Soil Science Society of American Journal Abstract Division S-2- Soil Chemistry66. 1159-1171.

Dinu, M. I. (2013). Metals Complexation with Humic Acids in Surface Water of Different Environ. Sci. Technol. 31(1): 1-17.

Fernandes, A.N., Giacomelli, C., Giovanela, M. Vaz, D.V. Szpoganicz, B. and Maria M. D. (2009). Potentiometric Acidity Determination in Humic Substances Influenced by Different Analytical Procedures.J. Braz. Chem. Soc. 20 (9):14.

Gamal, A. H. (2015). Stability Constants of Rhenium (V) Metal Complexes with Selected Drugs. Pyrex Journal of Research in Environmental Studies. 2(2): 006-014.

Janrao, D. M., Pathan, J., Kayande, D.D., and Mulla, J.J. (2014). An Over View of Potentiometric Determination of Stability Constants of Metal Complexes. Sci. Revs. Chem. Commun.: 4(1), 2014, 11-24.

Karimi, H. (2017). Effect of pH and Initial Pb(II) Concentration on the Lead Removal Efficiency from Waste Water Using $\mathrm{Ca}(\mathrm{OH})_{2}$. International Journal of Water and Waste Water Treatment 3.2

Kaschl, A. Romheld, V. and Chen, Y. (2010). Binding of Cadmium, Copper and Zinc to Humic Substances Originating from Municipal Solid Waste Compost. Israel Journal of Chemistry Vol. 42(1): 89-98.

Kostic, I. S., Tatjana, P, A., Nikolic, R. S., Cvetkovic, T. P., Pavlovic, D. D., Aleksandar, L.J. and Bojic, A. (2012). Comparative Study of Binding Strengths of Heavy Metals with Humic Acid. J.serb. Chem. Soc. 76(9) pp 1-20. 
BAJOPAS Volume 14 Number 1,June, 2021

Na'aliya, J. (2013). Determination of Stepwise Stability Constants and Gibbs free Energy Change of Trisprolina to Complexes of some Divalent Transition Metal ions. Bayero Journal of Pure and Applied Sciences 6(2): 112-114.

Omar, A. A. and Ali, E. A. (2015). Potentiometric Studies on Complexes of $\mathrm{Cr}$ (III) and $\mathrm{Zr}$ (IV) with some Carboxylic Acids. International Journal of Advanced Chemistry, 3(1) 25-

37.

Pandey, A. K. Pandey, S. D. and Misr, V. (2015).Stability Constants of Metal- Humic Acid Complexes and Its Role in Environmental Detoxification. J. Ecotoxicology and Environmental Safety. 47(1):195-200.

Ram, N. and Raman, K.V. (1984). Stability Constants of Complexes of Metals with
Humicand Fuvic Acids under Non- acidConditions. Journal of Plant Nutrition and Soil Sciences.

147:171-176.

Santosh, D. D., Ashok, B. K., Vijay, J. T., Shivraj, G. W. and Vinay, V. W. (2011). Potentiometric Studies of Elec-Trolyte Effects on Complex Equilibria of Some Substituted 5-(2-hydroxy Phenyl) Pyrazoles. Der pharm. 3 (6): 75-83.

Sayyed, H. and Abdul Rahim, M. F. (2012). Studies of Binary Complexes of Metal Ions with Mandelic Acid by Potentiometry. Chem. J. 02 (6): 206209.

Shirvani, M. Moradian, E. Khalili, B. Bakhtiary, S. (2015). Interaction of $\mathrm{Cd}$ and $\mathrm{Pb}$ with Humate-Palygorskite and HumateSepiolite Complexes. Journal of water, air and pollution 3: 220-228. 


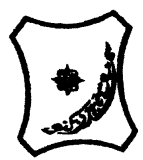

Bayero Journal of Pure and Applied Sciences, 14(1): 54 - 63

Received: November, 2020

Accepted: April, 2021

ISSN $2006-6996$

\title{
STABILITY CONSTANTS OF COMPLEXES OF METAL IONS WITH PEATSOIL HUMIC ACIDS UNDER NON-ACID-CONDITIONS
}

\author{
${ }^{* 1}$ Sabo, Yusuf ${ }^{2}$ Jimoh, W.L.O., ${ }^{3}$ Isa Baba Koki and ${ }^{4}$ Sholadoye, Q. 0. \\ ${ }^{1}$ Department of Pure and Industrial Chemistry, Bayero University, Kano \\ ${ }^{3}$ Department of Chemistry, Yusuf Maitama Sule University Kano. P.M.B. 3220 Kano, Nigeria. \\ ${ }^{4}$ Department of Chemistry, Nigerian Police Academy, Wudil, Kano-Nigeria
}

*Correspondence E-mail; saboyusuf18@yahoo.com

ABSTRACT

Stability constants of complexes of four divalent metal ions viz. $\mathrm{Cu}^{2+}, \mathrm{Pb}^{2+}, \mathrm{Mg}^{2+}$ and $\mathrm{Cd}^{2+}$ with humic acids (HA) were determined by potentiometric titration of humic acids with the corresponding salt of the divalent metals in aqueous media under non-acid-condition. The log $K$ (logarithm of the stability constant) ranged from 1.0942 to 2.7471 for metalhumic acid complexes were determined using point-wise computational method. The order of stability constants were obtained as follows: $\mathrm{Cu}>\mathrm{Pb}>\mathrm{Cd}>\mathrm{Mg}$ for metal $-\mathrm{HA}$ complexes respectively, indicating a higher degree of complexation with Cu metal ion.

Keywords: stability constant, humic acid, potentiometric titration, divalent metals, acid hydrolysis.

\section{NTRODUCTION}

The stability constant of a complex is the numerical expression of its stability and provides a quantitative measure of affinity of the metal ion to the complexing agent. An understanding of the relative stability of metal-complexes helps in predicting the behavior of metal ions in the soil (Ram and Raman, 1982). Extensive researches has been done to determine the stability constants of the complexes formed between humic acid (HA) with a number of metal ions. Ashok et al., (2000) reported that humic acid with hydroxyl, phenoxyl and carboxyl reactive groups can form coordination compound with metal ions at $\mathrm{pH}$ 3.5. The stability constants(Log K) for different metalhumic acid complexes indicated the following order of the stabilities of complexes formed between humic acid and metal ion, $\mathrm{Cu}>\mathrm{Fe}$ $>\mathrm{Pb}>\mathrm{Ni}>\mathrm{Co}>\mathrm{Ca}>\mathrm{Cd}>\mathrm{Zn}>\mathrm{Mn}>\mathrm{Mg}$. Andelkovic et al., (2010) investigated the binding of $\mathrm{Cd}$ (II) to soil humic acid at pH 6.5 and in $0.1 \mathrm{M} \mathrm{KNO}_{3}$ ionic medium. The stability constant for binding indicating greater stability in the case when carboxyl groups are involved in complexation reaction. Kostic et al.,(2012) investigated the complexation of humic acid with certain heavy metal ions (Co(II), $\mathrm{Ni}(\mathrm{II}), \mathrm{Cu}(\mathrm{II})$,
$\mathrm{Zn}(\mathrm{II})$, and $\mathrm{Pb}(\mathrm{II})$. The experiment was performed at $25^{\circ} \mathrm{C}$, at pH 4.0 and ionic strength of $0.01 \mathrm{M}$. Stability constant of complex between $\mathrm{Pb}$ (II) ions and humic acid is greater than stability constants of other investigated metalhumate complexes. Bogata and Sokolowska (2016) analyses the interaction between humic acids from different soils and $\mathrm{Zn}$ (II) ions at wide concentration ranges and at $\mathrm{pH} 5$. Studies have showed significant impact of $\mathrm{Zn}$ concentration, $\mathrm{pH}$ and some properties of humic acids with zinc.But all of these studies were limited to acidic $\mathrm{pH}$ range. Therefore, the present study was carried out to determine and compare the stability constants of complexes of metal ions with hydrolysed peat soil humic acid and unhydrolysed peat soil humic under non-acid conditions.

\section{MATERIALS AND METHODS}

Analytical grade chemicals used includes hydrochloric acid $(\mathrm{HCl})$, nitric acid $\left(\mathrm{HNO}_{3}\right)$, sodium hydroxide $(\mathrm{NaOH})$, lead nitrate $\mathrm{Pb}\left(\mathrm{NO}_{3}\right)_{2}$, copper nitrate $\mathrm{Cu}\left(\mathrm{NO}_{3}\right)_{2} \cdot 3 \mathrm{H}_{2} \mathrm{O}$, cadmium nitrate $\mathrm{Cd}\left(\mathrm{NO}_{3}\right)_{2} \cdot 4 \mathrm{H}_{2} \mathrm{O}$, magnesium nitrate $\mathrm{Mg}\left(\mathrm{NO}_{3}\right)_{2} \cdot 6 \mathrm{H}_{2} \mathrm{O}$, potassium nitrate $\left(\mathrm{KNO}_{3}\right)$, calcium chloride $\left(\mathrm{CaCl}_{2}\right)$, (sigma-Aldrich). Dowex 50WX8, (20-50 mesh) from Fluka. 


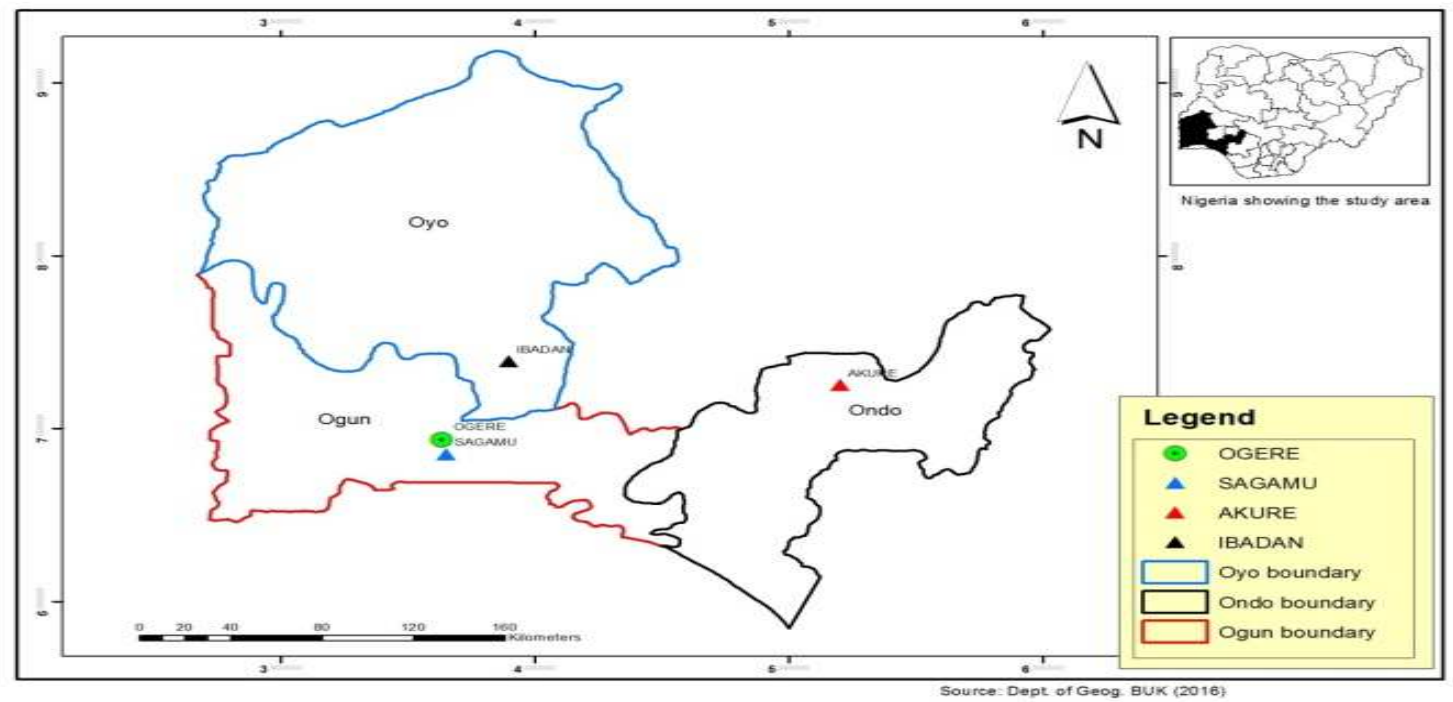

Figure 1: Map showing the sampling point at Sagamu Town, Ogun State.

\section{Description of Sampling Area}

Sagamu has geographical coordinates between $6^{\circ} 50^{\prime}$ north; $3^{\circ} 38^{\prime}$ east is located in south western region of Nigeria. The region has tropical wet and dry climate with a lengthy wet season and relatively constant temperatures throughout the course of the year. Wet season runs from March to October, November to December forms the region dry season. The vegetation type of the region is savannah which is really grassland with small bushes and occasional big trees. Grassland soils have substantially higher organic matter content than forest soils (Novackova, 2011).

\section{Sample Collection}

The Peatsoil samples were collected from four different sampling points $(0-10 \mathrm{~cm}$ depth) in Sagamu into polyethylene bag with plastic spoons. Samples were taken to the laboratory, extraneous materials were removed; the samples were air-dried, crushed and ground to a fine powder in a mortar passed through a $0.20 \mathrm{~mm}$ sieve. The samples were kept for analysis.

\section{Isolation and purification of humic acid from peat soil sample}

Peatsoil sample $(100 \mathrm{~g})$ was mixed with 1000 $\mathrm{cm}^{3}$ of $0.1 \mathrm{M} \mathrm{NaOH}$ solution, shaken for 3hours and left to stand overnight. Dark-coloured supernatant was obtained and decanted from solid residue. The dark-coloured supernatant was acidified to $(\mathrm{pH}=1.0)$ with $6 \mathrm{M} \mathrm{HCl}$ stirred and allowed to stand for 6 hours. Yellowish brown supernatant and dark-brown precipitate were obtained. The yellowish brown supernatant was decanted followed by centrifuge and discarded. The dark-brown precipitate was mixed with $500 \mathrm{~cm}^{3}$ of $0.1 \mathrm{M} \mathrm{NaOH}$ solution followed by passing through dowex resin. The dark-brown solution was acidified to $(\mathrm{pH}=1.0)$ with $6 \mathrm{M} \mathrm{HCl}$ stirred and allowed to stand for 3 hours. The dark-brown precipitate was washed several times with deionized water. The supernatant was treated with $\mathrm{AgNO}_{3}$ solution until no white precipitate observed. The humic acid was transferred to weighed crucible and dried at $60^{\circ} \mathrm{C}$ in an oven for 12 hours. The humic acid was cooled and dried in the desiccator, weighed and recorded. The obtained humic acid was dried again at $60^{\circ} \mathrm{C}$ for additional 6 hours cooled and dried in the desiccator, weighed and recorded constant weight was obtained (Baruah et al., 2015).

\section{FT-IR analysis}

FT-IR spectra of humic acid sample was analysed using Carry 630 FT-IR Agilent Technologies.

Unhydrolysed compost humic acid

The unhydrolysed humic acid was obtained after isolation and purification of compost humic acid and kept for investigation.

\section{Acid hydrolysis of Peatsoil acid}

Peatsoil humic acid sample (1g) was refluxed for 12 hours at $\left(160^{\circ} \mathrm{C}\right)$ with $50 \mathrm{~cm}^{3}$ of $6 \mathrm{M} \mathrm{HCl}$. The mixture was allowed to cool, decanted, and centrifuged after hydrolysis. The insoluble residues were washed with distilled water via centrifugation several times, and the supernatant was treated with $\mathrm{AgNO}_{3}$ solution until no white precipitate was observed. The residue was thoroughly dried over $\mathrm{CaCl}_{2}$ in a desiccator at room temperature (Chefetz et al., 2002). Finally, the obtained hydrolysed humic acid was kept for investigation. 
BAJOPAS Volume 14 Number 1,June, 2021 Potentiometric Titrations

Potentiometric measurements were carried out using a pH-meter Jenway (model 3510) with combine electrode, the sensitivity of the $\mathrm{pH}$ meter is 0.01 units. The $\mathrm{pH}$ meter was switched on half an hour before starting the titration for initial warm up of the instrument. The instrument was calibrated with an aqueous standard buffer solution of $\mathrm{pH} 4.00$ and 10.0 (borate buffer) prepared from a "Qualigens" buffer tablets.

The following sets of solutions were prepared in a $250 \mathrm{~cm}^{3}$ volumetric flask separately for $\mathrm{pH}$ metric titrations.

(i) $5 \mathrm{~cm}^{3} 0.1 \mathrm{M} \mathrm{HCl}+40 \mathrm{~cm}^{3}$ deionized water

(ii) $5 \mathrm{~cm}^{3} 0.1 \mathrm{M} \mathrm{HCl}+39 \mathrm{~cm}^{3}$ deionized water $+1 \mathrm{~cm}^{3} 0.15 \mathrm{gcm}^{-3}$ humic acid

(iii) $5 \mathrm{~cm}^{3} 0.1 \mathrm{M} \mathrm{HCl}+37 \mathrm{~cm}^{3}$ deionized water $+1 \mathrm{~cm}^{3} 0.15 \mathrm{gcm}^{-3}$ humic acid

$$
+2 \mathrm{~cm}^{3} \quad 0.01 \mathrm{M} \mathrm{Cu} \text { (II) }
$$

The solutions were titrated against standardized $0.110 \mathrm{MNaOH}$ separately. The total volume of each mixture was adjusted to $50 \mathrm{~cm}^{3}$ and the ionic strength of the solutions was maintained constant at by adding appropriate amount of stock solution of $1 \mathrm{M} \mathrm{KNO}_{3}$ (Gamal, 2015; Omar and Ali, 2015). A magnetic stirrer was used to achieve thorough mixing of the interacting solutions at $550 \mathrm{rpm}$. The same set of experimental conditions was applied for potentiometric titration of remaining samples.

\section{Evaluation of pKa of Hydrolysed peat soil Humic Acids}

The proton-ligand formation number $\mathrm{n}_{\mathbf{A}}$ were calculated by Irving and Rossotti expression (Omar and Ali, 2015).

$\mathrm{nA}=\mathrm{Y}-\frac{(\mathrm{V} 2-\mathrm{V1})(\mathrm{No}-\mathrm{Eo})}{(\mathrm{VO}+\mathrm{V1}) \mathrm{TCL}}$ 1

Where: $Y$ is number of dissociable proton, $\left(\mathrm{V}_{2^{-}}\right.$ $V_{1}$ ) is the measure of displacement of the ligand curve relative to acid curve, $\mathrm{N}^{\circ}$ and $\mathrm{E}^{\circ}$ are the resultant concentration of alkali solution, free acid solution, $\mathrm{T}_{\mathrm{cL}}{ }^{\circ}$ is the total ligand concentration, $\mathrm{V}^{\circ}$ is the total volume of titration solution, $V_{1}$ is the volume of alkali added to acid solution, $V_{2}$ is the volume of alkali added to acid solution + ligand solution, acid dissociation constants (pKa - values) of ligand were calculated by algebraic method point wise calculation (Tables 1 ). The dissociation constants (pKa) were calculated according to the following relation:

$\mathrm{pKa}=\mathrm{pH}+\log \left(\frac{n A}{1-n A}\right)$ 2

Where: pKa is the acid dissociation constant, $\mathrm{n}_{\mathrm{A}}$ is the Proton-ligand formation number and $\mathrm{pH}$ is the pH-values (Omar and Ali, 2015).

\section{Determination of metal-ligand stability constants $(\log K)$ of complexes}

The potentiometric measurement for the determination of stability constant of a complex in solution is based on the fact that the redox potential of the couple $\frac{M^{+(m-n)}}{M^{+m}}$ is shifted significantly on complexation of the metal ion with the ligand. This method involves change in hydrogen ion concentration $\left[\mathrm{H}^{+}\right]$due to the displacement or association of one or more protons taking place during complexation reaction. This change can be found out by titrating the solutions containing free acid, acid with ligand, and acid with ligand and metal ion, individually against a standard alkali solution at a constant ionic strength or temperature. Either ionic strength or temperature may be varied for different sets of solutions. In all the cases, the change in the $\mathrm{pH}$ of the solution is measured after each addition of a known amount of alkali to the reaction cell which contains the reaction mixture. The titration curves are then drawn by plotting the measured $\mathrm{pH}$ values against the corresponding volume of alkali added and the stability constants of the complexes are determined from the titration curves by employing $\mathrm{pH}$-metric titration technique given by (Irving and Rossoti).

Metal-ligand stability constants ( $\log \mathrm{K}$ ) were determined by using the following relations:

$$
\bar{n}=\frac{\left(V_{3}-V_{2}\right)\left(E^{0}+N^{0}\right)}{\left(V^{0}+V_{2}\right) \bar{n}_{A} T_{m}^{0}}
$$

and

$$
P L=\log _{10}\left\{\frac{1+\beta_{n}^{H} \frac{1}{[\text { anti } \log \mathrm{pH}]^{\mathrm{n}}}}{\mathrm{T}_{\mathrm{L}}^{0}-n \bar{T}_{m}^{0}} \mathrm{X} \frac{\left(V^{0}+V_{3}\right)}{V^{0}}\right\}
$$


BAJOPAS Volume 14 Number 1,June, 2021

Where $T_{L}, T^{\circ}, E^{\circ}$, and $V^{\circ}$ havethe same significance as in equation (1) above, $T_{m}$ denotes the total concentration of metal present in solution, $V_{3}$ is the volume of metal ions present in solution and $\beta^{H}$ is the overall proton ligand stability constant. The metal-ligand stability constants (log K) were determined by employing point wise computational Method (eq. 5 and 6).

$\operatorname{LogK}_{1}=\log \left(\frac{n}{1-n}\right)+\mathrm{pL}$ .5

$\operatorname{LogK}_{2}=\log \left(\frac{1-n}{2-n}\right)+\mathrm{pL}$ ...6

Where: Log $\mathrm{K}$ is the metal-ligand stability constant, $\mathrm{pL}$ is the Free ligand exponent function, $\mathbf{n}$ is the Average number of ligand attached with metal ion (Janraoet al., 2014). The results obtained were analyzed by an ORIGIN 2016 program using titration data and then the proton-ligand stability constants (pKa) and Metal-ligand stability constant (LogK) calculated (Omar and Ali, 2015).

\section{RESULTS AND DISCUSSION}

Fourier transformed infrared (FT-IR) spectra of isolated humic acid from peat soils Figure 2 had distinct clear absorption bands indicating the presence of major humic acid structural elemental groups such as $\mathrm{H}$ bonded $\mathrm{OH}$ $\left(3680 \mathrm{~cm}^{-1}\right.$ peak $), C=0$ of carbonyl $\left(1721 \mathrm{~cm}^{-1}\right.$ peak), functional groups of aliphatic components $\mathrm{CH}_{2}\left(2918 \mathrm{~cm}^{-1}\right.$ peak) and $\mathrm{C}-\mathrm{O}$ stretching of polysaccharide $\left(1168 \mathrm{~cm}^{-1}\right.$ peak). The positions of the absorption bands of the spectra fell within typical major absorption bands of humic acid which is at frequencies 3680, 2918, 1721, 1168 $\mathrm{cm}^{-1}$. The first peak centred in the vicinity of $3680 \mathrm{~cm}^{-1}$ region is attributed to phenol $\mathrm{OH}$ group bounded by intermolecular $\mathrm{H}$ bonds. The $2918 \mathrm{~cm}^{-1}$ band usually has absorption maximum at $2918 \mathrm{~cm}^{-1}$ which is due to $\mathrm{C}-\mathrm{H}$ stretching of alkane group $\left(\mathrm{CH}_{2}\right)$. The next major absorption band is $1721 \mathrm{~cm}^{-1}$. This band has been commonly ascribed to $\mathrm{C}=\mathrm{O}$ stretching of mainly carboxyl group $(\mathrm{COOH})$ with trace amount of ketones. The last peak was observed at 1168 $\mathrm{cm}^{-1}$ due to $\mathrm{C}-\mathrm{O}$ stretching of polysaccharides and this peak appeared also in the spectra of humic acid from peat soil. The FTIR spectra of the isolated humic acid contained all major characteristic absorption peaks of humic acid. These absorption peaks indicated the presence of the major structural elements of humic acid namely $\mathrm{H}$ bonded $\mathrm{OH}, \mathrm{C}=\mathrm{C}$ of aromatic ring, $\mathrm{C}=\mathrm{O}$ of carbonyl group (both carboxyl and ketonic), $\mathrm{CH}_{2}$ group. This strongly supports the presence of humic acid.

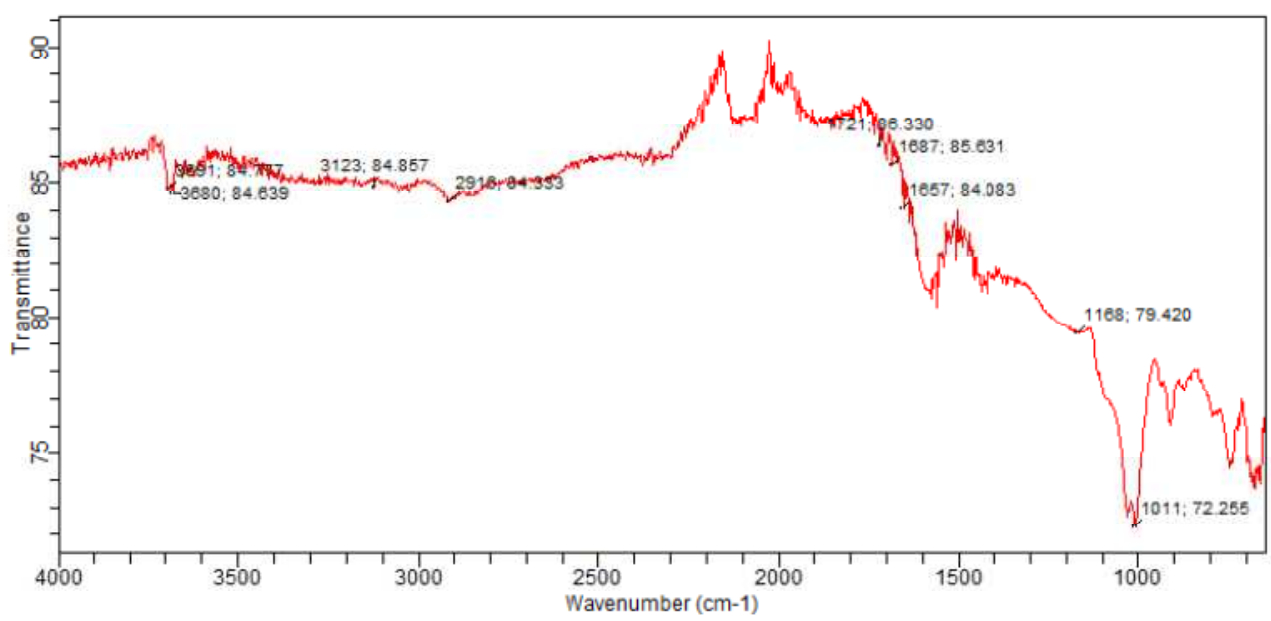

Fig. 2 : FT-IR spectraof peatsoilhumic acid (PSHA)

\section{Evaluation of acid dissociation constant (pka) of acid hydrolysed peat soil humicacid at phenolic group}

The value of the dissociation constant of the peat soil humic acid (PSHA) that underwent acidhydrolysis studied was found to be 8.9299 as shown Table 1, which is lower than the literaturevalues reported by Almeida and Szpoganics, (2015), Borges et al., (2005); Badr et al., (2012)and Fernandes et al,.(2009) of $9.73,9.47$ and 10.30. The difference between the obtained valuesand the reported values in this study might be probably as a result of acid hydrolysis of humicacid. 
BAJOPAS Volume 14 Number 1,June, 2021

Table 1: PKa of (Hydrolysed PSHA)

\begin{tabular}{|l|l|l|l|l|l|l|}
\hline $\mathrm{pH}$ & $\mathrm{BV}_{1}$ & $\mathrm{BV}_{2}$ & $\mathrm{~V}_{2}-\mathrm{V}_{1}$ & $\mathrm{nA}$ & $\log \left(\frac{n A}{1-n A}\right)$ & $\mathrm{pKa}$ \\
\hline 8.50 & 5.30 & 6.29 & 0.99 & 0.3594 & -0.2510 & 8.2490 \\
8.72 & 5.35 & 6.37 & 1.02 & 0.3400 & -0.2880 & 8.4320 \\
9.00 & 5.40 & 6.46 & 1.06 & 0.3141 & -0.3391 & 8.6609 \\
9.22 & 5.45 & 6.55 & 1.10 & 0.2882 & -0.3927 & 8.8273 \\
9.51 & 5.50 & 6.66 & 1.16 & 0.2494 & -0.4786 & 9.0314 \\
9.73 & 5.55 & 6.78 & 1.23 & 0.2041 & -0.5910 & 9.1390 \\
10.00 & 5.60 & 6.90 & 1.30 & 0.1589 & -0.7238 & 9.2762 \\
10.23 & 5.65 & 7.05 & 1.40 & 0.0941 & -0.9835 & 9.2465 \\
10.49 & 5.70 & 7.10 & 1.40 & 0.0941 & -0.9835 & 9.5065 \\
\hline
\end{tabular}

Average pKa $=8.9299 \pm 0.4186$

Table 2: PKa of (Unhydrolysed PSHA)

\begin{tabular}{|l|l|l|l|l|l|l|}
\hline $\mathrm{pH}$ & $\mathrm{BV}_{1}$ & $\mathrm{BV}_{2}$ & $\mathrm{~V}_{2}-\mathrm{V}_{1}$ & $\mathrm{nA}$ & $\log \left(\frac{\boldsymbol{n A}}{1-\boldsymbol{n}}\right)$ & $\mathrm{pKa}$ \\
\hline 8.50 & 5.30 & 5.81 & 0.51 & 0.6619 & 0.2919 & 8.7919 \\
8.72 & 5.35 & 5.90 & 0.55 & 0.6357 & 0.2418 & 8.9618 \\
9.00 & 5.40 & 6.00 & 0.60 & 0.6029 & 0.1813 & 9.1813 \\
9.22 & 5.45 & 6.10 & 0.65 & 0.5701 & 0.1226 & 9.3426 \\
9.51 & 5.50 & 6.20 & 0.70 & 0.5376 & 0.0654 & 9.5754 \\
9.73 & 5.55 & 6.33 & 0.78 & 0.4851 & -0.0259 & 9.7041 \\
10.00 & 5.60 & 6.47 & 0.87 & 0.4262 & -0.1291 & 9.8709 \\
10.23 & 5.65 & 6.62 & 0.99 & 0.3609 & -0.2481 & 9.9819 \\
10.49 & 5.70 & 6.80 & 1.10 & 0.2759 & -0.4690 & 10.0210 \\
\hline
\end{tabular}

Average pKa $=9.4923 \pm 0.4410$

Metal-ligand stability constant ( $\log \mathrm{K}$ )

The stabilityconstants require the accurate values of proton-ligand stability constants (Anil and Maroti, 2008). Metal titration curves crossed over ligand titration curve indicated the formation of complex upon proton release (Santosh, et al., 2011). If the values of n- are within range $0.2-0.8$ and $1.2-18$ this indicates the formation of $1: 1$ and 1:2 complexes (Sayyed and Mazahar, 2012).

The metal (II)-humate stepwise stability constants (log k) at phenolic group (Tables 318)

Table 3: Point-wise method, $\mathrm{Cu}$-(Hydrolysed PSHA)

\begin{tabular}{|l|l|l|l|l|l|l|l|l|}
\hline $\mathrm{pH}$ & $\mathrm{BV}_{1}$ & $\mathrm{BV}_{2}$ & $\mathrm{BV}_{3}$ & $\left(\mathrm{~V}_{3}-\mathrm{V}_{2}\right)$ & $\mathrm{n}$ & $\mathrm{pL}$ & $\log \left(\frac{n}{1-n}\right)$ & LogK $_{1}$ \\
\hline 8.50 & 5.30 & 6.29 & 6.33 & 0.04 & 0.5500 & 2.66 & 0.0871 & 2.7471 \\
8.72 & 5.35 & 6.37 & 6.41 & 0.04 & 0.5714 & 2.43 & 0.1249 & 2.5549 \\
9.00 & 5.40 & 6.46 & 6.50 & 0.04 & 0.6198 & 2.16 & 0.2122 & 2.3722 \\
9.22 & 5.45 & 6.55 & 6.59 & 0.04 & 0.6667 & 1.94 & 0.3010 & 2.2410 \\
\hline
\end{tabular}

LogK $_{1}$ (Average value) $=2.4788 \pm 0.2203$

Table 4: Point-wise method, $\mathrm{Cu}$-(Hydrolysed PSHA)

\begin{tabular}{|l|l|l|l|l|l|l|l|l|}
\hline $\mathrm{pH}$ & $\mathrm{BV}_{1}$ & $\mathrm{BV}_{2}$ & $\mathrm{BV}_{3}$ & $\left(\mathrm{~V}_{3}-\mathrm{V}_{2}\right)$ & $\mathrm{n}$ & $\mathrm{pL}$ & $\log \left(\frac{n-1}{2-n}\right)$ & LogK $_{2}$ \\
\hline 9.51 & 5.50 & 6.66 & 6.73 & 0.07 & 1.3509 & 1.70 & -0.2671 & 1.4329 \\
9.73 & 5.55 & 6.78 & 6.85 & 0.07 & 1.6383 & 1.51 & 0.2467 & 1.7567 \\
10.00 & 5.60 & 6.90 & 6.98 & 0.08 & 2.1783 & 1.31 & -0.2158 & 1.0942 \\
10.23 & 5.65 & 7.05 & 7.13 & 0.08 & 4.1904 & 1.27 & & \\
10.49 & 5.70 & 7.10 & 7.19 & 0.09 & 4.6920 & & & \\
\hline
\end{tabular}

Log $K_{2}($ Average value $)=1.4280 \pm 0.3312$ 
BAJOPAS Volume 14 Number 1,June, 2021

Table 5: Point-wise method, $\mathrm{Cu}$ (Unhydrolysed PSHA)

\begin{tabular}{|l|l|l|l|l|l|l|l|l|}
\hline $\mathrm{pH}$ & $\mathrm{BV}_{1}$ & $\mathrm{BV}_{2}$ & $\mathrm{BV}_{3}$ & $\left(\mathrm{~V}_{3}-\mathrm{V}_{2}\right)$ & $\mathrm{n}$ & $\mathrm{pL}$ & $\log \left(\frac{n}{n-1}\right)$ & Log $_{1}$ \\
\hline 8.50 & 5.30 & 5.81 & 5.85 & 0.04 & 0.2973 & 2.88 & -0.3736 & 2.5064 \\
8.72 & 5.35 & 5.90 & 5.95 & 0.05 & 0.3873 & 2.66 & -0.1992 & 2.4608 \\
9.00 & 5.40 & 6.00 & 6.05 & 0.05 & 0.4044 & 2.38 & -0.1681 & 2.2119 \\
9.22 & 5.45 & 6.10 & 6.15 & 0.06 & 0.5157 & 2.18 & -0.0272 & 2.2072 \\
9.51 & 5.50 & 6.20 & 6.27 & 0.07 & 0.6417 & 1.89 & 0.2530 & 1.1430 \\
\hline
\end{tabular}

$\operatorname{LogK}_{1}($ Average value $)=2.3059 \pm 0.6153$

Table 6:Point-wise method, $\mathrm{Cu}$ (Unhydrolysed PSHA)

\begin{tabular}{|l|l|l|l|l|l|l|l|l|}
\hline $\mathrm{pH}$ & $\mathrm{BV}_{1}$ & $\mathrm{BV}_{2}$ & $\mathrm{BV}_{3}$ & $\mathrm{~V}_{3}-\mathrm{V}_{2}$ & $\mathrm{n}$ & $\mathrm{pL}$ & $\log \left(\frac{n-1}{2-n}\right)$ & $\log \mathrm{K}_{2}$ \\
\hline 9.73 & 5.55 & 6.33 & 6.42 & 0.09 & 0.9000 & 1.69 & & \\
10.00 & 5.60 & 6.47 & 6.58 & 0.11 & 1.2578 & 1.44 & -0.4592 & 0.9808 \\
10.23 & 5.65 & 6.62 & 6.84 & 0.12 & 1.6137 & 1.26 & -0.2010 & 1.4610 \\
10.49 & 5.70 & 6.80 & 6.92 & 0.12 & 2.1052 & 1.03 & & \\
\hline
\end{tabular}

$\operatorname{LogK}_{2}$ (Average value) $=1.2209 \pm 0.3398$

Table 7:Point-wise method, Pb (Hydrolysed PSHA)

\begin{tabular}{|l|l|l|l|l|l|l|l|l|}
\hline $\mathrm{pH}$ & $\mathrm{BV}_{1}$ & $\mathrm{BV}_{2}$ & $\mathrm{BV}_{3}$ & $\left(\mathrm{~V}_{3}-\mathrm{V}_{2}\right)$ & $\mathrm{n}$ & $\mathrm{pL}$ & $\log \left(\frac{n}{1-n}\right)$ & LogK $_{1}$ \\
\hline 8.50 & 5.30 & 6.29 & 6.33 & 0.04 & 0.5500 & 2.66 & 0.0871 & 2.7471 \\
8.72 & 5.35 & 6.37 & 6.41 & 0.04 & 0.5714 & 2.43 & 0.1249 & 2.5549 \\
9.00 & 5.40 & 6.46 & 6.50 & 0.04 & 0.6198 & 2.16 & 0.2122 & 2.3722 \\
9.22 & 5.45 & 6.55 & 6.60 & 0.05 & 0.8333 & 1.96 & 0.6989 & 2.6589 \\
\hline
\end{tabular}

Log $_{\mathbf{1}}($ Average value $)=2.5832 \pm 0.1614$

Table 8:Point-wise method, Pb-(Hydrolysed PSHA)

\begin{tabular}{|l|l|l|l|l|l|l|l|l|}
\hline $\mathrm{pH}$ & $\mathrm{BV}_{1}$ & $\mathrm{BV}_{2}$ & $\mathrm{BV}_{3}$ & $\left(\mathrm{~V}_{3}-\mathrm{V}_{2}\right)$ & $\mathrm{n}$ & $\mathrm{pL}$ & $\log \left(\frac{n-1}{2-n}\right)$ & $\log \mathrm{K}_{2}$ \\
\hline 9.51 & 5.50 & 6.66 & 6.71 & 0.05 & 0.9650 & 1.67 & & \\
9.73 & 5.55 & 6.78 & 6.83 & 0.05 & 1.1702 & 1.44 & & \\
10.00 & 5.60 & 6.90 & 6.90 & 0.05 & 1.4864 & 1.22 & -0.0237 & 1.1963 \\
10.23 & 5.65 & 7.05 & 7.10 & 0.05 & 2.0190 & 1.09 & & \\
10.49 & 5.70 & 7.10 & 7.17 & 0.07 & 3.6492 & 1.00 & & \\
\hline
\end{tabular}

Log $K_{2}$ (Average value) $=1.1963$

Table 9: Point-wise method, Pb (Unhydrolysed PSHA)

\begin{tabular}{|l|l|l|l|l|l|l|l|l|}
\hline $\mathrm{pH}$ & $\mathrm{BV}_{1}$ & $\mathrm{BV}_{2}$ & $\mathrm{BV}_{3}$ & $\mathrm{~V}_{3}-\mathrm{V}_{2}$ & $\mathrm{n}$ & $\mathrm{pL}$ & $\begin{array}{l}\text { Log } \\
\left(\frac{n}{n-1}\right)\end{array}$ & Log $\mathrm{K}_{1}$ \\
\hline 8.50 & 5.30 & 5.81 & 5.85 & 0.04 & 0.2973 & 2.88 & -0.3736 & 2.5064 \\
8.72 & 5.35 & 5.90 & 5.94 & 0.04 & 0.3099 & 2.66 & -0.5477 & 2.3123 \\
9.00 & 5.40 & 6.00 & 6.05 & 0.05 & 0.4044 & 2.38 & -0.1681 & 2.2119 \\
9.22 & 5.45 & 6.10 & 6.15 & 0.06 & 0.5157 & 2.18 & 0.0272 & 2.2072 \\
9.51 & 5.50 & 6.20 & 6.26 & 0.07 & 0.6417 & 1.89 & 0.2530 & 2.1430 \\
9.73 & 5.55 & 6.40 & 6.40 & 0.07 & 0.7000 & 1.67 & 0.3680 & 2.0380 \\
\hline
\end{tabular}

LogK $_{1}$ (Average value) $=2.2364 \pm 0.1602$

Table 10: Point-wise method, Pb (Unhydrolysed PSHA)

\begin{tabular}{|l|l|l|l|l|l|l|l|l|}
\hline $\mathrm{pH}$ & $\mathrm{BV}_{1}$ & $\mathrm{BV}_{2}$ & $\mathrm{BV}_{3}$ & $\mathrm{~V}_{3}-\mathrm{V}_{2}$ & $\mathrm{n}$ & $\mathrm{pL}$ & $\log \left(\frac{n-1}{2-n}\right)$ & $\log \mathrm{K}_{2}$ \\
\hline 10.00 & 5.60 & 6.47 & 6.55 & 0.08 & 1.9503 & 1.41 & & \\
10.23 & 5.65 & 6.62 & 6.72 & 0.11 & 1.4792 & 1.26 & -0.0361 & 1.2239 \\
\hline
\end{tabular}

$\operatorname{LogK}_{2}$ (Average value) $=1.2239$

Table 11: Point-wise method, Mg (Hydrolysed PSHA)

\begin{tabular}{|l|l|l|l|l|l|l|l|l|}
\hline $\mathrm{pH}$ & $\mathrm{BV}_{1}$ & $\mathrm{BV}_{2}$ & $\mathrm{BV}_{3}$ & $\left(\mathrm{~V}_{3}-\mathrm{V}_{2}\right)$ & $\mathrm{n}$ & $\mathrm{pL}$ & $\log \left(\frac{n}{n-1}\right)$ & LogK $_{1}$ \\
\hline 8.50 & 5.30 & 6.29 & 6.31 & 0.02 & 0.2750 & 2.64 & -0.4290 & 2.2110 \\
8.72 & 5.35 & 6.37 & 6.39 & 0.02 & 0.2858 & 2.42 & -0.3978 & 2.0222 \\
9.00 & 5.40 & 6.46 & 6.49 & 0.03 & 0.4648 & 2.14 & -0.0612 & 2.0788 \\
9.22 & 5.45 & 6.55 & 6.59 & 0.04 & 0.6667 & 1.94 & 0.3010 & 2.2410 \\
\hline
\end{tabular}

$\log _{\mathbf{1}}($ Average value) $=2.1382 \pm 0.1046$ 
BAJOPAS Volume 14 Number 1,June, 2021

Table 12: Point-wise method, Mg (Hydrolysed PSHA)

\begin{tabular}{|l|l|l|l|l|l|l|l|l|}
\hline $\mathrm{pH}$ & $\mathrm{BV}_{1}$ & $\mathrm{BV}_{2}$ & $\mathrm{BV}_{3}$ & $\left(\mathrm{~V}_{3}-\mathrm{V}_{2}\right)$ & $\mathrm{n}$ & $\mathrm{pL}$ & $\log \left(\frac{n-1}{2-n}\right)$ & LogK $_{2}$ \\
\hline 9.51 & 5.55 & 6.66 & 6.71 & 0.05 & 0.9650 & 1.67 & & \\
9.73 & 5.55 & 6.78 & 6.84 & 0.06 & 1.4042 & 1.47 & -0.1686 & 1.3014 \\
10.00 & 5.60 & 6.90 & 6.93 & 0.06 & 1.7838 & 1.23 & 0.5593 & 1.7893 \\
10.23 & 5.65 & 7.05 & 7.10 & 0.06 & 3.1429 & 1.10 & & \\
10.49 & 5.70 & 7.10 & 7.18 & 0.07 & 3.6492 & 0.83 & & \\
\hline
\end{tabular}

LogK $_{2}($ Average value $)=1.5453 \pm 0.3450$

Table 13: Point-wise method, Mg (Unhydrolysed PSHA)

\begin{tabular}{|l|l|l|l|l|l|l|l|l|}
\hline $\mathrm{pH}$ & $\mathrm{BV}_{1}$ & $\mathrm{BV}_{2}$ & $\mathrm{BV}_{3}$ & $\mathrm{~V}_{3}-\mathrm{V}_{2}$ & $\mathrm{n}$ & $\mathrm{pL}$ & $\log \left(\frac{n}{n-1}\right)$ & $\operatorname{Log~}_{1}$ \\
\hline 8.50 & 5.30 & 5.81 & 5.85 & 0.04 & 0.2973 & 2.88 & -0.3736 & 2.5064 \\
8.72 & 5.35 & 5.90 & 5.94 & 0.04 & 0.3099 & 2.66 & -0.3477 & 2.3123 \\
9.00 & 5.40 & 6.00 & 6.04 & 0.04 & 0.3236 & 2.38 & -0.3202 & 2.0598 \\
9.22 & 5.45 & 6.10 & 6.15 & 0.05 & 0.4297 & 2.17 & -0.1230 & 2.0470 \\
9.51 & 5.50 & 6.20 & 6.26 & 0.06 & 0.5500 & 1.89 & 0.0871 & 1.9771 \\
9.73 & 5.55 & 6.33 & 6.40 & 0.07 & 0.7000 & 1.67 & 0.3680 & 2.0380 \\
\hline
\end{tabular}

LogK $_{1}$ (Average value) $=2.1568 \pm 0.2069$

Table 14: Point-wise method, Mg (Unhydrolysed PSHA)

\begin{tabular}{|l|l|l|l|l|l|l|l|l|}
\hline $\mathrm{pH}$ & $\mathrm{BV}_{1}$ & $\mathrm{BV}_{2}$ & $\mathrm{BV}_{3}$ & $\mathrm{~V}_{3}-\mathrm{V}_{2}$ & $\mathrm{n}$ & $\mathrm{pL}$ & $\log \left(\frac{n-1}{2-n}\right)$ & $\log \mathrm{K}_{2}$ \\
\hline 10.00 & 5.60 & 6.47 & 6.55 & 0.08 & 0.9148 & 1.41 & & \\
10.23 & 5.65 & 6.62 & 6.71 & 0.09 & 1.2102 & 1.20 & -0.5749 & 0.6251 \\
10.49 & 5.70 & 6.80 & 6.92 & 0.09 & 1.5968 & 1.03 & 0.1703 & 1.2003 \\
\hline
\end{tabular}

LogK $_{2}$ (Average value) $=0.9127 \pm 0.4070$

Table15:Point-wise method, Cd (Hydrolysed PSHA)

\begin{tabular}{|l|l|l|l|l|l|l|l|l|}
\hline $\mathrm{pH}$ & $\mathrm{BV}_{1}$ & $\mathrm{BV}_{2}$ & $\mathrm{BV}_{3}$ & $\left(\mathrm{~V}_{3}-\mathrm{V}_{2}\right)$ & $\mathrm{n}$ & $\mathrm{pL}$ & $\log \left(\frac{n}{1-n}\right)$ & LogK $_{1}$ \\
\hline 8.50 & 5.30 & 6.29 & 6.31 & 0.02 & 0.2750 & 2.64 & -0.4210 & 2.2190 \\
8.72 & 5.35 & 6.37 & 6.40 & 0.03 & 0.4286 & 2.42 & -0.1249 & 2.2951 \\
9.00 & 5.40 & 6.46 & 6.49 & 0.03 & 0.4648 & 2.14 & -0.0612 & 2.0788 \\
9.22 & 5.45 & 6.55 & 6.59 & 0.04 & 0.6667 & 1.96 & 0.3010 & 2.2610 \\
9.51 & 5.55 & 6.66 & 6.70 & 0.04 & 0.7720 & 1.67 & 0.5297 & 2.1997 \\
\hline
\end{tabular}

LogK $_{\mathbf{1}}$ (Average value) $=2.2108 \pm 0.0825$

Table 16: Point-wise method, Cd (Hydrolysed PSHA)

\begin{tabular}{|l|l|l|l|l|l|l|l|l|}
\hline $\mathrm{pH}$ & $\mathrm{BV}_{1}$ & $\mathrm{BV}_{2}$ & $\mathrm{BV}_{3}$ & $\left(\mathrm{~V}_{3}-\mathrm{V}_{2}\right)$ & $\mathrm{n}$ & $\mathrm{pL}$ & $\log \left(\frac{n-1}{2-n}\right)$ & Log $_{2}$ \\
\hline 9.73 & 5.55 & 6.78 & 6.83 & 0.06 & 1.4042 & 1.47 & -0.1686 & 1.3014 \\
10.00 & 5.60 & 6.90 & 6.95 & 0.06 & 1.7838 & 1.23 & 0.5593 & 1.7893 \\
10.23 & 5.65 & 7.05 & 7.10 & 0.06 & 3.1429 & 1.09 & & \\
10.49 & 5.70 & 7.10 & 7.16 & 0.06 & 3.1429 & 0.89 & & \\
& & & & & & & & \\
\hline
\end{tabular}

$\operatorname{LogK}_{2}$ (Average value) $=1.5453 \pm 0.3450$

Table 17: Point-wise method, Cd (Unhydrolysed PSHA)

\begin{tabular}{|l|l|l|l|l|l|l|l|l|}
\hline $\mathrm{pH}$ & $\mathrm{BV}_{1}$ & $\mathrm{BV}_{2}$ & $\mathrm{BV}_{3}$ & $\mathrm{~V}_{3}-\mathrm{V}_{2}$ & $\mathrm{n}$ & $\mathrm{pL}$ & $\log \left(\frac{n}{n-1}\right)$ & $\operatorname{Log~}_{1}$ \\
\hline 8.50 & 5.30 & 5.81 & 5.86 & 0.05 & 0.3717 & 2.88 & -0.2280 & 2.6520 \\
8.72 & 5.35 & 5.90 & 5.95 & 0.05 & 0.3873 & 2.66 & -0.1992 & 2.4608 \\
9.00 & 5.40 & 6.00 & 6.06 & 0.06 & 0.4853 & 2.38 & -0.0255 & 2.3545 \\
9.22 & 5.45 & 6.10 & 6.16 & 0.06 & 0.5157 & 2.18 & -0.0272 & 2.2072 \\
9.51 & 5.50 & 6.20 & 6.27 & 0.07 & 0.6417 & 1.89 & 0.2530 & 1.1430 \\
9.73 & 5.55 & 6.33 & 6.41 & 0.08 & 0.8000 & 1.69 & 0.6020 & 2.2920 \\
& & & & & & & & \\
\hline
\end{tabular}

$\operatorname{LogK}_{1}($ Average value $)=2.2516 \pm 0.5380$ 
BAJOPAS Volume 14 Number 1,June, 2021

Table 18: Point-wise method, Cd (Unhydrolysed PSHA)

\begin{tabular}{|l|l|l|l|l|l|l|l|l|}
\hline $\mathrm{pH}$ & $\mathrm{BV}_{1}$ & $\mathrm{BV}_{2}$ & $\mathrm{BV}_{3}$ & $\mathrm{~V}_{3}-\mathrm{V}_{2}$ & $\mathrm{n}$ & $\mathrm{pL}$ & $\log \left(\frac{n-1}{2-n}\right)$ & $\log \mathrm{K}_{2}$ \\
\hline 10.00 & 5.60 & 6.47 & 6.57 & 0.10 & 1.1434 & 1.43 & & \\
10.23 & 5.65 & 6.62 & 6.72 & 0.10 & 1.3448 & 1.23 & -0.2788 & 0.9512 \\
10.49 & 5.70 & 6.80 & 6.90 & 0.10 & 1.7742 & 1.03 & 0.5351 & 1.5651 \\
\hline
\end{tabular}

$\operatorname{LogK}_{2}($ Average value $)=1.2581 \pm 0.4340$

Table 19: Stepwise and overall Stability constants of thehydrolysed and unhydrolysed divalent metal (II) complexes

\begin{tabular}{|c|c|c|c|}
\hline Chelates & LogK $_{1}$ & $\log _{2}$ & Log $\beta$ \\
\hline [Cu (Hydrolysed PSHA-1) $\left.{ }_{2}\right]$ & 2.4788 & 1.4280 & 3.9068 \\
\hline$\left[\mathrm{Pb}(\text { Hydrolysed PSHA-1) })_{2}\right]$ & 2.5832 & 1.1963 & 3.7795 \\
\hline$\left[\mathrm{Cd}(\text { Hydrolysed PSHA-1 })_{2}\right]$ & 2.2108 & 1.5453 & 3.7561 \\
\hline$\left[\mathrm{Mg}(\text { Hydrolysed PSHA-1 })_{2}\right]$ & 2.1382 & 1.5453 & 3.6835 \\
\hline [Cu (Unhydrolysed PSHA-1) & 2.3059 & 1.2209 & 3.5268 \\
\hline$[\mathrm{Pb}$ (Unhydrolysed PSHA-1) 2$]$ & 2.2364 & 1.2239 & 3.4603 \\
\hline [Cd (Unhydrolysed PSHA-1) 2 ] & 2.2516 & 1.2581 & 3.5097 \\
\hline$[\mathrm{Mg}$ (Unydrolysed PSHA-1) & 2.1568 & 0.9127 & 3.0695 \\
\hline
\end{tabular}

The results obtained (Table19) shows the stepwise and overall stability constants to be not high indicating low stability of the complexes, because the solubility of most metal ions in the basic $\mathrm{pH}$ range is minimal due to metal hydroxide precipitation (Karimi, 2017). In general, the stepwise stability constants $\left(K_{1}\right.$ and $K_{2}$ ) follow the order $K_{1}>K_{2}$ for the copper, lead, magnesium and cadmium complexes respectively. The steady decrease of the values with increasing number of ligands is in agreement with the prediction made by researchers (Na'aliya, 2013). The decrease could be attributed to the fact that as the number of the ligands (Humate ions) that enters the coordination zone increases the aqua molecules available for replacement by the ligands become less. Thus, the metal ions become less electron loving with progressive intake of the ligand and this results in the decrease in the values of the constants (Na'aliya, 2013). Also the stability of the complexes is influenced by the size and number of the chelate rings(Mackay and Mackay,2002).All the complexes form rings in their structure as humate, a bidentate ligand, bond the metal ions in the ratio 1:2 (Boguta and Sokolowska, 2016) forming chelate rings. The values of the overall stability constants $(\log \beta)$ obtained for humate complexes are not high indicating low stability as the values are not high. LogK values for copper-humates (Table 3 to 6) obtained in this study are lower than those reported for the complexes of humic acids (Pandey et al., 2015; Dinu, 2013; Kaschl et al., 2010 and Gilbeto and Jorg, 2001). The values of LogK(Table 7 to 10 ) forlead-humates are lower than those reported for the lead in the literature (Dinu, 2013; Gilbeto and Jorg 2001). Log K values(Table 11 to 14 ) for magnesium-humates obtained in this study are close to those reported by (Pandey et al., 2015). Log K values of cadmium-humates (Table 15 to 18 ) obtained in this work near to the one reported by (Dinu, 2013 and Pandey et al., 2015).The difference between the reported values and the values obtained in this study might be probably as a result of acid hydrolysis of humic acid. The values of the overall stability constants $(\log \beta)$ of the copper humates complexes presented in Table 19 is high than that of other metal humate complexes, show relatively high stability of CuHA complexes, show the following order of stability: $\mathrm{Cu}>\mathrm{Pb}>\mathrm{Cd}>\mathrm{Mg}$; which are in close agreement to the findings of (Dinu, 2013 and Pandey et al., 2015).The high stability of Cuhumate chelate could be attributed to the existence of coordinate covalent bond between the complexing agents and the $\mathrm{Cu}^{2+}$ ions. Since, $\mathrm{Cu}^{2+}$ being a metal of the transitional series with $3 d^{9}$ electronic configurations can accept the electrons from the complexing agents. Similarly, the low stabilities of $\mathrm{Pb}, \mathrm{Cd}$ and $\mathrm{Mg}$ complexes could be explained by that $\mathrm{Pb}^{2+}$ with $6 s^{2}, \mathrm{Cd}^{2+}$ with $4 \mathrm{~d}^{10}$ and $\mathrm{Mg}^{2+}$ with $2 \mathrm{p}^{6}$ their electronic configuration has a completely filled $\mathrm{d}, \mathrm{p}$ and $\mathrm{s}$ orbitals. Moreover, the stabilities of metal ions with hydrolysed humic acid from peat soil were higher than those with unhydrolysed humic acid from peat soil; which is ascribed to the high content of acidity in hydrolysed humic acid than unhydrolysed humic acid. 
BAJOPAS Volume 14 Number 1,June, 2021 CONCLUSION

The values of logk for $\mathrm{Cu}(\mathrm{II})$ hydrolysed humic acid complex was higher followed by $\mathrm{Pb}$ (II), $\mathrm{Cd}(\mathrm{II})$ and $\mathrm{Mg}$ (II) hydrolysed humic acid complexes as compared with metal(II) unhydrolysed humic acid complexes. This indicates acid hydrolysis of humic acid can

\section{REFERENCES}

Almeida, V.R. and Szpoganicz, B. (2015). Humic Acid Potentiometric Response Patterns:Out- of Equilibrium Properties and Species Distribution Modelling. Chemical. Biol. Technol. Agric. 2: 17.

Anđelković, T., Nikolić, R., Bojić, A.,Anđelković, D., and Nikolic G.,(2010). Binding of Cadmium to Soil Humic Acid as A Function of Carboxyl Group Content. Macedonian Journal of Chemistry and Chemical Engineering.29(2): 215-224.

Anil, B. N. and Maroti, N. (2008). Studies on Influence of Die-Lectric Constants on Complex Equilibria between Substituted Py-Razalines and Lanthanide Metal Ions pH-Metrically. Amer.-Euras. scient. Res. 3(2): 212-216.

Ashok, K., Pandey, S. P. and Misra, V (2000). Stability Constants of Metal-Humic Acid Complexes and its Role in Environmental Detoxification. Journal of Ecotoxicology and Environmental Safety. 47(2):157-200.

Badr, M. H., El-Halafawi, M. H. and Abd El-al Zeid, E. R. (2012). Comparison Between the Effect of Ionic Strength on Acidity and Dissociation Constants of Humic Acids Extracted from Sewage Sludge and Nile Water Hyacinth Composts.Global Journal of Environmental Research 6 (1): 36-43.

Baruah, M.K., Borah, D., Saikia, P.P., Paul, S., Sharma, T. (2015). Evaluation of pKa Values of Soil Humic Acids and their Complexation Properties. International Journal of Plant \& Soil Science 6(4) : 218-228.

Boguta, P. Sokolowska, Z. (2016). Interactions of $\mathrm{Zn}$ (II) Ions with Humic Acids Isolated from Various Types of Soils. Effect of $\mathrm{pH}, \mathrm{Zn}$ Concentrations and Humic Acids Chemical Properties. Journal of Geochemical Explaration 168. 119-126.

Borges, F., Guimaraes, C., Lima, L.F.C., Pinto, I. and Reis, S.(2005). Potentiometric Studies on the Complexation of Copper(II) by Phenolic Acids as Discrete Ligand Models of enhance the complexation behavior of humic acid with metal (II) ions. However, the higher values of $\log \beta$ for $\mathrm{Cu}(\mathrm{II}), \mathrm{Pb}(\mathrm{II}), \mathrm{Cd}(\mathrm{II})$ and $\mathrm{Mg}(\mathrm{II})$ hydrolysed humic acid complexes indicates more stable stepwise complexes formed as compared with $\mathrm{Cu}(\mathrm{II}), \mathrm{Pb}$ (II), $\mathrm{Cd}$ (II) and $\mathrm{Mg}(\mathrm{II})$ unhydrolysed humic acid complexes.

Humic Substances Talanta 66 (2005) 670-673.

Chefetz, B., Salloum, M. J., Deshmulkin, A. P. and Hatcher, P. (2002). Structural Components of Humic Acids as Determined by Chemical Modifications and Carbon-13 NMR, Pyrolysis, and Thermochemolysis- Gas Chromatography/Mass Spectrometry. Soil Science Society of American Journal Abstract Division S-2- Soil Chemistry66. 1159-1171.

Dinu, M. I. (2013). Metals Complexation with Humic Acids in Surface Water of Different Environ. Sci. Technol. 31(1): 1-17.

Fernandes, A.N., Giacomelli, C., Giovanela, M. Vaz, D.V. Szpoganicz, B. and Maria M. D. (2009). Potentiometric Acidity Determination in Humic Substances Influenced by Different Analytical Procedures.J. Braz. Chem. Soc. 20 (9):14.

Gamal, A. H. (2015). Stability Constants of Rhenium (V) Metal Complexes with Selected Drugs. Pyrex Journal of Research in Environmental Studies. 2(2): 006-014.

Janrao, D. M., Pathan, J., Kayande, D.D., and Mulla, J.J. (2014). An Over View of Potentiometric Determination of Stability Constants of Metal Complexes. Sci. Revs. Chem. Commun.: 4(1), 2014, 11-24.

Karimi, H. (2017). Effect of pH and Initial Pb(II) Concentration on the Lead Removal Efficiency from Waste Water Using $\mathrm{Ca}(\mathrm{OH})_{2}$. International Journal of Water and Waste Water Treatment 3.2

Kaschl, A. Romheld, V. and Chen, Y. (2010). Binding of Cadmium, Copper and Zinc to Humic Substances Originating from Municipal Solid Waste Compost. Israel Journal of Chemistry Vol. 42(1): 89-98.

Kostic, I. S., Tatjana, P, A., Nikolic, R. S., Cvetkovic, T. P., Pavlovic, D. D., Aleksandar, L.J. and Bojic, A. (2012). Comparative Study of Binding Strengths of Heavy Metals with Humic Acid. J.serb. Chem. Soc. 76(9) pp 1-20. 
BAJOPAS Volume 14 Number 1,June, 2021

Na'aliya, J. (2013). Determination of Stepwise Stability Constants and Gibbs free Energy Change of Trisprolina to Complexes of some Divalent Transition Metal ions. Bayero Journal of Pure and Applied Sciences 6(2): 112-114.

Omar, A. A. and Ali, E. A. (2015). Potentiometric Studies on Complexes of $\mathrm{Cr}$ (III) and $\mathrm{Zr}$ (IV) with some Carboxylic Acids. International Journal of Advanced Chemistry, 3(1) 25-

37.

Pandey, A. K. Pandey, S. D. and Misr, V. (2015).Stability Constants of Metal- Humic Acid Complexes and Its Role in Environmental Detoxification. J. Ecotoxicology and Environmental Safety. 47(1):195-200.

Ram, N. and Raman, K.V. (1984). Stability Constants of Complexes of Metals with
Humicand Fuvic Acids under Non- acidConditions. Journal of Plant Nutrition and Soil Sciences.

147:171-176.

Santosh, D. D., Ashok, B. K., Vijay, J. T., Shivraj, G. W. and Vinay, V. W. (2011). Potentiometric Studies of Elec-Trolyte Effects on Complex Equilibria of Some Substituted 5-(2-hydroxy Phenyl) Pyrazoles. Der pharm. 3 (6): 75-83.

Sayyed, H. and Abdul Rahim, M. F. (2012). Studies of Binary Complexes of Metal Ions with Mandelic Acid by Potentiometry. Chem. J. 02 (6): 206209.

Shirvani, M. Moradian, E. Khalili, B. Bakhtiary, S. (2015). Interaction of $\mathrm{Cd}$ and $\mathrm{Pb}$ with Humate-Palygorskite and HumateSepiolite Complexes. Journal of water, air and pollution 3: 220-228. 


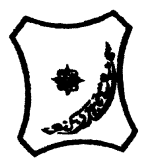

Bayero Journal of Pure and Applied Sciences, 14(1): 54 - 63

Received: November, 2020

Accepted: April, 2021

ISSN $2006-6996$

\title{
STABILITY CONSTANTS OF COMPLEXES OF METAL IONS WITH PEATSOIL HUMIC ACIDS UNDER NON-ACID-CONDITIONS
}

\author{
${ }^{* 1}$ Sabo, Yusuf ${ }^{2}$ Jimoh, W.L.O., ${ }^{3}$ Isa Baba Koki and ${ }^{4}$ Sholadoye, Q. 0. \\ ${ }^{1}$ Department of Pure and Industrial Chemistry, Bayero University, Kano \\ ${ }^{3}$ Department of Chemistry, Yusuf Maitama Sule University Kano. P.M.B. 3220 Kano, Nigeria. \\ ${ }^{4}$ Department of Chemistry, Nigerian Police Academy, Wudil, Kano-Nigeria
}

*Correspondence E-mail; saboyusuf18@yahoo.com

ABSTRACT

Stability constants of complexes of four divalent metal ions viz. $\mathrm{Cu}^{2+}, \mathrm{Pb}^{2+}, \mathrm{Mg}^{2+}$ and $\mathrm{Cd}^{2+}$ with humic acids (HA) were determined by potentiometric titration of humic acids with the corresponding salt of the divalent metals in aqueous media under non-acid-condition. The log $K$ (logarithm of the stability constant) ranged from 1.0942 to 2.7471 for metalhumic acid complexes were determined using point-wise computational method. The order of stability constants were obtained as follows: $\mathrm{Cu}>\mathrm{Pb}>\mathrm{Cd}>\mathrm{Mg}$ for metal $-\mathrm{HA}$ complexes respectively, indicating a higher degree of complexation with Cu metal ion.

Keywords: stability constant, humic acid, potentiometric titration, divalent metals, acid hydrolysis.

\section{NTRODUCTION}

The stability constant of a complex is the numerical expression of its stability and provides a quantitative measure of affinity of the metal ion to the complexing agent. An understanding of the relative stability of metal-complexes helps in predicting the behavior of metal ions in the soil (Ram and Raman, 1982). Extensive researches has been done to determine the stability constants of the complexes formed between humic acid (HA) with a number of metal ions. Ashok et al., (2000) reported that humic acid with hydroxyl, phenoxyl and carboxyl reactive groups can form coordination compound with metal ions at $\mathrm{pH}$ 3.5. The stability constants(Log K) for different metalhumic acid complexes indicated the following order of the stabilities of complexes formed between humic acid and metal ion, $\mathrm{Cu}>\mathrm{Fe}$ $>\mathrm{Pb}>\mathrm{Ni}>\mathrm{Co}>\mathrm{Ca}>\mathrm{Cd}>\mathrm{Zn}>\mathrm{Mn}>\mathrm{Mg}$. Andelkovic et al., (2010) investigated the binding of $\mathrm{Cd}$ (II) to soil humic acid at pH 6.5 and in $0.1 \mathrm{M} \mathrm{KNO}_{3}$ ionic medium. The stability constant for binding indicating greater stability in the case when carboxyl groups are involved in complexation reaction. Kostic et al.,(2012) investigated the complexation of humic acid with certain heavy metal ions (Co(II), $\mathrm{Ni}(\mathrm{II}), \mathrm{Cu}(\mathrm{II})$,
$\mathrm{Zn}(\mathrm{II})$, and $\mathrm{Pb}(\mathrm{II})$. The experiment was performed at $25^{\circ} \mathrm{C}$, at pH 4.0 and ionic strength of $0.01 \mathrm{M}$. Stability constant of complex between $\mathrm{Pb}$ (II) ions and humic acid is greater than stability constants of other investigated metalhumate complexes. Bogata and Sokolowska (2016) analyses the interaction between humic acids from different soils and $\mathrm{Zn}$ (II) ions at wide concentration ranges and at $\mathrm{pH} 5$. Studies have showed significant impact of $\mathrm{Zn}$ concentration, $\mathrm{pH}$ and some properties of humic acids with zinc.But all of these studies were limited to acidic $\mathrm{pH}$ range. Therefore, the present study was carried out to determine and compare the stability constants of complexes of metal ions with hydrolysed peat soil humic acid and unhydrolysed peat soil humic under non-acid conditions.

\section{MATERIALS AND METHODS}

Analytical grade chemicals used includes hydrochloric acid $(\mathrm{HCl})$, nitric acid $\left(\mathrm{HNO}_{3}\right)$, sodium hydroxide $(\mathrm{NaOH})$, lead nitrate $\mathrm{Pb}\left(\mathrm{NO}_{3}\right)_{2}$, copper nitrate $\mathrm{Cu}\left(\mathrm{NO}_{3}\right)_{2} \cdot 3 \mathrm{H}_{2} \mathrm{O}$, cadmium nitrate $\mathrm{Cd}\left(\mathrm{NO}_{3}\right)_{2} \cdot 4 \mathrm{H}_{2} \mathrm{O}$, magnesium nitrate $\mathrm{Mg}\left(\mathrm{NO}_{3}\right)_{2} \cdot 6 \mathrm{H}_{2} \mathrm{O}$, potassium nitrate $\left(\mathrm{KNO}_{3}\right)$, calcium chloride $\left(\mathrm{CaCl}_{2}\right)$, (sigma-Aldrich). Dowex 50WX8, (20-50 mesh) from Fluka. 


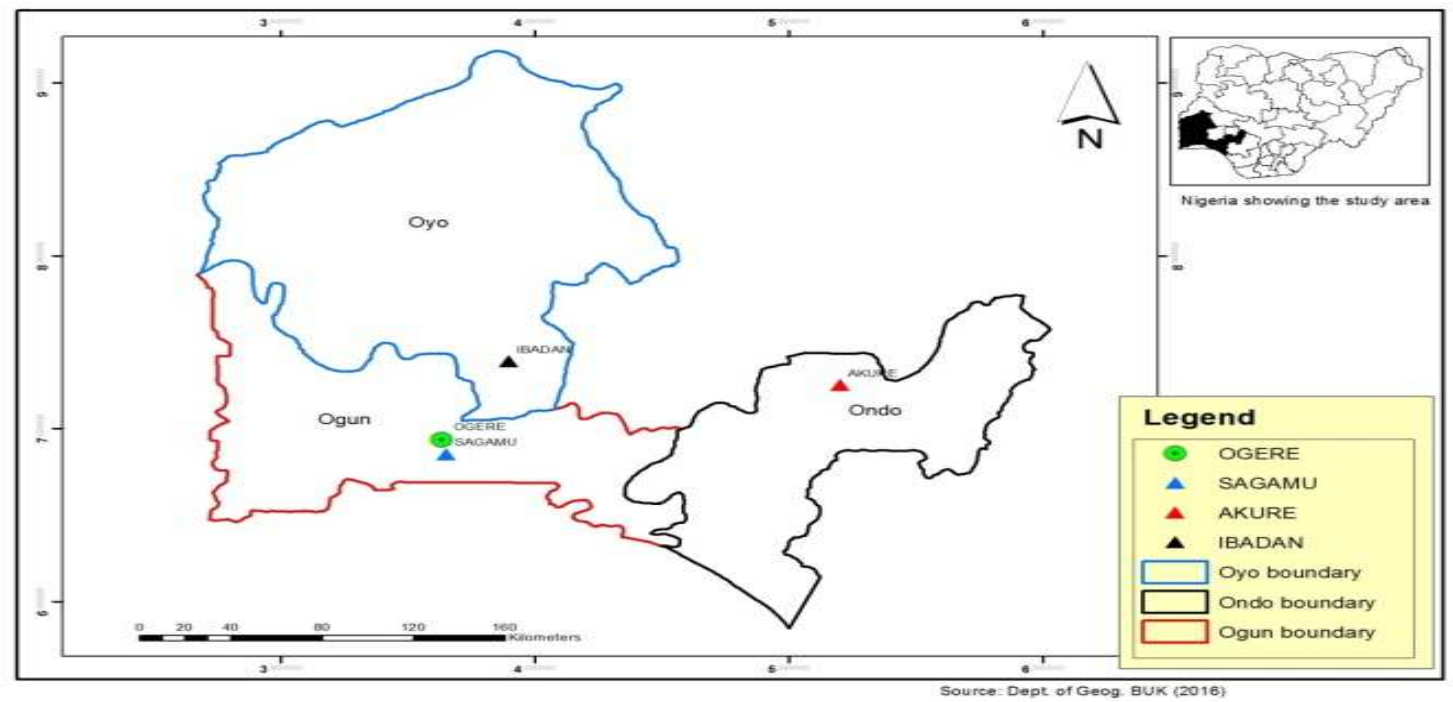

Figure 1: Map showing the sampling point at Sagamu Town, Ogun State.

\section{Description of Sampling Area}

Sagamu has geographical coordinates between $6^{\circ} 50^{\prime}$ north; $3^{\circ} 38^{\prime}$ east is located in south western region of Nigeria. The region has tropical wet and dry climate with a lengthy wet season and relatively constant temperatures throughout the course of the year. Wet season runs from March to October, November to December forms the region dry season. The vegetation type of the region is savannah which is really grassland with small bushes and occasional big trees. Grassland soils have substantially higher organic matter content than forest soils (Novackova, 2011).

\section{Sample Collection}

The Peatsoil samples were collected from four different sampling points $(0-10 \mathrm{~cm}$ depth) in Sagamu into polyethylene bag with plastic spoons. Samples were taken to the laboratory, extraneous materials were removed; the samples were air-dried, crushed and ground to a fine powder in a mortar passed through a $0.20 \mathrm{~mm}$ sieve. The samples were kept for analysis.

\section{Isolation and purification of humic acid from peat soil sample}

Peatsoil sample $(100 \mathrm{~g})$ was mixed with 1000 $\mathrm{cm}^{3}$ of $0.1 \mathrm{M} \mathrm{NaOH}$ solution, shaken for 3hours and left to stand overnight. Dark-coloured supernatant was obtained and decanted from solid residue. The dark-coloured supernatant was acidified to $(\mathrm{pH}=1.0)$ with $6 \mathrm{M} \mathrm{HCl}$ stirred and allowed to stand for 6 hours. Yellowish brown supernatant and dark-brown precipitate were obtained. The yellowish brown supernatant was decanted followed by centrifuge and discarded. The dark-brown precipitate was mixed with $500 \mathrm{~cm}^{3}$ of $0.1 \mathrm{M} \mathrm{NaOH}$ solution followed by passing through dowex resin. The dark-brown solution was acidified to $(\mathrm{pH}=1.0)$ with $6 \mathrm{M} \mathrm{HCl}$ stirred and allowed to stand for 3 hours. The dark-brown precipitate was washed several times with deionized water. The supernatant was treated with $\mathrm{AgNO}_{3}$ solution until no white precipitate observed. The humic acid was transferred to weighed crucible and dried at $60^{\circ} \mathrm{C}$ in an oven for 12 hours. The humic acid was cooled and dried in the desiccator, weighed and recorded. The obtained humic acid was dried again at $60^{\circ} \mathrm{C}$ for additional 6 hours cooled and dried in the desiccator, weighed and recorded constant weight was obtained (Baruah et al., 2015).

\section{FT-IR analysis}

FT-IR spectra of humic acid sample was analysed using Carry 630 FT-IR Agilent Technologies.

Unhydrolysed compost humic acid

The unhydrolysed humic acid was obtained after isolation and purification of compost humic acid and kept for investigation.

\section{Acid hydrolysis of Peatsoil acid}

Peatsoil humic acid sample (1g) was refluxed for 12 hours at $\left(160^{\circ} \mathrm{C}\right)$ with $50 \mathrm{~cm}^{3}$ of $6 \mathrm{M} \mathrm{HCl}$. The mixture was allowed to cool, decanted, and centrifuged after hydrolysis. The insoluble residues were washed with distilled water via centrifugation several times, and the supernatant was treated with $\mathrm{AgNO}_{3}$ solution until no white precipitate was observed. The residue was thoroughly dried over $\mathrm{CaCl}_{2}$ in a desiccator at room temperature (Chefetz et al., 2002). Finally, the obtained hydrolysed humic acid was kept for investigation. 
BAJOPAS Volume 14 Number 1,June, 2021 Potentiometric Titrations

Potentiometric measurements were carried out using a pH-meter Jenway (model 3510) with combine electrode, the sensitivity of the $\mathrm{pH}$ meter is 0.01 units. The $\mathrm{pH}$ meter was switched on half an hour before starting the titration for initial warm up of the instrument. The instrument was calibrated with an aqueous standard buffer solution of $\mathrm{pH} 4.00$ and 10.0 (borate buffer) prepared from a "Qualigens" buffer tablets.

The following sets of solutions were prepared in a $250 \mathrm{~cm}^{3}$ volumetric flask separately for $\mathrm{pH}$ metric titrations.

(i) $5 \mathrm{~cm}^{3} 0.1 \mathrm{M} \mathrm{HCl}+40 \mathrm{~cm}^{3}$ deionized water

(ii) $5 \mathrm{~cm}^{3} 0.1 \mathrm{M} \mathrm{HCl}+39 \mathrm{~cm}^{3}$ deionized water $+1 \mathrm{~cm}^{3} 0.15 \mathrm{gcm}^{-3}$ humic acid

(iii) $5 \mathrm{~cm}^{3} 0.1 \mathrm{M} \mathrm{HCl}+37 \mathrm{~cm}^{3}$ deionized water $+1 \mathrm{~cm}^{3} 0.15 \mathrm{gcm}^{-3}$ humic acid

$$
+2 \mathrm{~cm}^{3} \quad 0.01 \mathrm{M} \mathrm{Cu} \text { (II) }
$$

The solutions were titrated against standardized $0.110 \mathrm{MNaOH}$ separately. The total volume of each mixture was adjusted to $50 \mathrm{~cm}^{3}$ and the ionic strength of the solutions was maintained constant at by adding appropriate amount of stock solution of $1 \mathrm{M} \mathrm{KNO}_{3}$ (Gamal, 2015; Omar and Ali, 2015). A magnetic stirrer was used to achieve thorough mixing of the interacting solutions at $550 \mathrm{rpm}$. The same set of experimental conditions was applied for potentiometric titration of remaining samples.

\section{Evaluation of pKa of Hydrolysed peat soil Humic Acids}

The proton-ligand formation number $\mathrm{n}_{\mathbf{A}}$ were calculated by Irving and Rossotti expression (Omar and Ali, 2015).

$\mathrm{nA}=\mathrm{Y}-\frac{(\mathrm{V} 2-\mathrm{V1})(\mathrm{No}-\mathrm{Eo})}{(\mathrm{VO}+\mathrm{V1}) \mathrm{TCL}}$ 1

Where: $Y$ is number of dissociable proton, $\left(\mathrm{V}_{2^{-}}\right.$ $V_{1}$ ) is the measure of displacement of the ligand curve relative to acid curve, $\mathrm{N}^{\circ}$ and $\mathrm{E}^{\circ}$ are the resultant concentration of alkali solution, free acid solution, $\mathrm{T}_{\mathrm{cL}}{ }^{\circ}$ is the total ligand concentration, $\mathrm{V}^{\circ}$ is the total volume of titration solution, $V_{1}$ is the volume of alkali added to acid solution, $V_{2}$ is the volume of alkali added to acid solution + ligand solution, acid dissociation constants (pKa - values) of ligand were calculated by algebraic method point wise calculation (Tables 1 ). The dissociation constants (pKa) were calculated according to the following relation:

$\mathrm{pKa}=\mathrm{pH}+\log \left(\frac{n A}{1-n A}\right)$ 2

Where: pKa is the acid dissociation constant, $\mathrm{n}_{\mathrm{A}}$ is the Proton-ligand formation number and $\mathrm{pH}$ is the pH-values (Omar and Ali, 2015).

\section{Determination of metal-ligand stability constants $(\log K)$ of complexes}

The potentiometric measurement for the determination of stability constant of a complex in solution is based on the fact that the redox potential of the couple $\frac{M^{+(m-n)}}{M^{+m}}$ is shifted significantly on complexation of the metal ion with the ligand. This method involves change in hydrogen ion concentration $\left[\mathrm{H}^{+}\right]$due to the displacement or association of one or more protons taking place during complexation reaction. This change can be found out by titrating the solutions containing free acid, acid with ligand, and acid with ligand and metal ion, individually against a standard alkali solution at a constant ionic strength or temperature. Either ionic strength or temperature may be varied for different sets of solutions. In all the cases, the change in the $\mathrm{pH}$ of the solution is measured after each addition of a known amount of alkali to the reaction cell which contains the reaction mixture. The titration curves are then drawn by plotting the measured $\mathrm{pH}$ values against the corresponding volume of alkali added and the stability constants of the complexes are determined from the titration curves by employing $\mathrm{pH}$-metric titration technique given by (Irving and Rossoti).

Metal-ligand stability constants ( $\log \mathrm{K}$ ) were determined by using the following relations:

$$
\bar{n}=\frac{\left(V_{3}-V_{2}\right)\left(E^{0}+N^{0}\right)}{\left(V^{0}+V_{2}\right) \bar{n}_{A} T_{m}^{0}}
$$

and

$$
P L=\log _{10}\left\{\frac{1+\beta_{n}^{H} \frac{1}{[\text { anti } \log \mathrm{pH}]^{\mathrm{n}}}}{\mathrm{T}_{\mathrm{L}}^{0}-n \bar{T}_{m}^{0}} \mathrm{X} \frac{\left(V^{0}+V_{3}\right)}{V^{0}}\right\}
$$


BAJOPAS Volume 14 Number 1,June, 2021

Where $T_{L}, T^{\circ}, E^{\circ}$, and $V^{\circ}$ havethe same significance as in equation (1) above, $T_{m}$ denotes the total concentration of metal present in solution, $V_{3}$ is the volume of metal ions present in solution and $\beta^{H}$ is the overall proton ligand stability constant. The metal-ligand stability constants (log K) were determined by employing point wise computational Method (eq. 5 and 6).

$\operatorname{LogK}_{1}=\log \left(\frac{n}{1-n}\right)+\mathrm{pL}$ .5

$\operatorname{LogK}_{2}=\log \left(\frac{1-n}{2-n}\right)+\mathrm{pL}$ ...6

Where: Log $\mathrm{K}$ is the metal-ligand stability constant, $\mathrm{pL}$ is the Free ligand exponent function, $\mathbf{n}$ is the Average number of ligand attached with metal ion (Janraoet al., 2014). The results obtained were analyzed by an ORIGIN 2016 program using titration data and then the proton-ligand stability constants (pKa) and Metal-ligand stability constant (LogK) calculated (Omar and Ali, 2015).

\section{RESULTS AND DISCUSSION}

Fourier transformed infrared (FT-IR) spectra of isolated humic acid from peat soils Figure 2 had distinct clear absorption bands indicating the presence of major humic acid structural elemental groups such as $\mathrm{H}$ bonded $\mathrm{OH}$ $\left(3680 \mathrm{~cm}^{-1}\right.$ peak $), C=0$ of carbonyl $\left(1721 \mathrm{~cm}^{-1}\right.$ peak), functional groups of aliphatic components $\mathrm{CH}_{2}\left(2918 \mathrm{~cm}^{-1}\right.$ peak) and $\mathrm{C}-\mathrm{O}$ stretching of polysaccharide $\left(1168 \mathrm{~cm}^{-1}\right.$ peak). The positions of the absorption bands of the spectra fell within typical major absorption bands of humic acid which is at frequencies 3680, 2918, 1721, 1168 $\mathrm{cm}^{-1}$. The first peak centred in the vicinity of $3680 \mathrm{~cm}^{-1}$ region is attributed to phenol $\mathrm{OH}$ group bounded by intermolecular $\mathrm{H}$ bonds. The $2918 \mathrm{~cm}^{-1}$ band usually has absorption maximum at $2918 \mathrm{~cm}^{-1}$ which is due to $\mathrm{C}-\mathrm{H}$ stretching of alkane group $\left(\mathrm{CH}_{2}\right)$. The next major absorption band is $1721 \mathrm{~cm}^{-1}$. This band has been commonly ascribed to $\mathrm{C}=\mathrm{O}$ stretching of mainly carboxyl group $(\mathrm{COOH})$ with trace amount of ketones. The last peak was observed at 1168 $\mathrm{cm}^{-1}$ due to $\mathrm{C}-\mathrm{O}$ stretching of polysaccharides and this peak appeared also in the spectra of humic acid from peat soil. The FTIR spectra of the isolated humic acid contained all major characteristic absorption peaks of humic acid. These absorption peaks indicated the presence of the major structural elements of humic acid namely $\mathrm{H}$ bonded $\mathrm{OH}, \mathrm{C}=\mathrm{C}$ of aromatic ring, $\mathrm{C}=\mathrm{O}$ of carbonyl group (both carboxyl and ketonic), $\mathrm{CH}_{2}$ group. This strongly supports the presence of humic acid.

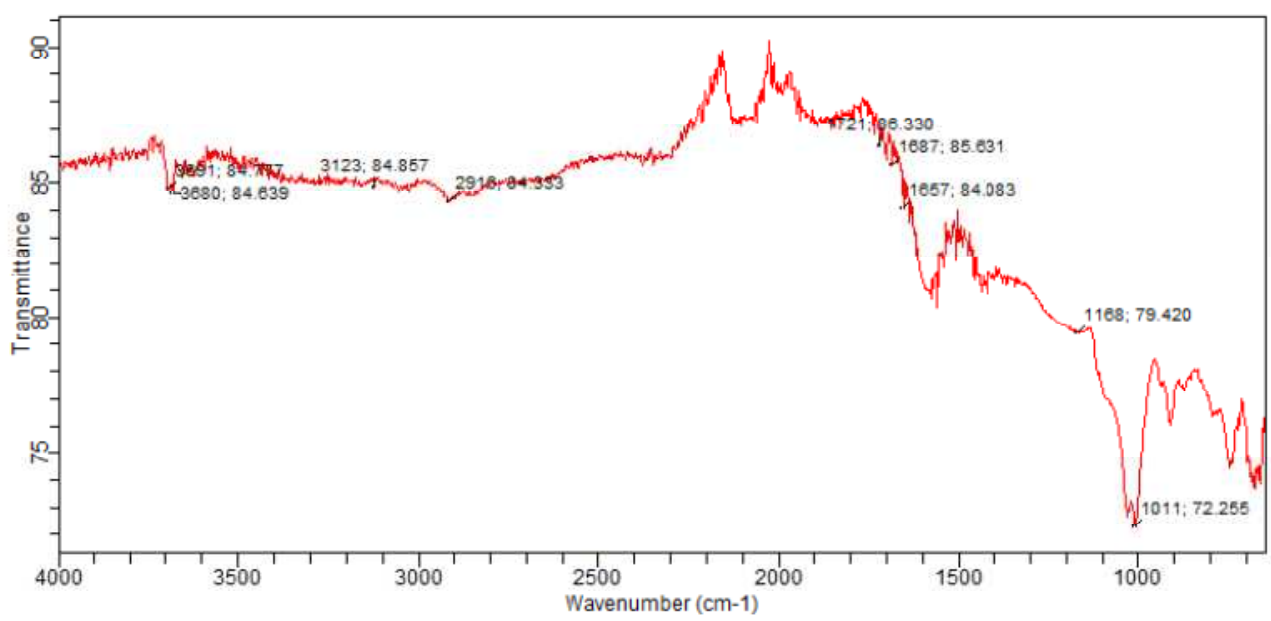

Fig. 2 : FT-IR spectraof peatsoilhumic acid (PSHA)

\section{Evaluation of acid dissociation constant (pka) of acid hydrolysed peat soil humicacid at phenolic group}

The value of the dissociation constant of the peat soil humic acid (PSHA) that underwent acidhydrolysis studied was found to be 8.9299 as shown Table 1, which is lower than the literaturevalues reported by Almeida and Szpoganics, (2015), Borges et al., (2005); Badr et al., (2012)and Fernandes et al,.(2009) of $9.73,9.47$ and 10.30. The difference between the obtained valuesand the reported values in this study might be probably as a result of acid hydrolysis of humicacid. 
BAJOPAS Volume 14 Number 1,June, 2021

Table 1: PKa of (Hydrolysed PSHA)

\begin{tabular}{|l|l|l|l|l|l|l|}
\hline $\mathrm{pH}$ & $\mathrm{BV}_{1}$ & $\mathrm{BV}_{2}$ & $\mathrm{~V}_{2}-\mathrm{V}_{1}$ & $\mathrm{nA}$ & $\log \left(\frac{n A}{1-n A}\right)$ & $\mathrm{pKa}$ \\
\hline 8.50 & 5.30 & 6.29 & 0.99 & 0.3594 & -0.2510 & 8.2490 \\
8.72 & 5.35 & 6.37 & 1.02 & 0.3400 & -0.2880 & 8.4320 \\
9.00 & 5.40 & 6.46 & 1.06 & 0.3141 & -0.3391 & 8.6609 \\
9.22 & 5.45 & 6.55 & 1.10 & 0.2882 & -0.3927 & 8.8273 \\
9.51 & 5.50 & 6.66 & 1.16 & 0.2494 & -0.4786 & 9.0314 \\
9.73 & 5.55 & 6.78 & 1.23 & 0.2041 & -0.5910 & 9.1390 \\
10.00 & 5.60 & 6.90 & 1.30 & 0.1589 & -0.7238 & 9.2762 \\
10.23 & 5.65 & 7.05 & 1.40 & 0.0941 & -0.9835 & 9.2465 \\
10.49 & 5.70 & 7.10 & 1.40 & 0.0941 & -0.9835 & 9.5065 \\
\hline
\end{tabular}

Average pKa $=8.9299 \pm 0.4186$

Table 2: PKa of (Unhydrolysed PSHA)

\begin{tabular}{|l|l|l|l|l|l|l|}
\hline $\mathrm{pH}$ & $\mathrm{BV}_{1}$ & $\mathrm{BV}_{2}$ & $\mathrm{~V}_{2}-\mathrm{V}_{1}$ & $\mathrm{nA}$ & $\log \left(\frac{\boldsymbol{n A}}{1-\boldsymbol{n}}\right)$ & $\mathrm{pKa}$ \\
\hline 8.50 & 5.30 & 5.81 & 0.51 & 0.6619 & 0.2919 & 8.7919 \\
8.72 & 5.35 & 5.90 & 0.55 & 0.6357 & 0.2418 & 8.9618 \\
9.00 & 5.40 & 6.00 & 0.60 & 0.6029 & 0.1813 & 9.1813 \\
9.22 & 5.45 & 6.10 & 0.65 & 0.5701 & 0.1226 & 9.3426 \\
9.51 & 5.50 & 6.20 & 0.70 & 0.5376 & 0.0654 & 9.5754 \\
9.73 & 5.55 & 6.33 & 0.78 & 0.4851 & -0.0259 & 9.7041 \\
10.00 & 5.60 & 6.47 & 0.87 & 0.4262 & -0.1291 & 9.8709 \\
10.23 & 5.65 & 6.62 & 0.99 & 0.3609 & -0.2481 & 9.9819 \\
10.49 & 5.70 & 6.80 & 1.10 & 0.2759 & -0.4690 & 10.0210 \\
\hline
\end{tabular}

Average pKa $=9.4923 \pm 0.4410$

Metal-ligand stability constant ( $\log \mathrm{K}$ )

The stabilityconstants require the accurate values of proton-ligand stability constants (Anil and Maroti, 2008). Metal titration curves crossed over ligand titration curve indicated the formation of complex upon proton release (Santosh, et al., 2011). If the values of n- are within range $0.2-0.8$ and $1.2-18$ this indicates the formation of $1: 1$ and 1:2 complexes (Sayyed and Mazahar, 2012).

The metal (II)-humate stepwise stability constants (log k) at phenolic group (Tables 318)

Table 3: Point-wise method, $\mathrm{Cu}$-(Hydrolysed PSHA)

\begin{tabular}{|l|l|l|l|l|l|l|l|l|}
\hline $\mathrm{pH}$ & $\mathrm{BV}_{1}$ & $\mathrm{BV}_{2}$ & $\mathrm{BV}_{3}$ & $\left(\mathrm{~V}_{3}-\mathrm{V}_{2}\right)$ & $\mathrm{n}$ & $\mathrm{pL}$ & $\log \left(\frac{n}{1-n}\right)$ & LogK $_{1}$ \\
\hline 8.50 & 5.30 & 6.29 & 6.33 & 0.04 & 0.5500 & 2.66 & 0.0871 & 2.7471 \\
8.72 & 5.35 & 6.37 & 6.41 & 0.04 & 0.5714 & 2.43 & 0.1249 & 2.5549 \\
9.00 & 5.40 & 6.46 & 6.50 & 0.04 & 0.6198 & 2.16 & 0.2122 & 2.3722 \\
9.22 & 5.45 & 6.55 & 6.59 & 0.04 & 0.6667 & 1.94 & 0.3010 & 2.2410 \\
\hline
\end{tabular}

LogK $_{1}$ (Average value) $=2.4788 \pm 0.2203$

Table 4: Point-wise method, $\mathrm{Cu}$-(Hydrolysed PSHA)

\begin{tabular}{|l|l|l|l|l|l|l|l|l|}
\hline $\mathrm{pH}$ & $\mathrm{BV}_{1}$ & $\mathrm{BV}_{2}$ & $\mathrm{BV}_{3}$ & $\left(\mathrm{~V}_{3}-\mathrm{V}_{2}\right)$ & $\mathrm{n}$ & $\mathrm{pL}$ & $\log \left(\frac{n-1}{2-n}\right)$ & LogK $_{2}$ \\
\hline 9.51 & 5.50 & 6.66 & 6.73 & 0.07 & 1.3509 & 1.70 & -0.2671 & 1.4329 \\
9.73 & 5.55 & 6.78 & 6.85 & 0.07 & 1.6383 & 1.51 & 0.2467 & 1.7567 \\
10.00 & 5.60 & 6.90 & 6.98 & 0.08 & 2.1783 & 1.31 & -0.2158 & 1.0942 \\
10.23 & 5.65 & 7.05 & 7.13 & 0.08 & 4.1904 & 1.27 & & \\
10.49 & 5.70 & 7.10 & 7.19 & 0.09 & 4.6920 & & & \\
\hline
\end{tabular}

Log $K_{2}($ Average value $)=1.4280 \pm 0.3312$ 
BAJOPAS Volume 14 Number 1,June, 2021

Table 5: Point-wise method, $\mathrm{Cu}$ (Unhydrolysed PSHA)

\begin{tabular}{|l|l|l|l|l|l|l|l|l|}
\hline $\mathrm{pH}$ & $\mathrm{BV}_{1}$ & $\mathrm{BV}_{2}$ & $\mathrm{BV}_{3}$ & $\left(\mathrm{~V}_{3}-\mathrm{V}_{2}\right)$ & $\mathrm{n}$ & $\mathrm{pL}$ & $\log \left(\frac{n}{n-1}\right)$ & Log $_{1}$ \\
\hline 8.50 & 5.30 & 5.81 & 5.85 & 0.04 & 0.2973 & 2.88 & -0.3736 & 2.5064 \\
8.72 & 5.35 & 5.90 & 5.95 & 0.05 & 0.3873 & 2.66 & -0.1992 & 2.4608 \\
9.00 & 5.40 & 6.00 & 6.05 & 0.05 & 0.4044 & 2.38 & -0.1681 & 2.2119 \\
9.22 & 5.45 & 6.10 & 6.15 & 0.06 & 0.5157 & 2.18 & -0.0272 & 2.2072 \\
9.51 & 5.50 & 6.20 & 6.27 & 0.07 & 0.6417 & 1.89 & 0.2530 & 1.1430 \\
\hline
\end{tabular}

$\operatorname{LogK}_{1}($ Average value $)=2.3059 \pm 0.6153$

Table 6:Point-wise method, $\mathrm{Cu}$ (Unhydrolysed PSHA)

\begin{tabular}{|l|l|l|l|l|l|l|l|l|}
\hline $\mathrm{pH}$ & $\mathrm{BV}_{1}$ & $\mathrm{BV}_{2}$ & $\mathrm{BV}_{3}$ & $\mathrm{~V}_{3}-\mathrm{V}_{2}$ & $\mathrm{n}$ & $\mathrm{pL}$ & $\log \left(\frac{n-1}{2-n}\right)$ & $\log \mathrm{K}_{2}$ \\
\hline 9.73 & 5.55 & 6.33 & 6.42 & 0.09 & 0.9000 & 1.69 & & \\
10.00 & 5.60 & 6.47 & 6.58 & 0.11 & 1.2578 & 1.44 & -0.4592 & 0.9808 \\
10.23 & 5.65 & 6.62 & 6.84 & 0.12 & 1.6137 & 1.26 & -0.2010 & 1.4610 \\
10.49 & 5.70 & 6.80 & 6.92 & 0.12 & 2.1052 & 1.03 & & \\
\hline
\end{tabular}

$\operatorname{LogK}_{2}$ (Average value) $=1.2209 \pm 0.3398$

Table 7:Point-wise method, Pb (Hydrolysed PSHA)

\begin{tabular}{|l|l|l|l|l|l|l|l|l|}
\hline $\mathrm{pH}$ & $\mathrm{BV}_{1}$ & $\mathrm{BV}_{2}$ & $\mathrm{BV}_{3}$ & $\left(\mathrm{~V}_{3}-\mathrm{V}_{2}\right)$ & $\mathrm{n}$ & $\mathrm{pL}$ & $\log \left(\frac{n}{1-n}\right)$ & LogK $_{1}$ \\
\hline 8.50 & 5.30 & 6.29 & 6.33 & 0.04 & 0.5500 & 2.66 & 0.0871 & 2.7471 \\
8.72 & 5.35 & 6.37 & 6.41 & 0.04 & 0.5714 & 2.43 & 0.1249 & 2.5549 \\
9.00 & 5.40 & 6.46 & 6.50 & 0.04 & 0.6198 & 2.16 & 0.2122 & 2.3722 \\
9.22 & 5.45 & 6.55 & 6.60 & 0.05 & 0.8333 & 1.96 & 0.6989 & 2.6589 \\
\hline
\end{tabular}

Log $_{\mathbf{1}}($ Average value $)=2.5832 \pm 0.1614$

Table 8:Point-wise method, Pb-(Hydrolysed PSHA)

\begin{tabular}{|l|l|l|l|l|l|l|l|l|}
\hline $\mathrm{pH}$ & $\mathrm{BV}_{1}$ & $\mathrm{BV}_{2}$ & $\mathrm{BV}_{3}$ & $\left(\mathrm{~V}_{3}-\mathrm{V}_{2}\right)$ & $\mathrm{n}$ & $\mathrm{pL}$ & $\log \left(\frac{n-1}{2-n}\right)$ & $\log \mathrm{K}_{2}$ \\
\hline 9.51 & 5.50 & 6.66 & 6.71 & 0.05 & 0.9650 & 1.67 & & \\
9.73 & 5.55 & 6.78 & 6.83 & 0.05 & 1.1702 & 1.44 & & \\
10.00 & 5.60 & 6.90 & 6.90 & 0.05 & 1.4864 & 1.22 & -0.0237 & 1.1963 \\
10.23 & 5.65 & 7.05 & 7.10 & 0.05 & 2.0190 & 1.09 & & \\
10.49 & 5.70 & 7.10 & 7.17 & 0.07 & 3.6492 & 1.00 & & \\
\hline
\end{tabular}

Log $K_{2}$ (Average value) $=1.1963$

Table 9: Point-wise method, Pb (Unhydrolysed PSHA)

\begin{tabular}{|l|l|l|l|l|l|l|l|l|}
\hline $\mathrm{pH}$ & $\mathrm{BV}_{1}$ & $\mathrm{BV}_{2}$ & $\mathrm{BV}_{3}$ & $\mathrm{~V}_{3}-\mathrm{V}_{2}$ & $\mathrm{n}$ & $\mathrm{pL}$ & $\begin{array}{l}\text { Log } \\
\left(\frac{n}{n-1}\right)\end{array}$ & Log $\mathrm{K}_{1}$ \\
\hline 8.50 & 5.30 & 5.81 & 5.85 & 0.04 & 0.2973 & 2.88 & -0.3736 & 2.5064 \\
8.72 & 5.35 & 5.90 & 5.94 & 0.04 & 0.3099 & 2.66 & -0.5477 & 2.3123 \\
9.00 & 5.40 & 6.00 & 6.05 & 0.05 & 0.4044 & 2.38 & -0.1681 & 2.2119 \\
9.22 & 5.45 & 6.10 & 6.15 & 0.06 & 0.5157 & 2.18 & 0.0272 & 2.2072 \\
9.51 & 5.50 & 6.20 & 6.26 & 0.07 & 0.6417 & 1.89 & 0.2530 & 2.1430 \\
9.73 & 5.55 & 6.40 & 6.40 & 0.07 & 0.7000 & 1.67 & 0.3680 & 2.0380 \\
\hline
\end{tabular}

LogK $_{1}$ (Average value) $=2.2364 \pm 0.1602$

Table 10: Point-wise method, Pb (Unhydrolysed PSHA)

\begin{tabular}{|l|l|l|l|l|l|l|l|l|}
\hline $\mathrm{pH}$ & $\mathrm{BV}_{1}$ & $\mathrm{BV}_{2}$ & $\mathrm{BV}_{3}$ & $\mathrm{~V}_{3}-\mathrm{V}_{2}$ & $\mathrm{n}$ & $\mathrm{pL}$ & $\log \left(\frac{n-1}{2-n}\right)$ & $\log \mathrm{K}_{2}$ \\
\hline 10.00 & 5.60 & 6.47 & 6.55 & 0.08 & 1.9503 & 1.41 & & \\
10.23 & 5.65 & 6.62 & 6.72 & 0.11 & 1.4792 & 1.26 & -0.0361 & 1.2239 \\
\hline
\end{tabular}

$\operatorname{LogK}_{2}$ (Average value) $=1.2239$

Table 11: Point-wise method, Mg (Hydrolysed PSHA)

\begin{tabular}{|l|l|l|l|l|l|l|l|l|}
\hline $\mathrm{pH}$ & $\mathrm{BV}_{1}$ & $\mathrm{BV}_{2}$ & $\mathrm{BV}_{3}$ & $\left(\mathrm{~V}_{3}-\mathrm{V}_{2}\right)$ & $\mathrm{n}$ & $\mathrm{pL}$ & $\log \left(\frac{n}{n-1}\right)$ & LogK $_{1}$ \\
\hline 8.50 & 5.30 & 6.29 & 6.31 & 0.02 & 0.2750 & 2.64 & -0.4290 & 2.2110 \\
8.72 & 5.35 & 6.37 & 6.39 & 0.02 & 0.2858 & 2.42 & -0.3978 & 2.0222 \\
9.00 & 5.40 & 6.46 & 6.49 & 0.03 & 0.4648 & 2.14 & -0.0612 & 2.0788 \\
9.22 & 5.45 & 6.55 & 6.59 & 0.04 & 0.6667 & 1.94 & 0.3010 & 2.2410 \\
\hline
\end{tabular}

$\log _{\mathbf{1}}($ Average value) $=2.1382 \pm 0.1046$ 
BAJOPAS Volume 14 Number 1,June, 2021

Table 12: Point-wise method, Mg (Hydrolysed PSHA)

\begin{tabular}{|l|l|l|l|l|l|l|l|l|}
\hline $\mathrm{pH}$ & $\mathrm{BV}_{1}$ & $\mathrm{BV}_{2}$ & $\mathrm{BV}_{3}$ & $\left(\mathrm{~V}_{3}-\mathrm{V}_{2}\right)$ & $\mathrm{n}$ & $\mathrm{pL}$ & $\log \left(\frac{n-1}{2-n}\right)$ & LogK $_{2}$ \\
\hline 9.51 & 5.55 & 6.66 & 6.71 & 0.05 & 0.9650 & 1.67 & & \\
9.73 & 5.55 & 6.78 & 6.84 & 0.06 & 1.4042 & 1.47 & -0.1686 & 1.3014 \\
10.00 & 5.60 & 6.90 & 6.93 & 0.06 & 1.7838 & 1.23 & 0.5593 & 1.7893 \\
10.23 & 5.65 & 7.05 & 7.10 & 0.06 & 3.1429 & 1.10 & & \\
10.49 & 5.70 & 7.10 & 7.18 & 0.07 & 3.6492 & 0.83 & & \\
\hline
\end{tabular}

LogK $_{2}($ Average value $)=1.5453 \pm 0.3450$

Table 13: Point-wise method, Mg (Unhydrolysed PSHA)

\begin{tabular}{|l|l|l|l|l|l|l|l|l|}
\hline $\mathrm{pH}$ & $\mathrm{BV}_{1}$ & $\mathrm{BV}_{2}$ & $\mathrm{BV}_{3}$ & $\mathrm{~V}_{3}-\mathrm{V}_{2}$ & $\mathrm{n}$ & $\mathrm{pL}$ & $\log \left(\frac{n}{n-1}\right)$ & $\operatorname{Log~}_{1}$ \\
\hline 8.50 & 5.30 & 5.81 & 5.85 & 0.04 & 0.2973 & 2.88 & -0.3736 & 2.5064 \\
8.72 & 5.35 & 5.90 & 5.94 & 0.04 & 0.3099 & 2.66 & -0.3477 & 2.3123 \\
9.00 & 5.40 & 6.00 & 6.04 & 0.04 & 0.3236 & 2.38 & -0.3202 & 2.0598 \\
9.22 & 5.45 & 6.10 & 6.15 & 0.05 & 0.4297 & 2.17 & -0.1230 & 2.0470 \\
9.51 & 5.50 & 6.20 & 6.26 & 0.06 & 0.5500 & 1.89 & 0.0871 & 1.9771 \\
9.73 & 5.55 & 6.33 & 6.40 & 0.07 & 0.7000 & 1.67 & 0.3680 & 2.0380 \\
\hline
\end{tabular}

LogK $_{1}$ (Average value) $=2.1568 \pm 0.2069$

Table 14: Point-wise method, Mg (Unhydrolysed PSHA)

\begin{tabular}{|l|l|l|l|l|l|l|l|l|}
\hline $\mathrm{pH}$ & $\mathrm{BV}_{1}$ & $\mathrm{BV}_{2}$ & $\mathrm{BV}_{3}$ & $\mathrm{~V}_{3}-\mathrm{V}_{2}$ & $\mathrm{n}$ & $\mathrm{pL}$ & $\log \left(\frac{n-1}{2-n}\right)$ & $\log \mathrm{K}_{2}$ \\
\hline 10.00 & 5.60 & 6.47 & 6.55 & 0.08 & 0.9148 & 1.41 & & \\
10.23 & 5.65 & 6.62 & 6.71 & 0.09 & 1.2102 & 1.20 & -0.5749 & 0.6251 \\
10.49 & 5.70 & 6.80 & 6.92 & 0.09 & 1.5968 & 1.03 & 0.1703 & 1.2003 \\
\hline
\end{tabular}

LogK $_{2}$ (Average value) $=0.9127 \pm 0.4070$

Table15:Point-wise method, Cd (Hydrolysed PSHA)

\begin{tabular}{|l|l|l|l|l|l|l|l|l|}
\hline $\mathrm{pH}$ & $\mathrm{BV}_{1}$ & $\mathrm{BV}_{2}$ & $\mathrm{BV}_{3}$ & $\left(\mathrm{~V}_{3}-\mathrm{V}_{2}\right)$ & $\mathrm{n}$ & $\mathrm{pL}$ & $\log \left(\frac{n}{1-n}\right)$ & LogK $_{1}$ \\
\hline 8.50 & 5.30 & 6.29 & 6.31 & 0.02 & 0.2750 & 2.64 & -0.4210 & 2.2190 \\
8.72 & 5.35 & 6.37 & 6.40 & 0.03 & 0.4286 & 2.42 & -0.1249 & 2.2951 \\
9.00 & 5.40 & 6.46 & 6.49 & 0.03 & 0.4648 & 2.14 & -0.0612 & 2.0788 \\
9.22 & 5.45 & 6.55 & 6.59 & 0.04 & 0.6667 & 1.96 & 0.3010 & 2.2610 \\
9.51 & 5.55 & 6.66 & 6.70 & 0.04 & 0.7720 & 1.67 & 0.5297 & 2.1997 \\
\hline
\end{tabular}

LogK $_{\mathbf{1}}$ (Average value) $=2.2108 \pm 0.0825$

Table 16: Point-wise method, Cd (Hydrolysed PSHA)

\begin{tabular}{|l|l|l|l|l|l|l|l|l|}
\hline $\mathrm{pH}$ & $\mathrm{BV}_{1}$ & $\mathrm{BV}_{2}$ & $\mathrm{BV}_{3}$ & $\left(\mathrm{~V}_{3}-\mathrm{V}_{2}\right)$ & $\mathrm{n}$ & $\mathrm{pL}$ & $\log \left(\frac{n-1}{2-n}\right)$ & Log $_{2}$ \\
\hline 9.73 & 5.55 & 6.78 & 6.83 & 0.06 & 1.4042 & 1.47 & -0.1686 & 1.3014 \\
10.00 & 5.60 & 6.90 & 6.95 & 0.06 & 1.7838 & 1.23 & 0.5593 & 1.7893 \\
10.23 & 5.65 & 7.05 & 7.10 & 0.06 & 3.1429 & 1.09 & & \\
10.49 & 5.70 & 7.10 & 7.16 & 0.06 & 3.1429 & 0.89 & & \\
& & & & & & & & \\
\hline
\end{tabular}

$\operatorname{LogK}_{2}$ (Average value) $=1.5453 \pm 0.3450$

Table 17: Point-wise method, Cd (Unhydrolysed PSHA)

\begin{tabular}{|l|l|l|l|l|l|l|l|l|}
\hline $\mathrm{pH}$ & $\mathrm{BV}_{1}$ & $\mathrm{BV}_{2}$ & $\mathrm{BV}_{3}$ & $\mathrm{~V}_{3}-\mathrm{V}_{2}$ & $\mathrm{n}$ & $\mathrm{pL}$ & $\log \left(\frac{n}{n-1}\right)$ & $\operatorname{Log~}_{1}$ \\
\hline 8.50 & 5.30 & 5.81 & 5.86 & 0.05 & 0.3717 & 2.88 & -0.2280 & 2.6520 \\
8.72 & 5.35 & 5.90 & 5.95 & 0.05 & 0.3873 & 2.66 & -0.1992 & 2.4608 \\
9.00 & 5.40 & 6.00 & 6.06 & 0.06 & 0.4853 & 2.38 & -0.0255 & 2.3545 \\
9.22 & 5.45 & 6.10 & 6.16 & 0.06 & 0.5157 & 2.18 & -0.0272 & 2.2072 \\
9.51 & 5.50 & 6.20 & 6.27 & 0.07 & 0.6417 & 1.89 & 0.2530 & 1.1430 \\
9.73 & 5.55 & 6.33 & 6.41 & 0.08 & 0.8000 & 1.69 & 0.6020 & 2.2920 \\
& & & & & & & & \\
\hline
\end{tabular}

$\operatorname{LogK}_{1}($ Average value $)=2.2516 \pm 0.5380$ 
BAJOPAS Volume 14 Number 1,June, 2021

Table 18: Point-wise method, Cd (Unhydrolysed PSHA)

\begin{tabular}{|l|l|l|l|l|l|l|l|l|}
\hline $\mathrm{pH}$ & $\mathrm{BV}_{1}$ & $\mathrm{BV}_{2}$ & $\mathrm{BV}_{3}$ & $\mathrm{~V}_{3}-\mathrm{V}_{2}$ & $\mathrm{n}$ & $\mathrm{pL}$ & $\log \left(\frac{n-1}{2-n}\right)$ & $\log \mathrm{K}_{2}$ \\
\hline 10.00 & 5.60 & 6.47 & 6.57 & 0.10 & 1.1434 & 1.43 & & \\
10.23 & 5.65 & 6.62 & 6.72 & 0.10 & 1.3448 & 1.23 & -0.2788 & 0.9512 \\
10.49 & 5.70 & 6.80 & 6.90 & 0.10 & 1.7742 & 1.03 & 0.5351 & 1.5651 \\
\hline
\end{tabular}

$\operatorname{LogK}_{2}($ Average value $)=1.2581 \pm 0.4340$

Table 19: Stepwise and overall Stability constants of thehydrolysed and unhydrolysed divalent metal (II) complexes

\begin{tabular}{|c|c|c|c|}
\hline Chelates & LogK $_{1}$ & $\log _{2}$ & Log $\beta$ \\
\hline [Cu (Hydrolysed PSHA-1) $\left.{ }_{2}\right]$ & 2.4788 & 1.4280 & 3.9068 \\
\hline$\left[\mathrm{Pb}(\text { Hydrolysed PSHA-1) })_{2}\right]$ & 2.5832 & 1.1963 & 3.7795 \\
\hline$\left[\mathrm{Cd}(\text { Hydrolysed PSHA-1 })_{2}\right]$ & 2.2108 & 1.5453 & 3.7561 \\
\hline$\left[\mathrm{Mg}(\text { Hydrolysed PSHA-1 })_{2}\right]$ & 2.1382 & 1.5453 & 3.6835 \\
\hline [Cu (Unhydrolysed PSHA-1) & 2.3059 & 1.2209 & 3.5268 \\
\hline$[\mathrm{Pb}$ (Unhydrolysed PSHA-1) 2$]$ & 2.2364 & 1.2239 & 3.4603 \\
\hline [Cd (Unhydrolysed PSHA-1) 2 ] & 2.2516 & 1.2581 & 3.5097 \\
\hline$[\mathrm{Mg}$ (Unydrolysed PSHA-1) & 2.1568 & 0.9127 & 3.0695 \\
\hline
\end{tabular}

The results obtained (Table19) shows the stepwise and overall stability constants to be not high indicating low stability of the complexes, because the solubility of most metal ions in the basic $\mathrm{pH}$ range is minimal due to metal hydroxide precipitation (Karimi, 2017). In general, the stepwise stability constants $\left(K_{1}\right.$ and $K_{2}$ ) follow the order $K_{1}>K_{2}$ for the copper, lead, magnesium and cadmium complexes respectively. The steady decrease of the values with increasing number of ligands is in agreement with the prediction made by researchers (Na'aliya, 2013). The decrease could be attributed to the fact that as the number of the ligands (Humate ions) that enters the coordination zone increases the aqua molecules available for replacement by the ligands become less. Thus, the metal ions become less electron loving with progressive intake of the ligand and this results in the decrease in the values of the constants (Na'aliya, 2013). Also the stability of the complexes is influenced by the size and number of the chelate rings(Mackay and Mackay,2002).All the complexes form rings in their structure as humate, a bidentate ligand, bond the metal ions in the ratio 1:2 (Boguta and Sokolowska, 2016) forming chelate rings. The values of the overall stability constants $(\log \beta)$ obtained for humate complexes are not high indicating low stability as the values are not high. LogK values for copper-humates (Table 3 to 6) obtained in this study are lower than those reported for the complexes of humic acids (Pandey et al., 2015; Dinu, 2013; Kaschl et al., 2010 and Gilbeto and Jorg, 2001). The values of LogK(Table 7 to 10 ) forlead-humates are lower than those reported for the lead in the literature (Dinu, 2013; Gilbeto and Jorg 2001). Log K values(Table 11 to 14 ) for magnesium-humates obtained in this study are close to those reported by (Pandey et al., 2015). Log K values of cadmium-humates (Table 15 to 18 ) obtained in this work near to the one reported by (Dinu, 2013 and Pandey et al., 2015).The difference between the reported values and the values obtained in this study might be probably as a result of acid hydrolysis of humic acid. The values of the overall stability constants $(\log \beta)$ of the copper humates complexes presented in Table 19 is high than that of other metal humate complexes, show relatively high stability of CuHA complexes, show the following order of stability: $\mathrm{Cu}>\mathrm{Pb}>\mathrm{Cd}>\mathrm{Mg}$; which are in close agreement to the findings of (Dinu, 2013 and Pandey et al., 2015).The high stability of Cuhumate chelate could be attributed to the existence of coordinate covalent bond between the complexing agents and the $\mathrm{Cu}^{2+}$ ions. Since, $\mathrm{Cu}^{2+}$ being a metal of the transitional series with $3 d^{9}$ electronic configurations can accept the electrons from the complexing agents. Similarly, the low stabilities of $\mathrm{Pb}, \mathrm{Cd}$ and $\mathrm{Mg}$ complexes could be explained by that $\mathrm{Pb}^{2+}$ with $6 s^{2}, \mathrm{Cd}^{2+}$ with $4 \mathrm{~d}^{10}$ and $\mathrm{Mg}^{2+}$ with $2 \mathrm{p}^{6}$ their electronic configuration has a completely filled $\mathrm{d}, \mathrm{p}$ and $\mathrm{s}$ orbitals. Moreover, the stabilities of metal ions with hydrolysed humic acid from peat soil were higher than those with unhydrolysed humic acid from peat soil; which is ascribed to the high content of acidity in hydrolysed humic acid than unhydrolysed humic acid. 
BAJOPAS Volume 14 Number 1,June, 2021 CONCLUSION

The values of logk for $\mathrm{Cu}(\mathrm{II})$ hydrolysed humic acid complex was higher followed by $\mathrm{Pb}$ (II), $\mathrm{Cd}(\mathrm{II})$ and $\mathrm{Mg}$ (II) hydrolysed humic acid complexes as compared with metal(II) unhydrolysed humic acid complexes. This indicates acid hydrolysis of humic acid can

\section{REFERENCES}

Almeida, V.R. and Szpoganicz, B. (2015). Humic Acid Potentiometric Response Patterns:Out- of Equilibrium Properties and Species Distribution Modelling. Chemical. Biol. Technol. Agric. 2: 17.

Anđelković, T., Nikolić, R., Bojić, A.,Anđelković, D., and Nikolic G.,(2010). Binding of Cadmium to Soil Humic Acid as A Function of Carboxyl Group Content. Macedonian Journal of Chemistry and Chemical Engineering.29(2): 215-224.

Anil, B. N. and Maroti, N. (2008). Studies on Influence of Die-Lectric Constants on Complex Equilibria between Substituted Py-Razalines and Lanthanide Metal Ions pH-Metrically. Amer.-Euras. scient. Res. 3(2): 212-216.

Ashok, K., Pandey, S. P. and Misra, V (2000). Stability Constants of Metal-Humic Acid Complexes and its Role in Environmental Detoxification. Journal of Ecotoxicology and Environmental Safety. 47(2):157-200.

Badr, M. H., El-Halafawi, M. H. and Abd El-al Zeid, E. R. (2012). Comparison Between the Effect of Ionic Strength on Acidity and Dissociation Constants of Humic Acids Extracted from Sewage Sludge and Nile Water Hyacinth Composts.Global Journal of Environmental Research 6 (1): 36-43.

Baruah, M.K., Borah, D., Saikia, P.P., Paul, S., Sharma, T. (2015). Evaluation of pKa Values of Soil Humic Acids and their Complexation Properties. International Journal of Plant \& Soil Science 6(4) : 218-228.

Boguta, P. Sokolowska, Z. (2016). Interactions of $\mathrm{Zn}$ (II) Ions with Humic Acids Isolated from Various Types of Soils. Effect of $\mathrm{pH}, \mathrm{Zn}$ Concentrations and Humic Acids Chemical Properties. Journal of Geochemical Explaration 168. 119-126.

Borges, F., Guimaraes, C., Lima, L.F.C., Pinto, I. and Reis, S.(2005). Potentiometric Studies on the Complexation of Copper(II) by Phenolic Acids as Discrete Ligand Models of enhance the complexation behavior of humic acid with metal (II) ions. However, the higher values of $\log \beta$ for $\mathrm{Cu}(\mathrm{II}), \mathrm{Pb}(\mathrm{II}), \mathrm{Cd}(\mathrm{II})$ and $\mathrm{Mg}(\mathrm{II})$ hydrolysed humic acid complexes indicates more stable stepwise complexes formed as compared with $\mathrm{Cu}(\mathrm{II}), \mathrm{Pb}$ (II), $\mathrm{Cd}$ (II) and $\mathrm{Mg}(\mathrm{II})$ unhydrolysed humic acid complexes.

Humic Substances Talanta 66 (2005) 670-673.

Chefetz, B., Salloum, M. J., Deshmulkin, A. P. and Hatcher, P. (2002). Structural Components of Humic Acids as Determined by Chemical Modifications and Carbon-13 NMR, Pyrolysis, and Thermochemolysis- Gas Chromatography/Mass Spectrometry. Soil Science Society of American Journal Abstract Division S-2- Soil Chemistry66. 1159-1171.

Dinu, M. I. (2013). Metals Complexation with Humic Acids in Surface Water of Different Environ. Sci. Technol. 31(1): 1-17.

Fernandes, A.N., Giacomelli, C., Giovanela, M. Vaz, D.V. Szpoganicz, B. and Maria M. D. (2009). Potentiometric Acidity Determination in Humic Substances Influenced by Different Analytical Procedures.J. Braz. Chem. Soc. 20 (9):14.

Gamal, A. H. (2015). Stability Constants of Rhenium (V) Metal Complexes with Selected Drugs. Pyrex Journal of Research in Environmental Studies. 2(2): 006-014.

Janrao, D. M., Pathan, J., Kayande, D.D., and Mulla, J.J. (2014). An Over View of Potentiometric Determination of Stability Constants of Metal Complexes. Sci. Revs. Chem. Commun.: 4(1), 2014, 11-24.

Karimi, H. (2017). Effect of pH and Initial Pb(II) Concentration on the Lead Removal Efficiency from Waste Water Using $\mathrm{Ca}(\mathrm{OH})_{2}$. International Journal of Water and Waste Water Treatment 3.2

Kaschl, A. Romheld, V. and Chen, Y. (2010). Binding of Cadmium, Copper and Zinc to Humic Substances Originating from Municipal Solid Waste Compost. Israel Journal of Chemistry Vol. 42(1): 89-98.

Kostic, I. S., Tatjana, P, A., Nikolic, R. S., Cvetkovic, T. P., Pavlovic, D. D., Aleksandar, L.J. and Bojic, A. (2012). Comparative Study of Binding Strengths of Heavy Metals with Humic Acid. J.serb. Chem. Soc. 76(9) pp 1-20. 
BAJOPAS Volume 14 Number 1,June, 2021

Na'aliya, J. (2013). Determination of Stepwise Stability Constants and Gibbs free Energy Change of Trisprolina to Complexes of some Divalent Transition Metal ions. Bayero Journal of Pure and Applied Sciences 6(2): 112-114.

Omar, A. A. and Ali, E. A. (2015). Potentiometric Studies on Complexes of $\mathrm{Cr}$ (III) and $\mathrm{Zr}$ (IV) with some Carboxylic Acids. International Journal of Advanced Chemistry, 3(1) 25-

37.

Pandey, A. K. Pandey, S. D. and Misr, V. (2015).Stability Constants of Metal- Humic Acid Complexes and Its Role in Environmental Detoxification. J. Ecotoxicology and Environmental Safety. 47(1):195-200.

Ram, N. and Raman, K.V. (1984). Stability Constants of Complexes of Metals with
Humicand Fuvic Acids under Non- acidConditions. Journal of Plant Nutrition and Soil Sciences.

147:171-176.

Santosh, D. D., Ashok, B. K., Vijay, J. T., Shivraj, G. W. and Vinay, V. W. (2011). Potentiometric Studies of Elec-Trolyte Effects on Complex Equilibria of Some Substituted 5-(2-hydroxy Phenyl) Pyrazoles. Der pharm. 3 (6): 75-83.

Sayyed, H. and Abdul Rahim, M. F. (2012). Studies of Binary Complexes of Metal Ions with Mandelic Acid by Potentiometry. Chem. J. 02 (6): 206209.

Shirvani, M. Moradian, E. Khalili, B. Bakhtiary, S. (2015). Interaction of $\mathrm{Cd}$ and $\mathrm{Pb}$ with Humate-Palygorskite and HumateSepiolite Complexes. Journal of water, air and pollution 3: 220-228. 


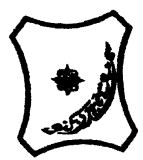

Bayero Journal of Pure and Applied Sciences, 14(1): 54 - 63

Received: November, 2020

Accepted: April, 2021

ISSN $2006-6996$

\title{
STABILITY CONSTANTS OF COMPLEXES OF METAL IONS WITH PEATSOIL HUMIC ACIDS UNDER NON-ACID-CONDITIONS
}

\author{
${ }^{* 1}$ Sabo, Yusuf ${ }^{2}$ Jimoh, W.L.O., ${ }^{3}$ Isa Baba Koki and ${ }^{4}$ Sholadoye, Q. 0. \\ ${ }^{1}$ Department of Pure and Industrial Chemistry, Bayero University, Kano \\ ${ }^{3}$ Department of Chemistry, Yusuf Maitama Sule University Kano. P.M.B. 3220 Kano, Nigeria. \\ ${ }^{4}$ Department of Chemistry, Nigerian Police Academy, Wudil, Kano-Nigeria
}

*Correspondence E-mail; saboyusuf18@yahoo.com

ABSTRACT

Stability constants of complexes of four divalent metal ions viz. $\mathrm{Cu}^{2+}, \mathrm{Pb}^{2+}, \mathrm{Mg}^{2+}$ and $\mathrm{Cd}^{2+}$ with humic acids (HA) were determined by potentiometric titration of humic acids with the corresponding salt of the divalent metals in aqueous media under non-acid-condition. The log $K$ (logarithm of the stability constant) ranged from 1.0942 to 2.7471 for metalhumic acid complexes were determined using point-wise computational method. The order of stability constants were obtained as follows: $\mathrm{Cu}>\mathrm{Pb}>\mathrm{Cd}>\mathrm{Mg}$ for metal $-\mathrm{HA}$ complexes respectively, indicating a higher degree of complexation with Cu metal ion.

Keywords: stability constant, humic acid, potentiometric titration, divalent metals, acid hydrolysis.

\section{NTRODUCTION}

The stability constant of a complex is the numerical expression of its stability and provides a quantitative measure of affinity of the metal ion to the complexing agent. An understanding of the relative stability of metal-complexes helps in predicting the behavior of metal ions in the soil (Ram and Raman, 1982). Extensive researches has been done to determine the stability constants of the complexes formed between humic acid (HA) with a number of metal ions. Ashok et al., (2000) reported that humic acid with hydroxyl, phenoxyl and carboxyl reactive groups can form coordination compound with metal ions at $\mathrm{pH}$ 3.5. The stability constants(Log K) for different metalhumic acid complexes indicated the following order of the stabilities of complexes formed between humic acid and metal ion, $\mathrm{Cu}>\mathrm{Fe}$ $>\mathrm{Pb}>\mathrm{Ni}>\mathrm{Co}>\mathrm{Ca}>\mathrm{Cd}>\mathrm{Zn}>\mathrm{Mn}>\mathrm{Mg}$. Andelkovic et al., (2010) investigated the binding of $\mathrm{Cd}$ (II) to soil humic acid at pH 6.5 and in $0.1 \mathrm{M} \mathrm{KNO}_{3}$ ionic medium. The stability constant for binding indicating greater stability in the case when carboxyl groups are involved in complexation reaction. Kostic et al.,(2012) investigated the complexation of humic acid with certain heavy metal ions (Co(II), $\mathrm{Ni}(\mathrm{II}), \mathrm{Cu}(\mathrm{II})$,
$\mathrm{Zn}(\mathrm{II})$, and $\mathrm{Pb}(\mathrm{II})$. The experiment was performed at $25^{\circ} \mathrm{C}$, at pH 4.0 and ionic strength of $0.01 \mathrm{M}$. Stability constant of complex between $\mathrm{Pb}$ (II) ions and humic acid is greater than stability constants of other investigated metalhumate complexes. Bogata and Sokolowska (2016) analyses the interaction between humic acids from different soils and $\mathrm{Zn}$ (II) ions at wide concentration ranges and at $\mathrm{pH} 5$. Studies have showed significant impact of $\mathrm{Zn}$ concentration, $\mathrm{pH}$ and some properties of humic acids with zinc.But all of these studies were limited to acidic $\mathrm{pH}$ range. Therefore, the present study was carried out to determine and compare the stability constants of complexes of metal ions with hydrolysed peat soil humic acid and unhydrolysed peat soil humic under non-acid conditions.

\section{MATERIALS AND METHODS}

Analytical grade chemicals used includes hydrochloric acid $(\mathrm{HCl})$, nitric acid $\left(\mathrm{HNO}_{3}\right)$, sodium hydroxide $(\mathrm{NaOH})$, lead nitrate $\mathrm{Pb}\left(\mathrm{NO}_{3}\right)_{2}$, copper nitrate $\mathrm{Cu}\left(\mathrm{NO}_{3}\right)_{2} \cdot 3 \mathrm{H}_{2} \mathrm{O}$, cadmium nitrate $\mathrm{Cd}\left(\mathrm{NO}_{3}\right)_{2} \cdot 4 \mathrm{H}_{2} \mathrm{O}$, magnesium nitrate $\mathrm{Mg}\left(\mathrm{NO}_{3}\right)_{2} \cdot 6 \mathrm{H}_{2} \mathrm{O}$, potassium nitrate $\left(\mathrm{KNO}_{3}\right)$, calcium chloride $\left(\mathrm{CaCl}_{2}\right)$, (sigma-Aldrich). Dowex 50WX8, (20-50 mesh) from Fluka. 


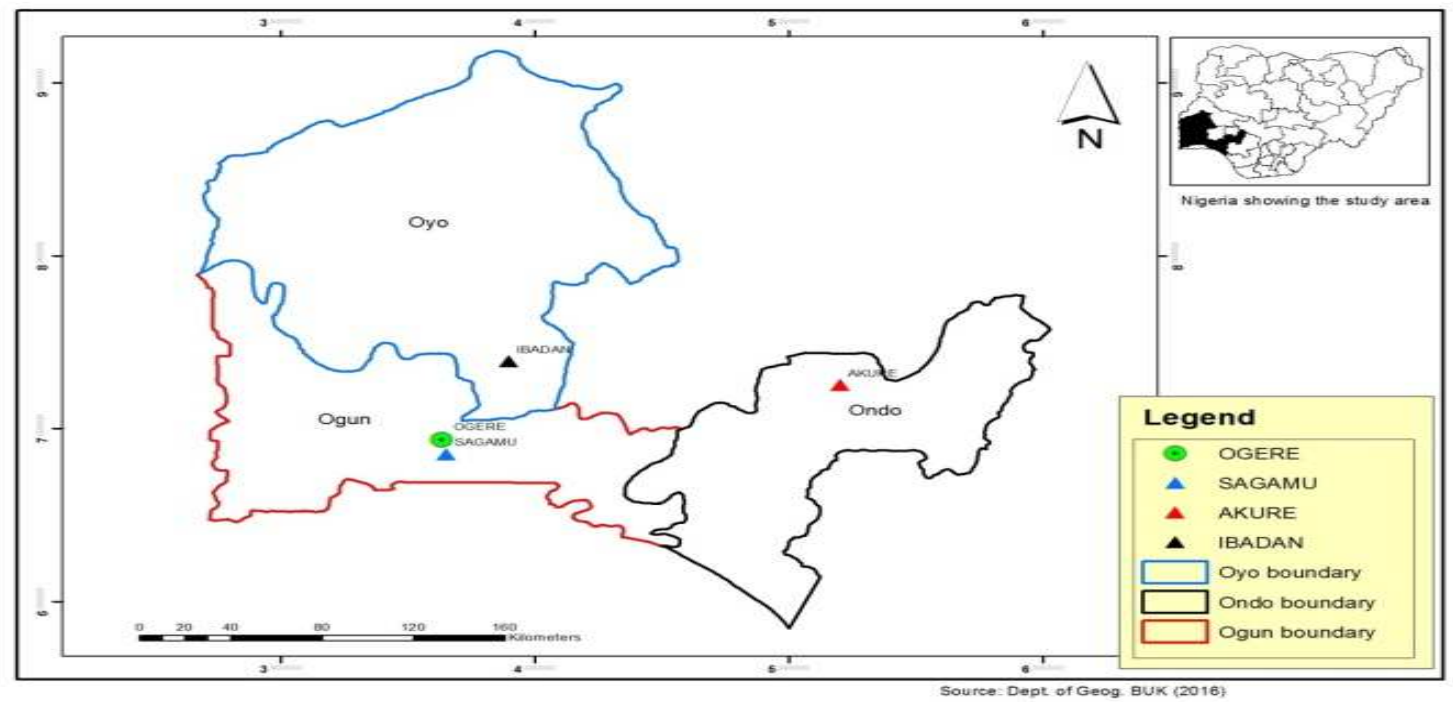

Figure 1: Map showing the sampling point at Sagamu Town, Ogun State.

\section{Description of Sampling Area}

Sagamu has geographical coordinates between $6^{\circ} 50^{\prime}$ north; $3^{\circ} 38^{\prime}$ east is located in south western region of Nigeria. The region has tropical wet and dry climate with a lengthy wet season and relatively constant temperatures throughout the course of the year. Wet season runs from March to October, November to December forms the region dry season. The vegetation type of the region is savannah which is really grassland with small bushes and occasional big trees. Grassland soils have substantially higher organic matter content than forest soils (Novackova, 2011).

\section{Sample Collection}

The Peatsoil samples were collected from four different sampling points $(0-10 \mathrm{~cm}$ depth) in Sagamu into polyethylene bag with plastic spoons. Samples were taken to the laboratory, extraneous materials were removed; the samples were air-dried, crushed and ground to a fine powder in a mortar passed through a $0.20 \mathrm{~mm}$ sieve. The samples were kept for analysis.

\section{Isolation and purification of humic acid from peat soil sample}

Peatsoil sample $(100 \mathrm{~g})$ was mixed with 1000 $\mathrm{cm}^{3}$ of $0.1 \mathrm{M} \mathrm{NaOH}$ solution, shaken for 3hours and left to stand overnight. Dark-coloured supernatant was obtained and decanted from solid residue. The dark-coloured supernatant was acidified to $(\mathrm{pH}=1.0)$ with $6 \mathrm{M} \mathrm{HCl}$ stirred and allowed to stand for 6 hours. Yellowish brown supernatant and dark-brown precipitate were obtained. The yellowish brown supernatant was decanted followed by centrifuge and discarded. The dark-brown precipitate was mixed with $500 \mathrm{~cm}^{3}$ of $0.1 \mathrm{M} \mathrm{NaOH}$ solution followed by passing through dowex resin. The dark-brown solution was acidified to $(\mathrm{pH}=1.0)$ with $6 \mathrm{M} \mathrm{HCl}$ stirred and allowed to stand for 3 hours. The dark-brown precipitate was washed several times with deionized water. The supernatant was treated with $\mathrm{AgNO}_{3}$ solution until no white precipitate observed. The humic acid was transferred to weighed crucible and dried at $60^{\circ} \mathrm{C}$ in an oven for 12 hours. The humic acid was cooled and dried in the desiccator, weighed and recorded. The obtained humic acid was dried again at $60^{\circ} \mathrm{C}$ for additional 6 hours cooled and dried in the desiccator, weighed and recorded constant weight was obtained (Baruah et al., 2015).

\section{FT-IR analysis}

FT-IR spectra of humic acid sample was analysed using Carry 630 FT-IR Agilent Technologies.

Unhydrolysed compost humic acid

The unhydrolysed humic acid was obtained after isolation and purification of compost humic acid and kept for investigation.

\section{Acid hydrolysis of Peatsoil acid}

Peatsoil humic acid sample (1g) was refluxed for 12 hours at $\left(160^{\circ} \mathrm{C}\right)$ with $50 \mathrm{~cm}^{3}$ of $6 \mathrm{M} \mathrm{HCl}$. The mixture was allowed to cool, decanted, and centrifuged after hydrolysis. The insoluble residues were washed with distilled water via centrifugation several times, and the supernatant was treated with $\mathrm{AgNO}_{3}$ solution until no white precipitate was observed. The residue was thoroughly dried over $\mathrm{CaCl}_{2}$ in a desiccator at room temperature (Chefetz et al., 2002). Finally, the obtained hydrolysed humic acid was kept for investigation. 
BAJOPAS Volume 14 Number 1,June, 2021 Potentiometric Titrations

Potentiometric measurements were carried out using a pH-meter Jenway (model 3510) with combine electrode, the sensitivity of the $\mathrm{pH}$ meter is 0.01 units. The $\mathrm{pH}$ meter was switched on half an hour before starting the titration for initial warm up of the instrument. The instrument was calibrated with an aqueous standard buffer solution of $\mathrm{pH} 4.00$ and 10.0 (borate buffer) prepared from a "Qualigens" buffer tablets.

The following sets of solutions were prepared in a $250 \mathrm{~cm}^{3}$ volumetric flask separately for $\mathrm{pH}$ metric titrations.

(i) $5 \mathrm{~cm}^{3} 0.1 \mathrm{M} \mathrm{HCl}+40 \mathrm{~cm}^{3}$ deionized water

(ii) $5 \mathrm{~cm}^{3} 0.1 \mathrm{M} \mathrm{HCl}+39 \mathrm{~cm}^{3}$ deionized water $+1 \mathrm{~cm}^{3} 0.15 \mathrm{gcm}^{-3}$ humic acid

(iii) $5 \mathrm{~cm}^{3} 0.1 \mathrm{M} \mathrm{HCl}+37 \mathrm{~cm}^{3}$ deionized water $+1 \mathrm{~cm}^{3} 0.15 \mathrm{gcm}^{-3}$ humic acid

$$
+2 \mathrm{~cm}^{3} \quad 0.01 \mathrm{M} \mathrm{Cu} \text { (II) }
$$

The solutions were titrated against standardized $0.110 \mathrm{MNaOH}$ separately. The total volume of each mixture was adjusted to $50 \mathrm{~cm}^{3}$ and the ionic strength of the solutions was maintained constant at by adding appropriate amount of stock solution of $1 \mathrm{M} \mathrm{KNO}_{3}$ (Gamal, 2015; Omar and Ali, 2015). A magnetic stirrer was used to achieve thorough mixing of the interacting solutions at $550 \mathrm{rpm}$. The same set of experimental conditions was applied for potentiometric titration of remaining samples.

\section{Evaluation of pKa of Hydrolysed peat soil Humic Acids}

The proton-ligand formation number $\mathrm{n}_{\mathbf{A}}$ were calculated by Irving and Rossotti expression (Omar and Ali, 2015).

$\mathrm{nA}=\mathrm{Y}-\frac{(\mathrm{V} 2-\mathrm{V1})(\mathrm{No}-\mathrm{Eo})}{(\mathrm{VO}+\mathrm{V1}) \mathrm{TCL}}$ 1

Where: $Y$ is number of dissociable proton, $\left(\mathrm{V}_{2^{-}}\right.$ $V_{1}$ ) is the measure of displacement of the ligand curve relative to acid curve, $\mathrm{N}^{\circ}$ and $\mathrm{E}^{\circ}$ are the resultant concentration of alkali solution, free acid solution, $\mathrm{T}_{\mathrm{cL}}{ }^{\circ}$ is the total ligand concentration, $\mathrm{V}^{\circ}$ is the total volume of titration solution, $V_{1}$ is the volume of alkali added to acid solution, $V_{2}$ is the volume of alkali added to acid solution + ligand solution, acid dissociation constants (pKa - values) of ligand were calculated by algebraic method point wise calculation (Tables 1 ). The dissociation constants (pKa) were calculated according to the following relation:

$\mathrm{pKa}=\mathrm{pH}+\log \left(\frac{n A}{1-n A}\right)$ 2

Where: pKa is the acid dissociation constant, $\mathrm{n}_{\mathrm{A}}$ is the Proton-ligand formation number and $\mathrm{pH}$ is the pH-values (Omar and Ali, 2015).

\section{Determination of metal-ligand stability constants $(\log K)$ of complexes}

The potentiometric measurement for the determination of stability constant of a complex in solution is based on the fact that the redox potential of the couple $\frac{M^{+(m-n)}}{M^{+m}}$ is shifted significantly on complexation of the metal ion with the ligand. This method involves change in hydrogen ion concentration $\left[\mathrm{H}^{+}\right]$due to the displacement or association of one or more protons taking place during complexation reaction. This change can be found out by titrating the solutions containing free acid, acid with ligand, and acid with ligand and metal ion, individually against a standard alkali solution at a constant ionic strength or temperature. Either ionic strength or temperature may be varied for different sets of solutions. In all the cases, the change in the $\mathrm{pH}$ of the solution is measured after each addition of a known amount of alkali to the reaction cell which contains the reaction mixture. The titration curves are then drawn by plotting the measured $\mathrm{pH}$ values against the corresponding volume of alkali added and the stability constants of the complexes are determined from the titration curves by employing $\mathrm{pH}$-metric titration technique given by (Irving and Rossoti).

Metal-ligand stability constants ( $\log \mathrm{K}$ ) were determined by using the following relations:

$$
\bar{n}=\frac{\left(V_{3}-V_{2}\right)\left(E^{0}+N^{0}\right)}{\left(V^{0}+V_{2}\right) \bar{n}_{A} T_{m}^{0}}
$$

and

$$
P L=\log _{10}\left\{\frac{1+\beta_{n}^{H} \frac{1}{[\text { anti } \log \mathrm{pH}]^{\mathrm{n}}}}{\mathrm{T}_{\mathrm{L}}^{0}-n \bar{T}_{m}^{0}} \mathrm{X} \frac{\left(V^{0}+V_{3}\right)}{V^{0}}\right\}
$$


BAJOPAS Volume 14 Number 1,June, 2021

Where $T_{L}, T^{\circ}, E^{\circ}$, and $V^{\circ}$ havethe same significance as in equation (1) above, $T_{m}$ denotes the total concentration of metal present in solution, $V_{3}$ is the volume of metal ions present in solution and $\beta^{H}$ is the overall proton ligand stability constant. The metal-ligand stability constants (log K) were determined by employing point wise computational Method (eq. 5 and 6).

$\operatorname{LogK}_{1}=\log \left(\frac{n}{1-n}\right)+\mathrm{pL}$ .5

$\operatorname{LogK}_{2}=\log \left(\frac{1-n}{2-n}\right)+\mathrm{pL}$ ...6

Where: Log $\mathrm{K}$ is the metal-ligand stability constant, $\mathrm{pL}$ is the Free ligand exponent function, $\mathbf{n}$ is the Average number of ligand attached with metal ion (Janraoet al., 2014). The results obtained were analyzed by an ORIGIN 2016 program using titration data and then the proton-ligand stability constants (pKa) and Metal-ligand stability constant (LogK) calculated (Omar and Ali, 2015).

\section{RESULTS AND DISCUSSION}

Fourier transformed infrared (FT-IR) spectra of isolated humic acid from peat soils Figure 2 had distinct clear absorption bands indicating the presence of major humic acid structural elemental groups such as $\mathrm{H}$ bonded $\mathrm{OH}$ $\left(3680 \mathrm{~cm}^{-1}\right.$ peak $), C=0$ of carbonyl $\left(1721 \mathrm{~cm}^{-1}\right.$ peak), functional groups of aliphatic components $\mathrm{CH}_{2}\left(2918 \mathrm{~cm}^{-1}\right.$ peak) and $\mathrm{C}-\mathrm{O}$ stretching of polysaccharide $\left(1168 \mathrm{~cm}^{-1}\right.$ peak). The positions of the absorption bands of the spectra fell within typical major absorption bands of humic acid which is at frequencies 3680, 2918, 1721, 1168 $\mathrm{cm}^{-1}$. The first peak centred in the vicinity of $3680 \mathrm{~cm}^{-1}$ region is attributed to phenol $\mathrm{OH}$ group bounded by intermolecular $\mathrm{H}$ bonds. The $2918 \mathrm{~cm}^{-1}$ band usually has absorption maximum at $2918 \mathrm{~cm}^{-1}$ which is due to $\mathrm{C}-\mathrm{H}$ stretching of alkane group $\left(\mathrm{CH}_{2}\right)$. The next major absorption band is $1721 \mathrm{~cm}^{-1}$. This band has been commonly ascribed to $\mathrm{C}=\mathrm{O}$ stretching of mainly carboxyl group $(\mathrm{COOH})$ with trace amount of ketones. The last peak was observed at 1168 $\mathrm{cm}^{-1}$ due to $\mathrm{C}-\mathrm{O}$ stretching of polysaccharides and this peak appeared also in the spectra of humic acid from peat soil. The FTIR spectra of the isolated humic acid contained all major characteristic absorption peaks of humic acid. These absorption peaks indicated the presence of the major structural elements of humic acid namely $\mathrm{H}$ bonded $\mathrm{OH}, \mathrm{C}=\mathrm{C}$ of aromatic ring, $\mathrm{C}=\mathrm{O}$ of carbonyl group (both carboxyl and ketonic), $\mathrm{CH}_{2}$ group. This strongly supports the presence of humic acid.

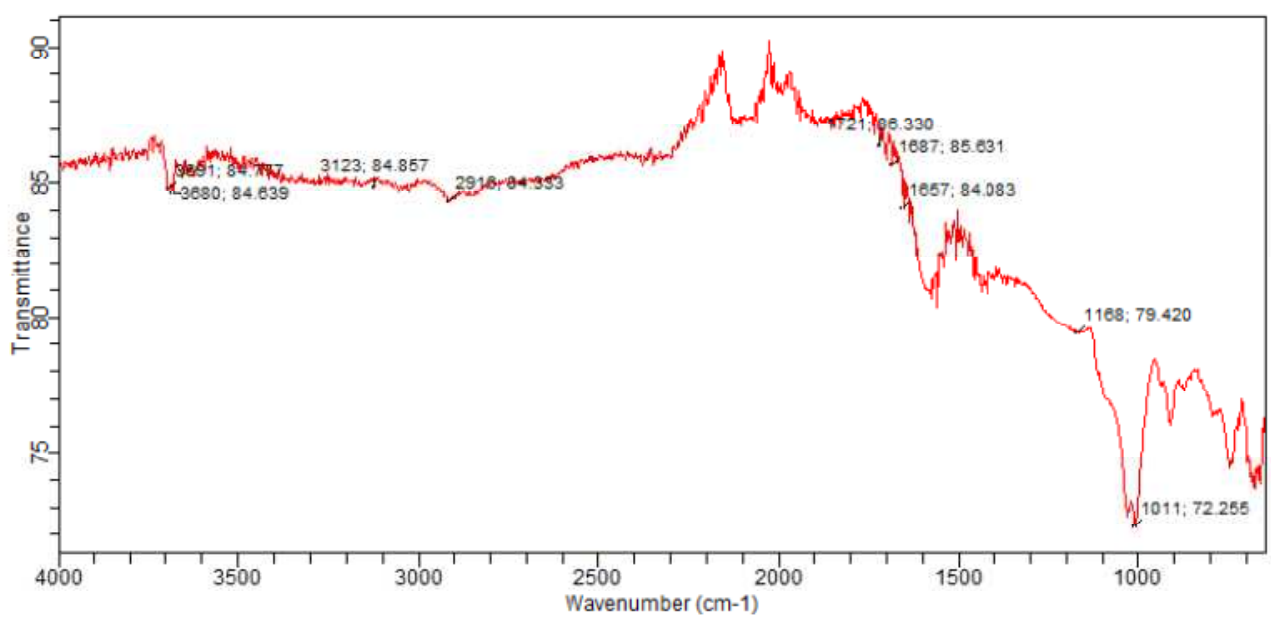

Fig. 2 : FT-IR spectraof peatsoilhumic acid (PSHA)

\section{Evaluation of acid dissociation constant (pka) of acid hydrolysed peat soil humicacid at phenolic group}

The value of the dissociation constant of the peat soil humic acid (PSHA) that underwent acidhydrolysis studied was found to be 8.9299 as shown Table 1, which is lower than the literaturevalues reported by Almeida and Szpoganics, (2015), Borges et al., (2005); Badr et al., (2012)and Fernandes et al,.(2009) of $9.73,9.47$ and 10.30. The difference between the obtained valuesand the reported values in this study might be probably as a result of acid hydrolysis of humicacid. 
BAJOPAS Volume 14 Number 1,June, 2021

Table 1: PKa of (Hydrolysed PSHA)

\begin{tabular}{|l|l|l|l|l|l|l|}
\hline $\mathrm{pH}$ & $\mathrm{BV}_{1}$ & $\mathrm{BV}_{2}$ & $\mathrm{~V}_{2}-\mathrm{V}_{1}$ & $\mathrm{nA}$ & $\log \left(\frac{n A}{1-n A}\right)$ & $\mathrm{pKa}$ \\
\hline 8.50 & 5.30 & 6.29 & 0.99 & 0.3594 & -0.2510 & 8.2490 \\
8.72 & 5.35 & 6.37 & 1.02 & 0.3400 & -0.2880 & 8.4320 \\
9.00 & 5.40 & 6.46 & 1.06 & 0.3141 & -0.3391 & 8.6609 \\
9.22 & 5.45 & 6.55 & 1.10 & 0.2882 & -0.3927 & 8.8273 \\
9.51 & 5.50 & 6.66 & 1.16 & 0.2494 & -0.4786 & 9.0314 \\
9.73 & 5.55 & 6.78 & 1.23 & 0.2041 & -0.5910 & 9.1390 \\
10.00 & 5.60 & 6.90 & 1.30 & 0.1589 & -0.7238 & 9.2762 \\
10.23 & 5.65 & 7.05 & 1.40 & 0.0941 & -0.9835 & 9.2465 \\
10.49 & 5.70 & 7.10 & 1.40 & 0.0941 & -0.9835 & 9.5065 \\
\hline
\end{tabular}

Average pKa $=8.9299 \pm 0.4186$

Table 2: PKa of (Unhydrolysed PSHA)

\begin{tabular}{|l|l|l|l|l|l|l|}
\hline $\mathrm{pH}$ & $\mathrm{BV}_{1}$ & $\mathrm{BV}_{2}$ & $\mathrm{~V}_{2}-\mathrm{V}_{1}$ & $\mathrm{nA}$ & $\log \left(\frac{\boldsymbol{n A}}{1-\boldsymbol{n}}\right)$ & $\mathrm{pKa}$ \\
\hline 8.50 & 5.30 & 5.81 & 0.51 & 0.6619 & 0.2919 & 8.7919 \\
8.72 & 5.35 & 5.90 & 0.55 & 0.6357 & 0.2418 & 8.9618 \\
9.00 & 5.40 & 6.00 & 0.60 & 0.6029 & 0.1813 & 9.1813 \\
9.22 & 5.45 & 6.10 & 0.65 & 0.5701 & 0.1226 & 9.3426 \\
9.51 & 5.50 & 6.20 & 0.70 & 0.5376 & 0.0654 & 9.5754 \\
9.73 & 5.55 & 6.33 & 0.78 & 0.4851 & -0.0259 & 9.7041 \\
10.00 & 5.60 & 6.47 & 0.87 & 0.4262 & -0.1291 & 9.8709 \\
10.23 & 5.65 & 6.62 & 0.99 & 0.3609 & -0.2481 & 9.9819 \\
10.49 & 5.70 & 6.80 & 1.10 & 0.2759 & -0.4690 & 10.0210 \\
\hline
\end{tabular}

Average pKa $=9.4923 \pm 0.4410$

Metal-ligand stability constant ( $\log \mathrm{K}$ )

The stabilityconstants require the accurate values of proton-ligand stability constants (Anil and Maroti, 2008). Metal titration curves crossed over ligand titration curve indicated the formation of complex upon proton release (Santosh, et al., 2011). If the values of n- are within range $0.2-0.8$ and $1.2-18$ this indicates the formation of $1: 1$ and 1:2 complexes (Sayyed and Mazahar, 2012).

The metal (II)-humate stepwise stability constants (log k) at phenolic group (Tables 318)

Table 3: Point-wise method, $\mathrm{Cu}$-(Hydrolysed PSHA)

\begin{tabular}{|l|l|l|l|l|l|l|l|l|}
\hline $\mathrm{pH}$ & $\mathrm{BV}_{1}$ & $\mathrm{BV}_{2}$ & $\mathrm{BV}_{3}$ & $\left(\mathrm{~V}_{3}-\mathrm{V}_{2}\right)$ & $\mathrm{n}$ & $\mathrm{pL}$ & $\log \left(\frac{n}{1-n}\right)$ & LogK $_{1}$ \\
\hline 8.50 & 5.30 & 6.29 & 6.33 & 0.04 & 0.5500 & 2.66 & 0.0871 & 2.7471 \\
8.72 & 5.35 & 6.37 & 6.41 & 0.04 & 0.5714 & 2.43 & 0.1249 & 2.5549 \\
9.00 & 5.40 & 6.46 & 6.50 & 0.04 & 0.6198 & 2.16 & 0.2122 & 2.3722 \\
9.22 & 5.45 & 6.55 & 6.59 & 0.04 & 0.6667 & 1.94 & 0.3010 & 2.2410 \\
\hline
\end{tabular}

LogK $_{1}$ (Average value) $=2.4788 \pm 0.2203$

Table 4: Point-wise method, $\mathrm{Cu}$-(Hydrolysed PSHA)

\begin{tabular}{|l|l|l|l|l|l|l|l|l|}
\hline $\mathrm{pH}$ & $\mathrm{BV}_{1}$ & $\mathrm{BV}_{2}$ & $\mathrm{BV}_{3}$ & $\left(\mathrm{~V}_{3}-\mathrm{V}_{2}\right)$ & $\mathrm{n}$ & $\mathrm{pL}$ & $\log \left(\frac{n-1}{2-n}\right)$ & LogK $_{2}$ \\
\hline 9.51 & 5.50 & 6.66 & 6.73 & 0.07 & 1.3509 & 1.70 & -0.2671 & 1.4329 \\
9.73 & 5.55 & 6.78 & 6.85 & 0.07 & 1.6383 & 1.51 & 0.2467 & 1.7567 \\
10.00 & 5.60 & 6.90 & 6.98 & 0.08 & 2.1783 & 1.31 & -0.2158 & 1.0942 \\
10.23 & 5.65 & 7.05 & 7.13 & 0.08 & 4.1904 & 1.27 & & \\
10.49 & 5.70 & 7.10 & 7.19 & 0.09 & 4.6920 & & & \\
\hline
\end{tabular}

Log $K_{2}($ Average value $)=1.4280 \pm 0.3312$ 
BAJOPAS Volume 14 Number 1,June, 2021

Table 5: Point-wise method, $\mathrm{Cu}$ (Unhydrolysed PSHA)

\begin{tabular}{|l|l|l|l|l|l|l|l|l|}
\hline $\mathrm{pH}$ & $\mathrm{BV}_{1}$ & $\mathrm{BV}_{2}$ & $\mathrm{BV}_{3}$ & $\left(\mathrm{~V}_{3}-\mathrm{V}_{2}\right)$ & $\mathrm{n}$ & $\mathrm{pL}$ & $\log \left(\frac{n}{n-1}\right)$ & Log $_{1}$ \\
\hline 8.50 & 5.30 & 5.81 & 5.85 & 0.04 & 0.2973 & 2.88 & -0.3736 & 2.5064 \\
8.72 & 5.35 & 5.90 & 5.95 & 0.05 & 0.3873 & 2.66 & -0.1992 & 2.4608 \\
9.00 & 5.40 & 6.00 & 6.05 & 0.05 & 0.4044 & 2.38 & -0.1681 & 2.2119 \\
9.22 & 5.45 & 6.10 & 6.15 & 0.06 & 0.5157 & 2.18 & -0.0272 & 2.2072 \\
9.51 & 5.50 & 6.20 & 6.27 & 0.07 & 0.6417 & 1.89 & 0.2530 & 1.1430 \\
\hline
\end{tabular}

$\operatorname{LogK}_{1}($ Average value $)=2.3059 \pm 0.6153$

Table 6:Point-wise method, $\mathrm{Cu}$ (Unhydrolysed PSHA)

\begin{tabular}{|l|l|l|l|l|l|l|l|l|}
\hline $\mathrm{pH}$ & $\mathrm{BV}_{1}$ & $\mathrm{BV}_{2}$ & $\mathrm{BV}_{3}$ & $\mathrm{~V}_{3}-\mathrm{V}_{2}$ & $\mathrm{n}$ & $\mathrm{pL}$ & $\log \left(\frac{n-1}{2-n}\right)$ & $\log \mathrm{K}_{2}$ \\
\hline 9.73 & 5.55 & 6.33 & 6.42 & 0.09 & 0.9000 & 1.69 & & \\
10.00 & 5.60 & 6.47 & 6.58 & 0.11 & 1.2578 & 1.44 & -0.4592 & 0.9808 \\
10.23 & 5.65 & 6.62 & 6.84 & 0.12 & 1.6137 & 1.26 & -0.2010 & 1.4610 \\
10.49 & 5.70 & 6.80 & 6.92 & 0.12 & 2.1052 & 1.03 & & \\
\hline
\end{tabular}

$\operatorname{LogK}_{2}$ (Average value) $=1.2209 \pm 0.3398$

Table 7:Point-wise method, Pb (Hydrolysed PSHA)

\begin{tabular}{|l|l|l|l|l|l|l|l|l|}
\hline $\mathrm{pH}$ & $\mathrm{BV}_{1}$ & $\mathrm{BV}_{2}$ & $\mathrm{BV}_{3}$ & $\left(\mathrm{~V}_{3}-\mathrm{V}_{2}\right)$ & $\mathrm{n}$ & $\mathrm{pL}$ & $\log \left(\frac{n}{1-n}\right)$ & LogK $_{1}$ \\
\hline 8.50 & 5.30 & 6.29 & 6.33 & 0.04 & 0.5500 & 2.66 & 0.0871 & 2.7471 \\
8.72 & 5.35 & 6.37 & 6.41 & 0.04 & 0.5714 & 2.43 & 0.1249 & 2.5549 \\
9.00 & 5.40 & 6.46 & 6.50 & 0.04 & 0.6198 & 2.16 & 0.2122 & 2.3722 \\
9.22 & 5.45 & 6.55 & 6.60 & 0.05 & 0.8333 & 1.96 & 0.6989 & 2.6589 \\
\hline
\end{tabular}

Log $_{\mathbf{1}}($ Average value $)=2.5832 \pm 0.1614$

Table 8:Point-wise method, Pb-(Hydrolysed PSHA)

\begin{tabular}{|l|l|l|l|l|l|l|l|l|}
\hline $\mathrm{pH}$ & $\mathrm{BV}_{1}$ & $\mathrm{BV}_{2}$ & $\mathrm{BV}_{3}$ & $\left(\mathrm{~V}_{3}-\mathrm{V}_{2}\right)$ & $\mathrm{n}$ & $\mathrm{pL}$ & $\log \left(\frac{n-1}{2-n}\right)$ & $\log \mathrm{K}_{2}$ \\
\hline 9.51 & 5.50 & 6.66 & 6.71 & 0.05 & 0.9650 & 1.67 & & \\
9.73 & 5.55 & 6.78 & 6.83 & 0.05 & 1.1702 & 1.44 & & \\
10.00 & 5.60 & 6.90 & 6.90 & 0.05 & 1.4864 & 1.22 & -0.0237 & 1.1963 \\
10.23 & 5.65 & 7.05 & 7.10 & 0.05 & 2.0190 & 1.09 & & \\
10.49 & 5.70 & 7.10 & 7.17 & 0.07 & 3.6492 & 1.00 & & \\
\hline
\end{tabular}

Log $K_{2}$ (Average value) $=1.1963$

Table 9: Point-wise method, Pb (Unhydrolysed PSHA)

\begin{tabular}{|l|l|l|l|l|l|l|l|l|}
\hline $\mathrm{pH}$ & $\mathrm{BV}_{1}$ & $\mathrm{BV}_{2}$ & $\mathrm{BV}_{3}$ & $\mathrm{~V}_{3}-\mathrm{V}_{2}$ & $\mathrm{n}$ & $\mathrm{pL}$ & $\begin{array}{l}\text { Log } \\
\left(\frac{n}{n-1}\right)\end{array}$ & Log $\mathrm{K}_{1}$ \\
\hline 8.50 & 5.30 & 5.81 & 5.85 & 0.04 & 0.2973 & 2.88 & -0.3736 & 2.5064 \\
8.72 & 5.35 & 5.90 & 5.94 & 0.04 & 0.3099 & 2.66 & -0.5477 & 2.3123 \\
9.00 & 5.40 & 6.00 & 6.05 & 0.05 & 0.4044 & 2.38 & -0.1681 & 2.2119 \\
9.22 & 5.45 & 6.10 & 6.15 & 0.06 & 0.5157 & 2.18 & 0.0272 & 2.2072 \\
9.51 & 5.50 & 6.20 & 6.26 & 0.07 & 0.6417 & 1.89 & 0.2530 & 2.1430 \\
9.73 & 5.55 & 6.40 & 6.40 & 0.07 & 0.7000 & 1.67 & 0.3680 & 2.0380 \\
\hline
\end{tabular}

LogK $_{1}$ (Average value) $=2.2364 \pm 0.1602$

Table 10: Point-wise method, Pb (Unhydrolysed PSHA)

\begin{tabular}{|l|l|l|l|l|l|l|l|l|}
\hline $\mathrm{pH}$ & $\mathrm{BV}_{1}$ & $\mathrm{BV}_{2}$ & $\mathrm{BV}_{3}$ & $\mathrm{~V}_{3}-\mathrm{V}_{2}$ & $\mathrm{n}$ & $\mathrm{pL}$ & $\log \left(\frac{n-1}{2-n}\right)$ & $\log \mathrm{K}_{2}$ \\
\hline 10.00 & 5.60 & 6.47 & 6.55 & 0.08 & 1.9503 & 1.41 & & \\
10.23 & 5.65 & 6.62 & 6.72 & 0.11 & 1.4792 & 1.26 & -0.0361 & 1.2239 \\
\hline
\end{tabular}

$\operatorname{LogK}_{2}$ (Average value) $=1.2239$

Table 11: Point-wise method, Mg (Hydrolysed PSHA)

\begin{tabular}{|l|l|l|l|l|l|l|l|l|}
\hline $\mathrm{pH}$ & $\mathrm{BV}_{1}$ & $\mathrm{BV}_{2}$ & $\mathrm{BV}_{3}$ & $\left(\mathrm{~V}_{3}-\mathrm{V}_{2}\right)$ & $\mathrm{n}$ & $\mathrm{pL}$ & $\log \left(\frac{n}{n-1}\right)$ & LogK $_{1}$ \\
\hline 8.50 & 5.30 & 6.29 & 6.31 & 0.02 & 0.2750 & 2.64 & -0.4290 & 2.2110 \\
8.72 & 5.35 & 6.37 & 6.39 & 0.02 & 0.2858 & 2.42 & -0.3978 & 2.0222 \\
9.00 & 5.40 & 6.46 & 6.49 & 0.03 & 0.4648 & 2.14 & -0.0612 & 2.0788 \\
9.22 & 5.45 & 6.55 & 6.59 & 0.04 & 0.6667 & 1.94 & 0.3010 & 2.2410 \\
\hline
\end{tabular}

$\log _{\mathbf{1}}($ Average value) $=2.1382 \pm 0.1046$ 
BAJOPAS Volume 14 Number 1,June, 2021

Table 12: Point-wise method, Mg (Hydrolysed PSHA)

\begin{tabular}{|l|l|l|l|l|l|l|l|l|}
\hline $\mathrm{pH}$ & $\mathrm{BV}_{1}$ & $\mathrm{BV}_{2}$ & $\mathrm{BV}_{3}$ & $\left(\mathrm{~V}_{3}-\mathrm{V}_{2}\right)$ & $\mathrm{n}$ & $\mathrm{pL}$ & $\log \left(\frac{n-1}{2-n}\right)$ & LogK $_{2}$ \\
\hline 9.51 & 5.55 & 6.66 & 6.71 & 0.05 & 0.9650 & 1.67 & & \\
9.73 & 5.55 & 6.78 & 6.84 & 0.06 & 1.4042 & 1.47 & -0.1686 & 1.3014 \\
10.00 & 5.60 & 6.90 & 6.93 & 0.06 & 1.7838 & 1.23 & 0.5593 & 1.7893 \\
10.23 & 5.65 & 7.05 & 7.10 & 0.06 & 3.1429 & 1.10 & & \\
10.49 & 5.70 & 7.10 & 7.18 & 0.07 & 3.6492 & 0.83 & & \\
\hline
\end{tabular}

LogK $_{2}($ Average value $)=1.5453 \pm 0.3450$

Table 13: Point-wise method, Mg (Unhydrolysed PSHA)

\begin{tabular}{|l|l|l|l|l|l|l|l|l|}
\hline $\mathrm{pH}$ & $\mathrm{BV}_{1}$ & $\mathrm{BV}_{2}$ & $\mathrm{BV}_{3}$ & $\mathrm{~V}_{3}-\mathrm{V}_{2}$ & $\mathrm{n}$ & $\mathrm{pL}$ & $\log \left(\frac{n}{n-1}\right)$ & $\operatorname{Log~}_{1}$ \\
\hline 8.50 & 5.30 & 5.81 & 5.85 & 0.04 & 0.2973 & 2.88 & -0.3736 & 2.5064 \\
8.72 & 5.35 & 5.90 & 5.94 & 0.04 & 0.3099 & 2.66 & -0.3477 & 2.3123 \\
9.00 & 5.40 & 6.00 & 6.04 & 0.04 & 0.3236 & 2.38 & -0.3202 & 2.0598 \\
9.22 & 5.45 & 6.10 & 6.15 & 0.05 & 0.4297 & 2.17 & -0.1230 & 2.0470 \\
9.51 & 5.50 & 6.20 & 6.26 & 0.06 & 0.5500 & 1.89 & 0.0871 & 1.9771 \\
9.73 & 5.55 & 6.33 & 6.40 & 0.07 & 0.7000 & 1.67 & 0.3680 & 2.0380 \\
\hline
\end{tabular}

LogK $_{1}$ (Average value) $=2.1568 \pm 0.2069$

Table 14: Point-wise method, Mg (Unhydrolysed PSHA)

\begin{tabular}{|l|l|l|l|l|l|l|l|l|}
\hline $\mathrm{pH}$ & $\mathrm{BV}_{1}$ & $\mathrm{BV}_{2}$ & $\mathrm{BV}_{3}$ & $\mathrm{~V}_{3}-\mathrm{V}_{2}$ & $\mathrm{n}$ & $\mathrm{pL}$ & $\log \left(\frac{n-1}{2-n}\right)$ & $\log \mathrm{K}_{2}$ \\
\hline 10.00 & 5.60 & 6.47 & 6.55 & 0.08 & 0.9148 & 1.41 & & \\
10.23 & 5.65 & 6.62 & 6.71 & 0.09 & 1.2102 & 1.20 & -0.5749 & 0.6251 \\
10.49 & 5.70 & 6.80 & 6.92 & 0.09 & 1.5968 & 1.03 & 0.1703 & 1.2003 \\
\hline
\end{tabular}

LogK $_{2}$ (Average value) $=0.9127 \pm 0.4070$

Table15:Point-wise method, Cd (Hydrolysed PSHA)

\begin{tabular}{|l|l|l|l|l|l|l|l|l|}
\hline $\mathrm{pH}$ & $\mathrm{BV}_{1}$ & $\mathrm{BV}_{2}$ & $\mathrm{BV}_{3}$ & $\left(\mathrm{~V}_{3}-\mathrm{V}_{2}\right)$ & $\mathrm{n}$ & $\mathrm{pL}$ & $\log \left(\frac{n}{1-n}\right)$ & LogK $_{1}$ \\
\hline 8.50 & 5.30 & 6.29 & 6.31 & 0.02 & 0.2750 & 2.64 & -0.4210 & 2.2190 \\
8.72 & 5.35 & 6.37 & 6.40 & 0.03 & 0.4286 & 2.42 & -0.1249 & 2.2951 \\
9.00 & 5.40 & 6.46 & 6.49 & 0.03 & 0.4648 & 2.14 & -0.0612 & 2.0788 \\
9.22 & 5.45 & 6.55 & 6.59 & 0.04 & 0.6667 & 1.96 & 0.3010 & 2.2610 \\
9.51 & 5.55 & 6.66 & 6.70 & 0.04 & 0.7720 & 1.67 & 0.5297 & 2.1997 \\
\hline
\end{tabular}

LogK $_{\mathbf{1}}$ (Average value) $=2.2108 \pm 0.0825$

Table 16: Point-wise method, Cd (Hydrolysed PSHA)

\begin{tabular}{|l|l|l|l|l|l|l|l|l|}
\hline $\mathrm{pH}$ & $\mathrm{BV}_{1}$ & $\mathrm{BV}_{2}$ & $\mathrm{BV}_{3}$ & $\left(\mathrm{~V}_{3}-\mathrm{V}_{2}\right)$ & $\mathrm{n}$ & $\mathrm{pL}$ & $\log \left(\frac{n-1}{2-n}\right)$ & Log $_{2}$ \\
\hline 9.73 & 5.55 & 6.78 & 6.83 & 0.06 & 1.4042 & 1.47 & -0.1686 & 1.3014 \\
10.00 & 5.60 & 6.90 & 6.95 & 0.06 & 1.7838 & 1.23 & 0.5593 & 1.7893 \\
10.23 & 5.65 & 7.05 & 7.10 & 0.06 & 3.1429 & 1.09 & & \\
10.49 & 5.70 & 7.10 & 7.16 & 0.06 & 3.1429 & 0.89 & & \\
& & & & & & & & \\
\hline
\end{tabular}

$\operatorname{LogK}_{2}$ (Average value) $=1.5453 \pm 0.3450$

Table 17: Point-wise method, Cd (Unhydrolysed PSHA)

\begin{tabular}{|l|l|l|l|l|l|l|l|l|}
\hline $\mathrm{pH}$ & $\mathrm{BV}_{1}$ & $\mathrm{BV}_{2}$ & $\mathrm{BV}_{3}$ & $\mathrm{~V}_{3}-\mathrm{V}_{2}$ & $\mathrm{n}$ & $\mathrm{pL}$ & $\log \left(\frac{n}{n-1}\right)$ & $\operatorname{Log~}_{1}$ \\
\hline 8.50 & 5.30 & 5.81 & 5.86 & 0.05 & 0.3717 & 2.88 & -0.2280 & 2.6520 \\
8.72 & 5.35 & 5.90 & 5.95 & 0.05 & 0.3873 & 2.66 & -0.1992 & 2.4608 \\
9.00 & 5.40 & 6.00 & 6.06 & 0.06 & 0.4853 & 2.38 & -0.0255 & 2.3545 \\
9.22 & 5.45 & 6.10 & 6.16 & 0.06 & 0.5157 & 2.18 & -0.0272 & 2.2072 \\
9.51 & 5.50 & 6.20 & 6.27 & 0.07 & 0.6417 & 1.89 & 0.2530 & 1.1430 \\
9.73 & 5.55 & 6.33 & 6.41 & 0.08 & 0.8000 & 1.69 & 0.6020 & 2.2920 \\
& & & & & & & & \\
\hline
\end{tabular}

$\operatorname{LogK}_{1}($ Average value $)=2.2516 \pm 0.5380$ 
BAJOPAS Volume 14 Number 1,June, 2021

Table 18: Point-wise method, Cd (Unhydrolysed PSHA)

\begin{tabular}{|l|l|l|l|l|l|l|l|l|}
\hline $\mathrm{pH}$ & $\mathrm{BV}_{1}$ & $\mathrm{BV}_{2}$ & $\mathrm{BV}_{3}$ & $\mathrm{~V}_{3}-\mathrm{V}_{2}$ & $\mathrm{n}$ & $\mathrm{pL}$ & $\log \left(\frac{n-1}{2-n}\right)$ & $\log \mathrm{K}_{2}$ \\
\hline 10.00 & 5.60 & 6.47 & 6.57 & 0.10 & 1.1434 & 1.43 & & \\
10.23 & 5.65 & 6.62 & 6.72 & 0.10 & 1.3448 & 1.23 & -0.2788 & 0.9512 \\
10.49 & 5.70 & 6.80 & 6.90 & 0.10 & 1.7742 & 1.03 & 0.5351 & 1.5651 \\
\hline
\end{tabular}

$\operatorname{LogK}_{2}($ Average value $)=1.2581 \pm 0.4340$

Table 19: Stepwise and overall Stability constants of thehydrolysed and unhydrolysed divalent metal (II) complexes

\begin{tabular}{|c|c|c|c|}
\hline Chelates & LogK $_{1}$ & $\log _{2}$ & Log $\beta$ \\
\hline [Cu (Hydrolysed PSHA-1) $\left.{ }_{2}\right]$ & 2.4788 & 1.4280 & 3.9068 \\
\hline$\left[\mathrm{Pb}(\text { Hydrolysed PSHA-1) })_{2}\right]$ & 2.5832 & 1.1963 & 3.7795 \\
\hline$\left[\mathrm{Cd}(\text { Hydrolysed PSHA-1 })_{2}\right]$ & 2.2108 & 1.5453 & 3.7561 \\
\hline$\left[\mathrm{Mg}(\text { Hydrolysed PSHA-1 })_{2}\right]$ & 2.1382 & 1.5453 & 3.6835 \\
\hline [Cu (Unhydrolysed PSHA-1) & 2.3059 & 1.2209 & 3.5268 \\
\hline$[\mathrm{Pb}$ (Unhydrolysed PSHA-1) 2$]$ & 2.2364 & 1.2239 & 3.4603 \\
\hline [Cd (Unhydrolysed PSHA-1) 2 ] & 2.2516 & 1.2581 & 3.5097 \\
\hline$[\mathrm{Mg}$ (Unydrolysed PSHA-1) & 2.1568 & 0.9127 & 3.0695 \\
\hline
\end{tabular}

The results obtained (Table19) shows the stepwise and overall stability constants to be not high indicating low stability of the complexes, because the solubility of most metal ions in the basic $\mathrm{pH}$ range is minimal due to metal hydroxide precipitation (Karimi, 2017). In general, the stepwise stability constants $\left(K_{1}\right.$ and $K_{2}$ ) follow the order $K_{1}>K_{2}$ for the copper, lead, magnesium and cadmium complexes respectively. The steady decrease of the values with increasing number of ligands is in agreement with the prediction made by researchers (Na'aliya, 2013). The decrease could be attributed to the fact that as the number of the ligands (Humate ions) that enters the coordination zone increases the aqua molecules available for replacement by the ligands become less. Thus, the metal ions become less electron loving with progressive intake of the ligand and this results in the decrease in the values of the constants (Na'aliya, 2013). Also the stability of the complexes is influenced by the size and number of the chelate rings(Mackay and Mackay,2002).All the complexes form rings in their structure as humate, a bidentate ligand, bond the metal ions in the ratio 1:2 (Boguta and Sokolowska, 2016) forming chelate rings. The values of the overall stability constants $(\log \beta)$ obtained for humate complexes are not high indicating low stability as the values are not high. LogK values for copper-humates (Table 3 to 6) obtained in this study are lower than those reported for the complexes of humic acids (Pandey et al., 2015; Dinu, 2013; Kaschl et al., 2010 and Gilbeto and Jorg, 2001). The values of LogK(Table 7 to 10 ) forlead-humates are lower than those reported for the lead in the literature (Dinu, 2013; Gilbeto and Jorg 2001). Log K values(Table 11 to 14 ) for magnesium-humates obtained in this study are close to those reported by (Pandey et al., 2015). Log K values of cadmium-humates (Table 15 to 18 ) obtained in this work near to the one reported by (Dinu, 2013 and Pandey et al., 2015).The difference between the reported values and the values obtained in this study might be probably as a result of acid hydrolysis of humic acid. The values of the overall stability constants $(\log \beta)$ of the copper humates complexes presented in Table 19 is high than that of other metal humate complexes, show relatively high stability of CuHA complexes, show the following order of stability: $\mathrm{Cu}>\mathrm{Pb}>\mathrm{Cd}>\mathrm{Mg}$; which are in close agreement to the findings of (Dinu, 2013 and Pandey et al., 2015).The high stability of Cuhumate chelate could be attributed to the existence of coordinate covalent bond between the complexing agents and the $\mathrm{Cu}^{2+}$ ions. Since, $\mathrm{Cu}^{2+}$ being a metal of the transitional series with $3 d^{9}$ electronic configurations can accept the electrons from the complexing agents. Similarly, the low stabilities of $\mathrm{Pb}, \mathrm{Cd}$ and $\mathrm{Mg}$ complexes could be explained by that $\mathrm{Pb}^{2+}$ with $6 s^{2}, \mathrm{Cd}^{2+}$ with $4 \mathrm{~d}^{10}$ and $\mathrm{Mg}^{2+}$ with $2 \mathrm{p}^{6}$ their electronic configuration has a completely filled $\mathrm{d}, \mathrm{p}$ and $\mathrm{s}$ orbitals. Moreover, the stabilities of metal ions with hydrolysed humic acid from peat soil were higher than those with unhydrolysed humic acid from peat soil; which is ascribed to the high content of acidity in hydrolysed humic acid than unhydrolysed humic acid. 
BAJOPAS Volume 14 Number 1,June, 2021 CONCLUSION

The values of logk for $\mathrm{Cu}(\mathrm{II})$ hydrolysed humic acid complex was higher followed by $\mathrm{Pb}$ (II), $\mathrm{Cd}(\mathrm{II})$ and $\mathrm{Mg}$ (II) hydrolysed humic acid complexes as compared with metal(II) unhydrolysed humic acid complexes. This indicates acid hydrolysis of humic acid can

\section{REFERENCES}

Almeida, V.R. and Szpoganicz, B. (2015). Humic Acid Potentiometric Response Patterns:Out- of Equilibrium Properties and Species Distribution Modelling. Chemical. Biol. Technol. Agric. 2: 17.

Anđelković, T., Nikolić, R., Bojić, A.,Anđelković, D., and Nikolic G.,(2010). Binding of Cadmium to Soil Humic Acid as A Function of Carboxyl Group Content. Macedonian Journal of Chemistry and Chemical Engineering.29(2): 215-224.

Anil, B. N. and Maroti, N. (2008). Studies on Influence of Die-Lectric Constants on Complex Equilibria between Substituted Py-Razalines and Lanthanide Metal Ions pH-Metrically. Amer.-Euras. scient. Res. 3(2): 212-216.

Ashok, K., Pandey, S. P. and Misra, V (2000). Stability Constants of Metal-Humic Acid Complexes and its Role in Environmental Detoxification. Journal of Ecotoxicology and Environmental Safety. 47(2):157-200.

Badr, M. H., El-Halafawi, M. H. and Abd El-al Zeid, E. R. (2012). Comparison Between the Effect of Ionic Strength on Acidity and Dissociation Constants of Humic Acids Extracted from Sewage Sludge and Nile Water Hyacinth Composts.Global Journal of Environmental Research 6 (1): 36-43.

Baruah, M.K., Borah, D., Saikia, P.P., Paul, S., Sharma, T. (2015). Evaluation of pKa Values of Soil Humic Acids and their Complexation Properties. International Journal of Plant \& Soil Science 6(4) : 218-228.

Boguta, P. Sokolowska, Z. (2016). Interactions of $\mathrm{Zn}$ (II) Ions with Humic Acids Isolated from Various Types of Soils. Effect of $\mathrm{pH}, \mathrm{Zn}$ Concentrations and Humic Acids Chemical Properties. Journal of Geochemical Explaration 168. 119-126.

Borges, F., Guimaraes, C., Lima, L.F.C., Pinto, I. and Reis, S.(2005). Potentiometric Studies on the Complexation of Copper(II) by Phenolic Acids as Discrete Ligand Models of enhance the complexation behavior of humic acid with metal (II) ions. However, the higher values of $\log \beta$ for $\mathrm{Cu}(\mathrm{II}), \mathrm{Pb}(\mathrm{II}), \mathrm{Cd}(\mathrm{II})$ and $\mathrm{Mg}(\mathrm{II})$ hydrolysed humic acid complexes indicates more stable stepwise complexes formed as compared with $\mathrm{Cu}(\mathrm{II}), \mathrm{Pb}$ (II), $\mathrm{Cd}$ (II) and $\mathrm{Mg}(\mathrm{II})$ unhydrolysed humic acid complexes.

Humic Substances Talanta 66 (2005) 670-673.

Chefetz, B., Salloum, M. J., Deshmulkin, A. P. and Hatcher, P. (2002). Structural Components of Humic Acids as Determined by Chemical Modifications and Carbon-13 NMR, Pyrolysis, and Thermochemolysis- Gas Chromatography/Mass Spectrometry. Soil Science Society of American Journal Abstract Division S-2- Soil Chemistry66. 1159-1171.

Dinu, M. I. (2013). Metals Complexation with Humic Acids in Surface Water of Different Environ. Sci. Technol. 31(1): 1-17.

Fernandes, A.N., Giacomelli, C., Giovanela, M. Vaz, D.V. Szpoganicz, B. and Maria M. D. (2009). Potentiometric Acidity Determination in Humic Substances Influenced by Different Analytical Procedures.J. Braz. Chem. Soc. 20 (9):14.

Gamal, A. H. (2015). Stability Constants of Rhenium (V) Metal Complexes with Selected Drugs. Pyrex Journal of Research in Environmental Studies. 2(2): 006-014.

Janrao, D. M., Pathan, J., Kayande, D.D., and Mulla, J.J. (2014). An Over View of Potentiometric Determination of Stability Constants of Metal Complexes. Sci. Revs. Chem. Commun.: 4(1), 2014, 11-24.

Karimi, H. (2017). Effect of pH and Initial Pb(II) Concentration on the Lead Removal Efficiency from Waste Water Using $\mathrm{Ca}(\mathrm{OH})_{2}$. International Journal of Water and Waste Water Treatment 3.2

Kaschl, A. Romheld, V. and Chen, Y. (2010). Binding of Cadmium, Copper and Zinc to Humic Substances Originating from Municipal Solid Waste Compost. Israel Journal of Chemistry Vol. 42(1): 89-98.

Kostic, I. S., Tatjana, P, A., Nikolic, R. S., Cvetkovic, T. P., Pavlovic, D. D., Aleksandar, L.J. and Bojic, A. (2012). Comparative Study of Binding Strengths of Heavy Metals with Humic Acid. J.serb. Chem. Soc. 76(9) pp 1-20. 
BAJOPAS Volume 14 Number 1,June, 2021

Na'aliya, J. (2013). Determination of Stepwise Stability Constants and Gibbs free Energy Change of Trisprolina to Complexes of some Divalent Transition Metal ions. Bayero Journal of Pure and Applied Sciences 6(2): 112-114.

Omar, A. A. and Ali, E. A. (2015). Potentiometric Studies on Complexes of $\mathrm{Cr}$ (III) and $\mathrm{Zr}$ (IV) with some Carboxylic Acids. International Journal of Advanced Chemistry, 3(1) 25-

37.

Pandey, A. K. Pandey, S. D. and Misr, V. (2015).Stability Constants of Metal- Humic Acid Complexes and Its Role in Environmental Detoxification. J. Ecotoxicology and Environmental Safety. 47(1):195-200.

Ram, N. and Raman, K.V. (1984). Stability Constants of Complexes of Metals with
Humicand Fuvic Acids under Non- acidConditions. Journal of Plant Nutrition and Soil Sciences.

147:171-176.

Santosh, D. D., Ashok, B. K., Vijay, J. T., Shivraj, G. W. and Vinay, V. W. (2011). Potentiometric Studies of Elec-Trolyte Effects on Complex Equilibria of Some Substituted 5-(2-hydroxy Phenyl) Pyrazoles. Der pharm. 3 (6): 75-83.

Sayyed, H. and Abdul Rahim, M. F. (2012). Studies of Binary Complexes of Metal Ions with Mandelic Acid by Potentiometry. Chem. J. 02 (6): 206209.

Shirvani, M. Moradian, E. Khalili, B. Bakhtiary, S. (2015). Interaction of $\mathrm{Cd}$ and $\mathrm{Pb}$ with Humate-Palygorskite and HumateSepiolite Complexes. Journal of water, air and pollution 3: 220-228. 


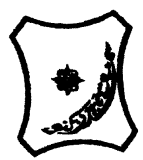

Bayero Journal of Pure and Applied Sciences, 14(1): 54 - 63

Received: November, 2020

Accepted: April, 2021

ISSN $2006-6996$

\title{
STABILITY CONSTANTS OF COMPLEXES OF METAL IONS WITH PEATSOIL HUMIC ACIDS UNDER NON-ACID-CONDITIONS
}

\author{
${ }^{* 1}$ Sabo, Yusuf ${ }^{2}$ Jimoh, W.L.O., ${ }^{3}$ Isa Baba Koki and ${ }^{4}$ Sholadoye, Q. 0. \\ ${ }^{1}$ Department of Pure and Industrial Chemistry, Bayero University, Kano \\ ${ }^{3}$ Department of Chemistry, Yusuf Maitama Sule University Kano. P.M.B. 3220 Kano, Nigeria. \\ ${ }^{4}$ Department of Chemistry, Nigerian Police Academy, Wudil, Kano-Nigeria
}

*Correspondence E-mail; saboyusuf18@yahoo.com

ABSTRACT

Stability constants of complexes of four divalent metal ions viz. $\mathrm{Cu}^{2+}, \mathrm{Pb}^{2+}, \mathrm{Mg}^{2+}$ and $\mathrm{Cd}^{2+}$ with humic acids (HA) were determined by potentiometric titration of humic acids with the corresponding salt of the divalent metals in aqueous media under non-acid-condition. The log $K$ (logarithm of the stability constant) ranged from 1.0942 to 2.7471 for metalhumic acid complexes were determined using point-wise computational method. The order of stability constants were obtained as follows: $\mathrm{Cu}>\mathrm{Pb}>\mathrm{Cd}>\mathrm{Mg}$ for metal $-\mathrm{HA}$ complexes respectively, indicating a higher degree of complexation with Cu metal ion.

Keywords: stability constant, humic acid, potentiometric titration, divalent metals, acid hydrolysis.

\section{NTRODUCTION}

The stability constant of a complex is the numerical expression of its stability and provides a quantitative measure of affinity of the metal ion to the complexing agent. An understanding of the relative stability of metal-complexes helps in predicting the behavior of metal ions in the soil (Ram and Raman, 1982). Extensive researches has been done to determine the stability constants of the complexes formed between humic acid (HA) with a number of metal ions. Ashok et al., (2000) reported that humic acid with hydroxyl, phenoxyl and carboxyl reactive groups can form coordination compound with metal ions at $\mathrm{pH}$ 3.5. The stability constants(Log K) for different metalhumic acid complexes indicated the following order of the stabilities of complexes formed between humic acid and metal ion, $\mathrm{Cu}>\mathrm{Fe}$ $>\mathrm{Pb}>\mathrm{Ni}>\mathrm{Co}>\mathrm{Ca}>\mathrm{Cd}>\mathrm{Zn}>\mathrm{Mn}>\mathrm{Mg}$. Andelkovic et al., (2010) investigated the binding of $\mathrm{Cd}$ (II) to soil humic acid at pH 6.5 and in $0.1 \mathrm{M} \mathrm{KNO}_{3}$ ionic medium. The stability constant for binding indicating greater stability in the case when carboxyl groups are involved in complexation reaction. Kostic et al.,(2012) investigated the complexation of humic acid with certain heavy metal ions (Co(II), $\mathrm{Ni}(\mathrm{II}), \mathrm{Cu}(\mathrm{II})$,
$\mathrm{Zn}(\mathrm{II})$, and $\mathrm{Pb}(\mathrm{II})$. The experiment was performed at $25^{\circ} \mathrm{C}$, at pH 4.0 and ionic strength of $0.01 \mathrm{M}$. Stability constant of complex between $\mathrm{Pb}$ (II) ions and humic acid is greater than stability constants of other investigated metalhumate complexes. Bogata and Sokolowska (2016) analyses the interaction between humic acids from different soils and $\mathrm{Zn}$ (II) ions at wide concentration ranges and at $\mathrm{pH} 5$. Studies have showed significant impact of $\mathrm{Zn}$ concentration, $\mathrm{pH}$ and some properties of humic acids with zinc.But all of these studies were limited to acidic $\mathrm{pH}$ range. Therefore, the present study was carried out to determine and compare the stability constants of complexes of metal ions with hydrolysed peat soil humic acid and unhydrolysed peat soil humic under non-acid conditions.

\section{MATERIALS AND METHODS}

Analytical grade chemicals used includes hydrochloric acid $(\mathrm{HCl})$, nitric acid $\left(\mathrm{HNO}_{3}\right)$, sodium hydroxide $(\mathrm{NaOH})$, lead nitrate $\mathrm{Pb}\left(\mathrm{NO}_{3}\right)_{2}$, copper nitrate $\mathrm{Cu}\left(\mathrm{NO}_{3}\right)_{2} \cdot 3 \mathrm{H}_{2} \mathrm{O}$, cadmium nitrate $\mathrm{Cd}\left(\mathrm{NO}_{3}\right)_{2} \cdot 4 \mathrm{H}_{2} \mathrm{O}$, magnesium nitrate $\mathrm{Mg}\left(\mathrm{NO}_{3}\right)_{2} \cdot 6 \mathrm{H}_{2} \mathrm{O}$, potassium nitrate $\left(\mathrm{KNO}_{3}\right)$, calcium chloride $\left(\mathrm{CaCl}_{2}\right)$, (sigma-Aldrich). Dowex 50WX8, (20-50 mesh) from Fluka. 


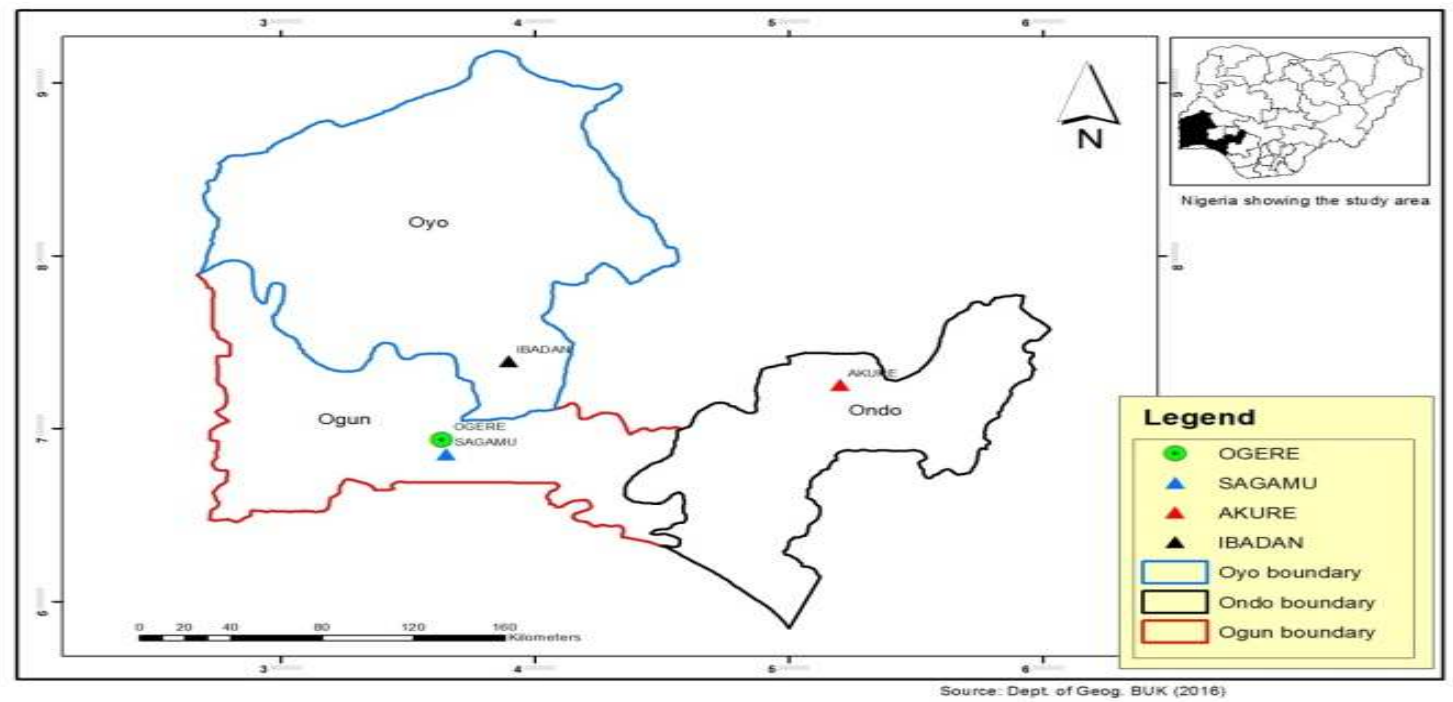

Figure 1: Map showing the sampling point at Sagamu Town, Ogun State.

\section{Description of Sampling Area}

Sagamu has geographical coordinates between $6^{\circ} 50^{\prime}$ north; $3^{\circ} 38^{\prime}$ east is located in south western region of Nigeria. The region has tropical wet and dry climate with a lengthy wet season and relatively constant temperatures throughout the course of the year. Wet season runs from March to October, November to December forms the region dry season. The vegetation type of the region is savannah which is really grassland with small bushes and occasional big trees. Grassland soils have substantially higher organic matter content than forest soils (Novackova, 2011).

\section{Sample Collection}

The Peatsoil samples were collected from four different sampling points $(0-10 \mathrm{~cm}$ depth) in Sagamu into polyethylene bag with plastic spoons. Samples were taken to the laboratory, extraneous materials were removed; the samples were air-dried, crushed and ground to a fine powder in a mortar passed through a $0.20 \mathrm{~mm}$ sieve. The samples were kept for analysis.

\section{Isolation and purification of humic acid from peat soil sample}

Peatsoil sample $(100 \mathrm{~g})$ was mixed with 1000 $\mathrm{cm}^{3}$ of $0.1 \mathrm{M} \mathrm{NaOH}$ solution, shaken for 3hours and left to stand overnight. Dark-coloured supernatant was obtained and decanted from solid residue. The dark-coloured supernatant was acidified to $(\mathrm{pH}=1.0)$ with $6 \mathrm{M} \mathrm{HCl}$ stirred and allowed to stand for 6 hours. Yellowish brown supernatant and dark-brown precipitate were obtained. The yellowish brown supernatant was decanted followed by centrifuge and discarded. The dark-brown precipitate was mixed with $500 \mathrm{~cm}^{3}$ of $0.1 \mathrm{M} \mathrm{NaOH}$ solution followed by passing through dowex resin. The dark-brown solution was acidified to $(\mathrm{pH}=1.0)$ with $6 \mathrm{M} \mathrm{HCl}$ stirred and allowed to stand for 3 hours. The dark-brown precipitate was washed several times with deionized water. The supernatant was treated with $\mathrm{AgNO}_{3}$ solution until no white precipitate observed. The humic acid was transferred to weighed crucible and dried at $60^{\circ} \mathrm{C}$ in an oven for 12 hours. The humic acid was cooled and dried in the desiccator, weighed and recorded. The obtained humic acid was dried again at $60^{\circ} \mathrm{C}$ for additional 6 hours cooled and dried in the desiccator, weighed and recorded constant weight was obtained (Baruah et al., 2015).

\section{FT-IR analysis}

FT-IR spectra of humic acid sample was analysed using Carry 630 FT-IR Agilent Technologies.

Unhydrolysed compost humic acid

The unhydrolysed humic acid was obtained after isolation and purification of compost humic acid and kept for investigation.

\section{Acid hydrolysis of Peatsoil acid}

Peatsoil humic acid sample (1g) was refluxed for 12 hours at $\left(160^{\circ} \mathrm{C}\right)$ with $50 \mathrm{~cm}^{3}$ of $6 \mathrm{M} \mathrm{HCl}$. The mixture was allowed to cool, decanted, and centrifuged after hydrolysis. The insoluble residues were washed with distilled water via centrifugation several times, and the supernatant was treated with $\mathrm{AgNO}_{3}$ solution until no white precipitate was observed. The residue was thoroughly dried over $\mathrm{CaCl}_{2}$ in a desiccator at room temperature (Chefetz et al., 2002). Finally, the obtained hydrolysed humic acid was kept for investigation. 
BAJOPAS Volume 14 Number 1,June, 2021 Potentiometric Titrations

Potentiometric measurements were carried out using a pH-meter Jenway (model 3510) with combine electrode, the sensitivity of the $\mathrm{pH}$ meter is 0.01 units. The $\mathrm{pH}$ meter was switched on half an hour before starting the titration for initial warm up of the instrument. The instrument was calibrated with an aqueous standard buffer solution of $\mathrm{pH} 4.00$ and 10.0 (borate buffer) prepared from a "Qualigens" buffer tablets.

The following sets of solutions were prepared in a $250 \mathrm{~cm}^{3}$ volumetric flask separately for $\mathrm{pH}$ metric titrations.

(i) $5 \mathrm{~cm}^{3} 0.1 \mathrm{M} \mathrm{HCl}+40 \mathrm{~cm}^{3}$ deionized water

(ii) $5 \mathrm{~cm}^{3} 0.1 \mathrm{M} \mathrm{HCl}+39 \mathrm{~cm}^{3}$ deionized water $+1 \mathrm{~cm}^{3} 0.15 \mathrm{gcm}^{-3}$ humic acid

(iii) $5 \mathrm{~cm}^{3} 0.1 \mathrm{M} \mathrm{HCl}+37 \mathrm{~cm}^{3}$ deionized water $+1 \mathrm{~cm}^{3} 0.15 \mathrm{gcm}^{-3}$ humic acid

$$
+2 \mathrm{~cm}^{3} \quad 0.01 \mathrm{M} \mathrm{Cu} \text { (II) }
$$

The solutions were titrated against standardized $0.110 \mathrm{MNaOH}$ separately. The total volume of each mixture was adjusted to $50 \mathrm{~cm}^{3}$ and the ionic strength of the solutions was maintained constant at by adding appropriate amount of stock solution of $1 \mathrm{M} \mathrm{KNO}_{3}$ (Gamal, 2015; Omar and Ali, 2015). A magnetic stirrer was used to achieve thorough mixing of the interacting solutions at $550 \mathrm{rpm}$. The same set of experimental conditions was applied for potentiometric titration of remaining samples.

\section{Evaluation of pKa of Hydrolysed peat soil Humic Acids}

The proton-ligand formation number $\mathrm{n}_{\mathbf{A}}$ were calculated by Irving and Rossotti expression (Omar and Ali, 2015).

$\mathrm{nA}=\mathrm{Y}-\frac{(\mathrm{V} 2-\mathrm{V1})(\mathrm{No}-\mathrm{Eo})}{(\mathrm{VO}+\mathrm{V1}) \mathrm{TCL}}$ 1

Where: $Y$ is number of dissociable proton, $\left(\mathrm{V}_{2^{-}}\right.$ $V_{1}$ ) is the measure of displacement of the ligand curve relative to acid curve, $\mathrm{N}^{\circ}$ and $\mathrm{E}^{\circ}$ are the resultant concentration of alkali solution, free acid solution, $\mathrm{T}_{\mathrm{cL}}{ }^{\circ}$ is the total ligand concentration, $\mathrm{V}^{\circ}$ is the total volume of titration solution, $V_{1}$ is the volume of alkali added to acid solution, $V_{2}$ is the volume of alkali added to acid solution + ligand solution, acid dissociation constants (pKa - values) of ligand were calculated by algebraic method point wise calculation (Tables 1 ). The dissociation constants (pKa) were calculated according to the following relation:

$\mathrm{pKa}=\mathrm{pH}+\log \left(\frac{n A}{1-n A}\right)$ 2

Where: pKa is the acid dissociation constant, $\mathrm{n}_{\mathrm{A}}$ is the Proton-ligand formation number and $\mathrm{pH}$ is the pH-values (Omar and Ali, 2015).

\section{Determination of metal-ligand stability constants $(\log K)$ of complexes}

The potentiometric measurement for the determination of stability constant of a complex in solution is based on the fact that the redox potential of the couple $\frac{M^{+(m-n)}}{M^{+m}}$ is shifted significantly on complexation of the metal ion with the ligand. This method involves change in hydrogen ion concentration $\left[\mathrm{H}^{+}\right]$due to the displacement or association of one or more protons taking place during complexation reaction. This change can be found out by titrating the solutions containing free acid, acid with ligand, and acid with ligand and metal ion, individually against a standard alkali solution at a constant ionic strength or temperature. Either ionic strength or temperature may be varied for different sets of solutions. In all the cases, the change in the $\mathrm{pH}$ of the solution is measured after each addition of a known amount of alkali to the reaction cell which contains the reaction mixture. The titration curves are then drawn by plotting the measured $\mathrm{pH}$ values against the corresponding volume of alkali added and the stability constants of the complexes are determined from the titration curves by employing $\mathrm{pH}$-metric titration technique given by (Irving and Rossoti).

Metal-ligand stability constants ( $\log \mathrm{K}$ ) were determined by using the following relations:

$$
\bar{n}=\frac{\left(V_{3}-V_{2}\right)\left(E^{0}+N^{0}\right)}{\left(V^{0}+V_{2}\right) \bar{n}_{A} T_{m}^{0}}
$$

and

$$
P L=\log _{10}\left\{\frac{1+\beta_{n}^{H} \frac{1}{[\text { anti } \log \mathrm{pH}]^{\mathrm{n}}}}{\mathrm{T}_{\mathrm{L}}^{0}-n \bar{T}_{m}^{0}} \mathrm{X} \frac{\left(V^{0}+V_{3}\right)}{V^{0}}\right\}
$$


BAJOPAS Volume 14 Number 1,June, 2021

Where $T_{L}, T^{\circ}, E^{\circ}$, and $V^{\circ}$ havethe same significance as in equation (1) above, $T_{m}$ denotes the total concentration of metal present in solution, $V_{3}$ is the volume of metal ions present in solution and $\beta^{H}$ is the overall proton ligand stability constant. The metal-ligand stability constants (log K) were determined by employing point wise computational Method (eq. 5 and 6).

$\operatorname{LogK}_{1}=\log \left(\frac{n}{1-n}\right)+\mathrm{pL}$ .5

$\operatorname{LogK}_{2}=\log \left(\frac{1-n}{2-n}\right)+\mathrm{pL}$ ...6

Where: Log $\mathrm{K}$ is the metal-ligand stability constant, $\mathrm{pL}$ is the Free ligand exponent function, $\mathbf{n}$ is the Average number of ligand attached with metal ion (Janraoet al., 2014). The results obtained were analyzed by an ORIGIN 2016 program using titration data and then the proton-ligand stability constants (pKa) and Metal-ligand stability constant (LogK) calculated (Omar and Ali, 2015).

\section{RESULTS AND DISCUSSION}

Fourier transformed infrared (FT-IR) spectra of isolated humic acid from peat soils Figure 2 had distinct clear absorption bands indicating the presence of major humic acid structural elemental groups such as $\mathrm{H}$ bonded $\mathrm{OH}$ $\left(3680 \mathrm{~cm}^{-1}\right.$ peak $), C=0$ of carbonyl $\left(1721 \mathrm{~cm}^{-1}\right.$ peak), functional groups of aliphatic components $\mathrm{CH}_{2}\left(2918 \mathrm{~cm}^{-1}\right.$ peak) and $\mathrm{C}-\mathrm{O}$ stretching of polysaccharide $\left(1168 \mathrm{~cm}^{-1}\right.$ peak). The positions of the absorption bands of the spectra fell within typical major absorption bands of humic acid which is at frequencies 3680, 2918, 1721, 1168 $\mathrm{cm}^{-1}$. The first peak centred in the vicinity of $3680 \mathrm{~cm}^{-1}$ region is attributed to phenol $\mathrm{OH}$ group bounded by intermolecular $\mathrm{H}$ bonds. The $2918 \mathrm{~cm}^{-1}$ band usually has absorption maximum at $2918 \mathrm{~cm}^{-1}$ which is due to $\mathrm{C}-\mathrm{H}$ stretching of alkane group $\left(\mathrm{CH}_{2}\right)$. The next major absorption band is $1721 \mathrm{~cm}^{-1}$. This band has been commonly ascribed to $\mathrm{C}=\mathrm{O}$ stretching of mainly carboxyl group $(\mathrm{COOH})$ with trace amount of ketones. The last peak was observed at 1168 $\mathrm{cm}^{-1}$ due to $\mathrm{C}-\mathrm{O}$ stretching of polysaccharides and this peak appeared also in the spectra of humic acid from peat soil. The FTIR spectra of the isolated humic acid contained all major characteristic absorption peaks of humic acid. These absorption peaks indicated the presence of the major structural elements of humic acid namely $\mathrm{H}$ bonded $\mathrm{OH}, \mathrm{C}=\mathrm{C}$ of aromatic ring, $\mathrm{C}=\mathrm{O}$ of carbonyl group (both carboxyl and ketonic), $\mathrm{CH}_{2}$ group. This strongly supports the presence of humic acid.

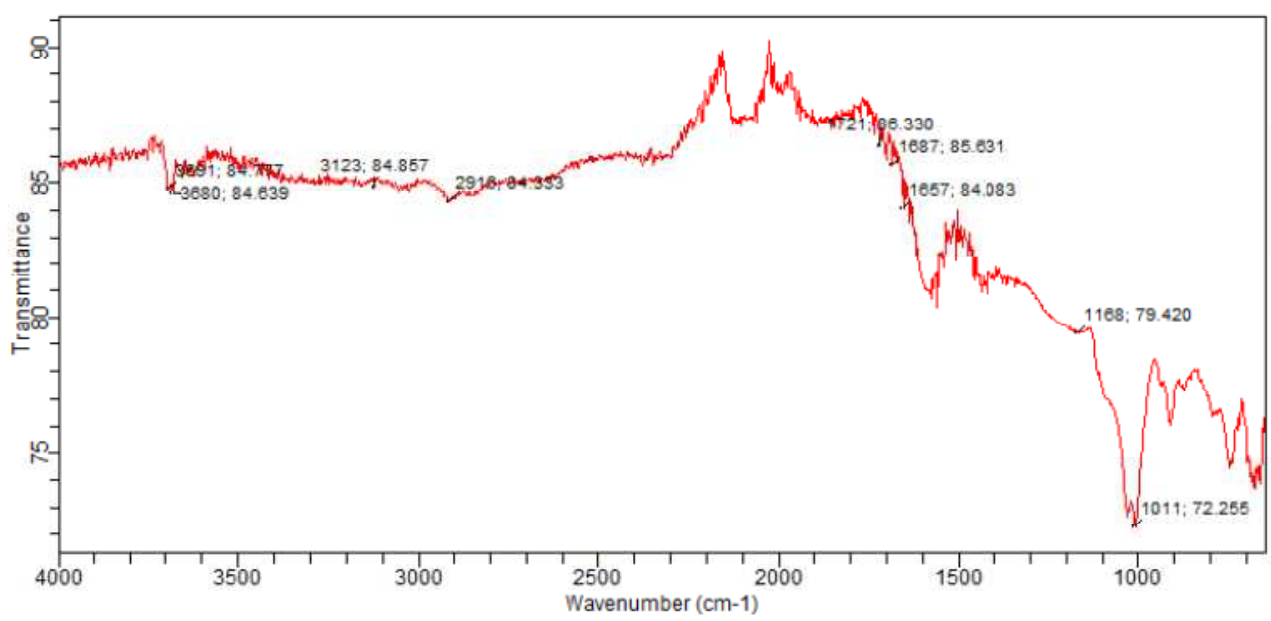

Fig. 2 : FT-IR spectraof peatsoilhumic acid (PSHA)

\section{Evaluation of acid dissociation constant (pka) of acid hydrolysed peat soil humicacid at phenolic group}

The value of the dissociation constant of the peat soil humic acid (PSHA) that underwent acidhydrolysis studied was found to be 8.9299 as shown Table 1, which is lower than the literaturevalues reported by Almeida and Szpoganics, (2015), Borges et al., (2005); Badr et al., (2012)and Fernandes et al,.(2009) of $9.73,9.47$ and 10.30. The difference between the obtained valuesand the reported values in this study might be probably as a result of acid hydrolysis of humicacid. 
BAJOPAS Volume 14 Number 1,June, 2021

Table 1: PKa of (Hydrolysed PSHA)

\begin{tabular}{|l|l|l|l|l|l|l|}
\hline $\mathrm{pH}$ & $\mathrm{BV}_{1}$ & $\mathrm{BV}_{2}$ & $\mathrm{~V}_{2}-\mathrm{V}_{1}$ & $\mathrm{nA}$ & $\log \left(\frac{n A}{1-n A}\right)$ & $\mathrm{pKa}$ \\
\hline 8.50 & 5.30 & 6.29 & 0.99 & 0.3594 & -0.2510 & 8.2490 \\
8.72 & 5.35 & 6.37 & 1.02 & 0.3400 & -0.2880 & 8.4320 \\
9.00 & 5.40 & 6.46 & 1.06 & 0.3141 & -0.3391 & 8.6609 \\
9.22 & 5.45 & 6.55 & 1.10 & 0.2882 & -0.3927 & 8.8273 \\
9.51 & 5.50 & 6.66 & 1.16 & 0.2494 & -0.4786 & 9.0314 \\
9.73 & 5.55 & 6.78 & 1.23 & 0.2041 & -0.5910 & 9.1390 \\
10.00 & 5.60 & 6.90 & 1.30 & 0.1589 & -0.7238 & 9.2762 \\
10.23 & 5.65 & 7.05 & 1.40 & 0.0941 & -0.9835 & 9.2465 \\
10.49 & 5.70 & 7.10 & 1.40 & 0.0941 & -0.9835 & 9.5065 \\
\hline
\end{tabular}

Average pKa $=8.9299 \pm 0.4186$

Table 2: PKa of (Unhydrolysed PSHA)

\begin{tabular}{|l|l|l|l|l|l|l|}
\hline $\mathrm{pH}$ & $\mathrm{BV}_{1}$ & $\mathrm{BV}_{2}$ & $\mathrm{~V}_{2}-\mathrm{V}_{1}$ & $\mathrm{nA}$ & $\log \left(\frac{\boldsymbol{n A}}{1-\boldsymbol{n}}\right)$ & $\mathrm{pKa}$ \\
\hline 8.50 & 5.30 & 5.81 & 0.51 & 0.6619 & 0.2919 & 8.7919 \\
8.72 & 5.35 & 5.90 & 0.55 & 0.6357 & 0.2418 & 8.9618 \\
9.00 & 5.40 & 6.00 & 0.60 & 0.6029 & 0.1813 & 9.1813 \\
9.22 & 5.45 & 6.10 & 0.65 & 0.5701 & 0.1226 & 9.3426 \\
9.51 & 5.50 & 6.20 & 0.70 & 0.5376 & 0.0654 & 9.5754 \\
9.73 & 5.55 & 6.33 & 0.78 & 0.4851 & -0.0259 & 9.7041 \\
10.00 & 5.60 & 6.47 & 0.87 & 0.4262 & -0.1291 & 9.8709 \\
10.23 & 5.65 & 6.62 & 0.99 & 0.3609 & -0.2481 & 9.9819 \\
10.49 & 5.70 & 6.80 & 1.10 & 0.2759 & -0.4690 & 10.0210 \\
\hline
\end{tabular}

Average pKa $=9.4923 \pm 0.4410$

Metal-ligand stability constant ( $\log \mathrm{K}$ )

The stabilityconstants require the accurate values of proton-ligand stability constants (Anil and Maroti, 2008). Metal titration curves crossed over ligand titration curve indicated the formation of complex upon proton release (Santosh, et al., 2011). If the values of n- are within range $0.2-0.8$ and $1.2-18$ this indicates the formation of $1: 1$ and 1:2 complexes (Sayyed and Mazahar, 2012).

The metal (II)-humate stepwise stability constants (log k) at phenolic group (Tables 318)

Table 3: Point-wise method, $\mathrm{Cu}$-(Hydrolysed PSHA)

\begin{tabular}{|l|l|l|l|l|l|l|l|l|}
\hline $\mathrm{pH}$ & $\mathrm{BV}_{1}$ & $\mathrm{BV}_{2}$ & $\mathrm{BV}_{3}$ & $\left(\mathrm{~V}_{3}-\mathrm{V}_{2}\right)$ & $\mathrm{n}$ & $\mathrm{pL}$ & $\log \left(\frac{n}{1-n}\right)$ & LogK $_{1}$ \\
\hline 8.50 & 5.30 & 6.29 & 6.33 & 0.04 & 0.5500 & 2.66 & 0.0871 & 2.7471 \\
8.72 & 5.35 & 6.37 & 6.41 & 0.04 & 0.5714 & 2.43 & 0.1249 & 2.5549 \\
9.00 & 5.40 & 6.46 & 6.50 & 0.04 & 0.6198 & 2.16 & 0.2122 & 2.3722 \\
9.22 & 5.45 & 6.55 & 6.59 & 0.04 & 0.6667 & 1.94 & 0.3010 & 2.2410 \\
\hline
\end{tabular}

LogK $_{1}$ (Average value) $=2.4788 \pm 0.2203$

Table 4: Point-wise method, $\mathrm{Cu}$-(Hydrolysed PSHA)

\begin{tabular}{|l|l|l|l|l|l|l|l|l|}
\hline $\mathrm{pH}$ & $\mathrm{BV}_{1}$ & $\mathrm{BV}_{2}$ & $\mathrm{BV}_{3}$ & $\left(\mathrm{~V}_{3}-\mathrm{V}_{2}\right)$ & $\mathrm{n}$ & $\mathrm{pL}$ & $\log \left(\frac{n-1}{2-n}\right)$ & LogK $_{2}$ \\
\hline 9.51 & 5.50 & 6.66 & 6.73 & 0.07 & 1.3509 & 1.70 & -0.2671 & 1.4329 \\
9.73 & 5.55 & 6.78 & 6.85 & 0.07 & 1.6383 & 1.51 & 0.2467 & 1.7567 \\
10.00 & 5.60 & 6.90 & 6.98 & 0.08 & 2.1783 & 1.31 & -0.2158 & 1.0942 \\
10.23 & 5.65 & 7.05 & 7.13 & 0.08 & 4.1904 & 1.27 & & \\
10.49 & 5.70 & 7.10 & 7.19 & 0.09 & 4.6920 & & & \\
\hline
\end{tabular}

Log $K_{2}($ Average value $)=1.4280 \pm 0.3312$ 
BAJOPAS Volume 14 Number 1,June, 2021

Table 5: Point-wise method, $\mathrm{Cu}$ (Unhydrolysed PSHA)

\begin{tabular}{|l|l|l|l|l|l|l|l|l|}
\hline $\mathrm{pH}$ & $\mathrm{BV}_{1}$ & $\mathrm{BV}_{2}$ & $\mathrm{BV}_{3}$ & $\left(\mathrm{~V}_{3}-\mathrm{V}_{2}\right)$ & $\mathrm{n}$ & $\mathrm{pL}$ & $\log \left(\frac{n}{n-1}\right)$ & Log $_{1}$ \\
\hline 8.50 & 5.30 & 5.81 & 5.85 & 0.04 & 0.2973 & 2.88 & -0.3736 & 2.5064 \\
8.72 & 5.35 & 5.90 & 5.95 & 0.05 & 0.3873 & 2.66 & -0.1992 & 2.4608 \\
9.00 & 5.40 & 6.00 & 6.05 & 0.05 & 0.4044 & 2.38 & -0.1681 & 2.2119 \\
9.22 & 5.45 & 6.10 & 6.15 & 0.06 & 0.5157 & 2.18 & -0.0272 & 2.2072 \\
9.51 & 5.50 & 6.20 & 6.27 & 0.07 & 0.6417 & 1.89 & 0.2530 & 1.1430 \\
\hline
\end{tabular}

$\operatorname{LogK}_{1}($ Average value $)=2.3059 \pm 0.6153$

Table 6:Point-wise method, $\mathrm{Cu}$ (Unhydrolysed PSHA)

\begin{tabular}{|l|l|l|l|l|l|l|l|l|}
\hline $\mathrm{pH}$ & $\mathrm{BV}_{1}$ & $\mathrm{BV}_{2}$ & $\mathrm{BV}_{3}$ & $\mathrm{~V}_{3}-\mathrm{V}_{2}$ & $\mathrm{n}$ & $\mathrm{pL}$ & $\log \left(\frac{n-1}{2-n}\right)$ & $\log \mathrm{K}_{2}$ \\
\hline 9.73 & 5.55 & 6.33 & 6.42 & 0.09 & 0.9000 & 1.69 & & \\
10.00 & 5.60 & 6.47 & 6.58 & 0.11 & 1.2578 & 1.44 & -0.4592 & 0.9808 \\
10.23 & 5.65 & 6.62 & 6.84 & 0.12 & 1.6137 & 1.26 & -0.2010 & 1.4610 \\
10.49 & 5.70 & 6.80 & 6.92 & 0.12 & 2.1052 & 1.03 & & \\
\hline
\end{tabular}

$\operatorname{LogK}_{2}$ (Average value) $=1.2209 \pm 0.3398$

Table 7:Point-wise method, Pb (Hydrolysed PSHA)

\begin{tabular}{|l|l|l|l|l|l|l|l|l|}
\hline $\mathrm{pH}$ & $\mathrm{BV}_{1}$ & $\mathrm{BV}_{2}$ & $\mathrm{BV}_{3}$ & $\left(\mathrm{~V}_{3}-\mathrm{V}_{2}\right)$ & $\mathrm{n}$ & $\mathrm{pL}$ & $\log \left(\frac{n}{1-n}\right)$ & LogK $_{1}$ \\
\hline 8.50 & 5.30 & 6.29 & 6.33 & 0.04 & 0.5500 & 2.66 & 0.0871 & 2.7471 \\
8.72 & 5.35 & 6.37 & 6.41 & 0.04 & 0.5714 & 2.43 & 0.1249 & 2.5549 \\
9.00 & 5.40 & 6.46 & 6.50 & 0.04 & 0.6198 & 2.16 & 0.2122 & 2.3722 \\
9.22 & 5.45 & 6.55 & 6.60 & 0.05 & 0.8333 & 1.96 & 0.6989 & 2.6589 \\
\hline
\end{tabular}

Log $_{\mathbf{1}}($ Average value $)=2.5832 \pm 0.1614$

Table 8:Point-wise method, Pb-(Hydrolysed PSHA)

\begin{tabular}{|l|l|l|l|l|l|l|l|l|}
\hline $\mathrm{pH}$ & $\mathrm{BV}_{1}$ & $\mathrm{BV}_{2}$ & $\mathrm{BV}_{3}$ & $\left(\mathrm{~V}_{3}-\mathrm{V}_{2}\right)$ & $\mathrm{n}$ & $\mathrm{pL}$ & $\log \left(\frac{n-1}{2-n}\right)$ & $\log \mathrm{K}_{2}$ \\
\hline 9.51 & 5.50 & 6.66 & 6.71 & 0.05 & 0.9650 & 1.67 & & \\
9.73 & 5.55 & 6.78 & 6.83 & 0.05 & 1.1702 & 1.44 & & \\
10.00 & 5.60 & 6.90 & 6.90 & 0.05 & 1.4864 & 1.22 & -0.0237 & 1.1963 \\
10.23 & 5.65 & 7.05 & 7.10 & 0.05 & 2.0190 & 1.09 & & \\
10.49 & 5.70 & 7.10 & 7.17 & 0.07 & 3.6492 & 1.00 & & \\
\hline
\end{tabular}

Log $K_{2}$ (Average value) $=1.1963$

Table 9: Point-wise method, Pb (Unhydrolysed PSHA)

\begin{tabular}{|l|l|l|l|l|l|l|l|l|}
\hline $\mathrm{pH}$ & $\mathrm{BV}_{1}$ & $\mathrm{BV}_{2}$ & $\mathrm{BV}_{3}$ & $\mathrm{~V}_{3}-\mathrm{V}_{2}$ & $\mathrm{n}$ & $\mathrm{pL}$ & $\begin{array}{l}\text { Log } \\
\left(\frac{n}{n-1}\right)\end{array}$ & Log $\mathrm{K}_{1}$ \\
\hline 8.50 & 5.30 & 5.81 & 5.85 & 0.04 & 0.2973 & 2.88 & -0.3736 & 2.5064 \\
8.72 & 5.35 & 5.90 & 5.94 & 0.04 & 0.3099 & 2.66 & -0.5477 & 2.3123 \\
9.00 & 5.40 & 6.00 & 6.05 & 0.05 & 0.4044 & 2.38 & -0.1681 & 2.2119 \\
9.22 & 5.45 & 6.10 & 6.15 & 0.06 & 0.5157 & 2.18 & 0.0272 & 2.2072 \\
9.51 & 5.50 & 6.20 & 6.26 & 0.07 & 0.6417 & 1.89 & 0.2530 & 2.1430 \\
9.73 & 5.55 & 6.40 & 6.40 & 0.07 & 0.7000 & 1.67 & 0.3680 & 2.0380 \\
\hline
\end{tabular}

LogK $_{1}$ (Average value) $=2.2364 \pm 0.1602$

Table 10: Point-wise method, Pb (Unhydrolysed PSHA)

\begin{tabular}{|l|l|l|l|l|l|l|l|l|}
\hline $\mathrm{pH}$ & $\mathrm{BV}_{1}$ & $\mathrm{BV}_{2}$ & $\mathrm{BV}_{3}$ & $\mathrm{~V}_{3}-\mathrm{V}_{2}$ & $\mathrm{n}$ & $\mathrm{pL}$ & $\log \left(\frac{n-1}{2-n}\right)$ & $\log \mathrm{K}_{2}$ \\
\hline 10.00 & 5.60 & 6.47 & 6.55 & 0.08 & 1.9503 & 1.41 & & \\
10.23 & 5.65 & 6.62 & 6.72 & 0.11 & 1.4792 & 1.26 & -0.0361 & 1.2239 \\
\hline
\end{tabular}

$\operatorname{LogK}_{2}$ (Average value) $=1.2239$

Table 11: Point-wise method, Mg (Hydrolysed PSHA)

\begin{tabular}{|l|l|l|l|l|l|l|l|l|}
\hline $\mathrm{pH}$ & $\mathrm{BV}_{1}$ & $\mathrm{BV}_{2}$ & $\mathrm{BV}_{3}$ & $\left(\mathrm{~V}_{3}-\mathrm{V}_{2}\right)$ & $\mathrm{n}$ & $\mathrm{pL}$ & $\log \left(\frac{n}{n-1}\right)$ & LogK $_{1}$ \\
\hline 8.50 & 5.30 & 6.29 & 6.31 & 0.02 & 0.2750 & 2.64 & -0.4290 & 2.2110 \\
8.72 & 5.35 & 6.37 & 6.39 & 0.02 & 0.2858 & 2.42 & -0.3978 & 2.0222 \\
9.00 & 5.40 & 6.46 & 6.49 & 0.03 & 0.4648 & 2.14 & -0.0612 & 2.0788 \\
9.22 & 5.45 & 6.55 & 6.59 & 0.04 & 0.6667 & 1.94 & 0.3010 & 2.2410 \\
\hline
\end{tabular}

$\log _{\mathbf{1}}($ Average value) $=2.1382 \pm 0.1046$ 
BAJOPAS Volume 14 Number 1,June, 2021

Table 12: Point-wise method, Mg (Hydrolysed PSHA)

\begin{tabular}{|l|l|l|l|l|l|l|l|l|}
\hline $\mathrm{pH}$ & $\mathrm{BV}_{1}$ & $\mathrm{BV}_{2}$ & $\mathrm{BV}_{3}$ & $\left(\mathrm{~V}_{3}-\mathrm{V}_{2}\right)$ & $\mathrm{n}$ & $\mathrm{pL}$ & $\log \left(\frac{n-1}{2-n}\right)$ & LogK $_{2}$ \\
\hline 9.51 & 5.55 & 6.66 & 6.71 & 0.05 & 0.9650 & 1.67 & & \\
9.73 & 5.55 & 6.78 & 6.84 & 0.06 & 1.4042 & 1.47 & -0.1686 & 1.3014 \\
10.00 & 5.60 & 6.90 & 6.93 & 0.06 & 1.7838 & 1.23 & 0.5593 & 1.7893 \\
10.23 & 5.65 & 7.05 & 7.10 & 0.06 & 3.1429 & 1.10 & & \\
10.49 & 5.70 & 7.10 & 7.18 & 0.07 & 3.6492 & 0.83 & & \\
\hline
\end{tabular}

LogK $_{2}($ Average value $)=1.5453 \pm 0.3450$

Table 13: Point-wise method, Mg (Unhydrolysed PSHA)

\begin{tabular}{|l|l|l|l|l|l|l|l|l|}
\hline $\mathrm{pH}$ & $\mathrm{BV}_{1}$ & $\mathrm{BV}_{2}$ & $\mathrm{BV}_{3}$ & $\mathrm{~V}_{3}-\mathrm{V}_{2}$ & $\mathrm{n}$ & $\mathrm{pL}$ & $\log \left(\frac{n}{n-1}\right)$ & $\operatorname{Log~}_{1}$ \\
\hline 8.50 & 5.30 & 5.81 & 5.85 & 0.04 & 0.2973 & 2.88 & -0.3736 & 2.5064 \\
8.72 & 5.35 & 5.90 & 5.94 & 0.04 & 0.3099 & 2.66 & -0.3477 & 2.3123 \\
9.00 & 5.40 & 6.00 & 6.04 & 0.04 & 0.3236 & 2.38 & -0.3202 & 2.0598 \\
9.22 & 5.45 & 6.10 & 6.15 & 0.05 & 0.4297 & 2.17 & -0.1230 & 2.0470 \\
9.51 & 5.50 & 6.20 & 6.26 & 0.06 & 0.5500 & 1.89 & 0.0871 & 1.9771 \\
9.73 & 5.55 & 6.33 & 6.40 & 0.07 & 0.7000 & 1.67 & 0.3680 & 2.0380 \\
\hline
\end{tabular}

LogK $_{1}$ (Average value) $=2.1568 \pm 0.2069$

Table 14: Point-wise method, Mg (Unhydrolysed PSHA)

\begin{tabular}{|l|l|l|l|l|l|l|l|l|}
\hline $\mathrm{pH}$ & $\mathrm{BV}_{1}$ & $\mathrm{BV}_{2}$ & $\mathrm{BV}_{3}$ & $\mathrm{~V}_{3}-\mathrm{V}_{2}$ & $\mathrm{n}$ & $\mathrm{pL}$ & $\log \left(\frac{n-1}{2-n}\right)$ & $\log \mathrm{K}_{2}$ \\
\hline 10.00 & 5.60 & 6.47 & 6.55 & 0.08 & 0.9148 & 1.41 & & \\
10.23 & 5.65 & 6.62 & 6.71 & 0.09 & 1.2102 & 1.20 & -0.5749 & 0.6251 \\
10.49 & 5.70 & 6.80 & 6.92 & 0.09 & 1.5968 & 1.03 & 0.1703 & 1.2003 \\
\hline
\end{tabular}

LogK $_{2}$ (Average value) $=0.9127 \pm 0.4070$

Table15:Point-wise method, Cd (Hydrolysed PSHA)

\begin{tabular}{|l|l|l|l|l|l|l|l|l|}
\hline $\mathrm{pH}$ & $\mathrm{BV}_{1}$ & $\mathrm{BV}_{2}$ & $\mathrm{BV}_{3}$ & $\left(\mathrm{~V}_{3}-\mathrm{V}_{2}\right)$ & $\mathrm{n}$ & $\mathrm{pL}$ & $\log \left(\frac{n}{1-n}\right)$ & LogK $_{1}$ \\
\hline 8.50 & 5.30 & 6.29 & 6.31 & 0.02 & 0.2750 & 2.64 & -0.4210 & 2.2190 \\
8.72 & 5.35 & 6.37 & 6.40 & 0.03 & 0.4286 & 2.42 & -0.1249 & 2.2951 \\
9.00 & 5.40 & 6.46 & 6.49 & 0.03 & 0.4648 & 2.14 & -0.0612 & 2.0788 \\
9.22 & 5.45 & 6.55 & 6.59 & 0.04 & 0.6667 & 1.96 & 0.3010 & 2.2610 \\
9.51 & 5.55 & 6.66 & 6.70 & 0.04 & 0.7720 & 1.67 & 0.5297 & 2.1997 \\
\hline
\end{tabular}

LogK $_{\mathbf{1}}$ (Average value) $=2.2108 \pm 0.0825$

Table 16: Point-wise method, Cd (Hydrolysed PSHA)

\begin{tabular}{|l|l|l|l|l|l|l|l|l|}
\hline $\mathrm{pH}$ & $\mathrm{BV}_{1}$ & $\mathrm{BV}_{2}$ & $\mathrm{BV}_{3}$ & $\left(\mathrm{~V}_{3}-\mathrm{V}_{2}\right)$ & $\mathrm{n}$ & $\mathrm{pL}$ & $\log \left(\frac{n-1}{2-n}\right)$ & Log $_{2}$ \\
\hline 9.73 & 5.55 & 6.78 & 6.83 & 0.06 & 1.4042 & 1.47 & -0.1686 & 1.3014 \\
10.00 & 5.60 & 6.90 & 6.95 & 0.06 & 1.7838 & 1.23 & 0.5593 & 1.7893 \\
10.23 & 5.65 & 7.05 & 7.10 & 0.06 & 3.1429 & 1.09 & & \\
10.49 & 5.70 & 7.10 & 7.16 & 0.06 & 3.1429 & 0.89 & & \\
& & & & & & & & \\
\hline
\end{tabular}

$\operatorname{LogK}_{2}$ (Average value) $=1.5453 \pm 0.3450$

Table 17: Point-wise method, Cd (Unhydrolysed PSHA)

\begin{tabular}{|l|l|l|l|l|l|l|l|l|}
\hline $\mathrm{pH}$ & $\mathrm{BV}_{1}$ & $\mathrm{BV}_{2}$ & $\mathrm{BV}_{3}$ & $\mathrm{~V}_{3}-\mathrm{V}_{2}$ & $\mathrm{n}$ & $\mathrm{pL}$ & $\log \left(\frac{n}{n-1}\right)$ & $\operatorname{Log~}_{1}$ \\
\hline 8.50 & 5.30 & 5.81 & 5.86 & 0.05 & 0.3717 & 2.88 & -0.2280 & 2.6520 \\
8.72 & 5.35 & 5.90 & 5.95 & 0.05 & 0.3873 & 2.66 & -0.1992 & 2.4608 \\
9.00 & 5.40 & 6.00 & 6.06 & 0.06 & 0.4853 & 2.38 & -0.0255 & 2.3545 \\
9.22 & 5.45 & 6.10 & 6.16 & 0.06 & 0.5157 & 2.18 & -0.0272 & 2.2072 \\
9.51 & 5.50 & 6.20 & 6.27 & 0.07 & 0.6417 & 1.89 & 0.2530 & 1.1430 \\
9.73 & 5.55 & 6.33 & 6.41 & 0.08 & 0.8000 & 1.69 & 0.6020 & 2.2920 \\
& & & & & & & & \\
\hline
\end{tabular}

$\operatorname{LogK}_{1}($ Average value $)=2.2516 \pm 0.5380$ 
BAJOPAS Volume 14 Number 1,June, 2021

Table 18: Point-wise method, Cd (Unhydrolysed PSHA)

\begin{tabular}{|l|l|l|l|l|l|l|l|l|}
\hline $\mathrm{pH}$ & $\mathrm{BV}_{1}$ & $\mathrm{BV}_{2}$ & $\mathrm{BV}_{3}$ & $\mathrm{~V}_{3}-\mathrm{V}_{2}$ & $\mathrm{n}$ & $\mathrm{pL}$ & $\log \left(\frac{n-1}{2-n}\right)$ & $\log \mathrm{K}_{2}$ \\
\hline 10.00 & 5.60 & 6.47 & 6.57 & 0.10 & 1.1434 & 1.43 & & \\
10.23 & 5.65 & 6.62 & 6.72 & 0.10 & 1.3448 & 1.23 & -0.2788 & 0.9512 \\
10.49 & 5.70 & 6.80 & 6.90 & 0.10 & 1.7742 & 1.03 & 0.5351 & 1.5651 \\
\hline
\end{tabular}

$\operatorname{LogK}_{2}($ Average value $)=1.2581 \pm 0.4340$

Table 19: Stepwise and overall Stability constants of thehydrolysed and unhydrolysed divalent metal (II) complexes

\begin{tabular}{|c|c|c|c|}
\hline Chelates & LogK $_{1}$ & $\log _{2}$ & Log $\beta$ \\
\hline [Cu (Hydrolysed PSHA-1) $\left.{ }_{2}\right]$ & 2.4788 & 1.4280 & 3.9068 \\
\hline$\left[\mathrm{Pb}(\text { Hydrolysed PSHA-1) })_{2}\right]$ & 2.5832 & 1.1963 & 3.7795 \\
\hline$\left[\mathrm{Cd}(\text { Hydrolysed PSHA-1 })_{2}\right]$ & 2.2108 & 1.5453 & 3.7561 \\
\hline$\left[\mathrm{Mg}(\text { Hydrolysed PSHA-1 })_{2}\right]$ & 2.1382 & 1.5453 & 3.6835 \\
\hline [Cu (Unhydrolysed PSHA-1) & 2.3059 & 1.2209 & 3.5268 \\
\hline$[\mathrm{Pb}$ (Unhydrolysed PSHA-1) 2$]$ & 2.2364 & 1.2239 & 3.4603 \\
\hline [Cd (Unhydrolysed PSHA-1) 2 ] & 2.2516 & 1.2581 & 3.5097 \\
\hline$[\mathrm{Mg}$ (Unydrolysed PSHA-1) & 2.1568 & 0.9127 & 3.0695 \\
\hline
\end{tabular}

The results obtained (Table19) shows the stepwise and overall stability constants to be not high indicating low stability of the complexes, because the solubility of most metal ions in the basic $\mathrm{pH}$ range is minimal due to metal hydroxide precipitation (Karimi, 2017). In general, the stepwise stability constants $\left(K_{1}\right.$ and $K_{2}$ ) follow the order $K_{1}>K_{2}$ for the copper, lead, magnesium and cadmium complexes respectively. The steady decrease of the values with increasing number of ligands is in agreement with the prediction made by researchers (Na'aliya, 2013). The decrease could be attributed to the fact that as the number of the ligands (Humate ions) that enters the coordination zone increases the aqua molecules available for replacement by the ligands become less. Thus, the metal ions become less electron loving with progressive intake of the ligand and this results in the decrease in the values of the constants (Na'aliya, 2013). Also the stability of the complexes is influenced by the size and number of the chelate rings(Mackay and Mackay,2002).All the complexes form rings in their structure as humate, a bidentate ligand, bond the metal ions in the ratio 1:2 (Boguta and Sokolowska, 2016) forming chelate rings. The values of the overall stability constants $(\log \beta)$ obtained for humate complexes are not high indicating low stability as the values are not high. LogK values for copper-humates (Table 3 to 6) obtained in this study are lower than those reported for the complexes of humic acids (Pandey et al., 2015; Dinu, 2013; Kaschl et al., 2010 and Gilbeto and Jorg, 2001). The values of LogK(Table 7 to 10 ) forlead-humates are lower than those reported for the lead in the literature (Dinu, 2013; Gilbeto and Jorg 2001). Log K values(Table 11 to 14 ) for magnesium-humates obtained in this study are close to those reported by (Pandey et al., 2015). Log K values of cadmium-humates (Table 15 to 18 ) obtained in this work near to the one reported by (Dinu, 2013 and Pandey et al., 2015).The difference between the reported values and the values obtained in this study might be probably as a result of acid hydrolysis of humic acid. The values of the overall stability constants $(\log \beta)$ of the copper humates complexes presented in Table 19 is high than that of other metal humate complexes, show relatively high stability of CuHA complexes, show the following order of stability: $\mathrm{Cu}>\mathrm{Pb}>\mathrm{Cd}>\mathrm{Mg}$; which are in close agreement to the findings of (Dinu, 2013 and Pandey et al., 2015).The high stability of Cuhumate chelate could be attributed to the existence of coordinate covalent bond between the complexing agents and the $\mathrm{Cu}^{2+}$ ions. Since, $\mathrm{Cu}^{2+}$ being a metal of the transitional series with $3 d^{9}$ electronic configurations can accept the electrons from the complexing agents. Similarly, the low stabilities of $\mathrm{Pb}, \mathrm{Cd}$ and $\mathrm{Mg}$ complexes could be explained by that $\mathrm{Pb}^{2+}$ with $6 s^{2}, \mathrm{Cd}^{2+}$ with $4 \mathrm{~d}^{10}$ and $\mathrm{Mg}^{2+}$ with $2 \mathrm{p}^{6}$ their electronic configuration has a completely filled $\mathrm{d}, \mathrm{p}$ and $\mathrm{s}$ orbitals. Moreover, the stabilities of metal ions with hydrolysed humic acid from peat soil were higher than those with unhydrolysed humic acid from peat soil; which is ascribed to the high content of acidity in hydrolysed humic acid than unhydrolysed humic acid. 
BAJOPAS Volume 14 Number 1,June, 2021 CONCLUSION

The values of logk for $\mathrm{Cu}(\mathrm{II})$ hydrolysed humic acid complex was higher followed by $\mathrm{Pb}$ (II), $\mathrm{Cd}(\mathrm{II})$ and $\mathrm{Mg}$ (II) hydrolysed humic acid complexes as compared with metal(II) unhydrolysed humic acid complexes. This indicates acid hydrolysis of humic acid can

\section{REFERENCES}

Almeida, V.R. and Szpoganicz, B. (2015). Humic Acid Potentiometric Response Patterns:Out- of Equilibrium Properties and Species Distribution Modelling. Chemical. Biol. Technol. Agric. 2: 17.

Anđelković, T., Nikolić, R., Bojić, A.,Anđelković, D., and Nikolic G.,(2010). Binding of Cadmium to Soil Humic Acid as A Function of Carboxyl Group Content. Macedonian Journal of Chemistry and Chemical Engineering.29(2): 215-224.

Anil, B. N. and Maroti, N. (2008). Studies on Influence of Die-Lectric Constants on Complex Equilibria between Substituted Py-Razalines and Lanthanide Metal Ions pH-Metrically. Amer.-Euras. scient. Res. 3(2): 212-216.

Ashok, K., Pandey, S. P. and Misra, V (2000). Stability Constants of Metal-Humic Acid Complexes and its Role in Environmental Detoxification. Journal of Ecotoxicology and Environmental Safety. 47(2):157-200.

Badr, M. H., El-Halafawi, M. H. and Abd El-al Zeid, E. R. (2012). Comparison Between the Effect of Ionic Strength on Acidity and Dissociation Constants of Humic Acids Extracted from Sewage Sludge and Nile Water Hyacinth Composts.Global Journal of Environmental Research 6 (1): 36-43.

Baruah, M.K., Borah, D., Saikia, P.P., Paul, S., Sharma, T. (2015). Evaluation of pKa Values of Soil Humic Acids and their Complexation Properties. International Journal of Plant \& Soil Science 6(4) : 218-228.

Boguta, P. Sokolowska, Z. (2016). Interactions of $\mathrm{Zn}$ (II) Ions with Humic Acids Isolated from Various Types of Soils. Effect of $\mathrm{pH}, \mathrm{Zn}$ Concentrations and Humic Acids Chemical Properties. Journal of Geochemical Explaration 168. 119-126.

Borges, F., Guimaraes, C., Lima, L.F.C., Pinto, I. and Reis, S.(2005). Potentiometric Studies on the Complexation of Copper(II) by Phenolic Acids as Discrete Ligand Models of enhance the complexation behavior of humic acid with metal (II) ions. However, the higher values of $\log \beta$ for $\mathrm{Cu}(\mathrm{II}), \mathrm{Pb}(\mathrm{II}), \mathrm{Cd}(\mathrm{II})$ and $\mathrm{Mg}(\mathrm{II})$ hydrolysed humic acid complexes indicates more stable stepwise complexes formed as compared with $\mathrm{Cu}(\mathrm{II}), \mathrm{Pb}$ (II), $\mathrm{Cd}$ (II) and $\mathrm{Mg}(\mathrm{II})$ unhydrolysed humic acid complexes.

Humic Substances Talanta 66 (2005) 670-673.

Chefetz, B., Salloum, M. J., Deshmulkin, A. P. and Hatcher, P. (2002). Structural Components of Humic Acids as Determined by Chemical Modifications and Carbon-13 NMR, Pyrolysis, and Thermochemolysis- Gas Chromatography/Mass Spectrometry. Soil Science Society of American Journal Abstract Division S-2- Soil Chemistry66. 1159-1171.

Dinu, M. I. (2013). Metals Complexation with Humic Acids in Surface Water of Different Environ. Sci. Technol. 31(1): 1-17.

Fernandes, A.N., Giacomelli, C., Giovanela, M. Vaz, D.V. Szpoganicz, B. and Maria M. D. (2009). Potentiometric Acidity Determination in Humic Substances Influenced by Different Analytical Procedures.J. Braz. Chem. Soc. 20 (9):14.

Gamal, A. H. (2015). Stability Constants of Rhenium (V) Metal Complexes with Selected Drugs. Pyrex Journal of Research in Environmental Studies. 2(2): 006-014.

Janrao, D. M., Pathan, J., Kayande, D.D., and Mulla, J.J. (2014). An Over View of Potentiometric Determination of Stability Constants of Metal Complexes. Sci. Revs. Chem. Commun.: 4(1), 2014, 11-24.

Karimi, H. (2017). Effect of pH and Initial Pb(II) Concentration on the Lead Removal Efficiency from Waste Water Using $\mathrm{Ca}(\mathrm{OH})_{2}$. International Journal of Water and Waste Water Treatment 3.2

Kaschl, A. Romheld, V. and Chen, Y. (2010). Binding of Cadmium, Copper and Zinc to Humic Substances Originating from Municipal Solid Waste Compost. Israel Journal of Chemistry Vol. 42(1): 89-98.

Kostic, I. S., Tatjana, P, A., Nikolic, R. S., Cvetkovic, T. P., Pavlovic, D. D., Aleksandar, L.J. and Bojic, A. (2012). Comparative Study of Binding Strengths of Heavy Metals with Humic Acid. J.serb. Chem. Soc. 76(9) pp 1-20. 
BAJOPAS Volume 14 Number 1,June, 2021

Na'aliya, J. (2013). Determination of Stepwise Stability Constants and Gibbs free Energy Change of Trisprolina to Complexes of some Divalent Transition Metal ions. Bayero Journal of Pure and Applied Sciences 6(2): 112-114.

Omar, A. A. and Ali, E. A. (2015). Potentiometric Studies on Complexes of $\mathrm{Cr}$ (III) and $\mathrm{Zr}$ (IV) with some Carboxylic Acids. International Journal of Advanced Chemistry, 3(1) 25-

37.

Pandey, A. K. Pandey, S. D. and Misr, V. (2015).Stability Constants of Metal- Humic Acid Complexes and Its Role in Environmental Detoxification. J. Ecotoxicology and Environmental Safety. 47(1):195-200.

Ram, N. and Raman, K.V. (1984). Stability Constants of Complexes of Metals with
Humicand Fuvic Acids under Non- acidConditions. Journal of Plant Nutrition and Soil Sciences.

147:171-176.

Santosh, D. D., Ashok, B. K., Vijay, J. T., Shivraj, G. W. and Vinay, V. W. (2011). Potentiometric Studies of Elec-Trolyte Effects on Complex Equilibria of Some Substituted 5-(2-hydroxy Phenyl) Pyrazoles. Der pharm. 3 (6): 75-83.

Sayyed, H. and Abdul Rahim, M. F. (2012). Studies of Binary Complexes of Metal Ions with Mandelic Acid by Potentiometry. Chem. J. 02 (6): 206209.

Shirvani, M. Moradian, E. Khalili, B. Bakhtiary, S. (2015). Interaction of $\mathrm{Cd}$ and $\mathrm{Pb}$ with Humate-Palygorskite and HumateSepiolite Complexes. Journal of water, air and pollution 3: 220-228. 


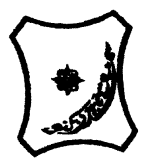

Bayero Journal of Pure and Applied Sciences, 14(1): 54 - 63

Received: November, 2020

Accepted: April, 2021

ISSN $2006-6996$

\title{
STABILITY CONSTANTS OF COMPLEXES OF METAL IONS WITH PEATSOIL HUMIC ACIDS UNDER NON-ACID-CONDITIONS
}

\author{
${ }^{* 1}$ Sabo, Yusuf ${ }^{2}$ Jimoh, W.L.O., ${ }^{3}$ Isa Baba Koki and ${ }^{4}$ Sholadoye, Q. 0. \\ ${ }^{1}$ Department of Pure and Industrial Chemistry, Bayero University, Kano \\ ${ }^{3}$ Department of Chemistry, Yusuf Maitama Sule University Kano. P.M.B. 3220 Kano, Nigeria. \\ ${ }^{4}$ Department of Chemistry, Nigerian Police Academy, Wudil, Kano-Nigeria
}

*Correspondence E-mail; saboyusuf18@yahoo.com

ABSTRACT

Stability constants of complexes of four divalent metal ions viz. $\mathrm{Cu}^{2+}, \mathrm{Pb}^{2+}, \mathrm{Mg}^{2+}$ and $\mathrm{Cd}^{2+}$ with humic acids (HA) were determined by potentiometric titration of humic acids with the corresponding salt of the divalent metals in aqueous media under non-acid-condition. The log $K$ (logarithm of the stability constant) ranged from 1.0942 to 2.7471 for metalhumic acid complexes were determined using point-wise computational method. The order of stability constants were obtained as follows: $\mathrm{Cu}>\mathrm{Pb}>\mathrm{Cd}>\mathrm{Mg}$ for metal $-\mathrm{HA}$ complexes respectively, indicating a higher degree of complexation with Cu metal ion.

Keywords: stability constant, humic acid, potentiometric titration, divalent metals, acid hydrolysis.

\section{NTRODUCTION}

The stability constant of a complex is the numerical expression of its stability and provides a quantitative measure of affinity of the metal ion to the complexing agent. An understanding of the relative stability of metal-complexes helps in predicting the behavior of metal ions in the soil (Ram and Raman, 1982). Extensive researches has been done to determine the stability constants of the complexes formed between humic acid (HA) with a number of metal ions. Ashok et al., (2000) reported that humic acid with hydroxyl, phenoxyl and carboxyl reactive groups can form coordination compound with metal ions at $\mathrm{pH}$ 3.5. The stability constants(Log K) for different metalhumic acid complexes indicated the following order of the stabilities of complexes formed between humic acid and metal ion, $\mathrm{Cu}>\mathrm{Fe}$ $>\mathrm{Pb}>\mathrm{Ni}>\mathrm{Co}>\mathrm{Ca}>\mathrm{Cd}>\mathrm{Zn}>\mathrm{Mn}>\mathrm{Mg}$. Andelkovic et al., (2010) investigated the binding of $\mathrm{Cd}$ (II) to soil humic acid at pH 6.5 and in $0.1 \mathrm{M} \mathrm{KNO}_{3}$ ionic medium. The stability constant for binding indicating greater stability in the case when carboxyl groups are involved in complexation reaction. Kostic et al.,(2012) investigated the complexation of humic acid with certain heavy metal ions (Co(II), $\mathrm{Ni}(\mathrm{II}), \mathrm{Cu}(\mathrm{II})$,
$\mathrm{Zn}(\mathrm{II})$, and $\mathrm{Pb}(\mathrm{II})$. The experiment was performed at $25^{\circ} \mathrm{C}$, at pH 4.0 and ionic strength of $0.01 \mathrm{M}$. Stability constant of complex between $\mathrm{Pb}$ (II) ions and humic acid is greater than stability constants of other investigated metalhumate complexes. Bogata and Sokolowska (2016) analyses the interaction between humic acids from different soils and $\mathrm{Zn}$ (II) ions at wide concentration ranges and at $\mathrm{pH} 5$. Studies have showed significant impact of $\mathrm{Zn}$ concentration, $\mathrm{pH}$ and some properties of humic acids with zinc.But all of these studies were limited to acidic $\mathrm{pH}$ range. Therefore, the present study was carried out to determine and compare the stability constants of complexes of metal ions with hydrolysed peat soil humic acid and unhydrolysed peat soil humic under non-acid conditions.

\section{MATERIALS AND METHODS}

Analytical grade chemicals used includes hydrochloric acid $(\mathrm{HCl})$, nitric acid $\left(\mathrm{HNO}_{3}\right)$, sodium hydroxide $(\mathrm{NaOH})$, lead nitrate $\mathrm{Pb}\left(\mathrm{NO}_{3}\right)_{2}$, copper nitrate $\mathrm{Cu}\left(\mathrm{NO}_{3}\right)_{2} \cdot 3 \mathrm{H}_{2} \mathrm{O}$, cadmium nitrate $\mathrm{Cd}\left(\mathrm{NO}_{3}\right)_{2} \cdot 4 \mathrm{H}_{2} \mathrm{O}$, magnesium nitrate $\mathrm{Mg}\left(\mathrm{NO}_{3}\right)_{2} \cdot 6 \mathrm{H}_{2} \mathrm{O}$, potassium nitrate $\left(\mathrm{KNO}_{3}\right)$, calcium chloride $\left(\mathrm{CaCl}_{2}\right)$, (sigma-Aldrich). Dowex 50WX8, (20-50 mesh) from Fluka. 


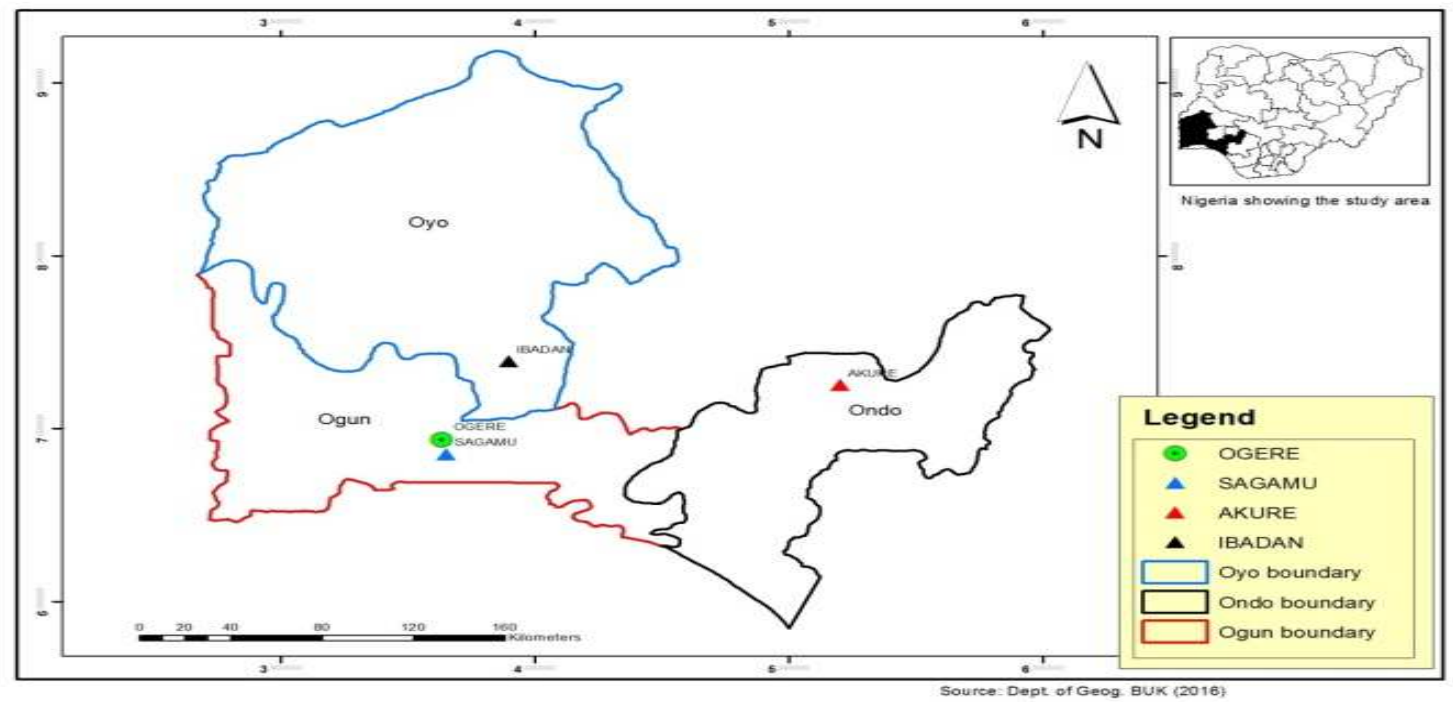

Figure 1: Map showing the sampling point at Sagamu Town, Ogun State.

\section{Description of Sampling Area}

Sagamu has geographical coordinates between $6^{\circ} 50^{\prime}$ north; $3^{\circ} 38^{\prime}$ east is located in south western region of Nigeria. The region has tropical wet and dry climate with a lengthy wet season and relatively constant temperatures throughout the course of the year. Wet season runs from March to October, November to December forms the region dry season. The vegetation type of the region is savannah which is really grassland with small bushes and occasional big trees. Grassland soils have substantially higher organic matter content than forest soils (Novackova, 2011).

\section{Sample Collection}

The Peatsoil samples were collected from four different sampling points $(0-10 \mathrm{~cm}$ depth) in Sagamu into polyethylene bag with plastic spoons. Samples were taken to the laboratory, extraneous materials were removed; the samples were air-dried, crushed and ground to a fine powder in a mortar passed through a $0.20 \mathrm{~mm}$ sieve. The samples were kept for analysis.

\section{Isolation and purification of humic acid from peat soil sample}

Peatsoil sample $(100 \mathrm{~g})$ was mixed with 1000 $\mathrm{cm}^{3}$ of $0.1 \mathrm{M} \mathrm{NaOH}$ solution, shaken for 3hours and left to stand overnight. Dark-coloured supernatant was obtained and decanted from solid residue. The dark-coloured supernatant was acidified to $(\mathrm{pH}=1.0)$ with $6 \mathrm{M} \mathrm{HCl}$ stirred and allowed to stand for 6 hours. Yellowish brown supernatant and dark-brown precipitate were obtained. The yellowish brown supernatant was decanted followed by centrifuge and discarded. The dark-brown precipitate was mixed with $500 \mathrm{~cm}^{3}$ of $0.1 \mathrm{M} \mathrm{NaOH}$ solution followed by passing through dowex resin. The dark-brown solution was acidified to $(\mathrm{pH}=1.0)$ with $6 \mathrm{M} \mathrm{HCl}$ stirred and allowed to stand for 3 hours. The dark-brown precipitate was washed several times with deionized water. The supernatant was treated with $\mathrm{AgNO}_{3}$ solution until no white precipitate observed. The humic acid was transferred to weighed crucible and dried at $60^{\circ} \mathrm{C}$ in an oven for 12 hours. The humic acid was cooled and dried in the desiccator, weighed and recorded. The obtained humic acid was dried again at $60^{\circ} \mathrm{C}$ for additional 6 hours cooled and dried in the desiccator, weighed and recorded constant weight was obtained (Baruah et al., 2015).

\section{FT-IR analysis}

FT-IR spectra of humic acid sample was analysed using Carry 630 FT-IR Agilent Technologies.

Unhydrolysed compost humic acid

The unhydrolysed humic acid was obtained after isolation and purification of compost humic acid and kept for investigation.

\section{Acid hydrolysis of Peatsoil acid}

Peatsoil humic acid sample (1g) was refluxed for 12 hours at $\left(160^{\circ} \mathrm{C}\right)$ with $50 \mathrm{~cm}^{3}$ of $6 \mathrm{M} \mathrm{HCl}$. The mixture was allowed to cool, decanted, and centrifuged after hydrolysis. The insoluble residues were washed with distilled water via centrifugation several times, and the supernatant was treated with $\mathrm{AgNO}_{3}$ solution until no white precipitate was observed. The residue was thoroughly dried over $\mathrm{CaCl}_{2}$ in a desiccator at room temperature (Chefetz et al., 2002). Finally, the obtained hydrolysed humic acid was kept for investigation. 
BAJOPAS Volume 14 Number 1,June, 2021 Potentiometric Titrations

Potentiometric measurements were carried out using a pH-meter Jenway (model 3510) with combine electrode, the sensitivity of the $\mathrm{pH}$ meter is 0.01 units. The $\mathrm{pH}$ meter was switched on half an hour before starting the titration for initial warm up of the instrument. The instrument was calibrated with an aqueous standard buffer solution of $\mathrm{pH} 4.00$ and 10.0 (borate buffer) prepared from a "Qualigens" buffer tablets.

The following sets of solutions were prepared in a $250 \mathrm{~cm}^{3}$ volumetric flask separately for $\mathrm{pH}$ metric titrations.

(i) $5 \mathrm{~cm}^{3} 0.1 \mathrm{M} \mathrm{HCl}+40 \mathrm{~cm}^{3}$ deionized water

(ii) $5 \mathrm{~cm}^{3} 0.1 \mathrm{M} \mathrm{HCl}+39 \mathrm{~cm}^{3}$ deionized water $+1 \mathrm{~cm}^{3} 0.15 \mathrm{gcm}^{-3}$ humic acid

(iii) $5 \mathrm{~cm}^{3} 0.1 \mathrm{M} \mathrm{HCl}+37 \mathrm{~cm}^{3}$ deionized water $+1 \mathrm{~cm}^{3} 0.15 \mathrm{gcm}^{-3}$ humic acid

$$
+2 \mathrm{~cm}^{3} \quad 0.01 \mathrm{M} \mathrm{Cu} \text { (II) }
$$

The solutions were titrated against standardized $0.110 \mathrm{MNaOH}$ separately. The total volume of each mixture was adjusted to $50 \mathrm{~cm}^{3}$ and the ionic strength of the solutions was maintained constant at by adding appropriate amount of stock solution of $1 \mathrm{M} \mathrm{KNO}_{3}$ (Gamal, 2015; Omar and Ali, 2015). A magnetic stirrer was used to achieve thorough mixing of the interacting solutions at $550 \mathrm{rpm}$. The same set of experimental conditions was applied for potentiometric titration of remaining samples.

\section{Evaluation of pKa of Hydrolysed peat soil Humic Acids}

The proton-ligand formation number $\mathrm{n}_{\mathbf{A}}$ were calculated by Irving and Rossotti expression (Omar and Ali, 2015).

$\mathrm{nA}=\mathrm{Y}-\frac{(\mathrm{V} 2-\mathrm{V1})(\mathrm{No}-\mathrm{Eo})}{(\mathrm{VO}+\mathrm{V1}) \mathrm{TCL}}$ 1

Where: $Y$ is number of dissociable proton, $\left(\mathrm{V}_{2^{-}}\right.$ $V_{1}$ ) is the measure of displacement of the ligand curve relative to acid curve, $\mathrm{N}^{\circ}$ and $\mathrm{E}^{\circ}$ are the resultant concentration of alkali solution, free acid solution, $\mathrm{T}_{\mathrm{cL}}{ }^{\circ}$ is the total ligand concentration, $\mathrm{V}^{\circ}$ is the total volume of titration solution, $V_{1}$ is the volume of alkali added to acid solution, $V_{2}$ is the volume of alkali added to acid solution + ligand solution, acid dissociation constants (pKa - values) of ligand were calculated by algebraic method point wise calculation (Tables 1 ). The dissociation constants (pKa) were calculated according to the following relation:

$\mathrm{pKa}=\mathrm{pH}+\log \left(\frac{n A}{1-n A}\right)$ 2

Where: pKa is the acid dissociation constant, $\mathrm{n}_{\mathrm{A}}$ is the Proton-ligand formation number and $\mathrm{pH}$ is the pH-values (Omar and Ali, 2015).

\section{Determination of metal-ligand stability constants $(\log K)$ of complexes}

The potentiometric measurement for the determination of stability constant of a complex in solution is based on the fact that the redox potential of the couple $\frac{M^{+(m-n)}}{M^{+m}}$ is shifted significantly on complexation of the metal ion with the ligand. This method involves change in hydrogen ion concentration $\left[\mathrm{H}^{+}\right]$due to the displacement or association of one or more protons taking place during complexation reaction. This change can be found out by titrating the solutions containing free acid, acid with ligand, and acid with ligand and metal ion, individually against a standard alkali solution at a constant ionic strength or temperature. Either ionic strength or temperature may be varied for different sets of solutions. In all the cases, the change in the $\mathrm{pH}$ of the solution is measured after each addition of a known amount of alkali to the reaction cell which contains the reaction mixture. The titration curves are then drawn by plotting the measured $\mathrm{pH}$ values against the corresponding volume of alkali added and the stability constants of the complexes are determined from the titration curves by employing $\mathrm{pH}$-metric titration technique given by (Irving and Rossoti).

Metal-ligand stability constants ( $\log \mathrm{K}$ ) were determined by using the following relations:

$$
\bar{n}=\frac{\left(V_{3}-V_{2}\right)\left(E^{0}+N^{0}\right)}{\left(V^{0}+V_{2}\right) \bar{n}_{A} T_{m}^{0}}
$$

and

$$
P L=\log _{10}\left\{\frac{1+\beta_{n}^{H} \frac{1}{[\text { anti } \log \mathrm{pH}]^{\mathrm{n}}}}{\mathrm{T}_{\mathrm{L}}^{0}-n \bar{T}_{m}^{0}} \mathrm{X} \frac{\left(V^{0}+V_{3}\right)}{V^{0}}\right\}
$$


BAJOPAS Volume 14 Number 1,June, 2021

Where $T_{L}, T^{\circ}, E^{\circ}$, and $V^{\circ}$ havethe same significance as in equation (1) above, $T_{m}$ denotes the total concentration of metal present in solution, $V_{3}$ is the volume of metal ions present in solution and $\beta^{H}$ is the overall proton ligand stability constant. The metal-ligand stability constants (log K) were determined by employing point wise computational Method (eq. 5 and 6).

$\operatorname{LogK}_{1}=\log \left(\frac{n}{1-n}\right)+\mathrm{pL}$ .5

$\operatorname{LogK}_{2}=\log \left(\frac{1-n}{2-n}\right)+\mathrm{pL}$ ...6

Where: Log $\mathrm{K}$ is the metal-ligand stability constant, $\mathrm{pL}$ is the Free ligand exponent function, $\mathbf{n}$ is the Average number of ligand attached with metal ion (Janraoet al., 2014). The results obtained were analyzed by an ORIGIN 2016 program using titration data and then the proton-ligand stability constants (pKa) and Metal-ligand stability constant (LogK) calculated (Omar and Ali, 2015).

\section{RESULTS AND DISCUSSION}

Fourier transformed infrared (FT-IR) spectra of isolated humic acid from peat soils Figure 2 had distinct clear absorption bands indicating the presence of major humic acid structural elemental groups such as $\mathrm{H}$ bonded $\mathrm{OH}$ $\left(3680 \mathrm{~cm}^{-1}\right.$ peak $), C=0$ of carbonyl $\left(1721 \mathrm{~cm}^{-1}\right.$ peak), functional groups of aliphatic components $\mathrm{CH}_{2}\left(2918 \mathrm{~cm}^{-1}\right.$ peak) and $\mathrm{C}-\mathrm{O}$ stretching of polysaccharide $\left(1168 \mathrm{~cm}^{-1}\right.$ peak). The positions of the absorption bands of the spectra fell within typical major absorption bands of humic acid which is at frequencies 3680, 2918, 1721, 1168 $\mathrm{cm}^{-1}$. The first peak centred in the vicinity of $3680 \mathrm{~cm}^{-1}$ region is attributed to phenol $\mathrm{OH}$ group bounded by intermolecular $\mathrm{H}$ bonds. The $2918 \mathrm{~cm}^{-1}$ band usually has absorption maximum at $2918 \mathrm{~cm}^{-1}$ which is due to $\mathrm{C}-\mathrm{H}$ stretching of alkane group $\left(\mathrm{CH}_{2}\right)$. The next major absorption band is $1721 \mathrm{~cm}^{-1}$. This band has been commonly ascribed to $\mathrm{C}=\mathrm{O}$ stretching of mainly carboxyl group $(\mathrm{COOH})$ with trace amount of ketones. The last peak was observed at 1168 $\mathrm{cm}^{-1}$ due to $\mathrm{C}-\mathrm{O}$ stretching of polysaccharides and this peak appeared also in the spectra of humic acid from peat soil. The FTIR spectra of the isolated humic acid contained all major characteristic absorption peaks of humic acid. These absorption peaks indicated the presence of the major structural elements of humic acid namely $\mathrm{H}$ bonded $\mathrm{OH}, \mathrm{C}=\mathrm{C}$ of aromatic ring, $\mathrm{C}=\mathrm{O}$ of carbonyl group (both carboxyl and ketonic), $\mathrm{CH}_{2}$ group. This strongly supports the presence of humic acid.

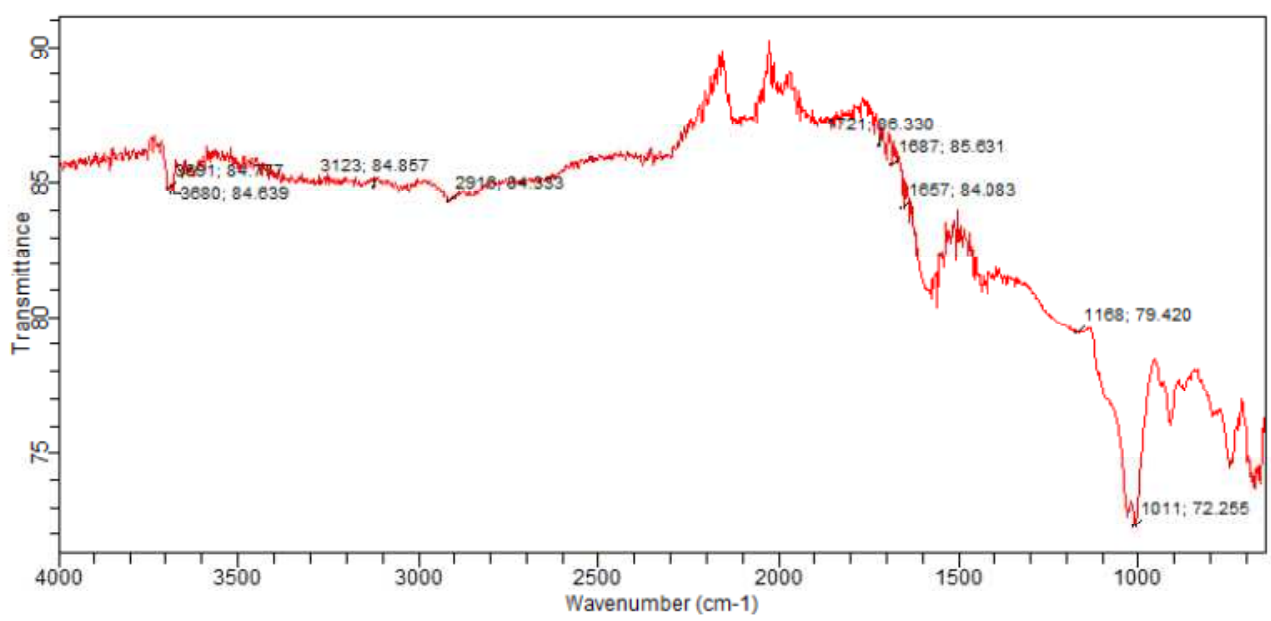

Fig. 2 : FT-IR spectraof peatsoilhumic acid (PSHA)

\section{Evaluation of acid dissociation constant (pka) of acid hydrolysed peat soil humicacid at phenolic group}

The value of the dissociation constant of the peat soil humic acid (PSHA) that underwent acidhydrolysis studied was found to be 8.9299 as shown Table 1, which is lower than the literaturevalues reported by Almeida and Szpoganics, (2015), Borges et al., (2005); Badr et al., (2012)and Fernandes et al,.(2009) of $9.73,9.47$ and 10.30. The difference between the obtained valuesand the reported values in this study might be probably as a result of acid hydrolysis of humicacid. 
BAJOPAS Volume 14 Number 1,June, 2021

Table 1: PKa of (Hydrolysed PSHA)

\begin{tabular}{|l|l|l|l|l|l|l|}
\hline $\mathrm{pH}$ & $\mathrm{BV}_{1}$ & $\mathrm{BV}_{2}$ & $\mathrm{~V}_{2}-\mathrm{V}_{1}$ & $\mathrm{nA}$ & $\log \left(\frac{n A}{1-n A}\right)$ & $\mathrm{pKa}$ \\
\hline 8.50 & 5.30 & 6.29 & 0.99 & 0.3594 & -0.2510 & 8.2490 \\
8.72 & 5.35 & 6.37 & 1.02 & 0.3400 & -0.2880 & 8.4320 \\
9.00 & 5.40 & 6.46 & 1.06 & 0.3141 & -0.3391 & 8.6609 \\
9.22 & 5.45 & 6.55 & 1.10 & 0.2882 & -0.3927 & 8.8273 \\
9.51 & 5.50 & 6.66 & 1.16 & 0.2494 & -0.4786 & 9.0314 \\
9.73 & 5.55 & 6.78 & 1.23 & 0.2041 & -0.5910 & 9.1390 \\
10.00 & 5.60 & 6.90 & 1.30 & 0.1589 & -0.7238 & 9.2762 \\
10.23 & 5.65 & 7.05 & 1.40 & 0.0941 & -0.9835 & 9.2465 \\
10.49 & 5.70 & 7.10 & 1.40 & 0.0941 & -0.9835 & 9.5065 \\
\hline
\end{tabular}

Average pKa $=8.9299 \pm 0.4186$

Table 2: PKa of (Unhydrolysed PSHA)

\begin{tabular}{|l|l|l|l|l|l|l|}
\hline $\mathrm{pH}$ & $\mathrm{BV}_{1}$ & $\mathrm{BV}_{2}$ & $\mathrm{~V}_{2}-\mathrm{V}_{1}$ & $\mathrm{nA}$ & $\log \left(\frac{\boldsymbol{n A}}{1-\boldsymbol{n}}\right)$ & $\mathrm{pKa}$ \\
\hline 8.50 & 5.30 & 5.81 & 0.51 & 0.6619 & 0.2919 & 8.7919 \\
8.72 & 5.35 & 5.90 & 0.55 & 0.6357 & 0.2418 & 8.9618 \\
9.00 & 5.40 & 6.00 & 0.60 & 0.6029 & 0.1813 & 9.1813 \\
9.22 & 5.45 & 6.10 & 0.65 & 0.5701 & 0.1226 & 9.3426 \\
9.51 & 5.50 & 6.20 & 0.70 & 0.5376 & 0.0654 & 9.5754 \\
9.73 & 5.55 & 6.33 & 0.78 & 0.4851 & -0.0259 & 9.7041 \\
10.00 & 5.60 & 6.47 & 0.87 & 0.4262 & -0.1291 & 9.8709 \\
10.23 & 5.65 & 6.62 & 0.99 & 0.3609 & -0.2481 & 9.9819 \\
10.49 & 5.70 & 6.80 & 1.10 & 0.2759 & -0.4690 & 10.0210 \\
\hline
\end{tabular}

Average pKa $=9.4923 \pm 0.4410$

Metal-ligand stability constant ( $\log \mathrm{K}$ )

The stabilityconstants require the accurate values of proton-ligand stability constants (Anil and Maroti, 2008). Metal titration curves crossed over ligand titration curve indicated the formation of complex upon proton release (Santosh, et al., 2011). If the values of n- are within range $0.2-0.8$ and $1.2-18$ this indicates the formation of $1: 1$ and 1:2 complexes (Sayyed and Mazahar, 2012).

The metal (II)-humate stepwise stability constants (log k) at phenolic group (Tables 318)

Table 3: Point-wise method, $\mathrm{Cu}$-(Hydrolysed PSHA)

\begin{tabular}{|l|l|l|l|l|l|l|l|l|}
\hline $\mathrm{pH}$ & $\mathrm{BV}_{1}$ & $\mathrm{BV}_{2}$ & $\mathrm{BV}_{3}$ & $\left(\mathrm{~V}_{3}-\mathrm{V}_{2}\right)$ & $\mathrm{n}$ & $\mathrm{pL}$ & $\log \left(\frac{n}{1-n}\right)$ & LogK $_{1}$ \\
\hline 8.50 & 5.30 & 6.29 & 6.33 & 0.04 & 0.5500 & 2.66 & 0.0871 & 2.7471 \\
8.72 & 5.35 & 6.37 & 6.41 & 0.04 & 0.5714 & 2.43 & 0.1249 & 2.5549 \\
9.00 & 5.40 & 6.46 & 6.50 & 0.04 & 0.6198 & 2.16 & 0.2122 & 2.3722 \\
9.22 & 5.45 & 6.55 & 6.59 & 0.04 & 0.6667 & 1.94 & 0.3010 & 2.2410 \\
\hline
\end{tabular}

LogK $_{1}$ (Average value) $=2.4788 \pm 0.2203$

Table 4: Point-wise method, $\mathrm{Cu}$-(Hydrolysed PSHA)

\begin{tabular}{|l|l|l|l|l|l|l|l|l|}
\hline $\mathrm{pH}$ & $\mathrm{BV}_{1}$ & $\mathrm{BV}_{2}$ & $\mathrm{BV}_{3}$ & $\left(\mathrm{~V}_{3}-\mathrm{V}_{2}\right)$ & $\mathrm{n}$ & $\mathrm{pL}$ & $\log \left(\frac{n-1}{2-n}\right)$ & LogK $_{2}$ \\
\hline 9.51 & 5.50 & 6.66 & 6.73 & 0.07 & 1.3509 & 1.70 & -0.2671 & 1.4329 \\
9.73 & 5.55 & 6.78 & 6.85 & 0.07 & 1.6383 & 1.51 & 0.2467 & 1.7567 \\
10.00 & 5.60 & 6.90 & 6.98 & 0.08 & 2.1783 & 1.31 & -0.2158 & 1.0942 \\
10.23 & 5.65 & 7.05 & 7.13 & 0.08 & 4.1904 & 1.27 & & \\
10.49 & 5.70 & 7.10 & 7.19 & 0.09 & 4.6920 & & & \\
\hline
\end{tabular}

Log $K_{2}($ Average value $)=1.4280 \pm 0.3312$ 
BAJOPAS Volume 14 Number 1,June, 2021

Table 5: Point-wise method, $\mathrm{Cu}$ (Unhydrolysed PSHA)

\begin{tabular}{|l|l|l|l|l|l|l|l|l|}
\hline $\mathrm{pH}$ & $\mathrm{BV}_{1}$ & $\mathrm{BV}_{2}$ & $\mathrm{BV}_{3}$ & $\left(\mathrm{~V}_{3}-\mathrm{V}_{2}\right)$ & $\mathrm{n}$ & $\mathrm{pL}$ & $\log \left(\frac{n}{n-1}\right)$ & Log $_{1}$ \\
\hline 8.50 & 5.30 & 5.81 & 5.85 & 0.04 & 0.2973 & 2.88 & -0.3736 & 2.5064 \\
8.72 & 5.35 & 5.90 & 5.95 & 0.05 & 0.3873 & 2.66 & -0.1992 & 2.4608 \\
9.00 & 5.40 & 6.00 & 6.05 & 0.05 & 0.4044 & 2.38 & -0.1681 & 2.2119 \\
9.22 & 5.45 & 6.10 & 6.15 & 0.06 & 0.5157 & 2.18 & -0.0272 & 2.2072 \\
9.51 & 5.50 & 6.20 & 6.27 & 0.07 & 0.6417 & 1.89 & 0.2530 & 1.1430 \\
\hline
\end{tabular}

$\operatorname{LogK}_{1}($ Average value $)=2.3059 \pm 0.6153$

Table 6:Point-wise method, $\mathrm{Cu}$ (Unhydrolysed PSHA)

\begin{tabular}{|l|l|l|l|l|l|l|l|l|}
\hline $\mathrm{pH}$ & $\mathrm{BV}_{1}$ & $\mathrm{BV}_{2}$ & $\mathrm{BV}_{3}$ & $\mathrm{~V}_{3}-\mathrm{V}_{2}$ & $\mathrm{n}$ & $\mathrm{pL}$ & $\log \left(\frac{n-1}{2-n}\right)$ & $\log \mathrm{K}_{2}$ \\
\hline 9.73 & 5.55 & 6.33 & 6.42 & 0.09 & 0.9000 & 1.69 & & \\
10.00 & 5.60 & 6.47 & 6.58 & 0.11 & 1.2578 & 1.44 & -0.4592 & 0.9808 \\
10.23 & 5.65 & 6.62 & 6.84 & 0.12 & 1.6137 & 1.26 & -0.2010 & 1.4610 \\
10.49 & 5.70 & 6.80 & 6.92 & 0.12 & 2.1052 & 1.03 & & \\
\hline
\end{tabular}

$\operatorname{LogK}_{2}$ (Average value) $=1.2209 \pm 0.3398$

Table 7:Point-wise method, Pb (Hydrolysed PSHA)

\begin{tabular}{|l|l|l|l|l|l|l|l|l|}
\hline $\mathrm{pH}$ & $\mathrm{BV}_{1}$ & $\mathrm{BV}_{2}$ & $\mathrm{BV}_{3}$ & $\left(\mathrm{~V}_{3}-\mathrm{V}_{2}\right)$ & $\mathrm{n}$ & $\mathrm{pL}$ & $\log \left(\frac{n}{1-n}\right)$ & LogK $_{1}$ \\
\hline 8.50 & 5.30 & 6.29 & 6.33 & 0.04 & 0.5500 & 2.66 & 0.0871 & 2.7471 \\
8.72 & 5.35 & 6.37 & 6.41 & 0.04 & 0.5714 & 2.43 & 0.1249 & 2.5549 \\
9.00 & 5.40 & 6.46 & 6.50 & 0.04 & 0.6198 & 2.16 & 0.2122 & 2.3722 \\
9.22 & 5.45 & 6.55 & 6.60 & 0.05 & 0.8333 & 1.96 & 0.6989 & 2.6589 \\
\hline
\end{tabular}

Log $_{\mathbf{1}}($ Average value $)=2.5832 \pm 0.1614$

Table 8:Point-wise method, Pb-(Hydrolysed PSHA)

\begin{tabular}{|l|l|l|l|l|l|l|l|l|}
\hline $\mathrm{pH}$ & $\mathrm{BV}_{1}$ & $\mathrm{BV}_{2}$ & $\mathrm{BV}_{3}$ & $\left(\mathrm{~V}_{3}-\mathrm{V}_{2}\right)$ & $\mathrm{n}$ & $\mathrm{pL}$ & $\log \left(\frac{n-1}{2-n}\right)$ & $\log \mathrm{K}_{2}$ \\
\hline 9.51 & 5.50 & 6.66 & 6.71 & 0.05 & 0.9650 & 1.67 & & \\
9.73 & 5.55 & 6.78 & 6.83 & 0.05 & 1.1702 & 1.44 & & \\
10.00 & 5.60 & 6.90 & 6.90 & 0.05 & 1.4864 & 1.22 & -0.0237 & 1.1963 \\
10.23 & 5.65 & 7.05 & 7.10 & 0.05 & 2.0190 & 1.09 & & \\
10.49 & 5.70 & 7.10 & 7.17 & 0.07 & 3.6492 & 1.00 & & \\
\hline
\end{tabular}

Log $K_{2}$ (Average value) $=1.1963$

Table 9: Point-wise method, Pb (Unhydrolysed PSHA)

\begin{tabular}{|l|l|l|l|l|l|l|l|l|}
\hline $\mathrm{pH}$ & $\mathrm{BV}_{1}$ & $\mathrm{BV}_{2}$ & $\mathrm{BV}_{3}$ & $\mathrm{~V}_{3}-\mathrm{V}_{2}$ & $\mathrm{n}$ & $\mathrm{pL}$ & $\begin{array}{l}\text { Log } \\
\left(\frac{n}{n-1}\right)\end{array}$ & Log $\mathrm{K}_{1}$ \\
\hline 8.50 & 5.30 & 5.81 & 5.85 & 0.04 & 0.2973 & 2.88 & -0.3736 & 2.5064 \\
8.72 & 5.35 & 5.90 & 5.94 & 0.04 & 0.3099 & 2.66 & -0.5477 & 2.3123 \\
9.00 & 5.40 & 6.00 & 6.05 & 0.05 & 0.4044 & 2.38 & -0.1681 & 2.2119 \\
9.22 & 5.45 & 6.10 & 6.15 & 0.06 & 0.5157 & 2.18 & 0.0272 & 2.2072 \\
9.51 & 5.50 & 6.20 & 6.26 & 0.07 & 0.6417 & 1.89 & 0.2530 & 2.1430 \\
9.73 & 5.55 & 6.40 & 6.40 & 0.07 & 0.7000 & 1.67 & 0.3680 & 2.0380 \\
\hline
\end{tabular}

LogK $_{1}$ (Average value) $=2.2364 \pm 0.1602$

Table 10: Point-wise method, Pb (Unhydrolysed PSHA)

\begin{tabular}{|l|l|l|l|l|l|l|l|l|}
\hline $\mathrm{pH}$ & $\mathrm{BV}_{1}$ & $\mathrm{BV}_{2}$ & $\mathrm{BV}_{3}$ & $\mathrm{~V}_{3}-\mathrm{V}_{2}$ & $\mathrm{n}$ & $\mathrm{pL}$ & $\log \left(\frac{n-1}{2-n}\right)$ & $\log \mathrm{K}_{2}$ \\
\hline 10.00 & 5.60 & 6.47 & 6.55 & 0.08 & 1.9503 & 1.41 & & \\
10.23 & 5.65 & 6.62 & 6.72 & 0.11 & 1.4792 & 1.26 & -0.0361 & 1.2239 \\
\hline
\end{tabular}

$\operatorname{LogK}_{2}$ (Average value) $=1.2239$

Table 11: Point-wise method, Mg (Hydrolysed PSHA)

\begin{tabular}{|l|l|l|l|l|l|l|l|l|}
\hline $\mathrm{pH}$ & $\mathrm{BV}_{1}$ & $\mathrm{BV}_{2}$ & $\mathrm{BV}_{3}$ & $\left(\mathrm{~V}_{3}-\mathrm{V}_{2}\right)$ & $\mathrm{n}$ & $\mathrm{pL}$ & $\log \left(\frac{n}{n-1}\right)$ & LogK $_{1}$ \\
\hline 8.50 & 5.30 & 6.29 & 6.31 & 0.02 & 0.2750 & 2.64 & -0.4290 & 2.2110 \\
8.72 & 5.35 & 6.37 & 6.39 & 0.02 & 0.2858 & 2.42 & -0.3978 & 2.0222 \\
9.00 & 5.40 & 6.46 & 6.49 & 0.03 & 0.4648 & 2.14 & -0.0612 & 2.0788 \\
9.22 & 5.45 & 6.55 & 6.59 & 0.04 & 0.6667 & 1.94 & 0.3010 & 2.2410 \\
\hline
\end{tabular}

$\log _{\mathbf{1}}($ Average value) $=2.1382 \pm 0.1046$ 
BAJOPAS Volume 14 Number 1,June, 2021

Table 12: Point-wise method, Mg (Hydrolysed PSHA)

\begin{tabular}{|l|l|l|l|l|l|l|l|l|}
\hline $\mathrm{pH}$ & $\mathrm{BV}_{1}$ & $\mathrm{BV}_{2}$ & $\mathrm{BV}_{3}$ & $\left(\mathrm{~V}_{3}-\mathrm{V}_{2}\right)$ & $\mathrm{n}$ & $\mathrm{pL}$ & $\log \left(\frac{n-1}{2-n}\right)$ & LogK $_{2}$ \\
\hline 9.51 & 5.55 & 6.66 & 6.71 & 0.05 & 0.9650 & 1.67 & & \\
9.73 & 5.55 & 6.78 & 6.84 & 0.06 & 1.4042 & 1.47 & -0.1686 & 1.3014 \\
10.00 & 5.60 & 6.90 & 6.93 & 0.06 & 1.7838 & 1.23 & 0.5593 & 1.7893 \\
10.23 & 5.65 & 7.05 & 7.10 & 0.06 & 3.1429 & 1.10 & & \\
10.49 & 5.70 & 7.10 & 7.18 & 0.07 & 3.6492 & 0.83 & & \\
\hline
\end{tabular}

LogK $_{2}($ Average value $)=1.5453 \pm 0.3450$

Table 13: Point-wise method, Mg (Unhydrolysed PSHA)

\begin{tabular}{|l|l|l|l|l|l|l|l|l|}
\hline $\mathrm{pH}$ & $\mathrm{BV}_{1}$ & $\mathrm{BV}_{2}$ & $\mathrm{BV}_{3}$ & $\mathrm{~V}_{3}-\mathrm{V}_{2}$ & $\mathrm{n}$ & $\mathrm{pL}$ & $\log \left(\frac{n}{n-1}\right)$ & $\operatorname{Log~}_{1}$ \\
\hline 8.50 & 5.30 & 5.81 & 5.85 & 0.04 & 0.2973 & 2.88 & -0.3736 & 2.5064 \\
8.72 & 5.35 & 5.90 & 5.94 & 0.04 & 0.3099 & 2.66 & -0.3477 & 2.3123 \\
9.00 & 5.40 & 6.00 & 6.04 & 0.04 & 0.3236 & 2.38 & -0.3202 & 2.0598 \\
9.22 & 5.45 & 6.10 & 6.15 & 0.05 & 0.4297 & 2.17 & -0.1230 & 2.0470 \\
9.51 & 5.50 & 6.20 & 6.26 & 0.06 & 0.5500 & 1.89 & 0.0871 & 1.9771 \\
9.73 & 5.55 & 6.33 & 6.40 & 0.07 & 0.7000 & 1.67 & 0.3680 & 2.0380 \\
\hline
\end{tabular}

LogK $_{1}$ (Average value) $=2.1568 \pm 0.2069$

Table 14: Point-wise method, Mg (Unhydrolysed PSHA)

\begin{tabular}{|l|l|l|l|l|l|l|l|l|}
\hline $\mathrm{pH}$ & $\mathrm{BV}_{1}$ & $\mathrm{BV}_{2}$ & $\mathrm{BV}_{3}$ & $\mathrm{~V}_{3}-\mathrm{V}_{2}$ & $\mathrm{n}$ & $\mathrm{pL}$ & $\log \left(\frac{n-1}{2-n}\right)$ & $\log \mathrm{K}_{2}$ \\
\hline 10.00 & 5.60 & 6.47 & 6.55 & 0.08 & 0.9148 & 1.41 & & \\
10.23 & 5.65 & 6.62 & 6.71 & 0.09 & 1.2102 & 1.20 & -0.5749 & 0.6251 \\
10.49 & 5.70 & 6.80 & 6.92 & 0.09 & 1.5968 & 1.03 & 0.1703 & 1.2003 \\
\hline
\end{tabular}

LogK $_{2}$ (Average value) $=0.9127 \pm 0.4070$

Table15:Point-wise method, Cd (Hydrolysed PSHA)

\begin{tabular}{|l|l|l|l|l|l|l|l|l|}
\hline $\mathrm{pH}$ & $\mathrm{BV}_{1}$ & $\mathrm{BV}_{2}$ & $\mathrm{BV}_{3}$ & $\left(\mathrm{~V}_{3}-\mathrm{V}_{2}\right)$ & $\mathrm{n}$ & $\mathrm{pL}$ & $\log \left(\frac{n}{1-n}\right)$ & LogK $_{1}$ \\
\hline 8.50 & 5.30 & 6.29 & 6.31 & 0.02 & 0.2750 & 2.64 & -0.4210 & 2.2190 \\
8.72 & 5.35 & 6.37 & 6.40 & 0.03 & 0.4286 & 2.42 & -0.1249 & 2.2951 \\
9.00 & 5.40 & 6.46 & 6.49 & 0.03 & 0.4648 & 2.14 & -0.0612 & 2.0788 \\
9.22 & 5.45 & 6.55 & 6.59 & 0.04 & 0.6667 & 1.96 & 0.3010 & 2.2610 \\
9.51 & 5.55 & 6.66 & 6.70 & 0.04 & 0.7720 & 1.67 & 0.5297 & 2.1997 \\
\hline
\end{tabular}

LogK $_{\mathbf{1}}$ (Average value) $=2.2108 \pm 0.0825$

Table 16: Point-wise method, Cd (Hydrolysed PSHA)

\begin{tabular}{|l|l|l|l|l|l|l|l|l|}
\hline $\mathrm{pH}$ & $\mathrm{BV}_{1}$ & $\mathrm{BV}_{2}$ & $\mathrm{BV}_{3}$ & $\left(\mathrm{~V}_{3}-\mathrm{V}_{2}\right)$ & $\mathrm{n}$ & $\mathrm{pL}$ & $\log \left(\frac{n-1}{2-n}\right)$ & Log $_{2}$ \\
\hline 9.73 & 5.55 & 6.78 & 6.83 & 0.06 & 1.4042 & 1.47 & -0.1686 & 1.3014 \\
10.00 & 5.60 & 6.90 & 6.95 & 0.06 & 1.7838 & 1.23 & 0.5593 & 1.7893 \\
10.23 & 5.65 & 7.05 & 7.10 & 0.06 & 3.1429 & 1.09 & & \\
10.49 & 5.70 & 7.10 & 7.16 & 0.06 & 3.1429 & 0.89 & & \\
& & & & & & & & \\
\hline
\end{tabular}

$\operatorname{LogK}_{2}$ (Average value) $=1.5453 \pm 0.3450$

Table 17: Point-wise method, Cd (Unhydrolysed PSHA)

\begin{tabular}{|l|l|l|l|l|l|l|l|l|}
\hline $\mathrm{pH}$ & $\mathrm{BV}_{1}$ & $\mathrm{BV}_{2}$ & $\mathrm{BV}_{3}$ & $\mathrm{~V}_{3}-\mathrm{V}_{2}$ & $\mathrm{n}$ & $\mathrm{pL}$ & $\log \left(\frac{n}{n-1}\right)$ & $\operatorname{Log~}_{1}$ \\
\hline 8.50 & 5.30 & 5.81 & 5.86 & 0.05 & 0.3717 & 2.88 & -0.2280 & 2.6520 \\
8.72 & 5.35 & 5.90 & 5.95 & 0.05 & 0.3873 & 2.66 & -0.1992 & 2.4608 \\
9.00 & 5.40 & 6.00 & 6.06 & 0.06 & 0.4853 & 2.38 & -0.0255 & 2.3545 \\
9.22 & 5.45 & 6.10 & 6.16 & 0.06 & 0.5157 & 2.18 & -0.0272 & 2.2072 \\
9.51 & 5.50 & 6.20 & 6.27 & 0.07 & 0.6417 & 1.89 & 0.2530 & 1.1430 \\
9.73 & 5.55 & 6.33 & 6.41 & 0.08 & 0.8000 & 1.69 & 0.6020 & 2.2920 \\
& & & & & & & & \\
\hline
\end{tabular}

$\operatorname{LogK}_{1}($ Average value $)=2.2516 \pm 0.5380$ 
BAJOPAS Volume 14 Number 1,June, 2021

Table 18: Point-wise method, Cd (Unhydrolysed PSHA)

\begin{tabular}{|l|l|l|l|l|l|l|l|l|}
\hline $\mathrm{pH}$ & $\mathrm{BV}_{1}$ & $\mathrm{BV}_{2}$ & $\mathrm{BV}_{3}$ & $\mathrm{~V}_{3}-\mathrm{V}_{2}$ & $\mathrm{n}$ & $\mathrm{pL}$ & $\log \left(\frac{n-1}{2-n}\right)$ & $\log \mathrm{K}_{2}$ \\
\hline 10.00 & 5.60 & 6.47 & 6.57 & 0.10 & 1.1434 & 1.43 & & \\
10.23 & 5.65 & 6.62 & 6.72 & 0.10 & 1.3448 & 1.23 & -0.2788 & 0.9512 \\
10.49 & 5.70 & 6.80 & 6.90 & 0.10 & 1.7742 & 1.03 & 0.5351 & 1.5651 \\
\hline
\end{tabular}

$\operatorname{LogK}_{2}($ Average value $)=1.2581 \pm 0.4340$

Table 19: Stepwise and overall Stability constants of thehydrolysed and unhydrolysed divalent metal (II) complexes

\begin{tabular}{|c|c|c|c|}
\hline Chelates & LogK $_{1}$ & $\log _{2}$ & Log $\beta$ \\
\hline [Cu (Hydrolysed PSHA-1) $\left.{ }_{2}\right]$ & 2.4788 & 1.4280 & 3.9068 \\
\hline$\left[\mathrm{Pb}(\text { Hydrolysed PSHA-1) })_{2}\right]$ & 2.5832 & 1.1963 & 3.7795 \\
\hline$\left[\mathrm{Cd}(\text { Hydrolysed PSHA-1 })_{2}\right]$ & 2.2108 & 1.5453 & 3.7561 \\
\hline$\left[\mathrm{Mg}(\text { Hydrolysed PSHA-1 })_{2}\right]$ & 2.1382 & 1.5453 & 3.6835 \\
\hline [Cu (Unhydrolysed PSHA-1) & 2.3059 & 1.2209 & 3.5268 \\
\hline$[\mathrm{Pb}$ (Unhydrolysed PSHA-1) 2$]$ & 2.2364 & 1.2239 & 3.4603 \\
\hline [Cd (Unhydrolysed PSHA-1) 2 ] & 2.2516 & 1.2581 & 3.5097 \\
\hline$[\mathrm{Mg}$ (Unydrolysed PSHA-1) & 2.1568 & 0.9127 & 3.0695 \\
\hline
\end{tabular}

The results obtained (Table19) shows the stepwise and overall stability constants to be not high indicating low stability of the complexes, because the solubility of most metal ions in the basic $\mathrm{pH}$ range is minimal due to metal hydroxide precipitation (Karimi, 2017). In general, the stepwise stability constants $\left(K_{1}\right.$ and $K_{2}$ ) follow the order $K_{1}>K_{2}$ for the copper, lead, magnesium and cadmium complexes respectively. The steady decrease of the values with increasing number of ligands is in agreement with the prediction made by researchers (Na'aliya, 2013). The decrease could be attributed to the fact that as the number of the ligands (Humate ions) that enters the coordination zone increases the aqua molecules available for replacement by the ligands become less. Thus, the metal ions become less electron loving with progressive intake of the ligand and this results in the decrease in the values of the constants (Na'aliya, 2013). Also the stability of the complexes is influenced by the size and number of the chelate rings(Mackay and Mackay,2002).All the complexes form rings in their structure as humate, a bidentate ligand, bond the metal ions in the ratio 1:2 (Boguta and Sokolowska, 2016) forming chelate rings. The values of the overall stability constants $(\log \beta)$ obtained for humate complexes are not high indicating low stability as the values are not high. LogK values for copper-humates (Table 3 to 6) obtained in this study are lower than those reported for the complexes of humic acids (Pandey et al., 2015; Dinu, 2013; Kaschl et al., 2010 and Gilbeto and Jorg, 2001). The values of LogK(Table 7 to 10 ) forlead-humates are lower than those reported for the lead in the literature (Dinu, 2013; Gilbeto and Jorg 2001). Log K values(Table 11 to 14 ) for magnesium-humates obtained in this study are close to those reported by (Pandey et al., 2015). Log K values of cadmium-humates (Table 15 to 18 ) obtained in this work near to the one reported by (Dinu, 2013 and Pandey et al., 2015).The difference between the reported values and the values obtained in this study might be probably as a result of acid hydrolysis of humic acid. The values of the overall stability constants $(\log \beta)$ of the copper humates complexes presented in Table 19 is high than that of other metal humate complexes, show relatively high stability of CuHA complexes, show the following order of stability: $\mathrm{Cu}>\mathrm{Pb}>\mathrm{Cd}>\mathrm{Mg}$; which are in close agreement to the findings of (Dinu, 2013 and Pandey et al., 2015).The high stability of Cuhumate chelate could be attributed to the existence of coordinate covalent bond between the complexing agents and the $\mathrm{Cu}^{2+}$ ions. Since, $\mathrm{Cu}^{2+}$ being a metal of the transitional series with $3 d^{9}$ electronic configurations can accept the electrons from the complexing agents. Similarly, the low stabilities of $\mathrm{Pb}, \mathrm{Cd}$ and $\mathrm{Mg}$ complexes could be explained by that $\mathrm{Pb}^{2+}$ with $6 s^{2}, \mathrm{Cd}^{2+}$ with $4 \mathrm{~d}^{10}$ and $\mathrm{Mg}^{2+}$ with $2 \mathrm{p}^{6}$ their electronic configuration has a completely filled $\mathrm{d}, \mathrm{p}$ and $\mathrm{s}$ orbitals. Moreover, the stabilities of metal ions with hydrolysed humic acid from peat soil were higher than those with unhydrolysed humic acid from peat soil; which is ascribed to the high content of acidity in hydrolysed humic acid than unhydrolysed humic acid. 
BAJOPAS Volume 14 Number 1,June, 2021 CONCLUSION

The values of logk for $\mathrm{Cu}(\mathrm{II})$ hydrolysed humic acid complex was higher followed by $\mathrm{Pb}$ (II), $\mathrm{Cd}(\mathrm{II})$ and $\mathrm{Mg}$ (II) hydrolysed humic acid complexes as compared with metal(II) unhydrolysed humic acid complexes. This indicates acid hydrolysis of humic acid can

\section{REFERENCES}

Almeida, V.R. and Szpoganicz, B. (2015). Humic Acid Potentiometric Response Patterns:Out- of Equilibrium Properties and Species Distribution Modelling. Chemical. Biol. Technol. Agric. 2: 17.

Anđelković, T., Nikolić, R., Bojić, A.,Anđelković, D., and Nikolic G.,(2010). Binding of Cadmium to Soil Humic Acid as A Function of Carboxyl Group Content. Macedonian Journal of Chemistry and Chemical Engineering.29(2): 215-224.

Anil, B. N. and Maroti, N. (2008). Studies on Influence of Die-Lectric Constants on Complex Equilibria between Substituted Py-Razalines and Lanthanide Metal Ions pH-Metrically. Amer.-Euras. scient. Res. 3(2): 212-216.

Ashok, K., Pandey, S. P. and Misra, V (2000). Stability Constants of Metal-Humic Acid Complexes and its Role in Environmental Detoxification. Journal of Ecotoxicology and Environmental Safety. 47(2):157-200.

Badr, M. H., El-Halafawi, M. H. and Abd El-al Zeid, E. R. (2012). Comparison Between the Effect of Ionic Strength on Acidity and Dissociation Constants of Humic Acids Extracted from Sewage Sludge and Nile Water Hyacinth Composts.Global Journal of Environmental Research 6 (1): 36-43.

Baruah, M.K., Borah, D., Saikia, P.P., Paul, S., Sharma, T. (2015). Evaluation of pKa Values of Soil Humic Acids and their Complexation Properties. International Journal of Plant \& Soil Science 6(4) : 218-228.

Boguta, P. Sokolowska, Z. (2016). Interactions of $\mathrm{Zn}$ (II) Ions with Humic Acids Isolated from Various Types of Soils. Effect of $\mathrm{pH}, \mathrm{Zn}$ Concentrations and Humic Acids Chemical Properties. Journal of Geochemical Explaration 168. 119-126.

Borges, F., Guimaraes, C., Lima, L.F.C., Pinto, I. and Reis, S.(2005). Potentiometric Studies on the Complexation of Copper(II) by Phenolic Acids as Discrete Ligand Models of enhance the complexation behavior of humic acid with metal (II) ions. However, the higher values of $\log \beta$ for $\mathrm{Cu}(\mathrm{II}), \mathrm{Pb}(\mathrm{II}), \mathrm{Cd}(\mathrm{II})$ and $\mathrm{Mg}(\mathrm{II})$ hydrolysed humic acid complexes indicates more stable stepwise complexes formed as compared with $\mathrm{Cu}(\mathrm{II}), \mathrm{Pb}$ (II), $\mathrm{Cd}$ (II) and $\mathrm{Mg}(\mathrm{II})$ unhydrolysed humic acid complexes.

Humic Substances Talanta 66 (2005) 670-673.

Chefetz, B., Salloum, M. J., Deshmulkin, A. P. and Hatcher, P. (2002). Structural Components of Humic Acids as Determined by Chemical Modifications and Carbon-13 NMR, Pyrolysis, and Thermochemolysis- Gas Chromatography/Mass Spectrometry. Soil Science Society of American Journal Abstract Division S-2- Soil Chemistry66. 1159-1171.

Dinu, M. I. (2013). Metals Complexation with Humic Acids in Surface Water of Different Environ. Sci. Technol. 31(1): 1-17.

Fernandes, A.N., Giacomelli, C., Giovanela, M. Vaz, D.V. Szpoganicz, B. and Maria M. D. (2009). Potentiometric Acidity Determination in Humic Substances Influenced by Different Analytical Procedures.J. Braz. Chem. Soc. 20 (9):14.

Gamal, A. H. (2015). Stability Constants of Rhenium (V) Metal Complexes with Selected Drugs. Pyrex Journal of Research in Environmental Studies. 2(2): 006-014.

Janrao, D. M., Pathan, J., Kayande, D.D., and Mulla, J.J. (2014). An Over View of Potentiometric Determination of Stability Constants of Metal Complexes. Sci. Revs. Chem. Commun.: 4(1), 2014, 11-24.

Karimi, H. (2017). Effect of pH and Initial Pb(II) Concentration on the Lead Removal Efficiency from Waste Water Using $\mathrm{Ca}(\mathrm{OH})_{2}$. International Journal of Water and Waste Water Treatment 3.2

Kaschl, A. Romheld, V. and Chen, Y. (2010). Binding of Cadmium, Copper and Zinc to Humic Substances Originating from Municipal Solid Waste Compost. Israel Journal of Chemistry Vol. 42(1): 89-98.

Kostic, I. S., Tatjana, P, A., Nikolic, R. S., Cvetkovic, T. P., Pavlovic, D. D., Aleksandar, L.J. and Bojic, A. (2012). Comparative Study of Binding Strengths of Heavy Metals with Humic Acid. J.serb. Chem. Soc. 76(9) pp 1-20. 
BAJOPAS Volume 14 Number 1,June, 2021

Na'aliya, J. (2013). Determination of Stepwise Stability Constants and Gibbs free Energy Change of Trisprolina to Complexes of some Divalent Transition Metal ions. Bayero Journal of Pure and Applied Sciences 6(2): 112-114.

Omar, A. A. and Ali, E. A. (2015). Potentiometric Studies on Complexes of $\mathrm{Cr}$ (III) and $\mathrm{Zr}$ (IV) with some Carboxylic Acids. International Journal of Advanced Chemistry, 3(1) 25-

37.

Pandey, A. K. Pandey, S. D. and Misr, V. (2015).Stability Constants of Metal- Humic Acid Complexes and Its Role in Environmental Detoxification. J. Ecotoxicology and Environmental Safety. 47(1):195-200.

Ram, N. and Raman, K.V. (1984). Stability Constants of Complexes of Metals with
Humicand Fuvic Acids under Non- acidConditions. Journal of Plant Nutrition and Soil Sciences.

147:171-176.

Santosh, D. D., Ashok, B. K., Vijay, J. T., Shivraj, G. W. and Vinay, V. W. (2011). Potentiometric Studies of Elec-Trolyte Effects on Complex Equilibria of Some Substituted 5-(2-hydroxy Phenyl) Pyrazoles. Der pharm. 3 (6): 75-83.

Sayyed, H. and Abdul Rahim, M. F. (2012). Studies of Binary Complexes of Metal Ions with Mandelic Acid by Potentiometry. Chem. J. 02 (6): 206209.

Shirvani, M. Moradian, E. Khalili, B. Bakhtiary, S. (2015). Interaction of $\mathrm{Cd}$ and $\mathrm{Pb}$ with Humate-Palygorskite and HumateSepiolite Complexes. Journal of water, air and pollution 3: 220-228. 


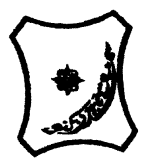

Bayero Journal of Pure and Applied Sciences, 14(1): 54 - 63

Received: November, 2020

Accepted: April, 2021

ISSN $2006-6996$

\title{
STABILITY CONSTANTS OF COMPLEXES OF METAL IONS WITH PEATSOIL HUMIC ACIDS UNDER NON-ACID-CONDITIONS
}

\author{
${ }^{* 1}$ Sabo, Yusuf ${ }^{2}$ Jimoh, W.L.O., ${ }^{3}$ Isa Baba Koki and ${ }^{4}$ Sholadoye, Q. 0. \\ ${ }^{1}$ Department of Pure and Industrial Chemistry, Bayero University, Kano \\ ${ }^{3}$ Department of Chemistry, Yusuf Maitama Sule University Kano. P.M.B. 3220 Kano, Nigeria. \\ ${ }^{4}$ Department of Chemistry, Nigerian Police Academy, Wudil, Kano-Nigeria
}

*Correspondence E-mail; saboyusuf18@yahoo.com

ABSTRACT

Stability constants of complexes of four divalent metal ions viz. $\mathrm{Cu}^{2+}, \mathrm{Pb}^{2+}, \mathrm{Mg}^{2+}$ and $\mathrm{Cd}^{2+}$ with humic acids (HA) were determined by potentiometric titration of humic acids with the corresponding salt of the divalent metals in aqueous media under non-acid-condition. The log $K$ (logarithm of the stability constant) ranged from 1.0942 to 2.7471 for metalhumic acid complexes were determined using point-wise computational method. The order of stability constants were obtained as follows: $\mathrm{Cu}>\mathrm{Pb}>\mathrm{Cd}>\mathrm{Mg}$ for metal $-\mathrm{HA}$ complexes respectively, indicating a higher degree of complexation with Cu metal ion.

Keywords: stability constant, humic acid, potentiometric titration, divalent metals, acid hydrolysis.

\section{NTRODUCTION}

The stability constant of a complex is the numerical expression of its stability and provides a quantitative measure of affinity of the metal ion to the complexing agent. An understanding of the relative stability of metal-complexes helps in predicting the behavior of metal ions in the soil (Ram and Raman, 1982). Extensive researches has been done to determine the stability constants of the complexes formed between humic acid (HA) with a number of metal ions. Ashok et al., (2000) reported that humic acid with hydroxyl, phenoxyl and carboxyl reactive groups can form coordination compound with metal ions at $\mathrm{pH}$ 3.5. The stability constants(Log K) for different metalhumic acid complexes indicated the following order of the stabilities of complexes formed between humic acid and metal ion, $\mathrm{Cu}>\mathrm{Fe}$ $>\mathrm{Pb}>\mathrm{Ni}>\mathrm{Co}>\mathrm{Ca}>\mathrm{Cd}>\mathrm{Zn}>\mathrm{Mn}>\mathrm{Mg}$. Andelkovic et al., (2010) investigated the binding of $\mathrm{Cd}$ (II) to soil humic acid at pH 6.5 and in $0.1 \mathrm{M} \mathrm{KNO}_{3}$ ionic medium. The stability constant for binding indicating greater stability in the case when carboxyl groups are involved in complexation reaction. Kostic et al.,(2012) investigated the complexation of humic acid with certain heavy metal ions (Co(II), $\mathrm{Ni}(\mathrm{II}), \mathrm{Cu}(\mathrm{II})$,
$\mathrm{Zn}(\mathrm{II})$, and $\mathrm{Pb}(\mathrm{II})$. The experiment was performed at $25^{\circ} \mathrm{C}$, at pH 4.0 and ionic strength of $0.01 \mathrm{M}$. Stability constant of complex between $\mathrm{Pb}$ (II) ions and humic acid is greater than stability constants of other investigated metalhumate complexes. Bogata and Sokolowska (2016) analyses the interaction between humic acids from different soils and $\mathrm{Zn}$ (II) ions at wide concentration ranges and at $\mathrm{pH} 5$. Studies have showed significant impact of $\mathrm{Zn}$ concentration, $\mathrm{pH}$ and some properties of humic acids with zinc.But all of these studies were limited to acidic $\mathrm{pH}$ range. Therefore, the present study was carried out to determine and compare the stability constants of complexes of metal ions with hydrolysed peat soil humic acid and unhydrolysed peat soil humic under non-acid conditions.

\section{MATERIALS AND METHODS}

Analytical grade chemicals used includes hydrochloric acid $(\mathrm{HCl})$, nitric acid $\left(\mathrm{HNO}_{3}\right)$, sodium hydroxide $(\mathrm{NaOH})$, lead nitrate $\mathrm{Pb}\left(\mathrm{NO}_{3}\right)_{2}$, copper nitrate $\mathrm{Cu}\left(\mathrm{NO}_{3}\right)_{2} \cdot 3 \mathrm{H}_{2} \mathrm{O}$, cadmium nitrate $\mathrm{Cd}\left(\mathrm{NO}_{3}\right)_{2} \cdot 4 \mathrm{H}_{2} \mathrm{O}$, magnesium nitrate $\mathrm{Mg}\left(\mathrm{NO}_{3}\right)_{2} \cdot 6 \mathrm{H}_{2} \mathrm{O}$, potassium nitrate $\left(\mathrm{KNO}_{3}\right)$, calcium chloride $\left(\mathrm{CaCl}_{2}\right)$, (sigma-Aldrich). Dowex 50WX8, (20-50 mesh) from Fluka. 


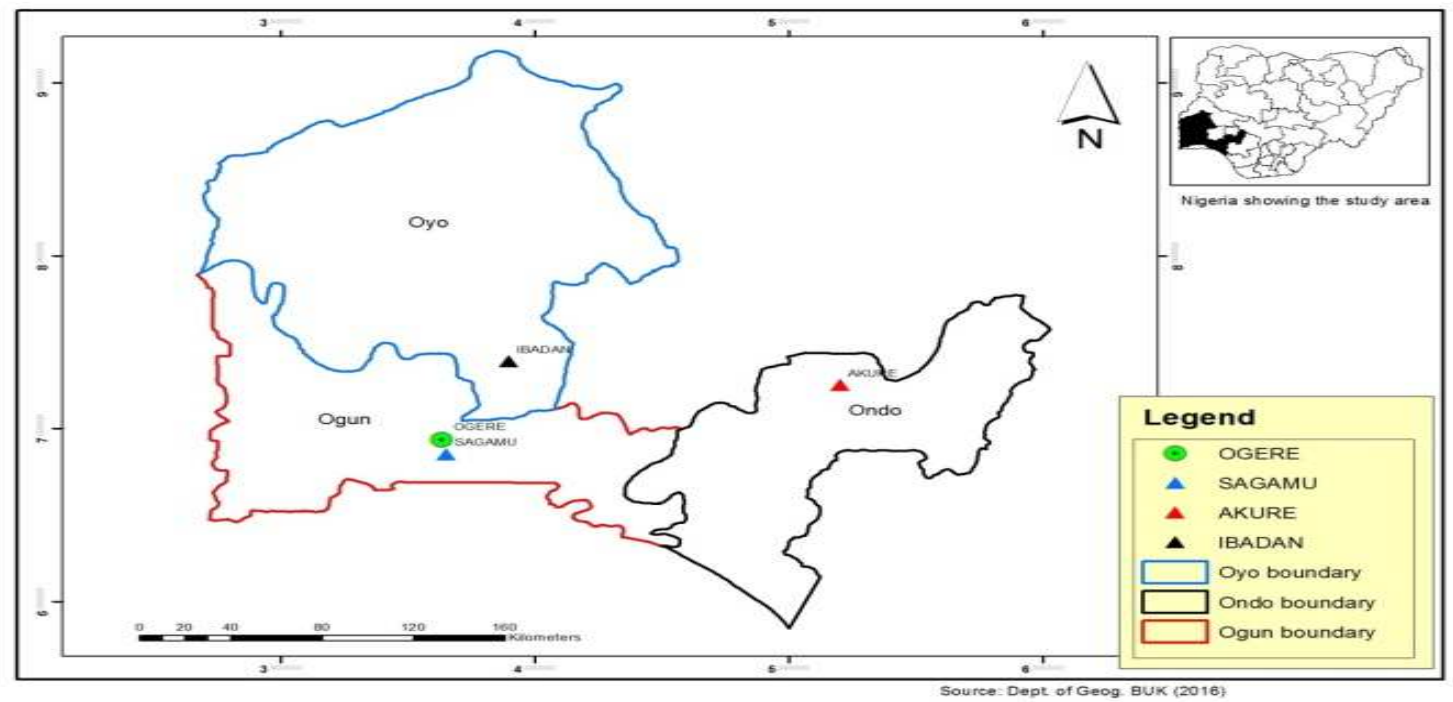

Figure 1: Map showing the sampling point at Sagamu Town, Ogun State.

\section{Description of Sampling Area}

Sagamu has geographical coordinates between $6^{\circ} 50^{\prime}$ north; $3^{\circ} 38^{\prime}$ east is located in south western region of Nigeria. The region has tropical wet and dry climate with a lengthy wet season and relatively constant temperatures throughout the course of the year. Wet season runs from March to October, November to December forms the region dry season. The vegetation type of the region is savannah which is really grassland with small bushes and occasional big trees. Grassland soils have substantially higher organic matter content than forest soils (Novackova, 2011).

\section{Sample Collection}

The Peatsoil samples were collected from four different sampling points $(0-10 \mathrm{~cm}$ depth) in Sagamu into polyethylene bag with plastic spoons. Samples were taken to the laboratory, extraneous materials were removed; the samples were air-dried, crushed and ground to a fine powder in a mortar passed through a $0.20 \mathrm{~mm}$ sieve. The samples were kept for analysis.

\section{Isolation and purification of humic acid from peat soil sample}

Peatsoil sample $(100 \mathrm{~g})$ was mixed with 1000 $\mathrm{cm}^{3}$ of $0.1 \mathrm{M} \mathrm{NaOH}$ solution, shaken for 3hours and left to stand overnight. Dark-coloured supernatant was obtained and decanted from solid residue. The dark-coloured supernatant was acidified to $(\mathrm{pH}=1.0)$ with $6 \mathrm{M} \mathrm{HCl}$ stirred and allowed to stand for 6 hours. Yellowish brown supernatant and dark-brown precipitate were obtained. The yellowish brown supernatant was decanted followed by centrifuge and discarded. The dark-brown precipitate was mixed with $500 \mathrm{~cm}^{3}$ of $0.1 \mathrm{M} \mathrm{NaOH}$ solution followed by passing through dowex resin. The dark-brown solution was acidified to $(\mathrm{pH}=1.0)$ with $6 \mathrm{M} \mathrm{HCl}$ stirred and allowed to stand for 3 hours. The dark-brown precipitate was washed several times with deionized water. The supernatant was treated with $\mathrm{AgNO}_{3}$ solution until no white precipitate observed. The humic acid was transferred to weighed crucible and dried at $60^{\circ} \mathrm{C}$ in an oven for 12 hours. The humic acid was cooled and dried in the desiccator, weighed and recorded. The obtained humic acid was dried again at $60^{\circ} \mathrm{C}$ for additional 6 hours cooled and dried in the desiccator, weighed and recorded constant weight was obtained (Baruah et al., 2015).

\section{FT-IR analysis}

FT-IR spectra of humic acid sample was analysed using Carry 630 FT-IR Agilent Technologies.

Unhydrolysed compost humic acid

The unhydrolysed humic acid was obtained after isolation and purification of compost humic acid and kept for investigation.

\section{Acid hydrolysis of Peatsoil acid}

Peatsoil humic acid sample (1g) was refluxed for 12 hours at $\left(160^{\circ} \mathrm{C}\right)$ with $50 \mathrm{~cm}^{3}$ of $6 \mathrm{M} \mathrm{HCl}$. The mixture was allowed to cool, decanted, and centrifuged after hydrolysis. The insoluble residues were washed with distilled water via centrifugation several times, and the supernatant was treated with $\mathrm{AgNO}_{3}$ solution until no white precipitate was observed. The residue was thoroughly dried over $\mathrm{CaCl}_{2}$ in a desiccator at room temperature (Chefetz et al., 2002). Finally, the obtained hydrolysed humic acid was kept for investigation. 
BAJOPAS Volume 14 Number 1,June, 2021 Potentiometric Titrations

Potentiometric measurements were carried out using a pH-meter Jenway (model 3510) with combine electrode, the sensitivity of the $\mathrm{pH}$ meter is 0.01 units. The $\mathrm{pH}$ meter was switched on half an hour before starting the titration for initial warm up of the instrument. The instrument was calibrated with an aqueous standard buffer solution of $\mathrm{pH} 4.00$ and 10.0 (borate buffer) prepared from a "Qualigens" buffer tablets.

The following sets of solutions were prepared in a $250 \mathrm{~cm}^{3}$ volumetric flask separately for $\mathrm{pH}$ metric titrations.

(i) $5 \mathrm{~cm}^{3} 0.1 \mathrm{M} \mathrm{HCl}+40 \mathrm{~cm}^{3}$ deionized water

(ii) $5 \mathrm{~cm}^{3} 0.1 \mathrm{M} \mathrm{HCl}+39 \mathrm{~cm}^{3}$ deionized water $+1 \mathrm{~cm}^{3} 0.15 \mathrm{gcm}^{-3}$ humic acid

(iii) $5 \mathrm{~cm}^{3} 0.1 \mathrm{M} \mathrm{HCl}+37 \mathrm{~cm}^{3}$ deionized water $+1 \mathrm{~cm}^{3} 0.15 \mathrm{gcm}^{-3}$ humic acid

$$
+2 \mathrm{~cm}^{3} \quad 0.01 \mathrm{M} \mathrm{Cu} \text { (II) }
$$

The solutions were titrated against standardized $0.110 \mathrm{MNaOH}$ separately. The total volume of each mixture was adjusted to $50 \mathrm{~cm}^{3}$ and the ionic strength of the solutions was maintained constant at by adding appropriate amount of stock solution of $1 \mathrm{M} \mathrm{KNO}_{3}$ (Gamal, 2015; Omar and Ali, 2015). A magnetic stirrer was used to achieve thorough mixing of the interacting solutions at $550 \mathrm{rpm}$. The same set of experimental conditions was applied for potentiometric titration of remaining samples.

\section{Evaluation of pKa of Hydrolysed peat soil Humic Acids}

The proton-ligand formation number $\mathrm{n}_{\mathbf{A}}$ were calculated by Irving and Rossotti expression (Omar and Ali, 2015).

$\mathrm{nA}=\mathrm{Y}-\frac{(\mathrm{V} 2-\mathrm{V1})(\mathrm{No}-\mathrm{Eo})}{(\mathrm{VO}+\mathrm{V1}) \mathrm{TCL}}$ 1

Where: $Y$ is number of dissociable proton, $\left(\mathrm{V}_{2^{-}}\right.$ $V_{1}$ ) is the measure of displacement of the ligand curve relative to acid curve, $\mathrm{N}^{\circ}$ and $\mathrm{E}^{\circ}$ are the resultant concentration of alkali solution, free acid solution, $\mathrm{T}_{\mathrm{cL}}{ }^{\circ}$ is the total ligand concentration, $\mathrm{V}^{\circ}$ is the total volume of titration solution, $V_{1}$ is the volume of alkali added to acid solution, $V_{2}$ is the volume of alkali added to acid solution + ligand solution, acid dissociation constants (pKa - values) of ligand were calculated by algebraic method point wise calculation (Tables 1 ). The dissociation constants (pKa) were calculated according to the following relation:

$\mathrm{pKa}=\mathrm{pH}+\log \left(\frac{n A}{1-n A}\right)$ 2

Where: pKa is the acid dissociation constant, $\mathrm{n}_{\mathrm{A}}$ is the Proton-ligand formation number and $\mathrm{pH}$ is the pH-values (Omar and Ali, 2015).

\section{Determination of metal-ligand stability constants $(\log K)$ of complexes}

The potentiometric measurement for the determination of stability constant of a complex in solution is based on the fact that the redox potential of the couple $\frac{M^{+(m-n)}}{M^{+m}}$ is shifted significantly on complexation of the metal ion with the ligand. This method involves change in hydrogen ion concentration $\left[\mathrm{H}^{+}\right]$due to the displacement or association of one or more protons taking place during complexation reaction. This change can be found out by titrating the solutions containing free acid, acid with ligand, and acid with ligand and metal ion, individually against a standard alkali solution at a constant ionic strength or temperature. Either ionic strength or temperature may be varied for different sets of solutions. In all the cases, the change in the $\mathrm{pH}$ of the solution is measured after each addition of a known amount of alkali to the reaction cell which contains the reaction mixture. The titration curves are then drawn by plotting the measured $\mathrm{pH}$ values against the corresponding volume of alkali added and the stability constants of the complexes are determined from the titration curves by employing $\mathrm{pH}$-metric titration technique given by (Irving and Rossoti).

Metal-ligand stability constants ( $\log \mathrm{K}$ ) were determined by using the following relations:

$$
\bar{n}=\frac{\left(V_{3}-V_{2}\right)\left(E^{0}+N^{0}\right)}{\left(V^{0}+V_{2}\right) \bar{n}_{A} T_{m}^{0}}
$$

and

$$
P L=\log _{10}\left\{\frac{1+\beta_{n}^{H} \frac{1}{[\text { anti } \log \mathrm{pH}]^{\mathrm{n}}}}{\mathrm{T}_{\mathrm{L}}^{0}-n \bar{T}_{m}^{0}} \mathrm{X} \frac{\left(V^{0}+V_{3}\right)}{V^{0}}\right\}
$$


BAJOPAS Volume 14 Number 1,June, 2021

Where $T_{L}, T^{\circ}, E^{\circ}$, and $V^{\circ}$ havethe same significance as in equation (1) above, $T_{m}$ denotes the total concentration of metal present in solution, $V_{3}$ is the volume of metal ions present in solution and $\beta^{H}$ is the overall proton ligand stability constant. The metal-ligand stability constants (log K) were determined by employing point wise computational Method (eq. 5 and 6).

$\operatorname{LogK}_{1}=\log \left(\frac{n}{1-n}\right)+\mathrm{pL}$ .5

$\operatorname{LogK}_{2}=\log \left(\frac{1-n}{2-n}\right)+\mathrm{pL}$ ...6

Where: Log $\mathrm{K}$ is the metal-ligand stability constant, $\mathrm{pL}$ is the Free ligand exponent function, $\mathbf{n}$ is the Average number of ligand attached with metal ion (Janraoet al., 2014). The results obtained were analyzed by an ORIGIN 2016 program using titration data and then the proton-ligand stability constants (pKa) and Metal-ligand stability constant (LogK) calculated (Omar and Ali, 2015).

\section{RESULTS AND DISCUSSION}

Fourier transformed infrared (FT-IR) spectra of isolated humic acid from peat soils Figure 2 had distinct clear absorption bands indicating the presence of major humic acid structural elemental groups such as $\mathrm{H}$ bonded $\mathrm{OH}$ $\left(3680 \mathrm{~cm}^{-1}\right.$ peak $), C=0$ of carbonyl $\left(1721 \mathrm{~cm}^{-1}\right.$ peak), functional groups of aliphatic components $\mathrm{CH}_{2}\left(2918 \mathrm{~cm}^{-1}\right.$ peak) and $\mathrm{C}-\mathrm{O}$ stretching of polysaccharide $\left(1168 \mathrm{~cm}^{-1}\right.$ peak). The positions of the absorption bands of the spectra fell within typical major absorption bands of humic acid which is at frequencies 3680, 2918, 1721, 1168 $\mathrm{cm}^{-1}$. The first peak centred in the vicinity of $3680 \mathrm{~cm}^{-1}$ region is attributed to phenol $\mathrm{OH}$ group bounded by intermolecular $\mathrm{H}$ bonds. The $2918 \mathrm{~cm}^{-1}$ band usually has absorption maximum at $2918 \mathrm{~cm}^{-1}$ which is due to $\mathrm{C}-\mathrm{H}$ stretching of alkane group $\left(\mathrm{CH}_{2}\right)$. The next major absorption band is $1721 \mathrm{~cm}^{-1}$. This band has been commonly ascribed to $\mathrm{C}=\mathrm{O}$ stretching of mainly carboxyl group $(\mathrm{COOH})$ with trace amount of ketones. The last peak was observed at 1168 $\mathrm{cm}^{-1}$ due to $\mathrm{C}-\mathrm{O}$ stretching of polysaccharides and this peak appeared also in the spectra of humic acid from peat soil. The FTIR spectra of the isolated humic acid contained all major characteristic absorption peaks of humic acid. These absorption peaks indicated the presence of the major structural elements of humic acid namely $\mathrm{H}$ bonded $\mathrm{OH}, \mathrm{C}=\mathrm{C}$ of aromatic ring, $\mathrm{C}=\mathrm{O}$ of carbonyl group (both carboxyl and ketonic), $\mathrm{CH}_{2}$ group. This strongly supports the presence of humic acid.

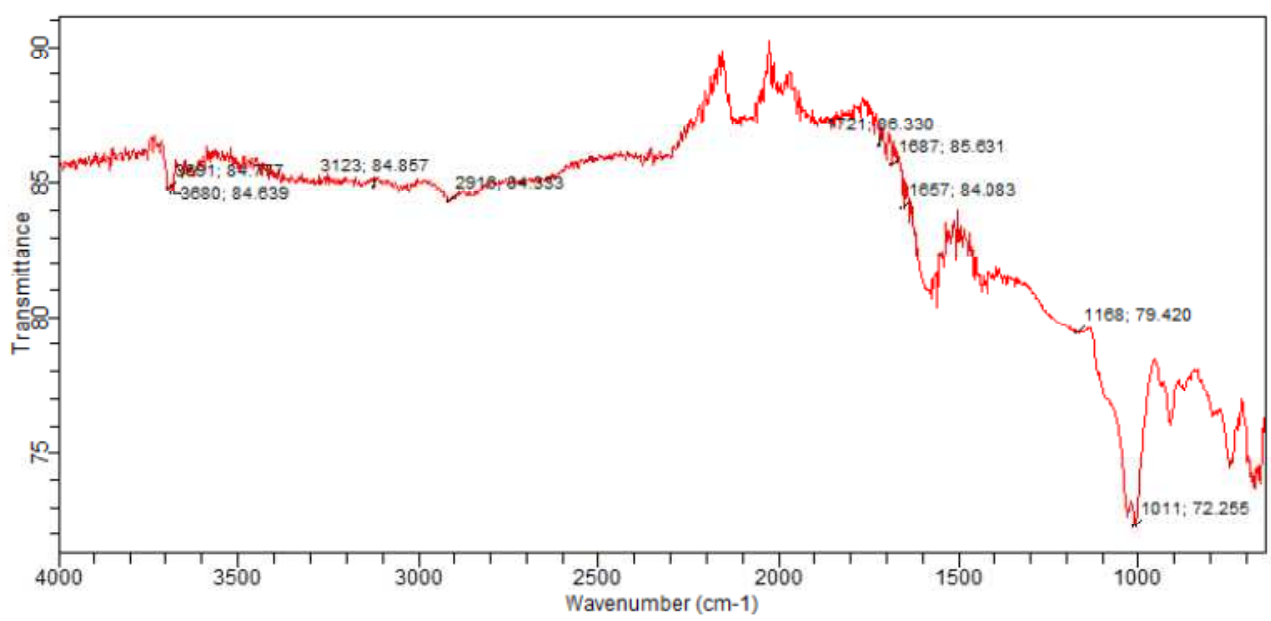

Fig. 2 : FT-IR spectraof peatsoilhumic acid (PSHA)

\section{Evaluation of acid dissociation constant (pka) of acid hydrolysed peat soil humicacid at phenolic group}

The value of the dissociation constant of the peat soil humic acid (PSHA) that underwent acidhydrolysis studied was found to be 8.9299 as shown Table 1, which is lower than the literaturevalues reported by Almeida and Szpoganics, (2015), Borges et al., (2005); Badr et al., (2012)and Fernandes et al,.(2009) of $9.73,9.47$ and 10.30. The difference between the obtained valuesand the reported values in this study might be probably as a result of acid hydrolysis of humicacid. 
BAJOPAS Volume 14 Number 1,June, 2021

Table 1: PKa of (Hydrolysed PSHA)

\begin{tabular}{|l|l|l|l|l|l|l|}
\hline $\mathrm{pH}$ & $\mathrm{BV}_{1}$ & $\mathrm{BV}_{2}$ & $\mathrm{~V}_{2}-\mathrm{V}_{1}$ & $\mathrm{nA}$ & $\log \left(\frac{n A}{1-n A}\right)$ & $\mathrm{pKa}$ \\
\hline 8.50 & 5.30 & 6.29 & 0.99 & 0.3594 & -0.2510 & 8.2490 \\
8.72 & 5.35 & 6.37 & 1.02 & 0.3400 & -0.2880 & 8.4320 \\
9.00 & 5.40 & 6.46 & 1.06 & 0.3141 & -0.3391 & 8.6609 \\
9.22 & 5.45 & 6.55 & 1.10 & 0.2882 & -0.3927 & 8.8273 \\
9.51 & 5.50 & 6.66 & 1.16 & 0.2494 & -0.4786 & 9.0314 \\
9.73 & 5.55 & 6.78 & 1.23 & 0.2041 & -0.5910 & 9.1390 \\
10.00 & 5.60 & 6.90 & 1.30 & 0.1589 & -0.7238 & 9.2762 \\
10.23 & 5.65 & 7.05 & 1.40 & 0.0941 & -0.9835 & 9.2465 \\
10.49 & 5.70 & 7.10 & 1.40 & 0.0941 & -0.9835 & 9.5065 \\
\hline
\end{tabular}

Average pKa $=8.9299 \pm 0.4186$

Table 2: PKa of (Unhydrolysed PSHA)

\begin{tabular}{|l|l|l|l|l|l|l|}
\hline $\mathrm{pH}$ & $\mathrm{BV}_{1}$ & $\mathrm{BV}_{2}$ & $\mathrm{~V}_{2}-\mathrm{V}_{1}$ & $\mathrm{nA}$ & $\log \left(\frac{\boldsymbol{n A}}{1-\boldsymbol{n}}\right)$ & $\mathrm{pKa}$ \\
\hline 8.50 & 5.30 & 5.81 & 0.51 & 0.6619 & 0.2919 & 8.7919 \\
8.72 & 5.35 & 5.90 & 0.55 & 0.6357 & 0.2418 & 8.9618 \\
9.00 & 5.40 & 6.00 & 0.60 & 0.6029 & 0.1813 & 9.1813 \\
9.22 & 5.45 & 6.10 & 0.65 & 0.5701 & 0.1226 & 9.3426 \\
9.51 & 5.50 & 6.20 & 0.70 & 0.5376 & 0.0654 & 9.5754 \\
9.73 & 5.55 & 6.33 & 0.78 & 0.4851 & -0.0259 & 9.7041 \\
10.00 & 5.60 & 6.47 & 0.87 & 0.4262 & -0.1291 & 9.8709 \\
10.23 & 5.65 & 6.62 & 0.99 & 0.3609 & -0.2481 & 9.9819 \\
10.49 & 5.70 & 6.80 & 1.10 & 0.2759 & -0.4690 & 10.0210 \\
\hline
\end{tabular}

Average pKa $=9.4923 \pm 0.4410$

Metal-ligand stability constant ( $\log \mathrm{K}$ )

The stabilityconstants require the accurate values of proton-ligand stability constants (Anil and Maroti, 2008). Metal titration curves crossed over ligand titration curve indicated the formation of complex upon proton release (Santosh, et al., 2011). If the values of n- are within range $0.2-0.8$ and $1.2-18$ this indicates the formation of $1: 1$ and 1:2 complexes (Sayyed and Mazahar, 2012).

The metal (II)-humate stepwise stability constants (log k) at phenolic group (Tables 318)

Table 3: Point-wise method, $\mathrm{Cu}$-(Hydrolysed PSHA)

\begin{tabular}{|l|l|l|l|l|l|l|l|l|}
\hline $\mathrm{pH}$ & $\mathrm{BV}_{1}$ & $\mathrm{BV}_{2}$ & $\mathrm{BV}_{3}$ & $\left(\mathrm{~V}_{3}-\mathrm{V}_{2}\right)$ & $\mathrm{n}$ & $\mathrm{pL}$ & $\log \left(\frac{n}{1-n}\right)$ & LogK $_{1}$ \\
\hline 8.50 & 5.30 & 6.29 & 6.33 & 0.04 & 0.5500 & 2.66 & 0.0871 & 2.7471 \\
8.72 & 5.35 & 6.37 & 6.41 & 0.04 & 0.5714 & 2.43 & 0.1249 & 2.5549 \\
9.00 & 5.40 & 6.46 & 6.50 & 0.04 & 0.6198 & 2.16 & 0.2122 & 2.3722 \\
9.22 & 5.45 & 6.55 & 6.59 & 0.04 & 0.6667 & 1.94 & 0.3010 & 2.2410 \\
\hline
\end{tabular}

LogK $_{1}$ (Average value) $=2.4788 \pm 0.2203$

Table 4: Point-wise method, $\mathrm{Cu}$-(Hydrolysed PSHA)

\begin{tabular}{|l|l|l|l|l|l|l|l|l|}
\hline $\mathrm{pH}$ & $\mathrm{BV}_{1}$ & $\mathrm{BV}_{2}$ & $\mathrm{BV}_{3}$ & $\left(\mathrm{~V}_{3}-\mathrm{V}_{2}\right)$ & $\mathrm{n}$ & $\mathrm{pL}$ & $\log \left(\frac{n-1}{2-n}\right)$ & LogK $_{2}$ \\
\hline 9.51 & 5.50 & 6.66 & 6.73 & 0.07 & 1.3509 & 1.70 & -0.2671 & 1.4329 \\
9.73 & 5.55 & 6.78 & 6.85 & 0.07 & 1.6383 & 1.51 & 0.2467 & 1.7567 \\
10.00 & 5.60 & 6.90 & 6.98 & 0.08 & 2.1783 & 1.31 & -0.2158 & 1.0942 \\
10.23 & 5.65 & 7.05 & 7.13 & 0.08 & 4.1904 & 1.27 & & \\
10.49 & 5.70 & 7.10 & 7.19 & 0.09 & 4.6920 & & & \\
\hline
\end{tabular}

Log $K_{2}($ Average value $)=1.4280 \pm 0.3312$ 
BAJOPAS Volume 14 Number 1,June, 2021

Table 5: Point-wise method, $\mathrm{Cu}$ (Unhydrolysed PSHA)

\begin{tabular}{|l|l|l|l|l|l|l|l|l|}
\hline $\mathrm{pH}$ & $\mathrm{BV}_{1}$ & $\mathrm{BV}_{2}$ & $\mathrm{BV}_{3}$ & $\left(\mathrm{~V}_{3}-\mathrm{V}_{2}\right)$ & $\mathrm{n}$ & $\mathrm{pL}$ & $\log \left(\frac{n}{n-1}\right)$ & Log $_{1}$ \\
\hline 8.50 & 5.30 & 5.81 & 5.85 & 0.04 & 0.2973 & 2.88 & -0.3736 & 2.5064 \\
8.72 & 5.35 & 5.90 & 5.95 & 0.05 & 0.3873 & 2.66 & -0.1992 & 2.4608 \\
9.00 & 5.40 & 6.00 & 6.05 & 0.05 & 0.4044 & 2.38 & -0.1681 & 2.2119 \\
9.22 & 5.45 & 6.10 & 6.15 & 0.06 & 0.5157 & 2.18 & -0.0272 & 2.2072 \\
9.51 & 5.50 & 6.20 & 6.27 & 0.07 & 0.6417 & 1.89 & 0.2530 & 1.1430 \\
\hline
\end{tabular}

$\operatorname{LogK}_{1}($ Average value $)=2.3059 \pm 0.6153$

Table 6:Point-wise method, $\mathrm{Cu}$ (Unhydrolysed PSHA)

\begin{tabular}{|l|l|l|l|l|l|l|l|l|}
\hline $\mathrm{pH}$ & $\mathrm{BV}_{1}$ & $\mathrm{BV}_{2}$ & $\mathrm{BV}_{3}$ & $\mathrm{~V}_{3}-\mathrm{V}_{2}$ & $\mathrm{n}$ & $\mathrm{pL}$ & $\log \left(\frac{n-1}{2-n}\right)$ & $\log \mathrm{K}_{2}$ \\
\hline 9.73 & 5.55 & 6.33 & 6.42 & 0.09 & 0.9000 & 1.69 & & \\
10.00 & 5.60 & 6.47 & 6.58 & 0.11 & 1.2578 & 1.44 & -0.4592 & 0.9808 \\
10.23 & 5.65 & 6.62 & 6.84 & 0.12 & 1.6137 & 1.26 & -0.2010 & 1.4610 \\
10.49 & 5.70 & 6.80 & 6.92 & 0.12 & 2.1052 & 1.03 & & \\
\hline
\end{tabular}

$\operatorname{LogK}_{2}$ (Average value) $=1.2209 \pm 0.3398$

Table 7:Point-wise method, Pb (Hydrolysed PSHA)

\begin{tabular}{|l|l|l|l|l|l|l|l|l|}
\hline $\mathrm{pH}$ & $\mathrm{BV}_{1}$ & $\mathrm{BV}_{2}$ & $\mathrm{BV}_{3}$ & $\left(\mathrm{~V}_{3}-\mathrm{V}_{2}\right)$ & $\mathrm{n}$ & $\mathrm{pL}$ & $\log \left(\frac{n}{1-n}\right)$ & LogK $_{1}$ \\
\hline 8.50 & 5.30 & 6.29 & 6.33 & 0.04 & 0.5500 & 2.66 & 0.0871 & 2.7471 \\
8.72 & 5.35 & 6.37 & 6.41 & 0.04 & 0.5714 & 2.43 & 0.1249 & 2.5549 \\
9.00 & 5.40 & 6.46 & 6.50 & 0.04 & 0.6198 & 2.16 & 0.2122 & 2.3722 \\
9.22 & 5.45 & 6.55 & 6.60 & 0.05 & 0.8333 & 1.96 & 0.6989 & 2.6589 \\
\hline
\end{tabular}

Log $_{\mathbf{1}}($ Average value $)=2.5832 \pm 0.1614$

Table 8:Point-wise method, Pb-(Hydrolysed PSHA)

\begin{tabular}{|l|l|l|l|l|l|l|l|l|}
\hline $\mathrm{pH}$ & $\mathrm{BV}_{1}$ & $\mathrm{BV}_{2}$ & $\mathrm{BV}_{3}$ & $\left(\mathrm{~V}_{3}-\mathrm{V}_{2}\right)$ & $\mathrm{n}$ & $\mathrm{pL}$ & $\log \left(\frac{n-1}{2-n}\right)$ & $\log \mathrm{K}_{2}$ \\
\hline 9.51 & 5.50 & 6.66 & 6.71 & 0.05 & 0.9650 & 1.67 & & \\
9.73 & 5.55 & 6.78 & 6.83 & 0.05 & 1.1702 & 1.44 & & \\
10.00 & 5.60 & 6.90 & 6.90 & 0.05 & 1.4864 & 1.22 & -0.0237 & 1.1963 \\
10.23 & 5.65 & 7.05 & 7.10 & 0.05 & 2.0190 & 1.09 & & \\
10.49 & 5.70 & 7.10 & 7.17 & 0.07 & 3.6492 & 1.00 & & \\
\hline
\end{tabular}

Log $K_{2}$ (Average value) $=1.1963$

Table 9: Point-wise method, Pb (Unhydrolysed PSHA)

\begin{tabular}{|l|l|l|l|l|l|l|l|l|}
\hline $\mathrm{pH}$ & $\mathrm{BV}_{1}$ & $\mathrm{BV}_{2}$ & $\mathrm{BV}_{3}$ & $\mathrm{~V}_{3}-\mathrm{V}_{2}$ & $\mathrm{n}$ & $\mathrm{pL}$ & $\begin{array}{l}\text { Log } \\
\left(\frac{n}{n-1}\right)\end{array}$ & Log $\mathrm{K}_{1}$ \\
\hline 8.50 & 5.30 & 5.81 & 5.85 & 0.04 & 0.2973 & 2.88 & -0.3736 & 2.5064 \\
8.72 & 5.35 & 5.90 & 5.94 & 0.04 & 0.3099 & 2.66 & -0.5477 & 2.3123 \\
9.00 & 5.40 & 6.00 & 6.05 & 0.05 & 0.4044 & 2.38 & -0.1681 & 2.2119 \\
9.22 & 5.45 & 6.10 & 6.15 & 0.06 & 0.5157 & 2.18 & 0.0272 & 2.2072 \\
9.51 & 5.50 & 6.20 & 6.26 & 0.07 & 0.6417 & 1.89 & 0.2530 & 2.1430 \\
9.73 & 5.55 & 6.40 & 6.40 & 0.07 & 0.7000 & 1.67 & 0.3680 & 2.0380 \\
\hline
\end{tabular}

LogK $_{1}$ (Average value) $=2.2364 \pm 0.1602$

Table 10: Point-wise method, Pb (Unhydrolysed PSHA)

\begin{tabular}{|l|l|l|l|l|l|l|l|l|}
\hline $\mathrm{pH}$ & $\mathrm{BV}_{1}$ & $\mathrm{BV}_{2}$ & $\mathrm{BV}_{3}$ & $\mathrm{~V}_{3}-\mathrm{V}_{2}$ & $\mathrm{n}$ & $\mathrm{pL}$ & $\log \left(\frac{n-1}{2-n}\right)$ & $\log \mathrm{K}_{2}$ \\
\hline 10.00 & 5.60 & 6.47 & 6.55 & 0.08 & 1.9503 & 1.41 & & \\
10.23 & 5.65 & 6.62 & 6.72 & 0.11 & 1.4792 & 1.26 & -0.0361 & 1.2239 \\
\hline
\end{tabular}

$\operatorname{LogK}_{2}$ (Average value) $=1.2239$

Table 11: Point-wise method, Mg (Hydrolysed PSHA)

\begin{tabular}{|l|l|l|l|l|l|l|l|l|}
\hline $\mathrm{pH}$ & $\mathrm{BV}_{1}$ & $\mathrm{BV}_{2}$ & $\mathrm{BV}_{3}$ & $\left(\mathrm{~V}_{3}-\mathrm{V}_{2}\right)$ & $\mathrm{n}$ & $\mathrm{pL}$ & $\log \left(\frac{n}{n-1}\right)$ & LogK $_{1}$ \\
\hline 8.50 & 5.30 & 6.29 & 6.31 & 0.02 & 0.2750 & 2.64 & -0.4290 & 2.2110 \\
8.72 & 5.35 & 6.37 & 6.39 & 0.02 & 0.2858 & 2.42 & -0.3978 & 2.0222 \\
9.00 & 5.40 & 6.46 & 6.49 & 0.03 & 0.4648 & 2.14 & -0.0612 & 2.0788 \\
9.22 & 5.45 & 6.55 & 6.59 & 0.04 & 0.6667 & 1.94 & 0.3010 & 2.2410 \\
\hline
\end{tabular}

$\log _{\mathbf{1}}($ Average value) $=2.1382 \pm 0.1046$ 
BAJOPAS Volume 14 Number 1,June, 2021

Table 12: Point-wise method, Mg (Hydrolysed PSHA)

\begin{tabular}{|l|l|l|l|l|l|l|l|l|}
\hline $\mathrm{pH}$ & $\mathrm{BV}_{1}$ & $\mathrm{BV}_{2}$ & $\mathrm{BV}_{3}$ & $\left(\mathrm{~V}_{3}-\mathrm{V}_{2}\right)$ & $\mathrm{n}$ & $\mathrm{pL}$ & $\log \left(\frac{n-1}{2-n}\right)$ & LogK $_{2}$ \\
\hline 9.51 & 5.55 & 6.66 & 6.71 & 0.05 & 0.9650 & 1.67 & & \\
9.73 & 5.55 & 6.78 & 6.84 & 0.06 & 1.4042 & 1.47 & -0.1686 & 1.3014 \\
10.00 & 5.60 & 6.90 & 6.93 & 0.06 & 1.7838 & 1.23 & 0.5593 & 1.7893 \\
10.23 & 5.65 & 7.05 & 7.10 & 0.06 & 3.1429 & 1.10 & & \\
10.49 & 5.70 & 7.10 & 7.18 & 0.07 & 3.6492 & 0.83 & & \\
\hline
\end{tabular}

LogK $_{2}($ Average value $)=1.5453 \pm 0.3450$

Table 13: Point-wise method, Mg (Unhydrolysed PSHA)

\begin{tabular}{|l|l|l|l|l|l|l|l|l|}
\hline $\mathrm{pH}$ & $\mathrm{BV}_{1}$ & $\mathrm{BV}_{2}$ & $\mathrm{BV}_{3}$ & $\mathrm{~V}_{3}-\mathrm{V}_{2}$ & $\mathrm{n}$ & $\mathrm{pL}$ & $\log \left(\frac{n}{n-1}\right)$ & $\operatorname{Log~}_{1}$ \\
\hline 8.50 & 5.30 & 5.81 & 5.85 & 0.04 & 0.2973 & 2.88 & -0.3736 & 2.5064 \\
8.72 & 5.35 & 5.90 & 5.94 & 0.04 & 0.3099 & 2.66 & -0.3477 & 2.3123 \\
9.00 & 5.40 & 6.00 & 6.04 & 0.04 & 0.3236 & 2.38 & -0.3202 & 2.0598 \\
9.22 & 5.45 & 6.10 & 6.15 & 0.05 & 0.4297 & 2.17 & -0.1230 & 2.0470 \\
9.51 & 5.50 & 6.20 & 6.26 & 0.06 & 0.5500 & 1.89 & 0.0871 & 1.9771 \\
9.73 & 5.55 & 6.33 & 6.40 & 0.07 & 0.7000 & 1.67 & 0.3680 & 2.0380 \\
\hline
\end{tabular}

LogK $_{1}$ (Average value) $=2.1568 \pm 0.2069$

Table 14: Point-wise method, Mg (Unhydrolysed PSHA)

\begin{tabular}{|l|l|l|l|l|l|l|l|l|}
\hline $\mathrm{pH}$ & $\mathrm{BV}_{1}$ & $\mathrm{BV}_{2}$ & $\mathrm{BV}_{3}$ & $\mathrm{~V}_{3}-\mathrm{V}_{2}$ & $\mathrm{n}$ & $\mathrm{pL}$ & $\log \left(\frac{n-1}{2-n}\right)$ & $\log \mathrm{K}_{2}$ \\
\hline 10.00 & 5.60 & 6.47 & 6.55 & 0.08 & 0.9148 & 1.41 & & \\
10.23 & 5.65 & 6.62 & 6.71 & 0.09 & 1.2102 & 1.20 & -0.5749 & 0.6251 \\
10.49 & 5.70 & 6.80 & 6.92 & 0.09 & 1.5968 & 1.03 & 0.1703 & 1.2003 \\
\hline
\end{tabular}

LogK $_{2}$ (Average value) $=0.9127 \pm 0.4070$

Table15:Point-wise method, Cd (Hydrolysed PSHA)

\begin{tabular}{|l|l|l|l|l|l|l|l|l|}
\hline $\mathrm{pH}$ & $\mathrm{BV}_{1}$ & $\mathrm{BV}_{2}$ & $\mathrm{BV}_{3}$ & $\left(\mathrm{~V}_{3}-\mathrm{V}_{2}\right)$ & $\mathrm{n}$ & $\mathrm{pL}$ & $\log \left(\frac{n}{1-n}\right)$ & LogK $_{1}$ \\
\hline 8.50 & 5.30 & 6.29 & 6.31 & 0.02 & 0.2750 & 2.64 & -0.4210 & 2.2190 \\
8.72 & 5.35 & 6.37 & 6.40 & 0.03 & 0.4286 & 2.42 & -0.1249 & 2.2951 \\
9.00 & 5.40 & 6.46 & 6.49 & 0.03 & 0.4648 & 2.14 & -0.0612 & 2.0788 \\
9.22 & 5.45 & 6.55 & 6.59 & 0.04 & 0.6667 & 1.96 & 0.3010 & 2.2610 \\
9.51 & 5.55 & 6.66 & 6.70 & 0.04 & 0.7720 & 1.67 & 0.5297 & 2.1997 \\
\hline
\end{tabular}

LogK $_{\mathbf{1}}$ (Average value) $=2.2108 \pm 0.0825$

Table 16: Point-wise method, Cd (Hydrolysed PSHA)

\begin{tabular}{|l|l|l|l|l|l|l|l|l|}
\hline $\mathrm{pH}$ & $\mathrm{BV}_{1}$ & $\mathrm{BV}_{2}$ & $\mathrm{BV}_{3}$ & $\left(\mathrm{~V}_{3}-\mathrm{V}_{2}\right)$ & $\mathrm{n}$ & $\mathrm{pL}$ & $\log \left(\frac{n-1}{2-n}\right)$ & Log $_{2}$ \\
\hline 9.73 & 5.55 & 6.78 & 6.83 & 0.06 & 1.4042 & 1.47 & -0.1686 & 1.3014 \\
10.00 & 5.60 & 6.90 & 6.95 & 0.06 & 1.7838 & 1.23 & 0.5593 & 1.7893 \\
10.23 & 5.65 & 7.05 & 7.10 & 0.06 & 3.1429 & 1.09 & & \\
10.49 & 5.70 & 7.10 & 7.16 & 0.06 & 3.1429 & 0.89 & & \\
& & & & & & & & \\
\hline
\end{tabular}

$\operatorname{LogK}_{2}$ (Average value) $=1.5453 \pm 0.3450$

Table 17: Point-wise method, Cd (Unhydrolysed PSHA)

\begin{tabular}{|l|l|l|l|l|l|l|l|l|}
\hline $\mathrm{pH}$ & $\mathrm{BV}_{1}$ & $\mathrm{BV}_{2}$ & $\mathrm{BV}_{3}$ & $\mathrm{~V}_{3}-\mathrm{V}_{2}$ & $\mathrm{n}$ & $\mathrm{pL}$ & $\log \left(\frac{n}{n-1}\right)$ & $\operatorname{Log~}_{1}$ \\
\hline 8.50 & 5.30 & 5.81 & 5.86 & 0.05 & 0.3717 & 2.88 & -0.2280 & 2.6520 \\
8.72 & 5.35 & 5.90 & 5.95 & 0.05 & 0.3873 & 2.66 & -0.1992 & 2.4608 \\
9.00 & 5.40 & 6.00 & 6.06 & 0.06 & 0.4853 & 2.38 & -0.0255 & 2.3545 \\
9.22 & 5.45 & 6.10 & 6.16 & 0.06 & 0.5157 & 2.18 & -0.0272 & 2.2072 \\
9.51 & 5.50 & 6.20 & 6.27 & 0.07 & 0.6417 & 1.89 & 0.2530 & 1.1430 \\
9.73 & 5.55 & 6.33 & 6.41 & 0.08 & 0.8000 & 1.69 & 0.6020 & 2.2920 \\
& & & & & & & & \\
\hline
\end{tabular}

$\operatorname{LogK}_{1}($ Average value $)=2.2516 \pm 0.5380$ 
BAJOPAS Volume 14 Number 1,June, 2021

Table 18: Point-wise method, Cd (Unhydrolysed PSHA)

\begin{tabular}{|l|l|l|l|l|l|l|l|l|}
\hline $\mathrm{pH}$ & $\mathrm{BV}_{1}$ & $\mathrm{BV}_{2}$ & $\mathrm{BV}_{3}$ & $\mathrm{~V}_{3}-\mathrm{V}_{2}$ & $\mathrm{n}$ & $\mathrm{pL}$ & $\log \left(\frac{n-1}{2-n}\right)$ & $\log \mathrm{K}_{2}$ \\
\hline 10.00 & 5.60 & 6.47 & 6.57 & 0.10 & 1.1434 & 1.43 & & \\
10.23 & 5.65 & 6.62 & 6.72 & 0.10 & 1.3448 & 1.23 & -0.2788 & 0.9512 \\
10.49 & 5.70 & 6.80 & 6.90 & 0.10 & 1.7742 & 1.03 & 0.5351 & 1.5651 \\
\hline
\end{tabular}

$\operatorname{LogK}_{2}($ Average value $)=1.2581 \pm 0.4340$

Table 19: Stepwise and overall Stability constants of thehydrolysed and unhydrolysed divalent metal (II) complexes

\begin{tabular}{|c|c|c|c|}
\hline Chelates & LogK $_{1}$ & $\log _{2}$ & Log $\beta$ \\
\hline [Cu (Hydrolysed PSHA-1) $\left.{ }_{2}\right]$ & 2.4788 & 1.4280 & 3.9068 \\
\hline$\left[\mathrm{Pb}(\text { Hydrolysed PSHA-1) })_{2}\right]$ & 2.5832 & 1.1963 & 3.7795 \\
\hline$\left[\mathrm{Cd}(\text { Hydrolysed PSHA-1 })_{2}\right]$ & 2.2108 & 1.5453 & 3.7561 \\
\hline$\left[\mathrm{Mg}(\text { Hydrolysed PSHA-1 })_{2}\right]$ & 2.1382 & 1.5453 & 3.6835 \\
\hline [Cu (Unhydrolysed PSHA-1) & 2.3059 & 1.2209 & 3.5268 \\
\hline$[\mathrm{Pb}$ (Unhydrolysed PSHA-1) 2$]$ & 2.2364 & 1.2239 & 3.4603 \\
\hline [Cd (Unhydrolysed PSHA-1) 2 ] & 2.2516 & 1.2581 & 3.5097 \\
\hline$[\mathrm{Mg}$ (Unydrolysed PSHA-1) & 2.1568 & 0.9127 & 3.0695 \\
\hline
\end{tabular}

The results obtained (Table19) shows the stepwise and overall stability constants to be not high indicating low stability of the complexes, because the solubility of most metal ions in the basic $\mathrm{pH}$ range is minimal due to metal hydroxide precipitation (Karimi, 2017). In general, the stepwise stability constants $\left(K_{1}\right.$ and $K_{2}$ ) follow the order $K_{1}>K_{2}$ for the copper, lead, magnesium and cadmium complexes respectively. The steady decrease of the values with increasing number of ligands is in agreement with the prediction made by researchers (Na'aliya, 2013). The decrease could be attributed to the fact that as the number of the ligands (Humate ions) that enters the coordination zone increases the aqua molecules available for replacement by the ligands become less. Thus, the metal ions become less electron loving with progressive intake of the ligand and this results in the decrease in the values of the constants (Na'aliya, 2013). Also the stability of the complexes is influenced by the size and number of the chelate rings(Mackay and Mackay,2002).All the complexes form rings in their structure as humate, a bidentate ligand, bond the metal ions in the ratio 1:2 (Boguta and Sokolowska, 2016) forming chelate rings. The values of the overall stability constants $(\log \beta)$ obtained for humate complexes are not high indicating low stability as the values are not high. LogK values for copper-humates (Table 3 to 6) obtained in this study are lower than those reported for the complexes of humic acids (Pandey et al., 2015; Dinu, 2013; Kaschl et al., 2010 and Gilbeto and Jorg, 2001). The values of LogK(Table 7 to 10 ) forlead-humates are lower than those reported for the lead in the literature (Dinu, 2013; Gilbeto and Jorg 2001). Log K values(Table 11 to 14 ) for magnesium-humates obtained in this study are close to those reported by (Pandey et al., 2015). Log K values of cadmium-humates (Table 15 to 18 ) obtained in this work near to the one reported by (Dinu, 2013 and Pandey et al., 2015).The difference between the reported values and the values obtained in this study might be probably as a result of acid hydrolysis of humic acid. The values of the overall stability constants $(\log \beta)$ of the copper humates complexes presented in Table 19 is high than that of other metal humate complexes, show relatively high stability of CuHA complexes, show the following order of stability: $\mathrm{Cu}>\mathrm{Pb}>\mathrm{Cd}>\mathrm{Mg}$; which are in close agreement to the findings of (Dinu, 2013 and Pandey et al., 2015).The high stability of Cuhumate chelate could be attributed to the existence of coordinate covalent bond between the complexing agents and the $\mathrm{Cu}^{2+}$ ions. Since, $\mathrm{Cu}^{2+}$ being a metal of the transitional series with $3 d^{9}$ electronic configurations can accept the electrons from the complexing agents. Similarly, the low stabilities of $\mathrm{Pb}, \mathrm{Cd}$ and $\mathrm{Mg}$ complexes could be explained by that $\mathrm{Pb}^{2+}$ with $6 s^{2}, \mathrm{Cd}^{2+}$ with $4 \mathrm{~d}^{10}$ and $\mathrm{Mg}^{2+}$ with $2 \mathrm{p}^{6}$ their electronic configuration has a completely filled $\mathrm{d}, \mathrm{p}$ and $\mathrm{s}$ orbitals. Moreover, the stabilities of metal ions with hydrolysed humic acid from peat soil were higher than those with unhydrolysed humic acid from peat soil; which is ascribed to the high content of acidity in hydrolysed humic acid than unhydrolysed humic acid. 
BAJOPAS Volume 14 Number 1,June, 2021 CONCLUSION

The values of logk for $\mathrm{Cu}(\mathrm{II})$ hydrolysed humic acid complex was higher followed by $\mathrm{Pb}$ (II), $\mathrm{Cd}(\mathrm{II})$ and $\mathrm{Mg}$ (II) hydrolysed humic acid complexes as compared with metal(II) unhydrolysed humic acid complexes. This indicates acid hydrolysis of humic acid can

\section{REFERENCES}

Almeida, V.R. and Szpoganicz, B. (2015). Humic Acid Potentiometric Response Patterns:Out- of Equilibrium Properties and Species Distribution Modelling. Chemical. Biol. Technol. Agric. 2: 17.

Anđelković, T., Nikolić, R., Bojić, A.,Anđelković, D., and Nikolic G.,(2010). Binding of Cadmium to Soil Humic Acid as A Function of Carboxyl Group Content. Macedonian Journal of Chemistry and Chemical Engineering.29(2): 215-224.

Anil, B. N. and Maroti, N. (2008). Studies on Influence of Die-Lectric Constants on Complex Equilibria between Substituted Py-Razalines and Lanthanide Metal Ions pH-Metrically. Amer.-Euras. scient. Res. 3(2): 212-216.

Ashok, K., Pandey, S. P. and Misra, V (2000). Stability Constants of Metal-Humic Acid Complexes and its Role in Environmental Detoxification. Journal of Ecotoxicology and Environmental Safety. 47(2):157-200.

Badr, M. H., El-Halafawi, M. H. and Abd El-al Zeid, E. R. (2012). Comparison Between the Effect of Ionic Strength on Acidity and Dissociation Constants of Humic Acids Extracted from Sewage Sludge and Nile Water Hyacinth Composts.Global Journal of Environmental Research 6 (1): 36-43.

Baruah, M.K., Borah, D., Saikia, P.P., Paul, S., Sharma, T. (2015). Evaluation of pKa Values of Soil Humic Acids and their Complexation Properties. International Journal of Plant \& Soil Science 6(4) : 218-228.

Boguta, P. Sokolowska, Z. (2016). Interactions of $\mathrm{Zn}$ (II) Ions with Humic Acids Isolated from Various Types of Soils. Effect of $\mathrm{pH}, \mathrm{Zn}$ Concentrations and Humic Acids Chemical Properties. Journal of Geochemical Explaration 168. 119-126.

Borges, F., Guimaraes, C., Lima, L.F.C., Pinto, I. and Reis, S.(2005). Potentiometric Studies on the Complexation of Copper(II) by Phenolic Acids as Discrete Ligand Models of enhance the complexation behavior of humic acid with metal (II) ions. However, the higher values of $\log \beta$ for $\mathrm{Cu}(\mathrm{II}), \mathrm{Pb}(\mathrm{II}), \mathrm{Cd}(\mathrm{II})$ and $\mathrm{Mg}(\mathrm{II})$ hydrolysed humic acid complexes indicates more stable stepwise complexes formed as compared with $\mathrm{Cu}(\mathrm{II}), \mathrm{Pb}$ (II), $\mathrm{Cd}$ (II) and $\mathrm{Mg}(\mathrm{II})$ unhydrolysed humic acid complexes.

Humic Substances Talanta 66 (2005) 670-673.

Chefetz, B., Salloum, M. J., Deshmulkin, A. P. and Hatcher, P. (2002). Structural Components of Humic Acids as Determined by Chemical Modifications and Carbon-13 NMR, Pyrolysis, and Thermochemolysis- Gas Chromatography/Mass Spectrometry. Soil Science Society of American Journal Abstract Division S-2- Soil Chemistry66. 1159-1171.

Dinu, M. I. (2013). Metals Complexation with Humic Acids in Surface Water of Different Environ. Sci. Technol. 31(1): 1-17.

Fernandes, A.N., Giacomelli, C., Giovanela, M. Vaz, D.V. Szpoganicz, B. and Maria M. D. (2009). Potentiometric Acidity Determination in Humic Substances Influenced by Different Analytical Procedures.J. Braz. Chem. Soc. 20 (9):14.

Gamal, A. H. (2015). Stability Constants of Rhenium (V) Metal Complexes with Selected Drugs. Pyrex Journal of Research in Environmental Studies. 2(2): 006-014.

Janrao, D. M., Pathan, J., Kayande, D.D., and Mulla, J.J. (2014). An Over View of Potentiometric Determination of Stability Constants of Metal Complexes. Sci. Revs. Chem. Commun.: 4(1), 2014, 11-24.

Karimi, H. (2017). Effect of pH and Initial Pb(II) Concentration on the Lead Removal Efficiency from Waste Water Using $\mathrm{Ca}(\mathrm{OH})_{2}$. International Journal of Water and Waste Water Treatment 3.2

Kaschl, A. Romheld, V. and Chen, Y. (2010). Binding of Cadmium, Copper and Zinc to Humic Substances Originating from Municipal Solid Waste Compost. Israel Journal of Chemistry Vol. 42(1): 89-98.

Kostic, I. S., Tatjana, P, A., Nikolic, R. S., Cvetkovic, T. P., Pavlovic, D. D., Aleksandar, L.J. and Bojic, A. (2012). Comparative Study of Binding Strengths of Heavy Metals with Humic Acid. J.serb. Chem. Soc. 76(9) pp 1-20. 
BAJOPAS Volume 14 Number 1,June, 2021

Na'aliya, J. (2013). Determination of Stepwise Stability Constants and Gibbs free Energy Change of Trisprolina to Complexes of some Divalent Transition Metal ions. Bayero Journal of Pure and Applied Sciences 6(2): 112-114.

Omar, A. A. and Ali, E. A. (2015). Potentiometric Studies on Complexes of $\mathrm{Cr}$ (III) and $\mathrm{Zr}$ (IV) with some Carboxylic Acids. International Journal of Advanced Chemistry, 3(1) 25-

37.

Pandey, A. K. Pandey, S. D. and Misr, V. (2015).Stability Constants of Metal- Humic Acid Complexes and Its Role in Environmental Detoxification. J. Ecotoxicology and Environmental Safety. 47(1):195-200.

Ram, N. and Raman, K.V. (1984). Stability Constants of Complexes of Metals with
Humicand Fuvic Acids under Non- acidConditions. Journal of Plant Nutrition and Soil Sciences.

147:171-176.

Santosh, D. D., Ashok, B. K., Vijay, J. T., Shivraj, G. W. and Vinay, V. W. (2011). Potentiometric Studies of Elec-Trolyte Effects on Complex Equilibria of Some Substituted 5-(2-hydroxy Phenyl) Pyrazoles. Der pharm. 3 (6): 75-83.

Sayyed, H. and Abdul Rahim, M. F. (2012). Studies of Binary Complexes of Metal Ions with Mandelic Acid by Potentiometry. Chem. J. 02 (6): 206209.

Shirvani, M. Moradian, E. Khalili, B. Bakhtiary, S. (2015). Interaction of $\mathrm{Cd}$ and $\mathrm{Pb}$ with Humate-Palygorskite and HumateSepiolite Complexes. Journal of water, air and pollution 3: 220-228. 


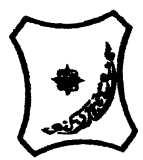

Bayero Journal of Pure and Applied Sciences, 14(1): 54 - 63

Received: November, 2020

Accepted: April, 2021

ISSN $2006-6996$

\title{
STABILITY CONSTANTS OF COMPLEXES OF METAL IONS WITH PEATSOIL HUMIC ACIDS UNDER NON-ACID-CONDITIONS
}

\author{
${ }^{* 1}$ Sabo, Yusuf ${ }^{2}$ Jimoh, W.L.O., ${ }^{3}$ Isa Baba Koki and ${ }^{4}$ Sholadoye, Q. 0. \\ ${ }^{1}$ Department of Pure and Industrial Chemistry, Bayero University, Kano \\ ${ }^{3}$ Department of Chemistry, Yusuf Maitama Sule University Kano. P.M.B. 3220 Kano, Nigeria. \\ ${ }^{4}$ Department of Chemistry, Nigerian Police Academy, Wudil, Kano-Nigeria
}

*Correspondence E-mail; saboyusuf18@yahoo.com

ABSTRACT

Stability constants of complexes of four divalent metal ions viz. $\mathrm{Cu}^{2+}, \mathrm{Pb}^{2+}, \mathrm{Mg}^{2+}$ and $\mathrm{Cd}^{2+}$ with humic acids (HA) were determined by potentiometric titration of humic acids with the corresponding salt of the divalent metals in aqueous media under non-acid-condition. The log $K$ (logarithm of the stability constant) ranged from 1.0942 to 2.7471 for metalhumic acid complexes were determined using point-wise computational method. The order of stability constants were obtained as follows: $\mathrm{Cu}>\mathrm{Pb}>\mathrm{Cd}>\mathrm{Mg}$ for metal $-\mathrm{HA}$ complexes respectively, indicating a higher degree of complexation with Cu metal ion.

Keywords: stability constant, humic acid, potentiometric titration, divalent metals, acid hydrolysis.

\section{NTRODUCTION}

The stability constant of a complex is the numerical expression of its stability and provides a quantitative measure of affinity of the metal ion to the complexing agent. An understanding of the relative stability of metal-complexes helps in predicting the behavior of metal ions in the soil (Ram and Raman, 1982). Extensive researches has been done to determine the stability constants of the complexes formed between humic acid (HA) with a number of metal ions. Ashok et al., (2000) reported that humic acid with hydroxyl, phenoxyl and carboxyl reactive groups can form coordination compound with metal ions at $\mathrm{pH}$ 3.5. The stability constants(Log K) for different metalhumic acid complexes indicated the following order of the stabilities of complexes formed between humic acid and metal ion, $\mathrm{Cu}>\mathrm{Fe}$ $>\mathrm{Pb}>\mathrm{Ni}>\mathrm{Co}>\mathrm{Ca}>\mathrm{Cd}>\mathrm{Zn}>\mathrm{Mn}>\mathrm{Mg}$. Andelkovic et al., (2010) investigated the binding of $\mathrm{Cd}$ (II) to soil humic acid at pH 6.5 and in $0.1 \mathrm{M} \mathrm{KNO}_{3}$ ionic medium. The stability constant for binding indicating greater stability in the case when carboxyl groups are involved in complexation reaction. Kostic et al.,(2012) investigated the complexation of humic acid with certain heavy metal ions (Co(II), $\mathrm{Ni}(\mathrm{II}), \mathrm{Cu}(\mathrm{II})$,
$\mathrm{Zn}(\mathrm{II})$, and $\mathrm{Pb}(\mathrm{II})$. The experiment was performed at $25^{\circ} \mathrm{C}$, at pH 4.0 and ionic strength of $0.01 \mathrm{M}$. Stability constant of complex between $\mathrm{Pb}$ (II) ions and humic acid is greater than stability constants of other investigated metalhumate complexes. Bogata and Sokolowska (2016) analyses the interaction between humic acids from different soils and $\mathrm{Zn}$ (II) ions at wide concentration ranges and at $\mathrm{pH} 5$. Studies have showed significant impact of $\mathrm{Zn}$ concentration, $\mathrm{pH}$ and some properties of humic acids with zinc.But all of these studies were limited to acidic $\mathrm{pH}$ range. Therefore, the present study was carried out to determine and compare the stability constants of complexes of metal ions with hydrolysed peat soil humic acid and unhydrolysed peat soil humic under non-acid conditions.

\section{MATERIALS AND METHODS}

Analytical grade chemicals used includes hydrochloric acid $(\mathrm{HCl})$, nitric acid $\left(\mathrm{HNO}_{3}\right)$, sodium hydroxide $(\mathrm{NaOH})$, lead nitrate $\mathrm{Pb}\left(\mathrm{NO}_{3}\right)_{2}$, copper nitrate $\mathrm{Cu}\left(\mathrm{NO}_{3}\right)_{2} \cdot 3 \mathrm{H}_{2} \mathrm{O}$, cadmium nitrate $\mathrm{Cd}\left(\mathrm{NO}_{3}\right)_{2} \cdot 4 \mathrm{H}_{2} \mathrm{O}$, magnesium nitrate $\mathrm{Mg}\left(\mathrm{NO}_{3}\right)_{2} \cdot 6 \mathrm{H}_{2} \mathrm{O}$, potassium nitrate $\left(\mathrm{KNO}_{3}\right)$, calcium chloride $\left(\mathrm{CaCl}_{2}\right)$, (sigma-Aldrich). Dowex 50WX8, (20-50 mesh) from Fluka. 


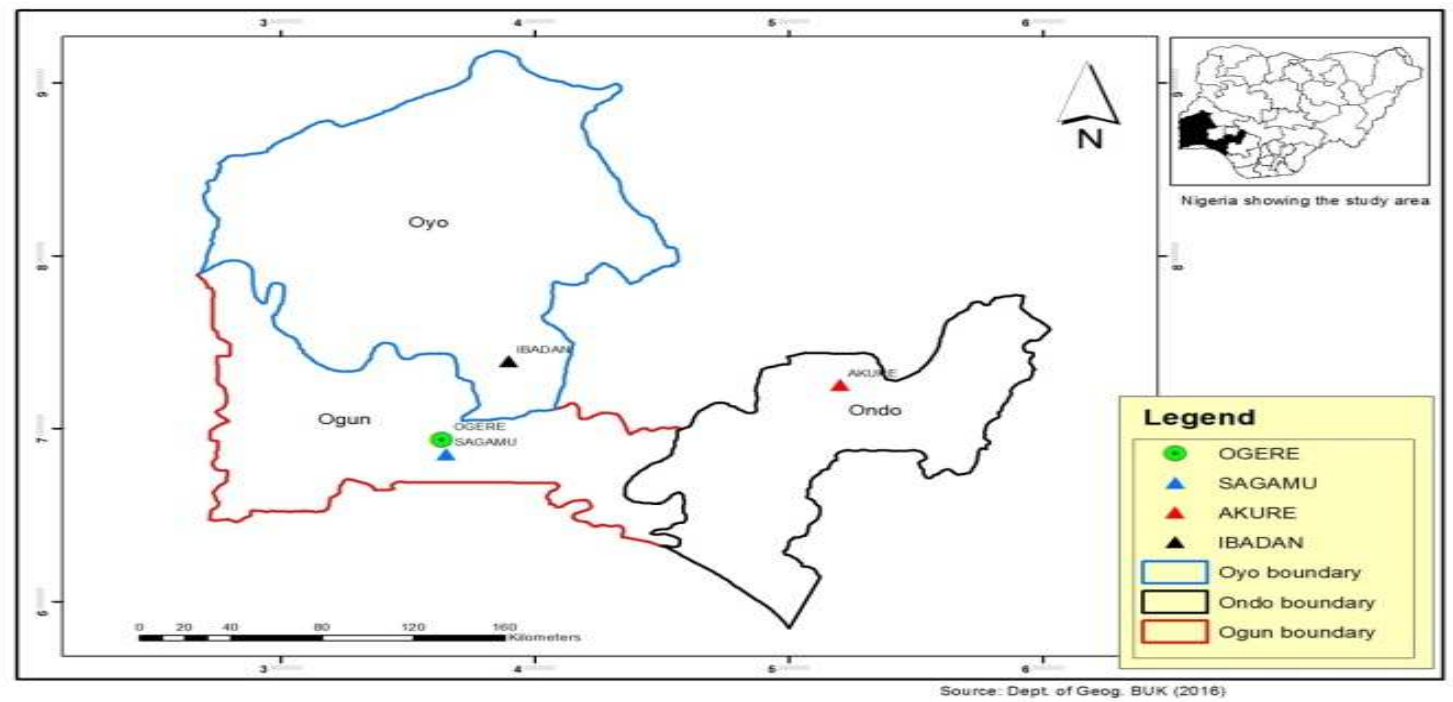

Figure 1: Map showing the sampling point at Sagamu Town, Ogun State.

\section{Description of Sampling Area}

Sagamu has geographical coordinates between $6^{\circ} 50^{\prime}$ north; $3^{\circ} 38^{\prime}$ east is located in south western region of Nigeria. The region has tropical wet and dry climate with a lengthy wet season and relatively constant temperatures throughout the course of the year. Wet season runs from March to October, November to December forms the region dry season. The vegetation type of the region is savannah which is really grassland with small bushes and occasional big trees. Grassland soils have substantially higher organic matter content than forest soils (Novackova, 2011).

\section{Sample Collection}

The Peatsoil samples were collected from four different sampling points $(0-10 \mathrm{~cm}$ depth) in Sagamu into polyethylene bag with plastic spoons. Samples were taken to the laboratory, extraneous materials were removed; the samples were air-dried, crushed and ground to a fine powder in a mortar passed through a $0.20 \mathrm{~mm}$ sieve. The samples were kept for analysis.

\section{Isolation and purification of humic acid from peat soil sample}

Peatsoil sample $(100 \mathrm{~g})$ was mixed with 1000 $\mathrm{cm}^{3}$ of $0.1 \mathrm{M} \mathrm{NaOH}$ solution, shaken for 3hours and left to stand overnight. Dark-coloured supernatant was obtained and decanted from solid residue. The dark-coloured supernatant was acidified to $(\mathrm{pH}=1.0)$ with $6 \mathrm{M} \mathrm{HCl}$ stirred and allowed to stand for 6 hours. Yellowish brown supernatant and dark-brown precipitate were obtained. The yellowish brown supernatant was decanted followed by centrifuge and discarded. The dark-brown precipitate was mixed with $500 \mathrm{~cm}^{3}$ of $0.1 \mathrm{M} \mathrm{NaOH}$ solution followed by passing through dowex resin. The dark-brown solution was acidified to $(\mathrm{pH}=1.0)$ with $6 \mathrm{M} \mathrm{HCl}$ stirred and allowed to stand for 3 hours. The dark-brown precipitate was washed several times with deionized water. The supernatant was treated with $\mathrm{AgNO}_{3}$ solution until no white precipitate observed. The humic acid was transferred to weighed crucible and dried at $60^{\circ} \mathrm{C}$ in an oven for 12 hours. The humic acid was cooled and dried in the desiccator, weighed and recorded. The obtained humic acid was dried again at $60^{\circ} \mathrm{C}$ for additional 6 hours cooled and dried in the desiccator, weighed and recorded constant weight was obtained (Baruah et al., 2015).

\section{FT-IR analysis}

FT-IR spectra of humic acid sample was analysed using Carry 630 FT-IR Agilent Technologies.

Unhydrolysed compost humic acid

The unhydrolysed humic acid was obtained after isolation and purification of compost humic acid and kept for investigation.

\section{Acid hydrolysis of Peatsoil acid}

Peatsoil humic acid sample (1g) was refluxed for 12 hours at $\left(160^{\circ} \mathrm{C}\right)$ with $50 \mathrm{~cm}^{3}$ of $6 \mathrm{M} \mathrm{HCl}$. The mixture was allowed to cool, decanted, and centrifuged after hydrolysis. The insoluble residues were washed with distilled water via centrifugation several times, and the supernatant was treated with $\mathrm{AgNO}_{3}$ solution until no white precipitate was observed. The residue was thoroughly dried over $\mathrm{CaCl}_{2}$ in a desiccator at room temperature (Chefetz et al., 2002). Finally, the obtained hydrolysed humic acid was kept for investigation. 
BAJOPAS Volume 14 Number 1,June, 2021 Potentiometric Titrations

Potentiometric measurements were carried out using a pH-meter Jenway (model 3510) with combine electrode, the sensitivity of the $\mathrm{pH}$ meter is 0.01 units. The $\mathrm{pH}$ meter was switched on half an hour before starting the titration for initial warm up of the instrument. The instrument was calibrated with an aqueous standard buffer solution of $\mathrm{pH} 4.00$ and 10.0 (borate buffer) prepared from a "Qualigens" buffer tablets.

The following sets of solutions were prepared in a $250 \mathrm{~cm}^{3}$ volumetric flask separately for $\mathrm{pH}$ metric titrations.

(i) $5 \mathrm{~cm}^{3} 0.1 \mathrm{M} \mathrm{HCl}+40 \mathrm{~cm}^{3}$ deionized water

(ii) $5 \mathrm{~cm}^{3} 0.1 \mathrm{M} \mathrm{HCl}+39 \mathrm{~cm}^{3}$ deionized water $+1 \mathrm{~cm}^{3} 0.15 \mathrm{gcm}^{-3}$ humic acid

(iii) $5 \mathrm{~cm}^{3} 0.1 \mathrm{M} \mathrm{HCl}+37 \mathrm{~cm}^{3}$ deionized water $+1 \mathrm{~cm}^{3} 0.15 \mathrm{gcm}^{-3}$ humic acid

$$
+2 \mathrm{~cm}^{3} \quad 0.01 \mathrm{M} \mathrm{Cu} \text { (II) }
$$

The solutions were titrated against standardized $0.110 \mathrm{MNaOH}$ separately. The total volume of each mixture was adjusted to $50 \mathrm{~cm}^{3}$ and the ionic strength of the solutions was maintained constant at by adding appropriate amount of stock solution of $1 \mathrm{M} \mathrm{KNO}_{3}$ (Gamal, 2015; Omar and Ali, 2015). A magnetic stirrer was used to achieve thorough mixing of the interacting solutions at $550 \mathrm{rpm}$. The same set of experimental conditions was applied for potentiometric titration of remaining samples.

\section{Evaluation of pKa of Hydrolysed peat soil Humic Acids}

The proton-ligand formation number $\mathrm{n}_{\mathbf{A}}$ were calculated by Irving and Rossotti expression (Omar and Ali, 2015).

$\mathrm{nA}=\mathrm{Y}-\frac{(\mathrm{V} 2-\mathrm{V1})(\mathrm{No}-\mathrm{Eo})}{(\mathrm{VO}+\mathrm{V1}) \mathrm{TCL}}$ 1

Where: $Y$ is number of dissociable proton, $\left(\mathrm{V}_{2^{-}}\right.$ $V_{1}$ ) is the measure of displacement of the ligand curve relative to acid curve, $\mathrm{N}^{\circ}$ and $\mathrm{E}^{\circ}$ are the resultant concentration of alkali solution, free acid solution, $\mathrm{T}_{\mathrm{cL}}{ }^{\circ}$ is the total ligand concentration, $\mathrm{V}^{\circ}$ is the total volume of titration solution, $V_{1}$ is the volume of alkali added to acid solution, $V_{2}$ is the volume of alkali added to acid solution + ligand solution, acid dissociation constants (pKa - values) of ligand were calculated by algebraic method point wise calculation (Tables 1 ). The dissociation constants (pKa) were calculated according to the following relation:

$\mathrm{pKa}=\mathrm{pH}+\log \left(\frac{n A}{1-n A}\right)$ 2

Where: pKa is the acid dissociation constant, $\mathrm{n}_{\mathrm{A}}$ is the Proton-ligand formation number and $\mathrm{pH}$ is the pH-values (Omar and Ali, 2015).

\section{Determination of metal-ligand stability constants $(\log K)$ of complexes}

The potentiometric measurement for the determination of stability constant of a complex in solution is based on the fact that the redox potential of the couple $\frac{M^{+(m-n)}}{M^{+m}}$ is shifted significantly on complexation of the metal ion with the ligand. This method involves change in hydrogen ion concentration $\left[\mathrm{H}^{+}\right]$due to the displacement or association of one or more protons taking place during complexation reaction. This change can be found out by titrating the solutions containing free acid, acid with ligand, and acid with ligand and metal ion, individually against a standard alkali solution at a constant ionic strength or temperature. Either ionic strength or temperature may be varied for different sets of solutions. In all the cases, the change in the $\mathrm{pH}$ of the solution is measured after each addition of a known amount of alkali to the reaction cell which contains the reaction mixture. The titration curves are then drawn by plotting the measured $\mathrm{pH}$ values against the corresponding volume of alkali added and the stability constants of the complexes are determined from the titration curves by employing $\mathrm{pH}$-metric titration technique given by (Irving and Rossoti).

Metal-ligand stability constants ( $\log \mathrm{K}$ ) were determined by using the following relations:

$$
\bar{n}=\frac{\left(V_{3}-V_{2}\right)\left(E^{0}+N^{0}\right)}{\left(V^{0}+V_{2}\right) \bar{n}_{A} T_{m}^{0}}
$$

and

$$
P L=\log _{10}\left\{\frac{1+\beta_{n}^{H} \frac{1}{[\text { anti } \log \mathrm{pH}]^{\mathrm{n}}}}{\mathrm{T}_{\mathrm{L}}^{0}-n \bar{T}_{m}^{0}} \mathrm{X} \frac{\left(V^{0}+V_{3}\right)}{V^{0}}\right\}
$$


BAJOPAS Volume 14 Number 1,June, 2021

Where $T_{L}, T^{\circ}, E^{\circ}$, and $V^{\circ}$ havethe same significance as in equation (1) above, $T_{m}$ denotes the total concentration of metal present in solution, $V_{3}$ is the volume of metal ions present in solution and $\beta^{H}$ is the overall proton ligand stability constant. The metal-ligand stability constants (log K) were determined by employing point wise computational Method (eq. 5 and 6).

$\operatorname{LogK}_{1}=\log \left(\frac{n}{1-n}\right)+\mathrm{pL}$ .5

$\operatorname{LogK}_{2}=\log \left(\frac{1-n}{2-n}\right)+\mathrm{pL}$ ...6

Where: Log $\mathrm{K}$ is the metal-ligand stability constant, $\mathrm{pL}$ is the Free ligand exponent function, $\mathbf{n}$ is the Average number of ligand attached with metal ion (Janraoet al., 2014). The results obtained were analyzed by an ORIGIN 2016 program using titration data and then the proton-ligand stability constants (pKa) and Metal-ligand stability constant (LogK) calculated (Omar and Ali, 2015).

\section{RESULTS AND DISCUSSION}

Fourier transformed infrared (FT-IR) spectra of isolated humic acid from peat soils Figure 2 had distinct clear absorption bands indicating the presence of major humic acid structural elemental groups such as $\mathrm{H}$ bonded $\mathrm{OH}$ $\left(3680 \mathrm{~cm}^{-1}\right.$ peak $), C=0$ of carbonyl $\left(1721 \mathrm{~cm}^{-1}\right.$ peak), functional groups of aliphatic components $\mathrm{CH}_{2}\left(2918 \mathrm{~cm}^{-1}\right.$ peak) and $\mathrm{C}-\mathrm{O}$ stretching of polysaccharide $\left(1168 \mathrm{~cm}^{-1}\right.$ peak). The positions of the absorption bands of the spectra fell within typical major absorption bands of humic acid which is at frequencies 3680, 2918, 1721, 1168 $\mathrm{cm}^{-1}$. The first peak centred in the vicinity of $3680 \mathrm{~cm}^{-1}$ region is attributed to phenol $\mathrm{OH}$ group bounded by intermolecular $\mathrm{H}$ bonds. The $2918 \mathrm{~cm}^{-1}$ band usually has absorption maximum at $2918 \mathrm{~cm}^{-1}$ which is due to $\mathrm{C}-\mathrm{H}$ stretching of alkane group $\left(\mathrm{CH}_{2}\right)$. The next major absorption band is $1721 \mathrm{~cm}^{-1}$. This band has been commonly ascribed to $\mathrm{C}=\mathrm{O}$ stretching of mainly carboxyl group $(\mathrm{COOH})$ with trace amount of ketones. The last peak was observed at 1168 $\mathrm{cm}^{-1}$ due to $\mathrm{C}-\mathrm{O}$ stretching of polysaccharides and this peak appeared also in the spectra of humic acid from peat soil. The FTIR spectra of the isolated humic acid contained all major characteristic absorption peaks of humic acid. These absorption peaks indicated the presence of the major structural elements of humic acid namely $\mathrm{H}$ bonded $\mathrm{OH}, \mathrm{C}=\mathrm{C}$ of aromatic ring, $\mathrm{C}=\mathrm{O}$ of carbonyl group (both carboxyl and ketonic), $\mathrm{CH}_{2}$ group. This strongly supports the presence of humic acid.

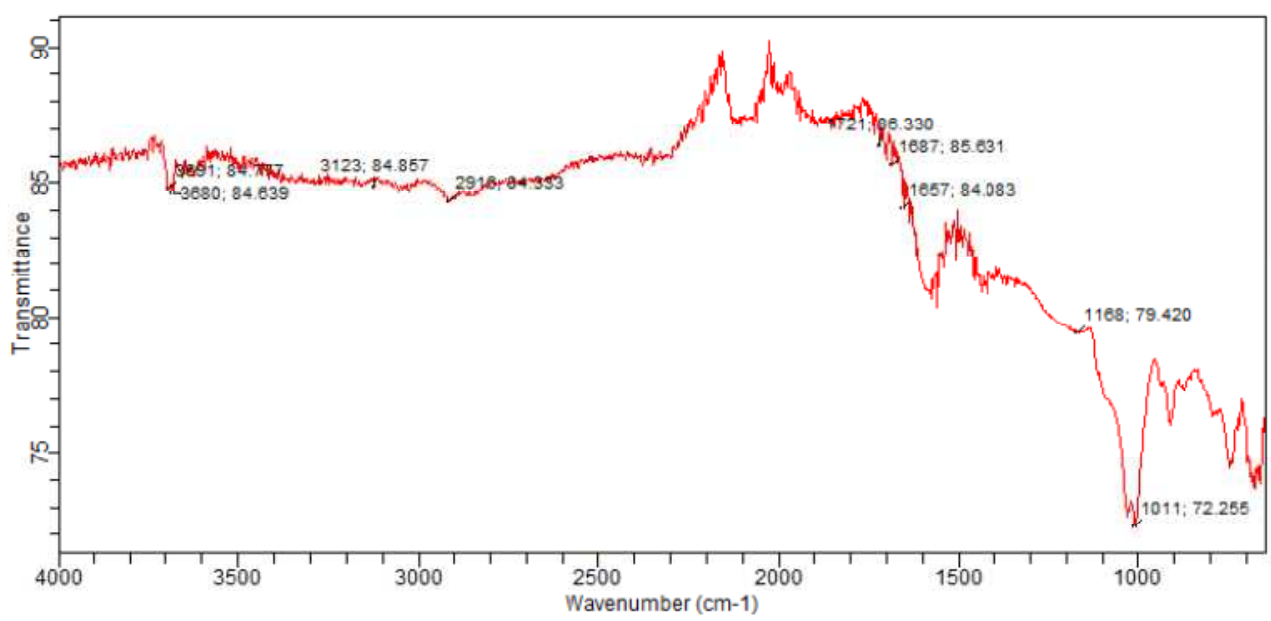

Fig. 2 : FT-IR spectraof peatsoilhumic acid (PSHA)

\section{Evaluation of acid dissociation constant (pka) of acid hydrolysed peat soil humicacid at phenolic group}

The value of the dissociation constant of the peat soil humic acid (PSHA) that underwent acidhydrolysis studied was found to be 8.9299 as shown Table 1, which is lower than the literaturevalues reported by Almeida and Szpoganics, (2015), Borges et al., (2005); Badr et al., (2012)and Fernandes et al,.(2009) of $9.73,9.47$ and 10.30. The difference between the obtained valuesand the reported values in this study might be probably as a result of acid hydrolysis of humicacid. 
BAJOPAS Volume 14 Number 1,June, 2021

Table 1: PKa of (Hydrolysed PSHA)

\begin{tabular}{|l|l|l|l|l|l|l|}
\hline $\mathrm{pH}$ & $\mathrm{BV}_{1}$ & $\mathrm{BV}_{2}$ & $\mathrm{~V}_{2}-\mathrm{V}_{1}$ & $\mathrm{nA}$ & $\log \left(\frac{n A}{1-n A}\right)$ & $\mathrm{pKa}$ \\
\hline 8.50 & 5.30 & 6.29 & 0.99 & 0.3594 & -0.2510 & 8.2490 \\
8.72 & 5.35 & 6.37 & 1.02 & 0.3400 & -0.2880 & 8.4320 \\
9.00 & 5.40 & 6.46 & 1.06 & 0.3141 & -0.3391 & 8.6609 \\
9.22 & 5.45 & 6.55 & 1.10 & 0.2882 & -0.3927 & 8.8273 \\
9.51 & 5.50 & 6.66 & 1.16 & 0.2494 & -0.4786 & 9.0314 \\
9.73 & 5.55 & 6.78 & 1.23 & 0.2041 & -0.5910 & 9.1390 \\
10.00 & 5.60 & 6.90 & 1.30 & 0.1589 & -0.7238 & 9.2762 \\
10.23 & 5.65 & 7.05 & 1.40 & 0.0941 & -0.9835 & 9.2465 \\
10.49 & 5.70 & 7.10 & 1.40 & 0.0941 & -0.9835 & 9.5065 \\
\hline
\end{tabular}

Average pKa $=8.9299 \pm 0.4186$

Table 2: PKa of (Unhydrolysed PSHA)

\begin{tabular}{|l|l|l|l|l|l|l|}
\hline $\mathrm{pH}$ & $\mathrm{BV}_{1}$ & $\mathrm{BV}_{2}$ & $\mathrm{~V}_{2}-\mathrm{V}_{1}$ & $\mathrm{nA}$ & $\log \left(\frac{\boldsymbol{n A}}{1-\boldsymbol{n}}\right)$ & $\mathrm{pKa}$ \\
\hline 8.50 & 5.30 & 5.81 & 0.51 & 0.6619 & 0.2919 & 8.7919 \\
8.72 & 5.35 & 5.90 & 0.55 & 0.6357 & 0.2418 & 8.9618 \\
9.00 & 5.40 & 6.00 & 0.60 & 0.6029 & 0.1813 & 9.1813 \\
9.22 & 5.45 & 6.10 & 0.65 & 0.5701 & 0.1226 & 9.3426 \\
9.51 & 5.50 & 6.20 & 0.70 & 0.5376 & 0.0654 & 9.5754 \\
9.73 & 5.55 & 6.33 & 0.78 & 0.4851 & -0.0259 & 9.7041 \\
10.00 & 5.60 & 6.47 & 0.87 & 0.4262 & -0.1291 & 9.8709 \\
10.23 & 5.65 & 6.62 & 0.99 & 0.3609 & -0.2481 & 9.9819 \\
10.49 & 5.70 & 6.80 & 1.10 & 0.2759 & -0.4690 & 10.0210 \\
\hline
\end{tabular}

Average pKa $=9.4923 \pm 0.4410$

Metal-ligand stability constant ( $\log \mathrm{K}$ )

The stabilityconstants require the accurate values of proton-ligand stability constants (Anil and Maroti, 2008). Metal titration curves crossed over ligand titration curve indicated the formation of complex upon proton release (Santosh, et al., 2011). If the values of n- are within range $0.2-0.8$ and $1.2-18$ this indicates the formation of $1: 1$ and 1:2 complexes (Sayyed and Mazahar, 2012).

The metal (II)-humate stepwise stability constants (log k) at phenolic group (Tables 318)

Table 3: Point-wise method, $\mathrm{Cu}$-(Hydrolysed PSHA)

\begin{tabular}{|l|l|l|l|l|l|l|l|l|}
\hline $\mathrm{pH}$ & $\mathrm{BV}_{1}$ & $\mathrm{BV}_{2}$ & $\mathrm{BV}_{3}$ & $\left(\mathrm{~V}_{3}-\mathrm{V}_{2}\right)$ & $\mathrm{n}$ & $\mathrm{pL}$ & $\log \left(\frac{n}{1-n}\right)$ & LogK $_{1}$ \\
\hline 8.50 & 5.30 & 6.29 & 6.33 & 0.04 & 0.5500 & 2.66 & 0.0871 & 2.7471 \\
8.72 & 5.35 & 6.37 & 6.41 & 0.04 & 0.5714 & 2.43 & 0.1249 & 2.5549 \\
9.00 & 5.40 & 6.46 & 6.50 & 0.04 & 0.6198 & 2.16 & 0.2122 & 2.3722 \\
9.22 & 5.45 & 6.55 & 6.59 & 0.04 & 0.6667 & 1.94 & 0.3010 & 2.2410 \\
\hline
\end{tabular}

LogK $_{1}$ (Average value) $=2.4788 \pm 0.2203$

Table 4: Point-wise method, $\mathrm{Cu}$-(Hydrolysed PSHA)

\begin{tabular}{|l|l|l|l|l|l|l|l|l|}
\hline $\mathrm{pH}$ & $\mathrm{BV}_{1}$ & $\mathrm{BV}_{2}$ & $\mathrm{BV}_{3}$ & $\left(\mathrm{~V}_{3}-\mathrm{V}_{2}\right)$ & $\mathrm{n}$ & $\mathrm{pL}$ & $\log \left(\frac{n-1}{2-n}\right)$ & LogK $_{2}$ \\
\hline 9.51 & 5.50 & 6.66 & 6.73 & 0.07 & 1.3509 & 1.70 & -0.2671 & 1.4329 \\
9.73 & 5.55 & 6.78 & 6.85 & 0.07 & 1.6383 & 1.51 & 0.2467 & 1.7567 \\
10.00 & 5.60 & 6.90 & 6.98 & 0.08 & 2.1783 & 1.31 & -0.2158 & 1.0942 \\
10.23 & 5.65 & 7.05 & 7.13 & 0.08 & 4.1904 & 1.27 & & \\
10.49 & 5.70 & 7.10 & 7.19 & 0.09 & 4.6920 & & & \\
\hline
\end{tabular}

Log $K_{2}($ Average value $)=1.4280 \pm 0.3312$ 
BAJOPAS Volume 14 Number 1,June, 2021

Table 5: Point-wise method, $\mathrm{Cu}$ (Unhydrolysed PSHA)

\begin{tabular}{|l|l|l|l|l|l|l|l|l|}
\hline $\mathrm{pH}$ & $\mathrm{BV}_{1}$ & $\mathrm{BV}_{2}$ & $\mathrm{BV}_{3}$ & $\left(\mathrm{~V}_{3}-\mathrm{V}_{2}\right)$ & $\mathrm{n}$ & $\mathrm{pL}$ & $\log \left(\frac{n}{n-1}\right)$ & Log $_{1}$ \\
\hline 8.50 & 5.30 & 5.81 & 5.85 & 0.04 & 0.2973 & 2.88 & -0.3736 & 2.5064 \\
8.72 & 5.35 & 5.90 & 5.95 & 0.05 & 0.3873 & 2.66 & -0.1992 & 2.4608 \\
9.00 & 5.40 & 6.00 & 6.05 & 0.05 & 0.4044 & 2.38 & -0.1681 & 2.2119 \\
9.22 & 5.45 & 6.10 & 6.15 & 0.06 & 0.5157 & 2.18 & -0.0272 & 2.2072 \\
9.51 & 5.50 & 6.20 & 6.27 & 0.07 & 0.6417 & 1.89 & 0.2530 & 1.1430 \\
\hline
\end{tabular}

$\operatorname{LogK}_{1}($ Average value $)=2.3059 \pm 0.6153$

Table 6:Point-wise method, $\mathrm{Cu}$ (Unhydrolysed PSHA)

\begin{tabular}{|l|l|l|l|l|l|l|l|l|}
\hline $\mathrm{pH}$ & $\mathrm{BV}_{1}$ & $\mathrm{BV}_{2}$ & $\mathrm{BV}_{3}$ & $\mathrm{~V}_{3}-\mathrm{V}_{2}$ & $\mathrm{n}$ & $\mathrm{pL}$ & $\log \left(\frac{n-1}{2-n}\right)$ & $\log \mathrm{K}_{2}$ \\
\hline 9.73 & 5.55 & 6.33 & 6.42 & 0.09 & 0.9000 & 1.69 & & \\
10.00 & 5.60 & 6.47 & 6.58 & 0.11 & 1.2578 & 1.44 & -0.4592 & 0.9808 \\
10.23 & 5.65 & 6.62 & 6.84 & 0.12 & 1.6137 & 1.26 & -0.2010 & 1.4610 \\
10.49 & 5.70 & 6.80 & 6.92 & 0.12 & 2.1052 & 1.03 & & \\
\hline
\end{tabular}

$\operatorname{LogK}_{2}$ (Average value) $=1.2209 \pm 0.3398$

Table 7:Point-wise method, Pb (Hydrolysed PSHA)

\begin{tabular}{|l|l|l|l|l|l|l|l|l|}
\hline $\mathrm{pH}$ & $\mathrm{BV}_{1}$ & $\mathrm{BV}_{2}$ & $\mathrm{BV}_{3}$ & $\left(\mathrm{~V}_{3}-\mathrm{V}_{2}\right)$ & $\mathrm{n}$ & $\mathrm{pL}$ & $\log \left(\frac{n}{1-n}\right)$ & LogK $_{1}$ \\
\hline 8.50 & 5.30 & 6.29 & 6.33 & 0.04 & 0.5500 & 2.66 & 0.0871 & 2.7471 \\
8.72 & 5.35 & 6.37 & 6.41 & 0.04 & 0.5714 & 2.43 & 0.1249 & 2.5549 \\
9.00 & 5.40 & 6.46 & 6.50 & 0.04 & 0.6198 & 2.16 & 0.2122 & 2.3722 \\
9.22 & 5.45 & 6.55 & 6.60 & 0.05 & 0.8333 & 1.96 & 0.6989 & 2.6589 \\
\hline
\end{tabular}

Log $_{\mathbf{1}}($ Average value $)=2.5832 \pm 0.1614$

Table 8:Point-wise method, Pb-(Hydrolysed PSHA)

\begin{tabular}{|l|l|l|l|l|l|l|l|l|}
\hline $\mathrm{pH}$ & $\mathrm{BV}_{1}$ & $\mathrm{BV}_{2}$ & $\mathrm{BV}_{3}$ & $\left(\mathrm{~V}_{3}-\mathrm{V}_{2}\right)$ & $\mathrm{n}$ & $\mathrm{pL}$ & $\log \left(\frac{n-1}{2-n}\right)$ & $\log \mathrm{K}_{2}$ \\
\hline 9.51 & 5.50 & 6.66 & 6.71 & 0.05 & 0.9650 & 1.67 & & \\
9.73 & 5.55 & 6.78 & 6.83 & 0.05 & 1.1702 & 1.44 & & \\
10.00 & 5.60 & 6.90 & 6.90 & 0.05 & 1.4864 & 1.22 & -0.0237 & 1.1963 \\
10.23 & 5.65 & 7.05 & 7.10 & 0.05 & 2.0190 & 1.09 & & \\
10.49 & 5.70 & 7.10 & 7.17 & 0.07 & 3.6492 & 1.00 & & \\
\hline
\end{tabular}

Log $K_{2}$ (Average value) $=1.1963$

Table 9: Point-wise method, Pb (Unhydrolysed PSHA)

\begin{tabular}{|l|l|l|l|l|l|l|l|l|}
\hline $\mathrm{pH}$ & $\mathrm{BV}_{1}$ & $\mathrm{BV}_{2}$ & $\mathrm{BV}_{3}$ & $\mathrm{~V}_{3}-\mathrm{V}_{2}$ & $\mathrm{n}$ & $\mathrm{pL}$ & $\begin{array}{l}\text { Log } \\
\left(\frac{n}{n-1}\right)\end{array}$ & Log $\mathrm{K}_{1}$ \\
\hline 8.50 & 5.30 & 5.81 & 5.85 & 0.04 & 0.2973 & 2.88 & -0.3736 & 2.5064 \\
8.72 & 5.35 & 5.90 & 5.94 & 0.04 & 0.3099 & 2.66 & -0.5477 & 2.3123 \\
9.00 & 5.40 & 6.00 & 6.05 & 0.05 & 0.4044 & 2.38 & -0.1681 & 2.2119 \\
9.22 & 5.45 & 6.10 & 6.15 & 0.06 & 0.5157 & 2.18 & 0.0272 & 2.2072 \\
9.51 & 5.50 & 6.20 & 6.26 & 0.07 & 0.6417 & 1.89 & 0.2530 & 2.1430 \\
9.73 & 5.55 & 6.40 & 6.40 & 0.07 & 0.7000 & 1.67 & 0.3680 & 2.0380 \\
\hline
\end{tabular}

LogK $_{1}$ (Average value) $=2.2364 \pm 0.1602$

Table 10: Point-wise method, Pb (Unhydrolysed PSHA)

\begin{tabular}{|l|l|l|l|l|l|l|l|l|}
\hline $\mathrm{pH}$ & $\mathrm{BV}_{1}$ & $\mathrm{BV}_{2}$ & $\mathrm{BV}_{3}$ & $\mathrm{~V}_{3}-\mathrm{V}_{2}$ & $\mathrm{n}$ & $\mathrm{pL}$ & $\log \left(\frac{n-1}{2-n}\right)$ & $\log \mathrm{K}_{2}$ \\
\hline 10.00 & 5.60 & 6.47 & 6.55 & 0.08 & 1.9503 & 1.41 & & \\
10.23 & 5.65 & 6.62 & 6.72 & 0.11 & 1.4792 & 1.26 & -0.0361 & 1.2239 \\
\hline
\end{tabular}

$\operatorname{LogK}_{2}$ (Average value) $=1.2239$

Table 11: Point-wise method, Mg (Hydrolysed PSHA)

\begin{tabular}{|l|l|l|l|l|l|l|l|l|}
\hline $\mathrm{pH}$ & $\mathrm{BV}_{1}$ & $\mathrm{BV}_{2}$ & $\mathrm{BV}_{3}$ & $\left(\mathrm{~V}_{3}-\mathrm{V}_{2}\right)$ & $\mathrm{n}$ & $\mathrm{pL}$ & $\log \left(\frac{n}{n-1}\right)$ & LogK $_{1}$ \\
\hline 8.50 & 5.30 & 6.29 & 6.31 & 0.02 & 0.2750 & 2.64 & -0.4290 & 2.2110 \\
8.72 & 5.35 & 6.37 & 6.39 & 0.02 & 0.2858 & 2.42 & -0.3978 & 2.0222 \\
9.00 & 5.40 & 6.46 & 6.49 & 0.03 & 0.4648 & 2.14 & -0.0612 & 2.0788 \\
9.22 & 5.45 & 6.55 & 6.59 & 0.04 & 0.6667 & 1.94 & 0.3010 & 2.2410 \\
\hline
\end{tabular}

$\log _{\mathbf{1}}($ Average value) $=2.1382 \pm 0.1046$ 
BAJOPAS Volume 14 Number 1,June, 2021

Table 12: Point-wise method, Mg (Hydrolysed PSHA)

\begin{tabular}{|l|l|l|l|l|l|l|l|l|}
\hline $\mathrm{pH}$ & $\mathrm{BV}_{1}$ & $\mathrm{BV}_{2}$ & $\mathrm{BV}_{3}$ & $\left(\mathrm{~V}_{3}-\mathrm{V}_{2}\right)$ & $\mathrm{n}$ & $\mathrm{pL}$ & $\log \left(\frac{n-1}{2-n}\right)$ & LogK $_{2}$ \\
\hline 9.51 & 5.55 & 6.66 & 6.71 & 0.05 & 0.9650 & 1.67 & & \\
9.73 & 5.55 & 6.78 & 6.84 & 0.06 & 1.4042 & 1.47 & -0.1686 & 1.3014 \\
10.00 & 5.60 & 6.90 & 6.93 & 0.06 & 1.7838 & 1.23 & 0.5593 & 1.7893 \\
10.23 & 5.65 & 7.05 & 7.10 & 0.06 & 3.1429 & 1.10 & & \\
10.49 & 5.70 & 7.10 & 7.18 & 0.07 & 3.6492 & 0.83 & & \\
\hline
\end{tabular}

LogK $_{2}($ Average value $)=1.5453 \pm 0.3450$

Table 13: Point-wise method, Mg (Unhydrolysed PSHA)

\begin{tabular}{|l|l|l|l|l|l|l|l|l|}
\hline $\mathrm{pH}$ & $\mathrm{BV}_{1}$ & $\mathrm{BV}_{2}$ & $\mathrm{BV}_{3}$ & $\mathrm{~V}_{3}-\mathrm{V}_{2}$ & $\mathrm{n}$ & $\mathrm{pL}$ & $\log \left(\frac{n}{n-1}\right)$ & $\operatorname{Log~}_{1}$ \\
\hline 8.50 & 5.30 & 5.81 & 5.85 & 0.04 & 0.2973 & 2.88 & -0.3736 & 2.5064 \\
8.72 & 5.35 & 5.90 & 5.94 & 0.04 & 0.3099 & 2.66 & -0.3477 & 2.3123 \\
9.00 & 5.40 & 6.00 & 6.04 & 0.04 & 0.3236 & 2.38 & -0.3202 & 2.0598 \\
9.22 & 5.45 & 6.10 & 6.15 & 0.05 & 0.4297 & 2.17 & -0.1230 & 2.0470 \\
9.51 & 5.50 & 6.20 & 6.26 & 0.06 & 0.5500 & 1.89 & 0.0871 & 1.9771 \\
9.73 & 5.55 & 6.33 & 6.40 & 0.07 & 0.7000 & 1.67 & 0.3680 & 2.0380 \\
\hline
\end{tabular}

LogK $_{1}$ (Average value) $=2.1568 \pm 0.2069$

Table 14: Point-wise method, Mg (Unhydrolysed PSHA)

\begin{tabular}{|l|l|l|l|l|l|l|l|l|}
\hline $\mathrm{pH}$ & $\mathrm{BV}_{1}$ & $\mathrm{BV}_{2}$ & $\mathrm{BV}_{3}$ & $\mathrm{~V}_{3}-\mathrm{V}_{2}$ & $\mathrm{n}$ & $\mathrm{pL}$ & $\log \left(\frac{n-1}{2-n}\right)$ & $\log \mathrm{K}_{2}$ \\
\hline 10.00 & 5.60 & 6.47 & 6.55 & 0.08 & 0.9148 & 1.41 & & \\
10.23 & 5.65 & 6.62 & 6.71 & 0.09 & 1.2102 & 1.20 & -0.5749 & 0.6251 \\
10.49 & 5.70 & 6.80 & 6.92 & 0.09 & 1.5968 & 1.03 & 0.1703 & 1.2003 \\
\hline
\end{tabular}

LogK $_{2}$ (Average value) $=0.9127 \pm 0.4070$

Table15:Point-wise method, Cd (Hydrolysed PSHA)

\begin{tabular}{|l|l|l|l|l|l|l|l|l|}
\hline $\mathrm{pH}$ & $\mathrm{BV}_{1}$ & $\mathrm{BV}_{2}$ & $\mathrm{BV}_{3}$ & $\left(\mathrm{~V}_{3}-\mathrm{V}_{2}\right)$ & $\mathrm{n}$ & $\mathrm{pL}$ & $\log \left(\frac{n}{1-n}\right)$ & LogK $_{1}$ \\
\hline 8.50 & 5.30 & 6.29 & 6.31 & 0.02 & 0.2750 & 2.64 & -0.4210 & 2.2190 \\
8.72 & 5.35 & 6.37 & 6.40 & 0.03 & 0.4286 & 2.42 & -0.1249 & 2.2951 \\
9.00 & 5.40 & 6.46 & 6.49 & 0.03 & 0.4648 & 2.14 & -0.0612 & 2.0788 \\
9.22 & 5.45 & 6.55 & 6.59 & 0.04 & 0.6667 & 1.96 & 0.3010 & 2.2610 \\
9.51 & 5.55 & 6.66 & 6.70 & 0.04 & 0.7720 & 1.67 & 0.5297 & 2.1997 \\
\hline
\end{tabular}

LogK $_{\mathbf{1}}$ (Average value) $=2.2108 \pm 0.0825$

Table 16: Point-wise method, Cd (Hydrolysed PSHA)

\begin{tabular}{|l|l|l|l|l|l|l|l|l|}
\hline $\mathrm{pH}$ & $\mathrm{BV}_{1}$ & $\mathrm{BV}_{2}$ & $\mathrm{BV}_{3}$ & $\left(\mathrm{~V}_{3}-\mathrm{V}_{2}\right)$ & $\mathrm{n}$ & $\mathrm{pL}$ & $\log \left(\frac{n-1}{2-n}\right)$ & Log $_{2}$ \\
\hline 9.73 & 5.55 & 6.78 & 6.83 & 0.06 & 1.4042 & 1.47 & -0.1686 & 1.3014 \\
10.00 & 5.60 & 6.90 & 6.95 & 0.06 & 1.7838 & 1.23 & 0.5593 & 1.7893 \\
10.23 & 5.65 & 7.05 & 7.10 & 0.06 & 3.1429 & 1.09 & & \\
10.49 & 5.70 & 7.10 & 7.16 & 0.06 & 3.1429 & 0.89 & & \\
& & & & & & & & \\
\hline
\end{tabular}

$\operatorname{LogK}_{2}$ (Average value) $=1.5453 \pm 0.3450$

Table 17: Point-wise method, Cd (Unhydrolysed PSHA)

\begin{tabular}{|l|l|l|l|l|l|l|l|l|}
\hline $\mathrm{pH}$ & $\mathrm{BV}_{1}$ & $\mathrm{BV}_{2}$ & $\mathrm{BV}_{3}$ & $\mathrm{~V}_{3}-\mathrm{V}_{2}$ & $\mathrm{n}$ & $\mathrm{pL}$ & $\log \left(\frac{n}{n-1}\right)$ & $\operatorname{Log~}_{1}$ \\
\hline 8.50 & 5.30 & 5.81 & 5.86 & 0.05 & 0.3717 & 2.88 & -0.2280 & 2.6520 \\
8.72 & 5.35 & 5.90 & 5.95 & 0.05 & 0.3873 & 2.66 & -0.1992 & 2.4608 \\
9.00 & 5.40 & 6.00 & 6.06 & 0.06 & 0.4853 & 2.38 & -0.0255 & 2.3545 \\
9.22 & 5.45 & 6.10 & 6.16 & 0.06 & 0.5157 & 2.18 & -0.0272 & 2.2072 \\
9.51 & 5.50 & 6.20 & 6.27 & 0.07 & 0.6417 & 1.89 & 0.2530 & 1.1430 \\
9.73 & 5.55 & 6.33 & 6.41 & 0.08 & 0.8000 & 1.69 & 0.6020 & 2.2920 \\
& & & & & & & & \\
\hline
\end{tabular}

$\operatorname{LogK}_{1}($ Average value $)=2.2516 \pm 0.5380$ 
BAJOPAS Volume 14 Number 1,June, 2021

Table 18: Point-wise method, Cd (Unhydrolysed PSHA)

\begin{tabular}{|l|l|l|l|l|l|l|l|l|}
\hline $\mathrm{pH}$ & $\mathrm{BV}_{1}$ & $\mathrm{BV}_{2}$ & $\mathrm{BV}_{3}$ & $\mathrm{~V}_{3}-\mathrm{V}_{2}$ & $\mathrm{n}$ & $\mathrm{pL}$ & $\log \left(\frac{n-1}{2-n}\right)$ & $\log \mathrm{K}_{2}$ \\
\hline 10.00 & 5.60 & 6.47 & 6.57 & 0.10 & 1.1434 & 1.43 & & \\
10.23 & 5.65 & 6.62 & 6.72 & 0.10 & 1.3448 & 1.23 & -0.2788 & 0.9512 \\
10.49 & 5.70 & 6.80 & 6.90 & 0.10 & 1.7742 & 1.03 & 0.5351 & 1.5651 \\
\hline
\end{tabular}

$\operatorname{LogK}_{2}($ Average value $)=1.2581 \pm 0.4340$

Table 19: Stepwise and overall Stability constants of thehydrolysed and unhydrolysed divalent metal (II) complexes

\begin{tabular}{|c|c|c|c|}
\hline Chelates & LogK $_{1}$ & $\log _{2}$ & Log $\beta$ \\
\hline [Cu (Hydrolysed PSHA-1) $\left.{ }_{2}\right]$ & 2.4788 & 1.4280 & 3.9068 \\
\hline$\left[\mathrm{Pb}(\text { Hydrolysed PSHA-1) })_{2}\right]$ & 2.5832 & 1.1963 & 3.7795 \\
\hline$\left[\mathrm{Cd}(\text { Hydrolysed PSHA-1 })_{2}\right]$ & 2.2108 & 1.5453 & 3.7561 \\
\hline$\left[\mathrm{Mg}(\text { Hydrolysed PSHA-1 })_{2}\right]$ & 2.1382 & 1.5453 & 3.6835 \\
\hline [Cu (Unhydrolysed PSHA-1) & 2.3059 & 1.2209 & 3.5268 \\
\hline$[\mathrm{Pb}$ (Unhydrolysed PSHA-1) 2$]$ & 2.2364 & 1.2239 & 3.4603 \\
\hline [Cd (Unhydrolysed PSHA-1) 2 ] & 2.2516 & 1.2581 & 3.5097 \\
\hline$[\mathrm{Mg}$ (Unydrolysed PSHA-1) & 2.1568 & 0.9127 & 3.0695 \\
\hline
\end{tabular}

The results obtained (Table19) shows the stepwise and overall stability constants to be not high indicating low stability of the complexes, because the solubility of most metal ions in the basic $\mathrm{pH}$ range is minimal due to metal hydroxide precipitation (Karimi, 2017). In general, the stepwise stability constants $\left(K_{1}\right.$ and $K_{2}$ ) follow the order $K_{1}>K_{2}$ for the copper, lead, magnesium and cadmium complexes respectively. The steady decrease of the values with increasing number of ligands is in agreement with the prediction made by researchers (Na'aliya, 2013). The decrease could be attributed to the fact that as the number of the ligands (Humate ions) that enters the coordination zone increases the aqua molecules available for replacement by the ligands become less. Thus, the metal ions become less electron loving with progressive intake of the ligand and this results in the decrease in the values of the constants (Na'aliya, 2013). Also the stability of the complexes is influenced by the size and number of the chelate rings(Mackay and Mackay,2002).All the complexes form rings in their structure as humate, a bidentate ligand, bond the metal ions in the ratio 1:2 (Boguta and Sokolowska, 2016) forming chelate rings. The values of the overall stability constants $(\log \beta)$ obtained for humate complexes are not high indicating low stability as the values are not high. LogK values for copper-humates (Table 3 to 6) obtained in this study are lower than those reported for the complexes of humic acids (Pandey et al., 2015; Dinu, 2013; Kaschl et al., 2010 and Gilbeto and Jorg, 2001). The values of LogK(Table 7 to 10 ) forlead-humates are lower than those reported for the lead in the literature (Dinu, 2013; Gilbeto and Jorg 2001). Log K values(Table 11 to 14 ) for magnesium-humates obtained in this study are close to those reported by (Pandey et al., 2015). Log K values of cadmium-humates (Table 15 to 18 ) obtained in this work near to the one reported by (Dinu, 2013 and Pandey et al., 2015).The difference between the reported values and the values obtained in this study might be probably as a result of acid hydrolysis of humic acid. The values of the overall stability constants $(\log \beta)$ of the copper humates complexes presented in Table 19 is high than that of other metal humate complexes, show relatively high stability of CuHA complexes, show the following order of stability: $\mathrm{Cu}>\mathrm{Pb}>\mathrm{Cd}>\mathrm{Mg}$; which are in close agreement to the findings of (Dinu, 2013 and Pandey et al., 2015).The high stability of Cuhumate chelate could be attributed to the existence of coordinate covalent bond between the complexing agents and the $\mathrm{Cu}^{2+}$ ions. Since, $\mathrm{Cu}^{2+}$ being a metal of the transitional series with $3 d^{9}$ electronic configurations can accept the electrons from the complexing agents. Similarly, the low stabilities of $\mathrm{Pb}, \mathrm{Cd}$ and $\mathrm{Mg}$ complexes could be explained by that $\mathrm{Pb}^{2+}$ with $6 s^{2}, \mathrm{Cd}^{2+}$ with $4 \mathrm{~d}^{10}$ and $\mathrm{Mg}^{2+}$ with $2 \mathrm{p}^{6}$ their electronic configuration has a completely filled $\mathrm{d}, \mathrm{p}$ and $\mathrm{s}$ orbitals. Moreover, the stabilities of metal ions with hydrolysed humic acid from peat soil were higher than those with unhydrolysed humic acid from peat soil; which is ascribed to the high content of acidity in hydrolysed humic acid than unhydrolysed humic acid. 
BAJOPAS Volume 14 Number 1,June, 2021 CONCLUSION

The values of logk for $\mathrm{Cu}(\mathrm{II})$ hydrolysed humic acid complex was higher followed by $\mathrm{Pb}$ (II), $\mathrm{Cd}(\mathrm{II})$ and $\mathrm{Mg}$ (II) hydrolysed humic acid complexes as compared with metal(II) unhydrolysed humic acid complexes. This indicates acid hydrolysis of humic acid can

\section{REFERENCES}

Almeida, V.R. and Szpoganicz, B. (2015). Humic Acid Potentiometric Response Patterns:Out- of Equilibrium Properties and Species Distribution Modelling. Chemical. Biol. Technol. Agric. 2: 17.

Anđelković, T., Nikolić, R., Bojić, A.,Anđelković, D., and Nikolic G.,(2010). Binding of Cadmium to Soil Humic Acid as A Function of Carboxyl Group Content. Macedonian Journal of Chemistry and Chemical Engineering.29(2): 215-224.

Anil, B. N. and Maroti, N. (2008). Studies on Influence of Die-Lectric Constants on Complex Equilibria between Substituted Py-Razalines and Lanthanide Metal Ions pH-Metrically. Amer.-Euras. scient. Res. 3(2): 212-216.

Ashok, K., Pandey, S. P. and Misra, V (2000). Stability Constants of Metal-Humic Acid Complexes and its Role in Environmental Detoxification. Journal of Ecotoxicology and Environmental Safety. 47(2):157-200.

Badr, M. H., El-Halafawi, M. H. and Abd El-al Zeid, E. R. (2012). Comparison Between the Effect of Ionic Strength on Acidity and Dissociation Constants of Humic Acids Extracted from Sewage Sludge and Nile Water Hyacinth Composts.Global Journal of Environmental Research 6 (1): 36-43.

Baruah, M.K., Borah, D., Saikia, P.P., Paul, S., Sharma, T. (2015). Evaluation of pKa Values of Soil Humic Acids and their Complexation Properties. International Journal of Plant \& Soil Science 6(4) : 218-228.

Boguta, P. Sokolowska, Z. (2016). Interactions of $\mathrm{Zn}$ (II) Ions with Humic Acids Isolated from Various Types of Soils. Effect of $\mathrm{pH}, \mathrm{Zn}$ Concentrations and Humic Acids Chemical Properties. Journal of Geochemical Explaration 168. 119-126.

Borges, F., Guimaraes, C., Lima, L.F.C., Pinto, I. and Reis, S.(2005). Potentiometric Studies on the Complexation of Copper(II) by Phenolic Acids as Discrete Ligand Models of enhance the complexation behavior of humic acid with metal (II) ions. However, the higher values of $\log \beta$ for $\mathrm{Cu}(\mathrm{II}), \mathrm{Pb}(\mathrm{II}), \mathrm{Cd}(\mathrm{II})$ and $\mathrm{Mg}(\mathrm{II})$ hydrolysed humic acid complexes indicates more stable stepwise complexes formed as compared with $\mathrm{Cu}(\mathrm{II}), \mathrm{Pb}$ (II), $\mathrm{Cd}$ (II) and $\mathrm{Mg}(\mathrm{II})$ unhydrolysed humic acid complexes.

Humic Substances Talanta 66 (2005) 670-673.

Chefetz, B., Salloum, M. J., Deshmulkin, A. P. and Hatcher, P. (2002). Structural Components of Humic Acids as Determined by Chemical Modifications and Carbon-13 NMR, Pyrolysis, and Thermochemolysis- Gas Chromatography/Mass Spectrometry. Soil Science Society of American Journal Abstract Division S-2- Soil Chemistry66. 1159-1171.

Dinu, M. I. (2013). Metals Complexation with Humic Acids in Surface Water of Different Environ. Sci. Technol. 31(1): 1-17.

Fernandes, A.N., Giacomelli, C., Giovanela, M. Vaz, D.V. Szpoganicz, B. and Maria M. D. (2009). Potentiometric Acidity Determination in Humic Substances Influenced by Different Analytical Procedures.J. Braz. Chem. Soc. 20 (9):14.

Gamal, A. H. (2015). Stability Constants of Rhenium (V) Metal Complexes with Selected Drugs. Pyrex Journal of Research in Environmental Studies. 2(2): 006-014.

Janrao, D. M., Pathan, J., Kayande, D.D., and Mulla, J.J. (2014). An Over View of Potentiometric Determination of Stability Constants of Metal Complexes. Sci. Revs. Chem. Commun.: 4(1), 2014, 11-24.

Karimi, H. (2017). Effect of pH and Initial Pb(II) Concentration on the Lead Removal Efficiency from Waste Water Using $\mathrm{Ca}(\mathrm{OH})_{2}$. International Journal of Water and Waste Water Treatment 3.2

Kaschl, A. Romheld, V. and Chen, Y. (2010). Binding of Cadmium, Copper and Zinc to Humic Substances Originating from Municipal Solid Waste Compost. Israel Journal of Chemistry Vol. 42(1): 89-98.

Kostic, I. S., Tatjana, P, A., Nikolic, R. S., Cvetkovic, T. P., Pavlovic, D. D., Aleksandar, L.J. and Bojic, A. (2012). Comparative Study of Binding Strengths of Heavy Metals with Humic Acid. J.serb. Chem. Soc. 76(9) pp 1-20. 
BAJOPAS Volume 14 Number 1,June, 2021

Na'aliya, J. (2013). Determination of Stepwise Stability Constants and Gibbs free Energy Change of Trisprolina to Complexes of some Divalent Transition Metal ions. Bayero Journal of Pure and Applied Sciences 6(2): 112-114.

Omar, A. A. and Ali, E. A. (2015). Potentiometric Studies on Complexes of $\mathrm{Cr}$ (III) and $\mathrm{Zr}$ (IV) with some Carboxylic Acids. International Journal of Advanced Chemistry, 3(1) 25-

37.

Pandey, A. K. Pandey, S. D. and Misr, V. (2015).Stability Constants of Metal- Humic Acid Complexes and Its Role in Environmental Detoxification. J. Ecotoxicology and Environmental Safety. 47(1):195-200.

Ram, N. and Raman, K.V. (1984). Stability Constants of Complexes of Metals with
Humicand Fuvic Acids under Non- acidConditions. Journal of Plant Nutrition and Soil Sciences.

147:171-176.

Santosh, D. D., Ashok, B. K., Vijay, J. T., Shivraj, G. W. and Vinay, V. W. (2011). Potentiometric Studies of Elec-Trolyte Effects on Complex Equilibria of Some Substituted 5-(2-hydroxy Phenyl) Pyrazoles. Der pharm. 3 (6): 75-83.

Sayyed, H. and Abdul Rahim, M. F. (2012). Studies of Binary Complexes of Metal Ions with Mandelic Acid by Potentiometry. Chem. J. 02 (6): 206209.

Shirvani, M. Moradian, E. Khalili, B. Bakhtiary, S. (2015). Interaction of $\mathrm{Cd}$ and $\mathrm{Pb}$ with Humate-Palygorskite and HumateSepiolite Complexes. Journal of water, air and pollution 3: 220-228. 


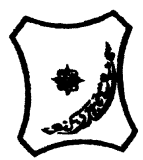

Bayero Journal of Pure and Applied Sciences, 14(1): 54 - 63

Received: November, 2020

Accepted: April, 2021

ISSN $2006-6996$

\title{
STABILITY CONSTANTS OF COMPLEXES OF METAL IONS WITH PEATSOIL HUMIC ACIDS UNDER NON-ACID-CONDITIONS
}

\author{
${ }^{* 1}$ Sabo, Yusuf ${ }^{2}$ Jimoh, W.L.O., ${ }^{3}$ Isa Baba Koki and ${ }^{4}$ Sholadoye, Q. 0. \\ ${ }^{1}$ Department of Pure and Industrial Chemistry, Bayero University, Kano \\ ${ }^{3}$ Department of Chemistry, Yusuf Maitama Sule University Kano. P.M.B. 3220 Kano, Nigeria. \\ ${ }^{4}$ Department of Chemistry, Nigerian Police Academy, Wudil, Kano-Nigeria
}

*Correspondence E-mail; saboyusuf18@yahoo.com

ABSTRACT

Stability constants of complexes of four divalent metal ions viz. $\mathrm{Cu}^{2+}, \mathrm{Pb}^{2+}, \mathrm{Mg}^{2+}$ and $\mathrm{Cd}^{2+}$ with humic acids (HA) were determined by potentiometric titration of humic acids with the corresponding salt of the divalent metals in aqueous media under non-acid-condition. The log $K$ (logarithm of the stability constant) ranged from 1.0942 to 2.7471 for metalhumic acid complexes were determined using point-wise computational method. The order of stability constants were obtained as follows: $\mathrm{Cu}>\mathrm{Pb}>\mathrm{Cd}>\mathrm{Mg}$ for metal $-\mathrm{HA}$ complexes respectively, indicating a higher degree of complexation with Cu metal ion.

Keywords: stability constant, humic acid, potentiometric titration, divalent metals, acid hydrolysis.

\section{NTRODUCTION}

The stability constant of a complex is the numerical expression of its stability and provides a quantitative measure of affinity of the metal ion to the complexing agent. An understanding of the relative stability of metal-complexes helps in predicting the behavior of metal ions in the soil (Ram and Raman, 1982). Extensive researches has been done to determine the stability constants of the complexes formed between humic acid (HA) with a number of metal ions. Ashok et al., (2000) reported that humic acid with hydroxyl, phenoxyl and carboxyl reactive groups can form coordination compound with metal ions at $\mathrm{pH}$ 3.5. The stability constants(Log K) for different metalhumic acid complexes indicated the following order of the stabilities of complexes formed between humic acid and metal ion, $\mathrm{Cu}>\mathrm{Fe}$ $>\mathrm{Pb}>\mathrm{Ni}>\mathrm{Co}>\mathrm{Ca}>\mathrm{Cd}>\mathrm{Zn}>\mathrm{Mn}>\mathrm{Mg}$. Andelkovic et al., (2010) investigated the binding of $\mathrm{Cd}$ (II) to soil humic acid at pH 6.5 and in $0.1 \mathrm{M} \mathrm{KNO}_{3}$ ionic medium. The stability constant for binding indicating greater stability in the case when carboxyl groups are involved in complexation reaction. Kostic et al.,(2012) investigated the complexation of humic acid with certain heavy metal ions (Co(II), $\mathrm{Ni}(\mathrm{II}), \mathrm{Cu}(\mathrm{II})$,
$\mathrm{Zn}(\mathrm{II})$, and $\mathrm{Pb}(\mathrm{II})$. The experiment was performed at $25^{\circ} \mathrm{C}$, at pH 4.0 and ionic strength of $0.01 \mathrm{M}$. Stability constant of complex between $\mathrm{Pb}$ (II) ions and humic acid is greater than stability constants of other investigated metalhumate complexes. Bogata and Sokolowska (2016) analyses the interaction between humic acids from different soils and $\mathrm{Zn}$ (II) ions at wide concentration ranges and at $\mathrm{pH} 5$. Studies have showed significant impact of $\mathrm{Zn}$ concentration, $\mathrm{pH}$ and some properties of humic acids with zinc.But all of these studies were limited to acidic $\mathrm{pH}$ range. Therefore, the present study was carried out to determine and compare the stability constants of complexes of metal ions with hydrolysed peat soil humic acid and unhydrolysed peat soil humic under non-acid conditions.

\section{MATERIALS AND METHODS}

Analytical grade chemicals used includes hydrochloric acid $(\mathrm{HCl})$, nitric acid $\left(\mathrm{HNO}_{3}\right)$, sodium hydroxide $(\mathrm{NaOH})$, lead nitrate $\mathrm{Pb}\left(\mathrm{NO}_{3}\right)_{2}$, copper nitrate $\mathrm{Cu}\left(\mathrm{NO}_{3}\right)_{2} \cdot 3 \mathrm{H}_{2} \mathrm{O}$, cadmium nitrate $\mathrm{Cd}\left(\mathrm{NO}_{3}\right)_{2} \cdot 4 \mathrm{H}_{2} \mathrm{O}$, magnesium nitrate $\mathrm{Mg}\left(\mathrm{NO}_{3}\right)_{2} \cdot 6 \mathrm{H}_{2} \mathrm{O}$, potassium nitrate $\left(\mathrm{KNO}_{3}\right)$, calcium chloride $\left(\mathrm{CaCl}_{2}\right)$, (sigma-Aldrich). Dowex 50WX8, (20-50 mesh) from Fluka. 


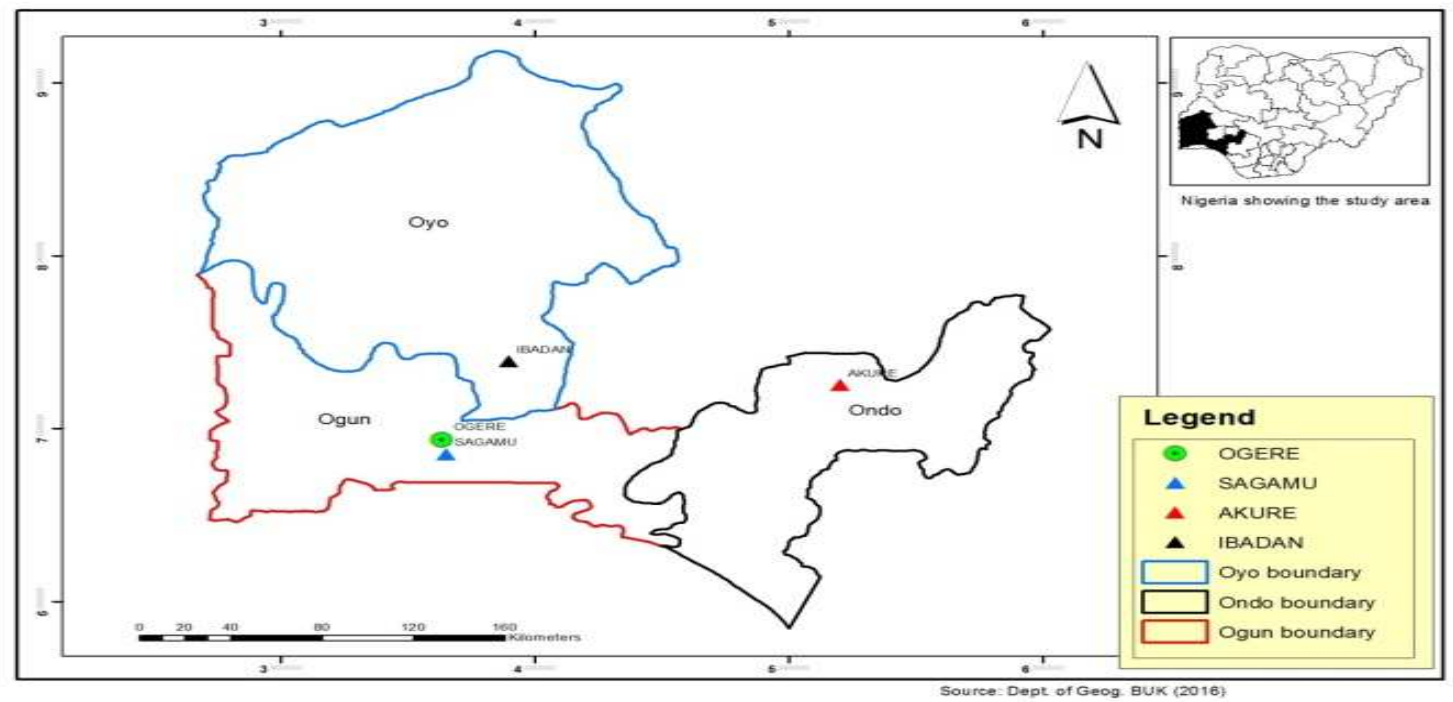

Figure 1: Map showing the sampling point at Sagamu Town, Ogun State.

\section{Description of Sampling Area}

Sagamu has geographical coordinates between $6^{\circ} 50^{\prime}$ north; $3^{\circ} 38^{\prime}$ east is located in south western region of Nigeria. The region has tropical wet and dry climate with a lengthy wet season and relatively constant temperatures throughout the course of the year. Wet season runs from March to October, November to December forms the region dry season. The vegetation type of the region is savannah which is really grassland with small bushes and occasional big trees. Grassland soils have substantially higher organic matter content than forest soils (Novackova, 2011).

\section{Sample Collection}

The Peatsoil samples were collected from four different sampling points $(0-10 \mathrm{~cm}$ depth) in Sagamu into polyethylene bag with plastic spoons. Samples were taken to the laboratory, extraneous materials were removed; the samples were air-dried, crushed and ground to a fine powder in a mortar passed through a $0.20 \mathrm{~mm}$ sieve. The samples were kept for analysis.

\section{Isolation and purification of humic acid from peat soil sample}

Peatsoil sample $(100 \mathrm{~g})$ was mixed with 1000 $\mathrm{cm}^{3}$ of $0.1 \mathrm{M} \mathrm{NaOH}$ solution, shaken for 3hours and left to stand overnight. Dark-coloured supernatant was obtained and decanted from solid residue. The dark-coloured supernatant was acidified to $(\mathrm{pH}=1.0)$ with $6 \mathrm{M} \mathrm{HCl}$ stirred and allowed to stand for 6 hours. Yellowish brown supernatant and dark-brown precipitate were obtained. The yellowish brown supernatant was decanted followed by centrifuge and discarded. The dark-brown precipitate was mixed with $500 \mathrm{~cm}^{3}$ of $0.1 \mathrm{M} \mathrm{NaOH}$ solution followed by passing through dowex resin. The dark-brown solution was acidified to $(\mathrm{pH}=1.0)$ with $6 \mathrm{M} \mathrm{HCl}$ stirred and allowed to stand for 3 hours. The dark-brown precipitate was washed several times with deionized water. The supernatant was treated with $\mathrm{AgNO}_{3}$ solution until no white precipitate observed. The humic acid was transferred to weighed crucible and dried at $60^{\circ} \mathrm{C}$ in an oven for 12 hours. The humic acid was cooled and dried in the desiccator, weighed and recorded. The obtained humic acid was dried again at $60^{\circ} \mathrm{C}$ for additional 6 hours cooled and dried in the desiccator, weighed and recorded constant weight was obtained (Baruah et al., 2015).

\section{FT-IR analysis}

FT-IR spectra of humic acid sample was analysed using Carry 630 FT-IR Agilent Technologies.

Unhydrolysed compost humic acid

The unhydrolysed humic acid was obtained after isolation and purification of compost humic acid and kept for investigation.

\section{Acid hydrolysis of Peatsoil acid}

Peatsoil humic acid sample (1g) was refluxed for 12 hours at $\left(160^{\circ} \mathrm{C}\right)$ with $50 \mathrm{~cm}^{3}$ of $6 \mathrm{M} \mathrm{HCl}$. The mixture was allowed to cool, decanted, and centrifuged after hydrolysis. The insoluble residues were washed with distilled water via centrifugation several times, and the supernatant was treated with $\mathrm{AgNO}_{3}$ solution until no white precipitate was observed. The residue was thoroughly dried over $\mathrm{CaCl}_{2}$ in a desiccator at room temperature (Chefetz et al., 2002). Finally, the obtained hydrolysed humic acid was kept for investigation. 
BAJOPAS Volume 14 Number 1,June, 2021 Potentiometric Titrations

Potentiometric measurements were carried out using a pH-meter Jenway (model 3510) with combine electrode, the sensitivity of the $\mathrm{pH}$ meter is 0.01 units. The $\mathrm{pH}$ meter was switched on half an hour before starting the titration for initial warm up of the instrument. The instrument was calibrated with an aqueous standard buffer solution of $\mathrm{pH} 4.00$ and 10.0 (borate buffer) prepared from a "Qualigens" buffer tablets.

The following sets of solutions were prepared in a $250 \mathrm{~cm}^{3}$ volumetric flask separately for $\mathrm{pH}$ metric titrations.

(i) $5 \mathrm{~cm}^{3} 0.1 \mathrm{M} \mathrm{HCl}+40 \mathrm{~cm}^{3}$ deionized water

(ii) $5 \mathrm{~cm}^{3} 0.1 \mathrm{M} \mathrm{HCl}+39 \mathrm{~cm}^{3}$ deionized water $+1 \mathrm{~cm}^{3} 0.15 \mathrm{gcm}^{-3}$ humic acid

(iii) $5 \mathrm{~cm}^{3} 0.1 \mathrm{M} \mathrm{HCl}+37 \mathrm{~cm}^{3}$ deionized water $+1 \mathrm{~cm}^{3} 0.15 \mathrm{gcm}^{-3}$ humic acid

$$
+2 \mathrm{~cm}^{3} \quad 0.01 \mathrm{M} \mathrm{Cu} \text { (II) }
$$

The solutions were titrated against standardized $0.110 \mathrm{MNaOH}$ separately. The total volume of each mixture was adjusted to $50 \mathrm{~cm}^{3}$ and the ionic strength of the solutions was maintained constant at by adding appropriate amount of stock solution of $1 \mathrm{M} \mathrm{KNO}_{3}$ (Gamal, 2015; Omar and Ali, 2015). A magnetic stirrer was used to achieve thorough mixing of the interacting solutions at $550 \mathrm{rpm}$. The same set of experimental conditions was applied for potentiometric titration of remaining samples.

\section{Evaluation of pKa of Hydrolysed peat soil Humic Acids}

The proton-ligand formation number $\mathrm{n}_{\mathbf{A}}$ were calculated by Irving and Rossotti expression (Omar and Ali, 2015).

$\mathrm{nA}=\mathrm{Y}-\frac{(\mathrm{V} 2-\mathrm{V1})(\mathrm{No}-\mathrm{Eo})}{(\mathrm{VO}+\mathrm{V1}) \mathrm{TCL}}$ 1

Where: $Y$ is number of dissociable proton, $\left(\mathrm{V}_{2^{-}}\right.$ $V_{1}$ ) is the measure of displacement of the ligand curve relative to acid curve, $\mathrm{N}^{\circ}$ and $\mathrm{E}^{\circ}$ are the resultant concentration of alkali solution, free acid solution, $\mathrm{T}_{\mathrm{cL}}{ }^{\circ}$ is the total ligand concentration, $\mathrm{V}^{\circ}$ is the total volume of titration solution, $V_{1}$ is the volume of alkali added to acid solution, $V_{2}$ is the volume of alkali added to acid solution + ligand solution, acid dissociation constants (pKa - values) of ligand were calculated by algebraic method point wise calculation (Tables 1 ). The dissociation constants (pKa) were calculated according to the following relation:

$\mathrm{pKa}=\mathrm{pH}+\log \left(\frac{n A}{1-n A}\right)$ 2

Where: pKa is the acid dissociation constant, $\mathrm{n}_{\mathrm{A}}$ is the Proton-ligand formation number and $\mathrm{pH}$ is the pH-values (Omar and Ali, 2015).

\section{Determination of metal-ligand stability constants $(\log K)$ of complexes}

The potentiometric measurement for the determination of stability constant of a complex in solution is based on the fact that the redox potential of the couple $\frac{M^{+(m-n)}}{M^{+m}}$ is shifted significantly on complexation of the metal ion with the ligand. This method involves change in hydrogen ion concentration $\left[\mathrm{H}^{+}\right]$due to the displacement or association of one or more protons taking place during complexation reaction. This change can be found out by titrating the solutions containing free acid, acid with ligand, and acid with ligand and metal ion, individually against a standard alkali solution at a constant ionic strength or temperature. Either ionic strength or temperature may be varied for different sets of solutions. In all the cases, the change in the $\mathrm{pH}$ of the solution is measured after each addition of a known amount of alkali to the reaction cell which contains the reaction mixture. The titration curves are then drawn by plotting the measured $\mathrm{pH}$ values against the corresponding volume of alkali added and the stability constants of the complexes are determined from the titration curves by employing $\mathrm{pH}$-metric titration technique given by (Irving and Rossoti).

Metal-ligand stability constants ( $\log \mathrm{K}$ ) were determined by using the following relations:

$$
\bar{n}=\frac{\left(V_{3}-V_{2}\right)\left(E^{0}+N^{0}\right)}{\left(V^{0}+V_{2}\right) \bar{n}_{A} T_{m}^{0}}
$$

and

$$
P L=\log _{10}\left\{\frac{1+\beta_{n}^{H} \frac{1}{[\text { anti } \log \mathrm{pH}]^{\mathrm{n}}}}{\mathrm{T}_{\mathrm{L}}^{0}-n \bar{T}_{m}^{0}} \mathrm{X} \frac{\left(V^{0}+V_{3}\right)}{V^{0}}\right\}
$$


BAJOPAS Volume 14 Number 1,June, 2021

Where $T_{L}, T^{\circ}, E^{\circ}$, and $V^{\circ}$ havethe same significance as in equation (1) above, $T_{m}$ denotes the total concentration of metal present in solution, $V_{3}$ is the volume of metal ions present in solution and $\beta^{H}$ is the overall proton ligand stability constant. The metal-ligand stability constants (log K) were determined by employing point wise computational Method (eq. 5 and 6).

$\operatorname{LogK}_{1}=\log \left(\frac{n}{1-n}\right)+\mathrm{pL}$ .5

$\operatorname{LogK}_{2}=\log \left(\frac{1-n}{2-n}\right)+\mathrm{pL}$ ...6

Where: Log $\mathrm{K}$ is the metal-ligand stability constant, $\mathrm{pL}$ is the Free ligand exponent function, $\mathbf{n}$ is the Average number of ligand attached with metal ion (Janraoet al., 2014). The results obtained were analyzed by an ORIGIN 2016 program using titration data and then the proton-ligand stability constants (pKa) and Metal-ligand stability constant (LogK) calculated (Omar and Ali, 2015).

\section{RESULTS AND DISCUSSION}

Fourier transformed infrared (FT-IR) spectra of isolated humic acid from peat soils Figure 2 had distinct clear absorption bands indicating the presence of major humic acid structural elemental groups such as $\mathrm{H}$ bonded $\mathrm{OH}$ $\left(3680 \mathrm{~cm}^{-1}\right.$ peak $), C=0$ of carbonyl $\left(1721 \mathrm{~cm}^{-1}\right.$ peak), functional groups of aliphatic components $\mathrm{CH}_{2}\left(2918 \mathrm{~cm}^{-1}\right.$ peak) and $\mathrm{C}-\mathrm{O}$ stretching of polysaccharide $\left(1168 \mathrm{~cm}^{-1}\right.$ peak). The positions of the absorption bands of the spectra fell within typical major absorption bands of humic acid which is at frequencies 3680, 2918, 1721, 1168 $\mathrm{cm}^{-1}$. The first peak centred in the vicinity of $3680 \mathrm{~cm}^{-1}$ region is attributed to phenol $\mathrm{OH}$ group bounded by intermolecular $\mathrm{H}$ bonds. The $2918 \mathrm{~cm}^{-1}$ band usually has absorption maximum at $2918 \mathrm{~cm}^{-1}$ which is due to $\mathrm{C}-\mathrm{H}$ stretching of alkane group $\left(\mathrm{CH}_{2}\right)$. The next major absorption band is $1721 \mathrm{~cm}^{-1}$. This band has been commonly ascribed to $\mathrm{C}=\mathrm{O}$ stretching of mainly carboxyl group $(\mathrm{COOH})$ with trace amount of ketones. The last peak was observed at 1168 $\mathrm{cm}^{-1}$ due to $\mathrm{C}-\mathrm{O}$ stretching of polysaccharides and this peak appeared also in the spectra of humic acid from peat soil. The FTIR spectra of the isolated humic acid contained all major characteristic absorption peaks of humic acid. These absorption peaks indicated the presence of the major structural elements of humic acid namely $\mathrm{H}$ bonded $\mathrm{OH}, \mathrm{C}=\mathrm{C}$ of aromatic ring, $\mathrm{C}=\mathrm{O}$ of carbonyl group (both carboxyl and ketonic), $\mathrm{CH}_{2}$ group. This strongly supports the presence of humic acid.

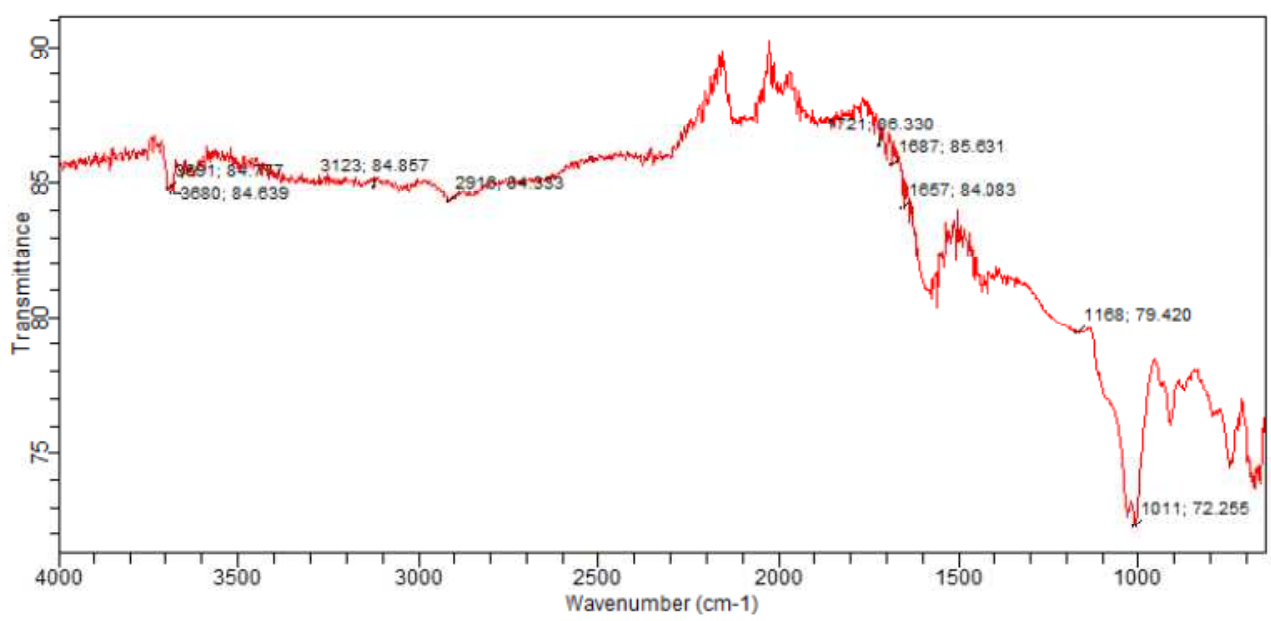

Fig. 2 : FT-IR spectraof peatsoilhumic acid (PSHA)

\section{Evaluation of acid dissociation constant (pka) of acid hydrolysed peat soil humicacid at phenolic group}

The value of the dissociation constant of the peat soil humic acid (PSHA) that underwent acidhydrolysis studied was found to be 8.9299 as shown Table 1, which is lower than the literaturevalues reported by Almeida and Szpoganics, (2015), Borges et al., (2005); Badr et al., (2012)and Fernandes et al,.(2009) of $9.73,9.47$ and 10.30. The difference between the obtained valuesand the reported values in this study might be probably as a result of acid hydrolysis of humicacid. 
BAJOPAS Volume 14 Number 1,June, 2021

Table 1: PKa of (Hydrolysed PSHA)

\begin{tabular}{|l|l|l|l|l|l|l|}
\hline $\mathrm{pH}$ & $\mathrm{BV}_{1}$ & $\mathrm{BV}_{2}$ & $\mathrm{~V}_{2}-\mathrm{V}_{1}$ & $\mathrm{nA}$ & $\log \left(\frac{n A}{1-n A}\right)$ & $\mathrm{pKa}$ \\
\hline 8.50 & 5.30 & 6.29 & 0.99 & 0.3594 & -0.2510 & 8.2490 \\
8.72 & 5.35 & 6.37 & 1.02 & 0.3400 & -0.2880 & 8.4320 \\
9.00 & 5.40 & 6.46 & 1.06 & 0.3141 & -0.3391 & 8.6609 \\
9.22 & 5.45 & 6.55 & 1.10 & 0.2882 & -0.3927 & 8.8273 \\
9.51 & 5.50 & 6.66 & 1.16 & 0.2494 & -0.4786 & 9.0314 \\
9.73 & 5.55 & 6.78 & 1.23 & 0.2041 & -0.5910 & 9.1390 \\
10.00 & 5.60 & 6.90 & 1.30 & 0.1589 & -0.7238 & 9.2762 \\
10.23 & 5.65 & 7.05 & 1.40 & 0.0941 & -0.9835 & 9.2465 \\
10.49 & 5.70 & 7.10 & 1.40 & 0.0941 & -0.9835 & 9.5065 \\
\hline
\end{tabular}

Average pKa $=8.9299 \pm 0.4186$

Table 2: PKa of (Unhydrolysed PSHA)

\begin{tabular}{|l|l|l|l|l|l|l|}
\hline $\mathrm{pH}$ & $\mathrm{BV}_{1}$ & $\mathrm{BV}_{2}$ & $\mathrm{~V}_{2}-\mathrm{V}_{1}$ & $\mathrm{nA}$ & $\log \left(\frac{\boldsymbol{n A}}{1-\boldsymbol{n}}\right)$ & $\mathrm{pKa}$ \\
\hline 8.50 & 5.30 & 5.81 & 0.51 & 0.6619 & 0.2919 & 8.7919 \\
8.72 & 5.35 & 5.90 & 0.55 & 0.6357 & 0.2418 & 8.9618 \\
9.00 & 5.40 & 6.00 & 0.60 & 0.6029 & 0.1813 & 9.1813 \\
9.22 & 5.45 & 6.10 & 0.65 & 0.5701 & 0.1226 & 9.3426 \\
9.51 & 5.50 & 6.20 & 0.70 & 0.5376 & 0.0654 & 9.5754 \\
9.73 & 5.55 & 6.33 & 0.78 & 0.4851 & -0.0259 & 9.7041 \\
10.00 & 5.60 & 6.47 & 0.87 & 0.4262 & -0.1291 & 9.8709 \\
10.23 & 5.65 & 6.62 & 0.99 & 0.3609 & -0.2481 & 9.9819 \\
10.49 & 5.70 & 6.80 & 1.10 & 0.2759 & -0.4690 & 10.0210 \\
\hline
\end{tabular}

Average pKa $=9.4923 \pm 0.4410$

Metal-ligand stability constant ( $\log \mathrm{K}$ )

The stabilityconstants require the accurate values of proton-ligand stability constants (Anil and Maroti, 2008). Metal titration curves crossed over ligand titration curve indicated the formation of complex upon proton release (Santosh, et al., 2011). If the values of n- are within range $0.2-0.8$ and $1.2-18$ this indicates the formation of $1: 1$ and 1:2 complexes (Sayyed and Mazahar, 2012).

The metal (II)-humate stepwise stability constants (log k) at phenolic group (Tables 318)

Table 3: Point-wise method, $\mathrm{Cu}$-(Hydrolysed PSHA)

\begin{tabular}{|l|l|l|l|l|l|l|l|l|}
\hline $\mathrm{pH}$ & $\mathrm{BV}_{1}$ & $\mathrm{BV}_{2}$ & $\mathrm{BV}_{3}$ & $\left(\mathrm{~V}_{3}-\mathrm{V}_{2}\right)$ & $\mathrm{n}$ & $\mathrm{pL}$ & $\log \left(\frac{n}{1-n}\right)$ & LogK $_{1}$ \\
\hline 8.50 & 5.30 & 6.29 & 6.33 & 0.04 & 0.5500 & 2.66 & 0.0871 & 2.7471 \\
8.72 & 5.35 & 6.37 & 6.41 & 0.04 & 0.5714 & 2.43 & 0.1249 & 2.5549 \\
9.00 & 5.40 & 6.46 & 6.50 & 0.04 & 0.6198 & 2.16 & 0.2122 & 2.3722 \\
9.22 & 5.45 & 6.55 & 6.59 & 0.04 & 0.6667 & 1.94 & 0.3010 & 2.2410 \\
\hline
\end{tabular}

LogK $_{1}$ (Average value) $=2.4788 \pm 0.2203$

Table 4: Point-wise method, $\mathrm{Cu}$-(Hydrolysed PSHA)

\begin{tabular}{|l|l|l|l|l|l|l|l|l|}
\hline $\mathrm{pH}$ & $\mathrm{BV}_{1}$ & $\mathrm{BV}_{2}$ & $\mathrm{BV}_{3}$ & $\left(\mathrm{~V}_{3}-\mathrm{V}_{2}\right)$ & $\mathrm{n}$ & $\mathrm{pL}$ & $\log \left(\frac{n-1}{2-n}\right)$ & LogK $_{2}$ \\
\hline 9.51 & 5.50 & 6.66 & 6.73 & 0.07 & 1.3509 & 1.70 & -0.2671 & 1.4329 \\
9.73 & 5.55 & 6.78 & 6.85 & 0.07 & 1.6383 & 1.51 & 0.2467 & 1.7567 \\
10.00 & 5.60 & 6.90 & 6.98 & 0.08 & 2.1783 & 1.31 & -0.2158 & 1.0942 \\
10.23 & 5.65 & 7.05 & 7.13 & 0.08 & 4.1904 & 1.27 & & \\
10.49 & 5.70 & 7.10 & 7.19 & 0.09 & 4.6920 & & & \\
\hline
\end{tabular}

Log $K_{2}($ Average value $)=1.4280 \pm 0.3312$ 
BAJOPAS Volume 14 Number 1,June, 2021

Table 5: Point-wise method, $\mathrm{Cu}$ (Unhydrolysed PSHA)

\begin{tabular}{|l|l|l|l|l|l|l|l|l|}
\hline $\mathrm{pH}$ & $\mathrm{BV}_{1}$ & $\mathrm{BV}_{2}$ & $\mathrm{BV}_{3}$ & $\left(\mathrm{~V}_{3}-\mathrm{V}_{2}\right)$ & $\mathrm{n}$ & $\mathrm{pL}$ & $\log \left(\frac{n}{n-1}\right)$ & Log $_{1}$ \\
\hline 8.50 & 5.30 & 5.81 & 5.85 & 0.04 & 0.2973 & 2.88 & -0.3736 & 2.5064 \\
8.72 & 5.35 & 5.90 & 5.95 & 0.05 & 0.3873 & 2.66 & -0.1992 & 2.4608 \\
9.00 & 5.40 & 6.00 & 6.05 & 0.05 & 0.4044 & 2.38 & -0.1681 & 2.2119 \\
9.22 & 5.45 & 6.10 & 6.15 & 0.06 & 0.5157 & 2.18 & -0.0272 & 2.2072 \\
9.51 & 5.50 & 6.20 & 6.27 & 0.07 & 0.6417 & 1.89 & 0.2530 & 1.1430 \\
\hline
\end{tabular}

$\operatorname{LogK}_{1}($ Average value $)=2.3059 \pm 0.6153$

Table 6:Point-wise method, $\mathrm{Cu}$ (Unhydrolysed PSHA)

\begin{tabular}{|l|l|l|l|l|l|l|l|l|}
\hline $\mathrm{pH}$ & $\mathrm{BV}_{1}$ & $\mathrm{BV}_{2}$ & $\mathrm{BV}_{3}$ & $\mathrm{~V}_{3}-\mathrm{V}_{2}$ & $\mathrm{n}$ & $\mathrm{pL}$ & $\log \left(\frac{n-1}{2-n}\right)$ & $\log \mathrm{K}_{2}$ \\
\hline 9.73 & 5.55 & 6.33 & 6.42 & 0.09 & 0.9000 & 1.69 & & \\
10.00 & 5.60 & 6.47 & 6.58 & 0.11 & 1.2578 & 1.44 & -0.4592 & 0.9808 \\
10.23 & 5.65 & 6.62 & 6.84 & 0.12 & 1.6137 & 1.26 & -0.2010 & 1.4610 \\
10.49 & 5.70 & 6.80 & 6.92 & 0.12 & 2.1052 & 1.03 & & \\
\hline
\end{tabular}

$\operatorname{LogK}_{2}$ (Average value) $=1.2209 \pm 0.3398$

Table 7:Point-wise method, Pb (Hydrolysed PSHA)

\begin{tabular}{|l|l|l|l|l|l|l|l|l|}
\hline $\mathrm{pH}$ & $\mathrm{BV}_{1}$ & $\mathrm{BV}_{2}$ & $\mathrm{BV}_{3}$ & $\left(\mathrm{~V}_{3}-\mathrm{V}_{2}\right)$ & $\mathrm{n}$ & $\mathrm{pL}$ & $\log \left(\frac{n}{1-n}\right)$ & LogK $_{1}$ \\
\hline 8.50 & 5.30 & 6.29 & 6.33 & 0.04 & 0.5500 & 2.66 & 0.0871 & 2.7471 \\
8.72 & 5.35 & 6.37 & 6.41 & 0.04 & 0.5714 & 2.43 & 0.1249 & 2.5549 \\
9.00 & 5.40 & 6.46 & 6.50 & 0.04 & 0.6198 & 2.16 & 0.2122 & 2.3722 \\
9.22 & 5.45 & 6.55 & 6.60 & 0.05 & 0.8333 & 1.96 & 0.6989 & 2.6589 \\
\hline
\end{tabular}

Log $_{\mathbf{1}}($ Average value $)=2.5832 \pm 0.1614$

Table 8:Point-wise method, Pb-(Hydrolysed PSHA)

\begin{tabular}{|l|l|l|l|l|l|l|l|l|}
\hline $\mathrm{pH}$ & $\mathrm{BV}_{1}$ & $\mathrm{BV}_{2}$ & $\mathrm{BV}_{3}$ & $\left(\mathrm{~V}_{3}-\mathrm{V}_{2}\right)$ & $\mathrm{n}$ & $\mathrm{pL}$ & $\log \left(\frac{n-1}{2-n}\right)$ & $\log \mathrm{K}_{2}$ \\
\hline 9.51 & 5.50 & 6.66 & 6.71 & 0.05 & 0.9650 & 1.67 & & \\
9.73 & 5.55 & 6.78 & 6.83 & 0.05 & 1.1702 & 1.44 & & \\
10.00 & 5.60 & 6.90 & 6.90 & 0.05 & 1.4864 & 1.22 & -0.0237 & 1.1963 \\
10.23 & 5.65 & 7.05 & 7.10 & 0.05 & 2.0190 & 1.09 & & \\
10.49 & 5.70 & 7.10 & 7.17 & 0.07 & 3.6492 & 1.00 & & \\
\hline
\end{tabular}

Log $K_{2}$ (Average value) $=1.1963$

Table 9: Point-wise method, Pb (Unhydrolysed PSHA)

\begin{tabular}{|l|l|l|l|l|l|l|l|l|}
\hline $\mathrm{pH}$ & $\mathrm{BV}_{1}$ & $\mathrm{BV}_{2}$ & $\mathrm{BV}_{3}$ & $\mathrm{~V}_{3}-\mathrm{V}_{2}$ & $\mathrm{n}$ & $\mathrm{pL}$ & $\begin{array}{l}\text { Log } \\
\left(\frac{n}{n-1}\right)\end{array}$ & Log $\mathrm{K}_{1}$ \\
\hline 8.50 & 5.30 & 5.81 & 5.85 & 0.04 & 0.2973 & 2.88 & -0.3736 & 2.5064 \\
8.72 & 5.35 & 5.90 & 5.94 & 0.04 & 0.3099 & 2.66 & -0.5477 & 2.3123 \\
9.00 & 5.40 & 6.00 & 6.05 & 0.05 & 0.4044 & 2.38 & -0.1681 & 2.2119 \\
9.22 & 5.45 & 6.10 & 6.15 & 0.06 & 0.5157 & 2.18 & 0.0272 & 2.2072 \\
9.51 & 5.50 & 6.20 & 6.26 & 0.07 & 0.6417 & 1.89 & 0.2530 & 2.1430 \\
9.73 & 5.55 & 6.40 & 6.40 & 0.07 & 0.7000 & 1.67 & 0.3680 & 2.0380 \\
\hline
\end{tabular}

LogK $_{1}$ (Average value) $=2.2364 \pm 0.1602$

Table 10: Point-wise method, Pb (Unhydrolysed PSHA)

\begin{tabular}{|l|l|l|l|l|l|l|l|l|}
\hline $\mathrm{pH}$ & $\mathrm{BV}_{1}$ & $\mathrm{BV}_{2}$ & $\mathrm{BV}_{3}$ & $\mathrm{~V}_{3}-\mathrm{V}_{2}$ & $\mathrm{n}$ & $\mathrm{pL}$ & $\log \left(\frac{n-1}{2-n}\right)$ & $\log \mathrm{K}_{2}$ \\
\hline 10.00 & 5.60 & 6.47 & 6.55 & 0.08 & 1.9503 & 1.41 & & \\
10.23 & 5.65 & 6.62 & 6.72 & 0.11 & 1.4792 & 1.26 & -0.0361 & 1.2239 \\
\hline
\end{tabular}

$\operatorname{LogK}_{2}$ (Average value) $=1.2239$

Table 11: Point-wise method, Mg (Hydrolysed PSHA)

\begin{tabular}{|l|l|l|l|l|l|l|l|l|}
\hline $\mathrm{pH}$ & $\mathrm{BV}_{1}$ & $\mathrm{BV}_{2}$ & $\mathrm{BV}_{3}$ & $\left(\mathrm{~V}_{3}-\mathrm{V}_{2}\right)$ & $\mathrm{n}$ & $\mathrm{pL}$ & $\log \left(\frac{n}{n-1}\right)$ & LogK $_{1}$ \\
\hline 8.50 & 5.30 & 6.29 & 6.31 & 0.02 & 0.2750 & 2.64 & -0.4290 & 2.2110 \\
8.72 & 5.35 & 6.37 & 6.39 & 0.02 & 0.2858 & 2.42 & -0.3978 & 2.0222 \\
9.00 & 5.40 & 6.46 & 6.49 & 0.03 & 0.4648 & 2.14 & -0.0612 & 2.0788 \\
9.22 & 5.45 & 6.55 & 6.59 & 0.04 & 0.6667 & 1.94 & 0.3010 & 2.2410 \\
\hline
\end{tabular}

$\log _{\mathbf{1}}($ Average value) $=2.1382 \pm 0.1046$ 
BAJOPAS Volume 14 Number 1,June, 2021

Table 12: Point-wise method, Mg (Hydrolysed PSHA)

\begin{tabular}{|l|l|l|l|l|l|l|l|l|}
\hline $\mathrm{pH}$ & $\mathrm{BV}_{1}$ & $\mathrm{BV}_{2}$ & $\mathrm{BV}_{3}$ & $\left(\mathrm{~V}_{3}-\mathrm{V}_{2}\right)$ & $\mathrm{n}$ & $\mathrm{pL}$ & $\log \left(\frac{n-1}{2-n}\right)$ & LogK $_{2}$ \\
\hline 9.51 & 5.55 & 6.66 & 6.71 & 0.05 & 0.9650 & 1.67 & & \\
9.73 & 5.55 & 6.78 & 6.84 & 0.06 & 1.4042 & 1.47 & -0.1686 & 1.3014 \\
10.00 & 5.60 & 6.90 & 6.93 & 0.06 & 1.7838 & 1.23 & 0.5593 & 1.7893 \\
10.23 & 5.65 & 7.05 & 7.10 & 0.06 & 3.1429 & 1.10 & & \\
10.49 & 5.70 & 7.10 & 7.18 & 0.07 & 3.6492 & 0.83 & & \\
\hline
\end{tabular}

LogK $_{2}($ Average value $)=1.5453 \pm 0.3450$

Table 13: Point-wise method, Mg (Unhydrolysed PSHA)

\begin{tabular}{|l|l|l|l|l|l|l|l|l|}
\hline $\mathrm{pH}$ & $\mathrm{BV}_{1}$ & $\mathrm{BV}_{2}$ & $\mathrm{BV}_{3}$ & $\mathrm{~V}_{3}-\mathrm{V}_{2}$ & $\mathrm{n}$ & $\mathrm{pL}$ & $\log \left(\frac{n}{n-1}\right)$ & $\operatorname{Log~}_{1}$ \\
\hline 8.50 & 5.30 & 5.81 & 5.85 & 0.04 & 0.2973 & 2.88 & -0.3736 & 2.5064 \\
8.72 & 5.35 & 5.90 & 5.94 & 0.04 & 0.3099 & 2.66 & -0.3477 & 2.3123 \\
9.00 & 5.40 & 6.00 & 6.04 & 0.04 & 0.3236 & 2.38 & -0.3202 & 2.0598 \\
9.22 & 5.45 & 6.10 & 6.15 & 0.05 & 0.4297 & 2.17 & -0.1230 & 2.0470 \\
9.51 & 5.50 & 6.20 & 6.26 & 0.06 & 0.5500 & 1.89 & 0.0871 & 1.9771 \\
9.73 & 5.55 & 6.33 & 6.40 & 0.07 & 0.7000 & 1.67 & 0.3680 & 2.0380 \\
\hline
\end{tabular}

LogK $_{1}$ (Average value) $=2.1568 \pm 0.2069$

Table 14: Point-wise method, Mg (Unhydrolysed PSHA)

\begin{tabular}{|l|l|l|l|l|l|l|l|l|}
\hline $\mathrm{pH}$ & $\mathrm{BV}_{1}$ & $\mathrm{BV}_{2}$ & $\mathrm{BV}_{3}$ & $\mathrm{~V}_{3}-\mathrm{V}_{2}$ & $\mathrm{n}$ & $\mathrm{pL}$ & $\log \left(\frac{n-1}{2-n}\right)$ & $\log \mathrm{K}_{2}$ \\
\hline 10.00 & 5.60 & 6.47 & 6.55 & 0.08 & 0.9148 & 1.41 & & \\
10.23 & 5.65 & 6.62 & 6.71 & 0.09 & 1.2102 & 1.20 & -0.5749 & 0.6251 \\
10.49 & 5.70 & 6.80 & 6.92 & 0.09 & 1.5968 & 1.03 & 0.1703 & 1.2003 \\
\hline
\end{tabular}

LogK $_{2}$ (Average value) $=0.9127 \pm 0.4070$

Table15:Point-wise method, Cd (Hydrolysed PSHA)

\begin{tabular}{|l|l|l|l|l|l|l|l|l|}
\hline $\mathrm{pH}$ & $\mathrm{BV}_{1}$ & $\mathrm{BV}_{2}$ & $\mathrm{BV}_{3}$ & $\left(\mathrm{~V}_{3}-\mathrm{V}_{2}\right)$ & $\mathrm{n}$ & $\mathrm{pL}$ & $\log \left(\frac{n}{1-n}\right)$ & LogK $_{1}$ \\
\hline 8.50 & 5.30 & 6.29 & 6.31 & 0.02 & 0.2750 & 2.64 & -0.4210 & 2.2190 \\
8.72 & 5.35 & 6.37 & 6.40 & 0.03 & 0.4286 & 2.42 & -0.1249 & 2.2951 \\
9.00 & 5.40 & 6.46 & 6.49 & 0.03 & 0.4648 & 2.14 & -0.0612 & 2.0788 \\
9.22 & 5.45 & 6.55 & 6.59 & 0.04 & 0.6667 & 1.96 & 0.3010 & 2.2610 \\
9.51 & 5.55 & 6.66 & 6.70 & 0.04 & 0.7720 & 1.67 & 0.5297 & 2.1997 \\
\hline
\end{tabular}

LogK $_{\mathbf{1}}$ (Average value) $=2.2108 \pm 0.0825$

Table 16: Point-wise method, Cd (Hydrolysed PSHA)

\begin{tabular}{|l|l|l|l|l|l|l|l|l|}
\hline $\mathrm{pH}$ & $\mathrm{BV}_{1}$ & $\mathrm{BV}_{2}$ & $\mathrm{BV}_{3}$ & $\left(\mathrm{~V}_{3}-\mathrm{V}_{2}\right)$ & $\mathrm{n}$ & $\mathrm{pL}$ & $\log \left(\frac{n-1}{2-n}\right)$ & Log $_{2}$ \\
\hline 9.73 & 5.55 & 6.78 & 6.83 & 0.06 & 1.4042 & 1.47 & -0.1686 & 1.3014 \\
10.00 & 5.60 & 6.90 & 6.95 & 0.06 & 1.7838 & 1.23 & 0.5593 & 1.7893 \\
10.23 & 5.65 & 7.05 & 7.10 & 0.06 & 3.1429 & 1.09 & & \\
10.49 & 5.70 & 7.10 & 7.16 & 0.06 & 3.1429 & 0.89 & & \\
& & & & & & & & \\
\hline
\end{tabular}

$\operatorname{LogK}_{2}$ (Average value) $=1.5453 \pm 0.3450$

Table 17: Point-wise method, Cd (Unhydrolysed PSHA)

\begin{tabular}{|l|l|l|l|l|l|l|l|l|}
\hline $\mathrm{pH}$ & $\mathrm{BV}_{1}$ & $\mathrm{BV}_{2}$ & $\mathrm{BV}_{3}$ & $\mathrm{~V}_{3}-\mathrm{V}_{2}$ & $\mathrm{n}$ & $\mathrm{pL}$ & $\log \left(\frac{n}{n-1}\right)$ & $\operatorname{Log~}_{1}$ \\
\hline 8.50 & 5.30 & 5.81 & 5.86 & 0.05 & 0.3717 & 2.88 & -0.2280 & 2.6520 \\
8.72 & 5.35 & 5.90 & 5.95 & 0.05 & 0.3873 & 2.66 & -0.1992 & 2.4608 \\
9.00 & 5.40 & 6.00 & 6.06 & 0.06 & 0.4853 & 2.38 & -0.0255 & 2.3545 \\
9.22 & 5.45 & 6.10 & 6.16 & 0.06 & 0.5157 & 2.18 & -0.0272 & 2.2072 \\
9.51 & 5.50 & 6.20 & 6.27 & 0.07 & 0.6417 & 1.89 & 0.2530 & 1.1430 \\
9.73 & 5.55 & 6.33 & 6.41 & 0.08 & 0.8000 & 1.69 & 0.6020 & 2.2920 \\
& & & & & & & & \\
\hline
\end{tabular}

$\operatorname{LogK}_{1}($ Average value $)=2.2516 \pm 0.5380$ 
BAJOPAS Volume 14 Number 1,June, 2021

Table 18: Point-wise method, Cd (Unhydrolysed PSHA)

\begin{tabular}{|l|l|l|l|l|l|l|l|l|}
\hline $\mathrm{pH}$ & $\mathrm{BV}_{1}$ & $\mathrm{BV}_{2}$ & $\mathrm{BV}_{3}$ & $\mathrm{~V}_{3}-\mathrm{V}_{2}$ & $\mathrm{n}$ & $\mathrm{pL}$ & $\log \left(\frac{n-1}{2-n}\right)$ & $\log \mathrm{K}_{2}$ \\
\hline 10.00 & 5.60 & 6.47 & 6.57 & 0.10 & 1.1434 & 1.43 & & \\
10.23 & 5.65 & 6.62 & 6.72 & 0.10 & 1.3448 & 1.23 & -0.2788 & 0.9512 \\
10.49 & 5.70 & 6.80 & 6.90 & 0.10 & 1.7742 & 1.03 & 0.5351 & 1.5651 \\
\hline
\end{tabular}

$\operatorname{LogK}_{2}($ Average value $)=1.2581 \pm 0.4340$

Table 19: Stepwise and overall Stability constants of thehydrolysed and unhydrolysed divalent metal (II) complexes

\begin{tabular}{|c|c|c|c|}
\hline Chelates & LogK $_{1}$ & $\log _{2}$ & Log $\beta$ \\
\hline [Cu (Hydrolysed PSHA-1) $\left.{ }_{2}\right]$ & 2.4788 & 1.4280 & 3.9068 \\
\hline$\left[\mathrm{Pb}(\text { Hydrolysed PSHA-1) })_{2}\right]$ & 2.5832 & 1.1963 & 3.7795 \\
\hline$\left[\mathrm{Cd}(\text { Hydrolysed PSHA-1 })_{2}\right]$ & 2.2108 & 1.5453 & 3.7561 \\
\hline$\left[\mathrm{Mg}(\text { Hydrolysed PSHA-1 })_{2}\right]$ & 2.1382 & 1.5453 & 3.6835 \\
\hline [Cu (Unhydrolysed PSHA-1) & 2.3059 & 1.2209 & 3.5268 \\
\hline$[\mathrm{Pb}$ (Unhydrolysed PSHA-1) 2$]$ & 2.2364 & 1.2239 & 3.4603 \\
\hline [Cd (Unhydrolysed PSHA-1) 2 ] & 2.2516 & 1.2581 & 3.5097 \\
\hline$[\mathrm{Mg}$ (Unydrolysed PSHA-1) & 2.1568 & 0.9127 & 3.0695 \\
\hline
\end{tabular}

The results obtained (Table19) shows the stepwise and overall stability constants to be not high indicating low stability of the complexes, because the solubility of most metal ions in the basic $\mathrm{pH}$ range is minimal due to metal hydroxide precipitation (Karimi, 2017). In general, the stepwise stability constants $\left(K_{1}\right.$ and $K_{2}$ ) follow the order $K_{1}>K_{2}$ for the copper, lead, magnesium and cadmium complexes respectively. The steady decrease of the values with increasing number of ligands is in agreement with the prediction made by researchers (Na'aliya, 2013). The decrease could be attributed to the fact that as the number of the ligands (Humate ions) that enters the coordination zone increases the aqua molecules available for replacement by the ligands become less. Thus, the metal ions become less electron loving with progressive intake of the ligand and this results in the decrease in the values of the constants (Na'aliya, 2013). Also the stability of the complexes is influenced by the size and number of the chelate rings(Mackay and Mackay,2002).All the complexes form rings in their structure as humate, a bidentate ligand, bond the metal ions in the ratio 1:2 (Boguta and Sokolowska, 2016) forming chelate rings. The values of the overall stability constants $(\log \beta)$ obtained for humate complexes are not high indicating low stability as the values are not high. LogK values for copper-humates (Table 3 to 6) obtained in this study are lower than those reported for the complexes of humic acids (Pandey et al., 2015; Dinu, 2013; Kaschl et al., 2010 and Gilbeto and Jorg, 2001). The values of LogK(Table 7 to 10 ) forlead-humates are lower than those reported for the lead in the literature (Dinu, 2013; Gilbeto and Jorg 2001). Log K values(Table 11 to 14 ) for magnesium-humates obtained in this study are close to those reported by (Pandey et al., 2015). Log K values of cadmium-humates (Table 15 to 18 ) obtained in this work near to the one reported by (Dinu, 2013 and Pandey et al., 2015).The difference between the reported values and the values obtained in this study might be probably as a result of acid hydrolysis of humic acid. The values of the overall stability constants $(\log \beta)$ of the copper humates complexes presented in Table 19 is high than that of other metal humate complexes, show relatively high stability of CuHA complexes, show the following order of stability: $\mathrm{Cu}>\mathrm{Pb}>\mathrm{Cd}>\mathrm{Mg}$; which are in close agreement to the findings of (Dinu, 2013 and Pandey et al., 2015).The high stability of Cuhumate chelate could be attributed to the existence of coordinate covalent bond between the complexing agents and the $\mathrm{Cu}^{2+}$ ions. Since, $\mathrm{Cu}^{2+}$ being a metal of the transitional series with $3 d^{9}$ electronic configurations can accept the electrons from the complexing agents. Similarly, the low stabilities of $\mathrm{Pb}, \mathrm{Cd}$ and $\mathrm{Mg}$ complexes could be explained by that $\mathrm{Pb}^{2+}$ with $6 s^{2}, \mathrm{Cd}^{2+}$ with $4 \mathrm{~d}^{10}$ and $\mathrm{Mg}^{2+}$ with $2 \mathrm{p}^{6}$ their electronic configuration has a completely filled $\mathrm{d}, \mathrm{p}$ and $\mathrm{s}$ orbitals. Moreover, the stabilities of metal ions with hydrolysed humic acid from peat soil were higher than those with unhydrolysed humic acid from peat soil; which is ascribed to the high content of acidity in hydrolysed humic acid than unhydrolysed humic acid. 
BAJOPAS Volume 14 Number 1,June, 2021 CONCLUSION

The values of logk for $\mathrm{Cu}(\mathrm{II})$ hydrolysed humic acid complex was higher followed by $\mathrm{Pb}$ (II), $\mathrm{Cd}(\mathrm{II})$ and $\mathrm{Mg}$ (II) hydrolysed humic acid complexes as compared with metal(II) unhydrolysed humic acid complexes. This indicates acid hydrolysis of humic acid can

\section{REFERENCES}

Almeida, V.R. and Szpoganicz, B. (2015). Humic Acid Potentiometric Response Patterns:Out- of Equilibrium Properties and Species Distribution Modelling. Chemical. Biol. Technol. Agric. 2: 17.

Anđelković, T., Nikolić, R., Bojić, A.,Anđelković, D., and Nikolic G.,(2010). Binding of Cadmium to Soil Humic Acid as A Function of Carboxyl Group Content. Macedonian Journal of Chemistry and Chemical Engineering.29(2): 215-224.

Anil, B. N. and Maroti, N. (2008). Studies on Influence of Die-Lectric Constants on Complex Equilibria between Substituted Py-Razalines and Lanthanide Metal Ions pH-Metrically. Amer.-Euras. scient. Res. 3(2): 212-216.

Ashok, K., Pandey, S. P. and Misra, V (2000). Stability Constants of Metal-Humic Acid Complexes and its Role in Environmental Detoxification. Journal of Ecotoxicology and Environmental Safety. 47(2):157-200.

Badr, M. H., El-Halafawi, M. H. and Abd El-al Zeid, E. R. (2012). Comparison Between the Effect of Ionic Strength on Acidity and Dissociation Constants of Humic Acids Extracted from Sewage Sludge and Nile Water Hyacinth Composts.Global Journal of Environmental Research 6 (1): 36-43.

Baruah, M.K., Borah, D., Saikia, P.P., Paul, S., Sharma, T. (2015). Evaluation of pKa Values of Soil Humic Acids and their Complexation Properties. International Journal of Plant \& Soil Science 6(4) : 218-228.

Boguta, P. Sokolowska, Z. (2016). Interactions of $\mathrm{Zn}$ (II) Ions with Humic Acids Isolated from Various Types of Soils. Effect of $\mathrm{pH}, \mathrm{Zn}$ Concentrations and Humic Acids Chemical Properties. Journal of Geochemical Explaration 168. 119-126.

Borges, F., Guimaraes, C., Lima, L.F.C., Pinto, I. and Reis, S.(2005). Potentiometric Studies on the Complexation of Copper(II) by Phenolic Acids as Discrete Ligand Models of enhance the complexation behavior of humic acid with metal (II) ions. However, the higher values of $\log \beta$ for $\mathrm{Cu}(\mathrm{II}), \mathrm{Pb}(\mathrm{II}), \mathrm{Cd}(\mathrm{II})$ and $\mathrm{Mg}(\mathrm{II})$ hydrolysed humic acid complexes indicates more stable stepwise complexes formed as compared with $\mathrm{Cu}(\mathrm{II}), \mathrm{Pb}$ (II), $\mathrm{Cd}$ (II) and $\mathrm{Mg}(\mathrm{II})$ unhydrolysed humic acid complexes.

Humic Substances Talanta 66 (2005) 670-673.

Chefetz, B., Salloum, M. J., Deshmulkin, A. P. and Hatcher, P. (2002). Structural Components of Humic Acids as Determined by Chemical Modifications and Carbon-13 NMR, Pyrolysis, and Thermochemolysis- Gas Chromatography/Mass Spectrometry. Soil Science Society of American Journal Abstract Division S-2- Soil Chemistry66. 1159-1171.

Dinu, M. I. (2013). Metals Complexation with Humic Acids in Surface Water of Different Environ. Sci. Technol. 31(1): 1-17.

Fernandes, A.N., Giacomelli, C., Giovanela, M. Vaz, D.V. Szpoganicz, B. and Maria M. D. (2009). Potentiometric Acidity Determination in Humic Substances Influenced by Different Analytical Procedures.J. Braz. Chem. Soc. 20 (9):14.

Gamal, A. H. (2015). Stability Constants of Rhenium (V) Metal Complexes with Selected Drugs. Pyrex Journal of Research in Environmental Studies. 2(2): 006-014.

Janrao, D. M., Pathan, J., Kayande, D.D., and Mulla, J.J. (2014). An Over View of Potentiometric Determination of Stability Constants of Metal Complexes. Sci. Revs. Chem. Commun.: 4(1), 2014, 11-24.

Karimi, H. (2017). Effect of pH and Initial Pb(II) Concentration on the Lead Removal Efficiency from Waste Water Using $\mathrm{Ca}(\mathrm{OH})_{2}$. International Journal of Water and Waste Water Treatment 3.2

Kaschl, A. Romheld, V. and Chen, Y. (2010). Binding of Cadmium, Copper and Zinc to Humic Substances Originating from Municipal Solid Waste Compost. Israel Journal of Chemistry Vol. 42(1): 89-98.

Kostic, I. S., Tatjana, P, A., Nikolic, R. S., Cvetkovic, T. P., Pavlovic, D. D., Aleksandar, L.J. and Bojic, A. (2012). Comparative Study of Binding Strengths of Heavy Metals with Humic Acid. J.serb. Chem. Soc. 76(9) pp 1-20. 
BAJOPAS Volume 14 Number 1,June, 2021

Na'aliya, J. (2013). Determination of Stepwise Stability Constants and Gibbs free Energy Change of Trisprolina to Complexes of some Divalent Transition Metal ions. Bayero Journal of Pure and Applied Sciences 6(2): 112-114.

Omar, A. A. and Ali, E. A. (2015). Potentiometric Studies on Complexes of $\mathrm{Cr}$ (III) and $\mathrm{Zr}$ (IV) with some Carboxylic Acids. International Journal of Advanced Chemistry, 3(1) 25-

37.

Pandey, A. K. Pandey, S. D. and Misr, V. (2015).Stability Constants of Metal- Humic Acid Complexes and Its Role in Environmental Detoxification. J. Ecotoxicology and Environmental Safety. 47(1):195-200.

Ram, N. and Raman, K.V. (1984). Stability Constants of Complexes of Metals with
Humicand Fuvic Acids under Non- acidConditions. Journal of Plant Nutrition and Soil Sciences.

147:171-176.

Santosh, D. D., Ashok, B. K., Vijay, J. T., Shivraj, G. W. and Vinay, V. W. (2011). Potentiometric Studies of Elec-Trolyte Effects on Complex Equilibria of Some Substituted 5-(2-hydroxy Phenyl) Pyrazoles. Der pharm. 3 (6): 75-83.

Sayyed, H. and Abdul Rahim, M. F. (2012). Studies of Binary Complexes of Metal Ions with Mandelic Acid by Potentiometry. Chem. J. 02 (6): 206209.

Shirvani, M. Moradian, E. Khalili, B. Bakhtiary, S. (2015). Interaction of $\mathrm{Cd}$ and $\mathrm{Pb}$ with Humate-Palygorskite and HumateSepiolite Complexes. Journal of water, air and pollution 3: 220-228. 


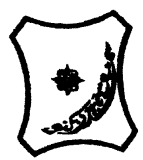

Bayero Journal of Pure and Applied Sciences, 14(1): 54 - 63

Received: November, 2020

Accepted: April, 2021

ISSN $2006-6996$

\title{
STABILITY CONSTANTS OF COMPLEXES OF METAL IONS WITH PEATSOIL HUMIC ACIDS UNDER NON-ACID-CONDITIONS
}

\author{
${ }^{* 1}$ Sabo, Yusuf ${ }^{2}$ Jimoh, W.L.O., ${ }^{3}$ Isa Baba Koki and ${ }^{4}$ Sholadoye, Q. 0. \\ ${ }^{1}$ Department of Pure and Industrial Chemistry, Bayero University, Kano \\ ${ }^{3}$ Department of Chemistry, Yusuf Maitama Sule University Kano. P.M.B. 3220 Kano, Nigeria. \\ ${ }^{4}$ Department of Chemistry, Nigerian Police Academy, Wudil, Kano-Nigeria
}

*Correspondence E-mail; saboyusuf18@yahoo.com

ABSTRACT

Stability constants of complexes of four divalent metal ions viz. $\mathrm{Cu}^{2+}, \mathrm{Pb}^{2+}, \mathrm{Mg}^{2+}$ and $\mathrm{Cd}^{2+}$ with humic acids (HA) were determined by potentiometric titration of humic acids with the corresponding salt of the divalent metals in aqueous media under non-acid-condition. The log $K$ (logarithm of the stability constant) ranged from 1.0942 to 2.7471 for metalhumic acid complexes were determined using point-wise computational method. The order of stability constants were obtained as follows: $\mathrm{Cu}>\mathrm{Pb}>\mathrm{Cd}>\mathrm{Mg}$ for metal $-\mathrm{HA}$ complexes respectively, indicating a higher degree of complexation with Cu metal ion.

Keywords: stability constant, humic acid, potentiometric titration, divalent metals, acid hydrolysis.

\section{NTRODUCTION}

The stability constant of a complex is the numerical expression of its stability and provides a quantitative measure of affinity of the metal ion to the complexing agent. An understanding of the relative stability of metal-complexes helps in predicting the behavior of metal ions in the soil (Ram and Raman, 1982). Extensive researches has been done to determine the stability constants of the complexes formed between humic acid (HA) with a number of metal ions. Ashok et al., (2000) reported that humic acid with hydroxyl, phenoxyl and carboxyl reactive groups can form coordination compound with metal ions at $\mathrm{pH}$ 3.5. The stability constants(Log K) for different metalhumic acid complexes indicated the following order of the stabilities of complexes formed between humic acid and metal ion, $\mathrm{Cu}>\mathrm{Fe}$ $>\mathrm{Pb}>\mathrm{Ni}>\mathrm{Co}>\mathrm{Ca}>\mathrm{Cd}>\mathrm{Zn}>\mathrm{Mn}>\mathrm{Mg}$. Andelkovic et al., (2010) investigated the binding of $\mathrm{Cd}$ (II) to soil humic acid at pH 6.5 and in $0.1 \mathrm{M} \mathrm{KNO}_{3}$ ionic medium. The stability constant for binding indicating greater stability in the case when carboxyl groups are involved in complexation reaction. Kostic et al.,(2012) investigated the complexation of humic acid with certain heavy metal ions (Co(II), $\mathrm{Ni}(\mathrm{II}), \mathrm{Cu}(\mathrm{II})$,
$\mathrm{Zn}(\mathrm{II})$, and $\mathrm{Pb}(\mathrm{II})$. The experiment was performed at $25^{\circ} \mathrm{C}$, at pH 4.0 and ionic strength of $0.01 \mathrm{M}$. Stability constant of complex between $\mathrm{Pb}$ (II) ions and humic acid is greater than stability constants of other investigated metalhumate complexes. Bogata and Sokolowska (2016) analyses the interaction between humic acids from different soils and $\mathrm{Zn}$ (II) ions at wide concentration ranges and at $\mathrm{pH} 5$. Studies have showed significant impact of $\mathrm{Zn}$ concentration, $\mathrm{pH}$ and some properties of humic acids with zinc.But all of these studies were limited to acidic $\mathrm{pH}$ range. Therefore, the present study was carried out to determine and compare the stability constants of complexes of metal ions with hydrolysed peat soil humic acid and unhydrolysed peat soil humic under non-acid conditions.

\section{MATERIALS AND METHODS}

Analytical grade chemicals used includes hydrochloric acid $(\mathrm{HCl})$, nitric acid $\left(\mathrm{HNO}_{3}\right)$, sodium hydroxide $(\mathrm{NaOH})$, lead nitrate $\mathrm{Pb}\left(\mathrm{NO}_{3}\right)_{2}$, copper nitrate $\mathrm{Cu}\left(\mathrm{NO}_{3}\right)_{2} \cdot 3 \mathrm{H}_{2} \mathrm{O}$, cadmium nitrate $\mathrm{Cd}\left(\mathrm{NO}_{3}\right)_{2} \cdot 4 \mathrm{H}_{2} \mathrm{O}$, magnesium nitrate $\mathrm{Mg}\left(\mathrm{NO}_{3}\right)_{2} \cdot 6 \mathrm{H}_{2} \mathrm{O}$, potassium nitrate $\left(\mathrm{KNO}_{3}\right)$, calcium chloride $\left(\mathrm{CaCl}_{2}\right)$, (sigma-Aldrich). Dowex 50WX8, (20-50 mesh) from Fluka. 


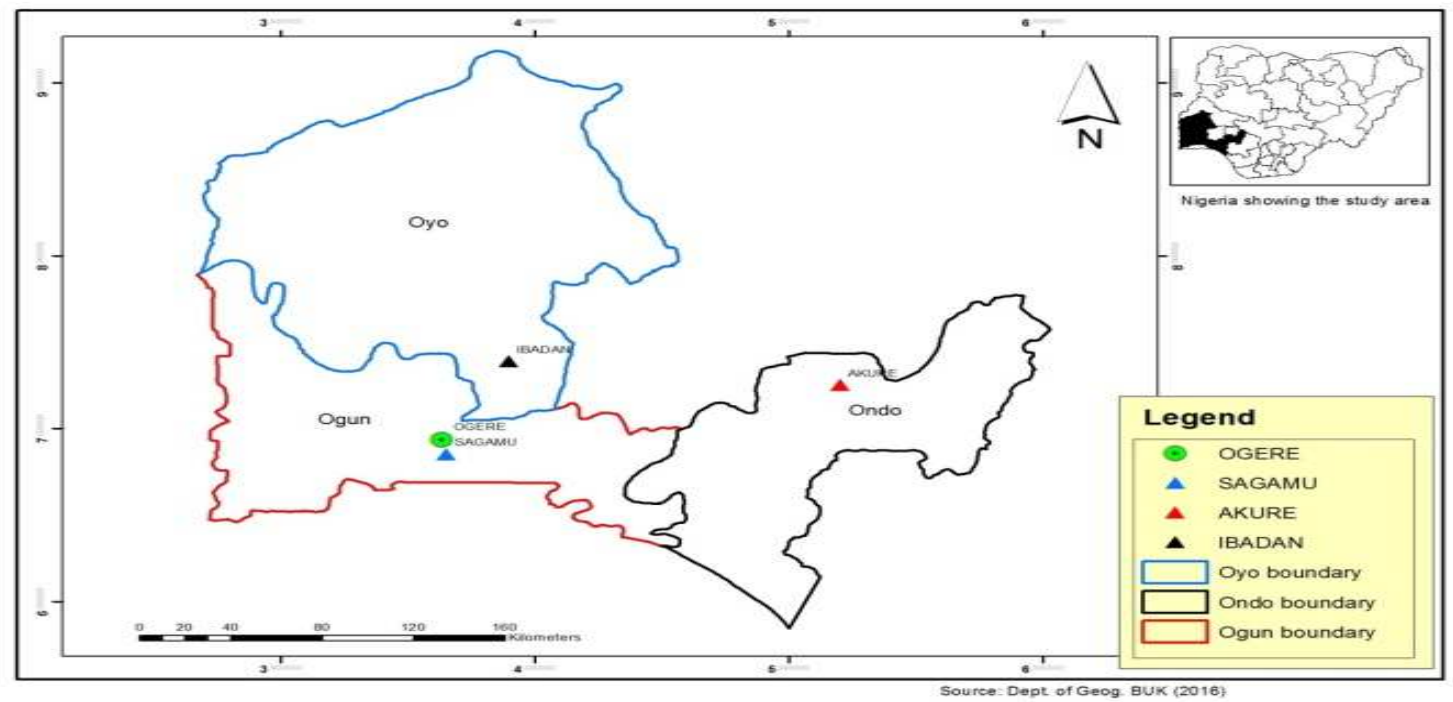

Figure 1: Map showing the sampling point at Sagamu Town, Ogun State.

\section{Description of Sampling Area}

Sagamu has geographical coordinates between $6^{\circ} 50^{\prime}$ north; $3^{\circ} 38^{\prime}$ east is located in south western region of Nigeria. The region has tropical wet and dry climate with a lengthy wet season and relatively constant temperatures throughout the course of the year. Wet season runs from March to October, November to December forms the region dry season. The vegetation type of the region is savannah which is really grassland with small bushes and occasional big trees. Grassland soils have substantially higher organic matter content than forest soils (Novackova, 2011).

\section{Sample Collection}

The Peatsoil samples were collected from four different sampling points $(0-10 \mathrm{~cm}$ depth) in Sagamu into polyethylene bag with plastic spoons. Samples were taken to the laboratory, extraneous materials were removed; the samples were air-dried, crushed and ground to a fine powder in a mortar passed through a $0.20 \mathrm{~mm}$ sieve. The samples were kept for analysis.

\section{Isolation and purification of humic acid from peat soil sample}

Peatsoil sample $(100 \mathrm{~g})$ was mixed with 1000 $\mathrm{cm}^{3}$ of $0.1 \mathrm{M} \mathrm{NaOH}$ solution, shaken for 3hours and left to stand overnight. Dark-coloured supernatant was obtained and decanted from solid residue. The dark-coloured supernatant was acidified to $(\mathrm{pH}=1.0)$ with $6 \mathrm{M} \mathrm{HCl}$ stirred and allowed to stand for 6 hours. Yellowish brown supernatant and dark-brown precipitate were obtained. The yellowish brown supernatant was decanted followed by centrifuge and discarded. The dark-brown precipitate was mixed with $500 \mathrm{~cm}^{3}$ of $0.1 \mathrm{M} \mathrm{NaOH}$ solution followed by passing through dowex resin. The dark-brown solution was acidified to $(\mathrm{pH}=1.0)$ with $6 \mathrm{M} \mathrm{HCl}$ stirred and allowed to stand for 3 hours. The dark-brown precipitate was washed several times with deionized water. The supernatant was treated with $\mathrm{AgNO}_{3}$ solution until no white precipitate observed. The humic acid was transferred to weighed crucible and dried at $60^{\circ} \mathrm{C}$ in an oven for 12 hours. The humic acid was cooled and dried in the desiccator, weighed and recorded. The obtained humic acid was dried again at $60^{\circ} \mathrm{C}$ for additional 6 hours cooled and dried in the desiccator, weighed and recorded constant weight was obtained (Baruah et al., 2015).

\section{FT-IR analysis}

FT-IR spectra of humic acid sample was analysed using Carry 630 FT-IR Agilent Technologies.

Unhydrolysed compost humic acid

The unhydrolysed humic acid was obtained after isolation and purification of compost humic acid and kept for investigation.

\section{Acid hydrolysis of Peatsoil acid}

Peatsoil humic acid sample (1g) was refluxed for 12 hours at $\left(160^{\circ} \mathrm{C}\right)$ with $50 \mathrm{~cm}^{3}$ of $6 \mathrm{M} \mathrm{HCl}$. The mixture was allowed to cool, decanted, and centrifuged after hydrolysis. The insoluble residues were washed with distilled water via centrifugation several times, and the supernatant was treated with $\mathrm{AgNO}_{3}$ solution until no white precipitate was observed. The residue was thoroughly dried over $\mathrm{CaCl}_{2}$ in a desiccator at room temperature (Chefetz et al., 2002). Finally, the obtained hydrolysed humic acid was kept for investigation. 
BAJOPAS Volume 14 Number 1,June, 2021 Potentiometric Titrations

Potentiometric measurements were carried out using a pH-meter Jenway (model 3510) with combine electrode, the sensitivity of the $\mathrm{pH}$ meter is 0.01 units. The $\mathrm{pH}$ meter was switched on half an hour before starting the titration for initial warm up of the instrument. The instrument was calibrated with an aqueous standard buffer solution of $\mathrm{pH} 4.00$ and 10.0 (borate buffer) prepared from a "Qualigens" buffer tablets.

The following sets of solutions were prepared in a $250 \mathrm{~cm}^{3}$ volumetric flask separately for $\mathrm{pH}$ metric titrations.

(i) $5 \mathrm{~cm}^{3} 0.1 \mathrm{M} \mathrm{HCl}+40 \mathrm{~cm}^{3}$ deionized water

(ii) $5 \mathrm{~cm}^{3} 0.1 \mathrm{M} \mathrm{HCl}+39 \mathrm{~cm}^{3}$ deionized water $+1 \mathrm{~cm}^{3} 0.15 \mathrm{gcm}^{-3}$ humic acid

(iii) $5 \mathrm{~cm}^{3} 0.1 \mathrm{M} \mathrm{HCl}+37 \mathrm{~cm}^{3}$ deionized water $+1 \mathrm{~cm}^{3} 0.15 \mathrm{gcm}^{-3}$ humic acid

$$
+2 \mathrm{~cm}^{3} \quad 0.01 \mathrm{M} \mathrm{Cu} \text { (II) }
$$

The solutions were titrated against standardized $0.110 \mathrm{MNaOH}$ separately. The total volume of each mixture was adjusted to $50 \mathrm{~cm}^{3}$ and the ionic strength of the solutions was maintained constant at by adding appropriate amount of stock solution of $1 \mathrm{M} \mathrm{KNO}_{3}$ (Gamal, 2015; Omar and Ali, 2015). A magnetic stirrer was used to achieve thorough mixing of the interacting solutions at $550 \mathrm{rpm}$. The same set of experimental conditions was applied for potentiometric titration of remaining samples.

\section{Evaluation of pKa of Hydrolysed peat soil Humic Acids}

The proton-ligand formation number $\mathrm{n}_{\mathbf{A}}$ were calculated by Irving and Rossotti expression (Omar and Ali, 2015).

$\mathrm{nA}=\mathrm{Y}-\frac{(\mathrm{V} 2-\mathrm{V1})(\mathrm{No}-\mathrm{Eo})}{(\mathrm{VO}+\mathrm{V1}) \mathrm{TCL}}$ 1

Where: $Y$ is number of dissociable proton, $\left(\mathrm{V}_{2^{-}}\right.$ $V_{1}$ ) is the measure of displacement of the ligand curve relative to acid curve, $\mathrm{N}^{\circ}$ and $\mathrm{E}^{\circ}$ are the resultant concentration of alkali solution, free acid solution, $\mathrm{T}_{\mathrm{cL}}{ }^{\circ}$ is the total ligand concentration, $\mathrm{V}^{\circ}$ is the total volume of titration solution, $V_{1}$ is the volume of alkali added to acid solution, $V_{2}$ is the volume of alkali added to acid solution + ligand solution, acid dissociation constants (pKa - values) of ligand were calculated by algebraic method point wise calculation (Tables 1 ). The dissociation constants (pKa) were calculated according to the following relation:

$\mathrm{pKa}=\mathrm{pH}+\log \left(\frac{n A}{1-n A}\right)$ 2

Where: pKa is the acid dissociation constant, $\mathrm{n}_{\mathrm{A}}$ is the Proton-ligand formation number and $\mathrm{pH}$ is the pH-values (Omar and Ali, 2015).

\section{Determination of metal-ligand stability constants $(\log K)$ of complexes}

The potentiometric measurement for the determination of stability constant of a complex in solution is based on the fact that the redox potential of the couple $\frac{M^{+(m-n)}}{M^{+m}}$ is shifted significantly on complexation of the metal ion with the ligand. This method involves change in hydrogen ion concentration $\left[\mathrm{H}^{+}\right]$due to the displacement or association of one or more protons taking place during complexation reaction. This change can be found out by titrating the solutions containing free acid, acid with ligand, and acid with ligand and metal ion, individually against a standard alkali solution at a constant ionic strength or temperature. Either ionic strength or temperature may be varied for different sets of solutions. In all the cases, the change in the $\mathrm{pH}$ of the solution is measured after each addition of a known amount of alkali to the reaction cell which contains the reaction mixture. The titration curves are then drawn by plotting the measured $\mathrm{pH}$ values against the corresponding volume of alkali added and the stability constants of the complexes are determined from the titration curves by employing $\mathrm{pH}$-metric titration technique given by (Irving and Rossoti).

Metal-ligand stability constants ( $\log \mathrm{K}$ ) were determined by using the following relations:

$$
\bar{n}=\frac{\left(V_{3}-V_{2}\right)\left(E^{0}+N^{0}\right)}{\left(V^{0}+V_{2}\right) \bar{n}_{A} T_{m}^{0}}
$$

and

$$
P L=\log _{10}\left\{\frac{1+\beta_{n}^{H} \frac{1}{[\text { anti } \log \mathrm{pH}]^{\mathrm{n}}}}{\mathrm{T}_{\mathrm{L}}^{0}-n \bar{T}_{m}^{0}} \mathrm{X} \frac{\left(V^{0}+V_{3}\right)}{V^{0}}\right\}
$$


BAJOPAS Volume 14 Number 1,June, 2021

Where $T_{L}, T^{\circ}, E^{\circ}$, and $V^{\circ}$ havethe same significance as in equation (1) above, $T_{m}$ denotes the total concentration of metal present in solution, $V_{3}$ is the volume of metal ions present in solution and $\beta^{H}$ is the overall proton ligand stability constant. The metal-ligand stability constants (log K) were determined by employing point wise computational Method (eq. 5 and 6).

$\operatorname{LogK}_{1}=\log \left(\frac{n}{1-n}\right)+\mathrm{pL}$ .5

$\operatorname{LogK}_{2}=\log \left(\frac{1-n}{2-n}\right)+\mathrm{pL}$ ...6

Where: Log $\mathrm{K}$ is the metal-ligand stability constant, $\mathrm{pL}$ is the Free ligand exponent function, $\mathbf{n}$ is the Average number of ligand attached with metal ion (Janraoet al., 2014). The results obtained were analyzed by an ORIGIN 2016 program using titration data and then the proton-ligand stability constants (pKa) and Metal-ligand stability constant (LogK) calculated (Omar and Ali, 2015).

\section{RESULTS AND DISCUSSION}

Fourier transformed infrared (FT-IR) spectra of isolated humic acid from peat soils Figure 2 had distinct clear absorption bands indicating the presence of major humic acid structural elemental groups such as $\mathrm{H}$ bonded $\mathrm{OH}$ $\left(3680 \mathrm{~cm}^{-1}\right.$ peak $), C=0$ of carbonyl $\left(1721 \mathrm{~cm}^{-1}\right.$ peak), functional groups of aliphatic components $\mathrm{CH}_{2}\left(2918 \mathrm{~cm}^{-1}\right.$ peak) and $\mathrm{C}-\mathrm{O}$ stretching of polysaccharide $\left(1168 \mathrm{~cm}^{-1}\right.$ peak). The positions of the absorption bands of the spectra fell within typical major absorption bands of humic acid which is at frequencies 3680, 2918, 1721, 1168 $\mathrm{cm}^{-1}$. The first peak centred in the vicinity of $3680 \mathrm{~cm}^{-1}$ region is attributed to phenol $\mathrm{OH}$ group bounded by intermolecular $\mathrm{H}$ bonds. The $2918 \mathrm{~cm}^{-1}$ band usually has absorption maximum at $2918 \mathrm{~cm}^{-1}$ which is due to $\mathrm{C}-\mathrm{H}$ stretching of alkane group $\left(\mathrm{CH}_{2}\right)$. The next major absorption band is $1721 \mathrm{~cm}^{-1}$. This band has been commonly ascribed to $\mathrm{C}=\mathrm{O}$ stretching of mainly carboxyl group $(\mathrm{COOH})$ with trace amount of ketones. The last peak was observed at 1168 $\mathrm{cm}^{-1}$ due to $\mathrm{C}-\mathrm{O}$ stretching of polysaccharides and this peak appeared also in the spectra of humic acid from peat soil. The FTIR spectra of the isolated humic acid contained all major characteristic absorption peaks of humic acid. These absorption peaks indicated the presence of the major structural elements of humic acid namely $\mathrm{H}$ bonded $\mathrm{OH}, \mathrm{C}=\mathrm{C}$ of aromatic ring, $\mathrm{C}=\mathrm{O}$ of carbonyl group (both carboxyl and ketonic), $\mathrm{CH}_{2}$ group. This strongly supports the presence of humic acid.

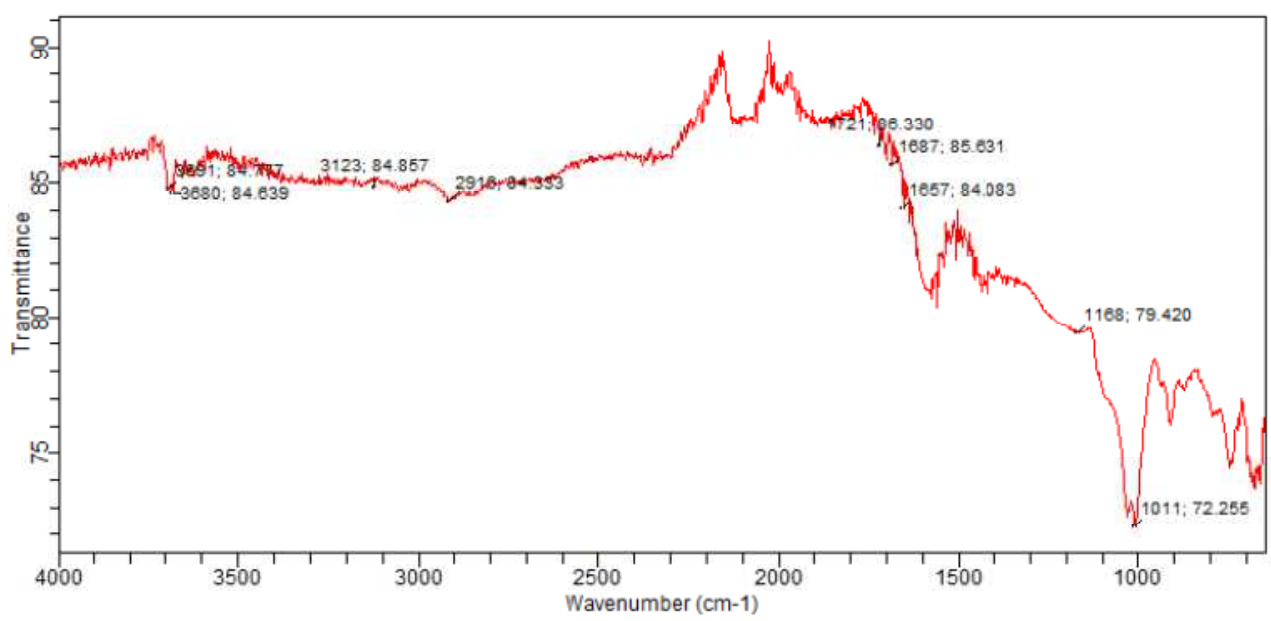

Fig. 2 : FT-IR spectraof peatsoilhumic acid (PSHA)

\section{Evaluation of acid dissociation constant (pka) of acid hydrolysed peat soil humicacid at phenolic group}

The value of the dissociation constant of the peat soil humic acid (PSHA) that underwent acidhydrolysis studied was found to be 8.9299 as shown Table 1, which is lower than the literaturevalues reported by Almeida and Szpoganics, (2015), Borges et al., (2005); Badr et al., (2012)and Fernandes et al,.(2009) of $9.73,9.47$ and 10.30. The difference between the obtained valuesand the reported values in this study might be probably as a result of acid hydrolysis of humicacid. 
BAJOPAS Volume 14 Number 1,June, 2021

Table 1: PKa of (Hydrolysed PSHA)

\begin{tabular}{|l|l|l|l|l|l|l|}
\hline $\mathrm{pH}$ & $\mathrm{BV}_{1}$ & $\mathrm{BV}_{2}$ & $\mathrm{~V}_{2}-\mathrm{V}_{1}$ & $\mathrm{nA}$ & $\log \left(\frac{n A}{1-n A}\right)$ & $\mathrm{pKa}$ \\
\hline 8.50 & 5.30 & 6.29 & 0.99 & 0.3594 & -0.2510 & 8.2490 \\
8.72 & 5.35 & 6.37 & 1.02 & 0.3400 & -0.2880 & 8.4320 \\
9.00 & 5.40 & 6.46 & 1.06 & 0.3141 & -0.3391 & 8.6609 \\
9.22 & 5.45 & 6.55 & 1.10 & 0.2882 & -0.3927 & 8.8273 \\
9.51 & 5.50 & 6.66 & 1.16 & 0.2494 & -0.4786 & 9.0314 \\
9.73 & 5.55 & 6.78 & 1.23 & 0.2041 & -0.5910 & 9.1390 \\
10.00 & 5.60 & 6.90 & 1.30 & 0.1589 & -0.7238 & 9.2762 \\
10.23 & 5.65 & 7.05 & 1.40 & 0.0941 & -0.9835 & 9.2465 \\
10.49 & 5.70 & 7.10 & 1.40 & 0.0941 & -0.9835 & 9.5065 \\
\hline
\end{tabular}

Average pKa $=8.9299 \pm 0.4186$

Table 2: PKa of (Unhydrolysed PSHA)

\begin{tabular}{|l|l|l|l|l|l|l|}
\hline $\mathrm{pH}$ & $\mathrm{BV}_{1}$ & $\mathrm{BV}_{2}$ & $\mathrm{~V}_{2}-\mathrm{V}_{1}$ & $\mathrm{nA}$ & $\log \left(\frac{\boldsymbol{n A}}{1-\boldsymbol{n}}\right)$ & $\mathrm{pKa}$ \\
\hline 8.50 & 5.30 & 5.81 & 0.51 & 0.6619 & 0.2919 & 8.7919 \\
8.72 & 5.35 & 5.90 & 0.55 & 0.6357 & 0.2418 & 8.9618 \\
9.00 & 5.40 & 6.00 & 0.60 & 0.6029 & 0.1813 & 9.1813 \\
9.22 & 5.45 & 6.10 & 0.65 & 0.5701 & 0.1226 & 9.3426 \\
9.51 & 5.50 & 6.20 & 0.70 & 0.5376 & 0.0654 & 9.5754 \\
9.73 & 5.55 & 6.33 & 0.78 & 0.4851 & -0.0259 & 9.7041 \\
10.00 & 5.60 & 6.47 & 0.87 & 0.4262 & -0.1291 & 9.8709 \\
10.23 & 5.65 & 6.62 & 0.99 & 0.3609 & -0.2481 & 9.9819 \\
10.49 & 5.70 & 6.80 & 1.10 & 0.2759 & -0.4690 & 10.0210 \\
\hline
\end{tabular}

Average pKa $=9.4923 \pm 0.4410$

Metal-ligand stability constant ( $\log \mathrm{K}$ )

The stabilityconstants require the accurate values of proton-ligand stability constants (Anil and Maroti, 2008). Metal titration curves crossed over ligand titration curve indicated the formation of complex upon proton release (Santosh, et al., 2011). If the values of n- are within range $0.2-0.8$ and $1.2-18$ this indicates the formation of $1: 1$ and 1:2 complexes (Sayyed and Mazahar, 2012).

The metal (II)-humate stepwise stability constants (log k) at phenolic group (Tables 318)

Table 3: Point-wise method, $\mathrm{Cu}$-(Hydrolysed PSHA)

\begin{tabular}{|l|l|l|l|l|l|l|l|l|}
\hline $\mathrm{pH}$ & $\mathrm{BV}_{1}$ & $\mathrm{BV}_{2}$ & $\mathrm{BV}_{3}$ & $\left(\mathrm{~V}_{3}-\mathrm{V}_{2}\right)$ & $\mathrm{n}$ & $\mathrm{pL}$ & $\log \left(\frac{n}{1-n}\right)$ & LogK $_{1}$ \\
\hline 8.50 & 5.30 & 6.29 & 6.33 & 0.04 & 0.5500 & 2.66 & 0.0871 & 2.7471 \\
8.72 & 5.35 & 6.37 & 6.41 & 0.04 & 0.5714 & 2.43 & 0.1249 & 2.5549 \\
9.00 & 5.40 & 6.46 & 6.50 & 0.04 & 0.6198 & 2.16 & 0.2122 & 2.3722 \\
9.22 & 5.45 & 6.55 & 6.59 & 0.04 & 0.6667 & 1.94 & 0.3010 & 2.2410 \\
\hline
\end{tabular}

LogK $_{1}$ (Average value) $=2.4788 \pm 0.2203$

Table 4: Point-wise method, $\mathrm{Cu}$-(Hydrolysed PSHA)

\begin{tabular}{|l|l|l|l|l|l|l|l|l|}
\hline $\mathrm{pH}$ & $\mathrm{BV}_{1}$ & $\mathrm{BV}_{2}$ & $\mathrm{BV}_{3}$ & $\left(\mathrm{~V}_{3}-\mathrm{V}_{2}\right)$ & $\mathrm{n}$ & $\mathrm{pL}$ & $\log \left(\frac{n-1}{2-n}\right)$ & LogK $_{2}$ \\
\hline 9.51 & 5.50 & 6.66 & 6.73 & 0.07 & 1.3509 & 1.70 & -0.2671 & 1.4329 \\
9.73 & 5.55 & 6.78 & 6.85 & 0.07 & 1.6383 & 1.51 & 0.2467 & 1.7567 \\
10.00 & 5.60 & 6.90 & 6.98 & 0.08 & 2.1783 & 1.31 & -0.2158 & 1.0942 \\
10.23 & 5.65 & 7.05 & 7.13 & 0.08 & 4.1904 & 1.27 & & \\
10.49 & 5.70 & 7.10 & 7.19 & 0.09 & 4.6920 & & & \\
\hline
\end{tabular}

Log $K_{2}($ Average value $)=1.4280 \pm 0.3312$ 
BAJOPAS Volume 14 Number 1,June, 2021

Table 5: Point-wise method, $\mathrm{Cu}$ (Unhydrolysed PSHA)

\begin{tabular}{|l|l|l|l|l|l|l|l|l|}
\hline $\mathrm{pH}$ & $\mathrm{BV}_{1}$ & $\mathrm{BV}_{2}$ & $\mathrm{BV}_{3}$ & $\left(\mathrm{~V}_{3}-\mathrm{V}_{2}\right)$ & $\mathrm{n}$ & $\mathrm{pL}$ & $\log \left(\frac{n}{n-1}\right)$ & Log $_{1}$ \\
\hline 8.50 & 5.30 & 5.81 & 5.85 & 0.04 & 0.2973 & 2.88 & -0.3736 & 2.5064 \\
8.72 & 5.35 & 5.90 & 5.95 & 0.05 & 0.3873 & 2.66 & -0.1992 & 2.4608 \\
9.00 & 5.40 & 6.00 & 6.05 & 0.05 & 0.4044 & 2.38 & -0.1681 & 2.2119 \\
9.22 & 5.45 & 6.10 & 6.15 & 0.06 & 0.5157 & 2.18 & -0.0272 & 2.2072 \\
9.51 & 5.50 & 6.20 & 6.27 & 0.07 & 0.6417 & 1.89 & 0.2530 & 1.1430 \\
\hline
\end{tabular}

$\operatorname{LogK}_{1}($ Average value $)=2.3059 \pm 0.6153$

Table 6:Point-wise method, $\mathrm{Cu}$ (Unhydrolysed PSHA)

\begin{tabular}{|l|l|l|l|l|l|l|l|l|}
\hline $\mathrm{pH}$ & $\mathrm{BV}_{1}$ & $\mathrm{BV}_{2}$ & $\mathrm{BV}_{3}$ & $\mathrm{~V}_{3}-\mathrm{V}_{2}$ & $\mathrm{n}$ & $\mathrm{pL}$ & $\log \left(\frac{n-1}{2-n}\right)$ & $\log \mathrm{K}_{2}$ \\
\hline 9.73 & 5.55 & 6.33 & 6.42 & 0.09 & 0.9000 & 1.69 & & \\
10.00 & 5.60 & 6.47 & 6.58 & 0.11 & 1.2578 & 1.44 & -0.4592 & 0.9808 \\
10.23 & 5.65 & 6.62 & 6.84 & 0.12 & 1.6137 & 1.26 & -0.2010 & 1.4610 \\
10.49 & 5.70 & 6.80 & 6.92 & 0.12 & 2.1052 & 1.03 & & \\
\hline
\end{tabular}

$\operatorname{LogK}_{2}$ (Average value) $=1.2209 \pm 0.3398$

Table 7:Point-wise method, Pb (Hydrolysed PSHA)

\begin{tabular}{|l|l|l|l|l|l|l|l|l|}
\hline $\mathrm{pH}$ & $\mathrm{BV}_{1}$ & $\mathrm{BV}_{2}$ & $\mathrm{BV}_{3}$ & $\left(\mathrm{~V}_{3}-\mathrm{V}_{2}\right)$ & $\mathrm{n}$ & $\mathrm{pL}$ & $\log \left(\frac{n}{1-n}\right)$ & LogK $_{1}$ \\
\hline 8.50 & 5.30 & 6.29 & 6.33 & 0.04 & 0.5500 & 2.66 & 0.0871 & 2.7471 \\
8.72 & 5.35 & 6.37 & 6.41 & 0.04 & 0.5714 & 2.43 & 0.1249 & 2.5549 \\
9.00 & 5.40 & 6.46 & 6.50 & 0.04 & 0.6198 & 2.16 & 0.2122 & 2.3722 \\
9.22 & 5.45 & 6.55 & 6.60 & 0.05 & 0.8333 & 1.96 & 0.6989 & 2.6589 \\
\hline
\end{tabular}

Log $_{\mathbf{1}}($ Average value $)=2.5832 \pm 0.1614$

Table 8:Point-wise method, Pb-(Hydrolysed PSHA)

\begin{tabular}{|l|l|l|l|l|l|l|l|l|}
\hline $\mathrm{pH}$ & $\mathrm{BV}_{1}$ & $\mathrm{BV}_{2}$ & $\mathrm{BV}_{3}$ & $\left(\mathrm{~V}_{3}-\mathrm{V}_{2}\right)$ & $\mathrm{n}$ & $\mathrm{pL}$ & $\log \left(\frac{n-1}{2-n}\right)$ & $\log \mathrm{K}_{2}$ \\
\hline 9.51 & 5.50 & 6.66 & 6.71 & 0.05 & 0.9650 & 1.67 & & \\
9.73 & 5.55 & 6.78 & 6.83 & 0.05 & 1.1702 & 1.44 & & \\
10.00 & 5.60 & 6.90 & 6.90 & 0.05 & 1.4864 & 1.22 & -0.0237 & 1.1963 \\
10.23 & 5.65 & 7.05 & 7.10 & 0.05 & 2.0190 & 1.09 & & \\
10.49 & 5.70 & 7.10 & 7.17 & 0.07 & 3.6492 & 1.00 & & \\
\hline
\end{tabular}

Log $K_{2}$ (Average value) $=1.1963$

Table 9: Point-wise method, Pb (Unhydrolysed PSHA)

\begin{tabular}{|l|l|l|l|l|l|l|l|l|}
\hline $\mathrm{pH}$ & $\mathrm{BV}_{1}$ & $\mathrm{BV}_{2}$ & $\mathrm{BV}_{3}$ & $\mathrm{~V}_{3}-\mathrm{V}_{2}$ & $\mathrm{n}$ & $\mathrm{pL}$ & $\begin{array}{l}\text { Log } \\
\left(\frac{n}{n-1}\right)\end{array}$ & Log $\mathrm{K}_{1}$ \\
\hline 8.50 & 5.30 & 5.81 & 5.85 & 0.04 & 0.2973 & 2.88 & -0.3736 & 2.5064 \\
8.72 & 5.35 & 5.90 & 5.94 & 0.04 & 0.3099 & 2.66 & -0.5477 & 2.3123 \\
9.00 & 5.40 & 6.00 & 6.05 & 0.05 & 0.4044 & 2.38 & -0.1681 & 2.2119 \\
9.22 & 5.45 & 6.10 & 6.15 & 0.06 & 0.5157 & 2.18 & 0.0272 & 2.2072 \\
9.51 & 5.50 & 6.20 & 6.26 & 0.07 & 0.6417 & 1.89 & 0.2530 & 2.1430 \\
9.73 & 5.55 & 6.40 & 6.40 & 0.07 & 0.7000 & 1.67 & 0.3680 & 2.0380 \\
\hline
\end{tabular}

LogK $_{1}$ (Average value) $=2.2364 \pm 0.1602$

Table 10: Point-wise method, Pb (Unhydrolysed PSHA)

\begin{tabular}{|l|l|l|l|l|l|l|l|l|}
\hline $\mathrm{pH}$ & $\mathrm{BV}_{1}$ & $\mathrm{BV}_{2}$ & $\mathrm{BV}_{3}$ & $\mathrm{~V}_{3}-\mathrm{V}_{2}$ & $\mathrm{n}$ & $\mathrm{pL}$ & $\log \left(\frac{n-1}{2-n}\right)$ & $\log \mathrm{K}_{2}$ \\
\hline 10.00 & 5.60 & 6.47 & 6.55 & 0.08 & 1.9503 & 1.41 & & \\
10.23 & 5.65 & 6.62 & 6.72 & 0.11 & 1.4792 & 1.26 & -0.0361 & 1.2239 \\
\hline
\end{tabular}

$\operatorname{LogK}_{2}$ (Average value) $=1.2239$

Table 11: Point-wise method, Mg (Hydrolysed PSHA)

\begin{tabular}{|l|l|l|l|l|l|l|l|l|}
\hline $\mathrm{pH}$ & $\mathrm{BV}_{1}$ & $\mathrm{BV}_{2}$ & $\mathrm{BV}_{3}$ & $\left(\mathrm{~V}_{3}-\mathrm{V}_{2}\right)$ & $\mathrm{n}$ & $\mathrm{pL}$ & $\log \left(\frac{n}{n-1}\right)$ & LogK $_{1}$ \\
\hline 8.50 & 5.30 & 6.29 & 6.31 & 0.02 & 0.2750 & 2.64 & -0.4290 & 2.2110 \\
8.72 & 5.35 & 6.37 & 6.39 & 0.02 & 0.2858 & 2.42 & -0.3978 & 2.0222 \\
9.00 & 5.40 & 6.46 & 6.49 & 0.03 & 0.4648 & 2.14 & -0.0612 & 2.0788 \\
9.22 & 5.45 & 6.55 & 6.59 & 0.04 & 0.6667 & 1.94 & 0.3010 & 2.2410 \\
\hline
\end{tabular}

$\log _{\mathbf{1}}($ Average value) $=2.1382 \pm 0.1046$ 
BAJOPAS Volume 14 Number 1,June, 2021

Table 12: Point-wise method, Mg (Hydrolysed PSHA)

\begin{tabular}{|l|l|l|l|l|l|l|l|l|}
\hline $\mathrm{pH}$ & $\mathrm{BV}_{1}$ & $\mathrm{BV}_{2}$ & $\mathrm{BV}_{3}$ & $\left(\mathrm{~V}_{3}-\mathrm{V}_{2}\right)$ & $\mathrm{n}$ & $\mathrm{pL}$ & $\log \left(\frac{n-1}{2-n}\right)$ & LogK $_{2}$ \\
\hline 9.51 & 5.55 & 6.66 & 6.71 & 0.05 & 0.9650 & 1.67 & & \\
9.73 & 5.55 & 6.78 & 6.84 & 0.06 & 1.4042 & 1.47 & -0.1686 & 1.3014 \\
10.00 & 5.60 & 6.90 & 6.93 & 0.06 & 1.7838 & 1.23 & 0.5593 & 1.7893 \\
10.23 & 5.65 & 7.05 & 7.10 & 0.06 & 3.1429 & 1.10 & & \\
10.49 & 5.70 & 7.10 & 7.18 & 0.07 & 3.6492 & 0.83 & & \\
\hline
\end{tabular}

LogK $_{2}($ Average value $)=1.5453 \pm 0.3450$

Table 13: Point-wise method, Mg (Unhydrolysed PSHA)

\begin{tabular}{|l|l|l|l|l|l|l|l|l|}
\hline $\mathrm{pH}$ & $\mathrm{BV}_{1}$ & $\mathrm{BV}_{2}$ & $\mathrm{BV}_{3}$ & $\mathrm{~V}_{3}-\mathrm{V}_{2}$ & $\mathrm{n}$ & $\mathrm{pL}$ & $\log \left(\frac{n}{n-1}\right)$ & $\operatorname{Log~}_{1}$ \\
\hline 8.50 & 5.30 & 5.81 & 5.85 & 0.04 & 0.2973 & 2.88 & -0.3736 & 2.5064 \\
8.72 & 5.35 & 5.90 & 5.94 & 0.04 & 0.3099 & 2.66 & -0.3477 & 2.3123 \\
9.00 & 5.40 & 6.00 & 6.04 & 0.04 & 0.3236 & 2.38 & -0.3202 & 2.0598 \\
9.22 & 5.45 & 6.10 & 6.15 & 0.05 & 0.4297 & 2.17 & -0.1230 & 2.0470 \\
9.51 & 5.50 & 6.20 & 6.26 & 0.06 & 0.5500 & 1.89 & 0.0871 & 1.9771 \\
9.73 & 5.55 & 6.33 & 6.40 & 0.07 & 0.7000 & 1.67 & 0.3680 & 2.0380 \\
\hline
\end{tabular}

LogK $_{1}$ (Average value) $=2.1568 \pm 0.2069$

Table 14: Point-wise method, Mg (Unhydrolysed PSHA)

\begin{tabular}{|l|l|l|l|l|l|l|l|l|}
\hline $\mathrm{pH}$ & $\mathrm{BV}_{1}$ & $\mathrm{BV}_{2}$ & $\mathrm{BV}_{3}$ & $\mathrm{~V}_{3}-\mathrm{V}_{2}$ & $\mathrm{n}$ & $\mathrm{pL}$ & $\log \left(\frac{n-1}{2-n}\right)$ & $\log \mathrm{K}_{2}$ \\
\hline 10.00 & 5.60 & 6.47 & 6.55 & 0.08 & 0.9148 & 1.41 & & \\
10.23 & 5.65 & 6.62 & 6.71 & 0.09 & 1.2102 & 1.20 & -0.5749 & 0.6251 \\
10.49 & 5.70 & 6.80 & 6.92 & 0.09 & 1.5968 & 1.03 & 0.1703 & 1.2003 \\
\hline
\end{tabular}

LogK $_{2}$ (Average value) $=0.9127 \pm 0.4070$

Table15:Point-wise method, Cd (Hydrolysed PSHA)

\begin{tabular}{|l|l|l|l|l|l|l|l|l|}
\hline $\mathrm{pH}$ & $\mathrm{BV}_{1}$ & $\mathrm{BV}_{2}$ & $\mathrm{BV}_{3}$ & $\left(\mathrm{~V}_{3}-\mathrm{V}_{2}\right)$ & $\mathrm{n}$ & $\mathrm{pL}$ & $\log \left(\frac{n}{1-n}\right)$ & LogK $_{1}$ \\
\hline 8.50 & 5.30 & 6.29 & 6.31 & 0.02 & 0.2750 & 2.64 & -0.4210 & 2.2190 \\
8.72 & 5.35 & 6.37 & 6.40 & 0.03 & 0.4286 & 2.42 & -0.1249 & 2.2951 \\
9.00 & 5.40 & 6.46 & 6.49 & 0.03 & 0.4648 & 2.14 & -0.0612 & 2.0788 \\
9.22 & 5.45 & 6.55 & 6.59 & 0.04 & 0.6667 & 1.96 & 0.3010 & 2.2610 \\
9.51 & 5.55 & 6.66 & 6.70 & 0.04 & 0.7720 & 1.67 & 0.5297 & 2.1997 \\
\hline
\end{tabular}

LogK $_{\mathbf{1}}$ (Average value) $=2.2108 \pm 0.0825$

Table 16: Point-wise method, Cd (Hydrolysed PSHA)

\begin{tabular}{|l|l|l|l|l|l|l|l|l|}
\hline $\mathrm{pH}$ & $\mathrm{BV}_{1}$ & $\mathrm{BV}_{2}$ & $\mathrm{BV}_{3}$ & $\left(\mathrm{~V}_{3}-\mathrm{V}_{2}\right)$ & $\mathrm{n}$ & $\mathrm{pL}$ & $\log \left(\frac{n-1}{2-n}\right)$ & Log $_{2}$ \\
\hline 9.73 & 5.55 & 6.78 & 6.83 & 0.06 & 1.4042 & 1.47 & -0.1686 & 1.3014 \\
10.00 & 5.60 & 6.90 & 6.95 & 0.06 & 1.7838 & 1.23 & 0.5593 & 1.7893 \\
10.23 & 5.65 & 7.05 & 7.10 & 0.06 & 3.1429 & 1.09 & & \\
10.49 & 5.70 & 7.10 & 7.16 & 0.06 & 3.1429 & 0.89 & & \\
& & & & & & & & \\
\hline
\end{tabular}

$\operatorname{LogK}_{2}$ (Average value) $=1.5453 \pm 0.3450$

Table 17: Point-wise method, Cd (Unhydrolysed PSHA)

\begin{tabular}{|l|l|l|l|l|l|l|l|l|}
\hline $\mathrm{pH}$ & $\mathrm{BV}_{1}$ & $\mathrm{BV}_{2}$ & $\mathrm{BV}_{3}$ & $\mathrm{~V}_{3}-\mathrm{V}_{2}$ & $\mathrm{n}$ & $\mathrm{pL}$ & $\log \left(\frac{n}{n-1}\right)$ & $\operatorname{Log~}_{1}$ \\
\hline 8.50 & 5.30 & 5.81 & 5.86 & 0.05 & 0.3717 & 2.88 & -0.2280 & 2.6520 \\
8.72 & 5.35 & 5.90 & 5.95 & 0.05 & 0.3873 & 2.66 & -0.1992 & 2.4608 \\
9.00 & 5.40 & 6.00 & 6.06 & 0.06 & 0.4853 & 2.38 & -0.0255 & 2.3545 \\
9.22 & 5.45 & 6.10 & 6.16 & 0.06 & 0.5157 & 2.18 & -0.0272 & 2.2072 \\
9.51 & 5.50 & 6.20 & 6.27 & 0.07 & 0.6417 & 1.89 & 0.2530 & 1.1430 \\
9.73 & 5.55 & 6.33 & 6.41 & 0.08 & 0.8000 & 1.69 & 0.6020 & 2.2920 \\
& & & & & & & & \\
\hline
\end{tabular}

$\operatorname{LogK}_{1}($ Average value $)=2.2516 \pm 0.5380$ 
BAJOPAS Volume 14 Number 1,June, 2021

Table 18: Point-wise method, Cd (Unhydrolysed PSHA)

\begin{tabular}{|l|l|l|l|l|l|l|l|l|}
\hline $\mathrm{pH}$ & $\mathrm{BV}_{1}$ & $\mathrm{BV}_{2}$ & $\mathrm{BV}_{3}$ & $\mathrm{~V}_{3}-\mathrm{V}_{2}$ & $\mathrm{n}$ & $\mathrm{pL}$ & $\log \left(\frac{n-1}{2-n}\right)$ & $\log \mathrm{K}_{2}$ \\
\hline 10.00 & 5.60 & 6.47 & 6.57 & 0.10 & 1.1434 & 1.43 & & \\
10.23 & 5.65 & 6.62 & 6.72 & 0.10 & 1.3448 & 1.23 & -0.2788 & 0.9512 \\
10.49 & 5.70 & 6.80 & 6.90 & 0.10 & 1.7742 & 1.03 & 0.5351 & 1.5651 \\
\hline
\end{tabular}

$\operatorname{LogK}_{2}($ Average value $)=1.2581 \pm 0.4340$

Table 19: Stepwise and overall Stability constants of thehydrolysed and unhydrolysed divalent metal (II) complexes

\begin{tabular}{|c|c|c|c|}
\hline Chelates & LogK $_{1}$ & $\log _{2}$ & Log $\beta$ \\
\hline [Cu (Hydrolysed PSHA-1) $\left.{ }_{2}\right]$ & 2.4788 & 1.4280 & 3.9068 \\
\hline$\left[\mathrm{Pb}(\text { Hydrolysed PSHA-1) })_{2}\right]$ & 2.5832 & 1.1963 & 3.7795 \\
\hline$\left[\mathrm{Cd}(\text { Hydrolysed PSHA-1 })_{2}\right]$ & 2.2108 & 1.5453 & 3.7561 \\
\hline$\left[\mathrm{Mg}(\text { Hydrolysed PSHA-1 })_{2}\right]$ & 2.1382 & 1.5453 & 3.6835 \\
\hline [Cu (Unhydrolysed PSHA-1) & 2.3059 & 1.2209 & 3.5268 \\
\hline$[\mathrm{Pb}$ (Unhydrolysed PSHA-1) 2$]$ & 2.2364 & 1.2239 & 3.4603 \\
\hline [Cd (Unhydrolysed PSHA-1) 2 ] & 2.2516 & 1.2581 & 3.5097 \\
\hline$[\mathrm{Mg}$ (Unydrolysed PSHA-1) & 2.1568 & 0.9127 & 3.0695 \\
\hline
\end{tabular}

The results obtained (Table19) shows the stepwise and overall stability constants to be not high indicating low stability of the complexes, because the solubility of most metal ions in the basic $\mathrm{pH}$ range is minimal due to metal hydroxide precipitation (Karimi, 2017). In general, the stepwise stability constants $\left(K_{1}\right.$ and $K_{2}$ ) follow the order $K_{1}>K_{2}$ for the copper, lead, magnesium and cadmium complexes respectively. The steady decrease of the values with increasing number of ligands is in agreement with the prediction made by researchers (Na'aliya, 2013). The decrease could be attributed to the fact that as the number of the ligands (Humate ions) that enters the coordination zone increases the aqua molecules available for replacement by the ligands become less. Thus, the metal ions become less electron loving with progressive intake of the ligand and this results in the decrease in the values of the constants (Na'aliya, 2013). Also the stability of the complexes is influenced by the size and number of the chelate rings(Mackay and Mackay,2002).All the complexes form rings in their structure as humate, a bidentate ligand, bond the metal ions in the ratio 1:2 (Boguta and Sokolowska, 2016) forming chelate rings. The values of the overall stability constants $(\log \beta)$ obtained for humate complexes are not high indicating low stability as the values are not high. LogK values for copper-humates (Table 3 to 6) obtained in this study are lower than those reported for the complexes of humic acids (Pandey et al., 2015; Dinu, 2013; Kaschl et al., 2010 and Gilbeto and Jorg, 2001). The values of LogK(Table 7 to 10 ) forlead-humates are lower than those reported for the lead in the literature (Dinu, 2013; Gilbeto and Jorg 2001). Log K values(Table 11 to 14 ) for magnesium-humates obtained in this study are close to those reported by (Pandey et al., 2015). Log K values of cadmium-humates (Table 15 to 18 ) obtained in this work near to the one reported by (Dinu, 2013 and Pandey et al., 2015).The difference between the reported values and the values obtained in this study might be probably as a result of acid hydrolysis of humic acid. The values of the overall stability constants $(\log \beta)$ of the copper humates complexes presented in Table 19 is high than that of other metal humate complexes, show relatively high stability of CuHA complexes, show the following order of stability: $\mathrm{Cu}>\mathrm{Pb}>\mathrm{Cd}>\mathrm{Mg}$; which are in close agreement to the findings of (Dinu, 2013 and Pandey et al., 2015).The high stability of Cuhumate chelate could be attributed to the existence of coordinate covalent bond between the complexing agents and the $\mathrm{Cu}^{2+}$ ions. Since, $\mathrm{Cu}^{2+}$ being a metal of the transitional series with $3 d^{9}$ electronic configurations can accept the electrons from the complexing agents. Similarly, the low stabilities of $\mathrm{Pb}, \mathrm{Cd}$ and $\mathrm{Mg}$ complexes could be explained by that $\mathrm{Pb}^{2+}$ with $6 s^{2}, \mathrm{Cd}^{2+}$ with $4 \mathrm{~d}^{10}$ and $\mathrm{Mg}^{2+}$ with $2 \mathrm{p}^{6}$ their electronic configuration has a completely filled $\mathrm{d}, \mathrm{p}$ and $\mathrm{s}$ orbitals. Moreover, the stabilities of metal ions with hydrolysed humic acid from peat soil were higher than those with unhydrolysed humic acid from peat soil; which is ascribed to the high content of acidity in hydrolysed humic acid than unhydrolysed humic acid. 
BAJOPAS Volume 14 Number 1,June, 2021 CONCLUSION

The values of logk for $\mathrm{Cu}(\mathrm{II})$ hydrolysed humic acid complex was higher followed by $\mathrm{Pb}$ (II), $\mathrm{Cd}(\mathrm{II})$ and $\mathrm{Mg}$ (II) hydrolysed humic acid complexes as compared with metal(II) unhydrolysed humic acid complexes. This indicates acid hydrolysis of humic acid can

\section{REFERENCES}

Almeida, V.R. and Szpoganicz, B. (2015). Humic Acid Potentiometric Response Patterns:Out- of Equilibrium Properties and Species Distribution Modelling. Chemical. Biol. Technol. Agric. 2: 17.

Anđelković, T., Nikolić, R., Bojić, A.,Anđelković, D., and Nikolic G.,(2010). Binding of Cadmium to Soil Humic Acid as A Function of Carboxyl Group Content. Macedonian Journal of Chemistry and Chemical Engineering.29(2): 215-224.

Anil, B. N. and Maroti, N. (2008). Studies on Influence of Die-Lectric Constants on Complex Equilibria between Substituted Py-Razalines and Lanthanide Metal Ions pH-Metrically. Amer.-Euras. scient. Res. 3(2): 212-216.

Ashok, K., Pandey, S. P. and Misra, V (2000). Stability Constants of Metal-Humic Acid Complexes and its Role in Environmental Detoxification. Journal of Ecotoxicology and Environmental Safety. 47(2):157-200.

Badr, M. H., El-Halafawi, M. H. and Abd El-al Zeid, E. R. (2012). Comparison Between the Effect of Ionic Strength on Acidity and Dissociation Constants of Humic Acids Extracted from Sewage Sludge and Nile Water Hyacinth Composts.Global Journal of Environmental Research 6 (1): 36-43.

Baruah, M.K., Borah, D., Saikia, P.P., Paul, S., Sharma, T. (2015). Evaluation of pKa Values of Soil Humic Acids and their Complexation Properties. International Journal of Plant \& Soil Science 6(4) : 218-228.

Boguta, P. Sokolowska, Z. (2016). Interactions of $\mathrm{Zn}$ (II) Ions with Humic Acids Isolated from Various Types of Soils. Effect of $\mathrm{pH}, \mathrm{Zn}$ Concentrations and Humic Acids Chemical Properties. Journal of Geochemical Explaration 168. 119-126.

Borges, F., Guimaraes, C., Lima, L.F.C., Pinto, I. and Reis, S.(2005). Potentiometric Studies on the Complexation of Copper(II) by Phenolic Acids as Discrete Ligand Models of enhance the complexation behavior of humic acid with metal (II) ions. However, the higher values of $\log \beta$ for $\mathrm{Cu}(\mathrm{II}), \mathrm{Pb}(\mathrm{II}), \mathrm{Cd}(\mathrm{II})$ and $\mathrm{Mg}(\mathrm{II})$ hydrolysed humic acid complexes indicates more stable stepwise complexes formed as compared with $\mathrm{Cu}(\mathrm{II}), \mathrm{Pb}$ (II), $\mathrm{Cd}$ (II) and $\mathrm{Mg}(\mathrm{II})$ unhydrolysed humic acid complexes.

Humic Substances Talanta 66 (2005) 670-673.

Chefetz, B., Salloum, M. J., Deshmulkin, A. P. and Hatcher, P. (2002). Structural Components of Humic Acids as Determined by Chemical Modifications and Carbon-13 NMR, Pyrolysis, and Thermochemolysis- Gas Chromatography/Mass Spectrometry. Soil Science Society of American Journal Abstract Division S-2- Soil Chemistry66. 1159-1171.

Dinu, M. I. (2013). Metals Complexation with Humic Acids in Surface Water of Different Environ. Sci. Technol. 31(1): 1-17.

Fernandes, A.N., Giacomelli, C., Giovanela, M. Vaz, D.V. Szpoganicz, B. and Maria M. D. (2009). Potentiometric Acidity Determination in Humic Substances Influenced by Different Analytical Procedures.J. Braz. Chem. Soc. 20 (9):14.

Gamal, A. H. (2015). Stability Constants of Rhenium (V) Metal Complexes with Selected Drugs. Pyrex Journal of Research in Environmental Studies. 2(2): 006-014.

Janrao, D. M., Pathan, J., Kayande, D.D., and Mulla, J.J. (2014). An Over View of Potentiometric Determination of Stability Constants of Metal Complexes. Sci. Revs. Chem. Commun.: 4(1), 2014, 11-24.

Karimi, H. (2017). Effect of pH and Initial Pb(II) Concentration on the Lead Removal Efficiency from Waste Water Using $\mathrm{Ca}(\mathrm{OH})_{2}$. International Journal of Water and Waste Water Treatment 3.2

Kaschl, A. Romheld, V. and Chen, Y. (2010). Binding of Cadmium, Copper and Zinc to Humic Substances Originating from Municipal Solid Waste Compost. Israel Journal of Chemistry Vol. 42(1): 89-98.

Kostic, I. S., Tatjana, P, A., Nikolic, R. S., Cvetkovic, T. P., Pavlovic, D. D., Aleksandar, L.J. and Bojic, A. (2012). Comparative Study of Binding Strengths of Heavy Metals with Humic Acid. J.serb. Chem. Soc. 76(9) pp 1-20. 
BAJOPAS Volume 14 Number 1,June, 2021

Na'aliya, J. (2013). Determination of Stepwise Stability Constants and Gibbs free Energy Change of Trisprolina to Complexes of some Divalent Transition Metal ions. Bayero Journal of Pure and Applied Sciences 6(2): 112-114.

Omar, A. A. and Ali, E. A. (2015). Potentiometric Studies on Complexes of $\mathrm{Cr}$ (III) and $\mathrm{Zr}$ (IV) with some Carboxylic Acids. International Journal of Advanced Chemistry, 3(1) 25-

37.

Pandey, A. K. Pandey, S. D. and Misr, V. (2015).Stability Constants of Metal- Humic Acid Complexes and Its Role in Environmental Detoxification. J. Ecotoxicology and Environmental Safety. 47(1):195-200.

Ram, N. and Raman, K.V. (1984). Stability Constants of Complexes of Metals with
Humicand Fuvic Acids under Non- acidConditions. Journal of Plant Nutrition and Soil Sciences.

147:171-176.

Santosh, D. D., Ashok, B. K., Vijay, J. T., Shivraj, G. W. and Vinay, V. W. (2011). Potentiometric Studies of Elec-Trolyte Effects on Complex Equilibria of Some Substituted 5-(2-hydroxy Phenyl) Pyrazoles. Der pharm. 3 (6): 75-83.

Sayyed, H. and Abdul Rahim, M. F. (2012). Studies of Binary Complexes of Metal Ions with Mandelic Acid by Potentiometry. Chem. J. 02 (6): 206209.

Shirvani, M. Moradian, E. Khalili, B. Bakhtiary, S. (2015). Interaction of $\mathrm{Cd}$ and $\mathrm{Pb}$ with Humate-Palygorskite and HumateSepiolite Complexes. Journal of water, air and pollution 3: 220-228. 


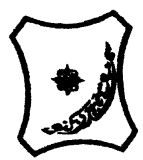

Bayero Journal of Pure and Applied Sciences, 14(1): 54 - 63

Received: November, 2020

Accepted: April, 2021

ISSN $2006-6996$

\title{
STABILITY CONSTANTS OF COMPLEXES OF METAL IONS WITH PEATSOIL HUMIC ACIDS UNDER NON-ACID-CONDITIONS
}

\author{
${ }^{* 1}$ Sabo, Yusuf ${ }^{2}$ Jimoh, W.L.O., ${ }^{3}$ Isa Baba Koki and ${ }^{4}$ Sholadoye, Q. 0. \\ ${ }^{1}$ Department of Pure and Industrial Chemistry, Bayero University, Kano \\ ${ }^{3}$ Department of Chemistry, Yusuf Maitama Sule University Kano. P.M.B. 3220 Kano, Nigeria. \\ ${ }^{4}$ Department of Chemistry, Nigerian Police Academy, Wudil, Kano-Nigeria
}

*Correspondence E-mail; saboyusuf18@yahoo.com

ABSTRACT

Stability constants of complexes of four divalent metal ions viz. $\mathrm{Cu}^{2+}, \mathrm{Pb}^{2+}, \mathrm{Mg}^{2+}$ and $\mathrm{Cd}^{2+}$ with humic acids (HA) were determined by potentiometric titration of humic acids with the corresponding salt of the divalent metals in aqueous media under non-acid-condition. The log $K$ (logarithm of the stability constant) ranged from 1.0942 to 2.7471 for metalhumic acid complexes were determined using point-wise computational method. The order of stability constants were obtained as follows: $\mathrm{Cu}>\mathrm{Pb}>\mathrm{Cd}>\mathrm{Mg}$ for metal $-\mathrm{HA}$ complexes respectively, indicating a higher degree of complexation with Cu metal ion.

Keywords: stability constant, humic acid, potentiometric titration, divalent metals, acid hydrolysis.

\section{NTRODUCTION}

The stability constant of a complex is the numerical expression of its stability and provides a quantitative measure of affinity of the metal ion to the complexing agent. An understanding of the relative stability of metal-complexes helps in predicting the behavior of metal ions in the soil (Ram and Raman, 1982). Extensive researches has been done to determine the stability constants of the complexes formed between humic acid (HA) with a number of metal ions. Ashok et al., (2000) reported that humic acid with hydroxyl, phenoxyl and carboxyl reactive groups can form coordination compound with metal ions at $\mathrm{pH}$ 3.5. The stability constants(Log K) for different metalhumic acid complexes indicated the following order of the stabilities of complexes formed between humic acid and metal ion, $\mathrm{Cu}>\mathrm{Fe}$ $>\mathrm{Pb}>\mathrm{Ni}>\mathrm{Co}>\mathrm{Ca}>\mathrm{Cd}>\mathrm{Zn}>\mathrm{Mn}>\mathrm{Mg}$. Andelkovic et al., (2010) investigated the binding of $\mathrm{Cd}$ (II) to soil humic acid at pH 6.5 and in $0.1 \mathrm{M} \mathrm{KNO}_{3}$ ionic medium. The stability constant for binding indicating greater stability in the case when carboxyl groups are involved in complexation reaction. Kostic et al.,(2012) investigated the complexation of humic acid with certain heavy metal ions (Co(II), $\mathrm{Ni}(\mathrm{II}), \mathrm{Cu}(\mathrm{II})$,
$\mathrm{Zn}(\mathrm{II})$, and $\mathrm{Pb}(\mathrm{II})$. The experiment was performed at $25^{\circ} \mathrm{C}$, at pH 4.0 and ionic strength of $0.01 \mathrm{M}$. Stability constant of complex between $\mathrm{Pb}$ (II) ions and humic acid is greater than stability constants of other investigated metalhumate complexes. Bogata and Sokolowska (2016) analyses the interaction between humic acids from different soils and $\mathrm{Zn}$ (II) ions at wide concentration ranges and at $\mathrm{pH} 5$. Studies have showed significant impact of $\mathrm{Zn}$ concentration, $\mathrm{pH}$ and some properties of humic acids with zinc.But all of these studies were limited to acidic $\mathrm{pH}$ range. Therefore, the present study was carried out to determine and compare the stability constants of complexes of metal ions with hydrolysed peat soil humic acid and unhydrolysed peat soil humic under non-acid conditions.

\section{MATERIALS AND METHODS}

Analytical grade chemicals used includes hydrochloric acid $(\mathrm{HCl})$, nitric acid $\left(\mathrm{HNO}_{3}\right)$, sodium hydroxide $(\mathrm{NaOH})$, lead nitrate $\mathrm{Pb}\left(\mathrm{NO}_{3}\right)_{2}$, copper nitrate $\mathrm{Cu}\left(\mathrm{NO}_{3}\right)_{2} \cdot 3 \mathrm{H}_{2} \mathrm{O}$, cadmium nitrate $\mathrm{Cd}\left(\mathrm{NO}_{3}\right)_{2} \cdot 4 \mathrm{H}_{2} \mathrm{O}$, magnesium nitrate $\mathrm{Mg}\left(\mathrm{NO}_{3}\right)_{2} \cdot 6 \mathrm{H}_{2} \mathrm{O}$, potassium nitrate $\left(\mathrm{KNO}_{3}\right)$, calcium chloride $\left(\mathrm{CaCl}_{2}\right)$, (sigma-Aldrich). Dowex 50WX8, (20-50 mesh) from Fluka. 


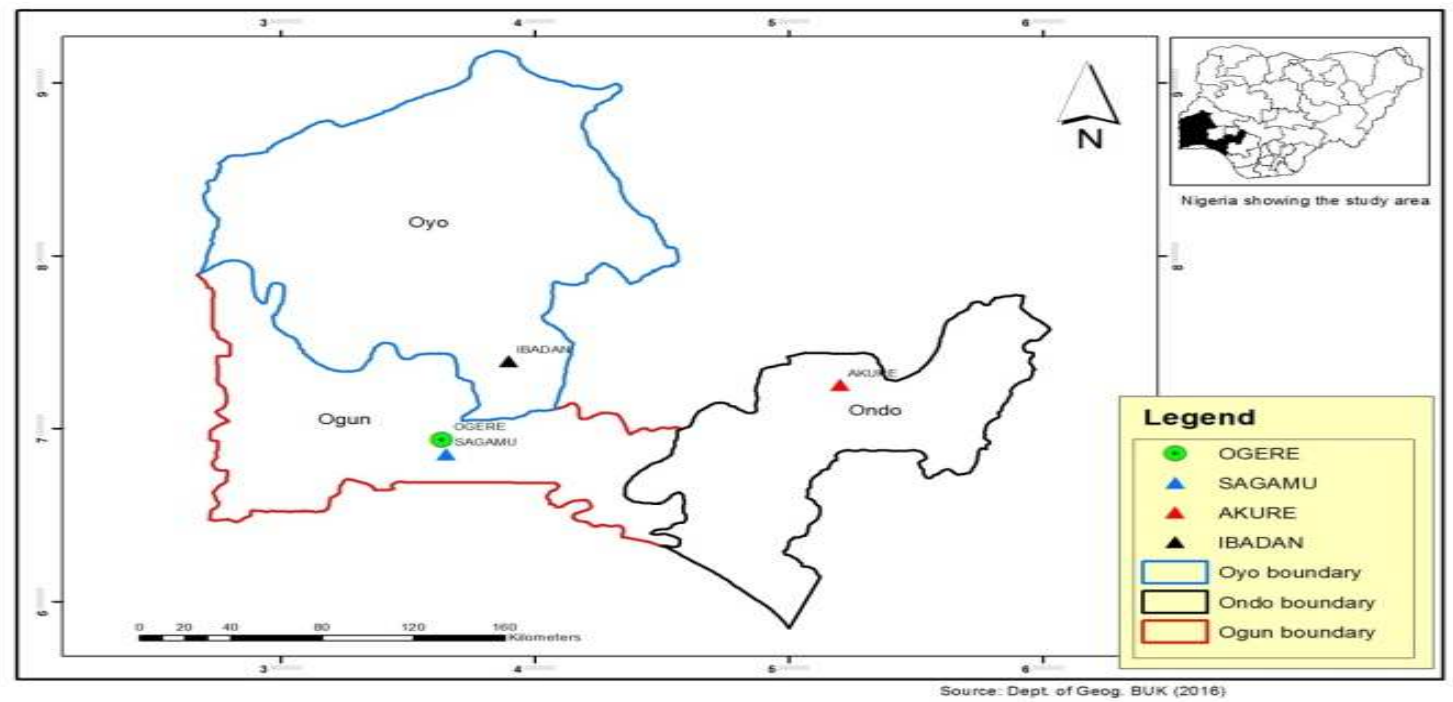

Figure 1: Map showing the sampling point at Sagamu Town, Ogun State.

\section{Description of Sampling Area}

Sagamu has geographical coordinates between $6^{\circ} 50^{\prime}$ north; $3^{\circ} 38^{\prime}$ east is located in south western region of Nigeria. The region has tropical wet and dry climate with a lengthy wet season and relatively constant temperatures throughout the course of the year. Wet season runs from March to October, November to December forms the region dry season. The vegetation type of the region is savannah which is really grassland with small bushes and occasional big trees. Grassland soils have substantially higher organic matter content than forest soils (Novackova, 2011).

\section{Sample Collection}

The Peatsoil samples were collected from four different sampling points $(0-10 \mathrm{~cm}$ depth) in Sagamu into polyethylene bag with plastic spoons. Samples were taken to the laboratory, extraneous materials were removed; the samples were air-dried, crushed and ground to a fine powder in a mortar passed through a $0.20 \mathrm{~mm}$ sieve. The samples were kept for analysis.

\section{Isolation and purification of humic acid from peat soil sample}

Peatsoil sample $(100 \mathrm{~g})$ was mixed with 1000 $\mathrm{cm}^{3}$ of $0.1 \mathrm{M} \mathrm{NaOH}$ solution, shaken for 3hours and left to stand overnight. Dark-coloured supernatant was obtained and decanted from solid residue. The dark-coloured supernatant was acidified to $(\mathrm{pH}=1.0)$ with $6 \mathrm{M} \mathrm{HCl}$ stirred and allowed to stand for 6 hours. Yellowish brown supernatant and dark-brown precipitate were obtained. The yellowish brown supernatant was decanted followed by centrifuge and discarded. The dark-brown precipitate was mixed with $500 \mathrm{~cm}^{3}$ of $0.1 \mathrm{M} \mathrm{NaOH}$ solution followed by passing through dowex resin. The dark-brown solution was acidified to $(\mathrm{pH}=1.0)$ with $6 \mathrm{M} \mathrm{HCl}$ stirred and allowed to stand for 3 hours. The dark-brown precipitate was washed several times with deionized water. The supernatant was treated with $\mathrm{AgNO}_{3}$ solution until no white precipitate observed. The humic acid was transferred to weighed crucible and dried at $60^{\circ} \mathrm{C}$ in an oven for 12 hours. The humic acid was cooled and dried in the desiccator, weighed and recorded. The obtained humic acid was dried again at $60^{\circ} \mathrm{C}$ for additional 6 hours cooled and dried in the desiccator, weighed and recorded constant weight was obtained (Baruah et al., 2015).

\section{FT-IR analysis}

FT-IR spectra of humic acid sample was analysed using Carry 630 FT-IR Agilent Technologies.

Unhydrolysed compost humic acid

The unhydrolysed humic acid was obtained after isolation and purification of compost humic acid and kept for investigation.

\section{Acid hydrolysis of Peatsoil acid}

Peatsoil humic acid sample (1g) was refluxed for 12 hours at $\left(160^{\circ} \mathrm{C}\right)$ with $50 \mathrm{~cm}^{3}$ of $6 \mathrm{M} \mathrm{HCl}$. The mixture was allowed to cool, decanted, and centrifuged after hydrolysis. The insoluble residues were washed with distilled water via centrifugation several times, and the supernatant was treated with $\mathrm{AgNO}_{3}$ solution until no white precipitate was observed. The residue was thoroughly dried over $\mathrm{CaCl}_{2}$ in a desiccator at room temperature (Chefetz et al., 2002). Finally, the obtained hydrolysed humic acid was kept for investigation. 
BAJOPAS Volume 14 Number 1,June, 2021 Potentiometric Titrations

Potentiometric measurements were carried out using a pH-meter Jenway (model 3510) with combine electrode, the sensitivity of the $\mathrm{pH}$ meter is 0.01 units. The $\mathrm{pH}$ meter was switched on half an hour before starting the titration for initial warm up of the instrument. The instrument was calibrated with an aqueous standard buffer solution of $\mathrm{pH} 4.00$ and 10.0 (borate buffer) prepared from a "Qualigens" buffer tablets.

The following sets of solutions were prepared in a $250 \mathrm{~cm}^{3}$ volumetric flask separately for $\mathrm{pH}$ metric titrations.

(i) $5 \mathrm{~cm}^{3} 0.1 \mathrm{M} \mathrm{HCl}+40 \mathrm{~cm}^{3}$ deionized water

(ii) $5 \mathrm{~cm}^{3} 0.1 \mathrm{M} \mathrm{HCl}+39 \mathrm{~cm}^{3}$ deionized water $+1 \mathrm{~cm}^{3} 0.15 \mathrm{gcm}^{-3}$ humic acid

(iii) $5 \mathrm{~cm}^{3} 0.1 \mathrm{M} \mathrm{HCl}+37 \mathrm{~cm}^{3}$ deionized water $+1 \mathrm{~cm}^{3} 0.15 \mathrm{gcm}^{-3}$ humic acid

$$
+2 \mathrm{~cm}^{3} \quad 0.01 \mathrm{M} \mathrm{Cu} \text { (II) }
$$

The solutions were titrated against standardized $0.110 \mathrm{MNaOH}$ separately. The total volume of each mixture was adjusted to $50 \mathrm{~cm}^{3}$ and the ionic strength of the solutions was maintained constant at by adding appropriate amount of stock solution of $1 \mathrm{M} \mathrm{KNO}_{3}$ (Gamal, 2015; Omar and Ali, 2015). A magnetic stirrer was used to achieve thorough mixing of the interacting solutions at $550 \mathrm{rpm}$. The same set of experimental conditions was applied for potentiometric titration of remaining samples.

\section{Evaluation of pKa of Hydrolysed peat soil Humic Acids}

The proton-ligand formation number $\mathrm{n}_{\mathbf{A}}$ were calculated by Irving and Rossotti expression (Omar and Ali, 2015).

$\mathrm{nA}=\mathrm{Y}-\frac{(\mathrm{V} 2-\mathrm{V1})(\mathrm{No}-\mathrm{Eo})}{(\mathrm{VO}+\mathrm{V1}) \mathrm{TCL}}$ 1

Where: $Y$ is number of dissociable proton, $\left(\mathrm{V}_{2^{-}}\right.$ $V_{1}$ ) is the measure of displacement of the ligand curve relative to acid curve, $\mathrm{N}^{\circ}$ and $\mathrm{E}^{\circ}$ are the resultant concentration of alkali solution, free acid solution, $\mathrm{T}_{\mathrm{cL}}{ }^{\circ}$ is the total ligand concentration, $\mathrm{V}^{\circ}$ is the total volume of titration solution, $V_{1}$ is the volume of alkali added to acid solution, $V_{2}$ is the volume of alkali added to acid solution + ligand solution, acid dissociation constants (pKa - values) of ligand were calculated by algebraic method point wise calculation (Tables 1 ). The dissociation constants (pKa) were calculated according to the following relation:

$\mathrm{pKa}=\mathrm{pH}+\log \left(\frac{n A}{1-n A}\right)$ 2

Where: pKa is the acid dissociation constant, $\mathrm{n}_{\mathrm{A}}$ is the Proton-ligand formation number and $\mathrm{pH}$ is the pH-values (Omar and Ali, 2015).

\section{Determination of metal-ligand stability constants $(\log K)$ of complexes}

The potentiometric measurement for the determination of stability constant of a complex in solution is based on the fact that the redox potential of the couple $\frac{M^{+(m-n)}}{M^{+m}}$ is shifted significantly on complexation of the metal ion with the ligand. This method involves change in hydrogen ion concentration $\left[\mathrm{H}^{+}\right]$due to the displacement or association of one or more protons taking place during complexation reaction. This change can be found out by titrating the solutions containing free acid, acid with ligand, and acid with ligand and metal ion, individually against a standard alkali solution at a constant ionic strength or temperature. Either ionic strength or temperature may be varied for different sets of solutions. In all the cases, the change in the $\mathrm{pH}$ of the solution is measured after each addition of a known amount of alkali to the reaction cell which contains the reaction mixture. The titration curves are then drawn by plotting the measured $\mathrm{pH}$ values against the corresponding volume of alkali added and the stability constants of the complexes are determined from the titration curves by employing $\mathrm{pH}$-metric titration technique given by (Irving and Rossoti).

Metal-ligand stability constants ( $\log \mathrm{K}$ ) were determined by using the following relations:

$$
\bar{n}=\frac{\left(V_{3}-V_{2}\right)\left(E^{0}+N^{0}\right)}{\left(V^{0}+V_{2}\right) \bar{n}_{A} T_{m}^{0}}
$$

and

$$
P L=\log _{10}\left\{\frac{1+\beta_{n}^{H} \frac{1}{[\text { anti } \log \mathrm{pH}]^{\mathrm{n}}}}{\mathrm{T}_{\mathrm{L}}^{0}-n \bar{T}_{m}^{0}} \mathrm{X} \frac{\left(V^{0}+V_{3}\right)}{V^{0}}\right\}
$$


BAJOPAS Volume 14 Number 1,June, 2021

Where $T_{L}, T^{\circ}, E^{\circ}$, and $V^{\circ}$ havethe same significance as in equation (1) above, $T_{m}$ denotes the total concentration of metal present in solution, $V_{3}$ is the volume of metal ions present in solution and $\beta^{H}$ is the overall proton ligand stability constant. The metal-ligand stability constants (log K) were determined by employing point wise computational Method (eq. 5 and 6).

$\operatorname{LogK}_{1}=\log \left(\frac{n}{1-n}\right)+\mathrm{pL}$ .5

$\operatorname{LogK}_{2}=\log \left(\frac{1-n}{2-n}\right)+\mathrm{pL}$ ...6

Where: Log $\mathrm{K}$ is the metal-ligand stability constant, $\mathrm{pL}$ is the Free ligand exponent function, $\mathbf{n}$ is the Average number of ligand attached with metal ion (Janraoet al., 2014). The results obtained were analyzed by an ORIGIN 2016 program using titration data and then the proton-ligand stability constants (pKa) and Metal-ligand stability constant (LogK) calculated (Omar and Ali, 2015).

\section{RESULTS AND DISCUSSION}

Fourier transformed infrared (FT-IR) spectra of isolated humic acid from peat soils Figure 2 had distinct clear absorption bands indicating the presence of major humic acid structural elemental groups such as $\mathrm{H}$ bonded $\mathrm{OH}$ $\left(3680 \mathrm{~cm}^{-1}\right.$ peak $), C=0$ of carbonyl $\left(1721 \mathrm{~cm}^{-1}\right.$ peak), functional groups of aliphatic components $\mathrm{CH}_{2}\left(2918 \mathrm{~cm}^{-1}\right.$ peak) and $\mathrm{C}-\mathrm{O}$ stretching of polysaccharide $\left(1168 \mathrm{~cm}^{-1}\right.$ peak). The positions of the absorption bands of the spectra fell within typical major absorption bands of humic acid which is at frequencies 3680, 2918, 1721, 1168 $\mathrm{cm}^{-1}$. The first peak centred in the vicinity of $3680 \mathrm{~cm}^{-1}$ region is attributed to phenol $\mathrm{OH}$ group bounded by intermolecular $\mathrm{H}$ bonds. The $2918 \mathrm{~cm}^{-1}$ band usually has absorption maximum at $2918 \mathrm{~cm}^{-1}$ which is due to $\mathrm{C}-\mathrm{H}$ stretching of alkane group $\left(\mathrm{CH}_{2}\right)$. The next major absorption band is $1721 \mathrm{~cm}^{-1}$. This band has been commonly ascribed to $\mathrm{C}=\mathrm{O}$ stretching of mainly carboxyl group $(\mathrm{COOH})$ with trace amount of ketones. The last peak was observed at 1168 $\mathrm{cm}^{-1}$ due to $\mathrm{C}-\mathrm{O}$ stretching of polysaccharides and this peak appeared also in the spectra of humic acid from peat soil. The FTIR spectra of the isolated humic acid contained all major characteristic absorption peaks of humic acid. These absorption peaks indicated the presence of the major structural elements of humic acid namely $\mathrm{H}$ bonded $\mathrm{OH}, \mathrm{C}=\mathrm{C}$ of aromatic ring, $\mathrm{C}=\mathrm{O}$ of carbonyl group (both carboxyl and ketonic), $\mathrm{CH}_{2}$ group. This strongly supports the presence of humic acid.

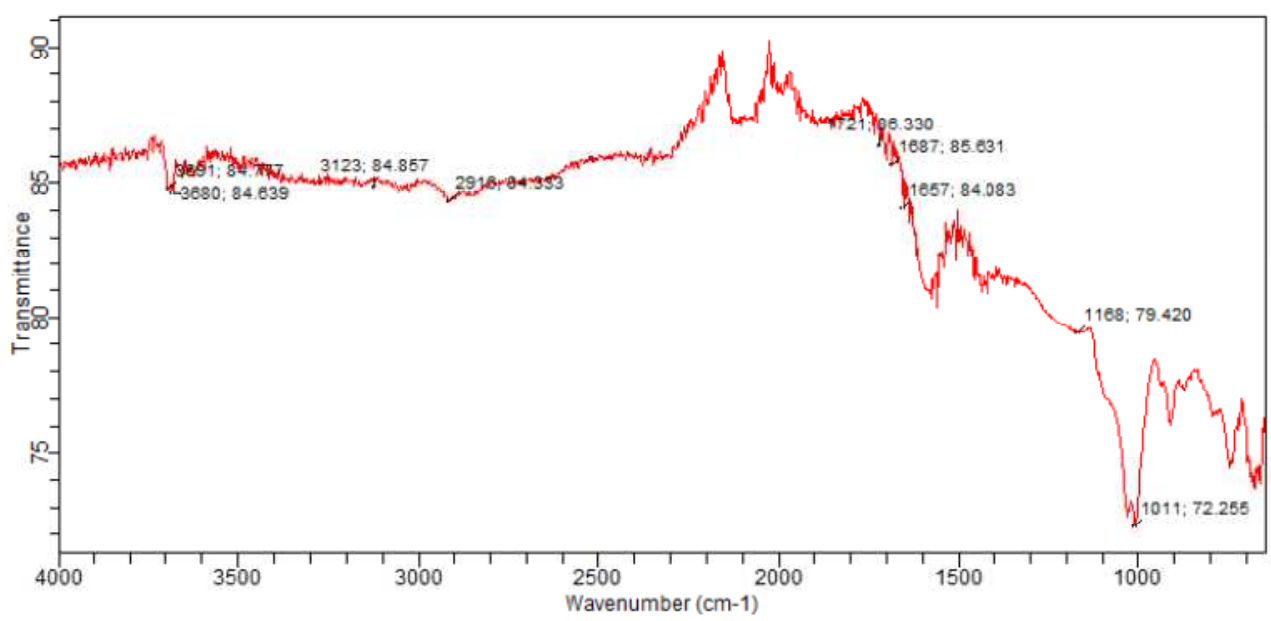

Fig. 2 : FT-IR spectraof peatsoilhumic acid (PSHA)

\section{Evaluation of acid dissociation constant (pka) of acid hydrolysed peat soil humicacid at phenolic group}

The value of the dissociation constant of the peat soil humic acid (PSHA) that underwent acidhydrolysis studied was found to be 8.9299 as shown Table 1, which is lower than the literaturevalues reported by Almeida and Szpoganics, (2015), Borges et al., (2005); Badr et al., (2012)and Fernandes et al,.(2009) of $9.73,9.47$ and 10.30. The difference between the obtained valuesand the reported values in this study might be probably as a result of acid hydrolysis of humicacid. 
BAJOPAS Volume 14 Number 1,June, 2021

Table 1: PKa of (Hydrolysed PSHA)

\begin{tabular}{|l|l|l|l|l|l|l|}
\hline $\mathrm{pH}$ & $\mathrm{BV}_{1}$ & $\mathrm{BV}_{2}$ & $\mathrm{~V}_{2}-\mathrm{V}_{1}$ & $\mathrm{nA}$ & $\log \left(\frac{n A}{1-n A}\right)$ & $\mathrm{pKa}$ \\
\hline 8.50 & 5.30 & 6.29 & 0.99 & 0.3594 & -0.2510 & 8.2490 \\
8.72 & 5.35 & 6.37 & 1.02 & 0.3400 & -0.2880 & 8.4320 \\
9.00 & 5.40 & 6.46 & 1.06 & 0.3141 & -0.3391 & 8.6609 \\
9.22 & 5.45 & 6.55 & 1.10 & 0.2882 & -0.3927 & 8.8273 \\
9.51 & 5.50 & 6.66 & 1.16 & 0.2494 & -0.4786 & 9.0314 \\
9.73 & 5.55 & 6.78 & 1.23 & 0.2041 & -0.5910 & 9.1390 \\
10.00 & 5.60 & 6.90 & 1.30 & 0.1589 & -0.7238 & 9.2762 \\
10.23 & 5.65 & 7.05 & 1.40 & 0.0941 & -0.9835 & 9.2465 \\
10.49 & 5.70 & 7.10 & 1.40 & 0.0941 & -0.9835 & 9.5065 \\
\hline
\end{tabular}

Average pKa $=8.9299 \pm 0.4186$

Table 2: PKa of (Unhydrolysed PSHA)

\begin{tabular}{|l|l|l|l|l|l|l|}
\hline $\mathrm{pH}$ & $\mathrm{BV}_{1}$ & $\mathrm{BV}_{2}$ & $\mathrm{~V}_{2}-\mathrm{V}_{1}$ & $\mathrm{nA}$ & $\log \left(\frac{\boldsymbol{n A}}{1-\boldsymbol{n}}\right)$ & $\mathrm{pKa}$ \\
\hline 8.50 & 5.30 & 5.81 & 0.51 & 0.6619 & 0.2919 & 8.7919 \\
8.72 & 5.35 & 5.90 & 0.55 & 0.6357 & 0.2418 & 8.9618 \\
9.00 & 5.40 & 6.00 & 0.60 & 0.6029 & 0.1813 & 9.1813 \\
9.22 & 5.45 & 6.10 & 0.65 & 0.5701 & 0.1226 & 9.3426 \\
9.51 & 5.50 & 6.20 & 0.70 & 0.5376 & 0.0654 & 9.5754 \\
9.73 & 5.55 & 6.33 & 0.78 & 0.4851 & -0.0259 & 9.7041 \\
10.00 & 5.60 & 6.47 & 0.87 & 0.4262 & -0.1291 & 9.8709 \\
10.23 & 5.65 & 6.62 & 0.99 & 0.3609 & -0.2481 & 9.9819 \\
10.49 & 5.70 & 6.80 & 1.10 & 0.2759 & -0.4690 & 10.0210 \\
\hline
\end{tabular}

Average pKa $=9.4923 \pm 0.4410$

Metal-ligand stability constant ( $\log \mathrm{K}$ )

The stabilityconstants require the accurate values of proton-ligand stability constants (Anil and Maroti, 2008). Metal titration curves crossed over ligand titration curve indicated the formation of complex upon proton release (Santosh, et al., 2011). If the values of n- are within range $0.2-0.8$ and $1.2-18$ this indicates the formation of $1: 1$ and 1:2 complexes (Sayyed and Mazahar, 2012).

The metal (II)-humate stepwise stability constants (log k) at phenolic group (Tables 318)

Table 3: Point-wise method, $\mathrm{Cu}$-(Hydrolysed PSHA)

\begin{tabular}{|l|l|l|l|l|l|l|l|l|}
\hline $\mathrm{pH}$ & $\mathrm{BV}_{1}$ & $\mathrm{BV}_{2}$ & $\mathrm{BV}_{3}$ & $\left(\mathrm{~V}_{3}-\mathrm{V}_{2}\right)$ & $\mathrm{n}$ & $\mathrm{pL}$ & $\log \left(\frac{n}{1-n}\right)$ & LogK $_{1}$ \\
\hline 8.50 & 5.30 & 6.29 & 6.33 & 0.04 & 0.5500 & 2.66 & 0.0871 & 2.7471 \\
8.72 & 5.35 & 6.37 & 6.41 & 0.04 & 0.5714 & 2.43 & 0.1249 & 2.5549 \\
9.00 & 5.40 & 6.46 & 6.50 & 0.04 & 0.6198 & 2.16 & 0.2122 & 2.3722 \\
9.22 & 5.45 & 6.55 & 6.59 & 0.04 & 0.6667 & 1.94 & 0.3010 & 2.2410 \\
\hline
\end{tabular}

LogK $_{1}$ (Average value) $=2.4788 \pm 0.2203$

Table 4: Point-wise method, $\mathrm{Cu}$-(Hydrolysed PSHA)

\begin{tabular}{|l|l|l|l|l|l|l|l|l|}
\hline $\mathrm{pH}$ & $\mathrm{BV}_{1}$ & $\mathrm{BV}_{2}$ & $\mathrm{BV}_{3}$ & $\left(\mathrm{~V}_{3}-\mathrm{V}_{2}\right)$ & $\mathrm{n}$ & $\mathrm{pL}$ & $\log \left(\frac{n-1}{2-n}\right)$ & LogK $_{2}$ \\
\hline 9.51 & 5.50 & 6.66 & 6.73 & 0.07 & 1.3509 & 1.70 & -0.2671 & 1.4329 \\
9.73 & 5.55 & 6.78 & 6.85 & 0.07 & 1.6383 & 1.51 & 0.2467 & 1.7567 \\
10.00 & 5.60 & 6.90 & 6.98 & 0.08 & 2.1783 & 1.31 & -0.2158 & 1.0942 \\
10.23 & 5.65 & 7.05 & 7.13 & 0.08 & 4.1904 & 1.27 & & \\
10.49 & 5.70 & 7.10 & 7.19 & 0.09 & 4.6920 & & & \\
\hline
\end{tabular}

Log $K_{2}($ Average value $)=1.4280 \pm 0.3312$ 
BAJOPAS Volume 14 Number 1,June, 2021

Table 5: Point-wise method, $\mathrm{Cu}$ (Unhydrolysed PSHA)

\begin{tabular}{|l|l|l|l|l|l|l|l|l|}
\hline $\mathrm{pH}$ & $\mathrm{BV}_{1}$ & $\mathrm{BV}_{2}$ & $\mathrm{BV}_{3}$ & $\left(\mathrm{~V}_{3}-\mathrm{V}_{2}\right)$ & $\mathrm{n}$ & $\mathrm{pL}$ & $\log \left(\frac{n}{n-1}\right)$ & Log $_{1}$ \\
\hline 8.50 & 5.30 & 5.81 & 5.85 & 0.04 & 0.2973 & 2.88 & -0.3736 & 2.5064 \\
8.72 & 5.35 & 5.90 & 5.95 & 0.05 & 0.3873 & 2.66 & -0.1992 & 2.4608 \\
9.00 & 5.40 & 6.00 & 6.05 & 0.05 & 0.4044 & 2.38 & -0.1681 & 2.2119 \\
9.22 & 5.45 & 6.10 & 6.15 & 0.06 & 0.5157 & 2.18 & -0.0272 & 2.2072 \\
9.51 & 5.50 & 6.20 & 6.27 & 0.07 & 0.6417 & 1.89 & 0.2530 & 1.1430 \\
\hline
\end{tabular}

$\operatorname{LogK}_{1}($ Average value $)=2.3059 \pm 0.6153$

Table 6:Point-wise method, $\mathrm{Cu}$ (Unhydrolysed PSHA)

\begin{tabular}{|l|l|l|l|l|l|l|l|l|}
\hline $\mathrm{pH}$ & $\mathrm{BV}_{1}$ & $\mathrm{BV}_{2}$ & $\mathrm{BV}_{3}$ & $\mathrm{~V}_{3}-\mathrm{V}_{2}$ & $\mathrm{n}$ & $\mathrm{pL}$ & $\log \left(\frac{n-1}{2-n}\right)$ & $\log \mathrm{K}_{2}$ \\
\hline 9.73 & 5.55 & 6.33 & 6.42 & 0.09 & 0.9000 & 1.69 & & \\
10.00 & 5.60 & 6.47 & 6.58 & 0.11 & 1.2578 & 1.44 & -0.4592 & 0.9808 \\
10.23 & 5.65 & 6.62 & 6.84 & 0.12 & 1.6137 & 1.26 & -0.2010 & 1.4610 \\
10.49 & 5.70 & 6.80 & 6.92 & 0.12 & 2.1052 & 1.03 & & \\
\hline
\end{tabular}

$\operatorname{LogK}_{2}$ (Average value) $=1.2209 \pm 0.3398$

Table 7:Point-wise method, Pb (Hydrolysed PSHA)

\begin{tabular}{|l|l|l|l|l|l|l|l|l|}
\hline $\mathrm{pH}$ & $\mathrm{BV}_{1}$ & $\mathrm{BV}_{2}$ & $\mathrm{BV}_{3}$ & $\left(\mathrm{~V}_{3}-\mathrm{V}_{2}\right)$ & $\mathrm{n}$ & $\mathrm{pL}$ & $\log \left(\frac{n}{1-n}\right)$ & LogK $_{1}$ \\
\hline 8.50 & 5.30 & 6.29 & 6.33 & 0.04 & 0.5500 & 2.66 & 0.0871 & 2.7471 \\
8.72 & 5.35 & 6.37 & 6.41 & 0.04 & 0.5714 & 2.43 & 0.1249 & 2.5549 \\
9.00 & 5.40 & 6.46 & 6.50 & 0.04 & 0.6198 & 2.16 & 0.2122 & 2.3722 \\
9.22 & 5.45 & 6.55 & 6.60 & 0.05 & 0.8333 & 1.96 & 0.6989 & 2.6589 \\
\hline
\end{tabular}

Log $_{\mathbf{1}}($ Average value $)=2.5832 \pm 0.1614$

Table 8:Point-wise method, Pb-(Hydrolysed PSHA)

\begin{tabular}{|l|l|l|l|l|l|l|l|l|}
\hline $\mathrm{pH}$ & $\mathrm{BV}_{1}$ & $\mathrm{BV}_{2}$ & $\mathrm{BV}_{3}$ & $\left(\mathrm{~V}_{3}-\mathrm{V}_{2}\right)$ & $\mathrm{n}$ & $\mathrm{pL}$ & $\log \left(\frac{n-1}{2-n}\right)$ & $\log \mathrm{K}_{2}$ \\
\hline 9.51 & 5.50 & 6.66 & 6.71 & 0.05 & 0.9650 & 1.67 & & \\
9.73 & 5.55 & 6.78 & 6.83 & 0.05 & 1.1702 & 1.44 & & \\
10.00 & 5.60 & 6.90 & 6.90 & 0.05 & 1.4864 & 1.22 & -0.0237 & 1.1963 \\
10.23 & 5.65 & 7.05 & 7.10 & 0.05 & 2.0190 & 1.09 & & \\
10.49 & 5.70 & 7.10 & 7.17 & 0.07 & 3.6492 & 1.00 & & \\
\hline
\end{tabular}

Log $K_{2}$ (Average value) $=1.1963$

Table 9: Point-wise method, Pb (Unhydrolysed PSHA)

\begin{tabular}{|l|l|l|l|l|l|l|l|l|}
\hline $\mathrm{pH}$ & $\mathrm{BV}_{1}$ & $\mathrm{BV}_{2}$ & $\mathrm{BV}_{3}$ & $\mathrm{~V}_{3}-\mathrm{V}_{2}$ & $\mathrm{n}$ & $\mathrm{pL}$ & $\begin{array}{l}\text { Log } \\
\left(\frac{n}{n-1}\right)\end{array}$ & Log $\mathrm{K}_{1}$ \\
\hline 8.50 & 5.30 & 5.81 & 5.85 & 0.04 & 0.2973 & 2.88 & -0.3736 & 2.5064 \\
8.72 & 5.35 & 5.90 & 5.94 & 0.04 & 0.3099 & 2.66 & -0.5477 & 2.3123 \\
9.00 & 5.40 & 6.00 & 6.05 & 0.05 & 0.4044 & 2.38 & -0.1681 & 2.2119 \\
9.22 & 5.45 & 6.10 & 6.15 & 0.06 & 0.5157 & 2.18 & 0.0272 & 2.2072 \\
9.51 & 5.50 & 6.20 & 6.26 & 0.07 & 0.6417 & 1.89 & 0.2530 & 2.1430 \\
9.73 & 5.55 & 6.40 & 6.40 & 0.07 & 0.7000 & 1.67 & 0.3680 & 2.0380 \\
\hline
\end{tabular}

LogK $_{1}$ (Average value) $=2.2364 \pm 0.1602$

Table 10: Point-wise method, Pb (Unhydrolysed PSHA)

\begin{tabular}{|l|l|l|l|l|l|l|l|l|}
\hline $\mathrm{pH}$ & $\mathrm{BV}_{1}$ & $\mathrm{BV}_{2}$ & $\mathrm{BV}_{3}$ & $\mathrm{~V}_{3}-\mathrm{V}_{2}$ & $\mathrm{n}$ & $\mathrm{pL}$ & $\log \left(\frac{n-1}{2-n}\right)$ & $\log \mathrm{K}_{2}$ \\
\hline 10.00 & 5.60 & 6.47 & 6.55 & 0.08 & 1.9503 & 1.41 & & \\
10.23 & 5.65 & 6.62 & 6.72 & 0.11 & 1.4792 & 1.26 & -0.0361 & 1.2239 \\
\hline
\end{tabular}

$\operatorname{LogK}_{2}$ (Average value) $=1.2239$

Table 11: Point-wise method, Mg (Hydrolysed PSHA)

\begin{tabular}{|l|l|l|l|l|l|l|l|l|}
\hline $\mathrm{pH}$ & $\mathrm{BV}_{1}$ & $\mathrm{BV}_{2}$ & $\mathrm{BV}_{3}$ & $\left(\mathrm{~V}_{3}-\mathrm{V}_{2}\right)$ & $\mathrm{n}$ & $\mathrm{pL}$ & $\log \left(\frac{n}{n-1}\right)$ & LogK $_{1}$ \\
\hline 8.50 & 5.30 & 6.29 & 6.31 & 0.02 & 0.2750 & 2.64 & -0.4290 & 2.2110 \\
8.72 & 5.35 & 6.37 & 6.39 & 0.02 & 0.2858 & 2.42 & -0.3978 & 2.0222 \\
9.00 & 5.40 & 6.46 & 6.49 & 0.03 & 0.4648 & 2.14 & -0.0612 & 2.0788 \\
9.22 & 5.45 & 6.55 & 6.59 & 0.04 & 0.6667 & 1.94 & 0.3010 & 2.2410 \\
\hline
\end{tabular}

$\log _{\mathbf{1}}($ Average value) $=2.1382 \pm 0.1046$ 
BAJOPAS Volume 14 Number 1,June, 2021

Table 12: Point-wise method, Mg (Hydrolysed PSHA)

\begin{tabular}{|l|l|l|l|l|l|l|l|l|}
\hline $\mathrm{pH}$ & $\mathrm{BV}_{1}$ & $\mathrm{BV}_{2}$ & $\mathrm{BV}_{3}$ & $\left(\mathrm{~V}_{3}-\mathrm{V}_{2}\right)$ & $\mathrm{n}$ & $\mathrm{pL}$ & $\log \left(\frac{n-1}{2-n}\right)$ & LogK $_{2}$ \\
\hline 9.51 & 5.55 & 6.66 & 6.71 & 0.05 & 0.9650 & 1.67 & & \\
9.73 & 5.55 & 6.78 & 6.84 & 0.06 & 1.4042 & 1.47 & -0.1686 & 1.3014 \\
10.00 & 5.60 & 6.90 & 6.93 & 0.06 & 1.7838 & 1.23 & 0.5593 & 1.7893 \\
10.23 & 5.65 & 7.05 & 7.10 & 0.06 & 3.1429 & 1.10 & & \\
10.49 & 5.70 & 7.10 & 7.18 & 0.07 & 3.6492 & 0.83 & & \\
\hline
\end{tabular}

LogK $_{2}($ Average value $)=1.5453 \pm 0.3450$

Table 13: Point-wise method, Mg (Unhydrolysed PSHA)

\begin{tabular}{|l|l|l|l|l|l|l|l|l|}
\hline $\mathrm{pH}$ & $\mathrm{BV}_{1}$ & $\mathrm{BV}_{2}$ & $\mathrm{BV}_{3}$ & $\mathrm{~V}_{3}-\mathrm{V}_{2}$ & $\mathrm{n}$ & $\mathrm{pL}$ & $\log \left(\frac{n}{n-1}\right)$ & $\operatorname{Log~}_{1}$ \\
\hline 8.50 & 5.30 & 5.81 & 5.85 & 0.04 & 0.2973 & 2.88 & -0.3736 & 2.5064 \\
8.72 & 5.35 & 5.90 & 5.94 & 0.04 & 0.3099 & 2.66 & -0.3477 & 2.3123 \\
9.00 & 5.40 & 6.00 & 6.04 & 0.04 & 0.3236 & 2.38 & -0.3202 & 2.0598 \\
9.22 & 5.45 & 6.10 & 6.15 & 0.05 & 0.4297 & 2.17 & -0.1230 & 2.0470 \\
9.51 & 5.50 & 6.20 & 6.26 & 0.06 & 0.5500 & 1.89 & 0.0871 & 1.9771 \\
9.73 & 5.55 & 6.33 & 6.40 & 0.07 & 0.7000 & 1.67 & 0.3680 & 2.0380 \\
\hline
\end{tabular}

LogK $_{1}$ (Average value) $=2.1568 \pm 0.2069$

Table 14: Point-wise method, Mg (Unhydrolysed PSHA)

\begin{tabular}{|l|l|l|l|l|l|l|l|l|}
\hline $\mathrm{pH}$ & $\mathrm{BV}_{1}$ & $\mathrm{BV}_{2}$ & $\mathrm{BV}_{3}$ & $\mathrm{~V}_{3}-\mathrm{V}_{2}$ & $\mathrm{n}$ & $\mathrm{pL}$ & $\log \left(\frac{n-1}{2-n}\right)$ & $\log \mathrm{K}_{2}$ \\
\hline 10.00 & 5.60 & 6.47 & 6.55 & 0.08 & 0.9148 & 1.41 & & \\
10.23 & 5.65 & 6.62 & 6.71 & 0.09 & 1.2102 & 1.20 & -0.5749 & 0.6251 \\
10.49 & 5.70 & 6.80 & 6.92 & 0.09 & 1.5968 & 1.03 & 0.1703 & 1.2003 \\
\hline
\end{tabular}

LogK $_{2}$ (Average value) $=0.9127 \pm 0.4070$

Table15:Point-wise method, Cd (Hydrolysed PSHA)

\begin{tabular}{|l|l|l|l|l|l|l|l|l|}
\hline $\mathrm{pH}$ & $\mathrm{BV}_{1}$ & $\mathrm{BV}_{2}$ & $\mathrm{BV}_{3}$ & $\left(\mathrm{~V}_{3}-\mathrm{V}_{2}\right)$ & $\mathrm{n}$ & $\mathrm{pL}$ & $\log \left(\frac{n}{1-n}\right)$ & LogK $_{1}$ \\
\hline 8.50 & 5.30 & 6.29 & 6.31 & 0.02 & 0.2750 & 2.64 & -0.4210 & 2.2190 \\
8.72 & 5.35 & 6.37 & 6.40 & 0.03 & 0.4286 & 2.42 & -0.1249 & 2.2951 \\
9.00 & 5.40 & 6.46 & 6.49 & 0.03 & 0.4648 & 2.14 & -0.0612 & 2.0788 \\
9.22 & 5.45 & 6.55 & 6.59 & 0.04 & 0.6667 & 1.96 & 0.3010 & 2.2610 \\
9.51 & 5.55 & 6.66 & 6.70 & 0.04 & 0.7720 & 1.67 & 0.5297 & 2.1997 \\
\hline
\end{tabular}

LogK $_{\mathbf{1}}$ (Average value) $=2.2108 \pm 0.0825$

Table 16: Point-wise method, Cd (Hydrolysed PSHA)

\begin{tabular}{|l|l|l|l|l|l|l|l|l|}
\hline $\mathrm{pH}$ & $\mathrm{BV}_{1}$ & $\mathrm{BV}_{2}$ & $\mathrm{BV}_{3}$ & $\left(\mathrm{~V}_{3}-\mathrm{V}_{2}\right)$ & $\mathrm{n}$ & $\mathrm{pL}$ & $\log \left(\frac{n-1}{2-n}\right)$ & Log $_{2}$ \\
\hline 9.73 & 5.55 & 6.78 & 6.83 & 0.06 & 1.4042 & 1.47 & -0.1686 & 1.3014 \\
10.00 & 5.60 & 6.90 & 6.95 & 0.06 & 1.7838 & 1.23 & 0.5593 & 1.7893 \\
10.23 & 5.65 & 7.05 & 7.10 & 0.06 & 3.1429 & 1.09 & & \\
10.49 & 5.70 & 7.10 & 7.16 & 0.06 & 3.1429 & 0.89 & & \\
& & & & & & & & \\
\hline
\end{tabular}

$\operatorname{LogK}_{2}$ (Average value) $=1.5453 \pm 0.3450$

Table 17: Point-wise method, Cd (Unhydrolysed PSHA)

\begin{tabular}{|l|l|l|l|l|l|l|l|l|}
\hline $\mathrm{pH}$ & $\mathrm{BV}_{1}$ & $\mathrm{BV}_{2}$ & $\mathrm{BV}_{3}$ & $\mathrm{~V}_{3}-\mathrm{V}_{2}$ & $\mathrm{n}$ & $\mathrm{pL}$ & $\log \left(\frac{n}{n-1}\right)$ & $\operatorname{Log~}_{1}$ \\
\hline 8.50 & 5.30 & 5.81 & 5.86 & 0.05 & 0.3717 & 2.88 & -0.2280 & 2.6520 \\
8.72 & 5.35 & 5.90 & 5.95 & 0.05 & 0.3873 & 2.66 & -0.1992 & 2.4608 \\
9.00 & 5.40 & 6.00 & 6.06 & 0.06 & 0.4853 & 2.38 & -0.0255 & 2.3545 \\
9.22 & 5.45 & 6.10 & 6.16 & 0.06 & 0.5157 & 2.18 & -0.0272 & 2.2072 \\
9.51 & 5.50 & 6.20 & 6.27 & 0.07 & 0.6417 & 1.89 & 0.2530 & 1.1430 \\
9.73 & 5.55 & 6.33 & 6.41 & 0.08 & 0.8000 & 1.69 & 0.6020 & 2.2920 \\
& & & & & & & & \\
\hline
\end{tabular}

$\operatorname{LogK}_{1}($ Average value $)=2.2516 \pm 0.5380$ 
BAJOPAS Volume 14 Number 1,June, 2021

Table 18: Point-wise method, Cd (Unhydrolysed PSHA)

\begin{tabular}{|l|l|l|l|l|l|l|l|l|}
\hline $\mathrm{pH}$ & $\mathrm{BV}_{1}$ & $\mathrm{BV}_{2}$ & $\mathrm{BV}_{3}$ & $\mathrm{~V}_{3}-\mathrm{V}_{2}$ & $\mathrm{n}$ & $\mathrm{pL}$ & $\log \left(\frac{n-1}{2-n}\right)$ & $\log \mathrm{K}_{2}$ \\
\hline 10.00 & 5.60 & 6.47 & 6.57 & 0.10 & 1.1434 & 1.43 & & \\
10.23 & 5.65 & 6.62 & 6.72 & 0.10 & 1.3448 & 1.23 & -0.2788 & 0.9512 \\
10.49 & 5.70 & 6.80 & 6.90 & 0.10 & 1.7742 & 1.03 & 0.5351 & 1.5651 \\
\hline
\end{tabular}

$\operatorname{LogK}_{2}($ Average value $)=1.2581 \pm 0.4340$

Table 19: Stepwise and overall Stability constants of thehydrolysed and unhydrolysed divalent metal (II) complexes

\begin{tabular}{|c|c|c|c|}
\hline Chelates & LogK $_{1}$ & $\log _{2}$ & Log $\beta$ \\
\hline [Cu (Hydrolysed PSHA-1) $\left.{ }_{2}\right]$ & 2.4788 & 1.4280 & 3.9068 \\
\hline$\left[\mathrm{Pb}(\text { Hydrolysed PSHA-1) })_{2}\right]$ & 2.5832 & 1.1963 & 3.7795 \\
\hline$\left[\mathrm{Cd}(\text { Hydrolysed PSHA-1 })_{2}\right]$ & 2.2108 & 1.5453 & 3.7561 \\
\hline$\left[\mathrm{Mg}(\text { Hydrolysed PSHA-1 })_{2}\right]$ & 2.1382 & 1.5453 & 3.6835 \\
\hline [Cu (Unhydrolysed PSHA-1) & 2.3059 & 1.2209 & 3.5268 \\
\hline$[\mathrm{Pb}$ (Unhydrolysed PSHA-1) 2$]$ & 2.2364 & 1.2239 & 3.4603 \\
\hline [Cd (Unhydrolysed PSHA-1) 2 ] & 2.2516 & 1.2581 & 3.5097 \\
\hline$[\mathrm{Mg}$ (Unydrolysed PSHA-1) & 2.1568 & 0.9127 & 3.0695 \\
\hline
\end{tabular}

The results obtained (Table19) shows the stepwise and overall stability constants to be not high indicating low stability of the complexes, because the solubility of most metal ions in the basic $\mathrm{pH}$ range is minimal due to metal hydroxide precipitation (Karimi, 2017). In general, the stepwise stability constants $\left(K_{1}\right.$ and $K_{2}$ ) follow the order $K_{1}>K_{2}$ for the copper, lead, magnesium and cadmium complexes respectively. The steady decrease of the values with increasing number of ligands is in agreement with the prediction made by researchers (Na'aliya, 2013). The decrease could be attributed to the fact that as the number of the ligands (Humate ions) that enters the coordination zone increases the aqua molecules available for replacement by the ligands become less. Thus, the metal ions become less electron loving with progressive intake of the ligand and this results in the decrease in the values of the constants (Na'aliya, 2013). Also the stability of the complexes is influenced by the size and number of the chelate rings(Mackay and Mackay,2002).All the complexes form rings in their structure as humate, a bidentate ligand, bond the metal ions in the ratio 1:2 (Boguta and Sokolowska, 2016) forming chelate rings. The values of the overall stability constants $(\log \beta)$ obtained for humate complexes are not high indicating low stability as the values are not high. LogK values for copper-humates (Table 3 to 6) obtained in this study are lower than those reported for the complexes of humic acids (Pandey et al., 2015; Dinu, 2013; Kaschl et al., 2010 and Gilbeto and Jorg, 2001). The values of LogK(Table 7 to 10 ) forlead-humates are lower than those reported for the lead in the literature (Dinu, 2013; Gilbeto and Jorg 2001). Log K values(Table 11 to 14 ) for magnesium-humates obtained in this study are close to those reported by (Pandey et al., 2015). Log K values of cadmium-humates (Table 15 to 18 ) obtained in this work near to the one reported by (Dinu, 2013 and Pandey et al., 2015).The difference between the reported values and the values obtained in this study might be probably as a result of acid hydrolysis of humic acid. The values of the overall stability constants $(\log \beta)$ of the copper humates complexes presented in Table 19 is high than that of other metal humate complexes, show relatively high stability of CuHA complexes, show the following order of stability: $\mathrm{Cu}>\mathrm{Pb}>\mathrm{Cd}>\mathrm{Mg}$; which are in close agreement to the findings of (Dinu, 2013 and Pandey et al., 2015).The high stability of Cuhumate chelate could be attributed to the existence of coordinate covalent bond between the complexing agents and the $\mathrm{Cu}^{2+}$ ions. Since, $\mathrm{Cu}^{2+}$ being a metal of the transitional series with $3 d^{9}$ electronic configurations can accept the electrons from the complexing agents. Similarly, the low stabilities of $\mathrm{Pb}, \mathrm{Cd}$ and $\mathrm{Mg}$ complexes could be explained by that $\mathrm{Pb}^{2+}$ with $6 s^{2}, \mathrm{Cd}^{2+}$ with $4 \mathrm{~d}^{10}$ and $\mathrm{Mg}^{2+}$ with $2 \mathrm{p}^{6}$ their electronic configuration has a completely filled $\mathrm{d}, \mathrm{p}$ and $\mathrm{s}$ orbitals. Moreover, the stabilities of metal ions with hydrolysed humic acid from peat soil were higher than those with unhydrolysed humic acid from peat soil; which is ascribed to the high content of acidity in hydrolysed humic acid than unhydrolysed humic acid. 
BAJOPAS Volume 14 Number 1,June, 2021 CONCLUSION

The values of logk for $\mathrm{Cu}(\mathrm{II})$ hydrolysed humic acid complex was higher followed by $\mathrm{Pb}$ (II), $\mathrm{Cd}(\mathrm{II})$ and $\mathrm{Mg}$ (II) hydrolysed humic acid complexes as compared with metal(II) unhydrolysed humic acid complexes. This indicates acid hydrolysis of humic acid can

\section{REFERENCES}

Almeida, V.R. and Szpoganicz, B. (2015). Humic Acid Potentiometric Response Patterns:Out- of Equilibrium Properties and Species Distribution Modelling. Chemical. Biol. Technol. Agric. 2: 17.

Anđelković, T., Nikolić, R., Bojić, A.,Anđelković, D., and Nikolic G.,(2010). Binding of Cadmium to Soil Humic Acid as A Function of Carboxyl Group Content. Macedonian Journal of Chemistry and Chemical Engineering.29(2): 215-224.

Anil, B. N. and Maroti, N. (2008). Studies on Influence of Die-Lectric Constants on Complex Equilibria between Substituted Py-Razalines and Lanthanide Metal Ions pH-Metrically. Amer.-Euras. scient. Res. 3(2): 212-216.

Ashok, K., Pandey, S. P. and Misra, V (2000). Stability Constants of Metal-Humic Acid Complexes and its Role in Environmental Detoxification. Journal of Ecotoxicology and Environmental Safety. 47(2):157-200.

Badr, M. H., El-Halafawi, M. H. and Abd El-al Zeid, E. R. (2012). Comparison Between the Effect of Ionic Strength on Acidity and Dissociation Constants of Humic Acids Extracted from Sewage Sludge and Nile Water Hyacinth Composts.Global Journal of Environmental Research 6 (1): 36-43.

Baruah, M.K., Borah, D., Saikia, P.P., Paul, S., Sharma, T. (2015). Evaluation of pKa Values of Soil Humic Acids and their Complexation Properties. International Journal of Plant \& Soil Science 6(4) : 218-228.

Boguta, P. Sokolowska, Z. (2016). Interactions of $\mathrm{Zn}$ (II) Ions with Humic Acids Isolated from Various Types of Soils. Effect of $\mathrm{pH}, \mathrm{Zn}$ Concentrations and Humic Acids Chemical Properties. Journal of Geochemical Explaration 168. 119-126.

Borges, F., Guimaraes, C., Lima, L.F.C., Pinto, I. and Reis, S.(2005). Potentiometric Studies on the Complexation of Copper(II) by Phenolic Acids as Discrete Ligand Models of enhance the complexation behavior of humic acid with metal (II) ions. However, the higher values of $\log \beta$ for $\mathrm{Cu}(\mathrm{II}), \mathrm{Pb}(\mathrm{II}), \mathrm{Cd}(\mathrm{II})$ and $\mathrm{Mg}(\mathrm{II})$ hydrolysed humic acid complexes indicates more stable stepwise complexes formed as compared with $\mathrm{Cu}(\mathrm{II}), \mathrm{Pb}$ (II), $\mathrm{Cd}$ (II) and $\mathrm{Mg}(\mathrm{II})$ unhydrolysed humic acid complexes.

Humic Substances Talanta 66 (2005) 670-673.

Chefetz, B., Salloum, M. J., Deshmulkin, A. P. and Hatcher, P. (2002). Structural Components of Humic Acids as Determined by Chemical Modifications and Carbon-13 NMR, Pyrolysis, and Thermochemolysis- Gas Chromatography/Mass Spectrometry. Soil Science Society of American Journal Abstract Division S-2- Soil Chemistry66. 1159-1171.

Dinu, M. I. (2013). Metals Complexation with Humic Acids in Surface Water of Different Environ. Sci. Technol. 31(1): 1-17.

Fernandes, A.N., Giacomelli, C., Giovanela, M. Vaz, D.V. Szpoganicz, B. and Maria M. D. (2009). Potentiometric Acidity Determination in Humic Substances Influenced by Different Analytical Procedures.J. Braz. Chem. Soc. 20 (9):14.

Gamal, A. H. (2015). Stability Constants of Rhenium (V) Metal Complexes with Selected Drugs. Pyrex Journal of Research in Environmental Studies. 2(2): 006-014.

Janrao, D. M., Pathan, J., Kayande, D.D., and Mulla, J.J. (2014). An Over View of Potentiometric Determination of Stability Constants of Metal Complexes. Sci. Revs. Chem. Commun.: 4(1), 2014, 11-24.

Karimi, H. (2017). Effect of pH and Initial Pb(II) Concentration on the Lead Removal Efficiency from Waste Water Using $\mathrm{Ca}(\mathrm{OH})_{2}$. International Journal of Water and Waste Water Treatment 3.2

Kaschl, A. Romheld, V. and Chen, Y. (2010). Binding of Cadmium, Copper and Zinc to Humic Substances Originating from Municipal Solid Waste Compost. Israel Journal of Chemistry Vol. 42(1): 89-98.

Kostic, I. S., Tatjana, P, A., Nikolic, R. S., Cvetkovic, T. P., Pavlovic, D. D., Aleksandar, L.J. and Bojic, A. (2012). Comparative Study of Binding Strengths of Heavy Metals with Humic Acid. J.serb. Chem. Soc. 76(9) pp 1-20. 
BAJOPAS Volume 14 Number 1,June, 2021

Na'aliya, J. (2013). Determination of Stepwise Stability Constants and Gibbs free Energy Change of Trisprolina to Complexes of some Divalent Transition Metal ions. Bayero Journal of Pure and Applied Sciences 6(2): 112-114.

Omar, A. A. and Ali, E. A. (2015). Potentiometric Studies on Complexes of $\mathrm{Cr}$ (III) and $\mathrm{Zr}$ (IV) with some Carboxylic Acids. International Journal of Advanced Chemistry, 3(1) 25-

37.

Pandey, A. K. Pandey, S. D. and Misr, V. (2015).Stability Constants of Metal- Humic Acid Complexes and Its Role in Environmental Detoxification. J. Ecotoxicology and Environmental Safety. 47(1):195-200.

Ram, N. and Raman, K.V. (1984). Stability Constants of Complexes of Metals with
Humicand Fuvic Acids under Non- acidConditions. Journal of Plant Nutrition and Soil Sciences.

147:171-176.

Santosh, D. D., Ashok, B. K., Vijay, J. T., Shivraj, G. W. and Vinay, V. W. (2011). Potentiometric Studies of Elec-Trolyte Effects on Complex Equilibria of Some Substituted 5-(2-hydroxy Phenyl) Pyrazoles. Der pharm. 3 (6): 75-83.

Sayyed, H. and Abdul Rahim, M. F. (2012). Studies of Binary Complexes of Metal Ions with Mandelic Acid by Potentiometry. Chem. J. 02 (6): 206209.

Shirvani, M. Moradian, E. Khalili, B. Bakhtiary, S. (2015). Interaction of $\mathrm{Cd}$ and $\mathrm{Pb}$ with Humate-Palygorskite and HumateSepiolite Complexes. Journal of water, air and pollution 3: 220-228. 


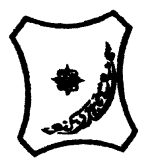

Bayero Journal of Pure and Applied Sciences, 14(1): 54 - 63

Received: November, 2020

Accepted: April, 2021

ISSN $2006-6996$

\title{
STABILITY CONSTANTS OF COMPLEXES OF METAL IONS WITH PEATSOIL HUMIC ACIDS UNDER NON-ACID-CONDITIONS
}

\author{
${ }^{* 1}$ Sabo, Yusuf ${ }^{2}$ Jimoh, W.L.O., ${ }^{3}$ Isa Baba Koki and ${ }^{4}$ Sholadoye, Q. 0. \\ ${ }^{1}$ Department of Pure and Industrial Chemistry, Bayero University, Kano \\ ${ }^{3}$ Department of Chemistry, Yusuf Maitama Sule University Kano. P.M.B. 3220 Kano, Nigeria. \\ ${ }^{4}$ Department of Chemistry, Nigerian Police Academy, Wudil, Kano-Nigeria
}

*Correspondence E-mail; saboyusuf18@yahoo.com

ABSTRACT

Stability constants of complexes of four divalent metal ions viz. $\mathrm{Cu}^{2+}, \mathrm{Pb}^{2+}, \mathrm{Mg}^{2+}$ and $\mathrm{Cd}^{2+}$ with humic acids (HA) were determined by potentiometric titration of humic acids with the corresponding salt of the divalent metals in aqueous media under non-acid-condition. The log $K$ (logarithm of the stability constant) ranged from 1.0942 to 2.7471 for metalhumic acid complexes were determined using point-wise computational method. The order of stability constants were obtained as follows: $\mathrm{Cu}>\mathrm{Pb}>\mathrm{Cd}>\mathrm{Mg}$ for metal $-\mathrm{HA}$ complexes respectively, indicating a higher degree of complexation with Cu metal ion.

Keywords: stability constant, humic acid, potentiometric titration, divalent metals, acid hydrolysis.

\section{NTRODUCTION}

The stability constant of a complex is the numerical expression of its stability and provides a quantitative measure of affinity of the metal ion to the complexing agent. An understanding of the relative stability of metal-complexes helps in predicting the behavior of metal ions in the soil (Ram and Raman, 1982). Extensive researches has been done to determine the stability constants of the complexes formed between humic acid (HA) with a number of metal ions. Ashok et al., (2000) reported that humic acid with hydroxyl, phenoxyl and carboxyl reactive groups can form coordination compound with metal ions at $\mathrm{pH}$ 3.5. The stability constants(Log K) for different metalhumic acid complexes indicated the following order of the stabilities of complexes formed between humic acid and metal ion, $\mathrm{Cu}>\mathrm{Fe}$ $>\mathrm{Pb}>\mathrm{Ni}>\mathrm{Co}>\mathrm{Ca}>\mathrm{Cd}>\mathrm{Zn}>\mathrm{Mn}>\mathrm{Mg}$. Andelkovic et al., (2010) investigated the binding of $\mathrm{Cd}$ (II) to soil humic acid at pH 6.5 and in $0.1 \mathrm{M} \mathrm{KNO}_{3}$ ionic medium. The stability constant for binding indicating greater stability in the case when carboxyl groups are involved in complexation reaction. Kostic et al.,(2012) investigated the complexation of humic acid with certain heavy metal ions (Co(II), $\mathrm{Ni}(\mathrm{II}), \mathrm{Cu}(\mathrm{II})$,
$\mathrm{Zn}(\mathrm{II})$, and $\mathrm{Pb}(\mathrm{II})$. The experiment was performed at $25^{\circ} \mathrm{C}$, at pH 4.0 and ionic strength of $0.01 \mathrm{M}$. Stability constant of complex between $\mathrm{Pb}$ (II) ions and humic acid is greater than stability constants of other investigated metalhumate complexes. Bogata and Sokolowska (2016) analyses the interaction between humic acids from different soils and $\mathrm{Zn}$ (II) ions at wide concentration ranges and at $\mathrm{pH} 5$. Studies have showed significant impact of $\mathrm{Zn}$ concentration, $\mathrm{pH}$ and some properties of humic acids with zinc.But all of these studies were limited to acidic $\mathrm{pH}$ range. Therefore, the present study was carried out to determine and compare the stability constants of complexes of metal ions with hydrolysed peat soil humic acid and unhydrolysed peat soil humic under non-acid conditions.

\section{MATERIALS AND METHODS}

Analytical grade chemicals used includes hydrochloric acid $(\mathrm{HCl})$, nitric acid $\left(\mathrm{HNO}_{3}\right)$, sodium hydroxide $(\mathrm{NaOH})$, lead nitrate $\mathrm{Pb}\left(\mathrm{NO}_{3}\right)_{2}$, copper nitrate $\mathrm{Cu}\left(\mathrm{NO}_{3}\right)_{2} \cdot 3 \mathrm{H}_{2} \mathrm{O}$, cadmium nitrate $\mathrm{Cd}\left(\mathrm{NO}_{3}\right)_{2} \cdot 4 \mathrm{H}_{2} \mathrm{O}$, magnesium nitrate $\mathrm{Mg}\left(\mathrm{NO}_{3}\right)_{2} \cdot 6 \mathrm{H}_{2} \mathrm{O}$, potassium nitrate $\left(\mathrm{KNO}_{3}\right)$, calcium chloride $\left(\mathrm{CaCl}_{2}\right)$, (sigma-Aldrich). Dowex 50WX8, (20-50 mesh) from Fluka. 


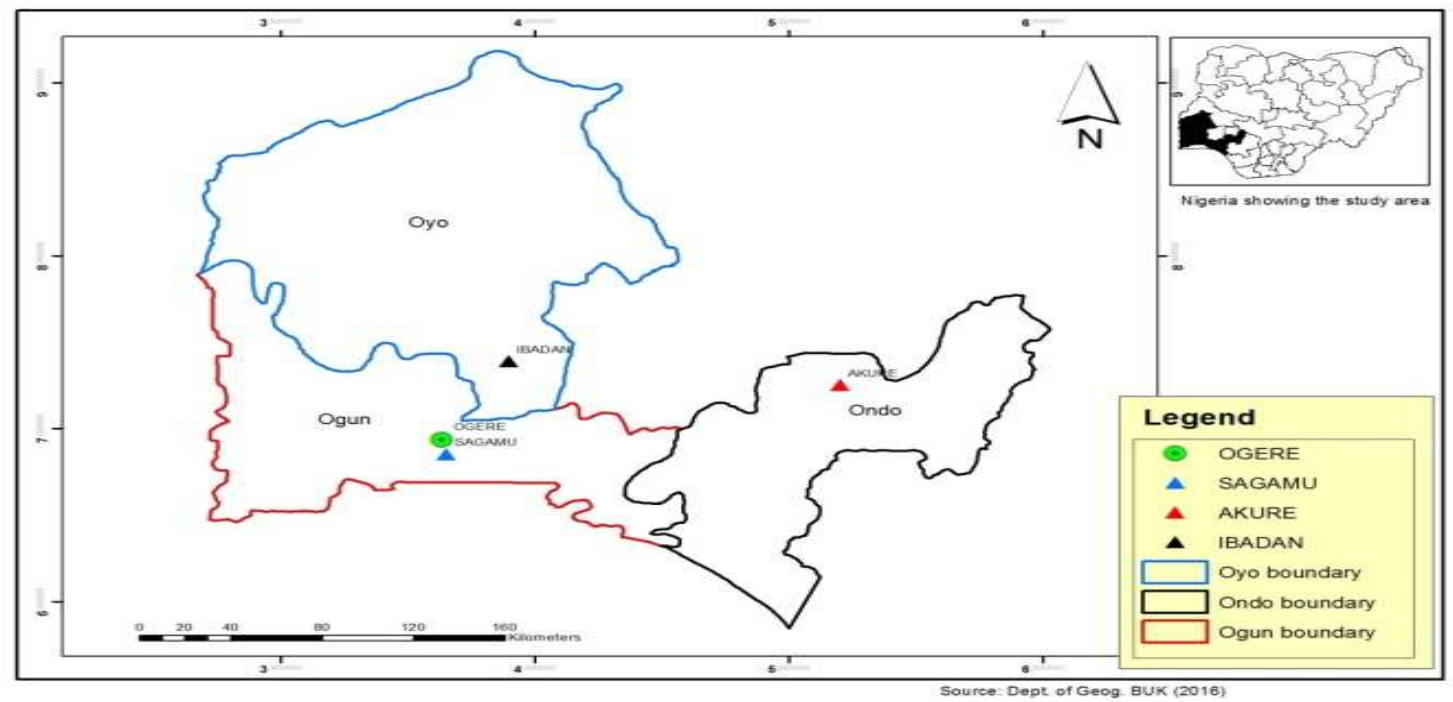

Figure 1: Map showing the sampling point at Sagamu Town, Ogun State.

\section{Description of Sampling Area}

Sagamu has geographical coordinates between $6^{\circ} 50^{\prime}$ north; $3^{\circ} 38^{\prime}$ east is located in south western region of Nigeria. The region has tropical wet and dry climate with a lengthy wet season and relatively constant temperatures throughout the course of the year. Wet season runs from March to October, November to December forms the region dry season. The vegetation type of the region is savannah which is really grassland with small bushes and occasional big trees. Grassland soils have substantially higher organic matter content than forest soils (Novackova, 2011).

\section{Sample Collection}

The Peatsoil samples were collected from four different sampling points $(0-10 \mathrm{~cm}$ depth) in Sagamu into polyethylene bag with plastic spoons. Samples were taken to the laboratory, extraneous materials were removed; the samples were air-dried, crushed and ground to a fine powder in a mortar passed through a $0.20 \mathrm{~mm}$ sieve. The samples were kept for analysis.

\section{Isolation and purification of humic acid from peat soil sample}

Peatsoil sample $(100 \mathrm{~g})$ was mixed with 1000 $\mathrm{cm}^{3}$ of $0.1 \mathrm{M} \mathrm{NaOH}$ solution, shaken for 3hours and left to stand overnight. Dark-coloured supernatant was obtained and decanted from solid residue. The dark-coloured supernatant was acidified to $(\mathrm{pH}=1.0)$ with $6 \mathrm{M} \mathrm{HCl}$ stirred and allowed to stand for 6 hours. Yellowish brown supernatant and dark-brown precipitate were obtained. The yellowish brown supernatant was decanted followed by centrifuge and discarded. The dark-brown precipitate was mixed with $500 \mathrm{~cm}^{3}$ of $0.1 \mathrm{M} \mathrm{NaOH}$ solution followed by passing through dowex resin. The dark-brown solution was acidified to $(\mathrm{pH}=1.0)$ with $6 \mathrm{M} \mathrm{HCl}$ stirred and allowed to stand for 3 hours. The dark-brown precipitate was washed several times with deionized water. The supernatant was treated with $\mathrm{AgNO}_{3}$ solution until no white precipitate observed. The humic acid was transferred to weighed crucible and dried at $60^{\circ} \mathrm{C}$ in an oven for 12 hours. The humic acid was cooled and dried in the desiccator, weighed and recorded. The obtained humic acid was dried again at $60^{\circ} \mathrm{C}$ for additional 6 hours cooled and dried in the desiccator, weighed and recorded constant weight was obtained (Baruah et al., 2015).

\section{FT-IR analysis}

FT-IR spectra of humic acid sample was analysed using Carry 630 FT-IR Agilent Technologies.

Unhydrolysed compost humic acid

The unhydrolysed humic acid was obtained after isolation and purification of compost humic acid and kept for investigation.

\section{Acid hydrolysis of Peatsoil acid}

Peatsoil humic acid sample (1g) was refluxed for 12 hours at $\left(160^{\circ} \mathrm{C}\right)$ with $50 \mathrm{~cm}^{3}$ of $6 \mathrm{M} \mathrm{HCl}$. The mixture was allowed to cool, decanted, and centrifuged after hydrolysis. The insoluble residues were washed with distilled water via centrifugation several times, and the supernatant was treated with $\mathrm{AgNO}_{3}$ solution until no white precipitate was observed. The residue was thoroughly dried over $\mathrm{CaCl}_{2}$ in a desiccator at room temperature (Chefetz et al., 2002). Finally, the obtained hydrolysed humic acid was kept for investigation. 
BAJOPAS Volume 14 Number 1,June, 2021 Potentiometric Titrations

Potentiometric measurements were carried out using a pH-meter Jenway (model 3510) with combine electrode, the sensitivity of the $\mathrm{pH}$ meter is 0.01 units. The $\mathrm{pH}$ meter was switched on half an hour before starting the titration for initial warm up of the instrument. The instrument was calibrated with an aqueous standard buffer solution of $\mathrm{pH} 4.00$ and 10.0 (borate buffer) prepared from a "Qualigens" buffer tablets.

The following sets of solutions were prepared in a $250 \mathrm{~cm}^{3}$ volumetric flask separately for $\mathrm{pH}$ metric titrations.

(i) $5 \mathrm{~cm}^{3} 0.1 \mathrm{M} \mathrm{HCl}+40 \mathrm{~cm}^{3}$ deionized water

(ii) $5 \mathrm{~cm}^{3} 0.1 \mathrm{M} \mathrm{HCl}+39 \mathrm{~cm}^{3}$ deionized water $+1 \mathrm{~cm}^{3} 0.15 \mathrm{gcm}^{-3}$ humic acid

(iii) $5 \mathrm{~cm}^{3} 0.1 \mathrm{M} \mathrm{HCl}+37 \mathrm{~cm}^{3}$ deionized water $+1 \mathrm{~cm}^{3} 0.15 \mathrm{gcm}^{-3}$ humic acid

$$
+2 \mathrm{~cm}^{3} \quad 0.01 \mathrm{M} \mathrm{Cu} \text { (II) }
$$

The solutions were titrated against standardized $0.110 \mathrm{MNaOH}$ separately. The total volume of each mixture was adjusted to $50 \mathrm{~cm}^{3}$ and the ionic strength of the solutions was maintained constant at by adding appropriate amount of stock solution of $1 \mathrm{M} \mathrm{KNO}_{3}$ (Gamal, 2015; Omar and Ali, 2015). A magnetic stirrer was used to achieve thorough mixing of the interacting solutions at $550 \mathrm{rpm}$. The same set of experimental conditions was applied for potentiometric titration of remaining samples.

\section{Evaluation of pKa of Hydrolysed peat soil Humic Acids}

The proton-ligand formation number $\mathrm{n}_{\mathbf{A}}$ were calculated by Irving and Rossotti expression (Omar and Ali, 2015).

$\mathrm{nA}=\mathrm{Y}-\frac{(\mathrm{V} 2-\mathrm{V1})(\mathrm{No}-\mathrm{Eo})}{(\mathrm{VO}+\mathrm{V1}) \mathrm{TCL}}$ 1

Where: $Y$ is number of dissociable proton, $\left(\mathrm{V}_{2^{-}}\right.$ $V_{1}$ ) is the measure of displacement of the ligand curve relative to acid curve, $\mathrm{N}^{\circ}$ and $\mathrm{E}^{\circ}$ are the resultant concentration of alkali solution, free acid solution, $\mathrm{T}_{\mathrm{cL}}{ }^{\circ}$ is the total ligand concentration, $\mathrm{V}^{\circ}$ is the total volume of titration solution, $V_{1}$ is the volume of alkali added to acid solution, $V_{2}$ is the volume of alkali added to acid solution + ligand solution, acid dissociation constants (pKa - values) of ligand were calculated by algebraic method point wise calculation (Tables 1 ). The dissociation constants (pKa) were calculated according to the following relation:

$\mathrm{pKa}=\mathrm{pH}+\log \left(\frac{n A}{1-n A}\right)$ 2

Where: pKa is the acid dissociation constant, $\mathrm{n}_{\mathrm{A}}$ is the Proton-ligand formation number and $\mathrm{pH}$ is the pH-values (Omar and Ali, 2015).

\section{Determination of metal-ligand stability constants $(\log K)$ of complexes}

The potentiometric measurement for the determination of stability constant of a complex in solution is based on the fact that the redox potential of the couple $\frac{M^{+(m-n)}}{M^{+m}}$ is shifted significantly on complexation of the metal ion with the ligand. This method involves change in hydrogen ion concentration $\left[\mathrm{H}^{+}\right]$due to the displacement or association of one or more protons taking place during complexation reaction. This change can be found out by titrating the solutions containing free acid, acid with ligand, and acid with ligand and metal ion, individually against a standard alkali solution at a constant ionic strength or temperature. Either ionic strength or temperature may be varied for different sets of solutions. In all the cases, the change in the $\mathrm{pH}$ of the solution is measured after each addition of a known amount of alkali to the reaction cell which contains the reaction mixture. The titration curves are then drawn by plotting the measured $\mathrm{pH}$ values against the corresponding volume of alkali added and the stability constants of the complexes are determined from the titration curves by employing $\mathrm{pH}$-metric titration technique given by (Irving and Rossoti).

Metal-ligand stability constants ( $\log \mathrm{K}$ ) were determined by using the following relations:

$$
\bar{n}=\frac{\left(V_{3}-V_{2}\right)\left(E^{0}+N^{0}\right)}{\left(V^{0}+V_{2}\right) \bar{n}_{A} T_{m}^{0}}
$$

and

$$
P L=\log _{10}\left\{\frac{1+\beta_{n}^{H} \frac{1}{[\text { anti } \log \mathrm{pH}]^{\mathrm{n}}}}{\mathrm{T}_{\mathrm{L}}^{0}-n \bar{T}_{m}^{0}} \mathrm{X} \frac{\left(V^{0}+V_{3}\right)}{V^{0}}\right\}
$$


BAJOPAS Volume 14 Number 1,June, 2021

Where $T_{L}, T^{\circ}, E^{\circ}$, and $V^{\circ}$ havethe same significance as in equation (1) above, $T_{m}$ denotes the total concentration of metal present in solution, $V_{3}$ is the volume of metal ions present in solution and $\beta^{H}$ is the overall proton ligand stability constant. The metal-ligand stability constants (log K) were determined by employing point wise computational Method (eq. 5 and 6).

$\operatorname{LogK}_{1}=\log \left(\frac{n}{1-n}\right)+\mathrm{pL}$ .5

$\operatorname{LogK}_{2}=\log \left(\frac{1-n}{2-n}\right)+\mathrm{pL}$ ...6

Where: Log $\mathrm{K}$ is the metal-ligand stability constant, $\mathrm{pL}$ is the Free ligand exponent function, $\mathbf{n}$ is the Average number of ligand attached with metal ion (Janraoet al., 2014). The results obtained were analyzed by an ORIGIN 2016 program using titration data and then the proton-ligand stability constants (pKa) and Metal-ligand stability constant (LogK) calculated (Omar and Ali, 2015).

\section{RESULTS AND DISCUSSION}

Fourier transformed infrared (FT-IR) spectra of isolated humic acid from peat soils Figure 2 had distinct clear absorption bands indicating the presence of major humic acid structural elemental groups such as $\mathrm{H}$ bonded $\mathrm{OH}$ $\left(3680 \mathrm{~cm}^{-1}\right.$ peak $), C=0$ of carbonyl $\left(1721 \mathrm{~cm}^{-1}\right.$ peak), functional groups of aliphatic components $\mathrm{CH}_{2}\left(2918 \mathrm{~cm}^{-1}\right.$ peak) and $\mathrm{C}-\mathrm{O}$ stretching of polysaccharide $\left(1168 \mathrm{~cm}^{-1}\right.$ peak). The positions of the absorption bands of the spectra fell within typical major absorption bands of humic acid which is at frequencies 3680, 2918, 1721, 1168 $\mathrm{cm}^{-1}$. The first peak centred in the vicinity of $3680 \mathrm{~cm}^{-1}$ region is attributed to phenol $\mathrm{OH}$ group bounded by intermolecular $\mathrm{H}$ bonds. The $2918 \mathrm{~cm}^{-1}$ band usually has absorption maximum at $2918 \mathrm{~cm}^{-1}$ which is due to $\mathrm{C}-\mathrm{H}$ stretching of alkane group $\left(\mathrm{CH}_{2}\right)$. The next major absorption band is $1721 \mathrm{~cm}^{-1}$. This band has been commonly ascribed to $\mathrm{C}=\mathrm{O}$ stretching of mainly carboxyl group $(\mathrm{COOH})$ with trace amount of ketones. The last peak was observed at 1168 $\mathrm{cm}^{-1}$ due to $\mathrm{C}-\mathrm{O}$ stretching of polysaccharides and this peak appeared also in the spectra of humic acid from peat soil. The FTIR spectra of the isolated humic acid contained all major characteristic absorption peaks of humic acid. These absorption peaks indicated the presence of the major structural elements of humic acid namely $\mathrm{H}$ bonded $\mathrm{OH}, \mathrm{C}=\mathrm{C}$ of aromatic ring, $\mathrm{C}=\mathrm{O}$ of carbonyl group (both carboxyl and ketonic), $\mathrm{CH}_{2}$ group. This strongly supports the presence of humic acid.

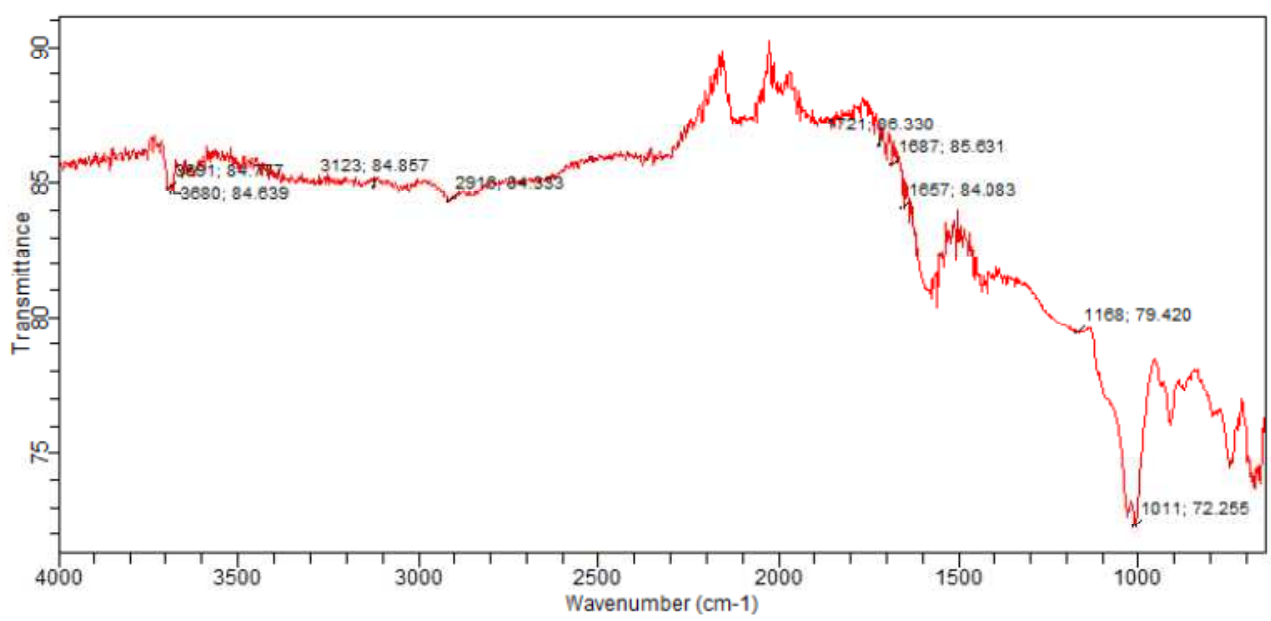

Fig. 2 : FT-IR spectraof peatsoilhumic acid (PSHA)

\section{Evaluation of acid dissociation constant (pka) of acid hydrolysed peat soil humicacid at phenolic group}

The value of the dissociation constant of the peat soil humic acid (PSHA) that underwent acidhydrolysis studied was found to be 8.9299 as shown Table 1, which is lower than the literaturevalues reported by Almeida and Szpoganics, (2015), Borges et al., (2005); Badr et al., (2012)and Fernandes et al,.(2009) of $9.73,9.47$ and 10.30. The difference between the obtained valuesand the reported values in this study might be probably as a result of acid hydrolysis of humicacid. 
BAJOPAS Volume 14 Number 1,June, 2021

Table 1: PKa of (Hydrolysed PSHA)

\begin{tabular}{|l|l|l|l|l|l|l|}
\hline $\mathrm{pH}$ & $\mathrm{BV}_{1}$ & $\mathrm{BV}_{2}$ & $\mathrm{~V}_{2}-\mathrm{V}_{1}$ & $\mathrm{nA}$ & $\log \left(\frac{n A}{1-n A}\right)$ & $\mathrm{pKa}$ \\
\hline 8.50 & 5.30 & 6.29 & 0.99 & 0.3594 & -0.2510 & 8.2490 \\
8.72 & 5.35 & 6.37 & 1.02 & 0.3400 & -0.2880 & 8.4320 \\
9.00 & 5.40 & 6.46 & 1.06 & 0.3141 & -0.3391 & 8.6609 \\
9.22 & 5.45 & 6.55 & 1.10 & 0.2882 & -0.3927 & 8.8273 \\
9.51 & 5.50 & 6.66 & 1.16 & 0.2494 & -0.4786 & 9.0314 \\
9.73 & 5.55 & 6.78 & 1.23 & 0.2041 & -0.5910 & 9.1390 \\
10.00 & 5.60 & 6.90 & 1.30 & 0.1589 & -0.7238 & 9.2762 \\
10.23 & 5.65 & 7.05 & 1.40 & 0.0941 & -0.9835 & 9.2465 \\
10.49 & 5.70 & 7.10 & 1.40 & 0.0941 & -0.9835 & 9.5065 \\
\hline
\end{tabular}

Average pKa $=8.9299 \pm 0.4186$

Table 2: PKa of (Unhydrolysed PSHA)

\begin{tabular}{|l|l|l|l|l|l|l|}
\hline $\mathrm{pH}$ & $\mathrm{BV}_{1}$ & $\mathrm{BV}_{2}$ & $\mathrm{~V}_{2}-\mathrm{V}_{1}$ & $\mathrm{nA}$ & $\log \left(\frac{\boldsymbol{n A}}{1-\boldsymbol{n}}\right)$ & $\mathrm{pKa}$ \\
\hline 8.50 & 5.30 & 5.81 & 0.51 & 0.6619 & 0.2919 & 8.7919 \\
8.72 & 5.35 & 5.90 & 0.55 & 0.6357 & 0.2418 & 8.9618 \\
9.00 & 5.40 & 6.00 & 0.60 & 0.6029 & 0.1813 & 9.1813 \\
9.22 & 5.45 & 6.10 & 0.65 & 0.5701 & 0.1226 & 9.3426 \\
9.51 & 5.50 & 6.20 & 0.70 & 0.5376 & 0.0654 & 9.5754 \\
9.73 & 5.55 & 6.33 & 0.78 & 0.4851 & -0.0259 & 9.7041 \\
10.00 & 5.60 & 6.47 & 0.87 & 0.4262 & -0.1291 & 9.8709 \\
10.23 & 5.65 & 6.62 & 0.99 & 0.3609 & -0.2481 & 9.9819 \\
10.49 & 5.70 & 6.80 & 1.10 & 0.2759 & -0.4690 & 10.0210 \\
\hline
\end{tabular}

Average pKa $=9.4923 \pm 0.4410$

Metal-ligand stability constant ( $\log \mathrm{K}$ )

The stabilityconstants require the accurate values of proton-ligand stability constants (Anil and Maroti, 2008). Metal titration curves crossed over ligand titration curve indicated the formation of complex upon proton release (Santosh, et al., 2011). If the values of n- are within range $0.2-0.8$ and $1.2-18$ this indicates the formation of $1: 1$ and 1:2 complexes (Sayyed and Mazahar, 2012).

The metal (II)-humate stepwise stability constants (log k) at phenolic group (Tables 318)

Table 3: Point-wise method, $\mathrm{Cu}$-(Hydrolysed PSHA)

\begin{tabular}{|l|l|l|l|l|l|l|l|l|}
\hline $\mathrm{pH}$ & $\mathrm{BV}_{1}$ & $\mathrm{BV}_{2}$ & $\mathrm{BV}_{3}$ & $\left(\mathrm{~V}_{3}-\mathrm{V}_{2}\right)$ & $\mathrm{n}$ & $\mathrm{pL}$ & $\log \left(\frac{n}{1-n}\right)$ & LogK $_{1}$ \\
\hline 8.50 & 5.30 & 6.29 & 6.33 & 0.04 & 0.5500 & 2.66 & 0.0871 & 2.7471 \\
8.72 & 5.35 & 6.37 & 6.41 & 0.04 & 0.5714 & 2.43 & 0.1249 & 2.5549 \\
9.00 & 5.40 & 6.46 & 6.50 & 0.04 & 0.6198 & 2.16 & 0.2122 & 2.3722 \\
9.22 & 5.45 & 6.55 & 6.59 & 0.04 & 0.6667 & 1.94 & 0.3010 & 2.2410 \\
\hline
\end{tabular}

LogK $_{1}$ (Average value) $=2.4788 \pm 0.2203$

Table 4: Point-wise method, $\mathrm{Cu}$-(Hydrolysed PSHA)

\begin{tabular}{|l|l|l|l|l|l|l|l|l|}
\hline $\mathrm{pH}$ & $\mathrm{BV}_{1}$ & $\mathrm{BV}_{2}$ & $\mathrm{BV}_{3}$ & $\left(\mathrm{~V}_{3}-\mathrm{V}_{2}\right)$ & $\mathrm{n}$ & $\mathrm{pL}$ & $\log \left(\frac{n-1}{2-n}\right)$ & LogK $_{2}$ \\
\hline 9.51 & 5.50 & 6.66 & 6.73 & 0.07 & 1.3509 & 1.70 & -0.2671 & 1.4329 \\
9.73 & 5.55 & 6.78 & 6.85 & 0.07 & 1.6383 & 1.51 & 0.2467 & 1.7567 \\
10.00 & 5.60 & 6.90 & 6.98 & 0.08 & 2.1783 & 1.31 & -0.2158 & 1.0942 \\
10.23 & 5.65 & 7.05 & 7.13 & 0.08 & 4.1904 & 1.27 & & \\
10.49 & 5.70 & 7.10 & 7.19 & 0.09 & 4.6920 & & & \\
\hline
\end{tabular}

Log $K_{2}($ Average value $)=1.4280 \pm 0.3312$ 
BAJOPAS Volume 14 Number 1,June, 2021

Table 5: Point-wise method, $\mathrm{Cu}$ (Unhydrolysed PSHA)

\begin{tabular}{|l|l|l|l|l|l|l|l|l|}
\hline $\mathrm{pH}$ & $\mathrm{BV}_{1}$ & $\mathrm{BV}_{2}$ & $\mathrm{BV}_{3}$ & $\left(\mathrm{~V}_{3}-\mathrm{V}_{2}\right)$ & $\mathrm{n}$ & $\mathrm{pL}$ & $\log \left(\frac{n}{n-1}\right)$ & Log $_{1}$ \\
\hline 8.50 & 5.30 & 5.81 & 5.85 & 0.04 & 0.2973 & 2.88 & -0.3736 & 2.5064 \\
8.72 & 5.35 & 5.90 & 5.95 & 0.05 & 0.3873 & 2.66 & -0.1992 & 2.4608 \\
9.00 & 5.40 & 6.00 & 6.05 & 0.05 & 0.4044 & 2.38 & -0.1681 & 2.2119 \\
9.22 & 5.45 & 6.10 & 6.15 & 0.06 & 0.5157 & 2.18 & -0.0272 & 2.2072 \\
9.51 & 5.50 & 6.20 & 6.27 & 0.07 & 0.6417 & 1.89 & 0.2530 & 1.1430 \\
\hline
\end{tabular}

$\operatorname{LogK}_{1}($ Average value $)=2.3059 \pm 0.6153$

Table 6:Point-wise method, $\mathrm{Cu}$ (Unhydrolysed PSHA)

\begin{tabular}{|l|l|l|l|l|l|l|l|l|}
\hline $\mathrm{pH}$ & $\mathrm{BV}_{1}$ & $\mathrm{BV}_{2}$ & $\mathrm{BV}_{3}$ & $\mathrm{~V}_{3}-\mathrm{V}_{2}$ & $\mathrm{n}$ & $\mathrm{pL}$ & $\log \left(\frac{n-1}{2-n}\right)$ & $\log \mathrm{K}_{2}$ \\
\hline 9.73 & 5.55 & 6.33 & 6.42 & 0.09 & 0.9000 & 1.69 & & \\
10.00 & 5.60 & 6.47 & 6.58 & 0.11 & 1.2578 & 1.44 & -0.4592 & 0.9808 \\
10.23 & 5.65 & 6.62 & 6.84 & 0.12 & 1.6137 & 1.26 & -0.2010 & 1.4610 \\
10.49 & 5.70 & 6.80 & 6.92 & 0.12 & 2.1052 & 1.03 & & \\
\hline
\end{tabular}

$\operatorname{LogK}_{2}$ (Average value) $=1.2209 \pm 0.3398$

Table 7:Point-wise method, Pb (Hydrolysed PSHA)

\begin{tabular}{|l|l|l|l|l|l|l|l|l|}
\hline $\mathrm{pH}$ & $\mathrm{BV}_{1}$ & $\mathrm{BV}_{2}$ & $\mathrm{BV}_{3}$ & $\left(\mathrm{~V}_{3}-\mathrm{V}_{2}\right)$ & $\mathrm{n}$ & $\mathrm{pL}$ & $\log \left(\frac{n}{1-n}\right)$ & LogK $_{1}$ \\
\hline 8.50 & 5.30 & 6.29 & 6.33 & 0.04 & 0.5500 & 2.66 & 0.0871 & 2.7471 \\
8.72 & 5.35 & 6.37 & 6.41 & 0.04 & 0.5714 & 2.43 & 0.1249 & 2.5549 \\
9.00 & 5.40 & 6.46 & 6.50 & 0.04 & 0.6198 & 2.16 & 0.2122 & 2.3722 \\
9.22 & 5.45 & 6.55 & 6.60 & 0.05 & 0.8333 & 1.96 & 0.6989 & 2.6589 \\
\hline
\end{tabular}

Log $_{\mathbf{1}}($ Average value $)=2.5832 \pm 0.1614$

Table 8:Point-wise method, Pb-(Hydrolysed PSHA)

\begin{tabular}{|l|l|l|l|l|l|l|l|l|}
\hline $\mathrm{pH}$ & $\mathrm{BV}_{1}$ & $\mathrm{BV}_{2}$ & $\mathrm{BV}_{3}$ & $\left(\mathrm{~V}_{3}-\mathrm{V}_{2}\right)$ & $\mathrm{n}$ & $\mathrm{pL}$ & $\log \left(\frac{n-1}{2-n}\right)$ & $\log \mathrm{K}_{2}$ \\
\hline 9.51 & 5.50 & 6.66 & 6.71 & 0.05 & 0.9650 & 1.67 & & \\
9.73 & 5.55 & 6.78 & 6.83 & 0.05 & 1.1702 & 1.44 & & \\
10.00 & 5.60 & 6.90 & 6.90 & 0.05 & 1.4864 & 1.22 & -0.0237 & 1.1963 \\
10.23 & 5.65 & 7.05 & 7.10 & 0.05 & 2.0190 & 1.09 & & \\
10.49 & 5.70 & 7.10 & 7.17 & 0.07 & 3.6492 & 1.00 & & \\
\hline
\end{tabular}

Log $K_{2}$ (Average value) $=1.1963$

Table 9: Point-wise method, Pb (Unhydrolysed PSHA)

\begin{tabular}{|l|l|l|l|l|l|l|l|l|}
\hline $\mathrm{pH}$ & $\mathrm{BV}_{1}$ & $\mathrm{BV}_{2}$ & $\mathrm{BV}_{3}$ & $\mathrm{~V}_{3}-\mathrm{V}_{2}$ & $\mathrm{n}$ & $\mathrm{pL}$ & $\begin{array}{l}\text { Log } \\
\left(\frac{n}{n-1}\right)\end{array}$ & Log $\mathrm{K}_{1}$ \\
\hline 8.50 & 5.30 & 5.81 & 5.85 & 0.04 & 0.2973 & 2.88 & -0.3736 & 2.5064 \\
8.72 & 5.35 & 5.90 & 5.94 & 0.04 & 0.3099 & 2.66 & -0.5477 & 2.3123 \\
9.00 & 5.40 & 6.00 & 6.05 & 0.05 & 0.4044 & 2.38 & -0.1681 & 2.2119 \\
9.22 & 5.45 & 6.10 & 6.15 & 0.06 & 0.5157 & 2.18 & 0.0272 & 2.2072 \\
9.51 & 5.50 & 6.20 & 6.26 & 0.07 & 0.6417 & 1.89 & 0.2530 & 2.1430 \\
9.73 & 5.55 & 6.40 & 6.40 & 0.07 & 0.7000 & 1.67 & 0.3680 & 2.0380 \\
\hline
\end{tabular}

LogK $_{1}$ (Average value) $=2.2364 \pm 0.1602$

Table 10: Point-wise method, Pb (Unhydrolysed PSHA)

\begin{tabular}{|l|l|l|l|l|l|l|l|l|}
\hline $\mathrm{pH}$ & $\mathrm{BV}_{1}$ & $\mathrm{BV}_{2}$ & $\mathrm{BV}_{3}$ & $\mathrm{~V}_{3}-\mathrm{V}_{2}$ & $\mathrm{n}$ & $\mathrm{pL}$ & $\log \left(\frac{n-1}{2-n}\right)$ & $\log \mathrm{K}_{2}$ \\
\hline 10.00 & 5.60 & 6.47 & 6.55 & 0.08 & 1.9503 & 1.41 & & \\
10.23 & 5.65 & 6.62 & 6.72 & 0.11 & 1.4792 & 1.26 & -0.0361 & 1.2239 \\
\hline
\end{tabular}

$\operatorname{LogK}_{2}$ (Average value) $=1.2239$

Table 11: Point-wise method, Mg (Hydrolysed PSHA)

\begin{tabular}{|l|l|l|l|l|l|l|l|l|}
\hline $\mathrm{pH}$ & $\mathrm{BV}_{1}$ & $\mathrm{BV}_{2}$ & $\mathrm{BV}_{3}$ & $\left(\mathrm{~V}_{3}-\mathrm{V}_{2}\right)$ & $\mathrm{n}$ & $\mathrm{pL}$ & $\log \left(\frac{n}{n-1}\right)$ & LogK $_{1}$ \\
\hline 8.50 & 5.30 & 6.29 & 6.31 & 0.02 & 0.2750 & 2.64 & -0.4290 & 2.2110 \\
8.72 & 5.35 & 6.37 & 6.39 & 0.02 & 0.2858 & 2.42 & -0.3978 & 2.0222 \\
9.00 & 5.40 & 6.46 & 6.49 & 0.03 & 0.4648 & 2.14 & -0.0612 & 2.0788 \\
9.22 & 5.45 & 6.55 & 6.59 & 0.04 & 0.6667 & 1.94 & 0.3010 & 2.2410 \\
\hline
\end{tabular}

$\log _{\mathbf{1}}($ Average value) $=2.1382 \pm 0.1046$ 
BAJOPAS Volume 14 Number 1,June, 2021

Table 12: Point-wise method, Mg (Hydrolysed PSHA)

\begin{tabular}{|l|l|l|l|l|l|l|l|l|}
\hline $\mathrm{pH}$ & $\mathrm{BV}_{1}$ & $\mathrm{BV}_{2}$ & $\mathrm{BV}_{3}$ & $\left(\mathrm{~V}_{3}-\mathrm{V}_{2}\right)$ & $\mathrm{n}$ & $\mathrm{pL}$ & $\log \left(\frac{n-1}{2-n}\right)$ & LogK $_{2}$ \\
\hline 9.51 & 5.55 & 6.66 & 6.71 & 0.05 & 0.9650 & 1.67 & & \\
9.73 & 5.55 & 6.78 & 6.84 & 0.06 & 1.4042 & 1.47 & -0.1686 & 1.3014 \\
10.00 & 5.60 & 6.90 & 6.93 & 0.06 & 1.7838 & 1.23 & 0.5593 & 1.7893 \\
10.23 & 5.65 & 7.05 & 7.10 & 0.06 & 3.1429 & 1.10 & & \\
10.49 & 5.70 & 7.10 & 7.18 & 0.07 & 3.6492 & 0.83 & & \\
\hline
\end{tabular}

LogK $_{2}($ Average value $)=1.5453 \pm 0.3450$

Table 13: Point-wise method, Mg (Unhydrolysed PSHA)

\begin{tabular}{|l|l|l|l|l|l|l|l|l|}
\hline $\mathrm{pH}$ & $\mathrm{BV}_{1}$ & $\mathrm{BV}_{2}$ & $\mathrm{BV}_{3}$ & $\mathrm{~V}_{3}-\mathrm{V}_{2}$ & $\mathrm{n}$ & $\mathrm{pL}$ & $\log \left(\frac{n}{n-1}\right)$ & $\operatorname{Log~}_{1}$ \\
\hline 8.50 & 5.30 & 5.81 & 5.85 & 0.04 & 0.2973 & 2.88 & -0.3736 & 2.5064 \\
8.72 & 5.35 & 5.90 & 5.94 & 0.04 & 0.3099 & 2.66 & -0.3477 & 2.3123 \\
9.00 & 5.40 & 6.00 & 6.04 & 0.04 & 0.3236 & 2.38 & -0.3202 & 2.0598 \\
9.22 & 5.45 & 6.10 & 6.15 & 0.05 & 0.4297 & 2.17 & -0.1230 & 2.0470 \\
9.51 & 5.50 & 6.20 & 6.26 & 0.06 & 0.5500 & 1.89 & 0.0871 & 1.9771 \\
9.73 & 5.55 & 6.33 & 6.40 & 0.07 & 0.7000 & 1.67 & 0.3680 & 2.0380 \\
\hline
\end{tabular}

LogK $_{1}$ (Average value) $=2.1568 \pm 0.2069$

Table 14: Point-wise method, Mg (Unhydrolysed PSHA)

\begin{tabular}{|l|l|l|l|l|l|l|l|l|}
\hline $\mathrm{pH}$ & $\mathrm{BV}_{1}$ & $\mathrm{BV}_{2}$ & $\mathrm{BV}_{3}$ & $\mathrm{~V}_{3}-\mathrm{V}_{2}$ & $\mathrm{n}$ & $\mathrm{pL}$ & $\log \left(\frac{n-1}{2-n}\right)$ & $\log \mathrm{K}_{2}$ \\
\hline 10.00 & 5.60 & 6.47 & 6.55 & 0.08 & 0.9148 & 1.41 & & \\
10.23 & 5.65 & 6.62 & 6.71 & 0.09 & 1.2102 & 1.20 & -0.5749 & 0.6251 \\
10.49 & 5.70 & 6.80 & 6.92 & 0.09 & 1.5968 & 1.03 & 0.1703 & 1.2003 \\
\hline
\end{tabular}

LogK $_{2}$ (Average value) $=0.9127 \pm 0.4070$

Table15:Point-wise method, Cd (Hydrolysed PSHA)

\begin{tabular}{|l|l|l|l|l|l|l|l|l|}
\hline $\mathrm{pH}$ & $\mathrm{BV}_{1}$ & $\mathrm{BV}_{2}$ & $\mathrm{BV}_{3}$ & $\left(\mathrm{~V}_{3}-\mathrm{V}_{2}\right)$ & $\mathrm{n}$ & $\mathrm{pL}$ & $\log \left(\frac{n}{1-n}\right)$ & LogK $_{1}$ \\
\hline 8.50 & 5.30 & 6.29 & 6.31 & 0.02 & 0.2750 & 2.64 & -0.4210 & 2.2190 \\
8.72 & 5.35 & 6.37 & 6.40 & 0.03 & 0.4286 & 2.42 & -0.1249 & 2.2951 \\
9.00 & 5.40 & 6.46 & 6.49 & 0.03 & 0.4648 & 2.14 & -0.0612 & 2.0788 \\
9.22 & 5.45 & 6.55 & 6.59 & 0.04 & 0.6667 & 1.96 & 0.3010 & 2.2610 \\
9.51 & 5.55 & 6.66 & 6.70 & 0.04 & 0.7720 & 1.67 & 0.5297 & 2.1997 \\
\hline
\end{tabular}

LogK $_{\mathbf{1}}$ (Average value) $=2.2108 \pm 0.0825$

Table 16: Point-wise method, Cd (Hydrolysed PSHA)

\begin{tabular}{|l|l|l|l|l|l|l|l|l|}
\hline $\mathrm{pH}$ & $\mathrm{BV}_{1}$ & $\mathrm{BV}_{2}$ & $\mathrm{BV}_{3}$ & $\left(\mathrm{~V}_{3}-\mathrm{V}_{2}\right)$ & $\mathrm{n}$ & $\mathrm{pL}$ & $\log \left(\frac{n-1}{2-n}\right)$ & Log $_{2}$ \\
\hline 9.73 & 5.55 & 6.78 & 6.83 & 0.06 & 1.4042 & 1.47 & -0.1686 & 1.3014 \\
10.00 & 5.60 & 6.90 & 6.95 & 0.06 & 1.7838 & 1.23 & 0.5593 & 1.7893 \\
10.23 & 5.65 & 7.05 & 7.10 & 0.06 & 3.1429 & 1.09 & & \\
10.49 & 5.70 & 7.10 & 7.16 & 0.06 & 3.1429 & 0.89 & & \\
& & & & & & & & \\
\hline
\end{tabular}

$\operatorname{LogK}_{2}$ (Average value) $=1.5453 \pm 0.3450$

Table 17: Point-wise method, Cd (Unhydrolysed PSHA)

\begin{tabular}{|l|l|l|l|l|l|l|l|l|}
\hline $\mathrm{pH}$ & $\mathrm{BV}_{1}$ & $\mathrm{BV}_{2}$ & $\mathrm{BV}_{3}$ & $\mathrm{~V}_{3}-\mathrm{V}_{2}$ & $\mathrm{n}$ & $\mathrm{pL}$ & $\log \left(\frac{n}{n-1}\right)$ & $\operatorname{Log~}_{1}$ \\
\hline 8.50 & 5.30 & 5.81 & 5.86 & 0.05 & 0.3717 & 2.88 & -0.2280 & 2.6520 \\
8.72 & 5.35 & 5.90 & 5.95 & 0.05 & 0.3873 & 2.66 & -0.1992 & 2.4608 \\
9.00 & 5.40 & 6.00 & 6.06 & 0.06 & 0.4853 & 2.38 & -0.0255 & 2.3545 \\
9.22 & 5.45 & 6.10 & 6.16 & 0.06 & 0.5157 & 2.18 & -0.0272 & 2.2072 \\
9.51 & 5.50 & 6.20 & 6.27 & 0.07 & 0.6417 & 1.89 & 0.2530 & 1.1430 \\
9.73 & 5.55 & 6.33 & 6.41 & 0.08 & 0.8000 & 1.69 & 0.6020 & 2.2920 \\
& & & & & & & & \\
\hline
\end{tabular}

$\operatorname{LogK}_{1}($ Average value $)=2.2516 \pm 0.5380$ 
BAJOPAS Volume 14 Number 1,June, 2021

Table 18: Point-wise method, Cd (Unhydrolysed PSHA)

\begin{tabular}{|l|l|l|l|l|l|l|l|l|}
\hline $\mathrm{pH}$ & $\mathrm{BV}_{1}$ & $\mathrm{BV}_{2}$ & $\mathrm{BV}_{3}$ & $\mathrm{~V}_{3}-\mathrm{V}_{2}$ & $\mathrm{n}$ & $\mathrm{pL}$ & $\log \left(\frac{n-1}{2-n}\right)$ & $\log \mathrm{K}_{2}$ \\
\hline 10.00 & 5.60 & 6.47 & 6.57 & 0.10 & 1.1434 & 1.43 & & \\
10.23 & 5.65 & 6.62 & 6.72 & 0.10 & 1.3448 & 1.23 & -0.2788 & 0.9512 \\
10.49 & 5.70 & 6.80 & 6.90 & 0.10 & 1.7742 & 1.03 & 0.5351 & 1.5651 \\
\hline
\end{tabular}

$\operatorname{LogK}_{2}($ Average value $)=1.2581 \pm 0.4340$

Table 19: Stepwise and overall Stability constants of thehydrolysed and unhydrolysed divalent metal (II) complexes

\begin{tabular}{|c|c|c|c|}
\hline Chelates & LogK $_{1}$ & $\log _{2}$ & Log $\beta$ \\
\hline [Cu (Hydrolysed PSHA-1) $\left.{ }_{2}\right]$ & 2.4788 & 1.4280 & 3.9068 \\
\hline$\left[\mathrm{Pb}(\text { Hydrolysed PSHA-1) })_{2}\right]$ & 2.5832 & 1.1963 & 3.7795 \\
\hline$\left[\mathrm{Cd}(\text { Hydrolysed PSHA-1 })_{2}\right]$ & 2.2108 & 1.5453 & 3.7561 \\
\hline$\left[\mathrm{Mg}(\text { Hydrolysed PSHA-1 })_{2}\right]$ & 2.1382 & 1.5453 & 3.6835 \\
\hline [Cu (Unhydrolysed PSHA-1) & 2.3059 & 1.2209 & 3.5268 \\
\hline$[\mathrm{Pb}$ (Unhydrolysed PSHA-1) 2$]$ & 2.2364 & 1.2239 & 3.4603 \\
\hline [Cd (Unhydrolysed PSHA-1) 2 ] & 2.2516 & 1.2581 & 3.5097 \\
\hline$[\mathrm{Mg}$ (Unydrolysed PSHA-1) & 2.1568 & 0.9127 & 3.0695 \\
\hline
\end{tabular}

The results obtained (Table19) shows the stepwise and overall stability constants to be not high indicating low stability of the complexes, because the solubility of most metal ions in the basic $\mathrm{pH}$ range is minimal due to metal hydroxide precipitation (Karimi, 2017). In general, the stepwise stability constants $\left(K_{1}\right.$ and $K_{2}$ ) follow the order $K_{1}>K_{2}$ for the copper, lead, magnesium and cadmium complexes respectively. The steady decrease of the values with increasing number of ligands is in agreement with the prediction made by researchers (Na'aliya, 2013). The decrease could be attributed to the fact that as the number of the ligands (Humate ions) that enters the coordination zone increases the aqua molecules available for replacement by the ligands become less. Thus, the metal ions become less electron loving with progressive intake of the ligand and this results in the decrease in the values of the constants (Na'aliya, 2013). Also the stability of the complexes is influenced by the size and number of the chelate rings(Mackay and Mackay,2002).All the complexes form rings in their structure as humate, a bidentate ligand, bond the metal ions in the ratio 1:2 (Boguta and Sokolowska, 2016) forming chelate rings. The values of the overall stability constants $(\log \beta)$ obtained for humate complexes are not high indicating low stability as the values are not high. LogK values for copper-humates (Table 3 to 6) obtained in this study are lower than those reported for the complexes of humic acids (Pandey et al., 2015; Dinu, 2013; Kaschl et al., 2010 and Gilbeto and Jorg, 2001). The values of LogK(Table 7 to 10 ) forlead-humates are lower than those reported for the lead in the literature (Dinu, 2013; Gilbeto and Jorg 2001). Log K values(Table 11 to 14 ) for magnesium-humates obtained in this study are close to those reported by (Pandey et al., 2015). Log K values of cadmium-humates (Table 15 to 18 ) obtained in this work near to the one reported by (Dinu, 2013 and Pandey et al., 2015).The difference between the reported values and the values obtained in this study might be probably as a result of acid hydrolysis of humic acid. The values of the overall stability constants $(\log \beta)$ of the copper humates complexes presented in Table 19 is high than that of other metal humate complexes, show relatively high stability of CuHA complexes, show the following order of stability: $\mathrm{Cu}>\mathrm{Pb}>\mathrm{Cd}>\mathrm{Mg}$; which are in close agreement to the findings of (Dinu, 2013 and Pandey et al., 2015).The high stability of Cuhumate chelate could be attributed to the existence of coordinate covalent bond between the complexing agents and the $\mathrm{Cu}^{2+}$ ions. Since, $\mathrm{Cu}^{2+}$ being a metal of the transitional series with $3 d^{9}$ electronic configurations can accept the electrons from the complexing agents. Similarly, the low stabilities of $\mathrm{Pb}, \mathrm{Cd}$ and $\mathrm{Mg}$ complexes could be explained by that $\mathrm{Pb}^{2+}$ with $6 s^{2}, \mathrm{Cd}^{2+}$ with $4 \mathrm{~d}^{10}$ and $\mathrm{Mg}^{2+}$ with $2 \mathrm{p}^{6}$ their electronic configuration has a completely filled $\mathrm{d}, \mathrm{p}$ and $\mathrm{s}$ orbitals. Moreover, the stabilities of metal ions with hydrolysed humic acid from peat soil were higher than those with unhydrolysed humic acid from peat soil; which is ascribed to the high content of acidity in hydrolysed humic acid than unhydrolysed humic acid. 
BAJOPAS Volume 14 Number 1,June, 2021 CONCLUSION

The values of logk for $\mathrm{Cu}(\mathrm{II})$ hydrolysed humic acid complex was higher followed by $\mathrm{Pb}$ (II), $\mathrm{Cd}(\mathrm{II})$ and $\mathrm{Mg}$ (II) hydrolysed humic acid complexes as compared with metal(II) unhydrolysed humic acid complexes. This indicates acid hydrolysis of humic acid can

\section{REFERENCES}

Almeida, V.R. and Szpoganicz, B. (2015). Humic Acid Potentiometric Response Patterns:Out- of Equilibrium Properties and Species Distribution Modelling. Chemical. Biol. Technol. Agric. 2: 17.

Anđelković, T., Nikolić, R., Bojić, A.,Anđelković, D., and Nikolic G.,(2010). Binding of Cadmium to Soil Humic Acid as A Function of Carboxyl Group Content. Macedonian Journal of Chemistry and Chemical Engineering.29(2): 215-224.

Anil, B. N. and Maroti, N. (2008). Studies on Influence of Die-Lectric Constants on Complex Equilibria between Substituted Py-Razalines and Lanthanide Metal Ions pH-Metrically. Amer.-Euras. scient. Res. 3(2): 212-216.

Ashok, K., Pandey, S. P. and Misra, V (2000). Stability Constants of Metal-Humic Acid Complexes and its Role in Environmental Detoxification. Journal of Ecotoxicology and Environmental Safety. 47(2):157-200.

Badr, M. H., El-Halafawi, M. H. and Abd El-al Zeid, E. R. (2012). Comparison Between the Effect of Ionic Strength on Acidity and Dissociation Constants of Humic Acids Extracted from Sewage Sludge and Nile Water Hyacinth Composts.Global Journal of Environmental Research 6 (1): 36-43.

Baruah, M.K., Borah, D., Saikia, P.P., Paul, S., Sharma, T. (2015). Evaluation of pKa Values of Soil Humic Acids and their Complexation Properties. International Journal of Plant \& Soil Science 6(4) : 218-228.

Boguta, P. Sokolowska, Z. (2016). Interactions of $\mathrm{Zn}$ (II) Ions with Humic Acids Isolated from Various Types of Soils. Effect of $\mathrm{pH}, \mathrm{Zn}$ Concentrations and Humic Acids Chemical Properties. Journal of Geochemical Explaration 168. 119-126.

Borges, F., Guimaraes, C., Lima, L.F.C., Pinto, I. and Reis, S.(2005). Potentiometric Studies on the Complexation of Copper(II) by Phenolic Acids as Discrete Ligand Models of enhance the complexation behavior of humic acid with metal (II) ions. However, the higher values of $\log \beta$ for $\mathrm{Cu}(\mathrm{II}), \mathrm{Pb}(\mathrm{II}), \mathrm{Cd}(\mathrm{II})$ and $\mathrm{Mg}(\mathrm{II})$ hydrolysed humic acid complexes indicates more stable stepwise complexes formed as compared with $\mathrm{Cu}(\mathrm{II}), \mathrm{Pb}$ (II), $\mathrm{Cd}$ (II) and $\mathrm{Mg}(\mathrm{II})$ unhydrolysed humic acid complexes.

Humic Substances Talanta 66 (2005) 670-673.

Chefetz, B., Salloum, M. J., Deshmulkin, A. P. and Hatcher, P. (2002). Structural Components of Humic Acids as Determined by Chemical Modifications and Carbon-13 NMR, Pyrolysis, and Thermochemolysis- Gas Chromatography/Mass Spectrometry. Soil Science Society of American Journal Abstract Division S-2- Soil Chemistry66. 1159-1171.

Dinu, M. I. (2013). Metals Complexation with Humic Acids in Surface Water of Different Environ. Sci. Technol. 31(1): 1-17.

Fernandes, A.N., Giacomelli, C., Giovanela, M. Vaz, D.V. Szpoganicz, B. and Maria M. D. (2009). Potentiometric Acidity Determination in Humic Substances Influenced by Different Analytical Procedures.J. Braz. Chem. Soc. 20 (9):14.

Gamal, A. H. (2015). Stability Constants of Rhenium (V) Metal Complexes with Selected Drugs. Pyrex Journal of Research in Environmental Studies. 2(2): 006-014.

Janrao, D. M., Pathan, J., Kayande, D.D., and Mulla, J.J. (2014). An Over View of Potentiometric Determination of Stability Constants of Metal Complexes. Sci. Revs. Chem. Commun.: 4(1), 2014, 11-24.

Karimi, H. (2017). Effect of pH and Initial Pb(II) Concentration on the Lead Removal Efficiency from Waste Water Using $\mathrm{Ca}(\mathrm{OH})_{2}$. International Journal of Water and Waste Water Treatment 3.2

Kaschl, A. Romheld, V. and Chen, Y. (2010). Binding of Cadmium, Copper and Zinc to Humic Substances Originating from Municipal Solid Waste Compost. Israel Journal of Chemistry Vol. 42(1): 89-98.

Kostic, I. S., Tatjana, P, A., Nikolic, R. S., Cvetkovic, T. P., Pavlovic, D. D., Aleksandar, L.J. and Bojic, A. (2012). Comparative Study of Binding Strengths of Heavy Metals with Humic Acid. J.serb. Chem. Soc. 76(9) pp 1-20. 
BAJOPAS Volume 14 Number 1,June, 2021

Na'aliya, J. (2013). Determination of Stepwise Stability Constants and Gibbs free Energy Change of Trisprolina to Complexes of some Divalent Transition Metal ions. Bayero Journal of Pure and Applied Sciences 6(2): 112-114.

Omar, A. A. and Ali, E. A. (2015). Potentiometric Studies on Complexes of $\mathrm{Cr}$ (III) and $\mathrm{Zr}$ (IV) with some Carboxylic Acids. International Journal of Advanced Chemistry, 3(1) 25-

37.

Pandey, A. K. Pandey, S. D. and Misr, V. (2015).Stability Constants of Metal- Humic Acid Complexes and Its Role in Environmental Detoxification. J. Ecotoxicology and Environmental Safety. 47(1):195-200.

Ram, N. and Raman, K.V. (1984). Stability Constants of Complexes of Metals with
Humicand Fuvic Acids under Non- acidConditions. Journal of Plant Nutrition and Soil Sciences.

147:171-176.

Santosh, D. D., Ashok, B. K., Vijay, J. T., Shivraj, G. W. and Vinay, V. W. (2011). Potentiometric Studies of Elec-Trolyte Effects on Complex Equilibria of Some Substituted 5-(2-hydroxy Phenyl) Pyrazoles. Der pharm. 3 (6): 75-83.

Sayyed, H. and Abdul Rahim, M. F. (2012). Studies of Binary Complexes of Metal Ions with Mandelic Acid by Potentiometry. Chem. J. 02 (6): 206209.

Shirvani, M. Moradian, E. Khalili, B. Bakhtiary, S. (2015). Interaction of $\mathrm{Cd}$ and $\mathrm{Pb}$ with Humate-Palygorskite and HumateSepiolite Complexes. Journal of water, air and pollution 3: 220-228. 


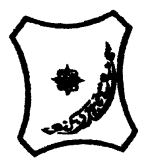

Bayero Journal of Pure and Applied Sciences, 14(1): 54 - 63

Received: November, 2020

Accepted: April, 2021

ISSN $2006-6996$

\title{
STABILITY CONSTANTS OF COMPLEXES OF METAL IONS WITH PEATSOIL HUMIC ACIDS UNDER NON-ACID-CONDITIONS
}

\author{
${ }^{* 1}$ Sabo, Yusuf ${ }^{2}$ Jimoh, W.L.O., ${ }^{3}$ Isa Baba Koki and ${ }^{4}$ Sholadoye, Q. 0. \\ ${ }^{1}$ Department of Pure and Industrial Chemistry, Bayero University, Kano \\ ${ }^{3}$ Department of Chemistry, Yusuf Maitama Sule University Kano. P.M.B. 3220 Kano, Nigeria. \\ ${ }^{4}$ Department of Chemistry, Nigerian Police Academy, Wudil, Kano-Nigeria
}

*Correspondence E-mail; saboyusuf18@yahoo.com

ABSTRACT

Stability constants of complexes of four divalent metal ions viz. $\mathrm{Cu}^{2+}, \mathrm{Pb}^{2+}, \mathrm{Mg}^{2+}$ and $\mathrm{Cd}^{2+}$ with humic acids (HA) were determined by potentiometric titration of humic acids with the corresponding salt of the divalent metals in aqueous media under non-acid-condition. The log $K$ (logarithm of the stability constant) ranged from 1.0942 to 2.7471 for metalhumic acid complexes were determined using point-wise computational method. The order of stability constants were obtained as follows: $\mathrm{Cu}>\mathrm{Pb}>\mathrm{Cd}>\mathrm{Mg}$ for metal $-\mathrm{HA}$ complexes respectively, indicating a higher degree of complexation with Cu metal ion.

Keywords: stability constant, humic acid, potentiometric titration, divalent metals, acid hydrolysis.

\section{NTRODUCTION}

The stability constant of a complex is the numerical expression of its stability and provides a quantitative measure of affinity of the metal ion to the complexing agent. An understanding of the relative stability of metal-complexes helps in predicting the behavior of metal ions in the soil (Ram and Raman, 1982). Extensive researches has been done to determine the stability constants of the complexes formed between humic acid (HA) with a number of metal ions. Ashok et al., (2000) reported that humic acid with hydroxyl, phenoxyl and carboxyl reactive groups can form coordination compound with metal ions at $\mathrm{pH}$ 3.5. The stability constants(Log K) for different metalhumic acid complexes indicated the following order of the stabilities of complexes formed between humic acid and metal ion, $\mathrm{Cu}>\mathrm{Fe}$ $>\mathrm{Pb}>\mathrm{Ni}>\mathrm{Co}>\mathrm{Ca}>\mathrm{Cd}>\mathrm{Zn}>\mathrm{Mn}>\mathrm{Mg}$. Andelkovic et al., (2010) investigated the binding of $\mathrm{Cd}$ (II) to soil humic acid at pH 6.5 and in $0.1 \mathrm{M} \mathrm{KNO}_{3}$ ionic medium. The stability constant for binding indicating greater stability in the case when carboxyl groups are involved in complexation reaction. Kostic et al.,(2012) investigated the complexation of humic acid with certain heavy metal ions (Co(II), $\mathrm{Ni}(\mathrm{II}), \mathrm{Cu}(\mathrm{II})$,
$\mathrm{Zn}(\mathrm{II})$, and $\mathrm{Pb}(\mathrm{II})$. The experiment was performed at $25^{\circ} \mathrm{C}$, at pH 4.0 and ionic strength of $0.01 \mathrm{M}$. Stability constant of complex between $\mathrm{Pb}$ (II) ions and humic acid is greater than stability constants of other investigated metalhumate complexes. Bogata and Sokolowska (2016) analyses the interaction between humic acids from different soils and $\mathrm{Zn}$ (II) ions at wide concentration ranges and at $\mathrm{pH} 5$. Studies have showed significant impact of $\mathrm{Zn}$ concentration, $\mathrm{pH}$ and some properties of humic acids with zinc.But all of these studies were limited to acidic $\mathrm{pH}$ range. Therefore, the present study was carried out to determine and compare the stability constants of complexes of metal ions with hydrolysed peat soil humic acid and unhydrolysed peat soil humic under non-acid conditions.

\section{MATERIALS AND METHODS}

Analytical grade chemicals used includes hydrochloric acid $(\mathrm{HCl})$, nitric acid $\left(\mathrm{HNO}_{3}\right)$, sodium hydroxide $(\mathrm{NaOH})$, lead nitrate $\mathrm{Pb}\left(\mathrm{NO}_{3}\right)_{2}$, copper nitrate $\mathrm{Cu}\left(\mathrm{NO}_{3}\right)_{2} \cdot 3 \mathrm{H}_{2} \mathrm{O}$, cadmium nitrate $\mathrm{Cd}\left(\mathrm{NO}_{3}\right)_{2} \cdot 4 \mathrm{H}_{2} \mathrm{O}$, magnesium nitrate $\mathrm{Mg}\left(\mathrm{NO}_{3}\right)_{2} \cdot 6 \mathrm{H}_{2} \mathrm{O}$, potassium nitrate $\left(\mathrm{KNO}_{3}\right)$, calcium chloride $\left(\mathrm{CaCl}_{2}\right)$, (sigma-Aldrich). Dowex 50WX8, (20-50 mesh) from Fluka. 


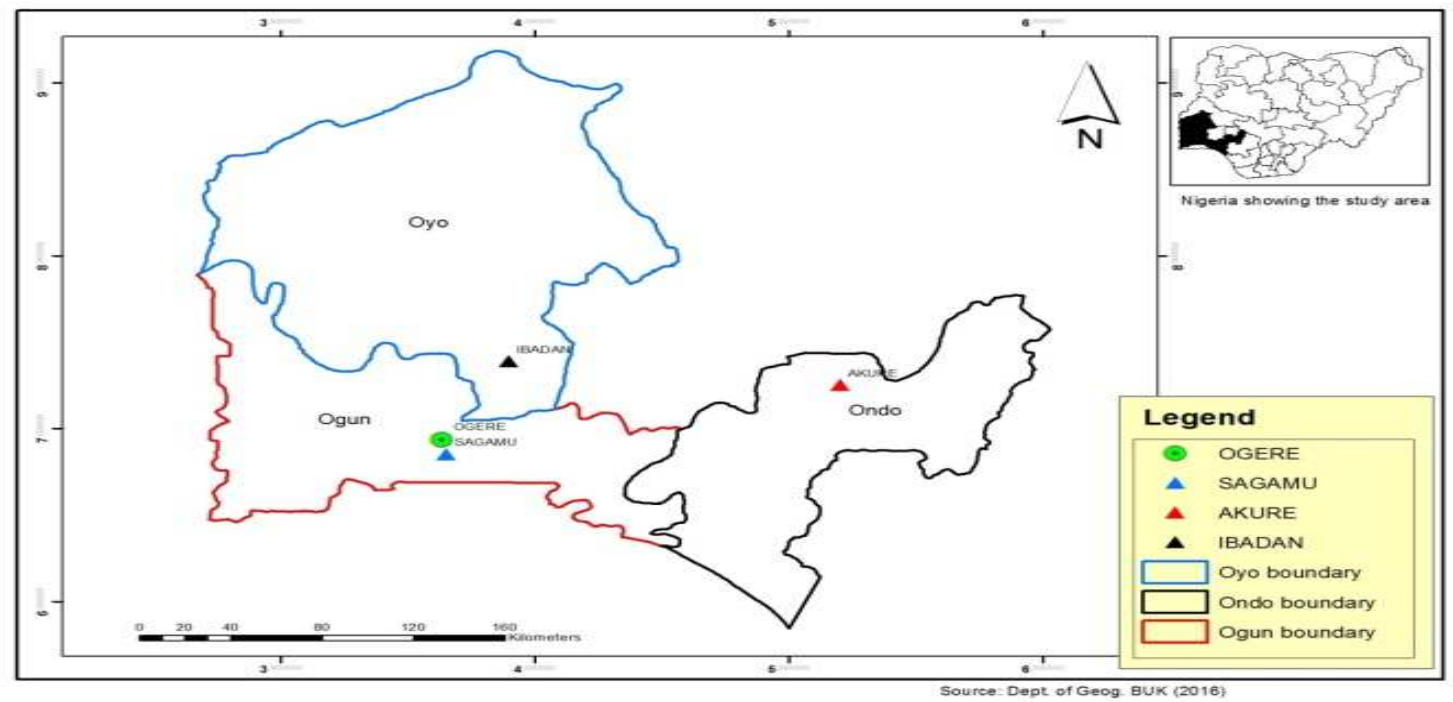

Figure 1: Map showing the sampling point at Sagamu Town, Ogun State.

\section{Description of Sampling Area}

Sagamu has geographical coordinates between $6^{\circ} 50^{\prime}$ north; $3^{\circ} 38^{\prime}$ east is located in south western region of Nigeria. The region has tropical wet and dry climate with a lengthy wet season and relatively constant temperatures throughout the course of the year. Wet season runs from March to October, November to December forms the region dry season. The vegetation type of the region is savannah which is really grassland with small bushes and occasional big trees. Grassland soils have substantially higher organic matter content than forest soils (Novackova, 2011).

\section{Sample Collection}

The Peatsoil samples were collected from four different sampling points $(0-10 \mathrm{~cm}$ depth) in Sagamu into polyethylene bag with plastic spoons. Samples were taken to the laboratory, extraneous materials were removed; the samples were air-dried, crushed and ground to a fine powder in a mortar passed through a $0.20 \mathrm{~mm}$ sieve. The samples were kept for analysis.

\section{Isolation and purification of humic acid from peat soil sample}

Peatsoil sample $(100 \mathrm{~g})$ was mixed with 1000 $\mathrm{cm}^{3}$ of $0.1 \mathrm{M} \mathrm{NaOH}$ solution, shaken for 3hours and left to stand overnight. Dark-coloured supernatant was obtained and decanted from solid residue. The dark-coloured supernatant was acidified to $(\mathrm{pH}=1.0)$ with $6 \mathrm{M} \mathrm{HCl}$ stirred and allowed to stand for 6 hours. Yellowish brown supernatant and dark-brown precipitate were obtained. The yellowish brown supernatant was decanted followed by centrifuge and discarded. The dark-brown precipitate was mixed with $500 \mathrm{~cm}^{3}$ of $0.1 \mathrm{M} \mathrm{NaOH}$ solution followed by passing through dowex resin. The dark-brown solution was acidified to $(\mathrm{pH}=1.0)$ with $6 \mathrm{M} \mathrm{HCl}$ stirred and allowed to stand for 3 hours. The dark-brown precipitate was washed several times with deionized water. The supernatant was treated with $\mathrm{AgNO}_{3}$ solution until no white precipitate observed. The humic acid was transferred to weighed crucible and dried at $60^{\circ} \mathrm{C}$ in an oven for 12 hours. The humic acid was cooled and dried in the desiccator, weighed and recorded. The obtained humic acid was dried again at $60^{\circ} \mathrm{C}$ for additional 6 hours cooled and dried in the desiccator, weighed and recorded constant weight was obtained (Baruah et al., 2015).

\section{FT-IR analysis}

FT-IR spectra of humic acid sample was analysed using Carry 630 FT-IR Agilent Technologies.

Unhydrolysed compost humic acid

The unhydrolysed humic acid was obtained after isolation and purification of compost humic acid and kept for investigation.

\section{Acid hydrolysis of Peatsoil acid}

Peatsoil humic acid sample (1g) was refluxed for 12 hours at $\left(160^{\circ} \mathrm{C}\right)$ with $50 \mathrm{~cm}^{3}$ of $6 \mathrm{M} \mathrm{HCl}$. The mixture was allowed to cool, decanted, and centrifuged after hydrolysis. The insoluble residues were washed with distilled water via centrifugation several times, and the supernatant was treated with $\mathrm{AgNO}_{3}$ solution until no white precipitate was observed. The residue was thoroughly dried over $\mathrm{CaCl}_{2}$ in a desiccator at room temperature (Chefetz et al., 2002). Finally, the obtained hydrolysed humic acid was kept for investigation. 
BAJOPAS Volume 14 Number 1,June, 2021 Potentiometric Titrations

Potentiometric measurements were carried out using a pH-meter Jenway (model 3510) with combine electrode, the sensitivity of the $\mathrm{pH}$ meter is 0.01 units. The $\mathrm{pH}$ meter was switched on half an hour before starting the titration for initial warm up of the instrument. The instrument was calibrated with an aqueous standard buffer solution of $\mathrm{pH} 4.00$ and 10.0 (borate buffer) prepared from a "Qualigens" buffer tablets.

The following sets of solutions were prepared in a $250 \mathrm{~cm}^{3}$ volumetric flask separately for $\mathrm{pH}$ metric titrations.

(i) $5 \mathrm{~cm}^{3} 0.1 \mathrm{M} \mathrm{HCl}+40 \mathrm{~cm}^{3}$ deionized water

(ii) $5 \mathrm{~cm}^{3} 0.1 \mathrm{M} \mathrm{HCl}+39 \mathrm{~cm}^{3}$ deionized water $+1 \mathrm{~cm}^{3} 0.15 \mathrm{gcm}^{-3}$ humic acid

(iii) $5 \mathrm{~cm}^{3} 0.1 \mathrm{M} \mathrm{HCl}+37 \mathrm{~cm}^{3}$ deionized water $+1 \mathrm{~cm}^{3} 0.15 \mathrm{gcm}^{-3}$ humic acid

$$
+2 \mathrm{~cm}^{3} \quad 0.01 \mathrm{M} \mathrm{Cu} \text { (II) }
$$

The solutions were titrated against standardized $0.110 \mathrm{MNaOH}$ separately. The total volume of each mixture was adjusted to $50 \mathrm{~cm}^{3}$ and the ionic strength of the solutions was maintained constant at by adding appropriate amount of stock solution of $1 \mathrm{M} \mathrm{KNO}_{3}$ (Gamal, 2015; Omar and Ali, 2015). A magnetic stirrer was used to achieve thorough mixing of the interacting solutions at $550 \mathrm{rpm}$. The same set of experimental conditions was applied for potentiometric titration of remaining samples.

\section{Evaluation of pKa of Hydrolysed peat soil Humic Acids}

The proton-ligand formation number $\mathrm{n}_{\mathbf{A}}$ were calculated by Irving and Rossotti expression (Omar and Ali, 2015).

$\mathrm{nA}=\mathrm{Y}-\frac{(\mathrm{V} 2-\mathrm{V1})(\mathrm{No}-\mathrm{Eo})}{(\mathrm{VO}+\mathrm{V1}) \mathrm{TCL}}$ 1

Where: $Y$ is number of dissociable proton, $\left(\mathrm{V}_{2^{-}}\right.$ $V_{1}$ ) is the measure of displacement of the ligand curve relative to acid curve, $\mathrm{N}^{\circ}$ and $\mathrm{E}^{\circ}$ are the resultant concentration of alkali solution, free acid solution, $\mathrm{T}_{\mathrm{cL}}{ }^{\circ}$ is the total ligand concentration, $\mathrm{V}^{\circ}$ is the total volume of titration solution, $V_{1}$ is the volume of alkali added to acid solution, $V_{2}$ is the volume of alkali added to acid solution + ligand solution, acid dissociation constants (pKa - values) of ligand were calculated by algebraic method point wise calculation (Tables 1 ). The dissociation constants (pKa) were calculated according to the following relation:

$\mathrm{pKa}=\mathrm{pH}+\log \left(\frac{n A}{1-n A}\right)$ 2

Where: pKa is the acid dissociation constant, $\mathrm{n}_{\mathrm{A}}$ is the Proton-ligand formation number and $\mathrm{pH}$ is the pH-values (Omar and Ali, 2015).

\section{Determination of metal-ligand stability constants $(\log K)$ of complexes}

The potentiometric measurement for the determination of stability constant of a complex in solution is based on the fact that the redox potential of the couple $\frac{M^{+(m-n)}}{M^{+m}}$ is shifted significantly on complexation of the metal ion with the ligand. This method involves change in hydrogen ion concentration $\left[\mathrm{H}^{+}\right]$due to the displacement or association of one or more protons taking place during complexation reaction. This change can be found out by titrating the solutions containing free acid, acid with ligand, and acid with ligand and metal ion, individually against a standard alkali solution at a constant ionic strength or temperature. Either ionic strength or temperature may be varied for different sets of solutions. In all the cases, the change in the $\mathrm{pH}$ of the solution is measured after each addition of a known amount of alkali to the reaction cell which contains the reaction mixture. The titration curves are then drawn by plotting the measured $\mathrm{pH}$ values against the corresponding volume of alkali added and the stability constants of the complexes are determined from the titration curves by employing $\mathrm{pH}$-metric titration technique given by (Irving and Rossoti).

Metal-ligand stability constants ( $\log \mathrm{K}$ ) were determined by using the following relations:

$$
\bar{n}=\frac{\left(V_{3}-V_{2}\right)\left(E^{0}+N^{0}\right)}{\left(V^{0}+V_{2}\right) \bar{n}_{A} T_{m}^{0}}
$$

and

$$
P L=\log _{10}\left\{\frac{1+\beta_{n}^{H} \frac{1}{[\text { anti } \log \mathrm{pH}]^{\mathrm{n}}}}{\mathrm{T}_{\mathrm{L}}^{0}-n \bar{T}_{m}^{0}} \mathrm{X} \frac{\left(V^{0}+V_{3}\right)}{V^{0}}\right\}
$$


BAJOPAS Volume 14 Number 1,June, 2021

Where $T_{L}, T^{\circ}, E^{\circ}$, and $V^{\circ}$ havethe same significance as in equation (1) above, $T_{m}$ denotes the total concentration of metal present in solution, $V_{3}$ is the volume of metal ions present in solution and $\beta^{H}$ is the overall proton ligand stability constant. The metal-ligand stability constants (log K) were determined by employing point wise computational Method (eq. 5 and 6).

$\operatorname{LogK}_{1}=\log \left(\frac{n}{1-n}\right)+\mathrm{pL}$ .5

$\operatorname{LogK}_{2}=\log \left(\frac{1-n}{2-n}\right)+\mathrm{pL}$ ...6

Where: Log $\mathrm{K}$ is the metal-ligand stability constant, $\mathrm{pL}$ is the Free ligand exponent function, $\mathbf{n}$ is the Average number of ligand attached with metal ion (Janraoet al., 2014). The results obtained were analyzed by an ORIGIN 2016 program using titration data and then the proton-ligand stability constants (pKa) and Metal-ligand stability constant (LogK) calculated (Omar and Ali, 2015).

\section{RESULTS AND DISCUSSION}

Fourier transformed infrared (FT-IR) spectra of isolated humic acid from peat soils Figure 2 had distinct clear absorption bands indicating the presence of major humic acid structural elemental groups such as $\mathrm{H}$ bonded $\mathrm{OH}$ $\left(3680 \mathrm{~cm}^{-1}\right.$ peak $), C=0$ of carbonyl $\left(1721 \mathrm{~cm}^{-1}\right.$ peak), functional groups of aliphatic components $\mathrm{CH}_{2}\left(2918 \mathrm{~cm}^{-1}\right.$ peak) and $\mathrm{C}-\mathrm{O}$ stretching of polysaccharide $\left(1168 \mathrm{~cm}^{-1}\right.$ peak). The positions of the absorption bands of the spectra fell within typical major absorption bands of humic acid which is at frequencies 3680, 2918, 1721, 1168 $\mathrm{cm}^{-1}$. The first peak centred in the vicinity of $3680 \mathrm{~cm}^{-1}$ region is attributed to phenol $\mathrm{OH}$ group bounded by intermolecular $\mathrm{H}$ bonds. The $2918 \mathrm{~cm}^{-1}$ band usually has absorption maximum at $2918 \mathrm{~cm}^{-1}$ which is due to $\mathrm{C}-\mathrm{H}$ stretching of alkane group $\left(\mathrm{CH}_{2}\right)$. The next major absorption band is $1721 \mathrm{~cm}^{-1}$. This band has been commonly ascribed to $\mathrm{C}=\mathrm{O}$ stretching of mainly carboxyl group $(\mathrm{COOH})$ with trace amount of ketones. The last peak was observed at 1168 $\mathrm{cm}^{-1}$ due to $\mathrm{C}-\mathrm{O}$ stretching of polysaccharides and this peak appeared also in the spectra of humic acid from peat soil. The FTIR spectra of the isolated humic acid contained all major characteristic absorption peaks of humic acid. These absorption peaks indicated the presence of the major structural elements of humic acid namely $\mathrm{H}$ bonded $\mathrm{OH}, \mathrm{C}=\mathrm{C}$ of aromatic ring, $\mathrm{C}=\mathrm{O}$ of carbonyl group (both carboxyl and ketonic), $\mathrm{CH}_{2}$ group. This strongly supports the presence of humic acid.

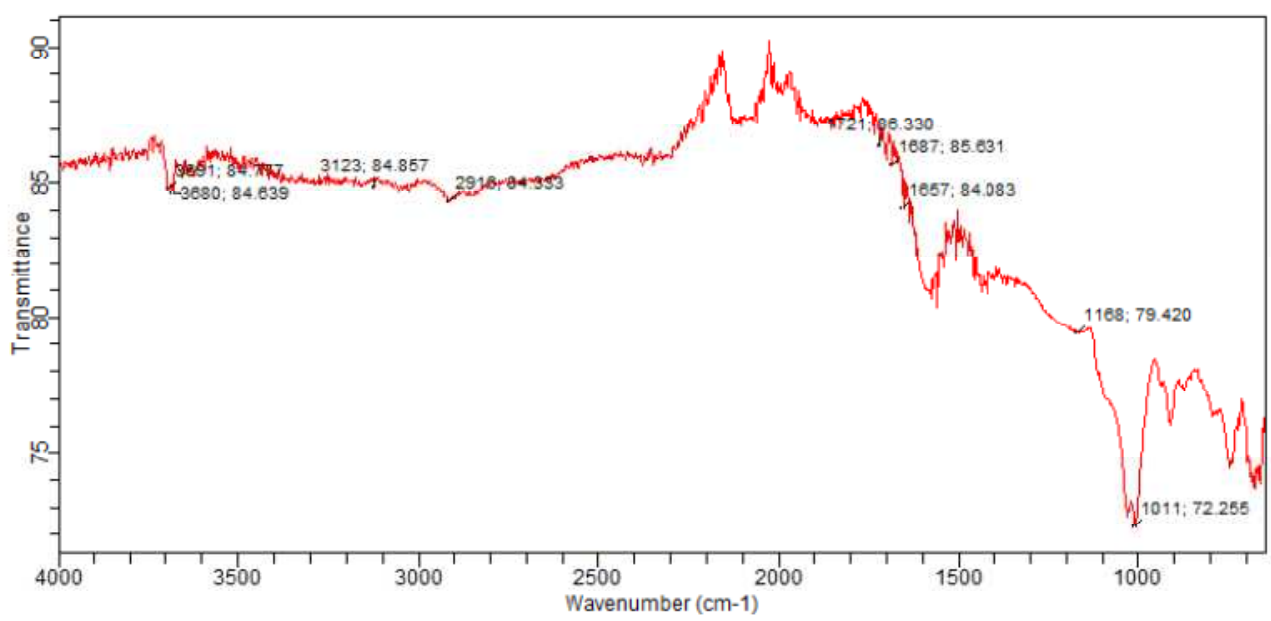

Fig. 2 : FT-IR spectraof peatsoilhumic acid (PSHA)

\section{Evaluation of acid dissociation constant (pka) of acid hydrolysed peat soil humicacid at phenolic group}

The value of the dissociation constant of the peat soil humic acid (PSHA) that underwent acidhydrolysis studied was found to be 8.9299 as shown Table 1, which is lower than the literaturevalues reported by Almeida and Szpoganics, (2015), Borges et al., (2005); Badr et al., (2012)and Fernandes et al,.(2009) of $9.73,9.47$ and 10.30. The difference between the obtained valuesand the reported values in this study might be probably as a result of acid hydrolysis of humicacid. 
BAJOPAS Volume 14 Number 1,June, 2021

Table 1: PKa of (Hydrolysed PSHA)

\begin{tabular}{|l|l|l|l|l|l|l|}
\hline $\mathrm{pH}$ & $\mathrm{BV}_{1}$ & $\mathrm{BV}_{2}$ & $\mathrm{~V}_{2}-\mathrm{V}_{1}$ & $\mathrm{nA}$ & $\log \left(\frac{n A}{1-n A}\right)$ & $\mathrm{pKa}$ \\
\hline 8.50 & 5.30 & 6.29 & 0.99 & 0.3594 & -0.2510 & 8.2490 \\
8.72 & 5.35 & 6.37 & 1.02 & 0.3400 & -0.2880 & 8.4320 \\
9.00 & 5.40 & 6.46 & 1.06 & 0.3141 & -0.3391 & 8.6609 \\
9.22 & 5.45 & 6.55 & 1.10 & 0.2882 & -0.3927 & 8.8273 \\
9.51 & 5.50 & 6.66 & 1.16 & 0.2494 & -0.4786 & 9.0314 \\
9.73 & 5.55 & 6.78 & 1.23 & 0.2041 & -0.5910 & 9.1390 \\
10.00 & 5.60 & 6.90 & 1.30 & 0.1589 & -0.7238 & 9.2762 \\
10.23 & 5.65 & 7.05 & 1.40 & 0.0941 & -0.9835 & 9.2465 \\
10.49 & 5.70 & 7.10 & 1.40 & 0.0941 & -0.9835 & 9.5065 \\
\hline
\end{tabular}

Average pKa $=8.9299 \pm 0.4186$

Table 2: PKa of (Unhydrolysed PSHA)

\begin{tabular}{|l|l|l|l|l|l|l|}
\hline $\mathrm{pH}$ & $\mathrm{BV}_{1}$ & $\mathrm{BV}_{2}$ & $\mathrm{~V}_{2}-\mathrm{V}_{1}$ & $\mathrm{nA}$ & $\log \left(\frac{\boldsymbol{n A}}{1-\boldsymbol{n}}\right)$ & $\mathrm{pKa}$ \\
\hline 8.50 & 5.30 & 5.81 & 0.51 & 0.6619 & 0.2919 & 8.7919 \\
8.72 & 5.35 & 5.90 & 0.55 & 0.6357 & 0.2418 & 8.9618 \\
9.00 & 5.40 & 6.00 & 0.60 & 0.6029 & 0.1813 & 9.1813 \\
9.22 & 5.45 & 6.10 & 0.65 & 0.5701 & 0.1226 & 9.3426 \\
9.51 & 5.50 & 6.20 & 0.70 & 0.5376 & 0.0654 & 9.5754 \\
9.73 & 5.55 & 6.33 & 0.78 & 0.4851 & -0.0259 & 9.7041 \\
10.00 & 5.60 & 6.47 & 0.87 & 0.4262 & -0.1291 & 9.8709 \\
10.23 & 5.65 & 6.62 & 0.99 & 0.3609 & -0.2481 & 9.9819 \\
10.49 & 5.70 & 6.80 & 1.10 & 0.2759 & -0.4690 & 10.0210 \\
\hline
\end{tabular}

Average pKa $=9.4923 \pm 0.4410$

Metal-ligand stability constant ( $\log \mathrm{K}$ )

The stabilityconstants require the accurate values of proton-ligand stability constants (Anil and Maroti, 2008). Metal titration curves crossed over ligand titration curve indicated the formation of complex upon proton release (Santosh, et al., 2011). If the values of n- are within range $0.2-0.8$ and $1.2-18$ this indicates the formation of $1: 1$ and 1:2 complexes (Sayyed and Mazahar, 2012).

The metal (II)-humate stepwise stability constants (log k) at phenolic group (Tables 318)

Table 3: Point-wise method, $\mathrm{Cu}$-(Hydrolysed PSHA)

\begin{tabular}{|l|l|l|l|l|l|l|l|l|}
\hline $\mathrm{pH}$ & $\mathrm{BV}_{1}$ & $\mathrm{BV}_{2}$ & $\mathrm{BV}_{3}$ & $\left(\mathrm{~V}_{3}-\mathrm{V}_{2}\right)$ & $\mathrm{n}$ & $\mathrm{pL}$ & $\log \left(\frac{n}{1-n}\right)$ & LogK $_{1}$ \\
\hline 8.50 & 5.30 & 6.29 & 6.33 & 0.04 & 0.5500 & 2.66 & 0.0871 & 2.7471 \\
8.72 & 5.35 & 6.37 & 6.41 & 0.04 & 0.5714 & 2.43 & 0.1249 & 2.5549 \\
9.00 & 5.40 & 6.46 & 6.50 & 0.04 & 0.6198 & 2.16 & 0.2122 & 2.3722 \\
9.22 & 5.45 & 6.55 & 6.59 & 0.04 & 0.6667 & 1.94 & 0.3010 & 2.2410 \\
\hline
\end{tabular}

LogK $_{1}$ (Average value) $=2.4788 \pm 0.2203$

Table 4: Point-wise method, $\mathrm{Cu}$-(Hydrolysed PSHA)

\begin{tabular}{|l|l|l|l|l|l|l|l|l|}
\hline $\mathrm{pH}$ & $\mathrm{BV}_{1}$ & $\mathrm{BV}_{2}$ & $\mathrm{BV}_{3}$ & $\left(\mathrm{~V}_{3}-\mathrm{V}_{2}\right)$ & $\mathrm{n}$ & $\mathrm{pL}$ & $\log \left(\frac{n-1}{2-n}\right)$ & LogK $_{2}$ \\
\hline 9.51 & 5.50 & 6.66 & 6.73 & 0.07 & 1.3509 & 1.70 & -0.2671 & 1.4329 \\
9.73 & 5.55 & 6.78 & 6.85 & 0.07 & 1.6383 & 1.51 & 0.2467 & 1.7567 \\
10.00 & 5.60 & 6.90 & 6.98 & 0.08 & 2.1783 & 1.31 & -0.2158 & 1.0942 \\
10.23 & 5.65 & 7.05 & 7.13 & 0.08 & 4.1904 & 1.27 & & \\
10.49 & 5.70 & 7.10 & 7.19 & 0.09 & 4.6920 & & & \\
\hline
\end{tabular}

Log $K_{2}($ Average value $)=1.4280 \pm 0.3312$ 
BAJOPAS Volume 14 Number 1,June, 2021

Table 5: Point-wise method, $\mathrm{Cu}$ (Unhydrolysed PSHA)

\begin{tabular}{|l|l|l|l|l|l|l|l|l|}
\hline $\mathrm{pH}$ & $\mathrm{BV}_{1}$ & $\mathrm{BV}_{2}$ & $\mathrm{BV}_{3}$ & $\left(\mathrm{~V}_{3}-\mathrm{V}_{2}\right)$ & $\mathrm{n}$ & $\mathrm{pL}$ & $\log \left(\frac{n}{n-1}\right)$ & Log $_{1}$ \\
\hline 8.50 & 5.30 & 5.81 & 5.85 & 0.04 & 0.2973 & 2.88 & -0.3736 & 2.5064 \\
8.72 & 5.35 & 5.90 & 5.95 & 0.05 & 0.3873 & 2.66 & -0.1992 & 2.4608 \\
9.00 & 5.40 & 6.00 & 6.05 & 0.05 & 0.4044 & 2.38 & -0.1681 & 2.2119 \\
9.22 & 5.45 & 6.10 & 6.15 & 0.06 & 0.5157 & 2.18 & -0.0272 & 2.2072 \\
9.51 & 5.50 & 6.20 & 6.27 & 0.07 & 0.6417 & 1.89 & 0.2530 & 1.1430 \\
\hline
\end{tabular}

$\operatorname{LogK}_{1}($ Average value $)=2.3059 \pm 0.6153$

Table 6:Point-wise method, $\mathrm{Cu}$ (Unhydrolysed PSHA)

\begin{tabular}{|l|l|l|l|l|l|l|l|l|}
\hline $\mathrm{pH}$ & $\mathrm{BV}_{1}$ & $\mathrm{BV}_{2}$ & $\mathrm{BV}_{3}$ & $\mathrm{~V}_{3}-\mathrm{V}_{2}$ & $\mathrm{n}$ & $\mathrm{pL}$ & $\log \left(\frac{n-1}{2-n}\right)$ & $\log \mathrm{K}_{2}$ \\
\hline 9.73 & 5.55 & 6.33 & 6.42 & 0.09 & 0.9000 & 1.69 & & \\
10.00 & 5.60 & 6.47 & 6.58 & 0.11 & 1.2578 & 1.44 & -0.4592 & 0.9808 \\
10.23 & 5.65 & 6.62 & 6.84 & 0.12 & 1.6137 & 1.26 & -0.2010 & 1.4610 \\
10.49 & 5.70 & 6.80 & 6.92 & 0.12 & 2.1052 & 1.03 & & \\
\hline
\end{tabular}

$\operatorname{LogK}_{2}$ (Average value) $=1.2209 \pm 0.3398$

Table 7:Point-wise method, Pb (Hydrolysed PSHA)

\begin{tabular}{|l|l|l|l|l|l|l|l|l|}
\hline $\mathrm{pH}$ & $\mathrm{BV}_{1}$ & $\mathrm{BV}_{2}$ & $\mathrm{BV}_{3}$ & $\left(\mathrm{~V}_{3}-\mathrm{V}_{2}\right)$ & $\mathrm{n}$ & $\mathrm{pL}$ & $\log \left(\frac{n}{1-n}\right)$ & LogK $_{1}$ \\
\hline 8.50 & 5.30 & 6.29 & 6.33 & 0.04 & 0.5500 & 2.66 & 0.0871 & 2.7471 \\
8.72 & 5.35 & 6.37 & 6.41 & 0.04 & 0.5714 & 2.43 & 0.1249 & 2.5549 \\
9.00 & 5.40 & 6.46 & 6.50 & 0.04 & 0.6198 & 2.16 & 0.2122 & 2.3722 \\
9.22 & 5.45 & 6.55 & 6.60 & 0.05 & 0.8333 & 1.96 & 0.6989 & 2.6589 \\
\hline
\end{tabular}

Log $_{\mathbf{1}}($ Average value $)=2.5832 \pm 0.1614$

Table 8:Point-wise method, Pb-(Hydrolysed PSHA)

\begin{tabular}{|l|l|l|l|l|l|l|l|l|}
\hline $\mathrm{pH}$ & $\mathrm{BV}_{1}$ & $\mathrm{BV}_{2}$ & $\mathrm{BV}_{3}$ & $\left(\mathrm{~V}_{3}-\mathrm{V}_{2}\right)$ & $\mathrm{n}$ & $\mathrm{pL}$ & $\log \left(\frac{n-1}{2-n}\right)$ & $\log \mathrm{K}_{2}$ \\
\hline 9.51 & 5.50 & 6.66 & 6.71 & 0.05 & 0.9650 & 1.67 & & \\
9.73 & 5.55 & 6.78 & 6.83 & 0.05 & 1.1702 & 1.44 & & \\
10.00 & 5.60 & 6.90 & 6.90 & 0.05 & 1.4864 & 1.22 & -0.0237 & 1.1963 \\
10.23 & 5.65 & 7.05 & 7.10 & 0.05 & 2.0190 & 1.09 & & \\
10.49 & 5.70 & 7.10 & 7.17 & 0.07 & 3.6492 & 1.00 & & \\
\hline
\end{tabular}

Log $K_{2}$ (Average value) $=1.1963$

Table 9: Point-wise method, Pb (Unhydrolysed PSHA)

\begin{tabular}{|l|l|l|l|l|l|l|l|l|}
\hline $\mathrm{pH}$ & $\mathrm{BV}_{1}$ & $\mathrm{BV}_{2}$ & $\mathrm{BV}_{3}$ & $\mathrm{~V}_{3}-\mathrm{V}_{2}$ & $\mathrm{n}$ & $\mathrm{pL}$ & $\begin{array}{l}\text { Log } \\
\left(\frac{n}{n-1}\right)\end{array}$ & Log $\mathrm{K}_{1}$ \\
\hline 8.50 & 5.30 & 5.81 & 5.85 & 0.04 & 0.2973 & 2.88 & -0.3736 & 2.5064 \\
8.72 & 5.35 & 5.90 & 5.94 & 0.04 & 0.3099 & 2.66 & -0.5477 & 2.3123 \\
9.00 & 5.40 & 6.00 & 6.05 & 0.05 & 0.4044 & 2.38 & -0.1681 & 2.2119 \\
9.22 & 5.45 & 6.10 & 6.15 & 0.06 & 0.5157 & 2.18 & 0.0272 & 2.2072 \\
9.51 & 5.50 & 6.20 & 6.26 & 0.07 & 0.6417 & 1.89 & 0.2530 & 2.1430 \\
9.73 & 5.55 & 6.40 & 6.40 & 0.07 & 0.7000 & 1.67 & 0.3680 & 2.0380 \\
\hline
\end{tabular}

LogK $_{1}$ (Average value) $=2.2364 \pm 0.1602$

Table 10: Point-wise method, Pb (Unhydrolysed PSHA)

\begin{tabular}{|l|l|l|l|l|l|l|l|l|}
\hline $\mathrm{pH}$ & $\mathrm{BV}_{1}$ & $\mathrm{BV}_{2}$ & $\mathrm{BV}_{3}$ & $\mathrm{~V}_{3}-\mathrm{V}_{2}$ & $\mathrm{n}$ & $\mathrm{pL}$ & $\log \left(\frac{n-1}{2-n}\right)$ & $\log \mathrm{K}_{2}$ \\
\hline 10.00 & 5.60 & 6.47 & 6.55 & 0.08 & 1.9503 & 1.41 & & \\
10.23 & 5.65 & 6.62 & 6.72 & 0.11 & 1.4792 & 1.26 & -0.0361 & 1.2239 \\
\hline
\end{tabular}

$\operatorname{LogK}_{2}$ (Average value) $=1.2239$

Table 11: Point-wise method, Mg (Hydrolysed PSHA)

\begin{tabular}{|l|l|l|l|l|l|l|l|l|}
\hline $\mathrm{pH}$ & $\mathrm{BV}_{1}$ & $\mathrm{BV}_{2}$ & $\mathrm{BV}_{3}$ & $\left(\mathrm{~V}_{3}-\mathrm{V}_{2}\right)$ & $\mathrm{n}$ & $\mathrm{pL}$ & $\log \left(\frac{n}{n-1}\right)$ & LogK $_{1}$ \\
\hline 8.50 & 5.30 & 6.29 & 6.31 & 0.02 & 0.2750 & 2.64 & -0.4290 & 2.2110 \\
8.72 & 5.35 & 6.37 & 6.39 & 0.02 & 0.2858 & 2.42 & -0.3978 & 2.0222 \\
9.00 & 5.40 & 6.46 & 6.49 & 0.03 & 0.4648 & 2.14 & -0.0612 & 2.0788 \\
9.22 & 5.45 & 6.55 & 6.59 & 0.04 & 0.6667 & 1.94 & 0.3010 & 2.2410 \\
\hline
\end{tabular}

$\log _{\mathbf{1}}($ Average value) $=2.1382 \pm 0.1046$ 
BAJOPAS Volume 14 Number 1,June, 2021

Table 12: Point-wise method, Mg (Hydrolysed PSHA)

\begin{tabular}{|l|l|l|l|l|l|l|l|l|}
\hline $\mathrm{pH}$ & $\mathrm{BV}_{1}$ & $\mathrm{BV}_{2}$ & $\mathrm{BV}_{3}$ & $\left(\mathrm{~V}_{3}-\mathrm{V}_{2}\right)$ & $\mathrm{n}$ & $\mathrm{pL}$ & $\log \left(\frac{n-1}{2-n}\right)$ & LogK $_{2}$ \\
\hline 9.51 & 5.55 & 6.66 & 6.71 & 0.05 & 0.9650 & 1.67 & & \\
9.73 & 5.55 & 6.78 & 6.84 & 0.06 & 1.4042 & 1.47 & -0.1686 & 1.3014 \\
10.00 & 5.60 & 6.90 & 6.93 & 0.06 & 1.7838 & 1.23 & 0.5593 & 1.7893 \\
10.23 & 5.65 & 7.05 & 7.10 & 0.06 & 3.1429 & 1.10 & & \\
10.49 & 5.70 & 7.10 & 7.18 & 0.07 & 3.6492 & 0.83 & & \\
\hline
\end{tabular}

LogK $_{2}($ Average value $)=1.5453 \pm 0.3450$

Table 13: Point-wise method, Mg (Unhydrolysed PSHA)

\begin{tabular}{|l|l|l|l|l|l|l|l|l|}
\hline $\mathrm{pH}$ & $\mathrm{BV}_{1}$ & $\mathrm{BV}_{2}$ & $\mathrm{BV}_{3}$ & $\mathrm{~V}_{3}-\mathrm{V}_{2}$ & $\mathrm{n}$ & $\mathrm{pL}$ & $\log \left(\frac{n}{n-1}\right)$ & $\operatorname{Log~}_{1}$ \\
\hline 8.50 & 5.30 & 5.81 & 5.85 & 0.04 & 0.2973 & 2.88 & -0.3736 & 2.5064 \\
8.72 & 5.35 & 5.90 & 5.94 & 0.04 & 0.3099 & 2.66 & -0.3477 & 2.3123 \\
9.00 & 5.40 & 6.00 & 6.04 & 0.04 & 0.3236 & 2.38 & -0.3202 & 2.0598 \\
9.22 & 5.45 & 6.10 & 6.15 & 0.05 & 0.4297 & 2.17 & -0.1230 & 2.0470 \\
9.51 & 5.50 & 6.20 & 6.26 & 0.06 & 0.5500 & 1.89 & 0.0871 & 1.9771 \\
9.73 & 5.55 & 6.33 & 6.40 & 0.07 & 0.7000 & 1.67 & 0.3680 & 2.0380 \\
\hline
\end{tabular}

LogK $_{1}$ (Average value) $=2.1568 \pm 0.2069$

Table 14: Point-wise method, Mg (Unhydrolysed PSHA)

\begin{tabular}{|l|l|l|l|l|l|l|l|l|}
\hline $\mathrm{pH}$ & $\mathrm{BV}_{1}$ & $\mathrm{BV}_{2}$ & $\mathrm{BV}_{3}$ & $\mathrm{~V}_{3}-\mathrm{V}_{2}$ & $\mathrm{n}$ & $\mathrm{pL}$ & $\log \left(\frac{n-1}{2-n}\right)$ & $\log \mathrm{K}_{2}$ \\
\hline 10.00 & 5.60 & 6.47 & 6.55 & 0.08 & 0.9148 & 1.41 & & \\
10.23 & 5.65 & 6.62 & 6.71 & 0.09 & 1.2102 & 1.20 & -0.5749 & 0.6251 \\
10.49 & 5.70 & 6.80 & 6.92 & 0.09 & 1.5968 & 1.03 & 0.1703 & 1.2003 \\
\hline
\end{tabular}

LogK $_{2}$ (Average value) $=0.9127 \pm 0.4070$

Table15:Point-wise method, Cd (Hydrolysed PSHA)

\begin{tabular}{|l|l|l|l|l|l|l|l|l|}
\hline $\mathrm{pH}$ & $\mathrm{BV}_{1}$ & $\mathrm{BV}_{2}$ & $\mathrm{BV}_{3}$ & $\left(\mathrm{~V}_{3}-\mathrm{V}_{2}\right)$ & $\mathrm{n}$ & $\mathrm{pL}$ & $\log \left(\frac{n}{1-n}\right)$ & LogK $_{1}$ \\
\hline 8.50 & 5.30 & 6.29 & 6.31 & 0.02 & 0.2750 & 2.64 & -0.4210 & 2.2190 \\
8.72 & 5.35 & 6.37 & 6.40 & 0.03 & 0.4286 & 2.42 & -0.1249 & 2.2951 \\
9.00 & 5.40 & 6.46 & 6.49 & 0.03 & 0.4648 & 2.14 & -0.0612 & 2.0788 \\
9.22 & 5.45 & 6.55 & 6.59 & 0.04 & 0.6667 & 1.96 & 0.3010 & 2.2610 \\
9.51 & 5.55 & 6.66 & 6.70 & 0.04 & 0.7720 & 1.67 & 0.5297 & 2.1997 \\
\hline
\end{tabular}

LogK $_{\mathbf{1}}$ (Average value) $=2.2108 \pm 0.0825$

Table 16: Point-wise method, Cd (Hydrolysed PSHA)

\begin{tabular}{|l|l|l|l|l|l|l|l|l|}
\hline $\mathrm{pH}$ & $\mathrm{BV}_{1}$ & $\mathrm{BV}_{2}$ & $\mathrm{BV}_{3}$ & $\left(\mathrm{~V}_{3}-\mathrm{V}_{2}\right)$ & $\mathrm{n}$ & $\mathrm{pL}$ & $\log \left(\frac{n-1}{2-n}\right)$ & Log $_{2}$ \\
\hline 9.73 & 5.55 & 6.78 & 6.83 & 0.06 & 1.4042 & 1.47 & -0.1686 & 1.3014 \\
10.00 & 5.60 & 6.90 & 6.95 & 0.06 & 1.7838 & 1.23 & 0.5593 & 1.7893 \\
10.23 & 5.65 & 7.05 & 7.10 & 0.06 & 3.1429 & 1.09 & & \\
10.49 & 5.70 & 7.10 & 7.16 & 0.06 & 3.1429 & 0.89 & & \\
& & & & & & & & \\
\hline
\end{tabular}

$\operatorname{LogK}_{2}$ (Average value) $=1.5453 \pm 0.3450$

Table 17: Point-wise method, Cd (Unhydrolysed PSHA)

\begin{tabular}{|l|l|l|l|l|l|l|l|l|}
\hline $\mathrm{pH}$ & $\mathrm{BV}_{1}$ & $\mathrm{BV}_{2}$ & $\mathrm{BV}_{3}$ & $\mathrm{~V}_{3}-\mathrm{V}_{2}$ & $\mathrm{n}$ & $\mathrm{pL}$ & $\log \left(\frac{n}{n-1}\right)$ & $\operatorname{Log~}_{1}$ \\
\hline 8.50 & 5.30 & 5.81 & 5.86 & 0.05 & 0.3717 & 2.88 & -0.2280 & 2.6520 \\
8.72 & 5.35 & 5.90 & 5.95 & 0.05 & 0.3873 & 2.66 & -0.1992 & 2.4608 \\
9.00 & 5.40 & 6.00 & 6.06 & 0.06 & 0.4853 & 2.38 & -0.0255 & 2.3545 \\
9.22 & 5.45 & 6.10 & 6.16 & 0.06 & 0.5157 & 2.18 & -0.0272 & 2.2072 \\
9.51 & 5.50 & 6.20 & 6.27 & 0.07 & 0.6417 & 1.89 & 0.2530 & 1.1430 \\
9.73 & 5.55 & 6.33 & 6.41 & 0.08 & 0.8000 & 1.69 & 0.6020 & 2.2920 \\
& & & & & & & & \\
\hline
\end{tabular}

$\operatorname{LogK}_{1}($ Average value $)=2.2516 \pm 0.5380$ 
BAJOPAS Volume 14 Number 1,June, 2021

Table 18: Point-wise method, Cd (Unhydrolysed PSHA)

\begin{tabular}{|l|l|l|l|l|l|l|l|l|}
\hline $\mathrm{pH}$ & $\mathrm{BV}_{1}$ & $\mathrm{BV}_{2}$ & $\mathrm{BV}_{3}$ & $\mathrm{~V}_{3}-\mathrm{V}_{2}$ & $\mathrm{n}$ & $\mathrm{pL}$ & $\log \left(\frac{n-1}{2-n}\right)$ & $\log \mathrm{K}_{2}$ \\
\hline 10.00 & 5.60 & 6.47 & 6.57 & 0.10 & 1.1434 & 1.43 & & \\
10.23 & 5.65 & 6.62 & 6.72 & 0.10 & 1.3448 & 1.23 & -0.2788 & 0.9512 \\
10.49 & 5.70 & 6.80 & 6.90 & 0.10 & 1.7742 & 1.03 & 0.5351 & 1.5651 \\
\hline
\end{tabular}

$\operatorname{LogK}_{2}($ Average value $)=1.2581 \pm 0.4340$

Table 19: Stepwise and overall Stability constants of thehydrolysed and unhydrolysed divalent metal (II) complexes

\begin{tabular}{|c|c|c|c|}
\hline Chelates & LogK $_{1}$ & $\log _{2}$ & Log $\beta$ \\
\hline [Cu (Hydrolysed PSHA-1) $\left.{ }_{2}\right]$ & 2.4788 & 1.4280 & 3.9068 \\
\hline$\left[\mathrm{Pb}(\text { Hydrolysed PSHA-1) })_{2}\right]$ & 2.5832 & 1.1963 & 3.7795 \\
\hline$\left[\mathrm{Cd}(\text { Hydrolysed PSHA-1 })_{2}\right]$ & 2.2108 & 1.5453 & 3.7561 \\
\hline$\left[\mathrm{Mg}(\text { Hydrolysed PSHA-1 })_{2}\right]$ & 2.1382 & 1.5453 & 3.6835 \\
\hline [Cu (Unhydrolysed PSHA-1) & 2.3059 & 1.2209 & 3.5268 \\
\hline$[\mathrm{Pb}$ (Unhydrolysed PSHA-1) 2$]$ & 2.2364 & 1.2239 & 3.4603 \\
\hline [Cd (Unhydrolysed PSHA-1) 2 ] & 2.2516 & 1.2581 & 3.5097 \\
\hline$[\mathrm{Mg}$ (Unydrolysed PSHA-1) & 2.1568 & 0.9127 & 3.0695 \\
\hline
\end{tabular}

The results obtained (Table19) shows the stepwise and overall stability constants to be not high indicating low stability of the complexes, because the solubility of most metal ions in the basic $\mathrm{pH}$ range is minimal due to metal hydroxide precipitation (Karimi, 2017). In general, the stepwise stability constants $\left(K_{1}\right.$ and $K_{2}$ ) follow the order $K_{1}>K_{2}$ for the copper, lead, magnesium and cadmium complexes respectively. The steady decrease of the values with increasing number of ligands is in agreement with the prediction made by researchers (Na'aliya, 2013). The decrease could be attributed to the fact that as the number of the ligands (Humate ions) that enters the coordination zone increases the aqua molecules available for replacement by the ligands become less. Thus, the metal ions become less electron loving with progressive intake of the ligand and this results in the decrease in the values of the constants (Na'aliya, 2013). Also the stability of the complexes is influenced by the size and number of the chelate rings(Mackay and Mackay,2002).All the complexes form rings in their structure as humate, a bidentate ligand, bond the metal ions in the ratio 1:2 (Boguta and Sokolowska, 2016) forming chelate rings. The values of the overall stability constants $(\log \beta)$ obtained for humate complexes are not high indicating low stability as the values are not high. LogK values for copper-humates (Table 3 to 6) obtained in this study are lower than those reported for the complexes of humic acids (Pandey et al., 2015; Dinu, 2013; Kaschl et al., 2010 and Gilbeto and Jorg, 2001). The values of LogK(Table 7 to 10 ) forlead-humates are lower than those reported for the lead in the literature (Dinu, 2013; Gilbeto and Jorg 2001). Log K values(Table 11 to 14 ) for magnesium-humates obtained in this study are close to those reported by (Pandey et al., 2015). Log K values of cadmium-humates (Table 15 to 18 ) obtained in this work near to the one reported by (Dinu, 2013 and Pandey et al., 2015).The difference between the reported values and the values obtained in this study might be probably as a result of acid hydrolysis of humic acid. The values of the overall stability constants $(\log \beta)$ of the copper humates complexes presented in Table 19 is high than that of other metal humate complexes, show relatively high stability of CuHA complexes, show the following order of stability: $\mathrm{Cu}>\mathrm{Pb}>\mathrm{Cd}>\mathrm{Mg}$; which are in close agreement to the findings of (Dinu, 2013 and Pandey et al., 2015).The high stability of Cuhumate chelate could be attributed to the existence of coordinate covalent bond between the complexing agents and the $\mathrm{Cu}^{2+}$ ions. Since, $\mathrm{Cu}^{2+}$ being a metal of the transitional series with $3 d^{9}$ electronic configurations can accept the electrons from the complexing agents. Similarly, the low stabilities of $\mathrm{Pb}, \mathrm{Cd}$ and $\mathrm{Mg}$ complexes could be explained by that $\mathrm{Pb}^{2+}$ with $6 s^{2}, \mathrm{Cd}^{2+}$ with $4 \mathrm{~d}^{10}$ and $\mathrm{Mg}^{2+}$ with $2 \mathrm{p}^{6}$ their electronic configuration has a completely filled $\mathrm{d}, \mathrm{p}$ and $\mathrm{s}$ orbitals. Moreover, the stabilities of metal ions with hydrolysed humic acid from peat soil were higher than those with unhydrolysed humic acid from peat soil; which is ascribed to the high content of acidity in hydrolysed humic acid than unhydrolysed humic acid. 
BAJOPAS Volume 14 Number 1,June, 2021 CONCLUSION

The values of logk for $\mathrm{Cu}(\mathrm{II})$ hydrolysed humic acid complex was higher followed by $\mathrm{Pb}$ (II), $\mathrm{Cd}(\mathrm{II})$ and $\mathrm{Mg}$ (II) hydrolysed humic acid complexes as compared with metal(II) unhydrolysed humic acid complexes. This indicates acid hydrolysis of humic acid can

\section{REFERENCES}

Almeida, V.R. and Szpoganicz, B. (2015). Humic Acid Potentiometric Response Patterns:Out- of Equilibrium Properties and Species Distribution Modelling. Chemical. Biol. Technol. Agric. 2: 17.

Anđelković, T., Nikolić, R., Bojić, A.,Anđelković, D., and Nikolic G.,(2010). Binding of Cadmium to Soil Humic Acid as A Function of Carboxyl Group Content. Macedonian Journal of Chemistry and Chemical Engineering.29(2): 215-224.

Anil, B. N. and Maroti, N. (2008). Studies on Influence of Die-Lectric Constants on Complex Equilibria between Substituted Py-Razalines and Lanthanide Metal Ions pH-Metrically. Amer.-Euras. scient. Res. 3(2): 212-216.

Ashok, K., Pandey, S. P. and Misra, V (2000). Stability Constants of Metal-Humic Acid Complexes and its Role in Environmental Detoxification. Journal of Ecotoxicology and Environmental Safety. 47(2):157-200.

Badr, M. H., El-Halafawi, M. H. and Abd El-al Zeid, E. R. (2012). Comparison Between the Effect of Ionic Strength on Acidity and Dissociation Constants of Humic Acids Extracted from Sewage Sludge and Nile Water Hyacinth Composts.Global Journal of Environmental Research 6 (1): 36-43.

Baruah, M.K., Borah, D., Saikia, P.P., Paul, S., Sharma, T. (2015). Evaluation of pKa Values of Soil Humic Acids and their Complexation Properties. International Journal of Plant \& Soil Science 6(4) : 218-228.

Boguta, P. Sokolowska, Z. (2016). Interactions of $\mathrm{Zn}$ (II) Ions with Humic Acids Isolated from Various Types of Soils. Effect of $\mathrm{pH}, \mathrm{Zn}$ Concentrations and Humic Acids Chemical Properties. Journal of Geochemical Explaration 168. 119-126.

Borges, F., Guimaraes, C., Lima, L.F.C., Pinto, I. and Reis, S.(2005). Potentiometric Studies on the Complexation of Copper(II) by Phenolic Acids as Discrete Ligand Models of enhance the complexation behavior of humic acid with metal (II) ions. However, the higher values of $\log \beta$ for $\mathrm{Cu}(\mathrm{II}), \mathrm{Pb}(\mathrm{II}), \mathrm{Cd}(\mathrm{II})$ and $\mathrm{Mg}(\mathrm{II})$ hydrolysed humic acid complexes indicates more stable stepwise complexes formed as compared with $\mathrm{Cu}(\mathrm{II}), \mathrm{Pb}$ (II), $\mathrm{Cd}$ (II) and $\mathrm{Mg}(\mathrm{II})$ unhydrolysed humic acid complexes.

Humic Substances Talanta 66 (2005) 670-673.

Chefetz, B., Salloum, M. J., Deshmulkin, A. P. and Hatcher, P. (2002). Structural Components of Humic Acids as Determined by Chemical Modifications and Carbon-13 NMR, Pyrolysis, and Thermochemolysis- Gas Chromatography/Mass Spectrometry. Soil Science Society of American Journal Abstract Division S-2- Soil Chemistry66. 1159-1171.

Dinu, M. I. (2013). Metals Complexation with Humic Acids in Surface Water of Different Environ. Sci. Technol. 31(1): 1-17.

Fernandes, A.N., Giacomelli, C., Giovanela, M. Vaz, D.V. Szpoganicz, B. and Maria M. D. (2009). Potentiometric Acidity Determination in Humic Substances Influenced by Different Analytical Procedures.J. Braz. Chem. Soc. 20 (9):14.

Gamal, A. H. (2015). Stability Constants of Rhenium (V) Metal Complexes with Selected Drugs. Pyrex Journal of Research in Environmental Studies. 2(2): 006-014.

Janrao, D. M., Pathan, J., Kayande, D.D., and Mulla, J.J. (2014). An Over View of Potentiometric Determination of Stability Constants of Metal Complexes. Sci. Revs. Chem. Commun.: 4(1), 2014, 11-24.

Karimi, H. (2017). Effect of pH and Initial Pb(II) Concentration on the Lead Removal Efficiency from Waste Water Using $\mathrm{Ca}(\mathrm{OH})_{2}$. International Journal of Water and Waste Water Treatment 3.2

Kaschl, A. Romheld, V. and Chen, Y. (2010). Binding of Cadmium, Copper and Zinc to Humic Substances Originating from Municipal Solid Waste Compost. Israel Journal of Chemistry Vol. 42(1): 89-98.

Kostic, I. S., Tatjana, P, A., Nikolic, R. S., Cvetkovic, T. P., Pavlovic, D. D., Aleksandar, L.J. and Bojic, A. (2012). Comparative Study of Binding Strengths of Heavy Metals with Humic Acid. J.serb. Chem. Soc. 76(9) pp 1-20. 
BAJOPAS Volume 14 Number 1,June, 2021

Na'aliya, J. (2013). Determination of Stepwise Stability Constants and Gibbs free Energy Change of Trisprolina to Complexes of some Divalent Transition Metal ions. Bayero Journal of Pure and Applied Sciences 6(2): 112-114.

Omar, A. A. and Ali, E. A. (2015). Potentiometric Studies on Complexes of $\mathrm{Cr}$ (III) and $\mathrm{Zr}$ (IV) with some Carboxylic Acids. International Journal of Advanced Chemistry, 3(1) 25-

37.

Pandey, A. K. Pandey, S. D. and Misr, V. (2015).Stability Constants of Metal- Humic Acid Complexes and Its Role in Environmental Detoxification. J. Ecotoxicology and Environmental Safety. 47(1):195-200.

Ram, N. and Raman, K.V. (1984). Stability Constants of Complexes of Metals with
Humicand Fuvic Acids under Non- acidConditions. Journal of Plant Nutrition and Soil Sciences.

147:171-176.

Santosh, D. D., Ashok, B. K., Vijay, J. T., Shivraj, G. W. and Vinay, V. W. (2011). Potentiometric Studies of Elec-Trolyte Effects on Complex Equilibria of Some Substituted 5-(2-hydroxy Phenyl) Pyrazoles. Der pharm. 3 (6): 75-83.

Sayyed, H. and Abdul Rahim, M. F. (2012). Studies of Binary Complexes of Metal Ions with Mandelic Acid by Potentiometry. Chem. J. 02 (6): 206209.

Shirvani, M. Moradian, E. Khalili, B. Bakhtiary, S. (2015). Interaction of $\mathrm{Cd}$ and $\mathrm{Pb}$ with Humate-Palygorskite and HumateSepiolite Complexes. Journal of water, air and pollution 3: 220-228. 


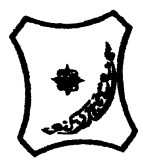

Bayero Journal of Pure and Applied Sciences, 14(1): 54 - 63

Received: November, 2020

Accepted: April, 2021

ISSN $2006-6996$

\title{
STABILITY CONSTANTS OF COMPLEXES OF METAL IONS WITH PEATSOIL HUMIC ACIDS UNDER NON-ACID-CONDITIONS
}

\author{
${ }^{* 1}$ Sabo, Yusuf ${ }^{2}$ Jimoh, W.L.O., ${ }^{3}$ Isa Baba Koki and ${ }^{4}$ Sholadoye, Q. 0. \\ ${ }^{1}$ Department of Pure and Industrial Chemistry, Bayero University, Kano \\ ${ }^{3}$ Department of Chemistry, Yusuf Maitama Sule University Kano. P.M.B. 3220 Kano, Nigeria. \\ ${ }^{4}$ Department of Chemistry, Nigerian Police Academy, Wudil, Kano-Nigeria
}

*Correspondence E-mail; saboyusuf18@yahoo.com

ABSTRACT

Stability constants of complexes of four divalent metal ions viz. $\mathrm{Cu}^{2+}, \mathrm{Pb}^{2+}, \mathrm{Mg}^{2+}$ and $\mathrm{Cd}^{2+}$ with humic acids (HA) were determined by potentiometric titration of humic acids with the corresponding salt of the divalent metals in aqueous media under non-acid-condition. The log $K$ (logarithm of the stability constant) ranged from 1.0942 to 2.7471 for metalhumic acid complexes were determined using point-wise computational method. The order of stability constants were obtained as follows: $\mathrm{Cu}>\mathrm{Pb}>\mathrm{Cd}>\mathrm{Mg}$ for metal $-\mathrm{HA}$ complexes respectively, indicating a higher degree of complexation with Cu metal ion.

Keywords: stability constant, humic acid, potentiometric titration, divalent metals, acid hydrolysis.

\section{NTRODUCTION}

The stability constant of a complex is the numerical expression of its stability and provides a quantitative measure of affinity of the metal ion to the complexing agent. An understanding of the relative stability of metal-complexes helps in predicting the behavior of metal ions in the soil (Ram and Raman, 1982). Extensive researches has been done to determine the stability constants of the complexes formed between humic acid (HA) with a number of metal ions. Ashok et al., (2000) reported that humic acid with hydroxyl, phenoxyl and carboxyl reactive groups can form coordination compound with metal ions at $\mathrm{pH}$ 3.5. The stability constants(Log K) for different metalhumic acid complexes indicated the following order of the stabilities of complexes formed between humic acid and metal ion, $\mathrm{Cu}>\mathrm{Fe}$ $>\mathrm{Pb}>\mathrm{Ni}>\mathrm{Co}>\mathrm{Ca}>\mathrm{Cd}>\mathrm{Zn}>\mathrm{Mn}>\mathrm{Mg}$. Andelkovic et al., (2010) investigated the binding of $\mathrm{Cd}$ (II) to soil humic acid at pH 6.5 and in $0.1 \mathrm{M} \mathrm{KNO}_{3}$ ionic medium. The stability constant for binding indicating greater stability in the case when carboxyl groups are involved in complexation reaction. Kostic et al.,(2012) investigated the complexation of humic acid with certain heavy metal ions (Co(II), $\mathrm{Ni}(\mathrm{II}), \mathrm{Cu}(\mathrm{II})$,
$\mathrm{Zn}(\mathrm{II})$, and $\mathrm{Pb}(\mathrm{II})$. The experiment was performed at $25^{\circ} \mathrm{C}$, at pH 4.0 and ionic strength of $0.01 \mathrm{M}$. Stability constant of complex between $\mathrm{Pb}$ (II) ions and humic acid is greater than stability constants of other investigated metalhumate complexes. Bogata and Sokolowska (2016) analyses the interaction between humic acids from different soils and $\mathrm{Zn}$ (II) ions at wide concentration ranges and at $\mathrm{pH} 5$. Studies have showed significant impact of $\mathrm{Zn}$ concentration, $\mathrm{pH}$ and some properties of humic acids with zinc.But all of these studies were limited to acidic $\mathrm{pH}$ range. Therefore, the present study was carried out to determine and compare the stability constants of complexes of metal ions with hydrolysed peat soil humic acid and unhydrolysed peat soil humic under non-acid conditions.

\section{MATERIALS AND METHODS}

Analytical grade chemicals used includes hydrochloric acid $(\mathrm{HCl})$, nitric acid $\left(\mathrm{HNO}_{3}\right)$, sodium hydroxide $(\mathrm{NaOH})$, lead nitrate $\mathrm{Pb}\left(\mathrm{NO}_{3}\right)_{2}$, copper nitrate $\mathrm{Cu}\left(\mathrm{NO}_{3}\right)_{2} \cdot 3 \mathrm{H}_{2} \mathrm{O}$, cadmium nitrate $\mathrm{Cd}\left(\mathrm{NO}_{3}\right)_{2} \cdot 4 \mathrm{H}_{2} \mathrm{O}$, magnesium nitrate $\mathrm{Mg}\left(\mathrm{NO}_{3}\right)_{2} \cdot 6 \mathrm{H}_{2} \mathrm{O}$, potassium nitrate $\left(\mathrm{KNO}_{3}\right)$, calcium chloride $\left(\mathrm{CaCl}_{2}\right)$, (sigma-Aldrich). Dowex 50WX8, (20-50 mesh) from Fluka. 


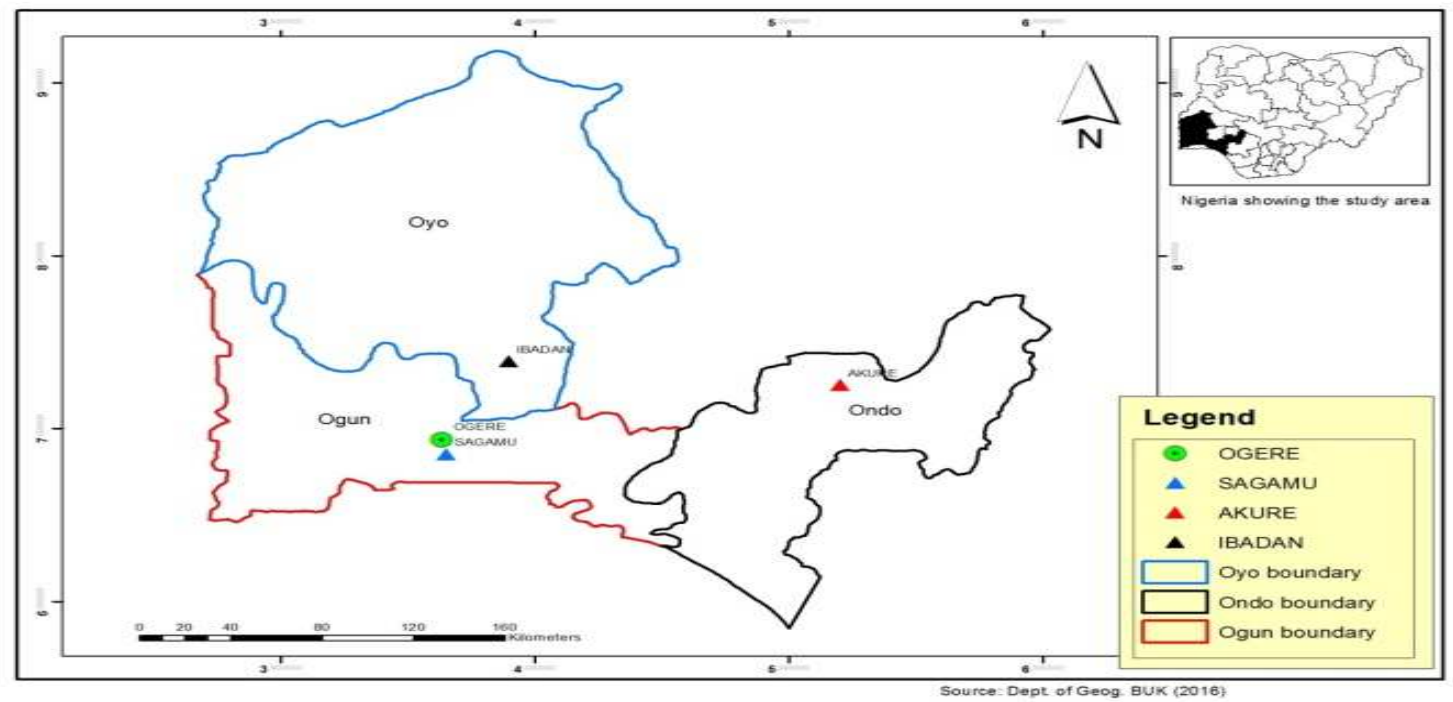

Figure 1: Map showing the sampling point at Sagamu Town, Ogun State.

\section{Description of Sampling Area}

Sagamu has geographical coordinates between $6^{\circ} 50^{\prime}$ north; $3^{\circ} 38^{\prime}$ east is located in south western region of Nigeria. The region has tropical wet and dry climate with a lengthy wet season and relatively constant temperatures throughout the course of the year. Wet season runs from March to October, November to December forms the region dry season. The vegetation type of the region is savannah which is really grassland with small bushes and occasional big trees. Grassland soils have substantially higher organic matter content than forest soils (Novackova, 2011).

\section{Sample Collection}

The Peatsoil samples were collected from four different sampling points $(0-10 \mathrm{~cm}$ depth) in Sagamu into polyethylene bag with plastic spoons. Samples were taken to the laboratory, extraneous materials were removed; the samples were air-dried, crushed and ground to a fine powder in a mortar passed through a $0.20 \mathrm{~mm}$ sieve. The samples were kept for analysis.

\section{Isolation and purification of humic acid from peat soil sample}

Peatsoil sample $(100 \mathrm{~g})$ was mixed with 1000 $\mathrm{cm}^{3}$ of $0.1 \mathrm{M} \mathrm{NaOH}$ solution, shaken for 3hours and left to stand overnight. Dark-coloured supernatant was obtained and decanted from solid residue. The dark-coloured supernatant was acidified to $(\mathrm{pH}=1.0)$ with $6 \mathrm{M} \mathrm{HCl}$ stirred and allowed to stand for 6 hours. Yellowish brown supernatant and dark-brown precipitate were obtained. The yellowish brown supernatant was decanted followed by centrifuge and discarded. The dark-brown precipitate was mixed with $500 \mathrm{~cm}^{3}$ of $0.1 \mathrm{M} \mathrm{NaOH}$ solution followed by passing through dowex resin. The dark-brown solution was acidified to $(\mathrm{pH}=1.0)$ with $6 \mathrm{M} \mathrm{HCl}$ stirred and allowed to stand for 3 hours. The dark-brown precipitate was washed several times with deionized water. The supernatant was treated with $\mathrm{AgNO}_{3}$ solution until no white precipitate observed. The humic acid was transferred to weighed crucible and dried at $60^{\circ} \mathrm{C}$ in an oven for 12 hours. The humic acid was cooled and dried in the desiccator, weighed and recorded. The obtained humic acid was dried again at $60^{\circ} \mathrm{C}$ for additional 6 hours cooled and dried in the desiccator, weighed and recorded constant weight was obtained (Baruah et al., 2015).

\section{FT-IR analysis}

FT-IR spectra of humic acid sample was analysed using Carry 630 FT-IR Agilent Technologies.

Unhydrolysed compost humic acid

The unhydrolysed humic acid was obtained after isolation and purification of compost humic acid and kept for investigation.

\section{Acid hydrolysis of Peatsoil acid}

Peatsoil humic acid sample (1g) was refluxed for 12 hours at $\left(160^{\circ} \mathrm{C}\right)$ with $50 \mathrm{~cm}^{3}$ of $6 \mathrm{M} \mathrm{HCl}$. The mixture was allowed to cool, decanted, and centrifuged after hydrolysis. The insoluble residues were washed with distilled water via centrifugation several times, and the supernatant was treated with $\mathrm{AgNO}_{3}$ solution until no white precipitate was observed. The residue was thoroughly dried over $\mathrm{CaCl}_{2}$ in a desiccator at room temperature (Chefetz et al., 2002). Finally, the obtained hydrolysed humic acid was kept for investigation. 
BAJOPAS Volume 14 Number 1,June, 2021 Potentiometric Titrations

Potentiometric measurements were carried out using a pH-meter Jenway (model 3510) with combine electrode, the sensitivity of the $\mathrm{pH}$ meter is 0.01 units. The $\mathrm{pH}$ meter was switched on half an hour before starting the titration for initial warm up of the instrument. The instrument was calibrated with an aqueous standard buffer solution of $\mathrm{pH} 4.00$ and 10.0 (borate buffer) prepared from a "Qualigens" buffer tablets.

The following sets of solutions were prepared in a $250 \mathrm{~cm}^{3}$ volumetric flask separately for $\mathrm{pH}$ metric titrations.

(i) $5 \mathrm{~cm}^{3} 0.1 \mathrm{M} \mathrm{HCl}+40 \mathrm{~cm}^{3}$ deionized water

(ii) $5 \mathrm{~cm}^{3} 0.1 \mathrm{M} \mathrm{HCl}+39 \mathrm{~cm}^{3}$ deionized water $+1 \mathrm{~cm}^{3} 0.15 \mathrm{gcm}^{-3}$ humic acid

(iii) $5 \mathrm{~cm}^{3} 0.1 \mathrm{M} \mathrm{HCl}+37 \mathrm{~cm}^{3}$ deionized water $+1 \mathrm{~cm}^{3} 0.15 \mathrm{gcm}^{-3}$ humic acid

$$
+2 \mathrm{~cm}^{3} \quad 0.01 \mathrm{M} \mathrm{Cu} \text { (II) }
$$

The solutions were titrated against standardized $0.110 \mathrm{MNaOH}$ separately. The total volume of each mixture was adjusted to $50 \mathrm{~cm}^{3}$ and the ionic strength of the solutions was maintained constant at by adding appropriate amount of stock solution of $1 \mathrm{M} \mathrm{KNO}_{3}$ (Gamal, 2015; Omar and Ali, 2015). A magnetic stirrer was used to achieve thorough mixing of the interacting solutions at $550 \mathrm{rpm}$. The same set of experimental conditions was applied for potentiometric titration of remaining samples.

\section{Evaluation of pKa of Hydrolysed peat soil Humic Acids}

The proton-ligand formation number $\mathrm{n}_{\mathbf{A}}$ were calculated by Irving and Rossotti expression (Omar and Ali, 2015).

$\mathrm{nA}=\mathrm{Y}-\frac{(\mathrm{V} 2-\mathrm{V1})(\mathrm{No}-\mathrm{Eo})}{(\mathrm{VO}+\mathrm{V1}) \mathrm{TCL}}$ 1

Where: $Y$ is number of dissociable proton, $\left(\mathrm{V}_{2^{-}}\right.$ $V_{1}$ ) is the measure of displacement of the ligand curve relative to acid curve, $\mathrm{N}^{\circ}$ and $\mathrm{E}^{\circ}$ are the resultant concentration of alkali solution, free acid solution, $\mathrm{T}_{\mathrm{cL}}{ }^{\circ}$ is the total ligand concentration, $\mathrm{V}^{\circ}$ is the total volume of titration solution, $V_{1}$ is the volume of alkali added to acid solution, $V_{2}$ is the volume of alkali added to acid solution + ligand solution, acid dissociation constants (pKa - values) of ligand were calculated by algebraic method point wise calculation (Tables 1 ). The dissociation constants (pKa) were calculated according to the following relation:

$\mathrm{pKa}=\mathrm{pH}+\log \left(\frac{n A}{1-n A}\right)$ 2

Where: pKa is the acid dissociation constant, $\mathrm{n}_{\mathrm{A}}$ is the Proton-ligand formation number and $\mathrm{pH}$ is the pH-values (Omar and Ali, 2015).

\section{Determination of metal-ligand stability constants $(\log K)$ of complexes}

The potentiometric measurement for the determination of stability constant of a complex in solution is based on the fact that the redox potential of the couple $\frac{M^{+(m-n)}}{M^{+m}}$ is shifted significantly on complexation of the metal ion with the ligand. This method involves change in hydrogen ion concentration $\left[\mathrm{H}^{+}\right]$due to the displacement or association of one or more protons taking place during complexation reaction. This change can be found out by titrating the solutions containing free acid, acid with ligand, and acid with ligand and metal ion, individually against a standard alkali solution at a constant ionic strength or temperature. Either ionic strength or temperature may be varied for different sets of solutions. In all the cases, the change in the $\mathrm{pH}$ of the solution is measured after each addition of a known amount of alkali to the reaction cell which contains the reaction mixture. The titration curves are then drawn by plotting the measured $\mathrm{pH}$ values against the corresponding volume of alkali added and the stability constants of the complexes are determined from the titration curves by employing $\mathrm{pH}$-metric titration technique given by (Irving and Rossoti).

Metal-ligand stability constants ( $\log \mathrm{K}$ ) were determined by using the following relations:

$$
\bar{n}=\frac{\left(V_{3}-V_{2}\right)\left(E^{0}+N^{0}\right)}{\left(V^{0}+V_{2}\right) \bar{n}_{A} T_{m}^{0}}
$$

and

$$
P L=\log _{10}\left\{\frac{1+\beta_{n}^{H} \frac{1}{[\text { anti } \log \mathrm{pH}]^{\mathrm{n}}}}{\mathrm{T}_{\mathrm{L}}^{0}-n \bar{T}_{m}^{0}} \mathrm{X} \frac{\left(V^{0}+V_{3}\right)}{V^{0}}\right\}
$$


BAJOPAS Volume 14 Number 1,June, 2021

Where $T_{L}, T^{\circ}, E^{\circ}$, and $V^{\circ}$ havethe same significance as in equation (1) above, $T_{m}$ denotes the total concentration of metal present in solution, $V_{3}$ is the volume of metal ions present in solution and $\beta^{H}$ is the overall proton ligand stability constant. The metal-ligand stability constants (log K) were determined by employing point wise computational Method (eq. 5 and 6).

$\operatorname{LogK}_{1}=\log \left(\frac{n}{1-n}\right)+\mathrm{pL}$ .5

$\operatorname{LogK}_{2}=\log \left(\frac{1-n}{2-n}\right)+\mathrm{pL}$ ...6

Where: Log $\mathrm{K}$ is the metal-ligand stability constant, $\mathrm{pL}$ is the Free ligand exponent function, $\mathbf{n}$ is the Average number of ligand attached with metal ion (Janraoet al., 2014). The results obtained were analyzed by an ORIGIN 2016 program using titration data and then the proton-ligand stability constants (pKa) and Metal-ligand stability constant (LogK) calculated (Omar and Ali, 2015).

\section{RESULTS AND DISCUSSION}

Fourier transformed infrared (FT-IR) spectra of isolated humic acid from peat soils Figure 2 had distinct clear absorption bands indicating the presence of major humic acid structural elemental groups such as $\mathrm{H}$ bonded $\mathrm{OH}$ $\left(3680 \mathrm{~cm}^{-1}\right.$ peak $), C=0$ of carbonyl $\left(1721 \mathrm{~cm}^{-1}\right.$ peak), functional groups of aliphatic components $\mathrm{CH}_{2}\left(2918 \mathrm{~cm}^{-1}\right.$ peak) and $\mathrm{C}-\mathrm{O}$ stretching of polysaccharide $\left(1168 \mathrm{~cm}^{-1}\right.$ peak). The positions of the absorption bands of the spectra fell within typical major absorption bands of humic acid which is at frequencies 3680, 2918, 1721, 1168 $\mathrm{cm}^{-1}$. The first peak centred in the vicinity of $3680 \mathrm{~cm}^{-1}$ region is attributed to phenol $\mathrm{OH}$ group bounded by intermolecular $\mathrm{H}$ bonds. The $2918 \mathrm{~cm}^{-1}$ band usually has absorption maximum at $2918 \mathrm{~cm}^{-1}$ which is due to $\mathrm{C}-\mathrm{H}$ stretching of alkane group $\left(\mathrm{CH}_{2}\right)$. The next major absorption band is $1721 \mathrm{~cm}^{-1}$. This band has been commonly ascribed to $\mathrm{C}=\mathrm{O}$ stretching of mainly carboxyl group $(\mathrm{COOH})$ with trace amount of ketones. The last peak was observed at 1168 $\mathrm{cm}^{-1}$ due to $\mathrm{C}-\mathrm{O}$ stretching of polysaccharides and this peak appeared also in the spectra of humic acid from peat soil. The FTIR spectra of the isolated humic acid contained all major characteristic absorption peaks of humic acid. These absorption peaks indicated the presence of the major structural elements of humic acid namely $\mathrm{H}$ bonded $\mathrm{OH}, \mathrm{C}=\mathrm{C}$ of aromatic ring, $\mathrm{C}=\mathrm{O}$ of carbonyl group (both carboxyl and ketonic), $\mathrm{CH}_{2}$ group. This strongly supports the presence of humic acid.

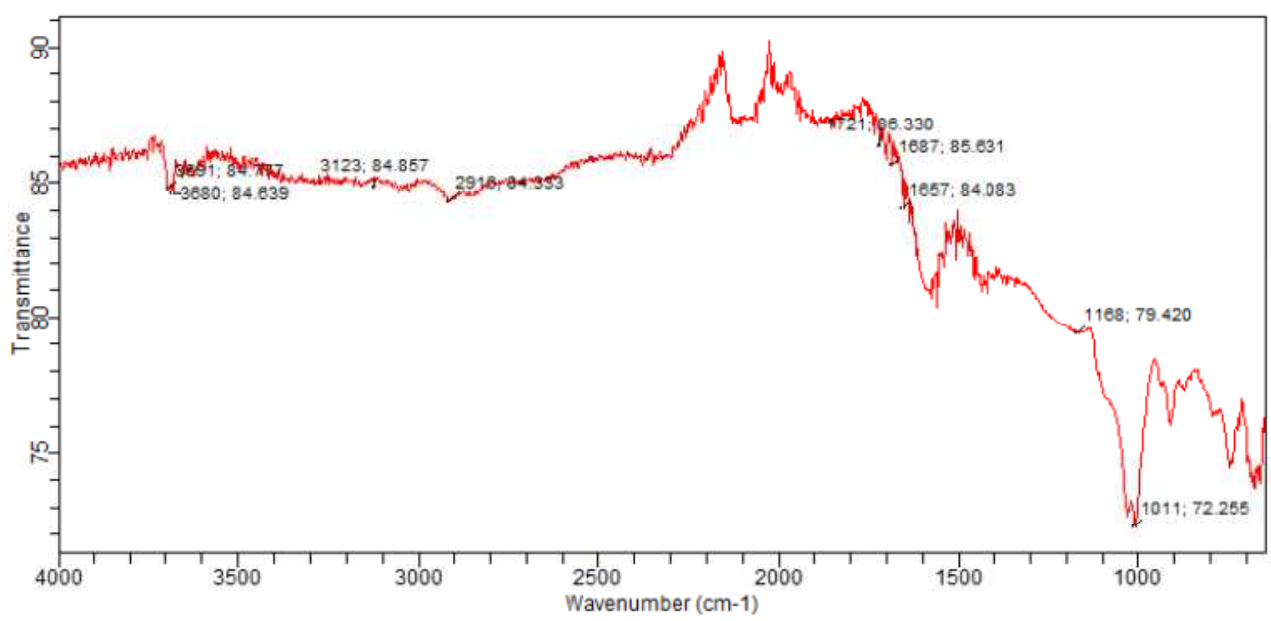

Fig. 2 : FT-IR spectraof peatsoilhumic acid (PSHA)

\section{Evaluation of acid dissociation constant (pka) of acid hydrolysed peat soil humicacid at phenolic group}

The value of the dissociation constant of the peat soil humic acid (PSHA) that underwent acidhydrolysis studied was found to be 8.9299 as shown Table 1, which is lower than the literaturevalues reported by Almeida and Szpoganics, (2015), Borges et al., (2005); Badr et al., (2012)and Fernandes et al,.(2009) of $9.73,9.47$ and 10.30. The difference between the obtained valuesand the reported values in this study might be probably as a result of acid hydrolysis of humicacid. 
BAJOPAS Volume 14 Number 1,June, 2021

Table 1: PKa of (Hydrolysed PSHA)

\begin{tabular}{|l|l|l|l|l|l|l|}
\hline $\mathrm{pH}$ & $\mathrm{BV}_{1}$ & $\mathrm{BV}_{2}$ & $\mathrm{~V}_{2}-\mathrm{V}_{1}$ & $\mathrm{nA}$ & $\log \left(\frac{n A}{1-n A}\right)$ & $\mathrm{pKa}$ \\
\hline 8.50 & 5.30 & 6.29 & 0.99 & 0.3594 & -0.2510 & 8.2490 \\
8.72 & 5.35 & 6.37 & 1.02 & 0.3400 & -0.2880 & 8.4320 \\
9.00 & 5.40 & 6.46 & 1.06 & 0.3141 & -0.3391 & 8.6609 \\
9.22 & 5.45 & 6.55 & 1.10 & 0.2882 & -0.3927 & 8.8273 \\
9.51 & 5.50 & 6.66 & 1.16 & 0.2494 & -0.4786 & 9.0314 \\
9.73 & 5.55 & 6.78 & 1.23 & 0.2041 & -0.5910 & 9.1390 \\
10.00 & 5.60 & 6.90 & 1.30 & 0.1589 & -0.7238 & 9.2762 \\
10.23 & 5.65 & 7.05 & 1.40 & 0.0941 & -0.9835 & 9.2465 \\
10.49 & 5.70 & 7.10 & 1.40 & 0.0941 & -0.9835 & 9.5065 \\
\hline
\end{tabular}

Average pKa $=8.9299 \pm 0.4186$

Table 2: PKa of (Unhydrolysed PSHA)

\begin{tabular}{|l|l|l|l|l|l|l|}
\hline $\mathrm{pH}$ & $\mathrm{BV}_{1}$ & $\mathrm{BV}_{2}$ & $\mathrm{~V}_{2}-\mathrm{V}_{1}$ & $\mathrm{nA}$ & $\log \left(\frac{\boldsymbol{n A}}{1-\boldsymbol{n}}\right)$ & $\mathrm{pKa}$ \\
\hline 8.50 & 5.30 & 5.81 & 0.51 & 0.6619 & 0.2919 & 8.7919 \\
8.72 & 5.35 & 5.90 & 0.55 & 0.6357 & 0.2418 & 8.9618 \\
9.00 & 5.40 & 6.00 & 0.60 & 0.6029 & 0.1813 & 9.1813 \\
9.22 & 5.45 & 6.10 & 0.65 & 0.5701 & 0.1226 & 9.3426 \\
9.51 & 5.50 & 6.20 & 0.70 & 0.5376 & 0.0654 & 9.5754 \\
9.73 & 5.55 & 6.33 & 0.78 & 0.4851 & -0.0259 & 9.7041 \\
10.00 & 5.60 & 6.47 & 0.87 & 0.4262 & -0.1291 & 9.8709 \\
10.23 & 5.65 & 6.62 & 0.99 & 0.3609 & -0.2481 & 9.9819 \\
10.49 & 5.70 & 6.80 & 1.10 & 0.2759 & -0.4690 & 10.0210 \\
\hline
\end{tabular}

Average pKa $=9.4923 \pm 0.4410$

Metal-ligand stability constant ( $\log \mathrm{K}$ )

The stabilityconstants require the accurate values of proton-ligand stability constants (Anil and Maroti, 2008). Metal titration curves crossed over ligand titration curve indicated the formation of complex upon proton release (Santosh, et al., 2011). If the values of n- are within range $0.2-0.8$ and $1.2-18$ this indicates the formation of $1: 1$ and 1:2 complexes (Sayyed and Mazahar, 2012).

The metal (II)-humate stepwise stability constants (log k) at phenolic group (Tables 318)

Table 3: Point-wise method, $\mathrm{Cu}$-(Hydrolysed PSHA)

\begin{tabular}{|l|l|l|l|l|l|l|l|l|}
\hline $\mathrm{pH}$ & $\mathrm{BV}_{1}$ & $\mathrm{BV}_{2}$ & $\mathrm{BV}_{3}$ & $\left(\mathrm{~V}_{3}-\mathrm{V}_{2}\right)$ & $\mathrm{n}$ & $\mathrm{pL}$ & $\log \left(\frac{n}{1-n}\right)$ & LogK $_{1}$ \\
\hline 8.50 & 5.30 & 6.29 & 6.33 & 0.04 & 0.5500 & 2.66 & 0.0871 & 2.7471 \\
8.72 & 5.35 & 6.37 & 6.41 & 0.04 & 0.5714 & 2.43 & 0.1249 & 2.5549 \\
9.00 & 5.40 & 6.46 & 6.50 & 0.04 & 0.6198 & 2.16 & 0.2122 & 2.3722 \\
9.22 & 5.45 & 6.55 & 6.59 & 0.04 & 0.6667 & 1.94 & 0.3010 & 2.2410 \\
\hline
\end{tabular}

LogK $_{1}$ (Average value) $=2.4788 \pm 0.2203$

Table 4: Point-wise method, $\mathrm{Cu}$-(Hydrolysed PSHA)

\begin{tabular}{|l|l|l|l|l|l|l|l|l|}
\hline $\mathrm{pH}$ & $\mathrm{BV}_{1}$ & $\mathrm{BV}_{2}$ & $\mathrm{BV}_{3}$ & $\left(\mathrm{~V}_{3}-\mathrm{V}_{2}\right)$ & $\mathrm{n}$ & $\mathrm{pL}$ & $\log \left(\frac{n-1}{2-n}\right)$ & LogK $_{2}$ \\
\hline 9.51 & 5.50 & 6.66 & 6.73 & 0.07 & 1.3509 & 1.70 & -0.2671 & 1.4329 \\
9.73 & 5.55 & 6.78 & 6.85 & 0.07 & 1.6383 & 1.51 & 0.2467 & 1.7567 \\
10.00 & 5.60 & 6.90 & 6.98 & 0.08 & 2.1783 & 1.31 & -0.2158 & 1.0942 \\
10.23 & 5.65 & 7.05 & 7.13 & 0.08 & 4.1904 & 1.27 & & \\
10.49 & 5.70 & 7.10 & 7.19 & 0.09 & 4.6920 & & & \\
\hline
\end{tabular}

Log $K_{2}($ Average value $)=1.4280 \pm 0.3312$ 
BAJOPAS Volume 14 Number 1,June, 2021

Table 5: Point-wise method, $\mathrm{Cu}$ (Unhydrolysed PSHA)

\begin{tabular}{|l|l|l|l|l|l|l|l|l|}
\hline $\mathrm{pH}$ & $\mathrm{BV}_{1}$ & $\mathrm{BV}_{2}$ & $\mathrm{BV}_{3}$ & $\left(\mathrm{~V}_{3}-\mathrm{V}_{2}\right)$ & $\mathrm{n}$ & $\mathrm{pL}$ & $\log \left(\frac{n}{n-1}\right)$ & Log $_{1}$ \\
\hline 8.50 & 5.30 & 5.81 & 5.85 & 0.04 & 0.2973 & 2.88 & -0.3736 & 2.5064 \\
8.72 & 5.35 & 5.90 & 5.95 & 0.05 & 0.3873 & 2.66 & -0.1992 & 2.4608 \\
9.00 & 5.40 & 6.00 & 6.05 & 0.05 & 0.4044 & 2.38 & -0.1681 & 2.2119 \\
9.22 & 5.45 & 6.10 & 6.15 & 0.06 & 0.5157 & 2.18 & -0.0272 & 2.2072 \\
9.51 & 5.50 & 6.20 & 6.27 & 0.07 & 0.6417 & 1.89 & 0.2530 & 1.1430 \\
\hline
\end{tabular}

$\operatorname{LogK}_{1}($ Average value $)=2.3059 \pm 0.6153$

Table 6:Point-wise method, $\mathrm{Cu}$ (Unhydrolysed PSHA)

\begin{tabular}{|l|l|l|l|l|l|l|l|l|}
\hline $\mathrm{pH}$ & $\mathrm{BV}_{1}$ & $\mathrm{BV}_{2}$ & $\mathrm{BV}_{3}$ & $\mathrm{~V}_{3}-\mathrm{V}_{2}$ & $\mathrm{n}$ & $\mathrm{pL}$ & $\log \left(\frac{n-1}{2-n}\right)$ & $\log \mathrm{K}_{2}$ \\
\hline 9.73 & 5.55 & 6.33 & 6.42 & 0.09 & 0.9000 & 1.69 & & \\
10.00 & 5.60 & 6.47 & 6.58 & 0.11 & 1.2578 & 1.44 & -0.4592 & 0.9808 \\
10.23 & 5.65 & 6.62 & 6.84 & 0.12 & 1.6137 & 1.26 & -0.2010 & 1.4610 \\
10.49 & 5.70 & 6.80 & 6.92 & 0.12 & 2.1052 & 1.03 & & \\
\hline
\end{tabular}

$\operatorname{LogK}_{2}$ (Average value) $=1.2209 \pm 0.3398$

Table 7:Point-wise method, Pb (Hydrolysed PSHA)

\begin{tabular}{|l|l|l|l|l|l|l|l|l|}
\hline $\mathrm{pH}$ & $\mathrm{BV}_{1}$ & $\mathrm{BV}_{2}$ & $\mathrm{BV}_{3}$ & $\left(\mathrm{~V}_{3}-\mathrm{V}_{2}\right)$ & $\mathrm{n}$ & $\mathrm{pL}$ & $\log \left(\frac{n}{1-n}\right)$ & LogK $_{1}$ \\
\hline 8.50 & 5.30 & 6.29 & 6.33 & 0.04 & 0.5500 & 2.66 & 0.0871 & 2.7471 \\
8.72 & 5.35 & 6.37 & 6.41 & 0.04 & 0.5714 & 2.43 & 0.1249 & 2.5549 \\
9.00 & 5.40 & 6.46 & 6.50 & 0.04 & 0.6198 & 2.16 & 0.2122 & 2.3722 \\
9.22 & 5.45 & 6.55 & 6.60 & 0.05 & 0.8333 & 1.96 & 0.6989 & 2.6589 \\
\hline
\end{tabular}

Log $_{\mathbf{1}}($ Average value $)=2.5832 \pm 0.1614$

Table 8:Point-wise method, Pb-(Hydrolysed PSHA)

\begin{tabular}{|l|l|l|l|l|l|l|l|l|}
\hline $\mathrm{pH}$ & $\mathrm{BV}_{1}$ & $\mathrm{BV}_{2}$ & $\mathrm{BV}_{3}$ & $\left(\mathrm{~V}_{3}-\mathrm{V}_{2}\right)$ & $\mathrm{n}$ & $\mathrm{pL}$ & $\log \left(\frac{n-1}{2-n}\right)$ & $\log \mathrm{K}_{2}$ \\
\hline 9.51 & 5.50 & 6.66 & 6.71 & 0.05 & 0.9650 & 1.67 & & \\
9.73 & 5.55 & 6.78 & 6.83 & 0.05 & 1.1702 & 1.44 & & \\
10.00 & 5.60 & 6.90 & 6.90 & 0.05 & 1.4864 & 1.22 & -0.0237 & 1.1963 \\
10.23 & 5.65 & 7.05 & 7.10 & 0.05 & 2.0190 & 1.09 & & \\
10.49 & 5.70 & 7.10 & 7.17 & 0.07 & 3.6492 & 1.00 & & \\
\hline
\end{tabular}

Log $K_{2}$ (Average value) $=1.1963$

Table 9: Point-wise method, Pb (Unhydrolysed PSHA)

\begin{tabular}{|l|l|l|l|l|l|l|l|l|}
\hline $\mathrm{pH}$ & $\mathrm{BV}_{1}$ & $\mathrm{BV}_{2}$ & $\mathrm{BV}_{3}$ & $\mathrm{~V}_{3}-\mathrm{V}_{2}$ & $\mathrm{n}$ & $\mathrm{pL}$ & $\begin{array}{l}\text { Log } \\
\left(\frac{n}{n-1}\right)\end{array}$ & Log $\mathrm{K}_{1}$ \\
\hline 8.50 & 5.30 & 5.81 & 5.85 & 0.04 & 0.2973 & 2.88 & -0.3736 & 2.5064 \\
8.72 & 5.35 & 5.90 & 5.94 & 0.04 & 0.3099 & 2.66 & -0.5477 & 2.3123 \\
9.00 & 5.40 & 6.00 & 6.05 & 0.05 & 0.4044 & 2.38 & -0.1681 & 2.2119 \\
9.22 & 5.45 & 6.10 & 6.15 & 0.06 & 0.5157 & 2.18 & 0.0272 & 2.2072 \\
9.51 & 5.50 & 6.20 & 6.26 & 0.07 & 0.6417 & 1.89 & 0.2530 & 2.1430 \\
9.73 & 5.55 & 6.40 & 6.40 & 0.07 & 0.7000 & 1.67 & 0.3680 & 2.0380 \\
\hline
\end{tabular}

LogK $_{1}$ (Average value) $=2.2364 \pm 0.1602$

Table 10: Point-wise method, Pb (Unhydrolysed PSHA)

\begin{tabular}{|l|l|l|l|l|l|l|l|l|}
\hline $\mathrm{pH}$ & $\mathrm{BV}_{1}$ & $\mathrm{BV}_{2}$ & $\mathrm{BV}_{3}$ & $\mathrm{~V}_{3}-\mathrm{V}_{2}$ & $\mathrm{n}$ & $\mathrm{pL}$ & $\log \left(\frac{n-1}{2-n}\right)$ & $\log \mathrm{K}_{2}$ \\
\hline 10.00 & 5.60 & 6.47 & 6.55 & 0.08 & 1.9503 & 1.41 & & \\
10.23 & 5.65 & 6.62 & 6.72 & 0.11 & 1.4792 & 1.26 & -0.0361 & 1.2239 \\
\hline
\end{tabular}

$\operatorname{LogK}_{2}$ (Average value) $=1.2239$

Table 11: Point-wise method, Mg (Hydrolysed PSHA)

\begin{tabular}{|l|l|l|l|l|l|l|l|l|}
\hline $\mathrm{pH}$ & $\mathrm{BV}_{1}$ & $\mathrm{BV}_{2}$ & $\mathrm{BV}_{3}$ & $\left(\mathrm{~V}_{3}-\mathrm{V}_{2}\right)$ & $\mathrm{n}$ & $\mathrm{pL}$ & $\log \left(\frac{n}{n-1}\right)$ & LogK $_{1}$ \\
\hline 8.50 & 5.30 & 6.29 & 6.31 & 0.02 & 0.2750 & 2.64 & -0.4290 & 2.2110 \\
8.72 & 5.35 & 6.37 & 6.39 & 0.02 & 0.2858 & 2.42 & -0.3978 & 2.0222 \\
9.00 & 5.40 & 6.46 & 6.49 & 0.03 & 0.4648 & 2.14 & -0.0612 & 2.0788 \\
9.22 & 5.45 & 6.55 & 6.59 & 0.04 & 0.6667 & 1.94 & 0.3010 & 2.2410 \\
\hline
\end{tabular}

$\log _{\mathbf{1}}($ Average value) $=2.1382 \pm 0.1046$ 
BAJOPAS Volume 14 Number 1,June, 2021

Table 12: Point-wise method, Mg (Hydrolysed PSHA)

\begin{tabular}{|l|l|l|l|l|l|l|l|l|}
\hline $\mathrm{pH}$ & $\mathrm{BV}_{1}$ & $\mathrm{BV}_{2}$ & $\mathrm{BV}_{3}$ & $\left(\mathrm{~V}_{3}-\mathrm{V}_{2}\right)$ & $\mathrm{n}$ & $\mathrm{pL}$ & $\log \left(\frac{n-1}{2-n}\right)$ & LogK $_{2}$ \\
\hline 9.51 & 5.55 & 6.66 & 6.71 & 0.05 & 0.9650 & 1.67 & & \\
9.73 & 5.55 & 6.78 & 6.84 & 0.06 & 1.4042 & 1.47 & -0.1686 & 1.3014 \\
10.00 & 5.60 & 6.90 & 6.93 & 0.06 & 1.7838 & 1.23 & 0.5593 & 1.7893 \\
10.23 & 5.65 & 7.05 & 7.10 & 0.06 & 3.1429 & 1.10 & & \\
10.49 & 5.70 & 7.10 & 7.18 & 0.07 & 3.6492 & 0.83 & & \\
\hline
\end{tabular}

LogK $_{2}($ Average value $)=1.5453 \pm 0.3450$

Table 13: Point-wise method, Mg (Unhydrolysed PSHA)

\begin{tabular}{|l|l|l|l|l|l|l|l|l|}
\hline $\mathrm{pH}$ & $\mathrm{BV}_{1}$ & $\mathrm{BV}_{2}$ & $\mathrm{BV}_{3}$ & $\mathrm{~V}_{3}-\mathrm{V}_{2}$ & $\mathrm{n}$ & $\mathrm{pL}$ & $\log \left(\frac{n}{n-1}\right)$ & $\operatorname{Log~}_{1}$ \\
\hline 8.50 & 5.30 & 5.81 & 5.85 & 0.04 & 0.2973 & 2.88 & -0.3736 & 2.5064 \\
8.72 & 5.35 & 5.90 & 5.94 & 0.04 & 0.3099 & 2.66 & -0.3477 & 2.3123 \\
9.00 & 5.40 & 6.00 & 6.04 & 0.04 & 0.3236 & 2.38 & -0.3202 & 2.0598 \\
9.22 & 5.45 & 6.10 & 6.15 & 0.05 & 0.4297 & 2.17 & -0.1230 & 2.0470 \\
9.51 & 5.50 & 6.20 & 6.26 & 0.06 & 0.5500 & 1.89 & 0.0871 & 1.9771 \\
9.73 & 5.55 & 6.33 & 6.40 & 0.07 & 0.7000 & 1.67 & 0.3680 & 2.0380 \\
\hline
\end{tabular}

LogK $_{1}$ (Average value) $=2.1568 \pm 0.2069$

Table 14: Point-wise method, Mg (Unhydrolysed PSHA)

\begin{tabular}{|l|l|l|l|l|l|l|l|l|}
\hline $\mathrm{pH}$ & $\mathrm{BV}_{1}$ & $\mathrm{BV}_{2}$ & $\mathrm{BV}_{3}$ & $\mathrm{~V}_{3}-\mathrm{V}_{2}$ & $\mathrm{n}$ & $\mathrm{pL}$ & $\log \left(\frac{n-1}{2-n}\right)$ & $\log \mathrm{K}_{2}$ \\
\hline 10.00 & 5.60 & 6.47 & 6.55 & 0.08 & 0.9148 & 1.41 & & \\
10.23 & 5.65 & 6.62 & 6.71 & 0.09 & 1.2102 & 1.20 & -0.5749 & 0.6251 \\
10.49 & 5.70 & 6.80 & 6.92 & 0.09 & 1.5968 & 1.03 & 0.1703 & 1.2003 \\
\hline
\end{tabular}

LogK $_{2}$ (Average value) $=0.9127 \pm 0.4070$

Table15:Point-wise method, Cd (Hydrolysed PSHA)

\begin{tabular}{|l|l|l|l|l|l|l|l|l|}
\hline $\mathrm{pH}$ & $\mathrm{BV}_{1}$ & $\mathrm{BV}_{2}$ & $\mathrm{BV}_{3}$ & $\left(\mathrm{~V}_{3}-\mathrm{V}_{2}\right)$ & $\mathrm{n}$ & $\mathrm{pL}$ & $\log \left(\frac{n}{1-n}\right)$ & LogK $_{1}$ \\
\hline 8.50 & 5.30 & 6.29 & 6.31 & 0.02 & 0.2750 & 2.64 & -0.4210 & 2.2190 \\
8.72 & 5.35 & 6.37 & 6.40 & 0.03 & 0.4286 & 2.42 & -0.1249 & 2.2951 \\
9.00 & 5.40 & 6.46 & 6.49 & 0.03 & 0.4648 & 2.14 & -0.0612 & 2.0788 \\
9.22 & 5.45 & 6.55 & 6.59 & 0.04 & 0.6667 & 1.96 & 0.3010 & 2.2610 \\
9.51 & 5.55 & 6.66 & 6.70 & 0.04 & 0.7720 & 1.67 & 0.5297 & 2.1997 \\
\hline
\end{tabular}

LogK $_{\mathbf{1}}$ (Average value) $=2.2108 \pm 0.0825$

Table 16: Point-wise method, Cd (Hydrolysed PSHA)

\begin{tabular}{|l|l|l|l|l|l|l|l|l|}
\hline $\mathrm{pH}$ & $\mathrm{BV}_{1}$ & $\mathrm{BV}_{2}$ & $\mathrm{BV}_{3}$ & $\left(\mathrm{~V}_{3}-\mathrm{V}_{2}\right)$ & $\mathrm{n}$ & $\mathrm{pL}$ & $\log \left(\frac{n-1}{2-n}\right)$ & Log $_{2}$ \\
\hline 9.73 & 5.55 & 6.78 & 6.83 & 0.06 & 1.4042 & 1.47 & -0.1686 & 1.3014 \\
10.00 & 5.60 & 6.90 & 6.95 & 0.06 & 1.7838 & 1.23 & 0.5593 & 1.7893 \\
10.23 & 5.65 & 7.05 & 7.10 & 0.06 & 3.1429 & 1.09 & & \\
10.49 & 5.70 & 7.10 & 7.16 & 0.06 & 3.1429 & 0.89 & & \\
& & & & & & & & \\
\hline
\end{tabular}

$\operatorname{LogK}_{2}$ (Average value) $=1.5453 \pm 0.3450$

Table 17: Point-wise method, Cd (Unhydrolysed PSHA)

\begin{tabular}{|l|l|l|l|l|l|l|l|l|}
\hline $\mathrm{pH}$ & $\mathrm{BV}_{1}$ & $\mathrm{BV}_{2}$ & $\mathrm{BV}_{3}$ & $\mathrm{~V}_{3}-\mathrm{V}_{2}$ & $\mathrm{n}$ & $\mathrm{pL}$ & $\log \left(\frac{n}{n-1}\right)$ & $\operatorname{Log~}_{1}$ \\
\hline 8.50 & 5.30 & 5.81 & 5.86 & 0.05 & 0.3717 & 2.88 & -0.2280 & 2.6520 \\
8.72 & 5.35 & 5.90 & 5.95 & 0.05 & 0.3873 & 2.66 & -0.1992 & 2.4608 \\
9.00 & 5.40 & 6.00 & 6.06 & 0.06 & 0.4853 & 2.38 & -0.0255 & 2.3545 \\
9.22 & 5.45 & 6.10 & 6.16 & 0.06 & 0.5157 & 2.18 & -0.0272 & 2.2072 \\
9.51 & 5.50 & 6.20 & 6.27 & 0.07 & 0.6417 & 1.89 & 0.2530 & 1.1430 \\
9.73 & 5.55 & 6.33 & 6.41 & 0.08 & 0.8000 & 1.69 & 0.6020 & 2.2920 \\
& & & & & & & & \\
\hline
\end{tabular}

$\operatorname{LogK}_{1}($ Average value $)=2.2516 \pm 0.5380$ 
BAJOPAS Volume 14 Number 1,June, 2021

Table 18: Point-wise method, Cd (Unhydrolysed PSHA)

\begin{tabular}{|l|l|l|l|l|l|l|l|l|}
\hline $\mathrm{pH}$ & $\mathrm{BV}_{1}$ & $\mathrm{BV}_{2}$ & $\mathrm{BV}_{3}$ & $\mathrm{~V}_{3}-\mathrm{V}_{2}$ & $\mathrm{n}$ & $\mathrm{pL}$ & $\log \left(\frac{n-1}{2-n}\right)$ & $\log \mathrm{K}_{2}$ \\
\hline 10.00 & 5.60 & 6.47 & 6.57 & 0.10 & 1.1434 & 1.43 & & \\
10.23 & 5.65 & 6.62 & 6.72 & 0.10 & 1.3448 & 1.23 & -0.2788 & 0.9512 \\
10.49 & 5.70 & 6.80 & 6.90 & 0.10 & 1.7742 & 1.03 & 0.5351 & 1.5651 \\
\hline
\end{tabular}

$\operatorname{LogK}_{2}($ Average value $)=1.2581 \pm 0.4340$

Table 19: Stepwise and overall Stability constants of thehydrolysed and unhydrolysed divalent metal (II) complexes

\begin{tabular}{|c|c|c|c|}
\hline Chelates & LogK $_{1}$ & $\log _{2}$ & Log $\beta$ \\
\hline [Cu (Hydrolysed PSHA-1) $\left.{ }_{2}\right]$ & 2.4788 & 1.4280 & 3.9068 \\
\hline$\left[\mathrm{Pb}(\text { Hydrolysed PSHA-1) })_{2}\right]$ & 2.5832 & 1.1963 & 3.7795 \\
\hline$\left[\mathrm{Cd}(\text { Hydrolysed PSHA-1 })_{2}\right]$ & 2.2108 & 1.5453 & 3.7561 \\
\hline$\left[\mathrm{Mg}(\text { Hydrolysed PSHA-1 })_{2}\right]$ & 2.1382 & 1.5453 & 3.6835 \\
\hline [Cu (Unhydrolysed PSHA-1) & 2.3059 & 1.2209 & 3.5268 \\
\hline$[\mathrm{Pb}$ (Unhydrolysed PSHA-1) 2$]$ & 2.2364 & 1.2239 & 3.4603 \\
\hline [Cd (Unhydrolysed PSHA-1) 2 ] & 2.2516 & 1.2581 & 3.5097 \\
\hline$[\mathrm{Mg}$ (Unydrolysed PSHA-1) & 2.1568 & 0.9127 & 3.0695 \\
\hline
\end{tabular}

The results obtained (Table19) shows the stepwise and overall stability constants to be not high indicating low stability of the complexes, because the solubility of most metal ions in the basic $\mathrm{pH}$ range is minimal due to metal hydroxide precipitation (Karimi, 2017). In general, the stepwise stability constants $\left(K_{1}\right.$ and $K_{2}$ ) follow the order $K_{1}>K_{2}$ for the copper, lead, magnesium and cadmium complexes respectively. The steady decrease of the values with increasing number of ligands is in agreement with the prediction made by researchers (Na'aliya, 2013). The decrease could be attributed to the fact that as the number of the ligands (Humate ions) that enters the coordination zone increases the aqua molecules available for replacement by the ligands become less. Thus, the metal ions become less electron loving with progressive intake of the ligand and this results in the decrease in the values of the constants (Na'aliya, 2013). Also the stability of the complexes is influenced by the size and number of the chelate rings(Mackay and Mackay,2002).All the complexes form rings in their structure as humate, a bidentate ligand, bond the metal ions in the ratio 1:2 (Boguta and Sokolowska, 2016) forming chelate rings. The values of the overall stability constants $(\log \beta)$ obtained for humate complexes are not high indicating low stability as the values are not high. LogK values for copper-humates (Table 3 to 6) obtained in this study are lower than those reported for the complexes of humic acids (Pandey et al., 2015; Dinu, 2013; Kaschl et al., 2010 and Gilbeto and Jorg, 2001). The values of LogK(Table 7 to 10 ) forlead-humates are lower than those reported for the lead in the literature (Dinu, 2013; Gilbeto and Jorg 2001). Log K values(Table 11 to 14 ) for magnesium-humates obtained in this study are close to those reported by (Pandey et al., 2015). Log K values of cadmium-humates (Table 15 to 18 ) obtained in this work near to the one reported by (Dinu, 2013 and Pandey et al., 2015).The difference between the reported values and the values obtained in this study might be probably as a result of acid hydrolysis of humic acid. The values of the overall stability constants $(\log \beta)$ of the copper humates complexes presented in Table 19 is high than that of other metal humate complexes, show relatively high stability of CuHA complexes, show the following order of stability: $\mathrm{Cu}>\mathrm{Pb}>\mathrm{Cd}>\mathrm{Mg}$; which are in close agreement to the findings of (Dinu, 2013 and Pandey et al., 2015).The high stability of Cuhumate chelate could be attributed to the existence of coordinate covalent bond between the complexing agents and the $\mathrm{Cu}^{2+}$ ions. Since, $\mathrm{Cu}^{2+}$ being a metal of the transitional series with $3 d^{9}$ electronic configurations can accept the electrons from the complexing agents. Similarly, the low stabilities of $\mathrm{Pb}, \mathrm{Cd}$ and $\mathrm{Mg}$ complexes could be explained by that $\mathrm{Pb}^{2+}$ with $6 s^{2}, \mathrm{Cd}^{2+}$ with $4 \mathrm{~d}^{10}$ and $\mathrm{Mg}^{2+}$ with $2 \mathrm{p}^{6}$ their electronic configuration has a completely filled $\mathrm{d}, \mathrm{p}$ and $\mathrm{s}$ orbitals. Moreover, the stabilities of metal ions with hydrolysed humic acid from peat soil were higher than those with unhydrolysed humic acid from peat soil; which is ascribed to the high content of acidity in hydrolysed humic acid than unhydrolysed humic acid. 
BAJOPAS Volume 14 Number 1,June, 2021 CONCLUSION

The values of logk for $\mathrm{Cu}(\mathrm{II})$ hydrolysed humic acid complex was higher followed by $\mathrm{Pb}$ (II), $\mathrm{Cd}(\mathrm{II})$ and $\mathrm{Mg}$ (II) hydrolysed humic acid complexes as compared with metal(II) unhydrolysed humic acid complexes. This indicates acid hydrolysis of humic acid can

\section{REFERENCES}

Almeida, V.R. and Szpoganicz, B. (2015). Humic Acid Potentiometric Response Patterns:Out- of Equilibrium Properties and Species Distribution Modelling. Chemical. Biol. Technol. Agric. 2: 17.

Anđelković, T., Nikolić, R., Bojić, A.,Anđelković, D., and Nikolic G.,(2010). Binding of Cadmium to Soil Humic Acid as A Function of Carboxyl Group Content. Macedonian Journal of Chemistry and Chemical Engineering.29(2): 215-224.

Anil, B. N. and Maroti, N. (2008). Studies on Influence of Die-Lectric Constants on Complex Equilibria between Substituted Py-Razalines and Lanthanide Metal Ions pH-Metrically. Amer.-Euras. scient. Res. 3(2): 212-216.

Ashok, K., Pandey, S. P. and Misra, V (2000). Stability Constants of Metal-Humic Acid Complexes and its Role in Environmental Detoxification. Journal of Ecotoxicology and Environmental Safety. 47(2):157-200.

Badr, M. H., El-Halafawi, M. H. and Abd El-al Zeid, E. R. (2012). Comparison Between the Effect of Ionic Strength on Acidity and Dissociation Constants of Humic Acids Extracted from Sewage Sludge and Nile Water Hyacinth Composts.Global Journal of Environmental Research 6 (1): 36-43.

Baruah, M.K., Borah, D., Saikia, P.P., Paul, S., Sharma, T. (2015). Evaluation of pKa Values of Soil Humic Acids and their Complexation Properties. International Journal of Plant \& Soil Science 6(4) : 218-228.

Boguta, P. Sokolowska, Z. (2016). Interactions of $\mathrm{Zn}$ (II) Ions with Humic Acids Isolated from Various Types of Soils. Effect of $\mathrm{pH}, \mathrm{Zn}$ Concentrations and Humic Acids Chemical Properties. Journal of Geochemical Explaration 168. 119-126.

Borges, F., Guimaraes, C., Lima, L.F.C., Pinto, I. and Reis, S.(2005). Potentiometric Studies on the Complexation of Copper(II) by Phenolic Acids as Discrete Ligand Models of enhance the complexation behavior of humic acid with metal (II) ions. However, the higher values of $\log \beta$ for $\mathrm{Cu}(\mathrm{II}), \mathrm{Pb}(\mathrm{II}), \mathrm{Cd}(\mathrm{II})$ and $\mathrm{Mg}(\mathrm{II})$ hydrolysed humic acid complexes indicates more stable stepwise complexes formed as compared with $\mathrm{Cu}(\mathrm{II}), \mathrm{Pb}$ (II), $\mathrm{Cd}$ (II) and $\mathrm{Mg}(\mathrm{II})$ unhydrolysed humic acid complexes.

Humic Substances Talanta 66 (2005) 670-673.

Chefetz, B., Salloum, M. J., Deshmulkin, A. P. and Hatcher, P. (2002). Structural Components of Humic Acids as Determined by Chemical Modifications and Carbon-13 NMR, Pyrolysis, and Thermochemolysis- Gas Chromatography/Mass Spectrometry. Soil Science Society of American Journal Abstract Division S-2- Soil Chemistry66. 1159-1171.

Dinu, M. I. (2013). Metals Complexation with Humic Acids in Surface Water of Different Environ. Sci. Technol. 31(1): 1-17.

Fernandes, A.N., Giacomelli, C., Giovanela, M. Vaz, D.V. Szpoganicz, B. and Maria M. D. (2009). Potentiometric Acidity Determination in Humic Substances Influenced by Different Analytical Procedures.J. Braz. Chem. Soc. 20 (9):14.

Gamal, A. H. (2015). Stability Constants of Rhenium (V) Metal Complexes with Selected Drugs. Pyrex Journal of Research in Environmental Studies. 2(2): 006-014.

Janrao, D. M., Pathan, J., Kayande, D.D., and Mulla, J.J. (2014). An Over View of Potentiometric Determination of Stability Constants of Metal Complexes. Sci. Revs. Chem. Commun.: 4(1), 2014, 11-24.

Karimi, H. (2017). Effect of pH and Initial Pb(II) Concentration on the Lead Removal Efficiency from Waste Water Using $\mathrm{Ca}(\mathrm{OH})_{2}$. International Journal of Water and Waste Water Treatment 3.2

Kaschl, A. Romheld, V. and Chen, Y. (2010). Binding of Cadmium, Copper and Zinc to Humic Substances Originating from Municipal Solid Waste Compost. Israel Journal of Chemistry Vol. 42(1): 89-98.

Kostic, I. S., Tatjana, P, A., Nikolic, R. S., Cvetkovic, T. P., Pavlovic, D. D., Aleksandar, L.J. and Bojic, A. (2012). Comparative Study of Binding Strengths of Heavy Metals with Humic Acid. J.serb. Chem. Soc. 76(9) pp 1-20. 
BAJOPAS Volume 14 Number 1,June, 2021

Na'aliya, J. (2013). Determination of Stepwise Stability Constants and Gibbs free Energy Change of Trisprolina to Complexes of some Divalent Transition Metal ions. Bayero Journal of Pure and Applied Sciences 6(2): 112-114.

Omar, A. A. and Ali, E. A. (2015). Potentiometric Studies on Complexes of $\mathrm{Cr}$ (III) and $\mathrm{Zr}$ (IV) with some Carboxylic Acids. International Journal of Advanced Chemistry, 3(1) 25-

37.

Pandey, A. K. Pandey, S. D. and Misr, V. (2015).Stability Constants of Metal- Humic Acid Complexes and Its Role in Environmental Detoxification. J. Ecotoxicology and Environmental Safety. 47(1):195-200.

Ram, N. and Raman, K.V. (1984). Stability Constants of Complexes of Metals with
Humicand Fuvic Acids under Non- acidConditions. Journal of Plant Nutrition and Soil Sciences.

147:171-176.

Santosh, D. D., Ashok, B. K., Vijay, J. T., Shivraj, G. W. and Vinay, V. W. (2011). Potentiometric Studies of Elec-Trolyte Effects on Complex Equilibria of Some Substituted 5-(2-hydroxy Phenyl) Pyrazoles. Der pharm. 3 (6): 75-83.

Sayyed, H. and Abdul Rahim, M. F. (2012). Studies of Binary Complexes of Metal Ions with Mandelic Acid by Potentiometry. Chem. J. 02 (6): 206209.

Shirvani, M. Moradian, E. Khalili, B. Bakhtiary, S. (2015). Interaction of $\mathrm{Cd}$ and $\mathrm{Pb}$ with Humate-Palygorskite and HumateSepiolite Complexes. Journal of water, air and pollution 3: 220-228. 


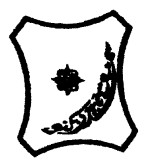

Bayero Journal of Pure and Applied Sciences, 14(1): 54 - 63

Received: November, 2020

Accepted: April, 2021

ISSN $2006-6996$

\title{
STABILITY CONSTANTS OF COMPLEXES OF METAL IONS WITH PEATSOIL HUMIC ACIDS UNDER NON-ACID-CONDITIONS
}

\author{
${ }^{* 1}$ Sabo, Yusuf ${ }^{2}$ Jimoh, W.L.O., ${ }^{3}$ Isa Baba Koki and ${ }^{4}$ Sholadoye, Q. 0. \\ ${ }^{1}$ Department of Pure and Industrial Chemistry, Bayero University, Kano \\ ${ }^{3}$ Department of Chemistry, Yusuf Maitama Sule University Kano. P.M.B. 3220 Kano, Nigeria. \\ ${ }^{4}$ Department of Chemistry, Nigerian Police Academy, Wudil, Kano-Nigeria
}

*Correspondence E-mail; saboyusuf18@yahoo.com

ABSTRACT

Stability constants of complexes of four divalent metal ions viz. $\mathrm{Cu}^{2+}, \mathrm{Pb}^{2+}, \mathrm{Mg}^{2+}$ and $\mathrm{Cd}^{2+}$ with humic acids (HA) were determined by potentiometric titration of humic acids with the corresponding salt of the divalent metals in aqueous media under non-acid-condition. The log $K$ (logarithm of the stability constant) ranged from 1.0942 to 2.7471 for metalhumic acid complexes were determined using point-wise computational method. The order of stability constants were obtained as follows: $\mathrm{Cu}>\mathrm{Pb}>\mathrm{Cd}>\mathrm{Mg}$ for metal $-\mathrm{HA}$ complexes respectively, indicating a higher degree of complexation with Cu metal ion.

Keywords: stability constant, humic acid, potentiometric titration, divalent metals, acid hydrolysis.

\section{NTRODUCTION}

The stability constant of a complex is the numerical expression of its stability and provides a quantitative measure of affinity of the metal ion to the complexing agent. An understanding of the relative stability of metal-complexes helps in predicting the behavior of metal ions in the soil (Ram and Raman, 1982). Extensive researches has been done to determine the stability constants of the complexes formed between humic acid (HA) with a number of metal ions. Ashok et al., (2000) reported that humic acid with hydroxyl, phenoxyl and carboxyl reactive groups can form coordination compound with metal ions at $\mathrm{pH}$ 3.5. The stability constants(Log K) for different metalhumic acid complexes indicated the following order of the stabilities of complexes formed between humic acid and metal ion, $\mathrm{Cu}>\mathrm{Fe}$ $>\mathrm{Pb}>\mathrm{Ni}>\mathrm{Co}>\mathrm{Ca}>\mathrm{Cd}>\mathrm{Zn}>\mathrm{Mn}>\mathrm{Mg}$. Andelkovic et al., (2010) investigated the binding of $\mathrm{Cd}$ (II) to soil humic acid at pH 6.5 and in $0.1 \mathrm{M} \mathrm{KNO}_{3}$ ionic medium. The stability constant for binding indicating greater stability in the case when carboxyl groups are involved in complexation reaction. Kostic et al.,(2012) investigated the complexation of humic acid with certain heavy metal ions (Co(II), $\mathrm{Ni}(\mathrm{II}), \mathrm{Cu}(\mathrm{II})$,
$\mathrm{Zn}(\mathrm{II})$, and $\mathrm{Pb}(\mathrm{II})$. The experiment was performed at $25^{\circ} \mathrm{C}$, at pH 4.0 and ionic strength of $0.01 \mathrm{M}$. Stability constant of complex between $\mathrm{Pb}$ (II) ions and humic acid is greater than stability constants of other investigated metalhumate complexes. Bogata and Sokolowska (2016) analyses the interaction between humic acids from different soils and $\mathrm{Zn}$ (II) ions at wide concentration ranges and at $\mathrm{pH} 5$. Studies have showed significant impact of $\mathrm{Zn}$ concentration, $\mathrm{pH}$ and some properties of humic acids with zinc.But all of these studies were limited to acidic $\mathrm{pH}$ range. Therefore, the present study was carried out to determine and compare the stability constants of complexes of metal ions with hydrolysed peat soil humic acid and unhydrolysed peat soil humic under non-acid conditions.

\section{MATERIALS AND METHODS}

Analytical grade chemicals used includes hydrochloric acid $(\mathrm{HCl})$, nitric acid $\left(\mathrm{HNO}_{3}\right)$, sodium hydroxide $(\mathrm{NaOH})$, lead nitrate $\mathrm{Pb}\left(\mathrm{NO}_{3}\right)_{2}$, copper nitrate $\mathrm{Cu}\left(\mathrm{NO}_{3}\right)_{2} \cdot 3 \mathrm{H}_{2} \mathrm{O}$, cadmium nitrate $\mathrm{Cd}\left(\mathrm{NO}_{3}\right)_{2} \cdot 4 \mathrm{H}_{2} \mathrm{O}$, magnesium nitrate $\mathrm{Mg}\left(\mathrm{NO}_{3}\right)_{2} \cdot 6 \mathrm{H}_{2} \mathrm{O}$, potassium nitrate $\left(\mathrm{KNO}_{3}\right)$, calcium chloride $\left(\mathrm{CaCl}_{2}\right)$, (sigma-Aldrich). Dowex 50WX8, (20-50 mesh) from Fluka. 


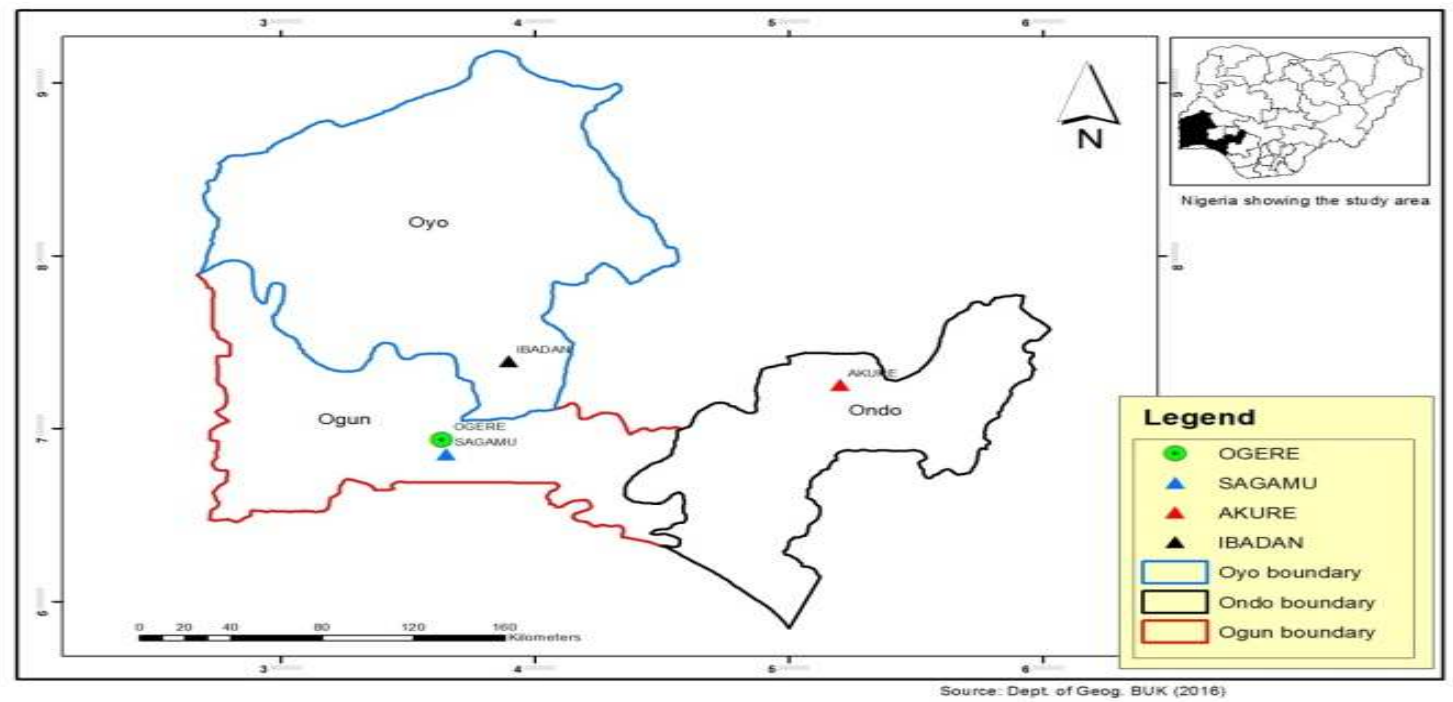

Figure 1: Map showing the sampling point at Sagamu Town, Ogun State.

\section{Description of Sampling Area}

Sagamu has geographical coordinates between $6^{\circ} 50^{\prime}$ north; $3^{\circ} 38^{\prime}$ east is located in south western region of Nigeria. The region has tropical wet and dry climate with a lengthy wet season and relatively constant temperatures throughout the course of the year. Wet season runs from March to October, November to December forms the region dry season. The vegetation type of the region is savannah which is really grassland with small bushes and occasional big trees. Grassland soils have substantially higher organic matter content than forest soils (Novackova, 2011).

\section{Sample Collection}

The Peatsoil samples were collected from four different sampling points $(0-10 \mathrm{~cm}$ depth) in Sagamu into polyethylene bag with plastic spoons. Samples were taken to the laboratory, extraneous materials were removed; the samples were air-dried, crushed and ground to a fine powder in a mortar passed through a $0.20 \mathrm{~mm}$ sieve. The samples were kept for analysis.

\section{Isolation and purification of humic acid from peat soil sample}

Peatsoil sample $(100 \mathrm{~g})$ was mixed with 1000 $\mathrm{cm}^{3}$ of $0.1 \mathrm{M} \mathrm{NaOH}$ solution, shaken for 3hours and left to stand overnight. Dark-coloured supernatant was obtained and decanted from solid residue. The dark-coloured supernatant was acidified to $(\mathrm{pH}=1.0)$ with $6 \mathrm{M} \mathrm{HCl}$ stirred and allowed to stand for 6 hours. Yellowish brown supernatant and dark-brown precipitate were obtained. The yellowish brown supernatant was decanted followed by centrifuge and discarded. The dark-brown precipitate was mixed with $500 \mathrm{~cm}^{3}$ of $0.1 \mathrm{M} \mathrm{NaOH}$ solution followed by passing through dowex resin. The dark-brown solution was acidified to $(\mathrm{pH}=1.0)$ with $6 \mathrm{M} \mathrm{HCl}$ stirred and allowed to stand for 3 hours. The dark-brown precipitate was washed several times with deionized water. The supernatant was treated with $\mathrm{AgNO}_{3}$ solution until no white precipitate observed. The humic acid was transferred to weighed crucible and dried at $60^{\circ} \mathrm{C}$ in an oven for 12 hours. The humic acid was cooled and dried in the desiccator, weighed and recorded. The obtained humic acid was dried again at $60^{\circ} \mathrm{C}$ for additional 6 hours cooled and dried in the desiccator, weighed and recorded constant weight was obtained (Baruah et al., 2015).

\section{FT-IR analysis}

FT-IR spectra of humic acid sample was analysed using Carry 630 FT-IR Agilent Technologies.

Unhydrolysed compost humic acid

The unhydrolysed humic acid was obtained after isolation and purification of compost humic acid and kept for investigation.

\section{Acid hydrolysis of Peatsoil acid}

Peatsoil humic acid sample (1g) was refluxed for 12 hours at $\left(160^{\circ} \mathrm{C}\right)$ with $50 \mathrm{~cm}^{3}$ of $6 \mathrm{M} \mathrm{HCl}$. The mixture was allowed to cool, decanted, and centrifuged after hydrolysis. The insoluble residues were washed with distilled water via centrifugation several times, and the supernatant was treated with $\mathrm{AgNO}_{3}$ solution until no white precipitate was observed. The residue was thoroughly dried over $\mathrm{CaCl}_{2}$ in a desiccator at room temperature (Chefetz et al., 2002). Finally, the obtained hydrolysed humic acid was kept for investigation. 
BAJOPAS Volume 14 Number 1,June, 2021 Potentiometric Titrations

Potentiometric measurements were carried out using a pH-meter Jenway (model 3510) with combine electrode, the sensitivity of the $\mathrm{pH}$ meter is 0.01 units. The $\mathrm{pH}$ meter was switched on half an hour before starting the titration for initial warm up of the instrument. The instrument was calibrated with an aqueous standard buffer solution of $\mathrm{pH} 4.00$ and 10.0 (borate buffer) prepared from a "Qualigens" buffer tablets.

The following sets of solutions were prepared in a $250 \mathrm{~cm}^{3}$ volumetric flask separately for $\mathrm{pH}$ metric titrations.

(i) $5 \mathrm{~cm}^{3} 0.1 \mathrm{M} \mathrm{HCl}+40 \mathrm{~cm}^{3}$ deionized water

(ii) $5 \mathrm{~cm}^{3} 0.1 \mathrm{M} \mathrm{HCl}+39 \mathrm{~cm}^{3}$ deionized water $+1 \mathrm{~cm}^{3} 0.15 \mathrm{gcm}^{-3}$ humic acid

(iii) $5 \mathrm{~cm}^{3} 0.1 \mathrm{M} \mathrm{HCl}+37 \mathrm{~cm}^{3}$ deionized water $+1 \mathrm{~cm}^{3} 0.15 \mathrm{gcm}^{-3}$ humic acid

$$
+2 \mathrm{~cm}^{3} \quad 0.01 \mathrm{M} \mathrm{Cu} \text { (II) }
$$

The solutions were titrated against standardized $0.110 \mathrm{MNaOH}$ separately. The total volume of each mixture was adjusted to $50 \mathrm{~cm}^{3}$ and the ionic strength of the solutions was maintained constant at by adding appropriate amount of stock solution of $1 \mathrm{M} \mathrm{KNO}_{3}$ (Gamal, 2015; Omar and Ali, 2015). A magnetic stirrer was used to achieve thorough mixing of the interacting solutions at $550 \mathrm{rpm}$. The same set of experimental conditions was applied for potentiometric titration of remaining samples.

\section{Evaluation of pKa of Hydrolysed peat soil Humic Acids}

The proton-ligand formation number $\mathrm{n}_{\mathbf{A}}$ were calculated by Irving and Rossotti expression (Omar and Ali, 2015).

$\mathrm{nA}=\mathrm{Y}-\frac{(\mathrm{V} 2-\mathrm{V1})(\mathrm{No}-\mathrm{Eo})}{(\mathrm{VO}+\mathrm{V1}) \mathrm{TCL}}$ 1

Where: $Y$ is number of dissociable proton, $\left(\mathrm{V}_{2^{-}}\right.$ $V_{1}$ ) is the measure of displacement of the ligand curve relative to acid curve, $\mathrm{N}^{\circ}$ and $\mathrm{E}^{\circ}$ are the resultant concentration of alkali solution, free acid solution, $\mathrm{T}_{\mathrm{cL}}{ }^{\circ}$ is the total ligand concentration, $\mathrm{V}^{\circ}$ is the total volume of titration solution, $V_{1}$ is the volume of alkali added to acid solution, $V_{2}$ is the volume of alkali added to acid solution + ligand solution, acid dissociation constants (pKa - values) of ligand were calculated by algebraic method point wise calculation (Tables 1 ). The dissociation constants (pKa) were calculated according to the following relation:

$\mathrm{pKa}=\mathrm{pH}+\log \left(\frac{n A}{1-n A}\right)$ 2

Where: pKa is the acid dissociation constant, $\mathrm{n}_{\mathrm{A}}$ is the Proton-ligand formation number and $\mathrm{pH}$ is the pH-values (Omar and Ali, 2015).

\section{Determination of metal-ligand stability constants $(\log K)$ of complexes}

The potentiometric measurement for the determination of stability constant of a complex in solution is based on the fact that the redox potential of the couple $\frac{M^{+(m-n)}}{M^{+m}}$ is shifted significantly on complexation of the metal ion with the ligand. This method involves change in hydrogen ion concentration $\left[\mathrm{H}^{+}\right]$due to the displacement or association of one or more protons taking place during complexation reaction. This change can be found out by titrating the solutions containing free acid, acid with ligand, and acid with ligand and metal ion, individually against a standard alkali solution at a constant ionic strength or temperature. Either ionic strength or temperature may be varied for different sets of solutions. In all the cases, the change in the $\mathrm{pH}$ of the solution is measured after each addition of a known amount of alkali to the reaction cell which contains the reaction mixture. The titration curves are then drawn by plotting the measured $\mathrm{pH}$ values against the corresponding volume of alkali added and the stability constants of the complexes are determined from the titration curves by employing $\mathrm{pH}$-metric titration technique given by (Irving and Rossoti).

Metal-ligand stability constants ( $\log \mathrm{K}$ ) were determined by using the following relations:

$$
\bar{n}=\frac{\left(V_{3}-V_{2}\right)\left(E^{0}+N^{0}\right)}{\left(V^{0}+V_{2}\right) \bar{n}_{A} T_{m}^{0}}
$$

and

$$
P L=\log _{10}\left\{\frac{1+\beta_{n}^{H} \frac{1}{[\text { anti } \log \mathrm{pH}]^{\mathrm{n}}}}{\mathrm{T}_{\mathrm{L}}^{0}-n \bar{T}_{m}^{0}} \mathrm{X} \frac{\left(V^{0}+V_{3}\right)}{V^{0}}\right\}
$$


BAJOPAS Volume 14 Number 1,June, 2021

Where $T_{L}, T^{\circ}, E^{\circ}$, and $V^{\circ}$ havethe same significance as in equation (1) above, $T_{m}$ denotes the total concentration of metal present in solution, $V_{3}$ is the volume of metal ions present in solution and $\beta^{H}$ is the overall proton ligand stability constant. The metal-ligand stability constants (log K) were determined by employing point wise computational Method (eq. 5 and 6).

$\operatorname{LogK}_{1}=\log \left(\frac{n}{1-n}\right)+\mathrm{pL}$ .5

$\operatorname{LogK}_{2}=\log \left(\frac{1-n}{2-n}\right)+\mathrm{pL}$ ...6

Where: Log $\mathrm{K}$ is the metal-ligand stability constant, $\mathrm{pL}$ is the Free ligand exponent function, $\mathbf{n}$ is the Average number of ligand attached with metal ion (Janraoet al., 2014). The results obtained were analyzed by an ORIGIN 2016 program using titration data and then the proton-ligand stability constants (pKa) and Metal-ligand stability constant (LogK) calculated (Omar and Ali, 2015).

\section{RESULTS AND DISCUSSION}

Fourier transformed infrared (FT-IR) spectra of isolated humic acid from peat soils Figure 2 had distinct clear absorption bands indicating the presence of major humic acid structural elemental groups such as $\mathrm{H}$ bonded $\mathrm{OH}$ $\left(3680 \mathrm{~cm}^{-1}\right.$ peak $), C=0$ of carbonyl $\left(1721 \mathrm{~cm}^{-1}\right.$ peak), functional groups of aliphatic components $\mathrm{CH}_{2}\left(2918 \mathrm{~cm}^{-1}\right.$ peak) and $\mathrm{C}-\mathrm{O}$ stretching of polysaccharide $\left(1168 \mathrm{~cm}^{-1}\right.$ peak). The positions of the absorption bands of the spectra fell within typical major absorption bands of humic acid which is at frequencies 3680, 2918, 1721, 1168 $\mathrm{cm}^{-1}$. The first peak centred in the vicinity of $3680 \mathrm{~cm}^{-1}$ region is attributed to phenol $\mathrm{OH}$ group bounded by intermolecular $\mathrm{H}$ bonds. The $2918 \mathrm{~cm}^{-1}$ band usually has absorption maximum at $2918 \mathrm{~cm}^{-1}$ which is due to $\mathrm{C}-\mathrm{H}$ stretching of alkane group $\left(\mathrm{CH}_{2}\right)$. The next major absorption band is $1721 \mathrm{~cm}^{-1}$. This band has been commonly ascribed to $\mathrm{C}=\mathrm{O}$ stretching of mainly carboxyl group $(\mathrm{COOH})$ with trace amount of ketones. The last peak was observed at 1168 $\mathrm{cm}^{-1}$ due to $\mathrm{C}-\mathrm{O}$ stretching of polysaccharides and this peak appeared also in the spectra of humic acid from peat soil. The FTIR spectra of the isolated humic acid contained all major characteristic absorption peaks of humic acid. These absorption peaks indicated the presence of the major structural elements of humic acid namely $\mathrm{H}$ bonded $\mathrm{OH}, \mathrm{C}=\mathrm{C}$ of aromatic ring, $\mathrm{C}=\mathrm{O}$ of carbonyl group (both carboxyl and ketonic), $\mathrm{CH}_{2}$ group. This strongly supports the presence of humic acid.

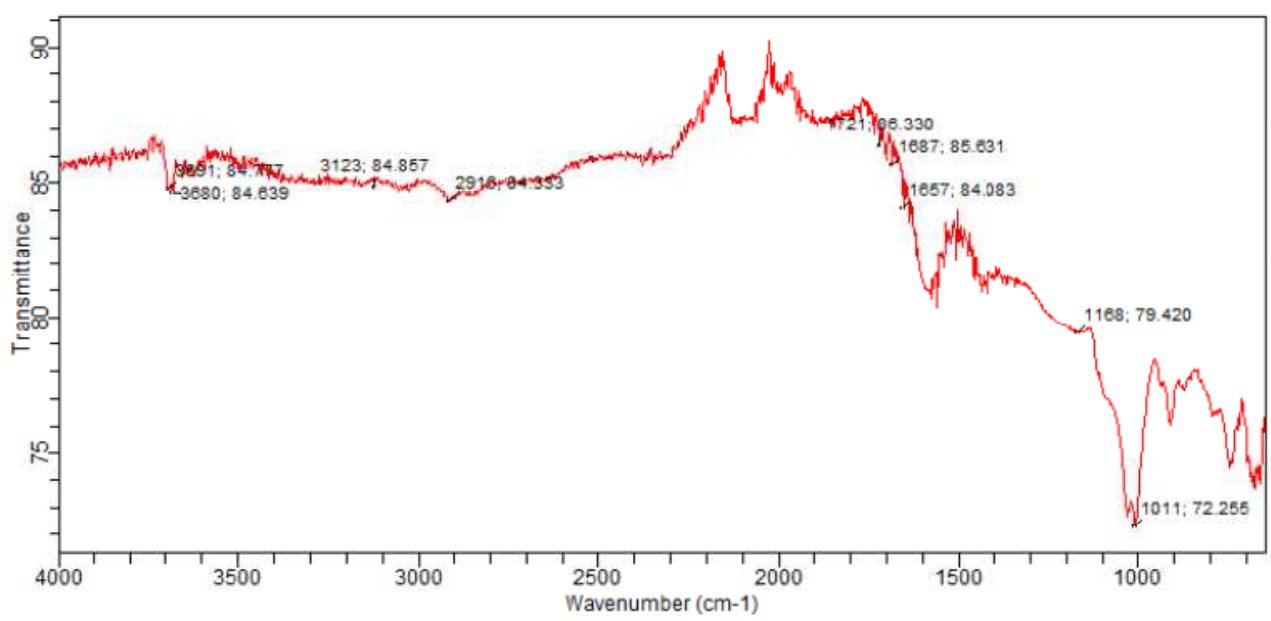

Fig. 2 : FT-IR spectraof peatsoilhumic acid (PSHA)

\section{Evaluation of acid dissociation constant (pka) of acid hydrolysed peat soil humicacid at phenolic group}

The value of the dissociation constant of the peat soil humic acid (PSHA) that underwent acidhydrolysis studied was found to be 8.9299 as shown Table 1, which is lower than the literaturevalues reported by Almeida and Szpoganics, (2015), Borges et al., (2005); Badr et al., (2012)and Fernandes et al,.(2009) of $9.73,9.47$ and 10.30. The difference between the obtained valuesand the reported values in this study might be probably as a result of acid hydrolysis of humicacid. 
BAJOPAS Volume 14 Number 1,June, 2021

Table 1: PKa of (Hydrolysed PSHA)

\begin{tabular}{|l|l|l|l|l|l|l|}
\hline $\mathrm{pH}$ & $\mathrm{BV}_{1}$ & $\mathrm{BV}_{2}$ & $\mathrm{~V}_{2}-\mathrm{V}_{1}$ & $\mathrm{nA}$ & $\log \left(\frac{n A}{1-n A}\right)$ & $\mathrm{pKa}$ \\
\hline 8.50 & 5.30 & 6.29 & 0.99 & 0.3594 & -0.2510 & 8.2490 \\
8.72 & 5.35 & 6.37 & 1.02 & 0.3400 & -0.2880 & 8.4320 \\
9.00 & 5.40 & 6.46 & 1.06 & 0.3141 & -0.3391 & 8.6609 \\
9.22 & 5.45 & 6.55 & 1.10 & 0.2882 & -0.3927 & 8.8273 \\
9.51 & 5.50 & 6.66 & 1.16 & 0.2494 & -0.4786 & 9.0314 \\
9.73 & 5.55 & 6.78 & 1.23 & 0.2041 & -0.5910 & 9.1390 \\
10.00 & 5.60 & 6.90 & 1.30 & 0.1589 & -0.7238 & 9.2762 \\
10.23 & 5.65 & 7.05 & 1.40 & 0.0941 & -0.9835 & 9.2465 \\
10.49 & 5.70 & 7.10 & 1.40 & 0.0941 & -0.9835 & 9.5065 \\
\hline
\end{tabular}

Average pKa $=8.9299 \pm 0.4186$

Table 2: PKa of (Unhydrolysed PSHA)

\begin{tabular}{|l|l|l|l|l|l|l|}
\hline $\mathrm{pH}$ & $\mathrm{BV}_{1}$ & $\mathrm{BV}_{2}$ & $\mathrm{~V}_{2}-\mathrm{V}_{1}$ & $\mathrm{nA}$ & $\log \left(\frac{\boldsymbol{n A}}{1-\boldsymbol{n}}\right)$ & $\mathrm{pKa}$ \\
\hline 8.50 & 5.30 & 5.81 & 0.51 & 0.6619 & 0.2919 & 8.7919 \\
8.72 & 5.35 & 5.90 & 0.55 & 0.6357 & 0.2418 & 8.9618 \\
9.00 & 5.40 & 6.00 & 0.60 & 0.6029 & 0.1813 & 9.1813 \\
9.22 & 5.45 & 6.10 & 0.65 & 0.5701 & 0.1226 & 9.3426 \\
9.51 & 5.50 & 6.20 & 0.70 & 0.5376 & 0.0654 & 9.5754 \\
9.73 & 5.55 & 6.33 & 0.78 & 0.4851 & -0.0259 & 9.7041 \\
10.00 & 5.60 & 6.47 & 0.87 & 0.4262 & -0.1291 & 9.8709 \\
10.23 & 5.65 & 6.62 & 0.99 & 0.3609 & -0.2481 & 9.9819 \\
10.49 & 5.70 & 6.80 & 1.10 & 0.2759 & -0.4690 & 10.0210 \\
\hline
\end{tabular}

Average pKa $=9.4923 \pm 0.4410$

Metal-ligand stability constant ( $\log \mathrm{K}$ )

The stabilityconstants require the accurate values of proton-ligand stability constants (Anil and Maroti, 2008). Metal titration curves crossed over ligand titration curve indicated the formation of complex upon proton release (Santosh, et al., 2011). If the values of n- are within range $0.2-0.8$ and $1.2-18$ this indicates the formation of $1: 1$ and 1:2 complexes (Sayyed and Mazahar, 2012).

The metal (II)-humate stepwise stability constants (log k) at phenolic group (Tables 318)

Table 3: Point-wise method, $\mathrm{Cu}$-(Hydrolysed PSHA)

\begin{tabular}{|l|l|l|l|l|l|l|l|l|}
\hline $\mathrm{pH}$ & $\mathrm{BV}_{1}$ & $\mathrm{BV}_{2}$ & $\mathrm{BV}_{3}$ & $\left(\mathrm{~V}_{3}-\mathrm{V}_{2}\right)$ & $\mathrm{n}$ & $\mathrm{pL}$ & $\log \left(\frac{n}{1-n}\right)$ & LogK $_{1}$ \\
\hline 8.50 & 5.30 & 6.29 & 6.33 & 0.04 & 0.5500 & 2.66 & 0.0871 & 2.7471 \\
8.72 & 5.35 & 6.37 & 6.41 & 0.04 & 0.5714 & 2.43 & 0.1249 & 2.5549 \\
9.00 & 5.40 & 6.46 & 6.50 & 0.04 & 0.6198 & 2.16 & 0.2122 & 2.3722 \\
9.22 & 5.45 & 6.55 & 6.59 & 0.04 & 0.6667 & 1.94 & 0.3010 & 2.2410 \\
\hline
\end{tabular}

LogK $_{1}$ (Average value) $=2.4788 \pm 0.2203$

Table 4: Point-wise method, $\mathrm{Cu}$-(Hydrolysed PSHA)

\begin{tabular}{|l|l|l|l|l|l|l|l|l|}
\hline $\mathrm{pH}$ & $\mathrm{BV}_{1}$ & $\mathrm{BV}_{2}$ & $\mathrm{BV}_{3}$ & $\left(\mathrm{~V}_{3}-\mathrm{V}_{2}\right)$ & $\mathrm{n}$ & $\mathrm{pL}$ & $\log \left(\frac{n-1}{2-n}\right)$ & LogK $_{2}$ \\
\hline 9.51 & 5.50 & 6.66 & 6.73 & 0.07 & 1.3509 & 1.70 & -0.2671 & 1.4329 \\
9.73 & 5.55 & 6.78 & 6.85 & 0.07 & 1.6383 & 1.51 & 0.2467 & 1.7567 \\
10.00 & 5.60 & 6.90 & 6.98 & 0.08 & 2.1783 & 1.31 & -0.2158 & 1.0942 \\
10.23 & 5.65 & 7.05 & 7.13 & 0.08 & 4.1904 & 1.27 & & \\
10.49 & 5.70 & 7.10 & 7.19 & 0.09 & 4.6920 & & & \\
\hline
\end{tabular}

Log $K_{2}($ Average value $)=1.4280 \pm 0.3312$ 
BAJOPAS Volume 14 Number 1,June, 2021

Table 5: Point-wise method, $\mathrm{Cu}$ (Unhydrolysed PSHA)

\begin{tabular}{|l|l|l|l|l|l|l|l|l|}
\hline $\mathrm{pH}$ & $\mathrm{BV}_{1}$ & $\mathrm{BV}_{2}$ & $\mathrm{BV}_{3}$ & $\left(\mathrm{~V}_{3}-\mathrm{V}_{2}\right)$ & $\mathrm{n}$ & $\mathrm{pL}$ & $\log \left(\frac{n}{n-1}\right)$ & Log $_{1}$ \\
\hline 8.50 & 5.30 & 5.81 & 5.85 & 0.04 & 0.2973 & 2.88 & -0.3736 & 2.5064 \\
8.72 & 5.35 & 5.90 & 5.95 & 0.05 & 0.3873 & 2.66 & -0.1992 & 2.4608 \\
9.00 & 5.40 & 6.00 & 6.05 & 0.05 & 0.4044 & 2.38 & -0.1681 & 2.2119 \\
9.22 & 5.45 & 6.10 & 6.15 & 0.06 & 0.5157 & 2.18 & -0.0272 & 2.2072 \\
9.51 & 5.50 & 6.20 & 6.27 & 0.07 & 0.6417 & 1.89 & 0.2530 & 1.1430 \\
\hline
\end{tabular}

$\operatorname{LogK}_{1}($ Average value $)=2.3059 \pm 0.6153$

Table 6:Point-wise method, $\mathrm{Cu}$ (Unhydrolysed PSHA)

\begin{tabular}{|l|l|l|l|l|l|l|l|l|}
\hline $\mathrm{pH}$ & $\mathrm{BV}_{1}$ & $\mathrm{BV}_{2}$ & $\mathrm{BV}_{3}$ & $\mathrm{~V}_{3}-\mathrm{V}_{2}$ & $\mathrm{n}$ & $\mathrm{pL}$ & $\log \left(\frac{n-1}{2-n}\right)$ & $\log \mathrm{K}_{2}$ \\
\hline 9.73 & 5.55 & 6.33 & 6.42 & 0.09 & 0.9000 & 1.69 & & \\
10.00 & 5.60 & 6.47 & 6.58 & 0.11 & 1.2578 & 1.44 & -0.4592 & 0.9808 \\
10.23 & 5.65 & 6.62 & 6.84 & 0.12 & 1.6137 & 1.26 & -0.2010 & 1.4610 \\
10.49 & 5.70 & 6.80 & 6.92 & 0.12 & 2.1052 & 1.03 & & \\
\hline
\end{tabular}

$\operatorname{LogK}_{2}$ (Average value) $=1.2209 \pm 0.3398$

Table 7:Point-wise method, Pb (Hydrolysed PSHA)

\begin{tabular}{|l|l|l|l|l|l|l|l|l|}
\hline $\mathrm{pH}$ & $\mathrm{BV}_{1}$ & $\mathrm{BV}_{2}$ & $\mathrm{BV}_{3}$ & $\left(\mathrm{~V}_{3}-\mathrm{V}_{2}\right)$ & $\mathrm{n}$ & $\mathrm{pL}$ & $\log \left(\frac{n}{1-n}\right)$ & LogK $_{1}$ \\
\hline 8.50 & 5.30 & 6.29 & 6.33 & 0.04 & 0.5500 & 2.66 & 0.0871 & 2.7471 \\
8.72 & 5.35 & 6.37 & 6.41 & 0.04 & 0.5714 & 2.43 & 0.1249 & 2.5549 \\
9.00 & 5.40 & 6.46 & 6.50 & 0.04 & 0.6198 & 2.16 & 0.2122 & 2.3722 \\
9.22 & 5.45 & 6.55 & 6.60 & 0.05 & 0.8333 & 1.96 & 0.6989 & 2.6589 \\
\hline
\end{tabular}

Log $_{\mathbf{1}}($ Average value $)=2.5832 \pm 0.1614$

Table 8:Point-wise method, Pb-(Hydrolysed PSHA)

\begin{tabular}{|l|l|l|l|l|l|l|l|l|}
\hline $\mathrm{pH}$ & $\mathrm{BV}_{1}$ & $\mathrm{BV}_{2}$ & $\mathrm{BV}_{3}$ & $\left(\mathrm{~V}_{3}-\mathrm{V}_{2}\right)$ & $\mathrm{n}$ & $\mathrm{pL}$ & $\log \left(\frac{n-1}{2-n}\right)$ & $\log \mathrm{K}_{2}$ \\
\hline 9.51 & 5.50 & 6.66 & 6.71 & 0.05 & 0.9650 & 1.67 & & \\
9.73 & 5.55 & 6.78 & 6.83 & 0.05 & 1.1702 & 1.44 & & \\
10.00 & 5.60 & 6.90 & 6.90 & 0.05 & 1.4864 & 1.22 & -0.0237 & 1.1963 \\
10.23 & 5.65 & 7.05 & 7.10 & 0.05 & 2.0190 & 1.09 & & \\
10.49 & 5.70 & 7.10 & 7.17 & 0.07 & 3.6492 & 1.00 & & \\
\hline
\end{tabular}

Log $K_{2}$ (Average value) $=1.1963$

Table 9: Point-wise method, Pb (Unhydrolysed PSHA)

\begin{tabular}{|l|l|l|l|l|l|l|l|l|}
\hline $\mathrm{pH}$ & $\mathrm{BV}_{1}$ & $\mathrm{BV}_{2}$ & $\mathrm{BV}_{3}$ & $\mathrm{~V}_{3}-\mathrm{V}_{2}$ & $\mathrm{n}$ & $\mathrm{pL}$ & $\begin{array}{l}\text { Log } \\
\left(\frac{n}{n-1}\right)\end{array}$ & Log $\mathrm{K}_{1}$ \\
\hline 8.50 & 5.30 & 5.81 & 5.85 & 0.04 & 0.2973 & 2.88 & -0.3736 & 2.5064 \\
8.72 & 5.35 & 5.90 & 5.94 & 0.04 & 0.3099 & 2.66 & -0.5477 & 2.3123 \\
9.00 & 5.40 & 6.00 & 6.05 & 0.05 & 0.4044 & 2.38 & -0.1681 & 2.2119 \\
9.22 & 5.45 & 6.10 & 6.15 & 0.06 & 0.5157 & 2.18 & 0.0272 & 2.2072 \\
9.51 & 5.50 & 6.20 & 6.26 & 0.07 & 0.6417 & 1.89 & 0.2530 & 2.1430 \\
9.73 & 5.55 & 6.40 & 6.40 & 0.07 & 0.7000 & 1.67 & 0.3680 & 2.0380 \\
\hline
\end{tabular}

LogK $_{1}$ (Average value) $=2.2364 \pm 0.1602$

Table 10: Point-wise method, Pb (Unhydrolysed PSHA)

\begin{tabular}{|l|l|l|l|l|l|l|l|l|}
\hline $\mathrm{pH}$ & $\mathrm{BV}_{1}$ & $\mathrm{BV}_{2}$ & $\mathrm{BV}_{3}$ & $\mathrm{~V}_{3}-\mathrm{V}_{2}$ & $\mathrm{n}$ & $\mathrm{pL}$ & $\log \left(\frac{n-1}{2-n}\right)$ & $\log \mathrm{K}_{2}$ \\
\hline 10.00 & 5.60 & 6.47 & 6.55 & 0.08 & 1.9503 & 1.41 & & \\
10.23 & 5.65 & 6.62 & 6.72 & 0.11 & 1.4792 & 1.26 & -0.0361 & 1.2239 \\
\hline
\end{tabular}

$\operatorname{LogK}_{2}$ (Average value) $=1.2239$

Table 11: Point-wise method, Mg (Hydrolysed PSHA)

\begin{tabular}{|l|l|l|l|l|l|l|l|l|}
\hline $\mathrm{pH}$ & $\mathrm{BV}_{1}$ & $\mathrm{BV}_{2}$ & $\mathrm{BV}_{3}$ & $\left(\mathrm{~V}_{3}-\mathrm{V}_{2}\right)$ & $\mathrm{n}$ & $\mathrm{pL}$ & $\log \left(\frac{n}{n-1}\right)$ & LogK $_{1}$ \\
\hline 8.50 & 5.30 & 6.29 & 6.31 & 0.02 & 0.2750 & 2.64 & -0.4290 & 2.2110 \\
8.72 & 5.35 & 6.37 & 6.39 & 0.02 & 0.2858 & 2.42 & -0.3978 & 2.0222 \\
9.00 & 5.40 & 6.46 & 6.49 & 0.03 & 0.4648 & 2.14 & -0.0612 & 2.0788 \\
9.22 & 5.45 & 6.55 & 6.59 & 0.04 & 0.6667 & 1.94 & 0.3010 & 2.2410 \\
\hline
\end{tabular}

$\log _{\mathbf{1}}($ Average value) $=2.1382 \pm 0.1046$ 
BAJOPAS Volume 14 Number 1,June, 2021

Table 12: Point-wise method, Mg (Hydrolysed PSHA)

\begin{tabular}{|l|l|l|l|l|l|l|l|l|}
\hline $\mathrm{pH}$ & $\mathrm{BV}_{1}$ & $\mathrm{BV}_{2}$ & $\mathrm{BV}_{3}$ & $\left(\mathrm{~V}_{3}-\mathrm{V}_{2}\right)$ & $\mathrm{n}$ & $\mathrm{pL}$ & $\log \left(\frac{n-1}{2-n}\right)$ & LogK $_{2}$ \\
\hline 9.51 & 5.55 & 6.66 & 6.71 & 0.05 & 0.9650 & 1.67 & & \\
9.73 & 5.55 & 6.78 & 6.84 & 0.06 & 1.4042 & 1.47 & -0.1686 & 1.3014 \\
10.00 & 5.60 & 6.90 & 6.93 & 0.06 & 1.7838 & 1.23 & 0.5593 & 1.7893 \\
10.23 & 5.65 & 7.05 & 7.10 & 0.06 & 3.1429 & 1.10 & & \\
10.49 & 5.70 & 7.10 & 7.18 & 0.07 & 3.6492 & 0.83 & & \\
\hline
\end{tabular}

LogK $_{2}($ Average value $)=1.5453 \pm 0.3450$

Table 13: Point-wise method, Mg (Unhydrolysed PSHA)

\begin{tabular}{|l|l|l|l|l|l|l|l|l|}
\hline $\mathrm{pH}$ & $\mathrm{BV}_{1}$ & $\mathrm{BV}_{2}$ & $\mathrm{BV}_{3}$ & $\mathrm{~V}_{3}-\mathrm{V}_{2}$ & $\mathrm{n}$ & $\mathrm{pL}$ & $\log \left(\frac{n}{n-1}\right)$ & $\operatorname{Log~}_{1}$ \\
\hline 8.50 & 5.30 & 5.81 & 5.85 & 0.04 & 0.2973 & 2.88 & -0.3736 & 2.5064 \\
8.72 & 5.35 & 5.90 & 5.94 & 0.04 & 0.3099 & 2.66 & -0.3477 & 2.3123 \\
9.00 & 5.40 & 6.00 & 6.04 & 0.04 & 0.3236 & 2.38 & -0.3202 & 2.0598 \\
9.22 & 5.45 & 6.10 & 6.15 & 0.05 & 0.4297 & 2.17 & -0.1230 & 2.0470 \\
9.51 & 5.50 & 6.20 & 6.26 & 0.06 & 0.5500 & 1.89 & 0.0871 & 1.9771 \\
9.73 & 5.55 & 6.33 & 6.40 & 0.07 & 0.7000 & 1.67 & 0.3680 & 2.0380 \\
\hline
\end{tabular}

LogK $_{1}$ (Average value) $=2.1568 \pm 0.2069$

Table 14: Point-wise method, Mg (Unhydrolysed PSHA)

\begin{tabular}{|l|l|l|l|l|l|l|l|l|}
\hline $\mathrm{pH}$ & $\mathrm{BV}_{1}$ & $\mathrm{BV}_{2}$ & $\mathrm{BV}_{3}$ & $\mathrm{~V}_{3}-\mathrm{V}_{2}$ & $\mathrm{n}$ & $\mathrm{pL}$ & $\log \left(\frac{n-1}{2-n}\right)$ & $\log \mathrm{K}_{2}$ \\
\hline 10.00 & 5.60 & 6.47 & 6.55 & 0.08 & 0.9148 & 1.41 & & \\
10.23 & 5.65 & 6.62 & 6.71 & 0.09 & 1.2102 & 1.20 & -0.5749 & 0.6251 \\
10.49 & 5.70 & 6.80 & 6.92 & 0.09 & 1.5968 & 1.03 & 0.1703 & 1.2003 \\
\hline
\end{tabular}

LogK $_{2}$ (Average value) $=0.9127 \pm 0.4070$

Table15:Point-wise method, Cd (Hydrolysed PSHA)

\begin{tabular}{|l|l|l|l|l|l|l|l|l|}
\hline $\mathrm{pH}$ & $\mathrm{BV}_{1}$ & $\mathrm{BV}_{2}$ & $\mathrm{BV}_{3}$ & $\left(\mathrm{~V}_{3}-\mathrm{V}_{2}\right)$ & $\mathrm{n}$ & $\mathrm{pL}$ & $\log \left(\frac{n}{1-n}\right)$ & LogK $_{1}$ \\
\hline 8.50 & 5.30 & 6.29 & 6.31 & 0.02 & 0.2750 & 2.64 & -0.4210 & 2.2190 \\
8.72 & 5.35 & 6.37 & 6.40 & 0.03 & 0.4286 & 2.42 & -0.1249 & 2.2951 \\
9.00 & 5.40 & 6.46 & 6.49 & 0.03 & 0.4648 & 2.14 & -0.0612 & 2.0788 \\
9.22 & 5.45 & 6.55 & 6.59 & 0.04 & 0.6667 & 1.96 & 0.3010 & 2.2610 \\
9.51 & 5.55 & 6.66 & 6.70 & 0.04 & 0.7720 & 1.67 & 0.5297 & 2.1997 \\
\hline
\end{tabular}

LogK $_{\mathbf{1}}$ (Average value) $=2.2108 \pm 0.0825$

Table 16: Point-wise method, Cd (Hydrolysed PSHA)

\begin{tabular}{|l|l|l|l|l|l|l|l|l|}
\hline $\mathrm{pH}$ & $\mathrm{BV}_{1}$ & $\mathrm{BV}_{2}$ & $\mathrm{BV}_{3}$ & $\left(\mathrm{~V}_{3}-\mathrm{V}_{2}\right)$ & $\mathrm{n}$ & $\mathrm{pL}$ & $\log \left(\frac{n-1}{2-n}\right)$ & Log $_{2}$ \\
\hline 9.73 & 5.55 & 6.78 & 6.83 & 0.06 & 1.4042 & 1.47 & -0.1686 & 1.3014 \\
10.00 & 5.60 & 6.90 & 6.95 & 0.06 & 1.7838 & 1.23 & 0.5593 & 1.7893 \\
10.23 & 5.65 & 7.05 & 7.10 & 0.06 & 3.1429 & 1.09 & & \\
10.49 & 5.70 & 7.10 & 7.16 & 0.06 & 3.1429 & 0.89 & & \\
& & & & & & & & \\
\hline
\end{tabular}

$\operatorname{LogK}_{2}$ (Average value) $=1.5453 \pm 0.3450$

Table 17: Point-wise method, Cd (Unhydrolysed PSHA)

\begin{tabular}{|l|l|l|l|l|l|l|l|l|}
\hline $\mathrm{pH}$ & $\mathrm{BV}_{1}$ & $\mathrm{BV}_{2}$ & $\mathrm{BV}_{3}$ & $\mathrm{~V}_{3}-\mathrm{V}_{2}$ & $\mathrm{n}$ & $\mathrm{pL}$ & $\log \left(\frac{n}{n-1}\right)$ & $\operatorname{Log~}_{1}$ \\
\hline 8.50 & 5.30 & 5.81 & 5.86 & 0.05 & 0.3717 & 2.88 & -0.2280 & 2.6520 \\
8.72 & 5.35 & 5.90 & 5.95 & 0.05 & 0.3873 & 2.66 & -0.1992 & 2.4608 \\
9.00 & 5.40 & 6.00 & 6.06 & 0.06 & 0.4853 & 2.38 & -0.0255 & 2.3545 \\
9.22 & 5.45 & 6.10 & 6.16 & 0.06 & 0.5157 & 2.18 & -0.0272 & 2.2072 \\
9.51 & 5.50 & 6.20 & 6.27 & 0.07 & 0.6417 & 1.89 & 0.2530 & 1.1430 \\
9.73 & 5.55 & 6.33 & 6.41 & 0.08 & 0.8000 & 1.69 & 0.6020 & 2.2920 \\
& & & & & & & & \\
\hline
\end{tabular}

$\operatorname{LogK}_{1}($ Average value $)=2.2516 \pm 0.5380$ 
BAJOPAS Volume 14 Number 1,June, 2021

Table 18: Point-wise method, Cd (Unhydrolysed PSHA)

\begin{tabular}{|l|l|l|l|l|l|l|l|l|}
\hline $\mathrm{pH}$ & $\mathrm{BV}_{1}$ & $\mathrm{BV}_{2}$ & $\mathrm{BV}_{3}$ & $\mathrm{~V}_{3}-\mathrm{V}_{2}$ & $\mathrm{n}$ & $\mathrm{pL}$ & $\log \left(\frac{n-1}{2-n}\right)$ & $\log \mathrm{K}_{2}$ \\
\hline 10.00 & 5.60 & 6.47 & 6.57 & 0.10 & 1.1434 & 1.43 & & \\
10.23 & 5.65 & 6.62 & 6.72 & 0.10 & 1.3448 & 1.23 & -0.2788 & 0.9512 \\
10.49 & 5.70 & 6.80 & 6.90 & 0.10 & 1.7742 & 1.03 & 0.5351 & 1.5651 \\
\hline
\end{tabular}

$\operatorname{LogK}_{2}($ Average value $)=1.2581 \pm 0.4340$

Table 19: Stepwise and overall Stability constants of thehydrolysed and unhydrolysed divalent metal (II) complexes

\begin{tabular}{|c|c|c|c|}
\hline Chelates & LogK $_{1}$ & $\log _{2}$ & Log $\beta$ \\
\hline [Cu (Hydrolysed PSHA-1) $\left.{ }_{2}\right]$ & 2.4788 & 1.4280 & 3.9068 \\
\hline$\left[\mathrm{Pb}(\text { Hydrolysed PSHA-1) })_{2}\right]$ & 2.5832 & 1.1963 & 3.7795 \\
\hline$\left[\mathrm{Cd}(\text { Hydrolysed PSHA-1 })_{2}\right]$ & 2.2108 & 1.5453 & 3.7561 \\
\hline$\left[\mathrm{Mg}(\text { Hydrolysed PSHA-1 })_{2}\right]$ & 2.1382 & 1.5453 & 3.6835 \\
\hline [Cu (Unhydrolysed PSHA-1) & 2.3059 & 1.2209 & 3.5268 \\
\hline$[\mathrm{Pb}$ (Unhydrolysed PSHA-1) 2$]$ & 2.2364 & 1.2239 & 3.4603 \\
\hline [Cd (Unhydrolysed PSHA-1) 2 ] & 2.2516 & 1.2581 & 3.5097 \\
\hline$[\mathrm{Mg}$ (Unydrolysed PSHA-1) & 2.1568 & 0.9127 & 3.0695 \\
\hline
\end{tabular}

The results obtained (Table19) shows the stepwise and overall stability constants to be not high indicating low stability of the complexes, because the solubility of most metal ions in the basic $\mathrm{pH}$ range is minimal due to metal hydroxide precipitation (Karimi, 2017). In general, the stepwise stability constants $\left(K_{1}\right.$ and $K_{2}$ ) follow the order $K_{1}>K_{2}$ for the copper, lead, magnesium and cadmium complexes respectively. The steady decrease of the values with increasing number of ligands is in agreement with the prediction made by researchers (Na'aliya, 2013). The decrease could be attributed to the fact that as the number of the ligands (Humate ions) that enters the coordination zone increases the aqua molecules available for replacement by the ligands become less. Thus, the metal ions become less electron loving with progressive intake of the ligand and this results in the decrease in the values of the constants (Na'aliya, 2013). Also the stability of the complexes is influenced by the size and number of the chelate rings(Mackay and Mackay,2002).All the complexes form rings in their structure as humate, a bidentate ligand, bond the metal ions in the ratio 1:2 (Boguta and Sokolowska, 2016) forming chelate rings. The values of the overall stability constants $(\log \beta)$ obtained for humate complexes are not high indicating low stability as the values are not high. LogK values for copper-humates (Table 3 to 6) obtained in this study are lower than those reported for the complexes of humic acids (Pandey et al., 2015; Dinu, 2013; Kaschl et al., 2010 and Gilbeto and Jorg, 2001). The values of LogK(Table 7 to 10 ) forlead-humates are lower than those reported for the lead in the literature (Dinu, 2013; Gilbeto and Jorg 2001). Log K values(Table 11 to 14 ) for magnesium-humates obtained in this study are close to those reported by (Pandey et al., 2015). Log K values of cadmium-humates (Table 15 to 18 ) obtained in this work near to the one reported by (Dinu, 2013 and Pandey et al., 2015).The difference between the reported values and the values obtained in this study might be probably as a result of acid hydrolysis of humic acid. The values of the overall stability constants $(\log \beta)$ of the copper humates complexes presented in Table 19 is high than that of other metal humate complexes, show relatively high stability of CuHA complexes, show the following order of stability: $\mathrm{Cu}>\mathrm{Pb}>\mathrm{Cd}>\mathrm{Mg}$; which are in close agreement to the findings of (Dinu, 2013 and Pandey et al., 2015).The high stability of Cuhumate chelate could be attributed to the existence of coordinate covalent bond between the complexing agents and the $\mathrm{Cu}^{2+}$ ions. Since, $\mathrm{Cu}^{2+}$ being a metal of the transitional series with $3 d^{9}$ electronic configurations can accept the electrons from the complexing agents. Similarly, the low stabilities of $\mathrm{Pb}, \mathrm{Cd}$ and $\mathrm{Mg}$ complexes could be explained by that $\mathrm{Pb}^{2+}$ with $6 s^{2}, \mathrm{Cd}^{2+}$ with $4 \mathrm{~d}^{10}$ and $\mathrm{Mg}^{2+}$ with $2 \mathrm{p}^{6}$ their electronic configuration has a completely filled $\mathrm{d}, \mathrm{p}$ and $\mathrm{s}$ orbitals. Moreover, the stabilities of metal ions with hydrolysed humic acid from peat soil were higher than those with unhydrolysed humic acid from peat soil; which is ascribed to the high content of acidity in hydrolysed humic acid than unhydrolysed humic acid. 
BAJOPAS Volume 14 Number 1,June, 2021 CONCLUSION

The values of logk for $\mathrm{Cu}(\mathrm{II})$ hydrolysed humic acid complex was higher followed by $\mathrm{Pb}$ (II), $\mathrm{Cd}(\mathrm{II})$ and $\mathrm{Mg}$ (II) hydrolysed humic acid complexes as compared with metal(II) unhydrolysed humic acid complexes. This indicates acid hydrolysis of humic acid can

\section{REFERENCES}

Almeida, V.R. and Szpoganicz, B. (2015). Humic Acid Potentiometric Response Patterns:Out- of Equilibrium Properties and Species Distribution Modelling. Chemical. Biol. Technol. Agric. 2: 17.

Anđelković, T., Nikolić, R., Bojić, A.,Anđelković, D., and Nikolic G.,(2010). Binding of Cadmium to Soil Humic Acid as A Function of Carboxyl Group Content. Macedonian Journal of Chemistry and Chemical Engineering.29(2): 215-224.

Anil, B. N. and Maroti, N. (2008). Studies on Influence of Die-Lectric Constants on Complex Equilibria between Substituted Py-Razalines and Lanthanide Metal Ions pH-Metrically. Amer.-Euras. scient. Res. 3(2): 212-216.

Ashok, K., Pandey, S. P. and Misra, V (2000). Stability Constants of Metal-Humic Acid Complexes and its Role in Environmental Detoxification. Journal of Ecotoxicology and Environmental Safety. 47(2):157-200.

Badr, M. H., El-Halafawi, M. H. and Abd El-al Zeid, E. R. (2012). Comparison Between the Effect of Ionic Strength on Acidity and Dissociation Constants of Humic Acids Extracted from Sewage Sludge and Nile Water Hyacinth Composts.Global Journal of Environmental Research 6 (1): 36-43.

Baruah, M.K., Borah, D., Saikia, P.P., Paul, S., Sharma, T. (2015). Evaluation of pKa Values of Soil Humic Acids and their Complexation Properties. International Journal of Plant \& Soil Science 6(4) : 218-228.

Boguta, P. Sokolowska, Z. (2016). Interactions of $\mathrm{Zn}$ (II) Ions with Humic Acids Isolated from Various Types of Soils. Effect of $\mathrm{pH}, \mathrm{Zn}$ Concentrations and Humic Acids Chemical Properties. Journal of Geochemical Explaration 168. 119-126.

Borges, F., Guimaraes, C., Lima, L.F.C., Pinto, I. and Reis, S.(2005). Potentiometric Studies on the Complexation of Copper(II) by Phenolic Acids as Discrete Ligand Models of enhance the complexation behavior of humic acid with metal (II) ions. However, the higher values of $\log \beta$ for $\mathrm{Cu}(\mathrm{II}), \mathrm{Pb}(\mathrm{II}), \mathrm{Cd}(\mathrm{II})$ and $\mathrm{Mg}(\mathrm{II})$ hydrolysed humic acid complexes indicates more stable stepwise complexes formed as compared with $\mathrm{Cu}(\mathrm{II}), \mathrm{Pb}$ (II), $\mathrm{Cd}$ (II) and $\mathrm{Mg}(\mathrm{II})$ unhydrolysed humic acid complexes.

Humic Substances Talanta 66 (2005) 670-673.

Chefetz, B., Salloum, M. J., Deshmulkin, A. P. and Hatcher, P. (2002). Structural Components of Humic Acids as Determined by Chemical Modifications and Carbon-13 NMR, Pyrolysis, and Thermochemolysis- Gas Chromatography/Mass Spectrometry. Soil Science Society of American Journal Abstract Division S-2- Soil Chemistry66. 1159-1171.

Dinu, M. I. (2013). Metals Complexation with Humic Acids in Surface Water of Different Environ. Sci. Technol. 31(1): 1-17.

Fernandes, A.N., Giacomelli, C., Giovanela, M. Vaz, D.V. Szpoganicz, B. and Maria M. D. (2009). Potentiometric Acidity Determination in Humic Substances Influenced by Different Analytical Procedures.J. Braz. Chem. Soc. 20 (9):14.

Gamal, A. H. (2015). Stability Constants of Rhenium (V) Metal Complexes with Selected Drugs. Pyrex Journal of Research in Environmental Studies. 2(2): 006-014.

Janrao, D. M., Pathan, J., Kayande, D.D., and Mulla, J.J. (2014). An Over View of Potentiometric Determination of Stability Constants of Metal Complexes. Sci. Revs. Chem. Commun.: 4(1), 2014, 11-24.

Karimi, H. (2017). Effect of pH and Initial Pb(II) Concentration on the Lead Removal Efficiency from Waste Water Using $\mathrm{Ca}(\mathrm{OH})_{2}$. International Journal of Water and Waste Water Treatment 3.2

Kaschl, A. Romheld, V. and Chen, Y. (2010). Binding of Cadmium, Copper and Zinc to Humic Substances Originating from Municipal Solid Waste Compost. Israel Journal of Chemistry Vol. 42(1): 89-98.

Kostic, I. S., Tatjana, P, A., Nikolic, R. S., Cvetkovic, T. P., Pavlovic, D. D., Aleksandar, L.J. and Bojic, A. (2012). Comparative Study of Binding Strengths of Heavy Metals with Humic Acid. J.serb. Chem. Soc. 76(9) pp 1-20. 
BAJOPAS Volume 14 Number 1,June, 2021

Na'aliya, J. (2013). Determination of Stepwise Stability Constants and Gibbs free Energy Change of Trisprolina to Complexes of some Divalent Transition Metal ions. Bayero Journal of Pure and Applied Sciences 6(2): 112-114.

Omar, A. A. and Ali, E. A. (2015). Potentiometric Studies on Complexes of $\mathrm{Cr}$ (III) and $\mathrm{Zr}$ (IV) with some Carboxylic Acids. International Journal of Advanced Chemistry, 3(1) 25-

37.

Pandey, A. K. Pandey, S. D. and Misr, V. (2015).Stability Constants of Metal- Humic Acid Complexes and Its Role in Environmental Detoxification. J. Ecotoxicology and Environmental Safety. 47(1):195-200.

Ram, N. and Raman, K.V. (1984). Stability Constants of Complexes of Metals with
Humicand Fuvic Acids under Non- acidConditions. Journal of Plant Nutrition and Soil Sciences.

147:171-176.

Santosh, D. D., Ashok, B. K., Vijay, J. T., Shivraj, G. W. and Vinay, V. W. (2011). Potentiometric Studies of Elec-Trolyte Effects on Complex Equilibria of Some Substituted 5-(2-hydroxy Phenyl) Pyrazoles. Der pharm. 3 (6): 75-83.

Sayyed, H. and Abdul Rahim, M. F. (2012). Studies of Binary Complexes of Metal Ions with Mandelic Acid by Potentiometry. Chem. J. 02 (6): 206209.

Shirvani, M. Moradian, E. Khalili, B. Bakhtiary, S. (2015). Interaction of $\mathrm{Cd}$ and $\mathrm{Pb}$ with Humate-Palygorskite and HumateSepiolite Complexes. Journal of water, air and pollution 3: 220-228. 


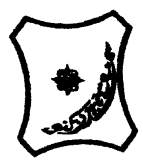

Bayero Journal of Pure and Applied Sciences, 14(1): 54 - 63

Received: November, 2020

Accepted: April, 2021

ISSN $2006-6996$

\title{
STABILITY CONSTANTS OF COMPLEXES OF METAL IONS WITH PEATSOIL HUMIC ACIDS UNDER NON-ACID-CONDITIONS
}

\author{
${ }^{* 1}$ Sabo, Yusuf ${ }^{2}$ Jimoh, W.L.O., ${ }^{3}$ Isa Baba Koki and ${ }^{4}$ Sholadoye, Q. 0. \\ ${ }^{1}$ Department of Pure and Industrial Chemistry, Bayero University, Kano \\ ${ }^{3}$ Department of Chemistry, Yusuf Maitama Sule University Kano. P.M.B. 3220 Kano, Nigeria. \\ ${ }^{4}$ Department of Chemistry, Nigerian Police Academy, Wudil, Kano-Nigeria
}

*Correspondence E-mail; saboyusuf18@yahoo.com

ABSTRACT

Stability constants of complexes of four divalent metal ions viz. $\mathrm{Cu}^{2+}, \mathrm{Pb}^{2+}, \mathrm{Mg}^{2+}$ and $\mathrm{Cd}^{2+}$ with humic acids (HA) were determined by potentiometric titration of humic acids with the corresponding salt of the divalent metals in aqueous media under non-acid-condition. The log $K$ (logarithm of the stability constant) ranged from 1.0942 to 2.7471 for metalhumic acid complexes were determined using point-wise computational method. The order of stability constants were obtained as follows: $\mathrm{Cu}>\mathrm{Pb}>\mathrm{Cd}>\mathrm{Mg}$ for metal $-\mathrm{HA}$ complexes respectively, indicating a higher degree of complexation with Cu metal ion.

Keywords: stability constant, humic acid, potentiometric titration, divalent metals, acid hydrolysis.

\section{NTRODUCTION}

The stability constant of a complex is the numerical expression of its stability and provides a quantitative measure of affinity of the metal ion to the complexing agent. An understanding of the relative stability of metal-complexes helps in predicting the behavior of metal ions in the soil (Ram and Raman, 1982). Extensive researches has been done to determine the stability constants of the complexes formed between humic acid (HA) with a number of metal ions. Ashok et al., (2000) reported that humic acid with hydroxyl, phenoxyl and carboxyl reactive groups can form coordination compound with metal ions at $\mathrm{pH}$ 3.5. The stability constants(Log K) for different metalhumic acid complexes indicated the following order of the stabilities of complexes formed between humic acid and metal ion, $\mathrm{Cu}>\mathrm{Fe}$ $>\mathrm{Pb}>\mathrm{Ni}>\mathrm{Co}>\mathrm{Ca}>\mathrm{Cd}>\mathrm{Zn}>\mathrm{Mn}>\mathrm{Mg}$. Andelkovic et al., (2010) investigated the binding of $\mathrm{Cd}$ (II) to soil humic acid at pH 6.5 and in $0.1 \mathrm{M} \mathrm{KNO}_{3}$ ionic medium. The stability constant for binding indicating greater stability in the case when carboxyl groups are involved in complexation reaction. Kostic et al.,(2012) investigated the complexation of humic acid with certain heavy metal ions (Co(II), $\mathrm{Ni}(\mathrm{II}), \mathrm{Cu}(\mathrm{II})$,
$\mathrm{Zn}(\mathrm{II})$, and $\mathrm{Pb}(\mathrm{II})$. The experiment was performed at $25^{\circ} \mathrm{C}$, at pH 4.0 and ionic strength of $0.01 \mathrm{M}$. Stability constant of complex between $\mathrm{Pb}$ (II) ions and humic acid is greater than stability constants of other investigated metalhumate complexes. Bogata and Sokolowska (2016) analyses the interaction between humic acids from different soils and $\mathrm{Zn}$ (II) ions at wide concentration ranges and at $\mathrm{pH} 5$. Studies have showed significant impact of $\mathrm{Zn}$ concentration, $\mathrm{pH}$ and some properties of humic acids with zinc.But all of these studies were limited to acidic $\mathrm{pH}$ range. Therefore, the present study was carried out to determine and compare the stability constants of complexes of metal ions with hydrolysed peat soil humic acid and unhydrolysed peat soil humic under non-acid conditions.

\section{MATERIALS AND METHODS}

Analytical grade chemicals used includes hydrochloric acid $(\mathrm{HCl})$, nitric acid $\left(\mathrm{HNO}_{3}\right)$, sodium hydroxide $(\mathrm{NaOH})$, lead nitrate $\mathrm{Pb}\left(\mathrm{NO}_{3}\right)_{2}$, copper nitrate $\mathrm{Cu}\left(\mathrm{NO}_{3}\right)_{2} \cdot 3 \mathrm{H}_{2} \mathrm{O}$, cadmium nitrate $\mathrm{Cd}\left(\mathrm{NO}_{3}\right)_{2} \cdot 4 \mathrm{H}_{2} \mathrm{O}$, magnesium nitrate $\mathrm{Mg}\left(\mathrm{NO}_{3}\right)_{2} \cdot 6 \mathrm{H}_{2} \mathrm{O}$, potassium nitrate $\left(\mathrm{KNO}_{3}\right)$, calcium chloride $\left(\mathrm{CaCl}_{2}\right)$, (sigma-Aldrich). Dowex 50WX8, (20-50 mesh) from Fluka. 


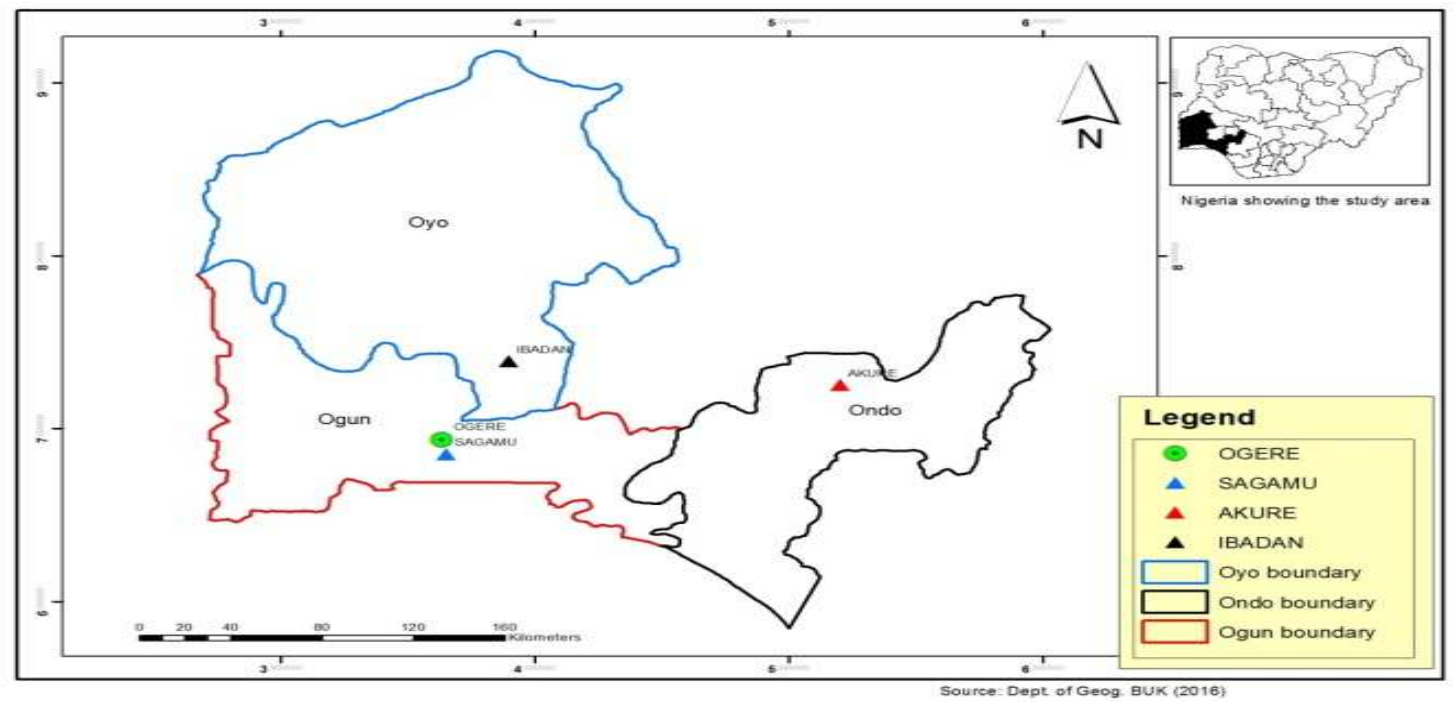

Figure 1: Map showing the sampling point at Sagamu Town, Ogun State.

\section{Description of Sampling Area}

Sagamu has geographical coordinates between $6^{\circ} 50^{\prime}$ north; $3^{\circ} 38^{\prime}$ east is located in south western region of Nigeria. The region has tropical wet and dry climate with a lengthy wet season and relatively constant temperatures throughout the course of the year. Wet season runs from March to October, November to December forms the region dry season. The vegetation type of the region is savannah which is really grassland with small bushes and occasional big trees. Grassland soils have substantially higher organic matter content than forest soils (Novackova, 2011).

\section{Sample Collection}

The Peatsoil samples were collected from four different sampling points $(0-10 \mathrm{~cm}$ depth) in Sagamu into polyethylene bag with plastic spoons. Samples were taken to the laboratory, extraneous materials were removed; the samples were air-dried, crushed and ground to a fine powder in a mortar passed through a $0.20 \mathrm{~mm}$ sieve. The samples were kept for analysis.

\section{Isolation and purification of humic acid from peat soil sample}

Peatsoil sample $(100 \mathrm{~g})$ was mixed with 1000 $\mathrm{cm}^{3}$ of $0.1 \mathrm{M} \mathrm{NaOH}$ solution, shaken for 3hours and left to stand overnight. Dark-coloured supernatant was obtained and decanted from solid residue. The dark-coloured supernatant was acidified to $(\mathrm{pH}=1.0)$ with $6 \mathrm{M} \mathrm{HCl}$ stirred and allowed to stand for 6 hours. Yellowish brown supernatant and dark-brown precipitate were obtained. The yellowish brown supernatant was decanted followed by centrifuge and discarded. The dark-brown precipitate was mixed with $500 \mathrm{~cm}^{3}$ of $0.1 \mathrm{M} \mathrm{NaOH}$ solution followed by passing through dowex resin. The dark-brown solution was acidified to $(\mathrm{pH}=1.0)$ with $6 \mathrm{M} \mathrm{HCl}$ stirred and allowed to stand for 3 hours. The dark-brown precipitate was washed several times with deionized water. The supernatant was treated with $\mathrm{AgNO}_{3}$ solution until no white precipitate observed. The humic acid was transferred to weighed crucible and dried at $60^{\circ} \mathrm{C}$ in an oven for 12 hours. The humic acid was cooled and dried in the desiccator, weighed and recorded. The obtained humic acid was dried again at $60^{\circ} \mathrm{C}$ for additional 6 hours cooled and dried in the desiccator, weighed and recorded constant weight was obtained (Baruah et al., 2015).

\section{FT-IR analysis}

FT-IR spectra of humic acid sample was analysed using Carry 630 FT-IR Agilent Technologies.

Unhydrolysed compost humic acid

The unhydrolysed humic acid was obtained after isolation and purification of compost humic acid and kept for investigation.

\section{Acid hydrolysis of Peatsoil acid}

Peatsoil humic acid sample (1g) was refluxed for 12 hours at $\left(160^{\circ} \mathrm{C}\right)$ with $50 \mathrm{~cm}^{3}$ of $6 \mathrm{M} \mathrm{HCl}$. The mixture was allowed to cool, decanted, and centrifuged after hydrolysis. The insoluble residues were washed with distilled water via centrifugation several times, and the supernatant was treated with $\mathrm{AgNO}_{3}$ solution until no white precipitate was observed. The residue was thoroughly dried over $\mathrm{CaCl}_{2}$ in a desiccator at room temperature (Chefetz et al., 2002). Finally, the obtained hydrolysed humic acid was kept for investigation. 
BAJOPAS Volume 14 Number 1,June, 2021 Potentiometric Titrations

Potentiometric measurements were carried out using a pH-meter Jenway (model 3510) with combine electrode, the sensitivity of the $\mathrm{pH}$ meter is 0.01 units. The $\mathrm{pH}$ meter was switched on half an hour before starting the titration for initial warm up of the instrument. The instrument was calibrated with an aqueous standard buffer solution of $\mathrm{pH} 4.00$ and 10.0 (borate buffer) prepared from a "Qualigens" buffer tablets.

The following sets of solutions were prepared in a $250 \mathrm{~cm}^{3}$ volumetric flask separately for $\mathrm{pH}$ metric titrations.

(i) $5 \mathrm{~cm}^{3} 0.1 \mathrm{M} \mathrm{HCl}+40 \mathrm{~cm}^{3}$ deionized water

(ii) $5 \mathrm{~cm}^{3} 0.1 \mathrm{M} \mathrm{HCl}+39 \mathrm{~cm}^{3}$ deionized water $+1 \mathrm{~cm}^{3} 0.15 \mathrm{gcm}^{-3}$ humic acid

(iii) $5 \mathrm{~cm}^{3} 0.1 \mathrm{M} \mathrm{HCl}+37 \mathrm{~cm}^{3}$ deionized water $+1 \mathrm{~cm}^{3} 0.15 \mathrm{gcm}^{-3}$ humic acid

$$
+2 \mathrm{~cm}^{3} \quad 0.01 \mathrm{M} \mathrm{Cu} \text { (II) }
$$

The solutions were titrated against standardized $0.110 \mathrm{MNaOH}$ separately. The total volume of each mixture was adjusted to $50 \mathrm{~cm}^{3}$ and the ionic strength of the solutions was maintained constant at by adding appropriate amount of stock solution of $1 \mathrm{M} \mathrm{KNO}_{3}$ (Gamal, 2015; Omar and Ali, 2015). A magnetic stirrer was used to achieve thorough mixing of the interacting solutions at $550 \mathrm{rpm}$. The same set of experimental conditions was applied for potentiometric titration of remaining samples.

\section{Evaluation of pKa of Hydrolysed peat soil Humic Acids}

The proton-ligand formation number $\mathrm{n}_{\mathbf{A}}$ were calculated by Irving and Rossotti expression (Omar and Ali, 2015).

$\mathrm{nA}=\mathrm{Y}-\frac{(\mathrm{V} 2-\mathrm{V1})(\mathrm{No}-\mathrm{Eo})}{(\mathrm{VO}+\mathrm{V1}) \mathrm{TCL}}$ 1

Where: $Y$ is number of dissociable proton, $\left(\mathrm{V}_{2^{-}}\right.$ $V_{1}$ ) is the measure of displacement of the ligand curve relative to acid curve, $\mathrm{N}^{\circ}$ and $\mathrm{E}^{\circ}$ are the resultant concentration of alkali solution, free acid solution, $\mathrm{T}_{\mathrm{cL}}{ }^{\circ}$ is the total ligand concentration, $\mathrm{V}^{\circ}$ is the total volume of titration solution, $V_{1}$ is the volume of alkali added to acid solution, $V_{2}$ is the volume of alkali added to acid solution + ligand solution, acid dissociation constants (pKa - values) of ligand were calculated by algebraic method point wise calculation (Tables 1 ). The dissociation constants (pKa) were calculated according to the following relation:

$\mathrm{pKa}=\mathrm{pH}+\log \left(\frac{n A}{1-n A}\right)$ 2

Where: pKa is the acid dissociation constant, $\mathrm{n}_{\mathrm{A}}$ is the Proton-ligand formation number and $\mathrm{pH}$ is the pH-values (Omar and Ali, 2015).

\section{Determination of metal-ligand stability constants $(\log K)$ of complexes}

The potentiometric measurement for the determination of stability constant of a complex in solution is based on the fact that the redox potential of the couple $\frac{M^{+(m-n)}}{M^{+m}}$ is shifted significantly on complexation of the metal ion with the ligand. This method involves change in hydrogen ion concentration $\left[\mathrm{H}^{+}\right]$due to the displacement or association of one or more protons taking place during complexation reaction. This change can be found out by titrating the solutions containing free acid, acid with ligand, and acid with ligand and metal ion, individually against a standard alkali solution at a constant ionic strength or temperature. Either ionic strength or temperature may be varied for different sets of solutions. In all the cases, the change in the $\mathrm{pH}$ of the solution is measured after each addition of a known amount of alkali to the reaction cell which contains the reaction mixture. The titration curves are then drawn by plotting the measured $\mathrm{pH}$ values against the corresponding volume of alkali added and the stability constants of the complexes are determined from the titration curves by employing $\mathrm{pH}$-metric titration technique given by (Irving and Rossoti).

Metal-ligand stability constants ( $\log \mathrm{K}$ ) were determined by using the following relations:

$$
\bar{n}=\frac{\left(V_{3}-V_{2}\right)\left(E^{0}+N^{0}\right)}{\left(V^{0}+V_{2}\right) \bar{n}_{A} T_{m}^{0}}
$$

and

$$
P L=\log _{10}\left\{\frac{1+\beta_{n}^{H} \frac{1}{[\text { anti } \log \mathrm{pH}]^{\mathrm{n}}}}{\mathrm{T}_{\mathrm{L}}^{0}-n \bar{T}_{m}^{0}} \mathrm{X} \frac{\left(V^{0}+V_{3}\right)}{V^{0}}\right\}
$$


BAJOPAS Volume 14 Number 1,June, 2021

Where $T_{L}, T^{\circ}, E^{\circ}$, and $V^{\circ}$ havethe same significance as in equation (1) above, $T_{m}$ denotes the total concentration of metal present in solution, $V_{3}$ is the volume of metal ions present in solution and $\beta^{H}$ is the overall proton ligand stability constant. The metal-ligand stability constants (log K) were determined by employing point wise computational Method (eq. 5 and 6).

$\operatorname{LogK}_{1}=\log \left(\frac{n}{1-n}\right)+\mathrm{pL}$ .5

$\operatorname{LogK}_{2}=\log \left(\frac{1-n}{2-n}\right)+\mathrm{pL}$ ...6

Where: Log $\mathrm{K}$ is the metal-ligand stability constant, $\mathrm{pL}$ is the Free ligand exponent function, $\mathbf{n}$ is the Average number of ligand attached with metal ion (Janraoet al., 2014). The results obtained were analyzed by an ORIGIN 2016 program using titration data and then the proton-ligand stability constants (pKa) and Metal-ligand stability constant (LogK) calculated (Omar and Ali, 2015).

\section{RESULTS AND DISCUSSION}

Fourier transformed infrared (FT-IR) spectra of isolated humic acid from peat soils Figure 2 had distinct clear absorption bands indicating the presence of major humic acid structural elemental groups such as $\mathrm{H}$ bonded $\mathrm{OH}$ $\left(3680 \mathrm{~cm}^{-1}\right.$ peak $), C=0$ of carbonyl $\left(1721 \mathrm{~cm}^{-1}\right.$ peak), functional groups of aliphatic components $\mathrm{CH}_{2}\left(2918 \mathrm{~cm}^{-1}\right.$ peak) and $\mathrm{C}-\mathrm{O}$ stretching of polysaccharide $\left(1168 \mathrm{~cm}^{-1}\right.$ peak). The positions of the absorption bands of the spectra fell within typical major absorption bands of humic acid which is at frequencies 3680, 2918, 1721, 1168 $\mathrm{cm}^{-1}$. The first peak centred in the vicinity of $3680 \mathrm{~cm}^{-1}$ region is attributed to phenol $\mathrm{OH}$ group bounded by intermolecular $\mathrm{H}$ bonds. The $2918 \mathrm{~cm}^{-1}$ band usually has absorption maximum at $2918 \mathrm{~cm}^{-1}$ which is due to $\mathrm{C}-\mathrm{H}$ stretching of alkane group $\left(\mathrm{CH}_{2}\right)$. The next major absorption band is $1721 \mathrm{~cm}^{-1}$. This band has been commonly ascribed to $\mathrm{C}=\mathrm{O}$ stretching of mainly carboxyl group $(\mathrm{COOH})$ with trace amount of ketones. The last peak was observed at 1168 $\mathrm{cm}^{-1}$ due to $\mathrm{C}-\mathrm{O}$ stretching of polysaccharides and this peak appeared also in the spectra of humic acid from peat soil. The FTIR spectra of the isolated humic acid contained all major characteristic absorption peaks of humic acid. These absorption peaks indicated the presence of the major structural elements of humic acid namely $\mathrm{H}$ bonded $\mathrm{OH}, \mathrm{C}=\mathrm{C}$ of aromatic ring, $\mathrm{C}=\mathrm{O}$ of carbonyl group (both carboxyl and ketonic), $\mathrm{CH}_{2}$ group. This strongly supports the presence of humic acid.

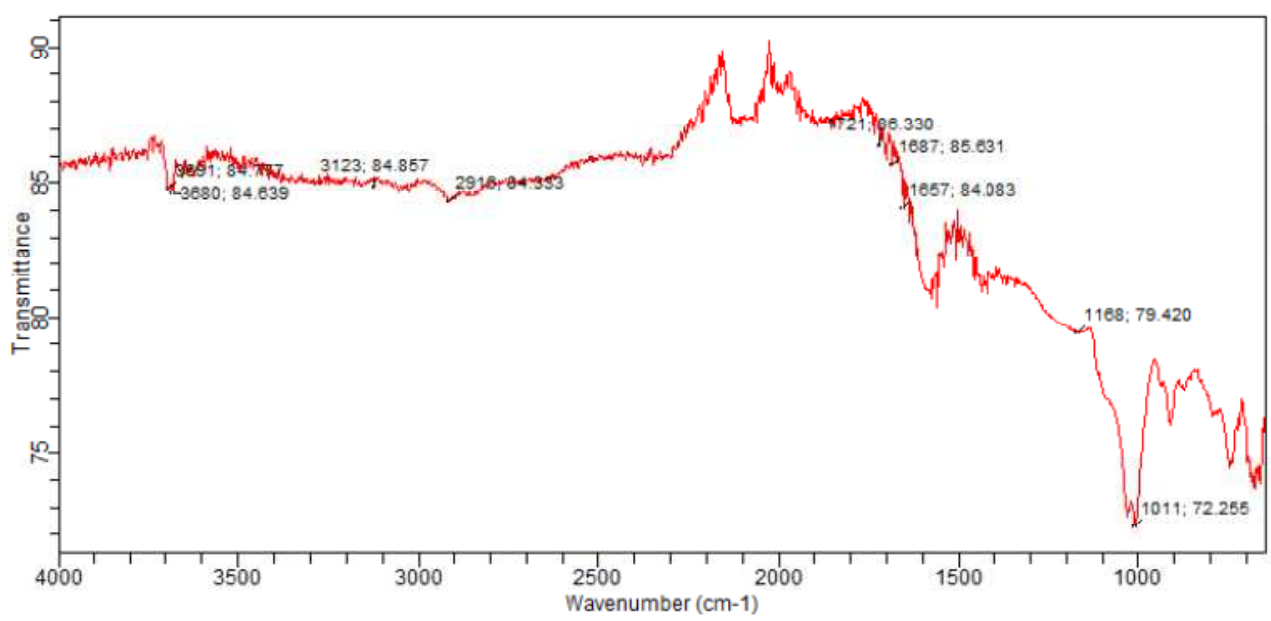

Fig. 2 : FT-IR spectraof peatsoilhumic acid (PSHA)

\section{Evaluation of acid dissociation constant (pka) of acid hydrolysed peat soil humicacid at phenolic group}

The value of the dissociation constant of the peat soil humic acid (PSHA) that underwent acidhydrolysis studied was found to be 8.9299 as shown Table 1, which is lower than the literaturevalues reported by Almeida and Szpoganics, (2015), Borges et al., (2005); Badr et al., (2012)and Fernandes et al,.(2009) of $9.73,9.47$ and 10.30. The difference between the obtained valuesand the reported values in this study might be probably as a result of acid hydrolysis of humicacid. 
BAJOPAS Volume 14 Number 1,June, 2021

Table 1: PKa of (Hydrolysed PSHA)

\begin{tabular}{|l|l|l|l|l|l|l|}
\hline $\mathrm{pH}$ & $\mathrm{BV}_{1}$ & $\mathrm{BV}_{2}$ & $\mathrm{~V}_{2}-\mathrm{V}_{1}$ & $\mathrm{nA}$ & $\log \left(\frac{n A}{1-n A}\right)$ & $\mathrm{pKa}$ \\
\hline 8.50 & 5.30 & 6.29 & 0.99 & 0.3594 & -0.2510 & 8.2490 \\
8.72 & 5.35 & 6.37 & 1.02 & 0.3400 & -0.2880 & 8.4320 \\
9.00 & 5.40 & 6.46 & 1.06 & 0.3141 & -0.3391 & 8.6609 \\
9.22 & 5.45 & 6.55 & 1.10 & 0.2882 & -0.3927 & 8.8273 \\
9.51 & 5.50 & 6.66 & 1.16 & 0.2494 & -0.4786 & 9.0314 \\
9.73 & 5.55 & 6.78 & 1.23 & 0.2041 & -0.5910 & 9.1390 \\
10.00 & 5.60 & 6.90 & 1.30 & 0.1589 & -0.7238 & 9.2762 \\
10.23 & 5.65 & 7.05 & 1.40 & 0.0941 & -0.9835 & 9.2465 \\
10.49 & 5.70 & 7.10 & 1.40 & 0.0941 & -0.9835 & 9.5065 \\
\hline
\end{tabular}

Average pKa $=8.9299 \pm 0.4186$

Table 2: PKa of (Unhydrolysed PSHA)

\begin{tabular}{|l|l|l|l|l|l|l|}
\hline $\mathrm{pH}$ & $\mathrm{BV}_{1}$ & $\mathrm{BV}_{2}$ & $\mathrm{~V}_{2}-\mathrm{V}_{1}$ & $\mathrm{nA}$ & $\log \left(\frac{\boldsymbol{n A}}{1-\boldsymbol{n}}\right)$ & $\mathrm{pKa}$ \\
\hline 8.50 & 5.30 & 5.81 & 0.51 & 0.6619 & 0.2919 & 8.7919 \\
8.72 & 5.35 & 5.90 & 0.55 & 0.6357 & 0.2418 & 8.9618 \\
9.00 & 5.40 & 6.00 & 0.60 & 0.6029 & 0.1813 & 9.1813 \\
9.22 & 5.45 & 6.10 & 0.65 & 0.5701 & 0.1226 & 9.3426 \\
9.51 & 5.50 & 6.20 & 0.70 & 0.5376 & 0.0654 & 9.5754 \\
9.73 & 5.55 & 6.33 & 0.78 & 0.4851 & -0.0259 & 9.7041 \\
10.00 & 5.60 & 6.47 & 0.87 & 0.4262 & -0.1291 & 9.8709 \\
10.23 & 5.65 & 6.62 & 0.99 & 0.3609 & -0.2481 & 9.9819 \\
10.49 & 5.70 & 6.80 & 1.10 & 0.2759 & -0.4690 & 10.0210 \\
\hline
\end{tabular}

Average pKa $=9.4923 \pm 0.4410$

Metal-ligand stability constant ( $\log \mathrm{K}$ )

The stabilityconstants require the accurate values of proton-ligand stability constants (Anil and Maroti, 2008). Metal titration curves crossed over ligand titration curve indicated the formation of complex upon proton release (Santosh, et al., 2011). If the values of n- are within range $0.2-0.8$ and $1.2-18$ this indicates the formation of $1: 1$ and 1:2 complexes (Sayyed and Mazahar, 2012).

The metal (II)-humate stepwise stability constants (log k) at phenolic group (Tables 318)

Table 3: Point-wise method, $\mathrm{Cu}$-(Hydrolysed PSHA)

\begin{tabular}{|l|l|l|l|l|l|l|l|l|}
\hline $\mathrm{pH}$ & $\mathrm{BV}_{1}$ & $\mathrm{BV}_{2}$ & $\mathrm{BV}_{3}$ & $\left(\mathrm{~V}_{3}-\mathrm{V}_{2}\right)$ & $\mathrm{n}$ & $\mathrm{pL}$ & $\log \left(\frac{n}{1-n}\right)$ & LogK $_{1}$ \\
\hline 8.50 & 5.30 & 6.29 & 6.33 & 0.04 & 0.5500 & 2.66 & 0.0871 & 2.7471 \\
8.72 & 5.35 & 6.37 & 6.41 & 0.04 & 0.5714 & 2.43 & 0.1249 & 2.5549 \\
9.00 & 5.40 & 6.46 & 6.50 & 0.04 & 0.6198 & 2.16 & 0.2122 & 2.3722 \\
9.22 & 5.45 & 6.55 & 6.59 & 0.04 & 0.6667 & 1.94 & 0.3010 & 2.2410 \\
\hline
\end{tabular}

LogK $_{1}$ (Average value) $=2.4788 \pm 0.2203$

Table 4: Point-wise method, $\mathrm{Cu}$-(Hydrolysed PSHA)

\begin{tabular}{|l|l|l|l|l|l|l|l|l|}
\hline $\mathrm{pH}$ & $\mathrm{BV}_{1}$ & $\mathrm{BV}_{2}$ & $\mathrm{BV}_{3}$ & $\left(\mathrm{~V}_{3}-\mathrm{V}_{2}\right)$ & $\mathrm{n}$ & $\mathrm{pL}$ & $\log \left(\frac{n-1}{2-n}\right)$ & LogK $_{2}$ \\
\hline 9.51 & 5.50 & 6.66 & 6.73 & 0.07 & 1.3509 & 1.70 & -0.2671 & 1.4329 \\
9.73 & 5.55 & 6.78 & 6.85 & 0.07 & 1.6383 & 1.51 & 0.2467 & 1.7567 \\
10.00 & 5.60 & 6.90 & 6.98 & 0.08 & 2.1783 & 1.31 & -0.2158 & 1.0942 \\
10.23 & 5.65 & 7.05 & 7.13 & 0.08 & 4.1904 & 1.27 & & \\
10.49 & 5.70 & 7.10 & 7.19 & 0.09 & 4.6920 & & & \\
\hline
\end{tabular}

Log $K_{2}($ Average value $)=1.4280 \pm 0.3312$ 
BAJOPAS Volume 14 Number 1,June, 2021

Table 5: Point-wise method, $\mathrm{Cu}$ (Unhydrolysed PSHA)

\begin{tabular}{|l|l|l|l|l|l|l|l|l|}
\hline $\mathrm{pH}$ & $\mathrm{BV}_{1}$ & $\mathrm{BV}_{2}$ & $\mathrm{BV}_{3}$ & $\left(\mathrm{~V}_{3}-\mathrm{V}_{2}\right)$ & $\mathrm{n}$ & $\mathrm{pL}$ & $\log \left(\frac{n}{n-1}\right)$ & Log $_{1}$ \\
\hline 8.50 & 5.30 & 5.81 & 5.85 & 0.04 & 0.2973 & 2.88 & -0.3736 & 2.5064 \\
8.72 & 5.35 & 5.90 & 5.95 & 0.05 & 0.3873 & 2.66 & -0.1992 & 2.4608 \\
9.00 & 5.40 & 6.00 & 6.05 & 0.05 & 0.4044 & 2.38 & -0.1681 & 2.2119 \\
9.22 & 5.45 & 6.10 & 6.15 & 0.06 & 0.5157 & 2.18 & -0.0272 & 2.2072 \\
9.51 & 5.50 & 6.20 & 6.27 & 0.07 & 0.6417 & 1.89 & 0.2530 & 1.1430 \\
\hline
\end{tabular}

$\operatorname{LogK}_{1}($ Average value $)=2.3059 \pm 0.6153$

Table 6:Point-wise method, $\mathrm{Cu}$ (Unhydrolysed PSHA)

\begin{tabular}{|l|l|l|l|l|l|l|l|l|}
\hline $\mathrm{pH}$ & $\mathrm{BV}_{1}$ & $\mathrm{BV}_{2}$ & $\mathrm{BV}_{3}$ & $\mathrm{~V}_{3}-\mathrm{V}_{2}$ & $\mathrm{n}$ & $\mathrm{pL}$ & $\log \left(\frac{n-1}{2-n}\right)$ & $\log \mathrm{K}_{2}$ \\
\hline 9.73 & 5.55 & 6.33 & 6.42 & 0.09 & 0.9000 & 1.69 & & \\
10.00 & 5.60 & 6.47 & 6.58 & 0.11 & 1.2578 & 1.44 & -0.4592 & 0.9808 \\
10.23 & 5.65 & 6.62 & 6.84 & 0.12 & 1.6137 & 1.26 & -0.2010 & 1.4610 \\
10.49 & 5.70 & 6.80 & 6.92 & 0.12 & 2.1052 & 1.03 & & \\
\hline
\end{tabular}

$\operatorname{LogK}_{2}$ (Average value) $=1.2209 \pm 0.3398$

Table 7:Point-wise method, Pb (Hydrolysed PSHA)

\begin{tabular}{|l|l|l|l|l|l|l|l|l|}
\hline $\mathrm{pH}$ & $\mathrm{BV}_{1}$ & $\mathrm{BV}_{2}$ & $\mathrm{BV}_{3}$ & $\left(\mathrm{~V}_{3}-\mathrm{V}_{2}\right)$ & $\mathrm{n}$ & $\mathrm{pL}$ & $\log \left(\frac{n}{1-n}\right)$ & LogK $_{1}$ \\
\hline 8.50 & 5.30 & 6.29 & 6.33 & 0.04 & 0.5500 & 2.66 & 0.0871 & 2.7471 \\
8.72 & 5.35 & 6.37 & 6.41 & 0.04 & 0.5714 & 2.43 & 0.1249 & 2.5549 \\
9.00 & 5.40 & 6.46 & 6.50 & 0.04 & 0.6198 & 2.16 & 0.2122 & 2.3722 \\
9.22 & 5.45 & 6.55 & 6.60 & 0.05 & 0.8333 & 1.96 & 0.6989 & 2.6589 \\
\hline
\end{tabular}

Log $_{\mathbf{1}}($ Average value $)=2.5832 \pm 0.1614$

Table 8:Point-wise method, Pb-(Hydrolysed PSHA)

\begin{tabular}{|l|l|l|l|l|l|l|l|l|}
\hline $\mathrm{pH}$ & $\mathrm{BV}_{1}$ & $\mathrm{BV}_{2}$ & $\mathrm{BV}_{3}$ & $\left(\mathrm{~V}_{3}-\mathrm{V}_{2}\right)$ & $\mathrm{n}$ & $\mathrm{pL}$ & $\log \left(\frac{n-1}{2-n}\right)$ & $\log \mathrm{K}_{2}$ \\
\hline 9.51 & 5.50 & 6.66 & 6.71 & 0.05 & 0.9650 & 1.67 & & \\
9.73 & 5.55 & 6.78 & 6.83 & 0.05 & 1.1702 & 1.44 & & \\
10.00 & 5.60 & 6.90 & 6.90 & 0.05 & 1.4864 & 1.22 & -0.0237 & 1.1963 \\
10.23 & 5.65 & 7.05 & 7.10 & 0.05 & 2.0190 & 1.09 & & \\
10.49 & 5.70 & 7.10 & 7.17 & 0.07 & 3.6492 & 1.00 & & \\
\hline
\end{tabular}

Log $K_{2}$ (Average value) $=1.1963$

Table 9: Point-wise method, Pb (Unhydrolysed PSHA)

\begin{tabular}{|l|l|l|l|l|l|l|l|l|}
\hline $\mathrm{pH}$ & $\mathrm{BV}_{1}$ & $\mathrm{BV}_{2}$ & $\mathrm{BV}_{3}$ & $\mathrm{~V}_{3}-\mathrm{V}_{2}$ & $\mathrm{n}$ & $\mathrm{pL}$ & $\begin{array}{l}\text { Log } \\
\left(\frac{n}{n-1}\right)\end{array}$ & Log $\mathrm{K}_{1}$ \\
\hline 8.50 & 5.30 & 5.81 & 5.85 & 0.04 & 0.2973 & 2.88 & -0.3736 & 2.5064 \\
8.72 & 5.35 & 5.90 & 5.94 & 0.04 & 0.3099 & 2.66 & -0.5477 & 2.3123 \\
9.00 & 5.40 & 6.00 & 6.05 & 0.05 & 0.4044 & 2.38 & -0.1681 & 2.2119 \\
9.22 & 5.45 & 6.10 & 6.15 & 0.06 & 0.5157 & 2.18 & 0.0272 & 2.2072 \\
9.51 & 5.50 & 6.20 & 6.26 & 0.07 & 0.6417 & 1.89 & 0.2530 & 2.1430 \\
9.73 & 5.55 & 6.40 & 6.40 & 0.07 & 0.7000 & 1.67 & 0.3680 & 2.0380 \\
\hline
\end{tabular}

LogK $_{1}$ (Average value) $=2.2364 \pm 0.1602$

Table 10: Point-wise method, Pb (Unhydrolysed PSHA)

\begin{tabular}{|l|l|l|l|l|l|l|l|l|}
\hline $\mathrm{pH}$ & $\mathrm{BV}_{1}$ & $\mathrm{BV}_{2}$ & $\mathrm{BV}_{3}$ & $\mathrm{~V}_{3}-\mathrm{V}_{2}$ & $\mathrm{n}$ & $\mathrm{pL}$ & $\log \left(\frac{n-1}{2-n}\right)$ & $\log \mathrm{K}_{2}$ \\
\hline 10.00 & 5.60 & 6.47 & 6.55 & 0.08 & 1.9503 & 1.41 & & \\
10.23 & 5.65 & 6.62 & 6.72 & 0.11 & 1.4792 & 1.26 & -0.0361 & 1.2239 \\
\hline
\end{tabular}

$\operatorname{LogK}_{2}$ (Average value) $=1.2239$

Table 11: Point-wise method, Mg (Hydrolysed PSHA)

\begin{tabular}{|l|l|l|l|l|l|l|l|l|}
\hline $\mathrm{pH}$ & $\mathrm{BV}_{1}$ & $\mathrm{BV}_{2}$ & $\mathrm{BV}_{3}$ & $\left(\mathrm{~V}_{3}-\mathrm{V}_{2}\right)$ & $\mathrm{n}$ & $\mathrm{pL}$ & $\log \left(\frac{n}{n-1}\right)$ & LogK $_{1}$ \\
\hline 8.50 & 5.30 & 6.29 & 6.31 & 0.02 & 0.2750 & 2.64 & -0.4290 & 2.2110 \\
8.72 & 5.35 & 6.37 & 6.39 & 0.02 & 0.2858 & 2.42 & -0.3978 & 2.0222 \\
9.00 & 5.40 & 6.46 & 6.49 & 0.03 & 0.4648 & 2.14 & -0.0612 & 2.0788 \\
9.22 & 5.45 & 6.55 & 6.59 & 0.04 & 0.6667 & 1.94 & 0.3010 & 2.2410 \\
\hline
\end{tabular}

$\log _{\mathbf{1}}($ Average value) $=2.1382 \pm 0.1046$ 
BAJOPAS Volume 14 Number 1,June, 2021

Table 12: Point-wise method, Mg (Hydrolysed PSHA)

\begin{tabular}{|l|l|l|l|l|l|l|l|l|}
\hline $\mathrm{pH}$ & $\mathrm{BV}_{1}$ & $\mathrm{BV}_{2}$ & $\mathrm{BV}_{3}$ & $\left(\mathrm{~V}_{3}-\mathrm{V}_{2}\right)$ & $\mathrm{n}$ & $\mathrm{pL}$ & $\log \left(\frac{n-1}{2-n}\right)$ & LogK $_{2}$ \\
\hline 9.51 & 5.55 & 6.66 & 6.71 & 0.05 & 0.9650 & 1.67 & & \\
9.73 & 5.55 & 6.78 & 6.84 & 0.06 & 1.4042 & 1.47 & -0.1686 & 1.3014 \\
10.00 & 5.60 & 6.90 & 6.93 & 0.06 & 1.7838 & 1.23 & 0.5593 & 1.7893 \\
10.23 & 5.65 & 7.05 & 7.10 & 0.06 & 3.1429 & 1.10 & & \\
10.49 & 5.70 & 7.10 & 7.18 & 0.07 & 3.6492 & 0.83 & & \\
\hline
\end{tabular}

LogK $_{2}($ Average value $)=1.5453 \pm 0.3450$

Table 13: Point-wise method, Mg (Unhydrolysed PSHA)

\begin{tabular}{|l|l|l|l|l|l|l|l|l|}
\hline $\mathrm{pH}$ & $\mathrm{BV}_{1}$ & $\mathrm{BV}_{2}$ & $\mathrm{BV}_{3}$ & $\mathrm{~V}_{3}-\mathrm{V}_{2}$ & $\mathrm{n}$ & $\mathrm{pL}$ & $\log \left(\frac{n}{n-1}\right)$ & $\operatorname{Log~}_{1}$ \\
\hline 8.50 & 5.30 & 5.81 & 5.85 & 0.04 & 0.2973 & 2.88 & -0.3736 & 2.5064 \\
8.72 & 5.35 & 5.90 & 5.94 & 0.04 & 0.3099 & 2.66 & -0.3477 & 2.3123 \\
9.00 & 5.40 & 6.00 & 6.04 & 0.04 & 0.3236 & 2.38 & -0.3202 & 2.0598 \\
9.22 & 5.45 & 6.10 & 6.15 & 0.05 & 0.4297 & 2.17 & -0.1230 & 2.0470 \\
9.51 & 5.50 & 6.20 & 6.26 & 0.06 & 0.5500 & 1.89 & 0.0871 & 1.9771 \\
9.73 & 5.55 & 6.33 & 6.40 & 0.07 & 0.7000 & 1.67 & 0.3680 & 2.0380 \\
\hline
\end{tabular}

LogK $_{1}$ (Average value) $=2.1568 \pm 0.2069$

Table 14: Point-wise method, Mg (Unhydrolysed PSHA)

\begin{tabular}{|l|l|l|l|l|l|l|l|l|}
\hline $\mathrm{pH}$ & $\mathrm{BV}_{1}$ & $\mathrm{BV}_{2}$ & $\mathrm{BV}_{3}$ & $\mathrm{~V}_{3}-\mathrm{V}_{2}$ & $\mathrm{n}$ & $\mathrm{pL}$ & $\log \left(\frac{n-1}{2-n}\right)$ & $\log \mathrm{K}_{2}$ \\
\hline 10.00 & 5.60 & 6.47 & 6.55 & 0.08 & 0.9148 & 1.41 & & \\
10.23 & 5.65 & 6.62 & 6.71 & 0.09 & 1.2102 & 1.20 & -0.5749 & 0.6251 \\
10.49 & 5.70 & 6.80 & 6.92 & 0.09 & 1.5968 & 1.03 & 0.1703 & 1.2003 \\
\hline
\end{tabular}

LogK $_{2}$ (Average value) $=0.9127 \pm 0.4070$

Table15:Point-wise method, Cd (Hydrolysed PSHA)

\begin{tabular}{|l|l|l|l|l|l|l|l|l|}
\hline $\mathrm{pH}$ & $\mathrm{BV}_{1}$ & $\mathrm{BV}_{2}$ & $\mathrm{BV}_{3}$ & $\left(\mathrm{~V}_{3}-\mathrm{V}_{2}\right)$ & $\mathrm{n}$ & $\mathrm{pL}$ & $\log \left(\frac{n}{1-n}\right)$ & LogK $_{1}$ \\
\hline 8.50 & 5.30 & 6.29 & 6.31 & 0.02 & 0.2750 & 2.64 & -0.4210 & 2.2190 \\
8.72 & 5.35 & 6.37 & 6.40 & 0.03 & 0.4286 & 2.42 & -0.1249 & 2.2951 \\
9.00 & 5.40 & 6.46 & 6.49 & 0.03 & 0.4648 & 2.14 & -0.0612 & 2.0788 \\
9.22 & 5.45 & 6.55 & 6.59 & 0.04 & 0.6667 & 1.96 & 0.3010 & 2.2610 \\
9.51 & 5.55 & 6.66 & 6.70 & 0.04 & 0.7720 & 1.67 & 0.5297 & 2.1997 \\
\hline
\end{tabular}

LogK $_{\mathbf{1}}$ (Average value) $=2.2108 \pm 0.0825$

Table 16: Point-wise method, Cd (Hydrolysed PSHA)

\begin{tabular}{|l|l|l|l|l|l|l|l|l|}
\hline $\mathrm{pH}$ & $\mathrm{BV}_{1}$ & $\mathrm{BV}_{2}$ & $\mathrm{BV}_{3}$ & $\left(\mathrm{~V}_{3}-\mathrm{V}_{2}\right)$ & $\mathrm{n}$ & $\mathrm{pL}$ & $\log \left(\frac{n-1}{2-n}\right)$ & Log $_{2}$ \\
\hline 9.73 & 5.55 & 6.78 & 6.83 & 0.06 & 1.4042 & 1.47 & -0.1686 & 1.3014 \\
10.00 & 5.60 & 6.90 & 6.95 & 0.06 & 1.7838 & 1.23 & 0.5593 & 1.7893 \\
10.23 & 5.65 & 7.05 & 7.10 & 0.06 & 3.1429 & 1.09 & & \\
10.49 & 5.70 & 7.10 & 7.16 & 0.06 & 3.1429 & 0.89 & & \\
& & & & & & & & \\
\hline
\end{tabular}

$\operatorname{LogK}_{2}$ (Average value) $=1.5453 \pm 0.3450$

Table 17: Point-wise method, Cd (Unhydrolysed PSHA)

\begin{tabular}{|l|l|l|l|l|l|l|l|l|}
\hline $\mathrm{pH}$ & $\mathrm{BV}_{1}$ & $\mathrm{BV}_{2}$ & $\mathrm{BV}_{3}$ & $\mathrm{~V}_{3}-\mathrm{V}_{2}$ & $\mathrm{n}$ & $\mathrm{pL}$ & $\log \left(\frac{n}{n-1}\right)$ & $\operatorname{Log~}_{1}$ \\
\hline 8.50 & 5.30 & 5.81 & 5.86 & 0.05 & 0.3717 & 2.88 & -0.2280 & 2.6520 \\
8.72 & 5.35 & 5.90 & 5.95 & 0.05 & 0.3873 & 2.66 & -0.1992 & 2.4608 \\
9.00 & 5.40 & 6.00 & 6.06 & 0.06 & 0.4853 & 2.38 & -0.0255 & 2.3545 \\
9.22 & 5.45 & 6.10 & 6.16 & 0.06 & 0.5157 & 2.18 & -0.0272 & 2.2072 \\
9.51 & 5.50 & 6.20 & 6.27 & 0.07 & 0.6417 & 1.89 & 0.2530 & 1.1430 \\
9.73 & 5.55 & 6.33 & 6.41 & 0.08 & 0.8000 & 1.69 & 0.6020 & 2.2920 \\
& & & & & & & & \\
\hline
\end{tabular}

$\operatorname{LogK}_{1}($ Average value $)=2.2516 \pm 0.5380$ 
BAJOPAS Volume 14 Number 1,June, 2021

Table 18: Point-wise method, Cd (Unhydrolysed PSHA)

\begin{tabular}{|l|l|l|l|l|l|l|l|l|}
\hline $\mathrm{pH}$ & $\mathrm{BV}_{1}$ & $\mathrm{BV}_{2}$ & $\mathrm{BV}_{3}$ & $\mathrm{~V}_{3}-\mathrm{V}_{2}$ & $\mathrm{n}$ & $\mathrm{pL}$ & $\log \left(\frac{n-1}{2-n}\right)$ & $\log \mathrm{K}_{2}$ \\
\hline 10.00 & 5.60 & 6.47 & 6.57 & 0.10 & 1.1434 & 1.43 & & \\
10.23 & 5.65 & 6.62 & 6.72 & 0.10 & 1.3448 & 1.23 & -0.2788 & 0.9512 \\
10.49 & 5.70 & 6.80 & 6.90 & 0.10 & 1.7742 & 1.03 & 0.5351 & 1.5651 \\
\hline
\end{tabular}

$\operatorname{LogK}_{2}($ Average value $)=1.2581 \pm 0.4340$

Table 19: Stepwise and overall Stability constants of thehydrolysed and unhydrolysed divalent metal (II) complexes

\begin{tabular}{|c|c|c|c|}
\hline Chelates & LogK $_{1}$ & $\log _{2}$ & Log $\beta$ \\
\hline [Cu (Hydrolysed PSHA-1) $\left.{ }_{2}\right]$ & 2.4788 & 1.4280 & 3.9068 \\
\hline$\left[\mathrm{Pb}(\text { Hydrolysed PSHA-1) })_{2}\right]$ & 2.5832 & 1.1963 & 3.7795 \\
\hline$\left[\mathrm{Cd}(\text { Hydrolysed PSHA-1 })_{2}\right]$ & 2.2108 & 1.5453 & 3.7561 \\
\hline$\left[\mathrm{Mg}(\text { Hydrolysed PSHA-1 })_{2}\right]$ & 2.1382 & 1.5453 & 3.6835 \\
\hline [Cu (Unhydrolysed PSHA-1) & 2.3059 & 1.2209 & 3.5268 \\
\hline$[\mathrm{Pb}$ (Unhydrolysed PSHA-1) 2$]$ & 2.2364 & 1.2239 & 3.4603 \\
\hline [Cd (Unhydrolysed PSHA-1) 2 ] & 2.2516 & 1.2581 & 3.5097 \\
\hline$[\mathrm{Mg}$ (Unydrolysed PSHA-1) & 2.1568 & 0.9127 & 3.0695 \\
\hline
\end{tabular}

The results obtained (Table19) shows the stepwise and overall stability constants to be not high indicating low stability of the complexes, because the solubility of most metal ions in the basic $\mathrm{pH}$ range is minimal due to metal hydroxide precipitation (Karimi, 2017). In general, the stepwise stability constants $\left(K_{1}\right.$ and $K_{2}$ ) follow the order $K_{1}>K_{2}$ for the copper, lead, magnesium and cadmium complexes respectively. The steady decrease of the values with increasing number of ligands is in agreement with the prediction made by researchers (Na'aliya, 2013). The decrease could be attributed to the fact that as the number of the ligands (Humate ions) that enters the coordination zone increases the aqua molecules available for replacement by the ligands become less. Thus, the metal ions become less electron loving with progressive intake of the ligand and this results in the decrease in the values of the constants (Na'aliya, 2013). Also the stability of the complexes is influenced by the size and number of the chelate rings(Mackay and Mackay,2002).All the complexes form rings in their structure as humate, a bidentate ligand, bond the metal ions in the ratio 1:2 (Boguta and Sokolowska, 2016) forming chelate rings. The values of the overall stability constants $(\log \beta)$ obtained for humate complexes are not high indicating low stability as the values are not high. LogK values for copper-humates (Table 3 to 6) obtained in this study are lower than those reported for the complexes of humic acids (Pandey et al., 2015; Dinu, 2013; Kaschl et al., 2010 and Gilbeto and Jorg, 2001). The values of LogK(Table 7 to 10 ) forlead-humates are lower than those reported for the lead in the literature (Dinu, 2013; Gilbeto and Jorg 2001). Log K values(Table 11 to 14 ) for magnesium-humates obtained in this study are close to those reported by (Pandey et al., 2015). Log K values of cadmium-humates (Table 15 to 18 ) obtained in this work near to the one reported by (Dinu, 2013 and Pandey et al., 2015).The difference between the reported values and the values obtained in this study might be probably as a result of acid hydrolysis of humic acid. The values of the overall stability constants $(\log \beta)$ of the copper humates complexes presented in Table 19 is high than that of other metal humate complexes, show relatively high stability of CuHA complexes, show the following order of stability: $\mathrm{Cu}>\mathrm{Pb}>\mathrm{Cd}>\mathrm{Mg}$; which are in close agreement to the findings of (Dinu, 2013 and Pandey et al., 2015).The high stability of Cuhumate chelate could be attributed to the existence of coordinate covalent bond between the complexing agents and the $\mathrm{Cu}^{2+}$ ions. Since, $\mathrm{Cu}^{2+}$ being a metal of the transitional series with $3 d^{9}$ electronic configurations can accept the electrons from the complexing agents. Similarly, the low stabilities of $\mathrm{Pb}, \mathrm{Cd}$ and $\mathrm{Mg}$ complexes could be explained by that $\mathrm{Pb}^{2+}$ with $6 s^{2}, \mathrm{Cd}^{2+}$ with $4 \mathrm{~d}^{10}$ and $\mathrm{Mg}^{2+}$ with $2 \mathrm{p}^{6}$ their electronic configuration has a completely filled $\mathrm{d}, \mathrm{p}$ and $\mathrm{s}$ orbitals. Moreover, the stabilities of metal ions with hydrolysed humic acid from peat soil were higher than those with unhydrolysed humic acid from peat soil; which is ascribed to the high content of acidity in hydrolysed humic acid than unhydrolysed humic acid. 
BAJOPAS Volume 14 Number 1,June, 2021 CONCLUSION

The values of logk for $\mathrm{Cu}(\mathrm{II})$ hydrolysed humic acid complex was higher followed by $\mathrm{Pb}$ (II), $\mathrm{Cd}(\mathrm{II})$ and $\mathrm{Mg}$ (II) hydrolysed humic acid complexes as compared with metal(II) unhydrolysed humic acid complexes. This indicates acid hydrolysis of humic acid can

\section{REFERENCES}

Almeida, V.R. and Szpoganicz, B. (2015). Humic Acid Potentiometric Response Patterns:Out- of Equilibrium Properties and Species Distribution Modelling. Chemical. Biol. Technol. Agric. 2: 17.

Anđelković, T., Nikolić, R., Bojić, A.,Anđelković, D., and Nikolic G.,(2010). Binding of Cadmium to Soil Humic Acid as A Function of Carboxyl Group Content. Macedonian Journal of Chemistry and Chemical Engineering.29(2): 215-224.

Anil, B. N. and Maroti, N. (2008). Studies on Influence of Die-Lectric Constants on Complex Equilibria between Substituted Py-Razalines and Lanthanide Metal Ions pH-Metrically. Amer.-Euras. scient. Res. 3(2): 212-216.

Ashok, K., Pandey, S. P. and Misra, V (2000). Stability Constants of Metal-Humic Acid Complexes and its Role in Environmental Detoxification. Journal of Ecotoxicology and Environmental Safety. 47(2):157-200.

Badr, M. H., El-Halafawi, M. H. and Abd El-al Zeid, E. R. (2012). Comparison Between the Effect of Ionic Strength on Acidity and Dissociation Constants of Humic Acids Extracted from Sewage Sludge and Nile Water Hyacinth Composts.Global Journal of Environmental Research 6 (1): 36-43.

Baruah, M.K., Borah, D., Saikia, P.P., Paul, S., Sharma, T. (2015). Evaluation of pKa Values of Soil Humic Acids and their Complexation Properties. International Journal of Plant \& Soil Science 6(4) : 218-228.

Boguta, P. Sokolowska, Z. (2016). Interactions of $\mathrm{Zn}$ (II) Ions with Humic Acids Isolated from Various Types of Soils. Effect of $\mathrm{pH}, \mathrm{Zn}$ Concentrations and Humic Acids Chemical Properties. Journal of Geochemical Explaration 168. 119-126.

Borges, F., Guimaraes, C., Lima, L.F.C., Pinto, I. and Reis, S.(2005). Potentiometric Studies on the Complexation of Copper(II) by Phenolic Acids as Discrete Ligand Models of enhance the complexation behavior of humic acid with metal (II) ions. However, the higher values of $\log \beta$ for $\mathrm{Cu}(\mathrm{II}), \mathrm{Pb}(\mathrm{II}), \mathrm{Cd}(\mathrm{II})$ and $\mathrm{Mg}(\mathrm{II})$ hydrolysed humic acid complexes indicates more stable stepwise complexes formed as compared with $\mathrm{Cu}(\mathrm{II}), \mathrm{Pb}$ (II), $\mathrm{Cd}$ (II) and $\mathrm{Mg}(\mathrm{II})$ unhydrolysed humic acid complexes.

Humic Substances Talanta 66 (2005) 670-673.

Chefetz, B., Salloum, M. J., Deshmulkin, A. P. and Hatcher, P. (2002). Structural Components of Humic Acids as Determined by Chemical Modifications and Carbon-13 NMR, Pyrolysis, and Thermochemolysis- Gas Chromatography/Mass Spectrometry. Soil Science Society of American Journal Abstract Division S-2- Soil Chemistry66. 1159-1171.

Dinu, M. I. (2013). Metals Complexation with Humic Acids in Surface Water of Different Environ. Sci. Technol. 31(1): 1-17.

Fernandes, A.N., Giacomelli, C., Giovanela, M. Vaz, D.V. Szpoganicz, B. and Maria M. D. (2009). Potentiometric Acidity Determination in Humic Substances Influenced by Different Analytical Procedures.J. Braz. Chem. Soc. 20 (9):14.

Gamal, A. H. (2015). Stability Constants of Rhenium (V) Metal Complexes with Selected Drugs. Pyrex Journal of Research in Environmental Studies. 2(2): 006-014.

Janrao, D. M., Pathan, J., Kayande, D.D., and Mulla, J.J. (2014). An Over View of Potentiometric Determination of Stability Constants of Metal Complexes. Sci. Revs. Chem. Commun.: 4(1), 2014, 11-24.

Karimi, H. (2017). Effect of pH and Initial Pb(II) Concentration on the Lead Removal Efficiency from Waste Water Using $\mathrm{Ca}(\mathrm{OH})_{2}$. International Journal of Water and Waste Water Treatment 3.2

Kaschl, A. Romheld, V. and Chen, Y. (2010). Binding of Cadmium, Copper and Zinc to Humic Substances Originating from Municipal Solid Waste Compost. Israel Journal of Chemistry Vol. 42(1): 89-98.

Kostic, I. S., Tatjana, P, A., Nikolic, R. S., Cvetkovic, T. P., Pavlovic, D. D., Aleksandar, L.J. and Bojic, A. (2012). Comparative Study of Binding Strengths of Heavy Metals with Humic Acid. J.serb. Chem. Soc. 76(9) pp 1-20. 
BAJOPAS Volume 14 Number 1,June, 2021

Na'aliya, J. (2013). Determination of Stepwise Stability Constants and Gibbs free Energy Change of Trisprolina to Complexes of some Divalent Transition Metal ions. Bayero Journal of Pure and Applied Sciences 6(2): 112-114.

Omar, A. A. and Ali, E. A. (2015). Potentiometric Studies on Complexes of $\mathrm{Cr}$ (III) and $\mathrm{Zr}$ (IV) with some Carboxylic Acids. International Journal of Advanced Chemistry, 3(1) 25-

37.

Pandey, A. K. Pandey, S. D. and Misr, V. (2015).Stability Constants of Metal- Humic Acid Complexes and Its Role in Environmental Detoxification. J. Ecotoxicology and Environmental Safety. 47(1):195-200.

Ram, N. and Raman, K.V. (1984). Stability Constants of Complexes of Metals with
Humicand Fuvic Acids under Non- acidConditions. Journal of Plant Nutrition and Soil Sciences.

147:171-176.

Santosh, D. D., Ashok, B. K., Vijay, J. T., Shivraj, G. W. and Vinay, V. W. (2011). Potentiometric Studies of Elec-Trolyte Effects on Complex Equilibria of Some Substituted 5-(2-hydroxy Phenyl) Pyrazoles. Der pharm. 3 (6): 75-83.

Sayyed, H. and Abdul Rahim, M. F. (2012). Studies of Binary Complexes of Metal Ions with Mandelic Acid by Potentiometry. Chem. J. 02 (6): 206209.

Shirvani, M. Moradian, E. Khalili, B. Bakhtiary, S. (2015). Interaction of $\mathrm{Cd}$ and $\mathrm{Pb}$ with Humate-Palygorskite and HumateSepiolite Complexes. Journal of water, air and pollution 3: 220-228. 


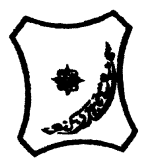

Bayero Journal of Pure and Applied Sciences, 14(1): 54 - 63

Received: November, 2020

Accepted: April, 2021

ISSN $2006-6996$

\title{
STABILITY CONSTANTS OF COMPLEXES OF METAL IONS WITH PEATSOIL HUMIC ACIDS UNDER NON-ACID-CONDITIONS
}

\author{
${ }^{* 1}$ Sabo, Yusuf ${ }^{2}$ Jimoh, W.L.O., ${ }^{3}$ Isa Baba Koki and ${ }^{4}$ Sholadoye, Q. 0. \\ ${ }^{1}$ Department of Pure and Industrial Chemistry, Bayero University, Kano \\ ${ }^{3}$ Department of Chemistry, Yusuf Maitama Sule University Kano. P.M.B. 3220 Kano, Nigeria. \\ ${ }^{4}$ Department of Chemistry, Nigerian Police Academy, Wudil, Kano-Nigeria
}

*Correspondence E-mail; saboyusuf18@yahoo.com

ABSTRACT

Stability constants of complexes of four divalent metal ions viz. $\mathrm{Cu}^{2+}, \mathrm{Pb}^{2+}, \mathrm{Mg}^{2+}$ and $\mathrm{Cd}^{2+}$ with humic acids (HA) were determined by potentiometric titration of humic acids with the corresponding salt of the divalent metals in aqueous media under non-acid-condition. The log $K$ (logarithm of the stability constant) ranged from 1.0942 to 2.7471 for metalhumic acid complexes were determined using point-wise computational method. The order of stability constants were obtained as follows: $\mathrm{Cu}>\mathrm{Pb}>\mathrm{Cd}>\mathrm{Mg}$ for metal $-\mathrm{HA}$ complexes respectively, indicating a higher degree of complexation with Cu metal ion.

Keywords: stability constant, humic acid, potentiometric titration, divalent metals, acid hydrolysis.

\section{NTRODUCTION}

The stability constant of a complex is the numerical expression of its stability and provides a quantitative measure of affinity of the metal ion to the complexing agent. An understanding of the relative stability of metal-complexes helps in predicting the behavior of metal ions in the soil (Ram and Raman, 1982). Extensive researches has been done to determine the stability constants of the complexes formed between humic acid (HA) with a number of metal ions. Ashok et al., (2000) reported that humic acid with hydroxyl, phenoxyl and carboxyl reactive groups can form coordination compound with metal ions at $\mathrm{pH}$ 3.5. The stability constants(Log K) for different metalhumic acid complexes indicated the following order of the stabilities of complexes formed between humic acid and metal ion, $\mathrm{Cu}>\mathrm{Fe}$ $>\mathrm{Pb}>\mathrm{Ni}>\mathrm{Co}>\mathrm{Ca}>\mathrm{Cd}>\mathrm{Zn}>\mathrm{Mn}>\mathrm{Mg}$. Andelkovic et al., (2010) investigated the binding of $\mathrm{Cd}$ (II) to soil humic acid at pH 6.5 and in $0.1 \mathrm{M} \mathrm{KNO}_{3}$ ionic medium. The stability constant for binding indicating greater stability in the case when carboxyl groups are involved in complexation reaction. Kostic et al.,(2012) investigated the complexation of humic acid with certain heavy metal ions (Co(II), $\mathrm{Ni}(\mathrm{II}), \mathrm{Cu}(\mathrm{II})$,
$\mathrm{Zn}(\mathrm{II})$, and $\mathrm{Pb}(\mathrm{II})$. The experiment was performed at $25^{\circ} \mathrm{C}$, at pH 4.0 and ionic strength of $0.01 \mathrm{M}$. Stability constant of complex between $\mathrm{Pb}$ (II) ions and humic acid is greater than stability constants of other investigated metalhumate complexes. Bogata and Sokolowska (2016) analyses the interaction between humic acids from different soils and $\mathrm{Zn}$ (II) ions at wide concentration ranges and at $\mathrm{pH} 5$. Studies have showed significant impact of $\mathrm{Zn}$ concentration, $\mathrm{pH}$ and some properties of humic acids with zinc.But all of these studies were limited to acidic $\mathrm{pH}$ range. Therefore, the present study was carried out to determine and compare the stability constants of complexes of metal ions with hydrolysed peat soil humic acid and unhydrolysed peat soil humic under non-acid conditions.

\section{MATERIALS AND METHODS}

Analytical grade chemicals used includes hydrochloric acid $(\mathrm{HCl})$, nitric acid $\left(\mathrm{HNO}_{3}\right)$, sodium hydroxide $(\mathrm{NaOH})$, lead nitrate $\mathrm{Pb}\left(\mathrm{NO}_{3}\right)_{2}$, copper nitrate $\mathrm{Cu}\left(\mathrm{NO}_{3}\right)_{2} \cdot 3 \mathrm{H}_{2} \mathrm{O}$, cadmium nitrate $\mathrm{Cd}\left(\mathrm{NO}_{3}\right)_{2} \cdot 4 \mathrm{H}_{2} \mathrm{O}$, magnesium nitrate $\mathrm{Mg}\left(\mathrm{NO}_{3}\right)_{2} \cdot 6 \mathrm{H}_{2} \mathrm{O}$, potassium nitrate $\left(\mathrm{KNO}_{3}\right)$, calcium chloride $\left(\mathrm{CaCl}_{2}\right)$, (sigma-Aldrich). Dowex 50WX8, (20-50 mesh) from Fluka. 


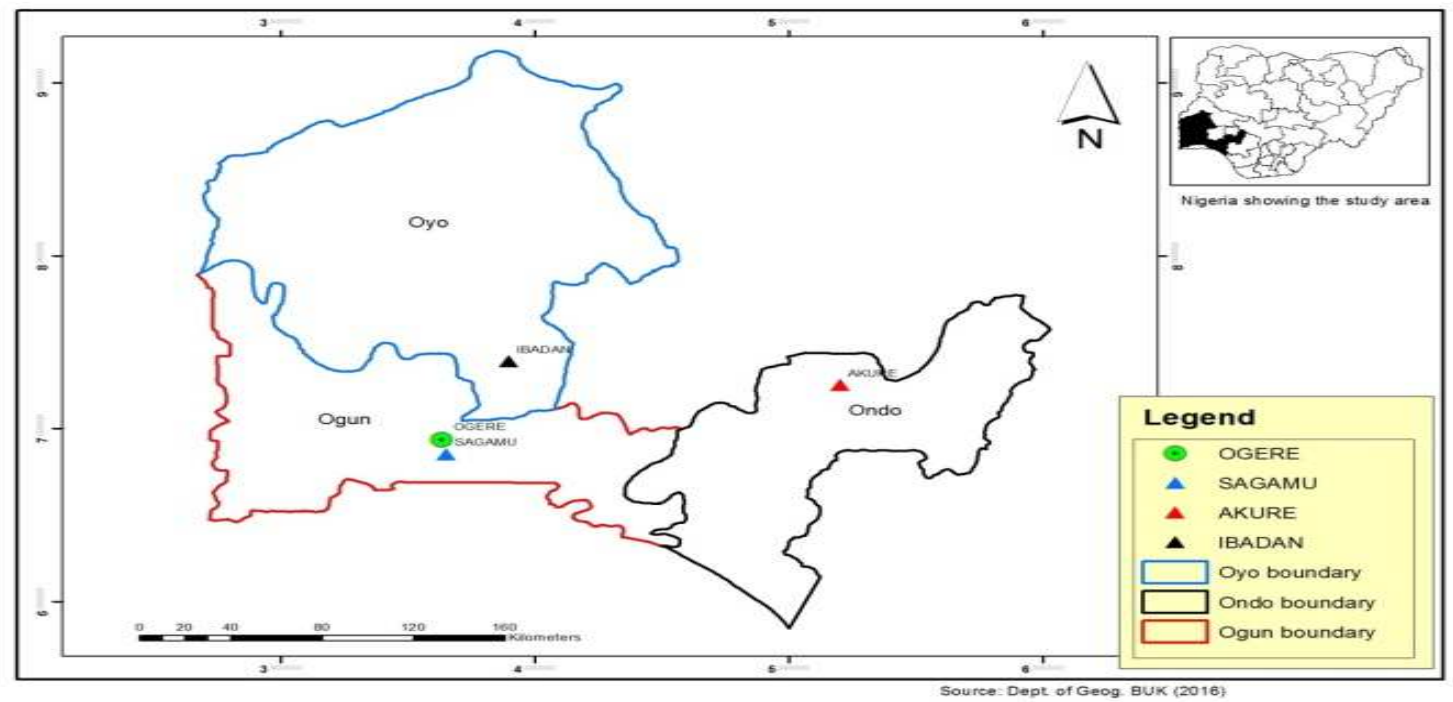

Figure 1: Map showing the sampling point at Sagamu Town, Ogun State.

\section{Description of Sampling Area}

Sagamu has geographical coordinates between $6^{\circ} 50^{\prime}$ north; $3^{\circ} 38^{\prime}$ east is located in south western region of Nigeria. The region has tropical wet and dry climate with a lengthy wet season and relatively constant temperatures throughout the course of the year. Wet season runs from March to October, November to December forms the region dry season. The vegetation type of the region is savannah which is really grassland with small bushes and occasional big trees. Grassland soils have substantially higher organic matter content than forest soils (Novackova, 2011).

\section{Sample Collection}

The Peatsoil samples were collected from four different sampling points $(0-10 \mathrm{~cm}$ depth) in Sagamu into polyethylene bag with plastic spoons. Samples were taken to the laboratory, extraneous materials were removed; the samples were air-dried, crushed and ground to a fine powder in a mortar passed through a $0.20 \mathrm{~mm}$ sieve. The samples were kept for analysis.

\section{Isolation and purification of humic acid from peat soil sample}

Peatsoil sample $(100 \mathrm{~g})$ was mixed with 1000 $\mathrm{cm}^{3}$ of $0.1 \mathrm{M} \mathrm{NaOH}$ solution, shaken for 3hours and left to stand overnight. Dark-coloured supernatant was obtained and decanted from solid residue. The dark-coloured supernatant was acidified to $(\mathrm{pH}=1.0)$ with $6 \mathrm{M} \mathrm{HCl}$ stirred and allowed to stand for 6 hours. Yellowish brown supernatant and dark-brown precipitate were obtained. The yellowish brown supernatant was decanted followed by centrifuge and discarded. The dark-brown precipitate was mixed with $500 \mathrm{~cm}^{3}$ of $0.1 \mathrm{M} \mathrm{NaOH}$ solution followed by passing through dowex resin. The dark-brown solution was acidified to $(\mathrm{pH}=1.0)$ with $6 \mathrm{M} \mathrm{HCl}$ stirred and allowed to stand for 3 hours. The dark-brown precipitate was washed several times with deionized water. The supernatant was treated with $\mathrm{AgNO}_{3}$ solution until no white precipitate observed. The humic acid was transferred to weighed crucible and dried at $60^{\circ} \mathrm{C}$ in an oven for 12 hours. The humic acid was cooled and dried in the desiccator, weighed and recorded. The obtained humic acid was dried again at $60^{\circ} \mathrm{C}$ for additional 6 hours cooled and dried in the desiccator, weighed and recorded constant weight was obtained (Baruah et al., 2015).

\section{FT-IR analysis}

FT-IR spectra of humic acid sample was analysed using Carry 630 FT-IR Agilent Technologies.

Unhydrolysed compost humic acid

The unhydrolysed humic acid was obtained after isolation and purification of compost humic acid and kept for investigation.

\section{Acid hydrolysis of Peatsoil acid}

Peatsoil humic acid sample (1g) was refluxed for 12 hours at $\left(160^{\circ} \mathrm{C}\right)$ with $50 \mathrm{~cm}^{3}$ of $6 \mathrm{M} \mathrm{HCl}$. The mixture was allowed to cool, decanted, and centrifuged after hydrolysis. The insoluble residues were washed with distilled water via centrifugation several times, and the supernatant was treated with $\mathrm{AgNO}_{3}$ solution until no white precipitate was observed. The residue was thoroughly dried over $\mathrm{CaCl}_{2}$ in a desiccator at room temperature (Chefetz et al., 2002). Finally, the obtained hydrolysed humic acid was kept for investigation. 
BAJOPAS Volume 14 Number 1,June, 2021 Potentiometric Titrations

Potentiometric measurements were carried out using a pH-meter Jenway (model 3510) with combine electrode, the sensitivity of the $\mathrm{pH}$ meter is 0.01 units. The $\mathrm{pH}$ meter was switched on half an hour before starting the titration for initial warm up of the instrument. The instrument was calibrated with an aqueous standard buffer solution of $\mathrm{pH} 4.00$ and 10.0 (borate buffer) prepared from a "Qualigens" buffer tablets.

The following sets of solutions were prepared in a $250 \mathrm{~cm}^{3}$ volumetric flask separately for $\mathrm{pH}$ metric titrations.

(i) $5 \mathrm{~cm}^{3} 0.1 \mathrm{M} \mathrm{HCl}+40 \mathrm{~cm}^{3}$ deionized water

(ii) $5 \mathrm{~cm}^{3} 0.1 \mathrm{M} \mathrm{HCl}+39 \mathrm{~cm}^{3}$ deionized water $+1 \mathrm{~cm}^{3} 0.15 \mathrm{gcm}^{-3}$ humic acid

(iii) $5 \mathrm{~cm}^{3} 0.1 \mathrm{M} \mathrm{HCl}+37 \mathrm{~cm}^{3}$ deionized water $+1 \mathrm{~cm}^{3} 0.15 \mathrm{gcm}^{-3}$ humic acid

$$
+2 \mathrm{~cm}^{3} \quad 0.01 \mathrm{M} \mathrm{Cu} \text { (II) }
$$

The solutions were titrated against standardized $0.110 \mathrm{MNaOH}$ separately. The total volume of each mixture was adjusted to $50 \mathrm{~cm}^{3}$ and the ionic strength of the solutions was maintained constant at by adding appropriate amount of stock solution of $1 \mathrm{M} \mathrm{KNO}_{3}$ (Gamal, 2015; Omar and Ali, 2015). A magnetic stirrer was used to achieve thorough mixing of the interacting solutions at $550 \mathrm{rpm}$. The same set of experimental conditions was applied for potentiometric titration of remaining samples.

\section{Evaluation of pKa of Hydrolysed peat soil Humic Acids}

The proton-ligand formation number $\mathrm{n}_{\mathbf{A}}$ were calculated by Irving and Rossotti expression (Omar and Ali, 2015).

$\mathrm{nA}=\mathrm{Y}-\frac{(\mathrm{V} 2-\mathrm{V1})(\mathrm{No}-\mathrm{Eo})}{(\mathrm{VO}+\mathrm{V1}) \mathrm{TCL}}$ 1

Where: $Y$ is number of dissociable proton, $\left(\mathrm{V}_{2^{-}}\right.$ $V_{1}$ ) is the measure of displacement of the ligand curve relative to acid curve, $\mathrm{N}^{\circ}$ and $\mathrm{E}^{\circ}$ are the resultant concentration of alkali solution, free acid solution, $\mathrm{T}_{\mathrm{cL}}{ }^{\circ}$ is the total ligand concentration, $\mathrm{V}^{\circ}$ is the total volume of titration solution, $V_{1}$ is the volume of alkali added to acid solution, $V_{2}$ is the volume of alkali added to acid solution + ligand solution, acid dissociation constants (pKa - values) of ligand were calculated by algebraic method point wise calculation (Tables 1 ). The dissociation constants (pKa) were calculated according to the following relation:

$\mathrm{pKa}=\mathrm{pH}+\log \left(\frac{n A}{1-n A}\right)$ 2

Where: pKa is the acid dissociation constant, $\mathrm{n}_{\mathrm{A}}$ is the Proton-ligand formation number and $\mathrm{pH}$ is the pH-values (Omar and Ali, 2015).

\section{Determination of metal-ligand stability constants $(\log K)$ of complexes}

The potentiometric measurement for the determination of stability constant of a complex in solution is based on the fact that the redox potential of the couple $\frac{M^{+(m-n)}}{M^{+m}}$ is shifted significantly on complexation of the metal ion with the ligand. This method involves change in hydrogen ion concentration $\left[\mathrm{H}^{+}\right]$due to the displacement or association of one or more protons taking place during complexation reaction. This change can be found out by titrating the solutions containing free acid, acid with ligand, and acid with ligand and metal ion, individually against a standard alkali solution at a constant ionic strength or temperature. Either ionic strength or temperature may be varied for different sets of solutions. In all the cases, the change in the $\mathrm{pH}$ of the solution is measured after each addition of a known amount of alkali to the reaction cell which contains the reaction mixture. The titration curves are then drawn by plotting the measured $\mathrm{pH}$ values against the corresponding volume of alkali added and the stability constants of the complexes are determined from the titration curves by employing $\mathrm{pH}$-metric titration technique given by (Irving and Rossoti).

Metal-ligand stability constants ( $\log \mathrm{K}$ ) were determined by using the following relations:

$$
\bar{n}=\frac{\left(V_{3}-V_{2}\right)\left(E^{0}+N^{0}\right)}{\left(V^{0}+V_{2}\right) \bar{n}_{A} T_{m}^{0}}
$$

and

$$
P L=\log _{10}\left\{\frac{1+\beta_{n}^{H} \frac{1}{[\text { anti } \log \mathrm{pH}]^{\mathrm{n}}}}{\mathrm{T}_{\mathrm{L}}^{0}-n \bar{T}_{m}^{0}} \mathrm{X} \frac{\left(V^{0}+V_{3}\right)}{V^{0}}\right\}
$$


BAJOPAS Volume 14 Number 1,June, 2021

Where $T_{L}, T^{\circ}, E^{\circ}$, and $V^{\circ}$ havethe same significance as in equation (1) above, $T_{m}$ denotes the total concentration of metal present in solution, $V_{3}$ is the volume of metal ions present in solution and $\beta^{H}$ is the overall proton ligand stability constant. The metal-ligand stability constants (log K) were determined by employing point wise computational Method (eq. 5 and 6).

$\operatorname{LogK}_{1}=\log \left(\frac{n}{1-n}\right)+\mathrm{pL}$ .5

$\operatorname{LogK}_{2}=\log \left(\frac{1-n}{2-n}\right)+\mathrm{pL}$ ...6

Where: Log $\mathrm{K}$ is the metal-ligand stability constant, $\mathrm{pL}$ is the Free ligand exponent function, $\mathbf{n}$ is the Average number of ligand attached with metal ion (Janraoet al., 2014). The results obtained were analyzed by an ORIGIN 2016 program using titration data and then the proton-ligand stability constants (pKa) and Metal-ligand stability constant (LogK) calculated (Omar and Ali, 2015).

\section{RESULTS AND DISCUSSION}

Fourier transformed infrared (FT-IR) spectra of isolated humic acid from peat soils Figure 2 had distinct clear absorption bands indicating the presence of major humic acid structural elemental groups such as $\mathrm{H}$ bonded $\mathrm{OH}$ $\left(3680 \mathrm{~cm}^{-1}\right.$ peak $), C=0$ of carbonyl $\left(1721 \mathrm{~cm}^{-1}\right.$ peak), functional groups of aliphatic components $\mathrm{CH}_{2}\left(2918 \mathrm{~cm}^{-1}\right.$ peak) and $\mathrm{C}-\mathrm{O}$ stretching of polysaccharide $\left(1168 \mathrm{~cm}^{-1}\right.$ peak). The positions of the absorption bands of the spectra fell within typical major absorption bands of humic acid which is at frequencies 3680, 2918, 1721, 1168 $\mathrm{cm}^{-1}$. The first peak centred in the vicinity of $3680 \mathrm{~cm}^{-1}$ region is attributed to phenol $\mathrm{OH}$ group bounded by intermolecular $\mathrm{H}$ bonds. The $2918 \mathrm{~cm}^{-1}$ band usually has absorption maximum at $2918 \mathrm{~cm}^{-1}$ which is due to $\mathrm{C}-\mathrm{H}$ stretching of alkane group $\left(\mathrm{CH}_{2}\right)$. The next major absorption band is $1721 \mathrm{~cm}^{-1}$. This band has been commonly ascribed to $\mathrm{C}=\mathrm{O}$ stretching of mainly carboxyl group $(\mathrm{COOH})$ with trace amount of ketones. The last peak was observed at 1168 $\mathrm{cm}^{-1}$ due to $\mathrm{C}-\mathrm{O}$ stretching of polysaccharides and this peak appeared also in the spectra of humic acid from peat soil. The FTIR spectra of the isolated humic acid contained all major characteristic absorption peaks of humic acid. These absorption peaks indicated the presence of the major structural elements of humic acid namely $\mathrm{H}$ bonded $\mathrm{OH}, \mathrm{C}=\mathrm{C}$ of aromatic ring, $\mathrm{C}=\mathrm{O}$ of carbonyl group (both carboxyl and ketonic), $\mathrm{CH}_{2}$ group. This strongly supports the presence of humic acid.

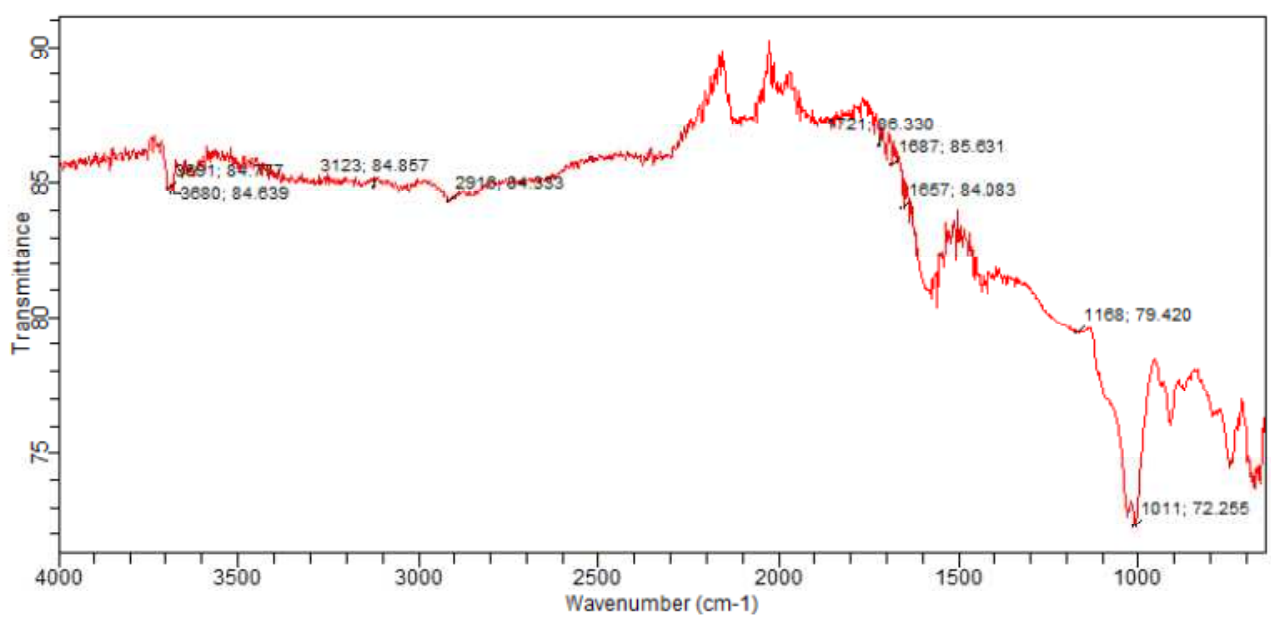

Fig. 2 : FT-IR spectraof peatsoilhumic acid (PSHA)

\section{Evaluation of acid dissociation constant (pka) of acid hydrolysed peat soil humicacid at phenolic group}

The value of the dissociation constant of the peat soil humic acid (PSHA) that underwent acidhydrolysis studied was found to be 8.9299 as shown Table 1, which is lower than the literaturevalues reported by Almeida and Szpoganics, (2015), Borges et al., (2005); Badr et al., (2012)and Fernandes et al,.(2009) of $9.73,9.47$ and 10.30. The difference between the obtained valuesand the reported values in this study might be probably as a result of acid hydrolysis of humicacid. 
BAJOPAS Volume 14 Number 1,June, 2021

Table 1: PKa of (Hydrolysed PSHA)

\begin{tabular}{|l|l|l|l|l|l|l|}
\hline $\mathrm{pH}$ & $\mathrm{BV}_{1}$ & $\mathrm{BV}_{2}$ & $\mathrm{~V}_{2}-\mathrm{V}_{1}$ & $\mathrm{nA}$ & $\log \left(\frac{n A}{1-n A}\right)$ & $\mathrm{pKa}$ \\
\hline 8.50 & 5.30 & 6.29 & 0.99 & 0.3594 & -0.2510 & 8.2490 \\
8.72 & 5.35 & 6.37 & 1.02 & 0.3400 & -0.2880 & 8.4320 \\
9.00 & 5.40 & 6.46 & 1.06 & 0.3141 & -0.3391 & 8.6609 \\
9.22 & 5.45 & 6.55 & 1.10 & 0.2882 & -0.3927 & 8.8273 \\
9.51 & 5.50 & 6.66 & 1.16 & 0.2494 & -0.4786 & 9.0314 \\
9.73 & 5.55 & 6.78 & 1.23 & 0.2041 & -0.5910 & 9.1390 \\
10.00 & 5.60 & 6.90 & 1.30 & 0.1589 & -0.7238 & 9.2762 \\
10.23 & 5.65 & 7.05 & 1.40 & 0.0941 & -0.9835 & 9.2465 \\
10.49 & 5.70 & 7.10 & 1.40 & 0.0941 & -0.9835 & 9.5065 \\
\hline
\end{tabular}

Average pKa $=8.9299 \pm 0.4186$

Table 2: PKa of (Unhydrolysed PSHA)

\begin{tabular}{|l|l|l|l|l|l|l|}
\hline $\mathrm{pH}$ & $\mathrm{BV}_{1}$ & $\mathrm{BV}_{2}$ & $\mathrm{~V}_{2}-\mathrm{V}_{1}$ & $\mathrm{nA}$ & $\log \left(\frac{\boldsymbol{n A}}{1-\boldsymbol{n}}\right)$ & $\mathrm{pKa}$ \\
\hline 8.50 & 5.30 & 5.81 & 0.51 & 0.6619 & 0.2919 & 8.7919 \\
8.72 & 5.35 & 5.90 & 0.55 & 0.6357 & 0.2418 & 8.9618 \\
9.00 & 5.40 & 6.00 & 0.60 & 0.6029 & 0.1813 & 9.1813 \\
9.22 & 5.45 & 6.10 & 0.65 & 0.5701 & 0.1226 & 9.3426 \\
9.51 & 5.50 & 6.20 & 0.70 & 0.5376 & 0.0654 & 9.5754 \\
9.73 & 5.55 & 6.33 & 0.78 & 0.4851 & -0.0259 & 9.7041 \\
10.00 & 5.60 & 6.47 & 0.87 & 0.4262 & -0.1291 & 9.8709 \\
10.23 & 5.65 & 6.62 & 0.99 & 0.3609 & -0.2481 & 9.9819 \\
10.49 & 5.70 & 6.80 & 1.10 & 0.2759 & -0.4690 & 10.0210 \\
\hline
\end{tabular}

Average pKa $=9.4923 \pm 0.4410$

Metal-ligand stability constant ( $\log \mathrm{K}$ )

The stabilityconstants require the accurate values of proton-ligand stability constants (Anil and Maroti, 2008). Metal titration curves crossed over ligand titration curve indicated the formation of complex upon proton release (Santosh, et al., 2011). If the values of n- are within range $0.2-0.8$ and $1.2-18$ this indicates the formation of $1: 1$ and 1:2 complexes (Sayyed and Mazahar, 2012).

The metal (II)-humate stepwise stability constants (log k) at phenolic group (Tables 318)

Table 3: Point-wise method, $\mathrm{Cu}$-(Hydrolysed PSHA)

\begin{tabular}{|l|l|l|l|l|l|l|l|l|}
\hline $\mathrm{pH}$ & $\mathrm{BV}_{1}$ & $\mathrm{BV}_{2}$ & $\mathrm{BV}_{3}$ & $\left(\mathrm{~V}_{3}-\mathrm{V}_{2}\right)$ & $\mathrm{n}$ & $\mathrm{pL}$ & $\log \left(\frac{n}{1-n}\right)$ & LogK $_{1}$ \\
\hline 8.50 & 5.30 & 6.29 & 6.33 & 0.04 & 0.5500 & 2.66 & 0.0871 & 2.7471 \\
8.72 & 5.35 & 6.37 & 6.41 & 0.04 & 0.5714 & 2.43 & 0.1249 & 2.5549 \\
9.00 & 5.40 & 6.46 & 6.50 & 0.04 & 0.6198 & 2.16 & 0.2122 & 2.3722 \\
9.22 & 5.45 & 6.55 & 6.59 & 0.04 & 0.6667 & 1.94 & 0.3010 & 2.2410 \\
\hline
\end{tabular}

LogK $_{1}$ (Average value) $=2.4788 \pm 0.2203$

Table 4: Point-wise method, $\mathrm{Cu}$-(Hydrolysed PSHA)

\begin{tabular}{|l|l|l|l|l|l|l|l|l|}
\hline $\mathrm{pH}$ & $\mathrm{BV}_{1}$ & $\mathrm{BV}_{2}$ & $\mathrm{BV}_{3}$ & $\left(\mathrm{~V}_{3}-\mathrm{V}_{2}\right)$ & $\mathrm{n}$ & $\mathrm{pL}$ & $\log \left(\frac{n-1}{2-n}\right)$ & LogK $_{2}$ \\
\hline 9.51 & 5.50 & 6.66 & 6.73 & 0.07 & 1.3509 & 1.70 & -0.2671 & 1.4329 \\
9.73 & 5.55 & 6.78 & 6.85 & 0.07 & 1.6383 & 1.51 & 0.2467 & 1.7567 \\
10.00 & 5.60 & 6.90 & 6.98 & 0.08 & 2.1783 & 1.31 & -0.2158 & 1.0942 \\
10.23 & 5.65 & 7.05 & 7.13 & 0.08 & 4.1904 & 1.27 & & \\
10.49 & 5.70 & 7.10 & 7.19 & 0.09 & 4.6920 & & & \\
\hline
\end{tabular}

Log $K_{2}($ Average value $)=1.4280 \pm 0.3312$ 
BAJOPAS Volume 14 Number 1,June, 2021

Table 5: Point-wise method, $\mathrm{Cu}$ (Unhydrolysed PSHA)

\begin{tabular}{|l|l|l|l|l|l|l|l|l|}
\hline $\mathrm{pH}$ & $\mathrm{BV}_{1}$ & $\mathrm{BV}_{2}$ & $\mathrm{BV}_{3}$ & $\left(\mathrm{~V}_{3}-\mathrm{V}_{2}\right)$ & $\mathrm{n}$ & $\mathrm{pL}$ & $\log \left(\frac{n}{n-1}\right)$ & Log $_{1}$ \\
\hline 8.50 & 5.30 & 5.81 & 5.85 & 0.04 & 0.2973 & 2.88 & -0.3736 & 2.5064 \\
8.72 & 5.35 & 5.90 & 5.95 & 0.05 & 0.3873 & 2.66 & -0.1992 & 2.4608 \\
9.00 & 5.40 & 6.00 & 6.05 & 0.05 & 0.4044 & 2.38 & -0.1681 & 2.2119 \\
9.22 & 5.45 & 6.10 & 6.15 & 0.06 & 0.5157 & 2.18 & -0.0272 & 2.2072 \\
9.51 & 5.50 & 6.20 & 6.27 & 0.07 & 0.6417 & 1.89 & 0.2530 & 1.1430 \\
\hline
\end{tabular}

$\operatorname{LogK}_{1}($ Average value $)=2.3059 \pm 0.6153$

Table 6:Point-wise method, $\mathrm{Cu}$ (Unhydrolysed PSHA)

\begin{tabular}{|l|l|l|l|l|l|l|l|l|}
\hline $\mathrm{pH}$ & $\mathrm{BV}_{1}$ & $\mathrm{BV}_{2}$ & $\mathrm{BV}_{3}$ & $\mathrm{~V}_{3}-\mathrm{V}_{2}$ & $\mathrm{n}$ & $\mathrm{pL}$ & $\log \left(\frac{n-1}{2-n}\right)$ & $\log \mathrm{K}_{2}$ \\
\hline 9.73 & 5.55 & 6.33 & 6.42 & 0.09 & 0.9000 & 1.69 & & \\
10.00 & 5.60 & 6.47 & 6.58 & 0.11 & 1.2578 & 1.44 & -0.4592 & 0.9808 \\
10.23 & 5.65 & 6.62 & 6.84 & 0.12 & 1.6137 & 1.26 & -0.2010 & 1.4610 \\
10.49 & 5.70 & 6.80 & 6.92 & 0.12 & 2.1052 & 1.03 & & \\
\hline
\end{tabular}

$\operatorname{LogK}_{2}$ (Average value) $=1.2209 \pm 0.3398$

Table 7:Point-wise method, Pb (Hydrolysed PSHA)

\begin{tabular}{|l|l|l|l|l|l|l|l|l|}
\hline $\mathrm{pH}$ & $\mathrm{BV}_{1}$ & $\mathrm{BV}_{2}$ & $\mathrm{BV}_{3}$ & $\left(\mathrm{~V}_{3}-\mathrm{V}_{2}\right)$ & $\mathrm{n}$ & $\mathrm{pL}$ & $\log \left(\frac{n}{1-n}\right)$ & LogK $_{1}$ \\
\hline 8.50 & 5.30 & 6.29 & 6.33 & 0.04 & 0.5500 & 2.66 & 0.0871 & 2.7471 \\
8.72 & 5.35 & 6.37 & 6.41 & 0.04 & 0.5714 & 2.43 & 0.1249 & 2.5549 \\
9.00 & 5.40 & 6.46 & 6.50 & 0.04 & 0.6198 & 2.16 & 0.2122 & 2.3722 \\
9.22 & 5.45 & 6.55 & 6.60 & 0.05 & 0.8333 & 1.96 & 0.6989 & 2.6589 \\
\hline
\end{tabular}

Log $_{\mathbf{1}}($ Average value $)=2.5832 \pm 0.1614$

Table 8:Point-wise method, Pb-(Hydrolysed PSHA)

\begin{tabular}{|l|l|l|l|l|l|l|l|l|}
\hline $\mathrm{pH}$ & $\mathrm{BV}_{1}$ & $\mathrm{BV}_{2}$ & $\mathrm{BV}_{3}$ & $\left(\mathrm{~V}_{3}-\mathrm{V}_{2}\right)$ & $\mathrm{n}$ & $\mathrm{pL}$ & $\log \left(\frac{n-1}{2-n}\right)$ & $\log \mathrm{K}_{2}$ \\
\hline 9.51 & 5.50 & 6.66 & 6.71 & 0.05 & 0.9650 & 1.67 & & \\
9.73 & 5.55 & 6.78 & 6.83 & 0.05 & 1.1702 & 1.44 & & \\
10.00 & 5.60 & 6.90 & 6.90 & 0.05 & 1.4864 & 1.22 & -0.0237 & 1.1963 \\
10.23 & 5.65 & 7.05 & 7.10 & 0.05 & 2.0190 & 1.09 & & \\
10.49 & 5.70 & 7.10 & 7.17 & 0.07 & 3.6492 & 1.00 & & \\
\hline
\end{tabular}

Log $K_{2}$ (Average value) $=1.1963$

Table 9: Point-wise method, Pb (Unhydrolysed PSHA)

\begin{tabular}{|l|l|l|l|l|l|l|l|l|}
\hline $\mathrm{pH}$ & $\mathrm{BV}_{1}$ & $\mathrm{BV}_{2}$ & $\mathrm{BV}_{3}$ & $\mathrm{~V}_{3}-\mathrm{V}_{2}$ & $\mathrm{n}$ & $\mathrm{pL}$ & $\begin{array}{l}\text { Log } \\
\left(\frac{n}{n-1}\right)\end{array}$ & Log $\mathrm{K}_{1}$ \\
\hline 8.50 & 5.30 & 5.81 & 5.85 & 0.04 & 0.2973 & 2.88 & -0.3736 & 2.5064 \\
8.72 & 5.35 & 5.90 & 5.94 & 0.04 & 0.3099 & 2.66 & -0.5477 & 2.3123 \\
9.00 & 5.40 & 6.00 & 6.05 & 0.05 & 0.4044 & 2.38 & -0.1681 & 2.2119 \\
9.22 & 5.45 & 6.10 & 6.15 & 0.06 & 0.5157 & 2.18 & 0.0272 & 2.2072 \\
9.51 & 5.50 & 6.20 & 6.26 & 0.07 & 0.6417 & 1.89 & 0.2530 & 2.1430 \\
9.73 & 5.55 & 6.40 & 6.40 & 0.07 & 0.7000 & 1.67 & 0.3680 & 2.0380 \\
\hline
\end{tabular}

LogK $_{1}$ (Average value) $=2.2364 \pm 0.1602$

Table 10: Point-wise method, Pb (Unhydrolysed PSHA)

\begin{tabular}{|l|l|l|l|l|l|l|l|l|}
\hline $\mathrm{pH}$ & $\mathrm{BV}_{1}$ & $\mathrm{BV}_{2}$ & $\mathrm{BV}_{3}$ & $\mathrm{~V}_{3}-\mathrm{V}_{2}$ & $\mathrm{n}$ & $\mathrm{pL}$ & $\log \left(\frac{n-1}{2-n}\right)$ & $\log \mathrm{K}_{2}$ \\
\hline 10.00 & 5.60 & 6.47 & 6.55 & 0.08 & 1.9503 & 1.41 & & \\
10.23 & 5.65 & 6.62 & 6.72 & 0.11 & 1.4792 & 1.26 & -0.0361 & 1.2239 \\
\hline
\end{tabular}

$\operatorname{LogK}_{2}$ (Average value) $=1.2239$

Table 11: Point-wise method, Mg (Hydrolysed PSHA)

\begin{tabular}{|l|l|l|l|l|l|l|l|l|}
\hline $\mathrm{pH}$ & $\mathrm{BV}_{1}$ & $\mathrm{BV}_{2}$ & $\mathrm{BV}_{3}$ & $\left(\mathrm{~V}_{3}-\mathrm{V}_{2}\right)$ & $\mathrm{n}$ & $\mathrm{pL}$ & $\log \left(\frac{n}{n-1}\right)$ & LogK $_{1}$ \\
\hline 8.50 & 5.30 & 6.29 & 6.31 & 0.02 & 0.2750 & 2.64 & -0.4290 & 2.2110 \\
8.72 & 5.35 & 6.37 & 6.39 & 0.02 & 0.2858 & 2.42 & -0.3978 & 2.0222 \\
9.00 & 5.40 & 6.46 & 6.49 & 0.03 & 0.4648 & 2.14 & -0.0612 & 2.0788 \\
9.22 & 5.45 & 6.55 & 6.59 & 0.04 & 0.6667 & 1.94 & 0.3010 & 2.2410 \\
\hline
\end{tabular}

$\log _{\mathbf{1}}($ Average value) $=2.1382 \pm 0.1046$ 
BAJOPAS Volume 14 Number 1,June, 2021

Table 12: Point-wise method, Mg (Hydrolysed PSHA)

\begin{tabular}{|l|l|l|l|l|l|l|l|l|}
\hline $\mathrm{pH}$ & $\mathrm{BV}_{1}$ & $\mathrm{BV}_{2}$ & $\mathrm{BV}_{3}$ & $\left(\mathrm{~V}_{3}-\mathrm{V}_{2}\right)$ & $\mathrm{n}$ & $\mathrm{pL}$ & $\log \left(\frac{n-1}{2-n}\right)$ & LogK $_{2}$ \\
\hline 9.51 & 5.55 & 6.66 & 6.71 & 0.05 & 0.9650 & 1.67 & & \\
9.73 & 5.55 & 6.78 & 6.84 & 0.06 & 1.4042 & 1.47 & -0.1686 & 1.3014 \\
10.00 & 5.60 & 6.90 & 6.93 & 0.06 & 1.7838 & 1.23 & 0.5593 & 1.7893 \\
10.23 & 5.65 & 7.05 & 7.10 & 0.06 & 3.1429 & 1.10 & & \\
10.49 & 5.70 & 7.10 & 7.18 & 0.07 & 3.6492 & 0.83 & & \\
\hline
\end{tabular}

LogK $_{2}($ Average value $)=1.5453 \pm 0.3450$

Table 13: Point-wise method, Mg (Unhydrolysed PSHA)

\begin{tabular}{|l|l|l|l|l|l|l|l|l|}
\hline $\mathrm{pH}$ & $\mathrm{BV}_{1}$ & $\mathrm{BV}_{2}$ & $\mathrm{BV}_{3}$ & $\mathrm{~V}_{3}-\mathrm{V}_{2}$ & $\mathrm{n}$ & $\mathrm{pL}$ & $\log \left(\frac{n}{n-1}\right)$ & $\operatorname{Log~}_{1}$ \\
\hline 8.50 & 5.30 & 5.81 & 5.85 & 0.04 & 0.2973 & 2.88 & -0.3736 & 2.5064 \\
8.72 & 5.35 & 5.90 & 5.94 & 0.04 & 0.3099 & 2.66 & -0.3477 & 2.3123 \\
9.00 & 5.40 & 6.00 & 6.04 & 0.04 & 0.3236 & 2.38 & -0.3202 & 2.0598 \\
9.22 & 5.45 & 6.10 & 6.15 & 0.05 & 0.4297 & 2.17 & -0.1230 & 2.0470 \\
9.51 & 5.50 & 6.20 & 6.26 & 0.06 & 0.5500 & 1.89 & 0.0871 & 1.9771 \\
9.73 & 5.55 & 6.33 & 6.40 & 0.07 & 0.7000 & 1.67 & 0.3680 & 2.0380 \\
\hline
\end{tabular}

LogK $_{1}$ (Average value) $=2.1568 \pm 0.2069$

Table 14: Point-wise method, Mg (Unhydrolysed PSHA)

\begin{tabular}{|l|l|l|l|l|l|l|l|l|}
\hline $\mathrm{pH}$ & $\mathrm{BV}_{1}$ & $\mathrm{BV}_{2}$ & $\mathrm{BV}_{3}$ & $\mathrm{~V}_{3}-\mathrm{V}_{2}$ & $\mathrm{n}$ & $\mathrm{pL}$ & $\log \left(\frac{n-1}{2-n}\right)$ & $\log \mathrm{K}_{2}$ \\
\hline 10.00 & 5.60 & 6.47 & 6.55 & 0.08 & 0.9148 & 1.41 & & \\
10.23 & 5.65 & 6.62 & 6.71 & 0.09 & 1.2102 & 1.20 & -0.5749 & 0.6251 \\
10.49 & 5.70 & 6.80 & 6.92 & 0.09 & 1.5968 & 1.03 & 0.1703 & 1.2003 \\
\hline
\end{tabular}

LogK $_{2}$ (Average value) $=0.9127 \pm 0.4070$

Table15:Point-wise method, Cd (Hydrolysed PSHA)

\begin{tabular}{|l|l|l|l|l|l|l|l|l|}
\hline $\mathrm{pH}$ & $\mathrm{BV}_{1}$ & $\mathrm{BV}_{2}$ & $\mathrm{BV}_{3}$ & $\left(\mathrm{~V}_{3}-\mathrm{V}_{2}\right)$ & $\mathrm{n}$ & $\mathrm{pL}$ & $\log \left(\frac{n}{1-n}\right)$ & LogK $_{1}$ \\
\hline 8.50 & 5.30 & 6.29 & 6.31 & 0.02 & 0.2750 & 2.64 & -0.4210 & 2.2190 \\
8.72 & 5.35 & 6.37 & 6.40 & 0.03 & 0.4286 & 2.42 & -0.1249 & 2.2951 \\
9.00 & 5.40 & 6.46 & 6.49 & 0.03 & 0.4648 & 2.14 & -0.0612 & 2.0788 \\
9.22 & 5.45 & 6.55 & 6.59 & 0.04 & 0.6667 & 1.96 & 0.3010 & 2.2610 \\
9.51 & 5.55 & 6.66 & 6.70 & 0.04 & 0.7720 & 1.67 & 0.5297 & 2.1997 \\
\hline
\end{tabular}

LogK $_{\mathbf{1}}$ (Average value) $=2.2108 \pm 0.0825$

Table 16: Point-wise method, Cd (Hydrolysed PSHA)

\begin{tabular}{|l|l|l|l|l|l|l|l|l|}
\hline $\mathrm{pH}$ & $\mathrm{BV}_{1}$ & $\mathrm{BV}_{2}$ & $\mathrm{BV}_{3}$ & $\left(\mathrm{~V}_{3}-\mathrm{V}_{2}\right)$ & $\mathrm{n}$ & $\mathrm{pL}$ & $\log \left(\frac{n-1}{2-n}\right)$ & Log $_{2}$ \\
\hline 9.73 & 5.55 & 6.78 & 6.83 & 0.06 & 1.4042 & 1.47 & -0.1686 & 1.3014 \\
10.00 & 5.60 & 6.90 & 6.95 & 0.06 & 1.7838 & 1.23 & 0.5593 & 1.7893 \\
10.23 & 5.65 & 7.05 & 7.10 & 0.06 & 3.1429 & 1.09 & & \\
10.49 & 5.70 & 7.10 & 7.16 & 0.06 & 3.1429 & 0.89 & & \\
& & & & & & & & \\
\hline
\end{tabular}

$\operatorname{LogK}_{2}$ (Average value) $=1.5453 \pm 0.3450$

Table 17: Point-wise method, Cd (Unhydrolysed PSHA)

\begin{tabular}{|l|l|l|l|l|l|l|l|l|}
\hline $\mathrm{pH}$ & $\mathrm{BV}_{1}$ & $\mathrm{BV}_{2}$ & $\mathrm{BV}_{3}$ & $\mathrm{~V}_{3}-\mathrm{V}_{2}$ & $\mathrm{n}$ & $\mathrm{pL}$ & $\log \left(\frac{n}{n-1}\right)$ & $\operatorname{Log~}_{1}$ \\
\hline 8.50 & 5.30 & 5.81 & 5.86 & 0.05 & 0.3717 & 2.88 & -0.2280 & 2.6520 \\
8.72 & 5.35 & 5.90 & 5.95 & 0.05 & 0.3873 & 2.66 & -0.1992 & 2.4608 \\
9.00 & 5.40 & 6.00 & 6.06 & 0.06 & 0.4853 & 2.38 & -0.0255 & 2.3545 \\
9.22 & 5.45 & 6.10 & 6.16 & 0.06 & 0.5157 & 2.18 & -0.0272 & 2.2072 \\
9.51 & 5.50 & 6.20 & 6.27 & 0.07 & 0.6417 & 1.89 & 0.2530 & 1.1430 \\
9.73 & 5.55 & 6.33 & 6.41 & 0.08 & 0.8000 & 1.69 & 0.6020 & 2.2920 \\
& & & & & & & & \\
\hline
\end{tabular}

$\operatorname{LogK}_{1}($ Average value $)=2.2516 \pm 0.5380$ 
BAJOPAS Volume 14 Number 1,June, 2021

Table 18: Point-wise method, Cd (Unhydrolysed PSHA)

\begin{tabular}{|l|l|l|l|l|l|l|l|l|}
\hline $\mathrm{pH}$ & $\mathrm{BV}_{1}$ & $\mathrm{BV}_{2}$ & $\mathrm{BV}_{3}$ & $\mathrm{~V}_{3}-\mathrm{V}_{2}$ & $\mathrm{n}$ & $\mathrm{pL}$ & $\log \left(\frac{n-1}{2-n}\right)$ & $\log \mathrm{K}_{2}$ \\
\hline 10.00 & 5.60 & 6.47 & 6.57 & 0.10 & 1.1434 & 1.43 & & \\
10.23 & 5.65 & 6.62 & 6.72 & 0.10 & 1.3448 & 1.23 & -0.2788 & 0.9512 \\
10.49 & 5.70 & 6.80 & 6.90 & 0.10 & 1.7742 & 1.03 & 0.5351 & 1.5651 \\
\hline
\end{tabular}

$\operatorname{LogK}_{2}($ Average value $)=1.2581 \pm 0.4340$

Table 19: Stepwise and overall Stability constants of thehydrolysed and unhydrolysed divalent metal (II) complexes

\begin{tabular}{|c|c|c|c|}
\hline Chelates & LogK $_{1}$ & $\log _{2}$ & Log $\beta$ \\
\hline [Cu (Hydrolysed PSHA-1) $\left.{ }_{2}\right]$ & 2.4788 & 1.4280 & 3.9068 \\
\hline$\left[\mathrm{Pb}(\text { Hydrolysed PSHA-1) })_{2}\right]$ & 2.5832 & 1.1963 & 3.7795 \\
\hline$\left[\mathrm{Cd}(\text { Hydrolysed PSHA-1 })_{2}\right]$ & 2.2108 & 1.5453 & 3.7561 \\
\hline$\left[\mathrm{Mg}(\text { Hydrolysed PSHA-1 })_{2}\right]$ & 2.1382 & 1.5453 & 3.6835 \\
\hline [Cu (Unhydrolysed PSHA-1) & 2.3059 & 1.2209 & 3.5268 \\
\hline$[\mathrm{Pb}$ (Unhydrolysed PSHA-1) 2$]$ & 2.2364 & 1.2239 & 3.4603 \\
\hline [Cd (Unhydrolysed PSHA-1) 2 ] & 2.2516 & 1.2581 & 3.5097 \\
\hline$[\mathrm{Mg}$ (Unydrolysed PSHA-1) & 2.1568 & 0.9127 & 3.0695 \\
\hline
\end{tabular}

The results obtained (Table19) shows the stepwise and overall stability constants to be not high indicating low stability of the complexes, because the solubility of most metal ions in the basic $\mathrm{pH}$ range is minimal due to metal hydroxide precipitation (Karimi, 2017). In general, the stepwise stability constants $\left(K_{1}\right.$ and $K_{2}$ ) follow the order $K_{1}>K_{2}$ for the copper, lead, magnesium and cadmium complexes respectively. The steady decrease of the values with increasing number of ligands is in agreement with the prediction made by researchers (Na'aliya, 2013). The decrease could be attributed to the fact that as the number of the ligands (Humate ions) that enters the coordination zone increases the aqua molecules available for replacement by the ligands become less. Thus, the metal ions become less electron loving with progressive intake of the ligand and this results in the decrease in the values of the constants (Na'aliya, 2013). Also the stability of the complexes is influenced by the size and number of the chelate rings(Mackay and Mackay,2002).All the complexes form rings in their structure as humate, a bidentate ligand, bond the metal ions in the ratio 1:2 (Boguta and Sokolowska, 2016) forming chelate rings. The values of the overall stability constants $(\log \beta)$ obtained for humate complexes are not high indicating low stability as the values are not high. LogK values for copper-humates (Table 3 to 6) obtained in this study are lower than those reported for the complexes of humic acids (Pandey et al., 2015; Dinu, 2013; Kaschl et al., 2010 and Gilbeto and Jorg, 2001). The values of LogK(Table 7 to 10 ) forlead-humates are lower than those reported for the lead in the literature (Dinu, 2013; Gilbeto and Jorg 2001). Log K values(Table 11 to 14 ) for magnesium-humates obtained in this study are close to those reported by (Pandey et al., 2015). Log K values of cadmium-humates (Table 15 to 18 ) obtained in this work near to the one reported by (Dinu, 2013 and Pandey et al., 2015).The difference between the reported values and the values obtained in this study might be probably as a result of acid hydrolysis of humic acid. The values of the overall stability constants $(\log \beta)$ of the copper humates complexes presented in Table 19 is high than that of other metal humate complexes, show relatively high stability of CuHA complexes, show the following order of stability: $\mathrm{Cu}>\mathrm{Pb}>\mathrm{Cd}>\mathrm{Mg}$; which are in close agreement to the findings of (Dinu, 2013 and Pandey et al., 2015).The high stability of Cuhumate chelate could be attributed to the existence of coordinate covalent bond between the complexing agents and the $\mathrm{Cu}^{2+}$ ions. Since, $\mathrm{Cu}^{2+}$ being a metal of the transitional series with $3 d^{9}$ electronic configurations can accept the electrons from the complexing agents. Similarly, the low stabilities of $\mathrm{Pb}, \mathrm{Cd}$ and $\mathrm{Mg}$ complexes could be explained by that $\mathrm{Pb}^{2+}$ with $6 s^{2}, \mathrm{Cd}^{2+}$ with $4 \mathrm{~d}^{10}$ and $\mathrm{Mg}^{2+}$ with $2 \mathrm{p}^{6}$ their electronic configuration has a completely filled $\mathrm{d}, \mathrm{p}$ and $\mathrm{s}$ orbitals. Moreover, the stabilities of metal ions with hydrolysed humic acid from peat soil were higher than those with unhydrolysed humic acid from peat soil; which is ascribed to the high content of acidity in hydrolysed humic acid than unhydrolysed humic acid. 
BAJOPAS Volume 14 Number 1,June, 2021 CONCLUSION

The values of logk for $\mathrm{Cu}(\mathrm{II})$ hydrolysed humic acid complex was higher followed by $\mathrm{Pb}$ (II), $\mathrm{Cd}(\mathrm{II})$ and $\mathrm{Mg}$ (II) hydrolysed humic acid complexes as compared with metal(II) unhydrolysed humic acid complexes. This indicates acid hydrolysis of humic acid can

\section{REFERENCES}

Almeida, V.R. and Szpoganicz, B. (2015). Humic Acid Potentiometric Response Patterns:Out- of Equilibrium Properties and Species Distribution Modelling. Chemical. Biol. Technol. Agric. 2: 17.

Anđelković, T., Nikolić, R., Bojić, A.,Anđelković, D., and Nikolic G.,(2010). Binding of Cadmium to Soil Humic Acid as A Function of Carboxyl Group Content. Macedonian Journal of Chemistry and Chemical Engineering.29(2): 215-224.

Anil, B. N. and Maroti, N. (2008). Studies on Influence of Die-Lectric Constants on Complex Equilibria between Substituted Py-Razalines and Lanthanide Metal Ions pH-Metrically. Amer.-Euras. scient. Res. 3(2): 212-216.

Ashok, K., Pandey, S. P. and Misra, V (2000). Stability Constants of Metal-Humic Acid Complexes and its Role in Environmental Detoxification. Journal of Ecotoxicology and Environmental Safety. 47(2):157-200.

Badr, M. H., El-Halafawi, M. H. and Abd El-al Zeid, E. R. (2012). Comparison Between the Effect of Ionic Strength on Acidity and Dissociation Constants of Humic Acids Extracted from Sewage Sludge and Nile Water Hyacinth Composts.Global Journal of Environmental Research 6 (1): 36-43.

Baruah, M.K., Borah, D., Saikia, P.P., Paul, S., Sharma, T. (2015). Evaluation of pKa Values of Soil Humic Acids and their Complexation Properties. International Journal of Plant \& Soil Science 6(4) : 218-228.

Boguta, P. Sokolowska, Z. (2016). Interactions of $\mathrm{Zn}$ (II) Ions with Humic Acids Isolated from Various Types of Soils. Effect of $\mathrm{pH}, \mathrm{Zn}$ Concentrations and Humic Acids Chemical Properties. Journal of Geochemical Explaration 168. 119-126.

Borges, F., Guimaraes, C., Lima, L.F.C., Pinto, I. and Reis, S.(2005). Potentiometric Studies on the Complexation of Copper(II) by Phenolic Acids as Discrete Ligand Models of enhance the complexation behavior of humic acid with metal (II) ions. However, the higher values of $\log \beta$ for $\mathrm{Cu}(\mathrm{II}), \mathrm{Pb}(\mathrm{II}), \mathrm{Cd}(\mathrm{II})$ and $\mathrm{Mg}(\mathrm{II})$ hydrolysed humic acid complexes indicates more stable stepwise complexes formed as compared with $\mathrm{Cu}(\mathrm{II}), \mathrm{Pb}$ (II), $\mathrm{Cd}$ (II) and $\mathrm{Mg}(\mathrm{II})$ unhydrolysed humic acid complexes.

Humic Substances Talanta 66 (2005) 670-673.

Chefetz, B., Salloum, M. J., Deshmulkin, A. P. and Hatcher, P. (2002). Structural Components of Humic Acids as Determined by Chemical Modifications and Carbon-13 NMR, Pyrolysis, and Thermochemolysis- Gas Chromatography/Mass Spectrometry. Soil Science Society of American Journal Abstract Division S-2- Soil Chemistry66. 1159-1171.

Dinu, M. I. (2013). Metals Complexation with Humic Acids in Surface Water of Different Environ. Sci. Technol. 31(1): 1-17.

Fernandes, A.N., Giacomelli, C., Giovanela, M. Vaz, D.V. Szpoganicz, B. and Maria M. D. (2009). Potentiometric Acidity Determination in Humic Substances Influenced by Different Analytical Procedures.J. Braz. Chem. Soc. 20 (9):14.

Gamal, A. H. (2015). Stability Constants of Rhenium (V) Metal Complexes with Selected Drugs. Pyrex Journal of Research in Environmental Studies. 2(2): 006-014.

Janrao, D. M., Pathan, J., Kayande, D.D., and Mulla, J.J. (2014). An Over View of Potentiometric Determination of Stability Constants of Metal Complexes. Sci. Revs. Chem. Commun.: 4(1), 2014, 11-24.

Karimi, H. (2017). Effect of pH and Initial Pb(II) Concentration on the Lead Removal Efficiency from Waste Water Using $\mathrm{Ca}(\mathrm{OH})_{2}$. International Journal of Water and Waste Water Treatment 3.2

Kaschl, A. Romheld, V. and Chen, Y. (2010). Binding of Cadmium, Copper and Zinc to Humic Substances Originating from Municipal Solid Waste Compost. Israel Journal of Chemistry Vol. 42(1): 89-98.

Kostic, I. S., Tatjana, P, A., Nikolic, R. S., Cvetkovic, T. P., Pavlovic, D. D., Aleksandar, L.J. and Bojic, A. (2012). Comparative Study of Binding Strengths of Heavy Metals with Humic Acid. J.serb. Chem. Soc. 76(9) pp 1-20. 
BAJOPAS Volume 14 Number 1,June, 2021

Na'aliya, J. (2013). Determination of Stepwise Stability Constants and Gibbs free Energy Change of Trisprolina to Complexes of some Divalent Transition Metal ions. Bayero Journal of Pure and Applied Sciences 6(2): 112-114.

Omar, A. A. and Ali, E. A. (2015). Potentiometric Studies on Complexes of $\mathrm{Cr}$ (III) and $\mathrm{Zr}$ (IV) with some Carboxylic Acids. International Journal of Advanced Chemistry, 3(1) 25-

37.

Pandey, A. K. Pandey, S. D. and Misr, V. (2015).Stability Constants of Metal- Humic Acid Complexes and Its Role in Environmental Detoxification. J. Ecotoxicology and Environmental Safety. 47(1):195-200.

Ram, N. and Raman, K.V. (1984). Stability Constants of Complexes of Metals with
Humicand Fuvic Acids under Non- acidConditions. Journal of Plant Nutrition and Soil Sciences.

147:171-176.

Santosh, D. D., Ashok, B. K., Vijay, J. T., Shivraj, G. W. and Vinay, V. W. (2011). Potentiometric Studies of Elec-Trolyte Effects on Complex Equilibria of Some Substituted 5-(2-hydroxy Phenyl) Pyrazoles. Der pharm. 3 (6): 75-83.

Sayyed, H. and Abdul Rahim, M. F. (2012). Studies of Binary Complexes of Metal Ions with Mandelic Acid by Potentiometry. Chem. J. 02 (6): 206209.

Shirvani, M. Moradian, E. Khalili, B. Bakhtiary, S. (2015). Interaction of $\mathrm{Cd}$ and $\mathrm{Pb}$ with Humate-Palygorskite and HumateSepiolite Complexes. Journal of water, air and pollution 3: 220-228. 


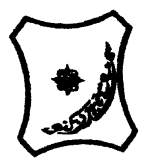

Bayero Journal of Pure and Applied Sciences, 14(1): 54 - 63

Received: November, 2020

Accepted: April, 2021

ISSN $2006-6996$

\title{
STABILITY CONSTANTS OF COMPLEXES OF METAL IONS WITH PEATSOIL HUMIC ACIDS UNDER NON-ACID-CONDITIONS
}

\author{
${ }^{* 1}$ Sabo, Yusuf ${ }^{2}$ Jimoh, W.L.O., ${ }^{3}$ Isa Baba Koki and ${ }^{4}$ Sholadoye, Q. 0. \\ ${ }^{1}$ Department of Pure and Industrial Chemistry, Bayero University, Kano \\ ${ }^{3}$ Department of Chemistry, Yusuf Maitama Sule University Kano. P.M.B. 3220 Kano, Nigeria. \\ ${ }^{4}$ Department of Chemistry, Nigerian Police Academy, Wudil, Kano-Nigeria
}

*Correspondence E-mail; saboyusuf18@yahoo.com

ABSTRACT

Stability constants of complexes of four divalent metal ions viz. $\mathrm{Cu}^{2+}, \mathrm{Pb}^{2+}, \mathrm{Mg}^{2+}$ and $\mathrm{Cd}^{2+}$ with humic acids (HA) were determined by potentiometric titration of humic acids with the corresponding salt of the divalent metals in aqueous media under non-acid-condition. The log $K$ (logarithm of the stability constant) ranged from 1.0942 to 2.7471 for metalhumic acid complexes were determined using point-wise computational method. The order of stability constants were obtained as follows: $\mathrm{Cu}>\mathrm{Pb}>\mathrm{Cd}>\mathrm{Mg}$ for metal $-\mathrm{HA}$ complexes respectively, indicating a higher degree of complexation with Cu metal ion.

Keywords: stability constant, humic acid, potentiometric titration, divalent metals, acid hydrolysis.

\section{NTRODUCTION}

The stability constant of a complex is the numerical expression of its stability and provides a quantitative measure of affinity of the metal ion to the complexing agent. An understanding of the relative stability of metal-complexes helps in predicting the behavior of metal ions in the soil (Ram and Raman, 1982). Extensive researches has been done to determine the stability constants of the complexes formed between humic acid (HA) with a number of metal ions. Ashok et al., (2000) reported that humic acid with hydroxyl, phenoxyl and carboxyl reactive groups can form coordination compound with metal ions at $\mathrm{pH}$ 3.5. The stability constants(Log K) for different metalhumic acid complexes indicated the following order of the stabilities of complexes formed between humic acid and metal ion, $\mathrm{Cu}>\mathrm{Fe}$ $>\mathrm{Pb}>\mathrm{Ni}>\mathrm{Co}>\mathrm{Ca}>\mathrm{Cd}>\mathrm{Zn}>\mathrm{Mn}>\mathrm{Mg}$. Andelkovic et al., (2010) investigated the binding of $\mathrm{Cd}$ (II) to soil humic acid at pH 6.5 and in $0.1 \mathrm{M} \mathrm{KNO}_{3}$ ionic medium. The stability constant for binding indicating greater stability in the case when carboxyl groups are involved in complexation reaction. Kostic et al.,(2012) investigated the complexation of humic acid with certain heavy metal ions (Co(II), $\mathrm{Ni}(\mathrm{II}), \mathrm{Cu}(\mathrm{II})$,
$\mathrm{Zn}(\mathrm{II})$, and $\mathrm{Pb}(\mathrm{II})$. The experiment was performed at $25^{\circ} \mathrm{C}$, at pH 4.0 and ionic strength of $0.01 \mathrm{M}$. Stability constant of complex between $\mathrm{Pb}$ (II) ions and humic acid is greater than stability constants of other investigated metalhumate complexes. Bogata and Sokolowska (2016) analyses the interaction between humic acids from different soils and $\mathrm{Zn}$ (II) ions at wide concentration ranges and at $\mathrm{pH} 5$. Studies have showed significant impact of $\mathrm{Zn}$ concentration, $\mathrm{pH}$ and some properties of humic acids with zinc.But all of these studies were limited to acidic $\mathrm{pH}$ range. Therefore, the present study was carried out to determine and compare the stability constants of complexes of metal ions with hydrolysed peat soil humic acid and unhydrolysed peat soil humic under non-acid conditions.

\section{MATERIALS AND METHODS}

Analytical grade chemicals used includes hydrochloric acid $(\mathrm{HCl})$, nitric acid $\left(\mathrm{HNO}_{3}\right)$, sodium hydroxide $(\mathrm{NaOH})$, lead nitrate $\mathrm{Pb}\left(\mathrm{NO}_{3}\right)_{2}$, copper nitrate $\mathrm{Cu}\left(\mathrm{NO}_{3}\right)_{2} \cdot 3 \mathrm{H}_{2} \mathrm{O}$, cadmium nitrate $\mathrm{Cd}\left(\mathrm{NO}_{3}\right)_{2} \cdot 4 \mathrm{H}_{2} \mathrm{O}$, magnesium nitrate $\mathrm{Mg}\left(\mathrm{NO}_{3}\right)_{2} \cdot 6 \mathrm{H}_{2} \mathrm{O}$, potassium nitrate $\left(\mathrm{KNO}_{3}\right)$, calcium chloride $\left(\mathrm{CaCl}_{2}\right)$, (sigma-Aldrich). Dowex 50WX8, (20-50 mesh) from Fluka. 


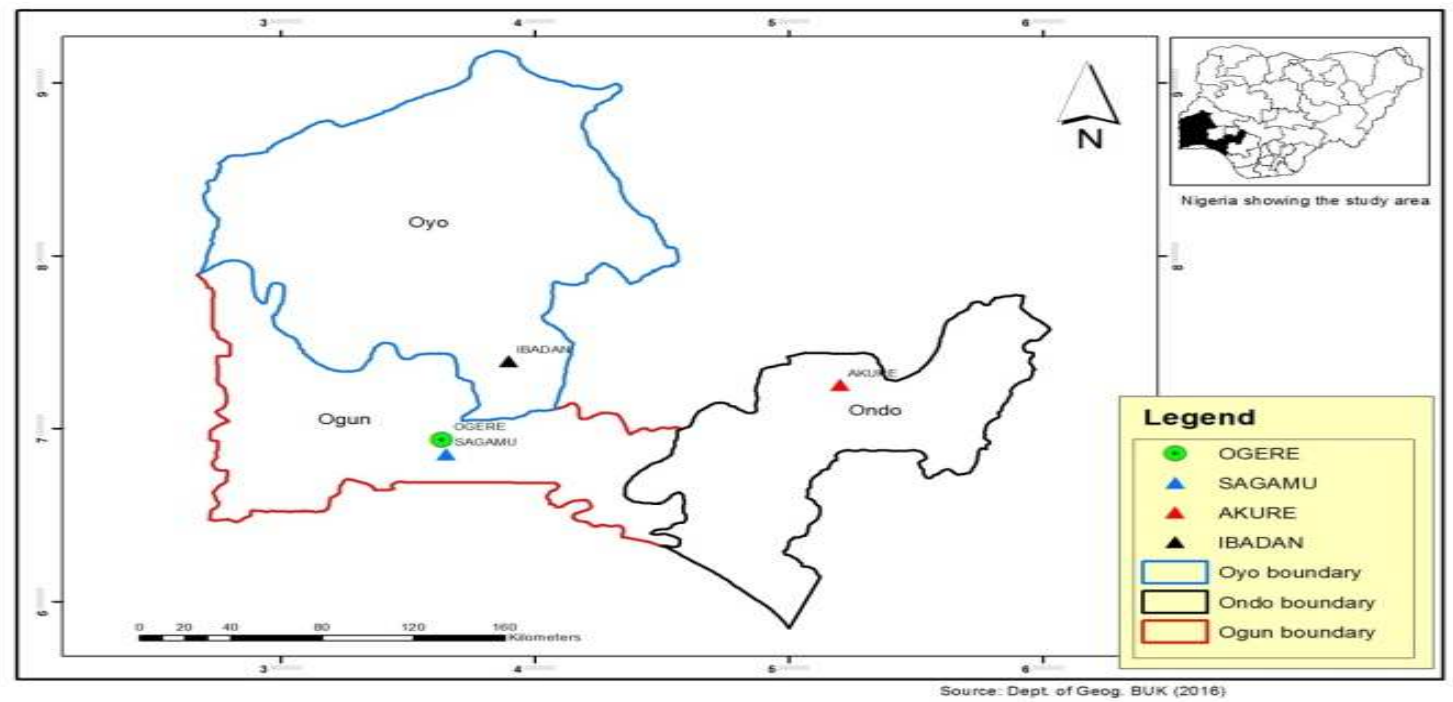

Figure 1: Map showing the sampling point at Sagamu Town, Ogun State.

\section{Description of Sampling Area}

Sagamu has geographical coordinates between $6^{\circ} 50^{\prime}$ north; $3^{\circ} 38^{\prime}$ east is located in south western region of Nigeria. The region has tropical wet and dry climate with a lengthy wet season and relatively constant temperatures throughout the course of the year. Wet season runs from March to October, November to December forms the region dry season. The vegetation type of the region is savannah which is really grassland with small bushes and occasional big trees. Grassland soils have substantially higher organic matter content than forest soils (Novackova, 2011).

\section{Sample Collection}

The Peatsoil samples were collected from four different sampling points $(0-10 \mathrm{~cm}$ depth) in Sagamu into polyethylene bag with plastic spoons. Samples were taken to the laboratory, extraneous materials were removed; the samples were air-dried, crushed and ground to a fine powder in a mortar passed through a $0.20 \mathrm{~mm}$ sieve. The samples were kept for analysis.

\section{Isolation and purification of humic acid from peat soil sample}

Peatsoil sample $(100 \mathrm{~g})$ was mixed with 1000 $\mathrm{cm}^{3}$ of $0.1 \mathrm{M} \mathrm{NaOH}$ solution, shaken for 3hours and left to stand overnight. Dark-coloured supernatant was obtained and decanted from solid residue. The dark-coloured supernatant was acidified to $(\mathrm{pH}=1.0)$ with $6 \mathrm{M} \mathrm{HCl}$ stirred and allowed to stand for 6 hours. Yellowish brown supernatant and dark-brown precipitate were obtained. The yellowish brown supernatant was decanted followed by centrifuge and discarded. The dark-brown precipitate was mixed with $500 \mathrm{~cm}^{3}$ of $0.1 \mathrm{M} \mathrm{NaOH}$ solution followed by passing through dowex resin. The dark-brown solution was acidified to $(\mathrm{pH}=1.0)$ with $6 \mathrm{M} \mathrm{HCl}$ stirred and allowed to stand for 3 hours. The dark-brown precipitate was washed several times with deionized water. The supernatant was treated with $\mathrm{AgNO}_{3}$ solution until no white precipitate observed. The humic acid was transferred to weighed crucible and dried at $60^{\circ} \mathrm{C}$ in an oven for 12 hours. The humic acid was cooled and dried in the desiccator, weighed and recorded. The obtained humic acid was dried again at $60^{\circ} \mathrm{C}$ for additional 6 hours cooled and dried in the desiccator, weighed and recorded constant weight was obtained (Baruah et al., 2015).

\section{FT-IR analysis}

FT-IR spectra of humic acid sample was analysed using Carry 630 FT-IR Agilent Technologies.

Unhydrolysed compost humic acid

The unhydrolysed humic acid was obtained after isolation and purification of compost humic acid and kept for investigation.

\section{Acid hydrolysis of Peatsoil acid}

Peatsoil humic acid sample (1g) was refluxed for 12 hours at $\left(160^{\circ} \mathrm{C}\right)$ with $50 \mathrm{~cm}^{3}$ of $6 \mathrm{M} \mathrm{HCl}$. The mixture was allowed to cool, decanted, and centrifuged after hydrolysis. The insoluble residues were washed with distilled water via centrifugation several times, and the supernatant was treated with $\mathrm{AgNO}_{3}$ solution until no white precipitate was observed. The residue was thoroughly dried over $\mathrm{CaCl}_{2}$ in a desiccator at room temperature (Chefetz et al., 2002). Finally, the obtained hydrolysed humic acid was kept for investigation. 
BAJOPAS Volume 14 Number 1,June, 2021 Potentiometric Titrations

Potentiometric measurements were carried out using a pH-meter Jenway (model 3510) with combine electrode, the sensitivity of the $\mathrm{pH}$ meter is 0.01 units. The $\mathrm{pH}$ meter was switched on half an hour before starting the titration for initial warm up of the instrument. The instrument was calibrated with an aqueous standard buffer solution of $\mathrm{pH} 4.00$ and 10.0 (borate buffer) prepared from a "Qualigens" buffer tablets.

The following sets of solutions were prepared in a $250 \mathrm{~cm}^{3}$ volumetric flask separately for $\mathrm{pH}$ metric titrations.

(i) $5 \mathrm{~cm}^{3} 0.1 \mathrm{M} \mathrm{HCl}+40 \mathrm{~cm}^{3}$ deionized water

(ii) $5 \mathrm{~cm}^{3} 0.1 \mathrm{M} \mathrm{HCl}+39 \mathrm{~cm}^{3}$ deionized water $+1 \mathrm{~cm}^{3} 0.15 \mathrm{gcm}^{-3}$ humic acid

(iii) $5 \mathrm{~cm}^{3} 0.1 \mathrm{M} \mathrm{HCl}+37 \mathrm{~cm}^{3}$ deionized water $+1 \mathrm{~cm}^{3} 0.15 \mathrm{gcm}^{-3}$ humic acid

$$
+2 \mathrm{~cm}^{3} \quad 0.01 \mathrm{M} \mathrm{Cu} \text { (II) }
$$

The solutions were titrated against standardized $0.110 \mathrm{MNaOH}$ separately. The total volume of each mixture was adjusted to $50 \mathrm{~cm}^{3}$ and the ionic strength of the solutions was maintained constant at by adding appropriate amount of stock solution of $1 \mathrm{M} \mathrm{KNO}_{3}$ (Gamal, 2015; Omar and Ali, 2015). A magnetic stirrer was used to achieve thorough mixing of the interacting solutions at $550 \mathrm{rpm}$. The same set of experimental conditions was applied for potentiometric titration of remaining samples.

\section{Evaluation of pKa of Hydrolysed peat soil Humic Acids}

The proton-ligand formation number $\mathrm{n}_{\mathbf{A}}$ were calculated by Irving and Rossotti expression (Omar and Ali, 2015).

$\mathrm{nA}=\mathrm{Y}-\frac{(\mathrm{V} 2-\mathrm{V1})(\mathrm{No}-\mathrm{Eo})}{(\mathrm{VO}+\mathrm{V1}) \mathrm{TCL}}$ 1

Where: $Y$ is number of dissociable proton, $\left(\mathrm{V}_{2^{-}}\right.$ $V_{1}$ ) is the measure of displacement of the ligand curve relative to acid curve, $\mathrm{N}^{\circ}$ and $\mathrm{E}^{\circ}$ are the resultant concentration of alkali solution, free acid solution, $\mathrm{T}_{\mathrm{cL}}{ }^{\circ}$ is the total ligand concentration, $\mathrm{V}^{\circ}$ is the total volume of titration solution, $V_{1}$ is the volume of alkali added to acid solution, $V_{2}$ is the volume of alkali added to acid solution + ligand solution, acid dissociation constants (pKa - values) of ligand were calculated by algebraic method point wise calculation (Tables 1 ). The dissociation constants (pKa) were calculated according to the following relation:

$\mathrm{pKa}=\mathrm{pH}+\log \left(\frac{n A}{1-n A}\right)$ 2

Where: pKa is the acid dissociation constant, $\mathrm{n}_{\mathrm{A}}$ is the Proton-ligand formation number and $\mathrm{pH}$ is the pH-values (Omar and Ali, 2015).

\section{Determination of metal-ligand stability constants $(\log K)$ of complexes}

The potentiometric measurement for the determination of stability constant of a complex in solution is based on the fact that the redox potential of the couple $\frac{M^{+(m-n)}}{M^{+m}}$ is shifted significantly on complexation of the metal ion with the ligand. This method involves change in hydrogen ion concentration $\left[\mathrm{H}^{+}\right]$due to the displacement or association of one or more protons taking place during complexation reaction. This change can be found out by titrating the solutions containing free acid, acid with ligand, and acid with ligand and metal ion, individually against a standard alkali solution at a constant ionic strength or temperature. Either ionic strength or temperature may be varied for different sets of solutions. In all the cases, the change in the $\mathrm{pH}$ of the solution is measured after each addition of a known amount of alkali to the reaction cell which contains the reaction mixture. The titration curves are then drawn by plotting the measured $\mathrm{pH}$ values against the corresponding volume of alkali added and the stability constants of the complexes are determined from the titration curves by employing $\mathrm{pH}$-metric titration technique given by (Irving and Rossoti).

Metal-ligand stability constants ( $\log \mathrm{K}$ ) were determined by using the following relations:

$$
\bar{n}=\frac{\left(V_{3}-V_{2}\right)\left(E^{0}+N^{0}\right)}{\left(V^{0}+V_{2}\right) \bar{n}_{A} T_{m}^{0}}
$$

and

$$
P L=\log _{10}\left\{\frac{1+\beta_{n}^{H} \frac{1}{[\text { anti } \log \mathrm{pH}]^{\mathrm{n}}}}{\mathrm{T}_{\mathrm{L}}^{0}-n \bar{T}_{m}^{0}} \mathrm{X} \frac{\left(V^{0}+V_{3}\right)}{V^{0}}\right\}
$$


BAJOPAS Volume 14 Number 1,June, 2021

Where $T_{L}, T^{\circ}, E^{\circ}$, and $V^{\circ}$ havethe same significance as in equation (1) above, $T_{m}$ denotes the total concentration of metal present in solution, $V_{3}$ is the volume of metal ions present in solution and $\beta^{H}$ is the overall proton ligand stability constant. The metal-ligand stability constants (log K) were determined by employing point wise computational Method (eq. 5 and 6).

$\operatorname{LogK}_{1}=\log \left(\frac{n}{1-n}\right)+\mathrm{pL}$ .5

$\operatorname{LogK}_{2}=\log \left(\frac{1-n}{2-n}\right)+\mathrm{pL}$ ...6

Where: Log $\mathrm{K}$ is the metal-ligand stability constant, $\mathrm{pL}$ is the Free ligand exponent function, $\mathbf{n}$ is the Average number of ligand attached with metal ion (Janraoet al., 2014). The results obtained were analyzed by an ORIGIN 2016 program using titration data and then the proton-ligand stability constants (pKa) and Metal-ligand stability constant (LogK) calculated (Omar and Ali, 2015).

\section{RESULTS AND DISCUSSION}

Fourier transformed infrared (FT-IR) spectra of isolated humic acid from peat soils Figure 2 had distinct clear absorption bands indicating the presence of major humic acid structural elemental groups such as $\mathrm{H}$ bonded $\mathrm{OH}$ $\left(3680 \mathrm{~cm}^{-1}\right.$ peak $), C=0$ of carbonyl $\left(1721 \mathrm{~cm}^{-1}\right.$ peak), functional groups of aliphatic components $\mathrm{CH}_{2}\left(2918 \mathrm{~cm}^{-1}\right.$ peak) and $\mathrm{C}-\mathrm{O}$ stretching of polysaccharide $\left(1168 \mathrm{~cm}^{-1}\right.$ peak). The positions of the absorption bands of the spectra fell within typical major absorption bands of humic acid which is at frequencies 3680, 2918, 1721, 1168 $\mathrm{cm}^{-1}$. The first peak centred in the vicinity of $3680 \mathrm{~cm}^{-1}$ region is attributed to phenol $\mathrm{OH}$ group bounded by intermolecular $\mathrm{H}$ bonds. The $2918 \mathrm{~cm}^{-1}$ band usually has absorption maximum at $2918 \mathrm{~cm}^{-1}$ which is due to $\mathrm{C}-\mathrm{H}$ stretching of alkane group $\left(\mathrm{CH}_{2}\right)$. The next major absorption band is $1721 \mathrm{~cm}^{-1}$. This band has been commonly ascribed to $\mathrm{C}=\mathrm{O}$ stretching of mainly carboxyl group $(\mathrm{COOH})$ with trace amount of ketones. The last peak was observed at 1168 $\mathrm{cm}^{-1}$ due to $\mathrm{C}-\mathrm{O}$ stretching of polysaccharides and this peak appeared also in the spectra of humic acid from peat soil. The FTIR spectra of the isolated humic acid contained all major characteristic absorption peaks of humic acid. These absorption peaks indicated the presence of the major structural elements of humic acid namely $\mathrm{H}$ bonded $\mathrm{OH}, \mathrm{C}=\mathrm{C}$ of aromatic ring, $\mathrm{C}=\mathrm{O}$ of carbonyl group (both carboxyl and ketonic), $\mathrm{CH}_{2}$ group. This strongly supports the presence of humic acid.

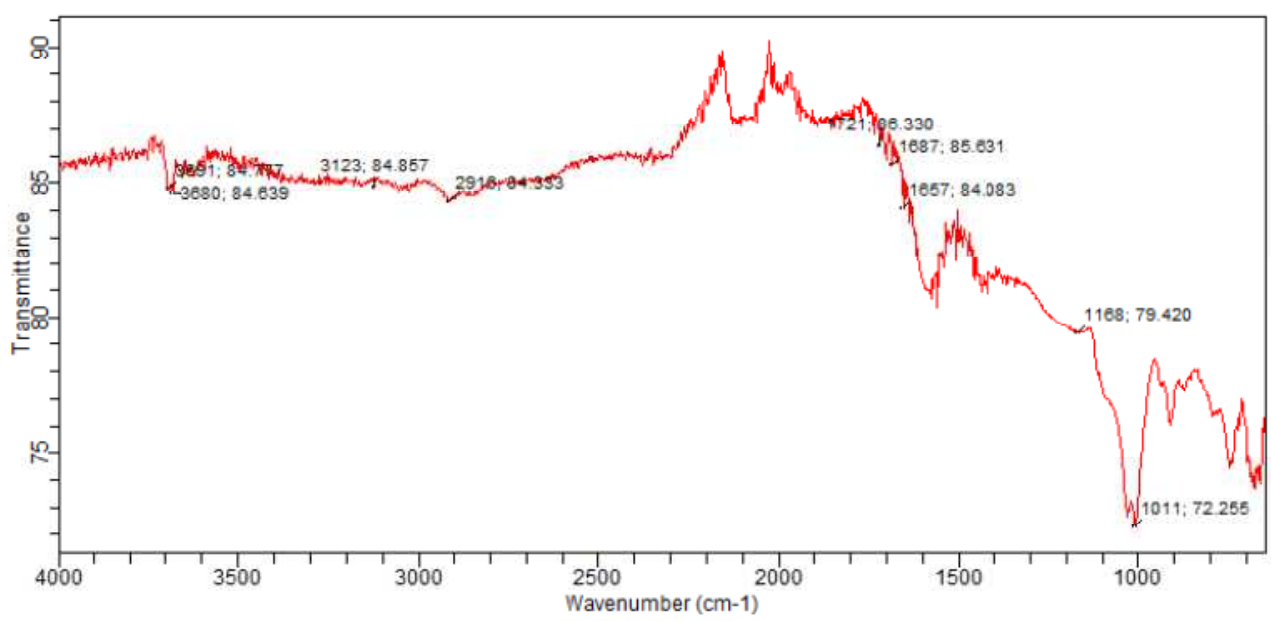

Fig. 2 : FT-IR spectraof peatsoilhumic acid (PSHA)

\section{Evaluation of acid dissociation constant (pka) of acid hydrolysed peat soil humicacid at phenolic group}

The value of the dissociation constant of the peat soil humic acid (PSHA) that underwent acidhydrolysis studied was found to be 8.9299 as shown Table 1, which is lower than the literaturevalues reported by Almeida and Szpoganics, (2015), Borges et al., (2005); Badr et al., (2012)and Fernandes et al,.(2009) of $9.73,9.47$ and 10.30. The difference between the obtained valuesand the reported values in this study might be probably as a result of acid hydrolysis of humicacid. 
BAJOPAS Volume 14 Number 1,June, 2021

Table 1: PKa of (Hydrolysed PSHA)

\begin{tabular}{|l|l|l|l|l|l|l|}
\hline $\mathrm{pH}$ & $\mathrm{BV}_{1}$ & $\mathrm{BV}_{2}$ & $\mathrm{~V}_{2}-\mathrm{V}_{1}$ & $\mathrm{nA}$ & $\log \left(\frac{n A}{1-n A}\right)$ & $\mathrm{pKa}$ \\
\hline 8.50 & 5.30 & 6.29 & 0.99 & 0.3594 & -0.2510 & 8.2490 \\
8.72 & 5.35 & 6.37 & 1.02 & 0.3400 & -0.2880 & 8.4320 \\
9.00 & 5.40 & 6.46 & 1.06 & 0.3141 & -0.3391 & 8.6609 \\
9.22 & 5.45 & 6.55 & 1.10 & 0.2882 & -0.3927 & 8.8273 \\
9.51 & 5.50 & 6.66 & 1.16 & 0.2494 & -0.4786 & 9.0314 \\
9.73 & 5.55 & 6.78 & 1.23 & 0.2041 & -0.5910 & 9.1390 \\
10.00 & 5.60 & 6.90 & 1.30 & 0.1589 & -0.7238 & 9.2762 \\
10.23 & 5.65 & 7.05 & 1.40 & 0.0941 & -0.9835 & 9.2465 \\
10.49 & 5.70 & 7.10 & 1.40 & 0.0941 & -0.9835 & 9.5065 \\
\hline
\end{tabular}

Average pKa $=8.9299 \pm 0.4186$

Table 2: PKa of (Unhydrolysed PSHA)

\begin{tabular}{|l|l|l|l|l|l|l|}
\hline $\mathrm{pH}$ & $\mathrm{BV}_{1}$ & $\mathrm{BV}_{2}$ & $\mathrm{~V}_{2}-\mathrm{V}_{1}$ & $\mathrm{nA}$ & $\log \left(\frac{\boldsymbol{n A}}{1-\boldsymbol{n}}\right)$ & $\mathrm{pKa}$ \\
\hline 8.50 & 5.30 & 5.81 & 0.51 & 0.6619 & 0.2919 & 8.7919 \\
8.72 & 5.35 & 5.90 & 0.55 & 0.6357 & 0.2418 & 8.9618 \\
9.00 & 5.40 & 6.00 & 0.60 & 0.6029 & 0.1813 & 9.1813 \\
9.22 & 5.45 & 6.10 & 0.65 & 0.5701 & 0.1226 & 9.3426 \\
9.51 & 5.50 & 6.20 & 0.70 & 0.5376 & 0.0654 & 9.5754 \\
9.73 & 5.55 & 6.33 & 0.78 & 0.4851 & -0.0259 & 9.7041 \\
10.00 & 5.60 & 6.47 & 0.87 & 0.4262 & -0.1291 & 9.8709 \\
10.23 & 5.65 & 6.62 & 0.99 & 0.3609 & -0.2481 & 9.9819 \\
10.49 & 5.70 & 6.80 & 1.10 & 0.2759 & -0.4690 & 10.0210 \\
\hline
\end{tabular}

Average pKa $=9.4923 \pm 0.4410$

Metal-ligand stability constant ( $\log \mathrm{K}$ )

The stabilityconstants require the accurate values of proton-ligand stability constants (Anil and Maroti, 2008). Metal titration curves crossed over ligand titration curve indicated the formation of complex upon proton release (Santosh, et al., 2011). If the values of n- are within range $0.2-0.8$ and $1.2-18$ this indicates the formation of $1: 1$ and 1:2 complexes (Sayyed and Mazahar, 2012).

The metal (II)-humate stepwise stability constants (log k) at phenolic group (Tables 318)

Table 3: Point-wise method, $\mathrm{Cu}$-(Hydrolysed PSHA)

\begin{tabular}{|l|l|l|l|l|l|l|l|l|}
\hline $\mathrm{pH}$ & $\mathrm{BV}_{1}$ & $\mathrm{BV}_{2}$ & $\mathrm{BV}_{3}$ & $\left(\mathrm{~V}_{3}-\mathrm{V}_{2}\right)$ & $\mathrm{n}$ & $\mathrm{pL}$ & $\log \left(\frac{n}{1-n}\right)$ & LogK $_{1}$ \\
\hline 8.50 & 5.30 & 6.29 & 6.33 & 0.04 & 0.5500 & 2.66 & 0.0871 & 2.7471 \\
8.72 & 5.35 & 6.37 & 6.41 & 0.04 & 0.5714 & 2.43 & 0.1249 & 2.5549 \\
9.00 & 5.40 & 6.46 & 6.50 & 0.04 & 0.6198 & 2.16 & 0.2122 & 2.3722 \\
9.22 & 5.45 & 6.55 & 6.59 & 0.04 & 0.6667 & 1.94 & 0.3010 & 2.2410 \\
\hline
\end{tabular}

LogK $_{1}$ (Average value) $=2.4788 \pm 0.2203$

Table 4: Point-wise method, $\mathrm{Cu}$-(Hydrolysed PSHA)

\begin{tabular}{|l|l|l|l|l|l|l|l|l|}
\hline $\mathrm{pH}$ & $\mathrm{BV}_{1}$ & $\mathrm{BV}_{2}$ & $\mathrm{BV}_{3}$ & $\left(\mathrm{~V}_{3}-\mathrm{V}_{2}\right)$ & $\mathrm{n}$ & $\mathrm{pL}$ & $\log \left(\frac{n-1}{2-n}\right)$ & LogK $_{2}$ \\
\hline 9.51 & 5.50 & 6.66 & 6.73 & 0.07 & 1.3509 & 1.70 & -0.2671 & 1.4329 \\
9.73 & 5.55 & 6.78 & 6.85 & 0.07 & 1.6383 & 1.51 & 0.2467 & 1.7567 \\
10.00 & 5.60 & 6.90 & 6.98 & 0.08 & 2.1783 & 1.31 & -0.2158 & 1.0942 \\
10.23 & 5.65 & 7.05 & 7.13 & 0.08 & 4.1904 & 1.27 & & \\
10.49 & 5.70 & 7.10 & 7.19 & 0.09 & 4.6920 & & & \\
\hline
\end{tabular}

Log $K_{2}($ Average value $)=1.4280 \pm 0.3312$ 
BAJOPAS Volume 14 Number 1,June, 2021

Table 5: Point-wise method, $\mathrm{Cu}$ (Unhydrolysed PSHA)

\begin{tabular}{|l|l|l|l|l|l|l|l|l|}
\hline $\mathrm{pH}$ & $\mathrm{BV}_{1}$ & $\mathrm{BV}_{2}$ & $\mathrm{BV}_{3}$ & $\left(\mathrm{~V}_{3}-\mathrm{V}_{2}\right)$ & $\mathrm{n}$ & $\mathrm{pL}$ & $\log \left(\frac{n}{n-1}\right)$ & Log $_{1}$ \\
\hline 8.50 & 5.30 & 5.81 & 5.85 & 0.04 & 0.2973 & 2.88 & -0.3736 & 2.5064 \\
8.72 & 5.35 & 5.90 & 5.95 & 0.05 & 0.3873 & 2.66 & -0.1992 & 2.4608 \\
9.00 & 5.40 & 6.00 & 6.05 & 0.05 & 0.4044 & 2.38 & -0.1681 & 2.2119 \\
9.22 & 5.45 & 6.10 & 6.15 & 0.06 & 0.5157 & 2.18 & -0.0272 & 2.2072 \\
9.51 & 5.50 & 6.20 & 6.27 & 0.07 & 0.6417 & 1.89 & 0.2530 & 1.1430 \\
\hline
\end{tabular}

$\operatorname{LogK}_{1}($ Average value $)=2.3059 \pm 0.6153$

Table 6:Point-wise method, $\mathrm{Cu}$ (Unhydrolysed PSHA)

\begin{tabular}{|l|l|l|l|l|l|l|l|l|}
\hline $\mathrm{pH}$ & $\mathrm{BV}_{1}$ & $\mathrm{BV}_{2}$ & $\mathrm{BV}_{3}$ & $\mathrm{~V}_{3}-\mathrm{V}_{2}$ & $\mathrm{n}$ & $\mathrm{pL}$ & $\log \left(\frac{n-1}{2-n}\right)$ & $\log \mathrm{K}_{2}$ \\
\hline 9.73 & 5.55 & 6.33 & 6.42 & 0.09 & 0.9000 & 1.69 & & \\
10.00 & 5.60 & 6.47 & 6.58 & 0.11 & 1.2578 & 1.44 & -0.4592 & 0.9808 \\
10.23 & 5.65 & 6.62 & 6.84 & 0.12 & 1.6137 & 1.26 & -0.2010 & 1.4610 \\
10.49 & 5.70 & 6.80 & 6.92 & 0.12 & 2.1052 & 1.03 & & \\
\hline
\end{tabular}

$\operatorname{LogK}_{2}$ (Average value) $=1.2209 \pm 0.3398$

Table 7:Point-wise method, Pb (Hydrolysed PSHA)

\begin{tabular}{|l|l|l|l|l|l|l|l|l|}
\hline $\mathrm{pH}$ & $\mathrm{BV}_{1}$ & $\mathrm{BV}_{2}$ & $\mathrm{BV}_{3}$ & $\left(\mathrm{~V}_{3}-\mathrm{V}_{2}\right)$ & $\mathrm{n}$ & $\mathrm{pL}$ & $\log \left(\frac{n}{1-n}\right)$ & LogK $_{1}$ \\
\hline 8.50 & 5.30 & 6.29 & 6.33 & 0.04 & 0.5500 & 2.66 & 0.0871 & 2.7471 \\
8.72 & 5.35 & 6.37 & 6.41 & 0.04 & 0.5714 & 2.43 & 0.1249 & 2.5549 \\
9.00 & 5.40 & 6.46 & 6.50 & 0.04 & 0.6198 & 2.16 & 0.2122 & 2.3722 \\
9.22 & 5.45 & 6.55 & 6.60 & 0.05 & 0.8333 & 1.96 & 0.6989 & 2.6589 \\
\hline
\end{tabular}

Log $_{\mathbf{1}}($ Average value $)=2.5832 \pm 0.1614$

Table 8:Point-wise method, Pb-(Hydrolysed PSHA)

\begin{tabular}{|l|l|l|l|l|l|l|l|l|}
\hline $\mathrm{pH}$ & $\mathrm{BV}_{1}$ & $\mathrm{BV}_{2}$ & $\mathrm{BV}_{3}$ & $\left(\mathrm{~V}_{3}-\mathrm{V}_{2}\right)$ & $\mathrm{n}$ & $\mathrm{pL}$ & $\log \left(\frac{n-1}{2-n}\right)$ & $\log \mathrm{K}_{2}$ \\
\hline 9.51 & 5.50 & 6.66 & 6.71 & 0.05 & 0.9650 & 1.67 & & \\
9.73 & 5.55 & 6.78 & 6.83 & 0.05 & 1.1702 & 1.44 & & \\
10.00 & 5.60 & 6.90 & 6.90 & 0.05 & 1.4864 & 1.22 & -0.0237 & 1.1963 \\
10.23 & 5.65 & 7.05 & 7.10 & 0.05 & 2.0190 & 1.09 & & \\
10.49 & 5.70 & 7.10 & 7.17 & 0.07 & 3.6492 & 1.00 & & \\
\hline
\end{tabular}

Log $K_{2}$ (Average value) $=1.1963$

Table 9: Point-wise method, Pb (Unhydrolysed PSHA)

\begin{tabular}{|l|l|l|l|l|l|l|l|l|}
\hline $\mathrm{pH}$ & $\mathrm{BV}_{1}$ & $\mathrm{BV}_{2}$ & $\mathrm{BV}_{3}$ & $\mathrm{~V}_{3}-\mathrm{V}_{2}$ & $\mathrm{n}$ & $\mathrm{pL}$ & $\begin{array}{l}\text { Log } \\
\left(\frac{n}{n-1}\right)\end{array}$ & Log $\mathrm{K}_{1}$ \\
\hline 8.50 & 5.30 & 5.81 & 5.85 & 0.04 & 0.2973 & 2.88 & -0.3736 & 2.5064 \\
8.72 & 5.35 & 5.90 & 5.94 & 0.04 & 0.3099 & 2.66 & -0.5477 & 2.3123 \\
9.00 & 5.40 & 6.00 & 6.05 & 0.05 & 0.4044 & 2.38 & -0.1681 & 2.2119 \\
9.22 & 5.45 & 6.10 & 6.15 & 0.06 & 0.5157 & 2.18 & 0.0272 & 2.2072 \\
9.51 & 5.50 & 6.20 & 6.26 & 0.07 & 0.6417 & 1.89 & 0.2530 & 2.1430 \\
9.73 & 5.55 & 6.40 & 6.40 & 0.07 & 0.7000 & 1.67 & 0.3680 & 2.0380 \\
\hline
\end{tabular}

LogK $_{1}$ (Average value) $=2.2364 \pm 0.1602$

Table 10: Point-wise method, Pb (Unhydrolysed PSHA)

\begin{tabular}{|l|l|l|l|l|l|l|l|l|}
\hline $\mathrm{pH}$ & $\mathrm{BV}_{1}$ & $\mathrm{BV}_{2}$ & $\mathrm{BV}_{3}$ & $\mathrm{~V}_{3}-\mathrm{V}_{2}$ & $\mathrm{n}$ & $\mathrm{pL}$ & $\log \left(\frac{n-1}{2-n}\right)$ & $\log \mathrm{K}_{2}$ \\
\hline 10.00 & 5.60 & 6.47 & 6.55 & 0.08 & 1.9503 & 1.41 & & \\
10.23 & 5.65 & 6.62 & 6.72 & 0.11 & 1.4792 & 1.26 & -0.0361 & 1.2239 \\
\hline
\end{tabular}

$\operatorname{LogK}_{2}$ (Average value) $=1.2239$

Table 11: Point-wise method, Mg (Hydrolysed PSHA)

\begin{tabular}{|l|l|l|l|l|l|l|l|l|}
\hline $\mathrm{pH}$ & $\mathrm{BV}_{1}$ & $\mathrm{BV}_{2}$ & $\mathrm{BV}_{3}$ & $\left(\mathrm{~V}_{3}-\mathrm{V}_{2}\right)$ & $\mathrm{n}$ & $\mathrm{pL}$ & $\log \left(\frac{n}{n-1}\right)$ & LogK $_{1}$ \\
\hline 8.50 & 5.30 & 6.29 & 6.31 & 0.02 & 0.2750 & 2.64 & -0.4290 & 2.2110 \\
8.72 & 5.35 & 6.37 & 6.39 & 0.02 & 0.2858 & 2.42 & -0.3978 & 2.0222 \\
9.00 & 5.40 & 6.46 & 6.49 & 0.03 & 0.4648 & 2.14 & -0.0612 & 2.0788 \\
9.22 & 5.45 & 6.55 & 6.59 & 0.04 & 0.6667 & 1.94 & 0.3010 & 2.2410 \\
\hline
\end{tabular}

$\log _{\mathbf{1}}($ Average value) $=2.1382 \pm 0.1046$ 
BAJOPAS Volume 14 Number 1,June, 2021

Table 12: Point-wise method, Mg (Hydrolysed PSHA)

\begin{tabular}{|l|l|l|l|l|l|l|l|l|}
\hline $\mathrm{pH}$ & $\mathrm{BV}_{1}$ & $\mathrm{BV}_{2}$ & $\mathrm{BV}_{3}$ & $\left(\mathrm{~V}_{3}-\mathrm{V}_{2}\right)$ & $\mathrm{n}$ & $\mathrm{pL}$ & $\log \left(\frac{n-1}{2-n}\right)$ & LogK $_{2}$ \\
\hline 9.51 & 5.55 & 6.66 & 6.71 & 0.05 & 0.9650 & 1.67 & & \\
9.73 & 5.55 & 6.78 & 6.84 & 0.06 & 1.4042 & 1.47 & -0.1686 & 1.3014 \\
10.00 & 5.60 & 6.90 & 6.93 & 0.06 & 1.7838 & 1.23 & 0.5593 & 1.7893 \\
10.23 & 5.65 & 7.05 & 7.10 & 0.06 & 3.1429 & 1.10 & & \\
10.49 & 5.70 & 7.10 & 7.18 & 0.07 & 3.6492 & 0.83 & & \\
\hline
\end{tabular}

LogK $_{2}($ Average value $)=1.5453 \pm 0.3450$

Table 13: Point-wise method, Mg (Unhydrolysed PSHA)

\begin{tabular}{|l|l|l|l|l|l|l|l|l|}
\hline $\mathrm{pH}$ & $\mathrm{BV}_{1}$ & $\mathrm{BV}_{2}$ & $\mathrm{BV}_{3}$ & $\mathrm{~V}_{3}-\mathrm{V}_{2}$ & $\mathrm{n}$ & $\mathrm{pL}$ & $\log \left(\frac{n}{n-1}\right)$ & $\operatorname{Log~}_{1}$ \\
\hline 8.50 & 5.30 & 5.81 & 5.85 & 0.04 & 0.2973 & 2.88 & -0.3736 & 2.5064 \\
8.72 & 5.35 & 5.90 & 5.94 & 0.04 & 0.3099 & 2.66 & -0.3477 & 2.3123 \\
9.00 & 5.40 & 6.00 & 6.04 & 0.04 & 0.3236 & 2.38 & -0.3202 & 2.0598 \\
9.22 & 5.45 & 6.10 & 6.15 & 0.05 & 0.4297 & 2.17 & -0.1230 & 2.0470 \\
9.51 & 5.50 & 6.20 & 6.26 & 0.06 & 0.5500 & 1.89 & 0.0871 & 1.9771 \\
9.73 & 5.55 & 6.33 & 6.40 & 0.07 & 0.7000 & 1.67 & 0.3680 & 2.0380 \\
\hline
\end{tabular}

LogK $_{1}$ (Average value) $=2.1568 \pm 0.2069$

Table 14: Point-wise method, Mg (Unhydrolysed PSHA)

\begin{tabular}{|l|l|l|l|l|l|l|l|l|}
\hline $\mathrm{pH}$ & $\mathrm{BV}_{1}$ & $\mathrm{BV}_{2}$ & $\mathrm{BV}_{3}$ & $\mathrm{~V}_{3}-\mathrm{V}_{2}$ & $\mathrm{n}$ & $\mathrm{pL}$ & $\log \left(\frac{n-1}{2-n}\right)$ & $\log \mathrm{K}_{2}$ \\
\hline 10.00 & 5.60 & 6.47 & 6.55 & 0.08 & 0.9148 & 1.41 & & \\
10.23 & 5.65 & 6.62 & 6.71 & 0.09 & 1.2102 & 1.20 & -0.5749 & 0.6251 \\
10.49 & 5.70 & 6.80 & 6.92 & 0.09 & 1.5968 & 1.03 & 0.1703 & 1.2003 \\
\hline
\end{tabular}

LogK $_{2}$ (Average value) $=0.9127 \pm 0.4070$

Table15:Point-wise method, Cd (Hydrolysed PSHA)

\begin{tabular}{|l|l|l|l|l|l|l|l|l|}
\hline $\mathrm{pH}$ & $\mathrm{BV}_{1}$ & $\mathrm{BV}_{2}$ & $\mathrm{BV}_{3}$ & $\left(\mathrm{~V}_{3}-\mathrm{V}_{2}\right)$ & $\mathrm{n}$ & $\mathrm{pL}$ & $\log \left(\frac{n}{1-n}\right)$ & LogK $_{1}$ \\
\hline 8.50 & 5.30 & 6.29 & 6.31 & 0.02 & 0.2750 & 2.64 & -0.4210 & 2.2190 \\
8.72 & 5.35 & 6.37 & 6.40 & 0.03 & 0.4286 & 2.42 & -0.1249 & 2.2951 \\
9.00 & 5.40 & 6.46 & 6.49 & 0.03 & 0.4648 & 2.14 & -0.0612 & 2.0788 \\
9.22 & 5.45 & 6.55 & 6.59 & 0.04 & 0.6667 & 1.96 & 0.3010 & 2.2610 \\
9.51 & 5.55 & 6.66 & 6.70 & 0.04 & 0.7720 & 1.67 & 0.5297 & 2.1997 \\
\hline
\end{tabular}

LogK $_{\mathbf{1}}$ (Average value) $=2.2108 \pm 0.0825$

Table 16: Point-wise method, Cd (Hydrolysed PSHA)

\begin{tabular}{|l|l|l|l|l|l|l|l|l|}
\hline $\mathrm{pH}$ & $\mathrm{BV}_{1}$ & $\mathrm{BV}_{2}$ & $\mathrm{BV}_{3}$ & $\left(\mathrm{~V}_{3}-\mathrm{V}_{2}\right)$ & $\mathrm{n}$ & $\mathrm{pL}$ & $\log \left(\frac{n-1}{2-n}\right)$ & Log $_{2}$ \\
\hline 9.73 & 5.55 & 6.78 & 6.83 & 0.06 & 1.4042 & 1.47 & -0.1686 & 1.3014 \\
10.00 & 5.60 & 6.90 & 6.95 & 0.06 & 1.7838 & 1.23 & 0.5593 & 1.7893 \\
10.23 & 5.65 & 7.05 & 7.10 & 0.06 & 3.1429 & 1.09 & & \\
10.49 & 5.70 & 7.10 & 7.16 & 0.06 & 3.1429 & 0.89 & & \\
& & & & & & & & \\
\hline
\end{tabular}

$\operatorname{LogK}_{2}$ (Average value) $=1.5453 \pm 0.3450$

Table 17: Point-wise method, Cd (Unhydrolysed PSHA)

\begin{tabular}{|l|l|l|l|l|l|l|l|l|}
\hline $\mathrm{pH}$ & $\mathrm{BV}_{1}$ & $\mathrm{BV}_{2}$ & $\mathrm{BV}_{3}$ & $\mathrm{~V}_{3}-\mathrm{V}_{2}$ & $\mathrm{n}$ & $\mathrm{pL}$ & $\log \left(\frac{n}{n-1}\right)$ & $\operatorname{Log~}_{1}$ \\
\hline 8.50 & 5.30 & 5.81 & 5.86 & 0.05 & 0.3717 & 2.88 & -0.2280 & 2.6520 \\
8.72 & 5.35 & 5.90 & 5.95 & 0.05 & 0.3873 & 2.66 & -0.1992 & 2.4608 \\
9.00 & 5.40 & 6.00 & 6.06 & 0.06 & 0.4853 & 2.38 & -0.0255 & 2.3545 \\
9.22 & 5.45 & 6.10 & 6.16 & 0.06 & 0.5157 & 2.18 & -0.0272 & 2.2072 \\
9.51 & 5.50 & 6.20 & 6.27 & 0.07 & 0.6417 & 1.89 & 0.2530 & 1.1430 \\
9.73 & 5.55 & 6.33 & 6.41 & 0.08 & 0.8000 & 1.69 & 0.6020 & 2.2920 \\
& & & & & & & & \\
\hline
\end{tabular}

$\operatorname{LogK}_{1}($ Average value $)=2.2516 \pm 0.5380$ 
BAJOPAS Volume 14 Number 1,June, 2021

Table 18: Point-wise method, Cd (Unhydrolysed PSHA)

\begin{tabular}{|l|l|l|l|l|l|l|l|l|}
\hline $\mathrm{pH}$ & $\mathrm{BV}_{1}$ & $\mathrm{BV}_{2}$ & $\mathrm{BV}_{3}$ & $\mathrm{~V}_{3}-\mathrm{V}_{2}$ & $\mathrm{n}$ & $\mathrm{pL}$ & $\log \left(\frac{n-1}{2-n}\right)$ & $\log \mathrm{K}_{2}$ \\
\hline 10.00 & 5.60 & 6.47 & 6.57 & 0.10 & 1.1434 & 1.43 & & \\
10.23 & 5.65 & 6.62 & 6.72 & 0.10 & 1.3448 & 1.23 & -0.2788 & 0.9512 \\
10.49 & 5.70 & 6.80 & 6.90 & 0.10 & 1.7742 & 1.03 & 0.5351 & 1.5651 \\
\hline
\end{tabular}

$\operatorname{LogK}_{2}($ Average value $)=1.2581 \pm 0.4340$

Table 19: Stepwise and overall Stability constants of thehydrolysed and unhydrolysed divalent metal (II) complexes

\begin{tabular}{|c|c|c|c|}
\hline Chelates & LogK $_{1}$ & $\log _{2}$ & Log $\beta$ \\
\hline [Cu (Hydrolysed PSHA-1) $\left.{ }_{2}\right]$ & 2.4788 & 1.4280 & 3.9068 \\
\hline$\left[\mathrm{Pb}(\text { Hydrolysed PSHA-1) })_{2}\right]$ & 2.5832 & 1.1963 & 3.7795 \\
\hline$\left[\mathrm{Cd}(\text { Hydrolysed PSHA-1 })_{2}\right]$ & 2.2108 & 1.5453 & 3.7561 \\
\hline$\left[\mathrm{Mg}(\text { Hydrolysed PSHA-1 })_{2}\right]$ & 2.1382 & 1.5453 & 3.6835 \\
\hline [Cu (Unhydrolysed PSHA-1) & 2.3059 & 1.2209 & 3.5268 \\
\hline$[\mathrm{Pb}$ (Unhydrolysed PSHA-1) 2$]$ & 2.2364 & 1.2239 & 3.4603 \\
\hline [Cd (Unhydrolysed PSHA-1) 2 ] & 2.2516 & 1.2581 & 3.5097 \\
\hline$[\mathrm{Mg}$ (Unydrolysed PSHA-1) & 2.1568 & 0.9127 & 3.0695 \\
\hline
\end{tabular}

The results obtained (Table19) shows the stepwise and overall stability constants to be not high indicating low stability of the complexes, because the solubility of most metal ions in the basic $\mathrm{pH}$ range is minimal due to metal hydroxide precipitation (Karimi, 2017). In general, the stepwise stability constants $\left(K_{1}\right.$ and $K_{2}$ ) follow the order $K_{1}>K_{2}$ for the copper, lead, magnesium and cadmium complexes respectively. The steady decrease of the values with increasing number of ligands is in agreement with the prediction made by researchers (Na'aliya, 2013). The decrease could be attributed to the fact that as the number of the ligands (Humate ions) that enters the coordination zone increases the aqua molecules available for replacement by the ligands become less. Thus, the metal ions become less electron loving with progressive intake of the ligand and this results in the decrease in the values of the constants (Na'aliya, 2013). Also the stability of the complexes is influenced by the size and number of the chelate rings(Mackay and Mackay,2002).All the complexes form rings in their structure as humate, a bidentate ligand, bond the metal ions in the ratio 1:2 (Boguta and Sokolowska, 2016) forming chelate rings. The values of the overall stability constants $(\log \beta)$ obtained for humate complexes are not high indicating low stability as the values are not high. LogK values for copper-humates (Table 3 to 6) obtained in this study are lower than those reported for the complexes of humic acids (Pandey et al., 2015; Dinu, 2013; Kaschl et al., 2010 and Gilbeto and Jorg, 2001). The values of LogK(Table 7 to 10 ) forlead-humates are lower than those reported for the lead in the literature (Dinu, 2013; Gilbeto and Jorg 2001). Log K values(Table 11 to 14 ) for magnesium-humates obtained in this study are close to those reported by (Pandey et al., 2015). Log K values of cadmium-humates (Table 15 to 18 ) obtained in this work near to the one reported by (Dinu, 2013 and Pandey et al., 2015).The difference between the reported values and the values obtained in this study might be probably as a result of acid hydrolysis of humic acid. The values of the overall stability constants $(\log \beta)$ of the copper humates complexes presented in Table 19 is high than that of other metal humate complexes, show relatively high stability of CuHA complexes, show the following order of stability: $\mathrm{Cu}>\mathrm{Pb}>\mathrm{Cd}>\mathrm{Mg}$; which are in close agreement to the findings of (Dinu, 2013 and Pandey et al., 2015).The high stability of Cuhumate chelate could be attributed to the existence of coordinate covalent bond between the complexing agents and the $\mathrm{Cu}^{2+}$ ions. Since, $\mathrm{Cu}^{2+}$ being a metal of the transitional series with $3 d^{9}$ electronic configurations can accept the electrons from the complexing agents. Similarly, the low stabilities of $\mathrm{Pb}, \mathrm{Cd}$ and $\mathrm{Mg}$ complexes could be explained by that $\mathrm{Pb}^{2+}$ with $6 s^{2}, \mathrm{Cd}^{2+}$ with $4 \mathrm{~d}^{10}$ and $\mathrm{Mg}^{2+}$ with $2 \mathrm{p}^{6}$ their electronic configuration has a completely filled $\mathrm{d}, \mathrm{p}$ and $\mathrm{s}$ orbitals. Moreover, the stabilities of metal ions with hydrolysed humic acid from peat soil were higher than those with unhydrolysed humic acid from peat soil; which is ascribed to the high content of acidity in hydrolysed humic acid than unhydrolysed humic acid. 
BAJOPAS Volume 14 Number 1,June, 2021 CONCLUSION

The values of logk for $\mathrm{Cu}(\mathrm{II})$ hydrolysed humic acid complex was higher followed by $\mathrm{Pb}$ (II), $\mathrm{Cd}(\mathrm{II})$ and $\mathrm{Mg}$ (II) hydrolysed humic acid complexes as compared with metal(II) unhydrolysed humic acid complexes. This indicates acid hydrolysis of humic acid can

\section{REFERENCES}

Almeida, V.R. and Szpoganicz, B. (2015). Humic Acid Potentiometric Response Patterns:Out- of Equilibrium Properties and Species Distribution Modelling. Chemical. Biol. Technol. Agric. 2: 17.

Anđelković, T., Nikolić, R., Bojić, A.,Anđelković, D., and Nikolic G.,(2010). Binding of Cadmium to Soil Humic Acid as A Function of Carboxyl Group Content. Macedonian Journal of Chemistry and Chemical Engineering.29(2): 215-224.

Anil, B. N. and Maroti, N. (2008). Studies on Influence of Die-Lectric Constants on Complex Equilibria between Substituted Py-Razalines and Lanthanide Metal Ions pH-Metrically. Amer.-Euras. scient. Res. 3(2): 212-216.

Ashok, K., Pandey, S. P. and Misra, V (2000). Stability Constants of Metal-Humic Acid Complexes and its Role in Environmental Detoxification. Journal of Ecotoxicology and Environmental Safety. 47(2):157-200.

Badr, M. H., El-Halafawi, M. H. and Abd El-al Zeid, E. R. (2012). Comparison Between the Effect of Ionic Strength on Acidity and Dissociation Constants of Humic Acids Extracted from Sewage Sludge and Nile Water Hyacinth Composts.Global Journal of Environmental Research 6 (1): 36-43.

Baruah, M.K., Borah, D., Saikia, P.P., Paul, S., Sharma, T. (2015). Evaluation of pKa Values of Soil Humic Acids and their Complexation Properties. International Journal of Plant \& Soil Science 6(4) : 218-228.

Boguta, P. Sokolowska, Z. (2016). Interactions of $\mathrm{Zn}$ (II) Ions with Humic Acids Isolated from Various Types of Soils. Effect of $\mathrm{pH}, \mathrm{Zn}$ Concentrations and Humic Acids Chemical Properties. Journal of Geochemical Explaration 168. 119-126.

Borges, F., Guimaraes, C., Lima, L.F.C., Pinto, I. and Reis, S.(2005). Potentiometric Studies on the Complexation of Copper(II) by Phenolic Acids as Discrete Ligand Models of enhance the complexation behavior of humic acid with metal (II) ions. However, the higher values of $\log \beta$ for $\mathrm{Cu}(\mathrm{II}), \mathrm{Pb}(\mathrm{II}), \mathrm{Cd}(\mathrm{II})$ and $\mathrm{Mg}(\mathrm{II})$ hydrolysed humic acid complexes indicates more stable stepwise complexes formed as compared with $\mathrm{Cu}(\mathrm{II}), \mathrm{Pb}$ (II), $\mathrm{Cd}$ (II) and $\mathrm{Mg}(\mathrm{II})$ unhydrolysed humic acid complexes.

Humic Substances Talanta 66 (2005) 670-673.

Chefetz, B., Salloum, M. J., Deshmulkin, A. P. and Hatcher, P. (2002). Structural Components of Humic Acids as Determined by Chemical Modifications and Carbon-13 NMR, Pyrolysis, and Thermochemolysis- Gas Chromatography/Mass Spectrometry. Soil Science Society of American Journal Abstract Division S-2- Soil Chemistry66. 1159-1171.

Dinu, M. I. (2013). Metals Complexation with Humic Acids in Surface Water of Different Environ. Sci. Technol. 31(1): 1-17.

Fernandes, A.N., Giacomelli, C., Giovanela, M. Vaz, D.V. Szpoganicz, B. and Maria M. D. (2009). Potentiometric Acidity Determination in Humic Substances Influenced by Different Analytical Procedures.J. Braz. Chem. Soc. 20 (9):14.

Gamal, A. H. (2015). Stability Constants of Rhenium (V) Metal Complexes with Selected Drugs. Pyrex Journal of Research in Environmental Studies. 2(2): 006-014.

Janrao, D. M., Pathan, J., Kayande, D.D., and Mulla, J.J. (2014). An Over View of Potentiometric Determination of Stability Constants of Metal Complexes. Sci. Revs. Chem. Commun.: 4(1), 2014, 11-24.

Karimi, H. (2017). Effect of pH and Initial Pb(II) Concentration on the Lead Removal Efficiency from Waste Water Using $\mathrm{Ca}(\mathrm{OH})_{2}$. International Journal of Water and Waste Water Treatment 3.2

Kaschl, A. Romheld, V. and Chen, Y. (2010). Binding of Cadmium, Copper and Zinc to Humic Substances Originating from Municipal Solid Waste Compost. Israel Journal of Chemistry Vol. 42(1): 89-98.

Kostic, I. S., Tatjana, P, A., Nikolic, R. S., Cvetkovic, T. P., Pavlovic, D. D., Aleksandar, L.J. and Bojic, A. (2012). Comparative Study of Binding Strengths of Heavy Metals with Humic Acid. J.serb. Chem. Soc. 76(9) pp 1-20. 
BAJOPAS Volume 14 Number 1,June, 2021

Na'aliya, J. (2013). Determination of Stepwise Stability Constants and Gibbs free Energy Change of Trisprolina to Complexes of some Divalent Transition Metal ions. Bayero Journal of Pure and Applied Sciences 6(2): 112-114.

Omar, A. A. and Ali, E. A. (2015). Potentiometric Studies on Complexes of $\mathrm{Cr}$ (III) and $\mathrm{Zr}$ (IV) with some Carboxylic Acids. International Journal of Advanced Chemistry, 3(1) 25-

37.

Pandey, A. K. Pandey, S. D. and Misr, V. (2015).Stability Constants of Metal- Humic Acid Complexes and Its Role in Environmental Detoxification. J. Ecotoxicology and Environmental Safety. 47(1):195-200.

Ram, N. and Raman, K.V. (1984). Stability Constants of Complexes of Metals with
Humicand Fuvic Acids under Non- acidConditions. Journal of Plant Nutrition and Soil Sciences.

147:171-176.

Santosh, D. D., Ashok, B. K., Vijay, J. T., Shivraj, G. W. and Vinay, V. W. (2011). Potentiometric Studies of Elec-Trolyte Effects on Complex Equilibria of Some Substituted 5-(2-hydroxy Phenyl) Pyrazoles. Der pharm. 3 (6): 75-83.

Sayyed, H. and Abdul Rahim, M. F. (2012). Studies of Binary Complexes of Metal Ions with Mandelic Acid by Potentiometry. Chem. J. 02 (6): 206209.

Shirvani, M. Moradian, E. Khalili, B. Bakhtiary, S. (2015). Interaction of $\mathrm{Cd}$ and $\mathrm{Pb}$ with Humate-Palygorskite and HumateSepiolite Complexes. Journal of water, air and pollution 3: 220-228. 


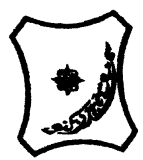

Bayero Journal of Pure and Applied Sciences, 14(1): 54 - 63

Received: November, 2020

Accepted: April, 2021

ISSN $2006-6996$

\title{
STABILITY CONSTANTS OF COMPLEXES OF METAL IONS WITH PEATSOIL HUMIC ACIDS UNDER NON-ACID-CONDITIONS
}

\author{
${ }^{* 1}$ Sabo, Yusuf ${ }^{2}$ Jimoh, W.L.O., ${ }^{3}$ Isa Baba Koki and ${ }^{4}$ Sholadoye, Q. 0. \\ ${ }^{1}$ Department of Pure and Industrial Chemistry, Bayero University, Kano \\ ${ }^{3}$ Department of Chemistry, Yusuf Maitama Sule University Kano. P.M.B. 3220 Kano, Nigeria. \\ ${ }^{4}$ Department of Chemistry, Nigerian Police Academy, Wudil, Kano-Nigeria
}

*Correspondence E-mail; saboyusuf18@yahoo.com

ABSTRACT

Stability constants of complexes of four divalent metal ions viz. $\mathrm{Cu}^{2+}, \mathrm{Pb}^{2+}, \mathrm{Mg}^{2+}$ and $\mathrm{Cd}^{2+}$ with humic acids (HA) were determined by potentiometric titration of humic acids with the corresponding salt of the divalent metals in aqueous media under non-acid-condition. The log $K$ (logarithm of the stability constant) ranged from 1.0942 to 2.7471 for metalhumic acid complexes were determined using point-wise computational method. The order of stability constants were obtained as follows: $\mathrm{Cu}>\mathrm{Pb}>\mathrm{Cd}>\mathrm{Mg}$ for metal $-\mathrm{HA}$ complexes respectively, indicating a higher degree of complexation with Cu metal ion.

Keywords: stability constant, humic acid, potentiometric titration, divalent metals, acid hydrolysis.

\section{NTRODUCTION}

The stability constant of a complex is the numerical expression of its stability and provides a quantitative measure of affinity of the metal ion to the complexing agent. An understanding of the relative stability of metal-complexes helps in predicting the behavior of metal ions in the soil (Ram and Raman, 1982). Extensive researches has been done to determine the stability constants of the complexes formed between humic acid (HA) with a number of metal ions. Ashok et al., (2000) reported that humic acid with hydroxyl, phenoxyl and carboxyl reactive groups can form coordination compound with metal ions at $\mathrm{pH}$ 3.5. The stability constants(Log K) for different metalhumic acid complexes indicated the following order of the stabilities of complexes formed between humic acid and metal ion, $\mathrm{Cu}>\mathrm{Fe}$ $>\mathrm{Pb}>\mathrm{Ni}>\mathrm{Co}>\mathrm{Ca}>\mathrm{Cd}>\mathrm{Zn}>\mathrm{Mn}>\mathrm{Mg}$. Andelkovic et al., (2010) investigated the binding of $\mathrm{Cd}$ (II) to soil humic acid at pH 6.5 and in $0.1 \mathrm{M} \mathrm{KNO}_{3}$ ionic medium. The stability constant for binding indicating greater stability in the case when carboxyl groups are involved in complexation reaction. Kostic et al.,(2012) investigated the complexation of humic acid with certain heavy metal ions (Co(II), $\mathrm{Ni}(\mathrm{II}), \mathrm{Cu}(\mathrm{II})$,
$\mathrm{Zn}(\mathrm{II})$, and $\mathrm{Pb}(\mathrm{II})$. The experiment was performed at $25^{\circ} \mathrm{C}$, at pH 4.0 and ionic strength of $0.01 \mathrm{M}$. Stability constant of complex between $\mathrm{Pb}$ (II) ions and humic acid is greater than stability constants of other investigated metalhumate complexes. Bogata and Sokolowska (2016) analyses the interaction between humic acids from different soils and $\mathrm{Zn}$ (II) ions at wide concentration ranges and at $\mathrm{pH} 5$. Studies have showed significant impact of $\mathrm{Zn}$ concentration, $\mathrm{pH}$ and some properties of humic acids with zinc.But all of these studies were limited to acidic $\mathrm{pH}$ range. Therefore, the present study was carried out to determine and compare the stability constants of complexes of metal ions with hydrolysed peat soil humic acid and unhydrolysed peat soil humic under non-acid conditions.

\section{MATERIALS AND METHODS}

Analytical grade chemicals used includes hydrochloric acid $(\mathrm{HCl})$, nitric acid $\left(\mathrm{HNO}_{3}\right)$, sodium hydroxide $(\mathrm{NaOH})$, lead nitrate $\mathrm{Pb}\left(\mathrm{NO}_{3}\right)_{2}$, copper nitrate $\mathrm{Cu}\left(\mathrm{NO}_{3}\right)_{2} \cdot 3 \mathrm{H}_{2} \mathrm{O}$, cadmium nitrate $\mathrm{Cd}\left(\mathrm{NO}_{3}\right)_{2} \cdot 4 \mathrm{H}_{2} \mathrm{O}$, magnesium nitrate $\mathrm{Mg}\left(\mathrm{NO}_{3}\right)_{2} \cdot 6 \mathrm{H}_{2} \mathrm{O}$, potassium nitrate $\left(\mathrm{KNO}_{3}\right)$, calcium chloride $\left(\mathrm{CaCl}_{2}\right)$, (sigma-Aldrich). Dowex 50WX8, (20-50 mesh) from Fluka. 


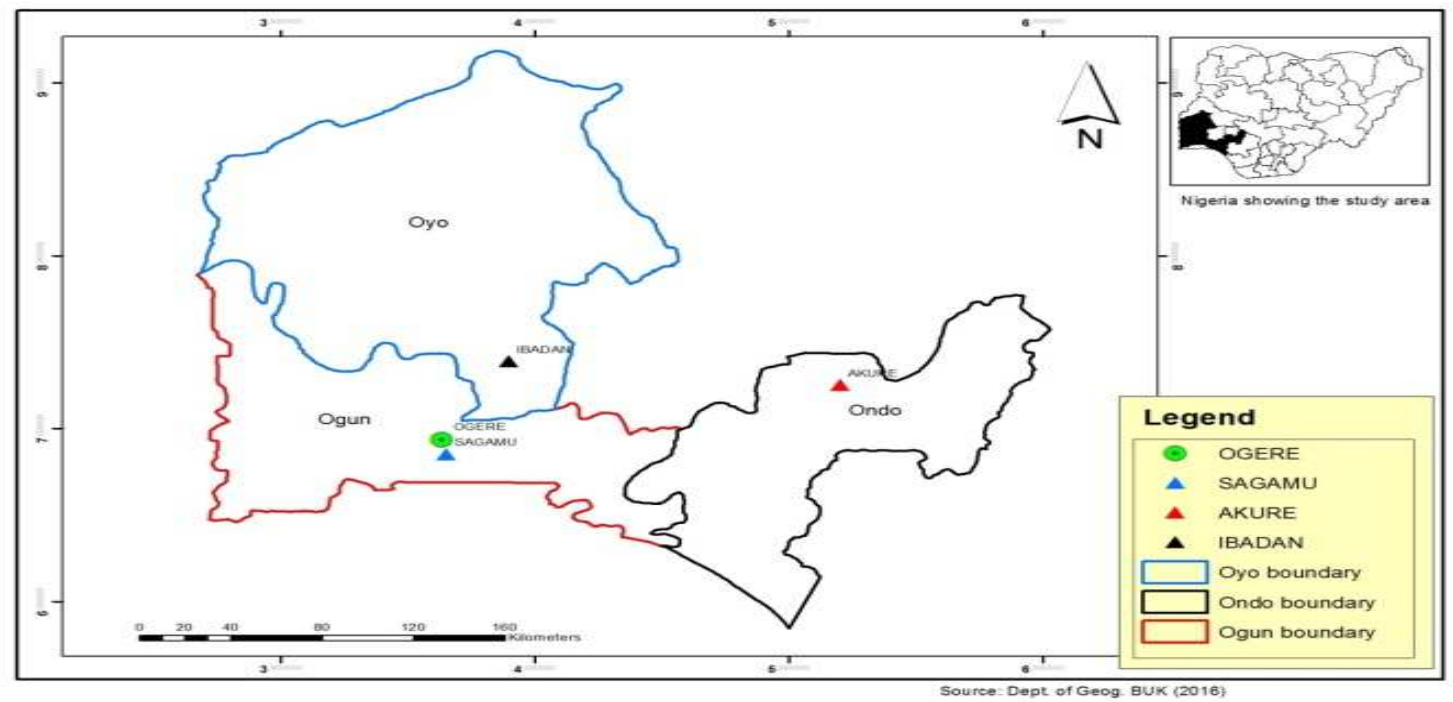

Figure 1: Map showing the sampling point at Sagamu Town, Ogun State.

\section{Description of Sampling Area}

Sagamu has geographical coordinates between $6^{\circ} 50^{\prime}$ north; $3^{\circ} 38^{\prime}$ east is located in south western region of Nigeria. The region has tropical wet and dry climate with a lengthy wet season and relatively constant temperatures throughout the course of the year. Wet season runs from March to October, November to December forms the region dry season. The vegetation type of the region is savannah which is really grassland with small bushes and occasional big trees. Grassland soils have substantially higher organic matter content than forest soils (Novackova, 2011).

\section{Sample Collection}

The Peatsoil samples were collected from four different sampling points $(0-10 \mathrm{~cm}$ depth) in Sagamu into polyethylene bag with plastic spoons. Samples were taken to the laboratory, extraneous materials were removed; the samples were air-dried, crushed and ground to a fine powder in a mortar passed through a $0.20 \mathrm{~mm}$ sieve. The samples were kept for analysis.

\section{Isolation and purification of humic acid from peat soil sample}

Peatsoil sample $(100 \mathrm{~g})$ was mixed with 1000 $\mathrm{cm}^{3}$ of $0.1 \mathrm{M} \mathrm{NaOH}$ solution, shaken for 3hours and left to stand overnight. Dark-coloured supernatant was obtained and decanted from solid residue. The dark-coloured supernatant was acidified to $(\mathrm{pH}=1.0)$ with $6 \mathrm{M} \mathrm{HCl}$ stirred and allowed to stand for 6 hours. Yellowish brown supernatant and dark-brown precipitate were obtained. The yellowish brown supernatant was decanted followed by centrifuge and discarded. The dark-brown precipitate was mixed with $500 \mathrm{~cm}^{3}$ of $0.1 \mathrm{M} \mathrm{NaOH}$ solution followed by passing through dowex resin. The dark-brown solution was acidified to $(\mathrm{pH}=1.0)$ with $6 \mathrm{M} \mathrm{HCl}$ stirred and allowed to stand for 3 hours. The dark-brown precipitate was washed several times with deionized water. The supernatant was treated with $\mathrm{AgNO}_{3}$ solution until no white precipitate observed. The humic acid was transferred to weighed crucible and dried at $60^{\circ} \mathrm{C}$ in an oven for 12 hours. The humic acid was cooled and dried in the desiccator, weighed and recorded. The obtained humic acid was dried again at $60^{\circ} \mathrm{C}$ for additional 6 hours cooled and dried in the desiccator, weighed and recorded constant weight was obtained (Baruah et al., 2015).

\section{FT-IR analysis}

FT-IR spectra of humic acid sample was analysed using Carry 630 FT-IR Agilent Technologies.

Unhydrolysed compost humic acid

The unhydrolysed humic acid was obtained after isolation and purification of compost humic acid and kept for investigation.

\section{Acid hydrolysis of Peatsoil acid}

Peatsoil humic acid sample (1g) was refluxed for 12 hours at $\left(160^{\circ} \mathrm{C}\right)$ with $50 \mathrm{~cm}^{3}$ of $6 \mathrm{M} \mathrm{HCl}$. The mixture was allowed to cool, decanted, and centrifuged after hydrolysis. The insoluble residues were washed with distilled water via centrifugation several times, and the supernatant was treated with $\mathrm{AgNO}_{3}$ solution until no white precipitate was observed. The residue was thoroughly dried over $\mathrm{CaCl}_{2}$ in a desiccator at room temperature (Chefetz et al., 2002). Finally, the obtained hydrolysed humic acid was kept for investigation. 
BAJOPAS Volume 14 Number 1,June, 2021 Potentiometric Titrations

Potentiometric measurements were carried out using a pH-meter Jenway (model 3510) with combine electrode, the sensitivity of the $\mathrm{pH}$ meter is 0.01 units. The $\mathrm{pH}$ meter was switched on half an hour before starting the titration for initial warm up of the instrument. The instrument was calibrated with an aqueous standard buffer solution of $\mathrm{pH} 4.00$ and 10.0 (borate buffer) prepared from a "Qualigens" buffer tablets.

The following sets of solutions were prepared in a $250 \mathrm{~cm}^{3}$ volumetric flask separately for $\mathrm{pH}$ metric titrations.

(i) $5 \mathrm{~cm}^{3} 0.1 \mathrm{M} \mathrm{HCl}+40 \mathrm{~cm}^{3}$ deionized water

(ii) $5 \mathrm{~cm}^{3} 0.1 \mathrm{M} \mathrm{HCl}+39 \mathrm{~cm}^{3}$ deionized water $+1 \mathrm{~cm}^{3} 0.15 \mathrm{gcm}^{-3}$ humic acid

(iii) $5 \mathrm{~cm}^{3} 0.1 \mathrm{M} \mathrm{HCl}+37 \mathrm{~cm}^{3}$ deionized water $+1 \mathrm{~cm}^{3} 0.15 \mathrm{gcm}^{-3}$ humic acid

$$
+2 \mathrm{~cm}^{3} \quad 0.01 \mathrm{M} \mathrm{Cu} \text { (II) }
$$

The solutions were titrated against standardized $0.110 \mathrm{MNaOH}$ separately. The total volume of each mixture was adjusted to $50 \mathrm{~cm}^{3}$ and the ionic strength of the solutions was maintained constant at by adding appropriate amount of stock solution of $1 \mathrm{M} \mathrm{KNO}_{3}$ (Gamal, 2015; Omar and Ali, 2015). A magnetic stirrer was used to achieve thorough mixing of the interacting solutions at $550 \mathrm{rpm}$. The same set of experimental conditions was applied for potentiometric titration of remaining samples.

\section{Evaluation of pKa of Hydrolysed peat soil Humic Acids}

The proton-ligand formation number $\mathrm{n}_{\mathbf{A}}$ were calculated by Irving and Rossotti expression (Omar and Ali, 2015).

$\mathrm{nA}=\mathrm{Y}-\frac{(\mathrm{V} 2-\mathrm{V1})(\mathrm{No}-\mathrm{Eo})}{(\mathrm{VO}+\mathrm{V1}) \mathrm{TCL}}$ 1

Where: $Y$ is number of dissociable proton, $\left(\mathrm{V}_{2^{-}}\right.$ $V_{1}$ ) is the measure of displacement of the ligand curve relative to acid curve, $\mathrm{N}^{\circ}$ and $\mathrm{E}^{\circ}$ are the resultant concentration of alkali solution, free acid solution, $\mathrm{T}_{\mathrm{cL}}{ }^{\circ}$ is the total ligand concentration, $\mathrm{V}^{\circ}$ is the total volume of titration solution, $V_{1}$ is the volume of alkali added to acid solution, $V_{2}$ is the volume of alkali added to acid solution + ligand solution, acid dissociation constants (pKa - values) of ligand were calculated by algebraic method point wise calculation (Tables 1 ). The dissociation constants (pKa) were calculated according to the following relation:

$\mathrm{pKa}=\mathrm{pH}+\log \left(\frac{n A}{1-n A}\right)$ 2

Where: pKa is the acid dissociation constant, $\mathrm{n}_{\mathrm{A}}$ is the Proton-ligand formation number and $\mathrm{pH}$ is the pH-values (Omar and Ali, 2015).

\section{Determination of metal-ligand stability constants $(\log K)$ of complexes}

The potentiometric measurement for the determination of stability constant of a complex in solution is based on the fact that the redox potential of the couple $\frac{M^{+(m-n)}}{M^{+m}}$ is shifted significantly on complexation of the metal ion with the ligand. This method involves change in hydrogen ion concentration $\left[\mathrm{H}^{+}\right]$due to the displacement or association of one or more protons taking place during complexation reaction. This change can be found out by titrating the solutions containing free acid, acid with ligand, and acid with ligand and metal ion, individually against a standard alkali solution at a constant ionic strength or temperature. Either ionic strength or temperature may be varied for different sets of solutions. In all the cases, the change in the $\mathrm{pH}$ of the solution is measured after each addition of a known amount of alkali to the reaction cell which contains the reaction mixture. The titration curves are then drawn by plotting the measured $\mathrm{pH}$ values against the corresponding volume of alkali added and the stability constants of the complexes are determined from the titration curves by employing $\mathrm{pH}$-metric titration technique given by (Irving and Rossoti).

Metal-ligand stability constants ( $\log \mathrm{K}$ ) were determined by using the following relations:

$$
\bar{n}=\frac{\left(V_{3}-V_{2}\right)\left(E^{0}+N^{0}\right)}{\left(V^{0}+V_{2}\right) \bar{n}_{A} T_{m}^{0}}
$$

and

$$
P L=\log _{10}\left\{\frac{1+\beta_{n}^{H} \frac{1}{[\text { anti } \log \mathrm{pH}]^{\mathrm{n}}}}{\mathrm{T}_{\mathrm{L}}^{0}-n \bar{T}_{m}^{0}} \mathrm{X} \frac{\left(V^{0}+V_{3}\right)}{V^{0}}\right\}
$$


BAJOPAS Volume 14 Number 1,June, 2021

Where $T_{L}, T^{\circ}, E^{\circ}$, and $V^{\circ}$ havethe same significance as in equation (1) above, $T_{m}$ denotes the total concentration of metal present in solution, $V_{3}$ is the volume of metal ions present in solution and $\beta^{H}$ is the overall proton ligand stability constant. The metal-ligand stability constants (log K) were determined by employing point wise computational Method (eq. 5 and 6).

$\operatorname{LogK}_{1}=\log \left(\frac{n}{1-n}\right)+\mathrm{pL}$ .5

$\operatorname{LogK}_{2}=\log \left(\frac{1-n}{2-n}\right)+\mathrm{pL}$ ...6

Where: Log $\mathrm{K}$ is the metal-ligand stability constant, $\mathrm{pL}$ is the Free ligand exponent function, $\mathbf{n}$ is the Average number of ligand attached with metal ion (Janraoet al., 2014). The results obtained were analyzed by an ORIGIN 2016 program using titration data and then the proton-ligand stability constants (pKa) and Metal-ligand stability constant (LogK) calculated (Omar and Ali, 2015).

\section{RESULTS AND DISCUSSION}

Fourier transformed infrared (FT-IR) spectra of isolated humic acid from peat soils Figure 2 had distinct clear absorption bands indicating the presence of major humic acid structural elemental groups such as $\mathrm{H}$ bonded $\mathrm{OH}$ $\left(3680 \mathrm{~cm}^{-1}\right.$ peak $), C=0$ of carbonyl $\left(1721 \mathrm{~cm}^{-1}\right.$ peak), functional groups of aliphatic components $\mathrm{CH}_{2}\left(2918 \mathrm{~cm}^{-1}\right.$ peak) and $\mathrm{C}-\mathrm{O}$ stretching of polysaccharide $\left(1168 \mathrm{~cm}^{-1}\right.$ peak). The positions of the absorption bands of the spectra fell within typical major absorption bands of humic acid which is at frequencies 3680, 2918, 1721, 1168 $\mathrm{cm}^{-1}$. The first peak centred in the vicinity of $3680 \mathrm{~cm}^{-1}$ region is attributed to phenol $\mathrm{OH}$ group bounded by intermolecular $\mathrm{H}$ bonds. The $2918 \mathrm{~cm}^{-1}$ band usually has absorption maximum at $2918 \mathrm{~cm}^{-1}$ which is due to $\mathrm{C}-\mathrm{H}$ stretching of alkane group $\left(\mathrm{CH}_{2}\right)$. The next major absorption band is $1721 \mathrm{~cm}^{-1}$. This band has been commonly ascribed to $\mathrm{C}=\mathrm{O}$ stretching of mainly carboxyl group $(\mathrm{COOH})$ with trace amount of ketones. The last peak was observed at 1168 $\mathrm{cm}^{-1}$ due to $\mathrm{C}-\mathrm{O}$ stretching of polysaccharides and this peak appeared also in the spectra of humic acid from peat soil. The FTIR spectra of the isolated humic acid contained all major characteristic absorption peaks of humic acid. These absorption peaks indicated the presence of the major structural elements of humic acid namely $\mathrm{H}$ bonded $\mathrm{OH}, \mathrm{C}=\mathrm{C}$ of aromatic ring, $\mathrm{C}=\mathrm{O}$ of carbonyl group (both carboxyl and ketonic), $\mathrm{CH}_{2}$ group. This strongly supports the presence of humic acid.

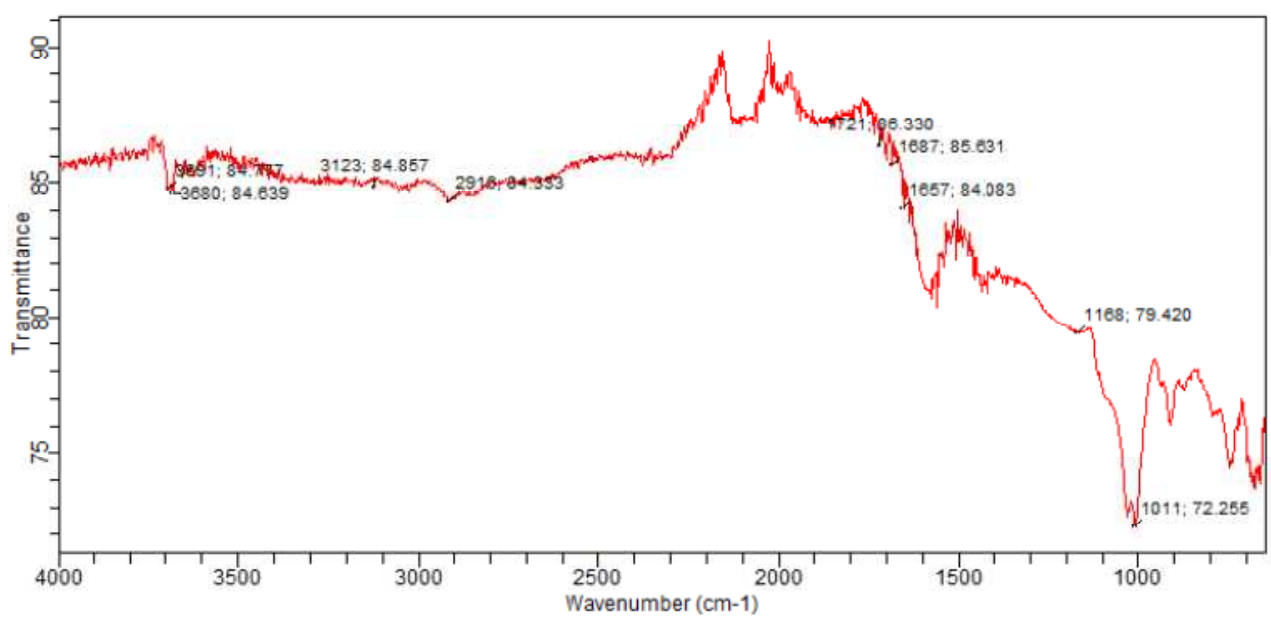

Fig. 2 : FT-IR spectraof peatsoilhumic acid (PSHA)

\section{Evaluation of acid dissociation constant (pka) of acid hydrolysed peat soil humicacid at phenolic group}

The value of the dissociation constant of the peat soil humic acid (PSHA) that underwent acidhydrolysis studied was found to be 8.9299 as shown Table 1, which is lower than the literaturevalues reported by Almeida and Szpoganics, (2015), Borges et al., (2005); Badr et al., (2012)and Fernandes et al,.(2009) of $9.73,9.47$ and 10.30. The difference between the obtained valuesand the reported values in this study might be probably as a result of acid hydrolysis of humicacid. 
BAJOPAS Volume 14 Number 1,June, 2021

Table 1: PKa of (Hydrolysed PSHA)

\begin{tabular}{|l|l|l|l|l|l|l|}
\hline $\mathrm{pH}$ & $\mathrm{BV}_{1}$ & $\mathrm{BV}_{2}$ & $\mathrm{~V}_{2}-\mathrm{V}_{1}$ & $\mathrm{nA}$ & $\log \left(\frac{n A}{1-n A}\right)$ & $\mathrm{pKa}$ \\
\hline 8.50 & 5.30 & 6.29 & 0.99 & 0.3594 & -0.2510 & 8.2490 \\
8.72 & 5.35 & 6.37 & 1.02 & 0.3400 & -0.2880 & 8.4320 \\
9.00 & 5.40 & 6.46 & 1.06 & 0.3141 & -0.3391 & 8.6609 \\
9.22 & 5.45 & 6.55 & 1.10 & 0.2882 & -0.3927 & 8.8273 \\
9.51 & 5.50 & 6.66 & 1.16 & 0.2494 & -0.4786 & 9.0314 \\
9.73 & 5.55 & 6.78 & 1.23 & 0.2041 & -0.5910 & 9.1390 \\
10.00 & 5.60 & 6.90 & 1.30 & 0.1589 & -0.7238 & 9.2762 \\
10.23 & 5.65 & 7.05 & 1.40 & 0.0941 & -0.9835 & 9.2465 \\
10.49 & 5.70 & 7.10 & 1.40 & 0.0941 & -0.9835 & 9.5065 \\
\hline
\end{tabular}

Average pKa $=8.9299 \pm 0.4186$

Table 2: PKa of (Unhydrolysed PSHA)

\begin{tabular}{|l|l|l|l|l|l|l|}
\hline $\mathrm{pH}$ & $\mathrm{BV}_{1}$ & $\mathrm{BV}_{2}$ & $\mathrm{~V}_{2}-\mathrm{V}_{1}$ & $\mathrm{nA}$ & $\log \left(\frac{\boldsymbol{n A}}{1-\boldsymbol{n}}\right)$ & $\mathrm{pKa}$ \\
\hline 8.50 & 5.30 & 5.81 & 0.51 & 0.6619 & 0.2919 & 8.7919 \\
8.72 & 5.35 & 5.90 & 0.55 & 0.6357 & 0.2418 & 8.9618 \\
9.00 & 5.40 & 6.00 & 0.60 & 0.6029 & 0.1813 & 9.1813 \\
9.22 & 5.45 & 6.10 & 0.65 & 0.5701 & 0.1226 & 9.3426 \\
9.51 & 5.50 & 6.20 & 0.70 & 0.5376 & 0.0654 & 9.5754 \\
9.73 & 5.55 & 6.33 & 0.78 & 0.4851 & -0.0259 & 9.7041 \\
10.00 & 5.60 & 6.47 & 0.87 & 0.4262 & -0.1291 & 9.8709 \\
10.23 & 5.65 & 6.62 & 0.99 & 0.3609 & -0.2481 & 9.9819 \\
10.49 & 5.70 & 6.80 & 1.10 & 0.2759 & -0.4690 & 10.0210 \\
\hline
\end{tabular}

Average pKa $=9.4923 \pm 0.4410$

Metal-ligand stability constant ( $\log \mathrm{K}$ )

The stabilityconstants require the accurate values of proton-ligand stability constants (Anil and Maroti, 2008). Metal titration curves crossed over ligand titration curve indicated the formation of complex upon proton release (Santosh, et al., 2011). If the values of n- are within range $0.2-0.8$ and $1.2-18$ this indicates the formation of $1: 1$ and 1:2 complexes (Sayyed and Mazahar, 2012).

The metal (II)-humate stepwise stability constants (log k) at phenolic group (Tables 318)

Table 3: Point-wise method, $\mathrm{Cu}$-(Hydrolysed PSHA)

\begin{tabular}{|l|l|l|l|l|l|l|l|l|}
\hline $\mathrm{pH}$ & $\mathrm{BV}_{1}$ & $\mathrm{BV}_{2}$ & $\mathrm{BV}_{3}$ & $\left(\mathrm{~V}_{3}-\mathrm{V}_{2}\right)$ & $\mathrm{n}$ & $\mathrm{pL}$ & $\log \left(\frac{n}{1-n}\right)$ & LogK $_{1}$ \\
\hline 8.50 & 5.30 & 6.29 & 6.33 & 0.04 & 0.5500 & 2.66 & 0.0871 & 2.7471 \\
8.72 & 5.35 & 6.37 & 6.41 & 0.04 & 0.5714 & 2.43 & 0.1249 & 2.5549 \\
9.00 & 5.40 & 6.46 & 6.50 & 0.04 & 0.6198 & 2.16 & 0.2122 & 2.3722 \\
9.22 & 5.45 & 6.55 & 6.59 & 0.04 & 0.6667 & 1.94 & 0.3010 & 2.2410 \\
\hline
\end{tabular}

LogK $_{1}$ (Average value) $=2.4788 \pm 0.2203$

Table 4: Point-wise method, $\mathrm{Cu}$-(Hydrolysed PSHA)

\begin{tabular}{|l|l|l|l|l|l|l|l|l|}
\hline $\mathrm{pH}$ & $\mathrm{BV}_{1}$ & $\mathrm{BV}_{2}$ & $\mathrm{BV}_{3}$ & $\left(\mathrm{~V}_{3}-\mathrm{V}_{2}\right)$ & $\mathrm{n}$ & $\mathrm{pL}$ & $\log \left(\frac{n-1}{2-n}\right)$ & LogK $_{2}$ \\
\hline 9.51 & 5.50 & 6.66 & 6.73 & 0.07 & 1.3509 & 1.70 & -0.2671 & 1.4329 \\
9.73 & 5.55 & 6.78 & 6.85 & 0.07 & 1.6383 & 1.51 & 0.2467 & 1.7567 \\
10.00 & 5.60 & 6.90 & 6.98 & 0.08 & 2.1783 & 1.31 & -0.2158 & 1.0942 \\
10.23 & 5.65 & 7.05 & 7.13 & 0.08 & 4.1904 & 1.27 & & \\
10.49 & 5.70 & 7.10 & 7.19 & 0.09 & 4.6920 & & & \\
\hline
\end{tabular}

Log $K_{2}($ Average value $)=1.4280 \pm 0.3312$ 
BAJOPAS Volume 14 Number 1,June, 2021

Table 5: Point-wise method, $\mathrm{Cu}$ (Unhydrolysed PSHA)

\begin{tabular}{|l|l|l|l|l|l|l|l|l|}
\hline $\mathrm{pH}$ & $\mathrm{BV}_{1}$ & $\mathrm{BV}_{2}$ & $\mathrm{BV}_{3}$ & $\left(\mathrm{~V}_{3}-\mathrm{V}_{2}\right)$ & $\mathrm{n}$ & $\mathrm{pL}$ & $\log \left(\frac{n}{n-1}\right)$ & Log $_{1}$ \\
\hline 8.50 & 5.30 & 5.81 & 5.85 & 0.04 & 0.2973 & 2.88 & -0.3736 & 2.5064 \\
8.72 & 5.35 & 5.90 & 5.95 & 0.05 & 0.3873 & 2.66 & -0.1992 & 2.4608 \\
9.00 & 5.40 & 6.00 & 6.05 & 0.05 & 0.4044 & 2.38 & -0.1681 & 2.2119 \\
9.22 & 5.45 & 6.10 & 6.15 & 0.06 & 0.5157 & 2.18 & -0.0272 & 2.2072 \\
9.51 & 5.50 & 6.20 & 6.27 & 0.07 & 0.6417 & 1.89 & 0.2530 & 1.1430 \\
\hline
\end{tabular}

$\operatorname{LogK}_{1}($ Average value $)=2.3059 \pm 0.6153$

Table 6:Point-wise method, $\mathrm{Cu}$ (Unhydrolysed PSHA)

\begin{tabular}{|l|l|l|l|l|l|l|l|l|}
\hline $\mathrm{pH}$ & $\mathrm{BV}_{1}$ & $\mathrm{BV}_{2}$ & $\mathrm{BV}_{3}$ & $\mathrm{~V}_{3}-\mathrm{V}_{2}$ & $\mathrm{n}$ & $\mathrm{pL}$ & $\log \left(\frac{n-1}{2-n}\right)$ & $\log \mathrm{K}_{2}$ \\
\hline 9.73 & 5.55 & 6.33 & 6.42 & 0.09 & 0.9000 & 1.69 & & \\
10.00 & 5.60 & 6.47 & 6.58 & 0.11 & 1.2578 & 1.44 & -0.4592 & 0.9808 \\
10.23 & 5.65 & 6.62 & 6.84 & 0.12 & 1.6137 & 1.26 & -0.2010 & 1.4610 \\
10.49 & 5.70 & 6.80 & 6.92 & 0.12 & 2.1052 & 1.03 & & \\
\hline
\end{tabular}

$\operatorname{LogK}_{2}$ (Average value) $=1.2209 \pm 0.3398$

Table 7:Point-wise method, Pb (Hydrolysed PSHA)

\begin{tabular}{|l|l|l|l|l|l|l|l|l|}
\hline $\mathrm{pH}$ & $\mathrm{BV}_{1}$ & $\mathrm{BV}_{2}$ & $\mathrm{BV}_{3}$ & $\left(\mathrm{~V}_{3}-\mathrm{V}_{2}\right)$ & $\mathrm{n}$ & $\mathrm{pL}$ & $\log \left(\frac{n}{1-n}\right)$ & LogK $_{1}$ \\
\hline 8.50 & 5.30 & 6.29 & 6.33 & 0.04 & 0.5500 & 2.66 & 0.0871 & 2.7471 \\
8.72 & 5.35 & 6.37 & 6.41 & 0.04 & 0.5714 & 2.43 & 0.1249 & 2.5549 \\
9.00 & 5.40 & 6.46 & 6.50 & 0.04 & 0.6198 & 2.16 & 0.2122 & 2.3722 \\
9.22 & 5.45 & 6.55 & 6.60 & 0.05 & 0.8333 & 1.96 & 0.6989 & 2.6589 \\
\hline
\end{tabular}

Log $_{\mathbf{1}}($ Average value $)=2.5832 \pm 0.1614$

Table 8:Point-wise method, Pb-(Hydrolysed PSHA)

\begin{tabular}{|l|l|l|l|l|l|l|l|l|}
\hline $\mathrm{pH}$ & $\mathrm{BV}_{1}$ & $\mathrm{BV}_{2}$ & $\mathrm{BV}_{3}$ & $\left(\mathrm{~V}_{3}-\mathrm{V}_{2}\right)$ & $\mathrm{n}$ & $\mathrm{pL}$ & $\log \left(\frac{n-1}{2-n}\right)$ & $\log \mathrm{K}_{2}$ \\
\hline 9.51 & 5.50 & 6.66 & 6.71 & 0.05 & 0.9650 & 1.67 & & \\
9.73 & 5.55 & 6.78 & 6.83 & 0.05 & 1.1702 & 1.44 & & \\
10.00 & 5.60 & 6.90 & 6.90 & 0.05 & 1.4864 & 1.22 & -0.0237 & 1.1963 \\
10.23 & 5.65 & 7.05 & 7.10 & 0.05 & 2.0190 & 1.09 & & \\
10.49 & 5.70 & 7.10 & 7.17 & 0.07 & 3.6492 & 1.00 & & \\
\hline
\end{tabular}

Log $K_{2}$ (Average value) $=1.1963$

Table 9: Point-wise method, Pb (Unhydrolysed PSHA)

\begin{tabular}{|l|l|l|l|l|l|l|l|l|}
\hline $\mathrm{pH}$ & $\mathrm{BV}_{1}$ & $\mathrm{BV}_{2}$ & $\mathrm{BV}_{3}$ & $\mathrm{~V}_{3}-\mathrm{V}_{2}$ & $\mathrm{n}$ & $\mathrm{pL}$ & $\begin{array}{l}\text { Log } \\
\left(\frac{n}{n-1}\right)\end{array}$ & Log $\mathrm{K}_{1}$ \\
\hline 8.50 & 5.30 & 5.81 & 5.85 & 0.04 & 0.2973 & 2.88 & -0.3736 & 2.5064 \\
8.72 & 5.35 & 5.90 & 5.94 & 0.04 & 0.3099 & 2.66 & -0.5477 & 2.3123 \\
9.00 & 5.40 & 6.00 & 6.05 & 0.05 & 0.4044 & 2.38 & -0.1681 & 2.2119 \\
9.22 & 5.45 & 6.10 & 6.15 & 0.06 & 0.5157 & 2.18 & 0.0272 & 2.2072 \\
9.51 & 5.50 & 6.20 & 6.26 & 0.07 & 0.6417 & 1.89 & 0.2530 & 2.1430 \\
9.73 & 5.55 & 6.40 & 6.40 & 0.07 & 0.7000 & 1.67 & 0.3680 & 2.0380 \\
\hline
\end{tabular}

LogK $_{1}$ (Average value) $=2.2364 \pm 0.1602$

Table 10: Point-wise method, Pb (Unhydrolysed PSHA)

\begin{tabular}{|l|l|l|l|l|l|l|l|l|}
\hline $\mathrm{pH}$ & $\mathrm{BV}_{1}$ & $\mathrm{BV}_{2}$ & $\mathrm{BV}_{3}$ & $\mathrm{~V}_{3}-\mathrm{V}_{2}$ & $\mathrm{n}$ & $\mathrm{pL}$ & $\log \left(\frac{n-1}{2-n}\right)$ & $\log \mathrm{K}_{2}$ \\
\hline 10.00 & 5.60 & 6.47 & 6.55 & 0.08 & 1.9503 & 1.41 & & \\
10.23 & 5.65 & 6.62 & 6.72 & 0.11 & 1.4792 & 1.26 & -0.0361 & 1.2239 \\
\hline
\end{tabular}

$\operatorname{LogK}_{2}$ (Average value) $=1.2239$

Table 11: Point-wise method, Mg (Hydrolysed PSHA)

\begin{tabular}{|l|l|l|l|l|l|l|l|l|}
\hline $\mathrm{pH}$ & $\mathrm{BV}_{1}$ & $\mathrm{BV}_{2}$ & $\mathrm{BV}_{3}$ & $\left(\mathrm{~V}_{3}-\mathrm{V}_{2}\right)$ & $\mathrm{n}$ & $\mathrm{pL}$ & $\log \left(\frac{n}{n-1}\right)$ & LogK $_{1}$ \\
\hline 8.50 & 5.30 & 6.29 & 6.31 & 0.02 & 0.2750 & 2.64 & -0.4290 & 2.2110 \\
8.72 & 5.35 & 6.37 & 6.39 & 0.02 & 0.2858 & 2.42 & -0.3978 & 2.0222 \\
9.00 & 5.40 & 6.46 & 6.49 & 0.03 & 0.4648 & 2.14 & -0.0612 & 2.0788 \\
9.22 & 5.45 & 6.55 & 6.59 & 0.04 & 0.6667 & 1.94 & 0.3010 & 2.2410 \\
\hline
\end{tabular}

$\log _{\mathbf{1}}($ Average value) $=2.1382 \pm 0.1046$ 
BAJOPAS Volume 14 Number 1,June, 2021

Table 12: Point-wise method, Mg (Hydrolysed PSHA)

\begin{tabular}{|l|l|l|l|l|l|l|l|l|}
\hline $\mathrm{pH}$ & $\mathrm{BV}_{1}$ & $\mathrm{BV}_{2}$ & $\mathrm{BV}_{3}$ & $\left(\mathrm{~V}_{3}-\mathrm{V}_{2}\right)$ & $\mathrm{n}$ & $\mathrm{pL}$ & $\log \left(\frac{n-1}{2-n}\right)$ & LogK $_{2}$ \\
\hline 9.51 & 5.55 & 6.66 & 6.71 & 0.05 & 0.9650 & 1.67 & & \\
9.73 & 5.55 & 6.78 & 6.84 & 0.06 & 1.4042 & 1.47 & -0.1686 & 1.3014 \\
10.00 & 5.60 & 6.90 & 6.93 & 0.06 & 1.7838 & 1.23 & 0.5593 & 1.7893 \\
10.23 & 5.65 & 7.05 & 7.10 & 0.06 & 3.1429 & 1.10 & & \\
10.49 & 5.70 & 7.10 & 7.18 & 0.07 & 3.6492 & 0.83 & & \\
\hline
\end{tabular}

LogK $_{2}($ Average value $)=1.5453 \pm 0.3450$

Table 13: Point-wise method, Mg (Unhydrolysed PSHA)

\begin{tabular}{|l|l|l|l|l|l|l|l|l|}
\hline $\mathrm{pH}$ & $\mathrm{BV}_{1}$ & $\mathrm{BV}_{2}$ & $\mathrm{BV}_{3}$ & $\mathrm{~V}_{3}-\mathrm{V}_{2}$ & $\mathrm{n}$ & $\mathrm{pL}$ & $\log \left(\frac{n}{n-1}\right)$ & $\operatorname{Log~}_{1}$ \\
\hline 8.50 & 5.30 & 5.81 & 5.85 & 0.04 & 0.2973 & 2.88 & -0.3736 & 2.5064 \\
8.72 & 5.35 & 5.90 & 5.94 & 0.04 & 0.3099 & 2.66 & -0.3477 & 2.3123 \\
9.00 & 5.40 & 6.00 & 6.04 & 0.04 & 0.3236 & 2.38 & -0.3202 & 2.0598 \\
9.22 & 5.45 & 6.10 & 6.15 & 0.05 & 0.4297 & 2.17 & -0.1230 & 2.0470 \\
9.51 & 5.50 & 6.20 & 6.26 & 0.06 & 0.5500 & 1.89 & 0.0871 & 1.9771 \\
9.73 & 5.55 & 6.33 & 6.40 & 0.07 & 0.7000 & 1.67 & 0.3680 & 2.0380 \\
\hline
\end{tabular}

LogK $_{1}$ (Average value) $=2.1568 \pm 0.2069$

Table 14: Point-wise method, Mg (Unhydrolysed PSHA)

\begin{tabular}{|l|l|l|l|l|l|l|l|l|}
\hline $\mathrm{pH}$ & $\mathrm{BV}_{1}$ & $\mathrm{BV}_{2}$ & $\mathrm{BV}_{3}$ & $\mathrm{~V}_{3}-\mathrm{V}_{2}$ & $\mathrm{n}$ & $\mathrm{pL}$ & $\log \left(\frac{n-1}{2-n}\right)$ & $\log \mathrm{K}_{2}$ \\
\hline 10.00 & 5.60 & 6.47 & 6.55 & 0.08 & 0.9148 & 1.41 & & \\
10.23 & 5.65 & 6.62 & 6.71 & 0.09 & 1.2102 & 1.20 & -0.5749 & 0.6251 \\
10.49 & 5.70 & 6.80 & 6.92 & 0.09 & 1.5968 & 1.03 & 0.1703 & 1.2003 \\
\hline
\end{tabular}

LogK $_{2}$ (Average value) $=0.9127 \pm 0.4070$

Table15:Point-wise method, Cd (Hydrolysed PSHA)

\begin{tabular}{|l|l|l|l|l|l|l|l|l|}
\hline $\mathrm{pH}$ & $\mathrm{BV}_{1}$ & $\mathrm{BV}_{2}$ & $\mathrm{BV}_{3}$ & $\left(\mathrm{~V}_{3}-\mathrm{V}_{2}\right)$ & $\mathrm{n}$ & $\mathrm{pL}$ & $\log \left(\frac{n}{1-n}\right)$ & LogK $_{1}$ \\
\hline 8.50 & 5.30 & 6.29 & 6.31 & 0.02 & 0.2750 & 2.64 & -0.4210 & 2.2190 \\
8.72 & 5.35 & 6.37 & 6.40 & 0.03 & 0.4286 & 2.42 & -0.1249 & 2.2951 \\
9.00 & 5.40 & 6.46 & 6.49 & 0.03 & 0.4648 & 2.14 & -0.0612 & 2.0788 \\
9.22 & 5.45 & 6.55 & 6.59 & 0.04 & 0.6667 & 1.96 & 0.3010 & 2.2610 \\
9.51 & 5.55 & 6.66 & 6.70 & 0.04 & 0.7720 & 1.67 & 0.5297 & 2.1997 \\
\hline
\end{tabular}

LogK $_{\mathbf{1}}$ (Average value) $=2.2108 \pm 0.0825$

Table 16: Point-wise method, Cd (Hydrolysed PSHA)

\begin{tabular}{|l|l|l|l|l|l|l|l|l|}
\hline $\mathrm{pH}$ & $\mathrm{BV}_{1}$ & $\mathrm{BV}_{2}$ & $\mathrm{BV}_{3}$ & $\left(\mathrm{~V}_{3}-\mathrm{V}_{2}\right)$ & $\mathrm{n}$ & $\mathrm{pL}$ & $\log \left(\frac{n-1}{2-n}\right)$ & Log $_{2}$ \\
\hline 9.73 & 5.55 & 6.78 & 6.83 & 0.06 & 1.4042 & 1.47 & -0.1686 & 1.3014 \\
10.00 & 5.60 & 6.90 & 6.95 & 0.06 & 1.7838 & 1.23 & 0.5593 & 1.7893 \\
10.23 & 5.65 & 7.05 & 7.10 & 0.06 & 3.1429 & 1.09 & & \\
10.49 & 5.70 & 7.10 & 7.16 & 0.06 & 3.1429 & 0.89 & & \\
& & & & & & & & \\
\hline
\end{tabular}

$\operatorname{LogK}_{2}$ (Average value) $=1.5453 \pm 0.3450$

Table 17: Point-wise method, Cd (Unhydrolysed PSHA)

\begin{tabular}{|l|l|l|l|l|l|l|l|l|}
\hline $\mathrm{pH}$ & $\mathrm{BV}_{1}$ & $\mathrm{BV}_{2}$ & $\mathrm{BV}_{3}$ & $\mathrm{~V}_{3}-\mathrm{V}_{2}$ & $\mathrm{n}$ & $\mathrm{pL}$ & $\log \left(\frac{n}{n-1}\right)$ & $\operatorname{Log~}_{1}$ \\
\hline 8.50 & 5.30 & 5.81 & 5.86 & 0.05 & 0.3717 & 2.88 & -0.2280 & 2.6520 \\
8.72 & 5.35 & 5.90 & 5.95 & 0.05 & 0.3873 & 2.66 & -0.1992 & 2.4608 \\
9.00 & 5.40 & 6.00 & 6.06 & 0.06 & 0.4853 & 2.38 & -0.0255 & 2.3545 \\
9.22 & 5.45 & 6.10 & 6.16 & 0.06 & 0.5157 & 2.18 & -0.0272 & 2.2072 \\
9.51 & 5.50 & 6.20 & 6.27 & 0.07 & 0.6417 & 1.89 & 0.2530 & 1.1430 \\
9.73 & 5.55 & 6.33 & 6.41 & 0.08 & 0.8000 & 1.69 & 0.6020 & 2.2920 \\
& & & & & & & & \\
\hline
\end{tabular}

$\operatorname{LogK}_{1}($ Average value $)=2.2516 \pm 0.5380$ 
BAJOPAS Volume 14 Number 1,June, 2021

Table 18: Point-wise method, Cd (Unhydrolysed PSHA)

\begin{tabular}{|l|l|l|l|l|l|l|l|l|}
\hline $\mathrm{pH}$ & $\mathrm{BV}_{1}$ & $\mathrm{BV}_{2}$ & $\mathrm{BV}_{3}$ & $\mathrm{~V}_{3}-\mathrm{V}_{2}$ & $\mathrm{n}$ & $\mathrm{pL}$ & $\log \left(\frac{n-1}{2-n}\right)$ & $\log \mathrm{K}_{2}$ \\
\hline 10.00 & 5.60 & 6.47 & 6.57 & 0.10 & 1.1434 & 1.43 & & \\
10.23 & 5.65 & 6.62 & 6.72 & 0.10 & 1.3448 & 1.23 & -0.2788 & 0.9512 \\
10.49 & 5.70 & 6.80 & 6.90 & 0.10 & 1.7742 & 1.03 & 0.5351 & 1.5651 \\
\hline
\end{tabular}

$\operatorname{LogK}_{2}($ Average value $)=1.2581 \pm 0.4340$

Table 19: Stepwise and overall Stability constants of thehydrolysed and unhydrolysed divalent metal (II) complexes

\begin{tabular}{|c|c|c|c|}
\hline Chelates & LogK $_{1}$ & $\log _{2}$ & Log $\beta$ \\
\hline [Cu (Hydrolysed PSHA-1) $\left.{ }_{2}\right]$ & 2.4788 & 1.4280 & 3.9068 \\
\hline$\left[\mathrm{Pb}(\text { Hydrolysed PSHA-1) })_{2}\right]$ & 2.5832 & 1.1963 & 3.7795 \\
\hline$\left[\mathrm{Cd}(\text { Hydrolysed PSHA-1 })_{2}\right]$ & 2.2108 & 1.5453 & 3.7561 \\
\hline$\left[\mathrm{Mg}(\text { Hydrolysed PSHA-1 })_{2}\right]$ & 2.1382 & 1.5453 & 3.6835 \\
\hline [Cu (Unhydrolysed PSHA-1) & 2.3059 & 1.2209 & 3.5268 \\
\hline$[\mathrm{Pb}$ (Unhydrolysed PSHA-1) 2$]$ & 2.2364 & 1.2239 & 3.4603 \\
\hline [Cd (Unhydrolysed PSHA-1) 2 ] & 2.2516 & 1.2581 & 3.5097 \\
\hline$[\mathrm{Mg}$ (Unydrolysed PSHA-1) & 2.1568 & 0.9127 & 3.0695 \\
\hline
\end{tabular}

The results obtained (Table19) shows the stepwise and overall stability constants to be not high indicating low stability of the complexes, because the solubility of most metal ions in the basic $\mathrm{pH}$ range is minimal due to metal hydroxide precipitation (Karimi, 2017). In general, the stepwise stability constants $\left(K_{1}\right.$ and $K_{2}$ ) follow the order $K_{1}>K_{2}$ for the copper, lead, magnesium and cadmium complexes respectively. The steady decrease of the values with increasing number of ligands is in agreement with the prediction made by researchers (Na'aliya, 2013). The decrease could be attributed to the fact that as the number of the ligands (Humate ions) that enters the coordination zone increases the aqua molecules available for replacement by the ligands become less. Thus, the metal ions become less electron loving with progressive intake of the ligand and this results in the decrease in the values of the constants (Na'aliya, 2013). Also the stability of the complexes is influenced by the size and number of the chelate rings(Mackay and Mackay,2002).All the complexes form rings in their structure as humate, a bidentate ligand, bond the metal ions in the ratio 1:2 (Boguta and Sokolowska, 2016) forming chelate rings. The values of the overall stability constants $(\log \beta)$ obtained for humate complexes are not high indicating low stability as the values are not high. LogK values for copper-humates (Table 3 to 6) obtained in this study are lower than those reported for the complexes of humic acids (Pandey et al., 2015; Dinu, 2013; Kaschl et al., 2010 and Gilbeto and Jorg, 2001). The values of LogK(Table 7 to 10 ) forlead-humates are lower than those reported for the lead in the literature (Dinu, 2013; Gilbeto and Jorg 2001). Log K values(Table 11 to 14 ) for magnesium-humates obtained in this study are close to those reported by (Pandey et al., 2015). Log K values of cadmium-humates (Table 15 to 18 ) obtained in this work near to the one reported by (Dinu, 2013 and Pandey et al., 2015).The difference between the reported values and the values obtained in this study might be probably as a result of acid hydrolysis of humic acid. The values of the overall stability constants $(\log \beta)$ of the copper humates complexes presented in Table 19 is high than that of other metal humate complexes, show relatively high stability of CuHA complexes, show the following order of stability: $\mathrm{Cu}>\mathrm{Pb}>\mathrm{Cd}>\mathrm{Mg}$; which are in close agreement to the findings of (Dinu, 2013 and Pandey et al., 2015).The high stability of Cuhumate chelate could be attributed to the existence of coordinate covalent bond between the complexing agents and the $\mathrm{Cu}^{2+}$ ions. Since, $\mathrm{Cu}^{2+}$ being a metal of the transitional series with $3 d^{9}$ electronic configurations can accept the electrons from the complexing agents. Similarly, the low stabilities of $\mathrm{Pb}, \mathrm{Cd}$ and $\mathrm{Mg}$ complexes could be explained by that $\mathrm{Pb}^{2+}$ with $6 s^{2}, \mathrm{Cd}^{2+}$ with $4 \mathrm{~d}^{10}$ and $\mathrm{Mg}^{2+}$ with $2 \mathrm{p}^{6}$ their electronic configuration has a completely filled $\mathrm{d}, \mathrm{p}$ and $\mathrm{s}$ orbitals. Moreover, the stabilities of metal ions with hydrolysed humic acid from peat soil were higher than those with unhydrolysed humic acid from peat soil; which is ascribed to the high content of acidity in hydrolysed humic acid than unhydrolysed humic acid. 
BAJOPAS Volume 14 Number 1,June, 2021 CONCLUSION

The values of logk for $\mathrm{Cu}(\mathrm{II})$ hydrolysed humic acid complex was higher followed by $\mathrm{Pb}$ (II), $\mathrm{Cd}(\mathrm{II})$ and $\mathrm{Mg}$ (II) hydrolysed humic acid complexes as compared with metal(II) unhydrolysed humic acid complexes. This indicates acid hydrolysis of humic acid can

\section{REFERENCES}

Almeida, V.R. and Szpoganicz, B. (2015). Humic Acid Potentiometric Response Patterns:Out- of Equilibrium Properties and Species Distribution Modelling. Chemical. Biol. Technol. Agric. 2: 17.

Anđelković, T., Nikolić, R., Bojić, A.,Anđelković, D., and Nikolic G.,(2010). Binding of Cadmium to Soil Humic Acid as A Function of Carboxyl Group Content. Macedonian Journal of Chemistry and Chemical Engineering.29(2): 215-224.

Anil, B. N. and Maroti, N. (2008). Studies on Influence of Die-Lectric Constants on Complex Equilibria between Substituted Py-Razalines and Lanthanide Metal Ions pH-Metrically. Amer.-Euras. scient. Res. 3(2): 212-216.

Ashok, K., Pandey, S. P. and Misra, V (2000). Stability Constants of Metal-Humic Acid Complexes and its Role in Environmental Detoxification. Journal of Ecotoxicology and Environmental Safety. 47(2):157-200.

Badr, M. H., El-Halafawi, M. H. and Abd El-al Zeid, E. R. (2012). Comparison Between the Effect of Ionic Strength on Acidity and Dissociation Constants of Humic Acids Extracted from Sewage Sludge and Nile Water Hyacinth Composts.Global Journal of Environmental Research 6 (1): 36-43.

Baruah, M.K., Borah, D., Saikia, P.P., Paul, S., Sharma, T. (2015). Evaluation of pKa Values of Soil Humic Acids and their Complexation Properties. International Journal of Plant \& Soil Science 6(4) : 218-228.

Boguta, P. Sokolowska, Z. (2016). Interactions of $\mathrm{Zn}$ (II) Ions with Humic Acids Isolated from Various Types of Soils. Effect of $\mathrm{pH}, \mathrm{Zn}$ Concentrations and Humic Acids Chemical Properties. Journal of Geochemical Explaration 168. 119-126.

Borges, F., Guimaraes, C., Lima, L.F.C., Pinto, I. and Reis, S.(2005). Potentiometric Studies on the Complexation of Copper(II) by Phenolic Acids as Discrete Ligand Models of enhance the complexation behavior of humic acid with metal (II) ions. However, the higher values of $\log \beta$ for $\mathrm{Cu}(\mathrm{II}), \mathrm{Pb}(\mathrm{II}), \mathrm{Cd}(\mathrm{II})$ and $\mathrm{Mg}(\mathrm{II})$ hydrolysed humic acid complexes indicates more stable stepwise complexes formed as compared with $\mathrm{Cu}(\mathrm{II}), \mathrm{Pb}$ (II), $\mathrm{Cd}$ (II) and $\mathrm{Mg}(\mathrm{II})$ unhydrolysed humic acid complexes.

Humic Substances Talanta 66 (2005) 670-673.

Chefetz, B., Salloum, M. J., Deshmulkin, A. P. and Hatcher, P. (2002). Structural Components of Humic Acids as Determined by Chemical Modifications and Carbon-13 NMR, Pyrolysis, and Thermochemolysis- Gas Chromatography/Mass Spectrometry. Soil Science Society of American Journal Abstract Division S-2- Soil Chemistry66. 1159-1171.

Dinu, M. I. (2013). Metals Complexation with Humic Acids in Surface Water of Different Environ. Sci. Technol. 31(1): 1-17.

Fernandes, A.N., Giacomelli, C., Giovanela, M. Vaz, D.V. Szpoganicz, B. and Maria M. D. (2009). Potentiometric Acidity Determination in Humic Substances Influenced by Different Analytical Procedures.J. Braz. Chem. Soc. 20 (9):14.

Gamal, A. H. (2015). Stability Constants of Rhenium (V) Metal Complexes with Selected Drugs. Pyrex Journal of Research in Environmental Studies. 2(2): 006-014.

Janrao, D. M., Pathan, J., Kayande, D.D., and Mulla, J.J. (2014). An Over View of Potentiometric Determination of Stability Constants of Metal Complexes. Sci. Revs. Chem. Commun.: 4(1), 2014, 11-24.

Karimi, H. (2017). Effect of pH and Initial Pb(II) Concentration on the Lead Removal Efficiency from Waste Water Using $\mathrm{Ca}(\mathrm{OH})_{2}$. International Journal of Water and Waste Water Treatment 3.2

Kaschl, A. Romheld, V. and Chen, Y. (2010). Binding of Cadmium, Copper and Zinc to Humic Substances Originating from Municipal Solid Waste Compost. Israel Journal of Chemistry Vol. 42(1): 89-98.

Kostic, I. S., Tatjana, P, A., Nikolic, R. S., Cvetkovic, T. P., Pavlovic, D. D., Aleksandar, L.J. and Bojic, A. (2012). Comparative Study of Binding Strengths of Heavy Metals with Humic Acid. J.serb. Chem. Soc. 76(9) pp 1-20. 
BAJOPAS Volume 14 Number 1,June, 2021

Na'aliya, J. (2013). Determination of Stepwise Stability Constants and Gibbs free Energy Change of Trisprolina to Complexes of some Divalent Transition Metal ions. Bayero Journal of Pure and Applied Sciences 6(2): 112-114.

Omar, A. A. and Ali, E. A. (2015). Potentiometric Studies on Complexes of $\mathrm{Cr}$ (III) and $\mathrm{Zr}$ (IV) with some Carboxylic Acids. International Journal of Advanced Chemistry, 3(1) 25-

37.

Pandey, A. K. Pandey, S. D. and Misr, V. (2015).Stability Constants of Metal- Humic Acid Complexes and Its Role in Environmental Detoxification. J. Ecotoxicology and Environmental Safety. 47(1):195-200.

Ram, N. and Raman, K.V. (1984). Stability Constants of Complexes of Metals with
Humicand Fuvic Acids under Non- acidConditions. Journal of Plant Nutrition and Soil Sciences.

147:171-176.

Santosh, D. D., Ashok, B. K., Vijay, J. T., Shivraj, G. W. and Vinay, V. W. (2011). Potentiometric Studies of Elec-Trolyte Effects on Complex Equilibria of Some Substituted 5-(2-hydroxy Phenyl) Pyrazoles. Der pharm. 3 (6): 75-83.

Sayyed, H. and Abdul Rahim, M. F. (2012). Studies of Binary Complexes of Metal Ions with Mandelic Acid by Potentiometry. Chem. J. 02 (6): 206209.

Shirvani, M. Moradian, E. Khalili, B. Bakhtiary, S. (2015). Interaction of $\mathrm{Cd}$ and $\mathrm{Pb}$ with Humate-Palygorskite and HumateSepiolite Complexes. Journal of water, air and pollution 3: 220-228. 


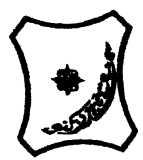

Bayero Journal of Pure and Applied Sciences, 14(1): 54 - 63

Received: November, 2020

Accepted: April, 2021

ISSN $2006-6996$

\title{
STABILITY CONSTANTS OF COMPLEXES OF METAL IONS WITH PEATSOIL HUMIC ACIDS UNDER NON-ACID-CONDITIONS
}

\author{
${ }^{* 1}$ Sabo, Yusuf ${ }^{2}$ Jimoh, W.L.O., ${ }^{3}$ Isa Baba Koki and ${ }^{4}$ Sholadoye, Q. 0. \\ ${ }^{1}$ Department of Pure and Industrial Chemistry, Bayero University, Kano \\ ${ }^{3}$ Department of Chemistry, Yusuf Maitama Sule University Kano. P.M.B. 3220 Kano, Nigeria. \\ ${ }^{4}$ Department of Chemistry, Nigerian Police Academy, Wudil, Kano-Nigeria
}

*Correspondence E-mail; saboyusuf18@yahoo.com

ABSTRACT

Stability constants of complexes of four divalent metal ions viz. $\mathrm{Cu}^{2+}, \mathrm{Pb}^{2+}, \mathrm{Mg}^{2+}$ and $\mathrm{Cd}^{2+}$ with humic acids (HA) were determined by potentiometric titration of humic acids with the corresponding salt of the divalent metals in aqueous media under non-acid-condition. The log $K$ (logarithm of the stability constant) ranged from 1.0942 to 2.7471 for metalhumic acid complexes were determined using point-wise computational method. The order of stability constants were obtained as follows: $\mathrm{Cu}>\mathrm{Pb}>\mathrm{Cd}>\mathrm{Mg}$ for metal $-\mathrm{HA}$ complexes respectively, indicating a higher degree of complexation with Cu metal ion.

Keywords: stability constant, humic acid, potentiometric titration, divalent metals, acid hydrolysis.

\section{NTRODUCTION}

The stability constant of a complex is the numerical expression of its stability and provides a quantitative measure of affinity of the metal ion to the complexing agent. An understanding of the relative stability of metal-complexes helps in predicting the behavior of metal ions in the soil (Ram and Raman, 1982). Extensive researches has been done to determine the stability constants of the complexes formed between humic acid (HA) with a number of metal ions. Ashok et al., (2000) reported that humic acid with hydroxyl, phenoxyl and carboxyl reactive groups can form coordination compound with metal ions at $\mathrm{pH}$ 3.5. The stability constants(Log K) for different metalhumic acid complexes indicated the following order of the stabilities of complexes formed between humic acid and metal ion, $\mathrm{Cu}>\mathrm{Fe}$ $>\mathrm{Pb}>\mathrm{Ni}>\mathrm{Co}>\mathrm{Ca}>\mathrm{Cd}>\mathrm{Zn}>\mathrm{Mn}>\mathrm{Mg}$. Andelkovic et al., (2010) investigated the binding of $\mathrm{Cd}$ (II) to soil humic acid at pH 6.5 and in $0.1 \mathrm{M} \mathrm{KNO}_{3}$ ionic medium. The stability constant for binding indicating greater stability in the case when carboxyl groups are involved in complexation reaction. Kostic et al.,(2012) investigated the complexation of humic acid with certain heavy metal ions (Co(II), $\mathrm{Ni}(\mathrm{II}), \mathrm{Cu}(\mathrm{II})$,
$\mathrm{Zn}(\mathrm{II})$, and $\mathrm{Pb}(\mathrm{II})$. The experiment was performed at $25^{\circ} \mathrm{C}$, at pH 4.0 and ionic strength of $0.01 \mathrm{M}$. Stability constant of complex between $\mathrm{Pb}$ (II) ions and humic acid is greater than stability constants of other investigated metalhumate complexes. Bogata and Sokolowska (2016) analyses the interaction between humic acids from different soils and $\mathrm{Zn}$ (II) ions at wide concentration ranges and at $\mathrm{pH} 5$. Studies have showed significant impact of $\mathrm{Zn}$ concentration, $\mathrm{pH}$ and some properties of humic acids with zinc.But all of these studies were limited to acidic $\mathrm{pH}$ range. Therefore, the present study was carried out to determine and compare the stability constants of complexes of metal ions with hydrolysed peat soil humic acid and unhydrolysed peat soil humic under non-acid conditions.

\section{MATERIALS AND METHODS}

Analytical grade chemicals used includes hydrochloric acid $(\mathrm{HCl})$, nitric acid $\left(\mathrm{HNO}_{3}\right)$, sodium hydroxide $(\mathrm{NaOH})$, lead nitrate $\mathrm{Pb}\left(\mathrm{NO}_{3}\right)_{2}$, copper nitrate $\mathrm{Cu}\left(\mathrm{NO}_{3}\right)_{2} \cdot 3 \mathrm{H}_{2} \mathrm{O}$, cadmium nitrate $\mathrm{Cd}\left(\mathrm{NO}_{3}\right)_{2} \cdot 4 \mathrm{H}_{2} \mathrm{O}$, magnesium nitrate $\mathrm{Mg}\left(\mathrm{NO}_{3}\right)_{2} \cdot 6 \mathrm{H}_{2} \mathrm{O}$, potassium nitrate $\left(\mathrm{KNO}_{3}\right)$, calcium chloride $\left(\mathrm{CaCl}_{2}\right)$, (sigma-Aldrich). Dowex 50WX8, (20-50 mesh) from Fluka. 


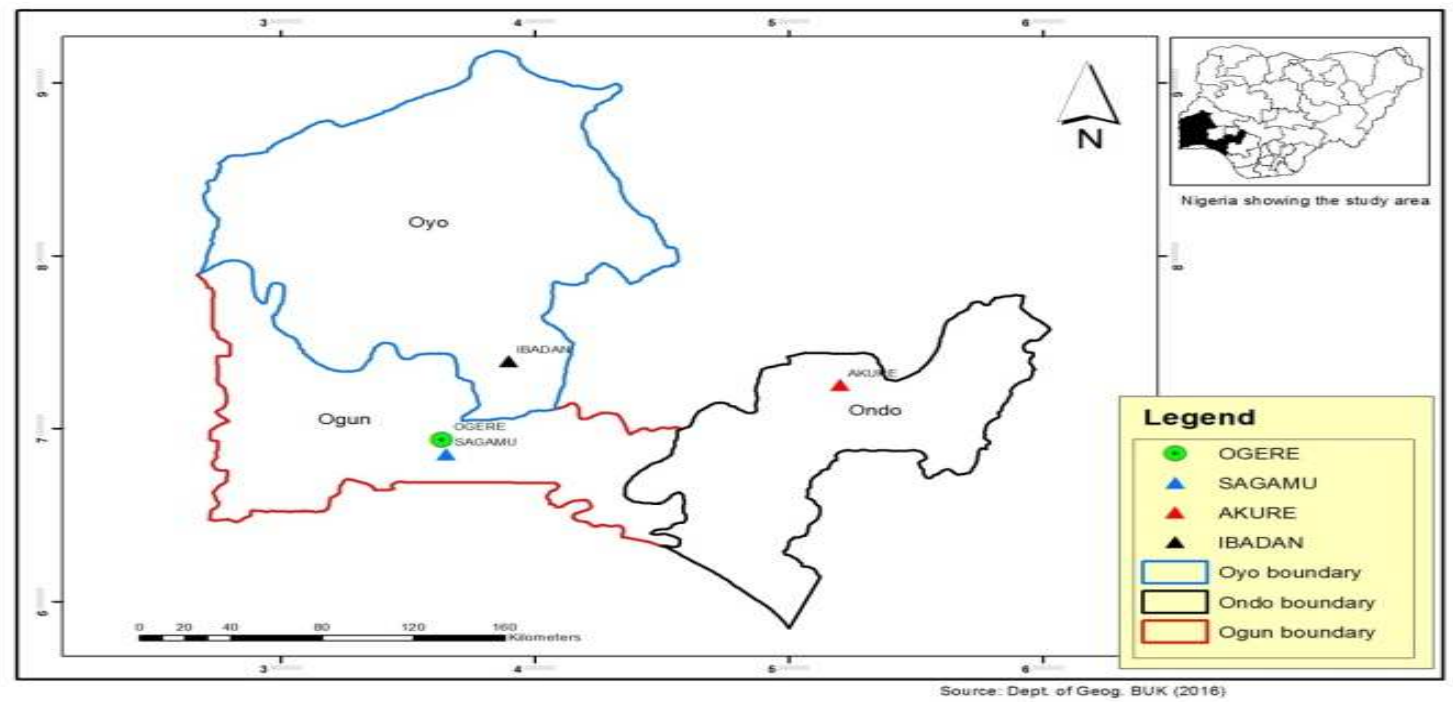

Figure 1: Map showing the sampling point at Sagamu Town, Ogun State.

\section{Description of Sampling Area}

Sagamu has geographical coordinates between $6^{\circ} 50^{\prime}$ north; $3^{\circ} 38^{\prime}$ east is located in south western region of Nigeria. The region has tropical wet and dry climate with a lengthy wet season and relatively constant temperatures throughout the course of the year. Wet season runs from March to October, November to December forms the region dry season. The vegetation type of the region is savannah which is really grassland with small bushes and occasional big trees. Grassland soils have substantially higher organic matter content than forest soils (Novackova, 2011).

\section{Sample Collection}

The Peatsoil samples were collected from four different sampling points $(0-10 \mathrm{~cm}$ depth) in Sagamu into polyethylene bag with plastic spoons. Samples were taken to the laboratory, extraneous materials were removed; the samples were air-dried, crushed and ground to a fine powder in a mortar passed through a $0.20 \mathrm{~mm}$ sieve. The samples were kept for analysis.

\section{Isolation and purification of humic acid from peat soil sample}

Peatsoil sample $(100 \mathrm{~g})$ was mixed with 1000 $\mathrm{cm}^{3}$ of $0.1 \mathrm{M} \mathrm{NaOH}$ solution, shaken for 3hours and left to stand overnight. Dark-coloured supernatant was obtained and decanted from solid residue. The dark-coloured supernatant was acidified to $(\mathrm{pH}=1.0)$ with $6 \mathrm{M} \mathrm{HCl}$ stirred and allowed to stand for 6 hours. Yellowish brown supernatant and dark-brown precipitate were obtained. The yellowish brown supernatant was decanted followed by centrifuge and discarded. The dark-brown precipitate was mixed with $500 \mathrm{~cm}^{3}$ of $0.1 \mathrm{M} \mathrm{NaOH}$ solution followed by passing through dowex resin. The dark-brown solution was acidified to $(\mathrm{pH}=1.0)$ with $6 \mathrm{M} \mathrm{HCl}$ stirred and allowed to stand for 3 hours. The dark-brown precipitate was washed several times with deionized water. The supernatant was treated with $\mathrm{AgNO}_{3}$ solution until no white precipitate observed. The humic acid was transferred to weighed crucible and dried at $60^{\circ} \mathrm{C}$ in an oven for 12 hours. The humic acid was cooled and dried in the desiccator, weighed and recorded. The obtained humic acid was dried again at $60^{\circ} \mathrm{C}$ for additional 6 hours cooled and dried in the desiccator, weighed and recorded constant weight was obtained (Baruah et al., 2015).

\section{FT-IR analysis}

FT-IR spectra of humic acid sample was analysed using Carry 630 FT-IR Agilent Technologies.

Unhydrolysed compost humic acid

The unhydrolysed humic acid was obtained after isolation and purification of compost humic acid and kept for investigation.

\section{Acid hydrolysis of Peatsoil acid}

Peatsoil humic acid sample (1g) was refluxed for 12 hours at $\left(160^{\circ} \mathrm{C}\right)$ with $50 \mathrm{~cm}^{3}$ of $6 \mathrm{M} \mathrm{HCl}$. The mixture was allowed to cool, decanted, and centrifuged after hydrolysis. The insoluble residues were washed with distilled water via centrifugation several times, and the supernatant was treated with $\mathrm{AgNO}_{3}$ solution until no white precipitate was observed. The residue was thoroughly dried over $\mathrm{CaCl}_{2}$ in a desiccator at room temperature (Chefetz et al., 2002). Finally, the obtained hydrolysed humic acid was kept for investigation. 
BAJOPAS Volume 14 Number 1,June, 2021 Potentiometric Titrations

Potentiometric measurements were carried out using a pH-meter Jenway (model 3510) with combine electrode, the sensitivity of the $\mathrm{pH}$ meter is 0.01 units. The $\mathrm{pH}$ meter was switched on half an hour before starting the titration for initial warm up of the instrument. The instrument was calibrated with an aqueous standard buffer solution of $\mathrm{pH} 4.00$ and 10.0 (borate buffer) prepared from a "Qualigens" buffer tablets.

The following sets of solutions were prepared in a $250 \mathrm{~cm}^{3}$ volumetric flask separately for $\mathrm{pH}$ metric titrations.

(i) $5 \mathrm{~cm}^{3} 0.1 \mathrm{M} \mathrm{HCl}+40 \mathrm{~cm}^{3}$ deionized water

(ii) $5 \mathrm{~cm}^{3} 0.1 \mathrm{M} \mathrm{HCl}+39 \mathrm{~cm}^{3}$ deionized water $+1 \mathrm{~cm}^{3} 0.15 \mathrm{gcm}^{-3}$ humic acid

(iii) $5 \mathrm{~cm}^{3} 0.1 \mathrm{M} \mathrm{HCl}+37 \mathrm{~cm}^{3}$ deionized water $+1 \mathrm{~cm}^{3} 0.15 \mathrm{gcm}^{-3}$ humic acid

$$
+2 \mathrm{~cm}^{3} \quad 0.01 \mathrm{M} \mathrm{Cu} \text { (II) }
$$

The solutions were titrated against standardized $0.110 \mathrm{MNaOH}$ separately. The total volume of each mixture was adjusted to $50 \mathrm{~cm}^{3}$ and the ionic strength of the solutions was maintained constant at by adding appropriate amount of stock solution of $1 \mathrm{M} \mathrm{KNO}_{3}$ (Gamal, 2015; Omar and Ali, 2015). A magnetic stirrer was used to achieve thorough mixing of the interacting solutions at $550 \mathrm{rpm}$. The same set of experimental conditions was applied for potentiometric titration of remaining samples.

\section{Evaluation of pKa of Hydrolysed peat soil Humic Acids}

The proton-ligand formation number $\mathrm{n}_{\mathbf{A}}$ were calculated by Irving and Rossotti expression (Omar and Ali, 2015).

$\mathrm{nA}=\mathrm{Y}-\frac{(\mathrm{V} 2-\mathrm{V1})(\mathrm{No}-\mathrm{Eo})}{(\mathrm{VO}+\mathrm{V1}) \mathrm{TCL}}$ 1

Where: $Y$ is number of dissociable proton, $\left(\mathrm{V}_{2^{-}}\right.$ $V_{1}$ ) is the measure of displacement of the ligand curve relative to acid curve, $\mathrm{N}^{\circ}$ and $\mathrm{E}^{\circ}$ are the resultant concentration of alkali solution, free acid solution, $\mathrm{T}_{\mathrm{cL}}{ }^{\circ}$ is the total ligand concentration, $\mathrm{V}^{\circ}$ is the total volume of titration solution, $V_{1}$ is the volume of alkali added to acid solution, $V_{2}$ is the volume of alkali added to acid solution + ligand solution, acid dissociation constants (pKa - values) of ligand were calculated by algebraic method point wise calculation (Tables 1 ). The dissociation constants (pKa) were calculated according to the following relation:

$\mathrm{pKa}=\mathrm{pH}+\log \left(\frac{n A}{1-n A}\right)$ 2

Where: pKa is the acid dissociation constant, $\mathrm{n}_{\mathrm{A}}$ is the Proton-ligand formation number and $\mathrm{pH}$ is the pH-values (Omar and Ali, 2015).

\section{Determination of metal-ligand stability constants $(\log K)$ of complexes}

The potentiometric measurement for the determination of stability constant of a complex in solution is based on the fact that the redox potential of the couple $\frac{M^{+(m-n)}}{M^{+m}}$ is shifted significantly on complexation of the metal ion with the ligand. This method involves change in hydrogen ion concentration $\left[\mathrm{H}^{+}\right]$due to the displacement or association of one or more protons taking place during complexation reaction. This change can be found out by titrating the solutions containing free acid, acid with ligand, and acid with ligand and metal ion, individually against a standard alkali solution at a constant ionic strength or temperature. Either ionic strength or temperature may be varied for different sets of solutions. In all the cases, the change in the $\mathrm{pH}$ of the solution is measured after each addition of a known amount of alkali to the reaction cell which contains the reaction mixture. The titration curves are then drawn by plotting the measured $\mathrm{pH}$ values against the corresponding volume of alkali added and the stability constants of the complexes are determined from the titration curves by employing $\mathrm{pH}$-metric titration technique given by (Irving and Rossoti).

Metal-ligand stability constants ( $\log \mathrm{K}$ ) were determined by using the following relations:

$$
\bar{n}=\frac{\left(V_{3}-V_{2}\right)\left(E^{0}+N^{0}\right)}{\left(V^{0}+V_{2}\right) \bar{n}_{A} T_{m}^{0}}
$$

and

$$
P L=\log _{10}\left\{\frac{1+\beta_{n}^{H} \frac{1}{[\text { anti } \log \mathrm{pH}]^{\mathrm{n}}}}{\mathrm{T}_{\mathrm{L}}^{0}-n \bar{T}_{m}^{0}} \mathrm{X} \frac{\left(V^{0}+V_{3}\right)}{V^{0}}\right\}
$$


BAJOPAS Volume 14 Number 1,June, 2021

Where $T_{L}, T^{\circ}, E^{\circ}$, and $V^{\circ}$ havethe same significance as in equation (1) above, $T_{m}$ denotes the total concentration of metal present in solution, $V_{3}$ is the volume of metal ions present in solution and $\beta^{H}$ is the overall proton ligand stability constant. The metal-ligand stability constants (log K) were determined by employing point wise computational Method (eq. 5 and 6).

$\operatorname{LogK}_{1}=\log \left(\frac{n}{1-n}\right)+\mathrm{pL}$ .5

$\operatorname{LogK}_{2}=\log \left(\frac{1-n}{2-n}\right)+\mathrm{pL}$ ...6

Where: Log $\mathrm{K}$ is the metal-ligand stability constant, $\mathrm{pL}$ is the Free ligand exponent function, $\mathbf{n}$ is the Average number of ligand attached with metal ion (Janraoet al., 2014). The results obtained were analyzed by an ORIGIN 2016 program using titration data and then the proton-ligand stability constants (pKa) and Metal-ligand stability constant (LogK) calculated (Omar and Ali, 2015).

\section{RESULTS AND DISCUSSION}

Fourier transformed infrared (FT-IR) spectra of isolated humic acid from peat soils Figure 2 had distinct clear absorption bands indicating the presence of major humic acid structural elemental groups such as $\mathrm{H}$ bonded $\mathrm{OH}$ $\left(3680 \mathrm{~cm}^{-1}\right.$ peak $), C=0$ of carbonyl $\left(1721 \mathrm{~cm}^{-1}\right.$ peak), functional groups of aliphatic components $\mathrm{CH}_{2}\left(2918 \mathrm{~cm}^{-1}\right.$ peak) and $\mathrm{C}-\mathrm{O}$ stretching of polysaccharide $\left(1168 \mathrm{~cm}^{-1}\right.$ peak). The positions of the absorption bands of the spectra fell within typical major absorption bands of humic acid which is at frequencies 3680, 2918, 1721, 1168 $\mathrm{cm}^{-1}$. The first peak centred in the vicinity of $3680 \mathrm{~cm}^{-1}$ region is attributed to phenol $\mathrm{OH}$ group bounded by intermolecular $\mathrm{H}$ bonds. The $2918 \mathrm{~cm}^{-1}$ band usually has absorption maximum at $2918 \mathrm{~cm}^{-1}$ which is due to $\mathrm{C}-\mathrm{H}$ stretching of alkane group $\left(\mathrm{CH}_{2}\right)$. The next major absorption band is $1721 \mathrm{~cm}^{-1}$. This band has been commonly ascribed to $\mathrm{C}=\mathrm{O}$ stretching of mainly carboxyl group $(\mathrm{COOH})$ with trace amount of ketones. The last peak was observed at 1168 $\mathrm{cm}^{-1}$ due to $\mathrm{C}-\mathrm{O}$ stretching of polysaccharides and this peak appeared also in the spectra of humic acid from peat soil. The FTIR spectra of the isolated humic acid contained all major characteristic absorption peaks of humic acid. These absorption peaks indicated the presence of the major structural elements of humic acid namely $\mathrm{H}$ bonded $\mathrm{OH}, \mathrm{C}=\mathrm{C}$ of aromatic ring, $\mathrm{C}=\mathrm{O}$ of carbonyl group (both carboxyl and ketonic), $\mathrm{CH}_{2}$ group. This strongly supports the presence of humic acid.

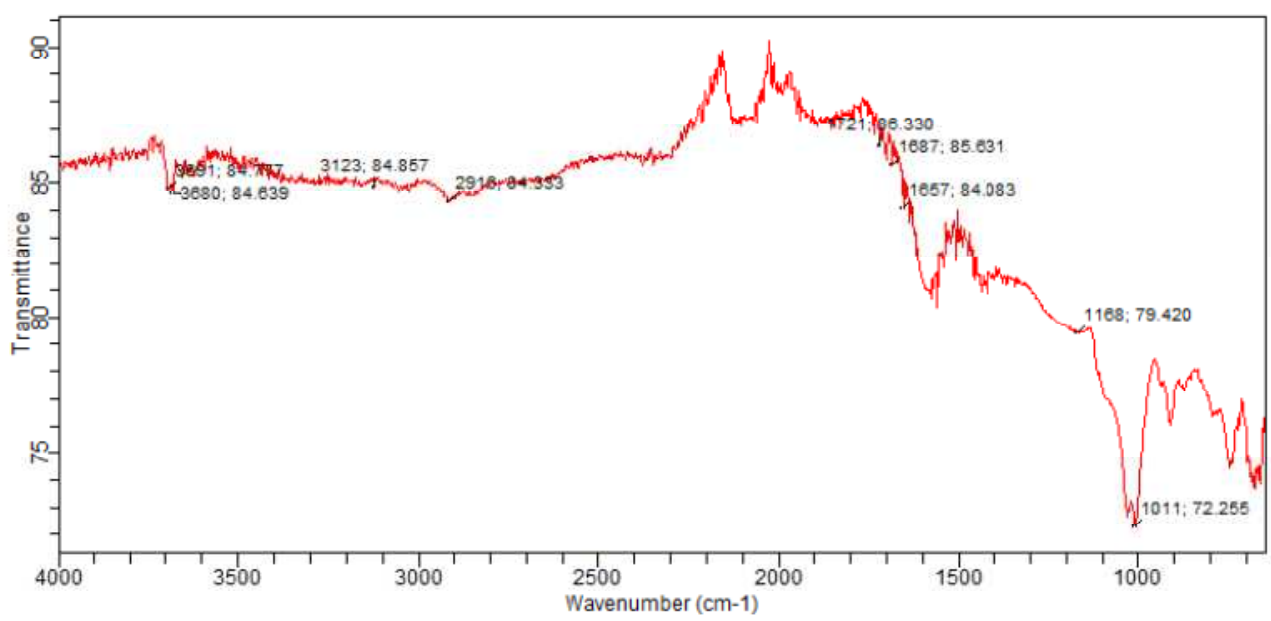

Fig. 2 : FT-IR spectraof peatsoilhumic acid (PSHA)

\section{Evaluation of acid dissociation constant (pka) of acid hydrolysed peat soil humicacid at phenolic group}

The value of the dissociation constant of the peat soil humic acid (PSHA) that underwent acidhydrolysis studied was found to be 8.9299 as shown Table 1, which is lower than the literaturevalues reported by Almeida and Szpoganics, (2015), Borges et al., (2005); Badr et al., (2012)and Fernandes et al,.(2009) of $9.73,9.47$ and 10.30. The difference between the obtained valuesand the reported values in this study might be probably as a result of acid hydrolysis of humicacid. 
BAJOPAS Volume 14 Number 1,June, 2021

Table 1: PKa of (Hydrolysed PSHA)

\begin{tabular}{|l|l|l|l|l|l|l|}
\hline $\mathrm{pH}$ & $\mathrm{BV}_{1}$ & $\mathrm{BV}_{2}$ & $\mathrm{~V}_{2}-\mathrm{V}_{1}$ & $\mathrm{nA}$ & $\log \left(\frac{n A}{1-n A}\right)$ & $\mathrm{pKa}$ \\
\hline 8.50 & 5.30 & 6.29 & 0.99 & 0.3594 & -0.2510 & 8.2490 \\
8.72 & 5.35 & 6.37 & 1.02 & 0.3400 & -0.2880 & 8.4320 \\
9.00 & 5.40 & 6.46 & 1.06 & 0.3141 & -0.3391 & 8.6609 \\
9.22 & 5.45 & 6.55 & 1.10 & 0.2882 & -0.3927 & 8.8273 \\
9.51 & 5.50 & 6.66 & 1.16 & 0.2494 & -0.4786 & 9.0314 \\
9.73 & 5.55 & 6.78 & 1.23 & 0.2041 & -0.5910 & 9.1390 \\
10.00 & 5.60 & 6.90 & 1.30 & 0.1589 & -0.7238 & 9.2762 \\
10.23 & 5.65 & 7.05 & 1.40 & 0.0941 & -0.9835 & 9.2465 \\
10.49 & 5.70 & 7.10 & 1.40 & 0.0941 & -0.9835 & 9.5065 \\
\hline
\end{tabular}

Average pKa $=8.9299 \pm 0.4186$

Table 2: PKa of (Unhydrolysed PSHA)

\begin{tabular}{|l|l|l|l|l|l|l|}
\hline $\mathrm{pH}$ & $\mathrm{BV}_{1}$ & $\mathrm{BV}_{2}$ & $\mathrm{~V}_{2}-\mathrm{V}_{1}$ & $\mathrm{nA}$ & $\log \left(\frac{\boldsymbol{n A}}{1-\boldsymbol{n}}\right)$ & $\mathrm{pKa}$ \\
\hline 8.50 & 5.30 & 5.81 & 0.51 & 0.6619 & 0.2919 & 8.7919 \\
8.72 & 5.35 & 5.90 & 0.55 & 0.6357 & 0.2418 & 8.9618 \\
9.00 & 5.40 & 6.00 & 0.60 & 0.6029 & 0.1813 & 9.1813 \\
9.22 & 5.45 & 6.10 & 0.65 & 0.5701 & 0.1226 & 9.3426 \\
9.51 & 5.50 & 6.20 & 0.70 & 0.5376 & 0.0654 & 9.5754 \\
9.73 & 5.55 & 6.33 & 0.78 & 0.4851 & -0.0259 & 9.7041 \\
10.00 & 5.60 & 6.47 & 0.87 & 0.4262 & -0.1291 & 9.8709 \\
10.23 & 5.65 & 6.62 & 0.99 & 0.3609 & -0.2481 & 9.9819 \\
10.49 & 5.70 & 6.80 & 1.10 & 0.2759 & -0.4690 & 10.0210 \\
\hline
\end{tabular}

Average pKa $=9.4923 \pm 0.4410$

Metal-ligand stability constant ( $\log \mathrm{K}$ )

The stabilityconstants require the accurate values of proton-ligand stability constants (Anil and Maroti, 2008). Metal titration curves crossed over ligand titration curve indicated the formation of complex upon proton release (Santosh, et al., 2011). If the values of n- are within range $0.2-0.8$ and $1.2-18$ this indicates the formation of $1: 1$ and 1:2 complexes (Sayyed and Mazahar, 2012).

The metal (II)-humate stepwise stability constants (log k) at phenolic group (Tables 318)

Table 3: Point-wise method, $\mathrm{Cu}$-(Hydrolysed PSHA)

\begin{tabular}{|l|l|l|l|l|l|l|l|l|}
\hline $\mathrm{pH}$ & $\mathrm{BV}_{1}$ & $\mathrm{BV}_{2}$ & $\mathrm{BV}_{3}$ & $\left(\mathrm{~V}_{3}-\mathrm{V}_{2}\right)$ & $\mathrm{n}$ & $\mathrm{pL}$ & $\log \left(\frac{n}{1-n}\right)$ & LogK $_{1}$ \\
\hline 8.50 & 5.30 & 6.29 & 6.33 & 0.04 & 0.5500 & 2.66 & 0.0871 & 2.7471 \\
8.72 & 5.35 & 6.37 & 6.41 & 0.04 & 0.5714 & 2.43 & 0.1249 & 2.5549 \\
9.00 & 5.40 & 6.46 & 6.50 & 0.04 & 0.6198 & 2.16 & 0.2122 & 2.3722 \\
9.22 & 5.45 & 6.55 & 6.59 & 0.04 & 0.6667 & 1.94 & 0.3010 & 2.2410 \\
\hline
\end{tabular}

LogK $_{1}$ (Average value) $=2.4788 \pm 0.2203$

Table 4: Point-wise method, $\mathrm{Cu}$-(Hydrolysed PSHA)

\begin{tabular}{|l|l|l|l|l|l|l|l|l|}
\hline $\mathrm{pH}$ & $\mathrm{BV}_{1}$ & $\mathrm{BV}_{2}$ & $\mathrm{BV}_{3}$ & $\left(\mathrm{~V}_{3}-\mathrm{V}_{2}\right)$ & $\mathrm{n}$ & $\mathrm{pL}$ & $\log \left(\frac{n-1}{2-n}\right)$ & LogK $_{2}$ \\
\hline 9.51 & 5.50 & 6.66 & 6.73 & 0.07 & 1.3509 & 1.70 & -0.2671 & 1.4329 \\
9.73 & 5.55 & 6.78 & 6.85 & 0.07 & 1.6383 & 1.51 & 0.2467 & 1.7567 \\
10.00 & 5.60 & 6.90 & 6.98 & 0.08 & 2.1783 & 1.31 & -0.2158 & 1.0942 \\
10.23 & 5.65 & 7.05 & 7.13 & 0.08 & 4.1904 & 1.27 & & \\
10.49 & 5.70 & 7.10 & 7.19 & 0.09 & 4.6920 & & & \\
\hline
\end{tabular}

Log $K_{2}($ Average value $)=1.4280 \pm 0.3312$ 
BAJOPAS Volume 14 Number 1,June, 2021

Table 5: Point-wise method, $\mathrm{Cu}$ (Unhydrolysed PSHA)

\begin{tabular}{|l|l|l|l|l|l|l|l|l|}
\hline $\mathrm{pH}$ & $\mathrm{BV}_{1}$ & $\mathrm{BV}_{2}$ & $\mathrm{BV}_{3}$ & $\left(\mathrm{~V}_{3}-\mathrm{V}_{2}\right)$ & $\mathrm{n}$ & $\mathrm{pL}$ & $\log \left(\frac{n}{n-1}\right)$ & Log $_{1}$ \\
\hline 8.50 & 5.30 & 5.81 & 5.85 & 0.04 & 0.2973 & 2.88 & -0.3736 & 2.5064 \\
8.72 & 5.35 & 5.90 & 5.95 & 0.05 & 0.3873 & 2.66 & -0.1992 & 2.4608 \\
9.00 & 5.40 & 6.00 & 6.05 & 0.05 & 0.4044 & 2.38 & -0.1681 & 2.2119 \\
9.22 & 5.45 & 6.10 & 6.15 & 0.06 & 0.5157 & 2.18 & -0.0272 & 2.2072 \\
9.51 & 5.50 & 6.20 & 6.27 & 0.07 & 0.6417 & 1.89 & 0.2530 & 1.1430 \\
\hline
\end{tabular}

$\operatorname{LogK}_{1}($ Average value $)=2.3059 \pm 0.6153$

Table 6:Point-wise method, $\mathrm{Cu}$ (Unhydrolysed PSHA)

\begin{tabular}{|l|l|l|l|l|l|l|l|l|}
\hline $\mathrm{pH}$ & $\mathrm{BV}_{1}$ & $\mathrm{BV}_{2}$ & $\mathrm{BV}_{3}$ & $\mathrm{~V}_{3}-\mathrm{V}_{2}$ & $\mathrm{n}$ & $\mathrm{pL}$ & $\log \left(\frac{n-1}{2-n}\right)$ & $\log \mathrm{K}_{2}$ \\
\hline 9.73 & 5.55 & 6.33 & 6.42 & 0.09 & 0.9000 & 1.69 & & \\
10.00 & 5.60 & 6.47 & 6.58 & 0.11 & 1.2578 & 1.44 & -0.4592 & 0.9808 \\
10.23 & 5.65 & 6.62 & 6.84 & 0.12 & 1.6137 & 1.26 & -0.2010 & 1.4610 \\
10.49 & 5.70 & 6.80 & 6.92 & 0.12 & 2.1052 & 1.03 & & \\
\hline
\end{tabular}

$\operatorname{LogK}_{2}$ (Average value) $=1.2209 \pm 0.3398$

Table 7:Point-wise method, Pb (Hydrolysed PSHA)

\begin{tabular}{|l|l|l|l|l|l|l|l|l|}
\hline $\mathrm{pH}$ & $\mathrm{BV}_{1}$ & $\mathrm{BV}_{2}$ & $\mathrm{BV}_{3}$ & $\left(\mathrm{~V}_{3}-\mathrm{V}_{2}\right)$ & $\mathrm{n}$ & $\mathrm{pL}$ & $\log \left(\frac{n}{1-n}\right)$ & LogK $_{1}$ \\
\hline 8.50 & 5.30 & 6.29 & 6.33 & 0.04 & 0.5500 & 2.66 & 0.0871 & 2.7471 \\
8.72 & 5.35 & 6.37 & 6.41 & 0.04 & 0.5714 & 2.43 & 0.1249 & 2.5549 \\
9.00 & 5.40 & 6.46 & 6.50 & 0.04 & 0.6198 & 2.16 & 0.2122 & 2.3722 \\
9.22 & 5.45 & 6.55 & 6.60 & 0.05 & 0.8333 & 1.96 & 0.6989 & 2.6589 \\
\hline
\end{tabular}

Log $_{\mathbf{1}}($ Average value $)=2.5832 \pm 0.1614$

Table 8:Point-wise method, Pb-(Hydrolysed PSHA)

\begin{tabular}{|l|l|l|l|l|l|l|l|l|}
\hline $\mathrm{pH}$ & $\mathrm{BV}_{1}$ & $\mathrm{BV}_{2}$ & $\mathrm{BV}_{3}$ & $\left(\mathrm{~V}_{3}-\mathrm{V}_{2}\right)$ & $\mathrm{n}$ & $\mathrm{pL}$ & $\log \left(\frac{n-1}{2-n}\right)$ & $\log \mathrm{K}_{2}$ \\
\hline 9.51 & 5.50 & 6.66 & 6.71 & 0.05 & 0.9650 & 1.67 & & \\
9.73 & 5.55 & 6.78 & 6.83 & 0.05 & 1.1702 & 1.44 & & \\
10.00 & 5.60 & 6.90 & 6.90 & 0.05 & 1.4864 & 1.22 & -0.0237 & 1.1963 \\
10.23 & 5.65 & 7.05 & 7.10 & 0.05 & 2.0190 & 1.09 & & \\
10.49 & 5.70 & 7.10 & 7.17 & 0.07 & 3.6492 & 1.00 & & \\
\hline
\end{tabular}

Log $K_{2}$ (Average value) $=1.1963$

Table 9: Point-wise method, Pb (Unhydrolysed PSHA)

\begin{tabular}{|l|l|l|l|l|l|l|l|l|}
\hline $\mathrm{pH}$ & $\mathrm{BV}_{1}$ & $\mathrm{BV}_{2}$ & $\mathrm{BV}_{3}$ & $\mathrm{~V}_{3}-\mathrm{V}_{2}$ & $\mathrm{n}$ & $\mathrm{pL}$ & $\begin{array}{l}\text { Log } \\
\left(\frac{n}{n-1}\right)\end{array}$ & Log $\mathrm{K}_{1}$ \\
\hline 8.50 & 5.30 & 5.81 & 5.85 & 0.04 & 0.2973 & 2.88 & -0.3736 & 2.5064 \\
8.72 & 5.35 & 5.90 & 5.94 & 0.04 & 0.3099 & 2.66 & -0.5477 & 2.3123 \\
9.00 & 5.40 & 6.00 & 6.05 & 0.05 & 0.4044 & 2.38 & -0.1681 & 2.2119 \\
9.22 & 5.45 & 6.10 & 6.15 & 0.06 & 0.5157 & 2.18 & 0.0272 & 2.2072 \\
9.51 & 5.50 & 6.20 & 6.26 & 0.07 & 0.6417 & 1.89 & 0.2530 & 2.1430 \\
9.73 & 5.55 & 6.40 & 6.40 & 0.07 & 0.7000 & 1.67 & 0.3680 & 2.0380 \\
\hline
\end{tabular}

LogK $_{1}$ (Average value) $=2.2364 \pm 0.1602$

Table 10: Point-wise method, Pb (Unhydrolysed PSHA)

\begin{tabular}{|l|l|l|l|l|l|l|l|l|}
\hline $\mathrm{pH}$ & $\mathrm{BV}_{1}$ & $\mathrm{BV}_{2}$ & $\mathrm{BV}_{3}$ & $\mathrm{~V}_{3}-\mathrm{V}_{2}$ & $\mathrm{n}$ & $\mathrm{pL}$ & $\log \left(\frac{n-1}{2-n}\right)$ & $\log \mathrm{K}_{2}$ \\
\hline 10.00 & 5.60 & 6.47 & 6.55 & 0.08 & 1.9503 & 1.41 & & \\
10.23 & 5.65 & 6.62 & 6.72 & 0.11 & 1.4792 & 1.26 & -0.0361 & 1.2239 \\
\hline
\end{tabular}

$\operatorname{LogK}_{2}$ (Average value) $=1.2239$

Table 11: Point-wise method, Mg (Hydrolysed PSHA)

\begin{tabular}{|l|l|l|l|l|l|l|l|l|}
\hline $\mathrm{pH}$ & $\mathrm{BV}_{1}$ & $\mathrm{BV}_{2}$ & $\mathrm{BV}_{3}$ & $\left(\mathrm{~V}_{3}-\mathrm{V}_{2}\right)$ & $\mathrm{n}$ & $\mathrm{pL}$ & $\log \left(\frac{n}{n-1}\right)$ & LogK $_{1}$ \\
\hline 8.50 & 5.30 & 6.29 & 6.31 & 0.02 & 0.2750 & 2.64 & -0.4290 & 2.2110 \\
8.72 & 5.35 & 6.37 & 6.39 & 0.02 & 0.2858 & 2.42 & -0.3978 & 2.0222 \\
9.00 & 5.40 & 6.46 & 6.49 & 0.03 & 0.4648 & 2.14 & -0.0612 & 2.0788 \\
9.22 & 5.45 & 6.55 & 6.59 & 0.04 & 0.6667 & 1.94 & 0.3010 & 2.2410 \\
\hline
\end{tabular}

$\log _{\mathbf{1}}($ Average value) $=2.1382 \pm 0.1046$ 
BAJOPAS Volume 14 Number 1,June, 2021

Table 12: Point-wise method, Mg (Hydrolysed PSHA)

\begin{tabular}{|l|l|l|l|l|l|l|l|l|}
\hline $\mathrm{pH}$ & $\mathrm{BV}_{1}$ & $\mathrm{BV}_{2}$ & $\mathrm{BV}_{3}$ & $\left(\mathrm{~V}_{3}-\mathrm{V}_{2}\right)$ & $\mathrm{n}$ & $\mathrm{pL}$ & $\log \left(\frac{n-1}{2-n}\right)$ & LogK $_{2}$ \\
\hline 9.51 & 5.55 & 6.66 & 6.71 & 0.05 & 0.9650 & 1.67 & & \\
9.73 & 5.55 & 6.78 & 6.84 & 0.06 & 1.4042 & 1.47 & -0.1686 & 1.3014 \\
10.00 & 5.60 & 6.90 & 6.93 & 0.06 & 1.7838 & 1.23 & 0.5593 & 1.7893 \\
10.23 & 5.65 & 7.05 & 7.10 & 0.06 & 3.1429 & 1.10 & & \\
10.49 & 5.70 & 7.10 & 7.18 & 0.07 & 3.6492 & 0.83 & & \\
\hline
\end{tabular}

LogK $_{2}($ Average value $)=1.5453 \pm 0.3450$

Table 13: Point-wise method, Mg (Unhydrolysed PSHA)

\begin{tabular}{|l|l|l|l|l|l|l|l|l|}
\hline $\mathrm{pH}$ & $\mathrm{BV}_{1}$ & $\mathrm{BV}_{2}$ & $\mathrm{BV}_{3}$ & $\mathrm{~V}_{3}-\mathrm{V}_{2}$ & $\mathrm{n}$ & $\mathrm{pL}$ & $\log \left(\frac{n}{n-1}\right)$ & $\operatorname{Log~}_{1}$ \\
\hline 8.50 & 5.30 & 5.81 & 5.85 & 0.04 & 0.2973 & 2.88 & -0.3736 & 2.5064 \\
8.72 & 5.35 & 5.90 & 5.94 & 0.04 & 0.3099 & 2.66 & -0.3477 & 2.3123 \\
9.00 & 5.40 & 6.00 & 6.04 & 0.04 & 0.3236 & 2.38 & -0.3202 & 2.0598 \\
9.22 & 5.45 & 6.10 & 6.15 & 0.05 & 0.4297 & 2.17 & -0.1230 & 2.0470 \\
9.51 & 5.50 & 6.20 & 6.26 & 0.06 & 0.5500 & 1.89 & 0.0871 & 1.9771 \\
9.73 & 5.55 & 6.33 & 6.40 & 0.07 & 0.7000 & 1.67 & 0.3680 & 2.0380 \\
\hline
\end{tabular}

LogK $_{1}$ (Average value) $=2.1568 \pm 0.2069$

Table 14: Point-wise method, Mg (Unhydrolysed PSHA)

\begin{tabular}{|l|l|l|l|l|l|l|l|l|}
\hline $\mathrm{pH}$ & $\mathrm{BV}_{1}$ & $\mathrm{BV}_{2}$ & $\mathrm{BV}_{3}$ & $\mathrm{~V}_{3}-\mathrm{V}_{2}$ & $\mathrm{n}$ & $\mathrm{pL}$ & $\log \left(\frac{n-1}{2-n}\right)$ & $\log \mathrm{K}_{2}$ \\
\hline 10.00 & 5.60 & 6.47 & 6.55 & 0.08 & 0.9148 & 1.41 & & \\
10.23 & 5.65 & 6.62 & 6.71 & 0.09 & 1.2102 & 1.20 & -0.5749 & 0.6251 \\
10.49 & 5.70 & 6.80 & 6.92 & 0.09 & 1.5968 & 1.03 & 0.1703 & 1.2003 \\
\hline
\end{tabular}

LogK $_{2}$ (Average value) $=0.9127 \pm 0.4070$

Table15:Point-wise method, Cd (Hydrolysed PSHA)

\begin{tabular}{|l|l|l|l|l|l|l|l|l|}
\hline $\mathrm{pH}$ & $\mathrm{BV}_{1}$ & $\mathrm{BV}_{2}$ & $\mathrm{BV}_{3}$ & $\left(\mathrm{~V}_{3}-\mathrm{V}_{2}\right)$ & $\mathrm{n}$ & $\mathrm{pL}$ & $\log \left(\frac{n}{1-n}\right)$ & LogK $_{1}$ \\
\hline 8.50 & 5.30 & 6.29 & 6.31 & 0.02 & 0.2750 & 2.64 & -0.4210 & 2.2190 \\
8.72 & 5.35 & 6.37 & 6.40 & 0.03 & 0.4286 & 2.42 & -0.1249 & 2.2951 \\
9.00 & 5.40 & 6.46 & 6.49 & 0.03 & 0.4648 & 2.14 & -0.0612 & 2.0788 \\
9.22 & 5.45 & 6.55 & 6.59 & 0.04 & 0.6667 & 1.96 & 0.3010 & 2.2610 \\
9.51 & 5.55 & 6.66 & 6.70 & 0.04 & 0.7720 & 1.67 & 0.5297 & 2.1997 \\
\hline
\end{tabular}

LogK $_{\mathbf{1}}$ (Average value) $=2.2108 \pm 0.0825$

Table 16: Point-wise method, Cd (Hydrolysed PSHA)

\begin{tabular}{|l|l|l|l|l|l|l|l|l|}
\hline $\mathrm{pH}$ & $\mathrm{BV}_{1}$ & $\mathrm{BV}_{2}$ & $\mathrm{BV}_{3}$ & $\left(\mathrm{~V}_{3}-\mathrm{V}_{2}\right)$ & $\mathrm{n}$ & $\mathrm{pL}$ & $\log \left(\frac{n-1}{2-n}\right)$ & Log $_{2}$ \\
\hline 9.73 & 5.55 & 6.78 & 6.83 & 0.06 & 1.4042 & 1.47 & -0.1686 & 1.3014 \\
10.00 & 5.60 & 6.90 & 6.95 & 0.06 & 1.7838 & 1.23 & 0.5593 & 1.7893 \\
10.23 & 5.65 & 7.05 & 7.10 & 0.06 & 3.1429 & 1.09 & & \\
10.49 & 5.70 & 7.10 & 7.16 & 0.06 & 3.1429 & 0.89 & & \\
& & & & & & & & \\
\hline
\end{tabular}

$\operatorname{LogK}_{2}$ (Average value) $=1.5453 \pm 0.3450$

Table 17: Point-wise method, Cd (Unhydrolysed PSHA)

\begin{tabular}{|l|l|l|l|l|l|l|l|l|}
\hline $\mathrm{pH}$ & $\mathrm{BV}_{1}$ & $\mathrm{BV}_{2}$ & $\mathrm{BV}_{3}$ & $\mathrm{~V}_{3}-\mathrm{V}_{2}$ & $\mathrm{n}$ & $\mathrm{pL}$ & $\log \left(\frac{n}{n-1}\right)$ & $\operatorname{Log~}_{1}$ \\
\hline 8.50 & 5.30 & 5.81 & 5.86 & 0.05 & 0.3717 & 2.88 & -0.2280 & 2.6520 \\
8.72 & 5.35 & 5.90 & 5.95 & 0.05 & 0.3873 & 2.66 & -0.1992 & 2.4608 \\
9.00 & 5.40 & 6.00 & 6.06 & 0.06 & 0.4853 & 2.38 & -0.0255 & 2.3545 \\
9.22 & 5.45 & 6.10 & 6.16 & 0.06 & 0.5157 & 2.18 & -0.0272 & 2.2072 \\
9.51 & 5.50 & 6.20 & 6.27 & 0.07 & 0.6417 & 1.89 & 0.2530 & 1.1430 \\
9.73 & 5.55 & 6.33 & 6.41 & 0.08 & 0.8000 & 1.69 & 0.6020 & 2.2920 \\
& & & & & & & & \\
\hline
\end{tabular}

$\operatorname{LogK}_{1}($ Average value $)=2.2516 \pm 0.5380$ 
BAJOPAS Volume 14 Number 1,June, 2021

Table 18: Point-wise method, Cd (Unhydrolysed PSHA)

\begin{tabular}{|l|l|l|l|l|l|l|l|l|}
\hline $\mathrm{pH}$ & $\mathrm{BV}_{1}$ & $\mathrm{BV}_{2}$ & $\mathrm{BV}_{3}$ & $\mathrm{~V}_{3}-\mathrm{V}_{2}$ & $\mathrm{n}$ & $\mathrm{pL}$ & $\log \left(\frac{n-1}{2-n}\right)$ & $\log \mathrm{K}_{2}$ \\
\hline 10.00 & 5.60 & 6.47 & 6.57 & 0.10 & 1.1434 & 1.43 & & \\
10.23 & 5.65 & 6.62 & 6.72 & 0.10 & 1.3448 & 1.23 & -0.2788 & 0.9512 \\
10.49 & 5.70 & 6.80 & 6.90 & 0.10 & 1.7742 & 1.03 & 0.5351 & 1.5651 \\
\hline
\end{tabular}

$\operatorname{LogK}_{2}($ Average value $)=1.2581 \pm 0.4340$

Table 19: Stepwise and overall Stability constants of thehydrolysed and unhydrolysed divalent metal (II) complexes

\begin{tabular}{|c|c|c|c|}
\hline Chelates & LogK $_{1}$ & $\log _{2}$ & Log $\beta$ \\
\hline [Cu (Hydrolysed PSHA-1) $\left.{ }_{2}\right]$ & 2.4788 & 1.4280 & 3.9068 \\
\hline$\left[\mathrm{Pb}(\text { Hydrolysed PSHA-1) })_{2}\right]$ & 2.5832 & 1.1963 & 3.7795 \\
\hline$\left[\mathrm{Cd}(\text { Hydrolysed PSHA-1 })_{2}\right]$ & 2.2108 & 1.5453 & 3.7561 \\
\hline$\left[\mathrm{Mg}(\text { Hydrolysed PSHA-1 })_{2}\right]$ & 2.1382 & 1.5453 & 3.6835 \\
\hline [Cu (Unhydrolysed PSHA-1) & 2.3059 & 1.2209 & 3.5268 \\
\hline$[\mathrm{Pb}$ (Unhydrolysed PSHA-1) 2$]$ & 2.2364 & 1.2239 & 3.4603 \\
\hline [Cd (Unhydrolysed PSHA-1) 2 ] & 2.2516 & 1.2581 & 3.5097 \\
\hline$[\mathrm{Mg}$ (Unydrolysed PSHA-1) & 2.1568 & 0.9127 & 3.0695 \\
\hline
\end{tabular}

The results obtained (Table19) shows the stepwise and overall stability constants to be not high indicating low stability of the complexes, because the solubility of most metal ions in the basic $\mathrm{pH}$ range is minimal due to metal hydroxide precipitation (Karimi, 2017). In general, the stepwise stability constants $\left(K_{1}\right.$ and $K_{2}$ ) follow the order $K_{1}>K_{2}$ for the copper, lead, magnesium and cadmium complexes respectively. The steady decrease of the values with increasing number of ligands is in agreement with the prediction made by researchers (Na'aliya, 2013). The decrease could be attributed to the fact that as the number of the ligands (Humate ions) that enters the coordination zone increases the aqua molecules available for replacement by the ligands become less. Thus, the metal ions become less electron loving with progressive intake of the ligand and this results in the decrease in the values of the constants (Na'aliya, 2013). Also the stability of the complexes is influenced by the size and number of the chelate rings(Mackay and Mackay,2002).All the complexes form rings in their structure as humate, a bidentate ligand, bond the metal ions in the ratio 1:2 (Boguta and Sokolowska, 2016) forming chelate rings. The values of the overall stability constants $(\log \beta)$ obtained for humate complexes are not high indicating low stability as the values are not high. LogK values for copper-humates (Table 3 to 6) obtained in this study are lower than those reported for the complexes of humic acids (Pandey et al., 2015; Dinu, 2013; Kaschl et al., 2010 and Gilbeto and Jorg, 2001). The values of LogK(Table 7 to 10 ) forlead-humates are lower than those reported for the lead in the literature (Dinu, 2013; Gilbeto and Jorg 2001). Log K values(Table 11 to 14 ) for magnesium-humates obtained in this study are close to those reported by (Pandey et al., 2015). Log K values of cadmium-humates (Table 15 to 18 ) obtained in this work near to the one reported by (Dinu, 2013 and Pandey et al., 2015).The difference between the reported values and the values obtained in this study might be probably as a result of acid hydrolysis of humic acid. The values of the overall stability constants $(\log \beta)$ of the copper humates complexes presented in Table 19 is high than that of other metal humate complexes, show relatively high stability of CuHA complexes, show the following order of stability: $\mathrm{Cu}>\mathrm{Pb}>\mathrm{Cd}>\mathrm{Mg}$; which are in close agreement to the findings of (Dinu, 2013 and Pandey et al., 2015).The high stability of Cuhumate chelate could be attributed to the existence of coordinate covalent bond between the complexing agents and the $\mathrm{Cu}^{2+}$ ions. Since, $\mathrm{Cu}^{2+}$ being a metal of the transitional series with $3 d^{9}$ electronic configurations can accept the electrons from the complexing agents. Similarly, the low stabilities of $\mathrm{Pb}, \mathrm{Cd}$ and $\mathrm{Mg}$ complexes could be explained by that $\mathrm{Pb}^{2+}$ with $6 s^{2}, \mathrm{Cd}^{2+}$ with $4 \mathrm{~d}^{10}$ and $\mathrm{Mg}^{2+}$ with $2 \mathrm{p}^{6}$ their electronic configuration has a completely filled $\mathrm{d}, \mathrm{p}$ and $\mathrm{s}$ orbitals. Moreover, the stabilities of metal ions with hydrolysed humic acid from peat soil were higher than those with unhydrolysed humic acid from peat soil; which is ascribed to the high content of acidity in hydrolysed humic acid than unhydrolysed humic acid. 
BAJOPAS Volume 14 Number 1,June, 2021 CONCLUSION

The values of logk for $\mathrm{Cu}(\mathrm{II})$ hydrolysed humic acid complex was higher followed by $\mathrm{Pb}$ (II), $\mathrm{Cd}(\mathrm{II})$ and $\mathrm{Mg}$ (II) hydrolysed humic acid complexes as compared with metal(II) unhydrolysed humic acid complexes. This indicates acid hydrolysis of humic acid can

\section{REFERENCES}

Almeida, V.R. and Szpoganicz, B. (2015). Humic Acid Potentiometric Response Patterns:Out- of Equilibrium Properties and Species Distribution Modelling. Chemical. Biol. Technol. Agric. 2: 17.

Anđelković, T., Nikolić, R., Bojić, A.,Anđelković, D., and Nikolic G.,(2010). Binding of Cadmium to Soil Humic Acid as A Function of Carboxyl Group Content. Macedonian Journal of Chemistry and Chemical Engineering.29(2): 215-224.

Anil, B. N. and Maroti, N. (2008). Studies on Influence of Die-Lectric Constants on Complex Equilibria between Substituted Py-Razalines and Lanthanide Metal Ions pH-Metrically. Amer.-Euras. scient. Res. 3(2): 212-216.

Ashok, K., Pandey, S. P. and Misra, V (2000). Stability Constants of Metal-Humic Acid Complexes and its Role in Environmental Detoxification. Journal of Ecotoxicology and Environmental Safety. 47(2):157-200.

Badr, M. H., El-Halafawi, M. H. and Abd El-al Zeid, E. R. (2012). Comparison Between the Effect of Ionic Strength on Acidity and Dissociation Constants of Humic Acids Extracted from Sewage Sludge and Nile Water Hyacinth Composts.Global Journal of Environmental Research 6 (1): 36-43.

Baruah, M.K., Borah, D., Saikia, P.P., Paul, S., Sharma, T. (2015). Evaluation of pKa Values of Soil Humic Acids and their Complexation Properties. International Journal of Plant \& Soil Science 6(4) : 218-228.

Boguta, P. Sokolowska, Z. (2016). Interactions of $\mathrm{Zn}$ (II) Ions with Humic Acids Isolated from Various Types of Soils. Effect of $\mathrm{pH}, \mathrm{Zn}$ Concentrations and Humic Acids Chemical Properties. Journal of Geochemical Explaration 168. 119-126.

Borges, F., Guimaraes, C., Lima, L.F.C., Pinto, I. and Reis, S.(2005). Potentiometric Studies on the Complexation of Copper(II) by Phenolic Acids as Discrete Ligand Models of enhance the complexation behavior of humic acid with metal (II) ions. However, the higher values of $\log \beta$ for $\mathrm{Cu}(\mathrm{II}), \mathrm{Pb}(\mathrm{II}), \mathrm{Cd}(\mathrm{II})$ and $\mathrm{Mg}(\mathrm{II})$ hydrolysed humic acid complexes indicates more stable stepwise complexes formed as compared with $\mathrm{Cu}(\mathrm{II}), \mathrm{Pb}$ (II), $\mathrm{Cd}$ (II) and $\mathrm{Mg}(\mathrm{II})$ unhydrolysed humic acid complexes.

Humic Substances Talanta 66 (2005) 670-673.

Chefetz, B., Salloum, M. J., Deshmulkin, A. P. and Hatcher, P. (2002). Structural Components of Humic Acids as Determined by Chemical Modifications and Carbon-13 NMR, Pyrolysis, and Thermochemolysis- Gas Chromatography/Mass Spectrometry. Soil Science Society of American Journal Abstract Division S-2- Soil Chemistry66. 1159-1171.

Dinu, M. I. (2013). Metals Complexation with Humic Acids in Surface Water of Different Environ. Sci. Technol. 31(1): 1-17.

Fernandes, A.N., Giacomelli, C., Giovanela, M. Vaz, D.V. Szpoganicz, B. and Maria M. D. (2009). Potentiometric Acidity Determination in Humic Substances Influenced by Different Analytical Procedures.J. Braz. Chem. Soc. 20 (9):14.

Gamal, A. H. (2015). Stability Constants of Rhenium (V) Metal Complexes with Selected Drugs. Pyrex Journal of Research in Environmental Studies. 2(2): 006-014.

Janrao, D. M., Pathan, J., Kayande, D.D., and Mulla, J.J. (2014). An Over View of Potentiometric Determination of Stability Constants of Metal Complexes. Sci. Revs. Chem. Commun.: 4(1), 2014, 11-24.

Karimi, H. (2017). Effect of pH and Initial Pb(II) Concentration on the Lead Removal Efficiency from Waste Water Using $\mathrm{Ca}(\mathrm{OH})_{2}$. International Journal of Water and Waste Water Treatment 3.2

Kaschl, A. Romheld, V. and Chen, Y. (2010). Binding of Cadmium, Copper and Zinc to Humic Substances Originating from Municipal Solid Waste Compost. Israel Journal of Chemistry Vol. 42(1): 89-98.

Kostic, I. S., Tatjana, P, A., Nikolic, R. S., Cvetkovic, T. P., Pavlovic, D. D., Aleksandar, L.J. and Bojic, A. (2012). Comparative Study of Binding Strengths of Heavy Metals with Humic Acid. J.serb. Chem. Soc. 76(9) pp 1-20. 
BAJOPAS Volume 14 Number 1,June, 2021

Na'aliya, J. (2013). Determination of Stepwise Stability Constants and Gibbs free Energy Change of Trisprolina to Complexes of some Divalent Transition Metal ions. Bayero Journal of Pure and Applied Sciences 6(2): 112-114.

Omar, A. A. and Ali, E. A. (2015). Potentiometric Studies on Complexes of $\mathrm{Cr}$ (III) and $\mathrm{Zr}$ (IV) with some Carboxylic Acids. International Journal of Advanced Chemistry, 3(1) 25-

37.

Pandey, A. K. Pandey, S. D. and Misr, V. (2015).Stability Constants of Metal- Humic Acid Complexes and Its Role in Environmental Detoxification. J. Ecotoxicology and Environmental Safety. 47(1):195-200.

Ram, N. and Raman, K.V. (1984). Stability Constants of Complexes of Metals with
Humicand Fuvic Acids under Non- acidConditions. Journal of Plant Nutrition and Soil Sciences.

147:171-176.

Santosh, D. D., Ashok, B. K., Vijay, J. T., Shivraj, G. W. and Vinay, V. W. (2011). Potentiometric Studies of Elec-Trolyte Effects on Complex Equilibria of Some Substituted 5-(2-hydroxy Phenyl) Pyrazoles. Der pharm. 3 (6): 75-83.

Sayyed, H. and Abdul Rahim, M. F. (2012). Studies of Binary Complexes of Metal Ions with Mandelic Acid by Potentiometry. Chem. J. 02 (6): 206209.

Shirvani, M. Moradian, E. Khalili, B. Bakhtiary, S. (2015). Interaction of $\mathrm{Cd}$ and $\mathrm{Pb}$ with Humate-Palygorskite and HumateSepiolite Complexes. Journal of water, air and pollution 3: 220-228. 


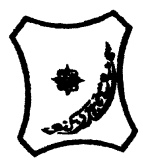

Bayero Journal of Pure and Applied Sciences, 14(1): 54 - 63

Received: November, 2020

Accepted: April, 2021

ISSN $2006-6996$

\title{
STABILITY CONSTANTS OF COMPLEXES OF METAL IONS WITH PEATSOIL HUMIC ACIDS UNDER NON-ACID-CONDITIONS
}

\author{
${ }^{* 1}$ Sabo, Yusuf ${ }^{2}$ Jimoh, W.L.O., ${ }^{3}$ Isa Baba Koki and ${ }^{4}$ Sholadoye, Q. 0. \\ ${ }^{1}$ Department of Pure and Industrial Chemistry, Bayero University, Kano \\ ${ }^{3}$ Department of Chemistry, Yusuf Maitama Sule University Kano. P.M.B. 3220 Kano, Nigeria. \\ ${ }^{4}$ Department of Chemistry, Nigerian Police Academy, Wudil, Kano-Nigeria
}

*Correspondence E-mail; saboyusuf18@yahoo.com

ABSTRACT

Stability constants of complexes of four divalent metal ions viz. $\mathrm{Cu}^{2+}, \mathrm{Pb}^{2+}, \mathrm{Mg}^{2+}$ and $\mathrm{Cd}^{2+}$ with humic acids (HA) were determined by potentiometric titration of humic acids with the corresponding salt of the divalent metals in aqueous media under non-acid-condition. The log $K$ (logarithm of the stability constant) ranged from 1.0942 to 2.7471 for metalhumic acid complexes were determined using point-wise computational method. The order of stability constants were obtained as follows: $\mathrm{Cu}>\mathrm{Pb}>\mathrm{Cd}>\mathrm{Mg}$ for metal $-\mathrm{HA}$ complexes respectively, indicating a higher degree of complexation with Cu metal ion.

Keywords: stability constant, humic acid, potentiometric titration, divalent metals, acid hydrolysis.

\section{NTRODUCTION}

The stability constant of a complex is the numerical expression of its stability and provides a quantitative measure of affinity of the metal ion to the complexing agent. An understanding of the relative stability of metal-complexes helps in predicting the behavior of metal ions in the soil (Ram and Raman, 1982). Extensive researches has been done to determine the stability constants of the complexes formed between humic acid (HA) with a number of metal ions. Ashok et al., (2000) reported that humic acid with hydroxyl, phenoxyl and carboxyl reactive groups can form coordination compound with metal ions at $\mathrm{pH}$ 3.5. The stability constants(Log K) for different metalhumic acid complexes indicated the following order of the stabilities of complexes formed between humic acid and metal ion, $\mathrm{Cu}>\mathrm{Fe}$ $>\mathrm{Pb}>\mathrm{Ni}>\mathrm{Co}>\mathrm{Ca}>\mathrm{Cd}>\mathrm{Zn}>\mathrm{Mn}>\mathrm{Mg}$. Andelkovic et al., (2010) investigated the binding of $\mathrm{Cd}$ (II) to soil humic acid at pH 6.5 and in $0.1 \mathrm{M} \mathrm{KNO}_{3}$ ionic medium. The stability constant for binding indicating greater stability in the case when carboxyl groups are involved in complexation reaction. Kostic et al.,(2012) investigated the complexation of humic acid with certain heavy metal ions (Co(II), $\mathrm{Ni}(\mathrm{II}), \mathrm{Cu}(\mathrm{II})$,
$\mathrm{Zn}(\mathrm{II})$, and $\mathrm{Pb}(\mathrm{II})$. The experiment was performed at $25^{\circ} \mathrm{C}$, at pH 4.0 and ionic strength of $0.01 \mathrm{M}$. Stability constant of complex between $\mathrm{Pb}$ (II) ions and humic acid is greater than stability constants of other investigated metalhumate complexes. Bogata and Sokolowska (2016) analyses the interaction between humic acids from different soils and $\mathrm{Zn}$ (II) ions at wide concentration ranges and at $\mathrm{pH} 5$. Studies have showed significant impact of $\mathrm{Zn}$ concentration, $\mathrm{pH}$ and some properties of humic acids with zinc.But all of these studies were limited to acidic $\mathrm{pH}$ range. Therefore, the present study was carried out to determine and compare the stability constants of complexes of metal ions with hydrolysed peat soil humic acid and unhydrolysed peat soil humic under non-acid conditions.

\section{MATERIALS AND METHODS}

Analytical grade chemicals used includes hydrochloric acid $(\mathrm{HCl})$, nitric acid $\left(\mathrm{HNO}_{3}\right)$, sodium hydroxide $(\mathrm{NaOH})$, lead nitrate $\mathrm{Pb}\left(\mathrm{NO}_{3}\right)_{2}$, copper nitrate $\mathrm{Cu}\left(\mathrm{NO}_{3}\right)_{2} \cdot 3 \mathrm{H}_{2} \mathrm{O}$, cadmium nitrate $\mathrm{Cd}\left(\mathrm{NO}_{3}\right)_{2} \cdot 4 \mathrm{H}_{2} \mathrm{O}$, magnesium nitrate $\mathrm{Mg}\left(\mathrm{NO}_{3}\right)_{2} \cdot 6 \mathrm{H}_{2} \mathrm{O}$, potassium nitrate $\left(\mathrm{KNO}_{3}\right)$, calcium chloride $\left(\mathrm{CaCl}_{2}\right)$, (sigma-Aldrich). Dowex 50WX8, (20-50 mesh) from Fluka. 


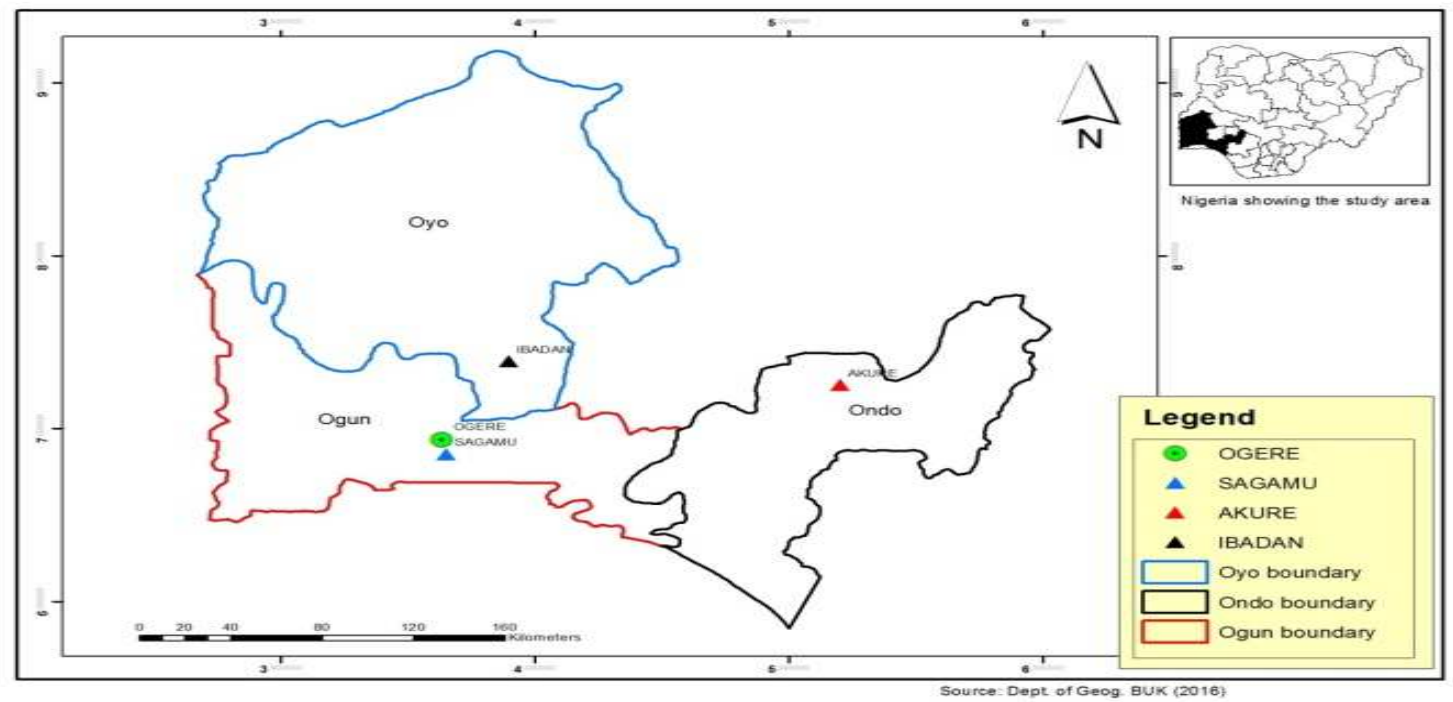

Figure 1: Map showing the sampling point at Sagamu Town, Ogun State.

\section{Description of Sampling Area}

Sagamu has geographical coordinates between $6^{\circ} 50^{\prime}$ north; $3^{\circ} 38^{\prime}$ east is located in south western region of Nigeria. The region has tropical wet and dry climate with a lengthy wet season and relatively constant temperatures throughout the course of the year. Wet season runs from March to October, November to December forms the region dry season. The vegetation type of the region is savannah which is really grassland with small bushes and occasional big trees. Grassland soils have substantially higher organic matter content than forest soils (Novackova, 2011).

\section{Sample Collection}

The Peatsoil samples were collected from four different sampling points $(0-10 \mathrm{~cm}$ depth) in Sagamu into polyethylene bag with plastic spoons. Samples were taken to the laboratory, extraneous materials were removed; the samples were air-dried, crushed and ground to a fine powder in a mortar passed through a $0.20 \mathrm{~mm}$ sieve. The samples were kept for analysis.

\section{Isolation and purification of humic acid from peat soil sample}

Peatsoil sample $(100 \mathrm{~g})$ was mixed with 1000 $\mathrm{cm}^{3}$ of $0.1 \mathrm{M} \mathrm{NaOH}$ solution, shaken for 3hours and left to stand overnight. Dark-coloured supernatant was obtained and decanted from solid residue. The dark-coloured supernatant was acidified to $(\mathrm{pH}=1.0)$ with $6 \mathrm{M} \mathrm{HCl}$ stirred and allowed to stand for 6 hours. Yellowish brown supernatant and dark-brown precipitate were obtained. The yellowish brown supernatant was decanted followed by centrifuge and discarded. The dark-brown precipitate was mixed with $500 \mathrm{~cm}^{3}$ of $0.1 \mathrm{M} \mathrm{NaOH}$ solution followed by passing through dowex resin. The dark-brown solution was acidified to $(\mathrm{pH}=1.0)$ with $6 \mathrm{M} \mathrm{HCl}$ stirred and allowed to stand for 3 hours. The dark-brown precipitate was washed several times with deionized water. The supernatant was treated with $\mathrm{AgNO}_{3}$ solution until no white precipitate observed. The humic acid was transferred to weighed crucible and dried at $60^{\circ} \mathrm{C}$ in an oven for 12 hours. The humic acid was cooled and dried in the desiccator, weighed and recorded. The obtained humic acid was dried again at $60^{\circ} \mathrm{C}$ for additional 6 hours cooled and dried in the desiccator, weighed and recorded constant weight was obtained (Baruah et al., 2015).

\section{FT-IR analysis}

FT-IR spectra of humic acid sample was analysed using Carry 630 FT-IR Agilent Technologies.

Unhydrolysed compost humic acid

The unhydrolysed humic acid was obtained after isolation and purification of compost humic acid and kept for investigation.

\section{Acid hydrolysis of Peatsoil acid}

Peatsoil humic acid sample (1g) was refluxed for 12 hours at $\left(160^{\circ} \mathrm{C}\right)$ with $50 \mathrm{~cm}^{3}$ of $6 \mathrm{M} \mathrm{HCl}$. The mixture was allowed to cool, decanted, and centrifuged after hydrolysis. The insoluble residues were washed with distilled water via centrifugation several times, and the supernatant was treated with $\mathrm{AgNO}_{3}$ solution until no white precipitate was observed. The residue was thoroughly dried over $\mathrm{CaCl}_{2}$ in a desiccator at room temperature (Chefetz et al., 2002). Finally, the obtained hydrolysed humic acid was kept for investigation. 
BAJOPAS Volume 14 Number 1,June, 2021 Potentiometric Titrations

Potentiometric measurements were carried out using a pH-meter Jenway (model 3510) with combine electrode, the sensitivity of the $\mathrm{pH}$ meter is 0.01 units. The $\mathrm{pH}$ meter was switched on half an hour before starting the titration for initial warm up of the instrument. The instrument was calibrated with an aqueous standard buffer solution of $\mathrm{pH} 4.00$ and 10.0 (borate buffer) prepared from a "Qualigens" buffer tablets.

The following sets of solutions were prepared in a $250 \mathrm{~cm}^{3}$ volumetric flask separately for $\mathrm{pH}$ metric titrations.

(i) $5 \mathrm{~cm}^{3} 0.1 \mathrm{M} \mathrm{HCl}+40 \mathrm{~cm}^{3}$ deionized water

(ii) $5 \mathrm{~cm}^{3} 0.1 \mathrm{M} \mathrm{HCl}+39 \mathrm{~cm}^{3}$ deionized water $+1 \mathrm{~cm}^{3} 0.15 \mathrm{gcm}^{-3}$ humic acid

(iii) $5 \mathrm{~cm}^{3} 0.1 \mathrm{M} \mathrm{HCl}+37 \mathrm{~cm}^{3}$ deionized water $+1 \mathrm{~cm}^{3} 0.15 \mathrm{gcm}^{-3}$ humic acid

$$
+2 \mathrm{~cm}^{3} \quad 0.01 \mathrm{M} \mathrm{Cu} \text { (II) }
$$

The solutions were titrated against standardized $0.110 \mathrm{MNaOH}$ separately. The total volume of each mixture was adjusted to $50 \mathrm{~cm}^{3}$ and the ionic strength of the solutions was maintained constant at by adding appropriate amount of stock solution of $1 \mathrm{M} \mathrm{KNO}_{3}$ (Gamal, 2015; Omar and Ali, 2015). A magnetic stirrer was used to achieve thorough mixing of the interacting solutions at $550 \mathrm{rpm}$. The same set of experimental conditions was applied for potentiometric titration of remaining samples.

\section{Evaluation of pKa of Hydrolysed peat soil Humic Acids}

The proton-ligand formation number $\mathrm{n}_{\mathbf{A}}$ were calculated by Irving and Rossotti expression (Omar and Ali, 2015).

$\mathrm{nA}=\mathrm{Y}-\frac{(\mathrm{V} 2-\mathrm{V1})(\mathrm{No}-\mathrm{Eo})}{(\mathrm{VO}+\mathrm{V1}) \mathrm{TCL}}$ 1

Where: $Y$ is number of dissociable proton, $\left(\mathrm{V}_{2^{-}}\right.$ $V_{1}$ ) is the measure of displacement of the ligand curve relative to acid curve, $\mathrm{N}^{\circ}$ and $\mathrm{E}^{\circ}$ are the resultant concentration of alkali solution, free acid solution, $\mathrm{T}_{\mathrm{cL}}{ }^{\circ}$ is the total ligand concentration, $\mathrm{V}^{\circ}$ is the total volume of titration solution, $V_{1}$ is the volume of alkali added to acid solution, $V_{2}$ is the volume of alkali added to acid solution + ligand solution, acid dissociation constants (pKa - values) of ligand were calculated by algebraic method point wise calculation (Tables 1 ). The dissociation constants (pKa) were calculated according to the following relation:

$\mathrm{pKa}=\mathrm{pH}+\log \left(\frac{n A}{1-n A}\right)$ 2

Where: pKa is the acid dissociation constant, $\mathrm{n}_{\mathrm{A}}$ is the Proton-ligand formation number and $\mathrm{pH}$ is the pH-values (Omar and Ali, 2015).

\section{Determination of metal-ligand stability constants $(\log K)$ of complexes}

The potentiometric measurement for the determination of stability constant of a complex in solution is based on the fact that the redox potential of the couple $\frac{M^{+(m-n)}}{M^{+m}}$ is shifted significantly on complexation of the metal ion with the ligand. This method involves change in hydrogen ion concentration $\left[\mathrm{H}^{+}\right]$due to the displacement or association of one or more protons taking place during complexation reaction. This change can be found out by titrating the solutions containing free acid, acid with ligand, and acid with ligand and metal ion, individually against a standard alkali solution at a constant ionic strength or temperature. Either ionic strength or temperature may be varied for different sets of solutions. In all the cases, the change in the $\mathrm{pH}$ of the solution is measured after each addition of a known amount of alkali to the reaction cell which contains the reaction mixture. The titration curves are then drawn by plotting the measured $\mathrm{pH}$ values against the corresponding volume of alkali added and the stability constants of the complexes are determined from the titration curves by employing $\mathrm{pH}$-metric titration technique given by (Irving and Rossoti).

Metal-ligand stability constants ( $\log \mathrm{K}$ ) were determined by using the following relations:

$$
\bar{n}=\frac{\left(V_{3}-V_{2}\right)\left(E^{0}+N^{0}\right)}{\left(V^{0}+V_{2}\right) \bar{n}_{A} T_{m}^{0}}
$$

and

$$
P L=\log _{10}\left\{\frac{1+\beta_{n}^{H} \frac{1}{[\text { anti } \log \mathrm{pH}]^{\mathrm{n}}}}{\mathrm{T}_{\mathrm{L}}^{0}-n \bar{T}_{m}^{0}} \mathrm{X} \frac{\left(V^{0}+V_{3}\right)}{V^{0}}\right\}
$$


BAJOPAS Volume 14 Number 1,June, 2021

Where $T_{L}, T^{\circ}, E^{\circ}$, and $V^{\circ}$ havethe same significance as in equation (1) above, $T_{m}$ denotes the total concentration of metal present in solution, $V_{3}$ is the volume of metal ions present in solution and $\beta^{H}$ is the overall proton ligand stability constant. The metal-ligand stability constants (log K) were determined by employing point wise computational Method (eq. 5 and 6).

$\operatorname{LogK}_{1}=\log \left(\frac{n}{1-n}\right)+\mathrm{pL}$ .5

$\operatorname{LogK}_{2}=\log \left(\frac{1-n}{2-n}\right)+\mathrm{pL}$ ...6

Where: Log $\mathrm{K}$ is the metal-ligand stability constant, $\mathrm{pL}$ is the Free ligand exponent function, $\mathbf{n}$ is the Average number of ligand attached with metal ion (Janraoet al., 2014). The results obtained were analyzed by an ORIGIN 2016 program using titration data and then the proton-ligand stability constants (pKa) and Metal-ligand stability constant (LogK) calculated (Omar and Ali, 2015).

\section{RESULTS AND DISCUSSION}

Fourier transformed infrared (FT-IR) spectra of isolated humic acid from peat soils Figure 2 had distinct clear absorption bands indicating the presence of major humic acid structural elemental groups such as $\mathrm{H}$ bonded $\mathrm{OH}$ $\left(3680 \mathrm{~cm}^{-1}\right.$ peak $), C=0$ of carbonyl $\left(1721 \mathrm{~cm}^{-1}\right.$ peak), functional groups of aliphatic components $\mathrm{CH}_{2}\left(2918 \mathrm{~cm}^{-1}\right.$ peak) and $\mathrm{C}-\mathrm{O}$ stretching of polysaccharide $\left(1168 \mathrm{~cm}^{-1}\right.$ peak). The positions of the absorption bands of the spectra fell within typical major absorption bands of humic acid which is at frequencies 3680, 2918, 1721, 1168 $\mathrm{cm}^{-1}$. The first peak centred in the vicinity of $3680 \mathrm{~cm}^{-1}$ region is attributed to phenol $\mathrm{OH}$ group bounded by intermolecular $\mathrm{H}$ bonds. The $2918 \mathrm{~cm}^{-1}$ band usually has absorption maximum at $2918 \mathrm{~cm}^{-1}$ which is due to $\mathrm{C}-\mathrm{H}$ stretching of alkane group $\left(\mathrm{CH}_{2}\right)$. The next major absorption band is $1721 \mathrm{~cm}^{-1}$. This band has been commonly ascribed to $\mathrm{C}=\mathrm{O}$ stretching of mainly carboxyl group $(\mathrm{COOH})$ with trace amount of ketones. The last peak was observed at 1168 $\mathrm{cm}^{-1}$ due to $\mathrm{C}-\mathrm{O}$ stretching of polysaccharides and this peak appeared also in the spectra of humic acid from peat soil. The FTIR spectra of the isolated humic acid contained all major characteristic absorption peaks of humic acid. These absorption peaks indicated the presence of the major structural elements of humic acid namely $\mathrm{H}$ bonded $\mathrm{OH}, \mathrm{C}=\mathrm{C}$ of aromatic ring, $\mathrm{C}=\mathrm{O}$ of carbonyl group (both carboxyl and ketonic), $\mathrm{CH}_{2}$ group. This strongly supports the presence of humic acid.

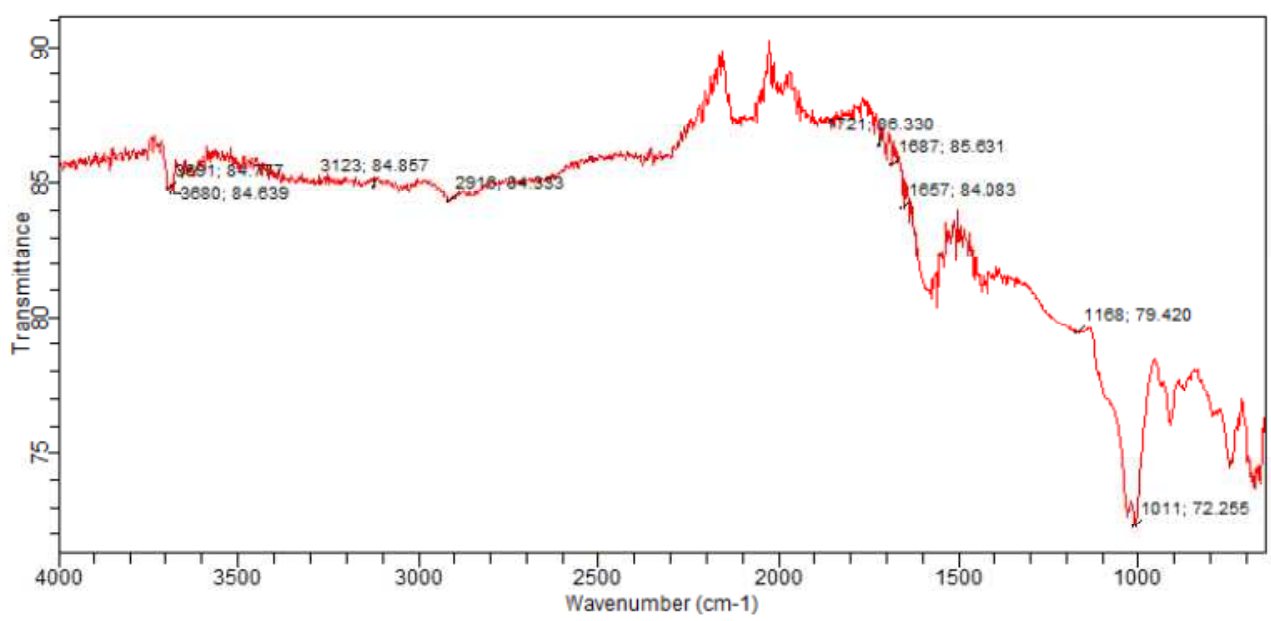

Fig. 2 : FT-IR spectraof peatsoilhumic acid (PSHA)

\section{Evaluation of acid dissociation constant (pka) of acid hydrolysed peat soil humicacid at phenolic group}

The value of the dissociation constant of the peat soil humic acid (PSHA) that underwent acidhydrolysis studied was found to be 8.9299 as shown Table 1, which is lower than the literaturevalues reported by Almeida and Szpoganics, (2015), Borges et al., (2005); Badr et al., (2012)and Fernandes et al,.(2009) of $9.73,9.47$ and 10.30. The difference between the obtained valuesand the reported values in this study might be probably as a result of acid hydrolysis of humicacid. 
BAJOPAS Volume 14 Number 1,June, 2021

Table 1: PKa of (Hydrolysed PSHA)

\begin{tabular}{|l|l|l|l|l|l|l|}
\hline $\mathrm{pH}$ & $\mathrm{BV}_{1}$ & $\mathrm{BV}_{2}$ & $\mathrm{~V}_{2}-\mathrm{V}_{1}$ & $\mathrm{nA}$ & $\log \left(\frac{n A}{1-n A}\right)$ & $\mathrm{pKa}$ \\
\hline 8.50 & 5.30 & 6.29 & 0.99 & 0.3594 & -0.2510 & 8.2490 \\
8.72 & 5.35 & 6.37 & 1.02 & 0.3400 & -0.2880 & 8.4320 \\
9.00 & 5.40 & 6.46 & 1.06 & 0.3141 & -0.3391 & 8.6609 \\
9.22 & 5.45 & 6.55 & 1.10 & 0.2882 & -0.3927 & 8.8273 \\
9.51 & 5.50 & 6.66 & 1.16 & 0.2494 & -0.4786 & 9.0314 \\
9.73 & 5.55 & 6.78 & 1.23 & 0.2041 & -0.5910 & 9.1390 \\
10.00 & 5.60 & 6.90 & 1.30 & 0.1589 & -0.7238 & 9.2762 \\
10.23 & 5.65 & 7.05 & 1.40 & 0.0941 & -0.9835 & 9.2465 \\
10.49 & 5.70 & 7.10 & 1.40 & 0.0941 & -0.9835 & 9.5065 \\
\hline
\end{tabular}

Average pKa $=8.9299 \pm 0.4186$

Table 2: PKa of (Unhydrolysed PSHA)

\begin{tabular}{|l|l|l|l|l|l|l|}
\hline $\mathrm{pH}$ & $\mathrm{BV}_{1}$ & $\mathrm{BV}_{2}$ & $\mathrm{~V}_{2}-\mathrm{V}_{1}$ & $\mathrm{nA}$ & $\log \left(\frac{\boldsymbol{n A}}{1-\boldsymbol{n}}\right)$ & $\mathrm{pKa}$ \\
\hline 8.50 & 5.30 & 5.81 & 0.51 & 0.6619 & 0.2919 & 8.7919 \\
8.72 & 5.35 & 5.90 & 0.55 & 0.6357 & 0.2418 & 8.9618 \\
9.00 & 5.40 & 6.00 & 0.60 & 0.6029 & 0.1813 & 9.1813 \\
9.22 & 5.45 & 6.10 & 0.65 & 0.5701 & 0.1226 & 9.3426 \\
9.51 & 5.50 & 6.20 & 0.70 & 0.5376 & 0.0654 & 9.5754 \\
9.73 & 5.55 & 6.33 & 0.78 & 0.4851 & -0.0259 & 9.7041 \\
10.00 & 5.60 & 6.47 & 0.87 & 0.4262 & -0.1291 & 9.8709 \\
10.23 & 5.65 & 6.62 & 0.99 & 0.3609 & -0.2481 & 9.9819 \\
10.49 & 5.70 & 6.80 & 1.10 & 0.2759 & -0.4690 & 10.0210 \\
\hline
\end{tabular}

Average pKa $=9.4923 \pm 0.4410$

Metal-ligand stability constant ( $\log \mathrm{K}$ )

The stabilityconstants require the accurate values of proton-ligand stability constants (Anil and Maroti, 2008). Metal titration curves crossed over ligand titration curve indicated the formation of complex upon proton release (Santosh, et al., 2011). If the values of n- are within range $0.2-0.8$ and $1.2-18$ this indicates the formation of $1: 1$ and 1:2 complexes (Sayyed and Mazahar, 2012).

The metal (II)-humate stepwise stability constants (log k) at phenolic group (Tables 318)

Table 3: Point-wise method, $\mathrm{Cu}$-(Hydrolysed PSHA)

\begin{tabular}{|l|l|l|l|l|l|l|l|l|}
\hline $\mathrm{pH}$ & $\mathrm{BV}_{1}$ & $\mathrm{BV}_{2}$ & $\mathrm{BV}_{3}$ & $\left(\mathrm{~V}_{3}-\mathrm{V}_{2}\right)$ & $\mathrm{n}$ & $\mathrm{pL}$ & $\log \left(\frac{n}{1-n}\right)$ & LogK $_{1}$ \\
\hline 8.50 & 5.30 & 6.29 & 6.33 & 0.04 & 0.5500 & 2.66 & 0.0871 & 2.7471 \\
8.72 & 5.35 & 6.37 & 6.41 & 0.04 & 0.5714 & 2.43 & 0.1249 & 2.5549 \\
9.00 & 5.40 & 6.46 & 6.50 & 0.04 & 0.6198 & 2.16 & 0.2122 & 2.3722 \\
9.22 & 5.45 & 6.55 & 6.59 & 0.04 & 0.6667 & 1.94 & 0.3010 & 2.2410 \\
\hline
\end{tabular}

LogK $_{1}$ (Average value) $=2.4788 \pm 0.2203$

Table 4: Point-wise method, $\mathrm{Cu}$-(Hydrolysed PSHA)

\begin{tabular}{|l|l|l|l|l|l|l|l|l|}
\hline $\mathrm{pH}$ & $\mathrm{BV}_{1}$ & $\mathrm{BV}_{2}$ & $\mathrm{BV}_{3}$ & $\left(\mathrm{~V}_{3}-\mathrm{V}_{2}\right)$ & $\mathrm{n}$ & $\mathrm{pL}$ & $\log \left(\frac{n-1}{2-n}\right)$ & LogK $_{2}$ \\
\hline 9.51 & 5.50 & 6.66 & 6.73 & 0.07 & 1.3509 & 1.70 & -0.2671 & 1.4329 \\
9.73 & 5.55 & 6.78 & 6.85 & 0.07 & 1.6383 & 1.51 & 0.2467 & 1.7567 \\
10.00 & 5.60 & 6.90 & 6.98 & 0.08 & 2.1783 & 1.31 & -0.2158 & 1.0942 \\
10.23 & 5.65 & 7.05 & 7.13 & 0.08 & 4.1904 & 1.27 & & \\
10.49 & 5.70 & 7.10 & 7.19 & 0.09 & 4.6920 & & & \\
\hline
\end{tabular}

Log $K_{2}($ Average value $)=1.4280 \pm 0.3312$ 
BAJOPAS Volume 14 Number 1,June, 2021

Table 5: Point-wise method, $\mathrm{Cu}$ (Unhydrolysed PSHA)

\begin{tabular}{|l|l|l|l|l|l|l|l|l|}
\hline $\mathrm{pH}$ & $\mathrm{BV}_{1}$ & $\mathrm{BV}_{2}$ & $\mathrm{BV}_{3}$ & $\left(\mathrm{~V}_{3}-\mathrm{V}_{2}\right)$ & $\mathrm{n}$ & $\mathrm{pL}$ & $\log \left(\frac{n}{n-1}\right)$ & Log $_{1}$ \\
\hline 8.50 & 5.30 & 5.81 & 5.85 & 0.04 & 0.2973 & 2.88 & -0.3736 & 2.5064 \\
8.72 & 5.35 & 5.90 & 5.95 & 0.05 & 0.3873 & 2.66 & -0.1992 & 2.4608 \\
9.00 & 5.40 & 6.00 & 6.05 & 0.05 & 0.4044 & 2.38 & -0.1681 & 2.2119 \\
9.22 & 5.45 & 6.10 & 6.15 & 0.06 & 0.5157 & 2.18 & -0.0272 & 2.2072 \\
9.51 & 5.50 & 6.20 & 6.27 & 0.07 & 0.6417 & 1.89 & 0.2530 & 1.1430 \\
\hline
\end{tabular}

$\operatorname{LogK}_{1}($ Average value $)=2.3059 \pm 0.6153$

Table 6:Point-wise method, $\mathrm{Cu}$ (Unhydrolysed PSHA)

\begin{tabular}{|l|l|l|l|l|l|l|l|l|}
\hline $\mathrm{pH}$ & $\mathrm{BV}_{1}$ & $\mathrm{BV}_{2}$ & $\mathrm{BV}_{3}$ & $\mathrm{~V}_{3}-\mathrm{V}_{2}$ & $\mathrm{n}$ & $\mathrm{pL}$ & $\log \left(\frac{n-1}{2-n}\right)$ & $\log \mathrm{K}_{2}$ \\
\hline 9.73 & 5.55 & 6.33 & 6.42 & 0.09 & 0.9000 & 1.69 & & \\
10.00 & 5.60 & 6.47 & 6.58 & 0.11 & 1.2578 & 1.44 & -0.4592 & 0.9808 \\
10.23 & 5.65 & 6.62 & 6.84 & 0.12 & 1.6137 & 1.26 & -0.2010 & 1.4610 \\
10.49 & 5.70 & 6.80 & 6.92 & 0.12 & 2.1052 & 1.03 & & \\
\hline
\end{tabular}

$\operatorname{LogK}_{2}$ (Average value) $=1.2209 \pm 0.3398$

Table 7:Point-wise method, Pb (Hydrolysed PSHA)

\begin{tabular}{|l|l|l|l|l|l|l|l|l|}
\hline $\mathrm{pH}$ & $\mathrm{BV}_{1}$ & $\mathrm{BV}_{2}$ & $\mathrm{BV}_{3}$ & $\left(\mathrm{~V}_{3}-\mathrm{V}_{2}\right)$ & $\mathrm{n}$ & $\mathrm{pL}$ & $\log \left(\frac{n}{1-n}\right)$ & LogK $_{1}$ \\
\hline 8.50 & 5.30 & 6.29 & 6.33 & 0.04 & 0.5500 & 2.66 & 0.0871 & 2.7471 \\
8.72 & 5.35 & 6.37 & 6.41 & 0.04 & 0.5714 & 2.43 & 0.1249 & 2.5549 \\
9.00 & 5.40 & 6.46 & 6.50 & 0.04 & 0.6198 & 2.16 & 0.2122 & 2.3722 \\
9.22 & 5.45 & 6.55 & 6.60 & 0.05 & 0.8333 & 1.96 & 0.6989 & 2.6589 \\
\hline
\end{tabular}

Log $_{\mathbf{1}}($ Average value $)=2.5832 \pm 0.1614$

Table 8:Point-wise method, Pb-(Hydrolysed PSHA)

\begin{tabular}{|l|l|l|l|l|l|l|l|l|}
\hline $\mathrm{pH}$ & $\mathrm{BV}_{1}$ & $\mathrm{BV}_{2}$ & $\mathrm{BV}_{3}$ & $\left(\mathrm{~V}_{3}-\mathrm{V}_{2}\right)$ & $\mathrm{n}$ & $\mathrm{pL}$ & $\log \left(\frac{n-1}{2-n}\right)$ & $\log \mathrm{K}_{2}$ \\
\hline 9.51 & 5.50 & 6.66 & 6.71 & 0.05 & 0.9650 & 1.67 & & \\
9.73 & 5.55 & 6.78 & 6.83 & 0.05 & 1.1702 & 1.44 & & \\
10.00 & 5.60 & 6.90 & 6.90 & 0.05 & 1.4864 & 1.22 & -0.0237 & 1.1963 \\
10.23 & 5.65 & 7.05 & 7.10 & 0.05 & 2.0190 & 1.09 & & \\
10.49 & 5.70 & 7.10 & 7.17 & 0.07 & 3.6492 & 1.00 & & \\
\hline
\end{tabular}

Log $K_{2}$ (Average value) $=1.1963$

Table 9: Point-wise method, Pb (Unhydrolysed PSHA)

\begin{tabular}{|l|l|l|l|l|l|l|l|l|}
\hline $\mathrm{pH}$ & $\mathrm{BV}_{1}$ & $\mathrm{BV}_{2}$ & $\mathrm{BV}_{3}$ & $\mathrm{~V}_{3}-\mathrm{V}_{2}$ & $\mathrm{n}$ & $\mathrm{pL}$ & $\begin{array}{l}\text { Log } \\
\left(\frac{n}{n-1}\right)\end{array}$ & Log $\mathrm{K}_{1}$ \\
\hline 8.50 & 5.30 & 5.81 & 5.85 & 0.04 & 0.2973 & 2.88 & -0.3736 & 2.5064 \\
8.72 & 5.35 & 5.90 & 5.94 & 0.04 & 0.3099 & 2.66 & -0.5477 & 2.3123 \\
9.00 & 5.40 & 6.00 & 6.05 & 0.05 & 0.4044 & 2.38 & -0.1681 & 2.2119 \\
9.22 & 5.45 & 6.10 & 6.15 & 0.06 & 0.5157 & 2.18 & 0.0272 & 2.2072 \\
9.51 & 5.50 & 6.20 & 6.26 & 0.07 & 0.6417 & 1.89 & 0.2530 & 2.1430 \\
9.73 & 5.55 & 6.40 & 6.40 & 0.07 & 0.7000 & 1.67 & 0.3680 & 2.0380 \\
\hline
\end{tabular}

LogK $_{1}$ (Average value) $=2.2364 \pm 0.1602$

Table 10: Point-wise method, Pb (Unhydrolysed PSHA)

\begin{tabular}{|l|l|l|l|l|l|l|l|l|}
\hline $\mathrm{pH}$ & $\mathrm{BV}_{1}$ & $\mathrm{BV}_{2}$ & $\mathrm{BV}_{3}$ & $\mathrm{~V}_{3}-\mathrm{V}_{2}$ & $\mathrm{n}$ & $\mathrm{pL}$ & $\log \left(\frac{n-1}{2-n}\right)$ & $\log \mathrm{K}_{2}$ \\
\hline 10.00 & 5.60 & 6.47 & 6.55 & 0.08 & 1.9503 & 1.41 & & \\
10.23 & 5.65 & 6.62 & 6.72 & 0.11 & 1.4792 & 1.26 & -0.0361 & 1.2239 \\
\hline
\end{tabular}

$\operatorname{LogK}_{2}$ (Average value) $=1.2239$

Table 11: Point-wise method, Mg (Hydrolysed PSHA)

\begin{tabular}{|l|l|l|l|l|l|l|l|l|}
\hline $\mathrm{pH}$ & $\mathrm{BV}_{1}$ & $\mathrm{BV}_{2}$ & $\mathrm{BV}_{3}$ & $\left(\mathrm{~V}_{3}-\mathrm{V}_{2}\right)$ & $\mathrm{n}$ & $\mathrm{pL}$ & $\log \left(\frac{n}{n-1}\right)$ & LogK $_{1}$ \\
\hline 8.50 & 5.30 & 6.29 & 6.31 & 0.02 & 0.2750 & 2.64 & -0.4290 & 2.2110 \\
8.72 & 5.35 & 6.37 & 6.39 & 0.02 & 0.2858 & 2.42 & -0.3978 & 2.0222 \\
9.00 & 5.40 & 6.46 & 6.49 & 0.03 & 0.4648 & 2.14 & -0.0612 & 2.0788 \\
9.22 & 5.45 & 6.55 & 6.59 & 0.04 & 0.6667 & 1.94 & 0.3010 & 2.2410 \\
\hline
\end{tabular}

$\log _{\mathbf{1}}($ Average value) $=2.1382 \pm 0.1046$ 
BAJOPAS Volume 14 Number 1,June, 2021

Table 12: Point-wise method, Mg (Hydrolysed PSHA)

\begin{tabular}{|l|l|l|l|l|l|l|l|l|}
\hline $\mathrm{pH}$ & $\mathrm{BV}_{1}$ & $\mathrm{BV}_{2}$ & $\mathrm{BV}_{3}$ & $\left(\mathrm{~V}_{3}-\mathrm{V}_{2}\right)$ & $\mathrm{n}$ & $\mathrm{pL}$ & $\log \left(\frac{n-1}{2-n}\right)$ & LogK $_{2}$ \\
\hline 9.51 & 5.55 & 6.66 & 6.71 & 0.05 & 0.9650 & 1.67 & & \\
9.73 & 5.55 & 6.78 & 6.84 & 0.06 & 1.4042 & 1.47 & -0.1686 & 1.3014 \\
10.00 & 5.60 & 6.90 & 6.93 & 0.06 & 1.7838 & 1.23 & 0.5593 & 1.7893 \\
10.23 & 5.65 & 7.05 & 7.10 & 0.06 & 3.1429 & 1.10 & & \\
10.49 & 5.70 & 7.10 & 7.18 & 0.07 & 3.6492 & 0.83 & & \\
\hline
\end{tabular}

LogK $_{2}($ Average value $)=1.5453 \pm 0.3450$

Table 13: Point-wise method, Mg (Unhydrolysed PSHA)

\begin{tabular}{|l|l|l|l|l|l|l|l|l|}
\hline $\mathrm{pH}$ & $\mathrm{BV}_{1}$ & $\mathrm{BV}_{2}$ & $\mathrm{BV}_{3}$ & $\mathrm{~V}_{3}-\mathrm{V}_{2}$ & $\mathrm{n}$ & $\mathrm{pL}$ & $\log \left(\frac{n}{n-1}\right)$ & $\operatorname{Log~}_{1}$ \\
\hline 8.50 & 5.30 & 5.81 & 5.85 & 0.04 & 0.2973 & 2.88 & -0.3736 & 2.5064 \\
8.72 & 5.35 & 5.90 & 5.94 & 0.04 & 0.3099 & 2.66 & -0.3477 & 2.3123 \\
9.00 & 5.40 & 6.00 & 6.04 & 0.04 & 0.3236 & 2.38 & -0.3202 & 2.0598 \\
9.22 & 5.45 & 6.10 & 6.15 & 0.05 & 0.4297 & 2.17 & -0.1230 & 2.0470 \\
9.51 & 5.50 & 6.20 & 6.26 & 0.06 & 0.5500 & 1.89 & 0.0871 & 1.9771 \\
9.73 & 5.55 & 6.33 & 6.40 & 0.07 & 0.7000 & 1.67 & 0.3680 & 2.0380 \\
\hline
\end{tabular}

LogK $_{1}$ (Average value) $=2.1568 \pm 0.2069$

Table 14: Point-wise method, Mg (Unhydrolysed PSHA)

\begin{tabular}{|l|l|l|l|l|l|l|l|l|}
\hline $\mathrm{pH}$ & $\mathrm{BV}_{1}$ & $\mathrm{BV}_{2}$ & $\mathrm{BV}_{3}$ & $\mathrm{~V}_{3}-\mathrm{V}_{2}$ & $\mathrm{n}$ & $\mathrm{pL}$ & $\log \left(\frac{n-1}{2-n}\right)$ & $\log \mathrm{K}_{2}$ \\
\hline 10.00 & 5.60 & 6.47 & 6.55 & 0.08 & 0.9148 & 1.41 & & \\
10.23 & 5.65 & 6.62 & 6.71 & 0.09 & 1.2102 & 1.20 & -0.5749 & 0.6251 \\
10.49 & 5.70 & 6.80 & 6.92 & 0.09 & 1.5968 & 1.03 & 0.1703 & 1.2003 \\
\hline
\end{tabular}

LogK $_{2}$ (Average value) $=0.9127 \pm 0.4070$

Table15:Point-wise method, Cd (Hydrolysed PSHA)

\begin{tabular}{|l|l|l|l|l|l|l|l|l|}
\hline $\mathrm{pH}$ & $\mathrm{BV}_{1}$ & $\mathrm{BV}_{2}$ & $\mathrm{BV}_{3}$ & $\left(\mathrm{~V}_{3}-\mathrm{V}_{2}\right)$ & $\mathrm{n}$ & $\mathrm{pL}$ & $\log \left(\frac{n}{1-n}\right)$ & LogK $_{1}$ \\
\hline 8.50 & 5.30 & 6.29 & 6.31 & 0.02 & 0.2750 & 2.64 & -0.4210 & 2.2190 \\
8.72 & 5.35 & 6.37 & 6.40 & 0.03 & 0.4286 & 2.42 & -0.1249 & 2.2951 \\
9.00 & 5.40 & 6.46 & 6.49 & 0.03 & 0.4648 & 2.14 & -0.0612 & 2.0788 \\
9.22 & 5.45 & 6.55 & 6.59 & 0.04 & 0.6667 & 1.96 & 0.3010 & 2.2610 \\
9.51 & 5.55 & 6.66 & 6.70 & 0.04 & 0.7720 & 1.67 & 0.5297 & 2.1997 \\
\hline
\end{tabular}

LogK $_{\mathbf{1}}$ (Average value) $=2.2108 \pm 0.0825$

Table 16: Point-wise method, Cd (Hydrolysed PSHA)

\begin{tabular}{|l|l|l|l|l|l|l|l|l|}
\hline $\mathrm{pH}$ & $\mathrm{BV}_{1}$ & $\mathrm{BV}_{2}$ & $\mathrm{BV}_{3}$ & $\left(\mathrm{~V}_{3}-\mathrm{V}_{2}\right)$ & $\mathrm{n}$ & $\mathrm{pL}$ & $\log \left(\frac{n-1}{2-n}\right)$ & Log $_{2}$ \\
\hline 9.73 & 5.55 & 6.78 & 6.83 & 0.06 & 1.4042 & 1.47 & -0.1686 & 1.3014 \\
10.00 & 5.60 & 6.90 & 6.95 & 0.06 & 1.7838 & 1.23 & 0.5593 & 1.7893 \\
10.23 & 5.65 & 7.05 & 7.10 & 0.06 & 3.1429 & 1.09 & & \\
10.49 & 5.70 & 7.10 & 7.16 & 0.06 & 3.1429 & 0.89 & & \\
& & & & & & & & \\
\hline
\end{tabular}

$\operatorname{LogK}_{2}$ (Average value) $=1.5453 \pm 0.3450$

Table 17: Point-wise method, Cd (Unhydrolysed PSHA)

\begin{tabular}{|l|l|l|l|l|l|l|l|l|}
\hline $\mathrm{pH}$ & $\mathrm{BV}_{1}$ & $\mathrm{BV}_{2}$ & $\mathrm{BV}_{3}$ & $\mathrm{~V}_{3}-\mathrm{V}_{2}$ & $\mathrm{n}$ & $\mathrm{pL}$ & $\log \left(\frac{n}{n-1}\right)$ & $\operatorname{Log~}_{1}$ \\
\hline 8.50 & 5.30 & 5.81 & 5.86 & 0.05 & 0.3717 & 2.88 & -0.2280 & 2.6520 \\
8.72 & 5.35 & 5.90 & 5.95 & 0.05 & 0.3873 & 2.66 & -0.1992 & 2.4608 \\
9.00 & 5.40 & 6.00 & 6.06 & 0.06 & 0.4853 & 2.38 & -0.0255 & 2.3545 \\
9.22 & 5.45 & 6.10 & 6.16 & 0.06 & 0.5157 & 2.18 & -0.0272 & 2.2072 \\
9.51 & 5.50 & 6.20 & 6.27 & 0.07 & 0.6417 & 1.89 & 0.2530 & 1.1430 \\
9.73 & 5.55 & 6.33 & 6.41 & 0.08 & 0.8000 & 1.69 & 0.6020 & 2.2920 \\
& & & & & & & & \\
\hline
\end{tabular}

$\operatorname{LogK}_{1}($ Average value $)=2.2516 \pm 0.5380$ 
BAJOPAS Volume 14 Number 1,June, 2021

Table 18: Point-wise method, Cd (Unhydrolysed PSHA)

\begin{tabular}{|l|l|l|l|l|l|l|l|l|}
\hline $\mathrm{pH}$ & $\mathrm{BV}_{1}$ & $\mathrm{BV}_{2}$ & $\mathrm{BV}_{3}$ & $\mathrm{~V}_{3}-\mathrm{V}_{2}$ & $\mathrm{n}$ & $\mathrm{pL}$ & $\log \left(\frac{n-1}{2-n}\right)$ & $\log \mathrm{K}_{2}$ \\
\hline 10.00 & 5.60 & 6.47 & 6.57 & 0.10 & 1.1434 & 1.43 & & \\
10.23 & 5.65 & 6.62 & 6.72 & 0.10 & 1.3448 & 1.23 & -0.2788 & 0.9512 \\
10.49 & 5.70 & 6.80 & 6.90 & 0.10 & 1.7742 & 1.03 & 0.5351 & 1.5651 \\
\hline
\end{tabular}

$\operatorname{LogK}_{2}($ Average value $)=1.2581 \pm 0.4340$

Table 19: Stepwise and overall Stability constants of thehydrolysed and unhydrolysed divalent metal (II) complexes

\begin{tabular}{|c|c|c|c|}
\hline Chelates & LogK $_{1}$ & $\log _{2}$ & Log $\beta$ \\
\hline [Cu (Hydrolysed PSHA-1) $\left.{ }_{2}\right]$ & 2.4788 & 1.4280 & 3.9068 \\
\hline$\left[\mathrm{Pb}(\text { Hydrolysed PSHA-1) })_{2}\right]$ & 2.5832 & 1.1963 & 3.7795 \\
\hline$\left[\mathrm{Cd}(\text { Hydrolysed PSHA-1 })_{2}\right]$ & 2.2108 & 1.5453 & 3.7561 \\
\hline$\left[\mathrm{Mg}(\text { Hydrolysed PSHA-1 })_{2}\right]$ & 2.1382 & 1.5453 & 3.6835 \\
\hline [Cu (Unhydrolysed PSHA-1) & 2.3059 & 1.2209 & 3.5268 \\
\hline$[\mathrm{Pb}$ (Unhydrolysed PSHA-1) 2$]$ & 2.2364 & 1.2239 & 3.4603 \\
\hline [Cd (Unhydrolysed PSHA-1) 2 ] & 2.2516 & 1.2581 & 3.5097 \\
\hline$[\mathrm{Mg}$ (Unydrolysed PSHA-1) & 2.1568 & 0.9127 & 3.0695 \\
\hline
\end{tabular}

The results obtained (Table19) shows the stepwise and overall stability constants to be not high indicating low stability of the complexes, because the solubility of most metal ions in the basic $\mathrm{pH}$ range is minimal due to metal hydroxide precipitation (Karimi, 2017). In general, the stepwise stability constants $\left(K_{1}\right.$ and $K_{2}$ ) follow the order $K_{1}>K_{2}$ for the copper, lead, magnesium and cadmium complexes respectively. The steady decrease of the values with increasing number of ligands is in agreement with the prediction made by researchers (Na'aliya, 2013). The decrease could be attributed to the fact that as the number of the ligands (Humate ions) that enters the coordination zone increases the aqua molecules available for replacement by the ligands become less. Thus, the metal ions become less electron loving with progressive intake of the ligand and this results in the decrease in the values of the constants (Na'aliya, 2013). Also the stability of the complexes is influenced by the size and number of the chelate rings(Mackay and Mackay,2002).All the complexes form rings in their structure as humate, a bidentate ligand, bond the metal ions in the ratio 1:2 (Boguta and Sokolowska, 2016) forming chelate rings. The values of the overall stability constants $(\log \beta)$ obtained for humate complexes are not high indicating low stability as the values are not high. LogK values for copper-humates (Table 3 to 6) obtained in this study are lower than those reported for the complexes of humic acids (Pandey et al., 2015; Dinu, 2013; Kaschl et al., 2010 and Gilbeto and Jorg, 2001). The values of LogK(Table 7 to 10 ) forlead-humates are lower than those reported for the lead in the literature (Dinu, 2013; Gilbeto and Jorg 2001). Log K values(Table 11 to 14 ) for magnesium-humates obtained in this study are close to those reported by (Pandey et al., 2015). Log K values of cadmium-humates (Table 15 to 18 ) obtained in this work near to the one reported by (Dinu, 2013 and Pandey et al., 2015).The difference between the reported values and the values obtained in this study might be probably as a result of acid hydrolysis of humic acid. The values of the overall stability constants $(\log \beta)$ of the copper humates complexes presented in Table 19 is high than that of other metal humate complexes, show relatively high stability of CuHA complexes, show the following order of stability: $\mathrm{Cu}>\mathrm{Pb}>\mathrm{Cd}>\mathrm{Mg}$; which are in close agreement to the findings of (Dinu, 2013 and Pandey et al., 2015).The high stability of Cuhumate chelate could be attributed to the existence of coordinate covalent bond between the complexing agents and the $\mathrm{Cu}^{2+}$ ions. Since, $\mathrm{Cu}^{2+}$ being a metal of the transitional series with $3 d^{9}$ electronic configurations can accept the electrons from the complexing agents. Similarly, the low stabilities of $\mathrm{Pb}, \mathrm{Cd}$ and $\mathrm{Mg}$ complexes could be explained by that $\mathrm{Pb}^{2+}$ with $6 s^{2}, \mathrm{Cd}^{2+}$ with $4 \mathrm{~d}^{10}$ and $\mathrm{Mg}^{2+}$ with $2 \mathrm{p}^{6}$ their electronic configuration has a completely filled $\mathrm{d}, \mathrm{p}$ and $\mathrm{s}$ orbitals. Moreover, the stabilities of metal ions with hydrolysed humic acid from peat soil were higher than those with unhydrolysed humic acid from peat soil; which is ascribed to the high content of acidity in hydrolysed humic acid than unhydrolysed humic acid. 
BAJOPAS Volume 14 Number 1,June, 2021 CONCLUSION

The values of logk for $\mathrm{Cu}(\mathrm{II})$ hydrolysed humic acid complex was higher followed by $\mathrm{Pb}$ (II), $\mathrm{Cd}(\mathrm{II})$ and $\mathrm{Mg}$ (II) hydrolysed humic acid complexes as compared with metal(II) unhydrolysed humic acid complexes. This indicates acid hydrolysis of humic acid can

\section{REFERENCES}

Almeida, V.R. and Szpoganicz, B. (2015). Humic Acid Potentiometric Response Patterns:Out- of Equilibrium Properties and Species Distribution Modelling. Chemical. Biol. Technol. Agric. 2: 17.

Anđelković, T., Nikolić, R., Bojić, A.,Anđelković, D., and Nikolic G.,(2010). Binding of Cadmium to Soil Humic Acid as A Function of Carboxyl Group Content. Macedonian Journal of Chemistry and Chemical Engineering.29(2): 215-224.

Anil, B. N. and Maroti, N. (2008). Studies on Influence of Die-Lectric Constants on Complex Equilibria between Substituted Py-Razalines and Lanthanide Metal Ions pH-Metrically. Amer.-Euras. scient. Res. 3(2): 212-216.

Ashok, K., Pandey, S. P. and Misra, V (2000). Stability Constants of Metal-Humic Acid Complexes and its Role in Environmental Detoxification. Journal of Ecotoxicology and Environmental Safety. 47(2):157-200.

Badr, M. H., El-Halafawi, M. H. and Abd El-al Zeid, E. R. (2012). Comparison Between the Effect of Ionic Strength on Acidity and Dissociation Constants of Humic Acids Extracted from Sewage Sludge and Nile Water Hyacinth Composts.Global Journal of Environmental Research 6 (1): 36-43.

Baruah, M.K., Borah, D., Saikia, P.P., Paul, S., Sharma, T. (2015). Evaluation of pKa Values of Soil Humic Acids and their Complexation Properties. International Journal of Plant \& Soil Science 6(4) : 218-228.

Boguta, P. Sokolowska, Z. (2016). Interactions of $\mathrm{Zn}$ (II) Ions with Humic Acids Isolated from Various Types of Soils. Effect of $\mathrm{pH}, \mathrm{Zn}$ Concentrations and Humic Acids Chemical Properties. Journal of Geochemical Explaration 168. 119-126.

Borges, F., Guimaraes, C., Lima, L.F.C., Pinto, I. and Reis, S.(2005). Potentiometric Studies on the Complexation of Copper(II) by Phenolic Acids as Discrete Ligand Models of enhance the complexation behavior of humic acid with metal (II) ions. However, the higher values of $\log \beta$ for $\mathrm{Cu}(\mathrm{II}), \mathrm{Pb}(\mathrm{II}), \mathrm{Cd}(\mathrm{II})$ and $\mathrm{Mg}(\mathrm{II})$ hydrolysed humic acid complexes indicates more stable stepwise complexes formed as compared with $\mathrm{Cu}(\mathrm{II}), \mathrm{Pb}$ (II), $\mathrm{Cd}$ (II) and $\mathrm{Mg}(\mathrm{II})$ unhydrolysed humic acid complexes.

Humic Substances Talanta 66 (2005) 670-673.

Chefetz, B., Salloum, M. J., Deshmulkin, A. P. and Hatcher, P. (2002). Structural Components of Humic Acids as Determined by Chemical Modifications and Carbon-13 NMR, Pyrolysis, and Thermochemolysis- Gas Chromatography/Mass Spectrometry. Soil Science Society of American Journal Abstract Division S-2- Soil Chemistry66. 1159-1171.

Dinu, M. I. (2013). Metals Complexation with Humic Acids in Surface Water of Different Environ. Sci. Technol. 31(1): 1-17.

Fernandes, A.N., Giacomelli, C., Giovanela, M. Vaz, D.V. Szpoganicz, B. and Maria M. D. (2009). Potentiometric Acidity Determination in Humic Substances Influenced by Different Analytical Procedures.J. Braz. Chem. Soc. 20 (9):14.

Gamal, A. H. (2015). Stability Constants of Rhenium (V) Metal Complexes with Selected Drugs. Pyrex Journal of Research in Environmental Studies. 2(2): 006-014.

Janrao, D. M., Pathan, J., Kayande, D.D., and Mulla, J.J. (2014). An Over View of Potentiometric Determination of Stability Constants of Metal Complexes. Sci. Revs. Chem. Commun.: 4(1), 2014, 11-24.

Karimi, H. (2017). Effect of pH and Initial Pb(II) Concentration on the Lead Removal Efficiency from Waste Water Using $\mathrm{Ca}(\mathrm{OH})_{2}$. International Journal of Water and Waste Water Treatment 3.2

Kaschl, A. Romheld, V. and Chen, Y. (2010). Binding of Cadmium, Copper and Zinc to Humic Substances Originating from Municipal Solid Waste Compost. Israel Journal of Chemistry Vol. 42(1): 89-98.

Kostic, I. S., Tatjana, P, A., Nikolic, R. S., Cvetkovic, T. P., Pavlovic, D. D., Aleksandar, L.J. and Bojic, A. (2012). Comparative Study of Binding Strengths of Heavy Metals with Humic Acid. J.serb. Chem. Soc. 76(9) pp 1-20. 
BAJOPAS Volume 14 Number 1,June, 2021

Na'aliya, J. (2013). Determination of Stepwise Stability Constants and Gibbs free Energy Change of Trisprolina to Complexes of some Divalent Transition Metal ions. Bayero Journal of Pure and Applied Sciences 6(2): 112-114.

Omar, A. A. and Ali, E. A. (2015). Potentiometric Studies on Complexes of $\mathrm{Cr}$ (III) and $\mathrm{Zr}$ (IV) with some Carboxylic Acids. International Journal of Advanced Chemistry, 3(1) 25-

37.

Pandey, A. K. Pandey, S. D. and Misr, V. (2015).Stability Constants of Metal- Humic Acid Complexes and Its Role in Environmental Detoxification. J. Ecotoxicology and Environmental Safety. 47(1):195-200.

Ram, N. and Raman, K.V. (1984). Stability Constants of Complexes of Metals with
Humicand Fuvic Acids under Non- acidConditions. Journal of Plant Nutrition and Soil Sciences.

147:171-176.

Santosh, D. D., Ashok, B. K., Vijay, J. T., Shivraj, G. W. and Vinay, V. W. (2011). Potentiometric Studies of Elec-Trolyte Effects on Complex Equilibria of Some Substituted 5-(2-hydroxy Phenyl) Pyrazoles. Der pharm. 3 (6): 75-83.

Sayyed, H. and Abdul Rahim, M. F. (2012). Studies of Binary Complexes of Metal Ions with Mandelic Acid by Potentiometry. Chem. J. 02 (6): 206209.

Shirvani, M. Moradian, E. Khalili, B. Bakhtiary, S. (2015). Interaction of $\mathrm{Cd}$ and $\mathrm{Pb}$ with Humate-Palygorskite and HumateSepiolite Complexes. Journal of water, air and pollution 3: 220-228. 


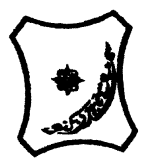

Bayero Journal of Pure and Applied Sciences, 14(1): 54 - 63

Received: November, 2020

Accepted: April, 2021

ISSN $2006-6996$

\title{
STABILITY CONSTANTS OF COMPLEXES OF METAL IONS WITH PEATSOIL HUMIC ACIDS UNDER NON-ACID-CONDITIONS
}

\author{
${ }^{* 1}$ Sabo, Yusuf ${ }^{2}$ Jimoh, W.L.O., ${ }^{3}$ Isa Baba Koki and ${ }^{4}$ Sholadoye, Q. 0. \\ ${ }^{1}$ Department of Pure and Industrial Chemistry, Bayero University, Kano \\ ${ }^{3}$ Department of Chemistry, Yusuf Maitama Sule University Kano. P.M.B. 3220 Kano, Nigeria. \\ ${ }^{4}$ Department of Chemistry, Nigerian Police Academy, Wudil, Kano-Nigeria
}

*Correspondence E-mail; saboyusuf18@yahoo.com

ABSTRACT

Stability constants of complexes of four divalent metal ions viz. $\mathrm{Cu}^{2+}, \mathrm{Pb}^{2+}, \mathrm{Mg}^{2+}$ and $\mathrm{Cd}^{2+}$ with humic acids (HA) were determined by potentiometric titration of humic acids with the corresponding salt of the divalent metals in aqueous media under non-acid-condition. The log $K$ (logarithm of the stability constant) ranged from 1.0942 to 2.7471 for metalhumic acid complexes were determined using point-wise computational method. The order of stability constants were obtained as follows: $\mathrm{Cu}>\mathrm{Pb}>\mathrm{Cd}>\mathrm{Mg}$ for metal $-\mathrm{HA}$ complexes respectively, indicating a higher degree of complexation with Cu metal ion.

Keywords: stability constant, humic acid, potentiometric titration, divalent metals, acid hydrolysis.

\section{NTRODUCTION}

The stability constant of a complex is the numerical expression of its stability and provides a quantitative measure of affinity of the metal ion to the complexing agent. An understanding of the relative stability of metal-complexes helps in predicting the behavior of metal ions in the soil (Ram and Raman, 1982). Extensive researches has been done to determine the stability constants of the complexes formed between humic acid (HA) with a number of metal ions. Ashok et al., (2000) reported that humic acid with hydroxyl, phenoxyl and carboxyl reactive groups can form coordination compound with metal ions at $\mathrm{pH}$ 3.5. The stability constants(Log K) for different metalhumic acid complexes indicated the following order of the stabilities of complexes formed between humic acid and metal ion, $\mathrm{Cu}>\mathrm{Fe}$ $>\mathrm{Pb}>\mathrm{Ni}>\mathrm{Co}>\mathrm{Ca}>\mathrm{Cd}>\mathrm{Zn}>\mathrm{Mn}>\mathrm{Mg}$. Andelkovic et al., (2010) investigated the binding of $\mathrm{Cd}$ (II) to soil humic acid at pH 6.5 and in $0.1 \mathrm{M} \mathrm{KNO}_{3}$ ionic medium. The stability constant for binding indicating greater stability in the case when carboxyl groups are involved in complexation reaction. Kostic et al.,(2012) investigated the complexation of humic acid with certain heavy metal ions (Co(II), $\mathrm{Ni}(\mathrm{II}), \mathrm{Cu}(\mathrm{II})$,
$\mathrm{Zn}(\mathrm{II})$, and $\mathrm{Pb}(\mathrm{II})$. The experiment was performed at $25^{\circ} \mathrm{C}$, at pH 4.0 and ionic strength of $0.01 \mathrm{M}$. Stability constant of complex between $\mathrm{Pb}$ (II) ions and humic acid is greater than stability constants of other investigated metalhumate complexes. Bogata and Sokolowska (2016) analyses the interaction between humic acids from different soils and $\mathrm{Zn}$ (II) ions at wide concentration ranges and at $\mathrm{pH} 5$. Studies have showed significant impact of $\mathrm{Zn}$ concentration, $\mathrm{pH}$ and some properties of humic acids with zinc.But all of these studies were limited to acidic $\mathrm{pH}$ range. Therefore, the present study was carried out to determine and compare the stability constants of complexes of metal ions with hydrolysed peat soil humic acid and unhydrolysed peat soil humic under non-acid conditions.

\section{MATERIALS AND METHODS}

Analytical grade chemicals used includes hydrochloric acid $(\mathrm{HCl})$, nitric acid $\left(\mathrm{HNO}_{3}\right)$, sodium hydroxide $(\mathrm{NaOH})$, lead nitrate $\mathrm{Pb}\left(\mathrm{NO}_{3}\right)_{2}$, copper nitrate $\mathrm{Cu}\left(\mathrm{NO}_{3}\right)_{2} \cdot 3 \mathrm{H}_{2} \mathrm{O}$, cadmium nitrate $\mathrm{Cd}\left(\mathrm{NO}_{3}\right)_{2} \cdot 4 \mathrm{H}_{2} \mathrm{O}$, magnesium nitrate $\mathrm{Mg}\left(\mathrm{NO}_{3}\right)_{2} \cdot 6 \mathrm{H}_{2} \mathrm{O}$, potassium nitrate $\left(\mathrm{KNO}_{3}\right)$, calcium chloride $\left(\mathrm{CaCl}_{2}\right)$, (sigma-Aldrich). Dowex 50WX8, (20-50 mesh) from Fluka. 


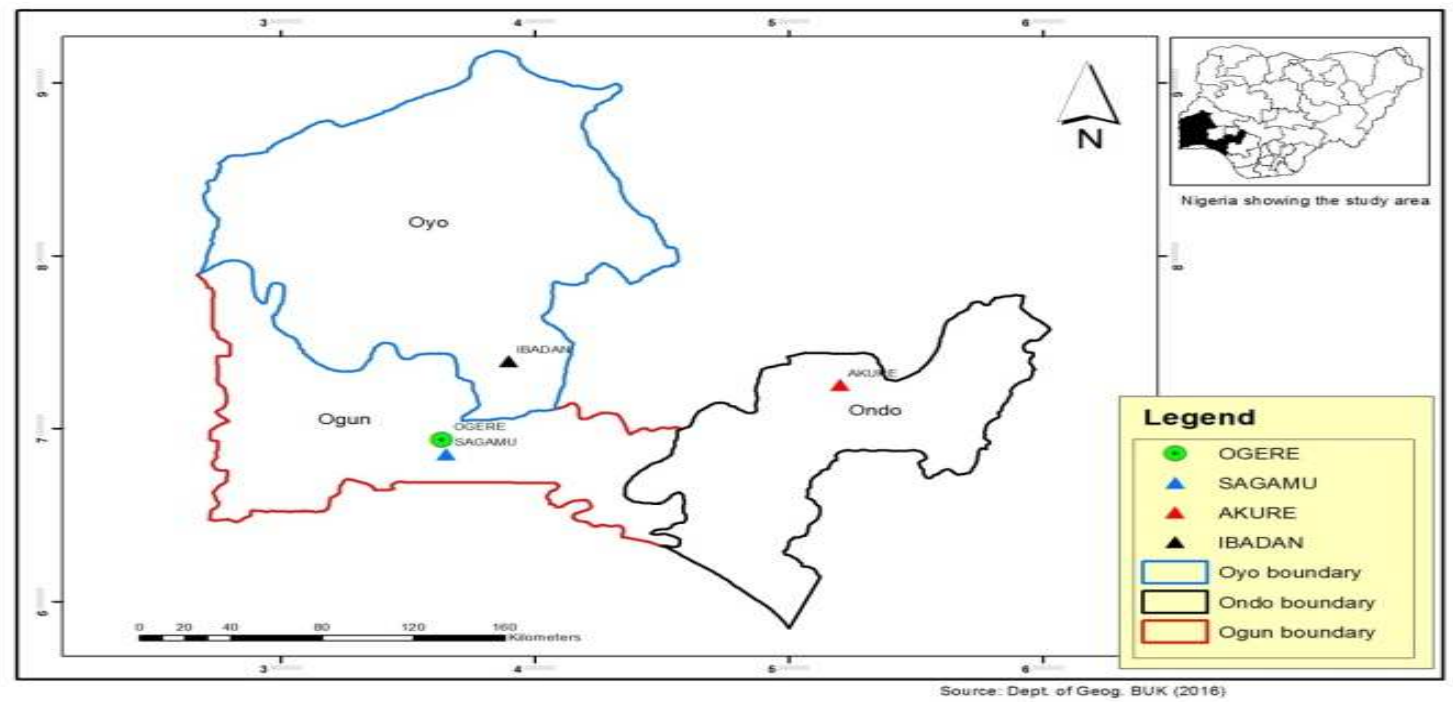

Figure 1: Map showing the sampling point at Sagamu Town, Ogun State.

\section{Description of Sampling Area}

Sagamu has geographical coordinates between $6^{\circ} 50^{\prime}$ north; $3^{\circ} 38^{\prime}$ east is located in south western region of Nigeria. The region has tropical wet and dry climate with a lengthy wet season and relatively constant temperatures throughout the course of the year. Wet season runs from March to October, November to December forms the region dry season. The vegetation type of the region is savannah which is really grassland with small bushes and occasional big trees. Grassland soils have substantially higher organic matter content than forest soils (Novackova, 2011).

\section{Sample Collection}

The Peatsoil samples were collected from four different sampling points $(0-10 \mathrm{~cm}$ depth) in Sagamu into polyethylene bag with plastic spoons. Samples were taken to the laboratory, extraneous materials were removed; the samples were air-dried, crushed and ground to a fine powder in a mortar passed through a $0.20 \mathrm{~mm}$ sieve. The samples were kept for analysis.

\section{Isolation and purification of humic acid from peat soil sample}

Peatsoil sample $(100 \mathrm{~g})$ was mixed with 1000 $\mathrm{cm}^{3}$ of $0.1 \mathrm{M} \mathrm{NaOH}$ solution, shaken for 3hours and left to stand overnight. Dark-coloured supernatant was obtained and decanted from solid residue. The dark-coloured supernatant was acidified to $(\mathrm{pH}=1.0)$ with $6 \mathrm{M} \mathrm{HCl}$ stirred and allowed to stand for 6 hours. Yellowish brown supernatant and dark-brown precipitate were obtained. The yellowish brown supernatant was decanted followed by centrifuge and discarded. The dark-brown precipitate was mixed with $500 \mathrm{~cm}^{3}$ of $0.1 \mathrm{M} \mathrm{NaOH}$ solution followed by passing through dowex resin. The dark-brown solution was acidified to $(\mathrm{pH}=1.0)$ with $6 \mathrm{M} \mathrm{HCl}$ stirred and allowed to stand for 3 hours. The dark-brown precipitate was washed several times with deionized water. The supernatant was treated with $\mathrm{AgNO}_{3}$ solution until no white precipitate observed. The humic acid was transferred to weighed crucible and dried at $60^{\circ} \mathrm{C}$ in an oven for 12 hours. The humic acid was cooled and dried in the desiccator, weighed and recorded. The obtained humic acid was dried again at $60^{\circ} \mathrm{C}$ for additional 6 hours cooled and dried in the desiccator, weighed and recorded constant weight was obtained (Baruah et al., 2015).

\section{FT-IR analysis}

FT-IR spectra of humic acid sample was analysed using Carry 630 FT-IR Agilent Technologies.

Unhydrolysed compost humic acid

The unhydrolysed humic acid was obtained after isolation and purification of compost humic acid and kept for investigation.

\section{Acid hydrolysis of Peatsoil acid}

Peatsoil humic acid sample (1g) was refluxed for 12 hours at $\left(160^{\circ} \mathrm{C}\right)$ with $50 \mathrm{~cm}^{3}$ of $6 \mathrm{M} \mathrm{HCl}$. The mixture was allowed to cool, decanted, and centrifuged after hydrolysis. The insoluble residues were washed with distilled water via centrifugation several times, and the supernatant was treated with $\mathrm{AgNO}_{3}$ solution until no white precipitate was observed. The residue was thoroughly dried over $\mathrm{CaCl}_{2}$ in a desiccator at room temperature (Chefetz et al., 2002). Finally, the obtained hydrolysed humic acid was kept for investigation. 
BAJOPAS Volume 14 Number 1,June, 2021 Potentiometric Titrations

Potentiometric measurements were carried out using a pH-meter Jenway (model 3510) with combine electrode, the sensitivity of the $\mathrm{pH}$ meter is 0.01 units. The $\mathrm{pH}$ meter was switched on half an hour before starting the titration for initial warm up of the instrument. The instrument was calibrated with an aqueous standard buffer solution of $\mathrm{pH} 4.00$ and 10.0 (borate buffer) prepared from a "Qualigens" buffer tablets.

The following sets of solutions were prepared in a $250 \mathrm{~cm}^{3}$ volumetric flask separately for $\mathrm{pH}$ metric titrations.

(i) $5 \mathrm{~cm}^{3} 0.1 \mathrm{M} \mathrm{HCl}+40 \mathrm{~cm}^{3}$ deionized water

(ii) $5 \mathrm{~cm}^{3} 0.1 \mathrm{M} \mathrm{HCl}+39 \mathrm{~cm}^{3}$ deionized water $+1 \mathrm{~cm}^{3} 0.15 \mathrm{gcm}^{-3}$ humic acid

(iii) $5 \mathrm{~cm}^{3} 0.1 \mathrm{M} \mathrm{HCl}+37 \mathrm{~cm}^{3}$ deionized water $+1 \mathrm{~cm}^{3} 0.15 \mathrm{gcm}^{-3}$ humic acid

$$
+2 \mathrm{~cm}^{3} \quad 0.01 \mathrm{M} \mathrm{Cu} \text { (II) }
$$

The solutions were titrated against standardized $0.110 \mathrm{MNaOH}$ separately. The total volume of each mixture was adjusted to $50 \mathrm{~cm}^{3}$ and the ionic strength of the solutions was maintained constant at by adding appropriate amount of stock solution of $1 \mathrm{M} \mathrm{KNO}_{3}$ (Gamal, 2015; Omar and Ali, 2015). A magnetic stirrer was used to achieve thorough mixing of the interacting solutions at $550 \mathrm{rpm}$. The same set of experimental conditions was applied for potentiometric titration of remaining samples.

\section{Evaluation of pKa of Hydrolysed peat soil Humic Acids}

The proton-ligand formation number $\mathrm{n}_{\mathbf{A}}$ were calculated by Irving and Rossotti expression (Omar and Ali, 2015).

$\mathrm{nA}=\mathrm{Y}-\frac{(\mathrm{V} 2-\mathrm{V1})(\mathrm{No}-\mathrm{Eo})}{(\mathrm{VO}+\mathrm{V1}) \mathrm{TCL}}$ 1

Where: $Y$ is number of dissociable proton, $\left(\mathrm{V}_{2^{-}}\right.$ $V_{1}$ ) is the measure of displacement of the ligand curve relative to acid curve, $\mathrm{N}^{\circ}$ and $\mathrm{E}^{\circ}$ are the resultant concentration of alkali solution, free acid solution, $\mathrm{T}_{\mathrm{cL}}{ }^{\circ}$ is the total ligand concentration, $\mathrm{V}^{\circ}$ is the total volume of titration solution, $V_{1}$ is the volume of alkali added to acid solution, $V_{2}$ is the volume of alkali added to acid solution + ligand solution, acid dissociation constants (pKa - values) of ligand were calculated by algebraic method point wise calculation (Tables 1 ). The dissociation constants (pKa) were calculated according to the following relation:

$\mathrm{pKa}=\mathrm{pH}+\log \left(\frac{n A}{1-n A}\right)$ 2

Where: pKa is the acid dissociation constant, $\mathrm{n}_{\mathrm{A}}$ is the Proton-ligand formation number and $\mathrm{pH}$ is the pH-values (Omar and Ali, 2015).

\section{Determination of metal-ligand stability constants $(\log K)$ of complexes}

The potentiometric measurement for the determination of stability constant of a complex in solution is based on the fact that the redox potential of the couple $\frac{M^{+(m-n)}}{M^{+m}}$ is shifted significantly on complexation of the metal ion with the ligand. This method involves change in hydrogen ion concentration $\left[\mathrm{H}^{+}\right]$due to the displacement or association of one or more protons taking place during complexation reaction. This change can be found out by titrating the solutions containing free acid, acid with ligand, and acid with ligand and metal ion, individually against a standard alkali solution at a constant ionic strength or temperature. Either ionic strength or temperature may be varied for different sets of solutions. In all the cases, the change in the $\mathrm{pH}$ of the solution is measured after each addition of a known amount of alkali to the reaction cell which contains the reaction mixture. The titration curves are then drawn by plotting the measured $\mathrm{pH}$ values against the corresponding volume of alkali added and the stability constants of the complexes are determined from the titration curves by employing $\mathrm{pH}$-metric titration technique given by (Irving and Rossoti).

Metal-ligand stability constants ( $\log \mathrm{K}$ ) were determined by using the following relations:

$$
\bar{n}=\frac{\left(V_{3}-V_{2}\right)\left(E^{0}+N^{0}\right)}{\left(V^{0}+V_{2}\right) \bar{n}_{A} T_{m}^{0}}
$$

and

$$
P L=\log _{10}\left\{\frac{1+\beta_{n}^{H} \frac{1}{[\text { anti } \log \mathrm{pH}]^{\mathrm{n}}}}{\mathrm{T}_{\mathrm{L}}^{0}-n \bar{T}_{m}^{0}} \mathrm{X} \frac{\left(V^{0}+V_{3}\right)}{V^{0}}\right\}
$$


BAJOPAS Volume 14 Number 1,June, 2021

Where $T_{L}, T^{\circ}, E^{\circ}$, and $V^{\circ}$ havethe same significance as in equation (1) above, $T_{m}$ denotes the total concentration of metal present in solution, $V_{3}$ is the volume of metal ions present in solution and $\beta^{H}$ is the overall proton ligand stability constant. The metal-ligand stability constants (log K) were determined by employing point wise computational Method (eq. 5 and 6).

$\operatorname{LogK}_{1}=\log \left(\frac{n}{1-n}\right)+\mathrm{pL}$ .5

$\operatorname{LogK}_{2}=\log \left(\frac{1-n}{2-n}\right)+\mathrm{pL}$ ...6

Where: Log $\mathrm{K}$ is the metal-ligand stability constant, $\mathrm{pL}$ is the Free ligand exponent function, $\mathbf{n}$ is the Average number of ligand attached with metal ion (Janraoet al., 2014). The results obtained were analyzed by an ORIGIN 2016 program using titration data and then the proton-ligand stability constants (pKa) and Metal-ligand stability constant (LogK) calculated (Omar and Ali, 2015).

\section{RESULTS AND DISCUSSION}

Fourier transformed infrared (FT-IR) spectra of isolated humic acid from peat soils Figure 2 had distinct clear absorption bands indicating the presence of major humic acid structural elemental groups such as $\mathrm{H}$ bonded $\mathrm{OH}$ $\left(3680 \mathrm{~cm}^{-1}\right.$ peak $), C=0$ of carbonyl $\left(1721 \mathrm{~cm}^{-1}\right.$ peak), functional groups of aliphatic components $\mathrm{CH}_{2}\left(2918 \mathrm{~cm}^{-1}\right.$ peak) and $\mathrm{C}-\mathrm{O}$ stretching of polysaccharide $\left(1168 \mathrm{~cm}^{-1}\right.$ peak). The positions of the absorption bands of the spectra fell within typical major absorption bands of humic acid which is at frequencies 3680, 2918, 1721, 1168 $\mathrm{cm}^{-1}$. The first peak centred in the vicinity of $3680 \mathrm{~cm}^{-1}$ region is attributed to phenol $\mathrm{OH}$ group bounded by intermolecular $\mathrm{H}$ bonds. The $2918 \mathrm{~cm}^{-1}$ band usually has absorption maximum at $2918 \mathrm{~cm}^{-1}$ which is due to $\mathrm{C}-\mathrm{H}$ stretching of alkane group $\left(\mathrm{CH}_{2}\right)$. The next major absorption band is $1721 \mathrm{~cm}^{-1}$. This band has been commonly ascribed to $\mathrm{C}=\mathrm{O}$ stretching of mainly carboxyl group $(\mathrm{COOH})$ with trace amount of ketones. The last peak was observed at 1168 $\mathrm{cm}^{-1}$ due to $\mathrm{C}-\mathrm{O}$ stretching of polysaccharides and this peak appeared also in the spectra of humic acid from peat soil. The FTIR spectra of the isolated humic acid contained all major characteristic absorption peaks of humic acid. These absorption peaks indicated the presence of the major structural elements of humic acid namely $\mathrm{H}$ bonded $\mathrm{OH}, \mathrm{C}=\mathrm{C}$ of aromatic ring, $\mathrm{C}=\mathrm{O}$ of carbonyl group (both carboxyl and ketonic), $\mathrm{CH}_{2}$ group. This strongly supports the presence of humic acid.

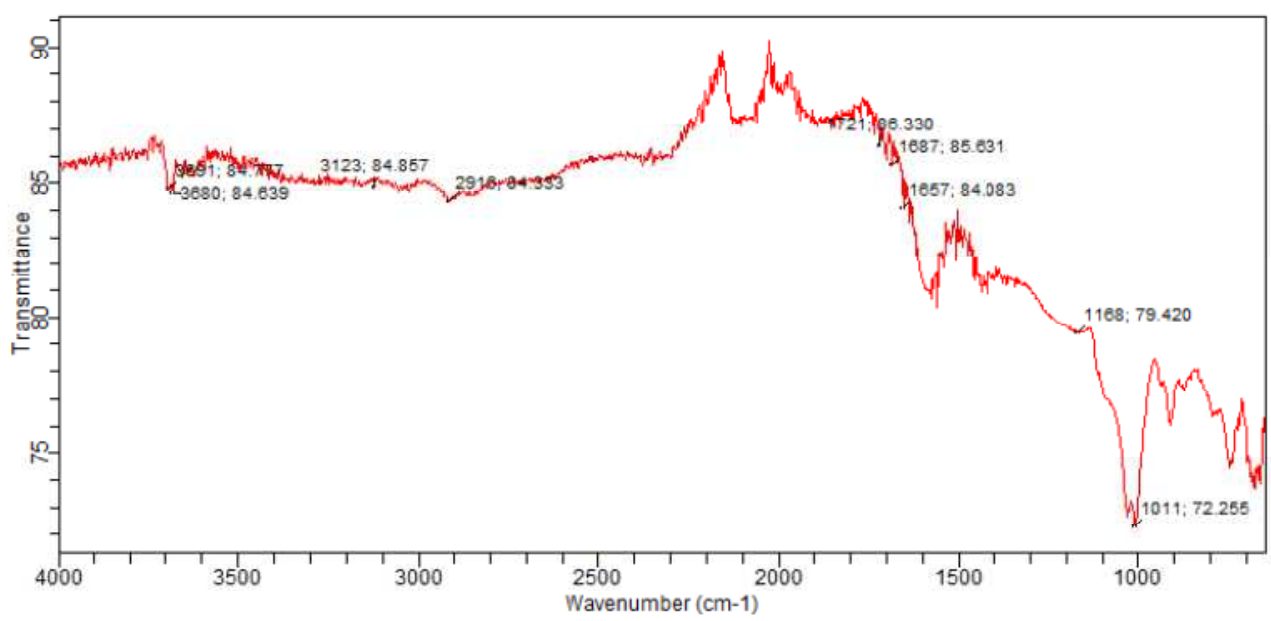

Fig. 2 : FT-IR spectraof peatsoilhumic acid (PSHA)

\section{Evaluation of acid dissociation constant (pka) of acid hydrolysed peat soil humicacid at phenolic group}

The value of the dissociation constant of the peat soil humic acid (PSHA) that underwent acidhydrolysis studied was found to be 8.9299 as shown Table 1, which is lower than the literaturevalues reported by Almeida and Szpoganics, (2015), Borges et al., (2005); Badr et al., (2012)and Fernandes et al,.(2009) of $9.73,9.47$ and 10.30. The difference between the obtained valuesand the reported values in this study might be probably as a result of acid hydrolysis of humicacid. 
BAJOPAS Volume 14 Number 1,June, 2021

Table 1: PKa of (Hydrolysed PSHA)

\begin{tabular}{|l|l|l|l|l|l|l|}
\hline $\mathrm{pH}$ & $\mathrm{BV}_{1}$ & $\mathrm{BV}_{2}$ & $\mathrm{~V}_{2}-\mathrm{V}_{1}$ & $\mathrm{nA}$ & $\log \left(\frac{n A}{1-n A}\right)$ & $\mathrm{pKa}$ \\
\hline 8.50 & 5.30 & 6.29 & 0.99 & 0.3594 & -0.2510 & 8.2490 \\
8.72 & 5.35 & 6.37 & 1.02 & 0.3400 & -0.2880 & 8.4320 \\
9.00 & 5.40 & 6.46 & 1.06 & 0.3141 & -0.3391 & 8.6609 \\
9.22 & 5.45 & 6.55 & 1.10 & 0.2882 & -0.3927 & 8.8273 \\
9.51 & 5.50 & 6.66 & 1.16 & 0.2494 & -0.4786 & 9.0314 \\
9.73 & 5.55 & 6.78 & 1.23 & 0.2041 & -0.5910 & 9.1390 \\
10.00 & 5.60 & 6.90 & 1.30 & 0.1589 & -0.7238 & 9.2762 \\
10.23 & 5.65 & 7.05 & 1.40 & 0.0941 & -0.9835 & 9.2465 \\
10.49 & 5.70 & 7.10 & 1.40 & 0.0941 & -0.9835 & 9.5065 \\
\hline
\end{tabular}

Average pKa $=8.9299 \pm 0.4186$

Table 2: PKa of (Unhydrolysed PSHA)

\begin{tabular}{|l|l|l|l|l|l|l|}
\hline $\mathrm{pH}$ & $\mathrm{BV}_{1}$ & $\mathrm{BV}_{2}$ & $\mathrm{~V}_{2}-\mathrm{V}_{1}$ & $\mathrm{nA}$ & $\log \left(\frac{\boldsymbol{n A}}{1-\boldsymbol{n}}\right)$ & $\mathrm{pKa}$ \\
\hline 8.50 & 5.30 & 5.81 & 0.51 & 0.6619 & 0.2919 & 8.7919 \\
8.72 & 5.35 & 5.90 & 0.55 & 0.6357 & 0.2418 & 8.9618 \\
9.00 & 5.40 & 6.00 & 0.60 & 0.6029 & 0.1813 & 9.1813 \\
9.22 & 5.45 & 6.10 & 0.65 & 0.5701 & 0.1226 & 9.3426 \\
9.51 & 5.50 & 6.20 & 0.70 & 0.5376 & 0.0654 & 9.5754 \\
9.73 & 5.55 & 6.33 & 0.78 & 0.4851 & -0.0259 & 9.7041 \\
10.00 & 5.60 & 6.47 & 0.87 & 0.4262 & -0.1291 & 9.8709 \\
10.23 & 5.65 & 6.62 & 0.99 & 0.3609 & -0.2481 & 9.9819 \\
10.49 & 5.70 & 6.80 & 1.10 & 0.2759 & -0.4690 & 10.0210 \\
\hline
\end{tabular}

Average pKa $=9.4923 \pm 0.4410$

Metal-ligand stability constant ( $\log \mathrm{K}$ )

The stabilityconstants require the accurate values of proton-ligand stability constants (Anil and Maroti, 2008). Metal titration curves crossed over ligand titration curve indicated the formation of complex upon proton release (Santosh, et al., 2011). If the values of n- are within range $0.2-0.8$ and $1.2-18$ this indicates the formation of $1: 1$ and 1:2 complexes (Sayyed and Mazahar, 2012).

The metal (II)-humate stepwise stability constants (log k) at phenolic group (Tables 318)

Table 3: Point-wise method, $\mathrm{Cu}$-(Hydrolysed PSHA)

\begin{tabular}{|l|l|l|l|l|l|l|l|l|}
\hline $\mathrm{pH}$ & $\mathrm{BV}_{1}$ & $\mathrm{BV}_{2}$ & $\mathrm{BV}_{3}$ & $\left(\mathrm{~V}_{3}-\mathrm{V}_{2}\right)$ & $\mathrm{n}$ & $\mathrm{pL}$ & $\log \left(\frac{n}{1-n}\right)$ & LogK $_{1}$ \\
\hline 8.50 & 5.30 & 6.29 & 6.33 & 0.04 & 0.5500 & 2.66 & 0.0871 & 2.7471 \\
8.72 & 5.35 & 6.37 & 6.41 & 0.04 & 0.5714 & 2.43 & 0.1249 & 2.5549 \\
9.00 & 5.40 & 6.46 & 6.50 & 0.04 & 0.6198 & 2.16 & 0.2122 & 2.3722 \\
9.22 & 5.45 & 6.55 & 6.59 & 0.04 & 0.6667 & 1.94 & 0.3010 & 2.2410 \\
\hline
\end{tabular}

LogK $_{1}$ (Average value) $=2.4788 \pm 0.2203$

Table 4: Point-wise method, $\mathrm{Cu}$-(Hydrolysed PSHA)

\begin{tabular}{|l|l|l|l|l|l|l|l|l|}
\hline $\mathrm{pH}$ & $\mathrm{BV}_{1}$ & $\mathrm{BV}_{2}$ & $\mathrm{BV}_{3}$ & $\left(\mathrm{~V}_{3}-\mathrm{V}_{2}\right)$ & $\mathrm{n}$ & $\mathrm{pL}$ & $\log \left(\frac{n-1}{2-n}\right)$ & LogK $_{2}$ \\
\hline 9.51 & 5.50 & 6.66 & 6.73 & 0.07 & 1.3509 & 1.70 & -0.2671 & 1.4329 \\
9.73 & 5.55 & 6.78 & 6.85 & 0.07 & 1.6383 & 1.51 & 0.2467 & 1.7567 \\
10.00 & 5.60 & 6.90 & 6.98 & 0.08 & 2.1783 & 1.31 & -0.2158 & 1.0942 \\
10.23 & 5.65 & 7.05 & 7.13 & 0.08 & 4.1904 & 1.27 & & \\
10.49 & 5.70 & 7.10 & 7.19 & 0.09 & 4.6920 & & & \\
\hline
\end{tabular}

Log $K_{2}($ Average value $)=1.4280 \pm 0.3312$ 
BAJOPAS Volume 14 Number 1,June, 2021

Table 5: Point-wise method, $\mathrm{Cu}$ (Unhydrolysed PSHA)

\begin{tabular}{|l|l|l|l|l|l|l|l|l|}
\hline $\mathrm{pH}$ & $\mathrm{BV}_{1}$ & $\mathrm{BV}_{2}$ & $\mathrm{BV}_{3}$ & $\left(\mathrm{~V}_{3}-\mathrm{V}_{2}\right)$ & $\mathrm{n}$ & $\mathrm{pL}$ & $\log \left(\frac{n}{n-1}\right)$ & Log $_{1}$ \\
\hline 8.50 & 5.30 & 5.81 & 5.85 & 0.04 & 0.2973 & 2.88 & -0.3736 & 2.5064 \\
8.72 & 5.35 & 5.90 & 5.95 & 0.05 & 0.3873 & 2.66 & -0.1992 & 2.4608 \\
9.00 & 5.40 & 6.00 & 6.05 & 0.05 & 0.4044 & 2.38 & -0.1681 & 2.2119 \\
9.22 & 5.45 & 6.10 & 6.15 & 0.06 & 0.5157 & 2.18 & -0.0272 & 2.2072 \\
9.51 & 5.50 & 6.20 & 6.27 & 0.07 & 0.6417 & 1.89 & 0.2530 & 1.1430 \\
\hline
\end{tabular}

$\operatorname{LogK}_{1}($ Average value $)=2.3059 \pm 0.6153$

Table 6:Point-wise method, $\mathrm{Cu}$ (Unhydrolysed PSHA)

\begin{tabular}{|l|l|l|l|l|l|l|l|l|}
\hline $\mathrm{pH}$ & $\mathrm{BV}_{1}$ & $\mathrm{BV}_{2}$ & $\mathrm{BV}_{3}$ & $\mathrm{~V}_{3}-\mathrm{V}_{2}$ & $\mathrm{n}$ & $\mathrm{pL}$ & $\log \left(\frac{n-1}{2-n}\right)$ & $\log \mathrm{K}_{2}$ \\
\hline 9.73 & 5.55 & 6.33 & 6.42 & 0.09 & 0.9000 & 1.69 & & \\
10.00 & 5.60 & 6.47 & 6.58 & 0.11 & 1.2578 & 1.44 & -0.4592 & 0.9808 \\
10.23 & 5.65 & 6.62 & 6.84 & 0.12 & 1.6137 & 1.26 & -0.2010 & 1.4610 \\
10.49 & 5.70 & 6.80 & 6.92 & 0.12 & 2.1052 & 1.03 & & \\
\hline
\end{tabular}

$\operatorname{LogK}_{2}$ (Average value) $=1.2209 \pm 0.3398$

Table 7:Point-wise method, Pb (Hydrolysed PSHA)

\begin{tabular}{|l|l|l|l|l|l|l|l|l|}
\hline $\mathrm{pH}$ & $\mathrm{BV}_{1}$ & $\mathrm{BV}_{2}$ & $\mathrm{BV}_{3}$ & $\left(\mathrm{~V}_{3}-\mathrm{V}_{2}\right)$ & $\mathrm{n}$ & $\mathrm{pL}$ & $\log \left(\frac{n}{1-n}\right)$ & LogK $_{1}$ \\
\hline 8.50 & 5.30 & 6.29 & 6.33 & 0.04 & 0.5500 & 2.66 & 0.0871 & 2.7471 \\
8.72 & 5.35 & 6.37 & 6.41 & 0.04 & 0.5714 & 2.43 & 0.1249 & 2.5549 \\
9.00 & 5.40 & 6.46 & 6.50 & 0.04 & 0.6198 & 2.16 & 0.2122 & 2.3722 \\
9.22 & 5.45 & 6.55 & 6.60 & 0.05 & 0.8333 & 1.96 & 0.6989 & 2.6589 \\
\hline
\end{tabular}

Log $_{\mathbf{1}}($ Average value $)=2.5832 \pm 0.1614$

Table 8:Point-wise method, Pb-(Hydrolysed PSHA)

\begin{tabular}{|l|l|l|l|l|l|l|l|l|}
\hline $\mathrm{pH}$ & $\mathrm{BV}_{1}$ & $\mathrm{BV}_{2}$ & $\mathrm{BV}_{3}$ & $\left(\mathrm{~V}_{3}-\mathrm{V}_{2}\right)$ & $\mathrm{n}$ & $\mathrm{pL}$ & $\log \left(\frac{n-1}{2-n}\right)$ & $\log \mathrm{K}_{2}$ \\
\hline 9.51 & 5.50 & 6.66 & 6.71 & 0.05 & 0.9650 & 1.67 & & \\
9.73 & 5.55 & 6.78 & 6.83 & 0.05 & 1.1702 & 1.44 & & \\
10.00 & 5.60 & 6.90 & 6.90 & 0.05 & 1.4864 & 1.22 & -0.0237 & 1.1963 \\
10.23 & 5.65 & 7.05 & 7.10 & 0.05 & 2.0190 & 1.09 & & \\
10.49 & 5.70 & 7.10 & 7.17 & 0.07 & 3.6492 & 1.00 & & \\
\hline
\end{tabular}

Log $K_{2}$ (Average value) $=1.1963$

Table 9: Point-wise method, Pb (Unhydrolysed PSHA)

\begin{tabular}{|l|l|l|l|l|l|l|l|l|}
\hline $\mathrm{pH}$ & $\mathrm{BV}_{1}$ & $\mathrm{BV}_{2}$ & $\mathrm{BV}_{3}$ & $\mathrm{~V}_{3}-\mathrm{V}_{2}$ & $\mathrm{n}$ & $\mathrm{pL}$ & $\begin{array}{l}\text { Log } \\
\left(\frac{n}{n-1}\right)\end{array}$ & Log $\mathrm{K}_{1}$ \\
\hline 8.50 & 5.30 & 5.81 & 5.85 & 0.04 & 0.2973 & 2.88 & -0.3736 & 2.5064 \\
8.72 & 5.35 & 5.90 & 5.94 & 0.04 & 0.3099 & 2.66 & -0.5477 & 2.3123 \\
9.00 & 5.40 & 6.00 & 6.05 & 0.05 & 0.4044 & 2.38 & -0.1681 & 2.2119 \\
9.22 & 5.45 & 6.10 & 6.15 & 0.06 & 0.5157 & 2.18 & 0.0272 & 2.2072 \\
9.51 & 5.50 & 6.20 & 6.26 & 0.07 & 0.6417 & 1.89 & 0.2530 & 2.1430 \\
9.73 & 5.55 & 6.40 & 6.40 & 0.07 & 0.7000 & 1.67 & 0.3680 & 2.0380 \\
\hline
\end{tabular}

LogK $_{1}$ (Average value) $=2.2364 \pm 0.1602$

Table 10: Point-wise method, Pb (Unhydrolysed PSHA)

\begin{tabular}{|l|l|l|l|l|l|l|l|l|}
\hline $\mathrm{pH}$ & $\mathrm{BV}_{1}$ & $\mathrm{BV}_{2}$ & $\mathrm{BV}_{3}$ & $\mathrm{~V}_{3}-\mathrm{V}_{2}$ & $\mathrm{n}$ & $\mathrm{pL}$ & $\log \left(\frac{n-1}{2-n}\right)$ & $\log \mathrm{K}_{2}$ \\
\hline 10.00 & 5.60 & 6.47 & 6.55 & 0.08 & 1.9503 & 1.41 & & \\
10.23 & 5.65 & 6.62 & 6.72 & 0.11 & 1.4792 & 1.26 & -0.0361 & 1.2239 \\
\hline
\end{tabular}

$\operatorname{LogK}_{2}$ (Average value) $=1.2239$

Table 11: Point-wise method, Mg (Hydrolysed PSHA)

\begin{tabular}{|l|l|l|l|l|l|l|l|l|}
\hline $\mathrm{pH}$ & $\mathrm{BV}_{1}$ & $\mathrm{BV}_{2}$ & $\mathrm{BV}_{3}$ & $\left(\mathrm{~V}_{3}-\mathrm{V}_{2}\right)$ & $\mathrm{n}$ & $\mathrm{pL}$ & $\log \left(\frac{n}{n-1}\right)$ & LogK $_{1}$ \\
\hline 8.50 & 5.30 & 6.29 & 6.31 & 0.02 & 0.2750 & 2.64 & -0.4290 & 2.2110 \\
8.72 & 5.35 & 6.37 & 6.39 & 0.02 & 0.2858 & 2.42 & -0.3978 & 2.0222 \\
9.00 & 5.40 & 6.46 & 6.49 & 0.03 & 0.4648 & 2.14 & -0.0612 & 2.0788 \\
9.22 & 5.45 & 6.55 & 6.59 & 0.04 & 0.6667 & 1.94 & 0.3010 & 2.2410 \\
\hline
\end{tabular}

$\log _{\mathbf{1}}($ Average value) $=2.1382 \pm 0.1046$ 
BAJOPAS Volume 14 Number 1,June, 2021

Table 12: Point-wise method, Mg (Hydrolysed PSHA)

\begin{tabular}{|l|l|l|l|l|l|l|l|l|}
\hline $\mathrm{pH}$ & $\mathrm{BV}_{1}$ & $\mathrm{BV}_{2}$ & $\mathrm{BV}_{3}$ & $\left(\mathrm{~V}_{3}-\mathrm{V}_{2}\right)$ & $\mathrm{n}$ & $\mathrm{pL}$ & $\log \left(\frac{n-1}{2-n}\right)$ & LogK $_{2}$ \\
\hline 9.51 & 5.55 & 6.66 & 6.71 & 0.05 & 0.9650 & 1.67 & & \\
9.73 & 5.55 & 6.78 & 6.84 & 0.06 & 1.4042 & 1.47 & -0.1686 & 1.3014 \\
10.00 & 5.60 & 6.90 & 6.93 & 0.06 & 1.7838 & 1.23 & 0.5593 & 1.7893 \\
10.23 & 5.65 & 7.05 & 7.10 & 0.06 & 3.1429 & 1.10 & & \\
10.49 & 5.70 & 7.10 & 7.18 & 0.07 & 3.6492 & 0.83 & & \\
\hline
\end{tabular}

LogK $_{2}($ Average value $)=1.5453 \pm 0.3450$

Table 13: Point-wise method, Mg (Unhydrolysed PSHA)

\begin{tabular}{|l|l|l|l|l|l|l|l|l|}
\hline $\mathrm{pH}$ & $\mathrm{BV}_{1}$ & $\mathrm{BV}_{2}$ & $\mathrm{BV}_{3}$ & $\mathrm{~V}_{3}-\mathrm{V}_{2}$ & $\mathrm{n}$ & $\mathrm{pL}$ & $\log \left(\frac{n}{n-1}\right)$ & $\operatorname{Log~}_{1}$ \\
\hline 8.50 & 5.30 & 5.81 & 5.85 & 0.04 & 0.2973 & 2.88 & -0.3736 & 2.5064 \\
8.72 & 5.35 & 5.90 & 5.94 & 0.04 & 0.3099 & 2.66 & -0.3477 & 2.3123 \\
9.00 & 5.40 & 6.00 & 6.04 & 0.04 & 0.3236 & 2.38 & -0.3202 & 2.0598 \\
9.22 & 5.45 & 6.10 & 6.15 & 0.05 & 0.4297 & 2.17 & -0.1230 & 2.0470 \\
9.51 & 5.50 & 6.20 & 6.26 & 0.06 & 0.5500 & 1.89 & 0.0871 & 1.9771 \\
9.73 & 5.55 & 6.33 & 6.40 & 0.07 & 0.7000 & 1.67 & 0.3680 & 2.0380 \\
\hline
\end{tabular}

LogK $_{1}$ (Average value) $=2.1568 \pm 0.2069$

Table 14: Point-wise method, Mg (Unhydrolysed PSHA)

\begin{tabular}{|l|l|l|l|l|l|l|l|l|}
\hline $\mathrm{pH}$ & $\mathrm{BV}_{1}$ & $\mathrm{BV}_{2}$ & $\mathrm{BV}_{3}$ & $\mathrm{~V}_{3}-\mathrm{V}_{2}$ & $\mathrm{n}$ & $\mathrm{pL}$ & $\log \left(\frac{n-1}{2-n}\right)$ & $\log \mathrm{K}_{2}$ \\
\hline 10.00 & 5.60 & 6.47 & 6.55 & 0.08 & 0.9148 & 1.41 & & \\
10.23 & 5.65 & 6.62 & 6.71 & 0.09 & 1.2102 & 1.20 & -0.5749 & 0.6251 \\
10.49 & 5.70 & 6.80 & 6.92 & 0.09 & 1.5968 & 1.03 & 0.1703 & 1.2003 \\
\hline
\end{tabular}

LogK $_{2}$ (Average value) $=0.9127 \pm 0.4070$

Table15:Point-wise method, Cd (Hydrolysed PSHA)

\begin{tabular}{|l|l|l|l|l|l|l|l|l|}
\hline $\mathrm{pH}$ & $\mathrm{BV}_{1}$ & $\mathrm{BV}_{2}$ & $\mathrm{BV}_{3}$ & $\left(\mathrm{~V}_{3}-\mathrm{V}_{2}\right)$ & $\mathrm{n}$ & $\mathrm{pL}$ & $\log \left(\frac{n}{1-n}\right)$ & LogK $_{1}$ \\
\hline 8.50 & 5.30 & 6.29 & 6.31 & 0.02 & 0.2750 & 2.64 & -0.4210 & 2.2190 \\
8.72 & 5.35 & 6.37 & 6.40 & 0.03 & 0.4286 & 2.42 & -0.1249 & 2.2951 \\
9.00 & 5.40 & 6.46 & 6.49 & 0.03 & 0.4648 & 2.14 & -0.0612 & 2.0788 \\
9.22 & 5.45 & 6.55 & 6.59 & 0.04 & 0.6667 & 1.96 & 0.3010 & 2.2610 \\
9.51 & 5.55 & 6.66 & 6.70 & 0.04 & 0.7720 & 1.67 & 0.5297 & 2.1997 \\
\hline
\end{tabular}

LogK $_{\mathbf{1}}$ (Average value) $=2.2108 \pm 0.0825$

Table 16: Point-wise method, Cd (Hydrolysed PSHA)

\begin{tabular}{|l|l|l|l|l|l|l|l|l|}
\hline $\mathrm{pH}$ & $\mathrm{BV}_{1}$ & $\mathrm{BV}_{2}$ & $\mathrm{BV}_{3}$ & $\left(\mathrm{~V}_{3}-\mathrm{V}_{2}\right)$ & $\mathrm{n}$ & $\mathrm{pL}$ & $\log \left(\frac{n-1}{2-n}\right)$ & Log $_{2}$ \\
\hline 9.73 & 5.55 & 6.78 & 6.83 & 0.06 & 1.4042 & 1.47 & -0.1686 & 1.3014 \\
10.00 & 5.60 & 6.90 & 6.95 & 0.06 & 1.7838 & 1.23 & 0.5593 & 1.7893 \\
10.23 & 5.65 & 7.05 & 7.10 & 0.06 & 3.1429 & 1.09 & & \\
10.49 & 5.70 & 7.10 & 7.16 & 0.06 & 3.1429 & 0.89 & & \\
& & & & & & & & \\
\hline
\end{tabular}

$\operatorname{LogK}_{2}$ (Average value) $=1.5453 \pm 0.3450$

Table 17: Point-wise method, Cd (Unhydrolysed PSHA)

\begin{tabular}{|l|l|l|l|l|l|l|l|l|}
\hline $\mathrm{pH}$ & $\mathrm{BV}_{1}$ & $\mathrm{BV}_{2}$ & $\mathrm{BV}_{3}$ & $\mathrm{~V}_{3}-\mathrm{V}_{2}$ & $\mathrm{n}$ & $\mathrm{pL}$ & $\log \left(\frac{n}{n-1}\right)$ & $\operatorname{Log~}_{1}$ \\
\hline 8.50 & 5.30 & 5.81 & 5.86 & 0.05 & 0.3717 & 2.88 & -0.2280 & 2.6520 \\
8.72 & 5.35 & 5.90 & 5.95 & 0.05 & 0.3873 & 2.66 & -0.1992 & 2.4608 \\
9.00 & 5.40 & 6.00 & 6.06 & 0.06 & 0.4853 & 2.38 & -0.0255 & 2.3545 \\
9.22 & 5.45 & 6.10 & 6.16 & 0.06 & 0.5157 & 2.18 & -0.0272 & 2.2072 \\
9.51 & 5.50 & 6.20 & 6.27 & 0.07 & 0.6417 & 1.89 & 0.2530 & 1.1430 \\
9.73 & 5.55 & 6.33 & 6.41 & 0.08 & 0.8000 & 1.69 & 0.6020 & 2.2920 \\
& & & & & & & & \\
\hline
\end{tabular}

$\operatorname{LogK}_{1}($ Average value $)=2.2516 \pm 0.5380$ 
BAJOPAS Volume 14 Number 1,June, 2021

Table 18: Point-wise method, Cd (Unhydrolysed PSHA)

\begin{tabular}{|l|l|l|l|l|l|l|l|l|}
\hline $\mathrm{pH}$ & $\mathrm{BV}_{1}$ & $\mathrm{BV}_{2}$ & $\mathrm{BV}_{3}$ & $\mathrm{~V}_{3}-\mathrm{V}_{2}$ & $\mathrm{n}$ & $\mathrm{pL}$ & $\log \left(\frac{n-1}{2-n}\right)$ & $\log \mathrm{K}_{2}$ \\
\hline 10.00 & 5.60 & 6.47 & 6.57 & 0.10 & 1.1434 & 1.43 & & \\
10.23 & 5.65 & 6.62 & 6.72 & 0.10 & 1.3448 & 1.23 & -0.2788 & 0.9512 \\
10.49 & 5.70 & 6.80 & 6.90 & 0.10 & 1.7742 & 1.03 & 0.5351 & 1.5651 \\
\hline
\end{tabular}

$\operatorname{LogK}_{2}($ Average value $)=1.2581 \pm 0.4340$

Table 19: Stepwise and overall Stability constants of thehydrolysed and unhydrolysed divalent metal (II) complexes

\begin{tabular}{|c|c|c|c|}
\hline Chelates & LogK $_{1}$ & $\log _{2}$ & Log $\beta$ \\
\hline [Cu (Hydrolysed PSHA-1) $\left.{ }_{2}\right]$ & 2.4788 & 1.4280 & 3.9068 \\
\hline$\left[\mathrm{Pb}(\text { Hydrolysed PSHA-1) })_{2}\right]$ & 2.5832 & 1.1963 & 3.7795 \\
\hline$\left[\mathrm{Cd}(\text { Hydrolysed PSHA-1 })_{2}\right]$ & 2.2108 & 1.5453 & 3.7561 \\
\hline$\left[\mathrm{Mg}(\text { Hydrolysed PSHA-1 })_{2}\right]$ & 2.1382 & 1.5453 & 3.6835 \\
\hline [Cu (Unhydrolysed PSHA-1) & 2.3059 & 1.2209 & 3.5268 \\
\hline$[\mathrm{Pb}$ (Unhydrolysed PSHA-1) 2$]$ & 2.2364 & 1.2239 & 3.4603 \\
\hline [Cd (Unhydrolysed PSHA-1) 2 ] & 2.2516 & 1.2581 & 3.5097 \\
\hline$[\mathrm{Mg}$ (Unydrolysed PSHA-1) & 2.1568 & 0.9127 & 3.0695 \\
\hline
\end{tabular}

The results obtained (Table19) shows the stepwise and overall stability constants to be not high indicating low stability of the complexes, because the solubility of most metal ions in the basic $\mathrm{pH}$ range is minimal due to metal hydroxide precipitation (Karimi, 2017). In general, the stepwise stability constants $\left(K_{1}\right.$ and $K_{2}$ ) follow the order $K_{1}>K_{2}$ for the copper, lead, magnesium and cadmium complexes respectively. The steady decrease of the values with increasing number of ligands is in agreement with the prediction made by researchers (Na'aliya, 2013). The decrease could be attributed to the fact that as the number of the ligands (Humate ions) that enters the coordination zone increases the aqua molecules available for replacement by the ligands become less. Thus, the metal ions become less electron loving with progressive intake of the ligand and this results in the decrease in the values of the constants (Na'aliya, 2013). Also the stability of the complexes is influenced by the size and number of the chelate rings(Mackay and Mackay,2002).All the complexes form rings in their structure as humate, a bidentate ligand, bond the metal ions in the ratio 1:2 (Boguta and Sokolowska, 2016) forming chelate rings. The values of the overall stability constants $(\log \beta)$ obtained for humate complexes are not high indicating low stability as the values are not high. LogK values for copper-humates (Table 3 to 6) obtained in this study are lower than those reported for the complexes of humic acids (Pandey et al., 2015; Dinu, 2013; Kaschl et al., 2010 and Gilbeto and Jorg, 2001). The values of LogK(Table 7 to 10 ) forlead-humates are lower than those reported for the lead in the literature (Dinu, 2013; Gilbeto and Jorg 2001). Log K values(Table 11 to 14 ) for magnesium-humates obtained in this study are close to those reported by (Pandey et al., 2015). Log K values of cadmium-humates (Table 15 to 18 ) obtained in this work near to the one reported by (Dinu, 2013 and Pandey et al., 2015).The difference between the reported values and the values obtained in this study might be probably as a result of acid hydrolysis of humic acid. The values of the overall stability constants $(\log \beta)$ of the copper humates complexes presented in Table 19 is high than that of other metal humate complexes, show relatively high stability of CuHA complexes, show the following order of stability: $\mathrm{Cu}>\mathrm{Pb}>\mathrm{Cd}>\mathrm{Mg}$; which are in close agreement to the findings of (Dinu, 2013 and Pandey et al., 2015).The high stability of Cuhumate chelate could be attributed to the existence of coordinate covalent bond between the complexing agents and the $\mathrm{Cu}^{2+}$ ions. Since, $\mathrm{Cu}^{2+}$ being a metal of the transitional series with $3 d^{9}$ electronic configurations can accept the electrons from the complexing agents. Similarly, the low stabilities of $\mathrm{Pb}, \mathrm{Cd}$ and $\mathrm{Mg}$ complexes could be explained by that $\mathrm{Pb}^{2+}$ with $6 s^{2}, \mathrm{Cd}^{2+}$ with $4 \mathrm{~d}^{10}$ and $\mathrm{Mg}^{2+}$ with $2 \mathrm{p}^{6}$ their electronic configuration has a completely filled $\mathrm{d}, \mathrm{p}$ and $\mathrm{s}$ orbitals. Moreover, the stabilities of metal ions with hydrolysed humic acid from peat soil were higher than those with unhydrolysed humic acid from peat soil; which is ascribed to the high content of acidity in hydrolysed humic acid than unhydrolysed humic acid. 
BAJOPAS Volume 14 Number 1,June, 2021 CONCLUSION

The values of logk for $\mathrm{Cu}(\mathrm{II})$ hydrolysed humic acid complex was higher followed by $\mathrm{Pb}$ (II), $\mathrm{Cd}(\mathrm{II})$ and $\mathrm{Mg}$ (II) hydrolysed humic acid complexes as compared with metal(II) unhydrolysed humic acid complexes. This indicates acid hydrolysis of humic acid can

\section{REFERENCES}

Almeida, V.R. and Szpoganicz, B. (2015). Humic Acid Potentiometric Response Patterns:Out- of Equilibrium Properties and Species Distribution Modelling. Chemical. Biol. Technol. Agric. 2: 17.

Anđelković, T., Nikolić, R., Bojić, A.,Anđelković, D., and Nikolic G.,(2010). Binding of Cadmium to Soil Humic Acid as A Function of Carboxyl Group Content. Macedonian Journal of Chemistry and Chemical Engineering.29(2): 215-224.

Anil, B. N. and Maroti, N. (2008). Studies on Influence of Die-Lectric Constants on Complex Equilibria between Substituted Py-Razalines and Lanthanide Metal Ions pH-Metrically. Amer.-Euras. scient. Res. 3(2): 212-216.

Ashok, K., Pandey, S. P. and Misra, V (2000). Stability Constants of Metal-Humic Acid Complexes and its Role in Environmental Detoxification. Journal of Ecotoxicology and Environmental Safety. 47(2):157-200.

Badr, M. H., El-Halafawi, M. H. and Abd El-al Zeid, E. R. (2012). Comparison Between the Effect of Ionic Strength on Acidity and Dissociation Constants of Humic Acids Extracted from Sewage Sludge and Nile Water Hyacinth Composts.Global Journal of Environmental Research 6 (1): 36-43.

Baruah, M.K., Borah, D., Saikia, P.P., Paul, S., Sharma, T. (2015). Evaluation of pKa Values of Soil Humic Acids and their Complexation Properties. International Journal of Plant \& Soil Science 6(4) : 218-228.

Boguta, P. Sokolowska, Z. (2016). Interactions of $\mathrm{Zn}$ (II) Ions with Humic Acids Isolated from Various Types of Soils. Effect of $\mathrm{pH}, \mathrm{Zn}$ Concentrations and Humic Acids Chemical Properties. Journal of Geochemical Explaration 168. 119-126.

Borges, F., Guimaraes, C., Lima, L.F.C., Pinto, I. and Reis, S.(2005). Potentiometric Studies on the Complexation of Copper(II) by Phenolic Acids as Discrete Ligand Models of enhance the complexation behavior of humic acid with metal (II) ions. However, the higher values of $\log \beta$ for $\mathrm{Cu}(\mathrm{II}), \mathrm{Pb}(\mathrm{II}), \mathrm{Cd}(\mathrm{II})$ and $\mathrm{Mg}(\mathrm{II})$ hydrolysed humic acid complexes indicates more stable stepwise complexes formed as compared with $\mathrm{Cu}(\mathrm{II}), \mathrm{Pb}$ (II), $\mathrm{Cd}$ (II) and $\mathrm{Mg}(\mathrm{II})$ unhydrolysed humic acid complexes.

Humic Substances Talanta 66 (2005) 670-673.

Chefetz, B., Salloum, M. J., Deshmulkin, A. P. and Hatcher, P. (2002). Structural Components of Humic Acids as Determined by Chemical Modifications and Carbon-13 NMR, Pyrolysis, and Thermochemolysis- Gas Chromatography/Mass Spectrometry. Soil Science Society of American Journal Abstract Division S-2- Soil Chemistry66. 1159-1171.

Dinu, M. I. (2013). Metals Complexation with Humic Acids in Surface Water of Different Environ. Sci. Technol. 31(1): 1-17.

Fernandes, A.N., Giacomelli, C., Giovanela, M. Vaz, D.V. Szpoganicz, B. and Maria M. D. (2009). Potentiometric Acidity Determination in Humic Substances Influenced by Different Analytical Procedures.J. Braz. Chem. Soc. 20 (9):14.

Gamal, A. H. (2015). Stability Constants of Rhenium (V) Metal Complexes with Selected Drugs. Pyrex Journal of Research in Environmental Studies. 2(2): 006-014.

Janrao, D. M., Pathan, J., Kayande, D.D., and Mulla, J.J. (2014). An Over View of Potentiometric Determination of Stability Constants of Metal Complexes. Sci. Revs. Chem. Commun.: 4(1), 2014, 11-24.

Karimi, H. (2017). Effect of pH and Initial Pb(II) Concentration on the Lead Removal Efficiency from Waste Water Using $\mathrm{Ca}(\mathrm{OH})_{2}$. International Journal of Water and Waste Water Treatment 3.2

Kaschl, A. Romheld, V. and Chen, Y. (2010). Binding of Cadmium, Copper and Zinc to Humic Substances Originating from Municipal Solid Waste Compost. Israel Journal of Chemistry Vol. 42(1): 89-98.

Kostic, I. S., Tatjana, P, A., Nikolic, R. S., Cvetkovic, T. P., Pavlovic, D. D., Aleksandar, L.J. and Bojic, A. (2012). Comparative Study of Binding Strengths of Heavy Metals with Humic Acid. J.serb. Chem. Soc. 76(9) pp 1-20. 
BAJOPAS Volume 14 Number 1,June, 2021

Na'aliya, J. (2013). Determination of Stepwise Stability Constants and Gibbs free Energy Change of Trisprolina to Complexes of some Divalent Transition Metal ions. Bayero Journal of Pure and Applied Sciences 6(2): 112-114.

Omar, A. A. and Ali, E. A. (2015). Potentiometric Studies on Complexes of $\mathrm{Cr}$ (III) and $\mathrm{Zr}$ (IV) with some Carboxylic Acids. International Journal of Advanced Chemistry, 3(1) 25-

37.

Pandey, A. K. Pandey, S. D. and Misr, V. (2015).Stability Constants of Metal- Humic Acid Complexes and Its Role in Environmental Detoxification. J. Ecotoxicology and Environmental Safety. 47(1):195-200.

Ram, N. and Raman, K.V. (1984). Stability Constants of Complexes of Metals with
Humicand Fuvic Acids under Non- acidConditions. Journal of Plant Nutrition and Soil Sciences.

147:171-176.

Santosh, D. D., Ashok, B. K., Vijay, J. T., Shivraj, G. W. and Vinay, V. W. (2011). Potentiometric Studies of Elec-Trolyte Effects on Complex Equilibria of Some Substituted 5-(2-hydroxy Phenyl) Pyrazoles. Der pharm. 3 (6): 75-83.

Sayyed, H. and Abdul Rahim, M. F. (2012). Studies of Binary Complexes of Metal Ions with Mandelic Acid by Potentiometry. Chem. J. 02 (6): 206209.

Shirvani, M. Moradian, E. Khalili, B. Bakhtiary, S. (2015). Interaction of $\mathrm{Cd}$ and $\mathrm{Pb}$ with Humate-Palygorskite and HumateSepiolite Complexes. Journal of water, air and pollution 3: 220-228. 


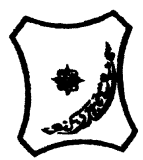

Bayero Journal of Pure and Applied Sciences, 14(1): 54 - 63

Received: November, 2020

Accepted: April, 2021

ISSN $2006-6996$

\title{
STABILITY CONSTANTS OF COMPLEXES OF METAL IONS WITH PEATSOIL HUMIC ACIDS UNDER NON-ACID-CONDITIONS
}

\author{
${ }^{* 1}$ Sabo, Yusuf ${ }^{2}$ Jimoh, W.L.O., ${ }^{3}$ Isa Baba Koki and ${ }^{4}$ Sholadoye, Q. 0. \\ ${ }^{1}$ Department of Pure and Industrial Chemistry, Bayero University, Kano \\ ${ }^{3}$ Department of Chemistry, Yusuf Maitama Sule University Kano. P.M.B. 3220 Kano, Nigeria. \\ ${ }^{4}$ Department of Chemistry, Nigerian Police Academy, Wudil, Kano-Nigeria
}

*Correspondence E-mail; saboyusuf18@yahoo.com

ABSTRACT

Stability constants of complexes of four divalent metal ions viz. $\mathrm{Cu}^{2+}, \mathrm{Pb}^{2+}, \mathrm{Mg}^{2+}$ and $\mathrm{Cd}^{2+}$ with humic acids (HA) were determined by potentiometric titration of humic acids with the corresponding salt of the divalent metals in aqueous media under non-acid-condition. The log $K$ (logarithm of the stability constant) ranged from 1.0942 to 2.7471 for metalhumic acid complexes were determined using point-wise computational method. The order of stability constants were obtained as follows: $\mathrm{Cu}>\mathrm{Pb}>\mathrm{Cd}>\mathrm{Mg}$ for metal $-\mathrm{HA}$ complexes respectively, indicating a higher degree of complexation with Cu metal ion.

Keywords: stability constant, humic acid, potentiometric titration, divalent metals, acid hydrolysis.

\section{NTRODUCTION}

The stability constant of a complex is the numerical expression of its stability and provides a quantitative measure of affinity of the metal ion to the complexing agent. An understanding of the relative stability of metal-complexes helps in predicting the behavior of metal ions in the soil (Ram and Raman, 1982). Extensive researches has been done to determine the stability constants of the complexes formed between humic acid (HA) with a number of metal ions. Ashok et al., (2000) reported that humic acid with hydroxyl, phenoxyl and carboxyl reactive groups can form coordination compound with metal ions at $\mathrm{pH}$ 3.5. The stability constants(Log K) for different metalhumic acid complexes indicated the following order of the stabilities of complexes formed between humic acid and metal ion, $\mathrm{Cu}>\mathrm{Fe}$ $>\mathrm{Pb}>\mathrm{Ni}>\mathrm{Co}>\mathrm{Ca}>\mathrm{Cd}>\mathrm{Zn}>\mathrm{Mn}>\mathrm{Mg}$. Andelkovic et al., (2010) investigated the binding of $\mathrm{Cd}$ (II) to soil humic acid at pH 6.5 and in $0.1 \mathrm{M} \mathrm{KNO}_{3}$ ionic medium. The stability constant for binding indicating greater stability in the case when carboxyl groups are involved in complexation reaction. Kostic et al.,(2012) investigated the complexation of humic acid with certain heavy metal ions (Co(II), $\mathrm{Ni}(\mathrm{II}), \mathrm{Cu}(\mathrm{II})$,
$\mathrm{Zn}(\mathrm{II})$, and $\mathrm{Pb}(\mathrm{II})$. The experiment was performed at $25^{\circ} \mathrm{C}$, at pH 4.0 and ionic strength of $0.01 \mathrm{M}$. Stability constant of complex between $\mathrm{Pb}$ (II) ions and humic acid is greater than stability constants of other investigated metalhumate complexes. Bogata and Sokolowska (2016) analyses the interaction between humic acids from different soils and $\mathrm{Zn}$ (II) ions at wide concentration ranges and at $\mathrm{pH} 5$. Studies have showed significant impact of $\mathrm{Zn}$ concentration, $\mathrm{pH}$ and some properties of humic acids with zinc.But all of these studies were limited to acidic $\mathrm{pH}$ range. Therefore, the present study was carried out to determine and compare the stability constants of complexes of metal ions with hydrolysed peat soil humic acid and unhydrolysed peat soil humic under non-acid conditions.

\section{MATERIALS AND METHODS}

Analytical grade chemicals used includes hydrochloric acid $(\mathrm{HCl})$, nitric acid $\left(\mathrm{HNO}_{3}\right)$, sodium hydroxide $(\mathrm{NaOH})$, lead nitrate $\mathrm{Pb}\left(\mathrm{NO}_{3}\right)_{2}$, copper nitrate $\mathrm{Cu}\left(\mathrm{NO}_{3}\right)_{2} \cdot 3 \mathrm{H}_{2} \mathrm{O}$, cadmium nitrate $\mathrm{Cd}\left(\mathrm{NO}_{3}\right)_{2} \cdot 4 \mathrm{H}_{2} \mathrm{O}$, magnesium nitrate $\mathrm{Mg}\left(\mathrm{NO}_{3}\right)_{2} \cdot 6 \mathrm{H}_{2} \mathrm{O}$, potassium nitrate $\left(\mathrm{KNO}_{3}\right)$, calcium chloride $\left(\mathrm{CaCl}_{2}\right)$, (sigma-Aldrich). Dowex 50WX8, (20-50 mesh) from Fluka. 


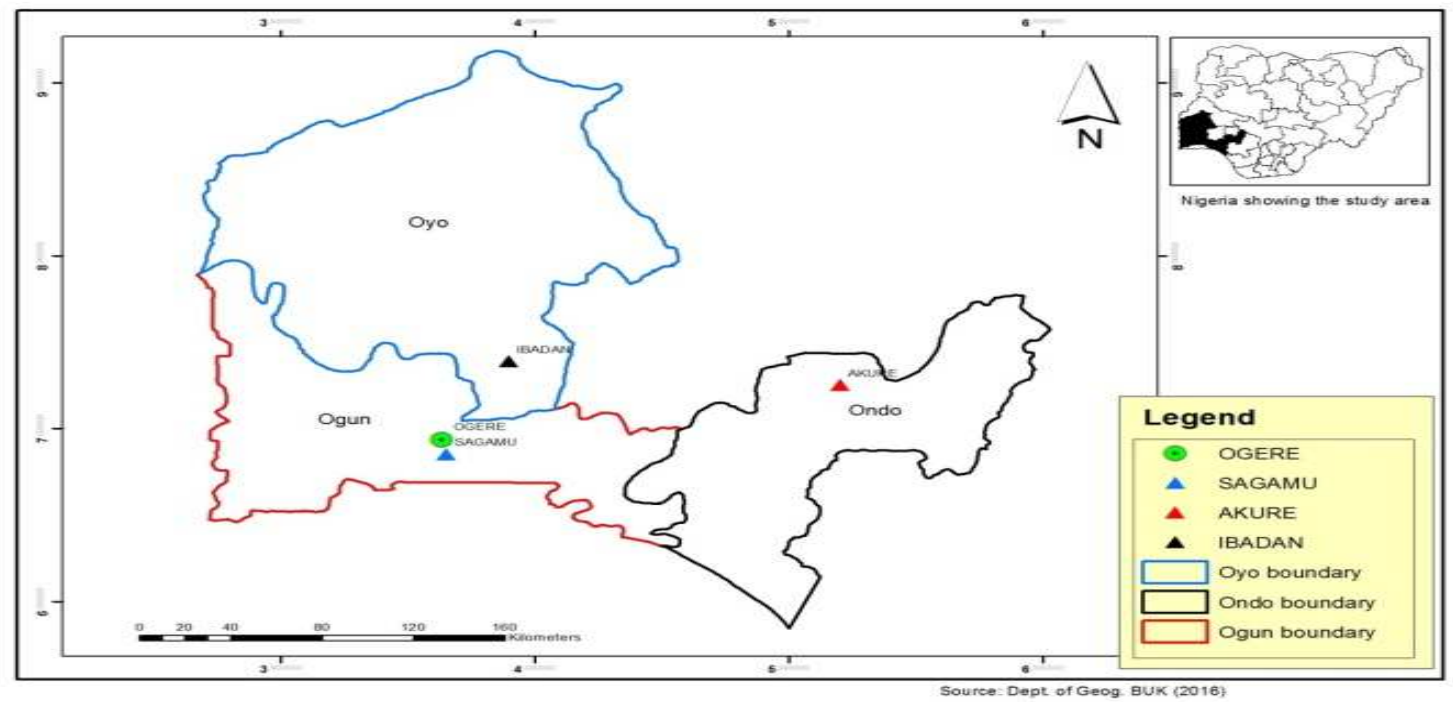

Figure 1: Map showing the sampling point at Sagamu Town, Ogun State.

\section{Description of Sampling Area}

Sagamu has geographical coordinates between $6^{\circ} 50^{\prime}$ north; $3^{\circ} 38^{\prime}$ east is located in south western region of Nigeria. The region has tropical wet and dry climate with a lengthy wet season and relatively constant temperatures throughout the course of the year. Wet season runs from March to October, November to December forms the region dry season. The vegetation type of the region is savannah which is really grassland with small bushes and occasional big trees. Grassland soils have substantially higher organic matter content than forest soils (Novackova, 2011).

\section{Sample Collection}

The Peatsoil samples were collected from four different sampling points $(0-10 \mathrm{~cm}$ depth) in Sagamu into polyethylene bag with plastic spoons. Samples were taken to the laboratory, extraneous materials were removed; the samples were air-dried, crushed and ground to a fine powder in a mortar passed through a $0.20 \mathrm{~mm}$ sieve. The samples were kept for analysis.

\section{Isolation and purification of humic acid from peat soil sample}

Peatsoil sample $(100 \mathrm{~g})$ was mixed with 1000 $\mathrm{cm}^{3}$ of $0.1 \mathrm{M} \mathrm{NaOH}$ solution, shaken for 3hours and left to stand overnight. Dark-coloured supernatant was obtained and decanted from solid residue. The dark-coloured supernatant was acidified to $(\mathrm{pH}=1.0)$ with $6 \mathrm{M} \mathrm{HCl}$ stirred and allowed to stand for 6 hours. Yellowish brown supernatant and dark-brown precipitate were obtained. The yellowish brown supernatant was decanted followed by centrifuge and discarded. The dark-brown precipitate was mixed with $500 \mathrm{~cm}^{3}$ of $0.1 \mathrm{M} \mathrm{NaOH}$ solution followed by passing through dowex resin. The dark-brown solution was acidified to $(\mathrm{pH}=1.0)$ with $6 \mathrm{M} \mathrm{HCl}$ stirred and allowed to stand for 3 hours. The dark-brown precipitate was washed several times with deionized water. The supernatant was treated with $\mathrm{AgNO}_{3}$ solution until no white precipitate observed. The humic acid was transferred to weighed crucible and dried at $60^{\circ} \mathrm{C}$ in an oven for 12 hours. The humic acid was cooled and dried in the desiccator, weighed and recorded. The obtained humic acid was dried again at $60^{\circ} \mathrm{C}$ for additional 6 hours cooled and dried in the desiccator, weighed and recorded constant weight was obtained (Baruah et al., 2015).

\section{FT-IR analysis}

FT-IR spectra of humic acid sample was analysed using Carry 630 FT-IR Agilent Technologies.

Unhydrolysed compost humic acid

The unhydrolysed humic acid was obtained after isolation and purification of compost humic acid and kept for investigation.

\section{Acid hydrolysis of Peatsoil acid}

Peatsoil humic acid sample (1g) was refluxed for 12 hours at $\left(160^{\circ} \mathrm{C}\right)$ with $50 \mathrm{~cm}^{3}$ of $6 \mathrm{M} \mathrm{HCl}$. The mixture was allowed to cool, decanted, and centrifuged after hydrolysis. The insoluble residues were washed with distilled water via centrifugation several times, and the supernatant was treated with $\mathrm{AgNO}_{3}$ solution until no white precipitate was observed. The residue was thoroughly dried over $\mathrm{CaCl}_{2}$ in a desiccator at room temperature (Chefetz et al., 2002). Finally, the obtained hydrolysed humic acid was kept for investigation. 
BAJOPAS Volume 14 Number 1,June, 2021 Potentiometric Titrations

Potentiometric measurements were carried out using a pH-meter Jenway (model 3510) with combine electrode, the sensitivity of the $\mathrm{pH}$ meter is 0.01 units. The $\mathrm{pH}$ meter was switched on half an hour before starting the titration for initial warm up of the instrument. The instrument was calibrated with an aqueous standard buffer solution of $\mathrm{pH} 4.00$ and 10.0 (borate buffer) prepared from a "Qualigens" buffer tablets.

The following sets of solutions were prepared in a $250 \mathrm{~cm}^{3}$ volumetric flask separately for $\mathrm{pH}$ metric titrations.

(i) $5 \mathrm{~cm}^{3} 0.1 \mathrm{M} \mathrm{HCl}+40 \mathrm{~cm}^{3}$ deionized water

(ii) $5 \mathrm{~cm}^{3} 0.1 \mathrm{M} \mathrm{HCl}+39 \mathrm{~cm}^{3}$ deionized water $+1 \mathrm{~cm}^{3} 0.15 \mathrm{gcm}^{-3}$ humic acid

(iii) $5 \mathrm{~cm}^{3} 0.1 \mathrm{M} \mathrm{HCl}+37 \mathrm{~cm}^{3}$ deionized water $+1 \mathrm{~cm}^{3} 0.15 \mathrm{gcm}^{-3}$ humic acid

$$
+2 \mathrm{~cm}^{3} \quad 0.01 \mathrm{M} \mathrm{Cu} \text { (II) }
$$

The solutions were titrated against standardized $0.110 \mathrm{MNaOH}$ separately. The total volume of each mixture was adjusted to $50 \mathrm{~cm}^{3}$ and the ionic strength of the solutions was maintained constant at by adding appropriate amount of stock solution of $1 \mathrm{M} \mathrm{KNO}_{3}$ (Gamal, 2015; Omar and Ali, 2015). A magnetic stirrer was used to achieve thorough mixing of the interacting solutions at $550 \mathrm{rpm}$. The same set of experimental conditions was applied for potentiometric titration of remaining samples.

\section{Evaluation of pKa of Hydrolysed peat soil Humic Acids}

The proton-ligand formation number $\mathrm{n}_{\mathbf{A}}$ were calculated by Irving and Rossotti expression (Omar and Ali, 2015).

$\mathrm{nA}=\mathrm{Y}-\frac{(\mathrm{V} 2-\mathrm{V1})(\mathrm{No}-\mathrm{Eo})}{(\mathrm{VO}+\mathrm{V1}) \mathrm{TCL}}$ 1

Where: $Y$ is number of dissociable proton, $\left(\mathrm{V}_{2^{-}}\right.$ $V_{1}$ ) is the measure of displacement of the ligand curve relative to acid curve, $\mathrm{N}^{\circ}$ and $\mathrm{E}^{\circ}$ are the resultant concentration of alkali solution, free acid solution, $\mathrm{T}_{\mathrm{cL}}{ }^{\circ}$ is the total ligand concentration, $\mathrm{V}^{\circ}$ is the total volume of titration solution, $V_{1}$ is the volume of alkali added to acid solution, $V_{2}$ is the volume of alkali added to acid solution + ligand solution, acid dissociation constants (pKa - values) of ligand were calculated by algebraic method point wise calculation (Tables 1 ). The dissociation constants (pKa) were calculated according to the following relation:

$\mathrm{pKa}=\mathrm{pH}+\log \left(\frac{n A}{1-n A}\right)$ 2

Where: pKa is the acid dissociation constant, $\mathrm{n}_{\mathrm{A}}$ is the Proton-ligand formation number and $\mathrm{pH}$ is the pH-values (Omar and Ali, 2015).

\section{Determination of metal-ligand stability constants $(\log K)$ of complexes}

The potentiometric measurement for the determination of stability constant of a complex in solution is based on the fact that the redox potential of the couple $\frac{M^{+(m-n)}}{M^{+m}}$ is shifted significantly on complexation of the metal ion with the ligand. This method involves change in hydrogen ion concentration $\left[\mathrm{H}^{+}\right]$due to the displacement or association of one or more protons taking place during complexation reaction. This change can be found out by titrating the solutions containing free acid, acid with ligand, and acid with ligand and metal ion, individually against a standard alkali solution at a constant ionic strength or temperature. Either ionic strength or temperature may be varied for different sets of solutions. In all the cases, the change in the $\mathrm{pH}$ of the solution is measured after each addition of a known amount of alkali to the reaction cell which contains the reaction mixture. The titration curves are then drawn by plotting the measured $\mathrm{pH}$ values against the corresponding volume of alkali added and the stability constants of the complexes are determined from the titration curves by employing $\mathrm{pH}$-metric titration technique given by (Irving and Rossoti).

Metal-ligand stability constants ( $\log \mathrm{K}$ ) were determined by using the following relations:

$$
\bar{n}=\frac{\left(V_{3}-V_{2}\right)\left(E^{0}+N^{0}\right)}{\left(V^{0}+V_{2}\right) \bar{n}_{A} T_{m}^{0}}
$$

and

$$
P L=\log _{10}\left\{\frac{1+\beta_{n}^{H} \frac{1}{[\text { anti } \log \mathrm{pH}]^{\mathrm{n}}}}{\mathrm{T}_{\mathrm{L}}^{0}-n \bar{T}_{m}^{0}} \mathrm{X} \frac{\left(V^{0}+V_{3}\right)}{V^{0}}\right\}
$$


BAJOPAS Volume 14 Number 1,June, 2021

Where $T_{L}, T^{\circ}, E^{\circ}$, and $V^{\circ}$ havethe same significance as in equation (1) above, $T_{m}$ denotes the total concentration of metal present in solution, $V_{3}$ is the volume of metal ions present in solution and $\beta^{H}$ is the overall proton ligand stability constant. The metal-ligand stability constants (log K) were determined by employing point wise computational Method (eq. 5 and 6).

$\operatorname{LogK}_{1}=\log \left(\frac{n}{1-n}\right)+\mathrm{pL}$ .5

$\operatorname{LogK}_{2}=\log \left(\frac{1-n}{2-n}\right)+\mathrm{pL}$ ...6

Where: Log $\mathrm{K}$ is the metal-ligand stability constant, $\mathrm{pL}$ is the Free ligand exponent function, $\mathbf{n}$ is the Average number of ligand attached with metal ion (Janraoet al., 2014). The results obtained were analyzed by an ORIGIN 2016 program using titration data and then the proton-ligand stability constants (pKa) and Metal-ligand stability constant (LogK) calculated (Omar and Ali, 2015).

\section{RESULTS AND DISCUSSION}

Fourier transformed infrared (FT-IR) spectra of isolated humic acid from peat soils Figure 2 had distinct clear absorption bands indicating the presence of major humic acid structural elemental groups such as $\mathrm{H}$ bonded $\mathrm{OH}$ $\left(3680 \mathrm{~cm}^{-1}\right.$ peak $), C=0$ of carbonyl $\left(1721 \mathrm{~cm}^{-1}\right.$ peak), functional groups of aliphatic components $\mathrm{CH}_{2}\left(2918 \mathrm{~cm}^{-1}\right.$ peak) and $\mathrm{C}-\mathrm{O}$ stretching of polysaccharide $\left(1168 \mathrm{~cm}^{-1}\right.$ peak). The positions of the absorption bands of the spectra fell within typical major absorption bands of humic acid which is at frequencies 3680, 2918, 1721, 1168 $\mathrm{cm}^{-1}$. The first peak centred in the vicinity of $3680 \mathrm{~cm}^{-1}$ region is attributed to phenol $\mathrm{OH}$ group bounded by intermolecular $\mathrm{H}$ bonds. The $2918 \mathrm{~cm}^{-1}$ band usually has absorption maximum at $2918 \mathrm{~cm}^{-1}$ which is due to $\mathrm{C}-\mathrm{H}$ stretching of alkane group $\left(\mathrm{CH}_{2}\right)$. The next major absorption band is $1721 \mathrm{~cm}^{-1}$. This band has been commonly ascribed to $\mathrm{C}=\mathrm{O}$ stretching of mainly carboxyl group $(\mathrm{COOH})$ with trace amount of ketones. The last peak was observed at 1168 $\mathrm{cm}^{-1}$ due to $\mathrm{C}-\mathrm{O}$ stretching of polysaccharides and this peak appeared also in the spectra of humic acid from peat soil. The FTIR spectra of the isolated humic acid contained all major characteristic absorption peaks of humic acid. These absorption peaks indicated the presence of the major structural elements of humic acid namely $\mathrm{H}$ bonded $\mathrm{OH}, \mathrm{C}=\mathrm{C}$ of aromatic ring, $\mathrm{C}=\mathrm{O}$ of carbonyl group (both carboxyl and ketonic), $\mathrm{CH}_{2}$ group. This strongly supports the presence of humic acid.

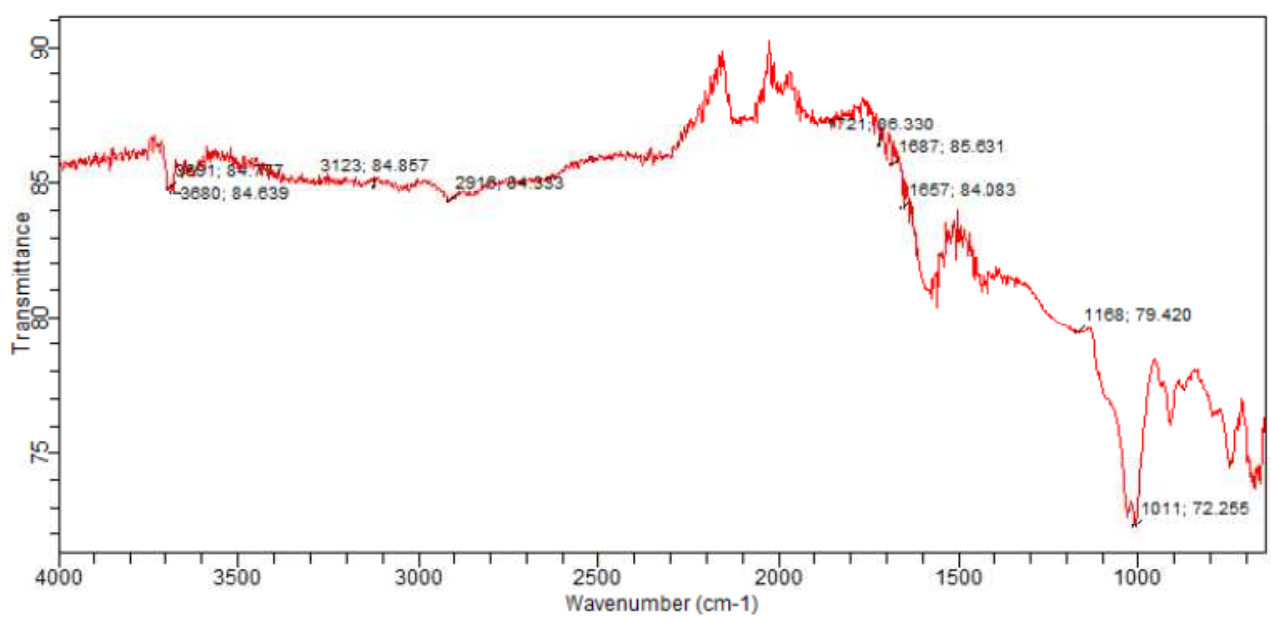

Fig. 2 : FT-IR spectraof peatsoilhumic acid (PSHA)

\section{Evaluation of acid dissociation constant (pka) of acid hydrolysed peat soil humicacid at phenolic group}

The value of the dissociation constant of the peat soil humic acid (PSHA) that underwent acidhydrolysis studied was found to be 8.9299 as shown Table 1, which is lower than the literaturevalues reported by Almeida and Szpoganics, (2015), Borges et al., (2005); Badr et al., (2012)and Fernandes et al,.(2009) of $9.73,9.47$ and 10.30. The difference between the obtained valuesand the reported values in this study might be probably as a result of acid hydrolysis of humicacid. 
BAJOPAS Volume 14 Number 1,June, 2021

Table 1: PKa of (Hydrolysed PSHA)

\begin{tabular}{|l|l|l|l|l|l|l|}
\hline $\mathrm{pH}$ & $\mathrm{BV}_{1}$ & $\mathrm{BV}_{2}$ & $\mathrm{~V}_{2}-\mathrm{V}_{1}$ & $\mathrm{nA}$ & $\log \left(\frac{n A}{1-n A}\right)$ & $\mathrm{pKa}$ \\
\hline 8.50 & 5.30 & 6.29 & 0.99 & 0.3594 & -0.2510 & 8.2490 \\
8.72 & 5.35 & 6.37 & 1.02 & 0.3400 & -0.2880 & 8.4320 \\
9.00 & 5.40 & 6.46 & 1.06 & 0.3141 & -0.3391 & 8.6609 \\
9.22 & 5.45 & 6.55 & 1.10 & 0.2882 & -0.3927 & 8.8273 \\
9.51 & 5.50 & 6.66 & 1.16 & 0.2494 & -0.4786 & 9.0314 \\
9.73 & 5.55 & 6.78 & 1.23 & 0.2041 & -0.5910 & 9.1390 \\
10.00 & 5.60 & 6.90 & 1.30 & 0.1589 & -0.7238 & 9.2762 \\
10.23 & 5.65 & 7.05 & 1.40 & 0.0941 & -0.9835 & 9.2465 \\
10.49 & 5.70 & 7.10 & 1.40 & 0.0941 & -0.9835 & 9.5065 \\
\hline
\end{tabular}

Average pKa $=8.9299 \pm 0.4186$

Table 2: PKa of (Unhydrolysed PSHA)

\begin{tabular}{|l|l|l|l|l|l|l|}
\hline $\mathrm{pH}$ & $\mathrm{BV}_{1}$ & $\mathrm{BV}_{2}$ & $\mathrm{~V}_{2}-\mathrm{V}_{1}$ & $\mathrm{nA}$ & $\log \left(\frac{\boldsymbol{n A}}{1-\boldsymbol{n}}\right)$ & $\mathrm{pKa}$ \\
\hline 8.50 & 5.30 & 5.81 & 0.51 & 0.6619 & 0.2919 & 8.7919 \\
8.72 & 5.35 & 5.90 & 0.55 & 0.6357 & 0.2418 & 8.9618 \\
9.00 & 5.40 & 6.00 & 0.60 & 0.6029 & 0.1813 & 9.1813 \\
9.22 & 5.45 & 6.10 & 0.65 & 0.5701 & 0.1226 & 9.3426 \\
9.51 & 5.50 & 6.20 & 0.70 & 0.5376 & 0.0654 & 9.5754 \\
9.73 & 5.55 & 6.33 & 0.78 & 0.4851 & -0.0259 & 9.7041 \\
10.00 & 5.60 & 6.47 & 0.87 & 0.4262 & -0.1291 & 9.8709 \\
10.23 & 5.65 & 6.62 & 0.99 & 0.3609 & -0.2481 & 9.9819 \\
10.49 & 5.70 & 6.80 & 1.10 & 0.2759 & -0.4690 & 10.0210 \\
\hline
\end{tabular}

Average pKa $=9.4923 \pm 0.4410$

Metal-ligand stability constant ( $\log \mathrm{K}$ )

The stabilityconstants require the accurate values of proton-ligand stability constants (Anil and Maroti, 2008). Metal titration curves crossed over ligand titration curve indicated the formation of complex upon proton release (Santosh, et al., 2011). If the values of n- are within range $0.2-0.8$ and $1.2-18$ this indicates the formation of $1: 1$ and 1:2 complexes (Sayyed and Mazahar, 2012).

The metal (II)-humate stepwise stability constants (log k) at phenolic group (Tables 318)

Table 3: Point-wise method, $\mathrm{Cu}$-(Hydrolysed PSHA)

\begin{tabular}{|l|l|l|l|l|l|l|l|l|}
\hline $\mathrm{pH}$ & $\mathrm{BV}_{1}$ & $\mathrm{BV}_{2}$ & $\mathrm{BV}_{3}$ & $\left(\mathrm{~V}_{3}-\mathrm{V}_{2}\right)$ & $\mathrm{n}$ & $\mathrm{pL}$ & $\log \left(\frac{n}{1-n}\right)$ & LogK $_{1}$ \\
\hline 8.50 & 5.30 & 6.29 & 6.33 & 0.04 & 0.5500 & 2.66 & 0.0871 & 2.7471 \\
8.72 & 5.35 & 6.37 & 6.41 & 0.04 & 0.5714 & 2.43 & 0.1249 & 2.5549 \\
9.00 & 5.40 & 6.46 & 6.50 & 0.04 & 0.6198 & 2.16 & 0.2122 & 2.3722 \\
9.22 & 5.45 & 6.55 & 6.59 & 0.04 & 0.6667 & 1.94 & 0.3010 & 2.2410 \\
\hline
\end{tabular}

LogK $_{1}$ (Average value) $=2.4788 \pm 0.2203$

Table 4: Point-wise method, $\mathrm{Cu}$-(Hydrolysed PSHA)

\begin{tabular}{|l|l|l|l|l|l|l|l|l|}
\hline $\mathrm{pH}$ & $\mathrm{BV}_{1}$ & $\mathrm{BV}_{2}$ & $\mathrm{BV}_{3}$ & $\left(\mathrm{~V}_{3}-\mathrm{V}_{2}\right)$ & $\mathrm{n}$ & $\mathrm{pL}$ & $\log \left(\frac{n-1}{2-n}\right)$ & LogK $_{2}$ \\
\hline 9.51 & 5.50 & 6.66 & 6.73 & 0.07 & 1.3509 & 1.70 & -0.2671 & 1.4329 \\
9.73 & 5.55 & 6.78 & 6.85 & 0.07 & 1.6383 & 1.51 & 0.2467 & 1.7567 \\
10.00 & 5.60 & 6.90 & 6.98 & 0.08 & 2.1783 & 1.31 & -0.2158 & 1.0942 \\
10.23 & 5.65 & 7.05 & 7.13 & 0.08 & 4.1904 & 1.27 & & \\
10.49 & 5.70 & 7.10 & 7.19 & 0.09 & 4.6920 & & & \\
\hline
\end{tabular}

Log $K_{2}($ Average value $)=1.4280 \pm 0.3312$ 
BAJOPAS Volume 14 Number 1,June, 2021

Table 5: Point-wise method, $\mathrm{Cu}$ (Unhydrolysed PSHA)

\begin{tabular}{|l|l|l|l|l|l|l|l|l|}
\hline $\mathrm{pH}$ & $\mathrm{BV}_{1}$ & $\mathrm{BV}_{2}$ & $\mathrm{BV}_{3}$ & $\left(\mathrm{~V}_{3}-\mathrm{V}_{2}\right)$ & $\mathrm{n}$ & $\mathrm{pL}$ & $\log \left(\frac{n}{n-1}\right)$ & Log $_{1}$ \\
\hline 8.50 & 5.30 & 5.81 & 5.85 & 0.04 & 0.2973 & 2.88 & -0.3736 & 2.5064 \\
8.72 & 5.35 & 5.90 & 5.95 & 0.05 & 0.3873 & 2.66 & -0.1992 & 2.4608 \\
9.00 & 5.40 & 6.00 & 6.05 & 0.05 & 0.4044 & 2.38 & -0.1681 & 2.2119 \\
9.22 & 5.45 & 6.10 & 6.15 & 0.06 & 0.5157 & 2.18 & -0.0272 & 2.2072 \\
9.51 & 5.50 & 6.20 & 6.27 & 0.07 & 0.6417 & 1.89 & 0.2530 & 1.1430 \\
\hline
\end{tabular}

$\operatorname{LogK}_{1}($ Average value $)=2.3059 \pm 0.6153$

Table 6:Point-wise method, $\mathrm{Cu}$ (Unhydrolysed PSHA)

\begin{tabular}{|l|l|l|l|l|l|l|l|l|}
\hline $\mathrm{pH}$ & $\mathrm{BV}_{1}$ & $\mathrm{BV}_{2}$ & $\mathrm{BV}_{3}$ & $\mathrm{~V}_{3}-\mathrm{V}_{2}$ & $\mathrm{n}$ & $\mathrm{pL}$ & $\log \left(\frac{n-1}{2-n}\right)$ & $\log \mathrm{K}_{2}$ \\
\hline 9.73 & 5.55 & 6.33 & 6.42 & 0.09 & 0.9000 & 1.69 & & \\
10.00 & 5.60 & 6.47 & 6.58 & 0.11 & 1.2578 & 1.44 & -0.4592 & 0.9808 \\
10.23 & 5.65 & 6.62 & 6.84 & 0.12 & 1.6137 & 1.26 & -0.2010 & 1.4610 \\
10.49 & 5.70 & 6.80 & 6.92 & 0.12 & 2.1052 & 1.03 & & \\
\hline
\end{tabular}

$\operatorname{LogK}_{2}$ (Average value) $=1.2209 \pm 0.3398$

Table 7:Point-wise method, Pb (Hydrolysed PSHA)

\begin{tabular}{|l|l|l|l|l|l|l|l|l|}
\hline $\mathrm{pH}$ & $\mathrm{BV}_{1}$ & $\mathrm{BV}_{2}$ & $\mathrm{BV}_{3}$ & $\left(\mathrm{~V}_{3}-\mathrm{V}_{2}\right)$ & $\mathrm{n}$ & $\mathrm{pL}$ & $\log \left(\frac{n}{1-n}\right)$ & LogK $_{1}$ \\
\hline 8.50 & 5.30 & 6.29 & 6.33 & 0.04 & 0.5500 & 2.66 & 0.0871 & 2.7471 \\
8.72 & 5.35 & 6.37 & 6.41 & 0.04 & 0.5714 & 2.43 & 0.1249 & 2.5549 \\
9.00 & 5.40 & 6.46 & 6.50 & 0.04 & 0.6198 & 2.16 & 0.2122 & 2.3722 \\
9.22 & 5.45 & 6.55 & 6.60 & 0.05 & 0.8333 & 1.96 & 0.6989 & 2.6589 \\
\hline
\end{tabular}

Log $_{\mathbf{1}}($ Average value $)=2.5832 \pm 0.1614$

Table 8:Point-wise method, Pb-(Hydrolysed PSHA)

\begin{tabular}{|l|l|l|l|l|l|l|l|l|}
\hline $\mathrm{pH}$ & $\mathrm{BV}_{1}$ & $\mathrm{BV}_{2}$ & $\mathrm{BV}_{3}$ & $\left(\mathrm{~V}_{3}-\mathrm{V}_{2}\right)$ & $\mathrm{n}$ & $\mathrm{pL}$ & $\log \left(\frac{n-1}{2-n}\right)$ & $\log \mathrm{K}_{2}$ \\
\hline 9.51 & 5.50 & 6.66 & 6.71 & 0.05 & 0.9650 & 1.67 & & \\
9.73 & 5.55 & 6.78 & 6.83 & 0.05 & 1.1702 & 1.44 & & \\
10.00 & 5.60 & 6.90 & 6.90 & 0.05 & 1.4864 & 1.22 & -0.0237 & 1.1963 \\
10.23 & 5.65 & 7.05 & 7.10 & 0.05 & 2.0190 & 1.09 & & \\
10.49 & 5.70 & 7.10 & 7.17 & 0.07 & 3.6492 & 1.00 & & \\
\hline
\end{tabular}

Log $K_{2}$ (Average value) $=1.1963$

Table 9: Point-wise method, Pb (Unhydrolysed PSHA)

\begin{tabular}{|l|l|l|l|l|l|l|l|l|}
\hline $\mathrm{pH}$ & $\mathrm{BV}_{1}$ & $\mathrm{BV}_{2}$ & $\mathrm{BV}_{3}$ & $\mathrm{~V}_{3}-\mathrm{V}_{2}$ & $\mathrm{n}$ & $\mathrm{pL}$ & $\begin{array}{l}\text { Log } \\
\left(\frac{n}{n-1}\right)\end{array}$ & Log $\mathrm{K}_{1}$ \\
\hline 8.50 & 5.30 & 5.81 & 5.85 & 0.04 & 0.2973 & 2.88 & -0.3736 & 2.5064 \\
8.72 & 5.35 & 5.90 & 5.94 & 0.04 & 0.3099 & 2.66 & -0.5477 & 2.3123 \\
9.00 & 5.40 & 6.00 & 6.05 & 0.05 & 0.4044 & 2.38 & -0.1681 & 2.2119 \\
9.22 & 5.45 & 6.10 & 6.15 & 0.06 & 0.5157 & 2.18 & 0.0272 & 2.2072 \\
9.51 & 5.50 & 6.20 & 6.26 & 0.07 & 0.6417 & 1.89 & 0.2530 & 2.1430 \\
9.73 & 5.55 & 6.40 & 6.40 & 0.07 & 0.7000 & 1.67 & 0.3680 & 2.0380 \\
\hline
\end{tabular}

LogK $_{1}$ (Average value) $=2.2364 \pm 0.1602$

Table 10: Point-wise method, Pb (Unhydrolysed PSHA)

\begin{tabular}{|l|l|l|l|l|l|l|l|l|}
\hline $\mathrm{pH}$ & $\mathrm{BV}_{1}$ & $\mathrm{BV}_{2}$ & $\mathrm{BV}_{3}$ & $\mathrm{~V}_{3}-\mathrm{V}_{2}$ & $\mathrm{n}$ & $\mathrm{pL}$ & $\log \left(\frac{n-1}{2-n}\right)$ & $\log \mathrm{K}_{2}$ \\
\hline 10.00 & 5.60 & 6.47 & 6.55 & 0.08 & 1.9503 & 1.41 & & \\
10.23 & 5.65 & 6.62 & 6.72 & 0.11 & 1.4792 & 1.26 & -0.0361 & 1.2239 \\
\hline
\end{tabular}

$\operatorname{LogK}_{2}$ (Average value) $=1.2239$

Table 11: Point-wise method, Mg (Hydrolysed PSHA)

\begin{tabular}{|l|l|l|l|l|l|l|l|l|}
\hline $\mathrm{pH}$ & $\mathrm{BV}_{1}$ & $\mathrm{BV}_{2}$ & $\mathrm{BV}_{3}$ & $\left(\mathrm{~V}_{3}-\mathrm{V}_{2}\right)$ & $\mathrm{n}$ & $\mathrm{pL}$ & $\log \left(\frac{n}{n-1}\right)$ & LogK $_{1}$ \\
\hline 8.50 & 5.30 & 6.29 & 6.31 & 0.02 & 0.2750 & 2.64 & -0.4290 & 2.2110 \\
8.72 & 5.35 & 6.37 & 6.39 & 0.02 & 0.2858 & 2.42 & -0.3978 & 2.0222 \\
9.00 & 5.40 & 6.46 & 6.49 & 0.03 & 0.4648 & 2.14 & -0.0612 & 2.0788 \\
9.22 & 5.45 & 6.55 & 6.59 & 0.04 & 0.6667 & 1.94 & 0.3010 & 2.2410 \\
\hline
\end{tabular}

$\log _{\mathbf{1}}($ Average value) $=2.1382 \pm 0.1046$ 
BAJOPAS Volume 14 Number 1,June, 2021

Table 12: Point-wise method, Mg (Hydrolysed PSHA)

\begin{tabular}{|l|l|l|l|l|l|l|l|l|}
\hline $\mathrm{pH}$ & $\mathrm{BV}_{1}$ & $\mathrm{BV}_{2}$ & $\mathrm{BV}_{3}$ & $\left(\mathrm{~V}_{3}-\mathrm{V}_{2}\right)$ & $\mathrm{n}$ & $\mathrm{pL}$ & $\log \left(\frac{n-1}{2-n}\right)$ & LogK $_{2}$ \\
\hline 9.51 & 5.55 & 6.66 & 6.71 & 0.05 & 0.9650 & 1.67 & & \\
9.73 & 5.55 & 6.78 & 6.84 & 0.06 & 1.4042 & 1.47 & -0.1686 & 1.3014 \\
10.00 & 5.60 & 6.90 & 6.93 & 0.06 & 1.7838 & 1.23 & 0.5593 & 1.7893 \\
10.23 & 5.65 & 7.05 & 7.10 & 0.06 & 3.1429 & 1.10 & & \\
10.49 & 5.70 & 7.10 & 7.18 & 0.07 & 3.6492 & 0.83 & & \\
\hline
\end{tabular}

LogK $_{2}($ Average value $)=1.5453 \pm 0.3450$

Table 13: Point-wise method, Mg (Unhydrolysed PSHA)

\begin{tabular}{|l|l|l|l|l|l|l|l|l|}
\hline $\mathrm{pH}$ & $\mathrm{BV}_{1}$ & $\mathrm{BV}_{2}$ & $\mathrm{BV}_{3}$ & $\mathrm{~V}_{3}-\mathrm{V}_{2}$ & $\mathrm{n}$ & $\mathrm{pL}$ & $\log \left(\frac{n}{n-1}\right)$ & $\operatorname{Log~}_{1}$ \\
\hline 8.50 & 5.30 & 5.81 & 5.85 & 0.04 & 0.2973 & 2.88 & -0.3736 & 2.5064 \\
8.72 & 5.35 & 5.90 & 5.94 & 0.04 & 0.3099 & 2.66 & -0.3477 & 2.3123 \\
9.00 & 5.40 & 6.00 & 6.04 & 0.04 & 0.3236 & 2.38 & -0.3202 & 2.0598 \\
9.22 & 5.45 & 6.10 & 6.15 & 0.05 & 0.4297 & 2.17 & -0.1230 & 2.0470 \\
9.51 & 5.50 & 6.20 & 6.26 & 0.06 & 0.5500 & 1.89 & 0.0871 & 1.9771 \\
9.73 & 5.55 & 6.33 & 6.40 & 0.07 & 0.7000 & 1.67 & 0.3680 & 2.0380 \\
\hline
\end{tabular}

LogK $_{1}$ (Average value) $=2.1568 \pm 0.2069$

Table 14: Point-wise method, Mg (Unhydrolysed PSHA)

\begin{tabular}{|l|l|l|l|l|l|l|l|l|}
\hline $\mathrm{pH}$ & $\mathrm{BV}_{1}$ & $\mathrm{BV}_{2}$ & $\mathrm{BV}_{3}$ & $\mathrm{~V}_{3}-\mathrm{V}_{2}$ & $\mathrm{n}$ & $\mathrm{pL}$ & $\log \left(\frac{n-1}{2-n}\right)$ & $\log \mathrm{K}_{2}$ \\
\hline 10.00 & 5.60 & 6.47 & 6.55 & 0.08 & 0.9148 & 1.41 & & \\
10.23 & 5.65 & 6.62 & 6.71 & 0.09 & 1.2102 & 1.20 & -0.5749 & 0.6251 \\
10.49 & 5.70 & 6.80 & 6.92 & 0.09 & 1.5968 & 1.03 & 0.1703 & 1.2003 \\
\hline
\end{tabular}

LogK $_{2}$ (Average value) $=0.9127 \pm 0.4070$

Table15:Point-wise method, Cd (Hydrolysed PSHA)

\begin{tabular}{|l|l|l|l|l|l|l|l|l|}
\hline $\mathrm{pH}$ & $\mathrm{BV}_{1}$ & $\mathrm{BV}_{2}$ & $\mathrm{BV}_{3}$ & $\left(\mathrm{~V}_{3}-\mathrm{V}_{2}\right)$ & $\mathrm{n}$ & $\mathrm{pL}$ & $\log \left(\frac{n}{1-n}\right)$ & LogK $_{1}$ \\
\hline 8.50 & 5.30 & 6.29 & 6.31 & 0.02 & 0.2750 & 2.64 & -0.4210 & 2.2190 \\
8.72 & 5.35 & 6.37 & 6.40 & 0.03 & 0.4286 & 2.42 & -0.1249 & 2.2951 \\
9.00 & 5.40 & 6.46 & 6.49 & 0.03 & 0.4648 & 2.14 & -0.0612 & 2.0788 \\
9.22 & 5.45 & 6.55 & 6.59 & 0.04 & 0.6667 & 1.96 & 0.3010 & 2.2610 \\
9.51 & 5.55 & 6.66 & 6.70 & 0.04 & 0.7720 & 1.67 & 0.5297 & 2.1997 \\
\hline
\end{tabular}

LogK $_{\mathbf{1}}$ (Average value) $=2.2108 \pm 0.0825$

Table 16: Point-wise method, Cd (Hydrolysed PSHA)

\begin{tabular}{|l|l|l|l|l|l|l|l|l|}
\hline $\mathrm{pH}$ & $\mathrm{BV}_{1}$ & $\mathrm{BV}_{2}$ & $\mathrm{BV}_{3}$ & $\left(\mathrm{~V}_{3}-\mathrm{V}_{2}\right)$ & $\mathrm{n}$ & $\mathrm{pL}$ & $\log \left(\frac{n-1}{2-n}\right)$ & Log $_{2}$ \\
\hline 9.73 & 5.55 & 6.78 & 6.83 & 0.06 & 1.4042 & 1.47 & -0.1686 & 1.3014 \\
10.00 & 5.60 & 6.90 & 6.95 & 0.06 & 1.7838 & 1.23 & 0.5593 & 1.7893 \\
10.23 & 5.65 & 7.05 & 7.10 & 0.06 & 3.1429 & 1.09 & & \\
10.49 & 5.70 & 7.10 & 7.16 & 0.06 & 3.1429 & 0.89 & & \\
& & & & & & & & \\
\hline
\end{tabular}

$\operatorname{LogK}_{2}$ (Average value) $=1.5453 \pm 0.3450$

Table 17: Point-wise method, Cd (Unhydrolysed PSHA)

\begin{tabular}{|l|l|l|l|l|l|l|l|l|}
\hline $\mathrm{pH}$ & $\mathrm{BV}_{1}$ & $\mathrm{BV}_{2}$ & $\mathrm{BV}_{3}$ & $\mathrm{~V}_{3}-\mathrm{V}_{2}$ & $\mathrm{n}$ & $\mathrm{pL}$ & $\log \left(\frac{n}{n-1}\right)$ & $\operatorname{Log~}_{1}$ \\
\hline 8.50 & 5.30 & 5.81 & 5.86 & 0.05 & 0.3717 & 2.88 & -0.2280 & 2.6520 \\
8.72 & 5.35 & 5.90 & 5.95 & 0.05 & 0.3873 & 2.66 & -0.1992 & 2.4608 \\
9.00 & 5.40 & 6.00 & 6.06 & 0.06 & 0.4853 & 2.38 & -0.0255 & 2.3545 \\
9.22 & 5.45 & 6.10 & 6.16 & 0.06 & 0.5157 & 2.18 & -0.0272 & 2.2072 \\
9.51 & 5.50 & 6.20 & 6.27 & 0.07 & 0.6417 & 1.89 & 0.2530 & 1.1430 \\
9.73 & 5.55 & 6.33 & 6.41 & 0.08 & 0.8000 & 1.69 & 0.6020 & 2.2920 \\
& & & & & & & & \\
\hline
\end{tabular}

$\operatorname{LogK}_{1}($ Average value $)=2.2516 \pm 0.5380$ 
BAJOPAS Volume 14 Number 1,June, 2021

Table 18: Point-wise method, Cd (Unhydrolysed PSHA)

\begin{tabular}{|l|l|l|l|l|l|l|l|l|}
\hline $\mathrm{pH}$ & $\mathrm{BV}_{1}$ & $\mathrm{BV}_{2}$ & $\mathrm{BV}_{3}$ & $\mathrm{~V}_{3}-\mathrm{V}_{2}$ & $\mathrm{n}$ & $\mathrm{pL}$ & $\log \left(\frac{n-1}{2-n}\right)$ & $\log \mathrm{K}_{2}$ \\
\hline 10.00 & 5.60 & 6.47 & 6.57 & 0.10 & 1.1434 & 1.43 & & \\
10.23 & 5.65 & 6.62 & 6.72 & 0.10 & 1.3448 & 1.23 & -0.2788 & 0.9512 \\
10.49 & 5.70 & 6.80 & 6.90 & 0.10 & 1.7742 & 1.03 & 0.5351 & 1.5651 \\
\hline
\end{tabular}

$\operatorname{LogK}_{2}($ Average value $)=1.2581 \pm 0.4340$

Table 19: Stepwise and overall Stability constants of thehydrolysed and unhydrolysed divalent metal (II) complexes

\begin{tabular}{|c|c|c|c|}
\hline Chelates & LogK $_{1}$ & $\log _{2}$ & Log $\beta$ \\
\hline [Cu (Hydrolysed PSHA-1) $\left.{ }_{2}\right]$ & 2.4788 & 1.4280 & 3.9068 \\
\hline$\left[\mathrm{Pb}(\text { Hydrolysed PSHA-1) })_{2}\right]$ & 2.5832 & 1.1963 & 3.7795 \\
\hline$\left[\mathrm{Cd}(\text { Hydrolysed PSHA-1 })_{2}\right]$ & 2.2108 & 1.5453 & 3.7561 \\
\hline$\left[\mathrm{Mg}(\text { Hydrolysed PSHA-1 })_{2}\right]$ & 2.1382 & 1.5453 & 3.6835 \\
\hline [Cu (Unhydrolysed PSHA-1) & 2.3059 & 1.2209 & 3.5268 \\
\hline$[\mathrm{Pb}$ (Unhydrolysed PSHA-1) 2$]$ & 2.2364 & 1.2239 & 3.4603 \\
\hline [Cd (Unhydrolysed PSHA-1) 2 ] & 2.2516 & 1.2581 & 3.5097 \\
\hline$[\mathrm{Mg}$ (Unydrolysed PSHA-1) & 2.1568 & 0.9127 & 3.0695 \\
\hline
\end{tabular}

The results obtained (Table19) shows the stepwise and overall stability constants to be not high indicating low stability of the complexes, because the solubility of most metal ions in the basic $\mathrm{pH}$ range is minimal due to metal hydroxide precipitation (Karimi, 2017). In general, the stepwise stability constants $\left(K_{1}\right.$ and $K_{2}$ ) follow the order $K_{1}>K_{2}$ for the copper, lead, magnesium and cadmium complexes respectively. The steady decrease of the values with increasing number of ligands is in agreement with the prediction made by researchers (Na'aliya, 2013). The decrease could be attributed to the fact that as the number of the ligands (Humate ions) that enters the coordination zone increases the aqua molecules available for replacement by the ligands become less. Thus, the metal ions become less electron loving with progressive intake of the ligand and this results in the decrease in the values of the constants (Na'aliya, 2013). Also the stability of the complexes is influenced by the size and number of the chelate rings(Mackay and Mackay,2002).All the complexes form rings in their structure as humate, a bidentate ligand, bond the metal ions in the ratio 1:2 (Boguta and Sokolowska, 2016) forming chelate rings. The values of the overall stability constants $(\log \beta)$ obtained for humate complexes are not high indicating low stability as the values are not high. LogK values for copper-humates (Table 3 to 6) obtained in this study are lower than those reported for the complexes of humic acids (Pandey et al., 2015; Dinu, 2013; Kaschl et al., 2010 and Gilbeto and Jorg, 2001). The values of LogK(Table 7 to 10 ) forlead-humates are lower than those reported for the lead in the literature (Dinu, 2013; Gilbeto and Jorg 2001). Log K values(Table 11 to 14 ) for magnesium-humates obtained in this study are close to those reported by (Pandey et al., 2015). Log K values of cadmium-humates (Table 15 to 18 ) obtained in this work near to the one reported by (Dinu, 2013 and Pandey et al., 2015).The difference between the reported values and the values obtained in this study might be probably as a result of acid hydrolysis of humic acid. The values of the overall stability constants $(\log \beta)$ of the copper humates complexes presented in Table 19 is high than that of other metal humate complexes, show relatively high stability of CuHA complexes, show the following order of stability: $\mathrm{Cu}>\mathrm{Pb}>\mathrm{Cd}>\mathrm{Mg}$; which are in close agreement to the findings of (Dinu, 2013 and Pandey et al., 2015).The high stability of Cuhumate chelate could be attributed to the existence of coordinate covalent bond between the complexing agents and the $\mathrm{Cu}^{2+}$ ions. Since, $\mathrm{Cu}^{2+}$ being a metal of the transitional series with $3 d^{9}$ electronic configurations can accept the electrons from the complexing agents. Similarly, the low stabilities of $\mathrm{Pb}, \mathrm{Cd}$ and $\mathrm{Mg}$ complexes could be explained by that $\mathrm{Pb}^{2+}$ with $6 s^{2}, \mathrm{Cd}^{2+}$ with $4 \mathrm{~d}^{10}$ and $\mathrm{Mg}^{2+}$ with $2 \mathrm{p}^{6}$ their electronic configuration has a completely filled $\mathrm{d}, \mathrm{p}$ and $\mathrm{s}$ orbitals. Moreover, the stabilities of metal ions with hydrolysed humic acid from peat soil were higher than those with unhydrolysed humic acid from peat soil; which is ascribed to the high content of acidity in hydrolysed humic acid than unhydrolysed humic acid. 
BAJOPAS Volume 14 Number 1,June, 2021 CONCLUSION

The values of logk for $\mathrm{Cu}(\mathrm{II})$ hydrolysed humic acid complex was higher followed by $\mathrm{Pb}$ (II), $\mathrm{Cd}(\mathrm{II})$ and $\mathrm{Mg}$ (II) hydrolysed humic acid complexes as compared with metal(II) unhydrolysed humic acid complexes. This indicates acid hydrolysis of humic acid can

\section{REFERENCES}

Almeida, V.R. and Szpoganicz, B. (2015). Humic Acid Potentiometric Response Patterns:Out- of Equilibrium Properties and Species Distribution Modelling. Chemical. Biol. Technol. Agric. 2: 17.

Anđelković, T., Nikolić, R., Bojić, A.,Anđelković, D., and Nikolic G.,(2010). Binding of Cadmium to Soil Humic Acid as A Function of Carboxyl Group Content. Macedonian Journal of Chemistry and Chemical Engineering.29(2): 215-224.

Anil, B. N. and Maroti, N. (2008). Studies on Influence of Die-Lectric Constants on Complex Equilibria between Substituted Py-Razalines and Lanthanide Metal Ions pH-Metrically. Amer.-Euras. scient. Res. 3(2): 212-216.

Ashok, K., Pandey, S. P. and Misra, V (2000). Stability Constants of Metal-Humic Acid Complexes and its Role in Environmental Detoxification. Journal of Ecotoxicology and Environmental Safety. 47(2):157-200.

Badr, M. H., El-Halafawi, M. H. and Abd El-al Zeid, E. R. (2012). Comparison Between the Effect of Ionic Strength on Acidity and Dissociation Constants of Humic Acids Extracted from Sewage Sludge and Nile Water Hyacinth Composts.Global Journal of Environmental Research 6 (1): 36-43.

Baruah, M.K., Borah, D., Saikia, P.P., Paul, S., Sharma, T. (2015). Evaluation of pKa Values of Soil Humic Acids and their Complexation Properties. International Journal of Plant \& Soil Science 6(4) : 218-228.

Boguta, P. Sokolowska, Z. (2016). Interactions of $\mathrm{Zn}$ (II) Ions with Humic Acids Isolated from Various Types of Soils. Effect of $\mathrm{pH}, \mathrm{Zn}$ Concentrations and Humic Acids Chemical Properties. Journal of Geochemical Explaration 168. 119-126.

Borges, F., Guimaraes, C., Lima, L.F.C., Pinto, I. and Reis, S.(2005). Potentiometric Studies on the Complexation of Copper(II) by Phenolic Acids as Discrete Ligand Models of enhance the complexation behavior of humic acid with metal (II) ions. However, the higher values of $\log \beta$ for $\mathrm{Cu}(\mathrm{II}), \mathrm{Pb}(\mathrm{II}), \mathrm{Cd}(\mathrm{II})$ and $\mathrm{Mg}(\mathrm{II})$ hydrolysed humic acid complexes indicates more stable stepwise complexes formed as compared with $\mathrm{Cu}(\mathrm{II}), \mathrm{Pb}$ (II), $\mathrm{Cd}$ (II) and $\mathrm{Mg}(\mathrm{II})$ unhydrolysed humic acid complexes.

Humic Substances Talanta 66 (2005) 670-673.

Chefetz, B., Salloum, M. J., Deshmulkin, A. P. and Hatcher, P. (2002). Structural Components of Humic Acids as Determined by Chemical Modifications and Carbon-13 NMR, Pyrolysis, and Thermochemolysis- Gas Chromatography/Mass Spectrometry. Soil Science Society of American Journal Abstract Division S-2- Soil Chemistry66. 1159-1171.

Dinu, M. I. (2013). Metals Complexation with Humic Acids in Surface Water of Different Environ. Sci. Technol. 31(1): 1-17.

Fernandes, A.N., Giacomelli, C., Giovanela, M. Vaz, D.V. Szpoganicz, B. and Maria M. D. (2009). Potentiometric Acidity Determination in Humic Substances Influenced by Different Analytical Procedures.J. Braz. Chem. Soc. 20 (9):14.

Gamal, A. H. (2015). Stability Constants of Rhenium (V) Metal Complexes with Selected Drugs. Pyrex Journal of Research in Environmental Studies. 2(2): 006-014.

Janrao, D. M., Pathan, J., Kayande, D.D., and Mulla, J.J. (2014). An Over View of Potentiometric Determination of Stability Constants of Metal Complexes. Sci. Revs. Chem. Commun.: 4(1), 2014, 11-24.

Karimi, H. (2017). Effect of pH and Initial Pb(II) Concentration on the Lead Removal Efficiency from Waste Water Using $\mathrm{Ca}(\mathrm{OH})_{2}$. International Journal of Water and Waste Water Treatment 3.2

Kaschl, A. Romheld, V. and Chen, Y. (2010). Binding of Cadmium, Copper and Zinc to Humic Substances Originating from Municipal Solid Waste Compost. Israel Journal of Chemistry Vol. 42(1): 89-98.

Kostic, I. S., Tatjana, P, A., Nikolic, R. S., Cvetkovic, T. P., Pavlovic, D. D., Aleksandar, L.J. and Bojic, A. (2012). Comparative Study of Binding Strengths of Heavy Metals with Humic Acid. J.serb. Chem. Soc. 76(9) pp 1-20. 
BAJOPAS Volume 14 Number 1,June, 2021

Na'aliya, J. (2013). Determination of Stepwise Stability Constants and Gibbs free Energy Change of Trisprolina to Complexes of some Divalent Transition Metal ions. Bayero Journal of Pure and Applied Sciences 6(2): 112-114.

Omar, A. A. and Ali, E. A. (2015). Potentiometric Studies on Complexes of $\mathrm{Cr}$ (III) and $\mathrm{Zr}$ (IV) with some Carboxylic Acids. International Journal of Advanced Chemistry, 3(1) 25-

37.

Pandey, A. K. Pandey, S. D. and Misr, V. (2015).Stability Constants of Metal- Humic Acid Complexes and Its Role in Environmental Detoxification. J. Ecotoxicology and Environmental Safety. 47(1):195-200.

Ram, N. and Raman, K.V. (1984). Stability Constants of Complexes of Metals with
Humicand Fuvic Acids under Non- acidConditions. Journal of Plant Nutrition and Soil Sciences.

147:171-176.

Santosh, D. D., Ashok, B. K., Vijay, J. T., Shivraj, G. W. and Vinay, V. W. (2011). Potentiometric Studies of Elec-Trolyte Effects on Complex Equilibria of Some Substituted 5-(2-hydroxy Phenyl) Pyrazoles. Der pharm. 3 (6): 75-83.

Sayyed, H. and Abdul Rahim, M. F. (2012). Studies of Binary Complexes of Metal Ions with Mandelic Acid by Potentiometry. Chem. J. 02 (6): 206209.

Shirvani, M. Moradian, E. Khalili, B. Bakhtiary, S. (2015). Interaction of $\mathrm{Cd}$ and $\mathrm{Pb}$ with Humate-Palygorskite and HumateSepiolite Complexes. Journal of water, air and pollution 3: 220-228. 


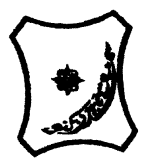

Bayero Journal of Pure and Applied Sciences, 14(1): 54 - 63

Received: November, 2020

Accepted: April, 2021

ISSN $2006-6996$

\title{
STABILITY CONSTANTS OF COMPLEXES OF METAL IONS WITH PEATSOIL HUMIC ACIDS UNDER NON-ACID-CONDITIONS
}

\author{
${ }^{* 1}$ Sabo, Yusuf ${ }^{2}$ Jimoh, W.L.O., ${ }^{3}$ Isa Baba Koki and ${ }^{4}$ Sholadoye, Q. 0. \\ ${ }^{1}$ Department of Pure and Industrial Chemistry, Bayero University, Kano \\ ${ }^{3}$ Department of Chemistry, Yusuf Maitama Sule University Kano. P.M.B. 3220 Kano, Nigeria. \\ ${ }^{4}$ Department of Chemistry, Nigerian Police Academy, Wudil, Kano-Nigeria
}

*Correspondence E-mail; saboyusuf18@yahoo.com

ABSTRACT

Stability constants of complexes of four divalent metal ions viz. $\mathrm{Cu}^{2+}, \mathrm{Pb}^{2+}, \mathrm{Mg}^{2+}$ and $\mathrm{Cd}^{2+}$ with humic acids (HA) were determined by potentiometric titration of humic acids with the corresponding salt of the divalent metals in aqueous media under non-acid-condition. The log $K$ (logarithm of the stability constant) ranged from 1.0942 to 2.7471 for metalhumic acid complexes were determined using point-wise computational method. The order of stability constants were obtained as follows: $\mathrm{Cu}>\mathrm{Pb}>\mathrm{Cd}>\mathrm{Mg}$ for metal $-\mathrm{HA}$ complexes respectively, indicating a higher degree of complexation with Cu metal ion.

Keywords: stability constant, humic acid, potentiometric titration, divalent metals, acid hydrolysis.

\section{NTRODUCTION}

The stability constant of a complex is the numerical expression of its stability and provides a quantitative measure of affinity of the metal ion to the complexing agent. An understanding of the relative stability of metal-complexes helps in predicting the behavior of metal ions in the soil (Ram and Raman, 1982). Extensive researches has been done to determine the stability constants of the complexes formed between humic acid (HA) with a number of metal ions. Ashok et al., (2000) reported that humic acid with hydroxyl, phenoxyl and carboxyl reactive groups can form coordination compound with metal ions at $\mathrm{pH}$ 3.5. The stability constants(Log K) for different metalhumic acid complexes indicated the following order of the stabilities of complexes formed between humic acid and metal ion, $\mathrm{Cu}>\mathrm{Fe}$ $>\mathrm{Pb}>\mathrm{Ni}>\mathrm{Co}>\mathrm{Ca}>\mathrm{Cd}>\mathrm{Zn}>\mathrm{Mn}>\mathrm{Mg}$. Andelkovic et al., (2010) investigated the binding of $\mathrm{Cd}$ (II) to soil humic acid at pH 6.5 and in $0.1 \mathrm{M} \mathrm{KNO}_{3}$ ionic medium. The stability constant for binding indicating greater stability in the case when carboxyl groups are involved in complexation reaction. Kostic et al.,(2012) investigated the complexation of humic acid with certain heavy metal ions (Co(II), $\mathrm{Ni}(\mathrm{II}), \mathrm{Cu}(\mathrm{II})$,
$\mathrm{Zn}(\mathrm{II})$, and $\mathrm{Pb}(\mathrm{II})$. The experiment was performed at $25^{\circ} \mathrm{C}$, at pH 4.0 and ionic strength of $0.01 \mathrm{M}$. Stability constant of complex between $\mathrm{Pb}$ (II) ions and humic acid is greater than stability constants of other investigated metalhumate complexes. Bogata and Sokolowska (2016) analyses the interaction between humic acids from different soils and $\mathrm{Zn}$ (II) ions at wide concentration ranges and at $\mathrm{pH} 5$. Studies have showed significant impact of $\mathrm{Zn}$ concentration, $\mathrm{pH}$ and some properties of humic acids with zinc.But all of these studies were limited to acidic $\mathrm{pH}$ range. Therefore, the present study was carried out to determine and compare the stability constants of complexes of metal ions with hydrolysed peat soil humic acid and unhydrolysed peat soil humic under non-acid conditions.

\section{MATERIALS AND METHODS}

Analytical grade chemicals used includes hydrochloric acid $(\mathrm{HCl})$, nitric acid $\left(\mathrm{HNO}_{3}\right)$, sodium hydroxide $(\mathrm{NaOH})$, lead nitrate $\mathrm{Pb}\left(\mathrm{NO}_{3}\right)_{2}$, copper nitrate $\mathrm{Cu}\left(\mathrm{NO}_{3}\right)_{2} \cdot 3 \mathrm{H}_{2} \mathrm{O}$, cadmium nitrate $\mathrm{Cd}\left(\mathrm{NO}_{3}\right)_{2} \cdot 4 \mathrm{H}_{2} \mathrm{O}$, magnesium nitrate $\mathrm{Mg}\left(\mathrm{NO}_{3}\right)_{2} \cdot 6 \mathrm{H}_{2} \mathrm{O}$, potassium nitrate $\left(\mathrm{KNO}_{3}\right)$, calcium chloride $\left(\mathrm{CaCl}_{2}\right)$, (sigma-Aldrich). Dowex 50WX8, (20-50 mesh) from Fluka. 


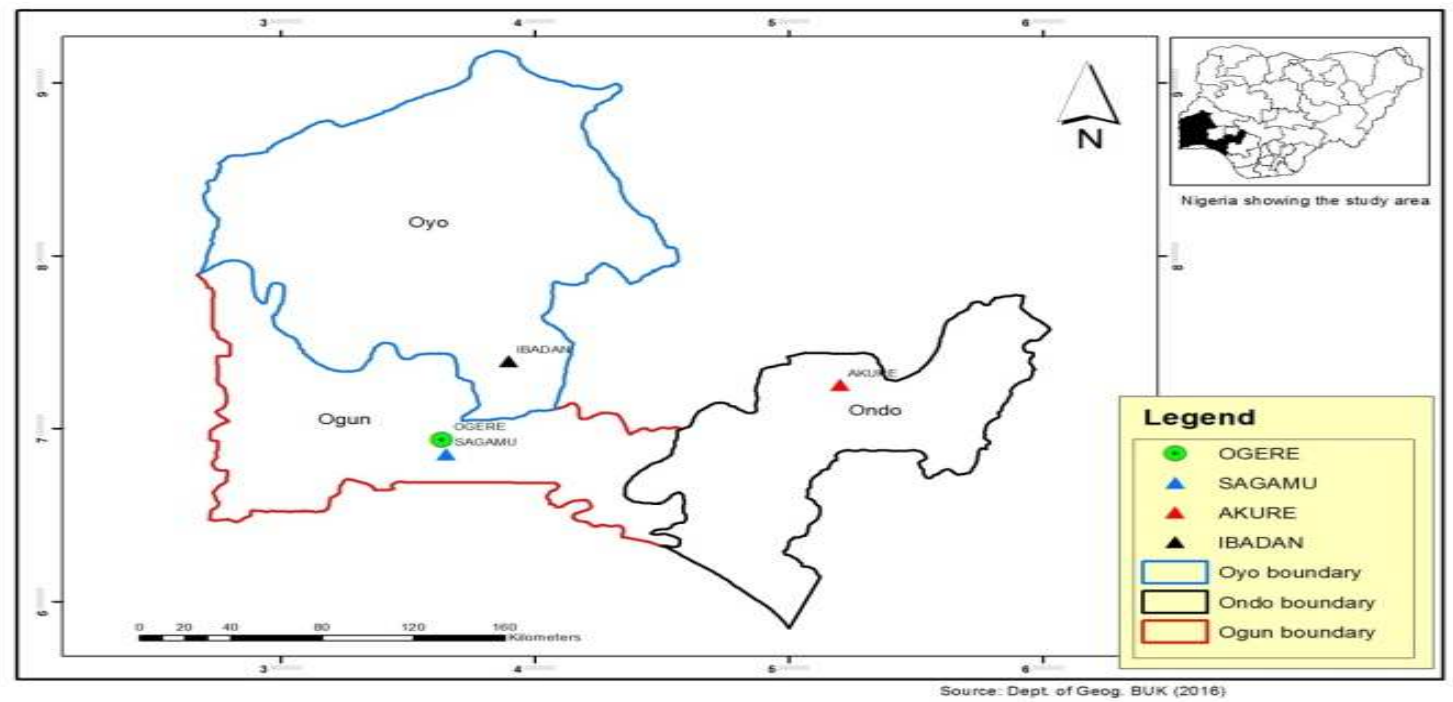

Figure 1: Map showing the sampling point at Sagamu Town, Ogun State.

\section{Description of Sampling Area}

Sagamu has geographical coordinates between $6^{\circ} 50^{\prime}$ north; $3^{\circ} 38^{\prime}$ east is located in south western region of Nigeria. The region has tropical wet and dry climate with a lengthy wet season and relatively constant temperatures throughout the course of the year. Wet season runs from March to October, November to December forms the region dry season. The vegetation type of the region is savannah which is really grassland with small bushes and occasional big trees. Grassland soils have substantially higher organic matter content than forest soils (Novackova, 2011).

\section{Sample Collection}

The Peatsoil samples were collected from four different sampling points $(0-10 \mathrm{~cm}$ depth) in Sagamu into polyethylene bag with plastic spoons. Samples were taken to the laboratory, extraneous materials were removed; the samples were air-dried, crushed and ground to a fine powder in a mortar passed through a $0.20 \mathrm{~mm}$ sieve. The samples were kept for analysis.

\section{Isolation and purification of humic acid from peat soil sample}

Peatsoil sample $(100 \mathrm{~g})$ was mixed with 1000 $\mathrm{cm}^{3}$ of $0.1 \mathrm{M} \mathrm{NaOH}$ solution, shaken for 3hours and left to stand overnight. Dark-coloured supernatant was obtained and decanted from solid residue. The dark-coloured supernatant was acidified to $(\mathrm{pH}=1.0)$ with $6 \mathrm{M} \mathrm{HCl}$ stirred and allowed to stand for 6 hours. Yellowish brown supernatant and dark-brown precipitate were obtained. The yellowish brown supernatant was decanted followed by centrifuge and discarded. The dark-brown precipitate was mixed with $500 \mathrm{~cm}^{3}$ of $0.1 \mathrm{M} \mathrm{NaOH}$ solution followed by passing through dowex resin. The dark-brown solution was acidified to $(\mathrm{pH}=1.0)$ with $6 \mathrm{M} \mathrm{HCl}$ stirred and allowed to stand for 3 hours. The dark-brown precipitate was washed several times with deionized water. The supernatant was treated with $\mathrm{AgNO}_{3}$ solution until no white precipitate observed. The humic acid was transferred to weighed crucible and dried at $60^{\circ} \mathrm{C}$ in an oven for 12 hours. The humic acid was cooled and dried in the desiccator, weighed and recorded. The obtained humic acid was dried again at $60^{\circ} \mathrm{C}$ for additional 6 hours cooled and dried in the desiccator, weighed and recorded constant weight was obtained (Baruah et al., 2015).

\section{FT-IR analysis}

FT-IR spectra of humic acid sample was analysed using Carry 630 FT-IR Agilent Technologies.

Unhydrolysed compost humic acid

The unhydrolysed humic acid was obtained after isolation and purification of compost humic acid and kept for investigation.

\section{Acid hydrolysis of Peatsoil acid}

Peatsoil humic acid sample (1g) was refluxed for 12 hours at $\left(160^{\circ} \mathrm{C}\right)$ with $50 \mathrm{~cm}^{3}$ of $6 \mathrm{M} \mathrm{HCl}$. The mixture was allowed to cool, decanted, and centrifuged after hydrolysis. The insoluble residues were washed with distilled water via centrifugation several times, and the supernatant was treated with $\mathrm{AgNO}_{3}$ solution until no white precipitate was observed. The residue was thoroughly dried over $\mathrm{CaCl}_{2}$ in a desiccator at room temperature (Chefetz et al., 2002). Finally, the obtained hydrolysed humic acid was kept for investigation. 
BAJOPAS Volume 14 Number 1,June, 2021 Potentiometric Titrations

Potentiometric measurements were carried out using a pH-meter Jenway (model 3510) with combine electrode, the sensitivity of the $\mathrm{pH}$ meter is 0.01 units. The $\mathrm{pH}$ meter was switched on half an hour before starting the titration for initial warm up of the instrument. The instrument was calibrated with an aqueous standard buffer solution of $\mathrm{pH} 4.00$ and 10.0 (borate buffer) prepared from a "Qualigens" buffer tablets.

The following sets of solutions were prepared in a $250 \mathrm{~cm}^{3}$ volumetric flask separately for $\mathrm{pH}$ metric titrations.

(i) $5 \mathrm{~cm}^{3} 0.1 \mathrm{M} \mathrm{HCl}+40 \mathrm{~cm}^{3}$ deionized water

(ii) $5 \mathrm{~cm}^{3} 0.1 \mathrm{M} \mathrm{HCl}+39 \mathrm{~cm}^{3}$ deionized water $+1 \mathrm{~cm}^{3} 0.15 \mathrm{gcm}^{-3}$ humic acid

(iii) $5 \mathrm{~cm}^{3} 0.1 \mathrm{M} \mathrm{HCl}+37 \mathrm{~cm}^{3}$ deionized water $+1 \mathrm{~cm}^{3} 0.15 \mathrm{gcm}^{-3}$ humic acid

$$
+2 \mathrm{~cm}^{3} \quad 0.01 \mathrm{M} \mathrm{Cu} \text { (II) }
$$

The solutions were titrated against standardized $0.110 \mathrm{MNaOH}$ separately. The total volume of each mixture was adjusted to $50 \mathrm{~cm}^{3}$ and the ionic strength of the solutions was maintained constant at by adding appropriate amount of stock solution of $1 \mathrm{M} \mathrm{KNO}_{3}$ (Gamal, 2015; Omar and Ali, 2015). A magnetic stirrer was used to achieve thorough mixing of the interacting solutions at $550 \mathrm{rpm}$. The same set of experimental conditions was applied for potentiometric titration of remaining samples.

\section{Evaluation of pKa of Hydrolysed peat soil Humic Acids}

The proton-ligand formation number $\mathrm{n}_{\mathbf{A}}$ were calculated by Irving and Rossotti expression (Omar and Ali, 2015).

$\mathrm{nA}=\mathrm{Y}-\frac{(\mathrm{V} 2-\mathrm{V1})(\mathrm{No}-\mathrm{Eo})}{(\mathrm{VO}+\mathrm{V1}) \mathrm{TCL}}$ 1

Where: $Y$ is number of dissociable proton, $\left(\mathrm{V}_{2^{-}}\right.$ $V_{1}$ ) is the measure of displacement of the ligand curve relative to acid curve, $\mathrm{N}^{\circ}$ and $\mathrm{E}^{\circ}$ are the resultant concentration of alkali solution, free acid solution, $\mathrm{T}_{\mathrm{cL}}{ }^{\circ}$ is the total ligand concentration, $\mathrm{V}^{\circ}$ is the total volume of titration solution, $V_{1}$ is the volume of alkali added to acid solution, $V_{2}$ is the volume of alkali added to acid solution + ligand solution, acid dissociation constants (pKa - values) of ligand were calculated by algebraic method point wise calculation (Tables 1 ). The dissociation constants (pKa) were calculated according to the following relation:

$\mathrm{pKa}=\mathrm{pH}+\log \left(\frac{n A}{1-n A}\right)$ 2

Where: pKa is the acid dissociation constant, $\mathrm{n}_{\mathrm{A}}$ is the Proton-ligand formation number and $\mathrm{pH}$ is the pH-values (Omar and Ali, 2015).

\section{Determination of metal-ligand stability constants $(\log K)$ of complexes}

The potentiometric measurement for the determination of stability constant of a complex in solution is based on the fact that the redox potential of the couple $\frac{M^{+(m-n)}}{M^{+m}}$ is shifted significantly on complexation of the metal ion with the ligand. This method involves change in hydrogen ion concentration $\left[\mathrm{H}^{+}\right]$due to the displacement or association of one or more protons taking place during complexation reaction. This change can be found out by titrating the solutions containing free acid, acid with ligand, and acid with ligand and metal ion, individually against a standard alkali solution at a constant ionic strength or temperature. Either ionic strength or temperature may be varied for different sets of solutions. In all the cases, the change in the $\mathrm{pH}$ of the solution is measured after each addition of a known amount of alkali to the reaction cell which contains the reaction mixture. The titration curves are then drawn by plotting the measured $\mathrm{pH}$ values against the corresponding volume of alkali added and the stability constants of the complexes are determined from the titration curves by employing $\mathrm{pH}$-metric titration technique given by (Irving and Rossoti).

Metal-ligand stability constants ( $\log \mathrm{K}$ ) were determined by using the following relations:

$$
\bar{n}=\frac{\left(V_{3}-V_{2}\right)\left(E^{0}+N^{0}\right)}{\left(V^{0}+V_{2}\right) \bar{n}_{A} T_{m}^{0}}
$$

and

$$
P L=\log _{10}\left\{\frac{1+\beta_{n}^{H} \frac{1}{[\text { anti } \log \mathrm{pH}]^{\mathrm{n}}}}{\mathrm{T}_{\mathrm{L}}^{0}-n \bar{T}_{m}^{0}} \mathrm{X} \frac{\left(V^{0}+V_{3}\right)}{V^{0}}\right\}
$$


BAJOPAS Volume 14 Number 1,June, 2021

Where $T_{L}, T^{\circ}, E^{\circ}$, and $V^{\circ}$ havethe same significance as in equation (1) above, $T_{m}$ denotes the total concentration of metal present in solution, $V_{3}$ is the volume of metal ions present in solution and $\beta^{H}$ is the overall proton ligand stability constant. The metal-ligand stability constants (log K) were determined by employing point wise computational Method (eq. 5 and 6).

$\operatorname{LogK}_{1}=\log \left(\frac{n}{1-n}\right)+\mathrm{pL}$ .5

$\operatorname{LogK}_{2}=\log \left(\frac{1-n}{2-n}\right)+\mathrm{pL}$ ...6

Where: Log $\mathrm{K}$ is the metal-ligand stability constant, $\mathrm{pL}$ is the Free ligand exponent function, $\mathbf{n}$ is the Average number of ligand attached with metal ion (Janraoet al., 2014). The results obtained were analyzed by an ORIGIN 2016 program using titration data and then the proton-ligand stability constants (pKa) and Metal-ligand stability constant (LogK) calculated (Omar and Ali, 2015).

\section{RESULTS AND DISCUSSION}

Fourier transformed infrared (FT-IR) spectra of isolated humic acid from peat soils Figure 2 had distinct clear absorption bands indicating the presence of major humic acid structural elemental groups such as $\mathrm{H}$ bonded $\mathrm{OH}$ $\left(3680 \mathrm{~cm}^{-1}\right.$ peak $), C=0$ of carbonyl $\left(1721 \mathrm{~cm}^{-1}\right.$ peak), functional groups of aliphatic components $\mathrm{CH}_{2}\left(2918 \mathrm{~cm}^{-1}\right.$ peak) and $\mathrm{C}-\mathrm{O}$ stretching of polysaccharide $\left(1168 \mathrm{~cm}^{-1}\right.$ peak). The positions of the absorption bands of the spectra fell within typical major absorption bands of humic acid which is at frequencies 3680, 2918, 1721, 1168 $\mathrm{cm}^{-1}$. The first peak centred in the vicinity of $3680 \mathrm{~cm}^{-1}$ region is attributed to phenol $\mathrm{OH}$ group bounded by intermolecular $\mathrm{H}$ bonds. The $2918 \mathrm{~cm}^{-1}$ band usually has absorption maximum at $2918 \mathrm{~cm}^{-1}$ which is due to $\mathrm{C}-\mathrm{H}$ stretching of alkane group $\left(\mathrm{CH}_{2}\right)$. The next major absorption band is $1721 \mathrm{~cm}^{-1}$. This band has been commonly ascribed to $\mathrm{C}=\mathrm{O}$ stretching of mainly carboxyl group $(\mathrm{COOH})$ with trace amount of ketones. The last peak was observed at 1168 $\mathrm{cm}^{-1}$ due to $\mathrm{C}-\mathrm{O}$ stretching of polysaccharides and this peak appeared also in the spectra of humic acid from peat soil. The FTIR spectra of the isolated humic acid contained all major characteristic absorption peaks of humic acid. These absorption peaks indicated the presence of the major structural elements of humic acid namely $\mathrm{H}$ bonded $\mathrm{OH}, \mathrm{C}=\mathrm{C}$ of aromatic ring, $\mathrm{C}=\mathrm{O}$ of carbonyl group (both carboxyl and ketonic), $\mathrm{CH}_{2}$ group. This strongly supports the presence of humic acid.

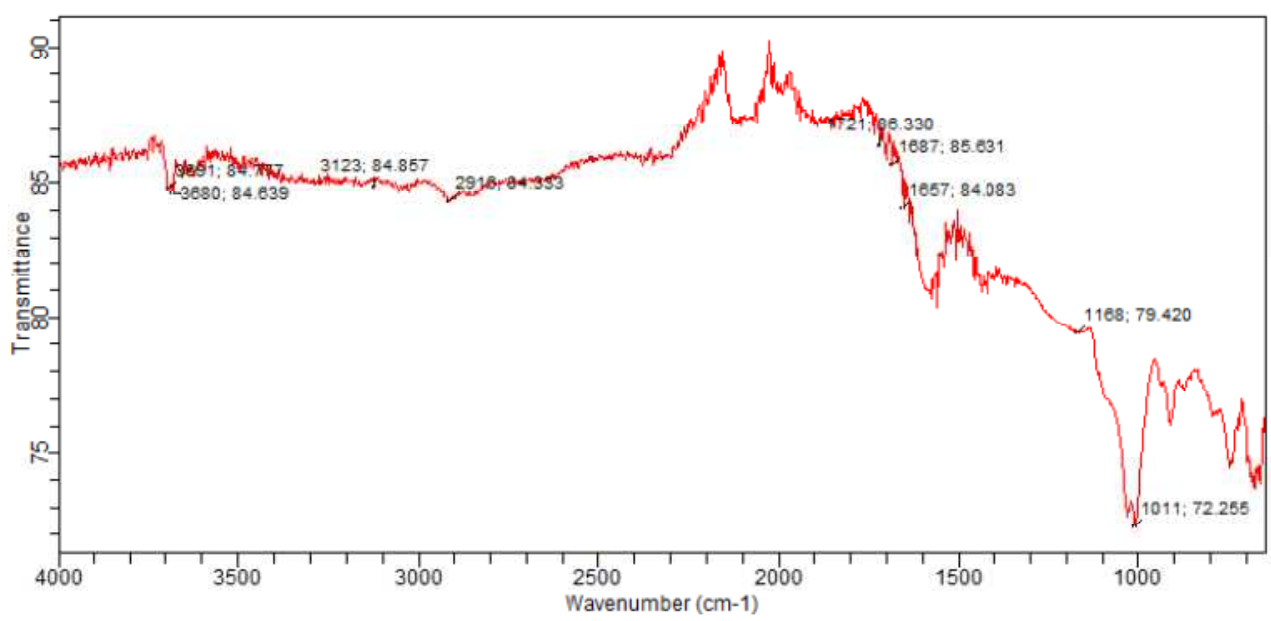

Fig. 2 : FT-IR spectraof peatsoilhumic acid (PSHA)

\section{Evaluation of acid dissociation constant (pka) of acid hydrolysed peat soil humicacid at phenolic group}

The value of the dissociation constant of the peat soil humic acid (PSHA) that underwent acidhydrolysis studied was found to be 8.9299 as shown Table 1, which is lower than the literaturevalues reported by Almeida and Szpoganics, (2015), Borges et al., (2005); Badr et al., (2012)and Fernandes et al,.(2009) of $9.73,9.47$ and 10.30. The difference between the obtained valuesand the reported values in this study might be probably as a result of acid hydrolysis of humicacid. 
BAJOPAS Volume 14 Number 1,June, 2021

Table 1: PKa of (Hydrolysed PSHA)

\begin{tabular}{|l|l|l|l|l|l|l|}
\hline $\mathrm{pH}$ & $\mathrm{BV}_{1}$ & $\mathrm{BV}_{2}$ & $\mathrm{~V}_{2}-\mathrm{V}_{1}$ & $\mathrm{nA}$ & $\log \left(\frac{n A}{1-n A}\right)$ & $\mathrm{pKa}$ \\
\hline 8.50 & 5.30 & 6.29 & 0.99 & 0.3594 & -0.2510 & 8.2490 \\
8.72 & 5.35 & 6.37 & 1.02 & 0.3400 & -0.2880 & 8.4320 \\
9.00 & 5.40 & 6.46 & 1.06 & 0.3141 & -0.3391 & 8.6609 \\
9.22 & 5.45 & 6.55 & 1.10 & 0.2882 & -0.3927 & 8.8273 \\
9.51 & 5.50 & 6.66 & 1.16 & 0.2494 & -0.4786 & 9.0314 \\
9.73 & 5.55 & 6.78 & 1.23 & 0.2041 & -0.5910 & 9.1390 \\
10.00 & 5.60 & 6.90 & 1.30 & 0.1589 & -0.7238 & 9.2762 \\
10.23 & 5.65 & 7.05 & 1.40 & 0.0941 & -0.9835 & 9.2465 \\
10.49 & 5.70 & 7.10 & 1.40 & 0.0941 & -0.9835 & 9.5065 \\
\hline
\end{tabular}

Average pKa $=8.9299 \pm 0.4186$

Table 2: PKa of (Unhydrolysed PSHA)

\begin{tabular}{|l|l|l|l|l|l|l|}
\hline $\mathrm{pH}$ & $\mathrm{BV}_{1}$ & $\mathrm{BV}_{2}$ & $\mathrm{~V}_{2}-\mathrm{V}_{1}$ & $\mathrm{nA}$ & $\log \left(\frac{\boldsymbol{n A}}{1-\boldsymbol{n}}\right)$ & $\mathrm{pKa}$ \\
\hline 8.50 & 5.30 & 5.81 & 0.51 & 0.6619 & 0.2919 & 8.7919 \\
8.72 & 5.35 & 5.90 & 0.55 & 0.6357 & 0.2418 & 8.9618 \\
9.00 & 5.40 & 6.00 & 0.60 & 0.6029 & 0.1813 & 9.1813 \\
9.22 & 5.45 & 6.10 & 0.65 & 0.5701 & 0.1226 & 9.3426 \\
9.51 & 5.50 & 6.20 & 0.70 & 0.5376 & 0.0654 & 9.5754 \\
9.73 & 5.55 & 6.33 & 0.78 & 0.4851 & -0.0259 & 9.7041 \\
10.00 & 5.60 & 6.47 & 0.87 & 0.4262 & -0.1291 & 9.8709 \\
10.23 & 5.65 & 6.62 & 0.99 & 0.3609 & -0.2481 & 9.9819 \\
10.49 & 5.70 & 6.80 & 1.10 & 0.2759 & -0.4690 & 10.0210 \\
\hline
\end{tabular}

Average pKa $=9.4923 \pm 0.4410$

Metal-ligand stability constant ( $\log \mathrm{K}$ )

The stabilityconstants require the accurate values of proton-ligand stability constants (Anil and Maroti, 2008). Metal titration curves crossed over ligand titration curve indicated the formation of complex upon proton release (Santosh, et al., 2011). If the values of n- are within range $0.2-0.8$ and $1.2-18$ this indicates the formation of $1: 1$ and 1:2 complexes (Sayyed and Mazahar, 2012).

The metal (II)-humate stepwise stability constants (log k) at phenolic group (Tables 318)

Table 3: Point-wise method, $\mathrm{Cu}$-(Hydrolysed PSHA)

\begin{tabular}{|l|l|l|l|l|l|l|l|l|}
\hline $\mathrm{pH}$ & $\mathrm{BV}_{1}$ & $\mathrm{BV}_{2}$ & $\mathrm{BV}_{3}$ & $\left(\mathrm{~V}_{3}-\mathrm{V}_{2}\right)$ & $\mathrm{n}$ & $\mathrm{pL}$ & $\log \left(\frac{n}{1-n}\right)$ & LogK $_{1}$ \\
\hline 8.50 & 5.30 & 6.29 & 6.33 & 0.04 & 0.5500 & 2.66 & 0.0871 & 2.7471 \\
8.72 & 5.35 & 6.37 & 6.41 & 0.04 & 0.5714 & 2.43 & 0.1249 & 2.5549 \\
9.00 & 5.40 & 6.46 & 6.50 & 0.04 & 0.6198 & 2.16 & 0.2122 & 2.3722 \\
9.22 & 5.45 & 6.55 & 6.59 & 0.04 & 0.6667 & 1.94 & 0.3010 & 2.2410 \\
\hline
\end{tabular}

LogK $_{1}$ (Average value) $=2.4788 \pm 0.2203$

Table 4: Point-wise method, $\mathrm{Cu}$-(Hydrolysed PSHA)

\begin{tabular}{|l|l|l|l|l|l|l|l|l|}
\hline $\mathrm{pH}$ & $\mathrm{BV}_{1}$ & $\mathrm{BV}_{2}$ & $\mathrm{BV}_{3}$ & $\left(\mathrm{~V}_{3}-\mathrm{V}_{2}\right)$ & $\mathrm{n}$ & $\mathrm{pL}$ & $\log \left(\frac{n-1}{2-n}\right)$ & LogK $_{2}$ \\
\hline 9.51 & 5.50 & 6.66 & 6.73 & 0.07 & 1.3509 & 1.70 & -0.2671 & 1.4329 \\
9.73 & 5.55 & 6.78 & 6.85 & 0.07 & 1.6383 & 1.51 & 0.2467 & 1.7567 \\
10.00 & 5.60 & 6.90 & 6.98 & 0.08 & 2.1783 & 1.31 & -0.2158 & 1.0942 \\
10.23 & 5.65 & 7.05 & 7.13 & 0.08 & 4.1904 & 1.27 & & \\
10.49 & 5.70 & 7.10 & 7.19 & 0.09 & 4.6920 & & & \\
\hline
\end{tabular}

Log $K_{2}($ Average value $)=1.4280 \pm 0.3312$ 
BAJOPAS Volume 14 Number 1,June, 2021

Table 5: Point-wise method, $\mathrm{Cu}$ (Unhydrolysed PSHA)

\begin{tabular}{|l|l|l|l|l|l|l|l|l|}
\hline $\mathrm{pH}$ & $\mathrm{BV}_{1}$ & $\mathrm{BV}_{2}$ & $\mathrm{BV}_{3}$ & $\left(\mathrm{~V}_{3}-\mathrm{V}_{2}\right)$ & $\mathrm{n}$ & $\mathrm{pL}$ & $\log \left(\frac{n}{n-1}\right)$ & Log $_{1}$ \\
\hline 8.50 & 5.30 & 5.81 & 5.85 & 0.04 & 0.2973 & 2.88 & -0.3736 & 2.5064 \\
8.72 & 5.35 & 5.90 & 5.95 & 0.05 & 0.3873 & 2.66 & -0.1992 & 2.4608 \\
9.00 & 5.40 & 6.00 & 6.05 & 0.05 & 0.4044 & 2.38 & -0.1681 & 2.2119 \\
9.22 & 5.45 & 6.10 & 6.15 & 0.06 & 0.5157 & 2.18 & -0.0272 & 2.2072 \\
9.51 & 5.50 & 6.20 & 6.27 & 0.07 & 0.6417 & 1.89 & 0.2530 & 1.1430 \\
\hline
\end{tabular}

$\operatorname{LogK}_{1}($ Average value $)=2.3059 \pm 0.6153$

Table 6:Point-wise method, $\mathrm{Cu}$ (Unhydrolysed PSHA)

\begin{tabular}{|l|l|l|l|l|l|l|l|l|}
\hline $\mathrm{pH}$ & $\mathrm{BV}_{1}$ & $\mathrm{BV}_{2}$ & $\mathrm{BV}_{3}$ & $\mathrm{~V}_{3}-\mathrm{V}_{2}$ & $\mathrm{n}$ & $\mathrm{pL}$ & $\log \left(\frac{n-1}{2-n}\right)$ & $\log \mathrm{K}_{2}$ \\
\hline 9.73 & 5.55 & 6.33 & 6.42 & 0.09 & 0.9000 & 1.69 & & \\
10.00 & 5.60 & 6.47 & 6.58 & 0.11 & 1.2578 & 1.44 & -0.4592 & 0.9808 \\
10.23 & 5.65 & 6.62 & 6.84 & 0.12 & 1.6137 & 1.26 & -0.2010 & 1.4610 \\
10.49 & 5.70 & 6.80 & 6.92 & 0.12 & 2.1052 & 1.03 & & \\
\hline
\end{tabular}

$\operatorname{LogK}_{2}$ (Average value) $=1.2209 \pm 0.3398$

Table 7:Point-wise method, Pb (Hydrolysed PSHA)

\begin{tabular}{|l|l|l|l|l|l|l|l|l|}
\hline $\mathrm{pH}$ & $\mathrm{BV}_{1}$ & $\mathrm{BV}_{2}$ & $\mathrm{BV}_{3}$ & $\left(\mathrm{~V}_{3}-\mathrm{V}_{2}\right)$ & $\mathrm{n}$ & $\mathrm{pL}$ & $\log \left(\frac{n}{1-n}\right)$ & LogK $_{1}$ \\
\hline 8.50 & 5.30 & 6.29 & 6.33 & 0.04 & 0.5500 & 2.66 & 0.0871 & 2.7471 \\
8.72 & 5.35 & 6.37 & 6.41 & 0.04 & 0.5714 & 2.43 & 0.1249 & 2.5549 \\
9.00 & 5.40 & 6.46 & 6.50 & 0.04 & 0.6198 & 2.16 & 0.2122 & 2.3722 \\
9.22 & 5.45 & 6.55 & 6.60 & 0.05 & 0.8333 & 1.96 & 0.6989 & 2.6589 \\
\hline
\end{tabular}

Log $_{\mathbf{1}}($ Average value $)=2.5832 \pm 0.1614$

Table 8:Point-wise method, Pb-(Hydrolysed PSHA)

\begin{tabular}{|l|l|l|l|l|l|l|l|l|}
\hline $\mathrm{pH}$ & $\mathrm{BV}_{1}$ & $\mathrm{BV}_{2}$ & $\mathrm{BV}_{3}$ & $\left(\mathrm{~V}_{3}-\mathrm{V}_{2}\right)$ & $\mathrm{n}$ & $\mathrm{pL}$ & $\log \left(\frac{n-1}{2-n}\right)$ & $\log \mathrm{K}_{2}$ \\
\hline 9.51 & 5.50 & 6.66 & 6.71 & 0.05 & 0.9650 & 1.67 & & \\
9.73 & 5.55 & 6.78 & 6.83 & 0.05 & 1.1702 & 1.44 & & \\
10.00 & 5.60 & 6.90 & 6.90 & 0.05 & 1.4864 & 1.22 & -0.0237 & 1.1963 \\
10.23 & 5.65 & 7.05 & 7.10 & 0.05 & 2.0190 & 1.09 & & \\
10.49 & 5.70 & 7.10 & 7.17 & 0.07 & 3.6492 & 1.00 & & \\
\hline
\end{tabular}

Log $K_{2}$ (Average value) $=1.1963$

Table 9: Point-wise method, Pb (Unhydrolysed PSHA)

\begin{tabular}{|l|l|l|l|l|l|l|l|l|}
\hline $\mathrm{pH}$ & $\mathrm{BV}_{1}$ & $\mathrm{BV}_{2}$ & $\mathrm{BV}_{3}$ & $\mathrm{~V}_{3}-\mathrm{V}_{2}$ & $\mathrm{n}$ & $\mathrm{pL}$ & $\begin{array}{l}\text { Log } \\
\left(\frac{n}{n-1}\right)\end{array}$ & Log $\mathrm{K}_{1}$ \\
\hline 8.50 & 5.30 & 5.81 & 5.85 & 0.04 & 0.2973 & 2.88 & -0.3736 & 2.5064 \\
8.72 & 5.35 & 5.90 & 5.94 & 0.04 & 0.3099 & 2.66 & -0.5477 & 2.3123 \\
9.00 & 5.40 & 6.00 & 6.05 & 0.05 & 0.4044 & 2.38 & -0.1681 & 2.2119 \\
9.22 & 5.45 & 6.10 & 6.15 & 0.06 & 0.5157 & 2.18 & 0.0272 & 2.2072 \\
9.51 & 5.50 & 6.20 & 6.26 & 0.07 & 0.6417 & 1.89 & 0.2530 & 2.1430 \\
9.73 & 5.55 & 6.40 & 6.40 & 0.07 & 0.7000 & 1.67 & 0.3680 & 2.0380 \\
\hline
\end{tabular}

LogK $_{1}$ (Average value) $=2.2364 \pm 0.1602$

Table 10: Point-wise method, Pb (Unhydrolysed PSHA)

\begin{tabular}{|l|l|l|l|l|l|l|l|l|}
\hline $\mathrm{pH}$ & $\mathrm{BV}_{1}$ & $\mathrm{BV}_{2}$ & $\mathrm{BV}_{3}$ & $\mathrm{~V}_{3}-\mathrm{V}_{2}$ & $\mathrm{n}$ & $\mathrm{pL}$ & $\log \left(\frac{n-1}{2-n}\right)$ & $\log \mathrm{K}_{2}$ \\
\hline 10.00 & 5.60 & 6.47 & 6.55 & 0.08 & 1.9503 & 1.41 & & \\
10.23 & 5.65 & 6.62 & 6.72 & 0.11 & 1.4792 & 1.26 & -0.0361 & 1.2239 \\
\hline
\end{tabular}

$\operatorname{LogK}_{2}$ (Average value) $=1.2239$

Table 11: Point-wise method, Mg (Hydrolysed PSHA)

\begin{tabular}{|l|l|l|l|l|l|l|l|l|}
\hline $\mathrm{pH}$ & $\mathrm{BV}_{1}$ & $\mathrm{BV}_{2}$ & $\mathrm{BV}_{3}$ & $\left(\mathrm{~V}_{3}-\mathrm{V}_{2}\right)$ & $\mathrm{n}$ & $\mathrm{pL}$ & $\log \left(\frac{n}{n-1}\right)$ & LogK $_{1}$ \\
\hline 8.50 & 5.30 & 6.29 & 6.31 & 0.02 & 0.2750 & 2.64 & -0.4290 & 2.2110 \\
8.72 & 5.35 & 6.37 & 6.39 & 0.02 & 0.2858 & 2.42 & -0.3978 & 2.0222 \\
9.00 & 5.40 & 6.46 & 6.49 & 0.03 & 0.4648 & 2.14 & -0.0612 & 2.0788 \\
9.22 & 5.45 & 6.55 & 6.59 & 0.04 & 0.6667 & 1.94 & 0.3010 & 2.2410 \\
\hline
\end{tabular}

$\log _{\mathbf{1}}($ Average value) $=2.1382 \pm 0.1046$ 
BAJOPAS Volume 14 Number 1,June, 2021

Table 12: Point-wise method, Mg (Hydrolysed PSHA)

\begin{tabular}{|l|l|l|l|l|l|l|l|l|}
\hline $\mathrm{pH}$ & $\mathrm{BV}_{1}$ & $\mathrm{BV}_{2}$ & $\mathrm{BV}_{3}$ & $\left(\mathrm{~V}_{3}-\mathrm{V}_{2}\right)$ & $\mathrm{n}$ & $\mathrm{pL}$ & $\log \left(\frac{n-1}{2-n}\right)$ & LogK $_{2}$ \\
\hline 9.51 & 5.55 & 6.66 & 6.71 & 0.05 & 0.9650 & 1.67 & & \\
9.73 & 5.55 & 6.78 & 6.84 & 0.06 & 1.4042 & 1.47 & -0.1686 & 1.3014 \\
10.00 & 5.60 & 6.90 & 6.93 & 0.06 & 1.7838 & 1.23 & 0.5593 & 1.7893 \\
10.23 & 5.65 & 7.05 & 7.10 & 0.06 & 3.1429 & 1.10 & & \\
10.49 & 5.70 & 7.10 & 7.18 & 0.07 & 3.6492 & 0.83 & & \\
\hline
\end{tabular}

LogK $_{2}($ Average value $)=1.5453 \pm 0.3450$

Table 13: Point-wise method, Mg (Unhydrolysed PSHA)

\begin{tabular}{|l|l|l|l|l|l|l|l|l|}
\hline $\mathrm{pH}$ & $\mathrm{BV}_{1}$ & $\mathrm{BV}_{2}$ & $\mathrm{BV}_{3}$ & $\mathrm{~V}_{3}-\mathrm{V}_{2}$ & $\mathrm{n}$ & $\mathrm{pL}$ & $\log \left(\frac{n}{n-1}\right)$ & $\operatorname{Log~}_{1}$ \\
\hline 8.50 & 5.30 & 5.81 & 5.85 & 0.04 & 0.2973 & 2.88 & -0.3736 & 2.5064 \\
8.72 & 5.35 & 5.90 & 5.94 & 0.04 & 0.3099 & 2.66 & -0.3477 & 2.3123 \\
9.00 & 5.40 & 6.00 & 6.04 & 0.04 & 0.3236 & 2.38 & -0.3202 & 2.0598 \\
9.22 & 5.45 & 6.10 & 6.15 & 0.05 & 0.4297 & 2.17 & -0.1230 & 2.0470 \\
9.51 & 5.50 & 6.20 & 6.26 & 0.06 & 0.5500 & 1.89 & 0.0871 & 1.9771 \\
9.73 & 5.55 & 6.33 & 6.40 & 0.07 & 0.7000 & 1.67 & 0.3680 & 2.0380 \\
\hline
\end{tabular}

LogK $_{1}$ (Average value) $=2.1568 \pm 0.2069$

Table 14: Point-wise method, Mg (Unhydrolysed PSHA)

\begin{tabular}{|l|l|l|l|l|l|l|l|l|}
\hline $\mathrm{pH}$ & $\mathrm{BV}_{1}$ & $\mathrm{BV}_{2}$ & $\mathrm{BV}_{3}$ & $\mathrm{~V}_{3}-\mathrm{V}_{2}$ & $\mathrm{n}$ & $\mathrm{pL}$ & $\log \left(\frac{n-1}{2-n}\right)$ & $\log \mathrm{K}_{2}$ \\
\hline 10.00 & 5.60 & 6.47 & 6.55 & 0.08 & 0.9148 & 1.41 & & \\
10.23 & 5.65 & 6.62 & 6.71 & 0.09 & 1.2102 & 1.20 & -0.5749 & 0.6251 \\
10.49 & 5.70 & 6.80 & 6.92 & 0.09 & 1.5968 & 1.03 & 0.1703 & 1.2003 \\
\hline
\end{tabular}

LogK $_{2}$ (Average value) $=0.9127 \pm 0.4070$

Table15:Point-wise method, Cd (Hydrolysed PSHA)

\begin{tabular}{|l|l|l|l|l|l|l|l|l|}
\hline $\mathrm{pH}$ & $\mathrm{BV}_{1}$ & $\mathrm{BV}_{2}$ & $\mathrm{BV}_{3}$ & $\left(\mathrm{~V}_{3}-\mathrm{V}_{2}\right)$ & $\mathrm{n}$ & $\mathrm{pL}$ & $\log \left(\frac{n}{1-n}\right)$ & LogK $_{1}$ \\
\hline 8.50 & 5.30 & 6.29 & 6.31 & 0.02 & 0.2750 & 2.64 & -0.4210 & 2.2190 \\
8.72 & 5.35 & 6.37 & 6.40 & 0.03 & 0.4286 & 2.42 & -0.1249 & 2.2951 \\
9.00 & 5.40 & 6.46 & 6.49 & 0.03 & 0.4648 & 2.14 & -0.0612 & 2.0788 \\
9.22 & 5.45 & 6.55 & 6.59 & 0.04 & 0.6667 & 1.96 & 0.3010 & 2.2610 \\
9.51 & 5.55 & 6.66 & 6.70 & 0.04 & 0.7720 & 1.67 & 0.5297 & 2.1997 \\
\hline
\end{tabular}

LogK $_{\mathbf{1}}$ (Average value) $=2.2108 \pm 0.0825$

Table 16: Point-wise method, Cd (Hydrolysed PSHA)

\begin{tabular}{|l|l|l|l|l|l|l|l|l|}
\hline $\mathrm{pH}$ & $\mathrm{BV}_{1}$ & $\mathrm{BV}_{2}$ & $\mathrm{BV}_{3}$ & $\left(\mathrm{~V}_{3}-\mathrm{V}_{2}\right)$ & $\mathrm{n}$ & $\mathrm{pL}$ & $\log \left(\frac{n-1}{2-n}\right)$ & Log $_{2}$ \\
\hline 9.73 & 5.55 & 6.78 & 6.83 & 0.06 & 1.4042 & 1.47 & -0.1686 & 1.3014 \\
10.00 & 5.60 & 6.90 & 6.95 & 0.06 & 1.7838 & 1.23 & 0.5593 & 1.7893 \\
10.23 & 5.65 & 7.05 & 7.10 & 0.06 & 3.1429 & 1.09 & & \\
10.49 & 5.70 & 7.10 & 7.16 & 0.06 & 3.1429 & 0.89 & & \\
& & & & & & & & \\
\hline
\end{tabular}

$\operatorname{LogK}_{2}$ (Average value) $=1.5453 \pm 0.3450$

Table 17: Point-wise method, Cd (Unhydrolysed PSHA)

\begin{tabular}{|l|l|l|l|l|l|l|l|l|}
\hline $\mathrm{pH}$ & $\mathrm{BV}_{1}$ & $\mathrm{BV}_{2}$ & $\mathrm{BV}_{3}$ & $\mathrm{~V}_{3}-\mathrm{V}_{2}$ & $\mathrm{n}$ & $\mathrm{pL}$ & $\log \left(\frac{n}{n-1}\right)$ & $\operatorname{Log~}_{1}$ \\
\hline 8.50 & 5.30 & 5.81 & 5.86 & 0.05 & 0.3717 & 2.88 & -0.2280 & 2.6520 \\
8.72 & 5.35 & 5.90 & 5.95 & 0.05 & 0.3873 & 2.66 & -0.1992 & 2.4608 \\
9.00 & 5.40 & 6.00 & 6.06 & 0.06 & 0.4853 & 2.38 & -0.0255 & 2.3545 \\
9.22 & 5.45 & 6.10 & 6.16 & 0.06 & 0.5157 & 2.18 & -0.0272 & 2.2072 \\
9.51 & 5.50 & 6.20 & 6.27 & 0.07 & 0.6417 & 1.89 & 0.2530 & 1.1430 \\
9.73 & 5.55 & 6.33 & 6.41 & 0.08 & 0.8000 & 1.69 & 0.6020 & 2.2920 \\
& & & & & & & & \\
\hline
\end{tabular}

$\operatorname{LogK}_{1}($ Average value $)=2.2516 \pm 0.5380$ 
BAJOPAS Volume 14 Number 1,June, 2021

Table 18: Point-wise method, Cd (Unhydrolysed PSHA)

\begin{tabular}{|l|l|l|l|l|l|l|l|l|}
\hline $\mathrm{pH}$ & $\mathrm{BV}_{1}$ & $\mathrm{BV}_{2}$ & $\mathrm{BV}_{3}$ & $\mathrm{~V}_{3}-\mathrm{V}_{2}$ & $\mathrm{n}$ & $\mathrm{pL}$ & $\log \left(\frac{n-1}{2-n}\right)$ & $\log \mathrm{K}_{2}$ \\
\hline 10.00 & 5.60 & 6.47 & 6.57 & 0.10 & 1.1434 & 1.43 & & \\
10.23 & 5.65 & 6.62 & 6.72 & 0.10 & 1.3448 & 1.23 & -0.2788 & 0.9512 \\
10.49 & 5.70 & 6.80 & 6.90 & 0.10 & 1.7742 & 1.03 & 0.5351 & 1.5651 \\
\hline
\end{tabular}

$\operatorname{LogK}_{2}($ Average value $)=1.2581 \pm 0.4340$

Table 19: Stepwise and overall Stability constants of thehydrolysed and unhydrolysed divalent metal (II) complexes

\begin{tabular}{|c|c|c|c|}
\hline Chelates & LogK $_{1}$ & $\log _{2}$ & Log $\beta$ \\
\hline [Cu (Hydrolysed PSHA-1) $\left.{ }_{2}\right]$ & 2.4788 & 1.4280 & 3.9068 \\
\hline$\left[\mathrm{Pb}(\text { Hydrolysed PSHA-1) })_{2}\right]$ & 2.5832 & 1.1963 & 3.7795 \\
\hline$\left[\mathrm{Cd}(\text { Hydrolysed PSHA-1 })_{2}\right]$ & 2.2108 & 1.5453 & 3.7561 \\
\hline$\left[\mathrm{Mg}(\text { Hydrolysed PSHA-1 })_{2}\right]$ & 2.1382 & 1.5453 & 3.6835 \\
\hline [Cu (Unhydrolysed PSHA-1) & 2.3059 & 1.2209 & 3.5268 \\
\hline$[\mathrm{Pb}$ (Unhydrolysed PSHA-1) 2$]$ & 2.2364 & 1.2239 & 3.4603 \\
\hline [Cd (Unhydrolysed PSHA-1) 2 ] & 2.2516 & 1.2581 & 3.5097 \\
\hline$[\mathrm{Mg}$ (Unydrolysed PSHA-1) & 2.1568 & 0.9127 & 3.0695 \\
\hline
\end{tabular}

The results obtained (Table19) shows the stepwise and overall stability constants to be not high indicating low stability of the complexes, because the solubility of most metal ions in the basic $\mathrm{pH}$ range is minimal due to metal hydroxide precipitation (Karimi, 2017). In general, the stepwise stability constants $\left(K_{1}\right.$ and $K_{2}$ ) follow the order $K_{1}>K_{2}$ for the copper, lead, magnesium and cadmium complexes respectively. The steady decrease of the values with increasing number of ligands is in agreement with the prediction made by researchers (Na'aliya, 2013). The decrease could be attributed to the fact that as the number of the ligands (Humate ions) that enters the coordination zone increases the aqua molecules available for replacement by the ligands become less. Thus, the metal ions become less electron loving with progressive intake of the ligand and this results in the decrease in the values of the constants (Na'aliya, 2013). Also the stability of the complexes is influenced by the size and number of the chelate rings(Mackay and Mackay,2002).All the complexes form rings in their structure as humate, a bidentate ligand, bond the metal ions in the ratio 1:2 (Boguta and Sokolowska, 2016) forming chelate rings. The values of the overall stability constants $(\log \beta)$ obtained for humate complexes are not high indicating low stability as the values are not high. LogK values for copper-humates (Table 3 to 6) obtained in this study are lower than those reported for the complexes of humic acids (Pandey et al., 2015; Dinu, 2013; Kaschl et al., 2010 and Gilbeto and Jorg, 2001). The values of LogK(Table 7 to 10 ) forlead-humates are lower than those reported for the lead in the literature (Dinu, 2013; Gilbeto and Jorg 2001). Log K values(Table 11 to 14 ) for magnesium-humates obtained in this study are close to those reported by (Pandey et al., 2015). Log K values of cadmium-humates (Table 15 to 18 ) obtained in this work near to the one reported by (Dinu, 2013 and Pandey et al., 2015).The difference between the reported values and the values obtained in this study might be probably as a result of acid hydrolysis of humic acid. The values of the overall stability constants $(\log \beta)$ of the copper humates complexes presented in Table 19 is high than that of other metal humate complexes, show relatively high stability of CuHA complexes, show the following order of stability: $\mathrm{Cu}>\mathrm{Pb}>\mathrm{Cd}>\mathrm{Mg}$; which are in close agreement to the findings of (Dinu, 2013 and Pandey et al., 2015).The high stability of Cuhumate chelate could be attributed to the existence of coordinate covalent bond between the complexing agents and the $\mathrm{Cu}^{2+}$ ions. Since, $\mathrm{Cu}^{2+}$ being a metal of the transitional series with $3 d^{9}$ electronic configurations can accept the electrons from the complexing agents. Similarly, the low stabilities of $\mathrm{Pb}, \mathrm{Cd}$ and $\mathrm{Mg}$ complexes could be explained by that $\mathrm{Pb}^{2+}$ with $6 s^{2}, \mathrm{Cd}^{2+}$ with $4 \mathrm{~d}^{10}$ and $\mathrm{Mg}^{2+}$ with $2 \mathrm{p}^{6}$ their electronic configuration has a completely filled $\mathrm{d}, \mathrm{p}$ and $\mathrm{s}$ orbitals. Moreover, the stabilities of metal ions with hydrolysed humic acid from peat soil were higher than those with unhydrolysed humic acid from peat soil; which is ascribed to the high content of acidity in hydrolysed humic acid than unhydrolysed humic acid. 
BAJOPAS Volume 14 Number 1,June, 2021 CONCLUSION

The values of logk for $\mathrm{Cu}(\mathrm{II})$ hydrolysed humic acid complex was higher followed by $\mathrm{Pb}$ (II), $\mathrm{Cd}(\mathrm{II})$ and $\mathrm{Mg}$ (II) hydrolysed humic acid complexes as compared with metal(II) unhydrolysed humic acid complexes. This indicates acid hydrolysis of humic acid can

\section{REFERENCES}

Almeida, V.R. and Szpoganicz, B. (2015). Humic Acid Potentiometric Response Patterns:Out- of Equilibrium Properties and Species Distribution Modelling. Chemical. Biol. Technol. Agric. 2: 17.

Anđelković, T., Nikolić, R., Bojić, A.,Anđelković, D., and Nikolic G.,(2010). Binding of Cadmium to Soil Humic Acid as A Function of Carboxyl Group Content. Macedonian Journal of Chemistry and Chemical Engineering.29(2): 215-224.

Anil, B. N. and Maroti, N. (2008). Studies on Influence of Die-Lectric Constants on Complex Equilibria between Substituted Py-Razalines and Lanthanide Metal Ions pH-Metrically. Amer.-Euras. scient. Res. 3(2): 212-216.

Ashok, K., Pandey, S. P. and Misra, V (2000). Stability Constants of Metal-Humic Acid Complexes and its Role in Environmental Detoxification. Journal of Ecotoxicology and Environmental Safety. 47(2):157-200.

Badr, M. H., El-Halafawi, M. H. and Abd El-al Zeid, E. R. (2012). Comparison Between the Effect of Ionic Strength on Acidity and Dissociation Constants of Humic Acids Extracted from Sewage Sludge and Nile Water Hyacinth Composts.Global Journal of Environmental Research 6 (1): 36-43.

Baruah, M.K., Borah, D., Saikia, P.P., Paul, S., Sharma, T. (2015). Evaluation of pKa Values of Soil Humic Acids and their Complexation Properties. International Journal of Plant \& Soil Science 6(4) : 218-228.

Boguta, P. Sokolowska, Z. (2016). Interactions of $\mathrm{Zn}$ (II) Ions with Humic Acids Isolated from Various Types of Soils. Effect of $\mathrm{pH}, \mathrm{Zn}$ Concentrations and Humic Acids Chemical Properties. Journal of Geochemical Explaration 168. 119-126.

Borges, F., Guimaraes, C., Lima, L.F.C., Pinto, I. and Reis, S.(2005). Potentiometric Studies on the Complexation of Copper(II) by Phenolic Acids as Discrete Ligand Models of enhance the complexation behavior of humic acid with metal (II) ions. However, the higher values of $\log \beta$ for $\mathrm{Cu}(\mathrm{II}), \mathrm{Pb}(\mathrm{II}), \mathrm{Cd}(\mathrm{II})$ and $\mathrm{Mg}(\mathrm{II})$ hydrolysed humic acid complexes indicates more stable stepwise complexes formed as compared with $\mathrm{Cu}(\mathrm{II}), \mathrm{Pb}$ (II), $\mathrm{Cd}$ (II) and $\mathrm{Mg}(\mathrm{II})$ unhydrolysed humic acid complexes.

Humic Substances Talanta 66 (2005) 670-673.

Chefetz, B., Salloum, M. J., Deshmulkin, A. P. and Hatcher, P. (2002). Structural Components of Humic Acids as Determined by Chemical Modifications and Carbon-13 NMR, Pyrolysis, and Thermochemolysis- Gas Chromatography/Mass Spectrometry. Soil Science Society of American Journal Abstract Division S-2- Soil Chemistry66. 1159-1171.

Dinu, M. I. (2013). Metals Complexation with Humic Acids in Surface Water of Different Environ. Sci. Technol. 31(1): 1-17.

Fernandes, A.N., Giacomelli, C., Giovanela, M. Vaz, D.V. Szpoganicz, B. and Maria M. D. (2009). Potentiometric Acidity Determination in Humic Substances Influenced by Different Analytical Procedures.J. Braz. Chem. Soc. 20 (9):14.

Gamal, A. H. (2015). Stability Constants of Rhenium (V) Metal Complexes with Selected Drugs. Pyrex Journal of Research in Environmental Studies. 2(2): 006-014.

Janrao, D. M., Pathan, J., Kayande, D.D., and Mulla, J.J. (2014). An Over View of Potentiometric Determination of Stability Constants of Metal Complexes. Sci. Revs. Chem. Commun.: 4(1), 2014, 11-24.

Karimi, H. (2017). Effect of pH and Initial Pb(II) Concentration on the Lead Removal Efficiency from Waste Water Using $\mathrm{Ca}(\mathrm{OH})_{2}$. International Journal of Water and Waste Water Treatment 3.2

Kaschl, A. Romheld, V. and Chen, Y. (2010). Binding of Cadmium, Copper and Zinc to Humic Substances Originating from Municipal Solid Waste Compost. Israel Journal of Chemistry Vol. 42(1): 89-98.

Kostic, I. S., Tatjana, P, A., Nikolic, R. S., Cvetkovic, T. P., Pavlovic, D. D., Aleksandar, L.J. and Bojic, A. (2012). Comparative Study of Binding Strengths of Heavy Metals with Humic Acid. J.serb. Chem. Soc. 76(9) pp 1-20. 
BAJOPAS Volume 14 Number 1,June, 2021

Na'aliya, J. (2013). Determination of Stepwise Stability Constants and Gibbs free Energy Change of Trisprolina to Complexes of some Divalent Transition Metal ions. Bayero Journal of Pure and Applied Sciences 6(2): 112-114.

Omar, A. A. and Ali, E. A. (2015). Potentiometric Studies on Complexes of $\mathrm{Cr}$ (III) and $\mathrm{Zr}$ (IV) with some Carboxylic Acids. International Journal of Advanced Chemistry, 3(1) 25-

37.

Pandey, A. K. Pandey, S. D. and Misr, V. (2015).Stability Constants of Metal- Humic Acid Complexes and Its Role in Environmental Detoxification. J. Ecotoxicology and Environmental Safety. 47(1):195-200.

Ram, N. and Raman, K.V. (1984). Stability Constants of Complexes of Metals with
Humicand Fuvic Acids under Non- acidConditions. Journal of Plant Nutrition and Soil Sciences.

147:171-176.

Santosh, D. D., Ashok, B. K., Vijay, J. T., Shivraj, G. W. and Vinay, V. W. (2011). Potentiometric Studies of Elec-Trolyte Effects on Complex Equilibria of Some Substituted 5-(2-hydroxy Phenyl) Pyrazoles. Der pharm. 3 (6): 75-83.

Sayyed, H. and Abdul Rahim, M. F. (2012). Studies of Binary Complexes of Metal Ions with Mandelic Acid by Potentiometry. Chem. J. 02 (6): 206209.

Shirvani, M. Moradian, E. Khalili, B. Bakhtiary, S. (2015). Interaction of $\mathrm{Cd}$ and $\mathrm{Pb}$ with Humate-Palygorskite and HumateSepiolite Complexes. Journal of water, air and pollution 3: 220-228. 